INDEX BRYOLOGICUS 


\section{INDEX BRYOLOGICUS}

SIVE

\section{ENUMERATIO MUSCORUM HUCUSQUE COGNITORUM}

ADJUNCTIS

SYNONYMIA DISTRBBUTIONEQUE GEOGRAPHICA

L OCUP L E T ISS I M IS

QUEM CONSCRIPSIT

\section{E. G. PARIS}

Socius corresp.

(Ex Actis Societatis Linneante Burdigalensis).

PARISIIS

APUD PAUL KLINGKSIECK

52 , rue des Écoles, 52

I 894.98 


\title{
MEMORI $\nexists$
}

\section{W. P. SCM I M PER I}

BRYOLOGI PRESTANTISSIMI

AMICI MAGISTRIQUE DILECTISSLMI

\section{HOC OPUS DICAT}

\author{
AUCTOR.
}




\section{NOMINA AUCTORUM ABBREVIATA}

$\mathrm{Abb},-\mathrm{Abbott}$.

Adans. - Adanson,

Afzel. - Afzelins.

A. Br. - Alexandre Braun.

All. - Allioni.

Angstr. - Angstroem.

Arn. - Arnell.

Aubl. - Aublet.

Aust. - Austin.

Bail. - Bailey.

Bals. - Balsamo.

Bell. - Bellard.

Berggr. - Berggreen,

Besch. - Bescherelle.

Bland. - Blandow.

Bonpl. - Bonpland.

Bosw. - Boswell.

Bott. - Bottini.

Boul. - Boulay.

Braithw. - Braithwaite.

Breidl. - Breidler.

Brid. - Bridel.

Broth. - Brotherus.

Br. et Sch. - Bruch et Schimper.

Buxb. - Buxbaum.

Card. - Cardot.

C. M. - Carl Müller.

Curt. - Curtis.

DC. - De Candolle.

De Not. - De Notaris.

Desf. - Desfontaines.

Desv. - Desvaux.

Dicks. - Dickson.

Dill. - Dillenius.

Dy, et W. - Duby et Welwitsch.

Dz. et Mk. - Dozy et Molkenboêr.

Drumm. - Drummond.

DR. - Durien de Maisonneuve.

Ehrh, - Ehrhardt.

FehIm. - Fehlmann.

Ferg. - Ferguson.

Fisch. Ost, - Fischer Oster.

Fior. Mazz. - Fiorini Mazzini.

Fr. - Fries.

Fürnr. - Fürnrobr.
Gaërtn. - Gaërtner.

Garov. - Garovaglio.

Geh. - Geheeb.

Gmel. - Gmelin.

Grev. - Greville.

Griff. - Griflith.

Groenw. - Groenwald.

Gümb. - Gümbel.

Grünn. - Grünner.

Hall. - Haller.

Hpe. - Hampe.

Hartm. - Hartmann.

Harv. - Harvey.

Hedw. - Hedwig.

Holim. - Hoffmann.

Holmgr. - Holmgreen.

Hook. - Hooker.

H, et T. - Hooker et Taylor.

Hook. f. et Wils., H. f. et W. - Hooker filius et Wilson.

H. et H. - Hoppe et Hornschuch.

Hornsch.-- Hornschuch.

Humb. - Humboldt.

Hüb. - Hübener.

Huds. - Hudson.

Husn. - Husnot.

Itzigs. - Itzigsohn.

Jaeg. - Jaeger.

Jam. - James.

Jur, - Juratzka.

Kindb. - Kindberg.

Klinggr. - Klinggraëfr.

Ky. - Kotschy.

Kth. - Kunth.

Kze. - Kunze.

Lac. - Lacoste (van der Sande).

Lam. - Lamarck.

Lesq. - Lesquereux.

Limpr. - Limpricht.

Lindb. - Lindberg.

L. et A. - Linberg et Arnell.

L. - Linnaeus.

L. f. - Linnaeus filius.

Ltz. - Lorentz.

Ludw. - Ludwig. 
Mac. - Macoun.

Mart. - Martius.

Maxim. - Maximovicz.

Menz. - Menzies.

Mich. - Michaux.

Mielichh. - Mielichhofer.

Mitt. - Mitten.

Mdo. - Molendo.

Mont ${ }_{2}$ - Montagne.

Moug. et Nestl. - Mougeot et Nestler.

Myr. - Myrin.

Neck. - Necker.

Nees ab Es. - Nees ab Esenbeck.

N. et H. - Nees et Homschuch.

Ed. - Eder.

Ol. Ham, - Olaüs Hammer.

P. B. - Palisot de Beauvois.

Par. - Paris.

Phil. - Philibert.

Poir. - Poiret.

Poll. - Pollich.

Rab. - Rabenhorst.

Rehm. - Rehmann.

Reichdt. - Reichardt.

Reinw. - Reinwald.

Ren, - Renaud.

R. et C. - Renaud et Cardot.

Rich. - Richard.

R. Br. - Robert Brown.

Roehl. - Roehling.

Sb. - Sauërbeck.

Saut. - Sauter.

Schleich. - Schleicher.

Schrad. - Schrader.

Schreb. - Schreber.

Schum. - Schumann.

Schwaegr. - Schwaegrichen.

Scop. - Scopoli.
Sendtn. - Sendtner.

Sibth. - Sibthorp.

Sm. - Smith.

Spreng. - Sprengel.

Spr, - Spruce.

Sull. - Sullivant.

S. et L. - Sullivant et Lesquereux.

Sw. - Swartz.

Tayl. - Taylor.

Thunb. - Thunberg.

Thw. et Mitt., T. et M. - Thwaites et Mitten.

Tomm. - Tommasini.

Turn. - Turner.

Ung. - Unger.

Vaill. - Vaillant.

Vent. - Venturi.

Vill. - Villars.

Viv. - Viviani.

Vahlenb. - Wahlenberg.

W. Arn. - Walker Arnott.

Wall. - Wallich.

Warnst. - Warnstorf.

Web. - Weber.

W. et M. - Weber et Mohr.

Weig. - Weigel.

Weinm. - Weinmann.

Welw. - Welwitsch.

Wib. - Wibel.

Wigg. - Wigger.

Willd, - Willdenow.

W. Sch. - Wilhelm Schimper.

W.P.Sch.-Wilhelm Philippe Schimper.

Wils. - Wilson.

With. - Withering.

Zenk. et Dietr., Z. et D. - Zenker et Dietrich.

Zett. - Zetterstedt.

\section{S I G N A}

1. - Monoicus.

2. - Dioicus.

Syn. - Synoicus.

c - Flos masculus.

$Q_{\lambda}$ - Flos feminaeus. 


\section{AD LECTOREM}

Ubi editi fuerunt et Bridelii liber "BRYologia UNIVERSALIS 》, præccipueque ii, quorum alter "BRYOLOGIA EUROPEA », cujus auctores Bruchius, Gümbelius ac W. P. Schimperus, alter C. Mülleri «Sxnopsis Musconum» inseribitur, herbariorum plurimi muscos investigandi studio sunt conati. Adde quod, fere eodem tempore, peregrinationes omnium spe celeriores, explsditioresque etiam ignotarum remotarumque regionum factæ fuerunt explorationes. Illa vero regionum quarum auctores, quos supra nominavimus, prope erant nescii, peragratio, magnum proventum attulit muscorum. Quorum quidem nescio an magis quam Bryologorum numerus creverit. Namque ut exemplum referamus :

Bryologia universalis constat ex........ 931 species.

Synopsis Muscorum................. 2364 》

Jaegeri et Sauërbeckii Adumbrationes .... 7442 ,

Quamvis certum specierum, quas in hoc opere recensuri sumus, numerum referre non possimus, quia nobis exactam earum rationem diligenter asservare, usquedum hujus libri editionem confeceremus, propositum sit contendere, tamen audebimus illas species decem transire, ac prope duodecim millia explere numerum.

Quæ autem, quin omnes veræ sint, jure incerto habetur. Bryologi enim nimii, ut ipsi confessi sunt, quasdam species, quin imo genera in frustula condiderunt; et ipse $C$. Müller, eruditissimus vir, nunc Bryologorum venerandus antiquior, postea illam tam 
prudentem legem nobis dedidicisse videtur, quam ab initio magna cum auctoritate tulerat (1). Quod si Bryologi species ex regionibus collectas, in quibus ista frustula reperta sunt, propius inspiciunt, ac cum ex finitimis regionibus speciebus comparant, tum profecto illis ad genera, imo ad species antea constitutas postrema referre licebit. Ceterum, ut eadem illa repetamus quæ alias (2) diximus, ne spes quidem ulla Bryologiam processum efficere, nisi familiæ monographice describantur. Quæ veru plures sunt quam ut fieri non possit, ut Bryologus etiam solertissimus quemdam muscum vel alio nomine inscriptum, vel in varietate reponendum, cujus omnia ignorat quæ ei cum specie nota communia, quibusque ex forma typica pendeat, nonnunquam existimet novum. Hic igitur Bryologus, quum Bryacearum, Hypnacearumque familias supra mille amplecti species et fere totidem ad Neckeraceanum familiam referri animadvertit, nonne eo deducitur ut, speciminibus collectis et permultis locis ac quam disjunctissimis consultis et exploratis, species esse jure eo nomine vocatas, et eas quæ falso id nomen sibi asseruerint, aut eximi posse, aut ex prioribus pendere ostendat? (3)

Primus vero $W$. P. Schimperus noster, ille clarissimus vir quo magistro usi sumus, quum in dies cresceret muscorum numerus, brevi necessitatem instare genera dilatandi, id est sub generis nomine sectiones amplectendi, quœdam propria perspectissimaque praebentes, etiamque nova novarum specierum genera instituendo, intellexic. Quippè qui, in europaeis Acrocarpis, nou Dicranellam a Dicrano, Bartramidulamque a Bartramia genere modo dignosceret, verum etiam Ångströmia, Campylosteleum, etc., genera crearet. In Pleurocarpis quoque praecipueque in speciebus ad Hypnum genus pertinentibus, quarum copia Bryologi quasi premebantur, eas sectiones, de quibus nulla fere jam est controversa, Amblystegium, Brachythecium, Hylocomium, Plagiotherium, etc. constituit.

Attamen hœc nova Muscorum partitio, quum statim in Suecia, Norvegia, Britanniaque ac in Gallia benigne reciperetur, germa-

(1) «Quid est, cur auctores tam multi in specimina pessima species novas suas condant? C. M. Syn. $I I$, p. 508 .

(2) Bulll. de la Soc. bot. de Fr., 1892, p. 53 ; Revue bryol. 1892, p. 41. (3) Cf. Aclocque in Revue scientifique 1894, II, p. 338: La notion de
l'espèce chez les Muscinées. 
nicis Bryologis non placuit. Simul enim, eodemque tempore quo « Bryologia europex» volumen VI, edebatur "SYNopsidis Muscorum » volumen II, quo in libro tantum aberat ut nova Muscorum genera poneret, ut contra multa a Bridelio antea constituta recideret, ac fere totam Pleurocarporum classem in Neckera, Pilotrichum, Hookeria et Hypnum generibus includeret; quam partitionem collegæ discipulique ejus, ut fieri solet, secuti sunt.

Ipsi autem, quum brevi specierum crescenti numero essent superati, quemadmodum inter generale specialeque interponerent sectionis nomen excogitaverunt (Hampæus, ni fallimur, primus hanc nomenclaturam aperuit). Sic scripserunt : Lepidopilum (Eriopus) flexicaule Hpe., vel (Chryso) Bypnum loriforme Hpe. Deinde cum sectionis ipsæ opplerentur, ut scriberent sunt perducti : Hypnum (Mallacodium, Cuspidaria) extenuatum C. M. Hac quidem nominum dispositione haud dubium est quin cuique speciei suam sectionem assignent; quid autem ei sit cum binaria nomenclatura, a quovis herbario petimus!

Quin etiam Bryologus qui, in generibus jam plurimis speciebus redundantibus, species antea in aliis probatissimisque generibus sepositas inscribit, quæque inter se fere omnino dissimillimæ sunt, ac quaedam tantum communia habent, ea necessitate constringitur, ne bis eadem appellatione utatur, ut speciale nomen mutet; quod in hanc opinionen adducit ut, dum novum pro nomine principi reponit, non aliqua cupiditatc huic suum addendi fortasse caruerit (1)!

Quod ad prioritatis jus attinet, nos quidem omni ope et opera sumus adnisi, ut Cærari quod Cæsaris est, id est, suum cuique redderemus. Non tamen ut opinionem nimis obsoletam Lindbergii teneamus. Quis enim non molestissime tulerit, quum modestos tum eruditos viros, qui species nunc in libris alieno nomine inscriptas ac signatas primi reperissent descripsissentque, eo honore omnino esse dejectos? Nos tamen existimavimus nullo modo fieri posse ut illa respuamus omniaque nomina mutemus; quæ enim si miscerentur, Bryologos ad implicatissimam confusionem redigerent.

(1) Cf. Lorentz in Bot. Zeit. 1866, p. 189 : Ueber Synonymenunfug und Autoritaetspiraterie. 
Quamvis autem plurimam curam operamque maximam ad hunc INDIOEM conficiendum adhibuerimus, quædam præterita profecto animadvertentur, quædam etiam errata reprehendentur. Ista impense petimus, ut nobis Bryologi patefaciant (quod quidem permagni scientiœ interest) ut in Appendice illa restituamus vel hac corrigamus, ut hoc opus quam minime sit imperfectum.

Quid jam denique restat, nisi ut (quod certe nobis miram quamdam suavitatem ac delectationdem offert) gratias illis viris agamus, qui nobis libentissime operam suam attulerunt. Ex his primum Em. Bescherelle (Parisiis) numerari decet, qui non tantum consiliis acutissimis censuraque amicissima juvavit, sed etiam tam comiter nobiscum egit, ut librorum, quorum penuria præcipue in provinciis apparet, commemorationem prœberet, speciminibusque sive criticis aut perraris donaret; Brotherus (Helsingfors, Fennia) quoque, J. Cardot (Stenay, Gallia), de Poli (Parisiis), Dixon (Northampton, Anglia), Husnot (Cahan, Gallia) nos et suis consiliis et suis operibus, librisque vel speciminibus adjuverunt. Cuique de nobis optime meritis gratiam referimus maximam.

AUCTOR.

DrNard (Ille-et-Vilaine, France), 7 brí 1894. 


\section{INDEX BRYOLOGICUS}

Acamptodous Duby, Choix de M. ex. 1880, p. 9 (sect. v. subgen. LePIDoPILI). ACANTHOCLADIUM Mitt. Austral, M, p. 37 (= Trismegistia, spec. omn HYPNa ejusd. nom.).

ACANTHODIUM Mitl. Sam. M. p. 182. deflexifolium Mitt. - Sematophyllım. papillatum Mitt. - Trichosteleum.

rigidum Mitt. - Sematophyllum complanatulum.

ACAULON C. $M$. in Bot. Zeit. 1847, p 99; Syn. I, p. 21, et II, p. 519. apiculatum $\mathrm{H}$. f. et W. - Sphærangium.

apiculatum $\mathrm{H}$. f. et W. var. turgidum Mitt. - Sph. apiculatum var. turgidum.

brisbanicum C. M. - Sphærangium.

capense C. M. - Sphrerangium.

carniolicum C. M. - Phascum.

Floërkeanum C. M. - Microbryum.

Floërkeanum var, $\beta$ C. M. - Microbryum Floërkeanum var. badium.

integrifolium C. M. - Sphærangium.

Lorentzi C. M. - Sphærangium.

mediterraneum Limpr. - Sphærangium.

minus Jaeg. - Sphærangium muticum var. minus.

muticum C. M. \{ Sphrerangium muticum p.p.

nanum C. M Sphærangium capense p.p.

piliger, M. - Sphærángium.

piligerum Limpr. - Sphærangium muticum, var. cuspidatum.

rufescens Jaeg. - Sphrerangium.

triquebum C. M. - Spherangium.

triquetrum var. Sull. et Lesq. - Sphærangium rufescens.

Schimperianum Sull. - Sphterangium.

Sullivani C. M. - Sphærangium. 
Uleanum C. M. - Sphærangium.

vesiculosum C. M. - Sphærangium.

Achrolepis Lindb. Contr. ud fl. crypl. As. bor. or. 1872, p. 276 (sect. Myurella, firsan gen. propr.).

ACIDODONTIUM Schroaegr Suppl. 11.

exaltatum Jaeg. - Bryum.

floresianum C. M. - Bryum

Kunthii $\left\{\begin{array}{l}\text { Hsch. - Brachymenium systylium. } \\ \text { Sehwaegr. - Bryum megalocarpum. }\end{array}\right.$

ramicolit Jaeg. - Bryum.

rhamphostegium Jaeg. - Bryum.

seminerve H. f. et W. - Bryum.

Sprucei Jaeg. - Bryum.

subrolundum H. f. et W. - Bryum Taylori.

ACIRHYNCHUM Hpe. in sched.

cupressinum Hpe. - Rhaphidostegium sphaerotheca.

Acisphagnum C. $M$. in Linn 1874, p. 548 (nom.) et in Fl. 1887, p. 404 (Sph. cuspidata).

Acocosphagnum C. $M$. in Fl. 1887, p. 405 (Sph. sericea).

Acoleos C. $M$. in Linn. 1874, p. 509 (sect. Bartramiæl.

ACOSTA C. $M$. in Linn. 1848, p. 91.

cuspidata C. M. - Leucomium cuspidatifolium.

Meyeniana C. M. - Ectropothecium.

Swartzii C. M, - Ectropothecium subdenticulatum.

ACRO CLADIUM Mitt. M. austr. am. pp. 22 et 531 (4 sp.).

Auberti (Schwaegr.) Besch. Fl. bryol. Réunion, etc., p. 175.

Hypnum Auberti Schroaegr. Suppl. I, II, p. 200; C. M. Syn. II, p. 262.

H. Stereodon Auberti Brid. Bryol. univ, II, $p, 50$.

Leskea nitens Brid. Sp. M. II, p. 556.

2. - - Afr.: Comor, magn., ins. Borbon., Franciæ.

auriculatum Mitt., p.p. $\left\{\begin{array}{l}\text { Colidium. } \\ \text { Colidium chlamydophyllum. }\end{array}\right.$ cuspidatum Lindb. - Hypnum.

mucronatum (C. M.) Jaeg. Ad. II, p. 509.

Hypnum mucronatum C. M. op. et $l$. co.

2. $\quad$ - Afr.: C. B. Sp.

Phyllogonium Jaeg. - A. politum.

politum (Hook. f. et Wils.) Mitt. M. austr. am. p. 531.

A. Phyllogonium Jaeg. Ad. II, p. 509.

Hypnum Phyllogonium C. M. Syn. I1, p. 262 (fid. Mitt. l. e.).

H. politum H. $f$. et W. in Lond. Journ. of Bot. 1844, p. 353 (Mitt.), p. 553 (C. M.) et Fl. Antarct. II, p. 416, t. 154, f. 2; C. M. op. cit. p 263.

Phyllogonium eallichroum Mont. in Ann. Sc. nat. 1845, IV, p. 87.

2. Lignic, rupic,, terr. hum. - Afr.: Ins. Kerguelen, C. B. Sp.. Am. merid.: And. Nov.-Granat, et Quitens., Chile, Euegia, ins, Eremita. Pac.: Austr., Nov.-Zel, Tasman.

trichocladium Bosw, in Lond. Journ. of Bot., 1892, p. 99.

Ster.

- Pac.: Austral. 
ACROGRY PHAA (1), Bryol. eur. V, Mon. Cryphaeae (9 sp.).

brachyodus Broth. in lilt.

A. brevidens Broth. in Mosen M. Brasil n. 89.

- Amer. mer.: Minas Geraës.

caripensis Hpe. - A. squarrosula.

concavifolia (Griff.) Bryol. jav. II, p. 106.

A. javanica Bryol. eur. l. $c$.

Cryphaea concavifolia Mitt. M. Ind. or. p. 125.

Orthotrichum concavifolium Griff. Not. p. 400 et Ic. Pl. asiat II, t. 76, f.3.

- As.: Nepal., Ceylan, Java, Celebes.

corymbosa $\beta$ Hpe. - A. squarrosula.

corymbosula Par. et W. P. Sch. Mon. Cryph. ined.

- Am. sept.: Mexic.

ferruginea (Lindb.) Par, et W. P.Sch. l. c.

A. Gardneri Jaeg. Ad. II, p. 94.

Cryphaea ferruginea Lindb. mem. a3 Aongstr, in Oefo.... 1876, p. 31 .

Cr. Gardneri Mitt, in Journ. of the Linn. Soc. 1859 et M. aust. am., p. 415.

Grimmia julacea Hsch. Fl. bras. p. 7, t. I, f. I, p.p.

- Am. sept.: Cuba. Am. merid.: And. Noy. Granat., Brasil. austr. or. Gardneri Jaeg. - A. ferruginea.

javanica Bryol. eur. - A. concavifolia.

julacea (Hsch.) W. P. Sch. mss.

Cryphaea julacea Mitt. M. austr. am. p. 415.

Cr. maynensis Tayl. in Spr. M. Amaz. n. 1279.

Grimmia julacea Hsch. l. e. p.p.

Pilotrichum julaceum C. M. Syn. II, p. 173 p.p.

- Am. merid.: Columb., And. Peruv., Brasil austr. or., Paraguay.

Exs.: Balansa Pl. parag. n. 1253.

" var. costa-ricensis Ren. et Card. mss.

- Am. sept.: Costa-Rica.

« var. subsquarrosa Broth. mss.

- Am. merid.: Brasil aust. or.

mexicana W. P. Sch. Mon. Cryph. ined.

Cryphiea Leiboldi C. M. in Linn. 1844, p. 680.

Pilotrichum julaceum $C$. M. Syn. $I I, p .173$ p.p.

- Am. sept : Mexic.

paraguensis Besch. in Rev. bryol. 1885, et in Journ. de bot. 1891.

- Am. merid.: Paraguay.

Exs.: Balansa Pl, parag, n. 3628.

rubricaulis (Mill.) Jaeg. Ad. II, p. 95.

Cryphaea rubricaulis Mitt. M, austr. am. p. 415.

- Am. merid.: And. Quitens, Brasil. centr.

squarrosula W. P. Sch. Mon. Cryph. ined.

A. caripensis Hpe. Enum. M. Brasil., p. 38.

1. corymbosa $\beta$ Hpe. in Krause M. Ecuador,

(1) Spec. omn. monoicre et, ut videtur, corticolse. 
Cryphaea caripensis C. M. in Linn. 1847, p. 210.

Cr. filiformis C. M. in op. et $l$. ec.

Moritzia caripensis Hpe, op. cit. p. 82.

Pilotrichum filiforme $\beta$ squarrosulum C. M. Syn. II, p. 169.

- Am. sept. : Mexic. Am. merid.: Veneziela.

ACROPORIUM Mitt. M. austr. am. p. 477 (sect. Sematophylli) et Sam. $M, p .182$ (gen. propr.)

brevicuspidatum Mitt. - Sematophyllum.

lamprophyllum Mitt. - Sematophyllum Mittenii.

macrorhynchum Mitt. - Sematophyllum.

AGROSGHISMA Hook. f. et Wils. in Lond. Journ. of Rot, 1844, pp. 536 et 538 (2 sp.).

andensis $\mathrm{Spr},-\mathrm{A}$. Wilsoni.

densifolia Wils. in Kew Journ. bot. IX, p. 289.

Andreaea densifolia Mitt. M. Ind. or. p. 7 .

- As. : Sikkim.

Wilsoni Hook. f. et Wils. l. c. et Fl. Antaret. II, p. 379, t. ${ }^{4} 51, f .3$.

A. andensis Spr. in Proc. of the Linn. Soc.

Andreaea Wilsoni $C . M$ Syn. $I, p .11$ et $I I, p .517$.

1. Rupic.?-Am. merid.: And. Peruv., Fuegia, ins. Eremit. Pac. : Ins. Auckland, Campbell.

Acrosphagnum C. M. in Fl. 1887, p. 405 (Sph. mucronata).

AGTiNODONTiU MI Schwäge. Suppl. II, II, I, p. 75, t. 174 (4 sp.).

ascendens Schwaegr. op. et l. cc.; Brid. Bryol. univ. II, p. 756; C. M. Syn. II, p.74; Bryol. jav. II, p. 36, p. 159.

1 ou Syn. - As. : M. Java.

hirsutum Besch. Fl. bryol. Réunion, etc. p. 137.

1. Arbor. - Af. : Ins, Borbon.

"var. ramosum Besch, op, et l.c.

Ut et ubi typ.

rhaphidostegum (C. M.) Bryol.jav. II. p. 37, t. 160.

Hookeria rhaphidostegum C. M. Syn. II, p. 677.
1. (C M.) 2 (Bryol, jav.).
- As. : Java.

Sprucei (Mitl.) Jaeg. Ad. II, p. 229.

Lepidopilum Sprucei Mitt. M. austr. am. p. 370.

2. Silvic. - Am. merid. : And. Quitens.

Acuminella C. M. Syn, I, p. 752 (sect. Schlothermiz).

ADELOTHECIUM Mitt. M. austr. am. p. 391.

bogotensis Mitt. - Hookeria.

Adelphodon Lindb. Contrib. ad Fl. crypt. As. bor. or. p. 245 (sect. LRSQUERRUXIA).

AEROBRYU M Dz et Mk. in Nederl. Kruidk. Arch. II, p. 279 (2i sp.). Bauerae C.M. miss. - Pac. : Austral.

« var. gracilis C. M, in Gehecb Neue Beitr. sur Moosfl. v. Neu Guin. p. 11 .

$$
\text { - Pac, : Nov. Guin. sept. }
$$


capense (W. P. Sch.) C. M. in Linn. 1876, p. 262.

Meteorium capense W. P. Sch. mss.

Neckera capensis C. M. in Bot. Zeit. 1858, p. 165.

2 ? - Afr. : C. B. Sp.

Exs. : Rehm. M. Afr. austr. n. 322.

«var. rupestris C. M. in Rehm, l, c, n, $322 b$.

Ut et ubi typ.

capillicaule Rer. et Card. mss.

- Afr. : Madagascar.

Conferva C. M. in Linn. 1878-79, p. 492.

- Am. merid.: Venezuela.

crispicuspe Besch. in Journ. de bot. 1891.

- Afr. : Ins. Seychelles.

cymatocheilos (C.M.) Par.

Eriocladium cymatocheilos C. M. in Fl. 1890, p. 493.

Ster. Silvic. - Afr, : Kilima N'Djaro.

detrusum C. M. in Linn. 1876, p. 262 (nom.).

- Pac. : Nov. Caledon.

hokinense Besch. in Ann. sc, nat. 1892, I, p. 74.

2. Fr. ign. Silvie. - As, : Yunnan.

integrifolium Besch. op. et $l$, cc.

2. Fr. ign. Silvic, - As, : Yunnan.

javanicum (Bryol. jav.) C. M. op. et l. cc.

Meteorium javanicum Bryol. jav. II, p. 87, t. 202.

2.

$$
\text { - As, : Java. }
$$

Ianosulum C. M. in Linn. 1876, p. 260.

2. Filicic. - A $r$ r.: Ins. Anjouan.

lanosum Mitt. Sam. M.p. 170.

Meteorium lanosum Mitt M. Ind. or. p. 90.

Meteorium longissimum Dz. et $M k$. M. frond. ined. Arch. ind p. 159, t. 48 ? (fid. Mitt.).

Meteorium longissimum $\beta$ terme Bryol jav. II, p. 87, t. 202 (fid. Mitt.).

Meteorium vitianum Sull. ? (fid. Mitt).

2.

$$
\text { - As. : Hong-Kong, Sikkim, Ceylan, Sumatra. }
$$

longipendulum (C. M.) Par.

Eriocladium longipendulum C. M. in Dusen M. Camer. n. 35 .

$$
\text { - Afr.: M. Cameroon. }
$$

Iongissimuin (Dz. et Mk.) C. M. op. et l. cc.

Meteorium longissimum Dz, et Mk. op. et l. cc. (fid. Mitt.): Bryol jav. l. c.

Neckera Dozyana C. M. Syn. II, pp. 141 et 672.

Neckera longissima Dz. et Mk. in Ann. se. nat. 1884, p. 313.

2. Arbor. - As. : Ins. Molucc., Borneo, Sumbawa, Java, Banca, Sumatra.

nanopteris (C. M.). Par.

Eriocladium manopteris C. M. in Dusen M. Camer, n. 268.

$$
\text { - Afr. : M. Cameruon. }
$$


plumarium (Hpe) Par.

Eriocladium plumarium Hpe, Enum. M. Brasil, p. 44.

Ster. - Am. merid. : Brasil austr. or.

postratulum $C, M$. op. et $l$. cc.

Neckera postratula C. $M$, in Linn. 1874, p. 560.

Ster. - As. : Ins. Philippin.

pseudo-capense C. M. in Besch. Fl. bryol. Réunion, etc., p. 127.

Meteorium capense Angstr.

2. Fr, ign. sept., Mayotte, Choa. - Afr.: Ins. Borbon,, Franciæ, Madagascar speciosum Dz. et Mk. in Nederl. Kruidk. Arch. II, p. 79 et Bryol. jav. II, p. 83, t. 198.

Meteorium speciosum Mitt. M. Ind. or. p. 87.

2 . - As. : Khasia, Ceylan, Amboine.

striatulum (Mitt.) Par.

Meteorium striatulum Mitt. Fl. vit. p. 395.

Ster. Terr. - Pac. : Nov. Hebrid., Ins. austral.

subpiligerum (Hpe.) Besch. Fl. bryol. Réunıon, elc., p. 127.

Neckera subpiligera Hpe, in Linn. 1864, p. 217.

Papillaria súbpiligera Besch. op. cit. p. 124.

Fr. ign. - Afr. : Madagascar.

trachypterum (C. M.) Par.

Eriocladium trachypterum C. M. in Dusen M. Camer. n. 450. - Afr.: M. Cameroon. vitianum (Sull.) C. M. in Linn. 1876, p. 262.

Meteorium vitianum Sull. in. Am. Expl. Exp. 1859, p. 22, t. 21. - Pac. : Ins. Viti.

Wallichii (D. C.) C. M. op. et l. cc.

Hypnum Wallichii Brid. Bryol, univ. II, p. 416.

Meteorium Wallichii Bryol. jav. II, p. 93, Mitt. M. Ind. or p. 89.

Neckera Wallichir D. C. in hb. Brid.; C. M. Syn. II, p. 141.

Ster. ?

Sumatra, Java. - As. : Japon., Nepal., Ind. temper. et tropic.,

AFZELIA Ehrh. pl. Crypt. exs.

cirrata Ehrh. - Dicranoweisia. cruspa Ehrh. - Weisia viridula.

heteromalla Ehrh. - Leptotrichum.

lanceolata Ehrh. - Pottia. inclinata Ehrh. - Distichium. pulvinala Ehrh. - Grimmia. pusilla Ehrh. - Seligeria.

Aloidella C. M. Syn. I, p. 202 (sect. Polytrichi); W. P. Sch. Syn. II ed. p. 188 (sect. Barbulae).

Aloina C. M. op. cil. p. 596 (sect. Barbulae).

Aloma C. M. in Dusen M. Camer. (sect. Fissidentis).

ALsIA Sull. in Proced. Am. Acad. III, p. 185 et in M of U. St. S. Pac. Exp. p. 25, t. 25 (4 sp.). 
abietina (Hook.) Sull. Ic. M. p. 115, t. 72 b.; Lesq. et Jam. Man. p. 279.

A. Macounii Kindb, in Bull. Torr. bot. Club XVII, p. 275.

Leptodon circinnatus Sull. in Pac. R. Rep. IV, p. 189, t. I (mala).

Neckera abietina Hook. M. ex. t. 27; C. M. Syn. II, p. 142.

Pilotrichum abietinum Brid. Bryol, univ. $I I, p .258$.

2. Arbor. - Am. sept. : Columb. brit., ins. Vancouver, Washington, Calif.

Eas. : Mac. Canad. M. n. 462.

Sull, et Lesq. M. bor. am. II ed., n. 400.

californica (Hook. et Arn.) Sull. in Proc. Am. Acad.et M. of U. St. ll. cc.; Lesq. et Jam. Man., p. 280.

Neckera californica H. et Arn. in Beechey's Voy. 1841,p. 162; C. M. Syn. $I I, p, 117$.

2. Arbor. - Am. sept. : Vancouver, Washington, Calif.

Exs. : Sull. et Lesq. M. bor. am. II ed. n. 398.

« var. flagellifera Ren. el Card. in Bot. Gaz. 1889, p. 97.

Ut typ. - Am. sept. : Calif.

circinnata Sull. Ic. M. t. 72; Lesq. in Trans. of the Am. phil. Soc. XIII (nom.) (1).

2. Arbor. - Am. sept. : Calif.

longipes Sull. Ic. M. Suppl., p. 85, Ł. 63; Lesq. el Jam. Man. p. 280.

2. Rupic. - Am. sept. : Calif.

Exs. : Sull, et I.esq. M. bor. am. II ed., n. 399.

Macounii Kindb. - A. abietina.

AMBLYODON P. B. Prodr. p. 4l, pp. (1 sp.). (2)

dealbatus P. B. l. c.; Bryol. eur. IV, t. 307; C. M. Syn. I, p. 127; W. P. Sch. Syn. II ed. p.496.

Bryum dealbatum Dicks. Fasc. II, pl. erypt. p. 8, t. 5; Drumm. M. bor. am. I ed., $n 249$.

Meesea dealbata Hedw. Sp. M. p. 174, t. 41; Brid. Bryol. univ. II, p. 63.

M. Macounii Aust, in Bull. Torr bot. Club, V, p. 22.

1. et Syn. Locis uligin., torfac., ad terr. et rup. humid. - Eur. : Reg. alpin. per zon. interm. et sept., rar. merid. As.: Caucas. Am. sept.:

Sin. Hudsun. Anticosti, Nov. Scotia, New Rrunswick, Gaspes,,

M. Rupestr,, Wisconssin, Colorado.

Exs : Mac. Canad. M. n. 155.

Rab. Bryoth eur. n. 438.

Sull, et L.esq. M. bor, am. II ed. n. 243.

minus P. B. - Meesea uliginosa v, minor.

stygium P. B. - Cinclidium.

uliginosus P. B. - Meesea.

Amblyophyllum C. M. Syn. $I, p, 286$ (sect. BRyı).

AMBLYSTEGIUM Bryol. Eur. VI (57 sp.).

adnatum (Hedio.) Jaeg. Ad. $I I$, p. 547.

Hypnum adnatum. Hedve. Sp. M. 248, t, 64; C. M. Syn. II, p. 339;

Sull. Ic. M. p. 197, t. 121; Lesq. et Jam. Man. p. 375.

H. Stereodon adnatus. Brid. Bryol. univ. II, p. 191.

Stereodon adnatus. Mitt. in Trans. of the Linn. Soc. 1891, p. 180.

(1) In Lesq. et Jam. Man. non indicata. An eadem ac praecedens?

(2) Conf. Lindb. in Oefv...... 1864, p. 599. 
1. Cortic. et rupic. - As. : Japon, Am, sept. : New Brunswick, Ontario, M. Rupestr., Montana, reg. sept, centr. et or.

Exs, : Drumm. M. bor, am. II ed, n. 112, 115 (Hypnum).

Mac. Canad. M. n. 322 p.p. 323 (Var.) (Hypnum).

Sull. et Lesq. M. bor, am. II ed., n. 521 (Hypnum).

- var, gracile (Sull.) Par.

Hypnum adnatum var. gracile Sull, M. bor. am, II ed., p. 86.

Ad rup. arenac. - Am. sept. : Ohio.

Exs. : Sull. et Lesq. I. c. n. 522 (Hypnum).

aduncum Lindb. - Hypnum uncinatum.

aduncum var. Blandowii Sanio, - Hypnum aduncum.

aduncum var. Hampei Sanio. - Hypnum aduncum var. Hampei.

aduncum var, legitimum Sanio. - Hypnum Sendtneri.

aduncum var. Schimperi Sanio. - Hypnum aduncum var. Schimperi.

afro, serpens C. M. in Dusen $M$. Camer. n. 867.

- Afr. : M. Cameroon.

alaskanum Lindb et Arn. - Hypnum.

ambiguum de Not. - Hypnum.

andinum Mitt. - Hypnum.

Anzianum de Not. - A. Sprucei var. Anzianum.

argillicola Lindb in Broth. Enum. M. Cauc. p. 102.

1. In argill. humid, - As, : Caucas, centr.

austro-fluviatile (C. M.) Par.

Hypnum austro-fluviatile C. M. Bryol. austr. Georg. p. 45.

Ster. Aquat. - Am. merid. : Austr. Georg.

badium Lindb. - Hypnum.

badium $\times$ latifolium Arn. - Hypnum badium $\times$ Wilsoni.

brunneo-fuscum Lindb. et Arn. - Hypnum.

campicolum (C. M.) Par.

Hypnum campicolum C. M. in Linn. 1878-1879, p. 444,

1. Muric et terr. - Am, merid. : Argentin. Cordob.

capillaceum Mitt. - Hypnum.

capillatum Mitt. - Pseudo-Leskea.

Cashii R. du Buysson Ess. II ed. p. 8.

1. Arenic - Eur. : Anglia (Lancashire).

chilense Ltz. in 3ot. Leit. 1886, p. 188.

Ster. ?

- Am. merid. : Valdivia.

chloropelma C M. in. Hildebr. M. Madag. n. 2076.

- Afr.: Madagascar or.

chrysophyllum de Not. - Hypnum.

commutatum de Not. $\left\{\begin{array}{l}\text { Hypnum. } \\ \text { Hypnum falcatum. }\end{array}\right.$

var. elegantulum de Not. - Hypnum commutatum var. elegantulum.

compactum (C. M.) Jaeg. Ad. II, p. 554.

A. serratum Bryol. eur. VI (mon. p. 11) et Sull. M. of U. St. p. 782.

Hypnum compactum C. M. Syn. II, p. 408; Sull. Io. M. p. 201, t. 123; Lesq. et Jam. Man, p. 375.

H. serpens var. compactum Hook in Drumm. M. bor, am. I ed., p. 188.

Stereodon compactus Mitt. in Journ. of the Linn. Soc, VIII, p. 43. 
1. Lignic, rupic. et terr. $-A m$. sept.: Terr. Nov., New. Brunswick, Ontario, lac Huron, M. Rupestr., Washington, Montana, Nevada, Utah.

complenatulum Lindb. - Hypnum aduncum var. complanatulum. compressum Mitt. - Pseudo-Leskea.

confervoides (Brid.) Bryol. eur. VI (mon. p. 6), t. 562; W P. Sch. Syn. II ed. p. 707 ; R. du Buysson. Ess, II ed., p. 9.

Hypnum Conferva Sohwaegr. Suppl. II, I, p. 158, t. 142.

H. confervoides Brid. Sp. M. II, p. 153; C. M. Syn. II, p. 142; Mac Canad M.p. 317 .

H. Stereodon confervoides Brid. Bryol. univ, II, p. 583.

H. jungermannioides Brid. op. cit. p. 549.

Leskea confervoides Spr. in Lond. Journ. of bot. 1845, p. 182.

I. Ad. saxa procip calcar. - Eur. : E reg. campestr. usq. in subalp. passim. As. : Cancas. occ. Am. sept, : New Brunswick, Ontario, M. Rupestr. Ohio, Nov. Angl.

Exs, : Rab. Bryoth, eur, n, 639, 774, 1295.

convolntifolium (Hpe.) Jaeg. Ad. II, p. 549.

Hypnum convolutifolium Hpe in Linn. 1859-60, p. 641.

1. Lignic. - Pac. : Austral. or.

cordifolium de Not. - Hypnum.

curvicaule Lindb. - Hypnum.

curvipes Bryol. eur. VI (mon, p. 14), t. 569; W. P. Sch. Syn. II ed. p. 717 .

Hypnum riparium var, curvipes $R$. du B. l. e.p. 20.

1. In stagn exsicc. - Eur. : Fennia? Palatin. As. : Jenissei, Caucas. (Tiflis). Am, sept, : Ottawa, Ontario.

decussasum Mitt. - Hypnum.

densum (Milde). Lindb. M. Scand. p. 32.

A. serpens var, cryptarum Arnold in Rab. Bryoth. eur, $n .841$.

Brachythecium densum Jur. l. c. n. 995.

Hypnum densum Milde Bryol. siles, p. 360.

Rhynchostegium tenellum var, brevifolium Lindb, in Rab. l, o. n. 750.

Ad rup calcar. - Eur. : Suecia, Palatin. super., Francon., Austria inf., Catalaun.

dilatatum Lindb. - Hypnum.

dissitifolium Kindb. in, Mac. Cat. p, 220.

2 ? $\supseteq$ ign. Ad rup. madid, $-A m$, sept. : Niagara, Owen Sound.

distantifolium Kindb. in op, cit. p. 222.

Ster. Rupic. - Am sept.: Terra Nov.

elodes Lindb. -- Hypnum.

enerve Bryol. eur. VI (mon p. 8) t. 563; W. P. Sch. Syn. II ed.p. 7 U9.

Stereodon enervis Lindb. M. Scand. p. 38.

1. Rupic. - Eur. : Norvegia (Dovre).

eugyrium Lindb. - Hypnum.

exannulatum de Not. - Hypnum.

falcatum Lindb. - Hypnum.

Falconeri Milt. in herb. of the late East Ind. Comp. n. 656

- 1s.: Himalaya sept. occ. 
fallaciosum Lindb. - Hypnum polygamum.

fallax Lindb. - A. irriguum var. spinifolium.

fenestratum Kindb in op. cit. $p .217$.

A. tennifolium Kindb. in Ott. Nat. IV, p. 65.

Ster. Ad terr. humid. - Am. sept. : Ontario.

flicinum de Not. - Hypnum.

var. curvicaule Mdo - Hypnum curvicaule.

var. fallax Lindb. - A. irriguum var. spinifolium.

var. gracillimum Sael, - Hypnum filicinum vas, gracillimum.

finmarchicum (Ltz.) R. du Buysson op. cil. p. 18.

Hypnum finmarchicum Lts in Hartm. Skand. Fl. X ed. pp. 20-21. 1.

- Eur. : Finmarck.

fluitans Mitt. (1876). - Hypnum austro-fluitans.

fluitans de Not. - Hypnum.

var. amphibium Sanio. - Hypnum fluitans var. amphibium.

var. aurantiacum Sanio. - Hypnum fluitans var. aurantiacum.

var. exannulatum Lindb. - Hypnum.

var. Rotae Lindb et Arn. - Hypnum exannulatum var. Rotae.

fluilans $x$ aduncum Lindb et Arn. - Hypnum.

fluviatile (Swo.) Bryol. eur. VI (mon. Supp.p. 1), t. 567; W. P. Sch. Syn. II ed $p 713 ; R$. du Buysson op. cit. $p .12$.

Hypnum arhizon. Brid. Bryol. univ. p. 535.

H. caucasicum Brid. l. c.

H. diffusum Bland, in Brid. Sp. M. II, p. 243; Brid. op. cit. p. 538.

H. filicinum \& lanatum Brid. op. cit. p. 531.

H. flagelliforme Brid. Sp. M. II, p. 240.

H. fluviatile Sw. M. Suec. p. 63 p. p.; Brid. Bryol. univ. II, p. 532; C. M. Syn. II, p. 420 .

H. fluviatile $\beta$ flagelliforme Brid. op, cit. p. 533.

H. lanatum Sterm. in Schrift. d. Gesellseh. d. Nat. hist. I, Heft II, p. 30.

H. luridum Sw. op. cit. p. 68.

H. palustre var. fluviatile Wahlenb. Fl. Suec.

H. Seligeri Brid. M. Rec. II, p. 67

H. Vallis Clausae Brid. Sp. M. II, p. 238 et Bryol. univ. II, p. 534 (1).

1. Ad saxa rivul. - Eur. : Reg. campestr, et mont. Scandin. German., Britann., Gall. sept., Am. sept. : Terr. Nov., New Brunswick, Gaspes., Ontario. New Jersey.

Exs. : Mac Canad. M. n, 446 (Hypnum).

Rab. Bryoth, eur, n. I094.

var. julaceum R. du Buysson, op. et $l$. cc.

Ut et ubi typ, in Eur.

fluviatile Bryol. eur. - A. irriguum.

var. irriguum R. du Buyss. - A. irriguum.

Formianum Dne Fior. Mazz. - Hypnum.

fuegianum C. M. - Hypnum.

giganteum de Not. - Hypnum.

glaucum Lincib. - Hypnum commutatum.

var. decipieus L. - Thuidium deciṕiens.

var. sulcatum L. - Hypnum sulcatum.

gracile Jur, - Pseudo-Leskea.

(1) Fid. C. M. 1. c.; cf. Renauld in Rev. bryol, 1885, p. 55. 
Haussmanni de Not. in. sched.; W. P. Sch. op, cil. p. 720 ,

A. riparium var. abbreviatum de Not. Epil. p. 147

1. Ad arbor, rad, et puteor. ductus. - Eur. : Austria, Tirol. merid.

homalostegium (C. M.) Jaeg. Ad. II, p. 547.

Hypnum homalostegium C. $M$. in Fl. 1873 (1).

Arbor. - Am. sept.: Alabama.

hygrophiloides W. P. Sch. in Savat. M. Jap, n. 715.

1? Terr. - As. : Japon.

hygrophilum W. P. Sch. et R. du Buyss. op. cc., p. p. 715 el 20.

A. saxatile W.P. Sch. Syn. I ed.pp. 595 et 700 .

I. Ad terr. aren. humid, et saxa. - Eur. : Alsatia inf., Silesia.

« var. limosum W. P. Sch. el R. du Buyss. op. cc. pp. 716 et 21.

Hypnum hygrophilum Jur. in H. Müll. Wesfal. Laubm. et in Rab. Bryoth. eur. n. 649.

In stagn, exsicc. - Eur, : Siegburg, Carinth.

inflalum Lindb. et Arn. - Hypnum.

intermedium Lindb. - Hypnum Cossoni.

var. revolvens Sanio. - Hypnum revolvens.

var. verum Sanio. - Hypnum Cossoni.

intermedium x vernicosum Lindb et Arn. - Hypnum Cossoni-vernicosum. ivrigatum Lindb. - Hypnum.

irriguum (Hook. f. et Wils.) Bryol. eur. VI (mon. Supp. p. 1), t. 566; W. P. Sch. op. cit. p. 712 .

A. fluviatile Bryol. eur. VI (mon. p. 11), t. 566.

A. fluviatile var. irriguum $R$. $d u B$, op, cit, $p, 12$.

Hypnum fluviatile Sw, M. Suec. p. 63, p.p.

H. irriguum H. f. et W. Bryol. brit. p. 361 .

1. Ad saxa praecip. silic., mur. molend. irrigat. - Eur.: Fere tota, rarius in septentr. As.: Caucas. occ. Afr. : Alger. Am. sepl.: Ontario, Montana, New Jersey, Virgin. oce.

Exs, : Rab. Bryoth, eur, n. 776.

val. fallax W. P. Sch. - A. irriguum var. spinifolium.

- var. spinifolium W. P. Sch. l. c.; R. du Buyss. op. cit. p. 13.

A. fallax Lindb. M. Scand p. 32

A. filicinum var, fallax Lindb. M. Seand. $p .35$

A. irriguum var. fallax W. P. Sch. Syn. I ed., p. 594; Rab. Bryoth. eur. n. 342 .

Hypnum fallas Brid. M. Rec. II, II, p. 66, t. 2, f. 1 (2).

H. flicinum var. fallax H. et T. Musc, brit. p. $109 ;$ Brid. Bryol univ. $I I, p .531 ?$ (2)

H. Huviatile C. M. Syn. II, p. 420 p.p.; Jam. in Proced. Acad. Philad. 1885, p. 447.

H. noterophilum Sull. M. of U. St. p. 78; Sull. et Lesq.M. bor. am $I$ ed. $n .348$.

Ad saxa praecip. calcar, saepius inund. - Eur.: Passim cum typ. As.: Jenissei sup., Caucas. occ. et cent. $1 \mathrm{f} r$.: Alger. Am. sepl.: Lac. Super., Pensilv,

Exs. : Mac. Canad. M. n. 32 (Hурпит). 
* var. tenellum W. P. Sch. Syn. I ed. p. 594 et II ed. l. c.; R. du Buysson, op. cit, p. 13.

Ut et ubi typ, in Eur.

Juratzkanum W. P. Sch. op. cc. pp. 693 et 710.

A. serpens var. Juratzkanum $R$. du B. op. cit. p. 18.

A. Yuratzkae Kindb. in Mac. Can. p. 218.

Hypnum Zuratzkae Mac. Canad. M. n, 466.

1. Ad saxa humídiuse.-- Eur. : Austria inf., Gall. austr. oce., $\mathrm{Pyr}$ As.: Caucas. Am. sept. : Ottawa, Ontario, Columb, brit.

Exs. : Rab. Bryoth, eur. n. 641.

Kneiffii Bryol, eur. - Hypnum aduncum var. Kneiffii.

Kochii Bryol. eur. VI (mon. p. 13), t. 568; W. P. Sch. Syn. II, ed. p. 716.

A. riparium var. Kochii $R$. du B. op, cit. p. 20.

A. trichopodium var. Kochii Lindb. et Arn.

1. Ad rad. Salic. et terr. humid. vel limos. - Eur.: Boruss. occ., Siles., Newmark, Westphal., Voges. As. : Amour. Am. sept.: Kansas.

Exs. : Rab. Bryoth. eur. n. 894, 895.

latifolium Lindb. et Arn. - Hypnum Sendtneri var. Wilsoni.

var. jenissiense Sanio. - Hypnum Sendtneri var. jenissiense.

leitense Mitt. - Hypnum.

leptophyllum W. P. Sch. in Bull. Soc. bot. Fr. 1867, p. 260 et Syn,

II ed., p. $719 ;$ R. du Buysson, op. cit. p. 15.

1. Lignic, et ad rup. humid. - Eur.: Austria super.

a var. cylindricum R. du Buysson Ess. I ed., p. 18 et op. cit. p. 16.

Ubi typ. - Eur.: Gall. (Arvern., Delphinat.).

Lescurii (Sull.) Jaeg. Ad. II, p. 554.

Hypnum Lescurii Sull. M. of U. St. p. 79 et Ic. M. p. 203, t. 24; Lesq. et Jam. Man, $p, 376$.

1. Ad rup. madid. - Am. sept. : Reg. sept. et or.

Exs. : Sull, et Lesq. M. bor, am. I ed., n. 529 (Hypnum).

longeacuminatum Broth. mss.

- As. : Japon.

longicuspis Arn. - Hypnum.

longifolium Mitt. - Hypnum

longisetum W. P. Sch. - A. madeirense.

lucidum Jaeg. - Plagiothecium.

lycopodioides de Not. - Hypnum.

lycopodioides Lindb. et Arn. - Hypnum vernicosum.

var. vernicosum eor. - Hypnum vernicosum.

lyeopodioides $\times$ fluitans eor. - Hypnum.

madeirense (Mitl) Jneg. Ad. II, p. 549.

Hypnum longisetum W. P. Seh, in Mandon Pl. Mad. n. 43 (ex ips. I),

H. madeirense Mitt. in Journ. of the Linn. Soo. 1863, p. 6.

1. Rupic. et terr. - Afr. : Ins. Canar., Madeir.

minutissimum (Sull, et Lesq.) Jaeg. Ad. II, p. 547.

Hypnum minutissimum Sull et Lesq. in Sull. Ic. M. p. 195, t. 120 et M. of U. St. p. 78; Lesq. et Jam. Man. p. 371 .

2. Ad rup. et terr. humid, - Am. sept. : Ontario, M. Rupestr., Columb brit., Illinois, Ohio, New Jersey, Peusilv., ete. 
Exs. : Mac. Cana'. M. n. 541 (Hypnum).

Sull, et Lesq, M. bor. am. II ed, n. 520 (Нурпит).

molle Lindb. - Hypnum.

var. alpinum Lindb. - Hypnum alpinum.

var. Schimperi Ltz. -- Hypnum molle. var. Schimperi

montanum Lindb. - Hypnum.

Mülleri (Hpe. et C. M.) Jaeg. Ad. II, p. 555.

Hypnum Mülleri Hpe et C. M. in Linn. 1853, p. 504.

-. Pac. : Austral, or.

obtusulum (Mitt) Jaeg. Ad. II, p. 551.

Hypnum obtusulum Mitt. M. Ind. or. p. 82 .

2 ? - As.: Himalaya oce.

ochraceum Lindb. - Hypnum.

oligorhizon Bryol.eur. VI (mon.p. 13), t.568; W. P. Sch. Syn. II ed.p. 712.

A. varium R. du Buysson Ess. II ed., p. 14.

A. varium $\beta$ oligorhizon Lindb. M. Seand.p. 32.

1. Ad rup. molass. umbr. -- Eur. : Fennia, Bavar.

orbieulare (Hpe.) Jaeg. Ad. II, p. 555.

Hypnum orbiculare Hpe. in sched.

- As. : Sikkim.

Orsinianum de Not. - Hypnum.

orthocladon (P. B.) Jaeg. op. et l. cc. (1).

A serpens var: orthocladon Aust. M. Appal.

Hypnum orthocladum P. B. Prodr. p. 67; Brid. Bryol. univ. II, p. 537; Sull. Ic. M. p. 199, t. 122; Lesq. et Jam, Man. p. 374.

H. serpens $\beta$ varium C. M. Syn. II, p. $412 p . p$.

I. Lignic., rupic. et terr. - Am. sept.: New Brunswick, Ontario, Washington, reg. sept., centr. et or.

Eœs. : Drumm. M. bor. am. Il ed. n. 138, 139, 142 (Hурпит).

Mac. Canad, M. n. 337 p.p. (Hypnum).

Snll et Lesq. m. bor. Am. II ed. n. 526 (Нурпит).

orthothecioides Lindb. - Hypnum uncinatum var, orthothecioides pachyrhizon Lindb. - A. porphyrhizum.

palustre Lindb. - Hypnurn.

var. subsphaericarpon Lindb. $-\mathrm{H}$. palustre var, subsphaerićarpon. pinnatulum Rehm. M. Afr. austr.

polare Lindb. - Hypnum.

$$
\text { - Afr.: C. B. Sp.? }
$$

polygamum Bryol eur. - Hypnum.

var. brevicuspis Lindb. - Hypnum polygamum var. brevicuspia.

var. fallaciosum Lindb. - Hypnam polygamum?

var. minus Bryol, eur. - Hypnum polygamuin var. minus.

porphyrhizum (Lindb.) W. P. Sch. op. cit. p. 715.

A. pachyrhizon Lindb. M. Scand. p. 32.

A. radicale Lindb. op. vit. p. 32 et n. 21.

Hypnum porphyrhizum Lindb. in Hartm. Skand. Fl. IX ed. (2).

H. radicale Lesq. et Jam. Man. p. 373 p.p. (fid. Mac. Cat. p. 219) Drumm. M. bor. am. I ed. n. 189.

(1) Cf. A. radicale.

(2) "Forsan id. ac. A. hygrophilum. (Ren. et Cayd, in Bot. Gaz. XVII, p. 83. 
1. Lignic. - Eur.: Suec., Dania, Fennia. Am. sept. : Labrador, Anticosti, ins. Miquelon, Nov. Scot., New Brunswick. Ottawa, Ontario, Manitoba, Saskatchewan, reg. sept, occ., M. Rupestr., Columb. brit., Kansas.

Exs, : Mac. Canad. M. n. 319 (Hypnum).

protensum Lindb. - Hypnum stellatum var, protensum.

pseudo-stramineum Lindb. - Hypnum.

radicale (P. B.) Bryol. ear. VI (mon. p. 10), t. 565; W. P. Sch. op. cit. $711 ;$ R. du Buysson op. cit. p. 10; Lesq. el Jam. Man. p. 373 (p.p. fid. Mac. Cat. p. 219).

A. serpens var, radicale Aust. M. Appal.

A. varium Lindb. M. Scand. p. 32.

Hypnum debile Brid. Sp. M. II, p. 250 (1).

H. humile P. B. Prodr. p. 68 (1).

H. inordinatum Brid. Sp. M. II, p. 182 et Bryol. univ. II, p. 483 (1).

H. pachypoma Schwaegr. Suppl. I, II, p. 259 et Suppl. III, II, II, t. 28\%; Brid. Bryol. wniv. II, p. $538(1)$.

H. radicale $P . B, P r, p .68$.

H. serpens $\beta$ varium C.M. Syn. II, p. $412 p . p$.

H. tenax Hedw. Sp. M. p. 277, t. 72; Brid. Bryol. univ. II, p. $496(1)$.

H. varium $P$. B. op. et l. ec. (1); Drumm. M. bar. am. II ed. n. $140,141$.

H. Stereodon radicalis Brid. op. cit. p, 651.

H. Stereodon varius Brid. op. cit. p. 652 (1).

Leskea varia Hedw. Sp. M. p. 216; t. 53, f. 15-20.

Stereodon varius Mitt. in Journ. of the Linn. Soc. VIII, p, 43.

1. Ad terr., lign. et arb. radic. in humid. - Eur.: Suec.. Angl., Gall. sept. et or., Alsat., Hassia, Wesphal., Rhöngeb.. Bavar., Austr. inf., Tirol., Ital. sup. As.: Jenissei med., Pers,, Cancas. occ. et centr. Am. sipt. : Anticosti, ins. Miquelon, New Brunswick. Ottawa, Manitoba, Saskaschewan, Columb. brit, Washington, Idaho, Montana, reg. sept., centr., or. et merid. Am. merid. : And, Quitens.

Exs. : Drumm. M. bor. am. II ed,, n. 143 (Hypnum).

Mac. Canad. M. n. 320 (Hypnum).

Rab. Rryoth. eur. n. 640.

Sull. et Lesq. M. bor. am. II ed,, n. 524, 525 (Hypnum).

« var. Lesquereuxii (Ren. et Card.) Par.

A. radicale Sull. et Lesq. M. bor am. I ed. n. 224?

A. varium var. radicale $R$. et C. Fl, ins. Miquel. p. 53.

Ut typ. - Am. sept. : Ins. Miquelon.

radicale Lindb. - A, porphyrizum.

radicale Sull. et Lesq. - A. radicale var. Lesquereuxii?

revolvens de Not. - Hypnum.

Richardsoni Lindb. et Ärn. - Hypnum.

var. robustum Lindb et Arn. -- Hypnum Richardsoni var. robustum.

riparioides (Hpe.) Jaeg. Ad, II, 553.

Serpo-hypnum riparioides Hpe. Symb, 1870, p. 291.

1. Lignic. - Am. merid. : Brasil. austr. or.

riparium (L.) Bryol. eur. VI (mon. p. 14), t. 570; W. P. Sch., op. cit. p. $717 ; R$. du Buysson op. cit. p. 18.

Fissidens Weberi Brid. M. Rec. II, I, p. 146.

(1) Forsan ad $A$. orthocladon referenda. - De Synonym. A. radiealis cf. Lindb. M. Scand. p. 32 et R, du Buysson in Rev. de Bot. IV, n. 42 et 43. 
Hypnum aquaticum, flagellis et teretibus et pinnatis Dill. Hist. M. p. 308, t. $40, f .44$.

H. flexipes Brid. Bryol. univ. II, p. 419.

H. hornum Web. Spic. Fl. Gött. p. 44?

H. laxifolium Brid. Sp. M. II, p. 94.

H. oligophyllum Brid, M. Rec, II, II, p. 181.

H. palustre lutescens, etc. Vill. $P l$. Dauph. III, p. 918.

H. palustre nigrescens Vill. op. cit. p. 917.

H. riparium L. Sp. pl. 1595 ; Brid. Bryol, univ. II, p. 412; C. M. Syn. II, p. 321 .

H. riparium var. homomallum

H. riparium var, oligophyllum

H. riparium var. pallidum

Brid. op. cit. p.p. 413-415.

H. Sipho P. B. Prodr. p. 70; Brid. op. cit. II, p. 391.

H. uncinatum var. plumosum Mac. Canad. M. n. 374.

Skitophyllum Weberi la Pyl. in Journ. bot. Desv. 1813, V, p. 62.

Stereodon riparius Mitt. op. et l. cc.

1. Ad saxa, ligna fabref. et putresc., terr. humid. etc. - Eur. : Tota usq. in arctic. As. : Tibet. occ. Afr.: Alger, ins. Canar, Am. sept. : Groeuland, Terr. Nov., New Brunswick, Ottawa, Ontario, Manitoba, Saskatchewan, reg. sept. occ., Alberta, M. Rupestr., Jolumb brit., ins. Vancouver, tota temperat., ins. Cuba.

Exs. : Drumm. M. bor. am. I ed. n. 170 et II ed. n. 115 (Hypnum).

Mac. Canad. M, n. 325 (Hypnum).

Rab. Bryoth. eur. n. 482.

Sull, et Lesq. M. bor. am. II ed. n. 527 (Нурпит).

Un. Itin. 1864, n. 1.

« var, abbreviatum Bryol. eur. l, c. t. 571; W. P. Sch.op. cit. p. 718

In siccior. - Eur. et $A m$. sept.: Hic. illic c. typ.

Exs. : Drumm. M. bor. am. II ed. n. 116, 117 (Hypnum).

Sull. et Lesq. M. bor. am II ed. n. 528 (Hурпиm).

var. abbreviatum de Not, - A. Haussmauni.

var. curvipes R. de B. - A. curvipes.

\& var. elongalum Bryol. eur. el W. P. Sch. ll. cc.; R. du Buysson op. cit. p. 19.

In udis. - Eur.: Hic illic c. typ. As. : Japon.

Exs. : Faurie PI. Japon. n. 475.

" var. Felisii W. P. Sch. et R. du Buysson ll. cc.

Ad arbor. rad. humid. - Eur. : Ut proeed.

\& var. flaccidum (Lesq. et Jam.) Par.

Hypnum riparium var. flaccidum L. et J. Man. p, 377.

Paludic, et in stagnin. - Am. sept. : Reg. sept.

« var. floridanum Ren, et Card, in Bot. Gaz. 1889, p. 98

A. riparium eor. in Rev. bryol. 1893, p. 24.

Lignic. et ad arbor. - Am. sept. : Florid., Ludovic.

* var, fluitans (Lesq. et Jam.) Par.

Hypnum riparium var. fluitans Lesq. et $J$. $l$. c.

Aquat. - Am. sept. : Ontario, lac. Super., Assiniboine, Culumb. brit., reg. sept.

Exs. : Mac. Canad, M. n. 326 (Hypnum).

\& var, inundatum W. P. Sch. el R. du Buysson ll. cc.

In stagnin. - Eur, : Hic illic c. typ.

var, Kochii R. du B. - A. Kochii. 
- var. longifolium (Schultz). W. P. Sch. et R. du Buyssun ll. cc.

Hypnum riparium Sehultz Fl. Starg. p. 335.

H. riparium $\beta$ petrophilum Brid. Sp. M. II, $p, 115$.

H. riparium $\delta$ petrophilum Brid. Bryol. univ. $I I$, p. 414.

In humid. praecip. ad ligna robusta. - Eur. : Hic illic c. typ. As. : Jeniss, sup. et. med. Am. sepl. : Washington, ins. Vancouver.

Exs. : Rab. Bryoth. eur. n. 1095, 1294.

« var. pratense (Brid.) Par.

H. riparium var. pratense Brid. Bryol univ. II, p. 415 (forsan. spec. propr.).

- Am. sept. : Terr. Nov.

« var. serratum Ren. et Card. in Bot. Gaz. 1889, p. 98.

Ad arbor. - Am. sept. : Kansas.

«var. subsecundum Bryol. eur., W. P. Sch. et R. du Buysson $7 l$. cc.

In siccior. - Eur. : Hic illic c. typ.

Exs. : Rab. Bryoth. eur. n. 483.

* var. tennis Jur. in Rab. Bryoth. eur. n. 1245.

Ad, radic. BetuI. in turfos, - Eur.: Salisburg.

«var. trichopodium (Schultz) Bryol. eur. W. P. Sch. et R. du Buysson ll. $c c$.

A. trichopodium Lindb, et Arn. M. As. bor, 1890, II, p. 115.

Hypnum trichopodium Schultz Fl. Starg. p. 324.

H. riparium var, trichopodium Brid. Bryol. univ. II, p. 415.

H. Schultzii Bland. M. exs. fasc. III, p. 150.

In prat. uligin. - Eur. : Hic illic c. typ.

rivicola (Mitt.) Jaeg. Ad. II, p. 549.

Hypnum rivicola Mitt. M. Ind. or. p. 83.

1. $\quad-A s$. : Tibet occ.

rivulare Lindb. - Hypuum alpestre.

sarmentosum de Not. - Hypnum.

saxatile W. P. Sch. - Hypnum hygrophilum.

Schlotthaueri Ren. et Card. in Bot. Centralbl. 1890, n. 51 (subsp. A 1. serpentis).

scorpioides Lindb. - Hypnum.

Sendtneri de Not. - Hypnum.

var. robustum Lindb. - Hypnum Sendtneri var. robustum.

serpens (L.) Bryol. eur. VI (mon. p. 9), t. 564; W. P. Sch. et R. du Buysson op. cit. p.p. 709 et 17.

Bryum repens Gmel. Syst. nat. II, p. 1333.

Gymnostomum serpens Schrank Baier's Fl. II, p. 439.

Hypnum capillare Fröhl, in $h b$, Brid.

H. clavellatum Schrank op. cit. p. 431.

H. contextum Hedw. Sp. M. p. 278, t. 72.

H. intextum Voit. M. Herbisp. p. $106^{\circ}$ et in Sturm. Deutsch. Fl. II, $\mathrm{X} I(p \cdot p)$.

H. repens Poll. pl. Palat. III, n. 1051, $f .11$.

H. serpens L. Sp. pl. II ed., p. 1596; C. M. Syn II, p. 411.

H. spinulosuin Hedv, op cit. p. 269, t. 69 .

H. trichodes serpens, setis et capsulis longis erectis Dill. Hist. M. p. 329 , t. $42, f .64$.

H. viride Lam. et D. C. Fl. fi.p. 536. 


\section{AMBL TSTEGIUM}

H. Stereodon serpens (incl.? var. aurantiacus, contextus, repens, spinulosus, viridis (1), brachyclados, byssoides, clavatus, crassinervius, falciformis, patentissimus, pensilvanicus, subtilis (2), crispabilis, cylindricus, excentricus, macrocarpus (3), Brid. Bryol. univ. II, pp. 642-649).

Neckera repens Willd. Prodr. fl. Berol. n. 935.

Trichostomum repens Schrank op. cit. p. 450.

1. Ad saxa, lign, putresc, arb. rad., rarius ad terr. in toto fere terrar. orbe. - Eur. : Tota, rarius in calidior, et in arctic. As. : Tibet occ. A fr.: Alger., etı: Am. sept. : Grönland, Labrador, Canada tot., Columb. brit., reg. sept., centr., occ. et or. Am. ${ }^{2}$ merid. : And. Quitens et Peruv. Pac. : Nov. Zeland. sept.

Exs.: Drumm M. bor. am. 1 ed. n. 187 (Hypnum).

Mac. Canad. M. n. 318 (Hypnum).

Rab. Bryoth. eur. n. 136 b, 777.

Sull. et Lesq. M, bor. am., II ed. n. 523 (Hypnum).

* var. $\beta$ (Hook. f. et Wils.). Par.

Hypnum serpens var. $\beta$ H. f. et W. Fl. antaret. p. 138 et Handb. of N. Zeal. Fl. p. 479.

- Pac.: Ins. Auckland.

« var. Columbiae Kindb. in Bull. Torr. bot. Club, XVII, p. 279

(Subspec.).

$$
\text { - Am. sept : Columb. brit. }
$$

var. cryptarum Arnold. - A. densum.

var. Juratzkanum R. du B. - A. Juratzkanum.

* var, major R. du Buysson op. el l. cc.

Ad radices arb. - Eur.: Hic illic.

var, orthocladon Aust. - A. densum.

« var. pinnatum W. P. Sch. op. cit. p. 710.

Ad rup. arenac. -- Eur. : Sudet.

var, radicale Aust. - A. radicale.

« var. rigidiusculum Lindb. et Arn. M. As, bor. 1890, II, . 113.

- As.: Jenissei med., Obi.

" var. serrulatum Breidl. in Broth. Enum. M. Cauc. p. 101.

- As. : Caucas.

«var. tenue (Schrad.) Bryol. eur. et W. P. Sch. ll. cc.

Hypnum tenue Schrad. Crypt. Gew. n. 81

H. Stereodon serpens var. tenuis Brid. Bryol. univ. II, p. 646.

Ad arbor. trunc. - Eur.: Reg. montana.

"var. xanthodictyon Kindb. in. Mac. Cat. p. 218.

A. serpens * lutescens Kindb. mss.

Ad saxa madid. - Am. sept. : Anticosti.

serpens * lutescens. Kindb. - A. serpens var. xanthodictyon.

serratum Bryol. Eur. - A compactum?

Smithii Lindb. - Hypnum arcticum.

sordidum Mitt. - Hypnum.

sparsifolium (Hpe.) Jaeg. Ad. II, p. 552.

Serpo-Hypnum sparsifolium Hpe. Symb. 1870, p. 290.

1. Lignic. - Am. merid. : Brasil. austr. or.

(1) Ad syn, supradicta referenda.

(2) "Quarum plures hujus speciei non sunt. " (W. P. Sch. Syn. I ed. p. 592).

(3) Fid. Schumann Fl. Sael. II, p. 83. 
sparsile (Milt.) Jaeg. Ad. II, p. 554.

Hypnum sparsile Mitt. M. Ind, or. p. 82.

1. - As.: Assam super.

speirophyllum Kindb. in Ott. Nat. IV, p. 64 et in Mac. Cat p. 217.

2 ? Ster. Rupic. - Am. sept.: New Brunswick.

Sprucei (Br.) Bryol. eur. VI (mon.p. 5), t. 561; W. P. Sch. op cit. p. $705 ;$ R. du Buysson op. cit, p. 5 .

Hypnum confervoides $H$. f. et W. in Drumm. M. bor. am. I ed., n. 190.

H. Jungermannia Hpe, in sched.

$\mathrm{H}$. Sprucei $\mathrm{Br}$. in C. M. Syn. II, p. 415.

Leskea Sprucei Br. in. litt.; Spr. in Lond. Journ. of bot. 1845, IV, p. 180.

Stereodon Sprucei Lindb.

2. In rupib. umbr. humid. - Eur. : Spitzberg, ins. Ursor., reg. mont., subalp. et alp. Scandin., Britann., Alp., Pyren., Arverniae. As, : Penins. Tschutschica, Jenissei, Obi, Caricas. centr. Am. sept.: Grônland, Gaspes., Ottawa, Ontar., reg. sept. occ., M. Rupestr., Columb. brit., ins. Vancouver, Washington, Idaho, Colorado, Nov. Mexic.

Exs.: Mac. Canad. M. n. 315 (Hypnum)

Rab. Bryoth. eur. n. 348 .

Un itin. 1864, n. 83; 1867, n. 16-24.

«var. Anzianurn R. du Buysson op. cit.p. 7 .

A. Anzianum de Not. Epil. p. 156.

- Eur. : Longobard.

stellatum Lindb. - Hypnum.

stramineum de Not. - Hypnum.

var. acutifolium Arn. - Hypnum stramineum var. acutifolium

var. apiculatum Arn. - Hypnum stramineum var. apiculatum.

var. patens Lindb. - Hypnum stramineum var. patens.

subcompactum C. M. et Kindb. in Mac. Cal. p. 221.

Hypnum compactum Mac. Canad. M. $n, 324$.

1. Ad. rup, et arb. rad. - Am. sept. : Niagara, Columb. brit.

subenerve Bryol. eur. - Hypnum.

suboligophyllum (Hpe.) Jaeg. Ad. II, p. 555.

Hypnum suboligophyllum Hpe. in. sehed.

$$
\text { - As.: Arracan. }
$$

subserpens W. P. Sch. in Savat. M. Jap. n. 709.

1. Ad terr. calcar. - As.: Japon.

subtile (Hedw.) Bryol. eur. VI (non. p. 4), t. 561; W. P. Sch. et R. du Buysson op, cit. pp. 706 et 7.

Hypnum minimum, foliis ovato-tanceolatis, capitulis erectis, operculis conicis Hall. Stiop. helv, $n, 1757$.

H. subtile Hoffm. Deutseh Fl. II, p. 70; C. M. Syn. II, p. 415.

Leskea subtilis Hedw. M. frond. IV, p. $23, t .9 ;$ Brid. Bryol. wniv. II, p. 309.

Neckera subtilis Brid. M. Rec. II, II, p. 45 .

1. Ad arb. silvat., praecip. Fagos, rar. ad saxa. - Eur. : Reg. montan. et subalp., rar. campestr.; deest in Britann. As.: Caucas. oce. et centr. Am. sept.: Ottawa, Ontar., Nov. Angl.

Exs. : Drumm. M. bor. am. I ed, n. 227 (Hypnum).

Mac. Canad. M. n. 316 (Нуриит)

Rab. Bryoth, eur, n. 775 .

Sull. et Lesq. M. bor. am. II ed. n. 519 (Hурпит).

tenuifolium Kindb. - A. fenestratum. 
tenuissimum Bryol. eur. VI (mon. p. 7), t. 562; W. P. Sch. el R. du Buysson op. cil. $p$ p. 707 et 7 .

1. Cortic. - Eur.: Fennia, Bavaria (Monach.), As.: Tibet, occ. tenuisetum Lindb. - Hypnum.

thuidioides W. P. Sch. in Savat. M. Jap. n. 720.

l. Terr. - As. : Japon.

tibetanum (Mitt.) Par.

Hypnum tibetanum Mitt. M. Ind. or. p. 83.

Ster.

- As.: Tibet oec.

trichopodium Lindb, et Arn. - A. riparium var, trichopodium.

var. Knchii eor. - A. Kochü.

trifarium de Not. - Hypnum.

Tundrae Arn. - Hypnum.

turgescens Lindb. et Arn. - Hypnum.

uncinatum $\left\{\begin{array}{l}\text { de Not. - Hypnum. } \\ \text { Mitt. (1876). - Hypnum austro-uncinatum. }\end{array}\right.$

var. drepanoides Sanio. - Hypnum uncinatum var, drepanoides.

var. plumulosum Sanio. - Hypnum uncinatum var. plumulosum.

var. suetum Sanio. -- Hypnum uncinatum var. suetum.

vacillans Sull. Ic. M, suppl.p. 96, $t .72$.

Hypnum vacillans Lesq. et Jam. Man. p. 377.

1. Aquat. - Am. sept. : M. Alb., Ontario.

varium Lindb. - A. radicale.

varium $\mathrm{R}$. du B. -. A, oligorhizon.

var. Lesquereuxii R. et C. - A, radicale var. Lesquereuxii.

var. oligorhizon Lindb. - A, oligorhizon.

vernicosum Lindb. - Hypnum.

var. gigas Lindb. - Hypnum vernicosum var. gigas.

var. lapponicum Lindb. - Hypnum vernicosum var. lapponicum.

var. majus Lindb. - Hypnum vernicosum var. majus.

viridulum Lindb. - Hypnum norvegicum.

Wilsoni Jindb. - Hypnum Sendtneri var. Wilsoni. var. hamalum Lindb. - Hypnum hamifolium.

Wollei Kindb. - Leskea (1).

Amblytropis Mill. M. auslr. am, p. 339 (sect. Hookeriz).

Amphidiopsis C. M. in Linn. 1878-79, p. 332 (sect. BarBUL ).

AMPHIDIUM Nees in Sturm Fl. Germ. II, p. 17; C. M. Syn. I, p. 667 et II, p. 636 (sect. Zygodontis); W. P. Sch. Coroll. p. 39.

lapponicum W. P. Seh. - Amphoridium.

Mougeotii W. P. Sch. - Amphoridium.

pulvinatum Nees. - Zygodon Forsteri.

AMPhORIDIUM W. P. Sch. Syn. I ed. p. 247 et II ed. p. 293 (9 sp.).

africanum C. M. in Rehm. M. Afr, austr. n, 143.

Ster.

caespitosum Lesq. et Jam. Man. p. 160.

Didymodon caespitosus Mitt, in Journ. of. the Linn. Soc. VIII, p. 18.

Ster.? Rupic. - Am. sept. : Columb. brit., ins. Vancouver.

(1) In Enumer. Kindberg. nomina nuda :

A. brachypelmatum $C . M$. । A. pachylomatum $C . M$. 
californicum (Hpe.) Lesq. el Jam. Man. p. 159.

A. Sullivantii Mao. Canad. M. n. 111.

Zygodon californicus Hpe. in Rot. Zeit. 1862, p. 361; Sull. Ic. M. Suppl. p. $47, t .32$.

2. Rupic. - Am. sept. : Columb. brit., ins. Vancouver, Washington, Calif.

canariense W. P. Sch. - A. curvipes.

curvipes (C. M.) Jaeg. Ad.p. 386.

A. canariense W. P. Sch. in Mandon Pl. Madeir. n. 13.

Anoectangium lapponicum Kze. in Holl. Pl. Madeir.

Zygodon curvipes C. M. Syn. I. p. 681 .

2. Rupic. ? - A fr. : Madeir.

cyathicarpum (Mont.) Jaeg. Ad. I, p. 386.

Didymodon cyathicarpus Mitt. in. Journ, of the Linn. Soc. 1859, p. 70.

Gymnostomum linearifolium Tayl. in Lond. Journ. of bot. 1846, p. 42.

Syrrhopodon tortuosus Hssh. in Linn. 1841, p. 117.

Zygodon cyathicarpus Mont. in Ann. sc. nat. 1845, p. 106 et Syll. p. 37; C. M. Syn. I, p. 682 .

1. Terr. - Afr. : Abyssin., Kilima N'Djaro, M. Cameroon, C. B. Sp. Am. sept. : (fid. Handb. of the N. Zeal. Fl.). Am. merid.: M. Pichincha, Chile. Pac. : Nov. Zeland, Tasman.

gracile de Not. - Zygodon.

Kilima N'Djaricum (C. M.) Par.

Zygodon Kilima N'Djaricus C. M. in Fl. 1890, p, 482.

Ster. - Afr. : Kilima N'Djaro,

lapponicum (Hedw.) W. P. Sch, op. et ll. cc.

Amphidium lapponicum W. P. Sch. Coroll, p. 39.

Anoectangium lapponicum Brid.Sp. M. I, p. 40.

A, striatum Brid. op. cit. p. 25 .

Bryum lapponicum Dicks. Fase. IV Pl. crypt.p. 10.

Cylicocarpus lapponicus Lindb. in Ofv... 1862.

Didymodon lapponicus Mitt. in Journ. of the Linn. Soc. VIII, p. 18.

Gymnostomum lapponicum Hedw. M. frond. III, p. 10, t. 5 .

G. striatum Brid. Bryol. univ I, p. 90.

Hedwigia lapponica Brid. M. Rec. II, p. 33.

Schistidium lapponicum Birid. Mant. M. p. 22.

Stereodon lapponicus Lindh. M. Scand. p, 38 .

Zygodon lapponicus Bryol, ewr. III (mon. p. 6), t. 206; C. M. Syn. I, p. 680 .

I. In fissur. rup. - Eur. : Reg. subalp. usq. in supraalp.; Spitzberg. As. : Penins. Tschutschica, Caucas centr. Am, sept. : Grônland, Anticosti, Nov. Scotia, New Brunswick, Gaspes., lac. Super., M. Rupestr., Columb. brit., ins. Vancouver, Washington, Idaho, Wyouning, Calif., reg. sept.

Exs. : Drumm. M. bor. am. I ed, n. 28 (Gymnostomum).

Mac. Canad. M. n. 110.

Rab. Bryoth, eur. n, 522.

Sull. et Lesq. M. bor. am. II ed. n. 171 (Zygodon).

Un itin. 1864, n. 43,$44 ; 1867$, n. 90.

Mougeotii (Bryol, eur.) W. P. Sch, op. cc. pp, 248 el 294.

Amphidium Mougeotii W. P. Sch. Coroll. p. 40.

Anoectangium Mougeotii Lindb. M. Scand. p. 29.

Barbula Woodii $W, P$. Sch. (fid. Husn. Muscol. gall.p. 147).
Cylicocarpus Mougeotii Lindb. in Ofo... 1862.

Gymnostomum Mougeotii $B r$. mss.; Hüb. Muscol. germ p. 59. Zygodon Mougeotii Bryol, eur. III (mon. p. 7), t. 206; C. M. Syn. I,
681 et II, p. 6577. 
2. In fissur. rup. - Eur. : Vulgatiss., rariss, fructif., copiose in Arvernia; Scotia, Salisburg,, etc. As. : Caucas, Am. sept.: M. Rupestr., Columb. brit., ins. Vancouver, Washington, Idaho, Oregon, M. Alb.. Pensilv.

Exs.: Mac. Canad. M. n. 420.

Rab. Bryoth. eur. n. 523, b, c, d, 565 .

Sull. et Lesq. M. bor. am. II ed, n. 170 (Zygodon).

Un itin. 1864, n. 42.

Peckii Sull. - Anoectangium.

Sullivantii (C. M.) Lesq. el Jam. Man. p. 159.

Syrrhopodon? excelsus Sull. M. Allegh. n. 170.

Zygodon Sullivantii C. M. Syn. I, p. 679; Sull. M. of U. St. p. 32 et Ic. M. $I, p .51, t, 32$.

Ster. Arbor. et rupic. - Am sept. : Carolin. super.

Exs. : Sull. et Lesq. M. bor. am. I ed.n. 1 [4 et II ed.n. 169 (Zygodon). Sullivantii Mae. - A, californicum.

viridissimum de Not. - Zygodon.

AMPHORITHECA Hpe. in Ann. sc. nat. V, ser. III, p. 340.

acidota Jaeg. - Entosthodon.

andicola Jaeg. - Entosthodon.

anguslifotia Jaeg. ..- Entosthodon.

Balansae Jaeg. - Fintosthodon.

Beccarii Hpe. - Entosthodon.

Bonplandii Hрe. - Entosthodon.

Buseana Jaeg. - Entosthodon.

clavellala Jaeg. - Entosthodon.

curviseta Jaeg. - Funaria.

diversinervis Jaeg. - Entosthodon

Dozyana Jaeg. - Entosthodon.

ericetorum Jaeg. - Entosthodon.

fascicularis Jaeg. - Funaria.

Jamesoni Hpe. - Physcomitrium.

Lindigii Hpe. - Entosthodon.

longicollis Jaeg. - Entosthodon.

longiseta Jaeg. - Entosthodon.

lutescens Hpe. - Entosthodon.

nutans Jaeg. - Entosthodon.

oblusifolia Jaeg. - Entosthodon.

? pilifera Jaeg. - Entosthodon.

planifolia Jaeg. - Entosthodon.

pseudo-maiginata Hpe. -- Entosthodon.

ramulosa Hpe. - Funaria.

ripariu Angstr. - Funaria.

submarginala Jaeg. - Entosthodor:,

undulaia Hpe. - Entosthodon.

? Wallichii (1) Jaeg. - Entosthodon.

Ampullaria C. M. Syn. I, p. 143 (sect. Splachi).

ANACALYTA Röhl. Moosgesch. Deulschl. I, p. 108; C. M. Syn. I, p. 547 et $I I$, p. $62 \mathrm{l}$ (sect. PotTI $\approx$ ).

affinis Fürnr. - Pottia Starkeana var. brachyodus.

brachyodus $\mathrm{H}_{\mathrm{p}}$, - Pottia.

(J) In Enum, Kindberg. nomen nudum :

A papillosa $C . M$. 
caespitosa N, et H. - Pottia.

caespitulosa Hpe. et C. M. - Pottia.

cucullata $\mathrm{Hpe}$ - - Pottia.

humillima Ängstr. - Pottia.

inclinata Nees. - Pottia.

lanceolala Röhl. - Pottia.

var. angustata Bryol. eur. - Pottia lanceolata var. angustata.

var. sibirica E. G. et G. G. Ror. - Pottia latifolia?

latifolia N. et H. - Pottia.

paraguensis Besch. - Pottia.

pilifera $\mathrm{Br}$. - Pottia latifolia var, pilifera.

recurvirostris $\mathrm{N}$. et $\mathrm{H}$. - Didymodon rubellus.

reflexa Fürnr. - v̀yroweisia.

rubella Hüb. - Didymodon rubellus.

Starkeana Br. - Pottia.

var. brachyodus Br. eur. - Pottia Starkeana var. brachyodus.

slellatifolia Hpe. - Pottia.

subcospitosa Hpe. - Pottia.

tophacea Br. - Trichostomum.

thraustophylla (1) Ångstr. - Pottia.

ANACAMPTODON Brid. Mant. M. p. 136, t. 2, f, 1i (4 sp.).

cubensis (Sull.) Mitt. M. austr. am. p. 540. (1869)

A. maynensis Spr. Cat. p. $18 . \quad(18$.

Fabronia cubensis Sull. in Proc. am. Acad. 1861.

1. Cortic. - Am. sept. : Cuba. Am merid.: Amazon,, And. Peruv.

fabronioides Welw. et Duby in Mem... Genève 1871, p. 2, 1. 1, f. 5.

1. Cortic. - Afr. : Angola.

Fortunei Milt. in Journ. of the Linn. Soc. 1864, p. 152.

maynensis $\mathrm{Spr}$ - As. : Chin, or.

pygmoeus Bryol. jav. - Schwetschkea. (1,554-71)

splachnoides (Froehl.) Brid. Mant. M. ll. cc. et Bryol. univ. II, p. 2'5;

Bryol. eur. V, t. 453; W. P. Sch. Syn. II ed.p. 586.

Campylodontium hypnoides Schwaegr. Suppl. III, I, I, t. 211.

Fabronia splachnoides C. M. Syn. II, pp. 38 et 662 .

Neckera splachnoides Schwaegr. Suppl. I, II, p. 151, t. 82.

1. Ad Fagos, rar. Abiet. putresc. - Eur, : Rar.: Voges., Silva nigra, Helvet., Siles., Bavar., Ticin, ; deest in Britann. As. : Caucas. oce.
Am. sept. : Reg. or.

Exs, : Drumm. M. bor: am. 11 ed. n. 94 (Neckera).

Sull. et Lesq. M, bor. am. II ed. n. 379.

Anacamptophyllum C. M. Syn. II, p. 439 (subsect Hrpsi.).

Anacamptosphagnum C. $M$. in Linn. 1875, p. 547 (nom., sect. SPHAGNI),

ANAGOLIA W. P. Sch. Syn. I ed. p. 421 (6'sp.)

abyssinica W. P. Sch. Syn. II ed.p. 514.

Bartramia abyssinica C. M. Syn. I, p. 506.

2. Rupic.? - Afr.: Abyssin, Choa.

(1) In Enumer. Kindberg. nom, nuda :
A. apiculati $K$ indb. et C. $M$.
A, austro-afra $C, M$.
A. gracillima $C, M$. 
Baueri (Hpe.) Par.

Bartramia Menziezii Turn. (fid. Lesq. et Jam.).

Glyphocarpa Baueri Hpe. in Linn. 1859, p. 457.

2. Terr. - Am. sept. : M. Calif.

intertexta (W. P. Sch.) Jaeg. Ad. II, p. 699.

Bartramia intertexta C. M. Syn. I, p. 503, p. p.

B. lamprocarpa W. P. Sch. in hb. Mus. Par.

B. setifolia Mitt. M. austr. am. p. 269, p. p.

Glyphocarpa intertexta $W . P$ Seh. in Beseh. Prodr, bryol. mexic, p. 58. 2. - Am. sept. : Mexic.

Menziezii (Turn.). Par.

Bartramia Menziezii Turn. in Kon. et Sims. Ann. bot. I, p. 525, t. II, f. I; Brid. Bryol, univ. II, p. 48; C. M. Syn. I, p. 505; Lesq. et Jam. Man. p. 204.

Glyphocarpa Menziezii Jaeg. Ad. I, p. 525.

Philonotis leiophylla Kindb. mss.; Mac. Canad. M. n. 151.

2. Rupic. - Am. sept.: Columb. brit., Alaska, ins. Vancouv., Washington, Idabo, Oregon, Calif.

Exs.: Sull. et Lesq. M. bor. am. II ed. n. 260 (Bartramia).

setifolia (Hook.) Jaeg. Ad. II, p. 699.

Bartramia intertexta C. M. Syn. I, p. 503, p. p.

B. setifolia Mitt. M. austr. am. p. 268.

Glyphocarpa setifolia Jaeg. Ad. I, p. 525.

Gymnostomum setifolium Hook. Ie. pl. rar. II. p. 135.

2. Rupic? - Am. merid. : And. Quit. et Peruv.

Webbii (Mont.) W. P. Sch. l. c.

Bartramia granatensis W.P. Sch. Coroll, p. 85, n. 7.

B. Webbii C. M. Syn. I, p. 504.

Glyphocarpus Webbii Mont. in Ann. se. nat. 1838, p, 56. n. 97 et Pl. cell. Can. p. 28, t. 2, f. 2; Syll.p. 29.

2. Terr. arid. - Eur. : Corsica, M. Granat. Afr. : Alger., Teneriff.

Exs.: Bourg. n. 603 et 1586 (Glyphocarpa).

Anasmagonium Mitt. M. aust. am. p. 615 (sect. Pogonati).

Anastrephidium Hpe. in Linn. 1876, p. 271 (sect. Porotrichi).

ANDREÄA Ehrh. in Hann. Mag. 1778 (63 sp.).

acuminata Mitt. in Journ. of the Linn. Soc, 1859, n. 64 et in Fl. Tasm. $I I, p .161, t .7, f .2$.

A. subappendiculata $C, M$.?

Ster. Rupic.? - Af $r$, : Ins. Kerguelen. Pac. : Tasman.

acutifolia Hook. f. et Wils. in Lond. Journ. of bot. 1844, p. 535 et Fl. Antarct. II, p. 396, t. 15l, f. 2; Handb. of N. Zeal. Fl. p. 400; C. M. Syn. I, p. 7 et II, p. 516; Mitt. M. austr. ain.p. 628.

- Afs: : Ins. Kerguelen. Am. sept.: Gronland (ster.). Am. merid.: And Peruv.?, Fuegia, ins. Eremit., Maclov. Pac.: N. Zel. sept., ins. Auckland, Campbell.

alpestris Bryol. eur. VI (mon. p. 16), t. 626; W. P. Sch. Syn. II ed. p. 814 .

A. petrophila var. alpestris Thed. Obs. de enerv. Scand. sp. gen. Andreăse in Nya Bot. Notiz 1849.

1. Ad saxa hum. proecip. secùs rivul. glacial. - Eur. : Scandin., Scot., summ. Alp. centr., Arvern., Longobard. Am. sept.: Grönland, Nova Scot. 
alpestris var. Mitt. - A. commutata.

alpina Turn. M. Hibern.; Brid. Bryol. univ. II, p. 728 p. p. ; Bryol. eur. VI (mon. p. 18) t. 628; C. M. Syn. I, p. 7 et II, p. 516; W. P. Sch. Syn. II ed., p. 819.

A. petrophila Ehrh. Beitr. I, p. 592 p. p.

Jungermannia alpina, surculis teretibus, foliis ovatis patentibus, calycibus imbricatis L. Sp. Pl. p. 1601.

Lichenastrum alpinum atro-rubens teres. calycibus squamosis Dill. Hist. M: $p .506, t .73, f .39$.

1. Saxa irror. in rivul. - Eur. : Alp. Cambrovall, Hibern., Scot. ; Norveg., ins. Finmarck. ; Arvern., summ. Alp.

Exs. : Rab. Bryoth. eur. n. 851, 1151.

alpina Ảngstr. - A. obovata.

alpina Brid., W. et M. - A. petrophila.

alpina Mitt. - A. pseudo-alpina.

var. $\beta$ Wahlenb. - A. obovata.

ambigua Wils. - A. commutata.

angustata Lindb. in Limpr. Laubm. Deutsclll. I, p. 144.

1. -Eur.: Stiria.

appendiculata W. P. Sch. in Bryol eur. VI (mon. p. 5); C. M. in Bot. Zeit. 1864, p. 373 ; Mitt. M. austr. am. p. 629.

A. rupestris $H$. f. et W. M. Antarct.

Fr. ign. Rupic.? - Am. merid. : C. Horn, ins. Eremit., Fuegia. arachnoidea C. M. in Linn. 1878-79, p. 220.

$2 . \quad-$ Am. merid.: Alp. Argent. subtrop.

asperula Mitt. in Journ. of the Linn. Soc. 1859, p. 65.

- Pac. : Alp. Austral.

assimilis C. M. in Bot. Centralbl. 1883, n. 2-4.

2. $\quad-A s .:$ Penins. Tchutstchica.

aterrima C. M. in Engler's Bot. Jahrb. 1883,p. 76 et in Forchungsreise... Bot. p. 8.

2. Rup. sicc. - Afr. : Ins. Kerguelen.

Blyttii Bryol. eur. VI (mon. p. 25), t. 635; W. P. Sch. Syn. II ed. p. 821 .

A. perichaetialis Zett. mon. Andr. p. 26.

2. Ad rup. juxtà niv. - Eur.: Ins. Parry, Ursorum, Spitzberg. Am. sept.: Grönland.

Exs. : Rab. Bryoth, eur. n. 501 et b, 953.

borbonica.Besch. Fl. bryol Réunionjete., p. 187.

2 ?

- Afr.: Ins. Borbon.

brevipes Spr. in Proc. of the Linn. Soc. 1859, p. $\quad$; Mitt. M. austr. am. p. 628.

Rupic. - Am. merid.: And. Nov. Granat. et Peruv.

commutata C. M. in Bot. Zeit. 1864, p. 373.

A. alpestris var. Mitt. in hb. Ind. or. n. 3 .

A. ambigua Wils, in Kew. journ. IX, p. 289.

A. petrophila Mitt. M. Ind. or. p. 6 .

2.

- As. : Sikkim.

commutata Limpr (1). - A. Huntii.

(1) Cf. Cardot in Rev. bryol. 1884, p. 87. 
compacta C. M. in Bot. Centralbl. 1883, n. 2-4.

1.

- As.: Penins. Tschutstehika.

crassinervia Br. in Denkschr. Acad. zì Münch. 1828; Bryol. eur. V1 (mon. p. 23), t.633; C. M. Syn. I, p. 10; W. P. Sch. Syn. II ed. p. 820 .

A. crassinervia $\beta$ Heinemanni $C . M . l . c$.

A. Heinemanni Hpe. et C. M. in. Bot. Zeit. 1846, p. 364, t.2.

1. Rup. madid. - Eur. : Norveg., Scot., Alp., Pyr. Am. sept. : Grỏnland, Nov, Anglia.

Exs, : Sull. et Lesq. M. bor. amer. II ed, n. 26.

crassinervia $\beta$ Heinemanni C. M. - A. crassinervia.

cuspidata C. M. in Bot. Centralbl. 1883, n. 2.

2.

- As.: Penins. T'schutschika.

densifolia Mitt. - Acroschisma.

faleata Bryol. eur. VI (mon. p. 24), t. 634; W. P. Sch. Syn. II ed. p. 821. (p.p.?)

A. Rothii $\beta$ papillosa $C . M$. Syn. I, $p, 9$.

1. Rup. madid. - Eur. : Scot?, Cambrovall., Hercyn?, Engadine, Pyr.

a var. heteromalla Lindb. M. Scand. p. 31.

Ut typ. - Eur. : Seandin.

falcata Rab. - A. Huntii.

Fauriei Besch. in Ann. sc. nat. 1893, XVIII, p. 392.

2.

Exs. : Faurie n. 138.

filiformis C. M. in Bot. Centralbl. 1883, n. 2-4.

Ster.

- As. : Penins. Tschutschica.

firma C. M. in. Fl. $1888, p .476$.

Ster. In gramin. - Afr. : Kilima N'Djaro.

flabellata C. M. in Engler's Bot. Jahrb. 18×3, p. 176 et in Forschungsreise... Bot. p. 9.

2. Rup. sicc. - Afr. : Ins. Kerguelen.

fragilis C. M. in Linn. 1878-79, p. 223.

Fl. et fr. ign.

- Am. merid. : Alp. Argentin. subtrop.

frigida var. sudetica Limpr. - A. rupestris var. grimsulana.

Hartmanni Thed. Obs. de enerv. Scand. sp. gen. Andreâa in Nya Bot. Notiz, 1849, p. 78, f. 1-17 et 23-26; Bryol. eur. VI (mon. p. 19), t. 629 ; C. M. Syn. II, p. 516; W P. Sch. Syn. II ed. p. 815 .

1. Ad saxa rivul. juxta niv. - Eur.: Alp. Scandin.

Exs. : Rab. Bryoth. eur. n. 605.

var. gracilis Zett. - A. Thedenii

var. Thedenii Lindb. - A. Thedenii.

Heinemanni Hpe. et C. M. - A. crassinervia.

Huntii Limpr. Laubm. Deutschl. p. 145.

A. commutata ej. Einige neue Art, und Form... 1883, p. 221 et Laubm. Deutschl. p. 145.

A. falcata Rab. Bryoth. eur. n. 1301 a et b (fid. Limpr).

1. Rupic. - Eur: : Norveg. occ., Britann., Harz, Bavar. Am. sept.: Ins. Vancouver.

indica Mitt. M. Ind. or, p. 6. 
Karsteniana C. M. in Linn. 1874, p. 572.

A. petrophila Mitt. M. austr, am. p. 628 ?

2. - Am. merid. : M. Pichincha.

Kilima N'Djarica Par.

A. striata C. M. in Fl. 1888, p. 406.

Gramin. - Afr. : Kilima N'lljaro.

Krauseana C. M. in Bot. Centralbl. 1883, n. 2-4.

2. $\quad-$ As. : Penins. Tschutschica.

laxifolia Hook. f. et Wils. l. c. p. 536 et Fl. Antarct. II, p. 397, t. 151, 1. f. 4 ; C. M. Syn. I, p. 8 et II, p. 5I7; Mitt. M. austr. amer.p. 629.

«var. minor C. M. l. c.

Cum typ.

Lorentziana C. M. in Linn. 1879-79, p. 221.

2.

- Am. merid. : Alp. Argentin. subtrop.

Macounii Kindb. in Bull. Torr. bot. Club April. 1890 et in Mac. Cat. p. 10.

2. Rupic. - Am. sept. : Columb. brit.

marginata Hook. f. et Wils. l. c. p. 535 et Fl. Antarct. II, p. 396, t. 151, 2.

f. 1; C. M. Syn. I, p. 7 et II, p. 516; Mitt. M. austr. amer. p. 629.

montana Mitt. in Journ. of the Linn. Soc. 1859, p. 64 et in Fl. Tasm. II, p. $161, t .7, f .1$.

Ster. Rupic. - Pac. : Tasman.

mutabilis Hook. f. et Wils. l. c. p. 536 ( $\alpha$ microphylla) et Fl. Antarct. I, p. 119, t. อ7; C. M. Syn. I, p. 8 et 1I, p. 516; Handb. of N. Zeal. Fl. p. 400 .

ins. Aucklaud, Campbell.

- Am. merid. : Ins. Maclov. Pac. : Nov. Zel., « var. subsecunda $C, M$. $l, c$.

« var, uncinata C. M. l. c.

$$
\text { - Am. merid. : Ins. Maclov. (ambo). }
$$

nana C. M. in Engler's Bot. Jahrb. 1883, p. 176 et in Forchungsreise... 2. Bot.p. 9.

Naumanni C. M. $l l . c c$. - Afr. : Ins. Kerguelen.

1. Rup. basalt. - Af $r$.: Ins. Kerguelen.

nitida Hook. f. et Wils. l. c. p. 535 et Fl. Antarct. I, p. 118, t. 57, f. 3; C. M. Syn. I, p. 6 et II, p. 515; Handb. of N. Zeal. Fl. p. 400.

Rupic. - Pac. : Ins. Aucklaud, Tasman.

nivalis Hook. in. Trans. of Linn. Soc. X, p. 395, t. 31, f. 4; Brid. Bryol. univ. II, p. 732; Bryol. eur. VI (mon. p. 25), t. 636; C. M. Syn. I, p. 9 ; W. P. Sch. Syn. II ed. p. 822.

2. Ad rup. aqua nival. irror. - Eur. : Alp. Scandin., Scot., Helvet., Pyr. Am. sept.: Oregon.

Exs. : Rab. Bryoth. eur. n. 259.

Un itin. 1864, n. 100.

* var. fuscescens Hook. l. c. f. 4 c, Lindb. M. Scand. p. 30, n. 406.

Ut typ. - Eur.: Lappon., Norveg. 
obovata Thed. l. c. p. 78, t. 2; Bryol. eur. VI (mon. p. 17) t. 627; C. M. Syn. II, p. 515; W. P. Sch. Syn. II ed.p. .81

A. alpina Angstr. in. Fr. Summ, Veg. Scand. I, p. 97.

A. alpina var. $\beta$ Wahlenb Fl. Suec. II ed., II, p. 809.

Jungermannia alpina, surculis teretibus, foliis ovatis patentibus, calycibus imbricatis L. Sp. Pl. p. 1601 p.p.

I. Rupic. ad rivul, nival. - Eur.: Spitzberg, Alp. Scand. Am. sept. : Grônland.

« var. acuminata Lindb. in Foerteckn. ofv. M... till Spitzb. 1858, och 1861.

Ut typ. - Eur. : Spitzberg.

papillosa Lindb. in Öv. af Vet. Ak. Forh. XXIII, p. 55, et in Hedroigia $1868, p .109$.

1. Rupic. - Eur. : Spitzberg. As.: Sibir. Am. sept. : Fret. Behring.

\& var. brevifolia Berggr. M. Spetsb. n. $155 \mathrm{c}$.

Ut. typ. - Eur.: Ins. Ursorum.

- var. gracilis Lindb. $l l . c c . ;$ Hedro. p. 110.

Ut typ. - Eur.: Spitzberg.

« var. latifolia Berggr. l. c. n. 155 b. et in K. Sv. Vet. Ak. Forh. XIII, n. 7. p. 93.

Ut typ. - Eur. : Ins. Parry, Spitzberg.

parallela C. M. in Engler's Bot. Jahrb. 1883, p. 76 et in Forchungsreise... Bot. p. 8.

2. Rup. sicc. - Afr.: Ins. Kerguelen.

parvifolia C. $M$. in $F l .1887, p .219$.

2.

- Am. sept. : Alaska.

patens C. M. in Bot. Centralbl. 1883, n. 2-4.

2.

- As. : Penins. Tschntschica.

perichotialis $\left\{\begin{array}{l}\text { Hook. f. - A. snbulata var. perichœtialis. } \\ - \text { Zett. }-\mathrm{A} \text {. Blyttii. }\end{array}\right.$

petrophila Ehrh. Beitr. I, p. 592 (excl. syn.): Bryol. eur. VI (mon. p. 13) t. 623 ; W. P. Sch. Syn. II ed. p. 812.

A. alpina W. et M. Bot. Taschb. t. II, f. 3-4; Brid. Bryol. univ. II p. 728.

A. rupestris Hedw. Sp. M.p. 47, t. 7, p. p.; C. M. Syn. I, p. 6;H.f. et W. Fl. Nov. Zel. II, p. 57 et Handb. of N. Zeal. Fl. p. 400.

Jungermannia alpina, surculis teretibus, foliis ovatis patentibus, calycibus imbricatis L. Sp. Pl. p. 1601 p. p.

1. Rupic. - Eur. : E reg. campestr. montos. usque in alp. As. : Japon.? Caucas. Am. sept.: Grỏnland, Labrador, Terr. Nov., ins. Miquelon, Nov. Scot., M. Alb., Ontario, M. Rupestr. et Selkirk, Columb. brit., ins. Vancouver, Washington, Idaho. Am. merid.: Summ. m. Pichincha (1), Fuegia. Pac.: N. Zel. sept., Tasman.

Exs. : Mac. Can. M. n. 16.

Rab. Bryoth. eur. n. 51, 1247.

Sull. et Lesq. M. bor. am. II ed, n. 24.

Un itin. 1867, n. 117, 118.

* var. acnminata Bryol. eur. l. c. t. 624; W. P. Sch. l. c. p. 813.

Ut typ. - Eur. : Suecia (prov. Upland).

Exs. : Rab. Bryoth. eur. n. 52, 369.

var. alpestris Thed. - A. alpestris.

* var. alpicola Bryol. eur. ll. cc.; W. P. $8 c h$ l. c.

(1) Cf. A. Karsteniana. 
Ut typ. - Eur. : Hercynia,

"var. flaccida Bryol. eur. ll, cc.; W. P. Sch. l. c.

Ut typ. - Eur. : Suecia (prov. Upland).

* var. gracilis Bryol. eur. $l l, c c . ;$ W. P. Sch. $l . c$.

Ut typ. - Eur.: Thuring.

« var. homomalla W. P. Sch. Syn. I ed., p. $66 \mathrm{l}$ et II ed. l. c.

A. rupestris W. et $M$. Bot. Taschenb. p. 384, t. II, f. 5-6; Brid. Bryol. univ. II. p. 726.

Ut typ. - Eur. : Septentr.

" var. pygmaea Bryol, eur. et W. P. Sch. ll. cc.

Ut typ. - Eur.: Alp, editior.

* var. robusta Bryol. eur. l. c. t. 625; W. P. Sch. l. c.

Ut typ. - Eur.: Voges.

« var. silvicola Bryol. eur. l. c. t. 624; W. P. Sch. l. c.

Ut typ. - Eur. : Silv. subalpin.

var. sparsifolia Lindb. - A. sparsifolia.

\& var. squarrosula Bryol. eur. ll. cc.; W. P. Sch. l.c.

Ut typ. - Eur.: Suecia (prov. Upland).

petrophila Ehrh. - A. alpina p. p.

petrophila Mitt $\left\{\begin{array}{l}\text { A. commutata. } \\ \text { A. Karsteniana? }\end{array}\right.$

planivervis Lindb in Broth. Enum. M. Caucas. p. 94 (nomen).

Rup. niv. - Eur.: Caucas, occid.

pseudo-alpina C. M. in. Bot. Zeit. 1859, p. 248.

A. alpina Mitt. M. austr. am, p. 620.

2. $\quad-$ Am. merid. : C. Horn., ins. Eremit.

pseudo-subulata C. M. - A. subulata var. rigida.

regularis C. M. Bryol. austr. Gearg. p. 10.

1.

- Am. merid.: Austr. Georg.

rigida Wils. in Kew Journ. bot. IX, p. 289 ; Mitt. M. Ind. or. p. 6. - As.: Sikkim.

Rothii Brid., C. M., W. et M. - A. rupestris.

var. grimsulana C. M. - A. rupestris var. grimsulana.

var. hamata Lindb. - A. rupestris var. hamata.

var. papillosa C. M. - A. faleata.

rupestris Hedw. Sp. M. p. 47, f. 2; Bryol. eur. VI (mon.p. 21) t. 631; W. P. Sch. Syn. II ed., p. 819.

A. Rothii W. et M. Bot. Tasehb. p. 386, t. II, f. 7, 8, 9; Brid. Bryol. univ. II, p. $730 ;$ C. M. Syл. I, p. 9.

Jungermannia rupestris, foliis subulatis, secundis L. Fl. Suec., p. 1045.

Lichenastrum alpinum, nigricans, foliis capillaribus reflexis Dill. Hist. $M$. p. 507, t. 73, f. $40 \mathrm{~A}$ (p. p.).

1. Rupic. procip. calcar, et in molib. errat. - Eur. : E reg. campestr. montos. usque in subalpin. Am. sept.: Grônland, sin. Hudson, NewYork, Georgia, Carol.

Exs. : Rab. Bryoth, eur. n. 604.

Sull. et Lesq. M. bor. Amer. II ed. n. 25.

"var. capensis Rehm. M. Afr. austr, n. 430.

Ut typ. - Afr. : C. B. Sp.

" var. grimsulana Bryol, eur. l. c. t. 632; W. P. Sch. l. c.

A. frigida Hüb. var, sudetica Limpr. Einig. neue Art. und Form,.. 1884.

A. Rothii $\gamma$ grimsulana $C, M . l, c$. 
Ad. rup. alp. madid, - Eur. : Suec., Scot., Alp. centr., Pyr.

"var. hamata (Lindb.) Par.

A. Rothii var. hamata Lindb. M. Soand. p. 31 (nom.)

Ut typ. - Eur. : Scandin.

" var. septentrionalis Bryol. eur. et W. P.Sch. ll. cc.

Ad scopul. apric. - Eur.: Norveg.

rupestris C. M. p. p. - A. striata.

rupestris C. M., Hedw. - A. pétrophila.

rupestris $\mathrm{H}$. f. et W. $\mathrm{A}$. petrophila.

(A. appendiculata.

rupestris W. et M. - A. petrophila var homomalla.

semi-squarrosa C. M. in. Linn. 1878-79, p. 222.

Fr. ign. $\quad-$ Am. merid.: Alp. Argent. subtrop.

sparsifolia Zett. monog. p. 32; W. P. Sch. Coroll. p. 94 in adn. et op. cit.

A. rupestris var. sparsifolia Lindb. M. Spetsb. p. 559.

1. Rupic. juxtà niv. - Eur. : Alp. Norveg., Ticin.

- var. sublaevis Kindb. ined.

- Am. sept. : Vancouver.

squamata C. M. in Engler's Bot. Jahrb. 1883, p. 77 et in Forchungsreise... Bot. p. 10.

2. Rup. sicc. et basalt. - Afr. : Ins. Kerguelen.

squarrosa Mitt. M. austr. am. p. 629.

- Am. merid. : And. Quit.

striata Mitt. l. c. p. 628.

A. rupestris C. M. Syn. I, p. 6 (quoad pl. Brasil.).

- Am. merid. : dnd. Quit., Brasil. austr. or.

striata C. M. - A. Kilima N'Djarica.

subappendiculata C. M. in Engler's Bot. Jahrb. 1883, p. 76 et in Forchungsreise... Bot., p. 8.

A. acuminata Mitt?

Ster. Rup. si c. - Afr. : Ins. Kerguelen.

subenervis Hook. f. et Wils. in Lond. Jour. of bot. 1847, p. 289; C. M. Syn. I, p. 8; Mitt. M. austr. am. p. 530.

- Am. merid, : And. Nov. Granat. et Quitens.

subulata Harv, in Hook. Pl. rar. III, t. 201; C. M. Syn. I, p. 10.

1. Rupic. - Afr.: C. B. Sp.

* var, perichaetialis Harv. et Hook. ll. cc.

A. perichaetialis H. f. et W. in Lond. Journ. of bot. 1844, p. 533.

Ut typ. - Am. merid. : Ins. Eremit., Maclov.

* var. rigida Harv. et C. M. ll. cc.

A. pseudo-subulata C. M. in Bot. Zeit. 1864, p. 373.

A. subulata $H$. $f$. et $W$. $F$. Antarct. I, $119, t .57, f .1$ et Handb. of $N$. Zeal. Fl. p. 400; Mitt. M. austr. am. p. 630.

Ut typ. - Am. merid. : Ins. Eremit., Fuegia. Pac. : Austral., N. Zeland., Tasman., ins. Auckland, Campbell.

subulata H. f. ct W. - A. subulata var. rigida.

Thedenii Bryol. eur. VI (mon. p. 20) t. 630; W. P. Sch. Syn. II ed. p. 816.

A. Hartmanni $\beta$ gracilis Zett. mon.?

A. Hartmanni var, Lindb. M. Scand. p. 31.

1. Ad et in rivul. nival, - Eur. : Norveg. (Dovre). 
turgescens W. P. Sch. in C. M. Syn. II, p. 515 .

- Am. sept. : Summ. m. Orizaba, Nevado de Toluca.

viridis C. M. Bryol, austr. Georg. p. 10.

2.

- Am. merid. : Austr. Georg.

vulcanica Ltz, Moosst. p. I5h.

2 .

- Am. merid. : M. Ilinitza.

Willii C, M. op. cit. p. 11 .

2.

- Am. merid. : Austr. Georg.

ÅNGSTRÖMIA Bıyol, eur. I (9 sp.)

acerosa Hpe. Prodr. Al. Nov. Granat. p. 355.

2. - Am. merid. : And. Nov. Granat.

andicola C. M. - A. julacea.

argentinica C. M. - Dicranella.

aulacocarpa C. M. - Dicranella.

austro-exiqua C. M. - Dicranella.

banatica Hpe. - Dicranella heterornalla.

bella C. M. - Dicranella.

Beyrichiana Hpe. - Dicranella.

bicolor C. M. - Dicranella.

bogotentis $\mathrm{Hpe}$. - Dicranella.

Borgeniana Hpe. - Dicranella.

brachyblepharis C. M. - Dieranella.

brevifolia Hpe. et Ltz. - Trichostomum Krauseanum.

callosa Hpe. - Dicranella.

Cameruniae C. M. - Dicranella.

campylophylla C. M. - Dicranella.

capituligera C. M. - Dicranella.

cerviculata C. M. - Dicranella.

clathrata C. M. - Dichodontium.

coarctata C. M. - Dieranella.

compacta C. M. - Dicranella.

consimilis Hpe. - Dicranella.

convoluta Hpe. - Dichodontium.

crassinervis $\mathrm{Hpe}$ - Dicranella.

crispa C. M. - Dicranella.

curvata C. M. -- Dicranella.

curviseta Hpe. - Campyloporium.

cylindrica C. M. - Trichodon.

cyrlodonta C. M. - Dicranella.

densa C. M. - Dieranella.

Dietrichice C. M. - Dicranella.

ditissima Hpe. - Dicranella.

euchlora C. M. - Microdus.

euphoroclada C. M. - Campylopodium.

exigua C. M. - Microdus.

exigua Wils. - Microdus pomiformis.

Fendleri C. M. - Campylopodium.

Gayana (Mont.) C. M. Syn. I, p. 427; W. P. Sch. Syn. I ed.p. 69; Mitt. M. austr. am. p. 27.

Dicranum Gayanum Mont. in Ann. sc. nat. 1845, IV, p.112 et in Gay Hist. Chil. Bot. orypt. t. 2, $T .3 ;$ Syll. p. 45 .

2. Terr. - Am, meicl. : Chil, austr.

Glasiovoii Hpe. - Dicranella.

Grevilleana C. M. - Dicranella. 
Guilleminiana C. M. - Dicranella.

heteromalla C. M. - Dicranella.

var. interrupta C. M. - Dicranella heteronalla var. interrupta.

var. orthocarpa C. M. - Dicranella heteromalla var, orthocarpa.

var. stricta C. M. - Dicranella heteromalla var. stricta.

Hilariana C. M. - Microdus.

himalayana Jaeg. - Dichodontium Hookeri.

Hookeri C. M. - Dichodontium Jamesoni.

integra C. M. - Microdus.

julacea (Hook.) Mitt. M. aust, am, p. 27.

A. andicola C. M. in Bot. Zeit. 1847, p. 189 et Syn. I, p. 428.

Gymnostomum julaceum Hook. M. ex. t. 42; Brid. Bryol. univ. I, p. 92.

Illecebraria julacea Hpe. Prodr. Fl. Nov, Gran. p. 354.

2.

Lamyi Boul. - Leptotrichum vaginans var. brevifolium.

Liebmanniana C. M. - Dicranella.

ligulifolia C. M. - Dicranella.

longipes (Somm.) Bryol. eur. I, t. $94 ;$ C. M. Syn. I, p. 426; W. P. Sch. Syn. II ed. p. 69.

Dicranum julaceum H. f. et W. in Drumm. M. bor. am. I ed., n. 100.

D. varium eor. l. c. n. $99 \mathrm{p} p$.

Weisia longipes Somm. Suppl. ad Wahlenb. Fl. Lapp. p. 54, t. 1.

2. Argill, aren. humid. - Eur. : Scandin., Engadine, Salisb., Pinzgow. Am. sept.: Grỏnland, M. Rupestr, et Selkirk, Colımb. brit.

Exs, : Rab. Bryoth. eur. n. 1226.

Un. itin. 1863, n. 8 .

Lorentzi C. M. - Dichodontium

Mac-Leana Rehm. M. Afr. austr. n. 440.

- Afr.: Transvaal.

maculata $C . M$. in Fl. $1875, n$, 34-35.

2. Terr. $-A m$. merid. : And. Nov. Granat.

Martiana Hpe. - Microdus.

microdonta (:. MI. - Microdus Liebmanni.

minuta Hpe. - Microdus.

muralis Hpe. - Microdus.

neo-caledonica C. M. - Campylopodium.

orientalis Mitt. in Trans, of the Linn. Soc. 1891, p. 154.

Ster. - As. : Sikkim, Bhotan, Birma.

Pabstiana C. M. - Dicranella.

pellucida C. M. - Dichodontium.

var. fagimontana C. M. - Dichodontium pellucidum var. fagimontana

var. serrata C. M. - - Dichodontium pellncidum var. serrata.

Perrotletii C. M. - Dicranella.

phascoides C. M. - Campylopodium.

Pilopogon C. M. - Campylopodium.

planinervia C. M. - Dicranella.

pusilla Hpe. - Microdus.

Reinwardti C. M. - Dichodontium.

rufescens C M. - Dicranella.

rupipes C. M. - Dichodontium.

rufo-aurea Hpe. - Dicranella.

Sartorii C. M. - Campylopodium.

Sauleri C. M - Dicranel a pumila.

Schmidii C. M. - Dicranella pumila.

Schreberi C. M. - Dicranella. 
squarrosa C. M. - Dicranella. strumulosa Hpe. - Dicranella.

var. minor Hpe. - Dicranella strumulosa var. minor. subcompressa Hpe. mss.; C. M. in Bot. Zeit. 1859, p. 215.

2. Rupic. - Afr. : C. B. Sp. subsubulata Hpe. - Dicranella. subsulcata Hpe. - Dicranella. subulata C. M. - Dicranella. tenuirostris C. M. - Microdus. tenuisela C. M. - Dicranella. tovariensis C. M. - Dicranella. trematodontifolia C. M. - Dicranella. tricruris C. M. - Dichodontium. Trumpffii Hpe, Dicranella. vaginata C. M. - Dichodontium varia C. M. - Dicranella.

var. tenuifolia C. M. - Dicranella varia var. tenuifolia.

var. Sull. - Dicranella chrysea.

virens $\mathrm{C}$. M. - Cynodontium.

var. compacta C. M. - Cynodontium virens var. compaeta.

vulcanica C. M. Syn. I, p. 427.

Dicranum filiforme Schwaegr. Suppl. II, p. 72, t. 122.

D. vulcanicum Brid. Bryol. univ. I, p. 124.

Weisia vulcanica Brid. Sp. M. I.p. 124.

2. Rup. basalt. - Afr. : Ins, Borbon, Madagascar. Am. sept. : Mexic., Jamaïc. Am. merid. : And Quitens.

Wahlenbergii C. M. - Cynodontium virens var. Wahlenbergii (1).

ANHYMENIUM Griff. Not.p. 471. polycarpus Griff. - Rhegmatodon. polysetus Griff, - Rhegmatodon orthostegius?

ANICTANGIUM (Vid. Ancectangium)

ANISODON, Bryol. eur. V (2 sp.).

acutirostris Bryol. eur. - Clasmatodon parvulus var. rupestris.

Bertrami W. P. Sch. Syn. I ed. p. 506 ; II ed. p. 588.

A. perpusillus Bryol. eur. $V, t$. 452 .

Clasmatodon perpusillus Lindb. in. Journ, of the Linn. Soc. XIII, p.71. Cl. parvulus Husn, Muscol. gall. p. 299.

C1. parvulus var. julacea C. M. in Linn. 1875, p. 437.

Neckera perpusilla C. M. Syn. II, p. 666 (exol. syn. Pterogonium perpusillum de Not.).

1. Ad trunc. Pini silvestr. .. Eur. : Saxon,, Boruss. ferrugineus Lindb, in, sched.

Clasmatodon ferrugineus Jaeg. Ad. II, p. 287. - Am. merid. : Brasil. austr. or. perpusillus Bryol. eur. - A. Bertrami.

ANISOSTICHIUM Mitt, in Journ. of the Linn. Soc. VI.

Bakeri Mitt. - Epipterygium Wrightii. prctum Mitt. - Webera.

Tozeri Mitt. - Webera.

(1) In Enum. Kindbergiana nomen nudum:

A. brevipes $\mathrm{Hpe}$. 
ANISOTHECIUM Mitl. $M$. austr. am, $p, 39$.

campylophyllum Mitt. - Dichodontium.

convolutum Mitt. -- Dichodontium.

crispum Lindb. - Dicranella Schreberi.

Grevillei Lindb. - Dicranella.

humile Lindb. - Dicranella varia var, tenella.

Jamesoni Mitt. - Dichodontium.

planinervium Mitt. - Dicranella.

pycnoglossum Broth. - Dicranella.

rubrum Lindb. - Dicranella varia.

var. obtusiusculum Lindb. - Dicranella varia var. obtusiuscula.

squarrosum Lindb. - Dicranella.

ANODON Rabenh. Deutsch. Krypt. Fl.

pulvinatus Rab. - Girimmia sphœrica.

ventricosus Rab. - Grimmia anodon.

ANODONTIUM Brid. Sp. M. I, p. 41.

prorepens Brid. - Drummondia clavellata.

ANODUS Bryol. Eur. I ( $\mathrm{sp}$.)

Donianns (Engl. Bot.) Bryol. eur. I, t. 109; W. P. Sch. Syn. II ed. p. 124. Gy ${ }^{\prime}$ nostomum Donianum Engl. Bot. t. 1582 ; Brid. Bryol. univ. I.p. 66.
G. pusillum Drumm. M. bor. am. I ed. n. 22 .

Seligeria Doniana C. M. Syn. I, p. 420 et II, p. 603.

1. Ad rup. aren. et calc. - Eur.: Norveg., Britann., German., Helvet., Jurass. As.: Jenissi super. Am. sept. : New York, Ontario, M. Rupestr.

\section{ANGCTANGIU M Schwaegr. Suppl. $I, I I, p .33$ (46 sp.)}

acaule Röhl. - Pharomitrium subsessile.

aestivum Mitt. M. austr, am. p. 175.

A. euchloron Mitt. in M. Jameson. - Am. merid. : And, Quitens.

aestivum Bryol. eur. - A. compactum.

afro compactum C. $M$. in Dusen $M$. Camer, $n, 342$. - Afr. . M. Cameroon.

andinum Mitt. $l$ c. $p, 17 \%$.

Rup. umbros. - Am, merid. : And. Quitens. angustifolium Mitt. in Journ. of the Linn. Soc. 1865, p 2.

A. Knyi Jur, in Bot. Zeit. 1866, p. 20.

A. Paivanum W. P. Sch. in Mandon M. Madeir. n. 2 . Rupic. - Afr.: Teneriffa.

apiculatum W. P. Sch. in Besch. Pr. Bryol. mexic. p. 15.

$$
\text { - Am. sept. : Mexic. }
$$

aquaticum Hedw. - Cinclidotus aquaticus.

borbonense Besch. Fl. bryol. Réunion, etc., p. 12

Terr. - Afr.: Ins. Borbon.

Breulelianum Bryol. eur. - A. enchloron.

bulbosum Hedw. - Cyatophorum.

caespiticiuini Schwaegr. - Stylostegium.

callidum Mill. M. austr. am. p. 177.

In stillicid, callid, - Am, merid.: And, Quitens. 
ciliatum $\left\{\begin{array}{l}\text { C. M. - Hedwigia nivalis. } \\ \text { Hedw. - Hedwigia ciliata. }\end{array}\right.$

var. rufescens W. Arn. - Hedwigidium imberbe.

cirrosum Hedw. - Macromitrium.

clarum Mitt. M. Ind. or. p. 31.

A. compactum var. Wils in Kew Journ. bot. IX, p. 326.

2.

- As. : Sikkim.

compactum Schwaegr. Suppl. I, I, p. 36, t. 11 ; Bryol. eur. (mon. p.

t.37; W. P. Sch. Syn. II ed. p. 47.

A. aestivum Bryol, eur. l. c.

Gymnostomum aestivum Bryol.germ. p. 173, t. XI, f. 25.

G. compactum Schleich. Crypt. helv. II Centur., n.7; Brid. Bryol. univ. $I, p .86$.

G. luteolum Engl. Bot, $t 2201$.

G. tristichum Wahlenb. Fl. Lapp. p. 303.

Hedwigia aestiva $\mathrm{Hook}$. Fl. Brit.

Pleurozygodon aestivus Lindb. M. Scand. p. 29.

Zygodon compactus C. M. Syn. I, p. 683 et II, p. 637.

2. In fissur. rup. madid. pæcip. micac. schistos. - Eur.: Reg. alp. tota, rarius in reg. subalp. et montana. As. : Caucas. Am. sept. : Groenland. Pac.: N. Zeland (?)

Exs. : Rab. Bryoth. eur. n. 123.

Un. itin. 1863, n. 5.

var, brevifolium Jur, in sched. ; Milde Bryol. siles., p. 109.

Ut typ. - Eur. : Sudet.

compactum var. Wils. - A, clarum.

condensatum W. P. Sch. in Besch. Pr. Bryol. mexic. p. 16.

$$
\text { - Am. sept. : Mexic. }
$$

? coronatum H. f. et W. - Erpodium.

crassinervium Mitt. - A, pusillum.

crispulum Wils, in Kew Journ. bot. IX, p. 325.

A. Thomsoni Mitt. M. Ind. Or p. 31.

Tortula " T. paludosæ allied ». Wils, l, c, p, 322.

2. domingense Schwaegr. - Erpodium.

Duseni C. M. in Dusen M. Camer. n. 157. - Afr.: M. Cameroon.

Erpodium domingense Brid. - Erpodium.

euchloron (Schwaegr.) Mitt. M. austr, am. p. 176.

A Breutelianum Bryol, eur. I (mon. p. 6, nom) et Besch. Pr. Bryol, mexic, $p, 16$.

A, tenellum Mitt. in Jameson M. exs. et in Lond. Journ. of bot.

Gymnostomum euchloron Schivaegr. Suppl. II. II, p. 83, t. 176.

G. guadeloupense Spreng. Syst.veg. IV, I, p. 145.

G. lamprocarpum Mont. in Ann. Se. nat. IX, 1838, p. 49 et Syll.p. 50.

Zygodon pusillus C. M. Syn. I, p. 684 et II p. 637.

Zygodon tenellus Mitt. in Lond. Journ. of bot. 185i, p. 56 ; C. M. Syn. II, p. 638.

2. Terr. - Am. sept.: Mexic., Guadel., Martinic., Guatemala. Am. merid. : Ins. Trinitat., Equat., And, Quitens.

euchloron Mitt. - A. aestivum.

eucollum Besch. - A. rufo-viride var. eucollum.

excelsum (C. M.) Par.

Zygodon excelsus $C, M$, ii Linn. 1878-79, $p, 369$. 


\section{ANEECTANGIUM}

2. - Am. mesid. : Argentin subtrop.

falcatum P. B. - Cinclidotus aquaticus.

ferrugineum Besch. in Ann. Sc, nat. 1893, p. 329.

2 Rupic. - As. : M. Japon.

Exs. : Faurie n. 3543.

flaccidum de Not. $\left\{\begin{array}{l}(f i l, C, M .), \text { - Grimmia anodon? } \\ (\text { fid. Husn. }) \text { - Grimmia sphœrica. }\end{array}\right.$

glaucescens W. P. Sch. in Besch. Pr. bryol, mexic. p. 16.

- Am. sept. : Mexic.

Hornschuchianum Funk in Fl. vel Regensb. Bot. Zeit. 1819, 1, p. 83 et $1820, I I$, p.82; Bryol. eur. I (mon. p. 6) t. 38; W. P. Sch. Syn. II ed. p. 48.

Gymnostomum Hornschuchianum Bryol. germ. I, p. 76, t. II; Brid. Bryol. univ. I, p. 88.

Molendoa Hornschuchiana Lindb. Utkast. nat. grupp. . , p. 29.
Hedwig:a Hornschuchiana Hook. M. exot. II, p. 3, $t$. 103.

Zygodon Hornschuchianus $C . M$. Syn. $I, p .685$.

2. Ad rupes cataract. - Eur. : Alp. Carinth., Rhaet.

Exs. : Rab. Bryoth. eur. n. 683, 1263.

Hornschuchirnum $\left\{\begin{array}{l}\text { Bryol. brit. - Trichostomum tophaceum var: terrestre. } \\ \text { Tayl. - Barbula cirrifolia }\end{array}\right.$

Humbloti Ren. et Card. in Bull. Soc. roy. bot, Belg. 1893, II, p. 9.

Ster.

Humboldti Brid. - Harrisonia.

- Afr. : Comor magn.

hymenodontoides (C.M.). Jaeg. Ad. I, p. 9 .

Zygodon hymenodontoides C. M. in. Linn. 1869-70, p. 40.

Ster. Cortic. - As. : Ceylan.

imberbe $\left\{\begin{array}{l}\text { Drumm. - Hedwigia ciliata var. viridis. } \\ \text { Hook et Tayl. - Hedwigidium. }\end{array}\right.$

impressum Hpe, in Linn. 1874, p. 208.

2.

indicum Mont. - Braunia.

- Afr. : Madagasc.

Kilima N'Djuricum Par.

A. pusillum Mitt, in Journ. of the Linn. Soc. 1886, p. 305. - Afr. : Kilima N'Djaro.

Knyi Jur. - A. angustifolium.

lapponicum f Hedw. - Amphoridium.

Kze. - Amphoridium curvipes.

laxifolium (Kze.) Par.

A. tenerrimum C. M. in Bot. Zeit. 1847, p. 801.

Gymnostomum laxifolium Kze. in Popp. Pl. Chil. III Coll. 268 (53).

Zygodon tenerrimus C. M. Syn. I, p.684.

2. Cortic. et rupic. - Am. merid. : Chil, auste.

Lechlerianum W. P. Sch. in Lechler Pl. Peruv, n. 2720; Mitt. M. austr. am. p. 177.

2. Rupic. - Am. merid : Peruv.

* vai. laetior Hpe. in Fl. 1865, p. 37.

C. typ.

Liebmanni W. P. Sch. in Besch. Pr. bryol. mexic. p. 15.

- Am. sept. : Mexic. (M. Orizaba). 
mafatense Ren. et Card. in Bull. Soc. roy. bot. Belg. 1890, 1, p. 167. - Afr. . Ins. Borbon.

mamabolense Rehm. M. Afr. austr. n. 435.

Ster?

- Afr. : Transvaal.

Mandonianum W. P. Sch. in Mandon M. Boliv, n. 1606.

Zygodon linearis C. M. in Linn. 1878-79, p. 370.

2. Rupic? - Am. merid. : And. Boliv., Alp. Argentin, subtropic

Mariei Besch. Fl. bryol. Réunion, etc. p. 13.

2. Fr. ign. Terr. - Afr. : Ins. Nossi-Be.

Mougeotii Lindb. - Amphoridium.

obtusicuspis Besch, in Ann. Sc. nat. 1892, I, p. 49.

2. Silvic. - As. : Yunnan.

Paivanum W. P. Sch. - A, angustifolium. parasiticum Brid. - Calymperes.

paucidentatum $C$. $M$. in $F l$. I888, p. 413.

Ster. Gramin, - Afr. : Kilima N'Djaro.

Peckii Sull. Jc. M. Suppl. p. 38, t. 25 et in Aust. M. Appal. n. 64 ; Lesq. et Jam. Man. p. 55.

Amphoridium Peckii Sull. in R. Rep. of Univ. of St. of N. York 1869, p. 57.

Ster. Rupic. - Am. sept. : New-York.

peruvianum Sull. in Am. Expl.Exp. 1859,t. 1; Mitt.M. austr. am. p. 177. - Am. merid. : M. Chimborazo.

? planifolium Hedw. Sp. M. p. 44, t. 6; Brid. Bryol. univ. II, p. 167; C. M. Syn. II, p. 173 (1)

- Pac. : Ins. austral.

porto-ricense Spreng. - Philonotis tenella var, humilis.

pulvinatum Mitt. in Trans. of the Linn. Soc. 1891, p. 160.

Ster. - As. : Japon.

pulvinatum Rỏhl. - Grimmia sphøerica.

pusillum Wils. in Kew Journ. bot. IX, p. 325.

A. crassinervium Mitt. M. Ind. or. p. 31 .

Ster. $\quad-$ As. : Tibet occid.

pusillum Mitt. - A. Kilima N'Djaricum.

rhaphidostegium C. M. in Besch. Fl. bryol. Réunion, etc. p. 13.

- Afr. : Ins. Comor. magn.

repens Hook. - Gigaspermum.

Roylei Mitt. M. Ind. or. p. 30.

2.

- As.: Himalaya occid.

rufo-virjde Besch. Fl. bryol. Réunion, etc., p. 13.

- Afr. . Ins. Comor. magn.

\& var. encollum Besch. l. c.

A, eucollum Besch, in Rev, bryol.

Cum typ.

Schliephackei (Limpr.) Par.

Molendoa lingurefolia Lindb, in sched.

Pleuroweisia Schliephackei Limpr.

Rup. calcar. - Eur.: Alp. helvet. .1s. : Caucas. centr. 
Schmidii Mitt. - Oreoweisia.

sciuroides Bals, et de Not. - Braunia.

secundum $\left\{\begin{array}{l}\text { Brid. - Braunia. } \\ \text { Mont. - Braunia indica. }\end{array}\right.$

Sendtnerianum Bryol. eur. I (mon. p. 7), t.39; W. P. Sch.Syn.I1ed., p. 49.

Molendoa Hornschuchii forma Lindb. Utkast. nat. grupp... p. 29.

M. Sendtneriana Limpr. Deutschl. Laubm. I, p. 250 .

Zygodon Sendtnerianus C. M. Syn. I, p. 686.

2. Rup, irror. - Eur. : Alp. centr. As, : Caucas.

setosum Hedw. - Cyrtopus.

sordidum Mitt. M. austr. am. p. 176.

- Am. merid. : M. Chimborazo.

spathulatum Mitt. in Journ. of the Linn. Soc. 1863, p. 150.

- Afr.: M. Cameroon.

sphaericum Spreng. - Physcomitrium.

Stracheyanum Mitt. - A. tortifolium.

striatum $\left\{\begin{array}{l}\text { Brid. - Amphoridium lapponicum. } \\ \text { Wils. - Hedwigia riliata var, striata. }\end{array}\right.$

subsessile Spreng. - Pharomitrium.

tenellum Mitt. - A. euchloron.

tenerrimum C. M. - A. laxifolium.

tenuinerve (Limpr.) Par.

Molendo: lenuinervis Limpr. Laubm. Deutschl., p. 258.

2. $\sigma$ ign. Lignic. - Eur. : Tirol.

Thomsoni Mitt. - A. crispulum.

torquatum Brid. - Helicophyllum.

torquescens Mitt. in Trans. of the Linn. Soc. I891, p. 160.

Ster.

- As. : Japon.

tortifolium Wils, in Kew Journ. bot. IX, p. 326.

A. Stracheyanum Mitt. M. Ind. or. p. 31.

2.

- As. : Himalaya occid.

trichodes Schwaegr. - Brachyodus.

viridatum (C. M.) Par:

Zygodon viridatus C. M. in Fl. 1890, p. 481 .

Ster.

- Afr. : Kilima N'Djaro (1).

ANOMOBRYUM W. P. Sch. Syn. I ed. p. 382.

abyssinicum Jaeg. - Bryum filiforme var. abyssinicum.

aurutum Jaeg. - Bryum.

concinnalum Jaeg. - Bryum.

cygnicollum Jaeg. - Bryum climacodontium.

filiforme Husn. -- Bryum.

filiforme Jaeg. - Bryum cymbifolium.

var. juliforme Husn. - Bryum juliforme.

julaceum W. P. Sch, - Bryum filiforme.

var. ? abyssinicum W. P. Sch. - Bryum filiforme var,? abyssinicum.

var. ? algerianum W. P. Sch. - Bryum juliforme.

var. ? concinnatum Zett. - 1sryum julaceum.

(1) In Enum. Kindberg. nomina nuda:
A. Eggersii $C . \boldsymbol{M}$.
A. subpusillum C. M. 
var, ? mexicanum W. P. Sch. - Bryum filiforme var. mexicanum.

var.? quitense W. P. Sch. - Bryum filiforme var.? quitense. juliforme Solms Laub. - Bryum.

leptostomoides W. P. Sch. - Bryum leptostomum.

mexicanum Jaeg. - Bryum filiforme var, mexicanum.

nitidum Jaeg. - Bryum.

orbiculatum Jaeg. - Bryum.

procerrimum Rehm. - Bryum.

prostratum Besch. - Bryum.

var. minus Besch. - Bryum prostratum var. minus.

quitense W. P. Sch. - Bryum.

Schmidii Jaeg. - Bryum.

semu-ovalum Jaeg. - Bryum.

sericeum de Lacr. - Bryum leptostomum.

spongiosum Jaeg. - Bryum.

Anomocladus Mitt. $M$. auslr. am. p. 56 (sect LeskeaE).

ANOMODON Hook et Tayl. Muscol. brit. (36 sp.).

abbreviatus Mitt. in Trans. of the Linn. Soc. 1891, p. 187.

A. brevisetus Broth, mss.

2.

Exs. : Faurie n. $39,827$.

acutifolius Milt. M. Ind. or. p. 126.

2. $\quad$ As. : Himalaya occ., Japon.

Exs. : Faurie n. 1II, 116, 130, 241, 3523.

angustutus (Tayl.) Jaeg. Ad. II, p. 300.

Hypnum angustatum C. M. Syn. II, p. 472.

Lesked angustata Tayl. in Lond. Journ. of bot. 1846, p. 62.

Porotricham insularum Mitt. M. austr. am. p. 464?

Arbor. - Am. merid. : Nov. Granat., Quito.

apiculatus Bryol. eur. V (nom,); W. P. Sch. Syn. II ed., p. 601.

Hypnum Riugelii C. M. Syn. II, p. 473.

2. Ad. arbor et rup. in montos. - $\boldsymbol{E} u r$ : Sept. et med. : Suecia, Silesia, Rhôngeb, Austr. inf., Helvet. As. : Saghalien, Caucas. occ. et cent. Am. sept. : Ottawa, Ontar., rég. sept. et or.

Exs, : Mac. Canad, M. n. 257.

Rab. Bryoth. eur, n. 1096.

Sull. et Lesq. M. bor. am. II ed. n. 358.

attenuatus (\$chreb.) Hüb. Muscol. germ. p. 562; Bryol. eur. V (mon.p 4), t. 475 ; W. P. Sch. op. cit. p. 600.

Hypnum attenuatum Schreb. Spic. Fl. Lips. p. 100, n. 1073; C. M. Syn. $I I, p p .473$ et 691 .

H. clavatum Bell. App, ad Fl. Pedem. p, 51.

H. fulvum Brid. Sp. M. II, p. 151.

H. repens, trichodes arboreum majus, caulibus ramosis Dill. Hist. $M$. p. $331, t .42$, f. $66 a-c$.

Leskea attenuata Hedw. M. frond. I, p. 33, t. 12; Brid. Bryol. univ. II, p. 317.

L. radicans Schrank Baiers Fl. II, p. 460.

2. Ad arbor. rad. et viar. cav, marg. - Eur. : Reg. campestr. et montos., excl. Britann. As. : Japon., Caucas, Am. sept. : Nov. Seotia, New Brunswick, Ottawa, Ontar., Columb. brit., reg. sept., centr., or, et merid. - Pac. :? (hb. de Poli). 
Exs. : Drumm. M. bor, am. I ed. n. 226, II ed, n. 103 (Hypnum).

Mac. Canad. M. n, 255.

Rab. Bryoth, eur. n. 334 .

Sull. et Lesq. M. bor. am. II ed. n. 361.

- var. brevifolius Ren. et Card. in Bot. Centralbl. 1890, p. 51.

Rupic? - Am. sept. : Indiana, lllinois, Wisconssin.

altenuatus Sull. - A. Wrightii.

brasiliensis Hpe. - Myrinia.

brevinervis Broth, in Oefv..... 1890, p.

Ster. Cortic. - Pac. : Austral, or. (Queensland).

brevisetus Broth. - A. abbreviatus.

brunneo-sordidus C. M. in Rev. bryol. 1892, p. 41 (nom.).

- As, : Himalaya.

californicus Lesq. in Mem. Calif. Acad. I, p. 30; Lesq. et Jam. Man.

Ster. p. 306.

cladorhizans Hüb, - Cylindrothecicum.

clavirameus Jaeg. - Pseudo-Leskea.

compressus $\mathrm{Br}$. - Cylindrothecium.

consanguineus (Mont.) Jaeg. Ad. II, p. 301.

Hypnum consanguineum C. M. Syn. II, p. 472.

Leskea consanguinea Mitt. $M$. Ind. or. p. 131 .

Pterogonium consanguineum Mont. in Ann. sc. nat. 1842, p. 249 et Syll. p. 21.

2 , - As. : Yunnan, M. Neilgherr.

curtipendulus $\mathrm{H}$, et $\mathrm{T}$. - Antitrichia.

devolutus Mitt M. Ind. or, p. 127.

Ster.

- As.: Japon., Chin. or., Hong-Kong, Himalaya.

Eckloni Hpe. mss.; Jaeg. Ad. II, p. 306. - Afr. : C. B. Sp.

exilis Mitt. in Journ. of the Linn. Soc. 1872, p. 309.

Ster. - Afr. : Natal.

filiformis Thw, et Mitt. in Journ. of the Linn. Soc. 1872, p. 308.

Ster. - As. : Ceylan.

filivagus $C . M$, in $F l .1890, p .495$,

Ster. - Afr.: M. Aberdare.

Filum Broth mss.

Ster.

flexilis $\mathrm{Hpe}$ - Papillaria.

fragilis Wils. - Leskea tristis.

gracillimus Jaeg. - Schwetschkea.

Grateloupii Mont. - Schwetschkea.

heteroideus Kindb. in Mac, Cat. p. 172.

Leskea nervosa var. flagellifera Kindb. in Ott. Nat, IV, p. 62.

L. nigrescens Kindb. in Bull. Torr. bot. Club, XVI, p. 97 ; Mac. Canad. M. n. 395 , et 252 p.p.

2. Ster. Ad saxa calcar, et rad. Acer. - Am. sept.: Ottawa, Ontario, M. Rupestr.

Huttonii Mitt. in Journ. of the Linn. Soc. 1872, p. 309.

Ster.

- Pac. : Nov. Zeland. 
integerrimus Mitt, M. Ind. or. p. 126.

Ster.

intricatus Hpe. - Pylaisia.

- As. : Nepal, Himalaya.

lagoënsis Hpe. Symb. 1870, p. 283.

1.

- Am. merid. : Brasil. austr. or.

Leikipiz C. M. - Pseudo-Leskea.

leskeoides (W. P. Sch.) Par.

Hypnum leskeoides W. P. Sch. in Drege Pl. Cap. n. 8058; C. M. in Bot. Zeit. 1855, p. 787. 1.

$$
\text { - Afr.: C. B. Sp. }
$$

longifolius (Schleich.) Hartm, Skand. Fl. Xerl., V, p. 339 ; Bryol. eur, V (mon. p. 3), t. 474 ; W. P. Sch. Syn. II ed. p. 599.

Grimmia cylindracea W. et M. Bot. Taschb. p. 157.

Hypnum longifolium C.M. Syn. II, pp. 474 et 691 .

Leskea longifolia Spr. M. Pyr. exs, n. 87 .

Pterigynandrum longifolium Schleich. Cent. IV Pl. helv. n. 8.

Pt. nervosum $\beta$ cylindraceum Roehl. Deutsch. Fl. III, $p .54$.

Pt. nervosum $\beta$ longifolium Brid. Bryol. univ. II, p. 190.

Pt. plumulosum $\beta$ longifolium Brid. Mant. M. p. 129.

2. Ad arbor., sax. et terr, lapid. - Eur. : Centr. et sept., in zon. intermed, et sept. ; rar. fructif. - As. ; Jenissei sup., Caucas. occ. et centr.

Exs. : Rab. Bryoth. eur. n. 474, 1036.

mexrcanus Jaeg. - Leskea.

minor Fürnr. - A. obtusifolius.

mutabilis Mont. - Lescuraea striata.

nervosus Hüb. - Leskea.

obscurus Jaeg. - Leskea.

obtusifolius Br, et Sch. in Drumm. M. bor. am. I ed. n. 163 et in Lond. Journ of bot. 1843, p. 66; Sull. Ic. M. p. 119, t. 74; Lesq. et Jam. Man. pp. 305 et 419 .

A. minor Fürnr. ; Lindb.

Hypnum stoloniferum P. B.Prodr. p. 70.

H. viticulosum $\beta$ brachycarpum C. M. Syn. II, p. 473.

Isothecium minus Sull. in Asa Gray Man. bot. U. St. I ed., p. 667, n. 6.

Neckera flaccida Brid. Sp. M. II, p. 37 et Mant. M. p. 139, n. 18 ? Sehroaegr. Suppl. I, II, p. 154?

N. minor Sull. M. Allegh. n. $74($ an P. B. Prodr. p. 78 ? fid. C. M. l. c.),

N. viticulosa $\beta$ minor Hedw. Sp. M. p. 209, t. 48, f. 6.-8; Brid. Sp. M. II, p. 37 et Bryol. univ. II, p. 233.

2. Cortic. - As. : Jenissei sup. Am. sept. : New Brunswick, Gaspes., Ontario, Niagara, reg. sept., centr. et occ.

Exs. : Mac. Canad. M. p. 256.

Sull. et Lesq. bor. am. II ed. n. 360.

obtusifolius Mac. - A. platyphyllus.

ovicarpus Besch, in. Ann. sc, nat. 1893, p. 366.

2. Cortic. - As, : Japon.

Exs. : Faurie n. 736.

platyphyllus Kindb, ined.

A. obtusifolius Mac. Canad. M. n. 256 et Cat, p. 171.

2. Ad rad. arb. in silv. humid. - Am. sept.. Ottawa, Ontario. 
pellucinervis (Mitt.) Jaeg. Ad. II, p. 30 5.

Leskea pellucinervis Mitt. M. Ind. or. $p .130$.

Ster.

- As.: Himalaya occ.

planatus Mitt. op. cit. p. 126.

Ster, Filicic. - As. : Himalaya, Japon.

pseudo-attenuatus (C.M.) Jaeg. Ad. II, p. 304.

Hypnum pseudo-attenuatum C. M. in Bot. Zeit. 1855, p. 786.

1.

- Afr.: C. B. Sp.

ramulosus Mitt. in Trans. of the Linn. Soc. 1891, p. 187.

Ster.

- As.: Chin., Japon.

repens Hüb. - Platygyrium.

robustus Rehm. M. Afr, austr. n. 639 b.

Ster. $\quad-A f r$.: Transvaal.

rostratus (Hedw.) W. P. Sch. Syn. I ed., p. 488 et II ed., p. 598.

Hypnum caturum P. B. Prodr. p. 62.

H. desmiphorum P. B. op. cit. p. 63 .

H. flavens $\mathrm{Mich}$.

H. imbricatulum P. B. op. cit. p. 65 .

H. julaceum, erectum sericeum repens, capsulis cylindraceis Dill. Hist. M. p. 322, $t, 41, f .58 c$.

H. rostratum P. B. Prodr. p. 69 ; C. M. Syn. II, pp. 475 e: 691.

H. sabinæfolium Brid. Mant. M. p. 166.

Lasia marginata Brid. op. cit. p. 133 et Bryol univers. II, p. 203.

Leskea imbricatula Hedw. Sp. M. p. 224, t. 52 .
L. rostrata Hedwo op. cit. p. 226, t. 55: Brid. Bryol. univ. II, p. 303; Bryol. eur. $V$ (mon. p. 4), $t, 473$.

Pterigynandrum crinitum Brid. op. cit. p. 192.

Pt. marginatum Rich. in Mich. Fl. bor. Amer. II, p. 292.

Pterogonium marginatum Schwaegr. Suppl. $I, I$, p. 168.

2. Ad arbor. rad. et saxa calcar. - Eur. : Steril! reg. inf. jugi alp. : Helvet., Pyren,, Ital, super, Carniol,, Austria. As.: Japon., Caucas, occ. et centr. Am. sept. : Nov. Scot, New Brunswick, Gaspes., Ontario, ius. Vancouver, reg. sept., centr., or, et merid.

Exs.: Drumm. M, bor am. I ed. n. 228 et II ed, n. 104 (Hypnum). Faurie n. $6,48,49,121$.

Mac. Canad. M. n. 254.

Rab. Bryoth, eur. n. 636.

sull. et Lesq. M. bor. am. Il ed. n. 366.

stratosus Jaeg. - Pseudo-Leskea.

striatus Hüb. - Lescuraea.

$\beta$ saxicola Hartm, - Lescuraea striata var. $\beta$ saxicola.

subpilifer Lindb. et Arn. M. As. bor. 1890, II, p. III.

2. Cortic, - As. : Jenissei med.

Toccoae Sull. et Lesq. in Sull. Ic. M. p. 121, t. 76 A; Sull. M. of U. St, p. 58; Lesq et Jam. Man. p. 306.

A. devolutus Mitt?

Ster. Rupic. - As. : Celebes, M. Javæ, Sumatræ. Am. sept. : Georg. sup.

Exs. : Sull. et Lesq. M. bor, am. I ed. n. 240 et II ed. n. 362.

tonkinensis Bescl. in Bull. Soc. bot. Fr. 1894, p. 84.

Rup. - As, : Tonkin.

tristichus W. P. Sch. mss ; Jaeg. Ad. II, p. 306.

$$
\text { - Afr. : C. B. Sp. }
$$

? tristis Sull, - Leskea. 
viticulosus (L.) Hook. et Tayl. Muscol. brit. p. 79; Bryol. eur. V. (mon p. 5), t. 476; W. P. Sch. Syn. II ed. p. 601 . Hypnum subhirsutum, viticulis gracilibus erectis, capsulis teretibus Dill
Hist. M. p. $347, t$. $39, f .43$.

H. viticulosum L. Sp. pl. p.1592; C. M. Syn. II, pp. 472 et 690.

Leskea viticulosa Spr. M. Pyr. exs. n. 100.

L. vivipara Willd.

Neckera Schlechtendalii Picpes de N. Schlechtendalii 1838, p.9, t. I.

N. viticulaeformis Picper op. cit. p. 8, t. I.

N. viticulosa Hedw. Fund. M. p. 209, t. 48; Brid. Bryol. univ. II, p. 231.

2. Ad saxa, mur. praepr. antiq., arb. annosior. - Eur. : Tota, arctic. except. As.: Chin., Jenissei sup., Nepal., Himalaya occ., Caucas., As, min. Afr.: Alger. Am. sept.: Gaspes., Ottawa, Ontario,
Niagara, Wisconssin.

Exs. : Drumm. M. bor, am. Il ed. n. 102 (Hypnum).

Rab. Bryoth, eur. n. 333.

Sull, et Lesq. M. bor. am. II ed. n. 359.

Wrightii $C, M$. mss.

A. attenuatus Sull. in Proced. Am. Acad..... 1861, p. 284.

2. Rupic. - Am. sept. : Cuba.

santhophyllus Hpe. et Ltz. - Lescuraea (1).

Antennidens $C . M$. in Linn. 1875, p. 364 (sect. Fissidentis, Conomitrit sensu Müller.).

ANTITRIGHIA Brid. Mant. M. p. 136 (3 sp.).

brasiliensis Hsch. - Pilotrichum.

californica Sull. et Lesq. in Trans. of Am. Phil. Soc. XIII, p. 357; Sull. Ic. M. Suppl. p. 79, t. 59; W. P. Sch. Syn. II ed. p. 577; Lesq. et
Jam. Man. p. 291.

A. curtipendula Sull. in Pac. R. Rep. IV, p. 189.

A. curtipendula var. hispanica W.P. Sch. Syn. I ed., p. 477; C. M. Syn.
II, p. 116 .

2. Ad arbor., mur. et rup. - Eur. : Hispan. - Afr.: Alger. Am, sept. : Culumb. brit., Alaska, ins. Vancouver, Washington, Idaho, Oregon, Californ.

Exs, : Mac. Canad. M. n. 246.

Sull et Lesq. M. bor. am. Il ed, n, 357 .

"var. ambigua Ren. et Card. in Bot. Gaz. 1890, p. 59.

$$
\text { - Am. sept. : Oregon. }
$$

curtipendula (L.) Brid. Bryol. univ. II, p. 222 ; Bryol. eur. V, t. 469 ; W. P. Sch. op. cit. p. 576.

Anomodon curtipendulus $H$. et T. Muscol. brit, p. 79, t. 22.

Cyrtopus curtipendulus $\$ p r$. M. Pyr, exs. n. 113 .

Hypnum curtipendulum L. Sp. pl. p. 1504 .

H. dentatum, curtipendulum viticulis rigidis Dill. Hist. M., p. 333, t. 43,f. 69.

Neckera curtipendula Hedw. Sp. M. p. ə)9; C. M. Syn. II, pp. 115 et 628.

N. hamulosa Vill. Cat. meth. p. 42.

(1) In Enum. Kindberg. nomina nuda :
A. Mac-Leai Rehm. pellicola $C . M$.
A. pseudo-tristis $C, M$.
Yokohamae $C . M$.


2. Ad. arbor, silvat, et rup. umbros. - Eur.: E reg. campestr, ad montan. zon. intermed, - As. : Caucas, occ. - Afr. : Ins. Canar., Alp. Abyssin., C. B. Sp. - Am. sept. : Grônland, Terr. Nov., ins Miquelon, lac. Super., ins. Vancouver, Washington, Oregon, Carol sept. - Am. mérid. : Patag.

Fixs, : Rab. Bryoth. eur, n. 289 b.

Sull. et Lesq. M. bor, am. II ed. n. 355 .

« var. gigantea Sull. et Lesq. l. c. n. 356; W. P. Sch. Syn. II ed., p. 577; Lesq. et Jam. Man. p. 291;

Arbor. - Am. sept. : Columb. beit., Alaska, fret. Behring, ins.

Vancouver, Sitka, Washington, Idaho, Calif.

Exs. : Mac. Canad, M. n. 245.

var. hispanica W. P. Sch. - A. californica.

curlipendula Sull. -- A. californica.

cuspidata Nees. - Papillaria illecebra.

tenella Kindb, in Bull. Torr. bot. Club, XVII, p. 27, et in Mac. Cat. p. 165

2. $\odot$ ign. Rupic. - Am. sepl. : Ins. Vancouver (1).

Apalodictyon C. M. Syn. I, p. 291 (sect. BRYI).

APALODIUM Mitt. M. austr. am. p. 238.

australe Mitt. - Orthodontium.

pellucens Mitt. - Orthodontium.

APHANOREGMA Sull. in Asa Gray Man. bot. U. St. I ed., p. 647.

patens Lindb. - Physcomitrella.

patens var. anomalum Hpe, - Physcomitrella Hampei.

serratum Sull. - Physcomitrium.

APIOC.ARPIA Hüb. Muscol. germ. p. 154.

elongata Hïb. - Mielichhoferia nitida var, elongata.

Mielichhoferi Hïb. - Mielichh steria nitida var. elongata.

APLODON R. Br. in Neu. Bot. Zeit. VII, Suppl. ad it. Parray. p. 299.

Wormskioldii R. Br. - Splachnum.

APODANThus la Pyl, in Journ, bot. Desv. $V$, p. 20, $t .33, f$. 1 . aphyllus P. B. - Splachnum luteum.

Aporodictyon Lindb. M. Scand.p. 23 (sect. Drerani).

APTYCHUS C. M. Syn. $I I, p, 325$ (subsect. Hypir, postuc gen. propr.; spec. omn. Rhaphidostegia (vel Trichostolra?j ejud, nom.).

ARGHIDIUM Brid. Bryol. univ, $1, p .547$ (26 sp.).

africanum Mitt, in Journ. of the Linn. Soc. 1885, p. 299.

1.

$$
\text { - Afr.: M. Usagara. }
$$

alternifolium (Dicks) W. P. Sch. Syn. I ed.p. 28 et 11 ed. pp. 23 et 810.

A. phascoides Brid. Bryol. univ. I. p. 747; Bryol. eur. I, t. 8 et VI, t. 637 (ic, emend.); C. M. Syn. I, p. 13, p.p. et II, p. 517.

Phascum alternifolium, caulibus capsuliferis nanis, sterilibus altioribus erectis, foliis inceolatis alteruis Dieks. Fasc. I Pl. crypt. t. I.

Ph. Bruchii Spreng in Syst. veget. IV, p. 142.

Ph. globiterum Br. in Fl. 1825, p. 281, t. I.

(1) In Enumer. Kindberg, nomen nudum :

A. oligoclada Kindb, 
1. In ericut. humid. - Eur. jMed, et merid, rar. septentr.

Eœs. : Rab. Bryoth, eur, n, 402 et b. amplexicaule C. M. in. Linn. 1880-82, p. 346.

- Am. merid.: Uruguay.

"van. brevistolonaceum C. M. l. o. p. 347 .

Ut et ubi typ.

Arechavaletae $C . M$, in Fl. $1888, n . I$.

-- Am. merid. : Monte-Video.

brisbanicum Broth. in Bail. Contr. Queensl. Fl. Bull. n. 7, p. 3 (nom.) et in Oefo... 1893, $p$.

1. Ad terr. humid, - Pac. : Austral or. (Queensland.)

capense Hsch, in Linn. 1841, p. 135 ; C. M. Syn. 1, p. 13. - Afr.: C. B. Sp.

chrysosporum W. P. Sch. in sched.; Jaeg. M. cleisloc. p. 9. - Afr. : C. B. Sp.

Exs. : Rehm. W. Afr, austr. n, 426.

crispulum W. P. Sch. in Savatier M. Japon. n. 530.

2.

- As.: Japon.

Durieuanum W. P. Sch. in Jaeg. Ad. I, p. 6; Besch. Cat. M. Alger.p. 3. - Afr.: Alger.

Ecklonianum Hpe. in sched.; Jaeg. M. cleistoc. p. 9.

Exs. : Rehm. M. Afr, austr. Sp.

ephemeroides C. M. in Linn. 1880-82, p. 345 .

- Amer. merid. : Uruguay.

falcatulum C. M. in Rehm, M. Afr. austr. n. 429, b et d. - Afr.: C. B. Sp.

Giberti Mitt. in. Journ. of the Linn. Soc. 1886, p. 300.

1. - Am. merid.: Monte-Video.

Hallii Aust, in Bull, Torr, bot. Club VI, p. 145.

1 .

- Am. sept. : Kansas, Texas.

indicum C. $M$. in Fl. $1888, n$. I.

$$
\text { - As. : Birman. }
$$

julaceum C. M. in Linn. 1880-82, p. 347.

- Am. merid : Uruguay.

laterale Br. in Fl. 1846, p. 132; C. M. Syn. I, p. 14.

1. $\quad-A f r$ : : C. B. Sp., Natal.

Lescurii Anst, - Pleuridium alternifolium var, robustum.

longifolium Lesq. et Jam. Man. p. 50,

Syn.

- Am. sept. : Florid.

Lorentzii C. M. in Linn. 1880-82, p. 343.

- Am. merid. : Uruguay.

ohioënse Brynl, eur. I (mon. p. 3, nom.); Sull. Ic. M. p. 16, t. 7;

C. M. Syn. II, p. 517.

A. phascoides Sull. M. Allegh. exs. n, 213; C. M. Syn. I, p. 13 p.p.; Drumm. M. bor, am. II ed. n. 12, 13.

1. Terr. - Am. sept. : Canada or., New Jersey, New York, Pensilv, Ohio, Kansas, Alabama septentr. 
Exs. : Sull. et Lesq. M. bor. am. I ed. n. 28, Il e.l. n. 35.

„var. Donnellii Lesq. et Jam, l. c.

Ut typ. - Am. sept. : Virgin., Florid.

phascoides Brid. - A. alternifolium.

phascoides Drumm. $\left\{\begin{array}{l}\mathrm{A} \text {. ohioënse. } \\ \mathrm{A} \text {. tenerrimum. }\end{array}\right.$

phascoides Sull. - A. ohioënse.

Ravenelii Aust. in Bull. Torr. bot. Club VI, p. 145.

Syn. $\quad-A m$. sept, : Carolin. (ambo), Florid.

Rehrnanni Milt. in Jour'n of the Linn. Soc. 1886, p. 300.

1.

Exs. : Rehm. n. 427.

sinense DR. in Bull. Soc. bot. de Fr. 1862, p. 61 .

1. - As. : China or.

stolonaceum C. $M$. in Fl. $1888, n$. $I$.

Syn?

-- Pac. : Austral.

subulatum C.M. l. $c$.

- Afr. : C. B. Sp.

tenerrimum Mitt. in Journ. of the Linn. Soc. VIII, p. 17.

A. phascoides Drumm. M. bor, am. II ed., n. II.

1 .

- Am. sept. : Ludovic.

ARCTOA Bryol. eur. I.

fulvella $\mathrm{Br}$, eur. - Dicranum.

hyperborea $\mathrm{Br}$. eur. - Dicranum.

Areodictyon C. M. Syn. I, p. 288 (sect. BRYI).

Areofissidens C. M. Syn I. p. 46 (subsect. Fissidentis).

Argyrobarbula $C . M$. Syn. $I, p .597$ (sect. Barbulae).

ARGYRO-BRYUM Hpe. in Linn. 1876, p 312.

subrotundum $\mathrm{H}_{\text {pe. }}$ - Bryum subrotundifolium.

Argyrothrix C. M, in Linn. 1871-1873, p. 41. (sect. Macromitril).

ARRHENOPTERUM Hedro. Sp. M. p. 198, เ. 46, f. 1-9.

heterostichum Hedw. - Aulacomnium.

turgidum Wahlenb. - Aulacomnium.

ARTHROCORMUS $D z$, el $M k$. M. frond. ined. Archip. ind. $p .75\left(6 s_{i}\right)$

africanus Broth in Bot. Centralbl. 1888, p. 85.

2.

asper Jaeg. - Leucophanes.

dentatus C. M. M. Polyn., p. 58.

Octoblepharum dentatum Mitt. Sam. M., p. 178.

2. - Pac. : lns. Samoa.

Hookeri Hpe. - Leucophanes cuspidatum? glaneum?

incrassatus (Mitt.) Par.

Octoblepharum incrassatum Mitt. Fl. Vit. p. 386.

Ster.

- Pac. : Ins. Samoa.

pulvinatus Dz. el Mk. Prodr. Fl. bryol. Surinam. p. 6, t. 2.

Octoblepharum pulvinatum Mitt. M. austr. am. p. 109. 
2 Arbor.-- Am. sept. : Ins. S. Vincent. Am. merid. : Guian batav., Para, Nov. Granat.

Schimperi Dz. et Mk. l. c. p. 76, t. 27 et Bryol.jav. I, p. 25; C. M. Syn. I, p. 85.

Leucophanes squarrosum Brid. Bryol. univ. I, p. 764.

Mielichloferia Schimperi Dz. et Mk. in Ann. Sc. nat. 1844, II, p. 312. M. irifaria eor. in $h b$. Lugdun. Batav.

2. Arbor. et terr. - As. : Ins. Philippin., Amboine, Borneo, Java. subdentatus Broth. in Engler's Bot. Jahrb. 1893, p. 476.

2 . - Pac. : Nov. Guinea.

ASCHISMA Lindb. Utkast. nat grup.... p, 28. carniolicum Iindb. - Phascum.

var. speciosum Limpr. - Phascum carniolicum var, speciosum.

ASCHISTODON Mont. in Ann. sc. nat. 1845, IV, $p, 109$. conicus Mont. - Leptotrichum. pinetorum Jaeg. - Leptotrichum.

Asteriscium C. M. in Linn. 1878-79, p. 342 (sect. Barbulae).

ASTOMIOPSIS C. M. in Linn. 1880-82, p. 391.

amblyocarpa C. M. - Pleuridiopsis. subulata C. M. - Pleuridiopsis.

ASTOMUM Hpe. in Linn. 1832, p. alternifolium $\mathrm{Hpe}$. - Pleuridium. brachycaulon C. M. - Pleuridium. Breutelianum Hpe. - Pleuridium. crispum Hpe. - Systegium. cylindricum Mitt. - Tetrapterum australe var, cylindricum. denticulatum C. M. - Pleuridium. globrferum C. M. - Pleuridium. Krauseanum Hpe. - Pleuridium exiguum. ludovicianum Sull. - Systegium. Mittenii Bryol eur. - Systegium. multicapsulare Bryol. eur. - Systegium. nervosum C. M. $\left\{\begin{array}{l}\text { Pleuridium. } \\ \text { Pleuridium Robinsoni. }\end{array}\right.$ nitidulum Bryol. eur? - Systegium.

var. pygmaeum Lesq. - Systegium nitidulum var. pygmaeum. nitidum Bryol. eur. - Pleuridium. Pappeanum C. M. - Pleuridium. polycarpum Hpe. - Systegium crispum. Robmsoni C. M. - Pleuridium. rostellatum Bryol. eur. - Hymenostomum. subacaule Jaeg. - Hymenostomum. Sullivantii Bryol, eur. - Systegium. subnervosum C. M. - Pleuridium. virude $\mathbf{C}$. M. - Pleuridium.

ASTRODONTIUM Schwaegr. Suppl. II, I, p. 128. canariense Schwaegr. - Leucodon. corsicum Jaeg. - Leucodon. cryptotheca Besch. - Leucodon. curvii ostre Besch. - Leucodon. indicum $\mathrm{Dz}$ et $\mathrm{Mk}$. - Clastobryum. secundum Besch. - Leucodon. 
sericeum Jaeg. - Leucodon.

submersum Besch. - Leucodon.

tenue Besch. - Leucodon.

ASTROPHYLLUM Lindb. M. Scand. p. 13.

Blyttii Lindb. - Mnium stellare.

ciliare Lindb. - Mnium.

cinclidioides Lindb. - Mnium.

confertidens Lindb. et Arn. - Mniurn.

curvatulum Lindb. - Mnium.

cuspidatum Lindb. - Mnium affine.

Drummondii Lindb. - Mnium.

heterophyllum Lindb. - Mnium.

hornum Lindb. - Mnium.

hymenophylloides Lindb. - Mnium.

immarginatum Lindb. - Mnium.

inclinatum Lindb. - Mnium.

lycopodioides Lindb. - Mnium.

magnirete Lindb. .- Mnium.

marginatum Lindb. - Mnium serratum.

medium Lindb. - Mnium.

orthorhynchum Lindb. - Mnium.

punctatum Lindb, - Mnium.

pseudo-punctatum Lindb. - Mnium subglobosum.

riparium Lindb. - Mnium.

rostratum Lindb. - Mnium.

Seligeri Lindb. - Mnium affine var. elatum

silvaticum Lindb. - Mnium cuspidatum.

spinosum Lindb. - Mnium.

var. microcarpon Lindb. - Mnium spinosam var. microcarpon.

spinulosum Lindb. - Mnium.

stellare Lindb. - Mnium.

undulatum Lindb. - Mnium.

ATRACTYLOCARI'US Mitt. M. austr, am. p. 71.

Spec. omn. Leptotrich a ejusd. nom.

ATRICHUM $P . B$. Prodr. p. 42 (30 sp.). 1805

androgynum (C. M.) Jaeg. Ad. I, p. 703.

Catharinea androgyna C. M. Syn. I, p. 193.

1.

- Afr.: Transvaal, C. B. Sp.

Exs. : Rehm. M. Afr. austr. n. 265, 571 .

angustatum (Brid.) Bryol. eur. IV (mon. p. 2), t. 4ll; W. P. Sch. Syn. II ed., p. 528.

A. controversum P. B. Prodr. p. 42.

A. ligulatum Mitt. in Kew Journ. bot. 1856, p. 262 ?.

Bryum juniperi foliis rugosis, capsulis rectioribus Dill. Hist. M. p. 362, t. $46, f .19$.

Br. juniperifolium Hoffm. Deutschl. Fl. II, p. 40, n. 37 in obs.?

Catharinea angustata Brid. Bryol. univ. II, p 105; C. M Syn. I, p. 193.

Polytrichum angustatum Hook, M. ex. II, p. $5, t .4 ;$ Brid. Sp. M. I, p. 78.

P. controversum Hedio. Sp. M. I, p. 98.

P. cylindricum Sw, in Muihlenb. Cat. pl. Amer. sept. p. 97 et Adnot. bot. p. $171, n .33$.

P. ligulatum Mitt, in Handb. of N. Zeal. Fl. p. 453?

P. indulatum $\beta$ minus Mich. Fl. bor. Amer. II, p. 295. 
2. Ad terr, arenac, in ericet. - Eur, : Rar. : Scandin., Britann., Europ. med., Pyren. As.: Japon., Caucas, occ. Amer sepı. : Terr. Nova, New Brunswick, Ontario; reg. sept., centr., or. et merid.

Exs. : Drumm. M. bor. am. I ed. n. 68 (Polytrichum)

Mac. Can. M. n. 215.

Sull. et Lesq. M. bor. am. II ed. n. 314.

anomalum Milde in Hedwo. 1869, p. 161.

Ster. Rupic. - Eur. : Sudet.

borbonicum Besch. Fl. bryol. Réunion, etc. p. 108.

- Afr.: Ins. Borbon.

controversum P. B. - A. angustatum.

crispulum W. P. Sch. in Savat. M. Jap. n. 530 ; Besch. in. Ann. Sc. nat. $1893, p .351$.

2. $\sigma^{\star}$ et fr. ign. - As, : Japon.

crispum (Jam.). Sull. M. of U. St. p. 41 et Ic. M. p. 73, t. 46; W. P. Sch. Syn. II ed. p. 530 ; Lesq. et Jam. Man. p. 257.

A. laxifolium Wils. mss.; Rab. Bryoth, eur. n. 893.

A. xanthopelma Mac. Canad. M. n. 463.

Catharinea crispa Jam. in Journ. of Acad. Phil. 1855, p. 445.

2. Ad rip. gramin, rivul, inter saxa et rup. - Eur. : Britann. (ster.) Am. sept. : New Jersey, Ontario, Columb. brit.

Exs. : Mac. Canad. M. p. 540.

Sull, et Lesq. M. bor am. II ed. n. 315.

" var. densifolium (Lindb.) Par.

Catharinea crispa var. densifolia Lindb. in Not. 1867, p. 150.

$\varnothing$ et fr. ign. - Eur. : Anglia (Cheshire).

fertile Haw. - A. Haussknechtii.

flavisetum (Wils.) Milt. M. Ind. or. p. 150.

Catharinea flaviseta Wils, in sched. p.p.

- As. : Nepal., Himalaya.

Haussknechtii. Jur. et Milde in Verh. d. K. K. Zool. bot. Ges. in Wien, 1870 , p. 598.

A. fertile Haw, in Hedwig. 1889, p. 359.

A. undulatum $\beta$ attenuatum Holl. Moosfl. d. Ostrach Alp. in Ber. d. natur. Ver. in Augsburg, 1887, p. 247.

Catharinea anomala Bryhn in Bot, Not. 1886, p. 157.

C. lateralis Vaiz, in Ann. of bot. 1I, p 69 (1).

1. Terr. - Eur. : Norveg. austr. or., Anglia, Bavar., Austr., Rossia. As. : Jenissei, Talysch, Caucas, oce.

hercynicum PB. - Oligotrichum.

hirtellum Ren, et Card. in Bull. Soc. roy. bot. Belg. 1892, I, p. 168.

2. In silvis. $-A m$. sept. ; Costa Rica.

laevifolium (Lindb. et Arn.) Par.

Catharinea laevifolia Lindb. et Arn. M. As. bor. 1890, II, p. 11.

Syn. - As.: Jenissei.

laxifolium Wils. - A. crispum.

leiophyllum Kindb. in Bull. Torr. bot. Club, XVII, p. 275 et in Mac. Cat. p. 148. 
2. Terr. in silv. humid. $-A m$. sept. : M. Selkirk, ins, Vancouver.

Exs. : Mac. Canad. M. n. 217.

Lescurii Jam. in Bull. Torr. bot. Club, VI, p. 33; Lesq. et Jam. Man. p. 257.

Oligotrichum Lescurii Mitt. in Trans, of the Linn. Soc. 1891, p. 191.

2 .

- As.: Japon. Am. sept. : Alaska, Sitka.

ligulatum Mitt. $\left\{\begin{array}{l}\text { A. angustatum? } \\ \text { A. Muilleri? }\end{array}\right.$

Mülleri (C. M, et Hpe.) Par.

A. ligulatum Mitt. in Kew Journ, bot. 1856, p. 262 ?

Catharinea Muilleri $C$. M. et Hpe, in Linn. $1853, p .500$.

$2 . \quad-P a c$. : Austral. fel., ins. Lord Howe; Tasman?

Mülleri W. P. Sch. - A. Schimperi.

obtusulum (C. M.) Jaeg. Ad. II, p. 717.

Catharinea obtusula $C . M$. in $F l .1878, n .6$.

Syn.

- As. : Himalaya bor. occ.

Erstedtianum (C. M.) Mitt. M. austr. am. p. 605.

Catharinea Erstedtiana C. M. Syn. II, p. 558.

2 .

- var, Longifolium (Lindb.) Par.

Catharinea CErstedtiana var. longifolia Lindb. in Not... 1867, p.104, n. 155. - Am. sept. : Honduras.

parallelum Mitt. in Journ. of the Linn. Soc, VIII, p. 48, t. 8; Sull. Ic. M. Suppl.p. 54, t. 38; Lesq. et Jam. Man. p. 258,

Polytrichum undulatum Drumm. M. bor. am. I ed., n. 286.

2. Ad rup. madid. - Am. sept. : M. Rupestr, et Selkirk.

Exs. : Mac. Canad, M. n. 426.

pastasanum Mitt, M. austr. am. p. 605.

2.

piriforme Jaeg. - Psilopilum.

- Am, merid. : And. Quitens.

planifolium (C. M.) Jaeg. Ad. I, p. 703.

'Catharinea planifolia C. M. in Bot. Zeit. 1868, n. 47-48.

Terr. - Am, merid. : And. Valdiv.

polyearpum (C. M.) W. P. Sch, mss.

Catharinea Callibryon $\delta$ brevilamellosa C. M. Syn. I, p. 193.

C. polycarpa C. M. l. c. II, p. 558 .

1. - Am. sept.: Mexic. Am. merid.: And. Nov.

Granat et Quitens.

polyphyllum Rehm. M. Afr. austr. n. 266 et 572.

- Afr. : Transvaal, Natal.

rigidum Ltz. Moosst. $p .157$.

2? Ad terr. arenac. $-A m$, merid. : Valdiv.

rosulatum C. M. el Kindb. in Mac. Cal. p. 148.

Ster, Terr. - Am, sept. : Columb. brit.

Schimperi Jaeg. Ad. I, p. 703.

A Mülleri W. P, Soh, in Besch. Prodr, bryol, mexic, p, 62.

2.

- Am. sept. : Mexic. (Orizaba). 
Selwyni Aust. in Coult. Bot. Gaz. II, p. 95.

2. In fissur. rup. - Am. sept. : M. Selkirk, Columb. brit., Idaho, Oregon.

Exs. : Mac. Canad, M. n. 216.

subserralum Mitt. - A. undulatum var. subserratum.

subulirostrum W. P. Sch, in op. cit. $p .61$.

2.

- Am. sept. : Mexic. (Orizaba).

tenellun (Roehl.) Bryol. eur. IV (mon. p. 2), t. 412; W. P. Sch. Syn. II ed., p. 529 .

Bryum orthorhynchum Brid Mant. M. p. 119.

Br. Polla orthorhyncha Brid. Bryol, univ. I, p. 691.

Catharinea tenella Roehl. in Ann. S. Wett. Ges. III, p. 234; Brid. op. cit. II, p. 104; C. M. Syn. I, p. 194.

C. undulata $\beta$ minor Hüb. Muscol. germ. p. 517 (exel. syn.).

Mnium orthorhynchum Brid. Sp. M. III, p. 45.

M. serratum var. orthorhynchum Hüb. op. cit. p. 419.

Polytrichum undulatum var. Sw. M. Suec. p. 78.

P. undulatum $\beta$ minus Funk Moostaschb. p. 70; Wahlenb. Fl. Lapp. p. 349.

P. undulatum $\beta$ tenellum Wahlenb. Fl. Suec. II ed., II, p. 768.

2. In terr. arenos. limos, et stagn. exsicc. - Eur. : Scandin., Britann., Batav., German. septr., Voges.

Exs. : Un. itin. 1867, n. 87.

torquescens W. P. Sch, in Besch. Prodr. bryol, mexic. p. 62.

- Am. sept. : Mexic. (Orizaba).

undulatiforme Ren. et Card. in Bull. Soc, roy. bot. Belg. 1892, I, p. 168.

2. Ad terram. - Am. sept. : Costa-Rica.

undulatum (L.) P. B. Prodr. p. 42; Bryol. eur. IV (mon. p. 8), t. 410; W. P. Sch. Syn. II ed. p. 528.

Bryum phylliditifolium Neek. Meth. M. p. 203.

Br. Phylliditis folio rugoso acuto, capsulis incurvis Dill. Hist. M. p. 360 , t. $46, f .18$.

Br. undulatum L. Sp. pl. 1532.

Callibryon polytrichoides Wibb. Fl. Werth. p. 290.

C. undulatum Zenk, et Dietr. M. Thur. Fasc. II, n. 41.

Catharinea Callibryon Ehrh. in Hannov. Mag. 1780, p. 934; C. M. Syn. $I, p, 192$.

C. Erhardti Voit M. Herbisp. p. 47.

C. undulata W. et M. Bot. Taschb. p. 216; Brid. Bryol. univ. II, p. 102.

Mnium undulatum L. jun. Meth. M. p. 364 (haud L. neo Neck., sed Sw., fid. Lindb.).

Oligotrichum undulatum Lam. et DC. Fl. fr. I, p. 292.

Polytrichum undulatum Hedw. M. frond. I, p. $43, t .16$ et 17.

1. In silv., virgult., mur. delaps, etc. - Eur. : Fere tota. A\&, : Japon., Chin., Cochinch., Pers., Caucas., As. min. Afr. : Alger., Madeir. Am. sept. : Terr. Nov., ins. Miquelon, M. Rupestr., Columb. brit., Washington, tota temperata.

Exs. : Drumm, M. bor. am. II ed, n. 66, 67 (Polytrichum).

Faurie Pl. Japon. n. 10, 34, 171, 203, 276, 31 1, 3508.

Mac. Canad. M. n. 214.

Mandon Pl. Madeir, n. 26.

Sull. et Lesq. M. bor. am. II ed, n. 313.

- var. abbreviatnm Bryol. eur. l.c.

Bryum juniperifolium Hoffm. Deutsch. Fl. II, p. 40, n. 37 in obs.?

Catharinea Callibryon $\gamma$ abbreviata $C . M$. l. c. p. 193.

C. undulata var, minor W. et M. op. cit. p. 287 ; Brid. Bryol. univ. II. p. 104. 
Oligotrichum undulatum $\beta$ minus Lam. et DC. op. cit. III ed. II, p. 492 Polytrichum controversum Brid. M. Rec. II, p. 93, n. 71 .

P. undulatum $\beta$ minus Hedio. Stirp. crypt. I, p. 43 et Sp. M. p. 98.

Ut et ubi typ. in Eur.

"var. alte-cristatum Ren. et Card. in Bot. Gaz. 1890, p. 58.

- Am. sept. : Pensilv., Montana, Oregon, Kansas.

« var. attenuatum Bryol. eur. l. c.

Catharinea Callibryon $\beta$ attenuata C.M. $l . c$.

Polytrichum undulatum var. I $H$. f. et W. in Drumm. M. bor, am. I ed. n. 66.

Ut et ubi typ. in Eur. et Am. sept.

var. attenuatum Holl. - A. Haussknechtii.

* var. gracilisetum Besch. in Ann. sc. nat. 1893, p. 351.

Exs. : Faurie n. 1367 .

«var. subserratum (Hook.) Par.

A. subserratum Mitt. M: Ind. or. p. 150.

Catharinea Callibryon $\varepsilon$ subserrata C. M. l. $c$.

C. subserrata Lindb. in Not.... 1867, p. 104, n, 54.

Polytrichum augustatum Griff. Not. p. 486 p.p.?

P. undulatum var. subserratum Hook. in Lond Journ. of bot. 1840, p. 3. - As. : Nepal,, Himalaya.

Winteri Besch. mss.; Jaeg. Ad. I. p. 706.

- Am. sept. : Mexic.

xanthopelma (C. M.) Lesq. et Jam. Man. p. 257.

Catharinea xanthopelma C. $M$. in Fl. 1873, p. 482.

2.

- Am. sept. : Kansas, Texas, Ludovic.

xanthopelma Mac. - A. crispum (1).

AULACOMITRIUM Mitt, in Trans. of the Linn. Soc. 1891, p. 161.

calycinum Mitt. - Macromitrium.

humillimum Mitt. - Macromitrium.

AULAGOMNIUM Schwaegr. Suppl. $I I I, I, I$ (8 sp.).

acuminatum (Lindb. et Arn.) Par.

Sphaerocephalus acuminatus $L$. et $A . M$. As, bor. $1890, I I, p, 27$.

2.

- As. : Jenissei med.

androgynum (L.) Schwaegr. Suppl. III, I, I, t. 215; Bryol. eur. IV (mon. p. ), t. 4U6; W. P. Sch. Syn. II ed. p. 503.

Bryum androgynum Hedw. Sp. M. p. 178.

Fusiconia androgyna P. B. in Mem. Soc. Linn. Par. I, t. 7, f. 5.

Gymnocephalus androgynus Schwaegr. Suppl. I, II, p. 87.

Gymnocybe androgyna Fr. St. agr. Femsj. p. 27.

Hypnum androgynum Sehrank Baiers Fl. II, p. 469.

Mnium androgynum L. Sp. pl. II ed. p. 1574; Brid. Bryol, univ. $I I, p .5$ C. M. Syn, I, p. 170 .

Mn. angustifolium Neck. Meth. M. p. 234.

Mn. perangustis et brevibus foliis Dill. Hist. $M . p, 230, t .31, f .1$.

Orthopyxis androgyna $P . B$. Prodr. $p .78$.

(1) In Enum. Kindb. nom, nud. :

A. synoicum $C$. $M$. 
2. Ad rup. quarz, terr., rad. arb. et trunc. putresc. in palud, - Eur, : Tota campestr. et montos. : fruct. frequentior. in zon. sept. $A m$. sept. : Terr. Nov., Nov. Scot., Columb. brit., ins. Vancouver, Washington, Oregon, Idaho, Montana, Calif.

Exs. : Drumm. M. bor. am. II ed. n. 78 (Bryum).

Mac. Canad. M. n. 207.

Rab. Bryoth. eur. n. 534, 1025.

Un, itin. 1864 , n. 6.

chilense C. M. - Rhizogonium mnioides.

flexifolium H. f. et W. - Zygodon squarrosus.

Gaudichaudi Mitt. - Leptotheca.

heterostichum (Hedvo.) Bryol. eur. IV (mon. p. 8), t. 403.

Arrhenopterum heterostichum Hedw. Sp. M. p. 198, $t .46, f$. 1-9.

Bryum heteropterum pellucidum Dill. Hist. M. p. 362, t. 45, f. 11.

B, heterostichum W. Arn. in Mem. Soc. hist. nat. Paris, II, p. 292.

Hypnum heterostichum $W$. et $M$. Ind. Mus. pl. crypt., 1803.

Mnium arrhenopterum Sm. in Trans. of the Linn, Soc. 1804, p. 263 p.p.

Mn. heterostichum Sw. in Mühl. Cat. pl. Am. sept. p. 94; Brid. Bryol. univ. II, p. 12;C. M. Syn. I, p. 169.

Orthopyxis heterosticha $P$. B. Prodr.p. 79.

1. Ad terr. humid. - As. : Japon. Ams. sept. : Ontario, reg. sept., centr., or. et merid.

Exs. : Drumm. M. bor. am. I ed. n. 274 et II ed. n. 77 (Arrhenopterum).

Faurie Pl. Japon. n. 83, 163, 177, 221, 408, 3509.

Sull. et Lesq. M. bor. am. II ed. n. 310.

a var. humilis (C. M.) Pur.

Bryum membranaceum foliis membranaceis obtusis Dill. Hist. M. p. 551, t. $85, f .9$.

Mnium heterostichum var. humile C.M. $l$. c. inter syn.

Mn. membranaceum Brid. M. Rec. II, III, p. 85 et Bryol. univ. II, p. 13.

Orthopyxis heterosticha var. humilis Lindb. de Mn. eur. p. 78.

Ut et ubi typ.

marginatum (Angstr.) Jaeg. Ad. II, p. 715.

Gymnocybe marginata Angstr. in Oefv.... 1876, n. 4, p. 20.

Ster.

- Am. merid. : Brasil. austr. or.

palustre (L.) Schvaegr. Suppl. III, I, I, t. 216; Bryol. eur. IV (nom. p. 9), t. 405; W. P. Sch. Syn.II ed. p. 504.

Bryum inordinatum Brid. Mant. M. p. 117,

Br, palustre Neek. Meth. M. p. 210.

Br, ventricosum Sibth, Fl. Oxon., p. 289.

Gymnocephalus inordinatus Brid. Sp. M. III, p. 3.

G. palustris Schwaegi. Suppl. $I, I \bar{I}$, p. 87.

Gymnocybe palustris $F r$. St. agr. Femsj. p. 27.

G. palustris vai. inordinata Lindb. de Mn. eur. p. 87.

Hypnum elodes W. et M. Bot. Taschb. p. 282.

H. palustre eor. Ind. Mus. pl. crypt., 1803.

Limnobryum palustre Rab. Krypt. Fl. Sachs., I, p. 502.

Mnium inordinatum Brid. M. Reo. II, III, p. 76 et Bryol. univ. II, p. 7.

Mn. majus, ramis longioribus bifurcatis Dill. Hist. M. p. 233, $t .31, f .3$.

Mn. palustre L. Sp. pl. I ed., II, p. $1110 ;$ Brid. Bryol. univ. II, p. $7 ;$ C. M. Syn. I, p. 169.

Mn. ramis brevibus inordinate progredientibus Dill. op. cit. p. 239, t. 31, f. 8 .

Mn. reclinatum Sm. in Act. Soc. Linn. VII, p. 262.

Orthopyxis palustris P. B. Prodr. p. 79.

Sphaerocephalus palustris Lindb. M. Seand. p. 14. 
2. In prat. palıd. et silvat. uligin. - Eur. : E reg. campestr. usq. in subalp.; Spitzberg, Septem Ins., ins. Ursor, As. : Penins. Samojed., Jenissei, Obi, Kamschatka, Amour, Okhotsk, Caucas. occ., Syr. A fr. : Alger., Alp. Abyss. Am. sept. : Groenland, Labrador, fret. Hudson et Kotzebüe, Terr-Nov., ins. Miquelon, Nov. Scot., New Rrunswick, Gaspes., Ontar., Athabasca, Saskatchewan., M. Rupestr., Columb. brit., ins. Vancouver, Sitka, Washington; reg. sept., centr., occ. et orient. Pac. : Tasman.

Exs. : Drumm M. bor. am. I ed. n. 242 (Bryum),

Mac. Canad. M. n. 208.

Rab. Bryoth. eur. n. 660.

Sull, et L.esq. M. bor. am. II ed, n. 308.

"var. alpestre W. P. Sch. Coroll.p. 81 et Syn. II ed.p. 505.

Gymnocybe palustris $\zeta$ alpestris Lindb. $l$. $。$.

In turf. uligin. - Eur. : Helvet. (Grimsel). Am. sept. : Reg. montana.

"var. congestum Boulay in Fl. ins. Miquelon, p. 48.

- Am. sept. : Ins. Miquelon.

"var, fasciculare (Funk) Bryol. eur. et W. P. Sch. Ul. cc.

Gymnocybe palustris $\delta$ fascicularis Lindb. $l$. $c$.

Mnium fasciculare Funk in Brid. Bryol univ. II, p. 733.

Mn. palustre var, fasciculare C. M. l. c.

In uligin, - Eur. : Alp. editior. Am. sept. : Reg. montana.

" var. imbrientum Bryol eur. et W, P. Sch, ll. cc.

Gymnocybe palustris $\gamma$ imbricata Lindb $l$. c.

Mnium palustre var. imbricatum C. M. l. c.

Ubi præced, in Eur. Am. sept. : Terra-Nov., Ontario, Columb. brit., ins. Vancouver.

Exs. : Mac. Canad. M. n. 209.

"var. laxifolium Kindb. in Mac. Cat. $p .1$ 1́5.

Ad terr. humid, - Am. sept. : M. Selkirk.

* var. polycephalum (Brid.) Hüb. Muscol. germ. p, 3i3; Bryol. eur. et W. P. Sch. ll. cc.

Bryum androgynum $\beta$ prolixum Roth Fl. Germ. III, p. 229.

B. palustre $\beta$ ramosum Turn. Muscol. Hib. p. 113.

Gymnocybe palustris $\varepsilon$ ramosa Lindb. $l$. $c$.

Limnobryum palustre var. polycephalum Rab. op cit. p. 503.

Mnium majus, minus ramosum, capitulis pulverulentis crebrioribus Dill. Hist. M. p. 235, t. -21, f. 4.

Mn. palustre $\beta$ flagelliferum Mart. Fl. crypt. Erlang. p. 65.

Mn. palustre $\beta$ majus Schwaegr. Suppl. $I, I I, p .122$.

Mn. palustre $\delta$ polycephalum $C . M$. $l$. $c$.

Mn. polycephalum Brid. Mant. M. p. 121 et Bryol univ, II, p. 10.

Mn. prolixum Neck. Meth. M. p. 135.

Mn. ramosum Huds. Fl. Angl. p. 403.

Orthopyxis ramosa $P$. B. Prodr. $p .79$.

In turfos. depress. - Eur, : Pracip. sept. As.: Caucas. occ. Am. sept. : Groenland, Labrador, Terr-Nov., New Brunswick, Ontario, M. Rupestr., ins. Vancouver, reg. montana.

Exs. : Mac. Canad. M. n. 210.

papillosum (C. M.) Lesq. et Jam. Man. p. 253.

Mnium papillosum C. $M$. in Fl. 1875, p. 93. 2 . - Am. sept. : Colorado.

pentastichum Mont. - Zygodon. 
turgidum (Wahlenb.) Schwaegr. Suppl. II, I, I, p. 7; Bryol. eur. IV (mon. p. ), t. 404 ; W. P. Sch. op. cit. p. 506.

Arrhenopterum turgidum Wahlenb. sec. W. et M. (fid. Brid. Bryol. univ. II, p. 11).

Bryum turgidum Sw. Summ, veg. Scand, $p$ 41.

Gymnocybe turgida Lindb. de Mn, eur. p. 85 .

Hypnum illecebrum L. Fl. Suec. II ed,, p. 399 et Fl. Lapp. p. 403.

H. turgidum Wahlenb. mss; W. et $M$. Ind. Mus. pl. crypt., 1803 (nom.)

Mnium arrhenopterum Sm. in Trans, of the Linn. Soc. 1804, p. 263 p.p.

Mn. turgidum Wahlenb. Fl. Lapp. p. 351, t. 27; Schwaegr. Suppl. I, II, p. 123, t.77; Brid Bryol. univ. II, p. 11; C M. Syn. I, p. 171.

Sphaerocephalus turgidus Lindb. M. Scand. $p .14$.

2. Ad terr. turfac. vel in rup. irrig. - Eur. : Alp. reg. sept., rar. med. : Spitzberg, Septem lns., ins. Ursor., Norveg., Lappon., Scot.; Anglia et Stiria (ster.). As. : Penins. Samojed, et Tschutschica, Taimyr, Jenissei, Obi, Ochotsk, Turkestan sept. Am. sept. : Groenland, Labrador, ins. Melville, fret. Baffin, Hudson, Kotzebuë, Smith et Behring, lac. Super., Nov. Angl., M. Alb. et Adirondack.

Exs. : Drumm. M. bor. am. I ec. n. 243 (Bryum).

Sull. et Lesq. M. bor. am. II ed. p. 307.

Un. itin. $1867, \mathrm{n} .48$.

«var. elongatum (Lindb. et Arn.) Par.

Sphaerocephalus turgidus var. elongatus Lindb. et Arn. M. As. bor. 1890, $I I, p .27$.

- As. : Jenissei inf.

«var. proliferum Geheeb in Fl. 1879, p. 476.

- As. : Alatau.

venezuelanum Dz. et Mk. in Mitt. M. austr. am. p. 317.

Ster.

- Am. merid. : Venezuela.

AULACOPILUM Wils. in Lond. Journ. of bot. 1848, p. 90 (6 sp.).

abbreviatum Mitt. in Journ. of the Linn. Soc. 1872, p. 308, t. VD.

1. Filicic. - As. : Ind. or.

Balansae C. M. - A. paraguense.

glaucum Wils. l. c. p. 9; C. M. Syn. II, p. 186.

Ad arbor. - Afr. : Austral. (fid. Mitt.). Pac. : Nov. Zeland.

incanum Mitt. in op. et $l$. cc.

Ad arbor. - $A f r$. : Anstral.

paraguense Besch. in Rev. bryol. 1885 , p. 18.

A. Balansa C. M. in Fl. 1887, p. 447,

1. Ad Aurant. - Am. merid. : Paraguay.

Exs. : Bal. Pl. Parag. n. 3643 .

trichophyllum Ångstr. mss.; C. M. in Bot. Zeil. 1862, p. 393.

1. - Afr. : C. B. Sp.

tumidulum Thwo et Mitt. in Journ. of the Linn. Soc. 1872, p. 307, t. VC.

1. Ad arbor. - As. : Ceylan

Wildii Broth. - Wildia solmsiellacea.

AUSTINIA C. $M$. in Linn. 1875, p. 439 (l sp.).

tenuinervis (Mitl.) C.M..,$c$.

Clasmatodon parvulus Sull. in Proeed. Am. acad. 1861, p. 283 et in Wrigt Pl. Cub. n. 65. 
Cl, trichelyma Sull. mss.

Hypnum tenuinerve Mitt. $M$, austr, am, p, 549.

1 ? Cortic. - Am. sept. : Cuba.

BARBULA Hedw. Fund. $M . I I, p .92$ (394 sp.). abyssinica (de Not.) Par.

Tortula abyssinica de Not. in Nuov. Giorn. bot. ital. 1872, p. 22.

2 ? - Afr. : M. Abyssin.

aciphylla Bryol. eur. II (mon. p. 42), t. 165; C. M. Syn. I, p. 643; W. P. Sch. Syn. II ed. p. 228.

B. Enderesii Garovagl. Bryol. austr. p. 372 ?

B. norvegica Lindb. in Oefv. Vet. Ak. Foerh. 1863, p. 387.

Syntrichia aciphylla Jur. Laubm. Oesterr. Ung. p. 142.

$\mathrm{S}$, norregica $W$. et $M$, in Archiv, für die Syst. Naturg. t. $V, f . a-i$; Brid. Bryol. univ. $I$, pp. 588 et 836.

S. norvegica var. alpina Wahlenb. Fl. Carpat. p. 338.

Tortula aciphylla Hartm. Skand. Fl. V ed. p. 381 ; de Not. Epil. p. 540 et M. Ital. I, p. 38, t. 16.

T. norvegica Wahlenb. mss.; Lindb. M. Scand, p. 20.

T. ruralis $\beta$ alpina de Not. Spec. de Tort. Ital. n. 4 .

2. Rupic. - Eur. : Reg. alpin. usque ad niv. aternas : ins. Ursorum, Lappon,, Norveg., Alp. Helvet., Jurass., Tırol., Salisb., Sabaud., Pyren.; deest in Britann. As. : Jenissei, Caucas. Am.'sept. : Groenland, Labrad., M. Rupestr. et Selkirk, Columb. brit.

Exs. : Mac. Can. M. n. 479.

Un. itin. 1863, n. 6; 1867, n. 103.

aculeata Wils. in Lond. Journ. of bot. 1851, p. 51; C. M. Syn. II, p. 632.

Tortula aculeata Mitt. M. austr. am. p. 173.

2. - Am. merid. : And. Quitens.

acnleonervis C. M. in Linn. 1878-79, p. 349.

Fl, et $\mathrm{fr}$. iga.

- Am. merid. : Argentin. Cordob.

acuminala Brid. - B. agraria.

acuta Brid. - 13. gracilis.

uestiva Schultz. - B. muralis var. aestiva.

affinis Hpe, in Linn. 1861-62, p. 520.

B. pichinchensis Tayl. (fid. Mitt.).

2. Terr. - Am. merid. : And. Nov. Granat.

afro-ruralis C. M. in Rehm. M. Afr. austr. n. 114.

Ster. - Afr.: C. B. Sp.

agraria (Sv.) Brid. Bryol. univ. I, p.532 et 825; C. M. Syn. I, p. 604.

B. acuminata Brid. M. Rec. II, I, p. 208.

B. agraria $\beta$ acuminata Brid. Bryol. univ, $l$. $c$.

B. conica Brid. M. Rec. II, I. p. 192.

B. domestica Brid. Mant. M. p. 89 et Bryol, univ. I, p. 536.

B. latifolia Brid. Bryol, univ. l.c.

B. pallens Brid. l. $o$

B. stellata Brid. Mant. M. p. 88.

Bryum acuminatum Sw. Prodr. p. 139.

Br, agrarium Brid. l. e.

Br. stellatum Dicks. Crypt. Fasc. IV, p. 6 (exol. syn.)

Tortula agraria Sw. Fl. Ind. occ. III, p. $1763 ;$ Mitt. M. austr, am. p. 167.

T, decipieus Brid. Spec. M. I, p. 247.

T. pallens Brid. l. c. p. 246.

T. pellucida Hook, et Grev. in Brewster Edinb. Journ, p. 296.

T. stellata cor, $l$. o. p. 286. 
1. Muric. et saxic. - Am sept. : Florid, Apalachicola, Cuba, ins. S. Christoph., S. Thom., Jamaïc, Guadel. \&m. merid. : Guian.

Exs. : Drumm. M. bor. am. n. 64 (Tortula).

albicuspis Milt. $M$. Ind. or. $p .35$.

Ster.

- As. : Sikkim.

alexandrina Ltz. M. Ehrenb. p. 32, tt. 6, f. 1-6 et 7. f. 7-20.

Ster. $\quad-A f r$. : Egypt. infer. (1).

aloides (Koch) Fürnr. et Br. in Regensb. Bot. Zeit. 1829, II, p. 598;

Bryol, eur. II (mon. p. 15) t. 139 ; C. M. Syn. I, p. 596; W. P. Sch.

Syn. II ed. p. 191.

Bryum rigidum Dicks, Dried. pl. n. 47.

Tortula aloides de Not. Syll. p. 177 p.p.

T. rigida $\mathrm{Sm}$. Fl. brit. III, p. 1249.

Trichostomum aloideum Koch in Brid. Bryol, univ. I, p. 816.

2. Muric. et terr. argill. - Eur. : Med, et merid. ; Britann., ins. Melit. As. : Minor. Afr. : M. Sinaï, Alger., Canar. Am, sept. : Terra Nov.

Exs, : Bourg. pl. Canar n. 286.

Rab. : Bry oth, eur. n. 786 et b.

alpigena Lindb. et Arn. - Didymo.lon rubellus var. dentatus.

alpina Bryol. eur. II (mon. p. 39) t. 163; C. M. Syn. I. p. $639 ; W . P$. Sch. Syn. II ed. p. 226.

Syntrichia alpina Jur. Laubm. Oster. Ung. p. 139.

Tortula alpina Wils. Bryol. brit. p. 134.

T. mucronifolia de Not. Syll. p. I71.

1. Muric. et rupic. - Eus. : Rar. : Alp. Tir., Salisb., Pinzgow., Rhœt. As. : Caucas. Am. sept. : Columb brit.

Exs. : Rab. Bryoth. eur. n. 460.

Un. itin, 1863, n. 26 et 27.

"var. inermisf W. [P. Sch. Syn. II ed., p. 226.

Ut typ. - Eur. : Austr. infer., Tirol,, Longobard.

Exs. : Rab. Bryoth. eur, n. 820.

ambigua Bryol. eur. II (mon. p. 14) t. 139 ; C. M. Syn I. p. 596 ; W. P. Sch. Syn. II ed. p. 190.

B. brevirostris Fürnr. et Br, in Regensb. Bot. Zeit. 18?9, II, p. 599.

B. rigida Hedu. M. frond. I, p. 65, t. 25, f. 3 et 5 (p.p. quoad ic.! Conf. W. P.Sch.l. c.); Brid. Brol. univ. I, pp. 528 et 824 (excl. syn. Schultz).

Bryum ericaefolium Neck. Meth. p. 193.

Tortula aloides de Not. Syll. p. 177 p.p.

T. ambigua de Not. M. ital. I, p. 16, t. 2.

T. ericrefolia Lindb. M. Scand. p. 20.

T. rigida Brid. Sp. M. I, p. 16, t. 2 .

2. Locis denudat. argill. - Eur. : Procip. med. er merid.; Britann., ins. Melit. As. : Jenissei super., Persia, As. min. Afr. : Alger. Am. sept. : M. Rupestr., Columb. brit., lllinois.

amblyophylla Jaeg. - Pottia.

amcena Schum. - B. unguiculata.

amphidiacea C. M. in Linn. 1874, p. 639.

B. glacialis Besch. Prodr, bryol. mexic, p. 38 ?

Ster,

- Ami. sept. : Mexic.

amphidiifolia $C, M$. in Linn. 1878-79, p. 332.

2. Terr. - Am. merid. : Argentin. Cordob.

(1) An Trichostomum nitidum? n Jaeg. Ad. II. p. 764. 
amplexa Lesq. in Trans. of Amer. Phil. Soc. XIII, p. 5; Lesq. et Jam. Man. p. 118.

Tortula humilis Drumm. M. bor, am. I ed., n. 137.

2. Rup. madid. - Am. sept. : (Tanada, Oregon, Calif.

Exs. : Sull, et Lesq. M. bor. am. II ed, n. 140.

amplexifolia (Mitt.) Jaeg. Ad. I, p. 272.

Tortula amplexifolia Mitt. M. Ind. or. p. 29.

2.

- As. : Himalaya occid.

anacamptophylla C. M. Bryol. austr. Georg. p. 34.

Ster.

- Am. merid. : Austro-Georg.

anostomosans C. M. in Linn. 1878-79, p. 337.

2.

- Am. merid. : Argentin. subtropic.

andicola (Mont.) C. M. Syn. I, p. 643.

Tortula andicola Mont. in Ann. sc. nat. 1838, p. 53 et Syll. p. 39 ; Mitt. M. austr. am. p. 170.

2. Terr. - Am. merid. : Summ. And. Columb.

angustata (Mitt.) Bryol. jav. II. p. 226.

Didymodon angustatus Jaeg. Ad. I, p. 215.

Tortula angustata Mitt. M. Ind. or. p. 28.

2.

- As. : Ceylan, Java.

angustata Braithw. - B. subulata var. angustata.

angustifolia (Hook. et Grev.) C. M. Syn. I. p 603.

B. tenuirostris Brid. Bryol. univ. I, p. 826.

Tortula angustifolia H. et Grev. in Brewster Edinb. Journ. I, p. 299 , t. 12 ; Mitt. l. e. 30 .

- As. : Nepal.

angustifolia Brid. - B. inclinata.

annulus C. M. in Linn. 1880-82, p. 430.

1. Arenic. $-A m$. meid. : Argentiu. Buenos Ayr.

anomala Mitt. - Trichostomum.

antaretica Hpe. in C. M. Syn. I, p. 638.

Syntrichia princeps Mutt. in Journ. of the Linn. Soo. p.p.

Tortula Miulleri H. f. et W. Fl. Antaret. p. 103 et Fl. N. Zeal. p. 71.

Syn.

Tasman.

apiculata Hpe. in Linn. 1861-1862, p. 519.

Tortula apiculata Mitt. M. austr. am. p. 153.

2.

- Am. merid. : And. Nov. Granat.

aprculata Hedw, - B. unguiculata var, apiculata.

appressa (Mitt.) Jaeg. Ad. I, p. 288.

Tortula appressa Mitt. l. c. p. 152.

2.

- Am. merid. : Chile.

appressifulia (Mitt.) Jaeg. Ad. I, p. 281.

Tortula appressifolia Mitt. l. c. p. 159.

- Am. merid. : And. Peruv.

aprica C. M. in Linn. $1875, p .402$.

2. Fr. ign. Rupic - Afr.: M. mar. Erythraei.

arcuata Griff. - B. comosa.

arenacea Jaeg. - Desmatodon. 
Arenae Besch, in Bull. Soc, bot. Fr. 1885, p. LIXet in Miss. scient. Cap. Horn V, Bot., p. 269, t. 2. f. 8.

2.

- Am. merid: F ret. Magellan.

arenaria Griff. - B. membranifolia.

argentinica $P$ ar.

B. rubiginosa C. M. in Linn. 1880-82, p. 433.

Ster.

- Am. merid. : Alp. Argentin, subtropic.

aristata $B r$, et Sch. in W. Sch. M. Abyss.

- Afr. : Abyss.

aristata Brid. - B. unguiculata.

aristatula C. M. in Jaeg. Ad. II, p. 674.

Encalypta aristata Hpe. in Linn. 1871-73, p. 513.

Ster?

- Pac. : Austral (Nov. Valesia).

artocarpa Lesq. in Trans. of Am. Phil. Soc. XIII, p. 4; Lesq. et Jam. Man. p. 126.

2. Terr. - Ant. sept. : Calif.

Exs. : Sull. et Lesq. M. bor. am. II ed.. n. 133.

asperifolia Mitt. M. Ind. or. p. 34 .

Ster,

- As. : Alatau, Sikkim.

Astoriensis Broth. in Roell M. bor. am. exs.

atlantica $\left\{\begin{array}{l}\text { Besch. - B. graminicolor. } \\ \text { Brid. Eucladium verticillatum. } \\ \text { W. P Sch. - B. orizabensis. }\end{array}\right.$

atro-virens (Sm.) W. P. Sch. Syn. II ed.p. 194.

B. circinalis C. M. in Linn. 1884, p. 703.

B. nervosa Milde Bryol. siles.

Desmatodom nervosus Bryol. eur. II (mon. p. 6) t. 132; Rah. Bryoth. eur. n. 830 et b, 871 ; Sull. et Lesq. M. bor. am. II ed. n. 121 p.p.

Desmatodon atro-virens Jur. Laubm. Oester. Ung. p. 136.

Didymodon capensis Spreng. Syst. veget. IV, II, p. 323.

D. nervosus Hook, et Tayl. Muse. brit. I ed. p. 66, t. 20 .

Grimmia atro virens Sm. Engl. Bot. t. 2015.

Tortula atro-virens Lindb. Trichost. eur. p. 27.

T. parvula Hook in Brid. Bryol. univ. I, p. 825 .

Trichostomum convolutum Brid. Sp. M. p. 232 et Bryol. univ. I, p. 492; C. M. Syn. I, p. 590 et II, p. 629; Rab. Bryoth. eur. n. 871; Un. itin. 1863, p. 19.

Tr. nervosum Br: in Fr, Müller M. Sardin. et in Hüb. Musc. germ. p. 295.

Tr. Schimperi Mont. (fide Mitt.)

Weisia nervosa Hook, in Brid. Bryol. univ. I, p. 808 ?

1. Muric. et in tert argill. - Eur. : Anglia, vall. Rhenan, Eur. merid, et occ. As. : Caucas., Syria. Af : : Alger, C. B. Sp. Am. sept. : Calif. Am. merid. : And, Chilens. Pac. : N. Zeland., Tasman.

, var. edentula W. P. Sch. $l . c$.

Desmatodon nervosus $\beta$ edentulus Bryol. eur. l. c.; Sull. et Lesq. l. c. p.p.

Ut typ. - Eur. : Ar noric. et Normann. marit., reg. merid. Afr. : c. B.

Sp. Am. sept. : Calıf, merid.

var. robusta W. P. Sch. - B. revolvens.

Australasix (Hook. et Grev.) Brid. Bryol. univ. I, p. 828 ; C. M. Syn. I, p. 619 .

B. Poeppigiana C. M. (fid. Mitt. M. austr. am. p. 149.)

B. rufiseta Tayl. in Lond. Journ. of bot. 1846, p. 51 . 
Tortula Australasiæ Hook. et Grev, in Brewster Edinb. Journ. I, p. 301, t. $12 ; \mathrm{Fl}$. N. Zeal. II, p. 70.

T. fuscescens eor, Fl. N. Zeal. II, p. 73, t. 85, f. I.

Trichostomum Australasiæe Jaeg. Ad. I, p. 245.

2. sept., Tasman. - Pac. : Fret. reg. Georges, Austral., N. Zeland. australis Par.

B. magellanica C. M. in Bot. Zeit. $1862, p .349$.

B. patagonica C. M. in Fl. $1885, p, 415$.

Tortula Andersonii Ångstr. in Oefv.... 1872, n. 4, p. 6.

2. Terr, aren. et cortic. - Am. merid. : Patagon., fret. Magellan., Fuegia.

Baileyi (Broth.) Par.

Tortula Baileyi Broth, in Oefv, af Finka Vet. Soc. Foerh. 1890, p.

2. Cortic. - Pac. : Austral, or. (Queensland).

basoutensis Rehm. - Hyophila.

Beccarii (Vent.) Jaeg. Ad. 1, p. 203.

Pleurochate Beccarii Vent. in Nwov. Giorn. bot. ital. 1872, p. 14.

2.

Beecheyi Lesq. - B. cylindrica.

- Afr. : Abyss. sept.

Berteroana C. M. in Bot. Zeit. 1862, p. 349.

2.

- Am. merid. : Chil.

Bescherellei Sb. in Jaeg. Ad. II, p. 673.

B. rigidula Besch, in Prodr. bryol, mexic. p. 36.

- Am. sept. : Mexic.

bicolor (Bryol. eur.) Lindb. Bitr. till Moss, syn. 1863 et in Oefv. Vet. Ak. Foerh. XX, p. 336; W. P. Sch. Syn. II ed. p. 215.

Gymnostomum bicolor Bryol. eur. II (mon. p. 4) t. 29.

Pottia bicolor C. M. Syn. I, p. 563.

Tortula bicolor Lindb. Trichost, evor, p. 40.

2. Terr. hum. - Eur. : Alp. Salisb, Bavar., Rhaet., Tirol. Pac. : Tasman?

Exs. : Rab. Bryoth: eur. n. 9 (Gymnostomum).

Un. itin. 1863, n. I, 2, 3 (Gymnostomum).

Blyttü W. P. Sch. Syn. 1I ed, p. 208.

Fl, et fr. ign.

- Eur. : Finmarek.

bogotensis Hpe, in Ann. sc. nat. sér. V, III, p. 349.

Tortula bogotensis Mitt. M, austr. am. p. 171.

- Am. merid. : And. Nov. Granat.

bokkepoldiana Rehm. M. A fr. austr. n.:108.

$$
\text { - Afr. : C. B. Sp. }
$$

Bolanderi Lesq. in. Trans. of Amer. Phil. Soc. XIII, p. 5 ; Lesq. et Jam Man. $p, 118$.

2. Rupic. - Am. sept. : Calif.

Exs. : Sull. et Lesq. M. bor. am. II ed. n. 139.

boliviana Par.

B. glaucescens W. P. Sch. in Mandon Pl. Boliv, n. 1622.

- Am. merid: And. Boliv. 
Bourgœana Besch. Prodr, bryol. mexic. p. 35.

- Am. sept. : Mexic.

brachyachme C. M. in Rehm. M. Afr. austr. n. 107.

Ster?

- Afr.: C. B. Sp.

brachyangia $C . M$. et Kindb. in Mac. Cat. p. 59 ,

2. Rnpic. - Am. sept. : Ins, Anticosti.

brachymenia (Mitt.) Jaeg. Ad. I, p. 303.

Tortula brachymenia Mitt. $M$. austr. am. p. 151.

2 .

- Am. merid. : And. Quitens.

brachyphylla Sull, in Bot. Pac. R. R. Survey (Whipple), p. 186, t.2 (1856);

Lesq. et Jam. Man. p. 123.

2. $\quad-A m$. sept. : Calif.

Exs. : Sull. et Lesq. M. bor. am. I ed. n. $100^{\circ}$ et $\mathrm{Il}$ ed. n. 135.

« var. angustifolia C. M. et Kindb. l. c. pp. 55 et 264.

Ster.

- Am. sept. : Columb. brit.

brachyphylla $\left\{\begin{array}{l}\text { Hpe. - B. Hampeana. } \\ \text { Sull, et Lesq. - B. pui }\end{array}\right.$

brachypus Brid. - B. unguiculata var. brachypus.

Brandisi C. M. in Fl, 1878, n. 6.

Desmatodon inermis Mitt. M. Ind. or, p. 37 ?

Syn.

- As. : Himalaya bor. occid.

Brebissoni Brid. Bryol. univ. I. p. 834 ; W. P. Sch. Suppl. Bryol. eur
fasc. III-IV.

B. cylindrica Wils, in Phytologist 1845, p. 282.

B. mucronata Brid. Sp. M. I, p. 268.

B. romana C. M. Bot. Zeit. 1856.

B. unguiculata var. latifolia de Bréb. M. de Norm. n. 104.

Cinclidotus Brebissoni Husn. Muscol. gall. p. 118.

C. riparius $\beta$ terrestris Bryol. eur. III (mon. $p$. 10) $t$.

Desmatodon Brebissoni Jur. Laubm. Oester. Ung. p. 136.

D, dichotomus Brid. Bryol, univ. I, p. 823.

Didymodon Cinclidotus de Not. Spec. de Tortul. Ital. p. 45.

Gümbelia riparia $\beta$ terrestris $C . M$. Syn. $I I, p .651$.

Rhacomitrium flavipes Brid. Bryol. univ. I, p. 224.

Tortula Brebissoni de Not. Epil. p. 547.

T. mucronata Lindb. Trichost. eur. p. 30.

Trichostomum flavipes Steud. Nomencl. crypt, p, 421.

2. Ad saxa humid. et rad, arbor. annosior. - Eur. : Med. et occid. Anglia, Italia. Afr. : Alger.

Exs. : Rab. Bryoth. eur. n. 980.

brevicaulis Schwaegr. - B. fallax var. brevicaulis .

brevifolia $\{$ Brid. - B. fallax var. brevifolia.

Lindb. - Trichostomurn tophaceum.

brevipes Lesq. in Mem. Calif. Acad. I, p. 12; Lesq. et Jam. Man. p. 119;

2. Muric., terr. - Am. sept. : Nevada oecid., Calif.

brevirostris Bryol. eur. II (mon. p. 16) t. 138 ; C. M. Syn. I, p. 597 (excl. in utroque syn. Hook. et Tayl.); W. P. Sch. Syn. II ed. p. 189.

Syn. Terr. argillac. - Eur.: Spitzberg., Scandin., Dania, Saxon., M. Cenis, As, : Jenissei. Am. sept. : Groenland, sin. Hudson, M. Rupestr.

Exs. : Drumm. M. bor. am. I ed. n. 136.

Mac. Canad. M. n. 72.

Rab. Brynth, eur. n. 981. 
brevirostris $\mathrm{Fülnr}$, et $\mathrm{Br}$. - - B. ambigua,

breviseta Mont. in Ann. sc. nat. 1845, p. 107; C. M. Syn 1, p. 644.

- Tortula brevisetit Mont. Syll.p. 39; Mitt. M. austr, am. p. 172.

2. Terr. - Am. merid. : Chile.

breviseta Hpe. et C. M. -- B. brevisetacea.

brevisetacea Jaeg. Ad. I, p. 299.

B. breviseta Hpe. et C. M. in Linn. 1853, p. 492.

2.

- Pac. : Austral. or.

Brotheri (Lindb.) Par.

Mollia Brotheri Lindb. in Broth. Enum. M. Caucas, p. 46.

2. Rup. calcar. - As. : Caucas. oce. et centr.

Buyssoni Philib. in Rev. bryol. 1886, p.36 et in Husn. Muscol.gall.p. 117.

I. Rup. trachyt. - Eur. : M. Arvern.

caespitosa (Schwaegr.) Schultz Rec, de Barb. p. 9, t. XXXII, fig. 7; Brid.

Bryol. univ. I, p. 535 ; W. P. Sch. Syn. I ed. p. 177 el II ed. p. 216.

B. cirrata Br. in Fr. Müller M. Sardin. (1829); Bryol.eur. II (mon.p. 24) $t, 149$.

B. humilis Hedw. Sp. M. p. 116, t. 25 ; Brid. Bryol univ. I, p. 537.

B. Northiana C. M. Syn. I, p. 602.

Bryum acaulon, foliis teneris confertis, capsulis conicis Dill. Hist. M. p. 389, t. 49, f. 56 (fid. Hedwig).

Mollia caespitosa Broth. Enum. M. Caucas, p, 48.

M. humilis Lindb.

Streblotrichum humile $P . B$. Prodr. p. 89.

Tortula caespitosa Schwaegr. Suppl. I, I, p. 120, t. 31.

T. cirrata Lag. in Ann. se. nat. XIV.

T. humilis Brid, Sp. M. I, p. 248.

T. intermedia de Not. Syll. p. $18 \mathrm{I}$.

T. Northiana Grev. in Trans. of the Linn. Soc. XV, II, p. 342, t. 3, f. 4.

-1. Ad terr. arenos. - Eur.: Merid. : Gall. austr., Sardin., Ital., Hispan. etc. As.: Caucas. Afr.: Alger., C. B. Sp. Am, sept.: Canada, ( Columb. lust. ; orient, centr. et merid. ; ins. Jamaic. Am. merid. : Brasil.

Exs. : Drumm. M. bor. am. II ed., n. 65 (Tortula).

Rab. Bryoth. eur. n. 1068.

Sull. et Lesq. M. bor. am. II ed. n. 136.

" var. abbreviata W. P. Sch. in Besch. Prodr, bryol mexic. p. 38 (nom.). - Am. sept. : Mexic.

"var. angustifolia Rehm. M. Afr. austr. n. 479.

a var. longiseta (Hpe.) Par. - Afr. : C. B. Sp.

B. cirrata var. longiseta Hpe. Symb, 1870, p. 268.

- Am. merid. : Brasil. aequinoct.

calceolifolia Spr. mss.

Tortula calceolifolia Mitt, M, austr, am, p. 157.

Terr. - Am. merid.: And, Quitens.

ealobolax C.M. in Engler's Bot. Jahrb. 1883,p. 80 et in Forchungsreise... Bot. p. 24.

Ster. Rupic. - Afr. : Ins. KKerguelen.

\& $v a r$, angustinervia $C . M$. l. c.

Ut typ. - Afr. : Eod. loc. (an stat. junior ?) 
calycina Schwaegr. Suppl. II, 1, p. 63, t. 119; Biid. Bryol. univ. I, pp. 541 et 828 ; C. M. Syn. I, p. 599.

Tortula calycina Hook, et Grev, in Brewster Edinb. Journ. I, p. 291.

T. flexuosa var. Hook. M, ex?

2. Arb. et terr. - As. : Ind. or. (fid. H. f. et W. Fl. Tasman. II, p. 174). Am. merid. : Chile. Pac. : Austral., N. Zeland, King's Isl., Tasman. « var. brevicaulis Hpe. in Linn. 1856, p. 204 (nom.) - Pac. : Austral. felix.

calyculosa (Mitt.) Jaeg. Ad. I, p. 266.

Tortula calyculosa Mitt. M. austr. am p. 156.

- Am. merid. : And. Quitens.

calymperifolia C. M. - B. javanica.

campylocarpa Tayl. in Lond. Journ. of bot. 1848, p. 187; C. M. Syn. 1, p. 619 .

Tortula campylocarpa Mitt. l. c. p. 159.

2.

Quitens.

- Am. sept. : Guatenuala. Am. merid. : And.

cancellata C. M. in Fl. 1873. p. 483.

2.

- Am. sept. : Texas.

canescens Br. in Fr. Müller M. Sardin. (1829): Bryol. eur. II (mon. p. 34) t. 158 ; C. M. Syn. I, p. 625 et II, p. 631 ; W. P. Sch. Syn. II ed., p. 201 .

Desmatodon canesceus Jur. Laubm. Oester. Ung. p. 133. Tortula canescens Mont. in Arch, de bot. I, p. 133, t. 4, f. 3 et
Syll, p. 40.

1. Loc. apric. ad rad. arb., rup. et terr. - Eur. : Occid. et merid. ; Anglia, vall, Rhen. As. : Caucas. Afr.: Alger.

Exs. : Rab. Bryoth. eur. n. 526, 788 et b.

caninervis (Mitt.) Jaeg. Ad. I, p. 30l,

Syntrichia caninervis Mitt. M. Ind. or., p. 39.

Tortula ruralis var. Wils, in Kew Jowrn. bot. IX, p. 322.

2 ? Rupic? - As. : Tibet. occident.

carnifolia C. M. et Kindb. in Mac. Cat.p. 52.

2 ? Ad rad. arb. et terr. - Am. sept. : Lac. Erie.

catillum C. M. in Linn. 1878-79, p. 329.

2.

- Am. merid. : Alp. Argent. subtropic.

cavifolia W. P. Sch. Suppl. Bryol. eur, fasc. III-IV et Syn. II ed. p.193.

B. concava W. P. Sch. in Fl. 1864, p. 210.

Pottia cavifolia var. barbuloides DR. in W. P. Sch. Syn. I ed. p. 122.

Pottia cavifolia var. gracilis Wils. Bryol. brit.; Rab. Bryoth. eur, n. 1051.

Pterigoneuron lamellatum Jur. Laubm. Oesterr. Ung. p. 97.

Tortula lamellata Lindb. Trichost. eur. p. 23.

1. Ad mur. et terr. argill. silic. - Eur.: Britann., German, sept., Eur. media tota, As. : Caucas.

Exs. : Rab. Bryoth. eur, n. 819.

characodonta C. M. in Linn. 1880-82, p. 431.

2.

- Am. merid. : Alp. Argentin, subtropic.

chimborazensis (Mitt.) Jaeg. Ad. 1, p. 295.

Tortula chimborazensis Mit'. M. austr. am. p. 163.

2.

- Am. merid. : M. Chimborazo. 
chionostoma Vent, in Rev. bryol. 1885, p. 64.

Syn. Rup. serpent. - Eur. : M. Rosa.

chloronotos Br. in Fr. Müller M. Sardin. (1829); Bryol. eur. 11 (mon. p. 18) t. 141 ; C. M. Syn. I, p. 598; W. P. Sch. Syn. II ed. p. 193.

Crossidium crassinerve Jur. Laubm. Oesterr. Ung. p. 128.

Tortula chloronotos Broth. Enum. M. Caucas. p. 42.

T. crassinervia de Not Spec. de Tortul. Ital. n. 15 et Syll. p. 176.

2. Muric. - Eur. :Rarior : Gall. austr., Sardin., ins. Melit, As, : Reg. transcaucas., Afghanistan. Af $r$.: Alger. Am. sept. : Colorado. Pac. :

N. Zeland. sept. (?).

Exs. : Rab. Bryoth. eur. n. 1272.

\& f. nivea Besch. Cat. M. Alger., p. 12.

Ut typ. - Afr, : Alger.

chloronotos Brid. - B. membranifolia.

chlorotricha (Broth. et Gelt.) Par.

Tortula chlorotricha $B$. et $G$. in Oef $v$... 1893, $p$.

2.

- Pac. : Austral. or. (Nov. Valesia).

chrysopila C. $M$. in Fl. 1885, p. 415.

1. Ster.

- Am. merid. : Fret. Magell,, Fuegia.

chrysopoda C. M. et Kindb. in Mac, Cat. p. 57.

2. Terr. - Am. sept. : Columb. brit.

circinalis C. M. - B, atro-virens.

circinatula C. M. et Kindb. l. c. p. 56.

2. Terr. - Am. sept. : Columb. brit.

cirrata $($ Rrid. - Dicranoweisia.

( Brid., Bryol. eur. - B. caespitosa.

cirrifolia W. P. Sch. Syn. II ed. p. 219.

Anoectangium Hornschuchianum Tayl. in Wils. Bryol. brit. p. 312.

B. hibernica Mitt.

2. Ad rup. h mid. - Eur.: Hibern.

Closteri Aust. in Coult. Bot. Gaz. I, p. 29 et IV, p. 30; Lesq. et Jam. Ster. Man. p. 127.

commutata Jur. in Verh. der K. K. sool. bot. Gesells. in Wien, 1874, p. 377 et Laubm. Oesterr. Ung. p. 119.

B. convoluta Jur. et Ung. in Ky, "die Insel Cypern. "

B. convoluta var, commutata Husn. Muscol. gall. p. 108.

B. convoluta var. densa Milde Bryol. siles p. 116.

B. convoluta var, sardoa C. M. Syn. I, p. 615 .

Trichostomum undatum W. P. Sch. Syn. II ed. p. 180.

2. Ad mur et rup. calcar. - Eur.: Westphal., Sardin., ins. Zante, Pyr. occid., Catalaun., ins. Balear. As. : Ins. Gypr.

comosa Dz. et Mk. M. frond, ined. Arch. ind.p. 46, t. 17 et Bryol. jav. 1, p. 103 ; C. M. Syn. I, p. 610 ; Mitt. M. Ind. or. p. 35.

B. arcuata G,iff. Not. p. 411 et Ic. pl. asiat. $I I$, t. $79, f . I$.

Trichostomum tortile Wils, in Kevo Jourve, bot. IX, p. $32 \mathrm{~L}$.

2. Terr. calcar. - As. : Ins. Amboine, Nepal., Sikkim, Khasia, Singapore, Java.

concava W. P. Sch. - B. cavifolia.

conferlifolia Mitt. - Desmatodon. 
conica $\left\{\begin{array}{l}\text { Brid. - B. agraria. } \\ \text { Spreng. - Ceratodon stenocarpus. }\end{array}\right.$

conotricha C. M. in Fl. I885, p. 416.

Syn. Lignic. - Am, merid. : Fuegia.

«var. fagicola C. M. l. $c$.

Arbor. - Am. merid. : Fuegia.

consanguinea (Thw. et Mitt.) Sb. in Jaeg. Ad. II, p. 673.

Tortula consanguinea Thw. et Mitt. in Journ. of the Linn. Soc, 1872, p. 300 .

2. Terr. - As. : Ceylan.

constricta Mitt. M. Ind. or. p. 33.

Tortula vinealis var. Wils, in Kew Journ. bot. IX, p. 322.

2. - As, : Nepal., Sikkim.

contorta Hpe. in C. M. Syn. I, p. 629.

Tortula contorta Mitt. M. austr, am. p. 169.

- Am. merid. : Chile.

convoluta Hedw. M. frond. I, p. 86, t. 32; Brid. Bryol. univ. I, p. 560; Bryol. eur. II (mon. p. 29) t. $154 ;$; . M. Syn. I, p. 614; W. P. Sch. Syn. II ed. p. 214.

B. purpurea Agh. (fid. Hsch. in Brid. l.c.)

B. setacea Hedw. Fund. M. II, p. 92.

Bryum convolutum Dicks. Crypt. fasc. II, p. 6 p.p.

Br. setaceum Vill. Pl. Dauph. III, p. 880. $\mathrm{Br}$. stellare, nitidum, pallidum, capsulis tenuissimis Dill. Hist. M. p. 381,
t. $48, f .41$.

Hypnum setaceum Weiss Crypt. Goett. p. 206.

Mnium setaceum Poll. Pl. Palat. III, n. $985, f$. 5 (ic. pessima).

Streblotrichum convolutum P. B. Prodr. pp. 27 et 89.

Tortula convoluta Schrad. Spic. Fl. germ. I, p. 66.

T. setosa P. B. l. c. p. 93 .

2. Ad terr. nud. vel herbos. - Eur.: Tota. As. : Japon., Jenissei merid., Caucas. Afr. : Alger, Am. sept. : Canada, M. Rupestr., Columb brit., ins. Vancouver, Wisconssin, Pensilv., Kansas, Calif.,
Alabama, etc.

Exs. : Drumm. M. bor. am. 1 ed. n. 138 (Tortula).

Faurie Pl. Japon. n. 167.

Mac. Canad. M. n. 76.

Rab. Bryoth. eur. n. 323 et b.

Sull. et Lesq. M. bor. am. II ed. n. 138.

* var. obtusata C. M. et Kindb. in Mac. Cat. p. 265.

Rupic. - Am. sept. : Ontario.

convoluta $\left\{\begin{array}{l}\text { Jur. et Ung. - B. commutata. } \\ \text { var. commutala Husn. - B. commutata. } \\ \text { var. densa Milde. - B. commutata. } \\ \text { var. sardoa C. M. - B, commutata. }\end{array}\right.$

cordata Lindb. - Didymodon.

costa-ricensis Ren. et Card. in Bull. Soc. roy. bot. Belg. 1892, I, p. 154.

2. Ad lapides. - Am. sept. : Costa-Rica.

costata (Mitt.) Jaeg. Ad. I, p. 281.

Tortula costata Mitt. M. austr. am. p. 159.

- Am. merid. : And. Quitens. 
crassinervia Tayl. in Linn. 1853, p. 492 (nom.) : Milt. in Handb. of N. Zeal. Fl. p. 447. Syn. - Pac. : N. Zeland. centr.

crenata (Mitt.) Jaeg. Ad. I, p. 289.

Tortula crenata Mitt. M. austr. am. p. 169.

2 ? - Am. merid. : And, Quitens.

crinita Schultz. - B. pilifera.

crispa Hedw. - Dicranella Schreberi,

crispata Hpe. - Streptopogon.

crispifolia (Mitt.) Jaeg. Ad. I, p. 27 b.

Tortula crispifolia Mitt. in Handb. of N. Zeal. Fl. p. 419.

crispula Hpe. - B. subulifolia.

crocea $\left\{\begin{array}{l}\text { Brid. - B. paludosa. } \\ \text { var. paludosa Roehl. - B. paludosa. }\end{array}\right.$

Crügeri Sonder in C. M. Syn. I, p. 618 et II, p. 630 ; Lesq. et Jam. Man. p. 122.

Tortula Crügeri Mitt. M. austr. am. p. 150.

2. Terr. - Am. sept. : Florid. et Ludovic. (ster.) ; Cuba, ins. S. Vincent, Barbades. Am. merid. : Ins. Trinitat., Venezuela, And. Quitens. et Peruv.

cucullatifolia C. M. in Linn. 1878-79, p. 331 .

2.

- Am. merid. : Alp. Argentin. Tucuman.

cucullifera (Mitt.) Jaeg. Adl. I, p. 273.

Tortula cucullifera Mitt. l. c. p. 155.

2.

- Am. mevid. : And. Quitens, et Peruv.

cuneifolia (Dicks.) Brid. Bryol. univ. I, pp. 549 et 829 (excl. syn.); Bryol. eur. II (mon. p. 31) t. 156 ; C. M. Syn. I; p. 628; W. P. Seh. Syn. II ed. p. 198.

B. Dicksoniana Sehultz Nor. Act. XI, I, p. 224, t. 34, f. 33.

B. mutica Brid. Mant. M. p. 92.

B. Solmsii W. P.Sch. (fid. Husn. Muscol. gall, p. 101).

Bryum cuneifolium Dicks. Fasc, III, Pl. corypt. p. 7.

$\mathrm{Br}$. humile, pilis carens, viride et pellucidum Dill. Hist. Mr.p. $356, t, 45, f .15$.

Desmatodon cuneifolius Jur. Laubm. Oestery. Ung. p. 133.

Tortula acuminata Brid. M. Recent. II, I. p. 188.

Tortula cuneifolia Roth Tent. Fl. Germ. III, I, p. 213.

T. mutica Brid. Sp. M. I, p. 251.

T. spathulaefolia de Not. Sp, de Tortut, ital, n. 10 et Syll. p. 174.

1. Muric. et in loc. humid. - Eur. : Occid, et merid.; Britann. A fr: : Alger., Canar. A m. sept. : Calif.

Exs. : Bourgeau PI, Can, n. 1130.

Rab. Bryoth. eur. n. 821 (Tortula) et 1072.

cuneifolia W. et M. - B. muralis var. aestiva.

curta Hedw. - Leptotrichum tortile var: pusillum.

curvipes C. M. in Linn. 1878-79, p. 344.

2. - Am. merid. : Alp. Argentin. sub́tropic.

curvirostris Lindb. - Gymnostomum. var. laeviuscula Linib. et Arn. - Gymnostomam curvirostro var.
loviusculum. 
cuspidata (Hook. f. et Wils.) Jaeg. Ad. II, p. 297.

Syntrichia princeps Mitt. in Journ. of the Linn. Soo.p.p.

Tortula cuspidata H. f. et W. Fl. Tasman. II, p. 175, t. 172. f. 9.

Syn.

- Pac. : N. Zeland., Tasman.

cuspidata Schultz. - B. unguiculata var. cuspidata.

cuspidatissima C. M. in Engler's Bot. Jahrb. 1883, p. 84 et in Forchungs-

2. reise...p. 42.

cylindrica (Tayl.) W. P. Sch. Syn. II ed. p. 208.

B. Beecheyi Lesq. ; Watson Bot. Calif. II, p. 372.

B, vinealis var. cylindrica Boulay M. Fr. p. 430.

B. vinealis var, flaccida Bryol. eur. II (mon. p. 24); Rab. Bryoth. eur. n. 982 ; Sull. et Lesq. M. bor. am. II ed. n. 131.

Tortula cylindrica Lindb. Adnot. bryol. 1865.

T. insulana de Not. Spec, de Tortul. ital. n. 38 et Syll. p. 180.

T. vinealis de Not. Epil. p. p.

Zygotrichia cylindrica Tayl, in Mac-Kay Fl.hibern. II p. 26.

2. Lignic. et ad terr. arenos. humid. - Eur.: Scandin., Britann., Voges., Sardin. As. : Caucas. Afr. : Alger. Am. sept. : Columb. brit., fret. Behring, ins. Vancouver, Washington, Oregon, Montana, Calif.

Exs. : Mac. Canad. M. n. 81 p.p.

Rub. Bryoth. eur. n. 982, 1274.

cylindrica $\left\{\begin{array}{l}\text { Mac. p.p. - B. tortellifolia. } \\ \text { Wils. - B. Brebissoni. } \\ \text { var, sinuosa Husn. - Didymodon. } \\ \text { var. vinealis Lindb. - B. cylindrica. }\end{array}\right.$

cylindrothesa (Mill.) Jaeg. Ad. I, p. 264.

Tortula cylindrotheca Mitt. M. Ind. or. p. 50.

Trichostomum bombayense Wils. in Kew Journ. bot. IX, p. 322.

2. - As. : Sikkim.

danica Lge. - B. pulvinata.

decidua (Mitt.) Par.

Tortula decidua Mitt. M. austr: am. p. 171.

2. Arbor. - Am. merid. : And. Nov, Granat. et Quitens.

decidua C. M. - B. uruguensis.

declivium C. M. in Linn. 1880-82, p. 425.

Fl. et fr. ign. Arenic. - Am. merid. : Argentin. Buenos-Ayr.

decolorans Hpe. in Ann. sc. nat. sér. V, III, p. 348.

Tortula decolorans Mitt. M. austr, am. p. 149.

- Am. merid. : And, Nov. Granat.

decursivula Kindb. in Mac. Cat. p. 264.

Ster. Rupic. et terr. - Am, sept. : M. Rupestr.

densifolia Hook. f. et Wils. in London Journ. of bot. 1844, p. 543; C. M. Syn. I, p. 631 et $I I$ p. 632.

2.

- Am, merid. : Ins. Maclov.

denticulata Wils. mss.; Mitt. in Lond. Journ. of bot. 1851 , p. 50 ; C. M. Syn, II. p. 631.

Toriula denticulata Mitt. l. c. p. 168.

2.

- Am. merid. : And. Quitens. 
depressa Sull. - B. flagellaris.

desertorum (Broth.) Par.

Tortula desertorum Broth. in Bot. Centralbl. 1888, n. 14.

2. Arenic. - As.: Transcasp.

deusta Brid. - Didymodon luridus (1).

Decksoniana Schultz. - B. cuneifolia.

Dieckei Broth, in Roell M. bor, an, exs.

- Am. sept.: Washington.

dimorpha C. M. in Rehm. M. Afr. austr. n. 102.

Ster, - Afr: : C. B, Sp.

dioritica C. M. in Linn. 1875, p. 402.

Ster. Rupic, - As, M. orient. mar. Erythraei.

domestica Brid. - B. agraria.

Donnellii (Aust.) Lesq. et Jam. Man. p. 128.

Tortula Donnellii Aust, in Coult. Bot. Gaz. III, p. 31 .

1. Terr. - Am, sept. : Florid.

Drummondii (Mitt.) Jaeg. Ad. I, p. 294.

B. fragilis Wils. in Bryol. ewr. VI, t. 639; W. P. Sch. Syn. II ed., p. 219 ; Un. itin. 1863, n. 21 .

Campylopus Hartmanni W. P. Sch. mss.; C. et R. Hartm. in Thed. Nya bot. notis. 1855, p. 48.

Didymodon fragilis H. f. et W. in Diumm. M. bor. am. Ied., n. 127.

Mollia fragilıs Lindb.

Tortula Drummondii Mitt. M. Ind. or. p. 27.

T. fragilis Wils. in Lond. Journ. of bot. III, $p .437$.

T. tortuosa var. inclinata Drumm. M. bor. am, I ed., $n$. 142.

Trichostomum fragile C. M. Syn. I, p. 586; Sull. et Lesq. M. bor. am. II ed, n. 149.

2. In terr. uligin. et fissur. rup. - Eur.: Spitzberg, ins. Ursorum, Scandin., Scot,, Hibern., Alp. helvet., Rhöngeb., M. Pisan. As. : Jenis sei infer., Caucas, occid, et centr., Sikkim. Am, sept. : Groenland, lac. Super., M. Rupestr. et Adirondack, New York, New Jersey.

Exs. : Rab. Bryoth, eur. n. 789.

«var. setacea R. Farneli M. prov. Pavia, 1891, p. 19.

Ster. Rup. apric. - Eur, : M. Pavia $\left(1700^{\mathrm{m}}\right)$.

dubia Brid. - B. unguiculata.

duriuscula (Wils.) Jaeg. Ad. I, p. 301.

Tortula duriuscula Mitt. M. Ind. or. p. 27.

Didymodon duriusculus Wils, in Kew Jown. bot. IX, p. 28.

2.

- As. : Ceylan,

Duseni C. M. in Dusen M. Camer. n. 120.

- Afr.: M. Cameroon.

Eglingii Schlieph. in Fl. 1887, p. 222.

2. $\quad-A m$. sept.: Tennessee,

Ehrenbergiana $C . M$. Sy,n I, p. 636.

2.

- Am. sept. : Mexic.

(1) B diaphana Brid. Bryol. univ. I, p. 577.

An Grimmia ? C. M. Syn, I, p. 615). Deleatur, 
elata DR. et Mont. Fl. Alg. ined. ; C. M. Syn. I, p. 620.

Tortula elata Mont. Syll. p. 41 .

2. Rupic. - Afr.: Alger. Am. sept. : Washington, Oregon, Calif.

elongata Wils, mss.; Mitt. in Lond. Journ. of bot. 1851, p. 51 ; C. M. Syn. 11, p. 630 .

Tortula elongata Mitt. M. austr. am. p. 164. 2.

emarginata Dz. et Mk, M. frond. ined. Arch. ind. p. 50, t. $20 ; C . M$. Syn. I, p. 626.

Tortula emarginata Mitt. in Trans. of the Linn. Soc. 1891, p. 160.

1. - As. : Japon.

Enderesii Garov. $\left\{\begin{array}{l}\text { - B. flavipes (Jur.) } \\ - \text { B. aciphylla? (W. P. Sch.) }\end{array}\right.$ ericetorum Brid, - B. unguiculata var, patagonica. erosa Hpe. mss. ; C. M. in Bot. Zeit. 1862, p. 348.

2. - Am. merid. : Venezuela.

erubescens C. M. in Nuov. giorn. bot. ital. 1872, p. 14.

2. - Afr.: Abyss.

erythrodonta Tayl. - Streptopogon.

erythroneura W. P. Sch, in Breutel M. Capens. ; Jaeg. Ad. I, p. 305. - Afr. : C. B. Sp.

erythropoda W. P. Sch. in Besch. Prodr, bryol. mexic. p. 36. - Am. sept. : Mexic.

enbryum C. M. in Fl. 1879, n. 24 .

Ster. - Afr. : M. Kenia.

eucalyx W. P. Sch. in Breutel M. Capens. ; Jaeg. Ad. I, p. 305. - Afr.: C. B. Sp.

eutrichostomum C. M. in Rehm. M. Afr. austr. n. 91 . - Afr.: C. B. Sp.

excavata (Mitt.) Jaeg. Ad. I, p. 275.

Tortula excavata Mitt. M. austr, am. p. 154.

2 . - Am. merid. : And. Quitens.

excurrens Broth, in Bot. Centralbl. $1888, n .14$.

2. Rup. calcar. $-A s$. : Transcasp.

fallax Hedw. M. frond. I, p. 62, t. 24; Brid. Bryol. univ. I, p. 556; Bryol. eur. II (mon. p. 23) t. 147; C. M. Syn. I, p. 616; W. P. Sch. Syn. II ed.p. 205.

B. fallax $\beta$ flavescens Brid. Bryol, univ. $l$, c.

B. fallax $\gamma$ reflexa Brid, $l, c$.

B. flavescens Brid. Mant. M. p. 92.

B. nervosa Schultz Fl. Starg. p. 305 (cxcl. syn. Brid.)

B. reflexa Brid. Mant. M. $l$. 0 .

Bryum fallax Dicks. Fasc. III Pl. crypt. p. 5.

Br. flavescens Dicks. Fasc. II, p. 4, t. 4, f. 5 .

Br. imberbe L. Mant. Pl. II, p. 309 .

Br. tenue, imberbe et pallidum, foliis crebrioribus Dill. Hist. M. p. 382 , t. $48, f .46$.

Dicranum pellucidum Dirumm. M. bor, am. I ed. $n .108$ (fid. Kindb.)

Mollia fallax Schrank Baiers. Fl. II, p. 458 , 
Tortula fallax Brid. Sp. M. I, p. 255.

T. flavescens Brid. Sp. M. I, p. 263.

T. imberbis $\mathrm{Sm} . \mathrm{Fl}$. brit. $I I I, p .1261$.

T. reflexa Brid. Sp. M. I, p. 255 .

2. Ad mur. et terr. humidiusc., feré ubique. - Eur. . In reg. campestr. vulgatiss. As. : Jenissei med. et infer., Caucas. A $r$. : Alger. Am. sept. : Groenland, Canada tot., M. Rupestr., Columb. brit., ins. Vancouver, reg. sept, occid. et orient.

Exs. : Drumm. M. bor. am. I ed. n. 139 (Torlula).

«var. brevicaulis Bryol. eur. et C, M. ll. cc.

B, brevicaulis Schwaegr. Suppl. I, I, p. 126, t. 32 ; Brid. Bryol. univ. I, p. 551 .

Tortula brevicaulis var. $\gamma$ Hook. et Grev, in Brewster Edinb. Journ. I, p. 300 .

Ut typ. - Euv. et Am. sept. : C. typ.

Exs. : Sull, et Lesq. M. bor. am. II ed. n. 129.

«var. brevifolia Schultz Rec. de Barbula p. 2", t. 33, f. 21 B; Bryol. eur. et C. M. ll. cc.

B. brevifolia Brid. Bryol, univ. I, p. 55.

Bryum brevifolium Dicks. Fasc. II Pl. crypt., p. 4.

Br. palustre, brevifolium, capsulis nigricantibus Dill. Hist. M. p. 377, t. 47, i. 39.

Tortula brevifolia Sm. Fl. brit. III, p. 1259.

Ut typ. - Eur. : Septentr. A $m$. sept. : Passim.

Exs.: Rab. Bryoth. eur. n. 1174.

Sull. et Lesq. M. bor. am. II ed. n. 122 (false sub, var. brevicauli).

fallax Sull. - B. subfallax.

fallas $\left\{\begin{array}{l}\text { var. flavescens Brid. - B. fallax. } \\ \text { var. reflexa Brid. - B. fallax (fid. C. M.). } \\ \text { var reflexa Brid. - B. recurvifolia (fid. Lindb.). } \\ \text { var. Turneri Brid. - Didymodon rubellus. } \\ \text { var. vinealis Hiib. - B. vinealis. }\end{array}\right.$

fastigiata Sehultz. - B. unguiculata var. fastigiata.

Fendleri C. M. in Linn. 1878-79, p. 483.

2.

- Am. merid.: Venezuela.

ferruginea W. P. Sch. in Besch. Prodr. bryol. mexic. p. 37.

- Am. sept. : Mexic.

filaris C. M. Bryol. auslr. Georg. p. 33.

Syn. Rupic. - Am. merid. : Austr. Georg.

Fiorii Vent. in Rev. bryol. 1885, p. 66.

2. Coll. arenac. - Eur.: Ital. (Modena).

flaccidiseta $L t z$. Moosstud. p. 161.

2.

- Am. sept. : Mexic.

flagellaris W. P. Sch. in Ann. sc. nal. II sér. VI, p. 146, t. 10;C. M. Syn. I, p. 642 .

B. depressa Sull. in U. St. Exxpl. Exped. (Wilkes) 1859, p. 5.

Tortula flagellaris Mitt. M. austr. am. p. 150.

2.

- Am. merid. : Chile, fret. Magell.

flavezcens (Hook, el Grev.) Brid. Bryol. univ. I, p. 613.

B. fuscescens Wall. Cat. $n, 7567$.

Tortula flavescens $H$. et Gr. in Brewster Edinb. Journ. I, p. 297, t. 12 ; Mitl. M. Ind. or, p. 29.

Terr. argill, - As. : Nepal. 
flavescens Brid. - B. fallax.

flavipes Bryol. eur. II (mon. p. 30), t. 155ं ; C. M. Syn. I, p, 62l ; W.P. Sch. Syn. II ed., p. 214.

B. Euderesii Garov. Enum. M. Austr. (fid. Jur.)

B. lutescens Laurer in sched.

Tortula flavipes Wils. Bryol. brit. p. 128.

2. Terr. humos. glareos, - Eur. : Alp. Bavar., Austr., Comens. : Francon.; deest in Britann. et in Scandin.

Exs. : Rab. Bryoth, eur. n, 624, 790 .

flexifolia Hpe. in Linn. 1859-60, p. 496.

2. Terr. - Am. sept. : S. Nevada Calif,, Oregon.

Exs. : Sull. et Lesq. M. bor, am. II ed. n. 132.

flexifolia Mac, - B. tortellifolia (1).

fleximarginata Hpe. et C. M. in Linn. 1853, p. 493.

2 .

- Pac. : Austral. fel.

flexuosa Scluuttz Rec. de Barbula p. 16, t. 33; Brid. Bryol. univ. I, p. 573; C. M. Syn. I, p. 609.

B. Hookeri Steud. Nom. crypt. p. 72.

Tortula flexuosa Hook. M. ex, t. 125.

$$
\text { - Afr.: C. B. Sp. }
$$

flexuosa Brid. - Cf. B. flexifolia ej. (1)

fontana C. M. Bryol. austr. Georg. p. 32.

Ster. Aquat. - Am. merid. : Austr. Georg.

fragilis Tayl. in Lond. Journ. of bot. 1847, p. 334 ; C. M. Syn. I, p. 634.

Tortula fragilis Mitt. M. austr. am. p. 172.

2 ?

- Am. merid. : M. Pichincha.

fragilis $\left\{\begin{array}{l}\text { Wils. - B. Drummondii. } \\ \text { var. setacea R. Farneti. }\end{array}\right.$

frigida C. M. in Bot. Zeit. 1858, p. 163.

2. Turfic. - Am. merid. : Summ. And. Peruv.

fuegiana (Mitt.) Jaeg. Ad. I, p. 301.

Syntrichia fuegiana Mitt. in Journ. of the Linn. Soc. 1859, p. 71.

Tortula fuegiana Mitt. M. austr. am. p. 174.

2. Arenic. - Afr. : Ins. Kerguelen? (2) Am. merid. : Fret. Magell., Fuegia, ins. Maclov.

Funkiana Schultz. - B, paludosa var. Funkiana.

fusca C. M. Syn. I, p. 610 .

Tortula fusca Mitt. l. c. p. 610.

2.

- Am. merid.: Chil.

fusca W. P. Sch. - B. Mandoni.

(1) flexifolia Brid. Bryol. univ I, p. 560.

B. flexuosa Brid. Mant. M. p. 93.

B. scoparia Schultz in Nov. Act. Phys. Med. Acad. Cresar, XI, II, p. 718.

Tortula flexuosa Brid. Sp.M. I,p. 256.

a An Macromitrium? ” (C M. Syn. I, p. 645,

(2) Cf. B. semirubra, 
fuscescens Wall. - B. flavescens.

fuscinervia (Mitt.) Jaeg. Ad. I, p. 275.

Tortula fuscinervia Mitt. l.c. p. 154.

2.

- Am. merid. : Ins. Chiloë.

fusco-mucronata Jaeg. - Desmatodon.

fuscula C. M. in Linn. 1878-79, p. 343.

Fl, et fr. ign.

- Am. merid. : Argentin. Cordob, et subtropic.

galeata C. M. l, c. p, 330 .

Fl, et fr, ign.

- Am. merid. : Alp, Argentin Saltens.

gangetica $C . M$. in op. cit. 1871-73, p. 177.

- As. : Bengal.

geheebiopsis C. M. - Geheebia Mülleri.

geniculata Mont. in Ann. sc. nat. 1815, p. 107; C. M. Syn. I, p. 620.

Tortula geniculata Mont. Syll. p. 39; Mitt. op. cit. p. 161.

2.

- Am. merid. : Chil.

gigantea Funk. - Geheebia cataractarum.

glacialis Kze. in Poeppig Coll. pl. Chil. III, n. 272; C. M. Syn. I, p. 631.

Tortula glacialis Mitt. l. c. p. 173.

2. Rupic. - Am. merid: And, Quitens et Chilens.

glacialis $\left\{\begin{array}{l}\text { Besch. }- \text { B. amphidiacea ? } \\ \text { Br. et Sch. -- B. subspathulata. }\end{array}\right.$

glaucescens Hpe. in Linn. 1863, p. 128.

Tortula glaucescens Mitt. l. c. p. 152.

2 ? Rupic. - Am, merid.: And. Nov. Granat.

glaucescens W. P. Sch, - B. boliviana.

Glaziowii Sb. - B. lurida.

goniospora C. M. in Rev. bryol. 1887, p. 57 (nom.)

- Pac. : Nov-Caledon.

Goudotii Hpe. in Ann. sc. nat. V sér., III, p. 350.

Tortula Goudotii Mitt. l. c. p. 171.

2. Arbor. - Am, merid. : And. Nov. Gran.

gracilenta Mitt. M. Ind. or. p. 35.

Tortula flavescens var. Wils, in Kev Jous, not. IX, p. 322.

2.

- As. : Himalaya occid.

gracilenta $\mathrm{Hpe},-\mathrm{B}$. lurida.

gracilescens W. P. Sch. in Besch. Prodr. bryol, mexic. p. 34.

- Am. sept.: Mexic.

fraciliformis W. P. Sch. in op. cit, p. 35.

- Am. sept. : Mexic.

g! acilis (Schleich.) Schwaegr. Suppl. I, 1, p. 125, t. 34; Brid. Bryol. univ. I, p. 536; Bryol. eur. II (mon. p. 22) t. $145 ;$ C. M. Syn. I, p. 609; W. P. Sch. Syn. II ed.p. 210.

B. acuta Brid. l. c. p. 554 .

B. rectifolia Tayl. in Lond. Journ. of bot. 1846, p. 49.

Tortula acuta Brid. Sp. M. I, p. 265 . 
T. gracilis Schleich. Cat. pl. helv, p. 30 .

T. rectifolia Mitt. M. austr. am. p. 158.

2. In glareos. calc. et arenos, argill. - Eur. : Media et precip. merid. As. : Cancas. Af. : Alger. Am. sept.: M. Rupestr., Vermont, Calif., Guatemala. Am. merid. : And. Nov. Granat. et Quitens.; Peruv.

Exs. : Rab. Bryoth. eur. n. 669.

«var. viridis Bryol. eur., C. M. et W. P. Sch. $l l$. cc.

Tortula fallax var, stricta de Not. Spec, de Tortul, ital. n. 26

T. viridis fallax var. Hook. et Grev. in Edinb. Journ. of sc. I, p. 300.

Ut typ. ... Eur. : Meridion. Afr. : Alger.

Exs.: Rab. Bryoth. eur, n. 818.

var. squarrulosa Kindb. - B. subicmadophila.

gracitis Sull. - B. subulifolia.

graminicolor C. M. Syn. I, p. 611 .

B. atiantica $W$. P. Sch. in sched. (fid. C. M.)

Tortula graminicolor Mitt. l. $c, p .160$.

2. Terr. - Am. merid. : Chile.

graminicolor Besch. - B. orizabensis.

gregaria (Mitt.) Jaeg. Ad. I, p. 272.

Tortula apiculata Wils. in Kew Journ. bot. IX, p. 322.

T. gregaria Mitt. M. Ind. or., p. 29.

Trichostomum brachyphyllum Wils. l. c. p. 321.

2.

- As. : Nepal, or., Tibet.

grimmiacea C. $M$. in Linn: 1880-82, p. 427.

2.

- Am. merid. : Argentin. Buenos Ayr.

grisea (Jur.) Boul. M. Fr. p. 434.

B. membranifolia Garov. Enum. M. Austr. 1840, p. 14.

B. membranifolia var. grisea. Vent, in Husn. Muse. Gall. p. 101.

Crossidium grise um Jur. Laubm. Oesterr. Ung. p. 128.

Desmatodon griseas Jur. in Verh. der K. K. zool. bot. Gesells. in Wion, 1864, p. 399.

Tortula squamigera var. pottioidea de Not.

1. Rup. dolomit. - Eur. : Helvet. oceid., Tirol., Istria, Austr. inf. As. : Transcaucas, , Syria.

Guepini (Bryol. eur.) W. P. Sch. Syn. II ed. p. 197.

Desmatodon Guepini Bryol, eur. II (mon. p. 8) t. 133.

Trichostomum Guepini C. M. Syn. I, p. 590.

1. In terr. argill. et coll. schist. - Eur. : Rariss. : Gall. sept. (Lille), occid. (Andegav.) et merid. (le Vigan, Hyères). Am: sept. :

Hampeana Par.

B. brachyphylla Hpe. in Linn. 1859, p. 625.

- Pac. : Austral, orient.

hastata Mitt. l. c. p. 31 .

T. comosa? Wils l. c.

2. -As.: Sikkim.

Haussknechtii Jur. et Milde Beitr.... p. 593.

2 ? Rupic. $-A s$, : Persia austr. 
Henrici Rau in Bull. of the Washb. Coll. Lab. I (1886), p. 172.

Ster. Rupic. - Am. sept.: Kansas (1).

hibernica Mitt. - B. cirrifolia.

Hildebrantii C. M. in Linn. 1876, p. 294.

Ster.

- Afr.: Somal.

himantina Besch. in Ann. sc. nat. 1893, p. 337.

2.

Exs.: Faurie n, 41.

Hookeri Steud. - B. flexuosa.

Hornschuchiana Schultz Rec. de Barbula p. 25, t.33, f. 25; Bryol. eur. II (mon. p. 28) t. 148; C. M. Syn. I, p. 608; W. P. Sch. Syn. II ed. p. 211 .

B. revoluta W. et M. Bot. Taschb. p. 210.

B. revoluta $\beta$ Hornschuchiana Brid. Bryol. univ. I, p. 572.

Tortula Hornschuchiana de Not. Syll. p. 179.

T. revoluta Hook, et Tayl. Muscol. brit. I ed., p. 33, t. 12.

2. In loc. glareos, argill, - Eur.: Med, et merid.; Dania. Afr. : Alger, Choa.

Exs, : Rab. Bryoth, eur, n. 671 .

horridifolia C. M. et Kindb. in Mac, Cat. p. 57.

Ster. Rup. humid, - Am. sept. : Colımb. brit.

humida (Mitt.) Jaeg. Ad. I., p. 282.

Tortula humida Mitt. M. austr. am. p. 162.

2. $\quad-$ Am. merid. : And. Quitens.

humilis Hedw. - B. caespitosa.

Husnoti W. P. Sch. in Besch. Fl. bryol. Antil. fr. p. 25.

1. Muric. - Am. sept. : Guadel., Martinic.

Exs. : Husn. n. 139.

hyalinotricha C. M. in Engler's Bot. Jahrb. 1833, p. 80 el in Forchungs reise.... p. 23.

Ster. Rupic. - Afr. : Ins. Kerguelen.

hyperborea Hook, in sched.; Jaeg. Ad. I, p, 305. - Pac, : Nov. Caled.

hyperborea $\left\{\begin{array}{l}\text { R. Brown? Brid. - B. mucronifolia. } \\ \text { Mont.- B. magellanica. }\end{array}\right.$

icmadophila Bryol.eur. II (mon.p. ) t. 146; C. M. Syn. I, p. 614 et II, p. 630 ; W. P. Sch. Syn. Il ed. p. 211.

Tortula icmadophila Lindb. Trichost. eur, p. 41.

2. Ad rup. cataract. - Eur. : Norveg. (Dovre), Pingzgov.; Arvern. As. : Caucas.

Exs. : Un. itin. 1863, n. 22, 23.

inaequalifolia Tayl. in Lond. Journ. of bot. 1816, p. 49, t. XVD; C. M. Syn. I, p. 616.

Tortula inaequalifolia Mitt. M. austr. am. p. 153.

2.

- Am. merid. : And. Quitens.

incerta Schum. - B. unguiculata.

(1) * Probab. Pharomitrium subsessile n. (Ren. et Cars. in Bot. Gaz. 1892, p. 82.) 
inclinans W. P. Sch. in Besch. Fl. bryol. Réunion, etc. p. 55. - Afr. : Ins. Franciae.

irrclinata Schwaegr. Suppl. I, I, p. 131, t. 33; Brid. Bryol. univ. I, p. 575 ; Bryol. eur. II (mon. p. 25) t. 150 ; C. M. Syn. I, p. 600 ; W. P. Sch. Syn. II ed.p. 217.

B. angustifolia Brid. l. e. p. 568 .

B. nervosa Brid. Mant. M. p. 95.

B. nervosa $\beta$ inclinata ej. $l$. $c$.

Mollia inclinata Lindb.

M. tortuosa var. inclinata Lindb.

Tortula curvata Schleich. in sched.

T. inclinata Hedw. $f$. in W. et $M$. Beiti. I, p. 123, t. 5 .

T. nervosa Brid. Sp. M. I, p. 262 (excl. syn.)

2. In glareos. et ad fluv. ripas. - Eur.: Med, (ster. in Scandin, et Britann.) - As. : Caucas, occ. et centr.

Exs.: Rab. Bryoth. eur, n. 421.

" $f$. acuminata R. Favneti M. prov. Pavia, 1891, p. I7.

Ut typ. - Eur. : Ital. super. (Pavia).

" var, brachypoda Besch. Cat. M. Alger, p. 14.

Ut typ. - Af 1 . : Alger.

«var. leptotheca Brid. Bryol. univ. I, p. 833.

T. inclinata $\beta$ Hook, et Grev, in Brewster Edinb. Journ. I, p, 298.

$$
\text { - Afr. : C. B. Sp. }
$$

inclinatula C. M. et Kindb. in Mac. Cat. p. 50.

2. Terr. et aren. - Am. sept. : Columb. brit.

Exs. : Mac. Canad, M. n. 512.

incrassata Lindb. in Broth. Enum. M. Cauc. p. 57.

Ster. Ad. rup. trachyt. - As. : Caucas, centr.

indica Brid, - Trichostomum orientale.

inermis Br. mss, ; W. P. Sch. Coroll. bryol. eur. p. 35 et Syn. II ed. p. $221 ;$; . M. Syn. I, p. 624.

B. subulata $\beta$ inermis Bryol. eur. II (mon. p. 3) tt. 161 p.p. et 167.

Desmatodon inermis Mitt. M. Jnd. or p. 37.

Syntrichia subulata $\gamma$ inermis Brid. Bryol. univ. I, p. 581.

Tortula inermis Mont. in Arch. de bot. I, p. 136, t. 4, f. 4 et Syll. p. 40.

T. subulata var. inermis Spr, in Ann. Mag. nat. hist. II ser., III, p. 376.

1. Terr,, muric. et in fissur. rup. - Eur. : Merid. : vall. Rhen., Gall. merid, Hispan. As. : Caucas. occid. et centr., Persia, Tibet. occid, Afr.: M. Sinaï, Alger. Am. sept.: Calif.

Exs.: Rab. Bryoth, eur. n. 456.

Sull, et Lesq. M. bor, am. II ed, n. 142.

Un. itin. 1863, n. 25.

inflexa (Duby) C. M. Syn. I, p. 605 ; Bryol. jav. I, p. 102, t. 82.

T'ortula inflexa Duby in Moritsi Verz. d. Zolling. Pfl. p. 33.

2. Ad terr. et sax. humid. - As. : Java.

insidiosa Milde. - B. rigidula.

intermedia W. P. Sch. Syn. JI ed. p. $2: 29$.

B. rupestris $\beta$ ruralis Bryol. eur. II (mon. p. 42); C. M. Syn. I, p. 640; Rab. Bryoth. eur. n. 667, 1070.

Syntrichia intermedia Brid. Bryol. univ. I, p. 586.

S. montana Nees in Fl. 1819, I, p. 301. (fid. Lindb. M. Sc.)

Tortula intermedia Berk. Handb, of brit. M. p. $251 ;$ Rab. l, c, n. 1016 , 
T. montana Lindb. M. Scand. p. 20, n. 170.

T. ruralis var, I Spr. in Ann. Mag, nat, hist. II ser., III, p. 375.

T. ruralis $\delta$ crinita de Not. Speo. de Tortul. ital. n. 5 et M. Ital. I, p. 36, t. 15.

T. ruralis $\beta$ minor Wils. Bryol. brit, p. 134.

T. ruralis $\beta$ rupestris Wils, l. c. Suppl.

2. Ad rup. et in mur. calcar. -- Eur. : Med. et merid. ; Suecia, Britann. As. : Minor, Caucas., Persia. Afr. : Alger., C. B. Sp. Am. sept.: Washington, Montana.

Exs. : Rab. Bryoth. eur. n. 1016 b, 1069.

« var. calva W. P. Sch. l. c.

B. ruralis var. calva Bryol. eur. l. c.

Ut typ. - Eur, : Suec, merid., Francon., Gall. orient.

var. pulvinata Husn. - B. pulvinata.

inundata (Mitt.) Jaeg. Ad. I, p. 270.

Tortula inundata Mitt. M. austr. am. p. 161.

2. Rupic. - Am. merid. : And. Quitens., Monte Video.

Ilsigohnii Hpe. - B. muralis.

Jamesoni Tayl. in Lond. Journ. of bot. 1846, p. 48; C. M. Syn. I. p. 581.

Didymodon Jamesoni Jaeg. Ad. I, p. 213.

Tortula Jamesoni Mitt. l, c. p. 162.

2. Loc. humid. - Am. merid, : And, Quitens et Boliv.

Exs. : Mandon Pl. boliv. n. 1623.

javanica Dz. et Mk. M. frond. ined. Arch. ind.p. 47, t. 18; Bryol. jav. 1, p. $101 ;$;. M. Syn. I, p. 605.

B. calymperifolia C. M. in Linn. 1844, p. 703.

Desmatodon javanicus Mitt. M. Ind. or, p. 38 .

2. Terr. - As. : Nepal, Himalaya, Celebes, Java،

Jooriana C. M. in Bull. Torr. bot. Club V, p. 49 el in Fl. 1888, p. 77.

B. Ravenelii Aust.?

2. Terr. argill. - Am. sept. : Carol. infer. ? Florid., Ludovic.

jugicola (Duby) Par.

B. cirrafa ? (fid. Hpe, in Fl. 1880, n. 21).

Tortula jugicola Duby Choix de M. exot. 1880, p. 2, t. 3, f. 2 .

- Am. merid. : M. Brasil. austr. or.

juniperoidea C. M. in Linn. 1880-82, p. 429.

Fl. et fr. ign. $\quad-$ Am. merid. : Alp. Argentin. subtropic.

khasiana (Mitt.) Jaeg. Ad. 1, p. 263.

Tortula khasiana Mitt. M. Ind. or. p. 29.

Ster.

$$
\text { - As. : Khasia subtropic. }
$$

Knightii (Mitt.) Jaeg. Ad. I, p. 281.

Tortula caespitosa var, Hook. f. et Wils. Fl. N. Zeal. II, p. 70.

Tortula Knightii Mitt. in Journ. of the Linn. Soc. 1859, p. 71 ; Fl. Tasman. II, p. 174, t. 172, f. 11; Handb. of N. Zeal. Fl. p. 420.

- Pac. : Nov. Zeland., Tasman.

Kunzeana C. M. in Linn. 1843, p. 586 et Syn. I, p. 630 .

Tortula Kunzeana Mitt. M. austr. am. p. 169.

T. marginata Kze, in Poeppig pl. Chil. $n .19$.

2. Terr, - Am. merid, : Chil, austr. 
Kurzii C. M. in Linn. 1872, p. 177.

2.

- As. : Bengal. septentr.

laevigata (Mitl.) Jaeg. l. c. p. 274.

'ortula laevigata Mitt. l. c. p. 160.

- Am. merid. : And. Quitens.

laevipila (Brid.) Bryol. eur. II (mon. p. 40) t. 164; C. M. Syn. 1, p. 638; W. P. Sch. Syn. II ed. p. 226.

Syntrichia laevipila Brid. Mant. M. p. $\frac{28}{8}$ et Bryol, univ. I, p. 586.

S. montana Nees in Regensb. Bot. Zeit. 1819, II, p. 301 (fid. C. M.).

S. ruralis var. laevipila Spreng. in Linn. Syst. veg. XVI ed., IV, I, p, 177.

Tortula laevipila Schwaegr. Suppl. II, I, p. 66, t. 120.

T. ruralis $\beta$ laevipila Hook. et Tayl. Muse. brit. II ed. p. 56.

1. Ad arbor. et rup. calcar. - Eur. : Tempurat. et calidior.; Britann. As.: Alger., Canar. Am. sepl. : Ins. Vancouver, Nevada, Calif.

Exs. : Rab. Bryoth. eur. n. $322 ; 822$ (Tortula).

Sull, et Lesq. M. bor. am. II ed. n. 143.

var. laevipilaeformis Husn. -- B. laevipila var. meridionalis.

* var. meridionalis W. P. Sch. Syn. I ed. p. 699 et II ed. l. c.

B. meridionalis var. laevipilaeformis Husn. Musc, gall, p. 14.

T. meridionalis var. marginata Lindb. Trichost. eur. p. 37.

T. laevipilaeformis de Not. Epil. p. 541 et M. ital. p. $39, t .17$.

Ad Oleas. - Eur. : Mediterr, : Istria, Ital, Hispan.

var. pagorum Husn. - B. pagorum.

laevipila $\left\{\begin{array}{l}\text { Garov. - B. papillosa. } \\ \text { Hpe. - B. Preissiana. } \\ \text { Mac. - B. lato-excisa. }\end{array}\right.$

laeviuscula Kindb. in Mac. Cat. p. 265.

2 Rupic. - Am. sept. : M. Rupestr.

lamprocalyx C. M. Syn. I, p. 599.

2 .

- Am. merid.: Chile.

lanceolata $\left\{\begin{array}{l}\text { Hedw. - B. unguiculata var. obtusifolia. } \\ \text { Schum. - B. unguiculata. }\end{array}\right.$

latifolia (Br.) Bryol, eur. II (mon. p. 4I), t. 164 ; C. M. Syn. I, p. 632; W. P. Sch. Syn. II ed, p. 227.

Syntrichia laevipila $\beta$ mutica Schultz Rec. de Barbula in Nov. Act. Leopold. Acad. XI, I, 1823, p. 230, t. 84, f. 4 B.; Brid. Bryol. univ. I p. 236.

S. latifolia Br. in Brid. l. c.

S. ruralis $\gamma$ latifolia Spreng. in L. Syst. veg. XVI ed., IV, I, p. 177.

Tortula latitolia Hartm. Skand. Fl. II ed., p. 322.

T. mutica Lindb. M. Scand. p. 20.

T. ruralis $\beta$ latifolia Arn. in Mem. Soc. hist. nat. Paris, 1825, II, p. 286.

2 Ad arbor., ligna fabref., rar. rup. - Eur.: Britann., Gall. orient., vall. Rhen., Boruss., Saxon. Am. sept.: Oregon, Colorado, Calif.

Exs. : Sull. et Lesq. M. bor. am. II ed. n. [44.

latifolia Brid. - B. agraria.

lato-excisa C. M. et Kindb. in Mac. Cat, p, 60.

B. laevipila Mac. Canad. M. n. 74 p.p.

2. Ad rad. arb. - Am. sept.. Ins. Vancouver.

latrobeana C. M. in Bot. Zeit. 1864, p. 358.

B. Preissiana Hpe, in Linn. 1874, p. 204.

2.

- Pac. : M. Austral, fel. 
Laureriana Llz. Moosst. p. 161.

$2 . \quad-A f r .:$ C. B. Sp.

Exs. : Rebm. M. Afr. austr. n. 95.

Lechleri C. M. in Bot. Zeit, 1859, p. 229.

1.

- Am. merid. : Fret. Magell.

Leikipiae C. $M$. in Fl. 1890, p. 480 .

Ster.

$$
\text { - Afr.: M. Kenia. }
$$

leptocarpa Besch, Prodr. bryol. mexic, p. 35.

- Am. sept.: Mexic.

leptopyxis C. M. in Bot. Centralbl. 1883, n. 2-4.

- As. : Penins. Tschutschica.

lepto-Syntrichia C. M. Bryol. austr. Georg. p. 34 .

2. Loc. humid, $-A m$. merid. : Austr. Georg.

leptotheca W. P. Sch. in Savatier M. Jap. n. 230; Besch. in Ann. sc. nat. 1893, p. 336.

leptotricha C. M. et Kindb. in Mac. Cat. p. 60.

2. Rupic. - Am. sept. : Manitoba.

leucocalyx Mont. in Ann. sc. nat. $1838, p .53$; C. M. Syn. I, p. 615.

Tortula leucocalyx Mont. in Gay Fl. Chil., Crypt. VII, p. 152 et syll. p. 38 ; Mitt. M. austr. am. p. 153.

2. Terr. - Am. merid. : Chile.

leucochlora C. M. in Engler's Bot. Jahrb. 1883, p. 84 et in ForchungsSter. reise... p. 42 .

leucostega C. M. Syn. I, p. 641 . - Afr. : Ins. Ascension.

2.

$$
\text { - Afr.: C. B. Sp. }
$$

leucostoma R. Br. in Suppl. app, ad iter Parrayan. p. 298; C. M. Syn, I, p. Gil.

Tortula leucostoma Hook. et Grev. in Brewster Edinb. Journ. I, p. 294. Zygotrichia leucostoma Brid. Bryol. univ. I, pp. 521 el 821.

ligularis (Mitt.) Par. - Am. sept. : Ins. Melville.

'Tortula ligularis Mitt. M. austr. am. p. 156.

2. - Am. merid. : M. Pichincha.

limbata Mill, in Hook. Kevo.Journ. III, p. 354.

Gymnostomum Jamesoni Tayl. in Lond. Jowrn. of bot. 1818, p. 279; C. M. Syn II, p. 624 .

Tortula limbata Mitt. M. austr. am. p. 168.

1. Terr. - Am. meril. : Summ. M. Pichincha.

limbata Lindb. - B. sublimbata.

Lindigiana Hpe. in litt.; Jaeg. Ad. I, p. 260.

Hyophila Lindigiana $H_{p e}$, in Ann, sc. nat. V ser. $I I I$, p. 343.

Weisia Lindigiana Mitt. l. c.p. 137.

$$
\text { - Am, merid. : And. Nov. Granat. }
$$

linearis Brid. Manl. M. p. 88 et Bryol. univ. I, p. 533 ; C. M. Syn. I, p. 608.

Tortula linearis Sw. Fl. Ind, oec. III, p. 1765; Mitt. l. c. p. 149.

2 ? Terr. calcar, $-A m$, sepl. : Hispaniola. Am. merid. : Ins. Trinitat. 
linearis Sull, - B. navicularis.

lingulata (Lindb.) Par.

Tortula lingulata Lindb. in Rev. bryol. 1880, p. 40.

2. Rup. et terr, aren. - Fur. : Scandin. (Livland.)

linoides Brid. - B. unguieulata.

lonchodonta C. M. in Linn. 1878-79, p. 335.

2. Limic. - Am. merid.: Argentin. Cordob.

longifolia Griff. - Didymodon.

longipedunculata $C$. M. Syn. I, p. 630.

2.

$$
\text { - Afr.: C. B. Sp. }
$$

longirostris Hpe, in Ann. sc. nat. V ser. III, p. 345.

Tortula longirostris Mitl. l. c. p. 157.

1. Am. merid. : And. Nov. Granat.

Lorentzi C. $M$. in Linn. 1878-79, p. 346.

2. Limic. - Am. merid. : Argentin. subtropic.

lurida Hsch. Fl. brasil. p. 18; C. M. Syn. I, p. 608.

B. Glaziovii $S b$. in Jaeg. Ad. II, p. 672.

B. gracilenta Hpe. Symb. 1874, p. 484 et Enum. M. Brasil. p. 10.

Hyophila lurida Jaeg. Ad. I, p. 205.

Weisia lurida Mitt. l. c. p. 137.

2.

- Am. merid. : Brasil. austr. or,

luri'a Lindb. - Didymodon.

luteola Mitt. - B. pungens.

lutescens Laurer. - B. flavipes.

Mac-Leana Rehm. M. Afr. austr. n. 482.

$$
\text { - Afr, : C. B. Sp. }
$$

macrocarpa Brid. - B. subulata?

macrogonia Besch, in Journ. de bot. 1894, p. 61 .

2. - Am. sept. : Guadalup.

macrorhyncha Kindb, in Mac. Cat. p. 50.

2. Terr. - Am, sept. : Ontario.

magellanica (Mont.) C. M. in Fl. 1885, p. 116.

B. hyperborea Mont. Voy. au Pỏle sud, p. 302 (excl, syn.).

Tortula magellanica Mont. Syll. p. 39.

magellanica C. M. (1862). - B. australis.

mallacophylla C. M. in Linn. 1875, p. 400.

Ster. Rupic. - As, : M. or, mar. Erythraei.

Mandoni $P(a)$.

B. fusca $W, P$, Sch, in Mandon Pl. boliv, $n, 1624$.

$$
\text { - Am. merid. : And. Boliv. }
$$

Manniae C. M. in Fl. 1887, p. 222.

- Am. sept. : Colorado.

marginata Bryol. eur. II (mon. p. 33), t. 158; C. M. Syn. I, p. 629 et II, p. 632 ; W. P. Sch. Syn. II ed. p. 199 .

B. pilifera Brid. Mant. M. p. 89.

B, subpilosa Brid. Bryol, univ. I, p, 534.

Desmatodon marginatus Mitt. M. Ind. or. p. 38.

Tortula acuminata Sic. Fl. Ind. oce. (1) (see. Mitt. M. aust, am. p. 167.)

(1) Nec in Brid, Bryol, univ, nec in C. M. Syn. Tortula acuminata Swarziana reperitur. 
T. caespitosa Hook. et Grev, in Edinb. Journ. of sc. I, p. 296.

T. marginata Spr. in Lond. Jowrn. of bot. IV, p. 192.

1. Muric. et saxic. - Eur. : Anglia, ins. Wight, Galloprov, Corsic., Sardin., Lusit., ins. Melit. As. : Ins. Cypr., Ind. or. A fr. : Alger. Am. sept. : Washington, Calif., Virgin.

Exs. : Rab. Bryoth. eur. n. 1015.

Mauchii Rehm. M. Afr. austr. n. 109.

$$
\text { - Afr.: C. B. Sp. }
$$

megalocarpa Kindb, in Bull. Torr. bot. Club XVI, p. 92.

2. Rupic. - Am. sept.: M. Rupestr., Columb. brit., ins. Vancouver.

Exs. : Mac. Canad. M. n. 79.

melanocarpa C. M. et Kindb. in Mac. Cat. p. 54.

2. Rupic. - Am. sept. : Columb. brit.

membranifolia (Hook.) Schultz Rec, de Barbula t. 34, f. 35; ; Bryol. eur. II (mon. p. 17) t. 140 ; C. M. Syn. I, p. 597; W. P. Sch. Syn. II ed.p. 192.

B. arenaria Girff. Not. p. 409 et Ic. pl. asiat. II, t. 103, f. I.

B. chloronotos Brid. Bryol. univ. I, p. 539 (excl. syn. B. chloronotos Schultz); Rab. Bryoth. eur, n. 672,

B. squamigera Viv, in Ann, bot, 1804, I, II, p. 191.

Crossidium squamigerum Jur, Lau3m. Oester. Ung.p. 127.

Desmatodon chloronotos Mitt. M. Ind. or. p. 38.

Tortula chloronotos Brid. Sp. M I, p. 253.

T. membranifolia Hook, M. exot. $I I, t .26$.

T. squamigera de Not. M. ital. I, p. 20, t. 5 .

1. Ad mur., rup. et coll, apric. - Eur.: Med. occid. et merid. : Vall. Ren., Lutet., Helvet. occid., Galloprov., Ital., Hispan. merid., Lnsitan. As. : Minor, Caucas,, Persia, Afr. : Penins. Sinaït., Alger. Am sept. : M. Rupestr., Colorado, .rizona occ.

Exs. : Rab. Bryoth. eur. n. 321,417 et b.

Sull, et Lesq. M. bor. am. II ed. n. 126.

* var. breviseta Besch. Cat. M. Alger. p. 12.

Ut typ. - Af $\because$ : Alger.

membranifolia Garov. - B. grisea.

var. grisea Vent. - B. grisea.

mendozensis (Mitt.) Jaeg. Ad. I, p. 275.

Tortula mendozensis Mitt. M. austr. am. $p, 154$.

2. $\quad-A m$, merid. : And. Chilens.

meruensis C. $M$. in Fl. 1890, p. 480.

Ster.

$$
\text { - Afr.: Kilima N'Djaro. }
$$

microcarpa Schultz. - B. unguiculata var. microcarpa.

minutirosula C. M. in Linn. I878-79, p. 349.

Fl, et fr. ign. $\quad-A m$. merid. : Argentin. Cordob.

mniifolia Sull. in Proc. Am. Acad. 1861, p. 277.

Tortula mnififolia Mitt. l. c. p. 167.

2. Ad saxa irror. - Am. sept. : Cuba. Am, merid. : And. Peru 7 . mnioides Schwaegr. - Streptopogon.

var, prostrata C. M. - Streptopogon mnioides var. prostrata.

mobilis C. M. in Linn. 1878-79, p. 482.

2.

- Am. merid.: Venczuela.

mollis Br. et Sch. in W. Sch. M. Abyss. n. 467 ; C. M. Syn I, p. 637

Syn. Ad rup. madid, - Afr.: Abyss. 
montana (Mitt.) Jaeg. Ad. I, p. 272.

Tortula montana Mitt. l. c. p. 156.

2.

- Am. merid. : And. Quitens.

montenegrina Breidl, et Szysz, - Desmatodon.

Moritziana C. M. in Linn. 1864, p. 604.

Ster.

- Am. merid.: Venezuela.

mucronata Brid. - B. Brebissoni.

mucronifolia (Schwaegr.) Bryol. eur. II (mon. p. 38) t. 162; C. M. Syn. I, p. 624 el II, p. 631 ; W. P. Sch. Syn. II ed.p. 225.

Desmatodon mucronifolius Mitt. M. Ind. or. p. 37.

Syntrichia mucronifolia Schultz Rec, de Barbula, p. 36, t. 34, f. 2; Brid. Bryol.univ. I, p. 582.

Tortula mucronifolia Schwaegr. Suppl. I, I, p. 136, t. 34 .

T. rosulata Wils. in Kew Journ. bot. IX, p. 322.

T. subulata Drumm. M. bor. am. I ed.n. 144 .

T. subulata var. laevifolia Lindb. Trichost. eur. p. 33.

T. subulata var. mueronifolia Roehl. Deutschl. Fl. III, p. 78.

1. In fissur. rup. - Eur. : Spitzverg, Alp. Norveg., German., Helvet, Sabaud, Pyr. As. : Jenissei, Obi, penins. Tschutschica, Amour, Tibet. occ., Caucas., Talysch. Am. sept. : Groenland, Nov. Scotia, ins. Anticosti, Ontario, Idaho ; reg. sept., orient. et centr.

Exs. : Mac. Canad. M. n. 80.

Rab. Bryoth. eur. n. 527.

Sull. et Lesq. M. bor, am. II ed, n. 141 .

ه var. arctica (Hook. el Grev.) Par.

Syntrichia hyperborea Brid. Bryol. univ. I, pp. 583 et 836.

S. mucronifolia $R$. Br. in Neu. Bot. Zeit, VII, Beil.p. 121 et in Pary's $I^{s t}$. Voy. App. t. 148 (excl. syn. Sehwaegr. et Wahlenb.)

Tortula mucronirolia Hook. in Parry's Voy. App.

Tortula mucronifolia $\beta$ arctica Hook. et Grev. in Brewster Edinb. Journ. I, p. 294.

Ut typ. - Am. sept. : Ins. Melville.

Mülleri (Br.) Bryol. eur. II (mon. p. 44) t. 168; W. P. Sch. Syn. II ed. p. 232.

B. princeps C.M. Syn. I. p. 636.

Syntrichia Muilleri Br, in Fr. Müller M. Sard, et in Fl, 1829.

S. princeps Mitt. M. Ind, or. p. 39.

Tortula laevipila var. Wils, in Kew Journ. bot. $I X, p .323$.

T. Milleri ej. Bryol. brit. p. 134, $t, 44$.

T. princeps de Not. Speo. de Tortul. ital. n. I et in Mem. Acad. Torin. $X L\{1838$, p. $288 ;$ Rab. Bryoth. ewr. n. 326, 823.

Syn. Ad arb. trunc. et rup. - Eur. : Norveg. oce, Scot, Hibern., Galloprov, Corsic., Sardin., Grœeia, Ital. merid,, Sicil,, Hispan. merid. As. : Ins. Cypr., Sikkim. Afr.: Alger. Am. sept. : Columb. brit., Alaska, ins, Vancouver, Washington, Idaho, Oregon, Montana occ., Nevada, Calif. (ubi vulgatiss.). Am. merid. : Chile (?). Pac. : Tasman. (?)

Exs. : Mac. Canad. M. n. 83.

Rab. Bryoth, eur. n, 1207.

Sull. et Lesq. M. bor, am. II ed, n. 147.

muralis (L.) Timm. Fl. Megapol. Prodr. p. 240 ; Brid. Biyol. univ. I, p. 546; Bryol, eur. II (mon. p. 35) t. 159 ; C. M. Sy S I, p. 625

W. P. Sck. Syn. II ed, p. 205.

B. Itzigsohni Hpe, in Linn. 1843, p. 673. 
B. muralis var, goettingensis Brid. l, c. p. 548.

Bryum murale L. Sp. Pl. I ed., II, p. 1117.

Br. pilosum Gmel. Syst. nat. II, p. 1036.

Br. subulatum $\beta$ Weiss Crypt, Goett. p. 189.

Br. tegulare, hamile, pilosum et incanum Dill. Hist. M. p. $335, t .45, f .15$.

Desmatodon muralis Jur. Laubm. Oesterr. Ung. p. 134.

Mnium murale L. jun. Meth. M. p. 364.

Mollia muralis Schrank Prim. Fl. Salisb. n. 382.

Tortula ainbigua Roehl Moosgesch. Deutschl. p. 389.

T. goettingensis Brid. M. Rec. II, I, p. 185.

T. muralis Hedw. Fund. M. II, p. 92.

T. muralis $\beta$ goettingensis Brid. Sp. M. I, p. 251.

T. pilosa Schrad. Spie. Fl. Germ. p. 66.

1. In mur, tect. tegul., ad lapid., rar. ad saxa, hic illic ad arb. rad., nunquam in terra. - Per totum fere terrarum orbem.

Exs. : Drumm. M. bor. am. II ed., n. 63 (Tortula).

Rab. Bryoth, eur. n. 231, 232, 564.

Rehm. M. Afr. austr. n. 87.

"var. aestiva Schum. Pl. Sael. II, p. 42 ; Bryol, eur., C. M: et W. P. Sch. ll. cc.

B. aestiva Sehultz Rec. do Barbula p. 31, t. 31, f. 32 ; Brid. Bryol. unio. I, $p, 548$.

B. cuneifolia W. et M. Bot. Taschb. p. 207.

Mollia tegularis Schrank Baier's Fl. II, p. 457.

Tortula aestiva $P, B . P r o d r, p .92$.

T. muralis var, aestiva Brid. Sp. M. I, p. 251.

In rup. fissur. praepr. silic,, forma compacta in Alp. - Eur. : Passim. As. : Caucas.

Exs. : Rab. Bryoth. eur. n. 459.

" var. brevipedunculata C. M. in Rehm. M. Afr. austi. n. 88.

- Afr.: C. B. Sp.

var. capen sis Brid. - B. muralis var. incana?

\& var, emarginata C. M. in Act. hort. Petrop. X, 1887.

- As. : Caucas.

* var. incana Bryol. eur., C, M. et W, P. Sch. ll. cc.

B. muralis var. capensis Brid. Bryol. univ. I, p. 548 ?

Grimmia crassa Spreng. Syst. veg. IV, II, p. 321.

Exs. : Rab. Bryoth. eur. n. 565 et b, 566.

In mur. calcar. sicc. - Eur. : Merl. et merid, Afr. : Agypt. int,, Alger., C. B. Sp.

\& var, obcordata W. P. Sch. l. c.

lisd, loc. ac proeed. - Eur. : Galloprov., Hispan. merid.

«var. rupestris Schultz Rec. de Barbula p. 29, t. 31, f. 293; Brid. Bryol. univ. I, p. 548; Bryol, eur. et W. P. Sch. ll. ce,

Ad rup. humid. et arb, putresc. - Eur.: Frequens. As. : Caucas. Afr. : Alger.

Exs. : Rab. Bryoth, eur. n. 567, 666.

muricola C. M. in Bot. Zeit. 1857, p. 384.

Tortula muricola Mitt. M. austr. am. p. 65.

2. Muric. - Am. merid. : Brasil, austr. or.

mutabilis Baumg. - Dicranella Schreberi.

mutica Brid. - B. cuneifolia.

vana $C, M$, in Linn. $1875, p .404$.

2. Fr. ign, Rupic, - As. : M, or. mar, Erythraei. 
napoana (de Not.) Jaeg: Ad. I, p. 286.

Tortula napoana de Not. in Mem. Acad. Torin. II ser., XVIII, p. 450. - Am. merid.: Columb.

natalensis $C . M$. in Rehm. M. Afr. austr. $n, 104$.

Ster. $\quad-A f r$. Natal.

navicularis (Mitt.) Par.

B. linearis Sull. in Proc. Am. Acad. 1861, p. 277.

Hyophila navicularis Jaeg. Ad. $I, p .206$.

Weisia navicularis Mitt. op. c. p. 139.

- Am. sept. : Cuba.

nervosa $\left\{\begin{array}{l}\text { Brid. - B. inclinata. } \\ \text { Milde. - B. atro-virens. } \\ \text { Schultz. - B. fallax. }\end{array}\right.$

var. inclinala Brid, - B. inclinata,

nigrescens Milt. M, Ind. or. $p .36$.

Tortula fallax Wils, in Kew Journ. bot. IX, p. 322.

2. - As. : Sikkim.

nitida (Lindb.) Jur. Laubm. Oesterr. Ung. p. 121 (1).

Tortula nitida Lindb. Trichost. europ. p. 45.

Trichostomum diffractum Mitt. in Seem. Journ. of bot. 1868, p. 98, t. 77, f. $5-6$.

Tr, mutabile var. robustius Jur. in Unger et Ky. " die Insel Cypern. * Tr. nitidum W. P. Sch. Syn. II ed.p. 179.

Ster, Rupic. - Eur. : Angl., Gibraltar, ins. Cypr. Afr. : Alger. Am. sept. : M. Rupestr.

Norlhiana C. M. - B. caespitosa.

norvegica Lindb. - B. aciphylla.

novo-granatensis Hpe. in Linn. 1861-62, p. 518.

Tortula novo-granatensis Mitt. M. austr. am. p. 158.

2. $\quad-$ Am. merid. : And, nov, Granat.

"var. gracilior Hpe. l. c. (2).

Ad iad. arb. - Am. merid. : C. typ.

oblongifolia W. P. Sch. - B. Vahliana.

obscura Mitt. M. Ind. or. p. 33.

2.

$$
\text { -As. : Sikkim. }
$$

obscura Sull, - B. Wrightii.

obtusifolia (Schleich.) Schwaegr. Suppl. I, I, p. 129, ı. 31 ; Brid. Bryol. univ. I, p. 552 (excl. syn.); W. P. Sch. Syn. II ed. p. 196.

Desmatodon arenaceus Sull. et Lesq. (fid. Hagen in Rev. biyol 1891, p. 1).

D, flavicans Bryol, eur. II (mon. p. 7), t. 133.

D. obtusifolius Jur. Laubm. Oesterr. Ung. p. 135.

Didymodon flavicans Funk in sched.

D. oblongifolius Hook. in Drumm. M. bor, am. I ed., n. 114.

Tortula humilis Hook, l. c. n. 137.

T. obtusifolia Schleich. Cat. pl. helv, p. 31.

Trichostomum flavicans C. M. Syn I, p. 591 et II, p. 629.

(1) Cf. Husn. Rev. Bryol, 1881, p. 49 et Philib. op. c. 1883, p. 77.

(2) a B. teretiusoula W. P. Sch, aemula : an spec. propria ? " Hpei l, c. 
1. Ad rup. praepr, calc. subhamid. - Eur. : Reg. subalp. et alp. Carinthiae, Helvetize. As. : Caucas. Afr..:Alger. Am. sept. : M. Rupestr, et Wasatch, Wisconssin, Calif.

«var. brevifolia W. P. Sch. l. c. p. 197.

Desmatodon flavicans $\beta$ obtusifolius Bryol. eur, $l, c$.

Ad rup. calcar, schist. - Eur. : Alp. Bern.

obtusifolia Schultz. - B. unguiculata var. obtusifolia.

obtusissima C. M. Syn. I, p. 640 .

Tortua obtusissima Mitt. M. austr. am. p. 174.

2.

- Am. sept. : Mexic.

obtusula Lindb. M. Scand, p. 22.

2. Rup. calcar. - Eur. : Suecia.

cenea (Didymodon ?) C. M, et Kindb. in Mac. Cat. p. 55.

2. Ster. Ad terr. humid, - Am. sept. : Columb. brit.

olivacea Besch. Prodr. bryol. mexic. p. 37.

Tortula olivacea Mitt. l. c. p. 631.

2. Terr, - Am. sepl. : Mexic.

orizabensis C. M. in Linn. 1876, p. 63.

B. atlantica W. P. Sch. in hb. Mus. Paris (fid. Besch.).

B. graminicolor Besch. Prodr: bryol. mexic, p, 37. Muric. - Am. sept. : Mexic.

orthodonta C. M. in Bot. Zeit. 1863, p. 57.

2. -As. : M. Neilgherr., Ceylan.

ovata Milt. M. Ind. or. p. 36.

Didymodon ovatus Jaeg. Ad. I, p. 215.

2.

- As. : Sikkim.

pachyloma Broth. in Oefv.... 1893, p.

- Pac.: Nov. Guin.

pagorum Milde in Bot. Zeit. 1862, p. 459; W. P. Sch. Syn. II ed. p. 231.

B. laevipila var, pagorum Husn. Muse, gall. p. 115.

T. laevipila var, propagulifera Lindb. Trichost. eur. p. 37.

T. pagorum de Not. Epil. p. 542.

Fr. ign. Rup. micac, - Eur. : Tirol, merid. (Meran).

Exs, : Rab. Bryoth, eur, n. 458.

pallens Brid. - $\mathrm{B}$. agraria.

paludosa Schroaegr. Suppl. I, I, p. 124, t. 30; Brid. Bryol. zeniv. I, p. 562 ; Bryol. eur II (mon. p. 21) t. 144 ; C. M. Syn. I, p. 607; W. P. Sch. Syn. II ed. p. 2l2.

B. crocea Brid. Mant. M.p. 93.

B. crocea $\beta$ paludosa Roehl Deutseh. Fl. III, p. 79.

Tortula crocea Brid. Sp. M. I, p. 257.

T. paludosa Hook, el Giev. in Edinz. Journ. of Se. I, p. 301.

2. In udis, præp. ealcar. - Eur.: Alp. Austr., Salisb., Bavar., rar.

Helvet, Pyr., Ital, super. ; deest in Scandin, et in Britann. Afr. : Alger.

Exs, : Rab. Bryoth. our. n. 3 t et b. 
«var. Funkiana Bryol, eur, C. M. et W. P. Sch. ll. cc.

B. Funkiana Schultz Rec. de Barbula p. 26, t. 33, f. 26; Brid. Bryøl. univ. $I, p p .512$ et 828.

Tortula crocea $\beta$ humilis Lindb. Trichost, eur. p. 39.

T. Funkiana Hook, et Grev, in Brewster Edinb. Journ. I, p. 29.

Ut typ. - Eur. : lisd loc.

Exs. : Rab. Bryoth, eur. n. 258.

panduraefolia Hpe. et C. M. in Linn. 1853, p. 493.

2.

- Pac. : Austral, fel.

papillinervis C. M. et Kindb. in Mac. Cat. p. 60.

2.

- Am. sept. : Labrador, Columb. brit.

papillosa (Wils.) C.M. Syn. I, p. 598 et II, p. 630; W. P. Sch. Syn. II ed. p. 231 .

B. laevipila Garov. Bryol. austr. p. 37.

B. rotundifolia Jens. Bryol. Dan. p. 110, $t \cdot 6, f$. $30 \mathrm{f}$ et $g$.

Syntrichia laevipila var. Ahnf. in $\mathrm{Fr}$. $\mathrm{Fl}$. Scand. p. 240.

S. papillosa Jur. Laubm. Oesterr. Ung. p. 141.

Tortula papillosa Wils. mss. et Bryol. brit. p. 135, t. 44.

T. rotundifolia Hartm. Skand. Fl. V ed. p. 381 ; C. M. Syn. II, p. 632.

T. ruralis var. Hook. et Tayl. Musc. brit. II ed.p. 56.

2. Ster. - Ad arb. campestr. prepr. ambulacr. - Eur. : Vulgatiss. Am. sept. : Reg. or. Am. merid.: And. Quitens., ins. Maclov. Pac. : Austral., N. Zeland, Tasman. (c. fr.!') (1)

Exs. : Rab. Bryoth. eur. n. 455, 785 et b, 915.

Sull, et Lesq. M, bor. am. II ed, n. 127.

parvula Spreng. - B. recurvata.

patagonica (Mill.) Jaeg. Ad. I, p. 273.

Tortula patagonica Mitt. M. austr, am. p. 156.

- Am, merid. : Patagon.

patagonica C. M. - B. australis.

pellucida de Not. - B. sublimbata.

percarnosa C. M. in Linn. 1878-79, p. 347.

2. Terr. - Am. merid. : Argentin. subtropic.

pernana C. M. in op. c. p. 338.

2. Limic. - Am. merid. : Argentin. subtropic.

perpusilla C. M. in op. c. p. 348 .

Fl, et fr. ign.

- Am. merid. : Argentin. subtropic. perrevoluta C. M. in op. c. p. 334 (nom. emend. p. 486).

2. - Am. merid. : Argentin. Cordob.

8 var. acutifolia C. M. in op. c. p. 335 .

Iisd, loc. ac typ.

\& var. linearifolia C. M. l. c.

Iisd. Jloc.

peruviana (Mitt.) Jaeg. Ad. I, p. 289.

Tortula per uviana Mitt. l. c. p. 169.

2. $\quad-$ Am. merid. : Peruv.

(1) An eadem species? Cf. Mitt. in Lond. Journ. of bot. VIIl, p. 259 et Lindb. Trichost. eur. p. 36 . 
pichinchensis Tayl. in Lond. Journ. of bot. 1847, p. 333; C. M. Syn. I, p. 628 .

B. affinis Hpe. in Linn. 1861-1862, p. 520 (fid. Mitt.).

Tortula pichinchensis Mitt. l. c. p. 174.

2. Cortic. et rupic. $-A m$. merid. : And. Nov. Granat. et Quitens.

pilifera (Hook.) Brid. Bryol, univ. p. 572 ; C. M. Syn. I, p. 611 ; Bryol. jav. I, p. 103, t. 83 .

B. crinita Sehultz in Nov. Act. Leop. XII, I, p. 226, t. 34.

Tortula pilifera Hook. M. exot. t. 12 .

2. merid, : Chile.

- As.: Manille, Java. Afr.: C. B. Sp. Am.

Exs. : Rehm. M. Afr. anstr. n. 110 et 478.

- var. aquatilis C. M. in Rehm. l. c. n. III.

$$
\text { - Afr.: C. B. Sp. }
$$

«var. gracilis C. M. Syn. I, p. 642 .

- As. : Manille. Afr. : C. B. Sp.

«var, sessilis C. M. in Rehm. l. c. n. 113.

$$
\text { - Afr.: C. B. Sp. }
$$

pilifera Brid. - B marginata.

platyneura C. M. et Kindb. in Mac. Cat.p. 52.

Ster. Rup. humid. - Am. sept. : Columb. brit.

plebeja C. M. in Linn. 1830-82, p. 426.

Fi. et fr. ign.

- Am. merid. : Uruguay.

Podocarpi C. $M$. in op. c. $1878-79, p .352$.

Fl, et fr. ign. Arbor. - Am. merid.: Argentin, subtropic.

Poeppigiana C. M. in Linn. 1843 el Syn, I, p. 606.

Tortula Australasiæ Hook. (fid. Mitt.).

2.

- Am. merid. : Chile.

porphyroneura C. M. in Nuov, giorn. bot. ital. 1872, p. 13.

2. $\quad-A f r$.: Abyssin.

Preissiana C. M. Syn. I, p. 642.

B. laevipila Hpe. in Preiss. pl. II, p. 114, coll.n. 2467.

2. Lignic. - Pac. : Anstral.

Preissiana Hpe. - B. latrobeana.

princeps C. M. - B. Mülleri.

prostrata Mont. - Streptopogon mnioides var. prostrata.

pruinosa (Mutt.) Jaeg. Ad. I, p. 233.

Tortula pruinosa Mitt. M. austr, am. p. 152.

2.

- Am. merid. : And. Quitens.

pseudo-caespitosa C. M. in Linn. 1878-79, p. 339.

Syn. Terr, et rupic. - Am. merid. : Argentin. Cordob.

\& var. brachybasis C. M. op. c. p. 340 .

Terr. in silv, $-A m$, merid. : Uruguay.

* var. pungens $C$. M. l.c.

Arbor. - Am. merid. : Argentin. subtropic.

pseudo-gracilis C. M. in Nuov, giorn, bot. ital. 1872, p, 13.

2 ,

- Afr. : Abyss, sept, 
pseudo-pilifera Hpe. et C. M. in Linn. 1853, p. 493.

2. Fr. ign. - Pac. : Tasman.

pseudo-rigidula Kindb. in Mac. Cat. p. 264.

B. rigidula Mac. Canad. M. n. 412 p.p.

2.

- Am. sept. : Columb. brit.

pulvinata Jur. in Verh. d. K. K. bot. Ges, in Wien 1863, p. 501; W. P.

Sch. Syn. II ed.p. 230.

B. danica Lge. Bryol. Bytr. bot. tidskr. Kjobenh, 1869.

B. intermedia var. pulvinata Husn. Muscol. gall. p. 117.

Syntrichia pulvinata Jur. Laubm. Oesterr. Ung. p. 144.

Tortula danica Lindb. M. Scand. p. 20.

T. virescens de Not. Epil.p. 539 ?

2. rar. fructif. Ad arb. annosior., rup, aren., in tect. lign. - Eur. : Suecia, Dania, Austria inf., Rhoet., Ital, super., Bad., Wurtemberg.

Exs. : Rab. Bryoth, eur. n, 670, 787, 1121 et b, 1122.

pungens (Hook. f. et Wils.).Jaeg. Ad. II, p. 672.

B. Itteola Mitt. in Kew Misc. 1857, p. 258.

B. tasmanica Hpe?

Tortula pungens $H$. f. et $W$. Fl. Tasman. II, p. 175, t. 172, f. 7 .

2. Rupic. - Pac. : Austral., Tasman.

purpurea $C . M$. in $\mathrm{Fl} .1875, p .78$.

B. brachyphylla Sull. et Lesq. M. bor. am. II ed. n. 135 p.p.

2. Rupic. - Am. sept. : Calif.

purpurea Agh. - B. convoluta.

pusilla (Ångst.) C. M. in Fl. 1885, p. 415.

Tortula pusilla Angstr. in Oefv.... 1872, n. 4, p. 7.

2 ? - Ain. merid.: Fuegia austr.

pygmaea $C$. $M$. in $F l$. 1888, p. 412 .

Ster. Gramin. - Afr. : Kilima N'Djaro.

quitoensis Tayl. in Lond. Journ. of bot. 1847, p. 332; C. M. Syn. I, p. 627 .

Tortula quitoensis Mitt. M. austr. am. p. 170.

2. Terr. et saxic. - Am. merid. : And. Quitens.

Raddei (Broth.) Par.

Tortula Raddei Broth. in Bot. Centralbl. 1888, n. 14.

2. Rup. calcar. - As. : Transcasp.

Raui A ust. in Bull. Torr. bot. Club VI, p. 43.

2. Rupic. - Am. sept. : Texas.

veclifolia Tayl. - B. gracilis.

recurvata (Hook.) Brid. Bryol. univ. I, pp. 530 et 825 ; C. M. Syn. I, p. 627.

B. parvula Spreng. Syst. veg. IV, I, p. 179.

Tortula recurvata Hook. M. ex, t. 130 .

1. Terr. - Afr. : C. B. Sp. Pac. : Tasman.

Exs, : Rehm, M. Afr. austr. n. 89.

" var. aristatula C. M. in Relim, l. c. n. 90, 480.

Ut typ. - Afr. : C. B. Sp. 
recurvifolia (Wils.) W. P. Sch. Coroll. Bryol. eur. Suppl. (ad calcem).

B. fallax Y reflexa Brid. Bryol. univ. I, p. 556 (fid. Lindb.).

B. reflexa ej. Mant, M. p. 92 (fid. Lindb.)

Schistidium? recurvifolium Spr. in Ann. Mag. nat. hist. II ser., III,

p. 491.
Tortula fallax nar, recurvifolia Wils, Bryol. brit. p. 124.

Tortula recurvifolia Berk. Handb. Brit. M. p. 258; Lindb. Trichost. eur. p. 43.

2. Mur. et rup. calcar. - Eur.: Suecia, Britann., Juras., Helvet, Bavar. As. : Caucas. Am. sept. : New Jersey, Niagara, Colorado.

Exs, : Rab. Bryoth. eur, n. 324.

Un, itin. 1863, n. 9.

recurvifolia Mitt. - Geheebia cataractarum.

recurvipatula C. M. in Linn. 1880-1882, p. 424.

Fl. et fr. ign. $\quad-$ Am. merid. : Argentin. Cordob.

Rehmanni C. M. in Rehm. M. Afr. austr. n. 101.

$$
\text { - Afr. : C. B. Sp. }
$$

reflexa Brid. $\left\{\begin{array}{l}\text { (fid. C. M.). }- \text { B. fallax. } \\ \text { (fid. Lindb.). }- \text { B. recurvifolia. }\end{array}\right.$

replicata Tayl. in Lond. Journ. of bot. 1846, p. 49, t. XVC; C. M. Syn. I, p. 623.

Tortula replicata Mitt. M. austr. am. p. 151.

2. Muric. - Am. merid. : And. Quitens.

reticularia C. M. in Rehm. M. Afr. austr. n, 106 .

Ster. - Afr.: C. B. Sp.

revoluta Schwoagr. Suppl. I, I, p. 127, ı. 32; Brid. Bryol. univ. 1, p. 571 ; Bryol. eur. II (mon. p. 27) t. 153 ; C. M. Syn. I. p. 62l; W. P. Sch. Syn. II ed. p. 213.

Tortula nervosa Engl. Bot. p. 2383.

T. revoluta Schrad. Syst. Samml. Krypt. Gevaechs. I, n. 12.

2. Muric. - Eur.: Copiosior in merid. quam in ined., rar. in sept. As. : Persia. Af $r$. : Alger.

Exs. : Rab. Bryoth, eur. n. 43 a, 130, 422.

revoluta W, et M. - B. Hurnschuchiana.

var. Hornschuchiana Brid, - B. Hornschuchiana.

revolvens W. P. Sch. Syn. II ed. p. 195.

B, atro-virens vas, robusta ej. in Husn. M. Gall. n. 513 a.

Desmatodon revolvens Husn. Musc, gall. p. 96.

1. Ad mur. muscos. - Eur. : Monspel., Galloprov.

rhaetica Amam in Rev, bryol. 1889, pp. 54 et 90 .

Ster. Ad terr. lapid. - Eur. : Alp. Rhat.

rigida Schulls Rec. de Barbula t. 32, f. I; Bryol. eur. II (mon. p. 13)

t. 137 ; C. M. Syn. 1, p. 595 ;. W. P. Sch. Syn. II ed. p. 189.

Bryum stellatum Schreb. Spic. Fl. Lips p. 80.

Desmatodon rigidus Mitt. M. Ind or. $p .38$.

Tortula brevirostris Grev. Scot. Crypt; Hook. et Tayl. Muse, brit. II ed., p. 53.

T. enervis eor. l. c. p. 52.t, suppl. 2.

T. rigida Schrad. Spic. Fl.Germ. p. 66; Brid. Sp. M. I, p. 24 (excl. syn.).

T, stellata Lindb. Trichost. eur. p. 24. 
2. Ad mur, et rup. schist. calc. et aren. semi-decompos. - Eur. : Temper. et calidior. As.: Caucas., Tibet. occ. Afr. : Alger. Am. sept. : Niagara, M. Rupestr., Colorado.

Exs. : Rab. Bryoth. eur. n. 325, 979.

Sull. et Lesq. M. bor. am. II ed. n. 125.

"var. mucronulata Bryol. eur. et W. P. Sch. ll. cc.

Ut. typ. - Eur. : Iisd. loc. Am. sept. : Calif. merid.

« var. obtusa (Jur.) Par.

Tortula rigida var. obtusa Jur. Laubm. Oesterr. Ung. p. 126.

Limic. - Eur. Cum typ.

- var. pilifera Bryol. eur. et W. P. Sch. $l l$. cc.

Tortula bifrons de Not. Sp. de Tortul, ital. n. 17 et Syll. n. 176.

Ut typ. - Eur. : Iisd. loc. Am. sept. : M. Rupestr.

rigida Brid. - B. ambigua.

rigidula (Hedw.) W. P. Sch. Syn. II ed, p. 206.

B. insidiosa Jur. et Milde in Hedve. 1867, p. 97; Rab. Bryoth. Eur, n. 1067.

B. spadicea Mitt. (fid. Lindb.).

Bryum Didymodon Gmel. Syst, nat. II, p. 1333.

Br. rigidulum Hoffm. Deutschl. Fl. $I I, p, 40$.

Didymodon rigidulus Hedw. M. frond. III, p. 8, t. IV; Brid. Bryol. univ. $I, p .514$.

D. spadicens Limpr. Deutschl. Laubm. I, p. 556.

D. Zetterstedtii (fid. Limpr. l. c.)

Tortula rigidula Lindb. Trichost. eur. p, 42.

Trichostomum rigidulum Sm. Fl. brit. III, p. 1288; Bryol. eur. II (mon. p. 10)t. 176 ; C. M. Syn. I, p. 570.

2. Ad mur. et rup, humid, et in tophac. - Eur. : Reg. campestr. et montan. præpr. subalp. As. : Jenissei med., Caucas. Am. sept. : Groenland, lac. Huron, Ontario, M. Rupestr., ins, Vancouver, Montana, Calif.

Exs. : Drumm. M. bor am. 1 ed. n. 121. (Didymodon.)

Rab. Bryoth, eur. n. 233, 376. (Trichostnmum).

Sull, et Lesq. M. bor. am. ed. n. 150 (Trichostomum).

\&var. densa W. P. Sch. l. c.

Desmatodon rupestris Funk in Brid. Bryol. univ. I, p. 822.

Tortula rigidula var, densa Lindb. Trich. eur. p. 42 .

Trichostomum rigidulum var. densum Bryol. eur. l. c.

Ut typ. - Eur. : Præpr. in subalp.

Exs, : Rab. 1. c. n. 430.

rigidula $\left\{\begin{array}{l}\text { Besch. - B. Bescherellei. } \\ \text { Mac. p.p. - B. pseudo-rigidula. }\end{array}\right.$

riparia C. M. in Linn. 1880-1882, p. 428.

2. Terr. - Am. merid. : Alp. Argentin, subtropic.

robusta (Hook. et Grev.) Brid. Bryol. univ. I, p. 834; C. M. Syn. I, p. 635 et $I I$, p. 632 .

B. speciosa H. f. et W, in Lond. Journ. of. bot. 1844, p. 543.

Mnium punctulatum Brid. l. e. II, p. 734.

Tortula punctulata Mitt. M. austr. am. p. 175.

T. robusta $H$, et Grev, in Brewster Edinb. Journ. I, p. 209, t. 12; Fl. Antarct $I I, p .409, t .153, f .2$. 
robustifolia C. M. el Kindb. in Mac. Cat. p. 56.

B. rubiginosa Mao. Canad. M. n. 75.

Ster. Rupic. - Am. sept. : Columb. brit., ins. Vancouver.

romana C. M, - 13. Brebissoni.

rolundata Lindb. et Arn. - Didymodon.

rotundo-emarginata C. M. et Kindb. in Mac. Cat. p. 60.

2.

- Am. sept. :

rotundifolia Jens. - B. papillosa.

rubella (Hook. f. et Wils.) Jaeg. Ad. I, p. 297.

Syntrichia princeps Mitt. in Journ. of the Linn. Soc.p.p.

Tortula rubella $H$. $f$. et $W$. Fl. Tasm. II, p. 176, t. 172, f. 10.

1.

- Pac.: Tasman.

rubella Mitt. - Didymodon.

var. brevifolia Lindb. et $\Lambda \mathrm{rn}$. - Didymodon rubella var. brevifolia.

rubiginosa Mitt. in Journ. of the Linn. Soc. VIII, p. 27, t. 5 ; Lesq. et Jam. Man. p. 126.

Pottia rubiginosa Wats, Bot, Calif. II, p. 362.

2.

- Am. sept. : Ins. Vancouver, Oregon.

rubiginosa $\left\{\begin{array}{l}\text { C. M. - B. argentinica. } \\ \text { Mac. - B. robustifolia. }\end{array}\right.$

rubra (Mitt.) Par.

Tortula robusta $\beta$ H. f. et W. Fl. Antaret. II, p. 409.

T. rubra Mitt. in Handb. of N. Zeal. Fl. p. 419.

2. Nov. Zeland. meà.

- Am. merid. : Ins. Maclov. Pac. : Austral., rubra Lindb. - Didymodon.

rufa W. P. Sch, in Besch, Fl. bryol, Réunion, etc. p. 56.

2 ?

- Afr. : Ins. Franciae.

rufa Jur. - Didymodon.

rufescens Hpe. in Jaeg. Ad. I, p. 279.

Rup. madid. - Am. sept. : Calif.

rufescens Mitt. - Hyophila.

rufipes W. P. Sch, in Besch. Prodr. Fl. bryol, mexic. p. 36.

- Am. sept. : - Mexic.

rufiseta Tayl. - B. Australasiae.

rancinata C. M. Bryol austr. Georg. p. 33 .

2. Loc. humid. - Am. merid. : Austro-Georg.

ruraliformis Besch. in Bull. Soc. bot. Fr. 1864, p. 335.

B. ruralis var, arenicola Braithw. Brit. Moosfl. p. 226.

2. Rupic. et terr, - Eur. : Anglia, Belg. et Gall, prepr. littor. Am. sept. : Washington, Montana.

*f. gigantea R. Farneti M. Prov. Pavia 1891, p. 24.

Ut typ. - Eur. : Ital. sup. (M. Lesina).

ruralis (L.) Hedio. Sp. M. p. 121; Bryol. eur. II (mon. p. 42) t. 166 ; C. M. Syn. I, p. 639.

Bryum rurale L. Sp. Pl. p. 1581.

$\mathrm{Br}$. rurale unguiculatum, hirsutum, elatius et ramosius Dill. Hist. $M$. p. $382, t .45, f .12$. 
Hypnum ruvale Weiss. Crypt. Goett. p. 210.

Mnium rurale L. jun. Meth. M. p. 364.

Mollia ruralis Schrank Prim. Fl. Salisb, n. 831.

Syntrichia ruralis W. et .K. Bot. Taschb. p. 215; Brid. Bryol, univ. 1, p. 584 .

Tortula ruralis Schwaegr. Suppl. I, p. 121.

2. Ad arbor. annosior., rup., tecta stram., in camp. incult. etc. Eur. : De reg. campestr. ubi vulgatiss. usq. in subalp.; Spitzberg, Septem Insul. ins. Ursorum. As, : Jenissei, Taimyr, Amour, Alatau, Tibet. occ , Kurdistan., Persia, Caucas., As. min. Afr. : Alger, C. B. Sp. or. Am. sept. : Groenland; tota, præpr. ad litt. Pacific. Pac. : Austral, merid.

Exs. : Drumm. M. bor. am. I ed. n. 143.

Mac. Canad. M. n. 82.

Rab. Bryoth, eur n. 225, 1070, 1309.

Rehm. M. Afr, austr, n. 477.

Sull, et Lesq. M. bor. am. II ed, n. 145.

var. arenicola Braithw. - B. ruraliformis.

" var. californica Sull. M. bor. am, II ed, p. 22.

Rupic. - Am. sept. : Calif.

Exs. : Sull, et Lesq. M. bor. am. II ed, n. 146.

var. calta Bryol. eur. - B. intermedia var, calva.

" var. densiretis Vent. in Rev. bryol. 1890, pp. 51-52.

- Eur. : Sardin.

« var. epilosa Vent. op, c. pp. 50-52.

"var. hirsuta Vent. op. et l. cc.

- Eur. : Ital. sup. (Lugano).

- Eur.: Sardin.

var. mpestris Bryol, eur. - B. intermedia.

«var. subintermedia Ren. et Card. in Rev. bryol. 1892, p. 84.

- Am. sept. : Arizona.

"var. virescens Bertol. Fl. Ilal. crypt. 217.

Tortula ruralis var. virescens de Not. Syll p. 171.

T. virescens $e j . M$. Ital. I, p. 4l, t. 18.

Ut typus. - Eur. : Merid.

ruricola C. M. in Bot. Zeit. 1857, p. 381.

1. Muric. - Am. merid. : Brasil.

Sarlorii Jaeg. - Desmatodon.

Saussuriann Brid. - Ceratodon purpureus.

Savatieri Besch. in Bull. Soc. bot. Fr. 18s5, p. LIX.

1.

- Am. merid.: Peruv.

scabrinervis C. M. Syn. I, p. 634 .

Tortula scabrinervis Mitl. M. austr. am. p. 173.

2. Arbor. - Am. merid, : Chil, austr.

Schmidii C. M. in Bot. Zeit. 1853, p. 58.

Syntrichia Schmidii Mitt. M. Ind, or. p. 39.

2. Arbor. - As. : M. Neilgherr.

Schnyderi C. M. in Linn. 1880-82, p. 424.

2. $\quad-$ Am, merid. : Argentin. Patag.

Schreberi Brid. - Dicranella, 
scleromitra Besch. in Bull. Soc. bot. Fr. 1894, p. 81.

2. In udis coctis, - As, : M. Tonkin.

sedifolia C. M. in Linn. 1878-79, p. 327.

Fl, et fr, ign.

- Am. merid. : Argent. Cordob.

semi-rubra C. M. in Engler's Bot. Jahrb. 1883, p. 80 et in Forchungsreise .... p. 23.

Tortula fuegiana Mitt. in Journ. of. the Limn. Soc, 1876.

2. Ster. Rupic. - Afr. : Ins, Kerguelen.

semi.torta Sull, in Pac. R. Rep. IV, p. 186, t. 3; Lesq. et Jam, Man. p. 126.

2. $\quad-$ Am sept. : Calif.

serripungens Ltz . et C. M. in Linn. 1878-79, p. 35 .

2. $\quad$ - Am. merid.: Argentin. Cordob.

"var, exesa Ltz, et C. M. op, c. p. 351.

Ut typ. $\quad-A m$. merid. : Argentin. subtropic.

serrulata (Hook. et Grev.) Brid. Bryol, univ. I, p. 833 ; C. M. Syn. I, p. 636.

Tortula serrulata H. et Grev, in Brewster Edinb. Journ I, p. 298, t. 12; Handb. of N, Zeal Fl. p. 419.

setacea Hedw. - B. convoluta.

sinuosa Jaeg. - Didymodon.

Solmsiana Hpe. - B, commutata.

Solmsii W. P. Sch, Syn. II ed. p. 200.

B. cuneifolia Brid. (fid. Husn. Muse. gall. p. 101).

I. Ad. rup. aren, semi-decomp. - Eur. : Lusitan. (Algarb.)

Somaliae C. $M$, in Linn. 1876, p. 294.

Ster. - Afr: : Somali.

sordida Besch. in Bull. Soc. bot. Fr. 1894, p. 80.

2.

- As. : M. Tonkin.

spadicea Mitt. mss. ; Braithw. Brit. Moosf. p. 266.

B. rigidula W. P. Soh. (fid. Lindb.); Mao. Canad. M. n, $41 \%$.

2. Terr. hum. - Am. sept. : Columb. brit.

sparsidens $C . M$. et Kindb in Mac, Cat, p. 54 .

2. Terr. - Am. sept. : Columb, brit.

spathulata Dz. et Mk, M. frond. ined. Archip. ind. p. 49, t. $12 ;$ Bryol. jav. I, p. 100 et II, p. 226 ; C. M. Syn. I, p. 604.

Desmatodon spathulatus Mitt. M. Ind. or. p. 39.

Gymnostomum spathulatum Harv, in Lond. Journ. of bot. 184n, II, p. $2 ;$ Hook, Ic. pl. rar, t. 17 .

Pottia Zollingeri C. M. in Bot. Zeit. 1856, p. 419.

Tortula spathulata Mitt. in Journ. of the Linn. Soc, 1891, p. 160.

2. Ad mur. et terr. calcar. - As. : Japon., Amboine, Sumatra, Java.

speciosa H. f. et W. - B. robusta.

spiralis W. P. Sch. in C. M. Syn. I, p. 622.

Tortula spiralis Mitt. M. austr, am. p. 151 .

2.

- Am. sept. : Mexic.

Sprengelii Schwaegr. - Trichostomum Berteroanum,

squamigera Viv. - B, membranifolia. 
squarrosa Brid. Bryol. univ. 1, p. 833: Bryol. eur. II (mon p. 26); t. 152 ; C. M. Syn. I, p. 601; W. P. Sch. Syn. II ed. p. 221.

Pleurochaete squarrosa Lindb. Trichost. eur. p. 47.

Tortella squarrosa Limpr. Deutsch. Laubm. I, p. 607.

Tortula squarrosa de Not. Syll. p. 180 et M. ital. I, p. 61, t. 31 .

2. In coll. sicc. et silv. arenac. - Eur. : Frequens per zon. merid., rar. et ster. in septentr.: Britann., vall, Rhen., Lutet., valloprov., Sardin., Ital., Sicil., Hispan. As.: Yunnan, Himalaya occ., Persia. Caucas. Afr. : Alger, ; ins. Canar. ? Am. sept. : Rariss. : Tennessee, Texas.

Exs. : Rab. Bryoth. eur. n. 457 et b; 1275 (Pleurochaete).

Un. itin. 1863, n. 8.

«var. nitida R. Farneti M. Prov. Pavia, 1891, p. 19.

-- Eur.: Ital. sup. (Pavia).

stellata Brid. - B. agraria.

stenocarpa Hpe. in Ann. sc. nat. V sér., III, p. 346.

Tortula stenocarpa Mitt. M. austr. am. p. 162.

1. Terr, - Am. merid. : And. Nov. Granat.

stenophylla (Mitt.) Jaeg. Ad. I, p. 263.

Tortula stenophylla Mitt. M. Ind. or, p. 28.

2. Arbor. - As. : Sikkim, M. Neilgherr.

slricla Hedw. - B. unguiculata.

subaristata Br. et Sch. in W. Sch. M. Abyss. n. 448; C. M. Syn. I, p. 644 .

2. Arbor. - Afr.: Alp. Abyss.

subealycina C. $M$. in Linn. 1867-68, p. $61 \%$.

2.

- Pac. : Austral. or.

subearnifolia $C$ M. et Kindb. in Mac. Cat.p. 52.

1 ? Ad ter. et rad, arb. - Am. sept. : Lac. Erie.

subcernua W. P. Sch. in Besch. Fl. bryol. Réunion, etc. p. 56 (nom.) - Afr. : Ins. Franciæ.

subcuneifolia Kindb. mss.

- Am. sept. : Alaska.

subcylindrica Broth, in Bot. Centralbl. 1890, n. 51 et in Roell M. bor. am. n. 329.

2. Fr. ign. - Am. sept. : Washington.

subduriuscula C. $M$. in Linn. $1874, p .554$.

2.

- As. : Ins. Philippin.

subfallax C. M. in Bot. Zeit. 1862, p. 338; Lesq. et Jam. Man. p. 121.

B, fallax Sull. in Bot. Pac. R. R. Survey (Whipple). p. 186.

2.

- Am. sept. : S. Nevada, Calif.

subgracilis C. M. et Kindb. in Mac. Cat. p. 53.

2. Rupic. - Am. sept. : Columb, brit.

" var. viridior Kindb. op. c. p. 263.

Kupic. - Am. sept. : Lac. Ontario.

subicmadophila C. M. et Kindb, in op. c.p. 53.

B. gracilis var. squarrulosa Kindb. in Bull. Tor. Bot. Club XVII, p. 89,

2. Ad rup. humid. - Am , sept. : Columb, brit. 
sublimbata (Mitt.) Jaeg. Ad. I, p, 290.

B. limbata Lindb, in Oef. Vet. Ak. Foerh. 1863, p. 387.

Desmatodon limbatus Mitt. M. Ind. or. p. 38.

D. sublimbatus ej. op. c. p. 158 (correct. pritecedentis).

Tortula limbata Lindb. Trichost. eur, p. 29.

T. pellucida de Not. $M$, ital. $I, p, 26, t .8$.

2.

-Eur. : Ital. infer., Hispan. merid. As. : Tibet, occ.

subnigra (Mitt.) Jaeg. Ad. I, p. 283.

Tortula subnigra Mitt. $M$. austr. am. p. 164.

Ster.

- Am. sept. : Mexic.

subpellucida Mitt. $M$. Ind. or. p. 35.

2.

- As. : Himalaya occ., Tibet.

subpilosa Brid. - B. marginata.

subrevoluta Hpe. in Linn, 1864, p. 208.

Fr. ign.

- Afr. : Madagascar.

subspathulata $C$. M. Syn. 1, p. 633.

B. glacialis Br. et Sch. in W. Sch. M. Abyss, n. 491.

2. Ad rup. madid. - Afr. : Alp. Abyssin.

subspiralis Hpe. in F. v, Müller Anal. drav. of Austral. M. t. 2.

- Pac. : Austral.

subtorquata Hpe. et C. M. in Linn. 1853, p. 492.

- Pac. : Austral. or.

subulata (L.) P. B. Prodr. p. 43; Bryol. eur. II (mon. p. 36) t. 160 ; C. M. Syn. I, p. 623 ; W. P. Sch. Syn. II ed. p. 223.

B. macrocarpa Brid. Sp. M. I, p. 26/? (1)

Bryum capsulis longis subulatis Dill. Hist. M. p. 350, t. 45, f. 10.

Br. subulatum L. Sp. Pl.p. 1581.

Desmatodon subulatus Jur. Laubm. Oesterr. Ung. p. 138.

Mnium subulatum L, jun. Meth. M. p. 365.

Mollia subulatit Schrank Prim. Fl. Salisb, n. 830.

Syntrichia alpiua Brid. Mant. M. p. 97.

S. subulata Schulta Rec. de Rarbula p. 34, t. 34, f. I A; Brid. Bryol. univ. $I$, p. 579 et 835 .

S. subulata $\beta$ alpina Brid. $l l$. cc.

S. subulata vas. macrocarpa ej. op. cit. p. 582 ? (1).

Tortula hercynica Schrad. Spic. Fl, Germ. p. 65.

T. subulata Hedw. Fund. M. II, p. 92, t. 8, f. 38-40.

1. Ad agger. præepr. aren., arb. rad, muros, etc. - Eur. : Feré tota. As. : Caucas. Afr. : Alger. Am. sept. : Canada occ., Manitobs, M. Rupestr., Columb. brit., Idaho, Montana, Arizona, Colorado, Calif.

Exs. : Drumm. M. bor. am. I ed. n. 144. (Tortula).

Rab. Bryoth. eur. n. 224 et b.

a var, angustata Bryol, eur, et W. P. Sch. ll, cc.

B. angustata Braithw. British. Moos. Fl. p. 221.

Desmatodon subulatus var. angustatus Jur. $l$. $c$.

Ut typ. - Eur. : In subalp. et reg. merid. Am. sept. : Lac. Erie, Ontario, M. Rupestr., Columb. brit.

Exs. : Mac. Canad. M. n. 413.

var. inermis Bryol, eur. - B. inermis.

(1) Conf. C, M, l. c, 
«var. integrifolia Boul. M. Fr. p. 412.

- Eur. : Gall. merid, Ital. sup.

«var. longifolia Kindb. in Mac. Cat. p. 58.

Terr. - Am. sept. : Columb. brit., ins. Vancouver.

- var, mucronata R. Farneti M. Prov. Pavia, 1891, p. 22.

In gramin. - Eur. : Ital. sup. (M. Lesina).

" var. mutica W. P. Sch. Syn. II ed.p. 224.

In calcar. - Eur. : Anglia, etc. Afr. : Alger. Am. sept. : Passim.

«var, recurvo-marginata Breidl. in sched.; Limpr. Deutschl. Laubm. I, p. 671 .

Ut praeced. - Eur. ; Stiria.

"var. subinermis Bryol. eur. et W. P. Sch. ll. cc.

Ut praeced. - Eur. : Anglia, etc. Afr, : Alger. Am. sept, : Passim. subulifolia Sull. in Proc. Am. Acad. 1861, p. 277.

B. crispula Hpe. in Jaeg. Ad. I, p. 286 (1).

B. gracilis Sull. $l$. c.

Tortula subulifolia Sull. $l$. $c$.

Tortula subulifolia Mitt. M. austr. am. p. 161.

2. Ad rup. irror. - Am. sept.: Cuba. Am. merid.: Guian., And. Quitens.

subunguieulata W. P. Sch. in Savatier M. Jap. n. 203; Besch. in Ann. 2. se. nat. 1893, p. 337.

syrrhopodontoides Rehm. M. Afr. austr. n. 476. - Afr. : Transvaal.

tasmavica Hpe. in Linn. 1852, p. 713.

B. pungens $H$. $f$. et $W$. ?

2.

- Pac. : Tasman. (2)

tenvirostris Brid. - B. angustifolia.

teretiuscula W. P. Sch. in C, M. Syn. I, p. 614.

Tortula teretiuscula Mitt $M$. austr. am. p. 160.

2.

tophacea Mitt. - Trichostomum.

- Am. sept. : Mexic.

thrausta C. M. in Dusen M. Camer. n. 352.

- Afr. : M. Cameroon.

torquata Tayl, in Lond. Journ. of bot. 1846, p. 50 ; C. M. Syn. I, p.611; Hook. $f$. el Wils Fl. N. Zeal. II, p. 70 el Handlb. p. 419.

Tortula torquata Mitt, in Journ. of the Linn. Soc. 1859, p. 70.

- Pac. : Austral., Nov. ZeIand. sept., Tasman.

torquescens W. P. Sch. in Bot. Zeit. 1853, p. 163.

2 ? $\quad-A$ fr. : C. B. Sp.

(1) Sec. Hpe. in Jaeg. op. c., pp. 269 et 287, pl. Wright. Cubens. n. 32 est B. subulifolia, pl. n. 27 B. crispula. - Mitt. sub nomine B. subulifoliae n. 27 et 32 conjungit.

(2) tenera Brid. Bryol, univ. I, pp. 577 et 835. Bryum tenerum Vill. Pl. Dauph. III, p. 366 (excl. syn. Dill.)

Tortula tenera P. B. Prodr. 93. 
tortellifolia C. M. et Kindb. in Mac. Cat. p. 56.

B. cylindrica Mac. Canad. M. n. 81, p.p.

B, flexifolia ej. l.c.n. 399.

2. Rup. humid. et marit. - Am. sept. : Columb. brit., ins. Vaneouver: tortelloides C. M. in Linn. 1878-79, p. 337 .

2. - Am. merid.: Argentin. subtropic.

tortuosa (L.) Web. el Mohr Bol. Taschenb, p. 205; Brid. Bryol. univ. 1, p. 574 ; Bryol. eur. II (mion. p. 26) t. 151 ; C. M. Syn. I, p. 601; W. P. Sch. Syn. II ed. p. 218.

B. tortuosa var, incrassata Brid. op. c. p. 575.

Bryum cirratum, setis et capsulis longioribus Dill. Hist. M. p. 377, t. 48, f. 40.

Br. tortuosum L. Sp. Pl. p. 1583.

Hypnum tortuosum Web. Spic. Fl. Goett. p. 90.

Mnium tortuosum L. jun. Meth. M. p. 364.

Mollia tortuosa Schrank Prodr. Fl. Salisb.

Tortella tortuosa Limpr, Deutschl. Laubm. I, p. 604.

Tortula incrassata Brid. Sp: M. I, p. 264.

T. tortuosa Hedw. f. in W. et M. Beitr. I, p. 121, t. 4.

2. Ad terram et rup. praecip. calcar. - Eur. : Feré tota in reg. mont., subalp. et alp. As. : Jenissei, Caucas., Persia, Afr. : Alger. (ster.) Am. sept.: Groenland, Anticosti, Terr. Nov., ins. Miquelon, New Brunswick, Gaspesia, New York, Pensilv., M. Alleghan., Niagara, M. Rupestr., Columb. brit., ins. Vancouver, Idaho, Virgin. oce.

Exs. : Drumm. M. bor. am. I ed. n. 141 (Tortula).

Mac. Canad. M. n. 77.

Rab. Bryoth. eur. n. 35, 1273.

Sull. et Lesq. M. bor. am. II ed. n. 137.

Un. itin, 1867, n. 104.

\&var. angustifolia Jur. Laubm. Oesterr. Ung. p. 123.

Ut typ. - Eur.: Stiria, Salisb., Tirol.

«var. fragilifolia Jur. op. et $l$. cc.

Ster. Calcic. - Eur. : Hungar., Austr., Dalmat., Tirol., Gall. merid, Ital. sup.

var, incrassata Brid. - B. tortuosa.

«var. ? longifolia Ren. in Rev. bryol. 1882, p. 92.

- Eur. : Gall. merid., Ital. super.

transcaspica (Broth.) Par.

Tortula transcaspica Broth. in Bot. Centralbl. 1888, n. 14.

1. Calcar, - As. : Transcasp.

Trianae C. M. in Bot. Zeit. 1857, p. 578.

Tortula Trianae Milt, M. austr. am. p. 172.

2 .

- Am. merid. : Nov. Granat.

trichostomacea C. M. in Rehm. M. Afr. austr. n, 97 et 483.

- Afr: : C. B. Sp.

《var, chlorophyllosa C. M. l. c. n. 98.

-Afr. : C. B. Sp.

trichostomoides Besch. Prodr. bryol. mexic, p. 38.

- Am. sept. : Mexic.

Turneri Brid. - Didymodon rubellus.

umbrosa C. M. in Linn. I878-79, p. 340.

2. Muric, et terr. $-A m$. merid. : Argentin. Cordob. et subtropie. 
uncinicoma C. M. op. cit, p. 345 .

2.

- Am. merid. : Argentin. Cordob.

unguiculata Hedvo. M. frond, I, p. 59, t. 23 ; Brid. Bryol. univ. I, p.563; Bryol. eur. II (mon. p. 19), t. 142; C. M. Syn. I, p. 612; W. P. Sch. Syn. Il ed.p. 203.

B. amøena Schum. Fl. Sael. II, p. 48 ; Brid. op. c. p. 538.

B. aristata Brid. Mant. M. p. 92 .

B. dubia ej. op. et $l$. $c c$.

B. incerta Schum. op. cit. p. 44.

B. lanceolata ej. op. cit. p. 4.

B. linoides Brid. Mant. M. p. 90 et Bryol. univ. I, p. 543.

B. stricta Hedw. Sp. M. p. 119, t. 26; Brid. Bryol. univ. I. p. 540.

B. unguiculata var. aristata Brid. op. cit. p. 567 .

B. unguiculata var. dubia ej. l. c.

Bryum aristatum Dicks. Fase. III Pl. crypt.p. 12, t. II, f. 7.

Br. barbatum Curt. Fl. Lond. fasc. IV, t. 65 .

Br. linoides Dicks. Fase. III Pl. crypt. p. 8, t. VIII, f. 3.

Br. mucronulatum ej. op. cit. p. 3.

Br. unguiculatum Huds. Fl. Angl. I ed., p. 410.

Br. unguiculatum et barbatum, tenuius et stellatum Dill. Hist. M. p. 384, t. $48, f .48$.

Br. unguiculatum et barbatum, surculis in summitate crassioribus $e j$. op. cit. p. $383, t .48, f .47-49$.

Dicranum laxum Brid. M. Recent. II, I, p. 175 (excl. syn.).

Mollia unguiculata Schrank Baiers. Fl. II, p. 457.

Orthopyxis aristata P. B. Prodr. p. 79.

Tortula amona Brid. Sp. M. I, p. 249.

T. aristata Sm. Fl. brit. III, p. 1261 .

T. barbata ej.op. cit. p. 1260.

T. decipiens Sibth. Fl. Oxon. p. 285.

T. dubia P. B. Prodr. p. 92.

T. fallax H. et Grev, in Edinb. Journ. of se. I, p. 300.

T. humilis Turn. Muso, hibern. p, 45.

T. linoides Brid. Mant. M. p. 90 et Bryol. univ. p. 543.

T. mucronulata $\mathrm{Sm}$. Fl. brit. III, p. 1250.

T. stricta Brid. Sp. M. I, p. 249.

T. unguiculata ej. op. cit. p. 258.

Trichostomum linoides ej. op. cit. p. 234.

2. In mur., rupib., camp., ad vias, etc. Eur.: Tota, vulgatiss. As.: Jenissei med., Japon., Caucas. Afr. : Alger. Am, sept. : Canad, or., Columb. krit.; fere tota.

Exs. : Drumm. M. bor. am. I ed. n. 140, II ed, n, 62 (Tortula).

Mac. Canad. M. n. 73.

Rab. Bryoth, eur. n. 420.

Sull. et Lesq. M. bor. am. II ed. n. 123.

«var. apiculata Bryol. eur. et W. P. Sch. ll. cc.

B. apiculata Hedw. Sp. M. p. 117, t. 26; Brid. Bryol. univ. I, pp. 560 et 831 .

Tortula apiculata Brid. Sp. M. I, p. 259.

T. unguiculata var, apiculata Hook. et Tayl. Musc. brit. p. 30.

Trichostomum pensilvanicum Spreng. Syst. veg. IV, I, p. 170.

Loc. argillos.-calear. - C. typo.

Exs. : Rab. Bryoth, eur. n. 1310.

var. aristata Brid. - B. unguiculata.

« var. brachypus C. M. l. c. p. 613.

B. brachypus Brid. Bryol. univ. I, p. 551.

Tortula acuminata ej. Sp. M. I, p. 252.

Ut typ. - Eur.: Thuring., Catalaun. 
"var. cuspidata Brid. Bryol. univ. I, p. 565; Bryol. eur. l.c. t. 143; C. M. op. cit. p. 613; W. P. Sch. op. cit. p. 204.

B. cuspidata Schultz Rec, de Barbula, p, 14, t. 32, $f, 14 a$.

Bryum nervosum Hoffm. Deutschl. Fl. II, p. 44.

Tortula mucronulata Sw, Disp. M. Suec. p. 40.

Tortula mucronulata $\beta$ Turn. Musc. Hibern. p. 47.

Ut typ. - Eur. : Iisd. loc. Afr.: Alger.

var. Iubia Brid. - B, unguiculata.

« var. fastigiata Bryol. eur. l. c.

B. fastigiata Schultz op, cit. t. 33 ; Brid. Bryol. univ, I, p. 551.

Ut. typ. - Eur: : Reg, alp..

var. latifolia de Breb. - B. Brebissonii.

«var, microcarpa Bryol. eur. et W. P. Sch. ll. cc.

B. microcarpa Schultz op. et l. co.; Brid. op. c. p. 561.

Ut et cum var. apicul.

«var. nitido-costata R. Farneli M. Prov. Pavia, 1891, p. 20.

Rup. umbros. - Eur.. Ital. super.

« var. obtusifolia Bryol. eur. et W. P. Sch.ll.ec.

B. lanceolata Hedw, Sp. M. p. 119, t. 26; Brid. Bryol. univ, I, p. 568.

B. obtusifolia Schultz op, cit. t. 32 .

Tortula lanceolata P. B. Prodr. p. 92 ; Brid. Sp. M. I, p. 260.

In agris. - Eur. : Rarior.

- var. patagonica C. M. in Linn. 1843, p. 583 et Syn. I, p. 613.

B. ericetorum Brid. M. Rec. II, I, p. 196.

Bryum ericetorum Dicks, Faso. II Pl. crypt. p. 5 ?

Br, ruralis facie, foliis minoribus et non pilosis Dill. Hist. M. p. 354, t. 45, f. 13.

Syntrichia ericetorum Brid. Bryol. univ. I, p. 588.

Tortula ericetorum Sm. Fl, brit. III, p. 1258.

Ui typ. - Eur. : Scotia? Am. merid. : Patagon.

unguiculatula $C$. M. in Linn. $1878-79, p .333$.

2.

- Am. merid. : Alp. Argentin. subtropic.

uruguensis $P$ ar.

B. decidua C. M. in Linn, 1880-82, p. 427.

2 .

- Am. merid. : Uruguay.

vaginata Lindb. in Act. Soc. pro Faun, et Fl. Fenn. $10^{\text {n }} 8^{\text {bri }} 1880$ (nom.). - Eur. : Suec. merid.

Vahliana Schults Rec, de Barbula p. 30, t. 34, f. 31 ; Brid. Bryol. univ. I, p. 545; Bryol. eur. II (mon. p. 33) t. 157; C. M. Syn. I, p. 626; W. P. Sch. Syn. II ed. p. 199.

B. oblongifolia W. P. Sch, Coroll. Suppl. (ad calcem) et Syn. I ed. p. 185.

Tortula extenuata de Not. Sp, de Tortul, ital. n. 12 et Syll, p. 174.

T. oblongifolia Wils. Bryol, brit. p. 129, $t .43$.

Tortula Vahliana ej. op. et $l$. $c c$.

T. Vahlii $\beta$ subflaccida Lindb. Trichost, eur. p. 29.

1. In terr. argill, humidiusc. - Eur.: Hibern., Galloprov., Sardin. Afr. : Alger, ins. Canar, Am. sept. : Columb. brit., Calif.

" var. minor Husn. Musc. gall. p. 102.

Ad rup. vulcan. - Afi: : Teneriffa.

validinervia C. M. in Engles's Bot. Jahrb. 1883, p. 79 et in Forchungsreise .... Bot. p. 79 .

2. Ster.

- Afr. : Ins. Kerguelen. 
vinealis Brid. Bryol. univ. I, p. 830; Bryol. eur. II (mon. p. 24) t. 148; C. M. Syn. I, p. 617; W. P. Sch. Syn. II ed. p. 209.

B. cylindrica var. vinealis Lindb.

B. fallax var. vinealis Hüb. Musc. germ. p. 327.

Tortula fallax ras: vinealis de Not. Syll. p. 180.

T. vinealis Spr. in Lond. Journ. of Bot. IV, p. 194.

Weisia monoclados Brid. op. cit. p. 360.

2. In mur. atque terr. lapid., rar. in mur. - Eur. : Britann., German. sept. (steril!), vall. Rhen., Galloprov., Ital., ins. Melit. As. : Yunnan, Nepal, Kurdistan., Persia, As. min. Afr.: Alger. Am. sepl. : Terr. Nov., Ontario, Calif., Mexic.

Exs. : Rab. Bryoth, eur. n. 668, 784 et b, 1071, 1311.

Sull. et Lesq. M. bor. am. II ed., n. 130.

var. cylindrica Boul.
var. flaccida Bryol. eur.

virescens Lesq. in Trans. A m. Phil.Soc. XIII, p. 4; Lesq.el Jam. Man.p. 124.

2. Rupic. - Am. sept. : Calif.

Exs. : Sull. et Lesq. M. bor. am. II ed, n. 134.

viridis W. P. Sch, in Rab. Bryoth. eur. n. 818. - Eur. : Gall. merid.

vuleanica Ltz. Moosst. p. I61.

2. Rupic. - Am. merid. : And. Equat.

Wallichii (Milt.) Jaeg. Ad. I, p. 296.

Desmatodon Wallichii Mitt. M. Ind. or. p. 38.

Trichostomum dentatum Wils. in Kew Journ. bot. IX, p. 299 p.p.

2.

- As. : Nepal., Sikkim.

Wildii Brolh. in Oefo..... 1890.

2. Calcar. - Pac.: Austral. (Queensland).

Woodii W. P. Sch. Syn. II ed. p. 207.

Ampboridium Mougeoti W. P. Sch. (fid. Husn. Musc, gall. p. 147).

Trichostomum Woodii Husn. op. cit. p. 86.

Ster. Mur, humid. - Eur. : Hibern.

Wrightii Sb. in Jaeg. Ad. II, p. 673.

B. obscura Sull. in Proc. Am. Acad. 1861.

Tortula obscura Mitt. M. austr. am. p. 150.

2.

- Ant. sept. : Cuba.

xanthocarpa C. M. in Linn. 1843 el Syn. I, p. 619.

$2 . \quad-A f r .:$ C. B. Sp.

Exs, : Rehm. M. Afr. austr. n. 94 (1).

(1) In Enumer. Kindberg, nomina nuda :

B acrophylla $C, M$.

anrectangiacea $C . M$.

aristata $C$. M. (an B. aristatula?)

aureola C.M.

brevipila Hpe. et C. M.

connivens Lindb.

Eggersii C. $M$.

exesa $C . M$. (an B. serripungens var, exesa?)

Fristedti $C, M$.

insulana de Not. (probab. B. cylindrica).

microglottis $C . M$.

murina $C . M$.
B. nivalis $S p r$.

pallido-virens C. $M$.

pallido-viridis C. M.

paramattana Mitt.

perlimbata Geh.

propinqua $C, M$.

punctulata Brid. (Quid ?)

rubricaulis $C . M$.

subdecidua (C. M.) Kindb. (an B. uruguensis ?)

subobscura (Sull.) Kindb. (an B. Wrightii ?

subrubiginosa (C. M.) Kindb. (an B, argentinica ?)

Sullivani C. $M$. 
BARTRAMIA Hedw. M. fr. II, p. III, t. 40 (83 sp.)

abyssinica C. M. - Anacolia.

acerosa C. M. et Hpe. in Linn. 185̌6, p. 208.

B. papillata $H$. f. et W. (fid. Mitt.)

2.

- Pac. : Austral. fel.

acicularis C. M. - Philonotis.

aciphylla Wils. - Breutelia.

acutissima C. M. - Philonotis.

affinis $\left\{\begin{array}{l}\text { Hook. - Philonotis. } \\ \text { Hsch. - Philonotis erythrocaulis. } \\ \text { Schwaegr. - Breutelia commutata }\end{array}\right.$

afro-scoparia C. M. - Breutelia.

afro-stricta C. M. in Rehm. M. A fr. austi. n. '203.

Ster.

- Afr. : C. B. Sp.

afro-uncinata C. M. - Philonotis.

alpina Schleich. - B. Ederi.

alto-gracilis C. M. - Philonotis.

ambigua Mont, in Ann. sc. nat. 1845, IV, p. 103 et Syll.p. 28; C. 1 . Syn. I, p. 502.

2. Terr. et rupic. - Am. merid. : Peruv., Chile.

amblyoblasta C. M. - Philonotis.

andina Mitt. - Philonotis.

androgyna Hpe. - Philonotis.

angulala Tayl. - Philonotis rufiftora.

angustata Wils. $\left\{\begin{array}{l}- \text { Philonotis angusta. } \\ \text { p.p. - Philonotis fontana var. falcata. }\end{array}\right.$

angustifolia Mitt. M. austr. am. p, 273.

B. longifolia ej, in Jameson M. exs.

- Am. merid. : And. Quitens.

angustissima C. M. - Philonotis.

anisothecioides (:. M. - Philonotis.

appressa $\mathrm{H}$. f. et W. - Philonotis.

aprica C. M. in Linn. 1875 , p. 397.

Syn., fr. ign. Rupic. - Afr. : Liltus occ. mar. Erythraei.

arbusculacea C. M. - Philonotis.

aristata W. P. Sch, in Lechl. Pl. Chil, n. 834; C. M. in Bot. Zeil. 1862,

p. 338 .

Rup. madid. - Am. mericl. : Valdiv.

aristata Mitt. - B. aristifolia.

aristifolia Jaeg. Ad. I, p. 533.

B. aristata Mitt. M, austr. am. p, 269.

2? Rupic. - Am. merid. : And. Quitens.

arcuala $\left\{\begin{array}{l}\text { Brid, - Breutelia. } \\ \text { Schwaegr. p.p. - Breutelia. }\end{array}\right.$

asperifolia Schwegr. - Breutelia tomentosa,

asperifolia (?. M. Philonotis.

australis $\left\{\begin{array}{l}\text { Mitt. (M. anstr. am.) - Conostomum. } \\ \text { Mitt. (1876). - Philonotis anisothecioides? }\end{array}\right.$

Mitt. (Handls.). - Philonotis. 
austro-arcuala C. M. - Breutelia.

austro-georgica Par.

B. subpatens C. M. Bryol. Austr, Georg. p. 29.

Syn. - Am. merid. : Austr. Georg.

baginsensis C. M. - Philonotis.

Berteroana C. M. - Philonotis.

var. flaccida C. M. - Philonotis Berteroana var. flaccida. bogolensis $\mathrm{Hpe}$ - - B. flavicans.

Boulayi Ren. el Card. in Bull. Soc, roy. bot. Belg. 1890, I, p. 177. - Afr. : Ins. Borbonize.

brachypus Br. et Sch. in W. Sch. M. Abyss. n. 441 ; C. M. Syn. I, p. 497.

Syn. $\quad-$ Afr: : M. Abyssin.

Breutelii W. P. Sch. in Breut. M. Cupens. ; C. M. in Bot. Zeit. 1858, p. 162 .

2. $-A f r:$ C. B. Sp.

brevifolia Brid. Bryol. univ. II, p. 737; C. M. Syn. II, p. 619.

B. Mülleri Mont, in C. M. Syn. I, p. 498 et Syll. p. 29; Mitt. M. austr. am. p. 273.

B. patens Hook, in Kth. Pl. Equinoct.p. 55.

B. potosica C. M. in Linn. 1817, p. 204; Hpe. op, cit. p. 76.

2 ?

- Am. merid. : Columb.

brevifolia W. P. Sch. -- B. Schimperi.

breviseta | Boul. - B. ityphylla var. rigidula.

I.indb. - B. ityphylla var. breviseta.

Brownii Brid, - Philonotis affinis.

caespitosa Wils. - Philonotis fontana var. caespitosa.

calabrica Lindb. - Philonotis rigida var, gracilis.

calcarea Bryol, eur. -- Philonotis.

Campylopus W. P. Sch. in C. M. Syn. II, p. 619.

- Am. sept. : M. Mexic.

carinata Mitt. - Breutelia.

catenulala $\mathrm{Hpe}$ - - Philonotis.

chilensis Ltz. in Bot. Zeit. 1866, p. 186.

2 ? Arenic ? - Am. merid. : Valdiv.

chrysea C. M. - Breutelia?

chrysura C. M. - Glyphocarpus.

var, elongala C. M. - GJyphocarpus chrysurus var, elongata.

var. nigrescens C. M. - Glyphocarpus ehrysurus var. nigrescens.

circinulata C. M. et Kindb. in Mac. Cat. p. 105.

2 ? Rupic, - Am, merid. : Columb. brit.

commutata Mitl. in Journ. of the Linn. Soc. 1863, p. 153.

B. patens Schavegr: Suppl. I, II, p. 55, t. 62 (fid. Mitt.).

Syn.

- Afr.: M. Cameroon.

commutala Hpe. - Breutelia.

comorensis C. M. - Philonotis.

comosa $\left\{\begin{array}{l}\text { Hpe. et C. M. - Glyphocarpus. } \\ \text { Hook. f. - Bientelia. }\end{array}\right.$

compacta Hsch. - Glyphocarpus.

condensata Schwaegr. - B. CEderi.

conosloma Bryol, eur. - Conostomum boreale.

consimilis Hook, f, - Breutelia. 
costa-ricensis C. M. Syn. II, p. 618.

Syn.

- Am. sept. : Costa-Rica.

crassa H. f. et W. - Brentelia.

crassinervia Mutt. in Handb. of the N. Zeal. Fl. p. 417.

Syn. Silvic. - Pac. : Nov, Zeland. med.

crassinervis Wils. p.p. $-\left\{\begin{array}{l}\text { Philonotis calcarea. } \\ \text { Philonotis fontana. } \\ \text { Philonotis lutea. }\end{array}\right.$

crenatula C. M. - Philonotis.

crispa Sw. - B. pomiformis var. crispa.

var. minor W. et M. - B. pomiformis.

var. pomiform is Lindb. - B. pomiformis,

crispata W. P. Sch. in Savatier M. Japon. n. 511; Besch. in Ann. sc. nat. $1893, p .348$.

1. Ad arbor, excav, - As. : Japon.

Exs. : Faurie n. 55, 69, 162, 164, 3501.

Cryptopodium C. M. - Cryptopodium bartramioides.

curvata Hpe. - Philonotis.

curvirostra Mitt. - Conostomum.

curvula C. M. - Philonotis.

cuspidatissina C. M. - Breutelia.

cygnaea Mont. - Bartramidula.

defecta C. M. - Philonotis.

defoliata C. M. in Linn. 1864, p. 597.

Ster.

- Am. merid. : And. Nov. Granat.

dicranacea C. M. - Breutelia.

dicranoides Wils. - Philonotis longicolla.

didymocarpa W. P. Sch. in Mandon Pl. boliv. n. 1669.

- Am. merid. : And. Boliv.

diminutiva C. M. in Engler's Bot. Jahrb. 1883, p. 79 el in Forchungsreise...... p. 20.

Syn,

divaricata $\left\{\begin{array}{l}\text { C. M. - - Breutelia Mülleri. } \\ \text { Hook. - Breutelia. }\end{array}\right.$

Dregeana C. M. - Philonotis.

dumosa Mitt. - Brentelia.

elegantula C. M. - Philonotis.

elongata Mitt. - Prionodon.

erecta Mitt. - Bartramidula.

erytkrocaulis C. M. - Philonotis.

exigua Sull. - Bartranidula.

faleala Hook, - Philonotis fontana var. falcata.

Fendleri C. M. - Bartramidula.

filiformis Hsch. - Philonotis tenella var. gracillima.

flavicans Mitt. in Lond. Journ. of bot. 1851, p. 55 et M. austr. am. p. 270: C. M. Syn. II, p. 618 .

B. bogotensis Hpe, in Linn. 1863, p. 142 et in Ann. sc. nat. V ser., III, p. 374 .

Syn.

- Am. merid.: And. Nov. Granat.

flavicans C. M. - Philonotis.

fontana Sctıwaegr. $-\left\{\begin{array}{l}\text { Philonotis. } \\ \text { Philonotis rigida. } \\ \text { Philonotis tenella var. humilis. }\end{array}\right.$ 
var, alpina Bryol, eur. - Philonotis fontana var. alpina.

var. falcata Bryol. eur. - Philonotis fontana var. falcata.

falcata Mont. - Philonotis macrocarpa?

var, marchica $\mathrm{H}$. et T, - Philonotis marchica?

fontanella Hpe. - Philonotis.

fontanoides Gill. et Grev. - Philonotis.

fragilis Mitt. - B. papillata.

fuscescens Angstr. in Oefv..... 1876, n. 4, p. 18.

2.

- Am. merid. : Brasil. austr. or.

Gardneri S. M. - Philonotis.

gemmascens C. M. - Philonotis.

gigantea $\left\{\begin{array}{l}\text { Bory. - Bartramia vulcanica, } \\ \text { H.f. et W. - Breutelia divaricata. }\end{array}\right.$

gigantea Schwaegr. - Breutelia.

glauca Ltz. Moosst. p. 160.

Ster.

- Am. sept. : Mexic.

glaucescens Hsch. - Philonotis.

glauco-viridis C. M, et Kindb. in Mac. Cat. p. 105.

1. Rup. humid. - Am. sept. : Columb. brit.

glomerala Wils. - Philonotis.

gnaphalea C. M. - Breutelia.

gonioclada Wils. - Philonotis fontana var, falcata.

gracilenta Hpe. - Philonotis.

gracilis Floërke. - Bartramia Ederi.

var. tomentosa C. M. - B. AEderi var. con lensata.

graminicola C. M. $-\left\{\begin{array}{l}\text { Philonotis, } \\ \text { Philonotis kerguelensis. }\end{array}\right.$

granatensis W. P. Sch. - Anacolia Webbii.

grandis Geh. et Hpe. - Breutelia.

Griffithiana Wils. $-\left\{\begin{array}{l}\text { Philonotis Griffithiana. } \\ \text { Philonotis imbricatula. }\end{array}\right.$

Halleriana Hedwo. M. frond. II, p. III; Brid. Bryol, univ. II, p. 33;

Bryol. eur. IV (mon. p. 14)t. 320; C. M. Syn. I, p. 425; W. P.

Sch. Syn. II ed.p. 511.

B. MLossmanniana C. M. (fid. Mitt.).

B. norvegica Lindb. M. Seand. $p .15$.

Bryum Bartramia Gmel. Syst. nat. II, p. 1335.

Br. foliis mollibus subulatis, setis brevissimis alaribus, capsulis ovatis Hall. Hist. se. Helv, n. $1802, t$. XLV, f. 8.

Br. laterale Ehrh. Crypt. exs. n. 33.

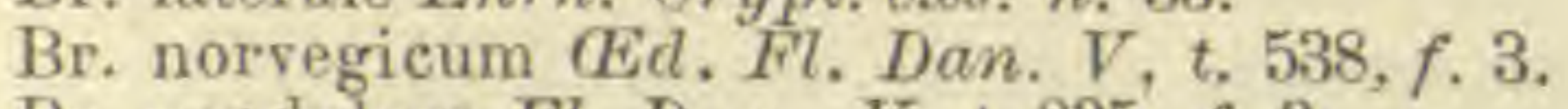

Br. pendulum $F l . D$ in. $V, t .835, f .3$.

Br. pomiforme var . I Scop. Fl. Carn. n. 1307.

Br. pomiforme $\beta$ Halleri Vill. Pl. Dauph. III, $p, 878$.

Br. recurvum Wulf in Jacq. Coll. II, p. 224.

Mnium laterale Hoffm. Deutsch. Fl. II, p. 54.

Webera clandestina Hedvo. Fund. M. II, p. 104, t. 6, f. 39.

W. Halleriana ej. op. cit. p. 95.

1. Ad rup, humid. umbr. - Eur. : Zon. sept. et med, rar. merid, reg. mont. usque in alp. As. : Alp. Yunnan, Himalaya, Caucas. Afr.: M. Cameroon (?) Am. sept. : M. Rupestr. - Pac. : Tasman?

Exs. : Drumm. M. bor. am. I ed. n. 239.

Rab. Bryoth. eur. n. 235, 74!).

Halleriana $\left\{\begin{array}{l}\text { H. f, et W. - B. Mossmanniana. } \\ \text { Mitt. - B. magellanica, }\end{array}\right.$ 
Hampeana C. M. in Bol. Zeit. 1858, p. 162.

Glyphocarpus asperrimus Hpe. in Jaeg. Ad. I, p. 512.

$2 . \quad-A f r:$ C. B. Sp.

Exs. : Rehm. M. Afr. austr. n. 200.

Hasskarliana Hpe. - Rreutelia.

Henoni Duby. - B. pomiformis var. crispa.

hercynica Floërke. - B. pomiformis var. crispa.

heteromalla Brid. - B. pomiformis var. crispa.

hispida Mitt. - Breutelia.

Hookeri Wils, - Philonotis Iongicollis.

humilis Mitt. - Glyphocarpus.

Hymenodon C. M. - Philonotis.

incana Tayl. - Breutelia.

inclinata Hpe, et Ltz. - Brentelia.

incrassala C. M. - Philonotis.

incurva Hoppe. - B. pomiformis var. crispa.

inserta Sull. et Lesq - Glyphocarpus.

integrifolia $\left\{\begin{array}{l}\text { Sull, - Breutelia aureola? } \\ \text { Tayl. - Breutelia. }\end{array}\right.$

intermedia $\mathrm{Hpe}$ - Breutelia.

intertexta C. M. p.p. $-\left\{\begin{array}{l}\text { Anacolia. } \\ \text { Anacolia setifolia. }\end{array}\right.$

ithyphylla Brid. Mant. M. III, p. 85 et Bryol. univ. II, p. 43 ; Bryol. eur. IV. (mon. p. II) t. 317 ; C. M. Syn. I, p. 493; W. P. Sch. Syn. II ed.p. 510.

B. pomiformis Sw. Disp. M. Suec. p. 75.

Bryum alpinum viridissimum et majus, capitulis crassissimis Hall. Enum. sc. Helv. p. 109, t. III, f. 7 .

Br, pomiforme L. Sp. Pl. p. 1580 p.p.

Br. pomiforme $\beta$ majus Web. Fl. Goett, p. 20.

Syn. Ad terr. et in fiss. rup. - Eur. : E reg. campestr. usq. in supra alp. prapr. zona septentr.; S. Nevada. As. : Kamschatka, Jenissei inf., Caucas. Am. sept. : Arctic. et bor. : Groenland, Labrador, M. Rupestr. et Selkirk, Columb. brit., Alaska, Sitka, ins. Vanconver, Washington, Idaho, Wyoming, Nevada, Oregon; M. Adirondack, Pensilv., Terr. Nov., ete.

Exs. : Drumm. M. bor. am. I ed, n. 238.

Rab. Bryoth, eur. n, 234, 1209.

Sulliv, et Lesq. M. bor. am. II ed, n. 255.

Un. itin. 1867, n. 83.

* var. Arenae Besch. in Miss. sc. Cap Horn, Bot. V, p. 288.

- Am. merid. : Fret. Magellan.

"var. breviseta Husn. Muscol. gall. p. 266.

B. breviseta Lindb. M. nov. Soand. in Not.... 1868, p. 255.

Ut typ. - Eur. : Finmark, Alp. centr. Am, sept. : Groenland, Behring.

- var. rigidula W. P. Sch. Syn. II ed. p. $5 \mathrm{I0}$.

B. rigidula Boulay $M$. $F r$.

Ut typ. - Eur. : Lappon., Alp. Norveg. Am. sept. : Groenland.

var. subulata Husn. - B, subulata.

ithyphylloides W. P. Set, in Lechl, M. Chil, n. s75; C. M. in Bot. Zeit. $18.99, p, 229$.

Am. merid. : Cuil.

- Am. sept. : Mexic. (fid. Besch. Prodr, p. 57). 
jamaicensis Mitt. - Breutelia.

Jamesoni Tayl. - Cryptopodium Hookeri.

javanica Dz. et Mk, in Zoll. Syst. Verz. pp, 24 et 50 et Bryol.jav. l, p. $154, t .123$. - As. : Java.

Karsteniana C. M. - Breutelia?

Kilima N'Djarica C. M. - Breutelia.

Krauseana C. M. in Bot. Centralbl. 1883, n. 2. 4.

Syn. $\quad-$ As.: Penins. Tschutschica.

Krausei $\left\{\begin{array}{l}\text { Bryol. eur. - Glyphocarpus compactus. } \\ \text { C. M. - Bartramidula. }\end{array}\right.$

lacte-virens Rehm. - Breutelia afro-scoparia.

laevisphaera Tayl. - Glyphocarpus.

lamprocarpa W. P. Sch. - Anacolia intertexta.

lanceolata Schrad. - B. Ederi.

laxissima C. M. - Philonotis.

Leikipiae C. M. in Fl. 1890, p. 479.

Ster.: $\quad-A f r .:$ M. Aberdare.

leptodonta Wils, in Kew Journ. bot. IX, p. 369 ; Mitt. M. Ind or. p. 58. 1. vel Syn. - As. : Himalaya.

leucolomacea C. M. Bryol. austr. Georg. p. 28.

2. In argillos. - Am. merid. : Austr. Georg.

Lindigii Mitt. - Bartramidula.

lineata C. M. in Linn. 1878-79, p. 464.

2 ?

- Am. merid. : Venezuela.

longicollis $\mathrm{Hpe}$. - Philonotis.

longifolia Hook. M. ex. t. 68 ; Brid. Bryol. univ. II, p. 39; C. M. Syn. I, p. 498 ; Mitt. M. austr. am. p. 273.

Rup, granitic. - Am, merid. : And, Nov. Gran.

longifolia $\left\{\begin{array}{l}\text { Hsch. - B. Martiana. } \\ \text { Mitt. - B. angustifolia. }\end{array}\right.$

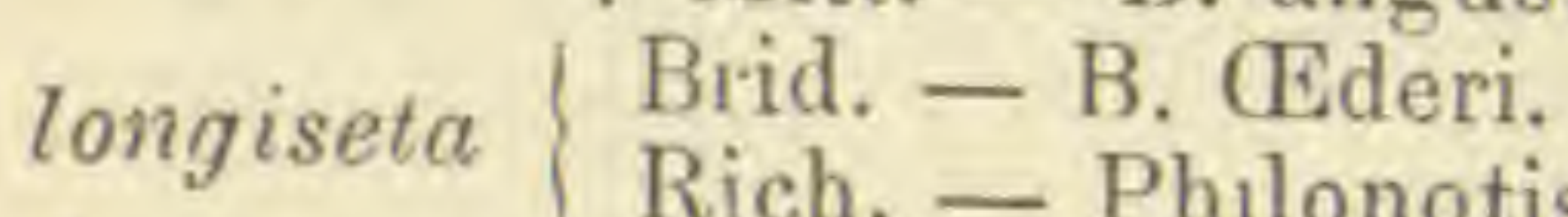

( Rich. - Phlonotis radicalis.

Lorentzi C. M. - Breutelia.

lutescens Mitt. - Cryptopodium.

macrocarpa $\{$ C. M. - Philonotis.

( Hpe. - Breutelia tomentosa.

macrodictya C. M. - Philonotis.

macro-subulata C. M. in Bot. Centralbl. 1883, n. 2.4 .

Syn.

- As. : Penins, Tschutschica.

macrotheca Hpe. - Breutelia tomentosa.

magellanica Angstr. in Oefv..... 1872, n. 4, p. 8.

B. Halleriana Mitt. l.c. p. 272.

1. Ad rup. madid. - Am. merid. : Fuegia, in fret, Magellan.

magellanica Mitt. - Conostomum.

marchica $\left\{\begin{array}{l}\text { Schwaegr. - Philonotis. } \\ \text { Sull. - Philonotis Müblenbergii. }\end{array}\right.$

marginalis Rehm. M. Afr. austr. n. 202.

Ster,

- Afr. : Orange. 
Martiana Hpe. Enum. M. Brasil, p. 22 (nom.)

B. longifolia Hsch. Fl. Brasil. I, p. 40.

- Am. merid. : Brasil. austr. or.

Matthewsii Mitt. op. cit. p. 273.

- Am. merid. : And. Quitens., Peruv.

Menziezii Turn. - Anacolia.

microbasis C. M. in Linn. 1880-82, p. 409.

Fl. et fr. ign. $\quad-$ Am. merid. : Argentin. Cordob.

microdonta Mitt. - Glyphocarpus.

microstoma Mitt. op. cit. p. 272.

- Am. sept. : Guatemala.

minuta Tayl. - Philonotis.

Mohriana C. M. - Philonotis.

mollis C. M. - Philonotis.

var. Wils. - Philonotis leptocarpa.

Moritsiana Hpe. - Philonotis.

Mossmanniana C. M. in Bot. Zeit. 1851, p. 552.

B. Halleriana $H$. $f$. et $W$. Fl. of the N. Zeal. II, p. 83 et Handb. p. 446 (jure, fid. Mitt. !)

1. Arb, et rupic. - Pac. : N. Zel, sept, et med., Tasman.

Mühlenbergii Schwaegr. - Philonotis.

Mülleri Mont. - B. brevifolia.

nanothecia C. M. - Philonotis.

nevadensis C. M. - B. thrausta.

Niam-Niamiae C. M. - Philonotis.

nitida Wils. - $\left\{\begin{array}{l}\text { Philonotis. } \\ \text { Philonotis Turneriana. }\end{array}\right.$

Normanni Holmgr. - B. pomiformis var. heterophylla.

norvegica Lindb. - B. Halleriana.

obtusifolia Mitt. - Philonotis.

Ederi (Gunn.) Schwaegr. Suppl. I, II, p. 49, t. 59; Brid. Bryol. univ. II, p. 46; Bryol. eur. IV (mon. p. 12) t. 3I8; W. P. Sch. Syn, II ed. p. 512 .

B. alpina Schleich. Cent. IV, n. 17 .

B. gracilis Floërke in Schrad. bot. Joum. 1799, II, p. 171 ; C. M. Syn.I, p. 508 ; Drumm, M. bor. Am. I ed. n. 240.

B. grandiflora Schucaegr. Suppl. I, II, p. 48, t. 50;Brid. Bryol. univ. II, p. 48.

B. lanceolata Schrad.

B. longiseta Brid, Mant. p. 116.

B. Ederiana Sw, in Schrad. Jowrn. 1800, II, p. 81.

B. CEderi $\gamma$ longiseta Brid. op. et $l$. oo.

B. pomiformis Sull, M. Allegh, $n, 121$.

B. subintegrifolia $P, R$. Prodr. $p .44$.

Bryum lacerum Vill. Pl. Dauph. III, p. 878.

Br. Gideri Gunn. Fl. Norveg. n. 1005.

Br. pomiforme $\beta$ CEderi Vill.op. et l. ce. p. 879.

Mnium gracile Funk Fasc. Crypt. IV. p. 93 .

Plagiopus CEderi Limpr. Deutschl, Laubm. II, p. 548.

Syn. Ad. rup. humid. præprim. calcar, - Eur. : Reg. mont. et subalp. As. : Penins. Trshutschica, Amour, Japon., Jenissei med., Himalaya, Caucas. Am. sept. : Reg. sept, de Nov. Angl. ad M. Rupestr.; Canada, Columb, brit. 
Exs. : Faurie Pl, Japon. n. 299.

Mac. Canad. M. n. 149.

Rab. Bryoth. eur. n. 132,368 et b.

Sull. et Lesq. M. bor. am. II ed, n. 258.

var. alpina Schwaegi. - B. CEderi var. condensata.

«var. condensata Brid. Sp. M. III, p. 87 et Bryol. unvv. II, p. 48.

B. gracilis $\beta$ tomentosa C. M. Syn. I, p. 509.

B. Ederi $\beta$ alpina Schwaegr. Suppl. I, II, p. 48.

B. Ederi var. microcarpa Kindb. Enum. Bryin. Dovr. p. 28.

B. CEderi var. subnivalis Mdo. Alg. Moosst. p. 82.

Plagiopus (Ederi var. condensata Limpr. Deutschl. Laubm. II, p. 550 (1).

Pl. serratus Brid. Sp. M. III, p. 87 et Bryol. univ. I, p. 596; C. M. Syn. I, p. $511(1)$.

In uligin. (Brid.); ad rup, apricas (Limpr.). - Eur. : Alp. Algov.,

Stir., Carinth., Tirol., Rhaet., Helvet.

a var. glacialis Mdo, in Un. itin. 1863, n. 20.

Rupic. - Eur. : Alp. Tirol.

var. longiseta Brid. - B. EEderi.

var. microcarpa Kindb. - B. CEderi var. condensata.

«var. minor Kindb, in Mac. Cat. p. 105.

Ad rup. madid, - Am. sept. : M. Rupestr., Colunb. brit.

var. subnivalis Mdo. - B. EEderi var, condensata.

Ederiana Sw. - B. Ederi.

Oreadella C. M. Bryol. austr. Georg. p. 29.

Syn. Rupic. - Am. merid. : Austr. Georg.

Osculatiana de Not. - Philonotis.

Pabstiuna (). M. - Philonotis.

var. plumosa C. M. - Philonotis Pabstiana var, plımosa.

pallida Hpe. - Philonotis.

papiliata Hook. f. et Wils. Fl. of the N. Zeal. p. 89, t. 86, f. 4 et Handb. p. $447 ; F l$, Tasman. II, p. 195

B. acerosa Hpe. (fid. Mitt: .

B. fragilis Mitt. in Jowrn. of the Linn, Soc. IV, p. 81 et Fl. Tas$\operatorname{man} .196, t .174, f .8$.

2.

Tasman.

- Pac.: Austral., N. Zeland. sept. et med.,

patens Brid. Sp. M. III, p. 82 et Bryol. univ. p. 38 (excl. syn. Schwaegr. et Turn.). C. M. Syn. I, p. 491; Mitl. M. austr. am. p. 275.

B. reticulata P. B. Prodi, p. 44.

Syn. Magell., ins. Eremilae, Maelov.

- Afr.: Ins. Kerguelen. Am. merid. : Terr.

patens $\left\{\begin{array}{l}\text { Hook. - B. brevifolia. } \\ \text { Schwaegr. (fid. C . M). - B. vulcanica. } \\ \text { Schwaegr. }\end{array}\right.$

Schwaegr. (fid. Mitt.), - B. commutata.

patula Mitt. - Bartramidula.

1) "Optandum est muscum hunc semel tantum lectum mox iterum reperiri, " C. M. 1. c. (1849).

" Die Gattung Plagiopus wurde, wie das Originalexemplar in Bridel's Herbar (Berliner botanisches Museum) zeigt, auf Bartramia Gederi var. $\beta$ gegrundet. " Limpr. op. cit, p. 548 (1893). 
Pechuelii C. M. - Philonotis.

pendula $\left\{\begin{array}{l}\text { Hook. - Breutelia. } \\ \text { Mitt. (1876) - Glyphocarpus chrysurus } \\ \text { Spreng. - Breutelia Sieberi. } \\ \text { Sull. - Breutelia dumosa? }\end{array}\right.$

penicillata C. M. in Linn. 1880-82, p. 409.

Fl. et fr. ign.

- Am. merid, : Argentin. Buenos-Ayr.

pentasticha Brid. - Conostomum australe.

perpumila C. M. in Linn. 1880-82, p. 411.

2. $\quad-$ Am. merid. : Alp. Argentin. subtropic. Tucuman.

pinnata Hpe, - 13reutelia.

polygastrica C. M. in Linn. 1874, p. 600.

Ster.

- Am. merid. : Summ. And. Peruv.

polymorpha C. M. - Philonotis.

polytrichoides C. M. in Linn. 1874, p. 597.

Ster.

- Am. merid. : And. Nov. Granat.

pomangium C. M. - Philonotis.

pomiformis (L.) Hedwo. Sp. M. p. I64; Brid. Bryol. univ. II, p. 39 ; Bryol. eur. IV (mon. p. 13) t. 319; C. M. Syn. I, p. 499; W. P. Sch. Syn. II ed. p. 511.

B. crispa $\beta$ minor W. et M. Bot. Taschb. p. 272.

B. crispa var. pomiformis Lindb, M. Scand. p. 15.

B. vulgaris Lam, et DC. Fl. fr. I, p. 509.

Bryum capillaceum, capitulis sphaericis Dill. Hist. M. p. 339, t. 44, f. I.

Br. pomiforme L. Sp. Pl. p. 1580, p.p.

Mnium pomiforme L. jun. Meth. M. p. 361.

Webera porriformis Hedw. Fund. M. II, p. 95.

1. Ad terr. lapid, et ad rup. præpr. aren. et granit. - Eur. : Reg. campestr. et montan. As. Amour, Japon., Kamschatka, Himalaya, Caucas, occ. Afr.: Alger. Am. sept.: Groenland, Labrador, Columb. brit., Behring, Terra Nov. ; reg. borealis tota. Am. merid. : Fret. Magell., Fuegia.

Exs. : Drumm. M. bor. am. II ed, n. 237.

Mac. Can. M. n. 150.

Rab. Bryoth, eur. n. 174.

Sull, et Lesq. M. bor. am. II ed, n. 257.

pomiformis $\left\{\begin{array}{l}\text { Sull. - B. Ederi. } \\ \text { Sw. - B. ithyphylla. }\end{array}\right.$

var. elongala Turn. - B. pomiformis var, crispa.

var, major $\mathrm{H}$. et T, - B. pomiformis var, crispa.

"var. crispa Bryol. eur., C, M. et W. P. Sch. ll. cc.

B. crispa Sw. Disp. M. Suec, p. 73; Brid. Bryol. univ, II, p. 41.

B. Henoni Duby in Mem. Soc .... Geneve 1876, II, 2, f. 2 (B. japonica in tab.)

B. hercynica Floërke in Schrad. Bot. Journ. 1799, II, p. 71.

B. incurva Hoppe in Sturm. Fl. Germ. erypt. fase. VI.

B. pomiformis $\beta$ elongata Turn. Ann. bot. I, p. 1526.

B. pomiformis $\beta$ major $H$. et T. Muscol. brit. $p .85$.

Locis humidior, - Eur. : Reg. montan. super. vel in zona frigida. 
As. : Unalaschka, Amour, Japon., Alp. Yunnan., Jenissei super., Caucas. Afr. : Alger. Am. sept. : Washington; cum typo (1).

Exs. : Rab. Bryoth. eur. n. 175.

«var. heteromalla (Brid.) C. M. l. c.

B. pomiformis Brid. $l$. $c$.

B. Normanni Holmgr. mss.; Hartm. Skand. Fl. X ed. II, p. 47.

Ut. typ. - Eur. : Scandin. - Am. sept. : Sine loc. spec. potosica Mont. in Ann. sc. nat. 1838, p. 56 et in d'Orbigny Voy. p. 95 ; Syll. p. 29; C. M. Syn, I, p. 494.

Arb. et rupic. - Am. merid. : And. Nov. Granat. et Quitenses, Chile. potosica C. M. et Hpe. - B. brevifolia.

Prabaktiana Dz. et Mk. - Philonotis secunda var. Prabaktiana. praetenuis Wils. - Philonotis angusta.

pseudo-Cryptopodium C. $M$. in Linn. 1880-82, p. 412.

Fl, et fr. ign. pic. Tucuman.

- Am. merid. : Alp. Argentin. subtropseudo-fontana C. M. - Philonotis.

pseudo-mollis C. M. - Philonotis.

pusilla $\left\{\begin{array}{l}\text { C. M. - Bartramidula. } \\ \text { Hook. - Bartramidula exigua. }\end{array}\right.$

pycnocoleos C. M. Bryol. austr. Georg. p. 2×.

Ster. Rupic. - Am. merid. : Austr. Georg.

pygmaeola C. M. - Philonotis.

quadrala C. M. - Glyphocarpus.

radicalis $\mathrm{P}$. B. - Philonotis.

var. H. f. et W. - Philonotis pallida.

var. plumulosa Ren. et Card, - Philonotis radicalis var. plumulosa. recurvifolia Duby. - Campylopus penicillatus.

remutifolia $\mathrm{H}$. f. et W. - Philonotis appressa.

reticulata $\mathrm{P}$. B. - B. patens.

rigida Bals. et de Not, - Philonotis.

Rietmanniana $H_{\rho}$, in Jaeg. Ad. I, p. 534.

- Pac. : Nov. Hebrid.

rigidissima W. P. Sch, in Mandon Pl. Boliv, n. 1674.

\section{- Am. merid. : And. Boliv.}

robusta Hook. f. et Wils, Fl. Antarcl., p. 133, t. 59, f. 4: Handb. N. Zeal. Fl.p. 447 ; C. M. Syn. I, p. 495 et II, p. 619.

2. Coll. humid. - Afi.: Ins. Kerguelen. Pac. : Ins. Auckland, Campbell. robusta Sull, et Lesq. - B. Wilkesiana.

Roylei C. M. - Bartramidula.

rufescens Hpe. Symb. 1874, p. 491.

2.

rufiflora $\mathrm{Hsch}$. - Philonotis.

- Am. merid. : Brasil. austr. or.

rupestris Mitt. - Breutelia.

rupta C. M. in Linn. 1880.82, p. 413.

Fl. et fr. ign.

- Am. merid. : Argentin. Cordob.

scabrida Schwaegr. - Philonotis uncinata.

scuriosula C. M. - Philonotis.

(I) In Mac. Catal, of Canadian Plants non indicata. 
Schimperi C. M. Syn. II, p. 617.

B. brevifolia W. P. Sch. in hb. Mus, Paris.

Syn. - Am. sept. : Mexic.

Schmidiana C. M. in Bot. Zeit. 1858, p. 1 h่2.

Syn. - As. : M. Neilgherr.

scoparia Schwaegr. $-\left\{\begin{array}{l}\text { Rreutelia. } \\ \text { Breutelia Sieberi. }\end{array}\right.$

secunda W. P. Sch. in Mandon Pl. Boliv. n. 1671.

- Am. merid. : And. Boliv.

sericea Hsch. - Glyphocarpus.

setifolia Mitt. p.p. $-\left\{\begin{array}{l}\text { Anacolia. } \\ \text { Anacolia intertexta. }\end{array}\right.$

Siebieri Hsch. - Breutelia.

simplex C. M. - Philonotis.

simplicissima C. M. - Philonotis.

Slateri Hpe. - Philonotis.

sparsifolia $\mathrm{H}$ pe. - Philonotis.

speciosa Griff. - Philonotis.

Spielhausi C. M. in Rehm. M. Afr. Austr.

- Afr. : C. B. Sp.

sphaerica Schwaegr. - Philonotis.

spiralis Hpe. - Philonotis.

squarrosa $\left\{\begin{array}{l}\text { Mitt. - Breutelia. } \\ \text { Turn. - B. vulcanica? }\end{array}\right.$

striata C. M. - Philonotis.

striatula Mitt. - Philonotis.

stricta Brid. Mant. M. p. 116 et Bryol. univ. II, p. 45 ; Bryol. eur. IV (mon. p. 10), t. 316; C. M. Syn. I, p. 500; W. P. Sch. Syn. II ed. p. 509 .

B. strietifolia Tayl. in Lond. Journ. of bot. 1846, p. 54.

Syn. Ad terr. et rup. - Eur.: Zon. merid. et mediterr.; Britann. ?

As, : Unalaschka (?), As, minor. Afr.: Alger., Canar., Madeir.,

M. Cameroon. Am. sept. : Colorado, Calif. Am. merid. : Frot.

Magell. (?) Pac. : Austral. (Swan River).

Exs. : Bourgeau Pl, Canar. n. 1585.

Mandon M. Madeir, n 25.

Rab. Bryoth, eur. n. 739 et b., 1208, 1288.

Sull. et Lesq. M. bor. am. II ed. p. 256.

stricta Schwaegr. - Glyphocarpus compactus.

strictae-affinis C. $M$, in Dusen $M$. Camer, $n .337$.

- Afr.: M. Cameroon.

striclifolia Tayl. - B. stricta.

strictula C. M. in Fl. 1889 , p. 412.

Ster.

- Afr.: Kilima N'Djaro.

subarcuata C. M. - Breutelia.

subasperrima C. M. in Rehm. M. A fr. austr. n. 199.

- Afr. : C. B. Sp.

subbrevifolia C. $M$. in Linn. 1880-82, p. 46 4.

2 ?

- Am. nerid. : Venezuela.

subdisticha $\mathrm{H}$ pe. - Breutelia. 
subexigua C. M. - Bartramidula subgnaphalea C. M. - Breutelia subintegrifolia P. B. - B. CEder. subithyphylla Besch. Prodr. bryol. mexic. p. 58.

Ster. $\quad-$ Am. sept.: Mexic.

subolescens C. M. - Philonotis.

subpatens Hpe. in Ann. sc. nat. V ser., III, p. 375.

Syn.

- Am. merid. : And. Nov. Gran.

subpatens C. M. - B. austro-georgica.

subpellucida Mitt. M. Ind. or. p. 59 .

Syn. $\quad$ As, : Himalaya.

subsessilis C. M. - Glyphocarpus laevisphaerus.

substricta W. P. Sch. mss. ; C. M. in Bot. Zeit. 1858, p. 162.

2.

- Afr.: C. B. Sp.

sublomentosa Hpe. - Breutelia.

subulata Bryol. eur. IV (mon. Suppl.p. I), t. 315; C. M. Syn. I, p. 493; W. P. Sch. Syn. II ed. p. 508.

B. ithyphylla var, subulata Husn. Musc. gall. p. 266.

Weisia viridissima Brid. Bryol. univ. I, p. 364 ?

Syn. In fissur. rup. - Eur. : Summ. Alp. Rhaet, Carinth., Salisburg. As. : Sikkim. Am. sept. : Alaska, Sitka, Colorado.

Exs. : Rab. Bryoth. eur, n. 173.

subulosa Griff. - Philonotis.

tahitensis C. M. - Philonotis.

tenella $\{$ C. M. - Philonotis,

Wils. - Philonotis imbricatula.

var., Wils, - Philonotis heterophylla.

var, erecta C. M. - Philonotis glaucescens.

var. gracillima C. M. - Philonotis tenella var, gracillima.

var. hun.ilis C. M. - Philonotis tenella var. humilis.

tenuicula Hpe. - Philonotis.

tenuis Tayl. - Philonotis.

thelioides C. M. in Fl. 1875, n. 34-35.

Ster.

- Am. merid.: And. Nov. Granat.

thrausta W. P. Sch. in Mandon Pl. Boliv. n. 1673.

B. nevadensis C. M. in Linn. $1880-82$, p. 410.

2 . tropic. - Am. merid.: And. Boliv., Alp. Argentin. subtomentosa $\{$ C. M. - Breutelia.

Schwaegr. - Breutelia gnaphalea.

Trianae Hpe. - Breutelia.

trichodonta C. M. - Philonotis.

tricolor C. M. - Philonotis.

Turneriana Schwaegr. - Philonotis.

uncinata $\left\{\begin{array}{l}\text { C. M. et W. - Philonotis Gardneri. } \\ \text { Schwaegr. - Philonotis. } \\ \text { Wils. - Philonotis lutea. }\end{array}\right.$

vagans Mitt. - Philonotis.

vaginans Rehm. M. Afr. austr. n. 201 et 531.

Ster.

- Afi: : Orange. 
versifolia Hpe. - Philonotis.

viridissima C. M. - Cryptopodium Hookeri.

vulcanica Brid. Bryol. univ, II, p. 37 ; C. M. Syn. 1, p. 497.

B. gigantea Bory Voy. en Afi. III, p. 96.

B. patens var. Schwaegr. Suppl. I, II, p. 55, t. 62.

B. squarrosa Turn. in Konig et Sims. Ann. bot. I, p. 329, t. 2, f. 2 ?

Syn, Rup. basalt. - Afr. : Ins. Borboniae.

vulgaris Lam, et DC. - B. pomiformis.

Wallisi C. M. - Philonotis.

Webbii C. M. - Anacolia.

Wilkesiana Par.

B. robusta Sull. in Wilkes Expl. Exped. p. 12; C. M. in Fl. 1885, p. 413. - Am. merid. : Fuegia.

Willii C. M. Bryol. auslr. Georg. p. 30.

Ster. Rupic. - Am, merid. : Austro-Georg.

Wilsoni C. M. - Bartramidula.

xantaochaeta W. P. Sch. in Mcondon Pl. Boliv, n. 1672. - Am. merid. : And. Boliv. (1)

BARTRAMIDULA Bryol, eur, IV (15̄ sp.).

Breuteliana W. P. Sch. in Breutel M. Capens.

Glyphocarpus Breutelii Jaeg. Ad. I, p. 524?

$$
\text { - Afr. : C. B. Sp. }
$$

cernua Lindb. - B. Wilsoni.

curta (Hpe.) Par.

Glyphocarpus curtus Hpe. Enum. M. Brasil. p. 21.

Philonotula curta Hpe. Symb. 1874, p. 722.

Syn.

- Am. merid. : Brasil. austr. or.

cygnaea (Mont.) Jizeg. Ad. II, p. 698.

Bartramia cygnaea Mont. in Ann.sc. nat. 1845, IV, p. 102 et Hist. Chil. Bot. erypt.t. 2, f. 2 ; Syll. p. 28 ; C. M. Syn. I, p. 479.

Glyphocarpus cygnaeus Jaeg. Ad. I, p. 523.

2. Palud, - Am. merid. : chile.

erecta (Mitt.) Jaeg. Ad. II, p. 598.

Bartramia erecta Mitt. M. austr. am. p. 255.

Glyphocarpus erectus Jaeg. Ad. I, p. 523.

1. Terr. - Am. merid. : And. Quitens.

exigua (Sull.). Jaeg. Ad, II, p. 698.

Bartramia exigua Sull. in U. St. Expl. Exp. p. II, t. 8.

B. pusilla Hook. Journ, bot. $1856, p .316$.

Glyphocarpus exiguus Jaeg. Ad. I, p. 522.

Fendleri (C. M.) Par.

$$
\text { - Am. merid. : Cap. Horn. }
$$

Bartramia Fen lleri C. M. in Linn. 1878-79, p. 463.

Syn.

- Am. merid. : Venezuela.

(1) In Enum, Kindberg, nom, nud. :

B. Mac Ivoriana $C . M$,

pygmaea $C . M$.

B. tezta C.M. 
Glaziovii (Hpe.) Jaeg. Ad. II, p. 598.

Glyphocarpus Glaziovii Hpe. Symb. 1872, p. 48.

2.

- Am. merid. : Brasil. austr. or.

Krausei (C. M.) Jaeg. Ad. II, p. 598.

Bartramia Krausei C. M. in Linn. 1874, p. 595.

Glyphocarpus Krausei Jaeg. Ad. I, p. 523 .

2.

- Am. merid. : Valdiv.

Lindigii (Hpe.) Jaeg. Ad. II, p. 698.

Bartramia Lindigii Mitt. M. austr. am. p. 255.

Glyphocarpus Lindigii Hpe. in Linn. 1861-62, p. 522.

Syn. Terr. - Am. merid. : And. Nov. Granat.

mexicana W. P. Sch, in Besch. Prodr. bryol. mexic. p. 58.

Glyphocarpus mexicanus Jaeg. Ad. I, p. 522 .

Syn. $\quad-A m$. sept. : Mexic. (Orizaba).

patula (Mitt.) Jaeg. Ad. II, p. 698.

Bartramia patula Mitt. op. cit. p. 255.

Glyphocarpus patulus Jaeg. Ad. I, p. 522.

Syn. Terr. - Am. sept, : Guatemala.

pusilla (Hook. f. et Wils.) Jaeg. Ad. 1I, p. 698.

Bartramia pusilla C. M. Syn. I, p. 480 et II, p. 616 .

Glyphocarpus pusillus H. $f$. et W. in Lond. Journ. of bot. 1844, p. 545 et Fl. Tasman. II, t. 174, f. 2 .

1.

- Pac. : Tasman.

Roylei Bryol. eur. IV (mon. p. 2).

Bartramia Roylei C. M. Syn. I, p. 478.

Glyphocarpa Roylei Hook.f. in Hook. Ic. pl. rar. II, t. 194 et in Lond. Journ. of bot. 1841, II, p. 8.

Syn.

- As. : Himalaya, M. Neilgherr.

subexigua (C. M.) Par.

Bartramia subexigua C. M. in Engler's Bot. Jahrb. 1883, p. 79 et in Forchungsreise..... p. 21.

Philonotis appressa Mitt, in Journ. of the Linn. Soc. 1876.

2.

- Afr.: Ins. Kerguelen.

Wilsoni Bryol. eur. IV, t. 327 ; W. P. Sch. Syn. II ed. p. 516.

Bartramia cernua Lindb. in Oefv.... 1863, n. 7, p. 7.

B. Wilsoni $C, M$. Syn. I, $p, 479$.

Glyphocarpus? cernuus Wils, in Lond. Journ of bot. 1841, p. 8 (nom.).

Glyphocarpus Wilsoni Jaeg. Ad. I, p. 521.

Syn. Ad terr. humos. - Eur. : Hibern., Scot., Cambrovall. As. : Yunnan. Afr. : Ins. Fernando Po. Am. sept. : New Jersey? (1)

BARTRAMIOPSIS Kindb, in Rev. bryol. 1894, p. 35.

Spec. omn. Atricha ejud, nom.

BEGGARIA C. M. in Nuov. giorn. bot. ital. 1872. p. II (2 sp.) elatior C. M. l. c.

1. vel ps, 2. Terr. - Afr. : Abyss.

(1) Catal. Rau et Hervey ; cf. Lesq. et Jam. Man. p. 207. 
minor $C . M, l . c$.

1. vel ps. 2. Rup. madid. - Afi. : Abyss.

BERGLA Fïrnr. in Bot. Zeit. 1829, Ergaenz. bl. p. 26.

(Absque nom. spec.). Entostodon Bergianus.

BESGHERELLIA Duby in Bull. Soc. bot. Fr. 1873, p. 3'), c. ic. (2 sp.). brevifolia Hpe. in Linn. 1876, p. 317.

2.

- Pac. : Austral. subtropic. or.

elegantissima Duby l. c, c. ic.

1. Cortic. - Pac. : Nov. Caledon.

BLINDIA Bryol. eur. II (24 sp.).

acuta (Dicks.) Bryol. eur. II, ı. 114; C. M. Syn. I, p. 342 et II, p. 584;

W. P. Sch. Syn. II ed. p. $13 \mathrm{I}$.

Br, acutum Dicks. Hb, sice. f. 17, p. 20.

Br, filiforme Vill. Pl. Dauph. III, p. 875.

Br, pilosum sphagni subulati tacie Dill. Hist. M. p. 37t, $t$ 47, f. 31 .

Br. splachnoides Dicks. Fase. II Pl. erypt., p. 5.

$\mathrm{Br}$, verticillatum Lightf. Fl. Scot. II, p. 733.

Br. verticillatum $\beta$ Huds. Fl. Angl, p, 411.

Dicranum Seligeri Brid. Bryol. univ. I, p. 429?

D. splachnoides ej. M. Rec. II, I, p. 181 .

Grimmia acuta $S m$. Fl. brit. III, p. 192.

Gr, rupincola W. et M. Reis, in Schued. p. 100, t. 2, f. 3.

Gr. schisti Engl. Bot. t. 1958.

Seligeria acuta de Not. Epil. p. 653.

Weisia acuta Hedw. M. frond. III, p. 85, t. 35; Brid. Bryol. univ. I, p. 362.

Weisia acuta $\beta$ rupestris Brid. op. cit. p. 363.

Weisia acuta $\gamma$ rupincola $e j . l$. c.

W. fastigiata Bryol. germ. II, I1, p. 120, t. 35, f. 31 .

W. rupestris Brid. Sp, M. p. 72, t. 14 .

2. Ad rup. granitic. vel schistos., nunquam ealcar. - Eur.: E subalp. usq. in supraalp. per tot. zon, interm. et septentr.; Island., Spizberg. As, : Cancas, Am. sept, : Groenland, M. Rupesti:, Columb. brit., ins. Vancouver, Oregon, Terr. Nov., M. Alb., Catskill, New York, etc. Am. mrerid. : Ins. Eremit. (?)

Exs. : Drumm. M. bor, am. I ed. n. 72 (Weisia).

Mac. Canad. M. n. 61.

Rab. Bryoth, eur, n. 31, 606.

Sull. et Lesq. M. bor, am. II ed. n. 113.

* var. arenacea Hpe. mss.; Jaeg. Ad. I, p. 179.

Ut typ. - Firr.: Hercyn., Alp. Algov.

var. curviseta Mitt. - Bl. curviseta.

\& var. flexipes Ren. et Card, in Rev. bryol. 1892, p. 79.

Ut typ. - Am. sept. : Oregon.

* var, irrorata Pfeff. Bryogeogr. Suud. p. 29 ; Jaeg. A,l. I, p. 179.

Ut typ. - Eur. : Engadin.

acula H. f. et W. - Bl. curviseta.

antarctica C. M. - Dicranoweisia.

areuata Mill. M, austr. am. p. 55.

Al. rup, madid. - Am. meril. : Fucgia, ins. Eiremit. 
aschistodontoides C. M. in Engler's Bot. Jaltrb. p. 1883, p. 78 et in ForSter. chungsieise..... p. 18.

" var. nigrescens C. M. in Forchungsreise.... l, c.

Cynodontium Hookeri Mitt. in Journ. of the Linn. Soc. 1876? -- Afr, : Ins. Kerguelen.

auriculata $C . M$, in Fl. 1885, p. 405.

1. Rupic. - Am. merid.: M. Fuegise. austro-crispula C. M. - Dicranoweisia. brevipes C. M. Bryol, austr. Georg. p. 24.

1. Rupic. - Am. merid. : Austr. Georg. caespilicia Lindb. - Stylostegium. ehuruccana Besch, in Bull. Soc. bol. Fr. 1885, p. LVIII et in Miss, sc. Cap Horn, V, Bot. p. 266. - Am. merid. : Terr. Magell.

cirrala C. M. - Dicranoweisia.

contecta C. M. - Dicranoweisia. crispula C. M. - Dicranoweisia.

var, atrata C. M. - Dicranoweisia var, atrata.

curviseta Milt. M. auslt. am. p. 56.

Bl. acuta H. f. et W. Fl. Antaret, p. 8 .

Bl. acuta var. curviseta Mitt. in Journ. of the Linn. Soc. 1859, p. 68.

2. Ad rup. madid, - Afr. : Ins. Kerguelen. Am. merid. : And, Quitens., Fuegia, ins. Eremit., Maclov. Pac. : Tasman.

dicranellacea C. M. Bryol, austr. Georg. p. 26.

Ster. Rupic, - Am. merid.: Austr. Genrg.

dryptodontoides C. M. in Engler's Bot. Jahrb. 1883, p. 79 et in Forchungsreise.... Bot. $p 18$.

2. Rupic. - Afr. : Ins. Kerguelen.

grimmiacea C. M. Bryol. austr. Georg. p. 23.

1. Rupic. - Am. merid. : Austr. Georg.

humilis $C . M$. in Fl. 1885, p. 404.

1. Rupic. - Am. meridl. : M. Fuegire.

leptotichacea C. M. in op, cit. p. 405.

2. Paludic. - Am. merid.: M. Fuegiae.

«var. strictiuscula C. M. in op. et $l$. cc.

Ut et ubi typus.

lygopodina C. M. in op, cit, p. 406.

2. Ad rup. marit. - Am. merid. : Fuegia.

magellanica W. P. Sch, mss, ; C, M. in Bot. Zeit. 1862, p. 328.

- Ain, merid, : Ins. Eremit.

microcarpa Mitt. - Dicranoweisia kerguelensis.

pulvinata C. M. in Engler's Bot. Jahrb. 1883, p. 79 et in Forchungsreise.... p. 19.

Cynodontium conicum Mitt. in Journ. of the Linn. Soc. 1876 ?

Ster. - Afr.: Ins. Kerguelen.

robusta Hpe. in Linn, 1859-6), p. 627.

- Pac. : Alp. Austral. felic. 
Savatieriana C. M. in Miss. sc. Cap Horn, V, Bot. p. 267.

1. $\quad-$ Am. merid. : Terr. Magell.

seligerioides Lindb. in Broth. Enum. M. Caucas. p. 64.

2. Ad rup. trachyt. - As. : Caucas. centr.

Sonsoniae C. M. in Linn. 1874, p. 593.

Ster. - Am. meri'. : And. Nov, Granat.

sordida (Wils.) C. M in Bot. Zeit. 1864, p. 349 .

Campylopus sordidus Jaeg. Ad. I, p. 138.

Dicranum sordidum Wils, in Kew Jowrn, bot. IX, p. 297; Mitt. M. Ind. or. p. 18.

- As. : Nepal. or.

stricta (Hook. f. et Wils.) C. M. Syn. I, p. 313, II, p. 585 et in Forchungsreise... Bol. p. 17 (descriptio locupletissima).

Leptotrichum strictum H.f. et W. Fl. Tasm. II, p. 177.

Weisia stricts H. f. et W. in Lond. Journ. of bot. 1814, p. 540 et Fl.

$2 . \quad-A f r$ : Ins, Kerguelen. Antarct. II, p. 404, t. 152,f. 4 .

Stylostegium C. M. - Stylostegium caespiticium.

subinclinata C. M, Bryòl. austr. Georg.p. 25.

1. Rupic. - Am. merid. : Austr. Georg.

Taylori Hpe. - - Syrrhopodon.

tenuifolia (Hook. f. el Wils.) Mitt. M. austr. am. p. 59.

Dicranum tenuifolium $H$. f. et W. in Lond. Journ, of bot. 1844, p. 542 et Fl. Antarct. II, p. 407, t. 152, f. 7; C. M. Syn. I, p. 365 et II, p. 592 .

- Am. merid. : Fuegia, ins. Eremit.

tortelloides C. M. - Dicranoweisia.

tortellifolia C. M. - Dicranoweisia.

trichodes Lindb. mss.; Philib. in Rev. bryol. 1884, p. 90.

Dicranum rupestre $W$. et $M$. Bot. Taschb. pp. 185 et 469 ? (fid. Lindb.)

D. Seligeri Brid. Bryol. univ. I, p. 429 (id.).

2. Ad rup. secus torrent. - Eur. : Anglia, Riesengeb., M. Corsicæ, Caucas (1).

Blindiadelphus Lindb. M. Scand. p. 25 (sect. Selgeriak).

BRACHELYMA W. P. Sch. Syn. II ed. p. 557 (I sp.)

subulatum W. P. Sch. op. cit.; Card. Mon. p. 132.

Cryphaea inundata Nees in Pflanz. Maxim. v. Wied., p. 27.

Dicnelyma subulatum Myr. in Act. reg. Acad. sc. Holm. 1832, t. 7 B, f. 10-11 ; Bryol. eur. V (mon. p. 9) t. 431 .

Fontinalis subulata P. B. Prodr. p. 158; Brid. Bryol. univ. II, p. 661.

Neckera subulata C. M. Syn. II, p. 145 .

2. Ad rup. et radic. arb. submers. - Am. sept.: Illinois, Arkansas, Georg., Ludovie.

Exs. : Drumm. M. bor, am. II ed. n. 153 (Fontinalis).

(1) In Enum. Kindberg. nomina nuda:

Bl. madeirensis Geh.

BI. pallidifolia C. $M$. 
BRACHYDONTIUM Fürnr. in Fl. 1827, II, Beil. pp. 37 et 12.

trichodes Fürnr. - Brachyodus.

BRAGHYMENIUIM Hook. M. exot. 11 (110 sp.).

abyssinicum Br. et Sch, in W. Sch. M. Abys. II., n. 434.

Bryum abyssinicum C. M. Syn. I, p. 265.

Syn ,

- Afr. : M. Abyss.

acuminatum Harv. in Hook. Ic. pl. rar. t. 19, f. 3 et in Lond. Journ. of bol. 1840, II, p. 10.

Br. cuspidatum Griff. Not. p. 442 et Ic. pl. asiat. t. 102, f. I.

Br. Harveyanum C. M. Syn. I, p. 313 ; Mitt. M. Ind. or. p. 68. - As. : Penang, Khasia, M. Neilgherr.

angolense (Welwo, et Duby) Par.

Bryum angolense $W$, et Dy. in Mem.... Genève 1870, p. $5, t$. I, f. 4 .

Arb, - Afi : Angola.

angustatum W. P. Sch. in Besch. Prodr, bryol. mexic, p. 51.

- Am. sept. . Mexic.

atro-purpureım W. P. Sch. in Mandon Pl. Boliv.n. 1661.

- Am. merid. : And. Boliv.

Barbae-Montis C. M. in Bull. Soc. roy. bot. Belg. 1892, 1, p. 165.

- Am. sept. : Costa-Rica.

Bordazii Ren, el Card. in Bull. Soc. roy Belg. 1890, I, p. 178.

Ster. Muric. - Am. sept. : Martinic.

Boigenianum Hpe. in Linn. 1874, p. 211.

2 .

- Afr. : Ins. Francice, Madagascar.

brachypelma C. M. in Bull. Soc. roy. bot. Belg. 1892, I, p. 162.

2.

- Am. sept.: Costa-Rica.

brevicaule (Hpe.) Jaeg. Ad. I, p. 582.

Bryum brevicaule Hpe. in C. M. Syn. I, p. 323.

Br. nepalense Dz. et Mk. M. Arch. ind, p. 12?

1 .

- As. : Java.

bryoides Hook. - Br. Weisia.

capillare W. P. Sch, mss, et in Besch. Prodr. bryol. mexic. p. 50.

Br. capillifolium C. M. Syn. II, p. 578 .

2.

- Am. sept. : Mexic.

«var. longicollis Besch, op. et $l$. cc.

Ut et ubi typ.

capitulatum (Mitt.) Par.

Bryum capitulatum Mitt. in Journ. of the Linn. Soc. 1886, p. 306 .

1. - Afi: : Usagara, Kilima N'Djaro, Madagasear, M. Cameroon.

cellulare (Hook.) Jaeg. Ad. I, p, 573.

Bryum cellulare Hook, in Schwaeyn. Suppl. III, I, t. 214; C. M. Syn. I,

p. 291 ; Mitt. M. Ind. or. p. 72.

Br, megalodictyon Sull. et Lesq.?

2 .

- As.: Nepal. 
cernuum W. P. Sch, in Savalier M. Japon. n. 385.

$\mathrm{Br}$. japonense Besch, in Ann, sc. nat. 1893, p, 340.

- As. : Japon.

ciliare Mont. - Br. leptostomoides.

clavariæforme (C. M.) Jaeg. Ad. I, p. 581 .

Bryum clavariaeform, C. M. in Bot. Zeit. 1853, p. 21.

2.

- As. : M. Neilgherr.

clavulum Mitt, in Trans, of the Linn. Soc. 1891, p. 165.

1.

- As. : Japon.

coaretatum (C. M.) Bryol.jav. I, p. 140, $\iota .115$.

Bryum coarctatum C. M. Syn. I, p. 312.

2. Calcic. - As. : Java. Pac. : Ins. Samoa, Toaga, Nov-Zeland., Nov. Caled.

commutatum (C. M.) Jaeg. Ad. I, p. 575.

Bryum commutatum C. M. in Bot. Zeit. 185s, p. 156.

Br. dicranoides W. P. Sch, in W. Sch. M. Abyss, n. A, 10 (fil. C. M.).

2 .

- Afr. : Abyss.

consimile (Mitı.). Jaeg. Ad. I, p. 582.

Bryum consimile Mitt. M. austr. am. p. 281.

2.

- Am. merid. : And. Quitens.

crinitum Jaeg. - Br. systylium.

cristatum (C. M.) Jaeg. Ad. I, p. 583.

Bryum cristatum C. M. Syn. II, p. 580.

2 .

- As. : Bombay.

cuspidatum Griff. - Br, acuminatum.

dicranoides (Hsch.) Jaeg. Ad. I, p. 575.

Bryum dieranoides Hsch. in Linn. 1811, p. 134 ; C. M. Syn. I, p. 309.

2. Muric. et rupic. - Afr. : C. B. Sp.

Exs. : Rehm. M. Afr, austr, n. 219.

didymodontium (Mitl.) Jaeg. Adl, I, p. 574.

Bryum didymodontium Mitt. M. aust". am. p. 289.

2.

- Am. sept. . Mexic.

ellipticum (Milt.) Jaeg. Ad. I, p. 575.

Bryum ellipticum Mitt. op. et $\ell$. ce.

2.

- Am. merid.: Chil.

eriophorum Rehm. M. Afr. austr, n. 545 .

Ster. $\quad-A f r$. : Transvaal.

erubescens (C.M.) Par.

Bryum erubescens C. M. in Linn. 1880-82, p. 379.

Fl. et fr. ign. $\quad-A m$, merid. : Argentin. tropic.

eurychaelinm Besch. Fl, bryol. Réunion, etc. p. 90.

1 ? Terr. - Afr. : Ins, Borbon.

exile (Dz. et Mk.) Bryol. jav. I, p. 139.

Bryum exile Dz, et Mk. in Ann. Sc, nat. 1810, p. 300 et M. frond. ined.

2. Areh, ind. p. 13, t. 5 ; C. M. Syn. I, p. 311.

- As. : Java. Sumatra. 
extenuatum (Mitt.) Jaeg. Ad. I, p. 578.

Bryum extenuatum Mitt. M. Ind. or. p. 68.

Syn.

- As. : Carnatic.

fabronioides (C.M.) Par.

Bryum fabronioides C. M. in Linn. 1878-79, p. 289.

2.

- Am. merid. : Argentin. subtropic.

fliforme $\left\{\begin{array}{l}\text { Griff. - Bryum cymbifolium. } \\ \text { Wils. p.p. - Bryum auratum. }\end{array}\right.$

flaccidisetum (C. M.) Jaeg. Ad, $I, p .576$.

Bryum flaccidisetum C. M. in Bot. Zeit. 1853, p. 23.

2.

- As. : M. Neilgherr.

flexifolium Br, et Sch. in W. Sch. M. Abyss, n. 452.

Bryum flexifolium C. M. Syn. I, p. 266.

2.

- Afr.: Abyss., M. Cameroon.

fragile (C. M.) Jaeg. II, p. 703.

Bryum fragile C. M. in Linn. 1865, p. 378.

Ster. Filicic. - Afr. : Niam-Niam.

fusiferum (Mitt.) Jaeg. Ad. I, p. 576.

Bryum fusiferum Mitt. M. austi. am. p. 290.

2. Terr. - Am, merid. : And. Quitens.

Gilliesii (Hook.) Jaeg. Acl. I, p. 574.

$\mathrm{Br}$. orthodontioides ej. $l$. $c$.

Bryum Gilliesii Hook. Misc. I, 1830, p. 3, t. 2; C. M. Syn. I, p. 292 ; Mitt. op. cit. p. 288.

Br. orthodontioides C. M. op. cit, p. 293 (fid. Mitt.)

Pohlia Gilliesii Mont. in d'Orbigny Voy. Am. merid. VII, II, p. 93 et $V I I, p, 18$.

Orthodontium julaceum Schwaegr. Suppl. $I I, I I, J I, p .123, t .188$.

2. Limic. - Am. merid. : Amazon. And. Chilens., Argentin. Cordob. glaucum (C.M.) Jaeg, Ad. I, p. 582.

Bryum glaucum C. M. in Linn, 1869-70, p. 36.

1.

globirameum (C. M.) Par.

Bryum globirameum C. M. in op. cit. $1878-79$, p. 478.

- Am. merid. : Venezuela.

globosum (Milt.) Jaeg. Ad. I, p. 574.

Bryum globosum Mitt. M. austi: am. p. 289.

2.

- Am. merid. : And. Quitens.

Heribaudi Ren. et Card. in Bull. Soc. roy. bot. Belg. 1891, II, p. 187. 2 ? - Afr.: Ins. Borbon.

heteroneuron (Spr.) Jaeg. Ad. I, p. 581.

Bryum heteroneuron Spr. in Mitt. op, cit. p. 281.

2. Arbor. - Am. merid. : And. Quitens.

Hornschuchianum Mart. Ic. crypt. Brasil. XXXVI, t, 20, f. 4 et in Fl. Brasil. I, p. 36.

Bryum Hornschuchianum C. M. Syn. 1, p. 322; Mitt. op. cit.p. 281.

2. Terr, in silv, - Am. merid. : Brasil. austr. or. 
huillense (Welvo, et Duby) Jaeg. Ad. 1, p. 572.

Bryum huillense W. et Dy. in Mem... Genève 1870, p. 6, t. I, f. 5 .

2. Arbor, - Afr.: Angola.

imbricatum W. P. Sch, mss, et $h b$.

Bryum inbricatifolium C. M. Syn. II, p. 578; Mitt. op. cit. p. 282.

2.

- Am. sept. : Mesic.

indicım (Dz. et Mk.) Bryol. jav. I, p. 141.

Bryum indicum Dz, et Mk. M. frond. ined. Arch, ind, p. 22, t. II; C. M. Syn. I, p. 313 .

Syn. Calcic. -. As, : Amboine, Java.

\& var. corrugatum Besch. Fl, bryol. Nov. Caled. p, 213.

Saxic. - Pac. : Nov. Caledon.

Jamesoni Tuyl. in Lond. Journ. of bot. 1848, p. 282.

Bryum Jamesoni C. M. Syn. II, p. 580; Mitt. op. cit. p. 283.

Peromnium Jamesoni Jaeg. Ad. I, p. 584 .

2. Arbor. - Am. sept. : Jamaïc. Am. merid. : And. Quitens. et Peruv. japonense Besch. - $\mathrm{Br}$. cernuum.

julaceum Hsch, in Linn. 1841, p. 133.

Bryum koratranum $C . M$. Syn. I, p. 324.

2. Arbor. - Afr. : C. B. Sp., Transvaal,

Exs.: Rehm. M. Afr, atstr. n. 218 et 546

Klotzschyi $(C, M$.) Par:

Br. Sellowianum Jaeg. Ad. I, p. 578.

Bryum Klotzschyi Mitt. op. cit. p. 283.

Bryum Sellowianum C. M. Syn. I, p. 319.

Didymodon Klotzschyi Sehwaegr. Suppl. IV, $t, 340$.

2. - Am. merid. : Brasil.

Krausei Hpe. et Ltz. in Bot Zeit. 1869.

Peromnium Krausei Jaeg. Ad. I, p. 585.

2. Silvic. - Am. meridl. : Equator.

lanceolatum Hook. f. et Wils. Fl, Tasm. II, p. 188, t. 173, f. 8. I. - Pac. : Tasman.

leptostomoides W. P. Sch. hb.

Bryum ciliare Mont. Syll. p. 34.

Bryum leptostomoides C. M. Syn. I, p. 321 ; Mitt. M. Ind. or. p. 74.

- As. : M. Neilgherr, Madras.

leucostomum Bryol. jav. I, p. 142, t. 116.

2. Saxic, - As, : Java.

leucotrichum C. M. in Linn. 1875, p. 377.

Ster. - Afr.: Niam-Niam.

longifolium W. P. Sch, in Mandon Pl. Boliv. n. 1662.

- Am. merid, : And. Boliv.

longipedicellatum (C. M.) Par.

Bryum longipedicellatum $C$. M. in Linn. 1878-79, p. 477.

2. - Am. merid. : Venezuela.

luteolum (C. M.) Jaeg. Ad. I, p. 579.

Bryum luteolum C. M. in Linn. 1871, p. 625.

2 ,

- Am. sept. : Mexic. 
macropoma (C.M.) Par.

Bryum macropoma C. M. in Linn. 1878-79, p. 290.

2. Cortic. - Am. merid. : Argentin. subtropie.

madagassum Hpe, in Linn. 1864, p. 212.

2. $\quad-A f r$. : Madagascar.

magellanicum (Sull.) Par.

Bryum magellanicum C. M. Syn. II, p. 579.

Peromnium magellanicum Sull. in Lond. Journ. of bot. 1850, p. 316.

Syn. - Am. merid. : Fuegia.

malachiticum (C.M.) Par.

Byrum malachiticum C. M. in Linn. 1880-83, p. 378.

2. Ad arbor. - Am. mevid. : Argentin. Tucum. subtropic.

megalacrion (Schwaegr.) Jag. Ad. I, p. 578.

Bryum megalacrion Schwaegr. Suppl. II, p. 104; C. M. Syn. I, p. 312. 2. - Afr. : Ins. Franciæ.

melanothecium (C. M.) Jaeg. Ad. I, p. 576.

Bryum coarctatum Mitt. Sam. M. p. 177?

Bryum melanothecium C. M. M. Polyn. p. 62.

Syn. Muric, - Pac. : Ins. Samoa, Tonga.

mexicanum Mont. in Ann. sc, nat. 1838, IX, p. 54 et Syll. p. 54.

Bryum erectum Hook, in Kunth Syn. pl, aequin. ?

Bryum mexicanum C. M. Syn. I. p. 252; Mitt. M. aust, am. p. 282.

Br. Webera erecta Brid. Bryol. univ. I, p. 626.

2.

- Am. sept. : Mexic.

Meyenianum (Hpe.) Jaeg. Ad. I, p. 1 \%5.

Bryum Meyenianum C. M. Syn. I, p. 296.

Mielichhoferia chilensis Hpe. in $h b$. reg. Berol.

Webera chilensis ej. in Linn. 1837, $p .278$.

2 .

- Am. merid. : Chile.

micans (Mill.) Jaeg. Ad. I, p. 583.

Bryum micans Mitt. M. Ind. or. p. 68.

2.

- As. : Ind, or.

microstomum Harv. in Hook. Ic. pl. rar. t. 19, f. 4 et in Lond. Journ. of bot. 1840, II, p. 10.

Bryum microstomum C. M. Syn. I, p. 325.

$$
\text { - As. : Nepal. }
$$

mielichhoferioides C. M. in Nuov. grom, bot. ilal. p. 16.

minutulum Hpe. in Bot. Zeit. 1870, p. 51.

2? Rupic. - Am. sept. : Mexic.

Molleri (C. M.) Par.

Bryam Molleri C. M. in Fl. 1886, p. 281.

2.

- Afr.: Ins. S. Thomas.

murale W. P. Sch. in Besch. Prodr, bryol. mexic. p. 51.

2 .

- Am. sept. Mexic.

nepalense Hook. in Schoaegr. Suppl. II, II, p. I31, t. 135; Brid. Bryol. univ. $I, p .602$.

Bryum brevicaule Hpe ( fid. Mitt.) 
Br. contortum Griff. Not, p. 440 et Ic. pl. asiat. II, p, 100, f. 2.

Br. Hookeri Spreng. Syst. veg. IV, p. 212; C. M. Syn. I, p. 323; Bryol. jav. $I, p .138, t .114$.

Br, nepalense Mitt. M. Ind. or, p. 73.

1. Arb. et terr. - As. : Nepal,, Borneo, Java, Sumatra.

Nietneri (C. M.) Jaeg. Ad. I, p. 576.

Bryum Nietneri C. M. in Linn. 1869-70, p. 37.

2.

- As. : Ceylan.

nigrescens Besch, Fl. bryol. Réunion, etc.p. 91.

1.

- Afr. : Madagascar.

orthodontioides Jaeg. - Br. Gilliesii.

orthopelma (C. M.) Jaeg. Ad. II, p. 703.

Bryum orthopelma C. M. in Linn. 1864, p. 550.

1. $\quad-\Lambda s$. : Ins. Philippin.

? ovatum H. f. et W. - Leptotheca Gaudichaudi.

papillosum (C, M.) Par.

Bryum papillosum C. M. Syn, I, p. 326 ; Mitt. M. austr. am. p. 290.

2. Saxic. et terr. - Am. sept. : Jamaic. Am. merid.: Venezuela, And,

Nov. Granat. et Peruv.

patulum W. P. Sch. mss. et hb.

Bryum patulum C. M. Syn. II, p. 579.

1. Arbor. - Am. sept. : Mexic.

pendulum Mont. in Ann. sc. nat. XVI, p. 254 et Syll. p. 34.

Bryum Montagneanum C. M. Syn. I, p. 225 ; Mitt. M. Ind. or. p 69.

2. Terr. in silv. - As. : M. Neilgherr.

peraristatum (C. M.) Par.

Bryum peraristatum C. M. in Linn. 1878-79, p. 478.

2. $\quad-$ Am merid.: Venezuela.

piriforme W. P. Sch. in Jaeg. Ad. I, p. 577.

- Afr. : C. B. Sp.

Pittieri Ren. el Card. in Bull. Soc, roy. bol. Belg. 1892, I, p. I63.

1.

- Am. sept. : And. Costa-Ricens.

Preissianum (Hpe.) Jaeg. Ad. I, p. 575.

Bryum Preissianum Hpe. Ic. M, t, 25; C. M. Syn. I, p. 310.

2? Rupic. - Pac. : Austral.

pulchellum Hsch. Fl. Brasil. fasc. I, p. 3ỏ.

Bryum Martianum C. M. Syn. I, p. 320; Mitt. M. austr. am. p. 283.

2 ? Arbor. - Am. merid. : Brasil.

pulchrum Hook. Bot. Misc. I830, I, p. 136, t. 38.

Bryum pulchrum C. M. Syn. I, p. 324 .

2. Arbor? - Afr. : C., B. Sp., Natal, Transvaal.

Exs. : Rehm. M. Afr. austr. n. 514 , b. et c.

radiculosum (Schwoaegr.) Par.

Bryum Peromnium C. M. Syn, I, p, 321.

$\mathrm{Br}$. radiculosum Mitt. op. oit. p. 283.

Peromninm radieulosum Schwaegr. Suppl. III, $I, I I, t, 250$.

2. Arbor, $-A m$. merid. : Brasil. austr. or. 
Regnellii Hpe. in Linn. 1849, p. 582.

Bryum Regnellii C. M. Syn. II, p. 581.

Streblopilum Regnellii Angstr. in Oefv... 1876, n. 4, p. 18.

2 . - Am. merid. : Brasil. austr, or.

rostratum (C. M.) Jaeg. Ad. I, p. 577.

Bryum rostratum C. M. in Bot. Zeit. 1858, p. 156.

Syn. Muric. - As.: Malabar.

rosulalum Besch. - Rhodobryum.

rugosum (C. M.) Jaeg. Ad. I, p. 580.

Bryum rugosum C. M. in Bot. Zeit. 1853, p. 23 ; Mitt. M. Ind. or. p. 69. 2. - As, : M. Neilgherr.

Salaminae (C. M.) Jaeg. Ad. 1, p. 577.

Bryum Salaminae C. M. in Linn. 1874, p. 580.

2.

- Am. merid. : And. Nov. Granat.

Sellovianum Jaeg. - Br. Klotzschyi.

semperlaxum (C. M.) Jaeg. Ad. I, p. 576.

Bryum semperlaxum C. M. in Linn. 1874, p. 582.

Syn.

- Pac. : Austral. or.

smaragdinum (C. M.) Jaeg. Ad. I, p. 577.

Bryum smaragdinum C. M. Syn. II, p. 576; Mitt. M. austr. am. p. 290 p.p.

2. - Am. merid, : And. Venezuel.

sordidissimum (C. M.) Par.

Bryum sordidissimum C. M. in Linn. 1878-79, p. 474.

2.

- Am. merid. : Venezuela.

spathidophyllum Besch. Fl. bryol. Réunion, etc. p. 90.

1 .

- Afr. : Ins. Borbon.

spathulifolium Ren, et Card. in Bull. Soc. roy. bot. Belg. 1892, I, p. 164

2. Ad terr. in silv. - Am. sept. : Costa-Rica.

speirocladum C. M. in Besch. op. cil. p. 91 .

2.

- Afr. : Comor. magn.

spirale Besch, in Journ. de bot. 1891.

2. - Am. merid, : Paraguay.

spirifolium (C. M.) Jaeg. Ad. I, p. 581 .

Bryum spirifolium C. M. in Linn. 1864, p. 623.

2. Ad arb. rad. - Am. sept. : Mexic.

splachnoides Harv, in Hook. Ic. pl. rar. t. 19, f. 2 et in Lond. Journ. of bot. $1840, I I, p .10$.

Bryum splachnoides C. M. Syn. I, p. 291.

$$
\text { - As. : Nepal., Yunnan. }
$$

stenopyxis C. M. in Rehm. M. Afr. austr, n. 220.

$$
\text { - Afr.: C. B. Sp. }
$$

stereoneuron C. M. in Nuov. giorn. bot. ital. 1872, p. 17.

2.

$$
\text { - Afr. : Abysin. }
$$

subcapillifolium (C. M.) Jaeg. Ad., I, p. 579.

Bryum subcapillifolium C. $M$, in Linn. 1874, p. 624.

2. Arbon. - Am. sept. : Mexic. (Orizaba). 
suberecturn Mitt. in Journ, of the Linn. Soc. 1863, p. 155.

1. $\quad-A f r$.: Ins. Fernando Po.

subglobosum W. P. Sch. in Besch. Fl. bryol. Antil. fr. p. 30.

Acidodontium subglobosum Jaeg. Ad. II, p. 703.

2. In terr. lapidos. - Am. sept : Guadalup.

subrotundum Tayl. - Bryum Taylori.

subsmaragdinum (C. M.) Jaeg. Ad. I, p. 577.

Bryum smaragdinum Mitt. in Spr. M. And. n. 355 et M. austr. am. p. 290 (quoad pl. Quitensem).

Br, subsmaragdinum $C . \dot{M}$. in Linn. 1874, p. 581.

2.

- Am. merid. : And. Quitens.

subuliferum Mitt, in Journ. of the Linn. Soc. 1863, p. 155.

1. - Afr. : Ins. S. Thomas.

systylium (C. M.) Besch. Fl. bryol. Réunion, etc, p. 50.

Acidodontium Kunthii Hseh. in Deppe et Schiede M. Mexic.

Bryum crinitum Jaeg. Ad. I, p. 581 .

Br. crinitum Mitt, in Lond. Jow n. of bot. III, p, $56 ;$, C. M. Syn. II, p. 580.

Br. systylium C. M. Syn. I, p, $320 ;$ Mitt. M. austr. am. p. 280. 2. - Am. sept. : Mexic. Am. merid.: And. Quitens.

tenellum W. P. Sch. mss, et hb.

Bryum tenellum C. M. Syn. II, p. 572.

2. - Am. sept. : Mexic. (M, Orizaba).

torquescens W. P. Sch. in Q. Dillon et Petit Pl. Abyss.

$$
\text { - Afr. Abyssin. }
$$

trachyticola (C. M.) Jaeg. Ad. I, p. 582.

Bryum trachyticola C. M. in Linn. 1871, p. 583.

2. Rupic. - Am. merid. : And. Quitens. velutinum (C. M.) Jaeg. Ad. I, p. 583.

Bryum velutinum C. M. in Bot. Zeit. 1853, p. 33; Mitt. M. Ind. or. p. 73. 2. - As. : M. Neilgherr.

Weisia Harv, in Hook, Ic, pl. rar. t. 19, f. I, et in Lond. Journ. of bot. $1840, I I, p .10$.

Bryum bryoides Hook. in Sehwaegr. Suppl. III, II, p. 134, t. 135; Brid. Bryol. univ. I, p. 603.

Br. exile Dz. et Mk. (fid. Mitt. M. Ind. or. p. 68).

Br. nepalense Spreng. Syst. veg IV, p. 211 ; C. M. Syn. I, p. 311.

Br. Weisia C. M. Syn. I, p. 325 ; Mitt. op. et l. $e c$.

1. Terr. - As.: Nepal., Himalaya, Khasia, M. Neilgherr.

Welwitschii (Duby) Par.

Bryum Welwitschii Duby in Mém.... Genéve 1870, $t .2, t .3$.

2. In spongios. - Afr. : Angola.

Wilsoni (Mitt.) Jaeg. Ad, I, p. 574.

Bryum Wilsoni Mitt. in Lond. Journ. of bot. $185 \mathrm{I}$, p. 55 et M. austr. am. p. 288 : C. M. Syn. $I I, p .582$.

Webera Wilsoni Jaeg. op. cit. p. 588.

2. Terr. - Am. merid. : And. Quitens. (1)

(1) In Enum. Kindberg. nomina nuda :

Br. clavigerum Mitt.

leptophyllum $B r$. et Sch.

Lefebvrei Beseh. 
BRACHYMITRIUM Tayl, in Lond. Journ. of bot. 1846, p. 44.

Jamesoni Tayl. - Tayloria.

BRACHYODON Fürnr. in Regensb. Bot. Zeit. 1827, II, Beil. I, p. 37 et II, p. 112.

trichodes Fürnr. - Brachyodus.

BRAGHYODUS Bryol. germ. II, II, p. 5 (2 sp.)

flexisetus Hpe. in Linn, 1863, p. 132.

2. Ad saxa ripar. - Am. merid. : And. Nov. Granat.

trichodes (Web. et Mohr.) Bryol. germ. II, II, p. 5; Bryol. eur. II, t. 115;

C. M. Syn. I, p. 416 ; W. P. Sch. Syn. II, p. 132.

Anoectangium trichodes Schwaegr. Suppl. I, I, p. 33, t. 10.

Brachydontium trichodes Fürnr. $l$. $c$.

Brachyodus trichodes $e j . l$. $c$.

Grimmia trichodes Engl. Bot. t. 2563.

Gymnostomum Davallianum Sm, in Sehrad. Neu Journ. I, p. 191 (1).

G. trichodes W. et M. Bot. Taschb. p. 85; Brid. Bryol. univ. I, p. 58.

Weisia trichodes $H$. et $T$. Musc. brit. p, 45, $t .15$.

1. Ad rup. aren., granit. et vulcan. humid., numquam calc. - Eur. :

Reg. mont. zon. sept. et occid.; copiose in Voges. et Silv. Nigr. ;

Siles., Saxon., Etruria. As. : Caucas. Am. sept. : Rariss. : Maine (M. Washington).

Exs. : Rab. Bryoth, eur. n. 454, 1003.

BRACHYPODIUM Brid. Bryol. univ. I, p. 147.

crispatum Brid. - Ptychomitrium.

parasilicum Brid. - Calymperes.

BRACH YSTELEUM Rchb. Consp. 34 ; Endl. Gen. n. 507.

australe Hpe. - Ptychomitrium.

brevifolizm C. M. - Ptychomitrium.

crispatum $\left\{\begin{array}{l}\text { Hsch. - Ptychomitrium. } \\ \text { C. M. p.p. - Ptychomitrium. } \\ \text { C. M. p.p. - Ptychomitrium nigricans. }\end{array}\right.$

$\beta$ brachycarpum Hsch. -- Ptychomitrium cucullatifolium.

cucullatifolium C. M. - Ptychomitrium.

cylindraceum C. M. - Ptychomitrium.

Drummondii C. M. - Glyphomitrium.

emersum C. M. - Ptychomitrium.

glyphomitrioidles C. M. - Ptychomitrium pusillum.

Hampeanum C. M. - Ptychomitrium incurvurn.

Howeanum Hpe. - Ptychomitrium.

incurvum C. M. - Ptychomitrium.

indicum C. M. - Ptychomitrium.

isoskelos Duby. - Ptychomitrium.

lepidomitrium C. M. - Ptychomitrium.

ligulalum (. M. - Piychomitrium.

Lindigii Hpe. - Ptychomitrium.

lineare C. M. - Ptychomitrium.

polyphyllum (:. M. p.p. $-\left\{\begin{array}{l}\text { Ptychomitrium. } \\ \text { Ptychomitrium nigricans. }\end{array}\right.$ 
Reichenbachianum Itz. - Ptychomitrium.

Sellowianum C. M. - Ptychomitrium.

serralum C. M. - Ptychomitrium.

uruguense C. M. - Ptychomitrium.

vernicosum C. M. - Ptychomitrium.

BRAGHYTHEGIUM Bryol, eur, V (173 sp.)

acuminatum (Hedvo.) Kindb. in Mac. Cat. p. 191.

Homalothecium acuminatum Jaeg. Ad. II. p. 375.

Hypnum acuminatum P. B. Prodr. p. $60 ;$ C. M. Syn. II, p. 334; Sull. Ic. M. p. 187, t. 116; Lesq. el Jam. Man. p. 336.

H. bryiforme Brid. M. Rec. II, II, p. 100.

H. erectum Drumm. M. bor, am. I ed., n. 224.

H. julaceum, erectum, Bryi argentei habitu Dill. Hist. M. p. 322, t. 41 A. B. D.

H. pulchrum Diumm, l. c. n. 180 p.p.

Isothecium bryiforme Brid. Bryol, univ. II, p. 365.

Leskea acuminata Hedw. Sp. M. p. 227, t. 56, f. 1-7 ; Brid. op. cit. p. 296.

L. Beyrichii Hpe. in Linn. 1839, p. 47 et Ic. M. t. 7.

L. imbricatula Hedw. Sp. M. p. 224, t. 2(fid. Card.)

2. Ad rad. arb. et terr. - Am. sept. : Nov. Scotia, New Brunswick, Ontario, Assiniboine, reg. sept., or. et centr.

Exs. : Mac. Canad. M. n. 282 (Hурпит).

Sull. et Lesq. M. bor. am. n. 330 (Hypnum).

« var. rupincolum (Hedu.) Ren. el Card. in Rev. bryol. 1893, p. 17.

Hypnum acuminatum var. rupincolum Sull. et Lesq. l. c. n. 33ij b; Lesq. et Jam. l. c.

H. rupincolum P. B. Prodr. p. 69.

Leskea rupincola Hedu. op. cit. p. $54 ;$ Brid. Bryol. univ. II, p. 302.

Rupic et terr. - Am. sept. : Cum typ.

«var. setosum (Hedwo.) Ren. el Card. l. c.

Hypnum acuminatum var. setosum Sull. et Lesq. l. c. n. 330 c. ; Lesq. et Jam. l. c.

H. setosum $P$. B. op. et $l$. cc.

Leskea setosa Hedvo. op. cit. p. $236, t .57$; Brid. op. et l. ec.

Lignic. - Am. sept, : Cum, typ.

"var. subalbicans Ren. et Card. in Bot. Gaz. 1890, p 60.

Ad arbor. - Am. sepl. : Florid., Ludovic.

acutum (Mitl.) Sull. Ic, M. Suppl. p. 99, t. 75.

Hypnum acutum Mitt. in Journ. of the Linn. Soc. VIII, p. 32, t. 6 ; Lesq. et Jam. Man. p. 337.

H. Mildeanum W. P. Seh. (fid. Lindb. M. Scand. p. 35 et n. 99) (I).

2 (Mitt.) ; 1, rar. 2 (Lindb.). -Eur, : Lappon,, Suec., Fenn., Dan. Am. sept : Fret. Hudson, Gaspes., Ontar., Columb. brit. ; Massachussets, Indiana, Illinois, Wisconssin.

afro-salebrosum C. $M$, in Rehm, M. Afr, austr. n. 385.

- Afr. : Austral.

afro-velutinum $C, M . l . c, n .379$.

- Afr. : Austral.

albieans (Neck.) Bryol. eur. VI (mon. p. 19), t. 553; W. P. Sch. Syn. II ed., n. 644 .

Hypnum albieans Neck. Meth. M. p. 180; Brid. Bryol. univ. II, p. 492 ; C. M.Syn. II, p. 360 .

(1) Cf. Br. salebrosum var, palustre. 
H. albicans $\beta$ flavescens Brid. op. cit. p. 494.

H. flavescens Roth Fl. germ. III, p. 303.

H. rivulare Brid. M. Rec. $I I, I I$, p. 177.

H. salebrosum Drumm. M. bor. am. I ed. n. 175 p.p.

H. sericeum, gracile, albicans, capsulis subrotundis Dill. Hist. M.p. 328, t. $42, f .63$.

Maschalocarpus Weissmannianus Spreng. (fid. Brid.)?

Neckera albicans Willd. Prodr. Fl. Berol. n. 940.

Pterigynandrum cirrosum Brid. Bryol. univ. II, p. 184.

2. In graminos., ad later. viar. silvat. et tecta stramin. - Eur.: Septentr. et intermed., sope ster.; in Britann. uberrime fructif. As. : Caucas. oce. Am. sept. : Groenland., Terr. Nov., Anticosti, New Brunswick, Ontario, M. Rupestr. et Selkirk, Columb. brit., fret. Behring, ins. Vancouver, Washington, Oregon, Montana, Wyoming, Idaho.

Exs. : Drumm. M. bor, am. I ed. n. 173 (Hypnum).

Mac. Canad. M. n. 285 p.p.

Rab. Bryoth. eur, n, 699.

«var. occidentale Ren. et Card. in Bot. Centralbl. 1890, n. 5l. -- Am. sept.: Washington, Montana.

albulum Besch. mss, ; Jaeg. Ad. I1, p. 389.

Saxic. - Am. sept. : Mexic.

ambiguum de Not. Epil. p. 112.

Hypnum illecebrum piliferum ej. Syll. n. 29.

? Scleropodium ambiguum Jaeg. Ad. II, p. 410.

- Eur. : Sardin.

amœnum Milde in Hedroigia 1869, p. 51.

Br. plumosum var. homomallum Milde Bryol. sỉles. p. 336.

1. Ad rupes quarz. - Eur. : Franconia.

Antipodum W. P. Sch. mss. ; Jaeg. Ad. II, p. 409.

- Pac.: Nov. Zeland.

Arnoldianum Milde mss.; Ltz. Moosst. p. 120.

- Eur. : Alp. Carinth.

asperrimum (Mitt.) Kindb. in Mac. Cat. p. 210.

Hypnumasperrimum Mitt. in Journ. of the Linn. Soc. VIII, p. 33, t. 6.

2. Lignic. et terr. - Am. sept. : Columb. brit., Washington, ins. Vancouver, Idaho, Calif.

asperulum (Hpe.) Jaeg. Ad. II, p. 398.

Br. plumosum (fid. Mitt.).

Hypnumasperulum Hpe. in Linn. 1863, p. 159.

1. Ad rivul. - Am. merid. : And. Bogotens. asprellum Jaeg. - Thelia. atrotheca (Duby) Besch. Fl, bryol. Réunion, elc. p. 153.

Hypnum atrotheca Duby in Mém.... Genéve, $1876, p .8, t .3, f .2$ et in Fl. 1877, n. 5 .

Isopterygium atrotheca Jaeg. Ad. II, p. 499.

1. Rupic. - Afr. : Ins. Borbon., Franciæ, Madagascar.

aureo-nitens Jaeg. - Meteorium.

aureum de Not. - Camptothecium.

auriculatum (Lindb.) Jaeg. Ad. II, p. 406.

Hypnum auriculatum Lindb, in Aot. Soc. sc. Feinn. 1872, p. 250.

2.

- As. : Saghalien. 
austro-alpinum (Hpe.) Jaeg. Ad. II, p. 403.

Hypnum austro-alpinum Hpe, in Linn. 1859), p. 640.

1.

- Pac. : Alp. Austral. fel.

austro-glareosum (C. M.) Par.

Hypnum austro-glareosum C. M. in Enjler's Bot. Jahrb. 1883, p. 82 et in Forchungsreise... Bot. p. 32.

Ster.

- Afr. : Ins. Kerguelen.

austro-salebrosum (C. M.) Par.

Hypnum austro-salebrosum C. M. in op. cc. pp. 82 et 31 .

H. salebrosum Mitt. in Journ. of the Linn. Soc. 1876.

Ster.

- Afr. : Ins. Kerguelen.

biventrosum (C.M.) Jaeg. Ad. II, p. 388.

Br. splendens Aust. in Coult. Bot. Gaz. II, p. III.

Hypnum biventrosum C. M. in Bull. Torr bot. Club V, p. 49 et in Fl. LV1II, p. 90; Lesq. et Jam, Man. p. 338.

1. In silv. profund. $-A m$, sept. : Carolin. sup., Florid., Ludovic.

Blackburnianum W. P. Sch. mss.; Jaeg. Ad. 1I, p. 747.

$$
\text { - Afr.: Ins. Francire. }
$$

Bolanderi (Lesq.) Jaeg. Ad. II, p. 390.

Hypnum Bolanderi Lesq. in Trans. of the Am. Phil. Soc. XIII, p. 12; Lesq. et Jam. Man. p. 341.

2. Terr. - Am. sept. : Washington, Calif.

Exs. : Sull. et Lesq. M. bor. am. II ed. n. 502 (Hypnum).

Borgenii (Hpe.) Besch. Fl. bryol. Réunion, etc. p. 154.

Sciuro-Hypnum Borgenii Hpe. in Linn. 1874, p. 220.

1.

- Afr. : Madagascar.

brevinerve Kindb - Plagiothecium brevi-pungens.

brunneo-alare (C. M.) Jaeg. Ad. II, p. 337.

Hypnum brunneo-alare C. M. in Linn. 1876, p, 654 .

1.

- Am. sepl. : Mexic.

Buchanani (Hook.) Jaeg. Ad. II, p. 407.

Hypnum Buchanani Hook, in Trans. of the Linn. Soe. IX, p. 320, t. 28, f. 3 ; C. M. Syn. II, p. 362 ; Mitt. M. Ind. or. p. 78.

2.

- As. : Nepal., Himalaya, Assam, M. Neilgherr.

Calerae (C. M.) Par.

Hypnum Calerae C. M. in Linn. 1876, p. 452.

2. Ster.

- Am. merid. : Argentin. Cordob.

californicum Jaeg. - Scleropodium.

cameratum (Mitt.) Jaeg. Ad. II, p. 410.

Hypnum cameratum Mitt. op. et l. co.

2.

- As. : Nepal., Himalaya, Japon.

eampestre (Br.) Bryol. eur. VI (mon. p. 12), t. 545; W. P. Sch. Syn. II ed. $p .634$.

Hypuun campestre $\mathrm{Br}$, in sched.

H. geniculatum Schleich, in sched.

H. rutabulum var, campestre C. M. Syn. $I I, p .368$. 
1. In coll. et camp. gramin., agr. et silvat. sicc. -- Eur.: Suec,, Folon., Siles., Westphal., vall. Rhen., Bavar., Hyren. As. : Jenissei sup., Talysch, Kashrnir, Cancas. Afr. : Alger. Am. sept. : New Brunswick, Nov. Angl., M. Alb., Idaho, Columb, brit., Colorado. Pac. : Tasman.

Exs. : Rab. Bryoth. eur. n. 1038.

camptocladum Besch. mss.; Jaeg. Ad. II, p. 399.

- Am. sept. : Mexic.

chrysocladon (Hpe.) Jaeg. Ad. II, p. 404.

Hypnum chrysocladon Hpe. in Ann, sc, nat. V ser,, p. 341; Mitt. M. austr. am, $p, 564$.

Ster. - Am. merid. : And, Nov. Granat.

? cirrosum (Schwaegr.) W. P. Sch. Syn. I ed. p. 696 et II ed.p. 806 (1).

Hypnum cirrosum Schwaegr. Suppl. I, II, p. 214 ; Brid. Bryol. univ. II, p. $495 ;$; . M. Syn. II, p. 377.

H. piliferum var, alpina Brid. Sp. M. II, p. 187.

H. turgidum Hartm. Skand. Fl. V ed., p. 328.

Rhynchostegium cirrosum Mdo. M. Tirol. n. 78.

2. fr. ignot. In fissur. rup. - Eur. : Summ. Alp. Scot,, Tirol,, Salisburg., Rhaetiae, ete. Pyren.; Spitzberg. As. : Taimyr, Caucas. centr. Am. sept. : Groenland.

Exs. : Rab. Bryoth. eur. n. 911, 1238.

Un. itin. 1864, n. 72.

var, Funkii Jaeg. - Br. Funkii.

6. var. gracillimum Mdo. Moosst. a. d. Alg. Alp. p. 93. - Eur.: Alp. Bavar., Tirol. merid.

cladoneuron (C.M.) Par.

Camptothecium cladoneuron Jaeg. Ad. II, p. 382.

Hypnum cladoneuron C. M. in Linn. 1874, p. 652.

2. - Am. sept. : Mexic.

clinocarpum Jaeg. - Eurhynchium.

collinum (Schleich.) Bryol. eur. VI (mon. p. 15), t. 548; W. P. Sch.op. cit. p. 647 .

Hypnum collinum Schleich, et Thom, in sched.; C. M. Syn. II, p. 429.

1. Ad rup. terr. et in fissur. rup. - Eur.: Spitzberg, summ. Alp. Norveg., Helvet,, Rhaet.; Pyren., Arvern. As. : Caucas. occ. et centr. Am, sept. : Groenland, Terr. Nov., Athabasca, Assiniboine, M, Rupestr., Columb. brit,, Washington, Oregon, Nevarla, Montana, Wyoming.

Exs. : Mac. Canad. M. n. 398. (Hypnum).

Un. itin. 1863, n. $66,67$.

* var, saporense Besch, in Ann. sc. nat. 1893, p. 373.

Exs. : Faurie n. 124.

coloradense (Aust.) Ren, et Card. l. c.

Hypnum coloradense Aust. in Coult. Bot. Gaz. II, p. 111; Lesq. Jam. Man. p. 412.

Ster. - Am. sept. : Colorado.

columbico-ratabulum Kindb. in Mac. Cat. p. 198.

1. Lignic. - Am. sept. : Columb. brit. 
comtifolium (C. M.) Jaeg. Ad. II. p. 387.

Hypnum comtifolium C. M. in Linn. 1876, p. 653.

2. $\quad-$ Am. sept.: Mexic.

conostomum (Tayl.) Jaeg. Ad. Il, p. 392.

Hypnum conostomum Tayl. in Lond. Journ. of bot. 1848, p. 194; C. M. Syn $I I, p, 364$.

H. Taylori Mitt. M. austr. am. p. 560.

Syn. Terr. - Am. merid. : And. Quitens, et Boliv.

cuspidiferum (Mitt.) Jaeg. II, p. 410.

Hypnum cuspidiferum Mitt. M. Ind. or. p. 78.

2 ?

- As. : Sikkim.

cylindricarpum (Mitt.) Par.

Hyocomium cylindricarpum Mitt. in Trans. of the Linn. Soc. 1891, p. 178.

2 ? - As. : Alp. Bhotan.

cyrtophyllum Kindb, in Ott. Nat. IV. p. 63 et in Mac. Cat. p. 191 (subsp. $B r$. acuminati).

Ad ulmos in silv. - Am. sept. : Ontario.

declivum Jaeg. - Br. velutinum.

decurvans (Mitt.) Jaeg. Ad. II, p. 410.

Hypnum decurvans Mitt. M. Ind. or. p. 78.

- As. : Himalaya occ., Sutledje.

densum Jur. - Amblystegium.

Dicksoni Rehm. M. Afr. austr. n. 383.

$$
\text { - Afr. : Natal. }
$$

digastrum C. M. et Kindb. in Bidr. p. 453 (nom.) et in Mac. Cat. p. 190.

1. Rupic. - Am. sept. : New Brunswick, Ontario.

Donnellii (Aust.) Ren. et Card. l. c.

Hypnum Donnellii Aust, in Coult. Bot. Gaz, IV, p. 162 ; Lesq. et Jam. Man. p. 338.

1. Lignic, - Am. sept. : Ontario, Florid.

Darieui de Not. -- Orthothecium?

duriusculum W. P. Sch. mss.

Hypnum duriusculum C. M. Syn. II, p. 426.

H. plumosum Mitt. M. arstr, am, p. 565 .

1. Ad rup. trachyt. - Am, sept. : Mexic.

Ehrenbergii Ltz. M. Ehrenb. p. 51, t. 13, f. 1-28.

Ster.

- As. : Syria.

erythropyxis C. M. in Rehm. M. Afr. austr. n. 382.

- Afr. : Natal.

erythrorhizon Bryol. eur, VI (mon, p. I4), t. 517; W. P. Sch. Syn. I1 ed. p. 646 (l).

Hypnum erythrorhizon Hartm. Skand. Fl. VI ed.

1. Lignic. et saxic. - Eur. : Scandin., Fennia, Karel. As. : Jenissei med. et sup., Obi, Am. sept. : Washington.

var, Thedenii Lindb. - Br. Thedenii.

1) Cf. Lindb. in Oefv.... 1879, p. 75 , c, ic. (in lingua suecica). 
eupopuleum (C. M.) Par.

Hypnum eupopuleum C. M. in Linn. 18/8-79, p. 500.

1. $\quad-$ Am. merid. : Venezuela.

euryblastum (C. M.) Jaeg. Ad. II, p. 401.

Hypnum euryblastum $C$. M. in sched.

- As. : Sikkim.

euryodictyon (C.M.) Par.

Hypnum euryodictyon C. M. in Engler's Bot. Jahrb. 1883, p. 82 et in Forchungreise,.... Bot. p. 32.

Ster. $\quad-A f r$, : Ins, Kerguelen.

eustegium Besch. in Ann. sc. nat. 1893, p. 375.

2.

Exs.: Faurie n, 3, 14.

Fendleri (Sull.) Jaeg. Ad. 1.1, p. 393.

Hypnum Fendleri Sull. M. of U. St., p. 76 et Ic. M. p. 189, t. 117; Lesq. et Jam. Man. p. 340.

H. velutinum $\delta$ microcarpum C. M. Syn. II, p. 400.

Leskea Fendleri Sull. in Mem. of the Am. Acad..... 1849, p. 169, t. I.

1. et syn. -Am. sept. : Nov. Mexic.

Exs. : Sull. et Lesq. M. bor. am. I ed. n. 334 et II ed. n. 501 (Hypnum).

Fit\%-Geraldi (C.M.) Ren. el Card. l. c.

Hypnum Fitz-Geraldi C. M. in Fl. 1887, p. 224; Lesq. et Jam. Man. p. 370.

2. Ster. - Am. sept. : Florid.

flesiventrosum (C. M.) Jaeg. Ad. II, p. 387.

Hypnum flexiventrosum C. M. in Linn. 1876, p. 653.

Ster.

- Am. sept. : Mexic.

frigidum (C. M.) Besch. Prodr. bryol. mexic. p. 101.

Hypnum frigidum C. in Bot. Zeit. 1856, p. 456.

Syn.

- Am. sept. : Mexic.

? Funkii (Hsch.) W. P. Sch. Syn. I ed. p. 697 et II ed., p. 807.

Br. cirrosum var. Funkii Jaeg. Ad. II, p. 406.

Hypnum Funkii Hsch. in sched.; C. M, Syn. II, p. 429.

Rynchostegium Funkii de Not. Epil. p, 83 .

1. (fid. C. M.)

Delphinat., Ital. sup.

Exs. : Rab. Bryoth, eur. n. 1042, 1192.

Geheebii Milde in Hedroig. 1869, p. 161; W. P. Sch. op. cit. p. 651.

2. Ad rup. basalt. umbr. - Eur. : Norveg., Siles., Bohem., Salisb., Rhôngeb., Baden.

Exs: Un. itin. 1863, n. 71.

gemmascens C.M. et Kindb. in Bidr.p. 453 (nom.) et in Mac. Cat. p. 195.

1. Lignic. - Am. sept. : Columb, brit.

georgico-glareosum (C. M.) Par.

Hypnum georgico-glareosum C. M. Bryol. austr. Georg. p. 42.

Ster, Aquat. $-A m$, merid. : Austr. Georg.

glaciale Bryol. Eur. VI (mon. p. 11), t. 542; W. P. Sch. Syn. II ed. p. 652 .

1. Ad terr. et sax, humid. juxta niv. - Eur. : Ins. Ursor., summ. Alp. Scotiae, Norveg., Helvet., Salisburg., Tirol.; Pyren. As. : Tibet. occ. Am. sept, : Grỏnland. 
glareosum (Br.) Bryol. eur. VI (mon.p. 19), t.552; W.P.Sch. op. cit.p. 644.

H. albicans var. minuidunense Brid. Bryol. univ. $I I, p .494$.

H. glareosum Br. in sched.; C. M. Syn. II. p. 361 .

H. lutescens Drumm. M. bor. am. I ed. n. 174.

H. plumosum Hedw. M. frond. IV. p. 37, t. 15, p.p.

H. salebrosum H. et Tayl. Muscol, brit. p. 166, t. suppl. 5, p.p.

2. In glareos, et gramin. - Eur. : Praecip. intermed, scepe ster. As. : Jenissei inf., Caucas. occ. et centr. Am. sepl, : Columb. brit. gloriosum (C. M.) Par.

Hypnum gloriosum $C$. $M$. in Fl. 1890, p. 498.

Ster. - Afr. : Kilima N'D jaro.

harpidioides C. M, el Kindb, in Bidr. p. 453 (nom.) et in Mac. Cat. p. 194.

2. Ster. Lignic. - Am. sept. : New Brunswick. Columb. brit.

helvolum (Mont.) Jaeg. Ad. II, p. 402.

Hypnum helvolum Mitt. M. austr. am. p. 564.

Leskea helvola Mont. Syll. p, 19.

Cortic. - Am. merid. : And. Quitens.

Hildebrandi (Lesq.) Sull. Ic. M. Suppl. p. 98, t. 74.

Hypnum.Hildebrandi Lesq. in Mem. Calif. Aead. I, p. 33; Lesq. et Jam. Man. p. 340.

1 .

- Am. sept. : Calif.

hirtipes W. P. Sch, in Mandon Pl. Boliv, n. 1703.

- Am. merid. : And. Boliv.

Hofferi (Welwo et Duby) Par.

Hypnum Hofferi $W$. et Dy. Choix de erypt.... 1871, p. 7, t. II, f. 2 .

1. Lignic. - Afr. : Ins. S. Thom.

idahense Ren. et Card. in Bot. Gas. 1890, p. 60, t. 9 c.

1. - Am. sept. : Idaho.

illecebrum de Not. - Scleropodium.

implicatum (Hsch.) Jaeg. Ad. II, p. 388.

Hypnum implicatum Hsch. in Mundt et Maire M. Capens,; $C_{+}, M+S_{y}$. 2 . $I I, p, 362$.

Inandae Rehm. M. Afr. austr. n, 381.

$$
-A f r .: \text { C. B. Sp. }
$$

- Afr. : Natal.

inconditum Besch. Fl. bryol. Réunion, elc, p. 155.

1. In gramin. humid. - Afr. : Ins. Borbon.

jenissense (Lindb et Arn.) Par.

Hypnum jenissense L. et A. M. As. bor. 1890, II, p. 133.

2. Terr. in silvul. - As. : Jenissei med.

jucundum de Nol. Epil. p. 118; W. P. Sch. Syn. II ed. p. 643.

1. $\quad-$ Eur: : Ital. (in Ossula super.).

julaceum W. P. Sch, in Mandon Pl. Boliv, n. $17(r 7$ bis.

- Am. merid. : And. Boliv.

kamounense (Harv.) Jaeg. A l. II, p. 410.

Hypnum kamounense Harv, in Lond. Journ. of bot. 1810, p. 19 et in Hook. Ic. pl. ras. t. 24, f. 10; C. M. Syn, II, p. 365; Mitt. M. Ind. or. p. 79. 
Kayseri Geheeb in Rev. bryol. 1876,p.4 (nom.). - Pac. : Austral. or. (Nov. Vales.).

Knysnae C. M. in Rehm. M. Afr. austr. n. 387. - Afr. : Austral.

Krausei (C. M.) Par.

Hypnum Krausei C. $M$. in $F l .1887$, p. 224.

1.

- Am. sept. : Alaska.

kuroischicum Besch. in Ann. sc. nat. 1893, p. 373.

1. - As. : Japon.

Exs : Faurie n. 2; 12, 41 b, 95, 99.

laetum (Brid.) Bryol. eur. VI (mon. p. 20); t. 554; W. P. Sch. Syn. II ed. p. 639 .

Hypnum laetum Brid. Bryol. univ. II, p. 479.

H. luteolum C. M. Syn. II, p. 357 .

H. salebrosum Drumm. M. bor, am. I ed. n. 175 p.p.

2. Ad. saxa calcar. rupesq, basalt. - Eur. : Saxon., Bavar., Francon., Helvet. - Am. sept. : Labrador, Anticosti, Terr. Nov., Nov. Scot., New Brunswick, Gaspes., Ontar., Washington, Montana, Idaho, reg. sept., centr., et or.

Exs. : Drumm. M. bor. am. II ed. n. 122, 123 (Hypnum). Mac. Canad, M. n. 281 (id.).

Rab. Bryoth. eur. n. 544.

Sull, et Lesq. M. bor. am. II ed. n. 488, 489, 490 (Hурпит).

- var. dentatum (Lrsq. et Jam.) Par.

Br. Sullivantii Bryol, eur. (mon.p. 21).

Hypnum laetum var, dentatum Lesq. et Jam. Man. p. 335.

H. salebrosum Sull. M. Allegh. n. 43.

Ut et ubi typ. in Amer. sept.

* var, fallax Ren. et Card in Bot. Centralbl. 1890, n. 5l.

- Am. sept. : Indiana, Calif.

"var. pseudo acuminatum eor. in op. el l. cc.

- Am. sept. : Indiana.

« var. Roellii eor. in op. et l. cc.

- Am. sept. : Indiana.

laevifolium (Mitt.) Jaeg. Ad. II, p. 745.

Hypnum laevifolium Mitt. M. austr. am. p. 565.

- Am. merid. : And. Nov. Granat.

laevisetum Kind. in Bull. Torr. bot. Club, XVII, p. 278 et in Mac. Cat. p. 193.

1. Lignic. - Am. sept, : Columb. brit.

lamprocarpum (C. M.) Jaeg. Ad. II, p. 387.

Hypnum lamprocarpum C. M. Syn. II, p. 359; Bryol. jav. II, p. 164, t. 263.

1. Arbor. (ad Gnaphulium javanicum). - As. : Java.

lamprochryseum C. M. et Kindb. in Bidr. p. 453 (nom.) et in Mac. Cat. p. 199.

1. Saxic. - Am. sept. : Ins. Vancouver.

? lapponicum W. P. Sch. Syn. I ed. p. 697 et II ed.p. 807.

Leucodon Lagurus Hook, var. borealis Wils.

Ster. In rivul, nivos. - Eur. : Lappon. Pitens. 
latifolium (Lindb.) Par.

Hypnum latifolium Lindb. M. nonnull. Scand. in Medd. af Soc. pr. Faun. et Fl. Fenn. 1879, p. 5 et M. Scand. p. 35, n. 98.

2. Ad. rup. madid. - Eur. : Lappon., Norveg., Alp. Vales, ct Longobard. As. : Jenissei med, Am. sept. : Ins, Miquelon.

lepidopiloides (C. M.) Par.

Hypnum lepidopiloides C. M. in Linn. 1878-79, p. 450.

Ster.

- Am. merid. : Argentio. Cordob.

lepturum (Tayl.) Jaeg. Ad. II, p. 395.

Hypnum lepturum Tayl, in Lond. Journ. of bot. 1846, p. 61; C. M. Syn. II, p. 454.

Ster.

- Pac. : Austral, or.

leskeifolium C. M. in Rehm. M. Afr. austr. n. 373.

$$
\text { - Afr. : C. B. Sp. }
$$

leucoglaucum C. M. et Kindb. in Bidr. p. 453 (nom.) et in Mac. Cat. p. 198.

1. Terr. - Am. sept. : New Brunswick.

Exs. : Mac. Canad. M. n. 591.

ligusticum (de Not.) W. P. Sch. Syn. I ed.p. 692 et Il ed. p. 642.

Hypnum ligusticum de Not. mss.

1. In pascuis humid, - Eur. : Ligur., Neapol. Afr. : Alger.

longicuspidatum (Mitt.) Jaeg. Ad. II, p. 409.

Hypnum longicuspidatum Mitt. M. Ind. or. p. 77.

2? - As. : Sikkim.

longidens (C.M.) Par.

Hypnum longidens $C . M$, in Fl. 1885, p. 427 .

1.

- Am. merid. : Fuegia.

Tutescens de Not. - Camptothecium.

Mac-0wani Rehm. M. Afr. austr. n. 380.

- Afr. : Natal.

macrocomum (C.M.) Par.

Hypnum macrocomum $C$. M. in Linn. 1878-79, $p .454$.

1.

- Am. merid. : Argentin. Salt.

\& var, robustius (C. M.) Par.

Hypnum macrocomum var. robustius $C . M$. in op. cit. $p$. 455.

- Am. merid. : Argentin. subtropic.

mammilligerum Kindb, in Mac. Cat. p. 192 (subsp. Br. salebrosi).

1. Lignic. - Am, sept. : Columb, brit.

melanangium C. M. in Hildebr. M. Madag. n. 2078.

- Afr. : Madagasc.

melanocarpum Jaeg. - Br. oxyrhynchum.

meridense (C. M.) Jaeg. Ad. 11, p. 393.

Hypaum meridense C. M. Syn. II, p. 433.

2

- Am. merid. : And. Venezuel.

micropus Bryol. eur. VI (mon. p. 9), t. 540; W. P. Sch.op. cit. p. 650.

1. Ad rup. micac, schistos. - Eur.: Helvet. (Grimsel). 
mirabundum C. M. et Kindb. in Bidr. p. 453 (nom.) et in Mac. Cat.p. 199.

1. Lignic. - Am, sept. : New Brunswick. molliculum (Lindb.) Par.

Hypnum molliculum Lindb, in Broth. Enum. M. Carc. p. 112.

2. Lignic. - As, : Caucas, occ.

molliculum Reichdt. - Isopterygium.

moriense Besch. in Ann. sc. nat. 1893, p. 375.

2. Terr. - As. : Japon.

Exs. : Faurie n. 3510.

nanopes C. M. et Kindb. in Bidr. p. 453 (nom.) el in Mac. Cat. p. 201.

1. Terr. - Am, sept. : Columb. brit.

Exs. : Mac. Canad. M. n. 548.

nematogonium (C. M.) Par.

Hypnum nematogonium C. M. in Linn. 1878-79, p. 453.

Ster. - Am. merid. : Argentin. Cordob.

nigro-viride (C.M.) Par.

Hypnum nigro-viride C. $M$. in $\mathrm{Fl} .1890, p .498$.

Ster. - Afr $r$ : Kilima N'Djaro.

noësicum Besch. in Ann. sc. nat. 1893, $\rho .377$.

2. -As, : Japon.

Exs. : Faurie n. 15 et 18 p.p., 56.

Novae Angliae (Sull. et Lesq.) Jaeg. Ad. II, p. 394.

Hypnum Novae Angliae Sull. et Lesq. M. bor. am. I ed. n. 338; Sull. M. U. St. p. 76 el Io. M. p. 191, t. 118 ; Lesq. et Jam. Man. p. 344.

Scleropodium Novae Angliae Besch. in Ann. sc. nat. 1893, p. 378.

2. $\quad$ As. : Japon. Am. sept. : Canada (fid. Card.), Nov. Angl, ins. Miquelon, Wisconssin.

Exs : Sull. et Lesq. M. bor. am. II ed. n. 507.

"var. Delamarei Ren, et Card. Fl. Miquel. p. 50. - Am. sept. : Ins. Miquelon.

Novae Valesiæ Geheeb in Rev. bryol. 1876, p. 4 (nom.).

- Pac. : Austral. or. (Nov. Vales.).

occidentale (Hpe.) Jaeg. Ad. II, p. 392.

Hypnum occidentale Hpe, in Ann. sc. nat. V ser., p. 314; Mitt. M. austr. am. p. 559 .

Saxic. - Am. merid. : And. Nov. Granat. et Quitens.

œdipodium (Mitt.) Kindb. in Mac. Cat. p. 197.

Hypnum curtum Lindb. M. Scand. p. 35, n. 95?

H. cedipodium Mitt, in Journ, of the Linn. Soc, VIII, p. 35, t. 5; Lesq. et Jam. Man. p. 342 .

1.

- Am. sept. : Terr. Nov., New Brunswick, Ottawa,

Exs. : Mac. Canad. M. p. 380, p.p. (Hypnum).

odistegum (C. M, J Jaeg. Ad. II, p. 410.

Hypnum oedistegum C. M. Syn. II, p. 350.

H. plumosum Schwaegr. (fid. Mitt. M. Ind. or. p. 79).

H. pseado-plumosum? Mont, in Ann. se, nat. 1842 , Crypt. Neilgh, $n, 12$. 1. - As. : Yunnan, Hirnalaya, M. Neilgherr. olympicum Jur, - Br, venustum. 
oxycladon (Brid.) Jaeg. Ad. II, p. 388.

Hypnum attenuatum Brid. Bryol. univ. II, p. 448.

H. oxycladon ej. Sp. M. II, p. 128; C. M. Syn. II, p. 360; Lesq. et Jam. Man. p. 411. 1. - Am. sept. : Pensilv.

oxyrhynchum (Dz. et Molk.) Jaeg. Ad. II, p. 387.

Br. melanocarpum Jaeg. Ad II, $p .392$.

Hypnum melanocarpum C. M. Syn, II, 433 .

Hypnum oxyrhynchum Dz. et Mk, in Ann. so, nat. 1844,p. 308; C. M. Syn. II, p. 451 ; Bryol. jav. II. p. 163, t 262.

H. velutinum Duby in Pl. Zoll. n. 1809 et in Moritzi Syst, Vorz. p. 131. 1. - As. : Java.

paradoxum (Hook. f. et Wils.) Besch. in Miss. sc. Cap Horn, V, Bot. p. 300 .

Hypnum paradoxum $H$. f. et W. in Lond. Journ. of bot. 1844, p. 551 et Fl. Antaret. II, p. 419, t. 155, f. 2; C.M. Syn. II, p. 324 et in Fl. 1885, p. 426 ; Mitt. M. aust. am. p. 563.

1. Terr. - Afr. : Ins. Kerguelen. Am. merid. : Fuegia, ins. Eremit. Pac. : Austral., Nov. Zeland., Tasman.

platycladum C. M. et Ktndb. Bidr.p. 453 (nom.) et in Mac. Cat. p. 195.

H. rutabulum Mao. Canad. M. n. 287 p.p.

2. Saxic. - Am, sept. : Ontario.

plicatum Bryol, eur. - Ptychodium.

plumeum C. M. in Dusen M. Camer, n. 297.

- Afr.: M. Cameroon.

plumosiforme W. P. Sch. mss.

Hypnum plumosiforme C. M. in Bot. Zeit. 1858, p. 171 .

1.

$$
\text { - Afr.: C. B. Sp. }
$$

plumosum (Sw.) Bryol, eur. V (mon. p. 4), t. 537; W. P. Sch. Syn. II ed. p. 657 .

Hypnum alpinum $S m$. Fl, brit. III, p. 1330.

H. aquaticum Funk Moosst. p. 61, t. 44.

H, asperulum Brid. Sp. M. II, p. 169.

H, chrysostomum Rich, in Mich. Fl. Am. bor. p. 319; Brid. Mant. M. p. 173 .

H. flagellare Hedw, Sp. M. p. 282, t. 73.

H. hygrophilum Brid. in sched.

H. laevisetum Crome in Magas, d. Naturf: $V$ Jahrg. p. 78, t. 3, f. 5-13,

H. ædistegum C. M. (fid. Mitt. M. Ind. or, p. 79).

H. plumosum Schvaegr. Suppl. III, I, I, t. 225 .

H. polyrhizon Brid. Sp. M. II, p. 176.

H. pseudo-plumosum Brid. Mant. M. p. 170 et Bryol. univ. II, p. 472; C. M. Syn. II, p. 350.

H. pseudo-plumosum $\beta$ asperulum Brid. Bryol, unic. II, p. 475.

$\mathrm{H}$. pseudo-plumosum $\gamma$ polyrhizon ej. op. et $l$. ce.

H. pseudo-pulmosum $\lambda$ chrysostonnum ej. op. cit. p. 489 .

H. saxatile ej M. Reo. II, $I I, p .153$.

H, secundum Mont. Syll. p. 9 (fid. Mitt, l, e.).

Leskea plumosa Sw, M. Suee, p. 66 (1).

(1) De Syn. cf. W. P. Sch, Syn, 1, c. 
1. Ad saxa, rup. et mur. irrigat, in et secus rivul, format. quarz. Eur. : Spitzberg; zon sept. et intermed., rar. merid. As. : Japon., Saghalien, Jenissei super, et med, Nepal,, Himalaya, Khasia, M. Neilgherr., Ceylan, Java, Caucas. occ. et centr. Afr. : Alger., Madeir. Am. sept. : Terr. Nov., ins. Miquelon, Nov. Scot., New Brunswick, Gaspes., Ontario, M. Rupestr., Columb. brit., reg. sept., centr. et or. Am. merid.: And. Nov. Granat et Quitens. Pac.: Nov. Zeland.

Exs. : Drumm. M. bor. am. I ed, n. 177 (Hypnum).

Mac. Canad. M. n. 289 (Hурпит).

Mandon Pl. Madeir. n. 39.

Rab. Bryoth. eur, n. 449, 484, 1040.

Sull. et Lesq. M. bor. am. II ed, n. 496 (Hyрnиm).

"var, homomallum Bryol. eur. l, c.

Ut et ubi typ. in. Eur. et Am. sept. :

Exs. : Sull, et Lesq. l, c. n. $497,498$.

var. homomallum Milde. - Br. amænum.

var. reflexum Aust. $-\mathrm{Br}$. populeum.

Popfferi Welw. et Duby in Memoires... Genève, 1871, p. , t. 2. Lignic. - Afr. : Ins. S. Thom.

populeum (Hedto.) Bryol, eur. V (mon. p. 3), t. 535; W. P. Sch. op. cit. p. 656 .

Br. plumosum var. reflexum Aust.

Hypnum concinnum Hartm. Skand. Fl. V ed. p. 328.

H. erythropodium Brid. Sp. M. II, p. 281.

H. implexum Turn. Muscol, hib. p. 173, $t$. 16.

$\mathrm{H}$. polysetum Bland. in sched.

H. populeum Hedw. Sp. M. p. 278, t. 70, f. 1-5; Brid. Bryol, univ. II, p. $470 ;$ C. M. Syn. II, p. 366 .

H. populeum $\gamma$ erythropodium Brid. op. cit. p. 471.

H. populeum $\beta$ nutans $e j$. op. et $l$. cce.

H. saxicola Voit in Sturm Deutsch. Fl. II, faso. 12 ,

H. viride Lam, et DC. Fl. fr. I, p. 536 .

1. Ad arbor. et saxa, rar. ad terr, -- Eur, : Fere tota in reg. campestr, As. : Japon., Jenisssi sup., Caucas. Am. sept : Ins. Miquelon, reg. orient., Nov. Scot., New Brunswick, Gaspesia, Ontario, M. Rupestr.

Eas.: Drumm. M. bor. am. I ed. n. 176 (Hypnum).

Faurie PI. Japon. n. 4, 67, 96, 103.

Mac. Canad M. n. 441 (Hурпит).

Rab. Bryoth, eur. n. 700, 773, 1041, 1296.

Sull. et Lesq. M. bor. am. II ed. n. 499 (Hypnum).

"var. angustifolium Besch. in Ann. sc. nat. 1893, p. 376.

Exs. : Faurie n. 206.

\& var. attenuatum Bryol. eur. l. c. t. 736; W. P. Sch. op. et l. cc.

Ad arbor. - Eur.: Ubi typ. As. : Japon. Afr.: Alger.

Exs. : Faurie n. 41.

"var. kominaticum Besch. in op. et l. cc.

Exs. : Faurie n. 38.

"var. longisetum Bryol. eur. et W. P. Sch. ll. cc.

In umbros. humid. ad saxa et terr. - Ubi typ. in Eur. et Am. sept.

«var. majus Bryol. eur. et W. P. Sch, op. et ll. cc.

Ad saxa madid, - Ubi typ. in Eur, et Am. sept, 
« var, rufescens Bryol. eur. et W. P. Sch. ll. cc.

Hypnum petrophilum Fink in sched.; Weinm. in Bull. Soc. imp. Moscou, 1845, p. 475; C. M. Syn. II, p. 402.

Ad saxa quartz. in silvat. montos. - Eur. : Passim.

«var. subfalcatum Bryol. eur. et W. P. Sch. ll. cc.

Ad arbor. - Eur.: Ubi typ. Afr. : Alger. Am. merid. : Ubi typ.

praelongum W. P. Sch. in Mandon Pl. Boliv, n. 1704.

- Am. merid. : And. Boliv.

prasophyllum (Hpe.) Jaeg. II, p. 394.

Hypnum prasophyllum Hpe, in Ann. sc, nat. V ser., p. 315.

- Am. merid. : And. Nov. Granat.

procumbens (Mitt.) Jaeg. II, p. 409.

Hypnum procumbens Mitt. M. Ind. or. p. 79.

2.

- As. : Nepal, M. Neilgherr.

pseudo-albicans Kindb. in Bull. Torr. bot. Club, XVII, p. 278 et in Mac. Cat. p. 194.

Hypnum albicans Mac. Canad. M. n. 235 p.p.

Ster. Arenic. - Am. sept. : Ins. Vancouver.

psen lo-collinum Kindb, in Mac. Cat. p. 196.

1. Ad puteum. - Am. sept, : New Brunswick,

pseudo laetum (C. M.) Jaeg. Ad. II, p. 387.

Hypnum laetum Sull. in Proced..... 1861, p. 289.

H. pseudo-laetum C. M. mss.

- Am. sept. : Cuba.

pseudo-populeum W. P. Sch, mss.

Hypnum pseudo-populeum C. M. in Bot. Zeit. 1858. p. 170.

2.

- Afr. : C. B. Sp.

pseuño-rutabulum (Hpe.) Par.

Hypnum pseudo-rutabulum Hpe, in Linn. 1863, p. 160; Mitt. M. austr. am. p. 562 .

Lignic et terr. - Am. merid. : And. Nov, Granat, et Quitens.

pseudo-Starkii Ren, et Card. in Bot. Centralbl. 1890, n. 51.

2.

- Am. sept. : Washington.

psendo-velutinum (Hpe.) Jaeg. II, p. 391 .

Hypnum pseudo-velutinum Hpe. in Bot. Zeit. 1858, p. 171.

1.

- Afr. : C. B. Sp.

reflexum (Stark) Bryol. eur. V (mon. p. 8), t. 539; W. P. Sch. Syn. II, ed. p. 650 .

Hypnum grimsulanum Bryol, eur. V (mon. p. II) in obs. (fid. C. M.).

H. reflexum Stark in W. et M. Bot. Tasehb. pp. 306 et 476; Brid. Bryol. univ. $I I, 461 ; C, M$. . Syn. II, p. 448.

H. subtenue Jam. in Proced. Acad. Philad. 1855, p. 447.

1. Ad Fagor. debil. trunc. et ramul. - Eur. : Reg. montana sup. et subalp. As. : Saghalien, Amour, Jenissei med, et inf., Caucas, occ. et centr. Am. sept. : Groenland, Labrador, Anticosti, Terr. Nov., ins. Miquelon, New Brunswick, Gaspes., Ontar., Manitoba, Columb. brit,, Washington, New Hampshire, Maryland. 
Exs. : Drumm. M. bor. am. II ed. n. 121 (Hypnum).

Mac. Canad. M. p. 286 (id.).

Rab. Bryoth, eur, n. 450.

Sull, et Lesq. M. bor. am. II ed, n. 503 (Hypnum).

Un, itin. 1863, n. 34.

«var. pacificum Ren. et Card. in Bot, Centralbl. 1890, n. 51.

- Am. sept. : Oregon.

rhynchostegioides C. M. in Rehm, M. Afr. austr, $n, 375$. - Afr. : Austral.

rivulare (Br.) Bryol. eur. V (mon. p. ) , t. 546; W. P. Sch. op. cit. p. 655 .

Camptothecium megaphilum Mac. Canad. M. n. 439.

Hypnum chrysostomum C.M. Syn. II, p. 368 .

H. flavescens Brid. Sp. M. II, p. 185.

$\mathrm{H}$. rivulare $\mathrm{Br}$, in sched.

H. rutabulum Drumm. M. bor. am. I ed. n. 178.

H. rutabulum var. flavescens Brid. Bryol, univ. II, p. 488 ?

H. rutabulum var, laxifolium ej. $l$. $c$.

H. vagans Drumm. l. c. n. 166 .

2. Ad scaturig. silvat., saxa et mur. irrigat. - Eur. : Ins. Ursor.; reg. campestr. montos. As. : Jenissei sup., Caucas. occ. et centr. Afr.: Madeir. Am. sept. : Groenland, Labrador, fret. Hudson et Kotzebuë, ins. Miquelon, New Brunswick, Ontar., M. Selkirk, Columb. brit,, Alaska, ins. Vancouver, Washington, Oregon, Wyoming, Idaho. Kansas, Montana, Wisconssin, Pensilv.

Exs. : Mac. Canad. M. n. 288 (Hypnum).

Rab. Bryoth, eur. n. 746.

Sull, et Lesq. M. bor. am. II ed. n. 505 (Hypnum).

Un, itin. 1863, n. 70.

«var. obtusulum Kindb. in Mac. Cat. p. 201.

Br. rivulare* Novae Brunsviciae ej. in Ott. Nat. IV, p. 3; Mac. Canad. M. n. 492 .

Ad rup. madid. - Am. sept. : New Brunswick, Ontario, Columb. brit.

rivulare* Novae Brunsviciae Kindb. - Br. rivulare var, obtusulum. rivulariforme W. P. Sch. in Mandon Pl. Boliv. n. 1705.

- Am. merid. : And. Boliv.

rivularioides (C. M.) Pur.

Hypnum rivularioides C. M. in Linn. 1878-79, p. 451.

Ster. Lignic. - Am. merid. : Argentin. Cordob.

Roellii Ren. et Card. in Bot. Centralbl. 1890, n. 51.

2 ? of et fr. ign.

- Am. sept. : Ins. Vancouver.

Rotaeanum de Not. Epil. p. 118; W. P. Sch. Syn. II ed. p. 640.

I. Ad radic. arbor. - Eur. : Ital, super. (Bergam.).

ruginosum (Mitt.) Par.

Hyocomium ruginosum Mitt. in Trans, of the Linn. Soc. 1891, p. 178.

2 ?

- As. : Simla, Japon.

rutabuliforme Kindb. in Mac. Cat. p. 198.

1. Saxic. - Am. sept. : Columb. brit.

rutabulum (L.). Bryol. eur. V (mon. p. II), ८. 513; W. P. Sch. op. c. p. 653 .

H. crenulatum Sm. Fl. brit. II, p. 1289. 
H. dentatum, vulgatissimum operculis obtusis Dill. Hist. M. p. 295, t. 38, f. 29 .

H. rutabulum L. Sp. pl. p. 1590 ; Brid. Bryol, univ, univ. II, p. 485 (incl. var. aureo-virens, crenulatum, exiguum, flaccidum, p. 487);C. M. Syn. II, p. 367.

I. Ad saxa, terr. umbros., rad. arb. lignaque putresc. Eur. : Tota in reg. campestr. plan. et montos., praeter arct. As. : Japon., Jenissei sup., Kashmir, Himalaya et Tibet. occ., Pers., Caucas., Syr., M. Olymp. Afr. : Alger. Am. sept. : Terr. Nov., ins. Miquel., Nov. Scot., New Brunswick, Ontario, ins. Vancouver, Washington, reg. sept., centr. et or. Am. merid. : And. Quitens. Pac. : Nov. Zeland., Tasman., ins. Campbell.

Exs, : Drumm. M. bor. am. I ed. n. 178, 179 (Hypnum).

Faurie Pl. Japon, n. 2, 3, 4.

Mac. Canad. M. n. 227 p.p. (Hypnum).

Rab. Bryoth. eur, n. 387.

Sull, et Lesq. M. bor. am. II ed. n. 494 (Hурпит).

" var. canadense Ren. et Card. in Rev. bryol. 1893, p. 19.

- Am. sept. : Ins. Miquel., Canada, Washington.

"var. densum Bryol. eur. l. c. t. 544; W. P. Sch. op. cit. p. 654.

In arb. trunc. semiputrid. - Hic illic cum typ. in Eur. et Am. sept.

var, explanatum Boëckm. - Br. Starkii var, praelongum.

« var. flavescens Bryol. eur. et W. P. Sch. ll. cc.

In gramin. ad ters. - Hic illic cum typ. in Eur. et Am. sept.

a var. longisetum (Brid.) Bryol. eur. et W. P. Sch. ll. cc.

Hypnum rutabulum var. longisetum Brid: Bryol. univ. II, p. 487.

Ut et ubi praeced.

Exs. : Sull. et Lesq. M. bor. am. 11 ed. n. 495.

" var. plumulosum Bryol. eur, et W. P. Sch. ll. cc.

In arb. trunc. semiputrid. - Hic illic cum typ. in Eur. et Am. sept.

* var. robustum Bryol. eur. el W. P. Sch. ll. cc.

Ad rad. arb. silvat. et saxa umbr. - Eur. : C. typ. As. : Caucas. occ. Am. sept. : C. typ.

Ryani Kaurin in sched.; Philib. in Rev. bryol. 1859, p. 59.

2.

- Eur. : Norveg. merid.

salebrosulum C. M. mss, ; Jaeg. Ad. II, p. 405.

- As. : Japon,

salebrosum (Hoffm.) Bryol. eur. V (mon. p. 16), t. 5t9; W. P. Sch. op. cit. p. 641 .

Hypnum fasciculatum Lam. Encyol. meth. bot. III, p. 177.

H. Lamarckii Brid. Sp. M. II, p. 256.

H. plumosum Hedw. M. frond. IV.p. 3i, t. 15 p.p.; Brid. Bryol. univ. $I I, p .475$.

H. plumosum $\beta$ salebrosum C. M. Syn. II, p. 359.

H. salebrosum Hoffm. Deutseh. Fl. II, p. 74; Brid. cp, cit. p. 478.

H. salebrosum $\gamma$ apiculatum Brid, op. cit. p. 478.

H. salebrosum $\delta$ paraphysigequm ej. op. cit. p. 479.

H. salebrosum $\beta$ Torreyanum ej. op. cit. p. 478.

1. In terr. humos. silvat, ad saxa, rad. arb. et trunc. putresc. Eur.: Ins. Ursor. : tota. As. : Japon., Amour, Saghalien, Obi, Jenissei, Himalaya et Tibet. occ., Caucas. Afr.: Alger. Am. sept. : Groenland, Terr. Nov., Nov. Scot., New Brunswick, Gaspes., Ontar., Assiniboine, Saskatehewan, M. Rupestr., Columb. brit., Alaska, fret. Kotzebuë, ins. Vancouver, reg. sept., occ, centr. et or. 
Exs, : Drumm. M. bor. am. 1 ed. n, 175 (Hypnum).

Faurie Pl. Jap. n. 102, 167.

Mac. Canad. M. n. 283 (Hypnum).

Rab. Bryoth, eur. n, 350, 782 .

Sull, et Lesq. M. bor. am. II ed., n. 487 (Hypnum).

" var. arcticum Berggr. M. Spetsb. n. 116 el in K. Sv. Vet. Ak. Handl. $X I I I$, n. 7, p. 79.

- Eur. : Ins. Parry, Spitzberg.

" var. cylindricum Bryol, eur. et W. P. Sch. ll. cc.

H. capillaceum Brid. Mant. M, p. 172 et Bryol. univ. II, p. 481.

H. salebrosum $\beta$ capillaceum $W$. et M. Bot. Taschb. p. 313 .

Ad arb. præcip. Popul. et Salic. semiputr. - Eur. : Cum typ. As. : Japon. Am. sept. : Cum typ.

Exs. : Faur. Pl, Japon. n. 71, 75, 90.

"var. densum Bryol, eur. et W. P. Sch. ll. cc.

Ad arb. rad. et sax. umbrosa. - Eur. : Cum typ.

"var. flaccidum Bryol. eur. et W. P. Sch. ll. cc.

In terr. silvat. præcip. zon. sept. Eur.

«var. longisetum Bryol. eur. et W. P. Sch, ll. cc.

In salebros. et ad tecta stramin. - Passim cum typ. in Eur, et in Am. sept.

"var. palustre W. P. Sch. Syn. II ed. p. 641.

H. acutum Mitt. (fid. Lindb. M. Scand. p. 35 et n. 99).

H. Mildeanum W.P.Sch. Syn. I ed. p. 641 .

In humid, vel uligin. - Passim c. typ, in Eur, et Am, sept.

" var. parvicarpum Besch. in Ann. sc, nat. 1893, p. 373.

Exs.: Faurie n. 182 .

"var, rostratum Besch, in op. et $l$. cc.

Exs. : Faurie n. 193. -As : Japon.

\& var. texanum (Aust.) Par.

Br. texanum Aust, in Bull. Torr, bot. Club, VI, p. 44.

Hypnum salebrosum var, texanum Lesq. et Jam. Man. p. 337. - Am. sept. : Texas.

«var Thomasii W. P. Sch. Coroll. p. 124.

Hypnum capillaceum $\beta$ Thomasii Brid. Bryol. univ. II, p. 482.

H. Thomasii ej. Mant. M. p. 172 .

In loc. apricis. .. Eur. : Hic illic.

\& var, turgidum (Lindb.) Par.

Hypnum plumosum var, turgidum Linnb. M. As, bor. 1890, II, p. 136. - As. : Penins. Samoied, Jenissei inf.

salicinum Bryol, eur. V (mon. p. 15), t. 548; W. P. Sch. op. cit. p.

1. Ad salic. semiputrid, et arb. annosior. - Eur. : Vall. Rhen., Delphinat.

seabrum (Milt.) Besch, in hb. Mus. Paris.

Hypnum scabrum Mitt. in hb. Griff. n. 700 .

-As. : Assam. 
Schlosseri Jaeg. - Rigodium.

secundum Jaeg. - Br. plumosum.

sericeo-nitens (C. M.) Par.

Hypnum sericeo-nitens C. M. in Fl. 1885, p. 427.

1. Rupic. - Am. merid.: Fuegia.

serpentinum C. M. in Dusen M. Camer. n. 276.

- Afr.: M. Cameroon.

Spegazzinii (C. M.) Par.

Hypnum Spegazzinii C. M. in Fl. 1885, p. 428.

1. Ad arbor. - Am. merid. : Fret. Magellan.

splendens Aust. - Br. biventrosum.

spurio-acuminatum C. M. et Kindb, Bidr. p. 453 (nom.) et in Mac Cat. p. 191.

1. Lignic. - Am. sept. : Ontario.

Exs. : Mac. Canad. M. n. 566.

spurio-rutabulum C. M. et Kindb. op. cc. pp. 453 (nom.) et 197.

1. Ad, rad. arbor, - Am, sept. : Columb, brit.

squalidissimum (C. M.) Par.

Hypnum squalidissimum C. M. in Linn. 1878-79, p. 452.

Ster. Rupic. - Am. merid. : Argentin. Cordob.

Starkii (Brid.) Bryol. eur. V (mon. p. 10), t.541; W. P. Sch. Syn. II ed., p. 651 .

Hypnum Starkii Brid. Mant. M. p. 170; C. M. Syn. II, p. 432.

H. Stereodon Starkii Brid. Bryol. univ. II, p. 595.

1. (W. P. Sch.); syn. (C. M.). Ad terr., lapid., rad. arb. et trunc. putrese. in silvat. - Eur. : Reg. montan, et subalp. per zon. sept. et intermed. As. : Amour, Jenissei sup., Caucas. occ. et centr. Am. sept. : Groenland, Terr. Nov., ins. Miquel., New Brunswick, Ontar., Nov. Angl., Pensilv.

Exs. : Mac. Canad. M. p. 284 (Hурпит).

Rab. Bryoth. eur. n. 1039, 1188.

Sull. et Lesq. M. bor. am. Il ed. n. 504 (Нурпит).

Un. itin. 1867 , n. 36 .

var. alpestre Bryol, eur. - Br. Starkii var. robustum.

* var. nipponense (W. P. Sch.) Besch. in Ann. sc. nat., p. 376.

Hypnum nipponense W. P. Sch. in Savatier M. Japon. n. 657.

- As.: Japon.

Eøs, : Faurie n. 26, 190, 218.

" var. praelongum W. P. Sch. Syn. I ed. p. 541 et II ed. p. 652.

Br. rutabulum var. explanatum Brockm. in Arch. Ver. Freund. Naturges Meckl. 1870, p. 23.

Hypuum curtum Lindb. M. nonnull. Scandin. 1879, p. 5.

H, rutabulum var. explanatum Brid. Bryol, univ. II, p. 488.

Ut et ubi typ. in Eur. As. : Jenissei sup.

" var. robustum W. P. Sch. Syn. ed. I, p.540 et II ed. l. c.

Br. Starkii var, alpestre Bryol. Eur, l. c.

Hypnum grimsulanum Bryol. eur. V, mon. p. 11 (, fid. Lindb).

Ut et ubi typ. in Eur.

stereopoma (Spr.) Jaeg. Ad. II, p. 393.

Hypnum stereopoma Spr, in Mitt. M, austr. am. p, 561. 
Lignic et terr. - Am. sept. : Jamaïc. - Am. merid. : Venezuela. And. Quitens. et Peruv.

subalbicans de Not. Epil. p. 118 ; W. P. Sch. Syn. II ed., p. 645.

1. In silvis. - Eur. : Ital. super. (Taurinum).

subpilosum (Hook. f. et Wils.) Par.

Br. subplicatum Jaeg. Ad. II, p. 399.

Hypnum rutabulum var. $H$. f. et W. Fl. Antaret. $I I, p .418$.

H. subpilosum ear. in Lond. Journ. of bot. 1844, p. 553 et Fl. Antaret, II, p. 418, t. $154, f .4 ;$ C. M. Syn. II, p. 366.

H. subplicatum Hpe. in C. M. Syn. II, p. 363.

1. - Am. merid. : Fuegia, ins. Eremitæ, Maclov.

subplicatum Jaeg. - Br. subpilosum.

subrutabulum (C. M.) Jaeg. Ad. II, p. 398.

Hypnum subrutabulum C. M. in Bot. Zeit. 1856, p. 455.

2.

- Afr. : C. B. Sp.

sulfureum (Geh. et Hpe.) Per.

Hypnum sulfureum $G$. et Hpe. in $F l .1881$.

1.

- Am. merid. : Brasil. austr. or.

Sullivantii Bryol. eur. - Br. laetum var. dentatum.

Tauriscorum Mdo, in Fl. 1866, p. 306 et $\mathbf{5} 33$.

-Eur, : Alp. German., Helvet., Vall. Tellin.

texanum Aust. - $\mathrm{Br}$. salebrosum var. texanum.

Thedenii (Hartm.) Bryol. eur. V (mon. p. 18), t. 551; W. P. Sch. op. cit. p. 645 .

Hypnum erythrorhizon var. Thedenii Lindb. M. Scand. p. 36.

H. Thedenii Hartm. Skand. Fl. VI ed.

2. Ad saxa umbrosa. - Eur. : Suecia, Fennia. As. : Jenissei sup. Am. sept. : New Hampshire.

trachypodioides W. P. Sch. in Mandon Pl. Boliv. n. 1707.

- Am. merid. : And. Boliv.

trachypodium (Brid.) Bryol. eur. V. (mon. p. 7), t. 517; W. P. Sch. Syn. II ed.p. 649. (1)

Hypnum trachypodium C. M. Syn. II, p. 367.

Isothecium trachypodium Brid. Bryol. univ. II, p. 766.

1. In fissur. rup. - Eur. : Spitzberg, Alp. Norveg., Carinth., Rhaet,, Tirol.; Arvern. As. : Caucas. Afr.: Alger. Am. sept. : Groenland. Exs.: Rab. Bryoth, eur. n. 6:33.

Un. itin. 1863, n. 68,69 .

truncatum Besch. in Ann. sc, nat. 1893, p. 374.

1.

Exs. : Faurie n. 161.

turgidum Hartm. Skand. $\mathrm{Fl} . \mathrm{X}$ ed. p. 16.

M. Rupestr.

- Eur. : Lappon., Scandin., Fennia. Am. sept. : Groenland, umbilicatum Jur èt Milde Beitr... p. 600.

I. $\quad-$ As. : Kurdistan.

(1) Cf. Amann in Rev. bryol. 1889, p. 55. 
utahense Jam. in Bot. King Exped. p. 409.

Hypnum utahense Lesq. et Jam. Man. p. 339.

Syn. Ad rup. arenac. - Am. sept. : Montana occ., Utah, Colorado.

vagans Milde in Hedwig. 1869, p. 50 et Bryol. siles. p. 331.

Syn. - Eur.: Westphal.

Valentini Besch. Fl, bryol. Réunion, etc. p. 154.

Ster. - Afr. : ins. Borbon.

vallium Sull. et Lesq. M. bor, am. II ed. p. 84.

Br. asperrimum $L$. et J. (fid. Jaeg. Ad. II, p. 398).

Rupic. - Am, sept. : Ins. Vancouver, Calif.

Exs. : Sull, et Lesq. M, bor. am. II ed. n, 506. (Hypnum).

vellereum (Mitt.) Jaeg. Ad. II, p. 406.

Hypnum vellereum Mitt. in Journ. of the Linn. Soc. 1863, p. 151.

2.

- Afr, : Abyssin., M. Cameroon.

Exs. : Dusen M. Camer. n. 294.

velutinum (L.) Bryol. eur V (mon. p. 5), t. 538; W. P. Sch. Syn. II ed. p. 648.

Br. declivum Jaeg. Ad. II, p. 394 .

Hypnum declivum Mitt. in Jowrn, of the Linn. Soc. VIII, p. 33, t. 6.

H. velutinum L. Sp. pl, 1595 ; Brid. Bryol, univ. $I I, p .457 ;$ C. M. Syn. $I I, p, 399$.

H. velutinum, eapsulis ovatis cernuis Dill. Hist, M. p. 326, t. $42, f .61$.

H. Stereodon Starkii $\beta$ tenellus Brid. op. cit. p. 596 p.p.

Leskea velutina Schrank Buiers Fl. III, p. 461.

I. Ad saxa, terr., rad, arbor. et trunc. putresc. - Eur.: Tota, proter arctic. As.: Saghalien, Jenissei sup., Persia, Cancas. Afr. : Alger. Am. sepl. : New Brunswick, Gaspesia, Vermont, New York, Ontario, Idaho, Columb. brit., Washington, Oregon.

Exs. : Mac. Canad. M. n. 379 (Hypnum).

Sull, et Lesq. M. bor. am. II ed., n. 500 (Hypnum).

var. condensatum W. P. Sch. - Br, velutinum var: sericeum.

" var, intricatum (Hedro.) Bryol. eur, et W. P. Sch. ll.cc.

Hypnum intricatum Hedro. M. frond. IV, p. 73,t. 28: Brid. op. cit. p. 461.

H. velutinum var. intricatum Brid. op. cit. p. $459 ;$ C. M. Syn. II, p. 400.

Ad terr. argill, et ad rup. - Eur, et $A f r$. : Hic illic.

\& var, praelongum Bryol, eur. et W. P. Sch. ll. cc.

Ad terr. silvat. arenac. - Eur. : C. typ.

* var, sericeum (Funk) Par.

Br. olympicum Jur. ? (1)

Br, velutinum $\gamma$ eondensatum Bryol. eur. et W. P. Sch. ll. co.

Hypnum sericeum Funk Moostaschb. p. 62, t. 44.

H. velutinum $\beta$ sericeum Brid. op. cit. p. $459 ;$ G. M. Syn. II, p. $400(\gamma)$.

Ad mur. delaps. et sax. aridiss. - Eur. : Praccip. zon. merid. ; Alp. Salisburg., sierra Nevada.

venustum de Not. Epil. Briol. ilal. (2).

$\mathrm{Br}$. olympicum Jur, in "die Insel Oypern" von Unger und Kotschy ; W. P. Seh, op. vit, p. 851 .

(1) Cf. Venturi in Rev. bryol. 1883 , p. 64.

(2) Cf. Venturi in Rev, bryol 1883, p. 61 . 
1 (C. $M$.) nec 2 ! (de Not.). Lignic. et ad rup. silic. - Eur. : Alp. Stir., Pyren. As. : M. Olymp., Cypr.

Villardi Ren. et Card. in Bot. Centralbl. 1890, n. 51.

1. - Am. sept. : Washington.

vineale Milde in Bot. Zeit. 1864, p. et in Hedwig, p. 30.

Muric. - Eur. : Tirol. merid.

? Weinmani (Nees) Par.

Hypnum Weinmani Nees mss.; C. M. Syn, II, p. 365.

Ad arbor. - Eur. : Rossia or.

Wilkesianum Jaeg. - Cylindrothecium (1).

BRACHYTRICHUM Roehl. in Ann. d. Wett. Gesells. III, p. 194.

cupulalum ej. - Orthot:ichum.

saxatile ej. - Orthotrichum.

BRAITHWAITEA Lindb. in Act. Soc. Fenn. X, 1872, p. 250 tn adnot. nematosa Jaeg. - Climacium sulcatum.

sulcata Lindb. - Climacium sulcatum.

BRAUNFELSIA Par. (2 sp.).

enervis (Dz. et Mk.) Par.

Dicranum macrocalyx Bryol. jav. II, p. 225.

Eucamptodon macrocalyx C. M. Syn. I, $p .346$.

Holomitrium enerve Dz. et Mk. M. frond. ined. Arch. ind. p. 8, t. 3 .

Solmsia (2) enervis Hpe, in Nuov. giorn. bot. ital. 1872, p. 273.

scariosa (Wils.) Par.

$$
\text { - As. : Java. }
$$

Dicranum edentulum Mitt. M. Ind. or. p. 14.

D. scariosum Wils. in Kew Journ. bot. IX, p. 294.

Eucamptodon edentulum C. M. in Linn. 1869-70, p. II.

Solmsia scariosa Hpe, in op, cit. p. 274.

2?

- As. . Borneo, Ceylan.

«var. compacta (C. M.) Par.

Eucamptodon edentulus var. compacta C. M. in Jaeg. Ad. I, p. 155.

Solmsia scariosa var. compacta Jaeg. op. cit. II, p. 652 .

Ut et ubi typ.

BRAUNIA Bryol, eur. III (19 sp.).

alopecura Limpr. - Br. sciuroides.

Andrieuxii Ltz. Moost. p. 164.

1.

- Am. sept. : Mexic.

argentinica C. M. in Linn. 1880-82, p. 465.

l. Saxic. et terr. - Am. merid. : Argentin. subtropic.

attenuata (Mitt.) Jaeg. Ad. II, p. 88.

Hedwigia attenuata Mitt. M. Ind. or. p. 123.

2?

(1) In Enumer. Kindberg, nomina nuda :

$\mathrm{Br}$, amazonicum Mitt. brevinerve $K$ indb. filirameum $C$. $M$. japonicum Mitt.

(2) Nom. generic, jam abusum.

Br. malacobolax C. M. myrticola Lindb. semi-postratum $C . M$. 
californica Lesq. in Trans. Am. Phul. XIII, p. 8; Sull. Ic. M. Suppl. p. 41, t. 27; Lesq. et Jam. Man. p. 153.

1. Rupic. - Am. sept.: Columb. brit., ins. Vancouver, Idaho, reg. occid., M. Calif.

Exs. : Mac. Canad. M. n. 109 p.p.

Sull. et Lesq. M. bor. am. II ed. n. 226.

« var. pilifera Lesq. et Janı. op. et l, cc.

Hedwigia pilifera Mitt, in Journ. of the Linn. Soc. VIII, p. 45, t. 7.

Ut typ. - Am. sept. : Ins. Vancouver.

Exs. : Mac. Canad. M. n. 109 p.p.

canescens W, P. Sch. in Mandon Pl. Boliv. n. 1641.

Br. incana C. M. in Linn. 1878-79, p. 377.

1. Cortic, - Am. merid. : And. Boliv., Argentin. subtropic.

cirrifolia (Wils.) Jaeg. Ad. 11, p.87.

Hedwigia cirrifolia Wils. in Mitt. M. austr. am. p. 406.

- Am. merid. : And. Quitens.

Delavaygi Besch, in Ann. sc. nat. 1892, I, p. 71.

1? Cortic. - As, : Yunnan.

diaphana (C. M.) Jaeg. Ad. 1, p. 88.

Neckera diaphana C. M. Syn. II, p. 105.

- Afr.: C. B. Sp.

Exs. : Rehm. M. Afr. austr. n. 598 b.

entodonticarpa C. M. in Fl. 1890, p. 485.

- Afr. : M. Kenia.

exserta C. M. in Linn. 1878.78, p. 379.

1. Cortic. et rupic. $-A m$. merid. : Argentin. subtropic

" var. reflexifolia C. M. in op. cit. p. 380 .

Ut et c. typ.

Humboldti Hook. - Harrisonia.

incana $\mathrm{C} . \mathrm{M} .-\mathrm{Br}$. canescens.

indica (Mont.) Par.

Anoectangium indicum Mont. in sched.

A. secundum ej. in Ann. sc. nat. 1812, n. 32.

Br. macropelma Jaeg. Ad. II, p. 87.

Hedwigia indica Mitt. M. Ind. or. p. 123.

Neckera macropelma C. M. Syn. II, p. 104.

1. Ad rup. basalt. - As. : M. Neilgherr.

Liebmanniana W. P. Sch. - Hedwigidium.

macropelma Jaeg. - Br. indica.

Mac-Owaniana Rehm. M. Afr. austr. n. 597 .

Ster.

- Afr.: Transyaal.

maritima C. M. in Relem. M. Afr. austr. n. 306.

- Afr. : C. B. Sp.

\& var, rufescens C. M. l. c. n. 307 b.

- Afr. : C. B. Sp.

plicata (Mitt.) Jaeg. Ad. II, p. 87.

Hedwigia plicata Mitt. M, austr. am. p. 406.

- Am. merid. : And. Quitens.; Boliv. 
rhabdocarpa C. M. - Hedwigidium.

rupestris (Mitt.) Par.

Hedwigia rupestris Mitt. in Journ. of the Linn. Soc. 1863, p. 160.

1. - Afr. : Abyss., M. Cameroon.

Exs. : Dusen M. Cameroon n. 298.

Schimperiana Bryol. eur. III (mon. p. 3).

Harrisonia Schimperiana Hpe, in exc. ad H. squar.ulosam in Ic. M. t. 19.

Hedwigia Schimperiana Br. et Sch. in W. Sch. M. Abyss. n. 464.

Neckera Schimperiana C. M. Syn. II, p. 104.

1. - Afr. : Abyssin., Choa, Kilima N'Djaro.

sciuroides (de Not.) Bryol, eur. III (mon. p. 3) t. 275; W. P. Sch. Syn. II ed. p. 286.

Anoectangium sciuroides Bals, et de Not, Pugill. p. 23.

Br. alopecura Limpr. Laubm. Deutschl. I, p. 824.

Harrisonia sciuroides Rab. Deutschl. Fl. II, 3, p. 153.

Hedwigia sciuroides de Not. Syll. p. 95.

Leucodon alopecurus Brid. Mant. M. p. 135 et Bryol. univ. II, p. 214.

Neckera alopecura C. M. Syn. II, p. 104.

Schistidium nudum Schleich. Cent. pl. helv.

1. et syn. Ad rup. calcar. sicc. - Eur. : Helvet. et Tirol. merid., Pyr. Ital, inerid.

Exs. : Rab. Bryoth, eur. n, 186, 509.

Un. itin. 1863 , n. 41.

secunda Bryol, eur. l. e. (1).

Anoectangium secundum Brid. Bryol. univ. II, p. 165.

Harrisonia secunda Spreng. Syst. veg. IV, p. 145 .

Hedwigia secunda Hook. M. ex. t. 46.

Neckera secunda C. M. Syn, II, p. 103.

1. Saxicol. - Afr. : Kilima N'Djaro. (?). Am. sept. : Mexic.

subsecunda W. P. Sch. in Jaeg. Ad. II, p. 86 (nom.).

- As. : M. Neilgherr.

teres C. M. - Hedwigidium.

BREUTELIA W. P. Sch. Coroll. p. 85 (56 sp.)

aciphylla (Wils.) Jaeg. Ad. I, p. 560.

Bartramia aciphylla Wils. mss.; Mitt. in Hook. Kew Journ. III, p. 356 et M. austr. am. p. 266.

Ster. - Am. merid, : And. Quitens.

affinis Mitt. - Philonotis.

afro-scoparia (C. M.) Par.

Bartramia afro-scoparia C. M. in M. Capens, Mac-Owanianis.

B. laete-virens Rehm. M. Afr. austr, n, 206.

$$
-A f r \text { : C. B. Sp. }
$$

angustifolia Rehm l.c. n. 538 .

Ster.

- Afr. : Transvaal.

(I) "An Br. indica, Schimperiana, sciuroides et secunda varictates unius et ejusd, spec.? 》. (Mitt. in Journ. of the Linn. Soc. 1886, p. 310.) 
arcuata (Dicks.) W. P. Sch. op.el l. cc.

Bartramia arcuata Schwaegr. Suppl. I, II, p. 61, t. 62 (excl. syn. Sw.) et suppl. III, I, p. 240; Brid. Bryol. univ, II, p. 35; Bryol. eur. IV (mon. p. 15) t. 321 ; C. M. Syn. I, p. 487.

Br. chrysocoma Lindb. M. Scand. $p .15$.

Hypnum chrysocomum Dicks. Fasc. II Pl, crypt. p. 1?.

H. palustre erectum, coma lutea, basi nigricante Dill. Hist. M. p. 302, t. $39, f .36$.

Mnium arcuatum Dicks, op. cit. Fasc. III, p. 2, t. 7, f. 3.

Mn. chrysocomum Hedw. Sp. M. p. 74.

2. Ad rup. humid. - Eur. : Norveg., Britann., Helvet., Westphal.; Corsica (ster.)

Exs. : Rab. Bryoth, eur. n, $172,1165$.

* var. major Besch. Prodr. bryol. mexic. p. 60 (1).

Ut typ. - Am. sept. : Mexic.

aureola Besch. in Bull. Soc. bot. Fr. 1885, p. LXVI et in Miss, sc. Cap Horn, V, Bot. p. 290, t. 4, f. 16.

Bartramia integrifolia Sull. in Wilkes Expl. Exp. p. 12.

Fr. ign. gellan.

- Am. merid.: Patagon, austr,, terr. Maaustro-arcuata (C.M.) Par.

Bartramia austro-arcuata C. M, in Linn. 1880-82, p. 406.

Fl. et fr. ign. Rupic. - Am, merid. : Argentin. subtropic.

brachycoma Besch. in op. et ll. cc., p. 15.

Br. comosa ej, in $\mathrm{Fl}, 1885$.

Fr, ign. - Am. merid. : Patagon. austr.

Brittoniae Ren. et Card, in Bull. Soc. roy, bot. Belg. II, p. 161.

2. Ster. - Am. sept. : Costa Rica.

carinata (Mitt.) Jaeg. Ad. I, p. 557.

Bartramia carinata Mitt. M. austr. am. p. 266.

Ster. - Am. merid. : And. Chilens.

chrysea (C. M.) Jaeg. Ad. I, p. 560.

Bartramia chrysea C. M. in Linn. 1874, p. 598.

Ster. - Am. merid. : And. Nov, Granat.

chrysocoma Lindb. $-\mathrm{Br}$, arcuata. commutata (Hpe.) Jaeg. Ad. II, p. 702.

Bartramia affinis Sehwaegr. Suppl. III, I, II, t. 237 (fid. Hpe.).

B. commutata Hpe. in Linn. 1876, p. 3er.

2.

- Pac. : Austral, Tasman.

comosa Mitt. in Journ. of the Linn. Soc. 1859, p. 82; Fl, Tasman. II, p. 195, t. 174, f. 7 .

Bartramia comosa Handb. of N. Zeal. Fl. p. 449.

2. Rupic. - Pac. : Nov. Zel. sept. et med., Tasman. comosa Besch. - Br. brachycoma.

consimilis (Hook. f. et Wils.) Jaeg. Ad. 1, p. 559 (2).

Bartramia consimilis Handb. of N. Zeal. Fl. p. 449.

(1) " An. spec. propria ? "Besch. 1, c.

(2) Cf. Mitt. in Journ, of the Linn. Soc. 1859, p. 83. 
Hypnum consimile $H$. f. et W. Fl. Antarct. p. 137, t. 60, f. 4; C. Syn. I, p. 492 et $I I$, p. 617.

Ster. - Pac. : Ins. Auckland.

crassa (Hook. f. et Wils.) Jaeg. Ad. I, p. 55 i.

Bartramia crassa H. f. et W. Fl. Tasm. II, p. 194, t. 174, f. 5.

2. Rup. madid. - Pac. : Tasman.

cuspidatissima (C. M.) Par.

Bartramia cuspidatissima C. M. in Linn. 1880-83, p. 408.

Fl. et fr. ign. Rupic. - Am. merid. : Argentin. subtropic. deflexa Wils. - Br. indica. dicranacea (C. M.) Mitt. M. Ind. or, p. 64.

Bartramia dicraceana C. M. in Bot. Zeit. 1853, p. 57. 2. - As. : M. Neilgherr.

diffracta Mitt. in Journ. of the Linn. Soc. 1863, p. 153.

2. - Afr. : M. Cameroon.

divaricata Mitt. in Journ. of the Linn. Soc. 1859, p. 83.

B. divaricata Fl. Tasm. II, p. 105; Handb. of N. Zeal. Fl. p. 449.

B. gigantea H.f. et W, Fl. N. Zeal. II, p. 90. 2.

- Pac. : Nov. Zeland., Tasman.

dumosa Mitt. in Journ. of the Linn. Soc. 1859, p. 82.

Bartramia dumosa ej. M. austr, am. p. 267 (p.p. fid. C. M.).

B. pendula Sull. in Wilkes Expl. Exped. p. 122.

2. - Afr. : Ins. Kerguelen. Am. merid. : Ins. Chiloë, Chil., Fuegia, ins. Eremit.

elegans Wright in Lond. Journ. of bot. 1892, p. 263.

- Am. merid. : Brasil, austr. or.

Eugeniae Angslr. in Oefv :..... 1872, n. 5, p. 120.

$\mathrm{Br}$. intermedia ej, prius.

2. - Pac. : Taïti.

gigantea (Schwaegr.) Bryol. jav. 1, p. 160, t. 130.

Bartramia gigantea Schwaegr. Suppl. II, II, p. 30, t. 161; Brid. Bryol. univ. II, p. 36 ; C. M. Syn. I, p. 489.

Dicranum giganteum Brid. Sp. M. 1, p. 97.

Hypnum arundinifolium Duby in Moritzi Verz. d. Zolling. Pfl. p. 131.

2. Rupic. et et terr. - As. : Java, Afr. : Ins, Borbon. gnaphalea (P. B.) W. P. Sch. hb.

Bartramia arcuata Brid. Bryol. univ. II, p. 35 p.p.

B. gnaphalea C. M. Syn. I, p. 489.

B. tomentosa Schwaegr. Sp. M. p.97.

Hypnum? gnaphaleum P.B. Prodi: p. 64 .

2. Fr. ign. - Afr. : Ins. Borbon., M. Cameroon. grandis (Geh. et Hpe.) Par.

Bartramia grandis Geh. et Hpe in Fl. 1881.
Prionodon robustus Hpe. Symb. 1872, p. 55 et Enum. M. Brasil. p. 48.

Ster. - Am. merid. : Brasil. austr. or.

Hariotiana Besch. in Bull. Soc. bot. Fr. 1885, p. LXVII et in Miss. sc. Cop Horn, V, Bot., p. 291, t. 4, f. 17.

Fr. ignot. - Am. merid. : Terr. Magell., Fuegia, ins. Eremitae. 
Hasskarliana (Hpe.) Jaeg. Ad. I, p. 561.

Bartramia Hasskarliana Hpe. in $\mathrm{Fl} .1865, n, 37$.

- Am. merid. : Peruv. or.

hispida (Milt.) Jaeg. Ad. I, p. 560.

Bartramia hispida Mitt. M. austr. am. p. 264.

- Am. sept. : Jamaïc.

incana (Tayl.) Jueg. Ad. I, p. 555.

Bartramia incana Tayl. in Lond. Journ. of bot. 1848, p. $189 ;$ C. M.

Syn. I, p. 501 ; Mitt. op. cit. p. 263.

2 ? Saxic. - Am. merid. : And, Quitens.

inclinata (Hpe, el Ltz.) Jaeg. l. c.

Bartramia inclinata Hpe, et Ltz. in Bot. Zeit. 1869, p.

2. Terr. - Am. merid. : And. Equator.

indica Mitt. M. Ind. or. p. 64.

Br. deflexa (forma minor. fol. magis deflexis) Wils, in sched.

- As.: Himalaya, M. Neilgherr.

integrifolia (Tayl.) Jaeg. Ad. I, p. 558.

Bartramia integrifolia Tayl. in op. cit. 1846, p. 55; C. M. Syn. I, p. 490 ; Mitt. M. austr. am. p. 267.

2. Ad rup. irror. - Am. mend. : M. Pichincha, And. Boliv.

Exs.: Mandon Pl, Boliv. n. 1679.

intermedia (Hpe.) Besch. Prodr. bryol. mexic. p. 60.

Bartramia intermedia Hpe. Sp. nov, mexic, in Verh. d. K. K. Zool, bot. 2. Ges. in Wien, 7a April. 1869.

intermedia Ảngstr. - Br. Eugeniae.

- Am. sept. : Mexic.

jamaïcensis (Mitt.) Jaeg. Ad. 1, p. 558.

Bartramia jamaïcensis Mitt. op. cit. p. 265.

- Am. sept. : Jamaïc.

Karsteniana (C. M.) Jaeg. Ad. I, p. 560.

Bartramia Karsteniana C. M. in Linn. 1874, p. 599.

2. $\quad-$ Am. merid.: Nov. Granat? (ster.), Aquator.

Kilima N'Djarica (C. M). Par.

Bartramia Kilima N'Djarica C. M. in Fl. 1888, p. 411.

Ster. In graminos. - Afr. : Kilima N'Djaro.

Lorentzi (C. M.) Par.

Bartramia Lorentzi C. M. in Linn. 1880-82, p. 4'6.

Fl, et fr. ignot. $\quad$ - $\quad-A m$ merid.: Argentin, subtropic.

Iuteola C. M. in Rev. bryol. 1876, p. 4 (nom.)

- Pac. : Austral. (Nov. Valesia).

Mac-Leana Rehm. M. Afr, austr, n. 539.

Ster.

- Afr. : Transvaal.

mniocarpa W. P. Sch. in Mandon Pl. Boliv. n. 1677.

- Am. merid. : And. Boliv.

Mülleri Jaeg. Ad. I, $p .561$.

Bartramia divaricata C. M. in Linn. 1864, p. 594.

Ster,

- Am. sept. : Costa-Riea, 
pendula (Hook.) Jaeg. Ad. I, p. 558.

Bartramia pendula Hook. M. ex. t. 21; C. M. Syn. I, p. 491; Fl. Tasm. II. p. 194 p.p.; Handb. of. N. Zeal, Fl. p. 448.

Bryum pendulum Brid. Mant. M. p. 120.

Mnium pendulum Sm. in Trans. of the Linn. Soc. VII, p. 262.

Philonotis pendula Brid. Bryol. univ. II, p. 27.

2. $-A f r$. : Ins. Kerguelen ? (1). Am. merid : Fuegia, ins. Eremitae. Pac. : Nov. Zeland,, Tasman,, ins. Campbell. pinnata (Hpe.) Jaeg. Ad. I, p. 559.

Bartramia pinnata Hpe. in Ann. sc. nat. V ser., III, p. 373; Mitt. M. austr. am. p. 265.

Ster.

- Am. merid. : And. Nov. Granat.

plicata Mitt. in Journ. of the Linn. Soc. 1859, p. 83.

Bartramia plicata ej. M. austr. am. p. 266.

Paludic. - Am. merid. : And. Chilens.

robusta (Hook. f. et Wils.) Jaeg. Ad. I, p. 560.

Bartramia robusta H. f. et W. Fl. Antarct. I, p. 133, t. 59 et Handb. N. Zeal. Fl. p. 447; C. M. Syn. I, p. 495 et II, p. 619.

Ster.

Campbell.

- Am. merid. : Fuegia. Pac. : Ins. Auckland, rupestris (Mitt.) Jaeg. l. c.

Bartramia rupestris Mitt. op, et l. co.

$\downarrow$ et fr. ign. Ad rup. maritim. - Am. merid. : Fuegia, ins. Eremitae. scoparia (Schwaegr.) W. P. Sch. hb.

241

Bartramia scoparia Schwaegr. Suppl. III. I, II, t. 2H; C. M. Syn. I,
p. 490. 2. - Am. sept. : Antill. gallic.

Sieberi (Hsch.) Mitt. in Journ. of the Linn. Soc. 1859, p. 83.

Bartramia pendula Spreng. Syst. veg. IV, II, p. 323.

B. scoparia Schwaegr. Sp. M. p. 98 .

B. Sieberi Hsch. in Sieb. M. Nov. Holl. n. 13; C. M. Syn. I, p. 491; Fl.

2. Tasm. II, p. 194, t. 174, f. 6 et Handb. N. Zeal. Fl. p. 449 .

Tasman.

- Pac. : Austral., Nov. Zeland. sept. et merid., squarrosa (Mitt.) Jaeg. $l$. c.

Bartramia squarrosa Mitt. M. austr. am. p. 265,

Ster. - Am. merid. : And. Nov. Granat.

subarcuata W. P. Sch, in Besch. Prodr, bryol, mexic. p. 60.

Bartramia subarcuata C. M. Syn. II, p. 617; Mitt. op. cit. p. 262.

2.

Granat.

- Am. sept. : Mexic. Am. merid. : And, Nov.

subdisticha (Hpe.) Jaeg. Ad. I, p. 556.

Bartramia subdisticha Hpe. Symb. 1872, p. 50.

$\delta^{t}$ et fr. ignot.

- Am. merid. : Brasil. austr. or.

subgnaphalea (C. M.) Par.

Bartramis subgnaphalea $C$. $\boldsymbol{M}$. in $\mathbf{F l}, 1890, p .480$.

2.

- Afr. : Kilima N'Djaro.

(1) Cf. Glyphocarpus chrysurus, 
subtomentosa (Hpe.) Jieg, l, c.

Bartramia subtomentosa Hpe. Symb. 1872, p. 49 et 1877, p. 723.

Ster.

- Am. merid. : Brasil, austr. or.

tomentosa (Swo.) W. P. Sch, hb,

Bartramia arcuata Schwoaegr. Suppl. I, II, p. 62.

B. macrocarpa Hpe. in Linn. 1863, p. 141.

B. macrotheca ej. in Ann. sc. nat. V ser., III, p. 373 (fid. Mitt.).

B. tomentosa C. M. Syn. I, p. 488.

Bryum tomentosum Siv. Fl. Ind. occ. III, $p .1837$.

Mnium tomentosum ej. Prodr. p. 139.

? Philonotis tomentosa Brid. Bryol. univ. II, p. 26.

2. $\quad-A f r$. : Alp. Abyssin. (fid. Jaeger). Am. sept. : Guadalup., Jamaic. Am. merid. : Venezuela, And. Nov. Granat., Quitens. et Boliv.

Exs. : Mandon Pl. Boliv. n. 1670 et 1699 bis.

Trianae (Hpe.) Jaeg. Ad. I, p. 558.

Bartramia Trianae Hpe. in Ann. sc. nat. V ser., III, p. 374.

Ster. - Am. merid. : And. Nov. Granat.

Wainioi Broth. in Bot. Centralbl. 1888, p. 86.

2. - Am. merid. : Brasil. or.

yunnanensis Besch. in Ann. sc. nat. 1892, I, p. 63.

Ster. $\quad-A s$. : Yunnan (1).

BROTHERA C. M. mss, (3 sp.)

Ankarcronos C.M. ms.s.

Lignic. - As. : Japon.

japonica Broth. mss.

Lignic. - As. : Japon.

Leana (Sull.) C. M. mss.

Campylopus Leanus Sull. M. of U. St. p. 19 et Ic. M. p. 29, t. 18 ; Lesq. et Jam. Man. p. 78.

Dicranum albicans Bryol, exer. (fid. Hpe, in Jaeg. Ad. II, p. 656).

Leucophanes? Leanus Siell. M. Allegh. I ed. n. $172 ; C$. M. Syn. I, p. 446.

Syrrhopodon Leanus Sull. l. c. (fid. Lesq. et Jam.l. c.).

2. Lignic. - As. : Simla, Japon. Am. sept. : Ohio, reg. centr.

Exs. : Sull. et Lesq. M. bor, am. II ed. n. 94 (Campylopus).

BRUGHIA Schwaegr. Suppl. II, p. 91 (18 sp.)

amcena C. M. in Fl. $1888, n$. 1 .

1 ?

- Pac. : Austral.

aurea Besch. Not. M. Paraguay, p. 259.

Br. ligulata C. M. in Fl. 1888, n. I.

1. -Am. merid.: Paraguay.

Exs. : Bal. Pl. Parag. n. 1261 et 3658.

Beyrichiana C. M. - Sporledera.

(1) In Enum. Kindberg. nomen nudum:

Br. Lycopodium C. $M$. 
Bolanderi Lesq. in Mem. Calif. Acall. I, p. 5 ; Sull. Ic, M. Suppl. p. 23, ı. 14 ; Lesq. et Jam. Man. p. 46. - Am. sept. : M. Calif.

brevicollis Lesq. et Jam. Man. p. 47.

Syn.

- Am. sept. : Carolin. infer.

brevifolia Sull. M. of U. St. p. 17 et Ic. M. p. 25, t. 15; Lesq. et Jam. Man. p. 48.

Br. vogesiaca n. $2 H$. f. et W. in Drumm. M. bor. am. II ed. n. 15 p.p. 1. Terr. arenos. - Am. sept. : Carolin. infer., Texas, Ludovic.

Exs. : Sull. et Lesq. M. bor. am. II ed, n. 44.

brevipes Hook. Ic. pl. rar. III, t. 231 p.p. ; Sull. Ic. M. p. 24, t. 14 p.p.; Lesq. et Jam. Man. p. 48.

Bi, flexuosa var. minor C. M. Syn. $I, p .20$.

1. Terr, argill. arenac. - Am. sept. : Carolin., Virgin., Florid., Ludovic.

Exs.: Drumm. M. bor. am. II ed. n. 16.

Sull. et Lesq. M. bor. am. II ed, n. 45.

brevipes Hook. p.p. - Br. elegans.

Caroliniae Aust. - Br. Ravenelii var, mollis.

curviseta Lesq. et Jam. Man. p. 47.

Br. vogesiaca n. $2 H$. f. et W. in Drumm. M. bor. am. II ed, n. 15 p.p. 1.

-- Am. sept. : Ludovic.

I onnellii Aust. in Bull. Torr. bot. Club, VI, p. 144; Lesq. et Jam. Man. p. 48.

1.

- Am. sept. : Florid.

Eckloniana C. M. - Sporledera.

elegans (Hsch.) Jaeg. M. cleistoc. p. 35.

Br. brevipes Hook, op. et l. cc. p.p.; C. M. Syn. I, p. 18.

Phascum elegans Hsch. in Linn. 1841, p. 114,

1.

exigua C. M. - Pleuridium.

- Afr. - C. B. Sp.

flexuosa (Schwaegr.) C. M. in Bot. Zeit. 1847, et Syn. I, p. 20 ; Lesq. et Jam. Man. p. 46.

Phascum flexuosum Sehwaegr. Suppl. II, p. 101; Brid. Bryol. univ. 1, p. 38.

2. (C. M.) ; 1 vel syn. (Lesq. et J.) - Am. sept. : Reg. merid.

"var. microcarpa (Wils.) Lesq. et Jam. l. c.

Br. microcarpa Wils, mss.; Dirumm, M. bor, am. II ed. n. 14.

Sporledera setifolia Jaeg. M. cleistoc. p. 35.

Ut et cum typ.

flexuosa Sull. - Br. Sullivantii.

var. minor C. M. - Br. brevipes.

var. nigricans Sull. - Br. Sullivantii var. nigricans.

Hallii Aust. in Bull. Torr. bot. Club, V, p. 21 ; Lesq. et Jam. Man. p. 47. - Am. sept. : Texas.

Hampeana C. M. - Sporledera.

ligulata C. M. - Br. aurea.

longicollis Eaton in Bull. Torr. bot. Club, 1890, p. 100, t. 101.

1. $\quad-A m$. sept. : New Hampshire. 
microcarpa Wils. - Br. flexuosa var. mierocarpa.

minuta Mitt. - Sporledera.

nigricans Aust. - Br. Sullivantii var. nigricans.

palustris C. M. - Sporledera.

Ravenelii Wils. mss.; Sull. M. of U. St. p. 17 et Ic. M. p. 26, t. 16; Lesq. et Jam. Man. p. 49.

Sporledera Ravenelii Jaeg. M. cleistoc. p. 35.

1. Terr, - Am. sept. : Carolin. inf.

Exs, : Sull. et Lesq. M. bor. am. II ed., n. 43.

* var, mollis Lesq. et Jam. l. c.

Br. Caroliniae Aust. in Bull. Torr, bot. Club, VI, p, 144.

Ut typ. - Am. sept. : Florid.

Relimanni C. M. - Sporledera.

repens Hsch. - Platygyrium.

Schwaegrichenii Jaeg. - Sporledera Hampeana.

Sullivantii Aust. in Bull. Torr. bot. Club, VI, p. 143; Lesq. el Jam. Man. $p, 46$.

Br. flexuosa Sull. Ic. M. p. 22 (excl. deseript.) t. 13.

1. Terr. argillac. - Am. sept, : Reg. merid.

"var. nigricans Lesq. et Jam l. c.

Br. flexuosa var, nigricans Sull, M. of U. St. p. 17; Sull. et Lesq. M. bor. am. I ed. $n .33$.

Br, nigricans Aust, in op, et $l$. oc.

Ut typ. - Am, sept. : Alabama.

Exs, : Sull, et Lesq. M. bor. am, ed. n. 42.

texana Aust. in op. c. $V, p, 21$.

1. $\quad$-Am. sept.: Texas.

trobasiana de Not. in Hb. critl. ital. fasc. XXXVI et Epil. p. 729:

W. P. Sch. Suppl. Bryol, eur. I-II, t. I et Syn. II ed. p. 29.

1. In prat. arid. - Eur. : Stiria, Lac. major (Trobaso).

uruguensis C. M. in Linn. I878-79, p. 231.

2.

$$
\text { - Am. merid. : Uruguay. }
$$

vogesiaca Schwaegr. Suppl. II, p. 91, Ł. $127 ;$ Bryol. eur. I, t. II; C. M. Syn. I, p. 20; W. P. Sch Syn. II ell., p. 28.

Saproma vogesiacum Brid. Bryol. univ. I, p. 53.

Voitia rogesiaca Hsch, in Moug. et Nestl. Stirp, crypt. Voges. rhen. fase. VIII, n. 706 .

1. In decliv. gramin. humid, et in turfac. - Eur.: Voges. (M. Hohneck), Palatin. super,, Salisburg.

Exs. : Rai. Bryoth, eur. n. 306, 1201.

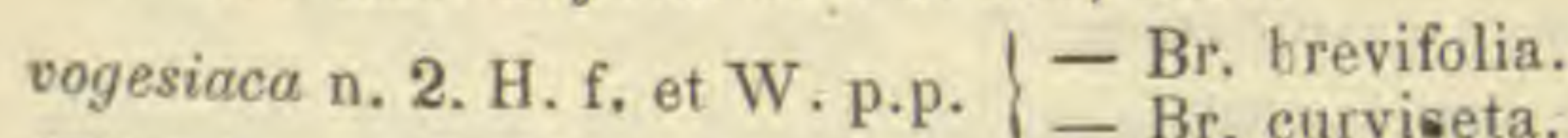

Whiteleggei C. M. - Sporledera (1).

BRYELLA Berk, Handb. of Brit. M. 1863.

recta Berk, - Phascum.

Bryotis C. M. in Linn. 1875, p. 380 (sect. Bryı.)

(1) In Enum. Kindb. nomen nudum :

Br. incana C. $M$. 
BRYOXIPHIUM (1) Mitt. M. austr. am. p. 580 (3 sp.)

mexicanum Besch. in op. et $l$. cc.

Br, norvegicum Mitt. $M$, austr. am. p, 580.

Eustichium norvegicum W. P. Sch. in M. Liebmann. Besch. Pr. bryol. mexic. p. 29.

$\rho$ et fr. ign. - Am. sept. : Mexic.

norvegicurn (2) (Brid.) Mitt. in Journ. of the Linn. Soc. XII, p. 580.

Eustichia norvegica C. M. Syn. I, p. $42 ;$ W. P. Sch. Syn. II ed. p. 148.

Eustichium norvegicum Bryol. eur. III, t. 195.

Fissidens imbricatus Desv, in Brid. Bryol. univ. II, p. 674.

Phyllogomium Eustichia norvegicum Brid. l. c.

$\mathrm{Ph}$. norvegicum Sull. Contrib. on Bryol. of N. Americ. c. ic.

2. Rupic. - Eur. : Norveg. ? Islan d. Am. sept.: de Ohio centr. ad Kentucky (ster.) ; Wisconssin (fert.!)

norvegicum $\left\{\begin{array}{l}\text { Mitt. - Br. mexicanum. } \\ \text { Bryol. eur. - Bryoxiphium. }\end{array}\right.$

Savatieri (Husn.) Mitt. M. and Hepatic. from Japan, 1891, p. 154.

Eustichia japonica Berggr. in Fl. 1881, p. 290 (fid. Geheeb in op. cit. 1883, n. 31).

E. norvegica W. P. Sch, in M. Savaties n. 148.

E. Savatieri Husn. Rev, bryol. V, p. 85.

2. Ad rup. madid. et in spelunc. - As. : Japon.

Exs. : Faurie n. 72, 80, 192, 523, 818, 824, 3524, 8641.

BRYUM Dill, Hist. M. p. 338 emend. (560 sp.)

abbreviatum Hpe. Enum. M. Brasil. p. 31. 2 ?

- Am. merid. : Brasil. austr, or.

Abduanum Rota Cat, M. Bergom ; de Not. Epil. p. 754 (3).

Ad rup. et aren. humid. - Eur. : Ital. sup. (Vall. Tellina).

aberrans Hpe. Symb. 1877, p. 724.

Ster. $\quad$ - Am. merid. : Brasil. austr, or.

abyssinicum C. M. - Brachymenium.

acanthoneuron Angstr. in Oefv.... 1876, n. 4, p. 20.

Ster. $\quad-A m$, merid. : Brasil. austr. or.

ucaulon $\left\{\begin{array}{c}\text { foliis teneris confertis, capsulis conicis Dill. - Barbula caes- } \\ \text { pitosa (fid. Hedw.). } \\ \text { heteromallum, selis longis pallidis Dill. - Leptotrichum pallidum. }\end{array}\right.$ aciculare L. - Rhacomitrium.

aciculariforme Hoffm. - Rhacomitrium sudeticum ?

aciphyllum Voit. - Mnium affine.

var., Voit. - Mnium cuspidatum.

acuminatum $\left\{\begin{array}{l}\text { Bryol. eur. - Webera. } \\ \text { Sw. - Barbula agraria. } \\ \text { Wils. - Webera himalayana. }\end{array}\right.$

var, arcuatum Bryol, eur. - Webena acuminata var. areuata.

var, minus Bryol, eur. - Webera acuminata var. minor.

(1) Sub Bryoziphio, nom, a cl. Bescherelle in Journ. de bot. 1892, p. 180 correcto.

2) Cf. G. Knight in Bull. of Torr. bot. Club, 7 bri 1883 et Rev. bryol. 1881, p. 15 (descript, fructus),

(3) Forsan Br. Mühlenbeckii (fid. Limpr.). 
var. polysetum Bryol. enr. - Webera acuminata var. polyseta.

var, tenellum Bryol. eur. - Webera acuminata var. tenella. acutiusculum $C . M$. in Fl. 1887, p. 220.

$2 . \quad-$ Am. sept. : Alaska.

acutum Lindb. in Mitth. v. Soc. pr. Faun. el Fl. Fenn. $5^{\mathrm{a}}$ Decembr. 1885, p. 239.

Br. calophyllum Berggr. M. Spetsb, n. 73.

Polyg. (Lindb.), 1 (Philib.) (1). Ad rip. aren. fluv. - Eur.: Lappon. ross., Norveg., Alp. Vales. As. : Jenissei inf. Ant. sept. : Groenland.

acutum P. B. - Blindia.

aequabile C. $M$. in Linn. 1880-83, p. 368.

Ster. Muric. - Am. merid. : Argentin. subtropic.

aestivum L. - Gymnostomum curvirostre .

affine $\left\{\begin{array}{l}\text { Brid. - Mnium. } \\ \text { Gmel. - Orthotrichum. } \\ \text { Lindb. - Br. cuspidatum. }\end{array}\right.$

afro-alpinum Rehm. M. Afr. auslr. n. 248.

$$
\text { - Afr. : Orange. }
$$

afro-crudum C. M. - Webera.

afro-julaceum C. M. in Dusen M. Cam. n. 295.

- Afr. : M. Cameroon.

afro-littorale C. M. in Engler's Bot. Jahrb. 1883, p. 88 et in Forchungsreise.... p. 62.

Ad terr. humid. - Afr. : Monrovia, Lagos, M. Cameroon.

Exs, : Dusen, M. Camer. n. 81.

agrarium Sw. - Barbula.

albicans Mitt. $\left\{\begin{array}{l}- \text { Webera. } \\ (1876) \text {. - Webera austro-albicans. }\end{array}\right.$

var. glaciale C. M. - Webera albicans var. glacialis .

albidum $\left\{\begin{array}{l}\text { L. - Octoblepharum. } \\ \text { et glaucum, fragile majus Dill. - Leucobryum glaucum. } \\ \text { et glaucum fragile minus Dill. - Leucobryum minus. }\end{array}\right.$

albo-pulvinatum C. $M$. in Fl. 1886, p. 507 .

Ster. $\quad$ Afr.: Angola.

albulum Mitt. M. Ind. or. p. 69.

$$
\text { - As. : India. }
$$

algovicum Sendtn. - Br. pendulum var. compactum.

alpiniforme Kindb. in Mac. Cat. p, 271.

Ster. Rupic. - Am. sept. : Ontario.

alpinulum Besch. Fl. bryol. Réunion, etc. p. 97.

2. Ster. - Afr. : Ins. Nossi-Bé.

alpinum L. Mant. M. II, p. 309 ; Brid. Bryol. univ. I, p. 663; Bryol. eur. IV (mon. p. 76), t. $380 ;$ C. M. Syn. I, p. 235; W. P. Sch. op. cit. p. 440.

Br. hypnoides pendulum sericeum, coma insigni atro-rubente Dill. Hist. M. $p .394, t .50, f .64$.

(1) In Rev. bryol. 1892, p. 35. 
Br. pachypoma Wils, in Lond. Journ. of bot. 1840, II, p. 364 p.p.

Br. teretiusculum Hook, in Wall. Cat. n. 7597; Harv, in Lond. Journ. of bot. l. c. p. 9 et Ic.pl, rar. t. 20, f. I (fid. Mitt.); C. M. Syn. I, p. 303.

Mnium alpinum L. jun. Meth. M. p. 366.

2. Ad rup. silic. madid. -- Eur. : E reg. campestr. usq. in subalp. per zon. interm. et sept., raro merid. As. : Tibet. occ., Nepal., Himalaya, Khasia, M. Neilgherr., Caucas. Afr.: Madeir., M. Cameroon, Kilima N'Djaro. Am. sept. : Columb. brit., reg. or.

Exs. : Rab. Bryoth. eur. n. 364, 582.

Sull, et Lesq. M. bor. am. II ed, n. 293.

« var. angustifolium Husn. Muscol, gall, p. 247.

Br. atlanticum Solms-Laub.

Ut typ. - Eur. : Gall. occ. et merid.

var. brevifolium Myr. - Br. Mühlenbeckii.

var. gemmiparum Husn. - $\mathrm{Br}$. gernmiparum.

var. mediterraneum de Not. .- Br. gemmiparum.

« var. meridionale W. P. Sch. op. cit. p. 441.

Præecip. ad rup. marit. - Eur. : Cornwall,, Lusit. Afr. : Ins. Canar., Madeir.

« var, viride Husn. $l, c$.

Ut et cum typ.

alpinum $\left\{\begin{array}{l}\text { Vill. - Br. Schleicheri. } \\ \text { viridissimum et majus, capilulis crassissimis Hall. - Bartramia } \\ \text { ithyphylla. }\end{array}\right.$ alte-operculatum Besch. op. cit. p. 93.

2. $\quad-A f r .:$ Ins. Borbon., Franciæ.

alticaule C. M. - Webcra.

var. robustior C. M. - Webera alticaulis var. robustior.

alto-roseum C. M. - Rhodobryum.

ambiguum Duby. - Br. plumosum.

Amblyodon C. M. in Linn. 1878-79, p. 293.

Syn. $\quad-A m$. merid. : Argentin. Tucum.

amplirete Rehm.M. Afr, austr.

$$
\text { - Afr. : Orange. }
$$

amplirete C. M. - Webera.

ampullaceum, foliis $\left\{\begin{array}{c}\text { et ampullis angustioribus Dill. - Tetraplodon } \\ \text { mnioides var. Brewerianus. } \\ \text { serpylli pellucidis, collo crassiore Dill. - Splach- } \\ \text { num sphaericum. } \\ \text { thymi pellucidis, collo strictiore Dill. - Splach- } \\ \text { num ampullaceum. }\end{array}\right.$
andicola Hook. - Rhodobryum.

androgynum Hedw. - Aulacomnium.

$\beta$ prolixum Roth. - Aulacomnium palustre var. polycephalum.

angolense W. et Duby. - Brachymenium.

angulosum Menz. - Conostomum australe.

augustifolium Brid. Bryol. univ. I, p. 685 ; C. M. Syn. 1, p. 309 ; Milt. 2.

M. austr, am. p. 300 .

$$
\text { - Am. sept. : Hispaniola. }
$$

angustifolium $\left\{\begin{array}{l}\text { Kaur. }- \text { Br. saltense. } \\ \text { W. P. Sch. - Br. bolivianum. }\end{array}\right.$ 
angustirete Kindb, in Bull. Torr, bot. Club, XVI, p. 94.

Syn. Terr. et rup. hum. - Am. sept. : M. Rupestr., Colımb. brit.

annotinum $\left\{\begin{array}{l}\text { Brid. - Mielichhoferia Jamesoni. } \\ \text { Hedw. - Webera. } \\ \text { lanceolatum pellucidum, capsulis oblongis pendulis Dill. - } \\ \text { Webera annotina. } \\ \text { palustre, capsulis ventricosis pendulis Dill. - Bryum } \\ \text { pseudo-triquetrum? }\end{array}\right.$ annulatum Hook. f. el Wils. Fl. Antaret. I, p. 134, t. 60; C. M. Syn. I, p. 577; Handb. of N. Zeal. Fl. p. 443.

2. Ad terr, argill. - Pac. : Nov. Zeland. sept. et med., ins. Camplell. anoectangiaceum C.M. et Kindb. Bidr. p. 454 (nom.) et in Mac. (iat. p. 130 .

1 ? Ad rup, torrent. - Am. sept. : Columb. brit., M. Rupestr.

Anomodon Mont. in Ann. sc. nat. 1857, p. 151.

$2 . \quad-A f r .:$ Ins. S. Anton. cap. Viridis.

antarcticum H. f. et W. - Webera.

Antillarum W. P. Sch. - Rhodobryum.

apalodictyoides C. M. in Bot. Zeit. 1853, p. 21 ; Mitt. M. Ind. or. p. 74. - As. : M. Neilgherr.

apiculatum Schoaegr. Suppl. I, II, p. 102, ı. 72; C. M. Syn. I, p. 308;

Mitt. $M$. austr, am. p. 301 (1).

2.

- Am. merid. : Brasil. austr. or., Monte Video.

apiculatum $\left\{\begin{array}{l}\text { Bryol. eur. }(1839),-\mathrm{Br} \text {. marginatum. } \\ \text { Dz. et } \mathrm{Mk},-\mathrm{Br} \text {. plumosum. } \\ \text { Wils, - Br. Mildeanum. }\end{array}\right.$

apocarpum L. - Grimmia.

var. aureum Retz. - Hedwigia ciliata.

var. incanum Thro. - Hedwigia ciliata.

var. $\beta$ L. - Hedwigia ciliata.

apocaulon Hoffm. - Grimmia apocarpa.

appressum Ren, et Card. in Bull. Soc. roy. bot. Belg. 1893, 1, p. 116.

2.

- Afr. : Madagascar.

appressum Wils. - Br. turbinatum.

aptychoides C. M. - Webera.

aquaticum $\left\{\begin{array}{l}\text { Gmel. - Cinclidotus. } \\ \text { Hoffm. - Dichodontium pellucidum. }\end{array}\right.$

arachnoideum $C . M$, in $F l$. $1879, n, 24$.

Ster.

- Afr. : M. Kenia.

archangelicum Bryal, eur. IV (mon. p. I), $\iota .333$; C. M. Syn. I, p. 271 et $I I$, p. 569 ; W. P. Sch. op cit. p. 416.

Br. Tauriscorum Limpr. in Schlesisch. Gesells. 1883, p. 241.

Syn. Terr. - Eur, : Spitzberg, Mar. alb., Dovre, Alp. Carinth., Salisb., Stir., Helvet. (Gemmi). As. : Jenissei inf. Am. sept. : Ins. Sabine, Gaspes., M. Rupestr.

arctico $X$ pallens Philib. $-\mathrm{Br}$. flavescens.

(1) Cl. Mitt. procul dubio errat, quam in M. Ind. or., p. 70, Br. apioulatum Schw. ad $B r$, nitens Hook, ut syn. ducit. 
arcticum (R. Br.) Bryol. eur. IV (mon. p. 2), t. 335 ; C. M. Syn I, p. 269 ; W. P. Sch. op. cit. p. 409.

Br. nutans var. Drumm. M. bor. am. I ed. n. 263 B.

Hemisynapsium arcticum Brid. Bryol. univ, $I, p .606$.

Pohlia arctica R. Br. Suppl. App. ad iter Parray. p. 196.

Syn. Ad terr, humos, et in rup. fiss. humid. - Eur. : Spitaberg, Sept. Insul., ins. Ursor., Alp. Scandin., Tatra, Salisb., Stir., Julian., Carinth., Bavar., Austr. sup. et inf., Tirol., Helvet., Jurass. ; deest in Britann. As. : Penins. Tschutschica, Jenissei. Am. sept. : Fret. Smith, ins. Melville, Groenland, Labrador, Gaspes., reg. sept. occ., M. Rupestr., M. Calif.

« var. helveticum (Phil.) Husn. Muscol. gall. p. 235.

Br. helveticum Philib. in Rev. bryol. 1886, p. 83.

Ut typ. - Eur. : Helvet.

arcticum Lindgr. - Br. Lindgrenii.

arcuatum Limpr. Einig. neue Art.... 1883, p. 237 et Laubm. Deutschl. II p. 304.

Syn, Ad rup. madid. umbros. - Eur. : Norvegia.

ardonense Breidl. in Oesterr. bot. Zeitschr. 1889, n. 4.

1.

- As. : Caucas.

Arenae C. $M$. in Fl. I885, p. 402.

2. Paludic. - Am. merid. : Fret. Magell.

arenarium Jur. Laubm. Oesterr. Ung. p. 273.

Br. atro-purpureum Garov. Enum. p. 28.

Br. atro-purpureum var, arenarium Husn. Muscol. gall. p. 244.

2. Limic. - Eur. : Austria, Salisburg., Gall. centr. (Bourbonnais).

arenarium $\left\{\begin{array}{l}\text { C. M. }-\mathrm{Br} . \text { Pootenianum. } \\ \text { Saut. }-\mathrm{Br} \text {. Blindii, }\end{array}\right.$

areoblastum $C$. $M$. in $F l .1886, p .280$.

2. Terr. - Afr. : Ins. S. Thomas.

argentatnm C. M. in Engler's Bot. Jahrb. 1883, p. 83 et in ForchungsSter. reise...p. 41.

argenteum L. Sp. pl. p. 1586 ; Brid. Bryol. univ. I, p. 657 ; Bryol. eur. IV (mon. p. 78), t. $384 ;$ C. M. Syn. 1, p. 314; W. P. Sch. op. cit. p. 448 .

Br. pendulum, julaceum, argenteum et sericeum Dill. Hist. M. p. 392, t. 5 .

Hypnum argenteum Schrank Baiers Fl. II, p. 469 .

Mnium argenteum Hoffm. Deutsch. Fl. II, p. 51.

2. Feré ubiq., except. arbor., per tot. fer. terrar. orbem, a Spitzb. et Groenl. ad terr, antaret.

Exs. : Drumm. M. bor. am I ed. n. 251.

Faurie Pl, Japon, n. 13, 89.

Mac. Canad. M. n. 177 .

Mand. Pl. Boliv, n. 1663.

Rab. Bryoth. eur. n. 92, 238.

Rehm. M. Afr, austr, n. 259.

W. Schimp. M. Abyss, n. 455 .

var, argyrotrichrum Mitt. - Br. argyrotrichum.

* var. australe C. M. in Rehm. M. Afr. austr. n. 260.

- Afr. : Orange. 
var, corrugatum Beseh. - Br, corrugatum.

« var. costa-ricense Ren. et Card. in Bull. Soc. roy. bot. Belg. 1892, $I, p .167$.

Ad mur, et terr, - Am. sept. : Costa-Rica.

\& var, lanatum Bryol, eur., C. M. et W. P. Sch. ll. cc.

Br. lanatum Brid. op. cit. p. 660.

Mnium lanatum P. B. Prodr. p. 75 .

ln mont. editior. ut in reg. campestr. zon. merid. - Eur. : Alp. Tirol., etc. Afr., utraque Amer. et Austral.

Exs. : Mandon Pl. Boliv. n. 1664.

« var. majus Schwaegr. Suppl, I, II, p. 88; Bryol. eur., C. M. et W. P. Sch. $l l . c c$.

Br. argenteum var. muticum Lindb. Spetsb. M. p. 546.

Br. julaceum Schrad. Spic. Fl. Germ. p. 70, n.2.

Loc. humidior, - Eur. et Am. sept. : Cum typ.

var. muticum Lindb. - Br. argenteum var. majus.

\& var. submuticum Besch. Fl. bryol. Réunion, etc. p. 93.

In carbonar. - $A f r$. : Ins. Borbon.

argentisetum $C . M$. in $F l .1890$, p. 478 .

Ster.

- Afr. : Kilima N'Djaro.

argutidens Rehm. -- Rhodobryum.

argyreum C. M. in Linn. 1880-83, p. 380.

2.

- Am. merid. : Uruguay.

argyrotrichum C. M. in Linn. 1865, p. 385.

Br. argenteum var, argyrotrichum Mitt. in Journ. of the Linn. Sos. $1886, p .307$.

Ster. Terr. - Afr. : Niam-Niam, Usagara.

\& var, laxum C. M. in op. et l. cc.

Ut typ. - Afr. : Niam-Niam.

aristatum Dicks, - Barbula unguiculata.

Arnellii Par.

Br. flexisetum Lindb. et Arn. M. As. bor, 1890, II, p. 44.

Syn. Ad terr. humid. - As. : Jenissei inf.

articulatum Sendtn, - Br. Funkii.

Aschersoni C. M. in Fl. 1874, $n$. 31 .

2. Ster. In foss, aquat. - Afr, : Oasis Dachel.

aterrimum C. M. in Rehm. M. Afr. austr, n. 235 .

$$
\text { - Afr. : C. B. Sp. }
$$

allanticum Solms-Laub. - Br, alpinum var. angustifolium.

atro-purpureum Wahlenb. in Web. et Mohr Ind. Mus. Vid. Lapp. p. 360 ? Bryol eur. IV (man. p. 73), t. 378; C. M. Syn. I, p. 306 et II, p. 576 ; W. P. Sch. op. cit, p. 438.

Br. bicolor Turn. Muscol. Hib. p. 121, t. II, f. 2 (an Dill. Hist. M. p. 397, t. 50, f. 66 fet g ?); Dicks. Fasc. IV Pl. crypt. p. 16 (fid. Lindb. M. Scand, $p$. 16).

Br. carneum $\beta$ atro-purpureum Schwaegr. Sp. M. p. 67.

Br. dichotomum Wils. Bryol. brit. p. 244, t, 50; H f.et W. Fl. of the N. Zeal. II, p. 85 . 
Br. erythrocarpon Brid. Bryol. univ. I, p, 654.

Br. erythrocarpon $\beta$ bicolor ej. l. c. p. 655 .

Br. pulchellum var. atro-purpureum Wahlenb Fl. Lapp. l. c.

Mnium bicolor P. B. Prodr. p. 74 .

2. Muric. et terr., in arenos. marit. - Eur. : Zon. merid., rar. intermed., rariss, septentr. As. : Caucas., Syria. Afr. : M. Sinaï, Alger,, ins. Canar., Madeir. Am. sept. : Niagara, Tennessee, Nevada, Illinois, Pensilv., New York, Florid., Alabama. Pac. : Austral,, Nov. Zeland.

Exs. : Bourg. Pl. Can. n. 1152.

Rab. Bryoth. eur, n. 87, 240, 1217, 1332.

Sull. et Lesq. M. bor. am. II ed. n, 291 .

var. arenarium Husn. - Br. arenarium.

« var. macrothecium Besch. Cat. M. Alger. p. 25.

- Afr. : Alger.

atro-purpureum $\left\{\begin{array}{l}\text { de Not. }-\mathrm{Br} \text {. murale. } \\ \text { Garov, - } \mathrm{Br} \text {. arenarium. }\end{array}\right.$

atro-sanguineum C. M. in Linn. 1880-83, p. 386.

2. Muric. et terr. - Am. merid. : Argentin. subtropic.

atro-virens Vill. - Br. erythrocarpum.

attenuatum \{ Dicks? Brid. (fid. C. M.) - Br. pallens var. abbreviatum.

Dicks? (fid. Lindb.) - Entosthodon Templetoni.

Atwateriæ C. M. in Fl. 1873, p. 76; Lesq. et Jam. Man. p. 234.

Br. Macounii Aust. in Coult. Bot. Gaz. II, p. 110.

2. Ad rup. humid. - Am. sept. : Ontario, Columb. brit., ins. Vancouver, Washington, Oregon, Calif.

Exs. : Mac. Canad. M. n. 176.

Auberti Brid. Mant. M. p. 119; C. M. Syn. 1, p. 262.

Br. Polla Auberti Brid. Bryol. univ. I, p. 711.

Mnium Auberti Sehwaegr. Suppl. I, II, p. 132, t, 80.

Syn.

- Afr. : Ins. Borbon., Franciæ.

Auberti I Hsch. - Bryum schistoneuron var. decumbens.

Schwaegr. - Bryum schistoneuron var. densifolium.

auratum Milt. $M$. Ind. or, p. 67.

Anomobryum auratum Jaeg. Ad. I, p. 604.

Brachymenium filiforme Wils. in Kev Journ. bot. $1 \mathrm{X}$, p. 363 p.p.

2. - As. : Nepal., Himalaya.

aureum Schreb. - Leptobryum piriforme.

auricomum Besch. Fl. bryol. Réunion, etc. p. 99.

2 .

- Afr. : Ins. Borboniæ.

auriculatum C. M. in Linn. $1875, p .379$.

Ster. Terr. - Afr. : Niam-Niam.

australe Hpe. Ic. M. t. 26 ; C. M. Syn. I, p. 285.

2.

- Pac. : Austral. or.

«var. minus Hpe, in Linn. $1852, p .714$ (nom.)

- Puc. : Austral.

auslro-albicans C. M. - Webera.

austro-caespiticium C. M. in Engler's Bot. Jahrb. 1883, p. 77 el in ForSyn. chungsreise...p. 13.

- Afr.: Ins. Kerguelen. 
austro-crudum C. M. - Webera.

austro-elongatum C. M. - Webera.

austro-nutans C. M. (Ins. Kerg.) - Webera pseudo-nutans.

austro-polymorphum C. M. - Webera.

austro-turbinatum C. M. in Linn. 1880-83, p. 368.

Ster.

- Am, merid. : Argentin. Cordob.

autumnale Limpr. Einig. neue Art... 1883, p. 239 et Laubm. Deutschl. II, p. 312 ,

Syn. In aren. humid. - Eur. : Norveg.

Axel-Blyttii Kaurin in Bot. Not. 1889, n. 2; Philib. in Rev. bryol. 1889,

1. - Eur. : Norveg. merid. p. 61 .

badium Br, in Bril. Bryol. univ, I, p. 850; W. P. Sch. op. cit, p. 444.

Br. caespiticium C. M. Syn. I, p. 284 p.p.

Br. caespiticium var, badium W.P. Sch, Coroll. p. 74.

Br. caespiticium var. gracillimum Bryol. eur. IV (mon, p. 71), t. 375 B.

2. In arenos. humid. - Eur. : Zon intermed. As. : Caucas. occ. et centr.

Exs. : Rab. Bryoth. eur, n, 91, 1086, b et c.

Baenitzi C. M. in Fl. $1888, p .417$ (1).

Syn.

- Eur. : Norveg. sept.

Baileyi Broth. in Bail. Syn. of the Queensl. Fl. IV Suppl. (nom.) et in Oefv.... 1890, p.

2. In lapidos. - Pac. : Australia (Queensland).

balanocarpum Besch. in Bull. Soc. bot. Fr. 1894, p. 82.

1. Terr. - As. : Tonkin.

baldense Vent, in de Not. Epil. et in Rev. bryol. 1881, p. 31.

2. Ad rivul. - Eur.: M. Baldo, Valesia.

barbatum Curt. - Barbula unguiculata.

barbulaceum C. M. in Linn. 1875, p. 389.

Br. coronatum Wils. in Gardn. M. Brasil, n. 35; C.M. Syn. I, p. 307 , . . 2.

Barnesi Wood in W. P. Sch. op. cit. p. 471 (2).

- Am. merid. : Brasil.

Br. argenteum $L$. (fid. Braithro. Brit. Mossf. II, p. 176).

Ster. In coll, arenac. - Eur.: Anglia (Westmoreland).

Baroni Mitt. mss.: C. H. Wright M. Madag, p. 5.

- Afr. : Madagascar.

Bartramia $\{$ Gmel. - Bartramia Halleriana.

Schwaegr, - Cryptopodium Bartramia.

bartramioides Rehm. M. Afr, austr. n. 257.

- Afr.: Orange.

bartramioides Hook. - Cryptopodium bartramioides.

bartramiopsis C. M. in Linn, 1880-83, p. 372.

Ster.

Baueri $H_{\mu e}$ in Linn, $1859-60, p .457$.

- Am. sept. : Sierra Nevada Calif.

(1) Forsan Bi. subglobosum Schlieph. (fid. Limpr. op. cit. p. 356).

(2. Br. lacustre forma bubilligera (Lirnpr. op. cit. p. 317). 
Bescherellei Jaeg. Ad. I, p. 627.

Br. erythrocarpoides W. P. Sch. in Besch. Fl, bryol. Nov. Caled. p. 214. Syn. - Pac. : Nov. Caledon.

Bescherellei Ren. et Sard. - Br. Rodriguezii.

Beyrichianum C. M. p.p. $\left\{\begin{array}{l}\text { - Rhodobryum Beyrichianum. } \\ \text { - Rhodobryum Swarzianum. }\end{array}\right.$

bicolor C. $M$, in Fl. 1890, p. 476.

2. In palud, edit. - Afr. : Kilima N'Djaro.

bicolor $\left\{\begin{array}{l}\text { Dicks. }- \text { Br. erythrocarpum (fid. Milde). } \\ \text { Turn. }- \text { Br. atro-purpureum. }\end{array}\right.$

Biddlecomiae Aust. in Coult. Bot. Gaz. II, p. 110; Lesq. et Jam, Man.

$$
\begin{gathered}
\text { p. } 226 . \\
\text { Syn. }
\end{gathered}
$$

Bigelowii Sull. - Webera.

Billardieri Schwoaegr. Suppl. I, II, p. 115, t. 76 ; Brid. Bryol. univ. I, p. 667 ; C. M. Syn. I, p. 253.

B. rufescens $H$. f. et W. ? (f. Mitt.)

Ad arbor. et rup. humid. - Pac. : M. Austral., Nov. Belg., Tasman., ins. Lord Howe.

Billardieri Bryol, eur. - Br. provinciale.

bimoideum de Not. Epil. p. 383.

$$
\text { - Eur. : Vall. Tellin. }
$$

bimum Schreb. Spic. Fl. Lips. p. 83; Brid. Bryol. univ. 1, p. 678; Bryol. eur. IV (mon. p.50), t. 363; C. M. Syn. I, p. 257; W. P. Sch. op. cit. p. 430.

Br. hybridum $\mathrm{Br}$. in sehed.

Br. pseudo-triquetrum Brid. l. c. p. 676 et auct. alior, p.p. (1).

Br, turbinatum Drumm. M. bor. am. I ed. n. 266.

Syn. In prat. uligin. et ad rup. madid. - Eur. : Reg. campestr. et montan., rar. alp. zon. septr. et interm.; ins. Melit. As, : Amour, Caucas. Afr. : Ins. Kerguelen. Am. sept. : Franz Joseph Fjord, Terr. Nov., Nov. Scot., New Brunswick, Gaspes., Ontario, lac. Sup., Manitoba, Columb. brit., ins. Vancouver, Washington, Oregon, Nevada, Illinois, Wisconss., Kansas, reg, centr. et or. Am. merid. : And. Nov. Granat, et Quitens. Pac. : Nov. Zeland., Tasman. Eœs. : Mac. Canad. M. n. 170.

Rab. Bryoth, eur. n. 239, 833, 932, 1027.

Sull, et Lesq. M. bor. am. II ed, n. 278.

- var, angustifolium Kindb. in Mac. Cat. p. 123.

Rupic. - Am. sept. : Ontario.

* var. atrotheca Ren. et Card. in Bot. Gaz. 1894, p. 238. - Am. sept. : Terr. nov.

var. cuspidatum Bryol, eur. - Br. cuspidatum.

«var. longicollum Warnst. Moosfl. Prov. Brandeb. p. 52.

- Eur. : Brandebourg.

ه var. obtusi-operculatum Warnst. l. c.

- Eur.: Brandeb.

«var. subnivale Mdo. Alg. Alp, p. 78.

- Eur. : Alp. Algov.

(1) De synon, antiq. cf. C. M. 1. c. 
bimo aff. Wils. - Br. pseudo-triquetrum.

bipartitum Dicks. - Ceratodon purpureum.

blandum Hook. f. et Wils, in Lond. Jowrn. of bot. 1844, p. 546 el Fl. Antarct. I, p. 134, t. 60; C. M. Syn. I, p.3is el II, p. 577; Handb. of $N$. Zeal. Fl. p. 441.

2. Paludic. - Pac. : Nov. Zeland, sept. et med., ins. Campbell.

"var. luridum Hook. f. et Wils. Fl. Tasm . p. 190.

- Pac. : Nov. Zeland., ins. austral.

Blindii Bryol, eur. IV (mon. suppl. p. II), t. 383; C. M. Syn. I, p. 298; W. P. Sch. l. c. p. 447.

Argyrobryum Blindii Kindb. Art. d. Laubm. Schw.u. Norveg. p. 78.

$\mathrm{Br}$ arenarium Saut. in Fl. Salsb. III, p. 46.

Br. Funkii var? Bryol. eur. mon. Bryi, p. 77.

Br. Funkii var. subsphœricum W. P. Sch. in Husn. Muscol. gall. p. 243.

2. In terr. arenos. v, argill. aren. et tophac. - Eur. : Alp. Rhaet., Pinzgov., Salisburg., Stir., Carinth., Helvet. Am. sept. : M. Rupestr. et Selkirk.

Exs, : Mac, Canad. M. n. 502.

Rab. Bryoth. eur. n. 1088, 1333.

Un itin. 1863, n. 25.

var. Payoti Husn. - Br. Payoti.

Boissieri de Not. - Webera longicolla.

Bolanderi Lesq. - Webera longicolla.

bolivianum Par.

Br. angustifolium W. P. Seh. in Mandon Pl. Boliv. n. 1605.

- Am. merid.: And. Boliv.

Bommanssonii Lindb. in Milth. v. Soc. pr. Faun. et Fl. Fenn. 1884, p. 183.

- Eur. : Fennia.

boreale Schwaegr. - Bi. pallescens var. boreale.

Botterii C. M. in Linn, 1874, p. 622.

2. Lignic. - Am. sept. : Mexic.

brachydontium Hpe. - Webera.

brachymeniopis C. M. in Linn. 1878-79, p. 301.

2.

- Am. merid. : Argentin. Tucuman.

brachyneuron Kindb, in Ott. Nat. V, p. 180.

Syn.

- Am. sept. : Fret. Behring.

brachyphyllum Milt. M, austr. am. p. 302. 2.

- Am. merid. : And. Quitens.

brasiliense Hpe. Symb. 1877, p. 725.

2.

- Am. merid. : Brasil, austr. or.

brevicaule W. P. Sch. mss.; Mitt. op. cil. p. 303.

Br. Liebmannianum $C, M$, Syn. II, p. 573.

2.

- Am. sept. : Mexic.

brevicaule $\left\{\begin{array}{l}\text { Hpe. - Brachymenium. } \\ \text { Hpe. (pl. Austr.) - Bryum curtum. } \\ \text { Vill. - Grimmia commutata. }\end{array}\right.$

breyicoma Hpe. Enum. M. Brasil. p. 31 .

2.

- Am. merid. : Brasil. austr. or. 
breviflorum Gmel. - Ceratodon purpurens.

brevifolium Dicks. $\left\{\begin{array}{l}\text { - Barbula fallax var. brevifolia. } \\ - \text { Trichostomum tophaceum var. brevifolium. }\end{array}\right.$

Bridelianum C. M. - Webera.

Brownianum Dicks, - Tetrodontium.

Brownii Bryol. eur. IV (mon. suppl. p. 3), t. 337 ; C. M. Syn. I, p. 273; W. P. Sch. op. cit. p. 411.

Hemisynapsium bryoides Brid. Bryol. univ. I, pp. 605 et 840 .

Pohlia bryoides $R . B r$. App. ad iter Parray. p, 196.

Syn. In aren. sœp. inund. terraq. turfac. - Eur. : Alp. Norveg. Am. sept.: Franz Joseph Fjord, ins. Melville, Labrador, Terr. nov., M. Rupestr.

brunnescens $\left\{\begin{array}{l}\text { Ren. }-\mathrm{Br} \text {. torquescens form. monoica. } \\ \text { Schleich. - Br, subrotundum. }\end{array}\right.$

bulbiferum Neck. - Phascum cuspidatum.

bulbifolium Lindb. in Not. ur Saells. pr. Faun, et Fl. Fenn. Foerh. 1873 et in Rev. Bryol. 1887, p. 63.

Syn. In argill. et arenos. humid. - Eur. : Lappon. Tornens.

bulbiforme aureum, calyptra quadrangulari, capsulis piriformibus nutantibus Dill, - Funaria hygrometrica.

bulbillicaule $C$. M. in $F l .1879, n$. 24 .

Ster.

$$
- \text { Afr. : M. Kenia. }
$$

bulbilliferum Rehm. M. Afr. austr. $n 252$.

- Afr.: C. B. sp.

bulbillinum C. M. in Linn. 1880-83, p. 384 .

2. Suxic. - Am, merid. : Argentin. Tucuman.

bulbillosum Mont. in Ann. sc. nat. XVI, 11, p. 268 et Syll.p. 33 ; C.M. Syn. I, p. 301.

Br. dichotomum (fid. Mitt.)

2 ?

- Am. merid. : Brasil. austr. or.

bullatum C. M. in Fl. 1887, p. 221 .

2. - Am. sept. : Alaska.

bullosum C. M. in Dusen M. Camer. n. 44. - Afr. : M. Cameroon.

caesium Vill. - Leptotrichum glaucum. caespiticiforme de $\mathrm{Not}$. - $\mathrm{Br}$, subrotundum.

caespiticium L. Sp. pl. p. 1586 ; Brid. Bryol. univ. I, p. 669; Bryol. eur. IV (mon. p. 70), t. 374 ; C. M. Syn. I, p. 284 p.p.; W. P. Sch. op. cit. p. 443.

Br. flaccidum $H$. f. et $W$. Fl. of the N. Zeal. II, p. 85?

$\mathrm{Br}$. pachypoma Wils. in Kew Journ, of bot. IX, p. 364 .

Br. pendulum ovatum caespiticium et pilosum, seta bicolori Dill. hist. M. p. $396, t .50, f .66$.

Hypnum caespiticium W. et M. Bot. Tasehb. p. 283.

Mnium caespiticium Brid. M. Rec. II, III, p. 96.

2. Ar mur., sax, et terr. - Eur.: Vulgatiss. As. : Jenissei med., Obi, Tairnyr, Jakoutsk, Saghalien, Kashmir, Himalaya occ., Khasia, Caucas, As. min. Afr. : Occid, et merid. Am. sep. : Tota a Groenland et Columb brit, ad Florid, et Ludovic. Pac. : Ins. Sandwic., Nov. Zeland., Tasman. 
Exs. : Mac. Canad, M. n. 178.

Rab. Bryoth. eur, n, 90.

Sull. et Lesq. M. bor, am. Il ed, n. 288.

var. badium Bryol. eur. - Br. badium.

var. comense Husn. - Br. comense.

« var, crinitum Hook. f. et Wils. Fl. Tasm. II, p. 191.

- Pac. : Tasman.

var. gracillimum Bryol, eur. - - Br. badium.

« var. imbricatum Bryol, eur, l. c. t. 37; W. P. Sch. l. c.

Br. crespiticium var. Kunzei Warnst. Moosfl. Prov. Brand. p. 53.

Br. Kuntzii $H$. et $H$. in $F l .1819, I, p .90$; Brid. Bryol, univ. $I$, p. 661 .

Br. tectorum de Not. in sched; Jaeg. Ad. I, p. 170.

In muris apric. sicc. - Eur.: Cum typ.

var. Kunzii Warnst. - Br, cæspiticium var, imbricatum.

«var. subrotundum Weinm. in Lin lb. et Arn. M. As. bor. 1890, II, p. 40.

- As. : Fret. Sinjawin.

var. warneum Schwaegr. - Br. warneum.

var., H. et T. - Br. lacustre.

var. hemisphaericum.

var. nigricans.

var. rupestre.

var. subsphaericarpon.

var. tenerum.

Brid, - Br. caespiticium?

caespiticium $\begin{aligned} & \text { C. M. p.p. - Br. badium. } \\ & \text { Drumm. - Br. pendulum. } \\ & \text { Hsch. - Br. congestum. } \\ & \text { Schwaegr. - Br. cirratum. } \\ & \text { Schwaegr. - Br. uliginosum. } \\ & \text { Wils. - Br. subrotundum. } \\ & \text { Wils. - Br. tibetanum. }\end{aligned}$

calcareum Vent. in Rev. bryol. 1880, p. 26.

1. In tophac. - Eur. : Tirol. (Alp. Trent., $2050 \mathrm{~m}$, alt.).

calcareum Dicks. - Seligeria.

californicum Sull. in Bot. Pac. R. R. Survey (Whipple) p. 188, t. 6; Lesq. et Jam. Man. p. 237.

2. Terr. - Am. sept. : Calif.

callistomum Philib, in Rev. bryol. 1885, p. 76.

Syn.

- Eur. : Norveg.

callistomum Dicks, - Dicranella varia var. collistoma.

calobolax C. M. in Bot. Centralbl. 1883, n. 2. 4.

2.

- As, : Penins. Tschutschica.

calophyllyum K. Br. Suppl. App. ad iter Parray. p. 196 ; C. M. Syn. I, p. 287 et $I I, p .571 ; W$. P. Sch, op. cit. p. 424 .

Br. intricatum Brid. Bryol. univ. I, p. 680.

Br. latifolium Bryol. eur. IV (mon. p. 19), t. 330 ; C. M. Syn. I, p. 286.

Br. pallens var. Wils, in Kew Journ. bot. IX, p. 366.

Cladodium calophyllum Brid. l. c. p. 622.

Pohlia calophylla Schwaegr. Sp. M. p. 75 .

P. latifolia $B r$, in sched.

Weisia fornicata Brid. l. c. p. 365. 
Syn. Ad terr. aren, humid. v. marit. et glareos. - Eur. : Spitzberg, Suec., Boruss. sept., Angl., vall. Rhen. As. : Penins. Tschutschica, Jenissei inf., Tibet. occ. Am. sept. : Groenland, ins. Melville, reg. sept., Calif.

Exs. : Rab. Bryoth. eur. n. 876, 930.

« var. procerum Lindb. et Arn. M. As. bor. 1890, II, p. 46. - As. : Jenissei infer.

calopyxis C, M. - Webera.

calycinum $\mathrm{Sw}$. Holomitrium.

calyptra exstinctorii forma, minus Dill. - Encalypta vulgaris.

cumpestre Lindb. - Br. juliforme.

campylocarpum Limpr. in LXI Jahrb. d. Schles. Ges. 1883, p. 218 et 1.

Laubm. Deutschl. II, p. 326.

campylopo dioides C. M. in Rev. bryol. 1878, p. 59 (nom.).

- Afr. : Ins. Franciæ.

campylothecium Tayl, - Rhodobryum.

canariense Brid. Mant. M. p. 118 et Bryol. univ. I, p. 672; W. P. Sch. op. cit. p. 453.

2. Rupic. - Eur. : Lusit. (Algarb.) Afr. : Ins. Canar.

canariense $\left\{\begin{array}{l}\text { C. M. p.p. }-\mathrm{Br} \text {. Mundtii, } \\ \text { Bryol. eur. - Br. provinciale. }\end{array}\right.$

var. provinciale Husn. - $\mathrm{Br}$. provinciale.

candicans Tayl. in Mitt. M. austr. am. p. 303.

2. Rupic. - Am. merid. : Amazon., And. Quitens.

candidum C. M. in Nuov. giorn. bot. ital. 1872, p. 18.

2.

- Afr.: Abyss.

candidum fragile, foliis recurvis Dill. - Leucobryum candidum.

canescens $\left\{\begin{array}{l}\text { Hoffm. - Rhacomitrium. } \\ \text { Vill. - Tetraplodon mnioidos var. Brewerianus. }\end{array}\right.$

capillaceum Gmel. - Distichium.

capillaceum Hull. $\left\{\begin{array}{l}\text { - Ulota Bruchï ? } \\ \text { - Ulota crispa ? } \\ \text { - Ulota crispula ? }\end{array}\right.$ breve, pallide et laete virens, capsulis ovatis Dill. - Wei-
sia viridula.

capsulis sphaericis Dill. - Bartramia pomiformis.

capillare L. Sp. pl. ed. II, p. 1586 p.p. ; Brid. Bryol. univ. $I, p .665$; Bryol. eur IV (mon. p. 60), t. $368 ;$ C. M. Syn. 1, p. $281 ; W . P$. Sch. Syn. II ed. p. 449.

Br. foliis latiusculis congestis, capsulis longis sutautibus Dill. Hist. M. p. 398, t. $50, f .67$.

Br. squalidum Vill. Pl. Dauph. III, p. 889, t, 54.

Hypnum capillare W, et M. Bot. Taschb. p. 286.

Mnium capillare L. Syst. veget. p. 947.

2. Mur., saxic., lignic. et terr. per totum feré terrar. orb.

Exs. : Mac. Canad. M. n. 179.

Rab. Bryoth. eur. n. 98, 839, 1029.

Sull, et Lesq. M. bor. am. Il ed, n 285.

var. affine Brid. - Br. cuspidatum.

var. angustalum Boul. - Br. capillare var. flaccidum. 
« var. brevicuspidatum Kindb. in Mac. Cat. p. 131.

Terr, - Am. sept. : Ins. Vancouver.

Foss.: Mac. Canad. M. n, 180.

"var. capense $C . M . l . c$.

-Afr.: C. B. Sp.

Exs. : Rehm. M. Afr. austr. n. 232.

var. corsicum Brid. - Br. Donianum.

\& var. carinthiaeum Bryol. eur. l. c. t. 369 ; W. P. Sch. op. cit.

Br. capillare var, compactum C. M. l. c. (excl. syn. Br. Fercheliij.

Ut typ. - Eur. : Alp. Carinth. As. : Caucas, occ.

var. cochlearifolium Bryol, eur. - Br. elegans.

var. compactum C. M. - Br. capillare var. carinthiacum.

« var. cuspidatum W. P. Sch. Coroll. p. 74.

Br. capillare var. macrocarpum Hüb. Muscol. germ. p. 442.

Br. capillare var. majus Bryol. eur. $l$. $c$.

Ut et cum typ. in Eur. et Am. sept.

Exs. : Rab. Bryoth. eur. n. 673.

? var. cymbifolium H. f, et W. - Br. cavum.

" var. domingense $C, M . l, c$.

Br. domingense C. M. in Linn. 1843, p. 594.

Br. flaccidum Brid. $l$. c. p. 667 .

Br. tomentosum Brid. l. c. p. 648.

- Am. sept. : Hispaniola.

var. elegans Husn, - Br. elegans.

a var. Ferchelii Bryol, eur. et W. P. Sch. ll. cc.

Br, elegans var. Ferchelii Breidl. Laubm. Steierm. p. 132.

Br. Ferchelii Funk in Brid. Bryol. univ. I, p. 847,

Br. Funkii var. Ferchelii Schwaegr. Sp. M. p. 69.

Ad mur, et rup. in subalp. et alp. præecip. calcar. - Eur. et Am. sept.

* var. flaccidum Bryol. eur. l. c.

Br. capillare var. angustatum Bowl. M. Est Fr. p. 396.

Terr. et lignic. in loc. urnbros. - Eur. et Am. sept.

var. laete-virens Hüb. $-\mathrm{Br}$, elegans.

var, macrocarpum Hüb. - Br. capillare var, cuspidatum.

var. majus Bryol, eur. - Br. capillare var. cuspidatum.

* var. meridionale Bryol, eur. et W. P. Sch. $u$. cc.

Br. ligusticum de Not. Epil. p. 395.

Ad mur. et terr. petros. zon. merid. - Eur. et Am, sept.

var, obconium Husn. - Br. obconicum.

* var. platyloma W. P. Sch. Syn. I ed. p. 371 et II ed. l. c.

Br. platyloma Schwaegr. Suppl.I, II, p. 116, t. 76; Brid. Bryol. univ. I, p. 668 .

Ad mur, et rup. zon. merid, - Eur, et Afr. : Alger.

var. torquescens Husn. - Br. torquescens.

var. triste Limpr. - Br. triste,

var., L. et J. - Br. sanguilentum.

capillareoides C. M. in Breutel M. Capens.

- Afr. : C. B. Sp. 
capillifolium C. M. - Brachymenium capillare.

capillisetum C. M. in Linn. 1880-83, p. 382.

2. In aren, rivul. $-A m$, merid. : Argentin. Cordob. eapitellatum C. M. et Kindb. in Mac. Cat. p. 127.

Br. miniatum Mac. Canad. M. n. 175 p.p.

Ster. Ad fossas. - Am. sept. : Ins. Vancouver.

capitulatum Mitt. - Brachymenium. capsulis longis subulatis Dill. - Barbula subulata. carinatum Boulay. - Webera cucullata var. carinata. carneum $\left\{\begin{array}{l}\text { Drumm. - Webera albicans. } \\ \text { L. - Webera carnea. }\end{array}\right.$

var. atro-purpureum Schwaegr. - Br. atro-purpureum.

var. pulchellum $\{$ Drumm. - Webera Drummondii.

catenulatum W. P. Sch. op. cit. p. 471.

Ster.

- Eur. : Scotia.

catillum C. M. in Jaeg. Ad. II, p. 707 (nom.).

- As. : Japon.

cavifolium W. P. Sch. in Besch. Fl, bryol. Antill. fr. p. 32.

Ster. - Am. sept. : Guadalup.

cavum C. M. in Bot. Zeit. 1845, p. 94 et Syn. I, p. 23; Mill. M. austr. am. p. 308.

Br. capillare ? var. cymbifolium H. f. et W. in Lond. Journ. of bot. 1844, p. 145 .

2. Ad murr, et terr. - Am. merid. : Brasil, austr. or., Montevideo.

cellulare Hook. - Brachymenium.

Celsii L. - Leratodon purpurens.

ceramiocarpum C. M. in Linn. 1878-79, p. 476.

2.

- Am. merid. : Venezuela.

cernuum $\left\{\begin{array}{l}\text { Brid. - Br. lacustre. } \\ \text { Bryol eur. - Br. pendulum. } \\ \text { Lindb, - Br. uliginosum. } \\ \text { Wils. - Br. subrotundum. }\end{array}\right.$

cerviculatum Dicks. - Dicranella.

chalarhodon C. M. - Rhodobryum.

chilense Reichdt. in Novara Exp. Bot. I, p. 175, t. 30.

Arbor. - Am. merid. : Chile.

chryseum Mitt. op, cit. p, 304.

2.

- Am. merid. : Guatemala.

chrysoblastum C. M, in Linn. 1878-79, p. 477.

2 .

- Am. merid. : Venezuela.

chrysoneuron C. M. in Bot. Zeit. 1851, p. 549; Handb. of. N. Zeal. Fl. p. 443.

Br. duriusculum $H$. f. et $W$. Fl. of the N. Zeal. $I I, p .84$.

2. Terr. - Pac. : Nov. Zeland sept. et med.

ciliare Grev. - Mnium.

ciliatum Dicks. - Hedwigia.

cinclidioides C. M. - Mnium. 
cirratum Hoppe et Hseh. in Fl. 1819, p. 70 ; Brid. Bryol. univ. I, p. 672 ; Bryol. eur. IV (mon. suppl. p. 8), t. 357; C. M. Syn. I, p. 278 et II, p. 570: W. P. Sch. op. cil. p. 429.

Br, caespiticium Schwaegr. Sp, M, p. 59.

Br. intermedium $\beta$ cirratum Bryol. eur, IV (mon. p. 475).

Br. paradoxum $\beta$ cirratum Jur, Laubm. Oesterr. Ung. p. 267.

Syn. In humid. subuligin. - Eur.: Spitzberg, Mar. alb., Alp. Scandin., German., Helvet., Stir., etc. As. : Jenissei, Luristan, Caucas., As, minor. Am. sept. Groenland, Terr. Nov. ? ins. Miquelon, Gaspes., Columb. brit, Washington, Wyoming, Colorado, M. Calif.

Exs. : Rab. Bryoth, eur. n. 837, 971, 1028.

Un. itin. 1867 , n. 55,64 .

var. cuspidatum Husn. - Br. cuspidaturn.

a var. megalosporum Kindb. in Mac. Cat. p. 122.

Ad rup, humid. - Am, sept. : Columb. brit.

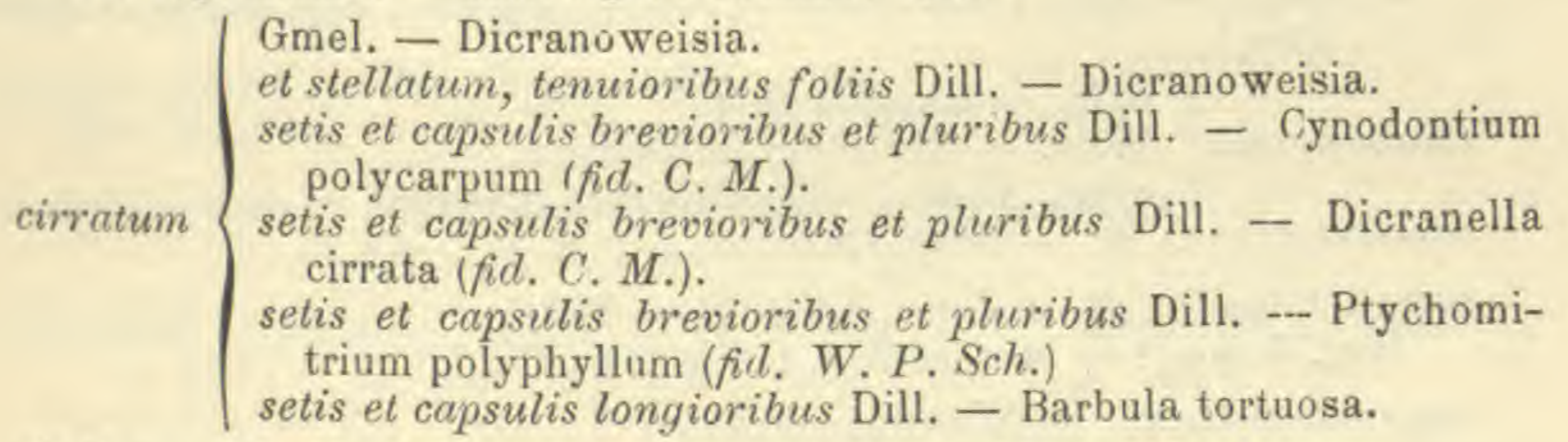
cirriferum (de Not.) Limpr. Laubm, Deutschl. II, p. 317.

Pohlia cirrifera de Not. Mant. n. 9 et Syll. n. 138.

Syn. Ad rivul. glacial. - Eur. : Simplon; Helvet, ?

clathratum Amon in Rev. bryol. 1889, p. 89.

2. Ad rivul. - Eur. : Rhaet.

clavaeforme $\mathrm{Hpe}$. - Webera.

clavariaeforme C. M. - Brachymenium.

clayatum (W, P. Sch.) C. M. Syn. I, p. 292 ; Mitt. M, austr. am. p. 307.

Pohlia clavata W. P. Sch. in Ann. sc. nat. II ser., VI, p. 148, t. 2.

2.

- Am. merid. : Chile.

clavalum H. f. et W. - Br. curvicollum.

clavicaule C. $M$. in Fl. $1875, n .34-35$.

2 ? Ster. $\quad-A m$. merid. : And. Nov. Granat.

claviger Kaurin in Rev. bryol. 1884, p. 48 (nom.).

- Eur, : Norveg. ?

Climacodontium Par.

Anomobryum cygnicollum Jaeg. Ad. I, p. 603.

Br. cygnieollum C. M. in Bot. Zeit. 1818 (1).

Climacodontium eygnicollum Hpe, in Jaeg. Ad. II, p. 713.

$$
\text { - Afr.: Abyss. }
$$

coaretatum $\left\{\begin{array}{l}\text { C. M. - Brachymenium. } \\ \text { Mitt. - Brachymenium melanothecium? } \\ \text { Schultz, - Webera nutans. }\end{array}\right.$

(1) Sec. Jaeg. 1. c. ; in Syn. deest. 
cognatum Mitt. M. Ind, or. p. 69.

Syn.

- As. : Ceylan.

coloratum C. M. in Linn. 1878-79, p. 296.

2. Arenic. - Am. merid, : Bolivia.

comatum Besch. - Rhodobryum.

? Combae de Not. Cron. d. briol. ital. Comm. II, n. 32 el Epil.p. 409.

Br. Gehecbii $C$. M. (fid. de Not.) (1).

Ster. - Eur.: M. Sardin. centr., Helvet. (Aargau, quoad $B r$. Geheebii).

comense W. P. Sch. op. cit. p. 444 (2).

$\mathrm{Br}$. caespiticium var. comense Husn. Muscol. gall. p. 242.

Br. caespiticium forma Vent. et Bott. Enum, n. 317 in adn.

Br. imbricatum de Not. Epil. p. 402.

Br. Philiberti Amann in Rev. bryol. 1889, p. 87.

2. Muric. - Eur. : Ital. super. (Como), Helvet., Alp. Rhaet.; Pyren. (ster.).

Commersonii $\left\{\begin{array}{l}\text { Brio. - Rhodobryum. } \\ \text { Wils. - Rhodobryum roseum. } \\ \text { affin, Wils. - Rhodobryum roseum. }\end{array}\right.$

commutatum C. M. - Brachymenium.

compactulum C. M. in Linn. 1880-83, p. 383.

Ster. Rupic. ? - Am. merid. : Argentin. Cordob.

compaclum Dicks. - Webera carnea.

compressidens C. M. Syn. I, p. 290.

Pohlia turbinata Schwaegr. Suppl. II, II, II, p. 150, t. 194.

2. In argill. et ad rup. madid. - As. : Nepal., ins. Bali.

compressulum C. $M$. in $\mathrm{Fl}$. 1888, p. 409.

Ster.

- Afr. : Kilima N'Djaro.

concavum Mitl. M. austr. am. p. 309.

2.

- Am. merid, : And, Quitens.

concinnatum Spr. M. Pyr. n. 121 et in Ann. and Mag. of nat. hist. 1849 , p. 155, n. $141 ;$ C. M. Syn. II, p. 575; W. P. Sch. op. cit. p. 468.

Anomobryum concinnatum Lindb. Man. M. I, p. 44.

A, julaceum var. concinnatum Zett. M. Pyr. p. 34 .

Br. filiforme $\delta$ concinnatum Boul. M. Fr. I, p. 294.

Br. julaceum var. concinnatum Wils. Bryol. brit. p. 246.

Br. nimbigerum Tayl, mss, ; Hartm. Skand. Fl. VIII ed. p. 367, n. 48.

2. Ad rup. madid. - Eur. : Alp. Seandin., Salisb., Stir., Carinth., Austr. inf., Frioul, Tirol., Helvet., Baval., Pyren. As. : Caucas. Am. sept. : Groenland, M. Catskill.

condensatum Hpe. mss. ; C. M. in Bot. Zeit. 1858, p. 5 5. - Afr.: C. B. Sp.

confertum Limpr. Laubm. Deulscht, p. 362.

Syn. fr. ign. $\quad-$ Eur. : Alp. Stir.

congestum Mitl. op. cit. p. 309.

Br. caespiticium Hsch. Fl, Brasil. I, p. 44.

2. Terr. - Am. merid. : And. Quitens., Brasil.

(1) Cf. Geheeb in Rev. bryol. 1886, p. 22.

(2) Cf, Philibert in Rev. bryol. 1889, p. 36 et Ann, 1. c. p. 52. 
conicum Hsch. op. cit.p. 43; C. M. Syn. 1, p. 301 ; Mitt. op. cit. p. 299. Br, Funkii Schwaegr, Sp, M. p. 69 ?

2. - Am. merid. : Brasil. austr. or.

conicum Dz. et Mk. - Rhodobryum Decaisnei.

conoideum Dicks. - Zygodon. consimile Mitt. - Brachymenium.

constrictum $\mathrm{Br}$. $-\mathrm{Br}$. Klinggraeffii.

contextum $\mathrm{H}$. et H. - Br. pallescens var. contextum.

contortum $\left\{\begin{array}{l}\text { Griff. - Brachymenium nepalense. } \\ \text { Wulf. }\end{array}\right.$

controversum Hoffm. - Weisia viridula.

convolutaceum C. M, in Linn. 1875, p. 388.

Br, coronatum Hpe. Prodr. Fl. Nov. Gran. p. 50.

2. - Am. merid.: Nova Granat.

convolutum Dicks, - Barbula.

Corbieri Philib. in Rev. bryol. 1887, p. 23.

Syn. In turfos. - Eur, : Normann, marit.

cordylocarpum C. M. in Rev. bryol. 1877, p. 43 (nom.).

- Afr. : C. B. Sp.

coronatum Schroaegr. Suppl. I, II, p. 103, เ.71; Brid. Bryol. univ. I, p. 650 ; C. M. Syn. I, p. 307 ; Bryol. jav. I, p. 145, Ł. 118.

2. Calcic. - As. : Nepal.? Amboine, ins. Banca, Java, Ceylan. Afr. :

Usagara. Am. sept.: Cuba, Jamaïc., Hispaniola, Florid. ; Guadal. ? Am. merid. : Guian., Peruv. Pac. : Nov. Caledon.

var, doliolum Jaeg. - Br. doliolum.

var, minus $\mathrm{Hpe} .-\mathrm{Br}$, pachytheca.

* var. orientale Hpe. in Nuov. giorn. bot, ital. 1872, p. 281. - As.: Bornéo.

var., Wils. - Br, nitens.

coronatum $\mid \begin{aligned} & \text { Besch. - Br. Hogbergii. } \\ & \text { C. M. p.p. - Br. Phallus. } \\ & \text { Hpe. Br. convolutaceum. } \\ & \text { Hpe. et Ltz. - Br. gracilifolium. } \\ & \text { H. f. et W. - Br. curtum? } \\ & \text { Wils. - Br. barbulaceum. }\end{aligned}$

corrugatum Hpe. Symb. 1870, p. 276.

Br. argenteum var. corrugatum Besch. Prodr, bryol. mexic, p. 53.

Br. argenteum $\beta$ lanatum $H s c h$, Fl. Brasil. $1, p$.

2.

Exs. : Bal. Pl. Parag. n. 1259.

- Afr.: Ins. Mayotte. Am. sept. el merid. : Tropic.

Marie M. Mad. n. 217.

* var. niveum Hpe. Symb. 187.2, p. 52.

- Am. merid. : Brasil, austr. or.

crassinervium Ltz, in Bot. Zeit. 1866, p. 186.

2. Rupic. - Am. merid. : Valdivia.

crassinervium Besch. - Br. Pancheri.

crassirameum Ren. et Card. in Bot. Gaz. 1890, p. 57, t. 8 B.

2 ,

- Am. sept. : Oregon. 
crassum Hook. f. et Wils. Fl. of the N. Zeal. p. 86, t. 86, f. 1 et Handb. 2. p. 442. - Pac. : Austral. or., Nov. Zeland., Tasman. creberrimum Tayl. in Lond. Journ. of bot. 1846, p. 54 ; C. M. Syn. I, 2. p. 283; Hındb. N. Zeal. Fl. p. 442.

cribrosum Hoffm. - Coscinodon pulvinatus. crinitum Mitt. - Brachymenium systylium. crispatum Dicks. - Rhabdoweisia denticulata.

crispum $\left\{\begin{array}{l}\text { Hoffm. - Ulota. } \\ \text { Schreb. - Dicranella Schreberi. }\end{array}\right.$

cristatum C. M. - Brachymenium. cruloides Sull, et Lesq. - Webera.

(Mitt. (M. a, a.) - Webera synoica-cruda?

crudum Mitt. (1876). - Webera austro-cruda.

Schreb. - Webera.

Crügeri Hpe. in C. M. Syn. I, p. 300 et II, p. 574; Mitt. M. austr. am. p. 298.

Br. Landsbergii Dz. et Mk. Prodr. Fl. Surin, p. 40, t. 4.

Br, ovalifolium Sull, in Proced. Am. Acad. 1861.

2. Ad rup. et terr. - Am. sept. : Cuba, Jamaïc., ins. S. Vincent. Am. merid. : Ins. Trinitat, Venezuela, Guian. batav., Amaz., And. Quitens. et Peruv.

cubitale Dicks. - $\mathrm{Br}$. pseudo-triquetrum.

cucullatum Schwaegr. - Webera.

Culmannii Limpr. Laubm. Deutschl. p. 357.

Syn. - Eur. : Helvet. (Gemmi).

cuneifolium Dicks. - Barbula.

cupulatum C. M. in Linn. 1871-73, p. 149.

2? - Pac. : Austral. fel.

curtum Par.

Br. brevicaule Hpe. in Linn. 1869-70, p. 518.

Br. coronatum H.f. et W. Fl. of the N. Zeal. p. ?

1.

- Pac. : Austral.

curvicollum Mitt, in Handb. of N. Zeal. Fl, p. 442.

Br. clavatum H. f. et W. Fl. of the N. Zeal. Fl. II, p. 84, t. 85, f. 2.

2. Terr. - Afr.: Ins. Tristan d'Acunha. Pac. : Nov. Zeland., Tasman. " var, extenuatum Mitt, op, cit. - Pac. : Nov. Zeland.

« var, $\gamma$ Mitt. op. cil.

Ut præced.

cuspidatum W. P. Sch. op, cit. p. 430.

Br. affine Lindb. M. Scand. p. 16.

Br. bimum var. cuspidatum Bryol. eur. IV (mon. p. 50).

Br. capillare $\gamma$ affine Brid. Bryol. univ. I, p. 848.

Br. cirratum var, cuspidatum Husn. Muscol. gall. p. 248.

Br. paradoxum Jur. Lavsbm. Oesterr. Ung. p. 266.

Pohlia paradoxa Hüb, Muscol. germ. p. 479.

Webera affinis Br. in Brid, Bryol, univ. I, p. 848.

Syn. Ad mur. et rup. humidiusc, - Eur.: Zon. sept. et intermed. As. : Caucas. Am. sept. : Ins. Vancouver, Washington, Oregon, Montana, 1daho, Wisconssin, Illinois. 
«var, obtusiusculum (Lindb, et Arn.) Par.

Br. affine var. obtusiusculum $L$. et $A$. M. As. bor. 1890, II, p. 43.

Ut typ. - As, : Jenissei inf.

cuspidatum $\left\{\begin{array}{l}\text { Drumm., Turn. - Mnium. } \\ \text { Gmel. - Pottia lanceolata. } \\ \text { Schreb. - Mnium affine. } \\ \text { Wils. p.p. Br. Thamsoni. } \\ \text { Wils. - Br. turbinatum. }\end{array}\right.$

cyclophyllum (Schwaegr.) Bryol. eur. IV (mon. p. 63), t. 70; C. M. Syn. $I, p .287$ et II, p. $57 \mathrm{I} ;$ W. P. Sch. op. cit. p. 455.

Br, obtusifolium Turn. M. Hib. p. 116, t. II, f. I; Brid. Bryol. univ. 1, p. 639 ? ejusd. hb.! (fid. C. M.)

Br. tortifolium Brid. op. cit.p. 844.

Mnium cyclophyllum Schwaegr, Suppl. II, II, p. 160, t. 194.

2. In terr. palud. stagn. exscic. et rup. madid. - Eur. : Suec., Dania mer., Boruss, occ., Siles., Belg. sept., Voges., Silva Nigra, Francon., Bavar.. Jurass. As. : Jenissei inf. Am, sept. : Fret. Smith, Groenland, Niagara, M. Rupestr., Pensilv.

Exs. : Mac. Canad. M. n. 538.

Rab. Bryoth, eur. n. 444.

Un. itin. $1864, n, 38$.

eygnicollum C. M. in Bot. Zeit. 1858, p. 156.

Syn. $\quad-$ Am, merid. : Summ. And. Chilens.

cygnicollum C. M. (1848), - Br, Climacodontium.

cylindricum $\left\{\begin{array}{l}\text { Dicks. - Webera elongata. } \\ \text { Mont. - Webera cylindrica. }\end{array}\right.$

cymbifolium Lindb. Man. M. I, p. 45.

Anomobryum filiforme Jaeg. Ad. 1, p. 604.

Brachymenium filiforme Griff. Not. p. 443 et Ic. pl. asiat. II, $t .102, f .2$

Bryum filiforme Mitt. M. Ind. or. p. 67.

- As. : Nepal., Himalaya, Khasia, Java.

cymbuliforme Card. - Webera cucullata var, carinata.

dalachanicum Jur. et Milde Beitr.... p. 596.

2.

- As. : Kurdistan., Persia.

Daviesii Dicks. - Glyphomitrium

dealbalum Dicks., Drumm. - Amblyodon.

Decaisnei $\mathrm{Dz}$. et Mk. - Rhodobryum.

decipiens Brid - Webera annotina.

decurrens C. $M$. in Bot. Zeit. 1855, p. 751.

Ster. - Afr.: C. B Sp.

delicalulum $\left\{\begin{array}{l}\text { Hedw. - Webera carnea. } \\ \text { Wils. - Webera delicatul }\end{array}\right.$

demissum Hook. - Zieria.

dendroides $\left\{\begin{array}{l}\text { L. j. - Mniodendron comosum. } \\ \text { Web. - Mnium undulatum. } \\ \text { polycephalum, phyllitidis folio undulato pellucido, thecis } \\ \text { ovatis pendulis Dill. - Mnium undulatum. }\end{array}\right.$

denticulatum Kindb, in Bull. Torr. bot. Club, XVII, p. 273.

2. - Am. sept. : Alberta, M. Selkirk.

dentiferun Hpe. Symb. 1877, p. 726.

Syn.

- Am. merid. : Brasil. austr. or. 
depressum C. M. in Dusen M. Camer. n. 663.

- Afr. : M. Cameroon.

diaphanum $\left\{\begin{array}{l}\text { Gmel. } \text { - Orthotrichum. } \\ \text { Web. - Tetraphis pellucida. }\end{array}\right.$

dichotomum Hedw. Sp. M. p. 183, t. 42; Brid. Bryol. univ. 1, p. 646;

C. M. Syn. I, p. 304; Mitt. M. austr. am.p. 301.

Br. bulbillosum Mont. Ifd. Mitt. l.c.)

Mnium dichotomum $P . B$. Prodr. p. 74.

2. Ad terr, et saxa. - Am. merid. : And. Quitens, Monte Video.

dichotomum Wils, ; H. f. et W. - Br. atropurpureum.

dicranoides $\left\{\begin{array}{l}\text { Hsch. - Brachymenium. } \\ \text { W. P. Sch. - Brachymenium commutatum. }\end{array}\right.$

Didymodon $\left\{\begin{array}{l}\text { Gmel. - Barbula rigidula. } \\ \text { Hoffm. - Leptotrichum tortile var. pusillum. }\end{array}\right.$

didymodontium Mitt. - Brachymenium.

dissolutinerve C. M. in Linn. 1880-83, p. 376.

Ster. Terr. - Am. merid. : Uruguay.

distans Wils. - Br. turbinatum.

doliolum Duby in Moritzi Syst, Vєrz. p. 133; C. M. Syn. II, p. 304.

Br. coronatum var. doliolum Jaeg. Ad. I, p. 617.

1. Terr, - As. : Java.

domingense $\left\{\begin{array}{l}\text { C. M. - Br. capillare var. domingeñse. } \\ \text { Steud, - Rhodobryum Antillarum. }\end{array}\right.$

Donianum Grev. in Trans. of the Linn. Soc. XV, II, p. 345, t. 3, f. 6 ; W. P. Sch. Coroll. p. 75 et Syn. II ed. p. 454.

Br, capillare var. corsicum Brid. Bryol. univ. I, p. 849.

Br, insulare de Not. Spic, p. 7 et Syll. p. 128.

Br. Mülleri Spr. in M. Pyr. n. 138 et in Ann. and Mag. of nat. hist. 1849, n. 160.

Br. platyloma Bryol. eur. IV (mon. p. 59), t. 366 ; C. M. Syn. I, p. 282 et $I I, p .571$.

2. In rup. et ad terr. glareos. - Eur. : Angl., Galloprov., Corsica, Sardin., Ital., Dalmat, ins. Ionic., Melit., Balear.; Algarb. Af $r$. : Alger., Madeir, ins. Canar.

Exs, : Rab. Bryoth, eur. n. 1280.

Donianum Kindb. - Br, heteroneuron.

dovrense W. P. Sch. Syn. 11 ed. p. 413.

Syn. Ad terr. humid. vel. turfos - Eur. : Alp. Norveg. (Dovre).

Drummondii C. M. - Webera.

Durieui W. P. Sch. mss; Besch. Cat. M. Alger, p. 24.

2. Terr. - Afr. : Alger.

duriusculum W. P. Sch. in Besch. Fl. bryol. N. Caled. p. 214.

2.

- Pac. : Nov. Caledon.

duriusculum $\mathrm{H}$. f, et W. - Br. chrysoneuron.

Duseni C. M. in Dusen M. Camer. $n .772$.

- Afr. : M. Cameroon.

Duvalii Voit in Sturm. Deutsch. Fl. crypt. Fasc. II; Brid. Bryol. univ. I, p. 679; Bryol. eur IV (mon. p. 64), t. 371; C. M. Syn. I, p. 26");

W. P. Sch, op. cit. p. 458.

Br. Sphagni Brid. Bryol, univ. I, p. 852. 
Br. ventricosum var. Schwaegr. Sp. M.p. 54.

Br. Weigelii Spreng. Mant. pr. add. p. 55 (fid. Limpr. Laubm. Deutschl. p. 429 .

Mnium Duvalii Schoaegr. Suppl. $I, I I, p .126, t, 179$.

2. Ad scaturig. et in pratis uligin. - Eur. : Norveg., Fennia, German., Bohem., Tatra, Stir., Bavar., Scotia, Voges., Gall. centr. (Arvernia). As.: Jenissei sup., Obi, Caucas. Am. sept. : Fret. Snith., Labrador, Terr. Nov., ins. Miquelon, Nov. Scot., Gaspes., Ottawa, Athabasca, M. Rupestr. et Selkirk, Nov. Angl., Washingt,on, Oregon, Calif., Nov. Mexic.

Exs. : Mac. Canad. M. n. 182.

Rab. Bryoth. eur. n. 835 et b, 1284 .

Sull. et Lesq. M. bor. am. II ed. n. 286.

* var. gaspeanum Kindb. in Mac. Cat. p. 272.

Ad rup. humid. - Am. sept. : Gaspes.

a var. lato-decurrens C. M. et Kindb. op. cit. p. 132.

Br. lato-decurrens Mac. Canad. M. n. 487.

Ad terr. humid. - Am. sept. : M. Selkirk, Columb. brit.

duvalioides Itz. - Br. pseudo-triquetrum var. flaccidum.

Eatoni Mitt. in Journ. of the Linn. Soc. 1876.

Syn.

- Afr. : Ins. Kerguelen.

Ecklonianum C. M. - Webera.

Edwarsianum C. M. et Kindb. in Bidr. p. 454 (nom.) et in Mac. Cat. p. 120.

Br. warneum Mac. Canad. M. n. 383.

1. Ad terr. aren, humid. - Am. sept. : New Brunswick.

Ehrenbergianum C. M. - Rhodobryum.

elegans Nees ab Es. in Brid. Bryol. univ. I, p. 849; W. P. Sch. op. cit. p. 452 .

Br. capillare rar, cochlearifolium Brid. l. c. p. 666, Bryol. eur. IV (mon. p. 61), t. 367; C. M. Syn. I, p. 281 p.p.

Br. capillare var. elegans Husn. Museol. gall. p. 241.

$\mathrm{Br}$. capillare var, laete virens Hüb. Muscol. germ. p. 442.

2. In rup, fiss. humid. - Eur.: Westphal., Riesengeb., Tatra, Austr. inf., Salisb., Stir., Alp. Algov., Carinth., Tirol,, Jurass., Helvet., Sabaud, Rhaet, Alp. Bavar. Am. sept. : Gaspes., ins. Mique-
lon.

elegans $\{$ Grev. - Br. pallens var. speciosum.

Vent, et Bot. p.p. - Br. Vemturii.

var. carinthiacum Breidl. - Br, capillare var, carinthiacum.

var. Ferchelii Breidl. - Br. capillare var. Ferchelii.

elegantulum Lts. Moost p. 157.

2.

- Am. merid.: Valdiv.

ellipsifolium C. M. in Fl. 1890, p. 47\%.

Ster.

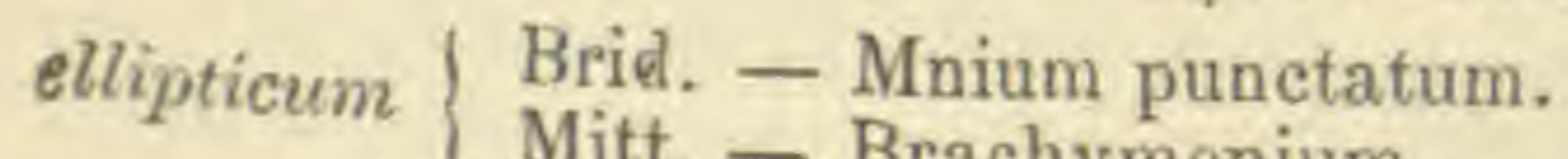

Mitt. - Brachymenium.

(Dicks. - Webera.

elongalum Drumm. - Webera cruda.

Dz. et Mk. - Webera leptocarpa. Hoffm, - Rhacomitrium canescens var, ericoides. Mitt. (1876). - Webera austro-elongata. 
var. alpinum Bryol, eur. - Webera longicolla.

var. longicollum $\mathrm{H}$. et T. - Webera longicolla.

var. macrocarpum Bryol. eur. - Webera elongata var, macrocarpa. elwendicum Fehln. in Hedwigia, 1887, p. 116.

Syn. Rupic. - As. : M. Elwend.

emergens C. M. - Webera?

Emodi C. M. in Jaeg. Ad. 1, p. 613 (nom.). - As, : Sikkim.

encalyptaceum C. M. in Linn. 1880-83, p. 366.

Ster.

- Am. merid. : Uruguay.

erectis capitulis brevibus, folits reflexis Dill. - Dicranella squarrosa. erectum Hook. - Brachymenium mexicanum?

ericetorum $\left\{\begin{array}{l}\text { Dicks. - Barbula unguiculata var. ericetorum. } \\ \text { Neck. - Pleuridium subulatum. }\end{array}\right.$ ericaefolium Neck. - Barbula ambigua.

ericoides Dicks. - Rhacomitrium canescens var, ericoides.

erubescens Kindb. in Mac. Cat. p. 118.

2. Ad ligna fabref. - Am. sept. : M. Rupestr.

erubescens C. M. - Brachymenium.

erythrinum Mitt. M. Ind. or. p. 70.

Br. pachypoma Wils. in Kew Journ. bot. IX, p. 364 p.p.

2. - As. : Sikkim.

erythrocarpoides Hpe. et C. M. in Linn. 1853, p. 495.

$2 . \quad-$ Pac. : Austral. or.

erythrocarpoides W. P. Sch. - Br. Bescherellei.

erythrocarpum Schroaegr. Suppl. I, II, p. I00, t. 70; Bryol. eur. IV (mon. p. 72), t. 376 ; C. M. Syn. I, p. 297; W. P.Sch. op. cit. p. 436.

Br. atro-virens Vill. Pl. Dauph. III, p. 878.
Br. bicolor Dicks. Fasc. IV pl. crypt.p. 16 (fid. Milde Bryol. Siles, p. 213).

$\mathrm{Br}$. Morisii $B r$. in F. Müll. M. Sardin.

Br. sanguineum Brid. Mant. M. p. 118 et Bryol. wniv. I, p. 671.

2. In terr. aren. ericet. et ad viar. - Eur. : Reg. campestr. montos. Afr.: Alger. Am.sept. : Alabama, Calif. Am. merid. :And, Quitens.

Exs, : Rab. Bryoth. eur. n. 471.

var. australis Hpe. - Br. suberythrocarpum.

var. bicolor Brid. - Br. atro-purpureum.

var. murarum W. P. Seh. - Br. murale.

* var. radiculosum Bryol. eur, et W. P. Sch. ll. cc.

Br. radiculosum Brid. Sp. M. III, p. 18 et op. cit. p. 655.

Ut et cum typ. in Eur et Afr.

var. turfaceum W. P. Sch. - Br. Klinggraeffii.

erythrocaule Hpe. - Webera.

erythrocaulon Brid. - Rhodobryum.

erythrocephatum C. M. - Rhodob:yum.

erythroneuron Mitt. M. austr. am. p. 312.

2. $\quad-A m$. merid. : And. Nov. Granat. et Quitens.

erythrophylloides Kindb, in Mac. Cal. p. 272.

Ster.

-. Am. sept. : Alberta. 
erythrophyllum Kindb. op. cit. p. 131.

Ster. Paludic. - Am. sept, : Nov. Scot., Ontario, Columb. brit., fret. Behring.

erythrostegum C. M. in Fl. 1886, p. 279.

2. Ad arbor. - Afr. : Ins. S. Thom.

erythrotropis C. M. in Linn. 1875, p. 383.

2. Ster. Ad arb. - Afr. : Niam-Niam.

eurystomum Ren, et Card. in Bull. Soc. roy. Belg. 189!, II, p. 188.

2. Muric. - Afr. : Ins. Borbon.

exaltatum Spr, in Mitl. op. cit. p. 285.

Acidodontium exaltatum Jaeg. Ad, I, p. 572.

2. Ad arbor. - Am. merid. : And. Quitens.

excurrens Lindb. in Bot. Notiz. I886, p. 99.

Br. versicolor Kaur, in op, eit. 1885, p. 161.

2. In aren. humid. - Eur. : Norveg.

exigum creberrimis capsulis rubris Dill. $\left\{\begin{array}{l}\text { f. A-E. - Pottia Wilsoni. } \\ \text { f, F-K. - Pottia truncata. }\end{array}\right.$ exile $\mathrm{Dz}$. et Mk. - Brachymenium.

eximium Milt, in Handb. of N. Zeal. Fl, p. 440.

Ster. $\quad$ - Pac. : Nov. Zeland. sept. et med.

exstans Mitt. M. Ind. or. p. 72.

Syn.

- As. : Tibet. occ.

exstinctorium $\{$ L. - Encalypta vulgaris.

forma majus et ramosum Dill. - Encalypta ciliata.

extenuatum Ren, et Card. in Bot. Gaz. 1890, p. 57, t. $8 \mathrm{~A}$.

2.

- Am. sept. : Oregon.

exlenuatum Mitt. - Brachymenium.

Fabronia C. M. in Linn. 188()-83, p. 387.

Ster, Terr. - Am. merid. : Argentin, temperat.

fabronioides C. M. - Brachymenium.

fallax Milde in Rab. Bryoth. eur. n. 242 c. diagn.; W. P. Sch. op. cit. p. 426.

Br. lacustre $\beta$ alpinum Bryol. eur. IV (mon, p. 16), t. $332 \beta$; C. M. Syn. I, p. 268.

Br. pallens $\beta$ fallax , Jur, Laubm. Oesterr. Ung. p, 287.

2. Loc, arenos, et ad rivul. - Eur. : Norveg., Westphal., Siles., Salisb., Carinth., Alp. Bavar., Helvet., Gall, centr, (Arvern.), Pyren. Am. sept. : Fret. Behring.

* var. baldense (Vent.) Limpr. Laubm. Deutschl. p.331.

Br. baldense Vent. mss.; de Not. Epil. p. 381.

Br. pallens var, baldense Vent. et Bot. En. critt. p. 31.

In sabulos, humid. - Eur: : Tirol., Helvet.

fallax Dicks. - Barbula.

fasciculare $\left\{\begin{array}{l}\text { Dicks. - Funaria. } \\ \text { Hoffm. - Rhacomitrium. }\end{array}\right.$

fasciculatum Dicks. $\left\{\begin{array}{l}\text { - Eucladium verticillatum. } \\ \text { - Gymnostomum curvirostre. }\end{array}\right.$ 
Fendleri C. M. in Linn, 1878-79, p. 475.

2. $\quad-$ Am. merid.: Venezuela.

Ferchetii Funk. - Br. capillare var. Ferchelii.

ferrugineum Jungh. - Mniodendron divaricatum.

filiforme Dicks. Fasc. IV Pl. crypt. p. 16; W. P. Sch. op. cit. p. 465.

Anomobryum filiforme Husn. Muscol. gall. p. 222.

A. julaceum $W . P$. Sch. Syn. I ed. p. 382.

Br. julaceum Sm. Fl. brit. III, p. 1357 ; Brid. Bryol. univ. I, p. 659; Bryol. eur. IV (mon, p. 79), t. 382; C. M. Syn. I, p. 315 el II, p. 577.

Webera julacea de Not. Epil. p. 416.

2. Ad rup, irrigat. - Eur. : Norveg. (ster. !), Britann., Alp. Stir., Carinth., Salisburg., Tirol., Helvet., Vall. Tellin., Delphinat., Pyren. Afr. : M. Cameroon. Am. sept. : Costa-Rica. Am. merid. : And. Nov. Granat. et Quitens., Brasil., Montevid.

Exs. : Rab. Bryoth. eur. n. 243, 363, 974, 1219.

Un, itin. 1863, n. 49.

« var. abyssinicum (W. P. Sch.) Par.

Anomobryum abyssinicum Jaeg. Ad. I, p. 602.

A. julaceum var.? abyssinicum W. P. Sch. Syn. I ed., p. 303 (nom.). - Afr. : M. Abyssin.

var. cancinnalum Boul. - Bryum.

«var. mexicanum (W. P. Sch.) Par.

Anomobryum mexicanum Jaeg. l. c. p. 603.

A. julaceum var. ? mexicanum W. P. Sch. l. $c$.

- Am. sept. : Mexic. or.

var. neapolitanum Boul. - Br. juliforme.

var. sericeum Boul, - Br. leptostomum.

filiforme $\left\{\begin{array}{l}\text { Mitt. - Br. cymbilifolium. } \\ \text { Will. - Blindia acuta. }\end{array}\right.$

filinerve Milt. M. austr. am. p. 305.

2. Lignic. - Am. merid. : And, Quitens.

filum W. P. Sch. Syn. II ed. p. 470.

Ster. Ad rivul. - Eur. : A lp. Sabaud. (M. Blane.).

flaccidisetum C. M. - Brachymenium.

flaccidum $\{$ Brid. - Br. capillare var. domingense.

f H. f. et W. - Br. caespiticium.

flaccum Wils, in Kevo Journ. bot. IX, p. $332 ;$ Milt. M. Ind. os. p. 72.

2 ? - As. : Sikkim.

flagellare $\left\{\begin{array}{l}\text { Brid, - Br. warneum. } \\ \text { Dicks. - Dicranum. }\end{array}\right.$

flagellicoma C. M. in Linn. 1880-83, p. 369 .

Ster.

- Am. merid. : Argentin. subtropic. flavescens Kindb. Enum. Bryin. Dovr. in Christiania Vid. Sels. Forh.
$1888, n .6$.

Br, arctico $\times$ pallens Philib. in Rev, bryor. 1889, p. 62.

2.

- Eur. : Norveg.

flavescens Dicks. $\left\{\begin{array}{l}\frac{- \text { Barbula fallax. }}{\text { (fid. Wils. in W. P. Scir.). - Dichodontium pellucidum }} \\ \text { var. serratum. }\end{array}\right.$ 
Havidulum C. M. in Jaeg. Ad. I, p. 653 (nom.)

- As. : Birman.

flexifolium $\left\{\begin{array}{l}\text { C. M. - Brachymenium. } \\ \text { Dicks. - Didymodon. }\end{array}\right.$

flexisetum Mitt. M. auslr. am. p. 295.

1 vel syn. Paludic. - Am. merill. : And. Quitens.

flexisetum Arn. - Br. Arnellii.

flexuosum Aust. in Coult. Bot. Gaz. IV, p. 152 ; Lesq. et Jam. Man. p. 227.

2? Arenic. - Am. sept. : Columb. brit.

flexuosum $\left\{\begin{array}{l}\text { C. M. - Webera. } \\ \text { L. p.p. - Campylopus. } \\ \text { L. p.p. - Campylopus torfacens. }\end{array}\right.$

floresianum (C. M.) Par.

Acidodontium floresianum C. M. in Bull. Soc. roy. bot. Belg. 1892, 1, 2. - Am. sept. : And. Costa Ricens.

floridanum Ren, et Card. in Rev. bryol. 1893, p. 4.

- Am. sept. : Florida.

fluminale C. M. - Rhodobryum.

lanceolalis falcalis, setis alaribus, capsula ovata inclinata Hall. Timmia megapolitana.

foliis laliusculis congestis, capsulis longis nutantibus Dill. - Br. capillare.

mollibus subulatis, setis brevissimis alaribus, capsulis ovatis Hall. - Bartramia Halleriana.

fontanum Sw. - Philonotis.

Forsteri Dicks. - Zygodon.

fragile $\left\{\begin{array}{l}\text { C. M. - Brachymenium. } \\ \text { Dicks. - Campylopus. }\end{array}\right.$

Froudei Kindb. in Ott. Natur. V, p. 180.

Syn. $\quad-A m$, sept. : Fret. Behring.

fulvellum Wils. in Kevo Journ. bot. IX, p. 330 ; Mitt. M. Ind. or. p. 69. 2 . - As. : Sikkim.

fulvellum $\left\{\begin{array}{l}\text { Dicks. - Dicranum. } \\ \text { Wils. }\end{array}\right.$

funarioides Brid, p.p. - Br. lacustre.

Funkii Schwaegr. Suppl. I, II, p. 89, t. 69; Brid. Bryol. univ. I, p. 660 ; Bryol. eur. IV (mon. p. 77), t. $382 ;$ C. M. Syn. I, p. 305; W. P. Sch, op. cit. p. 446.

Br. articulatum Sendtn. in sched. ? (fid. C. M. Syn. I, p. 305).

Br. Geheebii C. M. (1).

Br. julaceum Funk Fasc. crypt. IX, n. 194.

2. Ad terr. argill. aren. et mur. delaps. - Eur.: Transilv., Hungar., Bohem., Siles., Sudet., Boruss., Westphal, Harz, Austr. sup., Bavar., Prancon., Tirol., Helvet., vall. Rhen., Pyren. As. : Jenissei med., Caucas.

Exs. : Rab. Bryoth. eur. n. $3 j 5$.

(1) Fid. Milde in Hedwigia 1870, p. 48 ; cf. Geheeb inRev, bryol. 1886, p. 22. 
var. Ferchelii Schwaegr. - Br. capillare var. Ferchelii.

« var. tenue Husn. Muscol. gall. p. 242.

Br. tenue Ravaud in Bull. Soc. bot. Fr, 186i, p. 260.

Ut typ. - Eur. : Delphinat.

var, ? Bryol, eur. - Br. Blindii.

Funkii Schwaegr. - Br. conicum?

fuscescens Rola Cat. M. Bergom. ; de Not. Epil. p. 753.

Ad terr. aren. - Eur. : Ital, super. (vall. Tellin.).

fuscescens $\mathrm{Spr}$. . B Br. torquescens $f$. monoiva.

fuscum Lindb. in Bol. Notiz. 1864, p. 67.

Syn. In aren. humid. - Eur. : Fennia.

fusiferum Mitt. - Brachymenium.

gambirense C. M. in Linn. 1871-73, p. 148.

2. $\quad$ - Pac. : Austral. fel.

gamophyllum C. M. op. cit. 1880-1883, p. 270.

Ster. $\quad-$ Am, merid. : And. Boliv.

Gardneri Mitt. - Br. Pabstianum.

Garovaglii de Not. Cron. d. briol. ital. in Comm. II el Epil. p. 400;

W. P. Sch. op. cit. $p$; 445 .
2. (fid. de Not.); syn! (fid. Limpr.). - Eur. : Vall. Tell., M. Stelvio.

Gaudichaudi Spreng. - Leptotheca.

Gayanum Mont. in C. M. Syn. I, p. $26 \mathbf{i}$ et Syll. p. 33; Milt. M. austr.

Syn. am. p. 294.

gedeanum Bryol. jav. I, p. 547, t. 120.

- Am. merid. : Chile.

Br. pallescens Dz. et Mk. M. frond. ined. Archip, ind. p. 23.

2. Ad arbor. - As. : M. Java.

Geheebii C. M. $\left\{\begin{array}{l}-\mathrm{Br} \text {. Combae (fid. de Not.). } \\ -\mathrm{Br} \text {. Funckii (fid. Milde). }\end{array}\right.$

gelidum Hagen. - Webera Schimperi.

gemmaceolum C. M. in Engler's Bot. Jahrb. 1883, p. 77 et in Forchungs-

2. reise... p. 13.

gemmatum C. M. in Fl. 1885, p. 401.

2. Paludic. - Am. merid. : Fuegia austr.

gemmiparum de Not, Cron. d. briol. ital. in Comm. II, n. 28; W. P. Sch. op. cit. p. 442.

Br. alpinum vai. gemmiparum Husn. Muscol. gall. p. 247.

$\mathrm{Br}$. alpinum méditerraneum de Not. Syll. n. 162.

Br. laxifolium Lindb in Oefo... 1867-68, p. 4.

Br. muticum Lange Toskanske $M$. in Bot. Tidskr. Kjoebenh. 1868.

Br. Notarisii Mitt. in Proced. of the Linn. Soc. 1863, p. 3.

Mielichhoferia crassinervia Jur. in Bot. Zeit. 1866. pp. 20-78.

2. Loc. calcar, et in rivul, alv, - Eur.: Anglia, vall. Rhen., Belg., Galloprov., Sardin., Etruria, Graee. As, : Caucas. (Tiflis). Afr. Alger., Madeir.

geniculatum Brid. Bryol. univ. I, p. 842 ; C. M. Syn. I, p. 276.

Br. Webera geniculata Brid. l. c.

- Eur. : Tirol. 
Gerwigii Limpr. Laubm. Deutschl. p. 4ı9.

Hypnum Gerwigii C. M. mss.; Jack in Mitth. d. badisch. bot. Ver. 1891.

Ster. Ad rup. calcar. - Eur.: Helvet. (Schaffhausen.)

giganteum Hook. - Rhodobryum.

Gilliesii Hook. - Brachymenium.

glaciale Schleich. - Webera albicans var. glacialis.

glaucescens Dicks. - Leptotrichum.

glanco-viride C. M. in Linn. 1880-83, p. 374.

Ster.

- Am. merid. : Argentin. subtropic.

glaucum $\left\{\begin{array}{l}\text { C. M. - Brachymenium. } \\ \text { L. - Leucobryum. }\end{array}\right.$

globirameum C. M. - Brachymenium.

globirhodon C. M. - Rhodobryum.

globosum Lindb. in Oefv.... XXIII, p. 546.

Br. mammillatum var. globosum Berggr. M. Spetsb. n. 74 b el in K. Sv. Vet. Ak. Handl. 1875, p. 63.

2. (fid. Lindb.); syn! (fid. Limpr.) - Eur. : Spitzberg. As. : Jenissei inf.

globosum Mitt. - Brachymenium.

Goudotii Hpe. - Rhodobryum.

gracile Schleich, - Webera commutata var. gracilis.

gracilescens C. M. - Bryum schistoneuron.

var. decumbens C. M. - Bryum schistoneuron var. decumbens.

var. densifolium C. M. - Bryum schistoneuron var. densifolium.

gracilifolium C. M. in Linn. 1875, p. 390.

Br, coronatum Hpe. et Ltz. in Krause M. Ecuad. Bot. Zeit. 1868, p. 812.

2. Terr. - Am. merid. : And. Equat.

gracilisetum Hsch. Fl. Brasil. I, p. 44; C. M. Syn. I, p. 339 ; Milt. M. austr, am. p. 299.

? Terr. - Am. merid. : Brasil. austr. or.

Graeffeanum C. M. - Rhodobryum.

Graefianum Schlieph. in Fl. 1385, n. 19, $t$. VI.

Syn. Rupic. - Eur. : Helvet. (Via mala).

grammophyllum C. M. - Webera.

grammothecium C. M. in Rev. bryol. 1877, p. 15 (nom.).

- Afr. : Ins. Comor.

grandifolium C. M. - Rhodobryum.

Griffithianum Dicks. -- Edipodium.

Haamii Rehm. M. Afr. austr.

$$
\text { - Afr. : Orange. }
$$

haematocarpum C. M. et Kindb. in Bidr. p. 453 (nom.) et in Mac. Cal. p. 125.

2. Ad rup. humid. - Am. sept. : Columb. brit.

Exs. : Mac. Canad. M. n. 555 p.p.

haematoneuron C. M. in Nuov. giorn. bot. ital. 1872, p. 17.

2. $\quad-A f r$ : Abyssin.

haematophyllum Kindb, in Mac. Cat. p. 118.

2. Ad rup. humid. - Am. sept. : Anticosti, M. Rupestr.

Exs, : Mac, Canad, M. n 555 p.p. 
Hageni Limpr. Laubm. Deutschl, p. 335.

Syn. Rupic. - Eur. : Norveg. occ.

Haistii W. P. Sch. Syn. II ed, p. 419.

2. In mur, vinear. - Eur. : Helvet. occ. (Neufchâtel).

Hallerianum Neck. - Diphysicum foliosum.

hamipilum C. M. in Linn. 1880-83, p. 381 .

Ster.

- Am. merid. : Argentin. Tucuman.

hammatocaulon C. $M$, in Dusen $M$. Camer, n. 159.

- Afr.: M. Cameroon.

Harveyanum C. M. - Brachymenium acuminatum.

Heimii Gmel, - Pottia.

helveticum Philib. - $\mathrm{Br}$. arcticum var, helveticum.

hemisphaericarpon C.M. Syn. $11, p .576$.

2. $\quad-A s$.: Nepal,, Himalaya.

Hendersoni Ren, et Card. in Bot. Gaz. 1890, p. 44, t. 7 c.

2 ot ign.

- Am. sept. : Oregon, Calif.

heteromallum Dill, - Dicranella.

heteroneuron C. M. et Kindb. in Bidr. p. 453 (nom.) et in Mac. Cat. p. 130 (subsp. Bryii capill.).

Br. Donianum Kindb. in Bull. Torr. bot. Club, XVII, p. 273.

$\mathrm{Br}$, obconicum Kindb. l. c. p. 274; Mac. Canad. M. n. 181.

Br. provinciale Mac. l. c. n. 171.

2. Rupic. et terr. - Am. sept. : Ontario, Columb. brit., ins. Vancouver.

«var. brevicuspidatum Kindb. in Mac, Cat, p. 131.

Lignic. - Am. sept. : Ins, Vancouver.

Exs. : Mac. Canad. M. n. 180.

heteroneuron Spr. - Brachymenium.

heterophyllum Hook. - Mnium.

heleropterum pellucidum Dill. - Aulacomnium heterostichum.

helerostichum $\left\{\begin{array}{l}\text { Arn. - Aulacomnium heterostichum. } \\ \text { Hoffm, - Rhacomitrium. }\end{array}\right.$

Hieronymi C. M. - Rhodobryum.

Hogbergii C. M. in Linn. 1875, p. 391.

Br. coronatum Beseh. Prodr, bryol, mexic. p. 54.

2.

- Am. sept, : Mexic.

Holmgrenii Lindb, M. Scand. p. 17.

Syn. $\quad-$ Eur. : Lappon.

Hookeri Spreng. - Brachymenium nepalense.

Hornschuchianum C. M. - Brachymenium.

hornum Sw. - Mnium.

huillense W. et Duby. - Brachymenium.

humidulum Sull, in Proced. Am. Acad... 1859, p. 278.

2. Ad terr. humid, $-A f r$ : C. B. Sp.

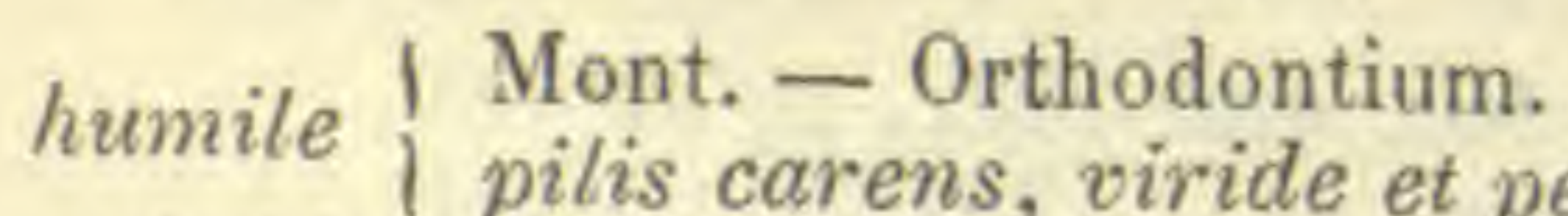

I pilis carens, viride et pellucidum Dill. - Barbula cuneifolia.

hybridum $\mathrm{Br}$. - Br. bimum.

hydrophilum Kindb. in Bull. Torr. bot. Club, p. 95.

Ster. Ad scaturig. - Am. sept. : Ins. Vancouver. 
hygrometricum Neck. - Funaria.

hymenoplyylloides Hartm. - Mnium.

hyperboreum Gunn. - Dicranum.

L. - Rhacomitrium lanuginosum.

Schreb. - Rhacomitrium canescens.

alpinum, setis et capsulis exiguis Dill. - Rhacomitrium microcarpum.

alpinum, operculis oblusis Dill. - Rhacomitrium sudeticum.

aquaticum, calyptris nigris acutis [1.ll. - Rhacomitrium protensum.

ericae facie, capsulis barbalis, alpinum Dill. - Rhacomitrium canescens var. ericoides.

hypnoides

et hirsulie virescens, fasciculare, alpinum Dill. - Rhacomitrium fasciculare.

hirsutie canescens, vulgare Dill. - Rhacomitrium canescens. hirsutie canescens, vulgare Dill. - Rhacomitrium heterostichum.

pendulum, sericeum, coma insigni atro-rubente Dill. Bryum alpinum.

polycephalum, lanuginosum, montanum Dill. - Rhacomitrium lanuginosum.

var. barbatum Retz. - Khacomitrium canescens var, ericoides.

var. microcarpum Retz. - Rhacomitrium microcarpum.

var. obtusum Retz, - Rbacomitrium sudeticum.

var. pilosum Retz. - Rhacomitrium canescens.

var. vireecens Retz. - Rhacomitrium fasciculare.

var. $\alpha$ Neck. - Rhacomitrium canescens,

var, $\beta$ L. - Rhacomitrium canescens.

var. $\gamma$ L. - Rhacomitrium canescens var, ericoides.

var. $\gamma$ Huds, - Rhacomitrium microcarpum.

var, $\delta$ Huds. - Rhacomitriam sudeticum.

var, $\eta$ Huds. - Rhacomitrium protensum.

imberbe L. - Barbula fallax.

imbricatifolium C. M. - Brachymenium.

imbricatulum C. M. Syn. II, p. 575 .

2.

- As.: Himalaya.

imbricatum (Schwaegr.) Bryol. eur. IV (mon. p. 29), l.340; C. M. Syn. I, p. 303: W. P. Sch. op. cit. p. 418 (1).

$\mathrm{Br}$, marginatum Brid. Bryol, univ. $I$, p. 849.

Pohlia imbricata Schwaegr, Suppl. I, II, p. 71, t. 64 .

Syn. burg.

- Eur.: Rariss. ; Alp. Helvet., Carinth., Salis-

imbricatum de Not. - Br. comense.

immarginatum Broth, in Bail. Contrib. Queensl. Fl. Bull. 13, p. 21 (nom.) et in Oefo.... 1893, p.

2. $\sigma^{\star}$ ign. Ad terr. arenos. - Pac. : Austral. or. (Queensland).

immersum Dicks. - Campylopus flexuosus.

inaequale Tayl. in Lond. Journ. of bot. $1816, p .342 ;$ C. M. Syn. I, p. 302. - Pac. : Austral. or.

(1) Cf, Philibert in Rev. bryol. 1889, p, 36, Aman 1. c. p. 58 et Limpr. Laubm. Deutschl, p. 328. 
inclinans Dicks, -- Cynoduntium polycarpum var, strumiferum.

inclinatum (Sw.) Bryol. eur. IV (mon. p. 17), t. 334 (p.p.); C. M. Syn. I, p. 269 p.p.; W. P.Sch. Syn. II ed.p. 419.

Cladodium inclinatum Brid. Bryol. univ. I, p. 621 .

Hypnum intermedium $W$. et M. Bot. Taschb. p. 482 (p.p., fid. C. M.).

Leskea inclinata eor. op. eit. p. 244.

Mnium intermedium var. Roehl. Deutsch, Fl. III, p. 93.

Pohlia inclinata Sw. M. Suec. pp. 45 et $96, t .5, f .11$.

Syn. Ad sax., mur., lign., terr. turfos. - Eur, : E reg. campestr. usq. ad subalp. in zon. temper. As. : Penins. Tschutschica, Jenissei inf., Himalaya (var.), Pers., Caucas. Afr.. Alger. Am. sept.: Fret. Hudsou et Kotzbië, Groenland, ins. Miquelon, Gaspes., Nov. Scot., M. Rupestr., Alaska, fret. Behring, reg, occ. et or.

Exs. : Mac. Canad. M. n. 381.

Rab. Bryoth. eur. n. 329, 1026, 1087.

«var. gracile Lindb. in Oefv...p. 547.

-Eur. : Spitzberg. Am. sept. : Groenland.

inclinatum $\left\{\begin{array}{l}\text { Bryol, eur. p.p. }-\mathrm{Br} \text {. longisetum. } \\ \text { Dicks. - Distichium. }\end{array}\right.$

inclusum C. M. in Fl. 1890, p. 477.

In gramin. edit. - Afr.: Ins. Mayotte.

Exs, : Mar. n. 77 p.p.

incurvifolium C. M. in Bot. Zeit. 1851, p. 549 (1).

2. Rupic. - Pac. : Nov. Zeland.

incurvum Huds, - Oligotrichum hercynicum.

indicum Dz. et Mk. - Brachymenium.

inflatum Philib, in Rev, bryol, 1886, p. 81 .

Syn.

- Eur. : Norvegia.

inflexum C. M. - Webera.

inordinatum Brid. - Aulacomnium palustre.

insulare de Not. - Br. Donianum.

integridens C. M. - Webera.

integrifolium Rehm. - Rhodobryum leucothrix.

intermedium (Web. et Mohr) Brid. Mant. M. p. 120; Bryol. eur. IV mon. p. 47), t. 356; C. M. Syn. I, p. 278; W. P. Sch. op, cit. p. 428.

Br, occidentale Mac. Canad. M. n. 390.

Br. pallescens Schwaegr. Sp. M. p, 61.

Br. turbinatum var. H. et T. Musc. brit. p. 122.

Br. Webera intermedia Brid, Bryol. univ. I, p. 632.

Hypnum intermedium W. et M. Bot. Taschb. p. 283, t. X, f. 6.

Mnium intermedium Ludu. Cent. M. I, n. 81.

Pohlia intermedia Brid. M. Rec. II, III, p. 144, t. 2, f. 12.

Webera intermedia Schwaegr. Suppl. I, II, p. 67, t. 75 (ic. part. ad $\mathrm{Br}$. uliginosum pertin.).

Syn. Ad sax. et terr. aren. - Eur. : Britann., Voges., Suec., Siles., Austria. As, : Jenissei, Himalaya (var.). Am. sept. : Groenland, fret. Hudson, Terr. nov., Nov. Scot., New Brunswick, Ontario, Alberta. Athabasca, Manitoba, M. Rupestr., Columb. brit., ins. Vancouver, reg. sept., or. et centr. Pac. : Nov. Zeland. ? Tasman.

Exs. : Mac. Canad. M. n, 169.

Rab. Bryoth, eur. n. 88, 874, 103؟, 1212.

Sull, et Lesq. M. bor. am, II' ed. n. 277.

(1) Species dubia! (Handb, p. 444). 
var, cirratum Bryol, eur. - Bryum.

« var. Limprichtii Warnst. Moosfl. Prov. Brandenb. p. 52.

In arenos. - Eur. : Brandeb.

«var, subcylindricum Limpr. Laubm. Deutschl, p. 351.

Ut et ubi praeced.

interruptinervium C. M. in Rev, bryol. 1877, p. 15 (nom.)

- Afr. : Ins. Comor.

interruptum Dicks. - Philonotis fontana.

intricatum Brid. - Bryum calophyllum.

Isleanum Besch. Not. M. des I, Sl-Paul et Amsterd. p. 3.

2.

- Afr. : Ins. S. Paul et Amsterdam.

iteratum Par.

Br. macropelma C. M. in Linn. 1872, p. 149.

2.

- Pac. : Austral. or.

Jackii C. M. in Bot. Zeit. 1864, p. 348.

2. Terr. - Eur. : Summ. Alp. Carinth.

Jamesoni Tayl. - Brachymenium.

julaceum $\left\{\begin{array}{l}\text { Funk. - Br. Funkii. } \\ \text { Kunth, - Br. semi-ovatum. } \\ \text { Schrad, - Br. argenteum var. majus. } \\ \text { Sm, - Br. filiforme. }\end{array}\right.$

var. concinnatum Wils. - Br. julaceum.

juliforme (Solms-Laub.) W. P. Sch. Syn. II ed. p. 465.

Anomobryum filiforme var, juliforme Husn. Muscoll. gall. p. 222.

A. julaceum var, ? algirianum W. P. Sch. Sym. I ed. p. 383.

A. juliforme Solms, Laub. Tent, bryogeogr. Algarv... 1867.

Br. campestre Lindb, Man. M. I, 1870, p. 41.

Br. filiforme var. neapolitanum Boul. M. Fr. I, p. 293.

Webera neapolitana de Not. Epil. p. 417 (1869).

2. Ad terr. humid, et subturfac. - Eur.: Norveg. occ,, Armoric. marit., Algarb., Corsic., Etrur., Neap. Afr. : Alger., Madeir.

Junghunianum Hpe. in Bryol. jav. I, p. I46, t. 119.

Br. pachy theca $D z$, et $M k$, in $P l$. Jungh. I, p. 323 .

2.

- As. : M. Java.

juniperi foliis rugosis, capsulis rectioribus Dill. - Atrichum angustatum. juniperifolium Hffm. - Atrichum angustatum?

Jusichum undulatum var. abbreviatum?

Juratzkae Milde Beils...p. p. 596 .

2. $\quad-A s$.: Persia.

Kaèrnbachii C. M. in Act. horl. Petrop. 1887, fasc. $I$.

2.

- As. : Cancas. (Batoum).

Kaurini Philib, in Rev, bryol. 1886, p. 21.

1. (1).

- Eur. : Norveg.

Kaurinianum Warnst, in Hedroig. 1882, n. 2.

Syn. Rupic. - Eur. : Norveg. sept. (Dovre).

Keniae C. M. in Fl. 1890, p. 475.

Ster.

- Afr.: M. Aberdare, Kenia.

(1) Sec. Limpr. Laubm. Deutschl. II, p. 296, synoicum nec a Br, aretico diversum. 
kerguelense Mitt. in Journ. of the Linn. Soc. 1876.

1. - Afr.: Ins. Kerguelen.

Kiaeri Lindb. M. Scand. p. 41 et n. 100 b.

2. In schist. micae, desaggr. - Eur. : Rar. : Norveg.

Kindbergii Philib. in Rev. bryol. 1885, p. 83.

Syn. $\quad-$ Eur. : Norveg., Helvet. (Vales.).

Klinggraeffii W. P. Sch.op. cit. p. 436.

Br. contrictum Br. ined. (fid. Husn. Muscol. gall. p. 245).

Br. erythrocarpum $\delta$ turfaceum $W$. P. Sch. Syn. I ed. p. 363.

Br. macrostomum Jur, in Verh. d. zool. bot. Ges. in Wien 1867, p. 542 et in Rab. Bryoth. eur. n. 1085.

Br. punilum Saut. in sched.

2. In terr. aren. vel. turf. humid. - Eur. : Scandin., Boruss, Siles, Salisburg., Galic., Austr. inf., Morav., Hungar., Stir., Carinth., Bavar., Tirol., Helvet., Palatin.

Klotzschii Mitt. - Brachymenium.

Knowltoni Barnes in Bot. Gaz. 1889, p. 44.

Polyg. Rupic, - Am. sept.: Terra nov.

koratranum C. M. - Brachymenium julaceum.

Korbianum C. M. - Webera.

Kunzii H. et H. - Bryum caespiticium var, imbricatum.

labradorense Phitib. in Rev. bryol. 1887, p. 55 et 1889, p. 61.

Polyg. brador. - Eur.: Lappon., Dovre. Am. sept.: La-

laceratum Besch. Fl. bryol. Réunion, etc. p. 99.

2. Terr. - Afr... Ins. Borbon.

"var. comorense Besch.l. c.

Ut typ. - Afr. : Comor. magn.

lacerum Vill, - Bartramia CEderi.

lacustre Bland in Brid. Mant. M. p. 120; Bryol. eur. IV (mon.p. 16), t. 332 ; C. M. Syn. I, p. 268; W. P. Sch. op. cit. p. 422.

Br. caespiticium var. H. et T. Muscol. brit. p. 121.

Br. cernuum Brid. Bryol. univ. I, p. 851 .

$\mathrm{Br}$. fulvellum Wils. in Kew Journ. bot. I, $p .330$.

Br. Webera lacustris Brid. op. cit. p. 637.

Hypnum lacustre W. et M. Bot. Taschb. p. 285.

Mnium lacustre Bland. Foso. M. III, n. 132 et in sturm. Fl. germ. crypt. fasc, $X$.

Pohlia lacustris Hüb. Muscol. germ. p. 483.

Syn. In gramin. aren, udis. - Eur. : Spitzberg. ins. Ur'sor., Suec., Boruss, sept., Ducat. Megapol., vall. Rhen,, Anglia. As. : Amour, Sikkim. Am. sept. : Ins. Kotzebuë, Groenland, Alaska.

Exs. : Rab. Bryoth. eur. n, 332, 969.

var, alpinum Bryol, eur, - Br. fallax.

«var. norvegicum Limpr. in LXI Jahresb. d. Schles. Ges. f. Vaterl. Cull. 1884.

- Eur.: Dovre.

laete-nitens C. M. in Besch. I. . bryol. Réunion, etc. p. 94.

Ster. - Afr.: Ins. Francize.

laetum Lindb. - Br, oblongum. 
laevigatum Hook. f, et Wils, in Lond. Journ. of bot. 1844, p. 546 et Fl. Antarct. $I$, p. 134, t. 60; C. M. Syn. 1, p. 319 el II, p. 577 ; Handb. of $N$. Zeal. Fl, p. 440.

2. $\quad$ - Am. meril. : Ins. Eremit,, Maclov., Fuegia. Pac, : Nov. Zeland, med. et merid.

lamprocarpum C. M. - Zieria.

lamprocomum C. M. in Linn. 1878-79, p. 292.

- Am. merid. : Argentin. Tucum.

lamprostegum C. M. in Bot. Zeit. 1853, p. 22; Mitt. M. Ind. or. p. 71. 2. - As. : M. Neilgherr.

lanalum Brid. - Br. argenteum var. lanatum.

lanceolatum $\left\{\begin{array}{l}\text { Dicks. - Pottiia. } \\ \text { pellucidum, capsulis subrotundis, pedicellis carneis Dill. - } \\ \text { Webera carnea. }\end{array}\right.$

Landsbergii Dz. et Mk. - Br. Crügeri.

lanuginosum Hoffm. - Rhacomitrium.

lapponicum Dicks, - Amphoridium.

laticeps C. M. in Linn. 1878-79, p. 295.

Ster. Limic. - Am. merill. : Argentin. Cordob.

Intifolium Lindb. in Medd. af Soc. pro Faun. el Fl. Fenn. 1879, V.

2. Ster. - Eur. : Lappon., Norveg., $\Lambda$ lp. Bergam. Am. sept. : Ins. Miquelon.

latifolium $\left\{\begin{array}{l}\text { Brid, - Br. Schleicheri var. latifolium. } \\ \text { Bryol, eur. - Br. calophyllum. } \\ \text { Dz, et Mk. - Br. Marattii. }\end{array}\right.$

lato-decurrens Mac. - Br. Duvalii var. lato-decurrens.

laxifolium Besch. Fl. bryol. Nov. Caled. p. 216.

2. Paludic. - Pac. : Nov. Caledon.

laxifolium Lindb. - Br. gemmiparum.

laxiroseum C. M. - Rhodobryum.

laxum Reichdt. - Webera nutans.

Lechleri C. M. - Bryum andicola.

leptoareoblastum C. M. in Dusen M. Camer, $n .71$. - Afr. : M. Cameroon.

leptoblepharon C. M. - Webera.

teptocladon Sull. - Zieria.

Leptodontium Mitt. - Webera.

leptoloma C. M. in Linn. 1878-79, p. 478.

2.

- Am. merid. : Venezuela.

leptophyllum Br. et Sch. in W. Sch. M. Abyss. II, n. 451 el $460 ;$ C. M. Syn. $I, p .273$.

1. Ad arbor. - Afr.: Abyss.

leptoroseum C. M. - Rhodobryum.

leptospeiron C. M. in Besch. Fl. bryol. Réunion, etc. p. 95.

2.

- Afr. : Ins. Francise, Comor. magn.

leptostomoides C. M. - Brachymenium.

leptostomum W. P. Sch. Syn. II ed, p. 467.

Anomobryum leptostomoides ej. in Husn. M. Gall, n. 271 et in Rab. Bryoth. eur. n. 1218. 
A. sericeum de Lac. mss.; Husn. Muscol. gall. p. 223.

Br. filiforme $\gamma$ sericeum Boul. M. Fr. I, p. 293.

2. In rup. humid. - Eur. : Alp. Rhaet., M. Dore Arverniae.

leptothecium Tayl, - Rhodobryum.

leptothrix C. M. - Rhodobryum.

leptotorquescens C. $M$. in Dusen $M$. Camer. $n$. 208.

- Afr.: M. Cameroon.

leptotrichaceum Rehm. M. Afr. austr. n, 256.

- Afi. : Orange.

Lescurianum Sull. - Webera.

leucomalatum C. M. et Kindb. in Bidr. p. 454 (nom,) et in Mac. Cat. p. 123.

Syn. Terr. - Am. sept. : Columb. brit.

Exs. : Mac. Canad. M. n. 543.

leucophyllum Dz. et Mk. M. frond. ined. Archip. ind. p. 15, t. 6; C. M. Syn. I, p. 315; Bryol. jav. I, p. 148.

2. Terr. - As. : Java.

leucurum C. M. in Linn. 1878-1879, p. 479. 2.

- Am. merid. : Venezuela.

Leveilleanum Dz. et Mk. - Br. plumosum.

Liebmanni W. P. Sch. - Rhodobryun.

Liebmannianum C. M. - Br. brevicaule.

ligulatum Schreb. - Mnium undulatum.

limbatum C. M. - Webera.

Limprichtii Kaurin in Bot. Not. 1885, p. 87.

Polyg. Ad. rup. madid, - Eur. : Norveg. (Dovre).

Lindbergii Kaur, in Bot. Notiz. 1886, p. 129. 1.

- Eur. : Norveg. occid.

Lindgrenii W. P. Sch. Syn. II ed. p. 412.

Br. arcticum Lindgr. M. Suec, n. 60.

Syn. Terr. - Eur. : Suec, merid.

Lindigianum Hpe. - Rhodobryum.

linearifolium C. $M$, in Linn. 1880-83, p. 365.

Ster.

-- Am. merid. : Argentin. subtropic.

linoides Dicks. - Barbula unguiculata.

Lisæ de Not. Epil. p. 383; W. P. Sch, op. cit. p. 457.

2. (de Not.); syn! (Limpr.). - Eur. : M. Pedemont.

lonchocaulon C. $M$. in Fl. $1875, p .93$.

Syn. $\quad-A m$. sept. : Colorado.

longicollum Sw. $\{$ - Webera cruda var. minor?

longifolium $\left\{\begin{array}{l}\text { C. M. et Hpe. - Webera. } \\ \text { Dicks. - Dicranum falcatum. } \\ \text { Dicks. - Dicranum. }\end{array}\right.$

longipedicellatum C. M. - Disuchymenium.

longirostrum $\left\{\begin{array}{l}\text { Brid. - Mnium rostratum. } \\ \text { Griff. - Mnium rostratum var. rhynehophorum }\end{array}\right.$ 
longisetum Bland. Fasc. V M. et in Brid. Bryol. univ. I, p. 673; W. P. Sch. op. cit. p. 420.

Br, inclinatum Bryol. eur. $I V$ (mon. p. 17), t. 334 p.p. ; C. M. Syn. I, p. 269 p.p.

Br. turbinatum var. $H$. et T. Musc, brit. p. 122.

Br. Willdenowii Jur, in Rab. Bryoth. eur. n. 973.

Meesea nutans Willd. Prodr. fl. Berol. n. 983.

Pohlia longiseta Hüb. Muscol. germ. p. 480.

Syn. In prat. palud. - Eur. : German. sept., Wurtemb., Bavar.

Exs. : Rab. Bryoth. eur. n. 97, 966.

Un. itin. 1864, n. 89, 90.

Lorentzii W. P. Sch. op. cit. p. 413.

Syn. In terr. turfac. et sphagnet. - Eur. : Norveg. (1).

Lorentzianum C. M. Rhodobryum.

luoidum $\left\{\begin{array}{l}\text { Dra E. G. Britt. - Mnium. } \\ \text { James. - Webera cruda. }\end{array}\right.$

Ludwigii $\begin{aligned} & \text { Brid. - Webera commutata. } \\ & \text { Spreng. - Webera. }\end{aligned}$

var. gracile Bryol. eur. - Webera commutata var. gracilis.

luridum Ruthe in Verh. d. bot. Ver. Brandenb. 1867 ; W. P. Sch. op cit. p. 410.

Syn. In cav. arenos. - Eur. : German. sept. (Neomark.) (1).

Exs. : Rab. Bryoth. eur. n. 1089.

luteolum C. M. - Brachymenium.

lutescens Dicks. - Rhacomitrium fasciculare.

lycopodiiforme Schleich. - Philonotis fontana.

lycopodioides $\left\{\begin{array}{l}\text { Hook. - Mnium. } \\ \text { Sw. - Syrihopodon. }\end{array}\right.$

maceratum C. $M$, in Linn. 1880-83, p. 385.

2.

- Am. merid. : Argentin. subtropic.

Macounii Aust. - Br. Atwaterire.

macrantherum C. M. in Engler's Bot. Jahrb. 1833, p. 77 et in Forchungsreise...p. 14.

Br. pendulum Mitt. in Journ, of the Linn. Soc. 1876.

Syn.

- Afr. : Ins. Kerguelen.

macrocarpum Hedw, - Leptostomum.

macropelma C. M. Syn. I, p. 275 .

2. $\quad-$ Am. merid. : Chil. austr.

macropelma C. M. - Br. iteratum.

macropoma C. M. - Brachymenium

macrorhodon C. M. - Rhodobryum.

macrostomum Jur. - $\mathrm{Br}$. Klinggraeffii.

magellanicum C. M. - Brachymenium.

malachiticum C. M. - Brachymenium.

mammillatum Lindb. in Hartm, Skand. Fl. IX ed. $I I, p .36, n .28$; W. P. Sch. op, cit. $p_{2} 417$.

1. Ad ripas aren. fluy. et in aren, marit. - Eur.: Ins. Ursor., Aland, Gothland.

var. globosum Berggr. - Br. globosum.

(1) Semel lectum. 
mammilligerum Kindb, in Mac. Cat. p. 122 (subsp. Br. inclinati).

Syn. Ad rup, humid. - Am. sept. : M. Rupestr.

mancum C. M. - Webera?

Marattii Wils. Bryol. brit. App. 9, t. 32, f. b.; Bryol. eur. IV (mon. suppl.p. 60), t. 640; W. P. Sch. op. cit. p. 423.

Br. latifolium $D z$. et Mk. Prodr. fl. batav.

1. In aren. humid. et ad rip. turfos. - Eur. : Scot., Anglia, Neerland., ins. Aland et Gothland, Suec., Dania, Boruss, marit.

Exs. : Rab. Bryoth, eur. n. 731, 1334.

Martianum Roth. - Philonotis marchica.

marginale Dicks. - Dicranella crispa.

marginatum Bryol. eur. IV (mon. p. 74), t. 379 (sub Br. apiculato); C. M. Syn. I, p. 297; W. P. Sch. op. cit. p. 437.

2. Ad rup. aren. - Eur.: Prope Bipontem Voges. semel lectum (W. P. Sch. 1. c.) ; pr. « Bar sur Seine » et Andegav. Galliae (C. M.).

marginatum $\left\{\begin{array}{l}\text { Brid. - Br. imbricatum. } \\ \text { Brid. - Webera Tozeri. } \\ \text { Dicks. - Mnium serratum. }\end{array}\right.$

var. orthorhynchum Hartm. - Mnium serratum.

var., Drumm. - Mnium inclinatum.

Mariei Besch. Fl. bryol. Réunion, etc. p. 94.

2. Ad cement. calc. $-A f r$. : lns, Nossi-Bé.

Martianum C. M. - Brachymenium pulchellum.

maynense Spr. in Mitt. M. austr. am. p. 312.

2. Ad lign. saxaq. inund. - Am nerid. : Ins. Trinitat., And. Quitens, et Peruv.

medianum Mitt. - Rhodobryum.

medium Vill. - Cynodontium polycarpum.

meeseoides Kindb. in Bull. Tor. bot. Club, 1889, p. 95.

2. Ad rup. humid. - Am, sept. : Anticosti, Gaspes,, M. Rupestr. et Selkirk, ins. Vancouver.

Exs. : Mac. Canad. M. n. 187.

negalacrion Schwaegr. - Brachymenium.

megalocarpum Hook. in Kunth Syn. pl. Equin, p. 59; C. M. Syn. I, p. 264 ; Mitl. op. cit. p. 286.

Acidodontium Kunthii Schwaegr. Suppl. II, II, p. 152, t. 196.

Megalangium Kunthii Brid. Bryol. univ. II, p, 29, t. suppl. 3 (in ic. sub Macrothecio).

2. Ad arbor. - Am. merid. : And. Nov, Granat et Quitens. megalodictyon Sull, in Proced. Ain. Acad... 1859, p. 279.

Br. cellulare Hook.?

2. Murlc. - As.: Ins. Loo-Choo.

megalostegium Sull. - Rhodobryum.

melanodon Rrid. - Webera carnea.

melanothecium C. M. - Brachymenium.

melvilleanum C. M. Syn. 1, p. 267.

Ptychostomum pulchellum R. Br. App. ad iter Parray. p. 197 et in Brid. Bryol, univ, I, p. 601. 
membranaceum, foliis membranaceis obtusis Dill. - Aulacomnium heterostichum var. humile.

Menziezii Hook. - Rhizogonium.

meruerse C. $M$, in $F l$. $1890, p .475$.

2. $\quad-A f r$ : : Kilima N'Djaro.

mexicanum C. M. - Brachymenium.

Meyenianum C. M. - Brachymenium.

micans Limpr. Einig. neue. Art. 1883, p. 236 et Laubm. Deutschl. II, p. 303.

Polyg. Ad terr. turfos, - Eur. : Norveg.

micans Mitt. - Brachymenium.

microblastum C. M. in Bot. Centralbl. 1853, n. 2-4.

2. $\quad-$ As. : Penins. Tschutschica.

microcarpum (Hsch.) C. M. Syn. I, p. 294; Mitt. M. austr. am. p. 310.

Cladodium microcarpum Hpe. Enum. M. Brasil. p. 30.

Pohlia microcarpa Hsch. Fl. Brasil. I, p. 38.

2. Terr. - Am, merid. : Brasil, austr. or.

microcarpum Gmel. - Rhacomitrium.

microcephalum C. M. et Kindb. in Bidr. p. 454 (nom.) et in Mac. Cat. 2. S. 134 . R.

2. Ster. Rupic. - Am. sept. : Columb. brit.

microchaeton Hpe. in Ann. sc. nat. V ser., III, p. 342; Mitt. op. cit. $2 ?^{p .298 .}$

micro-erythrocarpum C. M. et Kindb, $l l, c c . p p .454$ et 124 .

Br. murale Mac. Canad. M. $n .186$.

2. In aren. humid. - Am. merid. : Ins. Vaneouver.

microglobum C. M. el Kindb. $l t . c c . p .454$ et 129.

2. Terr. - Am. sept. : Ontario.

micro-laevigatum C. M. in Engler's Bot. Jahrb. 1883, p. 77 et in ForSter. chungsreise... p. 12.

micron C. M. in Linn. 1880-83, p. 372.

2.

- Am. merid. : Argentin.

micro-pendulum C. $M$. in op. cit. 1878-79, p. 476.

2.

- Am. merid. : Venezuela.

micro-pendulum C. M. - Br. nano-pendulum.

microrhodon C. M, - Rhodobryum.

microstegium Bryol. eur. IV (mon. suppl. p. 7), t. 362; C. M. Syn. 1, p. 279 ; W. P. Sch. Syn. II ed. p. 433.

Syn. Terr, - Eur. : Alp. Norveg., Tirol., Helvet. Am. sepl. : Groenland, Labrador.

microstomum C. M. - Brachymenium.

Dicks. - Hymenostomum.

microtheca C. M. Syn, I, p. 314 .

2.

-As, : Manilla. 
Mildeanum Jur. in Verh. d. Zool. bot. Ges. in Wien, 1862, p. 967; W. P. Sch. op. cil. p. 446.

Br. rubrum Milde mss,; Ltz. Bryol. Notizb. p. 46.

2. Ad terr. humid, et mur. - Eur. : Siles., Sudet., Bohem., Hungar., Austr. inf. et super., Salisb., Stir., Sarinth., Carniole, Bavar., Helvet., Westphal., Belg., Rhóngeb., Francon., Tirol., Delphinat. As.: Caucas.

Exs. : Rab. Bryoth. eur. n. 476.

miniatum Lesq. in Mem. Calif. Acad. 1, p. 23; Lesq. et Jam. Man. p. 233.

2. Ad rup. humid. - Am. sept. : Columb. brit., Calif.

niniatum Mac. - $\mathrm{Br}$. capitellatum.

minusculum C. $M$. in Fl. I885, p. 400.

2. Paludic. - Am. merid. : Fuegia austr.

minutirete C. $M$, in Fl. 1888, p. 409.

Ster. $\quad-A f r$. : Kilima N'Djaro.

minuti-rosatum C. M. - Rhodobryum.

minutulum W. P. Sch, in Besch. Prodr. bryol. mex, p. 53.

2. $\quad-A m$. sept.: Mexic.

minutum $\left\{\begin{array}{l}\text { Dicks. - Pottia Starkeana. } \\ \text { Groel. - Seligeria pusilla. }\end{array}\right.$

mirabile C. M. in Bot. Centralbl. 1883, n. 2-4.

Syn.

- As.: Penins. Tschutschica.

mnioides $\left\{\begin{array}{l}\text { Gmel. - Leptobryum piriforme. } \\ \text { Wils. - Mnium subglobosum. }\end{array}\right.$

mniopsis C. M. - Rhodobryum.

Moei W. P. Sch. op. cit. p. 417 ; Philib. in Rev. bryol. 1886, p. 20.

Syn.

- Eur. : Alp. Norveg.

Mohrii Lesq. in Bull. Torr. bot. Club. 1874, p. 50 (1).

- Am. sept. : Ludovic.

Molleri C. M. - Brachymenium.

moniliforme C. M. in Dusen M. Camer. n. 240 a.

- Afr.: M. Cameroon.

Montagneanum C. M. - Brachymenium pendulum.

montanum $\left\{\begin{array}{l}\text { Ed. - Distichium capillaceum. } \\ \text { hemiheterophylhum, operculis aculis Dill. - Rhacomitrium } \\ \text { - aciculare. }\end{array}\right.$ Morisii $\mathrm{Br}$. - Br. erythrocarpum.

mucronatum Mitl. in Handb. of N. Zeal. Fl. p. 442.

Hermaphr. Terr. - Pac. : Nov. Zeland.

mucronulatum Dicks. - Barbula unguiculata.

Mühlenbeckii Bryol. eur. IV (mon. suppl. p. Il), l. $381 ;$ C. M. Syil, I, p 286; W. P. Sch. op. cit. p. 441 .

Br. alpinum var, brevifolium Myr. Coroll. fl. Upsal. p. 68.

Br. Raui Aust. in Coult. Bot. Gaz. II, p. 110.
2. Ad rup. madid.; calcar. fugit. - Eur.: Scandin., Riesengeb., Gesenke, Tatra, Salisb., Stir., Tirol., Helvet., Carinth. As.; Caucas. Am. sept. : Groenland, Terr, nov, Wyoming, Oregon, Washing. ton, Nov. Mexic. 
Exs.: Rab. Bryoth. eur. n. 94, 472.

Mülleri Spr. - Br. Donianum.

multicaule Tayl. in Lond. Journ. of bot. 1846, p. 342; C. M. Syn. $I, p, 302$. - Pac. : Austral, or.

mulliflorum C, M. - Webera.

Mundtii C. M. in Bot. Zeit, 1859, p. 206.

Br. canariense ej. Syn. I, p. 253 p.p.

2. Ad arbor. - Afr. : C. B. Sp.

"var, flaceidum C. M. in op, et loc, cit.

Ut et cum typ.

murale Wils. in W. P. Sch. Syn. Il ed. p. 437.

Br, atro-purpureum de Not. Epil. p. 399.

$\mathrm{Br}$, erythrocarpum var. murorum $W . P$. Seh. Coroll. p. 73.

Br. murorum Wils, in Ltz. Bryol. Notizb. p. 46.

2. Ad cement. calcar. mur. - Eur.: Britann., vall. Rhen., Gall, Helvet. occ. As.: Caucas. Afr. : Alger., Madeir.

Exs. : Mandon M. Madeir. n. 21.

Rab. Bryoth, eur. n, 674, 1083.

murale $\left\{\begin{array}{l}\text { Mac. - Br. micro-eryth rocarpum. } \\ \text { L. - Barbula muralis. }\end{array}\right.$

murmanicum Broth. in Act. Soc. pr. Faun. et Fl. Fenn. V1, n. 4, p. 58.

Syn, Arenic. - Eur. : Lappon. Murman.

murorum Wils. - Br. murale.

muticum Lange. -- Br, gemmiparum.

Myurella C. M. in Linn. 1875, p. 380.

Ster. Terr. - Afr. : Dar Fertit.

Myurella C. M. - Br. myurelloides.

myurelloides $\mathrm{Par}$.

Br. Myurella C, M. in Dusen M. Camer. n. 314.

... Afr.: M. Cameroon.

nanocoma C. $M$, in Linn. 1880-83, p. 365.

2. $\quad-A m$, merid, : Argentin, subtropic.

nano-pendulum ej. in op. cit. p. 363.

Br, micro-pendulum ej. in op, cit. 1878-79, p. 294.

Syn.

- Am. merid. : Argentin. Tucuman.

nanopyxis ej, in Hildebr. M. Madag. n. 2059.

- Afr. : Ins. Nossi-Be.

nanorhodon C. M. in Besch. Fl. bryol. Réunion, etc. p. 90.

Sler.

nano-torquescens $C . M$. in Fl, 1890, p. 470 .

Ster.

nanum larignis foliis albis Dill. - Octoblepharum albidum. naviculare Hpe. Symb, 1877, p. 721.

Ster.

- Am, meril.: Brasil. austr. or.

naviculare Ren. et Card, - Webera cucullata var. carinata, 
neilgherriense $\left\{\begin{array}{l}\text { Mont. - Rhodobryum. } \\ \text { Mont. (fid. Mitt.) - Mnium rostratum var. ramosum. } \\ \text { affine Wils. - Rhodobryum roseum. }\end{array}\right.$ neodamense Itzigs. in Fl. 1841, p 360; C. M. Syn. I, p. 258; W. P. Sch. Syn. II ed., p. 460).

Br. pseudo-triquetrum var. cavifolium W. P. Sch. Coroll. p. 76.

2. In uligin. - Eur.: Spitzbeig, Scandin,, German. sept., Britann., Neerland, vall. Rhen., Pyren.

Exs. : Rab. Bryoth. eur. n. 877, 924, 972.

var, ovatum Lindb. et Arn. - Bryum ovatum.

nepalense $\left\{\begin{array}{l}\text { Dz. et Mk. - Brachymenium brevicaule? } \\ \text { Mitt. - Brachymenium. } \\ \text { Spreng. - Brachymenium Weisia. }\end{array}\right.$

nervosum Hoffm. - Barbula unguiculata var. cuspidata.

nevadense C. M. - Webera.

Nietneri C. M. - Brachymenium.

nigrescens Vill. - Rhacomitrium protensum.

nigricans Crome. - Br. caespiticium.

nimbigerum Tayl. - Br. concinnalum.

nigritum Dicks. - Catoscopium.

nitens Hook. in Wall. Cat. n. 7592 et Ic. pl. var. t. 20, f. 6; Harv. in Lond. Journ. of bot. 1810, II, p. 9; C. M. Syn. I, p. 339; Mitt. M. Ind. or. p. 70 (1).

Br. coronatum var. Wils. in Kew Journ. bot. IX, p. 333.

Br. pachypoma Mont. (fid. Mitt.).

2. - As. : Nepal., Ceylan, Java.

nitidulum Lindb. in Oefv ... XXIII, $1866, p .545$.

Syn.

land.

var, teres Berggr. $-\mathrm{Br}$. teres.

nitidum Mitl. op. cit, p. 67.

Anomobryum nitidum Jaeg. Ad. I, p. 604.

2.

- As. : Himalaya, Ceylan.

nivale C. M. Syn. I, p. 262.

Hermaphr.

- Am. merid. : Summ. And. Chil. austr. norvegicum CEd. - Rartramia Halleriana.

Notarisii Mitt. - Br. gemmiparum.

nudicaule Lesq. -- Webera.

nudum Dicks. - Discelium.
nutans
H. f. et W. - Webera clavaeformis?
Mitt. - Webera sphagnadelphus ?
Mitt. (1876). - Webera pseudo-nutans.
Schreb. - Webera.

var. bicolor. Bryol. eur. - Webera nutans var. bicolor.

var. crespitosum Bryol. eur. - Webera nutans var. cæspitosa.

var. longisetum Bryol. enr. - Webera nutans var. longiseta.

var. ninus Kth. - Mielichhoferia longiseta.

var. subdenticulatum Bryol. eur. - Webera nutans var, sudenticulata. var., Drumm. - Br. areticum. 
obconienm Hsch. mss.; Bryol. eur. IV (mon. p. 59), t. 367 ; C. M. Syn. I, p. 282 et II, p. 571 ; W. P. Sch. op. cil. p. $45 \mathrm{I}$.

Br. capillare var, obconicum Hüb. Muscol. germ. p. 44 ?.

2. Ad mur. et rup, aren - Eur. : Angl, vall. Rhen., Hercyn, Pyren. Am. sept. : Colorado, Calif., Florid. Pac. : Austral., Nov. Zeland, Tasman.

"f. longipes Besch. in Ann. sc. nat. 1892, 1, p. 66.

Terr. - As. : Yunnan.

obconicum $\left\{\begin{array}{l}\text { Kindb., Mac. - Br. heteroneuron. } \\ \text { Sulliv. - Br. sanguilentum. }\end{array}\right.$

obliquum C. M. Bryol. austr. Georg. p. 17.

2. $\quad-A m$. morid. : Austr. Georg.

oblongum Lindb. in Mitth. v. Soc. pr. Faun. et Fl. Fenn. $3^{\text {a }} X^{\text {bris }} 1881$ et in Rev. bryol. 1886, p. 33.

Br. lretum Lindb. l. c. 3a Febi. 1883.

2. Terr. - Eur. : Scandin. As. : Jenissei med.

obovatum Milt. in Journ. of the Linn. Soc. 1863, p. 4.

2. Terr. - Afr. : Madeir.

obtusifolium Lindb. in Oefv... 1866, p. 544.

2. Ster. - Eur. : Spitzb., Septem Ins, ins. Parry, Ursor. As. : Penins.

Samojed, Jenissei inf, Am. sepl. : Groenland, fret. Behring.

obtusifolium $\left\{\begin{array}{l}\text { Turn. - Br. cyclophyllum. } \\ \text { Vill. - Webera cucullata. }\end{array}\right.$

obtusum Dicks. - Entosthodon ericetorum.

occidentale Sull, in Bot. Pac. R. R. Survey (Whipple), p. 188, t. 7; Lesq. et Jam Man. p. 236.

2. Rupic. et terr. - Am. sept. : Calif.

occidentale Mac. - Br. intermedium.

var., Sull. et Lesq. - Br. sanguilentum.

ochropyxis C. M. in Rehm. M. Afr. austr. n. 233.

- Afr. : C. B. Sp.

octoblepharis Gmel, - Octoblepharum albidum.

Ederi Günn. - Bartramia CEderi.

clandicum Plitib, in Rev. bryol. 1887, p. 9.

1. In aren. marit, - Eur. : Ins. Eland.

oeneum Blylt in Bryol. eur IV (mon. suppl.p. 4), t. 338; W.P.Sch. Syn. II ed. p. 427.

Br, rutilans $C . M$. Syn. $I, p .274$,

2. In rup. fissur. humid. - Eur. : Spitzberg, ins. Parry, Ursor., Alp.

Norveg., Finmark. Am. sept. : Fret. Smith, ins. Sabine.

* var. gracilescens W. P. Sch. op, cit.

Ut typ. - Eur. : Alp. Norveg., Finmark.

Erstedlianuin C. M. - Webera.

oligochloron C. M. el Kindb. in Bidr. p. 454 (nom.) et in Mac. Cal. p. 129.

Ster. Rupic. - Am. sept. : Columb. brit.

Exs. : Mac, Canad, M. n. 5 54.

oncophorum Hpe. Symb. 1877, p. 726.
2 ?

- Am. merid. : Brasil. austr. or. 
ontariense Kindb. - Rhodobryum.

opdalense Limpr. Einig. neue Art... 1883, p. 238 et Laubm. Deutschl. $I I, p .310$.

Hermaphr. In aren. humid, - Eur. : Norvegia.

orbiculare pulvinatum, hirsutie canescens, capsulis immersis Dill. Grimmia pulvinata.

orbiculatum Milt. M. austr, am. p. 306.

Anomobryum orbiculatum Jaeg. Ad. I, p. 604.

Ster. Terr. - Am, merid. : M. Pichincha.

oreganum Sull. M. Wilkes Exp. p. 10, t. 7; Lesq. et Jam. Man. p. 230.

Syn. vel, polyg.

origanum Bosw. (1). - Br. Wesleyi.

orthocladon Br. et Sch. in W. Sch. M. Abyss. n. 589; C. M. Syn. 1, p. 31内

$2 . \quad-A f r .:$ Abyss.

orthodontioides C. M. - Br. Gilliesii.

orthodontum P. B. - Dissodon borbonicus.

orthopelma C. M. - Brachymenium.

o:thophyllun Besch. in Ann. sc. nal. VII ser. II, p. 90.

2. $\quad$ - Afr.: Ins. Mayotte.

Exs. : Marie, n. 9.

orlhorhynchum Brid. - Atrichum tenellum.

Orthotheciellae C. M in Engler's Bot. Jahrb. 1883, p. 78 et in Forchungs-

Syn. $\quad-A f r$. Ins. Kerguelen. reise... p, 15.

Osculatianum de Not. in Mem. Acad. Torin... II ser. XVIII, p. 442.

- Am. merid.: Columb.

ovale Hoffm. - Grimmia cornmutata.

ovalifolium Sull. - Br. Crügeri

ovatum Jur. Laubm. Oesterr. Ung. p. 291.

Br. neodamense var, ovatum Lindb. et Ain. M. As. bor. 1890, II. p. 34.

Br. pseudo-triquetrum $\delta$ cavifolium Saut. Fl. d. Herzogth Salzb. III,p.47.

2. Paludic. - Eur. : Salisburg., Stir. As. : Jenissei inf.

ovatum Dicks. - Pottia cavifolia.

Pabstianum C. M. in Bot. Zeit. 1852, p. 751 .

Br. Gardneri Mitt. in Hooker's Journ of bot. 1856, t. XI B et M. austr. am. p. 296.

Syn. Terr. - Am. merid. : And. Peruv., Brasil. austr. or.

Mont. - Br. plumosum.

Mont. (fid. Mitt.). - Br. nitens.

pachypoina Wils. p.p. - Br. alpinum.

Wils. p.p. - Br. caespiticium.

Wils. p.p. - Br, erythrinum.

pachytheca C. M. Syn. I, p. 307 p.p.

Br. coronatum $\beta$ minus Hpe. in Preiss Pl. N. Holl. p. 117.

2.

- Pac, : Austral. „ec,, Nov. Zeland., Tasman.

(1) Ob nimiam similitudinem cum praeced. nomen mutatum. 
« var. inflatum Hook, f. et Wils, Fl. Tasm, II, p. 191.

- Pac. : Austral., Nov, Zeland.

pachytheca $\left\{\begin{array}{l}\text { C. M. p.p. - Br. pseudo-pachytheca. } \\ \text { Dz. et Mk. - Br. Junghunianum. }\end{array}\right.$

pallens Sw. M. Suec. pp. 47 el 93, t. 4, f. 12 ; Briıl. Bryol. univ. I, p. 612 ; Bryol. eur. IV (mon. p. 68), t. 373; C. M. Syn. I, p. 256; W. P.

Sch. Syn. II ed.p. 456.

Br. turbinatum H. et T. Muse, brit.p. 122 p.p.

Br. turbinatum var. pallens Drumm. M. bor. am. I ed. n. 267.

Hypnum pallens $W$. et $M$. Bot. Taschb, $p$. 286.

Mnium gracile Schleich. Cent. II Pl. helv, p. 46.

Mnium pallens $P . B$. Prodr. p. 147 .

Pohlia pallens Brid. M. Rec. II, III, p. 145.

2. Ad scatur., terr, saxaq. humid. - Eur. : E reg. campestr. montos. nsq. in alp. As. : Caucas,, Jenissei. Am. sept.: Groenland, Gaspes., Ontario, M. Rupestr. et Selkirk, Columb. brit., ins. Vancouver, Oregon, Wyoming, New Hampshire, M. Adirondack. Am. merid. : And. Quitens.

Exs, : Rab. Bryoth. eur. n. 89 b, 583, 878 a, b, c, e, 928, 1213.

"var. abbreviatum Bryol. eur. et W. P. Sch. ll. cc.

Br. attenuatum Dicks. Fase. IV Pl, crypt. p. $8, t$. 10, f. 8 ? Brid. op. cit. p. 638 (quoad pl. Sudetomem).

Orthopyxis attenuata $P . B$. Prodr. p. 45.

Ut typ. - Eur. : Reg. alp.

4 var. angustifolium Breidl. Laubm. Steierm. p. 134.

Br. triste Jur, Laubm. p. 287.

Ad terr, et rup, calcar. - Eur. : Austr. inf., Stiria.

\& var, areuatum W. P. Sch. Syn I ed.p. 377.

Cynodontium cernuum Schleich. Cent. III Pl. helvet. $n 9$.

Ptychostomum cernuum Hüb. Musool. germ.p. 493.

In depressis. - Eur. : Neerland.

var. baldense Vent. et Bott. - Br. fallax var. baldense.

\& var, brovisetum Lindb. el Arn. M. As, bor. 1890, II, p. 36.

- As. : Jenissei inf.

var. fallax Jur. - Br. fallax.

var, microstoma Bryol, eur. - Br. pallens var, speciosum.

"var. conodes Limpr, in LXI Jahresb. d. Schles. Ges. f. Valerl.

Cult. 1884.

$$
\text { - Eur.: Norveg. (Dovre). }
$$

"var, speciosum (Voit) W. P. Sch. Syn. I ed. p. 377 el II ed. l. c.

Br. elegans Grev, in Tians, of the Linn. Soc. XV, p. 314, t. 3, f. 5 ?

Br. pallens vai, microstoma Bryol. eur, l. c.

Br. speciosum Voit in Sturm. Fl. germ. orypt. Faso. XIV; Brid. Bryol. univ. $I, p .666$.

Et typ. - Eur. : Reg. alp.

"var. vulturiense de Not. in Piccone M. Ligur, n. 161. - Eur. : Liguria.

var., Wils. - Br. calophyllum.

pallescens Schoaegr. Suppl. I, II, p. 107, t. 75; Brid. Bryol, unio. I, p. 645 ; Byol. eur. IV (mon. p, 51), t. $359 ;$ C. M. Syn. I, p. 279 et II. p. 570; W. P. Sch. op. cil. p. 433.

Br, turbinatum Drumm. M, bor. am. I ed, n. 266 p.p. 
1. Ad mur. et rup, aren. - Eur. : E reg. campestr. usq. in alp. As. : Kamschatka, Amour, Jenissei, Himalaya (var.), Caucas, Afr.: M. Cameroon. Am. sept, : Groenland, Labrador, Terr. nov.? ins. Miquelon, New Rrunswick, Ontario, M. Rupestr., Columb. brit., Washington, Utah, Colorado, Calif,, reg. sept.

Exs. : Mac. Canad, M. n. 177.

Rab. Bryoth. eur. n. 241 et b, 273, 537.

Sull. et Lesq. M. bũr. am. II ed. n. 279.

Un. itin. 1884, n. 132.

« var. boreale Bryol. eur. l. c. t. $360 ;$ W. P. Sch. op. cit. p. 434.

Br. boreale Schwaegr. Suppl. I, II, p. 96, t. 69; Brid. op. cit. p. 643.

Ut typ. - Eur. : Reg. alp.

« var. contextum Bryol. eur, et W. P. Sch. ll. cc.

Br. contextum H. et H. in Bot. Zeit. 1819, p. 91 ; Brid. l. c. p. 646.

Ut typ. - Eur. : Spitzberg, Scandin. As. : Jenissei, Am. sept.: Groenland.

« var. flexisetum Limpr. in op, cit.

$\rightarrow$ Eur. : Norveg.

var. intermedium Schwaegr. - Br. intermedium.

« var. laxifolium Kindb. in Bull. Torr. bot. Club, XVII, p. 274.

In silv. humid. - Am. sept. : M. Rupestr.

"var. longifolium Kindb, $l, c$.

In aren, humid. - Am. sept. : M. Rupestr.

var. subrotundum Bryol, eur. - Br. longifolium.

pallescens $\left\{\begin{array}{l}\mathrm{Dz} . \text { et } \mathrm{Mk},-\mathrm{Br} \text {. gedeanum. } \\ \text { Schwaegr. }-\mathrm{Br} \text {. intermedium. }\end{array}\right.$

pallidisetum Brid. - Webera carnea.

? palmifolium Brid. - Conomitrium.

pallidum Schreb. - Leptotrichum pallidum.

paludicola $W . P . S h$. op. cit. $p .415$.

Syn. (I in adnot.). In uligin. - Eur. : Alp. Norveg.

paludosum L. - Seligeria pusilla.

$\beta$ viridulum Web. - Weisia viridula.

Brid. - Didymodon rubellus.

Dicks. - Dicranella squarrosa.

L. - Gymnostomum curvirostre.

Sw. - Aulacomninm.

aestivum Confervae facie Dill. - Gymnostomum curvirostre. brevifolium capsulis nigricantibus Dill. - Barbula fallax var.

palustre brevifolia.

complicutum, rubens, capsulis turbinalis pendulis Dill. $\mathrm{Br}$. turbinatum.

pellucidum, capsulis et foliis brevibus recurvis Dill. .. Dichodontium pellucidum.

scopis teretibus slellatis, vertice multifulis Dill. .. Philonotis fontana.

var. ramosum Turn. - Aulacomnium palustre var. polycephalum.

Pancheri Jaeg. Ad. I, p. 639.

Br. crassinervium Besch. Fl. bryol. Nov. Caled. p. 215.

2. Ad terr, ferrug. - Pac. : Nov. Caled. 
papillosum $\left\{\begin{array}{l}\text { C. M. - Brachymenium. } \\ \text { Dicks. - Ceratod.nn purpureus. }\end{array}\right.$

Pappeanum C. M. in Bot. Zeit. 1855, p. 752 et 1859, p. 206. 1. - Afr.: C. B. Sp.

"var, humile C. M. in op. cit. p. 206.

Ubi typ.

paradoxum Schroaegr. Suppl. III, I, I, ı. 221; C. M. Syn. I, p. 290; Milt. M. Ind. or. $p, 74$. - As. : Nepal.

paradoxum Jur. - Br. cuspidatum.

var, cirratum Jur. - Br, cuspidatum var. cirratum.

paraguense Besch. Not. M, Parag.p. 264.

2. $\quad-$ Am. merid. : Paraguay.

Exs. : Bal. Pl. Parag. n. 1235.

parasiticum Sw, - Calymperus.

parvulum Dicks. - Dieranella cerviculata var. pusilla.

parvum surculls et setis geminalis Dill. - Ceratodon purpureus.

patens $\left\{\begin{array}{l}\text { Dicks. - Rhacomitrium. } \\ \text { Wils. - Rhodobrynm rigidum. }\end{array}\right.$

palulum C. M. - Brachymenium.

paucifolium $\left\{\begin{array}{l}\text { Dicks. - Seligeria subcernua (fid. Lindb.). } \\ \text { Dicks. - Gyroweisia tenuis (fid. W. P. Sch.). } \\ \text { Mitt. - Webera. }\end{array}\right.$

paulense C. M. in Forchungsreise... p. 39 (nom.).

- Afr. : Ins. S. Paul.

Payoti W. P. Sch. Syn. II ed. p. 470.

Br. Blindii var. Payoti Husn. Muscol. gall. p. 243.

Ster. Secus rivul. - Eur. : Alp. Sabaud. (M. Blanc).

pellucens Hook, - Orthodontium.

pellucidum $\left\{\begin{array}{l}\text { Abb. - Tetraphis. } \\ \text { L. - Dichodontium. }\end{array}\right.$

$\beta$ L. - Dicranella squarrosa.

pendulinum Hpe in Lins. 1874, p. 214.

- Afr. : Madagascar.

pendulum (Hsch.) W. P. Sch. Coroll. p. 70 et Syn. II ed. p. 414.

Br. caespiticium Drumm. M. bor. am. I ed. n. 265 p.p.

Br. cernuum Bryol, eur. IV (mon. p. 14), t. 331 ; C. M. Syn. I, p. 266.

Cynodon cernuus Brid. Mant. M. p. 99.

Cynodontium cernuum Schwaegr. Suppl. I, I, p. 110.

Cynontodium cernuum Hedio, Sp, M. p. 58, t. 9.

Didymodon cernuus Sw. M. Suec. p. 29, t. I, f. 9 (fid. Brid.).

Ptychostomum cernuum Hsch, in Fl. 1822, Syll. I, p. 61; Brid. Bryol. univ. $I, p .600$.

Pt. pendulum IHsch. I, c.; Brid l. c. p. 599.

Pt. radiculosum Brid, l. c. p. 838.

$\mathrm{Pt}$, radiculosum var, spadiceum Brid. $l$, c. p. 837 ?

Swartzia cernua Poir:

Sw. radiculosa Hedw, in $h b, D C$.

Syn. Ad mur., sax. et terr. - Eur. : E reg. campestr. usq. in alp. As. : Saghalien, Amour, Himalaya, Caucas, Afr.: Alger? Am. sept. : Fret. Smith, Groenland, Labrador, Anticosti, Terr. nov., New Brunswick, Ottawa, Manitoba, M. Rupestr., Wyoming, Columb, brit, fret. Behring, temper, tota. 
Exs, : Mac. Canad. M. n. 167.

Rab. Bryoth. eur. n. 443, 836 et b, 1118 et b, 1398.

Sull. et Lesq. M. bor. am. II ed, n. 262 .

« var. angustatum Ren. in Husn. M. Gall. n. 667 et Muscol. gall. p. 235. Ad mur. - Eur. : Pyren. (Tarbes).

« var. compactum (Hsch.) W. P. Sch. Coroll. p. 70 et op, cit. p. 415.

Br. algovicum Sendtn, in C. M. Syn. II, p. 569.

Ptychostomum compactum Hsch. l. c. p. 22; Brid. Bryol. univ. I, pp. 598 et 837.

Pt. caespiticium Brid. l. c. p. 837.

Rupic. - Eur. : In summ. Alp.

Brid. - Breutelia.

Ehrh. - Leptobryun piriforme.

F1. dan. - Bartramia Halleriana.

Mitt. (1876). - Br. maerantherum.

foliis variis pellucidis, thecis ovatis Dill. - Mnium affine et cuspidatum. pendulum $\left\{\begin{array}{c}\text { hornum molle, foliis et lanceolatis et gramineis Dill. - } \\ \text { Webera cruda. }\end{array}\right.$

julaceum argenteum et sericeum $\mathrm{Dill}$. - $\mathrm{Br}$. argenteum.

ovatum caespiticium et pilosum, seta bicolori Dill. - Br. caespiticium.

serpylli folio longiore pellucido, thecis oblongis cuspidatis Dill. - Mnium rostratum.

serpylli folio rotundiore pellucido, thecis ovatis Dill. Mnium punctatum.

penicillatum Hpe, in Linn. 1874, p. 215

2.

- Afr. : Nadagascar.

pennatum With. - Schistotega osmundacea.

pensilvanicum Brid. - Mnium serratum var. apiculatum?

peraristalum C. M. - Brachymenium.

percurrentinerve Kindb. in Bull. Torr. bot. Club. XVII, p. 274.

Ster. Ad rup. irror. - Am. sept. : Columb. brit.

Exs. : Mac. Canad. M. n. 505.

perimbricatum C. M. in Dusen $M$. Camer, n. 362.

- Afr. : M. Cameroon.

Peromnium C. M. - Brachymenium radiculosum.

pertenue Besch. in Journ. de bot. 1894, p. 60 .

2. Terr. - Am. sept. : Guadalup.

pertriste C. M. in Linn. 1878.79, p. 297 (sub Br. tristi, nom. correctum.) Calcic? - Am. merid. : Argentin subtropic.

Pfefferi de Not. Epil.p. 409.

Ad rup. granitic. - Eur. : Ital. super. (Vall. Tellina).

Phallus C. M. in Linn. 1875, p. 392.

Br. coronatum ej. Syn. I, p. 307 p.p. ; Mitt. M. austr. am. p. 321. 2.

- Am. merid. : Chile.

phascoides.Jaeg. - Diphyscium foliosum.

Philiberti Àman. - Br. comense.

Philippianum C. M. in Linn. 1844, p. 701 et Syn. I, p. 772.

Hermaphr.

- Am. merid. : Chile. 
philonoteum C. M. - Webcra.

Philonotula Hpe, in Hildebr. M. Madag. n. 2136.

- Afr. : Madagascar.

phyllitidifolium Neck, - Atrichum undulatum.

Phyllitidis folio rugoso acuto, capsulis incurvis Dill. - Atrichum undulatum.

physcomitrioides C. M. in Jaeg. Ad. II, p. 710.

- As. : Japon.

piliferum Br. et Sch, in W. Sch. M. Ahyss.

- Afr.: Abyss.

piliferum $\{$ Dicks. - Desmatodon latifolius var. brevicaulis (fid. C M.).

picks. - Pottia latifolia var. pilifera (fid. W. P. Sch.).

|Gmel. - Barbula muralis.

pilosum molle, setis intortis Dill. $\left\{\begin{array}{c}\text { - Campylopus flexuosus (fid. C. M.). } \\ \text { - Dicranodontium longirostre (fid. } \\ \text { W. P. Sch.). }\end{array}\right.$

sphagni subulati facie Dill. - Blindia acuta.

verticillatum Dill. - Eucladium.

piriforme $\left\{\begin{array}{l}\text { Hedw. - Leptobryum } \\ \text { L. - Physcomitrium. }\end{array}\right.$

plagiopodium W. P. Sch. in C. M. Syn. II. p. 572.

2.

- Am. sept. : Mexic.

planifolium Kindb. Art. d. Laubm Schwed. u. Norveg. p. 75.

Syn. - Eur.: Norveg. (Dovre).

planiusculum Lindb. et Arn. M. As. bor. 1890, II, p. 38 .

2. Terr.

- As, : Jenissei med.

platyloma $\left\{\begin{array}{l}\text { Bryol. ear. - Br. Donianum. } \\ \text { Schwaegr. - Br. capillare var. platyloma. }\end{array}\right.$

platyphylloides C. M. in Linn. 1878-79, p. 298.

2. Limic. - Am. merid. : Argentin. Cordob.

platyphyllum C. M. Syn. I, p. 291.

Pohlia platyphylla Schwaegr. Suppl, IV, p. 324.

2. Rupic. - Am. merid. : And, Chil, austr.

plumosum Dz. et Mk. M. frond, ined. Archip. and. p. 16, t $\mathbf{\tau} ;$ Bryol. jav. I, p. 143, t. 117 .

Br. ambiguum Duby in Moritzi Syst. Verz.p. 132 ; C. M. Syn. I, p. 294.

Br. apiculatum Dz, et Mk. M. frond. ined. Archip. ind. p. 24, t. 8.

Br. Leveilleanum eor. op. cit. p. 16.

Br. pachypoma Mont. in Ann. se, nat. 1815, IV, p. 104; C. M. Syn. I, p. 299.

Br. plumosum $\gamma$ Leveilleanum Bryol. jav. l. o.

2. Terr. - As. : Tonkin, Java, Sumatra.

- oar. elongatum Bryol. jav. l. c. p. 144.

Ut typ. - As. : Java.

var, Leveilleanum Bryol. jav. - Br. plumosum.

"var. majus Hpe. in Bryol. jav, l. c.

- As. : Java.

pohliaeforme W. P. Sch. in Besch. Prodr. Fl. mexic, p. 54.

2. $\quad-A m$. sept. : Mexic.

pohtiaeforme Brid. - Br. subrotundum. 
polycarpon Hoffm. - Cynodontium polycarpum. polycarpum Mitt. - Webera.

polychaete C. M. in Dusen M. Camer. p. 343. - Afr. : M. Cameroon.

polygamum Hpe. Symb. 1870, p. 275.

Hermaphr. - Am. merid. : Brasil. austr. or.

polymorphum $\left\{\begin{array}{l}\text { Bryol, eur. - Webera. } \\ \text { C. M. - Webera acuminata var. minor. } \\ \text { C. M. - Webera acuminata var. polyseta. } \\ \text { Neck. - Mnium affine. }\end{array}\right.$

var. affine Bryol. eur. - Webera polymorpha var. affinis.

var. brachycarpum Bryol, eur. - Webera polymorpha var. brachycarpa.

var. gracile Bryol, eur. - Webera polymorpha var. gracilis.

var, strictum Bryol. eur. - Webera polymorpha var. stricta. polyphyllum Dicks. - Ptychomitrium.

polytrichoides palustre, setis longioribus rubris sericeis Dill. - Cerato. don purpurens.

polytrichoideum C. M. in Bot. Zeit. 1859, p. 206.

2. Rupie. - Afr. : C. B. Sp.

pomiforme L. p.p. $\left\{\begin{array}{l}\text { - Bartramia. } \\ \text { - Bartramia ithy phylla. }\end{array}\right.$

var. Halleri Vill. - Bartramia Halleriana.

var. majus Web. - Bartramia ithyphylla.

var. Ederi Vill. - Bartramia CEderi.

var. I, Scop. - Bartramia Halleriana.

Pomoniae C. M. in Linn. 1876, p. 244.

2. Terr. - Afr.: Ins. Anjouan.

pootenianum Par.

Br. arenarium C. M. in Bot. Centralbl. 1883, n. 2-4.

2 vel syn, - As. : Penins. Tschutschica.

porphyroloma C. M. in Rehm. M. Afr. austr. n. 250.

- Afr. : C. B. Sp.

porphyroneuron C. M. in Bot. Zeit. 185s, p. 22; Mitt. M. Ind. or. p. 70. 2 .

pottiacfolium C. M. in Linn. 1875, p. 38?.

Syn, Terr. - As. : M, orient. mar. E:ythraei.

praemorso-obtusum C. M. in Dusen M. Camer, n. 321. - Afr.: M. Cameroon.

Preissianum Hpe. - Brachymenium.

procerrimum (Rehm.) Par.

Anomobryum procerrimum Rehm. M. Afr. austr. n. 540 .

Mielichhoferia procerrima Rehm. l. c. n. 219.

Ster.

procerum W. P. Sch. - Rhodobryum.

proliferum Mitt. M, austr, am̉. p. $31 \mathrm{l}$.

2. $\quad-A m$. merid. : And. Nov. Granat.

prostratum C. M. Syn. I, p. S.T; Mitt. op. cil. p. 306.

2. Saxic. - Am. merid. : And. Nov, Granat., Quitens et Boliv.

Exs. : Mandon Pl, Boliv. n. 1667. 
《 var. minus (Besch.) Par.

Anomobryum prostratum var, minus Besch. Prodr, bryol. mexic, p. 56 . - Am, sepl. : Mexic.

provinciale Philib. in W. P. Sch. Syn. II ed. p. 432.

Br. Billardieri Bryol, eur. IV (mon. p. 58), t. 336.

Br. canariense W. P. Sch. Syn. I ed., p. 374.

Br, canariense var, provinciale Husn. Muscol, gall. p, 239,

Syn. In pinet, suberet. et ad tumul. formic. - Eur. : Angl., Galloprov., Istria, Dalmat., Etrur., Roma. Afr. : Alger. Am. sept. : Florid., Calif.

provinciale Mac. - Br, heteroneuron.

pseudo-Acidodontium C. M. in Linn. 1880-83, p. 364 .

2. $\quad-$ Am merid. : Argentin, subtropic.

pseudo-capillare Besch. Fl. bryol. Antill. fr, p. 31.

2. - Am. sept.: Martinic.

pseudo-Funkii Anzi Enum. M. Longob. p. 20.

- Eur.: Ital. super. (Vall. Tellina).

pseudo-giganteum C. M. - Rhodobryum.

pseudo-Kunzei Limpr. Laubm. Deutschl. p. 359.

Syn. $\quad-$ Eur.: Helvet. (Vales.).

pseudo-marginatum Geh, et Hpe. - Rhodobryum.

pseudo-micron C. M. in Linn. 1880-83, p. 373.

Ster. $\quad-$ Am. merid.: Argentin temperat.

pseudo-pachytheca C. M. in Bot. Zeit. 1859, p. 207.

Br, pachytheca ej. Syn. I, p. 307 p.p.

2.

$$
\text { - As.: India. }
$$

pseudo-torquescens $C$. $M$. in op. cit. 1858, p. 155.

Br. torquescens W. P. Sch, in W. Sch. M. Abyss, II, n. 30.

Hermaphr.

- Afr. : Alp. Abyss.

pseudo-triquetrum Hedw. Sp. M. p. 190; Brid. Bryol. univ. I, p. 676 p. p. ; Bryol. eur. IV (mon. p. 54), t. 364; C. M. Syn. I, p. 258; W. P. Sch. Syn. II ed. p. 459 (1).

$\mathrm{Br}$. annotinum palustre capsulis ventricosis pendulis Dill. Hist. M. p. 404, t. $51, f .12$.

Br. bimo affine Wils. in Kew Journ. bot. IX, p. 366.

Br. cubitale Dicks. Fase. II Pl. crypt. t. 5 ; Brid. op, cit. p. 677 p.p.

Br, subobliquum Lindgr, in Bot. Not. 1842, p. 118.

Br. ventricosum Dicks. Fasc. I, p. 4.

Hypnum boreale W. et M. Bot. Taschb. p. 287 (? fid. W. P. Sch.).

Mnium pseudo-triquetrum Hedw. M. frond. III, p. 19, t. 7 p.p.

2. Ad terr. humid, in uligin. et ad rup. madid. - Eur. : E reg. eampestr. usq. in alp. : Spitzberg, ins. Ursovurn. As. : Jenissei, Obi, Tibet. occ., Caucas. Afr.: Alger. Am. sept. : Groenland, Anticosti, Terr. nov., ins. Miquelon, New Brunswick, Ottawa, Ontario, M. Rupestr., Columb. brit,, ins. Vancouver, Washington, Wyoming, Montana, tota temper.

Exs. : Mac. Canad, M. n. 183.

Rab. Bryoth, eur. n. 95, 271 et b, 1279.

Sull, et Lesq. M, bor. am. II, p. 281 .

(1) Desynon. antiquior, of. C. M. et W. P. Sch. 1l. cc. 
var. cavifolium $\left\{\begin{array}{l}\text { Saut. }-\mathrm{Br} \text {. ovatum. } \\ \text { W. P. Sch. - Br. neodamense. }\end{array}\right.$

« var. compactum W. P. Sch. Syn. I ed. p. 376 et op. cit., p. 460. Jenissei. - Eur. : Ad rup. marit. Norvegiae et in summ. Alp. As. :

Exs. : Rab. Bryoth. eur. n. 1278.

Un. itin. 1863, n. 2 ' .

« var. flaccidum W. P. Sch. Coroll. p. 76 et Syn. I ed. l. c.

Br. duvalioides Itz. mss.; Rab. Deutseh. Krypt. Fl. I ed. II, p. 214.

In uligin. aquos. - Eur. : Neomark.

a var. gracilescens W. P. Sch, ll. cc.

Ut praeced. - Eur. : Rhaet., Suec., etc. As. : Jenissei. Am. sept. : Washington, Wisconssin.

a var. hyalodontium C. M. et Kindb. in Mac. Cat. p: 133.

Ad rup. humid. - Am. sept. : M. Rupestr.

* var, polytrichoides Corbière in Husn. Muscol. gall, p. 250.

Marit. - Eur. : Normannia.

pseudo-triquetun Brid. p.p. - Rr. bimum.

ptychothecum Besch. - Rhodobryum.

Puiggarii Geh, el Hpe, in Fl. 1881.

1.

- Am. merid. : Brasil. austr. or.

pulchellum $\left\{\begin{array}{l}\text { Hedw. - Webera. } \\ \text { Sull, - Webera Lescuriana. }\end{array}\right.$

var, atro-purpureum Wahlenb. - Br. atro-purpureum.

pulchrum C. M. - Brachymeninm.

pulvinatum $\left\{\begin{array}{l}\text { C. M. - Webera. } \\ \text { L. - Grimmia. }\end{array}\right.$

pumilum $\left\{\begin{array}{l}\text { Saut. }-\mathrm{Br} \text {. Klingraeffii. } \\ \text { Wils, p.p. }-\mathrm{Br} \text {. subrotumd }\end{array}\right.$

punctatum $\left\{\begin{array}{l}\text { Drumm. - Mnium subglobosum. } \\ \text { Schreb. - Mnium. }\end{array}\right.$

pungens Tayl. in Lond. Journ. of bot. 1846, p. 342; C. M. Syn. I, p. 302; Mitt. M. austr. am. p. 304.

$$
\text { - Am. merid. : M. Pichincha. }
$$

purpurascens (R. Br.) Bryol, eur. IV (mon. suppl. p. 2), t. 336 ; C. M. Syn. I, p. 270 et 11 p. 569 ; W. P. Sch. op. cit. p. 410.

Hemisynapsinm arcticum $\beta$ purpurascens Brid. Bryol. univ. $I, p, 606$.

Pohlia arctica $\beta$ purpurascens Schwaegr. Sp. M. p. 74 .

P. purpurascens R. Br. Suppl. App, ad iter Parray. p. 197.

Syn. In humid, et spongios. - Eur.: Lappon., Alp. Norveg. As.: Jenissei inf. Am, sept. : Ins. Melville, Groenland, Labrador, fret. Smith, M. Rupestr., Columb. brit.

Exs. : Un. itin. 1867, n. 63?

purpuratum C. M. in Linn. 1880-83, p. 370.

2? $\quad-A m$. merid. : Argentin. subtropic.

purpureo-nigrum Duby in Mem... Genève, 1875, p. II, $t . I, f .3$.

2.

- AC. . Madagascar.

purpureum Philib. in Rev. bryol. 1886, p. 24.

2.

- Eur. : Norveg. 
purpureum Neck. - Ceratodon purpurens.

pusillum $\left\{\begin{array}{l}\text { Broth. - Rhodobryum. } \\ \text { Gmel. - Leptotrichum tortile var. pusillum. } \\ \text { Hedw. - Pottia cavifolia. } \\ \text { Hoffm. - Seligeria. }\end{array}\right.$

pycnodermum Limpr. in LXI Jahresb. d. Schles. Ges. für Vaterl, Cult. $1884, p .217$.

1. In aren. - Eur. : Norveg. (Dovre).

pycnopsis C. M. - Rhodobryum.

pygmaeo-alpinum C. M. el Kindb. in Bidr. p. 454 (nom.) et in Mac. Cat. p. 126.

Ster. Ad rup. humid. - Am. sept. : M. ins. Vancouver.

pygmaeum C. M. in Engler's Bot. Jahrb. 1883, p. 77 et in Forchungsreise... p. $12(1)$.

Ster. Ad rup. sicc. - Afr. : Ins. Kerguelen.

pyrothecium Hpe. et C. M. - Rhodobryum.

pyrothrix C. M. in Linn. 1880-1883, p. 307.

Ster. $\quad-A m$. merid. : Uruguay.

Quintasii Broth. - Rhodobryum.

quitense (W. P. Sch.) Par.

Anomobryum quitense W. P. Sch. in Mandon Pl. Boliv. n. 1664 bis. - Am. merid. : And. Boliv.

radicale C. M. in Hildebr. M. Madag. n. 2115.

- Afr. : Madagascar.

6. vur. leptoradiale C. $M$ l. c. n. 2118 .

Ubi typ.

radians $\mathrm{P} . \mathrm{B}$. - Entosthodon.

radicale Rehm. M. Afr. austr.

- Afr. : Orange.

radiculosum (Sclwoaegr.) Mitt, M. austr, am. p. 284.

Br. Peromnium C. M. Syn. I, p. 321.

Peromnium radiculosum Schwaegr. Suppl. III, I, t. 250.

2. Ad arbor. - Am. merid. : Brasil, austr. or.

radiculosum Brid. - Br. erythrocarpum var. radiculosum.

ramicola $S p r$. in Mitt. op. cit. p. 286.

Acidondontium ramicola Jaeg. Ad. I, p. 572.

2. Ad arbor. - Am, merid. : And. Quitens.

ramosum Mitt. - Mnium rostratum var. ramosum.

Raui Aust. - Br. Müchlenbeckü.

reclinalum, foliis falcatis scoparum effigie Dill. $\left\{\begin{array}{l}\text { - Dicranum majus. } \\ - \text { Dicranım scoparium. }\end{array}\right.$

recuréatum Hoffin. - Seligeria recurvata.

(1) " An Bryum ? An Mieliohhoferia? . C. M. 1. c. 
recurvifolium Tayl. in Edinb. Trans. of the Linn. Soc. 1845, 1I, 1; C.M. Ster. Syn. I, p. 340.

recurvirostrum $\left\{\begin{array}{l}\text { Dicks. - Didymodon rubellus. } \\ \text { Gmel. - Gymnostomum curvirostre. }\end{array}\right.$

recurvulum Mitt. $M$. Ind. or. p. 74.

2.

- As. : Nepal.

recurvum Wulf, - Bartramia Halleriana.

reflexulum C. M. in Jaeg. Ad. $I I, p .709$ (nom.)

- As.: Sikkim.

Regnelii C. M. - Brachymenium.

Rehmanni C. M. in Rehm. M. Afr. austr. n. 234.

$$
\text { - Afr. : C. B. Sp. }
$$

Remelii $C$. $M$. in Fl. $1874, n .31$.

Ster. Muric. - Afr. : Egypt. super.

remotifolium Hpe. in Linn. 1863, p. 131.

2. Terr. - Am. merid. : And. Nov. Granat.

repens Gmel. - Amblystegium serpens.

restitutum de Not. Epil. p. 408 ; W. P. Sch. Syn. 11 ed.p. 469.

Ster. In pascuis. - Eur. : Ital. sup. (agr. Comens.)

reticulatum Dicks. - Dissodon Froehlichianus.

revolutum C. $M$. in Linn. 1878-79, p. 291.

2. Ad rup. gneiss. - Am. merid. : Argentin. Tucuman.

Reyeri Breidl, in Rev. bryol. 1888, p. 35.

Ster, -- Eur. : Pustherthal.

rhaeticum Rota Cat. M. Bergom. ; de Not. Epil. p. 754.

$$
\text { - Eur.: M. Ital. super. }
$$

rhamphostegium (Hpe.) Par.

Acidodontium rhamphostegium Jaeg. Ad. I, p. 571.

Cladodium rhamphostegium Hpe. in Ann. sc. nat. V ser., IV, p. 339.

2. Ad arbor.? - Am. merid. : And. Nov. Granat.

rhodocladon Berggr. in sched, (1).

- Am. sept. : Groenland sept.

rhypariocaulon C. $M$. in Fl. 1886, p. 507.

Ster. Ad arbor. - Afr. : Ins. Fernando Po.

rigescens Wils. - Webera.

rigidulum Dicks. - Barbula.

rigidum $\{$ C. M. - Rhodobryum.

Huds. - Barbula aloides.

rivale C. M. in Linn. $1878.79, p .300$.

2. Ad aren, rivul. $-A m$, merid. : Argentin. subtropic. Tucuman et Jujuiens.

rivulare Hoffm. - Rhacomitrium protensum.

robustulum C. M. - Rhodobryum?

robuslum $\mathrm{Hpe}$ - Rhodubryum? 
Rodriguezii Ren. et Card. in Bull. Soc. roy. bot. Belg., 1893, 1, p. 129.

Br. erythrocarpoides eor. in op. cit. 1891, II, p. 188.

2.

$$
\text { - Afr. : Ins. Borbon. }
$$

Roellii Philib. in Rev. bryol. 1890, p. 56.

$$
\text { Polyg. } \quad-\text { Am. sept.: Washington. }
$$

Roscheri Llz. Moost. p. 157.

2. In sabulos, - Afr. : Zanzibar.

roseolum C. M. - Rhod»bryum.

$\operatorname{roseum}\left\{\begin{array}{l}\text { Mitt. - Rhodobryuum minuti-rosatum. } \\ \text { Schreb. - Rhodobryum. } \\ \text { W. Arn. - Rhodobryum Beyrichianum. }\end{array}\right.$

var. brachycarpum Wright. - Rhodobryum roseum var. brachycalpum.

rostratum \{ C. M. - Brachymenium.

rosulatulum C. M. - Rhodobryum.

rosulatum C. M. - Rhodobryum.

rosulicoma Ren. et Card. - Rhodobryum

rubellum $\left\{\begin{array}{l}\text { Brid. - Webera carnea. } \\ \text { Hoffin. - Didymodon. }\end{array}\right.$

rubens Milt. in Hook. Journ. of bot. 1856, p. 232 (1) et M. Ind. or. p. 69.

2. ‥ Eur. : Temperat. As.: Temperat. ; Sikkim, Assam. Am. sept. : Temperat.

rubicundulum C. M. el Kindb. in Bidrag (nom.) p. 454 et in Mac. Cat. 129.

2. Rupic. ad nives aet. $-A m$. sept. : M. Selkirk.

Exs. : Mac. Canad, M. n. 519.

rubicundum C. M. in Bot. Zeil. 1859, p. 207.

- $\quad$ - Afr.: Cap. virid.

rubiginosum Hook. f. et Wils. Fl. Tasm. II, p. 190, t. 173, f. 9.

2. Ster. - Pac.: Tasman.

rubrifolium W. P. Sch, in Besch. Fl, bryol. Antill. fr. p. 32 .

2.

- Am. sept. : Guadalup.

rubro-costatum C. M. in Engler's Bot. Jahrb. 1883, p. 83 el in Forchungs.

Ster. reise.... p. 40 .

rubrum Huds, - Dicranella varia.

$$
\text { - Afr. : Ins. Ascension. }
$$

rufescens Hook. f. et Wils. Fl. Tasm. II. p. 192, t. 174, f. I et Handb. of N. Zeal. Fl. p. 439.

Br. Billardieri Sohwaegr. ? (f. Mitt.).

2.

- Pac. : Tasman.

* var, brevifolium $H$. f. et W. $l l$. cc.

- Pac. : Tasman

" var. mammillatum eor. $l l . c c$.

- Pac. : Tasman.

rufescens Dicks. - Dicranella.

(1) Quid ? 1sf. Limpr. Laubm. Deutschl, p. 390. 
rufinerve C. M. in Linn. 1874, p. 549 .

2.

- As. : Ins. Philippin.

rufo-limbatum Ren, et Card. in Bull. Soc. roy. bot. Belg. 1892, I, p. 165. 2.

- Am. sept. : And. Costa-Ricens.

rufo-nitens Hpe. Symb. 1877, p. 725.

Ster. $\quad-$ Am. merid. : Brasil, austr. or. rufum Fergus. mss.; Limpr. Laubm. Deutschl. p. 296.

Syn.

- Eur.: Anglia.

rugosum $\left\{\begin{array}{l}\text { C. M. - Brachymenium. } \\ \text { Hoffm. - Dicranum undulatum. }\end{array}\right.$

rupeum Neck. - Leptobryum piriforme.

rurale $\left\{\begin{array}{l}\text { L. - Barbula. } \\ \begin{array}{c}\text { unguiculatum, hirsutum elatius et ramosius. Dill. - Barbula } \\ \text { ruralis. }\end{array}\end{array}\right.$ ruralis facie, foliis minoribus et non pilosis Dill. - Barbula unguiculata var. patagonica.

rulilans $\left\{\begin{array}{l}\text { Brid. - Webera ? } \\ \text { Bryol. eur. - Webera Schimperi. } \\ \text { C. M. - Bryum aeneum. }\end{array}\right.$

Salaminae C. M. - Brachymenium.

salinum Hagen in sched. ; Limpr. Laubm. Deutschl. p, 334.

Syn. In arenos, marit. - Eur. : Norveg, occ.

saltense Par.

Br. angustifolium Kawrin in Bot. Notiz. 1887, p. 113. c. ic.

1.

- Eur. : Norveg. sept.

Sandii Dz. et Mk. M. frond. ined. Archip. ind. p. 21, t. 10; C. M.

Syn. I, p. 300 ; Bryol jav. 1. p. 145.

1 et hermaphr. $\quad-A s$. : Java.

sanguineum Brid. - Br. erythrocarpun.

sanguilentum Ren. et Card. mss.

Br. capillare var. Lesq. et Jam. Man, p. 236.

Br. obconicum Sull. M. bor. am, I ed. n. 187 b.

Br, occidentale var. obconicum Sull. el Lesq. M. bor. am. II ed. n. $283,284$.

2. Lignic, - Am. sept. : Calit.

saprophilum C. M. - Rhodobryum.

Sartorii W. P. Sch. - Rhodobryum.

Sauteri Bryol, eur, IV (mon. suppl. p. 10), t. 377; C. M. Syn. I, p. 280; W. P. Sch. op. cit. p. 435 .

1. Ad terr. aren. humid. - Eur.: Salisburg,, Vall. Tell. super. As. Caucas.

Sawyeri Ren. et Card. in Bot. Gaz. 1889, p. 95, t. XIII C.

2 ? Arenic. et lignic. - Am. sept. : Florid., Ludovic.

scabridens Mitt. - Webera.

Schimperi C. M. - Webera.

schisti Ed. - Cynodontium.

schistoneuron (Kze.) Par.

Br. gracilescens C. M. Syn. I, p. 261.

Mnium schistoneuron Kze. in Poeppig Pl. Chil. n. 231.

2.

- Am. merid. : Peruvia. 
- var. decumbens (C. M.) Par.

Br. Auberti Hsch. Fl. Brasil. p. 45, t. 2, f. I.

$\mathrm{Br}$. gracilescens var. decumbens $C$. M. l. $o$.

- Am. merid. : And. Quitens., Brasil. austr. or.

" var, densifolium (Bridl.) Par.

Br. Auberti Schuaegr. Sp. M. p. 54 et Suppl, II, II, II, p. 195.

Br, densifolium Mitt. M. austr. am. p. 313.

Br. gracilescens var. densifolium C. M. 7. c.

Br. Polla densifolia Brid. Bryol, univ. I, p, 855.

- Am. merid. : And. Quitens. et Peruv., Brasil. austr. or.

schizotrichum C. M. in Rehm. M. Afr. austr. n. 241.

? - Afr. : C. B. sp.

Schleicheri Schwaegr. Suppl. I, II, p. 113, t. 73; Brid. Bryol. univ. I, p. 683 ; W. P. Sch. op. cit, p. 462.

Br. alpinum Vill. Pl. Dauph. III, p. 889.

Br. turbinatum $H$, et T. Musc. brit. p. 122.

Br. turbinatum $\beta$ gracilescens Bryol, eur. IV (mon. p. 65, t. $372 \beta$ ).

Br. turbinatum $\beta$ praelongum de Not. Epil. p. 379; C. M. Syn. I, p. 259. Mnium Schleicheri Brid. Sp. M. III, p. 60.

2. Ad scaturig. - Eur. : Reg. subalp. et alp. zon. central.; Pyren., Sierra Nevada. As. : Tibet. occ., Caucas. occ. et centr. Am. sept. : Groenland, M. Rupestr. et Selkirk, Utah, Calif.

Exs. : Drumm. M. bor. am. I ed. n. 264.

Mac. Canad. M. n. 516.

" var. angustatum W. P. Sch, op, cit p. 463.

Ut et cum typ. in Eur. - Afr.: Alger. Am, sept. : Nevada.

- var. latifolium W. P. Sch. $l$. $c$.

Br. latifolium Brid. Mant. p. 120.

Br. Schleicheri Schwaegr. Suppl. I, II, p. 113, t. 73 (fid. Husn. Muscol. gall. $p$. 252.)

Br. turbinatum var. latifolium Bryol, eur. l. c. t. $372 \gamma$.

Br. Polla latifolia Brid. Bryol. univ. I. p. 713.

Mnium latifolium Schwaegr. Suppl. I, II, p. 138.

Ad rivul, frigid. - Eur. : Ins. Ursorum, Shetland, Sierra Nevada ; Alp. omn. As. : Himalaya, Pers., Caucas., penins, Sinaït. Am. sept.: Groenland, Utah, Calif.

Exs. : Rab. Bryoth. eur, n. 622, 967.

Schleicheri Schwaegr. $\left\{\begin{array}{c}\text { (Sp. M. fid. C. M.). - Webera albicans var. } \\ \text { glacialis. } \\ \text { (Suppl. fid. Husn.). - Bryum albicans var. lati- } \\ \text { folium. }\end{array}\right.$

Sehmidii C. M. in Bot. Zeit. 1853, p. 24; Mill. M. Incl. or. p. 68.

Anomobryum Schmidii Jaeg. Ad. I, p. 602.

2.

$$
\text { - As. : M. Neilgherr. }
$$

Schnyderi C. M. in Linn. 1880-83, p. 362.

1. Loc. humid, - Am. merid. : Argentin. Buonos-Ayr.

Schweinfurthii C. M. in op. cit. $[875$, p. 396.

2. Terr. - Afr, : Djour.

scoparium L. - Dicranum.

secunclun Gmel. - Rhacomitrium leterostichum.

Sellowianum C. M. - Brachymenium Klotzschyi. 
seni-limbatum Kiaer in Borgen M. Madag. n. 13.

- Afr. : Madagascar centr.

serui-marginatum Hpe. in Ann. sc. nat. V ser., IV, p. 341 ; Mitt. M. austi: Syn. am. p. 296.

seminerve (Hook. f. et Wils.) C. M. Syn. 1, p. 264; Milt. op. cit. p. 285.

Acidodontium seminerve H. f. et W. in Lond. Jown of bot. 1846, p. 45l, t. $16 \mathrm{~J}$.

2. Ad arbor. ? - Am. sept. : Jamaïc. Am. merid.: And. Quitens. semi-ovatum Brid. Bryol. univ. I, p. 846; C. M. Syn. I, p. 316; Mitt.op. cit. p. 305.

Anomobryum semi-ovatum Jaeg. Ad. I, p. 602.

Br. julaceum Kth. Syn. pl. Equin. p. 56 .

2. Ad terr. et sax. - Am. sept. : Costa Rica. Am. merid. : And. Quitens. et Peruv.

semi-reticulatum C. M. in Linn. 1878-79, p. 301 el 1889-83, p. 377.

Ster. - Am. merid. : Argentin. Salt.

semi-rubrum C. M. in Linn. 1875, p. 385.

Ster. Terr. - Afr. : Niam-Niam.

semi-vacuum Vill. - Orthotrichum affine. semperlaxum C. M. - Brachymenium.

senopyxis C. M. in Linn. 1880-83, p. 363.

2. Terr. - Am. merid. : Uruguay.

sericeum Mitt. op. cit. p. 305.

2. Saxic. - Am. merid. : And. Quitens.

sericeum $\left\{\begin{array}{l}\text { Hpe, et C. M. - Leptobryum. } \\ \text { Huds, - Cynodontium virens. }\end{array}\right.$

serotinum Lindb. M. Scand p. 17.

Syn. Arenic. - Eur, : Suec, Fennia. As. : Jenissei inf.

serpyllifolium $\left\{\begin{array}{l}\text { Sw. - Mnium punctatum. } \\ \text { pellucidum, capsulis piriformibus Dill. (fig. A-K). - } \\ \text { Funaria fascicularis, } \\ \text { pellucidum, capsulis piriformibus Dill. (fig. L.) - Phys- } \\ \text { comitrium puriforme. }\end{array}\right.$

var. undulalum Huds. - Mnium.

var. $\beta$ Huds, - Mnium rostratum.

var. $\gamma$ Huds. - Mnium cuspidatum.

serratum Schrad. ? $\left\{\begin{array}{l}\text { - Mnium? } \\ \text { - Mnium orthorhynchum. }\end{array}\right.$

setaceum $\left\{\begin{array}{l}\text { Jacq. - Seligeria recurvata. } \\ \text { Vill. - Barbula. }\end{array}\right.$

var. $\beta$ Huds. - Didymodon rubellus.

sibiricum Lindb. et Arn. M. As. bor. 1890, II, p. 37.

2. Terr. - As. : Jenissei med.

silvalicum Gmel. $\left\{\begin{array}{l}\text { - Ulota Bruchii ? } \\ \text { - Ulota crispa ? } \\ \text { - Ulota crispula? }\end{array}\right.$

simplex $\left\{\begin{array}{l}\text { Kindb. - Muium lucidum. } \\ \mathrm{L}-\text { Dieranella varia var, tenella. }\end{array}\right.$ 
smaragdinum $\left\{\begin{array}{l}\text { C. M. - Brachymenium. } \\ \text { Mitt. p.p. - Brachymenim }\end{array}\right.$

Mitt. p.p. - Brachymenium subsmaragdinum.

soboliferum Tayl. in Lond. Journ. of bot. 1846, p. 51; C. M. Syn. 1, 2. p. 340 ; Mitt. M. austr. am. p. 309.

socorrense (Hpe.) Mitt. op. cit. p 295.

Cladodium socorrense Hpe. in Ann. sc. nat. V ser., IV, p. 338.

2. Saxic, - Am. merid. : And. Nov. Granat et Quitens.

sollyanum Griff. - Rhodobryum giganteum.

sordidissimum C. M. - Brachymenium.

sordidum Hpe. in op. cit. p. 341 ; Milt. op. cil. p. 306.

2. $\quad-A m$. merid. : And, Nov. Granat.

spalhulosifolium C. M. - Rhodobryum.

spec? Wils. - Rhodobryum roseum.

speciosum $\left\{\begin{array}{l}\text { Mitt. - Leptotheca? } \\ \text { Voit. - Br pallens. }\end{array}\right.$

spectabile C. M. - Webera.

Spegazzinii C. $M$. in $F l .1885, p .400$.

Syn. Ad terr. et rup, humid. $-A m$. merid. : Fuegia austral.

speirocladum C. $M$. in Rev. bryol. 1877, p. 15 (nom.).

- Afr. : Ins. Comor.

sphaericarpon Sw. - Philonotis.

sphagnadelphus C. M. - Webera.

Sphagni $\left\{\begin{array}{l}\text { Brid. - Br. Duvalii. } \\ \text { C. M. p.p. - Webera sphagnicola. }\end{array}\right.$

sphagnicola Bryol, eur. - Webera sphagnicola.

sphagnoides Jais. - Hedwigia ciliata.

spinidens Ren. et Card. in Bull. Soc. roy. bot. Belg. 1893, I, p. 117.

2.

- Afi. : Madagascar.

spinosum $\left\{\begin{array}{l}\text { Drumm. - Mnium spinulosum. } \\ \text { Voit. - Mnium, }\end{array}\right.$

spirifolium C. M. - Brachymenium.

splachnobryoides C. M. in Engler's Bot. Jahrb. 1883, p. 77 el in ForSter. chungsieise... p. 13.

splachnoides $\left\{\begin{array}{l}\text { C. M. - Brachymenium. } \\ \text { Dicks. - Blindia acuta. }\end{array}\right.$

splachnoideum C. M. in Engler's Bot. Jahrb. 1883, p. 77 et in Forchungs. Ster. reise...p. 13 .

spongiosum Welvo. et Duby in Mem... Genève, 1870, p. 4, t. 1, f. 3.

Anomobryum spongiosum Jaeg. Ad. I, p. 603 .

Ster. Rupic. - Afr. : Angola.

Sprucei Mitt. M. austr. am. p. 285.

Acidodontium Sprucei Jaeg. Ad. I. p. 572.

2. Arboric.? - Am. merid. : And. Quitens.

spurium Dicks. - Dicranum ?

squalidum Vill. - Bryum capillare. 
squarripilum C. M. in Fl. 1886, p. 280.

Ster. Terr. - Afr. : Ins. S. Thom.

squarrosum L. Drumm. - Paludella.

Slarkeanum Hoffm. - Pottia

Roth. - Mnium.

hornum silvarum, eapsulis magnis nutantibus Dill. - Mnium hornum.

lacustre, foliis rubris capillaceis Dill. - Didymodon rubellus. nitidum, pallidum, capsulis tenuissimis Dill. - Barbula convo. stellare luta.

roseum majus, capsulis ovatis pendulis Dill. - Rhodobryum roseum.

roseum, pendulum minus, capsulis el selis longioribus Dill. Mnium stellare.

stellalum $\left\{\begin{array}{l}\text { Dicks. - Barbula agraria. } \\ \text { Laln et DC. (fid. Brid.). - Mnium stellare. } \\ \text { Lam. et DC. (fid. Lindb.). - Mnium hornum. } \\ \text { Schreb. - Barbula rigida. }\end{array}\right.$

stelligerum Dicks. - Gymrostomum curvirostrum.

stenocarpum Limpr. in LXI Jahresb. d. Schles. Ges. f. Vaterl. Cult. 188t, 1 . p. 219 et Laubm. Deutschl. II, p. 292.

stenopyxis C. $M$. in Linn. 1878-1879, p. 480.

2. $\quad-A m$. merid. : Venezuela.

stenotrichum C. $M$. in Fl. 1887, p. 219.

Syn. - Am. sepl.: Alaska.

Stittoni W. P. Sch. Syn. II ed.p. 470.

$2 ; \&$ et fr. ign.

- Eur. : M. Scotiae.

striatum L. - Orthotrichum leiocarpon.

var. $\delta$ L. $\left\{\begin{array}{l}\text { - Ulota Bruchii } \\ \text { - Ulota crispa? } \\ \text { - Ulota crispula? }\end{array}\right.$

striclum Dicks. - Ceratodon purpureus.

strigosum Wils, in Keu Joumn. bot. p. 369.

Br. Wightii Mitt. M. Ind. os. p. 74 .

- As. : M. Neilgherr., Ceylan.

strumiferum Dicks. - Cynodontium polycarpum var. strumiferum styrticum Ren. - Br. torquescens $f$. monoica.

subaeneum Hpe. el C. M. in Linn. 1853, p. 494.

2. - Pac.: Austral. fel.

subapiculatum Hpe. Symb. 1872, p. 51.

1. $\quad-$ Am merid.: Brasil, austr. or.

subareoblastum C. M. in Dusen M, Camer, n. 115 a.

- Afr. : M. Cameroon.

subargenteum Hpe. in Linn. 1874, p. 213.

$2 . \quad-A f r$ : Madagascar.

Exs. : Rab. Bryoth. eur. n. 1277.

subatropurpureum C. M. in Linn. 1871-73, p. 147.

2. - Pac.: Austral, or.

subcapillifolium C. M. - Brachymenium. 
subcurvatum Mitt. - Webera.

subenerve Brid. - Eriopus remotifolius?

suberythrocarpon C. M. in Bot. Zeit. 1\$56, p. 407.

Br. erythrocarpon var, australis $\mathrm{H}_{\mathrm{pe}}$, in Pl. Preiss, Nov. Holl.

2. $\quad-$ Pac, : Austral.

subglobosum Schtieph. in Fl. LXXI, p. 176.

Syn. In fiss, rup. - Eur. : Helvet. (Albula).

subobliquem Lindgr. - Br. pseudo-triquetrum.

subobtusifolium C. M. in Centralbl. n. 2-4.

2 .

- As. : Penins, Tschutschica.

subpachypoma Hpe. in Linn. 1869-70, p. 518.

2? $\quad$ - Pac. : Austral, fel.

subpilosum Mitt. M. austr. am. p. 307.

2. $\quad-$ Am. merid. : And. Quitens. ; Peruv.

subpurpurascens Kindb, in Mac. Cat. p. 119.

2. Terr. humid. - Am sept. : Columb. brit.

Exs. : Mac. Canad. M. p. 593.

subroseum Besch. - Rhodobryum.

subrotundifolium Jaeg. Ad. II, p. 707.

Argyro-Bryum subrotundum Hpe. in Linn. 1876, p. 312.

Ster. - Pac. : Austral or.

subrotundum Brid. Mant. M. p. 118 et Bryol. univ, 1, p. 673; Bryol. eur. IV (mon. suppl. p. 9), t. 361; C. M. Syn. I, p. 275; W. P. Sch. Syn. II ed. p. 434.

$\mathrm{Br}$, brunnescens Sahleich, in sched.

Br. caespiticiforme de Not. Epil. p. 398 ?

$\mathrm{Br}$. caespiticium Wils, in Kew, Jourm, bot. p. 331.

Br. cernuum ej. l. c.

Br. pallescens $\delta$ subrotundum Bryol. eur. IV (mon. p. 53), t. $360 \delta$

Br. pohliaeforme Brid, Bryol, univ. I, p. 687.

Br. pumilum Wils. $l$. $c$.

1. Ad terr. humos, et in rup. fiss. - Eur. : Alp. Norveg., Sudet., Salisb., Stir., Austria super., Carinth., Tirol., Helvet. As.: Jenissei inf., Himalaya. Am. sept. : Groenland, Columb. brit., Wyoming, Colorado, Calif.

Exs. : Mac. Canad. M. n. 458.

subrotundum Mitt. - Br. Taylori.

subsmaragdinum C. M. - Brachymenium.

sublurbinatum C. M. - Br. turbinatum var. imbricatum.

subulatum L. - Barbula.

var. $\beta$ Weiss. - Barbula muralis.

Svaraianum C. M. - Rhodobryum.

Sullivani C. M. mss. ; Broth. in Oefv... 1893, p.

2 ; o ign. $\quad-$ Pac. : Austral. (Victoria).

synoico-caespiticium C. M. el Kindb. in Bidr. p. 454 (nom.) et in Mac. Cat. p. 128.

Syn. Ad terr. aren. - Am, sept. : Columb. brit.

Exs. : Mac. Canad. M. n. 513.

synoico-crudum C. M. - Webera.

syntrichioides C. M. - Rhodobryum. 
syriacum $L t z . M$. Ehrenb p. $45, t$. XII.

Webera sacra ej. (fid. Jur, et Milde Beitr... p. 597).

W. sinaïtica $e j . p l$. of (forsan ! fid. iisd.).

2? - As. : Pers., Caucas., Taurus, Syr.

sysphinctum Limpr. Eimige neue Art... 1883, p. 240 et Laubm. Deutschl. $I I, p .352$.

Syn. In aren. humid. - Eur. : Norveg.

systylium C. M. - Brachymenium.

Taitae C. M. in Fl. 1879, n. 24.

Ster.

- Afr. : M. Kenia.

tasmanicum Hpe. in Linn. 1852, p. 714.

Syn.

- Pac. : Tasman.

tauriscorum Limpr. - Br. archangelicum.

Taylori C. M. Syn. I, p. 264 .

Acidodontium subrotundum H. f. et W. in Lond. Journ. of bot. 1846, p. $451, t .164$.

Brachymenium subrotundum Tayl. in op. cit. p. 56.

Bryum subrotundum Mitt. M. austr, am, p. 287.

2. Ad arbor. - Am. merid. : And. Quitens.

tectorum de Not. - Br. caespiticium $x a r$. imbricatum.

tegulare, humile, pilosum et incanum Dill. - Barbula muralis.

tenellum C. M. - Brachymenium.

Teneriffae Hpe. mss, ; C. M. in Bot. Zeit. 1862, p. 12.

2.

- Afr.: Ins. Teneriff.

tenerum Vill. - Barbula.

tenue $\left\{\begin{array}{l}\text { Dicks. - Ceratodon purpurens. } \\ \text { Ravaud. - Br. Funkii var. tenue. } \\ \text { imberbe et pallidum, foliis crebrioribus Dill. - Barbula fallax. } \\ \text { stellatum, setis purpureis Dill. - Ceratodon purpureus. }\end{array}\right.$

tenuicaule Mont. in Ann. sc. nat. 1845, IV, p. 104 el Syll. p. 32 ; C. M. 2.

Syn. I, p. 293; Mitt. M. austr. am. p. 307.

tenuifolium H. f. et W. - Webera?

tenuissimum Tayl. - Eccremidium arcuatum.

terebellum Hpe. in Limn. 1863, p. 130; Mitt. op. cit. p. 311.

Hermaphr. (Hpe.) 2 (Mitt.). Terr. - And. merid. : And. Nov. Granat. et Boliv.

Exs. : Mandon PJ. Boliv, n. 1666.

teres Lindb. in Oefv... 1866, p. 545.

Br. nitidulum var. teres Berggr. M. Spetsb, $n .76 b$.

1. Terr. - Eur. : Spitzberg, ins. Ursor. Am. sept. : Franz Joseph Fjord, ins. Sabine.

teretiusculum Hook. - Br. alpinum.

terminale C. M. in Linn. 1878-79, p. 30 ?

2. - Am, merid. : Argentin. Tueum.

tetragonum Dicks. - Conostomum boreale.

Thomsoni Mitt. M. Ind. or. p. 73.

Br. cuspidatum Wils. in Kew Journ, bot. IX, p. 364.

2.

- As. : Tibet. oce. 
tibetanum Mitt. op. cit. p. 72.

Br. caespiticium Wils, op. cit, p. 332.

1.

- As. : Tibet. occ.

comentosum $\left\{\begin{array}{l}\text { Brid. - Br. capillare var. domingense. } \\ \text { Sw. - Breutelia. }\end{array}\right.$

tophaceum DR. et Mont. in Ann. sc. nat. XII, p. 319 el Mont. Syll. p. 33;

C. M. Syn. II, p. 574 .

2. Ad rivul. - Afr.: Alger.

torquescens Brysl. eur. IV (mon.p. 49), t. 358 ; C. M. Syn. I, p. 277;

W. P. Sch. op. cil. p. 431.

Br. capillare var. torquescens Husn. Muscol. gall, p. 240.

Syn. Ad terr. lapidos., mur. et rup. - Eur. : Snec., Angl., Hibern.,

vall, Rhen., Helvet, occ., zona merid. As, : Himalaya occ., Kashmir, Pers., Caucas,, As. min. Afr.: Alger,, ins. Canar, Madeir.,

Transvaal, C. B. Sp. Am. sept. : Nov. Scot? Gaspes. ? Nevada,

Texas, Calif. Am. merill. : Ins. Chıloë, Montevideo. Pac.: Austral.,

Nov. Zeland., Tasman.

Exs. : Mandon M. Mad. n. 20 bis.

Rab. Bryotb. eur. n. 331, 875, 933.

Rehm. M. Afr. austr. n. 560.

Sull, et Lesq. M. bor, am. II ed. n. 280.

* var. brevifolium Lindb, in Bolet. d. Soc. Broter. 1839, VII.

- Eur. : Lusitan.

" var. gracile Besch Cal. M. Alger. p. 24.

- Afr. : Alger.

" $f$. monoica Spi. M. Pyr. n. 131 et in Edinb. Tians. 185"), III, p. 158

$\mathrm{Br}$. brunnescens Ren. in Rev. bryol. 1883, p. 81.

Br. fuscescens Spr. in Edinb. Trans. l. $\sigma$.

Br. styrticum Ren, in op. eit. p. 82.

1.

- Eur. : Pyren.

torquescens W. P. Sch. - Br. pseudo-torquescens.

tortifolium Brid. - Br. cyclophyllum.

tortuosum L. - Barbula.

Tozeri Grev. - Webera.

trachyticola C. M. - Brachymenium.

trematodonteum C. M. - Weber:

Drumm. - Meesea uliginosa var. alpina.

Hedw. - Webera nutans.

L. - Meesea uliginosa.

acaulon palustre minimum, setis et capsulis oblong is Dill.

- Ceratodon purpurens.

trichodes

acaulon palustre minimum, setis el capsulis brevissimis Dill.

- Seligeria pusilla.

aureum capilulis piriformibus nutantibus Dill. - Leptobryum piriforme.

aureum capsulis incurvis oblusis in selis longis Dill. Meesea uliginosa.

capsulis rubris cernuis Dill. - Dicranella varia.

late virens capilutis cernuis oblongis Dill. ... Webera nutans.

var, longiseta Drumm. - Meesea uliginosa.

var, minor Drumm. - Meesea uliginosa var, minor. 
Irifarium Gmel. - Didymodon luridus.

triquelrum Drumm. - Meesea Albertini.

triste de Not. Cron. briol. ital. et Epil.p. 393 ; W. P. Sch. op. cit p. 457.

Br. capillare var. triste Limpr. Laubm. Deutschl. II, p. 377.

2. Ad saxa granit. madid. - Eur.: Alp. Rhaet., Ital. sup. (pr. lac. Major.).

triste C. M. - Br. pertriste.

truncatulum $\left\{\begin{array}{l}\text { Ehrh. - Pottia lanceolata var. gymnostoma. } \\ \text { L. - Pottia truncata. }\end{array}\right.$

Iruncalum Gmel. - Pottia truncata.

Brid. - Rhodobryum.

H. f. et W. - Rhodobryum leptothecium.

trucorum H. f. et W. - Rhodobryum subtomentosum?

W. P. Sch. -- Rhodobryum Lechleri.

Wils, - Mnium rostratum var, ramosum.

Tryoni Broth. in Oefv... 1893, p.

2. $\delta^{*}$ ign. $\quad-$ Pac, : Austral. or. (Queensland).

turbinatum (Hedw.) Schwaegr. Suppl, 1, II, p. 109; Brid. Bryol. univ. 1, p. 681; Bryol. eur. 1V (mon. p. 65), t. 372 (excl. var. $\gamma$ ) ; C. M. Syn. I, p. 259 ; W. P. Sch. op. cit. p. 461.

Pr. appressum Wils. in Kew Journ. bot. p. 365.

Br cuspidatum ej. p. 364 p.p.

Br. distans ej. $l$. c.

Br. nigricans Dicks. Fasc. IV Pl. crypt. p. 15, t. II, f. 10; Brid. op. cit. p. 682.

Br. palustre complicatum rubens, capsulis turbinatis pendulis Dill. Hist. M. p. 406, $t .5 \mathrm{l}, f .74$.

Br. turbinatum var. nigricans $H$. et T. Musc, brit. p, 122.

Hypnum turbinatum W. et M. Bot. Taschb. p. 282.

Mnium nigricans Brid. M. Rec. II, III, p. 90.

Mn, turbinatum Hedw. M. frond. III, p. 22, t. 8.

2. In loc. aren., glareos, et turfos. - Eur. : Ex Ital. super, usq. in Seandin. As. : Tibet. occ., Kurdistan., Caucas, occ. et centr., Syr., Arab. Petr. Am. sept. : Groenland, Gaspes., Ontario, Athabasea, Columb, brit., ins. Vancouver, Utah. Am. merid. : And. Quitens.

Exs. : Rab. Bryoth. eur. n. 96, 675, 970, 1278.

Sull. et Lesq. M. bor. am. II ed,, p. 287.

var. gracilescens Bryol, eur, - Br. Schleicheri.

" var, gracilifolium Besch. Cat. M. Alger, p. 26. - Afr. : Alger.

" var, imbricatum W. P. Sch. in W. Sch. M. Abyss. I1, n. 46.

Br. subturbinatum C. M. in Bot. Zeit. 1858, p. 155.

$$
\text { - Afr. : Alp. Abyss. }
$$

var. latifolium Bryol, eur. - Br. Schleicheri var. latifolium.

var. minus Kth. - Mielichhoferia Jamesoni.

var. nigricans $\mathrm{H}$, et $\mathrm{T}$. $-\mathrm{Br}$. turbinatum.

var. pallens Drumin. \{ (fid. C. M.). - Br, uliginosum.

(fid. Kindb.). - Br. pallens.

var. praelongum C. M. - Br. Schleicheri.

var., $\mathrm{H}$, et $\mathrm{T}$. $-\mathrm{Br}$. intermedium.

var., eor. $-\mathrm{Br}$. longisetum.

var., Schwaegr, $-\mathrm{Br}$, versicolor. 

turbinatum $\left\{\begin{array}{l}\text { Drumm, - Br. bimum. } \\ \text { Drumm. p.p. - Br. pallescens. }\end{array}\right.$ $\mathrm{H}$, et Tayl. - Br. pallens. eor. - Br. Schleicheri.

turbinitiforme W. P. Sch, in W. Sch. M. Abyss.

- Afr.: Abyss.

turgidum Sw, - Aulacomnium.

uliginosum (Br.) Bryol. eur. IV (mon. p. 18), t. 335; C. M. Syn. 1, p. 271 ; W. P. Sch. op. cit.p. 425.

Br, caespiticium syn. Schwaegr, Sp. M. p. 60.

Br. cernuum Lindb. M. Scand, p. 16.

Br, turbinatum var, pallens Drumm. M. bor, am. I ed, n. 267 (fid. C. M.).

Clndodium uliginosum Brid. Bryol. univ. I, p. 811.

Cynontodium cernuum Hedw. Sp. M. p. 58, t. 9 (fid. Limpr.).

Didymodon cernuus Sw. M. Suec. p. $29, t . I, i, 9$ (fid. Lindb. l. c.).

Pohlia uliginosa $\mathrm{Br}$. in schsd.

Syn. Loc, uligin. et ad rivul. - Eur, : Suec., Boruss, sept, Dania merid., Hanovr., Harz, Westphal., Siles., Rhoengeb., Hassia, Salisb, Hungar., Austr. inf., Tirol., Alp. Rhaet., Angl., Normann., vall. Rhen., Gall. centr. (Morvan). As. : Amour, Saghalien, Caucas. Am. sept. : Labrador, Anticosti, Terr, nov., New Brunswick, Gaspes., lac. Super., Columb. brit., Wyoming, Montana, reg. sept., oce. et or.

Exs. : Mac. Canad M. n, 168.

Rab. Bryoth, eur, n. 274, 931,

Sull. et Lesq. M. bor. am, II ed. n. 263.

- var rivale Limpr. in LXI Jahresb. d. Schles. Ges. f. Vaterl. Cult. 1884, p. 224 et Laubm. Deulschl. II, p. 325.

Arenic. - Eur. : Norveg. (Dovre).

Umbraculum Burch. - Rhodobryum.

undulatum $\left\{\begin{array}{l}\text { L. - Atrichum. } \\ \text { Roth. - Mnium. }\end{array}\right.$

unguiculatum $\left\{\begin{array}{c}\text { Huds. - Barbula. } \\ \text { el barbatum surculis in summitate crassioribus Dill. - } \\ \text { Barbula unguiculata. } \\ \text { et barbatum tenuius et stellatum crassioribus Dill. - } \\ \text { Barbula ungaiculata. }\end{array}\right.$

unilaterale Gmel. - Leptotrichum homomallum.

urnigerum Neck. - Pogonatum.

utriculatum C. M. in Bot. Centralbl. 1883, n. 2. 4.

Syn.

- As. : Penins. Tschutschica.

vagans $\mathrm{H}$. f. et $\mathrm{W}$. - Philonotis.

Valdiviae Lts. Moosl. p. 157.

2.

- Am. merid. : Valdiv.

Valenciae C. $M$, in Linn. 1378-79, p. 479.

2.

- Am. merid. : Venezuela.

validinervium C. M. in Engler's Bot. Jahrb. 1883, p. 77 el in ForchungsSyn. reise...p. 15.

validius Hpe. Enum. M. Brasil. p. 32.

- Am. merid. : Brasil. austr. or. 
vancouveriense Kindb. in Bull. Torr. bot, Clıb, 1889, p. 95.

2. Ad decliv. humid. - Am. sept. : Ins. Vancouver.

Exs. : Mac. Canad. M. n. 457.

varians C. M. in Engler's Bot. Jahrb. 188:3, p. 87 et in Forchungsreise... p. 60 .

Br. varium $H$. $f$. et $W$. ?

2. Ad terr. humid. - Pac. : Nov. Zeland.

« var. mucronatum C., M, l, $c$.

Ut et cum typ.

varium Hook. f. et Wils. Fl. of the N. Zeal. II, p. 85, t. $85, f .4$ et Handb. p. 444.

velutinum C. M. - Brachymenium.

ventricosum \{ Dicks. - Bryum psendo-triquetrum.

var., Schwaegr. - Br. Duvalii.

Venturii C. M. in de Not. Epil. p. 408; W. P. Sch. op. cit. p. 469.

Br, elegans Vent, et Rott. Enum. p. 35 p.p.

Fl. et fr. ignot, In irrig, editior. - Eur. : Tirol. merid. veronense de Not. Epil.p, 409 ; W. P. Sch. op cit. p. 469.

$\mathrm{Br}$. claviger et virescens (fid. Limpr. Laubm. Deutschl. I1, p. 418).

Fl, et fr. ignot. In aren. Athesis. - Eur. : Ital. super. (Verona).

versicolor A. Br. in Bryol, eur. IV (mon. p. 75), t. 379 ; C. M. Syn. I, p. 308; W. P. Sch. op. cit. p. 439.

Br, turbinatum var. Schwaegi. Sp. M. p. 56 (fid. C. M.).

2. In aren. ad fluv. rip. - Eur.: Westphal,, vall. Rhen., Helvet., Tirol. merid., Salisburg., Stiria. (Marinth., Austr., Pedem Am. sept. : Florid.

Exs. : Rab. Bryoth. eur. n. 330, 934.

versicolor Kaurin. - $\mathrm{Br}$. excurrens.

verticillatum $\left\{\begin{array}{l}\text { Dicks. - Gymnostomum eurvirostre. } \\ \text { Hpe. - Rhodobryum. } \\ \text { Lightf. - Blindia acuta. } \\ \text { L. - Eucladinm. }\end{array}\right.$

var. $\beta$ Huds. - Blindia acuta.

vinosulum Besch. in Ann. se. nat, VII ser., II, p. 91.

Ster. $\quad-A f r$. Ins. Mayotte.

Exs. : Mar. n. 264.

virens $\left\{\begin{array}{l}\text { Dicks. - Weisia viridula. } \\ \text { Sw. - Cynodontium. }\end{array}\right.$

virescens Kindb. in Rev. bryol. 1884, p. 22.

Argyrobryum virescens ej. Laubm. Schwed. et Norv. p. 78.

Br, claviger et veronense (fid. Limpr. Laubm. Deutschi. IJ, p. 418).

Fl. et fr. ignot. Saxic. in rivul, - Eur: : Norveg.

viridans Wils. (1) $\left\{\begin{array}{l}\mathrm{Br} \text {. inclinatum var. } \\ \mathrm{Br} \text {. intermedium var. } \\ \mathrm{Br} \text {. pendulum. }\end{array}\right.$

(1) Cl, Mitt. (M, Ind, or. p. 71) has tres spec. ad unam, contra fere omn. bryolog: sententiam, reducens, cui earum no... Bryi viridantis imposuit $\mathrm{cl}$. Wilson mili latet. 
viridatum C. M. - Webera.

viride Philib. in Rev. bryol. 1886, p, 25.

Syn.

- Eur. : Norveg.

viridescens Welw, et Duby in Mem... Genève, 1870, p. 4, t. II, f. 2.

1. In prat. - Afr. : Angola.

viridissimum Dicks. - Zygodon.

viridulum $\left\{\begin{array}{l}\text { Dicks. - Fissidens exilis. } \\ \text { L. - Weisia. }\end{array}\right.$

Wagneri C. M. Syn. $I I, p .570$.

2 .

- Am. merid. : Columb.

Wahlenbergii Schwaegr. - Webera albicans.

var. glaciale Bryol. eur. - Webera albicans var. glacialis.

warneum Bland. in Brid. Bryol. univ, 1, p 675; Bryol. eur. IV (mon. p. 20), t. $340 ;$ C. M. Syn. I, p. 272; W. P. Sch. op. cit. p. 425.

Br. caespiticium $\beta$ warneum Schwaegr. Suppl. III, I, II, p. 109.

Br. flagellare Brid. Mant. M. p. 118.

Hypnum caespiticium $W$. et M. Bot. Tasch. p. 285 p.p.

Pohlia cirrifera de Not. Mant. M. n. 9.

P. warenensis Schwaegr. Suppl. III, I, p. 2, t. 236.

1. rar. syn. In udis aren, et limos. - Eur.: Suec,, Angl., German. sept., Siles., Hungar., Ital, super. As. : Himalaya occ. Am. sept. : Calif.

Exs. : Rab. Bryoth. eur, n. 623, 834 et b, 1084.

Un. itin. 1867, n. 105.

warneum Mac. - Br. Edwardsianum.

Weigelii Spreng. - Webera commutata.

Weisia $\{$ C. M. - Brachymenium.

Dicks. - Leptotrichum homomallum.

Welvoitschii Duby. - Brachymenium.

Wesleyi Par.

Br. origanum Bosw. in Lond. Jowrn. of bot. Febr. 1880 et in Rev. bryol. 1880, p. 45.

Ster.

- Eur. : Anglia (Teesdale).

Wightii Mitt. - Rhodobryum strigosum.

Willdenovii Jur. - Br. longisetum.

Wilsoni Mitt. - Brachymenium.

Wrightii Sull. in Proced. Am. Acad... 1859, p. 278.

1 vel. syn. $\quad-A m$. sept. : Fret. Rehring.

Wrightii Mitt. - Leptotheca.

Zierii Dicks., Drumm. - Zieria julacea.

Zollingeri $\left\{\begin{array}{l}\text { Duby. - Rhodobryum. } \\ \text { Wils. - Rhodobryum roseum. }\end{array}\right.$

zonatiforme $\mathrm{Par}$.

Br. zonatum C. M. in Dusen M. Camer, n. 340.

- Afr. : M. Cameroon.

zonatum W. P. Sch. op. cit. p. 472.

Ster. In humid. - Eur. : Norveg. sept.

sonatum C. M. - Br. zonatiforme. 
zygodontoides C. M. in Engler's Bot. Jahrb. 1883, p. 83 et in Forchungs.

2. reise,.. Bot. p. 40.

BRYUM POLLA Adans, ; Brid. Bryol. univ. I, p. 688.

affinis Schwaegr. - Mnium.

Auberti Schwaegr. - Bryum.

binervis Brid. - Lepidopilum polytrichoides.

Commersoni Schwaegr. - Rhodobryum.

cruda L. - Webera

cuspidata L. - Mnium.

cylindrica Hsch. - Mnium? (Cf. Brill. l. c. p. 712).

elliptica Brid. - Mnium punctatum.

erythrocaulon Sehwaegr. - Rhodobryum.

heterophylla Hook. - Mnium.

horna L. - Mnium.

latifolia Schwaogr. - Bryum Schleicheri var. latifolium.

ligulata Schreb. - Mnium undulatum.

lycopodioides Schwaegr. - Mnium.

orthorhynch \& Brid. - Atrichum tenellüm.

punctata Brid. - Mnium.

rosea L. - Rhodobryum.

$\beta$ dominghensis Brid. - Rhodobryum Antillarum.

$Y$ gigantea Schwaegr. - Rhodobryum giganteum.

rostrata Schrad. - Mnium.

servatr Schrad. - Mnium.

$\beta$ pensilvanica Brid. - Mnium serratum var. apiculatum?

spinosa Voit p.p. $\left\{\begin{array}{l}\text { - Mnium. } \\ \text { - Mnium affine. }\end{array}\right.$

stellaris Reich. - Mnium

subenervis Schwaegr. - Eriopus remotifolius.

truncorum Brid. - Rhodobryum.

Umbraculum Burch. - Rhodobryum.

BRYUM WEBERA Brid. Bryol. univ. I, p. 264.

alpina $\mathrm{H}$, et $\mathrm{H}$. - Webera longicolla.

$\beta$ bracliycarpa Hsch. - Webera longicolla.

bicolor $\mathrm{H}$, et $\mathrm{H}$. - Webera nutans var. bicolor. cuespitosa eor. - Webera nutans var. caespitosa.

erecta Kth. - Brachymenium mexicanum.

fasciculata $\mathrm{H}$. et H. - Weiera nutans.

flexuosa Brid. - Webera Brideliana.

geniculata Brid. - Bryum.

(1) In Enum. Kindberg. nomina nuda :

Br. afro-turbinatum Rehm. arcuatum $H$. f. et Wils. (nom. mutandum ? Cf. no 30 ). aulacomnioides $\boldsymbol{C}$. $M$. austro-triste $C . M$. capensi-argenteum $C, M$. Fusijame $\mathcal{C}$. $M$. gracili-torquescens $C$. M homalobolax C. M. et Kinulb. leucothrix $C . M$.

lonchopyxis $C . M$. longinerve Lindb.
Br. Massabieae C. M. pervirens $C, M$. pseudo-sclerodictyon C. M. pulchellum $H$. $f$. et $W$. subaterrimum Rehm. subcrispatulum C. M. subcrispatum C. $M$. subleptosphaeroideum C. $M$. subleptothecium C. M. (an Rhodobryum ?) uremiocarpum $C, M$. viridulum $C . M$. 
grimsulana Brid. - Webera longicolla.

intermedia Brid. - Bryum.

lacustris W. et M. - Bryum.

longicolla Brid. - Webera.

longiseta Brid. - Webera nutans var. longiseta.

macrocarpa $\mathrm{H}$. et $\mathrm{H}$. - Webera elongata var. macrocarpa.

nulans Brid. - Webera.

$\beta$ minor Brid. - Mielichhoferia longiseta.

pendula Hsch. - Webera nutans var. subdenticulata.

piriformis L - Leptobryum.

subdenticulata Brid. - Webera nutans var. subdenticulata.

BUXBAUMIA Hall. Hist. stirp. Helvet. II, p. 83, n. 27 (5 sp.).

aphylla Hall. l. c.; Bryol. eur. IV (mon. p. 5 et Suppl. p. 4), t. 427 et VI, t. 641 ; C. M. Syn. I, p. 15l; W. P. Sch. Syn. 11 ed. p. 549.

B. caulescens Selmid. Diss, de Buxb. p. 25, n.I, c. ic.

B. vulgaris Brid. Bryol, univ, I, p. 329 .

Hippopodium aphyllum Fabr. Prim. Fl. Butisb, p. 31; Roehl. Deutsch. Fl. II ed., III, p. 120.

Muscus capillaceus, aphyllus, capitulo crasso bivalvi Buxb. Cent. II, p. 18, t. 4; Dill. Hist. M. p. 477, $t .58, f .5$.

Saccophorus aphyllus $P$. B. Prodr. pp. 30 et 87 .

2. In ericet. - Eur. : E reg. campestr. usq. in alp. per zon, iutermed. As. : Volga, Jenissei sup., Amour. Am. sept. : Nov. Scot., Quebec, Nov. Angl., Massachussets, Columb. brit.

Exs. : Sull. et Lesq. M, bor. am. Il ed. n. 331.

aphylla Schwaegr. p.p. - B. indusiata.

var. indusiata Wahlenb. - B. indusiata.

var, viridis Moug, et Nestl, - B. indusiata.

caulescens Schmid. - B, aphylla.

foliosa L. - Dị hyscium.

indusiata Brid. Bryol. univ. 1, p. 331; Bryol, eur. IV (mon.p. 6 et Suppl.p. 5), t. 428 et VI, t. 641 ; C.M. Syn I, p. 152 et II, p. 553; W. P. Sch. Syn. II ed. p. 550.

B, aphylla Sehwaegr. in L. Sp. pl. Ved., V, II, p. 24, n. I p.p.

B. aphylla var. indusiata Wahlenb. Fl. Suec. II ed., II, p. 760.

B. aphylla var, viridis Moug. et Nesll, in DC. Fl. fr., III ed., V, p. 227, n. 1323 et Stirp. crypt. Voges. Rhen, n. 724.

2. Lignic. - Eur. : Ut praecedens: sporadica. As. : Caucas. Am. sept. : Columb. brit.

Exs. : Rab. Bryoth, eur, n. 110 b.

javanica C. M. Syn. I, p. 152; Bryol. jav. I, p. 34, t. 24 (1).

1. Lignic, et rupic. - As. : Java.

Piperi Besl. in Bull. Torr. bot. Club, 1893, p. 116.

2. Lignic. - Am. sept. : Washington, Idaho.

sessilis Schmid. - Diphyseium foliosum.

tasmanica Mitt. in Journ. of the Linn. Soc. 1859, p. 96.

- Pac. : Tasman.

vulgaris Brid. - B. aphylla.

(1) Cf. W, P. Sch. Syn, II ed. p. 550. 
Gacodon Lindb, in Mitth, Soc. pr. Faun. et Fl. Fenn, $9^{\text {bri }} 1882$ (subgen. Pohliae $=$ Webera $)$.

CALLIBRYON Zenk. et Dietr. M. Thur, fasc. XI, n. 41. polytrichoides Wieb. - Atrichum undulatum. undulatuin Z. et D. - Atrichum undulatum.

CALLICOSTA $C M$. in Linn, 1848, p. 187.

affinis C. M. - Pilotrichum.

bipinnata C. M. - Pilotrichum. composita C. M. - Pilotrichum. delicatula Besch. - Pilotrichum. evanescens C. M. - Pilotrichum bipinnatum var, evanescens, filiformis C. M. - Hookeria. hypnoides C. M. - Pilotrichum.

CALLicostella $C$. M. Syn. II, p. 216 (sect. Hookrriar, poslea gen. propr.). abrupta Mitt. - Hookeria. africana Mitt. - Hookeria. apophysala Mitt. - Hookeria. Ascensionis Mitt. - Hookeria. aspera Mitt. - Hookeria. asprella Mitt - Hookeria. Beccariana Mitt. - Hookeria. Belangeriana Mitt. - Hookeria. Beyrichiana Mitt. - Hookeria. bisexualis Mitt. - Hookeria. caldensis Mitt. - Hookeria. Campbelliama Mitt. - Hookeria. chionophylla C. M. - Hookeria. ciliata Jaeg. - Hookeria. crenata Jaeg. - Hookeria. cruceana Jaeg. - Hookeria. cuspidatissima Jaeg. - Hookeria. daltonioides Jaeg. - Schizomitrium. depressa Jaeg. - Hookeria. depressula Jaeg. - Hookeria. disticha Angstr. - Hookeria. filescens Jaeg. - Hookeria. Herminieri Jaeg. - Hookeria. heterophylla Ångstr. - Hookeria. Hornschuchiana Jaeg. - Hookeria. hypnacea Jaeg. - Hookeria. lacerans Jaeg. - Hookeria. Leprieurii Jaeg. - Schizomitrium. leptocladula C. M. - Hookeria. longipedunculata Jaeg. - Hookeria. lorifolia Jaeg. - Hookeria. Marliana Jaeg. - Hookeria. Merkelii Jaeg. - Hookeria. microcarpa Jaeg. - Hookeria. mollis Jaeg. - Hookeria. obliqua Jaeg. - Schizomitrium. oblongifolia Jaeg. - Hookeria. obscura Jaeg. - Schizomitrium. Erstedliana Jaeg. - Hookeria. pallida Jaeg. - Ilookeria. 
papillata $\left\{\begin{array}{l}\text { C. M. - Hookeria. } \\ \text { Mitt. (Sam, M.). }\end{array}\right.$

pellucida Jaeg. - Hookeria

Prabaktiana Bryol. jav. - Hookeria.

pycnoptera C. M. - Hookeria.

radicans Jaeg. - Hookeria.

rivularis Jaeg. - Hookeria.

rufescens Jaeg. - Hookerla.

saxalilis Jaeg. - Hookeria.

scabriseta Jaeg. - Hookeria.

scabriuscula Jaeg. - - Hookeria

strumulosa Jaeg. - Hookeria.

Taylori Jaeg. - Hookeria.

tristis Rehm. - Hookeria.

Calliergon Lesq. et Jam. Man. p. 404 (subgen. Hypsi).

GALOMNION Hook. f. et Wils. Fl. of the N. Zeal. II (2 sp.).

denticulatum Mitt. in Jown. of the Linn. Soc. X, p. 192.

Arbor. - Pac. : Ins. Samoa.

laetum Hook. f. el Wils, op. cit. t. 87, f. 5 et Handb. N. Zeal. Fl. p. 490.

Gymnostomum (Eucladon) complanatum eor. in Lond. Joum, of bot. 1844, p. $538 ;$; . M. Syn. I, p. 190.

2. Filicic. et lignic. - Pac. : Nov. Zeland, sept, et med.

GALXMPERES Sw. Jahrb. d. Gewaechsk. von Sprengel, Schrad. und Link, 1818, t. I, f. I (95 sp.).

aeruginosum Hpe. mss.; Lac. Sp. nov. M. Arch. ind. p. 7, t. 5 A.

2. Ster. Arbor. - As. : Ins. Philippin., Celebes.

africanum (Mitt.) Par.

Thyridium africanum Mitt, in Jown. of the Linn. Soc. 1886, p. 303.

Ster. - Afr. : M. Usagara.

Afzelii.Schwaegr. Suppl. II, II, p. 3, t. I p.p.;Brid, Bryol. univ. II, p. $86 ;$; . M. Syn. I, p. 523.

C. Palisoli Schwaegr. Suppl. I, I, p. 334 p.p.

Dieranum astulatum Brid. op. cit. $I, p .458$.

2. Arbor. - Afr. : Sierra Leone, ins. Principis.

var. moluccense Brid. $-\mathrm{C}$, moluccense.

albo-vaginatum W. Arn. - Syrrhopodon.

androgynum Mont. - Syrrhopodon rigidus.

arcuatum C. M. in Engler's Bot. Jahrb. 1883, p. 85 et in Forchungsreise...p 51 ,

Ster. Arbor. - Pac. : Nov. Guinea.

Ascensionis C. M, in op. eit. pp. 84 et 42.

Ster.

- Afr. : Ins. Ascension.

asperum C. $M$. in Dusen M. Camer. n. 400.

- Afr. : M. Cameruon.

asterigerum ej. I. c. n. 82 .

asteristylum ej. l. c. n. 751 .

- Afr. : M. Cameroon. 
Beccarii Hpe. in Nuov. Giorn. bot. ital. 1872, p. 279.

- As. : Borneo (1).

Borg ni Kiaër in Borgen M. Mad.

- Afr. : Madagascar.

brachypelma C. M. in Dusen M. Camer, $n .85$.

- Afr. : M. Cameroon.

campylopodioides $C . M . l$. c. n. 151 .

- Afr.: M. Cameroon.

caudatum C. M. in Fl. $1879, n .24$.

Ster.

- Afr. : M. Kenia.

chamaelonteum C. M. in Engler's Bol. Jahrb. 1883, p. 86.

- Pac. : Nov. Guinea.

\& var. nanum C. $M$. in op. et $l$. cc.

Arbor. - Pac. : Nov. Hannovria.

chlorosum Hpe. Enum. M. Brasil. p. 6.

Ster.

- Am. merid. : Brasil. austr. or.

chrysoblastum C. M. in Engler's Bot. Jahrb. 1883, p. 88 et in Forchungsreise... p. 63.

Ster. Terr. humid. - Afr. : Monrovia.

constrictum-Sull, in Wilkes Exped. p. 6, t. 3, f. A.

Thyridium constrictum Mitt. Sam. M. p. 188.

Arbor. - Pac. : Ins. Samoa.

couguiense Besch. Fl. bryol. Nov. Caled. p. 206.

2 ? Cortic. - Pac. : Nov. Caledon.

crassilimbatum Ren. et Card, in Bull. Soc. roy. bot. Belg. 1893, 11, p. 18.

Ster. - Afr. : Ins. Borbon.

crassinerve (Mitt.) Jaeg. Ad. 1, p. 329.

Codonoblepharum crassinerve C. M. Polyn. p. 67.

Thyridium crassinerve Mitt. in Proc. of the Linn. Soc. 1868, p. 189.

Arbor. - Pac. : Ins. Samoa.

? crispum Aust. in Coult. Bot. Gaz. IV, p. 151.

Syrrhopodon? crispus ej. in op. cit. $I I$, p. 109.

Ster.

- Am. sept. : Florid.

cristatum Hpe. in Nuov. Giorn. bot. ital. p. 278. - As. : Borneo.

croceum (Mitt.). C. M. M. Polyn. p. 63.

Syrrhopodon croceus Mitt. M. Ind. or, p. 41.

S. glanco-virens Mitt. Sam. M. p. 75.

Ster. Arbor. -- As. : Ins. Labuan, Singapore, ins. Banca, Java, Sumatra. Pac. : Ins. Fidji, Samoa.

Crügeri C. M. Syn. I, p. 527 ; Mitt. M. austr. am. p. 128.

2. $\quad-A m$. merid.: Ins. Trinitat.

decolorans C. M. in Besch. Fl. bryol. Réunion, etc. $p .58$.

2. $\quad-A f r$. : Ins. Mayotte, Sanct. Maria de Madag.

(1) Berterii Spreng. in Neve Entdeck. III, i. I; C. M. Syn. I, p. 528. Deleatur. 
denticulatum C. M. in Engler's Bot. Jahrb. 1883, p. 86 el in Forchungsreise... p. 52 .

2. Arbor. - Pac. : Nov. Guinea.

disciforme C. M. in Linn. 1848, p. 183 el Syn. 1, p. 525 : Mill. M. austr. am. p. 126.

Arbor. - Am. sept. : Florid. Am. merid. : Ins. Trinitat, Surinam.

Donnellii Aust. - C. Richardi var. Donnellii.

Dozyanum Milt. M. Ind. or. p. 42.

C. moluccense Bryol. jav. I, p. 47, t. 38 (1).

2.

- As. : Ind, or., Java.

Dozyanem Mitt. (Sam. M.) - C. obliquatum.

Duseni $C, M$. in Dusen M. Camer. n. 917.

- Afr.: M. Cameroon.

erosum C. M. in Linn. 1848, p. 182 et Syn. I, p. 524; Mitt. M. austr. am. p. 127 ,

2. Arbor, - Am. merid.: Amazon., Surinam.

fasciculatum $\left\{\begin{array}{l}\text { Dz. et Mk. - C. moluccense. } \\ \text { Mitt. - Syrrhopodon. }\end{array}\right.$

var, heterophyllum Dz. et Mk. - C. moluccense var. heterophyllum.

Gardneri Hook. - Syrrhopodon.

Glaziovii Hpe. Symb. 1877, p. 716.

Ster. $\quad$ - Am. merid. : Brasil. austr. or.

Graeffeanum C. M. M. Polyn. p. 64.

2. Arbor. - Pac. : Ins. Samoa.

Guildingii Hook, el Grev. in Brevoster Edinb. Journ. I1I, p. 223; C.M.

Syn. I. p. 528 ; Milt. M. austr. am. p. 128.

Arbor. - Am. sept. : Ins. S. Vincent, Guadalup.

Hampei Bryol.jav, I, p. 48, t. 39 et II, p. 223.

2. Arbor. et rupic. - As. . Java, Banca, Timor.

Hildebrandti C. M. in Linn. 1876, p. 246.

Ster. Cortic. - Afr.: Ins. Anjouan.

hispidum Ren. et Card. in Bull. Soc, roy. bot. Belg. II, p. 14

2.

- Afr. : Madagascar, ins. S. Maria.

Hobsoni Grev. - Syrrhopodon.

inaequifolium C. M. in Bot. Zeit. 1864, p. 348.

Ster.

-As. : Poulo-Penang.

incurvatum C. M. M. Polyn. p. 64 .

Ster.

integrifolium $C, M$. in Fl. 1886, p. 514 .

Arbor. - Afr: : Kiulu.

intra-limbatum C., M. in op, eit. p. 513 .

2. Muscic. - Afr. : Mossamedes.

Isleanum Besch. Fl. hryol. Réunion, etc. p. 56.

2. Arbor. - Afr. Ins. Seychelles, Nossi-Be.

(1) Cr. Bryol. jav. I1, p. 223. 
Kaernbachii Broth. in Engler's Bot. Jahvrb. 1893, p. 477.

Ster. $\quad-$ Pac. : Nov. Guinea.

Kennedyanum Hpe, in Linn. 1876, p. 303.

Ster.

- Pac. : Austral.

Kurzianum Hpe. in Fl. 1878, n. 6.

- As. : Ins. Andaman.

lanceolatum Hpe. Enum. M. Brasil. p. 6.

Ster.

- Am. merid. : Brasil. austr. or.

latifolium Hpe. in Pl. Preiss. p. 116 ; C. M. Syn. I, p. 525.

2 ? $\quad-$ Pac. : Austral. occid.

leucocoleos C. M. in Dusen M. Camer, n. 76.

- Afr. : M. Cameroon.

leucomitrium C. M. in $\mathrm{Fl}$. 1886, p. 512 .

2. Arbor. - Afr. : Niger.

ligulare Mitt. in Journ. of the Linn. Soc. 1886, p. 303.

- Afr. : M. Usagara.

Lindigii Hpe. in Ann. sc. nat. V ser, III, p. 342; Milt. M. austr. am. p. 127 .

Arbor. - Am. merid. : Nov. Granat.

linealifolium C. M. l. c. n. 756 .

- Afr.: M. Cameroon.

linearifolium C. M. M. Polyn. p. 65.

Ster.

- Pac. : Ins. Samoa.

lonchophyllum Schwaegr. Suppl. I, 11, p. 133, t. 98; Brid. Bryol. univ. $I I$, p. 88 (excl. syn. C. Palisoti); C. M. Syn. I, p. 526; Mitt. M. austr, am. p. 129.

2. Arbor. - Am, sept. : Guadalup. Am, merid.: Ins. Trinitat., Guian. gall., Amazon., Brasil, austr. or.

longifolium Mitt. - C. Motleyi.

loreum Lac. Sp. nov. M. Archip. ind. p. 7, t. 4 C.

2. Ster.

- As. : Borneo.

lorifolium Mill. Sam. M. p. 173.

2 ? Filic. - As. : Borneo, Pac, : Ins, Fidji, Samoa.

"var, neo-caledonicum Besch. Fl. bryol. Nov. Caled. p. 207.

Silvic. - Pac. : Nov, Caled.

Malimbae C. $M$. in Fl. 1886, p. 513 .

2.

- Afr.: Gabon.

Mariei Besch. Fl. bryol. Réunion, etc. p. 57.

2.

- Afr. : Ins. Nossi-Be.

megamitrium C. M. in Dusen M. Camer, n. 495.

- Afr.: M. Cameroon.

microblastum C. M. l. c. n. 807 .

- Afr. : M. Camieroor.

moluccense Sclwoaegr. Suppl. II, II, p. 99, t. 127; C. M. Syn. I, p. 523; Bryol. jav. I, p. 47, t. 37 .

C. Afzelii $\beta$ moluccense Brid. Biyol, univ, II, p. 87.

C. fasciculatum Bryol. jav. I, p.50,t. 41 et II, p. 223 (fid. Mitt.). 
2. Lignic. - As. : Hong-Kong, Amboine, Celebes, ins. Labuan, Rauwack, Ceram ; Singapore, Java, Banca.

« var. heterophyllum Par.

C. fasciculatum var. heterophyllum Bryol. jav. II, p. 223. - As. : Java.

Motleyi Mitt. in Bryol. jav. I, p. 48, t. 38.

C. longifolium ej. in Journ. of the Linn. Soo. 1868, p. 173.

2.

- As. : Ins, Labuan, Borneo.

Mülleri Mitt. - Syrrhopodon.

nanum C. $M$. in Linn. 1875, p. 398.

Ster.

- Afr.: Monbouttou.

Nietneri C. M. in Bot. Zeit. 1864, p. 348.

- As. : Ceylan.

Nossi-Combae Besch. Fl. bryol. Réunion, etc. p. 57.

Fr.ign. - Afr. : Ins, Mayotte, Nossi-Comba.

Exs, : Marie n, 230.

obliquatum C. M. M. Polyn. p. 65.

C. Dozyanum Milt. Sam. M. p. 172.

Ster. Arbor. - Pac. : Ins. Samoa, Tonga, Nov. Gainea.

pachyloma Hpe. in Linn. 1876, p. 247.

Fr, ign.

- Afr. : Ins, Anjouan.

pachyneuron C. M. M. Polyn. p. 65.

Ster.

- Pac. : Ins. Samoa, Tonga.

Palisoti Schwaegr. p.p. $\left\{\begin{array}{l}\text { C. Afzelii. } \\ \text { C. Ricbardi. }\end{array}\right.$

Pandani C. M. in Engler's Bot. Jahrb. 1883, p. 87 et in Forchungsreise...p. 58.

2. Ad Pandanos. - As, : Amboine.

parasiticum (Sw.) Hook. et Grev. in Brewster Edinb. Journ. I, p. 131 ; Milt. M. austr. am. p. 127.

Anoectangiam parasiticum Brid. Sp. M. I, p. 270. Brachypodium? parasiticum Brid. Bryol, univ. I, p. 149; C. M. Syn. I,
p. 750 .

Bryum parisiticum Siv. Prodr. Fl. Ind. oce. p. 139.

Encalypta parasitica $S w$. Fl Ind. occ. III, p. 1739 .

Glyphomitrium parasiticum Brid. Mant. M. p. 31.

Weisia parasitica Mohr in Koen. et Sims, Ann. bot, II, p. 515.

Arbor. - Am. sepl. : Hispaniola. Am. merid. : And, Quitens.

platyloma Milı. M. austr. am. p. 128.

- Am. merid.: Guian. brit.

porrectum Mill. Sam, M. p. 172.

Ster. Lignie. - Pac. : Ins. Samoa.

Principis Broth. in Bal. da Soc. Broter. VIII, 1893.

2. Fr. ign. Arbor. $-A f r$. Ins. Prineip.

pungens C. M. in Engler's Bot. Jahrb. 1833, p. 87 et in Forchungsreise... p. 57 .

Ster. Arbor. - As, : Amboine.

Quintasi Brolh. in Bol. da Soc. Broter. VIII, 183).

2. Arbor. - Afr.: Ins. S. Thomas. 
Rabenhorsti Hpe, et C. $M$, in Fl. I886, p. 512.

2. - Afr. : Sin. Guineens.

repens C. M. - Syrrhopodon.

rhypariophyllum C. $M$. in $\mathrm{Fl}$. 1883, p. 512 .

2. Arbor. - Afr. : Niger.

Kichardi C. M. Syn. I, p. 524 et II, p. 620 ; Mitt. M. auslr. am. p. 127.

C. Palisoti Schwaegr. Suppl, I, I, p. 334 p.p.

2. Arbor. - Am. sept.: Florid., ins. S. Vincent., Guadalup. Am. merid.: Guian., Amazon., Brasil austr. or., ins. Fernando Noronha.

\& var. Donnellii Lesq. et Jam. Man. p. 184.

C. Donnellii Aust. in Coult. Bot. Gaz. IV, p. 151 .

C. Richardi ej. M. Appal. Suppl. n. 489.

$$
\text { - Am. sept. : Florid. }
$$

Richardi Aust. - C. Richardi vas. Donnellii..

rotundatum Besch, in Ann. sc. nat. 1894, p.

2 ? Cortic. - Pac. : Tahiti.

rupestre C. M. in Dusen M. Camer. $n .53$.

- Afr.: M. Cameroon.

Sanctae Mariae Besch, Fl, bryol. Réunion, etc. p. 58.

Ster. $\quad-A f r .:$ S. Mar. de Madagase.

"var. mayottensis Besch. in Ann. sc. nat. VII ser., 1I, p. 89.

Ster. -Afr. Ins, Mayotte.

Exs. : Marie n. 214.

saxatile C. M. in Dusen M, Camer. n. 94 .

- Afr. : M. Cameroon.

seaberrimum Broth. in Oefv... 1893.

2. Cortic. - Pac, : Nov, Guinea.

secundulum C.M. l. c. n. 154.

- Afr. : M. Cameroon.

semi-liberum Mitt. M. Ind. or. p. 41.

2. Arbor, - As.: Penins, Malace.

semi-marginatum C. $M$. in Engler's Bot, Jahrb, 1883, p. 87 et in Forchungsreise... Bot. p. 57.

Ster. Arbor, - As. : $\Lambda$ mboine.

serratum A. Br. in C. M. Syn. I, p. 527 ; Milt. M. Ind. or. p. 41 ; Bryol. jav, I, p. 49, t. 40 et $I I, p .223$.

1. Filicic. - As.: Hong-Kong, Celebes, ins, Labuan, Borneo, Java, Ceylan. Pac. : Ins, Samoa.

setosum C. M, M. Polyn, p. 64.

Ster.

- Pac. : Ins. Samoa.

stylophyllum C. M, in Engler's Bot. Jahrb. 1883, p. 85 el in Forchungsreise... Bot. p. 51.

Ster. Arbor, - Pac. : Nov, Guin.

subdisciforme C. M. in Dusen M. Camer, n. 500.

- Afr.: M. Cameroon.

taitense Mith. - Syrrhopodon.

tenellifolium ej. l. c. n. 432 .

- Afr.: M. Cameroon. 
tenellum ej.l.c.n. 419.

$$
\text { - Afr. : M. Cameroon. }
$$

tenerum C. M. in Linn. 1871-73, p. 174.

Ster. Arbor, - As. : Calcutta.

tenuifolium Sull. - Syrrhopodon.

thomeanum C. $M$. in Fl. 1886, p. 286.

Ster. Muscic. - Afr: : Ins. S. Thomas.

Welwitschii Duby in Mem... Geneve, 1871, p. 20, t. 4, f. 8.

Ster. Ad rad. arbor. secus rivul. $-A / r$. : Angola.

Wullschlaegeli L८z. Moost. p. 160.

Ster.

batav. (1).

- Am. sept.: Haïti. Am. merid.: Guian.

CALYMPERIDIUM Bryol. jav. I, p. 51 .

Mülleri Bryol, jav. - Syrrhopodon.

Galymperopsis C. M. in Dusen $M$. Camer. (sect. Calymperidis).

Galyptoporus Lindl., M. Scand. p, 28 (sect. Ortнотricht).

CALYPTOTHECIUM Mitt. Sam. M. p. 190 (gen. propr.) et M. austr. am. p. 427 (sect. Pterobryi).

africanum Mitt. - Trachyloma.

praelongum. - Neckera Eugeniae.

GAMPTOGH㞋TE Reichdt. in Novara Exped, Bot. I, p. 190 (7 sp.). angustata (Milt.) Jaeg. Ad. II, p. 214.

Isothecium angustatum Hook. f. Handb. of the N. Zeal. Fl. p. 465.

Ptilocladus angustatus Lindb. in Act. Soc. se. Fenn. 1872, p. 278.

Stereodon angustalus Mitt. in Journ. of the Linn. Soc. 1859, p. 88. 2 ? - Pac. : Nov. Zeland. sept. et med.

Arbuscula (Hook.) Jaeg. l.c.

Hookeria Arbuscula Sm. in Trans. of the Linn. Soe. IX, p. 280, t. 23.

Hypnum Arbuscula Hook. M. ex. II, p. 20, t. 112 ; C. M. Syn. II, p. 228.

Isothecium Arbascula Brid. Bryol. univ. II, p. 372.

Ptilocladus Arbuscula Lindb. $l$. $c$.

Thamniella? Arbuscula Besch. Fl. bryol. Nov. Caled. p. 240.

2.

- Pac. : N. Zeland., Tasman.

deflexa (Wils.) Jaeg. op. cit. p. 313.

Hypnum deflexum Wils. in Stephens. M. N. Zeland.; C. M. Syn. II, p. 680.

Isothecium Arbuscula $\beta$ deflexi Handb, of the N. Zeal. Fl. l.e.

Ptilocladus deflexus Lindb. I. c.

Stereodon deflexus Mitt. l. $c$.

2. Arbor. et terr. - Pac. : Austral. felix, Nov. Hebrid, Tasman,, ins. Auckland, Campbell.

(1) In Enum. Kindberg. nomina nuda:
C. bahiense C. M.
C. Bodeni $C . M$. 
excavata (Tayl.) Jaeg. l, c. p. 214 .

Hypnum excavatum Tayl. in Phytolog. 1844, p. 1095; C. M. Syn. II, p. 229. 2 ?

- Pac. : Austral., ins. Five.

gracilis (Hook. f. et Wils.) Par.

Hypnum gracilescens C. M. Syn. II, p. 271 .

H. gracile H. $f$. et W. in Lond. Journ. of bot. 1844, p. 553 et Fl. Antarct. $I$, p. 140.

H. micans eor. op. cit. II, $p .421$ ?

Isothecium gracile eor. Fl. N. Zeal. II, p. 106, et Fl. Tasm. II, p. 205.

Microthamnium gracile Jaeg. Ad. II, p. 492.

Ptilocladus gracilis Lindb. 1 . $c$.

Stereodon gracilis Mitt. $l$. $c$.

2. Ad rup. madid. - Pac. : Nov. Zeland., Tasman., ins. Auckland. pulvinata (Hook. f. et Wils.) Jaeg. A d. II, p. 213.

Hypnum pulvinatum H. f. et W. in Lond. Journ. of bot. 1844, p. 155 ; C. M. Syn. II, p. 500 .

Isothecium pulvinatum eor. Fl. N. Zeal. II, p. 105, t. 88, f. 5 et Handb.
p. 465 .

Ptilocladus pulvinatus Lindb. $l$. $c$.

Thamniella ? pulvinata Besch. $l$. $o$.

ramulosa (Mitt.) Jaeg. . . c.

- Pac, : Nov. Zel. sept.

Isothecium ramulosum Mitt. in Handb. of the Zeal. Fl, p. 465.
Ptilocladus ramulosus Lind. l. $\mathrm{C}$.

Arbor. - Pac. : Nov. Zeland., ins. Chatham. (1).

GAMPTOTHEGIUM Bryol, eur. V (14 sp.).

alsioides Kindb. in Pittonia, 1892, p. 243.

- Am. sepl. : Calif.

Amesiae Ren. et Card. in Bol. Gaz. 1888, p. 202, t. 20.

2. Washington, Oregon, Calif.

arenarium (Lesq.) Jaeg. l. c.

Hypnum arenarium Lesq. in Trans. Am. Phil. Soc. XIII, p. 13; Lesq. et
Jam. Man. . 333 ,

2. Arenic. - Am. sept. : Ins. Vancouver, Calif.

Exs. : Sull. et Lesq. M. bor. am. II ed, n. 512 (Hypnum).

aureum (Lag.) Bryol. eur. VI (mon. p. 7), t. 559; W. P. Sch. Syn. II ed. p. 636 ,

Brachythecium aureum de Not, Epil.

Hypnum aureseens C. M. Syn. II, p. 371 .

H. aureum Lag. in Ann. d. Cienc, nat. n. 14; Brid. Bryol, univ. II,
p. 469 . Isothecium aureum Spr. in Ann. and Mag. of nat. hist. 1819, et M. Pyr.
$n .85$.

2. Loc. sice. et ad rup. arid. - Eur. : Galloprov., Etrur., Sardin., Pyren., Hispan. Afr: : Alger. Am. sept. : Hispaniola (fid. Brid.),
ins, Vancouver.

Exs. : Rab. Bryoth, eur. n. 689 .

(1) In Enum, Kindberg. nomen nudum;

C. dendroclada C. M. 
cladoneuron Jaeg. - Brachythecium.

dolosum Ren. et Carcl. in Bot. Centralbl, 1890, n.51 (subsp. C. œnei.). - Am. sept. : Columb. brit., ins. Vancouver, Washington, Idaho.

fulgescens Mitt. in Bol. Zeit. 1878, p. 170.

Lignic. - Am. sept. : M. Selkirk, Columb, brit.

hamatidens Kindb, - C. Nuttallii.

lutescens (Huds.) Bryol. eur. VI (mon.p. 6), t. 558; W. P. Sch.op. cit. p. 635).

Brachythecium lutescens de Not. Epil.

Climacium lutescens Voit M. Herbisp. p. 79.

Hypnum cassubicum Scop. Fl. Carn. II ed., p. 1327.

H. lutescens Huds. Fl. Angl. p. 421 ; Brid. Bryol. unit. II, p. 466; C. M. Syn. II, $p, 370$.

H. myosuroides Lag. Ann, d, Cienc, nat. $n, 24$.

H, myosuroides $\beta$ praelongum Web. Spicil. Fl. Goett. p. 95.

H. sericeum, surculis longioribus et teretioribus, capsulis incurvis Dill. Hist. M. p. 325, t. 42, f. 60.

H. sericeum $\beta$ praelongum Weiss Crypt. Goett. p. 255.

H. strigosum $\beta$ ramosum Neck. Meth. M. p. 180.

Isothecium lutescens Spr. in Ann. and Mag. of nat. hist. 1849, et M. Pyr. n. 88.

Leskea longifolia Ehrh. Crypt. exs. n. 281.

Neekera lutescens Willd. Prodr. fl. Berol. n. 939.

2. In petros. sicc. et ad silvar. marg. - Eur. : Fere tota. As. : Boreal., Caucas, occ., Taurus Cilic. Am. sept. : Fret. Behring et Kotzebuë, Columb. brit., Alaska, ins. Vancouver, Washington, Oregon, Idaho, Calif.

Exs. : Kotschy It. Cilic. n. 440.

\& var. occidentale Ren. et Card. l. c. - Am. sept. : Washington.

megaptilum Sull. Ic. M. Suppl, p. 102, t. 78.

Hypnum megaptilum Lesq. et Jam. Man, p. 331.

2. Terr. in silv, conifer. - Am. sept. : Oregon, Idaho.

megaptilum Mac. - Brachythecium rivulare.

nevadense (Lesq.) Par.

Homalothecium nevadense Ren. et Card.

Hypnum nevadense Lesq. in Mem. Calif. Acad. I, p. 33; Lesq. et.Jam. Man. p. 332.

H. pseudo-sericeum Mac. Canad. M. n. 435.

2. Rupic. - Aim. sept, : Columb. brit., ins. Vancouver, Nevada, Calif. var, subulatum Ren. et Card. - Homalothecium sericeoides.

nitens (Schreb.) W. P. Sch. Syn. I ed. p. 530 et II ed. p. 637.

Hypnum insigne Mohl et Sehlecht. in Bot. Zeit. 1861, p. ; Milde in Rab. Bryoth, ever, n. 489 et $b$.

H, nitens Schreb, Spie. Fl. Lips. p. 92; C. M. Syn. II, p. 381 ; Bryol. eve. VI (mon. p. 53), t. 622.

H. palustre, erectum, trichodes, ramulis crebris lateo et rufo viridibus Dill. Hist. M. p. 303, t. 39, f. 37.

H. trichodes Pall. Fl. Palat. n. 1047.

H. Stereodon nitens Brid, Bryol. univ. II, p. 560.

Neckera nitens Moench Pl, Marp. p. 738. 
2. In pratis palud, et turfos. - Eur. : E reg, campestr. usq, in alpin., praecip. zon. septentr. : Spitzberg, ins. Ursor. As. : Amour, Jenissei, Taimyr, Ochotsk. Am. sepl. : Groenland, fret. Hudson et Kotzebuë, ins. Melville, Anticosti, Terr. nov., Ottawa, Ontar., Saskatehewan, M. Rupestr., Columb. brit., Alaska, reg. sept. et centr.

Exs. : Drumm. M. bor, am. I ed. n. 172 (Hypnum).

Mac. Canad. M. n. 278 (Hypmum).

Rab. Bryoth, eur, n, 764 et b.

Sull. et Lesq. M. bor. am. II ed, n. 486 (Hypnum).

Nuttallii (Wils.) Bryol. eur. VI (mon. p. 6).

C. hamatidens Kindb. in Mac. Cat. p. 189 (fid. Ren. et Card.),

Hypnum hamatidens Kindb. in Bull. Tor, bot. Club, XVI, p. 97.

H. Nuttallii Wils. Bryol. brit. pp. 334 et 339 ; Sull. Ie, M. p. 211, t. 128; Lesq. et Jam. Man. p. 332.

H. pinnatifidum Mac. Canad. M. n. 280.

Leskea californica Hpe, in Linn. 1860, p, 460.

L. campylocarpa $H_{p e}$, in sched.

2. Ad arbor, et rup. - Am. sept.: Columb. brit., ins. Vancouver, Oregon, ldaho, Calif.

Ess. : Sull, et Lesq. M. bor. am. II ed. n. 514 (Hypnum.)

" var. tenue (Kindb.) Ren. et Card. in Rev. bryol. 1893, p. 16.

C. hamatidens var, tenue Kindb, in Bull. Tom. bot. Club, XVII, p, 277.

Ad rup, vertical. - Am. sept.: Columb. brit.

Exs. : Mac. Canad, M. n. 392 (Hypnum).

oeneum (Milt.) Jaeg. Ad. 1I, p. 381.

Hypnum oeneum Mitt, in Jowrn. of the Linn. Soc. VIII, p. 31, t.5; Lesq. et Jam. Mart. p. 331.

2.

ton, Oregon, Idaho, Sierra Nevada, pinnatifidum (Sull, el Lesq.) Jaeg. Ad. II, p. 383. Man. p. 333.

2. Rupic. - Am. sept. : Calif,

Exs. : Sull. et Lesq. M. bor. am. Il ed. n. 513 (Hypnum).

pseudo-lutescens (Hpe.) Jaeg. Ad. II, p. 381. Hypnum pseudo-lutescens Hpe. in Ann. sc. nat. V ser, p. 314 ; Mitt. M.
austr. am. p. 564 .

Ad arbor. - Am, merid. : And. Nóv. Granat.

Campyliadelphus Lindb. M. Scand. p. 32 (sect. HrpNr).

CAMPYLIUM Sull. M. and Hepat. of U. St. p. 677; W. P. Sch. Syn. I ed. p. 599 (sect. HypNi, gen. propr. nonnull.).

Halleri Lindb. - Hypnum.

hispidulum Mitt. - Hypnum.

var. Sommerfeldti Lindb. - Hypnum Sommerfeldti.

CAMPYLOCH ETIUM Besch. Prodr, bryol, mexic. p. 24.

mexicanum Besch. - Campylopodium.

CAMPYLODONTIUM Schroaegr. Suppl. III, I, I.

diepanioides Ren, et Card. - Entodon, 
flavescens Bryol, jav. - Fabronia.

hypnoi 'es Schwaegr. - Anacamptodon splachnoides.

onustum Jaeg. - Entodon.

Regnellianum Jaeg.. - Entodon.

striatum Dz. et Mk. - Fabrovia flavescens.

Gampylodryptodon W. P. Sch. Syn. I ed.p. 226 (sect. RнасомгтriI).

Gampylophyllum W. P. Sch. Syn. II ed. p. 721 (subgen. HyPNI).

CA MPYLOPODIU M C. M. Syn. I, p. 429 (subgen. ANGSTRokMtaE). (12 sp.) curvisetum (Hpe.) Par.

Ảngstroemia curviseta Hpe. Prodr, Fl. Nov. Granat, p. 19.

Dicranella curviseta Mitt. M. austr, am. p. 38.

- Am. merid.: And. Nov. Granat.

cygnœum (Angstr.) Par.

Dicranella cygnoea Angstr. in Oefv... 1878, n. 5, p. 47.

2.

- Afr.: Ins. S. Helen.

euphorocladum (C. M.) Besch. Fl. bryol. Nov. Caled, p. 189.

Ångstroemia euphoroclada C. M. Syn. I, p. 429.

Campylopus euphorocladus Bryol. jav, I, p. 79, t. 66.

Dicranella euphoroclada Jaeg. Ad. II, p. 637.

Didymodon grimmioides Duby in Moritzi Verz, d. Zolling. Pfl, p. 134 ?

D. medius ej.l. $c_{+}$?

2. Rupic. et terr. - As, : Java.

var. $\beta$ squarrosum Besch. - C. neo-caledonicum.

Fendleri (C. M.) Par.

Angstroemia Fendleri C. M. in Linn. 1878-79, p. 470.

Dicranella Fendleri Jaeg. Ad. II, p. 637.

2.

- Am. merid. : Venezuela.

khazianum $(G, i f f$.) Par.

Campylopus tenuis Wils. in sched. et in Kev Journ. bot. IX, p. 296.

Dicranella khaziana Jaeg. $A d$. $I I, p .637$.

Dicranum khazianum Griff. Not. p. 418 et Ic. pl. asiat. II, p. 94, f. 2.

Leptotrichum khazianum Mitt. M. Ind. or, p. 8 .

2 ?

- As. : Sikkim, Khasia, Ceylan.

mexicanum Besch, in litt.

Campylochaetium mexicanum ej. Prodr. bryol. mexic. p. 24.

Dicranella mexicana Jaeg. Ad. $I I, p .637$.

- Am. sept. : Mexic.

neo-caledonicum (C. M.) Par.

Ángstroemia neo-caledonica C. M. mss.

C. euphorocladum var, squarrosum Besch. Fl, bryol. Nov. Caled. p. 189.

Dicranella neo-caledonica Jaeg. Ad II, p. 637.

Terr, argill. - Pac. : Nov. Caled.

phascoides $(C, M$.) $P a r$.

Angstroemia phascoides C. M. in Bot. Zeit. 1853, p. $39 ;$ Mitt. M. Ind. or.

p. 8.
Dicranella phascoides Jaeg. Ad. II, p. 637.

2.

- As. : M. Neilgherr. 
Pilopogon (C.M.) Par.

Angstroemia Pilopogon C. M. in Linn. 1874, p. 630.

Dicranella Pilopogon Jaeg. Ad, II, $p, 637$.

2.

- Am. sept. : Mexic.

Sartorii (C. M.) Par.

Angstroemia Sartorii C. M. in op. cit, p. 629 ,

Dicranella Sartorii Jaeg. Ad. II, p. 637 .

2.

- Am. sept. : Mexic.

taïtense Besch. in Ann. sc. nat. 1894, p.

1. In argill, - Pac. : Taïti.

trichophyllum (Mitt.) Par.

Dicranella trichophylla Mitt. Fl. Vit. p. 386.

Leptotrichum trichophyllum Mitt. in Seem. Bonpl. 1861, p. 366

2.

-Pac. : Ins. Viti, Ovalau.

CAMPYLOPUS Brid. Mant. M. p. 71 (319 sp.) (1).

abyssinicus de Not. in Nuov. Giorn. bot. ital. 1872, p, 21.

$$
\text { - Afr. : M. Abyssin. }
$$

abyssinicus W. P. Sch. - C. subflexuosus.

acervatus Mitt. M. austr, am. p. 87.

- Am. merid. : Absque loco.

acrocaulon (C.M.) Par.

Dicranum acrocaulon C. M. in Fl. 1888, p. 410.

Ster.

acuminatus Mitt. M. austr. am. p. 90.

- Afr. : Kilima N'Djaro.

Dicranum acuminatum C. M. in Fl. 1885, $p 409$,

Ster.

- Am. merid. : Fuegia, ins. Eremit.

adustus de Not. Epil. p. 649; W. P. Sch. Syn. II ed p. 107.

Ster. - Eur. : Ital. sup. (ad Verbanum).

aemulans (Hpe.) Jaeg. Ad. I, p. 148 ,

Thysanomitrium aemulans Hpe. Symb. 1870, p. 273.

Ster. - Am. merid. . Brasil, austr, or. aethiops Welw. et Duby in Mem... Genève 1870, p. 7, t. 3, f. 2,

Ster,

- Afr. : Angola.

afro-concolor C. M. in Dusen M. Camer. n. 653.

albescens (C. M.) Par.

Dicranum albescens C. M. in Bot. Zeit. 1853, p. 36; Nitt. M. Ind. or.p. 16. -As. : M, Neilgherr.

alopecurus (C. M.) Par.

Dicranum alopecurum C. M. in Linn. 1880-82, p. 401.

Arbor. - Am. merid. : Argentin. subtropic.

alpicola Jaeg. - C. torfaceus var. alpicola.

alpinus W. P. Seh. - Dicranodontium longirostre.

(1) Species omnes dioice, 
altissimus (C. M.) Jaeg. Ad. 11, p. 645 .

Dicranum altissimum $C$. M. in $F l .1875, n .34-35$.

- Am. merid. : And. Nov. Granat.

amabilis (C. M.) Par.

Dicranum amabile C. M. in Linn. 1880-82, p. 399.

Arbor. - Am. merid. : Argentin. subtropic.

ampliretis C. M. in Rehm. M. Afr. auslr. n. 60 .

Ster.

- Afr.: C. B. Sp. (Montagu).

Anderssonii (C. M.) Jaeg. A l. 1, p. 140.

Dicranum Anderssonii C. M. in Bot. Zeit. 1856, p. 169.

-Am. merill. : Ins. Gallapagos.

Ảngstroemii Besch. Fl. bryol. Réunion, elc. p. 38.

C. aureo-nitens Angstr. in Defv... 1873, p. 43.

- Afr. : Ins. Franciae.

angustiretis (Aust.) Lesq. et Jam. Man. p. 80.

Dicranum angustirete Aust. in Coult. Bot. Gaz. IV, p. 150.

- Am. sept. : Florid. merid.

annotinus Mitt. M. austr. am. p. 80.

- Am. merid. : And. Nov. Granat.

appressifolius Mitt. in Handb. N. Zeal. Fl. p. 414.

C. clavatus H. f. et W. Fl. N. Zeal, II, p. 69 p.p.

- Afi. : Ins. Kerguelen. Pac. : Nov. Zeland.

Arbogasti Ren. et Card, in Bull. Soc. roy. bot. Belg. 1891, II, p. 183.

Ster, Aren. - Afr. : Madagascar.

artocarpus (Hsch.) Mitt, M. austr. am. p. 87.

Dicranum artocarpum Hsch. Fl. Brasil. I, p. 12 ; C. M. Syn. I, p. 398.

D. stenocarpum C. M. in op, cit. p. 404 (fid. Mitt.).

- Am. merid.: Venezuela, Brasil. austr. or., MonteVideo.

arlocarpus Mitt. p.p. - C, crispicoma.

arcuatus Lac, mss.; C. H. Wright M. Mad. p. 4.

$$
\text { - Afr. : Madagascar. }
$$

Arduennae Lib. - C. fragilis.

arenicola (C. M.) Mitt. op. cit. p. 77.

Dieranum arenicola C. M. in Bot. Zeit. $1885, p .762$.

In aren. marit. - Am. merid. : Brasil, austr. or.

areodictyon (C. MI) Mill. op. cit. p. 85 .

Dicranum areodictyon C. M. Syn. I, p. 394.

Lignic. - Am. sepl. : Guatemala. Am. merid, : And. Columb., Nov. Granat., Quitens. et Boliv.

Exs. : Mandon Pl. Boliv. n. 1612.

"var. gracilescens W. P. Sch, in Mandon b, c. n. 1613. - Am. merid. : And, Boliv.

Arizonae Besch, mss,

- Am. sept, : Arizona. 
asperifolius Mitt, op. cit. p. 79.

Ster. - Am. merid. : And, Quitens et Chilens.

atro-lutens $C, M$. in Rehm. M. Afr. austr. n. 63.

Ster. - Afr. : C. B, Sp.

atro-sordidus $C, M$ in Dusen $M$. Camer, $n .347$. - Afr. : M. Cameroon.

atro-virens de Not. - C. longipilus.

var. adustus Husn. - C. longipilus.

var. falcata Braithw. - C. longipilus var. falcata.

attenuatus W. P. Sch. mss.; Jaeg. Ad. I, p. 148.

- Am. sept. : Jamaïc?

auseo-nitens (C. M.) Besch..Fl. bryol. Réunion, elc. p. 38.

C. introflexus Brid. Bryol, univ, I, p. 472 p.p.

Dicranum aureo-aitens C. M. Syn. I, p. 406. - Afr.: Ins. Borboniae.

aureo-nitens Angstr. - C. Angstroemii.

aureo-viridis W. P. Sch. mss.; Jaeg. Ad. I, p. 139

- Apr.: C. B. Sp.

aureus Bryol. jav. 1, p. 80, t. 67 .

Arbor. - As. : Java, ins. Nicobar.

aurificus (C. M.) Par.

Dicranum aurificum C. M. in Linn, 1880-8', p. 399.

Ster. - Am. merid. : Uruguay.

* var. flavescens (C. M.) Par.

Dieranum aurificum var. flavescens $C . M . l . c$.

Ut et cum typ.

australiensis Duby in Mem... Genève, 1869, p. 9, t. 4, f. I. - Pac. : Austral.

austro-alpinus (C. M.) Par.

Dicranum austro-alpinum C. M. in Linn. 1880-82, p. 398.

Ster. man.

- Am. merid. : Alp. Argentin. subtropic. Tucu-

Balansaeanus Besch. Fl. bryol. Nov. Caled. p. 199.

Arbor, in silv. - Pac, : Nov, Caledon.

bartramiaceus C. M. in Reltm. M. A fr, auslr.

Ster. - Afi. : C. B. Sp.

Bertereoanns Duby in Mem... Genève, 1875, p. 12, ı. I, f. 4 .

C. introflexus Mont. in Ann. sc. nat. 1835.

Silvic. - Am. merid. : Ins. Juan Fernandez.

Beyrichianus Duby Choix de crypt. ex. 1869, p. 9, t. 1, f. 3.

- Am. merid. : Brasil. austr, or.

- var, elatius (1) (Hpe.) Par.

Dicranum Beyrichianum var. elatius Hpe. Symb. 1877, p. 719.

Ut et cum typ. 
bicolor (Hsch.) Handb. of the N. Zeal. Fl. p. 415.

Dicranum bicolor Hsch. in Sieber M. exs. n. 9; C. M. Syn. I, p. 392; Fl $N$, Zeal. $11, p .69$.

- Pac. : Austral., Nov. Zeland., Tasman.

bicolor Besch. - C. pachycomus.

Blumii Bryol, jav. - C. lozyanus.

Boivinianus Besch. Fl. hryol. Réunion, etc. p. 32.

- Afr.: Ins. Franciae.

Boryanus Besch. op. cit. p. 31 .

- Afr. : Ins. Borboniae.

brachymastyx C. M. in Besch. op. cit. p. 36.

Fr. ign. $\quad-A f r$. : Ins. Franciae.

brachymitrius (Geh, et Hpe.) Par.

Dicranum brachymitrium Geh, et Hpe. in Fl. 1881.

- Am. merid. : Brasil. austr. or.

brachyphyllus Wils. in sched.

Dicranum brachyphyllum Mitt. in Lond. journ. of bot. 1851, p. 52 et M. austr, am. p. $81 ;$; . M. Syn. II, p. 597 .

- Am. merid. : And. Quitens.

brachyphyllus C. M. - C. subbrachyphyllus.

brevifolius W. P. Sch. Suppl. ad Bryol. eur. I-II el Syn. II ed., p. 106.

C. subulatus ej. in Rab. Bryoth. exr. n. 451.

Orthopus subulatus Wulfsb. in Christiania Vid. Selsk, Forh. 1875, p. 351 (1).

Fr. ign. Ad rup. granitic. - Eur.: Belgia, Stir., Carinth., Bavar., Tirol. merid., Helvet., Simplon, Gall. centr.

"var. elongatus Bosw. in the Naturalist. 1883, p. 28.

In uligin. - Eur. : Anglia.

brevifolius de Not. - C. Mildei.

brevipilus Bryol. eur. I (mon, p. 6) t. 92; W. P. Sch. Suppl. ad Bryol. eur. I-II, t. 2 el Syn. II ed. p. 106.

Dicranum brevipilum $C . M$. Syn. $I, p .412$.

$\sigma^{*}$ et fr, ign. In ericet. et subturfac. - Eur. : Dania, Westphalia, Neerland., Britann., Gall. centr. et occ. $A / r$. : Alger.

Exs. : Rab. Bryoth. eur. n. 577.

«var. Molkenbouri (Lac. mss.) Milde Bryol. siles. p. 79 ; Jaeg. Ad. I, p. 142.

Ut typ. - Eur. : Neerland.

brevis Rehm. M. Afr. austi. n. 44 .

Ster.

- Afr. : C. B. Sp. (Stinkwater).

Cacti (C. M.) Par.

Dicranum Cacti $C$. M. in Linn. 1880-82, p. 403.

- Am. merid. : Uruguay.

caespilicius Brid, - Grimmia sulcata.

cuespitosus Jaeg. - Dicranodontium.

(1) Cf. Lindb. M, Scand, p. 25, n. 268. 
Cailleae Ren. el Card, in Bull. Soc. roy, bol. Belg. I, p. 114.

Ster. Ad terr, argill. - Afr. : Nossi-Comba.

caldensis Angstr. in Oefv... 1876, n. 4, p. 5 .

Ster. $\quad-A m$. merid. : Brasil. austr. or.

calymperidictyon (Geh, et Hpe.) Par.

Dicranum calymperidictyon Geh. et $\mathrm{Hpe}_{\mathrm{p}}$ in $\mathrm{Fl}$. 1881, p.

- Am. merid. : Brasil, austr. or.

Cambouei Ren. et Card. in Bull. Soc. roy. bot. Belg. 1891, II, p. 182.

Ster. Terr. aryill, - Afr. : Madagascar.

canaliculatus (Geh. el Hpe.) Par.

Dicranum canaliculatum Geh. et Hpe. Erum. M. Biasil. p. 20.

- Am. merid. : Brasil, austr. or.

canescens W. P. Sch. in Lechter Pl. ins, Maclov, n. 90 (1).

Dicranum canescens C. M. in Bot. Zeit. 1859, p. 220.

- Am. merid. : Ins. Maclov.

capensis W. P. Sch. - C. lepidophyllus.

capillaceus (Brid.) Par.

Dicranun capillaceum Brid. Bryol. univ, I, p. 460; C. M. Syn. I, p. 396. - Afr. : Madagascar.

capillaceus H. f, et W. - C. Holomitrium.

capillatus Hook. f. et Wils. Fl. Tasm. II, p. 172, $t .172, f .4$. - Pac. : Austral.

eapitiflorus Mont. Syll.p. 42.

Dicranum capitiflorum C. M. Syn. II, p. 598.

$-A f r$ : Ins. Borbon.

“. var. pachycomus Besch. Fl. bryol. Réunion, etc. p. 34.

Arbor, - Afr, I Ins. Franciae.

caracasanus (C. M.) Par.

Dicranum Richardi $C . M$. Syn. I, p. 413 p.p.

Thysanomitrium caracasanum ej. in Linn. 1878-79, p. 471. - Am. merid. : Venezuela.

carassensis (Broth.) Par.

Thysanomitrium carassense Broth. in Act. Soc. sc. Fenn. 1891, n. 5 .

Ster. Terr. - Am. merid. : Minas Geraës.

eatharractitis C. M. in Rehm. M. Afr. austr. n, 64.

Ster.

$$
-A / r \text { : C. B. Sp. }
$$

caudatus (C.M.) Bryol. jav. I, p. 78, t. 65 .

C. flexuosus Mont. in Ann. se, nat. 1842, Crypt. Neilgherr. n. 52.

Dicranum caudatum C. M. Syn. I, p. 401; Mitt. M. Ind, or. p. 18. - As. : M. Neilgherr., Java.

cavifolins Mitt. M. austr. am. p. 87 .

- Am. merid. : And. Quitens.

chalarobasens C. M. in Dusen M. Camer, n. 262.

- Afr. : M. Cameroon.

(1) Cr. C. introflexus. 
chilensis de Nol. in Mitt. M. austr, am. p. 85.

Ster.

- Am. merid. : Chile.

chionophilus (C. M.) Mitt. op. cit. p. 81 .

Dicranum chionophilum C. M. Syn. I, p. 398.

- Am. merid, : And. Columb. et Nov. Granat.

chlorophyllosus (C. M.) Jaeg. Ad. I, p. 132.

Dicranum chlorophyllosum C. M. Syn. I, p. 395.

Ster. $\quad-A f r$ : Transvaal, C. B. Sp.

Exs. : Rehm. M. Afr, austr. n. 46 et 446.

« var, compactus C. M. in Rehm. l. c. n. 49.

- Afr. : C. B. Sp.

«var, rivularis C. M. l. c. n. 48.

- Afr. : C. B. Sp.

«var. tristis C.M. l. c. n. 47.

- Afr. : C. B. Sp.

chlorotrichus C. M. l. c. n. 53 et 449 .

- Afr. : C. B Sp., Natal.

Chrismari (C. M.) Mitt. op. cit. p. 88.

Dicranum Chrismari C. M. in Bot. Zeit. 1855, p. 761.

- Am. sept. : Mexic.

chryseolus C. M, in Besch. Fl. bryol. Réunion, elc. p. 37.

- Afr. : Comor, magn.

chrysodictyon (Hpe.) Mitt. op. cit. p. 78.

Dicranum chrysodictyon Hpe. in Ann. se. nat. V ser., V, p. 338.

- Am. merid. : And, Nov. Granat.

cirralus Hsch, - Cynodontium gracilescens var. inflexa.

Civa Lı. Moosst. p. 159 (1).

Ster.

- As. : India.

clavatus (R. Br.) Hook. f. et Wils. Fl. of the N. Zeal. II, p. 69 p.p.

Dicranum clavatum R. Br. in Schwaegr. Suppl. III, II, I. t. 255; C. M. Syn. I, p. 412.

D. pudicum Hsch, in Sieber M. N. Holl, n. 24 p.p. (fid. Mitt.). - Afr. : Ins. S. Paul. Pac. : Austral., Nov. Zeland., Tasman.

( H. f. at W. p p. - C. appressifolius.

clavatus $\mathrm{H}$. f. et W. pp. - C. insititius.

Rehm. - C. pseudo-clavatus.

comatulus Besch. Not. M. des I. St-Paul et Amsterdam, p. 4 .

Ster. - Afr. : Ins. Amsterdam.

comatus Ren. el Card. in Bull. Soc. roy. bot. Belg. II, p. 183.

Ster. Silvic. - Afr. : Madagascar, ins. Sancta Maria.

comosus (Hsch. el Reinw.) Bryol. jav. I, p. 75, t. 63.

Dicranum comosum Schwaegr. Suppl. II, II, II, p.114, 181; C. M. Syn. I, p. 397. 
Sphaerothecium comosum Hpe. in Ann. se. not. V ser., III, p. 361 ; Mitt. op. cit. p. 38.

Thysanomitrium comosum Hsch. et Reinw, in Nov. Act. Leop. XIV, II, Suppl. p. 706, t. 39, f. c.

Th. phascoides Hpe. in Linn. $1863, p .136$.

Terr. - As. : Java. Am. merid. : And, Nov, Granat.

"var. elatius (Milt.) Par.

Sphaerothecium var. elatius Mitt. l. c.

- Am. merid. : And. Nov, Granat.

compactus Wils. p.p. - C. Goughii.

concolor (Hook.) Brid. Bryol. univ. I, p. 476; Mitt, op. cit. p. 82.

Dicranum concolor Hook. M. ex. p. 10, t. 138 ; C. M. Syn. I, p. 391.

D. Jamesoni Hook. Ic. pl. rar, t. 179; C. M. l. c.

Lignic. - Am. merid. : And. Columb, et Nov. Granat,

conlortus Brid, - Grimmia.

controversus (Hpe.) Jaeg. Ad. II, p. 649.

Dicranum controversum Hpe. Symb. 1872, p. 42. - Am. merid, : Brasil, austr. or.

crassinervis Wils. - Dicranum albicans.

crassissimus Besch, in Bull. Soc. bot. Fr, 1885, p. LVIII el in Miss. sc. Ster. Cap Horn, V, Bot., p. 265, t. 2, f. 7.

crateris Besch, Fl. Bryol. Réunion, etc., p. 39.

Ster. Ad rupes vulcan? - Afr.: Ins. Borbon (1).

Crishna Llz. Moosst. p. 159 (2).

Ster. - As. : India.

crispicoma (C. M.) Par.

C. arctocarpus Mitt. op. cit, p. 87 p.p.

Dicranum arctocarpum C. M. in Fl. 1875, n. 34-35.

Ster. - Am. merid. : Venezuela.

cubensis Sull, - C. filifolius.

Cummingii Duby in Mem... Geneve, 1869, p. 11, t, II, f. 3 . - Am. merid. : Chile.

curvifolius Brid. - Grimmia commutata.

cuspidatus (Hsch.) Mitt. op. cit. p. 90.

Dicranum cuspidatum Hsch. Fl. Brasil. I, p. 13 ; C. M. Syn. I, p. 414.

Ster. - Am. merid. : Brasil. austr. or.

cygnœus (Hedro.) Brid. Bryol. univ. I, p. 475; Mitt. op. cit. p. 76.

Dicr an um cygnoeum Hedw. Sp. M. p. 148, t. 37 ; C. M. Syn. I, p. 388. - Aim. sept. : Hispaniola.

densifolius Ångstr. in Oefv... 1872, n. 4, p. 18.

- Pac. : Ins. Sandwic.

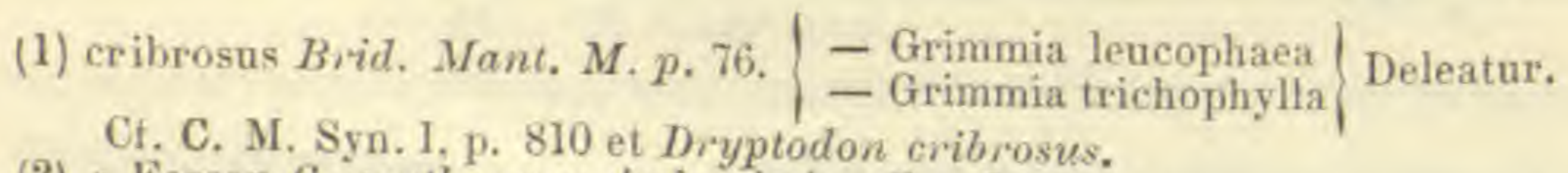

(2) " Forsan $C$. erythrognaphalo nimis aff. $v$. Ltz. 
densus Bryol, eur. - C. fragilis.

var. fragilis Wils, - C. fragilis.

destructilis (C. M.) Jaeg. Ad. I, p. 134.

Dicranum destructile C. M. in Bot. Zeit. 1859, p. 220.

Ster.

- Am. sepl. : Mexic.

detonsus (Hpe.) Par.

Dicranum detonsum Hpe. in Fl. 1881, p.

- Am. merid. : Brasil. austr. or.

dichotomus Brid, Mant. M. p. 77. - Cf. Dryptodon dichotomus.

dicranelloides Ren. et Card. in Bull. Soc. roy. Belg. 1890, I, $\rho, 171$.

C. perpusillus Mitt. ?

Ster. Tere, argill. - Afr. : Madagascar.

dictycion (false: dictyon) Jaeg. - Dicranodontium.

Didrichsenii (C. M.) Jaeg. Ad. I, p. 128.

Dicranum Didrichsenii C. M. in Bot. Zeit. 1862, p. 329.

Ster. $\quad$ - Pac. : Ins. Sandwic.

Didymodon Jaeg. - Dicranodontium.

Dietrichiae (C. M.) Par.

Dicranum Dietrichiae C. M. M. Polyn. p. 62.

Ster.

- Pac. : Ins. Tonga.

discriminatus (Hpe.) Par.

Dicranum discriminatum Hpe. Symb. 1877, p, 718.

- Am. merid. : Brasil. austr. or.

dissitus C. M. in Dusen M. Camer, n. 261 .

- Afr. : M. Cameroon.

ditrichoides Broth. in Act. Soc. sc. Fenn. 1891, n. 5.

Ster. Terr. - Am. merid. : Minas Geraës.

divaricatus (Mitt.) Jaeg. Ad. II, p. 645.

Dicranum divaricatum Mith. in Journ. of the Linn. Soe. 1863, p. 14!.

Ster. - Afr. : Ins. Princip.

divisus (Geh, et Hpe.) Par.

Dicranum divisum Geh, et Hpe. in Fl. 1881, p.

- Am. merid. : Brasil, austr. or.

dolosus Besch. Fl, bryol, Réunion, etc. p. 32.

Terr. - Afr. : Ins. Borbon.

Donnellii (Aust.) Lesq. et Jam. Man. p. 79.

Dicranum Donnellii Aust. in Coult. Bot. Gaz. IV, p. 150.

D. subleucogaster ej. M. Appal. exs Suppl. I, n, 470.

Ster. $\quad-A m$. sept. : Florid, merid.

Dozyanus (C.M.) Jaeg. Ad. I, p. 122.

C. Blumii Bryol, jav. I, p. $81, t .68$.

Dicranum elavatum Wils, in Kew Journ. bot. $I X, p, 298$.

D. Dozyanum C.M. Syn. I, p. 385 .

D. ericetorum Mitt. M. Ind. or. p. 20 p.p.

Trichostomum Blumii Dz, et Mk. in Ann. sc. nat. 1844, II, p. 316.

Arbor, et rupic. - As.: Sikkim, Assam, M. Neilgherr, Ceylan, Java, Borneo. Pac. : Ins. Societat. 
Duseni $C, M$, in Dusen M. Camer. $n, 304$.

- Afr. : M. Cameroon.

Echernieri Besch. Fl. Bryol. Réunion, elc. p. ‘35.

Dieranum arcuatum Brid. Bryol. univ. I, p. 463 p.p.; C. M. Syn. I, p. 388 p.p.

Ster. Loc. cavis humid, et aquatic. $-A f r$. : Ins. Borbon.

echinatus Rehm. M. Afr. austr. n. 67.

Ster. - Afr. : C. B. Sp.

a var, leucobasis Rehm, l, c, n. 71 .

- Afr. : C. B. Sp. (Montagu).

« var. turgescens Rehm.l.c.n. 69. - Afr. : C. B. Sp. (Campo-Bay).

- var, umbrosus Rehm. l. c. n. 72. - Afr. : C. B. Sp. (Knysma).

«var. Vallis Gratiae Rehm. l. c. n. 70. - Afr.: C. B. Sp. (Montagu).

ellipticus Brid. - Rhacomitrium.

elongatus Brid. Bryol. univ. I, p. 815 .

Dicranum Grateloupii $C . M$. Syn. I, $p .387$ et II, p. 596.

$\sigma^{*}$ et fr. ign. - Eur. : Gall. austr. occ.

erectus (C. M.) Mitt. M. austr. am. p. 89.

C. strictus C. M. in Linn. 1847, p. 207.

Dicranum erectum C.M. Syn. I, p. 408.

Thysanomitrium inflexum Hpe, in Linn. 1847, p. 74. - Am. merid. : Venezuela, Columb.

ericoides (Griff.) Jaeg. Ad. I, 128.

Dicranum ericoides Griff. Not. p, 420 ; Mitt. M. Ind. or. p. 18. - As. : Nepal, Khasia.

erythrocaulon Broth, in Boll. da Soc. Broter. 1890.

Ster. $\quad-A f r$ : Ins, S. Thomas.

erythrodontius (Hpe.) Par.

Dicranum erythrodontium Hpe. Symb, 1877, p. 720.

- Am. merid.: Brasil. austr. or.

erythrognaphalon (C. M.) Jaeg. Ad. I, p. 143.

Dicranum erythrognaphalon C. M. in Bot. Zeit. 1853, p. 37; Mitt, op. cit. p. 21.

$$
\text { - As. : M. Neilgherr. }
$$

erythropoma Duby in Mem... Geneve, 1869, p. 10, t. 3, f. 2. - Pac.: Austral.

euphorocladus Bryol. jav. - Campylopodium.

exalaris (Hpe.) Par.

Dicranum exalare Hpe. Symb. 1877, p. 721.

- Am. merid. : Brasil. austr. or.

exaltatus (C. M.) Par.

Dicranum exaltatum C. M. in Linn. 1878-79, p. 472.

Ster.

- Am. merid. : Venezuela. 
exasperatus Brid. Bryol. univ. I, p. 493; Bryol. jav. I, p. 83, ı. 69.

Dicranum exasperatum $C$. M. $-8 y n, I, p, 384$.

Thysanomitrium exasperatom Nees in Act. Acad. nat. Leo s. XI, II, p. 134, t. 15, f. 2, a-e.

Trichostomum exasperatum Schwaegr. Suppl. II, II, II, p. 112, t. 181. - As. : Ceylan, M. Java. Pac. : Ins. Hawaï, Kauï.

eximius Reichdt in Exp. Novara 1870, p. 167, t. 28.

C. introflexus Mitt. Fl. Vit, p. 385.

- Afr. : Ins. S. Paul. Pac. : Nov. Daledon.

exustus Mitt. M. austr. a,m. p. 83.

- Am. merid. : And. Peruv.

falcifolius Mitt. in Journ. of the Linn. Soc. XIV, p. 78.

- Afr. : Ins. St Paul.

Fendleri (C. M.) Par.

Dicranum Fendleri $C$. $M$. in Linn. 1878-79, p. 472.

- Am. merid. : Venezuela.

filescens Ren. et Card. in Bull. Soc. roy. bot. Belg. 1890, I, p. 169.

Lignic. - Afr. : Madagascar.

filicaulis (Hpe.) Mitt. M. austr. am, p. 74.

Dicranum filicaule Hpe, in Ann. sc. nat. V ser., V. p. 337.

Silvic. int. musc. - Am. merid. : And. Nov. Granat.

filifolius (Hsch.) Mitt. M. op. cit. p. 76.

C. cubensis Sull. in Proc. Am. Acad. August. 1861.

C. Mülleri Ltz.

Dicranum filifolium Hsch. Fl. Brasil. I, p. 12; C. M. Syn. I, p. 403.

Lignic. - Am. sept. : Cuba, Porto Rico. Am. merid. : Brasil. austr. or.

fimbriatus Mitt. op. cit. p. 88.

Arbor. - Am. merid. : And. Quitens.

fliaccidus Ren. et Card, in Bull. Soc, roy, bot. Belg. 1893, II, p. 11.

Ster. In sphagnet. - A fr. : Madagascar.

flagellaceus (C. M.) Mitl. op. cit. p. 77.

Dicranum flagellaceum C. M. Syn. II, p. 597.

Ster.

- Am. sept. : Mexic.

flagelliferus (C. M.) Jaeg. Ad. I, p. 127.

Dicranum flagelliferum C. M. in Bot. Zeit. 1853, p. 35; Mitt. M. Ind or. p. 18.

- As. : Summ. M. Neilgherr.

Flageyi Ren, et Card, in Bull. Soc. roy. bol. Belg. 1893, 11, p. 12.

In silv. - Afr. : Madagasear.

flavescens Rehm, M. Afr. austr. n. 445.

- Afi. : Transvaal.

flavicoma C. M. in Dusen M. Camer. n. 299.

- Afr.: M. Cameroon.

flavissimus (C. M.) Par.

Dicranum flavissimum C. M. in Fl. 1885, p. 409.

Ster.

- Am. merid. : Fuegia. 
flexifolius (Hsch.) Bryol. jav. I, p. 76.

Dicranum flexifolium Hsch. in Schwaegr. Suppl. II, II, II, p. 115, t. $185 ;$ C. M. Syn. I, p. 399.

D. flexuosum Hsch. in Nov. Aet. Leop. XIV, II, Suppl.p. 703 ? - As. : Java.

flexuosus (L.) Brid. Bryol, univ. I, p. 469 p.p. ; Bryol.eur. I (mon. p. 3) t. 89 ; W. P. Sch. Syn. II ed. p. 102.

Bryum flesuosum L. Sp. Pl. p. 1583 p.p.

Br, immersum Dicks. Pl. crypt, Fasc. IV, p. 13.

Br. pilosum molle, setis intortis Dill. Hist. M. p. 3i3, t. 47, f. 33 F. G.

Dicranum flexuosum Hedw. Sp. M. p. 146, t. 38, f. 1-6 p.p.; C. M. Syn. I, p. 400.

D. palustre la Pyl, in Brid. op. eit. I, p. 814 (fid. C. M.)

Thysanomitrium flexuosum W. A, . Disp. M. p. 33 (excl, var.).

Weisia immersa Brid. Sp, M. I, p. 124.

Ad terr, et saxa silic. - Eur. : Reg. campestr. montos. silvat.; copios. in Vogeso et Silva Nigra. Afr.: Alger.; Abyssin. Pac. : Austral. fel.

Exs. : Rab. Bryoth. eur. n. 85, 576, 976.

W. Schimp. Un. itin. n. 456 .

var. major Boul, - C. flexuosus var. zonatus.

* var. pachyneuros Milo. Moost. a. d. Algov. Alp. 1865.

Ut typ. - Eur.: Alp. Alg., Bavar.

« var. zonatus (Mdo.) Limpr, Laubm, Deutschl, I, p. 391.

C. flexuosus $\beta$ major Boul. M. Fr. p. 511.

C. zonatus Mdo. Bayern's Laubm.p. 53.

Ut typ. - Eur. : Bavar.

flexuosus $\left\{\begin{array}{l}\text { Brid. p.p. - C. torfaceus. } \\ \text { Mont. - C. caudatus. } \\ \text { Sull. - Dicranodontium Millspaughii. }\end{array}\right.$

fragilis (Dicks.) Bryol. eur. I (mon. p. 4) t. 90; W. P. Sch. l.c.

Bryum fragile Dicks. Pl. crypt. Fasc. III, p. 5.

C. Arduennae Libert in Pl, exs. crypt. Arduenn.

C. densus Bryol. eur. l. c. p. 6 et t. 93 .

C. densus $\beta$ tragilis Wils, Bryol. brit.

C. fragilis var. densus Wulfsb. in Christiania Vid. Selsk. Forh 1875 ?

C. penicillatus Rog, in Brid, Bryol. univ. I, p. 478 .

Dicranum densum Funk. cent. n. 634.

D. Funkii C. M. Syn. I, p. 392 et II, p. 598.

D. flexuosum $\beta$ fragile Turn. Muscol. hib, p. 74 .

D. Schleicheri C. M. Syn. I, p. 393.

In fissur. rup, arenac, et granitic, - Eur. : Britann., Voges., Silva Nigra, Hercyn., Francon, Helvet. occid.? As. : Caucas., M Neilgherr. Afr.: Madeira.

Exs. : Mandon Pl. Madeir. n. 4.

Rab. Bryoth, eur. n, 504.

var, densus Wulfsb. - C. fragilis?

friabilis (Hpe.) Jaeg. Ad. I, p. 136.

Dicranum friabile Hpe. mss, ; C. M. in Bot. Zeit. 1859, p. ?20.

- Am. sept. : Costa Rica.

frigidns Lesq. in Port. et Coull. Fl. of Colorado, p. 155; Lesq. el Jam. Man. p. 79 .

Ster.

- Am. sept. : Summ. M. Colorado. 
funalis Brid. - Grimmia.

fuscatus Besch. in Journ. de Bot. 1891, p.

Ster.

- Am. merid. : Monte Video.

fusco-croceus (Hpe.) Jaeg. Ad. II, p. 646.

Dicranum fusco-croceum Hpe. Symb. 1872, p. 45.

Ster. - Am. merid. : Brasil. austr. or.

Gardneri (C. M.) Mitt. M. austr. am. p. 83.

Dicranum flexuosum rar. Vils. in Gardn. M. Brasil, n. 20.

D. Gardneri C. M. in Bot. Zeit. 1857, p. 379.

Rupic. - Am. merial. : Brasil.

Gaudichaudii Besch, in Journ. de Bot. 1891, p.

Ster.

- Am. merid. : Chile.

geniculatus Ångstr. in Oefo .. 1872, n. 4, p. 18.

- Pac. : Ins. Sandwic.

giganteus Sull, - C. penicillatus.

Glaziovii (Hpe.) Jaeg. Ad. II, p. 649.

Dicranum Glaziovii Hpe. Symb. 1874, p. 488.

- Am. merid. : Brasil. austr. or.

Goughii (Mitt.) Jaeg. Ad. I, p. 128.

C. compactus Wils, in Kew Journ. bot. IX, p. 297 p.p.

Dieranum Goughii Mitt. M. Ind. or. p. 17.

Ceylan.

- As. : Nepal., Sikkim, Khasia, M. Neilgherr.,

gracilicaulis (Mitt.) M. austr. am. p. 83.

Terr. - Am. sept. : Florid. merid. : Am. merill. : Amazon., And. Peruv.

gracilis (Mitt.) Jaeg. Ad. I, p. 131.

Dicranum gracile Mitt. M. Ind. or, $p .17$.

D. sericeum Wils, in op. et l. co.

- As. : Sikkim.

grimmioides (C. M.) Par.

Dicranum grimmioides C. M. in Linn. 1880-83, p. 397.

Ster.

- Am. merid. : Argentin. Cordob.

griseus (Hsch). Jaeg. Ad. I, p. 147.

Dicranum griseum C. M. Syn. I, p. 406.

Thysanomitrium griseum Hsch. Fl. Brasil, I, p. 16.

- Am. merid, : Monte Video.

guadalupensis Mill. M. austr. am. p. 77.

Dicranum guadalupense Brid. Bryol. univ. I, p. 463 ; C. M. Syn. I, p. 386.

$q$ et fr. ign. $\quad-$ Am. sept. : Guadalup.

Hallii Lesq. in Port. et Coult. Fl. of Color. p. 155 ; Lesq. et Jam. Man. p. 79.

Ster, - Am. sept. : Summ. M. Colorado.

Hartmanni W. P. Sch. - Barbula Drummondii.

hawaïanus (C. M.) Jaeg. Ad. I, p. 140. (false hawaïcus).

Dicranum hawaianum C. M. in Bot. Zeit. 1862, p. 328.

Ster.

- Pac.; Ins, Hawaî. 
helenicus (C.M.) Jaeg. I, p. 135 .

C. Sanctae Helence W, P. Sch, in sched.

Dicranum helenicum C. $M$. Syn. II, p. 599 .

Filicic. - Afr. : Ins, S, Helena.

Hellerianus (Hpe.) Besch. Prodr. bryol, mexic. p. 23.

Dieranum Hellerianum Hpe. Sp. M. nov. Meize. in Verh, d. K. K. zool. bot. Gesells, in Wien, 7a April. 1869.

Ster. - Am. sept.: Mexic.

hemitrichius (C. M.) Jaeg. Ad. II, p. 648 .

Dicranum hemitrichium C. M. in Linn, 1874, p. 553.

Ster. - As. : Ins. Philippin.

Henrici Ren. et Card. in Bot. Gaz. 1888, p. 197, t. 14.

Ster. - Am. sept. : Kansas.

Heribaudi Ren. et Card, in Bull. Soc. roy, bot. Belg. 1890, I, p. 168. - Afr. : Madagascar.

heterophyllıs Mitt. M. auslr. am. p. 77. - Am. merid. : And. Nov, Granat.

heterostachys Hpe. in Fl. 1865, n. 37. - Am. merid. : And, Peruv.

Hildebrandtii (C. M.) Besch. Fl. bryol. Réunion, etc. p. 32.

Dicranum Hildebrandtii C. M. in Linn. 1876, p. 236.

Humic. - Afr. : Ins. Anjouan.

hispidus Ren. et Card. in Bull. Soc, roy. bot. Belg. 1890, 1, p. 171.

Ster. Terr. argill. silic, - Afr. : Madagascar.

Hoehneli (C. M.) Par.

Dicranum Hoehneli $C . M$. in Fl. 1890, p. 473.

Ster.

$$
\text { - Afr. : Kilima-N'Djaro. }
$$

Holomitrium (C. M.) Jaeg. Ad. I, p. 135.

C. capillaceus $H$. f. et W. in Lond. Journ. of bot, 1844, p. 543.

Dicranum Holomitriam C. M. Syn. I, p. 389.

$$
\text { -Pac. : Nov. Zeland. }
$$

Hoffmanni Ren, et Card. - Dicranum.

horridus Welvo. et Duby in Mem... Genève, 1870, c. ic.

$$
\text { - Afr. : Angola, Loanda. }
$$

humifugus (C. M.) Par.

Dicranum humifugum C. M. in Linn. 1880-82.

Lignic. - Am, merid. : Argentin. subtropic.

humilis Mont. in Ann. sc. nat. 1845, IV, p. 110 et Syll. p. 43 ; Mitt. M. austr. am. p. 76.

Dicranum humile C. M. Syn. I, p. 384.

Lignic. - Am. merid. : Brasil.

hygrometricus Rehm. M. Afr. austr. $n, 59$.

Ster, - Afr. : Orange.

Imandae Rehm, l, c, n. 43.

Ster, - Afr. : Natal. 
incrassatus (Kze.) C. M. in Linn. 1844, p. 686; Milt. op. cit. p. 89.

Dicranum incrassatum Kze, in Poepp. Pl. Chil. n. 22; C. M. Syn. I, p. 408 .

$$
\text { - Afr. : Chile. }
$$

insititius Hook. f. et Wils. Fl. Tasm. II, p. 172, t. 172, f. 3.

C. clavatus eor. p.p. (fid. Mitt.).

$$
\text { - Pac. : Tasman. }
$$

intermedius Wils. - Dicranodontium longirostre.

interruptulus C. M. in Besch. Fl. bryol. Réunion, etc. p. 36.

Ster. - Afr. : Ins. Franciae.

introflexus (Hedwo.) Mitl. op. cit.p. 84; Duby Choix de crypt. ex. 1875, p. $13, t .1, f .5$ (1).

C. leucotrichus Sull. et Lesq. in Sull. Io. M. p. 28, t. 17 et M. bor, am. II ed. n. 92 .

D. introflexum Hedw. Sp. M. p. 147, t. 29; C. M. Syn. I, p. 405.

Rupic. - Am. sepl.: Alabama. Am. merid.: Monte Video, ins. Maclov. Pac. : Austral. or., Nov. Zeland, Tasman., ins. Auckland, Campbell.

introflexus $\left\{\begin{array}{l}\text { Brid. p.p. - C. aureo-nitens. } \\ \text { Mitt. - C. eximius. } \\ \text { Mont. - C. Berteroanus. }\end{array}\right.$

involutus (C. M.) Jaeg. Adl. I, p. 122.

Dicranum involutum C. M. in Bot. Zeit. 1853, p. 34 ; Mitt. M. Ind. or. p. 18.

- As. : M. Neilgherr.

irregularis Ltz. - Leptotrichum homomallum var, zonatum.

jamaïcensis Mitt. M. austr. am. p. 82.

- Am. sept. : Jamaïc.

japonicus Broth. mss.

Ster. Rupic. - As. : Japon.

Johannis Meyeri (C. M.) Par.

Dicranum Joannis Meyeri C. M. in Fl. 1888, p. 410.

Ster. $\quad-A f r$ : Kilima N'Djaro.

Joinvillianus (Hpe.) Jaeg. Ad. II, p. 646.

Dicranum Joinvillianum Hpe. Symb. 1872, p. 45. - Am. merid. : Brasil, austr. or.

Jucrangae Rehm. M. Afr. austr. n. 42.

Ster. - Afr. : Natal.

(1) Cl. Mitten (1. c.) huic speciei every variable in externat apprarenee o synonym. sequent. ducit:

c. griseus $H$ sch.

C. lamellatus Mont.

C. lutescens W. P. Seh.

C. polytrichoides de Not.

C. xanthophyllus Mont.

Dicranum leptocephalum C.M.

D. truncatum $C . M$.

Et forsan; C, canescens W, P. Sch. et C. capensis e). 
julaceus (Hpe) Jaeg. Ad. I, p. 648.

Dicranum julaceum Hpa. Symb. 1872, p, 46.

$\sigma^{*}$ et fr. ign.

- Am. merid. : Brasil. austr. or.

julacers Rehm. - C. psendo-julaceus.

Krauseanus (Hpe. et Ltz.) Par.

Dicranum areodictyon Hpe. et Lts. in Krause M. Ecuador.

D. Krauseanum eor, in Bot. Zeit, 1869, $p$.

Rupic, et sphagnic. - Am. mericl. : And. Aquator.

laete-virens (C. M.) Jaeg. Ad. I, p. 128.

Dicranum laete-virens C. M. in Eot. Zeit. 1862, p. 12.

Ster. - Afr. . Ins. Canar.

Iaetus (Mitt.) Jaeg. Ad. I, p. 121.

Dicranum laetum Mitt. M. Ind. or, p. 19.

Arbor, et rupic. - As. : Khasia.

laevigatus W. P. Sch, in Besch. Prodr, bryot, mexic, p. 23.

Dicranum laevigatum $C . M$. Syn. II, p. 601, - Am. sept, : Mexic.

laevigatus Brid. - Grimmia leucophaea.

laevis Tayl. in Lond. Journ. of. bot. 1846, p. 47; Mitt. M. austr. am.
p. 91.

Dicranum laeve C. M. Syn. I, p. 409. Pilopogum piliferus Hpe. in Ann. se. nat. 1865, p. 362 (ex ips. in litt. ad
Besch.!).

Pichincha. Am. merid. : And. Nov. Granat., M. Chimborazo et

lamellatus Mont, in Ann. sc. nat. 1838, IX, p. 52 et in d'Orbigny Voy. p. $90 ;$ Syll. p. 43.

C, introflexus Mitt. (fid. ipsi).

Dicranum lamellatum C. M. Syn. I, p. 41 .

Terr, - Am. merid. : Peruv.

lamellicosta W. P. Sch. in Besch. Prodr. bryol. mexic. p. 23.

Dicranum lamellieosta $C . M$. Syn. $I I, p .60$. - Am. sept, : Mexic.

lamprodictyon (Hpe.) Mitt. op. cit. p. 78.

Dicranum lamprodictyon Hpe. in Ann. se. not. V ser., V, p. 131. - Am. merid. : And. Nov. Granat. laniger Besch. in Bull. Soc. bot. Fr. 1885, LVI et in Miss. sc. Cap Horn,
V, Bot, p. 262.

Dicranum laniger $C . M$. in $\mathrm{Fl} .1885, \mathrm{p} .410$.

Ster.

- Am. merid. : Fuegia, ins Eremit.

latinervis (Mitt.) Jaeg. Ad, I, $p .130$.

Dicranum latinerve Mitt. M. Ind. or, p. 17.

- As. : Nepal. or., Sikkim, M. Neilgherr., Ceylan.

latitextus Lac. Sp. nov. M. Archip. ind. p. 10, ८.7 A. - As. : Java.

Leanus Sull, - Brothera.

Lechleri W. P. Sch, in Lechl. Pl. Chil.

Arbor, et terr. - Am. merid. : Valdiv, 
lepidophyllus (C. M.) Jaeg. Ad, I, p. 139.

C. capensis W.P. Sch. in Breut. M. Capens.

Dicranum lepidophyllum C. M. Syn. I, p. 407.

D. pudicum Hsch, in Drege M. Capens.

- Afr. : C. B. Sp.

Exs. : Rehm. M. Afr. austr. n. 66.

leptocephalus (C.M.) Jaeg. l. c.

Terr. - Pac. : Austral. felix, Nov' Zeland.

leptodus Mont. in Ann. sc. nat. 1845, IV, p. 111 et in Gay Hist. Chil.

Bot, crypt.t. 3, f. 2; Syll. p. 43; Hook. r. et Wils. Fl. of the N.

Zeal. II, p. 68 ; Mill. M. austr. am. p. 91.

Trichostomum leptodus Mitt. in Handb. N. Zeal. Fl. p. 416.

Nov. Zeland, ins. Auckland.

leptodus Mont. p.p. - C. Richardi.

leucochlorus (C. M.) Par.

Dicranum leucochlorum C. M, in Fl. 1888, p. 411.

Ster. $\quad-A f r$ : Kilima N'Djaro.

leucogaster (C. M.) Mitt. M. austr. am. p. 75.

Ster. $\quad-$ Am. sept. : Mexic.

Dicranum filiforme Hsch, in Deppe et Schiede M. Mexic.

D. leucogaster C. M. Syn. I, p. 387 .

leucotrichus Sull, et Lesq. - C. introflexus.

Liebmanni $W . P$. Sch. $h b$.

Dicranum Liebmanni C. M. Syn. II, p. 601.

- Am. sept. : Mexic.

lonchoclados C. M. in Besch. Fl. bryol. Réunion, elc. p. 38.

Fr. ign. - Rupic. - Afr. . Ins. Franciae.

longescens $C ., M$, in Rehm, M. Afr. austr. n. 40.

Ster.

- Afr. : C. B. Sp. (Knysma).

" var. firmus $C, M, l, c, n, 41$.

Ut et ubi praeced.

longifolius W. P. Sch. in Besch. Fl. bryol. Réunion, elc. p. 35.

Cecălyphum fasciatum $P . B$. Prodr. p. 51 ?

Dicranum arcuatum Brid. Bryol. univ. I, p. 463 p.p. ; C. M. Syn, I, p. 368 p.p.

Ster.

P. B.).

longipilus Brid. Bryol. univ. I, p. 477 p.p. ; Bryol. eur. Suppl. I-II; W. P. Sch. Syn. II ed. p. 104.

C. atro-virens de Not. Epil. p. 221 ; Bryol. eur. I, mon. p. 5, t. 92.

Dicranum atro-virens C.M. Syn. I, p. 414 et $I I, p .603$.

D. ericetorum Mitt. M. Ind, or. p. 20 p.p.

D. flexuosum $\gamma$ piliferum Tum. Muscol. hib. p. 74, t. V, f. 2 ,

Ster. (1) Rupic. - Eur.: Norveg. occ., Britann., ltal. super., Pyr. Afr.: M. Cameroon (fid. Mitt.).

Exs. : Rab. Bryoth. eur, n, 262, 312, 505 et b, 938.

(1) Fid. W, P. Sch. 1. c. ; non! fid. Limpr. Laulsm. Deutschl. I, p. 399. 
« var. falcata (Braitho.) Par.

C. atro-virens var. falcatum Braithu, in Husn. Muscol. gall. p. 46.

Ut et ubi typ.

longipilus Brid. p.p. - C. polytrichoides.

Lorentzi C. M. in Linn. 1880-83, p. 404.

Fl, et fr. ign. tropic.

- Am. merid. : Alp. Argentin. sub-

luridus W. P. Sch. in Besch. Prodr. bryol mexic. p. 24.

Ster.

- Am. sept. : Mexic. (Orizaba).

lutescens W. P. Sch. in Besch. op. et l, cc.

Dicranum lutescens C. M. Syn. II, p. 602.

luteus (C. M.) Par.

$$
\text { - Am. sepl. : Mexic. }
$$

Thysanomitrium luteum C. M. in Linn. 1878-79, p. 470.

- Am. merid. : Venezuela.

Mac-Leanus Rehm. M. Afr. austr. n. 447.

- Afr. : Transvaal.

macrophyllus (Kze.) Mitt. M. austr. am. p. 80).

Dicranum filifolium C. M. in Linn. 1844, p. 691 p.p. Dicranum macrophyllum Kze. in Poepp. Coll. III, n. 231 ; C. M. Syn. I,
p. 402.

$$
\text { - Am. merid. : Peruv. }
$$

macrotis C. M. in Dusen. M. Camer. n. 699.

- Afr: : M. Cameroon.

madecassus Besch. Fl. bryol. Réunion, elc. p. 33.

- Afr. : Madagascar.

Mandoni W. P.Sch. in Mandon Pl. Boliv, n. 1610.

- Am. merid. : And. Boliv.

Marilacii Rehm. M. Afr. austr. n. 65.

Ster.

$$
\text { - Afr. : C. B. Sp. (Montagu). }
$$

matarensis Besch. Fl. bryol. Réunion, elc. p. 35.

Ster.

$$
\text { - Afr. : Ins. Borbon. }
$$

megalotus Besch. Not. M. des I. S. Paul et Amsterdam, p. 2.
Ster.
$-A f r .:$ Ins. S. Paul.

micans Wulfsb, in Christiania Vid. Selsk. Forh, 1875 et in Rev. bryol. $1885, p .15$.

Rupic. - Eur. : Norveg

microstomus Mitt. - C. porphyreodictyon.

Mildei Limpr. Deutschl. Laubm. I, p, 396.

C. brevitolins de Not. Epil. p. 650 et in Erbar, critt. ital. n. 1412.

C. brevifolius forma Milde in Bot. Zeit. 1870, p, 450.

Ster. Terr. - Eur.: Ticin., lac. Major.

minor Besch, op, cit, p. 4.

- Afr: Ins. Amsterdam.

minutus Lindb. in Ångslr. Prim. lin. p. 5 (nom.).

- Am. merid. ; Brasil. austr. or. 
Mittenii (C. M.) Jaeg. A $J . I, p .137$.

D. erectum Mitt. in Lond. Journ. of bot. 1851, p. 53.

D. Mittenii C. M. Syn. II, p. 600 .

- Am. merid. : And. Quitens. et Boliv.

Exs, : Mandon Pl. Boliv, n. 1608.

mollis C. M. in Rehin. M. Afr. austr. n. 36 .

Ster.

- Atr. : Natal.

montanus Welno. el Duby in Mem... Genève 1870, p. 7, $t .3, f I$.

Ster. Lignic et rupic. - Afr. : Angola.

Mülleri $\left\{\begin{array}{l}\text { Jaeg. - C. Richardi. } \\ \text { Jur. - C, torfaceus var. fragilis , } \\ \text { Ltz. - C. filifolius. }\end{array}\right.$

multicapsularis W. P. Sch. in Mandon Pl. Boliv, n. 1611.

- Am. merid. : And. Boliv.

Nadaudianus Besch. in Ann. sc. nat, 1894, p.

Ad terr, et rhizom. Pteridis, - Pac. : Taiti.

nano-phyllus C. M. in Dusen M. Camer. n. 305.

- Afr. : M. Cameroon.

nano-tenax C. M. in Jaeg. Ad. 1I, 761.

Ster.

- Air. : Zoulouland.

nanus C. M. in Bot. Zeit. 1847, p. 804 p. p.

Dicranum flexuosum var. Hsch. in Linn. 1841, p. 124.

D. nanum C. M. Syn. I, p. 383 p.p. et in Bot.Zeit. 1859, p. 189.

$$
\text { - Afr.: C. B Sp. }
$$

Exs, : Rehm. M. Afr. austr, n, 34.

nanus Bryol. jav. - C. subnanus.

natalensis Rehm. M. Afr, austr. n. 51 .

Ster.

$-\Lambda f r$. : Natal.

Naumanni (C. M.) Par.

Dicranum Naumanni C. M. in Engler's Bot. Jahrb. 1883, p. 84 et in Forchungsreise... p. 41.

Ster.

$$
\text { - Afr. : Ins. Ascension. }
$$

nepalensis (Brid.) Jaeg. Ad. I, p. 120.

? Dicranum nepalense C. M. Syn. I, p. 384.

? Didymodon nepalensis Brid. Bryol. univ. I, p. 82.

Ster.

$$
\text { - As. : Nepal. }
$$

Nietneri (C. M.) Jaeg. Ad. I, p. 136.

Dicranum latinerve Mitt. M. Ind. or. p. 17 p.p. ? (fid. C. M.)

D. Nietneri C. M. in Linn. 1869-70, p. 35.

Ster. - As. : Ceylan.

nigrescens (Miti.) Jaeg. Ad. I, p. 121.

Dicranum Dozyanum Wils, in Kew Journ. bot. IX, p. 298.

D. exasperatum Griff. Not. p. 421 et Ic. pi. asiat. t. 94, t. I.

D. nigrescens Mitt. M. Ind. or. p. 10.

Rupic. As. : Japon. ? Hong-Kong? Sikkim, Khasia, Assam, Ceylan. nigrescens Duby. - C. Richardi.

nilghiriensis (Mitt.) Jaeg. Ad. I, p. 130.

Dicranum nilghiriense Mitt. op. ^. p. 16. 
D. nivale C. M. Syn. I, p. 393 p p.

D. Perrottetii Mont. in Ann. so. nat. 1843, p. 241 p.p. - As. : M. Neilgherr.

nitidus $D_{z}$. et $M k$. frond. ined. Arch, ind. p. 139, t. 43.

C. uncinatus Bryol. jav. I, p. 78 p.p.

Dicranum nitidum Dz. et $M k$. Pl. Jungh. I, p. 330 ; Mitt, op. cit. p, 16. - As.: Borneo, Java, Ceylan.

nivalis Brid. Bryol. univ. 1, p. 477.

Dieranum nivale C. M. Syn. I, p. 393 p.p. ; Mitl. op. cit. p. 16.

Weisia nivalis Brid. Mant. M. p. 48. - Afr. : Ins. Borbon., M. Cameroon.

nodiflorus (C. M.) Jaeg. Ad. I, p. 144.

Dicranum nodiflorum C. M. in Bot. Zeit. 1853, p. 38 ; Mitt. op. cit. p. 21. Ster. - As. : M. Neilgherr.

nudus (Hpe.) Jaeg. Ad. II, p. 125.

Dicranum nudum Hpe, in Linn. 1859-60, p. 630.

- Pac. : Austral. or.

obscurus Ångstr. in Oefv..., 1873, n. 5, p. 119.

$$
\text { - Pac. : Taïti. }
$$

occultus Mitt. M. austr. am. p. 86 .

Lignic. - Am. merid, : Brasil, austr. or.

ochrodictyon Angstr. in Oefv... 1873, n. 5, p. 146. - Afr. : Ins. S. Helena.

CErstedtianus (C. M.) Mitt. op. cit. p. 81 .

Dicranum CErstedtianum C. M. Syn. II, p. 596.

Ster.

- Am. sepl. : And. Costa Ricens.

orthocomus Besch in Bull. Soc. bot. Fr. 1855, p. LVII el in Miss. sc.

Cap Horn, V, Bot. p. 263, t. 2, f. 5 .

Dicranum orthocomum C. M. in Fl. 1885, p. 409.

Ster.

- Am. merid. : Fuegia.

ovatus Brid. - Grimmia commutata.

pachycomus Besch, in litt.

C. bicolor ej. Prodr, bryol, mexic p. 22. - Am. sept. : Mexic.

pallescens Besch. Fl. bryol. Réunion, elc. p. 32. - Afr: : Ins. Borbon.

pallidus H. f, et W. p.p. - C. torquatus. paradoxus Wils, in W. P. Sch. Syn. II ed, p. 108.

Ster. Terr, humos, torfac. - Eur. : Anglia, Belgia. patens Brid. - Rhacomitrium. pauper (Hpe.) Mitt. op. eit. p. 74.

Dicranum pauper Hpe. in Linn. 1863, p. 137.

Terr. - An. merid. : Ind. Nov. Granat.

" var. minus (Hpe.) Jaeg. Al. I, p. 133.

Dicranum pauper var. minus Hpe. $l$. c.

Ut et ubi typ. 
penicillatus (Hsch.) Jaeg. Ad. I, p. 146.

Bartramia recurvifolia Duby Choix de M. ex 1880, p. 2, t. 3 (fid Hpe. in Fl. 1880, n. 21).

Campylopus giganteus Sull. in Proc. Am. Acad. August. 1861.

Dicranum concolor C. M. in Bot. Zeit. 1844, p. 709.

D. lamellinerve ej. Syn. I, p. 390; Mitt. op. cit. p. 81.

D. penicillatum Hsch. Fl. Brasil. p. 13; C. M. op. oit. p. 415. - Am. sept. : Cuba, Jamaïc. Am. merid.: Brasil.

austr. or.

penicillatus Rog. - C. fragilis.

perincanus $(C, M$.) Par.

Dicranum perincanum C. $M$. in $\mathrm{Fl} .1885, p .410$.

Terr. - Am. merid. : Fuegia. perpusillus Mitt. in Journ. of the Linn. Soc. 1886, p. 301.

C. dicranelloides Ren, et Card. ?

$$
\text { - Afr. : Ougogo. }
$$

Pes Funariae (C. M.) Par.

Thysonomitrium Pes Funariae C. M. in Linn. 1884, p. 551.

- As. : Ins. Philippin.

pilifer Brid. - C. polytrichoides.

pilosissimus W. P. Sch, in Besch. Prodr. bryol. mexic. p. 24.

Ster.

- Am. sept. : Mexic.

piriformis Schultz. - C. torfacens.

var. Mülleri Braithw. - C. torfacens var. fragilis.

platyneuron (Hpe.) Par.

Dicranum platyneuron Hpe. Symb. 1874, p. 489.

- Am. merid. : Brasil. austr. or.

poasensis Ren. et Card. in Bull. Soc, roy. bot. Belg. 1892, I, p 148.

- Am. sept. : And. Costa Ricens.

polyanthus Besch. Fl. bryol. Nov. Caled. p. 199.

Humic. in silv, - Nov. Caledon.

polytrichoides de Not. Syll. M. p. 222; Bryol. eur. Suppl. 1-II, t.4;

W. P. Sch. Syn, II ed p. 101.

C. longipilus Brid. Bryol. univ. I, p. 477 ; p.p.; B> yol. eur. I (mon.p. 6 t. 93 .

C. pilifer Brid. Mant. M. p. 72.

Dicranum flexuosum var. piliferum Turn. Musc. Hib. p. 74, t. V, f. 2 p.p.

D. longipilum C. M. Syn. I, p. 411.

Saxic. et torfac. - Eur. : Hibern., Anglia, Eur. occid. et merid. (ubi hucusque semper sterile); Lusitan. (c. fr.! fid. Venturi in Rev. bryol 1881, p. 19). Afr. : Alger., Madeir.

Exs, : Mandon Pl. Madeir. n. 4 bis.

Rab. Bryoth. eur. n. 507 et b, 1060.

a var. Daldiniar,us Jaeg. Ad. I, p. 145.

Ut typ, - Eur. : Ital. super, (ad lac. Major.).

- var. elongatus C. M. l. c.

Ut typ. - Eur. : Gall, occid. (Andegav.).

\& var, vaporarus Jaeg. l. c.

C. vaporarius Roll. Erb. critt. n. 1210.

Ut typ, - Eur. : Ital. (ins, Inarimes). 
porphyreocaulis (C.M.) Par.

Dicranum porphyrcocaulon C. M. in Linn. 1880-1883, p. 472.

- Am. merid. : Venezuela.

porphyreodictyon (C. M.) Mitt. M. austr. am. p. 75.

C. microstomus Mitt, in Spr. Cat.

C. tenuissimus Sull, in Proc. Am. Acad. 1861.

Dicranum aretocarpum C. M. in Linn. 1847, p. 205.

D. porphyreodictyon ej. Syn. I, p. 395 .

Thysanomitrium aretocarpum $\beta$ Moritzianum Hpe. in Linn. 1847, p. 75.

Lignic., saxic, et terr, $-A m$. sept. : Cuba, Jamaïc. Am. merid. : Ins.

Trinitat., Columb, Nov. Granat., Brasil. tropic., And. Peruv.

praemorsus (C. M.) Jaeg. Ad. I, p. 140.

Dicranum praemorsum C. M. in Bot. Zeit. 1862, p. 337.

Ster.

- Pac. : Ins. Hawaï.

procerus (C. M.) Par.

Dicranum procerum C. M. in $\mathrm{Fl}$. 1890. p. 472.

Ster. - Afr. : Kilima N'Djaro.

proliferus (C. M.) Mitt. op. cit. p. 85.

Dicranum proliferum C. M. Syn. II, p. 602.

Ster. - Am. merid. : Venezuela.

propinquus (Hpe.) Mitt. op. cit. p. 75.

Dicranum propinquum Hpe. in Ann. sc. nat. $V$ ser, $I I I, p, 367$.

- Am. merid. : And. Nov, Granat.

pseudo-filifolius (C.M.) Par.

Dicranum pseudo-filifolium C. M. in Linn. 1878-79, p. 471.

pseudo-julaceus Par.

- Am. merid. : Venezuela.

C. julaceus Rehm. M. Afr. austr. n. 58 .

Ster.

- Afr. : Orange.

pseudo-nanus (C. M.) Jaeg. Ad. 1, p. 120.

Dicranum pseudo-nanum C. M. in Bot. Zeit. 1859, p. 190.

- As. : Java.

pteroneuron (C. M.) Jaeg. Ad. II, p. 121.

Dicranum pteroneuron $C . M$. in Linn. 1869-70, p. 34.

Ster. - As. : Ceylan.

pudicus (Hsch.) Jaeg. Ad. 1, p. 139.

Dicranum pudicum Hsch, in Sieb. M. Nov. Holl. n. 24 p.p.; C. M. Syn. I, p. 407.

$\rho$ et fr. ign.

- Pac. : Austral, or.

Puiggarii (Geh. el Hpe.) Par.

Dicranum Puiggarii Geh. et Hpe. in Fl. 1881, p.

- Am. merid. : Brasil, austr. or.

pulvinatus Rehm. M. Afr, auslr. n. 62 .

Ster.

pulvinatus Brid. - Grimmia.

- Afr. : C. B. Sp. (Stinkwater).

var. tenuis Wahlenb. - Grimmia Mühlenbeckii.

purpurascens Llz. Moost. p. 118.

Ster.

- Afr.: C. B. Sp. 
pusillus W. P. Sch. in Besch. Prodr. bryol, mexic. p. 21 ,

- Am. sept. : Mexic.

Quintasii Broth. in Bol. da Soc. Berter. 1890.

Ster.

- Afr. : Ins. S. Thomas.

Rabenii Ltz. Moost. p. 158.

- Am. merid. : Brasil. austr. or.

Rauei Aust. - Dicranum Mühlenbeckii.

reconditus (Thw. el Milt.) Jaeg. Ad. $I I$, p. 648.

Sphaerothecium reconditum $T$. et M. in Jowin. of the Linn. Soc, 1872, p. 204.

- As. : Ceylan.

rectisetus (Hpe). Jaeg. Ad. $I I, p .649$.

Dicranum rectisetum Hpe. Symb. 1874, p. 487.

- Am. merid. : Brasil. austr. or.

recurvus (Mitt.) Jaeg. Ad. II, p. 122.

Dicranum recurvum Mitt. M. Ind. or. p. 20.

- As. : M. Neilgherr.

reduncus (Hsch. et Reinuc.) Bryol. jav. I, p. 75, t. 62.

Dicranum Auberti Bel. Voy. Ind. p. 104.

D. concolor Nees et Bl. in Nov. Act. Leop. XI, I, p. 133, t. 16.

D. reduncum H. et R. ibid. XIV, II, Suppl. p. 703; C. M. Syn. I, p. 396 et $I I, p .599 ;$ Mitt. op. cit. p. 18.

D. sinuosum Brid. Bryol. univ. I, p. 427, p.p.

Terr. - As, : Ceylan, Java.

Richardi Brid. Bryol. univ. I, p. 474 ; Mitt. M. austr. am. p. 90.

C. leptodus Mont. p.p.

C. Mülleri Jaeg. Ad. I, p. 146.

C. nigrescens Duby Choix de Crypt. ex. 1867, t. I, f. I.

Dicranum Ricliardi C. M. Syn. I, p. 413.

Thysanomitrium Mülleri Hpe. in Ann. sc. nat. V ser., III, p. 363.

Th. Richardi Sohwaegi: Suppl. II, I, p. 61, t. 118.

Rupic. et terr. - Am. sept. : Costa Rica, Guadalup. Am. merid.

And. Nov. Granat., Quitens, et Peruv.; Chile.

rigidiuseulus (Hpe.) Jaeg. Ad. I, p. 136.

Dicranum rigidiusculum Hpe. Symb. 1870, p. 272.

- Am. merid. : Brasil. austr. or.

rigidus (Hsch.) Jaeg. Ad. I, p. 147.

Dicranum rigidum C. M. Syn. I, p. 409.

Thysanomitrium rigidum Hisch. Fl. Brasil. I, p. 15.

- Am. merid. : Brasil. austr. or.

ripicolus Besch. Fl. bryol. Réunion, etc. p. 38.

Ster.

- Afr. : Ins. Borbon.

rosulatus (Hpe.) Mitt. op. cit. p. 79.

Dicranum rosulatum Hpe in Linn. 1863, p. 139.

Terr. - Am. merid. : And. Nov. Granat.

rugosus Besch, Fl. bryol. Nov. Caled. p. 198.

Arbor. in silv. - Pac. : Nov. Caled.

Robillardi Besch. Fl. bryol. Réunion, etc. p. 34.

Ster.

- Afr. Ins. Franciae, Nossi-Be. 
Saddleanus Besch. in Bull. Soc. bot. Fr. 1885, LVIIl et in Miss. sc. Cap Horn, V, Bot. p. 264, ı. 2, f. 6.

Dicranum Saddleanum C. $M$. in Fl. 1885, p. 407.

Ster. - Am. merid. : Fuegia.

Sancti Caroli Besch. in Journ. de Bot. 1891, p. - Am. merid. : Chile austr.

Sauteri Mdlo, in sched. ; Jaeg. Ad. I, p 129.

C. Schimperi (fid. Limpr. Deutschl. Laubm. p. 381).

$$
\text { - Eur. : Alp. Austriae. }
$$

savannarum (C. M.) Mitt, M. austr, am. p. 85.

Dicranum savannarum C. M. Syn. II, p. 596.

Ster. Terr. - Am. merid. : Guian. batav.

saxicola Brid. - Campylosteleum.

scabrellus Mitt. op. cit. p. 86.

$$
\text { - Am. merid. : Brasil. }
$$

Schemkei C. M. in Rehm. M. Afr. austr. n. 39.

Ster.

Schimperi Milde in Bot. Zeit. 1864, Beil.p. 13; W. P. Sch. Syn. I ed. p. $658, I I$ ed. p. 107.

C. subulatus var. Schimperi Husn. Muscol. gall. p. 43.

Ad rup. humid. - Eur. : Ins. Shetland, Scot., Scandin, Salisb., Stir., Carinth., Alp. Algov., Tirol., Alp. Pyr. As. : Caucas. Am. sept. : Groenland.

Exs. : Rab. Bryoth. eur. p. $658,1113$.

Schmidii (C. M.) Jaeg. 1, p. 143.

Dicranum Schmidii C. M. in Bot. Zeit 1853, p. 37; Mitt. M. Ind. or. p. 21. - As. : M. Neilgherr.

Schwaegrichenii Duby in Mem... Genève, $1869, p .10, t . I V, f .2$.

C. trachyblepharon C. M. ?

$$
\text { - Am. merid. : Brasil austr. or. }
$$

Schwartzii Bryol. eur. Suppl. I-II, ı. I; W. P. Sch. \$yn. II ed. p. 105.

Ster. Ad rup. irror. - Eur. : Norveg. occid., Hibern., Scot., Rhaet., Tirol., Salisb.

Ecs. : Rab. Bryoth, eur. n. 925.

sciuroides Welvo. el Duby in Mem... Genève, 1870, p. 6, t. XI, f. 4.

Ster. Rupic. - Afr. : Angola.

scsttianus Brid, - Dieranum.

Sellowianus (Hpe.) Jaeg. Ad. II, p. 649.

Dicranum Sellowianum Hpe. Symb, 1872, p. 43.

Thysanomitrium scabrisetum ej. Ic. M. t. $23 \mathrm{~B}$. - Am. merid. : Brasil, austr. or.

semidorsus C. M. in Rehm. M. Afr. austr. n. 45.

Ster.

- Afr. : C. B. Sp.

serratus Lac. Sp. nov. M. Archip. ind. p. II, t. $7 \mathrm{~B}$.

- As. : Ins. Banea.

setaceo-rigidus (Hpe.) Par.

Dicranum setaceo-rigidum Hpe. Symb. 1877, p. 721.

Ster.

- Am. merid. : Brasil. austr. or. 
setifolins Wils. Bryol. brit. II ed.p. 89, t. 40 ; Bryol, eur. Suppl. III-IV t. 6 ; W. P. Sch. Syn. II ed.p. 106.

Ster. Ad rup. et in turfos. - Eur. : Hibern., ins. Skye.

Exs. : Rab. Bryoth. eur. n. 1059.

Shawi Wils, in W. P. Sch. Syn, II ed. p. 851.

Fl, et fr. ign.

- Eur. : Ins. Hebrid.

“ var. hamata W. P. Sch. l. c.

Ut et ubi typ.

smaragdinus (Brid.) Jaeg. Ad. I, p. 136.

Dicranum smaragdinum C. M. Syn. I, p. 401.

Didymon smaragdinus Brid. Bryol, univ. I, p. 819.

Ster.

- Afr. : Ins. Ascension.

sordidus Jaeg. - Slindia.

Spegazzinii (C. M.) Par.

Dicrauum Spegazzinii $C, M$, in $F l .1885, p .410$.

Ster. In prat. turfos. - Am. merid. : Fuegia.

Sprucei Milt. M. austr. am. p. 81.

- Am. merid. : Amazon.

squalidus Brid. - Rhacomitrium lanuginosum var. squalida.

stenocarpus (Hpe.) Jaeg. Ad. I, p. 138.

C. arctocarpus Mitt, op, cit. p. 87 p.p.

Dicranum stenocarpum C. M. Syn. II, p. 600.

D. stenopus ej. op. cit. $I, p .401$ (excl. syn. Thysanomitrio scabriseto).

Thysanomitrium stenocarpum Hpe, Ic. M. t. $23 \mathrm{~A}$. - Am. merid. : Monte Video.

stenopelma C. M. in Rehm. M. Afr, austr: n. 52.

- Afr. : C. B. Sp.

stramineus (Mitl.) Jaeg. Ad. I, p. 546.

Dicranum stramineum Mitt, in Journ, of the Linn. Soc. 1863, p. 143. - Afr. : M. Cameroon.

Exs. : Dusen M. Camer. n. 349.

strictifolius Broth. in Act. Soc. sc. Fenn. 1891, n. 5.

Ster, Arbor? - Am, merid. : Minas Geraes.

strictus W. P. Sch, in Besch. Prodr. bryol. mexic. p. 23.

Ster. $\quad-$ Am. sept. : Mexic.

striclus C. M. - C. erectus.

subarctocarpus (Hpe.) Par.

Dicranum subarctocarpum Hpe. Symb. 1877, p. 719.

- Am, mevill. : Brasil, austr. or.

subbartramiaceus C. M. in Relem. M. Afr. austr, $n .55$,

Ster.

-Afr: : C. B. Sp.

subbrachyphyllus Par.

C. brachyphyllus C. M. in Dusen M. Camer $n .655$.

- Afr.: M. Cameroon.

subconcolor (Hpe.) Milt, M. austr, am. p. 86 .

Dieranum subconcolor Hpe, in Linn. 1863, p. 138.

Terr, - Am, merid. : An l. Nov, Granat. 
subcuspidatus (Hpe.) Jeeg. Ad. 1, p. 145

Dicranum subcuspidatum Hpe. Symb. 1870, p. 273.

Ster. $\quad-A m$. merid. : Brasil, austr. ur.

subexasperatus (C. M.) Par.

Dicranum subexasperatum C. M. in Linn. 1874, p. 169.

- As. : M. ins, Phllippin.

subfalcatus (Hsch.) Jaeg. Ad. I, p. 146.

Dicranum subfalcatum Hsch. Fl. Brasil. I, p. 13 ; C. M. Syn. I, p. 415.

Ster. - Am. merid. : Brasil. subflexuosus Par.

C. abyssinicus W. P. Sch. in W. Sch. M. Abyss.

$$
\text { - Afr.: Abyssin. }
$$

subgriseus (Hpe.) Jaeg, Ad. II, p. 648.

Dicranum subgriseum Hpe. Symb. 1872, p. 47.

Ster.

- Am. merid. : Brăsil. austr. or.

subincrassatus (Hpe.) Jaeg. $l . c$.

Dicranum subincrassatum Hpe. $l$. c.

Ster. - Am. merid. : Brasil. austr. or.

sublencogaster (C. M.) Lesq. el Jam. Man. p. 79.

Dicranum subleucogaster C. M. in Bull. Torr. bot. Club, V, p. 50 ,

Ster. Terr. argill. humid. - Am. sept. : Alabama.

subluteus (Mitt.) Jaeg. Ad, I, p. 121.

Dicranum subluteum Mitt. M. Ind. or. p. 19.

Ster. $\quad-A s$. : Ind. or., penins. Malacc.

subnanus (C. M.) Jaeg. Ad. I, p. 119.

C. flexuosum Dz. et Mk. M. frond. ined. Archip. ind. $p, 138$ ?

C. nanus Bryol. jav. I, p. 74, t. 61 .

Dicranum nanum C. M. Syn. I, p. 384 p.p.

D. subnanum ej. in Bot. Zeit. p. 190.

Sandwic., Nov. Caledon.

- As. : Java, ins. Sundaëns., Borneo. Pac.: Ins. subpolyanthus (C.M.) Par.

Dicranum subpolyanthum C. M. in Rev. bryol. 1887, p. 5 !' (nom.)

$$
\text { - Pac. : Nov. Caledon. }
$$

subproliferus C. M. in Bull. Soc. roy. bot. Belg. 1892, I, p. 149.

In silvis. - Am, sept, : And, Costa Ricens.

subreconditus (Geh, el Hpe.) Par.

Dicranum subreconditum Geh, et Hpe, in Fl. 1881, p.

- Ain. merid. : Brasil, austr, or.

subsecundus Lindb. mss. ; Angstr. in Oefo... 1876, n. 4, p. 5.

- Am. merid. : Brasil. austr. or.

subtorquatus C. M. in Rev. bryol. 1876, p. 3 (nom.)

- Pac. : Austral. (Nova Valesia).

subtricolor Ltz. Moost.p. 159.

Ster.

- As, : India.

subulatus W. P. Sclı, - C, brevifolins.

var. Schimperi Husn. - C. brevifolius var. Schimperi. 
subnlifolius Thro. el Milt. in Journ. of the Linn. Soc. 1872, p. 297.

$$
\text { - As. : Ceylan. }
$$

surinamensis C. M. in Linn. 1848; p. 186.

Dicranum surinamense $e j$. Syn. $I, p .386$.

$\rho$ et fr. ign. Terr. - Am. merid. : Guian. batav.

tallulensis Sull. et Lesq. in Sull. Ic. M. p. 27, t. 17; Lesq. el Jam. Man.p. 78.

Ster. Ad rup. irror. - Am. sept. : Georgia.

Exs. : Sull. et Lesq. M. bor. am. I ed. n. 73 b, II ed. n. 93.

tenax Relim. M. Afr. austr. n. 54.

$$
\text { Ster. } \quad-A f r .: \text { C. B. Sp. }
$$

tenuissimus Sull. - C. porphyreodictyon.

terebrifolius (C. M.) Jaeg. Ad. $1 I, p .649$.

Dicranum terebrifolium C. M. in Linn. 1874, p. 593.

Ster.

- Am. merill. : M. Pichincha.

tenuis Wils. - Campylopodium khasianum.

Thwaitesii (Milt.) Par.

Dicranum Thwaitesii Mitt. M. Ind. or. p. 19.

Ster. - As. : Ceylan.

torfaceus Bryol. eur. I (mon. p. 4) t. 91; W. P. Sch. Syn. II ed. p. 103.

Bryum flexuosum L. Sp.pl. p. 1593 p.p.

C. flexuosus Brid. Bryol. univ. T, p. 469 p.p.

C. piriformis Schultz Fl. Starg. Suppl. p. 73; Brid. l. c. p. 471.

Dicranum flexuosum var. Schultz op. cit. p. 298.

D. pinetorum Grift. Not. p. 419 et Ic. pl. asiat. II, t. 94, f. 3.

D. turfaceum C. M. Syn. I, p. 399.

Thysanomitrium piriforme Rab. Deutschl. krypt. Fl. II, III, p. 140.

In turfos. - Eur. : Fere tota. As. : Khasia.

Exs. : Rab. Bryol, eur. n. 506.

« var. alpicola (Jaeg.) Par.

C. alpicola Jueg. Ad. $I, p, 46$.

C. torfaceus W, P. Sch. in W. Sch. M. Abyss. II coll., n. 12.

Cephalogonium densum W. P. Sch, in Jaeg. Ad. II, p. 650 ?

Dicranum alpicolum C. M. in Bot. Zeit. 1858, p. 161.

- Afr.: Summ. Alp. Abyssin.

"var. fragilis Jur. Laubm. Oesterr. Ung. p. 56.

C. Mülleri ej, in sched. ; Milde Bryol, siles. p. 77.

C. piriformis \& Miilleri Braitho. Brit. Moosft. p. 128.

Ut typ. - Eur.: Westphal.

torfaceus W. P. Sch. - C. torfaceus var. alpicola.

toryuatus Mitt. Fl. Tasm, p. 173.

C. pallidus H.f. et W. Fl. of the N. Zeal. $I I, p .68, t .84, f .3$ p.p.; Handb. p. 414 .

Dicranum flexuosum C. M. in Adnot, ad M. Mossmann. in Bot. Zeit. 1851, p. 551 (fid. Mitl.).

D. torfaceum Mitt. in Hook. Kew Misc. 1856, p, 257.

D. torquatum Mitt. in Joum. of the Linn. Soc. 1859, p. 69 ,

Ster. - Pac. : Austral., Nov. Zeland., Tasman., ins. Campbell.

trachyblepharon (C. M.) Mitt. M. austr, ami. p. 80.

C. Schwaegrichenii Duby?

Dicranum concolor Hsch. Fl. Brasil. I, p. II.

D, trachyblepharon C. M. Syn. I, p. 389.

- Ams, merid. : Brasil. 
trachythecius (C. M.) Jaeg. Ad. I, p. 127.)

Dicranum trachythecium C. M. in Linn. 1869-70, p. 33.

- As. : Ceylan.

transvaaliensis Rehm. M. Afr. austr. n. 450.

Ster.

- Afr. : Transvaal.

trichodes Ltz. Moossl. p. 159.

Ster. $\quad-A f i$.: Orange, C. B. Sp.

Exs. : Rehm. M. Afr. austr. n. 56 et b.

tricolor (C. M.) Par.

Dicranum tricolor C. M. in Bot. Zeit. 1853, p. 36; Mitt. M. Ind. or. p. 21.

As. : M. Neilgherr.

truncatus C. M. in Linn. 1844, p. 687.

C. xanthophyllus Mont. in Ann. sc. nat. 1845, p. III, et in Gay Hist.

Chil. Bot. crypt.t. 4, f. 2; Syll. p. 43.

Dicranum truncatum C. M. Syn, I, p. 410.

- Am. merid. : Chile austr. Pac. : Nov. Zeland.

umbellatus W. Ain. Disp. p. 34.

Trichostomum umbellatum Schwaegr, in Freycinet Voy. Bot,, p. 224.

- Pac. : Ins. Hawai.

uncinatus Bryol. jav. p.p. $\left\{\begin{array}{l}-\mathrm{C} \text {. nitidus. } \\ - \text { Dicranodontium. }\end{array}\right.$

Valentini Besch. Fl. bryol. Réunion, etc. p. 37.

Ster. $\quad-A f r$. : Ins. Borbon.

Vernieri Duby in Mem... Genève, $1875, p .12, t .2, f .5$.

Arbor. - Pac. : Taiti.

verrucosus Besch. Fl. bryol. Nov. Caled. p. 200.

- Pac. : Nov. Caledon.

verticillatus (Hpe.) Par.

Dicranum verticillatum Hpe. Enum. M. Brasil. p. 19. - Am. merid. : Monte Video.

villicaulis (Hpe.) Jaeg. Ad. II, p. 645.

Dicranum villicaule $H p e$, Symb. 1872, p, 44.

Ster. $\quad-A m$. merid. : Brasil, austr, or

virescens Besch. Fl, bryol. Réunion, etc. p. 36.

Ster. $\quad-A f r$. : Ins. Borbon.

virginicus Lesq. el Jam, Man. p. 80.

Dicranum virginicum Aust. in Coult. Bot. Gas. IV, p. 150.

Ster. $\quad-A$ Am. sept. : Virgin. occid.

viridatulus C. M. in Dusen M. Camer. n. 132.

$$
\text { - Afr.: M. Cameroon. }
$$

viridis Sull, et Lesq. - Dicranum.

Vitzliputzli Llz. Moost. p. 158.

- Am. sept. : Mexic.

Walkeri (Milt.; Jaeg. Ad, I, p. 133.

Dicranum Walkeri Mitt. M. Ind. or. p. 18.

- As. : Ceylan. 
Wallisii Sb. in Jaeg. Ad. II, p. 646.

Dicranum purpurascens C. M. in Linn. 1874, p. 552.

Ster.

- As. : Ins. Philippin.

Wawreanus Reichdt. Beilr...p. 565.

Terr. - Pac. : Ins. Sandwic.

Weddelii Besch. in Journ. de bot. 1891, p.

Ster.

- Am. merid. : Peruv.

Widgrenii (C. M.) Mitt. M. ausir. am. p. 88.

Dicranum Widgrenii $C . M$. in Bot. Zeit. 1856, p. 418.

- Am. merid. : Brasil.

xanthophyllus Mont. - C. truncatus.

Zollingerianus (C. M.) Bryol. jav. I, p. 77, Ł. 64 .

Dicranum Zollingerianum C. M. Syn. II, p. 599.

Rupic. - As. : Java, Sumbawa.

sonatus Mdo. - C. flexuosus var. zonatus.

zygodonticarpus (C. M.) Par.

Dicranum zygodonticarpum C. M. in Linn. 1879-80, p. 471.

- Am. merid, : Venezuela (1).

GAMPYLOSTELEUIM Bryol, eur. II (3 sp.)

americanum Solms. - C. saxicola.

saxicola (Web. et Mohr.) Bryol. eur. II (mon. p. 3), t. 116; C. M. Syn.

$I$, p. 41 i et II, p. 603; W. P. Sch. Syn. II ed.p. 133.

Campylopus saxicola Brid. Mant. M. p. 72.

Campylosteleum americanum Solms in Jaeg. Ad. I, p. 176.

Dicranum saxicola $W$. et M. Bot. Taschb. p. 167.

Dryptodon saxicola Brid. Biyol. univ. I, p. 770.

Grimmia genieulata Sehwaegr. Suppl. I, I, p. 82, t. 22; Brid. op. c. p. 189.

Gr. saxicola $H$. et $T$. Muscol, brit. II ed. $p .87, t .13$.

Ptychomitrium geniculatum Hpe. in Fl. 1837.

Trichostomum saxicola Hsch. in Spreng. Syst. veg. IV, p. 171.

Weisia saxicola Brid. Mant. M. p. 38.

1. Ad saxa aren. et granit. humid. - Eur. : Hibern., Anglia; media valde sporadice: Galic, Bohem., Saxon., Austr. sup. et inf., Siles,, German., vall. Rhen., Tirol., Helvet. ; Ital. (Como); in Scandin. deest Am. sept.: Ins. Prince Edouard, Massachussets, Kentucky.

Exs. : Rab. Bryoth. eur. n. 415, 613.

Soll. et Lesq. M. bor. arn. Il ed., n. 114.

strictum Solms Laub. Tent. bryol. geogr. Algarv, p. 42 ; W. P. Sch. Syn. II ed.p. 134.

Weisia We!witschii W.P. Seh. l, e. p. 52.

1. In fissur. rup. granit. - Eur. : Lusitania (pr. Mouchique Algarb.)

(1) In Enum. Kindberg. nomina nuda :

C. convolutus Ângstr.

C. ericelorum Mitt. (forsan C. Dozyanus).

C. latifolius Rehm.

C. latipilis C.M.

(.) leucobasis C.M.

C. madeirensis Geh.

C. pyenangius $C . M$.

C. rectipilis $C . M$.

C. rigescens $C, M$.

C. subchlorophyllosus $C . M$.

C. subclavatus (Rehm.) (an C.pseudoclavatus ?)

C. substygius $C . M$.

C. Woolsii C.M. 
venezuelianum $D$ s, et Mk. Prodr, fl. bryol. Surinam, p. 38, t. 5. 2.

Capillidium C. M. in Linn, 1878-79 (sect. ARroBryI).

Carpoëcia Vent. in Rev. bryol. 1881, p. 20 (sect. CAMpyLopodis).

Gatagonium C. $M$. in Fl. 1885, p. 425 (sect. HyPNI).

Catenularia C. $M$, in op. cit. p. 411 (sect. Philonotidis.)

CATHARINEA Ehrh. Beiti. 1, p. 178.

Abriaquix C. M. - Polytrichadelphus.

aloides Roehl. - Pogonatum.

alpina Roehl. - Pogonatum.

androgyna C. M. - Atrichum.

angustala Brid. - Atrichum.

anomala Bryhn. - Atrichum Haussknechtii.

antarctica C. M. - Psilopilum.

aristala Hpe. - Polytrichadelphus.

Arnoldi Hpe. - Polytrichadelphus.

Australasiz Hpe. - Polytrichadelphus.

callibryon Ehrh. - Atrichum undulatum.

bogotensis Hpe. - Atrichum.

canaliculata C. M. - Oligotrichum.

ciliata C. M. - Polytrichadelphus.

compressa C. M. - Psilopilum.

crispa Jam, - Atrichum.

$\beta$ densifolia Lindb. - Atrichum crispum var, densifolia.

dendroides Hpe. - Polytrichadelphus.

Dixoni Braithw. - Polytrichum gracile.

Ehrharlli Voit. - Atrichum undulatum. erosa Hpe. - Oligotrichum.

flaviseta Wils. p.p. - Atrichum.

glabrata Hook. - Psilopilum arcticum.

gymnostoma C. M. - Psilopilum areticum.

Haussknechtii Broth. - Atrichum.

hercynica Ehrh. - Oligotrichum.

$\beta$ sancla Brid. - Oligotrichum hercynicum?

innovans C. M. - Polytrichadelphus.

intermedia Bel. - Pogonatum Belangeri.

javanica Hpe. - Oligotrichum hercynicum ?

laevifolia Lindb. et Arn. - Atrichum.

laevigata Brid. - Psilopilum arcticum.

lateralis Valz. - Atrichum Haussknechtii.

magellanica $\{$ Brid - Polytrichadelphus.

Molinae C. M. M. (Syn. 11, p. 560). - Polytrichadelphus semi-angulatus.

. Oligotrichum.

Mülleri C. M. et Hpe. - Atrichum.

nana Roehl. - Pogonatum.

Nietneri C. M. - Olıgotrichum.

oblusata C. M. - Atrichum.

Erstedliana C. M. - Atrichum.

piriformis Hpe. - Psilopilum.

planifolia C. M. - Atrichum.

polycarpa W. P. Sch. - Atrichum.

pseudo-polytrichum Raddi, - Polytrichadelphus magellanicus. 
pulverulenla Roehl. - Pogonatum urnigerum.

Riedeliana Hpe. - Oligotrichum.

sancta Brid. - Oligotrichum hercynicum?

semi-angulata Hpe. - Polytrichadelphus.

semi-lamellata Hpe. - Oligotrichum.

squamosa C. M. - Polytrichadelphus.

subserrata Lindb. - Atrichum undulatum var. subserrata.

sudetica Presl. - Oligotrichum hercynicum.

tapes C. M. - Psilopilum.

terella Roehl. - Atrichum.

tenuirostris Brid. - Oligotrichum.

tschutschica C. M. - Psilopilum.

Trianae C. M. - Polytrichadelphus.

trichodon C. M. - Psilopilum.

undulata Roehl. - Atrichum.

var. abbreviata C. M. - Atrichum undulatum var. abbreviata.

var. attenuata C. M. - Atrichum undulatum var. attenuata.

var. brevilamellosa C. M. - Atrichum polycarpum.

var. minor $\{$ Hüb, - Atrichum tenellum.

var. minor $\{$ W. et M. - Atrichum undulatum var, abbreviata.

var. subserrata C. M. - Atrichum undulatum var, abbreviata.

Valenciae C. M. - Polytrichadelphus.

xanthopelma C. M. - Atrichum.

Gatharinella C. M. Syn. I, p. 213 (sect. PolytrichI),

CATHAROMNIUM Hook. f. et Wils. Fl. of the N. Zeal. II, p. 119.

ciliatum $\mathrm{H}$. f. et W. - Hypoterygium.

GATO SCOPIUM Brid. Mant. M. I, p. 368 (1 sp.).

Martianum Hïb. - Oreas.

nigritum (Hedw.) Brid. Bryol, univ. I, p. 368; Bryol. eur. IV (mon. p. 4), t. 313; C. M. Syn. I, p. 510; W. P. Soh. Syn. II ed. p. 498. Bryum nigritum Dicks. Fasc. III Pl. orypt. p. 9.

Grimmia nigrita Sm. Fl. brit. III, p. 1195.

Weisia nigrita Hedw. M. frond. III, p. 97, t. 39; Drumm. M. bor, am. $I$ ed. $n .73$.

2. In ericet. turf, et fissur. rup. - Eur. : Sporad. in zon. intermed., capiosiss, in Alp. reg. septent. et aret. : Spitzberg, ins. Ursorum, Norveg., Neerland, inglia. As.: Jenissei infer. Am. sept. : Groenland., sin. Hudson, Terra nov., lac. Super., Huron, Ontario, M. Rupestr., Columb. brit.

Exs. : Mac. Canad. M. n. 154.

Rab. Bryoth. eur. n. 128.

Sull. et Lesq. M. bor. am. Il ed, n. 249.

Un itin. 1863, n. $51 ; 1867$, n. 86.

CECALYPHUM P. B. Prodr. p. 50.

calycinum P. B. - Holomitriurn

condensatum P. B. - Dicranum spurium.

cylindraceum P. B. - Holonitrum vaginatum.

dichotomum P. B. - Dicranum.

fasciatum P. B. - Campylopus longifolius?

longivostratum P, B. - Dicranum scoparium.

multiflorun P. B. - Cynodontiurn polycarpum.

perichaetiale $\mathrm{P}$. B. - Holomitrium. 
sciuroides P. B. - Leucodon.

scoparium P. B. - Dicranum.

scrofulosum P. B. - Dicranum falcatum.

? semi-completum P. B. - Conomitrium Hedwigii.

spurium P. B. - Dicranum.

strumiferum P. B. - Cynodontium polycarpum var. stı umiferum.

torlile P. B. - Ptychomitrium polyphyllum.

undulatum P. B. - Dicranum Schraderi.

CEPHALOGONIUM W. P. Sch. in Jaeg. Ad. II, p. 650.

densum W. P. Sch. - Campylopus torfaceus var. alpicola?

CEPHALOTRICHUM Br. et Sch. in W. Sch. M. Abyss. el Bryol. eur. IV. oligodus Br. et Sch. - Pogonatum.

simcnse Eor. - Pogonatum.

GERATODON Brid. Bryol, univ. I, p. 480 (18 sp.).

amblyocalyx C. M. - C. purpureus var, amblyocalyx.

brasiliensis Hpe. Symb. 1872, p. 39.

2.

- Am. merid. : Brasil, austr. or.

ealycinus Hpe. in Reichdt. Exp. Novara.

C. purpureus Mitt. Fl. Vit., p. 385.

- Afr. : Ins. S. Paul.

capensis W. P. Sch, in Breulel M. Capens.

Pottia ceratodontea $C . M$. ?

- Afr. : C. B. Sp.

chloropus Brid. Bryol. univ. I, p, 486; W. P. Sch. Syn. II ed. p. 136.

Cheilothela chloropus Lindb. in Ulk. till... 1878.

Dicranum chloropus Brid. Mant. M. p. 70 (emend.).

Didymodon ictericus de Not. Spic. p. 13.

Trichostomum strictum Bryol. eur. II (mon. p. ), t. 177; C. M. Syn. I, p. 576.

2. Terr. - Eur. : Galloprov., Sardin., Etrur,, Roma. Afr. : Alger.

Exs. : Rab. Bryoth. eur. n. 1258.

condensatus W. P. Sch, in Breutel M. Capens.

Leptotrichum Vallis Gratiae Hpe. in sched.

$$
\text { - Afr. : C.'B. Sp. }
$$

conicus Lindb, - Trichostomum.

convolutus Reichalt. in Novara Exp., Bot. 1, p. 171.

C. purpureus $H, f$. et W. Fl. of the N. Zeal. $1 I, p .75$. - Pac, : Nov. Zeland.

corralensis Jaeg. - Zygodon.

corsicus Bryol, eur. II (mon. p. ) t. $191 ;$ C. M. Syn. II, p. 633. 2. Loc, steril. - Eur. : Galloprov., Corsic., Sardin., Algarb. Afr. :
C. B. Sp.

Exs. : Rehm. M. Afr. austr. n. 122.

crassinervis Ltz. in Bot. Ztit. 1866, p. 187.

2. Terr. - Am. merid. : Valdiv. Pac, : Tasman.

cylindricus Bryol, eur. - Trichodon, 
dimorphus Philib. in Rev. bryol. 1888, p. 28.

2. Muric. - Eur.: Alp. Vales., Simplon.

heterophyllus Kindb. in Mac. Cat.p. 26I.

2. Terr. - Am. sept, : Fret. Behring.

javanicus $\mathrm{Dz}$, et Mk. - C. purpureus.

kerguelensis C. M. in Forchungsreise...p. 3 (nom.).

- Afi. : Ins. Kerguelen.

minor Aust. in Coult. Bot. Gaz. II, p. 89 ; Lesq. et Jam. Man. p. 92.

2. Terr. humid, - Am. sepl. : Columb. brit., ins. Vancouver.

novo-granatensis Hpe, in Ann. sc. nat. V ser., $I I 1, p$.

- Am. merid. : And. Nov. Granat.

oblongus Lindb. in Oefv... 1866, p. 554.

Trichodon oblongus ej. Trichost. ever. p. 15.

Trichostomum cylindricum ej. in Oefv... XVIII, p. 190, n. 18.

2.

- Eur. : Spitzberg.

perichaetialis W. P. Sch. in Besch. Prodr. bryol. mexic. p. 30 (nom.) - Am. sept. : Mexic.

purpureus (L.) Bril. Bryol. univ. 1, p. 480 (uncl. var. $\beta, \gamma, \delta, \varepsilon, \zeta, \eta, \theta$ ?); Bryol. eur. II (mon. p. 5), t. 189 et $190 ; C, M$. Syn. I, p. 646 ;W. P. Sch. Syn. II ed. p. 632.

Barbula Saussuriana Brid. Mant. M. p, 94.

Bryum basiflorum Gmel. Syst. nat. II, p. 1332.

Br. bipartitum Dicks. Fasc. II Pl. cmypt. p. 7.

Br. Celsii L. Sp. pl. p. 1585.

$\mathrm{Br}$, papillosum Dicks. Fase. IV Pl. crypt. p. 12, t. XI, f. 5 .

$\mathrm{Br}$. parvum surculis et setis geminatis Dill. Hist. M. p. $385, t .49, f .50$.

$\mathrm{Br}$. polytrichoides palustre, setis longioribus rubris sericeis ej. op. eit. p. $387, t .49, t .52$.

Br. purpureum Neck. Meth. M. p. 211.

Br. strictum Dicks, op. cit. p. 13.

Br, tenue ej. Fasc. III Pl. crypt, p. 8.

$\mathrm{Br}$. tenue, stellatum, setis purpureis Dill. op. cit. p. 386, $t, 49, f .51$.

$\mathrm{Br}$. trichodes acaulon minimum setis et capsulis oblongis ej. op. cit. $p .388$ t. 49, f. 54 .

Ceratorlon javanicus $D z$, et $M k . P l$. Jungh. I, p. 337.

Dicranum bipartitum $S m$. Fl. brit. $I I I, p, 1218$.

D. Celsii Hedw. Sp. M. p. 149, t. 33, f, 1-4.

D. intermedium ej. op. cit. p. $138, t, 31, f .1-6$.

D. longisetum Brid. $\dot{M}$. Rec. $I I, I, p .66$.

D. palustre ej. op. cit. p. 174.

D. purpurascens Hedio, op cit. p. 137, t. 35, f. 1-7.

D. purpureum ej. op. cit. p. $136, t .36$.

D. strictum $S m$. op. et $l$. cc.

Didymodon papillosus Bvid. Sp. M. I, p. I60.

D. purpureus H. et T. Museol. brit. p. 65, t. 20 ; Drumm. M. bor. am. I ed. n. 116.

Fuscina purpurea Schkrank Baiers. Fl. II, p, 453.

Mnium purpureum L. Sp. pl. p. 1571.

Tortula Saussuriana Brid. M. Rec. II, I, p. 203.

Trichostonum basiflorum Schrank op. cit. p. 449.

Tr. krintjingianum Dz. et Mk. in Zoll, Syst. Verz. p.p. 25 et 31.

Tr. papillosum Sm. op, cit. p. 1238.

Tr. purpureum de Not. Epil.

Tr. tortum Schrank op. et l. ev.

2. In ericet., agger., ad mur., ete. - Per totım orb. fere terrar. : a Spitzberg, ins. Ursor. et Groenland. ad reg. antaret. 
Exs. : Bourgeau Pl. Can. n. 1128.

Faurie Pl. Japon, n. 167, 169, 3520.

Mac. Canad. M. n. 56 .

Rab. Reyoth. eur. n, 463.

Sull, et Lesq. M. bor. am. II ed, n. 159.

"var. amblyocalyx C. $M$. in Fl. 1885, p. 417.

C. amblyocalyx ej. in Angstr, Prim. lin. p. 50.

C. purpureus Angstr, in Fregate Eugenie... p. 6.

Ut typ. - Am. merid. : Terr. Magellan.

«var. aristatus Aust. M. Appal. n. 17; Lesq. el Jam. Man. p. 92.

A renic. - Am. sept. : New Jersey.

* var. brevidens W. P. Sch. in Besch. Fl. bryol. Réunion, elc. p. 51. - Afr. : Ins. Franciae.

" var. brevifolius Milde in Bot. Zeit. 1862, p. 460.

Ut, typ. - Eur. : German. merid.

"var. flavisetus Limp. Deutschl. Laubm. p. 487.

Ut typ. - Eur. : Stiria, Tirol.

"var. Graeffii (Schlieph.) Limpr. l. c.

C. Graeffii Schlieph. mss.

Didymodon cuspidatus W. P.Sch. mss.; Milde Bryol. sil. p. 119.

Ut typ. - Eur. : Alp. Helvet.

\& var. obtusifolius Limpr. l. c.

Ut typ. - Eur. : Stiria.

«var. xanthopus Sull. M. bor. am. II ed. p. 29 ; Lesq. et Jam. Man. l. c.

Terr, et rup. - Am. sepı.: Ins. Vancouver, Calif.

Exs. : Sull. et Lesq. M. bor. am. II ed, n. 160.

purpureus $\left\{\begin{array}{l}\text { Angstr. - C. purpureus var. amblyocalyx. } \\ \text { H, f. et W. - C. convolutus. }\end{array}\right.$

parpureus Mitt. - C. calycinus.

Wils. - Trichostomum tophaceum.

var. palustris Mont. - C. stenocarpus.

stenocarpus Bryol. eur. II (mon. p. 4, nom.); C. M. Syn. I, p. 617.

Barbula conica Spreng. Syst, veg. IV, II, p. 323.

C. purpureus var. palustris Mont. in M. Neilgher.r. n. 57.

Didymodon stenocarpus Mitt. M. Ind. or, $p$. 24 .

2. Rupic. et terr. - As. : Bhotan, M. Neilgherr. Af $r$, : Ins. Borboniae, Madagascar sept. Am. sept.: Mexic., And. Costa Ricens. Am. merid. : Jolumb. Pac. : Tasman.

stenocarpus? Wils, - Trichostomum tophaceum.

venezuelensis C. M. in Limn. p. 481.

- Am. merid. : Venezuela.

xanthocarpus Hsch. - Trichostomum.

Garatodontium C. M. in Forclungsreise... p. 38 (sect, Or Hнотrichr).

Chœetomitriella C. M. in Engler's Bot. Jahrlb. 1883, p. 85 (sect. HrPA).

GHATOMITRIUMI Dz. et Mk. M. Archip, ind. (27 sp. .

acanthocarpum Bryol. jav. II, p. 53, t. 173.

2 .

$-A s$. : Ins. Ceram. 
borbonicum Besch. Fl. bryol. Réunion, elc. p. 145.

1. Lignic. - Afr. : Ins. Borboniae.

callichroum Besch. Fl. bryol. Nov. Caledon. p. 228.

- Pac.: Nov. Caledon.

cataractarum Besch, Fl. bryol. Réunion, elc, p. 145.

2 ?

- Afr. : Ins. Nossi-Be.

ciliatum Bryol. jav. 1I, p. 46, t. 168.

2.

- As. : Java.

comorense Hpe, in Linn. 1376, p. 253.

Lignic. - $A f r$. : Ins. Anjouan.

confertum Tho, et Mitt. in Jousn, of the Linn. Soc. 1872, p. 317.

- As. : Ceylan.

cygnœum C. M. in Geheeb Neue Beitr. zur. Moosfl. v. Neu Guin., p. 6, t. 4 .

2.

- Pac.: Nov. Guin merid.

Deplanchei Duby. - Holoblepharum.

depressum Mitt. Sam. M. p. 190.

Arb. - Pac.: Ins. Samoa.

Duseni C. $M$. in Dusen $M$. Camer. n. 421 .

- Afr.: M. Cameroon.

elegans Geheeb op. cit. p. 6, $\iota .5$.

$2 . \quad-P a c$ : Nov. Guin. merid.

elongatum Dz. et Mk. M. frond, ined. Archip. ind. p. 119, t. 38 et Bryol. jav. $I I, p .43$.

Hookeria elongata eor. in Ann. sc. nat. 1844, II, p. 305; C. M. Syn. II, p. 213.

2. Arbor. - As, : Ins, Boeroe Molucc., Borneo, Java.

fimbriatum Bryol. jav. II, p. 48.

Hypnum fimbriatum C. M. Syn. II, p. 402.

Leskea fimbriata $D z$, et $M k$. M. frond. ined. Arch. ind. p. 177, t. 58.

2 .

- As. : Amboine, Borneo. Pac. : Nov. Guinea.

frondosum Milt. Sami. M. p. 189.

Arbor. - Pac. : Ins, Samoa,

Hookeri Jaeg. - Hypnum.

horridulum Bryol. jav. $I I$, p. 40, . 167.

2.

- As. : Java.

lanceolatum Bryol. jav. II, p. 49, t. 170.

- As. : Java.

leptopoma (Schrocegr.) Bryol. jav. II, p. 52.

Holoblepharum leptopoma Dz, et Mk. M. frond, ined. Arohip. ind. $p .113, t, 36$.

Hookeria leptopoma C. M. Syn. II, pp. 215 et 618 .

Hypnum leptopoma Schwaegs. Suppl. IV.,p. 323.

Stereodon venustus Mitt. M. Ind. or. p. 114.

2. Lignic. - As. : Java.

muricatum Bryol. jav. $I I, p .51$, t. 172.

2.

- As. : Java. 
nematosum Broth. in Bail, Syn. of the Queensland Fl. IV Suppl. p, 99 (nom.) et in Oefv... 1890, p.

2. Ster. Cortic. - Pac. : Austral. (Queensland).

obscurum Bryol. jav. II, p. 50 ,

2

$$
\text { - As. : M. Java. }
$$

orthorhynchum Bryol. jav. $I I, p .45$.

Holoblepharum orthorhynchum Dz. et $M k$. $M$. frond. ined. Archip, ind. p. $114, t .37$.

Hookeria orthorhyncha eor. in Ann. se. nat. 1844, II, p. 305; C. M. Syn. $-I I, p .214$.

2. Cortic. - As, : Borneo, Java, Sumatra.

papillifolium Bryol. jav. II, p. 50, t. 171.

2. $-A s$. : Java.

philippinense (Mont.) Bryol, jav, $11, p .44, t .166$.

Hookeria philippinensis Mont. in Lond. Journ. of bot. 1845, p. 11 et Syll. p. 15 ; C. M. Syn. II, p. 213.

2. Arbor. - As. : Ins. Philippin, Ceram, Java.

rugifolium Mitt. - Holoblepharum.

speciosum Mitt,- Holoblepharum.

taïtense Sull. in Am. Expl. Exp. 1859, p. 22, Ł. 23.

- Pac. : Ins, Societat., Tailti.

torquescens Bryol. jav. 11, p. 47, $t .169$.

2. Arbor. - As.: lns. Ceram, Java.

volutum Milt. M. Ind, or. p. 115.

Cortie. - As. : Ceylan.

Vrieseanum Bryol. jav. 1I, p. 54, t. 174.

2. Silvic. - As, : Ins, Ceram.

CHATEPHOKd Brid. Mant. M. p, 148.

cristala Brid. - Eriopus.

incurva Hsch. - Hookeria.

Langsdorffii Hook. - Hook ria.

orthotrichsiles Raddi. - Macromitrium filiforme?

pendula Hook. - Hookeria.

Perrini Spreng. - Lepidopilum polytrichoides.

CHATEPHORA ERIOPUS Brid. Bryol. univ, $1 I$, p. 339.

cristatus Brid. - Eriopus.

Chasmocalyx Lindl. M. Scand. p, 30 (sect. Andrea.e).

Cheilothela Lindb. in Ulk. till ... 1878 (sect. CERATodontis = C. chloropus).

GHIONOSTOMUM C. M, in Linn. $1870-i 1, p .21$.

glauco-virens (Mitt.) Jaeg. Ad. II, p. 338.

Stereodon glauco-virens Mitt. M. Ind. or, p. 103.

- As. : Assam super.

rostratum (Griff.) C. M. in c, co l. $l$. ce.

Neckera rostrata Griff. Not. p. 456 et Ic. pl, asiat. II, t. 87, f. I.

Stereodon rostratus Mitt. op. cit. p, 102.

1. Cortic. - As. : Khasia, Ceylan. 
Chorisodontium Mitl. M. austr. am.p. 6 i (sect. Diorixi).

Ghrysoblastia C. M. in Linn. 1878.79, p. 438 (sect. Hypsi).

\section{CHRYSOBRYUM Lindb.}

micans Lindb. - Hypnum.

CHRYSO-HYPNUM Hpe. Moosbild. p. 19.

Spec. omn. non indicatae sunt miorothamsia ejusd, nom.

camptorhynchum Hpe. - Microthamnium Widgrenii.

GINGLIDIUM Sw, in Schrad, Bot. Journ. 1801, p. 25, t. 2 (4 sp.).

arcticum W. P. Sch. Coroll. p. 80 et Syn. II ed. p. 494; C. M. Syn. 1 , p. 154.

Mnium Cinclidium arcticum Bryol. eur. IV (mon. supp. p. 1), t. 386.

2. Paludic. - Eur.: Spitzberg, ins. Ursorum, Scandin. sept. (Dovre). Exs, : Rab. Bryoth. eur. n. 975.

hymenophyllum Lindb. - Mnium.

latifolium Lindb, in Hedwig. 1877, p. 77.

2.

- As. : Jenissei infer.

stygium Sw. l. c.; Brid. Bryol. univ. 1, p. 714; C. M. Syn. 1, p. 153 ; W. P. Sch. Syn. II ed. p. 492.

Amblyodon stygius P. B. Prodr. p. 41.

Cinclidium subrotundum Mac. Canad. M. n. 206.

Meesea stygia Brid. M. Rec. II, III, p. 175.

Mnium Cinclidium stygium Bryol. eur. IV (mon. p. 17), t. 385.

Syn. Paludic. - Eur.: Scandin., Anglia, German. sept., Belgia, Rhaet., Stir., Salisb., Alp. Helv. et Gall. As. : Kamschatka (an præcedens?). Am. sept.: Groenland., Labrador, Anticosti, Nov. Scotia.

Exs. : Drumm. M. bor. am. ed. n. 272 p.p. Rab. Biyoth. eur. n. 105, 1020, 1220.

Un, itin. 1863, n. 50 .

subrotundum Lindb. de Mniac. 1867, p. 73; W. P. Sch. Syn. I1. p. 494.

Syn. Paludic. - Eur. : Mar. Album, Lapon., Norveg. As. : Jen:ssei infer. Am. sept. : Groenland,, Labrador; Terra nov.?

GIN GLIDOTUS P. B. Prodr. p. 28 (3 sp.).

aquaticus (L.) Bryol. eur. II (mon. p. 8), l. 276; W. P. Sch. Syn. II ed. p. 237.

Anoectangium aquaticum Hedeo, Sp. M. p. 41.

A. falcatum P. B. Prodr. p. 42.

Bryum aquaticum Gmel. Syst. nat. II, p. 1331.

Fontinalis capillacea Scop. Fl. Carn. II ed. n. 1287.

Gümbelia aquatica $C . M$. Syn. $I I, p .652$.

Gymnostomum aquaticum Brid. Mant. M. p. 19 et Bryol. univ. I, p. 93.

Harrisonia aquatica Spreng. Syst. veg. XVI, IV ed. I, p. 145.

Hedwigia aquatica $H e d w, M$. frond. $I I I, p .29, t$. XI.

Hypnum aquaticum Jaeg. Fl. Austr. Cat. III, p. 48, t. 290.

$\mathrm{H}$. aquaticum nigricans, foliis angustis falcatis Dill. Hist. M. p. 334, t. $43, f .70$.

H. nigricans Vill. Pl. Dauph. III, p. 904.

Muscus squamosus aquaticus Mich. Nov. gen. p. 115, n. 100.

Sekra aquatica Lind6, M. Scand. p. 23. 
2. Ad rup. et sax. calcar. in rivul. - Eur. : Med. et merid, : deest in Scandin., Britan., German. sept. Af $r$ : Alger.

Exs, : Rab. Bryoth, eur, n. 214 et b, 1133.

"var. falcatus (Kindb.) Par.

C. falcatus Kindb. in Rev, bryol. 1887, p. 43 et in Malpighia, 1891, p. 560.

Ut typ. - Eur. : Montenegro, Bosnia, Gruec.

Brebissoni Husn. - Barbula.

falcalus Kindb. - C. aquaticus var. falcatus.

fontinaloides (Hedwo.) P. Beauv. Prodr. p. 52; Brid. Bryol. univ. I,

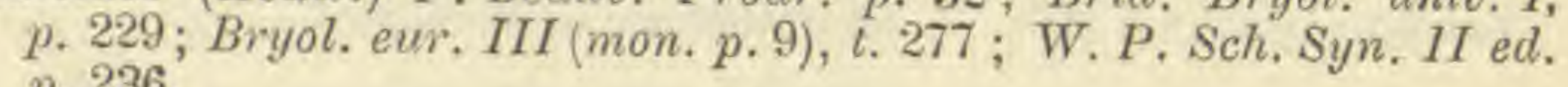
p. 236 .

C. minor Lindb. Trichost. eur. p. 31.

Fontinalis alpina Dicks. Fasc. II Pl. crypt. p. 2, t. 4, f. I.

F. erecta Vill. $P l$. Dauph. III, p. 919.

F. minor L. Sp. pl. p. 1572 . F. triangularis minor, carinata e cymis fructifera Dill. Hist, M. p. 252,
$t .32, f .2$.

Gümbelia fontinaloides C. M. Syn. II, p. 652.

Hypnum antipyreticum $\beta$ minus Neck. Meth. M. p. 152.

Fontinalis alpina Dicks. Fasc. II Pl. crypt. p. 2, t. 4, f. I.

H. fontinaloides Lam. Encycl. meth. bot. III, p. 164.

Rhacomitrium fontinaloides Brid. Mant. M. p. 80 .

Sekra minor Lindb, M. Scand. p. 23.

Trematodon fontinaloides Roehl. Fl. Germ. III, p. 65.

Trichostomum fontinaloides Hedw. M. frond, III, $p .36, t .14$.

2. Ut praecedens, - Eur. : Fere tota. As.: Tibet. occ., Luristan., Caucas. Af $r$ : Alger. Am. sept. : Ontario (ster. !).

Exs. : Rab. Bryoth. eur. n. 133, 216, 1131,1230 (forma), 1231. Un. itin. 1863, n. 29.

* var. Lorentzianus Mdo. Bayer. Laubm. p. 115; Llz. in Bol. Zeit. 1869 , p. 553.

Scouleria? Geheebii de Not. Epil. p. 755.

Ut typ. - Eur. : Os Elbae, Rhoengeb., Bade, Helvet.

minor Lindb. -. C. fontinaloides.

riparius (Host.) Bryol, eur. III (mon. p. 10), Ł. 278; W. P. Sch. op. cit. p. 235.

Gümbelia riparia C. M. Syn. II, p. 65l.

Gymnostomum riparium Host. Syn. $f$. Austr. p. 563.

Rhacomitrium riparium Brid. Mant. M. p. 80 et Bryol. univ. I, p. 223.

Trichostomum aquaticum Schleich. Cent. pl. Helv, n. 20.

Tr. nigricans Brid. Sp. M. I, p. 242.

Tr. riparium $W$. et $M$. Bot. Tasehb. p. 120.

2. Ad sax. et ligna in rivul. reg. campestr. et subalp. - Eur. : Gall., Helvet., Austria, Tirol.

Exs. : Rab. Bryoth. eur, n. 215.

var. terrestris Bryol. eur. - Barbuka Brebissonii.

CLADODIUM Brid. Bryol. univ. $I, p, 620$.

Spec, omn. Brya ejusd, nom.

CLADOMNION Hook, f. et Wils. FI, of the N. Zeal. II, p. 96 (6 sp.). ericoides (Hook.) H. f. el W. op. cit. p. 99 et Handb. p. 458.

Hypnum ericoides C. M. Syn. II, p. 458.

Leskea ericoides Hook. M. ex. t. 28 ; Brid. Bryol. univ. II, p. 293.

1.

- Pac. : Nov. Zeland. 
gracile (Hpe.) Mitt. M. austr. am. p. 535 .

Leskea distans Mont. in Ann. sc. nat. 1845, p. 90 et Syll. p. 18.

Leucodon gracilis Hpe. Io. M. t. 18.

Neckera Poeppigiana C. M. Syn. II, p. 115.

2. Cortic. - Am. merid. : Chil. austr.

Müllerianum (Hpe.) Jaeg, Ad. II. p. 130.

Glyphothecium Müllerianum Hpe. in Linn. 1859, p. 637.

Filicic. - Pac. : Austral. felix.

octangulum (C. M.) Bryal, jav. II, pp. 105 et 228, t. 216.

Leskea sciuroides Dz. et Mk. M. frond. ined. Archip. ind. p. 178.

Neckera octangula C. M. Syn. II, p. 668.

2. Lignic. - As. : Java.

pallens Lac. Sp. nov. Archip. ind. p. 12.

2.

- As. : Java.

seiuroides (Hook.) H. f. et W. op. cil.p. 100 .

Leskea sciuroides Hook. M. ex. t. 175; Brid. Bryol. univ. II, p. 286.

Neckera glyphotheca C. M. Syn. II, p. 669.

Stereodon sciuroides Mitt. in Journ. of the Linn. Soc. 1859, p. 89.

2. Cortic. - Pac. : Austral, felix, Nov. Zeland., Tasman.

setosum. H. f. et W. - Cyrtopus.

CLADOPANTHUS $D z$, et $M k$. $M$. Arch, ind. pilifer Dz. et Mk. - Leucobryum.

Glaopodium Lesq. et Jain, Man. p. 327 (subgen. HyPni $=$ Thuidum).

CLASMATODON Hook. f. et Wils. in Lond. Journ. of bot. 1842, p. 421, t. 25 ( 2 sp.).

Bertrami Lindb. - Anisodon.

ferrugineus Jaeg. - Anisodon.

parvulus (Hpe.) Sull. M. of U. St. p. 60 el Ic. M. p. 126, ᄂ. 79; Lesq. et Jam, Man. p. 297.

Cl. pusillus H. f. et W. l. e. et in Drumm. M. bor, am. II ed. n. 80.

Hypnum parvulum C. M. Syn. II, p. 409.

Leskea parvula Hpe. in Linn. 1839, p. 46.

Pterogonium marginatum? Schwein mem, in Bryol. eur. V (mon. p. 4).

Rhegmatodon parvulus Hpe. Ic. M. t. 14.

1. Arbor, - Am. sept.: Reg. merid.

Eos. : Sull. et Lesq. M. bor. am. 1 ed. n. 246 et II ed n. 368.

« var. rupestris Sull. el Lesq. l. c. n. 246.

Anisodon acutirostris Bryol. eur. V (mon. p. 4).

Ad rup. irror. - Am. sept. : Reg. merid.

Exs. : Sull, et Lesq. M. bor. am. II ed, n. 369.

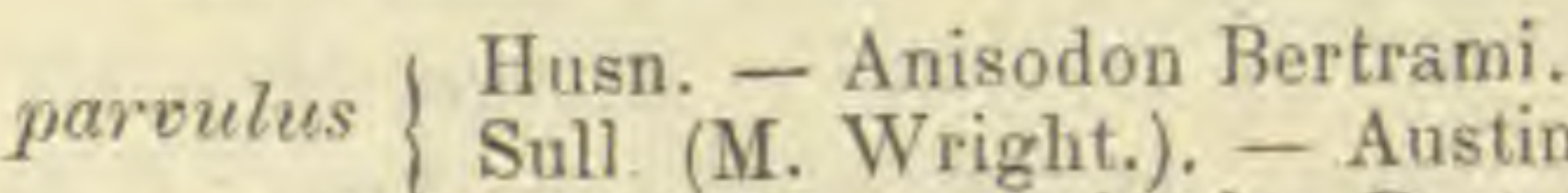

Sull. (M. Wright.). - Austinia tenuinervis.

var. julacea C. M. - Anisodon Bertrami.

pellucidus Hpe. Symb. 1874 , p. 152. 
GLASTOBRYUM Dz. et Mk. M. frond, ined. Archip, ind. (1 sp.).

indicum Ds. el Mk. op. cil. p. 43, l. 16; Bryol. jav. II, p. 129.

Astrodontium indicum eor. in Ann. se. nat. 1844, II, p. 299.

Neckera Clastobryum C.M. Syn. II, p. 91.

1. Cortic. et terr. - As. : Borneo, Java.

CLEISTOSTOMA Brid, Bryol, univ, I, p. 153 (1 sp.).

albo-vaginalum Schwaegr, - Syrrhopodon.

ambiguum Brid. op. cit. p. 154 ; Mitt. M. Ind. or. p. 125.

Neckera ambigua C. M. Syn. II, p. 107 .

Pterogonium ambiguum Hook. in Trans. of the Linn. Soc. IX, p. 310, t. $26, f .4$.

2? Cortis. - As. : Nepal.

Gardneri Schwaegr. - Syrrhopodon.

? incompletum Schwaegr. - Syrrhopodon. involutum Schwaegr. - Syrrhopodon.

Taylori Schwaegr. - Syrrhopodon.

Glimacio-pterobryum C. M. in Bull. Soc. bot. Fr. 1878, p. 65 (sect. PTEROBRYELLAE).

CLIMACODONTIUM Hpe. in Jaeg. Ad. II, p, 713. cygnicollum Hpe. - Bryum climacodontium.

GLIMAGIUM Web, et Mohr Reise in Schwed, p. 96 (6 sp.).

americanum Brid. Bryal. univ. II, p. 273; Sull. 1c. M. p. 151, t. 97; Lesq. el Jam. Man. p. 314.

Neckera dendroides $\beta$ americana $C . M$. Syn. II, $p .122$.

2. Lignic. - Am. sept. : Terr, nov., Nov. Scot,, New Brunswick, Gaspes., Ontario, M. Rupestr., reg. sept., centr., or. et merid.

Exs. : Drumm. M. bor. am. I ed. n. 231, II ed. n. 120.

Mac. Canad. M. p. 265.

Sulliv. et Lesq. M, bor. am. Il ed. n. 408.

«var. Kindbergii Ren. et Card. in Bot. Gaz. 1890, p. 59. - Am. sept. : Indiana, Massachussets, Ludovic.

dendroides (L.) Web. et Mohr. l. c. et in Bot. Taschb. p. 252, t. 10, f. 2 ; Brid. Bryol. univ. II, p. 271 ; Bryol. eur. V, t. 437; W. P. Sch. Syn. II ed. p.

Cl. europaeum P. B. Mem. Soc, Linn. Par, I, t. 9, f. 8.

Hypnum dendroides L. Sp, pl. p. 1593.

H. dendroides sericeum setis et capsulis longioribus erectis Dill. Hist. M. p. $213, t, 40, f .48$.

Leskea déndroides Hedu. Sp. M. p. 228.

Neckera dendroides Brid. M. Rec. II, II, p. 15; C. M. Syn. II, p. 121.

2. In prat. udis, ad marg. fossar. et ped. muror. - Eur, : E reg. campestr. usq. in montan. As. : Japon., Jenissei, Obi, Caucas., oce. et centr. $A m$, sept.: Groenland., Terr. nov., ins. Miquel., New Brunswick. Gaspesia, Ontario, Columb. brit., New York, M. Alb, Wisconssin, Minnesota, Idaho, Washington, Kansas, Calif.

Exs. : Drumm. M. bor, am. I ed,, n, 230.

Faurie Pl. Japon. n. 6.

Mac. Canad. M. n. 264. 
" var. inundatum $M$ do.

Subaquat. - Eur. : Bavaria.

« var. oregonense Ren. et Card. in Bol. Gaz. 1890, p. 59.

- Am. sept. : Oregon.

europaeum P. B. - Cl, dendroides.

japonicum Lindb. in Act. Soc. Fenn. 1872, p. 22.

Hypnum dendroides Thbg. Fl. jap. p. 363?

Pterobryum imbricatum Duby in Mèmoires... Genève, XXVI, p. 6, t. I, f I. 2.

Exs, : Faurie Pl. Jap. n.

Savatier ibid. n. 627 .

lutescens Voit. - Camptothecium.

neckeroides Brid. - Porotrichum dendroides.

ramulosum (Milt.) Jaeg. Ad. II, p, 364.

Neckera ramulosa Mitt. in Joum. of the Linn. Soc. 1863, p. 160. - Afr. : M. Cameroon.

ruthenicum (Weinm.) Lindb. op. cit. p. 248 ; Sull. Ic. M. Sutppl. p. 77, t. 58 ; Lesq. et Jam. l. c.

Hypnodendron Savatieri W. P. Seh. in Savat. M. Jap. n. 828.

Hypnum ruthenicum Weinm. in Bull. Soc. imp. Moscou, 1845, II, p. 485, n. 34 ; C. M. Syn. II, p. 503.

H. spectabile H. f. et W. in Wils. Bryol. brit. p. 382, n. 58 in obs. (1855). 2.

Vancouver, Alaska, fret. Behring.

Exs. : Faurie Pl. Japon. n. 821.

sulcatum (Hook.) Brid. Bryol. univ. 11, p. 274.

Braithwaitea nematosa Jaeg. Ad. II, p. 365.

Br, suleata Lindb. in op. cit. p. 250 in adn.

Dendro-Leskea suleata Hpe. in sched.

Isothecium sulcatum H. . et W. Fl. of the N. Zeal. II, p. 101 et Handb, p. 464 .

Leskea sulcata Hook. M. ex. t. 164.

Neckera sulcata C. M. Syn. II, p. 122.

Pilotrichum nematosam ej. in Bot. Zeit. 1864, p. 273 et in Linn. 18157-68, 2? p. $614(1)$.

- Pac. : Austral. or., Nov. Zeland. med. et merid.

Glimacocaulon C. $M$. in Linn. 1878-79, p. 329 (sect. BARBULAE).

CODONOBLEPHARUM Schoaegr. Suppl. 11, p. 142, t. 137.

aculifolium Jaeg. - Zygodon.

brevicolle Jaeg. - Zygodon.

crassinerve C. M. - Calymperes.

fusciculalum Bryol, jav. - Syrrhopodon.

linguiforme Jaeg. - Zygodon.

luteum C. M. - Syrrhopodon.

Menziezii Schwaegr. - Zygodon.

neglectum Jaeg. - Zygodon.

oblusifolium Schwaegr. - Zygodon.

papillatum Schwaegr. - Zygodon.

peruvianum Schwaegr. - Zygodon. 
pungens Sehwaegr. - Zygodon.

subfasciculalum $\mathrm{H}$ pe, - Syrrhopodon.

subluteum C. M. - Syrrbopodon.

Schworgrichenii Jaeg. - Zygodon.

uncinalum Jaeg. - Zygodon.

undulatum Dz. et Mk. - Syrrhopodon Codonoplepharum.

GCELIDIUM Hook. f. et Wils. Fl, of the N. Zeal. p. 110 (subgen. HyPNI); Reichdt. in Nova:a Exp. Bot. I, p. $39 \mathrm{I}$ (gen. propr.) (9 sp.).

apertum Jaeg. - Ectropothecium inflectens.

var. condensalum Jaeg. - Ectropothecium inflectens var, condensatum.

auriculatum (Mont.) Jaeg. Ad. I1, p. 318.

Aerocladium auriculatum Mitt. M. austr. am. p. 532 p.p.

Hypaum auriculatum Mont. Voy. au Póle Sud, Crypt. p. 331, t. 20, f. 3 et Syll. p. 8; C. M. Syn. II, p. 373 .

Plagiothecium magellanicum W. P. Sch. in h5. Mus. Paris.

Rupic. et terr. - Am. merid. : Patagon. austr., terr. Magellan., Fuegia.

chlamydophyllum (H.f.e $\iota$ W.) Jaeg. Ad, II, p. 384.

Acrocladium auriculatum Mitt. l. c. p.p.

Hypnum acrocladium $H$. f. et W. in Lond. Journ. of bot. 1844, p. 552 et Fl. Antaret. I, p. 139, t. 61; C. M. Syn. II, p. 374.

Stereodon auriculatus Mitt. in Joum of the Linn. Soc. 1859, p. 88.

1. In silv. humid. - Am, merid.: Fuegia? (ex Handb. of N. Zeal, Fl.). Pac. : Nov. Zeland. sept. et med., Tasman., ins. Campbell.

chlorocladum (C.M.) Par.

Hypnum chlorocladum C. M. in Linn. 1867-68, p. 622.

2 ?

- Pac.: Austral. or.

clandestinum (Hook. f. et Wils.) Jaeg. l. c.

Hypnum clandestinum H. f. et W. Fl. Tasm. II, p. 201; Fl. of the N. Zeal. III, t. 90, f. 3 et Handb. p. 480.

Lembophyllum clandestinum Lindb. Contrib. ad Fl. bryol, As, bor. or. $1872, p, 277$ (in adn.).

I. In sily, humid, - Pac. : Austral, Nov. Zeland, med., Tasman. cochlearifolium (Schwaegr.) Jaeg. l. c. p. 383.

Hypnum cochlearifolium Selwwaegr. Suppl. I, II, p. 22l, t. $88 ;$ C. M. Syn. II, p.373; H. f. et W. Fl. Tasm. TI, p. 211, Fl. of the N. Zeal.
II, p. III et Handb.p. 480 .

H. flexile Hook. M, ex, t. 110 .

Isothecium flexile Brid. Bryol. univ. II, p. 361 p.p.

Lembophyllum cochlearifolium Lindb. $l$. $c$.

Stereodon cochlearifolius Mitl, $l, c$.

2. Rupic. - Am. merid. : Ins. Chiloë. Pac. : Austral. or., Nov, Zeland. sept. et med., Tasman., ins. Auckland, Campbell.

a var, minus (Hpe.) Par.

Hypnum cochlearifolium var, minus Hpe. in Linn. 1852, p. 715 (nom.).

Ut typ. ? - Pac. : Tasman.

divulsum (Hook, f, et Wils.) Par.

Hypnum divulsum $H$. f. et W. in Lond. Journ of bot. 1844, p. $556 ; \mathrm{Fl}$. of the N. Zeal. II, p. 111, t. 90, f. 4 et Handb. p. 481; C. M. Syn. II, P. 466 . 
Lembophyllum divulsum Lindb. $l$. $c$.

Thamniella divulsa Besch. Fl. bryol. Nov. Caled. p, 240.

2. Terr. humid. -- Pac. : Austral, Nov. Zeland, sept. et med., Tasman.

inflatum (Hook. f. et Wils.) Jaeg. Ad. II, p. 384.

Hypnum inflatum $H$. f. et $W . F l$. of the $N$. Zeal. $I I, p .111, t .90, f .5$ et Handb. p. 481.

Ster.

- Pac. : Nov. Zeland. sept, et med.

porotrichoides (Besch.) Par.

Thamniella porotrichoides Besch, $l, c$.

2. Ad rup. humid, - Pac. : Nov. Caledon.

vagum (Hsch.) Par. Hypnum vagum Hseh. in Sieb. M. Nov. Holl. n. 23; C. M. Syn. II,
p. 466 .

Lembophyllum vagum Lindb. $l$. $c$.

Rigodium vagum Reichdt. in Novara Exp. Bot. I, p. 188.

Thamniella vaga Besch. $l$. $c$.

2 .

- Pac. : Austral., Tasman.; Nov. Zel, sept. ?

Comatosphagnum C. M. in Fl. 1887 p. 404 (Sph. subsecunda).

Comatulina C. M. Syn. II, p. 503 (subgen. Hypni = Mniodendron).

Cometium Thw. et Mill, in Journ. of the Linn. Soc. 1872, p. 302 (sect. MACROMITRII).

Complanaria C. $M$. in Linn. 1878-79, p. 409 (sect. Porotrichi)

COMPLANATO-HYPNUM Hpe. Symb. 1877, p. 732.

leptostegium Hpe. - Stereophyllum.

GONOMITRIUM Mont. in Ann. sc. nat, 1837, p. 25') (22 sp.)

acutifolium Lindb, - Fissidens Lindbergii.

aggeslum Besch. - Fissidens.

amoenum C. M. - Fissidens.

amphibium C. M. in Linn. 1875, p. 35 ธ̃.

Octodiceras amphibium Jaeg. Ad. II, p. 52.

Ster.

- Afr. : Niam-Niam.

anguste-limbalum Jaeg. - Fissidens.

assinile Hpe. - Fissidens.

asterodontium C. M. - Fissidens.

Beccarii Hpe. in Nuov. Giorn. bot. ital. 1872, p. 290.

Octodiceras Beccarii Jaeg. Ad. II, p. 52.

1.

- As. : Borneo.

bengalense $\mathrm{Hpe}$. - Fissidens.

Berterii Monı. in Ann. sc. nat. 1838, p. 250 ; C. M. Syn, II, p. 52 1.

Fissidens Berterii C. M. Syn. I, p. 45.

Octodiceras Berterii Jaeg. Ad. II, p. 51 .

1. Ad saxa in scaturig. - Am. merid. : Chile.

bi-areolatum C. $M$. in Linn. 1878-79, p. 466.

2.

- Am. merid. : Venezuela. 
borbonicum C. M. - C. palmifolium. brachypus Jaeg. - Fissidens.

Braunii C. M. - Fissidens.

Bryum C. M. in Dusen M. Camer. n. 834. - Afr.: M. Cameroon.

capense C. M. Syn. II, p. 524 .

Fissidens Barterii ej. Syn. I, p. 45 p.p.; Mitt. M. austr, am. p. 581.

Octodiceras capense Jaeg. l. $c$.

Fl, et fr. ign, $\quad-A f r,:$ C. B. Sp.

Exs. : Rehm M. Afr. austr. n. 581.

«var, nigrescens Rehm. l. c. n. 278 et 582. - Afr. : Orange, Transvaal.

caripense Hpe. et C. M. - Fissidens.

cylindraceum Jaeg. - Fissidens.

deserlorum C. M. - Fissidens.

Dillenii (la Pyl.) Mont. l. c. ; C. M. l. c.

Fissidens Dillenii C. M. Syn. n. p. 45.

F. parvus Mitt. l. c.

F. semi-completus Hedw. Stirp, crypt. III, p. 34, t. B p.p.

Fontinalis parva, foliis lanceolatis Dill. Hist. $M$. p. 259, $t$. 33. f. 4 .

Octodiceras Dillenii Brid. Bryol. univ. II, p. 667 .

Skitophyllum Dillenii la Pyl. in Desv, Journ. bot. 1813, V, p. 52, t. 31.

1. $\quad-A m$. merid. : Chil., Patagon., ins. Provident. Pac. : Austral, Nov. Zeland.

diplodus Jaeg. - Fissidens.

erosulum C. M. - Fissidens.

faniense Besch, - Fissidens.

Glaziowii Hpe. - Fissidens.

gracile $\mathrm{Hpe}$ - Fissidens.

granulatum Hpe. et Geh. - Fissidens.

gumangense C. M. - Fissidens,

Hallianun Sull. et Lesq. in Aust. M. Appal. n. 108; Sull. Ic. M. Suppl. p. 43, t. 28 ; Lesq. et Jam. Man. p. 90.

Octodiceras Hallianum Jaeg. l. c. p. 52.

1. Lignic. in puteis et rupic. - Am. sept. : New Jersey, New York, Illinois, Idaho, Florid.

Hallianum Mac. - C. Julianum.

Hedwigii Mont. l. $c$,

Cecalyphuzn ? semi-completum P. b. Prodr, $p .57$.

Fissidens Hedwigii $C . M$. Syn. I, p. 45.

F. semi-completus Hedw. l. c. $t .13$ p.p.; Mitt. $l$. c, p. 583.

Octodiceras fissidentoides Brid, Bryol. univ. II, p. 676.

o. Hedwigii Jaeg, l, e. p, 50 .

Skitophyllum semi-completum la Pyl. l.c.

1.

- Am. merid. : Chile.

hians Hpe. - Fissidens.

hyalinum C. M. - Fissidens.

Hydropogon (Spr.) Par.

Fissidens Hydropogon Spr. in Mitt. l. c. p. 585.

Octodiceros Hydropogon Jaeg. l.e. p. $5 \mathrm{i}$.

1.

- Am. merid. : And. Quitens. 
immersum (Mitt.) Par,

Fissidens immersus Mitt. l. c. p. 584.

Octodiceras immersum Jaeg. $l$. c. - Am. merid. : Brasil, tropic.

incequale Jaeg. - Fissidens.

inclinatulum C. M. - Fissidens.

inflalum C. M. - Fissidens.

intra-marginatum $\mathrm{Hpe}$ - Fissidens.

Julianum (Savi) Mont. I. c. ; C. M. Syn. II, p. 524; W. P. Sch. Syn. II ed. p. 122.

C. Hallianum Mac. Canad. M. n. 54.

Fissidens debilis Sohwaegr. Suppl. 1, II, p. 11 ; Brid. Bryol. univ. II, p. 706.

F. Julianus W. P. Sch. in Regensb. Bot. Zeit. 1838, I, p. 271; C. M. Syn. $I, p, 44$.

F. semi-completus Drmm. M. bor. am. II ed. n. 44.

Fontinalis Juliana Savi in Poll. Fl. Veron. III, p. 385.

Muscus pinnatus aquaticus ramosissimus, Linariae foliis.... Micheli Gen. p. 114.

Octodiceras fontanum Lindb, Bidrag... p. 23.

O. Julianum Brid. l. c. II, p. 678; Bryol. eur. I, t. 108.

Skitophyllum fontanum $l a P y l$. $l$. $c$.

Sk. Julianum Lindb. M. Scand. p. 13.

1. Ad saxa in livul. et ad pariet. lapid. fontium. - Eur.: Temperat. et calidior. passim ; deest in Britann. Afr. : Alger.; C. B. Sp. ? $A m$. sept.: Ontario, M. Rupestr., Calif., reg. orient., centr. et merid.

Exs. : Rab Bryoth. eur. n. I a-c, 1290.

Sull, et Lesq. M. bor. am. II ed., n. 112 .

« var. mexicanum W. P. Sch. in Besch. Prodr. bryol. mexic. p. 27.

Conomitriun Julianum C. M. in Bot. Zeit. 1860.

Fissidens Julianus Mitt. M. austr. am. p. 584.

Octodiceras Julianum Jaeg. l. c. p, 50.

Ster.

- Am. sepl. : Mexique.

laxifolium C. M. - Fissidens.

Lindigï Hpe. - Fissidens.

Mariei Besch. Fl. Bryol. Réunion, etc, p. 47.

2. Humic. - Afr.: Ins. Nossi-Be.

Metsegeria C M. - Fissidens.

mexicanum C. M. - C. Julianum var. mexicanum.

microcarpum Jaeg. - Fissidens.

molle C. $M$, in Linn. 1878-79, p. 247.

F1, et fr. ign.

- Am. meriel. : Uruguay.

Mülleri Hpe in Linn. 1859, p. 214 et 1859, p. 644.

Octodiceras Mülleri Jaeg. l. e. p. 51.

1 .

- Pac. : Austral, felix.

osmundioides C. M. - Fissidens.

palmatum C. M. - Fissidens.

palmifolium Besch. I. c.

? Bryum palmifolium Brid. Bryol. univ. I, p. $687 ;$ C. M. Syn, I, p. 341.

C. borbonicum C. M. in Bot. Zeit. 1864.

Mnium palmifolium P. B. Prodr. p. 76.

Octodiceras borbonicum Jaeg. l. e. p. 50 .

Ster.? Aquat. - Afr: : Ins. Borbon, 
palustre C. M. - Fissidens.

Pechuellii C. M. - Fissidens.

pellucidum (:. M. - Fissidens.

perfolialum C. M. - Fissidens.

perpusillum C. M. - Fissidens australiensis.

polycarpum Besch, in Journ. de Bot. 1891 p.

- Am. merid. : Paraguay.

psalyrocheilon Schlieph. - Fissidens.

pseudo-servatum C. M. - Fissidens.

Puiggarii Hpe. et Geh. - Fissidens.

radicans C. M. - Fissidens.

reflexum Jaeg. - Fissidens.

reticulosum C. M. - Fissidens.

rubiginosum Hpe. - Fissidens.

sanguineo-nerve C. M. - Fissidens.

Schweeinfurthii C. M. - Fissidens.

scleromitrium Besch. l.c.

1.

- Afr. : Madagasear.

semi-limbatum Schlieph. - Fissidens Pabstii.

semi-abscurum C. M. - Fissidens.

serratum C. M. $\left\{\begin{array}{l}\text { - Fissidens. } \\ \text { - Fissidens pseudo-serratus. } \\ \text { - Fissidens Wilsoni. }\end{array}\right.$

sinense Rab. Bryoth. eur. n. 1212.

- As. : Cochinchin.

smaragdinum Ltz. et C. M. in Linn. 1879-80, p. 248.

FI, et fr. ign. $\quad-$ Am. merid. : Argentin. Cordob.

splachnifolium C. M. - Fissidens.

stissotheca C. M. Syn. II, p. 525 .

Fissidens stissotheca Hpe. mss. in C, M. l. c.

I.

- Am, merid. : Brasil, austr.

subpalmatum $\left\{\begin{array}{l}\text { Hpe. (Jaeg. p. 762) - Fissidens evadiinervis. } \\ \text { Jaeg. p. 41, - Fissidens. }\end{array}\right.$ subulatum Jaeg, - Fissidens.

trachelyma (Sull.) C. M. in Linn. 1878-79, p. 466.

Fissidens trachelyma Sull. mss.

2.

- Am. merid. : Venezuela,

Ulna C. M. - Fissidens.

undatum C. M. - Fissidens.

vilreum C. M. - Fissidens,

Wrightii Jaeg. - Fissidens flexinervis (1).

GONOS TOMUM Sw, in Schrad. Neu Bot. Journ. I, III, p. 14, t. 5 (8 sp.). requatoriale W. P. Sch. in Mandon. Pl. Boliv. n. 1681.

- Am. merid. : And. Boliv.

(1) In Enum. Kindberg. nomina nuda :

C. monandrum $L$. (?)

C. subnigrescens (C. M.).

C. Wilsoni $C, M$. 
arcticum Sw. - C. boreale.

australe Sw. l. c. p. 31, t. 6; Brid. Bryol. univ. J, p. 152; C. M. Syn. 1, p. 470 ; Fl. Antarct. p. 132 ; Fl. of the N. Zeal. II, p. 87; Handb. p. 411 ; Fl. Tasman. II, p. 196.

Bartramia australis Mitt. M. austr, am. p. 287.

B. pentasticha Brid. $M$. Ree. II, III, p. 134, $t, I, f .8$.

Bryum angulosum Menz. (fid. Brid. Bryol. univ. l. e.).

C. pentastichum Lindb, in Oefv... 1863 et Bidrag. p. 8.

Philonotis australis Mitt. in Journ. of the Linn. Soc. 1859, p. 81,

Weisia pentasticha Hedw, in Brid. Bryol. univ, l. c.

1. Rupic. - Afr.: Ins. Kerguelen? (I). Am. merid. : And. Quitens., terr. Magellan., Fuegia, ins. Maclov., Eremitae. Pac. : Nov. Zeland. sept. et med., Tasman., ins. Auckland et Campbell.

boreale Svo. l. c. p. 24. Ł. 5; 5rid. Bryol. univ. 1, p. 150; C. M. Syn. I, p. 469 et II, p. 615; W. P. Sch. Syn. Il ed. p. 514.

Bartramia conostoma Bryol. eur. IV (mon. p. 16;, t, 322 ,

Bryum tetragonum Dicks. Fasc. Pl. erypt. II, p. 8, t. 4, f. 9.

C. arcticum Sw. in Brid. Sp. M. I, p. 127.

C, tetragonum Lindb. in Oefv... 1863, p. 8 .

Grimmia conostoma Sm. Fl. brit. p. 1169.

2. Terr. humid. - Eur. : Spitzberg, ins. Urзorum, summ. Alp. procip. reg. septentr. As. : Jenissei infer., penins. Samojed, et Tschutsch., Kamschatka. Am. sept. : Prœecip. arctic. : Groenland., ins. Sabine, fret. Kotzebuë et Smith, M. Rupestr., Columb. brit., Alaska, ins. Vancouver, Gaspesia, M. Alb. et Adirondack, Terra nov,

Eas. : Drumm. M. bor. am. I ed. n. 53.

Mac. Canad. M. n. 205.

Rab. Bryoth, eur. n. 1271.

Sull. el Lesq. M. bor. am. II ed. n. 261.

Un. itin. 1867, n. 85.

curvirostre (Mitı.) Par.

Bartramia curvirostris Mitt. in Journ of the Linn. Soc. 1859, p. 81.

- Pac. : Austral. (Victoria).

magellanicum Sull, in Hook. Journ. of bot. 1850, p. 316; C. M. Syn. II, p. 615 .

Bartramia magellanica Mitt. M. austr, am. p. 268.

1. Kr. ign. Ad rup. madid. - Am, merid. : Fuegia.

parvulum Hpe. - C. pusillum.

pentastichum Lindb. - C. australe.

pusillum Hook. f. et Wils. Fl. of the N. Zeal. II, p. 88, t. 86, f. 2 et Handb. p. 445.

C. parvulum Hpe. in Linn. 1856, p. 207.

Philonotis pusilla Mitl. in Journ. of the Linn. Soe. 1859, p. 81.

1 (Milı.) 2 (Hре.). Ad rup. madid. - Pac. : Alp. Austral. or., N. Zeland. sept. et med., Tasman.

rhynchostegium C. M. Bryol. austr. Georg. p. 27.

2. Paludic. - Am, merid. : Austr. Georg.

speirostichum C. M. in Linn. 1874, p. 594.

Ster.

- Am. merid. : M. Pichincha. 
tetragonum Lindb, - C. boreale.

variegatum Brid. - Weisia zonata (I).

GOSGINODON Spreng. Einleit. in d. Stud. d. Krypt. Gewaechse, 1804, p. 281 ( 6 sp.).

acipleyllus Brid, - Pottia lanceolata var. aciphylla.

connatus Brid, - Pottia lanceolata.

cribrosus $\mathrm{Spr},-\mathrm{C}$, pulvinatus.

elongatus Brid. - Eucladium verticillatum.

Hookeri Hpe. - Grimmia calyptrata.

humilis Milde in Bot. Zeit. 1864, Beil. p. 13; W. P. Sch. Syn. II ed., p. 288.

2. Ad rup. silic. - Eur. : Tirol, merid., Engadine, Pyren.

lanceolalus Brid. - Pottia lanceolata.

latifolius Lindb. et Arn. M. As. bor. 1890, II, p. 99.

1.

- As. : Jenissei super.

longivostris $\left\{\begin{array}{l}\text { Brid. - Microdus. } \\ \text { Hsch. - Microdus exiguus. }\end{array}\right.$

nudus Brid. - Discelium.

pallidisetus Brid. - Microdus.

Persoonii Hpe, - C. pulvinatus.

pilifer Hpe. - Pottia lanceolata var. pilifera.

plagiopus Spreng. - Grimmia plagiopodia.

pullulans Brid. - Trichostomum tenue.

pulvinatus Spreng. l. c.; Bryol, eur. III (mon. p. 3), t. 230 ; W. P. Sch. Syn. 11 ed. p. 287.

Bryum cribrosum Hoffm. Deutschl. Fl. II, p. 31.

C. cribrosus Spr, in Ann. and Mag. of nat. hist. p. 188; C. M. Syn. 1, p. 765 .

C. Persoonii Hpe. in Fl. $1837, p .280$

Grimmia cribrosa Hedw. M. frond. III, p. 73, t. 31 ; Brid. Bryol. univ. I, p. 174.

2. Ad rup. humid, - Eur: : Per totam sporadice, except. Britann. As.: Caucas. occ. et centr. Am. sept.: Columb. brit., Alaska, Idaho.

Exs. : Rab. Bryoth. eur. n. 127, 1317.

* var. subperforatus Philib. in Rev. bryol. 1880, p. 43.

Ut typ. - Eur. : Gall. centr. (Ardèche).

Raui (Aust.) Lesq. et Jam, Man. p. 155.

Grimmia Raui A ust, in Bull. Torr, bot. Club VI, p, 46.

1.

- Am. sept. : Colorado, Minnesota.

Renauldi Cand. in Bot. Gaz. 1890, p. 41, t. 6 B.

1. - Am. sept. : Colorado, Kansas.

verticillatus Brid. - Eucladium,

Wrightii (Aust.) Sull. M. of U. St.p. 38, l. 4 et Ic. M. p. 71, t. 45; Lesq. et Jam. l. $c$.

Grimmia Wrightii A ust. $l$. c.

1. Rupic. - Am. sept. : Colorado, Kansas, Texas, Nov. Mexic.

Exs. : Sull, et Lesq. M. bor. am. I ed. n. 132 , II ed. n. 197.

(1) In Enum. Kindberg, nomen nudum :

C. Lorentzi $C, M$. 
Grassidicranum Limpr. Laubm. Deutschl. I, p. 370 (sect. Dicrani).

Gratoneur un Sull.; W. P. Sch. Syn. II edl. p. 739 (subgen. HyPNı).

CROSSIDIUM Jur. Laubm. Osterr. Ung. p. I27.

crassinerve Jur. - Barbula chloronotos.

griseum Jur. - Barbula.

squamigerum Jur. - Barbula membranifolia.

GROSSOMITRIUM C. M. in Linn. 1874, p. 611 (t1 sp.).

Crügeri $C . M . l . c$.

Hookeria Patrisiae ej, Syn. $I I, p .198, p . p$.

2. Cortic. - Am. sept. : Antill, Am. merid. : Ins. Trinitat.

epiphyllum (Mitt.) C. M. op. cit. p. 613.

Lepidopilum epiphyllum Mitt. M. aust, am. p. 370.

2. Ad fol, emort. - Am. merid. : And. Quitens.

fontanum (Milt.) Jaeg. Ad. II, p. 242.

Lepidopilum fontanum Mitt, in Journ. of the Linn. Soc. 1863, p. 4 .

Ster.

- Af $r$ : Madeira.

Herminieri (W. P. Sch.) Jaeg. op. cit. p. 241.

Lepidopilum Herminieri W. P. Sch, in Besch. Fl. bryol. Antill. fr. p. 54.

Fr. ign.

- Am. sept. : Guadalup.

Erstedtianum $C$, $M$, in Fl. 1875, n. 34-35.

Ster.

- Am. sepl. : Costa Rica.

Patrisiae (Brid.) C. M. in Linn. 1874, p. 612 p.p.

Hypnum Patrisiae Brid. Bryol. univ. II, p. 539 (1).

2. Cortic. - Am. merid, : Guian. gall.

Sellowii C. M. l. c.

Hookeria Patrisiae Hpe. Ic. M. t. I ; C. M. Syn. II, p. 198 p.p.

2. Ad fol, emort. - Am. merid. : Brasil, austr, or.

Splitgerberi (Mont.) C. M. l.c.p. 613 (2).

Hookeria Splitgerberi Mont. Syll.p. 14.

Lepidopilum Splitgerberi Milt. M. austr, am. p. 370.

Fl, et fr, ign. Ad fol, emort. - Am. merid. : Guian, batav.

Spruceanum C. M. l. c.

Lepidopilum Patrisiae Mitt. op. cit. pp 369-370 p.p.

2.

- Am. merid. : And. Quitens.

subepiphyllum (Besch.) Jaeg. Ad, II, p. 241.

Lepidopilum subepiphyllum Besch. Fl. bryol. Antill. fr. p. 54.

Fr. ign.

- Am. sept.: Guadalup.

Wallisii $C M$. in Fl. 1875, n. 34-35.

Ster.

- Am. merid. : Nov. Granat.

(1) Cf. C. M. 1. c.

(2) "An Cr, Patrisiae verum? ", C, M. 1. c. 
CRYPHAEA Brid, Mant. M. p. 139 ( $\gamma 1$ sp.) (1).

acuminata Hook, f. et Wils. Fl. Nov. Zeal. p. 102, t. 28, f. 4 el Handb. p. 461 .

- Pac. : Nov, Zeland. sept.

affinis Mitt. - Cr. ramosa.

apiculata Bryol. eur. V (mon. p. 5); C. M. Syn. II, p. 675; W. P. Sch. el Par. Mon. Cryph. ined.

Cr. cuspidata W. P. Sch, in Besch. Prodr. biyol. mexic. p. 69.

- Am. sept. : Mexic.

apiculala Mitt. - $\mathrm{Cr}$. Mittenii.

arborea Lindb. - $\mathrm{Cr}$, heteromalla.

attenuata Bryol, eur. l. c. ; C. M. op. cil. p. 674; W. P. Sch. et Par. op. cit.; W. P. Sch. in Besch. op. cit. p. 72.

Cr. patens Hpe. in hb. Schlechtendaliano! C. M. in Linn. 1844, p. 679 p.p.

Cr. protensa C. M. in hb. Schlecht. !

- Am. sept. : Mexic., Orizaba.

Aurantiorum C. M. in Linn. 1880-82, p. 469.

- Am. merid. : Argentin. Buenos Ayr.

Balansae C. M. - Cr. guarapensis.

Blumeniana Hpe. Enum. M. Brasil. p. 38.

- Am. merid. : Brasil.

boliviana W. P. Sch. in Mandon Pl. Boliv. n. 1688 et Mon. Cryph. ined. - Am. merid. : And. Boliv.

brasiliensis $\mathrm{Hpe}$ - $\mathrm{Cr}$. filiformis.

Breuteliana W. P. Sch. in Breutel M. Capens, et op. cit.

- Afr. : C. B. Sp. (Montagne Pass).

brevidens C. M. in Rev. bryol. 1876, p. 4 (nom.).

- Pac. : Austral. (Nov. Vales.).

brevipila Mitt. M. austr. am, p. 413.

- Am. merid. : M. Chimborazo.

caldensis Ängstr. in Oefv... 1876, n. 4, p. 31.

- Am. merid. : Brasil, austr. or.

calomiera Broth, in litt.

Cr. gracilis ej. in Mosen Pl, Brasil. n. 88.

- Am. merid. : Brasil.

caripensis C. M. - Acrocryphaea squarrosula.

concavifolia Mitt. - Acrocryphaea.

consimilis Mont, in Ann. sc. nal. 1845, p. 100 et Syll. p. 25.

Pilotrichum consimile $C ., M$, Syn. $I I, p .166$.

- Am. merid. : Chile austr.

consimilis $\mathrm{H}$, $\mathrm{f}$, et $\mathrm{W}$, - Cr. parvula.

crenulala Mitt. - Cyptodon?

cuspidata Sull. in U. St. Ex,l Exped. t. 23 A; W. P. Sch. et Par. op,cit. - Am. mer id. : Chile.

(I) Species omnes monoicae et, ut videtur, corticolae. 
cuspidata $\{$ Hpe. - Cr. Lindigiana.

orspidata W. P. Sch. - Cr. apiculata.

decurrens Mitt. - Cr. patens var. decurrens.

dentata Milt. in Journ. of the Linn. Soc. 1886, p. 311. - Afr. : M. Usagara.

dilatata H. f, et W. - Cyptodon.

Duseni C. M. in Dusen M. Camer, n. 675.

- Afr.: M. Cameroon.

evanescens C. M. in Ule Pl. Brasil. n. 73 jet 903 .

- Am. merid. : Brasil.

exigua (C. M.) Jaeg. Ad. $1 I, p .95$.

Pilotrichum exiguum C.M. Syn. II, p. 166.

- Afr.: C. B. Sp., Transvaal.

Exs. : Rehm. M. Afr, austr. n. 315 et 600.

fasciculata Duby in Besch. Fl. bryol. Nov. Caled. p. 221.

Dendropogon fasciculatus Jaeg. Ad. $I I, p .103$.

- Pac. : Nov. Galed.

fasciculosa Mitt. M. austr. am. p. $41 \mathrm{I}$.

- Am. merid. : And. Quitens.

ferruginea $\{$ Lindb. - Acrocryphaea.

filiformis Brill. Bryol. univ. II, p. 252; W. P. Sch, et Par. op cit.

Cr. brasiliensis Hpe. in sched.

Daltonia filiformis $W, A r n$. Disp. p. 54 .

Fontinalis filiformis Sw. Prodr. Fil. Ind. occ. p. 138.

Hypnum filiforme Gmel. Syst. nat. II, p. 1340.

Neckera filiformis Hedw, M. frond. III, p. 41, t. 16.

Pilotrichum filiforme $P$. B. Prodr. $p, 83 ; C$. M. Syn. II, p. 169.

- Am. sept. : Mexic., Guatemala, Cuba, S. Doming.

Am. merid. : Venezuela, Columb., Brasil.

filiformis $\left\{\begin{array}{l}\text { Hsch. - Cr. Sehiedeana. } \\ \text { Sull. - Cr. glomerate. }\end{array}\right.$

furcinervis C. M. in Linn. 1880-82, p. 467.

- Am. merid. : Argentin. subtropic.

Gardneri Mitt. - Acrocryphaea ferruginea.

glomerata Brgol. eur, l. c. ; Lesq. el Jam. Man. p. 276.

C. filiformis Sull. M. Allegh. n. 81 .

Pilotrichum heteromallum $\gamma$ filiforme $C . M . S y n . I I, p .168$.

- Am. sept. : Ohio, Georg., Carol. utraq., Ludovic., etc.

Exs. : Sull. et Lesq. M. bor. am. II ed, n. 347.

« var. pendula (Lesq. et Jam.) Par.

Cryphaea pendula $L$. et $J_{2}$. in Proced. Am. Acad. XIV, p. 138 et Man. p. 276.

Daltonia heteromalla var. Drumm. M. bor. am. II ed, n. 99.

Ad Tillandsiam. etc. - Am. sept. : Georg. Florid., Ludovic.

Gorveana Mont. - Ilendrocryphaea.

gracilis Mitt. Fl. Vil. p. 393.

- Pac. ; Ins. Fidji, Samoa. 
gracilis Broth. - $\mathrm{Cr}$. calomicra.

guarapensis Besch. in Rev. bryol. 1885, p. 18 (nom.).

Cr. Balansae C. M. mss.

- Am. merid. : Paraguay.

Exs. : Balansa Pl. Parag. n. 3629.

heliclophylla $\left\{\begin{array}{l}\text { Àngstr. - Papillaria Ángstroemii. } \\ \text { Mont. - Meteorium. } \\ \text { Wils. - Lindigia imponderosa, }\end{array}\right.$

Henscheni C. M. mss. ; Ảngstr. in Oefv... 1876, n. 4, p. 29.

- Am. merid. : Brasil, austr, or.

heteromalla (Hedwo.) Brid. Mant. M. p. 139 et Bryol. univ. II, p. 250; Bryol. eur. V, t. 438; W. P. Sch. Syn. II ed. p. 561 .

$\mathrm{Cr}_{\mathrm{r}}$ arborea Lindb. in Oefv... 1863, p. 392, n. 15.

Cr. vermicularis Brid. Bryol. univ. II, p. 253?

Daltonia heteromalla $H$. et T. Musc, brit. p. 81, c. 22.

Fontinalis secunda $L$. jun. Meth. M. p. 368.

Grimmia arborea Schrank Bayers. Fl. II, p. 445.

Hypnum heteromalum Gmel. Syst. nat. p. 1340.

H. polycephalum Neck. Meth. M. p. 190.

Neckera heteromalla Hedw. M. frond. III, p. 38, $t .15$.

Phaseum repens With. Bot. Arrang. p. 785.

Pilotrichum arboreum P. B. Prod, , p. 37.

P. heteromallum Fümr. in Fl. X, II, Beil. I, p. 82; C. M. Syn. II, p. 167 (excl. var. $\beta$ ).

Sphagnum arboreum Huds. Fl. angl. I ed. p. $396 ;$ L. Sp.pl. II ed., II, p. 1570 .

Sph. heteromallum, polycephalum Dill. Hist. M. p. 248, t. 32, f. 6.

Ad Oleas, Popul., Ulmos, etc. - Eur.: Britann., Neerland., vall. Rhen., occid. et merid. Af $r$. : Alger.

Exs. : Rab. Bryoth. eur, n. 684 et b.

var. aqualica de Not, - $\mathrm{Cr}$, heteromalla var, aquatilis.

" var, aquatilis Wils. Bryol. brit. p. 420; W. P. Sch. Syn. I ed. p. 420 et II ed. I. c.

Cr. heternmalla var. aquatica de Not. Epil. p. 208 in obs.

Cr. heteromalla var. Lamyi Boulay FI. orypt. de l Est, $p .356$.

Cr. Lamyi C, M. in Linn. 1844, p. 680. Daltonia Lamyana Mont. in Ann. Sc. nat. ser. II, VI, p. 327, t. 18 et
Syll. p. 22,

Pilotrichum heteromallum $\beta$ aquatile $C . M$. op. et $l$. ce.

Ad arb., rup. et sax. ab aqua fluit. superfusa. - Eur. : Angl. merid, Gall, occid., Lusitan., Etruria.

heterophylla Bric. - Neckera.

indicu Mitt. - Lasia.

intermedia C. M. in Linn. 1847, p. 212.

Pilotrichum intermedium ej. Syn. $I I$, p. 171.

- Am. sept. : Mexic.

? inundata Nees in Pl. Maxim. v. Wied, p. $27 ;$ Sull. M. of U. St. p. 56 (1).

Aquat. - Am. sept. : Illinnie,

(1) " E descriptione pauperrima nil aliud nisi Diohelyma capillacerm vel subulatum videtur. "L.esq. et Jam. Man. p. 413. 
Jamesoni Tayl. in Lond. Journ. of Bot. 1848, p. 192.

Pilotrichum Jamesoni $C$. M. Syn. II, p. 172.

- Am. merid. : And. Quitens.

Lamyi C. M. - Cr. heteromalla var. aquatilis.

latifolia Mitt. M. austr. am. p. 411.

- Am. merid.: And. Quitens.

laxifolia Mitt. in Journ. of the Linn. Soc. 1886, p. 310.

- Afr. : M. Usagara.

Lechleri C. M. - Dendrocryphaea.

Leiboldti C. M. - Acroeryphaea mexicana.

leiophylla Bryol. eur. V (mon p. 5); C. M. Syn. II, p.674; W. P. Sch. et Par. Mon. Cryph, ined. (1).

- Am. sept. : Mexic.

leptoclada Sull. in Proced. of the Amer. Acad... 1861, p. 283.

Ster.

- Am. sept. : Cuba.

leptophylla W. P. Sch. Mon. Cryph. ined.; Besch. Pirodr, bryol. mexic. p. 70 (excl. syn. Cr. leiophylla).

- Am. sept. : Mexic.

leptopteris C. M. in Ule Pl. Brasil. n. 71.

- Am, merid. : Brasil.

Lindigiana W. P. Sch. et Par. Mon. Cryph, ined.

Cr. cuspidata Hpe. in Ann. se. nat. 1865, ser. V, IV, p. 353.

- $\Lambda m$. merul. : And. Nov. Granat.

longifolia W. P. Sch. - Cr. nitidula var. longifolia.

Lorentziana C. M. in Linn. 1880-1882, p. 468.

- Am. merill. : Argentin, subtropic.

lutescens W. P. Sch. Mon. Cryph.ined.

- Am. sept. : Mexic.

madagassa C. M. in Abhandl. Brem. VII, p. 210.

- Afr. : Madagascar.

maynensis Tayl, - Acrocryphaea julacea.

microcarpa W. P. Sch. - Cr. nitidula.

microcyathea Jaeg. - Hedwigia.

Mittenii Jaeg. Ad. II, p. 96.

Cr. apiculata Mitt. M. austrs am. p. 411.

- Am. sept. : Ins. Gorgone.

Moseni Broth. in Mosen Pl. Brasil. n. 87 a.

-- Am. merid. : Brasil (Minas Geraës).

Mülleriana W. P. Sch. - Cr. Sartorii.

nanoclada Angstr. Prim. lin. p. 30.

- Am. merid. : Brasil, austr. or.

nervosa (Hook. f. et Wils.) Bryol. eur. V (mon. p.5); Lesq. et Jam. Man. p. 2i\%.

Daltonia nervosa H. f. et W. in Lond. Jourve of bot. 1842, II, p. 420 , t. 24 et in Drumm. M. bor. am. II ed. n. $100 ;$ Sull. Ic. M. p. 109, t. 68.

Pilotrichum nervosum $C$. M. Syn. II, p. 169.

- Am. sept. : Alabama, Ludovic. 
nitens W. P. Sch. in Mandon Pl. Boliv, n. 1689 el Mon. Cryph. ined. - Am. merid. : And. Boliv.

nitidula W. P. Sch. Mon. Cryph, ined. et in Besch. Prodr. bryol. mexic. p. 69.

Cr. microcarpa ej. in sched.

- Am, sept. : Mexic., And. Costa Ricens.

" var. longifolia W. P. Sch. Mon. Cryph. ined.

$\mathrm{Cr}$, longifolia ej, in sehed.

$$
\text { - Am. sept. : Mexic. }
$$

novo-granatensis Hpe. in Ann. sc. nat. 1865, V ser., IV, p. 352; W. P.

Sch. et Par. Mon. Cryph. ined.

- Ami. merid, : And, Nov. Granat.

orbifolia Besch. in Journ. de bot. 1891, p.

- Am. merid.: Monte Vídeo.

orizabensis W. P. Sch. - $\mathrm{Cr}$. subsimplex.

ovalifolia (C. M.) Jaeg. Ad. II, p. 98.

Pilotrichum ovalifolium C. M. in Bot. Zeit. 1851, p. 564.

Filicic. - Pac. : Austral. (Queensland).

pachycarpa W. P. Sch. Mon. Cryph. ined. et in Besch. Prodr. bryol mexic. p. 71,

- Am. sept. : Mexic.

paraguensis Besch. in Bal. Pl. Parag. n. 3628.

- Am. merid.: Paraguay.

parvula Mitt, in Handb. of the N. Zeal. Fl. p. 460.

Cr. consimilis H. f. et W. Fl. N. Zeal. II, p. 101 et Fl. Tasman. II, p. 204.

- Pac. : Austral., Nov. Zeland., Tasman.

patens Hsch, in Deppe et Schiede M. Mexic. (excl. syn. Hypnum patens Hook.); W. P. Sch. et Par. Mon. Cryph. ined.; Mitt. M. austr. am. p. 413.

Pilotrichum Deppii (nomen mutatum) C.M. Syn. II, p. 674.

P. patens ej. op. cit. p. 171 .

- Am. sept.: Mexic, Am. merid. : And. Quitens.

" var, decurrens (C. M.) W. P. Sch. Mon. Cryph, ined.

Cr. decurrens Mitt. op. cit. p. 414.

Pilotrichum decurrens C. M. op. cit. p. 172.

- Am. sept. : Mexic.

patens $\mathrm{Hpe}$ - - Cr. attenuata.

pendula Lesq. et Jam. - Cr. glomerata var. pendula.

pilifera Tayl. in Spruce M. Amaz. et And. n. 1287; Mitt. op. cil. p, 412.

- Am. merid. : And, Nov. Granat., Quitens. et Boliv.

pinnata Bryol. Eur. V (mon. p. 5, nom.); C. M. Syn.II, p.675; W. P.

Sch. in Besch. Prodr, bryol, mexic. p. 70.

- Am. sept. : Mexic.

plicata Nees. - Garovaglia.

polycarpa W, P. Sch. Mon, Cryph. ined. et in Besch. op. cit. p. 71.

- Am. sept. : Mexic. 
protensa Br. et Sch. in W. Sc\%. M. Abyss. II, n. 487.

Pilotrichum protensum C. M. Syn. II, p. 170? (1).

- Afr. : Abyss.

pulchella Par. et W. P. Sch. Mon. Cryph. ined.

Cr. tenella Mitt. M. austr. am. p. 414.

- Am. merid. : Chile.

Raddiana (Brid.) Hpe. Enum. M. Brasil. p. 39 (nom.).

Hypnum Raddianum Brid. Bryol. univ. II, p. 5ll; C. M. Syn. II, p. 510 .

- Am. merid. : Brasil, austr. or.

ramosa Wils, in Spruce M. Amaz. et And, n. 1284 b.

Cr. affinis Mitt. in sched.

- Am. merid. : And. Quitens.

Ravenelii Aust, in Coult. Bot. Gaz. II, p. 89; Lesq. et Jam. Man. p. $277(2)$.

- Am. sept. : Georg.

reticulata Besch. op. cit. $p 69$.

- Am. sept. : Mexic.

rhacomitrioides C. $M$. in Linn. 1880-82, p. 466.

- Am. merid. : Argentin. Tucuman.

* var. gracilis ej. in op. et $l$. cc.

Ut et ubi typ.

vubricaulis Mitt. - Acrocryphaea.

rufescens $\mathrm{C}$. M. - Dendropogon.

Kutenbergii $C$. M. in Abhandl. Brem. VII, p. 210.

- Afr. : Madagascar.

Sartorii W. P. Sch. Mon. Cryph. ined. et in Besch. op. cit. p. 72.

Cr. Mülleriana ej in sched.

- Am. sepl. : Mexic.

scariosa C. $M$. in Fl. 1890, p. 486.

Ster, - Afr. : Kilima N'Djaro.

Schiedeana (C. M.) Milt. op. cit, p. 413.

Cr. filiformis Hsch, in Deppe et Schiede M. Mexic.

Pilotrichum Schiedeanum C. M. Syn. II, p. 167.

- Am. sept. : Mexic.

Schleinitziana (Dendropogon) C. M. - Dendropogon?

sphaerocarpa Brid. Bryol. univ. II, p. 251 ; Mitt. M. Ind. or. p. 125.

Neckera sphaerocarpa Hook. in Trans. of the Linn. Soc. IX, p. 312, t. 27, f. $I$.

Pilotrichum sphaerocarpum C. M. Syn. II, p. 170.

- As.: Nepal., Himalaya.

squarrulosa Hpe. - Cyptodon.

subintegra Ren. et Card. in Bull. Soc. roy. bot. Belg. 1892, II, p. 105.

- Afr. : Madagasear. 
subsimplex W. P. Sch. Mon. Cryph. ined.

Cr. orizabensis ej. in sched. et in Besch. (Cr. Orizabae) op, cit. p. 70.

"var. congesta W. P. Sch. et Par. Mon. Cryph. ined.

Ut et ubi typ.

tasmatica Mitt. in Journ. of the Linn. Soc. 1859, p. 90; Hook. f. et Wils.

Fl. Tasman. II, p. 204, t. 175, f. 9 (ic. pessima!) et Handb. of the

N. Zeal. Fl. p. 462.

Rupic. - Pac. : Nov. Zeland., Tasman.

tenella Hsch, in Sieb. M. Nov. Holl.

Neckera tenella Schwaegr. Suppl. II, II, t. 198.

Pilotrichum tenellum $C . M . S_{y n} . I I, p .166$.

- Pac. : Austral.

tenella Mitt. - Cr. pulchella.

tenuissima $\mathrm{H}$. f. et W. - Meteorium.

vermicularis Brid. - $\mathrm{Cr}$. heteromalla?

viliana C. M. - Dendropogon Schleinitzianus.

Welwitschii Duby in Mem... Geneve, XXI, p. 3, t. 2, f. I.

Ad Coffeam arabicam et Diospyr. - Afr.: Angola, M. Usagara, Kilima N'Djaro, Madagascar.

viridissima C. $M$. in Wild $P l$. Austral. n. 465.

- Pac. : Austral. (Queensland.).

Gryphæadelphus $C, M$. Syn. $M, I I, p, 144$ (subsect. NeckeraE).

CRYPHIDIUM Mitt. M. nustr. am. p. 457 (sect. Neckerae) ; Jaeg. Ad. 1I, p. 178 (propr. gen.)

leucocoleum Jaeg. - Neckera.

GRYPTANGIUM C. M, in I.inn. 1843 , p. 599 (1 sp.).

gymnostomum (Bryol. eur.) Card. mon. p. 41.

Cr. Schomburgkii C. M. in Linn. 1843, p. 599.

Fontinalis gymnostoma Bryol. eur. V (mon. p. 4), $t$.

Hydropogon gymnostomum Mitt. M. austr, am. p. 449.

Pilotrichum gymnostomum C.M. Syn. II, p. $15 \%$.

1. Aquat. - Am. merid. : Guian. angl.

CRYPTOCARPON Dz, et Mk. in Ann. sc, nat. 1844, II, p. 502.

apiculatum eor. - Cryptocarpus.

GRYPTOCARPUS $\mathrm{D}_{z}$. et Mk. M. frond. ined. $\Lambda$ rehip. ind. p. 37 (3 sp.)

apiculatus eor. l. c. t. 15; C. M. Syn. I, p. 718; Bryol. jav. I, p. 110 et $I I, p .226$.

Cryptocarpon apiculatum eor. in Ann. sc. nat. 1844, II, p. 5(1)2,

Macromitrium brachiatum Hook. $f$. et Wils. in Hook. Ic. pl. rar. 1845, t. $746 \mathrm{~B}$.

Syn. Ad arbor. - As, : Ins. Philippin., Amboine, Borneo, Java, Sumatra.

cymosus Mitt, in Fl. Vit. p. 381.

- Pac. : Nov. Caledon.

marginatulus C. M. mss. ; Jaeg. Ad. II, p. 92 (nom.).

- As. : Birman. 
CRYPTOGONIUM Lindb. in Oefv.... 1873, p. 603.

cylindricum Lindi. - Phyllogonium.

CRYPTOPODIA Roehl. Deutsch. Fl. III, p. 82.

pennata Roehl. - Neckera.

CRYPTOPODIUIM Brid. Bryol. univ. II, p. 30 (5 spec.).

Bartramia Schwaegr. - $\mathrm{Cr}$. bartramioides.

bartramioides (Hook.) Brid. Bryol. univ. II, p. 3L; Hook. f. et Wils, $\mathrm{Fl}$. of the Nov. Zel. II, p. 88 et Handb. p. 446.

Bartramia Cryptopodium C. M. Syn. II, p. 507.

Bryum Bartramia Schwaegr. Suppl. II, II, p. 25, t. 160.

Br. bartramioides Hook. M. ex. t. 18.

Cr. Bartramia Schwaegr. Sp. M. p. 90.

2 .

- Pac. : Ins, Sandwic., Nov. Zeland.

bartramioides Ảngstr. - Rhizogonium strictum.

eapillare Hpe. Symb. 1874, in adn. no 47 (nom.).

2.

- Am. merid. : Brasil. austr. or.

Hookeri Hpe. in Linn. 1847, p. 75.

Bartramia Jamesoni Tayl. in Lond. Journ. of bot. 1847, p. 334; C. M. Syn. I, p. 500 et II, p. 619. Mitt. M. austr, am. p. 269.

B. viridissima C. M. op. cit. I, p. 496.

Leucodon bartramioides Hook, Ic, pi. rar. I, t. 71 .

Syn. Ad arbor. - Am. sept. : Jamaïc. Am. merid. : Columb., And,

Nov. Granat. et Quitens.

"var. borbonicum Besch. Fl. bryol. Réunion, etc. p. 102.

- Afr. : Ins, Borbon?

lutescens (Hpe.) Jaeg. Ad. I, p. 538.

Bartramia lutescens Hpe. in Ann. se, nat. III ser, p. 339: Mitt. l. c.

- Am. merid. : And. Nov. Granat.

piligerum Hpe. Symb. 1874, n. 47.

2. Ster.

- Am. merid. : Brasil. austr. or.

CRYPTOTHECA Hsch. in Deppe et Schiede M. Mexic.

Species omn. Pterobrya ejusd. nom.

CTENIDIUM W. P. Sch. Syn. I ed.p. 631 (subgen. Hypni); Mill. M. auslr. am. (gen. propr.).

Species omn. non indicatae sunt HyPNA ejusd, nom.

Berthelotianum Mitt. - Hylocomium.

Gtenium W. P. Sch. l. e. (subgen. Hypni).

Gupressina C. M. Syn. M. I1, p. 289 (sect. HypNi).

Gupressinadelphus C. M. Syn. II, p. 215 (subsect. Hookeriat).

GYATOPHORUM P. Beauv. Prodr. p. 52 (10 spec.).

Adiantum (Griff.) Milt. M. Ind. or. p. 147; Bryol. jav. II, p. 4, t. 134.

Neckera Adiantum Griff. Ic. pl. asiat. II, t. 85, f. 2 ?

2 .

- As. : Sikkim, Ktasia, M. Java. 
bulbosum (Hedv.) C. M. Syn. I1, p. 54.

Anoectangium bulbosum Hedw. Sp. M. p. 43, t. 6.

C. pennatum Brid. Bryol univ, II, p. 722 .

C. pteridioides P. B. Prodr. p. 52.

Hookeria pennata Sm. in Trans. of the Linn. Soc. IX, p. 277; Hook. M. ex. t. 163.

Leskea pennata Labill. Pl. Nov. Holl. II, p. 106, t. 253.

Pterygophyllum pennatum Brid. Mant. p. 154.

- Pac, : Austral. fel., Nov, Zeland, ins. Auckland.

a var. apiculatum Hook. f. et Wils. Handb, N. Zeal. Fl. p. 490.

- Pac. : Nov. Zeland. med.

* var. minus eor. Fl. Antaret. $I$, p. 143, t. 62, f. 3 .

- Pac. : Tasman, ins. Auckland.

densirete Broth. in Oefv... 1893, p.

2. Ad arbor. - Pac. : Tasman.

Hookerianum (Griff.) Mitl. op. et l. ce.

Neckera Hookeriana Griff. Ie. pl, asiat. II, t. 84. f. 2 A.

- As. : Sikkim, Khasia.

intermedium Mitt. op. cit. p. 148.

Ster.

- As. : Himalaya oce.

parvifolium Bryol. jav. $I I, p .5, t$. 135.

2. Ster?

- As. : M. Jaỵa.

pennatum Brid. - C. bulbosum.

pteridioides P. B. - C. bulbosum.

splendidissimum (Mont.) Hpe. et Ltz. in Bot. Zeit. 1866, p. 188.

Hookeria speciosissima Schroaegr. t. 328 (fid. Mitt.).

H. splendidissima Mont. in Arn. sc, nat. II ser., IV, p. 96 et in d'Orbigny Voy. Amer. VII, Crypt. p. 110; C. M. Syn. II, p. 203.

Lamprophyllum splendidissinum W. P. Sch. Coroll. p. 101.

Lepidopilum splendidissimum Mitt. M. austr, am. p. 378.

2. Cortic. - Am. merid. : Ins. Juan Fernandez, Chile, Valdivia.

sublimbatum Thw, et Mitt. in Journ. of the Linn. Soc. 1872, p. 309.

Ster.

- As. : Ceylan.

taïtense Besch. in Ann. sc. nat. 1894, p.

2. Cortic? - Pac. : Taïti.

tenerum Bryol.jav. II, p. 6, t. 136.

Hookeria spinosa Dz. et Mk, in Zoll. Syst. Verz. p. 26.

2. Ster. ?

- As. : Ins. Bima, Sumatra.

CYCLODICTYON Mill, in Jowrn. of the Linn. Soc. 1863, p, 163 (postea sect.

Hookeriae).

laetevirens Mitt. - Hookeria.

CYLICOCARPUS Linub. in Oefv... 1862.

lapponicus Lindb. - Amphoridium.

Mongeotii Lindb. - Amphoridium.

GYLINDROTHECIUM Bryol. eur. V (I07 spec.).

abbreviatum Bryol. eur. V (mon. p. , nomen); W. P. Sch. in Besch. Prods. bryol, mexic. p. 93.

Entodon abbreviatus Jaeg. Ad. II, p, 356. 1.

- Am. sept. : Mexic. 
aciculare (C. M. et Kindb.) Par.

Entodon acicularis C. M. et K. in Bidrag p. 454 (nom.) et in Mae. Cat. p. 176.

Ster. Rupic.

- Am. sept. : Ontario.

amplirete Wright. - Lepidopilum.

angustifolium (Mitt.) Par.

Entodon angustifolius Jaeg. Ad. $I I, p, 353$.

Stereodon angustifolius Mitt. M. Ind. or. p. 106.

Ster. - As. : Tonkin, Sikkim.

angustifolium Besch. - C. Hahnianum.

argyraeum Besch. in Rev. bryol. 1885, p. 19 et in Journ. de bot. 1891, p.

Entodon denticulatus C. M. in Rev. bryol. 1887, p. 57.

1. Cortic. - Am. merid. : Paraguay.

Exs. : Bal. n. 3678.

attenuatum (Mitt.) Par.

Entodon attenuatus Mitt. in Trans, of the Linn. Soc, 1891, p. 179.

1.

Eas. : Faurie n. 122, 213.

aurescens (Hpe.) W. P. Sch. in op. cit. p. 96.

Entodon aurescens Hpe. in Ann. sc, nat. 1865, p. 369.

Ad arbor. - Am. sepl. : Mexic. (Orizaba). Am, merid. : Ind. Nov, Granat.

«var. major Besch.in sched.

Ut et ubi typ. in $A m$. sept.

aureum (Hook.) Par.

Entodon aureus Jaeg. Ad. II, p. 743.

Leskea aurea Harv. in Lond. Journ. of bot. 1840, II, p. 16.

Neckera aurea C. M. Syn. II, p. 86.

Platygyrium aureum $S b$. in Jaeg. $A d$. $I I, p .743$.

Pleuropus densus G・iff. Not. p. 467 et Ie. pl. asiat. II, t. 89, f. 1, t. 90 , f. 2 et in Calcutta Journ. nat. hist. III, t. 17.

Pterigynandrum aureum Brid. Bryol. univ. II, p. 180.

Pterogonium aureum Hook. M. ex, t. 147.

Stereodon aureus Mitt. M. Ind. or. p. 94.

1.

- As. : Nepal., Himalaya, Khasia.

Bandongiae (C. M.) Bryol. jav. II, p. 127, t. 230.

Neckera Bandongiae C. M. Syn. II, p. 665.

1. Ad arbor. - As. : Celebes, Java, Sumatra.

Batangae (C. M.) Par.

Entodon Batangae C. M. in Dusen M. Camer, n. 682. - Afr.: M. Cameroon.

Beyrichii (Schwaegr.) Par.

Entodon Beyrichii C. M. in Linn. 1844, p. 701 ; Mitt. M. austi. am. p.525.

Neckera Beyrichíi Schroaegr. Suppl. II, II, II, p. $162, t .197 ;$ C. M. Syn. I1, p. 66 .

1. Ad arbor. - Am. sept. : Nicaragua. Am. merid. : Peruv., Brasil (1).

(1) Quid Cylindrothecium breve W. P. Sch. a cl. Ragazzi in Choa lectum

(Cf. R. Pirotta in Annuar, del R. Istit. bot. di Roma, 1893, V, fasc. II)? 
brevipes W. P. Sch. in Besch. Prodr. bryol, mexic, p. 94.

Entodon brevipes Jaeg. Ad, II, p. 356.

I. - Am. sept. : Mexic.

brevirostre Bryol. eur. V (mon p. , nomen); W. P. Sch. in op. cil. p. 93.

Entodon brevirostris Jaeg. Ad. II, p. 355.

- Am. sept. : Mexic. (M. Orizaba).

brevisetum (Hook. f. et Wils.) Bryol, eur. V (mon. p. 4); Sull. M. of U. St. p. 65 et Ic. M. p. 150, t. 96; Lesq. et Jam. Man. p. 311.

Entodon brevisetus Jaeg. Ad. II, p. 357.

Neckera breviseta $H . f$. et $W$, in Lond. Jowin. of bot. 1842, p. 419, t. 24; C. M. Syn. II, p. 70.

1. Lignic. - Am. sept. : Terr. nov., New Brunswick, reg, sept. et centr.

Exs. : Drumm. M. bor am. II ed, n. 95 (Neckera).

Sull. et Lesq. M. bor. am. II ed, n. 391.

caliginosum (Mitt.) Par.

Entodon caliginosus Jaeg. Ad. II, p. 351.

Stereodon caliginosus Mitt. M. Ind. or. p. 108.

1.

- As. Nepal. or.

Cameruniae (C. M.) Par.

Entodon Cameruniae C. M. in Dusen M. Camer, n. 220.

- Afr.: M. Cameroon.

cernuum (C. M.) Par.

Entodon cernuus Jaeg. Ad. II, p. 361.

Neckera cernua C. M. Syn. II, p. 364 .

1 .

- As. : Java.

Challengeri Par.

Entodon abbreviatus Mitt. in Trans. of the Linn. Soc. 1891, p. 179 ; Faurie $\mathrm{Pl}$. Japon. n. 122 et 213.

1. Lignic. - As. : Japon.

cladorhizans (Hedvo.) W. P. Sch. Sym. 1 ed. p. 514 et II ed. p. 625.

Anomodon cladorhizans Hüb. Muscol. yerm, p. 557.

C. Sehleicheri Bryol. eur V (mom. p. 5), t. 468 (ic, sub Fntod. europ.).

Entodon cladorhizans C. M. in Linn. 1844, p. 707.

E. Schleicheri Lindb. M. Scand. p. 39.

E. transilvanicus Demetr. in Hedio. 1884, p. 81 (1).

Hypnum cladorhizuns Poir.

Neckera cladorhizans Hedwo. Sp. M. p. 207, t. 47; Bryol. univ. II, p. 229; C. M. Syn. II, p. 70.

1. Ad mur., rup,, saxa et (in Amer.) rad, arb. - Eur. : In vall, tract. alp. zon, interm. : Voges., Silv. Nigr+, Helvet., Ital, super., Austr. inf., etc.; deest in Scandin, Britann. et Germann. sept. As. : Caucas. Am, sept. : New Brunswick, Ottawa, Ontar., reg. sept., or., centr. et merid.

Exs. : Drumm. M. bor. am. I ed., n. 160 p.p. et II ed, n, 96 (Neckera). Mac. Canad. M. n. 263.

Rab. Bryoth, eur. n. 343 et b, 767.

Sull. et Lesq. M. bor. am. II ed. n. 386 .

Un itin. 1863, n, 33.

(1) Cf. Demeter in Rev. bryol. 1885, p. 85. 
columnare (Schwaegr.) Par.

Entodon columnaris Mitt. $M$. ustr, am. p. 528.

E. Schwaegrichenii C. M. in Linn, 1844, p. 705.

Neckera columnaris Schwaegr. Suppl. IV, p. 319; C. M. Syn. II, p. 62. 1.

- Am. merid. : Brasil.

comes (Griff.) Par.

Entodon comes Jaeg. Ad. II, p. 360.

Neckera comes Griff. Not. p. 458 et Ic. pl. asiat. t. 86, f. 2 .

Stereodon comes Mitt. M. Ind. or. p. 109.

- As, : Himalaya, Khasia, Ceylan.

complanatum W. P. Sch. in Besch. Prodr. bryol. mexic. p. 95.

Entodon complanatus Jaeg. Ad. II, p. 349.

1.

- Am. sept. : Mexic.

complicatum (C. M.) Par.

Entodon complicatus Mitt. M. austr. am. p. 525.

E. myurus Hpe. in Linn. 1847, p. 82?

Neckera complicata C. M. Syn. II, pp. 66 et 665 .

1.

-- Am. merid. : Venezuela.

compressum (Hedwo.) Bryol. eur. V (mon. p. 4); Sulliv. M. of U. St. p. 64 et Ic. M. p. 147, t. 93; Lesq. et Jam. Man. p. 312.

Anomodon compressus $\mathrm{Br}$. mss.

Entodon compressus C. M. in Linn. 1844, p. 707.

Hypnum Mühlenbergii $P$. B. Prodr. p. 66 .

H. pensilvanicum Poir. Encycl. bot. Suppl. III, p. 707.

Isothecium compressum Hpe. mss.; Sull. in A. Gray Man. bot. of $E$. St. I ed. p. 667.

Leskea compressa Hedw. Sp. M. p. 232, t. 56; Brid. Bryol. univ. II, p. 287.

Neckera compressa $C . M$. Syn. $I I, p .66$.

1. Ad arbor. - As. : Jenissei sup., Japon. Am. sept.: de Pensilv. ad Missouri; Ohio, reg. merif.

Exs. : Sull. et Lesq. M. bor. am. Il ed, n. 388.

concinnum (de Not.) W. P. Sch. Syn. I ed. p. 515 et II ed. p. 626.

C. Montagnei Bryol. eur. V (mon. p. 6), t. 469.

Entodon insidiosus Spr. in Ann. and Magaz. of nat. Hist. 1849 et $M$. Pyren. n. 102.

E. Montagnei C. M. in Linn. 1844, p. 708.

E. orthocarpus Lindb. M. Scand. p. 39.

Hypnum concinnum de Not. Mant. n. 18 et Syll. M, ital.p. 45.

H. orthocarpum la Pyl. in Brid. Bryol. univ. II, p, 422.

H. paradoxum Mont. in sched.

H. Schreberi $\gamma$ orthocarpum Brid. op. et $l$. ce.

Isothecium insidiosum Mont. in Ann. sc. nat. 1843, p. 352, t. 15 et Syll. p. 18.

Neckera orthocarpa C. M. Syn. II, p. 69.

2. In pratis sicc., ad agger. et in steril, etc. - Eur.: Fere tota, praecip. in calcar., rariss. fructif. As.: Jenissei sup. et med, Persia, Caucas. occ, et centr. Am. sept. : Colorado.

cupressiforme (Hpe.) Par.

Entodon cupressiformis Hpe, in Ann. sc. nat. V ser., IV, p. 372 ; Mitt. M. austr. am.p. 530 .

Ad arbor. - Am. merid. : And. Nov. Granat.

curvatum (Griff.) Par.

Entodon curvatas Jaeg. Ad. II, p. 359.

Neckera curvata Griff. Not. p. 451 et Io. pl. asiat, II, t, 86, f. I.

Ad rup. torrent. - As. : Khasia. 
Daemeli (C. M.) Par:

Entodon Daemeli $C, M$, in sched.

- Pac. : Austral. or. (Queensland).

Delavayi (Besch.) Par.

Entodon Delavayi Besch, in Ann. sc. nat, 1892, I, p. 87,

1. Saxic. - As. : Yunnan.

"var. rufulum (Besch.) Par.

Entodon Delavayi var. rufulus Besch. op. cit.p. 88.

Ut et ubi typ.

Demetrii Ren, et Card, in Rev, bryol. 1893, p. 14 (nom.) (1).

- Am. sept. : Missouri.

distans (C. M.) Par.

Entodon distans Mitt. M. austr. am. p. 527.

E. Hampeanus C. M. in Linn. 1847, p. 214.

Neckera distans ej. Syn. II, p, 61.

1. $\quad-$ Am. merid. : Venezuela.

Dregeanum (Hsch.) Par.

Entodon Dregeanus C. M. in Linn. 1844, p. 706.

Neckera Dregeana Hsch. in eod. op. 1841, p. 139 ; C. M. Syn. II, p. 63. 1. $-A f r$. Transvaal, C. B. Sp.

Exs. : Rehm. M. Afr. austr. n, 648 b.

« var. imbricatum Rehm. M. Afr, austr, n. 330 et 649 b.

Entodon enervis ej. in Rev. biyol. 1878, p. 71 (nom.).

$$
\text { - Afr. : Transvaal, Natal. }
$$

Drummondii Bryol. eur. V (mon. p. 4, nom.) ; Sull. M. of U. St. p. 64 et Ic. M. p. 148, t. 94 ; Lesq. et Jam. Man. p. 312.

C. Regelianum Bryol. eur. l. c.

Entodon Drummondii Jaeg. Ad. $I I, p, 348$.

Neckera cladorhizans $H$. f. et W. in Drumm. M. bor. am. II ed, n. 96 . Lignic. et saxic. - Am. sepl. : Reg. merid.

Exs. : Sull, et Lesq. M, bor, am. II ed. n. 390.

Drummondii Mac. p.p. $\left\{\begin{array}{l}\text { - C. Macounii. } \\ - \text { Hypnum subflaccum. }\end{array}\right.$ erythropus (Mitt.) Par.

Entodon erythropus Mitt. M. austr. am. p. 525.

1.

- Am. merid. : And. Quitens.

? expallens (C. M. et Kindb.) Par.

Entodon (Rhaphidostegium ?; expallens C. M. et K. in Mac. Cat.p. 177.

Ster. Paludic. in silv. - $A m$, sept, : Summ. M. Rupestr.

Felicis (Ren. et Card.) Par.

Entodon Felicis R. et C. in Bull. Soc. roy. bot. Belg. 1892, II, p. 108. - Afr. : Madagasc.

flavescens (Schwaegr.) Par.

Entodon flavescens Jaeg. Ad. II, p. 359 (excl. syn. Hook.).

Neckera coarctata C. M. Syn+ II, p. 69 p.p. (fid. Mitt. M. Ind. or. p. 108). 

N. flavescens Schwaegr. Suppl. II, II, p. 116, t. 141; Brid. Bryol.
univ. II, p. 234.

Stereodon Schwaegrichenii Mitt. op. et $l$, oc,

1. - As. : Nepal.

flavo-virens (C. M.) Par.

Entodon flavo-virens $C$. M. in Linn. 1878-79, p. 426. - Am. merid. : M. Argentin. subtropic.

«var. flagellaceus (C. M.) Par.

Entodon flavo-virens var, flagellaceus C. M. $l$. c.

Ubi typ.

floridanum Duby in Fl. 1875, p. 284 et Choix de crypt. ex. 1875, p. 10, t. $2, f .4$.

Entodon floridanus Jaeg. Ad. II, p. 349.

fulvo-nitens (Mitt.) Par. - Am. sept. : Florid.

Entodon fulvo-nitens Jaeg. Ad. II, p. 360.

Stereodon fulvo-nitens Mitt. M. Ind, or. p. 109.

Ster, - As. : Nepal.

geminidens Besch. Fl. bryol. Réunion, etc. p. 152.

1. Terr. - Afr. : Ins. Borbon.

gracile Ångstr, in Oefv... 1876, p. 45.

Entodon gracilis Jaeg. Ad. II, p. 352.

- Am. merid. : Brasil. austr. or.

gracilescens Bryol. eur. - C. Sullivantii.

gracilisetum (Hpe.) Par.

Entodon gracilisetus Hpe. in Ann, sc, nat. V sex, IV, p. 368; Mitt. M. austr. am. p. 529.

Griffithii (Mitt). Par.

- Am. merid. : And. Nov. Granat.

Entodon Griffithii Jaeg. Ad. II, p. 359.

Stereodon Griffithii Mitt. M. Ind. or. p. 108.

1. - As. : Assam super., Yunnan.

guinense Ängstr. - Trichosteleum.

Hahnianum (Jaeg.) Par.

C. angustifolium Besch, in sched.

Entodon Hahnianus Jaeg. Ad. p. 356.

Hampeanum (C. M.) Par. - Am. sept. : Mexic.

Entodon Hampeanus C. M. in Linn. 1844, p. 705; Mitt. M. austr am. p. 526 .

Neckera Hampeana ej. Syn. II, p. 60.

1.

- Am. merid. : Venezuela, And, Quitens.

Hartmanni (C. M.) Par.

Entodon Hartmanni C. M. in Rev. bryol. 1877, p. 43 (nom.).

incurvatum (Hsch.) Par.

- Pac. : Austral. or. (Queenslind.).

Entodon incurvatus Mitt. M. austr. am. p. 531.

Neckera incurvata Hsch. Fl. Brasil. I, p. 53; C. M. Syn. II, p. 320.

- Am, merid. : Brasil. 
Jamesoni (Tayl.) Par.

Entodon Jamesoni Mitt. op, cit. p, 528.

E. lutescens Hpe, in Ann. sc, nat. V ser, IV, p. 370 (fid. Mitt. l. c.).

E. polycarpus Hpe, l. 's. (fid. Mitt. l. o.).

Neckera leptocarpa $H$. $f$. et $W$. in Lond. Journ. of bot. 1846, p. 452, t. 15 L; C. M. Syn. II, p. 61 .

Pterogonium Jamesoni Tayl, in Lond. Journ. of bot. l. c. p. 59.

1 ? Ad arbor. .. Am. merid. : And. Nov. Granat. et Quitens.

japonicum (C. M.) Par.

Entodon japonicus C. M. mss. ; Jaeg. Ad. II, p. 357.

$$
\text { - As.: Japon. }
$$

laetum (Mitt.) Par.

Entodon laetus Jaeg. Ad. 1I, p. 361.

Neckera laeta Griff. Not.p. 459 et Ic. pl, asiat. II, $t .87, f .7$.

Stereodon laetus Mitt. M. Ind. or. p. 107.

1. - As. : Khasia.

Lindbergii (Hpe.) Par.

Entodon Lindbergii Hpe.Symb. p. 274.

E. subenervis Jaeg. Ad. $I I, p .354$.

1. Ad arbor. et rup. - Am. merid. : Brasil.

longifolium (C. M.) Par.

Entodon Iongifolius Jaeg. Ad. II, p. 361.

Neckera longifolia C. M. Syn+ II, p. 60.

I?

- As, : Bombay.

luridum (Griff.) Par.

Entodon luridus Jaeg. Ad. II, p. 360.

Neckera lurida Griff. Not. p. 452.

Stereodon Iuridus Mitt. M. Ind. or. p. 109.

Rupic. - As, : Khasia.

lutescens (Hpe.) Par.

Entodon Jamesoni (fid. Mitt. M. austr. am, p. 528),

E. lutescens $H_{p}$, in Ann. sc. nat. $V$ ser., IV, p. 370.

Mac-Kaviense (C. M.) Par.

- Am. merid. : And, Nov. Granat.

Entodon Mac-Kaviensis C. M. in Linn. 1871-73, p. 155.

I.

- Pac. : Austral. or.

Macounii (C. M. et Kindb.) Par:

C. Drummondii Mao. Canad. M. n. 436 p.p.

Entodon Macounii C. M. et $K$. in Bidr. p. 454 (nom.) et in Mao. Cat. p. 177 .

2. Terr. - Am. sept. : Ontario.

macropodum (Hedro.) Par.

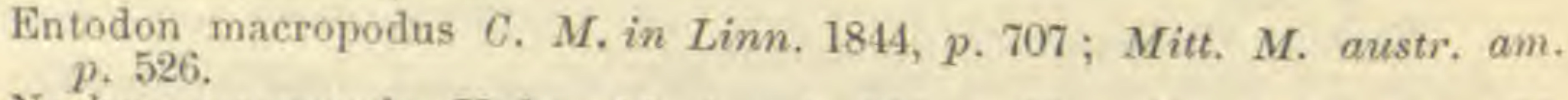
Neckera macropoda Hedw. M. frond. $I I I, p .55, t .23 ;$ C. M. Syn. II,
$p, 59$

N. Distichia macropoda Brid. Bryol. univ, $I I$, p. 248.

1 ? Ad arbor. - Am. sept. : Jamaïc, Cuba. Am. merid. : Venezuela, Nov, Granat, Brasil.

madagassum (C. M.) Par.

Entodon madagassus C. M. in Abhandl, Brem, VII, p. 211.

1.

- Afr. : Madagascar. 
Mandoni W. P. Sch, in Mandon Pl. Boliv, n, 1693.

- Am. merid. : And. Boliv.

mechoacanum (C. M.) Besch. Prodr, bryol, mexic. p. 96.

Entodon mechoacanus Jaeg. Ad. II, p. 356.

Neckera mechoacana C. M. in Bot. Zeit. 1855, p. 766.

1 .

- Am. sept. : Mexic.

micropodon (Besch.) Pur.

Entodon micropodus Besch, in Ann, se. nat. 1892, I, p. 87.

1.

- As. : Yunnan.

Montagnei Bryol, eur. - C. concinnum.

Motelayi Besch. in Jour'n. de bot. 1891, p.

1. Ster.

- Afr. : Ins. Franciae.

Mühlenbergii Bryol. cur. - C. seductrix.

myosurella (C. M.) Par.

Entodon myosurella C. M. in Rev, bryol. 1876, p. 4 (nom.).

- Pac. : Austral, or. (Nov. Valesia.).

myurum (Schwoegr.) Par.

Entodon myurus Jaeg. Ad. II, p. 360.

Neckera myura Schwaegr. Suppl. III, I, I, t. 217; G. M. Syn. II, p. 67.

Pterigynandrum myurum Brid. Bryol. univ. II, pp. 176 et 750 .

Pterogonium myurum Hook. M. ex, t. 148.

Stereodon Gardneri Mitt. M. Ind. or. p. 107.

1.

- As. : Nepal., Himalaya.

\& var. hokinense (Besch.) Par.

Entodon myurus var. hokinensis Besch, in Ann. sc. nat. 1892, I, p. 86.

In silv. - As. : Yunnan.

natalense (Rehm.) Par.

Entodon natalensis Rehm. M. Afr, austr, n. 331.

- Afr. : Natal.

neglectum (C. M.) Besch. Prodr. bryol. mexic. p. 97.

Entodon neglectus Mitt. M. austr. am. p. 527.

Leskea sciuroides Hsch. in Deppe M. Mexic.

Neckera neglecta C. M. in Bot. Zeit. 1856, p. 437.

1.

- Am. sept. : Mexic.

N'goloae (C. M.) Par.

Entodon N'goloae C. M. in Dusen M. Camer, n. 679.

- Afr. : M. Cameroon.

nitens W. P. Sch, in Besch. Prodr, bryol, mexic, p. 95.

Entodon nitens Jaeg. Ad. $I I, p, 345$.

1. - Am. sept. : Mexic. (Orizaba, Cordoba).

Novae Valesiae (Hpe.) Par.

Entodon Novae Valesiae Hpe. mss. ; Jaeg. Ad. I1, p. 744.

- Pac. : Austral. or. (Nov. Valesia).

orizabanum W. P. Sch, in op. et l. cc.

Entodon orizabanus Jaeg. Ad. II, p. 349 ,

1.

- Am. sept. : Mexic. (Orizaba). 
pallescens (C. M.) Par.

Entodon macropodus C. M. in Linn. 1847, p. 214.

E. pallescens Mitt. M. austr. am. p. 526 .

Neckera pallescens C.M. Syn. II, p. 63 .

1. - Am. sept. : Jamaïc. Am. merid.: Venezuela, And, Quitens.

pallidisetum (Mitt.) Par.

Entodon pallidisetus Mitt. op. et $l$. cc.

Ad arbor. - Am. merid. : And. Quitens, et Peruv.

pallidum (Mitt.) Besch. Fl. bryol. Nov. Caledon. p. 236.

Entodon pallidus Mitt. Fl. Vit, p, 398.

In silv, ad Corallia emerg. - Afr. : Ins, S. Paul. Pac. : Ins. Taití,

Nov. Hibern., Nov. Hebrid, Nov. Caledon., ins. Lord Howe.

Pancherianum Besch. op. cit. p. 235.

1. Ad terr. argill. - Pac. : Nov. Caledon.

platygyrioides (C. M.) Par.

Entodon platygyrioides C. M. in Linn. 1878-79, p. 431.

Ster.

- Am, merid. : Argentin. subtropic.

plicatum (C. M.) Par.

Entodon plicatus C. M. in Linn. 1844, p. 706.

Isothecium Beyrichii Mont. in Ann. sc. nat. 1842, M. Neilgherr. n. 19.

Neckera plicata C. M. Syn. II, p. 60.

Pterogonium aureum Griff. Not. p. 449.

Stereodon plicatus Mitt. M. Ind. or. p. 106.

1. - As. : Nepal., Sikkim, Khasia, Assam, Madras, M. Neilgherr., Ceylan.

polycarpum (Hpe.) W. P. Sch. in Besch. Prodr. bryol. exic. p. 93.

Entodon Jamesoni (fid. Mitt. M. austr. am. p. 528).

E. polycarpus Hpe, in Ann, sc. nat. 1865, p. 370.

Nov, Granat.

propinquum (Hpe.) Par.

Entodon propinquus Hpe. in Ann. se. nat. 1865, p. 369; Mitt. M. austr. am. p. 530.

- Am. merid. : And. Nov. Granat.

prorepens (Mitt.) Par.

Entodon prorepens Jaeg. Ad, II, p. 360.

Stereodon prorepens Mitt. M. Ind. or. p. 107.

1 .

$$
\text { - As. : Nepal, Assam. }
$$

pseudo-seductrix (C. M.) Par.

Entodon pseudo-seductrix Jaeg. Ad, II, p. 358.

Neckera pseudo-seductrix C. M. in Bot. Zeit. 1859, p. 230.

1.

pulchellum (Griff.) Par. - Afr. : Ins. Cap. Viridis.

Entodon pulchellus Jaeg. Ad. II, p. 360.

Neckera pulchella Griff. Not. p. 453 et Ic. pl. asiat. II, t. 87, f. 6.

Stereodon pulchellus Mitt. op. cit. p. 109.

In silv. - As. : Khariu.

ramosissimum (Hpe.) Par.

Entodon ramosissimus Hpe, in op. cit. p. 371 ; Mitt. op. cit. p. 529.

Ad arbor. - Am, merid.: And, Nov, Granat. 
ramulosum (Mitt.) Par.

Entodon ramulosus Mitt. in Trans, of the Linn. Soc. 1891, p. 179.

E. subcompressus Broth. in sched.

2.

-As.: Japon.

repens de Not. - Platygyrium.

rubicundum Wils. in sched.

Entodon rubicundus Jaeg. Ad, II, p. 351.

Neckera coarctata C. M. Syn. II, p. 69 p.p. (fid. Mitt. M. Ind. or. p. 108).

N. flavescens Hook. in Trans. of the Linn. Soc. IX, p. 314, t. 27, f. 2; Brid. Bryol. univ. II, p. 234.

Stereodon rubicundus Mitt. op. et $l$. ce.

1. - As. : Nepal., Sikkim, Khasia.

Rugelianum Bryol, eur. - C. Drummondii.

Rutenbergii (C. M.) Par.

Entodon Rutenbergii C. M. in Abhandl Brem. VII, p. 211.

1 .

- Afr. Madagascar.

scabridens (Lindb.) Par.

Entodon scabridens Lindb. in Act. Soc. sc. Fenn. 1872, p. 253.

1 .

- As. : Saghalien.

Schimperi (Hpe.) Par.

Entodon abyssinicus Jaeg. Ad. II, p. 359.

E. Schimperi Hpe, in Linn. 1847, p. 83.

Leptohymenium julaceum Br. et Seh. in W. Sch. M. Abyss. n. 423.

Neckera abyssinica C.M. Syn. II, p. 71.

Stereodon abyssinicus Mitt. in Journ. of the Linn. Soc. 1863, p. 157.

l. Ad arbor. - Afr. : Abyssin., Choa, M. Carneroon.

Schleicheri Bryol, eur. - C. cladorhizans.

Schlimianum (C. M.) Par.

Entodon Schlimianus C. M. in sehed.

- Am. merid. : Nov. Granat.

seductrix (Hedwo.) Sull. M. of U. St. p. 64 et Ic, M. p. 145, t. 92.

C. Mühlenbergii Bryol. eur. V (mon.p. 4).

Entodon seductrix C. M. in Linn. 1847, p. 214.

Neckera clodorhizans Drumm. M. bor, am. I ed, n, 160 p.p.

N. seductrix Hedw. Sp. M. p. 208, t. 47; Brid. Bryol. univ. II, p. 131; C. M. Syn. II, p. 72 (incl. $\beta$ gracilis).

Pterigynandrum carolinianum Brid. op, eit. p. 184.

Pt. obtusifolium ej. op. cit. p. 182.

Pterogenium carolinianum Schwaegr. Sroppl. I, I, p. 108.

1. Lignic. - Am. sept.: Ontario, Washington, Idaho, Wyoming, reg. sept., centr. or. et merid.

serrulatum (Mitt.) Par.

Entodon serrulatus Mitt. M. austr, am. p. 632.

- Am. merid. : Guatemala.

Solanderi Angstr. in Oefv... 1873, n. 5, p. 122.

Entodon Solanderi Jaeg. Ad. II, p. 358.

1 ? Lignic. - Pac. : Taïti.

splendidulum (Hpe.) Par.

Entodon splendidulus Hpe. Symb. 1870, p. 274.

1. Terr. - Am. merid, : Brasil. austr. or. 
stenocarpum Bryol, eur. V (mon. p. 4, nom.); W, Sch. in Besch. Prodr. bryol. mexic. p. 94.

Entodon stenocarpus Jaeg. Ad. II, p. 356.

Isothecium stenocarpum W. P. Sch. in hb. Mus. Paris. - Am. sept. : Mexic.

stramineum Besch. Fl, bryol. Nouv. Caled. p. 236.

Entodon stramineus Jaeg. Ad. II, p. 357.

1. In silv, - Pac. : Nov, Caledon.

suberythropus (C. M.) Par.

Entodon suberythropus C. M. in Linn. 1878-79, p. 427.

1. Ad mur. et terr. - Am. merid. : And. Boliv., Argentin. subtropic.

« var. complanatulum (C. M.) Par.

Entodon suberythropus var. complanatulus C. M. in op. cit. p. 428.

Ut typ. - Am. merid, : Argentin. subtropic.

" var. ellipticum (C, M.) Par.

Entodon suberythropus var. ellipticus C. M. in op, et $l$.cc.

Ut et ubi praeced.

"var, flaceidum (C. M.) Par.

Entodon suberythropus var. flaccidus $C$. M, in op. cit. p, 430.

Ut et ubi praeced.

“ var. gracillimum (C, M.) Par.

Entodon suberythropus var, gracillimus $C$. M. in op, et l. cc.

Ad arbor. et rup. - Ubi praeced.

«var. lutescens (C. M.) Par.

Entodon suberythropus var. lutescens $C$. M. in op. et $l$. cc.

Ut et uki prim, var.

" var. microtheca (C.M.) Par.

Entodon suberythropus var. microtheca C. M. in op. et $l$. cc.

Ut et ubi praeced.

\& var. myosuroides (C. M.) Par.

Entodon suberythropus var. myosuroides C. M. in op, cit. p, 429.

Ut et ubi praeced.

*var. rufulum (C. M.) Par.

Entodon suberythropus var, rufulus C. M. in op. et. $l \mathrm{cc}$.

Ut et ubi praeced,

subsecundum W. P. Sch, in Besch. Prodr. bryot. mexic. p. 96.

Entodon subsecundus Jaeg. Ad, $I I, p, 351$.

1.

- Am. sept. : Mexic.

Sullivantii Bryol. eur. V (mon. p. 4, nom.) ; Sull. M. of U. St. p. 64 et Ic. M. p. 149, t. 95 .

C. gracilescens Bryol. eur. $l$. c.

Entodon Sullivantii Lindh, Costrib, ad fl. erypt. As. bor, or. p. 233.

Leskea compressa Sull. M. Allegh. n. 64 .

Neckera Sullivantii $C$. M. Syn, $I I, p .65$.

1. Saxic. in sillv. - As. : Japon. Am. sept.: Tẹnnessee, Carol, infer. Exs, : Sull, et Lesq. M, bor, am, II ed, n, 389. 
tenellum W. P. Sch, in sclied.

Entodon tenellus Jaeg. Ad. II, p. 350.

Thumsoni (Mitt.) Par.

$$
\text { - Am. sepl. : Mexic. }
$$

Entodon Thomsoni Jaeg. Ad. II, p. 360.

Stereodon Thomsoni Mitt. M. Ind. or. p. 107.

1.

- As. : Himalaya oec.

Toowomba (C. M.) Par.

Entodon Toowomba C. $\boldsymbol{M}$. in Rev. bryol, 1877, $p, 43$ (nom.).

truncatum (C. M.) Par. - Pac. : Austral. or. (Queensland).

Entodon truncatus Mitt. M. austr. am. p. 528.

Neekera truncata $C . M$. Syn. II, p. 62 .

1.

- Am. merid. : Chile.

truncorum (Mitt.) Par.

Entodon truncorum Mitt, in Hook. f. Handb, of N. Zeal. Fl. p. 467. - Pac. : Nov. Zeland.

? turgidum $\stackrel{\circ}{n g s t r .}$ in Oefv... 1873, n. 5, p. 124.

? Entodon turgidus Jaeg. Ad. $I I, p, 358$.

Ster, - Pac. : Taïti.

virens (Hook. f. et Wils.) Par.

Entodon fissidens C. M. in Bot. Zeit. 1844, p. 740.

E. virens Mitt. M. austr, am. p. 527 .

Neckera virens $H$. $f$. et W. in Lond. Journ. of bol. 1844, p. 158; C. $M$. Syn. II, p. 64 .

1. Rupic. - Am. merid.: Brasil. austr. or.

viride Duby in Menı... Genève, 1869, p. 14, t. 4, f. 3.

Entodon viridis Jaeg. Ad. II, p. 345 .

1. Ad arbor. - Am. sept. : Mexic.

Wagneri (Ltz.) Par.

Entodon Wagneri Ltz. Moost. p. 164.

1. Rupic. - Am, merid. : M. Pichincha.

Wilkesianum (Sull.) Par.

Entodon Wilkesianus Reichdt. Beitr. p. 581.

Hypnum Wilkesianum Sull, in Proced... 1854.

- Pac. : Ins. Hawaï, S. Vincent (1).

CYMBARIA Tayl. in Lond. Journ. of bot. VII, p. 190.

Jamesoni Tayl. - Eustichia longirostris.

CYNODON Brid. Mant. M. p. 99 et Bryol, univ. I, p. 500.

cernuus Brid. - Bryum pendulum.

inclinatus Brid. - Distichium.

latifolius Brid. - Desmatodon cernuus.

luridus Brid. - Didymodon.

proscriptus Brid. - Leptotrichum.

(1) De nomin. nudis in Enum. Kindberg. cf, gen. Entodon. 
Cynodontiella Limpr, Laubm. Deutschl. I, p. $28 \mathrm{l}$ (sect. Cynodontit).

GYNODONTIUM Brid. Sp. M. I, p. 155 (12 sp.)

alpestre Lindb. ? (I) ; Milde. - C. gracilescens var, alpestre.

brevipes (Lindb.) Par.

Oncophorus brevipes Lindb. M. Scand, p. 27 (nom.).

- Eur. : Suecia, Fennia.

Bruntoni Bryol, eur. - Dicranoweisia.

canadense Mitt. - Dichodontium.

capillaceum Schwaegr. - Distichium.

cernuum $\left\{\begin{array}{l}\text { Schleich. }-\mathrm{Br} \text {. pallens var, arcuatum. } \\ \text { Schwaegr }- \text { Br. }\end{array}\right.$

cirratum Kindb. - C. gracilescens var. inflexum.

conicum Mitt. (1876). - Blindia pulvinata.

crassirete Angstr. in Oefv... 1876, n. 4, p. 4.

- Am. merid. : Brasil. austr. or.

crispifolium (Mitt.) Jaeg. Ad. I, p. 634.

Didymodon crispifolius Mitt, in Journ. of the Linn. Soc. 1864, p. 148.

Oncophorus crispifolius Lindb. in Contrib. ad fl. crypt. As. bor. or. p. 229 .

1.

- As. : Japon.

decumbens (Tho. et Mitt.) Jaeg. l. c.

Dicranum decumbens Thw. et M. in Journ. of the Linn. Soc. 1872, $p, 296$.

2.

- As. : Ceylan.

debile Jaeg. p.p. $\left\{\begin{array}{l}\text { - Dicranella Beyrichiana. } \\ \text { - Microdus exiguus. } \\ \text { - M. Martianus. }\end{array}\right.$

fallax Limpr. - C, gracilescens var. alpestre.

flexicaule Schwaegr. - Leptotrichum.

glaucescens (Lindb. et Arn.) Par.

Oncophorus glausescens L. et A. M. As. bor. 1890, II, p. 93.

1. Terr. - As. : Jenissei inf., Amour.

gracilescens (Web, et Mohr) Bryol. eur. I (mon, p. 13), tt. 45 el 46; W. P. Sch. Syn. II ed. p. 62.

Dicranum alpestre $\beta$ majus Wahlenb. Fl. Lapp. p. 339.

D. gracilescens W. et M. Bot. Taschb. p. 184 ; Brid. Bryol. univ. I, p. 441 .

D. mixtum de Not. Mant. n. 52 et Syll. p. 210.

D. polycarpum Wils, in Kew Jowrn. bot. IX, p. 295.

D. polycarpum $\beta$ gracilescens $C . M . S y n . I I, p .591$.

Diobelon gracilescens Hpe. Fl. Hercyn.

Oncophorus gracilescens Lindb. M. Scand, p. 27.

1. In fissur. rup. - Eur. : Reg. subalp. rarius alp. As.: Amour, Sikkim, Caucas, occ. et centr. Am. sept. : Groenland, M. Alb., A dirondack et Rupestr.

Exs. : Rab. Bryoth. eur, n. 462, 1261.

Sull, et Lesq. M. bor. am. II ed. n. 57.

(1) Cf. Limpr, op. cit. pp. 283 et 287. 
« var. alpestre (Walelenb.), W. Sch. op. et $l$. c.

C. alpestre Milde Bryol. siles. p. 51 , Lindb. in Limpr. op. c. p. 283?

C. fallax Limpr. Larebm. Deutschl. I, p. 287.

C. gracilescens Un. crypt. $1863, n .6$.

C. gracilescens $\gamma$ tenellum Bryol. eur. $l$. $c$.

C. tenellum Limpr. Krypt. v. Schles. I, p. 425.

C. torquescens Limpr. Laubm. Deutschl. I, p. 288.

Dicranum alpestre Wahlenb. Fl. Lapp. p. 309; Brid. Bryol. univ, I, p. 442.

D. polycarpum $\delta$ tenellum $C, M, l$. $c$.

D. torquescens $B r$. in M. Un. itin. 1828.

? Diobelon alpestre Hpe. Fl. Hercyn.

Oncophorus alpestris Lindb. M. Scand. p. 227.

O. nigricans Kindb. in Bot. Not. 1882, p. 146 et Laubm. Schwed. p. 143.

O. obtusatus Lindb. in Meddel... III, p. 192.

O. torquescens Lindb. et Arn. M. As. bor. 1890, II, p. 92.

Ut typ. - Eur. : Scandin., Bohem., Hercyn,, Rhaet, Tirol., Helvet. As. : Amour, penins. Tschutsch., Jenissei inf. Am. sept. : Groenland., M. Rupestr.

var. curvisetum Bryol, eur. - C. gracilescens var. inflexum.

«var. inflexum W. P. Sch. Syn. I ed. p. 61 el 11 ed. p. 62.

Campylopus cirratus Hsch. in Brid. Bryol. univ. I, p. 479.

Cynodontium cirratum Kindb. Laubm. Schwed.p. 102.

C. gracilescens $\beta$ curvisetum Bryol. our, l. c.

Dicranum gracilescens $\delta$ pusillum Pfeff. Bryol Stud. p. 17.

D. polycarpum $\gamma$ curvisetum $C, M . l . c$.

Dryptodon Campylopus Brid. op. cit. p. 773.

Oncophorus cirratus Lindb. M. Scand. p. 27.

Ut typ. - Eur. : Ubi typ. Am. sept. : Reg. or.

var. tenellum Bryol, eur. - C. gracilescens var. alpestre,

gracilescens Un. crypt. - C. gracilescens var. alpestre.

Hookeri Mitt. (1876). - Blindia aschistodontoides var, nigrescens ?

inclinatum Hedw. - Distichium.

latifolium Schwa gr. - Desmatodon cernuus.

longirostrun Mart. - Dicranodontium.

polycarpum (Ehrh.) W. P. Sch. Coroll, p. 12 et Syn. II ed. p. 63.

Bryum cirratum setis et capsulis brevioribus et pluribus Dill. Hist. $M$. p. 278, t. $48, f .41$.

Br. medium Vill. Pl. Dauph. III, p. 78.

Br. polyearpum Hoffm. Deutsch. Fl. II, p. 37.

Cecalyphum multiflorum P. B. Prodr, p. 51.

Dicranum polycarpum Ehrh. Deo. n. 84; Bryol. eur. I (mon. p. 14), t. $47 ; C . M$. Syn. $I I, p .591$.

D. scottianum Drumm, M. bor, am. I ed. n. 107.

Didymodon Jenneri W. P. Sch. mss.; Horoie in Trans. Edinb. bot. Soc. 1868, p. 198 (fid. Limpr. Laubm. Deutschl. I, p. 290),

Diobelon polycarpum Hpe. Fl. Hercyn.

Fissidem polycarpos Hedw. M. frond. $I I$, p. $85, t .31$.

Oncophorus polycarpus Brid. Bryol. univ. I, p. 397.

o. strumifer $\beta$ substrumosus ej. op. oit. p. 396.

1. In rup. silic. fissur. humid, - Eur. : E reg. campestr. montos. usq. in alp.; Spitzberg, ins. Ursor. As. : Japon. (form.), Amour, Cancas. or. Am. sept. : Groenland, Terr. nov., Nov. Scot., New Brunswick, Ontario, lac. Super., Columb. brit., Alaska, reg. sept. or.; Vancouver, Washington, Idaho, Wyoming.

Exs. : Mac. Canad. M. n. 21 p.p.

Sull, et Lesq. M. bor. am. 11 ed. n. 58. 
\& var. strumiferum (W. et M.) W. P. Sch. $l l . c c$.

Bryum inclinans Dicks. Fase. IV Pl. erypt. p. II, t. 11, f. 9.

Br. strumiferum ej. Fasc. $I I I$, p. 8.

Cecalyphum strumiferum $P$. B. Prodr. $p, 5 \%$.

Cynodontium strumiferum de Not. Epil. p. 280.

Dicranum gibbosum Brid. Sp. M. I, p. 225.

D. polycarpum $\beta$ strumiferum Bryol. eur. $I$ (mon.p. 14),t. $47 \beta$.

D. strumiferum W. et M. Bot. Tasehb. p. 181; C. M. Syn. II, p. 592; Drumm. M. bor, am. I ed. n, 107.

Diobelon strumiferum Hpe. $\mathrm{Fl}$. Hercyn.

Fissidens strumifer Hedw, M. frond. II, p. 88, t. 32.

Hypnum strumosum Gmel. Syst. nat. II, p. 1339.

Oncophorus strumifer Brid. Bryol. univ. $I, p .395$.

Ut typ. - Eur.: Hic illic c. typ. As. : Fret. Sinjawin, Amour, Jenissei med. et inf., Caucas. oce. Am. sept. : Groenland., Labrador, Ontario, M. Rupestr., Columb. brit., ins. Vancouver, lac. Super., Minnesota.

Exs. : Mac. Canad. M. n. 21 p.p.

Rab. Bryoth, eur, n. 261.

a var. tenellum W. P. Sch. Syn. II ed. p. 63.

In reg. montos. hic illic in Eur.

Schisti (GEd.) Lindb. de Tortula p. 230 ; W. P. Sch. op, cit. p. 61.

Bryum Schisti Ed. Fl. Dan. t. 538?

Dicranum splachnoides Brid. M. Rec. II, I, p. 81.

Grimmia Schisti Sm. Fl. brit. III, p. 1185.

Oncophorus Schisti Lindb. M. Scand. p. 27.

Rhabdoweisia Scbisti Bryol. eur. I (mon. p. 5), t. 43.

Weisia Schisti Bvid. Mant. M. p. 39 et Bryol. univ. I, p. $339 ;$ C. M. Syn. I, p. 650 .

W. striata $\beta$ minor $H$. et T. Muscol. brit. p. 45, t. 15 p.p.

1. In rup. praepr. schistos. fissur. - Eur, : Anglia (rid. C. M.); Scandin., Harz ?, Siles. inf., Bohem., Transilv., Salisburg., Stir. merid., Tirol., Engad., Helvet. As. : Jenissei sup. Am. sepl. : Groenland., Terr. nov., M. Rupestr.

serrulatum Jur. - Oreweisia.

strumiferum de Not. - C. polycarpum var. strumiferum.

strumulosum C. M. et Kindb. in Mac. Cat. p. 16 (nom.).

- Am. sept. : M. Rupestr.

subalpestre Kindb. in Mac. Cat. pp. 17 et 257.

C. gracilescens Mae. Canad. M. n. 20.

Dicranum gracilescens Aust. M. Appal. n. $46 \%$.

D. polycarpum Drumm. M. bor. am. I ed. n. 103 p.p.

Rupic. - Am. sepl. : Labrador, Gaspes., lac. Huron, Super.

tenellum Limpr.
torquescens ej. $\{-$ C. gracilescens var. alpestre.

trifarium Brid. - Didymodon luridus.

virens (Hedro.) W. P. Sch. Coroll. p. 12 et Syn. II ed, p. 64.

Angstroemia virens C. M. Syn. II, p. 609.

Bryum sericeum Huds, Fl. Angl. p. 487.

Br. virens Sw. Nov. act. Ups, IV,p. 241.

Dicranum strumiferum Wils. in Kew Jown, bot. IX, p. 295.

D. virens Hedw. M. frond. III, p. 77, t. 32; Bryol. eur. I (mon. p. 15), t. 48 ,

Diobelon virens Hpe. Fl. Hercyn.

Leptotrichum virens Mitt. $M$. Ind. or. $p, 11$.

Oncophorus virens Brid. Bryol. univ. $\dot{I}, p, 399$. 
1. Ad terr., sax. lignaq. putrid, secus rivul. - Eur. : Spitzberg, ins. Ursor., Septem Ins.; Alp. omnes. As. : Kamschatka, penins. Tschutschica, Saghalien, Jenissei, Ochotsk, Tibet. occ., Caucas. Am. sept. : Groenland., Labrador, fret. Smith et Hudson, Terr. nov., A thabasca, M. Rupestr., Columb. brit., Washington, Colorado.

Exs. : Drumm. M. bor. am. I ed, n. 106 (Dicranum).

Mac. Canad. M. n. 22.

Rab. Bryoth, eur, n, 48, 411 a-c.

Sull. et Lesq. M. bor, am. II ed. n. 59.

« var. arcticum Berggr. M. et Hep. Speetsb. p. 35.

- Eur. : Spitzberg, ins. Parry.

"var. compactum W. P. Sch. $l l . c c$.

Ångstroemia virens var. compacta C. M. l. c.

Dicranum Homanni Beck. in Hartm. Skand. Fl. IV ed. p. 384.

D. virens $\delta$ compactum Bryol. eur. l. c. t. 49.

Ut typ. - Eur. : Summ. Alp. : Norveg., Vall. Tell., etc. Am. sept. : Groenland., Labrador, Anticosti, Gaspes., Ontar., M. Alb. et Rupestr., Calif.

" var. fragile Berggr. in K. Sv. Vet. Ak. Handl. XIII, n. 7, p. 35 et M. Speetsb, n. 5 b.

Ster.

$$
\text { - Eur. : Spitzberg. }
$$

"var. serratum W. P. Sch. ll. cc.

Dicranum virens var. serratum Bryol. eur. $l$. c.

Ad cataract. et secus rivul, frigid, - Eur. : Helvet,, Tirol. Am. sept. :

Fret. Smith, Anticosti, Gaspes., M. Selkirk et Rupestr., Columb.

brit, ins. Vancouver, Oregon.

Exs, : Mac. Canad M. n. 488.

Un. itin. 1863, n. 7.

« var. Wahlenbergii $(H i i b) . W . P . S c h, l l . c c$.

Angstroemia Wahlenbergii C. M. l. c. p. 610.

C. Wahlenbergii C. Hartm. Fl. Skand. X ed. p. 113.

Dicranum compactum Funk in sched.

D. microcarpum Hook. in Drumm. M. bor. am. I ed. n. 115.

D. Richardsoni ej. l. c. n. 104.

D. virens Wahlenb. Fl. Lapp. p. 338 p.p.

D. virens $\beta$ Wahlenbergii Hüb. Muscol. germ. p. 231 ; Bryol. eur. l. $c$.

Leptotrichum Wahlenbergii Mitt. M. Ind. or. p. 12.

Oncophorus strumifer var, fuscescens Weinm, in Lindb. et Arn. M. As. boi. $1890, I I$, p. 92 ?

0. Wahlenbergii Brid. Bryol. univ. $I$, p. 400.

Ut typ. - Eur, :spitzberg, Scandin., Alp. Sabaud. As. : Kamschatka, penins. Samojed. et Tsehutschica, Amour, Saghalien, Obi, Jenissei, Japon., Alp. Yunnan, Sikkim, Caucas. occ. Am. sept. : Groenland., Labrador, fret. Smith et Behring, Anticosti, Terr. nov., Nov. Scot., New Brunswick, Gaspes., Ortario, Manitoba, M. Rupestr., Alaska.

Exs. : Mac. Canad. M. n. 23.

Rab. Bryoth. eur. n. 260, 862, 1223.

Wahlenbergii Hartm, - C. virens var. Wahlenbergii.

CYNONTODIUM P. B. Prodr. $p, 52$.

affine Mitt. - Leptotrichum.

ancenum Thw. et Mitt. - Leptotrichum.

australe Mitt. - Lophiodon strictus. 
bogotense Hpe. - Leptotrichum pallidum var. strictum.

capillaceum $\left\{\begin{array}{l}\text { Hedw. - Distichium. } \\ \text { Mitt. - Distichium setifolium. }\end{array}\right.$

cernum Hedw. - Bryum pendulum.

conicum Mitt. - Leptotrichum.

crinale Mitt. - Leptotrichum.

elongalum Mitt. - Trichostomum.

gracile Mitt. - Leptotrichum.

Hookeri Mitt. - Leptotrichum.

hyalinum Mitt. - Leptotrichum.

inclinatum Hedw. - Distichinm.

rufescens Mitt. - Leptotrichum.

strictum Mitt. - Leptotrichum pallidum var. strictum.

Trematodon P. B. - Trematodon Iongicollis.

trifarium Hedw. - Didymodon luridus.

Gyphoma Hook. f. et Wils. Fl. Tasman. p. 200 (sect. Polytrichi).

GYPT ODON (1) Par. et W. P. Sch. Mon. Cryphaeac. ined, (4 sp.) (2).

? crenulatus (Mitt.) Par.

Cryphaea crenulata Mitt. in Journ. of the Linn. Soc, p. 1859, p. 90.

Dendropogon crenulatus Jaeg. Ad. II, p. 103.

- Fac. : Austral. (Victoria).

dilatatus (Hook. f. et Wils.) Par, et W. P. Sch. op. cit.

Cryphata dilatata H. f. et W. Fl. of the N. Zeal. p. 102, t. 88, f. 2.

1. Rupie. - Pac. : Nov. Zeland.

Muilleri (Hpe.) Par. et W. P. Sch. op. cit.

- Dendropogon Mülleri Hpe. in Linn. 1856, p. 212.

1.

- Pac. : Austral, felix.

squarrosulus (Hpe.) Par, et W. P. Sch, op, cit.

Cryphaea squarrosula Hpe. in Linn. $1859-60$, p. 636.

Dendropogon squarrosulus Jaeg. Ad, II, p. 103.

I.

- Pac. : Austral, felix.

CYRTODON R. Br. Suppl. ad it. Parray.

splachnoides ej. - Dissodon.

CYRTO-HYPNUM Hpe. Moosb. p. 20.

Spec. omn. Thuidia ejusd. nom.

CYRTOPUS Brid. Bryol. univ. II, p. 23. (sect. Neckera); Hook. f. Handb, of the N. Zeal. Fl. (gen, propr.) (3 spec.).

bescherellioides C. M. in Rev. bryol. I876, p. 4 (nom.). - Pac. : Austral. or. (Nov. Valesia).

eryphaeoides C. M. M. Polyn, p.

Ster. Ad arbor. - Pac. : Ins. Viti.

curtipendulus Spr. - Antitrichia.

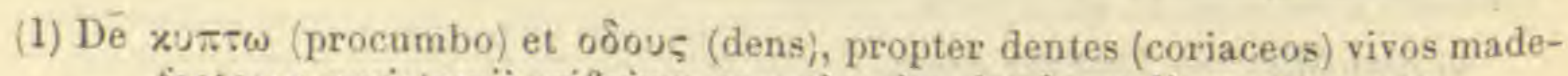
factosve peristomii orificium capsulae fere horizontaliter obtegentes.

(2) Species omn. monoicae et, ut videtur, subaquaticae. 
setosus (Hedw.) Hook. f. Handb. of N. Zeal. Fl. p. 461.

Anoectangium setosum Hedic. Sp. M. p. 43, t. I, f. 4-6.

Cladomnium setosum H. f. et W. Fl. of the N. Zeal. II, p. 100.

Neckera setosa Hook. M. ex. t. 7 ; Brid. Bryol. univ. II, p. 235.

Pilotrichum setosum C. M. Syn. II, p. 162.

Spiridens setosus Mitt. in Journ. of the Linn. Soc. IV, p. 89.

2. - Am. merid. : (fid. Handb.) Pac. : los. Sandwic., Nov. Zeland., Tasman.

taïtensis W. P. Sch. - Garovaglia.

DALTONIA Hook, et Tayl. Muscol. brit. I, p. 80 (50 spec.).

affinis W. Arn. - Pilotrichum.

androgyna Geh, et Hpe. in Fl. 1881.

1. vel syn.? $\quad-A m$. merid. : Brasil. austr. or.

angustifolia Dz. et $M k . M$. frond. ined. Archip. ind. p. 31, t. I3; C. $M$.

Syn. II, pp. 18 et 660 ; Bryol. jav. II, p. 30.

1. Ad arbor. et terr. - As.: Borneo, Java.

apiculata Mitt. M. Ind. or. p. 145.

1 ?

- As, : Nepal.

aristata Geh. et Hpe. Enum. M. Brasil. p. 49.

1. Lignic. - Am. merid. : Brasil.

bilimbata Hpe. in Linn. 1863, p. 151; Mitt. M. austr. am. p. 400.

1. Ad arbor. - Am, merid. : And. Nov. Granat.

binervis $\mathrm{Hpe}$ - - Lepidopilum daltoniaceum.

bipinnata W. Arn. - Pilotrichum.

brasiliensis Mitt. M. austr. am. p. 399.

I vel syn.?

brevipedunculata Mitt.:M. Ind. or. p. 146.

1 vel syn.? $\quad-A s$. Bombay.

composita W. Arn. - Pilotrichum.

compressa Mitt. M. austr. am. p. 400.

l vel syn. Cortic. - Am. merid. : And. Quitens.

contorta C. M. Syn. II, p. 660 ; Bryol.jav. II, p. 32, t. 155.

1. $-A s$. : Java, Ceylan.

crispata Bryol. eur. V (nom.); W. P. Sch. in Besch. Prodr. bryol. mexic. p. 84 .

$$
\text { - Am. sept. : Mexic. }
$$

cucullata Hpe. in Linn. 1863, p. 151.

1. Cortic. - Am. merid. : And. Nov. Granat.

disticha W. Arn. - Neckera.

Duseni C. $M$, in Dusen M. Camer. $n .776$.

- Afr. : M. Cameraon.

elegantula W. P. Sch. hb.; C. H. Wright M. Madag. p. 6 (nom.)

- Afr.: Madagascar. 
Fendleri C. M. in Linn. 1878-1879, p. 491.

$$
\text { I. } \quad-A m \text {. merid. : Venezuela. }
$$

filamentosa W. Arn, - Meteorium.

filiformis W. Arn. - Cryphaea.

flexifolia Mitt. M. Ind. or. p. 146.

1. $\quad-$ As. : Nepal, Ceylan.

fuscescens W. Arn, - Papillaria.

gracilis Mitt. M. austi, am. p. 402.

I vel syn.? Cortic, et foliic. -- Am, merid. : And. Quitens.

Hampeana Geh, in Hpe. Enum. M. Brasil. p. 50 et in Rev. bryol. 1879,

1. p.67. $\quad-$ Am. meril. : Brasil.

heteromalla H, et T. - Cryphaea.

var. H. f. et W. - Cryphaea glomerata var. pendula.

heterophylla W. Arn. - Neckera.

hypnoides W. Arn. - Pilotrichum.

imbricata Spreng. - Pilotrichella versicolor.

intermedia W. Arn. - Neckera.

irrorata Milt. M. austr. am. p. 399.

1 vel syn. Lignic, et ad saxa irror. - Am. merid. : And. Nov. Granat.

Jamesoni Tayl. in Lond. Journ. of bot. 1848, p. 283; C. M. Syn. II, p. $19 ;$ Mitt. op. cit. p. 401 .

1. $\quad-A m$. merid. : Summ. M. Pichincha.

Lamyana Mont. - Cryphaea heteromalla var. aquatilis.

latimarginata Besch. Fl. bryol. Réunion, etc., p. 136.

Syn. $\quad-A f r$ : Ins. Borboniae.

Leucoloma Hpe, Symb. 1874, p. 502.

1. - Am, merid. : Brasil. austr. or.

Lindigiana Hpe, in Ann. sc. nat. 1865, p. 363.

Ad rup. madid. - Am, mericl, : And. Nov. Granat.

longifolia Toyl. in Lond. Journ. of bot. 1848, p. 284; C. M. Syn. II, 1. p. 19 ; Mitt. op. cit. p. 399.

longinervis Mitt. in Journ. of the Linn. Soc. 1863, p. 163.

1. $\quad-A f r$, : Ins. Fernando Po.

longipedunculata C. M. Syn. II, p. 18; Bryol. jav. II, p. 31, t. 154.

1. - As. : Borneo, M. Java.

lorifolia $C . M$. in $F l .1875, n .34$ el 35 .

Ster. Cortic. - Am. sept. : Costa Rica.

miacrotheca Mitt, M. austr. am. p. 402.

1 vel syn.? $\quad$ Am. merid.: M. Chimborazo.

madagassa W. P. Sch. hb.; C. H. Wright M. Madag. p. 6 (nom.).' - Afr. : Madagascar.

marginata Mitt. M. Incl. or. p. 145.

1. Cortic. - As. : Khasia.

minor Besch, Fl. bryol. Réunion, etc. p. 136.

- Afr.: Ins. Borbon. 
mucronata Bryol. jav. II, p. 32, t. 156.

Syn.

- As. : Java.

nervosa (Hook. f. et Wils.) Hpe. in C. M. Syn. II, pp. 17 et 660 ; Handb. Fl. N. Zeal. p. 496.

D. Novae Zeelandiae Mitt. in Journ. of the Linn. Soc. 1859, p. 95.

Hookeria nervosa H. f. et W. in Lond. Journ. of bot. 1844, p. 549 et Fl. Antarct. $I, p .142, t .61$.

1. Ad ramul. arb. - Pac. : Nov. Zeland. sept., ins. A uckland.

nervosa H. f. et W. - Cryphaea.

Novae Zeelandiae Mitt. - D. nervosa.

ocanniana $C . M$, in $F l .1875, n .34-35$.

Syn.

- Am. merid. : And. Nov. Granat.

ovalis Toyl. in Lond. Journ. of bot. 1846, p. 66; C. M. Syn. II, p. 19 ; Mitt. M. austr. am. p. 401 .

1. Ad arbor. - Am. merid. : And. Quitens.

patula Mitt, in Journ, of the Linn. Soc. 1863, p. 163.

1.

$$
\text { N'Djaro. }
$$

- Afr. : Ins. Fernando Po, M. Usagara, Kilima

pennata. W. Arn. - Neckera.

peruviana Mitt. M. austr. am. p. 401.

I vel syn. - Am. merid. : And, Peruv.

polytrichoides W. Arn, - Lepidopilum.

pulvinata Mitt. op. cit. p. 398 .

l. vel syn.

- Am. merid. : And. Nov, Granat.

pusilla Hook. f. et Wils. Fl. Tasman. II, p. 221, t. 177, f. 5 .

1. Lignic. et ad fontes, - Pac. : Tasman.

reticulata C. M. in Linn. 1869-70, p. 20.

1. $-A s$, : Ceylan.

robusta Angstr, in Oefv ... 1873, n. 5, p. 117.

1. $\quad-$ Am. merid.: Ins. Gallapagos.

scaberula Mitt. M. Ind. or. p. 146.

1.

- As. : Ceylan.

scabriseta W. Arn. - Lepidopilum.

semi-torta Mitt. op. et l. cc.

1. Cortic. - As.: Sikkim.

splachnoides (Sm.) Hook, el Tayl. Muscol. brit. I ed., p. 90, tt. 3 et 22; Brid. Bryol. univ. 11, p. 255; C. M. Syn. 1I, pp. 17 et 660; Bryol. eur. V, t. 449; W. P. Sch. Syn. II ed. p. 579.

Hookeria splachnoides Hook. Engl. Fl. V, I, p. 74 et Fl. Hibern. II, p. 37.

Neckera splachnoides Engl. bot.t. 2564 (excl, syn. Sehwaegr:).

I et syn. Ad rup. humid. umbros., rar. ad arb. - Eur. : Hibern. Afr.: Madeir,, ins. Fernando Po. Am. sept.: Mexic.; Antill. (fid. W. P. Sch, 1. c.).

stenoloma Besch. Fl. bryol. Réunion, etc. p. 136.

l vel syn.? $-A f r$. : Ins. Borbon.

stenophylla Mitt. $M$, austr. am, p. 402.

I vel syn, ?

- Am. merid. : And. Quitens 
strictifolia Mitt, M. Ind. or, p. 146.

1 et syn.

- As. : Ceylan, Java.

tenella Broth. in Act. Soc. Fenn. 1891, n. 5.

1.

- Am. merid. : Minas Geraës.

tenuifolia Mitt. M. austr. am. p. 402.

I vel Syn. Ad arbor. - Am, merid. : And. Quitens.

trachyodonta Mitt. op. cit. p. 400.

1 vel syn. Cortic. - Am, merid. : And, Quitens.

undulata W. Arn. - Neckera.

Wallisi C. M. in Fl. 1875, n. 34-35.

l.

- Am. merid. : And. Nov. Granat.

DASYMITRIUM Lindb. in Lond. Journ. of bot. 1864, $p$.

Spec. omn. non indicatae sunt Macromitria ejusd. nom.

? villosum Jaeg. - Drummondia.

DAWSONIA Rob, Br, in Trans, of the Linn. Soc. X, p. 316, 1. 23, f.

(4 spec.).

appressa Hpe, in Linn. 1859-60, p. 635.

Rupic. - Pac. : Austral. or.

longiseta Hpe. in op. cit. p. 634.

- Pac. : Austral. or.

polytrichoides R. Br. in op. et l. cc.; Brid. Bryol. univ. 1I, p. I56;

C. M. Syn. I, p. 226.

Triplocoma polytrichoides la Pyl. in Desv. Journ. bot. 1813, p. ₹.

2. - Pac. : Austral. or., Nov. Zeland.

superba Grev. in Ann. and Mag. of nat. hist. 1847, p. 226, t. 12; C. M. Syn. I, p. 226.

Polytrichum longifolium Bryol. eur. IV (mon. p. 2, nom.)?

2. - Pac, : Austral., Nov. Zeland. sept. et med, Tasman. (1)

DEGODON C. M. mss. (2 spec.).

brasiliensis (Broth.) C. M. in Act. Soc. sc. Fenn. 189l, n. 5.

1. Lignic, - Am. merid. : Minas Geraës.

transvaaliensis $C . M$. in op. et $l$. cc. (nom.).

- Afr. : Transvaal.

DENDROGRYPH EA Par, et W. P. Seh, Mon. Cryphæac. ined. (2 spec.).

Gorveana (Mont.) Par. et W. P. Sch, op, cit.

Cryphaea Gorveana Mont. in Ann. so. nat. 1845, p. 99 et in Gay Hist. Chil. Bot. crypt. t. 5, f. 3; syll. p. 24.

Dendropogon Gorveanus Jaeg. Ad. II, p. 103.

Pilotrichum Gorveanum C. M. Syn. II, p. 175.

1.

- Am. merid. : Chile.

(1) In Enumer. Kindberg, nomina nuda:

D. altissima Geh.

I D, intermedia C. M. 
Lechleri (C. M.) Par. et W. P. Sch. op. cit,

Cryphaea Gorveana W. P. Sch, in Lechles Pl. Chil, n. 474.

Cr. Lechleri C. M. mss.

D. ramosissima Par. et W. P. Sch. priis.

1. via.

- Am. sept. : Guadalup. (???) Am. merid. : Valdiramosissima Par. et W. P. Sch. - D. Lechleri.

Dendrodium C. M. in Dusen M. Camer. (sect., Porotrichr).

Dendroglossophyllum C. M. Syn. $I 1, p .223$ (sect. НоокекіA E).

DENDRO-HYPNUM Hpe. Moosb. p. 21.

Beccarii ej. - Hypnodendron.

Leichhardti ej, - ? Ptychomium.

praenitens ej. - Pterobryella.

DENDRO-LESKEA Hpe. in Bot. Zeit. 1869, n. 28 ?

Krauseana Hpe. - Porotrichum.

Dendroligotrichum C. M. Syn. $I, p .99$ et $I I, p .559$ (sect. PoLytric日i sensu Müller.).

DENDROPOGON W. P. Sch. in Bot. Zeit. 1843, p. 377, t. I (4 spec.).

capensis ej. - Papillaria africana.

crenulatus Jaeg. - Cyptodon?

? dentatus Mitt. in Trans. of the Linn. Soc. 1891, p. 170.

Ster. o ign. Ad arbor, et rup. - As. : Japon.

Exs, : Faurie n. 4482.

"var. filiformis Besch, in Ann, sc. nat. 1893, p. 357.

Exs. : Savatier n. 618.

fasciculatus Jaeg. - Cryphaea.

? ferrugineus (Mitt.) Par.

Cryphaea ferruginea Mitt. M. Ind. or. p. 125.

Ster.

- As. : M. Neilgherr.

Gorveyanus Jaeg. - Dendrocryphaea.

helictophyllus Jaeg. - Meteorium.

Mülleri Hpe. - Cyptodon.

rufescens W. P. Sch, in Bot, Zeit. l. c. et Mon. Cryph, ined.

Cryphaea rufescens C. M. in Linn. 1841, p. 682; Mitt. M. austr. am. p. 416.

Pilotrichum rufescens C. M. Syn. II, p. 176.

1. Ad arbor. - Am. sept. : Mexic., ins. S. Thomas,

? Schleinitzianus (C. M.) Par.

Cryphaea (Dendropogon) Schleinitziana C. M. in Engler's Bot. Jahrb. 1883, p. 84.

Ster, ?

- Pac. : Ins. Fidji, Tonga.

squarmolosus Jaeg. - Cyptodon. 
DERMATODON Ḧ̈b. Muscol. germ. p. 109.

affinis Hüb. - Pottia Starkeana var. brachyodus.

cernuus Hüb. - Desmatodon.

caespitosus Hüb. - Pottia.

Funkii Hüb. - Pottia latifolia var, pilifera.

lanceolatus Hüb. - Pottia.

latifolius Hüb. - Pottia.

Starkii Hüb, - Pottia.

DESMAT OD ON Brid, Mant. M. p. 86 et Bryol, univ. I, p. 523 (26 spec.). adustus Mitt. - Pottia brachypus.

amblyophyllus Mont. in Ann. sc. nat. IV, p. 108 et Syll. p. 41.

Tortula platyphylla Mitt. M. austr. am. p. 167.

Trichostomum amblyophyllum C. M. Syn. I, p. 592.

2. Terr. - Am. merid. : Chile.

arenaceus Sull. M. of U. St.p. 28 et Ic. M. p. 45, t. 29; Lesq. et Jam. Man. p. IIl.

Barbula arenacea Jaeg. Ad, $I I, p, 671$.

B. obtusifolia Schwaegr. (fid. Hagen in Rev, bryol. 1891, p. 1).

D. ohioensis W.P. Sch. Syn. I ed. p. 159.

Pseudo 2. Rupic. - Eur.: Norvegia. Am, sept. : Ohio, Kansas, reg. centr.

Exs. : Sull. et Lesq. M. bor. am. I ed., n. 93 et II ed,, n. 120.

atro-virens Jur. - Barbula.

bogosicus C. M. in Nuov. Giorn. bot. ital. 1872, p. 12.

2.

- Afr. : Abyssin.

Brebissoni Jur. - Barbula,

brevicaulis Brid, - D. latifolius var, brevicaulis.

bulbosus de Not. - Pottia latifolia.

caespitosus de Not. - Pottia.

camptothecius Kindb. in Mac. Cat. p, 48.

1. Rup, marit. - Am. sept. : Gaspesia.

canescens Jur. - Barbula.

cernuus (Hüb.) Bryol. eur. II (mon. p. 8), t, 134; W. P. Sch. II ed. p. 186.

Cynodon latifolius Brid. Bryol. univ. I, p, 502.

Cynodontium latifolium Schwaegr. Suppl. I, I, p. 110, t. 28.

Dermatodon cernuus Hüb. Musool. germ. $p$, 11 .

Desmatodon inclinatus Serdin. in Regensb. Denkschr. 1841, p. 144.

Didymodon latifolius Wahlenb. Fl. Lapp. p. 313, t. 20 .

Tortula cernua Lindb. M. Scand. p. 20.

Trichostomum cernuum Lindb. Trichost. ewr, p. 14.

Tr, inclinatum C. M. Syn. I, p. 593.

1. In rup. fissur, et ad mur. humid, - Eur. : Scandin., Sudet., Tirol., Carinth., Helvet., Salisb., Stir., Alp. Bavar. As. : Tibet. oceid. Am. sept. : Groenland., Anticosti, New Brunswick, reg. sept. occid.,

M. Rupestr., Columb. brit., Nevada.

Exs. : Mac. Canad, M. n. 71.

Rab. Bryoth, eur. n. 168, 957.

" var. xanthopus Kindb. in Mac. Cat. p. 48.

Terr. - Am. sept. : Manitoba.

chloronotos Mitt. - Barbula. 
confertifolius (Mitt.) Jaeg. Ad. 1, p. 252.

Barbula confertifolia Mitt. M. Ind, or, $p, 36$.

Ster. - As. : Nepal.

corticola W. P. Sch. in W. Sch. M. Abyss. - Afr. : Abyssin.

cuneifolius Jur. - Barbula.

curtus Brid, - Leptotrichum tortile var. pusilla.

dichotomus Brid. - Barbula Brebissonii.

eucalyptratus Limpr. - D. latifolius var. glacialis.

flavicans Bryol. eur. - Barbula obtusifolia.

var. obtusifolius Bryol. eur. - Barbula obtusifolia var. brevifolia. flexifolius Hpe. - Didymodon.

fusco-mucronatum (C. M.) Par.

Barbula fusco-mucronata Jueg. Ad. II, p, 671.

Trichostomum fusco-mucronatum C. M. in Linn. 1876, p. 295.

Ster. Terr. - Afr. : Somali.

Garberi Lesq. et Jam. Man. p. 112.

Pseudo 2.

- Am. sept. : Florid.

glacialis Funk. - D. latifolius var. glacialis.

gracilis Anzi Enum. M. Longobard, sup. in Rev. bryol. 1876, p. 62.

D. latifolius var. brevicaulis (fid. Limpr.).

1. Ad mur. calcar. - Eur. : Ital. super. (Bormio).

griseus Jur. - Barbula.

Guepini Bryol. eur. - Barbula.

Güntheri Sendtn. - D. latifolius.

inermis Mitt. $\left\{\begin{array}{l}\text { - Barbula Brandisi? (fid. C. M.). } \\ \text { - Rarbula (fid. Jur.). }\end{array}\right.$

inclinatus Sendtn. - D. cernuus.

involutus Mitt. - Hyophila.

javanicus Mitt. - Rarbula.

lanceolatus de Not. - Pottia.

laterum W. P. Sch. - D. plinthobius.

latifolius (Hedho.) Brid. Bryol. univ. 1, p. 524; Bryol. eur. II (mon. p. 5), t. $129 ;$ W. P. Sch. Syn. Il ed. p. 184.

D. Güntheri Sendtn. in sched.; C. M. Syn. I, p. 588.

D. latifolius $\gamma$ lutescens Brid. op. cit. p. 525.

Dicranum lanceolatum Schleich. Cent. IV Pl, helv. n. 12.

D. latifolium Hedvo. M. frond. I, p. 89, t. 33; Drumm. M. bor. am. I ed. n. 109 (fid. Kindb.).

Mnium latifolium Gmel. Syst. nat. XIII ed., II, p. 1328.

Swartzia pilifera Brid. in Schrad. Journ. 1800, p. 289.

Tortula latifolia Lindb. M. Scand. p. 20.

Trichostomum latifolium Schwaegr. Suppl. I, I, p. 145; C. M. Syn. I. p. 588 (1).

1. Ad terr. humid. usq. ad niv. cetern. - Eur. : Spitzberg, reg. alp. et subalp.; desideratur in Britann. As. : Talysch, Kamsehatka, Sikkim, Caucas. Am. sept. : Groënland, Labrador, Columb. brit., M. Rupestr., reg. sept. occ., Washington, Oregon, Colorado, Nevada, Calif.

Exs. : Mac. Canad. M. n. 69 p.p.

Rab. Bryoth, eur. n. 1264.

Sull, et Lesq. M, bor, am. II ed, n, 122.

(1) De synonym. antiquior. cf. W. P. Sch. I. c. 
« var. brevicaulis W. P. Sch, op. cit. p. 185.

Bryum piliferum Dicks. Fasc, IV Pl. crypt. t. II, f. I.

D. gracilis $A n z i$ ( fid. Limpr. op, oit, $p, 650$ ).

D. brevicaulis Brid. Mant. M. p. 87 (excl. syn.) et Bryol. univ. I, p. 525 p.p.

Dicranum latifolium $\beta$ piliferum $H$. et $T$. Muscol. brit. p. 22.

Trichostomum piliferum Sm. Fl. brit. III, p. 1245 (fid. C. M.; non! fid. Lindb. Trichost. eur. p. 14; sed. : Hüb. Muscol. germ. p. 293, excl. syn.).

Ut et cum typ.

\& var. glacialis (Funk) W. P. Sch. Syn. I ed. p. 157 et II ed. p. 185.

D. latifolius Funk in Brid. Bryol. univ. I, p. 822.

D. latifolius $\beta$ muticus Brid. op. cit. p. $525 ;$ Bryol. eur. l. c. t. 130.

D. spathulatus Hartm. in Fries Summ. veg. p. 94.

Dicranum latifolium Wahlenb. Fl. Lapp. p 342 ; Drumm. l. c. (fid. C. M.).

Didymodon apiculatus $\alpha W$. Arn. in Mem. Soc. hist.nat. Paris, II, p, 283.

D. pilifer $\beta$ spathulatus Wahlenb. Fl. Suec. I ed. II, p. 755.

D. spathulatus de Not. in Mem. Acad. Torin. 1836, p. 233.

D. Theobaldi Pfeff. (fid. Limpr. op, cit. p. 649).

Tortula eucalyptrata Lindb, in Bot. Notis, 1886, p. 100 (fid. Limpr, op, cit. p. 650).

Tortula latifolia $\beta$ mutica Lindb. M. Scand, $p .20$.

Trichostomum Hoppeanum Schultz in Syll. Ratisb. 1828, p. 40.

Tr. latifolium $\beta$ muticum C. M. $l$. $c$.

Ut typ. - Eur. : Cum typ. As. : Caucas. Am. sept. : M. Rupestr.

Exs. : Rab. Bryoth, eur. n. 253.

var. lutescens Brid. - Desmatodon latifolius.

var. muticus Brid. - Desmatodon latifolius var. glacialis.

Laureri (Schults) Bryol, eur. II (mon. p. 9), t. 135; W. P. Sch. Syn. 11 ed. p. 187.

Didymodon Blyttii Hartm. Skand. Fl. IV ed, p. 381 .

D. nitens Liebm. in Fl. Dan. Suppl. I, p. 12, t. 50.

Tortula bryoides Hook. in Drumm. M. bor am. I ed. n. 135.

T. Laureri Lindb. Trichost, cur. p. 35.

Trichostomum latifolium $\beta$ Laureri Hüb. Muscol. germ. p. 292.

Tr. Laureri Schultz in Bot. Zeit. 1827, p. 163; C. M. Syn. I, p. 594.

1. Ail terr. humos. - Eur. : Rar.: Spitzberg, Alp. Norveg., Carinth.,

Salisb., Stir., Bavar., Algov., Tirol., Helvet. Am. sept. : Groenland., M. Rupestr., ins. Vancouver, Colorado.

Laureri Wils. - D. Thomsonii.

leucostomus Berggr. - D. obliquus.

limbatus Mitt. - Barbula sublimbata.

longirostris (Griff.) Mitt. M. Ind. or. p. 37.

Hymenostylium longirostre Griff. Not, p. 395 et Ic.pl. asiat. II, t. 95, f. 3.

Lignic. - As. : Khasia.

marginatus Mitt. - Barbula.

montenegrinus (Breidl, et Saycz.) Par.

Barbula montenegrina Br. et S. in Mem. Acad. Cracon. XIX.

\section{- Eur. : Montenegro.}

mucronifolius Mitt. - Barbula.

neo-mexicanus Sull. et Lesq. M. bor. am. I ed. n. 95; Lesq. et Jam. Man. p. 113.

1. Terr. - Am. sept. : Texas.

Exs. : Sull. et Lesq. 1. c. II ed. n. 124. 
nitens Liebm. - D. Laureri.

obliquus Bryol. eur. II (mon.p. 10), t. 136; W. P. Sch. Syn. II ed.p. 187. Barbula leucostoma R. Br. (fid. Berggr, in K. Sv. Vet. Akad. Handl, $X I I I, n .7, p, 46)$.

D. leucostomus Berggr. M. Speetsb, n. 34 .

D. obliquus $\beta$ apiculatus |

D. obliquus $\gamma$ muticus

Lindb. in Oefv... XXIII, p. 553.

D. suberectus Limpr. Laubm. Deutschl. I, p. 651.

Tortula suberecta Drumm. M. bor. am. I ed. n. 145.

Trichostomum obliquum C. M. Syn. I, p. 594 et II, p. 629.

1. Ad terr. hamos. - Eur. : Rariss. : Alp. Norv g., Carinth., Salisb., Stir., Bavar. et Algov., Tirol, Helvet. As. : Penins. Tschutsch. Am. sept. : Ins. Sabine, M, Rupestr.

var. apioulatus Lindb.
var, muticus Lindb.

obtusifolius W. P. Sch. - Barbula.

ohioensis W. P. Sch. - D. arenaceus.

plinthobius Sull. M. of U. St. p. 28, t. 2 et Ic. M. p. 47, t. 30; Lesq. et Jam. Man. p. 112.

D. laterum W. P. Sch. Syn. I ed. p. 159.

2. Ad mur. argill. - Am. sept. : Pensilv., Tennessee, Texas., Carol. infer., Georgia, Ludovic. ; Kansas?

Exs. : Sull, et Lesq. M, bor. am. I ed. n, 94 et II ed, n. 123.

Porteri Jam. et Aust, M. Appal, n. 123; Sull. 1c. M. Suppl, p. 36, t. 23 ; Lesq. et Jam, Man. p. 112.

2. Rupic. - Am. sept. : Lac. Erie, Niagara, New York, Pensilv.

Exs. : Mac. Canad. M. n. 70.

recurvus (Griff.) Mitt. M. Ind. or. p. 37.

Gymnostomum recurvum Griff. Not.p. 97 et Ic. pl. asiat. II, $t, 92, f .2$ (1).

Tortula cacuminata Wils, in Kew Jown. bot. IX, p. 322.

2 ?

- As. : Sikkim.

reflexidens (Hpe.) Jaeg. Ad. I, p. 257.

Trichostomum reflexide.as Hpe. in Linn. 1859-60, p. 625.

- Pac. : Austral. or.

revolvens Husn, - Barbula.

rigidus Mitt. - Barbula.

rupestris Funk. -- Barbula rigidula var. densa.

Sartorii (C. M.) Par.

Barbuld Sartorii Jaeg. Ad. II, p. 671.

Trichostomum Sartorii C. M. in Linn. 1874, p. 637.

$$
\text { - Am. sept. : Mexic. }
$$

Schimperi (Mont.) Jaeg. Ad. I, p. 252.

Barbula atro-virens W. P. Sch. (fid. Mitt.).

Trichostomum Schimperi Mont, in Ann. se, nat. 1845, IV, p. 103 et in Gay. Hist. Chil. Bot. orypt. t. 2, f. I; Syll.p. 38; C. M. Syn. I, p. 592.

2. Terr. - Am. merid. : Chile. 
spathulatus $\left\{\begin{array}{l}\text { Hartm. - Desmatodon latifolius var, glacialis. } \\ \text { Mitt. - Barbula. }\end{array}\right.$

Starkii de Not. - Pottia.

suberectus Limpr. - D, obliquus.

sublimbatus Mitt. - Barbula.

subtorquescens C. M. et Kindb. in Mac. Cat. p. 48.

1. Terr. - Am. sept. : Gaspesia.

Exs. : Mac. Canad. M. n. 69 p.p.

subulatus Jur. - Rarbula.

var. angustata Jur. - Barbula subulata var. angustata.

systylius Bryol. eur. II (mon.p. ), t. 131 ; W. P. Sch. Syn. II ed. p. 185.

Anacalypta latifolia $\beta$ pilifera Hook, in Drumm. M. bor. am. I ed. n. 70 (fid. Wils.).

Tortula systylia Lindb. M. Seand. p. 20.

Trichostomum systylium C. M. Syn. I, p. 589.

1. In terr. arenac. humos. - Eur. : Norveg., Alp. Salisb., Stir., Carinth., Bavar. et Algov., Tirol., Helvet. As. : Caucas. Am. sept. : Groenland., Manitoba, M. Rupestr., Colorado, Calif.

Exs. : Mac. Canad. M. n. 7 l p.p.

Rab. Bryoth, eur. n. 598.

Thomsonii (C. M.) Jaeg. Ad. 1, p. 254.

D. Laureri Wils, in hb. Ind. or. n. 273; Mitt. M. Ind. or. p. 37.

Trichostomum Thomsonii C. M. in Bot. Zeit. 1864, p. 359.

1. - As, : Himalaya, Tibet. occ.

tonkinensis Besch. in Bull. Soc. bot. Fr. 1893, p. 80.

Ad rhizom. Filic. - As. : Tonkin.

Wallichii Mitt. - Barbula.

DESMOSTOMUM Hsch. in Linn. 1841, p. 116.

absque nom. spec. - Entosthodon Bergianus.

Dialytrichia $W . P$. Sch. Syn. $1 I$ ed. $p .222$ (subgen. Barbulat).

Diaphanophyllum Lindb. in Oefv... 1862 (sect. LEPTotrichi).

DICHELYMA Myr. in Act. Acad, reg. sc. Holm, 1832 (6 spec.).

antarcticum C. $M$. in Engler's Bot. Jahrb. 1883, p. 82 et in Forchungsreise... $n .31$.

Ster. Ad lapid. in aquosis. - Afr.: Ins. Kerguelen.

capillaceum (Dicks.) Bryol, eur. V (mon. p. 7), t. 436; W. P. Sch. Syn. II ed p. 558. Card. Mon. p. 135.

D. capillaceum $\beta$ subulifolium Bryol. eur. $V($ mon. p. 8), t. $435 \beta 1,2,2 \alpha$.

D. pallescens Sull, et Lesq. M. bor, am. II ed. n. 346.

Fontinalis capillacea Dicks. Fase. II Pl. crypt. p. 1; Brid. Bryol. univ. $I I$, p. 660 .

F. Capillacea calycibus styli instar cuspidatis Dill. Hist, M. p. 260, t. 33, $f .5$.

F. falcata Hpe. in $\operatorname{Linn} .1839$, p. 45.

Neckera capillacea $C . M . S_{y, u}, I I, p .144$.

2. Ad lapid, et ligna in rivul. et stagn. - Eur. : Scotia (ster.), Suecia, Dania, Brandebourg., Siles. Am. sept. : New Brunswick, Ontario. New Jersey, Pensilv., Nov. Angl., New York. 
Exs. : Aust. M. Appal. n. 252.

Drumm. M. bor. am. I ed, n. 234 p.p. (Fontinalis).

Rab. Bryoth. eur. n. 778.

Sull. M. Allegh. n. 151.

Sull. et Lesq. M, bor. am. II ed, n, 345, 346.

«var. elongatum Kindb. in Mac. Cat.p. 160.

Ut typ. - Am. sept. : Lac. Super.

capillaceum $\left\{\begin{array}{l}\text { Bryol, eur. pp. - D. pallescens. } \\ \text { C. M. - D. uncinatum. }\end{array}\right.$

var. subulifolium Bryol. eur. - D. capillaceum.

cylindricarpum Aust. - D. uncinatum var, cylindricarpum.

? distichum Myr. - Fontinalis.

falcatum (Hedw.) Myr. in op. cit. p. 274, t. 6 ; Bryol. eur. V (mon. p. 6),

t. 433 ; W. P. Sch. Syn. II ed.p. 557 ; Card. Mon. p. 135.

Fontinalis capillacea $L$. Fl. Suec, $n .982$.

F. falcata Hedw. M. frond. III, p. 57, t. 24.

Neckera falcata $C$. M. Syn. $I I, p .143$.

2. Ad saxa fluvior., rivul. et stagn. - Eur.: Island., Lappon., Scandin,, Fennia, Brandebourg, Sudet., Transsilv. As, : Jenissei sup, Am. sept. : M. Adirondack, Alb. et Castkill.

Exs. : Husn. M. Gall. n. 736.

Limpr. Bryoth. siles, n. 34.

Rab. Bryoth. eur. n. 628, 779, 1132.

Sull. et Lesq. M. bor. am. I ed, n. 229 b, II ed. n, 343.

Un. itin. 1867, n. 33.

longinerve Kindb. - Hypnum.

Novæ Brunsviciae Mac. - D. obtusulum.

obtusulum Kindb. in Mac. Cat. p. 159.

D. Novæ Brunsviciae Mac. Canad. M. p. 534.

D. pallescens (fid. Cardot in Rev. Bryol. 1893, p. 10).

2. In stagn. - Am. sept. : New Brunswick.

pallescens Bryol. eur. V, Suppl.p. I, t. 435 : Card. Mon. p. 142.

D. capillaceum Myr. in op. cit. t. $7 \mathrm{~A} ;$ Bryol. eur. V, t. 435 (excl. $\beta 1,2,2 \alpha)$.

Fontinalis capillacea Hook. in Drumm. M. bor. Am. I ed, n. 234 p.p.

Neckera leucoclada $C . M$. Syn. II, p. 144.

2. Ad rad, arbor, in stagn. - Am. sept. : New Brunswick, Gaspes., Ottawa, Massachussets, New York, Pensilv.

Exs. : Aust. Appal. M. Suppl. I, n. 525.

Mac. Canad. M, n. 235.

pallescens Sull, et Lesq. - D. capillaceum.

subulatum Myr. - Brachelyma.

Swartzii Lindb. - Hypnum fluitans var.

uncinatum Mitt, in Journ. of the Linn. Soc. VIII, p. 44, t. 8; Lesq. et Jam. Mare. p. 273 ; Card. Mon. p. 137.

D. capillaceum J. M. in Roell M. Amer. n. 90, 1201, 1203, 1204 et 1530.

2. Ut praeced. - Am. sept. : Columb, brit., ins. Vancouver, Washington, Oregon, Wyoming.

Exs. : Leib. M. from Koutnai (Idaho) n. 81.

Mac. Canad. M. n. 234.

« var. cylindricarpum (Aust.) Card. Mon. p. 139.

D. cylindricarpum Aust. in Bot. Gaz. II, p. 111; Lesq. et Jam. Man. p. 274. 
Ut typ. - Ain. sept. : Washington, Oregon, Idaho; Texas ? Columb. brit.

Exs. : Roell M. Am. n. n. 1202.

DICHODONTIUM W. P. Sch. Coroll. p. 12 (18 spec.).

canadense (Mitt.) Lesq. et Jam. Man. p. 621.

Cynodontium canadense Mitt. in Joum. of the Linn. Soc. VIII, p. 17.

Dicranella Schreberi var. occidentalis Aust. in Bull. Torr, bot. Club, VI, p. 344 .

Leptotrichum canadense Jaeg. Ad. I, p. 236.

2.

- Am. sept. : Columb. brit., Oregon.

clathratum (Hook, f. et Wils.) Jaeg. Ad. 1, p. 86.

Angstroemia clathrata $C, M$. Syn. II, p. 608.

Dicranella clathrata $H$. $f$. et W. Fl. of the N. Zeal. II, p. 65.

Dicranum clathratum eor, in Lond. Jowrn. of Bot. 1844, p. 542 et Handb. of N. Zeal. Fl. p. 411.

2. Ad rup, irror. - Pac, : Nov, Zeland.

convolutum (Hpe,) Par.

Ångstroemia convoluta Hpe. in Ann. so. nat. V ser., III, p. 336.

Anisothecium convolutum Mitt. $M$. austr, am, p. 40.

Dicranella convoluta Jaeg. Ad, I, p. 85.

1. $-A m$, merid. : And. Nov. Granat.

elegans (Duby) Jaeg. Ad. II, p. 634.

Dicranum elegans Duby in Mem... Genéve 1869, t. 1, f. 1.

2.

- Am. merid. : Chile.

ferrugineum (Hook, f. et Wils.) Jaeg. l. c. p. 635.

Dicranum ferrugineum $H$. f. et W. Fl. Tasm. p. 171, t. 172, f. I.

2. Terr, - Pac. : Tasman.

flavescens Lindb. - D. pellucidum var. serratum.

Hookeri (Wils.) Par.

Dicranella himalayana Jaeg. Ad. I, p. 84.

Didymodon vaginatus Hook. in Lond. Journ. of bot. 1840, II, p. 5 et Io. pl.var. t. $18 ;$; C. M. Syn. I, p. 462.

Leptotrichum himalayanum Mitt. M. Ind. or. $p .12$.

Symblepharis dilatata Wils, in Kew Journ. bot, $I X$, p. 293 p.p.

S. Hookeri ej. in op. cit. p. 292.

$$
\text { - As. : Himalaya, Sikkim. }
$$

Jamesoni (Tayl.) W. P. Sch. Syn. l ed. p. 66.

Ångstroemia Hookeri C. M. Syn. II, p. 607.

Anisothecium Jamesoni Mitt. op. c. p. 39.

Dicranum Jamesoni Tayl, in Lond. Journ. of bot. 1848, p. 281.

D. vaginatum $H$. $f$. et $W$. in sehed. Antaret.

2 . mitae.

- Afr. : Ins, Kerguelen, Am, merid. : Ins, Ere-

Exs, : Lecbler Pl, Magell. n. 1016.

Krausei (Ltz.) Jaeg. Ad. I, p. 68.

Dicranella Krausei Ltz. in Bot. Zeit. 1866, p. 86.

2, Rupie, - Am. merid. : Valdiv.

Lorentzi (C, M), Par.

Ángstroemia Lorentzi C. M. in Linn. 1880-1883, p. 389. 
olympicum Ren, et Curd. in Rev. bryol. 1892, p. 74.

2.

- Am. sept. : Washington.

Paludella Besch. in Bull. Soc. bot. Fr. 1885, p. LVI et in Miss. sc. Cap 2. Horn, V, Bot. p. 257, t. I, f. 4 .

pellucidum 'L.) W. P. Sch. Coroll, p. 12 et Syn. $1 I$ ed. p. 66.

Angstroemia pellucida C. M. Syn. II, p. 606.

Bryum aquaticum Hoffm. Fl. Germ. II, n. 35.

Br. palustre, pellucidum, capsulis et foliis brevibus recurvis Dill. Hist. $M$. p. $364, t .46$, f. 23.

Br. pellucidum L. Sp. pl. p. 1583.

Dicranum aquaticum Ehrh. Dec. n. 216.

D. pellucidum Hedw. Sp. M. p. 142 ; Brid. Bryol, wniv. I, p. 349; Bryol. eur. I (mon. p. 16), t. 50-5l.

D. Rogeri Brid. Sp. M. I, p. 195.

Didymodon Woodii W. P. Sch. in Braithe. Brit. Moosfl. p. 162 (fid. Limpr. op. cit. p. 298).

Diobelon pellucidus Hpe. Fl. Hercyn.

Mnium pellucens Gmel. Syst. nat. II, p. 1328.

Tridontium pellucidum Lindb. in Oefv... 1834, p. 230.

2. Ad saxa humida, rar. in terr. - Eur. : Reg. montana zon. interm., rar. septentr.; ins. Ursorum, $A s$.; Caucas. occ, et centr. Am. sept.: Groenland., M. Rupesir., Columb. brit., ins. Vancouver, Washington, New Brunswick, Gaspesia, Terr. nov., Ontario, Oregon, fret. Behring.

Exs. : Mac. Canad. M. n. 451.

Rab. Bryoth. eur. n. 77, 425, 1260.

Sull. et Lesq. M. bor. am. II ed. n. 96.

"var. americanum Lesq. in Lesq. et Jam. Man. p. 62.

Ut typ. - Am. sept. : New Jersey, New York, Vermont

«var. fagimontanum (Brid.) W. P.Sch. $l l$. co.

Angstroemia pellucida $\beta$ fagimontana $C . M . l . c$.

Dicranum pell reidum Drumm. M. bor, am. I ed. n. 108.

D. pellucidum $\beta$ fagimontatum Brid. Sp. M. I, p. 192 et Bryol univ., $I$, p. 441 ; Bryol. eur. l. o.

Ut typ. - Eur. : Cum typ. - As. : Caucas. occ. Am. sept. : M. Rupestr.

« var. Lamyi Husn. Muscol. gall. p. 19.

D. pellucidum var. serratum Lamy in Husn. M. Gall. n. 303.

Ut typ. - Eur. : Gall, centr.

var. Mildei Limpr. Laubm. Deutschl. I, p. 300.

Ster. centr.

«var. serratum W. P.Sch. ll.cc. (1).

Angstroemia pellucida var. serrata $C . M$. . . c.

Bryum flavescens Dicks. Fasc. II Pl. crypt. p. 4, t. 4, f. 6 (fid. Wils.).

Br. lineare ej. Fasc. III, p. 6, t. 8, f. 2 (fid. Wils.).

D. flavescens Lindb. M. Seand. $p, 27$.

Dicranum flavescens $H$. et T. Musool. brit. p. 55, t. 17.

D. gracilescens $\beta$ flavescens Brid. Bryol, univ. I, p. 442.

D. lineare eJ. l. c. p. 446.

D. pellucidum var. serratum Bryol. eus. l. $c$.

Trichostomum lineare Brid. Mant. M. p. 84.

(1) Cf. Rev. bryol. 1892, pp. 9 et 19. 
Ut typ. - Eur. : Cum typ. Am. sept. : Labrador, Columb. brit., ins. Vancouver, ldaho, Oregon, Washington, Montana.

Exs. : Mac. Canaḋ. M. n. 402.

Reinwardti (Dz. et Mk.) Bryol. jav. I, p. 85.

Ångstroemia Reinwardti C. M. Syn. T, p. 437.

Dicranum Reinwardti Dz. et $M k$. in Ann. sc. nat. 1844, II, p. 303.

Gyrophyllum Reinwardti eor. M. frond. ined. Arch. ind. t. 45.

Leptotrichum Reinwardti Mitt. M. Ind. or, p. 12.

Symblepharis breviseta Wils, in Kev Journ. bot. IX, p. 293.

S. dilatata ej. $l$. $c$.

S. Reinwardti Bryol. jav, $I I, p, 225$.

1 .

- As. : Sikkim, Java, Borneo.

? rufipes (C. M.) Par.

Änstroemia rufipes C. M. in Linn. 1880-83, p. 388.

2.

- Am. merid. : Argentin. Tucuman.

squarrosum W. P. Sch. - Dicranella.

subclathratum (Ltz.) Par.

Dicranella subclathrata Ltz. Moosst. p. 159.

2.

- Am. merid. : Valdiv.

tasmanicum (Hook.) W. P. Sch. Syn. I ed. p. 66.

Dicranum tasmanicum Hook. f. Handb. of N. Zeal. Fl. p. 410.

Didymodon tasmanicus Mitt. in Journ. of the Linn. Soc. 1859, p. 70.

Tridontium tasmanicum Hook, f. Ic, pl. rar. III, t. 148 et Fl. of the N. Zeal. II, p. 65 ; C. M. Syn. I, p. 648 et II, p. 633 .

2. Ad rup. irror. - Pac. : Nov. Zeland., Tasman.

tricrure (C. M.) Jaeg. Ad. I, p. 68.

Angstroemia tricuris C. M. in Linn, 1867-68, p. 616 .

- Pac. : Austral. or.

vaginatum (Hook.) Jaeg. I, p. 67 (1).

2. - Am. merid. : And. Nov. Granat. et Quitens.

Angstroemia vaginata $C . M . S y n . I I, p, 608$.

Anisothecium vaginatum Mitt. $M$. austr. am. $p, 39$.

Dicranum vaginatum Hook. M. ex. t. I4i p.p. ; Brid. Bryol. univ, I, p. 465. 2. - Am. merid. : And. Nov. Granat. et Quitens.

Dichotomaria C. M. Syn. II, p. 164 (subsect. Pilotrichi).

DICKSONIA Ehrh. Crypt. Dec. n. 65.

pusilla Ehrh, - Schistostega osmundacea.

DICNEMON (2) Schwaegr. Suppl. II, II, I, p. 72 (10 spec.).

Banksii C. M. in Bot. Zeit. 1858, p. 161.

- Pac. : Ins. Taïti.

calycinum (Hook.) Schoaegr. l. c.; Brid. Bryol. univ. II, p. 215; C. M.

Syn. I, p. 347; Handb. of N. Zeal. Fl. p. 409.

Hollia myrmecodes Sieb. in Fl. 1826, p. 223.

Leucodon calycinus Hook. M. ex. II, p. 12, t. 17.

1.

- Pac. : Nov. Zeland.

(1) Cf. Duby in Mem... Genève 1869 , pp. 4-5.

(2) De nomine ef, Lindb. in Oefv... 1864, p. 602 
connivens Besch. Fl. bryol. Nov. Caled. p, 190.

Cortic. - Pac. : Nov, Caledon.

cuspidatus Besch. op. cit. p. 191.

- Pac. : Nov. Caledon.

enervis C. M. in Rev, bryol. 1876, p. 3 (nom.).

- Pac. : Austral. (Nov. Valesia).

obsoletinervis Hpe. et C. M. in Linn. 1853, p. 496.

- Pac. : Nov. Zeland.

Pancheri Besch. op. cit. p. 193.

2. Lignic. - Pac. : Nov. Caledon.

"var. sericeus Besch. l. c.

Ubi praeced.

planifolius Besch, op. et l. cc.

Terr. ferrugin. - Pac. : Nov. Caledon.

rugosus (Hook.) Schwaegr. 1. c. p. 127; Brid. Bryol. univ. 1, p. 216 ;

C. M. Syn. 1, p. 347 .

Leucodon rugosus Hook. M. ex. II, p. 12, t. 20.

1.

- Pac. : Austral.

rugosus? Mont. - Trachypus.

spathoideus (Duby) Besch. op. cit. p. 191.

Synodontia spathoidea Duby miss.

Lignic. - Pac. : Nov. Caledon.

DICNEMONELLA Hpe. in sched.

Sieberiana Hpe. - Leucoloma.

DIGRANELLA W. P. Sch. Coroll. p. 13 (112 spec.).

abruptifolia C. M. in Rehm. M. Afr. austr, n, 25.

$-A f i$ : C. B. Sp.

affinis Angstr. in Oefv... 1876, n. 4, pp. 3-4.

2. $\quad-$ Am. mevid. : Brasil, anstr. or.

amplexans (Mitt.) Jaeg. Ad. I, p. 80.

Leptotrichum amplexans Mitt. M. Ind. or: p. 9.

1. -As. : Nepal.

angustifolia Milt. M. austr. ame. p. 35.

2.

- Am. merid. : And. Nov. Granat, et Quitens.

argentinica (C. M.) Par.

Angstroemia argentinica C. M. in Linn. 1878-79, p. 308.

2? Rupic. - Am. merid. : Argentin. Cordob.

ascensionica Mitt. in Melliss's S. Helena, 1875, p. 357.

-. Afr.: Ins. Ascension.

asperula C. M. mss.; Jaeg. Ad. II, p. 638.

- As.: : Sikkim.

attenuata Wils, - Dicranodontium.

aulacocarpa (Mont.) Mitt, op. cit, p. 36.

Angstroemia aulacocarpa $C, M$. Syn, $, p, 431$.

Dicranum aulacocarpum Mont, in Ann. se, nat. 1815, IV, p. 113 et Syll.

2. p. 45.

- Am. merid. : Chile, ins. Chiloë. 
batbensis Ren. et Card. in Bull. Soc. roy. bot. Belg. 1892, I, p. 145.

2. Terr. in silv. - Am, sept. : Costa Rica.

Belangeriana Besch. Fl. bryol. Antill. fr. p. 9.

2. Terr. calcar. - An. sept. : Martinic.

bella (C. M.) Par.

Angstroemia bella G, M. in Dusen M. Camer. n. 881 .

- Afr.: M. Cameroon.

Beyrichiana Hpe. Enum. M. Brasil. p. 14.

Ångstroemia Beyrichiana ej. Symb. 1872, p. 40.

Cynodontium debile Jaeg. Ad. p.p. (excl. syn. Schwaegr., C. M. et Mitt., ic., exs. et loc. insul.).

Dicranum piervulum Hsch. Fl. Brasil. I, p. 14 p.p.

2 ?

- Am. merid. : Brasil, austr. or.

bicolor (C. M.) Jaeg. Ad. I, p. 90.

Angstroemia bicolor C. M. Syn. I, p. 44.

Dicranum densum ej. in Linn. 1847, $I, p, 206$.

D. densum $\beta$ minus Hpe. ibid. II, p. 73.

2.

- Am. merid. : And. Columb.

bogotensis (Hpe.) Mitt. M. austr. ame. p. $3 \dot{7}$.

Angstroemia bogotensis Hpe, in Ann. sc. nat. V ser., III, p. 357.

2. - Am. merid. : And. Nov. Granat.

borbonica Besch. Fl. bryol. Réunion, etc, p, 18.

2 ?

- Afr. : Ins. Borbon.

Borgeniana (Hpe.) Jaeg. Ad. I, p. 88.

Angstroemia Borgeniana Hpe. in Bot. Zeit. 1870, p. 33.

2. - Afr.: Natal.

brachyblepharis (C. M.) Besch. Prodr. bryol. mexic. p. 19.

Angstroemia brachyblepharis C. M. Syn. I, p. 435.

Dicranum curvatum Hsch, in M. Deppe et Schiede.

2.

- Am. sept. : Mexic.

caespitans Besch. Fl. bryol. Antill. fi, p, 9.

2.

- Am. sept. : Guadalup.

caldensis Angstr. in Oefv... 1876, n. 4, pp. 3-4.

2. - Am merid. : Brasil. austr. or.

eallosa (Hpe.) Jaeg. Ad. I, p. 81 .

Angstroemia callosa $H_{p e}$. in Linn. 1863, p. 134.

2. Terr. - Am. merid. : And. Nov, Granat. et Boliv.

Exs. : Mandon, Pl. Boliv, n. 1607.

Camerunia (C. M.) Par.

Ångstroemia Cameruniæ C. M. in Dusen M. Camer. n. 7.

- Afr. : M. Cameroon.

campylophylla (Tayl.) Jaeg. Ad. I, p. 86.

Angstroemia campylophylla C. M. Syn. II, p. 608.

Anisothecium campylophyllum Mitt. M. austr. am. p. 40.

Dicranum eampylophyllum Tayl. in Lond. Journ. of bot. 1848, p. 281; H. $f$. et W. Fl. of the N. Zeal. II, p. 65 et Handb. p. 411 .

2.

- Am. merid. : And. Quitens. Pac.: Nov. Zeland. sept. 
capituligera (C. M.) Par.

Angstroemia capituligera C. M. in Linn. 1878-79, p. 308.

2 .

- Am. merid. : Argentin. Cordob.

caucasica C. M. in Act. Hort. Petrop. 1887. f. 1 .

1.

- Eur.: Batoum.

cerviculata (Hedw.) W. P. Sch. Coroll. p. 13 et Syn, 11 ed. p. 73.

Angstroemia cerviculata $C, M$. Syn. I, p. 430.

Bryum cerviculatum Dicks. Fasc. III Pl. crypt. p. 7.

D. hybrida Sanio in Milde Bryol. Siles. p. 58 (fid. Jur.) Dicranum cerviculatum Hedw. M. fiond. III, p. 89, $t .37$ b ; Bmyol. eur: I
(mon. p. ) t. 56 .

D. flavidum Schwaegr, Suppl. I, I, p. 192, t. 45.

Oncophorus cerviculatus Brid. Bryol. univ. I, p. 391.

0. flavidus ej. op. cit. p. 392.

2. In turfac. - Eur. : E. reg. campestr. usq. in alp. As. : Penins. Tschutschica, Kamschatka, Otchosk, Obi, Jenissei inf. Am. sept. : Groenland, Labrador, New Brunswick, ins. Miquelon, Columb. brit, M. Rupestr, et Selkirk, Ohio, M. Alb.

Exs. : Drumm. M. bor. am. II ed, n. 65. (Dicranum)

Mac. Canad. M. n. 476.

Rab. Bryoth. eur. n. 269, 1003 et $b$.

« var, pusilla (Hedw.) W. P. Sch. Syn. I ed. p. 72 et II ed. l. c.

Bryum parvulum Dicks. op. c.p. 3.

Br, uncinatum ej.op. cit. Fasc, IV, p. 11, t. II, f. 8.

Dicranum cerviculatum $\beta$ pusillum W. et M. Bot. Tasehb. p. 193

D. parvulum Dieks. op. cit. Fasc. III, p. 3.

D. pusillum Hedu. M. frond. II, p. 80, t. 29, $f .13$.
D. uncinatum Sm. Fl. brit.p. 1207.

Mnium pusillum Gmel. Syst, nat. II, p. 1528.

Oncophorus cerviculatus $\beta$ uncinaius Rrid, op. cit, p. 392.

O. pusillus ej. op. cit. p, 390.

Ut et ubi typ.

cerviculatula Kindb. mss.

- Am. sept. . Labrador, fret. Hudson.

chrysea C. M. in sched.; Jaeg. Ad. $1, p .83$.

Angstroemia varia var. Sull, in Wright M. Cubens. n. 37 .

Anisothecium varium Mitt. M. austr. am. p. 40.

2 ? - Am. sept. : Cuba.

clatlerata $\mathrm{H}$. f, et W, - Dichodontium.

coarctata (C. M.) Bryol. jav. 1, p. 84, t. 70.

Ångstroemia coaretata $C$. M. Syn. I, p. 431 .

2. Terr. - As. : Java.

compacta W. P. Sch, in Besch. Prodr. bryol, mexic. p. 19.

Angstroemia compacta $C, M$. Syn. $I I, p .696$.

2.

- Am. sept. : Mexie.

condensata Angstr. in Oefv.... 1873, n. 5, p. 148.

2.

- Afr. : Ins. S. Helena.

consimilis (Hpe.) Mitl, M. austr, am. p. 32.

Angstroemia consimilis Hpe. in Ann, sc. nat. V ser, III, p. 336.

- Am. merid. : And. Nov, Granat. 
convoluta Jaeg. - Dichodontium.

crassinervis (Hpe.) Jaeg. Ad. I, p. 87.

Angstroemia crassinervis Hpe. in Linn. 1863, p. 133.

Dicranella heteromalla (fid. Mitt.)

2. Terr. - Am. merid. : And. Nov. Granat.

crinalis Geh. et Hpe. in Fl. 1881, p.

2.

- Am. merid. : Brasil. austr. or.

crispa (Hedvo.) W. P. Sch. Coroll. p. 13 et Syn. 11 ed. p. 70.

Angstroemia crispa C. M. Syn. I, p, 439.

Bryum unarginale Dicks. Fasc. III Pl. erypt.p. 8.

Dicranum crispum Hedw. M. frond. JI, p. 91, t. 33 ; Brid. Biyol, univ. I, p. 451 ; Bryol. eur. I imon. p. 20), t. 55.

Hypnum crispatum Gmel. Syst. nat. II, p. 1340.

1. Terr. arenos. humid. - Eur. : Spitzberg, Scandin., Anglia, Boruss, Siles., Galic., Saxon., Tatra, Harz, Francon., Hercyn., Westphal., Iuxemb., Taunus, Helvet., Engad., Stir., Carinth., Vall, Tellin., Tirol, Salisburg. As. : Jenissei med. et inf. Am. sept. : Groenland, M. Rupestr. et Selkirk, Columb. brit., Alaska, fret. Kotzebuë, Idaho.

Eas.: Drumm. M. bor. am. I ed, n. 101 (Dicranum).

Mac. Canad. M. n, 504.

Rab. Bryoth. eur. n. 49.

curvata (Hedlo.) W. P. Sch, Coroll, l, c, et Syn, HI, p. 76.

Angstroemia curvata C. M. Syn. $I, p .431$.

D. subulata var. curvata Rab. Kryptfl. v. Sachsen, I, p. 421.

Disranum curvatum Hedw. Sp, M. p. 132, t. 31; Brid. Bryol. univ. I, p. 425; Bryol. eur. I (mon. p. 24; t. 61.

D. heteromallum var. curvatum Hook, et Tayl, Muscol. brit.

D. subulatum $\beta$ curvatum Hub. Muscol. germ. p. 259.

2. Ad rup, arenac. humid. - Eur. : Rar.: Voges., Silva Nigr., Hercyn., Gall. centr. (Arvernia), Am. sept. : Perrar. : Pensilv., M. Alb.

Exs, : Rab. Bryoth, eur. n, 413, 1002.

curviseta Mitt. - Campylopodium.

cygnoea Angstr. - Campylopodium.

eyrtodonta (C. M.) Par.

Angstroemia cyrtodonta C. M. in Engler's Bot. Jahrb. 1883, p. 87 et in Forehungsieise... p. 61.

2. Terr. argill, hum. - Pac. : Nov. Zeland.

debilis Lesq. et Jam, - Mierodus.

decipiens Milde in Bot. Zeit. 1864, Beibl. (I).

In lapidos. - Eur. : Tirol. merid.

Dietrichiae (C, M.) Jaeg. Ad. 1, p. 85.

Ångstroemia Dietrichiae C. M. in Linn. 1867-68, p. 617.

2.

- Pac. : Austral. or.

ditissima (Hpe.) Milt. M. custr. am. p. 34.

Ångstroemia ditissima Hpe. in Linn. 1863, p. 134.

2. Terr. - Am. merid. : And. Nov. Granat.

(1) Cf. Limpr, Laubm. Deutschl. I, p. 332. 
divaricata (Mitt.) Jaeg. Adl. I, p. 80.

Dicranum cerviculatum Wils, in Kew Journ, bot. $I X, p, 296$.

D. subulatum Griff. Not. p. 417 .

Leptotrichum divaricatum Mitt. M. Ind. or. p, 9.

2. - As. : Khasia.

Duchassaingii W. P. Sch. - Microdus longirostris. edentata Mitt. in Journ. of the Linn. Soc. 1872, p. 295.

\section{- As. : Ceylan.}

elata W. P. Sch, in Lechl. Pl. Peruv, n. 2280; Mitt. M. austi, am. p. 33.

1. Rupic. - Am. merid. : Amazon., And. Quitens.; Peruv.

eustegia Besch. in Bull. Soc. bot. Fr. 1885, p. 95 ot 1894 , p. 77.
2. Terr. - As.: Tonkin.

exigua Hpe. - Microdus,

falcularia C. M. in Dusen M. Camer. n. 333 .

- Afr.: M. Cameroon.

fallax Wils. - D, varia var, tenuifolia.

Fitz-Geraldii Ren. et Card, in Bot. Gaz. 1888, p. 197, t. 13 et M. bor. exs.

2. n. 156.

flaccidiseta Mitt. - Microdus.

- Am. sept. : Ohio, Florid.

flava Besch. Fl, bryol. Antill. fr. p. 7.

2.

- Am. sept. : Marlinic.

flavipes Besch. Fl. bryol. Réunion, etc. p. 18.

2.

- Afr. : Ins. Borbon.

fusca Broth. in Act. Soc. sc. Fenn. 1891, n. 5.

2. Terr. - Am. merid.: Minas Geraes.

glanea Beseh. Fl. bryol. Nov, Caled. p. 189.

2. Terr. humid, - Pac.: Nov, Caledon.

Glaziovii Hpe. Enum. M. Brasil.p. 14.

Angstroemia Glaziovii ej. Symb, 1877, p. 717 .

Ster.

- Am. merid. : Brasil. austr. or.

graciliramea Rehm, M. Afr. austr. n. 441. - Afr. : Natal.

gracillima (Mitt.) Par.

Anisothecium gracillimum Mitt. in Trans, of the Nevo. Zeal, Inst, 1893, $p 287$.

2. Terr. - Pac. : Nov. Zeland.

Grevilleana (Brid.) W. P. Sch. Coroll. p. 13 et Syn. 11 ed.p. 71.

Angstroemia Grevilleana C. M. Syn. I, p. 439.

Anisothecium Grevillei Lindb. M. Scand, p. 26.

Dicranum Grevilleanum Bryol. eur. I (mon. p. 19), t. 54.

D. Schreberi var. Grevilleana Brid. Bryol. univ. I, p. 450.

D. Schreberianum Grev. Scot, crypt, fase. 22 , t. 116; Drumm. M. bor. am. I ed. n. 97 .

1. Terr. argill. humidiusc. - Eur.: Spitzberg, reg. mont, et subalp. Scandin., Scot., Tirol, Carinth., Stir., Helvet., Jurass., Rhet., Salisb., Austr., Bavar., Alp. Algov., Etruriae; Ticin.? As, : Jeniss. sup, et med., Caucas, occ, Am. sept.: Sin. Hudson, Anticosti, M. Rupestr. et Selkirk, Columb, brit., Idaho. 
Exs. : Mac. Canad. M. n. 482.

Rab. Bryoth. eur. n. 267, 1222.

Griffithii (Mitt.) Jaeg. Ad. I, p. 80.

Dicranum Khasianum A majus Griff. Not. p, 418.

Leptotrichum Griffithii Mitt. M. Ind. or. $p .9$.

2. Ad rup. madid. - As, : Khasia.

guadalupensis Mitt. $M$. austr, am, p. 37 .

- Am. sept. : Guadalup.

guadalupensis W. P. Sch. - D. stenocarpa.

Guilleminiana (Mont.) Hpe. Enum, M. Brasil. p. 14.

Angstroemia Guilleminiana C. M. \$yn. I, p. 440.

Dicranum Guilleminianum Mont. in Ann. sc. nat. 1841, p. 267 et Syll. p. 44.

D. sulcatum C. M. in Bot. Zeit. 1844, p. 709 et 1845, p. 93.

2. Rupic. et terr. - Am. sept. : Guadalup. Am. merid. : Brasil, austr. or.

Herminieri Besch. Fl. bryol. Antill, fr. p. 6.

2.

- Am. sept. : Guadalup.

heteromalla (L.) W. P. Sch. Coroll, p. 13 et Syn. II ed. p. 77.

Ångstroemia banatica Hpe. mss.; Jur. Laubmfl. Oester. Ung. p. 34.

A. crassinervis ej. (fld. Mitt.).

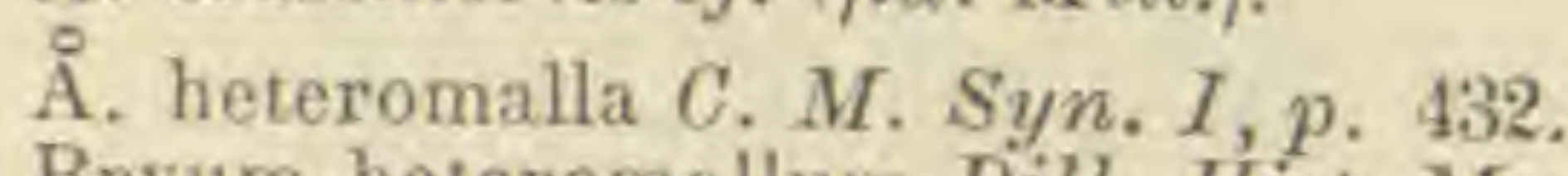

Bryum heteromallum Dill. Hist. M. p. 275, t. 47, f. 37.

$\mathrm{Br}$. pilosum interruptum ej. op. cit. p. $376, t, 47, f .38$.

Br. Weisia Hffm. Deutschl. Fl. p, 33 .

Dicranum heteromallum Hedv. $M$, frond. $I$, p. $68, t .26$; Brid. Bryol. univ. I, p. 423; Bryol. eur, I mon. p. 25), t. 62.

D. interruptum Brid. op. cit. p. 438.

Fuscina heteromalla Sehrank Bä̈ers Fl. II, p. 454.

Hypnum heteromallum Web. Spic. Fl. Goett. p. 72.

Leptotrichum heteromallum Mitt. M. Ind or. p. 11 .

Mnium heteromallum Gmel. Syst. nat. II, p. 1320.

2. Ad terr, denudat. et rup. aren. - Eur.: Vulg. in reg. campestr. et mont. As. : Saghalien, Amour, Japon., Sikkim, Caueas, Am. sept. : Nov. Scotia, New Brunswick, ins. Miquelon, Terra nov., Gaspes., Ontario, Columb. brit., Alaska, ins. Vancouver, Washington, Oregon, Wisconssin, Illinois, Indiana, temperat, tot.

Exs. : Drumm. M. bor. am. I ed. n, 95, 96 et II ed. n. 51 (Dicranum).

Mac. Canad. M. n. 29.

Rab. Bryoth. eur, n. 73 et b, 265 b.

Sull. et Lesq. M. bor. am. II ed, r. 67.

" var. curvipes Lindb. Conlr. ad fl, crypt. As, bor. or. p. 243.

- As. : Saghalien.

" var, interrupta W. P. Sch. Il. cc.

Ângstroemia heteromalla var. interrupta $C, M, l . c$.

Dicranum caducum Brid, op. eit. I, 425.

D. hetoromallum vas, interruptum W. et M. Bot. Taschb. I, p. 121; Bryol. eur. l. c.

D. interruptam Hedw. Sp, M. p. 129, t. 29.

Ut et cum typ. in Eur. et in Am, sept.

Exs. : Rab. Bryoth, eur. n. 809, 1001 (fid, Limpr.).

"var. orthocarpa (Hedw.) Par.

Angstroemia heteromalla var, orthocarpa C, M. l. c.

Dicranum heteromallum var. 2 Sull. $M$. Allegh. $n .166$.

D. orthocarpum Hedw. Sp. M. p, 134, t. 30.

Ut et cum typ. in Eur, et in Am. sept. ; As. : Caucas. 
Ess, : Drumm, M. bor. am. II ed. n. 53.

Sull. et Lesq. M. bor. am. II ed, n, 68.

"var, orthophylla Lesq. et Jam. Man. p, 67.

Ut et cum typ. in Am. sept.

"var. Pittieri Ren. et Card. in Bull. Soc. roy. bot. Belg. 1892, 1, p. 145.

In silvat. humid. - Am. sepl. : And, Costa Ricens.

var. saxicola H. M. - D. heteromalla var, sericea.

* var, sericea W. P. Sch. Syn. II ed.p. 78.

D. heteromalla var: saxicola H. Müll. Westfal. Laubin. n. 415.

Dicranodontium sericeum Bryol. eur. Suppl. faso, I, II.

Ad rup. arenac. - Eur.: Voges., Westphal,, Riesengeb,, Gall. centr. (Fontainebleau c. fr. !).

Exs, : Rab. Bryoth. eur. n. 809, 1001 (fid. Limpr.).

" var, stricta W. P. Sch. Coroll, et Syn. II ed, ll. cc.

Angstroemia heteromalla var. stricta C. M. Syn. l. c.

Dicranum heteromallum var, strictum Bryol, eur. $l$. $e$.

Ut et ubi typ.

Hilariana Mitt. - Microdus.

himalayana Jaeg. - Dichodontium Hookeri.

homomalla Besch, Fl. byyol. Antill. fr. p. 10.

2.

- Am. sept. : Antill. gall.

Howei Ren, et Card. ined.

- Am. sept. : Calif.

humilis Ruthe. - D. varia var. tenella.

hybrida Sanio. - D. cerviculata.

Krausei Ltz. - Dichodontium.

Kunzeana Mitt. - Microdus tenuss.

Langloisii Ren. et Card. in Bot. Gas. p. 39, f. 5 A.

2. Terr. - Am. sept. : Ludovic.

laxiretis Ren. et Card. ined.

- Am. sept.: Ludovic.

lenta Wils, - D. Schreberi var, elata.

leptorhyncha Ren, et Card, in Bull. Soc. roy. bot. belg. 1892, 1, p. 145.

2. Ad terr. humid. -- Am. sept. : Costa Rica.

leptotrichoides Ren, et Card. in Bot. Gas, 1894, p. 238.

2. Terr. - Am. sept. : Ludovic., Alabama.

Levieri C. M. in Broth. En. M. Canc. p. 67 .

2.

- As. : Caucas, occ.

Liebmanniana Besch. Prodr: bryal, mexic. p. 19.

Angstroemia Liebmanniana $C$. M. Syn. II, p. 605 .

2 .

- Aim. sept.: Mexic.

ligulifolia (C. M.) Par.

Angstroemia ligulifolia C. M. in Fl. 1886, p. 507 .

2. Limic. - Afr. : Old Calabar.

Lindigiana Mitt, - Microdus.

longirostris Mitt. - Microdus.

luteola Mitt. M. austr. am. p. 33.

2 .

- Am, merid. : And, Quitens, 
Mac-Leana Relm. M. Afr. austr. n. 442.

$$
\text { - Afr.: Transvaal. }
$$

microdonta Mitt. - Microdus Liebmanni.

mollicula (Mitt.) Jaeg. Ad. I, p. 85.

Dicranum patulum Wils, in Kew Jowrn, bot. IX, p. 295 p.p.

Leptotrichum molliculum Mitt. M. Ind. or. p. II.

$2 . \quad-$ As.: Himalaya.

Mülleri W. P. Sch. in Besch. Prodr. bryol. mexic, p. 19.

2. $\quad-$ Am. sept. : Mexic.

muralis (Hpe.) Mitt. M. austr. um, p. 33 .

Ångstroemia muralis Hpe. in Ann. sc. nat. V ser., III, p. 357 .

1. Muric. - Am. merid. : And. Nov. Granat.

nitida Broth, in Act. Soc. sc. Fenn. 1891, n. 5.

2. Terr, aren. - Am. merid. : Minas Geraës.

nodicoma C. M. in Dusen M. Camer. n. 336.

$$
\text { - Afr. : M. Cameroon. }
$$

obscura Sull, et Lesq. in Proc. Am. Acad. 1859, p. 277.

2. Terr. - As. : Hong-Kong.

Pabstiana (C. M.) Jaeg. Ad. I, p. 90.

Ångstroemia Pabstiana C. M. in Bot Zeit. 1857, p. 380.

2. Ad terr. humid. - Am. merid. : Brasil.

parvula Kindh, in Bull. Torr. bot. Club, 1889, n. 4 .

2. Terr. - Am, sept. : M. Rupestr.

patula (Wils.) Jaeg. Ad. I, p. 85.

Dicranum patulum Wils. l. c.p.p.

Leptotrichum patulum Mitt. M. Ind. or. p. II.

2 ?

- As. : Sikkim.

Perrottetii (Mont.) Mitt. M, austr, am. p. 35.

Ångstroemia Perrottetii C. M. Syn. I, p. 434.

Dicranum Perrottetii Mont. in Ann. sc. nat. 1843, p. 241 et Syll. p. 44.

D. sclerocarpum $H$. $f$. et $W$. in Lond. Journ. of bot. 1847, p. 291, t. 2 (fid, C. M.).

2. $\quad-$ Am. sept. : Antill, gall. Am. merid. : Ins. Trinitat., Nov. Granat.

pertenella C. M. in Dusen M. Camer, n. 460.

- Afr. : M. Cameroon.

Pervilleana Beseh. Fl. bryol. Réunion, elc., p. 19.

2.

- Afr. : Madagascar, S. Maria.

planinervia (Tayl.) Jaeg. Adl. I, p. 80.

Ångstroemia planinervia C. M. Syn. II, p. 605.

Anisothecium planinervium Mitt, $M$. austr, am. p. 40.

Dicranum planinervium Tayl. in Lond. Journ. of bot. 1848, p. 281, - Am. merid. : M. Pichincha.

polaris Kindb, mss.

2. - Aim. sepl.: Alaska, mar. Behring.

Polii Ren. et Card. in Bull. Soc roy. bot. Belg. I, p. 113.

- Afr. : Nossi Combe. 
Puiggarii Geh, et Hpe, in Fl. 1881, p.

2.

- Am. merid. : Brasil, austr. or.

pumila Saut. Fl. v. Salsburg, III, p. 22 .

Angstroemia Sauteri C. M. Syn. I, p. 430.

Dicranum falcatum var, pumilum Limpr. Deutschl. Laubm. p. 340.

D, pumilum Saut. in Fl. $1839, I, p .264$.

1. Ad rup. irror. - Eur. : Alp. Salisburg., Rhaet, et Bavar., Tatra.

pycnoglossa (Broth.) Par.

Anisotheciam pyenoglossum Broth, in Bail. Syn. of the Queensl. Fl. III Suppl.p. 95 (nom.) et in Oefv... 1890.

2. Terr, argill. - Pac. : Austral. (Queenslanu).

pyrrhotricha Besch. Not. M. des 1. S. Paul et d Amsterdam, p. 2. - Afr.: Ins. S. Paul.

remotifolia Besch. Fl. bryol. Antill. fr. p. 11.

2. Ster.

- Am. sept. : Guadalup.

rufescens (Turn.) W. P. Sch. Coroll. p. 13 et Syn, II ed, p. 75.

Angstroemia rufescens C. M. Syn. $I, p, 436$.

Anisothecium rufescens Lindb. $M$. Scand, $p, 26$.

Bryum rufescens Dicks. Fase. III Pl. crypt. p. 6, t. 8, f. I.

Dicranum carneum Bland. in Strerm Deutsch. Fl. II, fasc. II.

D. survatum Schultz Suppl. Fl. Starg. p. 71.

D. rufescens Turn. Muscol. Hib. p.66; Brid. Bryol. univ. I, 1. 437; Bryol. eur. (mon, p. 22), t. 66 .

D. varium $\beta$ rufescens Brid. Mant, $M, p, 62$.

2. Terr, argill. et subaren. humid. $-E u r$. : Reg. campestr. zon. interm., rar. sept. As. : Japon., Cancas. occ. Am. sept. : New Brunswick, Ontario, Columb. brit., Washington, Oregon; tota sept. et centr.

Exs. : Mac. Canad. M. n. 27.

Rab. Bryoth, eur. n. 266 et $b$.

Sull, et Lesq. M. bor. am. II ed. n. 64.

rufo-aurea (Hpe.) Jaeg. Ad. I, p. 83.

Ângstroemia rufo-aurea Hpe, in Linn. 1859-60, p. 627

2.

- Pre. : Alp. Austral. or.

Sartorii Jaeg. - Campylopodium.

Schmidii (C. M.) Jaeg. Ad. I, p. 89.

Ångstroemia Schmidii C. M. in Bot. Zeit. 1853, p. 39.

1.

- As. : M. Neilgherr.

Schreberi (Sin.) W. P. Sch. Corall. p. 13 et Syn. II ed. p. 72.

Ängstroemia Schreberi $C_{+}, M$. Syn. $I, p .438$.

Anisothecium crispum Lindb. M. Scand. p. 26.

Barbula crispa Hedw. Fund. M. II, p. 92.

B. mutabilis Baumg. Fl. Lips. n. 1263.

B. Schreberi Brid. M. Rec. II. I, p. 207.

Bryum crispum Schreb. Spic. Fl. Lips, p. 79 ,

Dicranum recornitum Roehl. Moosg. Deutsch. p. 377.

D. Schreberi Sw. M. Suec. pp. 37 et $88, t$. II. f. 6; Brid. Bryol. univ. I, p. $449 ;$ Bryol. eur. I (mon. p. 18), t. 53.

2. Terr. argill. et aren. humid. - Eur. : Reg. campestr. zon. interm. et septente. As. : Jenissei, Obi, Kamschatka; Caucas, Am, sept. : Sin. Hudson, Ontario, M. Rupestr., Columb. brit., Washington, M. Adirondack, Alb., Nov. Angliae; Pensilv., etc. Pac.: Nov. Zeland. 
Exs. : Drumm. M. bor, an. I ed, n, 97 (Dicranum).

Rab. Bryoth, eur. n. 1112.

" var. elata W, P. Sch. Syn. l.c.

D. lenta Wils. mss.; Braithw. in Journ. of bot. 1871, p. 289.

J.oc. uligin. - Eur.: Ánglia (ster.); Suecia, Rhoengeb. Am, sept.: Washington.

Exs, : Rab. Bryoth, eur. n. 74.

avar. occidentalis Aust, in Bull. Tor, bot, Club, VI. p. 344 (1); Losq. et Jam. Man. p. 65.

Ut typ. - Am. sept. : Oregon.

Exs. : Mac. Canad. M. n. 495.

a var, robusta Sull, et Lesq. M. bor, am. II ed, n, 61 .

Ut et ubi typ, in $A m$, sept.

secunda Lindb. - D. subulata.

var, brachycarpa Lindb. - D, subulata var, brachycarpa.

setifera (Mitt.) Jaeg. Ad. 1, p. 80.

Leptotrichum setiferum Mitt. M. Ind, or, p. 11.

2. - As. : Sikkim, Assam.

simplex Brockm. - D. varia $\gamma$ tenella.

simuosa Wils, - Didymodon.

spiralis (Mill.) Par.

Leptotrichum spirale Mitt, op. cit, p. 158.

2. - As. : Himalaya or.

squarrosa (Schrad.) W. P. Sch, Syn, ed. I, p. 71 el ed II, p. 72.

Ångstroemia squarrosa C. M. Syn. $I, p .438$.

Anisothecium squarrosum Lindb. $M$. Scand. $p, 26$.

Bryum erectis capitulis brevibus, folis inflexis Dill. Hist. M. p. 305, t. 46, f. 34 .

Br. palustre Dicks, Fasc, IV Pl. crypt. p. 11.

Br, pellucidum $\beta L, S p, p l, p, 1583$.

Dichodontium squarrosum W. P. Sch, Coroll. $p, 13$.

Dicranum squarrosum Sehrad. Journ. bot. $V, p .68 ;$ Bryol. eur. I (mon. p. 17), t. 52 .

Diobelon squarrosus Hpe. Ft. Hereyn.

Oncophorus squarrosus Brid. Bryol, univ, I, p, 404.

2. In terra saxos, humid, et prat, uligin. - Eur. : Reg, mont. et subalp. zon. intermed, et sept. - As. : Caucas. occ. Am. sept. : Groenland, Anticosti, New Brunswick, M. Selkirk, Alaska, Columb. brit.

Exs, : Rab. Bryoth, eur. n. 943.

«var. frigida Ltz. Moosst. p. 85.

Ad stagn. nival. - Eur. : Helv., Tirol.

stenocarpa Besch. Fl. bryol. Antill. fr. p. 8.

D. guadalupensis W. P. Sch. in Husn. M. Antill. fr, n. 128.

2. Ad terr. saxus. et calear. - Am. sept. : Antill. gall. 
«var, minor Besch, l. c.

Ut typ. - Am: sept.: Martinic.

stricta W. P. Sch. Syn. II ed. p. 77 (1).

2.

- Eur. : Lappon.

strumulosa (Hpe.) Jaeg. Ad. 1, p. 81.

Angstroemia strumulosa Hpe. in Linn. 1863, p. 133.

2. Terr. - Am. merid. : And. Nov. Granat.

« var. minor (Hpe.) Jaeg. l. $c$.

Angstroemia strumulosa var. minor Hpe. $l$, c.

Ut typ. - Am. merid. : Summa Cordillier.

subclathrata Ltz. - Dichodontium.

subcompressa W. P. Sch. in sched.; Jaeg. Ad. I, p. 91.

$$
\text { - Afr. : C. B. Sp. }
$$

subinclinata Ltz. Moosst. p. 160.

2. Terr. - Am. sept. : Panama.

subsubulata (Hpe.) Jaeg. Ad. I, p. 79.

Angstroemia subsululata Hpe. mss. ; C. M. in Bot. Zeit. 1858, p. 162.

2.

- Afr. : C. B. Sp.

subsulcata Hpe. Enum. M. Brasil. p. 54.

Angstroemia subsulcata ej. Symb. 1872, p. 42.

2 ?

- Am. mericl. : Brasil, austr. or.

subulata (Hedwo.) W. P. Ssh. Coroll. p. 13 et Syn. 11 ed. p. 75.

Angstroemia subulata C. M. Syn. $I, p .433$.

D. secunda Lindb. M. Scand. n. 26.

Dicranum heteromallum $\beta$ minus Wahlenb. Fl. Lapp. p. 310.

D. secundum Suc. Act. Holm. 1795, p. 244,

D. subulatum Hedw. Sp. M. p. 128, t. $31 ;$ Brid. Bryol. univ. I, p. 426;

Bryol. eur. I (mon. p. 23), t. 60.

D. sudeticum Sehwaegr. Suppl. I, I, p. 175, t. 45.

2. Ad terr. humid. - Eur, : Reg. subalp, et alp.; Spitzberg. As. : Jenissei, Saghalien, Amour. Am. sept.: Groenland, Gaspes., New Brunswick, M. Rupestr. et Selkirk, Columb brit., fret. Behring, reg. occid. et or., Idaho, Oregon.

Exs, : Drumm. M. bor. am. I ed. n, 98 (Dicranum).

Mac. Canad. M. n. 28.

Rab. Bryoth. eur. 11. 414.

Sull, ei Lesq, M. bor, am. II od, n, 66.

" var. brachycarpa (Lindb.) Par.

D. secunda var, brachycarpa Lindb. $l$. $c$.

Ut typ. - Eur. : Norvegia, Suecia. As. : Caucas. occ.

var, curvata Rab. - D. curvata.

tenuiseta (C. M.) Par.

Angstroemia tenuiseta C. M. in Reo. bryol. 1887, p. 57 (nom.)

- Pac. : Nov. Caledon.

Tonduzii Ren, et Card. in Bull. Soc. roy. bot. Belg. 1892, I, p. 144.

2. Terr. - Am. sept. : Costa Rica.

(1) Dierani Starkii forma, fid. Lindb, in Act. Soc. pr. Fl. et Faun...2a April, 1881. 
tovariensis (C. M.) Jaeg. Ad. I, p. 90.

Angstroemia tovariensis C. M. Syn. I, p. 443.

Dicranum Perrottetii ej. in Linn. $1847, I, p .206$.

2.

- Am. merid. : Columb., Venezuela.

trematodontifolia (C. M.) Par.

Angstroemia tremadontifolia C. M. in $\operatorname{Linn} .1874$, p. 630.

- Am. sept. : Mexic.

trichodontoidea C. $M$. in Rev. bryol. $1876, p .3$ (nom,)

- Pac. : Austral. (Nov. Vales.).

trichopliylla Mitt. - Campylopodium.

Trumpffii (Hpe.) Jaeg, Ad. I, p. 91.

Angstroemia Trumpffii Hpe. mss. ; C. M. in Bot. Zeit. 1859, p. 215.

2.

- Am. merid. : And. Venezuel.

varia (Hedw.) W. P. Sch. Coroll. p. 13 et Syn. II ed. p. 74.

Angstroemia varia $C . M$. Syn. I, p. 435.

Anisothecium rubrum Lindb. M. Scand. p. 26.

Bryum rubrum Huds. Fl. Angl: I ed., p. 413.

Br. trichodes capsulis rutris cernuis Dill. Hist. M. p. 390, t. 50, f. 59.

Dicranum rigidulum $S w, M$, Swec. $p .89, t, 3$.

D. vubrum Bovlay M. Fi, p. 505.

D. varium Hedw. M. frond II. p. 95, t. 34; Brid. Bryol. univ. I, p. 435; Bryol. eur. I (mon. p. 20), $t, 57-58$.

D. varium $\alpha$ viride $H$, et T. Muscol. brit. II ed., p. 107, t. 17 p.p.; Drumm. M. bor, am. I ed. n. 99 p.p. et II ed, n. 50.

2. In terr. argill, arenac, humidiusc. - Eur. : In reg. campestr. vulgatiss. As. : Jenissei, Obi, Persia, Caucas., Syria, etc. Am. sept. : Canada or., Athabasea, M. Rupestr., Montana, llinois, reg. or. et centr.

Exs. : Mac. Canad. M. n. 26.

Rab. Bryoth. eur. n. 72.

Sull, et Lesq. M. bor. am. II ed n. 63.

"var. callistoma W. P.Sch. $11, c c$.

Bryum callistomum Dicks. Fasc. III Pl. crypt. p. 5, t. 8, f. 10.

Dicranum callistomum Brid. Sp. M.I, p. 187.

D. varium var. callistoma Bryol, eur, $l$. $c$.

Ut et cum typ. in Eus.

E:s. : Rab. Bryoth. eur, n, 268.

" $f$. irrigata H. Müll. Westfal. Laubm, n. 417.

Ad rup. schist. irrigat. - Eur..: Westphal.

* var. obtusifolia Berggr. M. et Hepat. Spetsb. p. 36 et M. Spetsb. n. 9.

Ut typ. - Eus. : Spitzberg.

"var: obtusiuscula (Lindb.) Par.

Anisothecium rubrum var. obtusiusculum Lindb. et Am. M. As. bor. 1890 ,
II. p. 85 . - As. : Jenissei inf.

* var tenella W. P. Sch. Il, cc.

Anisothecium humile Lindb.

Bryum simplex L. Sp.Pl.p. 1587.

Dicranella humilis Ruthe in Hedroigia $1873, p .147$.
D. simplex Brockm. Laubm. Mecklenb. p. 62.

Dicranum laxifolium Brid. Bryol, univ, $I, p .431$. 
D. varium var. tenellum Bryol. ewr. $l$. $c$.

Fuscina simplex Schrank Bä̈ers Fl. II, p. 453.

Ut typ. $\delta$ et fr. ign. - Eur. : Fennia, Germania. As, : Ross. or., Jenissei inf.

Exs. : Rab. Bryoth, eur. n. 1321.

« var. tenuifolia W, P. Sch. $l l$. ce.

Angstroemia varia var. tenuifolia C.M. . c c.

D. fallax Wils. mss, ; Braithw. in Journ. of bot. 1870, p. 327, ı. 109, f. 3.

Dicranum varium ear. t cnuifolia Bryol. ewr. l. c.

D. tenuifolium Br. in F. Müller M. Sardin.

Ut typ. - Eur. : Anglia, reg. merid. Af $:$ : Alger.

villicaulis Hpe. in sched, ; Jaeg. Ad. 1I, p. 638 (1).

- As.: Sikkim.

Dicranobryum C. M. Syn. I, p. 309 (subsect. Bry1).

DICRANODONTIUM Bryol. eur., I (15 spec.).

aristatum Bryol. eur. Suppl. I-II; W. P. Sch. Syn. II ed. p 99.

D. longirostre va). aristatum Jur, Laubm. Oster, Ung, p. 52.

D. longirostre var. intermedium Milde in Hedvig, 1870, p, 414.

D. lutescens W. P. Sch. mss.; Mdo. Bayer. Laubm. p. 49.

Didymodon aristatus Lindb. M. Scand. $p$. 25.

2. Ad rup. silic. - Eur. : Norveg. occ., Roruss. or., Sudetes, Alp. Carinth., Salisburg.

Exs. : Rab. Bryoth, eur. n. 318.

\& var. scoticum W. P. Sch. l. c. p. 100.

D. asperulum Wils. p.p. (fid. Jaeg. Ad. II, p. 644).

Didymodon asperulus Lindb.

Ad. rup. aren. - Eur: : Scotia.

asperulum Wils, in Kew Journ. bot. IX, p. 296 p.p.

Campylopus asperulus Kindb. Laubm. Schw. et Norv. p. 88?

D. aristatum var. scoticum (fid. Jaeg. l. c.)

Dicranum asperulum Mitt. M. Ind. or. p. 22.

- Eur. : Scotia. As. : Sikkim, Alp. Yunnan.

Exs. : Rab. Bryoth. eur. n. 940.

asperulum Wils. p.p. $-\left\{\begin{array}{l}\text { D. aristatum var. scoticum? } \\ \text { D. caespitosum. } \\ \text { D. uncinatum. }\end{array}\right.$

attenuatum Wils. l. c. p. 297.

Dicranum attenuatum Mitt. op, et l. ec.

2 .

- As. : Sikkim.

caespitosum (Mitt.) Par.

Campylopus caespitosus Jaeg. Ad. I, p. 138.

D. asperulum Wils. $l$. c. p.p.

Dicranum caespitosum Mitt. op, et $l$, ec.

2.

- As. : Sikkim.

circinatum (Wils.) W. P. Sch. Syn. II ed. p. 99.

Campylopus uncinatus Kindb. Laubm. Sehwed et Noiveg. p. 88.

(1) In Enum. Kindberg. nomen nudum :

D. tenax C. $M$. 
D. Longirostre var. circinatum Milde in Bot. Zeit. 1870, $p, 414$.

Dicranum circinatum Wils, Bryol. brit. II ed. p. 76; Bryol. eur. Suppl. I-II.

D. comptum W. P. Sch. (fid. Limpr.).

Didymodon uncinatus Lindb.

2. In decliv. herbos. - Eur.: Norveg. oce., Scot., Sudet., Alp., Rhaet. dicticyon (Mitt.) Jaeg. Ad. II, p. 644.

Campylopus dicticyon ej. Ad. I, p. 138.

Dicranum dicticyon Mitt. op. eit. $p, 21$.

D. uncinatum Wils, in Kew Journ. bot. IX, p. 21.

2. - As. : Sikkim.

Didymodon (Griff.) Par.

Campylopus Didymodon Jaeg. Ad. I, p. 138.

Dicranum Didymodon Griff. in Calcutta Joum. nat. hist. II, p. 99 ; Mitt. op. et $l$. oc.

D. relaxum Wils. in op. cit. p. 294.

Didymodon dicranoides Griff. Not. p. 435 et Ie. pl. asiat. II, t. 82, f. 2. - As. : Khasia.

dimorphum Mitt. miss,

- As, : Bhotan.

flexipes Mitt. mss.; Hook. f. Handb. Fl. N. Zeal. p. 413.

Dicranum proscriptum H. f. et Wils. Fl. of the N. Zeal. II, p. 67.

2 .

- Pac. : Nov. Zeland. sept.

" var. $\beta=$ var. $\gamma\}$ Hook, f. l.c.

Ut et cum typ.

leptodrepanium C. M. in Dusen M. Camer. n. 348.

Afr. : M. Cameroon.

lineare Mitt. mss,; Hook. f. Handb. Fl. N. Zeal. p. 413.

1.

- Pac. : Nov. Zeland. med.

longirostre (Web. et Mohr) Bryol. eur. I (mon. p. 2), t. 88.

Bryum pilosum molle, setis intortis Dill. Hist. M. p. 373, t. 47, f. A-E.

Campylopus alpinus Bryol. eur. Suppl. fasc. I-II (1).

C. denudatus Kindb. Laubm. Schwed, et Norveg. p. 87.

Cynodontium longirostre Mart. Fl. Erlang. erypt. p. 94,

Dicranum denudatum Brid. Sp. M. I, p. 403 et $I I, p .600$.

D. flexuosum Brid. M. Rec. II, I, p, 163 .

Didymodon denudatus Lindb. M. Scand. $p .25$.

D. longirostris W. et M. Bol. Taschb. p. $155 ;$ Brid. Bryol, univ. I, p. 512. Trichostomum longirostre Hartm. Skand. Fl.

2. Lignic., rupic, et in turf. - Eur. : Reg. campestr., mont. et subalp. As. : Temperat. : Caucas. Am. sept. : New Brunswick, M. Allegh., Ohio, reg. or.

Exs. : Rab. Bryoth. eur. n. 799, 936, 937.

Sull. et Lesq. M. bor. am. II ed. n. 90.

« var. alpinum (W. P. Sch.) Milde in Bot. Zeit. 1870, p. 414.

Campylopus alpinus W. P.Sch. Bryol. eui. Suppl. I.II, t. 5; Rab. Bryoth. eur. n. 936 a et $b, 937$.

C. intermedius Wils. mss.

C. pachyneuros Mdo, Moosst. p. 63.

(1) Cf. Aman in Rev, bryol, 1889, p. 53. 
In turfos. - Eur. : Riensengeb., Fichtelgeb., Alp. Algov., Helvot. var. aristatum Jur., Milde. - D. aristatum.

var. circinatum Milde. - D. circinatum.

« var. fulgidum Milde, in op. et l. cc.

Ad rup. arenac. - Eur. : Silesia.

var. intermedium Milde. - D, aristatum.

«var. montanum Milde in op. et $l$. cc.

Ad cataract. et stagn. - Eur. : Riesengeb.

var. subalpinum Milde. - Dicranum longifolium var. subalpinum.

lutescens W. P. Sch. - D. aristatum.

Millspaughii Dna E. G. Britt. in Millsp. Prel. Cat. of the Fl. of W.

Virg. p. 488.

Campylopus flexuosus Sull.

- Am. sept. : Virgin. occid.

aitidurn Jam. - Dicranum longifolium var, plumosum.

perfalcatum C. M. in Rehm. M. Afr. austr.

- Afr.: C. B. Sp.

robustum Seq. - Dicranoweisia.

sericeum Bryol. eur. Suppl. - Dicranella heteromalla var, sericea.

uncinatum (Harv.) Jaeg. Ad. II, p. 644 (1).

Campylopus uncinatus Bryol. jav. I, p. 78 p.p.

D. asperulum Wils. l. c. p.p.

Dicranum uncinatum C.M. Syn. I, p. 404.

Thysanomitrium uncinatum Harv. in Hook. Ic. pl. rar. t. 22 et in Lond. Journ. of. bot. 1840, II, p. 6.

2. Ad rup. madid. - As. : Nepal., Himalaya, Khasia, Assam, Java.

uncinatulum C. M. mss. ; Jaeg. Ad. II, p. 645.

- As: Japonia.

virginicum $D^{\text {na }} E$. G. Britt, in Millsp. op. et l. cit.

- Am. sept. : Virgin. occ.

DICRANÓWEISIA Lindb. M. Scand. (20 spec.)

alpina (Mill.) Par.

Holomitrium alpinum Mitt. M. Ind. or. p. 25.

Weisia indica Wils, in Kew Joum. of bot. IX, p+ 291 p.p.

- As. : Sikkim.

antarctica (C. M.) Par.

Blindia antaretica C. M. Syn. I, p. 344 et $I I, p, 584$.

Dicranum antareticum Mitt. M. austr. am. p. 63.

Weisia crispula $H$. $f$. et $W$. Fl. antarct. $I, p .127, t .58, f .2 ;$ Handb. of N. Zeal. Fl. p. 404,

1. Rupic. - Am. merid.: Fuegia, ins. Eremitse. Pac. : Ins. Campbell. austro-crispula (C. M.) Par.

Blindia austro-crispula C. M. in Fl. $1885, p .404$.

1. Rupic. - Am. merid, : Fuegia.

(1) Cl. Mitt. M. Ind. or. p. 21 in una et ead. spec. Dieranod. asperulum, circinatum et uncinatum conjungit. 
Bruntoni (Sm.) W. P. Sch. Syn. II ed. p. 56.

Cynodontium Bruntoni Bryol. eur. I (mon. p. 3), t. 44.

Dicranum Bruntoni Engl. Bot. t. 2509; C. M. Syn, II, p. 590.

D. polycarpum H, et T. Muscol. brit. I ed.,p. 57.

Didymodon Bruntoni eor. II ed., p. 117, $t$. suppl. 4 .

D. Obscurus Kaulf. in Sturm Deutsch. Fl. orypt. fase. 16; Brial. Bryol. univ, $I, p .516$.

Diobelon Bruntoni Hpe. Fl. Hercyn.

Onchophorus Bruntoni Lindb. M. Seand. p, 27.

Oreoweisia Bruntoni Milde Bryol. sil.p, 54.

Trichostomum obscurum de Not. Syll. p. 194.

Weisia Bruntoni ej. Epil. p. 597.

1. In fiss, rup, silic. - Eur. : Suecia., Britann., Sudetes, Voges, Silv. Nigr., Hercyn., Thuring., Pyr., Gall. centr., Ital. sup., Hispan.

Exs, : Rab. Bryoth. eur. n. 412 (Cynodontium).

cirrata (Hedw.) Lindb. M. Scand. p. 25; W. P. Sch. op. cit. p. 55.

Afzelia cirrata $E \psi r h$, in litt.

Barbula cirrata Brid. M. Rec. II, I, p, 203.

Blindia cirrata $C . M$. Syn. II, p. 585 .

Bryum cirratum Gmel. Syst. nat. II, p. 1631. Br. cirratum et stellatum tenuioribus foliis Dill, Hist. M. p. 379, t. 48, f. 42
(? W.P. Seh.).

Dicranum cirratum Timm, Prods. Fl, Megap.p. 783.

Encalypta cirrata Sw. M. Suec. p. 25.

Grimmia cirrata Sm. Fl. birit. III, p. 1189.

Gr. Dicksoni Brid. M. Rec. II, I, p. 72.

Gymnostomum cirratum Schrank Baïers Fl. II, p. 436.

Hypnum cirratum Weis Crypt. Goett. p. 207.

Leersia cirrata Willd. Prodr. fl. Berol. p. 902.

Mnium cirratum L. Sp. pl. p. 1576 (? W. P. Sch.),

Tortula cirrata Claire. Man. p. 315.

Weisia cirrata Hedw. Sp. M. p. 69, t. 12; Brid. Bryol. univ. I, p. 343 ; Bryol, eur. I (mon. p. 9), t. 25.

W. Dicksoni Brid. M. Rec, $I I, I, p .72$.

1. Lignic., rupic. et ad tecta stramin. - Eur. : Med. et sept. : nunquam in Alp. As.: Caucas. A fr. : Alger. Am. sept. : Columb. brit., Washington, ins. Vaneouver, Oregon, Wyoming, Illinois, Calif. Pac. : Tasman.

Exs. : Mac. Canad, M. п. 19.

Rab. Bryoth. eur. n. IU6, 366, 808 (Weisia).

Sull, et Lesq. M. bor, am. II ed, n. 48 .

compacta (Schleich.) W. P. Sch. op. cit. p. 53.

D. crispula var, compacta Lindb. M. Scand. p. 25.

Grimmia compacta Schleich. Pl, helv, exs.

Weisia atro-virens Bryol. Germ. II, II, p. 56, t. 29.

W. compacta Brid. Mant, M. p. 42 et Bryol. univ, I, p. 345; Bryol. eur. I (mon. p. 8), t. 24; C. M. Syn. I, p. 654 .

W. condensata Brid. Mant. M. p. 41.

1. Ad rup. aren. et schistos, - Eur. : Rara: Sumn. Alp. Norveg., Carinth., Salisburg., Tirol, Helvet.

contecta (Hook. f. et Wils.) Par.

Blindia contecta C. M. Syn. I, p. 344 et $I I$, p. 584.

Weisia contecta H. f. et W. in Lond. Journ. of bot. 1844, p. 540 ; Fl. Antarct. I, p. 127, t. 58; Handb. of N. Zeal. Fl. p. 405. 2?

- Afr.: Ins. Kerguelen. Am. merid. : Fret.

Magell. Pac. : Ins, Campbell.

crispula (Hedwo.) Lindb. l. c.; W. P. Sc7. op. cit. p. 54 ,

Blindia crispula C. M. Syn. II, p. 584. 
Grimmia crispula $S m$. Fl. brit. III, p. 1192.

Holomitrium crispulum Mitt. $M$. Ind. or. $p .25$,

Weisia cirrata $\beta$ crispula Wahlenb. Fl. Lapp. p. 303.

W. crispula Hedw. Sp. M. p. 68,t. 12; Brid. Bryol, univ. I, p. 316 ; Bryol. eur. I (mon, p. 9), t. 26.

W. falcata Bryol. germ. II, p. 71, t. 31. f. 10.

1. Ad. rup., rariss. calcar, - Eur. : E reg. mont. usq. in alp. super. : Spitzberg, ins. Ursorum. As. : Penins, Tschutschica, Kamschatka, Jenissei, Sikkim, Caucas. Afr.: Alger. Am. sept.: Groenland, Labrador, fret.. Smith, Gaspesia, M. Rupestr. et Selkirk,fColumb. brit., Oregon, Utah, Idaho, Calif.

Exs. : Drumm. M. bor, am. I ed, n. 69 (Weisia).

Mac. Canad. M. n. 477.

Rab. Bryoth. eur. n. 793 (Weisia).

« var. atrata W. P. Sch. l.c.

Blindia crispula var, atrata C. M. $l$. $c$.

Weisia crispula var. atrata Bryol. eur. $l$. c.

W. crispula $\beta$ nigrescens |

W. crispula $\gamma$ atrata

Byrol. germ. II, p. 67, t. 30, f. 15-16.

Ad nives. - Eur. : Spitzberg, ins. Ursorum, summ. Alp.

var. compacta Lindb. - Dicranoweisia.

cryptodon (Mont.) Par.

Dicranum cryptodon Mitt. M. austi: am. p. 63 .

Weisia cryptodon Mont. in Ann. sc. nat. 1845, IV, p. 120 et Syll. p. 49 ; C. M. Syn. I, p. 652 .

- Am. merid. : Chil. austr.

fastigiata (Tayl.) Par.

Dicranum fastigiatum Tayl, in Mitt. op, et l. cc.

Rupic. - Am. merid.: Summ. M. Pichincha.

indica (Wils.) Par.

Holomitrium indicum Mitt. M. Ind. or. p. 24.

Leptotrichum indicum Wils, in Keu Journ. bot. IX, p. 321.

Weisia indica $e j$. in op. cit. $p, 292$ p.p.

1.

- As. : Sikkim.

inermis (Mitt.) Par.

Dicranum inerme Mitt. op. oit. p. 63.

- Am. merid. : And. Quitens.

kerguelensis $\mathrm{Par}$.

Blindia microcarpa Mitt, in Journ. of the Linn. Soc. 1876 (1).

1.

- Afr. : Ins. Kerguelen.

microcarpa (Hook. f. et Wils.) Par.

Holomitrium cirratum Mitt. op. cit. 1859, p. 70.

Weisia microcarpa $H$. f. et W. Fl. Tasman. II, p. 166, t. 171, f. 5 . 1.

- Pac.: Tasman.

microdonta W. P. Sch. - Microdus Liebmanni.

? obliqua Kindb. in Mac. Cat. p. 256 (nom.).

1. Rupic. - Am. sept. : Fret. Behring, M. Selkirk.

(1) An eadem ac sequens? 
pallidifolia (C. M.) Par.

Blindia pallidifolia C. M. Bryol, austr. Georg, p. 25

1. Rupic. - Am. merid. : Austr. Georgia.

riparia (Hpe.) Par.

Weisia riparia Hpe. in Linn. $1859-60$, p. 626.

- Pac. : Austral. felix.

robusta (Seq.) Venturi in Rev. bryol. 1882, p. 61.

Dicranodontium robustum Sequeira in Rev. d. Soc. de Instruct. d. Porto $\mathrm{X}^{\text {bri }} 1881$.

1.

- Eur. : Lusitan. (Porto).

tortelloides (C. M.) Par.

Blindia tortelloides C. M. in Engler's Bot. Jahrb. 1883, p. 78 et in Forchungsreise...p. 18.

Ster.

- Afr. : lns. Kerguelen.

tortifolia (Hook. f. et Wils.) Par.

Blindia tortifolia C. M. Syn. I, p. 343 et II, p. 584.

Weisia tortifolia H. f. et W. in Lond. Journ. of bot, 1844, p. $540 \mathrm{et} \mathrm{Fl}$. Antaret, $1 I, p .404, t .152, f .5$.

2.

- Afr. : Ins. Kerguelen.

DICRANU M Hedw, Fund. M. II, p. 91 (179 spec).

acanthoneuron C. $M$. in Fl. 1890, p. 474.

Ster. In gramin. - Afr.: Kilima N'Djaro.

aciculare Hedw, - Rhacomitrium.

$\beta$ fluitans Turn. - Rhacomitrium protensum.

$\gamma$ Turn. - Rhacomitrium microcarpum.

aciphyllum Hook, et Wils. in Lond. Journ. of bot. 1844, p. 541 et Fl. Antarct. 11, p. 405, , . 52, f. 3; C. M. Syn. 1, p. 378 et II, p. 594 ; Mitt. M. austr, am. p. 64 .

2. Lignic. et terr. - Am. meril. : Patagon. austr., Archip. Magell. ins. Maclov.

acrocaulon C. M. - Campylopus.

acuminatum C. M. - Campylopus.

adiantoides $\mathrm{Sw}$, - Fissidens.

aduncum Hpe. - Leucoloma.

affine Funk. - Dieranum Schraderi .

albescens C. M. - Campylopus.

aggregatum Brid. - Ptychomitrium polyphyllum.

albicans Bryol. eur. $I$ (mon.p. ) ), ı. 73; W. P. Sch. Syn. II ed.p. 87.

Campylopus albescens Kindb. Laubm. Schwed. et Norveg. p. 86.

C. crassinervis Wils, in Kew Journ, bot. IX, p. 297.

C. Leanus (fid, Hpe. in Jaeg. Ad. II, p. 656; of. Brothera Leana),

Dicranum enerve Thed. in Hartm. Skand. Fl. V ed., p. 393 ; C. M. Syn, II, p, 594 (1):

D. Kasbeckianum Kolenati in sched.

D. stramineum Lindb.

2. Ad terr. humos, et in fiss, rup. reg. alp. et supraalp. - Eur.: Lappon., Scandin., Transilv., Tatra, Alp. Salisburg., Stir., Carinth.,

(1) Lindb. M. Scand. p. 23 n. 234 in adn. 
Austr, sup., Carniol., Alp. Bavar. et Algov., Tirol., Rhreet., Helvet., Vall. Tellin. As.: Sikkim, Caucas. Am. sept. : Groenland, M. Rupestr. et Selkirk, Columb. brit., Colorado.

Exs. : Mac. Canad. M. n. 404.

Rab. Bryoth. eur. n. 264, 620, 1111.

Un. itin. 1863 , n. 12.

«var. denticulatum Kindb. in Mac. Cal. p. 261.

Rupic. - Am. sept. : M. Rupestr, et Selkirk.

Exs. : Mac. Canad. M, n. 589.

albicans Schwaegr. - Leucobryum longifolium

albidum Brid. - Leucobryum minus.

albulum Sull. - Leucoloma.

alopecurus C. M. - Campylopus.

alpestre Wahlenb. - Cynodontium gracilescens var. alpestre.

var. majus Wahlenb. - Cynodontium gracilescens.

alpicolum C. M. - Campylopus torfacens var. alpicola.

altissimum C. M. - Campylopus.

amabile C. M. - Campylopus

ambiguum Hedw, - Trematodon.

Andersonii Wichura in Fl. 1859, n. 27; W. P. Sch. Syn. I ed. p. 689 (1). 1.

$$
\text { - Eur. : Lappon. }
$$

Anderssonii C. M. - Campylopus.

Andrieuxii Besch. Prodr. bryol. mexic. p, 20.

1.

- Am. sept. : Mexic.

angustifolium Hook. f. et Wils. Fl. Tasm. p. 170, t. 172, f. 2.

Ster. - Pac.: Tasman.

angustifolium Kindb. - D. Kindbergii.

angustinerve Mitt. in Journ. of the Linn. Soc. 1859, p. 68; Fl. Tasm. p. 170, t. 171, f. 9.

2. Lignic, - Pac. : Tasman.

angustirete Aust. - Campylopus.

angustum Lindb. in Mitth, v. Soc. pr. Faun. et Fl. Fenn, $6^{a} 9^{\text {tri }} 1880$ et in Rev. bryol. 1882, p. 83.

2. vel pseudn-I. Paludic. - Eur. : Lappon., Fennia. As. : Penins. Samoied, Jenissei med, et inf.

antarcticum Mitt. - Dicranoweisia.

aquaticum \{ Brid. - Rhacomitrium protensum.

Ehrh. - Dichodontium pellucidum.

areticum Bryol. eur. Suppl. fasc. III-IV; W. P. Sch. Syn. II ed. p. 93.

D. glaciale Berggr, in Bidr. till. Skand. bryol. 1866 et in Hedvigia 1868, p. 25.

D. molle Wils. Bryol. brit. p. 75 (ut syn.).

D. Starkei var. molle ej, op. eit. p. 74.

1. Ad nives. - Eur. : Spitzberg, septem Ins., ins. Ursorum, Seandin.; Scot. (ster.). As. : Penins. Tschutschica. Am. sept. : Groenland, Labrador, fret. Behring.

(1) In Syn. II ed. omissum. Cf. Lindb. M. Scand. p. 25, n. 261. 
arctoœoides C. M. in Engler's Bot. Jahrb. 1883, p. 79 et in Forchungsreise... p, 19.

- Afr.: Ins. Kerguelen.

a)ctocarpon $\left\{\begin{array}{l}\text { C. M. - Campylopus porphyreodictyon. } \\ \text { Hsch. - Campylopus. }\end{array}\right.$

arcuatum $\left\{\begin{array}{l}\text { Brid. p.p. - Campylopus Echernieri. } \\ \text { Brid. p.p. - Campylopus longipilus. } \\ \text { Schleich. - Rhacomitrium patens. }\end{array}\right.$

arenicolum C. M. - Campylopus.

areodictyon $\left\{\begin{array}{l}\text { C. M. - Campylopus. } \\ \text { Hpe. et Ltz. - Campylopus Krauseanus. }\end{array}\right.$

argutum Hpe, in Linn. 1869-70, p. 516.

2? $\quad-$ Pac.: Austral. (Nov. Valesia).

argyrocaulon C. M. in Linn. p. 588.

Ster. Paludic. - Am, merid, : And. Nov. Granat.

aristatum Wils. - Dicranodontium circinatum.

asperrimum C. M. - I.eucoloma.

asperulum Mitt. - Dicranodontium.

asplenioides $\mathrm{Sw}$. - Fissidens.

assimile Hpe, 1c. M. t. 24; C. M.Syn. 1, p.362; Bryol.jav. 1, p. 66, t. 54.

D. polysetum $\beta$ assimile Dz. et Mk. M. frond ined. Archip. ind. p. $14 \overline{\text {. }}$

2. Arbor. - As. : Borneo, M. Java.

assimile Mitt. - D. crispifolium.

atratum Geh. in Fl. 1879, p. 473.

Ster.

- As.: Os flum. Obi.

atro-virens C. M. - Campylopus longipilus.

attenuatum Mitt. - Dicranodontium.

Auberti Bel. - Campylopus reduncus.

axilacocarpum Mont. - Dicranella.

aureo-nitens C. AI. - Campylopus.

aurificum C. M. - Campylopus.

var. flavescens C. M, - Campylopus aurificus var. flavescens.

australe Besch. in Bull. Suc. bot. Fr. 1885, p. LV èt in Miss. sc. Cap Horn, V, Bot. p. 260, t. I, f. 2.

Ster. $\quad-$ Am. merid. : Terr. Magellan.

austro-alpinum C. M. - Campylopus.

austro-georgicum C. M. Bryol. austr. Georg. p. 22.

Ster. Rupic. - Am. merid. : Aastro-Georg.

Bambergeri W. P. Sch. - D. spadiceum.

bartramioides Broth in Oefv... 1893.

2. - Pac, : Ins. Lord Howe.

Bergeri Bland. - D. Schraderi.

Berterianum Brid. - Syrrhopodon Berteroanus.

Beyrichii Duby. - Campylopus.

var. elatius Hpe. - Campylopus Beyrichii var, elatior.

bicolor Hsch. - Campylopns.

Billardieri Schoaegr. Suppl. II, p. 70, t. 12l ; Brid. Bryol. univ. 1, p. 401 ; C. M. Syn. I, p. 368; Mitt. M. austr. ant. p. 66.

Onchophorus Billardieri Brid. op. et l, oe. (1)

(1) Cr. Duby in Memoires... Genève, 1869, pp. 6-8. 
Lignic.-Am. merid. : Perav., Chile,, ins, Juan Fernardez, Máaiov. Pac.: Austral, Nov. Zeland, Tasman., ins, Aucklánd. Campbell. « var. duriusculum Hook. Fl. Antarct. I, p. 129.

Ut typ, - Pac. : Ins. Auckland, Campbell.

Billardieri $\left\{\begin{array}{l}\text { Besch. - D. Pancheri. } \\ \text { C. M. p.p. - D. commutatum. } \\ \text { Wils. - D. gymnostomum. }\end{array}\right.$

bipartitum Sm. - Ceratodon purpureus.

biplicatum Hpe. - Leucoloma.

blindioides Besch. in Ann. sc. nat. 1892, I, p. 51.

1.

- As. : Alp. Yunnan.

Blumii Nees ab Es. in Nov. Act. Leop. XI, I, p. 131, $t$. 15; Brid. Bryol. univ. I, p. 453 ; C. M. Syn. I, p. 379; Bryol. jav. I, p. 71, t. 58.

2. Arbor. - As. : Ceylan, M. Java.

Blyttii Bryol. eur. I (mon. p. 26), t. 63; C. M. Syn, I, p. 364; W. P. Sch. Syn. II ed. p. 81 .

Bryum Schisti Günn. Fl. Norveg. II, p. 138.

D. Schisti Lindb. in Act. Soc. se. Fenn. 18̃i, p. 11.

D. Sendtneri var. Flot. mss. (fid. Limpr.); Milde Bryol. Sil. p. 61.

1. Ad rup. granitic., micac. - Eur. : Spitzberg, ins. Parry, Ursorum, Britann., Norveg., Dania, Riesengeb., Tatra, Alp. Salisb., Helvet., Tirol., Stir., Silv. nigr., Voges. Gall, centr. (Arvernia). Am. sept.: Groenland, Anticosti, M. Selkirk, Columb. brit., ins. Vancouver, Nov. Anglia, M. Alb., Idaho.

Exs. : Mac. Canad. M. n. 32.

Rab. Bryoth. eur. n. 1004, 1170.

Sull. et Lesq. M. bor. am. Il ed. n. 69.

Bonjeani C. M. - D. palustre.

var. alatum Barnes. - D. palustre var. alatum.

var, atralum Pfeiff, - D. palustre var, atratum.

var. calcareum Braithw. - D. palustre var. calcareum.

var. juniperifolium Braithw. - D. palustre var. juniperifolium.

var. polycladum C. M. - D. palustre var, polycladum.

var. Roellii Barnes. - D. palustre var. Roellii.

var. Schlotthaueri Barnes, - D. palustre var. Schlotthaueri.

Boryanum $\left\{\begin{array}{l}\text { H. f. et W. - D. kerguelense. } \\ \text { Schwaegr. - D. dichotomum. }\end{array}\right.$

brachycaulon Kindb. in Mac. Cat. p. 34.

D. spurium Mac. Canad. M. n. 46 p.p.

1 ? Ad rup. humid. - Am. sept. : Nova Scotia.

brachymitrium Geh, et Hpe. - Campylopus.

brachypelma C. M. Syn. II, p. 595; Bryol. jav. I, p. 69, t. 56.

2.

- As. : Java. Pac.: Nov, Zeland (?)

brachypelma C. M. (Bot. Zeit.). - D. kaiparense.

brachyphyllum $\left\{\begin{array}{l}\text { Hsch. - Leucobryum candidum. } \\ \text { Mitt. - Campylopus. }\end{array}\right.$

Braunii C. M. in Bryol. jav. I, p. 69, t. 57.

D. dicarpum Dz. et Mk. M. frond. ined. Archip. ind. p. I4I.

2. Arbor. - As. : Java, Sumatra.

brevifolium Lindb. M. Scand. p. 24.

D. congestum $\varepsilon$ cirratum $W, P, S c h$. Coroll. p. 16.

D. dipteroneuron C. M. in Fl. 1887, p. 221. 
D. fuscescens $\varepsilon$ cirratum W. P. Sch. Syn. 1 ed. p. 88 (fid. Lindb).

D. Hostianum Schwaegr.?

D. Mühlenbeckiî var. alpinum Jur. Laubmft. Desterr. Ung. p+ 46 ?

D. Mühlenbeckii $\beta$ brevifolium Lindb. Bot. Not. 1865.

2. - Eur. : Lappon., Scandin., Fennia. As. : Jenissei inf., Caucas. Am. sept. : Groenland, Labrador, sin. Hudson, M. Rupestr., Columb, brit, Alaska.

Exs. : Mac. Canad. M. n. 588.

brevifolium Schleich. in hb. DC. - Cf. Dryptodon.

brevipilum C. M. - Campylopns.

brevisetum $D z$, et $M k$. in Ann. sc. nat. 1814, II, p. $302 ; C . M$. Syn. I, p. 375 ; Bryol. jav. 1, p. $6 \mathrm{~S}$.

Didymodon brachypus Hpe. in sched.

Megalostylium brevisetum Dz. et Mk. M. frond. ined. Arohip, ind. p. $146, t .44$.

2. Cortic. - As. : Ceylan, M. Java. Pac. : Nov. Caledon.?

« var. argenteum Bryol. jav. II, p. 225.

Ut typ. - As, : Java.

brevisetum $\left\{\begin{array}{l}\text { Brid. - Leucoloma bifidum. } \\ \text { Wils. }\end{array}\right.$

Wils. - Dieranum subreflexifolium.

Bridetianum C. M. - Leucoloma serrulatum.

Bruntoni Engl. Bot. - Dicranoweisia.

bryoiles $\left\{\begin{array}{l}\text { Roth. - Fissidens. } \\ \text { Sw. - Fissidens exilis. } \\ \text { Sw. - Fissidens osmundioides, }\end{array}\right.$

$\alpha$ H. et T. - Fissidens osmundioides.

$\beta$ eor. - Fissidens incurvus.

var. minus Turn. - Fissidens exiliz.

bullatum Sommerf, - Pottia latifolia var. pilifera.

Cacti C. M. - Campylopus.

caducum Brid. - Dicranella heteromalla var. interrupta.

caesium Milt. in Trans. of the Linn. Soc. 1891, p. 155.

D. subscoparium W. P. Sch. in Savatier M. Jap. $n^{\circ} 91$.

Ster. - As. : Japon.

caespitans W. P. Sch, in Besch. Prodr. bryol. mexic. p. 20.

2.

- Ane. sept. : Mexic.

caespitosum Mitt. - Dicranodontium.

caespitulans C. M. - Leucoloma.

callistomum Brid. - Dieranella varia var. callistoma.

calycinum $\left\{\begin{array}{l}\text { Brid. - Holomitrium vaginatum. } \\ \mathrm{Sw} \text {. - Holomitrium. }\end{array}\right.$

calympericliclyon Geh. et Hpe. -- Campylopus.

campylophyllum Tayl. - Dichodontium.

canadense Kindb, in Bull. Torr. bot. Club, XVII, p. 87.

1. Terr. - Am. sept. : Columb. brit.

canaliculatum Geh. et Hpe. -- Campylopus.

canariense Hpe. in Bot. Zeit. 1862, p. 11.

Arbor. - Afr. : Ins. Canariens.

candidum Brid, - Leucobryum.

canescens C. M. - Campylopus.

capillaceum Brid. - Campylopus.

capitiflorum C. M. -- Campylopus. 
carneum Bland. - Dicranella rufescens.

caudatum C. M. - Campylopus.

Celsii Hedw. - Ceratodon purpureus.

cerviculatum $\left\{\begin{array}{l}\text { Hedw. - Dicranella. } \\ \text { Wils. p.p. - Dicranella divaricata. } \\ \text { Wils. p.p. - Dicranella decipiens. }\end{array}\right.$

$\beta$ pusillum W. et M. - Dicranella cerviculata var. pusilla.

chionophilum C. M. - Campylopus.

chlorocladum C. M. in Rev. bryol. 1876, p. 3 (nom.).

- Pac. : Austral. (Nov. Valesia).

chlorophyllosum C. M. - Campylopus.

chloropus Brid. - Ceratodon.

Chrismari C. M. -- Campylopus.

chryseo-basilare C. M. - Leucoloma.

chrysodictyon Hpe. - Campylopus.

circinatum $\{$ Brid. - Syrrhopodon.

cirs. - Dicranodontium.

cirratum Timm. - Dicranoweisia.

cirrifolium W. P. Sch. mss, ; C. M. in Fl. 1885, p. 409.

Terr. - Am. merid. : Fret. Magellan.

clathratum H. f. et W. - Dichodontium.

clavalum $\left\{\begin{array}{l}\text { R. Br. - Campylopus. } \\ \text { Wils. - Campylopus Dozyanus. }\end{array}\right.$

Columbiae Kind. in Bull. Torr. bot. Club, XVII, p. 86.

2. Terr. in silv. humid. - Am. sept. : Columb. brit., ins. Vancouver.

Commersonianum C. M. - Leucoloma bifidum.

commutatum Hpe. mss. ; Jaeg. Ad. Il, p. 759.

D. Billardieri C. M.p.p. (quoad pl. Capens.).

$$
\text { - Afr. : C. B. Sp. }
$$

comosum Schwaegr. - Campylopus.

compactum Funk. - Cynodontium virens var. Wahlenbergii.

comptum W. P. Sch. Syn. II ed. p. 97.

Dicranodontium circinatum W. P. Sch. (fid. Limpr.).

Ster,

- Eur. : Pinzgovia.

concolor $\left\{\begin{array}{l}\text { C. M. (Bot. Zeit.) - Campylopus penicillatus. } \\ \text { Hook. - Campylopus. } \\ \text { Hsch. - Campylopus trachyblepharum. } \\ \text { Nees et Bl. - Campylopus reduncus. }\end{array}\right.$

condensutum Hedw. p.p. $-\left\{\begin{array}{l}\text { D. Mühlenbeckii. } \\ \text { D. sabuletorum. } \\ \text { D. scoparium. }\end{array}\right.$

confine C. M. el Hpe. in Linn, 1856, p. 206.

- Pac. : Austral. felix.

congestiforme C. M. et Kindb. in Mac. Cat. p, 29.

2. Ad rup. humid. - Am. sept. : Columb. brit.

congestum Brid. p.p. $-\left\{\begin{array}{l}\text { D. fuscescens. } \\ \text { D. fuscescens var, longirostre (pro max, part.). }\end{array}\right.$

var. cirratum W. P. Sch. - D. brevifolium.

var. flexicaule Bryol. eur. - D. fuscescens var, flexicaule.

var. longirostre Bryol. eur. - D. fuscescens var. longirostre.

var, robustum Bryol. eur. - D. fuscescens var, robustum.

var. rupestre Roehl. - D. fuscescens. 
consobrinum Ren, et Card. in Bot. Gaz. 1890, p. 39, t. 5 B.

Syn. - Am. sept. : Minnesota.

contortum Wahlenb. - Grimmia.

controversum Hpe. - Campylopus.

convolutu,n Hpe. in C. M. Syn. I, p. 358 et II, p. 589.

- As. : Siber. transbaïcal,

crispicoma C. M. - Campylopus.

crispifolium C. M. in Bot. Zeit. 1864, p. 349.

D. assimile Mitt. M. Ind, or. p. 15.

D. scoparium var. Wils, in hb. Ind. or. n. 50 et 68 .

- As. : Himalaya, Madras, Alp. Yunnan.

" var. leptothecium Besch. in Ann. sc, nat. 1892, I, p. 52. - As. : Alp. Yunnan.

crispo-falcatum W. P. Sch. in Savatier M. Japon. $n, 81$ a ; Besch, in

Ann. sc. nat. 1893, p. 331 .

3.

- As. : Japon.

crispulum C. M. et Kindb. in Mac. Cat. p. 27.

2. Lignic. - Am. sepl. : Columb. brit., ins. Vancouver.

crispum Hedw. - Dicranella.

cristatum Wils. - D. lorifolium.

Crïgerianum C. M. - Leucoloma.

cryptocarpum $\mathrm{C}, \mathrm{M}$, - Leucoloma.

cryptodon Mitt. - Dicranoweisia.

cuneifolium Hpe. - Leucoloma.

curvatum $\left\{\begin{array}{l}\text { Hedw. - Dicranella. } \\ \text { Hsch, - Dicranella brachyblepharis. } \\ \text { Schultz. - Dicranella rufescens. }\end{array}\right.$

curvifolium Schleich. - D. Starkii.

cuspidatum $\left\{\begin{array}{l}\text { Griff. - D. fragile. } \\ \text { Hsch. - Campylopus. }\end{array}\right.$

cygnoum Hedw. - Campylopus.

cylindraceum Brid. - Holomitrium vaginatum.

cylindricum W. et M. - Trichodon.

cylindrothecium Mitt. in Trans. of the Linn. Soc. 1891, p. 157.

$$
\text { - As. : Japon. }
$$

decipiens Mitt. M. Ind. or. p, 16.

D. cerviculatum Wils. in Kew Joum. bot. IX, p. 296.

D. lubricum ej. in op, cit. p. 297.

Ster?

- As. : Sikkim, Khasia.

debile $\mathrm{H}$. $\mathrm{f}$. et $\mathrm{W}$. - Microdus.

decumbens Thw, et Mitt. - Cynodontium.

deflexicaulon C. M. in Linn. 1874, p. 589.

Ster. Paludic, - Am. merid. : And. Nov. Granat.

Delavayi Besch. in Ann. sc. nut. 1892, I, p. 51.

2.

- As. : Alp. Yunnan.

densum $\left\{\begin{array}{l}\text { C. M. - Dicranella bicolor. } \\ \text { Funk. - Campylopus fragilis. } \\ \text { Hook. - Mierodus. }\end{array}\right.$

$\beta$ minus Hpe. - Dicranella bicolor.

denudatum Brid, - Dicranodontium longirostre, 
Deplanchei Duby Choix de crypt. ex. 1869, p. 2, t. 2, f. 1.
2.

- Pac.: Nov, Caledon.

destructile C. M. - Campylopus.

detonsum Geh. et Hpe, - Campylopus.

diaphanoneuron Hpe. in Linn. 1869-70, p. 515.

- Pac. : Austral, felix.

dicarpum Hsch, in Sieb. M. Nov. Holl. n. 10; C. M. Syn. 1, p. 363 el II,

p. 590 ; Hook. f. et Wils. Fl. of the N. Zeal. II, p. 66.

D. leucolomoides C. M. (fid. Mitt.).

D. subaggregatum R. Br. in Schwaegr. Suppl. III, II, I, t. 251 . 1 .

Banks.

- Pac. : Austral., Nov. Zeland., Tasman., ins.

« var. spinosum Hook. f. et Wils. Fl. Tasm. p. 169.

- Pac. : Austral., Nov, Zeland., Tasman.

dicarpum Dz. et Mk. - D. Braunii.

dichelymoides C. M. - Lencoloma.

dichotsmum Brid. Mant. M. p. 55; C. M. Syn. I, p. 362 et II, p. 590 (1).

Cecalyphum dichotomum $P . B$. Prodr, p. 51 .

D. Boryanum Schwaegr. Suppl. II, I, p. 71, t. 121.

Oncophorus dichotomus Brid. Bryol. univ. I, p. 401.

2.

car.

- Afr.: Kilima N'Djaro, ins, Borbon., Madayas-

dichotomum P. B. (p. 53). - Cf. Dryptodon.

dicticyon Mitt. - Dicranodontium.

Didrichseni C. M. - Campylopus.

Didymodon Griff. - Dicranodontium.

Dielrichiae C. M. - Campylopus.

Dillenii Tayl. - D. scoparium.

diminutum Brid. - Sematophyllum subulatum?

dipteroneuron C. M. - D. brevifolium.

discriminalum Hpe. - Campylopus.

divaricatum Mitt. - Campylopus.

dives C. M. in Bryol. jav. 1, p. 72, t. 59 ,

2. - As, : Java.

divisum Geh. et Hpe. - Campylopus.

Donnellii Aust. - Campylopus.

Dozyanum $\left\{\begin{array}{l}\text { C. M. - Campylopus. } \\ \text { Wils. - Campylopus }\end{array}\right.$

drepanocladium C. M. - Lencoloma.

Drummondii C. M. Syn. I, p. 356 p.p. ; Sull. M. of U. St, p. 23 et Io, M.

Suppl. p. 48, t. 33; Lesq. el Jam. Man. p. 76.

D. Starkii var. major Drumm. M. bor, am. I ed. n. 84 .

D. undulatum var. Drumm. l. $c . n, 86$.

2. In pinet. - Am. sept.: Ontario, M. Rupestr. or., Nov. Anglia, New Jersey, New York.

Exs. : Mac. Canad. M. n. 47.

Sull, et Lesq. M. bor. am. II ed. n, 88 ,

"var. trachyneuron Kindb. in Mac, Cat, p. 34.

Ut typ. - Am, sept. : Ontario.

(1) Cf. Duby in Mémoires... Genève 1869, pp. 6-8. 
Diummondii C, M. pp. -- D, elatum.

durum Lag. - Grimmia commutata.

ecaudatum C. M. - Leucoloma.

Eckloni Ltz. - Leucoloma.

edentulum Mitt. - Braunfelsia.

elatum Lindb. Adnot. bryol. et M. Scand. p. 24; W. P. Sch. Syn. 11 ed. p. 96.

D. Drummondii C. M. Syn. I, p. 356 p.p.

D. robustum Blytt in Bryol, eur. I (mon. p. 43), $t .84$.

2. In silvat. humid. - Eur. : Lappon., Norveg.

Exs, : Rab. Bryoth, eur. n. 1063.

elegans Duby. - Dichodontium.

ellipticum Turn. - Rhacomitrium.

elongatum Schwaegr. Suppl. I, 1, p. 71, t. 43; Brid. Bryol. univ. I, p. 429 ; Bryol. eur. I (mon. p. 35), t. 76; C. M. Syn. I, p. 365; W. P. Sch. Syn. JI ed. p. 88.

D. Macounii Aust. in Coult. Bot. Gaz. II, p. 96.

2. Ad rup. humid, - Eur. Spitz.berg, ins. Ursorum, omn. Alp. passim. As. : Jenissei, os flum. Obi, Am. sept. : Groenland. Labrador, sin. Hudson, fret. Smith, ins. Miquelon, Terra Nov., lac. Super., M. Rupestr., fret. Kotzebuë, ins. Vancouver, M. Alb.

Exs. : Drumm. M. bor. am. I ed. n. 91.

Mac. Canad. M. n. 592.

Rab. Bryoth. eur. n. 263, 733.

Sull. et Lesq. M. bor. am. n. 79.

var. minor Drumm. - D. strictum.

* var, orthocarpum Bryol. eur., C. M. et W. P. Sch. ll. cc.

D. groenlandicum Brid. Bryol. univ. I, p. 460 (incl. v. $\beta$ secundum ?)

D. labradoricum C. M. (fid. Limpr. et plurim. auct.) D. Sphagni Wahlenb. Fl. Lapp. p. 337; Brid. op. c. p. 461. (excl. syn.
Dill.).

Gymnostomum aestivum Brid. Sp. M. I. p. 38 (excl. syn. omn.).

G. curvirostrum Roehl Ann. Wett. Ges. I, p. 28.

Hypnum alpinum Neck. Meth. M. p. 190.

Sphagnum alpinum L. Sp.pl. p. $15 \%$.

In turfac. - Eur. : Reg. alp. zon. septentr. Am. sept. : Groenland.

enerve Thed. - D. albicans.

erectum $\{$ C. M. - Campylopus.

erectum Mitt. - Campylopus Mittenii.

ericelorum Mitt. p.p. - $-\left\{\begin{array}{l}\text { Campylopus Dozyanus. } \\ \text { Campylopus longipilus. }\end{array}\right.$

ericoides Griff. - Campylopus.

erythrodontium Hpe. mss.; C. M. in Bot. Zeit, 1862, p. 11.

- Afr. Teneriffa.

erythrognaphalon C. M. - Campylopus.

erythropodium Hpe. Campylopus.

euchlorum Mont. - Mierodus.

eurydictyon Besch. in Ann. sc. nat. 1893, p. 333.

Ster.

Exs. : Faurie n. 13. - As. : Japon.

exalare Hpe. - Campylopus,

exaltatum C. M. - Campylopus. 
exasperatum $\left\{\begin{array}{l}\text { C. M. - Campylopus. } \\ \text { (iriff. - Campylopus nigrescens. }\end{array}\right.$

fagimontanum Brid. - D. fuscescens?

falcatum Heclw. Sp. M. p. 150, t. 32 ; Bryol. eur. I (mon. p. 22), t. 65 ;

C. M. Syn. I, p. 363 ; W. P. Sch. Syn. II ed. p. 81.

Bryum longifolium Disks. Fasc. III Pl. cmypt.p. 7.

Cecalyphum scrofulosum $P . B$. Prodr. p. 51 .

D. Sendtneri Flot. mss. (fid. C. M.).

Oncophorus falcatus Brid. Bryol, univ, I, p. 393.

J. Ad rup. et terr. - Eur.: Reg. alp. et supraalp. zon. intermed. et sept. : Scotia, Pyr. Am. sept. : M. Rupestr., Oregon, reg. orient.

Exs.: Rab, Bryoth, eur. n. $942,934$.

\& var. Hendersoni Ren. et Card. in Bot. Gaz. 1890, p. 39.

Ut typ. - Am. sept. : Oregon.

var. pumilum Limpr. - Dicranella.

"var. setaceum Husn. M. Gall, n. 506 et Muscol. gall. p, 28.

Ut typ. - Eur.: Pyren.

falcatum Schrad. - D. Schraderi.

falcifolium Hook, - Drepanophyllum fulyum.

fasciatum Hedwo. Sp. M. p. 127, t. 28; Brid. Bryol. univ. I, p. 432

(excl. syn. P. B.); C. M. Syn. I, p. 371; Hook. f. et Wils. Fl. of the

N. Zeal. II, p. 66 et Handb. p. 412.

- Pac. : Nov. Zeland.

fasciatum Spreng. - Leucoloma Sprengelianum.

fastigiatum $\left\{\begin{array}{l}\text { Schultz. - D. Schraderi. } \\ \text { Tayl. - Dicranoweisia. }\end{array}\right.$

Fendleri C. M. - Campylopus.

ferrugineum $\mathrm{H}$. $\mathrm{f}$. et W. - Dichodontium.

filicaule Hpe. - Campylopus.

filifolium $\left\{\begin{array}{l}\text { C.M. M.p. - Campylopus macrophyllus. } \\ \text { Hsch. - Campylopus. }\end{array}\right.$

filiforme $\{$ Hsch. - Campylopus leucogaster.

Schwaegr. - Ângstroemia vuleanica.

flaccidissimum C. M. in Linn. 1874, p. 584.

Ster. Paludic. - Am. merid. : And. Nov. Granat.

flagellaceum C. M. - Campylopus.

flagellare Hedw. M. frond. $I I I, p .1$, , 1 ; Brid. Bryol. univ. I, p. 422 ;

Bryol. eur. 1 (mon. p. 30), t. 68; W. P. Sch. Syn. II ell. p. 84.

Bryum flagellare Dicks. Fasc. III Pl. crypt. p. 6.

D. scoparium var. flagellare H. et T. Muscol, brit, p. 58.

D. strictum Drumm. M. bor. am. I ed. n. 81 .

2. Lignic. - Eur. : Reg. campestr. et mont. zon. intermed, et sept. : deest in Britann. As. : Jenissei sup., Obi, Amour, Japon., Caucas. Afr.: Ins. Canar. Am. sept. : New Brunswick, Ontario, Manitoba, lac. Super., Columb. brit., Indiana, reg. sept, et orient.

Exs, : Mac. Canad. M. n. 35.

Rab. Bryoth. eur. n. 82 et b, 864, $985,1169$.

Sull. et Lesq. M. bor. am. II ed. n. 72.

- var. compactum Jur. Laubm. Oesterr. Ung. p. 42.

Ut typ. - Eur. : German.

« var. subfluitans Aust, in Bull. Torr, bot. Club, VI, p. 344.

In lacunos. rup, - Am. sept. : New York (ster!). 
flagellare $\left\{\begin{array}{l}\text { Engl. Bot. - D. scottianum. } \\ \text { Funk. - D. longifolium. }\end{array}\right.$

flagelliferum C. M. - Campylopus.

flavescens $\mathrm{H}$. et T. - Dichodontium pellucidum var. serratum

flavidum Schwaegr. - Dicranella cerviculata.

flavissimum C. M. - Campylopus.

flexicaule Brid. - D. fuscescens var. flexicaule.

flexifolium $\left\{\begin{array}{l}\text { Hook. - Trichostomum laxifolium. } \\ \text { Hsch. - Campylopus. }\end{array}\right.$

flexuosum $\left\{\begin{array}{l}\text { Brid. - Dicranodontium longirostre. } \\ \text { C. M. p.p. - Campylopus torquatus. } \\ \text { Hedw. - Campylopus, } \\ \text { Hsch. - Campylopus flexifolius? }\end{array}\right.$

$\beta$ fragıle Turn. - Campylopus fragilis.

var. piliferum Turn. . $\left\{\begin{array}{l}\text { Campylopus longipilus. } \\ \text { Campylopus polytrichoides. }\end{array}\right.$

var. Hsch. - Campylopus nanus.

var. Schultz. - Campylopus torfaceus.

var. Wils. - Campylopus Gardneri.

fragile Hook. M. exot. II. p. 10, t. 134; Brid. Bryol. univ, 1, p. 419 ;

C. M. Syn. I, p. 377 ; Mitt. M. Ind. or. p. 15.

D. cuspidatum Griff. Not. p. 416 et Io. pl. asiat. II, t. 91, f. 4.

In pinet. - As. : Nepal., Khasia.

fragile Hedw. - D. spurium.

fragilifolium Lindb. in Bryol, eur. Suppl, fasc. III-IV, Dicr. $t$. II; W. P. Sch. Syn II. p. 91.

2. Lignic, et ad terr. turfac. - Eur. : Lappon., Norveg. As. : Jenissei med. et sup., os fl. Obi. Am. sept. : Lac. Super., reg. sept. occid., ins. Vancouver.

Exs. : Mac. Canad, M. n. 41.

Rab. Bryoth. eur. n. 619.

friabile Hpe. - Campylopus.

frigidum C. M. in Bot. Zeit. 1859, p. 219 ; Mitt. M. austr. am p. 67.

D. validum Hpe, in Linn. 1861-62, p. 522 (fid. Mitt.)

Lignic. - Am. sept. : And. Costa Ricens. Am. merid, : And. Venezuel., Nov. Granat. et Quitens.

fulvastrum Besch. Not. M. der. I. St-Paul et d'Amsterdam, p. 4.

Ster. - Afr. : Ins. Amsterdam.

fulvellum (Dicks.) Sm. Fl. brit. p. 1209; Brid. Bryol. univ, I, p. 813; C. M. Syn. I, p. 371 et II, p. 593; W. P. Sch. Syn. II ed. p. 78.

Arctoa fulvella Bryol. eur. $I$, mon. p. $45, t .86$.

Blindia fulvella Kindb. Laubm. Schwed. u. Norveg. p. 95.

Bryum fulvellum Dicks, Fase. IV Pl. orypt. p. 10, t. XI, f. I.

D. Mœrchii Hsch, in Fl. 1825, I, p. 78 (fid. Limpr.).

D. rupestre $W$. et $M$. Bot. Taschb. pp. 185 et 469 ifid. Brid.).

D. Seligeri Brid, op, cit. p. 429 (? C. M.).

Weisia acuta $H$. et T. Muscol. brit. p, 48 (fid. Brid.).

W. flexuosa Bryol. germ. II, p. 121, t. 35 .

1. Ad terr. humid. et in fiss, rup, - Eur. : Spitzberg, ins. Parry, Island., Lappon., Norveg., Pennia, Scot., Anglia, Tatra, Sudet., Alp. Salisb., Stir., Carinth., Tirol., Helvet., Rhaet., Ticin., Pyren. Am. sept. : Groenland, Nov. Anglia, New York, Oregon.

Exs. . Sull. et Lesq. M. bor. am. II ed. n. 89. 
fulvellum Grev. p.p. - D. hyperboreum.

fulvuin Hook. M. ex. t. 149; W. P. Sch. Syn. 11 ed. p. 85.

Campylopus fulvus Kindb. Laubm. Schwed, u. Norr. p. 81 .

D. interruptum Bryol, eur. I (mon. p. 30), t. 69; C. M. Syn. I, p. 380.

Syrrhopodon? Ra"i Aust. in Bull. Torr, bot. Club, VI, p. 74 .

2. Ad saxa aren. vel granit. - Eur.: Voges., Silv. Nigr., Helvet., Trrol mer., Bavar, Carinth., Stir, Austr.; Pyren. (fid. C. M.). Am. sept. : Nov. Scotia, New Rrunswick, Quebec, Ontario, reg. sept. et orient.

Exs. : Drumm. M. bor, am. II ed, n. 49.

Mac. Canad. M. n. 37.

Rab. Bryoth. eur. n, 508, 983.

Sull. et Lesq. M, bor. am. II ed, n. 73.

Funkii C. M. - Campylopus fragilis.

fuscescens Turn. Muscol. Hib. p. 60, t. 5; W. P. Sch. Syn. I1. edl. p. 89.

D. congestu... Brid. Mant. M. p. 57 et Bryol. univ. I, p. $418 ;$ Bryol. eur. I (mon. p. 36), t. 77; C. M. Syn. I, p. 360 et II, p. 590; Mac.

Can. M. n. 408.

D. congestum var. rupestre Rab. Deutsch. Kryptfl. II, III, p. 146.

D. fagimontanum Rrid. Bryol. univ. $I, p .419$ ?

D. Kinlayanum W. P. Sch. (fid. Limpr.).

D. rupestre Brid. op. cit. p. 419.

D. scoparium $\beta$ fuscescens $H$. et T. Muscol. brit. p. 58 .

D. scoparium var, rupestre Roehl. Devtsch, Fl. III, p. 66.

D. Sendtneri Limpr. Laubm. Deutschl. I, p. 360.

2. Lignic. et rupic. - Eur. : E reg. montan. usq. in alp. ; Spitzberg, ins. Parry, Ursorum. As.: Jenissei, Obi, Altaï, Amour, Saghalien, Japon., Caucas. Am. sept. : Groenland, Labrador, Terr. Nov., ins. Miquelon, Anticosti, New Brunswick, Nov. Scotia, Gaspesie, Ontario, Athabasca, Manitoba, lac. Super., M. Rupestr., Columb. brit., Sitka, ins. Vancouver, Washington, Idaho, Oregon, etc.; Calif. (rar,).

Exs, : Drumm. M. bor, am. I ed. n. 82.

Mac. Canad. M. n. 39.

Rab. Bryoth, eur, n. 865.

* var. angustifolium W. P. Sch, Syn, II ed.p. 90.

Ut typ, in reg. subalp. Eur. et Am. sept.

var, apenninum de Not. - D. fuscescens var. robustum.

"var. brevirostre Kindb. in Mac. Cat. p. 30.

Ut typ. - Am. sept. : Ontario, Columb, brit.

var. cirratum W. P. Sch. - D. brevifolium.

var. compactum Stirt. - D. fuscescens var. flexicaule.

"var. falcifolium Braithw. Brit. Mossfl. 1, p. 153.

Ad radic. Pinor, vetust, - Eur. : Anglia, Germ. sept.

- var. flexicaule W. P. Sch. Syn. I ed. p. 88 et.II ed.p. 90.

D. fuscescens var. compactum Stirt. in Journ, de Bot. 1871, p. 289.

D. congestum var. flexicaule Bryol, eur. l.c.

D. flexicaule Brid. Bryol. univ. I, p. 421.

Lignic. et ad terr. humos. - Eur. : Reg. Pini Pumilionis et Rhododendri. As. : Jenissei sup., Caucas. Am. sept. : C. typ.

* var. longirostre W. P. Sch, ll. cc.

D. congestum Brid. op. cit. pr. max. p.

D. congestum var. longirostre. Bryol, eur. l.c. 
D. longirostre Schwaegr. Suppl. 1, I, p. 42],

Ut typ. - Eur. : Reg. subalp. ; in Jurass. et Alp. vulgatiss. Am. sept.: Cum typ.

" var. remotum Lindb. M. Scand. p. 23.

Ut typ. - Eur. : Suecia, Fennia.

* var, robustum W. P. Sch, l. e. p. 88.

D. apenninum de Not. Epil.p. 622.

Rupic. - Eur.: Reg. alp. Am. sept.: Groenland, Labrador, reg mont. sept.

Eøs. : Rab, Bryoth. eur. n. 1172.

Sull. et Lesq. M. bor. am. II ed. n. 80 .

fusco-croceum Hpe. - Campylopus.

Gardneri C. M. - Campylopus.

Gayanum Mont. -- Angstroemia.

gibbosum Brid. - Cynodontium polycarpum var. strumiferum.

giganteum Brid. - Breutelia.

glaciale Berggr. - D, areticum.

glaucum Hedw. - Leucobryum.

$\beta$ albidum $\left\{\begin{array}{l}\text { Brid. - Leucobryum sediforme. } \\ \text { W. et M. - Leucobryum minus. }\end{array}\right.$

$\gamma$ sanctum Brid. - Leucobryum.

Glaziovii Hpe. - Campylopus.

Goeppertianum Sendtn. - D. scoparium var. orthophyllum.

Goudotii Hpe. in Ann, sc, nat. V ser., III, p. 365.

2. Cortic. - Am. merid.: And. Nov. Granat.

Goughii Mitt. - Campylopus.

gracile Mitt. - Campylopus.

gracilescens W. et M. - Cynodontium.

$\beta$ flavescens Brid, - Dichodontium pellucidum var. serratum.

$\delta$ pusillum Pfeiff. - Cynodontium gracilescens var. inflexum.

Graeffeanum C.M. M. Polyn, p, 62 .

Ster.

- Pac.: Ins. Samoa.

Grateloupii C. M. - Campylopus elongatus.

Grevilleanum Bryol, eur. - Dicranella.

grimmioides C. M. - Campylopus.

griseum C. M. - Campylopus.

groënlandicum $\left\{\begin{array}{l}\text { Brid. - D. elongatum var. orthocarpum. } \\ \text { C. M. - D. labradoricum. }\end{array}\right.$

guadalupense Brid. - Campylopus.

Guilleminianum Mont. - Dicranella.

gymnostomum Mitt. M. Ind, or. p. 14 (1).

D. Billardieri Wils. in Kev Journ. bot. IX, p, 295.

D. rugulosum ej. in op, cit. p. 294.

2.

- As. : Himalaya.

" var, hokinense Besch, in Ann. sc. nat. 1892, I, p. 51.

- As. : Alp. Yunnan.

hamulosum Mitt. in Trans. of the Linn. Soc. 189I, p. 156.

2.

- As, : Japon. 
Harioti C. M. in Fl. 1885, p. 408.

Ster. $\quad-$ Am. nerid. : Fuegia.

havaïanum C. M. - Campylopus.

helenicum C. M. - Campylopus.

Hellerianum Hpe. - Campylopus.

hemitrichium C. M. - Campylopus.

heteromallum Hedw. - Dicranella.

var, 2 Sull. - Dicranella var. orthocarpa.

var. curvalum $\mathrm{H}$. et $\mathrm{T}$. - Dicranella curvata.

var. interruplum Bryol. eur. - Dicranella heteromalla var. interrupta.

$\beta$ minus Wahlenb. - Dicranella subulata.

var. strictum Bryol. eur. - Dicranella heteromalla var. stricta.

Hilarianum Mont. - Microdus.

Hildebrandti C. M. - Campylopus.

himalayanum Milt. op. cit. p. 14.

D. scariosum Wils. in op. cit. p. 294,

2 ?

- As. : Himalaya.

Hoffmanni C. M. in Linn. 1874, p. 592.

Campylopus Hoffmanni Ren. et Card. in Bull. Soc, roy. bot. Belg. 1892, $1, p .147$.

Ster. Paludic. - Am. sept. : And, Costa Ricens.

Hoehneli C. M. - Campylopus.

Holomitrium C. M. - Campylopus.

Homanni Boeck. - Cynodontium virens var. compactum.

Hookeri W. P. Sch. - D. robustum.

Hostianum Schwaegr. $-\left\{\begin{array}{l}\text { D. brevifolium ? (fid. Lindb.) } \\ \text { D. montanum (fid. Limpr.). } \\ \text { D. Mühlenbeckii? (fid. W. P. Sch.). } \\ \text { D. scottianum? (fid. C. M.). }\end{array}\right.$

Howellii Ren. et Card. in Bot. Gaz. 1889, p. 93, ı. 12 B.

- Am. sept. : Washington, Oregon.

humifugum C. M. - Campylopus.

humile C. M. - Campylopus.

hyperboreum (Günn.) Sm. Fl. bril. 111, p. $1277 ;$ Brid. Bryol. unio. 1, p. 458 ; C. M. Syn. I, p. 372 ; W. P. Sch. Synn. I ed. p. 78 et II ed. p. 79 .

Arctoa hyperborea Bryol. eur. I (mon. p. 5), t. 87.

Bryum hyperboreum Günn. Fl. Norveg. n. 1060.

D. fulvellum Grev. Scot. Fl. IV, t. 188 p.p.

1. Ad rup. sicc. - Eur. : Lappon., Alp. Norveg. Am. sept. ; Groenland, Oregon.

Exs : Rab. Bryoth. eur. n. 986.

* var. papillosum Ren. et Card. in Bot. Gaz. 1889, p. 91.

- Am. sept. : Groenland.

hyperboreum Engl. Bot. - Gymnostomum curvirostre.

imponens Mont. in Ann. sc. nat. 1841, p. 241 el Syll.p. $44 ;$ C. M. Syn. J,

p. 366 et $I 1$, p. 592 ; Mitt. M. austr. am. p. 65.

D. involutifolium Sull, in Keut Journ. bot. II, p. 316.

Ster.

- Am. merid. : Patag, austr., terr. Magell.

incanum Hook. - Leucoloma.

incrassalum Hpe. - Campylopus. 
incurvum W. et M. - Fissidens.

inerme Mitt. - Dicranoweisia.

innovans C. M. - Microdus Hilarianus.

insigne C. M. - Leucoloma.

inlermedium $\left\{\begin{array}{l}\text { Crome, - D. Schraderi. } \\ \text { Hedw. - Ceratoảon purpureus. }\end{array}\right.$

interruptum $\left\{\begin{array}{l}\text { Brid. - Dicranella heteromalla. } \\ \text { Bryol. eur. - D. fulvum. } \\ \text { Hedw. - Dicranella heteromalla var. interrupta. }\end{array}\right.$

introflexum Sull. - Campylopus.

involutifolium Sull. - D. imponens.

involutum Lac. Sp. nov. M. Archip. ind, p. 9, t. $6 \mathrm{~A}$.

2. Ster. - As. : Borneo.

involutum C. M. - Campylopus.

Jamesoni $\left\{\begin{array}{l}\text { Hook. - Campylopus concolor. } \\ \text { Tayl. -- Dichodontium. }\end{array}\right.$

japonicum Mitt. in Trans. of the Linn. Soc. 1891, p. 155.

- As. : Japon.

« var. aomoriense Besch. in Ann. sc. nat. 1893, p. 332.

Ster. $\quad$ As. : Japon.

Exs. : Faurie n. 565.

Johannis Meyeri C. M. - Campylopus.

Johnstoni Milt. op. cit. 1886, p. 300.

Ster. $\quad-A f r$ : Kilima N'Djaro.

Joinvillianum Hpe. - Campylopus.

jubulatum W. P. Sch. mss.; Jaeg. Ad. I, p. 92.

- Am. sept. : Iabrador.

julaceum $\{$ Hpe. - Campylopus.

julaceum $\left\{\begin{array}{l}\text { H. f. et W. - Angstroemia longipes. } \\ \text { H. }\end{array}\right.$

juniperifolium Sendtn. - D. palustre var. juniperifolium.

juniperoideum $\left\{\begin{array}{l}\text { Brid. - Leucobryum. } \\ \text { Hsch. - Leucobryum clavatum. }\end{array}\right.$

kaïparense $P a r$.

D. brachypelma C. M. in Bot. Zeit. 1851, p. 550 (1).

D. Menziezii Tayl. (fid. Mitt.).

2. Lignic. et rupic. - Pac. : Nov. Zeland.

Kasbeckianum Kolen. - D. albicans.

kerguelense C. M. Syn. I, p. 370.

D. Boryanum H. f. et W. in sched. M. Antarct.

- Afr. : Ins. Kerguelen.

khasianum Griff. - Campylodontium.

A. majus Griff. - Dicranella Griffithii.

Kindbergii Par.

D. angustifolium Kindb. in Bull. Torr. bot. Club, XVII, p. 86.

Ster. Ad rup. humid. - Am. sept. : Yolumb. brit., fret. Behring, ins.

Vancouver.

Exs.: Mac. Canad, M. n. 409.

(1) Nomen jam. abusum Syn. 1I, p. 595. 
Kinlayanum W, P. Sch. in Un. itin. 1865.

D. fuscescens W. P. Sch. (fid. Limpr.).

- Eur. : M. Scotiae.

Krauseanum Hpe. et Ltz. - Campylopus.

Kroneanum C. M. in Rev. bryol. $1881, p .26$ (nom.).

- Pac. : Tasman.

labradoricum C. M. Syn. I, p. 366.

D. groenlandicum $C . M$. in sched.

D. tenuinerve Zett. in K. Sv. Vet. Akad. Handl, 1876, n. 13.

2. - Eur.: Finmarck. As.: Penins. Tschutschica, Jenissei inf. Am. sepl. : Groenland, Labrador, fret. Hudson, Anti. costi, Terr. nov., ins. Miquelon.

laete-virens C. M. - Campylopus.

laenum Mitt. - Campylopus.

laeve C. M. - Campylopus.

laevigatum C. M. - Campylopus.

lamellatum C. M. - Campylopus.

lamellicosta C. M. - Campylopus.

lamellinerve C. M. - Campylopus penicillatus.

lamprodictyon Hpe. - Campylopus.

lanceolatum Schleich. - Desmatodon latifolius.

lanigerum C. M. - Campylopus

latifolium $\left\{\begin{array}{l}\text { Hedw, - Desmatodon. } \\ \text { Hook, - Desmatodon latifolius var, glacialis. } \\ \text { Turn. - Pottia lanceolata. }\end{array}\right.$

var. piliferum $\mathrm{H}$. et T. - Desmatodon latifolius var. brevicaulıs.

latinerve Mitt. - Campylopus.

laxifolium Brid. Campylopus Nietneri?

laserelichanella varia var. tenella.

tasum Brid. - Barbula unguiculata.

Leichardti Hpe. - Leucoloma.

leioneuron Kindb. in Bull. Torr. bot. Club, XVI, p. 92.

2. Ster. Silv. humid. - Am, sept. : Anticosti.

Eoss. : Mac. Canad. M. n. 44 p.p.

lepidophyllum C. M. - Campylopus.

leptocaule C. M. mss. ; Jaeg Ad. II, p. 641.

leptocephalum C. M. - Campylopus.

- As. : Sikkim.

leucobasis C. M. et Kindb. in Mac. Cat. p. 30.

2. Ad rad, arb. - Am. sept. : M. Selkirk, Columb.,brit.

leucochloron C. M. - Campylopus.

leucogaster C. M. - Campylopus.

leucophyllum. Hpe, mss.; Lac. Sp. nov. M. Archip. ind. p. 10, t. 6 B,

- As.: Java, Sumatra.

leucolomoides C. $M$, in Bot. Zeit. 1851, p. 549.

D. dicarpum Hsch. (fid. Mitt.).

2. Arbor. et rupic. $-P x c$. : Nov, Zeland.

leucopterum C. $M$. in Fl. 1885, p. 407.

2. Terr. - Am. merid. : Fuegia. 
" var, onchophoriopsis C. M. op. cit. p. 468.

Terr. - Am. merid. : Fuegia austr. or.

Liebmanni C. M. - Campylopus.

lineare Brid. - Dichodontium pellucidum var. serratum. longicollum Brid. - Trematodon.

longifolium Hedwo. M. frond. III, p. 24, І. 9; Brid. Bryol. univ. I, p. 430; Bryol. eur. I (mon. p. 32), t.72; C. M. Syn. I, p. 37t; W. P. Sch. Syn. II ed. p. 86.

Bryum longifolium Dicks. Fasc. III Pl. crypt. p. 7.

Campylopus longifolius Kindb. Laubm. Schwed. u. Norveg. p. 87.

D. flagellare Funk Fase, crypt $I I, n .35$.

2. Ad Fagos et saxa. - Eur.: Reg. subalp, ; in montan. et Britann. steril. As. : Jenissei sup., Saghalien, Caucas, Am. sept. : Groenland, lac. Super., M. Rupestr. et Selkirk, ins. Miquelon, reg. orient. Exs.: Rab. Bryoth, eur. n. 81, 939.

* var. compactum Ren. el Card. Fl. Miquelon. - Am. sept. : Ins. Miquelon.

* var, hamatum Jur. Laubm. Oesterr. Ung. p. 43. - Eur. : Alp., Sudet, Boehmerwald, ete.

" var. plumosum Lesq. et Jam, Man. p. 71.

Dicranodontium nitidum Jam. in Bull. Tor\% bot. Club, VI, p, 34.

- Am. sept. : New Hampshire.

"var. strictius Aust. in Bu?l. Torr. bot. Club, VI, p. 344.

In lacun, rup. - Am. sept. : New-York.

«var, subalpinum Milde Bryol. Siles, p. 68.

Dicranodontium longirostre ej. in Bot. Zeit. 1870, p. 714.

Ad rup. siec. - Eur. : Reg. subalp., Westphal., Thuring., Harz. Sudet, etc.

longipilum C. M. - Campylopus polytrichoides.

longirostratum Hedw. - D. spurium.

longirostre Schwaegr. - D. fuscescens var. longirostre.

longisetum Hook. M. ex, t. 129; Brid. Bryol. univ. 1, p. 428; C. M. Syn. I, p. 372; Mitt. M, austi, am. p, 68.

D, macrodon Hpe. in Ann. se, nat. V sér., III, p. 366.

1. Arbor. - Am. merid.: And. Venezuel., Columb., Nov. Granat, et Quitens.; Brasil.

longisetum Brid, - Ceratodon purpureus.

lophoneuron C. M. Syn. II, p. 589.

- Am, sept. : Mexic.

lorifolium Mitt. M. Ind. or. p. 15.

D. cristatum Wils. in Kew Journ. bot. IX, p. 295.

D. scoparium Griff. Not. p. 417 et Ic. pl. asiat. II, t. 82, f. 3; Wils. l. 6 2. - As. : Kashmir, Nepal, , Khasia.

Iubricum Wils, - D. dacipiens.

lutescens C. M. - Campylopus.

? lycopodioides Sw, - Syrrhopodon.

Macounii Aust. - D. elongatum.

macrocalyx Bryol. jav. - Braunfelsia enervis.

macrodon $\left\{\begin{array}{l}\text { Hpe, }- \text { D. longisetum. } \\ \text { Hook, - Leucoloma. }\end{array}\right.$ 
macrophyllum Kze. - Campylopus.

macropus Kze. in Poepp. pl. Chil. III, n. 271 ; C. M. Syn. I, p. 374.

2. Lignic. et rupic. - Am. merid. : Chil. austr.

majus Turn. Muscol. Hib. p. 59; Bryol. eur. I (mon. p. 43), t. 85; C. M. Syn. I, p. 360 el II, p. 590 ; W. P. Sch. Syn. II ed. p. 92.

Bryum reclinatum, foliis falcatis, scoparum effigie Dill. Hist. M. p. 357, $t, 46, f .16 \mathrm{D}$.

D. polysetum Brid. Bryol, univ. I, p. 413 p.p.

D. scoparium T. Tayl. in Ann. and Mag. of nat. hist. 1843, p. 113.

D. scoparium var. $\alpha$ H. et T. Muscol. brit. p. $58, t$. 18 , f. dextr.?

D. scoparium $\beta$ majus W, et M. Bot. Taschb. p. 174.

2. In silvatic.-Eur. : Zon. intermed. et septentr. As. : Jenissei, Saghalien, Amour. Caucas. Am, sept.: Ins. Miquelon, Anticosti, Nov, Scotia, Gaspes., Ontario, ins. Vancouver, Sitka, Washington.

Exs, : Mac. Canad. M. n. 44 p.p.

Rab. Bryoth. eur. n. 654 .

var. Savatieri Besch. - D. Savatieri.

Martianum Hsch, - Leucobryum.

megalophyllum $\left\{\begin{array}{l}\text { Brid. p.p. (fid. Besch.). - Leucobryum Boryanum. } \\ \text { Mont. - Leucobryum neilgherriense. } \\ \text { Raddi (fid. Mitt.). - Leucobryum giganteum. } \\ \text { Raddi (fid. C. M.). - Leucobryum longifolium. }\end{array}\right.$

Menziezi Tayl. in Phytol. I, p. 1093; Hook. f. et Wils. Fl. Antarct. I, p. 128, t. 58 et Handb. p. 412; C. M. Syn. 1I, p. 593 (1).

D. kaiparense (fid. Mitt.).

Arbor. - Am. merid. : Chile. Pac. : Austral, or., Nov. Zeland., ins Auckland, Norfolk; Polynes.

- var. rigidum Hook. f. el Wils. Fl. of the N. Zeal. II, p. 170. - Nov. Zeland.

mexicanum W. P. Sch, in Besch. Prodr. bryol, mexic. p. 20.
2?

- Am. sept. : Mexic.

microcarpum $\left\{\begin{array}{l}\text { Hook, - Cynodontium virens var. Wahlenbergii. } \\ \text { Schrad, - Rhacomitrium. }\end{array}\right.$

microdus Ltz, in Bot. Zeit. 1866, p, 186.

2.

microdus Kze. - Microdus Jiebmanni.

- Am. merid. : Valdiv.

miquelonense Ren. et Card. Fl. Miquel. p. 42 et in Bol. Gaz. 1889, p. 89,

t. XIID; M. am, bor. n. 7 .

Ster. Rupic, et terr. $-A m$. sept. : Ins. Miquelon.

Mittenii C. M. - Campylopus.

mixtum de Not. - Cynodontium gracilescens.

Molkenboëri Bryol. jav. II, p. 225.

Holomitrium dicranoides $D_{3}$. et $M k$. M. frond, ined. Archip. ind. p. 9,

2. 4 el Bryol. jav. I, p. 87 .

2? Ad rad, arbor: - As.: Java.

molle $\left\{\begin{array}{l}\text { C. M. - Leucoloma. } \\ \text { Wils. - D, areticum. }\end{array}\right.$

(1) Cf, Duby in Memoires,... Genève 1869, p. 8. 
montanum Hedio. Sp. M. p. 145, t. 35; Brid. Bryol. univ. I, p. 454; Bryol. eur. I (mon. p. 29), t. 67; C. M. Syn. 1, p. 379; W. P. Sch. Syn. II ed. p. 82.

D. Hostianum Sehwaegr. Suppl. I, I, p. 177 (fid. Limpr.).

D. scottianum var. montanum Hook. et T. Muscol. brit. p. 56.

Weisia truncicola de Not. Epil. p. 598.

2. Lignic. et ad trunc. conifer. - Eur. : E reg. campestr. usq. in subalp., zon. merid. calidior. except. As. : Jenissei inf. et med, Obi, Caucas. Am. sept. : Terra nov., ins. Miquelon, New Brunswick, Nov. Scotia, Gaspesia, lac. Super. et Huron, Manitoba, M. Rupestr., New Ýork, reg. septr.

Exs. : Mac. Canad. M.n. 34.

Rab. Bryoth. eur. n. 109, 798.

Sull. et Lesq. M. bor. am. II ed, n. 71.

«var. flaccidum Wulfsb. in Christiania Vid. Sels. Fork. 1875 et in Rev. bryol. $1885, p, 15$.

$$
\text { - Eur.: Norveg. }
$$

$\left.\begin{array}{l}\text { Moerkianum (fid. C. M.). } \\ \text { Moerkii (fid. Limpr.). }\end{array}\right\}$ Hsch. - D. fulvellum.

Mühlenbeckii Bryol. eur. 1 (mon. p. 38), t. 78; C. M. Syn. I, r. 370 et II, p. 592 ; W. P. Sch. Syn. II ed.p. 90.

Campylopus Rauei Aust. in Coult. Bot. Gaz. I, p. 28.

D. condensatum Hedw. Sp. M. p. 139, t, 34; (fid. Card. in litt. !) Brid. Bryol. univ, $I, p .421$ ?

D. Hostianum Sehwaegr. Suppl. I, p. 177 excl. syn. ?(W. P. Sch.). (1)

D. scottianum Pokorny Vorarb. z. Kryptfl. v. Unt. Oesterr. p. 105.

2. Lignic., ad rup. et terr. lapid. - Eur. : Spitzberg, Septem Ins., Ursorum, penins. Kola, Suec., Sudet., Francon., Khoet., Helvet. occ., Tirol. merid. As. : Jenissei sup., Caucas. Am. sept. : Groenland, Labrador, fret. Smith. Ontario, M. Rupestr. et Selkirk, Columb. brit., Noy. Mexic.; Wyoming?

Exs. : Mac. Canad. M. n. 481.

Rab. Bryoth. eur, n. 527 b, 529, 866 et b.

Sull. et l.esq. M. bor. am. II ed. n. 81 .

Un. itin. 1863, 13? 14.

var. alpinum Pfeff. - D. brevifolium.

var. brevifolium Lindb. - D. brevifolium.

var. negleclum Pfeff. - D. spadiceum.

multisulcatum Duby in Memoires... Genève 1869, t. I, f. 2.

Ster. - Am. merid. : Brasil.

nanum C. M. p.p. $-\left\{\begin{array}{l}\text { Campylopus. } \\ \text { Campylopus pseudo-nanus. }\end{array}\right.$

Naumanni C. M. - Campylopus. neglectum Jur. - D. spadiceum. ? nepalense C. M. - Campylopus. nervifolium Schleich. - D. Starkii.

Nietnerz C. M. - Campylopus. nigrescens Mitt. - Campylopus. nigricaule $\stackrel{\circ}{A}$ gstr. in Oefo... 1872, n. 4, p. 6.

D. kerguelense forma (fid. C. M.!.

- Am. merid. : Archip. Magellan. 
nilgherriense Mitt. - Campylopus neilgherriensis

nipponense Besch. - D. rufescens.

nitidum Mitt. - Campylopus.

nivale C. M. p.p. $-\left\{\begin{array}{l}\text { Campylopus neilgherriensis. } \\ \text { Campylopus. }\end{array}\right.$

nodiflorum C. M. - Campylopus.

Nove Hollandiz Hsch. - Hookeria aurea.

nudum Hpe. - Campylopus.

obliquatum Mitt. in Journ. of the Linn. Soc. 1863, p. 148.

2. Cortic. - Afr. : Ins. Fernando Po.

oceanicum C. M. - Leucoloma tenuifolium.

Erstedtianum C. M. - Campylopus.

orthocarpon Brid. - Dicranella varia var. orthocarpa.

orthocomum C. M. - Campylopus.

osmundioides Sw. - Fissidens.

ovale Hedw. - - Grimmia commutata.

ovatum $\left\{\begin{array}{l}\text { Funk. - Grimmia ovata. } \\ \text { Hedw. - Grimmia commutata. }\end{array}\right.$

pallescens Wils. - Leucoloma Zeyheri.

pallidum $\left\{\begin{array}{l}\text { C. M. - D. scoparium var. pallidum. } \\ \text { Bryol. eur. D. sabuletorum. } \\ \text { W. et M. - Ditrichum. }\end{array}\right.$

palmatum $\mathrm{Sw}$. - Fissidens.

palustre la Pyl. in Brid. Bryol. univ. I, p. 814; Bryol. eur. I (mon. p. 39),

t. 79 ; W. P. Sch. Syn. II ed. p. 94 .

D. Bonjeani de Not. Syll. p. 213 ; C. M. Syn. I, p. 369.

D. scoparium Wils. in Kew Journ. bot. IX, p. 295 p.p.

D. undulatum Auct, anglor.

1 rar. 2. In turfac. - Eur, : In reg. campestr. et mont. zon. interm. et septr. ; Spitzberg. As. : Jenissei med, Obi, Himalaya, Caucas. Am. sept. : Groenland, Terr. Nov., ins. Miquelon, Ontario, Manitoba, Columb. brit., ins. Vancouver, Sitka, Washington, Idaho, Wyoming, Wisconssin, Ohio, Pensilv.

Exs.: Mac. Canad. M. n. 409.

Rab. Bryoth, eur. n. 416,861 a et b, 11062 .

Sull. et Lesq. M. bor. am. II ed. n. 83.

- var, alatum (Barnes) Par.

D. Bonjeani var. alatum Barnes in Bot. Centralbl. 1890, n. 51.

var. atratum (Pfeff.) Par. - Am. sept. : lllinois.

D. Bonjeani var. atratum Pfeff. Bryol. Stud. p. 23.

- Eur. : Alp. Rhaet.

- var. Brewerianum Lesq. in Mem. Calif. Acad. I, p. 7 et in Lesq. et Jam. Man. p. 75 .

- Am. sept. : M. Calif.

- var, calcareum (Braitho.) Par.

D. Bonjeani var, calcareum Braithw. Mossfl, p. 150, t. 21.

- Eur.: Cum typo.

* var. juniperifolium (Sendln.) Par.

D. Bonjeani var. juniperifolium Braithw. Brit. Mossft. p. 149. 
D. juniperifolium Sendtn. in Fl. 1840, I, p. 59 et in Denkschrifı d. K. bot. Ges, zи Regensb. III, p. 144.

cas. Am. sept. : Groenland.

-Eur. : Spitzberg, Scandin., German. As. : Sau-

"va*. polycladum Bryol. eur. $l, c$.

D. Bonjeani var. polycladum C.M. $l$. c.

- Eur. : In turfac. planitiei.

" var, Roellii (Barnes) Par.

D. Bonjeani var. Roellii Barnes in op. et $l$. co.

- Am. sept. : Ins. Vancouver.

«var, Schlotthaueri (Barnes) Par.

D. Bonjeani var. Schlotthaueri Barnes in op. et $l$.cc.

- Am. sept.: Washington, Oregon, Wyoming, ldaho.

palustre $\left\{\begin{array}{l}\text { Brid. - Ceratodon purpureus. } \\ \text { la Pyl. - Campylopus flexuosus (sec. C. M. Syn. 1, p. 401). }\end{array}\right.$

Pancheri $C$. M. in hb. Mus. Paris.

D. Billardieri Besch. in Fl. bryol. Nov. Caled. p. 198.

Lignic. - Pac. : Nov. Caledon.

paramicolum C. M. in Linn. 1874, p. 591 .

Ster. $\quad-$ Am. merid. : And. Nov, Granat.

parvulum ( Dicks. - Dicranella cerviculata var. pusilla.

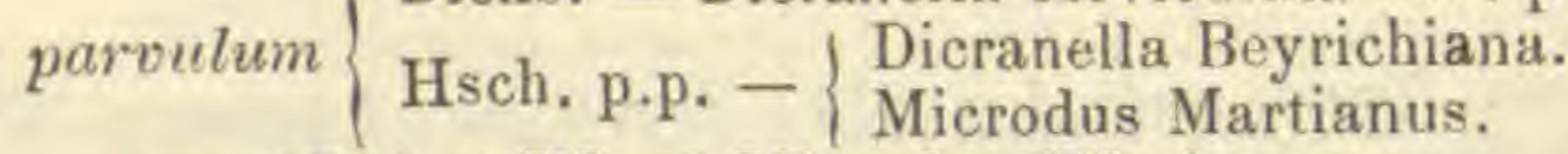

var. H. f. et W. .. Microdus Hilarianus.

patens $\mathrm{Sm}$. - Rhacomitrium.

patulum Wils. p.p. $-\left\{\begin{array}{l}\text { Dicranella. } \\ \text { Dicranella mollicula. }\end{array}\right.$

pauperum $\mathrm{Hpe}$ - Campylopus.

var. minus Hpe. - Campylopus pauper var. minus.

pellucidum $\left\{\begin{array}{l}\text { Drumm. - Barbula fallax (fid. Kindb.). } \\ \text { Hedw. - Dichodontium. }\end{array}\right.$

$\beta$ fagimontanum Brid. -- Dichodontium pellucidum var. fagimontanum.

$\gamma$ servatum Bryol. eur. - Dichodontium psllucidum var. serratum.

var. Sw. - Trichostomum tophaceum.

penicillatum Hsch. - Campylopus.

perincanum C. M. - Campylopus.

Perrottelii $\left\{\begin{array}{l}\text { C. M. - Dicranella tovariensis. } \\ \text { Mont. p.p. - Dieranella. } \\ \text { Mont. p.p. - Campylopus neilgherriensis. }\end{array}\right.$

phascoides Hook. - Garckea.

? phascoideum P. B. - Grimmia apocarpa.

piliferum Schleich. - Grimmia alpestris.

pinetorum Griff. - Campylopus torfaceus.

piriforme Brid. - Campylopus torfacens.

Pittieri Ren. et Card. iu Bull. Soc, roy. bot. Belg. 1892, I, p. 146.

1. Lignic. - Am. sept. : And. Costa Ricens.

planinervium Tayl. - Dicranella.

plano-alare C. M. et Kindb. in Mac. Cat, p. 31.

2. Ster. ? Terr. - Am, sept. : Columb. brit.

platyloma Besch. Fl. bryol. Nov. Caled. p. 196.

Cortic. - Pac. : Nov. Caledon. 
platyneuron Hpe. - Campylopus.

plicatum Lac. Sp. nov. M. Arclip. ind. p. 9, t. 6 B.

2.

- As. : Java.

polycarpum $\left\{\begin{array}{l}\text { Ehrh. - Cynodontium. } \\ \text { H. it T. Dicranoweisia Bruntonï. } \\ \text { Wils. - Cynodontium gracilescens. }\end{array}\right.$

var. curvisetum C. M. - Cynodontium gracilescens var, inflexum.

var, gracilescens C. M. - Cynodontium gracilescens.

var. strumiforum Bryol, eur. - Cynodontium polycarpum var. strumiferum.

var. tenellum C. M. - Cynodontium gracilescens var, alpestre. polymorplum Duby. - D. reflexum. polyphyllum Sm. - Ptychomitrium. polypodioides Sw. - Fissidens.

polysetum Hpe. in Linn. 1859, p. 629.

2. Rupic, - Pac. : Austral. felix.

polysetum $\left\{\begin{array}{l}\text { Brid. - D. majus. } \\ \text { Sw, - D , undulatim. }\end{array}\right.$

var. assimile Dz. et $\mathrm{Mk},-\mathrm{D}$, assimile.

porphyrocaule C. M. - Campylopus.

porphyreodictyon C. M. - Campylopus.

proenorsum C. M. - Campylopus.

procerem C. M. - Campylopus.

proliferum C. M. - Campylopus.

propinquum Hpe. - Campylopus.

proscriplum H. f. et W. - Dicranodontium flexipes.

pseudo-filifolium C. M. - Campylopus.

pseudo-leucoloma C. M. in Linn. 1880-83, p. 397.

Ster.

- Am. merid. : Argentin. Patagon.

pseudo-nanum C. M. - Campylopus.

pteroneuron C. M. - Campylopus.

pudicum (Hsch. (M. Drege). - Campylopus lepidophyllus.

Hsch. (M. Sieber p.p.). - C Campylopus.

pulvinatum

var. argentatum Turn, - Grimmia pulvinata var. Iongipila.

pumilum Mitt. M. austr. am. p. 64.

- Am. merid. : Fuegia, ins. Eremitae.

pumilum $\left\{\begin{array}{l}\text { C. M. - Leucoloma. } \\ \text { Sant. - Dicranella. }\end{array}\right.$

punctulatum $H_{p e}$. in Linn. 1859-60, p. 628.

- Pac. : Alp. Austral. or.

pungens $\mathrm{H}$. f. et W. -

var. lucidum Mitt. - $\{$ D, robustum var. pungens.

purpurascens $\left\{\begin{array}{l}\text { C. M. - Campylopus Wallisii. } \\ \text { Hedw. }\end{array}\right.$

purpureum Hedw. Hedw. - Ceratodon purpureus.

pusillum Hedw. - Ceratodon purpureus.



ramulosum Milt, M. auslr. am. p. 64.
1.

- Am. merid. : Fuegia, ins. Eremitae.

recognitum Roehl, - Dicranella Schreberi. 
rectisetum $\mathrm{Hpe}$ - Campylopus.

recurvatum Schultz. - D. scoparium var. recurvatum.

recurvum Mitt. - Campylopus.

reduncum $\left\{\begin{array}{l}\text { Duby. - D. reflexum. } \\ \text { Hsch. et Reinw. - Campylopus. }\end{array}\right.$

reflexifolium C. M. Syn. I, p. 382; Bryol. jav. I, p. 72, t. 60.

2.

- As. : Java.

reflexifolium Mitt. - D. subreflexifolium.

reflexisetum C. $M$. in Linn. 1874, p. 586.

2. Paludic. - Am. merid. : And. Nov. Granat.

reflexum C. M. Syn. I, p. 373; Bryol. jav. I, p. 67, t. 55 (1).

D. polymorphum Duby in Pl. Jav. Zolling. Coll. n. 2101.

D. reduncum ej. $l$. $c$.

2. Arbor. - As. : Java.

Reinwardti Dz. et Mk. - Dichodontium.

relaxum Wils. - Dicranodontium Didymodon.

rhabdocarpum Sull. in Mem. Am. Acad. IV, 1849, p. 172, t. 3; C.M.

Syn. II, p. 594 ; Lesq. et Jam. Man. p. 73.

2. Arbor. - Am. sept. : M. Rupestr., Arizona, Nov. Mexic.

Exs. : Sull. et Lesq. M. bor. am. II, p. 82.

Richardi C. M. $-\left\{\begin{array}{l}\text { Campylopus. } \\ \text { Campylopus caracasanus. }\end{array}\right.$

Richardsoni Hook, - Cynodontium virens var. Wahlenbergii.

rigens Bessh. in Bull. Soc. bot. Fr. 1885, p. LVI et in Miss. sc. Cap Horn,

V; Bol.p. 258, t. I, f. 3 .

- Am. merid. : Patagon, austr.

rigidiusculum $\mathrm{Hpe.} \mathrm{-} \mathrm{Campylopus.}$

rigidulum Sw. - Dicranella varia var. tenella.

rigidum C. M. - Campylopus.

robustum Hook. f. et Wils. in Lond. Journ. of bot. 1844, p. $542 \mathrm{el} \mathrm{Fl}$.

Antarct. $I I$, p. 406, t. 152, f. 3; C. M. Syn. I, p. 361 et 11, p. 590 ;

Mitt. M. austr. am, p. 66.

D. Hookeri W. P. Seh. in Lechl. Pl. Magell.

2?

Eremitae. Pac. A Am. merid. : Chil., fret. Magell., Fuegia, ins. Campbell.

« var. pungens Hook. f. Handb. N. Zeal. Fl, p. 412.

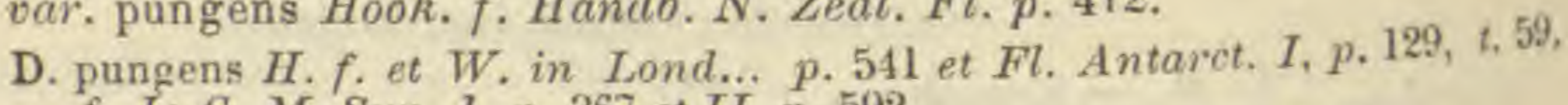
f. I; C. M. Syn. 1, p. 367 et II, p. 592.

D. pungens var. lucidum Mitt. in Journ. of the Linn. Soc. 1876.

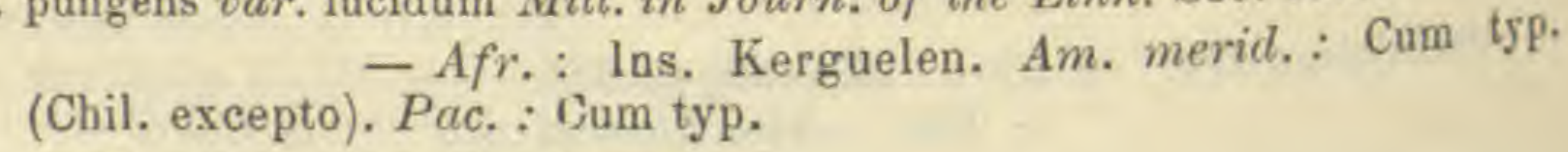

robustum Bryol, eur. - D. elatum.

Rogeri Brid. - Dichodontium pellucidum. rosulatum Hpe. - Campylopus.

rufescens W. P. Sch. in Savatier M. Jap. n. 89.

D. nipponense Besch, in Ann. sc, nat. 1893, p. 332.

Exs. : Faurie n, 86, 567 .

(1) Cf, Duby, Mèmoires... Genève 1869, p. 65. 
" var. lacustre (Besch.) Par.

D, nipponense var. lacustre Besch. l. c.

Exs. : Faurie n. 3504 .

- As. : Japon.

a var. mucronatum (Besch.) Par.

D. nipponense var, mucronatum Besch. $l$. c.

Ess. : Faurie n. 216. -As. : Japon.

rufescens Turn. - Dicranella.

rufifolium Besch. in Ann. sc. nat. 1894, p. 16.

2. Ad terr. in silv. - Pac. : Ins. Marquises.

rugosum $\left\{\begin{array}{l}\text { Brid. - D, undulatum. } \\ \text { Kindb. - D. Schraderi. }\end{array}\right.$

var. rugulosum Kindb. - D. Schraderi.

rugulosum Wils. - D. gymnostomum.

rupestre $\left\{\begin{array}{l}\text { Brid. - D. fuscescenc. } \\ \text { W. et M. - D. fulvellum (fid. Brid.). }\end{array}\right.$

W, et M. - Blindia trichodes (fid. Lindb).

Rutenbergii C. M. - Leucoloma.

sabuletorum Ren, et Card. in Bot. Gaz. 1889, p.9I, t.12 A et M. bor. am. n. 9 .

Cecalyphum condensatum P. B. Prodr, p. 50 ?

D. condensatum Hedw. Sp. M. p. 139, t. 34 p.p. (fid. Card. ex autops.); Brid. Bryol, univ. I, p. 421 .

D. pallidum Bryol. eur. I (mon. p. 39).

D. spurium var. condensatum Sull. et Lesq. M. bo: am. I ed. n, 686, II ed. n. 85, 86; Lesq. et Jam. Man. p. 76.

1. rar. 2. In sabulos. - Am. septent. : Reg. merid.

Saddleanum C. M. - Campylopus.

sanctum Nees. - Leucobryum.

sandwichense Sull. in U. St. Expl. Exp. 1859, p. 3.

- Pac. : Ins. Sandwic.

" var, condensatum Sull. l. c.

Ut et cum typ.

" var. elongatum Sull. l. c.

Ut et cum typ.

Sauteri Bryol. eur. I (mon. p. 33), t. 71; C. M. Syn. I, p. 375 et II, p. 594 ; W. P. Sch. Syn. II ed. p. 87.

Campylopus Sauteri Kindb. Laubm. Schwed. u. Norveg. p. 87.

D. longifolium var. (,id. Boulay M. Fr. $)$.

2. Ad Fagos et rup. - Eur. : Tatra, Beskid., Boehmerwald, Francon.,

Alp. Austr., Bavar. et Algov., Silva Nigr., Helvet., Rhaet., Alp.

Julien., Apenn. tose., Pyr. centr. As. : Caucas.

Eas, : Rab. Biyoth. eur. n. 75 et b.

" var, curvulum Lindb, mss.; Braitho. Bril. Mossfl. p. 158, t. 24.

Ut typ. - Eur. : Scandin.?, Anglia, Gall. centr.

"var. pachytrichum Kindb. in Mac. Cal. p. 260.

Ad ramul. subinund, - Am. septent. : Columb. brit.

Savannarum C. M. - Campylopus.

Savatieri W. P. Sch, in Savatier M. Japon. n. 512.

D. majus var. Savatieri Besch. in Ann, so. nat. 1893, p. 333.

2.

- As. : Japon. 
saxicola W. et M. - Campylosteleum.

Schisti Lindb. - D. Blyttii.

scariosum Wils. p.p. $\left\{\begin{array}{l}\text { Braunfelsia. } \\ \text { D. himalayanum. }\end{array}\right.$

Schleicheri C. M. - Campylopus fragilis.

Schmidii C. M. - Campylopus fragilis.

Schraderi Schwaegr. Suppl. I, I, p. 66, t. 61; Bryol. eur. I (mon. p. 40), t. 80; W. P. Sch. Syn. II ed. p. 95.

Cecalyphum undulatum P. B. Prodr. p. 52

D. affine Funk Fasc, crypt. VI, n. 136.

D. Bergeri Bland. M. frond. exs. III, n. 114; C. M. Syn. I, p. 357.

D. falcatum Schrad. in Schleich. Crypt. helv, n. 15.

D. fastigiatum Schultz Fl. Starg. p. 300.

D. intermedium Crome Samml. Crypt. Gevo, n. 66, p. 21.

D. rugosum Kindb, in Ottawa Naturalist, $1 V, p .61$.

D. rugosum var, rugulosum $e j . l$. c.

D. undulatum Schrad. Spic. Fl. Germ. p. 59 ; Brid. Bryol. univ, I, p. 415. Hypnum scoparium $\beta$ Web. Spic. Fl. Goett. p. 72.

1 rar. 2. Loc. uliginos. - Eur. : Reg. mont. et subalp. As. : Jenissci, Obi, Amour, Sikkim. Am. sept. : Groenland, Terr. Nov., ins. Miquelon, New Brunswick, Anticosti, Ontario, Manitoba, M. Rupestr. et Selkirk, fret. Kotzebuë, Columb. brit,, Wisconssin, reg. sept, et orient.

Exs. : Drumm. M. bor. am. I ed. n. 87, 88.

Mac. Canad. M. n. 45.

Rab. Bryoth. eur. n. 79 et b, 1171 .

Sull. et Lesq. M. bor, am. II ed. n. 84.

“ var. acutifolium Lindb. et Arn. M. As. bor. 1890, II, p. 79.

- As. : Jenissei inf.

Schreberi Hedw. - Dicranella.

var. Grevilleanum Brid. - Dicranella Grevilleana.

Schreberianum Grev, - Dicranella Grevilleana.

Schwaneckeanum Hpe. in Linn. 1852, p. 361.

Ster. Arbor. - Am, sept. : Porto Rico.

sciuroides Sw, - Leucodon.

sclerocarpum H. f, et W. - Dicranella Perrottetii? (fid. C. M.).

scopareolum C. M. in Linn. 1876, p. 238.

Ster. $\quad-A f r$.: Madagascar, ins. Anjouan.

scoparioides W. P. Sch. in Besch. Prodr. bryol. mexic. p. 20.

2? - Am. sept. : Mexic.

scoparium (L.) Hedv. Fund. M. II, p. 92, t. 8, f. 41-42; Brid. Bryol. univ. I, p. 410 ; Bryol. eur. I (mon. p. 34), t. 74-75; C. M. Syn. I, p. 359 et $I I$, p. $589 ;$ W. P. Sch. Syn. II ed. p. 91. p. 359 et $I I, p .589 ;$ W. P. Sch. Syn. II ed. p. 91.
Bryum reclinatum, foliis falcatis, scoparum efligie Dill. Hist. M. p. 357 ,
t. $46, f .16$ A. B. C.

Br. scoparium L. Sp. pl. p. 1582.

Cecalyphum scoparium P. B. Prodr. p. 51.

D. condensatum Hedw. Sp. M. p. 139, t. 34, p.p. (fid. Card. ex autops.) in

D. Dillenii T. Tayl. in Ann. and Mag. of nat. Hist. 1813, p. 113 et in Bot. Zeit. 1843, p. 695.

D. scoparium var, crispulum de Not. Syll.

D. scoparium var, reflectens Brid. l. e. p. 41 ?.

Fuscina scoparia var. reflectens Schrank Baïers Fl. II, p. 452.

Hypnum scoparium var. reflectens Weiss Crypt. Goett. p. 71,

Mnium scoparium var. reflectens Gmel. Syst. nat. II, p. 1328. 
2. Ubique, rarius ad terr. - Eur. : Vulgatiss. As. : Septentr. tota, Japon., Caucas. Am. sept. : Arctic, septentr. et temper.

Exs. : Drumm. M. bor. am. I ed, n. 80.

Mac. Canad. M. n. 42.

Rab, Bryoth, eur. n. $83,530,734,868$.

Sull. et Lesq. M. bor. am. n. 75, 78.

- var, alpestre Hüb. Muscol. germ. p. 236.

D. spadiceum Zett. (fid. Husn. Muscol. gall. p. 35).

Ad tecta stramin. - Eur. : Sudet., Pyren. As. : Altaï.

« var, compactum Ren. et Card. Fl. Miquel.p. 44 ; Boulay M. Fr. p. 484. - Am. sepl. : Ins. Miquelon.

var. crispulum de Not. - D. scoparium.

- var, curvulum Brid. l. c, ; Bryol. eur. et W. P. Sch. ll. cc.

Ad saxa sicc. - Eur. : Reg, alpestr. Am. sept.: Washington, Oregon.

var. flagellare $\mathrm{H}$. et T. - D. flagellare.

" var. flexicaule Ren. et Card. op. et $l, c c$.

In turfac. - Am, sept. : Ins. Miquelon.

var. fuscescens $\mathrm{H}$. et T. - D. fuscescens.

* var, integrifolium Lindb, in Oefv ... XXXIII, p. 555.

D. spadiceum Zett. (fid, Limpr. Deutschl. Laubm. p. 353.)

- Eur, : Spitzberg. Am. sept. : Groënland.

var. majus W. et M. - D. majus.

" var. orthophyllum Brid. Sp. M. I, p. 173 et l. c. p. $412 ;$ Bryol. eur. et W. P. Sch. $l l . c c$.

D. Goeppertianum Sendtn. mss. ; Limpr, Laubm. Deutschl. I, p. 352.

- Eur. : Loc. humidior. Am. sept. : Vancouver.

- var. pallidum Lesq. et Jam. Man. p. 74.

D. pallidum C. M. Syn. I, p. 359 et II, p. 590.

D. scoparium Sull. M. Allegh. n. 155 (fid. C. M.).

D. scoparium var. Sull, et Lesq. M. 3or. am. I ed. $n .61$ et II ed. n. 77 - Am. sept. : Reg. orient.

"var. paludosum Bryol. eur. et W. P. Sch. ll. cc.

In turfac. - Eur. : Passim. Am. sept. : Reg. orient.; Washington.

" var. polycarpum Breidl. in sched.; Limpr. l. c.

- Eur. : C. typ.

" var. recurvatum Brid. et Bryol. eur. ll. cc.

D. recurvatum Schultz Fl. Starg. p. 295.

Ad rup. umbros. humid. - Eur. : Passim. Am. sepl. : Vancouver.

var, rupestre Roehl. - D. fuscescens.

" var. rupicolum H. Müll. Weslf. Laubm. n. 211.

$$
\text { - Eur. : C. typ. }
$$

- var. scopariiforme Kindb. in Bull. Torr, bot. Club, XVI, p. 92.

Lignic. et terr. - Am. sept. : New Srunswick, Nov. Scot., Ontario, M. Rupestr., Columb, brit., ins. Vancouver, Terr. Nov.

Exs.: Mac. Canad. M. n. 43.

* var. squarrosum Lesq. et Jam. l, c.

D. scoparium var. Sull, et Lesq. M. bor, am. I ed. n. 60 et II ed. n. 76. Ad rup. granitic. - Am. sept. : M. Allegb., Pensilv., etc. reg. orient. 
var, spadiceum Ren, et Card. - D. spadiceum.

«var, sulcatum Ren. et Card. op. cit., t. XII c.

Lignic. et in turfac. - $A m$. sept. : Ins. Miquelon.

“var, tectorum H. Müll. l. c. n. 412; Limpr. l. c.

$$
\text { - Eur. : C. typ. }
$$

“ var, turfosum Milde Bryol. siles. p. 71.

In turfac. - Eur.: Passim.

- var. Venturii Mitt. in Trans. of the Linn. Soc. 1891, p. 156.

D. scoparium var. paludosum (fid. Limpr.).

$$
\text { - As. : Japon. }
$$

Griff. - D. lorifolium.

scoparium $\left\{\begin{array}{l}\text { Tayl. - D. majus. } \\ \text { Sull. - D. majus var. pallidum. }\end{array}\right.$

Wils. - D. lorifolium.

Wils. p.p. - D. palustre.

var, $\alpha$ H. et T. - D. majus.

var. Sull, et Lesq. - D. majus. var. squarrosum.

var. Wils. - D, crispifolinm.

var. atratum Brid. -
var. condensatum Brid. -

var. convolutum Brid. -

D. scoparii formae?

var. fastigialum Brid. -

scottianum Turn. Muscol. Hib. p 75, t, 6, f. I; Brid. Bryol. univ. I, p. 455 ; Bryol. eur. I (mon. p. 31), t. 70; C. M. Syn. I, p. 381;

W. P. Sch. Syn. II ed. p. 85 .

Bryum cirratum, setis et capsulis longioribus Dill. Hist. M. p. 377, t. 48, f. $40 \mathrm{E}-\mathrm{H}$. (fid. Lindb.).

Campylopus scottianus Brid. Mant. M. p. 72 .

D. flagellare Engl. Bot, t. 1977 ; ibid. t. 1391 ?

D. Hostianum Schwaegr. Suppl. I, I, p. 177, t. 44 (fid. C. M.); Brid. Bryol, univ, I, $p, 457$.

2. Ad rup. granit. - Eur. B Britann., Normann., Helvet., Austr. inf. et Alp. Jul. (fid. C. M.). Af $r$. : Ins. Canar, Madeir.

Exs. : Mandon M. Madeir. n. 3.

Rab. Bryoth. eur. n. 941.

scottianum $\left\{\begin{array}{l}\text { Drumm. - Cynodontium polycarpum. } \\ \text { Pok. - D. Muihlenbeckii. }\end{array}\right.$

var, montanum H. et T. - D. Mühlenbeckii.

secundum Sw. - Dicranella subulata.

Seligeri Brid. $-\left\{\begin{array}{l}\text { Blindia acuta? } \\ \text { Blindia trichodes ? (fid. Lindb.). } \\ \text { D. fulvellum? (fid. (J. M.). }\end{array}\right.$

Sellowianum Hpe. - Campylopus.

Sellovoii Hsch. - Microdus Hilarianus.

Sendtneri Limpr. Deutschl. Laubm, p. 360.

2. $\sigma^{x}$ ign. Rupic. - Eur. : Sudet.

Sendtneri v. Flot. - D. falcatum (fid. C. M.).

D. Blyttii (fid. Limpr.).

sericeum $\left\{\begin{array}{l}\text { Hsch. - Ditrichum homomallum var. zonatum. } \\ \text { Wils. - Campylopus gracilis. }\end{array}\right.$

setaceo-rigidum Hpe. - Campylopus.

setosum Hook. f. et Wils, in Lond. Journ. of bot. 1844, p. 541; Fl.

Antarct. I, p. 129, t. 158 et Handb. N. Zeal. Fl. p. 412 ; C. M. Syn.

Syn. I, p. 368 et II, p. 592. 
Lignic. et terr. - Am. merid. : Chil., fret. Magell. Pac. : Nov. Zeland., Tasman, ins, Auckland, Campbell.

« var. attenuatum $F l$. Anlarct. l. $c$.

- Pac. : Cum typ.

Sieberianum Hsch. - Leucoloma.

simplex Hedw. - D. varia var. tenella.

sinuosum Brid. p.p. $-\left\{\begin{array}{l}\text { Leucoloma. } \\ \text { Campylopus reduncus. }\end{array}\right.$

smaragdinum C. M. - Campylopus reduncus.

sordide-viride C. M. in Rev. bryol. $1876, p .3$ (nom.).

- Pac. : Austral. (Nov. Valesia).

sordidum Wils. - Blindia.

spadiceum Zett. M. Pyr. p. 70 et in K. Sv. Vet. Akad. Handl. 1876.

D. Bambergeri $W . P$. Sch, mss.

D. Mühlenbeckii var, neglectum Pfeff. Bryol. Stud. p. 23.

D. neglectum Jur. mss.; Milde in Bot. Zeit. 1864 (fid. Kindb. in Mac. Cat, 260).

D. scoparium var. alpestre (fid. Husnot. Muscol, gall. p. 35).

D. scoparium var. integrifolium (fid. Limpr.).

D. scoparium var. spadiceum Ren. et Card. Fl. Miquelon, p. 44.

D. spurium Garov. Enum. p. 17.

Rupic. - Eur. : Finmark., Pyr., summ. Alp. centr. As. : Jenissei, Caucas. Am. seplent. : Ins. Afiquelon, M. Rupestr.

Exs. : Mac. Canad. M. v. 537.

speciosum Hook. f. et Wils. in Lond. Journ. of bot. 1847, p. 291, t, II;

C. M. Syn. I, p. 378; Mitt. M. austr. am. p. 65.

- Am. merid. : And. Nov. Granat. et Quitens.

speciosum Saut. - Geheebia cataractarum.

spectabile W. P. Sch. in Mandon Pl. Boliv. n. 1609.

- Am. merid. : And. Boliv.

Spegaszinii C. M. - Campslopus.

speirophyllum Mont. in Voy. Bonile, Crypt. p. 27 et Syll.p. 45; C. M.

Syn. $11, p .595$.

- Pac. : Ins. Sandwic.

Sphagni Wahlenb. - D. elongatum var. orthocarpum.

spiripes C. M. in Linn. J874, p. 585.

- Am. merid. : And. Nov. Granat.

splachnoides Brid. $-\left\{\begin{array}{l}\text { Blindia acuta. } \\ \text { Cynodontium Schisti. }\end{array}\right.$

spengelianum C. M. - Leucoloma.

spurium Hedvo. M. frond. 11, p. 32, t. 30; Brid. Bryol. univ. I, p. 416;

Bryol, eur. I (mon. p. 41), t. 81; C. M. Syn. I, p. 356; W. P. Sch.

Syn. II ed. p. 96.

Bryum spurium Dicks. Fasc. IV, Pl. crypt. p. 13 ?

C. spurium longirostratum P. B. Prodr. p. $5 \mathrm{i}$.

C. spurium ej. l. $c$.

D. tragile Brid. Mant. M. p. 55.

D. longirostratum ej. $l$. $c$.

Mnium spurium Gmel. Syst. nat. II, p. 1328.

Oneophorus conglomeratus Brid. Irryol. univ. I, p. 405.

0. fragilis ej. op. cit. p. 403.

0 , longirostris $e j$. op. et $l$. co. 
1 rar. 2. In pinet. et ericet., rar. turfac. - Eur. : Reg. intermed. et septentr. Am. sept. : Nov. Scot., Gaspes., Ontario, lac. Super.

Exs. : Drumm. M. bor. am. I ed. n. 90 et 1 I ed. n. 47.

Mac. Canad. M. n. 46 p.p.

Rab. Bryoth. eur. n. $84,1325$.

spurium Garov. - D. spadiceum.

var. condensatum Lesq. et Jam. - D. sabuletorum.

squarrosulum C. M. - Jeucoloma.

squarrosum Sehrad. - Dicranella.

Starkii Web. et Mohr Bot. Taschb. p. 189; Bryol, eur. I (mon. p. 27),

t. 64; C. M. Syn. I, p. 364; W. P. Sch Syn. II ed. p. 80.

D. curvifolium Sehleich, Cent. Pl. helvet, IV, n. 14.

D. nervifolium ej. (nom. eron. in Brid. et Schwaegr.) (1).

Oncophorus Starkii Brid. Bryol. univ, I, p. 394.

1. Ad rup. et terr. precip. granit. - Eur. : Reg. subalp. et alp. (ubi vulgatiss.) ; Spitzberg, ins. Ursor. As. : Caucas. Am. sept. : Labrador, Gruenland, fret. Smith, Terr. Nov., Gaspes., M. Rupestr. et Selkirk, Columb. brit., ins. Vancouver, Washington, Idaho, M. Alb., reg. or.

Ecs.:Drumm, M. bor. am. I ed, n. 83.

Mac. Canad. M. n. 30.

Rab. Bryoth. eur. n. 869.

Sull, et Lesq. M. bor. am. II ed. n. 70.

var. major Drumm. - D. Drummondii.

var. molle Wils. - D. arcticum.

stellatum Brid. - leptodontium.

stenocarpum C. M. - Campylopus.

stenodictyon Kindb. - Monocranum.

stenopus (erratim !) C. M, - Campylopus stenocarpus !

stramineum $\left\{\begin{array}{l}\text { Lindb. - D. albicans. } \\ \text { Mitt. - Campylopus. }\end{array}\right.$

striatulum Mitt. in Trans. of the Linn. Soc. 1891, p. 156.

Ster. - As. : Japon.

strictulum C. M. in Linn. 1874, p. 587.

- Am. merid. : And. Nov. Granat.
strictum Schleich. Cent. III Pl. helv. n. 26; Brid. Bryol. univ. I, p. 459; Bryol. eur. I (mon. p. 28), t. 66; C. M. Syn. I, p. 376; W. P. Sch. Syn. II, ed. p.

D. elongatum var. minor Drumm. M. bor. am. I ed. n. 81 .

2. Lignic. et ad rad. arbor., rar, terr. - Eur. : Rar.: Brandeb., Salisb., Stir., Carniol., Tirol., Valesia, M. Sempione, Bosnia, Alp. Sabaud., Gall. centr.(Arvernia), Pyr. centr.; M. Pind. Thessaliae (C. M.). Am. sept. : New Brunswick, lac. Super., Manitoba, Athrbasca, Columb. brit., fret. Behring, ins. Vancouver, Washington, Oregon, Montana, Idaho, M. Calif.

Exs. : Mac. Canad. M. n. 33.

strictum $\left\{\begin{array}{l}\text { Drumm. - D. flagellare. } \\ \text { Sm. - Ceratodon purpureus. }\end{array}\right.$

strigulosum C. M. in Bull. Soc, roy. bot. Belg. p. 147.

1. Iignic. - Am. sept. : And, Costa-Ricens.

(1) Cf. Limpr. Laubm. Deutschl, I, p. 342. 
strumiferum $\{$ C. M. - Cynodontium polycarpum var. strumiferum. Wils. - Cynodontium virens.

Stuhlmanni Broth, in Engler's Bot. Jahrb. 1894, p. 177.

2. $\quad-A f r$. : Tropic. or. (reg. lacustr.).

? stygium Brid. Bryol. univ. I, p. 444; C. M. Syn. I, p. 645 (1).

Ster. $\quad-$ Eur. : Alp. Delphinat.

subaggregalum $\mathrm{R}, \mathrm{Br}$. - D. dicarpon.

subarctocarpum Hpe. - Campylopus.

subbasilare Drumm. -- Fissidens.

subconcolor Hpe. - Campylopus.

subconfine Besch. Not. M. des I. S. Paul et d'Amslerdam, p. 4.

Ster. - Afr.: Ins. Amsterdam.

subcuspidatum Hpe. - Campylopus.

suberectum Hpe. in Linn. 1859, p. 629.

- Pac. : Austral. felix.

subexasperatum C. M. - Campylopus,

subfalcatum Hsch. - Campylopus.

subgriseum Hpe. - Campylopus.

subimmarginalum C. M. - Leucoloma.

subincrassatum Hpe. - Campylopus.

sublencogaster. $\left\{\begin{array}{l}\text { Aust. - Campylopus Donnellii. } \\ \text { C. M. - Campylopus. }\end{array}\right.$

subluteum Mitt. - Campylopus.

subnanun C. M. - Campylopus.

subpalustre C. M. et Kindb. in Mac. Cat. p. 33.

1 rar. 2. Rupic. et terr. - Am. sept, : Columb, brit., M. Rupestr. subpolyanthus C. M. - Campylopus.

subpungens Hpe. in Linn. 1859. p. 629.

- Pac. : Austral. felix.

subreconditum Geh, et Hpe. - Campylopus.

subreflexifolium C. M. in Bot. Zeit. 1864, p. 349.

D. brevisetum Wils, in hb. Ind, or. n. 53.

D. reflexifolium Mitt. M. Ind. or, p. 15.

- As. : Khasia, Assam.

subscoparium W. P. Sch. - D, cosium.

subulatum $\left\{\begin{array}{l}\text { Griff. - Dicranella divaricata. } \\ \text { Hedw. - Dicranella. } \\ \text { Roehl. - Rhacomitrium protensum. }\end{array}\right.$

var. curvatum Rab. - Dicranella curvata.

subulifolium Kindb, in Bull. Torr. bot. Club, XVI, p. 87.

Lignic, - Am. sept. : Reg, sept. occid., ins. Vancouver.

sudeticum Schwaegr. - Dicranella subulata.

sulcatum Kindb, in op. et $l$. cc.

2. Lignic. et terr, - Am. sept. : Columb. brit., ins. Vancouver.

Exs. : Mac. Canad, M. n, 406.

sulcatum C. M. - Dicranella Guilleminians.

(1) In Bryol. eur, et W. P. Sch. Syn. deest; spec, dubia. 
Sumichrasti Duby in Memoires.... Genève, $1869, t .3, f . I$. - Am. sept. : Mexic.

sumnamense C. M. - Campylopus.

tabulare Rehm. M. Afr. austr. n. 32.

- Afr. : C. B. Sp.

tamarindifolium Turn. - Fissidens incurvus var. tamarindifolius. tasmanicum H. f. - Dichodontium.

taxıfolium Sw. - Fissidens.

tenui-cuspidatum C. M. Bryol, austr. Georg. p. 23.

Ster. In graminos. - Am. merid. : Austro-Georg.

tenuifolium $\left\{\begin{array}{l}\text { Brid. - Dicranella varia var. tenuifolia. } \\ \text { H. f. et W. - Blindia. }\end{array}\right.$

tenuinerve Zett. in K. Sv. Vet. Ak, Handl. 1876.

D. labradoricum (fid. Lindb. et Arn. M. As. bor. 1890, II, p. 77). - Eur. : Finmark. Ami. sept. : Ins. Miquelon.

tenuirostre Kze. - Microdus.

thraustum $\{$ Hpe. - Leucoloma.

| W. P. Sch. - D. viride.

terebrifolium C. M. - Campylopus.

Thwaitesii Mitt. - Campylopus.

torquatum Mitt. - Campylopus.

torquescens $\mathrm{Br}$. - Cynodontium gracilescens var. alpestre.

toriile W. et M. - Ditrichum.

? tortuosum Hpe, in Linn. 1852, p. 361 .

Ster. Terr. - Am. sept. : Ins. Porto-Rico.

trachyblepharum C. M. - Campylopus.

trachythecium C. M. - Campylopus.

trichodes Wils. $M$, brit. $n, \boldsymbol{7 7}$.

- Eur. : Britann. (sine loc. spec.).

trichophyllum Hpe, in Linn. 1871-73, p. 515.

- Pac. : Ins. Chatham.

trichopodon Mitt. mss.; Hook. f. Handb. N. Zeal. Fl. p. 411.

- Pac. : Nov. Zeland.

tricolor C. M.-- Campylopus.

truncatum C. M. - Campylopus.

truncorum W. P. Sch. in Lechler pl. Chil. n. 612.

Lignic. - Am. merid. : And. Valdiv.

Tundrae Lindb. et Arn. M. As. bor, 1890, II, p. 82.

2. Ad. terr. humid. - As. : Jenissei inf.

turfaceum $\left\{\begin{array}{l}\text { C. M. - Campylopus. } \\ \text { Mitt. - Campylopus torquatus. }\end{array}\right.$

uncinatum $\left\{\begin{array}{l}\text { C. M. - Dicranodontium. } \\ \text { Sm. - Dicranella cerviculata var. pusilla. } \\ \text { Wils. - Dicranodontium dicticyon. }\end{array}\right.$

undulatum Voit M. Herb. p. $39 ;$ Bryol. eur. I (mon. p. $\quad$ ), t. 82, 83; C.

M. Syn. I, p. 355; W. P. Sch. Syn. 11 ed. p. 97.

Bryum rugosum Hoffm. Deutsch. Fl. II, p. 39. Bryum rugosum Hoffm. Deutsch. Fl. II, p. 39.
D. polysetum Su. M. Suec. pp. 34 et 87, t. $3, f .5 ;$ Brid. Bryol. unit. I,
p. 413 p.p.

D. rugosum Brid. op. cit.p. 414, 
1 rar. 2, Loc. humid. - Eur. : Reg. campestr. et mont. ; deest in

Britann. As. : Jenissei, Obi, Kamschatka, Caucas. Am. sept. : Ins.

Miquelon, New Brunswick, Ontario, Manitoba, Columb. brit., ins.

Vancouver, reg. orient.

Exs. : Drumm. M. bor. am. I ed, n. 85.

Mac. Canad. M. n, 48.

Rab. Bryoth. eur. n. 80, 867.

Sull, et Lesf. M. bor. am. II ed. n. 87.

"var. laevigatum C. M. in Act. hort. Petrop.

- As. : Caucas.

undulatum \{ Auct. angl, - D, palustre.

var. Drumm. - D. Drummondii.

undulifolium C. M. el Kindb. in Mac. Cat. p. 32 ,

2. Terr. - Am. sept. : Ins. Vancouver.

ustulatum Brid. - Calymperes Afzelii.

vaginatum Hook. - Dichodontium.

H. f, et W. - Dichodontium Jamesoni.

validum Hpe, in Linn. 1861-1862, p. 522.

D. frigidum C. M. (fid, Mitt.).

2. In silv. - Am. merid. : And. Nov. Granat.

varium $\left\{\begin{array}{l}\text { Drumm. p.p. - A Angstroemia Iongipes. } \\ \text { Hedw. - Dicranella. }\end{array}\right.$

var. rufescens Brid. - Dicranella rufescens.

var. tenuifolium Bryol. eur. - Dicranella varia var. tenuifolia.

var. viride $\mathrm{H}$. et T. - Dicranella varia.

Venturii de Not. Epil. p. 616.

D. scoparium var. paludosum (fid. Limpr.).

In palud. mont. - Eur. : Scot., Angl., Cambrovall., ltal.

verticillatum $\mathrm{H}_{\mathrm{pe}}$ - Campylopus.

vesiculare Hpe. in Ann: sc. nat. V ser., 111, p. 337.

2 .

- Am. merid. : And. Nov. Granat.

villicaule $\mathrm{Hpe}$ - Campylopus.

virens $\{$ Hedw. - Cynodontium.

virg Wahlenb. - Cynodontium virens var. Wahlenbergii,

virginicum Aust. - Campylopus.

viride (Sull. et Lesq.) Lindb. in Hedroigia, 1863, p. 70 ; Bryol. eur. Suppl.

III-IV, Dicr. t. I; W. P. Sch. Syn. II ed. p. 83; Lesq. et Jain. Man. p. 69 .

Campylopus viridis Sull. M. of U. St. p. 103 et Ic. M. p. 28, t. 17; Sull. et Lesq. M. bor am. I ed. n. 72.

D. thraustum $W . P$. Sch. mss.

2. Arbor. - Eur. : Fennia, German., Austria, Salisb., Stir., Carinth., Carniol., Tirol., Helvet., Bavar, Silva Nigra, Voges., Ital. super. As. : Caucas, Am. sepl.: Terr. nov.. New Brunswick, Ontario, M. Rupestr. ; a Nov. Angl. usq. ad Ohion.

Exs. : Mac. Canad. M. n. 35 .

Rab. Bryoth. eur: n. 735 et b, 1061, 1110 , 1326.

Sull. et Lesq. M. bor, am. II ed. n. 91.

"vor. irroratum Mulo. Bayer's Laubm. p. 40 ,

- Enr. : Alp. Bavar. 
viridissimum $\mathrm{Sm}$. - Zygodon.

viridulum $\left\{\begin{array}{l}\text { Sm. - Fissidens exilis. } \\ \text { Sw. - Fissidens bryoides. }\end{array}\right.$

vulcanicum Brid. - «ngstroemia.

Walkeri Mitt. - Campylopus.

Wallisii C. M. in Linn. 1874, p. 590.

- Am, merid. : And. Nov. Granat.

Widgrenii C. M. - Campylopus.

xanthodon Hedw. - Weisia viridula.

xanthophyllum Mont. - Campylopus truncatus.

Zeyheri C. M. - Leucoloma.

Zollingerianum C. M. - Campylopus.

zygodonticarpum C. M. - Campylopus (1).

DIDYMODON Hedw. M. frond. IIl, p. 8 et II, p. 72. (40 spec.). abyssinicus W. P. Sch. in W. Sch. M. Abyss.

$$
\text { - Afr. : Abyss. }
$$

acutifolius Jaeg. - Leptodontium.

aeruginosus Hook. - Ditrichum glaucum var, brevipedunculatum. aggregalus Jaeg. - Leptodontium.

alpigenus Jur, - D, rubellus var. dentatus.

angustatus Jaeg. - Barbula.

apiculatus var. $\alpha$ W. Arn. - Desmatodon latifolius var. glacialis.

A nomodon de Not. Epil. p. 564; W. P. Sch. Syn. II ed.p. 161.

D. rubellus (fid. Limpr. Deutschl. Laubm. p. 545).

Trichostomum Anomodon Bals. et de Not. Syll. p. 191 ; C. M. Syn. $I I, p .625$.

Syn. Ad vias. - Eur, : Ital. (Neapol.).

arislatus Lindb. - Dicranodontium.

asperulus Lindb. - Dicranodontium asperulum var. scoticum.

aureus de Not. - Ditrichum subulatum.

Baden-Powellii Kindb, in Ottawa Naturalist, V, p. 179.

2.

- Am. sept. : Fret. Behring.

Benthami Arn. - Trichostomum mutabile.

Blyttii Hartm. - Desmatodon Laureri.

bombayensis (C. M.) Jaeg. Ad. I, p. $2 \mathrm{I} 6$.

Tortula bombayensis Mitt. M. Ind. or, p. 28.

Trichostomum bombayense C. M. Syn. II, p. 628 .

2.

- As. : Bombay.

brachydontius Wils. - Trichostomum mutabile.

(1) In Enum. Kindberg. nomina nuda :

D. albo-alare $C . M$. arcuatipes $C, M$. arenarium Ren. et Card. blindiaceum $C . M$. callocaulon C. M. chiloënse C. $M$. chryso-drepanium C. M. cylindropyxis C. $M$. exile $C . M$.

D. helvolum $C, M$. nano-caespitosum C. $M$. orthopyxis Schlieph, et C. M. palliceum C.M. Pilopogon C. M. pseudo-australe C. M. pseudo-truncorum C. M. subsetosum C. $M$. subtenuifolium Sehlieph. et C. M. 
bracleypus Hpe. - Dicranum brevisetum.

brasiliensis Jaeg. - Leptodontium.

brevisetus Jaeg. - Leptodontium.

Biuntoni H. et T. - Dicranoweisia.

bulhosus Hartm. - Pottia latifolia.

bullatus Hartm. - Pottia latifolia var. pilifera.

caespitosus Mitt. - Amphoridium.

calyptralus Tayl. - D. cylindricus.

Camusi Husn. - Diphyscium foliosum var. acutifolium.

canadensis Kindb. in Mac. Cat.p. 44.

2. Rupic. - Am. sept. : M. Rupestr.

capensis Spreng. - Barbula atro-virens.

capillaceus W. et M. - Distichium.

cernues Sw. - $\{$ Bryun pendulum (fid. Brid.).

Cinclidotus de Not. Bryum uliginosum (fid. Lindb.).

cirifolius $\left\{\begin{array}{l}\text { Harv. - Distichium capillaceum. } \\ \text { Jaeg. - Leptodontium. } \\ \text { Mont. - Ditrichum plicatum. }\end{array}\right.$

citrinus Jaeg. - Leptodontium.

cordatus Jur, in Bot. Zeit. 1864 et 1866, p. 177, c. ic. ; W. P. Sch. Syn.

II ed.p. 162.

Barbula cordata Lindb.

Trichostomum cordatum Milde Bryol. Sil. p. 103.

2. $\sigma^{*}$ et fr. ign. Muric. - Eur. : Helvet. or., Saxon, occ., Thuring., Rhoengeb., Wuirtemb., Austria. inf., Hungar., Stir., Siles., Etruria. As. : Caucas.

Exs. : Rab. Bryoth. eur. n. 923,959 et b.

crenulatus Mitt. - Rhabdoweisia.

crinalis Tayl. - Ditrichum.

crispifolius Mitt. - Cynodontium.

crispulus Wils. (fid. C. M.). $-\left\{\begin{array}{l}\text { Trichostomum mutabile. } \\ \text { Trichostomum. }\end{array}\right.$

cuspidatus (Bryol. jav.) Jaeg. Ad. 1, p. 216.

Trichostomum cuspidatum Bryol. jav. $I, p, 96, t .78$.

2. Arbor. - As.: M. Java.

cuspidatus W. P. Sch. - Ceratodon purpurens var. Graefii. cyathicarpus Mitt. - Amphoridum. cylindricus (Br.) Bryol. eur. II (mon. p. 5), t. 187; W. P. Sch. Syn. II
ed. p. 164.

D. calyptratus Tayl. in Lond. Journ. of bot. 1848, p. 188 ; C. M. Syn. I,

D. Iongifolius Griff. Not. p. 433 et Ic. pl. asiat. II, t. 80, f. 4.

Mollia tenuirostris, in Lond. Journ. of bot. 1841, p. 376.

Tortula cylindrica Lindb. M. Scand. p. 21.

T. tenuirostrisica Mitt. M. Ind. or. p. 28.

Trichostomus Mitt. M, austr. am. p. 148.

Tr. tenuirostre eylindricum $C . M$. Syn.,I, p. 586 et II, p. 627.

Weisia cirrata Lindb. Trichost. Eur. p. 15.

W. colindrita vas: cylindrica Hüb. Muscol. germ. p. 127.

univ. I, p. 806.

2. Ad rup. et H. et T. Muscol. brit. II ed. p. 83, Suppl. 3.

tann., Palat. granit.; calcar. fugit. - Eus. : Norveg. occ., BriStir., Italat., Voges,, Silva Nigr., Thuring., Sudet., Salisburg., Sti., Ital. As. : Nepal., Siklim, Khasia, Ceylan. Am. sept. ; Groen- 
land, ins. Miquelon, Ontario, M. Alb., Allegh., Catskill; Pensilv. Am. merid. : And, Quitens.

Exs, : Rab. Bryoth. eur. n. 1266.

Sull, et Lesq. M. bor, am. II ed, n, 1266.

«var. Daldinianus de Not. Epil. p. 165 ; W. P. Sch. l, c. p. 165.

Ut typ. - Eur. : Seotia, Ital. sup. (lac. Major.).

«var. gemmiparus W. P. Sch.l. c.

Lignic. - Eur. : Alsatia.

"var. Holtii Braithw. Brit. Mossfl. p, 248.

- Eur. : Britann.

« var. irriguus Limpr. Laubm, Deutschl. I, p. 571.

Ster. In rivul. - Eur. : Riesengeb.

“var, robustus W. P. Sch.l, c.

Ut typ. - Eur. : Britann.

cylindricus Wahlenb. - Trichodon.

densifolius Mitt. - Leptodontium.

dentalus $\left\{\begin{array}{l}\text { Jur. - Didymodon rubellus var. dentatus. } \\ \text { Mitt. - Leptodontium. }\end{array}\right.$

denticulatus W. P. Sch. - Philonotis fontana.

denudatus Lindb. - Dicranodontium longirostre.

dicranoides Griff. - Dicranodontium Didymodon.

distans Jaeg. - D. leptocarpus.

distichus $\left\{\begin{array}{l}\text { Brid. - Distichium capillaceum var, brevifolium. } \\ \text { Schwaegr. - Eustichia longirostris. }\end{array}\right.$

duriusculus Wils. - Barbula.

epunclatus Jaeg. - Leptodontium.

erubescens Mitl. in Hook. f. Handb. N. Zeal. Fl. p. 421.

1.

filescens Jaeg. - Leptodontium.

flavicans Funk. - Barbula obtusifolia.

flexicaulis Brid. - Ditrichum.

flexifolius (Dicks.) Hook. et Tayl. Muscol. brit. II ed. p. 45, t. 20 ; Bryol. eur. II (mon. p. 6), t. 188; W. P. Sch. Syn. II ed. p. 163.

Bryum flexifolium Dicks. Fase. III Pl. crypt. p. 5, t. 7, f. 9.

Desmatodon flexifolius Hpe. Veget. cell. Coll. $n .112$.

Leptodontium flexifolium $e j$. in Linn. 1847, II, $p .70$.

Trichostomum flexifolium Sm. Fl. brit. III, p. $1246 ;$ Brid. Bryol.; univ. $I, p .499 ; C, M$, Syn. I, p. 577 et II, p. 625.

Zygotrichia cylindrica Tayl, in Mac-Kay Fl. Hibern. p. 26 (fid. C. M.).

2. In lapidos. et turfac. exust., ad tecta stramin. - Eur. : Britann. (copiose); rar. in Normann., Hercynia, Westphal., Luxemb., Voges, ; Hassia sup, et Palat. (ster.) ; Helvet.? Lusitan. (fid. C. M.). Afr.: M. Cameroon, ins. Fernando Po.

Exs. : Rab. Bryoth. eur, n, 662, 1265.

"var. gemmiferus W. P. Sch. l, c.

Ut typ. - Eur, : Anglia, Normann.

fontanus Relem. M. Afr. austr. n. 82.

Ster. - Afr. : Natal.

fragilis $\mathrm{H}$. f. et Wils. - Barbula Drummondii. gigonteus Jur. - Geheebia cataractarum. glacialis H. f. et W. - Ditrichum. glaucescens W. et M. - Ditrichum. 
gracilis $\left\{\begin{array}{l}\text { Hook. - Pilopogon, } \\ \text { W. P. Sch. - Zygodon. }\end{array}\right.$

grimmioides Duby. - Campylopodium euphorocladum.

Hendersoni Ren. et Card, in Bot. Gaz. 1890, p. 40, t. 5 c.

2. In fiss. rup. - Am. sept. : Oregon.

heteromallus $\mathrm{H}$, et T. - Ditrichum.

homomallus Hedw. - Ditrichum.

ictericus de Not. - Ceratodon chloropus.

inclinalus Sw. - Distichium.

insularis Besch. Fl. bryol. Nov, Caled. p. 204.

2. Terr. - Pac. : Nov. Caled.

interruptus Mitt. - Trichostomum.

Jamesoni Jaeg. - Barbula.

Jenneri W. P. Sch. - Cynodontium polycarpum (fid. Limpr.).

Klolzschyi Schwaegr. - Brachymenium Sellowianum.

Knysmæ Rehm. M. Afr. austr.

$$
\text { - Afr. : C. B. Sp. }
$$

Lamyi W, P. Sch. Syn. II ed. p. 163.

Trichostomum Lamyanum ej. in Boulày Fl, erypt. Est Fr.

2. Ad rup. trachyt. - Eur. : Gall. centr. (M. Dore Arverniae).

lapponicus Mitt. - Amphoridium.

latifolius Wablenb. - Desmatodon cernuus.

laxifolius Mitt. - Oreoweisia.

leptocarpus Br. et Sch. in W. Sch. M. Abyss. II, n. 462.

D. distans Jaeg. Ad. I, p. 213.

Trichostomum distans Hpe. in C. M. Syn. I, p. 582.

1. Paludic. - Af $r$, : M. Abysin.

longicaulis Jaeg. - Leptodontium.

longifolius (Griff.) Jaeg. Ad. I, p. 214.

Barbula longifolia Griff. Not. p. 410 et Io. pl. asiat. II, t. 79, f. II.

Tortula longifolia Mitl. M. Ind, or, p. 28.

$$
\text { - As. : Khasia. }
$$

longifolius $\left\{\begin{array}{l}\text { Griff. - D. cylindricus. } \\ \text { H. f. et W. (in sched.). - Ditrichum Hookeri. }\end{array}\right.$

H. f. et W. (Fl, N. Zeal.). - Lophiodon strictus.

var, penicillatus eor. - Lophiodon strictus.

var. tenuiflorus eor. - Ditrichum hyalinum.

longirostris W. et M. - Dicranodontium.

luridus Hsch. in Spreng. Syst. Veget. IV, p. 173; Bryol. eur. II (mon.

p. 4), ८. I86; W: P. Sch. Syn. II ed.p. 161.

Barbula deusta Brid. Bryol. univ. I, p. 553.

B. lurida Lindb. M. Seand. p. 22.

B. trifaria Mitt. in Journ. of the Linn. Soc. I, Suppl. p. 36.

Bryum trifarium Gmel. Syst, nat. II, p. 1331.

Cynodon luridus Brid. Br. univ. I, p. 818 .

Cynodontium trifarium ej. $\mathrm{Sp} . M ., \mathrm{I}, \mathrm{p} .157$,

Cynontodium trifarium Hede. Sp. M. I, p. 57.

D. trifarius Sw. M. Suec p. 28; Brid. Bryol. univ. I, p. 508; Drumm. $M$. bor am. I ed. $n$, 120 .

Swartzia trifaria Hedw. M. frond. II, p. 76, t. 28 ,

Trichostomum linoides Engl. Bot. t. 2295 .

Tr. Luridum Spr. in Ann, and Mag, nat, hist. II, III ser., 1849. 
Tr. trifarium Sm. Fl, brit. III, p. 1235 (fd. C. M. ; non! fid. Lindb. Trich. Eur. p. 16); C. M. Syn. I, p. $5 \%$.

2. In terr. argill. arenac, et ad rup. aren. - Eur. : Passim. As. : Caucas., Persia, Afr. : Alger. Am. sept. : Niagara, M. Rupestr., lac. Erie, Minnesota.

Exs. : Mac. Canad. M. n. 64.

Rab. Bryoth. eur. n. 661 et b.

a var. cuspidatus W. P. Sch. l. c.

Muric. - Eur. : Hassia. Am. sept. : Passim.

« var, intermedius Rutle in Warnst. Moosfl. Prov. Brandenb. p. 40 (1). Muric. - Eur. : Brandeb.

luteolus Jaeg. - Leptodontium.

luteus Tayl. - Leptodontium.

Macromitrium W. P. Sch. - Trichostomum Bescherellei.

medius Duby. - Campylopodium euphorocladum.

megalocarpus Arn. - Mielichloferia Jamesoni.

mexicanus Besch. Prodr. bryol. mexic. p. 28.

$$
\text { 1. } \quad-A m \text {. sept. : Mexic. }
$$

Mildei W. P. Sch. Syn, 11 ed. p. 166 (2).

Ster. Rupic. - Eur. : Silesia.

mollis W.P. Sch. op. cit. p. 167.

Ster. Terr. - Eur. : Alp. Sabaud. (M. Blanc).

Neasii Mitt. M. Ind. or, p. 23.

Trichostomum Neesii Bryol, jav, II, p. 225.

2.

- As. : M. Java.

nepalensis Brid. - Campylopus?

nervosus $\mathrm{H}$. et T. - Barbula atro-virens.

oblongifolius Hook. - Barbula obtusifolia,

obscurus Kaulf. - Dicranoweisia Bruntoni.

oeneus W. P. Sch. in Bescl.. Prodr. bryol. mexic. p. 28.

Tortula oenea Mitt. M. austr. am. p, 162.

Trichostomum oeneum C. M. Syn. II, p. 628.

Syn.

- Am. sept. : Mexic., Guatemala.

ovatus Jaeg, - Barbula,

pallidus P. B. - Ditrichum.

papillatus Hook. f. et Wils. in Lond. Journ. of bot. 1844, p. $544 ;$ Fl. of the N. Zeal. II, p. 73, t. 85, f. 2 et Handb. p. 421 ; C. M. Syn. I, p. 686 .

Zeland,

- Afr. : Austral. (ex Handb.). Pac. : Austral., Nov.

? papillatus Preiss. - Zygodon Preissianus.

papillosus $\left\{\begin{array}{l}\text { Brid. - Ceratodon purpurens. } \\ \text { Jaeg. - Leptodontium. }\end{array}\right.$

perichaelialis Griff, - Holomitrium Griffithianum.

? pichinchensis Tayl. - Zygodon.

pilifer $\beta$ spathulatus Wahlenb. - Desmatodon latifolius var. glacialis.

(1) Cf. W. P. Sch. Syn. II ed. p. 161 et Limpr. Laubm. Deutschl. I, p. 551.

(2) Sec, Limpr, Barbula unguiculata of 
plicatus Mont. - Ditrichum.

polycephalus Mont, in Ann. sc. nat. 1845, p. 108 et Syll. p. 50; C. M. Syn, 1, p, 462.

2. Arenic. - Am, merid. : Chil. austr.

pomiformis Griff. - Microdus.

purpureus $\mathrm{H}$. et T. - Ceratodon.

pusillus Hedw. - Ditrichum tortile var. pusillum.

radicosus Mitt. - Leptodontium.

recurvifolius Tayl. in Wils, Bryol. brit. p. 110, t.41; W. P. Sch. op. cit. p. 165.

Ster. Ad terr. et rup. humid. - Eur. : Hibern., Scot., ins. Shetland, Vales, ? lac. Major (1).

rigidulus Hedw. - Barbula.

$\beta$ trifarius Hartm, - Trichostomum erispulum var, angustifolium. rotundatus (Lindb, et Arn.) Par.

Barbula rotundata Lindb. et Arn. M. as, bor. 1890, II, p. 172.

Syn. Terr, - As. : Jenissei inf.

rubellus (Roth) Bryol, eur. II (mon. p, 3), t. 185; W. P. Sch, op. cit. p. 161 .

Anacalypta recurvirostris Bryol. germ. II, II, p. 151, t. 37 .

A. rubella Hüb. Museol. germ. p. 119.

Barbula fallax $\delta$ Turneri Brid. Bryol. univ, I, p. 559.

B. rubella Mitt. in Journ. of the Linn. Soc. 1869, p. I62.

B. Turneri Brid. Mant. M. p. 93.

Bryum palustre ej. M. Rec. II, III, p. 35.

Br. recurvirostrum Dicks. Fase. II Pl. erypt. n. 7.

Br, rubellus Hoffm. Deutsch. Fl. II, p. 33 .

Br. setaceum $\beta$ Huds. Fl. Angl. p. 482.

Br. stellare, lacustre, foliis rubris capillaceis Dill. Hist. M. p. 382, t. 48, f. 45.

Grimmia curvirostra W. et M. Bot. Taschb. p. 135.

Gr, recurvirostra $S m$. Fl. brit. $I I I$, p. 190.

Gr. rubella Roth. Tent. fl. Germ. III, I, p. 147.

Tortula lacustris P. B. Prodr. p. 92.

T, unguiculata Turn. Muscol. Hib. p. 47.

Trichostomum recurvirostre Lindb. de Tortul. el cet. Trich. p. 226.

Tr. rubellum Rab. Deutsch. Krypt. II, p. $115 ;$ C. M. Syn. I, p. 581.

Weisia curvirostra Brid. Bryol. univ. I, p. 347 (inel. var. $\beta$ revoluta et $\gamma$ lacustris); Drumm. M. bor. am. I ed, n. 71.

W. recurvirostra Hedw. M. frond. I, p. 19, t. 7 (fid. W. P. Sch.; non! fid. Lindb. Trichost. Eur, p. 16).

W. revoluta Schleich. Cat. 1821.

W. rubella Roehl. Moosgesch. Deutseh. p. 142.

I vel syn. - Ad mur., rup. saxa et terr. - Eur. : Vulgatiss, ; Spitzberg. As. : Jenissei, Kamschatka, Amour, penins. Tschutschica, Tibet occ., Persia, Caucas., Taurus. Afr.: Alger., Abyssin. Am. sept. : Groenland, Canada tot., Columb. brit., ins. Vancouver, zon. temperat, tota.

Exs. : Mac. Canad. M. n. 63 .

Rab. Bryoth. eur. n. 375 et b, 860, 1033.

Sull. et Lesq. M. bor. am. II ed. n. 157.

"var. brevifolius (Lindb. et Arn.) Par.

(1) Fid, Jaeg. Ad. I, p. 212, sed erratim, ex confus, cum D. Daldiniano ! 
Barbula rubella var, brevifolia Lindb. et Arn. M. As. bor. 1890, II, p. 71 .

- As. : Jenissei inf.

a var. dentatus (Jur.) W. P. Sch. Syn. 1 ed. p. 131 et 11 ed. l. c.

Barbula alpigena Lindb. et Arn. op. cit. p. 72.

J). alpigenus Jur. Laubm. Oesterr. Ung. p. 98.

D, dentatus $e j$. in sehed.

Trichostomum alpigenum Vent, in sched.

Ad rad. arb. et in lapid. -- Eur. : Tirol., Salisburg. As.: Penins, Tschutschica.

var. cavernarum Mdo. - D. ruber.

ruber Jur. Laubm. Oeslerr. Ung. p. 99 (I).

Barbula rubra Lindb.

D. rubellus var. cavernarum Mdo, in Fl. 1864, p. 564.

2. Rupic. - Eur. : Stir., Carinth., Tirol., Alp. Vales. As. : Caucas. rufus Ltz, Moost. p. 88; W. P. Sch. Syn. 1 I ed. p. 168.

Barbula rufa Jur, op, cit. p. 113.

2. ơ et fr. ign. In fiss. rup. - Eur. : Alp. Sabaud.; Carinth., Alp. Salisburg. Am. sept. : Groenland.

Exs. : Rab. Bryoth, europ. n, 621.

sinuosus (Wils.) W. P. Sch. op. cit. p. 166.

Barbula cylindrica var, sinuosa Husnot Muscol. gall. p. 166.

B. sinuosa Jaeg. Ad. I, p. 286.

Dicranella sinuosa Wils. mss.

Trichostomum sinuosum (Mitt.) Jaeg. Ad. 1, p. 240.

Ster. Muric, et terr. - Eur. : Anglia, Gall, aept. or. As. : Caucas.

smaragdinus Brid. - Campylopus

spadiceus Limpr. - Barbula rigidula.

spathulatus de Not, - Desmatodon latifolius var. glacialis.

sphagnifolius Arn. - Leucobryum cuspidatum (an : glaucum ?)

splachnifolius Hook. - Splachnobryum obtusum.

squarrosus $\{$ Brid. - Leptodontium epunctatum.

Hook. - Leptodontium.

stellatus Jaeg. - Leptodontium.

stenocarpus Mitt. - Ceratodon.

stiriacus Jur, mss. ; Husn. Muscol. gall. p. 81 .

- Eur. : Alp. Stir.

? subalpinus Jaeg. - Trichostomum.

subcirrifolius Jaeg. - Leptodontium.

subdenticulatus Jaeg. - Leptodontium.

subulatus $\left\{\begin{array}{l}\text { Br. - Ditrichum. } \\ \text { Schk. - Distichium capillaceum var. brevifolium. }\end{array}\right.$

subulirostris W. P. Sch. in W. Sch. M. Abyss. n. 1339.

- Afr. : Abyssin.

sulfureus Jaeg. - Leptodontium.

var. panamense Jaeg. - Leptodontium sulfureum var. panamense.

? syntrichioides C. M. in Jaeg. Ad. I, p. 209.

Trichostomum syntrichoides C. M. in Linn. 1874, p. 602.

Ster, Paludic, - Am, merid. : And. Nov. Granat.

(1) Cf. Philibert in Rev, bryol. 1885, p. 89. 
tusmanicus Mitt. - Dichodontium.

? tenellus Hedwo, f. in hb. DC. et in Brid. Bryol. univ. $I, p .821 ; C . M$. Syn. I, p. 463.

Absque patria.

tenuifolius Jaeg. - Leptodontium.

lenuirostris Wils. - D. cylindricum.

Theobaldi Pfeff. in Jahrb. d. Naturf. Ges. Graubünd. 1868, p. 83 et in Bryogeog. Stud, a. d. Rhaet. Alp. 1869, p. 31 .

Desmatodon latifolius var. glacialis (fid. Limpr. Deutschl. Laubm. p. 649). - Eur. : Helvet. (Rheinwald Gletscher).

Therioti Corbière in Rev. bryol. 1874, p. 88.

Fl. et fr. ign. Ad lapid. in rivul, - Eur. : Pyren.

tophaceus Jaeg. - Trichostomum.

tortilis Arn. - Ditrichum.

Tortula Harv. - Ptychomitrium.

tricolor Bals. et de Not. - Trichostomum flavo-virens.

trifarius $\left\{\begin{array}{l}\text { H. et T. - Trichostomum tophaceum. } \\ \text { Sw. - D. luridus. }\end{array}\right.$

ulocalyx Jaeg. - Leptodontium.

uncinatus Lindb. - Dicranodontium circinnatum.

vaginatus $D z$. et $M k$. M. frond. ined. Archip. ind. p. 134, t. $42 ;$ Bryol. jav. $I, t .98$. - As. : Sumatra.

vaginatus Hook. - Dichodontium.

validus Limpr. Deutschl. Laubm. p. 557.

2. $\sigma^{\top}$ et fr. ign. Ad rup. calcar. - Eur. : Tirol., Carinth.

Wallisii C. M. mss.; Jaeg. Ad. I, p. 210.

- Am. merid. : Nov. Granat.

Woodii W. P. Sch. - Dich sdontium pellucidum.

Zetterstedti W. P. Sch. Syn. II ed. p. 167.

Barbula rigidula (fid. Limpr. Deutschl. Laubm. I, p. 556).

Ster. Rupic? - Eur. : Suecia.

DIMERODONTIUM Mitt. M. austr. am. p. 540 (8 spec.).

acuminatum C. M. in Linn. 1878-79, p. 398.

1. Arb. in inund.? - Am. merid. : Uruguay.

africanum C. $M$. in Rev, bryol. 1878, p. 72 (nom.).

- Afr. : Austral.

aurescens C. M. in Linn. 1878-79, p. 398.

1. $\quad-$ Am. merid. : Uruguay.

Balansae C. M. in Besch. Not. M. Paraguay, p. 227.

1. Cortic. - Am. merid. : Paraguay.

Exs. : Bal. M. Parag. n. 1207.

chlorophyllosum C. M. in Linn. 1878-79, p. 397.

1.

mendozense Mitt. op, cit. p. 541 .

- Am. merid. : Uruguay.

Arbor. - Am. merid.: Argentin. Cordob., Monte Video, And. Chilens. 
pellucidum (Hook.) Mitt. op. cit. p. 540.

Hypnum Sclerodontium C. M. Syn. II, p. 476.

Leskea pellucida Hook. mss.

Sclerodontium pellucidum Schwaegr. Suppl. III, II, II, t. 292.

1.

- Am. merid. : And. Chilens.

Schnyderi C. M. in Linn. 1880-83, p. 471.

1. Arbor. - Am. merid, : Argentin. Buenos Ayr.

DIOBELON Hpe. Fl. Hercyn.

? alpestre Hpe. - Cynodontium gracilescens var. alpestre.

Bruntoni Hpe. - Dicranoweisia.

gracilescens Hpe, - Cynodontium.

pellucidum Hpe. - Dichodontium.

polycarpum Hpe. - Cynodontium.

squarrosum Hpe. - Dicranella.

strumiferum Hpe. - Cynodontium polycarpum var. strumiferum.

virens Hpe. - Cynodontium.

DIPHYSGIUM Mohr. Obs. bot, p. 34; Web. et Mohr Bot. Taschb. 1807, p. 377 , t. II, f. I (11 spec.).

auriculatum Besch. Fl, bryol, Nov. Caled. p. 220.

Ad rup, humid, - Pac. : Nov, Caledon.

fasciculatum Mitt. M. Ind, rr. p. 150.

- As. : Ceylan.

Fendleri C. M. in Finn. 1878-79, p. 468.

2.

- Am. merid. : Venezuela.

foliosum (L.) Mohr l. c.; Brid. Bryol. univ. I, p. 326 ; Bryol. eur. IV, t. 428 et VI, t. 641 ; C. M. Syn. I, p. 812; W. P. Sch. Syn. II ed. p. 547.

Bryum Hallerianum Neck. Meth. M. p. 233.

Br. phascoides Jacq. Coll. II, p. 220.

Buxbaumia foliosa L. Syst. veg. XIV ed, p. 925.

B. sessilis Schmid. Diss, de Buxbaum, c. ic.

v. foliosum $\beta$ dominghense Brid. Bryol, univ. II, p. 740 (fid. C. M.).

D. sessile Lindb. in Oefv.... 1863, p. 3953, n. 18.

Hymenopogon heterophylluin $P . B$. Prodr. $p .80$.

Phascum Halleri O. F. Müll. Act. Holm. 1764, c. ic.

Ph. Hallerianum Poil. Fl. Pal. III, n. 974.

Ph. maximum Lightf. Fl. Soot. II, p. 693.

$\mathrm{Ph}$. montanum Huds, Fl. Angl. Il, p. 466.

Ph. subulatum EEd. Fl. Dan. II, fase. V, p, 2, n. 249 p.p.

Ph. subulatum $\beta$ Huds. Fl. Angl. I ed. p. 397.

Sphagnum acaulon, maximum, foliis in centro ciliaribus Hall. in Dill.

Hist. M.p. 253, t. 32, f. 13.
Webera Diphyscium Ehih. Hann. Mag. 1779, p, 257 et Beitr. I, p. 177.

W. sessilis Lindb. in Oefo... XX, p. 393.

2. Ad rup. et terr. muscos. - Eur. : E reg. mont. usq. in alp. As.: Caucas. occ. Am. sept. : Nov. Scotia. Ontario.

Exs. : Drumm. M. bor. am. Il ed. n. 74.

Mac. Canad, M. n. 226.

Sull. et Lesq. M. bor. am. Il ed. p. 332.

«var, acutifolium Lindb.

Didymodon Camusi Husn, Muscol. gall. p. 80.

Ut typ. - Eur. : Scandin., Gall. sept.

Exs. : Husn, M. Gall. n, 275, 
var. dominghense Brid. - D. foliosum.

fulvifolium Mitt, in Trans. of the Linn. Soc. 1891, p. 193.

- As. : Japon.

involutum Mitt. $M$. Ind. or, p. 149.

- As.: Khasia, Ceylan.

longifolium Griff. Not. p. 390 et Ic. pl. asiat. IIJ, t. 96; C. M. Syn. I, p. 812 .

Rupic. - As. : Khasia, Ceylan.

mucronifolium Mitt. in Bryol. jav. I, p. 35, t. 26.

1. Ad rup. humid, - As. : Ins. Labouan, Borneo.

peruvianum Spr, in Mitt. M. austr. am. p. 622.

2. $\quad$ - Am. merid. : And. Peruv.

rupestre Dz. et Mk. in Pl. Jungh. p. 340; Bryol. jav. I, p. 34, t. 25.

1. Ad rup. humid. - As, : Ins, Labouan, Borneo, M. Java.

sessile Lindb. - D, foliosum.

submarginatum Mitt. Fl. Vit., p. 403.

Ster, $\quad$ - Pac. : Ins. Viti.

DIPLOCOMIUM Brid. Mant. M. p. 122, t. 2, f. 14 et Bryol. univ. II, p. 65. hexastichum Fk. - Meesea Albertini.

longisetum $\left\{\begin{array}{l}\text { Brid. p.p. - Meesea Albertini. } \\ \text { Brid. p.p. - Meesea tristicha. } \\ \text { Mong. et Nestl. - Meesea tristicha. }\end{array}\right.$

tristichum Sk. - Meesea tristicha.

DiPLOSTICHUM Mont. Fi. Chil. VII, p. 67 et Syll. p. 27.

longirostre Mont. - Eustichia.

DISGELIU M Brid. Bryol. univ. I, p. 365 (1 spec.).

nudum (Dicks.) Brid. op. cit. p. 366; Bryol. eur. III, t. 2y7; C. M. Syn. I, p. 812 ; W. P.Sch. Syn. II ed. p. 372.

Bryum nudum Dicks. Fasc, IV Pl. orypt. p. 7, t. 10, f. 15.

Coscinodon nudus Brid. Mant. M. p. 48 .

Grimmia nuda $S m$. Fl. Brit. III, p. 1197 .

Weisia incarnata Schwaegr. Suppl. I, I, p. 66, t. 18.

W. nuda H. et T. Muscol. brit. p. 43, t. 14.

W, rosea Wahlenb. Fl. Lapp. p. 325 ,

2. Ad terr. argill. humid, - Eur. : Seandin., Scot., Angl., Gall. septr., Silesia. As.: Saghalien, Jenissei med. Am. sept. : Perrar. : Illinois. Exs. : Rab. Bryoth, eur. n. 659, 1031, 1268.

DisCOPHYLLITM Mitt. Sam. M. p. 191 (gen. propr.) et M. austr. am. p. 396 (sect. DistichopHyLLI).

flavescens Mitt. - Distichophyllum.

DISSODON Grev, et Arn, in Ann. Soc, Linn, 1826, p. 229 (23 spec.).

andinus W. P. Sch, in Mandon Pl. Boliv. $n, 1642$.

bolivianus W. P. Sch.l, c.n. 1643.

- Am. merid. : And. Boliv.

- Am. mericl, : And, Boliv. 
borbonicus (Bory) Par.

Bryum orthodontum P. B. Prodr, p. 48.

D. serratus C. M. Syn. I, p. 141 p.p.

Orthodon borbonicus Bory mss.; Besch. Fl. bryol. Réunion, ete, p. 83.

0. serratus Bory in Schwaegr. Suppl. II, p. 23, t. $106 ;$ Brid. Sp. M. I. p. 86.

Tayloria Boryana Mitt. M. Ind. or. p. 57.

2. Terr. - Afr. : Ins. Borbon., Madagascar septr., M. Cameroon.

calophyllus C. M. in Bot. Zeit. 1851, p. 546.

Eremodon robustus $H$. f. et W. Fl. of the N. Zeal. II, p. 93, $t, 87, f, 2$ et Handb. p. 452.

Arbor, et terr. - Pac. : Nov. Zeland, sept., Tasman.

Cameruniae C. M. in Dusen M. Camer. n. 256 a.

- Afr. : M. Cameroon.

cuspidalus C. M. - D. octoblepharum.

Fromhlichianus (Hedio.) Grev. et Arn. Tent. meth. M. p. 122; Bryol. eur. III (mon. p. Э) t. 282; C. M. Syn. I, p. 138; W. P. Sch. Syn. II ed. p. $35 \%$.

Bryum reticulatum Dicks. Fasc. II Pl. crypt. p. 4, t. 4, f. 6.

Splachnum Froehlichianum Hedw. M. Frond. III, p. 99, t. 40; Brid. Bryol. univ. $I, p .244$.

Spl. punctatum Brid. Sp. M. I, p. 149.

Spl. reticulatum Sw. Disp. M. Suec. p. 24.

Hermaphr. vel. polyg. Ad terr. humos, et in fiss. rup. - Eur.:

Reg. alp, usq. ad nives aeternas; deest in Britann. As. : Caucas. centr. Am. sepl. : Groenland, M. Rupestr.

Exs. : Drumm. M. bor. am. I ed. n. 44, 45 (Splachnum).

Mac. Canad. M. n. 138.

Rab. Bryoth, eur. n. 158.

Hornschuchii Grev. et Arn. l. c.; Bryol. eur. III (mon. p. 7), t. 281; C. M. Syn. I, p. 137; W. P. Sch. Syn. II ed. p. 356.

Systylium splachnoides Hsch. Comment. de Voitia et Systyl.p. 19, l, 2 ct Bot. Zeit. 1820, p. 176 c. ic.; Brid. Bryol. univ. I, p. 264; Drumam. M. bor. am. I ed, n. 46.

1. Ut præced. -- Eur. : Summ. Alp. Carinth., Salisb., Stir., Tirol. Am. sept. : M. Rupestr., Oregon, Colorado.

imbricatus (Thw. et Mitt.) Jaeg. Ad, I, p. 472.

Tayloria imbricata Thw, et Mitt. in Journ. of the Linn. Soc. 1872, p. 305. 1. - As. : Ceylan.

indicus (Mitt.) C. $\mathrm{M}$ in $\mathrm{Fl}$. 1874, $p$.

Octoblepharum serratum Hook. M. ex. I1, p. 5, t. 136 (excl. syn.).

Tayloria indica Mitt. M. Ind. or. p. 57. - As. : Nepal., Himalaya. Afr. : Madagascar.

Isleanus (Besch.) Par.

Orthodon Isleanus Beseh. Fl. bryol. Réunion, eto. p. 85.

0. serratus Brid. Bryol. univ. I, p. 232 p.p. f. 2 ?

2.

- As. : Nepal, Afr. : Ins, Borbon.

Jacquemontii Bryol. eur. III (mon. p. 6, nom.) ; C. M. Syn. I, p. 139.

Tayloria Jacquemontii Mitt. op, et l. ce.

1.

- As. : Himalaya oce. 
madagassus C. M. in Jaeg. Ad. 11, p. 767.

- Afr. : Madagascar.

magellanicus Hpe in C. M. Syn. $I 1, p .551$.

Eremodon magellanicus Brid. Bryol. univ. I, p. 236; C. M. Syn. I, p. 148.

Splachnum magellanicum Schwaegr. Suppl. I, I, p. 47, t. 14.

Tayloria magellanica Mitt. M. austr. am. p. 251.

Ad rup. humid. - Pac. : Terr. Magellan.

marginatus $C . M$. in $F l .1874, n .18$.

D. serratus ej. Syn. I, p. 141 p.p.

2.

- As. : Nepal., Sikkim.

octoblepharum (Hook.) Par.

D. cuspidatus C. M. Syn. I, p. 142 et $I I, p .550$.

Splachnum octoblepharum Hook. M. ex, t. 167.

2. Lignic. - Pac. : Austral, or., Tasman., ins. Auckland, Campbell.

plagiopus (Mont.) C. M. Syn. II, p. 551 .

Eremodon octoblepharis H. f. et W. Fl. of the N. Zeal. II, p. 94 et Hand. p. 452.

Splachnum octoblepharum $\beta H$. f. et $W$. in sehed. $M$. antarct.

Spl. plagiopus Mont. in Ann. sc. nat. 1845, 1V, p. 121 et Syll.p. 51 ; C. M. Syn. I, p. 143.

1 (Mont.). 2 (C. M.). ins. Auckland, Campbell.

- Pac.: Austral. or., Tasman.,

"var. major (H.f. et W.) Jaeg. Ad. I, p. 472.

Eremodon octoblepharis var. major H.f. et W. Fl. Antarct 123, t. 57, f. 4 et Fl. of the N. Zeal. et Handb. ll. cc.

Arb, et rupic. - Pac. : Tasman,, ins. Auckland, Campbell.

* var. minor C. M. et Hpe. in Linn. 1853, p. 491 (nom.).

- Pac. : Austral.

* var. piriformis (H. f. et W.) Jaeg. l. c.

Eremodon octoblepharis var. piriformis H. f. et W. ll. oc.

Ut praeced.

plagiopus Ângstr. - Hymenocleiston magellanicum ?

purpurascens (Hook. f. et Wils.) C. M. Syn. 1I, p. 550.

Eremodon purpurascens Hook. f. Handb. of N. Zeal. Fl. p. 452.

Splachnum purpurascens $H$. f. et $W$. in Lond. Journ. of bot. 184t, p, 529 2. et Fl. Antarct. I, p. 123, t. 57; C. M. Syn. I, p. 142.

- Pac. : Ins. Auckland, Campbell.

rolundifolius $\{$ C. M. - Splachnobryum obtusum.

Sull. - Splachnobryum Wrightii.

scabrisetus (Hook.) Grev, et Arn. l. c. ; C. M. Syn. I, p. 140.

Splachnum scabrisetum Hook. M. ex. I, p. 6, t. 32 ; Brid. Bryol. univ. $I, p, 245$.

Tayloria scabriseta Mitt, M, austr, am. p. 250.

1.

- Am. merid. : And. Nov, Granat. et Quitens.

Schmidii C. M. in Fl. 1874, n. 18.

D. serratus ej. in sched.

2.

- As. : M. Neilgherr. 
serratus C. M. p.p. $-\left\{\begin{array}{l}\text { D. borbonicus. } \\ \text { D. marginatus. } \\ \text { D. Schmidii. }\end{array}\right.$

splachnoides (Thunb.) Grev. et Arn. op. cit. t. 13, n. 39-44; Bryol. eur. III (mon. p. 10), t. 283 ; C. M. Syn. I, p. $139 ;$ W. P. Sch. Syn. II ed. p. 358 .

Cyrtodon splachnoides Kr. Br. in Parry's first Voy. Ver. bot. Schrift I, p. 442 .

Eremodon splachnoides Brid. Bryol. univ, I, p. 231.

Grimmia splachnoides Engl. Bot. $t .2164$.

Splachnum lingulatum Dicks. Fasc. IV Pl. crypt. p. 4, t. 10, f. 6.

Tayloria lingulata Lindb. M. Scand. p. 19.

Weisia splachnoides Thunb. in Schwaegr. Suppl. I, I, p. 63, t. 17.

W. turbinata Drumm. M. bo", am. I ed. n. 64 .

Hermaphr. vel polyg. In gramin. uligin. - Eur. : Reg. alp. zon. intermed. et sept.; in alp. Norvegiae vulgatiss. As. : Jeniss. med. Am. sept. : Groenland, sin. Hudson, Gaspesia, M. Rupestr. et Selkirk, Columb. brit.

Exs, : Rab. Bryoth. eur. n. 815.

Un. itin. 1863, n. 18, 47.

subglaber (Griff.) C. M. in Fl. 1874, n. 18.

Orthodon subglaber Griff. Not. p. 399 et Ic. pl. Asiat. II, t. 76, f. 2.

Tayloria subglabra Mitt. M. Ind. or. p, 57.

2. Arbor. et rupic. - As. : Khasia, Ceylan, alp. Yunnan.

tenellus C.M. $l$. c.

Tayloria tenella Mitt. l.c.

1 ?

- As. : Himalaya occ.

thomeanus (Broth.) Par.

Orthodon thomeanus Broth. in Bol. da Soc. Broter. VIII, 1890, p.

2. Arbor. - Afr. : Ins. S. Thom. (1).

DISTICHIA C. $M$. in $F l .1890, p .489$.

afro-Vicloriae C. M. - Neckera.

platyantha C. M. - Neckera.

DISTIGHIUM Bryol, eur. I (8 spec.).

austro-Georgicum C. M. Bryol. austr. Georg. p. 12.

Ster.

- Am. merid. : Austr. Georgia.

austro-inclinatum C. M. in Linn. 1880-83, p. 396.

1.

- Am. merid. : Alp. Argentin. temperat.

capillaceum (L.) Bryol. eur. II (mon. p. 4), t. 193; C. M. Syn. I, p. 40;

W. P. Sch. Syn. II ed. p. 146.

Bryum capillaceum Gmel. Syst. nat. II, p. 1332.

Br. montanum Ed, Fl. Dan. t. 1000, f. 1 .

Cynodontium capillaceum Schwaegr. Suppl. I, I, p. 114.

Cynontodium capillaceum Hedwo. Sp. M. p. 57. Cynontodium capillaceum Hedw. Sp. M. p. 57 .
Didymodon capillaceus W. et M. Bot. Taschb. $155 ;$ Brid. Bryol, unit.
$I, p .504$.

D. cirrifolius Harv, in Land. Tourn, of Bot. 1840, II, p. 5 et in Hook. Ic. pl. var. t. 18 ; C. M. Syn. I, p. 462.

(1) In Enum. Kindberg. nomen nudum :

D. Novae Valesiae C. M. 
Leptotrichum capillaceum Mitt. in Journ. of the Linn. Soc. 1859, p. 67.

Mnium capillaceum $L$. $F l$. Lapp.

Swartzia capillacea Hedw. M. frond. II, p. 72, t. 26.

Sw. montana Lindb. M. Scand. p. 26.

Trichostomum capillaceum Sm. Fl, brit. III, p. 1236.

1. In rup. fiss. - Eur. : Spitżberg, vall, Rhen., omn. Alp. - As. : Penins. Samoied. et Tschutschica, Jenissei, Amour, Kamschatka, Alp. Yunnan, Nepal., Sikkim, Tibet., Caucas, A $\mathrm{r} r$. : Alger., Abyssin., M. Cameroon. Am. sept. : Groenland, Jabrador, sin. Huds., Gaspesia, New Brunswick, Terra nov., Anticosti, lac. Super., Niagara, Manitoba, Athabasca, M. Rupestr., Columb. brit., ins. Vancouver, fret. Kotzebuë, Washington, Idaho, Nov. Anglia, reg. sept. et orient, Pac. : Tasman.

Exs. : Drumm. M. bor. am. I ed. n. 122, 123 (Didymodon).

Mac. Canad. M. n. 57.

Rab. Bryoth. eur. n. 37 et b, 377, 531, 1109.

Sull. et Lesq. M. bor. am. II ed, n. 161 .

W. Sch. M. Abyss. II Coll. n. 454, 473.

- var. brevifolium Bryol. eur. et W. P. Sch. ll. cc.

Didymodon distichus Brid. Bryol. univ. I, p. 507.

D. subulatus Schk. Deutsch. M. p. 63, t, 28.

Ut typ. - Eur. : Spitzberg, summ. Alp. Am. sept. : Groenland.

capillaceum H. $\hat{\mathrm{r}}$. et W. - Lophiodon strictus.

inclinatum (Hedw.) Bryol. eur. 11 (mon. p. 5), ı. 194 ; C. M. l. c. p. 41 ;

W. P. Sch. l. c. p. 147.

Afzelia inclinata Ehrh. Crypt. 193.

Bryum inclinatum Dicks. Fase. II Pl. crypt. p. 9.

Cynodon inclinatus Brid. Bryol. univ. I, p. 501 .

Cynodontium inclinatum Hedw. Sp. M. I, p. 155.

Cynondotium inelinatum ej.. . c. p. 58 .

Didymodon inclinatus $S_{w}$. Disp. M. Suec. p. 28.

Grimmia inclinata Sm. Fl. brit. III, p. 1193.

Leptotrichum inclinatum Mitt. M. Ind. or. $p .10$.

Swartzia inclinata Hedw. M. Frond. II, $p .74, t$. 2 .

Trichostomum (?) scitulum Aust. in Goult. Bot. Gaz. I, p. 29 ?

1. In rup. fiss. irror. et terr. uligin. - Eur. : Spitzberg, omm. Alp. As. : Penins. Tschutschica, Taymir, Jenissei, Tibet, Sikkim, Caucas. Am. sept. : Groenland, Labrador, Anticosti, Terr. nov., Gaspes, lac. Super., M. Rupestr., Montana, Wyoming, Colorado, Nevada, Nov, Anglia.

Eos. : Drumm. M. bor. am. I ed. n. 124 (Didymodon).

Mac. Canad. M. n. 58.

Rab. Bryoth. eur. n. 741 .

Sull. et Lesq. M. bor. am II ed. n, 162.

* var, tenue Bryol. eur. et W. P. Sch. ll. cc.

Ut typ. - Eur. : Reg. alp.

kilina n'djaricum C. M. in Fl. 1890, p. 471.

Ster.

- Afr. : Kilima N'D jaro.

Lorentzi C. M. in Linn. 1880-83, p. 395.

1. $\quad-A m$. merid. : Alp. Argentin. Catamarc.

Macounii C. M. et Kindb. in Mac. Cat. p. 40.

Ster. Rupic. - Am, sept. : Columb. brit.

Exs. : Mac. Canad. M. n. 490. 
setifolium C. M. in Linn. 1880-83, p. 396.

Cynontodium capillaceum Mitt. M. austr. am. p. 41 (fid. C. M.). 1.

- Am. merid. : And. Quitens.

DISTICHOPHYLLUM Dz. et Mk. M. frond, ined. Archip. ind. p. 99

(39 spec.).

acuminatum Bryol. jav. II, p. 26, t. 150.

Mniadelphus acuminatus Jaeg. Ad. II, p. 228.

Syn.

- As. : M. Java.

andicola Sp. - Mniadelphus,

aristatum Geh. et Hpe. Enum. M. Brasil. p. 54.

Syn. $\quad-$ Am. merid. : Brasil.

auralum Mitt. - Mniadelphus.

Beccarii (C. M.) Par.

Mniadelphus Beccarii C. M. in Rev. bryol. 1881, p. 26.

- Pac. : Tasman.

capillatum Mitt. in Proc. of the Linn. Soc. of N. S. Wales, 1882, I, p. 100 - Pac. : Nov. Hebrid. (Aneitum).

ceylanicum (Mitt.) Par.

Mniadelphus ceylanicus Mitt. $M$. Ind. or. $p .145$.

Ster. - As. : Ceylan.

cristatum Dz. et Mk. - Eriopus remotifolius.

cubense Mitt. - Mniadelphus.

cuspidatum Dz. et Mk. op. cit. p. 101, t. 33 ; Bryol. jav. II, p. 19.

Hookeria cuspidata eor. in Ann. sc. nat. III ser., 1844, II, p. 305.

Mniadelphus cuspidatus C. M. Syn. II, p. 26.

2. Cortic. - As. : Java, Sumatra. Pac. : Ins. Societat.

Dicksoni (Hook.) Mitt. M. austr. am. p. 396.

Hookeria Dicksoni Hook. in Lond. Journ. of bot. 1844, p. 549.

Mniadelphus Dicksoni C. M. Syn. II, p. 25.

2.

- Am. merid. : Fuegia, ins. Eremitae, Maclov.

elongatum Mitt. - Mniadelphus.

Eremitae (C. M.) Jaeg. Ad. $I I, p .227$.

D. procumbens Mitt. op. et $l$. co.

Mniadelphus Eremitae C. M. in Fl. 1885, p. 423. 1.

- Am. merid. : Fuegia, ins. Eremitae.

fasciculatum Mitt, in Journ. of the Linn. Soc. 1877, p. 71.

1.

- Afr. : Ins. Marion.

flaccidum Mitt. - Mniadelphus.

flavescens (Mitt.) Par.

Discophyllum flavescens Mitt. Sam. M. p. 191.

Mniadelphus flavescens C. M. M. Polyn.p. 79.

Ster.

- Pac. : Ins. Fidji.

Freycineti (Schwaegr.) Mitt. Fl. Vit. p. 392.

Hookeria Freycineti Mont. in Voy. Bonite, Bot. I, p. 296 et Syll. p. 15.

Hypnum Freycineti Schwaegr. Suppl.III, II, t. 279; C. M. Syn. I, p. 160 
Mniadelphus Freycineti $C . M$. Syn. $I I, p .26$.

Mnium giganteum Schwaegr. in Frey Itin. per orbem, I, p. 227.

Ster.

- Pac. : Ins. Sandwic.

Griffithii (Mitt.) Par.

Hookeria pulchella Griff. Not. p. 476 ; Ic. pl. asiat. $I I, t, 99, f .3$.

Mniadelphus Griffithii Mitt. M. Ind. or. p, 145.

1. - As. : Nepal., Khasia.

gracile Angstr. Prim. lin. p, 29.

Mniadelphus gracilis Jaeg. Ad. II, p. 224.

Ster.

- Am. merid. : Brasil. austr. or.

heterophyllum (Wils.) Par.

Mniadelpus heterophyllus Wils. in sched.; Mitt. op. cit. p. 144.

2? Ster.

- As. : Sikkim.

humifusum (Wils.) Par.

Mniadelphus humifusus Wils, in sched. ; Mitt. op. et l. ce.

2 ? Ster.

- As. : Himalaya oec.

imbricatulum Mitt. in Journ. of the Linn. Soc. 1877, p. 71.

- Afr.: Ins. Marion.

jungermannioides (C. M.) Bryol. jav. $I I, p .22$.

Mniadelphus jungermanniosdes C. M. Syn. II, p. 600.

2.

- As. : Java.

limbatulum (C. M.) Par.

Mniadelphus limbatulus $C . M . M$. Polyn. p. 78.

1.

- Pac. : M. ins. Fidji.

limpidum Thw. et Mitt. - Mniadelphus.

longicuspes Brolh, in Oef... 1893.

1. $\quad-$ Pac. : Ins. Lord Howe.

Mariei Besch. in Rev. bryol. 1891, p. 77.
I.

- Am. sept. : (iuadalup.

mascarenicum Besch. Fl. bryol. Réunion, etc. p. 135.

Syn.

Mittenii Bryol. jav. II, p. 25, t. 149.

- Afr. : Ins. Mascaren.

Mniadelphus spathulatus Mitt. M. Ind. or. p. 144.

1 et syn. Arbor. - As. : Ceylan, Java. Pac.: Nov. Caledon.

molle Besch. in Miss. sc. cap Horn, V, Bot. p. 296.

Ster.

? monofarium Geh, et Hpe. in Fl. 1881 .

Ster.

- Am. merid. : Brasil, austr. or.

Montagneanum (C. M.) Bryol. jav. II, p. 23, t. 151.

Hookeria mniifolia Mont. Crypt. Neilgherr. n. 21 in Ann. sc. nat. 1812 et Syll. p. 15.

Mniadelphus Montagneanus C.M. Syn. II, p. $22 ;$ Mitt. M. Ind. or, p. 145.

1. Ad rad, frutic. - As. : M, Neilgherr.

mueronatum Tho, et Mitt. in Journ. of the Linn. Soc. 1872, p. 311.

Mniadelphus mucronatus Jaeg. Ad. II, p. 228.

Syn.

- As. : Ceylan. 
Nadeaudii Besch, in Ann. sc. nat. 1894, I, p. 43.

2 ? Cortic. - Pac. : Taïti.

nanum (Dz. et Mk.) Bryol. jav. II, p. 21, t. 148.

Mniadelphus nanus Dz, et Mk. in Zolling. Syst. Veirz.p. 26.

2. Arbor. - As, : Java, Sumbawa.

nigricans Besch. in Miss. sc. Cap Horn, V, Bot. p. 296.

Ster.

- Am. merid, : Fuegia.

nigricaule Mitt. in Bryol. jav. II, p. 19, t. 147.

Mniadelphus nigricaulis Jaeg. l. c.

obovatùm (Griff.) Par.

- As. : M. Java.

Hookeria obovata Griff. Not. p. 474 et Ic. pl. asiat. II, t. 99, f. I.

Mniadelphus obovatus Mitt. M. Ind. or. p. 144.

2 ? - As. : Khasia.

Palmarum Mitt. - Mniadelphus.

paradoxum (Mont.) Mitt. Fl. Vit.p. 392.

Hookeria paradoxa Mont. in Voy. Bonite, Bot. p. 596 et Syll. p. 15.

Mniadelphus paradoxus C. M. Syn. II, p. 24.

2 ? Cortic. - Pac. : Ins. Sandwic.

patagonicum Besch. op. cit. p. 295.

Ster.

- Am. merid. : Patag. austr.

procumbens Mitt, in Journ. of the Linn. Soc. 1863, p. 163.

1.

- Afr. : Ins. Fernando Po.

procumbens Mitt. (pl. amer.). - D. Eremitae.

pungeris Mitt. - Mniadelphus.

pusillum Mitt. - Mniadelphus.

spathulatus Dz. et Mk. M. frond. ined. Archip.ind.p. 103, t. 34 et 35 A;

Bryol. jav. 11, p. 24.

Hookeria seminervis Mont. in Ann. sc. nat. 1845, p. 93 et Syll. p. 16.

H. spathulata Dz. et Mk, in Ann, sc, nat. 1844, p. 305.

Mniadelphus spathulatus C. M.Syn. II, pp. 24 et 661.

2. Lignic. - As, : Java, Sumatra, Sumbawa.

taïtense Besch, in Ann. sc. nat. 1894, I, p. 43.

Syn. Ad terr. humid. - Pac. : Taïti.

tortile Bryol. jav. $11, p .127, t .152$.

Mniadelphus tortilis Jaeg. Ad. II, p. 228.

2. Ad fol, emort. - As. : Ins. Banca, Java.

undulatum Bryol. jav, II, p. 28, t. 153.

Mniadelphus undulatus Jaeg. Ad. $I I, p .226$.

1. Arbor. - As. : Java.

vitianum (Sull.) Besch. Fl. bryol. Nov. Caled,p. 227. Mniadelphus vitianus Sull. in Proced. Am. Acad. 1854 et in lexp. Wit-
kes 1854, p. 24, t. 24.

2 rar. 1. Cortic. - Pac, : Ins. Fidji, Samoa, Nov, Caledon.

DITRIGHUM Timm. Fl. Megapol, (1870) p, 177 (57 spec.).

affine (C. M.) Hpe. in Fl. 1867, pp. 181-182.

Cynontodium affine Mitt. $M$. austr, am. p. 42. 
Diaphanophyllum setosum Lindb. in Oefv... 1863, p. 605 .

Leptotrichum (1) affine C. M. in Bot. Zeit. 1847, p. 825 et Syn. I, p. 452.

Trichostomum setos"m $H$. f. et $W$. Fl. of the N. Zeal. II, p. 73, $t$. 84, f. 6.

1. Terr. - Am. merid, : Valäiv., ins. Juan Fernandez, Patagon. Pac. : Austral., Dov. Zeland.

ambiguum Best in Bull. Torr. bot. Club, 1893, p.

2. Ad terr. humid. - Am. sept. : Washington.

amoenum (Thw. et Mitt.) Par.

Cynodontium amœenum Jaeg. Ad, II, p. 634 .

Cynontodium amoenum T. et M. in Jowin. of the Linn. Soe. 1872, p. 296.

1. Terr. - As. : Ceylan.

apophysatum Hpe, in sched.; Jaeg. op. cit. p. 662.

arcticum (W. P. Sch.) Par.

Leptotrichum arcticum $W . P$. Seh. Syn. II ed. p. 142.

L. vaginans Un. erypt. itin. 1868, in sched.

2. Ad terr. arenos. humid. - Eur. : Alp. Norveg. septentr.

astomoides Limpr. Laubm. Deulschl. I, p. 511.

D. pallidum $\times$ Pleuridium subulatum Breidl. in litt.

1. In dumet. - Eur. : Stiria.

auriculatum (Mitt.) Par.

Atractylocarpus auriculatus Mitt. in sehed.

- As.: Bhotan.

bolivianum (W. P. Sch.) Par.

Leptotrichum bolivianum W. P. Sch. in Mandon Pl. Bol, n, 1621.

- Am. merid. : And. Boliv.

Boryanum (C. M.) Hpe. in Fl. pp. 181-182.

Diaphanophyllum Boryanum Lindb. in Oefv... 1863, p. 605.

Leptotrichum Boryanum C. M. Syn. I, p. 452; Bryol.jav. I, p. 94, t. 76.

Trichostomum difficile Duby in Moritzi Vers, d. Zolling. Pf. p. 131.

Tr. longifolium Dz. et Mk. M. frond. ined. Archip, ind. p. 136.

2. palldum Brid. hb.; Dz. et Mk. op. cit. p. 135.

2. Ad terr, et lapid, in silv, - As. : Borneo, Java. Afr. : Ins. Borbon., Franciae, Madagascar.

" var. robistum (Besch.) Par.

Leptotrichum Boryanum var. robustum Beseh. Fl. bryol. Nov. Caledon.
p. 205 .

Ad arbor. - Pac. : Nov. Caledon.

brachycarpum Hpe. in Linn. 1871-73, p. 514.

Breidleri Limpr. Laubm. Deutschl. I, p. 508.

- Pac. : Austral. or. (Nov. Vales.).

Sporledera palustris $\times$ Ditrichum pallidum Bieidl. mss.

1. Ad rivul. - Eur. : Stiria.

brevifolinm (Kindb.) Par.

Leptotrichum brevifolium Kindb. in Mac. Cat. p. 16 (subsp. D. flexicaulis).

2. Rupic. - Am. sept. : M. Rupestr.

(1) Nomen jam abusum. Leptotrichum Hpe, in Linn. 1847, p. 74: Leptotrichum Corda Ic. Fung. V, p. 51, t. II, f, 16 (1842), genus Fungorum. 
capense (C. M.) Par.

Leptotrichum capense C. M.Syn. I, p. 453.

1. $\quad-A f r$ : C. B. Sp., Transvaal, Natal.

Exs, : Rehm. M. Afr. austr. n. 84, 464 et b (Leptotrichum).

\& var. Vallis Gratiae (C. M.) Par.

Leptotrichum capense var. Vallis Gratiae C. M. in Rehm. l. c. n. 1885 ,

$$
\text { - Afr. : C. B. Sp. }
$$

capillifolium (W. P. Sch.) Par.

Leptotrichum capillifolium W. P. Sch, hb.; Jaeg. Ad, I, p. 236.

conicum (Mont.) Par.

$$
\text { - Am. sepl. : Mexic. }
$$

Aschistodon conicus Mont. in Ann. Sc. nat. 1845, IV, p. 109 et Syll. p. 42.

Cynontodium conicum Mitt. M. austr. am.p. 44.

Leptotrichum Montagnei C. M. Syn. I, p. 448.

2. Ad arbor. ? - Afr. : Ins. Kerguelen? (1). Am. merid. : Chile, ins. Chiloë.

costa-ricense (C. M.) Hpe. in Fl. 1867, p. 181-182.

Leptotrichum costa-ricense C. M. in Bot. Zeit. 1858, p. 161.

2.

- Am. sept. : Costa Rica.

crinale (Tayl.) Par.

Cynontodium crinale Mitt. M. austr, am. p. 44.

Didymodon crinalis Tayl. in Lond. Jow of . bot. 1848, p. 280.

Leptotrichum crinale Mitt. in Lond. Jow'n. of bot. 1851, p. 53 ; C. M. Syn. II, p, 612.

2.

- Am. merid. : And. Quitens.

cylindricarpum (C. M.) Par.

Leptotrichum eylindricarpum C. M. in Bot. Zeit. 1851, p. 551.

2. Rupic. - Pac. : Tasman.

divaricatum Mitt. in Trans. of the Linn. Soc. 1891, p. 155; Besch. in Ann. sc. nat. 1893, p. 336 (descript. locuplet).

$$
\text { - As. : Japon. }
$$

dolichopodon (Rehmi). Par.

Leptotrichum dolichopodon Rehm. M. Afr. austr. n.86.

$$
\text { - Afr. : Orange. }
$$

ferrugineum (Mill.) Par.

Leptotrichum ferrugineum Mitt, in Journ. of the Linn. Soc. 1859, p. 67.

2. Terr. - Pac. : Tasman.

flexicaule (Schwaegr.) Hpe. in Fl. 1867, pp. 181-182.

Cynodontium flexicaule Schwaegr. Suppl. I, p. 113, t. 29.

Diaphanophyllum flexicaule Lind $b$. in Oefv... 1863, p. 605.

Didymodon flexicaulis Brid. Bryol. univ, $I, p, 506$.

Leptotrichum flexicaule Hpe. in Linn. 1847, p. 74; C. M. Syn. I, p. 449: W. P. Sch. Syn. I ed. p. 144 et II ed. p. 142.

Trichostomum flexicaule Bryol. eur, II (mon. p. 15), t. 180.

2. Ad rup. et in terr. lapid. calcar. - Eur. : E reg. montan usi. in subalp.; Spitzberg., ins. Ursor. As. : Jenissei, Caucas. Afr. : Alger. Am. sept. : Groenland, Anticosti, Nov. Scotia, M. Rupestr., Columb. brit., Idaho, Montana. 
Exs. : Drumm. M. bor. am. I ed. n. 125, 126 (Leplotrichum).

Mac. Canad. M. n. 66 (Leptotrichum).

Rab. Bryoth, eur, n. 423 et b, 961, 1307 (Leptotrichum).

- var. densum (W. P. Sch.) Par.

Leptotrichum flexicaule var, densum W. P. Sch. Syn, I et II ed. ll. cc.

Ut typ. - Eur. : Reg, sept. Am. sept. : M. Rupestr., Columb. brit., Alaska.

flexifolium Hpe. - Trichostomum laxifolium.

glaciale (Hook, f, et Wils.) Par.

Didymodon? glacialis $H$. f. et $W . F l$. antarct. $I I, p .408, t .152, i .6$.

Leptotrichum flaciale C. M. Syn. II, p. 611.

Ster. - Am. merid. : Ins. Cockburn.

glaucescens (Sw.) Hpe, in Fl. 1867, pp. 181-182.

Bryum caesium Vill. Pl. Dauph. III, p. 879.

Br. glaucescens Dicks. Fasc. IV Pl. crypt. p. 10.

Diaphanophyllum glaucescens Lindb. in Oefo.... 1863, p. 695.

Dirlymodon glaucescens W. et M. Bot. Taschb. p. 158; Brid. Bryol. univ. $I$, p. 513.

Leptotrichum glaucescens Hpe. in Linn. 1847, p. 74; W. P. Soh. Syn. I ed. p. 146 et II ed. p. 145.

Saelania cesia Lindb. Utk, nat. grupp. bladm. p. 35.

Trichostomum glaacescens Sw. in Hedw. M. frond. III, p. 91, t. $37 \mathrm{~B}$; Biyol, eur. II (mon. p. 18), t. 184 ; C. M. Syn. I, p. 569.

I. In gramin., ad mur. et in fiss. rup. - Eur. : Alp. et subalp., in Norveg. montan, ; hic illic in Alp. Seot.; Spitzberg. As. : Jenissei, Cuucas, occ, et centr. Am. sepl. : Groenland, fret. Hudson, Labrador, Gaspes., Ontario, M. Rupestr., Columb. brit., mar. Behring, Vermont, lac. Super., Minnesota.

Exs.: Drumm. M. bor. am. I ed, n. 117 (Didymodon).

Mac. Canad. M. n. 168 (Leptotrichum).

Rab. Bryoth. eur, n, 627 (Leptotrichum).

Sull. et Lesq. M. bor. am, Il ed. n. 156 (Leptotrichum).

"var. brevipedunculatum (C. M.) Par.

Didymodon aeruginosus Hook. in Brid. Bryol, univ. I, p. 516.

Leptotrichum glaucescens var: brevipedunculatum $C$. M. . . c. p. 570.

Ut et cum typ.

gracile (Mitt. Par).

Cynontodium gracile Mitt. M. austr. am. p. 43.

Leptotrichum gracile $e j$, in Kew Journ. bot. III, p. 353.

L. neurophyllum Spr. Cat.

2. Saxic. - Am, merid. : And. Quitens.

homomallum (Hedro.) Hpe. in Fl. 1867, pp. 181-182.

Afrelia homomalla Ehrb. Pl. crypt. exs. $n .173$.

Bryum unilaterale Gmel. Syst. nat. II, p. 1335.

Br. Weisia Dicks. Fasc. III Pl, crypt, p, 5.

Diaphanophyllum homomallum Lindb. in Defe.... 1863, p. 605.

Didymodon heteromallus $H$. et $T$. Muscol. brit. p. $68, t .20 ;$ Dremm. $M$. bor: am. I ed. n. 119.

D. homomallus Hedw. Sp. M. p. 105, t. 23 ; Brid, Bryol, univ. I, p. 510.

Grimmia heteromalla $W$. et $M$. Bot Tasch b. p. 137.

Gr. homomalla $S_{m}$. Fl, brit, III, p. 1191.

Gymnostomam homomallum Brid. Biryoi. univ, $I, p, 757$,

Leptotrichum homomallum Hpe. in Linn. 1847, p. 74; C. M. Syn. I, P. 453 et $I I, p .612 ; W$. . P. Seh. Syn. I ed. p. 143 et II ed. p. 141.

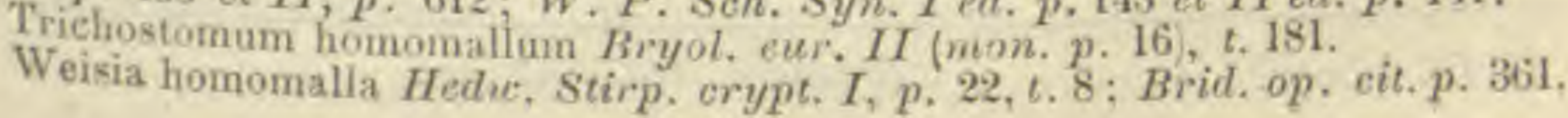


2. In terr, aren, et subargill, - Eur. : Tota, calidiss. et frigidiss. except. Am. sept. : M. Rupestr., Washington, M. Alb., reg. sept. et or.

Exs. : Rab. Bryoth, eur. n. 424, 663 (Leptotrichum).

« var. zonatum Lindb. M. Scand. p. 26 p.p.

Campylopus irregularis Ltz, in Verh. d. zool. bot, Gesells. in Wien, 1867, p. $683, t .22$.

Dicranum sericeum Hsch. in Brid. Rryol. univ. I, p. 364.

Ditrichum zonatum Limpr. Laubm. Deutschl. I, p. 495.

Leptotrichum Molendianu-.. Ltz, in op. $e_{*} \cdot l$. ce.

L. homomallum $\beta$ zonatum Vent. et Bott. Enum. cr, p. 15.

L. zonatum Ltz. in Fl. 1869.

Weisia zonata Brid. op. et l. cc.

Ut typ., sed rarius. - Eur.: Scandin., Harz, Bohem., Alp. Stir., Salısb., Carinth., Helvet, Longobard., Pyr, or. (1).

homomallum $\beta$ zonalum Lindb. p.p. - D. vaginans var. nivale.

Hookeri (C. M.) Hpe. in Fl. 1867, pp. 181-182.

Cynontodium Hookeri Mitt. M. austr. am. p. 42.

Diaphanophyllum longifolium Lindb. in Oefv .... 1863, p. 605.

Didymodon longifolius $H$. f. et $W$. in sehed.

Leptotrichum Hookeri C. M. Syn. I, p. 450. 1. - Am. merid.: Fuegia, fret. Magell., ins. Eremitae.

hyalinum (Mitt.) Par.

Cynontodium hyalinum Mitt. $M$. austr. am. p. 43.

Didymodon longifolius $\beta$ tenuifolius $H . f$. et $W$. Crypt. antarct. p. 102.

Leptotrichum hyalinum Mitt. in Joum. of the Linn. Soo. 1859.

2. Terr. - Am. merid. : Fuegia, cap: Horn, ins. Eremitae, Maclov.

Knappii (Jur.) Limpr. Laubm. Deutschl. I, p. 508.

Leptotrichum Knappii $J u r$. in Verh. d. Zool. bot. Gesells. in Wien, 1866, pp. 67 et 486.

1. In silv, subalp, - Eur, : Hungaria.

laxissimum (Mitt.) Par.

Leptotrichum laxissimum Mitt. M. Ind. or. p. 10.

Trichostomum delicatulum Wils, p.p. in Kev Journ. bot. IX, p. 321. - As, : Sikkim.

leptocarpum Hpe, in op. et $l$. cc. Leptotrichum leptocarpum W. P. Sch. in Besch. Prodr. bryol. mexic.
p. 30 .

1. Sortic - Am. sept. : Mexic.

leptorhynchum Hpe, in op. et $l$, cc. Leptotrichum leptorhynchum W. P. Seh. hb. ; Jaeg. Ad. I, p. 236 et $I 1$,
p. 763 .

$$
\text { - Afr. : Madagascar. }
$$

longisetum (Ltz.) Hpe. in op. et $l$, cc.

Leptotrichum longisetum Ltz, in Bot. Zeit, 1866, p. 186.

1. Rupic. - Am. merid. : Valdiv., Patagon, austr., fret. Magell.

Mac-Leanum (Reltm.) Par.

Leptotrichum Mac-Leanum Rehm. M. Afr, austr, n. 465.

- Afr.: Transvaal.

(1) Cf. Limpr. 1. c. 
madagassum (Ren, et Card). Par.

Leptotrichum madagassum R. et C. in Bull. Soc. roy. bot. Belg. 1891, II, p. 184 et M. Masc. Mad. n. 208.

1. In terr, argill. - Afr. : Madagascar.

mexicanum Hpe. in op. et $l$. co.

Atractylocarpus mexicanus Mitt. $M$. austr. am. p. 71 p.p. ?

Leptotrichum mexicanum $W$. P. Sch. in Besch. Prodr. biyol. mexic. p. 30.

1. Terr. - Am. sept. : Mexic.

Mittenii (Besch.) Par.

Atractylocarpus mexicanus Mitt. op. et $l$. cc.

Leptotrichum Mittenii Besoh. op. cit. p. 31 .

1 .

- Am. sept. : Mexic.

montanum (Leib.) Par.

Leptotrichum montanum Leib. in Bull. Torr. bot. Club, 1893, p. 112.

1. $\Lambda \mathrm{d}$ arbor. - Am. sept. : Idaho.

Oldfieldi (Mitt.) Par.

Leptotrichum Oldfieldi Mitt. in Journ. of the Linn. Soc. 1859, p. 67.

1. Terr. - Pac. : Tasman.

pallidum (Schreb.) Hpe. in op. el l. cc.

Bryum acaulon heteromallum, setis longis pallidis Dill. Hist. M. p. 389 , t. 49, f. 57 .

Br. pallidum Schreb. Spic. fl. Lips, p. 80.

Cynontodium bogotense Hpe. in Linn. 1864, p. 135 et in Ann. sc. nat. V ser., III, $p, 360$.

C. strictum Mitt. M. austr: am. p. 42 .

Diaphanophyllum pallidum Lindb, in Oefo,... 1863, p. 605.

Dicranum pallidum W. et M. Bot. Tasch. p. 196.

Didymodon pallidus $P$. B. Prodr. p. 56.

Leptotrichum pallidum Hpe. in Linn. 1847, 74; C. M. Syn. I, p. 451 ; W. P. Sch. Syn. I ed. p. 146 et II ed. p. 147.

Trichostomum pallidum Hedw. Stirp. erypt.p. 71, t. 27; Brid. Bryol. univ. I, p. 489 ; Bryol, eur. II (mon. p. 18), t. 183.

Tr. pallidum $\beta$ strictum Schwoaegr. Suppl. II, I, p. 77, t. 123.

Tr. strictum Sw. Fl. Ind. oce. III, p. 1781.

1. Ad terr. silvat. argill, - Eur. : Reg. campestr. zon. interm. et subseptentr.; deest in Britann. As.: Japon, China or., Caucas. occ. Afr. : Madagascar. Am. sept. : Ontario, temperata tota, Jamaïc. Am, merid. And. Nov. Granat.

Exs. : Druunm. M. bor. am. II ed. n. 56 (Leptotrichum).

Mac. Canad. M. n. 67 (Leptotrichum).

Rab. Bryoth. eur. n. 167, 654, 1262 (Leptotrichum).

Sull. et Lesq. M. bor. am. II ed. n. 155 (Leptotrichum).

pallidum $\times$ Pleuridium subulatum Breidl. - D. astomoides.

paulense Geh. et Hpe. in Fl. 1881.

1.

- Am. merid. : Brasil. austr. or.

pinetorum (C. M.) Par.

Aschistodon pinetorum Jaeg. Ad. II, p. 662.

Leptotrichum pinetorum G. M. in Linn. 1874, p. 627.

Lignic, - $A m$, sepl. : Mexic.

plagiacron (C, M.) Par.

Leptotrichum plagiacron C. M. in Linn. 1871-73, p. 169.

1.

- As. : Ins, Philippin. 
plicatum (Mont.) Hpe. in Nuov. Giorn. bot. ital. 1872, p. 273.

Didymodon plicatus Mont. Syll. p. 49.

D. cirrifolius ej. in Crypt. Nilgherr. Ann. sc. nat. 1842, n. 56.

Leptotrichum plicatum C. M. Syn. I, p. 446.

1. In silv. - As. : M. Neilgherr., Ceylan.

plumosum (C. M.) Par.

Leptotrichum plumosum C. M. in Linn. 1878-79, p. 470.

1 .

- Am, merid. : Venezuela.

praealtum (Mitt.) Par.

Leptotrichum praealtum Mitt. in Journ. of the Linn. Soc. 1859, p. 66.

2 .

- Am. merid. : Patagon. ausir.

proseriptum (Hsch.) Par.

Cynodon proscriptus Hsch. in Hor. phys. Berol. p. 60, t. 12 ; Brid. Bryol. univ. $I, p .517$.

Leptotrichum Hornchuchii C. M. Syn, I, p. 450.

2.

- Afr.: Ins. S. Helena.

pusillum Hpe. - D. tortile.

rufescens Hpe, in Fl. 1867, pp. 181-182.

Cynontodium rufescens Mitt. $M$. austr. am. p. 44.

Leptotrichum rufescens Hpe. in Linn. 1862, p. 521.

2 .

- Am. merid. : And. Nov. Granat.

Schimperi (Lesq.) Par.

Leptotrichum Schimperi Lesq. in Mem. of the Calif. Acad. I, p. 9; Sull. Ic. M. Suppl. p. 37, t. 24; Lesq. et Jam. Man. p. 108.

1.

- Am. sept. : Oregon, M. Calif.

strictum $\mathrm{Hpe}$, - Lophiodon.

subflexuosum (W. P. Sch.) Par.

Leptotrichum subflexuosum W. P. Sch. in Mandon Pl. Boliv, n. 1620.

- Am. merid. : And. Boliv.

subrufescens Broth. in Act. Soc. sc. Fenn. 1891, n. 5.

1. Terr. - Am. merid. : Brasil. (Minas Geraës).

subulatum $H p e$, in $F l$. 1867, pp. 181-182.

Diaphanophyllum subulatum Lindh. in Oefv.... 1863, p. 605.

Didymodon aureus de Not. Syll. p. 199.

D. subulatus Br. in Salzm. Pl. Tingit, et in de Not. l. c.

Leptotrichum subulatum Hpe. in Linn. 1847, p. 74; C. M. Syn. I, p, 448 et II, p. $611 ;$ W. P. Sch. Syn. I ed. p. 145 et II ed. p. 143.

Trichostomum subulatum Bryol. eur. II (mon. p. 17), t. 182.

1. Ad terr. denud. et viar. latera. - Eur. : Zon. merid, : Combrovall., Gall. merid., Corsic., Sardin., Sicil., Algarb. A fr. : Septentr.

tenue Hpe. - Trichostomum.

tenuisetum (C. M). Par.

Leptotrichum tenuisetum C. M. in Journ. of bot. 1877, p. 228 (nom:

Lignic. - Am. sept. : Costa Rica.

tomentosum (Kindb.) Par.

Leptotrichum tomentosum Kindb. mss.

Ster.

- Am. sept. : Alaska.

tortile (Schrad.) Lindb. M. Scand. p. 26.

Diaphanophyllum tortile Lindb. in Oefo.... 1863, p. 605. 
Dicranum tortile $W$. et $M$. Bot. Taschb. p. 198, t. 7, f. 12-13.

Didymodon tortilis $W$. Arn. Dispos. p. 37.

Ditrichum pusillum Hpe. in Fl. 1867, pp. 181-182.

Leptotrichum tortile C. M. Syn. I, p. 454; W. P. Sch. Syn, I ed. p. 142 et $I I$ ed. p. 139.

Mnium tortile Gmel. Syst. nat. II. p. 1328.

Trichostomum tortile Schrad. Syst. Samml. crypt. Gevaechse n. 49 ; Brid. Bryol. univ. I, p. 488; Bryol. eur. II (mon. p. 14), t. 179.

2. Ad viar. margin. - Eur. : Reg. campestr. montan. As. : Nepal., Sikkim, Caucas. Afr. : Alger. Am. sept. : Fret. Hudson, Labrador, Terr. nov., Nov. Scot., New Brunswick, lac. Super., reg. sept., or. et centr.

Exs. : Drumm, M. bor. am. I ed, n. 118 (Didymodon) et 11 ed. n. 57? (Leptotrichum).

Mac. Canad. M. n. 65 (Leptotrichum).

Rab. Bryoth. eur. n. 43 b, 872 et b (Leptotrichum).

Sull, et Lesq. M. bor. am. II ed. n. 152 (Leptotrichum).

" var, pusillum (Timm.) Lindb. M. Scand. p. 26.

Barbula curta Hedvo. M. frond. III, p. 75, t. 31 .

Bryum Didymodon Hoffm. Deutsch. Fl. II, p. 43.

Br. pusillum Gmel. Syst. nat. II, p. 1333.

Desmatodon curtus Brid. Bryol. univ. I, p. 526.

Didymodon pusillus Hedie. Sp. M. p. $104 ;$ Brid. op. oit. p. $5(19$.

Ditrichum pusillum Timm. Prodr. $f$. Megapol $n$. 777. Leptotrichum tortile var. pusillum C. M. (excl. syn. Sull.) et W. P. Sch.
ll. cc.

Tortula curta Sw. M. Suec. p. 41.

Trichostomum pusillum Hedu. M. frond. I, p. '78, t. 28, ff. 2, 4, 9, 10 (fid. C. M. l. c.).

Tr. tenue Hedw. (fid. Ren. et Card.).

Tr. tortile var, pusillum Bryol, eur. $l$. c.

Ad saxa et terr. argill, - Eur. : Passim c. typ. As, : Jenissei super. Am. sept. : Pensilv., Indiana.

Exs. : Drumm. M. bor. am. II ed. n. 59 (Leplotrichum).

Rab. Bryoth, eur, n. 949 (Leptotrichum).

Sull, et Lesq. M. bor. am. II ed, n, 153 (Leplotrichum).

tortipes (Mitt.) Par.

Leptotrichum tortipes Mitt. M. Ind. or. p. 10.

Trichostomum delicatulum Wils, in Kev Journ, bot. IX, p. 321 p.p. 1 . - As. : Sikkim.

vaginans (Sull.) Hpe, in Fl. 1867, pp. 181-I8?.

Diaphanophyllum vaginans Lindb. in Oefv.... 1863, p. 605.

Leptotrichum avimontanum $W . P$. Sch. in sehed.

L. homomallum $\beta$ strictum ej. Syn. I ed. p. 144.

L. vaginans ej. . $y n$. II ed. p. 140 .

Trichostomum homomallum $\beta$ densum Bryol, eur. II (mon. p. 16).

Tr. pusillum Hedes. $M$. frond. $I, p .78, t .28, \pi f .2,4,9,10$ (fid. W. P.

Tr. vaginans $S$ iull. M. bor. am. I ed. $n, 60,61$.

M. bor. am Sull M. Allegh. n. 176 et Ic. M. I, p. 43, t. 28; Sull. el Lesq.

2. Ad ter. am. I ed. n, 104.

Ad terr. humid. arenac. et turfac. - Eur.: Hassia, Westphal.,
Voges., Hercyn or, et centr.

Exs. : Rab. Bryoth. eur. n. 824, 1322 (Leptotrichurm).

Sull. et Lesq. M. bor, am. II ed. n. 154 p.p. (Leptotrichum).

* var. brevifolium (Grav.) Par.

Angstroemia Lamyi Boulay M. E. Fr. p. 553. 
Leptotrichum vaginans var. brevifolium Gravet in Husn. Museol, gall. p. 62 .

«var. nivale (C. M.) Par:

D. homomallum $\beta$ zonatum Lindb. M. Scand. p. 26 et in Braithw, Brit. Mossf.p. 100 p.p. (fid. Limpr.).

D. nivale Limpr. Laubm. Deutschl. I, p, 498.

Leptotrichum glaciale Jur. mss, ; Pfeff. Bryol. Stud. p. 33.

L. nivale C. M. Syn. $I I, p .611$.

L. tenue $\beta$ glaciale W.P. Sch. Coroll. p. 29.

L. vaginans $\beta$ glaciale $W$. P. Sch. Syn. II ed. p. 140.

L. vaginans $\beta$ nivalis Jur. Laubmft. Oesterr. Ung. p. 78.

Trichostomum tenue var. glaciale Bryol, eur. II (mon. p. 13).

Ut typ. - Eur. : Alp. Helvet.; Salisburg.? Am. sept. : New Brunswick.

Exs. : Drumm. M. bor. am. II ed. n. 58 (Leptotrichum).

Mac. Canad. M. n. 386 (Leptotrichum).

Vallis-Gratiae Hpe. - Ceratodon condensatus.

zonalum Limpr. - D, homomallum var. zonatum (1).

Divaricatella C. M. in Dusen M. Camer. (sect. Ángstroemiak).

Dolichomitria Lindb, Contrib. ad fl. crypt. As, bor. or. p. 231 (sect, ISOTHECII).

DOLICOTHECA Lindb. Man. M. II, $p .417$.

repens Lindb. - Hypnum repens.

Doliolidium C. M. in Linn. 1875, p. 388 (subsect. BrYi).

\section{DORCADIUM Lindb.}

Spec, omn. non indicatæe ortнotricha ejusd. nom.

affine $\beta$ fastigiatum Lindb. - Orthotrichum fastigiatum. pallidum Lindb, et Arn. - Orthotrichum pallens var. parva. striatum Lindb. - Orthotrichum leiocarpum.

DOZYA Lac. in Miq. Ann. Mus. bot. Lugd. Batav. Il, p. 296 (I spec.). japonica Lac. $\ell$. $c$.

- As. : China, Japon.

Drepanium W. P. Sch. Syn. I ed. p. 618 (sect. Hrpsi).

Drepanocladus C. M. Syn, II, p. 321 (subsect. HүPNI=Harpidium W. P. Sch.).

DREPANO-HYPNUM Hpe. Moosb. p. 19.

Spec. omn. HYPNA ejusd. nom.

Drepanophyllaria C. M. Syn. II, p. 418 (subsect. HyPsi).

(1) In Enum. Kindb. nom. nud. (sub Leptotricho):

D, Baileyi (C. M.) Par. 
DREPANOPHYLLUM Rich, in Hook, M. ex. II p. 3, t. 14 (1820) (2 spec.) (1).

fulvum Rich. l. c. ; Brid. Bryol. univ. II, p. 669; C. M. Syn. I, p. 39 ; Mitt, M. austr, am. p. 318.

Dicranum falcifolium Hook. M, ex. $T, t .82$.

Fissidens falcifolius Schwaegr. Suppl. I, II, p. 9.

2. Lignic. et rupic. - Afr.: Ins. Borbon.? Am. sept.: Hispaniola. Am. merid. : Guian, batav., Amazon.

oppositifolium Thw. et Mitt. in Journ. of the Linn. Soc. 1872, p. 305.

Ster. - As. : Ceylan.

ramulinum Spr. - Mniomalia viridis. semi-limbatum Mitt. - Mniomalia.

viride Mitt. .- Mniomalia.

DRUMMONDIA Hook, in Drumm. M. bor, am. I ed. (184l)n. 62 (3 spec.) (2).

brevifolia Wils, in Kew Journ, bot. IX, p. 325.

Dr. Thomsoni Mitt. M. Ind. or. p. 46.

I. Rupic. - As. : Tibet, occ.

"var. tapintzensis (Besch.) Par.

Dr. Thomsoni var, tapintzensis Besch, in Ann. sc, nat. 1892, I, p. 57.

Arbor, - As. : Alp. Yunnan.

clavellata Hook. l. c.; Sull. Ic. M. p. 52, t. 33; C. M. Syn. 1, p. 687;

Lesq. et Jam. Man, p. 160.

Anodontium prorepens Brid. Sp. M. I, p. 41 .

Gymnostomum prorepens Hedw. Sp. M. p. 35, t. 3, f. I-4.

Hypnum clavellatum parvum, repens, setis brevibus Dill. Hist. M. p. 551, t. $85, f .17$.

Leiotheca clavellata Brid. Bryol. univ. I, p. 728.

Macromitrium clavellatum Schwaegr. Suppl. II, II, p. 130.

Orthotrichum clavellatum $H$. et Gr. in Brewster Edinb. Journ. I, p. 114, t. 4.

2. Arbor. - As. : Japon. Am. sept. : Ontario, Carol., Maryl., Virgin., etc.

Exs. : Drumm. M. bor. am. I ed. n. 62 , II ed, n. 8 l.

Mac. Canad. M. n. 525.

Sull, et Lesq. M. bor. am. II ed, n. 194.

* var. canadensis Kindb, in Mac. Cat. p. 160.

Arbor. - Am. sept. : Lac. Erie.

Thomsoni Mitt. - Dr. brevifolia.

var. Lapintzensis Besch. - Dr. brevifolia var. tapintzensis.

? villosa Besch. Fl. bryol. N. Caled. p. 207.

Dasymitrium villosum Jaeg. Ad. II, p. 687.

2? Cortic. - Pac. : Nov. Caledon. (2).

DRYPTODON Brid. Bryol univ. $I, p .191$.

Spec. omn. non indicatae Grimsix ejusd, nom.

1) Nomen jam abusum. Drepanophyllum Wib. 1799 (U'mbelliferae), sed

hune ut syn. gen. Falearia acceptum.

(2) Nomen jam abusum, Drummondia DC. Prodr. IV, p. 50, 1830 (Saxifrageae),

(3) In ut syn. gen. Mitellopsis acceptum,

Dr. Kindb. nomen nudum :

Dr, oppositifolia C. $\boldsymbol{M}$. 
brevifolius Brid. - Grimmia pulvinata?

caesprticius Brid. - Grimmia sulcata (! C. M. ; ? W. P. Sch.).

muticus Brid. - ?

Campylopus Brid. - Dynodontium gracilescens var. inflexum.

carnosus Brid. - Rhacomitrium heterostichum.

cribrosus Brid. - Grimmia leucophaea et trichophylla. - Delend.

crispulus H. f. et W. - Rhacomitrium.

crispus Brid. - Ditrichum capense.

curvifolius Brid. - Grimmia commutata.

dichotomus Brid. - $\left\{\begin{array}{l}\text { Campylopus dichotomus Brid. M. M. p. } 77 \\ \text { Dicranum dichotomum P. B. Prodr.p. } 53\end{array}\right\}$ Delend. ellipticus Brid. - Rhacomitrium.

fontinaloides Brid. - Hydropogon.

incurvus Brid. - Grimmia elatior.

obtusus Brid. p.p. $\left\{\begin{array}{l}\text { - Grimmia orbicularis. } \\ \text { - Grimmia pulvinata var. obtusa. }\end{array}\right.$

ovatus Brid, - Grimmia commutata.

patens Brid. - Rhacomitrium.

pulvinatus $\beta$ argentatus Brid. - Grimmia pulvinata var. longipila?

$\gamma$ alpestris Brid. - Grimmia pulvinata.

rupestris $\mathrm{H}$. f. et W. - Rhacomitrium.

saxicola Brid. - Campylosteleum.

Schullaii $\left\{\begin{array}{l}\text { Brid. - Grimmia. } \\ \text { Hartm. - Grimmia Muihlenbeckii. }\end{array}\right.$

spiralis Brid. - Grimmia funalis.

sudeticum Brid. - Rhacomitrium.

DUSENIA Broth. in Engler's Bot. Jahrb. 1894, p. 195.

incrassata Riroth. - Forstroemia.

ECGREMIDIUM Hook. f. et Wils. in Lond. Journ, of hot. 1846, p. 450)

(2 spec.).

arcuatum H.f. et W. l. c,; C. M. Syn. I, p. 435.

Bryum tenuissimum Tayl. in Land. Journ. of bot. 1846, p. 52.

Schistidium arcuatum $H$. f. et W. in Hook. Ie. pl. rar.t. 738 A. - Pac. : Austral. or.

pulchellum $H . f$. et W., C. M. ll. cc.

Schistidium pulchellum $H$. f. et W. in Hook. op. cit. t. 738 B.

- Pac. : Austral. or.

Eccremothecium Mitt, M, austr. am. p. 294 (subsect. BRY1).

ECHINODIUM Jur. in Bot. Zeit. 1866, p. 20.

Spec. omn. non indicatae sunt scraromia ejusd. nom.

madeirense Jur. - Sciaromium spinosum.

Paivanum Jaeg. - Sciaromium prolixum.

EGTROPOTHECIUM Mitt. in Journ. of the Linn. Soc. 1868 (160 spec.).

acinacifolium (Hpe.) Jaeg. Ad. II, p. 532.

Hypnum acinacifolium $H p e$, in C. M. Syn. $I I, p .329$.

H. sandwichense Hook. et Arn. (fid. Mitt.).

1. Arbor. - Pac. : Nov. Zeland. 
aeruginosum (C. M.) Mitt. op. cit. p. 513.

Hypnum aeruginosum C. M. Syn. II, p. 304.

1. - Am. merid.: Venezuela, Amazon., And. Quitens, et Peruv.

albo-viride Ren. in Rev. bryol. 1889, p. 85.

1.

- Afr. : Madagascar.

* var, rufulum Ren, et Card. in Bull. Soc, roy. bot. Belg. 1893, I, p. 125. Cum typo.

amabile Hpe, in sched.; Mitt. op. et $l$. cc.

Hypnum subimponens Hpe. in Ann. sc. nat. V ser., III, p. 321.

Ster.

- Am. merid. : And, Quitens.

amphibolum Spr. in Mitt. op. et $l$. cc.

Arb. et rupic. - Am. sept. : Cuba, Guadalup. Am. merid.: Ins. Trinitat., Amazon., And. Quitens, et Peruv., Brasil.

angusto-textum (Geh.) Par.

Hypnum angusto-textum Geh. Neue Beitr. zur. Moosfl, v. N. Guinea, Ster. - Pac. : Nov. Guin. mer.

apiculatum (Hsch.) Mitt. op. cit. p. 512.

Hypnum apiculatum Hsch. Fl. Brasil. I, p. 87; C. M. Syn. I1, p. 305. 1. Granat., Brasil. or. Am. sept. : Jamaïc. Am. merid. : And. Nov . areuatum (Sull.) Mitt. Fl. Vil. p. 400.

Hypnum arcuatum Sull. in Proc. Am. Acad.... 1854.

Arbor. - Pac. : Ins. Sandwic.

australe (C. M.) Jaeg. Ad. II, p. 524.

Hypnum australe C. M. Syn. II, p. 302 . H. limatum H. f. et W. Fl. Antarct. Suppl. II, p, $545^{\circ}$ et Fl. Tasman. II,

H. Terrae-Novae var. australe eor. Fl. Antarct. I, p. 142, t. 61 .

2. Lignic. - Pac. : Austral., Tasman, ins. Auckland, Campbell.

Ayresii W. P. Sch. in Besch. Fl. bryol. Réunion, etc. p. 178.

1. Saxic. - Afr. Ins. Franciae.

baliense (Bryol. jav.) Jaeg. Ad. II, p. 532.

Hypnum baliense Bryol. jav. II, z. 228.

Sauloma baliensis ibid. p. $110, t$. 220. 1 ,

- As. : Java, ins. Bali.

Bescherellii Ren. in Rev, bryol. 1888, p. 89. 1.

- Afr. : Ins. Franciae.

Boivini (C. M.) Besch. Fl. bryol. Réunion, etc. p. 178.

Hypnum Boivini C. M. in Rev. bryol. 1877, p. 14.

brachystelium (Hpe.) Par,

- Afr. : Ins. Mayotte.

Hypnum brachystelium Hpe. Enum, M. Brasil p. 67.

Syn. Cortic - Am. merid. : Brasil. austr. or. 
brachytheciopsis (C. M.) Par.

Hypnum brachytheciopsis C. M. in Engler's Bot. Jahrb. 1883, p. 85 et in Forchungsreise.... p. 47. 1 ? - Pac. : Nov. Hannov.

brevifalcatum (C. M.) Kindb. Enum, Bryin. ex.

Hypnum brevifalcatum C. M. in Fl. 1886, p. 284.

Ster. Arbor. - Afr, : Ins. S. Thomas.

brevisetum (Hsch.) Mitt. M. austr. am. p. 515.

Hypnum brevisetum Hsch. op. cit. I, p. 78; C. M. Syn. II, p. 286.

1. Cortic. - Am, merid. : Brasil, austr. or.

bryifolium (C.M.) Jaeg. Ad. II, p. 533 .

Hypnum bryifolium C. M. in Angstr. Prim. lin. p. 52.

H. inflectens Aingstr. in Oefv.... 1872, $p, 125$.

- Pac. : Taïti.

bryocarpum (C. M.) Par.

Vesicularia bryoearpa C. M. in Dusen M. Camer. n. 311.

$$
\text { - Afr. : M. Cameroon. }
$$

Buitenzorgi (Bel.) Jaeg. Ad. II, p. 524 (1).

Hypnum Buitenzorgi Bel. Voy. Ind. or. Bot. II, Crypt. p. 94, t. 2, f. I; C. M. Syn. II, p. 302 ; Bryol. jav. II, p. 199, t. 298.

Stereodon Buitenzorgi Mitt. M. Ind. or. p. 99.

2.

- As. : Amboine, Ceram, Java, Sumatra, Ceylan.

callichroides (C.M.) Jaeg. Ad. II, p. 524 .

Hypnum callichroides C. M. in Linn. 1874, p. 562.

Ster. $\quad-$ As. : Ins. Philippin.

calodictyon (C. M.) Jaeg. Ad. II, p. 535.

Hypnum calodictyon C. M. M. Polyn. p. 80. 1. - Pac, : Ins. Samoa.

" var, glauca (C.M.) Jaeg. l.c.

Hypnum calodictyon var, glaucum C. M. l, c.

- Pac. : Ins. Samoa.

campanulatom Mitt. M. austr. am. p. 512.

- Am. merid. : Nov, Granat.

campylosciadium (C. M.) Par.

Vesicularia campylosciadium C. M. in Dusen M. Camer, $n .366$.

$$
\text { - Afr. : M. Cameroon. }
$$

capillisetum (C.M.) Kindb, op. cit.

Hypnum capillisetum C. $M$, in $F l$. 1886, p. 521.

1. Rupic. - Afr. : Angola.

Chamissonis (Hsch.) Jaeg. Ad. 11, p. 528. Hypnum Chamissonis Hsch. Hor. phys. Berol. p. 66, t. 13 ; C. M. Syn. II,
p. $305 ;$ Bryol. jav. II, p. 198, t. 297.

H. Stereodon Chamissonis Brid. Bryol, univ. $I I, p .617$.

1. Cortic. - As. : Borneo, ins. Banca, Radak.

(1) “ An Hypnum Drepanium? „ Jaeg. 1. c. 
Chenagoni Ren. et Card. in Bull. Soc. roy. Belg. 1893, I, p. 125.

Ster.

- Afr. : Madagascar.

chloroticum Besch, in Bull. Soc. Bot. Fr. 1887, p. 99.

1. Ad rad. abor. secus rivul. vel submers. - As. : Tonkin.

" var. dong-hamense Besch. l. c.

Rupic. - As.: Tonkin.

clandestinum (Lindb.) Ängstr. Prim. lin. p. 43.

Hypnum clandestinum Lindb. mss.

- Am. merid. : Brasil. austr. or.

codonopyxis (C. M.) Par.

Hypnum codonopyxis $C . M$. in Fl. 1886, p. 518.

1. Arbor. - Afr. : Ins, Fernando Po.

compressifolium (Mitt.) Jaeg. Acl. II, p. 524.

Stereodon compressifolius Mitt. M. Ind, or. p. 99.

2 ?

- As. : Khasia, Assam super.

conostegum (C.M.) Mitt. M. austr. am. p. 5 I9.

Hypnum conostegum $C . M$. Syn. II, p. 242.

Leskea (Omalia) rutilans $\beta$ porto-ricensis Brid. Bryol. univ, $I I, p .332$ 1. - Am. sept. : Cuba, Porto-Rico.

contractum (Lac.) Jaeg. Ad. II, p. 532.

Hypnum contractum Lac. Sp. nov. M. Archip. ind. 1872, p. 12, t. 7 C. 1.

- As.: M. Java.

crassicaule Mitt. op. cit. p. 517.

Hypnum Montagnei Sull. in Proced. Am. Acad.

- Am. sept.: Cuba.

crassirameum Ren, et Card, in Bull. Soc. roy. bot. Belg. 1893, I, p. 126.

Ster. - Afr. : Madagascar.

crassireticulatum (Hpe.) Jaeg. Ad. II, p. 535.

Hypnum crassireticulatum $\mathrm{Hpc}$, in sched. - As. : Ind. or. (Yonnah).

cristato-pinnatum W. P. Sch, in Besch. Fl. bryol. Antill. fr. p. 85.

1. - Am. sept. : Guadalup.

cubense (C. M.) Mitt. op. cit. p. 514.

Hypnum cubense $C, M, S y n . I I, p .267$.

Leskea adnata Scllwaegr. in Poepp. M. Cub.

1. Cortic. - Am. sept. : Cuba.

cupressoides (C. M.) Mitt. op. cit. p. 511.

Hypnum cupressoides C. M. in Bot. Zeit. 1845, p. 109 et Syn. II, p. 303.

H. cyparissoides Wils, in Gardn. M. Brasil. n. 111 .

1 . - Am. merid. : Birasil. austr. or.

curvulum Mitt. mss.; C. H. Wright M. Madag. n. 7 (nom.).

$$
\text { - Afr. : Madagascar centr. }
$$

cygnicollum (Mitt.) Jaeg. Ad. II, p. 523.

Stereodon cygnicollus Mitt. M. Ind. or. p. 100.
1. 
cylindricum (Hsch.) Mitt. M. austr. am. p. 516.

Hypnum Estrellae C. M. Syn. II, p. 275.

Leskea cylindrica Hsch. Fl. Brasil. I, p. 73.

2 ? Cortic. - Am. merid. : Brasil. or.

cyparissioides (Hsch.) Mitt. op. cit.p. 512.

Hypnum cyparissioides Hsch. op. cit. p. 88 ; C. M. Syn. II, p. 304.

1. $\quad-$ Am. merid. : Brasil. or.

cyperoides (Hook.) Jaeg Ad. 11, p. 523.

Hypnum cyperoides Hook. in Wall. Cat. n. 7653; Harv. in Lond. Jowrh. of bot. $1840, I I$, p. 19 et in Hook. Ic. pl. var. I, t. 23, f. 5; C. M. Syn. II, p. $288 ;$ Bryol. jav. II, p. 195, t. 294.

Stereodon cyperoides Mitt. M. Ind. or. p. 99.

1 ?

- As. : Celebes, Java, Sumatra, Ceylan, Nepal.

dealbatum (Hsch. et Reinvo.) Jaeg. Ad. II, p. 528.

Hypnum dealbatum Hsch. et Reinw, in Nov. Act. Acad. Coesar, Leop. Carol. XIV, II, Suppl. p. 279 ; C. M. Syn. II, p. 306; Bryol. jav. Il. p. $194, t, 293$.

H. ochron Schwaegr. Suppl. III, II, t. 285.

1.

- As. : Borneo, Java, Sumatra.

distichellum (C. M.) Kindb. op. cit.

Hypnum distichellum C. M. in Th. Saves M. Nov. Caled. n, 21.

- Pac. : Nov. Caledon.

diffusum (Milt.) Jaeg. Ad. II, p. 524.

Stereodon diffusus Mitt, in Journ. of the Linn. Soc. 1863, p. 157.

2. - Afr.: Ins. Fernando- $\mathrm{P}_{0}$, Principis.

Dozyanum (C. M.) Jaeg. Ad. 1I, p. 531.

Hypnum Dozyanum C. M. Syn. II, p. 276; Bryol. jav. II, p. 147, t. 245.

H. verrucosum Dz. et Mk. in Ann. sc. nat. 1844, p. 309. 2. - As. : Java.

Drepanopyllum Broth. in Bol. da Soc. Brot. 1890.

Ster. Lignic. - Afr. : Ins. S. Thom.

Dubyanum (C. M.) Jaeg. Ad. II, p. 536.

Hypnum Dubyanum C. M. Syn. II, p. 241 ; Bryol. jav. II, p. 182, t. 280.

H. reticulatum Duby in Pl. Zolling. n. 1580 .

1. Arbor. - As. : Amboine, ins. Banca, Java. eleganti-pinnatum (C. M.) Jaeg. Ad. II, p. 526.

Hypnum eleganti-pinnatum C. M. in Linn: 1874, p. 564.

1. - As. : M. ins. Philippin.

eurycladium Besch. Fl. bryol. Antill. fr. p. 86 .

2 ? Ster. - Am. sept. : Guadalup.

eurydictyon Besch, op. cit. p. 85.

exiguum (Geh. et Hpe.) Par.

Hypnum exigunm G. et H. Enum. M. Brasil. p. 68 . 1. - Am, merid. : Brasil. or.

? falciforme (Dz. et Mk.) Jaeg. Ad. II, p. 522 (I).

(1) "An Hypnum, Drepanium seu pseudo-Chaetomitrium? o Jaeg. l. c. 
Hypnum falciforme Dz. et $M k$. in Ann. sc. nat. 1844, IV, p. 306; C. M. Syn. II, p. 299; Bryol. jav. II, p. 203, t. 302.

1 (C. M.) 2 (Bryol. jav). - As. : Celebes, Borneo, Java, Sumatra. ferrugrineum (C. M.) Jaeg. Ad. II, p. 525.

Hypnum ferrugineum C. M. in Linn. 1874, p. 561.

Ster. - As. : Ins. Philippin.

llavo-viride Mill. M. austr. am. p. 518. - Am. sept. : Cuba.

fuscescens Mitt. - E, inflectens.

var. condensatum Jaeg. - E. inflectens var, condensatum.

galerulatum (Dub.) Besch. Fl. bryol. Réunion, etc. p. 180.

Hypnum galerulatum Duby Choix de M. in Mem.... Geneve, 1877, p. 7, t. 2, I. f. I (exel. b. et e. qux ad Brachytecium atro-thecam pertin ?).

glaucinum Besch. Not. M. Paraguay, p. 271.

1 .

Eoss.: Rab. n, 1198, 1271. - Afr.: Ins. Franciae.

glaucissimum (C. M.) Besch. Fl. bryol Réunion, elc. p. 180.

Hypnum glaucissimum C. M. in Linn. 1876, p. 276.

$$
\text { - Afr. : Ins. Anjouan. }
$$

glauculum Broth. in Bol. da Soc. Brot. 1890.

1. Arbor, - Afr. : Ins, S. Thom.

globitheca (C. M.) Mitt. np. cit. p. 512 ,

Hypnum globitheca C. M. Syn. II, p. 300,

1.

-Am. sept.: Cuba, Jamaïc., Guadalup. Am. merid.: golungense (Welwo. et Duby) Jaeg. Ad. II, p. 538.

Hypnum golungense $W$. et $D$. in Mem.... Genéve, 1881, p. 8, t. 2, f. 4.

1. Ad rup, humid, - Afr. : Angola. gracílicaule (Lac.) Jaey. Ad. 11, p. 524.

Hypnum gracilicaule Lac. in sched?

$$
\text { - As. : Java. }
$$

gracilisetum (Hsch, et Reinw.) Milt. Fl. Vit. p. 400.

Hypnum gracilisetum $H$, et $R$. in Nov. Act. Acad. Crs. Leop, Carol. XIV

II, Suppl. p. 727; C. M. Syn. II, p. 312: Bryol. jav. II, p. 192, t. 191

H. mundulnm Sull, in Proced. Am, Acad. 1854.

Isopterygium gracilisetum Jaeg. Ad. II, p. 499. 1.

Sandwic. - As, : Celebes, Borneo, M. Java. Pac.: Ins,

gracillimum (Hsch.) Mitt, M. austr. am. p. 596.

Hypnum gracillimum Hseh. Fl. Brasil. I, p. 78 ; C. M. Syn. II, p. 278.

graminicolor (̊̊ngstr.) Jaeg. Ad. II, p. ј34.

- As. : Brasil. or.

Hypuum graminicolor Angsti. in Oefv... 1872, n, 4, p. 15

Ster. $\quad-$ Pac. : Ins, Sandwic.

(1) Forsan E. dealbati var, , C. M. I. c. 
hapalypterum (C.M.) Par.

Hypnum hapalypterum $C, M$. in $F l .1886, p .519$.

Ster.

- Afr.: Gabon.

hookerioides (C. M.) Mitt. op. cit. p. 516.

Hookeria hypnoides Hsch, op. cit. p. 67.

Hypnum hookerioides C. M. Syn. II, p. 342 .

1.

- Am. merid. : Brasil. austr. or.

hygrobium Besch. Fl. bryol. Réunion, etc. p. 179.

- Afr. : Ins. Borbon.

ichnotocladum (C. M.) Jaeg. Ad. II, p. 523.

Hypnum ichnotocladum C. M. Syn. I1, p. 301; Bryol. jav. II, p. 197, t. 296.

Stereodon ichnotocladus Mitt, M. Ind. or. p. 99.

2.

Amboine.

incubans (Hsch, et Reinwo.) Jaeg. Ad. II, p. 528.

Hypnum incubans $H$. et R. op. eit. p. $730 ;$ C, M. Syn. $I I, p .306(1)$ Bryol. jav. II, p. 195.

1 .

- As. : Java.

inflectens (Brid.) Jaeg. Ad. II, p. 532.

Coelidium apertum Jaeg. op. cit. p. 384.

E. fuscescens Mitl. Sam. M. p. 180.

Hypnum apertum Sull, in Exped. Wilkes 1859, M. p. 18, t. 16. f. A

H. fuscescens Hook, et Arn. in Capt. Beechey's Voy. bot. 1841, p. 76. t. $19 ;$ C. M. Syn. II, p. 341.

H. inflectens C. M. l. c. p. 239.

H. loxocarpum Aingstr. in Oefv... 1872, n. 5, p. 126.

Leskea Omalia in flectens Brid. Bryol, univ. II, p. 331.

1? Ad arbor, et rup. humid. - Pac.: Ins. Samoa, Societat., Viti, Taïti, Nov, Caledon., ins. Admiral.

" var. condensatum (Jaeg.) Par.

Colidium apertum var. condensatum Jaeg. l. c.

E. fuscescens var. condensatum Jaeg. Ad. $I I, p .533$.

- Pac. : Ins. Sandwic.

intorquatum (Dz. et Mk.) Jaeg. Ad. II, p. 521 (1).

Hypnum intorquatum Dz. et Mk. in . Ann. sc. nat. 1844, IV, p. 307; C. M. 2. Syn. II, p. 300; Bryol. jav. II, p, 202, t. 301.

Sumatrra.

ischyropteris (C, M.) Par.

Vesicularia ischyropteris $C . M$. in Dusen $M$. Camer, n. I. - Afr. : M. Cameroon.

Kurzii (Bryol. jav.) Jaeg. Ad. II, p. 536.

Hypnum Kurzii Bryol. jav. II, p. 183, t. 281.

1. Arbor, - As. : Ins. Banca.

laevifolium Mitt. M. auslr. am. p. 517.

1.

- Am. merid.: And. Nov. Granat.

(1) a An Hypnum, Drepanium seu pseudo-Chaetomitrium ? "Jaeg, 1.6 
laevigatum Thw. et Mitt, in Journ. of the Linn, Soc. 1872, p. 320.

1 . - As. : Ceylan, Tonkin.

lamprophyllum (Hpe.) Jaeg. Ad. II, p. 530.

Hypnum lamprophyllum Hpe. Symb. 1874, p. 517.

1. Cortic. - Am. merid. : Brasil, austr. or.

latifolium (Tayl). Jaeg. Ad. II, p. 522.

Hypnum latifolium Tayl. in Lond. Journ. of bot. 1848, p. 196; C. M. 2 ? - Am. merid. : And. Quitens.

laxum (Hpe.) Jaeg. Adl, II, p, 530.

Hypnum laxum Hpe. Symb. 1874, $p .516$. 1. - Am. merid. : Brasil, austr. or.

leiophyllum (Mitt.) Jaeg. Ad. II, p. 532.

Stereodon leiophyllus Mitt. M. Ind. or, p. 101. 1. - As. : Ceylan.

Lepervanchei Besch. Fl. bryol. Réunion, etc. p. 179.

1. Lignic. - Afr.: Ins. Borbon.

leucocladium W. P. Sch. in Besch. Fl. bryol. Antill. fr. p. 86 .

1. Ad lapid, et terr, - Am. sept. : Guadalup., Martinic. leucoflavum (C. M.) Par.

Vesicularia leucoflava C. M. in Dusen M. Camer: n. 110. - Afr. : M. lameroon.

longisetum W. P. Sch. op. cil. p. 84.

1. Terr. - Am, sept.: Guadalup.

longo-fluitans (C, M.) $P x r$.

Vesicularia longo-fluitans C. M. in Dusen M. Camer, n, 494. - Afr. : M. Cameroon.

loricatifolium (C. M.) Broth. in Engler's Bot. Jahrb. 1893, p. 480.

Hypnum loricatifolium C. M. mss. 1.

- Pac. : Nov. Guinea.

Luzoniae (C. M.) Jaeg. Ad. II, p. 524.

Hypnum Luzoniae C. M. in Linn. 1874, p. 563 .

2 .

macrobolax (C.M.) Kinclb, op. cit.

- As. : M. ins. Philippin.

Hypnum macrobolax C. M. in Engler's Bot. Jahrb. 1883, p. 86 et in Forchungsreise... p. 55.

Ster. Arbor. - Pac. : Nov. Guinea.

malacoblastum (C, M.) Jaeg. Ad. II, p. 526.

Hypnum malacoblistum C. M. M. Polyn. p. 82.

- Pac. : Ins. Samoa.

mayumbense Besch, in Journ. de bot. 1894, p.61.

I?

Meyenianum (Hpe.) Jaeg. Ad. II, p. 532 ,

-- Afr. : Congo gall. (Brazzaville).

Acosta Meyeniana C. M. in Linn. 1848, p. 194.

Hookeria Meyeniana Hpe. Is. M. t. 3 .

Hypnum Meyenianum ej. in C. M. Syn. II, p. 233.

- As. : Manille. 
micropyxis Broth. in Mitth. aus d. deutseh. Schutzgeb. 1893, 11I, p. 5 (nom.).

$$
\text { - Afr. : Togo. }
$$

mollicellum (Mitt.) Jaeg. Ad. II, p. 5:4.

Stereodon mollicellus Mitt. in Journ. of the Linn. Soc. 1863, p. 157.

2. - Afr.: M. Cameroon.

Montagnei (Bel.) Jaeg. Ad. II, p. 533.

Hypnum Montagnei C. M. Syn. II, p. 234; Bryol. jav. 1I, p. 181, t. 279; Mont. in Hist. Cuba, Crypt. p. 530, t. 20, f. I.

Pterygophyllum Montagnei Bel. Voy. Ind. or. 1835, Bot. II, Crypt. p. 85, t. $9, f . T$.

1 .

- As. : Amboine, Borneo, Java, Sumatra.

monumentorum (Duby) Jaeg. Ad. II, p. 523.

Hypnum monumentorum Duby in Moritzi Verz. d. Zoll. Pf. p. 132; C. M. Syn. II, p. 301 ; Bryol. jav. II, p. 196, t. 295.

1. Ad tumulos. - As. : Ins. Banca, Java, Sumatra.

Moritzii (C. M) Jaeg. Ad. II, p. 526.

Hypnum Moritzii C. M. Syn. II, p. 303 ; Bryol. jav. II, p. 200, t. 299.

H. venustum Duby op. cit. p. 131. Syn,
Java.

? mundum (C. M.) Par.

Hypnum mundum C. M. in Fildebr. M. Mad. n. 2077.

- Afr. : Madagascar or.

mycostelium (Hpe.) Par.

Hypnam mycostelium Hpe. Enum. M. Brasil. p. 70.

1. Lignic. - Am. merid. : Brasil, austr. or.

nanocarpum (C.M.) Par.

Hypnum nanocarpum C. M. in Verh. d. bot. Ver. Brandenb. 1890, p. 62.

$$
\perp \text { Afr. : Tropic. occid. }
$$

nano-crista-castrensis (C. M.), Kindb, op. cit.

Hypnum nano-crista-castrensis C. M. in Hildebr: M. Mad. n. 2127.

- Afr. : Madagascar.

Novarae (Reichdt.) Jaeg. Ad. II, p. 531. varae (Reichdt.) Jaeg. Ad. II, p. 531 .
Hypnum Novarae Reichdt. in Novara Exped. Bot. I, p. $192, t .33$ et it
Hedurigia, $1868, n .12$.

Arbor. - Pac. : Taïti.

nutans (Nees) Jaey. Ad. I1, p. 536. ans (Nees) Jaey. Ad. II, p. 536 .
Hypnum nutans Nees in C. M. Syn II, p. 240; Bryol. jar. II, p. 186,
t. 284 .

1. Ad lapid. - As. : Java.

omepetense (Sull. et Lesq.) Mitt. M. austr. am. p. 515.

Hypnum omepetense S, et $L$. in Proced. Am. Acad. 1859, p. 281.

1. Cortic. - Am. sept. : Nicaragua.

oreadelphum (C.M.) Par.

Vesicularia oreadelpha C. M. in Dusen M. Camer. n. 255.

$$
\text { - Afr.: M. Cameroon. }
$$


oxyodon (Welvo, et Duby) Jaeg: Ad. 11, p. 537.

Hypnum axyodon $W$. et D. in Mémoires.... Genève, $1871, p, 8, t, 3, f .7$.

1. Arbor. - Afr. : Angola.

pacificum Mitt. Sam. M. p. 180.

Hypnum pacificum C. M. M. Polyn. p. 81 .

1 (Mitt.) ; polyg. (C. M.).

Hebrid., Nov. Caledon.

- Pac. : Ins. Samoa, Nov.

Pailloti Ren. et Card. in Bull. Soc. roy. bot. Belg. 1893, I, p. 124.

2.

- Afr. : Madagascar.

paulense (Geh. et Hpe.) Par.

Hypnum paulense $G$. et $H$. in $F l$. 1891, $p$.

1. - Am. merid.: Brasil. austr, or.

perangustum (C. M.) Kindb. op. cil.

Hypnum perangustum $C . M$. in Rev. bryol. 1887, $p, 57$ (nom.)

- Pac. : Nov. Caledon.

perpallidum (C. M.) Par.

Vesicularia perpallida C. M. in Dusen M. Camer. n. 707.

- Afr.: M. Cameroon.

perviride (Angstr.) Par:

Hypnum perviride Angst, in Oefo,... 1872, n. 4, p. 15 (sub H. graminicoSter, ori; cf. err. op. cit. 1873 p. $15 \mathrm{I}$ ).

plano-falcatulum Broth, in Engler's Bot. Jahrb. 1893, p. 481.

Ster. Cortic. - Pac. : Nov. Guinea.

plumulum Mitt. M. austr. am, p. 513.

Hypnum cupressoides Sull. in Proced. Am. Acad.

1. Lignic. - Ani. sept, : Cuba.

polyandrum (Ångstr.) Jaeg. Ad. II, p. 524.

Hypnum polyandrum Angstr. in Oefv.... 1873, n. $5, p .129$.

- Pac. : Taïti.

a var, fulvo-virens Besch. Fl, bryal. Taiti, etc.

polypterum Mitt. op, cit. p. 514.

Ster. $\quad-A m$. sept. : Jamaï., Guadalup.

pycnodontium (C. M.) Pai:

Hypnum pycnodontium C. M. in Engler's Bot. Jahrb. 1883, p. 85 et in Forehungsreise..., p. 47.

1. Arbor. - Pac.: Nov. Hannov.

regulare (C. M.) Besch. Fl. bryol. Réunion, etc. p. 174.

Hypnum regulare C. M. Syn. II, p. 307 .

H. Stereodon cupressiforme $\zeta$ regulare Brid, Bryol, univ. II, p. 609.

2. Cortic, - Afr. Ins. Borbon.

" var. minus Ren, in Rev. bryol, 1889, p. 85.

- Afr. : Ins. Franciae.

reticulatum (Dz. et $M k$, Jaeg. Ad. II, p. 535.

Hspnum reticulatum Dz. et Mk. in Ann. sc, nat. 1814, IV, p. 309; C. M. Syn. II, p. 236; Bryol. jav. II, p. 185, $t, 283$. 
Stereodon reticulatus Mitt. M. Ind. or, p. 101.

1. - As. : Nepal., Sikkim, Klıasia, Sumatıa, Java, Celebes, Pac. : Nov. Caledon.

robuste-pinnatum (Hpe.) Jaeg. Ad. Il, p. 538.

Hypnum robuste-pinnatum $H_{p e}$. in sched.

- As. : Birmania.

Rodriguezii Ren. et Card. in Bull. Soc. roy. Belg. 1890, I, p. 185.

1.

- Afr. : Ins. Borbon.

rostellatum (Mitt.) Jaeg. Ad. II, p. 522.

Stereodon rostellaius Mitt. op. cit. p. 100.

2.

- As. : Nepal.

rufulum Ren, et Card.

- Afr. : Madagascar.

rutilans (Brid.) Mitt. M. austr, am, p. 519.

Hypnum rutilans $C . M . S y n . I I, p .234$.

Leskea Omalia rutilans Brid. Bryol. univ. II, p. 332.

2 ?

- Am. sept. : Porto-Rico. Am. merid.: Venezuela, Brasil. austr. or., Paraguay.

sandwichense (Hook, et Arn.) Mitt. Fl, Vit. p. 400.

Hypnum acinacifolium Hpe. (fid. Mitt.).

H. sandwichense Hook. et Arn. Bot. of Capt. Beechcy's Voy. 1841.p. 109; C. M. Syn.II, p. 319; Fl. of the N. Zeal. II, p. 113.

Plagiothecium sandwichense Jaeg. Ad. II, p. 520.

1. Arbor. - Pac.: Ins. Sandwic., Sansov, Kermadec, Nov. Zeland. sept., ins. Lord Howe.

sarcoblastum (C.M.) Par.

Vesicularia sarcoblasta C. M. in Dusen M. Canar, $n, 108$.

- Afr. : M. Cameroon.

Savaicum (C. M.) Jaeg. Ad. II, p. 525.

Hypnum Savaicum C. M. M. Polyn. p. 82.

Ster.

- Pac.: Ins. Samoa.

? scaturiginum (Brid.) Besch. Fl, bryol. Réunion, etc. p. 181.

Hypnum scaturiginum Brid. Bryol. univ, II, p. 418; C. M. Syn. II, p. 236 ; Bryol. jav. II, p. 180, t. 278.

Stereodon scaturiginus Mitt. in Journ. of the Linn. Soc. 1863. p. 157.

1. Submers. - As.: Java. Afr. : Ins, Borbon., Rodriguez, Fernando. Po, Principis.

Seychellarum Besch, op: cit. p. 177.

2 ?

- Afr. : Ins. Seychell.

sigmangium (C. M.) Par.

Vesicularia sigmangia $C, M$. in Dusen M. Camer, n. a 6 .

- Afr. : M. Cameroon.

Slateri (Hpe.) Jaeg. Ad. 11, p. 534.

Hypnum Slateri Hpe, in Linn. 1876, p. 321.

- Pac. : Austral. or.

sodale (Sull.) Mitt. Sam. M. p. 180 (1). 
Hypnum calpaecarpum Angstr. in Oefv.... 1872, n. 5, p. 128.

H. molluscoides Sull. in Proced. Am. Acad. $1853 \mathrm{et}$ notul. ej. in Am. Expl. Exp.p. 15.

H. sodale ej. in Exped. Wilkes 1859, M. p. 15, t. 12, f. B. - Pac. : Ins, Marquis,, Societat,, Samoa, Taïti.

Soyauxii (C. M.) Par.

Hypnum Soyauxii C. M. in Fl. 1886, p. 519.

1. - Afr. : Gabon.

? sparsipilum (Bryol. jav.) Jaeg. Ad, II, p. 522.

Hypnum sparsipilum Bryol. jav. $I I, p .201, t, 300$.

2. Arbor, - As. : M. Java.

sphœrocarpon (C. M.) Besch. op, cit. p. 180.

Hypnum sphoerocarpon C. M. Syn. II, p. 238.

Leucomium sphoerocarpon Jaeg. Ad. II, p. 540.

1. - Afr.: Ins. Borbon., Franciae, Nossi-Be, NossiComba, Galega.

splendidulum (Hsch.) Mitt. M. austr. am. p. 516.

Hypnum splendidulum Hsch. op. cit. p. 78; C. M. Syn. II, p. 283. 1.

- Am. merid. : Brasil. austr. or.

stramineolum (C. M.) Jaeg. Ad. II, p. 533 .

Hypnum stramineolum C. M. M. Polyn. p. 81.

Ster.

- Pac. : Ins. Samoa.

subbrevisetum (Hpe.) Jaeg. Ad. II, p. 529.

Hypnum subbrevisetum Hpe. Symb. 1874, p. 515.

2? Cortic. - Am. merid. : Brasil. austr. or.

subdenticulatum (C. M.) Mitt. M. austr. ain. p. 518.

Acosta Swartzii C. M. in Linn. 1848, p. 191.

Hypnum subdenticulatum ej. Syn. II, p. 242.

1. Lignic. - Am. sept.: Jamaïc, Porto-Rico. Am. merid. : Venezuela, ins. Trinitat, Guian., Brasil, austr. or., And. Peruv.

subenerve Mitt. in Philos. Trans, of the Roy. Soc. 1879 (extra vol.), p. 393.

Ster.

sublimatum (Ltz.) Par.

- Afi:. Ins. Rodriguez.

Hypnum limatum H. f. et W. ?

H. sublimatum Ltz. in Bot. Zeit. 1866, p. 188 .

- Am. merid. : Chile.

subretusum Thw, et Mitl. in Journ. of the Linn. Soo. 1872, p. 321.

2 ?

- As. : Ceylan.

M. in Bull. Soc. roy. Belg. 1S94, II, p. 134 el in Ren.

M. Masc. Mad. n. 141 .

subsarcoblastum (C. M.) Par.

Afr.: Ins. Borbon.

Vesicularia subsarcoblasta C. M. in Dusen M. Camer. n. 826.

- Afr. : M. Cameroon.

suburceolatum (Hpe. et Ltz.) Jaeg. Ad. $1 I, p .529$.

Hypnum suburceolatum Hpe. et Ltz. in Bot. Zeit. 1868, n. 48 et 1869, n. 28.

1. Lignicol. - Am, merid.: And. Equator. 
subulnsum Mitt. in Philos, Trans, of the Roy. Soc. 1879 (extra vol).p.394.

Ster. Ad rup, argill. secus torrent, - Af $r$ : Ins. Rodriguez.

succosum (Mitt.) Jaeg. Ad. II, p. 536.

Stereodon succosus Mitt. M. Ind. or. p. 101.

1.

- As. : Nepal or.

sulfureo-flavum (C. M.) $\mathrm{Par}$.

Vesicularia sulfureo-flava $C . M$. in Dusen M. Camer. $n .8$.

$$
\text { - Afr. : M. Cameroon. }
$$

surinamense (Dz. et Mk.) Jaeg. Ad. II, p. 537.

Hypnum surinamense Dz. et Mk. Prodr. bryol. Surinam. p. 25, t. 14.

1. Arbor. - Am. merid. : Guian. batav.

taïtense (Ångstr.) Jaeg. Ad. II, p. 535 .

Hypnum taitense Angstr. in Oefv.... 1873, n. 5, p. 125.

1. - Pac, : Taiti.

tenaci-insertum (C.M.) Par.

Hypnum tenaci-insertum C. M. in Fl. 1886, p. 518.

1. - Afr.: Gabon.

tenuatipes (C. M.) Par.

Hypnum tenuatipes $C . M$. in op. cit. p. 520 .

1. Terr. - Afr. : Old Calabar.

terrestre (C.M.) Par.

Hypnum terrestre $C$. $M$. in op. et $l$. cc.

1. Terr. - Afr. : Ins. Fernando-Po.

Tholloni Besch. in Journ. de bot. 1894, p. 60.

1. $\quad-A f r$.: Congo gall. (Brazzaville).

tonkinense Besch. in Journ. de Bot. 1890, p.

- As. : Tonkin.

tophigerum Broth. in Engler's Bot. Jahrb. 1893, p. 480.

Ster.

- Pac. : Nov. Guinea.

trinitense (C. M.) Mitt. M. austr. am. p. 514.

Hypnum trinitense C. M. Syn. 1I, p. 284.

1. $\quad-$ Am. merid. : Ins, Trinitat.

triviale $(C, M$.$) Kindb. op. cit.$

Hypnum triviale $C . M$. in $F l .1886, p .521$.

Terr. - Afr: : Ins. Fernando-Po.

truncatulum (C. M.) Mitt. op. cit. p. 517.

Hypnum truncatulum C. M. Syn. II, p. 263.

Trichosteleum truncatulum Jaeg. Ad. II, p. 481.

Syn. $\quad-A m$. merid, : And. Quitens, et Peruv.

? tuberculatum (Mitt.) Jaeg. Ad. II, p. 532 (1).

Stereodon tuberculatus Mitt. M. Ind. or. p. 101.

1.

- As. : Ceylan. 
tutuilum (Sull.) Mitt. Sam. M. p. 180 (1).

Hypnum tutuilum Sull. in Exped. Wilkes, 1859, M. p. 15, t. 10, f. A.

2? Arbor. - Pac. : Ins. Samoa, Viti.

urceolatum (Hsch.) Mitt. M. austr. am. p. 515.

Hypnum urceolatum Hsch. op, cit. p. 87, t. 4; C. M. Sỷn. II, p. 240. 1. - Am. merid.: Brasil. austr. or.

Valentini Besch. Fl. bryol. Réunion, etc, p. 176.

2. - Afr.: Ins. Borbon.

"var. minus Ren, in Rev. bryol. 1889, p. 85. - Afr. : Ins. Franciae.

verrucosum (Hpe.) Jaeg. Ad, II, p. 536.

Hypnum verrucosum Hpe. Ie. M. t. 10; C. M. Syn. II, p. 237 ; Bryol. jav, $I I, p .190, t .289$.

1. Arbor, et calcic. - As. : Java, Sumatra.

vesiculare (Schwaegr.) Mitt. op, cit. p. 518.

Hookeria Poeppigiana Hpe. Ic. M. t, 4.

H. praelonga $W$. Arn. Disp. M, p. 56 .

Hypnum Poeppigianum Hpe. in C. M. Syn. II, p. 235.

H. vesiculare Schwaegr. Suppl. II, II, t. 199; C. M. op. et $I$. ce.

1. $-A m$, sept. : Jamaïc. Am, merid.: And. Nov. Granat. et Peruv.

? viridulum (Brid.) Besch. Fl. bryol. Réunion, elc. p. 181.

Hypnum viridulum Brid. Mant. M. p. 179; C. M. Syn. II, p. 307.

H. Stereodon leptorhynchum $\beta$ viridulum Brid. Bryol. univ. II, p. 622. - Afr. : Ins. Borbon.

Wainioi Broth, in Act. Soc. sc. Fenn. 1891, n. 5.

1. In terr, argill. $-\Lambda \mathrm{m}$. merid. : Minas Geraës.

Zollingeri (C. M.) Jaeg. Ad. II, p. 536.

Hypnum Zollingeri C. M. Syn. II, p. 241 ; Bryol. jav. II, p. 189, t. 288.

1. Ad arb., sax. madid. et terr. humid. - As.: Amboine, Celebes, Java (2).

Elodium Lesq. el Jam. Man. p. 329 (subgen. HypNi = H. (Thuidrum Nob.) paludosum).

ENGALYPTA Schreb. Gen. PJ, p. 1643 (32 spec.) (3).

affinis Hedw. f. $\left\{\begin{array}{l}\text { (fid. Lindb.) } \\ \text { (fid. W - E. apophysata. }\end{array}\right.$

affinis Schwaegr. (fid. W. P. Sch.). - E. rhabdocarpa.

alaskana Kindb. in Mac. Cat. p. 269.

1. Terr. - Am. sept. : Frel. Rehring.

alpina Wahlenb. - E. commutata.

(1) " An Hypnum-Drepanium ? " Jaeg. op. c. p. 525.

(2) In Enum Kindberg. nomina nuda :

E. mammillosulum (C. M.

(3) De gen. Encolifolium (C. $\dot{M}$.) E. semi-globosum (C.M.). in adn, 
apophysata Bryol. Germ. II, p. 42,t. 15; Bryol. eur. III (mon. p. II),

i. 201 ; C. M. Syn. I, p. 518; W. P. Sch. Syn. 11 ed. p. 344.

E. affinis Hedw, f. in W. et M. Beitr, zur. Naturk, I, p. 12I, t. 4 (fid. de Not., Lindb., etc.).

E. cylindrica Bryol. germ. II, p. 52.

Leersia affinis Lindb. M. Scand. p. 20.

1. Ad terr. et in fiss. rup. - Eur.: Summ. Alp. Scandin., Sudet., Salisb., Stir., Carinth., Tirol., Ticin., Helvet., Gall, As.: Jenissei inf., Caucas, occ. et centr. Am. sept.: M. Rupestr.

Exs. : Rab. Bryoth, eur. n. 816.

aristata Hpe. - Barbula aristatula.

var, $c$ Rab. - E. microphylla.

asperifolia Mitt. M. austr. am. p. I81.

1. Saxic. - Am. meritl. : And. Quitens. et Peruv.

australis Mitt, in Journ. of the Linn. Soc 1859, p. 72; Fl. Tasman. II, p. 423 ; Handb. of N. Zeal. Fl. p. 422.

1 .

Zeland, Tasman.

borealis Kindb. - E. Macounii.

brevicolla $B r$, in sched. Un. itin. 1829 ; Bryol. eur. VI, t. 637; C. M.

Syn. 1, p. 619; W. P. Sch. op. cit. p 346.

E. longicolla var, brevicolla Bryol. eur. III (mon. p. 12), t. 202, f. $\beta$.

Leersia brevicolla Lindb. l. $c$.

1. - Eur.: Rariss.; Alp. Scandin., I.appon.

Eos, : Un. itin. 1867, n. 91 (E. ciliatae immixt.).

capillata Schk. - E. commutata.

caucasica Rupr. in Bull. Soc. imp. Nat. Moscou, 1846, p. 521 ; C. M. Syn. I, p. 522.

E. commutata (fid Lindb.).

1.

- As. : Caucas. centr.

ciliata Hedvo. Sp. M. p. 6; Bryol. eur. III (mon. p. 10), t. 300; C. M. Syn. I, p. 517; W. P. Sch. op. cit p. 343.

Bryum caule folioso calyptra cylindrica longe aristata Hall. Stirp. helv. III, t. $45, f, 3$.

Br. ciliare Gmel. Syst. nat. II, p. 1332.
Br, extinctorium forma majus et ramosum Dill. Hist. M. p. $350, t .45, f .9$.

E. clausa Wallr. Fl. Germ. crypt. I, p. 125.

E. elongata Funk in Brid. Bryol. univ, I, p. 787.

E. fimbriata Brid. op. oit. p. 145.

E. fimbriata var, elongata ej. op. cit. p. 787.

E. laciniata Lindb. Contr. ad ft. crypt. As. bor, or, p. 269.

Leersia ciliata Hedw. M. frond. I, p. 49, t. 19.

L. extinctoria $\beta$ Leyss. Fl. Hall, $n, 1053$.

L. fimbriata Brid. M. Rec. $I I, I, p .53$.

L. laciniata Hedw, op cit. II, p. 103.

I. In rup. fissur. et muror. interst. - Eur. : E, reg. mont. usq. in slp. As. : Jenissei med., Amour, Himalaya occ., Caucas. Af $r$. : Alg., Abyss., C. B. Sp. Am. sept. : M. Rupestr., litt. Pacif, Idaho, Montana, Minnesota, Nov. Angl. (1).

Exs. : Mac. Canad. M. n. 132.

Rab. Bryoth. eur. n. 489, 1270. 
Sull. et Lesq. M. bor. am. II ed. n. 165.

W. Sch. M. Abyss. n. 430, 470 (f. gymnostoma).

"var. microstoma (Bals, et de Not.) Bryol, eur, l. c. f. 16-21; W. P. Sch. op. cit. p. 344 .

E. microstoma Bals. et de Not. Pug. p. 18 et Syll. p. 269 ; C. M. Syn. I, p. 514 .

Ut typ. - Eur. : Summ. Alp. Stir., Salisb., Carinth., Tirol., Helvet. As. : Caucas, occ. et centr.

var. rhabdocarpa H. et T. - E. rhabdocarpa.

"var. sibirica Weinm, in Bull. Soc. imp. nat. Moscou, 1845, p. 448, n. 2; Lindb. Contrib. ad Fl. crypt. As. bor. or. 1872, p. 268.

Leersia sibirica Lindb. et Arn. M. As. bor. 1890, p. 64.

Ut typ. - As. : Sibiria (Irkoutsk.).

ciliala Hoppe. - E. streptocarpa.

cirruta Sw. - Dicranoweisia.

clausa Wallr. - E. ciliata.

coarctata Mitt. M. austr. am. p. 181.

1.

- Am. merid. : Summ. Pichincha.

commutata Bryol. germ. 1I, p. 46, t. 15; Bryol. eur. III (mon. p. 8),

t. 198 ; C. M. Syn. I, p. 513; W. P. Sch. op. cit. p. 340.

E. affinis (1) Schwaegr. Suppl. I, I, p. 68, t. 16; Brid. Bryol. univ. I, p. 143 ; Drumm. M. bor. am. I ed. $n .49$.

E. alpina (1) Wahlenb. Fl. Lapp. p. 312.

E. capillata Schkuhr Deutsch. M. p. 46, t. 20.

E. fimbriata $\beta$ alpina $H$, et T. Muscol. brit. $p$. 35 .

E. lacera de Not. Mant. n. 66 et Syll. p. 268;C. M. Syn. II, p. 514.

Leersia alpina $L i n d b, l$. $c$.

1. Ad terr. et in fiss, rup. - Eur. : Spitzberg, ins. Tirsorum, summ. Alp. zon. intermed, et sept.; Jurass. - $A s$. : Jenissei inf., Tibet occ. Am. sept.: M. Rupestr., Alaska, Nevada, Colorado, Idaho.

Eics. : Rab. Bryoth, eur. n. 69.

corniculata Wahlenb. - Trichostomum.

contorta Lindb. - E. streptocarpa.

crispala Schwaegr. - Ptychomitrium.

cucullata O. M. et Kindb. in Mac. Cat. p. 96.

E. rhabdocarpa Drumm. M. bor. am. I ed, $n .52$,

1. Terr. - Am. sept. : Columb, brit.

Exs. : Mac. Canad, M. n. 491.

cuspidata Br. el Sch. in W. Sch. M. Abyss. n. 492 b; C. M. Syn. I, p. 515 .

1.

- M. Abyss.

cylindrica Bryol. germ. - E. apophysata.

Daviesii Sm. - Glyphomitrium.

elongala Funk, - E. ciliata.

$\underset{2 \text { ? }}{\text { emersa } C . M .}$ in Linn. $1878-79$, p. 354.

- Am. merid. : Argentin. subtrop.

extinctoria Sw. - E. vulgaris.

(1) Cf. W. P. Sch. Syn. I ed. p. 285 et II ed, p. 341. 
filiformis Roth. -- Pterigynandrum.

fimbriata Brid. - E. ciliata.

var. alpina H. et T. - E. commutata.

var. elongata Brid. - E. ciliata.

gracilis Roth. - Pterogonium.

grandis Sw. - E. streptocarpa.

intermedia Jur. Beitr.... p. 595.

1.

- As. : Kurdistan.

lacera Ren, et Card, in Rev. bryol, 1892, p. 91.

- Am. sept. : Oregon.

lacera de Not. - E. commutata.

laciniata Lindb. - E. ciliata.

laevigata $\mathrm{Br} .-\mathrm{E}$. vulgaris var, mutica.

lanceolata Hedw. - Pottia.

leiocarpa Kindb. in Bult. Torr. bot. Club., XVII, p. 273.

1. Rupic, - Am. sept. : Alp. Columb. brit.

leiomitria C. M. et Kindb. in Mac. Cat. p. 94.

E. rhabdocarpa var. leiomitria Kindb. in Ott. Natur. $I V, p .61$.

1. Rupic. - Am. sept. : Athabasca.

leptodon $\left\{\begin{array}{l}\mathrm{Hpe} \text { - } \mathrm{E} \text {. rhabdocarpa. } \\ \mathrm{Br}, \text { - E. vulgaris. }\end{array}\right.$

var. extinctoria Lindb. - E. vulgaris.

? ligulata Spr. - Scopelophila.

longicolla Bryol, eur. III (mon. p. 12), 202; C. M. Syn. I, p. 518; W. P. Sch. op. cit. p. 345 .

1. Terr. - Eur.: Alp. Norveg., Carinth., Tirol., Jurass., Helvet., Carniol., Bavar.

Exs.: Un. itin. 1873, n. 46.

var, brevicolla Bryol, eur. - E. brevicolla.

longipes Mitt. - E. procera.

Macounii Aust. in Coult. Bot. Gaz. I1, p. 97.

E. borealis Kindb.

E. ciliata Drumm. M. bor, am. I ed. n. 50 .

1. Rupic. - Am. sept. : Groenland, New Brunswick, Gaspes., Ontario, lac. Erie, Super., Athabasca, M. Rupestr., Columb. brit., fret. Behring, ins. Vancouver.

Exs. : Mac. Canad. M. n. 133.

mexicana C. M. Syn. I, p. 516.

1 .

$$
\text { - Am. sept. : Mexico. }
$$

microphylla Bryol.germ. I1, p. 44, t. 14; C. M. Syn. I, p. 517 (1).

E. apophysata var. c. Rab. Deutsch. Kryptfl. II, III, p. 171. E. apophysata var. c. Rab. Deutsch. Kryptfl, II, III, p.
E. rhabdocarpa forma? Lindb. Contrib. ad Fl. erypt. As. bor. or. p. 269,
in adn.

1.

- Eur.: Tirol.

microstoma Bals, et de Not. - E. ciliata var. microstoma.

Novae Valesiae Hpe, in Linn. 1871-73, p. 513.

- Pac. : Austral. or.

(1) Cf. Limpr. Laumb. Deutsch]. I, p, 117. 
obtusifolia Funk. - E. valgaris var. mutica.

Orsinii de Not. - E. vulgaris.

parasitica Sw. - Calymperes.

pilifera Funk. - E. vulgaris var, pilifera.

procera Br. in sched. Un. itin. 1829 et in Denkschr. Akad. au München, 1828, p. 283, t. II; Bryol. eur. III (mon. p. 14), t. 205; C. M. Syn. I, p. 521; W. P. Sch. op. cit. p. 346.

E. longipes Mitt. in Journ. of the Linn. Soe. VIII, p. 29, t. 5; Mac. Canad. M. n. 474.

E. streptocarpa Hook, in Drumm. M. bor. am, I ed. n, 48.

Leersia procera Lindb. M. Scand, p. 20.

1. In rup. fissur. humid, - Eur. : Spitzberg, ins. Ursorum, Norveg., Dania. As. : Jenissei med, et infer. Am. sept. : Groenland, Ontario, M. Rupestr., Columb. brit.

Exs.: Mac. Canad, M. 565.

rhabdocarpa Schwaegr. Suppl. I, I, p. 56, t. 17; Brid. Bryol. univ. 1, p. 142 ; Bryol. eur. III (mon. p. 13), t. 204; C. M. Syn. I, p. 520; W. P. Sch. op. cit. p. 342 .

E. affinis Hedw. f. in W. et M. Beitr. I, p. 121, t.4 (fid. W. P. Sch.).

E. ciliata $\beta$ rhabdocarpa $H$. et T. Muscol. brit. $p .35$.

E. leptodon Hpe. in sched.

E. rhabdoearpa $\beta$ leptodon Lindb, in Oefv ... XXIII, $p .551$.

E. streptocarpa Wahlenb. Fl. Lapp. p. 312.

E. vulgaris var. elongata Milde Bryol. Siles. p, 182.

E. Wimmeriana Sendtn. mss.; Milde Bryol. Siles. p. 182 (fid. Limpr.).

Leersia rhabdocarpa Lindb. M. Scand. p. 20 (1).

L. vulgaris $\beta$ alpina Brid. M. Rec. II, $I, p .53$.

1. Ad terr. et in fiss. rup. - Eur.: Spitzberg, ins. Ursorum ; in subalp. et alp. zon. intermed. et sept. As, : Penins. Tschutschica, Jeniss, med. et inf., Tibet occ., Kurdistan, Pers., Caucas. occ, et centr. Am. sept.: Groenland, Gaspes., Alberta, M. Rupestr., Columb brit., Alaska, Washington, Colorado, Idaho. Nevada, Montana.

Exs. : Drumm. M. bor, am. I ed, n. 51.

Mac. Canad. M. n. 131.

Rab. Bryoth. eur. n. 70, 427, 535, 1306.

Sull, et Lesq. M. bor. am. II ed. n. 166.

Un. itin. 1867, n, 92, 93.

" var. gymnostoma (Lindb. et Arn.) Par.

Leersia rhabdocarpa var. gymnostoma $L$, et A. M. As. bor. 1890, $I I, p .63$. - As. : Jenissei inf.

" var. microstoma Breidl, in sched. el in Limpr. Laubm. Deutschl. I, p. 115 .

Ad rup. ealcar. - Eur. : Alp. Stir.

rhabdocarpa Drumm. - E. cucullata.

var. leiomitria Kindb. - E, leiomitria.

var. leptodon Lindb. - E. rhabdocarpa.

var. pilifera Schwaegr. - E. spathulata.

forma? Lindb. - E. microphylla.

sandwichensis Sull. Am. Expl. Exped. 1859, p. 6. 1 .

- Pac. : Ins. Sandwic.

(1) Cf. Lindb. 1. c, n. 162 in adnot. 
Selwyni Aust, in Coult. Bot. Gas. II, p. 109.

Leersia Selwyni Dna E. G. Britt. in Bull. Torr. bot. Cluh, 1891, p. 50.

1. Rupic. - Am. sept. : Athabasca, M. Rupestr., Columb. brit., ins. Vancouver, Idaho.

Exs. : Mac. Canad, M. n. 134.

spathulata C. M. Syn. I, p. 519 (1).

E. rhabdocarpa $\beta$ pilifera Schwaegr. in Wilk. M. Hispan.

Leersia spathulata Lindb. M. Scand. p. 20.

1. Ad mur et rup. - Eur. : Transilv., Stiria, Tirol., alp. Hispan.

Exs. : Rab. Bryoth. eur. n. 1163.

spathulata Mac. - E. subspathulata.

squarrosa Brid. - Leptodontium epunctatum.

streptocarpa Hedw. Sp. M. p. 62, t. 10; Brid. Bryol. univ. I, p. 44;

Bryol. eur. III (mon. p. 15), t. 204; C. M. Syn. I, p. 521; W. P.

Sch. op. cit, p. 347.

Bryum ciliare Dicks. Fasc. IV Pl. Crypt. p. 16.

Br. contortum Wulf in Jacq. Coll. II, p. 236.

E. ciliata Hoppe in Sturm Deutsch. Fl. II, III.

E. contorta Lindb. in Oefv.... 1863, n. 7.

E. grandis Sw. in Schrad. Bot. Journ. II, p. 172.

Hypnum saxatile erectum ramulis teretibus foliis subrotundis saturate viridibus Dill. Hist. M. p. 385, t. 43, f. 71.

Leersia contorta Lindb. M. Scand. p. 20.

Streptocarpus contortus Schwaegr. in Hpe. Fl. Hercyn.

2. Ad mur., saxa, rupes. - Eur. : E reg. campestr, usq. in alp. zon. interm., rar, sept. As. : Jenissei med., Caucas, occ. et centr. Am. sept. : Ontario, M. Rupestr., Allegh., New Jersey, Pensilv., Calif.

Exs, : Mac. Canad. M. p. 135.

Rab. Bryoth. eur. n. 68.

streptocarpa $\left\{\begin{array}{l}\text { Hook. - E. procera. } \\ \text { Wahlenb. - E. rhabdocarpa. }\end{array}\right.$

subspathulata C. M. et Kindb, in Mac. Cat. p. 93.

E. spathulata Mac. Canad. M. n. 421.

1. Terr. - Am. sept. : Columb. brit.

tasmanica Hpe. in Linn. 1853, p. 491.

E. vulgaris ej. op. cit. $1852, p .713$.

1. $\quad$ - Pac.: Austral.

tibetana Mitt. M. Ind. or. $\mu .42$.

1.

- As, : Tibet occ.

trachymitria Rip, - E, vulgaris var. trachymitria.

vernicosa W. P. Sch. in Mandon Pl. Boliv. n. 1626.

- Am. merid. : And. Boliv.

vulgaris Hedvo. Sp. M. p. 60 ; Brid. Bryol, univ. I, p. 139 ; Bryol. eur, III (mon. p. 9), ı. $198 ;$; C. M. Syn. I, p. 5l6; W. P. Sch. Syn. II ed.
p. 341.

Bryum calyptra extiuctorii forma minus Dill. Hist. M. p. 249, t. 45, f.8.

Br. extinctorium L. Sp. Pl.p. 158 p.p.

E. extinctoria Svo. M. Suec.p. 24.

E. leptodon $\mathrm{Br}$. in sched. (f.,peristom.).

(1) Cf. W. P. Sch. Syn. II ed. p. 342 et Lindb. Manip. M. 11, p. 412. 
E. leptodon var. extinctoria Lindb. in Act. Soc, sc. Fenn, 1872, p. 268.

E. Orsinii de Not. Syll. p. 267.

E. vulgaris $\beta$ apiculata Brid. Bryol. univ. I, p. 541.

Leersia extinctoria Leyss. Fl. Hall. n. 1053.

L. marginata Hedw. Fund. M. II, p. 103.

L. vulgaris ej. $M$. frond. $I, p .46, t .18$.

Mnium extinctorium L. f. Meth. M. p. 365.

1. Ad terram et mur. - Eur. : Reg. campestr., zon frigidiss. except. As. : Lac. Baïkal, Tibet occ., Caucas. occ. et centr., Persia, Mesopot., As. min. Afr.: Alger., C. B. Sp. Am. sept.: Terr. nov., Ontario, Alaska, M. Rupestr., Oregon, Idaho, Montana, Nov. Angl, Calif. Pac. : Tasman.

Exs. : Rab. Bryoth. eur. n. 70, 254, 427, 964.

Sull. et I.esq. M. bor. am, n. 167 .

var. apiculata Brid. - E. vulgaris.

* var. elongata Bryol. eur. et W. P. Sch. ll. cc.

In fiss. rup. calcar. - Eur, : Jura helvet. et germ, Am. sept. : Passim.

var, elongata Milde. - E. rhabdocarpa.

" var. mutica Brid. Mant. M. p. 28 et Bryol. univ. l. c.

E. laevigata Br. mss. ; Bryol. germ. II, I, p. 35, t. 14, f. I.

E. mutica $\beta$ obtusa Bryol. germ. II, I, p. 35 .

Ut typ. - Eur. : Cum typ. As, : Caucas. (Tiflis), Am. sept.: Passim : Colorado, Idaho, etc. Pac.: Tasman.

var. obtusa Bryol. eur. - E. vulgaris var. mutica.

« var. pilifera Bryol. eur. et W. P. Sch. ll. cc.

E. pilifera Funk in Brid. Biyol. univ, I, p. 141.

Leersia extinctoria $\beta$ pilifera Lindb. M. Scand. p. 20.

Ad mur. calcar. - Eur.: Passim; Ross. or. Am. sept.: Passim; Idaho, Washington, etc.

"var, trachymitria (Rip.) Husnot Muscol. gall. p. 197.

E, trachymitria Ripart in Rev. bryol. 1877, p. 51 .

$$
\text { - Eur. : Gall. centr. }
$$

Wimmeriana Sendtn. - E. rhabdocarpa (1).

ENDOTRIGHELLA C. M. in Linn. 1871-73, p. 156 (9 spec.).

angustifolia (Mitt.) C. M. M. Polyn. p. 75.

Garovaglia angustifolia Mitt. Sam. M. p. 170.

$$
\text { - Pac. : Absque loc. spec. }
$$

Campbelliana $H_{p e}$. in Linn. 1874, p. 665.

Garovaglia Campbelliana Jaeg. Ad. II, p. 137.

2.

-Pac.: Nov. Hebrid. (Aneitum).

Dietrichiae C. M. in Linn. 1872, p. 155. 2.

- Pac. : Austral. or.

Graeffeana C. M. M. Polyn.p. 174.

Endotrichum elegans Sull. in Exped. Wilkes, p. 20 ? 2.

- Pac, : Ins. Fidji.

(1) In Enum. Kindberg. nom, nudum:

E. brevipes $C$. $\dot{M}$. 
lepida $C . M$, in Linn. $1872, p, 157$.

Ster. - Pac. : Austral. sept. or.

moluccensis Jaeg. - Garovaglia.

Novae Hannoverae C. M. in Engler's Bot. Jahrb. 1883, p. 84 et in Forchungsreise.... p. 46.

Ster. Arbor. - Pac. : Nov. Hannovria.

pulchra Mitt. in Proced. of the Linn. Soc. of N. S. Wales, 1882, p. 105. - Pac. : Nov. Guinea.

samoana C. M. Polyn. p. 73.

Garovaglia samoana Mitt. Sam. M. p. 167.

2.

- Pac.: Ins. Samoa.

Wallisii $C, M$. op, cit. p. 74 .

2.

- As. : Ins. Philippin.

ENDOTRICHUM Bryol. jav. II.

Species omn, non indicatae sunt GAROVAGLIA ejusd, nom.

ceylonicum Jaeg. - Pterobryum.

crassicaule Jaeg. - Pterobryum.

densum \{ Dz, et Mk. - Garovaglia plicata.

Sull. - Garovaglia Powellii ?

japonicum Besch. - CEdicladium.

ENTODON G. M. in Bot. Zeit. 1844, p. 740 (emend.) (4 spec.).

Spec. omn. non indicatae sunt cylindrothecia ejusd. nom.

abbreviotus Mitt. - Cylindrothecium Challengeri.

abyssinicus Jaeg. - Cylindrothecium Schimperi.

angustifolius Besch. - Cylindrothecium Hahnianum.

argentinicus C. M. - Erythrodontium.

compressus C. M. - Cylindrothecium concinnum.

consanguinens Mitt. - Frythrodontium.

densus Mitt. - Erythrodontium.

denticulatus C. M. - Cylindrothecium argyraeum.

drepanioides (Ren. et Card.) Par.

Campylodontium drepanioides $R$. et C. in Bull. Soc. roy, bot. Belg. 1894, p. 201.

2 ? ${ }^{*}$ ign. Ad ramul. - Am. sept. : Costa Riea.

enervis Rehm. - Cylindrothecium Dregeanum var, imbricatum.

Engleri Broth. - Erythrodontium.

rvopaeus Bryol. eur. (in tabula). - Cylindrothecium cladorhizans.

fissidens C. M. - Cylindrothecium virens.

Hampeanus C. M. p.p. $\{$ Cylindrothecium.

Cylindrothecium distans.

insidiosus Spr. - Cylindrothecium concinnum.

Cylindrothecium pallesceas.

Montagnei C. M. - Cylindrothecium concinnum. myurus Hpe. - Cylindrothecium complicatum?

onustus (Hpe.) Mitt. M. austr. am. p. 523.

Campylodontium onustus Jaeg. Ad. II, p. 344.

Mesodon onustus Hpe, in Ann. sc. nat. 1865, p. 366,

1. Ad arbor. - Am. merid. : And. Nov, Granat et Peruv. 
orthocarpus Lindb. - Cylindrothecium concinnum.

palatinus Lindb. - Platygyrium repens.

pallidisimus C. M. - Erythrodontium.

perjulacens C. M. - Erythrodontium.

plicatus Hpe, - E. Regnellianus.

? Puiggarii Geh. et Hpe. mss.; Jaeg. Ad. 1I, p. 775.

- Am. merid. : Brasil. austr. or.

Regnellianus (C. M.) Mitt. M. austr. am. p. 523 .

Campylodontium Regnellianum Jaeg. Ad. II. p. 344.

E. plicatus Hpe, in Linn. 1849, p. 582.

Neckera Regnelliana C. M. Syn. II, p. 168.

1. Cortic. - Am. merid. : Brasil. or.

rotundifolius $\mathrm{C}$. M. - Erythrodontium.

rupestris C. M. - Erythrodontium cylindricaule var. rupestris.

Schleicheri Lindb. - Cylindrothecium cladorhizans.

Schroaegrichenii C. M. - Cylindrothecium columnare.

squarrosus Mitt. - Erythrodontium.

teres Mitt. - Erythrodontium.

transsilvanicus Demet. - Cylindrothecium cladorhizans.

ENTOPOGON $C . M . m s s$.

cylindricus C. M. - Eriodon conostomus.

ENTOSTHODON Schwaegr. Suppl. II, I, p. 44 (emend.) (75 spec.).

acidotus (Tayl.) C. M. Syn. II, p. 547; Mitt. M. austr. am. p. 245.

Amphoritheca acidotus Jaeg. Ad. I, p. 497.

Gymnostomum acidotum Tayl. in Lond. Journ. of bot. 1848, p. 279.

1.

-- Am. merid.: And, Quitens.

acutifolius Hpe. mss. ; C. M. in Bot. Zeit. 1859, p. 198.

1 .

- Am. merid. : And. Venezuel.

Amblyodon W. P. Sch. in W. Sch. M. Abyss.

- Afr. : Abyssin.

ampliretis Rehm. - E. marginatus.

andicola Mitt. op. cit. p. 244.

Amphoritheca andicola Jaeg. l. $c$.

- Am. merid. : And. Quitens.

angustifolius Jur. et Milde Beitr.... p. 595.

Amphoritheca angustifolia Jaeg. l. $c$. - As. : Kurdistan.

antarcticus C. M. in Engler's Bot. Jahrb. 1883, p. 77 et in Forchungsreise,... p. 10 .

- Afr.: Ins. Kerguelen.

apiculatus W. P. Sch, in Mandon Pl. Boliv. n. 1646.

- Am. merid. : And. Boliv.

apophysatus (Tayl.) Mitt. in Journ. of the Linn. Soc. 1859, p. 80.

E. Taylori C. M. Syn. I, p. 122.

Gymnostomum apophysatum Tayl. in Lond. Journ. of bot, 1846, p, 43.

Physcomitrium apophysatum Wils. ibid. p. 448; H. f. et W. Fl. of the

N. Zeal. $F l . I I$, p. $91, t .86, f .6$ et Handb. p. 451 .

- Pac. : Austrul. or., Nov. Zeland., Tasman. 
aristatus (Broth.) Par.

Funaria aristata Broth. in Oefv.... 1893.

1. Terr. - Pac. : Austral, or. (Nov. Vales.).

Balansae Besch. Not. M. Paraguay, p. 263.

Amphoritheca Balansæ Jaeg. Ad. II, p. 696.

Terr. - Am. merid.: Paraguay.

Exs. : Bal. Pl. Parag. n. 1226, 1227, 1228, 1233.

Beccarii (Hpe.) Par.

Amphoritheca Beccarii Hpe. in Nuov, Giom. bot, ital. 1872, p. 273.

2.

- As. : Ceylan.

Bergianus Bryol, eur. III (mon. p. 4) ; C. M. Syn. I, p. 126 et II, p. 458,

Bergia (absque nom. spec.) Fürnr. in Bot. Zeit. 1829, Erganz. Bl. p. 20.

Dermostomum (id.) Hsch, in Linn. 1841, p. 116.

Physcomitrium E. Bergianum C. M, in Linn. 1844, p. 696.

Weisia Bergiana Hsch, in Hor. Phys. Berol, p. 59, t. 12.

- Afr.: C. B. Sp.

Ess.: Rehm. M. Afr.austr. n. 172.

Bolanderi Lesq. in Trans. of the Am. Phil. Soc. XIII, p. 10; Sull. Ic. M. Suppl. p. 28, t. 17; Lesq. et Jam. Man. p. 199.

1. In terr. argill. - Am. sept. : Calif.

Exs. : Sull, et Lesq. M. bor. am. II ed., n. 236.

Bonplandi (Brid.) Mitt. M. austr. am. p. 245.

Amphoritheca Bonplandi Hpe. Enum. M. Brasil. p. 5.

Gymnostomum Physcomitrium Bonplandi Brid. Bryol, univ, I, p. 101.

Physcomitrium Bonplandi C.M. Syn. I, p. 118.

Terr. - Am. merid. : Brasil. austr, or., Chile.

borbonicus Besch. Fl. bryol. Réunion, etc. p. 87.

1. Terr. - Afr. : Ins. Borboniae.

brachyodus Mont. - E. Mathewsi var. integrifolius.

Buseanus Bryol. jav. I, p. 31, t. 22; Mitt. M. Ind. or. p. 54 .

Amphoritheca Buseana Jaeg. Ad. I, p. 496.

Entostodon flavescens Wils, in Kew Journ. bot. IX, $p .329$.

$$
\text { - As. : M. Neilgherries, Ceylan. }
$$

var. robustior Bryol, jav. -- E. Dozyanus.

chiloënsis Mitt. M. austr, am. p. 245.

- Am. merid.: Ins. Chiloë.

chlorophyllosus Rehm, M. Afr. austr. $n, 522$.

$$
\text { - Afr. : C. B. Sp. }
$$

clavaeformis Hpe. el C. M. in Linn. 1853, p. 490.

- Pac. : Austral. or.

clavellatus Mitt. op. cit. p. 244.

Amphorithera clavellata Jaeg. l. c. p. 498.

$$
\text { - Am. merid. : Montevideo. }
$$
commutatus DR. et Mont, in Fl. Alg. t. 35, f. 3 et Syll. p. 31 ; C. M.
Syn. II, p. 548 .

Funaria commutata Lindb, in Notiz.

Terr, in coll, - Eur. : Neap. Afr. : Alger.

Curnovii Dav. - E. ericetorum. 
? curvi-apiculatus C. M. in Fl. 1874, n. 31 .

E. pallescens fol. latior, $L t z$, ?

1. Muric. - Afr. : Aggpt. sup.

curvipes C. M. Syn. I, p. 123 et $I I, p .548$.

Physcomitrium E. curvipes ej. in Linn. 1844,p. 697.

- Afr. : Alp. Abyss., M. Cameroon.

"var. robustior C. M. Syn. ll. cc.

Funaria radians $\mathrm{Br}$. et Sch, in W. Sch. M. Abyss, n. 450.

- Afr.: Abyss.

curvisetus C. M. - Funaria.

diversinervis C. M. in Bot. Zeit. 1853, p. 20 ; Mitt. M. Ind. or. p. 55.

Amphoritheca diversinervis Jaeg. Ad. I, p. 498.

1.

- As. : M. Neilgherr.

Dozyanus C. M. in Bot. Zeit. 1853 (1).

Aphanorhegma Dozyanum Jaeg. Ad. II, p. 696.

E. Buseanus $\beta$ robustior Bryol. jav. I, p. 31, t. 22 .

1 .

- As.: Java.

Drummondii Sull. M. of U. St. p. 51, t. 4 et Ic. M. p. 91, t. 55 ; Lesq. et Jam. Man. p. 199.

E. obtusifolius H. f. et W. in Drumm. M. bor. am. II ed. n. 36 .

Funaria Drummondii Lindb. Manip. M. I, p. 62.

1. Ad terr. argill. - Am. sept. : Rar. : Carol. mer., Alabama inf., Ludnvic.

Exs. : Sull, et Lesq. M. bor, am. I ed. n. 156 b et II ed. n. 235.

Durieui Mont. Fl. Alg. t. 35, f. 4 et Syll. p. 30 ; C. M. Syn. II, p. 547.

1. Ad rup. calc. humid. - Af $r$. : Alger.

Exs. : Rab. Bryoth. eur. n, 1056.

ericetorum (Bals. et de Not.) C. M. Syn. I, p. 122 et II, p. 547; W. P. Sch. Syn, II ed, p. 378.

Amphoritheca ericetorum Jaeg. Ad. I, p. 496.

Bryum obtusum Dicks. Fase. II Pl. crypt. p. 5, t. 4, f. 7.

E. Curnovii Dav. in Lindb. Man. M. I, p. 59 in adn. (nom.) et p. 66 (ut syn.)

E. obtusus Lindb. in Oefv,... 1864, p. 221 (in obs.).

Funaria obtusa $e j$. Man. M. I, p. 65 .

Gymnostomum affine Hüb. Muscol. germ. p. 42 p.p.

G. Bonplandi Bchgr. in Reg. Bot. Zeit. 1836, I, p. III.

G. dubium Brid. M. Rec. II, I, p. 42 .

G. ericetorum Bals, et de Not. Pug. p. 27.

G. fasciculare Hook, et Tayl. M. brit. p. 23, t. 7 .

G. Heimii $\beta$ obtusum Hook. Muscol. brit. $p$, 12 .

G. obtusum Hedw. Sp. M. p. 34, t. 2, f. I-3; Brid. Bryol. univ. I, p. 73.

Physcomitrium Bonplandi de Not. Syll. p. 283.

$\mathrm{Ph}$, ericetorum Bryol, eur. III (mon. p. 13), t. 300.

1. In ericet. - Eur, : Reg. campestr. zon. interm, et merid. Afr.: Alger.

Ers, : Rab. Bryoth. eur. n. 22, 428, 655, 1391.

var, Ahnfeldti W. P. Sch.Syn. I ed. p. 317 et II ed. l, c.

Gymnostomum ericetorum Fr. Novit, et in Hartm, Skand. Fl. 1 II ed, p. 263.

(1) Fid. Jaeg. Ad, I, p. 500 ; non inveni. 
Hymenostomum ericetorum Grev. mss. ; Fr. St. agr. Femsj. p. 100.

Physcomitrium ericetorum Hartm. Skand. Fl. IV ed., p. 365.

Ut typ. - Eur. : Scandin. (Smolandia).

"var. longifolia W. P. Sch. l. c.

Ut typ. - Eur. : Palat., Alsat., Gall. mer. occ., Sardin.

« var. Notarisii W.P. Sch, l. c.

E. Notarisii ej, in de Not. Epil. p. 455.

Ut typ. - Eur. : Liguria.

enrystomus Mitt. M. austr. am. p. 245.

- Am. merid.: And. Quitens.; Peruv.

fascicularis C. M. - Funaria.

flavescens Wils. - E. Buseanus.

flexisetus C. M. in Linn. 1878-79, p. 263.

1. Limic. - Am. merid. : Argentin. subtrop.

gracilis Hook. f, et Wils. Fl. of the N. Zeal. II, p. 91,t.86,f.7 et Handb, p. 45l.

- Pac. : Nov. Zeland., Tasman.

Hildebrandti $C$. $M$. in Fl. 1879, p. 379.

- Afr.: M. Kenia, Kilima N'djaro.

Holstii (Broth.) Par.

Funaria Holstii Broth. in Engler's Bot. Jahrb. 1894, p. 187.

1.

- Afr. : Usambara.

Husnoti W. P. Sch. in Besch. Fl. bryol. Antill. fr. p. 29.

Ad terr. humid. - Am. sept. : Martinic.

italicus Rota Cat, M. Bergom.; de Not, Epil. p. 753.

In argill. - Eur. : Ital, super.

japonicus Lindb. - Physcomitrium.

javanicus Dz. et $M k$. in Pl. Jungh. p. 321; Bryol. jav. 1, p. 33, t. 24.

1. Terr. - As. : Java.

Krausei Besch. in Journ. de Bot. 1894, p. 44, t. I, fig. 5-8.

- Afr.: Teneriffa.

latifolius Hook. - E. Mathewsii var. latifolius.

laxits H. f. et W. - Physcomitrium.

Lepervanchei Besch. Fl. bryol, Réunion, etc. p. 87.

- Afr.: Ins. Borbon.

limbatus C. M. in Bot. Zeit. 1858, p. 155.

E. submarginatus W. P. Sch. in Breutel M. Capens.

$$
\text { - Afr. : C. B. Sp. }
$$

Lindigii (Hpe.) Mitt. M. austr, am. p. 243.

Amphoritheca Lindigii Hpe. in Ann. Sc. nat. V, ser. III, p. 341.

Terr. - Am. merid. : And. Nov. Granat.

longicollis Mitt. op. cit. p. 244.

Amphoritheca longicollis Jaeg. Ad. I, p. 498.

- Am. merid. : And. Quitens.

longicollis W. P. Sch. - E. Rottleri. 
longisetus W. P. Sch. in Besch. Prodr, bryol. mexic. p. 48.

Amphoritheca longiseta Jaeg. Ad. I, p. 499.

- Am. sept. : Mexic.

lutescens (Hpe.) Mitt. op. cit. p. 245.

Amphoritheca lutescens Hpe. op, cit. p. 339.

I.

- Am. merid. : And. Nov. Granat.

Mandoni W. Sch, in Mandon Pl. Boliv, n. 1625.

- Am. merid. : And. Boliv.

marginatulus C. M. in Abhandl. Brem. VII, p. 204.

- Afr.: Madagascar.

marginatus C. M. Syn. 1, p. 125 et $I I, p .548$.

E. ampliretis Rehm. M. Afr. austr. n. 174 .

- Afr. : C. B. Sp., Natal.

Exs. : Rehm. M. Afr. austr. n. 520.

Mathewsii Hook. Ic. pl. rar. IV, 1841, t. 245 B; C. M. Syn. 1, p. 124;

Mitt. op. et l. cc.

Physcomitrium E. Mathewsii $C . M$. in Linn. 1844, p. 697.

Ad terr. humid. - Am. merid.: Peruv.

" var. integer C. M. Syn. I, l. c. et II, p. 548.

E. brachyodus Mont, in sched, et in Fl. Chil.

Funaria Fontanesii Bryol. eur. $1 I I$ (mon, p. 5), et C. M. Syn. I, p. 112 (quoad pl. Chil.).

Ut typ. - Am. merid. : Chile.

* var. latifolius $C . M$. ll. c.c.

E. latifolius Hook. l. c, t. 245 c.

Physcomitrium E. Mathewsii $C . M$. $l$. c.

- Am. merid.: Peruv.

mauritianus W. P. Sch. in Besch, Fl. bryol. Réunion, etc. p. 87.

Syn, Terr. - Afr, : Ins. Franciae.

micropyxis C. M. in Rehm. M. Afr. austr. n. 175.

- Afr. : C. B. Sp.

minimus Husn. - Splachnobryum Wrightii.

Mittenii Bryol. jav, I, p. 32, t. 23.

Meesea Mittenii C. M. in Bot. Zeit. 1856, p. (fic. Jaeg. Ad. I, p. 517). 1 .

$$
\text { - As, : Java. }
$$

Mustaphae Trabut Atl. Fl. d'Alg. et in Rev. bryol. 1887, p. 13.

Ad rup. calcar. - Afr, : Alger.

niloticus W. P. Sch. in Bot. Zeit. 1855, p. 247; Ltz. M. Ehrenb. p. 38, t. $8, f .3$.

Terr. - Afr, : Egypt. inf.

Notarisii W. P. Sch. - E. ericetorum var. Notarisii.

noumeanus Besch. Fl. bryol. Nov. Caled. p. 212.

- Pac. : Nov. Caled.

nutans (Wils.) Mitt. M. Ind. or. $p, 55$.

Amphoritheca nutans Jaeg. Ad. I, p. 499.

Physcomitrium nutans Wils. in Kew Journ. bot. $I, p, 329$. 
obtusifolius 11 ook. Ic. pl. $\operatorname{rar} . t .245$ A ; C. M. Syn. I, p. 125 el II, p.548; Milt. M. austr. am. p. 244.

Amphoritheca obtusifolia Jaeg. Ad. I, p. 498.

Physcomitrıum E. obtusifolium C. M. in Linn. 1844, p. 697.

- Am. merid. : Peruv.

obtusifolius H. f. et W. - E. Drummondii.

obtusus Lindb. - E. ericetorum.

orthocarpus Jaeg. - Funaria.

pallescens Jur, in Ung. et Ky. « die Insel Cypern " p. 70.

inf.

- Eur.: Ins. Zante. As. : Ins. Cypr, Afr, : Egypt.

papillosus C. $M$, in Linn. $1880-83$, p. 358 .

- Am. merid. : Argentin. Tucum.

pellucidus C. M. in Bot. Zeit. 1855, p. 747.

I.

- Am. sept. : Martinic.

Perrottetii (Mont.) Mitl. M. Ind. or. p. 55.

Physcomitrium ? Perrottetii Mont. in Ann. sc. nat. 1811, p. 256 et Syll. p. $30 ;$ C. M. Syn. I, p. 117.

Terr. - As. : M. Neilgherr. Pac. : Nov. Zeland.

pilifer Mitt. op. et $l$. cc.

? Amphoritheca pilifera Jaeg. Ad. II, p. 696.

- As, : Tibet occ.

phycomitrioides Mitt, - Funaria.

plagiothecius C. M. in Linn. 1878-79, p. 261.

Ster.

- Am. merid. : Uruguay.

planifolius Thwo et Mitt. in Journ. of the Linn. Soc. 1872, p. 304.

Amphoritheca planifolia Jaeg. Ad. I, p. 497.

1. - As. : Ceylan.

productus Mitt, in Journ. of the Linn. Soc. 1859, p. 81); Fl. Tasm. II, p. $197, t .175, f . I$.

1. Terr. - Pac. : Tasman.

pseudo-marginatus (Hpe.) Mitt. M. austr. am. p. 243.

Amphoritheca pseudo-marginata Hpe. in Ann. sc. nat. V ser, $I I I, p .310$. - Am. merid. : And. Nov. Granat.

Puiggarii Geh. et Hpe, in Fl. 1881, p.

2. - Am. merid. : Brasil, austr. or.

radians (Hedw.) C. M. Syn. I, p. 122 et $I I, p .548$.

Bryum radians P. B. Prodr. p. 49.

Eremodon radians Brid. Bryol, univ. I, p. 236.

Weisia radians Hedw. Op. posth. p. 73, t. 13.

- Pac. : Ins. austral., Tasman.

rhizomaticus C. $M$, in Linn. 1878-79, p. 262.

1.

- Am. merid.: Alp. Argentin. Tucuman.

rhomboideus Shaw in Rehm. M. Afr. austr. n. 523 et $b$.

- Afr.: C. B. Sp.

Rottleri (Schooagr.) C. M. Syn. I, p. 121.

E. longicollis W. P. Seh. in Breutel M. Capens.

Gymnostomum Rottleri Schwaegr. Suppl. I, I, p. 24, t. 3. 
Physcomitrium Rottleri Hpe, in Linn. I844, p, 696

Rottleria gymnostomoides Brid. Bryol. univ. I, p. 105.

2. Muric. - As. : Tranquebar. Af. : C. B. Sp.

rupestris Brid. - E. Templetoni.

submarginatus C. M. in Bot. Zeit. 1853, p. 20.

Amphoritheca submarginata Jaeg. Ad. I, p. 495.

1.

- As. : M. Neilgherr.

submarginatus W. P. Sch. - E, limbatus.

Taylori C. M. - E. apophysatus.

Templetoni (Hook.) Schwaegr. Suppl. II, I, p. 44, t. 113; Brid. Bryol. univ. I, p. 879 ; Bryol. eur. III (mon. p. 3), t. 302; C. M. Syn. I, p. 124 et II, p. 548 ; W. P. Sch. Syn. II ed. p. 379.

Bryum attenuatum Dicks. Fasc. IV Pl. crypt.p. 8 ; Brid. Bryol. univ. I, p. 638 p.p. (fid. Lindb.).

Entosthodon rupestris Brid. Bryol. univ. I, p. 379 (int. syn.).

Eremodon longicollis ej. l. c. p. 234 .

Funaria attenuata Lindb. Man. M. I, p. 63.

F. Fontanesii Bals. et de Not. Prodr. Fl. Mediol. p. 32.

F. Templetoni Engl. Bot. t. 2524.

Gymnostomum Physcomitrium latıfolium Thom. in Brid. l.c. p. 760.

G. piriforme Brid. Sp. M. I, p. 27 p.p.

Urthopyxis ? attenuata $P . B$. Prodr. p. 79 (fid. Lindb.).

Physcomitrium Entosthodon Templetoni C. M. in Linn. 1844, p. 696.

Ph. latifolium Brid. Bryol. univ. II, p. 815.

Ph. Soleirolii Mont. in Ann. sc. nat. 1857.

Splachnum Juressi Schwaegr. Suppl. I, I, p. 55; Brid. Bryol. univ. I, p. $263 ;$ C. M. Syn. I, p. 148.

Weisia longicollis Link, mss. ; Brid. Mant. M. p. 45.

W. Templetoni Hook. in Curt. Fl. Lond. II ed., c. ic.; H. et T. Muscol. brit, $p .42, t .14$.

1. Ad terr. humid, et in rup. fiss. - Eur.: Britann., zon. merid. As. : M. Sinaï. Afr. : Alger., Ægypt., Teneriff,, Madeir,, ins Azor. Am. sept. : Calif.

Exs.: Mandon Pl. Mad. n. 17.

Rab. Bryoth. eur, n. 508.

Trumffii C. $M$, in Bot. Zeit. 1859, p. 198.

1.

- Am. merid. : And, Venezuel.

undulatus (Hpe.) Mitt. op. cit. p. 243.

Amphoritheca undulata $H$ pe. in Ann, se. nat. V ser., III. p. 340.

- Am. merid. : And. Nov. Granat.

usambaricus (Brolh.) Par.

Funaria usambarica Broth. in Engler's Bot. Jahrb. 1894, p, 187.

1.

Wallichii Mitt. M. Ind, or. p. 55.

- Afr. : Usambara.

? Amphoritheca Wallichii Jaeg. Ad. II, p. 696.

Weisia Templetoı.i Griff. Not. p. 406 et Ic, pl. asiat, II, t. 78, f. II.

- As. : Nepal., Khasia (1).

ENTOSTHYMENIUM Brid. Bryol. univ, 1, p. 761 (1 spec.).

mucronifolium $\mathrm{Br}$. - Pottia lanceolata var. angustata.

(1) In Enum. Kindberg. nomina nuda :

E. ampullaceus $C, M$.

E. Frietzei Geh.

E. Sullivani C. M.

E, varius Mitt. 
tristichum Brid. l.c.; C. M. Syn. II, p. 635.

2? - Eur.: Gall. austr. occ. (1).

EPHEMERELLA C. M. Syn. I, p. 34 (5 spec.).

caldensis C. M. in Bot. Zeil. 1859, p. 197.

Phascum caldense Lindb, in Oefv... 1863.

1. Paludic, - Am. merid., Brasil. or.

Flotowiana (Funk) Bryol. eur. Suppl. fasc. I-II, t, I; W. P. Sch. Syn. II ed. p. 10.

Ephemerum cohærens Bryol, eur. I (mon, p. 6), t. I p.p.; C. M. Syn. I, p. 32 p.p.

E. cohaerens $\gamma$ Flotowianum $\mathrm{H}_{p}$ e. in $\mathrm{Fl}$. 1837, $p .285$.

E. Flotowianum Limpr. Laubm. Deutschl. I, p. 168.

Phascum Flotowianum Fk, in Brid. Bryol, univ. I, p. 754.

2. In terra subaren, - Eur.: Brandenbourg.

pachycarpa C. M. - E. recurvifolia.

recurvifolia (Dicks.) W. P. Sch. Syn. I ed. p, 7 et $I I$ ed.p. 9.

E. pachycarpa C. M. Syn. I, p. 34 et II, p. 522.

Ephemerum pachycarpum Hpe. in Fl. 1837, p. 285; Bryol. eur. I (mon.

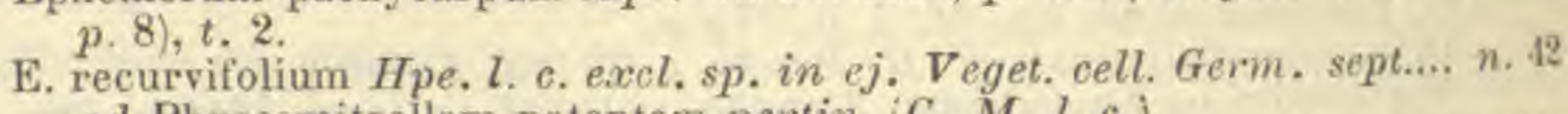
ad Physcomitrellam patentem pertin. (C. M. l. c.).

E. stenophyllum Voit in Sturm. Deutsch. Fl. II, Heft. 14 (fid, Lindb. Trich. eur. p. 3).

Phascum crassinervium Grev. Scot. crypt. $\mathrm{Fl}$.

Ph. Dicksoni Brid. Mant. M. p. T.

Ph. pachycarpum Schwaegr. Suppl. I, I, p. 4,t,2 (? fid. W. P. Sch.).

Ph. patens $\beta$ recurvifolium $S m$. Fl, brit. III, $p .1180$.

Ph. recurvifolium Dicks. Fasc. IV Pl. crypt. p. I, t. 10, f. 2; Brid. Bryol.

univ. I, $p, 31$.
Physedium pachycarpum C. M. in Bot. Zeit. 1847, p. 101.

2. Ad terr. argill. - Eur. : Fenn., Angl., Gall., German., Etrur.

Exs. : Rab. Bryoth. eur. n. 1053.

Rehmanni $C$. $M$. in Fl. 1888, $n .1$.

- Afr. : C. B. Sp.

verrucosa Besch. Fl, bryol. Nov. Caled. p. 187.

1 vel 2, Ad terr, humid, - Pac. : Nov. Caled.

EPHEMERUM Hpe. in Fl. 1837, p. 285 (24 spec.).

rquinoctiale Spr. in Mitt. M. austr. am. p. 239 ; Jaeg. M. cleisl. p. 41 . Terr. - Am. merid. : Amazon.

rethiopicum Welro. et Duby in Mémoires... Genève, 1871, p. 19, t. 3, f.8.

2. Ad terr. humid, - $A f r$. : Angola.

Austini Sull. mss.

Micromitrium Austini Aust. M. Appal. n. 45; Sull. Ic. M. Suppl. p. 21, t. $12 ;$ Lesq. et Jam. Man. p. 37 .

Syn. Ad terr. humid. - Am. sept. : New Jersey.

capense C. M. in Fl. $1888, n$. 1 .

$$
\text { - Afr.: C. B. Sp. }
$$


cohaerens (Hedvo.) Hpe. in Fl. 1837, p. 285; Bryol. eur. I (mon. p. 6), t. I p.p.; C. M. Syn. I, p. 32 p.p.; W. P. Sch. Syn. Il ed.p. 4 ; Jaeg. M. cleist. p. 41 .

Phascum cohaerens Hedw. Sp. M. p. 25, t. 1, f. 1-6; Brid. Bryol. univ, I, p. 29.

2. In terr, arenac. argill. humid. - Eur.: Vall. Rhen., Thuring., Siles., Hungar., Bohem., Austr., Carniole, Istria, Gall. centr. Am. sept. : Reg. or.

Exs. : Drumm. M. bor. am. I ed, n. 4. (Phascum).

Rab. Bryoth, eur. n. 160, 1101.

Sull. et Lesq. M. bor. am. Il ed, n. 29.

* var. heterophyllum Bryol. eur. l. c.

Phascum heterophyllum de Not. Spic. p. 23 et Syll, p. 313.

Ut typ. - Eur. : Pedemont.

cohaerens Bryol. eur. p.p. - Ephemerella Flotowniana,

var, Flotovoianum Hpe. - Ephemerella.

conicum C. M. in Linn. 1878-79, p. 233 et 1880-83, p. 349.

2? - Am. merid.: Paraguay.

conicum Besch. - E. homomallum.

crassinervium (Schwaegr.) C. M. Syn. I, p. 33; Sull. Ic. M. p. 17, t. 8; Jaeg. M. cleist, p. 43.

Phascum crassinervium Schuaegr. Suppl. I, p. 4, t. 2; Brid. Rryol.univ. $I, p .32 ;$ Sull, $M$. of. U. St. p. 14.

Pseud. 2, In terr. argill, humid, - Am. sept. : Reg. centr. et or.

Exs.: Drumm. M. bor. am. II ed, n. 3.

Sull. et Lesq. M. bor. am. II ed, n, 28 p.p.

crassinervium $\mathrm{H}$ pe. - E, stenophyllum.

cristatum C. M. in Bot. Zeit. 1847, p. 101 et Syn. I, p. 321 ; Jaeg. M. cleist. p. 44 .

Phascum cristatum H. f. et W. in Hook, Io. pl, rar. t. 737 a et Fl. Tasm. $I I$, p. 163.

- Pac. : Austral. or., Tasman.

fimbriatum C. $M$. in Linn. 1871-73, p. 145.

1.

- Pac.: Austral. or.

Flolowianum Limpr. - Ephemerella.

homomallum C. $M$. in $\mathrm{Fl}$. 1888, n. 1 .

E. conicum Besch, in Rev, bryol. 1885, p. 17.

Terr. - Am. merid. : Paraguay.

Exs, : Bal. Pl. Parag. n. 3621.

hystrix Lindb. Manip. M. $I I, p .411$.

Phascum serratum var. angustifolium Drumm. M. bor, am. II ed. n. 2,p.p.

Pseudo 2. Terr. - Am. sept. : Ludovicia.

intermedium Mitt. - E. serratum var. intermedium.

ligulatum C. M. in Rev. bryol. 1887, p 57.

E Am. merid.: Paraguay.

Exs. : Bal. Pl. Parag. n. 3708.

longifolium W. P. Sch. Syn. II ed. n.6; Jaeg. M. cleist. p. 43.

- Afr. : Alger.

longifolium Phil. - E. tenerum var. Philiberti. 
minutissimum Lindb. - E. serratum var, angustifolium. novale Mitt. - E. serratum var. angustifolium. pachycarpum Hpe. - Ephemerella recurvifolia.

pallidum W. P. Sch. Syn. I ed.p. 5 (nom.); Jaeg. M. cleist. p. 42 .

E. stenophyllum Lesq. et Jam. Man.p. 39 p.p.

- Am. sept. : Ohio.

papillosum Aust. M. Appal. n. 50 ; Sull. Ic. M. Suppl. p. 19, t. 10 ; Lesq. et Jam. Man. p. 38.

Pseud. 2. Terr, et rupic. - Am. sept. : New Jersey, Kansas.

patens Hpe. - Physcomitrella.

Pechuelii C. $M$. in Fl. 1886, p. 502.

2. - Afr. : Stanley Pool.

Philiberti Besch. - E, tenerum var. Philiberti. recurvifolium Hpe. pp. $-\left\{\begin{array}{l}\text { Ephemerella. } \\ \text { Physcomitrella patens. }\end{array}\right.$

Rutheanum W. P. Sch. Syn. 11 ed. p. 6; Jaeg. M. cleist.p. 41.

E. serratum var. Rutheanum Jur, Laubm. Esterr. Ung. p. 5.

Pseud. 2. Terr. ulig. - Eur. : Brandenbourg, Gall. or. (Burgondia). Exs. : Rab. Bryoth, eur, n. 1251.

serratum (Schreb.) Hpe. in Linn. 1837, p. 285; Bryol. eur. I (mon. p. 6), t. I; C. M. Syn. I, p. 31 et II, p. 521; W. P. Sch. Syn, II ed.p. 3; Jreg. M. cleist. p. 39 .

Phascum confervoidis Brid. M. Rec. $1 I, I, p .12$.

Ph. serratum Schreb. de Phasco p. 9, $t, 2$; Brid. Bryol. unit. 1, pp. 28 e: 754 .

Ph. serratum $\beta$ stoloniferum $H$, et T. Muscol. brit. p. 5.

Ph. stoloniferum Dicks. Fasc. III Pl. crypt, p. I, t. 7, f. I; Brid. op, oit. $p .50$.

Ph. velutinum Hoffm. Deutsch. Fl. II, p. 20.

Pseud, 2. Ad terr. aren. et argill. humid. - Eur. : Reg. campestr. Am. sept. : New Jersey, New York, Calif.

Exs. : Rab. Bryoth, eur. n. 159 et b.

a var. angustifolium Bryol, eur. $l$. c.

E. minutissimum Lindb. Man. M. II, p. 411.

E. novale Mitt.

Phascum serratum Drumm. M. bor, am. I ed, n. 10.

Ut typ. - Eur.: Praepr. merid. Amer, sept.: Gaspesia, Massachuss., Saaskatchewan.

Exs. : Mac. Canad. M. n. 465.

« var. intermedium Husn. Muscol. gall, p. 208.

E. intermedium Mitt, in Braithw. Brit. Mossfl. p. 184.

E. intermedium var, precox Walt. et Mdo. Laubm. Obenfr. p. 89.

E. tenuinerve Lindb, mss.

Ut et cum typ.

var. praecox Walt. et Mdo. - E. serratum var, intermedium. var. Rutheanum Jur. - E. Rutheanum.

* var. subulatum Boul. Musc. Fr. $p .577$.

Ut typ. - Eur. : Gallia.

var. tenerum Hpe. - E. tenerum.

sessile Bryol. eur. - E. stenophyllum.

var. stenophyllum Bryol. eur. - E. stenophyllum var, brevifolium. 
spinulosum W. P. Sch. Syn. I ed. p. 6; Jaeg. M. cleist. p. 43; Lesq. el Jam. Man. p. 38.

Phascum crassinervium var. (?) Sull. M. of U. St, p. 14.

Ph. serratum $\beta$ angustifolium $H$. f. et $W$, in Drumm. M. bor, am. II ed. n. 2 p.p.

Pseud, 2. Ad terr, argill, humid. - Am. sept. : Reg, centr, et merid.

Exs. : Sull, et Lesq. M. bor, am, n, 28 p.p.

stellatum Philib. in Rev. bryol. 1879, p. 62; Husn. Muscol. gall. n. 208.

2.

- Eur. : Gall. or. (Burgondia).

stenophyllum (Voit) W, P. Sch. Syn. I ed. p. 5 et II ed. p, 6; Jaeg. M. cleist. p. 42 .

E. crassinervium Hpe. in Fl. 1837, p. 885 et 1847, p, 101; C. M. Syn. 1, p. 33 .

E. sessile Bryol. eur. I (mon. p. 7), t. 2; C. M. Syn. I, l. c. et II, p. 522.

Phascum stenophyllum Voit in Sturm Deutsch. Fl. II, Heft 14 (fid. W. P. Sch.); Brid. Bryol. univ. I, p. 30.

Pseud. 2. In terr. argill. humid. - Eur. : Angl., Palatin., German., Helvet. occ., Sardin. ; A ustria infer. ? Stiria ? Am, sept. : New Jersey, Ohio.

Exs, : Drumm. M. bor, am. II ed., n. 3.

"var. brevifolium W. P. Sch. ll.cc.

E. sessile var. stenophyllum Bryol, eur. $l, c$.

Ut et cum typ.

stenophyllum Lesq. et Jam. p.p. - E. pallidum.

synoicum James in Trans, of the Am. Phil. Soc. 1865, p. 106; Jaeg. $M$. cleist. p. 4I.

Micromitrium synoicum Aust. M. Appal. n. 46 ; Sull. Ic. M. Suppl. p. 22, t. $13 ;$ Lesq. et Jain. Man, p. 37.

Syn, Ad terr. argill. - Am. sept. : New Jersey.

tenerum (Br.) Hpe. in Fl. 1837, p. 285; Bryol. eur. I (mon. p. 4), t. 1;

C. M. Syn. I, p. 31 et II, p. 521 ; Jaeg. M. cleist. p. 40.

E. serratum var, tenerum $\mathrm{Hpe}$. in $\mathrm{Fl}$. 1837, p. 285.

Micromitrium megalosporum Aust. M. Appal. II, n. 47; Sull. Ie. M. Suppl.p. 20, t. II: Lesq. et Jam. Man, p, 37.

Nanomitrium tenerum Lindb. Manip. M. II, p, 409.

Phascum tenerum Br. in litt. ad Breutel.

1. Limic. - Eur. : Lusatia, Luxembourg? Am, sept. : New Jersey.

* var. Philiberti Husn. Muscol. gall. p. 208.

E. Iongifolium Philib. in Rev. bryol, 1878, p. 48.

E. Philiberti Besch. ibid. 1881, p. 48.

E. tenerum Phillb. ibid. 1878, p. 26.

tenerum Philib, - E. tenerum var. Philiberti.

tenuinerve Lindb. - E. serratum var. intermedium.

Wrightii C. M. in Linn. 1880-83, p. 351 .

- Am. sept. : Cuba,

EPIPTERYGIUM Lindb, in Oefv, af K. Vet. Akad, Foerh. 1863, p. 599.

(6 spec.).

Duseni C. M. in Dusen M. Camer. $n .12$.

- Afr. : M. Cameroon.

immarginatum Mitt. $M$, austr, am, p. 319 .

- Am. sept. : Guatemala. 
jamaïcense $L$ indb. in op. c. p. 603 .

2.

- Am, sept. : Jamaïc.

orbifolium C. M. in Linn. 1878-79, p. 473.

- Am. sept. : Venezuela.

Polakowskyi C. M. in Journ. of the Linn. Soc. 1877, p. 229 (nom.). In udis. - Am. sept. : Costa Rica.

rigidum Lindb. - Webera,

Toseri Lindb. - Webera.

W rightii (Sull.) Lindb, in op. cit. p. 604; Mitt. op. et l. cit. p.p. (1).

Anisostichium Bakeri Mitt. in Journ. of the Linn. Soc. VII, p. 119.

Mnium Wrightii Sull, in Proced. Am. Acad. 1861.

2.

- Am. sept. : Cuba.

EREMODON Brid. Bryol. univ. J, p. 233.

longicollis Brid. - Entosthodon Templetoni.

magellanicus Brid. - Dissodon.

octoblepharis $\mathrm{N}$. et $\mathrm{H}$. - Dissodon plagiopus.

var. major eor. - Dissodon plagiopus var. major.

var, piriformis eor. - Dissodon plagiopus var. piriformis.

purpurascens H. f. - Dissodon.

radians Brid. - Entosthodon.

robustus H. f. et W. - Dissodon calophyllus.

Rudolphianus Nees. - Tayloria.

spathulalus $\mathrm{H}$. f. et W. - Tayloria.

splachnoides Brid. - Dissodon.

Wormskioldii Brid. - Splachnum.

ERIOCLADIUM C. $M$. in Linn. 1874, p. 561 (sect. Negker e, postea gen. propr.).

Spec. omn. non indicatae sunt Ærobrya ejusd. nom.

comorense Hpe. - Æ, lanosulum.

ERIOD ON Mont. in Ann. se. nat. 1845, p. 98 et Syll. p. 12 (3 spec.).

conostomus Mont. l. c. et Hist. Chil. Bot. crypt. t. 5, f. 2.

Entopogon cylindricus $C . M$. in sched.

Hypnum conostomum Mitt. M. austr. am. p. 550.

Neekera Eriodon C. M. Syn. II, p. 85.

1. Arbor. - Am. merid. : Chil., ins. Chiloë.

Mittenii Jaeg. - Helicodontium.

radicalis $S p r$. Cat. p. 20.

Hypnum Sprucei Mitt. op, et l. cc.

I? Arbor. - Am, merid.: And. Quitens.

salicicola (Spr.) Jaeg. Adl. II, p. 388.

Hypum salicicola Spr. in Mitt. op, eit, p. 551.

H. salicinum ej. Cat. p. 21. 
ERIOPUS Brid. Bryol, univ. II, p. 339 ( 15 spec.).

albescens (Hpe.) Jaeg. Ad. II, p. 774.

Lepidopilum albescens Hpe. Symb. 1877, p. 729.

- Am. merid. : Brasil. austr. or.

apiculatus (Hook, f. et Wils.) Mitt. op, cit. p. 393; Jaeg. Ad. II, p. 243.

Hookeria apiculata $H$. f. et W. in Lond. Journ. of bot. 1844, p. 549 et Fl. Antarct. $I I, p .421, t$. 155; C. M. Syn. $I I, p .203$.

Pterygophyllum apiculatum Jaeg. op. cit. p. 246.

2. $\quad-A m$. merid. : Fuegia, ins. Eremitae. Pac. : Nov. Zeland., Tasman.

asplenioides (Brid.) Besch. Fl. bryol. Réunion, elc. p. 140.

Hookeria asplenioides W. Arn. Disp. M. p. 56; C. M. Syn. II, p. 202.

Pterygophyllum asplenioides Brid. Mant. M. p. 351 et Bryol. univ, 1I, p. 345 .

2 ?

- Afr. : Ins, Borbon.

Bonianus Besch, in Bull. Soc. Bot. Fr. 1894, p. 83.

Ster, Cortic. et rupic. $-A s$. : Tonkin.

cristatus (Hedw.) Jaeg. Ad. II, p. 242.

Choetophora cristata Brid. Bryol. univ. II, p. 339.

Hookeria cristata W. Arn, Disp. M. p. 56; C. M. Syn. II, p. 205; Handb. of N. Zeal. Fl, p. 496.

Leskea cristata Hedw. Sp. M. p. 211, t. 49

2. Arbor. - Pac. : Nov. Zeland sept. et med.

deflexus C. M. in Linn. 1874, p. 609.

- Am.merid. : And. Nov. Granat.

flexicaulis (Hpe.) Par.

Lepidopilum flexicaule Hpe. Symb. 1874, p. 503.

2 ?

- Am. merill. : Brasil. austr. or.

flexicollis (Mitl.) Jeeg. Ad. II, p. 242.

Hookeria flexicollis Mitt. in Handb. of N. Zeal. Fl. p. 496.

2 ? Ad rup. humid, - Pac, : Nov. Zeland, med.

fragilis C. M. in Linn. 1876, p. 254.

Ster. $\quad-A$ Afr. : Ins. Anjouan.

Jelineki C. M. M. Polyn. p. 78.

Hookeria cristata Reichdt. in Novara Exped. Bot. I, p. 185.

Ster. $\quad-$ Pac. : Nov. Zeland., ins. Auckland.

lucidus Thro. et Mitl, in Journ. of the Linn. Soc. 1872, p. 311.

- As.: Ceylan.

Mniadelphus Spr. in Mitt. M. austr. am. p. 392.

1.

- Am. merid. : And. Quitens.

nutans (Hpe.) Mitt. op. cit, p. 392.

Lepidopilum nutans Hpe. in Linn. 1863, p. 153.

2. Arbor. - Am. merid. : And. Nov. Granat.

remotifolius C. M. in Bot. Zeit. 1847, p. 828.

Bryum Polla subenervis Brid. Bryol. univ. II, p. 712.

Br. subenerve ej. Mant. M. p. 120?

Distichophyllum cristatum Dz. et Mk. M. frond, ined. Archip. Ind. p. 104, t. $35 \mathrm{~B}$. 
Hookeria cristata Hsch, et Reinw. in Nov. Act. Acad, Cos. Leop. Carol. XIV, Suppl. p. 718, t. 40.

H. remotifolia C. M. Syn. $I I, p .207$.

Mnium subenerve Schwaegr. I, II, p. 138, t. 79?

2. Ad lapid. et terr. - As. : Borneo, M. Java, Sumatra.

setigerus Mitt. op. et l. cc.

Mitrapoma ciliatum Duby Choix de M. ex. 1880, p. 5, t. II, f. I (fid. Hpe. in $\mathrm{Fl}, 1880, n .21)$.

1. Lignic. - Am, merid. : Brasil, austr, or. (1).

ERPODIOPSIS C. M. in Fl. 1890, p. 470 (1 spec.).

Kilima N'Djarica C. M. in op. et $l$. cc.

Ster. In gramin. editior. - Afr. : Kilima N'Djaro.

ERPODIUM Brid. Bryol. univ. II, p. 167 (22 spec.).

Balansae C. $M$. in Fl. 1887, p. 449.

E. coronatum Besch. in Rev. bryol 1885, p. 18 et in Bal. M. Parag. n. 3645 a.

1. Ad Aurant. - Am, merid. : Paraguay.

Beccarii C. M. in Nuov. Giorn. bot. ital. 1872, p. 18.

Aulacopilum Beccarii Mitt. in Journ, of the Linn. Soc. XIII, p. 308.

1. - Afr. : M. Abyss.

Bellii Mitt. in Journ. of the Linn. Soc. 1872, p. 307, t. 5, f. B.

1. Cortic. - As. : Ceylan.

brasiliense C. M. - E. coronatum.

ceylanicum Thw. et M. - Solmsiella.

chlorophyllosum C. M. in Linn. 1878-79, p. 382.

1. Cortic. in silv. - Am. merid. : Argentin. subtropic.

coronatum (Hook, f. et Wils,) Mitt. M. austr. am. p. 403.

Anoectangium? coronatum H.f. et W. in Lond. Journ, of bot. 1814, p. 150.

E. brasiliense C. M. in Bot. Zeit. $1845, p .90$.

Pilotrichum coronatum ej. Syn. II, p. 184.

1. Cortic. - Am. merid, : Guayaquil, Brasil.

coronatum $\left\{\begin{array}{l}\text { Besch. - E. Balansae. } \\ \text { W. P. Sch. - E. Schimperi. }\end{array}\right.$

diversifolium (Angstr.) Par.

Pilotrichum diversifolium Angstr. mss.; C. M. in Bot. Zeit. 1862, p, 392. 1. - Am. sept. : Mexic.

domingense (Brid.) C. M. in Bot. Zeit. 1843, p. 773.

Anoectangium domingense Schwaegr. Suppl. III, II, I, t, 267.

A. E. domingense Brid. Bryol, univ. II, $p, 167$.

Pilotrichum domingense C. M. Syn. II, p. 184.

1. Cortic. - Am. sept. : Hispaniola.

exsertum Besch. in Reo. bryol. 1885, p. 18 et in Journ. de Bot. 1891, p.
1.

- Am. merid. : Paraguay.

(1) In Enum. Kindb. nomen nudum :

E. Zürni Schlieph, et C. M. 
Glaziovii Hpe. Symb. 1872, p. 54.

1. Cortic. - Am. merid. : Brasil, austr. or.

grossirete C. M. in Verh. d. K. K. zool. bot. Gesell. in Wien, XLIII, pp. 13-14.

- Afr. : Reg. Zambeziana.

Hanningtoni Mitl. in Journ. of the Linn. Soc, 1886, p. 313.

1. Ad Adansoniam digit. - Afr. : Lac. Nyanza.

Hodgkinsoniae Hpe, et C. M. in Fl. 1887, p. 448. - Pac. : Austral. (Nov. Vales. austr.).

Holstii Broth. in Engler's Bot Jahrb. 1894, p. 215.

1.

- Afr. : Usambara.

japonicum Mitt, in Journ. of the Linn. Soc, 1886, p. 314.

1 ?

- As. : Japon.

Johannis Meyeri C. $M$. in Fl. $1890, p .486$.

1. Cortic. - Afr. : Kilima N'Djaro.

lanceolatum Besch. - E. paraguense.

Lorentzianum C. M. in Linn. 1878-79, p. 384.

1. Cortic. in silv. - Am, merid. : Argentin. subtropic.

Mangiferae C. M. in Linn. 1871-73, p. 178.

Ster.

- As. : Bengal. sept.

Mengharthii C. M. in Verh. d. K. K. Gesell. in Wien, XLIII, pp. 13-14. - Afr. : Reg. Zambeziana.

paraguense Besch. Not. M. Paraguay, p. 265.

E. lanceolatum ej. in Rev. Bryol. 1885, p. 18 et in Bal. Pl. Par. n. 3644. Cortic. - Am. mer.: Paraguay.

Exs. : Bal. Pl. Parag. n. 1214.

Perrottetii (Monl.) Jaeg. Ad. II, p. 90.

Leptangium Perrottetii Mont. Syll. p. 26.

Pilotrichum Perrottetii C. M. Syn. II, p. 185.

Schistidium Perrottetii Mont. in Ann. sc. nat. 1838, p. 51.

1 ? Terr. - Afr. : Senegal.

Schimperi C. M. in Fl. 1887, p. 449.

E. coronatum W. P. Sch. in W. Sch. M. Abyss.

- Afr. : Abyss.

Schweinfurthïi C. M. in Linn. 1875, p. 412.

2. Cortic, $-A f r$. : Bongo.

sinense Vent. - Venturiella.

Erythrocarpidium C. M. in Linn. 1876, p. 244 (nom., subsect. BRY1).

ERYTHRODONTIUM Hpe. Symb. I870, p. 279 ; C. M. in Linn. 1878-79,

p. 434 (sect. ENTodontis) (10 spec.).

argentinicum $C . M . l . c$.

Entodon argentinicus ej. in op. cit. p. 432.

1.

- Am. merid. : Argentin. subtropic. 
brasiliense (Hpe.) C. M. in op. cit. p. 434.

Leptohymenium brasiliense Jaeg. Ad. II, $p .345$.

Pterigynandrum brasiliense Hpe, Symb. 1870, p. 280.

1. Arbor, $-A m$. merill. : Brasil, austr. or.

consanguineum (Hpe.) C. M. in op. cit. p. 340.

Entodon consanguineus Mitt, M. austr. am. p. 524.

Leptohymenium consanguineum Hpe. in Ann. sc. nat. V ser, III, p. 372. - Am, merid. : And. Nov. Granat. et Quitens.

cylindricaule C. M. in op. cit. p. 434 .

Leptohymenium cylindricaule Besch, Prodr, bryol. mexic. p, 101.

L. longisetum Hpe. in Linn. 1847, p. 83.

Neckera cylindricaulis C. M. Syn. II, pp. 100 et 667 .

N. julacea ej. in Linn. 1847, p. 214 p.p.

$\mathrm{N}$. longiseta Hsch, in Deppe et Schiede M. Mexic, n. 1086.

1. Cortic. et saxic. - Am. sept.: Mexic., Costa Rica. Am, merid.; Venezuela, Nov, Granat.

« var. rupestre (Hpe.) Par.

Entodon rupestris C. $M$. in Linn. 1878-79, p. 434.

I.eptohymenium eylindricaule var. rupestre Hpe. in Ann. sc. nat. 1865, $I V, p .373$.

- Am. merid. : And. Nov. Granat.

densum (Hook.) C. M. in op. cit. p. 434.

Entodon densus Mitt. M. austr, am. p. 531 .

Hypnum brachycladon W. Arn. Disp. M. p. 61 .

H. $\operatorname{densum} C$. M. Syn. $I I, p .375$.

Leskea densa Hook. in Kunth Pl. Aquin. I, p. 61; Brid. Bryol. univ. $I I$, p. 299.

2. Saxic. - Am. sept. : Mexic. Am. merid.: And. Quitens.

Engleri (Broth.) Par.

Entodon Engleri Broth. in Engler's Bot. Jahrb. 1894, p. 204.

1. Cortic, - Afr. : Kilima N'Djaro, Usambara.

julaceum (Hook. ?) C. M. in op. cit. p. 435 . Neckera julacea Schwaegr. Suppl. III, I, II, t. $255 ;$ C. M. Syn. II,
p. 101.

Pterogonium julaceum Hook. in Schwaegr, l.c. (fid. C. M. !)

1. Ceylan, Tonkin,

juliforme (Mitt.) Par. forme (Mitt.) Par.
Pterogonium julaceum Hook. in Schwaegr. Suppl. III, I, II, t. 255
(fid. Mitt!).

Pt. squarrosum Griff. Io. pl. Asiat. II, t. 98.

Stereodon juliformis Mitt. M. Ind. or, p. 92 .

1.

- As.: Nepal,, Sikkim, Khasia, Assam sup., M. Neilgherr., Tonkin, Yunnan.

latifolium (Angstr.) C. M. in op. cit. p. 434.

Leptohymenium latifolium Jaeg. Ad. II, p. 346.

Pterigynandrum latifolium angstr. in Oefo.... 1876, p. 45 (nom.).

Ad rup. vulcan. - Am. sept. : Honduras.

longisetum (Hook.) C. M. in op. et l. cc.

Isothecium longisetum W: P.Sch. in sched.

Leptohymenium longisetum Besch. Prodr. Bryol, mexic. p. 101. 
Neckera longiseta Hook. M. ex. t. 43 ; Brid. Bryol. univ, II, p. 228; C. M. Syn. II, p. 99.

1. Cortic., lignic. et saxic. - Am. sept. : Mexic. Am, merid.: And. Nov. Granat. et Quitens., Brasil.

pallidissimum C. $M$. in op. et $l$. cc.

Entodon pallidissimus C. M. in Linn. 1878-79, p. 494.

Ster. $\quad-$ Am. merid, : Venezuela.

perjulaceum (C. M.) Par.

Entodon porjulaceus C. M. in Dusen M. Camer. n. 674. - Afr. : M. Cameroon.

rotundifolium (C.M.) Par.

Entodon rotundifolius C. $M$. in Fl. 1890, p. 494.

Pterogonium gracile Mitt. in Journ. of the Linn. Soc. 1886, p. 316 ? (fid. C. M.).

Ster. lacustr. - Afr.: Kilima N'Djaro, Usambara, reg.

Schweinfurthii C. M. in Linn. 1878-79, p. 434.

Leptohymenium Schweinfurthii Sb, in Jaeg. Ad. II, p. 743.

Pterigynandrum Schweinfurtbii C. M. in Linn. 1875, p. 451.

1. Ad arbor. - Afr.: Niam-Niam.

squarrosum C. $M$. in op, et l. $c c$.

Entodon squarrosus Mitt. $M$. austr. am. p. 524.

Leptohymenium julaceum Hpe. in Linn. 1847, p, 83.

L. squarrosum Jaeg. Ad. II, p, 345 .

Neckera julacea C. M. in Linn. 1847, p. 214.

N. squarrosum ej. Syn. $I I, p .100$.

1. Ad arbor. - Am. merid. : Venezuela, And. Nov. Granat et Quitens., Brasil, austr. or.

" var, griseum Besch. Not. M. Parag. n. 268.

Exs. : Bal. Pl. Parag. n. 1262.

squarrulosum (Mont.) C. M. in op. et $\mathrm{l}$. cc.

Neckera squarrulosa C. M. Syn. II, p. 101.

Platygyrium julaceum Bryol. eur. V (mon. p. 4, nom.); Bryol. jav. II, p. 187, t. 217.

Pl. squarrulosum Jaeg. Ad. II, p. 343.

Pterogonium squarrulosum Mont. in Lond. Journ. of bot. 1845, p. $9 \mathrm{et}$ Syll.p.21.

I. Ad arbor, et sax. - As.: Ins. Philippin., Celebes, Java, Sumatra. subjulaceum C. M. in op. et $l$. cc.

Platygyrium subjulaceum Jaeg. Ad. II, $p, 342$.

Pterigynandrum subjulaceum C. M. in Linn. 1875, p. 453.

1. Ad arbor. - Afr. : Niam-Niam, regio lacustr.

teres $C, M$. in op. et $l$. cc.

Entodon teres Mitt, M. austr, am. p. 524 ,

Leptohymenium julaceum Besch. Prodr, bryol. Mexic. p. 102 (ex ips. 1).

L, teres Jaeg. Ad. II, p. 173. 1.

Neckera teres C. M. Syn. II, p. 98 p.p.

Warmingii Hpe. Symb. 1870, p. 279.

- Am. sept. : Mexic.

Leptohymenium Warmingii $S b$, in Jaeg. Ad. $I I, p .743$.

Pterogoniella Warmingii Jaeg, l, c. p. 114 .

1. Ad arbor, - Am, merid. : Brasil. austr. or. 
Erythrophyllum Lindb. de Tortul. p. 213 (sect. Didymodontis).

ESENBECKIA Brid. Bryol. univ. II, p. 753. cuspidatc Mitt - Garovaglia setigera. plicata Brid. - Garovaglia.

Euamblystegium Lindb. M. Scand. p. 32 (Amblystega vera) Euandreaæa Lindb. op. cit. p. 31 (sect. ANDREAAR E). Euangstroemia $C . M$. Syn. I, $p .426$ (ANGSTRORMI E VERAE). Euarchidium C. M. in Linn. 1880-83, p. 345 (sect. ARCH1Dn). Euaulacomnium Milt. M. austr. am. p. 317 (Aulacomira vera). Eubarbula C. M. Syn. I, p, 623 (sect. BarbulaE).

Eubartramia C. M. Syn. I, p. 499 (sect. Bartramiak).

Eublindia Lind.b. M. Scand.p. 25 (BLINDIA verak).

Eubraunia C. $M$. in Fl. $1890, p, 485$ (Brauniae verae).

Eubruchia C. M. Syn. I, p. 20 (sect. Bruchiae).

Eubryum C. M. Syn. I, p. 252 (sect. BRyi).

Eubuxbaumia Lindb. M. Scand. p. 12 (Buxbaumiae verae).

Eucalymperes C. M. Syn. I, p. 526 (sect. CALYMPERIDIs).

EUCAMPTODON Mont. in Ann. sc. nat. 1845, p. 121), t. 14, f. 3 et Syll, p. 46 (5 spec).

Balansaanus Besch. Fl. bryol. Nov. Caled.p. 195.

- Pac. : Nov. Caledon.

ciliatus Besch. op. et $l$. cc.

- Pac. : Nov. Caledon.

edentulus C. M. - Braunfelsia squarrosa.

var. compactus C. M. - Braunfelsia squarrosa var. compacta.

macrocalyx C. M. - Braunfelsia enervis.

Mülleri Hpe. el C. M. in Linn. 1869-70, p. 513.

2.

- Pac. : Austral. or. (Victoria).

perichaetialis Mont. op. cit. C. M. Syn. I, p. 346.

1. Terr. - Am. merid, : Chil, austi.

piliferus Mitt. - Holomitrium.

squarrosus Besch. op. cit. p. 194.

- Pac. : Nov, Caledon.

EUGLADIUM Bryol, eur. I (2 spec.).

irroratum (Milt.) Par.

Weisia irrorata Mitt. in Handb, of N. Zeal. Fl. p. 403.

- Pac. : Nov. Zeland, sept.

verticillatum (L.) Bryol. eur. I (mon. p. 3), t. 40; W. P. Sch. Syn. II ed. p. 45.

Barbula atlantica Brid. Bryol. univ, I, p. 559.

Bryum fasciculatum Dicks. Fasc. III Pl. crypt. p. 3.

Br. pilosum verticillatum Dill. Hist. M. p. 374, t. 47, f. 35.

Br. verticillatum L. Sp. pl. p. 1595 (? W. P. Sch.).

Coscinonon elongatus Brid. l. c. p. 376.

C. verticillatus ej. $l$. c. p. 374 .

Grimmia fragilis $W$. et $M$. Archiv. p. 129, $t$. 4, $f .4$.

Gr. verticillata eor. Bot. Taschb. p. 129.

Hymenostylium verticillatum Mitt. M. Ind. $0 \%$. p. 32.

Mollia verticillata Lindb. M. Scand. p. 21. 
Tortula atlantica Brid. Sp. M. p. 255.

'T. verticillata Mitt. in Voy. H. M. S. Challenger, II, p. 89.

Trimatium tophaceum Froehl. in hb. Brid.

Weisia gypsacea Schleich. Cat. pl. Helvet. 1807, p. 31.

W. verticillata Brid. Sp. M. I, p. 656 .

2. Ad mur. et rup. calcar, irror. - Eur. : Temperat. tota. As.: Kurdistan., Caucas., As. min. A fr. : Agypt., Alger., Tenerif,, Madeir. Am. sept.: Terr. nov., Columb. brit., Calif., ins. Bermud.

Exs. : Rab. Bryoth. eur. n, 21 et b, 1157, 1305.

* var. angustifolium Lindb. Trichost. Eur. p. 22.

Ut typ. - Eur. : Hispan. austr. (Granata). Afr. : Tenerif.

var. angustifolium Jur. - E. verticillatum var. dalmaticum.

"var. clinotheca Besch. Cat. M. Alger. p. 5.

Ut typ. - Afr. : Alger.

"var. dalmaticum Par.

E. verticillatum var, angustifolium $J u r$. Laubm. Oesterr. Ung. p. 17.

Ut typ, - Eur. : Dalmatia.

a var. inundatum R. Farneti $M$. d. Prov. Pavia, 1891.

Loc. inundat. - Eur. : Ital. super.

* var. penicilliforme ej. $l$. $c$.

Ad rup. - Eur. : Ital. super.

* var. setaceum W. P. Sch. in Mandon M. Mad, n. 6.

- Afr.: Madeira.

Eucryphæa C. M. Syn. M. II, p. 165 (subsect. Pilotrichi).

Eudichelyma ej. op. cit. p. 143 (subsect. Neckera).

Eudicranum Mitt. $M$, austr. am. p. 67 (sect. Dicrani).

Euditrichum Lindb. M. Scand. p. 26 (sect. Ditrichi).

Euentosthodon Mitt. op. cil. p. 245 (sect. Entosthodontis).

Euerpodium Mitl. op. cit. p. 403 (sect. ErPodi).

Eufabronia $C . M$. op. cil. p. 31 (sect. Fabroniar).

Eufissidens $C . M$. op. cit. $I, p .50$ (sect. Fissidentis).

Eufunaria Lindb. op. cit. p. 18 (sect. Funariae).

EUGLOSSOPHYI.LUM C. $M . S y n . I I, p .231$ (subsect. HyPNI); Hpe. Symb. 1870 , p. 277 , gen propr.

brevipes $\mathrm{Hpe}$ - Stereophyllum.

radiculosum $\mathrm{Hpe}$ - Stereophyllum rhamphostegium.

Eugrimmia C. M. Syn. I, p. 783 (sect. Grimmiat).

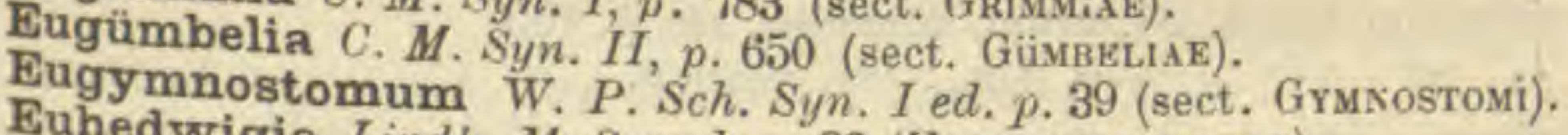

Euhedwigia Lindb. M. Scand. p. 39 (Hedwigia e verae).

Euhookeria C. M. op, cit. p. 187 (sect. Hookrriak).

Euhylocomium Lindb. op. cit. p. 36 (sect. HyLocovin).

Euhypnella $C . M$. op. cit. $I I, p .211$ (subsect. Hookeria E).

Euhy popterygium $C$. $M$. op. cit. $p .3$ (HYPOPTERYGIA verA).

Euisopterygium Lindb. op. cit. p. 39 (sect. Plagiothroit).

Euisothecium Lindb. op. cit. p. 36 (= I. myurum).

Eulepidopilum Mitt, M. austr. ant. p. 373 (sect. Lrpinopru).

Euleucobryum Mitt. op. cit. p. 110 (sect. Lrucobry).

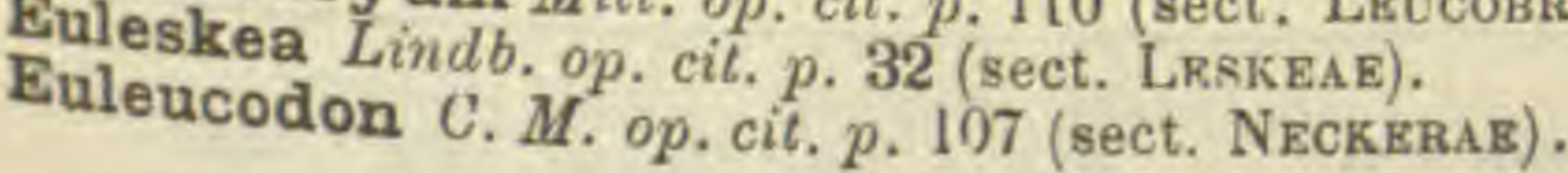


Eumacromitrium C. M. op. cit. $1, p .723$ (sect. MachomitriI).

Eumnium $C . M$. op. cit. p. 155 (MNIA vera).

Euneckera C. M. op. cit. II, p. 41 (sect. Neckerae).

Euoligotrichum Lindb, op. cit. $p .12$ (Оligotricha vera).

Euomalia C. M. op. cit. p. 243 (sect. Hypst),

Euoncophorus Lindb. op. cit. p. 27 (sect. CyNononti1).

Euorthotrichum C. M. op. cit. I, p. 694 (sect. OnтнотRichi).

Euphilonotis Mitt. op. cit. p. 256 (PhiLONOTIDES VRRAE).

Euplagiothecium Lindb. Animadv. p. 26 (sect. Pl.Agiothen).

Eupleuridium Lindb. M. Scand. p. 27 (Pleuridia vera).

Eupogonatum Mitt. op. cit. p. 613 (sect. L'ogonati).

Eupolytrichum C. M. op. cit. p. 17 (Polytricha vera).

Eupottia $C . M, p, 550$ (sect. PottiaE).

Eupterobryella C. M. in Bull. Soc. bot. Fr. 1878, p. 65 (sect, PreroBRYELLAE).

EUPTYGhIUM W. P. Sch. in Mem. Acad. Dresde, 1865 (3 spec.). mucronatum Hpe, in Linn. 1874, p. 666.

2.

- Pac. : Ins, Lord Howe.

neo-Caledonicum W. P. Sch, op. cit.

Garovaglia cuspidata Mitt.? (fid. Mitt. in Journ. of the Linn. Soc. 1867 p. 170).

2. Ad arbor. rad. - Pac. : Nov. Caledon.

robustum Hpe. in Linn. 1874, p. 667.

- Pac. : Ins. Lord Howe.

Eurhizogonium Mitt. M. austr. am. p. 328 (sect. RHIzogosir).

Eurhynchiopsis Kindb. Check-List... p. 73 (sect. BrachytнECH).

EURHYNCHIUM Bryol, eus. V (74 spec.).

abbreviatum (Turn.) W. P. Sch. Syn. 11 ed. p. 674.

E. praelongum $\varepsilon$ abbreviatum Bryol. eur. (mon. p. 8), $t, 525$.

E. Schleicheri Hartm. Skand. Fl. $\mathrm{X}^{\circ}$ ed.

Hypnum abbreviatum Turn. Muscol. brit. p. 160.

H. praelongum $\beta$ abbreviatum Brid. Sp. M. p. 103 et Bryol. univ. Il p. 401.

H. Schleicheri Hedw, f, in W. et M. Beitr. I, p. 128, t. 7 (1).

2. Ad terr. silvat, praepr. argill. - Eur. : Gall, occid., Palatin., Westphal., Silv. nigr., Hercyn.

? acicladium Besch. Fl. bryol. Réunion, elc. p. 155.

1. - Afr.: Ins. Borbon.

acuticuspis Jaeg. - Isothecium.

afro-myosuroides C. M. in Rehm, M. Afr. austr. n. 369 .

$$
\text { - Afr.: C. B. Sp. }
$$

afro-strigosum C. M. l. c. n. 364 .

$$
\text { - Afr. : C. B. Sp. }
$$

androgynum W. P. Sch, - E. speciosum. 
anomalum (Hpe.) Par.

Hypnum anomalum $H$ pe. in Linn. 1863, p. 162.

2 ?

- Am. merid. : And. Nov. Granat.

apiculigerum (Lindb. et Arn.) Par.

Hypnum apiculigerum $L$. et $A$. M. As. bor. 1890, II, p. 132.

2. Lignic. - As. : Jenissei inf.

asperrimum Jaeg. - Brachythecium.

austrinum (Hook. f. et Wils.) Jaeg. Ad. II, p. 422.

Hypnum austrinum $H$. f. et $W$. Fl. of the $N$. Zeal. $I I, p .188, t .89, f .4$ et Handb. p. 477.

1.

- Pac. : Austral., Nov. Zeland,, Tasman.

Bigelowii Jaeg. - Thamniurn.

Boscii (Schwaegr.) Jaeg. Ad. I1, p. 427.

Hypnum Boscii Schwaegr. Suppl. I, II, p. 223; Brid. Bryol. univ. II, p. 420 ; C. M. Syn. II, p. 375 ; Sull. Io. M. p. 167, t. 106; Lesq. et Jam. Man. p. 352.

H. cupressiforme rotundius, vel illecebrae aemulum Dill. Hist. M. p. 3ll, t. $40, f .46 \mathrm{c}$.

H. illecebrum Hedw. Sp. M. p. 252, t. 66, f. 1-2; Dirmm, M. boi. am. $I$ ed. n. 192.

H. illecebrum $\beta$ americanum Brid. Sp. M. II, p. 126.

H. tumidiusculum Lam.

2. Ad rup. et terr. - Am. sept.; Ontario? Reg. orient., centr. et merid.

Exs. : Drumm. M. bor. am. II ed, n. $1: 32$ (Hypnum).

Sull. et Lesq. M. bor. am. II ed, n. 435 (Hypnum).

brevirostre Rehm. M. Afr. austr. n. 366.

$$
\text { - Afr. : Natal. }
$$

Brewerianum Jaeg. - Isothecium.

canariense (Hpe, et C. M.) Jaeg. Ad. II, p. 417.

Hypnum canariense Hpe, et C. M. in Bot. Zeit. 1862, p. 13.

Ster. - Afr. : Tenerif.

Cardoti (Kindb.) Par.

Isothecium Cardoti Kindb. in Mac. Cat. pp. 203 et 275.

1. ton, Oregon.

- Am. sept. : Columb. brit., Vancouver, Washingcavifolium Rehm. M. Af, austr. n. 654 et b, 655 b.

- Afr. : Transvaal, Natal.

circinatum (Brid.) Bryol. eur. V (mon. p. 4), t.521; W. P. Sch. Syn. II ed. p. 665 .

Hypoum circinatum Brid. Mant. M. p. 165; C. M. Syn. II, p. 479.

H. distans Brid. Sp. M. II, p. 109 et Bryol. univ. II, p. 409.

H. Grevillei Rab. Deutsch. Krypt. II, p. 291.

H. Leskea Greo, in Trans, of the Linn. Soc, II, p. 342, t. 3, f. 4.

H. mediterraneum Sendtn. in Bot. Zeit. 1818, n. 5 .

H. strigosum $\beta$ circinatum Brid. Bryol, univ. II, p. 447.

Leskea circinata Jaeg. Ad. II, p. 298.

Rhynchostegium circinatum de Not. Epil.

2. vel ps, 1. In apric. aủ terr., rup. calcar, et mur. - Eur. : Zon. merid. praecip. marit, ; Britann. (ster.). As. : As, min., Pers. Afr.: Alger. Exs, : Rab. Bryoth. eur. n, 846. 
« var. deflexifolium Boulay. M. Fr.p. 114.

Hypnum circinatum var, inundatum ej, in Husn. M. Gall. n. 579.

H. deflexifolium Solms-Laub.

Scorpiurium rivale W. P.Sch. (fid. Boul., Husn., etc.).

Ad lapid. et saxa secus torrent. - Eur. : liall. occid, et merid.

var. rivale Besch. - Scorpiurium.

cirrosum Mdo. - E. Vaucheri $\beta$ julaceum.

clinocarpum (Tayl.) Par.

Brachythecium clinocarpum Jaeg. Ad. II, p. 393.

E. Regnellii ej. $l . c, p .422$.

E. rugisetum ej. l. c. p. 424.

Hypnum clinocarpum Tayl. in Lond. Journ. of bot. 1848, p. 194 ; C. M. Syn. II, p. 355.

H. longipes Lindb, in sched. H. Regnellii Hpe. in C. M. Syn. II, p. 447 et Enum. M. Brasil. p. 77
(fid. Mitt.).

H. remotifolium Mitt. M. austr. am. p. 556.

H. rugisetum Hpe, in Ann, sc. nat. 1865, p. 342 ? (fid. Mitt.).

Syn. Ad terr. et saxa. - Am. merill. : Venezuela, Guian., And. Quitens., Brasil. or.

colpophyllum Sull. 1c. M. Suppl. p. 95, t. 71.

Hypnum colpophyllum ej. mss. ; Lesq. et Jam. Man. p. 352.

- Am. sept.: Washington? Calif.

"var. flagelliforme Barnes in Bot. Gaz. 1891, p. 207.

- Am. sept. : Calif.

compressulum Jaeg. - Tripterocladium.

confertum Milde. - Rhynchostegium.

var. Daldinianum Husn, - Rhynchostegium confertum var. Daldinianum.

var. Delognei Husn. - Rhynchostegium confertum.

cordatum Jaeg. -- E. hians.

corralense (Ltz.) Jaeg. Ad. II, p. 417.

Hypnum corralense Ltz. in Bot. Zeit. 1866, p. 189.

2? Muric. - Am. merid. : Valdivia.

crassinervium (Tayl.) Bryol. eur. V (mon. p. 14), t. 529; W. P. Sch. op. cit. p. 669.

Hypnum crassinervum Tayl. in Mackay Fl. Hibern. II, p. 43; C. M. Syn. II, p. 371.

Rhynchostegium crassinervium de Not. Epil.

2 vel ps. 1. Ad saxa umbr. - Eur. : Zon. intermed. tota, rar. septentr. vel merid. As, : Caucas. occ. et centr. Afr.: Alger.

Exs.: Rab, Bryoth. eur. n. 335, 478.

Un. itin. 1863, n. 76.

- var. laxorete Kindb. in Mac. Cat. p. 207 (vel nov.sp.?).

$q$ et fr. ign. Terr. in silv. - Am. sept. : Columb. brit.

curvisetum Husn. - Rhynchostegium.

cygnisetum Jaeg. - Ptychomium.

Dawsoni Kindb, in Bull. Torr. bot. Club, XVII, p. 279.

2? Ster. Rupic, - Am. sept. : Columb, brit., ins. Vancouver.

demissum Milde. - Rhaphidostegium.

depressum Milde. - Rhynchostegium.

devexum (Bosw.) Par. 
Hypnum devexum Bosu, in Journ. of bot. 1892, p. 99.

distans (Lindb.) Par.

$$
\text { - Pac. : Austral, or. }
$$

E. praelongum W. P. Sch.p.p. (fid. Lindb.).

Hypnum distans Lindb. M. Seand. p. 34 et n. 74 (in adn.).

2.

- Eur. : Suecia, Fennia, Ross. or. As. : Jenissei sup., Obi.

diversifolium Bryol. eur. V(mzon.p. 4), t. 520; W. P.Sch.op. cat.p. 664 (1).

Hypnum diversifolium Schleich. p.p.

H. strigosum var. diversifolium Lindb. M. Soand. p. 34 .

Leskea fasciculosa Hedw. Sp. M. p. 217, t. 14 (fid. Card.).

2. Ad terr. lapidos. - Eur.: Spitzberg, Alp. Norveg. (Dovre). As. :

Caucas, occ. st centr. Am . sept.: Groenland, Ottawa, lac. Super., reg. sept. occ., Columb. brit., Washington, Calif, New Jersey, Ohio, Wisconssin, Montana.

Exs.: Mac. Canad. M. n. 500.

Sull. et Lesq. M. bor. am. II ed, n, 432.

dumosum (Mitt.) Jaeg. Ad. 11, p. 412.

Hypnum dumosum Mitt. M. Ind. or. p. 80.

2.

- As. : Sikkim.

encalyptratum W. P. Sch, in Lechler M. Antarct.

Terr. - Am. merid. : Fret. Magellan.

euchloron (Br.) Jur. et Milde Beitr.... p. 601.

Hypnum euchloron $B r$, in C. M. Syn. II, p. 464.

2.

- As. : Caucas., litt. Caspic., Persia.

exasperatum (Hpe.) Jaeg. Ad. II, p. 427.

Hypnum exasperatum $H_{\text {pe }}$, in Linn. 1863, p. 162.

H. praelongum L. (fid. Mitt. M. austr. am, p. 557).

Rupic. - Am. sept, : Mexic. Am. merid. : Guian, batav., And. Nov. Granat. et Quitens,, Peruv.

germanicum Grebe, - E. Vaucheri var. germanicum.

graminicolor (Brid.) Par.

E. Sullivantii Jaeg. Ad. II, p. 420.

Hypnum graminicolor Brid. Sp. M. II, p. 254 et Bryol. univ, II, p. 455; C. $M+$ Syn. II, p. 263.

H. praelongum var. Sull. M. Allegh. $n, 44$.

H. Sullivantii $R$. Spr. in Giay's Man. of bot. $1848 ;$ C. M. op. cit. p. 430 ; Sull. M. of U. St. p. 69 et Ic. M. p. 165, t. 105; Lesq. et Jam. Man. p. 353 ; Mac. Canad. M. n. 296; Sull, et Lesq. M. bor. am. II ed. 76. 430 (fid. Caind in litt. ex autops, spec. Hedwig.).

Trichosteleum graminicolor Jaeg. Ad. II, p. 481.

2. Terr. - Am. sept. : Nov, Scot., New Brunswick, Gaspesia, Ontario, Pensilv, reg. centr., Florid. ; Terra nov.?

" var. Holzingeri (Ren. el Card.) Par.

E. Sullivantii var. Holzingeri $R$. et C. in Bot. Gas. 1893, p. 239.

- Am. sept. : Washington Columbia.

hians (Hedro.) Ren. et Card. in Bot. Gaz. 1892, p. 84.

E. cordatum Jaeg. Ad. II, p. 424 .

Hyprum cordatum Harv, in Hook. Ie. pl, rar. t. 24, f. $9(2) ; C . M$. Syn. II, p. 451. 
H. hians Hedw. Sp. M. p. 272, t. 270 ; Brid. Bryol. univ. II, p. 456; Sull. M. of U. St. p. 69 et Ic. M. p. 163, t. 104; Lesq. et Jam. p. 354. H. praelongum C.M. Syn. II, p. 446 p.p.

Pterigynandrum apiculatum Brid. M. Rec. Suppl. I, p. 137 et Bryol univ. $I I$, p. 19.

4. 2. Ad terr. humid. umbros. - Eur. :(fid. Mitt.). As. : Japon., Nepal., Himalaya, Tibet. occ., Khasia, Caucas. occ. Am. sept.: Nov, Scot., New Brunswick, Virgin. occ., Ottawa, Columb, brit.

Exs, : Drumm. M. bor. am. II ed, n. 134 (Hypnum).

Mac. Canad. M. n. 442 p.p. (Hypnum).

Sull. et Lesq. M. bor. am. II ed. n. 428 (Hypnum).

* var. pachyneuron (Lindb.) Par.

Hypnum hians var. pachyneuron Lindb. M. Scand, p. 34 et $n .73$ in adn, - Eur. : Suecia.

histrio Mdo. - E. Vaucheri $\beta$ julaceum.

integrifolium W. P. Sch. in Mandon Pl. Boliv. n, 1702.

- Am. merid. : And. Boliv.

Juratzkanum R. Farneti. - Amblystegium.

laevisetum Geheeb in Rev. bryol. 1876, p. 4 (nom.).

- Pac. : Austral. or. (Nov. Valesia).

laxifolium Jaeg. - Thuidium.

leucocladulum Jaeg. - Tripterocladium.

longifolium (Mitt.) Par.

Hypnum longifolium Mitt. in Trans. of the Linn. Soc. 1891, p. 183.

Ster. - As. : Japon.

? macrostegium (Sull. et Lesq.) Jaeg. Ad. I1, p. 428.

Hypnum macrostegium Sull. et Lesq. in Proced... 1859, p. 280.

2. Terr. - As. : Japon.

megapolitanum Milde. - Rhynchostegium.

var. meridionale Milde. - Rhynchostegiun megapolitanum var. mertdionale.

mexicanum Besch. - Microthamnium.

murale Milde. - Rhynchostegium.

Mülleri Rehm. M. Afr. austr. n. 363.

$$
\text { - Afr. : C. B. Sp. }
$$

muriculatum (Hook. f. et Wils.) Jaeg. Ad. 11, p. 417.

Hypnum muriculatum $H$. f. et $W$. F' . of the N. Zeal. II, p. 108, t. 89, f.3 et Handb. p. 477.

- Pac. : Ins. Norfolk, Nov. Zeland., Tasman.

« var. $\beta$ (Hook. f. et Wils.) Par.

Hypnum muriculatum var. $\beta$ eor. $l l$. $c c$.

$$
\text { - Pac. : Nov. Zeland. }
$$

myosuroides (L.) W. P. Sch. Syn. I ed. p. 549 et II ed. p. 632.

Hypnum myosuroides $L . S p . p l . p .1596 ; C . M$. Syn. II, p. 499.
H. myosuroides tenuius, capitulis nutantibus Dill. Hist. M. p. 317, t. 41 , f. 51 .

H. myosurum Sehrad. Syst. Samml. Crypt. Gew. I, p. 17, n. 79.

H. tenuius Vill. Pl. Dauph. III, p. 904. H. tenuius Vill. Pl. Dauph. III, p. 904 .
Isothecium myosuroides Brid. Bryol. univ. II, p. $369 ;$ Bryol. eur. V
(mon. p. ), t. 534 . 
Leskea myosuroides Roth Tent. Fl. Germ, I, p, 464.

Rhynchostegium myosuroides de Not. Epil.

$2 \mathrm{vel}$ ps. I. Ad arbor. rad., terr. et saxa proepr. arenac. et granit. Eur. : Fere tota. Afr.: Alger., ins. Canar. Am. sept. : Terr. nov., Nov. Scot., M. Alb., Columb. brit., ins. Vancouver, Oregon, Washington, Calif.

Exs. : Bourg. Pl. Canar. n. 616.

Mac. Canad. M. n. 291 p.p. (Hypnum).

Rab. Bryoth, eur, n. 481,766 et b.

Sull. et Lesq. M. bor. am. II ed, 1. 424 (Hypnum).

" subsp. hylocomioides (Kindb.) Par.

Isothecium myosuroides subsp. hylocomioides Kindb.

Lignic. - Am. sept.: Vancouver.

novo-caledonicum (C.M.) Par.

Hypnum novo-caledonicum C. M. in Rev. bryol, 1887, p. 57 (nom.). - Pac.: Nov. Caledon.

oreganum (Sull.) Jaeg. Ad. II, p. 427.

Hypnum Douglasii Hook. mss. ifld. Mitt. in Proced. of the Linn. Soc. 1864, p. 36 .

H, oreganum Sull. in Mem. of the Am. Acad.... 1849, p. 172 et in M. U. S. S. Pac. Expl. (Wilkes), p. 16, t. 13; C. M. Syn. II, p. 450: Lesq. 'et Jam. Man. p. 355.

2. Lignic. - Am. sept. : Columb. brit, ins. Vancouver, Washington, Oregon.

Exs. : Mac. Canad, M. n. 298 (Hypnum).

Sull. et Lesq. M. bor. am. I ed. n. 434 (Нyрnum).

orientale (Mitt.) Jaeg. Ad. II, p. 412.

Stereodon orientalis Mitt. M. Ind. or. p. 111.

2.

- As. : Assam.

ovalifolium Rehin. M. Afr. austr. n. 658.

Ster.

- Afr. : Transvaal.

pendulum (C. M.) Jaeg. Ad. II, p. 424 .

Hypnum denticulatum exiguum, pendulum, atro-virens Dill. Hist. $M$. p. $332, t .43, f .67$.

H. pendulum C. M. Syn. II, p. 467.

Isothecium pendulum Brid. Bryol. univ. II, p. 765.

Ad arbor. - Am. merid. : Patagon.

penicillatum (Mitt.) Jaeg. Ad. II, p. 412.

Stereodon penicillatus Mitt. M. Ind. or, p. 112.

2.

- As. : Sikkim.

Perraldieri W. P. Sch. in hb. Mus. Paris, - Afr. : Ins. Canar.

piliferum (Schreb.) Bryol. eur. V (mon. p. 16), t. 531; W: P. Sch, op. cit. p. 671 .

Hypnum cassubicum Dioks. Fasc. III Pl, crypt. p. 10.

H, piliferum Schreb. Spic. Fl. Lips, p. 91 ; Brid. Bryol. univ, II, p. 489 ; C. $M . S y n . I I, p .369$.

H. rutabulum $\beta$ piliferum Leyss. Fl. Hall. n. 1084.

Rhynchostegium piliferum de Not. Epil.

2 vel ps. 1. Ad agger., in prat. et fruticet. - Eur. : Zona interm.. passim. As. : Jenissei sup., Caucas. Am, sepl.: Groenland, Terr. nov., New Brunswick, reg. sept. 
Exs, : Rab. Bryoth, eur, n. 339.

Sull. et Lesq. M. bor. am. II ed. n, 429 (Hурпит).

polystictum (Mitt.) Par.

Hypnum polystictum Mitt. in Trans, of the Linn. Soc, 1891, p. 183.

2. Ad arbor. - As, : Japon.

praelongum (L.) Bryol, eur. V (mon. p. 8), t. 524; W. P. Sch. op. cit. p. 673.

Hypnum Clarionis Lam. et DC. Fl. fr. I, p. 320.

H. praelongum L. Sp. pl. p. 159L; Brid. Bryol, univ, II, p. 401; C. M. Syn. II. p. 446.

H. praelongum \& Clarionis Brid. Sp. M. II, p. 103.

Rhynchostegium praelongum de Not. Epil.

2. Lignic.; ad terr. et fol. emort. - Eur. : Tota, aretica except. As. : Japon., Kurdistan., Batoum. Afr. : Alger., ins. S. Helena. Am. sepl.: New Brunswick, Indiana, Illinois, Minnesota, Ludovic., Mexic. Am. merid.: Surinam, And, Nov. Granat., Quitens. et Peruv.

Exs. : Rab, Bryoth. eur. n, 480, 698, 1097.

var. abbreviatum Bryol. eur. - E. abbreviatum.

"var, atro-virens (Szo.) Bryol. eur. l. c. t. 525 et W. P. Sch, l.c.

E. Swartzii $R$. Farneti in Atti dell. Istit. brt. della $R$. Univ. di Pavia, 1893.

H. praelnngum Sw. M. Suec, p. 65.

H. praelongum $\delta$ atro-virens Brid. Bryol. univ. II, p. 402 p.p.

H. praelongum $\beta$ scariosum C. M. l. c.p.p.

H. scabrum Koch, in hb. DC. (fid, Brid. l. c.).

H. Swartzii Turn. Muscol. Hibern. p. 151, $t .14$.

Ut typ. - Eur. : Zon, intermed, et sept. Ital. super. As, : Jenissei med. et sup., Caucas. oce. et centr. A fr. : Alger., Madeir., ins, Azor.

var. meridionale Boul. - E. praelongum var, rigidum.

var. pumitum Bryol. eur, - F. pumilum.

" var. rigidum Boulay M. Fr, p. 103.

E. praelongum var. meridionale ej. in Husn. M. Gall. n. 480.

Ad terr. calcar. umbr. - Eur. : Gallia, praepr. merid.

pseudo-piliferuin (Hpe.) Jaeg. Ad. I1, p. 421.

Hypnum pseudo-piliferum Hpe. in Ann. sc. nat. 1865, p. 324.

2. Saxic. - Ani, merid. : And. Nov. Granat.

pseudo-serrulatum Kindb. - Rhynchostegium.

pseudo-striatum (C. M.) Jaeg. Ad. II, p. 417.

Hypnum pseudo-striatum C. M. in Bot. Zeit. $1856, p .458$.

Stereodon pseudo-striatus Mitt. M. Ind. or, $p .114$.

$$
\text { - As.: Nepal. }
$$

pseudo-Teesdalii Jaeg. - Rhynchostegium.

pumilum (Wils.) W. P. Sch. Coroll, bryol. eur. p. 119 et op, cil. p. 675.

E. praelongum $\beta$ pumilum Bry ol. eur. $V$ (mon. p. 8), t. 525 . H. pallidirostrum A. Br. in Brid. Bry ol. univ. II, p. 767; C. M. Syn. II,
p. 413 .

H. praelongum var, pallidirostrum $B$ rid. $l$. $c$.

H. pumilum Wils, Engl. Bot. Suppl. t. 2942.

H. Swartzii $\beta$ minus Turn. Muscol, Hib. p. 151.

2. Ad terr. et saxa arenac. umbr. - Eur.: Hibern., Angl., Normann.,

Westphal., Ligur., Etrur., Pyren. Afr. : Madeir.

Exs. : Rab. Bryoth. eur, n. 479, 1237. 
Regnelii Jaeg. - E. clinocarpum.

remotifolium (Grev.) Jaeg. Ad. II, p. 422 p.p.

Hypnum asperipes Mitt. in Journ. of the Linn, Soc. 1859, p. 85 et in Fl. Tasm. II, p. 209, t. 176, f. 4.

H. remotifolium Grev. mss.; H. f. et W. Fl. of the N. Zeal, II, p. 108 (fid. Jaeg. l. c.) et Handb. p. 477 . 1. - Pac. : Nov. Zeland, Tasman.

revelstokense Kindb. - Rhynchostegium.

rigidissimum (C. M.) Jaeg. $A d, I I, p .413$.

Hypnum rigidissimum C. M. in Linn. 1869-70, p. 16.

Ster. - As. : Ceylan.

rotundifolium Milde. - Rhynchostegium. rugisetum Jaeg. - E. clinocarpum. rusciforme Milde. - Rhynchostegium.

Savatieri W. P. Sch. mss.; Besch, in Ann. sc, nat. 1893, p. 378.

2. - As.: Japon.

Exs. : Savatier n, 476 b, 672.

"var, abbreviata Besch. l. c.

Ubi typ.

Exs. : Savatier, n, 672 b.

"var. prolixa Besch. l. c.

Ubi typ.

Exs. : Savatier n. 677 p.p.

scabrisetum (Schwaegr.) Par.

Hypnum scabrisetum Schwaegr. Suppl. III, II, II, t. 281; C. M. Syn. II, p. $250 ;$ Mitt. M. Ind. or. p. 80 .

Leskea remotifolia Hook, mss. (fid. C. M.! non! fid. Mitt, l, c. pp. 80 et 135).

Thuidium remotifolium Jaeg. Ad. II, p. 740 (1).

l. - As. : Nepal. (?), Sikkim; Assam sup. (?)

seariosissimum C. M. mss. ; Jaeg. Ad. II, p. 418.

Schleicheri Hartm. - E. abbreviatum.

scleropus Bryol, eur. V (mon, p. 11), t. 527; W. P. Sch. op. cit.p. 673.

2. Ad rup. granit. umbros. - Eur. : Voges, super. : rariss.

semi-asperum (Brachythecium?) C. M. et Kindb. in Bidr. 454 el in Mac. Cat. p. 20 ?.

1. Rupic. - Am. sept. : Columb. brit.

Exs. : Mac. Canad. M. n. 507.

semi-tortum (Mitt.) Par.

Hypnum sэmi-tortum Mitt. M. austr, am. p. 556.

2? Ster. Cortic. - Am. merid. : And. Nov. Granat.

serrulatum Kindb. - Rhynchostegium.

subsp, eriense Kindb. - Rhynchostegium serrulatum subsp, eriense.

subsp. hispidifolium Kindb. - Rhynchostegium serrulatum subsp. hispidifolium.

Shawii Rehm, M. Afr, austr, n. 656 b.

- Afr. : Natal.

(1) . An Brachythecium ? $n$ Jaeg. 1. c. p. 755 . 
speciosum (Brid.) W. P. Sch. Syn. II ed.p. 672.

E. androgynum W. P. Sch. Coroll, p. 119.

Hypnum androgynum Wils. mss.

H. fontium Brid. Bryol. univ. II, p. 417?

H. praelongum $\beta$ scariosum $C$. M. Syn. II, p. 417 p.p.

H. praelongum var. speciosum Brid. Bryol, univ. II, p. 403.

H. riparioides var. speciosum Schwaegr. Suppl. I, II, v. 196.

H. speciosum Brid. Mant. M. p. 156.

Rhynchostegium androgynum Bryol. eur. V (mon. p. ), t. 527.

Syn. Ad rad. arb, et saxa in aquosis. - Eur, : Angl,, Voges, super, German. sept., Helvet., Gall, merid., Lusit. Afr.: Ins, Canar.? (H. fontium).

Exs. : Rab. Bryoth. eur. n. 389, 1098.

spiculiferum (Mitt.) Jaeg. Ad. II, p. 413.

Hypnum spiculiferum Mitt. in Journ. of the Linn. Sac. VIII, p. 34.

lsothecium spiculiferum Kindb, in Mac. Cat. p. 204.

2.

Washington.

- Am. sept. : Columb. brit., ins, Vancouver,

spiculosum (Mitt.) Jaeg. Ad, II, p. 422.

Hypnum spiculosum Mitt. in op. cit. 1863, p. 156.

1. Ad arbor. - Afr.: M. Cameroon.

spinulaenerve Kiaer in Borgen M. Madag, n. 48.

- Afr. : Madagasc. centr.

Sprengelii (C. M.) Jaeg. 11, p. 414.

Hypnum Sprengelii C. M. in Jiot. Zeit. 1855, p. 785.

2. Saxic. - Afr, : C. B. Sp.

Stokesii (Turn.) Bryol. eur. V (mon. p. 10), t. 526; W. P. Sch. op. cit. p. 677 .

Hypnum Fulgeriense la Pyl. in hb. Brid.

H. hians Mac. Ganad. M. n. 442 p.p.

H. Ludwigii Brid. in sched.

H. orthorhynchum ej. Sp. M. II, p. 106.

H. praelongum Turn. Museol. Hibern. p. 160.

H. praelongum var. orthorhynchum Brid. Bryol. univ. II, p. 403.

H. praelongum $\gamma$ Stokesii $e j$. op. cit. p. 401.

H. pseudo-delicatulum Raddi in Opusc. se. di Bolon. II, p. 360.

H. repens, triangularibus parvis foliis, praelongum Dill. Hist. M. p. 278, t. $35, f .15$.

$H$, rigidiusculum Bland. $M$, exs. Fase, $V, n .230$.

H. Stokesii Turn. l. c. p. $159 ;$ C. M. Syn. II, p. 448.

2. Ad rup, et saxa secus rivul, in umbros. - Eur.: Fere tota. As.: Caucar. (Tiflis). Afr.: Alger., Teneriff, Madeir, ins, Azor. Am. sept. : Terr. nov., Idaho, Oregon, Washington, ins. Vancouver, Columb brit.

Exs. : Bourg. Pl, Canar. n. 1580 (Hypnum).

Mac. Canad. M. n. 297 (Hypnum).

Mandon Pl. Madeir. n. 4I.

Rab. Bryoth. eur, n. 677 et b.

Sull. et Lesq. M. bor. am. II ed. n. 433 (Hypnum).

stoloniferum (Hook.) Jaeg. Ad, II, p. 412.

Hypnum myosuroides $\beta$ stoloniferum C. M. Syn. $I I, p .500$.

H. stoloniferum Hook. M. ex. t. 74.

Isothecium stoloniferum Brid. Bryol. univ. II, p. 371.

2. Ad arbor. et rup. - Am. sept.: De Alaska ad Calif.; Idaho, Indiana. Exs. : Sull, et Lesq. M. bor. am. II ed. n, 425. 
striatellum W. P. Sch. - Rigodium Lechleri.

striatulum (Spr.) Bryol. eur. V (mon. p. 5), t. 522; W. P. Sch. op. cit. p. 665 .

H. filescens Brid. Sp. M. II, p. 170; C. M. Syn. II, p. 462 p.p.

H, praelongum \& filescens Brid. Bryol. univ. $I I, p, 402$.

H. striatulum Spr. M. Pyr. n. 12 et in Ann. and Mag. nat. hist. 1849; M. Pyr, n. 79 .

Rhynchostegium striatulum de Not. Epil.

2 vel ps. 1. Ad rup. calcar., mur. delaps, , terr. argill. et arb. - Eur. : Reg. merid., rar. interm. : Hibern., Angl., Gall. centr. (Iutet.) et merid., Pyren., Corsic., Sardin., ins. Melit., Bavar., Francon., Westphal. As. : Caucas, occ. Afr. : Alger.

Eos. : Rab, Bryoth. eur. n. 388.

Un. itin. 1863, n. 75 .

"var. cavernarum $M$ do.

- Eur. : frall. merid.

striatum (Schreb.) Bryol. eur. V(mon. p. 6), t. 525; W. P. Sch, op. cit. p. 666 .

Hypnum Adiantum Neck. Meth. M. p. 181.

H, elasticum Brid. Sp. M. II; p. 256.

H. longirostrum Ehrh. Pl, crypt. exs. n. 75 ; Rrid. Bryol, univ. II, p. 502.

H. rutabulum $\beta$ cuspidatum Web. Spic. Fl. Goelt. p. 92.

H. striatum Schreb. Spic. Fl. Lips. p. 91; C. M. Syn. II, p. 460.

H. unguiculatum La Tour Chlor. Lugd. $p$. 33 ; Schleich. in sched.

H. vulgare dentatum, operculis cuspidatis Dill. Hist. M. p. 297, t. 38,
f. $30 \mathrm{~B}$.

Pleurozium striatum Kindb. Check List.... p. 19.

Rhynchostegium striatum de Not. Epil.

$2 \mathrm{vel}$ ps. 1. Ad terr. in silv. - Eur. : Fere tota, arctic. except, in reg. campestr, et mont. As. : Caucas. Afr.: Alger.

Exs, : Rab. Bryoth, eur. n. 356 et b.

* var. meridionale Bryol. eur. et W. P. Sch. ll. cc.

Hypnum filescens $C$. M. Syn. II, p. 462 p.p.

H. Hildebrandti Garov. mss.

H. longirostre var. Durieui Mitt, in Godman's Nat, hist. of Azores, p. 310.

H. meridionale W. P. Sch. mss.

H. striatum var. Durieui Mont. in DF. M. Astur.

Rhynchostegium striatum de Not. Epil.

Ut typ., praeçip. in Pinetis. - Eur.: Zon. merid, Afr. : Alger., Madeir., ins. Azores.

Exs. : Rab. Bryoth. eur. n. 337, 905.

strigosum (Hoffm.) Bryol. eur. V (mon. p. 2), t. 519; W. P. Sch. op. cit. p. $662(1)$.

Hypnum abbreviatum Schleich. Cent. IV, n. 25.

H. pulchellum Hedv. Sp. M. p. 265, t. 68 .

H. strigosum Hsch. in Brid. Bryol. univ. II, p. 390 p.p. II, p. 428. Hoffm. Deutsch. Fl. p. 76; Brid. op. cit.p. 446; C. M. Syn.

H. $\mathrm{s}$

H. substrigosum Mac. Canad. M. n. 449 p.p.

$\mathrm{H}$, velutinoides Brid. M. Rec. II, II, p. 99, t. 3, $f .2$.

Leskea fascicides Voit $M$. Herbip, $p .99$.

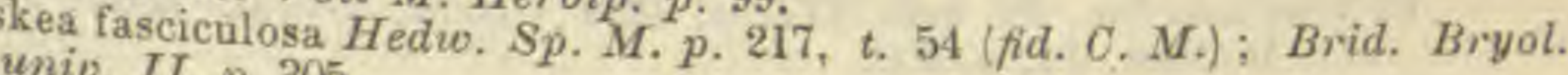
univ. II, p. 305.

Rhynchostegium strigosum de Not. Epil.

2 vel ps. 1. Ad terr. umbros., rup. arborumque rad. - Eur. : Reg. cam- 
pestr, et mont. zon. interm, et sept. As. : Groenland, Anticosti, Nov.

Scot., New Brunswick, Gaspes., Ontar., Manitoba, M. Rupestr., Columb. brit., Alaska, Washington, Oregon, Idaho, Wyoming, Montana, reg. sept., or. et centr. Am. merid. : Chile?

Exs, : Drumm. M. bor. am. I ed, n. 183 et 11 ed. n. 131 (Hypnnm).

Rab. Bryoth, eur. n. 745.

Sull, et Lesq. M. bor. am. II ed. n. 431 (Hypnum).

Un. itin. 1863, n. 37.

- var. Barnesi Ren. et Card. in Bot. Gaz. 1889, p. 97, t. XIV R.

- Am. sept. : Idaho, Washington.

"var. fallax Ren. el Card. in op. et l. cc. et M. bor. am. n. 116.

- Am. sept. : Washington, Idaho, Montana.

a var. imbricatum Bryol. eur. el W. P. Sch. ll. cc.

Hypnum praecox Sw. in Hedw. Sp. M. p. 249, t. 65.

H. Stereodon praecox Brid. Bryol. univ. II, p. 589.

H. strigosum $\beta$ praecox Lindb. M. Scand. $p .34$.

In loc. sicc. glareos. - Eur.: Suec., German. sept., Vales., Ital. super. As. : Jenissei inf. et sup., Obi. Afr. : Alger.

subdenticulatum W. P. Sch. in Mandon Pl. Boliv. n. 1701.

$$
\text { - Am. merid. : And. Boliv. }
$$

suberectum (Mitl.) Jaeg. II. p. 421.

Hypnum suberectum Mitt. M. austr. am. p. 562.

Leucodon scabrisetus Tayl. in Lond. Journ. of bot. 1848, p. 282? (fid, Mitt.).

Neckera scabriseta C. M. Syn. II, p. 114 ? (id.).

- Am. merid, : And. Quitens.

subintegrifolium Kindb. - Rhynchostegium.

subscabridum Kindb.

H. Sullivantii Mac. Cat. p. 206 et Canad. M. n. 296.

Ps. I v. 2. Rupic. - Am. sept. : Nov. Scot., New Brunswick, Gaspes., Ontario.

subsquarrosulum (Hpe.) Jaeg. Ad. II, p. 415.

Hypnum subsquarrosulum Hpe. in sched.; C. M. in Bot. Zeit. 1858, p. 171.

2.

- Afr. : C. B. Sp.

substrigosum Kindb. in Bidr. p. 452 (nom.) et in Mac. Cat. p. 205.

Hypnum substrigosum Mac. Canad. M. n. 449 p.p.

1. Rupic. - Am. sept. : Columb. brit.

Sullivantii Jaeg. - E. graminicolor.

var. Holzingeri Ren, et Card. - E. graminicolor var. Holzingeri.

Swartzii R. Farneti. - E, praelongum var, atro-virens.

Teesdalii (Sm.) W. P. Sch. Syn. II ed. p. 676. Hypnum intricatum Dicks. Fasc. II Pl. Crypt. p. 10 (excl. syn. Engl.
Bot. t. 202).

H. pachyneuron Tayl. mss.; Wils. Bryol. brit. 350 (ut syn.).

H. Teesdalii Sm. Fl. brit. III, p. 1291; Brid. Bryol. univ. II, p. ${ }^{416}$; C. M. Syn. II, p. 400.

1. Ad saxa humida umbr. - Eur.: Suec., Angl., Hibern., Gall. centr.

(Lutet.) As. : Caucas. occ. Afr. : Alger.

Teesdalii Milde. - Rhynchostegium curvisetum.

teesdalioides Jaeg. - Rhynchostegium.

tenellum Milde. - Rhynchostegium. 
Tommasinii Husn. - E. Vaucheri

var. fagineum H. Müll. - E. Vaucheri var, tenuicaule,

trichocladon (Bryol. jav.) Jaeg. Ad. 11, p. 412.

Hypnum trichocladon Bryol. jav. II, p. 155, t. 254.

2.

- As.: Ins. Celebes, Ceram, Java.

uliginosum Warnst, in Abhandl, d. bot. Ver, d. Prov. Brandenb. 1885. - Eur. : Brandebourg.

Vaucheri Bryol. eur. V (mon. p. 15), t. 530 ; W. P. Sch. op. cit. p. 670.

E. Tommasinii Husn. Muscol. gall, p. 338.

Hypnum Tommasinil Sendtn. mss.

H. Vaucheri W. P. Sch. mss.; C. M. Syn. I1, pp. 372 et 687.

2. Ad rup, et saxa calcar, umbros. - Eur. : Westphal,, Jurass,, Silva nigr., Francon., Alp. Jul., Austr. inf., Pyren., etc.; deest in Britann. et in Ital. Am. sept.: Gaspes., M. Rupestr., Columb. brit., fret. Behring.

Exs. : Rab. Bryoth. eur. n. 13 b, 338, 758, 1189.

Un. itin. 1863, n. $77,70,91$.

"var. germanicum (Grebe) Par.

E. germanicum Grebe in Hedwig. 1894, p. 339.

Ad rad. Fagor. et saxa. - Eur, : Westphal.

"var, julaceum Bryol. eur, et W. P. Sch. lt. cc.

Brachythecium cirrosum W, P.Seh. (fid. Husn.).

E. cirrosum Mdo, in sched. et in Ltz. Moost, p. 95.

E. histrio ej. Bayern's Laubm. p. 224 .

Myurium herjedalicum W. P, Sch. (fid. Husn.).

Ut typ. - Eur.: Alp. Helvet, Savar.

Exs. : Un. itin. 1863, n. 78 .

"var. tenuicaule (Spr.) Par.

E. Tommasinii var, fagineum H. Müll. mss.; Husn. Muscol. gall. p. 338.

Hypnum tenuicaule Spr. in Ann, and Mag. nat. hist. $1849 ;$ M. Pyr. n. 72 (fid. Husn. op cit. p. 437); C. M. Syn. II, p, 416.

H. Tommasinï var, fagineum Boulay M. Fr. p. 409 .

Ad arb. vetust. necnon saxa. - Eur.: Voges., Jurass., Arvern., Alp., Pyren.

velutinoides (Br.) Bryol. eur. V (mon, p. 12), t. 528; W. P. Sch. Syn. II ed. p. 668.

Hypnum filiforme C. M. Syn. II, p. 370.

H. Flotownianum Sendtn, in Regensb. Denkschr. 1841.

H. Reichenbachianum Hüb. in Bot, Zeit, 1847, n, $41 \mathrm{c}$, ic.

$\mathrm{H}$. velutinoides $B$ r. in sehed. 1836 .

Rhynchostegium Locarnense de Not. Epil.?

2 vel ps. 1. Ad saxa aren. et rup. argill, schist. - Eur.: Norveg. German. sept., vall, Rhen.; Ital, super.? As. : Persia, Caucas. occ, Exs, : Rab. Bryoth. eur. n. 635 .

Welwitschii Husn, - Rhaphidostegium (1).

Eurybrochis Ren. et Card. in Bot. Gaz. XV, p. 60 (sect. HeTEroci.Adi). Eurystomum Hook. f. et Wils. Fl, of the N. Zeal. p, 92 et Fl. Tasm. II, p. 178 (sect. Heowigiz sensu H. f. et W. = Gigaspermem Lindb.).

(1) In Enum. Kindberg. nomina nuda :

E. dives $C . M$.
Krausei $C . M$. (an Brachythecium Krausei?). 
Euschistophyllum Lindb. M. Scand. $p$. 13 (Fissidentes veri).

Euschlotheimia Mitt. M. austr, am, p. 222 (sect. Schlotheimiak).

Euseligexia C. M. Syn. I, p. 418 (sect. Sei.igrriak).

EUSTIChIA C. M. Syn. I, p. 41 emend. (1 spec.).

Jamesoni C. M. - E. longirostris.

japonica Berggr. - Bryoxyphium Savatieri.

longirostris (Brid). C. M. Syn. 1, p. 42 et II, p. 523.

Cymbaria Jamesoni Tayl. in Lond. Journ of bot. 1848, p. 190.

Didymodon distichus Schuaegr. Suppl. II, t. 183 (sub D. compresso):

Diplostichum longirostre Mont. in Ann. sc. nat. 1845, IV, p. 116 et Syll. p. 27.

E. Jamesoni C. M. Syn. II, p. 523.

Fissidens Eustichium Rehm, M. Afr. austr, n. 279.

Phyllogonium E. longirostris Brid. Bryol. univ. II, p. 674.

Pterigynaudrum longirostre Brid. op. cit. p. 195.

2. Lignic. et terr. - Afr. : Ins. Tristan d'Acunha, Orange, C. B. Sp., Madagasc., ins. Borbon. Am. merid. : And. Quitens.

norvegica C. M. - Bryoxiphium.

Savatieri Husn. - Bryoxiphium (1).

EUSTICHIUM Bryol. eur. III.

norvegicum $\left\{\begin{array}{l}\text { Bryol. eur. - Bryoxiphium. } \\ \text { Besch., W. P. Sch. - Bryoxiphium mexicanum. }\end{array}\right.$

Eusyrrhopodon C. M. Syn. 1, p. 540 (sect. SyrRhopodontrs).

Eutetraplodon Lindb. M. Scand. p. 19 (sect. Terraplodontis).

Eutrichostomum C. M. Syn. 1, p. 581 (sect. Trichosтомi).

Eutrichum W. P. Sch. Coroll. p. 28 (subgen. Trichostomi).

Euwebera Limpr. Deutsch. Laubm. II, p. 248 (sect. WebrraE).

Euweisia C. M. Syn. I, p. 651 (sect. W HISLAE).

EUZYGODON C. M. Syn. I, p. 671 (sect. Zygodonts); Jur. Laubm. Osterr. Ung.p. 191 (gen, propr.).

Sendtneri Jur. - Zygodon.

FIEDLERIA Rab. Deutsch. Krypt. $I 1, p .98$.

subsessilis Rab. - Pharomitrium.

FABRONIA Raddi in Att. dell. Acad, d. Scienz, di Siena, IX, p. 230 (76 spec.).

abyssinica C. M. Syn. $11, p .35$.

F. macroblepharis Br, et Sch. in W. Sch. M. Abyss, n. 466 et 477.

1. Rupic. - Afr, : Abyssin.

andina Mitt. M. austr. am. p. 538. 1.

- Am. merid. : And. Quitens., ins. Chiloë.

angolensis Welwo, et Duby in Mém.... Genève, 1871, p. 1, t. 1, f. 2.

1. Ad Lichen, et rad. arb. - Afr. : Angola.

(1) In Enum. Kindberg, nomen nudum :

Diplostichum Lorentzi $C . M$. 
argentinica C. M. in Linn. 1878-79, p. 387.

1. Cortic. - Am, merid.: Argentin. subtropic.

aureo-nitens Rehm, M. Afr. austr. n. 628.

- Afr. : C. B. Sp. or.

australis Hook. M. ex. t. 160 ; Brid. Bryol. univ. II, p. 171 ; C. M. Syn. II, p. 37; Handb. of N. Zeal. Fl. p. 456.

I. - Pac. : Fret. reg. Georges, Nov. Zeland. sept.

Ralansae Besch, in Rev. Jryol. 1885, p. 18 el in Journ. de bot. 1891, p.

1. -Am. merid.: Paraguay.

Exs. : Bal, Pl. Parag. n. 3656.

basilaris C. M. in Linn. 1878-79, p. 390.

Syn. vel polyg. Terr. - Am. merid, : Argentin. subtropic.

Beccarii Hpe, in Nuov. Giorn. bot, ital. 1872, p. 275.

1. Cortic. - Am. merid, : Ceylan.

Breutelii Hpe. mss. ; C. M. in Bot. 2eit. 1859, p. 247.

2 ?

- Afr.: C. B. Sp.

Cameruniæ C. M. in Dusen M. Camer, n. 166.

- Afr. : M. Cameroon.

Campenoni Ren. et Carl. in Bull. Soc, roy. bot. Belg. 1892, p. 107.

1. Ad arbor. - Afr. : Madagascar.

caroliniana Sull. et Lesq. - F. Ravenelii.

ciliaris Brid. - F. octoblepharis.

condensata W. P. Sch. mss, ; Jaeg. Ad. II, p. 284.

- Afr.: Abyssin.

crassiretis Ren. et Card. in op. cit. 1894, II, p. 128.

2. In silv. - Afr. : Madagascar.

cubensis Sull. - Anacamptodon.

curvirostra $D z$. et $M k$, in Ann. sc. nat. 1844, II, p. 304 et $M$. frond, ined.

Archip. ind. p. 7, t. 21; C. M. Syn. II, p. 36; Bryol jav. II, p. 130.

1. Cortic. - As. : Java.

densifolia Relem. M. Afr. austr. n. 348.

dentata W. P. Sch, hb.

- Afr. : Austral.

F. polycarpa var. patens Besch. Prodr, bryol, mexic. p. 87.

1. - Am. sept. : Mexic. (M. Orizaba).

denticulata W. P. Sch. mss. ; Jaeg. Ad. II, p. 284.

- Am. sept. : Mexic.

Donnellii Aust. in Coult. Bot, Gaz. I1, p. 111 ; Lesq: et Jam. Man p. 295.

Ad Quercus. - Am. sepl, : Florida.

Duseni C. M, in Dusen M. Camer, n. 249.

- Afr. : M. Cameroon.

Eckloniana Hpe. mss.; C. M. in Bot. Zeit. 1859, p. 247.

1. $-A f r,:$ C. B. Sp.

fastikiata Ren. et Card. in Bull. Soc, roy. bot. Belg. 1892, II, p. 106.

- Afr. : Madagascar. 
flavescens (Hook.) Par.

Campylodontium flavescens Bryol. jav. II, p. 128.

C. striatum Dz. et $M k$, in $A n n$. sc. nat. $1844, I I, p .301$ et $M$. frond, ined. Archip. ind. p. 123, t. 39.

F. striata C. M. Syn. II, p. 139.

Neckera flavescens C. M. Syn. II, p. 68 (fid. Bryol, jav.).

Pterigynandrum flavescens Brid. Bryol, univ, II, p. 193.

Pterogonium flavescens $H o o k . M$. ex. $I I, t .155$.

Stereodon flavesceus Mitt. M. Ind. or. p. 93.

1.

- As. : Nepal., Himalaya, Khasia, Ceylan, Java

flavinervis $C . M$. in Linn. $1876, p .645$.

F. polycarpa Besch. Prodr. bryol. mexic. p. 87.

Ad arbor, et mur. - Am. sept. : Mexic.

Gardneriana C. M. Syn, II, p. 34.

F. macroblepharis ej. in Bot. Zeit. 1845, p. 107.

F. polycarpa Wils, in M. Gardner. (etiam Hook. M. ex. t. 3 fid. Mitt.) 1.

- Am. merid. : Brasil. or.

Goughii Mitt. M. Ind. or. p. 7 .

F. secunda $C . M$. in Schmidt $M$. Neelgherr.

I. - As. : M. Neelgherr., Ceylan.

gracilicarpa Hpe. mss.; Jaeg. Ad. 1I, p. 284.

- $\Lambda$ m. merid. : Columb.

grandifolia C. M. in Dusen M. Camer, n. 316.

- Afr.: M. Cameroon.

guarapiensis Besch. in Rev. bryol. 1885, p. 18 et in Journ de bot.

$1891, p$.

1. Cortic. - Am. meriel.: Paraguay.

Exs. : Bal. Pl. Parag. n. 3681 p.p.

Gueinzii Hpe. mss. ; C. M. Syn. II, p. 37.

2.

$$
\text { - Afr. : C. B. Sp. }
$$

gymnostoma Sull, et Lesq. in Sull. Ic. M. p. 136, t. 86; Lesq. et Jam. Man. p. 294.

I. - Am. sepl. : Nov, Mexic.

Exs. : Sull. et Lesq. M. bor. am. II ed. n. 378.

Hampeana Sonder in Hpe. Ic. M. t. 13; C. M. Syn. II, p. 34.

F. incana Tayl. in Lond. Journ. of bot. p. 1846, p. 58.

F. tomentosa H. f. et W. in Hook. Ic. pl. rar. t. $739 \mathrm{c}$.

1. Cortic. - Am. sept. : Mexic. (fid. Besch.)? Pac.: Austral. oce t or.

hypnoides Rehm, M. Afr. austr. n. 629.

$$
\text { - Afr.: Transvaal. }
$$

imbricata Hpe. Symb. 1877, p. 728.

- Am. merid. : Brasil. austr. or.

incana Tayl. - F. Hampeana.

jamaicensis Ltz. Moosst p. 163.

1.

- im. sept. : Jamaic.

Jamesoni Tayl. in Lond. Journ. of bot. 1848, p. 197; C. M. Syn. II,

p. $33 ;$ Mitt. M. austr. am. p. 538.

1. Cortic. - Am. merid. : Paraguay.

Exs. : Bal. n, 1256. 
julacea Besch. Not. Parag. p. 265.

1. Cortic. - Am. merid.: Paraguay.

Exs.: Bal, Pl. Parag. n. 1256.

jungermannioides Brid, - F. Persoonii.

latidens Duby Choix de crypt. ex.... 1869, p. 12, t. 2, f. 4.

1.

- Am. merid. : Chile.

Leikipiae C. $M$. in Fl. 1890, p. 487.

1.

- Afr. : M. Aberdare.

Leveilleana (Bryol. jav.) Jaeg. Ad. II, p. 283.

Hypnum Leveilleanum Bryol. jav. II, p. 165, t. 264.

1.

- As, : Java.

Lindigiana Hpe. in Linn. 1861-62, p. 226; Mitt. M. austr. um. p. 538.

1. Cortic. - Am. merid. : And. Nov, Granat.

longidens Duby op. cit. 1867, p. 12, t. 4, f. I; Mitt. op. cit. p. 539.

1. Cortic. - Am. merid. : Patagon. austr.

longipila Broth. in Engler's Bot. Jahrb. 1894, p. 208.

1. Cortic. - Afr. : Usambara.

Lorentzi C. M. in Linn. 1878-79, p. 389.

1. Cortic. - Am. merid. : Argentin. Cordob.

macroblepharis Schwaegr. Suppl. III, I, II, t. 247; C. M. Syn. II, p. 32 ;
Mitt. op. et l. cc.

1. Lignic. - Am. merid. : Brasil.

macroblepharis $\left\{\begin{array}{l}\text { Br, et Sch. - F, abyssinica. } \\ \text { C. M. - F. Gardneriana. }\end{array}\right.$

major de Not. - F. octoblepharis.

minuta Mitt. M. Ind. or. p. 76.

I. $\quad$ minutissima Duby op. cit. 1880, t. $11, f .2$.

- As. : Himalaya occ.

F. andina? (fid. Hpe, in Fl. 1880, n. 21).

- Am. merill. : Chile.

Niam-Niamiae C. $M$. in Linn. 1875, p. 428.

Ster. Cortic. - Afr. : Niam-Niam.

Nietneri C. M. in Linn. 1869-70, p. 18.

1.

nivalis Mont. As. : Ceylan.

merid.

2. Te. 107, t. 3, f. 3 et Syll. p. 22; C. M. Syn. II, p. 35.

octoblephat - Amerid. : And. Quitens., summ. And. Boliv.

eur. Vhis (Schleich.) Schwaegr. Suppl. I, 1I, p. 338, t. 99; Bryol.

ed. V (mon. p. 4), t. 451 ; C. M. Syn. II, p. 33; W. P. Sch. Syn. II

F. ciliaris

F. major Brid. Bryol, univ. II, p. 171.

F. pusilla Sohroaegyll. M. p. 85 .

F. pusilla $\beta$ Bryogr. op. oit. p. 337.

Hrpnum ciryol. eur. $l$. c.

Pterogonium

1. Ad mur. Helv. exs.

zon. centr. A Exs. Am, sept. : Illinois, Kansas.

Escs. : Rab. Bryoth. eur. n. 468. 
palmicola C. M. in Linn. 1878-79. p. 392.

1. Cortic. - Am. merid. : Uruguay.

patentissima C. M. in Linn. 1869-70, p. 19.

1.

- As. : Ceylan.

Persoonii Schwaegr. Suppl. I, II, p. 339, t. 99; C. M. Syn. II, p. 33.

F. jungermannioides Brid. Bryol. univ, II, p. 169 .

Hypnum coronopifolium P. B. in hb. Brid.

1. Lignic. - Afr. : Ins. S. Thomas, Borbon., Franciae.

physcomitriocarpa C. M. in Linn. 1878-79, p. 393.

1. Terr, - Am. merid. : Argentin, subtropic.

pilifera Hsch. in Lınn. 1841, p. 136; C. M. Syn. 11, p. 35.

1. Cortic. - Afr. : C. B. Sp.

pilifera C. M. p.p. - F. Vallis Gratiae.

pilifolia C. M. in Journ. of the Linn. Soc. 1877, p. 229 (nom.).

Ad arbor. - Am. sept. : Costa Rica.

Podocarpi C. M. in Linn. 1878-79, p. 388.

1. Cortic. - Am. merid. : Argentin. subtropic.

polycarpa Hook. M. ex. II, p. 3, t. 3; Brid. Bryol, univ. 1I, p. 172;

C. M. Syn. $1 I$, p. 37.

1. Ad arbor, et saxa. - Am. merid.: Venezuela, And. Nov. Granat. et Peruv., Brasil., Montevideo.

polycarpa $\left\{\begin{array}{l}\text { Besch. - Fl. flavinervis. } \\ \text { Br. et Sch, - F. Schimperiana. } \\ \text { Wils. - F. Gardneriana, }\end{array}\right.$

var. patens Besch, - F. dentata.

pusilla Raddi Att. d. Acad. d. Scienz. di Siena, IX. p. 230 ; Brid. Bryol. univ. II, p. 170 ; C. M. Syn. II, p. 31; Bryol. eur. V (mon.p. 3), t. 450 (excl. fig. 6 ad F, octoblepharem pertin.) ; W. P. Sch. Syn. II ed. p. 584.

Grimmid inconspicua Bertol. Amoen. p. 53.

1. Ad arbor,, rar. ad saxa. - Eur. : Helvet. occ.; zon. merid.; deest in Britann. Afr. : Alger., Madeir. An. sept.: Columb. brit., Minnesota, Calif. inf., Nov, Mexic.

Ess. : Mac. Canad. M. n. 508.

Rab. Bryoth. eur. n. 687, 1181, 1264.

«var. ciliata Lesq. et Jam. Man. p. 294.

F. Schimperiana de Not. Epil.p.p. 226 et 228 (1).

- Am. sept. : Calif., Nov. Mexic.

pusilla Schwaegr. - F. octoblepharis.

var. $\beta$ Bryol. eur, - F. octoblepharis.

Ravenelii Sull. M. of U. St. p. 61, t. 4 et Ic. M. p. 135, t. 85; Lesq. e

Jam. Man. p. 292. Jam. Man. p. 292 .
F. caroliniana Sull. M. of U. St. p. 62 ; Sull. et Lesq. M. bor. am. I d.
n. 253 .

1. Lignic et rupic. - Am. sepl.: Carolin. inf., Florida.

Exs. : Sull, et Lesq. M. bor, am. I ed. n. 252 et II ed. n. $376,377$.

(1) Cf, Lindb, in Journ, of the Linn. Soc. 1868, p. 72. 
Rehmanni C. M. in Rehm. M. Afr, austr, n, 347 .

- Afr. : C. B. Sp.

a var. julacea Rehm. l, c. n. 627.

- Afr.: Natal.

Schimperiana Hpe. mss.

F. abyssinica $C . M$. p.p.

F. polycarpa Br, et Sch. in W. Sch. M. Abyss, n. 443.

1.

- Afr. : Abyssin.

Schimperiana de Not. - F. pusilla var. ciliata.

Schmidii C. M. in Bot. Zeit. 1854, p. 558; Mitt. M. Ind. or. p. 76.

1. - As. : M. Neilgherr.

Schweinfurthi C. M. in Linn. $1875, p .426$.

1. Terr. - Afr. : M. occid, mar, Erythraei.

Scottiae C. M. in Linn. 1867-68, p. 620.

1.

- Pac. : Austral. or.

secunda Mont. in Ann. sc. nat. 1842, p. 251 et Syll, p. 22 ; C. M. Syn. II,

p. 36 ; Mitt. op, cit. p. 76.

1. Cortic. - As.: M. Neilgherr., Ceylan, Java.

secunda C. M. - F. Goughii.

? Sendtneri W. P. Sch. Syn. II ed. p. 585.

FI, et fe. ign, Cortic, - Eur. : Istria.

seriola C. M. - Ischyrodon.

Bocotrana Mitt. in Trans. of the roy. Soc. of Edinb. 1887, p. 335.

Ster, - Afr.: Ins. Socotora.

splachnoides C. M. - Anacamptodon.

striata C. M. - F. flavescens.

subpolycarpa C. M. in Hpe. Enum. M. Brasil.p. 48.

- Am. merid. : Brasil, austr. or.

Tayloriana Hpe, in Linn. 1869-70, p. 522 .

1.

tomentosa H. f, et W. - F. Hampeana,

- Pac. : Austral. or.

uruguensis C. $\boldsymbol{M}$. in Linn. 1878-79, p. 391.

1. Cortic, - Am. merid.: Uruguay.

Vallis-Gratiae Hpe. mss. ; C. M. in Bol. Zeit. 1859, p. 247.

F. pilifera C.M. Syn. II, p. 35 p.p.

- Afr. : C. B. Sp.

Wrightii Sull. M. of U. St.p. 61 et Ic. M. p. 132, t. 84; Lesq. et Jum. Man. p. 295.

1.

Exs.: Sull, et Lesq Am. sept.: Texas.

Wullschlaegelii Ltz, Moost. p. 163.
I.

- Am. sept. : Jamaic.

Zollingeri C. M. in Bot. Zeit. 1854, p. 363; Bryol. jav. II, p. I3I.

1. Filic, - As. : Java (1).

(I) In Enumer. Kindberg. nomina nuda :

F. Baileyi C. M. brachyodonta $C . M$.

F. obtuso-acuminata $C, M$. 
FABRONIELLA Ltz. mss. (1 spec.).

Krausei Ltz. mss. ; C. M. in Linn. 1873, p. 442 (nom.).

- Am. merid. : Chile.

FAURIELLA (1) Besch. in Ann. sc. nat. 1893, XVIII, p. 363 (l spec).

lepidoziacea Besch. l. c.

2. Cortic. - As. : Japon.

Exs. : Faurie n. 24, 113, 199, 564.

FISSIDENS Hedw. Fund. M. II, p. 91 (424 spec.).

abbreviatus Milt, Fl. Vit, p. 385.

1. - Pac. : Ins. Raoul.

? acacioides Brid. Bryol. univ. II, p. 705; C. M. Syn. I, p. 71 et II, p. $535(2)$.

Hypnum acacioides $L . S p . p l . p .1588$.

Skitophyllum acacioides $L \dot{a}$ Pyl. in Desv. Journ. bot. $1813, p .45, t .35, f . \hat{\imath}$. - Am. merid. : Patagon.

acutifolius Mitt. M. Ind. or. $p, 137$.

Ster.

- As, : Assam super.

acutus Jaeg. Ad. II, p. 9.

F. pungens Sult. in Proced. Am. Acad. 1859, p. 276.

1. Rupic. - As. : Hong-Kong.

adelphinus Besch, in Ann. sc. nat. 1893, p. 344.

1. In graminos. - As. : Japon.

Exs. : Faurie n. 17, 181, 197.

adiantoides (L.) Hedro. M. frond. III, p. 62, t, 29 ; Brid. Bryol. univ. II,

p. 702; Bryol. eur. I (mon. p. 10), $\iota .105 ;$ C. M. Syn. I, p. 51 p.p.

el II, p. 529; W. P. Sch. Syn. II ed.p. 11 . .

Dicranum adiantoides Sw, M. Suec. p. 31 ; Drumm. M. bor, am. I ed. n. 110.

F. major Mitt. in Journ. of the Linn. Soc. XXI, p. 550.

F. taxifolius $\beta$ Wahlenb. Fl. Lapp. p. 332.

Hypnum adiantoides $L . S p . p l . p .1588$.

H. taxiforme palustre majus et erectum Dill. Hist. $M$, p. 264, t. 34, f. 3.

Skitophyllum adiantoides $l a$ Pyl. op cit, p. $55, t .36$.

1. vel 2. Terr. in turfos., ad rad, arbor. et mur. - Eur.: Reg. campestr. tota. As. : Japon., Hong-Kong. Af $r$. : Alger, Am. sepl. Terr. nov., New Brunswick, Anticosti, Gaspesia, Nov. Scotia. Ontario, ins. Vancouver, Washington, Oregon, Montana, Calif. reg. sept. et or. Pac. : Nov. Zeland., Tasman.

Exs. : Faurie P1. Jap. n. 62, 92.

Mac. Canad. M. n. 52.

Rab. Bryoth, eur. n. 257, b et c, 828 et b.

* var. brachyphyllus Kindb. in Mac. Cat, p. 37.

Ut typ. - Am. sept. : Ontario.

- var. immarginatus Lindb.

- Am. sept. : Canada, Idaho.

(1) A ce genre doivent probablement se rattacher les Heterooladium tentue ct - leucotrichum Mitt. du Japon, qui ne sauraient ètre maintenus dans le genre "Heterocladium tel qu'il est circonscrit dans le Bryologia europaea. "Besch. I. c. (2) " Planta dubia, forsan Drepanophyllum. » C.M. l. c. 
adiantoides $\left\{\begin{array}{l}\text { C. M. pp. - F. polyphyllus. } \\ \text { Mitt. (fid. I.impr }\end{array}\right.$

var, marginatus Brid, $-\mathrm{F}$, decipiens

var. rupestris Limpr, - F. decipiens.

var. Savatieri Besch. - F. Savatieri.

var, tener Mdo. - F. decipiens.

aeruginosus Hook. f. et Wils. Fl. of the N. Zeal. II, p. 62, t. 83, f. 5 et Handb, p, 408.

1.

- Pac. : Nov. Zeland. sept.

aggestus (Besch.) Par.

Conomitrium aggestum Besch. in Bull. Soc. bot. Fr. 1894, p. 79.

2? In agger. - As. : Tonkin.

alexandrinus $L t z . M$. Ehrenb. p. 17, t. 1 et 2.

F. cyprius (fid. Limpr.).

Syn.

- Afr, : Agypt. inf.

algarvicus Solms Laubach. Tent. bryol. geog. Algarv. p. 41 ; W. P. Sch. op. cit. p. 115.

F. insurvus var, algarvicus Husn. Fl. $N$, O.p. 54.

F. pusillus var, algarvicus Boul. Fl. de l'E., p. 529.

2. In argill. humid. - Eur. : Armoric., Normann., Pyren, or., Algarv. alomoides C. $M$. in Dusen $M$. Camer. $n .505$.

- Afr. : M. Cameroon.

amcenus C. M. in Bot. Zeit. p. 38 el Syn. I, p. 66; Mitl. M. austr. am. p. 589 .

Conomitrium amœenum ej, Syn. 11, p. 527.

2.

- Am. merid. : Venezuela.

androgynus $\mathrm{Br}$. in $\mathrm{Fl} .1846, p .134 ; \mathrm{C} . \mathrm{M}$. Syn. I, p. 57 el $I I, p .532$. -- Afr. : C. B. Sp.

angolensis Weho, et Duby in Mèm.... Genève, 1870, $t, 4, f .6$.

2. Arenic. - Afr.: Angola.

anguste-limbatus Mitt. op, cit, p. 6i)l.

Conomitrium anguste-limbatum Jaeg. Ad. II, p. 42.

1. Terr. - Am. merid. : Brasil.

angustifolius Sull. in Proced. Am. Acad. 1861, p. 275; Mitt. op. cit. p. 598 ,

1. Terr. - Am. sept. : Cuba. Am. merid. : Ins. Trinitat.

angustus Thw. et Mitt. in Journ. of the Linn. Soc. 1872, p. 324.

Ster.

anomalus Mont. in Ann. sc. nat. 184l, p. 267 et Syll. p. $3 ;$ C. M. Syn. I, p. 53 et $I I$, p. $529 ;$ Mitl. M. Ind. or. p. 137.

F. cryptotheca Bryol.jav. p. 7,t.6.

F, neckeroides Griff. Not. p. 426 et Ie. pl. asiat. $I I, t .83, f . I$. 2.

- As.: Sikkim, Khasia, M. Neilgherr., Ceylan, Java.

Antrophyi C. M. in Linn. $1869.70, p .31$.

Ster. Pilicic. - As. : Ceylan.

aporrocheilos C. M. in Linn. I871-73, p. 167.

Ster. $\quad-$ Am, merid. : Venezuela.

Arbogasti Ren, el Card. in Bull. Soc. roy. bot. Belg. 1893, II, p. 13. 2?

- Afr.: S. Maria de Madagasc. 
arboreus Broth. in Oefv.... 1890, p.

1. Cortic. - Pac.: Austral. (Queensland). arcuatus Besch. Fl. bryol. Nov. Caled. p. 202.

1. $\quad-$ Pac. : Nov. Caledon. (Ins. Pinor.).

Archeri F. v. Müll, in sched. ; Mitt, in Trans, and Proced of the roy. Soc. of Victoria, 1883, p. 93 (nom).

- Pac. : Austral.? Tasman.?

areolatus Griff. Not. p. 428 et 1c. pl. asiat. 11, p. 83, t. 2; Milt. op. cit. p. 138.

F. polypodioides var. Wils. in Keu Journ. bot. IX, p. 294. - As. : Sikkim, Khasia, Ava.

Arnoldi Ruthe in Hedwo. 1870, p. 77.

2. Ad rup. in alv. fluvior, - Eur. : Thuring., Bavar., os Elbae. asperisetus Lac. Sp. nov, M. Archip. Ind. p. 2, t. 1 B. 1. - As. : Celebes.

asplenioides Heduo. M. frond. III, p. 65, t. 28; Brid. Bryol. univ. II, p. 697 ; C. M. Syn. I, p. 69 et II, p. 528 ; Mill. M. austr. am. p. 591. Dicranum asplenioides Sw. Fl. Ind, occ. III, p. 1770.

F. turbinatus Tayl. in Lond. Journ. of bot. 1848, p. 90; C. M. Syn. I1, p. 532.

Hypnum asplenioides Sw. Prodi. p. 140.

Skitophyllum asplenioides la Pyi. op. cit. p. 47, t. 36, f. 8-9.

2. Rupic. et terr. - Afr.: Ins. Tristan d'Acunha. Am. sept. : Jamaïc. Am. merid. : And. Nov. Granat., Quitens. et Peruv.; ins. Juan Fernandez, Pac, : Nov. Zeland., Tasman.

asplenioides $\left\{\begin{array}{l}\text { Brid. p.p., Hsch. - F. Thunbergii. } \\ \text { Mitt. p.p. - F. flabellatus. }\end{array}\right.$

var. polyphyllus Wils. - F. polyphyllus.

var. serrulalus Wils. - F. serrulatus.

assimilis (Hpe.) Par.

Conomitrium assimile Hpe. Symb. 1877, p. 738.

2 ?

- Am. merid. : Brasil. austr. or.

Asterodontium (C. M.) Mitt. op. cit. p. 587.

Conomitrium Asterodontium C. M. Syn. II, p. 527.

2. Terr. - Am. merid. : Brasil.

atro-viridis Besch, in Ann. sc. nat. VII ser., II, p. 86.

Terr. - Afr. : Ins. Mayotte.

auriculatus C. M. in Linn. 1871-73, p. 166.

Ster.

- As. : Bengal. sept.

"var, aquatica ej. op. cit, p. 167.

Ad saxa irror. - As. : Cum typ.

australiensis Jaeg. Enum. Fiss. p. 24.

Conomitrium perpusillum C. M. et Hpe. in Linn. 1855-55, p. 214 et 1859-60, p. 645 .

F. tenellus H. f. et W. Fl. of the N. Zeal.? (fid. Hpe.).

2. In turfac. - Pac. : Austral, fel, Tasman.

austro-africanus $P a r$,

F. pseudo-rufescens Rehm. M. Afr. austr. n. 589.

Ster.

- Afr. : Orange.

axilliflorus Thwo et Mitt, in Journ. of the Linn. Soc. 1872, p. 325.

- As, : Ceylan. 
Balansaeanus Besch. Not. M. Parag. p. 260.

Syn. Ad puteos. - Am. merid.: Paraguay.

Exs.: Hal. Pl. Parag. n. 1241.

- var. limosus Besch. op. cit.p. 261. Ad terr. - Am. merid.: Paraguay. Exs. : Bal. Pl. Parag. n. 1245.

Bambergeri W. P. Sch, op. cit.p. 115.

2 (W. P. Sch.); polyg. (Limpr.). Ad terr, aren, micac. - Eur. : Tirol. merid. Am. sept. : Kansas, Ludovic.

Exs, : Rab. Bryoth, eur, n, 656.

Barbae montis C. M. in Bull. Soc, roy. bot. Belg. 1892, I, p. 152.

2. Ad lapid. rivul, - Am. sept, : Costa Rica.

basicarpus C. M. in Engler's Bot. Jahrb. p. et in Forchungsreise... p. 62 .

1. Ad terr. humid. - Afr. : Monrovia.

basilaris Hpe. et C. M. in Linn. 1853, p. 501.

2. $\quad$ - Pac. : Austral. or.

Beckettii Mitt. in Journ. of the Linn. Soc. 1872, p. 325.

Terr. - As. : Ceylan.

bengalensis (Hpe.) Par.

Conomitrium bengalense Hpe. in Jaeg. Ad. II, p. 47.

In Bambuset. - As. : Calcutta.

Berterii C. M. p.p. $-\left\{\begin{array}{l}\text { Conomitrium. } \\ \text { Conomitrium capense. }\end{array}\right.$

bicolor Thw. et Mitt. in Journ. of the Linn. Soc. 1872, p. 322.

Terr. - As. : Ceylan.

biformis Mitt. M. Ind. or. p. 141.

F. viridulus Wils. op, cit. p. 294.

2 ?

- As. : Ceylan.

bifrons W, P. Sch, mss, ; C. M. in Bot. Zeit. 1859, p. 198. 2 ? - Afr. : C. B. Sp.

Bloxami Wils, - F, exilis.

bogosicus C. M. in Nuov. Giorn. bot. ital. 1872, p. 10. 2.

$$
\text { - Afr. : Abyss. }
$$

Boiviniamıs Besch. Fl. bryol. Réunion, elc. p. 43. Ster, - Afr. : Comor. magn.

- var. longifolius Besch. . c.

- Afr.: Usambara, ins. Borbon.

Bonvaleti W. P. Sch. et Par. in Rab. Bryoth, eur. n, 945.

F. taxifolius var. Bonvaleti Besch. Cat. M. Alger. p. 7.

1. Ad terr, in dumet. - Eur.: Sardin. Afr. : Alger.

Borgenii Hpe, in Bot, Zeit. 1870, p. 36. 2. - Afr.: Natal.

Boryanus Besch, op, cit. p. 43. 2 ? Ster, - Afr.: Ins. Borbon.

Bourgaeanus Besch. Prodr, bryol. mexic. p. 26. 2 . 
brachypus Mitl. $M$. austr. am. p. 590 .

Conomitrium brachypus Jaeg. Ad. II, p. 44.

Filicic. - Am. merid. : Amazon.

Braunil Bryol. jav. I, p. I.

Conomitrium Braunii C. M. Syn. II, p. 527.

2. Terr. - As. : Java.

Breutelii W. P. Sch. mss. ; C. M. in Bot. Zeit. 1859 , p. 198.

2. - Afr. : C. B. Sp.

brevitolius Hook. f. et Wils. Fl. of the N. Zeal. II, p. 61, t.83,f. 4 et Handb. p. 408; Mitt. op. cit. p. 596.

2. $\quad-A f r$ : Austral. Am. merid.: (fid. Handb. !). Pac. : Nov. Zeland., Tasman.

- var. floribundus eor. Fl. Tasm. II, p. 167.

- Pac.: Tasman.

brevifrnns Mitt, in Philos. Trans. of the roy. Soc. 1879 (extr. vol.), p. 396. Ad rup. argill. - Afr. : Ins. Rodriguez.

brevipes Besch. in Journ. de bot. 189', p

1. Arbor. - Am, merid. : Paraguay.

Exs. : Bal. Pl. Parag. n. 3698.

Brotheri Par.

F. leptophyllus Broth. in Engler's Bot. Jahrb. 1894, p. 182.

2. Terr. - Afr: : Togo.

bryodictyon Besch. in Rev. biyol. 1891, p. 50.

2.

- Am. sept. : Guadalup.

bryoides (L.) Hedwo. M. frond. III, p. 67, t. 29 (excl. f. 10): Brid. Bryol. univ. II, p. 646 : Bryol. eur. I (mon. p. 8), t. $101 ;$ C. M. Syn. I, p. 58 et $I I, p .529$ (excl. syn. F. exilis); W. P. Sch. Syn. II ed. p. 111.

Dicranum bryoides Roth Tent. fl. germ. III, p. 181; Drumm. M. bor. am. I ed. n. 113 et II ed n. 39 et 40.

D. viridulum Sw. M. Sueo. pp. 31 et 84, t. 2, f. 3.

F. viridulus Wahlenb. Fl. Carpath. p. 342 et Fl. Lapp. p. 331 (1).

Fucina bryoides Schrank Baiers Fl. II, p. 451.

Hypnum bryoides L. Sp. pl. p. 1588.

$\mathrm{H}$. taxiforme exiguum vecsus extremitatem capsuligerum Dill. Hist. $M$. p. $262, t$. $34, f-I$.

Schistophyllum viridulum Lindb. M. Scand. p. 13.

Skitophyllum bryoides la Pyl. op, cit. $p, 42, t .35$.

1. Terr. in loc. nmbros, - Eur. : Reg. campestr. As. : Jenissei med. et sup., Obi, Himalaya occ., Khasia, Bengal, Caucas. centr. Afr.: Ins. Canar., Madeir., M. Cameroon. Am. sepl. : Ontario, M. Rupestr., Columb. brit,, ins. Vancouver, Idaho, reg. or. Pac.: Nov. Zeland.

Exs. : Mac. Canad. M. n. 49.

Mand. Ml. Mad. n. 5 bis.

Rab. Bryoth. eur, n. 767 et b, 827.

« var. caespitans W. P. Sch, l. c.

F. Curnowii Mitl, in Journ, of the Linn. Soc. 1885, p. 554.

Ad rupes cataract. - Eur. : Cambrovall. Afr. : Teneriffa. Am. sepl.:

New Hampshice. Pac. : Austral. (Nov. Valesia).

Exs, : Rab. Bryoth. eur. n. 826.

(1) Fid, C. M. ; species propria secundum nonnull, auctor, recentior. 
var, exilis Roehl. $-\mathrm{F}$. exilis.

var. Hedwigii Limpr. - F. exilis.

" var. impar Mitt, in op. et $l$. cc.

- Eur. : Hibern. As. : Sibir. Am. sept. : Canada.

var. inconstans Ruthe. - F, inconstans ,

var. intermedius Ruthe. - F. exilis.

var, rivularis $\mathrm{Spr}$, - F rivularis.

var, Hffm. - F, exilis (1).

bryoides $\left\{\begin{array}{l}\text { C. M. p.p. }- \text { F. exilis. } \\ \text { H. f. et W - F. minutulus. } \\ \text { Roehl. }- \text { F. osmundioides. }\end{array}\right.$

Büttneri Broth, in Engler's Bot. Jahrb. 1894, p. 181.

1. Terr. - Afr.: Togo.

caespitosus Hpe. in Jaeg. Ad. II, p. 39 (nom.).

- Am. sept. : Calif.

calcicolus C. M. in Linn. 1876, p. 290.

Saxic. - Afr. : Somali.

caldensis Angstr. Prim. lin. p. 47.

Ster.

- Am. merid, : Brasil, austr.

calodictyon Broth. in Oefv.... 1890, p.

2. Terr. - Pac. : Austral. (Queesnland).

caloglottis C. $M$. in Fl. 1888, p. 407.

Ster. In gramin, - Afr. : Kilima N'Djaro.

Cameruniae $C . M$. in Dusen $M$. Camer. n. 123.

- Afr. : M. Cameroon.

campyloneuros C. $M$. in Trans. of the N. Zeal. Inst. 1892, p, 295.

¿? Ter'. - Pac.: Nov. Zeland.

Campylopus Mont. in Ann. sc. nat. 1845, p. 116 et Syll. p. 4; C.M.

Syn. I, p. 66 et $1 I$, p. 52১; Mitt. op. cit. p. 592 .

1. Terr. - Am. merid. : Chil. ausir.

capitatus Hook, f. et Wils. in Lond. Journ. of bot. 1844, p. 547; C. M. Syn. I, p. et II, p. 533 .

1.

- Pac.: Nov. Zeland.

caripensis (Hpe. et C. M.) Par.

Conomitrium caripense Hpe. el. C. M. in Linn. 1874, p. 574. 1.

- Am. merid. : And. Venezuel.

cellulosus Mitt. in Journ, of the Linn. Soc. 1886, p. 319.

Ster.

- Afr. : M. Usagara.

ceylonensis Dz, et $M k$. in Ann. sc. nat. 1844, p. 304; C. M. Syn. I, p. 59 ,

et II, p. 532 ; Mitl. M. Ind. or. p. 141 ; Bryol. jav. I, p. 2, Ł. 3.

F. incurvus var. Wils. op. cit. p. 294.

2 .

- As. : Himalaya, M. Neilgherr., Ceylan.

chioneuros C. $M$, in Linn. 1871-93, p. 167.

Ster.

- Afr.: Ins. S. Helena.

(1) In M. As. bor. 1890, II, p. 14, cl. Lindberg enumerat variet. : $\operatorname{impar}(F, i m-$ par Mitt. ?), subimpar, varium et intermedium, a numero et situ androěciorum et at.theridiarum constitutas. 
chrysopoma C. M. in Journ. of the Linn. Soc. 1877, p. 227 (nom.).

Terr. - Am. sept. : Costa Rica.

circinalis Mitt. op. cit, p. 138.

Ster.

- As.: Ava.

circinans W. P. Sch. in sched. ; C. M. in Bot. Zeit. 1864, p. 340; Mitt. M. austr. am. p. 586.

2.

- Am. sept. : Mexic.

clavipes Sull. in Proced. Am. Acad.... 1861, p. 57 ;.

Ad rup, humid. - Am. sept. : Cuba.

Closteri Aust. in Bull. Torr, bot. Club, V, p. 21; Sull. Ic. M. Suppl. p. 44, t. 2y; Lesq. et Jam. Man. p. 81.

1. Terr. - Am. sept. : New Jersey.

collinus Mitt. - F. decipiens.

comorensis C. M. in Linn. 1877 p. 233.

Ster. Terr. - Afr. : Ins. Mayotte, Nossi-Be.

«var, acuminatus Besch. Fl. bryol. Réunion, elc. p. 42.

- Afr.: Ins. Mayotte, Nossi-Comba.

corneus Hpe, in Jaeg. 1I, p. 39 .

- As. : Birmania.

corticola W. P. Sch, in Besch, Fl. bryol, Antill. fr. p. 17; Besch, in Rev. bryol. 1891, p. 52.

1. Ad arbor. - Am. sept. : Guadalup., Martinic.

costa ricensis Besch, in Bull. hb. Boissier, 1894, p. 391).

2. In humid. - Am. sept. : Costa-Rica.

crassicollis Besch. in Rev. bryol. 1891, pp. 50 et 51.

1. Ad arbor. - Am. sept.: Guadalup, Martinic.

crassinervis Lac. Sp. nov. M. Archip. Ind. p. 3, t. 2 A.

2. Terr. - As : Borneo, ins. Banca, Java.

crassinervis Thw, et Mitt. - F. Mittenii.

crassipes Wils, in Bryol, eur. I (mon. p. ), t. 100; W. P. Sch. Syn. II ed. p. 113.

F. fontanus W. P. Sch, in Spr. M. Pyr. n. 316.

F. incurvus $\gamma$ crassipes $W . P$. Sch. Syn. I ed. p. 104.

F. incurvus var, fontanus C. M. Syn. I, p. 59 et II, p. 530; Bryol. Brn. (mon, p. 6), t. 99, f. $\beta$.

F, viridulus $\beta$ fontanus Braithw. Brit. Moosfl. p. 71 (p.p. fid. Limpr.).

F. viridulus var. major Wils. Bryol. brit., $p .303, t .53 \gamma$.

Schistophyllum crassipes Lindb. M. Seand. p. 13.

1. Ad rup, irror. - Eur. : Fere tota. Afr. : Alger. Am. sept.: Absque loco (Jaeg. Enum. Fissid. p. 77).

Exs, : Rab. Bryoth. eur, n, 311, 469.

* var. curtus Ruthe mss.; Limpr. Deutschl. Laubm. p. 44 I. -- Eur.: Saxon.

« var. rufipes W. P. Sch. Syn II ed. p. 113.

F. hydrophilus Jaeg. Enum. Fissid.p. 20 et Ad. II, p. 27.

F. incurvus $\delta$ fontanus W. P. Seh. Syn. I ed.p. 105.

F. Mildeanus ej. in Rab. Bryoth. ewr. n. 470.

F. rufipes Jaeg. op. et $\mathrm{ll}$. oc. 
Ad rupes submers. - Eur. : Jurass, gall., Helvet., Bavar., Tirol, Austr. super., Salisb.

Exs. : Rab. Bryoth, eur. n. 311 b, 470.

" var. Philiberti Besch. Cal. M. Alger. p. 7.

- Afr.: Alger.

crassipes Lechl, - F. rigidulus.

crenulatus Mitl. M. Ind. or. p. 140.

i.

- As. : Nepal.

crispus Mont, in d'Orbigny Voy. VIII, Crypt. p. 97 ; in Ann. des sc. nat. 1837, p. 37 et Syll. p. 4; C. M. Syn. I, p. 61 et II, p. 532; Mitt. M. austr, am p. 600 .

Ad terr, arenos. - Am, merid. : Corrientes.

cristatus Wils, in Kew Journ. bot. IX, p. 294 ; Mitt. M. Ind. or. p. 137.

F. decipiens (fid. Limpr.).

2.

- As.: Khasia, Java.

? cryptarum C. M. in Linn. 1875, p. 352.

2 ? Ster. Loc. humid. - Afr.: Bongo.

cryplotheca $\mathrm{Dz}$. et Mk. - F. anomalus.

Curnowii Mitt. - F. bryoides var. caespitans.

curvatus Hsch. in Linn. 1841, p. 148; C. M. Syn. I, p. 59 et II, p. 532.

2 ? Muric. - Afr.: C. B. Sp.

curvifolius Mitt. in M. herb. Hook. 1860, p. 55, ı. 6, f. 14.

2 ? Terr. - Afr. : Niger.

cuspidatulus Sull. - F. elegans.

cuspidatus C. M. in Linn. 1843, p. 558 ; Syn. I, p. 48 et II, p. 530.

2. Terr. $-A f r .:$ C. B. Sp.

cylindraceus Mitt. M. austr. am. p. 590.

Conomitrium cylindraceum Jaeg. Ad. II, p. 144.

- Am. merill. : M. Chimborazo.

cyprius Jur. in Unger et Ky, « die Ins. Cypern » p. 167.

F. alexandrinus Ltz.

Polyg. Terr. calcar. - Eur. : Etrur., ins. Melit. As. : Ins. Cypr.

daltoniaefolius C. M. M. Pol. p. 59.

Ster.

- Pac. : Ins. Samoa.

Danckelmanni C. $M$. in $\mathrm{Fl}$. $1886, p .505$.

Ster, Arbor. - Afr.: Sinus Guineens.

Darnty1 W. P. Sch. in Besch. Fl. bryol. Réunion, etc. p. 46.

2. Ad terr. humid. - Afr. : Ins. Francise.

dasyphus Welvo. et Duby in Mém... Genève, 1870, t. 4, f. 2.

2. In argill. reg, mont. $-A f r$. : Angols.

dealbatus Hook. f. et Wils, Fl. of the N. Zeal. II, p. 63, t. 84, f. 2 et Handb. p. 407.

2. Ad rup. madid, - Pac. : Nov. Zeland, Tasman.

debilis Schwaegr. - Conomitrium Julianum.

Wils. - F. diversifolius. 
decipiens de Not. Epil. p. 479; Sulliv. Ic. M. Suppl. p. 46, t. 31; W. P. Sch. Syn. II ed.p. 118 (1).

F. adiantoides Mitt. in Journ. of the Linn. Soc. 1885, p. 550 (fid. Limpr.).

F. adiantoides $\beta$ marginatus Brid. Bryol, univ. II, p. 704 (fid. Jur.).

F. adiantoides var. rupestris Limpr. Kryptfl. von Schles. I, p. 187.

F. adiantoides var. tener Mdo. Laubm. Oberfir. p. 110.

F. collinus Mitt. in Journ. of the Linn. Soc. 1885, p. 550.

F. dubius P. B. Prodr. p. 57; Brid. Sp. M. I, p. 169.

F. rupestris Wils. M. brit. n. 311 .

Schistophyllum decipiens Lindb. M. Scand. p. 13.

Skitophyllum. adiantoides $\beta$ marginatus $P$. B. op. cit. p. $55, t .36, f .15$.

2. Ad terr. et rup. præpr. calcar. - Eur. : Fere tota. As, : Saghalien, Caucas. Am. sept. : Gaspes., Ontario, lac. Super., reg. or. et merid.

Exs. : Drumm. M. bor. am. II ed. n, 41.

Mac. Canad. M. n. 400.

Rab. Bryoth. eur. n. 825.

decursivus C. $M$. in Linn. 1878-79, p. 245.

Ster. Rupic. in silv. - Am. merid. : Argentin. Cordob.

delicatulus Angstr. in Oefv.... 1872, n. 4, p. 20 (2).

Ster. Vales.).

densiretis Sull. in Proced. Am. Acad .. 1861 ; Mitt. M. austr. am. p. 595.

Terr. - Am. sept. : Cuba.

denticulatus $\left\{\begin{array}{l}\text { Mont. - F. Wilsoni. } \\ \text { Willd_- Plagiothecium. }\end{array}\right.$

desertorum (C. M.) Par.

Conomitrium desertorum C. M. in Linn. 1875, p. 368.

1. Paludic. - Afr. : Djour.

dicarpos Brid. - F. osmundioides.

Dietrichix C. M. in Linn. 1874, p. 146.

2.

- Pac. : Austral. or.

\section{Dillenii $\left\{\begin{array}{l}\text { C. M. - Conomitrium. } \\ \text { Mitt. - Conomitrium Mülleri. }\end{array}\right.$}

dimorphus C. M. Syn. II, p. 533 ; Mitt. op. cit. p. 596 .

2. Saxic. - Am. merid.: Brasil.

diplodus Mitt. op. cit. p. 589.

Conomitrium diplodus Jaeg. Ad. II, p. 44

2? Arbor. - Am. merid. : And. Quitens.

discolor Wils. in Kero Journ. bot IX, p. 294; Mitt. M. Ind. or. p. 139.

$2 . \quad-A s$ : : Ceylan.

dissitifolius Sull. in Proced. Am. Acad.... 1861, p. 275 ; Milt. M. austr. am. p. 600 (3).

2. Rupic. - Am. merid.: Cuba:

(1) Cf. Philibert in Rev. bryol. 1883, p. 65.

(2) Bis indicat. in Jaeg. Adumbr. II, p. 4, n. 20 et p. 7, n. 41.

F. gracilescens Àngstr. (op. et cit. n. 42) non reperitur in Oefv.

(3) "La Pylaie's fig. of his Skitoph. longifolium gives a fair idea of F. dissitifolius. w Mitt. 1, c. 
distichellus Besch, in Journ. de bot. 1891, p.

2.

- Am. merid. : Monte Video.

diversifolius Mitt. M. Ind. or.p. 140.

F. debilis Wils. in Kew Journ. bot. IX, p. 140.

2 ?

- As. : Himalaya, Bhotan.

divisus Hpe. in Ann, sc, nat. V ser., III, p. 332.

- Am, merid, : And. Nov, Granat.

domincensis Brid, - Neckera duplicata.

dongensis Besch. in Bull. Soc. bot. Fr. 1894, p. 79.

1. Ad limos. in spelunc. - As. : Tonkin.

Donnellii Aust. in Coult. Bot. Gas. IV, p. 151 ; Lesq. et Jam. Man. p. 85.

2. Ad rad. Cupress, in palud, - Am. sept. : Florida.

dubius P. B. - F. decipiens.

Dubyanus Jaeg. Ad. II, p. 23.

F. macrophyllus Duby in Mém.... Genève $1870, t .3, f .3$.

1. Ad terr. umbros. - Afr. : Angola.

Duseni C. M. in Dusen. M. Camer. $n, 211$. - Afr. : M. Cameroon.

elamellosus C. M. et Hpe, in Linn. 1856, p. 214.

2.

- Pac. : Austral.

elegans Brid. Bryol. univ. II, p. 691 ; C. M. Syn. II, p. 534; Mitt. M. austr. am. p. 595.

F. cuspidatulus Sull. in Proced. Am. Acad... 1861.

Skitophyllum elegans la Pyl. op. cit. p. 43, t. f. 18.

l (Mitt.) 2 ? (C. M.). $\quad-A m$. sept.: Cuba, Jamaïc., Haïti, ins. Tabago. Am. merid. : Amazon, And. Peruv.

ellipticus Besch. Fl. bryol. Réunion, etc. p. 43.

Ster.

elongatus Mitı. M. Ind, or. p. 139.

- Afr. : Ins. Borbon.

F. n. 10 Griff. Not.p. 431.

Ster. Cortic. - As.: Khasia.

erosulus (C.M.) Par.

Conomitrium erosulum C. M. in Linn, 1875, p. 367.

2. Saxic. - Afr, : Niam-Niam.

Eustichium Rehm. - Eustichium longiroste.

evadiinervis $P$ ar.

Conomitrium subpalmatum Hpe, Symb, 1877, p. 737.

2.

- Am. merid. : Brasil. austr, or.

exasperatus Ren. et Card, in Bull, soc, roy. bot, Belg. 1892, II, p. 102.

1. Arbor. - Afr.: Madagascar.

excavatus Besch. in Rev. bryol. 1891, pp. 50 et 52.

2.

- Am. sept. : Guadalup.

exiguns Sull. in Mem. of the Am. Acad... I846, III, p. 60, t. 2; M. Allegh. p. 44 ; Ic. M. p. 36, , .23 et M. of U. St. pp. 24 et 103 ;

C. M. Syn. 1, p. 64 el II, p. 531 ; Lesq. et Jam. Man. p. 84.

F. incuivus var, exiguus Aust. M. Appal, n. 103. 
2. Ad saxa irror. - Am. sept. : Ontario, Columb. brit., reg. centr., or. et merid., Colorado,

Exs. : Sull. M. Allegh, n. 192.

Sull. et Lesq. M. bor. am. II ed. n. 100.

exilis Hedro. Sp. M. I, 152, t. 38: Brid, Bryol. univ. 11, p. 683; W. P.

Sch. Syn. II ed. p. 111 .

Bryum viridulum Dicks. Fasc. I Pl. crypt. p. 3, t. 1. f. 5.

Dicranum bryoides Sw. Act. Holm. 1795, p. 240 (non M. Suec.).

Dicranum bryoides var. minus Turn. Muscol. Hib, p. 57.

D. viridulum Sm. Fl. brit. $I I I$, p. 1280.

Fi. Bloxami Wils. in Lond. Journ. bot. IV, 1845, t. 9 A; Bryol. eus. I (mon.p. ), $t .100 ; C . M$. Syn. I, p. 66 et II, p. 531.

F. bryoides C. M. Syn. I, p. 58 p.p.

F. bryoides var. Hoffm. Deutsch. Fl. II in add.

F. bryoides var. exilis Roehl. Deutsch. Fl. III, p. '76.

F. bryoides var. gymnandrus Ruthe.

F, bryoides var. Hedwigii Limpr. Deutschl. Laubm. p. 429 (1).

F. bryoides var. intermedius Ruthe in Rab. Bryoth. eur, n. 1160.

Grimmia viridula Roth Fl. Germ. III, p. 141.

Hypnum bryoides var. Poll. Fl. Pal. III, p. 123.

Skitophyllum exile $l a ~ P y l$. op. cit. p. 34, t. 38, $f$. 1 .

Weisia viridula Roth. Fl. Germ, $I$, p. 456 ?

1. Ad terr. umbros. et sax. aren. humid, - Eur. : Reg. campestr. zon. interm. et sept. : Spitzberg, Rossia orient.

Exs. : Rab. Bryoth, eur. n. 356, 1107.

" f. integra Limpr. Laubm. Deutschl. 1, p. 448.

F. Lylei Wils. in Braithw. Brit. Moosfl. p. 68.

F. pusillus var, integra ej. Bryol. brit. p. 304 .

F. sepincola Mitt, in Journ. of the Linn. Soc. 1885, p. 555.

- Eur. : Anglia.

falcatulus Ren. el Card. in Bot. Gaz. 1894, p. 237, t. XXI, f. B.

Ster. Lignic. - Am. sept. : Ludovic.

falcatus Lindb. in Angstr. Prim. lin. p. 49.

Ster.

- Am. merid. : Brasil. austr. or.

falcatus Wils. - F. silvaticus.

falcifolius Schwaegr. - Drepanophyllum fulvum.

faniensis (Besch.) Par.

Conomitrium faniense Besch. in Bull. Soc. bot. Fr. 1894, p. 78.

1. - As.: Tonkin.

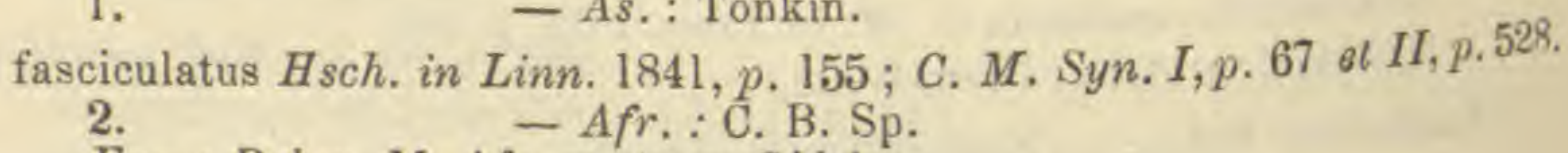

Exs. : Rehm. M. Afr. austr. n. $24 \mathrm{~L}$ b.

Fendleri C. M. in Linn. 1878-79, p. 465.

2. $\quad-A m$. merid.: Venezuela.

ferrugineus C. M. in Bot, Zeit. 1864, p.

Ster. $\quad-A f r$, : Madagascar.

filicinus Bryol, jav. - F. nobilis.

firmiusculus Besch, in Rev. bryol. 1891, pp. 50 et 53.

1. Terr. - Am. sept. : Guadalup.

firmus Mitt. M. Ind. or. p. 139.

2 ?

- As.: Ceylan.

(1) Cf. Limpr. 1. c. 
firmus Lindb. - F. Henriquezi.

fissicaulis C. M. M. Pol. p. 59 .

Ster.

- Pac. : Ins. Fidji.

flabellatus Hsch. Fl. Brasil. I, p. 91, Ł. 2, f. 2; C. M. Syn, 1, p. 62 el II, p. 534 .

F, asplenioides Mitt, M. austr ${ }^{2}$, am, p. 591 p.p.

2. Terr. - Afr. : Ins, Canar., Madeir., Azor. (tid. Mitt.). Am. merid. : Brasil.

flabellulum Thw, et Mitt. in Journ. of the Linn. Soc. 1872, p. 324.

- As, : Ceylan.

flaccidus Mitl. in M. hb. Hook. 1860, p. 56, t. 6, f. I8.

2 ? Ad rup, argill. - Afr. : Niger, ins, Rodriguez.

flaccidus C. M. - F. irawadensis.

flagellaris Lindb. - Leucodon.

flavifrons Besch. in Rev, bryol. 1891, p.p. 50 el 54.

2? Ster. Terr. - Am. sepl. : Guadalup.

flavinervis Mitt. M, austr, am. p. 592.

1 ? Cortic, et lignic. - Am. merid. : Amazon., Nov. Granat.

flavo-limbatus Besch. Fl. bryol. Réunion, etc. p. 44.

2. Ad rup. humid. - Afr. : Ins. Borbon.

flexifrons Besch. in Rev. bryol. 1891, pp. 50 et 51 .

2. Terr. - Am. sept. : Guadalup.

flexinervis Milt, op. cit. p. 588.

Conpmitrium Wrightii Jaeg. ad. II, p. 47.

F. rufulus Sull. in Proced, Am. Acad.... 1861.

F. Wrightii Jaeg. Enum, Fiss, $p, 12$.

1? Cortic, lignic. et terr. - Am. merid.: Orinoc, Amazon., Nov. Granat., And. Peruv.

floridanus Lesq. et Jam, Man. p. 83.

1. $\quad-A m$. sept. : Florida.

fontanus W. P.Sch. - F. crassipes.

fossicolus C. M, in Linn. 1880-83, p. 354.

fratris $P$ ar.

- Am. merid. : Argentin. Buen. Ayres.

F. papillosus Lindb. in Angstr. Prim. lin. p. 48.

Ster,

- Am, merid. : Brasil. austr. or.

fusco-viridis Thu. et Mitt. in Journ. of the Linn. Soc. 1872, p. 323.

Cortic. - As. : Ceylan.

Garberi Lesq. et.Jam, in Proced. Am. Acad. XIV, p. 37 el Man. p. 86.

Syn. ? vel 2 ? Cortic. - Am. sept. : Florida, Ludovic.

Gardneri Mitt. op, cil. p. 593.

Ster.

Geheebii C. M. in Linn. 1878-79, p. 242.

- Am. merid. : Brasil.

2.

- Am. merid. : Utuguay. geminiflorus $D$ z. et $M k$. in Pl. Jungh. p. $316 ;$ Biyol, jav, 1, p. 10, t. 9.
2.

- As. : Borneo, Java, Sumatra.

genunervis C. M. Syn. 1, p. 70 el II, p. 535 ; Mitt op. cit. p. 592.

Ster.

- Am. merid.: Venezuela. 
Gladiolus Mitt, in M. hb. Hooker, 1860, p. 51, l. 6, f. 16. 2 ? - Afr. : Intertrop.

glaucescens Hsch. in Linn. 1841, p. 154 ; C. M. Syn. I, p. $5 \mathrm{I}$ et II. p. 528.

F. mucronatus W. P. Seh. (fid. Hpe).

2. - Afr. : C. B. Sp.

Exs.: Rehm. M. Afr. austr. n. 283.

" var, crispus C, M. in Rehm. l. c. n. 286.

- Afr.: Ibid.

var, crispulus Rehm. - F, lanceolatus.

" var. mahorensis Besch. in Ann. sc, nat. VII ser, , II, p. 86. - Afr.: Ins. Mayotte.

"var, minor C. M, in Rehm. l. c. n. 284 . - Afr.: C. B. Sp. ? (Rondebosch).

var. natalensis Rehm, - F. natalensis.

glaucifrons Besch. in Journ. de Bol. 1891, p.

2. Terr. - Am. merid. : Paraguay.

Exs. : Bal, n. 3697.

glaucissimus Welw, et Duby in Mém.... Gerìve, 1870, t. 3, f.4.

2. Speluncic. - Afr. : Angola.

« var, minor eor, l. $c$.

$$
\text { - Afr.: Ibid. }
$$

glaucopteris C. M. in Dusen M. Camer. n. 99.

Glaziovii (Hpe.) Pas.

$$
\text { - Afr.: M. Cameroon. }
$$

Conomitrium Glaziovii Hpe.Symb, 1874, p. 526.

1. - Am. merid. : Brasil, austr. or,

glossophyllus C. M. in Linn. 1878-79, p. 236.

2. $\quad-A m$. merid, : Argentin, subtropic.

« var. brevifolius C. M. l. c. p. 237.

Ster. $\quad-$ Am. merid. : Argentin. Cordob.

gracilescens Ängstr. - (f. F. delicatulus (in ailn.). gracilis (Hpe.) Par.

Conomitrium gracile Hpe, mss, ; C, M. in Bot. Zeit. 1859, p. 197.

2. - Afi: : C. B. Sp.

gracilis Brid. $-\mathrm{F}$. incurvus.

grandifrons Bril. Mant. M. p. 191 et Bryol. univ. 11, p. 701 ; Bryol. eur. (mon.p. I1), t. 106; C. M. Syn. I, p. 46 et II, p. 528; W. P.
Sch. Syn. II ed. p. 121 .

H. palmiforme Ram.

Skitophyllum congestum la Pyl. op. cit. p. 57, t. 39, f. 16. 2. (1) Ad rup, calcar, irror. vel submers, - Eur.: Gall. occ. et centr. vall. Rhen., Pyren. As. : Tibet occ. Afr, : Alger. Am. sept. : Nisgara, Alberta, M. Rupestr., New York, Ohio, Illinois, Missouri, Idaho, Oregon, Nevada, Calif.

Exs, : Mac. Canad, M. n. 53.

Rab, Bryoth. eur, n. 63,946 .

Sull, et Lesq. M. bor, am. II ed. n. 11 l.

(1) Cf. Bechin in Rev. bryol. 1884, p. 30 (descript. of) et Limpr. Laulm. Deutschl, I, p. 456 (descript. fruct.). 
grandifrons Wils, - F. subgrandifrons.

var. strictus Besch. - F. insignis.

granulatus (Geh. et Hpe.) Par.

Conomitrium granulatum Geh, et Hpe. in Jaeg. Ad. II, p. 762.

- Am. merid. : Brasil. austr, or.

grossiretis C. M. in Linn. 1875, p. 356.

Ster, Loc, humid. - Afr. : Monbouttou.

guadalupensis W.P. Sch. in Besch. Fl. bryol. Antıll. fr. p. 19 ; Besch. in Rev. bryol. 1891, p. 54.

2. Ad saxa in riv. - Am. sept. : Guadalup.

guarapensis Besch, in Rev. bryol. 1885, p. 17 et in Journ. de Bot. $1891, p$.

F. stenocarpus C. M. in Rev. bryol. 1887, p. 57.

Terr. - Am, merid. : Paraguay.

Exs, : Bal, Pl. Parag. n. 3699.

Gueinzii C. M. in Linn. 1871-73, p. 168.

Syn.

- Afr. : C. B. Sp.

guianensis Mont, in Ann. sc. nat. 1840, p. 340 et Syll. p. 5; C, M.

Syn. II, p. 534; Mitt. M. austr. am. p. 587.

2? Cortic. - Am. merid.: Guian. gall.

gumangensis (C. M.) Par.

Conomitrium gumangense C. M. in Linn. 1875, p. 366 .

2. Ad Lycopod. - Af. : Niam-Niam.

gymnandrus Buze in M. Neerl. n. 77 et Ann. Soc. bot. Neerl.; W. P. Sch. op. cit. p. 114.

F. bryoides var. gymnandrus Ruthe in Hedwig. 1870, p. 178.

1. Ad rivul, - Eur. : Neerland, vall. Rhen., Helvet., Tirol, Carinth., Stir., Austr. inf., Siles.

Exs. : Rab. Bryoth, eur, n. 1106. Hallii Aust. in Coult. Bot. Gaz. II, p. 67; Lesq. et Jam. Man, p. 85 .
2. - Am. sept. : Texas.

hamatus Hpe. in Jaeg. Ad. II, p. 40 (nom.). - As. : M. Java.

Hasskarlii Jaeg. op. cit. p. 5 .

F. pachyloma Lac. Sp. nov, M. Arehip, ind, p. 3, t, I D.

2. Lignic.? - As. : M. Java.

Hedroigii C. M. - Conomitrium.

helenicus Mitt. in Melliss's S. Helena, p. 366, t. 56 a, fig. 1, 2, 3 . 1.

helictocanlos C. M. in Bot. Zeit. 1864, p. 341. - Afr. : Ins. S. Helena.

F. Schimperi W. P. Sch, in W. Sch. M. Abyssin.

1. Rupic. - Afr, : Alp. Abyssin.

hemiloma Besch, in Rev, bryol. 1891, pp. 50 et 52. 1.

- Am. sept.; Guadalup.

- var atro-virens Besch. l, c.

- Am. sept. : lbid. 
Henriquezi Par.

F. firmus Lindb. in Bol. da Soc. Broter. 1889, p. $($ nom.)

hians (Hpe.) Par.

- Eur. : Lusitan. (Coimbre).

Conomitrium hians Hpe. mss.; C. M. in Forehungsreise... p. 62 (nom). - Afr. : Lagos.

Hildebrandti C. M. in Linn. 1876, p. 291.

Ster. - Afr. : Somali.

Holleanus Bryol. jav. I, p. 4. $t .4$. 1 et 2 .

$$
\text { - As.: Java. }
$$

holomitrius Spr. in Lond, Journ. of bot. 1880, p. 358 et in Rev. bryol. 1881, p. 53 .

F. pusillas (fid. Limpr.).

1. Terr. aren. - Eur, : Pyren. centr.

Holstii Brolh. in Engler's Bol. Jahrb. 1894, p. 181.

2. Terr. - Afr. : Usambara.

horizonticarpus C. $M$. in $\mathrm{Fl} .1886$, p. 504 .

2.

- Afr.: Kuilu.

Hornschuchii Mont. in Ann. sc. nat. XIV; in Lond. Journ. of bot, 1845, p. 196 et Syll. p. 4 ; C. M. Syn. I, p. 54 et II, p. $532 ;$ Mitt. M. austr. am. p. 593.

F. serrulatus $\mathrm{Hsch}$. Fl. Brasil. I, p. 91, t. 2.

1 .

- Am. merid, : Guian., Para, Brasil, austr., Paraguay.

hyalinus Hooh. f. et Wils. in Lond. Journ. of bot. III, p. 89, l. 2; Sull. M. of U. St. p. 24 et Ic. M. p. 34, t. 31 ; C. M. Syn. I, p. 47; Lesq.et Jam. Man. p. 84.

Conomitrium hyalinum C. M. Syn. II, p. 525.

2. Ad terr, et rup. humid, - Am. sept. : Perrar. : Ohio, Pensilv.

Exs, : Sull, M. Allegh, n. 18 ?.

hydrophilus Jaeg. - F. crassipes var. rufipes.

Hydropogon Spr. - Conomitrium.

Hymenodon Besch, in Ann. sc. nat. VII, p. 85.

2. Lignic. - Afr.: Ins. Mayotte.

hyophilus Mitt, in Trans. and Proced. of the roy. Soc. of Viclorit, 1883 , p. 92.

1.

- Pac. : Austral. or.

imbricalus Desv. - Bryoxiphium norvegicum.

immersus $\left\{\begin{array}{l}\text { Lindb. - Leucodon. } \\ \text { Mitt. - Conomitrium. }\end{array}\right.$

impar Mitt. - F. bryoides var. impar.

inaequalis Mitt, op. cit. $p, 589$.

Conomitrium inaequale Jaeg. $A d . I I, p .40$.

1 ?

inclinatulus (C. M.) Par.

Conomitrium inclinatulum $C . M$. in $F l .1886, p$. 503.

1. - Afr : old Calabar.

inconspicuus Mitt. M. Sam. p. 185.

1. Filicic, - Pac.: Ins. Samoa. 
inconstans W.P. Sch. Syn. II ed.p. 114.

F. bryoides var. inconstans Ruthe in Limpr. Laubm. Deutschl. I, p. 430.

F. incurvus var, inconstans Husn, Muscol. gall. p. 50.

F. synoicus Sull. M. of U. St. p. 103.

1. Terr. - Eur.: Anglia, Boruss. or., Tirol. Am. sept.: Texas.

incrassatus Sull. in Proced. Am. Acad.... 1859, p. 276.

2. Rupic. - As, : Hong Kong, Macao.

incurvis (Web. et Mohr) Schwaegr. Suppl. I, II, p. 5 et I, t. 49; Bryol. eur. I (mon. p. 6), t. 99; C. M. Syn. I, p. 58 el II, p. 529; W. P. Sch. op. cit.p. 112.

Dicranum bryoides $\beta$ Hook. et Tayl. Muscol, brit.p. 49.

D. incurvum $W$. et $M$. Bot. Taschb, p. 162.

F. gracilis Brid, Bryol, univ, II, p. 700.

F. sardous de Not. Epil. p. 486.

F, viridulus var. Wils. Bivyol. brit. p. 303, t. $53 \mathrm{\varepsilon}$.

Skitophyllum gracile la Pyl. op. oit. p. 37, t. 36 .

Sk. incurvum ej. op. cit. p. 37, $t .35, f .2$,

1. Ad terr. argill. - Eur. : Fere tota; Spitzberg. As. : Mesopot.,

Caucas, oce. Afr. : Alger. Am. sept.: Groenland, Ontario, ins.

Vancouver, reg. or, centr. et merid. Pac.: Nov. Zeland., Tasman.

Exs. : Mac, Canad. M. n. 50 p.p.

Rab, Bryoth, eur. n. 310 et b.

Sull, et Lesq. M. bor, am. II ed. n. 104.

var. algarvicus Husn. - F, algarvicus.

" var. brevifolius Ren. et Card. in Bot. Gas, 1889, p. 94.

Terr, in silv. - Am. sept. : Ludovic.

var. crassipes W. P. Sch. - F, crassipes.

var. exiguus Aust, - F. exiguus.

var. fontanus $\{$ C. M. - F. crassipes.

W. P. Sch, - F. crassipes $\beta$ rufipes.

var, inconstans Husn. - F. inconstans.

var, minutulus Aust. - F. minutulus.

var. pusillus W. P. Sch. - F, pusillus.

var. $\beta$ Braithw, $-\mathrm{F}$. incurvus var, tamarindifolius.

var. Wils. $\left\{\begin{array}{l}\text { (Kew Journ.) }- \text { F. ceylonensis. } \\ \text { (Fl. Tasm.) - F. pungens. }\end{array}\right.$

"var, tamarindifolius (Brid.) Husn. Muscol. gall, p. 50.

Dicranum tamarindifolium Tusn. Muscol. Hib. p. 55?.

Fissidens incurvus $\beta$ Braithx. Brit. Moosfl.p. 69.

F. tamarindifolius Brid. Bryol. univ. I1, p. 684 .

F. trichomanoides Wils, in Braithw. Brit. Moosfl, p. 70 ,

Skitophyllum tamarindifolium la Pyi. op. cit. p. 37 .

Ut typ. - Eur. : Cum typ. Am. sept. : Ottawa, reg. sept. occ., Columb. brit.

Exs, : Mac. Canad, M. n. 406.

indistinctus C. M. in Linn. $1878-79$, p. 238.

1. Limic, - Am. merid. : Argentin, subtropic.

« var, major C.M.l.c.

Muric. - Am, merid. : Ibid.

inflatus (C. M.) Par.

Conomitrium inflatum C. M. in Linn. 1875, p. 375.

2. Terr. - Afr.: Bongo. 
insignis W. P. Sch, in hb. Hpe.; C. M. in Bot. Ztit. 1864, p. 339; Mitt.

M. austr. am, p. 586 .

F. grandifrons var, strictus Besch. Prodr. bryol. mexic. p. 27.

Ster. - Am. sept. : Mexic.

integerrimus Mitt. in Journ. of the Linn. Soc. 1859, p. 94 ; Fl. Tasm. II, p. $168, t .17 i, f .8$.

2 ? - Pac.: Tasman.

intermedius C. M. Syn. I, p. 56 et II, p. 530 ; Mitt. op. cit. p. 594 .

1.

- Am. merid.: Guian. batav,

intra-limbatus Ruthe in Hedwig. 1870, p. 177.

1.

- Eur. : Lusitan. merid.

intra-marginatus (Hpe.) W. P. Sch, hb.; Mitt. op. cil. p. 594.

Conomitrium intra-marginatum Hpe. in Linn. 1862, p. 531.

1 (Mitt.) 2 (Hpe.).

- Am. merid. : And. Nov. Granat.

involutus Wils. in Kevo Journ. bot. 1X, p. 294; Mitt. M. Ind. or. p. 138. - As. : Sikkim.

irawaddensis $P$ ar.

F. flaccidus $C . M$. in Jaeg. Ad. $I I, p, 40$ (nom.).

- As. : Birman., Pegu.

ischyro-bryoides C, M. in Relim. M. A fr $r$ austr. $n, 290$.

- Afr.: C. R. Sp.

japonicus Dz. et Mk, in Pl. Jungh. p. 313 ; Bryol. jav. I, p. 9, t. 8 .

$2 . \quad$ As.: Japon., Hong-Kung.

Exs. : Faurie n. 63, 740, 816.

javanicus Bryol. jav. - F. silvaticus.

Kaernbachii Broth. in Engler's Bot. Jahrb. 1893, p. 476.

1. Cortic. - Pac. : Nov. Guinea.

Kerianus C. M. mss.; Broth. in Oefv. af Finskra Vet.-Soc. Foerh. 1895, p. 53.

2. -Pac, : Austral, or. (Queensland).

Kriegeri W. P. Sch. in Besch. Fl. bryol. Nov. Caled, p; 201.

2. Arbor. - Pac. : Nov. Caledon.

laxus Sull. in Proced. Am. Acad... 1859, p. 276.

2.

- As. : Hong-Kong.

Lechleri Hpe. - F, rigidulus.

Lefebvrei Besch. in Rev, bryol. 1891, pp. 50 et 53. 1.

lepidopiloides C. M. in Linn. 1875, p. 353.

- Am. sept.: Guadalup.

1. Loc. humid, - Afr.: Djour. Niam+Niam.

leptocheilos C. M. in Linn. 1876, p. 290.

Ster, Terr. - Afr. : Somali.

leptophyllus Mont. in Ann. sc. nat. 1840 et Syll. p. 5 ; C. M. Syn. II,

p. $530 ;$ Mitt. $M$. austr, am. p. 587 .

2. Terr. - Am. merid.: Guian. gall.

leptopliyllus Broth. - F. Brotheri.

leucocinctus Hpe. in Linn. 1874, p. 222.

Ster.

- Afr.: Madagascar. 
liliputanus C. M. in Linn. $1875, p .354$.

2. Ster. Terr, - Afr. : N'Gama sept.

limbatus Sull. in Bot. Pac. R. R. Surv. (Whipple) p. 185, t. I; Lesq. et Jam. Man, p. 82.

1. Terr. - Am. sept. Ins. Vancouver, Oregon, Idaho, Calif.

Exs. : Sull. et Lesq. M. bor. am. II ed. n. 105.

lindbergii Mitt. op, cit, $p, 602$.

Conomitrium acutifolium Lindb, in sched.; C. M. in Bot. Zeit. 1864, p. 317. $\delta$ et fr. ign.

- Am. merid. : Brasil. austr. or.

Lindigii (Hpe.) Par.

Conomitrium Lindigii Hpe, in Linn. 1862, p. 532.

1.

- Am. merid. : And. Nov. Granat.

linealis Bryol. eur. I (mon. p. 12), t. 6; C. M. Syis. I, 46 ol II, p. 528.

1. $\quad-A f r .:$ C. B. Sp.

lineari-limbatus C. $M$. in Fl. 1890 , p. 471 .

Ster.

- Afr. : M. Kenia.

linearis Brid. Bryol. univ. II, p. 71 et II, p. 532 .

Ster. $\quad-$ Pac,: Australia.

lonchothecius C. M. in Linn. $1878-79$, p. 239.

2. Arbor. - Am. merid. : Argentin. subtropic.

longifolius Brid. Bryol. unix. II, p. $682 ; C$. M. Syn. I, p. 65 et II, p. 534 ; Mitt. op. cit. p. 599.

2 ? $\quad-A m$. merid. : Hispaniola.

longipedicellatus C. $\boldsymbol{M}$. in Act. Soc. sc. Fenn. 1891, n. 5.

i. Terr. - Am. merid. : Minas Geraës.

longipes Welvo. et Duby in Mém.... Genève, 1870, t. 4, f. 3.

2. Rupic. - Afr. : Angola.

longisetus Griff. Not. p. 425 et Ic. pl. asiat. II, p. 81, t. 4 ; Mitt. M. Ind. or. p. 141.

1 .

- As, : Assam super.

Loscosianus Jur, in Hedunig. 1867, n. 10.

- Eur.: Arragon.

luridus Ren. et Card. in Bull. Soc. roy. bot. Belg. 1890, I, p. 172.

2 ?

- Afr. : Madagascar.

lusitanicus Par.

F. Welwitschii W. P. Sch. Syn. II ed., p. 120.

ot et fr. ign. Terr. in silv. - Eur. : Lusitan.

luteo-viridis Lindb. in Angstr. Prim. lin.

Ster.

- Am. merid. : Brasil. austr. or.

Lylei Wils. - F. exilis $f$. integra.

maceratus Milt. in Trans, and. Proced. of the roy. Soc. of Victoria, 1883, p. 91 .

- Pac. : Austral, or.

Mac-Leanus Rehm. M. Afr. austr. n. 583.

- Afr.: C. B. Sp. or.

macro-bryoides C. M. in Linn, 1878-79, p. 243.

2. $\quad-A m$, merid. : Uruguaj subtropic.

macrodus Hpe. in Linn. 1859, p. 615.

1. Terr, - Pac. : Austral. or. 
macrophyllus Mitt. M. austr. am. p, 600.

Peruv,

- Am. merid.: Ins. Trinitat., And, Quitens, et

macrophyllus Duby. - F. Dubyanus.

macropus Hpe. in Linn. 1859, p. 645.

1. In turfac. - Pac. : Austral. felix.

madecassus W. P. Sch. mss. ; C. M. in Bot. Zeit. 1864, p. 340.

$2 . \quad-A f r$ : Madagascar.

najus Mitt. - F. adiantoides.

mammillosus C. M. in Linn. 1875, p. 349.

Ster. Loc. humid. - Afr.: Dar Fertit.

mangarevensis Mont, in Voy. au Pôle Sud., Crypt. p. 344 ; in Ann. sc. nat. 1845, p. 113 et Syll. p. 4 ; C. M. Syn. I, p. 62 et II, p. 534.

2? o ign. Rupic. et cortic. - Pac. : Archip. Gambier, Taït.

* var, taitensis Besch. Fl. bryol. Taïl, etc., p. 22.

Cortic. - Pac, : Taïti.

marginatus W. P. Sch.mss. ; C. M. in Bot. Zeit. 1858, p. 154.

2. $\quad-A f r$ : C. B. Sp.

martinicae Besch. Fl, bryol. Antill. fr. p. 18 et in Rev. bryol. 1891,p. 55 .

Ster. Terr. - Am. sept. : Martinic.

maschalanthus Mont. in Ann. sc. nat. 1845, p. 11 et Syll. p. 3; C.M. Syn. I, p. 53 et $I I$, p. 528; Mitt. op. cit. p. 591 .

2. Terr. - Am. merid. : Chil. austr.

megalotis W. P. Sch. mss, ; C. M. in Bot. Zeil. 1858, p. 154.

Rupic. - Afr. : C. B. Sp.

Metzgeria (C. M.) Par.

Conomitrium Metzgeria C. M. in Linn. 1875, p. 358.

Polydiopsis Metzgeria Jaeg. Ad. I1, p. 48.

Ster. Subaquat. - Afr. : Monbouttou.

mexicanus Mitt. - Conomitrium Julianun var. mexicannm.

microcarpus Mitt. in Joum. of the Linn. Soc. 1863, p. 162.

Conomitrium microcarpum Jaeg. Ad. $I I, p, 41$.

1. Lignic. - Afi. : Tropic. littor.

microcladus Thw. el Mitt. in Journ. of the Linn. Soc. 1872, p. 324.

- As. : Ceylan.

Mildeanus W. P. Sch. - F. crassipes var. rufipes.

minutulus Sull, in Mem. Acad... Nov. ser. III, p. 58, t. $2 \Lambda ; M$. Allegh.
p. $44 ; M$. of U. St. p. 24 et Ic. M. p. 37, t. $24 ; C . M$. Syn. I, p. 56

et II, p. 530 ; Lesq. el Jam. Man. p. 85.

F. bryoides $H$. $f$. et W. in Drumm. M. bor, am. II ed. $n$. 39 et 40 ,

F. incurvus var. minutulus A ust. M. Appal. n. 102.

F. pusillus var. madidus Spr. in Journ. of Bot, 1880, p. 361.

I et 2. Ad rup. humid, in silv. - Eur. : Normann. marit. Ant. seph.:

Nov. Scotia. Ontario, ins. Vancouver, Calif, reg. or.

Exs. : Sull. M. Allegh. n. 183.

Sull, et Lesq. M. bor, am. II ed. n. 10L.

minutulus Sull. - F. monandrus.

var. Sull. - F. repandus? 
minutus Thw. et Mitt. in Journ. of the Linn. Soc. :872, p. 323.

Cortic. - As, : Ceylan.

Mittenii For.

F. crassinervis Thw, et Mitt. op, et l. oc.

- As. : Ceylan.

Monkemoyeri C. $M$. in Fl. 1886, p. 504.

1. - Afr.: Ins. Fernando-Po.

mollis Mill. M. austr, am. p. 600.

2. $\quad-$ Am. sept. : Jamaïc.

monandrus Milt. op. cit. p. 598.

F. minutulus Sull. in Proced. Am. Acad... 1881.

- Am. sept.: Cuba.

Moritzianns C. M. in Bot. Zeit. 1864, p. 340 ; Mitt. op. cit. p. 594. 1 . - Am. merid.: Venezuela.

mucronatus W. P. Sch. mss. ; C. M. in Bot. Zeil. 1858, p. 154.

F. glaucescens Hsch. (fid. Hpe.).

2. - Afr. : C. B. Sp.

Mülleri Mitt. - Conomitrium.

multiflorus Thwo et Mitt. op. cit. p. 325.

- As. : Ceylan.

muriculatus Spr. in Mitt. M. austr. am. p. 593.

Lignic. - Am. merid : Amazon,, And, Quitens,

Nadeaudii Besch, in Ann. sc. nat. 1894, p.

2 ? Terr. secus torrent. - Pac. : Taiti

natalensis Rehm. M. Afr. austr, n. 593 et c.

F. glaucescens var. natalensis ej. l. c. n. 285.

- Afr.: Natal, Transvaal.

neckeroides Griff. - F. anomalus.

nematopteris C. $M$, in Dusen M. Camer, n. 200.

- Afr. : M. Cameroon.

neo-caledonicus Besch. Fl. bryol. Nov. Caled. p. 201.

1. Terr. - Pac. : Nov. Caledon.

nigricans W. P. Sch. in Besch. Fl. bryol. Antill. fr. p. 18.

2. Terr. - Am, sept. : Guadalup.

nobilis Griff. Not. p. 427 et Ic. Pl. asiat. II, t. 83, f. 3; Mitt. M. Ind. or. p. 137 .

F. filicinus Ds, et Mk. in Ann. sc. nat. 1844, II, p. 301; C. M. Syn. I, p. 70 et II, p. $529 ;$ Bryol. jav, I, p. 8, t. 7 .

2. Ster. Java, Hong-Kong.

nossianus Besch. Fl, bryol. Réunion, elc. p. 45. 2.

Novae hollandiae Brid. - Rhizogonium.

- Afr. : Ins. Nossi-Be.

n. 9 Griff, $-\mathrm{F}$, obscurus.

n. 10 Griff. - F. elongatus.

oblongifolius Hook, f. et Wils, in Lond. Journ. of Bot. 1844, p. 517; 
Fl. of the N. Zeal. II, p. 62, l. 83, f. 8 et Handb. p. 407; C: M. Syn. I, p. 62 et II, p. 531 .

1. Ad rup. madid. - Pac. : Austral. or., Nov. Zeland., Tasman. obscurus Mitl. op. cit. p. 138.

F. n. 9 Griff. Not. p. 430.

Ster. Ad. rup. irror. - As. : Khasia.

obscurus Mitt. - F. subobscurus.

obsoletidens C. M. in Besch. Fl. bryol. Réunion, etc. p. 44.

1. Ad lapid. et terr. - Afr. : Usambara, ins. Mayotte, Nossi-Be.

obtusatus Hpe. Symb. 1872, p. 59.

Ad rup. humid. - Am. merid. : Brasil, austr. or.

obtusifolius Wils. in Lond. Journ. of bot. 1845, IV, p. 196, t. IX B;

Sull. M. of U. St. p. 24 et Ic. M. p. 35, t. 22; C. M. Syn. I, p. 64 et II, p. 531 ; Lesq. et Jam. Man. p. 86.

Z. Rupic. - Am. sept. : Pensilv., Ohio, Missouri, Illinois, Colorado, Kansas, Texas, Ludovic.

Exs. : Sull, M. Allegh, n. 181.

Sull. et Lesq. M. bor. am, n. 99.

" var. kansanus Ren. et Card. in Bol. Gaz. 1890, p. 40. - Am. sept. : Kansas.

odontoloma C. M. in Linn. 1878-79, p. 242.

Ster. - Am. merid. : Alp. Argentin. subtropic.

Erstedtianus C. M. Syn. II, p. 529; Mitt. M. austr. am. p. 586. 2. - Am. sept. : Costa Rica.

opacifolius Milt. in M. herb. Hook. $1860, p .54, t .5, f$. II. 1. - Afr. : Niger, Natal.

Orrii (Lindb.) Par.

Schistophyllum Orrii Lindb. in Rev. bryol. 1880, p. 97.

1. Terr. limos, aren, - Eur. : Hibern. or.

osmundioides (Sw.) Hedvo. Sp. M. p. 153, t. 30; Brid. Bryol, univ. II, p. 689 ; Bryol eur. I (mon. p. 8), t. 103 ; C. M. Syn. I, p. 60; W. P. Sch, Syn. II ed. p. 116.

Conomitrium osmundioides C.M. l. c. II, p. 526.

Dicranum bryoides Sw. M. Sueo. p. 32 .

Dicranum bryoides $\alpha$ elongatum $H$. et T. Muscol. brit. p. 49.

D. osmundioides Sw. Act. Holm. 1795, p. 240.

F. bryoides Roehl, Deutsch. Fl. III, p. 77.

F. dicarpos Brid. op. cit. p. 698.

Hypnum asplenioides Dicks. Fasc. II Pl. Crypt. p. 10, t. 5, f, 5 lexol. Syn. Sw.).

H. bryoides Ehr.h. Crypt. $n .124$.

Osmundula fissidentoides Kab. Krypt. Fl. Sachs. I, p. 609.

Skitophyllu:.: osmundioides la Pyl. op. cit. p. $38, t .25, f .5$.

2. In uligin. et turfac. - Eur. : Reg. subalp., rar. mont.; Spitzberg. As. : Jeniss. med. et inf. Am. sept. : Groenland, Anticosti, New Brunswick, Nov. Scotia, Gaspes., Ontario, M. Rupestr., Columb. brit., Idaho, reg. or. et centr., Terra nov.

Exs, : Drumm, M, bor. am. I ed, n. 112 (Dicranum).

Mac. Canad. M. n. 51.

Rab. Bryoth. eur. n. 358 b, c, 863 a, b, c.

Sull, et Lesq. M, bor. am. II ed. n. 109. 
* var. microcarpus Bryol. eur, et W. P. Sch. ll. cc.

Ut typ. - Eur. : Alp. Helvet,, Pinzgov.

Exs. : Un. itin, 1863, n. 5 .

ovatus Brid. Bryol. univ. II, p. 696; C. M. Syn. I, p. 70 et II, p. 528.

Ster. Rupic. in rivul. - Afr.: Ins. Borbon,, Franciae,

" var. elatior Ren. et 'Carl. in Bull. Soc. roy. bot. Belg. 1894, II,

p. 115 et M. Masc.-Mad. n. 111.

- Afr.: Ins. Borban.

a var. planifolius Besch. Fl. bryol. Réunion, elc. p. 42.

- Afr. : Ins, Nossi-Be.

Pabstii Jaeg. Enum. Fissid, p, 23.

Conomitrium semi-limbatum Sćhlieph. in Bot. Zeit. 1885, p. 423.

1. Terr. - Am. merid. : Brasil. austr. or.

pachyloma C. M. in Bot. Zeit. 1864, p. 341.

Ster.

pachyloma Lac. - F. Hásskarlii. - Afr. : Alp. Abyss.

pacificus Angstr. in Defv... 1872, n. 4, p. 21.

2. - Pac. : Ins. Sandwic, Austral. or. (Nov. Vales.).

pallidicaulis Mitt. in Godman's Nat. hist. of Azores, p. 314.

F. taxifolius Bourg. Pl. Canar. exs.

1 .

- Afr. : Ins. Madeir., Ténerif.

pallidinervis Mitt. $M$. austr. am. p. 592.

1 ?.

- Am. merid. : And. Peruv.

pallidus Hook f. el Wils. Fl. of the N. Zeal. p. 62, t, 83, f. 7 et Handb. p. 407.

2. $\sigma^{x}$ ign

palmatulus Besch, in Rev. bryol. 1891, p. 50.

1.

- Am. sept. : Guadalup.

palmatus (Sro.) Heduo. M. frond. III, p. 69, t. 30 A ; C. M. Syn, I, p. 48;

Mitt. op. cit. p. 599.

Conomitrium palmatum C. M. Syn. II, p. 526.

Dicranum palmatum Sw. Fl. Ind. occ. III, p. 1714.

Hypnum palmatum ej. Prodr. p. 141 .

Skitophyllum palmatum P. B. op. cit. p. $36, t .35, f .6 ;$ Brid. Bryol.

univ. II, p. 680.

I (Mitt.). 2 (C. M.) (1). Arbor. - Am. sept.: Jamaï., ins. S. Thomas.

palustris C. M. in Forchungsreise... p. 62.

Conomitrium palustre ej. in Engler's Bot. Jahrb. 1883, p. 88.

1. Paludic. - Afr. : Monrovia.

papillosus Lac, Sp. nov. M. Archip. ind, p. 1, f. I A.

Syn. Lignic. $-A s$, : M. Java.

papillosus $\{$ Lindb. - F. fratris.

Thw. et Mitt. - F. Thwaitesianus.

(1) "The male flower is describeb as terminal on a separate plant in C. M. 1, c. ;

tion s. (Mitt, as in many other instances in the genus, it is variable in its posi- 
papulans Besch, in Rev, bryol, 1891, pp. 50 et 51.

2. Arbor. -- Am. sept. : Guadalup.

Parkii Mitt. in M. herb. Hook. 1860, p. 56, t. 6, f. 19.

2 ?

- Afr.: Tropic. inter.

parvus Mitt. - Conomitrium Dillenii.

patens Wahlenb. - Rhacomitrium.

paucifolius Besch. Fl. bryol. Nov. Caled. p. 200.

2.

- Pac. : Nov. Caled.

pauperculus A. Howe in Erythea, 1894, p. 97 c. ic.

2. Terr. hum. - Am. sept. : Calif.

pauperrimus C. M. in Abhandl. Brem. VII, p. 213.

Ster.

- Pac. : Australia.

Pechuelii $(C, M$.) Par.

Conomitrium Pechuelii $C$. M. in Fl. 1886, p. 503.

Ster. In aren. humid, - Afr. : Congo infer.

pellucidus Hsch. in Linn. 184I, p. 145; C. M. Syn. I, p. 47; Mitt. M. austr. am. p. 588.

Conomitrium pellucidum $C . M, S y n . I I, p, 525$.

- Am. merid. : Surinam.

pellucidus Ångstr. - F. Widgrenii.

pendulus Lindb. et Arn. - Leucodon.

pennatulus Thro. et Mitt. in Journ. of the Linn. Soc. 1872, p. 325.

Terr. - As. : Ceylan.

perangustus C. M. in Rev. bryol. 1887, p. 57 (nom.).

- Pac. : Nov. Caledon.

perfoliatus (C. M.) Par.

Conomitrium perfoliatum C. M. in Linn. $1875, p .374$.

2. Terr. - Afr. : Djour.

perpusillus Wils. in Kew Journ. bot. IX, p. 294; Mitt. M. Ind. or.p. 141. 2 .

- As. : Ceylan.

persicus Ruthe in Jur. et Milde Beitr... p. 591.

- As. : Persia.

petrophilus Sull. in Proced. Am. Acad... 1861, p. 276; Mitt. M. austr. am. p. 587.

Rupic. - Am. sept. : Cuba.

plagiothecioides C. $M$. in Linn. 1878-79, p. 241.

Ster.

- Am. merid. : Argentin. subtropic.

planicaulis Besch, in Ann. sc. nat. 1893, p. 335.

Exs. : Faurie n, 162 et 194.

planifrons Besch. in Ann. sc. nat. VII ser., II, p. 85.

Terr. - Afr. : Ins Mayotte.

«var. corticeus Besch. l. c. p. 86.

Cortic. - Afr. : Ibid.

platybryoides $C$. $M$. in Fl. $1886, p .505$.

Syn. Terr, - Afr. : Old Calabar. 
plumosus Hsch. in Linn. 1841, p. 15I : C. M. Syn. I, p. 68 et II, p. 528. 2. - Afr.: C. B. Sp.

Exs. : Rehm. M. Afr. austr. p: 280.

Plunula Thoo, et Mitt, in op.et l. cc. - As. : Ceylan.

polycarpos Hedw. - Cynodontium.

polyphyllus Wits. in Bryol, exir. I (mon. p. ), t. 107 ; W. P. Sch. Syn, II ed.p. 121 (1).

F, adiantoides C. M. Syn. I, p. 51 p.p.

$\mathrm{F}$, asplenioides var, polyphyllus Wils. Bryol. brit. $p, 306$.

2. Ad rup. humid. - Eur.: Hibern., Cambrovall,, Pyren.

Exs. : Rab. Bryoth, eur, n, 944.

polypodioides (Sw.) Hedw. M. frond. III, p. 63, 6, 27; Brid. Bryol. univ. $1 I$, p. 695 ; Sull. Ic. M. p. 42, t. 27 ; C. M. Syn. I, p. 52 et II, p. 529 ; Mitt. op. cit. p. 595 ; Lesq. el Jam. Man. p. 88.

Dicranum polypodioides Sw. Fl. Ind. occ. III, p. 1772.

Hspnum polypodioides ej. Prodr. p. 140.

Skitophyllum polypodioides la Pyl. op. oit. p. 45, t. 35, f. 10 .

2. Ad rup. humid. - Am. sept.: Georgia sup., Florida, Ludovic., Mexic., Antill. gall., Cuba, Jamaic., Haïti. Am. merid. : Columb., Venezuela, Equat.

Exs, : Sull. et Lesq. M. bor. am. I ed. n, 27, II ed.n. 11').

var. Wils, - F, areolatus.

porrectus Mitt. in M. hb. Hook. 1860, p. 56, t. 6, f. 17.

Ster. Ad rup. madid. - Afr, ; Niger.

prionocheilos C. M. in Linn. 1878-79, p. 245.

Ster.

- Am. merid. : Uriguay.

prionodes Mont. in Ann, sc. nat. II ser., III, ᄂ. 3, f. 1 et Syll, p.5; C. M.

Syn. I, p. 67 et II, p. 534 ; Mitt. M. austr, am. p. 590.

2, - Am. merid.: Guian, gall,, And, Quitens, et Peruv.

procumbens Mitt. in Philos. Trans, of the roy. Soc. 1879 (extr, vol.), p. 393.

Ster. - Afr.: Ins. Rodriguez.

psatyrocheilon (Schlieph.) Mitt, op. cit, p. 597.

Conomitrium psatyrocheilon Sehl. in Bot. Zeit. 1855, p. 421.

2.

- Am. merid. : Ins. Trinitat.

pseudo-bryoides Schlieph. in op. et l. cc.; Mitt. op. et $l$. cc.

2. Terr. - Am. merid. : Brasil, austr. or.

pseudo-limbatus Vent, in Nuov: Giorn. bot, ital. 1872, p. 10. 2 . - Afr.: Abyss.

pseudo-rufescens C, $M$, in $F l .1879, n$. 24 .

2. $\quad-A f r$. M. Kenia.

pseudo-rufescens Rehm. - F. austro-africanus.

pseudo-serratus (C. M.) Jaeg. Enum. Fissid. p. 24

Conomitrium pseudo-serratum C. M. in Bot. Zeit. 1859; p. 197 p.p.

(1) Cf, Boulay in Rev, bryol. 1885, p. 50. 
C. serratum ej. Syn. M. II, p. 527 p.p.

Fissidens serratus $e j . l$. $c . I, p .65 p \cdot p$.

2.

$$
\text { - Afr. : C. B. Sp. }
$$

pugionifolius C. M. in Linn. 1875, p. 351 .

Ster. Terr. - Afr. : Niam-Niam.

Puiggarii (Geh. et Hpe.) Par.

Conomitrium Puiggarii Hpe. et Geh. in Jaeg. 1878, p. 69.

- Am. merid.: Brasil, austr. or.

pulchellus Mitt. M. Ind. or. p. 140.

1.

- As. : Sikkim.

pulcher C. M. in Dusen M. Camer. n. 429.

- Afr.: M. Cameroon.

pulvinatus Hedw. - Grimmia.

var. africanus Hedw, - Grimmia pulvinata var. obtusa.

punctatus Hpe. in Jaeg. Ad. $I I$, p. 39 (nom.).

- Pac. : Australia (Nov. Valesia).

punctulatus Lac. Sp. nov. M. Archip. ind. p. 2, t. I C.

1. - As.: Ins. Saparoa.

pungens Hpe. et C. $M$. in Linn. 1853, p. 502.

F. incurvus var. Wils. in Fl. Tasm. II, p. 167.

2.

- Pac. : Austral, or.

pungens Sull. - F. acutus.

pusillus Wils, in W. P. Sch. Syn. 11, p. $113(1)$.

F. incurvus Mac. Canad. M. n, 50 p.p.

F. incurvns var pusillus W. P. Sch. Syn. I ed. p. 104.

F. synanthus Mitt. in Joum. of the Linn. Soe. 1885, p. 550.

F. viridulus $\beta$ pusillus Wils. Bryol. brit. p. 303.

Schistophyllum pusillum Lindb. M. Seand. p. 13.

2 vel syn. Ad terr. calcar. aren, - Eur.: Anglia, Westphalia; Galloprov., Corsica, ete. Afr.: Alger. Am. sept.: Ontario.

var. algarvicus Boul. - F. algarvicus.

ه var. fallax Limpr. Deutschl. Laubm. p. 438.

1. Rupic. - Eur, : Helvet., German. tota.

a var. irriguus Limpr. op. cit. p. 437.

2. Rupic. - Eur. : Silesia.

var. Lylei Wils. - F. exilis $f$. integra.

var. madidus Spr. - F. minutulus.

pycnoglosus C. M. in Linn. 1878-79, p. 246.

Ster. Terr, - Am. merid. : Argentin. Cordob.

pycnophyllus C. M. in Rehm. M. Afr. austr. n. 293 et 584.

- Afr. : C. B. Sp., Transvaal.

pygmaeus Hsch, in Linn. 1841, p. 147; C. M. Syn. I, p. 63 et II, p. 531.
2 ? Muric. - Afr.: C. B. Sp.

pygmaens Tayl. - F. Taylori.

(1) Cf. Mitten in Journ, of the Linn. Soc. 1885, p. 555. 
radicans Mont. in Ann. sc. nal. 1840, p. 345 cl Syll. p. 6; Mitl. M. austr. am. p. 587 .

Conomitrium radicans C. M. Syn, $11, p, 526$.

1. Arbor. - Am. merid. : Guian. gall., Para.

ramiger C. M. in Trans. of the N. Zeal. Inst. 1892, p. 294.

1. Terr. - Pac. : Nov. Zeland.

ramulosus Mitt. in M. Hb. Hook. 1860, p. $54, t .5$, f. 12.

2 ?

- Afr. : Niger.

Ravenelii Sull. in Mem. of the Am. Acad... 1849, p. 171, t. 2; M. of U. St. p. 24 et Ic. M. p. 39, t. 25; C. M. Syn. II, p. 5i33; Lesq. el Jom. Mau, p. 85.

2. Terr, argill. humid, - Am, sept. : Carol, ambo, Florida, Ludovic. Ess. : Sull. et Lesq. M. bor. am. II ed. n. 102.

reclinatulus $C$. $M$. in $M$. Polakowskyani et in Bull. Sac. roy. bot. Belg. $1892, I$, p. 153.

2. Terr. et lignic. - Am. sept. : Costa Rica.

reflexus Hpe. in Linn. 1874, p. 221.

Cononitrium reflexum Jaeg. Ad. II, p. 43. - Afr. : Madagascar.

Relimanni C. M. - F. lanceolatus.

remotifolius C. M. Syn. I, p. 60 et $I I$, p. 530.

Exs. : Rehm. M. Afr. austr. n. 590,591 .

repandus Wils, in Kew Journ, bot, III; Mitt, op. cit. p. 601 .

F. minutulus var. Sull. in Proced. Am. Acad... I861, p. 274?

2. Arbor., rupic. et terr. - Am. sept.: Cuba? Am. merid.: Amazon., And. Quitens.

reticulosus W. P. Sch. mss.; Mitt. op. cit. p. 603.

Conomitrium reticulosum C. M. Syn. II, p. 525. 1.

- Am. sept. : Mexic.

revolvens W. P.Sch. in Mandon Pl. Boliv. n. 1614.

- Am. merid, : And. Boliv.

rigidulus Hook. f. et Wils. Fl. of the N. Zeal. p. 61, t. 83, f. 3; Mitt. op. cit. p. 602.

F. erassipes Lechl. Pl. Chil. n. 1460.

F. Lechleri Hpe, in Bot. Zeit. 1864, p. 340.

2. Ad rup. madid. - Am. merid.: And. Nov. Granat. et Quitens. Pac, : Alp. Austral, or., Nov. Zeland., Tasman.

riparius Aman in Rev. bryol. 1889, p. 54.

Ster. Ad rivul. - Eur.: Alp. Rhaet.

ripensis Mitt. in .M. hb. Hook. $18 \% 0, p .55$, t. $6, f .15$.

Ster. Ad rup. madid, $-A f r$. Niger. rivularis Bryol. eur. I (mon.p. ) ), t. 102 ; W. P. Sch. Syn. II ed.
p. 114.

F. bryoides var. rivularis $S p r . M$. Pyr. n. 318 et in Trans. Edinb. Bot. Soe... III, II, p. 193.

1. Ad, rup. irror. - Eur. : Luxembourg, Pyren. 
rubiginosus (Hpe.) Pav.

Conomitrium rubiginosum Hpe. Symb. 1874, p. 526.

1.

- Am. merid. : Brasil. austr. or.

rufescens Hsch. in Linn. 1841, p. 153; C. M. Syn. I, p. 54 et $I$, , p. 532. 1. $\quad-A f r .:$ Usambara, Natal, C. Y. Sp.

Exs. : Rehm. M. Afr. austr. 291, b, c, d, 587.

"var. orthopyxis Rehm. l. c.n. 291 e, 588.

- Afr.: C. B. Sp.

rufipes W. P. Sch. - F. crassipes var. rufipes.

rufulus Bryol, eur. I (mon, p. ) $t, 102$.

F. ventricosus Lesq. (fid. Da E. G. Britton in Bull. Torr. bot. Club 1889, p. 107).

1. Ad. rup. cataract. - Eur.: Vall. Rhen, med,, Tirol, Bavar., Austr, sup., Stir., Salisb., Morav. Am. sept.: Oregon, Idaho, Calif.

Exs.: Rab. Bryoth, eur, n. 108, 357 et b, 469, 1105.

rufulus Sull, - F. flexinervis.

rupestris Wils. - F. decipiens.

samoanus C. M. M. Polyn. p. 59.

Ster. Terr. - Pac. : Ins. Fidji, Samoa.

sanguineo-nervis (C.M.) Par.

Conomitrium sanguineo-ner:e C. M. in Linn. 1875, p. 371.

2 ? Terr. - Afr.: Dar Fertit,

sarcophyllus $C$. $M$, in Dusen $M$. Camer. $n, a 13$.

- Afr. : Mi. Cameroon.

Sardagnae Vent, in Rev. bryol. 1883, p. 93.

2 vel pseudo-1. $\quad-$ Eur. : Sardin, merid.

sardous de Not, - F. incurvus.

Savatieri W. P. Sch, in Savatier M. Japon. n. 119.

F. adiantoides var, Savatierî Besch. in Ann, se. nat, 1893, p. 335.

$$
\text { - As. : Japon. }
$$

scabrisetus Mitl. Sam. M. p. 184.

1 .

- Pac.: Ins. Samoa.

scalaris Mitt. M, austr. am. p, 596.

F. brevifolius $H$. f. et W. Fl. of the N. Zeal. p. 61 in adn.!fid. Mitt. l.c.).

1. - Am. merid.: M. Chimborazo, And. Chilens, Pac, : Nov, Zeland,? Tasman?

scariosus Mitt. op. cit. p. 599.

1. Terr. - Am. merid. : And. Peruv.

Schimperi W. P. Sch, - F. helictocaulos.

Schmidii C. M. in Bot. Zeit. 1853, p. 18; Mitt. M. Ind or. p. 141.

2.

Schweinfurthii (C. M.) Par.

- As. : M. Neilgherr.

Conomitrium Schweinfurthii C, M. in Linn. 1875, p. 369.

2. Ad Lycopod. - A fr. : Niam-Niam.

sciophyllus Mitt. in M. hb. Hook. 1860, p. 55, t. 6, f. 13. 
sciuroides Hedw. - Leucodon.

semi-completus $\left\{\begin{array}{l}\text { Drumm. - Conomitrium Julianum. } \\ \text { Hedw. p.p. }\{\text { - Conomitrium Dillenii. }\end{array}\right.$

semi-limbatus C. M. et Hpe. in Limn. 1853, p. 591.

2.

- Pac. : Austral, or.

semi-marginatus $C ., M$. in Bot. Zeit. 1847, p. 38; Syn. I, p. 55 et II,

p. 532; Mitt. M. austr. am. p. 593.

Syn. Terr. - Amin, merid. : Columb.

semi-obscurus (C. M.) Par.

Conomitrium semi-obscurum C. M. in Linn. 1875, p. 376.

2. T'err. - Afr. : Niam-Niam.

sepincola Mitt. - F. exilis $f$. integra.

sericeus Broth. in Engler's Bot. Jahrb. 1894, p. 181.

2. Terr. - Afr.: Usambara.

serratus C. M. in Bot. Zeit. 1847, p. 804 et Syn. 1, p. 65 p.p. ; Bryol. jav. $I, p, I$ p.p.

Conomitrium serratum ej. Syn. II, p. 527 p.p. et in Eot: Zeit. 1859, p. $197 p \cdot p$.

1. Lignie. - As. : M. Java.

serratus $\{$ C. M. p.p. - F. pseudo-serratus.

C. M. p.p. - F. Wilsoni.

serrulatus Brid. Sp. M. I, p. 170 et Bryol. univ. I1, p. 704; Bryol. eur.

VI, ı. 638; C. M. Syn. I, p. 69 el II, p. 5:9.

F, asplenioides var, serrulatus Wils. Bryol. brit.

F. Langei de Not. Epil.

2. Ad terr. umbros, et rup. - Eur. : Cambrovall., Armoric., Galloprov., Ligur., Etrur., Pyren., Lusit. Afr.: Alger., Tenerif., Madeir., ins. Azor.

Exs. : Mandon M. Mad. n. 5.

* var. africanus Besch. Cat. M. Alger, p. 7.

Ut typ. - Afr.: Alger.

serrulatus Hsch, - F. Hornschuchii.

sigmocarpus C. $M$. in Dusen $M$. Camer. $n .433$.

- Afr. : M. Cameroon.

silvaticus Griff. Not. p. 429 et Ic. pl. Asiat. II, t. 81, f. 1; Mitt. M. Ind. p. 138.

F. falcatus Wils. in adn, ad F. pallidum in Fl. of the N. Zeal. $I I_{1} p, 62$.

F. javanicus Bryol. jav, $t, 3$.

- As: : Himalaya, Khasia, Madras.

simensis W. P. Sch.-in .W. Sch. M. Abyss. Coll. II, n. 38; C. M. in Bot. Zeit. 1864, p. 341.

2?

- Afr. : Alp. Abyssin.

similiretis Sull, in Proced. Am. Acad... 1861, p. ;-Milt. M. austr, am. p. 590 .

Rupic. - Am. sept. : Cuba.

socialis C. M. in Linn. $1869-70$, p. 31.

Ster.

- As. : Ceylan. 
Somaliae C. M. in Linn. 1876, p. 289.

Ster. Terr. - Afr. : Somali.

sphagnifolius Sull. in Proced. Am. Acad... 1861, p. 275; Mitt. op, cil. p. 591 .

2. Terr. - Am. sept.: Cuba.

splachnifolius Hsch, in Linn. 1841, p. 145: C. M. Syn. 1, p. 46.

Conomitrium splachnifolium C. M. op. c. II, p. 525.

- Afr. : C. B. Sp.

Exs. : Rehm. M. Afr. austr. n. 295, 586.

splachnoides Broth. in Bail. Coutr. Queensl. Fl. Bull. 13, p. 21 (nom.) el in Oef... 1893, p.

2. Terr. - Pac. : Austral. (Queensland.).

Splitgerberianus Dz. et Mk. Prodr. Fl. Surin. p. 4, t. I; Mitt. op. cit. p. 595 .

1. (Mitt.) 2 (Dz et Mk.). Terr. - Am, merid.: Guian, batav., Amazon. stenocarpus C. M. - F. guarapensis.

stenophyllus Angstr. Prim. lin. p. 47.

Ster.

- Am. merid. : Brasil. austr. or.

? stenopteryx Besch. in Rev. bryol. 1791, pp. 50 et 54.

1. Ster.

- Am. sept. : Guadalup.

stenosemus W. P. Sch. in Mandon Pl. Boliv. n. 161 .

- Am. merid. : And. Boliv.

stipitatus Angslr. Prim. lin. p. 47.

Ster.

- Am. merid. : Brasil. or.

stissotheca Mitt. - Conomitrium.

stolonaceus $C$. 4 . in Linn. 1878-79, p. 244.

- Ster. $\quad-$ Am. merid. : Argentin. Cordob.

strictus Hook. f. et Wils. Fl. Tasm, 1I, p. 167, t. 171, f. .7.

1.

- Pac. : Tasman.

strumifer Hedw. - Cynodontium polycarpum var. strumifer.

subbasilaris Hedw. Sp. M. p. 155, t. 39; Brid. Bryol. univ. II, p. 694;

C. M. Syn. I, p. 50 et II, n. 529; Sull. M. of U. St. p. 25 et Ic. M. p. 41, t. 26 ; Lesq. et Jam. Man. p. 88.

Dicranum subbasilare Drumm. M. bor. am. I ed. $n$. III et II, n. 42 .

Skitophyllum subbasilare la Pyl. op. cit. p. 62, t. 35 .

2. Arbor. et terr. - Am. sept. : Ontario, Wisconssin, reg. sept. et centr.

Exs. : Sull. M. Allegh. n. 184.

Sull, et Lesq. M. bor. am. II ed, n. 107.

subcrenatus W. P. Sch. in C. M. Syn. II, p. 531 ; Mitt. M. austr. an. p. 588 .

$2 . \quad-A m$. sept.: Mexic.

subcrispus Besch. Not. M. Paraguay, p. 260.

2 ? In herbos. - Am. merid.: Paraguay.

Exs. : Bal. Pl. Parag. n. 1202.

subglaucissimus Brolh. in Bol. da Soc. Broter. 1890, p.

2. Terr. - Afr. : Ins. Princip., S. Thom., Togo. 
subgrandifrons C. M. in Bot. Zeit. 1864, p. 339.

F. grandifrons Wils. in hb. Ind. or, $n .629$ et 632 ; Mitt. M. Ind. or. p. 138.

Ster.

- As. : Tibet occ.

subimmarginatus Philib. in Rev. bryol. 1884, p. 56 et in Husn. Muscol. gall.p. 48.

1. Terr. - Eur. : Perrar. : Galloprov.

submarginatus $\mathrm{Br}$. in Fl. 1846, p. 133; C. M. Syn. 1, p. 56 et $I I, p, 530$. 1. - Afr.: Natal.

subobscurus Par.

F. obscurus Mitt. op, cit. p. 139.

2 .

- As. : Ceylan.

subpalmatus C. M. in Linn. 1872, p. 164.

Conomitrium subpalmatum Jaeg. Ad. II. p, 41 .

2. - As. : Bengal. sept.

subulatus Mitt. M.' austr. am. p. 589.

Conomitrium subulatum Jaeg. Ad. II, p. 43.

1 ?

- Am. merid. : Amazon.

synanthus Mitt. - F. pusillus.

synoicus C. M. in Linn. 1S78-79, p. 240.

Syn.

- Am. merid. : Argentin. subtropic.

synoicus Sull, - F. inconstans.

tamarindifolius Brid. - F. incurvus var. tamarindifolius.

taxifolius (L.) Hedio. Sp. M. p. 155, t. 39 ; Brid. Bryol. univ. II, p. 692;

Bryol. eur. (mon. p. ), t. 104; C. M. Syn. I, p. 50 et II, p. 529;

W. P, Sch. Syn. II ed. p. 118.

Dicranum taxifolium Sw. M. Suec. p. 31 .

Fuscina taxifolia Schrank Baiers Fl. II, p. 451.

Hypnum taxifolium $L . S p . p l$. p. 1587.

H. tasifolium minus basi capsulifera Dill. Hist. M. p. 263, t. 34, f. 2 .

Skitophyllum taxifolium la Pyl. op. cit. p. 60, t. 35 .

1. Ad terr. argill. umbr. - Eur. : Regio campestr. As.: Nepal., Khasia, Persia, Caucas. Afr.: Ins. Canar, Madeir, ; ins. Mascaren. (? îd. C. M.) Am, sept.: Tota.

Exs. : Drumm. M, bor, am. II ed. n. 43.

Faurie Pl. Jap. n. 617, 1494.

Mandon M. Madeir, n. 5 bis.

Rab. Bryoth. eur. n. 64, 829, 1058.

Savatier M. Jap. n. 119 p.p.

Sull. et Lesq. M. bor, am, II ed. n. 106.

" var. Langloisii Ren, et Card. in Rev. bryol. 1892, p. 78.

- Am. sept. : Ludovic.

taxifolius Bourg. - F. pallidicaulis.

var. $\beta$ Wahlenb. $-\mathrm{F}$, adiantoides.

var. Bonvaleti Besch. - F. Bonvaleti.

Taylori C. M. Syn. I, p, 65 et $I I, p .531$.

F. pygmaeus Tayl. in Lond. Journ. of bot. 1846, p, 66.

1. Terr. - Pac.: Austral, or., Tasman. 
tenellus Hook. f. et Wils, in Fl. of the N. Zeal. $I 1, p .61, t$. 171, f. 6 . F. australiensis? (fid. Hpe.).

1. - Pac. : Austral. or., Nov. Zeland., Tasman.

Teneriffae Hpe. in Jaeg. Ad. II, p. 39 (nom.).

- Afr.: Tenerif.

tenerrimus C. M. in Acl. Soc. sc. Fenn. 1891, n. 5.

Syn. Lignic. - Am. merid. : Minas Geraès.

tenuifolius Mitt. M. auslr, am. p. 596.

1.

- Am. merid. : And. Peruv.

tequendamensis Mitt. op. cit. p. 601 .

2 ?

- Am. merid.: And. Nov. Granat.

teraïcola C. M. in Linn. 1871-73, p. 164.

2 ?

- As. : Bengal, sept.

terminiflorus Tho. et Mitt. in Journ. of the Linn. Soc. 1872, p. 322. 2. - As. : Ceylan.

texanus Lesq. in hb. Sull. 1850 et in Lesq. et Jam. Man, p. 86. 2. - Am. sept. : Texas.

Teysmannianus Dz. et Mk, in Pl. Jungh. p. 317 ; Bryol.jav. I, p. 6, II, p. $221, t .5$.

1.

- As. : Borneo, ins. Banca, Java.

Thunbergii Brid. Bryol. univ. II, p. $699 ;$ C. M. Syn.I, p. $72 ;$ Linlb. in Oefv... 1864, p. 607.

F. asplenioides Brid. Sp. M. I. p. 169 p.p.; Hsch. in Linn. p. 157.

Hypnum asplenioides Thus b. Prodr. Fl. Cap. II, $p .175$.

$2 \sigma^{*}$ et fr. ign.

-Afr.: C. B. Sp.

Thwaitesii Par.

F. papillosus Thwo, et Mitt. in op. cit. p, 323.

1.

- As. : Ceylan.

titalayanus C. M. in Linn: 1871-73, p. 165.

1.

- As.: Bengal. sept.

\& var, elatior C. M. l. c. p. 166.

- As.: Ibid.

tortilis Hpe. et C. M. in Bot. Zeit. 1864, p. 340; Mitt. M. austr, am. p. 597 .

2 .

- Am. sept. : Mexic.

tortuosus Geh. et Hpe. in Rev. bryol. 1881, p. 27.

Ster. Ad saxa irror. ? - Pac.: Tasman.

trachelyma Sull. - Conomitrium.

trichomanoides Wils, - F. incurvus var: tamarindifolîus.

trinitensis Hpe. in Jaeg. Ad. II, p. 39 (nom.).

- Am. merid. : Ins. Trinitat.

turbinatus Tayl, - F. asplenioides.

Ulna (C. M.) Par.

Conomitrium Ulna C. M. Linn. 1875, p. 372.

2. Terr. - Afr.: Dar Fertil.

uncinatus Angstr. Prim. lin. p. 48.

Ster.

- Am. merid. : Brasil. austr. or. 
undatus (C.M.) Par:

Conomitrium undatum C. M. in Linn. 1875, p. 362.

2. Ad saxa inund. - Afr.: Dongo, Djour.

undifolius $C$. $M$. in Fl. $1888, p .407$.

Ster, In graminos, - Afr.: Kilima N'Djaro.

usambaricus Broth, in Engler's Bot. Jahrb. 1894, p. 182.

2. Terr. - Afr.: Usambara.

validienstatus Sull. in Linn. 1878-79, p. 465.

2.

- Am. merid. : Venezuela.

ventricosus Lesq, in Mem. Calif. Acad. I, p. 7; Sull. Ic. M. Suppl. p. 45, t. 30; Lesq. et Jam. Man. p. 84 .

F. rufulus W. P. Soh. (Dna E. G. Britton).

1. Ad rup, inund, - Am, sept. : Oregon, Idaho, Calif.

vietorialis Mitl. in Trans. and Proced, of the roy. Soc. of Vicloria, 1883, p. 92 .

Ster.

- Pac. : Austral. or. et sept. occ.

virens Thin, el Mutt. in Journ. of the Linn. Soc. 1872, p. 324.

- As.: Cejlan.

viridulus $\left\{\begin{array}{l}\text { Wahlenb. }-\mathrm{F} \text {. bryoides. } \\ \text { Wils. p.p. }-\mathrm{F} \text {. biformis. } \\ \text { Wils. p.p. }-\mathrm{F} \text {. incurvus. }\end{array}\right.$

var. fontanus Braithw. - F. crassipes p.p.

var. major Wils. - F. crassipes.

var. pusillus Wils. - F. pusillus.

vitreus (C. M.) Par.

Conomitrium vitreum C. M. in Jaeg. Ad, II, p. 43 (nom).

- Am. merid. : Ins. Trinitat.

vittatus Hoak. f. el Wils. Fl. Tasm. II, p. 167, t. 171, f. 6.

- Pac.: Austral. or., Tasman.

Vogelianus Mitt. in M. hb. Hook. 1860, p. 54, t. 5, f. 10.

1. $\quad-A f r$. : Niger, ins. Rodriguez.

Wallisii C. M, in Linn. 1874, p. 574.

Ster.

- Am, merid. : And. Nov. Granat.

Weberi Brid. - Amblystegium riparium.

Weirii Mitt. M. austr. am. p. 602.

2 ? Arbor. - Am. meridl. : Brasil.

Welwitschii Duby in Mém... Genève, 1870, p. 8, t. 2, f. 5 .

2 . Lignic, et rupic, - Afr. : Angola,

Welroilschii W. P. Sch. - F. lusitanicus.

Widgrenit Par.

F. pellucidus Aingstr: Prim. lin. p. 49.

Ster.

- Am. merid. : Brasil. austr. or

Wildii Broth , in Oefo... 1890, p.

2. Terr. - Pac.: Australia (Queensland).

Wilsoni Mont, mss.

Conomitrium serratum C. M. Syn. II, p. 527 p p.

F. denticulatus Mont, in M. Neilgherr. 
F. serratus C. M. Syn. I, p. 65 p.p.; Mitt. M. Ind. or. p. 140; Bryol. jav. $I, p . I$ p.p.

2. - As. : M. Neilgherr.

Wrightii Jaeg. - F. flexinervis.

yunnanensis Besch. in Arn. sc. nat. 1892, I, p. 53.

2. Terr. - As.: Alp. Yunnan.

Zippelianus Bryol. jav. I, p. 2 et $I I, p .221, t .2$.

2. Ad rivul. - As. : Hong Kong, Java, Sumatra.

Zollingeri Mont. in Ann. sc. nat. 1845, IV, p. 114 et Syll. p. 3; C, M. Syn. I, p. 47 et II, p. 529;Bryol. jav. I, p. 221, t. I.

Syn. Ad terr. turf. - As.: Java.

« var. major Besch. Fl. bryol. Nov. Caled. p. 200.

Speluncic. - Pac. : Nov. Caledon. (1).

Flabellaria C. M. Syn. $I I, p .497$ (subsect. HyPNi).

FLORIBUNDARIA C. $M$. in Linn. 1876, p. 267 (sect. Papilliriae, postea gen. propr.).

Spec. omn. Papillariae ejusd. nom.

FONTINALIS L. et omn. tere. auct.; Card. Monog. (40 spec.).

abjssinica W. P. Sch. Syn. II ed. p. 556.

$$
\text { - Afr.: M. Abyss. }
$$

albicans Web. - Hedwigia ciliata.

alpina Dicks. - Cinclidotus fontinaloides.

androgyna Ruthe. - F. hypnoides.

antipyretica L. Sp. pl. 11 ed. p. 1571; Brid. Bryol. univ. II, p. 655; Bryol. eur. V (mon. p. 4), t. 429 ; W. P. Sch. op. cit. p. 552 ; Card. Mon. p. 48.

F. triangularis, major, complicata, e foliorum alis capsulifera Dill. Hist. M. p. 254, t. 33, f. I (fid. W. P. Sch.).

F. trifaria Voit $M$. Herbip. p. 125.

Hypnum antipyreticum Neck. Meth. M. p. 191.

Pilotrichum antipyreticum C.M. Syn. II, p. 148.

2. Ad rad. arbor. et sax. in aq. fluent. - Eur. : Tota. As. : Jenissei sup., Caucas. occ. et centr. $\Lambda f r$ : Alger., Tunet. Am. sept.: Groenland, Anticosti, Terr. nov., ins. Miquel., Nov. Scot., New Brunswick, Ontar., Columb. brit., Oregon, Wyoming., Calif.

Exs. : Drumm. M. bor. am. I ed. n. 232.

Mac. Canad. M. n. 227 p.p.

Rab. Bryoth. eur. n, 431.

Sull, et Lesq. M. bor. am. II ed., n. 323 .

(1) In Enum. Kindberg. nomina nuda :

F. afro-asplenioides $C . M$. gracilescens Angstr. (Cf. F. delicatulus).

Mac-Owani C. $M$.

malaco-bryoides ej. (An F. macro-bryoides ?).
F. platygyrioides $C . M$. polycarpus Besch. (delend., Besch. in litt. !)

stolonifer Rehm.

undato-decurrens $C . M$.

varians Besch. (ut suprà!) 
antipyretica Erb. critt. ital. - F. hypnoides.

var. alpestris Milde, -- F. Heldreichii ?

var, ambigua Card. - F. Kindbergii

var. arvernica Husn. - F. arvernica.

* var. californica Card. Mon. p. 54.

F. californica Sull. in Pac. R. Rep. IV, p. 189.

In rivul, mont. - Am. sept.: Calif.

var. crassa Mdo. - F. Heldreichii.

var, cuspidata C. M. - F. Kindbergii.

" var. gigantea Sull. Ic. M. p. 106, t. 66; W. P. Sch. Syn. II ed, p. 552 ; Card. Mon. p. 52 .

F. Eatoni Sull. et Lesq. M. bor. am. I ed. n. 224 c. (fid. L. et I.).

F. gigantea Sull. l. c. n. 224.

In aquis minus frig. lentiusq. fluent. - Eur.: Hic illic, rarior. typ. Am. sept.: Terr. nov., ins. Miquel., Nov. Scot., New Brunswick, Ontario, Columb. brit., ins. Vanconver, New Jersey, New York.

Exs. : Aust. M. Appal. n. 243.

Mac. Canad. M. n. 228.

var, minor Brid. $-\{$ F, antipyretica var, gracilis (fid. Lindb.).

F. squamosa (fid. C. $M$ ).

\& var. gracilis (Lindb.) W. P. Sch. op. et l. cc.; Card. Mon. p. 56.

F. antipyretica $\beta$ minor Brid. Bryol. univ. II, p. 657 (f. Lindb. l. c.).

F. gracilis Lindb. in Not. ur Saellsk pr. Faun et Fl. Fenn Foerhandl. 1868 et in Hedwig. 1867, p. 39.

F. subglobosa Wils, mss. 1869 .

In rivis et rivul. frigid. - Eur.: Fere tota : Oural, Lapon,, Scandin., Scot., Boruss., Riesengeb., Bohem, Salisb., Carinth., Francon., Alsat., Luxemb., Bade, Tirol, Bavar., Hercyn., Rhoengeb., Helvet., Alp. Sabaud., Ital., Dalmat.

Exs.: Rab. Bryoth. eur. n. 1229.

Sull. et Lesq. M. bor. am. II ed. n. 335.

var. Heldreichii Geh. - F. Heldreichii.

" var. latifolia Mille Bryol. sil. p. 276.

Ster. In stagnis. - Eur. : Borussia.

" var, laxa Milde op. et $l$. cc.

Ster. In stagn. et font. - Eur. : Siles,, Boruss: occ., Hambourg, Bade (I).

"var. montana H. Müll. Westf. Laubm. n. 378 et in Verhandl, d. nat. Ver. A. Rheinl. XXIV Jahrg., III Folge, IV Band, p. 133.

Ster. In montos. - Eur. : Westphal.

* var: ureganensis Ren, et Card. in Rev. bryol. 1888, p. 71; Card. Mon. p. 54.

Ad rad, arbor, in palud. - As. : Jenissei inf. Am. sept. : Oregon.

var. purpurascens C. M. - F. Kindbergii.

"var. rigens Ren. el Card. in Bot. Centralbl. 1890, n. 51; Card. Mon. p. 55 . Exs. : Mac. Canad. M. n. 227 p.p. Roell M. Am. n. 83, 453.

II) " Forsan spec. propria ". (Limpr. Laubm. Deutschl. II, p. 656). 
«var. rufescens Besch. Cat. M. Alger* p. 30; Card. Mon. p. 53 .

$$
\text { - Afr. : Kabyl. or. }
$$

var. Sull. et Lesq. - F. neo-mexicana.

apocarpa L. jun. - Grimmia.

arduennensis Gravet. - F. squamosa.

arvernica Ren. in Rev. bryol. 1888, p. 69 ; Card. Mon. p. 57.

F, antipyretica var, arvernica Husn. Muscol. gall. p. 286.

I. (Card.) 2 (Limpr.) ${ }^{\star}$ ign. - Eur. : Gall. centr. (Arvernia), Ticin.? Istria? (1).

baltica (Limpr.) v. Klinggr. Leberm. $u$. Lauibm. W. $u$. O. Preuss. p. 230.

F. dalecarlica var. baltica Limpr. in Schrift d. Natürf. Ges. z. Dan$z i g, 1883, N . F ., V I$ Band, I Heft.

Syn. Ad arb. et saxa subinund. - Eur. : Norveg. ? Boruss. occid.

biformis Sull. M. of U. St. p. 54 p.p. et Ic. M. p. 99, tt. 59 et 60; Lesq.

et Jam. Man. p. 270; Card. Mon. p. 72.

F. disticha var. Sull. M. Allegh. n. 191 et 192.

Pilotrichum distichum C, M. Syn. II. p. 150.

P. sphagnifolium $e j . l$. $c$.

Exs. : Aust. M. Appal. n. 245.

- Am. sept.: Ohio, Wisconssin.

Sull. et Lesq. M. bor. am. I ed. n. 226,226 b (f. vernalis) ef 226 c ( $f$. aestivalis) et II ed. n. 337 ( $f$. vernalis) et 338 (f. aestivalis).

bogotensis Hpe. in Ann. sc. nat. V ser., IV, p. 351 ; Card. Mon. p. 89.

Ster.

- Am. merid. : And. Nov. Granat. ; Peruv.?

Bovei Card. Mon, p. 110.

F. fasciculata Herb. Hort. bot. Bruxelles et hb. Boissier.

Ster.

- Afr.: Alger.

californica Sull. - F. antipyretica var. californica.

capillacea $\left\{\begin{array}{l}\text { calyoibus styli instar cuspidatis Dill. -Dichelyma capillaceum. } \\ \text { Dicks. - Dichelyma capillaceum. } \\ \text { Hook. - Dichelyma pallescens. } \\ \text { L. - Dichelyma falcatum ? } \\ \text { Scop. - Cinclidotus aquaticus. }\end{array}\right.$

Caravaeana R. Farnetii in Att. dell' Istit, bot. della R. Univ. d. Pavia, $1893, p .10, t .14$.

Ster.

- Eur. : Ital, super.

Cardoti Ren, in Card. Tabl. meth. in Rev, bryol. 1891, pp. 8.3 et $86 ;$

Card. Mon. p. 95.

2. ot ign. In rivul, - Am. sept. : Virginia.

chrysophylla Card. Tabl. meth. in op. cit. pp. 82 et 81, et Mon, p. 17.

2.

- Am. sept.: Washington.

crispa Sw. - Neckera undulata.

dalecarlica (Bryol. eur. V (mon. p. 7), t. 431 ; W. P. Sch. Syn. Il. p. 554 ; Card. Mon. p. 86.

F. 'squamosa Auct. Scand. pr. max. part.; Sull. M. of U. St. p. 54:

Drumm. M. bor. am. I ed.n. 233.

F. squamosa var, dalecalica Husn. Muscol. gall. p. 237.

(1) Cf. Limpr. Laubm, Deutschl. II, p. 657. 
F. squamosa var. Sull. M. Allegh. n. 189.

Pilotrichum dalecarlicum C. M. Syn. II, p. 149.

2. In rivul. - Eur. : Lappon., Scandin., Fennia. Am. sept. : Groenlaud, Terr, nov., Nov. Scot., New Brunswick, Ontario, Athabusca, Nov. Angl, Virgin., Carol. sept

Exs.: Aust. M. Appal. n. 251.

Husnot M. Gall. n. 674 (e Suec.).

Mac. Canad. M. n. 230.

Rab. Bryoth. eur. n. 1179.

Sull. et Lesq. M. bor. am. I ed. n. 229 et Il ed. n. 342.

var. ballica Limpr. - F. baltica.

" var. gracilescens Warnst. mss. ; Card. Mon. p. 88.

F. microphylla W. P. Sch. mss, ; v. Klinggr. Topog. Fl. W. Preuss. p. 112 .

F. seriata ej. Leberm, u. Laubm. W. u. O. Preuss. p. 229.

Ster. In stagn. - Eur.: Boruss, occ. Am. sept.: Canada.

Exs. : Mac. Can... M. n. 231.

"var. Macounii Card, in Rev. bryol. 1893, p. 9.

- Am. sept.: Reg. sept. oec.

Delamarei Ren. et Card. in Bot. Gaz. 1889, p. 96, t. 14 A; Card. Mon. p. 84.

F. squamosa eor. Fl. Ins, Miqueton, p. 49.

2. 0 ign. $\quad-A m$. sept.: Ins. Miquel.; New Jersey? Exs. : Cardot M. bor. am. n. 72 .

dichelymoides Lindb. in Oefv.... 1869, p. 76 ; Card. Mon. p. 122.

2 rariss. 1. Ad frutic. et rup. submers. - Eur.: Fennia (lae. Piojaervi). Am. sepl. : Minnesota.

Exs.: Broth. M. Fenn, n. 24.

dichelymoides Arn, et Nordst. - F, gothica.

disticha Hook. f. et Wils, in Drumm. M. bor. am. II ed. n. 151; Sull. M. of U. St, p. 54 et Ic, M. p. 103, u. 63 et 65 ; Lesq. et Jam. Man. p. 272; Carl. Mon. p. 77.

? Dichelyma distichum Myr. in Act, reg. Acad. Holm. 1832.

Pilotrichum distichum C. M. Syn. II, p. 150 p.p.

2. In rivul. - Am. sept. : Ludovic., Alabama.

Exs. : Sull. M. Allegh. n. 190, 192.

Sull. et Lesq. M. bor. am. I ed. n. 227 et II ed., n. 339 pp.

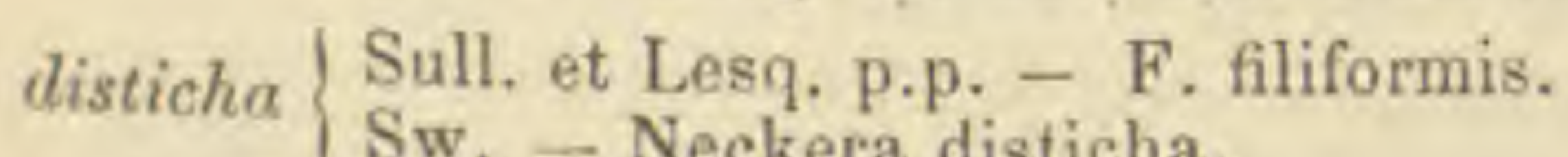

Neckera disticha.

var. tenuior Sull. - F. filiformis.

var. Sull. - F. biformis.

yar. Sull. - F. dalecarlica.

Durieui W. P. Sch. Syn. 11 ed. n. 555 ; Card. Mon. p. 111.

F. hypnoides var. Durieui Husn. Musc. gall.p. 287.

2. In font. frigid, et ad lac. - Eur: (iall. merid, Sardin., Ital. super. et centr., ins. Minore., Hispan. centr., Algarb., Graecia. Afr. : Alger., Maroc, Am. sept. : Calif.

Eatoni Sull. \{ (fid. Card.), - F. Novae Angliae var. Eatoni. ereota (fid. L. et J.). - F. antipyretica var. gigartea. ereota Vill. - Cinclidotus fontinaloides.

falcala $\begin{aligned} & \text { Hpe. - Dichelyma capillaceum. } \\ & \text { Hedw. - Dichelyma falcatum. }\end{aligned}$ 
fasciculata Lindb. in Oefv... 1869, p, 76; Card. Mon. p. 108.

F. fascicularis W. P. Sch. II ed. p. 555; Besch. Cat. M. Alger. p. 30.

Ster. - Afr. : Alger.

fasciculata $\mathrm{Hb}$. Boiss. et Braxel. - F. Bovei.

fascicularis W. P. Sch., Resch. - F. fasciculata.

filicina Sw. - Pterobryum.

filiformis Sull. et Lesq. in Lesq. et Jam. Man. p. 271 ; Card. Mon. p. 124.

F. disticha eor, M. bor. am, II ed. n. 339

F. disticha var. tenuior Sull. Io. M. p. 103, t. 64 .

2. In stagnin. - Am. sept. : Kentucky, Missouri, Illinois, Ludovic.

Exs. : Aust. M. Appal. n. 250.

" var. tenuifolia Card. Mon. p. 126.

In lac. - Am. sept.: Ludovic.

filiformis Sw. - Cryphaea.

flaccida Ren. et Card, in Bot. Gaz. 1988, p. 201, t. 19; Card.Mon.p. 118.

F. Lescurii Sull. et Lesq. M. bor. am. II ed. n. 340 p.p.

2. Ad arbor. submers, in stagn. - Am, sept. : Columb, brit., reg. or., Alabama, Judovic.

« var.? vel sp. nov.? Card. Mon. pp. 120 et 147. - Am. sept. : Ohio, Missouri.

fluitans Lam. - Hypnum.

Frostii Sull. - F. Lescurii var. ramosior.

gigantea Sull. - F. antipyretica var. gigantea.

gothica Card. et Arn. in Rev. bryol. 1891, p. 87; Card. Mon. p. 71.

F. dichelymoides Arn. et Nordstedt in sched.

2. ot fr. ign. $\quad-$ Eur. : Suec. merid.

gracilis Lindb. -- F. antipyretica var. gracilis.

gymnostoma Br. eur. - Hydropogonella.

Heldreichii C. M. in Heldr. It. Thess. n. 38 ; Kindb. in Rev. bryol. 1887,

p. 53; Card. Mon. p. 69 (1).

F. antipyretica var. alpestris Milde Bryol. siles, p. 276 ?

F. antipyretica var. Heldreichii Geh. in Fl. 1886, $n .22$.

F. antipyretica $\beta$ crassa Mdo. et Ltz. Beitr. p. 21 (2).

Ster. In rivul. - Eur. : Gall, centr. (Arvern.), Thessal.

Exs. : Heldr. Herb. Graec. norm. n. 1000.

heterophylla Lour. - Neckera.

Howei Aust. - F. Novae Angliae var. Howei.

Howellii Ren. et Card. in Bot. Gaz. 1888, p. 200, t. 18; Card. Mon. p. 66.

2. Ad rad. arbor. in palud. - Am. sept.: Washington, Oregon.

Exs. : Koell M. Am. n. 207.

hypnoides Hartm. Skand. Fl. IV ed. p. 434; Bryol. eur. V (mon. p. 8),

t. 432 ; W. P. Sch. Syn. II ed.p. 556 ; Card. Mon. p. 98. t. 432 ; W. P. Sch. Syn. II ed. p. 556; Card. Mon. p.
?. androgyna Ruthe in Hedwig. 1872, p. 166 et in Rab. Bryoth. eur.
n. 1292.

F. antipyretica Erbar. Critt. ital. n. 1103.

(2) Cf. Limpr. Laubm. Deutschl. II, pp. 654 et 656. 
F, hypnoides var, Ravaui Card. Tabl, syn, p. 83.

F. Ravaui Hy in Mem. Soc. Agric, so. es arts d'Angers, 1882 et in Husnot M. Gall. n. 776.

F. squamosa $\beta$ tenella Bryol. eur. l. $c$.

Pilotrichum Stroembackii C. M. Syn. II, p. 150.

2 (syn. in $F$. androgyna). Ad trunc. et ramul, in stagn. - Eur. : Suec,, ins. Aland, Fennia, Dania, Boruss. sept., Saxon., Austr., Carniol., Ital. sup., Gall. occ. (Armoric.) ; deest. in Britann. As. : Jenissei sup., Obi. Am. sept. : Assiniboine, Manitoba, Saskatchewan, Columb. brit., ins. Vancouver, Montana, Wyoming, Illinois. Exs. : Broth. M. Fennia n. 199.

Mac, Canad, M. n. 232.

Rab. Bryoth, eur. n. 629, $1228,1313$.

Roell M. Am. n. 1432 ad 1434, 1554, 1582, 1583.

hypnoides Sw. - Pilotrichum.

var. Durieui Husn. - F. Durieui.

" var. pungens $v$. Klinggr, Leberm, und Laubm. W. et O. Preuss, p. 228. In paludos. - Eur.: Boruss.

* var. ramosa $R$. Farnetti in Att. d. Istit. bot, d. R. Univ. di Pavia, $1893, p .9$, t. 14, f. 1-8.

- Eur. : Ital. super.

var. Ravaui Card. - F. hypnoides.

involuta Ren. et Caid. hb.; Card. Tabl. meth. in Rev. bryol. 1891, . pp. 83 et 86 et Mon. p. 96.

F. Leseurii var. ? cymbifolia A ust. M. Appol. n. 248 p.p. ?

F. squamosa Drumm. M. bor am. II ed. n. 152.

Ster. Ad rad, arb. zecus rivul. - Am. sept.: New Jersey, Ludovic. ; Florid, ?

Exs. : Cardot M. bor. am. n. 186.

islandica Card. Tabl. meth. in Rev. bryol. 1891, pp. 82 et 84 et Mon. p. 70 .

Ster. - Eur, : Island.

juliana Savi. - Conomitrium.

Kindbergii Ren. et Card. in Bot. Gaz. 1890, p. 58, t. IX A; Card. Mon. p. 62 .

F. antipyretica var. ambigua Card. Tabl. meth. l. c.p. 82.

$\mathrm{F}$, antipyretica var, cuspidata $C . M$. in Roell $M$. Am.

F. antipyretica $v a r$, purpurascens $e j . l$. $c$.

F. neo-mexicana var. robusta C. M. mss.; Roell in Hedw, 1893, p. 205.

F. subbiformis Ren. et Card. mss.

2. In stagn. et palud. - Eur. : Gall. sept. or. (Ardennes)? Ital. sept. ? Am. sept.: Columb. brit,, ins. Vancouver, reg. sept. occ., Washington, Oregon, Idaho.

Exs. ; Leiberg M. fr. Kootenai-Idaho, n. 85.

Mac. Canad. M. n. 233.

Roell M. Am. n. 84 ad 87,89 p.p., 655 ad 668,821 ad 823 , $1196,1197,1200$.

Langloisii Card. Tabl. meth. in Rev. bryol. 1891, pp. 84 et 86 et Mon. p. 126.

Ster. Ad ligna putresc, in stagn. - Am. sep $\iota$. : Ludovic.

Lescurii Sull. M. of U. St.p. 54 et Ic. M. p. 101 (excl. var. Y), t. 61; Lesq. et Jam. Man. p. 271 pp. ; Card. Mon. p. 125.

2. Ad rup. irror. $-A m$. sept.: Ontario, Alaska, Nov. Angl., reg. or.; Idaho? 
Exs. : Mac. Canad. M. n. 23! p.p.

Sull, et Lesq. M. bor. am. I ed, n. 228 et II ed. n, 340 p.p.

"var. ramosior Sull, Ic. M. p. 101, t. 62 ; Card. Mon. p. 117.

F. Frostii Sull. mss.

F. Sullivantii Lesq. et Jam. Man. p. 271.

In rivul, - Am, sept.: New Hampshire.

Lescurii $\left\{\begin{array}{l}\text { Aust. - F. Novae Angliae. } \\ \text { S. et L. p.p. - F. flaccida. }\end{array}\right.$

var. cymbifolia Aust. - F. Novae Angliae.

var. gracilescens Sull. - F. Sullìvantii.

var. $D^{n a} E$. G. Britt. - F. tenella.

longifolia C. Jensen in Bot. Not. 1885, p. 83; Card. Mon.p. 106.

Ster. - Eur. : Island.

maritima C. M. in Fl. 1887, p. 225; Card. Mon. p. 61 .

2.

- Am. sept. : Fret. S. Juan de Fuca.

mercediana Lesq. - F. neo-mexicana.

microdonta Ren. in Card. Mon. p. 120.

F. Sullivantii Card. Tabl. meth. in Rev. bryol. 1891, pp. 83 et 85 .

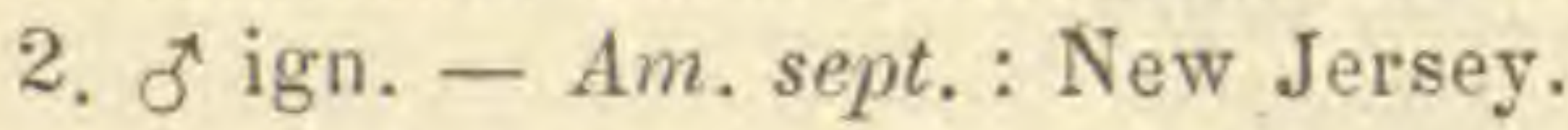

microphylla W. P. Sch, - F. dalecarlica var. gracilescens, minor L. - Cinclidotus fontinaloides.

mollis C. M. in Bol. Centralbl. 1890, n. 51 ; Card. Mon. p. 90.

2 .

Exs. : Roell M. Am. n. 292.

neo-mexicana Sull. et Lesq. M. bor. am. I ed. n. 224 b.; Sull. Ic. M.

Suppl.p. 76, t. 57; Lesq. et Jam, p. 269 ; Card. Mon. p. 59.

F. antipyretica var. Sull. et Lesq. $l$ c. II ed. $n$. 334.

F. mercediana Lesq. in Proced. Calif. Acad. I, p. 28.

2. In rivul. montan. - Am. sept. : Columb. brit., M. Rupestr., ins. Vancouver, Washington, Idaho, Montana, Colorado, Calif,, Nor. Mexic.

Exs. : Aust. M. Appal, n. 251 b.

Mac. Canad. M. n. 229.

«vir. columbica Card. Mon. p. 61.

Calif.

- Am. sept.: Columb. brit., Washington, Idahô,

Exs. : Roell M. Am. n. 661 p.p. et 1125.

var. robusta C. M. - F. Kindbergii.

nitida Lindb. et Arn. M. As. bor. 1899, II, p. 161; Card. Mon. p. 103.

2. Ad rup, et Salic. in rivul. - As.: Jenissei, Obi. Am, sept. : Columb. brit., Manitoba, Ontar.

Novae Angliae Sull. M. of U. St. p. 104 et Ic. M. p. 105, t. 65; Lesq. of Jam. Man.p. 270; Card. Mon. p. 91.

F. Lescurii Aust. M. Appal. n. 246 et 247.

F. Lescurii var, cymbifolia ej. l. $c . n .248$.

2 .

New York, Pensilv., New Jersey, Ohio, Virgin.

Exs. : Aust. M. Appal. n. 244.

Cardot M. bor, am. n. 185.

Sull, et Lesq. M. bor. am. I ed. n, 225 et II ed, n. 336. 
"var. Eatoni (Sull.) Card. in Rev. bryol. 1893, p.9.

? F. Eatoni Sull. in Sull. el Lesq. M. bor. am. I ed, n. 224 c.

- Am. sepl.: New Hampshire.

"var, Howei (Aust.) Card. in op. et l. cc.

F. Howei A ust. miss..

-- Am. sept.: New York.

- parva, foliis lanceolatis Dill. - Conomitrium Dillenii.

pennata $\left\{\begin{array}{l}\text { Huds. - Neckera pumila. } \\ \text { L. - Neckera. }\end{array}\right.$

Ravaui Hy. - F. hypnoides.

Renauldi Card. - F. Sullivantii.

secunda L. jun. - Cryphaea heteromalla.

seriata Lindb, in Act. Soc. pr. Faun. et Fl. Fenn. 1881 et in Rev. bryol. 1882, p. 85 ; Card. Mon. p. 107.

2. $\delta$ igu. Ad saxa in flumin. - Eur. : Scandin., Helvet. (Genov.).

seriata v. Klinggr. - F. dalecarlica var. gracilescens.

sparsifolia Limpr. Laubm. Deutscht. II, p. 659.

2. $\sigma^{*} \mathrm{ign}$.

- Eur.: Alp. Norveg.

squamosa L. Sp. pl. p. 1571; Brid. Bryol. univ, 1I, p. 657; Bryol. eur. V (Mon. p. 6), t. 430; W. P. Sch. Syn. 11 ed. p. 554 ; Card. Mon. p. 80.

F. antipyretica $\beta$ minor Brid. op. et $l$. cc. (fid. C. M.).

F. squamosa tenuis sericea, atro-virens Dill. Hist. $M$. p. $259, t, 33, f .3$.

F. arduennensis Gravet in Piré Nouv. rech. bryol. fasc. IV.

Hynum squamosum Neck. Meth. M. p. 192.

Pilotrichum squamosum C. M. Syn. II, p. 149.

2. In rival. frigid. - Eur. : Norveg. occ.; reg. mont. occ. et centr. usque ad Pyr. ; in Carinth., Salisb., Tirol. et Helvet. deest. ; Longobard, Corsica; Lusit. ? A fr. : Alger.

Exs. : Billot Fl. Gall, et Germ. exs, n. 587.

de Brebiss. M. de Normand. n. 52.

Durien Pl. select. Hisp. Lusit, sect. 1. Asturicae, n. 144

Gravet Bryoth. belg. n. 231 ( $f$. latifolia) et 334.

Husnot M. Gall. n. 88 et 775 ( $f$. latifolia),

Limpricht Biyoth, siles. n. 33 .

Rab. Bryoth. eur. n. 432, 630, 631 ( $p l$. mascula sub v. (s tenella. W. P Sch.), 927 (f. latifolia) et 1314.

Wils, M. Brit. n. 443.

" var. Curnowii Card. Mon. p, 84.

F. squamosa Rab, Bryoth. eur. n. 926.

- Eur.: Angl. (Cambrovall., Derbyshire).

Auct. scand. p. max, part; Sull. ; Drumm. - F. dalecarlica.

squamosa $\left\{\begin{array}{l}\text { Drumm. - F. involuta. } \\ \text { Rab. - F. involuta var. Curnovii. }\end{array}\right.$

Ren. et Card. - F. Delamarei.

tenuis sericea, atro-virens Dill. - F. squamosa.

var, dalecarlica Husn, - F. dalecarlica,

$\beta$ tenella Bryol. eur. $\rightarrow$ F, hypnoides.

subbiformis Ren. et Card. - F. Kindbergii.

subglobosa Wils, - F. antipyretica var. gracilis.

Sullivantii Lindb. in Oefv... 1869, p. 77 ; Card. Mon. p. 76.

F. Lescurii var: gracilescens sull. Io. M. p. 101.

F. Renauldi Card. Tabl. meth. in Rev. bryol. 1891, pp. 82 et 85 . 
2. Ad rad. arb. in palud. - Am. sept. : New Jersey, Pensilv.

Exs. : Aust. M. A ppal, n. 249 et Suppl. I, n. 524?

Sull. et Lesq. M. bor. am. II ed. n. 341 .

Sullivantii $\left\{\begin{array}{l}\text { Card. }- \text { F. microdonta. } \\ \text { L. et J, - F. Lescurii var, ramosior. }\end{array}\right.$

subulala P. B. - Brachelyma.

tenella Card. Tabl. meth. in Rev. bryol. 1891, pp. 83 et 85 et Mon. p. 105.

F. Lescurii var. Dna E. G. Britton in Leib. M. Kootenai. Idaho n. 137:

2. $\delta$ ign. Ad arbor. rupesq. granit. subm. - Am. sepl. : Idaho.

Exs.: Mac. Canad. M. n. 432.

Roell M. Am. n. 1242 p.p.

tenuissima Borsczovo in Rupr. Fl. bor: ural. p. 44.

- Eur. : Petchora.

triangularis $\left\{\begin{array}{c}\text { major complicata, et foliorum alis capsulifera Dill. - } \\ \text { Cinclidotus fontinaloides (fid. C. M.). } \\ \text { major complicata, el foliorum alis capsulifera Dill. - } \\ \text { F. antipyretica (fid. W. P. Sch.). }\end{array}\right.$ trifaria Voit. - F. antipy retica.

FORSTROEMIA Lindb. in Oefv... 1869, p. 75.

australis (C. M.) Par.

Lasia (1) australis C. M. in Linn. 1867-68, p. 620.

1. - Pac.: Austral. or.

« var. stricta (C. M.) Par.

Lasia australis var. stricta C. M. in op. oit. p. 621.

Ubi typ.

Borgeni (C. M.) Par.

Lasia Borgeni C. M. in Borgen M. Madag. n. 24 .

- Afi. : Madagascar.

coronata (Mont.) Par.

Lasia coronata C. M. in Linn. $1878-79, p .424$.
Leptodon coronatus Mont. in d'Orbigny Voy. Bot. crypt. p. 108 et Syll. p. 25.

Leucodon coronatus Mitt, M. austr. am. p. 409.

Neckera coronata C. M. Syn. II, p. 94.

1.

- Am. merid. : Corrientes.

\& var. tenuis (C. M.) Par.

Lasia coronata var, tenuis C. M. in Bal. Pl. Parag. n. 3669.

$$
\text { - Am. merid.: Paraguay. }
$$

flagellacea (C. M.) Par.

Lasia flagellacea C. M. in Fl. 1890, p. 487.

$$
\text { - Afr, : M. Aberdare. }
$$

fruticella (Mitt.) Par.

Lasia fruticella Mitt. in Trans. of the Linn. Soc. 1891, p. 173.

$$
\text { - As. : Japon. }
$$

(1) Nomen jam abusum : Lasia (genus Aroidearum) Lour. Fl. Cochinch. (1790; Brid. Mant. M. (1819). 
geniculata (Mitt.) Par.

Lasia geniculata Jaeg. Ad. II, p. 108.

Leucodon geniculatus Mitt. M. austr. am. p. 409.

Cortic. - Am. sept. : Jamaïc. Am. merid.: Amazon., And. Peruv., Brasil. austr. or.

incrassata (Broth.) Par.

Dusenia incrassata Broth, in Engler's Bot. Jahrb. 1894, p, 195.

1 .

- Afr.: Usambara.

indica (Mont.) Par.

Cryphaea indica Mitt. M. Ind. or. p. 125.

Lasia indica Jaeg. Ad. II, p. 108.

Neckera indica C. M. Syn. II, p. 94.

Pterogonium indicum Mont. in Ann. sc. nat. 1842, p. 250 et Syll.p. 21.

2. Cortic. - As. : Himalaya occ., M. Neilgherr. japonica (Besch.) Par.

Lasia japonica Besch. in Ann. sc. nat. p. 356.

2.

- As. : Japon.

Exs. : Faurie n. 51, 127, 240, 273, 970.

nitida Lindb. - Leptodon.

occulta (Besch.) Par.

Lasia occulta Besch. in Rev. bryol. 1885, p. 18 et in Journ. de bot. 1891. Cortic. - Am. merid. : Paraguay.

Exs.: Bal. Pl. Parag. n. 3663.

ohioënsis Lindb. - Leptodon.

paraguensis (Besch.) Par.

Lasia paraguensis Besch. Note M. Parag. p. 266.

Cortic - Am. merid.: Paraguay.

Exs. : Bal, Pl. Parag. n. 1252.

producta (Hsch.) Par.

Lasia producta Jaeg. op. et $l$. oc.

Neckera producta Hsch, in M. Capens. a Mundt et Maire lect, ; C. M. Syn. II, p. 94,

Pterogonium productum Hsch, in Linn. 1841, p. 138.

1.

Ers.: Rehm, M. Afr, C. B. Sp.

Schimperi (Wils.) Par.

Lasia Schimperi Wils, in hb. Mus. Paris.

sinensis (Besch.) Par.

- Am. sept. : Ind, occid. (sine loco spec.).

Lasia sinensis Besch. in Ann. se. nat. 1892, I, p. 72.

1.

- As. : Alp. Yunnan.

subcoronata (Besch.) Par.

Lasia subcoronota Besch. Note M. Parag. p. 266.

1. Cortic. - Am, merid. : Paraguay.

Exs. : Bal. P1. Parag. n. 1252.

" var. patens (Besch.) Par.

Lasia subcoronota var. patens Besch, op, et $l$. co.

Ut et ubi typ. 
subproducta (C. M.) Par.

Lasia subproducta C. M. in Rev. bryol. 1877, p. 43 (nom.).

- Pac. : Austral. or. (Queensland).

trichonomitria (Hedwo.) Lindb. in Oefv... 1862, p. 605.

Hypnum micropodon Brid. M. Rec. II, II, p. 151.

H. myosuroides, setis brevissimis Dill. Hist. M. p. 551, t. 85, f. 18.

H. Saladinianum Neck. Meth. p. 483.

Lasia trichomitria P. B. Prodr. pp. 25 et 72 ; Brid. Bryol. univ. II, p. 201.

Leptodon trichımitrius Mohr. l. cit.; Sull. M. Allegh. n. 88 et Ic. M. p. 112, t. 71 ; Lesq. et Jam. Man. p. 278.

Neckera trichomitria C. M. Syn. II, p. 116.

Pterigynandrum trichomitrium Hedw. Sp. M. p. 82, t. 16.

Pterogonium trichomitrium Schwaegr. Suppl. I, I, p. 107; Drumm. M. bor. am. I ed. $n .78$ et II ed, n. 92.

1. Cortic. - As,: Japon. Am. sept.: Ontario, Niagara, reg. sept., centr, et merid.

Exs. : Faurie n. 46, 217, 242.

Mac. Canad. M. n. 236.

Sull. et Lesq. M. bor. am. II ed, n, 352 .

" var. immersa Lindb. l. c.

Leptodon immersus Sull. M. of U. St. p. 57; Sull. et Lesq. M. bor. am. I ed. $n .234$.

L. trichomitrius var, immersus Sull. Ic. M. p. 112.

Ut typ. - Am. sept. : Reg. merid.

Exs. : Sull, et Lesq. M. bor. am. II ed. n. 353.

" var. irrigua (Ren.) Par.

Leptodon trichomitrius var, irriguus Ren. in Lesq. et Jam, op. et l. cc.

Ad rup. madid, - Am, sept. : Florida (1).

FUNARIA Schreb. Gen, pl, n. 1650 (64 spec.).

abyssinica W. P. Sch. in W. Sch. M. Abyss, n. 1029. - Afr.: Abyssin.

acaulis Hpe. - F. glabra.

acicularis $C$. $M$. in $F l .1886$, p. 279.

1. Terr. - ifr. : Ins. S. Thom.

aequidens Lindb, in Broth. Enum. M. Caucas, p. 32.

1. Ad terr. calcar. - As, : Caucas. centr.

americana Lindb. - F. Mühlenbergii.

androgyna Brid. - F. hygrometrica.

angustifolia Brid. - F. hygrometrica.

annulata Besch. Prodr. bryol. mexic. p. 48 ,

- Am sepl. : Mexic.

anomala Jur. in Ung. et Ky. “ die Ins. Cypern » 1885, p. 170.

austr. Afr. : Egypt. inf.

, Ins. Cypr., Syr., Taurus, Mesopotam., Pers.

aristala Broth. - Entosthodon.

(1) In Enum. Kindberg. nom. nudum;

Lisia cuspidala $E . M$. 
aristatula C. $M$. in Linn. 1878-79, p. 254.

1. Rupic. - Am. merid. : Argentin. Cordob.

attenuata Iindb. -- Entosthodon Templetonii.

Berteroana Hpe. mss. ; C. M. in Bot. Zeit. 1862, p. 327.

F. Fontanesii Bryol, eur, III (mon, p. 5) p.p.

1. Terr, - Am. merid. : Chile.

Beyrichii Hpe. Enum. M. Brasil. p. 5.

- Am. merid. : Brasil. austr. or.

bogosica C. M. in Nuov. Giorm bot. ital. 1872, p. 16.

2.

- Afr. : Alp. Abyss.

boliviana W. P. Sch, in Mandon Pl. Boliv, n. 1647.

- Am. merid. : And. Boliv.

calcarea Wahlenb. in Nov. Act. Holm. 1806, t. 4, f. 2; W. P. Sch. Syn. I ed. p. 320 et II ed. p. 382.

Bryum funarioldes Brid, Mant. M. p. 120 et Bryol. univ. II, p. 55.

F. dentata Crome Samml. deutsch. Laubm. II Nachl. n. 12.

F, hibernica Hook. in Curt. Fl. Lond. II ed. p. 371, c, ic.; Brid. Bryol. univ. II, p. 56; Bryol. eur. III (mon. p. 7), t. 304; C. M. Syn. I, p. 110 et $I I$, p. 543.

F. mediterranea Lindb. in Oefv... 1863, p. 398 et 1864, p. 598.

F. Mühlenbergii Schwaegr. Suppl. I, II, p. 78, t. 66 (quoad pl. Eur.); Brid. op. cit. p. 55 et 739 p.p.; Bryol. eur. III (mon. p. 6), t. 303; C. M. Syn. I, p. 109 et II, p. 543 p. p.; Drumm. M. bor. am. I ed. n. 236.

I. Ad rup. et mur. - Eur. : Fere tota. As. : Himalaya occ.? Mesopot,, Syr. Caucas., etc. Afr. : Septentr. tota. Am. sept.: M. Rupestr., Utah, Calif.

Exs, : Rab. Bryoth. eur. n. 308 et b, 812, 1164, 1203.

var. convexa Husn. - F. convexa.

" var, flaccida W. P. Sch. Syn. I ed. p. 320 et II ed. p. 383.

F, Mühlenbergii var. flaccida Bryol. eur. $l$. $c$.

Ut et cum typ.

" var. occidentalis Ren, et Card. in Bot. Gaz. 1890, p. 43, t. 6 c, - Am. sept. : Oregon.

"var. patula W, P. Sch, $l l . c c$.

F. Fontanesii Schwaegr. Suppl. I, II, p. 80, t. 66 p.p.; Brid. Bryol. univ. $I I$, p. 56 p.p.

F. laxissima C. M. Syn. II, p. 541 .

F. Mühlenbergii $\beta$ patula Bryol. eur. et C. M. ll. cc.p.p.

F. neglecta de Not. mss.

F. Schwaegrichenii Mdo. Bay, Laubm.p. 105.

Ut typ. - Eur.: Cum typ. Afr.: Alger. Am. merid.: Brasil.? (fid. Bridel.).

californica Sull. Ic. M. Suppl.p. 29, t. 18; Lesq. et Jam, p. 201.

1. Ad terr. argill. - Aum. sept. ; Oregon, Calif.

Exs. : Sull. et I.esq. M. bor. am. II ed, n. 238.

calvescens Schwaegr, - F. hygrometrica var. calvescens.

Campylopus Brid. - F. hygrometrica.

commutata Lindb. - Fintosthodon.

connivens C. M. in Bot. Zeit. 1855, p. 747; Mitt. M. Ind. or. p. 56.

F. hygrometrica Mont, in Perrottet M. Neilgherr, n. 42; C. M. in Bot. 1 . Zeit. $1853, p, 19$.

- As, : M. Neilgherr, Yunnan. 
convexa Spr. M. Pyr. n. 149 et in Ann. and Mag. of nat. hist. 1849, n. 197 ; C. M. Syn. II, p. 541 ; W. P. Sch. Coroll. p. 62 et Syn. II ed. p. 383 .

F. calcarea var. convexa Husn. Muscol, gàll, p. 217.

F. serrata Bryol. eur. III (mon. p. 8), t. 304; C. M. Syn. I, p. III (excl. syn. P. B).

1. Ad terr. humid. - Eur.: Gall. merid., Sardin., Hispan., Roma. As.: Minor. Afr. : Alger., Madeir.

Exs. : Mandon M. Madeir. n. 18.

Rab. Bryoth, eur. n. 409, 813.

convoluta Hpe. in Linn. 1859-60, p. 455; Lesq. et Jam. Man. p. 202.

Terr. - Am. sept. : Sierra Nevada Calif.

crispula Hook. f. et Wils. Fl. Tasì. II, p. 198, t. 175, f. 2.

F. radians Mitt. in Journ, of the Linn. Soc. 1859, p. 80.

1. Rupic. - Pac.: Tasman.

curviseta (Schwoegr.) Milde Bryol. Sil.p. 196; W. P. Sch. Syn. II ed. p. 382 .

Amphoritheca curviseta Jaeg. Ad. II, p. 696.

Entosthodon curvisetus C.M. Syn. I, p. 121: W. P. Sch. Coroll. p. 61. Gymnostomum curvatum $D^{\text {na }} F$. Mazs, Spec. bryol. Rom. I ed. p. 4.

G. curvisetum Schwaegr. Suppl, II, I, p. 17, t. 105.

G. Physcomitrium curvisetum Brid. Bryol. univ. I, p. 103.

Physcomitrium curvisetum Bryol, eur. III (mon, p. 10), t. 301.

1. Ad terr. humid. - Eur.: Normann., Francon,, reg. merid. Afr.: Alger., ins. Canar.

Exs. : Rab. Bryoth, eur, n, 429, 1032, 1392.

cuspidata Hook. F. et Wils. Fl. of the N. Zeal. II, p. 91, t. 86, f. 3 et Handb. p. 450.

$$
\text { - Pac.: Nov. Zeland. sept. }
$$

dentata Crome. - F. calcarea.

Drummondii Lindb. - Entosthodon.

Durieui W. P. Sch. mss.; Besch. Cat. M. Alg. p. 23.

1. Terr. - Afr.: Alger.

erectiuscnla Milt. M, austr, am, p. 247.

- Am. merid. : And. Chit.

fascieularis (Dicks.) W. P. Sch. Syn. II ed.p. 381.

Amphorithera fascicularis Hpe. Fl. Fl. Hercyn.

Bryum fasciculare Dicks. Fasc. III Pl. crypt. p. 3, t. 7 .

Br. serpyllifolium, pellucidum, capsulis piriformibus Dill. Hist. M. p. 315, t. $44, f .6 \mathrm{~A}-\mathrm{K}$.

Entosthodon fascicularis C. M. Syn. I, p. 120; W. P. Sch. Coroll. p. 61.

Gymnostomum fasciculare Hedw, Sp. M. p. 38, t. 4, f. 5-8.

G. Physcomitrium fasciculare Brid. Bryol. univ. I, p. 101. Bryol. eur. III (mon. p. 13), t. 301 et 637.

1. Ad terr. argill, humid. - Eur.: Sporad. per tot, aretic. except. As. : Alger.

Exs. : Rab. Bryoth, eur. n. 55, 270, 355 et b, 890.

« var. minor de Not. Epil. p, 453.

Ut typ. - Eur. : Sardin.

flavicans Rich. in Mich. Pl. bor. am. II, p. 303; Brid. Bryol. unio. II, p. 54; C. M. Syn. I, p. 108; Sull. M. of U. St. p. 50 et Ic. M. p. 87, t. 53 ; Lesq. et Jam. Man. p. 202.

Strephedium flavicans $P . B$. Prodr, pp. 25 et 89 , 
1. Ad terr. argill. humid. - Afr.: Abyssin. Am. sept.: Centr. et merid.

Exs. : Schimp. M. Abyss. n. 444.

Sull. et Lesq. M. bor. am. I ed, n. 158 et II ed. n. 240.

- var. humilis Schwaegr. Suppl. $I, I I, p .75, t .65$ (spec. duo ad dexlr. - $t a b$.$) ; C. M. l. c.$

Ut typ. - Am. sept. : Cum typ.

Fontanesii Schwaegr. Suppl, I, II, p. 80, t. 66; Brid. Bryol. univ. II, pp. 56 et 739 ; C. M. Syn. I. p. 112 p.p, et II, p. 541.

1. Terr, - Afr. : Aggyt., ins. Canar,, Madeir.

Fontanesii $\left\{\begin{array}{l}\text { Bals. et de Not. - Entosthodon Templetoni. } \\ \text { Bryol. eur. p.p. F. Berteroana. } \\ \text { Bryol. eur. et C. M. pp. - Entosthodon Mathewsii var. integer. } \\ \text { Schwaegr. p.p. - F. calcarea var. patula. }\end{array}\right.$ fuegiana C. M. - F, hygrometrica var. fuegiana.

glabra Tayl. in Lond. Journ. of bot. $1846, p .57 ;$ C. M. Syn. I, p. 112 et II, p. 542; Hook. f. et Wils. Fl. of the N. Zeal. II, p. 91 et Handb. p. 450 .

F. acaulis Hpe. in Linn. 1860, p. 624.

F, radians Mitt. in Kew Journ. bot. VIII, p. 259.

Weisia radians Hedw. Sp. M. p. 73, $t$. XIII, $f$. $1-4$ ?

Tasman.

- Pac.: Austral. or., Nov. Zeland., Nov. Caled.,

gracilescens W. P. Sch. mss, ; C. M. in Bot.Zeit. 1858, p. 154.

- Afr. : C. B. Sp.

hibernica Hook. - F. calcarea.

hybrida Ruthe mss. ; Limpr. Laubm. Deutschl. II. p. 200.

Entosthodon fascicularis $+\times \mathrm{F}$. hygrometrica $\delta^{*} \mathrm{ej} . l . c$.

Funaria ??? Bayrh. Uebers, d. M... des Taunus, p. 18.

Terr. - Eur, : Taunus.

hygrometrica (L.) Hedw. Sp. M. p. 112 ; Brid. Bryol. univ. II, $p .51$ et

738; Bryol. eur. III (mon. p. 8), t. 305; C. M. Syn. I, p. 107; W.

P. Sch. Syn. II ed. p.

Bryum bulbiforme, aureum, calyptra quadrangulari, capsulis piriformibus nutautibus Dill. Hist. M. p. 407, t. 52, f. 75 .

Br. hygrometricum Neck. Meth. M. p. 221 .

F. androgyna Brid. op. cit. p. 58.

F. angustifolia $e j$. op. et $l$. co.

F. Campylopus ej. op. cit. $p, 739$.

F. ramilicans ej. op. cit. p. 738 .

Koelrenteria hygrometrica Hedw. Fund. M. I, t. 5. f. 21-26: II, p. 95, t. $3, f . I I: t .5, f .25-26 ; t .6, f .27$ et $t .10, f .58-61$.

Mnium hygrometricum L. Spl. pl. $p .1575$.

Strephedium hygrometricum $P, B$, Prodr, $p .89$.

1. Ubique, per fere tot, terrar, orbem.

Exs, : Drumm. M. bor. am. I ed, n. 235.

Mac. Canad. M. n. 148.

Mandon, M. Madeir. n. 19.

Rab. Bryoth. eur, n. 309.

Rehm, M. Afr, austr. n. 526 et b, 527 .

Sull. et Lesq. M. bor. am. II ed. n. 241 .

* var, arctica Berggr. M. Spetsb. n. 58 el in K. Sv. Vet. Ak. Handl. $X I I I, n .7, p .57$.

Groenland.

- Eur.: Spitzberg. As.: Jenissei, Am. sept. : 
"var, calvescens Bryol. Eur. l. c. p. 9 f. $\gamma$.

F. calvescens Schwaegr. Suppl. I, II, p. 77, t. 65 ; Brid. op, cit. p. 53 et 739 ; C. M. l. c.; Bryol. jav. I, p. 31 .

- Eur.: Zon. merid. As.: Intertropic. Afr.: Ins. Canar., Abyss., reg. lacustr., Cameroon, Kilima N'Djaro, ins. Amsterdam. Am. sept.: New Brunswick, reg. centr., merid. et tropic. Am. merid.: Reg. tropic. et subtropic.

Exs.: Bal. Pl. Paraguay n. 1242, 1243, 1244.

Drumm. M. bor. am. Il ed. n, 75 .

Schimp. M. Abyss, n. 463.

Sull. et Lesq. M. bor. am. II ed, n. 242.

« var. crispa C.M. . . c.

- Am. merid. : Chil.

« var. fuegiana (C. M.) Besch, in Miss. sc. Cap Horn, Bot. V, p. 284. F. fuegiana $C . M$. in Fl. 1885, p. 396.

- Am. merid. : Fuegia.

"var, mauritiana Besch. Fl. bryol. Réunion, etc. p. 88.

In Carbonet. - Afr. : Ins. Franciae.

« var. patula Bryol. eur. et C. M. ll. cc.

F. Ravenelii Aust. in Coult. Bot. Gaz. I, p. 29.

- Eur. et Am. sept. : Locis calidior.

"var. planifolia Rehm. M. Afr. austr. n. 528.

- Afr. : Natal.

hygrometrica Mont. - F. connivens.

hygrometricoides W. P. Sch. in Mandon Pl. Boliv. n. 1648.

- Am. merid. : And. Boliv.

incompleta C. M. in Linn. 1878-79, p. 253.

1. $\quad-$ Am. merid. : Alp. Argentin. subtropic.

Jannesoni Tayl, in Lond. Journ. of bot. 1848, p. 189 ; C. M. Syn. Il, p. 540 ; Mitt. M. austr. am. p. 247.

- Am. merid. : And. Quitens.

jujuiensis C. M. in Linn. 1878-79, p. 256.

1. Muric. et terr. - Am. merid. : Argentin. subtropic.

laevis Mitt. M. austr. am, p. 248.

Terr. - Am. merid. : And. Quitens, et Peruv.

laxissima C. M. - F. calcarea var. patula.

leptopoda Griff. Not. p. 437; Mitt. M. Ind. or. p. 56.

F. nepalensis C. M. in Bot. Zeit. 1855, p. 748.

- As. : Nepal., Khasia, Java.

* var. gemmacea Besch. in Ann. sc, nat. 1892, 1, p. 61.

Terr. - As. : Alp. Yunnan.

linearidens $C$. $M$. in Linn. 1878-79, p. 25:2.

$1 . \quad-A m$. meril. : Argentin. subtropic.

lonchopelma C. M. in Rehm. M. Afr. austr. n. 181 et 525.

- Afr. : C. B. Sp., Transvaal.

Lorentzi C. M. in Linn. 1878-79, p. 256.

Syn. $\quad$ - Am. merid. : Argentin. Cordob.

mediterranea Lindb. - F. calcarea. 
meeseacea C. $M$. in op. cit. $1880-83, p .357$.

- Am. merid. : Argentin. subtropic.

megalostoma Mitt. M. austr. am. p. 246.

- Am. merid. : And. Peruv.

mexicana Duby in Mém... Genève, $1869, p .12, t . I I, t .2$.

2.

- Am. sept. : Mexic. or.

microstoma Bryol. eur. III (mon. p. 9) t. 306 ; C. M. Syn. I, p. 106.

1. In gla reos. humid. et ad rup. quartz. - Eur.: Angl. Normann., Helvet., Rhaet., Tirol., Bavar., Carinth., Engad., Boruss. or., Delphinat., Galloprov., Ital. super.

mucronata Hartm. in Fries Summ. veg. Scand. p. 88; C. M. Syn. I, p. 112 (nom.).

- Eur. : Norvegia.

Mühlenbergii Schroaegr. Suppl. I, II, p. 78, t. 66 pp.; Brid. Bryol. univ. II, p. 55 p.p. ; C. M. Syn. I, p. 109 (omnes quoad pl. americ.); Lesq. et Jam, Man. p. 201.

F. americana Lindb. in Oefv... 1863, p. 398 et 1864, p. 597.

- As. : Himalaya occ. (fid. Mitt. M. Ind. or. p. 56 ;

an potius F. calcarea?). Am. sept. : Pensilv.

Mühlenbergii Bryol, eur., Drumm. - F. calcarea.

var. flaccida Bryol, eur, - F. calcarea var. flaccida.

var. patula Bryol, eur. - F. calcarea var. patula.

neglecta de Not. - F. calcarea var. neglecta.

nepalensis C. M. - F. leptopoda.

obtusa Lindb. - Entosthodon ericetorum.

obtusata W. P. Sch. in C. M. Syn. II, p. 540.

- Am. sept. : Mexic.

obtusifolia Weissm. Syll. M. p. 438; C. M. Syn. I, p. 108.

- As. : Sibiria (fret. Sinjawin.).

orizabensis C. M. in Linn. 1874, p. 621 .

Terr. cale. - Am. sept. : Mexic.

orthocarpa Mitt. M. Ind. or. p. 56.

Entosthodon orthocarpus Jaeg. Ad. I, p. 50I. 1 .

- As. : Tibet occ.

pallescens W. P. Sch. in W. Sch. M. Abyss.

papillata Hpe. in Linn. $1876, p .302$.

- Afr. : Abyss. 1.

- Pac. : Austral. or.

physcomitrioides Mont, in Ann. sc. nal. 1841, p. 253 el Syll.p. 38 ; C. M. Syn. I, p. 111 p.p. et $I 1$, p. 543.

Entosthodon physcomitrioides Mitt, M. Ind. or. p. 55. 1.

- As. : M. Neilgherr.

physcomitrioides C. M. p.p. - F. subnuda.

plagiostoma C. M. in Bot. Zeit. 1855, p. 748.

1. Arenic - Afr.: C. B. Sp.

pulchella Philib. in Rev. bryol. 1884, p. 41 et in Husn. Muscol gall. p. 217.

Syn., rar. 1. Muric. - Eur.: Gall, centr. (Ardèche). 
palchricolor C. M. in Linn. 1878-79, p. 251.

1 .

- Am. merid.: Argentin. subtropic.

(Br. et Sch. - Entosthodon curvipes var, robustior.

radians $\left\{\begin{array}{l}\text { Mitt. (Linn. Soc.). - F, crispula. } \\ \text { Mitt. (Kew Journ.). - F, glabra, }\end{array}\right.$

ramificans Brid. - F. hygrometrica.

ramulosa (Hpe.) Par.

Amphoritheca ramulosa Hpe. Symb. p. 1874, p. 480.

1.

- Am. merid. : Brasil, austr. or.

Ravenelii Aust. - F. hygrometrica var. patula.

riparia Lindb. Manip. M. I, 1870, p. 58.

Amphoritheca riparia Angstr. Prim. lin. p. 16.

1. In aren, humid. - Am. merid. : Brasil, austr. or.

Sartorii C. M. in Linn. 1874, p. 620.

- Am. sept. : Mexic.

saxicola Hpe. - Thiemea Hampeana .

Schnyderi C. M. in Linn. 1880-83, p. 356.

Muric. - Am. merid. : Argentin. Buenos Ayr.

serrata P. B. in Brid. Mant. M. p. 124 et Bryol. univ. II, $\mu .124$;

C. M. Syn. II, p. 542; Sull. Ic. M. p. 89, t. 54; Lesq. et Jam. Man.

p. 201.

1. Ad terr, argill, et rup, aren, humid. - Am, sept. : Reg. merid.

Exs, : Drumm. M. bor. am. II ed. n. 76.

Sull. M. Allegh. I ed,, n. I26.

Sull. et Lesq. M. bor. am. II ed, n. 239.

serrata Bryol, eur. - F. convexa.

Smithhurstii Broth. et Geh. - Entosthodon.

sorotensis P. Sch. in Mandon Pl. Boliv. n. 1647 bis.

- Am. merid.: And. Boliv.

spathulata W. P. Sch. in Breutel M. capens.

- Afr.: C. B. Sp.

sphaerocarpa C, M. in Bot. Zeit. 1851, p. 546.

1. Ad rup. marit. - Pac. : Austral. felix, Tasman., ins. Lord Howe.

suberecta Mitt. M. austr. am. p. 248.

- Am. merid. : And. Quitens.

subleptopoda Hpe. in Linn. 1874, p. 207.

- Afr. : Madagascar.

subnuda Tayl. in Lond. Journ. of bot. 1846, p. 57; C. M. Syn. II, p. 542.

F. physcomitrioides C. M. Syn. I, p. 111 p.p.

- Pac. : Austral. or,

tasmanica Hpe. et C. M. in Linn. 1853, p. $490 ;$ F. v. Müller Austral.
M. t. 1.

- Pac. : Tasman.

Templetoni Engl. Bot. - Entosthodon.

tenella C. M. in Linn. 1878-79, p. 248. 
usambarica Broth. - Entosthodon (1).

FUSCINA Schrank Baiers Tl. II.

bryoides Schr. - Fissidens.

glauca Schr. - Leucobryum.

heteromalla Schr. - Dicranella.

purpurea Schr. - Ceratodon.

sciuroides Schrank. - Leucodon.

scoparia Schr. - Dicranum.

simplex Schr. - Dicranella varia var. tenella.

taxifolia Schr. - Fissidens.

trichomanoides Schr. - Homalia.

FUsiconia P. B. in Mém. Soc. Linn. Par, $I, t, 7, f .5$.

androgyna P, B, - Aulacomnium.

GAGEA Raddi Nuov. Raccolt.

compacta R. - Zygodon Forsteri ?

GARGKEA C. M. in Bot, Zeit 1845, p. 865 (4 spec.).

Bescherellei C. M. in Besch. Fl. bryol. Réunion, etc. p. 51.

2.

- Afr.: Ins. Borbon., Mayotte, Nossi-Be.

Hildebrandti C. M. in Fl. 1886, p. 510 et in Hildebr. M. Mad. n. 2061.

2.

- Afr.: Ins. Nossi-Re.

Mcenkemeyeri C. M. in op. cit. p. 509.

2. Terr. - Afr.: Old Calabar.

phascoides (Hook.) C. M. in Bot. Zeit. 1845, p. \$65 et Syn. 1, p. 421;

Dz. et Mk. M. frond, ined. Archip. ind. p. $180, t .59 ;$ Mitt. M. Ind. or.

p. 8; Bryol.jav. I, p. 92.

Dicranum phascoides Hook. Misc. bot. 1830, I, p. 39, t. 21.

Grimmia comosa $D z$. et $M k$. in Ann. sc, nat. $1844, I I, p .304$.

Gr. flexuosa Griff. Not. p. 412 et Ic. pl. asiat. II, p. 79, f. 3.

Weisia flexuosa Hpe, in sched.

2. Terr. - As. : Penins, ind., Pegou, Sumatra, Java, penins. Malay., Tonkin or.

"var. gracilis C. M. in Jaeg. Acl. I, p. 226.

- As. : Arracan.

GAROVAGLIA Endl. Gen. n. 590 (31 spec.).

acuminata (Hook.) Par.

Endotrichum acuminatum Jaeg. Ad. II, p. 137.

Meteorium acuminatum Mitt. M. Ind. or. p. 86.

Neekera acuminata Hook. M. ex. t. 151 ; Brid. Bryol. univ. II, p. 236; 2 ? C. M. Syn. II, p. 95 .

angustifolia Mitt. - Endotrichella.

(1) In Enum. Kindb. nomina nuda :

F, cuspidatissima $C$. $M$.

subserrata (Rehm.).

Taylori Lindb, (an Entosthodon apophysatus?). 
aristata Bryol. jav. II, p. 80, t. 195.

Endotrtchum aristatum Jaeg. Ad. II, p. 135,

2. Arbor, - As.: Borneo, ins. Bima.

Aurantium (C. M.) Par.

Endotrichum Aurantium Jaeg. Ad. II, p. 136.

Pilotrichum Aurantium C. M. in Linn. 1869-70, p. 26.

Ster. - As. : Ceylan.

austro-caledonica Besch. Fl. bryol. Nov. Cal. p. 226.

Endotrichum austro-caledonicum Jaeg. Ad. II, p. 135.

$$
\text { - Pac. : Nov. Caledon. }
$$

Bauerlenii (Geh.) Par.

Endotrichum Bauerlenii Geh. Neue Beitr, zur Moosf, v, N, Guin., p. 4.

Ster. - Pac. : Nov. Guin. littor.

brisbanica (C.M.) Par.

Endotrichum brisbanicum C. M. in Rev. bryol. 1878, p. 59 (nom.).

- Pac. : Australia or. (Queensland).

Campbelliana Jaeg. - Endotrichella.

earinata Mitt. in Journ. of the Linn. Soc. 1872, p. 314.

Endotrichum carinatum Jaeg. Ad. II, p. 136.

- As. : Bhotan.

compressa Mitt, in op, et l. cc.

Endotrichum compressum Jaeg. Ad. II, p. 135.

- As. : Borneo.

cuspidata Mitt. - G. setigera.

densifolia Thw, et Mitt. in Journ. of the Linn. Soc. 1872, p. 310.

Endotrichum densifolium Jaeg. $l$. c. - As. : Ceylan.

Dietrichice Mitt. - Endotrichella.

Duseni C. M. in Dusen M, Camer, n. 289.

- Afr.: M. Cameroon.

elegans (Dz. et Mk.) Hpe. mss. ; Bryol. jav. II, p. 81.

Endotrichum elegans $D z$, et Mk. in Ann. sc. nat. 1844, p.303et M. frond. ined. Archip. ind. $I, t .2$.

Pilotrichum elegans C. M. Syn. II, pp. 159 et 674 .

2. Arbor. - As. : Ins. Bima, M. Java, Sumatra.

flexipes (Mitt.) Par.

Endotrichum flexipes Jaeg. Ad. II, p. 137.

Meteorium flexipes Mitt. M. Ind. or. p. 85 .

- As. : M. Neilgherr., Ceylan.

Foulkesiana (Milt.) Par.

Endotrichum Foulkesianum Jaeg. l. c.

Meteorium Foulkesianum Mitt, $l, c$.

2

- As. : M. Neilgherr.

frondosa (Mill.) Par.

Endotrichum frondosum Jaeg. $l$. $c$.

Meteorium fror.dosum Mitt. op. cit. p. 86.

2 .

- As. : Ceylan. 
hamata (C. M.). Par.

Endotrichum hamatum Jaeg. Ad. II, p. 136.

Pilotrichum hamatum C. M. in Linn. 1869-70, p. 26.

Ster,

- As. : Ceylan.

laevifolia Thro, et Mitt. in Journ. of the Linn. Soc. 1872, p. 313.

Endotrichum laevifolium Jaeg. Ad. II, p. 135.

- As. : Ceylan.

lanceolata (Wright) Par.

Endotrichum lanceolatum Wright in Lond. Journ. of bot. 1892, p. 263.

- As. : Borneo.

lepida Mitt. - Endotrichella.

moluccensis Bryol. jav. $I I, p .82, t .196$.

Endotrichella moluccensis Jaeg. Ad. II, p. 134.

2. Arbor. in silv. - As, : Ins. Ceram.

mucronata Mitt. - Euptychium.

Mülleri (Hpe.) Mitt. in Trans, and Proced. of the roy. Soc. of Victoria, $1883, p .80$.

Endotrichum Mülleri Hpe. in Linn. 1876, p. 318.

2.

- Pac. : Austral. tropic, or.

nematosa (C. M.) Par.

Endotrichum nematosum Jaeg. Ad. II, p. 726.

Meteorium nematosum C. M. in Fl. 1878, n. 6.

Ster.

- As. : Pegou.

obtusifolia Thro, et Mitt. in op. et l. cc.

Endotrichum obtusifolium Jaeg. Ad, II, p. 135.

- As. : Ceylan.

patentissima Hpe. in Linn. 1874, p. 219.

Endo richum patentissimum $C, M$, in Abhandl. Brem. VII, p. 209.

2.

- Afr, : Madagascar.

- var, brevis (C. M.) Par.

Endotichum patentissimum var, brevis $C . M . l$. $c$.

$$
\text { - Afr. : Madagascar. }
$$

plicatu (Nees) Endl. Gen. p. 57, n. 590; Bryol. jav. 11, p. 29.

Cryphaea plicata Nees mss.

Endotrichum densum Ds. et Mk. in Ann. sc. nat. 1844, p. 303 et M. frond. ined Archip. ind. $I, t, I$.

E. plicatum Jaeg. Ad. II, p. 135.

Esenbeckia plicata Brid. Bryol. univ. II, p. 751.

Meteorium plicatum Mitt. M. Ind. or. p. 84 .

Neckera plicata Schwaegr. Suppl. III, II, I, t. 268.

Pilotrichum plicatum $C, M$, Syn. $I I, p .158$.

2. Cortic. L As. : Himalaya or., Sumatra, Java, ins. Ceram.

Powellii Mitt. Sam. M. p. 169.

Endotrichum densum Sull. in Exped. Wilkes, p. 20?

E. Powellii Jaeg. Ad. II, p. 136.

Pilotrichum Powellii C. M. M. Polyn. p. 75.

Arbor. - Pac. : Ins. Samoa.

robusta Mitt. - Euptychium.

samoana Mitt. - Endotrichella. 
scabriuscula (Mitt.) Par.

Endotrichum scabriusculum Jaeg. Ad. II, p. 137.

Meteorium scabrisculum Mitt. M. Ind. or. $p, 85$.

2.

- As. : M. Concan, Ceylan.

Schmidii (C, M.) Par.

Endotrichum Schmidii Jaeg. Ad. II, p. 138.

Meteorium Schmidii Mitt, op. cit. p. 91.

Neckera Schmidii C. M. in Bot. Zeit. 1854, p. 571.

2.

- As. : M. Neilgherr., Ceylan.

sciuroides Mitt. - Cladomnium.

setigera (Sull.) Mitt, Fl. Vit. p. 396.

Endotrichum setigerum Sull. in Exped. Wilkes, p. 20, t. 18 B.

Euptychium cuspidatum Mitt. in F. von Müller's Fragm. Phyt. Aus. tral. XI, Suppl, p. 114.

E. neo-caledonicum W. P. Sch. ? (fid. Mitt. in Journ. of the Linn. Soc. 1867, p. 170).

G. cuspidata Mitt. in Lond. Journ. of bot. 1856, p. 263.

Meteori'm setigerum ej. in Bonplandia, 1861, p. 366.

Pilotrichum setigerum Sull. in Proced. Am. Acad. Januar. 1854.

- Pac. : Ins. Fidji, Austral. (Queensland, Victoria).

simplex C. $M$. in Dusen M. Camer. n. 444.

- Afr. : M. Cameroon.

taïtensis Besch. in Ann. sc. nal. 1894, p.

Cyrtopus taitensis W. P. Sch, in sched.

2. Ad arbor. - Pac. : Taïti.

tortifolia Mitt. in Journ. of the Linn. Soc. 1872, p. 314.

Endotrichum tortifolium Jaeg. Ad. II, p. 136.

- As. : Borneo.

Wightii (Mitt.) Par.

Endotrichum Wighti Jaeg. Ad. II, p. 137.

Meteorium Wightii Mitt. M. Ind. or. p. 85.

- As. : Nepal., Rangoon.

Gasterogrimmia W. P. Sch. Syn. II ed. p. 202 (subgen. Grimmiat).

GEHEFBIA W. P. Sch. Syn, 11 ed. p. 233 (2 spec.).

cataractarum W. P. Sch, l, c.

Barbula gigantea Funk in sched.

B. nivalis Jaeg. Ad. I, p. 279 (fid. A. Gepp).

B. recurvifolia Mitt. M. Ind. or. p. 34 .

B. robusta Sendtn. in sched.; Rab. Deutsch, krypt. Fl. II, III, p. 116.

B. squarrosa Ltz. Beitr, p. 13.

Dicranum speciosum Saut. mss. : Rab, op. et $l$. co.

Didymodon giganteus Jur. Laubm. Oesterr. Ung. p. 102.

G. gigantea Boulay Musc. Fr. p. 39 o.

Grimmia gigantea W. P.Sch. Syn. I ed., p. 695.

Schistidium apocaspum Wils. in Kew Journ. bot. IX, p. 323.

Tortula fallax $e j$. in op, cit. $p .322$.

T. gigantea Lindb. Trichost. Eur. p. 42.

T. vinealis var. glacialis Spr. M. Pyr. n. 185 .

Trichostomum rubellum $\beta$ spectabile Rab. op. et $l$, cc.

2. $\delta^{t}$ et ir. ign. Ad rup, irror. cataract. - Eur. : Hibern.? Scot., Vales., Tatra, Bavar., Alp., Pyren. As, : Sikkim., Tibet.

Exs. : Rab. Bryoth. eur. n. 317, 1126.

Un. itin. 1863 , n. 39 . 
gigantea Boul. - G. cataractarum.

Mülleri Par.

Barbula geheebiopsis C. M. in Engler's Bot. Jahrb. 1883, p. 80 et in Forchungsreise... p. 23.

Ster.

- Afr. : Ins. Kerguelen.

GENTHIA Bayrh. in Jahresber. d. Ver. f. Naburk. in Herzogt. Nassau, 1849, Heft V, p. 2.

patens B. - Physcomitrella.

GEORGIA Ehrh, in Hannov. Mag. 1780, p. 931.

Brovoniana C. M. - Tetrodontium

var. repanda Lindb. - Tetrodontium repandum.

geniculata Lindb. - Tetraphis.

Mnemosymon Ehrh. - Tetraphis pellucida.

pellucida Rab. - Tetraphis.

repanda $\mathrm{C}$. M. - Tetrodontium.

GIGASPERMUM Lindh. in Oefy.... 1864, p. 599 (4 spec.).

Breutelii (C. M.) Par.

Leptangium Breutelii Jaeg. Ad. II, p. 71.

Physcomitrium Breutelii C. M. in Bot. Zeit. 1855, p. 749.

1.

imbricatum (Mitt.) Par. - Afr. : C. B. Sp.

Leptangium imbricatum Mitt. M. austr. am + p. 240

Terr. - Am. merid. : Brasil., Montevideo.

repens (Hook.) Lindb. in op. et $l$. cc.

Anoectangium repens Hook. M. ex. p. 8, t. 106.

Hedwigia repens H. f. et W. Fl. of the N. Zeal. II, p. 92 et Handb. p. 424 ; Fl. Tasm. II, p. 178.

Physcnmitrium repens $C . M$. Syn. $11, p_{+} 544$.

Schistidium repens Brid. Bryol, univ. I, p. 120.

1. Terr. - Pac. : Austral. occ. et or., Nov. Zeland., Tasman.

tumidum (Mitt.) Lindb. in op. et $l$. cc.

Leptangium tumidum Mitt, in Trans, and Proced. of the roy. Soc. of Victoria, 1883, p. 66.

- Pac. : Tasman.

Girgensohnia Lindb, Contr, ad fl. crypt. As, bor. or. 1872, p. 249 (sect. Climacir).

GLAUCODJPSIS $K$. Sch.

frigida K. Sch. - Leucobryum glaucum.

Glossophyllu C. M. Syn. II, p. 229 (sect. Hrpsi); Hpe. Enum. M. Brasil. p. 59, (gen, propr.).

Spec. omn. Strkeophylia ejusd. nom.

GLYPHOGARPUS (sub Glyphocarpa) R. Br. in Apn. Soc. Linn. Lond. XII, p. 575 (I8 spec). abysinicus Jaeg. - Anacolia. 
aristarius C. M. in Rehm. M. Afr. austr. n. 184 et $b$

$$
\text { - Afr. : C. B. Sp. }
$$

* var. plumosus C. M. l. c. n. 185.

$$
\text { - Afr, : Natal. }
$$

asperrimus Hpe. - Bartramia Hampeana.

Baueri Hpe. - Anacolia.

Breutelii Jaeg. - Bartramidula Breuteliana?

capensis $\mathrm{R}$. Br. - Gl. sericeus.

cernuus Wils, - Bartramidula Wilsoni.

chrysurus (C. M.) Par.

Bartramia chrysura C. M. in Engler's Bot. Jahrb. 1833, p. 79 et in Forchungsrerse... p. 19

B. pendula Mitt, in Journ, of the Linn. Soc. 1876?

Ster.

- Afr.: Ins. Kerguelen.

" var, elongata (C. M.) Par.

Bartramia chrysura var, elongata C.M. l. c.

- Afr: : Cum typ.

«var, nigrescens (C.M.) Par.

Bartramia chrysura var, nigrescens $C . M . l$. $c$.

$$
\text { - Afr. : Ibid. }
$$

comosus (Hpe. et C. M.) Hpe. in Jaeg. Ad. I, p. 526.

Bartramia comosa IIpe. et C. M. in Bot.Zeit. 1859, p. 221.

Exs. : Rehm, M. Afr. austr. n. 188.

compactus (Hsch.) Jaeg. Ad. I, p. 523.

Bartramia compacta Hsch. Hor. Phys. Berol. p. 63, t. 13; C. M. Syn. I,

B. Krausei Bryol. eur. IV (mon. p. 10), $t$.

B. stricta Schuaegr. Sp. M. p. 104.

Arb. et terr. - Afr.: C. B. Sp.

curtus Hpe. - Bartramidula.

cygnoeus Jaeg. - Bartramidula.

erectus Hpe. in Linn. 1876, p, 305.

Bartramidula Hampei Mitt in Trans, and Proced, of the roy. Soc. Victoria, $1883, p .68$.

- Pac. : Austral. or.

exiguus Jaeg. - Bartramidula.

Glasiovii Hpe. - Bartramidula.

humilis (Mitt.) Jaeg. l. c.

Bartramia humilis Mitt. M. austr. am. p. 270.

Phascum Jamesoni Tayl. in Lond. Journ. of bot. 1848, p. 187; C. M. Syn. II, p. 518. Syn.

- Am. merid. : And. Nov. Granat. et Quitens.

humilis Rehm. - Gl. Mac-Leanus.

Hymenodon C. M. in Rehm. M. Afr. austr, n. 186.

$$
\text { - Afr. : C. B. Sp. }
$$

insertus (Sull.) Jaeg. Ad. I, p. 524.

Bartramia inserta Sull. in Proced. Am. Acad. 1859, p. 279.

2. Ad rup. vertic. humid. $-A f r$. : C. B. Sp. 
intertextus W. P. Sch. - Anacolia.

Krausei Jaeg. - Bartramidula.

laevisphaerus (Tayl.) Par.

Bartramia laevisphaera C. M. Syn. I.p. 506.

B. subsessilis Tayl. in Lond. Journ. of bot. $1847, p .334 ; C, M$. op, c. p. 507; Mitt. M. austr. am.p. 268.

G1. laevispharrus Tayl, in op. cit. 1846, p. 56; Jaeg. Ad.1, p. 526.

Gl. subsessilis Jaeg. Ad. $I, p, 524$.

Gl. Taylori Hpe. in Ann. sc. nat. V ser..., III, p. 370.

2 ?

- Am. merid. : And. Nov. Granat. et Quitens.

Lindigii Hpe. - Bartramidula.

Mac-Leanus Par.

Gl, humilis Rehm. M. Afr. austr. $n$. 530 .

$$
\text { - Afr. : C. B. Sp. or. }
$$

marionensis Mitt. in Voy. H. M. S. Challenger, Bot. IV, p. 199.

Bartramia quadrata ej. in Journ. of the Linn. Soc. XV, p. 70.

Ster. Rupic.

- Afr. : Ins. Marion.

Menzieaii Jaeg. - Anacolia.

mexicana Jaeg. - Anacolia.

microdonta (Mitt.) Jaeg. Ad. I, p 527.

Bartramia microdonta Mitt. M. austr. am. p. 263.

Ad rup. humid. - Am. merid. : Brasil.

patulus Jaeg. - Bartramidula.

pseudo-comosus Rehm. M. Afr. austr. n. 190.

$$
\text { - Afr.: Orange. }
$$

pusillus $\mathrm{H}$. f, et W. - Bartramidula.

quadratus (Hook.) Brid. Bryol. univ. 11, p. 92.

Bartramia quadrata C. M. Syn. I, p. 503.

Gymnostomum quadratum Hook. M. ex. $t .122$.

2. Ad rup. madid. - Afr.: C. B. Sp.

Roylei Hook, - Bartramidula.

rostratus Hpe. in sched.

$$
\text { - Fac. : Alp. Austral.. }
$$

Scioanus Brizzi in Annuar. d. roy. Istit. bot. d. Roma, 1893, V. fasc. 2.

1 ? Ad terr. humid. - Afr. : Lit. occ. mar. Erythr.

sericeus (Hsch.) Jaeg. Ad. 1, p. 524.

Bartramia sericea Hsch. in Hor. Phys. Berol, p. 63, t. 13; C. M. Syn. I, p. 502.

G1. capensis R. Br. in Trans, of the Linn. Soc. XII, p. 575; Brid. Bryol. univ. II, p. 91 .

Gymnostomum capense Hook. M. ex. t. 165.

Syn. Arbor. - Afr. : C. B. Sp.

retifolius Jaeg. - Anacolia.

strumosus Hpe. in Linn. 1863, p. 139.

Syn. $\quad-$ Am. merid.: And, Nov, Granat.

subsessilis Jaeg. - GI. laevisphaerus.

Taylori Hpe. - Gl, laevisphaerus. 
Webbii Mont. - Anacolia (1).

GLYPHOMITRIUM Brid. Mant. M. p. 31 et Bryol. univ. I, p. 267 (5 spec.).

Omn. spec. non indicatae Pтүсномiтria ejusd. nom. canadense Mitt. in Journ. of the Linn. Soc. VIII, p. 21; Lesq. et Jam. Man. p. 158. 1. - Am. sept. : Columb, brit.

Daviesii (Dicks.) Brill. op. et ll. cc. ; Bryol. eur. III (mon. p. 3), t, 230; C. M. Syn. I, p. 766 ; W. P. Sch. Syn. II ed. p. 292.

Bryum Daviesii Dicks. Fasc. II Pl. crypt. p. $3, t .7, f .6$.

Encalypta Daviesii $S m$. Fl, brit. III, p. 1188 .

Griflithia Daviesii $R, B r$, in Trans, of the Linn. Soc. XII, II, p. 375.

Grimmia Daviesii Turn. Museol. Hib. p. 24.

1. Ad rup. marit., proecip. basalt. et granit. - Eur. : Britann., Norveg. occ.

Exs.: Rab. Bryoth. eur. n. 1161.

Drummondii (Hook. f. et Wils.) W. P. Sch. op. et l. cc. (nom.).

Brachysteleum Drummondii C. M. Syn. I, p. 770.

Grimmia Drummondii $H$. $f$. et W. in Lond. Journ. of bot. 1842, III, p. 90. $t .3$ et $I V, p .422, t .25 \mathrm{~B}$.

Ptychomitrium Drummondii Sull. M. of U. St. p. 36 et Io. M. p. 65, t. 40; Lesq. et Jam. Man p. 157.

1. Arbor. - Am. sept.: Tennessee, Virgin. merid.

Exs. : Drumm. M. bor. am. Il ed, n, 30.

Sull, et Lesq. M. bor. am. II ed. n. 196.

Krausei W. P. Sch, in Breut. M. Capens.

$$
\text { - Afr. . C. B. Sp. }
$$

latifolium Broth. in Oefv. af Finska Vet.-Soc. Foerh. 1895, p. 58.

Ster. Rupic. - Pac, : Tasman.

parasiticum Brid. - Calymperes.

pulvinare Mitt. - Ptychomitrium nigricans.

rugosum Mitt. - Ptychomitrium nigricans.

saxicola Mitt. - Campylosteleum.

serratum Mitt. $\left\{\begin{array}{l}\text { (pl. Am.). - Ptychomitrium. } \\ \text { (pl. Tasm.). - Ptychomitrium Mittenii. }\end{array}\right.$

GLYPHOTHECIUM Hpe. in Linn. 1859, p. 637?

Müllerianum Hpe. - Cladomnium.

Gomphoneuron C. M. in Linn. 1888-79, p. 310 (sect. PotTIAE).

GONIOBRYUM Lindb. in Oefv... 1864, p. 606.

? retrculatum Lindb. - Rhizogonium.

subbusilare Lindb, - Rhizogonium.

(1) In Enum. Kindb, nomina nuda :

G]. pilulifer C.M.

subhumilis (Rehm.) (an Gl. Mac-Leanus ?), 
GONIOMITRIUM $H$. f. et W. in Lond. Journ. of bot. 1846, p. 142, t. 3. acuminatum $\mathrm{H}$. f. et W. - Physcomitrium Goniomitrium. enerve eor. - Physcomitrium.

Goniostoma Mitt. M. austr, am. p. 198 (sect. MacromitriI).

Gracilaria C. M. Syn. $1, p .751$ (sect. Schlotheimiae).

GRIFFITHIA $R$. Br. in Trans, of the Linn. Soc. XII, II, p. 375.

Daviesii R. Br. - Glyphomitrium.

GRIMMIA Ehrh. Beitr. I, p. 176 (193 spec.).

abyssinica Br. et Sch. in W. Sch. M. Abyss, n. 435.

Gümbelia abyssinica Hpe. in Bot. Zeit. 1846, p. 24; C. M. Syn. I, p. 772.

1 (Mitt.). 2 (C. M.). -Afr.: Abyss., M. Cameroon.

acicularis C. M. - Rhacomitrium.

aciphylla W. et M. - Pottia lanceolata var, aciphylla.

acuta $\mathrm{Sm}$. - Blindia.

aethiopica C. M. in Bot. Zeit. 1855, p. 795.

Gr. Hoffmanni ej. Syn. I, p. 780 p.p.

Schistidium pulvinatum Br, et Sch, in W. Sch. M. Abyss.

1. Rupic. - Afr.: Summ. Alp. Abyssin.

affinis Bryol. germ. - Gr. ovata var. affinis.

Lindb. - Rhacomitrium heterostichum var, alopecurnm.

var, macrocarpa Bryol germ. - Gr. ovata var. affinis.

var. ramosissima Bryol. germ, - Gr, ovata var, affinis.

africana $\left\{\begin{array}{l}\text { de Not. - Gr. orbicularis. } \\ \mathrm{Hpe} \text { - Gr. pygmaea. }\end{array}\right.$

Agassizii (Sull. et Lesq.) Lesq. et Jam. Man. p. 136.

Schistidium Agassizii S. et L. in Sull. M. of U. St. p. 101.

1. Ad rup. irror. - Am. sept. : Ontario, lac. Super.

Exs. : Sull. et Lesq. M. bor. am. I ed, n. 137 et 11 ed. n. 203. albida Spreng. - Gr. campestris.

alpestris Schleich. Cent. II pl. Helv. n. 13; Bryol, eur. III (mon. p. 27), t. 251 ; W. P. Sch. Syyn. Il ed. p. 265.

Dicranum piliferum Schleich. l. c. n. 12.

Dryptodon pulvinatus $\gamma$ alpestris Brid. Bryol. univ, $1, p .198$.

Gr. lamellosa C. M. in Bot. Zeit. 1854, p. 318.

Gr. Ungeri Jur. (fid. Jaeg. Ad. II, p. 765).

Gümbelia alpestris Hpe. in Bot. Zeit. 1846, p. $124 ;$ C. M. Syn. I, p. 772.

Trichostomum pulvinatum $\beta$ alpestris W. et M. Bot. Taschb. p. 110.

2. Ad mur. et rup. sicc. - Eur. : Alp. omn., calcar except. As.: Caucas. occ. et centr, Am. sept.: fraspes., M. Rupestr. et Selkirk, Columb. brit, Oregon, Utah.

Eoss. : Mac Canad. M. n. 414.

- var. subimberbis Berggr. in K. Sv. Vet. Ak. Handl. XIII, n. 7, p. 49.

Gr. arctica $C$. M. ?

Gr. sulcata $\beta$ subimberbis Lindb. in Oefv... XXIII, p. 552.

Ut typ. - Eur. : Spitzberg. Am. sept.: Groenland. 
var. microstoma Bryol. eur. - Gr. subsulcata.

var. Ungeri Husn. - Gr. Ungeri.

alpestris Rab, - Gr. subsulcata.

alpestris hybrida Chalubinski p.p. $\left\{\begin{array}{l}\text { - Gr. sessitana. } \\ \text { - Gr. subsulcata. }\end{array}\right.$

alpestris mutica de Not. - Gr. sulcata.

alpicola Sw. - Gr. apocarpa var, alpicola.

var. helvetica Brid. - Gr. apocarpa var, helvetica.

var. maritima Wahlenb. - Gr. maritima.

alpina Kindb. Enum. Bryin. Dovre in Christiania Vid. Sels. Forh. 1888, $n .6$.

$$
\text { - Eur.: Norvegia. }
$$

ambigua Sull. Ic. M. I. p. 66, t. 41 ; Lesq. et Jam. Man. p. 135.

Gümbelia ambigua C. M. Syn. I, p. 649.

Schistidium ambiguum Sull. in Mem, of the Am. Acad... 1849, p. 170 et M. of U. St. p. 36 .

1. Ad rup. sicc. - Am. sept. : New Jersey, Pensilv., Nov. Mexic. amblyophylla $C . M$. Syn. $I, p .779$.

Gr, apocarpa var. H. f. et W. in sched. M. antarct. p.p.

1. $-A f r$. : Ins. Kerguelen. Am. merid.: Ins. Eremitae, fret. Magellan.

anceps Boul. (1) $\left\{\begin{array}{l}\text { - Gr. sessitana? (Husn.) ! (Limpr.). } \\ \text { - Gr. Ungeri? (W. P. Sch.). }\end{array}\right.$

ancistroides $\left\{\begin{array}{l}\text { Lesq. - Gr. Watsoni. } \\ \text { Mont. - Gr. trichophylla var. meridionalis. }\end{array}\right.$

andina Mitt. M. austr. am. p. 97.

Ad sax. aquat. - Am. merid. : And. Quitens.

andreaaecea C. M. in Linn. 1880-83, p. 453.

Ster. $\quad-$ Am. merid.: Argentin, subtropic.

andreaaeoides Limpr. Deutschl. Laubm. p. 776.

2. $\sigma^{t}$ et fr, ign. Rupic. - Eur. : Tirol., Pinzgov.

andreaaeopsis C. M. in Bot. Centralbl. 1883, n. 2-4.

Ster.

- As.: Penins. 'Tschutschica.

angustifolia Mitt. op. et l. cc.

I. Rupic. - Am. merid.: Summ. M. Pichincha.

anodon Bryol. eur. III (man. p. 8), t. 286; C. M. Syn. I, p. 780 et II, p. 655 ; W. P. Sch. op. cit. p. 245.

Anodon ventricosus Rab. Deutsch. Krypt. Fl. II, III, p. 154.

Anoectangium flaccidum de Not. Mant. M, ad ft. Pedem. p. 46 ?

Gr. alpina ( $f$ ld. Limpr.;

Schistidium pulvinatum Brid. Bryol. univ. $I, p, 114$ p.p.

1. Ad rup. aridiss et mur. calcar. - Eur.: Palatin., Francon., Siles., Tatra, Carinth., Salisb., Stir., Austr. inf., Tirol., Helvet., Gall. merid., Pyren. As.: Tibet occ., Kurdistan., Persia. Afr.: Alger. Am. sepl, : New Brunswick, Columb. brit., Nevada, Idaho, Montana, Utah, Colorado, Calif.

Exs. : Mac. Canad. M. n. 89.

Rab. Bryoth. eur. n. 319 a, 1011. 
\& var. sinaitica Ren. et Card. in Bull. hb. Boissier, 1894, p. 33. - As. : M. Sinaï.

anomala Hpe. in W. P. Sch. op. cit. p. 270.

Ster. Rupic. - Eur. : Valesia, Algov.

apiculata Hsch. in Fl. I, p. 85 et II, p. 443; Brid. Bryol. univ. I, p. 186 ; Bryol. eur. III (mon. p. 13), t. 241; C. M. Syn. I, p. $791 ;$ W. P. Sch. op. cit. p. $23^{i}$.

1. Ad rup. silic. humid. - Eur.: Alp. Norveg., Salisb., Rhaet., Tatra, Stir., Garinth., Tirol., Sabaud. (Mont Blanc); Voges,? Helvet. apocarpa (L.) Hedro. M. frond. I, p. 104, t. 39; Brid. Bryol. univ. I, p. 167; C. M. Syn. 1, p. 776; W. P. Sch. Coroll. p. 45 et op. cil. p. 242 .

Bryum apocarpum L. Sp. Pl.p, 1579.

Br. apocaulon Hoffm. Deutsch. Fl. II, p. 30.

Dicranum? phascoideum P. B. Prodr. p. 54 ; Brid. Bryol. univ. I, p. 467 ?

Fontinalis apocarpa L. jun. Meth. M. p, 366.

Gr, apocarpa $\beta$ apocaulos Brid. op. cit. p. 169.

Gr. apoearpa $\xi$ floribunda ibid. p. 170.

Gr. apocarpa var. stricta Drumm. M. bor, am. I ed. n. 55.

Gr. apocaulos DC. Fl. fr. I, p. 458.

Gr. fasciculata Brid. Mant. M. p. 33 .

Gr. fusca Bryol. germ. II, I, p. $120, t .19$ p.p.

Gr. polyodon Ehrh. Beitr. p. 169.

Gr. robusta Bryol. germ. II, I, p. 120, t. 20.

Gr. strigosa Brid. Bryol. univ. I, p. 171 .

Gr. Torreyana ibid, $p, 172$.

Schistidium apocarpum Bryol. eur. III (mon. p. ) ), t. 233.

Sphagnum subhirsutum obscure virens, capsulis rubellis Dill. Hist. $M$. p. $243, t .32, f .4$.

1. In mur., sax., tectis, etc., rar, ad arb. in toto fere terr. orb., tropic. except. - Eur. : Spitzberg, ins. Parry, Ursor, etc. As.: Obi, Jeniss., Japon., Caucas. Syr., etc. Afr.: Alger., C. B. Sp., ins. Kerguelen, etc. Am. sept.: Groenland, Labrador, fret. Yehring, tota extratropic. Am. merill. : Ins. Eremit, fret. Magellan. Pac. : Austral. or., Nov. Zeland, Tasman, Taïti.

Escs. : Mac. Canad. M. n. 85.

Rab. Bryoth. eur, n. $280,840$.

Rehm. M. Afr. austr. $13 \mathrm{I}, 494 \mathrm{~b}$.

Sull, et Lesq. M, bor, am. II ed, n. 198.

var. alpicola (Szo.) Hook, in Tayl. Musc. brit. p. 87; W. P. Sch. il. $c c$.

Gr. alpicola Sw M. Suec. pp. 27 et 8I, t. I, f. I; Brid. Bryol. unie, I, p. 165.

Gr, alpicoia $\beta$ helvetica Brid. Mant. M. p. 33 et op. cit. p. 166.

Gr. helvetica Schk. Deutseh. M. p. 48, t. 21.

Schistidium alpicola Limpr. Deutsehl. Laubm. I, p. 707.

Sch. apocarpum var. alpicola Rryol. eur. $l$, c. $t$. 234.

Ad rivul, zon. sept. - Eur. : Spitzberg, ins. Ursorum, elc. Am. sepl. : Groenland, Alaska.

Esss, : Rab. Bryoth. eur. n. 1255.

var. apocaulos Brid. - Gr. apocarpa.

var. atro-fusca Husn. - Gr. atro-fusca.

*. var. auresiana Besch. Cat. M. Alger. p. 16.

Ut typ. - Afr. : Alger. (M. Aurès).

var. conferta C. M. - Gr. conferta. 
\& var. filiformis Lindb. in Oefv.... XXIII, p. 552.

Gr. tenera Zett. M, et Hepat. Finmarck in Oefv... 1870 et in Rev, bryol. 1876, p. $95(1)$.

- Eur.: Spitzberg. Am. sept.: Groenland.

var. floribunda Brid. - Gr. apocarpa. .

" var. gracilis (Schleich.) Schk. Deutsch. M. p. 47, t. 21, f. 3; C. M. et W. P. Sch. ll. cc.

Gr. apocarpa var. Schleicheri Brid. Mant. M. p. 33 et Bryol, unio, I, p. 169 .

Gr. apocarpa var. stricta Mitt. M. Ind. or. p. 43.

Gr. gracilis Schleich. Cent. III Crypt. Helv. n. 14; Bvid. op, eit. p. 170,

Gr. Scheicheri Spreng. Einleit. in d. Stud. d. Krypt. Gew, p, 277, t.7, f. 59 .

Gr. stricta Turn. Muscol. Hib. p. 20, t. 2, f. I.

Gr. trichodon Brid. op, cit. p. I7I.

Schistidium apocarpum var, gracile Bryol. l. et t. co.

Sch. gracile Limpr. Deutschl. Laubm. I, p. 705.

Ut typ. - Eur. : Reg. mont. et subalp., præcip. calc. As. : Himalaya, Caucas, occ, et centr. Am. sept.: New Brunswick, Gaspes., lac. Super., M. Rupestr., Columb. brit., Oregon, Idaho, Calif., Terr. nov., reg. or.

Exs. : Mac. Canad. M. n. 86.

Sull. et Lesq. M. bor. am. II ed. n. 199.

Un, itin. 1867 , n. 94.

" var. latifolia Berggr. M. Spetsb, n, $4 \mathrm{l} c$ el in K. Sv. Vet, Ak. Handl. $\mathrm{X} 111, n .7, p .48$.

Rupic. - Eur: : Spitzberg, Scandin. sept. Am. sept. : Groenland.

var. mutica $\mathrm{H}$, f, et W. - Gr. mutica.

var. pilifera Brid. - Gr. pilifera.

var. platyphylla Lindb. - Gr. platyphylla.

var. pruinosa Husn. - Gr. pruinosa.

" var, pumila W. P. Sch. Syn. II ed, p. 243.

Ut typ. - Eur. : Alp. precip, zon. septentr.

"var. rivularis (Schwaegr.) Schk. l. c.f. m. n.; C. M. (excl. syn.) et W. P. Sch, ll. cc.

Gr, apocarpa Diumm, M. bor, am, I ed, n. 54 .

Gr, rivularis Schwaegr. Suppl. I, I, p. 96, t. 23; Bvid. Bryol. univ, I, p. 166.

Schistidium apocarpum var, rivulare Bryol, eur, l. et t. ce.

Ad rivul. in sax, sce. submers. - Eur. : Passim. Am, sept.: Groenland, sin. Hudson, New Brunswick, Gaspes., lac. Super., reg. sept. occ., M. Rupestr., Columb., ins. Vancouver, Washington, Oregon, Idaho, Wyoming, reg. sept.

Exs. : Mac. Canad. M. n. 87.

Rab. Bryoth. eur. n. 857.

Sull. et Lesq. M. bor. am. II ed. n. 200.

var. Schleicheri Brid. - Gr, apocarpa var, gracilis.

" var, stricta C, M. in Relem. M. Afr. austr. n. 132.

$$
\text { - Afr.: Orange. }
$$

var. stricta $\left\{\begin{array}{l}\text { Drumm. - Gr. apocarpa. } \\ \text { Mitt. - Gr. apocarpa var. gracilis. }\end{array}\right.$

var. H. f. et W, - Gr. amblyophylla. 
epocaipa $\left\{\begin{array}{l}\text { Drumm. }-\mathrm{Gr}_{\mathrm{r}} \text { apocarpa var. rivularis. } \\ \text { Mitt. (18;6), - Gr. serrato-mucronata. }\end{array}\right.$

apocaulos DC. - Gr. apocarpa.

apophysata Hpe. in Jaeg. Ad. I, p, 344 (nom.).

- As. : Sikkim.

aquatica C. M. - Rhacomitrium protensum.

arborea Schrank. - Cryphaea heteromalla.

arctica C. M. in Koldewey's Nord-Pol. Exp.p. 73.

Gr. sulcata $\beta$ subimberbis Lindb.?

-Eur, : Kaiser Franz Joseph's Fjord.

arcuata de Not. - Rhacomitrium patens.

arcuatifolia Kindb, in Bull. Torr. bot. Club, 1889, p. 93.

Ster. Rupic. - Am. sept.: Ins. Vancouver.

arenaria Hpe. - Gr. curvula.

argyrotricha $C . M$. in Fl. 1890, p. 485.

Ster.

- Afr. : Kilima N'Djaro.

Arizonae Ren. el Card. in Rev, bryol, 1892, p. 85.

2.

- Am. sept. : Arizona.

arvernica Philib, - Gr. plagiopodia var. arvernica.

asperula Sanio. - Gr. elatior var. asperula.

aterrima C. M. - Rhacomitrium.

atrata Mielich. et Hsch, in Bot. Zeit. II, p. 85; Brid. Bryol. univ. I, p. 184; Bryol. eur. III (mon. p. 30), ı. 261; C. M. Syn. I.p. 803 ; W, P. Sch, op. cit. p. 269.

Dryptodon atratus Limpr. Deutschl. Laubm. I, p. 791.

2. Ad rup. schist. et talcac. humid. - Eur. : Norveg. (ster.), Nordland., Scol., Cambrovall., Pyren., Alp. Salisb., Stir., Carinth., Tirol., Helvet.; Sabaud. (Mont Blane)?

atrata Drumm. - Gr. unicolor.

atricha C. M. et Kindb. in Mac. Cat. p. 65.

1. Ad rup. decompos. - Am. sepl. : Columb. brit.

atro-fusca W. P. Sch. op. cit. p. 240.

Gi. apocarpa var, atro-fusca Husn. Muscol. gall, p. 123.

Schistidium atro-fuscum Limpr. Deutschl. Laubm. I, p. 713.

1. Rupic. - Eur.: Helvet. (M. Righi), Tirol., Stir., Salisburg.

abro-virens $\mathrm{Sm}$, - Barbula.

aurasia Besch. Cal. M. Alger. p. 17.

$$
\text { - Afr. : Alger. (M. Aurés). }
$$

austro-leucophaea Besch. in Bull. Soc. bot. Fr. 1885, p. LX et in Miss. se. Cap Horn, V, Bot. p. 271.

- Am. merid. : Fuegia.

austro-patens C. M. - Rhacomitrium austro-georgicum.

basaltica Milt, in Handb. of the N. Zeal. Fl. p. 425.

1. Ad rup. basalt. - Pac.: Nov. Zeland. med.

bifrons de Nol, Cron, d. Briol, ital. el Epil. p. 702.

- Eur.: M. Sardin. centr.

bohemica Schk. - Gr. Doniaira. 
brachyodon. Aust. - Gr. montana var. brachyodon. Brandegei Aust. - Gr. plagiopodia vav. pilifera.

brevisela Lindb. et Arn. - Rhacomitrium.

Brotheri Lindb. in Broth. Euzm. M. Caucas. p. 89.

2. Ad saxa silic. - As, : Caucas. occ.

Browniana Engl. Bot. - Tetrodontium.

brunnescens (Limpr.) Par.

Schistidium brurnescens Limpr. Deutsehl. Laubm. I, p. 714.

1. Ad rup. calcar. - Eur: : Austria infer.

caespiticia Jur. - Gr. sulcata.

caffra Rehm. M. Afi. austr. n. 130.

- Afr.: Orange.

calcarea Sm. - Seligeria.

californica Sull. in Bot. Pac, R. R. Survey (Whipple), p. 187, 1. 4; Lesq. el Jam. Man. p. 142.

2. Rupic. - Am. sept. : Oregon, Calif.

Exs. : Sull. et Lesq. M. bor. am. II ed. n. 205, 206.

californica Mac. - Gr. trichophylla.

callosa Hpe. et C. M. in Linn. 1853, p. 498.

1.

- Pac. : Austral. felix.

calotricha C. $M$. in Linn. $1880-83, p .454$.

Ster.

- Am. merid. : Argentin. Cordob.

calyculata C. $M$. in Fl. 1884, p. 414 et $1890, p .484$.

2. $\quad-A f r .:$ Kilima N'Djaro.

calyptrata Hook. in Drumm. M. bor. am. 1 ed. n. 60; Sull. Ic. M. p. 69,

t. 44; Lesq. et Jam. Man. p. 144.

Coscinodon Hookeri Hpe. in Jaeg. Ad. 1, p, 377.

Gümbelia calyptrata C. M. Syn. I, p. 775 et $I I, p .650$.

2. Ad rup. sicc. - Am. sepl.: M. Rupestr., Columb. bril., Idaho, Montana, Kansas, Nov. Mexic., Calif.

Exs. : Sull. et Lesq. M. bor, am. I ed. n. 139 et 11 ed. n. 211.

Camonia Rota Cal, M. Bergom, ; de Not. Epil. p. 755.

Ad rup. humid. - Eur. : Ital. sup. (M. Tonale).

campestris Burch. in Hook. M. ex. t. 129 ; C. M. in Bot. Zeil. 1854, p. 164.

Dryptodon campestris Hook, in Brid. Bryol. univ. I, p. 774.

Gr. leucophaea C. M. Syn. I, p. 794 p.p.

Gr, albida spreng. Syst. Veg. IV, II, p, 321.

2.

Exs. : Rehm. M. Aft. austr. n. 135 et 497.

canpylotricha C. $M$. in Fl. $1888, p: 414$.

Ster.

- Afr. : Kilima N'Djaro.

canariensis W. P. Sch. in IIusn. M. Can. n. 181ª.

- Afr. : Ins. Ganar.

canescens $\{$ C. M. - Rhacomitrium.

var. ericoides B. M. - Rhacomitrium canescens var. ericoides.

capillata $\left\{\begin{array}{l}\text { de Not. - Gr. crinita var. elongata. } \\ \text { Mœnch. - Ulota crispa. }\end{array}\right.$ 
catenulata W. et M. - Pseudo-Leskea.

caucasica C. M, in Bot. Zeit. 1856, p. 421 .

2.

- As. : Caucas.

cavifolia Linclb, et Arn. M. As. bor. 1890, II, p. 103.

2. Ad rup. granit. -- As, ; Jenissei sup.

cernua Bryol, germ. - Gr. funalis.

chloroblasta Kindb, in Mac. Cat. p. 64.

Gr. coscinodontes ej. in Bull. Torr. bot. Club, XVII, p. 271.

1. Ad rup. sicc. - Am. sept.: Columb. brit.

Exs. : Mac. Canad. M. n. $41 \epsilon$.

chlorocarpa Mitt. - Rhacomitrium.

chrysoblasta C. M. - Rhacomitrium.

chrysoneura C. M. in Engler's Bot. Jahrb. 1853, p. 80 et in Forchungsreise...p. 25.

1. Rupic. - Afr. : Ins, Kerguelen.

cinclidodontea C. M. in Bot. Centralbl. 1890, n. 51.

1. Ad rup. irror. - Am, sept.: Washington.

cirrata $\mathrm{Sm}$. - Dicranoweisia.

coloradensis Aust. in Coult. Bot. Gaz, II, p. 109; Lesq. et Jam. Man. p. 143.

1. - Am. sept. : Colorado.

commutata Hüb. Muscol. germ. p. 185; Bryol. eur. III (mon. p. 25), t. 256 ; W. P. Sch. op. cit. p. 263.

Bryum brevicaule Yill. Pl. Dauph. III, p, 871.

Br. ovale Hoffin. Deutsch. Fl. I1, p, 35.

Campylopus curvifolius Brid. Mant. M. p. 78.

C. ovatus ej. op. cit. p. 76 .

Dicranum durum Lag. Ann. d. Ciene. nat. IV, p. 177.

D, ovale Hedre. Sp. M. p. 140.

D. ovatum ej. $M$. frond. III, p. 8I, $t$. 3I.

Dryptodon curvifolins Brid. Bryol. unit. T, p. 201.

Dr. ovatus ej. op. cit. p. 202.

Gr. elliptica Funk Moostachb. p. 16, t, II,

Gr, incana o Wils. in Kew Journ. bot. IX, p. 323 (quoad n. 281).

Gr, ovalis Lindb. M. Soand. p. 30.

Gr. orata H. et T. Musool. brit. p. 39, t. 13.

Gümbelia elliptica Hpe in Bot. Zeit. 1846, p. 124.

G. nvalis C, M. Syn. I, p, 774.

Trichostomum ovatum W. et M. Bot. Tasehb. p. 110.

2. Ad rup. quarz. et porphyr. sicciss - Eur. : Reg. campestr. et mont. infer., arctic. except. As. : Kashmir, Himalaya, Tibet, Kurdistan., Pers., Caucas, Af : : Alger., Madeir, Am. sept.: M. Rupestr., Columis. brit., Idaho, Wisconssin, Calif.

Exs, : Mac. Canad, M. n. 509.

Mandon M. Mad. n. 8 bis.

Rab. Bryoth. eur. n. $56^{\circ}, 680,1129,1320$.

commutata $\left\{\begin{array}{l}\text { Mae. p.p. - Gr. ovata. } \\ \text { Wils. - Gr. khasiana. }\end{array}\right.$

comosa Dz, et Mk. - Garcksa phascoides.

compacta Schleich. - Dieranoweisia.

Conferruminata Wallr. in Limn. 1840 , p. 683 ; C. M. Syn. I, p. 809.
Ster.

- Eur, : Hêrcyn. 
conferta Funk Moostaschb. p. 18, t. 12; W. P. Sch. Coroll. p. 45 el op. cil. p. 239.

Gr. apocarpa $\delta$ conferta C. M. Syn. I, p. 777.

Gr. fusca Bryol. germ. I1, I, p. 120, t. 19 p.p.

Gr, glacialis eor, p. 119 .

Gr. latifolia Brid, Bryol. univ. I, p. 162.

Schistidium confertum Bryol. eur. III (mon. p. 7), t. 232 ,

1. Rupic. - Eur. : E reg. campestr. usq. in alp. As.: Pers., Cancas. occ. et centr. Afr.: Abyss. Am. sept. : Anticosti, Nov. Seot., New Rrunswiek, Gaspesia, Ontario, Athabasca, M. Rupestr., Columb. brit., Washington, Idaho, Wyoming, reg. sept. et or.

Ess. : Mac. Canad. M. n. 84 .

Rab. Bryoth. eur. n. 562.

Sull. et Lesq. M. bor. am. II ed. n. 201.

"var. compacta Lesq. el Jam. Man. p. 135.

Ut typ. - Am. sept. : Lac. Super.

« var. obtusifolia W. P. Sch. Syn. I ed.p. 200 et $1 I$ ed.p. 240.

Ut typ. - Eur.: Loc. umbros. humidior. Am. sept.: M. Rupestr., ldaho, reg. sept. or.

Exs. : Sull, et Lesq. 1. c. n. 202.

var. pruinosa Braithw, - Gr. pruinosa.

« var, urceolaris (Bryol. germ.) W. P. Sch. Il. cc.

Gr. urceolaris Bryol. germ. II, I, p. 121.

Ut et cum proced. in Eur.

comata Kaulf. - Pottia lanceolata.

conostoma $\mathrm{Sm}$. - Conostomum boreale.

consobrina Kze. in Poepp. Pl. Chil.; C. M. Syn. I, p. 785.

2.

- Am. merid. : And. Chil. austr.

contermina C. M. - Rhacomitrium.

contorta (Wahlenb.) W. P. Sch. ll. cc. pp. 209 et 252.

Campylopus contortus Brid. Mant. M. p. 74.

Dicranum contortum Waklenb. Fl. Carpath. p. 348, $t .4$.

Dryptodon contortus Brid. Bryol. univ. $I, p .199$.

Gr. incurva Sehwaegr. Suppl. $, 1,1$, p. 90, t. $97 ;$ C. M. Syn. I, p. 788.

Gr. uncinata Kaulf. in Sturm Deutsch. Fl. erypt. faso. 15; Bryal. eur. III (mon. p. 19), t. 248.

2. Ad saxa silic. - Eur. : Spitzberg, Lappon., Norveg. or., Scot.. German. centr., Sudet., Carpath., Voges., Arvern., Pyren., Larum. As.: Caucas. oce. et centr. Am. sept. : Groenland, Columb. brit., Calif.

Exs. : Rab. Bryoth. eur. n. 1205.

controversa W. et M. - Weisia viridula.

convoluta C. M. - Rhacomitrium.

coscinodontes Kindb. - Gr, chrysoblasta.

Cossoni Besch. Cat. M. Alger, p. 18.

$$
\text { - Afr. : Alger. }
$$

erassa C. M. in Jaeg. Ad. Ip. 360.

$$
\text { - Afr. : C. B. Sp. }
$$

crassa Spreng. - Barbula muralis var. incana.

crassifolia Lindb. in Broth. Enum. M. Cauc. p. 84.

Ster. Ad rup. calcar. - As. : Caucas, occ. 
crassinervia (C. M.) Par.

Gr, maritima Mao. Canad. M. n. 88.

Gümbclia crassinervia C. $M$. in Bot. Centralbl. 1890, n. 51 .

1.

Vancouver.

- Am. sept.: Columb. brit., fret. Buhring, ins.

cribrosa Hedw. - Coscinodon pulvinatus.

crinita Brid. Mant, M. p. 32 et Bryol. univ. I, p. 163; Bryol, eur. III (mon. p. 10), t. 237 ; W. P. Sch. Syn. II ed. p. 246.

Gümbelia crinita Hpe, in Bot. Zeit. 1846, p. 124; C. M. Syn, I, p. 771.

Gymnostomum decipiens W. et M. Bot. Taschb.p. 79.

1. In cemento calc. mur. - Eur. : Proecip. merid, - Afr, : Alger.

Exs. : Rab. Bryoth, enr. n. 50, $5 i 1$.

c var. elongata W. P. Sch. Syn. I ed. p. 205 et $I I, p, 247$.

Gr. capillata de Not. Mant. M. ad Fl. Pedem. p. 40.

Ad mur, humidior. - Eur. : Gall, merid., Sardın. Afi, : Alger.

var. Garov. - Gr. tergestina.

crinito $\vec{x}$ lencophaea Card. in Rev. bryol. 1890, p. 18.

Ad rup. granit. - Eur. : Gall. centr. (Arvern.).

crispa Roth. - Weisia viridula.

crispata $\left\{\begin{array}{l}\text { Hook. - Ptychomitrium. } \\ \text { Roth. - Rhabdoweisia fugax. }\end{array}\right.$

crispatula $H_{p e}$. et C. $M$. in Linn. 1853, p. 499.

2. Ad sasa irror. - Pac. : Austral. or.

crispipila C. M. - Rhacomitrium.

erispula $\left\{\begin{array}{l}\text { C. M. - Rhacomitrium. } \\ \text { Sm. - Dicranoweisia. }\end{array}\right.$

cucullatifolia Mitt. - Rhacomitrium.

cupularis C. M. in Engler's Bot. Jahrb. 1883, p. 80 et in Forclungsreise...

p. 26.

1. Rupic. - Afr.: Ins. Kerguelen,

curvirostris W. et M. - Didymodon rubellus.

carvula Bryol. eur. III (mon. p. II), t. 238; W. P. Sch. Syn, II ed. p. 249.

Gr. arenaria Hpe. in Linn, 1835-36, p. 404; C. M. Syn. I. p. 784.

Gr. incurva Schleich, in sched.

Gr. Zahlbríckneri Garov. Bryol. austr, p. 26.

1. Ad rup. schist. et aren. - Eur.: Hercyn., Carinth,, Tirol., Helvet.

Gall. occ., Pyr., Ital super.

Exs, : Rab. Bryoth, eur. n. 614.

curvula Husn. (M. Gall.). - G. orbicularis var. longipila.

eyathocarpa (Hpe.) Par.

Gimbelia cyathocarpa Hpe, in Linn. 1874, p. 515.

2. Ripar. videtur. - Pro. : Austral. or.

cygnicolla Tayl. - Gr. pulvinata var. obtusa.

cylundrica Bryol. germ, - Gr. ovata var. cylindrica.

W.et M. - Anomodon longifolius.

Daviesii Turn. - Glyphomitrinm.

decipiens Lindb. - Gr. Schultzii.

densa Kindb. - Gr. depilata. 
defoliata C. M. in Engler's Bot. Jaherb. 1883, p. 81 et in Forchungsreise... p. 29.

Ster. Rupic. - Afr.: Ins. Kerguelen.

depilata Kindb. in Mac. Cat. p. 69.

Gr. densa ej. in Bull. Torr. bot. Club, XVII, p. 271.

2. Rupic. - Am, sepl. : Ins. Vancouver.

depilis C. M. Syn. I, p. 778 .

1.

$$
\text { - Afr. : C. B. Sp. }
$$

depressa C. M. in Fl. 1885, p. 421 .

2. Cortic. et lignic, - Am. merid.: Euegia.

« var. terrestris C.M. l. c.

In glareos, marit. - Ani. merid. : Ibid.

Dicksoni Sm. - Dicranoweisia cirrata.

didyma Mont. - Rhacomitrium.

Doniana Sm. Fl. brit. III, p. 1198 ; W. P. Sch. Coroll. p. 48 et op cit. p. 259.

Gr. bohemica Schk. in Brid. Bryol. univ. I, p. 176.

Gr, obtusa Schwaegr. Suppl. I, I, p. 88, t. 25; Brid Bryol. univ. I. p. 174; B, yol. eur. III (mon. p. 20), t. 249; C. M. Syn. I, p. 796.

1. Ad rup. quarz. - Eur. : E reg. mont. super. usq. in supraalp. praecip. zon. interm, et sept. : Spitzberg. As. : Penins. Tschutschica, Kamschatka, Caucas. or. Am. sepl. : Alberta, Washington, Idaho, M. Alb.

Exs.: Rab. Bryoth. eur. n. 371 et b, 858, 1316.

Sull. et Lesq. M. bor. am. Il ed. n. 216.

a var. curviseta Lesq. et Jam. Man. p. 142.

- Am. sept. : M. Cascade, Calif.

"var. elongata W. P. Sch. ll. cc.

Gr. obtusa var. elongata Bryol. eur. $l$. $e$.

Ut et cum typ. in Eur.

"var. sudetica W. P. Sch. ll. cc.

Gr. Doniana Brid. op. cit. p. 175.

Gr. obtusa vas: sudetica Bryol eur, $l$. c.

Gr. Doniana Schwaegr. l. c. p. S7.

Ut et cum typ. in Eur.

Doniana Brid. - Gr. Doniana var. sudetica.

Drummondii H. f. et W. - Glyphomitrium.

dura C. M. - Rhacomitrium.

Duseni (C. M.) Par.

Gümbelia Duseni C. M. in Dusen M. Camer. n. 320.

$$
\text { - Afr. : M. Cameroon. }
$$

Eckloni Spreng. Syst. veg. IV, II, p. 321 ; C. M. Syn. I, p. 787.

1. Saxic. - Afr.: C. B. Sp.

Exs. : Rehm. M. Afr, austr. n. 133, 491.

elatior Bryol. eur. III (mon. p. 17), t. 245; C. M. Syn. I, p. 798; W. P.

Sch. op. cit. p. 258.

Dryptodon incurvus Brid. Bryol. univ. I, p. 194.

Gr. Iunalis var, robusta de Not. Syll et Epil.

Rhacomitrium incurvum Hüb. Muscol. germ, p. 201.

Trichostomum fnnale Isch. Crypt. Cent. I, Dec, 4,

Tr. incurvum ej. in Fl. 1819, p. 89. 
2. Ad rup. quarz, - Eur, : Scandin., Alp. Helvet,, German., Pyren.; deest in Britann., Voges., Silva Nigra. As.: Obi, Alatau, Caucas. occ. et centr. Am. sept. : Groënland, M. Rupestr.

Exs. : Rab. Bryoth. eur. n. 618 et b.

Un. itin. 1863, n. 34 .

elliptica $\left\{\begin{array}{l}\text { C. M. - Rhacomitrium. } \\ \text { Funk. - Gr. commutata. }\end{array}\right.$

elongata Kaulf. in Sturm Deutschl. Fl. crypt. II, p. 15 ; Brid. Bryol. univ. I, p. 179; Bryol. eur. III (mon. p. 28), t. 259; C. M. Syn. I, p. $792 ;$ W. P. Sch. op. cit. p. 268.

Gr. orientalis Wils, in Kew Jowrn. bot. IX, p. 323.

Gr, sessitana Rab. Bryoth, eur. n. 117.

2. Ad rup. humid. -- Eur. : Scot., Alp. Norveg., Stir., Rhœe., Sabaud.

(M. Blanc), Vall. Tell., Tirol. merid, As.: Sikkim, Caucas, occ. Ams, sept. : Groenland.

Exs.: Rab. Bryoth, eur, n, 616.

" var, patula Bryol. eur., C. M. et W. P. Sch.ll. cc.

Ad rup. sicc. - Eur. : Alp. Tirol.

emersa C. M. - Rhacomitrium.

ericoides Brid. - Rhacomitrium microcarpon.

Lindb. - Rhacomitrium canescens var. ericoides.

var. canescens Lindb. - Rhacomitrium canescens.

var, robusta Lindb. et Arn. - Rhacomitrium canescens var, robusta.

falcata Hook. f. et Wils, in Lond. Journ. of bot. 1844, p. 540 el in Fl. anlarcl. II, p. 400, t. 151, f. 8; C. M. Syn. I, p. 782 et II, p. 655.

2 .

- Afr.: Ins. Kerguelen.

fascicularis C. M. - Rbacomitrium.

fasciculata Brid. $-\left\{\begin{array}{l}\text { Gr, apoearpa. } \\ \text { Orthotrichum. }\end{array}\right.$

filiformis W. et M. - Pterigynandrum.

flaccida $\{$ Lindb. - Gr. sphaerica.

Royle, - Oreoweisia laxifolia.

flexicaulis C. M. in Linn. 1880-83, p. 454. 1.

flexifolia Hpe. in Linn. 1859-60, p. 632.

- Am. merid, : Alp. Argentin. subtropic.

- Pac. : Austral. or.

flexipilis Lindb. in Broth. Enum, M. Cauc, p. 92 .

1. Ad saxa silic. - As. : Caucas, centr.

flexiseta W. P. Sch. in Jardin Enum. p. 19 (nom.).

- Am. sepc. : Calif. (S. Francisco).

flexuosa Griff. - Garckea phascoides.

fontinaloides Hook. - Hydropogon.

Forsleri $\mathrm{Sm}$, - Zygodon.

fragilis W. P. Sch. Syn. II ed. p. 257,

2. Ad rup. granit. - Eur. : Lusitan.

frogitis W. et M. - Eueladium verticillatum,

frondosa Jam, in Bull. U. Stat. nat. Mus. III, p. 25,

- Afr.: Ins. Kerguelen,

fuliginosa W. P. Sch. in C. M. Syn. 1, p. 778.

- Am. sept. : Mexic. (M. Orizaba). 
funalis (Schroaegr.) W. P. Sch. Syn. 1 ed. p. 211 et II ed.p. 254.

Campylopus funalis Brid. Mant. M. p. 75.

Dryptodon funalis $e j$ op. cit. $p .193$.

Dr, spiralis ej. Bryol, univ. I, p. 771 .

Gr. cernua Bryol. germ. II, I, p. 174, t. 24.

Gr. spiralis H. et T. in Drunm. M. Scot. V, a, n. 29 ; Bryol. eur. III (mon. p. 14), t. 242; C. M. Syn. I, p. 789.

Rhacomitrium funale Hüb. Muscol, germ. p. 200.

Trichostomum funale Schwaegr. Suppl. I, I, p. 150, t. 37.

Tr. patens $\beta$ funalis $H$. et $T$. Muscol. brit. p. 60 .

2. Ad rup. silic. - Eur. : Reg. subalp. et alp. As. : Alatan, Caucas.

Afr. : Alger,, ins. Canar. Am. sept. : Fret. Smith, Wyoming. Pac.:

Tasman.

Exs. : Bourg. Pl. Canar, n 232.

Rab. Bryoth eur, n. 466 .

Un. itin. 1863, n. 30, 31 .

" var epilosa Zett. Grimm. et Andr. exs. n. 11 et Rev. Grimm. Scand. p. 74 .

Gr. imberbis Kindb.

Ut typ. - Eur. : Scandin., Riesengeb., Salisb., Stir.

«var. laxa W, P. Sch, ll. cc.

Ut typ. - Vall. Tellin.

var. robusta de Not. - Gr. elatior.

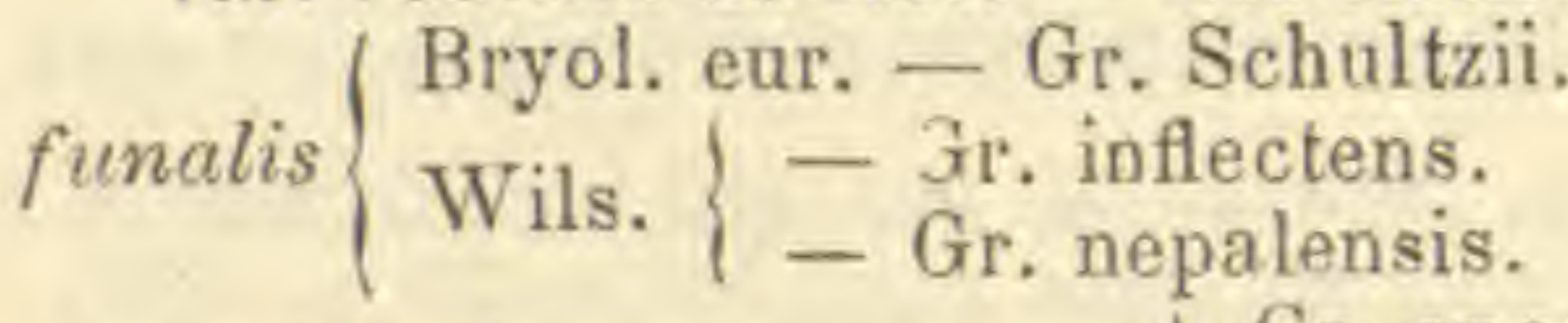

fusca Bryol. germ. p.p. $-\left\{\begin{array}{l}\text { Gr. apocarpa. } \\ \text { Gr. conferta. }\end{array}\right.$

fuscescens Mitt. - Rhacomitrium.

fusco-lutea Hook. M. ex. II, p. 9, t. 63; Brid. Bryol. univ. I, p. 188;

C. M. Syn. I, p. 790.

1. $\quad-A m$ sept. : Mexic.

Ganderi Limpr. Einig. neue Art. in LXI Jahresb. d. Schl, Gesells. p. 215.

1. Ad rup. schistos, - Eur. : Tirol., Pinzgov. (1).

geniculata Schwaegr. - Campylosteleum saxicola.

genuflexa C. M. in Engler's Bot. Jahrb. 1883, p. 81 et in Forohungsreise...p. 29.

2. Aquat. ? - Af $r$, : Ins. Kerguelen.

Giberti Mitt. M. austr. am. p. 100.

- Am. merid.: Brasil., Monte Video.

gigantea W. P. Sch. - Geheebia cataractarum.

glacialis $\left\{\begin{array}{l}\text { Bryol. germ. - Gr. conferta. } \\ \text { C. M. - Rhacomitriam. }\end{array}\right.$

glyphomitivides Bals. et de Not. - Ptychomitrium pusillum.

gracilis Schleich. - Gr. apocarpa var. gracilis.

Haliakalae Reichdl. Beitr. p. 567.

Ster, Ad rup, vulcan. - Pac.: Ins, Hawai.

hamulosa Lesq. in Mem. Calif. Acad. I, p. 14; Lesq. et Jam. Man p. 139.

2. In sabul. - Am. sept. : Calif.

(1) Gebhardi Spreng, in Steud. Nom. crypt. p. 189, in Syst. veg. omissa, et in ej. herbar. defic. - ? Deleatur. (C. M. Syn. 1, p. 810). 
Hartmani W. P. Sch. Syn. I ed. p. 214 el II ed. p. 258.

Dryptodon Hartmanni Limpi. Deutschl. Laubm. I, p. 789.

Gr. incurva Hartm. Skand, Fl. VI ed., p. 407.

Gr. montenegrina Breidl ot Szysz, in Mem. Acad. Cracov. XIX.

2. Rariss. fructif. Ad saxa quarz. umbros. Eur. : Reg, montan. As. : Caucas. occ. et centr.

Ers. : Rab. Bryoth. eur. n. 465 a, b, c, 510, 682 a, b.

Hausmanniana de Not. Cron. in Comment. II, p. 101 et Epil. p 694.

1.

- Eur. : Tirol. (Bautzen).

helvelica Schleich. - Gr, apocarpa var, alpicola.

Hendersoni Ren, et Card. in Rev. bryol. 1892, p. 86.

- Am. sept. : Oregon.

heteromalla W. et M. - Leptotrichum homomallum.

heterophylla Kindb. in Bull. Torr. bot. Club, XVII, p. 271 (nom.) et in Mac. Cat. p. 64.

1. Rupic. - Am, sept. : Columb. brit.

heterosticha C. M. - Rhacomitrium.

var. alopecura C. M. - Rhacomitrium heterostichum var. alopecurum.

var, gracilescens C. M. - Rhacomitrium heterostichum var. gracilescens.

himalayana Mitt. - Rhacomitrium.

Hoffmanni C. M. p.p. $\left\{\begin{array}{l}\text { - Gr. aethiopica. } \\ - \text { Gr. sphrerica. }\end{array}\right.$

Holleri Mdo, in Fl. 1867, p. 40; W. P. Sch. op. cit. p. 250.

1. Ad rup. gneiss. - Eur.: Alp. Helvet., Salisburg,, Carinth., Tirol. homomalla Sm, - Leptotrichum.

Hookeri Drumm, - Ptychomitrium incurvum.

humilis Mitt. M. austr, am. p, 100.

I.

- Am. merid, : Patag. austr.

hyalino-cuspidala C. M. - Rhacomitrium.

hypnoides Lindb. - Rhacomitrium lanuginosum.

imberbis Kze, hb.; C. M. Syn. I, p. 788.

2. Rupic. - Am. sept. : Mexic. Am. merid.: Chil, austr. , imberbis Kindb. - Gr. funalis var. epilosa.

immergens C. M. in Fl. 1890, p. 483.

Ster, - Afr. : Kilima N'Djaro.

immerso-leucophaea (C. M.) Par.

Giimbelia immerso-lencophaea C. M. Bryol. austr. Georg. p. $4 \mathrm{l}$.

2. Rupic. - Am. merid. : Austr. Georg.

incana of Wils. - Gr. commutata.

inclinata $\mathrm{Sm}$. - Distichium.

inconspicua Bert. - Fabronia pusilla.

(Bryol. eur. - Gr. Mühlenbeckii.

incusartm. - Gr. Hartmanni.

incurva Mühlenb. - Ptychomitrium.

Schleich. - Gr. curvula.

Schwaegr. - Gr. contorta.

inflectens Mitt. M. Ind. or. p. 43.

Gr. funalis Wils, in Keu Journ. bot. $I X$, pr $^{3} 323$.

1.

- As. : Nepal. 
insularis Mitt, in Journ, of the Linn. Soc. 1877, p. 73.

1. - Afr. : Ins. Heard, Kerguelen.

integridens C. M. in Linn. 1880-83, p. 460.

2.

- Am. merid.: Alp. Argentin. subtropic. Tucum.

intermedia Ferg. - Gr. Ungeri ?

khasiana Mitt. op, cit. p. 45.

Gr. commutata Wils. op. cit. $p .324$.

Ster.

- As. : Khasia.

Jacquini Garov. - Gr. sulcata.

Jamesii Aust. - Gr. montana var. truneata.

japonica Dz. et Mk. - Rhacomitrium.

julacer Hsch. - Acrocryphaea.

Kidderi James in Bull. U. St. nat. Mus. III, p. 25.

- Afr.: Ins, Kerguelen.

laevidens Broth. Enum. M. Cauc. p. 88.

1. Ad saxa silic. - Ain. merid. : Cancas. occ.

laevigata $\left\{\begin{array}{l}\text { Brid. - Gr. leucophaea. } \\ \text { Mitt. - Rhacomitrium. }\end{array}\right.$

lamellosa C. M. - Gr. alpestris.

lamprocarpa C. M. - Rhacomitrium.

lanceolata W. et M. - Pottia.

lanuginosa $\mid$ C. M. - Rhacomitrium.

Titt. (1876). - Rhacomitrium chrysoblastum.

latifolia $\left\{\begin{array}{l}\text { Brid. - Gr. conferta. } \\ \text { W. et M. - Pottia. }\end{array}\right.$

Zett. (fid. Ren. et Card.). - Gr. platyphylla.

laxa C. M. in Bot. Zeit. 1847, p. 801.

Gümbelia laxa ej. Syn. $I, p .771$ et $I I, p .649$.

2.

- Am. sept.: Mexic. (M. Orizaba).

laxifolia Hook. - Oreoweisia.

Leibergii Par.

Gr. pachyphylla Lindb, in Bull. Tor, bot. Club, 1893, p. 113.

2. Rupic. - Am. sept. : Idaho. leiocarpa Tayl. in Lond. Journ. of bot. 1846, p. 44; Hpe. el C. M. in
Linn. 1853, p. 498 .

Gr, leucophaea $\beta$ subrotunda Wils, in Lond. Journ, of bot. 1846, p. 449 ; c. M. Syn. I, p. 794.

2 .

- Pac.: Austral. or.

leucophaea Grev, in Trans. of the Linn. Soc. IV, t. 6, el Scot. crypl. Fl. t. 284; Bryol. eur. III (mon. p. 23), t. 257; C. M. Syn. I, p. 794; W. P. Sch. Syn. II ed. p. 261.

Campylopus laevigatus Brid. Mant. M. p. 76.

Dryptodon leucophaeus ej. Bryol. univ. I, p. 773. Dryptodon leucophaeus ej. Bryol. univ. I, p. 773 .
Gr. campestris Burch. in Hook. M. ex. t. 129 p.p.; Lindb. M. Scand.
p. 30 .

Gr. laevigata Brid. op. cit. p. 183.

Gr. (Ertzeniana Sehults in Syll. Ratisb. 1828, p. 134.

Gr. subfusoa Wils. in Kew Journ. bot. IX, p. 323.

2. Ad rup. granit, porphyr, et quarz. - Eur. : Reg. campestr. mont. zon. præcip. merid. As, : Khasia, Pers., Caucas. Afr. : Mediterr., 
ins. Canar., Kilima N'Djaro, C. B. Sp. Am. sept.: Reg. orient., centr. et merid., Washington, Oregon, Montana; Wisconssin, Idahn, Kansas, Calif., etc. Pac.: Tasman., Austral, or.

Exs. : Bourg. Pl. Canar. n. 26.

Drumm. M. bor. am. II ed, n. 31 .

Rab. Bryoth, eur. n. 185, 920, 1329, 1382.

Sull, et Lesq. M, bor. am. Il ed. n. 212.

var. epilosa Warnst. - Gr. lencophaea var, latifolia.

* var. latifolia Limpr. Bryoth, siles, n. 163 el Laubm. Deutschl. I, p. 742. Gr. leucophaea var. epilosa Warnst. Moosft. prov, Brandenb. p. 47. Rupic. - Eur. : Brandenbourg, Riesengeb.

leucophaea $\left\{\begin{array}{l}\text { C. M. p.p. - Gr. campestris. } \\ \text { Hsch. Gr. Schiedeana. } \\ \text { W.P. Sch. - Gr. subleucophaea. }\end{array}\right.$

var. subrotunda Wils. - Gr. leiocarpa.

leucophaeola C. M. in Linn. 1880-83, p. 456.

2. $\quad-$ Am. merid. : Alp. Argentin. Tucuman.

Lisae de Not. - Gr. trichophylla var. meridionalis.

longirostris Hook. M. ex. t. 62 ; Brid. Bryol. univ. I, p. 182; C. M. Syn. I, p. 795; Mitt. M. austr. am. p. 101.

Gr. peruviana Sull. in U. St. Expl. Exped. 1859, p. 8, t. 5.

1. Saxic. - Am. merid. : And. Peruv, et Boliv.

Exs. : Mandon Pl. Boliv. n. 1631.

Lorentziana (C. M.) Par.

Gümbelia Lorentziana C. M. in Linn. 1880-83, p. 450. 1.

- Am. merid. : Argentin. Tucum, subtropic.

Lubdomedae Rab. - Gr, subtumida.

lurida Wils. $\left\{\begin{array}{l}\ldots \text { Gr. ovata. } \\ \text { - Gr. ovata var. affinis. }\end{array}\right.$

Mac Leana Relun. M. Afr. austr. n. 493.

$$
\text { - Afr. : C. B. Sp. or. }
$$

macrotheca Mitt. M. Ind. or, p. 44.

Gr, oblonga Wils, in Kew Jou,n. bot. IX, p. 323.

I. - As. : Sikkim.

mammillaris Poech. - Gr. orbicularis.

Mannise C. M. in Fl. 1887, p. 223.

2. Ad rup. sicc. - Am. sept. : Columb. brit., Calif.

maritima Turn. Muscol. Hib. p. 23, t. 3; Brill. Bryol, univ. 1, p. 164; C. M. Syn. 1, p. 781 ; W. P. Sch. Coroll. p. 46 et Syn. Il ed. p. 244.

Gr. alpicola $\beta$ maritima Wahlenb. Fl. Lapp. p. 320.

Gr. rigida Brid. op. cit. p. 768 .

Schistidium maritimum Bryol, eur. III (mon, p. 10), t. 235.

1. Ad scopul. silic, marit. - Eur.: Ins. Ursor., Scandin., Britann., Armoric, Am. sept. : Terr. nov., ins. Miquelon, Massachussets.

Exs. : Rab. Bryoth. eur. n. 183, 1081.

maritima Mac. - Gr. crassinervia. membranacea Mitt. - Rhacomitrium.

microcarpa C. M. p. p. $\left\{\begin{array}{l}\text { - Rhacomitrium. } \\ - \text { Rhacomitrium sudeticum. }\end{array}\right.$ 
micromitria W. P. Sch, in Mandon Pl. Boliv. n. 1632.

- Am. merid. : And. Boliv.

microtricha C. M. et Kindb. in Mac. Cat. p. 70.

1 et 2. Rupic. - Ain. sept. : Columb. brit.

minuta C. M. in Engler's Bot. Jahrb. 1883, p. 81 et in Forchungsreise... p. 30.

2 .

- Afr.: Ins. Kerguelen.

minutifolia C. $M$. in op. cc. pp. 81 et 27 .

Ster. Rupic. - Afr.: Ins. Kerguelen.

mollis Bryol. eur. III (inon. p. $\quad$ ), t. 253; C. M. Syn. II, p.656;

W. P. Sch. op. cit. p. 266.

Gr, orthotrichoides Hartm. Skand. Fl. V ed., p. 378.

2. Ad rup. et sax. humid. - Eur. : Lappon., Alp. Norveg. Am. sept.: Groenland.

Exs, : Rab. Bryoth. eur. n. 464, 512.

Un. itin. 1863, n. 38.

"var, aquatica W. P. Sch. Syn.I ed.p. 222 el 11 ed. l. c.

In lacun. rup. et ad rivul, niv. - Eur. : Alp. Norveg., Val. Tell., Rhaet., summ. Pyr., Sierra Nevada. As. : Caucas, occ.

Exs. : Un itin, 1863, n. 37.

montana (Hpe.) Bryol. eur. III (mon. p. 26), t. 250; W. P. Sch.op. cit. p. 264.

Gümbelia montana Hpe. in Bot. Zeit. 1846, p. 124 ; C. M. Syn. I, p. 7nt.

2. Ad rup, aren. granit. et porphyr. - Eur. : Scand., Westphal.,

Hassia, Tatra, Stiria, Carinth., Tirol., Helvet., Vall. Rhen., Gall. occ. Am. sept. : Groenland, M. Rupestr., Columb. brit., Oregon, Montana, Wyoming, Idaho, Nevada, M. Calif.

Exs.: Mac. Canad. M. n. 509.

Rab. Bryoth, eur, n. 183, 563, 1318.

Sull. et Lesq. M. bor. am. II ed. n. 215.

"var. brachyodon (Aust.) Lesq. et Jam. Man. p. 145.

Gr. brachyodon Aust. in Bull. Tor\%. bot. Club, VI, p, 45.

Ut typ. - Am. sept. : M. Rupestr., Idaho.

"var. truncata Lesq. el Jam, l. c.

Gr. Jamesii Aust. l.c.

Gr, orbicularis James in Bot. King's Exped. p. 403.

Ut typ. - Am. sept.: M. Rupestr.

montenegrina Breidl. et Szysz. - Gr. Hartmani.

Mühlenbeckii W. P. Sch, Syn. I ed, p. 212 et II ed. p. 255. Campylopus pulvinatus var. tenuis Wahlenb. Fl. Suec. I ed., p. 748 at
II, p. 776 . II, p. 776 .
Dryptodon Schultzii Hartm. Skand. Fl. IV ed. p. 373, n. 4 (p.p.? fid.
Lindb.).

Gr. incurva Bryol. eur. III (mon. p. 15), t. 243; Hartm. Skand. Fl. V. $V I$ et VII ed. p.p.

Gr. Hartmani W. P. Sch. Coroll. p. 47 p.p. (fid. Lindb.) 1815, p. 88 sine

Gr. rugulosa Lindgr, in sched. et Lindbl. in Bot. Not. 1815, p. diagn.).

Gr. trichophylla Hartm. Skand. $F l, V-I X$ ed. p.p. ?

Gr. trichophylla var. Mühlenbeckii Husn. Muscol. gall.p. 135.

Gr. tricho phylla var, septentrionalis W. P. Sch. Coroll. p. 47 et Syn, I ed. p. 213. 
2. Ad rup. aren. et granit. - Eux.: Reg. mont. et subalp. : Scandin. med., 'Tirol., Voges., Alp. Am. sept.: Terr. nov., M. Rupestr., Columb. brit., Idaho, M. Calif.

Exs. : Rab. Bryoth. eur, n. 10!2, 1206.

Un. itin. 1863, n. 15 ?, 32, 33.

Mühlenbergii P. B. - Ptychomitrium incurvum.

mulabilis Opitz. - Lescuraea striata.

mutica Hpe. in Linn. 1859-60, p. 631.

Gr. apocarpa $\beta$ mutica $H$.f. et W. Fl. N. Zeal.?

- Pac. : Austral. or. (1).

neilgherriensis C. M. in Bot. Zeit. I853, p. 62 ; Mitt. M. Ind. or. p. 44.

Gr, ovata Mont. in M. Neilgh. n. 54 ?

2.

- As.: M. Neilgherr.

nepalensis Mitt. op. cit. p. 46.

Gr. funalis Wils, in Kev Journ. bot, IX, p, 323.

1.

- As. : Nepal. or.

Nevii C. M. - Rhacomitrium.

nigricans Lam, et DC. - Gr. ovata.

nigrita $\left\{\begin{array}{l}\text { C. M. - Rhacomitrium. } \\ \mathrm{Sm} . \text { - Catoseopium. }\end{array}\right.$

nigro-viridis $\mathrm{H}$. et $\mathrm{T}$. - Gr. apncarpa.

nivalis $\mathrm{Kindb}$. - Gr, tenerrima.

nuda Turn. - Discelium.

$n^{\circ} 3$ Griff. Not. p. 413 . - Bartramia?

nutans $B r$. in Fl. 1829, p. 391 .

$$
\text { - As, : Minor (Smyrn.). }
$$

obliqua Bryol, germ. - Gr. ovata $x a r$. obliqua.

oblonga $\left\{\begin{array}{l}\text { Sehrank. - Orthotrichum leiocarpum. } \\ \text { Wils. - Gr. macrotheca. }\end{array}\right.$

oblusa $\left\{\begin{array}{l}\text { Brid, - Gr. plagiopodia. } \\ \text { Lindb. - Rhacomitrium sudeticum. }\end{array}\right.$

Schwaegr. - Gr. Donniana.

var. elongata Bryol. eur. - Gr. Donniana var. elongata.

var. sudetica Bryol, eur. - Gr. Donniana var. sudetica.

obtusata (Hpe. el C. M.) Par.

Gümbelia obtusata Hpe. et C. M. in Linn. 1853, p. 497.

l. . $\quad$ Pxc.: Austral, felix.

obtuso-linealis C. $M$. in Fl. 1890, p. 484.

Ster.

- Afr. : Kilima N'Djaro.

occulta C. M. Bryol. austr. Georg. p. 38.

1.

- Am. merid. : Austr. Georg.

ochracea C. M. in Engler's Bot. Jahrb. 1883, p. 81 et in Forchungsieise.. p. 30.

Gr. chlorocarpa Mitt.?

1. Rupic. - Afr. : Ins, Kerguelen.

Ertseniana Schultz. -- Gr. leucophaea.

(1) nana Schleich. in Steud, Nom, crynt. p. 189; C. M. Syn. I. p. 810. - 
Olneyi Sull. M. of U.St.p. 37 el Ic.M.p.67, t. 42; Lesq. el.Jam. Man.p. 142. 2. Rupic. - Am. sept. : Ontario, Kansas, reg. or. Exs. : Sull, et Lesq. M. bor, am. I ed, n. 14 l et II ed, n. 209.

orbicularis Bryol. eur. III (mon. p. 13), t. 240; W. P. Sclt. op. cil. p. 247.

Dryptodon obtusus Brid. Bryol. unix. I, p. 198 p.p.

Gr. africana de Not. Syll.

Gr. mammillaris Poech in M. Bohem.

Guimbelia orbicularis C. M. Syn. I, p. 775 .

1. Ad mur. calcar. - Eur. : Reg. med. et merid. As. : Persia, Caucas., As. minor. Af $r$ : Alger.

Exs, : Rab. Bryoth. eur. n. 316, 513, 1319.

«var. africana Besch. Cat. M. Alger. p. 17.

Ut typ. - $\Lambda$ fr. : Alger.

« var. longipila Husn. Muscol. gall. p. 134.

Gr. curvula ej. M. Gall. n. 217.

Ut typ. - Eur. : Gall. sept. occ.

" var. Therioti Corbière in Rev. bryol. 1890, p. 21.

Ut typ. - Eur.: Gall. (Le Mans).

orbicularis James. - Gi. montana var. truncata.

orientalis Wils. - Gr. elongata.

ornithopodioides W. et M. - Pterogonium gracile.

orthotrichiacea C. M. - Rhacomitrium.

orthotrichoides Hartm. - Gr. mollis.

ovalis Lindb. -- Gr. commutata.

ovata Web. et Moler It. Suec. p. 132, t. 2, f. 4 ; Brid. Bryol. unio. I, p. 176; Bryol. eur. 111 (mon. p. 21), t. 54; C. M. Syn. I, p. 796; W. P. Sch. op. cit. p. 260.

Dicranum ovatum Funk Fasc. IV Crypt. n. 86.

Gr. commutata Mac. Canad. M. n. 94 p.p.

Gr. lurida Wils. in Kevo Journ. bot. IX, p. 44 p.p.

Gr. nigricans Lam. et DC. Syn. Fl. Gall. n. 1215? Brid. op. cit. p. 178.

Gr. patens Bryol. germ. II, I, p. 148, t. 21.

Gr. sciuroides Ibid. $p .155, t, 22$.

Gümbelia bogotensis Hpe, in Ann. sc. nat. V ser. III, p. 375 et in Linn. 1863. p. 143.

1. Saxic. - Eur, : E reg. montan. usq. in supraalp. As.: Penins. Tschutschica, Jenin. sup., Alp. Yunnan, Khasia, Sikkim, M. Neilgherr., Ceylan, Caucas. occ. el centr. Am. sept.: Groenland, Labrador, Ontario, lac. Super., M. Rupestr, Columb. brit., Idaho, Nevada occ., M. New Jersey, Guatemala. Am. merid $\therefore$ And. Nor. Granat. et Quitens.

Exs. : Drumm, M. bor. am. I ed. n. 59.

Rab. Bryoih. eur. n. 216, 1082.

Sull. et I.esq. M. bor. am. II ed. n. 213.

* var. affinis (Bryol. germ.) Bryol. eur. l. c. t. $255 ;$ C. M. l. c.; $W$. P. Sch. l. c., p. 261.

Gr. aflinis Bryol. germ. II, I, p. 142, t. 2I; Brid., op. cit.p. 178.

Gr. affinis var. macrocarpa ibid.

Gr. aflinis var. ramosissima ibid.

Gr, canescens Schleich. Catal. pl. Helv. 1807, n. 29.

Gr. lurida Wils. in sched. n. 285 p.p.

Gr. ovata $\gamma$ canescens Brid. op. cit. p. 177.

Loc. irrig. - Eur.: Passim. As.: Caucas. occ. et eentr. Am. sept.:

M. Rupestr., Nov. Mexic.

Exs, : Sull. et Lesq. M. bor. am. II ed. n. 214. 
\& var. cylindrica (Bryol. germ.) Bryol. eur., C. M. eı W. P. Sch. ll. cc. Gr. cylindrica Bryol. germ. l. c. p. 161, t. 23 ,

Locis umbr. vall, alp, in Eur.

* var. obliqua (Bryol. germ.) Bryol. eur., C. M. et W. P. Sch.ll. cc.

Gr. obliqua ibid. p. 153, t. 22; Brid. op. cit. p. 180.

Loc. siceiss, ventos, in Eur.

\& var. subturbinata Brid. op. cit. p. 177.

- As.: Kamschatka.

ovata $\left\{\begin{array}{l}\text { H. et T. - Gr. commutata, } \\ \text { Mont. - Gr. neilgherriensis ? }\end{array}\right.$

Schrank. - Orthotrichum anomalum.

var, canescens Brid. - Gr. ovata var, affinis. pachyloma Mont. - Sciaromium.

pachyneurula C. M. el Kindb. in Mac. Cat.p. 65.

Ster. Rupic. - Am. sept, : Columb. brit.

pachyphylla $C$. $M$. in $\mathrm{Fl}$. 1885, $p .422$.

2. Rupic. - Am. merid. : M. Fuegiae.

pachyphylla Leib. - - Gr. Leibergii,

Panschii C. M. in Kolderoey's Nord-Pol. Exped. p. 72.

- Am. sept. : Ins. Sabine.

papillosa Kindb. - Gr. elatior. var. asperula.

parasitica Voit. - Seligeria recurvata.

patagonica Mitt. - Seouleria.

patens ;ryol. eur. - Rhacomitrium.

I Bryol. germ. - Gr. ovata.

pensilvanica Schwaegr. - Gr. pilifera.

peruviana Sull. - Gr. longirostris.

Philibertiana Dna E. G. Britton in Bull. Torr, bot. Club, 1891, p. 51 .

2. Ad rup. quarz. - Am. sept. : Idaho.

phyllantha Lindb, in Broth, Enum. M. Cauc. p. 83.

Ster. Rupic, - As.: Caucas, oec.

pilifera P. B. Prodr. p. 58 ; Brid. Bryol. univ. I, p. 173; C. M. Syn. 1, p. 271 .

Gr. apocarpa $\beta$ pilifera Brid. Sp. M. I, p. 97.

Gr. pensilvanica Schuaegr. Suppl, I. I. p. 21, t. 45; Sull. M. of U. St. p. 37 et Ic. M. p. 68, t. 43; Drumm. M. bor. am. I ed. n. 56 ; Sull. et Lesq. M. bor. am. I ed. n. 138 e: II ed. n. 210.

Weisia pilifera Roehl. in Ann. Wetl. Ges. p. 113.

2. Rupic. - Am. sept. : Niagara, reg. or. et centr.

plagiopodia Hedvo. Sp. M. p. 78, t. 15; Brid. Brycl. univ. I, p. 162; Bryol. eur. III (mon. p. 9), t. 236; C.M. Syy. I, p. 779; W. P. Sch. op. cit. p. 246.

Coscinodon plagiopus Spreng.

Gr. obtusa Brid. in Schrad, Journ. IV, p. 276,

Gr. plagiopus Schwaegr. Suppl. I, I, p. 95.

1. Ad rup. arenac. - Eur. : German. (vall. Saalae) ; Pyren. (fid. C. M.); deest. in Britann. et in Gall. As. : Caicas. Am. sept.: Alberta, Columb. brit., M. Rupestr., Missouri,

Eors. : Rab. Bryoth, eur. n. 126.

Sull, et Lesq. M. bor. am. II ed. n. 204. 
* var. arvernica Husn, Muscol. gall. p. 125.

Gr. arvernica Philib, in Rev, bryol. 1882, p. 24.

Muric. - Eur.: Gall, centr. (Arvernia).

* var. pilifera Lesq. et Jam. Man. p. 138.

Gr. Brandegei Aust. in Bull. Torr. bot. Club, VI, p. 45?

Ad rup. sicc. - Am. sept.: Columb. brit., Colorado, Missouri.

Exs. : Mac. Canad. M. n. 511.

plagiopus Schwaegr. - Gr. plagiopodia.

platyphylla Mitt. in Journ. of the Linn. Soc. VIII, p. 20; Lesq. el Jam. Man. $\rho .136$.

Gr. apocarpa var. platyphylla Lindb. in Meddel... 1886, p. 253.

Schistidium latifolium Zeti. Rev. Grimm, p. 53 (fid. Linipr., Ren. et Cari). 1.

- Eur.: Norveg., Tatra. As. : Jenissei. Ant. sept,: Fret. Davis, M. Rupestr.

plicala Opitz. - Lescuraea.striata.

polyodon Ehrh. - Gr. apocarpa.

? pomiformis Brid. - Syrrhopodon.

praemorsa (C. M.) Par.

Gümbelia praemorsa C. M. in Liñ. 1880-83, p. 452.

1.

- Am. merid.: Alp. Argentin. Catamarc.

procera Bals, et de Not. - Rhacomitrium sudeticum.

procumbens Mitt, in Trans, and. Proced, of the roy. Soc. of Viclona, 1883, p. 56.

Guimbelia procumbens F. v. Müller, Frag. Phyt. Austral. X1, Suppl. p. 114 .

2.

- Pac. : Austral. (Victoria).

prolifera C. M. et Kindb, in Mac. Cat, p. 67.

Ster. - Am. sept.: Columb. brit.

pruinosa Wils, in W. P. Sch. Syn. II ed.p. 241.

Gr. apocarpa vas: pruinosa Husn. Muscol. gall. p. 123.

Gr. conferta var. pruinosa Braithw. Brit. Mossfl.

1. Ad rup. basalt. - Eur, : Scotia. Am, sept. : Idaho.

pseudo-patens C. M. - Rhacomitrium.

pullulans Spreng. - Trichostomum tenue.

pulvinata (L.) Hook. el Tayl. Muscol, brit. p. 38, t. 13; Bryol. eur. IIl

(mon. p. 12), t. 239 ; C. M. Syn. I, p. 783; W. P. Sch. op. cit. p. 248.

Afzelia pulvinata Ehrh. Crypt, p. 163. Afzelia pulvinata Ehrh. Crypt, p. 163 .
Bryum orbiculare, pulvinatum, hirsutie canescens, capsulis immersis Dill.
Hist. M. p. $395, t .50, f .65$.

Br. pulvinatum L. Sp, pl. p. 1586.

Campylopus pulvinatus Brid. Mant. M. p, 75.

Dicranum pulvinatum Sehwaegr. Suppl. I, 1, t. 189.

Dryptodon pulvinatus Brid. Bryol, univ. I, p. 196.

Fissidens pulvinatus Hedvo. Sp. M. t. $58, f .40$.

Leersia pulvinata Feduc. Fund. M. I, t. 10, f. 65 .

Trichostomum pulvinatum W. et M. Bot. Taschb. p. 109.

L. In mur., tect., sax., rar. ad arb. - Eur. : Vulgatriss., arctic. except. As. : Pers., Caucas. occ et centr. Afr. : Alger., ins. Azor., Abyss. Am. sept. . Columb. brit., Washington, Montana, Ltah, Abyss. Am. sept. . Columb. brit., Washington, Montana,
Nevada, Idaho, Arizona, Calif. Pac. : Alp. Austral., Nov. Zeland.
Tasman. 
Exs.: Mac. Canad. M. n. 90.

Rab. Bryoth, eur. n. 319 b, 1257.

W. Sch. M. Abyss. n. 465.

var. af ricana $\mathrm{H}$. f. et W. - Gr. pulvinata var. obtusa.

« var. asphaltica Ren. et Card. in Bull. Soc. roy. bot. Belg. 1894, Il, p. 113.

- Afr.: Palaestina.

" var, longipila W, P. Sch. Syn. I ed. p. 206 el II ed. p. 249.

Dicranum pulvinatum var, argentatum Turn. Musc. Hib. p. 78, $\iota, 3, f . I$ ?

Dryptodon pulvinatus var. argentatus Rrid, op. cit. p. 197?

Precip. calcic. - Eur. : Reg. sept., Stiria.

« var. obtusa (Brid.) Bryol. eur. l. c.; C. M. et W. P. Sck. ll. cc.

Dryptodon obtusus Brid. op. cit. p. 198 p.p.

Fissidens pulvinatus $\beta$ africanus Hedvo. Sp. M. p. 159, t. 40.

Gr. cygnicolla Tayl. in Lond. Journ. of bot. 1846, p. 449.

Gr. pulvinata var, africana $H$. f. et $W$. Fl. of the N. Zeal. $I I, p .75$.

Ad saxa arenac. - Eur. : Cum typ. Afr.: Austral. Am. sept.: Columb. brit., Oregon, Idaho. Pac.: Austral., Nov. Zeland., Tasman.

"var, viridis W. P. Sch. Syn. I el II ed. ll. cc.

Loc. humid. ? - Eur. : Gall, centr. (Limoges), Luxembourg, Neumark.

pulvinatula C. M. in Engler's Bot. Jahrb. 1883, p. 81 et in Forchungsreise...p. 27.

1. Rupic. - Afr. : Ins. Kerguelen.

pusilla Schrad. - Seligeria.

pygmaea C.M. Syn. I, p. 787.

Gr. africana Hpe. in Pl. Preiss. ed. Lehmann II, p. 116.

Gr. trichophylla var, australis ej. in Preiss. M. exs.

1. Rupic. - Pac. : Austral., Tasman.

quadricruris C. M. in Linn. 1880-83, p. 462.
$\quad$ 1.

- Am. merid.: Argentin, subtropic, (1).

ramulosa Lindb. - Rhacomitrium microcarpum.

Raui Aust. - Coscinodon.

recurvata Hedw. - Seligeria.

recurvirostris $\mathrm{Sm}$. - Didymodon rubellus.

redunca Wils, in Kevo Journ. bot. IX, p. 323; Mitt. M. Ind. or. p. 43.

2? -As. : Sikkim.

reflexidens $C, M$. Syn, I, p. 795; Mitt. M. austr. am. p. 101.
2.

- Am, merid.: Chil. austr.

? retorla Wils. - Hyophila rufescens.

rhaphidostega C. M. in Linn. 1880-83, p. 459.

rigida Brid, - lir, maritima.

- Am. merid.: Alp. Argent. Salt. subtropic.

rivularis Schwaegr. - Gr. apocarpa var. rivularis.

robusta $\left\{\begin{array}{l}\text { Bryol, germ. - Gr. apocarpa. } \\ \text { Ferg. - Gr. Schultzii. }\end{array}\right.$

(1) ramosa Schleich, in Steud. Nom. crypt, p. 189; C. M. Syn. I, p. 810. - 
rubella Roth. - Didymodon.

rufa C.M. in Engler's Bot. Jahrb. 1883, p. 81 et in Forchungsreise... p. 27.

2. Rupic, - Afr.: Ins. Kerguelen.

rugulosa Lindgr. - Gr. Mühlenbeckii.

rupestris C. M. - Rhacomitrium.

rupincola W. et M. - Blindia acuta.

sarcocalyx Kindb. in Bull. Torr. bot. Club, XVII, p. 271 (nom.) et in Mac. Cat. p. 66.

2. Rupic. - Am, merid. : Columb, brit.

sardoa de Not. - Gr. trichophylla var. meridionalis.

saxatilis Mitt. op, cit. p. 97.

Ad saxa aquat. - Am. merid.: And. Quitens.

saxicola H. et T. - Campylosteleum.

Schiedeana C. M. in Bot. Zeit. 1855, p. 765.

Gr. leucophaea Hsch, in Deppe et Sch. M. Mexic.

$$
\text { - Am. sept. : Mexic. }
$$

Schimperi Br. et Sch. in W. Sch. M. Abyss. n. 584 ; C. M. Syn. I, p. 792.

2. - Afr.: Abyss.

Schisti $\left\{\begin{array}{l}\text { Engl. Bot. - Blindia acuta. } \\ \text { Sm. }\left\{\begin{array}{l}\text { (fid. C. M.). - Cynodontium. } \\ \text { (fid. Limpr.). - Dieranum fulvellum. }\end{array}\right.\end{array}\right.$

Schleicheri Spreng. - Gr. apocarpa var. gracilis.

Schubartiana Ltz - Oreas Martiana.

Schultzii (Brid.) Wils. Bryol. brit. p. 157, t. 44; W. P. Sch. Syn. Il ell. p. 251 .

Dryptodon Schultzii Brid. Bryol. univ. I, p. 199.

Gr. decipiens Lindb, in Hartm. Skand. Fl. VIII ed. p. 386.

Gr. funalis Bryol. eur. III (mon. p. 17), $t, 247 ;$ C. M. Syn. I, p. 799.

Gr. robusta Ferg, mss.: Braithw, in Lond. Journ. of bot. 1872, p. 196, $t, 124$.

Trichostomum decipiens Schultz. Fl. Starg.p. 70.

1. Ad saxa silic. - Eur. : Reg. campestr. montos. et montan., rar. subalpin. Afr.: Alger.

Exs, : Rab. Bryoth. eur. n. 561, 1256 et b.

sciuroides Bryol. germ. - Gr. ovata.

Scouleri C. M. - Scouleria aquatica.

Seligeri W, et M. - Seligeria pusilla.

serrato-mucronata C. $M$, in Engler's Bot. Jahrb. 1883, p. 81 et in Forchungsreise... p. 26.

Gr. apocarpa Mitt. in Journ. of the Linn. Soc. 1876, n. 84 ?

1. Rupic. - Afr. : lns. Kerguelen.

sessitana de Nol. Epil. p. 704 (1).

Gr. alpestris hybrida Chalubinski Grimm. Tati: p. 68 p.p.

Gr. anceps Boul. M. Fr. 1, p. 271.

1. Rupic. - Eur.: Tatra, Salisb., Tirol., Helvet., Alp. Sabaud. (M. Blanc), Pedemont. As.: Caucas, occ. et centr. 
sessitana Rab. - Gr. elongata.

silvatica Willd. - Ulota crispa.

sinaica (Hpe.) Bryol, eur. III (mon. p. 11).

Gümbelia sinaica Hpe (1) in Bot. Zeit. 1816, p. 121; C. M. Syn. I, p. 772.

1 .

- As.: Persia. Afi : : M. Sinaï.

speciosa C. M. - Rhacomitrium.

sphaerica W. P. Sch. Slirp. norm, 184 el op. cit. p. 239.

Anodon pulvinatus Rab. Deutsch. Krypt. Fl.

Anoectangium flaccidum de Not. in Mem. Acad. Tor. 1836, p. 251.

A. pulvinatum Roehl. in Ann. Wett. Ges. II, p. 207.

Gr. flaccida Lindb. M. Scand. p. 30.

Gr. Hoffmanni $C$. M. Synt. I. p. 780.

Gymnostomum pulvinatum Hedw. Sp. M. p. 36, t. 3.

Schistidium pulvinatum Brid. Bryol, univ. I, p. 114; Bryol, eur. III (mon, p. 6', $t, 231$.

1. Ad rup. basalt. et silic. - Eur.: E reg. campestr. montos. usq. in subalp. in zon. intermed. As. ; Caucas, occ. et centr. Afr. : Alger, Abyss. Am. sept. : Canada.

spiralis $\mathrm{H}$. et T. - Gr. funalis.

splachnoides $\left\{\begin{array}{l}\text { Engl. Bot. }- \text { Dissodon. } \\ \text { Sm. - Tayloria tenuis. }\end{array}\right.$

Starkeana W. et M. - Pottia.

Stirtoni W. P. Sch. op. cil. p. 270.

Ster, Ad rup. basalt. - Eur. : Scot.

stolonifera C. M. in Engler's Bot, Jahrb. 1883, p. 81 et in Forchungsreise...p. 28.

1. Rupic. - Afr. : Ins. Kerguelen.

streptophylla Sull. in Am. Expl. Exp. 1859, p. 8, $t, 6$.

1.

- Am. merid.: And. Peruv.

streptophylla Kindb. — 'ỉr. tortifolia.

striata $\left\{\begin{array}{l}\text { Hedw. }- \text { Orthotrichum leiocarpum. } \\ \text { W. ot M. - Rhabdoweisia fugax. }\end{array}\right.$

stricla Turn, - Gr. apocarpa var. gracilis.

strictifolia Mitt. - Rhacomitrium.

strigosu Brid. - Gr. apocarpa.

stylostegia C. M. in Engler's Bot. Jahrb. 1883, p. 80 et in Forchungsreise... p. 25.

1. Rupic. - Afr. : Ins. Kerguelen.

subcrispipila C. M. - Rhacomitrium.

subfuscu Wils, - Gr. leucophaea.

subinearva Aust. in Coult. Bot, Gaz. III. p. 31; Lesq. el Jam. Man. p. 135 .

Ster. $\quad-$ Am. sept.: ?

sublamprocarpa C. M. - Rhacomitrium.

subleucophaea C. M. in Bot. Zeit. 1853, p. 164.

Gr. leucophaea W. P. Sch, in W. Soh. M. Abyss. n. 472 . 2. - Afr.: Abyss.

sublurida Stirt. - Rhacomitrium heterostichum var: slopecurum.

(1) Ex Hpe, ips, forsan forma depauper, Gr. leucophaeae. 
subnigrita C. M. - Rhacomitrium.

subortholrichacea C. M. - Rhacomitrium.

subovata W. P. Sch, in Mandon Pl. Boliv. $n, 1634$.

- Am. merid. : And. Boliv.

\& var. laevipila ej, l.c. n. 1635.

- Am. merid. : Ibid.

subsecunda Mitt. - Rhacomitrium.

subsquarrosa Wils. in W. P. Sch. Syn. II ed. p. 270.

Ster. Ad rup. basalt. - Eur.: Scotia.

subsulcata Limpr. Deutsehl. Laubm. p. 757.

Gr. alpestris Rab. Bryo:h. eur. n. 1127.

Gr. alpestris hybrida Chalubinski Grimm, Tatr. p. 68 p.p.

1. Ad rup. silic. - Eur. : Norveg., Tatra, Stiria, Tirol. As. : Cavcas., occ. et centr.

subtumida W. P. Sch. in Jaeg. Ad. I, p. 353.

Gr. Lubdomedae Rab. Bryoth. eur. n. 510 .

2. Ad rup, aren. - Eur. : Transilvan.

sudetica Schwaegr. - Gr. Donniana var. sudetica.

sulcata Saut. in Fl. 1841, I, p. 39; Bryol. eur, III (mon. p. 27), t, 252;

W. P. Sch. op. cit. p. 265.

Campylopus caespiticius Brid. Mant. p. 77.

Dryptodon caespiticius ej. Bryol. univ. I, p. 200 (! fid, C. M. ; vix, fid. W. P. Sch.).

Gr. alpestris mutica de Not. Syll, $n, 325$.

Gr. caespiticia Jur. Laubm. Oesterr. Ung. p. 172.

Gr. Jacquini Garov. Bryol. austr. exc. 1840, p. 25 et Cat. di ale. crittog. 1837, pp. 7 et 25.

Gümbelia caespiticia C. M. Syn. I, p. 773.

2. In rup. schist. semidecomp. - Eur. : Alp. Salísb., Tatra, Morav ", Stir., Carinth., Vall. Tell., Saband., Helvet., Arvern., Pyren. As. : Taimyr, Caucas. occ. et centr. Am. sept.: Groenland.

var. subimberbis lindb. - Gr. alpestris var, subimberbis. sulcipila C. M. - Rhacomitrium. sundaica Mitt. - Rhacomitrium. symphyodonta C. M. $\left\{\begin{array}{l}\text { - Rhacomitrium. } \\ \text { - Rhacomitrium nigritum (fid. Mitt.). }\end{array}\right.$

syntrichiacea C. M. Bryol. austr. Georg. p. 39.

Ster. Rupic. - Am, merid. : Austro-Georg.

tenella (C.M.) Par.

Gümbelia tenella C. M. in Bot. Centralbl. 1890, n. 51.

2. Ad rup. sicc. - Am, merid. ; Columb, brit., Idaho.

Exs, : Mac. Canad. M. n. 501.

tenera Zett. - Gr. apocarpa var. filiformis.

tenerrima Ren. et Card. in Bot. Gaz. 1890, p. 40, t. 6 А. Gr. nivalis Kindb. in Bull. Torr. bot. Club, XVII, p. 271 ; Mac. Canad.
M. n. 415 .

1. $\sigma^{7}$ ign. Rupic. - Am. sept. : Columb. brit., Idaho.

tenuicaulis Hpe. (?) in Jaeg. Ad. I, p. 350.

- Am. merid.: Chile. 
teretinervis Limpr. Einig: neue Art... p. 13.

? Schistidium teretinerve ej. Deutschl. Laubm. I, p. 717.

2. $c^{7}$ et fr. ign. Ad rup. calc. umbr. - Eur. : Austria super , Stir., Tirol, Helvet.

tergestina Tomm. in Bryol. eur. III (mon. p. 24), t. 259; C. M. Syn. 1, p. $794 ;$ W. P. Sch. op. cil. p. 262.

Gr. crinita var. Gavov. M. Com. Dec. VII.

2. Ad rup. calc. umbr. - Eur.: Wurtemb., Galloprov., Tirol., Tatra, Siles., Morav., Salisb., Stir., Helv., Istria, Austria sup. As. : Tibet occ.

Exs. : Rab. Bryoth. eur. n, 184, 370.

Un. itin. 1863, n, 35, 36.

tergestina $\times$ orbicularis Philib. in Husn. Muscol. gall. p. 127.

- Eur. : Galloprov.

torquata Grev. Seot. crypt. Fl. n. 40, t. 199; W. P. Sch. Syn. I ed. p. 210 et II ed. p. 253 ; Braitho. Brit. Moossf. XI, t. 47 E. (1).

Dryptodon torquatus Brid. Bryol, univ. I, p. 772.

Gr. torta Bryol. germ. II, I, p. 279, t. 24.

Zygodon torquatus Liebm. in Wickstroem Jahresb. Deutsoh. v. Beilsohm., f. $1839-42, p .430$ (exel. fruct. ad Amphoridium lapponicam pertin.); C. M. Syn. I, p. 682 .

2. Ad rup. praerupt. - Eur.: Reg. subalp, et alp. zon. intermed. et septentr. : Spitzberg. Am. sept.: Groenland, M. Rupestr., Columb. brit., ins, Vancouver, fret. Behring, Washington, Idaho (c. fr. !), Wyoming (c. fr.!).

Exs.: Drumm. M. bor. am. I ed., n. 58.

Mac. Canad. M. n. 91.

Rab. Bryoth. eur. n. 277, 617, 1128.

Un. itin. 1867, n. 95 .

Torreyana Brid. - Gr. apocatpa.

torla Bryol. germ. - Gr. torquata.

tortifolia Kindb. in Mae. Cat. p. 68.

Gr. streptophylla ej. in Bot. Notis. 1881, pp. 184-187 et in Fev, biyol. 1884, p. 13 .

2. Rupic. - Eur. : Norveg. Am. sept. : Columb. brit.

tortuosa Hook. f. el Wils. in Lond. Journ. of bot. $1844, p .540$ et Fl, 2. Antarct. II, p. 400, t. 151, f. 7 ; C. M. Syn. I, p. 782.

- Am. merid. : Ins. Maclov.

trichodes EngI. Bot. - Brachyodus.

trichodon Brid. - Gr. apocarpa var. gracilis.

trichophylla Grev. Scot. crypt. Fl. II, t. 100 ; Brid. Bryol. univ. I, p. 188 ;

Bryol. eur. III (mon. p. 16), t. 244 (excl. syn. Gr. Schultzii); C. M.

Syn. I. p. 785 (id.); W. P. Sch. op. cit. n. 256.

Dryptodon trichophyllus Brid. op, cit. p. 771 .

Gr. californica Mac. Canad. M. n. 93.

2. Ad saxa arenac. et granit. - Eur. : Reg. campestr. montos. et montan. zon. intermed. As. : Minor. A fr.: Alger, Madeir. Am. sept. : M. Rupestr., Columb. brit., ins. Vancouver, Washington, Oregon, Idaho, Calif. Pac. : Nov. Zeland., Tasman.

i1) Cf. Dan E. G. Britton in Rev, bryol. 1889, pp. 38 et 61, et in Bull. Torr. bot. Club, 1889, pp. 106-111, c. ic, fructus. 
Exs. : Mac. Canad. M. n. 92.

Rab. Bryoth. eur. n, 681 et b.

Sull, et Lesq. M. bor. am. II ed. n. 207, 208.

var. australis Hpe. - Gr. pygmaea.

« var. lusitanica W. P. Sch. op. cit. p. $25 \pi$.

Ad rup. granit. - Eur. : Lusitan.

« var. meridionalis Bryol, eur., C. M. et W. P. Sch. ll. cc.

Gr. ancistroides Mont. Syll.p. 35; C. M. Syn. I, p. 786.

Gr. Lisae de Not. Epil. p. 15 et Syll.p. $241 ;$ C. M. l. o.

Gr. sardaa de Not. et C. M. ll. cc.

Ut typ. -- Eur, : Merid., insul, et peninsul, As.: Caucas, or. Afr.: Alger. Am. sept. : Calif.

var. Mühlenbeckii Husn. - Gr. Mühlenbeckii.

var. septentrionalis W. P. Sch. - Gr. Mühlenbeckii.

trichophylloidea W. P. Sch. in Mandon Pl. Boliv. n. 1633.

- Am. merrd. : And. Boliv.

trifaria W. et M. - Seligeria tristicha.

triformis de Not. Cron. brial, ital. in Comm. I1, p. 102 el Epil. p.707;

W. P. Sch. op. cit. p. 242.

1. In praerupt. umbros. - Eur. : Ital, sup. (pr. Sessitem).

tristicha Schwaegr. - Seligeria.

uncinala Kaulf. - $\mathrm{Gr}$, contorta.

Ungeri Jur. in Ung. el Ky. « die Ins. Cypern» p. 160; W. P. Sch. op. cit. p. 853 .

Gr. alpestris Schleich. (fid. Jaeg. Ad. II, p. 765).

Gr. alpestris var. Ungeri Husn. Muscol. gall. p. 129.

Gr. anceps Bowlay M. Fr. p. 371 ? (fid. W. P. Sch.).

Gr. intermedia Ferg. in Braithw. Brit. Mossf. II, p. 26 (ad Gr. alpestrem refertam)?

1. In rup. aphanit. - Eur.: Scotia, Alp. Stir., Tirol., Pedemont. (M. Blanc, quoad Gr. ancipitem). As. : Cypr.

unicolor Grev. Scot. crypt. Fl. II, p. 123 ; Brid. Bryol. univ. I, p. 182;

Bryol. eur. III (mon. p. 29), t. 260; C. M. Syn. I, p. 793; W. P. Sch. op. cit.p. 268.

Gr. atrata Drumm. M. bor. am. I ed., n. 57.

2. Ad rup. humid. - Eur. : Scandin.. Angl., Rhaet., Salisburg., Stiris, Tirol., Helvet., Alp. Saband. (M. Blanc); Hercyn. (ster.). Am. sept. : Lac. Super., Columb. brit., M. Alb. et Rupestr., Minnesots.

Exs. : Mac. Canad. M. n. 95.

Rab. Bryoth. eur. n. 615 .

unicruris C. M. in Linn, 1880-83, p. 463.

2.

- Am. merid. : Alp. Argentin. subtropic.

urceolaris Bryol, germ. - Gr. conferta var. urceolaris.

urnulacea C. M. Bryol, austr. Georg. p. 37.

1. Rupic. - Am. merid. : Austro-Georg.

varia Mitt. - Rhacomitrium (1).

(1) ventricosa Schleich. in Steud. Nom, crypt. p. 189 ; C. M. Syn. I, p. $810 .-$ Deleatur. 
vernicosula C. $M$. in Linn. 1880-85, p. 458.

2.

- Am. merid. : Argentin. subtropic.

verticillata W. et M. - Eucladium.

viridula Roth. $\left\{\begin{array}{l}\text { (fid. Brid.). - Fissidens exilis. } \\ \text { (fid, Limpr.), - Weisia. }\end{array}\right.$

vulcanica Besch. Fl. bryol. Réunion, elc. p. 63.

Ster,

- Afr. : Ins. Borbon.

Watsoni Lesq. et Jam. Man. p, 140.

Gr. ancistroides Lesq. in Mem. Calif. Acad. I, p. 13.

2. Rupic. - Am. sept. : Calif.

Willii C. M. - Rhacomitrium.

Wrightii Aust. - Coscinodon.

Zahlbrückneri Garov, - Gr. curvula.

sygodontoides C. M, - Rhacomitrium (I).

GUMBELIA Hpe, in Bot. Zeit. 1846, p. 124.

Spec. omn, non indicatae Griммгж ejusd, nom.

aquatica G. M. - Cinclidotus.

austro-leucophaea C. M. - Grimmia .

bogotensis Hpe. - Gr. ovata.

caespiticia C. M. - Gr. suleata.

elliptica Hpe. - Grimmia commutata.

fontinaloides $\mathrm{C}, \mathrm{M}$. - Cinclidotus.

ovalis C. M. - Grimmia commutata.

riparia C. M. - Cinclidotus.

$\beta$ terrestris C. M. - Barbula Brebissonii.

Scouleri C. M. - Scouleria aquatica.

GYMNOCEPHALUS Schwaegr. Suppl. $1,11, p .87$.

androgynus Schw. - Anlacomnium.

conoidens Schw. - Zygodon Forsteri.

inordinatus Brid. - Aulacomnium palustre.

palustris Schwaegr. - Aulacomnium.

GYMNOCYBE Fr. St. agr. Femsj. p. 27.

androgyna $\mathrm{Fr}$. - Aulacomnium.

marginata Ángstr. - Aulacomnium

polustris Fr. .- Aulacomnium.

var, alpestris Lindb. - Aulacomnium palustre var, alpestris.

var. fascicularis Lindb. - Aulacomnium palustre var fascicularis.

var. imbricata Lindb - Aulacomnium palustre var, imbricata.

var. inordinata Lindb. - Aulacomnium palustre var. inordinata.

var. ramosct Lindb. - Aulacomnium palustre var, polycephale.

turgida Lindb. - Aulacomnium.

GYMNOPIL.UM W.P. Sch. $h b$.

dendroides W. P. Sch. - Polytrichadelphus.

magellanicum W. P. Sch. - Polytrichadelphus.

(1) In Enum. Kindb, nomina nuda :

Gr. Boschbergiana C. $M$. exannulata $L i n d b$. leptotricha C.M.

leucophaeoides $C, M$.

Gr. minutula C. $M$.

subovata C. M. (nom, mutandum; cf. n. 159). 
Gymnoporus Lind.b. M. Scand. p. 28 (sect. ORTHотR10HI).

GYMNOSTO MUM Hedw. Fund. M. II, p. S7, t. 7, f. 31 (37 spec.). acaule W. et M. - Pharomitrium subsessile. acidotum Tayl. - Entosthodon. acuminatum Schleich. - Physcomitrium. aeruginosum $\left\{\begin{array}{l}\text { Bryol. germ. }-\mathrm{G} \text {. curvirostre. } \\ \mathrm{Sm},- \text { G. rupestre. }\end{array}\right.$ aestivum $\{$ Brid. - Dicranum elongatum var. orthocarpum. affine $\{$ Bryol. germ. - Pottia Heimii. affine \{ Hüb. - Entosthodon ericetorum.

Ahnfeldti $\mathrm{Fr}$. - Entosthodon ericetorum var. Ahnfeldti. amblyophyllum Hook. - Pottia. antarcticum Ångstr. - Pottia magellanica. apophysatum Tayl. - Entosthodon. aquaticum Bryol. germ. - Cinclidotus. arliculatum Bryol. germ. - G. rupestre var, stelligarum. aurantiacum (Mitt.) Par.

G. xanthocarpum Wils, in Kew Journ. bot. $I X, p .291$.

Hymenostylium aurantiacum Mitt. M. Ind. or. $p, 32$. 2. - As. : Sikkim, Tibet occ.

bahiense Duby. - G. Jam soni. Barbula $\left\{\begin{array}{l}\text { H. f. et W. - Hyophila Wilsoni. } \\ \text { Preiss. - Trematodon vaginatus. } \\ \text { Schwaegr. - Hyophila. }\end{array}\right.$

bicolor Bryol, eur. - Barbula.

blandum H. f. et W. - Hyophila.

Bonplandi $\left\{\begin{array}{l}\text { Brid. - Physcomitrium. } \\ \text { Buchgr. - Entosthodon ericetorum. }\end{array}\right.$

Breutelii $\mathrm{Br}$, et Sch, in sched.

G. ligulatum Hook. ? (fid. Jaeg.).

Hymenostomum cylindricum Bryol. ex. I (mon. p. 3, nom.)?

Weisia Breutelii C. M. Syn. I, p. 664 . 1.

- Am. sept.: lns. S. Thom.

brevicaule Tayl. - Pottia.

brevisehum Bryol. germ. - G. rupestre var. pallidisetum.

Brownei Par.

G. longirostrum R. Br. in Trans. of the N. Zeal. Inst. 1893, p. 300 .

Terr. - Pac. : Nov. Zeland.

caespiticium W. et M. - Stylostegium.

calcareum Bryol. germ. I. p. 153, t. 10; Brid. Bryol. univ. I, p. 65;

Bryol. eur. I (mon. p. 6), t. 32; W. P. Sch. Syn. II eil. p. 40.

G. calcareum var, gracillimum Bryol, eus. l.c.

G. gracillimum Bryol. germ. $I, p .149, t, 10$.

G. tortile Drumm. M. Bor. am I ed, n. 23.

Hymenostylium calcareum Mitt. M. Ind. or. p. 33.

Mollia calcarea Lindb. in Braithw. Moosfl. I, p. 239.

Mollia calcarea var. gracillima $e j$.

Trichostomum calcareum $в j$. Trichost. Eur. p. 19.

Trichostomum calcare"m var, gracillimum ej. l. c.

Weisia calcarea C. M. Syn. I, p. 659.

2. Ad mur, et rup. calcar, - Eur. : Reg. merid, et part. merid. zon. interm.; Helvetia, Salisburg., Italia, Hispania, utc. As.: Jenissel 
sup., Tibet occ., Caucas, As. min. Afr. : Alger., ins. Azor., Tristan d' $\Lambda$ cunha. Am. sept. : Terra noya, Nov. Scotia, Niagara, lac. Winnipeg, etc. Am. merid.: And Quitens. Pac.: Nov. Zeland., Tasman. Eos.: Rab. Bryoth. eur. n. 62, 351 et b, 1155 et b.

" var. brevifolium W. P. Sch. Syn. 1 ed., p. 40 et II, p. 41 .

G. viridulum Bryol, eur, l. c. t. 31 ; Brid. Bryol. univ. I, p. 66 ?

Ut typ. - Eur.: Galloprov., Bosnia. Am, sept. : Ontario.

var. gracillimum Bryol, eur. - G. calcareum.

* var. intermedium W. P. Sch, op, cit.

G. calcareum $\gamma$ viridulum Bryol. eur. $l$, c. in descript. et t. $32 \gamma(e x c)$. Syn. Brid. de G, viridulo).

Mollia calcarea var, víridula Lindb.

Weisia calcarea var. viridula C.M.. . $6 .($ excl. ut supra $)$.

Ut typ. - Eur. : Gallopov,, Sardin. As. : Caucas.

- var. perpusillum Sull, in Pac. R. Rep. IV, p. 185; Lesq. et Jam, Man. p. 53 .

Ad terr, argill. - Am. sept. : Calif.

* var. tenellum Bryol, eur, et W. P. Sch.ll. ce.

Weisia calcarea var, tenella $C . M . l$. c.

Ut typ. - Eur. : Gall, centr. (Mende).

var, viridulum Bryol, eur. - G. calcareum var. intermedium.

canescens Schrank. - Rhacomitrium.

capense Hook. - Glyphocarpus sericeus.

carbunculoides de Not. - Pottia caespitosa.

ceratodonteum (C. M.) Par.

Ceratodon capense W. P. Sch. ?

Pottia ceratodontea C. M. Syn. I, p. 561.

2.

- Afr. : C. B. Sp.

ciliatum Roth. - Hedwigia.

cirratum Schkrank. - Dicranoweisia.

chloropus Besch. Fl. bryol. Réunion, elc. p. 11.

2. Terr. - Afr. : Ins. Borboniae.

circumscissum Roehl. - Pottia truncata.

Clintoni Aust. - G. rupestre.

Combae de Not. - Pottia Wilsoni.

commutatum Mitt. - G, curvirostre.

compactum Schleich. - Anoectangium.

complanulum (Eucladon) H. f, et W. - Calomnium laetum.

condensalum Voit. - Hymenostomum tortile.

conicum Schwaegr. - Pottia Starkeana var, brachyodus.

crispatum W. P. Sch. - Hymenostomum.

cucullatum Jaeg, - Hymenostomum.

curvatum Dna F. Mazz. - Funaria curviseta.

curvirostrum (Ehrh.) Hedlo. M. frond. II, p. 88, t. 34: Brid. Bryol. univ. I, p. 84; Bryol. eur. I (mon. p. 8), tt. 35 et 33 ; W. P. Sch. op. cit. p. 43 .

Barbula curvirostra Lindb. M. Scand.

Bryum aestivum $L, S p$. pl. p. 1585 .

$\mathrm{Br}$, eurvirostrum Gmel. Syst. nat. II, p. 1334.

Br. fasciculatum Dicks. Fasc. III Pl. crypt.

Br. palustre, aestivum, confervae facie Dill. Hist. M. p. 273, t. 47, f. 38. 
Br. palustre, L. Syst. veg.p. 948.

$\mathrm{Br}$. stelligerum Dicks. Fase. III Pl. crypt. p. $3, t .3, f .4$

Br, verticillatum $e j$. hb. sicc. Fasc. $V, n, 19$.

Dicranum hyperboreum Engl. Bot. t. 2552.

G. aeruginosum Bryol. germ. p. 160, t. 10, f. 19 ; Brid. l. c. p. 89 p.p.

G. stelligerum Sm. Fl, brit. III, p. 1164 et Engl. Bot. $t, 2202 ;$ Brid, op. c. p. 89 p.p.

Hymenostylium commutatum Mitt. M. Ind. or. p. 3 ?.

H. curvirostrum Mitt. op. et l. ce.

Pottia curvirostra Ehrh. Pl. crypt.p. 93.

Weisia curvirostris C. M. Syn. $I, p, 658$.

2. Ad rup. calc. et moles tophac. - Eur.: Spitzberg, reg. subalp. tota. As. : Himalaya, vall. Indus, Tibet oce., Khasia, Cancas. Am. sept. : Anticosti, Gaspes., Ontario, Niagara, reg. sept. occ., M. Rupestr., Columb, brit,, Idaho, Minnesota, reg. centr. et or.

Exs. : Drumm. M. bor. am. J ed, n. 25, 26.

Mae. Canad. M. n. 17.

Rab. Bryoth. eur. n. 1252, 1253.

Sull, et Lesq. M. bor. am. II ed. n. 52, 53 .

Un. itin 1853, n. 4.

* var. cataractarum W. P. Sch. Syn, I ed. p. 43 et II ed. p. 44.

G. curvirostre $\beta$ pomiforme Bryol. eur. l. c.

G. pomiforme Bryol. germ. I, p. 158, t. 10 ex p. ? Brid. l. c. p. 79.

Weisia curvirostris $\beta$ pomiformis C. M. $l . c$.

Ad rup. schist. ot granit. Alp. - Eur. : Norvegia (Dovre), Tirol,

Valesia, Pyren., etc.

Exs. : Rab. Bryoth. eut. n. 60, 399.

"var. laeviusculum (Lindb. et Arn.) Par.

Barbula curvirostris var. laeviuscula Lindb. et Arn. M. As. bor. 1890, II, p. 74.

- As, : Jenissei inf.

"var. micrecarpon (Bryol. germ.) Bryol. eur. et W. P. Sch, ll. cc.

G. microcarpon Bryol. germ. l. c. p. 161, t. 10 ; Brid. l. c. p. 81.

Weisia curvirostris $\gamma$ microcarpa C. M. $l$. c.

Ut et ubi var. cataractarum.

"va). pallidisetum (Bryol, germ.) Bryol, eur et W. P.Sch. ll.cc.

G. brevisetum Bryol. ge*m. l. c p. 164, t. 10: Brid. l. o. p. 82.

G. pallidisetum Bryol. germ. l. t. p. 166, t. If; Brid. l. c. p. 83.

Weisia eurvirostris var. pallidiseta $C . M$. $l$. $c$.

Ut et ubi proced.

Exs. : Rab. Bryoth. enr. n. 725.

"var. scabrum Lindb. M. Scand. p. 22 .

- Eur. : Reg. alp.

var. pomiforme Bryol. eur. - G. curvirostre var. cataractarum.

curvirostrum Roehl. - Dicranum elongatum var, orthocarpum.

curvisetum Schwaegr. - Funaria.

cuspidatum Roehl. - Poltia truncata.

cylindricum Hook. - Hyophila.

Davallianum Sm. - Brachyodus trichodes.

decipiens W. et M. - Grimmia crinita.

dilatatum P. B. - Physcomitrum turbinatum.

Donianum Engl. Bot. - Anodus.

dubium Brid. - Entosthodon ericetorum.

edentulum Jaeg. - Hymenostomum. 
ericelorum Bals, et de Not. - Entosthodon.

erythrostomum Brid. - G. rupestre.

euchlorum $\left\{\begin{array}{l}\text { Schwaegr. - Anoectangiun. } \\ \text { Zeyh. - Hyophila Zeyheri. }\end{array}\right.$

eurystomum Nees. - Physcomitrium.

var. subpatula Lindb. et Aın. - Physcomitrium eurystomum var. subpatula.

fasciculare $\left\{\begin{array}{l}\text { Hedw. - Funaria. } \\ \text { H. et T. - Entosthodon ericetorum. }\end{array}\right.$

foliosum Roehl. in Ann. Vett. Ges. II, p. 129̊; Brirl. Bryol. univ. 1, p. 95 ; C. M. Syn. I, p. 565.

- Eur. : Suecia.

gracile $\left\{\begin{array}{l}\text { Hook. - Leptostomum. } \\ \text { Mossm. - Leptostomum flexipile. }\end{array}\right.$

gracillimum Bryol. germ. - G. calcareum.

Griffithianum Sm. - Edipodium.

guadelupense Spreng. - Ancectangium euchloron.

Hedroigia W. et M. - Hedwigia ciliata.

Heimii $\left\{\begin{array}{l}\text { Drumm. var. 1, 2, 3; Hedw. - Pottia. } \\ \text { Timm. - Pottia lanceolata var. gymnostoma. }\end{array}\right.$

$\beta$ obtusum Hook. - Entosthodon ericetorum,

homomallum Brid. - Leptotrichum.

Hornschuclianum $\left\{\begin{array}{l}\text { Bryol. germ. - Anoectangium. } \\ \text { Bryol germ. pp. - Anoectangium Sendtnerianum. }\end{array}\right.$

hymenostomoides Poech. - Hymenostomum tortile.

imberbe Engl. Bot. - Hedwigidium.

immersum Sull. - Physcomitrium.

inclinans Hook. - Leptostomum.

inconspicuum (Griff.) Par.

Hymenostylium inconspicuum Griff. Not. p. 394; Mitt. M. Ind. or. p. 33.

Kupic. - As. : Kbasia.

incurvans W. P. Seh. in Besch. Prodr. bryal. mexic. p. 15.

Ster.

- Am. sepı. : Mexic.

inflexum Tayl, - Pottia.

intermedum Turn. - Pottia lanceolata var. gymnostoma.

involutum $\left\{\begin{array}{l}\text { Hook. - Hyophila. } \\ \text { Mont. - Hyophila Leprieurii. }\end{array}\right.$

irretitum Brid. - Gyroweisia reflexa.

Jamesoni W. Arn, in Wern. Trans. V, p. 200 el Disp. M, p. $10 ; C . M$.

Syn. $I, p .119$.

G. bahiense Duby in Mem... Geneve, $f .5, a, b, c$ (fid. Hpe.).

Weisia Jamesoni Mitt. M. austr, am. p. 132.

2 ?

- Am. merid.: Brasil. austr. or.

Jamesoni Tayl. - Barbula limbata.

japonicum Hedw. - Physcomitrium.

jabanicum Nees, - Hyophila.

julaceum Hook. - Ångtroemia andicola.

Kunzeanum (C. M.) Par.

G. longirostre Kze. in Poepp. Pl. Chil. Coll. III, n. 230.

(1) flacoidum Brid. Bryol. univ. I, p. 86 ; C. M. Syn. 1, p. 565 ? Quid? Delen-
dum. 
Pottia Kunzeana C. M. Syn. II, p. 624.

P. longirostris ej. Syn. I, p, 562 (error. corr.).

Weisia longirostris Mitt, M, aust, am. p. 134 .

2.

- Am. merid. : Chile austr.

Kurzianum Hpe, in sched.; Jaeg. Ad. II, p. 631.

- As.: Sikkim.

lamprocarpum Mont. - Anoectangium euchloron.

lapponicum Hedw. - Amphoridium.

latifolium Hook. - Physcomitrium Hookeri.

laxifolium Kze. - Anoectangium tenerrimum.

Leptostomum Hook. - Leptostomum erectum.

Lessonii Besch. in Journ. de Bot. 1891. p.

- Afr.: Ins. Ascens.

ligulatum R. Br. in Trans. of the N. Zeal. Inst. 1893, p. 299.

Terr. - Pac. : Nov. Zeland.

ligulatum Hook. - G. Breutelii.

linearifolium Tayl. - Amphoridium cyathicarpum.

longifolium Scbleich. - Physcomitrium piriforme.

longirostre Br.et Sch. in W. Sch. M. Abyss. II, n. 475.

Pottia longirostris Hpe, in C. M. Syn. I, p. 552.

1.

- Afr.: M. Abyssin.

longirostre Kze. - G. Kunzeanum.

longirostrum R. Br. - G. Brownii (1).

luteolum Engl. Bot. - Anoectangium compactum.

magnocarpum $\mathrm{R}$. Br. - G. megalocarpum.

marginatum Kze, in Poepp. Pl. Chil.

Weisia Kunzeana $C$. M. Syn. I, p. 656.

2.

- Am. merill. : Chile.

megalocarpum Par.

G. magnocarpum R. Br. in Trans, of the Zeal. Inst. 1893, p.,300 (nom. male institutum).

Terr. - Pac. : Nov. Zeland.

Menziezii Hook. - Leptostomum.

micaceum Schlecht. - Hymenostomum.

microcarpon Bryol. germ. - G. curvirostrum var. microcarpon.

microstomum Hedw. - Hymenostomum. var. brachycarpum W. P. Sch. - Hymenostomum microstomum var.
brachyearpum.

var, brevirostre Jaeg. -- Hymenostomum microstomum var, brevirostre.

var. elatum Jaeg. - Hymenostomum microstomum var. elatum.

var, obliquum Jaeg. - Hymenostomum microstomum var. obliquum.

var. Schultz. - Weisia mucronata.

minutulum Schwaegr. - Pottia.

Mosis Jur. et Milde. - Gyroweisia.

Mougeoti Br. - Amphoridium.

murale W. P. Sch. - Hymenostomum.

niloticum Del, - Physcomitrium.

obtusatum Relim. M. Afr auslr, n, 436.

Ster.

- Afr.: Transvaal.

(1) Ob mimiam similit. cum praeced, nom. mutatum. 
obtusifolium R. Br. - Pottia Heimii var. aretica. obtusum Hedw. - Entosthodon ericetorum. Orbignyanum Mont. - Physcomitrium.

orizabanum W. P. Sch. in Besch. Prodr. bryol. mexic. p. 15. 2. - Am. sept. : Mexic.

osmundaceum Hoffm. - Schistostega.

ovatum Hedw. - Pottia cavifolia.

var. epilosum Bryol. germ. - Pottia cavifolia var. epilosa.

var. gracile $\mathrm{H}$. et T. - Pottia cavifolia var. gracilis,

var, incanum Bryol. germ. - Pottia cavifolia var. incana. var. oblongum Brid, - Pottia cavifolia var. oblonga.

Pabstianum (C. M.) Par.

Weisia Pabstiana C. M. in Bot. Zeit. 1857, p. 382.

W. viridula (fid. Mitt. M. austr, am. p. 133).

2. Limic. - Am. merid. : Brasil, austr. or.

pachyloma Mont. - Sciaromium.

pallidisetum Bryol: germ. - G. curvirostrum var. pallidisetum.

Pancherianum Besch. Fl. bryol. Nov. Caled. p. 188.

Hymenostomum Pancherianum Jaeg. Ad. $I I, p .630$.

1. Terr. - Pac. : Nov. Caledon.

paucifolium Engl. Bot. $\left\{\begin{array}{l}(\mathrm{sec} . \text { C. M.) - Gyroweisia tenuis. } \\ (\text { sec. Lindb.) - Seligeria subcernua. }\end{array}\right.$ pennatum Hedw. - Schistostega osmundacea.

phascoides Drumm. - Systegium Drummondii

piriforme $\left\{\begin{array}{l}\text { Brid. p.p. - Entosthodon Templetoni. } \\ \text { Hedw. - Physcomitrium. }\end{array}\right.$

juvenile Voit. - Pyramidula tetragona.

platyphyllum Kindb. in Bull. Torr. bot. Club, Apr. 1889.

2. Ad rup. irror. - Am. sept. : Columb. brit.

pomiforme Bryol. germ. - G. curvirostre var. cataractarum. prorepens Hedw. - Drummondia clavellata.

pulchellum Griff. - Physcomitrium.

pulvinatum $\left\{\begin{array}{l}\text { Hedw. - Grimmia sphaerica. } \\ \text { Lag. - Pottia cavifolia. }\end{array}\right.$

pusillum $\left\{\begin{array}{l}\text { Drumm. - Anodus Donianus. } \\ \text { Hedw. - Pottia cavifolia. }\end{array}\right.$

var. oblongum Hedw. - Pottia cavifolia.

pygmaeum R. Br. in Trans. of the N. Zeal. Inst. 1893, p. 298.

Rupic. - Pac. : Nov, Zeland.

quadratum Hook. - Glyphocarpus.

Rauanum Aust. - Weisia viridula var. gymnostoma.

recurvum Griff. $\left\{\begin{array}{l}\text { - Desmatodon. } \\ \text { - Hyophila rufescens. }\end{array}\right.$

reflexum Brid. - Pottia Starkeana virr. brachyodus.

repandum Griff. - Physcomitrium.

rigescens $B r$. et Sch, in W. Sch. M. Abyss. n. 447.

Weisia rigescens C. M. Syn. I, p. 659.

2. Rupic. - Afr.: M. Abyss.

riparium Host. - Cinclidotus.

rostellatum W. P. Sch.-Hymenostomum.

Rottleri Schwaegr. -- Fintosthodon, 
rufescens $\left\{\begin{array}{l}\text { Hook. - Hyophila. } \\ \text { Schutt. }\end{array}\right.$

rupestre Schwaegr. Suppl. I, I, p. 31, t. 11 ; Brid. Bryol, univ. I, p. 77;

Bryol. eur, I (mon. p. 7), tt. 33 et 34; W. P. Sch. op. cit. p. 42.

G. aeruginosum Sm. Fl. brit. III, p. 1163 et Engl. Bot, t. 2200; Brid. Bryol. univ. I, p. 80 p.p.

G. Clintoni Aust. in Bull. Torr. bot. Club, VI, p. 42.

G. erythrostomum Brid. op. c. p. 85.

Mollia aeruginosa Lindb. M. Scand. $p .21$.

Trichostomum aruginosum ej. Trichost Eur. p. 19.

Weisia rupestris C. M. Syn. I, p. 657 .

2. In fissur, rup. granit. et schistos. - Eur. : Reg. subalp. et alp, a

Lappon. usq. ad Hispan. merid. As. : Jenissei sup., Caucas. Afr.:

Ins. Canar. Am. sept.: L Labrador, Terr, nov., lac. Super., Niagara,

M. Rupestr., Columb. brit., Idaho, reg. or.

Exs. : Drumm. M. bor. am. I ed. n. 24, et II ed. n. 21.

Mac. Canad. M. n. 18.

Rab. Bryoth, eur. n. 406.

Sull. et Lesq. M. bor. am. II ed. n. 50.

" var. compactum Bryol, eur. et W. P. Sch, ll. cc.

Weisia rupestris $\delta$ cornpacta $C . M . l$. $c$.

Ut typ. - Eur. : Alp. Scandin., Helvet,, etc.

Exs, : Rab. Bryoth, eur, n. 604.

- var. ramosissimum Bryol. eur. et W. P. Sch. ll. ce.

Weisia rupestris var, ramosissima C.M. l. c.

«var. rigidum W. P. Sch. Syn. II ed.p. 42.

Ad rup. tophac. irror. - Eur. : Lac. Leman.

" var, stelligerum (Schk.) Bryol. eur. et W. P. Sch. ll. cc.

G. articulatum Schkuhr op. cit. p. 29, t. 10, f. c.; Bryol. germ. I, p. 156, t. 10, f. 17 ; Brid. l. e. p. 78.

G. stelligerum Bryol. germ. I, p. 68, t. 11 .

G. tophaceum Aust. in Bull. Tor, bot. Club, VI, p. 42.

Weisia rupestris $\gamma$ stelligera C. M. l. c.

Ad cataract. in calcar. - Eur. : Helvet., Rhaet, Salisburg., etc, Am. sept. : Gaspes., Texas.

var. Sull. - G, stillicidiorum.

rutilans Hedw. - Weisia mucronata.

scaturiginosum Besch. Fl. bryol. Réunion, etc., p. 12.

Ad rup. aquat. vel submers. - Afr.: Ins. Borbon.

Schimperi Mdo. - Hymenostomum tortile var. alpinum.

secundum (C. M.) Par.

Hymenostylium secundum C. M. in Linn. 1876, p. 299.

Ster. Ad terr. calc. vel humos. - Afr.: Somali.

senocarpum Jaeg. - Hymenostomum.

sepincola Sk. - Hymenostomum microstomum var. brevirostre.

serpens Schrank. - Amblystegium.

setifolium Hook. - Anacolia.

simplicissimum Brid. Bryol. univ. I, p. 67 ; C. M. Syn. I, p. 561.

Sphagnum simplicissimum Loureir Fl. Cochinch. II, p. 839.

Cortic. et muric. - As. : Cochinchina (1), 
solivagum Green, - Pottia Wilsoni. socotranum (Mitb.) Par.

Weisia socotrana Mitt, in Trans, of the Soc. of Edinb. 1887, p. 331. 2. - Afr. : Ins, Socotora.

spathulatum \{ Harv. - Barbula.

I Hsch. - Physcomitrium spathulatum var. brevicaule, sphaericum $\left\{\begin{array}{l}\text { Roehl. - Physcomitrium eurystomum. } \\ \text { Schwaegr. - Physcomitrium. }\end{array}\right.$ var, Bryol. germ. \{ Physcomitrium acuminatum? splachnoideum Hook. - Physcomitrium turbinatum. squarrosum Wils. - Hymenostomum. stelligerum $\left\{\begin{array}{l}\text { Bryol. germ. - G. rapestre var. stelligerum. } \\ \text { Sn. - G. curvirostrum. }\end{array}\right.$

Stevensii R. Br. in Trans, of the N. Zeal. Inst. 1893, p. 299.

Terr. - Pac. : Nov. Zeland. stillicidiorum (Mitt.) Par.

G. rupestre var. Sull. in P,oced. Am. Acad... 1861.

Weisia stillicidioru:n Mitt. M. austr, am, $p$. 134.

2. Rupic. et terr. - Am. sept. : Cuba. Am. merid. : And. Quitens. striatum Brid. - Amphoriäium lapponicum. subsessile Schwaegr. - Pharomitrium. subulatum Brid. - Stylostegium caespiticium. systylium Funk, - Pottia heimii. tenue Schrad. - Gyroweisia. tetragonum Schwaegr. - Pyramidula. tophaceum Aust. - G. rupestre var. stelligerum. tortile $\left\{\begin{array}{l}\text { Drumm. - G. calcareum. } \\ \text { Schwaegr. - Hymenostomum. }\end{array}\right.$

var. subcylindricum Jaeg. - Hymenostomum tortile var. subeylindricum.

tortipes Hook. - Physcomitrium australe.

Tortula Schwaegr. - Hyophila.

trafoiense W. P. Sch. - Weisia mucronata. trichodes W. et M. - Brachyodus, tristichum Wahlenb. - Anoectangium compactum. truncalulum Hedw. - Pottia truncata.

var. $\beta$ Hoffm. - Pottia lanceolata var. gymnostoma.

truncatum $\left\{\begin{array}{l}\text { Hedw. - Pottia truncata. } \\ \text { Roehl. - Pottia lanceolata var. gymnostoma. } \\ \text { W }\end{array}\right.$

var, majus . et M. - Pottia minutula var. rufescens.

var. majus Wahlenb., W, et M. - Poltia lanceolata var. gymnosloma.

var. minimum Voit, - Pottia minutula. turbinatum Rich. - Physcomitrium Hookeri. umbrosum Jaeg. - Hymenostomum. venezuelensis $(C, M$.) Par.

Weisia venezuelensis C. M. in Lin. 1878-79, p.480. 2. - Am. merid. : Venezuela.

viridissimum $\mathrm{H}$, et $\mathrm{T}$. $-\mathrm{Zyg}$ godon. vitridulum Brid. - G. calcareum var. brevifolium. vernicosum Hook, - Pottia.

wainakariense R. Br. in Trans. of the N. Zeal. Inst. 1893, p. 299.

Terr. - Pac. : Nov, Zeland. 
Wilsoni Hook. $\left\{\begin{array}{l}\text { - Pottia crinita. } \\ \text { - Pottia. }\end{array}\right.$

Wimmerianum Sendtn. - Weisia.

Wrightii $R . B r$. in Trans. of the N. Zeal. Inst. 1893, p. 300.

Terr. - Pac. : Nov. Zeland.

xanthocarpum Hook. M. ex. II, $t$. 153.

Hymenostylium xanthocarpum Brid. Bryol, univ, $I I$, p. 8?.

Pottía xanthocarpa C. M. Syn. I, p. 563 .

2.

- As, : Nepal. Afr.: M. Abyssin.

xanthocarpum Wils, - G. aurantiacum.

yemense C. $M$, in Hedw. 1891, p. 219 (nom.).

- As.: M. Yemen (1).

GYMNOSTOMUM PHYSCOMITRIUM Brid. Bryol. univ, I, p. 97.

Bonplandi Brid. - Entosthodon.

curvisetum Brid, - Funaria.

fasciculare Brid. - Funaria.

B Schullzii Bryol. germ. - Funaria fascicularis. latifolium Thomas. - Entosthodon Templetoni.

piriforme Brid. - Physcomitrium.

sphaercum Brid. - Physcomitrium.

splachnoideum Brid. - Physcomitrium turbinatum.

tortipes Brid. - Physcomitrium turbinatum var. tortipes.

turbinatum Brid. - Physcomitrium turbinatum.

Gymnotrematodon C. M. in Hedw. 1895, p. 118 (nom., sect, TrematoDONTIS).

Gymnoweisia W. P. Sch. I ed., p. $37^{\circ}$ (subgen. Gymnostomi).

GYROPHYLLUM $D z$, et $M k$. $M$. frond. Archip, ind.

Reinwardti Dz, et Mk, - Dichodontium.

GYROWEISIA W. P. Sch. Syn. II ed. p. 38 ( 8 spec.).

acutifolia Philib. in Rev. bryol. 1882, p. 3 et in Husn, Muscol. gall. p. 8. 2. Ad rup. calcar. - Eur. : Helvet. or.

Arosis (Ltz.) Par.

Trichostomum Aronis Ltz. M. Ehrenb. p. 29, t. 5, f. 1-9 et t. 6, $f .10-21$.

Ster.

- Afr.: M. Sinaï.

Hildebrandti (C. M.) Par.

Weisia Hildebrandti C. M. in Linn. 1876, p. 298.

Ster. $\quad-A f r_{\text {. }}$ Somali.

Mosis (Ltz). Par.

Gymnostomum Mosis Jur, et Milde Beitr... p. 590.

Trichostomum Mosis Ltz. $i$. c. p. $28, t .3, f .1-7$ et $4, f .8-22$.

2. - As, : Pers, austr. Afr.: M. Sinaĩ.

reflexa (Brid.) W. P. Sch. op. cit. p. 39.

Anacalypta reflexa Fürnr. in Fl. 1829, II, Erganz. p. 25.

(1) In Enum. Kindb, nom, nudum :

G. lingulatum Rehm. 
Gymnostomum irretitum Brid. Bryol, univ. I, p. 758.

Trichostomum reflexum Lindb. Trichost. Eur. p. 20.

Weisia reflexa Brid. op. cit. p. 355; Bryol. eur, I (mon. p. 7), t. 24; C. M. Syn. I, p. 654 .

Weisiodon reflexus W. P. Sch. Coroll. p. 9.

2. Ad rup. calcar. - Eur.: Gall. merid. Afr. : Alger.

Rohlfsiana (C. M.) Pur.

? Weisia Rohlfsiana C. M. in Fl. 18/4, n. 31 .

Ster, Muric. - Afr. : Egypt. super.

tenuis (Schrad.) W. P. Sch. op. cit. p. 38.

Beyum paucifolium Dicks, Fasc, IV Pl, crypt. p. 7, t. 11, f. 3 (f, W. P. Sch.).

Gymnostomum paucifolium Engl. Bot.t. 2806 (f. C. M.).

G. tenuis Schrad. Coll. Pl. crypt. n. 31; Brid. Bryol. univ, I, p. 64; Bryol eur. I (mon. p. 5), t, 30.

Mollia tenuis Lindb. M. Scand. p. 21.

Trichostomum reflexum $\beta$ gymnostomum Lindb. Trichost. Eur. p. 20.

Weisia tenuis C. M. Syn. I. p, 660 .

2. Ad mur, et rup, aren, et aren, calc. - Eur. : Media et reg, merid. part. septentr. Am. sept. : Ontario, lac. Winnipeg.

Exs.: Drumm. M. bor. am. I ed. n. 21 (Weisia).

Rab. Bryoth. eur. n. 61, 405. 738.

Un. itin. 1863, n. 1, 2, 3.

* var. badia Limpr. Deutschl, Laubm.p. 236.

Rupic. - Eur. : Voges., Bade, Helvet., Salisburg.

tophicola (C. M.) Par.

Weisia tophicola C. M. in Linn. 1876, p. 297.

Ster.

- Afr. : Somali.

HABRODON W. P. Sch. Syn. I ed. p. 505 (2 spec.).

nicaensis de Not. Epil. p. 224; W. P. Sch. Syn. 11 ed. p. 588 (1).

Ster. Ad Oleas vetustas semel lectum, - Eur. : Gall. austr. or.

Notarisii W. P. Sch. op. cit.p. 587 et Bryol. eur. Suppl. fasc. 1II-IV, t. 1 .

Clasmatodon perpusillus Lindb, in Jowrn, of the Linn. Soc. XIII, p. 70.

H. perpusillus Lindb. in Oefv... 1863, $p .401$.

Pterogonium perpusillum de Not. Spic. p. 12 et Syll. M.p. 84.

Pt? subenerve Spr, in Trans, of the bot. Soc. of Edinb. 1849, III, p. 150.

2. Cortic. - Eur. : Norveg. occ., Scot., Angl., Gall. centr., Surdin., Ligur., ins, lac. Major., Jusit. - Afr. Alger. Am. sept.: Ohio centr. (ster.).

Exs. : Rab. Bryoth. eur. n. $903,1080$.

perpusillus Lindb. - H, Notarisii,

Sendlneri Ltz, - Fabronia.

HAMPEELLA C. M. in Bot. Centralbl. 188I, n. 37 (I spec.).

Kurzii C. M. l, c.

- As. : Java.

(1) Verosimil, var, H. Notarisii (W. P. Sch. 1. c.). "In herb. de Nntaris deest. (Husnot, Muscol, gall. p. 298). 
Haplocladium C. $M$, in Linn. $1878-79$, p. 459 (subsect. HrPNI). Haplodon Lindb. M. Scand. p. 18 (cf. AplodoN).

HAPLODONTIUM Hpe, in Ann. sc. nat. 1865, V ser., p. 336.

Spec, omn. Mielichhoferiae ejusd, nom.

HAPLOHYIMEIUIM Dz. et Mk. in Ann. sc. nat. $1844, p .310$ (2 spec.). abbreviatum W. P. Sch, hb.

Leskea abbreviata ej. in W. Sch. M. Abyss.

$$
\text { - Afr.: Abyss. }
$$

densum W. P. Sch, in Besch. Prodr. bryol, mexic. p. 89.

1. -Am. sept, : Mexic.

Sieboldi Dz. et Mk. - Leskea tristis.

Harpidium Sull.; W. P. Sch. Syn. I, p. 604 (subgen. HrPNI = Drepanocladus $C . M$.).

HARPOPHYLLUM Spr, Cat. aureum Spr. - Hookeria.

HARRISONIA (1) Spreng. Syst. veg. $1 V, I, p .145$ (1827).

Spec, omn. non indicatae sunt rHACOCARPI ejusd. nom.

aquatica Spreng. - Cinclidotus.

emersa C. M. et Hpe. - Hedwigidium.

glyphocarpa Hpe. - Hedwigidium.

rhabdocarpa Hpe. - Hedwigidium.

Schimperiana Hpe. - Braunia.

secunda Spreng. - Braunia.

squarrosula Hpe. - Hedwigidium.

HEDWIGIA Ehrh. Hannov. Mag. 1781, n. 69, p. 1109 (10 spec.).

aestiva Hook. - Anoectangium.

albicans Lindb. - H. ciliata.

anodon Ehrb. -- H. ciliata.

apocarpa Leyss. - H. ciliata.

aquatica Hedw. - Cinclidotus.

attenuata Mitt. - Braunia.

ciliata (Dicks.) Ehrh. in op, et l. cc. ; Bryol. eur. 111, tl. 272-273; W, P. Sch. Syn. II ed. p, 283. Anictangium ciliatum Hedw. Sp. M. p. 40 ; Drumm. M. bor. am. I ed.
n. 29.

Bryum apocarpum $\beta$ L. Sp.pl.p. 1579.

Br. apocarpum var, aureum Rets. Prodr. Fl. Sc. n. 1216.

Br. apocarpum $\beta$ incanum Ehrh. in op. cit. 1780, p. 136.

Br. ciliatum Dicks. Fasc. IV Pl. crypt. p. 6.

Bv. sphagnoides Jacq. Coll. II, p. 222.

Fontinalis albicans Web. Spic. Fl. Goett. p. 38.

Gymnostomum ciliatum Roth. Fl. Germ. III, I, p. 129.

G. Hedwigia W. et M. Bot. Taschb. p. 78.

$H$. albicans Lindb. M, Scand. p. 40.

H. anodon Ehrh. Beitr. 1789, I, p. 187.

(1) Nom. jam abusum : Harrisonia R, Br. mss. (1825); Adr. de Juss. in Mèm. Mus. Paris, XII, p. 517, t. 28, f. 47 (Simarubeae); etc. 
H. apocarpa Leyss. Fl. holl. n. 1049.

H. diaphana P. B. Prodr. p. 60.

H. integrifolia ej. $l$. $c$,

Hedwigidium ciliatum Hartm. Skand. Fl. VI ed.

Pilotrichum ciliatum C. M. Syn. II, p. I64.

Schistidium ciliatum Brid. Bryol, univ. I, p. 116.

Sphagnum nodosum, hirsutie incanescens Dill. Hist. M. p. 246, t. 32, f. 5.

1. Ad. rup, aren, et granit. - Eur. : Reg. campestr. et montan. As. : Jenissei sup., Alatau. Japon., Nepal., Caucas. A fr. : Alger., Madeir., Teneriff,, Madagascar. Am. sept. : Groenland, Terr. nov., ab Atlantico ad Pacif.; ins. Vancouver. Am. merid. : And. Nov. Granat. et Quitens, Pac. : Austral, fel., Nov. Zeland., Tasman.

Exs. : Mac. Canad. M. n. 106.

Rab. Bryoth. eur. n, 514 .

Sull. et Lesq. M. bor. am. II ed, n. 224, 225.

" var, leucophaea Bryol. eur. et W. P. Sch. ll. cc.

Ut typ. - Eur. : Zon. merid. Am. sept. : Ubi typ.

Exs. : Mac. Canad, M. n. 107.

Rab. Bryoth. eur, n. 679.

\& var. secunda Bryol. eur. et W. P. Sch, ll. cc.

Pilotrichum ciliatum var, secundum C. M. $l$. c.

Ad rup. umbros. - Eur. : Ubi typ. Am. sept. : Ontario, etc.

" var. striata (Wils.) Bryol. eur. l. c. t. 273 et W. P. Sch. l. c.

Anoectangium striatum Wils, in Hook, Engl. Fl. p. 12.

Pilotrichum eiliatum var, striatum C. M. $l$. $c$.

Ad rup. granit. - Eur. : Hibern., Angl.

"var. viridis Bryol, eur. et W. F. Scl, $l l$. cc.

Anoeciangium imberbe Drumm. M, bor: am. I ed. n. 30.

Ad rup. umbros. - Eur. : Ubi typ. Afr. : Alger. Am, sept. : Gaspes., Nov. Scot., Ontario, Manitoba, ete.

Exs. : Mac. Canad. M. n. 108.

Rab. Bryoth. eur. n. 678.

ciliata Mitt. - H. Johannis Meyeri.

var. ? Jaeg. - H. Juratskae.

cirrifolia Wils. - Braunia.

decalvata Mitt. - Rhacocarpus imberbis.

diaphana P. B. - H. ciliata.

Emodica Hpe. in Fl. 1878, n. 6.

Hornschuchiana Hook.

- As. : Himalaya

Humboldti Hook. - Rhacocarpus.

$\beta$ australis H. f. et W. - Rhacocarpus australis.

imberbis Mitt. - Hedwigidium rhabdocarpum.

imberbis Sp. - Hedwigidium.

indica Mitt. - Braunia.

integrifolia P. B. - H. ciliata.

Johannis Meyeri C. M. in Fl. 1888, p. 415.

H. ciliata Mitt, in Journ. of the Linn. Soe. 1886, p. 310.

1. In gramin. edit. - Afr. : Kilima N'Djaro.

Juratrkae C. M. in Rev. bryol. 1876, p. 3 (nom.).

H. ciliata var. ? Jaeg. $A d, I I, p .722$.

- Pac. : Austral. (Nov. Valesia).

lapponica Brid. - Amphoridium. 
Mac-Owaniana C. M. in Fl. 1888, p. 415 (nom.) et Rehm. M. Afr. austr. $n .596$ b.

1. ? Ad rup. basalt. - Afr. : C, B, Sp.

microcyathea (C. M.) Par.

Cryphaea microcyathea Jaeg. Ad. II, p. 98.

H. ciliata (fid. Mitt.).

Pilotrichum microcyatheum C. M. in Bot. Zeit. 1851, p. 564.

I. Rupic. - Pac. : Austral. or., Tasman.

nivalis (C. M.) Mitt. M. austr. am. p. 405.

Anoectangium ciliatum C. M. in Linn. 1846, I, p. 199.

Pilotrichum nivale ej. Syn. II, p. 165.

Schistidium ciliatum Hpe. in Linn. 1847, II, p. 70.

1. $\quad-A m$, merid.: Venezuela.

orbiculata Mitt. - Rhacocarpus.

pilifera Mitt. - Braunia californica var, pilifera.

plicata Mitt. - Braunia.

repens $\mathrm{H}$. f. et W. - Gigaspermum.

rupestris Mitt. - Braunia.

Schimperiana Br. et Sch. - Braunia.

Schmidtii Hook. - Leucodon canariensis.

sciuroides de Not, - Braunia.

secunda Hook. - Braunia.

serricola C. M. in Ule Bryoth. brasil. n. 78.

- Am. merid. : Brasil, subtropic. or.

subnuda Kindb. in Mac. Cat. p. 78 (subsp. H. ciliatae).

1. Rupic. - Am. sept. : Ontario.

subrevoluta (C. M.) Besch. Prodr. bryol. mexic. p. 40.

Pilotrichum subrevolutum C. M. Syn, II, p. 165.

1. Rupic. - Am. sept. : Mexic.

HEDWIGIDIUM Bryol, eur. III (9 spec.).

ciliatum Hartm. - Hedwigia.

Drummondit (Tayl.) Jaeg. Ad. II, p. 89.

H. imberbe (fid. Mitt.).

Neckera Drummondii C. M. Syn. II, p. 106.

Schistidium Drummondii Tayl. in Lond. Journ. of bot. 1846, p. 37.

1 ?

- Pac. : Austral, or.

emersum (C. M. et Hpe.) Jaeg. l. c.

Harrisonia emersa C. M. et Hpe. in Linn. 1853, p. 502.

Hedwigidium imberbe? (fid. Mitt.).

1.

- Pac. : Austral, or.

glyphocarpum (Hpe.) Jaeg. Ad. 1I, p. 772.

Harrisonia glyphocarpa Hpe. Symb. 1877, p. 727.

- Am. merid. : Brasil. austr. or.

imberbe (Sm.) Bryol. eur. III, t. 274 et W. P. Sch. Syn. Il ed. p. 284.

Anoectangium ciliatum var, rufescens W. Arn. Disp. M. p. 11 .

A, imberbe $H$. et $T$. Muscol. brit. p. 14, t. 6 .

Gymnostomum imberbe Engl. Bot. t. 2237 .
Hedwigia imberbis Spr. M. Pyr. n. 338 et in Ann. and Mag. of nat. Hist. 1849, p. 187.

Neckera imberbis C. M. Syn. II, p. 105.
Schistidium imberbis Bryol. germ. I, p. 99, t. 8; Brid. Bryol. univ. I, p. 118 (incl. var. $\beta$ atro-virens et $\gamma$ gracile). 
I et Syn. Rupic. - Eur. : Norveg. occ., Finmarck, Angl., Hibern., Voges, sup., Pyren. As, : Ceylan (?). Afr. : M. Cameroon. Pac. : Tasman.

Exs, : Rab. Bryoth. eur, n. 921.

Liebmannianum W. P. Sch. Syn. I ed. p. 239 (nom.).

Brannia Liebmanniana W. P. Sch, prius,; Besch. Prodr, bryol. mexic. p. 41.

Neckera Liebmanniana C, M. Syn. II, p. 668.

Hermaphr. $\quad-A m$. sept. : Mexic.

rhabdocarpum (Hpe.) Jaeg. Ad. II, p. 772.

Braunia rhabdocarpa C. M. in Linn. 1878-79, p. 378.

Harrisonia rhabdocarpa Hpe. Prodr. Fl. N. Gran. p, 68.

Hedwigia imberbis Mitt. M. austr. am. p. 405.

1. Rupic. - Am. merid. : And. Nov. Granat, Quitens. et Boliv.; Argentin. subtropic.

Exs. : Mandon Pl. Boliv. n. 1638.

Serrae C. M. in Ule Brysth. brasil, n. 79.

- Am. merid.: Brasil. subtropic. or.

squarrosulum (Hpe.) Bryol. eur. III (mon. Brauniae, p. 3).

Harrisonia squarrosula Hpe. Ie, M. t. 19.

Neckera sphaerocarpa C.M. Syn. II, p. 105.

1.

- Am. sept. : Mexic., Guatemala.

teres (C. M.) Par.

Braunia teres C. M. in Fl. 1888, p. 415 .

1.

- Afr. : Kilima N'Djaro.

Helicoblepharum Spr, in Mitt. M. Austr. am. p. 371 (sect. Lepidopit).

HeLICODONTIUM Schwaegr. Suppl. III, II, II (13 spec.).

applanatum (Thw. et Mitt.) Jaeg. Ad. II, p. 292.

Hypnum applanatum Thw. et Mitt, in Jown. of the Linn. Soc. 1861, 1.

- As. : Ceylan.

capillate (Sw.) Besch. Not. M. Parag. p. 268.

Hypnum capillare Sw. Prodr. Fl. Ind. oec. p. 141; C. M. Syn. II, p. 410; Mitt. M. austr, am. p. 548.

H. furcatum Brid. Sp. M. $I I$, p. 151.

H porto-ricense Balb, in sched.

Leskea capillaris Hedv. M. frond. IV, p. 25, t. 10; Brid. Bryol. univ. $I I, p, 308$.

L. minutula Brid. Sp. M. II, p. 69.

1 ? Ad arbor, et rup. - Am. sept. : Mexic., Jamaic., Hispaniola, Porto-Rico, Cuba. Am. merid. : Brasil, auste, or., Paraguay.

Exs. : Bal. Pl. Parag. n. 1208.

Clarazii (Duby) Par.

Hypnum Clarazii Duby Choix de Crypt..., 1867, p. 14, c. io.

? Rudia Clarazii Jaeg. Ad. II, p. 293.

1 ? Cortic. - Am. merid.: Brasil. austr., Uruguay.

exilissimum (Sull.) Jaeg. Ad. $I I, p, 291$.

Hypnum exilissimum Sull. in Proced. Am. Acad... 1861, p. 286 ; Mitt. M. austr. am. p. 549.

Rhynchostegium exilissimum Jaeg. Ad. II, p. 430.

i. Cortic, - Am. sept. : Cuba. 
Fabronia Schwaegr. - Microthamnium.

laevisetum (Mitt.) Jaeg. Ad. II, p. 292.

Hypnum laevisetum Mitt. op. cit. p. 550.

1? - Am. merid.: And, Quitens.

lanceolatum (Hpe. et C. M.) Par.

Hypnum lanceolatum C.M. Syn. II, p. 411.

Leskea lanceolata Hpe. et C. M. in Linn. 1844, p. 702.

1. In silv. - Af $r$ : C. B, $\mathrm{S}_{\mathrm{H}}$.

leptodontium (Mitt.) Jaeg. Ad. II, p. 291.

Hypnum leptodontium Mitt. op. cit.p. 548.

1 ?

- Am. merid. : And. Peruv.

Mittenii $(S p r$.$) Par.$

Eriopus Mittenii Jaeg. Ad. II, p. 338.

Hypnum Mittenii Spr. Cat. p. 21 et in Mitt. op. cit. p. 551.

1? Cortic. - Am. merid. : And. Quitens.

oblique-rostratum (Mitt.) Jaeg. Ad. II, p. 291.

Hypnum oblique-rostratum Mitt. op. oit. p. 548.

1 ? Cortic. - Am. merid. : And, Quitens, et Peruv.

pervirens (C.M.) Par.

Hypnum pervirens C. M. in Linn. 1878-79, p. 456.

1. In silv. - Am. merid. : Argentin. Urug.

pervirens Besch. $-\mathrm{H}$. tenuirostre.

pseudo.Limnobium (C. M.) Par.

Hypnum pseudo Limnobium C. M. in Linn. 1880-83, p. 482.

1. $\quad-$ Am. merid.: Argentin. Buenos-Ayr.

pulvinatum Lindb. - Myrinia.

seminerve Schwaegr. Suppl. III, JI, II, in indice.

Hypnum seminerve C. M. Syn. II, p. 244.

Juratzkaea seminervis Ltz, in Bot, Zeit. 1866, p. 188.

Leskea seminervis Kze. in Poepp. Pl. Chil. I, n. 273.

Stereophyllum seminerve Mitt. M. austr. am. p. 542.

1. Ad arbor. - Am. merid.: Chile, Valdiv.

tenuirostre Schwaeg. op. et l. cc., t. 293.

Hypnum Helicodontium C. M. Syn. II, p. 689.

H. tenuirostre ej. op. cit. p. 411 .

Leskea tenuirostris Hook. in sched.

Myrinia venuirostris Ltz. in op. ot $l$. cce.

1. Ad arb. saxaq. inund. - Am. sept.: Mexic. Am. merid.: And.

Peruv, et Chil., Brasil. austr, or., Paraguay.

«var. paraguaricense (C.M.) Par.

H. pervirens Besch, in Rev, bryol. 1885, p. 18 et in Bal. Pl. Parag. n. 3687. Hypnum tenuirostre var, paraguaricense C. M. in Rev. br.yol. 1887, p. 5 ? - Am. merid. : Paraguay.

HELICOPHYLLUM Brid. Bryol, univ. II, p. 771 (2 spec.). australe Hpe. in Linn. 1869-70, p. 524.

Powellia involutifolia (fid. Mitt).

2.

- Pac. : Austral. fel. 
torquatum Brid. op. et l. cc. ; C. M. Syn. II, p. 15; Mitt. M. austr. am. p. 331.

Anoectangium torquatum Hook. M. ex. t. 41.

Schistidium torquatum Brid. op. cit. $I$, p. 121.

2. Ad arbor. - Ant. sept.: Mexic., Porto-Rico, Jamaïc,, Cuba. Ain. merid. : Amazon., Brasil austr. or., And. Peruv.

Heliconema Mitt. M. austr. am. p. 112 (sect. Syrrhopodontis).

Helicopogon Mitl. op. cit. p. 150 (sect. Barbulae).

Hemicampylus Milt. op. cil. p. 66 (sect. DicranI),

HEM(RAGIS Brid. Bryol. univ. Il, p. 334 (sect. Leskeae); Besch. gen. propr:

Spec. omn, non indicatae Hookeriak ejusd. nom.

striata Besch, - H. aurea.

HEMISYNAPSIUM Brid. Bryol, unir. $I 1, p .604$.

arcticum Brid, - Bryum.

$\beta$ purpurascens Brid. - Bryum purpurascens.

bryoides Brid. - Bryum Brownii.

HEMITHECA Lindb. mss., 1879, et in Braithus. Sphagn. pp. 30 et 35.

cyclophylla Lindb. - Sphagnum.

Pylaeai Lindb. - Sphagnum.

Henicodium C. M. in Linn. 1875, p. 470 (sect. Hxpn sensu Müll.).

HENNEDIA $R$. Br. in Trans, of the N. Zeal. Inst. 1892, p. 286 (1) (vid. HRinediella).

\section{HENNEDIELLA Par. (3 spec.).}

intermedia (R. Br.) Par.

Hennedia intermedia $R$. Br. in Trans, of the N. Zeal. Inst. 1892, p. 286.

Terr. - Pac. : Nov. Zeland.

macrophylla (R. Br.) Par.

Hennedia macrophylla $R$. Br. in op. et $l$. ec.

Terr. - Pac. : Nov, Zeland.

mierophylla (R. Br.) Par.

Hennedia microphylla $R, B r$, in op. et $l$. $c c$.

Terr. - Pac. : Nov. Zeland.

HENONIELLA Duby in Mém... Genève, 1876, p. 3 (1 spec.).

japonica Duby in op. el l. cc., t. 2, f. I.

Ptychomitrium Wilsoni Sull. et Lesq. ? (fid. Mitt.).

Terr. - As. : Japon.

(1) Nomen jam abusum : Hennedya Harv., 1860 (Algae). 
Herpetineuron C. M. in Fl. 1890, p. 495 (sect. Anomodontis).

HETEROGLADIUM Bryol, eur, V (1l spẹc.).

aberrans Ren, et Card. in Bot. Gaz. 1890, p. 59, t. IX B.

H. homoeopterum C. M. et Kindb, in Mac. Canad. M. n. 484.

$\sigma^{\star}$ ign. Cortic. et rupic. - Am. sept. : Columb. brit., Washington, Idaho.

dimorphum (Brid.) Bryol, eur. V (mon. p. 3), t. 479; W. P. Sch, Syn. Il ed. p. 606.

H. squarrosulum Lindb. M. Scand. p. 37.

Hypnum dimorphum Brid. Mant. M. p. 163.

H. squarrosulum Voit M. Herbip. p. 100.

H. Stereodon dimorphus Brid. Mant. M. p. 165 et Bryol. univ. II, p. 581 .

2. Saxic, et terr. - Eur. : Fere tota, capiosior in silv. alp. As.: Cancas. centr. Am. sept, : Groenland, Nov. Scot., New Brunswick, Terr. nov., M. Alb.. Idaho, Washington. Am. merid.: And. Quitens.

Exs. : Rab. Bryoth, eur. n. 993.

Un. itin. 1863 , n. 60.

frullaniopsis C. M. et Kindb. in Mac. Cat. p. 183.

2. Cortic. inter Hepatic. - Am. sept. : New Brunswick.

gastrodes (Welwo. et Duby) Jaeg. Ad. II, p. 312.

Hypnum gastrodes $W$. et D. in Mém... Geneve, 1871, $p, 15, t .5, f .1$.

2. Ad arbor, et rup. - Afr. : Angola.

heteropterum (Spr.) Bryol. eur. V (mon.p. 4), t. 480; W. P. Sch. op. cit. p. 607.

Hypnum catenulatum H. et T. Muscol. brit. II ed.. p. 160 ; Brid. Bryol. univ. II, p. 450 p.p.: Drumm. M. bor. am. I ed. n. 219.

H. heteropterum Spr. M. Pyr. n. 56 et in Ann. and Mag. of nat, Hist. 1849, M. Pyr. n. $15 ;$ C. M. Syn. II, p. 437.

Leptohymenium heteropterum Hüb. Muscol. germ. p. 553.

Pterigynandrum heteropterum Brid. Bryol. univ. II, p. 176 (quoad sp. Voge̊s., fid. C. M.; non! fid. W. P. Sch.).

Pterogonium heteropterum Br. in Sohwaegr. Suppl. III, I, I, t. 210.

2. Rupic. - Eur. : Britann, German. sept, Hercyn., Sudet., Voges., Silv. Nigr., Tirol., Helvet., Pyren. As. : Penins. Tschutschica. Am. sept. : Groenland, Columb. brit., ins. Vancouver, Washington, Idaho, Oregon.

Exs. : Mac. Canad. M. n. 267.

Rab. Bryoth. eur. n. 539, 643.

Un. itin. 1863, n. 59.

« var. fallax Milde Bryol. Siles. p. 269.

$\mathrm{H}$. hetoropterum var, cavernarum Mdo,

Ut et ubi proced. in Eur.

homoeopterum C. M. et K. - H. aberrans. implexum Kze. - Rigodium.

Kurrii Bryol eur. V (mon. p. 5), t. 480 et W. P Sch.op. cit. p. 608.

1. Terr. - Eur. : Alp. Norveg. (Dovre).

Lechleri W. P. Sch. - Rigodium.

leucotrichum Mitt, in Trans. of the Linn. Soc. 1891, p. 176.

Ster.

- As.: Japon. 
mexicanum W. P. Sch. - Psendo-Leskea praslonga.

papillosum Lindb. - Leskea.

procurrens (Mitt.) Jaeg. Ad. II, p. 312 (1).

Pterogonium prosurrens Mitt. in Journ. of the Linn. Soc. VIII, p. 37, t. 7 .

2. Ad rup. humid. - Am. sept. : M. Rupestr. et Selkirk, Colunb, brit.

Exs. : Mac. Canad. M. n. 498.

prolixum W. P. Sch, - Rigodium.

squarrosulum Lindb. - H. dimorphum.

subintegrum Mitl. M. Ind. or. p. 135 .

Ster. - - As.: Himalaya occ.

tenue Mitt, in Trans, of the Linn. Soc. 1891, p. 176.

2.

- As.: Japon.

vancouveriense Kindb. in Mac Cat. p. 183.

Thuidium vancouveriense $e j$. in Bull. Torr. bot. Club, XVII, p. 277.

2. Rupic. - Am, sept. : Ins. Vancouver, Washington.

Heterodictyon W. P. Sch. Coroll. p. 77 (subgen. BRYi= АкомовRYuM).

HETEROPHYLLIUM W.P.Sch.Syn. I ed.p. 629 (subgen. Hypsi); Kindb.

Chek-List of Eur. and N. Amer. M. p. 72 (gen. propr.).

nemorosum Kindb. - Hypnum.

HETEROPHYLLUM $C$. $M$. in Dusen $M$. Camer.

Spec. omn, sunt rhaphidostegia ejụsd. nom.

HILDEBRANDTIELLA C. M. in Linn. 1876, p. 257 (9 spec.).

Cameruniae C. M. in Dusen M. Camer. n. 115 ,

- Afr. : M. Cameroon.

cuspidans Besch, in Ann. sc. nat. VII ser., II, p. 91.

2. $\quad-A f r$.: Ins. Mayotte.

endotrichelloides C. M. in Linn. 1876, p. 257.

Cortic. - Afr. : Ins, Anjouan.

Holstii Broth. in Engler's Bot. Jahrb. 1894, p. 195.

2. Cortic. - Afr.: Usambara.

longiseta Ren. et Card, in Bull. Soc. roy. bot. Belg. 1891, II, p. 189. 2 ?

- Afr.: Madagascar.

pachyclada Besch. Fl. bryol. Réunion, etc. p. 123; Broth. in Engler's

Bot. Jahrb. 1894, p. 195 (descript. locupletior).

2 ?

- Afr.: Usambara, ins. Borbon., Franciae.

perpinnata Broth, in op. cit.p. 196.

2. $\sigma^{t}$ et fr. ign. Secus rivul. - Afr.: Cameroon.

puccinigera C. M. in Rev. bryol. 1878, p. 59 (nom.).

- Afr.: Ins. Franciae.

(1) False $H$. procumbens. 
thomeana Broth. in Bol. d. Soc. Brot. VIII, 1890 (1),

Ster. Ad arbor. - Afr. : Ins. S. Thom.

Himantocladium Mitt. Sam. M, p. 168 (sect. Neckerak).

Himantophyllum ej. op. cit. p. 173 (sect. CALYMPERIDIS = EucALYMPERES C. M.).

HIPPOPODIUM Fabric. Fl. Ratisb. p. 31.

aphyllum ej. - Buxbaumia.

HOLLIA Sieb. in Fl. 1826, $p 223$.

myrmecodes ej. - Dicnemon calycinum.

HOLMGRENIA Lindb. in Oefv ... 1862 (spec. omn. ORTHothecia europ.).

HOLOBLEPHARUM Dz. et Mk. M. frond. ined. Archip. ind. p. 113 (3 spec.).

Deplanchei (Duby) Besch. Fl. bryol. Nov. Caledon. p. 227.

Chœtomitrium Deplanchei Duby mss.

2. Ad ramos arb. - Pac. : Nov. Caledon.

leptopoma $\mathrm{Dz}$. et $\mathrm{Mk}$. - Hookeria.

orthorhynchum eor. - Chætomitrium.

rugifolium Sull. in Am. Expl. Exped. 1859, p. 23, t. 22.

Choetomitrium rugifolium Mitt. Fl. Vit. p. 392.

2. Ad arbor. - Pac. : Ins. Ovalan, Viti, Salomon.

speciosum Sull. in op. et l. cc., t. 21.

Choetomitrium speciosum Mitt. op. et l. cc.

- Pac.: Ins. Samoa.

Holodontium Mitt. M. austr. am. p. 63 (sect. DicRaN1).

HOLOMITRIUM Brid. Bryol. univ. I (sub Olomitrio) (35 spec.).

acutum Wright in Lond. Journ. of bot. 1892, p. 263.

$$
\text { - Afr. : Zambez. or. }
$$

alpinum Mitt. - Dicranoweisia.

antennatum Mitt. M. austr. am. p. 59.

$$
\text { - Am. merid. : Brasil. austr. or. }
$$

arboreum ej. op. cit. p. 58.

$$
\text { - Am. merid. : And. Quitens, et Peruv. }
$$

borbonicum Hpe. in Besch. Fl. bryol. Réunion, etc. p. 40.

H. vaginatum Brid. op. cit. p. 227 p.p.

calycinum (Sro.) Mitt. op. cit. p. 58.

- Afr.: Madagasc., ins. Borbon., Franciae.

Bryum calycinum Sw. Prodr. Fl. Ind. occ, p. 139.

Cecalyphum calycinum P. B. Prodr. p. 50.

Dicranum calycinum Sw. Fl. Ind. occ. III, p. 1768.

Weisia calycina Hedw. Sp. M. p. 70, t. 14.

1.

- Am. sept. : Jamaíc.

(1) In Enum. Kindberg. nom. nud. :

H. madagassa $C$. $M$. 
"var. gracilis (Hpe.) Par.

H. crispulum Mart. in Fl. orypt. Brasil, p. 53, t. 18, f. 2; Hsch. Fl. Bras. p. $35 ;$;. M. Syn. I, p. 350.

H. calycinum var, gracilis Hpe. Symb. 1874, p. 487.

H. Sellowii Mitt. op. cit. p, 59.

Weisia Sellowii Schwaegr. Suppl, IV,p. 309.

Cortic, et rupic. $-A m$, merid.: $\Lambda$ nd. Nov, Granat et Quitens., Brasil. capense C. M. in Rehin. M. Afr. austr. n. 73. - Afr. : C. B. Sp.

cirratum Mitt. - Dicranoweisia microcarpa.

comorense C. M. in Linn. 1876, p. 236.

Lignic. - Afr. : Ins. Anjouan.

( Mart. - H. calycinum var. gracilis.

crispulum Mitt. - Dicranoweisa.

Sull. - H. marginatum.

var, gracilis $\mathrm{H}_{\mathrm{p}} \mathrm{H}_{0}-\mathrm{H}$. calycinum var, gracilis.

dicranoides Dz. et Mk. - Dicranum Molkenbœri.

Dietrichiae C. M. in Linn. 1874, p. 149.

- Pac. : Austral, or.

enerve Dz. et Mk. - Braunfelsia.

flagellare C. M. mss. ; Jaeg. Ad. II, p. 761.

Ster.

- Afr.: Madagascar.

flexuosum Mitt. $M$. austr. am, $p .57$.

- Am. merill.: And. Quitens.

Glaziowii Geh. et Hpe. in Fl. 1881, p.

- Am, merid.: Brasil. austr. or.

Griffithianum Mitt. M. Ind. or. p. 24.

Didymodon perichœetialis Griff. Not. p. 431 et Ic. pl. asiat. t. 80, f. 1

Symblepharis densifolia Wils. in Kew journ, bot. IX, p. 292.

2 ?

- As. : Assam, Khasia.

bamatum C. M. in Bull. Soc. roy. bot. Belg. 1894, II, p. 112. - Afr. : Madagascar (Diego Suarez).

Hildebrandtii C. M. in Hillebr. M. Madag. n. 2099.

indicum Mitt. - Dicranoweisia.

- Afr. : Madagascar.

javanicum Bryol. jav. 1, p. 86, t. 71 .

2.

- As. : Java.

Lehmanni Besch. in Journ. de bot. 1894, p.

- Am. merid.: And. Nov. Granat.

longifolium Hpe. in Ann. sc. nat. V ser. III, p. 364.

- Am. merid. : And. Nov. Granat.

lutescens C. M. in Linn. 1878-79, p. 473.

- Am. merid. : Venezuela.

marginatum Mitt. M, austr, am, p. ̌̄7.

H, crispulum Sull, in Proced. Am. Acad... Aug. 1861.

- Am. sept. : Cuba.

Moritzianum Hpe. in Linn. 1847, p. 70.

- Am, merid.: Culumí. 
Mülleri Hpe. in Linn. 1869.70, p. 514. - Pac. : Austral. (Vietoria).

Novae Valesiae C. M. in Rev. bryol. 1876, p. 3 (nom). - Pac. : Austral, or. (Nov. Vales.).

Olfersianum Hsch, Fl. Brasil. p, 18; C. M. Syn. I, p. 349 , 1. - Am. merid. : Brasil.

paraguense Besch, in Journ. de Bot. 1891, p.

Ad rup. vulcanic. - Am. merid.: Paraguay.

perichaetiale (Hook.) Brid. Bryol, univ. I, p. 227 ; C. M. Syn. I, p. 351 . Cecalyphum perichaetiale $P . B$. Prodr, p. 51 .

Sprucea perichaetialis $H$. f. et $W$. in sched. M. Antarct. I, p. 128.

Symblepharis perichaetialis Wils, in Fl. of the N. Zeal. p, 60 .

Trichostomum perichaetiale Hook. M. ex. I, t. 73 et $I I, p$. 11 .

1. $-A f r$. : Ins. Franciae (fid. Handb. of N. Zeal. Fl.).

Pac. : Austral. or., Nov. Zeland., Tasman., ins. Campbell.

piliferum (Mitt.) Besch. Fl. bryol. Antill. fr. p. 15.

Eucamptodon piliferus Mitt. M. austr. am. p. 69.

Cortic. - Am. sept.: Guadalup., ins. S. Margarit. Am. merid. Ins. Trinitat.

proliferum Mitt. op. cit. p. 61 .

- Am. merid. : Brasil, tropic.

pulchellum Mitt. op, cit, p. 60 .

- Am. merid.: And. Quitens.

pumilum Mitt. mss.

Symblepharis pumila Mitt. in Hook. Handb. of N. Zeal. Fl. p. 405.

Terr. - Pac. : Nov. Zeland. med.

Sellowii Mitt, - H. calycinum var, gracilis.

serratum (W. P. Sch.) C. M. Syn. II, p. 587.

Cecalyphum serratum W. P. Sch. mss.

Leptodontium brevisetum Mitt. M. austr. am. p. 50 ?

- Am. sept. : Mexic. (M. Orizaba).

terebellatum C. M, in Bull. Soc. roy. bot. Belg. 1892, I, p. 151.

1. $\quad-$ Am. sept.: And. Costa Ricens.

tortuosum Mitt. M. austr. am. p. 58.

- Am. merid. : And. Quitens.

undulatum Mitt. op. cit. p. 59.

\section{- Am. merid. : And. Quitens.}

vaginatum (Hook.) Brid. Bryol. univ, I, p. 227 ; C. M. Syn. I, p. 350.

Cecalyphum cylindraceum $P . B$ Prodr. p. 51.

Dicranum calycinum Brid. op. cit. p. 452 (excl. syn.).

D. cylindraceum ej. op, cit. p. 458.

Trichostomum vaginatum Hook. $M$. ex. $I, t .64, I I, p .11$.

Weisia vaginans Brid. op. eit. p. 807 . 1. Arbor. - Afr. : Usambara, ins. Borbon., Franciae, C. B. Sp. Pac,:
Taït.

« var, obtusifolium Besch. Fl. bryol. Réunion, etc., p. 40.

Ster.

- Afr. : Madagascar.

vaginatum Brid. p.p. - H. borbonicum. 
Wrightii Sull. in Proced. Am. Acad... 1861, p. 279; Mitt. M. austr. am. $p, 61$.

$$
\text { - Am. sept.: Cuba. }
$$

HOMALIA Bryol, eur. V (sub Omalia) (53 spec.).

ankaratrensis Kiä̈r in Borgen M. Madag. n. 38.

- Afr. : Madagase. centr.

arcuata Brybl. jav, II, p. 56, $t .176$.

2.

- As. : Ins. Halmaheira Molluc., Sumatra.

auriculata Hook. f. el Wils. Fl. of the N. Zeal. II, p. :15, t.92, f. 4 et Handb. p. 483.

Ster. Ad arbor. - Pac. : Nov. Zeland. sept.

australasica C. M. in Ångstr. Prim. lin. p. 51 .

H. intermedia Angstr. in Oefv,.. 1872, n. 4, p. 17.

Porotrichum dendroides (fid. Mitt. in Proc. of the roy. Soc. 1879 (extra vol.), p. 101).

2. - Pac. : Ins. Hawai (Honolulu).

Besseri Lobarz, - Neckera Sendtneriana.

bibrachiata (C.M.) Par.

Hypnum bibrachiatum C. M. in Engler's Bot. Jahrb. 1883, p. 86 et in Forchungsreise... Bot. p. 54.

$$
\text { - Pac. : Nov. Guinea. }
$$

complanata de Not. - Neckera.

defoliata (C. M.) Jaeg. Ad. II, p. 201.

Hypnum defoliatum $C . M$. in Bot. Zeit. 1869, p.

Ster.

- Am. merid. : Brasil. austi, or.

densa Boswell in Journ. of bot. 1892, p. 98.

2 .

- Pac. : Ins. Oahu.

dentata (Griff.) Jaeg. Ad. II, p. 202.

Neckera dentata Griff. Not. p. 463 et Ic. pl. asiat., t. 88, f. 2; Mitt. M. Ind. or. p. 119.

$$
\text { - As. : Assam. }
$$

elongata Welwo. et Duby in Mém... Genève, 1871, p. 5, Ł. 2, $f .3$.

2. Lignic. - Afr. : Angola,

erosifolia C. M. mss.; Jaeg. Ad. II, p. 203.

- As.: Pegu.

exigua Bryol. jav, $I I, p .55, t .175$.

2 .

- As.: Celebes, Borneo, Java, Sumatra, Tonkin. Afr.: Ins. Franciae. Pac.: Taiti.

falcifolia Hook, f. et Wils. Fl, of the N. Zeal. II, p. 115, t. 92, f. I et Handb. p. 483.

Hypnum falcifolium eor in Lond. Journ. of bot. 1844, p. 554; C. M. 2. Syn. II, p. 230.

flabellata (Dicks.) Bryol. jax. II, p. 58, Ł. 178.

Hookeria flabellata $S m$. in Trans. of the Linn. Soc. $1 X, p, 280, t, 23, f .2$. Hypnum flabellatum Dicks, in hb. L. jun.; C. M. Syn II, p. 225.

Leskea Omalia flabellata Brid. Bryol, unio. $I I, p .325$. 
Neckera flabellata Mitt. M. Ind. or, p. 118.

Porotrichum flabellatum ej. in Trans. of the Linn. Soc. 1891, p. 175.

2. - As.: M. Neilgherr., Ceylan, Japon., Ternate, ins. Halmaheira et Saporaea. Molucc., Borneo, penins. Malay., Java, Sumatra.

glabella (Swo.) Mitt. M. austr. am. p. 458.

Hypnum glabellum Sw. Prodr. Fl. Ind. occ, p. 140.

Leskea glabella Hedw. Sp. M. p. 235, t. 59.

Neckera Distichia glabella Brid. Bryol. univ. II, p. 242.

N. glabella Sic. Fl. Ind. oce, III, p. $1782 ;$ C. M. Syn. II, p. 44.

N. patagonica Brid. M. Rec. II, II, p. 4?

Pilotrichum patagonicum P. B. Prodr. p. 83 ?

Sphagnum pennatum, planum Dill. Hist. M. p. 249 , . 32, f. 7 (! fid. Brid. ;? fid. C. M.).

Ad arbor. - Am. sept. : Mexic., Jamaic.

glossophylla (Mitt.) Jaeg. 1I, p. 198.

Neckera glossophylla Mitt. M. Ind. or. p. 119.

Ster.

- As. : Sikkim, Khasia.

Goughiana (Mitt.) Jaeg. Ad. II, p. 200.

Neckera Goughiana Mitt. op. cit. p. 120.

2.

- As. : M. Neilgherr.

gracilis Jam. in Rep. Reg. N. York Univ. 1869, p. 57 ; Sull. Ic. M. Suppl. p. 82, t. 25; Lesq. et Jam. Man. p. 285.

$f$ et fr. ign. kill.

Hookeriana Bryol. jav. $11, p .57, t .177$.

Neckera Hookeriana Mitt. op. cit. p. 118. 2. - As. : Sikkim, Khasia, ins. Bali.

intermedia Ângstr. - H, australasica.

. amesii W. P. Sch. Coroll. p. 100 ; Lesq. et Jam. Man. p. 285.

1. $\quad-$ Am. sept.: M. Alb. et Catskill, Pensilv.

Exs. : Sull, et Lesq. M. bor. am. II ed. n. 397.

javanica (C. M.) Bryol. jav. II, p. 54 .

Neckera dendroides Hsch. et Reinw, in Nov. Act. Acad. Caes. Leop, XIV, II, Suppl. p. 714 .

N. javanica $C . M$. Syn. II, p. 41 ,

2 .

- As. : Japon. ? Java, Ceylan.

laxiretis (C. M.) Jaeg. Ad. II, p. 203.

Hypnum laxirete C. M. in Bot. Zeit. 1869, p.

Ster, Ad arbor. - Am. merid.: Aquator.

lentula Wils, in Ann. and Mag. of nat. Hist. 1847, p. 379 ; C. M.

Syn. II, p. 46 (1).

Ster, Ad arbor. - Am, sept. : Jamaic.

ligulaefolia (Mitt.) Bryol. jav. I1, p. 59, t. 179.

Neckera ligulaefolia Mitt. $M$. Ind. or. p. 119.

2. Ad arbor. - As.: Ceylan, Sumatra, Java.

linguaefolia Welvo et Duby in Mém... Genéve, 1871, p. 7, t. 3, f. 6.

1. Ad arbor. - Afr.: Angola. 
lusitanica W. P. Sch. Coroll. p. 101 et Syn. II ed. p. 572.

H. trichomanoides Rab. Bryoth, eur, n. 467.

1. Ad rup. irror., rarjus ad arb. - Eur.: Gall, merid., Catalaun., Lusit., Etrur., 1stria, Afr. : Alger.

Macounii C. M. et Kindb, in Bidr. p. 454 (nom.) et in Mac. Cat. p. 163.

H. obtusata Lesq. et Jam. Man, p. 285 ; Mac. Canad. M. n. 243.

H. trichomanoides eor. $l l, c o, p .285$ et $n .242$.

Hypnum trichomanoides Drumm, M. bor, am. I ed. n. 171 .

1. Cortic., rupic. et terr. - Am, sept,: Terr. nov., Nov. Scot., New Brunswick, Gaspes., Ontario, lac. Super., Columb, brit., ins. Vancouver.

microdendron (Mont.) Jaeg. Ad. II, p. 200.

Hookeria? microdendron Mont, in Voyage Bonite, Crypt. p. 150, f. 3 et Syll, p. 15 .

Hypnum microdendron C. M. Syn. M. II, p. 231.

2. Ster. Ad arbor. - As, ; Cochinchin.

Mobriana (C. M.) Jaeg. Ad. II, p. 202.

Neckera Mohriana C. M. in Linn. 1876, p. 646.

Ster. Cortic. in silv, $-A m$, sept, : Mexic.

Montagneana (C. M.) Jaeg. Ad. II, p. 203.

Hookeria longissima Mont in sched.

Hypnum Montagneanum C. M. in Bot. Zeit. 1856, p. 436.

2. Arbor, - As.: Yunnan, M. Neilgherr.

nitidula Mitt. in Journ. of the Linn. Soc, p. 155; Besch. in Ann. sc. nat. $1893, p .360$ (descript. fruct.).

1.

Exs. : Faurie n, 307.

oblongifolia Hook. f. et Wils. Fl. of the N. Zeal. II, p. 115, t. 91, f. 6 et Handb. n. 483.

Hookeria punctata var. oblongifolia ear, in Lond. Journ. of bot. 1844. p. $550 ;$ C. M. Syn. II, p. 28 .

2. Ad arbor. - Pac. : Nov. Zeland. sept.

obtusata (Mitt.) Jaeg. Ad. II, p, 201.

Neekera obtusata Mitt. M. Ind. or. p. 118. 1.

- As. : Tibet, oce,

oblusata Lesq, et Jam, -- H. Macounii.

Pabstiana W, P. $5 c h, h b$.

Neekera Pabstiana C. M. in Bot. Zeit. 1855, p. 766.

1. Ad arbor. - Am, merid.: Brasil, austr. or.

paraguensis Besch. - Stereophyllum.

pendula W. P. Sch. - Porotrichum piniforme.

periduliramea (C. M.) Jaeg. Adl. II, p. 202 ,

Neekera penduliramea $C . M$. in Linn. 1876, p. 617.

Ster. Ad rup. trachyt. irror. - Am. sept.: Mexic.

Pourretiana Roumeg. - Neckera Sendtneriana.

praelonga Reichdt, Beitr, p. 573 .

2. Ster.

- Pac.: Ins. Sandwic.

pseudo-exigua Besch. Fl. bryol. Taiti, elc., p. 42.

Ster, Cortic et rupic. - Pac.: Taïti. 
pulchella Hook. $f$. et Wils. Fl. of the N. Zeal. II, p. 114, t. 91, f. 5 et Handb. p. 483 .

Hookeria punctata eor. in Lond. Jouin. of bot. 1844, p. 550; C. M. Syn. II, p. 28.

2. Ad arbor. - Pac. : Nov. Zeland, sept. et med,, ins. Norfolk, Tasman.

pusilla Bryol. jav. 1I, p. 56, $t .176$.

Ster.

- As.: Ins. Ceram.

rectifolia (Mitt.) Jaeg. Ad. II, p. 203.

Neckera rectifolia Mitt. M. Ind. or. $p, 119$.

2.

- As. : Khasia.

rotundata (Hpe.) Jaeg. Ad. II, p. 201.

Hypnum rotundatum Hpe. insched.

- As.: Birman.

rotundifolia W. P. Sch. - Neckera Sendtneriana var, rotundifolia.

Sakontala Llz. Moosst. p. 166.

Ster.

- As. : India.

scalpellifolia (Mitl.) Bryol. jav. II, p.60, t. 180.

Neckera scalpellifolia Mitt. op, oit, p. 119.

Porotrichum scalpellifolium $e j$. in Trans, of the Linn. Soc. 1891, p. 175,

2. Ad arbor. - As. : Japon., Tonkin, Amboine, Ternate, ins. Ceram,

Halmaheira et Saparaea Molucc., Borneo, Java, Sumatra, Ceylan.

Exs. : Savat. Pl, Japon. n. 568.

Sendineriana W. P. Sch. - Neckera.

spathulaefolia (C. M.) Jaeg. Ad. II, p. 198.

Hypnum spathulaefolium C. M. Syn. M. II, p. 231.

Neckera spathulaefolia Mitt. op. cit. p. 118.

2.

- As. : India.

Stracheyana (Mitt.) Jaeg. Ad. II, p. 213.

Neckera Stracheyana Mitt. M. Ind. or. p. 118.

- As. : Himalaya.

subexigua C. M. in Rev, bryol. 1878, p. 59 (nom.).

- Afr.: Ins. Franciae.

subrecta (Mitt.) Jaeg. Ad. II, p. 200.

Neckera subrecta Mitt. in Journ. of the Linn. Soc. 1863, p. 7.

1. Inter musc. - Afr. : Madeir.

Targioniana Gough mss.

Neckera Targioniana Mitt, op. cit. p. 117.

2 .

- As. : M. Neilgherr., Yunnan.

trichomanoides (Schreb.) Bryol. eur V (mon. p. 3), t. 446; W. P. Sch. Syn. II ed. p. 571.

Fuscina trichomanoides Schrank Baïers Fl. II, p. 451.

Hypnum complanatum $\beta$ obtusum Ehrh. Hannov. Mag. 1870, p. 237. Hypnum complanatum $\beta$ obtusum Ehrh. Hannov. Mag. $187, p .25 .9 .269$
H. pennatum, trichomanoides, splendens, ramosum Dill. Hist. M.p.
t. $34, f .8$. H. $34, f .8$.
H. trichomanoides Schrb. Spic. Fl. Lips. p. $88 ;$ C. M. Syn. II, pp. 929
et 681 .

Leskea trichomanoides Hedw. Sp. M. 232.

L, Omalia trichomanoides Brid. Bryol, univ. II, p. 329.

Neckera trichomanoides $H$ artm. Skand. Fl. V ed. $p, 338$. 
1. Ad arbor. trunc, et rad., terr. et sax. in silv. - Eur, : Med., rar. sept. vel. merid. As. : Jenissei sup., Caucas, occ. et centr.

Exs. : Rab. Bryoth, eur. n. 71 b.

trichomanoides $\left\{\begin{array}{l}\text { Lesq. et Jam. - H. Macounii. } \\ \text { Rab. exs. - H. lusitanica. }\end{array}\right.$

truncata Welwo. et Duby in Mém... Genève, 1871, p. 6, t. 3, f. 5 .

1. Ad rup. umbros. - Afr. : Angola.

Valentini Besch. Fl. bryol. Réunion, elc., p. 133.

2.

- Afr.: Ins, Borbon., Franciae,

variifolia Welwo et Duby in op. cit. p. $5, t .4, f .5$.

Ster. Ad rup. madid. - Afr. : Angola.

Webbiana (Mont.) W. P. Sch. Coroll. p. 101.

Hookeria Webbiana Mont. in Hist. Il. Canar. p. 12, t. I, f. I et Syll. p. 16.

Hypnum Webbianum C. M. Syn. $I I, p .230$.

1. In silv. ; cortic. ? - Afr. : Ins. Teneriff.

Wrightii Sull. M. of U. St. p. 65.

Hypnum Wrightii Sull. Ic. M. p. 209, t. 127; Lesq. et Jam. Man. p. 411.

1. Ad arbor. - Am. sept.: Texas, Nov. Mexic.

Exs. : Sulliv, et Lesq. M. bor. am. I ed, n, 269 et II ed. n. 536.

Zetterstclti Jaeg. - Sauloma.

Homalocarpus Mitt. M. austr. am, p. 85 (sect. CAMPYLOPODIS).

HOMALOTHEGIUM Bryol, eur. V (23 spec.).

acuminalum Jaeg, - Brachythecium.

algerianum Besch. Cat. M. Alger. p. 35.

- Afr. : Alger.

Boivinianum Besch, Fl, bryol. Réunion, etc. p. 152.

Bonplandii (Hook.) Jaeg. II, p. 379.

- Afr.: Comor. magn.

Hookeria leskeoides Hook. M. ex. t. 55 p.p.

Hypnum Bonplandii C. M. Syn. II, p. 463; Mitt. M. austr. am. p. 558.

H. pseudo-salebrosum Hpe. (id. Mitt, l. c.).

Leskea Bonplandii Hook in Kth. Syn. Pl. Equin. I, p. 61; Brid. Bryol. univ, II, p. 318.

2. Rupic. - Afr.: Ins. Tristan d'Acunha, C. B. Sp. Am, merid. : And. Nov. Granat, et Quitens. ; Peruv.

caucasicum (Lindb.) Par.

Hypnum caucasicum Linnb, in Broth. Enum. M. Caucas, p. 117.

2 . Ad arbor. et rup. - As. : Caucas.

congestum (Suc.) Jaeg. Ad. II, p. 377.

Hypnum congestum Sw. Prodx. Fl. Ind, occ. p. 142; C. M. Syn, II, p. 358; Mitt, M. austr. am. p. 559 .

Leskea congesta Brid. Bryol. univ. II, p. 323 p.p.

2. Ad arbor. - Am, sept. : Jamaic., ins, Montserrat. Am. merid.: Guian. bat.

corticola Kindb. in Bull. Torr. bot. Club XV11, p. 276 el in Mac. Cat. pp. 175 et 274 .

1. Rupic, - Am. sept. : Ins. Vaneouver. 
? decorum (Mitt.) Jaeg. Ad. II, p. 746.

Hypnum decorum Mitt. M. Ind. or. p. 77.

Leskea longirostris Sclwwaegr. t. 290 A (fld. Mitt. ; deest in C. M. Syn.). - As. : Nepal.

fallax Philib. in W. P. Sch. Syn. II ed.p. 644.

2. Ad sax, et terr. petros, calc. - Eur.: Gall, occ, Galloprov.

fulgescens (Mitt.) Jaeg. Ad. 1I, p. 375.

Hypnum fulgescens Mitt. in M. Douglas et in Bot. Zeit. 1858, p. 170. 2. - Am. sept. : Columb. brit.

? incompletum (Griff.) Jaeg. Ad. II, p. 746.

Hypnum incompletum Mitt. M. Ind. or, p. 77.

Leskea incompleta Griff. Not. p. 478 et Ic. pl, asiat. II, t. 102, f. 3. - As. : Assam.

? laevisetum (Sande. Lac.) Par.

Hypnum laevisetum S. Lac. in Miq. Ann. Mus, bot. Lugd, Batav, JI, p. $298, t .186, f . I$.

2.

- As. : Japon.

laeviusculum Jaeg. - H. neckeroides.

luteolum (Mitt.) Jaeg. Ad. 1I, p. 379.

Hypnum luteolum Mitt. M. austr. am. p. 558.

- Am. sept. : Ins. S. Vincent.

? macrostegium (Sull, et Lesq.) Par.

Hypnum macrostegium S, et L. in Proced. Am. Acad... IV, p. 280.

$$
\text { - As. : Japon. }
$$

Mandoni Mitt, in Goodman's Nat. hist. of the Asores, 187', p. $31 \mathrm{ll}$ (1).

H. sericeum var: madeirense $W, P . S c h . h b$.

H. sericeum var. meridionale ej. in Mandon Pl. Mad. n. 36 et 37 .

2.

$$
\text { - Afr. : Madeir. }
$$

? neckeroides (Griff.) Par.

H. laeviusculum Jaeg. Ad. II, p. 745.

Hypnum laeviusculum Mitt. M. Ind. or. $p$. 76 .

Pterogonium neckeroides Griff. Not. p. 450 et Ic. pl. asiat. II, t. 98, f. 3. Ad arbor. - As. : Khasia.

nevadense Ren. et Card. - Camptothecium.

var, subulatum eor. - H. sericeoides.

Nutlallii Jaeg. - Camptothecium. Philippeanum (Spr.) Bryol. eur. V (mon. p. 3), t. 457; W. P. Sch.
Syn. II ed. n. 633 .

Hypnum Philippeanum C. M. Syn. II, p. 356.

Isothecium Philippeanum Spr, M. Pyr,n. 77 et in Ann. and Mag. of nat. Hist. 1849, M. Pyr. n. 88.

2. Ad rup, et sax. umbrosa, praecip, calcar. - Eur. : Jurass. helvet. et germ., Alp. Sabaud., Austr., Siles., Ital. sup., Pyren. As, : Caucas, oce. et centr. Afr. : Alger.

Exs.: Rab. Bryoth. eur, n 344, 487, 1190.

Un. itin. 1863, n. 65. 
pseudo-sericeum (C. M.) Lesq. et Jam. Man. p. 310.

Hypnum pseudo-sericeum $C . M$, in $F l .1875, p .89$.

2. Rupic. - Am. sept. : Columb. brit., Oregon, Idaho.

Exs. : Mac. Canad, M. n. 435.

sciureum (Mitt.) Besch, in Ann, sc. nat. 1893, p. 372.

Hypnum sciureum Mitt. in Trans. of the Linn. Soc. 1891, p. 184.

Exs.: Faurie n. 162 p.p.

- As. : Japon.

sericeoides C. M. et Kindb. in Bidr. p. 454 (nom.) et in Mac. Cat. p. 175.

Camptothecium nevadense var. subulatum Ren. et Card, in Bot. Centralbl. $1890, n .51$.

Hypnum Brittoni Mitt. mss.

2. Ster. Ad rup. granit. - Am. sept. : Columb. brit., Washington, Idaho.

Exs. : Mac. Canad. M. n. 496.

sericeum (L.) Bryol, eur V (mon. p. 3), t. 456; W. P. Sch, op. et l. cc.

Hypnum sericeum L. Sp. pl. p. 1595; C. M. Syn. II, p. 356.

H. vulgare sericeum recurvum, capsulis erectis cuspidatis Dill. Hist. M. p. $325, t .42, f .59$

Isothecium sericeum $S p r$, M. Pyr. n. 76 .

Leskea sericea Hedw. M. frond. IV, p. 43, t. 17; Brid. Bryol. univ. II, p. 295.

Neckera sericea Hedw. Fund. M. II, p. 93.

2. Ad arbor. et mur., rar, rup. - Eur.: Fere tota, in intermed, et merid. vulgatiss, As, : Caucas,, Kurdistan,, Pers. Afr. : Alger., ins. Canar., Madeir. Am. sept.: M. Rupestr., ins. Vancouver.

Exs. : Bourg, PI. Canar. n. 1584.

Drumm. M. bor. am. J ed. n. 169 (Hypnum).

Mac. Canad. M. n. 549 .

Rab. Bryoth, eur. n. 446.

var, madeirense W. P. Sch. - H. Mandoni.

var. meridionale W. P. Sch. - H. Mandoni.

" var, tenellum Lge. in Bot. Tidskr. 1867-68, p. 248.

- Eur. : Belgia.

subcapillatum (Hedvo.) Sull. M. of U. St. p. 63, t. 5 et Ic. M. p. 14I, t. 90.

Hypnum subcapillatum C. M. Syn. II, p. 352.

Lasia subcapillata Brid. Bryol, unit. II, p, 202.

Pterigynandrum subcapillatum Hedw. Sp. M. p. 83, t. 16, f. 9-12.

Pterogonium decumbens Sehwaegr. Suppl. II, I, p. 32, t. 110.

Pt. subcapillatum ej. Suppl. $I, I, p, 107$.

1. Cortic. in silv. - Am. sept. : Reg. or. et centr.

Exs.: Drumm. M. bor, am, II ed. n. 88 (Hypnum).

Sull, et Lesq. M. bor. am. II ed, n, 384.

tenerrimum (C.M.) Jaeg. Ad. $I I, p, 377$.

Hypnum tenerrimum C. M. in Bot. Zeit. 1856.

Rhynchostegium tenerrimum Jaeg. Ad. II, p. 429.

1. Filicic, - Am. sept. : Guatemala.

tokiadense (Mitt.) Besch. in Ann. sc. nat. 1893, p. 372 (descript, frucl.).

Hypnum tokiadense Mitt, in Trans. of the Linn, Soc. 1891, p. 184.

2.

Exs, : Faurie n. $64, \overline{84}, 117$, $125,213,1428,3512$.

Homomallia C. M. Syn. II, p. 425 (subsect. HrPN1).

Homomallium W, P. Sch. Syn. I ed. p. 616 (subgen. Hypsi). 
HOOKERIA Sm, in Trans. of the Linn. Soc, 1X, p. 275 (234 spec). abrupta (Mitt.) Par.

Callicostella abrupta Mitt. in Journ. of the Linn. Soc. 1863, p. 61. Hypnella abrupta Jaeg. Ad. II, p. 269.

2. - Afr. : lns. Fernando-Po.

acicularifolia C. M. in Dusen M. Camer. $n .245$.

- Afr.: M. Cameroon.

acicularis Mitt. M. austr. am. p. 354 .

Hookeriopsis acicularis Jaeg. Ad. II, p. 263.

- Am. sept. : Guatemala, Jamaic.

acuminata Mitt. op. cit. p. 357.

Hookeriopsis acuminata Jaeg. Ad. II, p. 265.

2 . - Am. merid. : And. Quitens.

acutifotia Hook. - Pterygophyllum.

var. Sull. -- Mniadelphus cubensis.

adunca Mitt. op. cit. p. 362.

Hookeriopsis adunca Jaeg. Ad.p. 267.

Lignic. - Am. merid.: And. Quitens.

aeruginosa Mitt. op. cit. p. 346.

2. Lignic. - Am. merid.: And. Quitens, et Peruv.

affinis $\left\{\begin{array}{l}\text { C. M. - Lepidopilum. } \\ \text { W. Arn. - H. depressa. }\end{array}\right.$

africana (Milt.) Par.

Callicostella africana Mitt, in Trans, of the Linn. Soc. XXXIII, p. 53, t.5,, 9.9. Syn. - $A f r .:$ Ins. Fernando-Po, Niger, inf.

albata C. M. Syn. II, p. 191 ; Mitt. op. cit. p. 343. 1 ?

\section{- Am. merid. : Ins. Trinit.}

albicans (Sro.) Hook. Muscol. brit. 1818, p. 90; C. M. Syn. 1I, p. 189;

Mitt. op. et l. cc.

Hypnum albens Gmel. Syst. nat. II, p. 1343.

H. albicans Sw. Prodr. Fl. Ind. occ. p, 140.

H. pallidum Brid. M. Rec. 1I, II, p. 127.

Leskea albicans Hedw. Sp. M. p. 218, t. 54; Sw. Fl. Ind. occ. III, p. 1811.

Pterygophyllum albicans Brid. Bryol. unix. II, p. 349 p.p.

1 ? - Am. sept.: Mexic., Jamaic. Am. merid. : Ins. Trinitat, And. Nov, Granat. et Quitens.

albicans Tayl, $-\mathrm{H}$. laete virens.

albicaulis W. P. Sch, in Besch. Fl. bryol. Antill. fr.p. 58.

Ster. - Am. sept. : Guadalup.

amblyophylla H. f. et W. - Mniadelphus.

ancistroides Mont. - Meteorium.

angolensis W. et Duby. - Lepidopilum.

anomala C. M. - Pterygophyllum.

Antillarum Mitt. - Pilotrichidium.

apiculata Sande Lac, in Miq. Ann. Mus. bot. Lugd. Batav. II, p 296;

Dz. et Mk. M. frond. ined. Archip. ind. t. 52 (sine nom, diago. aut loc. natal.). 
apiculata H. f. et W. - Eriopus.

apophysata Hpe. Symb. 1874, p. 514.

Callicostella apophysata Jaeg. Ad. $I I$, p. 256.

Syn.

- Am. merid. : Brasil, austr, or.

Araucariae C. M. in Ule Bryoth. brasil. n. 157.

Ad terr. humid. in silv, $-A m$, merid. : Brasil, subtropic. or.

Arbuscula $\mathrm{Sm}$. - Camptochaete.

arcuata Bryol. jav. II, p. 56, t. 176.

- As. : Ins. Halmaheira, Sumatra.

Ascensionis C. M. in Engler's Bot. Jahrb. 1883, p. 84 et in Forchungsreise... Bot. p. 42.

Ster. - Afr. : Ins. Ascension.

aspera Mitt. M. austr. am, p. 352 .

Callicostella aspera Jaeg. Ad. II, p. 258.

Lignic. - Am. merid. : Venezuela, Amazon., Guayaquil, And. Quitens.

asplenioides $\left\{\begin{array}{l}\text { W. Arn. - Eriopus. } \\ \text { nervo subcontinuo Mont. - Pterygophyllum Orbignyanum. }\end{array}\right.$ asprella Hpe. Symb. 1877, p. 730.

Callicostella asprella Jaeg. Ad. II, p. 774.

1.

- Am. merid. : Brasil, austr. or.

atro-virens Col, - Pterygophyllum.

attenuata C. M. in op. cc. pp. 88 et 63 .

Ad arbor. - Afr. : Monrovia.

Auberti (P. B.) C. M. Syn. II, p. 190.

Neckera Auberti Brid. Sp. M. II, p. 28.

Pterygophyllum albicans ej. Bryol, univ. II, p. 349 p.p.

Rhacopilum Auberti P. B. Prodr, p. 87.

1 ? Saxic. - Afr.: Ins. Borbon., Franciae.

aurea (Lam.) Mitt. op. cit. p. 348.

Dicranum Novae Hollandiae Hsch, in Sieb. M. exs, $n$. 7.

Harpophyllum aureum Spr. Catal.; Husnot M. Antill. n. 187.

Hemiragis striata Besch. Fl. bryol. Antill. fr. $p, 68$.

Hypnum aureum Lam. Encycl. meth, bot. III, p. 172; C. M. Syn. II, p. 386.

H. congestum Hedu. Sp. M. p. 283, t. 74, f. 4-7.

H. phryscophyllum $W$. Arn. Dispos.

Leskea congesta Brid. Bryol. univ. II,"p. 323.

L. striata Sohwaegr. Suppl. 1, II, p. 180, t. 86.

L. Hemiragis striata Brid. op. cit. p. 334.

Mnium aureum $P . B . P$ rodr. $p$. 74 .

1. Ad arbor. - Am. sept. : Costa Rica, Guadalup. Am. merid. : Ins. Trinitat., And. Quitens.

aureo-purpurea Geh, et Hpe. in Fl. 1881, p.

2.

- Am. merid. : Brasil. austr. or.

Baileyi Broth, in Bail. Syn. of the Queensl. Fl. IV, Suppl. p. 98 (nom.) et in Oefv ... 1890, p.

Syn. Lignic. - Pac. : Austral. or. (Queensland).

Beccariana Hpe. in Nuov. Giorn. bot. ital. 1872, p. 282.

Callicostella Beccariara Jaeg. Ad. II, p. 259.

1. Ad arbor. - As.: Yorneo. 
Belangeriana Besch. Fl. bryol. Antill. fr. p. 59.

Callicostella Belangeriana Jaeg. Ad. II, p. 257.

Syn.

- Am. sept.: Martinic.

Bernouillii W. P. Sch. mss, ; Jaeg. Ad. II, p. 734.

Bescherellei Par.

$$
\text { - Am. sept. : Guatemala }
$$

H. rugulosa Besch. Fl, bryol. Nov. Caled, p. 229.

1. Terr. - Pac. : Nov, Caledon.

Beyrichiana Hpe. Symb. 1872, p. 57.

Callicostella Beyrichiana Jaeg. Ad. II, p. 261.

H. Langsdorflii Hsch. Fl. Brasil. I, p. 61 p.p.

2. Ad arbor. et rup. humid. - Am. merid.: Brasil. auste, or.

bicolor W. P. Sch. in Besch. Fl, bryol. Antill. fr. p. 58.

- Am. sepl. : Guadalup.

bisexualis Besch. Fl. bryol. Nov. Caled. p. 230.

Callicostella bisexualis Jaeg. Ad. II, p. 260.

1. vel syn. Ad arbor. - Pac. : Nov. Caledon.

blanda Ltz. Moosst. p. 166.

1.

$$
\text { - Am. sept. : Jamaic. }
$$

Blumeana C. M. Syn. II, p. 676.

Pterygophyllum Blumeanum Bryol. jav. II, p. 38, t. 161.

Syn.

- As.: M. Java, Sumatra occ.

bogotensis Hpe. in Ann. sc. nat. V ser., p. 303.

Adelothecium bogotense Mitt. M, austr, am, p. 391.

2. -Am. sept.: Cuba, Jamaic. Am. merid.: And.

Nov. Granat, Brasil. tropic.

bombonasica Mitt, op. cit. p. 342 .

Syn.

- Am. merid. : And. Quitens.

borbonica Besch. Fl. bryol. Réunion, etc, p. 142.

1?

" $f$. inundata Besch. $l$. c. Aquat.? - Afr.: Ins. Borbon.

Breuteliana Hpe. mss, ; C. M. in Bot. Zeit. 1859, p. 247. 2?

- Afi.: C. B. Sp.

breviseta Hpe. Symb. 1877, $\dot{p} .730$.

Hookeriopsis breviseta Jaeg. Ad. II, p. 774.

2?

- Am. merid.: Brasil. austr. or.

brunnescens W. P. Sch. - Pilotrichidium.

caespitosa Mitt. M, austr. am. p. 347 .

2 ?

- Am. merid. : And, Quitens.

caldensis Angstr. Prim. lin. p. 25.

Callicortella caldensis Jaeg. Ad. II, p. 261.

Syn.

- Am. merid. : Brasil.

californica W. P. Sch, in Jardin Enum. p, 20 (nom.). - Am. sept. : Calif. (ins. Cervorum).

callicostata C. M. - Pilotrichidium. 
Campbelliana Hpe, in Linn. 1874, p. 668.

Callicostella Campbelliana Jaeg. Ad. II, p. 260.

1. - Pac. : Nov. Hebrid.

capillata Mitt. M. austr. am. p. 341.

Lignic. - Am. merid..: Nov. Granat., And. Quitens.

castanea Mitt, op. et $l$. cc.

2 ?

- Am. merid. : And. Quitens.

cavilolia Mitt, op, cil. p. 361 .

Hookeriopsis cavifolia Jaeg. Ad. I1, p. 267.

- Am. merid. : And. Quitens.

ceylanica Thw. et Mitt, in Journ. of the Linn. Soc. 1872, p. 310.

1 et syn.

- As.: Ceylan.

cheiloneura C. M. in Dusen M. Camer, n. 415.

- Afr.: M. Cameroon.

chimborazensis Mitt. M. austr. am. p. 346.

2.

- Am. merid.: M. Chimborazo.

chionophylla (C. M.) Par.

Callicostella chionophylla $C$. M. in Fl. 1886, p. 282.

Ad arbor. - Afr. : Ins. S. Thomas.

chlorina Besch. Fl. Bryol. Taïti, etc. p. 45.

2 ? Cortic. - Pac. : Nuka-Hiva.

chloroneura Tayl. - Lepidopilum.

ciliata W. P. Sch. in Besch. Prodr. bryol. mexic. p. 87.

Callicostella ciliata Jaeg. Ad. II, p. 259.

- Am. sept. : Mexic.

cirrifolia W. Arn. - Rhaphidostegium.

cirrosa Hpe. Symb. $1874, p .512$.

Hookeriopsis cirrosa Jaeg. Ad. II, p. 268.

1.

- Am. merid. : Brasil. austr. or.

commutata Par.

H. leptorhyncha $\mathrm{Hsch} . \mathrm{Fl}$. Brasil. I, p. 68 (1).

2 ?

- Am. merid. : Brasil. austr, or.

complanala Hpe. - Pterygophyllum. confusa Par.

H. heterophylla Geh, et Hpe, in litt. ad. Jaeg. 1878-79, Ad. II, p. 774.

- Am. merid. : Brasil, austr. or.

constricta C. M. in Fl. $1886, p .515$.

Terr. - Afr. : Ins. Fernando-Po.

contortifolia Mont. - Mniadelphus.

convallium C. M. - Lepidopilum.

convoluta Spreng. - Leptodon Smithii.

corcovadensis Reichdt, in Novara Exped. Bot. I, p. 186, t. 36.

Hookeriopsis corcovadensis Jaeg. Ad. II, p. 263.

- Am. merid. : Brasil. austr. or.

(1) In herbar. Beyrichiano non asservata. Stirps dubia, "Hpe. Enum. M. Brasil. p. 65 . 
corticola C. M. in Ule Bryoth, brasil. n. 85.

Ad truncos arb. - Am. merid. : Brasil, subtropic. or.

crenata Mitt. M. austr. am. p. 351.

H. Merkelii Sull. in Proced. Am. Acad... 1861, p. 286.

Syn. $\quad-A m$. sept. : Ins, S, Vincent, Cuba.

crispa C. M. in Bot. 1855, p. 768 ; Mitt. op. cit. p. 354.

H. undata C. M. Syn. $I I, p .209$.

Hookeriopsis crispa Jaeg. Ad. II, p. 262.

1. Ad arbor. Am. sept.: And. Costa Ric. Am. merid.: Venezuela, And. Nov. Granat, et Quitens., Brasil austr. or.

crispula H. f. et W. - Mniadelphus.

cristata $\left\{\begin{array}{l}\text { Dz. et Mk. - Eriopus remotifolius. } \\ \text { Reichdt. - Eriopus Jelinckii. } \\ \text { W. Arn. - Eriopus. }\end{array}\right.$

Cruceana Duby Ckoix de crypt. ex... 1867, p. 12, t. 4; Mitt. op. cit. p. $34 y$.

Callicostella Cruceana Jaeg. Ad. II, p. 257.

1. Ad arbor. - Am. sept. : Florida (ster.); Mexic.

Crügeriana C. M. Syn. II, p. 208; Mitt. op. cit.p. 355.

Hookeriopsis Crigeriana Jaeg. Ad. II, p. 263.

2. Ad arbor. - Am, sept. : Ins. Barbad. Am. merid.: Ins. Trinitat, Amazon., And. Peruv.

"var. dimorpha C.M. $l . c$.

$$
\text { - Am. merid. : Ins. Trinitat. }
$$

cupressiformis C. M. - H. leptorhyncha.

curvifolia Mitt. op. cit. p. 362.

Hookeriopsis curvifolia Jaeg. Ad. II, p. 267.

- Am. merid. : And. Quitens.

cuspidata C. M. Syn. II, p. 189 ; Mitt. op. cit. p. 344.

Hookeriopsis cuspidata Jaeg. Ad. II, p. 263.

1. - Am. merid. : Venezuela, And. Nov. Granat. et Quitens., Brasil. austr. or.

cuspidata $\left\{\begin{array}{l}\mathrm{Dz}_{\mathrm{z}} \text { et Mk. - Distichophyllum. } \\ \text { Mitt. }-\mathrm{H} \text {. quitensis. }\end{array}\right.$

cuspidatissima Hpe. Symb. 1874, p. 514.

Callicostella cuspidatissima Jaeg. Ad. II, p. 260.

Ster.

- Am. merid. : Aquator.

cymbifolia Hpe. in Linn. 1852, p. 362 ; Mitt. op. cit.p. 344.

Hypnella cymbifolia Jaeg. Ad. II, p. 269.

Syn. Lignic. - Am. sepl. : Guadalup., Cuba, Porto-Rico.

debilis Sull, - Leucomium.

Deppeana C. M. - Lepidopilum.

denticulata Mitt. op. cit. p. 347 . Ad saxa irror. - Am, sept. : Guadalup. ? Martinic.? Am. merid.:
And. Peruv.

denticulata H. f. et W. - Pterygophyllum.

var. latifolia C. M. - Pterygophyllum denticulatum var, latifolia. 
depressa (Sw.) Hook, et Tayl. Muscol. brit. p. 90; C. M. Syn. II, p. 218.

Callicostellá depressa .Jaeg. Ad. II, p. 256.

H. affinis W. Arn, in Trans, of Wern. Soc. V et Disp. p. 56.

Hypnum depressum Sw. Prodr. Fl. Ind. occ. p. 141.

H. guadalupense Spreng, in Brid. Bryol. univ. II, p. 351.

Leskea depressa Hedw. Sp. M. p. 215, t. 53.

Pterygophyllum depressum Brid. op. cit. p, 351.

1. Jamaic., Porto Rico.

- Am. sept.: Guadalup.? Cuba, Hispaniola, depressula C. M. in Besch. Fl. bryol. Antill. fr. p. 59.

Callicostella depressula Jaeg. Ad, II, p. 256.

1. - Am. sept.: Guadalup.

diaphana W. Arn. - Lepidopilum.

Dicksoni Hook. - Distichophyllum.

diffusa Wils, in Mitt. M, austr. am. p. 354.

Hookeriopsis diffusa Jaeg. II, p. 263.

- Am. merid. : Panama.

disticha (Ångstr.) Par.

Callicostella disticha Angstr, in Oefv.., 1873, n. 5, p. 150.

2.

- Afr. : Ins. S. Jose.

divaricala Mitt. - Lepidopilum.

diversifolia Mitt. op. cit. p. 364 .

2. $\quad-$ Am. merid.: And. Quitens.

elongata Dz. et Mk. - Chaetomitrium.

erectiuscula $\{$ C. M. - Lepidopilum Krauseanum.

Tayl. - Lepidopiltim.

erythrochaete W. P. Sch. in Besch. Fl. bryol. Antill. fr. p. 66.

Hypnella erythrochaete Jaeg. Ad, II, p. 270.

2 ?

- Am. sept, : Guadalup.

exigua Mitt, op. cit, p. 358.

Hookeriopsis exigua Jaeg. Ad. II, p. 265.

2.

- Am. merid. : And. Quitens.

falcata Hook. M. ex. t. 14; C. M. Syn. II, p. 216; Mitt. op. cit. p. 361.

Hookeriopsis falcata Jaeg. Ad. II, p. 267.

Pterygophyllum falcatum Brid. Bryol. univ. II, p. 353.

1. Ad arbor. - Am. sept. : Guadalup. Am. merid. : Venezuela, And.

Nov. Granat. et Quitens.

falcatula W. P. Sch, in Besch. Fl. bryol. Antill, fr. p. 63.

Hookeriopsis falcatula Jaeg. Ad. II, p. 267.

1.

- Am. sept. : And. Costa Ric., Guadalup.

Fendleri C. M, in Linn. $1878-79$, p. 495.

1. $\quad-A m$. merid.. Venezuela.

filescens W, P. Sch. in Besch. Fl. bryol. Antill fr. p. 61 .

Ster.

- Am. sept.: Guadalup.

filiculaeformis $\mathrm{Sm}$. - Hypopterygium.

filiformis Hook, in Spreng. Syst. Veg. IV, p. 197; C. M. Syn. II, p. 212; Mitl. op. cit, p. 365.

Callicostella filiformis C, M. in Linn. 1848, p. 189. 
Hypnella filiformis Jaeg. Ad. II, p. 271.

1 ? $\quad-A m$, sept. : Guadalup., ins. S. Vincent.

fissidentella Besch. Fl. bryol. Réunion, etc. p. 143.

In silvic, - $A f r$, : Ins. Borbon.

fissidentoides Hook. f. et Wils, in Hook, Ic. pl. rar. t. 739; C. M.

Syn. II, p. 217 ; Mitt. op. cit. p. 357.

Hookeriopsis fissidentoides Jaeg. Ad. II, p. 265.

$$
\text { - Am. sept. : Jamaic. }
$$

flabellata $\mathrm{Sm}$. - Homalia.

flaccida H. f, et W. - Mniadelphus.

flava Col. - Pterygophyllum.

flavescens Hook. et Grev. in Brewster Edinb. Journ. II, p. 296, t. 5. t. I;

C. M. Syn. $I I, p .211$.

Hypnella flavescens Jaeg. Ad. II, p. 211.

1.

- Am. sept. : lns S. Vincent.

flexicollis Mitt. - Eriopus.

flexifolia C. M. - Lepidopilum.

flexilis Sm. - Pilotrichella.

flexuosa Mitt. - Mniadelphus.

fluminensis Geh. et Hpe. in Fl, 1881.

2.

- Am. merid. : Brasil. austr. or.

Freycineti Mont. - Distichophyllum.

fridrichsthaliana (Reichdt.) Par.

Hemiragis fridrichsthaliana Reichdt. Beitr. p. 579 (in adn... - Am. sept. : Guatemala.

gemmacea Mitt. M. austr. am. p. 340 .

2. Ster. Lignic. et ad rap. irror. - Am. merid. : And. Nov. Granat.

gigantea Hsch. - H. Parkeriana.

glandulifera Hpe. in Linn. 1863, p. 156.

Hookeriopsis glandulifera Jaeg. Ad. II, p. 266.

Lignic. - Am. merid. : And. Nov. Granat.

Glaziowii Hpe. Symb. 1874, p. 508.

Hookeriopsis Glaziovii Jaeg. Ad. 1I, p. 264.

Syn. $\quad-$ Am. merid. : Brasil. austr. or.

gracilis Mitt. op. cit. p. 360 .

Hookeriopsis gracilis Jaeg. Ad. p. 2 C6.

- Am, merud. : And. Quitens.

Graeffeana C. M. M. Polyn. p. 77.

1. $\quad-P a c$ : Ins. Fidji.

Grevilleana $\left\{\begin{array}{l}\text { Griff. - Pterygophyllum acutifolium. } \\ \text { Tayl. - Lepidopilum. }\end{array}\right.$

guadalupensis (Brid.) C. M. Syn. II, p. 212; Mitt. op. cit. p. 359.

Hookeriopsis guadalupensis Jaeg. Ad. II, p, 266.

Hypnum guadalupense Brid. Bryol. univ. II, p. 395.
H. repens $H$. et Grev. in Brewster Edinb. Journ. II, p. 231, f. 5.

1 vel syn.

- Am. sepl. : Guadalup., ins S. Vineent.

"var. longifolia Besch. Fl. bryol. Antill. fr.p. 64. 
Habniana Besch, op. cit. p. 60.

1 vel syn.

- Am. sept. : Guadalup., Martinic.

hepaticcefolia Jaeg. - Pterygophyllum.

Herminieri W. P. Sch, in Besch, op. cit. p. 59.

Callicostella Herminieri Jaeg. Ad. II, p. 257. - Am. sept. : Guadalup.

var. rubella Besch. - H. rubella.

heterophylla (Ångstr.) Par.

Callicostella heterophylla Angstr. in Oefv... 1873, n. 5, p. 150.

2.

- Afr. : Ins. S. Jose.

heteropleylla Geh, et Hpe. - H. confusa.

Hildebrandtii $C, M$. in Linn. 1876, p. 251.

1.

- Afr. : Ins. Comor.

hispidula Mitt. op. cit. p. 339.

- Am. merid. : And. Nov, Granat.

Hornschuchiana Hpe. Symb. 1874, p. 509.

Callicostella Hornschuchiana Jaeg. Ad. p, 260.

H, Langsdorffii Hsch. Fl. Brasil. I. p. 61 p.p.

2? Ad saxa madid. - Am. merid. : Brasil. austr. or.

Hornschuchiana Hpe. (Ic.). - H. microcarpa.

hospitans W. P. Sch. in Besch. op. cit. p. 62.

Hookeriopsis hospitans Jag. Ad. II, p. 265.

2. Ad folia emort. - Am. sept.: Guadalup., Martinic.

humilis Mitt. op. cit. p. 342.

Ad saxa irror. - Am. merid. : Nov. Granat., And Peruv.

hyalina W. P. Sch, in Besch. op. cit. p. 57.

- Am. sept. : Guadalup.

hyaloblasta C. M. in Dusen M. Camer, n. 110.

- Afr.: M. Cameroon.

hypnacea C. M. in Bot. Zeit 1856, p. 421 ; Mitt. op. cit. p. 363.

H. repens Hsch. Fl. Brasil. I, p. 68.

H. variabilis ej. in sched.

Hookeriopsis hypnacea Jaeg. Ad. $I I, p .268$.

I et syn. - Lignic, - Am. merid.: And. Nov. Granat., Brasil, austr. or,

hypniformis Besch. op. cit. p. 63.

Hookeriopsis hypniformis Jaeg. Ad. II, $p 266$.

2 ? Rupic. - Am. sepl. : Guadalup.

hypnoides Hsch. - Ectropothecium hookerioides.

incurva Hook. et Grev. in Brevoster Edinb. Journ. II, p. 23I; C. M.

Syn. II, p. 192 ; Mitt. op. cit. p. 350.

Chaetophora incurva Hsch, in Hor. phys. Berol. p. 65, t. 13; Brid. Bryol. univ. $I I, p .336$.

1. Lignic. - Am, merid. : Ins. Trinitat., Venezuela, Brasil. or., And. Peruv., Chile.

incurva Dz. et Mk. - Lepidopilum Sumatrae.

intermedia C. M. - Lepidopilum. 
iporangeana Geh, el Hpe. in Fl. 1881. 2. - Am. merid. : Brasil. austr. or.

Jagiana C. M. Syn. II, p. 191 ; Mitt. op. cit. p. 343. Ster. - Am. merid. : Venezuela.

Jardini W. P. Sch. - H. oblongifolia.

Karsteniana Broth, et Geh. in Oefv... 1893, p. Syn. - Pac. : Austral. or. (Queensland).

Krauseana Hpe. et Ltz, in Bot. Zeit. 1869, p.

1. Ad arbor. - Am. merid. : Equator.

lacerans C. M. in Linn. 1876, p. 250.

Callicostella lacerans Jaeg. Ad. II, p, 260.

- Afr. : Usambara, ins, Anjouan, Mayotte.

« var. aequilenta Besch. Fl. bryol. Réunion, elc.p. 144. - Afr.: Ins. Nossi-Comba.

\& var. nossiana Besch, op. et $l$. cc.

- Afr. : Ins, Nossi-Comba.

laete-virens Hook. et Tayl, Muscol. brit. I ed., p. 89, t. 27; C. M. Syn. II, p. 187 ; Bryol. eur. V, t. 447 ; W. P. Sch. Syn. II ed. n. 581.

Cyclodictyon laete-virens Mitt. in Journ. of the Linn. Soc. 1863, p. 163. H. albicans Tayl. Fl. Hibern. II, p. 36 .

Pterygophyllum laete-virens Brid, Bryol. univ. II, p. 350.

1. Ad rup. humid. - Eur. : Hibern. Afr, : Madeir., ins, Fernando Po. Exs, : Mandon Pl. Madeir. n, 34.

Rab. Bryoth. eur. n. 586.

laevinervis (Ren. et Card.) Par.

Hookeriopsis laevinervis $R$. et C. in Bull. Soc. roy. bot. Belg. 1894, I, p. 196.

2? In silv. - Am. sept. : Costa Rica.

laeviuscula (Mitt.) Par.

Callicostella laeviuscula Mitt. in Philos. Trans, of the roy. Soc. 1879 $($ extra-vol.), p. 392, t. $37 \mathrm{~B}$.

Syn.

- Afr.: Ins, Rodriguez,

Langsdorffii Hook. M. ex. t. 121 ; C. M. Syn. 11, p. 193; Mitt. M. austr. am. p. 356 (1).

Chatophora Langsdorffii Brid. Bryol, univ. II, p. 337.

Hookeriopsis Langsdorffi Jaeg. Ad. II, p. 264.

Syn, Ad rup, irror, - Am. merid. : Brasil. austr. or.

Langsdorffii $\left\{\begin{array}{l}\text { Hsch. p.p. - H. Beyrichiana. } \\ \text { Hsch. p.p. - H. Hornschuchiana. } \\ \text { Schwaegr. - H. Schwaegrichenii. }\end{array}\right.$

latifolia Mitt. M. austr. am. p. 345 .

Ster. $\quad-A m$, merid. : And, Quitens.

latifolia C. M. - Lepidopilum.

? Le Duceana Mont. in Voy. Bonite p. 292 et Syll, p. 13.

1. Cortic, $-A f r$. : Ins. Borbon.

Le Duceana Mont. p.p. - Rhaphidostegium Duisabonae var. Le Duceanum.

(1) Cr. Duby Choix de M. ex. 1890, p. 10, t. I, f. 3 et Hpe. in Fl. 1880, n. 21. 
leiophylla Besch, Fl. bryol. Antill. fr. p, 66 .

Hookeriopsis leiophylla Jaeg. Ad. II, p. 268.

2. Rupic. - Am. sept. : Martinic.

? lepida Mitt. in Trans. and. Proced. of the roy. Soc. of Victoria, 1883, p. 78.

Ster.

- Pac.: Austral. or. (Queensland).

leptocladula (C. M.) Par.

Callicostella leptocladula $C$. M. in Dusen M. Camer. n. 47. - Afr.: M. Cameroon.

leptopoma C. M. - Chaetomitrium.

leptorhyncha Hook, et Grev. in Breuóter Edinb. Jou'n. II, p. 228, t. 5;

C. M. Syn. II, p. 213; Mitt. op. cit. p. 365.

H. cupressiformis C. M. l. c. p. 215.

Hypnella leptorhyncha Jaeg. Ad. 1I, p. 270. 2 ?

Trinitat.

- Am, sept.: Ins. S. Vincent. Am. merid.: Ins.

leplorhyncha Hsch. - H. commutata.

leskeoides Hook. - Homalothecium Bonplandi.

Liebmanni W. P. Sch. in Besch. Prodr. bryol. mexic. p. 86.

Ster.

- Am. sept. : Mexic.

limbata Hpe. Symb. 1874, p. 507.

H, sarmentosa Duby Choix de M. ex. 1880, p. 9, t. I, f. I (fid. Hpe. in $F l .1880, n .21)$.

Syn.

- Am. merid. : Brasil, austr. or.

Lindbergii (Par).

H. viridissima Lindb, mss.; Angstr, in Oefv... 1876, n. 4, p. 25.

- Am. merid. : Brasil. austr. or.

Lindenbergii Hpe. - Lepidopilum uticamundianum?

Lindigiana Hpe. in Linn. 1863, p. 156; Mitt. M. austr. am. p. 340.

l. Ad arbor. - Am. merid.: And. Nov, Granat.

- var. flaccida Hpe. in op, et $l$. cc.

Ut et ubi typ.

longipedunculata C. M. Syn. 1I, p. 221; Mitt. op. cit. p. 352.

Callicostella longipedunculata Jaeg. Ad. $I I$, p. 258.

Syn.

- Am. merid. : Ins. Trinitat.

longissima Mont. - Neckera Montagneana.

Lorentzi C. M. in Linn. 1880-83, p. 474.

lorifolia Hpe. Symb. 1874, p. 510.

- Am. merid. : Alp. Argentin, subtropic. Tucuman.

Callicostella lorifolia Jaeg. Ad. II, p. 260.

Syn.

- Am. merid. : Brasil, austr. or.

loriformis Hpe. et Ltz. $-\mathrm{H}$. pendula.

lucens $\mathrm{Sm}$. - Pterygophyllum.

var. acuminata C, M. - Pterygophyllum acuminatum.

luteo-rufescens Besch. Fl, bryol. Antill. fr, p. 67.

2 ? Ster. Ad arbor. - Am. sept. : Martinic. 
luteo-viridis Besch. in Rev. bryol. 1885, p. 19 et in Journ, de bot. 1891, p. Syn. Cortic. - Am. merid. : Paraguay.

Exs. : Bal. Pl. Parag. n. 3638.

macropyxis Rehm. M. Afr. austr. n. 339.

- Afr. : Natal.

marginata Hook. f. et Wils, in Lond. Journ. of bot. 1844, p. 60; C. M. Syn. II, p. 188 ; Mitt. op. cit. p. 341.

- Am. merid. ; Brasil. austr. or.

Martiana Hsch. Fl. Brasil. I, p. 63, t. 3 ; C. M. Syn. II, p. 219; Mitt. op. cit.p. 349.

Callicostella Martiana Jaeg. Ad. II, p. 255.

l (C. M.) ; Syn. (Mitt.).

- Am. merid. : Brasill. austr. or.

melanotheca Duby in Besch. Fl. bryol. Nov. Caled. p. 230.

1. - Pac. : Nov. Caledon.

membranacea C. M. - Lepidopilum.

Merkelii Hsch. op, cit. p. 62 ; C. M. Syn. II, p. 218; Mitl. op. et l. cc.

Callicostella Merkelii Jaeg. Ad. II, p. 255.

Syn. Terr. - Am. merid. : Brasil. austr. or.

Merkelii Sull, - H. crenata.

Meyeniana Hpe. - Ectropothecium.

microcarpa Hsch. op. et l. cc.; C. M. Syn, II, p. 217 ; Mitt. op. cit.p. 350.

Callicostella microcarpa Jaeg. Ad. II, p. 257.

H. Hornschuchiana Hpe. Ic. M. (in eontextu H. Poeppigianae).

Pilotrichum obtusifolium Brid. Bryol, univ. II, p. 860.

1. Ad arbor, et sax. irror. - Am. merid. : Amazon., Brasil, austr. or.

? microdendron Mont. - Homalia.

Minarum Ångstr. in Oefv... 1876, n. 4, p. 25.

1. $\quad-$ Am. merid. : Brasil. austr. or.

minor ej. in op, et $l$. cc.

2 ?

- Am. merid. : Brasil, austr. or.

Mittenii Jaeg. - H. tenella.

mniacea C. M. - Pterygophyllum.

mniifolia $\{$ Hsch. - Mniadelphus Hornschuchii.

Mont. - Distichophyllum Montagneanum.

? mollis Wils. in Lont. Journ. of. bot, 1848, p. 283; C. M. Syn. II, p. 222.

- Am. merid.: Brasil.

Mülleri C. M. - Lepidopilum.

natalensis Rehm. M. Afr. austr, n, 622.

Pterygophyllum natalense ej. l. c. n. 338.

$$
\text { - Afr.: Natal. }
$$

nervosa $\mathrm{H}$. f. et Wils. - Daltonia.

nigella eor. - Pterygophyllum.

nitens Hsch. op. cit. p. 65; C. M. Syn. II, p. 193; Mitt. op. cit. p. 357.

Hookeriopsis nitens Jaeg. Ad. II, p. 193.

2 ? Lignic. - Am. merid. : Brasil, austr, or. 
nitida Mitl. op, cit, p. 348 .

Stenodictyon nitidum Jaeg. Ad. II, p, 262.

- 2 ,

- Am. merid.: And, Quitens.

nivalis C. M.Syn. II, p. 188 ; Mitt.op. cit. p. 346.

2? - Am merid.: Venezuela, And. Nov. Granat.

nivea C. M. - Lepidopilum.

nouka-hivensis Besch. Fl. bryol. Taiti, elc. p. 45.

H. pallens W. P. Sch, in Jard, Enum. p. 20 (nom.).

Syn. Cortic.

- Pac. : Nouka-Hiva.

obliqua Hpe. - Sehizomitrium.

oblongifolia Sull. in Proced. Am. Acad... Januar. 1854.

Callicostella papillata Mitt. Sam. M. p. 190.

H. papillata Sull, in Wilkes Exped. p. 23.

Schizomitrium papillatum $e j, l . c$.

Syn. Terr. et ad filic. putresc. - Pac. : Ins. Fidji, Samoa, Taïti, NukaHiva.

obovata Griff. - Distichophyllum.

obscura Mont. - Pterygophyllum.

obscurifolia Mitl. op. cit. p. 342.

2. $\quad-$ Am. merid.: And. Quitens.

oblusifolia Harv. - Stereophyllum indicum.

Erstedtiana C. M. Syn. II, p. 679; Mitl. op. cit. p. 351.

Callicostella (Erstedtiana Jaeg. Ad. II, p. 258.

Syn.

- Am. sept. : Costa Rica.

Olfersiana Hsch. op. cit. p. 61, t. 3 ; C. M. Syn. II, p. 188; Mitt. op. cit, p. 344 . 1.

Orbignyana Mont. - Pterygophyllum.

ornans (Reichdt.) Par.

Hemiragis ornans Reichdt. Beitr, p. 577.

Ster. Filicic. - Pac. : Ins. Sandwic.

orlhor hyncha Dz. et Mk. - Chaetomitrium.

ovata Mitt. op. cit. p. 339.

Ster. Ad rup, irror. - Am. merid: And. Nov. Granat.

pallens Milt. op. cit. $p .345$.

2 ? Lignic. - Am. merid. : Amazon.

pallens W. P. Sch. - H. nuka-hivensis.

pallescens Hook. M. ex. t. 38; C. M. Syn. II, p. 2ll; Mill. op. cil. p. 363.

Hypnella pallescens Jaeg. Ad. II, p, 269.

Plerygophyllum pallescens Brid. Bryol. univ. II, p. 351 .

l. Cortic. et Lignic - Am. merid. : Orinoc., Amazon, And. Quitens. pallida Hsch. op. cit. p. 64 ; C. M. Syn. II, p. 221 ; Mitt. op. cit. p. 351 .

Callicostella pallida Jaeg. Ad. II, p. 257.

H. scabriseta Schwaegr. Suppl. III, II, I, t. 275.

H. Weigeliana C. M. in Linn. 1848, $p, 190$.

Syn. Ad arbor, et sax, irror, - Am, merid. : Panama, ins. Trinitat, Guian. bat., Amazon., Brasil. or., And. Quitens. 
pallidifolia Mitt. in Melliss. S. Helena 1875, p. 362.

1. In gramin. - Afr.: Ins. S. Helena.

pandurifolia Mitt, op. cit, p. 345.

Ster.

- Am. merid. : And, Peruv.

papillata Mont. in Ann. sc. nat. 1845, IV, p. 93 et Syll. p. 13; C. M.

Syn. $11, p p .219$ el 678.

Callicostella papillata Mitt. M. Ind. or. p. 136 ; Bryol.jov. II, p. 39, t. 162.

Syn. Cortic. et lignic. - As, : Bengal., Sumatra, Java, Borneo. Pac.:

Ins. Fidji, Taïti, Samoa, Nov. Caledon.

papillata $\left\{\begin{array}{l}\text { Sull. }- \text { H. oblongifolia. } \\ \text { Tayl. }- \text { H. Taylori. }\end{array}\right.$

Pappeana Hpe. Ic. M. t. 2; C. M. Syn. II, p. 194.

Hookeriopsis Pappeana Jaeg. Ad. II, p. 264.

1. Ad arbor. - Afr, : C. B. Sp.

paradoxa Mont. - Distichophyllum.

paraguensis C. M. - H. shbdepressa.

Parkeriana Hook. in Spreng. Syst. veg. IV, p. 197; C. M. Syn. 1I, p. 194 ; Mitt. op. cit. p. 356.

H. gigantea Hsch. op. cit. p. 67; C. M. Syn. II, p. 209.

Hookeriopsis gigantea Jaeg. Ad. II, p. 263.

H. Parkeriana ej. $l$. c, p. 264.

2. Ad arbor. - Am. merid. : Guian. bat., Amazon.

parvifolia Tayl. - Stereophyllum.

Patrisiae \{ C. M. p.p. - Crossomitrium Crügeri.

Patrisiae He. - Crossomitrium Sellowii.

paupera C. M. in Engler's Bot. Jahrb. 1883, p. 86 et in Forchungsreise... Bot. p. 54.

2. Ad arbor. - Pac. : Nov. Guinea.

pellucida Mitt. M. austr. am. p. 353.

Callicostella pellucida Jaeg. Ad. II, p, 259.

2? Lignic. - Am. merid. : Amazon.

pendula Hook. M. ex. t. 53 ; C. M. Syn. II, p. 210 ; Mitt. op. cit.p. 365 ,

Chaetophora pendula Brid. Bryol. univ. 1I, p. 338.

$\mathrm{H}$. loriformis Hpe, et Ltz. in Krause M. Ecuador exs.

Hookeriopsis pendula Jaeg. Ad. II, p, 268.

2 ? Lignic. - Am, merid. : And, Quitens.

pennata Sm. - Cyatophorum bulbosum.

pernutans $C .: M$. in Linn. 1878-79, p. 496.

1.

- Am. merid.: Venezuela.

Perrini Spreng. - Lepidopilum polytrichoides.

philippinensis Mort. - Chaetomitrium.

Philonotula C. M. in Linn. 1878-79, p. 496.

2. $\quad-A m$. merid.: Venezuela.

pilifera Hook. f. et Wils, in Lond. Journ. of bot. 1844, p. 160; C. M.

Syn. II, p. 210; Mitt, op. cit. p. 364.

Hypnella pilifera Jaeg. Ad. II, p. 270.

1. Lignic. et arl sax. irror. - Am. merid.: And. Nov. Granat. et Quitens,, Parana, Brasil. austr. or. 
planiuscula Hpe. Symb. 1874, p. 511.

Hookeriopsis planiuscula Jaeg. Ad. I1, p. 268.

1.

- Am. merid.: Brasil. austr. or.

plumicaulis C. $M$, in Linn, I878-79, p, 496.

1.

- Am. merid. : Venezuela.

polytrichoides Spreng. - Lepidopilum.

Poeppigiana Hpe. - Ectropothecium vesiculare.

prabaktiana C. M. Syn. II, p. 678.

Callicostella prabaktiana Biyol. jav. $I I, p, 40, t, 163$.

Syn. Ad terr. et rup. trachyt. - As.: Borneo, Java.

praelonga W. Arn. - Ectropothecium vesiculare.

prasiophylla Besch. in Journ de Bot. 1894, $p$.

1. - Am. sept. : Guadalup.

Preussii Broth. in Engler's Bot. Jahrb. 1894, p. 201.

Syn. - Afr.: Cameroon.

prostrata Harv. - Stereophyllum? tavoyense.

pseudo-pilifera Hpe, in Linn. 1852, p. 362.

Hypnella pseudo-pilifera Jaeg. Ad. II, p. 270.

Ad arbor. -- Am. sept. : Porto-Rico.

pterygophylloides Broth. in Engler's Bot. Jahrb. 1893, p. 478.

Syn.

- Pac. : Nov. Guinea.

Puiggarii Geh. el Hpe. Enum. M. Brasil. p. 62.

Syn.

- Am. merid. : Brasil.

pulchella $\{$ Griff. - Distichophyllum Griffithii.

H. f. et W. - Mniadelphus.

punctata H. f. et W. - Homalia pulchella.

var. oblongifolia eor. - Homalia oblongifolia.

pyenoptera (C. M.) Par.

Callicostella pycnoptera C. M. in Dusen M. Camer, n. 921. - Afr. : M. Cameroon.

quadrifaria Hook, - Mniadelphus.

Quintasii Broth. in Bol. d. Soc. Brot. VIII. 1890.

Syn.

quitensis $P a r$.

- Afr.: Ins. S. Thom.

H. cuspidata Mitt. M. austr: am. p. 355.

Ad arbor. - Am, merid. : And. Quitens.

radicans Besch. Fl, bryol. Antill. fr. p. 60.

Callicostella radicans Jaeg. Ad, $I I, p .257$.

1.

- Am. sept. ; Martinic.

radiculosa $\left\{\begin{array}{l}\text { Hook, }- \text { Stereophyllum. } \\ \text { Hsch }- \text { Stereophyllum }\end{array}\right.$

Regnellii C. M. mss. ; Ängstr. in Oef.. 1876, n. 4, p. 22.

Syn, - Am. mericl.: Brasil. austr. or.

remotifolia C. M. - Eriopus.

repens Hsch. - H. hypnacea.

rhaphidostega C. M. - Actinodontium. 
rigida W. Arn. Disp. M.p. 56; C. M. Syn. II, p. 222.

Hypnum rigidum Schwaegr. Suppl. I, II, p. 189.

Lepidopilum polytrichoides? (fid. Mitt.).

Pterygophyllum rigidum Brid. Bryol, unix. II, p. 348. - Am. merid.: ?

riparia Mitl. op. cit. p. 345.

Ster. Terr. - Am. merid. : And. Quitens.

rivularis Mitt. op. cit. $p .353$.

Ad sax, irror, $-A m$, merid. : And. Quitens. et Peruv.

Robillardi C. M. in Rev. bryol. 1878, p. 59 (nom.).

- Afr.: Ins. Franciae.

vobusta $\{$ H. f. et W. (Fl. Antarct, et N. Zel.). - Pterygophyllum. Pobusta eor. (Fl. Tasman.). - Pterygophyllum Hookeri.

rorida Hpe. in Linn 1863, p. 155 ; Mitt. op. cit. p. 344.

Rupic. - Am. merid. : And, Nov. Granat.

rotulata $\mathrm{Sm}$. - Hypopterygium.

rotundifolia $\mathrm{H}$. f. et W. - Mniadelphus.

rubella $W . P$. Sch. herb.

H. Herminieri var, rubella Besch. Fl, bryol. Antill. fr. p. 59.

Ad arbor, - Am. sept. : Guadalup.

rubriseta Mitt. op. cit. p, 341.

- Am. merid. : And. Nov. Granat.

rufa W. P. Sch, in Besch. op. cit. p, 62.

Hookeriopsis rufa Jaeg. Ad. 1I, p. 267.

2 ? Ad arbor. - Am. sept. : Guadalup.

rufescens Milt. op, cit. p. 352.

Callicostella rufescens Jaeg. Ad. II, p. 259.

- Am. merid. : Guian. bat., Amazon.

rugulosa Mitt. op. cit. p. 358.

Hookeriopsis rugulosa Jaeg. Ad. II, p. 265.

2 .

- Am. merid. : And. Quitens.

rugulosa Besch. - H. Bescherellei.

Salaziae Besch. Fl. bryol. Reunion, etc. p. 143.

Syn, Lignic. - Afr.: Ins, Borbon.

sandwicensis Reichdt. Beilr. p. 576.

1. Ad rup. madid. - Pac. : Ins. Sandwic.

sarmentosa Duby. - H. limbata.

saxatilis Mitt. op. cit. p. 352.

Callicostella saxatilis Jaeg. Ad. $I I$, p. 258.

Ad lapid. et rad, inund. - Am. merid. : And. Quitens.

scabrella Mitt. op. cit. p. 362.

Hookeriopsis scabrella Jaeg. Ad. II, p. 267.

- Am. merid, : And. Quitens.

scabriseta Hook. M. ex. ᄂ. 52 ; C. M. Syn. II, p 220 ; Mitt. op. cit. p. 353.

Callicostella scabriseta Jaeg. Ad. II, p. 254.

Lepidopilum binerve Brid. Bryol. univ. II, p. 269.

2? Ad saxa irror. - Am. sept.: Mexic. Am. merid, : And. Caripens. 
scabriseta Schwaegr. - H. pallida.

scabriuscula C. M. in Linn. 1848, p. 191 et Syn. 11, p. 22I ; Mitt. op. cil. $p, 351$.

Callicostella scabriuscula Jaeg. Ad. $I I, p .258$.

Syn. - Am. merid. : Chile.

Schwaegrichenii Hpe. Enum. M. Brasil.p. 64.

H. Langsdorffii Sehwaegr. Suppl. II, t. 162 (cxcl. ealyptra).

Syn.

- Am. merid. : Brasil, austr, or.

secunda Griff. - Lepidopilum.

Sellowiana Hpe. Symb. 1874, p. 513.

1. - Am. merid. : Brasil. austr. or.

Sellovii Hsch. - Microthamnium.

seminervis Mont. - Distichophyllum spathulatum.

serrata Angstr. in Oefv... 1876, n. 4, p. 26.

Hookeriopsis serrata Jaeg. Ad. II, p. 268.

- Am. merid.: Brasil. anstr. or.

setosa Mitt op. cit, p. 339.

- Am. merill. And, Quitens.

sexfaria Col. - Pterygophyllum.

seychellensis Besch. Fl, bryıl. Réunion, etc. p. 144.

Syn. Secus rivul. - Afr. : Ins. Seychelles.

shillicatensis Spr. in Mitt. op. cit. p. 344.

Syn. Ad sax, et fol, emort. - Am, merid. : And. Q itens, et Peruv.

sinuata Milt. op. cit. p. 358.

Hookeriopsis sinuata Jaeg. Ad, II, p, 265.

Ster.

- Am. merid. : And. Quitens.

sinuosa H. f, et W. - Mniadelphus.

spathulata Dz. et Mk, - Distichophyllum.

speciosissima Schwaegr. - Cyatophorum splendidissimum ?

spinosa C. M. - Lepidopilum.

splachnoides ' Hook. - Daltonia.

Sphleich. - Tayloria.

splendidissima Mont. - Cyatophorum.

Splitbergeri Mont. - Crossomitrium.

squarrosula (W. P. Sch.) Par.

Ctenodontium squarrosuluin $W, P, \boldsymbol{S} c h$. herb.

Hookeriopsis squarrosula Jaeg. Ad. $I I, p .269$. - Afr.: Ins. Borbon.

strumosa Hsch, - Leucomium.

strumulosa Hpe. et Ltz. in Bot. Zeit. 1869, p.

Callicostella strumulosa Jaeg. Ad. 1I, p. 259.

2? In silv. - Am. merid. : Equator.

subaurescens Geh, et Hpe, in Fl, 1881.

I. $\quad$ Am. merid.: Brasil. austr. or.

subdepressa Besch, in Rev. bryol. 1885, p. 19 et in Journ, de bot. $1891, p$.

H. paraguensis C, M. in Rev, bryol. 1887, p. 57. 
1.

Exs. : Bal. PI. Parag, n. 3689.

- Am. merid, : Paraguay.

subenervis Hpe. - Lepidopilum.

subfalcata Hpe. in Ann. sc. nat. V ser, IV, p. 305; Mitt. op. cit. p. 360.

Hookeriopsis subfalcata Jaeg. Ad. II, p. 266.

Ad arbor. - Am. merid. : And. Nov. Granat.

subfissidentoides W. P. Sch. in Besch. Fl. bryol. Antill. fr. p. 61 .

H:okeriopsis subfissidentoides Jaeg. Ad. II, p. 265.

$2 . \quad-A m$. sept, : Guadalup.

sublimbata C. M. Syn, II, p. 191 ; Milt. op. cil. p. 343.

1. $\quad-$ Am. merid. : Chile.

submarginata Angstr. in Oefv... 1876, n. 4, p. 24.

1.

- Am. merill.: Brasil. austr. or.

submicrocarpa Geh. et Hpe. in Fl. 1881.

- Am. merid, : Brasil, austr. or.

subnitens ear, in op. et l.cc.

2.

- Am. merid. : Brasil. austr, or.

subrotunda Hpe. -- Pterygophyllum.

subsecunda Mitt. op. cit. p. 358.

Hookeriopsis subsecunda Jaeg. Ad. II, p. 265.

2 .

- Am. merid.: And. Quitens.

subsermulala Col, - Mniadelphus.

? Sullivantii C. M. in Lesq. et Jam. Man . p. 293.

H. acutifolia Sull. M. of U. St. p. 66.

Ster. - Am, sept. : Perrar.; Ohio centr., M. Alleghan., Carol. sept., Calif.

surinamensis C. M. - Lepidopilum.

? Swartzii Schwaegr. Suppl. III, II, II, t. 276 ; C. M. Syn. II, p. 200.

1.

- Am. sept.: Jamaic.

tamariscina Sm. p.p. - Hypopterygium.

? Taylori C. M. Syn. II, p. 222.

Callicostella Taylori Jaeg. Ad. $I I, p .261$.

H. papillata Tayl, in Lond. Journ. of bot. 1818, p. 283.

Cortic. et lignic. - Am. sept. : And. Nov, Granat, et Quitens.

tenella Milt. op. cit. p. 342.

H. Mittenii Jaeg. Ad. II, p. 253.

2 ?

- Am. merid. : And. Quitens.

tenella H. f, et W. - Sauloma.

tenera Hpe. Symb. 1874, p. 511.

Hookeriopsis tenera Jaeg. Ad. II, p. 268.

1. $\quad-A m$ merid.: Brasil austr, or.

tenuicuspis Mitt. op. cit. p. 347.

Stenodesmus tenuicuspis Jaeg. Ad. II, p. 262.

2 ?

- Am. merid. : And. Quitens. 
tenuifolia Mitt. op. cit. p. 359.

Hookeriopsis tenuifolia Jaeg. Ad. II, p. 265.

Syn.

- Am. merid. : Brasil. tropic.

tenuis Mitl. op. cit. p. 355.

Hookeriopsis tenuis Jaeg. Ad. II, p. 264.

- Am. merid. : And. Peruv.

terrestris Milt. op. cit. p. 356.

Hookeriopsis terrestris Jaeg. l. c.

2? Terr. - Am. merid. : And. Peruv.

thomeana Broth. in Bol. d. Soc. Brot. VIII, 1890.

Syn. Lignic. $-A f r$. : Ins. S. Thom.

tomentosa Grev. - Rhacopilum.

var. subinlegrifolia W. Arn, - Rhacopilum cuspidigerum.

tristis (Rehm.) Par.

Callicostella tristis Rehm. M. Afr. austr, n. 342.

$$
\text { - Afr. : Natal. }
$$

uliginosa $C, M$. in $\operatorname{Linn} .1880-83$, p. 476.

- Am. merid. : Argentin. Buenos Ayr.

ulophylla Besch. in Journ. de bol. 1894, p.

2. Ad terr. humid - Am. sept. : Guadalup.

undata (Hedwo.) C. M. in Bot. Zeit. 1855, p. 782.

Hookeriopsis undata Jaeg. Ad. II, p. 263.

Hypnum undatum $P$. B. Prodr. p. 72.

Leskea undata Hedw. Sp. M. p. 214, t. 52.

Pterygophyllum undatum Rrid. Bryol, univ. II, p. 353.

1.

- Am. sept. : Jamaic., Porto Rico.

undala C. M. - H. crispa.

usambarica Broth. in Engler's Bot. Jahrb. 18y4, p. 202.

Syn. Lignic. - Afr. : Usambara.

ulacrmundiana Mont. - Lepidopilum.

vaga Mitt. op. cit. p. 360 .

Hookeriopsis vaga Jaeg. Ad. II, p. 266.

- Am. merid. : And. Quitens.

Vallis-Gratiae Hpe, mss, ; C. M. in Bot. Zeil. 1858, p. 169.

1. $\quad-A f r,:$ C. B. Sp.

Exs.: Rehm. n. 341 .

variabilis $H_{s c h}$. in hb. Hook, ; Mitt. op. cit. p. 359.

Hookeriopsis variabilis Jaeg. Ad. II, p. 266.

1. vel syn. Lignic. - Am. merid. : And. Nov. Granat., Brasil, austr. ol.

variabilis Hsch. - H. bypnacea.

varians Sull. in Proced. Am. Acad... 1861 ; Mitt. op. cit, p. 346.

Polyg. Lignic. - Am. sept. : Florid., Cuba.

var. Sull, - Pilotrichidium Antillarum.

velutina Hpe. in Linn. 1861-62, p. 528; Mitt. op. cil. p. 343.

Hookeriopsis velutina Jaeg. Ad. II, p. 257.

2. Ad arbor, - Am, merid. : And, Nov, Granat, 
verrucosa Hpe. Symb. 1872, p. 58.

Hypnella verrucosa Jaeg. Ad. Il, p. 269.

1.

- Am. meridl. : Brasil. austr. or.

versicolor W. P. Sch. in Besch. Fl. bryol. Antill, fr, p, 64.

Hookeriopsis versicolor Jaeg. Ad, II, p. 266.

1 .

- Am. sept.: Gradalup.

versicolor Mitt. - Lepidopilum.

Vescoana Besch. Fl. bryal. Taiti, elc. p. 44.

1 et syn. Cortic. - Pac. : Taïti.

vesicularia C.M. in Dusen M. Camer. n. 69. - Afr.: M. lameroon.

vesiculata C. M. M. Polyn. p. 76.

Ster. - Pac. : Ins. Samoa.

vesiculosa C. M. Syn. II, p. 190.

Hypnum vesiculosum Brid. Sp. M. II, p, 100.

Pterygophyllum albicans ej. Bryol. univ. II, p. 319 p.p.

1 ?

- Afr.: Usambara, ins. Borbon.

viridissina Mitt. op. cit. p. 362 .

Hookeriopsis viridissima Jaeg. Ad. II, p. 267. Lignic. - Am. merid. : And. Nov. (iranat.

viridissima Lindb. - H. Jindbergii.

viridula Mitt. op. cit. $p$. 345.

Ster. - Am. merid. : And. Peruv.

Wainioi Broth, in Act. Soc. sc. Fenn. 1891, n. 5.

- Am. merid. : Minas Geraës.

Webbiana Mont. - Homalia.

Weigeliana C. M. - H. pallida.

Wrightii Sull. et Lesq. in Proced. Am. Acad... 1859, p. 281; Mitt. op. cil. p. 365.

Hookeriopsis Wrightii Jaeg. Ad. II, p. 270.

2.

- Am. sept. : Nicaragua.

Zettersdtedti C. M. - Sauloma (1).

HOOKERIOPSIS Besch. in Ann, sc. nat. 1876 (subgen. Hook ERIAE); Jacg. Ad. II, p. 262 (gen. propr.).

Omnes Hook ERIOPSIDEE non indicatae sunt Hookeriak ejusd. nom. gigantea Jaeg. - H. Prabaktiana.

Hydrofissidens $C . M$. Syn. $I, p .44$ (sect. Fissidentis = ConomitriuM).

HYDROGONIUM C. M. in Linn. 1876, p. 297 (sect. Trichostomi); Jaeg. Ad. II, p. 669 (gen. propr.).

Bolleanum Jaeg. - Meesea.

(1) In Enum. Kindberg. nomina nuda: H. Bərteroi $C$. M. flava Col. 
Ehrenberqii Jaeg. - Trichostomum. fontanum Jaeg. - Trichostomum.

mediterraneum Fitz. G. et Broth. - Trichostomum Ehrenbergii.

HYDROPOGON Brid. Bryol, univ. I, p. 769.

brevinerve Hpe. $-\mathrm{H}$, fontinaloidec.

fontinaloides (Hook.) Brid. l. c. p. 770; Card. Mon. p. 38.

Dryptodon fontinaloides Brid. Bryol. univ. I, p. 205.

Grimmia fontinaloides Hook. M. ext. t. 2 p.p.

H. brevinerve Hpe. Addit... (fid. Cart, Mon. p. 145).

Pilotrichum fontinaloides C. M. Syn. II, p. 151 .

1. Ad arbor. et rup. submers. - Am. merid.: Orinoc., Cassiquiare, Amazon.

gymnostomum Mitt. - Hydropogonella.

HYDROPOGONELLA Card, in litt. ad Le Jolis in Rev. bryol. 1895, p. 18 (1 spec.).

gymnostoma (Bryol. eur.) Card. in litl

Cryptangium (1) gymnostomum Card. Mon. p. 4I.

Cr. Schomburgkii C. M. in Linn. 1843, p. 599.

Fontinalis gymnostoma Bryol. eur. V (mon, p. 45).

Hydropogon gymnostomum Mitt. M. austr. am. p. 449.

Pilotrichum gymnostomum C. M. Syn. II, p. 152.

1. Aquat. - Am. merid. : Guian, angl.

Hygrohypnum Lindb. M. Scand, p. 33 (sect. HYPNI=LIMNoBIum).

HYLOGOMIUM Bryol, eur. V-VI (22 spec.).

alaskanum Kindb. - Hypnum.

Ankarcronae Broth. mss.

Ster.

- As.: Japon.

bartramiophilum (C.M.) Par.

Hyocomiella bartramiophila Kindb. Enum, Bryin.

Hypn'm bartramiophilum C. M. in Fl. 1890, p. 497.

Ster. $\quad-A f r$ : Kilima N'Djaro.

Berthelotianmm (Mont.) Geheeb in Fl, 1886, n. 22.

Ctenidium Berthelotianum Mitt, in Godman's Nat. hist. of Azores, 1870.

Eurhynchium Berthelotianum Jaeg. Ad. II, p. 427.

Hypnum Berthelotianum Mont in Hist. des I. Canar. p. 4, t, I, f. 2 et Syll. p. 8:C. M. Syn. II, p. 375 .

H. Hochstetteri W. P. Sch, in Seubert Fl. Azor, p. 14 ?

Ad arbor. - Afr, : Marleir, Teneriffa, ins. Azores.

brevirostrum (Elerh.) Bryol, eur. VI (mon. p. 10), t. 493; W. P. Sch. Syn. II ed.p. 801 .

Hypnum brevirostrum Ehrh. M. exs. n. 85 ; Brid. Bryol. univ. II, p. 506 ; C. M. Syn. II, p. 459.

H. brevirostrum $\beta$ interruptum Brid. Mant. M, p. 175 et Bryol. univ. II, p. 508 .

I) Nomen jam abusum : Cryptangium Schrad. ex Nees in Mart. Fl. Brasil. 1812 Cyperacex) $;$ in Indice p, 302 ut syn. modo servandum. 
H. erectum Raddi Sp. nov. aut rar. erypt. p. 6, t. 2.

H. interruptum Brid. $M$. Rec. II, II, p. 156, t. V, f. I et Sp. M. II, p. 194.

H. rutabulum $\beta$ brevirostrum ej. $M$. Rec. $I I, 1 I, p .162$.

H, rutabulum var. $S m$. Fl. brit. III, $p, 1320$.

H. triquetum $\beta$ brevirostrum Poll. Fl. Ver. $I I I, p .357$.

H. triquetum $\beta$ minus W. et M. Bot. Taschb. p. 534 .

Pleurozium brevirostrum Kindb. Check-List of Eur. a. N. Amer. M. p. 19 .

2. Ad sax., rup. et arbor. radic. - Eur. : Temperat., in silv, montos. As. : Japon. Afr. : Alger., ins. Borbon. Ams. sept. : Ins. Miquel,

Nov. Scot., Gaspes., Ontar,, Pensilv., New Jersey, M. Alleghan.

Exs.: Drumm. M. bor. am. II ed. n. 135. (Hyproum).

Mac. Canad. M. n. 373 (Hypnum).

Rab. Bryoth. eur. n. 391.

Sull, et Lesq. M. bor, am. II ed, n. 418 (Hypnum).

calvescens Jaeg. - H. squarrosum var. subpinnatum.

cavifolium Sande Lac, in Miq. Ann. mus, bol. Lugd. Bal, II, p. 373.

Ad arbor. - As. : Japon.

Ehrenbergianum (C. M.) Besch. Prodr. bryol. mexic. p. 111.

Hypnum Ehrenbergianum C. M. in Bot. Zeit. 1856, p. 408.

Pleurozium Ehrenbergianum Mitt. M. austr. am. p. 537.

2.

- Am. sept. : Mexic.

fimbriatum Bryol, eur. - H. Oakesii.

Flemmingii Aust. - H. robustum

Forstenii (Bryol. jav.) Jaeg. Ad. II, p. 615.

Hypnum Forstenii Bryol. jav. II, p. 153, t. 251.

2. Fr. ign. - As. : Celebes.

hirualayanum (Mitt.) Jaeg. Ad. II, p. 612.

Stereodon himalayanus Mitt. M. Ind. or. p. 113.

- As.: Nepal, Sikkim, Japon.

incompletum Spr. - Microthamnium.

japonicum W. P. Sch. in Savat. M. Japon, n. 798 b; Besch. in Ann. sc. nat. 1893, p. 390.

2.

- As: Japon.

loreum (L.) Bryol. VI (mon. p. 7), t. 490; W. P. Sch. op, cil. p. 804.

Hypnum heterophyllum Hoffm. Deutsch. Fl. II, p. 66. Hypnum heterophyllum Hoffm. Deutsch. Fl. II, p. 66.
H. Ioreum L. Sp. pl. p. $1593 ;$ Brid. Bryol. univ. Il, p. $515 ;$ C. M.
Syn. II, p. 442 .

H. loreum $\beta$ heterophyllum Brid. op. cit. $p$ 517. H. loreum $\beta$ heterophyllum Brid. op. cit. $p$ 517.
H. loreum montanum. capsulis subrotundis Dill. Hist. M. p. 305, t. 39 ,
f. 40 .

H. squarrosum $\beta$ loreum Web. Spic, Fl. Goett, p, 70.

2. Terr, et ad rad. arb., in ericet. - Eur.: Fere tota, in silvat. montos, Am. sept. : Ins. Miquel., Terr. nov., Nov, Scot., M. Rupestr., Columb, brit., Alaska, Sitka, Vancouver, Washington, Oregon, Idaho.

Exs.: Mac. Canad. M. n. 372 (Hypnum).

macrocarpum (Hsch.) Par.

H. paraphysale Jaeg. Ad. II, p. 614 . H. paraphysale Jaeg. Ad. II, p. 614.
Hypnum discriminatum Mont. in C. M. Syn. II, p. 452 et Syll. p. 10
(fid. Mitt. M. Ind. or. p. II3):

H. macrocarpum Hsch. in Nov, Act. Acad. Caes. Leop. XIV. II, Suppl. p. 725 ; C. M. Syn. II, p. 438 ; Bryol. jav. II, p. 152, t. 250. 
H, paraphysale C. M. in Bot. Zeit. 1854, p. 572 (fid. Mitt. l.c.).

Microthamnium discriminatum Jaeg. Ad. II, p. 417.

M. macrocarpum ej. $l$. c.

Stereodon macrocarpus Mitt. $l$. c.

2.

- As.: Nepal., Himalaya, Khasia, Assam, M. Neilgherr, Malabar, Ceylan, Sumatra, Java, Borneo, Amboine.

Mertensii (Weinm.) Jaeg. Ad. II, p. 616.

Hypnum Mertensii Weinm. in Bull. Soc. imp. Moscou, 1845, p. 488; C. M. Syn. $I I, p .439$.

- As. : Sibiria.

Oskesii (Sull.) W. P. Sch. Coroll. p. 139 et op, cit. p. 800.

H. fimbriatum Bryol. eur. VI mon. p. 7, $t .489$.

H. pyrenaicum Lindb. M. Scand. p. 37 ; Mac. Canad. M. n. 369,

Hypnum fimbriatum Hartm. Skand. Fl. V ed., p. $330 ; C$. M. Syn. II, p. 46 b.

H. Oakesii Sull, in Gray Man. of bot. p. $673 \mathrm{et}$ in Mem. Am. Acad... IV, p. $173, t .5 ; C, M . l . c, p .461$.

H. pyrenaicum Spr. M. Pyr. n, 4 et in Ann. and Mag. of nat. Hist. 1849, M. Pyr. n. 6, t. $12 ;$ C. M. l. e. p. 456.

Pleurozium pyrenaicum Kindb, Check-List of Eur. a. N. Amer. M. p. 19.

2. In silv, et dumetos, alp. - Eur. : Scotia, Norveg., Sndet., Rhoengeb., Salisburg., Stir., Bavar,, Tirol,, Helvet., Jurass., Pyren. As. . Jenissei inf., Caucas. occ. et centr. Am. sepl. : Now Brunswick, M. Alb., Ontar., Columb. brit.

Fas, : Rab. Bryoth. eur. n. 638.

Sull, et Lesq. M. bor, am. II ed. n. 421 (Hypnum).

Un, itin. 1863, n. 97 et $98 ; 1866$, n. $3 ; 1867$, n. 5.

* var. cuspidatum (Lindb, et Arn.) Par.

H. pyrenaicum var, cuspidatum L. et A. M, As, bor, 1890, II, p. 142.

- As. : Jenissei inf.

paludosum Jaeg. - Thuidiun.

paraphysale Jaeg. - H. macrocarpum.

parietinum Lindb. - Hypnum Schreberi.

var. elongatum Lindb. - Hypnum Schreberi var, elongatum.

var. laevigatum Lindb. - Hypnum Schreberi var. laevigatum. proliferum Lindb. - H. splendens.

var, oblusifolium Geh. $-\mathrm{H}$. splendens var. obtusifolium. pyrenaicum Lindb. - H. Oakesii.

var. cuspidatum L. et A. - H. Oakesii var. cuspidatum.

robustum (Hook.) Kindb. in Mac. Cat. p. 250.

H. Flemmingii Aust. in Bull. Tor bot. Club $, V, p .24$.

Hypnum Fleminingii Lesq. et Jam Man. p. 410.

H. robustum Hook. in D, umm. M. bor, am. I ed, n. 199.

2. Terr. - Am. sept.: M, Rupestr., Columb. brit., Vancouver, Washington, Oregon.

Exs.: Mac. Canad. M. n. 312 (Hypnum).

rugosum de Not. - Hypnum.

? Rutenbergii (C. M.) Par.

Hypnum Rutenbergii $C . M$, in Abhandl. Brem. VII, p. 213.

Ster.

Schreberi de Not. - Hypnum. splendens (Hedw.) Bryol. eur. VI (mon p. 5), t, 487; W. P. Sch. op. cit.
p. 798 .

H. proliferum Lindb, M. Scand. p. 37. 
Hypnum filicinum, Tamarisci foliis majoribus splendentibus Dill. Hist, $M$. p. $274, t .35, f]$.3 .

H. parietinum L. Sp. pl. p. 1590.

H. pinnatum Lam. Encycl, meth. bot. III, p. 168.

H. proliferum L. Mant. p. 507.

H. splendens Hedw. Sp. M. p. 262, t. 67; Brid. Bryol. univ, II, p. 435; C. M. Syn. I1, p. 457.

Pleuroziopsis prolifera Kindb. Check-List of Eur. a. N. Amer. M. p. 19.

2. Ad terr. et rad. arb. in silvat. montos. - Eur.: Spitzberg, ins. Parry, Ursur., tota As.: Japon., Amour, penins. Samojed., Obi, Jenissei, Ochotsk, Caucas. Af $r$.: Alger., Canar., ins. S. Helena (indig.?). Am. sept. : Groenland, Labrador, Anticosti, Terr, nov., ins. Miquel., $a b$ Atlant. ad Pacif. et fret. Pehring, zon. merid. except.

Exs.: Drumm, M. bor am. I ed. n. 218 et Il ed. n. 136 (Hypnum).

Mac. Canad. M. n. 367 (Hypnum).

Sull. et Lesq. M. bor, am. II ed. n. 419 (Нурлит).

"var. compactum (Lesq. et Jam.) Par.

Hypnum splendens var. compactum L. et J. Man. p. 407.

- Am. sept. : Labrador.

a var, obtusifolium (Geh.) Par.

H. proliferum var. obtusifolium Geh. in Fl. $1879, p .477$.

\section{- As,: Altaí.}

squarrosum (L.) Bryol eur. VI (mon. p. 9), $\iota$ 492; W. P. Sch. op. cit. p. 802 .

Hypnum repens, triangularibus foliis reflexis, majus Dill. Hist. M. p. 303 , t. $39, f .38$.

H. scorpioides Timm. Prodr. Fl. Megap. n. 825. Syn. $I I, p .443$.

2. In gramin. umbros. et in silv. - Eur.: Spitzberg, fere tota. As.: Japon., Jenissei. A fr. : Ins. Azor. (ster.). Am. sept.: Groenland, Anticosti, Terr. nov., Nov. Scot., Columb. brit., fret. Behring, Sitka, Oregon, Idaho, M. Alleghan., Pensilv.

Exs.: Mac. Canad. M. n. 370 (Hypnum).

Rab. Bryoth. eur. n. 138 b, 845 .

«var. subpinnatum (Lindb.) W. P. Sch. op. cil. p. 803.

H. calvescens Jaeg. Ad. II, p. 614 .

H. subpinnatum Lindb. in
in Hedvig. 1867 . p. 41 .

Hypnum brevirostre Hartm. Skand. Fl. I ed. p. 330 p.p.

H. calvescens Wils. Bryol. brit.p. $337 ;$ Mae. Canad. M. n. 450.

H. subpinnatum Lindb in Hartm. Skand. Fl. IX ed. II, p. I3, n. 76(1861),

Pleurozium calvescens Kindb. Check-List of Eur, a. N. Amer. M. p. 19.

Ut typ. - Eur. : Britann., Scandin., German. As.: Japon., Saghalien, Jenissei sup. Am. sept. : Nov. Scot., New Brunswick.

Exs. : Rab. Bryoth. eur. n. 139 p.p., 1043.

submacrocarpum (Hpe.) Jaeg. Ad. II, p. 497.

Hypnum submacrocarpum $H_{p e}$ in sched.

- As. : Sikkim.

subpinnatum Lindb. - HI. squarrosum var. subpinnatum. triquetrum (L.) Bryol. eur. VI (mon. p. 8), t. 491 ; W. P. Scli. op. cit.
p. 803 .

Hypnum sagittaefolium Voit. M. Herbip. p. 97. 
H. triquetrum L. Sp, pl. p. 1589; Brid. Bryol, univ, II, p. 508; C. M. Syn. II, p. 444.

H. vulgare, triangulum, maximum et pallidum Dill. Hist. M. p. 293, t. 38, f. 28.

Pleuroziopsis triquetra Kindb, Check-List of Eur, a. N. Amer, M. p. 19.

2. Terr. in silv. - Eur. : Vulgatiss. As. : Japon., Amour, Saghalien, Jenissei, Obi, Caucas. Am. sept. : Anticosti, ins. Miquel., ab Atlant. ad Pacif. et fret. Behring, reg. sept., occ. et or.

Exs. : Drumm. M. bor. am. I ed., n. 182 (Hypnum).

Mac. Ganad. M. n. 371 (Hypnum).

Rab. Bryoth. eur. n. 392.

Sull. et Lesq. M. bor. am. II ed, n. 417 (Hypnum).

" var. californicum Ren. et Card, in Bot. Gaz. 1890, p. 61.

Ut typ. - Am. sepl. : Washington, Calif.

umbratuin (Ehrh.) Bryol. eur. VI (mon. p. 6), t. 488; W. P. Sch. op. cit. p. 799.

Hypnum proliferum $\beta$ umbratum Wahlenb. Fl. Lapp. p. 373.

H, umbratum Ehrh. Crypt. exs, n. 66; Brid. Bryol. univ. II, p. 433; C. M. Syn. II, p. 457 .

Pleurozium umbratum Kindb. Check-List of Eur. a. N. Amer. M. p. 19.

2. Ad sax., rup. et rad. arb. in silvat. - Eur.: Reg. montan. et subalp. As.: Japon., Caucas. occ. Am. sept.: Terr. nov., ins. Miquel., Nov. Scotia, New Brunswick, Gaspes., M. Adirondack et Catskill, reg. sept. et or.

Exs. : Mac. Canad. M. n. 368 p.p. (Hypnum).

Rab. Bryoth. enr. n. 1185.

Sull, et Lesq. M: bor. am. Il ed, n. 420 (Hypmum).

Un. itin. $1 \times 63, n, 99$.

umbratum Mac. p.p. - Hypnum alaskanum.

varians Mitt, in Trans, of the Linn. Soc. 1891, p. 182.

Ster.

- As. : Japon.

yunnanense Besch. in Ann. sc. nat. 1892, I, p. 93.

2. In silv: -- As. : Yunnan (1).

HYLOMNIUM Spr. Cat.

frondiforme Spr. - Prionodon lycopodioides.

Hylotapis Spr. Cat. p. $10 \mathrm{el}$ in Mitl. M. austr. am. p. 363 (subsect. HooKERTAE).

HYMENOCLEISTON Duby in Mem... Genève, 1875 (1 spec.).

magellanicum Duby in op. cit. p. $8, t .2, f .1$.

Dissodon plagiopus Angstr, in Oef... 1872, n. 4 ?

Rupic. - Am, meril. : Patagon. austr., terr. Magellan.

- var. edenensis Besch. in Bull. Soc. bot. Fr. 1885, p. LXV.

- Am. merid.: Patagon, occid.

HYMENODON Hook. f. et Wils. in Lond. Journ. of bot. 1844, p. 548 (5 spec).

(1) In Enum. Kindberg. nomen nudum :

H. plicatum Miti. 
aeruginosus (Hook. f. el Wils.) C. M. in Bot. Zeit. 1847, p. 804 et Syn. 1, p. 179.

Rhizogonium aeruginosum $H$. f. et $W$. in op, cit. fasc. Mart.

2. Filicic. - Am. merid. : Brasil. austr. or.

angustifolius Sande Lac. Sp. nov. M. Archip, ind. p. 8, t. 5 B.

2. Ster. Ad arbor. - As. : Crlebes.

ovatus C. M. - Leptotheca Gaudichaudii.

piliferus Hook. f. Wils, in op el l. cc. ; C. M. Syn. I, p. 179.

Rhizogonium piliferum $H$. f. et $W$. in op. cit. p. 538.

2. Ad Cyatheam dealbat. - Pac.: Austral. (Victoria), Nov. Zeland. sept. et med., Tasman.

sericeus (Dz, et Mk.) C. M. in Bot. Zeit. 1847, p. 803 et Syn. 1, p. 118; Bryol. jav. II, p. 3.

Mielicchoferia sericea Dz. et Mk. in Ann. sc, nat. 1844, II, p. 312 et M. frond ined. Archip, ind. p. $85, t .39$.

2. Lignic. - As. : Borneo, Java.

sphaerothecus Besch. Fl. bryol, Nov. Caled. p. 218.

2. Filicic. - Pac. : Nov. Caledon (1).

HY MENOSTOMUM R. Br. in Trans, of the Linn. Soc. XII, Il, p. 573 ('9 spec.).

abyssinicum W. P. Sch. herb.

- Afr. : Abyssin.

Ahnfeldti Grev. - Entosthodon ericetorum var, Ahnfeldti.

argentinicum (C.M.) Par.

Weisia argentinica C. M. in Linn. 1878-79, p. 352.

2.

- Am. merid. : Argentin. Cordob.

Balansaeanum Besch. Not. M. Parag. p. 259.

Phascum recurvirostrum C. $\mathrm{M}$. in Fl. 1888, n. I.

Ad terr. htmid. - Am. merid. : Paraguay.

Exs. : Bal. Pl. Parag. n. 1197, 1280, 3657.

brachycarpum Bryol, germ. - H. microstomum var. brachycarpum brachypelma (C. M.) Par.

Weisia brachypelma $C$. M. in $F l .1879, n .24$.

2. $\quad-A f r .:$ M. Kenia.

Cameruniae C. M. in Dusen M. Camer, n. 286.

- Afr.: M. Cameroon.

contortum Kze. - Hyophila.

crispatum Bryol. germ. 1, p. 205, t. 12 ; Brill. Bryol. univ. II, p. 80;

Bryol, eur. I (mon. p. 6), Ł. 19; W. P. Sch. Syn. II ed. p. 36.

Gymnostomum crispatum W. P. Sch. Syn. I ed. p. 36.

H. Mülleri Br, in Bot. Zeit. 1829, p. 387.

Weisia crispata C. M. Syn. I, p. 662.

1. Ad terr. argill. calcar, - Eur. : Galloprov., Sardin., Istr., Dalmat.

(1) In Enum. Kindberg. nomen nudum :

H. helvolus $C, M$. 
crispatum de Not. - H. microstomum.

cucullatum (C.M.) Par.

Gymnostomum cucullatum Jaeg. Ad. II, p. 278.

Weisia cucullata C. M. in Bot. Zeit. 1858, p. 163.

1. - Afr.: C. B. Sp.

cylindricum Bryol. eur. - Gymnostomum Breutelii.

edentulum (Mill.) Besch. in Bull. Soc. bot. fr. 1887, p. 95.

Gymnostomum edentulum Jaeg. Ad. I, p. 277.

Weisia edentula Mitt. M. Ind. or. p. 27 .

1. Ad terr, et mur. - As. : Tonkin, Madras, Ceylan.

fasciculatum Hpe. Symb. 1872, p. 39.

2. $\quad-A m$, merid.: Brasil. austr, or.

involutifolium C. M. - Hyophíla.

? lineaefolium (C. M.) Par.

Weisia lineaefolia C. M. in Linn. 1875, p. 406.

Terr. - Afr. : Dar Fertit.

micaceum (Schlecht.) Hpe. Symb. 1874, p. 485.

Gymnostomum micaceum Schlecht. in Linn. 1835, p. 443.

H. subglobosum Hsch. Fl. Brasil. I, p. 6.

Weisia micacea C. M. Syn. I, p. 662 .

2. Terr. - Am. merid. : Brasil, austrs or.

microstomum (Hedw.) R. Br. in Trans. of the Linn. Soc. XII, II, p. 578;

Brid. Bryol. univ. II, p. 77; Bryol. eur. I (mon. p. ), t. 16;

W. P. Sch. op. cit. p. 34 .

Bryum microstomum Dicks. Fasc. IV Pl. crypt. p. 9.

Gymnostomum microstomum Hedio. M. frond. III, p. 71, t. 30; W. P.

Sch. Syn. I ed.p. 34 .

H. crispatum de Not, Epil. p. 607.

Mollia microstoma Lindb. M. Scand. p. 22.

Simophyllum nicrostomum ej. Rev, orit. ic. Fl. dan, p. 74.

Weisia microstoma C. M. Syn. I, $p, 660$.

1. Ad terr. argill, arenac, - Eur, : Tota. As, : Caucas, Afr. : Alger. Am. sept. : (fid. Jaeg. Ad. I, p. 38, sin. loc.).

« var. brachjcarpon (Bryol, germ.) Bryol, eur. et W. P. Sch. ll. cc.

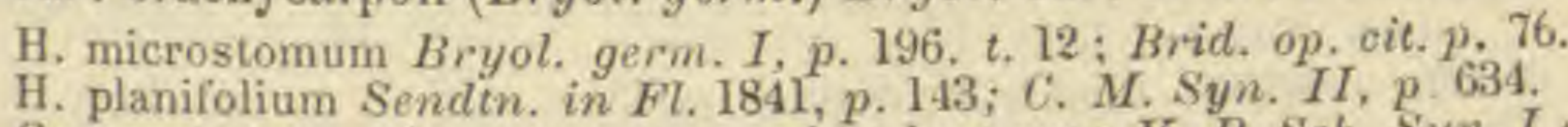

Gymnostomuin microstomum var, brachycarpon V.P. Sch. Syn. I ed. l, c.

Weisia brachycarpa Jur. Laubm. Oesterr. Ung. p. 9 .

Weisia microstoma $v a r$, brachycarpa $C$. M. Syn. $I, p .660$.

Ut et cum typ. in Eur.

Exs. : Rab. Bryoth. eur. n. 859.

" var, brevirostre Bryol. eur, et W. P. Sch. Il. cc.

Gymnostomum microstomum var, brevirostre Jaeg. Ad. I, p. 278.

G. sepincola Funk, in Brid. op. oit. p. 74.

Weisia microstoma var, brevirostris C. M. l. o.

Ut et cum typ, in Eur.

Exs. : Rab. Bryoth. eur. n. 832.

"var. elatum Bryol. eur, et W. P. Sch.ll.cc.

Gymnostomum microstomum var. elatum Jaeg. l. c.

Weisia microstoma var, elata C. M. l. c.

Ut et eum typ, in Eur.

var, mutilatum Hüb. - H, rostellatum. 
" var. obliquum (Bryol. germ.) Bryol. eur. et W. P. Sch. ll. cc.

Gymnostomum microstomum var. obliquum Jaeg. $l$. $c$.

H. obliquum Bryol. germ. 1, p. 194, t. 12 ; Brid, op. cit. p. 75.

Mollia microstoma var. obliqua Brailhe. Brit. Mossf. I, p. 234.

Weisia microstoma var, obliqua C. M. l. $c$.

Ut et cum typ. in Eur.:

Exs, : Rab. Bryoth. eur. n. 307, 407.

microstomum Aust. - Weisia viridula var. gymnostoma. Mülleri Br. - H. crispatum.

murale Spr. M. Pyr. n, 236; W. P. Sch. Syn. Il ed. p. 37.

Gymnostomum murale W.P. Sch. Syn. I ed.p. 37.

Mollia Wimmeriana var. subgymnostoma Limpr.

Weisia Wimmeriana C.M. Syn. II, p. 633 p.p.

Syn. Muric. - Eur.: Gall. merid. occ. (S. Marie d'Oleron). As.: Caucas. (Imeretia).

obliquum $\left\{\begin{array}{l}\text { Bryol. germ. - H. microstomum var. obliquum. } \\ \text { Wils, - H. rostellatum. }\end{array}\right.$

obtusifolium C. M. - Hyophila blanda.

Paucherianum Jaeg. - Gymnostomum.

? perpusillum (C. M.) Par.

Phascum perpusillum C. M. in Linn, 18'1-73, p. 145.

- Pac.: Austral. or. .

phascoides Wils. - H. rostellatum.

planifolium Sendtn. - H. microstanum var. brachycarpum.

pulicare Besch. Fl. bryol. Réunion, etc. p. 11.

Weisia pulicaris ej. in Rev, bryol. 1877, $p$.

2 .

- Afr.: Ins. Mayotte.

rostellatum (Brid.) W. P. Sch. Syn. II ed.p. 33.

Astomum rostellatum Bryol, eur. I (mon. p. 13), t. 12.

? A. rostratum Hpe. in Fl. 1837, p. 285.

Gymnostomum rostellatum W. P.Sch. Syn. $I$ ed. p. 33.

H. microstomum $\beta$ mutilatum Hüb. Museol. germ. $p, 67$.

H. obliquum Wils. Engl. Bot. Suppl. t. 2831.

H. rostellatum Wils, in Bryol. eur. (mon. p. ), t. 15 zogth. Nassau, 1849, V, p. 3.

Mollia rostellata Lindb. M. Scand. p. 43.

Phascum rostellatum Brid. Mant. M. p. Il et Bryol. univ. I, p. 46; C. M. Syn. I, p. 24 et $I I, p .520$.

Systegium rostellatum Boulay M. E. Fr. p. 586.

Weisia phascoides C. M. Syn. II, p. 634 .

W. rostellata Lindb. de Tort.

1. In argillos. humid. - Eur. : Reg. campestr., sporad.

Exs. : Rab. Bryoth. eur. n. 162.

rutilans Bryol. germ. - Weisia mucronata.

subacaule (Mitt.) Par.

Astomum subacaulon Jaeg. M. Cleistor. p. 13.

Systegium subavaulon Mitt. in Spr. Cat. M. Amaz. et And. n. 240.

Weisia subacaulis ej. M. austr. am. p. 131.

Ad. terr. humid. - Am. merid. : And. Quitens. et Boliv.

semi-involutum (C.M.) Par.

Weisia semi-involuta C. M. in Linn. 1880-83, p. 438.

- Am, merid. : Argentin. tropic. 
senocarpum (C. M.) Par.

Gymnostomum senocarpum Jaeg. Ad. I, p. 280.

Weisia senocarpa C. M. Syn. II, p. 633.

2.

- Am. merid. : And. Costa-Ric.

squarrosum Bryol. germ. I, p. 193, ı. 12; Brid. Bryol. univ. II, p. 74 ; Bryol. eur. I (mon. p. 5), t 7; W. P. Sch. op. cit. p. 34.

Gymnostomum squarrosum Wils. Bryol. brit. p. 43, t. 38; W. P. Sch. Syn. I ed.p. 34.

Mlollia squarrosa Lindb. M. Scand. p. 22.

Systegium squarrosum Boulay M. Fr: p. 560.

Weisia squarrosa C. M. Syn. I, p. 663 .

1. Ad terr, argillos. - Eur.: Dania, Anglia merid,, Palatin., Siles., Boruss, Austr, inf., Gall. occid.

Exs.: Rab. Bryoth. eur, n. 24,404.

striatum Geh, et Hpe. Enum. M. Brasil. p. 12.

1. $-A m$. merid. : Brasil, austr. or.

subglobosum $\left\{\begin{array}{l}\text { Bryol. germ. - Weisia viridula. } \\ \text { Hsch. - H. micaceum. }\end{array}\right.$

submicaceum (C. M.) Par.

Weisia submicacea C. M. in Ule Bryoth. brasil.n. 127.

- Am. merid. : Brasil. subtropic. or.

subrostellatum W. P. Sch, in hb. DR.; Besch, Cat. M. Alger. p. 4. - Afr. : Alger.

Termitidarun (C. M.) Par.

Weisia Termitidarum C. M. in Linn. 1875, p. 405.

2. Terr. - Afr. : N'Gama sept.

tortile (Schwoaegr.) Bryol. eur. I (mon. p. 6), t. 15; W. P. Sch. op. cit. p. 35.

Gymnostomum condensatum Voit. M. Herbip. p. 14.

G. hymenostomoides Poech. M. Bohem.

G. tortile Schwaegr. Suppl. I, I, p. 29, t.10; Brid. Bryol. univ. II, p. 74: W. P. Sch. Syn. I ed. p. 35.

Mollia condensa Lindb, de Tort. p. 230.

M, tortilis Braithw. Brit, Mossf. I, p. 235.

Weisia involuta Brid. op. cit. p. 336 ?

W. tortilis C.M. Syn. I, p. 661 .

1. Ad mur. et in fissur. rup. pracip. calcar. - Eur.: Zon, merid., reg. calidior. zon. interm., rar. in zon. sept. As. Caucas. Afr. : Alger; austral. (fid, Handb. of N. Zeal. Fl.), Pac. : Nov. Zeland.

Exs.: Rab. Bryoth, eur. n. 408.

* var. alpinum W. P. Sch. op. cil. p. 36.

Gymnostomum Schimperi Mdo, in sched. 1864 et Moosst, in d. Alg. Alp. p. 58.

Ut typ. - Eur. : Scandin., Dania, Alp. Bavar.

"var. subcylindricum Bryol, eur. l. c. t. 19 et W. P. Sch. l. c.

Gymnostomum tortile var. subcylindricum Jaeg. Ad. I, p. 278.

Ut typ. - Eur. : Reg. merid.

nmbrosum (Mill.) Far.

Gymnostomum umbrosum Jaeg. Ad. I, p. 280.

Weisia umbrosa Mitt. M. austr, am. p. 133.

2 ? Rupic, et terr. - Am. merid. : And. Quitens. et Peruv, 
unguiculatum Philib. in W. P. Sch. Syn. 11 ed. p. 37.

Trichostomum mutabile var. unguiculatum Husn. Muscol. gall. p. 87.

1. Ad terr. lapid, et in fissur. rup. calcar. - Eur.: Galloprovincia. urceolare Hpe. Enum. M. Brasil, p. 12.

Hyophila urceolaris ej.Symb. 1870, p. 269.

Terr. - Am. merid. : Brasil, austr, or.

Vallis-Gratiae Hpe, in sched, ; Jaeg. Ad. $I I, p .63 \mathrm{l}$. - Afr.: C. B. Sp. (1).

HYMENOSTYLIUM Brid. Bryol, univ. $I I, p .81$.

Spec. omn. non. indicatae sunt gYMNOsTOMA ejusd. nom.

commutatum Mitt. - Gymnostomum curvirostre.

Mulleri Br. - Trichostomum mutabile.

vernicosum Mit. - Pottia.

verticillatum Mitt. - Eucladium.

HYOcomiella C. M. in Fl. 1890, p. 437 (sect. HyPN1); Kindb. Enum.

Bryin. (gen. propr.).

bartramiophila Kindb. - Hylocomium.

HYOCOMIUM Bryol, eur. VI (1 spec.).

capillifolium Mitt. - Hypnum.

cylindricarpum Mitt. - Brachythecium.

exaltalum Mitt. - Hypnum.

flagellare (Dicks.) Bryol, eur. VI, t. 532; W. P. Sch. Syn. II ed, p. 660.

Hypnum armoricum Brid. Bryol. univ. II, p. 525.

Hypnum flagellare Dicks. Fase. II Pl. crypt. p. 12; C. M. Syn. II, p. 436.

Hypnum pseudo-commutatum La Pyl. in hb. Bridel.

Pleurozium flagellare Kindb Check-List of Eur. a. N. Amer. M. p. 19.

2. Ad, rup. quarz, irror. secus rivul, et cataract. - Eur. : Norveg. occ., Britann., Armoric., Voges., Silva Nigr., Bavar., Pyren. ruginosum Mitt. - Brachythecium.

HY OPHILA Brid. Bryol, univ. I, p. 760 (63 spec.).

acutiuscula Broth. in Engler's Bot. Jahrb. 1894, p. 183.

2. Ster, Terr. - Afr.: Usambara.

agoy anensis Jaeg. - Scopelophila.

anoectangioides C. M. in Dusen M. Camer. n. 97.

- Afr. : M. Cameroon.

arborea (Mitt.). Jaeg. Ad. II, p. 205.

Weisia arborea Mitt. M. austr, am. p. 138.

2. Ad arbor. - Am. merid. : Brasil.

assimilis Broth. in Hedwig. 1895, p. 125.

Cortic. - Am, merid. : Brasil. or. (Goyaz).

baginsensis C. M. in Linn. 1875, p. 399.

Ster. Rupic. - Afr. : Niam-Niam.

(1) In Enumer. Kindberg. nom. nud, :

H. Pabstii $C, M$. 
bahiensis (C. M.) Jaeg. l. c.

Pottia bahiensis C. M. in Bot. Zeit. 1855, p. 764.

2.

- Am. merid. : Bahia.

Barbula (Schwaegr.) Hpe in Bot. Zeit. 1846, p. 267.

Gymnostomu $\approx$ Barbula Schwaegr, Suppl. II, I1, I, p. 77, t. 751.

Pottia Barbula C. M. Syn. I, p. 558.

Tortula melanocarpa Mitt. in Journ. of the Linn. Soc, 1877, p. 60 (fid. ips, in Voy, of H. S. M. Challenger, Bot. II, p. 885).

Weisia Barbula Mitt. M. austr, am. p. 135.

2. Rupic. - Am. sept. : Florid., Cuba.

bassoutensis Rehm. M. Afi. austr. n. 458.

Barbula bassoutensis ej. $l$. c. n. 100.

- Afr. : Bassoutoland, C. B. Sp.

"var, tenella ej. $l$. c. n. 459.

- Afr.: C. B. Sp.

Bescherellei C. M. - Trichostomum.

blanda (Hook. f. et Wils.) Jaeg. A l. I. p. 200.

Gymnostomum blandum $H$. f. et $W$. in Lond. Journ. of bot. 1844, p. 151.

Hymenostomum obtusifolium C. M. in Bot. Zeit. 1855, p. 91.

H. Gardneri Hpe, in Bot. Zeit. 1846, p. 267.

Pottia blanda C. M. Syn. 1, p. 553.

Weisia blanda Mitt. M. austr. am. p. 138.

2. Rupic. - Am. merid. : Brasil.

brevifolia Hpe. Enum. M. Brasil. p. 8.

Ster.

- Am. merid. : Brasil, or.

Cameruniae C. M. in Dusen $M$. Camer. $n .22$.

- Afr.: M. (Jameroon.

caripensis Hpe. - H. involutifolia.

Cataractae (Milt.) Jaeg. Ad. I, p. 206.

Weisia Cataractae Mitt. M. austr. am. p. 135.

Rupic. - Am. merid. : And. Quitens.

circinata (C. M.) Jaeg. Ad. I, p. 205.

Pottia circinata C. M. in Linn. 1869-70, p. 38.

Tortula cylindrica Mitt. M. Ind. or. p. 28 p.p. ? (fid. C. M. l. c.).

Ster.

- As.: Ceylan.

compacta (Welvo. et Duby) Jaeg. Ad. 1, p. 203.

Pottia compacta $W$. et D. in Mém... Genéve, $1870, p .11, t .3, f .5$.

Terr, arenac. ad Termitid. conos. - Afr. : Angola.

contermina (C. M.) Jaeg. Ad. I, p. 204.

Pottia contermina C. M. Syn. II, p. 623.

Weisia contermina Mitt. M. austr, am, p. 135.

2 .

- Am. sept. : Costa Riea.

contorta (Kze.) Jaeg. Ad, I, p. 204.

Hymenostomum contortum Kze. in Fl. 1830, II, p. 373.

Pottia Hollii C. M. Syn. I, p. 561 .

2. Rupic. - Afr. : Madeir.

crenulata C. M. in Dusen M. Camer. n. 111. - Afr.: M. Cameroon.

cylindrica (Hook.) Jaeg. A l. I, p 204.

Gymnostomum cylindricum Hook. in Lond. Journ. of bot. I840, II, p. 2 et Ic. $p l$, ras: $t, 17$. 
Hyophila Harveyana Hpe. in Bot. Zeit. 1846, p. 267.

Pottia cylindrica C. M. Syn. I, p. 562.

2.

- As. : Nepal.

Gardneri Hpe. - H. blanda.

Gardneriana C. M. - H. obtusifolia.

goyasensis Broth. in Hedwig. 1895, p. 124.

1. Terr. - Am. merid. : Brasil, or. (Goyaz.).

gymnostomoides (Welw. et Duby) Jaeg. Ad. I, p. 202.

Pottia gymnostomoides W. et D. in Mém... Genève, 1870, p. 12, t. 4, f. 4.

Rupic. - Afr, : Angola.

Harveyana Hpe. - H. cylindrica.

Holstii Broth. in Engler's Bot. Jahrb. 1894, p. 183.

2. Ster. - ifr. : Usambara.

Hookeri Hpe. - H. involuta.

incurva (Mitt.) Jaeg. Ad. I, p. 205.

Weisia incurva Mitt. M. austr. am. p. 138.

- Am. sept. : Guatemala.

involuta (Hook.) Jaeg. Ad. I, p. 202.

Desmatodon involutus Mitt. $M$. Ind. or. $p_{\text {. }} 39$.

Gymnostomum involutum Hook. M. ex. t. 154; Brid. Bryol. wniv. I, p. 75.

H. Hookeri Hpe. in Bot. Zeit. 1846, p. 267.

Pottia involuta C. M. Syn. I, p. 560.

2.

$$
\text { - As. : Nepal. }
$$

involutifolia (C. M.) Jaeg. Ad. I, p. 203.

Hymenostomum involutifolium C. M. in Linn. 1847, p. 198.

Hyophila caripensis Hpe. in op. cit. p. 68.

Pottia involutifolia $C . M$. Syn. $I, p .560$.

Weisia involutifolia Mitt. M. austr. am. p. 136.

2.

- Am. merid..: Venezuela.

javanica Brid. Bryol. univ. 1, p. 761.

Gymnostomum javanicum Nees in Nov. Act. Acad. Coes. Leop. XI, I, p. 129, t. $14 ;$ f. 2 ; Brid. op. cit. p. 757.

Pottia javanica C. M. Syn. I, p. $560 ;$ Bryol. jav. I, p. 64, t. 52.

Rottleria javanica Brid.op. cit. p. 106.

1 (Bryol. jav.). 2 (C. M.). -As. : Java.

laxiretis Broth. in Heducig. p. 1895, p. 124.

1. Rupic, - Am. merid. : Brasil. or. (Goyaz.).

Leprieurii (Monl.) Par.

Gymnostomum involutum Mont. in Ann. sc. nat. XIV, II, p. 350.

- Pottia Leprieurii ej. Syll.p. 50.

- Weisia Leprieurii Mitt, op, cit.p. 137.

Ad arbor. - Am. merid. : Guian.

Lindigii Jaeg. - Barbula Lindigiana.

loxorhyncha Angstr. in Oefv... 1876, n. 4, p. 9.

$\mathrm{H}$. rubiginosa Hpe?

Syrrhopodon loxorhynchus Angstr, in sched.

Rupic. in silv. - Am. merid. : Brasil. austr. or.

lurida Jaeg. - Barbula.

Martinicae Ren. et Card. in Bull. Soc. roy. bot. Bely. 1890, I, p. 174.

Ster. Muric. - Am. sept. : Martinic. 
melanostoma (Mitt.) Jaeg. Ad. I, p. 205.

Weisia melanostoma Mitt. M. austr. am. p. 138.

2. Arenic. et cortic. - Am. merid. : Amazon.

Micholitzii Broth. in Oef... 1893, p. 28.

2.

- Pac. : Nov. Guinea.

minutissima (Mitt.) Jaeg. Ad. I. p. 206.

Weisia minutissima Mitt. op. et $l$. $c c$.

Lignic. - Am. merid. : Brasil.

Mülleri (Duby) Par.

Pottia Mülleri Duby in Mém... Genéve, $\quad$,p. 20, t. I, f. 4.

2. Terr. - As. : Malabar.

navicularis Jaeg, - Barbula.

Niam-Niamiae C. M. in Linn. 1875, p. 400.

Ster.

- Afr. : Niam-Nirm.

obtusifolia (C.M.) Par.

Gymnostomum Barbula H. f. et Wils, in Lond. Journ. of bot., 1844, p.151,

H. Wilsoni Hpe, in Bot. Zeit. 1846, p. 267.

Pottia obtusifolia C. M. Syn. I, p.559 (sub P. Gardneriana, err. in indioe correcta).

Weisia obtusifolia ej. in Bot. Zeit. 1845. p. 91; Mitt. op. cit.p. 139.

2.

- Am. merid. : Brasil.

(Erstedtiana (C. M.) Jaeg. Ad. I, p. 201.

Pottia CErstedtiana C. M. Syn. II, p. 622.

Weisia Erstedtiana Mitt, op. cit. p. 136.

2.

- Am. sept. : Nicaragua.

ovalifolia Hpe. Symb: 1874, p. 481.

Pottia ovalifolia ej. op, cit. 1872, p. 36.

1.

- Am. merid. : Brasil. austr, or.

papillinervis (Ltz.) Jaeg. Ad. 1. p. 205.

Pottia papillinervis Ltz. Moosst. p. 160.

Ster.

- Afr. : Zanzibar.

perannulata Ren. et Card in Bull. Soc. roy. bot. Belg. 1895, p. 60.

2.

-As. : Sikkim.

phyalothecia C. M. - Lepidopilum.

plicata Mitt. in Journ. of the Linn. Soc, 1886, p. 304.

1. Terr. - Afr. : M. Usagara.

Polakovoskyi C. M. - Lepidopilum.

Poeppigiana (C.M.) Jaeg. l. c.

Pottia Poeppigiana C. M. Syn. I. p. 562.

Weisia Poeppigiana Mitt. op. cit. p. 137.

2.

- Am. merid. : Chile austr.

Potieri Besch. Fl. bryol. Réunion, elc. p. 53.

Terr. - Afr. : Usambara, ins. Borbon., Nossi-Be.

- var, denticulata Broth, in Engler's Bot. Jahrb. 1894, p. 183.

Rupic. - Afr.: Usambara.

punctulata (Mitt.) Par.

Weisia punctulata Mitt. in Trans. of the roy. Soc. of Edinb. 1887, p. 132, - Afr. : Ins. Socotora. 
pygmaea $C . M$, mss.

- As, : Birman, super.

Regnellii C. M. mss.; Angstr. Prim.lin. p. 8.

- Am. merid. : Brasil. austr. or.

Roscheri (Ltz.) Jaeg. Ad. I, p. 200.

Pottia Roscheri Ltz. Moosst. p. 160.

Weisia Roscheri Mitt. in Philos. Trans, of the roy. Soc. 1879 (extr, vol.;. p. 389.

Ster.

- Afr. : Zanzibar, ins. Rodriguez.

rubiginosa Hpe. Enum. M. Brasil. p. 8.

H. loxorhyncha Angstr?

Ster.

- Am. merid. : Brasil. austr. or.

rufescens (Hook.) Jaeg. Ad. 1, p. 204.

Barbula rufescens Mitt. $M$, Ind, or. p. 33

Grimmia? remota Wils, in Kew Journ. bot. IX, p. 323.

Gymnostomum recurvum Griff. Not. p. 397 et Ic. pl. asiat. II, t. 92, f. 2.

G. rufescens Hook. in Sehwaegr. Suppl. III, II, I, t. 206.

Pottia rufescens C. M. Syn. $I, p .561$.

2.

- As.: Nepal.

samoana Milt. Sam. M. p. 193.

Pottia samoana C. M. M. Polyn. p. 68.

Ster.

- Pac.: Ins. Samoa, Tonga.

Somaliae C. M. in Linn. 1876, p. 293.

Ster.

$-A f r$ : Somali.

spathulata (C. M.) Jaeg. Ad. I, p. 200.

Pottia spathulata C. M. Syn. I, p. 559.

2 .

- As. : Nepal., Himalaya occ.

subcontermina Ren. et Card, in Bull. Soc. roy. bot. Belg. 1892, I, p. 154.

2. Ad muros. - Am. sept.: Costa-Rica.

Tortula (Schwaegr.) Hpe. in Bot. Zeit. 1846, p. 267.

Gymnostomum Tortula Sohwaegr. Suppl. II, II, I, p. 78, t. 17.

Pottia Tortula C. M. Syn. I, p. 559.

Weisia Tortula Mitt. M. austr. am. p. 13 (exel. pl. cubens.).

2. Saxic. - Am. sept. : Jamaic., ins, Carribb. Am. merid. : Nov, Granat., Amazon., And. Quitens, et Peruv., Brasil.

var. brasiliensis $\mathrm{Hpe}$ - $\mathrm{H}$. variegata.

Uleana Broth. in Hedwig. 1895, p. 125.

1. Rupic. - Am. merid. : Brasil. or. (Goyaz).

urceolaris $\mathrm{Hpe}$ - Hymenostomum.

usambarica Broth. in Engler's Bot. Jahrb. 1894, p. 183.

Ster. Terr. - Afr.: Usambara.

Vallis-Gratiae Hpe. mss. ; Jaeg. Ad. 11, p. 665.

variegata Ängstr. Prim. lin. p. 8.

$$
\text { - Atr. : C. B. Sp. }
$$

H. Tortula $\beta$ brasiliensis Hpe. Symb. 1894, p. 481 .

- Am. merid. : Brasil. austr. or.

Victoriae C. M. in Dusen M. Camer. n. 312. 
vitiana (C. M.) Jaeg. Ad. 11, p. 665.

Pottia vitiana C. M. M. Polyn. p. 68.

Ster.

- Pac. : Ins. Fidji.

Wagneri (C. M.) Jaeg. Ad. 1, p. 203.

Pottia Wagneri C. M. Syn. II, p. 62 ?.

Weisia Wagneri Mitt. M. austr. am. p. 139.

- Am. merid. : Columb.

Warmingii Hpe. Symb. 1870, p. 269.

Lignic. et terr. - Am. merid. : Brasil. austr. or.

* var, angustifolia Broth. in Hedroig. 1895, p. 124.

Cortic. - Am. merid. : Brasil, or. (Goyaz).

Wilsoni Hpe, - H. obtusifolia.

Wrightii (C, M.) Jaeg. Ad. I, p. 201.

Pottia Tortula Sull. in Wright M. Cubens, n, 2.

P. Wrightii $C . M . h b$.

Weisia Tortula Mitt. op, cit. p. 135 (quoad loc. nat. Cub.).

2. Rupic, - Am, sept. : Cuba.

Zeyheri (Hpe.) Jaeg. Ad. 1, p. 203.

Gymnostomum euchlorum Zeyh. Pl. Capens, n. 480.

Pottia Zeyheri Hpe, in C. M. Syn. I, p. 561.

2.

- Afr. : C. B. Sp. (1).

Hyophiladelphus C. M. Syn. I, p. 604 (sect. Barbulaz).

Hyophilidium C. M. Syn. I, p. 528 (sect. Syrrhopodontis).

Hyophilina ej.l.c. p. 523 (sect. Calymperidis).

hypNella C. M. Syn. 11, p. 208 (sect. Hookrrtar); Jaeg. Ad. II (gen. propr.).

HyPNRleEaE omnes sunt Hookertae ejusd, nomin.

Hypnidium W. P.Sch. Syn. I ed. $p .640$ (subgen. HyPNi).

HYPNODENDRON C. M. Syn. II, p. 496 (sect. HyPNi); Lindb. in Bryol. jav. 1.1 p. 132 (gen. prepr.) (25 spec.).

arborescens (Miit.) Lindb, in op. cit. p. 133, t. 232.

Trachyloma arborascens Mitt. M. Ind. or, p. 91 .

2.

- As. : Ceylan, Sumatra, Java.

"arborescens Mitt. (Sam. M.). - H. subspinineroinm.

Archeri (Mitt.) Jaeg. Ad. II, p. 623.

Isothecium Archeri H.f. et W. Fl. Tasm. 11, p. 206, t. 175, f. 3 .

Trachyloma Archeri Mitt. in Journ. of the Linn. Soc. 1859, p. 86. 2.

- Pac. : Tasman.

arcuatum Mitt. - H. spininervirum var, arcuatum.

Beccarii (Hpe.) Jaeg. Ad. II, p. 622.

Dendrn-Hypnum Beccarii Hpe. in Nuov. Giorn. bot, itai. 1872, p. 284. 2.

- As. : Borneo.

(1) In Enum. Kindb. nom. nud. :

H. angustifolia $C M$.

macrocarpa $W . P, S c h$.

H. pugionifolia C.M. robusta Lindb. 
Chalmessii Mitt. in Proced. of the Linn. Soc. of N.S. Wales, 1882, p. 193. - Pac, : Nov. Guinea.

Colensoi Mitt. - Mniodendron comatum.

comosum Mitt. - Mniodendron.

fusco-aciculare C. M. in Geh. Neue Beitr. zur Moosfl. v. Neu Guin.

p. 10, t. 8 .

2.

- Pac. : Nov, Guinea merid.

fusco-mucronatum (C.M.) Jaeg. Ad. II, p. 624 .

Hypnum fusco-mucronatum C. M. in Bot. Zeit. 1862, p. 393.

2.

- As, : Ins. Philippin.

Graëffeanum Jaeg. - H. vitiense.

Junghunii (C. M.) Lindb. in Oef... 1861, p. 74 et in Bryol. jav. II, p. , t. 531 .

Hypnum Junghunii C. M.Syn. II, pp. 506 et 693.

H. Reinwardti Hsch. in Nov. Act. Acad. Caes. Leop. XIV, Suppl. II, p. 722 p.p., t. 41, f. (ठ) a. 1 b.

2.

- As, : Sumatra, M. Java.

Kerrii (Mitt.) Par.

Isothecium Kerrii Hook, f. Handb. of N. Zeal. Fl. p. 466.

Sciadocladus Kerrii Jaeg. Ad. II, p. 625.

Trachyloma Kerrii Mitt. in Joum. of the Linn. Soc. 1859, p. 86.

- Pac. : Nov. Zeland.

Krausei (C. M.) Jaeg. Ad. II, p. 624.

Hypnum Krausei C. M. in Linn. 1874, p. 619.

2. Saxic, - Am. merid. : Chile.

marginatum (Hook. f. et Wils.) Jaeg. l. c.

Hypnum limbatum Sull.?

H. marginatum $H$. f. et W. in Lond. Journ. of bot. 1844, p. 554; C. M. Syn. II, pp. 508.

Isothecium marginatum $H$. f. et $W$. Fl. of the N. Zeal. II, p. 106, t.89, f. 2 et Handb. p. 466.

\section{- Pac. : Nov. Zeland.}

Menriezii (Hook.) Par. Hypnum Menziezii Hook. M. ex. p. 19, t. 33; C. M. Syn. II, pp. 506
et 693 .

Isothecium Menziezii Brid. Bryol. univ. I1, p. 376; H. f.et W. Fl. of the N. Zeal, II, p. 105 et Handb. p. 465.

Sciadocladus Menziezii Jaeg. Ad. II, $p, 625$.

Terr. - Pac. : Nov. Zeland.

microstictum Mitt. M. austr. am. p. 566.

2.

- Am. merid, : Chile.

Milnei Mitt. - Mniodendron.

Naumanni (C. M.) Far. Hypnum Naumanni C. M. in Engler's Bot. Jahrb. 1883, p. 83 es in For
chungsreise.., Bot. p. 38 .

Ster. In silvis. - Am. merid. : Fret. Magellan., Fuegia.

palmaeum Mitt. in Proced. of the Linn. Soc. of N.S. Wales, 1882, p. 103. - Pac. ? Absque loco.

praenitens Mitt. - Pterobryella.

Reinwardti (Hsch.) Lindb. in Bryol. jav. I1, p. 135, t. 233.

Hypnum orthocarpum Nees in sched. 
H. Reinwardti Hsch. in Nov. Act. Acad. Cos. Leop. XIV, II, Suppl. p. 722 p.p., t. 41, f. a (except. I b.); Schwaegr. Suppl. III, I, I, t.223 (except. figg. 2, 7, 9); C. M. Syn. II, p. 505.

Phaenicobryum Reinwardti Lind $b$. in Oefv... 1861, p. 374.

Trachyloma Reinwardti Mitt. M. Ind. or. p. 91 (in obs.).

2. - As.: Malabar, Sumatra, Java, Borneo, Ceram, Celebes. Pac. : Ins. Fidji, Samoa.

rigidum Mitt. Fl. Vit. p. 401 ,

Ster. $\quad-$ Pac. : Nov. Hebrid. (Aneitum).

samoanum Mitt. Sam. M. p. 192.

Ster. Cortic. et rupic. - Pac, : Ins, Samoa.

Sieberi Mitt. - Mniodendron.

speciosissimum Mitt. p.p. $\left\{\begin{array}{l}\text { - Pterobryella longifrons. } \\ \text { - Pterobryella. }\end{array}\right.$

spininervium (Hook.) Jaeg. Ad. II, p. 623.

Hypnum spininervium Hook. M. ex. t. 29; Brid. Bryol. univ. II, p. 396 ; C. M. Syn. II, pp. 507 et 693 .

Isothecium spininervium $H . f$. et $W$. Fl. of the N. Zeal. II, p. 105, Handb. p. 466 et Fl. Tasm. II, p. 206.

2. Rupic. et terr. - Am. merid. : Valdivia. Pac.: Austral. or., Nov. Zeland., Tasman.

- var. arcuatum (H. f. et W.) Par.

H. arcuatum Mitt. in Trans, and Proced of the roy. Soc. of Victoria, 1883, p. 90.

lsothecium spininervium var. arcuatum $H$. f, et W. $l$. c.

Trachyloma arcuatum Mitt. in Journ. of the Linn. Soc. 1859, p, 86.

splendidum Besch. Fl. bryol. Nov. Caled. p. 245.

Sciadocladus splendidum Jaeg. Ad. II, p. 625.

2. Ad terr. humid. - Pac. : Nov. Caled.

stipitatum (Mitt.) Jaeg. Ad. II, p. 624.

Trachyloma stipitatum Mitt. in Journ. of the Linn. Soc. 186.3, p. 156.

Ster. ?

- Afr. : Ins. Fernando Po.

subarborescens C. M. in Geheeb Neue Beitr. sur Moosf. v. N. Guin. p. 10.

2.

- Pac. : Nov. Guin. merid.

subspininervium (C. M.) Jaeg. Ad. II, p. 623 .

Braithwaitea arborescens Mitt. in Proced. of the Linn. Soc. 1879 (extr. vol.),p. 101 .

H. arborescens ej. Sam. M. p. 190.

Hypnum Reinwatdti Sull. in Wilkes Exped.?

H. subspininervium C.M. in Bot. Zeit. 1857, p. 782.

Trachyloma arborescens Mitt. in Bompland. 1861, p. 366.

Lignic. - Pac. : Ins. Fidji, Samoa, Nov. Hebrid. (Aneitum).

tricostatum (Sull.) Jaeg. Ad. $I I$, p. 624.

Hypnum tricostatum Sull, in U. St. Expl. Exped. Wilkes, p. 13, t. 9. - Par. : Ins. Sandwic.

Vescoanum Besch. Fl. bryol, Taiti, etc., p. 56 .

Hypnum spininerre Sull. in Exped. Wilkes.

2. Terr. - Pac, : Taiti.

vitiense Mitt. Fl. Vit.p. 401.

H. Gräffeanum Jaeg. Ad. II, p. 621. 
Hypnum Graeffeanum C. M. M. Polyn. p. 90.

Trachyloma Junghunii Mitt, in Bonpland. 1861, p. 366.

Ster.

- Pac. : Ins. Fidji (1).

Hypnolepidopilum $C . M$. in Linn. 1876, $p, 252$ (sect. LeProOPILt).

HYPNUM Dill. Hist. M. p. 261 (emend. sensu Schimperiano) (322 spec.).

abbreviatum $\left\{\begin{array}{l}\text { Hedw. - Rhynchostegium murale. } \\ \text { Schleich. - Eurhynchium strigosum. } \\ \text { Turn. - Eurhynchium. }\end{array}\right.$

abietinum L. - Thuidium.

var minor Hook. - Thuidium gracile (fid. C. M.).

var, minor Hook. - Thuidium scitum (teste Kindb.).

var. paludosum Wahlenb. - Thuidium Blandowii. acacioides L. - Fissidens.

acanthoneuron Schwaegr. - Rhizogonium Menziezii.

acanthophyllum Mont. - Rhynchostegium.

aciculare $\left\{\begin{array}{l}\text { Brid. - Ptychomnium. } \\ \text { H.f. et W. p.p. - Ptychomnium cygnisetum. } \\ \text { Scop. - Rhacomitrium. }\end{array}\right.$

var, aquaticum Web. - Rhacomitrium protensum.

aciculatum C. M. - Lindigia.

acinacifolium Hpe. - Ectropotheciurn.

aciphyllum W. et M. - Mnium affine.

acistrostegium Sull. - Rhaphidostegium.

acrophyllum Hpe. - Leucomium.

acrorhizon Hsch. - Microthamnium.

acuminatum P. B. - Brachythecium.

var, rupincolum Sull. - Brachythecium acuminatum var, rupincolum.

var. setosum Sull. - Brachythecium acuminatum var. setosum. acuminulatum Hsch. - Taxithelium planum var. acuminulatum. acuticuspis Mitt, - Isothecium.

acutifolium H. f. et W. - Rhynchostegium.

acutum Mitt. - Brachythecium.

adiantoides L. - Fissidens.

Adiartum Neck. - Eurhynchium striatum.

admistum Sall. - Rhaphidostegium microcarpon var, anisocarpon.

adnatum $\left\{\begin{array}{l}\text { Hedw. - Amblystegium. } \\ \text { Turn. - H. palustre. }\end{array}\right.$

var. gracile $\mathrm{S}$, et L. - Amblystegium adnatum var. gracile.

- var. Mac. - Amblystegium adnatum

adscendens (Lindb.) Jaeg. Ad. II, p. 592.

Stereodon adscendens Lindb. in Act. Soc. sc. Fenn. 1872, p. 251.

2. Lignic. - As. : Amour, Saghalien.

adspersum Hpe. - Sematophyllum.

aduncoides C. M. Syn. II, p. 295.

H. Stereodon cupressiforme $\varphi$ aduncoides Brid. Bryol, univ. II, p. 612.

Ster. - Afr. : Ins. Borbon.

aduncum Hedw. M. frond. IV, p. 62, t. 24 (excl. syn. L.); Bryol. eur. VI (mon p. 35), t. 604; W. P. Sch. Suppl. Bryol. eur, fasc.

(1) In Enum. Kindb, nom, nuda:

H. Helmsii $C, M$. leiopysis C. M. 
III-IV (Hypnum), t. 1 el Syn. (1) II ed. p. 727; C. M. Syn. II, p. 323.

Amblystegium aduncum $\alpha$ Blandowii Sanio in Lindb. et Arn. M. As. bor, $1890, I I(2)$.

H. aduncum $\alpha$ Blandowii $e j$. Beschr. p. 25.

H. flavescens Schleich. Cent IV Crypt. helv, n. 34 (fid. Brid.).

H. longisetum ej. l. c. n. 33 (fid. C. M.).

H. palustre ereetum summitatibus aluncis Dill. Hist. M. p, 292, t. 37, f. 26.

H. psilocaulon Card. in Rev. bryol. 1883, p. 55.

H. Stereodon aduncus Brid. Bryol. univ. II, p. 623.

H. Stereodon aduncus $\delta$ longipes ej. op, cit. p. 625 .

Neckera adunca Willd. Prodv. Fl. Berol. n. 937.

2. In turfos. - Eur. : E. planitie usq. in reg. mont. super. zon. inter. med. et sept. As.: Penins. Tchutschica, Taimyr, Ienissei sup. et med., Caucas. Afr.: Alger. Am. sept.: Groenland, Iabrator, Saskatchewan, M. Rupestr., Columb, brit,, reg. sept, occ., centr. et or.

Exs. : Sull. et Lesq. M. bor, am II ed, n. 466.

Un. itin. 1864, n. 91, 92, 101.

- var. aquaticum Sanio in Bol. Centralbl. 1880.

Submers, - Eur, : Boruss. or., Gall, or.

* var, asturicum Ren, in Husn. Muscol. gall. p. 372.

In paludosis salsis. - Eur.: Hispan. (Astur.).

" var, attenuatum Boulay M. Fr. II, p. 61.

In turfos? - Eur.: Gall. Am. sept.: Montana.

var. Blandowii Sanio, - H. aduncum.

" var, complanatulum (Lindb.) Par.

Amblystegium complanatulum Lindb. M. Scand. p. 33

Ut typ. - Eur. : Fennia.

" $f$. falcata Ren. in op. cit. p. 369.

- Eur. : Gall. centr. Am. sept. : Montana.

* var, filiforme (Berggr.) Par.

H. Kneiffii var. filiforme Berggr, M. Spetsh. n. 126 et in K. Sv. Vet. Ah. Handl. XIII, n. 7, p. 83.

Terr. - Eur. : Spitzberg, ins. Ursor. Am, sept. : Fret. Bell?

var. filiforme Ren, et Card. -- H. aduncum var. Roellii.

* var. flexile Ren, in op. cit. p. 373. ins, Vancouver.

- Eur.: Gall. centr. et occ. Am. sept.: Indiana,

var. giganteum Bryol, eur. - H. hamifolium.

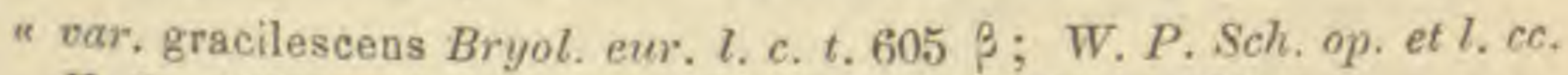

H. Kneiffii var. gracilescens Kindb, in Mac. Cat. p. 226.

In uligin. - Eur.: Gall, Hercyn. As.: Obi. Am. sept.: Columb. brit., Pensilv., Wisconssin, Montana, Wyoming.

(1) \& Plura ab auct. relata syn, quam maxime incerta, omitto., W. P. Sch. I ed. p. 606 .

(2) Cf. ¿Beschreibung der Harpidieen, welche namentlich von Dr Arnell waehrend der Schwedischen Expedition nach Sibirien in J. 1876 gosammelt wurden, sin a Bidrag till K. Sv. Vet. Ak. Handl. Bd. X, n. I. Stockholm, 1885, p.p. 1-60, "von Dr Sanio. 
Exs. : Mac. Canad. M. n. 447.

Sull. et Lesq. M. bor, am. 1 ed, n. 316 b et II ed, n, 467 .

var. hamalum Bryol, eur. - H. hamifolium.

«var. Hampei Sanio Beschr. p. 29.

Amblystegium aduncum var. Hampei Sanio l. c. (1).

- Eur. : Ross. or. As. : Jenissei, Obi.

"var. intermedium W. P. Sch. Suppl. Bryol. eur. fasc. III-IV (Hypnum), t. I. f. 1-8 et op. et $l$. cc.

Ut et ubi typ. in Eur. et Am, sept. As. : Jenissei inf.

« var. intermedium-laxum (Sanio) Par.

Amblystegium aduncum var, intermedium-laxum San. $l$. c. - As. : Jenissei sup. et med.

* var. inundatum W. P. Sch. in Rab. Bryoth, eur. n. 917.

H. vernicosum (fid, Ren.).

Aquat. - Eur. : Palatinat.

«var. Kindbergii Par.

H. Kneiffii var. laxum Kindb. in Mac, Cat. p. 226.

In paludos. - Am. sept : Ottawa.

«var. Kneiffii W. P. Sch. op. cit. p. 727.

Amblystegium Kneiffii Bryol. eur. VI (mon. p. 17), t. 573.

H. aduncum Mac. Ganad. M. n. 332; Kindb. l. c.

H. Kneiffii W. P. Sch. Coroll. p. 135.

Stereodon Kneiffii Mitt.

Ad foss. marg. et in foss. exsicc. - Eur. : Passim, semel fert. (Argentorati) lect. As. : Talysch, Afr. : Alger. Am. sept. : Hic illic. Pac. : Nov. Zeland. ?

Exs. : Mac. Canad. M. n. 333.

Rab. Bryoth. eur. n. 692, b, c, d, e, 898, 1243.

« var. Iaxifolium Sanio in op. cit. p. 9.

In turfos. - Eur. : Germ. sept.

" var. laxum Milde Bryol. siles. p. 351 el in Rab. Bryoth. eur. n. $546,1198$.

As. : Jenissei. Am. Eur. : Gall., Belg., Westphal., Siles., Salisburg. var. molle Sanio. - H. Sendtneri var. Wilsoni.

var. molle bineroe Sanio. - H. longicuspis.

var. molle H jeniseiense Sanio, - H. Sentneri var, molle jeniseiense.

«var. paternum Sanio.

In argill. - Eur. : Gall, or.

\& $f$. penna Sanio in op. cit. p. 10.

In udis argill. - Eur. : Gall. or.

\& var. platyphyllum (Kindb.) Par.

H. Kneiffi var. platyphyllum Kindb. $l$. $c$.

Ad rup. humid. - Am. sept, : Ottawa.

(1) C1. Sanio enumerat formas sequentes : densum-julaceım, densum-sciurum. (1) $\mathrm{Cl}$. Sanio enumerat formas sequentes: densum-julacelom, denstom-sene, tenue-
perourrens, tenue (an tenue Bryol. eur. ?), tenue-densum, tenue-filiforme,
robustius. 
a var. polycarpum (Bland.) Bryol. eur. l. c. t. 605 Ү; W. P. Sch. op. et $l$. ce.

H. polycarpum Bland. in Sturm Deutsch. Fl. crypt, Fasc. XIV; Brid. Bryol. univ. 11, p. 771 .

In terr. arenos. et uligin. subexsicc. - Eur. : Gall. centr. et occ., Belgia, Boruss, As. : Jenissei. Am. sept. : Montana.

Exs. : Rab. Bryoth. eur. n, 400, 692 f.

var. pseudo-stramineum Ren. et Card. - H.

« var. pungens H. Müll. in Limpr. Bryoth, sil. n. 286; Milde Bryol. siles.

Am. sept. : Wyoming.

- Eur. : Gall, Boruss, sept., Siles. As. : Jenissei.

* var. rectifolium (Kindb.) Par.

H. Kneiffii var, rectifulium Kindb. in Mac. Cat. l. c.

Ad rup. madid. - Am. sept. : Ottawa.

"var. Roellii Par.

H. aduncum var. fliforme Ren. et Card. in Bot. Centralbl. 1890, n. 51 .

- Am. sept. : Wisconssin, Idaho.

var, rugosum H, et T. - H. lycopodioides.

- var. Schimperi Sanio Beschr. p. 41.

Amblystegium aduncum var. Schimperi $e j$. in Lindb. et Arn. M. As, bor. 1890, II.

H. capillifolium Warnst. (fid. Ren.).

- As. : Jenissei sup.

"var. strictum (Berggr.) Par.

H. Kneiffii var. strictum Berggr, ll, ec. n. 126 et p. 82.

Terr. - Eur. : Spitzberg. Am. sept. : Groenland.

- var. subalpinum Mille Bryol, siles. p. 351.

- Eur. : Riesengeb.

a var. tenue Bryol. eur. l. c. t. $605 \delta ;$ W. P. Sch. op. et l. cc.

- Eur. : Gall. occ., Helvet., Magn. Dueat.

Megapol, Fennia. Am. sept. : Montana, Idaho, Wisconssin, Washington.

" f. turficola Ren. in op. et l. cc.

In turfos. - Bur. : German, sept.

aduncum Drumm. - H. vernicosum.

aeruginosum C. M. - Eetropothecium.

affine Hook in Kunth Syn. pl. Equinoct.p. 64; Brid. Bryol. univ. II,

p. 124 ; C. M. Syn. II, p. 256.

Steorodon affinis Mitt. M, austr. am. p. 533.

1.

- Am. merid. : And. Nov. Granat.

affine $\left\{\begin{array}{l}\text { Besch. - H. Mohrianum. } \\ \text { Crome. - Thuidium Blandowii. } \\ \text { Hoffm. - H. filicinum. } \\ \text { Sommerf. - H. Sommerfeldti. }\end{array}\right.$

africanum W. et Dy. - Thamnium.

afro-acuminatulum C. M. - Taxithelium.

afro-eupressiforme C. M. in Borgen M. Mall. $n, 67$.

- Afr. : Madagascar centr. 
afro-demissum C. M. - Rhaphidostegium.

afro-glareosum Broth. - Brachythecium.

afro-molluscum C. M. in Dusen M. Camer. n. 130.

- Afr. : M. Cameroon.

afro-purum Rehm. M. Afr. austr. n. 403.

- Afr. : Orange.

aggregatum Mitt. - Isothecium.

agnatum Hpe, - Rhaphidostegium.

Alaguelae C. M. - Rigodium.

alamazautrense Kiaer ined.

- Afr.: Madagascar.

» var. Berthioei Ren. et Card. in Bull. Soc. roy. bot. Belg. 1893, I, p. 128. In silv. - Afr. : Madagascar.

Alaskae Kindb. ined.

2.

- Am. sept. : Alaska.

alaskanum Lesq. et Jam. in Proced. Am. Acad... XIV, p. 139 et Man. p. 405.

Amblystegium alaskanum Lindb, et Arn. M. As. bor. 1890, II, p. 127.

Hylocomium alaskanum Kindb. in Mac. Cat. p. 248.

Hylocomium umbratum Mac. Canad. M. n, 368 p.p.

Pleuroziopsis alaskana Kindb. Check-List of Eur. a. N. Amer M.p. 19).

2. Ster. Terr. - As.: Penins. Tschutschica. Am. sept. : Saskatchewan,

Columb. brit., Alaska, Unalaschka.

albens Gmol. - Hookeria albicans.

albescens Schwaegr. - Isopterygium.

albicans $\left\{\begin{array}{l}\text { Neck. - Brachythecium. } \\ \text { Sw. - Hookeria. }\end{array}\right.$

var. flavescens Brid. - Brachythecium albicans.

var, minnidunense Brid, - Brachythecium glareosum.

albulum C. M. - Plagiothecium micans.

var. fulvum L: et J. - Plagiothecium micans var. fulvum.

var. Sull. - Plagiothecium micans var, ursorum.

alleghaniense C. M. - Thamnium.

Alleni L. et J. - Thuidium.

alopecuroides $\left\{\begin{array}{l}\text { Hook. - Thamnium. } \\ \text { Lam. - Isothecium myurum. }\end{array}\right.$

var. hibernicum Hook, - Rhynchostegium rusciforme.

alopecurum $\left\{\begin{array}{l}\text { L. - Thamnium. } \\ \text { Mont. - Thamnium Schmidii. }\end{array}\right.$

alpestre Sw. M. Suec. p. 63 (non tabula!); W. P.Sch, Syn. I ed.p.774.

Amblystegium rivulare Lindb.

H. molle C. M. Syn. $I I, p, 431$ p.p

H. rupestre Sohleich, Cent. II Crypt. helv, n. 47 (teste Brid.).

H. Stereodon alpestris Brid. Bryol. univ. II, p. 571 .

H. Stereodon mollis ej. op. cit. p. 578 (excl. syn. Dieks).

Limnobium alpestre B.yol. eur, VI (mon. p. 4), t. 57 i (except. $f .1$ et 16, quae ad $\mathrm{H}$. dilatatum pertinent).

1. Ad rivul, frigidior. saxa silic. - Eur. : Spitzberg, ins. Ursor., Scandin., Alp. Carinth., Tirol. merid., etc.; desider. in Britann. As.: Jenissei inf. Am. sept. : Groenland, M. Rupestr.

Exs. : Mac, Canad M. n. 396.

Rab. Bryoth, eur, n, 913.

alpestre $\left\{\begin{array}{l}\text { Grev. }- \text { H. arcticum. } \\ \text { Sw. (Ic!) - H. alpinum. }\end{array}\right.$ 
alpinum W. P. Sch. Syn. II ed,p. 777.

H. alpestre Sw. M. Suec. t. 6, f. 15 (non descriptio I).

Limnobium molle Bryol. eur. VI, t. 576 (non descriptio !).

1. Ad rivul. - Eur. : Scandin., Alp. Helvet. et Saband. (M. Ylanc).

alpinum $\left\{\begin{array}{l}\text { Neck. - Dicranum elongatum var, orthocarpon. } \\ \mathrm{Sm} . \text { - Brachythecium plumosum (1). }\end{array}\right.$

alto-pungens C. M. - Sematophyllum.

aluminicolum C. M, Syn. II, p. 291.

Stereodon aluminicola Mitt. M. austr, am. p. 534.

1. In spelunc, - Am. sept. : Mexic.

ambiguum (de Not.) Jaeg. Ad. $11, p .569$.

Amblystegium ambiguum de Not. Epil. p. 144.

H. Notarisii $S b$, in Jaeg. Ad. II, p. 597,

Limnobium ambiguum de Not. Epil. p. 163.

L. palustre ej. in Erbar. critt. ital. n. 906.

Ad rivul. - Eur. : Longobard., Apennin. Ligustic.

ambiguum $\left\{\begin{array}{l}\text { Harv. - Ectropothecium cyperoides. - } \\ \text { Schrad. - H. revolvens (2). }\end{array}\right.$

amblyacron C. M. - Rhynchostegium.

amblyostegum Wils. in sched.

Stereodon amblyostegus Mitt. M. Ind. or. p. 97 .

2.

- As. : Sikkim.

amblyostomum C. M. - Thuidium.

var. attenualifolium C. M. - Thuidium amblyostomum var. attenuatifolium.

var. paludicolum C. M. - Thuidium ainblyostomum var. paludicolum. amblystegiocarpum C. M. - Rhaphidostegium.

ainonum $\left\{\begin{array}{l}\text { Hedw. - Rhaphidostegium. } \\ \text { Hook. I- Rhaphidostegium recurvans. }\end{array}\right.$

amplexicaule Rehm. M. Afr. austr. n. 122.

- Afr. : Natal.

anceps Bryol. jav. - Rhynchostegium.

andicolum Hook, - Microthamnium.

andinum (Mitt.) Jaeg. Ad. II, p. 568.

Amblystegium andinum Mitt. M. austr. am. p. 568.

In uligin. - Am. merid. : And. Quitens.

andinum Hpe. - Plagiothecium andicola.

Andrienxii C. M. - Rozea.

androgynum \{ Schrank, - Aulacomnium.

Wils. - Eurhynchium speciosam.

andungense W. et Dy. - Rhaphidostegiun.

var. major W. et Dy. - Rhaphidostegium andungenso var. major.

aneurodictyon C. M. - Leucomium.

aneuron Duby. - Sematophyllum.

angustatum C. M. - Anomodon.

(1) alternans Brid. Bryol. univ, II, P. 542 ; C. M. Syn. II, p. 508. - Ex Australia. Quid ? Delendum.

(2) ambiguum Vill. Pl. Dauph. III, p. 904; Brid. Eryol. univ. II, p. 545 ; C. M. Syn. H, p. 502. Fid. Brid. Brachythecium populeum. - Delendum. 
angusticymbeum C. M. - Rhaphidostegium angustifolium $\mathrm{H}$ pe. et C. M. - Pseudo-Leskea. angustissimum C. M. in Abhandl. Brem. VII, p. 212. - Afr. : Madagascar.

angusto-textum Geh. - Eetropothecium. anisophyllum C. M. in Dusen M. Camer. n. 119. - Afr. : M. Cameroon.

annotinum W. et M. - Webera annotina. anomalum Hpe. - Eurhynchium.

anotis Rehm. M. Afr. austr. n. 413 et $b$.

H. crassicaule ej. l. c.n. 414 (H, anotidis forma palustris, robusta). - Afr. : C. B. Sp., Natal.

antarcticum C. M. - Plagiothecium. antipyreticum Neek. - Fontinalis.

var, minus Neck. - Cinclidotus fontinaloides. aoratum Duby $\left\{\begin{array}{l}\text { (fid. Besch.). - Isopterygium intortum? } \\ \text { (fid. Jaeg.). - Trichosteleum. }\end{array}\right.$ apertum Sull, - Ectropothecium inflectens. apiculatum $\left\{\begin{array}{l}\text { Hartm. - Myurella. } \\ \text { Hsch, - Ectropothecium. }\end{array}\right.$ apiculigerum L. et A, - Eurhynchium. apocladum Mitt. - Isothecium. applanatum Thw, et Mitt. - Helicodontium. appressum $\left\{\begin{array}{l}\text { Brid. - Pylaisia intricata. } \\ \text { Hsch. - Parillaria. }\end{array}\right.$ aptychopsis C. M. - Plagiothecium. Funk. - Bracythecium plumosum. Hpe. - Rhynchostegium. Jaeg. - Cinclidotus. Poll. - Rhynchostegium rusciforme var. inundatum. aquaticum flagellis et lerelibus et pinnatis Dill. - Amblystegium ripanigricans, foliis angustis falcatis Dill. - Ciuclidotus aquaticus. prolixum, foliis ovatis Dill. - Rhynchostegium rusciforme var. prolixum.

aquatile Mart. - H. palustre.

aquicolum C. M. - Sematophyllum.

arabicum C. M. in Hedwig. 1891, p. 219 (nom.). - As. : M. Yemens.

Arabs C. M. in op, et $l$. cc. (nom.). - As. : M. Yemens.

Araucarieti C. M. in Ule Bryoth, brasil. n. 93.

2. $\quad-A m$. merid. : Brasil subtropic. or.

Araucariobryum ej.l.c. n. 72.

2. Lignic. - Am. merid. : Brasil subtropic. or.

arborescens C. M. - Rigodium Lechleri.

arboreum sciuroides Dill. - Leucodon sciuroides.

Arbuscula $\left\{\begin{array}{l}\text { Brid. - Thamnium alopecurum. } \\ \text { Hook. - Camptochaete. } \\ \text { P. B. - Hypopterygium Thouini? }\end{array}\right.$

arbusculans $\mathrm{C} . \mathrm{M}$. - Thamnium. 
areticum Sommerf. Suppl. ad Wahlenb. Fl. Lapp. p. 65, t. 2 ; C, M. Syn. II, p. 432; W. P. Sch. Syn. I ed. p. 638 el II ed. p. 779.

Amblystegium Smithii Lindb. M. Scand. p. 33.

H. alpestre Grev. Scot. crypt. Fl. t. 282.

H. Smithii Lindb. in Act. Soc. sc. Fenn p. 277 (in adn.),

Leskea Smithii Sw, in Liljeb!. Sv. Fl, III ed., p. 549, n. 6.

Limnobium arcticum Bryol eur. VI (mon. p. 6), t. 578.

Stereodon arcticus Mitt in Journ. of the Linn. Soc. VIII, p. 4?.

1. Ad saxa rivul. - Eur. : Scot., Scandin., Sudet., Stir., Tirol., Alp. Rhaet., Pyren. Am. sepl. : Groenland, New Jersey, Gaspes., Ontar.,

M. Selkirk et Rupestr., Culumb. brit., Idaho.

Exs.: Mac. Canad. M. n. 358.

Rab. Bryoth, eur. n, 648, 912.

var. C. M. - Rhynchostegium obtusifolium.

areuatiforme Kindb. in Mac. Cat, p. 238.

2? of ign. Terr. - Am. sept.: Ontario.

arcuatum Lindb. in Act. K. Vet. Ak. Holm. 1861, p. 371; W. P. Sch. op. cit. p. 758 .

H. curvifolium C. M. Syn. II, p. 213 p.p.

H. Lindbergii Mitt.

H. Patientia Lindb, in Milde Bryol. siles.

H. pratense $\beta$ hamatum W. P. Sch. Syn. I ed. p. 628.

Stereodon arcuatus Lindb.

2. Ad terr, in gramin. et ad foss. marg. - Eur. : E reg. campestr. usq. in alp., rariss, fructif. As.: Japon., Amour, Jenissei, Obi, Cancas. occ. et centr, Am. sept. : Groenland, Terr. nov., Miquel., New Brunswick, Pensilv., Wisconssin, Indiana, Montana, Florid.

Exs. : Faurit Pl. Jap. n. 155, 3502 b.

Rab. Bryoth. eur. n. 476, 743 .

Un. itin. 1867, n. 8.

"var. americanum Ren, et Card. in Bot. Gaz. 1889, p. 99.

Arenic, et lignic. - Am. sept. : Ladovicia.

"var, demissum W. P. Sch. op. et l. cc.

Ut typ. - Eur.: Austria inf. Am. sept. : Maryland, Idaho.

a var, elatum W. P. Sch. op, et $l$. cc.

Ut typ. - Eur. : Scandin., Ducat. Badens., Bavar., Pyren., etc. Am. sept. : Miquelon.

"var. flaccidum de Not. Epil. p. 180.

Ut et ubi typ. in Eur.

"var. fluitans de Not. l. c.

Aquat. - Eur. : Ubi typ.

arcuatum $\mid$ Hedw. - Rhacopilum.

aremarium Sull, - Ectropothecium.

arenarium Lesq. - Camptothecium.

argentatum Mitt, - Struckia.

argenteum Rehm. M. Afr. austr. n. 673.

- Afr.: Natal.

argenteum Schrank. - Bryum.

argentinicum C. M. - Rigodium.

argute-serratum C. M. - Microthamnum Sellowii.

argyroleucon C. M. in Borgen M. Mad. n. 46.

- Afr. : Madagascar centr.

arhrison Brid, - Amblystegium fluviatile. 
aristatum $\left\{\begin{array}{l}\text { H. f. et W. - Rhynchostegium. } \\ \text { Sull. - Sciaromium hispidum. }\end{array}\right.$

armoricum Brid, - Hyocomium flagellare.

arquifolium Bryol. jav. - Isopterygium.

arrectum $\left\{\begin{array}{l}\text { Mitt. - Rhaphidostegium Welwitschii? } \\ \text { Vill. - H. chrysophyllum. }\end{array}\right.$

arundinifolium Duby. - Breutelia gigantea.

Arzobispae C. M. - Thuidium.

asperipes Mitt. - Iurhynchium remotifolium.

asperisetum C. M. - Rhynchostegium.

asperrimum Mitt. - Brachythecium.

asperulum $\left\{\begin{array}{l}\text { Brid. - Brachythecium plumosum. } \\ \text { Hpe. - Brachythecium. }\end{array}\right.$

asplenioides $\left\{\begin{array}{l}\text { Dicks. - Fissidens osmundioides. } \\ \text { Sw. - Fissidens. } \\ \text { Thbg. - Fissidens Thunbergii. }\end{array}\right.$

asprellum Schwaegr. - Thelia.

ussurgens Sull, et L. - Thuidium?

athrocladum Mitt. - Brachythecium.

atlanticum Desf. - Rhynchostegium rusciforme var. lutescens.

attenuatum $\left\{\begin{array}{l}\text { Brid. - Brachytbecium oxycladon. } \\ \text { Schreb. - Anomodon. }\end{array}\right.$

atro-virens $\left\{\begin{array}{l}\mathrm{Sm} . \text { - Pseudo-Leskea. } \\ \mathrm{Sw} \text { - Eurhynchium praelongum var, atro-virens. }\end{array}\right.$

Auberti Schwaegr, - Acrocladium.

aureolum Hpe. - Rhapbidostegium.

var. minus $\mathrm{Hpe}$ - Rhaphidostegium aureolum var. minus.

aureo-nitens Hook. - Meteorium.

aureo-sulfureum C. M. - Rhaphidostegium.

aurescens C. M. - Camptothecium anreum.

aureum $\{$ Lag. - Campthothecium aureum.

auriculatum $\left\{\begin{array}{l}\text { Lindb. - Brachythecium. } \\ \text { Mont. - Lembophyllum. }\end{array}\right.$

aurifolium (Mitt.) Jaeg. Ad. II, p. 594.

Ctenidium aurifolium Mitt. M. austr. am. p. 509.

Ster.

- Am. merid. : Brasil. tropic.

australe C. M. - Ectropothecium.

austrinum H. f. et W. - Eurhynchium.

austro-aduncum C. M. in Engler's Bot. Jahrb. 1883, p. 82 et in Forchungsveise... Bot. p. 33.

Ster. - Afr. : Ins. Kerguelen.

austro-alpinum Hpe. - Brachythecium.

austro-catenulatum C. M. - Pseudo.Leskea.

austro-fluitans C. M. in Engler's Bot. Jahrb. 1883, p. 82 el in Forchungsreise... Bot. p. 34.

Amblystegium fluitans Mitt. in Journ. of the Linn. Soc. 1876.

H. fluitans $H$. $f$. et $W . M$. Antaret.

2.

- Afr. : Ins. Kerguelen.

austro-fluviatile C. M. - Amblystegium.

austro-glareosum C. M. - Brachythecium.

austro-montamum Hpe. - Rhynchostegium.

austro-pulchellum C. M. - Plagiothecium.

austro-pusillum C. M. - Isopterygium. 
austro-salebrosum C. M. - Brachythecium. austro-serpens C. M. - Thuidium.

austro-stramineum C. M. Bryol. austr. Georg. p. 43.

Ster, Paludic. - Am, merid. : Austr, Georg.

" var. gracillimum ej. $l$. c.

Ut et ubi typ.

\& var. subfluitans ej.l. c. p: 44.

Ut et ubi typ.

austro uncinatum C. M. in Engler's Bol. Jahrb. 1883, p. 82 et in Forchungsreise... Bot. p. 34.

Amblystegium uncinatum Mitt, in op, cit.

1.

- Afr. : Ins. Kerguelen.

badense A. Br. - H. Haldanianum.

badium Hartm. Skand. Fl. V ed. p. 332 ; W. P. Sch. op. cit. p. 795.

Amblystegium badium Lindb, M. Scand. $p, 33$.

2. In paludos, et ad rup, irror. - Eur.: Spitzberg, ins. Ursor., Aip.

Scandin. As.: Jenissei inf, Am. sept.: Groenland, Labrador.

Exs. : Rab. Bryoth, eur. n. 1300.

badio $\times$ Wilzoni Sanio Beschr. p. 52 .

Amblystegium badium $\times$ latifolium Arn, M. As. bor. 1890, II, p. 122.

Ster.

- Jenissei inf.

baliense Bryol. jav. - Ectropothecium.

Bambergeri W. P. Sch. Syn. 1 ed.p. 698 et 11 ed.p. 763.

H. circulare Jaeg. Ad. II, p, 580.

Stereodon circularis Mitt. in Journ. of the Linn. Soc. VIII, p. 42.

St. Bambergeri Lindb. M. Scand. p. 38.

2 f et fr. ign. Ad terr. humidinsc, praepr. calc. - Eur. : Spitzberg, ins. Ursor., Alp. Scot., Scandin., Helvet,, Tirol,, Rhaet., Salisburg., Stir. Am. sept. : Ins. Beechey, canal. Wellington, Groenland.

Exs. : Rab. Bryoth. eur. n. 908.

Un itin. 1863, n. 92, 93.

* var. flexuosum Berggr.

Stereoron Bambergeri var. flexuosus Lindb. M. Scand. p. 38. - Eur.: Norvegia.

bancanum Bryol, jav, - Isopterygium.

Barbeyi Ren. et Card, in Bull. herb. Boissier 1894, p. 32.

2 ? Paludic. - Am. merid.: And Boliv.

Eøs. : Mandon, Pl, Boliv, n, 1712 bis.

bartramiocarpum C. M. - Trichosteleum.

bartramiophilum C. M. - Hylocomium.

Basilaniae C. M. - Trichosteleum.

bavaricum Voit. - Thuidium minutulum.

Bergenense Aust. - H. chrysophyllum var, tenellum.

Berthelotianum Mont. - Hylocomium.

Berteroanum Mont. - Rhynchostegium.

Beskeanum C. M. - Rhynchostegium.

Beyrichii ) Hsch. - Rhaphidostegium.

bibrach Wright. - Rhaphidostegium sericifolium.

bibrachiatum C. M. - Homalia. 
bicolor Belang. Voy, Ind. or. Bot. 1I, Crypt. p. 92, t. 10, f. 2; C. M. Syn. II, p. 407.

Ad arbor. rad. - Afr, : Ins. Borbon.

bifarium Hook. - Rhizogonium.

bifidum Brid. - Leucoloma.

Bigelowii Sull. - Thamnium.

bistrumosum C. M. - Trichosteleum.

biventrosun C. M. - Brachythecium.

Blandowii W. et M. - Thuidium.

blandum Lyell. - Scleropodium illecebrum.

blepharophyllum C. M. - Thuidium.

Blyttii Bryol, eur. VI (mon. p. 16), t. 586; W. P. Sch. op, cil. p. 747.

Stereodon incurvatus $\beta$ Blyttii Lindb. M. Scand. p. 38.

1. Ad sax. umbrosa. - Eur. : Norveg. merid.

bogosicum V, d. B. et Lac. - Sematophyllum?

Boivini C. M. - Ectropothecium.

Bolanderi Lesq. - Brachythecium.

bolivianum W. P. Sch. in Mandon Pl. Boliv. n. 1708.

- Am. merid.: And. Boliv.

Bonplandii $\left\{\begin{array}{l}\text { C. M. - Homalothecium. } \\ \text { Mitt. - Orthothecium neilyherriense var. ceylanicum. }\end{array}\right.$

borbonicum C. M. - Trichosteleum.

borbonicum $\{$ Besch., Mitt. - Semataphyllum Pickeringii.

boreale W. et M. - Bryum pseudo -triquetrum.

Borrerianum Spr. - Plagiothesium elegans,

? Boryanum Brid. Bryol. univ. II, p. 393; C. M. Syn. II, p. 245. - Afr.: Ins. Borbon.

Boschii Dz. et Mk. - Trichosteleum.

Boscii Schwaegr, - Eurhynchium.

Boswellii Geh. - Rhaphidostegium.

Bottinii Breidl. - Plagiothecium.

Bourgaeanum $\left\{\begin{array}{l}\text { Mitt. - Rhynchostegium. } \\ \text { Sb. - H. plicatile. }\end{array}\right.$

brachiatum Milt. in Hook. Handb. of the N. Zeal. Fl. p. 472.

- Pac.: Nov. Zeland. bor. et med.

brachycarpum (Mitt.) Par.

Stereodon brachycarpus Mitt. in Trans. of the Linn. Soc. 1891, p. 181. 1.

- As.: Japon.

brachycarpum Hpe. - Rhaphidostegium.

brachycladon W. Arn. - Erythrodontium densum.

brachycladulum $C$. $M$. in Dusen M. Camer. n. 486.

- Afr.: M. Cameroun.

brachyneuron C. M. - Isopterygium.

brachypelma C. M. -- Rhaphidostegium.

brachypodium C. M. - Rigodium.

brachypoma Schwaegr. - Rhaphidostegium subsimplex.

brachypterum Hsch. - Rhynchostegium.

brachypus Hpe. - Rhaphidostegium.

brachypyxis C. M. - Thuidium.

brachystelium C. M. - Ect-opothecium.

brachytheciopsis C. M. - Fetropothecium. 
bracteatum C. M. - Rhaphidostegium.

Brandegei Aust. - Rhynchostegium.

Brandisi C. M. - Thuidium.

brasiliense $\mathrm{Hpe}$. - Plagiothecium subaequans.

Braunii C. M. - Sematophyllum.

var. oxyporon Bryol. Jav. - Sematophyllum Braunii var. oxyporon. Breidleri Jur. - H. Richardsoni.

brevicuspidatuin C. M. - Sematophyllum.

brevifalcatum C. M. - Ectropothecium.

brevifolium Lindb. in Defv... XXIII, p, 54 .

H. Lycopodioidés var. brevifolium Berggr. M. Spetsh, n. 127 et in $K$. Sv. Vet. Ak. Handl. XIII, n. 7, p. 83.

Ster. Terr. - Eur, : Spitzberg, ins. Ursor. Am. sept. : Groenland.

brevifolium Rehm, - H. natalense.

brevimucronatum C. M. - Rhaphidostegium.

brevipes C. M. - Stereophyllum.

brevirostrum $\left\{\begin{array}{l}\text { Ehrh. - Hylocomium. } \\ \text { Hartm. p.p.-Hylocomium squarrosum var, subpinnatum. }\end{array}\right.$

var. interruptum Brid. - Hylocomium brevirostre.

brevisetulum C. M. - Sematophyllum.

brevisetum Hsch. - Ectropothecium.

Brenerianum Lesq. - Isothecium.

var. lutescens L. et J. - Isothecium Brewerianum var. lutescens.

var. Sull, - Isothecium Brewerianum var. Litescens.

Brittoni Mitt. - Homalothecium sericeoides.

Bruchii Dz. et Mk. - Sematophyllum.

brunneo-alare C. M. - Brachythecium.

brunneo-fuscum C. $M$, in Bot. Centralbl. 1883, n. 2-4.

Amblystegium brunneo-fuscum L. et A. M. As. bor. $1890, I I, p .127$.

Ster.

- As. : Penins. Tschutschica.

bryifolum C. M. - Eetropothecium.

bryiforme Brid. - Brachythecium acuminatum.

bryoides $\left\{\begin{array}{l}\text { Ehrh. - Fissidens osmundioides. } \\ \text { L. - Fissidens bryoides (1). }\end{array}\right.$

var. Poll. - Fissidens exilis.

Buchanani Hook. - Brachythecium.

Buitenzorgii Bel, - Ectropothecium,

bulvense Broth. - Rhynchostegium.

bunodicarpum C. M. - Trichosteleum.

Büttnerianum C. M. in Verhandl. d. bot. Ver. Prov. Brandenb. 1890, p. 67.

- Afr.: Tropic. occid.

byssicaule C. M. - Isopterygium.

byssirameum C. M. et Kindb.in Bidr. p. 454 (nom.) el in Mac. Cat.p. 223.

Ster. Lignic. - Am. sept. : Ontario.

Cacti C. M. - Isopterygium.

cacticolum C. M. - Rhynchostegium.

caespitans C. M. - Seleropodium caespitosum.

caespiticium W. et M $\left\{\begin{array}{l}\text { - Brytim. } \\ -- \text { Bryum }\end{array}\right.$

-. Biyum Warneum.

(1) bryoides Vill. Pl. Dauph. III, p. 91 ; C. M. II, p. 509. - An Rhacomitrium miorocarpum? Delendum. 
C. M. p.p. - Rhaphidostegium galipense.

caespitosum

Sull. - Rhaphidostegium lamprophyllum.

Sw. - Rhaphidostegium.

Wils. - Scleropodium.

filamentosum, minimum subflexum Dill. - Thuidium gracile var. lancastriense.

calderense Sull. - Sematophyllum.

Calerae C. M. - Brachythecium.

californicum Lesq. - Scleropodium.

callichroides C. M. - Ectropothecium.

callichroum C. M. Syn. 1I, p. 294; Bryol. eur. VI (mon. p. 27), t.596;

W. P. Sch. op. cit. p. 753.

H. hamulosum Wils. Bryol, brit.

H. micranthum ej. mss.

H. Stereodon callichroum Brid. Bryol. univ. II, p. 631.

2. Ad rup. humid. et terr. lapidos. - Eur. : Reg. montan. super. et suvalp. : Spitzberg, ins. Parry; Scandin.? Alp. Scot., Angl,; Voges,, Silv. Nigr., Helvet., Sudet., Salisburg., Pyren. As. : Jenissei inf., Caucas. occ. et centr. Am. sept.: Groenland, Nov. Scot.

Exs, : Rab. Bryoth. eur. n. 347.

Un. itin. 1863, n. 89.

« var. laete-viride W. P. Sch. Syn. I ed. p. 624 et II ed. p. 754.

Ad rup, irror. - Eur. : Alp. Delphinat., Austr. sup.

callidioides C. M. - Rhaphidostegium.

callidum \{ Mont. - Rhaphidostegium.

callidum \{ Wright. - Rhaphidostegium xylophilum.

calodiclyon C. M. - Ectropothecium.

var. glauca C. M. - Ectropothecium calodictyon var. glauca. caloosiense Aust. - Rhynchostegium?

calpaecarpum Ángstr. - Ectropothecium sodale.

calvescens Wils. - Hylocomium squarrosum var. subpinnatum.

calyptratum Sull. - Thuidium.

cameratum Mitt. - Brachythecium.

campestre $\mathrm{Br}$. - Brachythecium.

campicolum C. M. - Amblystegium.

campylocarpum C. M. - Rhynchostegium.

canadense Kindb. in Bull. Torr. bot. Club, XVII, p. 280, in Mac. Cat.

p. 236 et Canad. M. n. 314.
2. Lignic. - Am. sept. : Terr. nov,, summ. M. Rupestr., Alaska. canariense (Mitt.) Jaeg. Ad. 11, p. 584.

H. subcupressiforme W. P. Sch. in Mandon M. Madeir. n. 46.

H. uncinulatum Jur. in Bot. Zeit. 1866, p. 21.

Stereodon canariensis Mitt. in Journ. of the Linn. Soc. 1863, p. 5. 2. - Eur.: Hibern. Afr.: Ins, Canar., Madeira, Azor.

canariense $\left\{\begin{array}{l}\text { Brid. - Leucodon. } \\ \text { Hpe. et C. M. }\end{array}\right.$

candidum C. M. - Isopterygium.

candidulum C. M. - Isopterygium.

canescens Web. - Rhacomitrium lanuginosum.

var. ericoides Web. - Rhacomitrium canescens var. ericoides.

var. hirsutum Weiss. - Rbacomitrinm lanuginosum.

var. pilosum Weiss. - Rhacomitrium canescens.

caperatum (Mitt.) Jaeg. Ad. II, p. 585.

Stereodon caperatus Mitt. M. Ind. or. p. 97.

2.

- As.: Himalaya occ. 
capillaceum W. P. Sch, in Lechl. Pl. Peruv. n. 3101,

Amblystegium capillaceum Mitt. M..austr, am. p. 570.

Ster. In uligin. - Am. merid. : And. Peruv.

capillaceum $\left\{\begin{array}{l}\text { Brid. - Brachythecium salebrosum var. cylindricum. } \\ \text { Vill. - H. Juliani. }\end{array}\right.$

var, Thomasii Brid. - Bráchythecium salebrosum var. Thomasii.

capillare $\left\{\begin{array}{l}\text { Sw. - Helicodontium. } \\ \text { W. et M. - Bryum. }\end{array}\right.$

capillifolium (Milt.) Par.

Hyocomium capillifolium Mitt. in Trans. of the Linn. Soc. 1891, p. 177. - As. : Japon.

capillifolium Warnst, - H. fluitans var. capillifolium.

capillipes Bryol. jav. - Isopterygium.

capillisetum C. M. - Ectropothecium.

carantae C. M. - Thuidium (1).

carneum W, et M. - Webera.

carolinianum C. M. - Rhaphidostegium demissum var, carolınianum.

casuarinum C. M. - Thuidium.

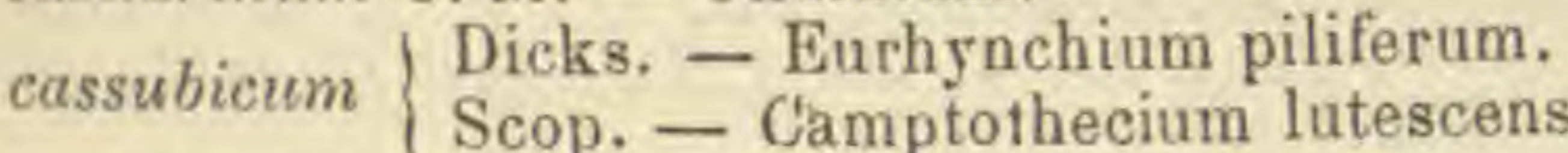

Camptothecium lutescens.

cataractitis C. M. - Rhaphidostegium.

catenatum Vill. - Pseudo-Leskea catenulata?

catenulatum $\left\{\begin{array}{l}\text { Brid. - Pseudo-Leskea. } \\ \text { H. et T. - Heterocladium dimorphum. }\end{array}\right.$

catillum C. M. - Rhaphidostegium.

caturum P. R. - Anomodon rostratus.

caucasicum $\left\{\begin{array}{l}\text { Brid. - Amblystegium fluviatile. } \\ \text { Lindb. - Homalothecium. }\end{array}\right.$

caudatum Bryol. jav. - Sematophyllum.

caudiforme C. M. - Microthamnium.

caulibus prostratis, foliis lanceolatis reflexis, operculo conico Hall. -

H. Halleri.

cavifolium C. M. - Rhaphidostegium.

celatum (Mitt.) Jaeg. Ad. 1I, p. 590.

Leskea polyantha Harv., excl. fig. in Hook. Ic. pl. rar. t. 23, f. 3, quae fol. St. aurei repraesentat (fid. Mitt. M. Ind. or. p. 99).

Stereodon celatus Mitt. op. et $l$. cc.

Ster.

- As. : Nepal.

celebicum Bryol, jav. - Rhynchostegium.

cerviculatum H, f, et W. - Rhaphidostegium.

ceylonense Hpe. - Rhaphidostegium.

chalarocladum C. M. - Pseudo-Leskea.

Chanissonis Hsch. - Ectropothecium.

chimborazense Mitt, in $5 p r$. Cat. p. 15 et exs. n. 1032.

- Am. merid.: And. Quitens.

chinense Sb. in Jaeg. Ad. II, p. 754.

H. oblongifolium Sull. et Lesq. in Proced. of the Am. Acad... 1859, p. 279. 1.

- As.: Hong-Kong.

(1) carinatum Scop. FI. Carn. II ed. n, 1307 ; Brid. Bryol. univ.; II, p. 544; C, M. Syn. II, p. 508, - Forsan Platygyrium repens, fid. Brid. - Delendum. 
chlamydophyllum H. f. et W. .-- Lembophyllum. chlorisans W. et Dy. - Microthamnium.

chlorochroum Jur. in Un, itin. $1863, n .88$,

Ad terr. calcar. argill. - Eur. : Alp. Bavar.

chlorocladum C. M. - Lembophyllum.

chlorophyllum Hsch. - Stereophyllum.

chloropsis C. M. - Thuidium.

chloropterum C. M. et Kindb. in Mac. Cat. p. 2:31.

H. Novae Angliae Mac. Canad. M. n. 440.

1. Ad rup. et terr, umbr. - Am, sept.: Terr. nov., New Brunswick

chloropterum C. M. - Trichosteleum.

chlorosum Hpe. - Isopterygium.

Chrismari C. M. - Plagiothecium.

chryseum Schwaegr. - Orthothecium.

chrysocladon Hpe. - Brachythecium.

chrysocomum Dicks. - Breutelia arcuata.

chrysogaster C. M. Syn. $I I, p .295$.

H. cupressiforme $H$. $f$. et W. Fl. antarct. p. 141.

H. patale eor. Fl. of the N. Zeal. II, p. $112, t .90, f .6$ et Handb. p. 495 ; $\mathrm{Fl}$, Tasman. $I 1, p .212$.

Stereodon chrysogaster Mitt. in Journ, of the Linn. Soc. 1859, p. 87.

2. Lignic. - Pac. : Tasman., ins. Auckland.

clirysophylloides $\left\{\begin{array}{l}\text { C. M. p.p. - Plagiothecium Mühlenbeckii var. chry- } \\ \text { sophylloides. } \\ \text { C. M. pp. - Orthothecium intricatum. } \\ \text { Hpe. - Rhynchostegium. }\end{array}\right.$

chrysophyllum Brid. M. Rec. II, II, p. 84, t. 2, f. $2 ;$ C. M. Syn. II, p. 435; W. P. Sch. Syn. I ed. p. 602 et II ed.p. 724.

Amblystegium chrystophyllum de Not.

H. arrectum Vill, Pl. Dauph. III, p. 903.

H. fragile Brid. Sp. M. II, p. 198 et Bryol. univ. II, p. 597.

H. Halleri $\beta$ majus Wahlenb, Fl, Lapp, p. 375.

H. polymorphum $H$. et T. Muscol, brit. p. 107, t. 26; Bryol. eur. VI (mon. p. 13), t. 583.

H. squarrosulum Brid. M. Rec. II, II, p. 149, t. 4, f. 2.

H. stellatum var. chrysophyllum Drumm, M. bor. am. I ed. n. 185.

H. stellatum $\beta$ minus W. et M. Bot. Taschb, p. 352 .

H. Stereodon chrysophyllus Brid. Bryol. univ. II, p. 598.

H. Stereodon chrysophyllus $\beta$ squarrosulus ej. op, cit. p. 599 .

2. Ad rup. humid. praecip. calc., rar. ad terr. - Eur.: Reg. campestr. et mont., praecip. zon. sept. As.: Japon., Jenissei, Obi, Caucas, occ. et centr. Am. sept.: Terr. nov., Nov. Scot., New Brunswick, Gaspes., Ottawa, Ontario, Manitoba, Saskatchewan, M. Rupestr, Columb. brit., reg. sept., or., centr., merid.

Exs. : Faurie Pl. Jap, n. 85.

Mac. Canad. M. n. 329.

Rab. Bryoth. eur. n. $493,791$.

Sull. et Lesq. M. bor. am. 11, p. 716.

Un itin. 1864, n. 86.

var, subnivale Mdo. - H. Preverianum.

"var. tenellum W. P. Sch. $l l . c c$.

H. Bergenense Aust. M. Appal. n. 391. 
H. polymorphum $\beta$ chrysophyllum Bryol. eur. $l$. $c$.

H. polymorphum var. minus Sull. M. bor. am, II ed., p. 86 ?

In siccior. - Eur. : Ubi typ. Am. sept. : Pensilv., Montana, Florida.

Exs, : Drumm. M. bor. am. II ed. n. 145, 146.

Sull. et Lesq. M. bor. am. II ed. n. 557.

thrysostegum C. M. - Rhaphidostegium.

chrysostomum $\left\{\begin{array}{l}\text { C. M. - Brachythecium rivulare. } \\ \text { Rich. - Brachythecium plumosum. }\end{array}\right.$

ciliare Brid. - Fabronia octoblepharis.

eincinnatum $\left\{\begin{array}{l}\text { Brot. - Pterogonium gracile. } \\ \text { Santi. - Leptodon Smithi. }\end{array}\right.$

circinale Hook. M. ex. t. 107 ; C. M. Syn. II, p. 318.

H. Stereodon circinalis Brid. Bryol. univ. II, p. 621.

Stereodon circinalis Mitt. in Trans. of the Limn. Soc. 1891, p. 181.

1 (Sull, et Lesq.); 2 (Ren. et Card.) Cortic. et lignic. - Eur. : Hibern.

As. : Japon. Am. sept. : Columb. brit., Alaska, Vancouver, fret. Kot-

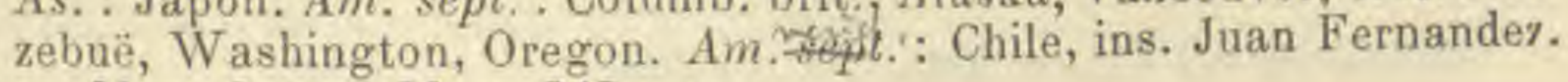

Exs. : Mac. Canad. M. n. 347 p.p.

circinale Mac. p.p., Sull. et Lesq. - H. Sequoieti.

circinans W. P. Sch. - Isothecium myurum var. circinans.

circinatulum W. P. Sch, in Savat. M. Japon. n. 99 ; Besch. in Ann. sc. nat. 1893, p. 389.

2 ?

- As. : Japon.

circinicaule C. M. - Rhaphidostegium.

circinatum Brid. - Eurhynchium.

var, inundatum Boul. - Scorpiurium rivale.

? circinulatum W. P. Sch. in Jardin Enum. p. 20 (nom.).

- Pac. : Taïti.

circulare Jaeg. - H. Bambergeri.

circulifolium C. M. et Kindb. in Bidr. p. 454 (nom.) et in Mac. Cat: p. 242.

Ster. Ad rup. madid. - Am. sepl. : New Brunswick.

cirratum $\left\{\begin{array}{l}\text { Brid. - Macromitrium cirrosum. } \\ \text { Weiss. - Dicranoweisia. }\end{array}\right.$

cirriferum Spreng, - Meteorium patulum.

cirrifolium $\left\{\begin{array}{l}\text { Schwaegr. - Papillaria. } \\ \text { Schwaegr. - Rhaphidostegium. }\end{array}\right.$

cirroso-revolvens W. P. Sch, in Mandon Pl. Boliv, n. 1708 p.p.

- Am. merid. : And. Boliv.

cirrosum $\left\{\begin{array}{l}\text { Schwaegr. - Brachythecium. } \\ \text { Sw. - Macromitrium. }\end{array}\right.$

citrinum Hpe. - Sematophyllum.

cladoneuron C. M. - Brachythecium.

cladorhizans Poir. - Cylindrothecium.

clandestinum $\left\{\begin{array}{l}\text { H. f. el W. - Lembophyllum. } \\ \text { Lindb. - Ectropothecium. }\end{array}\right.$

Clarasii Duby. - Helicodontium.

clarescens Wils. - Microthamnium.

Clarionis Lam, et DC. - Eurhynchium praelongum

clavatum Bell. - Anomodon attenuatus.

(Hedw. - Rhynchostegium confertum.

clavellatum L. - Rhynchostegium murale.

Schrank. - Amblystegium serpens. parvum, repens, setis brevibus Dill. - Drummondia. 
clavirameum C. M. - Pseudo-Leskea.

var. denudalum C. M. - Pseudo-Leskea claviramea var. denudata. clinocarpum Tayl. - Eurhynchium.

Closteri Aust. - H. molle.

cochlearifolium Schwaegr. - Lembophyllum.

co)fonopyxis C. M. - Ectropothecium.

çlophylum Mdo, - H. Vaucheri var. cłlophyllum.

collatum $\mathrm{H}$. f, et W. - Rhynchostegium tenuifolium.

var, laxifolium eor. - Khynchostegium tenuifolium var. laxifolium.

var. minus eor. - Rhynchostegium tenuifolium var, minus.

var. $\delta$ eor. - Rhynchostegium tenuifolium var.

collinum Schleich. - Brachythecium.

coloradense Aust, in Coult. Bot. Gaz. II, p. 111.

Ster.

- Am. sept. : Colorado.

colpophyllum Sull. - Eurhynchium.

Columbiae Kindb. in Mac. Cat.p. 224.

Amblystegium serpens Columbiae ej. in Bull. Torr. bot. Club, XVII, p. 279.

2. Lignic, - Am. sept. : Columb, brit.

columbico-palustre C. M. et Kindb. in Bidr. p. 454 (nom.) in Mac. Cat.

p. 241 et Canad. M. n. 493.

1. Rupic. - Am. sept. : Columb. brit.

columbicum C. M. - Leskea gracillima.

coma lutescente, extremitatibus stellatis Dill. - H. stellatum.

comatum C. M. - Mniodendron.

commixtum C. M. - Leucomium.

commutatum Hedro. M. frond. IV, p. 68, t. 26 ; Brid. Bryol. univ. II, p. 523 ; C. M. Syn. II, p. 422 ; Bryol. eur. VI (mon. p. 38), t. 607 ; W. P. Sch. op. cet. p. 741.

Amblystegium glaucum Lindb.

A. commutatum de Not. Epil.

H. diastrophyllum Sw. M. Suec. p. 58.

H. filicinum Vill. Pl. Dauph. III, p. 987.

H. glaucum Lam. et DC. Syn. fl. gall.p. 108.

H. repens filicinum crispum Dill. Hist. M. p. 282, p. 36, f. $19 \mathrm{~A}-\mathrm{F}$.

H. vitellinum Brid, op. cit. p. 769.

2. Locis aquos. calcar. - Eur. : E reg. campestr. montos. usq. in mont. super. As. : Japon., Kamschatka, Himalaya et Tibet. occ., Kashmir, Kurdistan., Cau cas., Assyr., Syr. Am. sept. : New Brunswick, New York, Ontario, Columb. brit., M. Rupestr., Colorado, Calif.

Exs. : Mac. Canad. M. n. 448.

Rab. Bryoth. eur. n. 349, 744.

var. condensalum Wils. - H. falcatum.

* var, elegantulum (de Not.) Jaeg. Ad. II, p. 574.

Ut et ubi typ.

var. falcatum C. M. - H. falcatum.

var. fuctuans Bryol. eur. - H. falcatum var. virescens.

a var. sulcatum Lindb.

- Eur.: Spitzberg. Am. sept. : Groenland.

Comorze C. M. - Rhynchostegium. 
C. M. p.p. - Mniodendron Kroneanum.

comosum Hsch. - Mniodendron Sieberi.

La Bill, - Mniodendron.

Mossm. - Mniodendron comatum.

Vill. - H. stellatum.

compactum $\left\{\begin{array}{l}\text { C. M. - Amblystegium. } \\ \text { Mac. }\end{array}\right.$

complanatulum C. M. - Sematophyllum.

complanatum L. - Neckera.

3 obtusum Ehrh. - Homalia trichomanoides.

complanum Mitt. - Rhynchostegium.

complexum (Mitt.) Lesq. et Jam. Man. p. 396.

Stereodon complexus Mitt. in Journ. of the Linn. Soc. VIII, p. 41.

2. Rupic. - Am. sept, : New Brunswick, Columb. brit.

compositum Sw. - Pilotrichum.

compressifolium Mitt. - Rhynchostegium.

compressulum $\left\{\begin{array}{l}\text { Besch. - H. subeompressulum. } \\ \text { C. M. - Eurhynchium. }\end{array}\right.$

compressum $\left\{\begin{array}{l}\text { Roth. }- \text { H. molluscum. } \\ \text { Schreb. }- \text { H. Schreberi. }\end{array}\right.$

Schultz. - H. cupressiforme.

comtifolium C. M. - Brachythecium.

concavifolium H. f. et W. - Rhaphidostegium circinale.

concavum Hook. - Taxithelium planum.

conchophyllum Tayl. - Rhynchostegium.

concinnum $\left\{\begin{array}{l}\text { de Not. - Cylindrothecium. } \\ \text { Hartm. - Brachythecium populeum. } \\ \text { Wils. - Myuroclada. }\end{array}\right.$

condensatum W. P. Sch. Syn. L.ed. p. 698 et $1 I$ ed. p. 761.

Ster.

Helv., etc.

Exs. : Un, itin. 1867, n. 17.

confertum $\left\{\begin{array}{l}\text { Dicks. - Rhynchostegium. } \\ \text { Engl. Bot. - Rhynchostegium murale. } \\ \text { P. B. - Hypnum polyanthos. }\end{array}\right.$

var, depressum Brid. - Rhynchostegium.

var. majus H. f. et W. - Rhynchostegium tenuifolium.

var. megapolitanum $\mathrm{Br}$. - Rhynchostegium.

var. rolundifolium Brid. - Rhynchostegium.

Conferva Schwaegr. - Amblystegium confervoides.

confervoides $\left\{\begin{array}{l}\text { Rrid. - Amblystegium. } \\ \text { H. f. et W. - Amblystegium Sprucei. }\end{array}\right.$

confine (Mitt.) Par.

Stereodon confinis Mitt. in Trans. of the Linn. Soc. 1891, p. 181.

1. Ad arbor. - As. : Alp. Bhotan.

conflatum C. M. et Kindb. in Bidr. p. 454 (nom.) et in Mac. Cal. p, 230.

H. fluitans Mac. Canad. M. n. 366 pp.

H. Sendtneri ej. l. c. n. 334 p.p.

2. Paludic. - Am. sept. : Labrador, Ontario, Columb. brit.

confluens C. M. - Sciarominm.

congestum $\left\{\begin{array}{l}\text { Hedw. - Hookeria aurea. } \\ \text { Sw. - Homalothecium. } \\ \text { Wils, - Pseudo-Leskea. }\end{array}\right.$ 
congruens Hpe. - Rhaphidostegium. conostegum C. M. - Ectropothecium. conostomum $\left\{\begin{array}{l}\text { Mitt. - Eriodon. } \\ \text { Tayl. - Brachythecium. }\end{array}\right.$ consanguineum $\left\{\begin{array}{l}\text { C. M. - Anomodon. } \\ \text { Hpe. - Sematophyllum. }\end{array}\right.$ consimile $\mathrm{H}$. $\mathrm{f}$, et W. - Breutelia. conspissatum $\left\{\begin{array}{l}\text { eor. - Sciaromium. } \\ \text { Sull. - Sciaromium confluens? }\end{array}\right.$ conspurcatum Brid, - H. filicinum var. trichodes. constrictum C. M. - Rhaphidostegium. conterminum C. M. - Rhaphidostegium affine. contextum $\left\{\begin{array}{l}\text { Hedw. - Amblystegium serpens, } \\ \text { Schleich. - Plagiothecium nitidulum. }\end{array}\right.$

contiguum $\left\{\begin{array}{l}\text { H. f. et W. - Rhaphidostegium crassiusculum. } \\ \text { Nees. - H. uncinatum. }\end{array}\right.$

contorte-operculatum C. M. - Stereophyllum.

contortulum Wils. - Thuidium.

contractum Lac. - Ectropothecium.

controversum Wils.- - H. falcatum.

Cooleyanum Spreng. - H. Haldanianum.

convolutifolium $\mathrm{Hpe}$. - Rhynchostegium.

convolutum Bryol. jav. - - Sematophyllum.

cordatum Harv, (fid. Mitt. M. Ind. or. p. 81)). - Eurhynchium hians. cordatum Harv. I (fid. Mitt. M. Ind. or. p. 88). - Meteorium.

cordifolium Hedvo. M. frond. IV, p. 97, t. 37; C. M. Syn. II, p. 379;

Bryol. eur. VI (mon. p. 47), t. 615; W. P. Sch. op. cit. p. 785.

Amblystegium cordifolium de Not. Epil. p. 136.

H. crassum Schumach. Pl. Saeland, II, p. 80.

H. cuspidatum $\beta$ bicolor Turn, Musc, hibern. p. 17k. 7

H. fontanum Schleich. Cent. II Girypt. helv, n. 53.

H. phyllorhizans P. B. Prodr. p. 67:

1. In pratis uligin. et foss. aquos. - Eur.: Rar. : zon, intermed., rar. sept. vel merid. As. : Amour, Jerissei. Am. sept. : Groenland, Labrador, Terr. nov., Nov. Scot., New Brunswick, Ottawa, Ontar., lac.

Super., M. Rupestr., Washington, Oregon, reg. sept., or., centr.

Exs. : Mac. Canad. M. n. 361.

Rab. Bryoth, eur. n. 498.

Sull. et Lesq. M. bor. am. II ed. n. 457.

Un. itin. 1864, n. 21, 22.

* var. compactum C. M. l, c. p. 380 .

H. cordifolium Drumm. M. bor. am. I ed., n. 209 (fid. C. M.).

Ut typ. - Am. sept. : (conf. H. giganteum).

var. stenodictyon Bryol. eur. - H. giganteum.

(Drumm. (fid. C. M.). - H. cordifolium var. compactum. cordifolium Drumm. (fid. Kindb. et Mitt.). - H. giganteum. ! pler. Auct. Suec. - H. giganteum.

cordovense C. M. - Isopterygium.

coronopifolium P. B. - Fabronia Persoonii.

corralense Ltz. - Eurhynchium. Cossoni W. P. Sch. Bryol. eur. Suppl. III-IV (Hypnum), t. 5 et Syn. II
ed. p. 730 (1).

Amblystegium intermedium Lindb. M. Scand. p. 33; Sanio in Lindb, et Arn. M. bor. Am. 1890, II, p. 117. 
$\mathrm{H}$. intermedium ej. in Hartm. Skand. $\mathrm{Fl}$. $\mathrm{X}$ ed.

H. revolvens var. Cossoni et intermedium Ren, in Husn. Musc, gall. pp. $391-392, t .112, f, 5$ a, $7,8,12$ et 13.

H. revolvens var. intermedium Lesq. et Jam. Man. p. 384.

H. vernicosum Lindb. (fid. Milde Bryol. siles.).

2. In uligin. et turfos. - Eur. : Gall. centr., sept. et or., Pyr., Belg., Rhaet., Tirol., Bavar., Salisb. As. : Causas. occ. Am. sept. : Groenland, lac. Super., M. Rupestr., New York.

Exs. : Mac. Canad. M. n. 338.

Cossoni $x$ vernicosum Par.

Amblystegium intermedio-vernicosum Lindb. et Arn. M. As. bor. 1890 , $I 1, p .122$.

H. intermedium $\times$ vernicosum Samio.

$$
\text { - As, : Jenissei inf. }
$$

crassicaule Rehm. - H. anotis.

crassicollum Tayl. - Taxithelium planum.

crassinervium Tayl. - Eurhynchium.

crassireticulatum Hpe. - Ectropothecium.

crassiusculum | Brid. - Rhaphidostegium.

, H. f. et W. - Rhaphidostegium microcarpum.

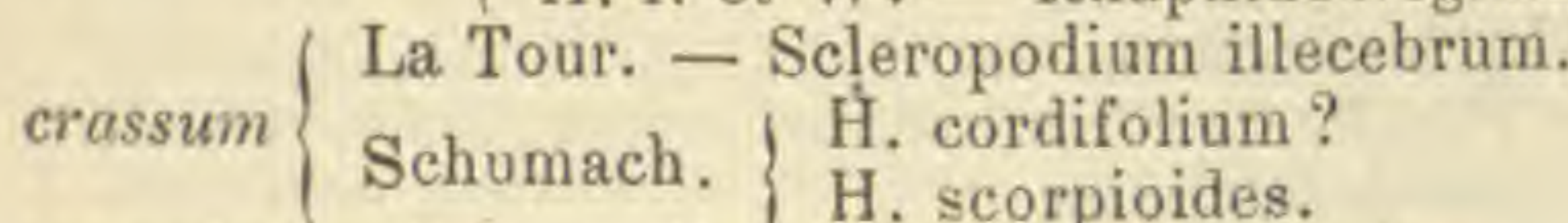

crenulatum Sch. - Brachythecium rutabulum.

creperum Wils. in sclieil.

Stereodon creperus Mitt. M. Ind. or. p. 98.

1.

- As. : Sikkim.

crinale Schleich. - H. fertile.

crinitifolium C. M. - Leucomium.

crinitum Hook $f$. et Wils, in Lond. Journ. of. bot. 1844, p. 555 et Fl.

Tasman. II, p 215 (1).

H. extenuatum C. M. Syn. II, p. 391 p.p.

2. Ad arbor. - As. : Borneo. Pac. : Austral. or., Nov. Zeland., Tasman., ins. Auekland.

crispatulum Hook, - Trachypus.

crispatum Gmel. - Dicranella crispa.

crispifolium Hook. - Thuidium.

crispo-hamosum C. M. in Dusen M. Camer, n. 59.

crispulifolium C. M. - Rhaphidostegium.

$$
\text { -. Afr. : M. Cameroon. }
$$

crispum $\left\{\begin{array}{l}\text { L. - Neckera. } \\ \text { cupressiforme, }\end{array}\right.$

Crista-castrense L. Sp. $p l . p .1591$ (excl. syn. Dill.); Brid. Bryol. unio. II. p. 517; C. M. Syn. II, p. 296; Bryol. eur. VI (mon. p. 30), t. $599 ;$ W.P. Sch. op. cit. p. 770.

H. Hedwigii Lam. et DC. Fl. fr. n. 1348 ?

H. scalare Zenk, et Dietr. M. Thuring. n. 26.

Ptilium Crista-castrense de Not. Briol. ital. p. 101.

Stereodon Crista-castrensis Mitt. M. Ind. or. p, 96.

2. Ad. terr. musc. praecip. silv, aceros. - Eur. : Reg. mont. et subalp.,

(I) Cf. Hpe. in Linn. 1853, p. 504. 
rar. campestr. zon. interm, et sept. As. : Japon., Ochotsk, Yunnan, Amour, Saghalien, Jenissei, Obi, Sikkim, Caucas, occ. et centr. Am. sept. : Labrador, Anticosti, Terr. nov., Miquel., Nov. Scot., New Brunswick, Gaspes,, Ottawa, Ontar., Manitoba, Saskatchewan,

M. Selkirk et Rupestr., Columb. brit., reg. sept. et or.

Exs. : Drumm. M. bor. am. I ed. n. 212.

Faurie Pl. Japon. n. 832.

Mac. Canad. M. n. 343.

Sull. et Lesq. M bor. am. II ed, n. 470.

Un. itin, 1864, n. 68, 69 .

Crista castrense Roth. - H. molluscum.

cristula Kindb. - H. subimponens var. cristula.

crithmifolium Hpe. - Rhaphidostegium tequedamense.

crudum W. et M. - Webera.

Ctenium W. P. Sch. in Savat. M. Jap. n. $77^{\mathrm{a}}$; Besch, in Ann. sc. nat. 1893, p. 389.

Ster, - As. : Japon.

cubense C. M. - Ectropothecium.

cucullatifolium $\mathrm{Hpe}$. - Rhaphidostegium.

cucullatum Mitt. - Rhychostegium.

cucullifolium P. B. - Ptychomnion aciculáre.

cuculligerum Lac. - Sematophyllum.

cultelliforme Sull. - Stereophyllum.

cupressetorum Brid. - Rhaphidostegium recurvans.

cupressiforme L. Sp. pl. 1592; C. M. Syn. II. p. 289; Bryol. eur. VI (mon. p. 25), t. 594; W. P. Sch. op. cit.p. 755.

H. compressum Schultz Prodr. Fl. Starg. n, 898.

H. crispum cupressiforme, foliis aduncis Dill. Hist. M. p. 287, t. 37, f. 23.

H. decipiens Hoffm. Deutsch. Fl. p. 73.

H. fastigiatum Wieb. Fl. Werth, p. 301 .

H. filicinum, sericeum, molle et pallidum, mucronibus aduncis Dill, Hist. M. p. $286, t .36, f .22$.

H. homomallum Bert. Pl. rar. Ital. Dec. IV, n. 13.

H. nitens Timm. Prodr. Fl. Megap. n. 828.

H. repens, crispum cupressiforme, minus, foliis magis confertis Dill. Cat. p. 217.

H. tenuifolium Schleich, in sched.

H. Stereodon cupressiformis Brid. Bryol. univ. II, p. 605 (incl. var. chry. socomus, complanatus, conicus, corruscans, decipiens, fragilis; leucanthemum? plumosus, stiviatus, tenuifolius pp. 608-612).

Neckera cupressiformis Willd. Prodr. Fl. Berol. n. 936.

2. Ad arbor., mur., rup. et sax., in tect, et ad terr. per tot. orb, fere terr., alpin, et arctic. vel antarct. except., vulgatiss.

Exs. : Bourgeau Pl. Canar. n. 159l.

Mac. Canad. M. n. 35l.

Rab. Bryoth. eur. n. 415, b, 763, b, c.

Sull. et L.esq. M. bor. am. II ed., n. 472 .

« var, brevisetum W. P. Sch. Syn. I ed. p. 626 et 1 I ed.p. 756.

Ad ligna fabrecata, - Eur. et Am. sept.: Cum typ.

Exs. : Rab. Bryoth. eur. n. 963 e.

var. complanatum Hpe. - H. pratense.

a var. compressum (Brid) Par.

Stereodon cupressitormis var. compressus Brid. l. c. p. 608.

- Afr.: Ins. Azor., Canar., Madeir.

"var. elatum Bryol, eur. l. c. t. 595; W. P. Sch. op. el l. cc. 
In ericet. humid. praecip. arenac. - Eur, et $A m$. sept. : Hic illic.

Exs. : Rab. Bryoth. eur. n. 763 d, 918.

" var. ericetorum Bryol. eur. et W. P. Sch. ll. cc.

In ericetis ad terr. - Eur. : Hic illic. Afr.: Alger.; ins. Borbon. ? Am. sept, : Hic. illic.

Exs., Rab. Bryoth, eur. n. $763 \mathrm{f}$.

" var. filiforme (Brid.) Bryol, eur. et W. P. Sch, ll. cc.

H. cupressiforme var. tenue H. et T. Muscol. brit. p. 113 ?

H. extenuatum Hoffm. Deutsch. Fl. II, p. 63.

H. repens, crispum, cupressiforme, minus et foliolis minus confertis Dill. Cat. Giess. p. 216.

H. Stereodon cupressiformis var, filiformis Brid. Sp. M. p. 216 et op. eit. p. 609 .

Ad arbor. silvat. trunc. vel ramul. - Eur.: Hic illic. As.: Jenissei sup. Am. sept. : Hic illic. Pac. : Tasman.

Exs. : Rab. Bryoth. eur. n. 496.

Sull. et Lesq. M. bor. am. Il ed. p. 473.

var, foliis angustioribus Hook. - H. pallescens.

var. julaceum Zett. - H. Vaucheri var. julaceum.

* var. Iacnnosum (Brid.) Par.

H. lacunosum Wieb. Fl. Werth. p. 209.

H. Stereodon cupressiformis var. lacunosus Brid. Bryol. univ. II, p. 610.

Stereodon cupressiformis var. lacunosus Mitl. M. austr. am. p. 534.

Ad terr. - Eur. : Dania, German., Francon. Am. sept. : And. Quitens.

"var. Lauri (Brid.). Par.

H. Stereodon cupressiformis var. Lauri Brid. op. c. p. 609.

Ad Laurum canar. - Afr. : Ins. Azor., Canar., Madeir.

* var. longirostre Bryol. eur. et W. P. Sch. Il. cc.

Ad arb. rad. in silv. campestr. - Eur. et Am, sept. : Hic illic.

\& var. longisetum (Brid.) Par.

H. Stereodon cupressiformis var. longisetus Brid. op. cit. p. 611.

- Afr. : Ins. Azor., Canar., Madeir.

"v, var. mamillatum (Brid.) Bryol. eur. et W. P. Sch. Il. cc.

H. Stereodon cupressiformis var, mamillatus Brid. Sp. M. p. 215 et op. cit. p. 608.

Ad arbor. rad, et in sax. - Eur. et $A m$. sept. : Hic illic.

var. Mossmanne Mitt.

* var. pseudo-imponens R. Farneti in Atli dell'Instit. bot. della R. univ. di Pavia, 1893.

- Eur.: Ital, super.

- var. pyrenaicum Ren. in Fl. Miquel. p. 55.

- Eur. : Pyren. Am. sept. : Ins. Miquelon.

\& var, resupinatura (Wils.) W. P. Sclt. Coroll. p. 133 et op. cil. p. 757.

H. multiflorum Tayl. Fl. Hibern. Mackay II. p. 46 (fid. W. P. Seh.i.

H. polyanthos Engl. Bot. t. 1664.

H. resupinatum Wils, Bryol. brit. p. 398.

Ad arbor. et sax. arenac. - Eur.: Hibern., Angl., Ital. super.

Exs, : Rab. Bryoth, eur, n. 900, 1050.

* var. subjulaceum Mdo.

Stereodon cupressiformis var, subjulaceus Lindb. et A,n. M. As. bor, $1890, I I, p .14^{\mathrm{Q}}$

- Eur. : Alp. Bavar. ? As. : Ienissei sup. 
“ var. tectorum (Brid.) Bryol. eur. l. c. t. 595 ; W. P. Sch. op. et l. cc. H. myosuroides, sericeum, tenuius, capsulis erectis Dill. Hist. M. p. 318, t. $41, f .93$.

H. nigro-viride Turn. Muscol. Hibern. p. 541.

H. Stereodon cupressitormis var. nigro-viridis Brid. op. cit. p. 611.

H. Stereodon cupressiformis var. tectorum ej. op. cit. p. 612.

Ad mur. et tecta. - Eur. : Ubi typ. Afr. : lns. Borbon. ? Am, sept. : Ubi typ.

var, tenue H. et T. - H. cupressiforme var, filiforme.

"var, uncinatulum Bryal. eur. et W. P. Sch. $l l$, cc.

Ad arbor. et lign. fabref. sicea. - Eur. et Am. sept. : Hic illic.

var. Bals et de Not, - H. Haldanianum.

var. Hook. - H. fastigiatum.

var. Hsch. - Rhaphidostegium Gueinzii.

Hook. (fid. C. M.). - H. imponens.

Hook. (fid. Kindb.). - H. hamulosum.

H. f, et W. - H. chrysogaster.

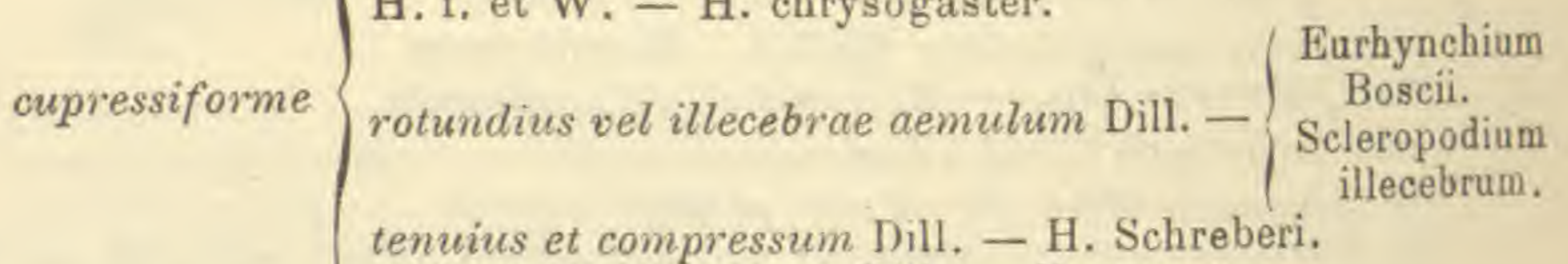
vulgare, foliis obtusis Dill. - H. purum.

cupressoides $\left\{\begin{array}{l}\text { C. M. - Ectropothecium. } \\ \text { Sull. - Ectropothecium plumulum. } \\ \text { W. P. Sch. - H. Lechleri. }\end{array}\right.$

curlandicum Brid. - H. Schreberi.

curlipendulum L. - Antitrichia.

curtum Lindb. - Brachythecium Starkii var. praelongum.

curvatum Fl. Suec. - Isothecium myurum.

curvicaule Jur. in Verh. d. zool. bot. Ges. in Wien., 1864, p. 103; W. P.

Sch. op. cit. p. 806 (1).

Amblystegium curvicaule Lindb. M. Scand. p. 32.

A. filicinum var. curvicaule Mdo, Bayern's Laubm. p. 238.

Limnobium curvicaule de Not. Epil. p. 164.

Fl. et fr. ign. - Eur.: Spitzberg, ins. Ursor., Alp. Jul., Bavar., Rhœet., Salisburg., Austria.

curvicollum C. M. - Isopterygium.

curviculatum H. f. et W. - Rhaphidostegium.

curvifolium Hedu. Sp. M. p. 285, t. 75 ; Sull. M. of U. St. p. 74 et Ic. M. p. $183, t .114$.

H. Stereodon curvifolius Brid. Bryol. univ. II, p. 613.

Stereodon curvifolius Mitt. in Trans. of the Linn. Soc. 1891, p. 181.

2. Lignic. - As. : Japon. Am. sept.: Terr. nov., ins. Miquel., Nov.

Scot., New Brunswick, Gaspes., Ottawa, Ontar., Columb. brit., reg. sept., centr. et or.

Exs. : Drumm. M. bor. am. I ed. n. 197 et II ed. n. 148.

Faurie Pl. Jap. n. 32, 1422,1423 (ster.).

Mac. Canad. M. n. 353.

Sull. et Lesq. M. bor. am. II ed. n. 480,481 .

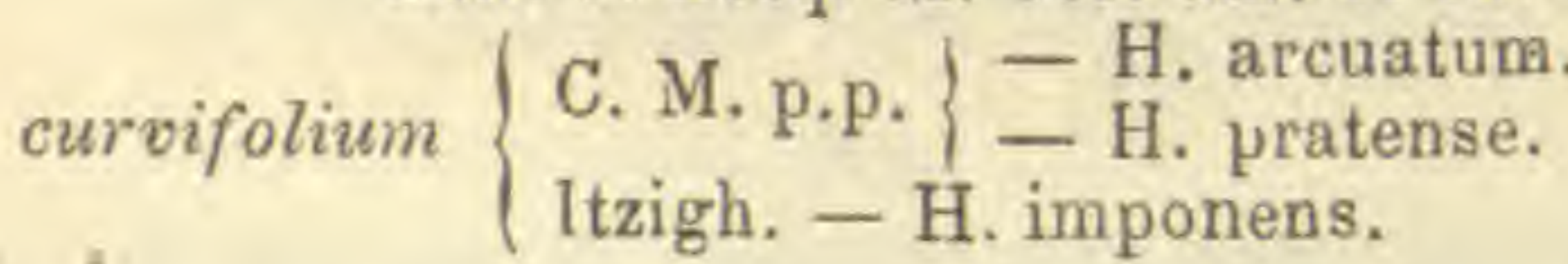

(1) Cf. Venturi in Rev. bryol. 1881, p. 82. 
curvirostrum Brid. - H. Haldanianum.

curvirostre C. M. - Rhaphidostegium.

curvisetum Brid. - Rhynchostegium.

var, longinerve Lindb - Rhynchostegium curvisetum var. longinerve. curvulum Hurv. - Rhaphidostegium propinquum.

cuspidalifolium C. M. - Lencomium.

cuspidatulum C. M. - Rhaphidostegium.

cuspidatum L. Sp. pl. 1595; C. M. Syn. 11, p. 383; Bryol. eur. VI (mon. p. 51), t.619; W. P. Sch. op. cit. p. 789.

Acrocladium cuspidatum Lindb. M. Scand. p. 39.

H. flexile Brid. Bryol. univ. II, p. 417.
H. heterophyllum Hüb. Muscol. germ. p. 633 .

H. palustre extremitatibus cuspidatis et pungentibus Dill. Hist. M. p. 300, t. $39, f .34$.

H. Stereodon cuspidatus Ririd. op. oit. p. 562.

2. In gramin, humid, et foss, prator. - Eur. : Vulgatiss, in reg. campestr, et montos. As.: Japon, Jenissei, Obi, Caucas. centr., Syr. Afr.: Alger., ins. Azores. Am. sept.: Terr. nov., ins. Miquel., New Brunswick, Columb. brit., Vancouver, Washington, Wyoming, reg. sept. et or.

Exs. : Faurie Pl. Jap. n. 91.

Mac. Canad. M. n. 385.

Rab. Bryoth, eur. n. 507.

Sull. et Lesq. M. bor. am. Il ed. p. 454.

var. bicolor Turn. - H. cordifolium.

var. inerme Weiss, - H. Schreberi.

* var. pungens W. P. Sch. Syn. I ed. p. 644 et II ed. l. c.

In aquos. - Eur, : Bavar., Salisburg.

* var. submersum R. Farneti in Atti dell Istit. bot. della R. univ. di Pavia, 1893.

- Eur. : Ital. super.

cuspidatum Schrank. - Mnium affine.

cuspidiferum Mitt. - Brachythecium.

cuspidigerum Schwaegr, - Rhacopilum.

cyathothecium C. M. - Trichosteleum

cyclophyllum Mdo. in Un. itin. 1863, n. 95.

Ad terr. petros. subhumid. - Eur.: Tirol.

cygnisetum C. M. - Ptychomnion.

cylindricarpum C. M. - Rhaphidostegium.

\begin{tabular}{l|l} 
cylindricum & $\begin{array}{l}\text { Br. - H. Haldanianum. } \\
\text { Hsch. et Reinw. - Rhaphidostegium leptocarpon. }\end{array}$
\end{tabular}

cymbifolium $\left\{\begin{array}{l}\text { Dz. et Mk. - Thuidium. } \\ \text { Duby. - Thuidium Meyenianum. } \\ \text { Sull. - Thuidium hawaïense. }\end{array}\right.$

cyparioides Brid. - Rhaphidostegium

cyparissoides $\left\{\begin{array}{l}\text { Hsch. }- \text { Ectropothecium. } \\ \text { Wils. }\end{array}\right.$

Wils. - Ectropothecinm cupressoides.

cyperoides Hook. - Ectropothecium.

daltonioides W. P. Sch. - Sematophylltam Pickeringri.

Danckelinanni C. M. - Rhaphidostegium.

dealbatum Hsch. et Reinw, - Eetropothecium.

decipiens $\{$ Hoffm. $-\mathrm{H}$. cupressiforme.

decliur Kindb. - Thuidium.

declivem Mitt. - Brachythecium velutinum.

decolorans W. et Dy. - Thamnium. 
decorum Mitt. - Homalothecium.

decrescens Bryol. jav. II, p. 168, ı. 266 (1).

2. Ster. -As. : Celebes.

decumbens Wils. - Rhaphidostegium.

decurrens Sull. in Proced. of the Am. Acad... 1859 el in U. St. Expl. Exped. Wilkes, p. 14, $\iota .14$.

- Pac.: Ins. Sandwic.

decursivulum C. M. et Kindb. in Bidr. p. 454 (nom.) et in Mac. Cat. p. 220.

H. Sommerfeldti Mac. Canad, M. n. 514 p.p.

Ster. Lignic. - Am. sept. : Terra nov., M. Selkirk.

decurvans Mitt. - Brachythecium.

debile $\{$ Brid. - Amblystegium radicale.

debile \{ c. M. - Leucomium.

decussatum Hook. f. et Wils. Fl. of the N. Zeal. II, p. 110, t.90, f. 2 et Fl. Tasm. II, p. 211.

Amblystegium decussatum Mitt. in Journ. of the Linn. Soc, 1876.

2.

Zeland. sept. et med., Tasmar.

deflexifolium Solms-Laub. Tent. bryogeogr. Algarv. ; W. P. Sch. Syn. II ed. p. 714 .

ot et fr, ign. Ad mol. granit. irror. - Eur. : Algarb.

deflexum Wils. - Camptochaete.

defoliatum C. M. - Homalia.

delicatulum $\left\{\begin{array}{l}\text { C. M. - Thuidium tamariscinum. } \\ \text { Hedw. - Thuidium. } \\ \text { Hsch. Thuidium aequatoriale. } \\ \text { L. - Thuidium reeognitum. }\end{array}\right.$

delicatum Ehrh. - Thuidium tamariscinum,

delilescens Boul. - H. mollusum var. squarrosulum.

demissum $\left\{\begin{array}{l}\text { de Not. - Rhaphidostegium. } \\ \text { Mac. - Rhaphidostegium recurvans. }\end{array}\right.$

var. carolinianum L. et J. - Rhaphidostegium demissum var. carolinianum. nianum.
var. marylandicum eor. - Rhaphidostegium demissum var. marylan-
dicum.

var. Sull. - Rhaphisdostegium demissum var, marylandicum.

var. Sull. et Lesq. - Rhaphidostegium demissum var, carolinianum.

dendroidles $\left\{\begin{array}{l}\text { I., - Climacium. } \\ \text { Thbg. - Climacium japonicum? } \\ \text { obscurius, setis et capsulis brevioribus subnutuntibus Dill. } \\ \text { Thamnium alopecurum. } \\ \text { sericeum setis el capsulis longioribus erectis Dill, - Clims- } \\ \text { cium dendroides. } \\ \text { Brid. - Ptychomnion. } \\ \text { Spreng. - Rhaphidostegium caespitosum. }\end{array}\right.$
densifolium
densum $\left\{\begin{array}{l}\text { C. M. - Erythrodontium. } \\ \text { Milde. - Amblystegium. } \\ \text { Sw. - Prionodon. }\end{array}\right.$

(1) * An Trichosteleum? ) Jaeg. Ad. II, p, 609. 
dentatum, $\left\{\begin{array}{c}\text { curtipendulum, viticulis rigidis Dill. - Antitrichia curtipen- } \\ \text { dula. } \\ \text { vulgatissimum, operculis oblusis Dill. - Brachythecium ruta- } \\ \text { bulum. }\end{array}\right.$

? denticulatum P. B. Prodr. p. 81.

- Afr. . Ins. Borbon.

C. M. - Plagiothecium silvaticum.

L. - Plagiothecium.

pinnatum, pinnulis duplicibus recurvis Dill. - Plagiothe-

denticulatum

pinnulatum, pinnulis rarioribus simplicibus Dill. - Plagiothecium silvaticum.

exiguum, pendulum, atro-virens Dill. - Eurhynchium pendulum.

var. Donianum Hook. - Plagiothecium piliferum.

var. laelum Lindb. - Plagiothecium.

var. obtusifolium Turn. - Plagiothecium denticulatun var. obtusifolium.

var. piliferum Wahlenb, - Plagiothecium.

var. silvaticum Turn. - Plagiothecium.

denticulosum Mitt. - Thuidium.

dentifer um Hpe. - Rhynchostegium.

deplanalum Sull. - Rhynchostegium.

depressulum $C$. $M$. in $\mathrm{Fl}$. $1875, p .91$.

H. hamulosum? Sull. et Lesq. M. bor, am. II ed, n. 478.

Lignic, - Am. sepl. : M. Alb.

depressum $\left\{\begin{array}{l}\text { Br. - Rhynchostegium. } \\ \text { Sull. et Lesq. - Rhynchostegium geophilum. } \\ \text { Sw. - Hookeria. }\end{array}\right.$

desmiocladum C. M. - Pseudo-Leskea.

desmiphorum P. B. - Anomodon rostratus.

deveoum Bosw. - Enrhyncbium?

diapleanum Sw. - Lepilopilum.

diastrophyllum $\left\{\begin{array}{l}\text { Lam. et DC. - H. lycopodioides. } \\ \text { Sw. - H. commutatum. }\end{array}\right.$

Dicksoni Gmel. - Neckera pumila.

dicladum C. $M$. in Bot. Zeit. 1855, p. 784.

Ster.

Exs. : Rehm. M. Afr, austr. n. 416.

Dieckeï Ren. et Card, in Bot. Centralbl. 1890, n. 51

2. ot ign. $\quad-A m$, sept.: Washington, Oregon.

diffusum Bland. - Amblystegium fluviale.

dilatatum Wils. in W. P. Sch. Syn. II ed. p. 776 (1).

Amblystegium dilatatum Lindb. M. Scand. p. 33 .

H. molle Wils. Bryol. brit. p.p.; C. M. Syn. II, p. 431 p.p. ; Drumm. M. bor, am, I ed. n. 194; Rab. Bryoth. cur, n. S99.

Limnobium molle Bryol. eur, VI (mon. p. 5), t. 577 (except. f. 2 quce ad $\mathrm{H}$. alpestre pertinet).

I. In rivul, frigid, sax, inund, - Eur.: E reg. montan. usq. in alp.;

(1) De syn. cf. W. P. Sch. 1, c. 
rarius in Britann. As. : Jønissei sup. Am. sept. : Groenland, Ontar., lac. Super., M. Selkirk et Rupestr., Idaho, reg. or.

Exs.: Mac. Canad. M. n. 577.

diminutivum Hpe. - Microthamnium.

dimorphum C. M. p.p.) - Pseudo Leskea tectorum.

$\beta$ tectorum Rab.

discriminalum Mont. - Hylocomium macrucarpum.

disparifolium Tayl. - Microthamnium substriatum?

dispersum Sull. et Lesq. in Proced. of the Am. Acad... 1859, p. 279 (1).

1. Ad terr. arid. - As. : Japon., ins. Loo-Choo.

dissolutum Sull. - Rhaphidostegium galipense.

distans $\left\{\begin{array}{l}\text { Brid. - Eurhynchium circinatum. } \\ \text { Lindb. }\end{array}\right.$

distichellum C. M. - Ectropothecium.

distichophyllum Hpe. - Trichosteleum.

distichum Sw. - Rhizogonium.

distratum Hpe. - Rhynchostegium.

divaricatissimum C. M. in Linn. 1876, p. 657.

Cortic in silv. - Ant. sept. : Mexic.

divaricalulum C. M. - Rhaphidostegium.

divaricalum Hsch. et Reinw, - Mniodendron.

diversifolium L. et J. - Eurhynchium.

diversiforme Mitt. - Isothecium.

divulsum H. f. et W. - Lembophyllum.

djurense C. M. - Thuidium.

dolomiticum Milde Crypt. fl. Tir. n. 101 et in Bot. Zeit. 1864, Anh. p. 21 ; W. P. Sch. Syn. II ed. p. 762.

H. fastigiatum var, dolomiticum Mdo. M. Tir. n. 46.

Ster. Ad saxa calc., rar. gneiss. v. micac. - Eur.: Alp. Helvet., Rhaet., Tirol. merid.

Exs.: Rab. Bryoth. eur. n, 695.

dolosum de Not. Epil. p. 170.

$$
\text { - Eur.: Ital. }
$$

Donianum $\left\{\begin{array}{l}\text { Mitt. p.p. -- Plagiothecium magellanicum? } \\ \text { Sm. - Plagiothecium denticulatom }\end{array}\right.$

Donnellii Aust. - Brachythecium (2)

Douglasii Hook. (fid. Mitt.). - Eurhynchium oreganum.

Dozyanum C. M. - Ectropothecium.

Draytoni Sull. - Isopterygium.

Dregei C. M. - Rhaphidostegium.

drepanocladioides C. M. - Rhynchostegium.

drepanophyllum C. M. - H. semi-revolutum?

Drummondii Tayl. - Rhaphidostegium homomallum.

dubium Brid. - H. filicinum var: trichodes.

Dubyanum C. M. - Ectropothecium.

Duisabonae C. M. - Rhaphidostegium.

dumosum Mitt. - Eurhynchium.

duplicatum Schwaegr. - Neckera.

Duriaei Mont. - Orthothecium?

(1) n An Thuidium? "Jaeg. Ad. II, p. 609. (1) n An Thuidium ? Jaeg. Ad. II, p. 609 . M. Syn. II, p. 508. - Ex Andibus.
(2) dorsale Brid. Bryol, univ. 1I, p. 433 ; C, M. Syn. Delendum. 
duriusculum C. M. - Brachythecium.

eccrenocarpum C. M. - Thuidium.

Ehrenbergianum C. M. - Hylocomium.

elachistos Duby. - Rhynchostegium.

Elaeis C. M. in Dusen M. Camer. n. 371.

- Afr.: M. Cameroon.

elasticum Brid. - Eurhynchium striatum.

elatulum C. M. - Porotrichum.

elegans $\left\{\begin{array}{l}\text { Ehrh. - H. purum. } \\ \text { Hook. - Plagiothecium. }\end{array}\right.$

var. collinum Wils. - Plagiothecium elegans.

eleganti-pinnatum C. M. - Ectropothecium.

elegantissimum C. M. - Porotrichum.

elegantulum Hook. - Microthamnium.

elodes Spr. in Lond. Journ. of bot. 1845, IV, p. 174; C. M. Syn. II, p. 434 ; W. P. Sch. Coroll. p. 130 et Syn. II ed. $n 723$.

Amblystegium elodes Lindb. M. Scand. $p .32$.

H. polymorphum Tayl. Fl. Hibern.

Stereodon polymorphus Mitt. M. Ind. or. p. 115.

2. Loc. uligin. ad rad, arb., etc. - Eur, : Hibern,, Angl. ; Eur. med. :

Alsat., Suec., Siles., etc. As. : Himalaya occ.

Exs. : Rab. Bryoth. eur. n. 395.

"var, hamulosum W. P. Sch. Syn. II ed.p, 724.

Praecip, ad sax. - Eur. : Alsat., etc.

Elodes W. et M. - Aulacomnium palustre.

elusum Mitt. - Rhynchostegium.

emarginatum Schleich. - Leskea tristis.

erectiusculum $\mathrm{S}$. et Lesq. - Pylaisia?

erectum $\left\{\begin{array}{l}\text { Drumm. - Brachythecium acuminatum. } \\ \text { Lesq. et Jam. - Thuidium. } \\ \text { Raddi. - Hylocomium brevirostrum. } \\ \text { non ramosum spinarim halecum aemulum Dill. - Rhizogo- } \\ \text { nium spiniforme. } \\ \text { vel fluitans, foliis oblong is angustis peracutis Dill. - H. fluitans. }\end{array}\right.$ ericetorw Rrid, - Trachypus (?) serrulatus.

encoides C. M. - Sladomnium.

erythrocaule (Mitt.) Jaeg. Ad. II, 1. 586.

Stereodon erythrocaulis Mitt. M. Ind. or. p. 97.

2 ?

- As, : Sikkim.

crythrocaulon Aingstr. - Sematophyllum.

erythropodium $\left\{\begin{array}{l}\text { Brid. - Brachythecium populeum. } \\ \text { C. M. - Microthamnium elegantulum. } \\ \text { Hpe. - Sematophyllum. }\end{array}\right.$

crythrorhizon C. M. - Brachythecium.

var. Thedenii Lindb. - Brachythecium Thedenii.

esmeraldicum C. M. - Rhaphidostegium microcladon.

Estrellae C. M. - Ectropothecinm cylindricum.

cuchloron Br. - Eurbynchium.

Eudorae Sull. - Isopterygium.

eugyrium W. P. Sch. Syn. I ed. p. 639 et II ed. n. 781.

Amblystegium eugyrium Lindb. M. Seand. p. 33.

Limuobium eugyrium Bryol. eur. VI (mon. Suppl. p. I), ı. 579.

1. Ad sax, irror, rivul et cataract. - Eur. : Silva nigr, Helvet. occ. 
Am. sept. : Terr. nov,, ins. Miquel., Nov. Scot., New Brunswick, Nov. Angl., New York, M. Rupestr.

Exs.: Mac. Canad. M. n. 535.

Rab. Bryoth, eur. n. 650.

Sull. et Lesq. M. bor. am. II ed, n. 450.

Un. itin. 1868, n, 28.

n var. Mackayi W. P. Sch. Syn. II ed. p. 782.

Ut typ. - Eur. : Suecia merid., Britann., Gall. centr. Am. sept.: Tennessee.

" var. miquelonense Ren. et Card. in Rev. bryol. 1893, p. 28.

- Am. sept. : Ins. Miquelon.

eupopuleum C. M. - Brachythecium.

euryblaston C. M. - Brachythecium.

euryodictyon C. M. - Brachythecium.

eutryphaeum C. M. - Isopterygium.

exaltatum (Milt.) Par.

Hyocomium exaltatum Mitt. in Trans, of the Linn. Soc. 1891, p. 177. - As. : Japon.

exannulatum Bryol. eur. VI (mon. p. 34), t. 602; W. P. Sch. op, cit. p. $73: 3$ (1).

Amblystegium exannulatum de Not. Briol. ital. p. 142.

A. fluitans var. exannulatum Lindb. M. Seand.

2. In pratis uligin, et ad stagn. marginem. - Eur.: Spitzberg, ins. Ursor. ; a Lappon. usq. ad Ital. super., e reg. campestr. usq. in alp. Hudson, Labrador, Terr. nov., ins. Miquel, M. Catskill, Ontario, M. Selkirk, Columb. brit., reg. sept., occid., centr. et or.

Exs. : Faurie M. Jap. n. 837.

Mac. Canad. M, n, 382.

Rab. Bryoth. eur. n. $774,849,796$ et b, 916.

Un. itin. 1864, n. 28, 62.

var. alpicola de Not. - H. exannulatum var. purpurascens.

"var. brachydictyon Ren. in Husn. Muscol. gall. p. 385, l, 110, f. 10-11. H. fluitans $\Theta$ alpinum $e j$. in Revue bryol. 1881, $p$.

In turfos. alp. - Eur. : Voges., Pyren., Alp., Tirol.

var. Cochleae Aust. - H. fluitans var. Swartzii.

\& var. falcifolium Ren. in op. cit. p. 38\%, t. 111, f. 4-5.

In turfosis. - Eur. : Gall,, praepr. alp.: Belg. Am. sept.: Montana, Wyoming.

\& $f$. fontinaloides Ren, in op. et $l$. cc. - Eur.: Pyren.

"var. glaciale Ren. in op. et $l$. cc.

Ad nives deliquesc. - Eur.: Pyren.

« f. gracilescens Ren, in op. et $l$. cc. - Eur. : Armoric., Voges.

var. immersum Aust. - H. fluitans var. Swartzii.

(1) Cf. Sanio, Beschreibung der Harpidieen... Ienissei ; formae acutum, acttum-assimile, acutum-orthophyllum, paludosum, typicum, typicum-cuspidatum. typioum-fumigatum, typicum-purpurascens (pp. 8-15). 
\& $f$. inundata Ren. in op. cit. p. 388.

- Eur.: Gall. (Arvernia).

a var, irrigatum Ren, in op. cit. p. 386.

Ad nives deliquesc. - Eur.: Pyren., Riesengeb.

var. orthophyllum Milde. $-\mathrm{H}$. exannulatum var. Rotae.

a var. pinnatum Bryol. eur. t. 604 p.p.: Boulay M. Fr, 1I, p. 62; Ren. in op. cit.p. 385, t. 110, f. 7, \&, 9, 16.

- Eur. : Gall., Belg. Am. sept. : Ins. Miquel.

"var. purpuraseens W. P. Sch. op. cit. p. 734.

H. exannulatum var, alpicola de Not. Epil.

In aquis stagn. et in turfos. Alp. - Eur.: Voges., Helvet., Rhaet.,

Stir., Sudet. As. : Jenissei infer.

"f. Renauldi Sanio in Hedvrig. 1887; Ren. in op. cit. p. 386, t. 110, f. 4. - Eur.: Pyren.

\& var, Rotae Pfeff. Bryogeog. Stud. d. Rhat. Alp.; W. P. Sch, op. et 1. co.

H, exannulatum var, orthophyllum Milde Bryol. siles.

H. exannulatum var, serratum ej.l. $c$.

H. Rotae de Not. Epil.

H. slenophyllum Wils, mss. (fid. W. P. Seh.).

In aquis stagn. - Eur.: Keg. subalp. et alp. As. : Jenisset inf.

Exs, : Rabenh. Bryoth. eur, n. 1100.

var. serratum Milde. - H. exannulatum var. Rotae.

a $f$. viridis Boul. M. Fr. p. 63; Ren. in op. cit. p. 388, t. 111, p. 7. - Eur. : Gall. or., Belg.

exasperatum Hpe, - Eurhynchium.

excavatum Tayl. - Camptochaete.

exiguum $\left\{\begin{array}{l}\text { Bland. - Rhynchostegium tenellum. } \\ \text { Geh. et Hpe. - Ectropothecium (1). }\end{array}\right.$

exilissinum Sull. - Helicodontium.

? eximium Sull, et Lesq. in Proced. of the Am. Acad... 1859, p. 281.

Lignic. - As. : Ins, Bonin.

expallescens C. M. - Rhynchostegium.

expansum Tayl. $\left\{\begin{array}{l}\text { (fid. Mitt.), - Porotrichum. } \\ \text { (fid. Wils.). - Porotrichum longirostre. }\end{array}\right.$

extenuatum Brid. Bryol, univ. II, p. 484; C. M. Syn. II, p. 391 p.p.; Hook. f. et Wils. Fl. Tasman. II, p. 214 el Handb. of N. Zeal. Fl. p. 481 .

Acanthocladium extenuatum Mitt. in Trans, and Proced. of the roy. Soc. of Victoria, 1883, p. 85 .

H. crinitum H, f. et W. Fi. of the N. Zeal. $I I, p .114, t .91, f .4$.

H. glaucescens Hsch, in Sieber M. Austral.

Rhynchostegium glaucescens Mitt, in op, cit. p. 89.

2. Ad arbor. - Pac. : Austral. or., Nov. Zeland., Tasman., ins. Auckland.

extenuatum \{ C. M. p.p. - H. crinitum.

Hoffm, - H. cupressiforme var, filiforme.

extricatum Hoffm. - H. filicinum.

Fabronia Hook. - Microthamnium. 
fabroniadelphus C. M. - Rhynchostegium. fabroniaefolium C. M. - Pylaisia subàenticulata.

falcatum Brid. Sp. M. II, p. 212 et Bryol. univ. II, p. 526; W. P. Sch. op. cit. p. 742 .

Amblystegium falcatum Lindb. M. Scand. p. 33.

A. commutatum de Not. Epil.p. p.p.

H. commutatum var, condensatum Wils. Bryol. brit.

H. commutatum $\beta$ falcatum C. M. Syn. II, p. 423; Bryol. eur. VI (mon. p. 38), t. 608.

H. controversum Wils. mss.

2. Loc. aquos. calcar., ad font. et rivul, - Eur.: E reg. montan, usi. in alp. As. : Persia, Caucas, occ. et centr. Afr.: Alger. Am, sept.: Labrador, Terr. nov, M. Rupestr., Culumb. brit., Colorado.

Exs.: Mac. Can. M. p. 340.

Rab. Bryoth. eur. n. 742 et b, 897.

"var. gracilescens W. P. Sch. $l, c$.

Ut typ. - Eur. : Alp. usq. ad niv.

«var, microphyllum Kindb. in Mac. Cal. p. 232.

- Am. sept. : Terr. nov.

"var. pachyneuron W. P. Sch. l. c.

Ad sax, calcar, rivul. - Eur. : Reg. subalp. et alp.

"var, virescens W. P. Sch, $l, c$.

H. commmutatum $\gamma$ fluctuans Bryol. eur. l. c. t. 608 ; Rab. Bryoth. ewr. n. 495 .

H. irrigatum (fid. Husn. Muscol. gall. p. 396).

H. virescens Boul. M. Fr.

2. fruct. rariss. Ut praeced. - Eur. : Reg. montan. usq. in alp.

falcifolium C. M. - Homalia.

falciforme $\mathrm{Dz}$. et $\mathrm{Mk}$. - Ectropothecium?

fallaciosum Jur. - H. polygamum var. fallaciosum.

fallax Brid. - Amblystegium irriguum var. spiniforme (1).

fasciculatum $\left\{\begin{array}{l}\text { Lam. - Brachytheeium salebrosum. } \\ \text { Sw. - Porotrichum. }\end{array}\right.$

fastigiatum (Brid.) C. M. Syn. II, p. 298; Bryol. eur. VI (mon. p. 19),

t. $589 ;$ W. P. Sch. op. cit. p. 749.

H. cupressiforme var. conicum Brid. Bryol. univ. $I I, p, 610$.

H. cupressiforme var, crispatissimum ej. op. cit. p. 610.

H. cupressiforme var. fragile ej. op. cit. p. 611 .

$\mathrm{H}$, cupressiforme $v a r$. hamulosum ej. op, oit. p. 610 .

H. cupressiforme var. Hook. in Drumm. M. bor. am. I ed, n. 206.

H. hamulosum Froehl in sched.

H. mamillatum Funk in sched.

H. Stereodon fastigiatus Brid. op. c. p. 620.

1. Ad rup, praecip. silic,-calcar. - Eur.: Scandin., Alp. German, et Helvet. : desider, in Britann. As. : Penins. Tschutschica (2). Am. sepı. : Groenland, Ontar., M. Rupestr.

Exs. : Rab. Bryoth. eur. n. 398, 696.

Un. itin. 1863, n. 86.

fastigiatum Wieb. - H. cupressiforme.

var. doloniticum Mdo. - H. dolomiticum.

var. Ravaudi Husn.- - H. Ravaudi. 
faulense Reichdı. - Thuidium.

Fendleri Sull. - Brachythecium.

ferricolum C. M. - Thuidium.

ferrugineum C. M. - Ectropothecium.

fertile Sendtn. in Denkschr. d. bot. Ges. z. Regensb. III, p. 147; C. M. Syn. II, pp. 293 et 685; Bryol. eur VI (mon. p. 22), t. 591; W. P. Sch. op. cit. p. 751.

H. crinale Schleich, in sched.

Stereodon fertilis $L i n d b$.

1. In trunc. deject. aceros. putresc. - Eur. : Voges., Silva nigr., Helvet., Bavar., Tirol., Alp. Salisburg. et Austr., Francon., Sudet. As. : Japon., Caucas. centr. Am, sept.: Anticosti, New Brunswick, Gaspes. Ontar., Columb. brit., reg. sept.

Exs. : Faurie Pl. Jap. n. 244, 3514.

Mac. Canad. M. n. 346 p.p.

Rab. Bryoth. eur. n. 1241.

Sull. et Lesq. M. bor. am. n. 479.

filamentosum Bert. - Pseudo Leskea atro-virens.

var. brachycladon C. M. - Pseudo Leskea atro-virens var. brachyclada.

var. papillosum C. M. -. Pseudo Leskea atro-virens var. papillosa. var. tenue C. M. - Pseudo Leskea.

filescens $\left\{\begin{array}{l}\text { Brid. - Eurhynchium striatulum. } \\ \text { C. M. p.p. - Eurhynchium striatum var. meridionale. }\end{array}\right.$ filiciforme Huds. - Pylaisia polyantha.

filicinum L. Sp. pl. p. 1590? Brid. Bryol. univ. I1, p. 527; C. M. Syn. II, p. 419; Bryal, eur. VI (mon. p. 40), t. 609; W. P. Sch. op. cil. p. 740.

Amblystegium filicinum de Not.

H. affine Hoffm. Deutsch. Fl. II, $p 61$.

H. compressum Brid. M. Rec. II, II, p. 58.

H. extricatum Hoffm. op. cit. p. 62.

H. filicinum $\gamma$ pendulum Brid. op. cit, p. 532.

H. filicinum $\eta$ pinnatum ej. op. cit. $p, 532$.

H. flaccidum Sehleich. in sched.

H. glareosum ej. l. c.

H. polycarpum Voit in Sturm. Deutschl. Fl. crypt. Fasc. IV.

H. prolixum Vill. Pl. Dauph. III, p. 914.

2. Ad sax., mur, terr, et lign. madid. in aqnos. calcar. - Eur. : Spitzberg, reg. campestr. et montan. As. : Japon., Yunnan, Saghalien, Ochotsk, Jenissei, Himalaya et Tibet. occ., Luristan., Kurdistan., Syr. Afr. : Alger. Am. sept, : Fret. Hudson, Anticosti, Terr. nov, Nov, Scot., New Brunswick. Gaspes., Ontar., Athabasca, Assiniboine, Saskatchewan, M. Rupestr., Columb. brit., Vancouver, Washington, Calif., reg. sept, centr, or. Pac. : Nov. Zeland.

Exs. : Faurie Pl. Jap. n. 181, 3507.

Mac. Canad. M. n. 339.

Rab. Bryoth. eur. n. 998 et b, 1047.

Sull. et Lesq. M. bor. am. n. 469.

Un itin. 1867, n. 22.

" var. aciculinum C, M. et Kindb. in Mac. Cat. p. 231.

Ad rup. madid. - Am. sept. : Columb. brit.

"var. elatum W. P. Sch. op. et l. cc.

In spongios, - Eur. : Alp. Salisburg. Am. sept. : Hic illic. 
var. fallax H. et T. - Amblystegium irriguum var. spiniforme (1).

« var. filiforme Berggr, M. Spetsb, $n .136$ b et in K. Sv. Vet, Ak. Handl. XIII, n. 7, p. 87.

Aquat. - Eur. : Ins. Ursor.

* var. floridanum Ren, in Lesq. et Jam. Man, p. 387. - Am. sept. : Florida.

" var. gracilescens (Bland.) Brid. op. cit. p. 531 ; W. P. Sch. op. et l. cc.

H. gracilescens Bland. in Brid. Sp. M. II, p. 211.

Ad rup. minus humid. - Eur. et Am. sept. : Cum typ.

"var. gracillimum (Sael.) Par.

Amblystegium filicinum var. gracillinum Sael. in Act. Soc. pr. F. el Fl. Fenn. VI, $n, 4$ (M. Lapp. Kolaensis).

- Eur. : Karelia.

var. Lanatum Brid, - Amblystegium fluviatile.

\begin{tabular}{l|l} 
var. pendulum \\
var. pinnatum
\end{tabular} Brid. - H. filicinum.

« var. supra-alpinum Mdo. Allg. Moosst. 1865, p. 102.

- Eur. : Alp. Algov.

\& var, tenue Berggr. $l l . c c . n .136 c$.

Rupic. - Eur.: Spitzberg, ins. Ursor.

"var. trichodes Brid.l. c. p. 529; W. P. Sch. Syn. I ed. p. 614 el Il ed. $l . c$.

H. conspurcatum Brid. in sehed.

H. dubium Dicks. Fasc. III Pl. crypt. p. $10 ;$ Brid. M. Rec. II, p. 64.

H. repens, filicinum trichodes palustre Dill. Hist. M. p, 286, $t .36, f, 21$.

H. rubrum Vill. $P l$. Dauph. III, p. 897.

Ad scaturig. herbos., terr, et saxa. - Eur. et Am. sept. : Ubi typ.

Vill. - H. commutatum.

Cristam castrensem repraesentans Dill. - H. molluscum. - sericeum, molle et pallidum, mucronibus aduncis Dill. H. cupressiforme,

filicinum Tamarisci foliis majoribus splendentibus Dill. - HylocoTamarisci foliis minimis non splendentibus, sels capsulisque brevioribus Dill. - Thuidium delicatulum, Tamarisci folizs minoribus non splendentibus Dill. - Th. tamariscinum.

filiculaeforme P. B. - Hypopterygium.

filidens C. M. - Microthamnium elegantulum.

filifolium L. - Pylaisia polyantha.

filiforme $\left\{\begin{array}{l}\text { C. M. - Eurhynchium velutinoides. } \\ \text { Gmel. - Cryphaea. } \\ \text { Huds. - Pylaisia polyantha. } \\ \text { Timm. - Pterigynandrum. } \\ \text { Vill. - Pseudo-Leskea atro-virens. }\end{array}\right.$

filum (1. M. - Pseudo-Leskea?

fimbriatum $\left\{\begin{array}{l}\text { C. M. - Chaetomitrium. } \\ \text { Hartm. - Hylocomium Oakesii. }\end{array}\right.$ 
finitimum Hpe, - Rhynchostegium.

finmarchicum Ltz. - Amblystegium

Fissidens C. M. - Rhynchostegium.

fissidentoides $\{$ Brid, - Rhizogonium Novae Hollandiae.

Fit;-Geraldi $\left\{\begin{array}{l}\text { C. M. - Brachythecium. } \\ \text { Ren. - Plagiothecium. }\end{array}\right.$

flabellatum Dicks, - Homalia.

flaccens Besch. in Ann. sc. nat. 1892, $I, p .92$.

2. Ster. In silv. - As. : Yunnan.

flaccidifoliun C. M. - Rhaphidostegium.

flaccidulum Rehm. M. Afr. austr. n, 676.

Ster.

- Afr. : C. B. Sp.

faccidum $\left\{\begin{array}{l}\text { Schleich. - H. filicinum. } \\ \text { S. et L. - Isopterygium. }\end{array}\right.$

flaccum C. M. et Kindb. in Bidr. p. 454 (nom.) el in Mac. Cal. p. 240.

Ster. lignic. v. rupic. - Am. sept. : New Brunswick, Ontario (I).

flagellare $\left\{\begin{array}{l}\text { Dicks. - Hyocomium. } \\ \text { Gmel. - H. Halleri. } \\ \text { Haxatile, capsulis gracilibus Dill. - Rhynchostegium rusci- } \\ \text { forme var. lutescens. }\end{array}\right.$ flagelliferum $\mathrm{Hpe}$ - - Porotrichm.

flagelliforme Brid. - Amblystegium fluviatile.

flagellis instar caudae vulpinae Dill. - Leucodon canariensis.

flavens Mich. - Anomodon rostratus.

flavescens $\left\{\begin{array}{l}\text { Brid. - Brachythecium rivulare. } \\ \text { Roth. - Brachythecium albicans. } \\ \text { Schleich. - H. aduncum. } \\ \text { Wils. - Rhynchostegium demissum. }\end{array}\right.$

flavo-nitens C. M. - Stereophyllum leucostegum.

Flemmingii L. et J. - H. robustum.

flexile $\left\{\begin{array}{l}\text { Brid. - H. cuspidatum. } \\ \text { Hook. - Lembophyllum cochlearifolium. } \\ \text { Sw. - Pilotrichella. }\end{array}\right.$

flexipes Brid. - Amblystegium riparium.

flexiventrosum C. M. - Brachythecium.

flexuosam Berggr, in Bot. Not, 1872 et in Rev, bryol. 1884, p. 94.

- Eur. : Norveg. sept. (Tromsoë).

flexuosum Sull. - Leucomium.

floribundum C. M. - Papillaria.

floridum Tayl. (fid. Mitt.). - Porotrichum longirostre.

Flolovonianum Sendtn. (fid. C. M.). - Eurhynchium velutinoides.

a (fid. W. P. Sch.). - H. pallens.

fluitans L. Fl. Suec. $-1074 ;$ C. M. Syn. II, p. 323 ; Bryol. eur. VI (mon. p. 33), t. 602; W. P. Sch. op. cit. p. 734 (2).

Amblystegium fluitans de Not.

Fontinalis fuitans Lam, Fl. fr. I. p, 640.

1) flagellare Vill. Pl. Dauph. III, p. 910 ; Brid. Bryol. univ. II, p. 517; C. M. Syn. II, p. 509, a An Angmodon viticulosus? vel A. attenuatus? Delendum.

(2) Cr. Sanio Beschreib. d. Havpidien... p. 8. 
H. erectum vel fluitans, foliis oblongis angustis peracutis Dill. Hist. $M$. p. $299, t, 38$.

H. Stereodon fluitans Brid. Bryol. univ, II, p. 626 a et parte maxima quoque varietates sequentes. o $C . M$. $l$. $c$.

1. In prat. spong. et aq. stagn. - Eur. : Spitzberg, ins. Ursor. : fere tota. As.: Septentr. Afr.: Ins. Azores, Orange, ins. Kerguelen. Am. sept. : Groenland, Labrador, Anticosti, Terr. nov., ins. Miquel., Nov. Scot., New Rrunswick, liaspes., Ontario, lac. Super., M. Selkirk, Columb. brit., reg. sept., occ., centr. et or. Am. merid. : Ins. Eremit. Pac. : Tasman., ins. Campbell.

Exs.: Drumm. M. bor. am. I ed. n. 203, 204.

Mac. Canad, M. n. 336 p.p.

Rab. Bryoth. eur. n, 1014.

Rehm. M. Afr. austr. n. 399 et b.

Un, itin. 1864, n. 62. $77 ; 1867$, n. 26.

« var. alpinum W. P. Sch. Syn. I ed. p. 61]; Ren. in Husn. Muscol. gall. p. 383, t. 110, fig. 1 .

- Eur. : Suecia.

Exs. : Rab. Bryoth. eur, n, 1045.

« var. amphibium Sanio Beschr. p. 14.

Amblystegium fluitans var. amphibium San. in L. et A. M. As. bor. 1890, $I I, p .117(1)$.

- As, : Jenissei med, et inf.

« var. Arnellii Sanio Beschr. p. 15; Ren. in Husn. Muscol. gall. p. 384, t. 110.

Ster. - Eur. : Suecia.

\& var. aurantiacum (San), Par.

Amblystegium fluitans var, aurantiacum San. in Hedwig. 1867, p. et l. c. $(2)$.

- As. : Jenissei super.

a var. Brotheri Sanio in Hedvig. 1897.

- Eur. : Fennia.

" var. capillifolium (Warnst), Ren. et Card. in Rev. bryol. 1893, p. 25.

Dichelyma longinerve Kindb. in Bull. Torr. bot. Club, XVI, p. 97 et in

Mac, Canad. M. n. 391. gall. p. 376.

H. longinerve Kindb. in Mac. Cat. p. 239.

Ster. In stagn. exsice. - Eur.: German., Suecia. As, : Siberia. Am. sept. : Columb. brit., Vancouver, Washington, Idaho.

f. condensala Sanio. - H. fluitans $f$. terrestris.

"var. Delamarei Ren. et Card. in Husu. op. cit. p. 384, t. 109.

H. fluitans var. stenophyllum eor. M. Am. sept. n. 133.

1.

- Am. sept.: Ins. Miquelon.

a var. elatum Ren. et Arn. in Husn. op. cit. p. 38I, t. 113, f. 12. 1.

- Eur.: Suecia.

a var. falcatum Bryol. eur, et W. P. Sch. ll. cc.

H. Stereodon falcatus $\gamma$ aduncoides Brid. op. cit. p. 628 ? 
In udis. - Eur, : Reg. mont., subalp. et zon. sept. Am, sept. : Groenland, Labrador, hic illie ubi typ.

\& var. gracile Boulay M. Fr.p. 63 .

In turfos, - Eur. : Gall, occ, et centr.

* var. hemineuron Ren. el Card. in Husn. op. cit. p. 388, t. 113.

Ster.

- Am. sept. : Labrador.

* var. Holleri Sanio in Bot. Centralbl. 1880.

Ster.

- Eur. : Suecia? German.; Belg. ?

"var. Jamesii Lesq, et Jam. Man. p. 384.*

- Am. sept. : M. Alb.

* var. Jeanbernati Ren. in Rev. bryol. 1879, $p$.

I.

- Eur.: Pyren. Am. sept. : Ins. Miquelon.

* var, laculosum (C. M.) Par.

H. laculosum C. M. in Fl. 1885, p. 425.

Ster. Subaquat. - Am. merid. : Fuegia.

* var. I.indbergii (Sanio) Par.

H. capillifolium var. Lindbergii Sanio; Ren. Husn. Muscol. gall. p. 376.

- Eur. : Suecia?

" var. longifolium Rehm. M. Afr. austr. n. 400.

- Afr. : Orange.

var. pseudo-stramineum Milde. - Hypnum.

var. serratum Lindb. - H. fluitans var. Swartzii.

* var. Payoti Ren. in op. c. p. 381 .

Ster. In lacunis. - Eur.: Alp. Sabaud. (M. Blanc.).

" var. procerum Ren, et Arn. in op. cit. p. 383, t. 110.

Ster.

- Eur. : Suecia.

" var. setiforme Ren. in op. cil. p. 382.

Ster. $\quad-$ Eur.: Gall. occ. (Normann.).

" var. stenophyllum (Wils.) Ren. et Card. in Rev. bryol. 1893, p. 25(1).

H. stenophyllum Wils, mss.?

- Eur. : Hic illic. Am. sept.: Ins. Miquel.

"var. submersum W. P. Sch. Syn. I ed. p. 609 et II ed. l. c.

In stagn, praesert. prator, turfac, - Eur. et Am. sept. : Ubi typ.

- var. Swartzii (Lindb.) Ren. et Card. l. c. (2).

Dichelyma Swartzii Lindb. in Hartm. Skand, Fl. VIII ed.

H. exannulatum var. Cochleae Aust. in Coult. Bot. Gas. II, p. 111.

H. exannulatum var, immersum ej. l. c.

H. fluitans var, serratum Lindb, in Hartm. Skand. Fl IX ed. p. 18.

Ster. Calif.

\& var. tenellum Ren, et Card. Fl. ins. Miquel. p. 54.

- Eur. : Pyr. Am. sept. : Ins. Miquelon.

" $f$. terrestris Sanio; Ren. in op. cit. p. 381 .

H. fluitans $f$. condensata San, et Ren. in op. et l. ce.

- Am. sept. : Ins. Miquelon.

(1) Cf, $I$, exannulatum v. Rotae.

(2) Cf. W. P. Seh. Syn. II, ed. p. 559 et Lesq. ot Jain. Man. p. 275. 
"var, tricolor Sanio; Ren, in op. cit. p. 383, t. 110, fig. 2.

- Eur. : Suecia (Smaeland).

fluitans $\left\{\begin{array}{l}\text { Mac. p.p. - H. conflatum. } \\ \text { Mitt. - H. austro-fluitans. }\end{array}\right.$

fluitans $\times$ aduncum Sanio Beschr.p. 47 (1).

Amblystegium fluitans $\times$ aduncum $L$, et $A$. M. As, bor. 1890, II, p. 122.

1 v. 2. - Jenissei med, et inf.

fluminense Hpe. - Rudia.

fluviatile Sw. - Amblystegium.

var. flagelliforme
Bw. B.p. - Amblystegium irriguum

foliis rusciformibus, capsulis subrotundis Dill, - Rhynchostegium rusciforme.

fontanum $\left\{\begin{array}{l}\text { Schleich. }- \text { H. cordifolium. } \\ \text { Schranck, - Philonotis. }\end{array}\right.$

fontinaleum C. M. in Ule Bryoth. brasil. $n .187$.

2. Ad saxa madida. - Am. merid.: Brasil. austr. or.

fontinaliopsis C. M. in Engler's Bot. Jahrb. 1883, p. 82 et in Forchungsreise.... Bot. p. 34.

Ster. Aquat. - Afr.: Ins. Kerguelen.

fontinaloides (Hpe.) Jaeg. Ad. II, p. 569.

Amblystegium fontinaloides Mitt. in Trans, and Proced. of the roy. Soc. of Victoria, 1883, p. 87.

Drepano-Hypnum fontinaloides Hpe, in Linn. 1871-73, p. 518.

Ster.

- Pac. : Austral. or. (Nov. Valesia).

fontinaloides Lam. $\left\{\begin{array}{l}\text { (fid. C. M.). - Cinclidotus. } \\ \text { (fid. Limpr.) - Neckera pumila. }\end{array}\right.$

fontium Brid. - Eurhynchium speciosum?

formianum W. P. Sch.op. cit.p. 741 (2).

Amblystegium formianum Dan Fior. Mazz, in Att. d. Acad. Pontif. d. nuovi Lincei, 1874, e. ic.

H. Vallis Clausae Brid. Bryol. univ. 1I, p. 534 (fid. Renauld).

2. In aquis rapid. fluent. - Eur.: Ital. (Neapol.).

Exs. : Rab. Bryoth, eur. n. 1293.

Forstenii Bryol. jav. - Hylocomium.

fragile $\{$ Brid. $-\mathrm{H}$. chrysophyllum.

fragilirostrum Hpe. - Rhaphidostegium.

Freuchenianum Hsch. in Fl. 1825, p. 78; C. M. Syn. II, p. 324. - Eur.: Islandia.

Freycineti Sehwaegr. - Distichophyllum.

frigidum C. M. - Brachythecium.

frondicola C. M. - Rhynchostegium.

Frontinoae C, M. - Thuidium.

frullaniadelphus C. M. - Rhaphidostegium.

fuciforme Brid, - Thuidium.

(1) Formae : alpinum, exannulatum, paludosum, vulgare.

2) Cl. Geheeb in Hedwig. 1874, p. et Renauld in Rev. bryol. 1885, p. 55. 
fuegianum (Mitt.) C. M. in Fl. 1885, p. 426.

Amblystegium fuegianum Mitt. M. austr. am. $p, 570$.

- Am. merid. : Fuegia, ins. Eremitae.

fulgens Sw. - Phyllogonium.

fulgeriense la Pyl. - Eurbynchium Stokesii.

fulgescens Mitt. - Homalothecium.

Funkii Hsch. - Brachythecium.

fulvastrum Hook. - Thuidium.

fulvum $\begin{aligned} & \text { Brid. - Anomodon attenuatus. } \\ & \text { C. M. - Stereophyllum. } \\ & \text { H. f. et W. - Plagiothecium micans var. fulvum. }\end{aligned}$

furcalum Brid. - Helicodontium capillare.

furfurosum H. f. et W. p.p. $\left\{\begin{array}{l}\text { - Thuidium fulvastrum. } \\ \text { - Thuidium. }\end{array}\right.$

fuscescens $\mathrm{H}$. et Arn. - Ectropothecium inflectens.

fusco-caule C. M. - Trichosteleum.

fusco-mucronatum C. M. - Hypnodendron.

fuscum Schleich. - H, scorpioides.

galerulatum Duby. - Ectropothecium.

galipense C. M. - Rhaphidostegium.

Gardnerianum C. M. - Stereophyllum leucostegum.

gastrodes W. et Dy. - Heterocladium.

Gaudichaudi Mont, - Rhynchostegium.

Gayanum Sull, - Thuidium gracile.

gedeanum C. M. - Sematophyllum.

geminum L. et J. - Plagiothecium.

geniculatum Scleich. - Brachythecium campestre.

geophilum L. et J. - Rhynchostegium.

georgicn-antarcticum C. M. - Plagiothecium.

georgico-glareosum C. M. - Rrachythecium.

georgico-uncinatum C. M. Bryol. austr. Georg. p. 44.

Ster. Paludic. - Am. merid. : Austr. cieorg.

Genoigii C. M. - Bryum.

gibbosulum C. M. - Rhaphidostegium.

giganteum W. P. Sch. Syn. I ed.p. 642 el 11 ed. p. 787.

Amblystegium giganieum de Not. Briol. ital. p, 135.

H. cordifolium Drumm. M. bor, am. I ed. $n$. 209 (fid. Kindb. et Mitt.) et plerumq. auct. Suec.

H. cordifolium var, stenodictyon Bryol, eur. VI (mon. p. 47).

Stereodon giganteus Mitt. in Journ. of the Linn. Soc. VIII, p. 42.

2. In turfos. profund, uligin, et ad rip. rivul. - Eur.: Spitzberg, ins. Ursor.; reg. campestr, zon. intermed. et sept. As. : Jenissei. Am. sept.: Groenland, Anticosti, New Brunswick, New York, Pensilv., Ottawa, Ontar, Manitoba, Saskatchewan, M. Rupestr., Columb. brit., Vancouver, Washington, Montana, Idaho, Wisconssin.

Exs. : Mac. Canad. M, n, 362.

Rab. Bryoth. eur. n. 549 et b, 762 et b.

Sull. et Lesq. M. bor. am. II ed. n, 458 et 468 .

Un. itin. 1863, n. $94 ; 1866$, n. 65 et 86.

* var. Iabradorense Ren, et Card. in Bot, Gas. 1894, p. 240.

- Am. sept. : Labrador.

giganteum Sull. et Lesq. - H. hamifolium (fid. Ren.).

glabellum Sw. - Homalia.

glareosum $\left\{\begin{array}{l}\text { Br. }- \text { Brachythecium. } \\ \text { Schleich. - H. tilicinum. }\end{array}\right.$ 
glaucescens Hsch. - H, extenuatum.

glaucissimum C. M. - Ectropothecium.

glaucocarpum Reinw. in Schwaegr. Suppl. III, I, p. 2, t. 228; C. M. Syn. II, p. 441; Bryol. jav. 11, p. 148, t. 246.

Hookeria leptopoma C. M. Syn. II, p. 215 (fid. Mitt., quae tamen ab auct. dioica dicitur).

H. retroflexum Hook, in Wall. Cal. n. 7656 ; Harv. in Lond. Joum. of bot. II, p. 19 et in Hcok. Ic. pl. rar. I, t. $23 ; f .6 ;$ C. M. l. c. p. 287.

H. venustum Hseh. et Reine. in Nov. Act. Acad. Caes, Leop. XIV, II, Suppl. p. $726, t .41$.

Stereodon glaucocarpus Mitt. M. Ind. or, p. 115.

1. - As.: Sikkim, Java.

glauco-virescens C. M. - Rhynchostegium.

glauco-viride Mitt. - Sciaromium.

glaucum $\left\{\begin{array}{l}\text { Lam. et DC. - H. commutatum. } \\ \text { Weiss. - Leucobryum. }\end{array}\right.$

Glasiovii Hpe. - Rhaphidostegium.

globipyxis C. M. - Rhynchostegium.

globitheca C. M. - Ectropothecium.

glossoides Bryol. jav, II, p. 146, t. 243.

2.

- As. : Java.

gloriosum C. M. - Brachythecium.

gnaphaleum P. B. - Breutelia.

golungense W. et Dy. - Eetropothecium.

Gottscheanum C. M. - Trichosteleum.

Goulardi W. P. Sch. Syn. II ed.p. 778.

1. In rivul. frigid. - Eur.: Norveg. (Dovre), Pyren. (Maladetta). Am. sept. : Anticosti, Gaspes.

Goulardi Mac. - H. torrentis.

gracile $\left\{\begin{array}{l}\text { Br. et } \mathrm{Sch} \text { - Thuidium. } \\ \text { H. f. et W. - Camptochaete. } \\ \text { L. - Pterogonium. } \\ \text { Weim - Myurella Careyana. } \\ \text { ornithopodioides Dill. - Pterogonium. }\end{array}\right.$

var. lancastriense Sull. - Thuidium gracile var. lancastriense.

var. Ravenelii Sull. - Thuidium gracile var. Ravenelii.

(Bland. - H. filicinum var. gracilescens.

gracilescens C. M. - Camptochaete gracilis.

P. B. - Leskea obscura.

gracilicaule $\left\{\begin{array}{l}\text { Bryol. jav. - Sematophyllum. } \\ \text { S. Lac. - Ectropothecium. }\end{array}\right.$

gracilirameum C. M. in Rev. bryol. 1878, p. 59 (nom.).

- Afr.: Ins, Franciae.

gracilisetum Hsch. et Reinw, - Ectropothecium.

gracillimum Hsch. - Ectropothecium.

Graeffeanum C. M. - Hypnodendron.

graminicolor $\left\{\begin{array}{l}\text { Angstr. - Ectropothecium. } \\ \text { Brid. - Trichosteleum. }\end{array}\right.$

granulatum Hpe. - Thuidium.

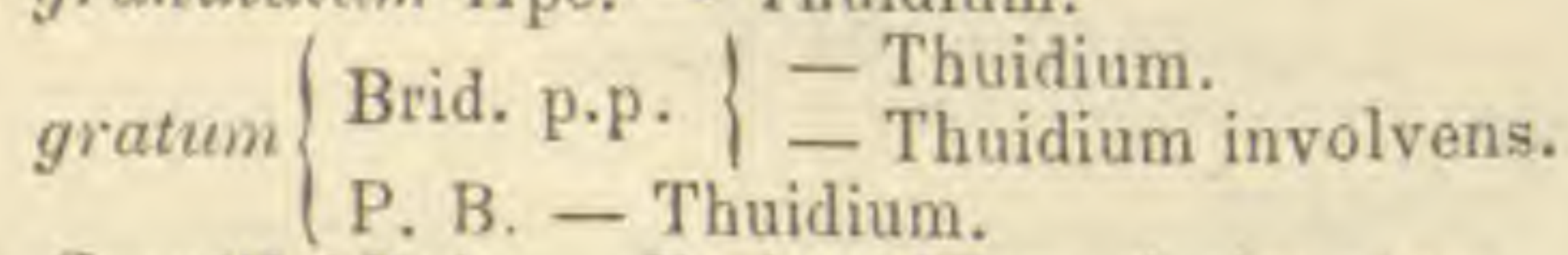

Grevillei Rab. - Eurhynchium circinnatum. 
grimsulanum W. P. Sch. $\left\{\begin{array}{l}\text { (fid. C. M.), - Brachythecium reflexum. } \\ \text { (fid, Lindb.). - Brachythecium Starkii var. } \\ \text { robustum. }\end{array}\right.$

guadalupense $\left\{\begin{array}{l}\text { Brid. - Hookeria. } \\ \text { Spreng, - Hookeria depressa. }\end{array}\right.$

Gueinsii Hpe. - Rhaphidostegium.

var. prostrata C. M. - Rhaphidostegium Gueinzii var. prostrata.

guinense C. M. -- Trichosteleum.

gymnopodum C. M. - Porotrichum.

hakoniense Mitt. - Ptychodium.

Haldanianum Grev, in Ann. of the Lyc. of. Nat. hist. of New-York, 1825, p. 275, t. 23 ; C. M. Syn. II, p. 254; Bryol, eur. VI (mon. p. 23), t. $592 ;$ W. P. Sch. op. cit. p. 765.

$\mathrm{H}$. badense $A$. Br. mss.

H. Cooleyańum Spreng. 1833 (fid. Sull.).

H. cupressiforme var, Bals. el de Not. M. Mediol. 1834, II, n. 29.

H. curvirostrum Brid. Bryol, univ, II, p. 482 ,

H. pulchrum Hook, in Rab. Deutsch. Krypt. Fl. II, p. 273.

Leskea badensis A. in Drumm. M. bor. am. I ed. n. 180 p.p.

Stereodon Haldanei Br. mss.

Lindb. M. Scand. p. 38.

Neerland. Ital, super, Westphal., Magn. Ducat. Bad., Siles., Salisburg., Am. sept. : Nov apon., Jenissei sup., Obi, Caucas. occ. et centr. centr. et or. Nov. Scot., Brunswick, Ottawa, Ontar., reg. sept.,

Exs.: Drumm. M. bor. am. II ed. n. 114.

Faurie PI. Japon. n. 1, 27, 28, 29, 33, 101, 173 b, 188, 190, 191; $207,208,219,3504,3505$.

Mac. Canad. M. n. 355.

Rab. Bryoth. eur. n, 346 et b.

Sull. et Lesq. M. bor. am. II ed, n. 482.

"var. Roellii Ren. et Card. in Bot. Centralbl. 1890, n. 51.

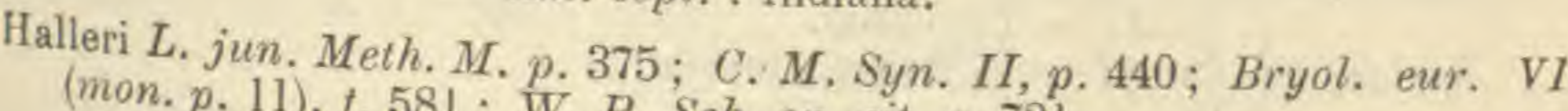
- Am. sept. : Indiana.

Campylium Halleri Lindb. M. Scand, $p .38$.

H. caulibus prostratis, foliis lanceolatis reflexis, operculo conico Hall. Hist. stirp. Helv, n. 1734.

H. Stereodon Halleri Syst. nat. II, p. 1346.

Leskea flagellaris Sch Brid. Bryol. univ, II, p. 603.

1. Ad rup. etis Sehrank Baiers FI. II, p. 462.

deest in sax. praecip. calcar. - Eur. : Reg. montan. et subalp.,

Exs.: Rab.

Un. Bryoth. eur. n. 499, 756, 999.

Balleri Drumm. - H. Macounii.

var, majus Wah. Holluscum.

var, H. f, et W

W. - H. hispidulum.

bamiens Kindb. - Camptothecium Nutallii.

hamatum (Mitt.) Jaeg. Ad, 11, p. 572.

Stereodon hamatus Mitt. M. austr. am. p. 533.

I. Cortic. - Am. sept.: Guatemala. Am. merid. : And. Nov, Granat. et Quitens. 
hamatum Dz. et Mk. - Trichosteleum.

var. semi-mammillosum C. M. - Trichosteleum hamatum vir. semimammillosum.

hamifolium W. P. Sch. Syn. 11 ed. p. 732.

Amblystegium Wilsoni var. $\beta$ hamatum Lindb, M. Scand. $p .33$.

H. aduncum var, giganteum Bryol, eur, VI (mon, p. 35), t. 606.

H. aduncum var. hamatum Bryol. eur. l. $c$.

'H. giganteum Sull. et Lesq. M. bor, am. I ed. n. 316 et II ed. n, 468 (fid. Ren.).

H. Yycopodioides (subsp. Wilsoni) var. americanum Ren, in Husn, Muscol. gall. p. 370.

H. lycopodioides (subsp. Wilsoni) var. hamatum Ren. in op. et l. oc.

Ster. In prat. spongios. - Eur.: Suec., Fenn., Ducat, Megap., Angl., Alsat,, Belg., Helvet. occ., Regiomont. Am. sept.: Minnesota, Wisconssin, Nov. Angl.

Hampeanum C. M. - Rhaphidostegium circinale.

- hamulosum Bryol, eur. VI (mon, p. 20), t. 590; W. P. Sch. op. cil. p. 752.

H. cupressiforme Drumm. M. bar. am. I ed. n. 205 (fd, Kindb.).

H. cupressiforme vai, crispatissinum (Brid.) Br. It. pl. Norveg. un. itin. 1828 .

Stereodon hamulosus Lindb. M. Scand. p. 38.

1. Ad rup. humid, - Eur. : Spitzberg, Scandin., Scot., Alp. Salisburg., Carinth., Bavar., Rhaet. Am. sept.: Groenland, Labrador, Anticosti, Terr, nov., Gaspes., M. Rupestr., Washington.

Exs : Rab. Bryoth, eur, n, 491.

Sull. et Lesq. M. bor. am. Il ed. n. 478?

" var. sikkimense Ren. et Card. in Bull. Soc, roy. bot. Belg. 1895, I, p. 78.

Ster. - As. : Sikkim.

hamulosum $\left\{\begin{array}{l}\text { Froehl, }- \text { H. fastigiatum. } \\ \text { Sull. }- \text { H. depressulum? } \\ \text { Wils. }- \text { H. callichroum. }\end{array}\right.$

hapolypternm C. M. - Ectropothecium.

haplohymenium Harv, - Thuidium.

hastalum $\left\{\begin{array}{l}\text { C. M. - Thuidium. } \\ \text { Duby. - Philonotis laxissima. } \\ \text { Hpe. - Thuidium Stuartii. }\end{array}\right.$

hastile (Mitt.) Jaeg. Ad, II, p. 594.

Stereodon hastilis Mitt. in Journ. of the Linn. Soc. 1864, p. 153.

- As. : Japon.

Hedwigii Lam, et DC, $-\mathrm{H}$. Crista castrensis.

Helicodontium C. M. - Helicodontium tenuirostre.

helvolum Mitt. - Brachythecium.

Henoni Duby Choix de crypt. ex. 1876, p. 11, t. I, f. 5et in Fl. 1877, p. 93

? Raphidostegium Henoni Jaeg. Ad. 1I, p. 474.

Stereodon Henoni Mitt. in Trans. of the Linn, Soc. 1891, p. 181.

Muric. - As, : Japon.

herbaceum Mitt. - Rhynchostegium.

herjedalicum Hartm. - Myurium.

hermaphodilum C. M. - Sematophyllum.

herpetium C. M. - Trichosteleum.

heterochlorum Wils, mss.; Hpe Moosb. p. 19 (nom.).

-?

heteromallum $\left\{\begin{array}{l}\text { Gmel. - Cryphaea. } \\ \text { Wib. - Dicranella. }\end{array}\right.$ 


$$
\begin{aligned}
& \text { heterophyllum }\left\{\begin{array}{l}
\text { Hoffm. - Hylocomium loreum. } \\
\text { Hüb. - H. cuspidatum. } \\
\text { Neck. - H. palustre. } \\
\text { Poir. - Neckera. } \\
\text { aquaticum, polycephalum Dill. - Leskea polycarpa } \\
\text { var. paludosa. } \\
\text { aquaticum, polycephalum repens Dill. - H. palustre. }
\end{array}\right. \\
& \text { heteropterum } \mathrm{Spr} \text { - - Heterocladium. } \\
& \text { heterostachys } \mathrm{Hpe} \text { - Microthamnium. } \\
& \text { heterostichum W. et M. - Aulacomnium. }
\end{aligned}
$$

Heufleri Jur. - H. revolutum.

var. Villardi Ren, et Card. - H. revolutum var, Villardi.

hecastichum Schwaegr. - Pilotrichella.

hians Hedw. - Eurhynchium.

Hildebrandtii $\left\{\begin{array}{l}\text { S., M. - Thamnium. } \\ \text { Garov. - Eurhynchi }\end{array}\right.$

Hillebrandi Lesq. - Brachythecium striatum var. meridionale.

hillianum Hpe. - Leucomiun.

hirtellum C. M. - Thelia.

var, furcatum C. M. - Thelia asprella.

hispidulum Brid. Sp. M. II, p. 198; C. M. Syn. II, p. 440; Lesq. et Jam. Man. p. 378.

Campylium hispidulum Mitt. M. austr, am. p. 631.

H. Halleri var. ? H. f. et W. in Drumm, M. bor. am. II ed. n. 147 .

H. Stereodon stellatus $\delta$ hispidulus Brid. Bryol. univ. II, p, 603 .

1. Ad arbor. - Am. sept.: Nov. Scot., New Brunswick, Gaspes., Ottawa, Ontar., Alberta, Columb. brit., Montana, reg. sept., centr.,

Exs.: : Mac. Canad. M. p. 327 . And. Nov. Granat.

Sull, et Lesq. M. bor. am. II ed. p. 518.

hispidum H, f. et W. - Sciaromium.

Hochsletteri W. P. Sch. - Hyolocomium Berthelotianum.

Hofferi W. et Dy. - Brachythecium.

Hoehneli C. M. in Fl. 1890, p. 497.
Ster.

Holstii Broth. - Rhynchostegium.
homaliocaulon C. M. - Rhynchostegium.

- Afr. : Kilima N'Djaro, M. Aberdare.

homalostegium C. M. - Amblystegium.

lomomallum $\{$ Bert. - H. cupressiforme,

Hookeri (Mitt.) Jaeg. Ad. II, p. 274.

Chaetomitrium Hookeri ej. l. c. p. 558.

Stereodon Hookeri Mitt. M. Ind. or. p. 114.

- As, : Sikkim.

How . - Ectropothecium.

hornum $\mid$ W. et M. - Trichosteleum ambiguum.

hospitans Wib. - Mnium.

Horoeans Hpe. - Isopterygium.

hutitomum C. M. - Plagiothecium,

humile $\left\{\begin{array}{l}\text { Harv. - Rhaphidostegium. } \\ \text { P. B. - Amblystegium radicale. } \\ \text { hiumillimum Mitt. - Rhynchostegium. }\end{array}\right.$ 
Husnoti W. P. Sch, in Besch. Fl. bryol. Antill. fr. p. 88. - Am. sept. : Guadalup., Martinic.

lyalinum Reinw. - Sematophyllum.

hydrophilum C. M. - Ectropotbecium.

hygrophilum $\left\{\begin{array}{l}\text { Brid. - Brachythecium plumosum. } \\ \text { Jur. - Amblystegium plumosum var. limosum. }\end{array}\right.$

hydropteryx K. Sch. - Rhynchostegium rusciforme.

ichnotocladum C. M. - Ectropothecium.

illecebrinum W. P. Sch. - Myuroclada concinna.

illecebrum $\left\{\begin{array}{l}\text { Hedw. - Eurhynchium Boscii. } \\ \text { L. p.p. }\left\{\begin{array}{l}\text { - Aulacomnium turgidum. } \\ - \text { H. purum. } \\ \text { Schultz. - Scleropodium. }\end{array} \text { - trifarium. }\right.\end{array}\right.$

var. americanum Brid, - Eurhynchium Boscii.

var. piliferum de Not. - Brachythecium ambiguum.

var. Tourreltii Brid, - Scleropodium illecebrum.

imbricalulum P. B. - Anomodon rostratus.

imbricatum P. B. - Pilotrichella.

implexum $\left\{\begin{array}{l}\text { Brid. - Pseudo-Leskea atro-virens. } \\ \text { C. M. - Rigodium. } \\ \text { Turn. - Brachythecium populeum. }\end{array}\right.$

iinplicatum C. M. - Brachythecium.

imponens Hedw. Sp. M. 290, t. 77; C. M. Syn. 1I, p. 291; Bryol. eur. VI

(mon. p. 28), t. 597; W. P. Sch. Syn. II ed. p. 754.

H. cupressiforme Hook, in Drumm, M. bor, am. I ed. n. 205 (fid. C. M.).

H. imponens $\beta$ chrysocytus C, M. l. c, p. 292.

H. Stereodon imponens Brid. Bryol. univ. II, p. 618.

H. St. Terrae Novae ej. l. c. p. 619.

Stereodon imponens Mitt. M. Ind. or. p. 96.

2. Lignic., ad terr. et sax. quarzos, et ad rad. arb. - Eur. : Suec., Boruss. sept., Neerland., Voges., Gall. occ. merid. As, : Japon,?, Kashmir, Sikkim. Am. sept.: Terr. nov., ins. Miquel., Nov. Scot, New Brunswick, Ottawa, Ontar., Columb. brit., Vancouver, reg. sept. et centr.

Exs : Mac. Canad. M. n. 348.

Rab. Bryoth. eur. n. 644, 1046, 1246.

Sull. et L.esq. M. bor. am. II ed. 475.

imponens Jam. - H. Watsoni.

var, chrysocytus C. M. - H. imponens.

inaequirameum C. M. - Sciaromium.

inclinatum Mitt. - Rhynchostegium.

incompletum Mitt. - Homalothecium ?

inconspicuum Hsch. - Raphidostegium.

incubans Hsch. et Reinw. - Ectropothecium.

incurvatum Solvad. Crypt. Gevo. n. 80; Brid. Bryol, univ. II, p. 451 ; C. urvatum Scliad. Crypt. Gevo. n. 80 ; Brid. Bryol, univ. II, p. ${ }^{4}$. Sch.
M. Syn. II, p. $416 ;$ Bryol. eur. VI (mon. p. 15), t. $585 ;$ W. P.
op. cit. p. 746.

H. incurvatum $\beta$ leskioides Brid. op. cit. $p, 453$.

H. incurvatum $\gamma$ Swartzii $e j . l$. $c$.

H. leskeoides ej. $S p, M, I I, p, 177$.

H. plumosum Sw. in Act. Holm.

H. Swartzii Brid. op. cit. p. 178.

Leskea plumosa Sw. M. Suec. p. 69.

Plagiothecium incurvum de Not. Epil.

Stereodon incurvatus Mitt. in Trans. of the Linn. Soc. 1891, p. $18 \mathrm{I}$. 
1. In sax. et mur. umbros. - Eur. : Reg. campestr. montos. As. : Japon., Jenissei sup., Caucas, Am, sept.: Terr. nov, ? (fid. C. M.).

Exs. : Rab. Bryoth, eur. n. 1114.

incurvatum P. B. - Pseudo-Leskea atro-virens.

var, leskioides Brid. - H. incurvatum.

var, Swartaii Brid. - H. incurvatum.

incurvum Hpe. - Rhaphidostegium.

indicum C. M. - Stereophyllum.

inerme $\{$ Mitt. - Rhynchostegium.

Schrank. - H. Schreberi (1).

intlatum C.M. in Bot. Centralbl. 1883, n. 2-4.

Amblystegium inflatum Lindb. et Arn. M. As. bor. 1890, II, p. 127.

Ster.

inflatum H. f. et W. - Lembophyllum.

inflectens $\left\{\begin{array}{l}\text { Angstr. - Ectropothecium bryifolium. } \\ \text { C. M. - Ectropothecium. }\end{array}\right.$

inflexirameum C. M. in scherl.; Jaeg. Ad. II, p. 607. - As. : Japon.

inflexum Harv. - Platygyrium.

inordinatum Brid, - Amblystegium radicale.

insigne Milde. - Camptothecium nitens.

instratum Brid. - Trichosteleum.

insulosum Sull. - Rhaphidostegium.

intermedium $\left\{\begin{array}{l}\text { Hpe. - Thuidium Arzobispae. } \\ \text { Lindb. }\{\text { H. Cossoni. } \\ \text { W. et M. (p. 283). - Bryum interm dium. } \\ \text { W. et M. (p. 482). - Brym inclinatum. } \\ \text { × vernicosum San. - H. Cossoni x vernicosum. }\end{array}\right.$

interruptum Brid. - Hylocomium brevirostrum.

intertextum $\left\{\begin{array}{l}\text { Brid. - H. palustre var. julaceum. } \\ \text { Mühlenb. Thuidium scitum. } \\ \text { Voit. - Rhynchostegium rotundifolium. }\end{array}\right.$

intextum Voit. p.p. \{ - Amblystegium serpens.

intorquatum $\mathrm{Dz}$, et $-\mathrm{H}$. palustre var. julaceum.

Tutum Dz, et Mk. - Ectropothecium.

intorto -plicatum Lobarz. in Haiding. Naturw. Abh. I, p. 58; C. M. Syn.

$11, p, 296$.

Ster.

intortum P. B. - Isopterygium.

intricatum $\left\{\begin{array}{l}\text { C. M. - Pylaisia. } \\ \text { Dicks. - Eurhynchium Teesdalii. } \\ \text { Hedw. - Brachythecium velutinum var, intricatum. } \\ \text { Vill. - H. inextricatum. }\end{array}\right.$

inundatum | Brid, - Rhynchostegium rusciforme var. inundatum.

investe Mitt. Dicks. - Leskea polyantha var. paludosa.

involoe Mitt. - Thuidium.

irrepens P. B. - Thuidium.

Tepens Duby. - Rhaphidostegium.

(1) inegtricatum Brid. Bryol. univ. II, p. 548 ; C. M. Syn. II, p. 509.

H. intricatum Vill. Pl. Dauph. III, p. 914.

Brid. 1, e. Rhychostegium oontertum? An Eurhynchium praelongum ? 
irrigatum Zett. M. Pyr. p. 48 et in K. Sv. Akad. Handl. V, n. 10. Amblystegium irrigatum Lindb.

H. napaeum Limpr. - Eur. : Pyren., Ital. super. As. : Caucas.

irriguum $\mathrm{H}$. f. et W. - Amblystegium. irroratum C. M. - Orthothecium? isocladon Bryol. jav. - Trichosteleum. Jacquemonti Br. et Sch. - Thuidium, Jacquini Garov. - Rhynchostegium curvisetum. jamaicense Gmel. - Neckera undulata. Jamesii $\left\{\begin{array}{l}\text { Aust. }- \text { H. uncinatum var. fragile. } \\ \text { L. et J. - Rhaphidostegium. }\end{array}\right.$ Jamesoni Tayl. - Microthamnium. javanicum Bel. - Rhynchostegium. jenissiense L. et A, - Brachythecium. Jolliffi Hook. f. - Rhaphidostegium.

$$
\begin{aligned}
& \text { v. M. p. p. - Myurella apiculata. } \\
& \text { L. - Lencodon. } \\
& \text { Vill. - Myurella. } \\
& \text { julaceum } \\
& \text { erectum sericeum repens, capsulis cylindraceis Dill. - } \\
& \text { Anomodon rostratus. } \\
& \text { Bryi argentei habitu Dill. - Brachytecium acuminatum. } \\
& \text { perichretio setas paene aequante Dill. - Leucodon jula- } \\
& \text { ceus (1). }
\end{aligned}
$$

Jungermannia Hpe. - Amblystegium Sprucei.

jungermannioides Brid, - Amblystegium confervoides.

Junghunii C. M. - Hypnodendron.

kamonense Harv. - Brachythecium.

Kegelianum C. M. - Rhaphidostegium.

var. tenue C. M. - Rhaphidostegium Kegelianum var, tenue.

Kiskii C. M. in Trans, of the N. Zeal. Inst. 1883, p. 294.

Arbor, - Pac. : Nov. Zeland.

Kneiffii W. P. Sch. - H. aduncum var. Kneiffii.

var. filiforme Berggr. - H. aduncum var. filiforme.

var. gracilescens Kindb. - H. aduncum var. gracilescens.

var. laxum Kindb. - H, aduncum var. Kindbergii.

var. platyphyllem Kindb. - H. aduncum var. platyphyllum.

var. reclifoluem Kindb. - H. aduncum var, rectifolium.

var. strictum Berggr. - H. aduncum var. strictum.

Knuthei Rehm. M. Afr. austr, $n, 670$.

Ster.

$$
\text { - Afr.: Transvaal. }
$$

Korthalsii $\{$ Dz. et Mk. - Mniodendron.

hrahatar. - Sematophyllum lancifolium.

krakakammae D. M. - Rhaphidostegium.

Krausei C. M. $\left\{\begin{array}{l}\text { - Brachythecium. } \\ \text { - Hypnodendron. }\end{array}\right.$

kroneanum C. M. - Mniodendron.

Kuitui C. M. - Trichosteleum.

kuripanum Dz. et Mk. - Thuidium Meyenianum.

Kurzii S. Lac. - Ectropothecium.

11) Juliani Brid, Bryol, univ. II, p. 545: C. M. Syn. II, p. 509.

H. capillaceum Vill. Pl. Dauph. III, p. 907.

- An Heterocladium dimorphum? B Brid, 1. c, - Delendum. 
Iacerulum (Mitt.) Jaeg. Ad. II, p, 559.

Stereodon lacerulus Mitt. M. Ind. or. p. 115. 1.

- As. : Ind, or. (sine loc, spec.).

laculo um C. M. - H. fluitans var. laculosum.

Lacunosum Wieb. - H. cupressiforme.

lacustre W. et M. - Bryum.

laete-virens Sm. - Rhynchostegium confertum.

laetum $\{$ Brid. - Brachythecium.

Sull. - Brachythecium pseudo-laetum.

var, denlalum L. et J. - Brachythecium laetum var. dentatum.

laevifo'ium initt. - Brachythecium.

laeviselum $\left\{\begin{array}{l}\text { Crome. - Brachythecium plumosum. } \\ \text { Mitt. - Helicodontium. }\end{array}\right.$

S. Lac. - Homalothecium.

leviusculum $\{$ Hook, f, - Thuidium.

Lamarckii , Mitt. - Homalothecium neckeroides.

Lamarckii Brid. - Brachythecium salebrosum.

lamasicum Spr. - Rhynchostegium.

lamprocarpum C. M. - Brachythecium.

lamprophyllum $\left\{\begin{array}{l}\text { C. M. - Sematophyllum Mittenii. } \\ \text { Hpe. - Eetropothecium. }\end{array}\right.$

lamprostaclyys Hpe. - Plagiothecium.

lanatum Sterm. - Amblystegium fluviatile.

lanceolatum C. M. - Helicodontium.

lancifolium C. M. - Sematophyllum.

lancifrons $\mathrm{Hpe}$ - Porotrichum.

Langsclorffi Hook, - Microthamnium.

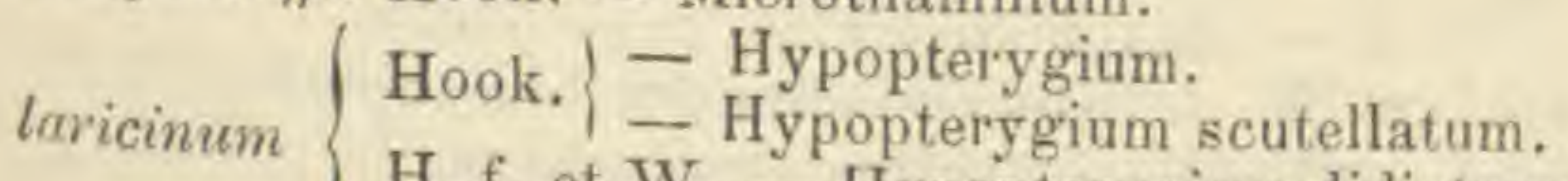

H. f. et W. - Hypopterygium didictyon.

lasiomitrium C. M. - Thuidium Blandowii.

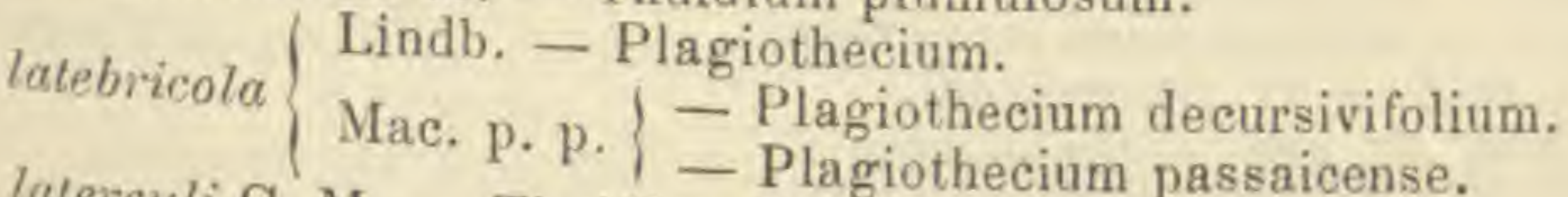

laterculi C. M. - Thuidium ?

latifolium $\left\{\begin{array}{l}\text { Lindb. - Brachythecium. } \\ \text { Tayl. - Ectropothecium. }\end{array}\right.$

lato-caespitosum C. M. in Hildebr. M. Mad. n. 2074.

- Afr. : Madagasc. merid.

Laureri Funk. - Rhynchostegium?

laxatum Mitt. - Rhynchostegium.

laxe-patulum L. et J. - Rhaphidostegium delicatulum.

lasifolium $\left\{\begin{array}{l}\text { Brid. - } A \text { mblystegium riparium. } \\ \text { Schwaegr. - Thuidium. }\end{array}\right.$

laxirete C. M. - Homalia. Thuidium.

laxo-pinnatum Homalia.

lasum

Leche. - Ectropothecium (1).

Lechleri C. M. in Bot. Zeit. 1856, p. 455.

H. cupressoides W. P. Sch, in Lechl. Pl. Chil. n, 619.

S.

- Am. merid. : Valdiv., ins, Juan Fernandez.

(1) laxum P. B. Prodr. p. 65: C. M. Syn. II, p. 509.
H. Stereodon

H. Stereodon laxus Brid. Bryol. univ. II, p. 653.
if Rhacopilum

" Rhacopilum quoddam! : C. M. I. c. - Delendum. 
Lecoultriae Duby. - Rhaphidostegium Duisabonae var. rigidiusculum. Leibergii $\mathrm{D}^{\mathrm{na}} \mathrm{E}$. G. Br. - Thamnium.

leitense (Mitl.) Jaeg. Ad. II, p. 568.

Amblystegium leitense Mitt. M. austr. am. p. 571.

Ster. Paludic. - Am. sept. : Guatemala. Am. merid. : And. Quitens.

Lejolisii Besch. Prodx. bryol. mexic. p. 108.

2. Cortic. - Am. sept. : Mexic. (Mejico, Oajaca).

lentum Mitt. - Isothecjum.

lepidopiloides C. M. - Brachythecium.

lepidum Wils, in sched.

Stereodon lepidus Mitt. M. Ind. or. p. 98.

2 ?

- As. : Sikkim.

Lepineanum W. P. Sch, - Trichostoleum Vernieri.

leptoblastum C. M. - Isopterygium.

leplocarpon Schwaegr. - Rhaphidostegium.

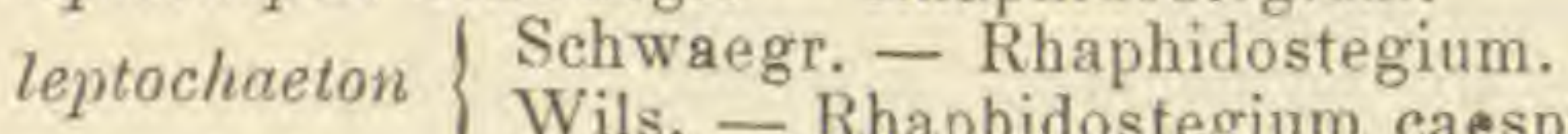

leptoelad

leptodontium Mitt. - Helicodontium.

leptomerocarpon C. M. - Rhynchostegium.

leptomiton C. M. - Isopterygium.

leptopoma Schwaegr. - Hookeria.

leptorhynchoides Mont. - Rhaphidostegium.

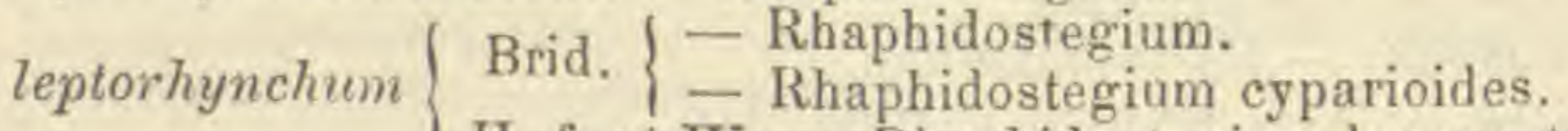

H. f. et W. - Rhaphidostegium leucocytus.

var. $\beta$ Fl. Antarct. - Rhaphidostegium cerviculatum.

lepturum Tayl. - Brachythecium.

Lescurii Sull. - Amblystegium.

Leskea Grev. - Eurhynchium circinnatum.

leskeoicles $\{$ Brid. - H. incurvatum.

W. P. Sch. - Anomodon.

leucochloron (Hpe.) Jaeg. Ad. II, p. 588.

Stereodon leucochloron Mitt. in Trans, and Proced. of the roy. soc. of Victoria, 1883, p. 87 .

Drepano-Hypnum leucochloron Hpe, in Linn. 1874, p. 669.

1. Ad arbor. et terr. - Pac. : Ins, Lord Howe.

leucocladulum C. M. - Tripterocladium.

leucocytus C. M. - Rhaphidostegium.

leuconeuron Sull, - Thuidium.

leucophanes Hpe. - Isopterygium.

leucophyllum Hpe. - Isopterygium.

leucostegum C. M. - Stereophyllum.

leucostomum Hpe. - Rhaphidostegium.

leucotrichum Tayl. - Pilotrichella.

Leveilleanum Bryol. jav. - Fabronia.

lignicola Mitt. - Isopterygium.

Ligularia C. $M$. in Dusen M. Camer. n. 330.

- Afr. : M. Cameroon.

ligulatum $\{$ C. M. - Stereophyllum.

1. W. et M. - Mnium undulatum.

ligusticum de Not. - Brachythecium.

lillipulanum Mont. - Rhaphidostegium. 
limatum H. f. et W. - Ectropothecium australe.

limbatulum C. M. - Sciaromium.

limbatum Sull. - Sciaromium.

Lindbergii $\left\{\begin{array}{l}\text { Bryol. jav, - Trichosteleum. } \\ \text { Mitt. - H. arcuatum. }\end{array}\right.$

Lindigii Hpe. - Rhaphidostegium.

lithophilum $\left\{\begin{array}{l}\text { H. f. et W. - Rhaphidostegium secundifolium. } \\ \text { Hsch. (Fl. Bras.) - Rhaphidostegium loxense var. litho- } \\ \text { philum. } \\ \text { Hsch. (M. Capens.) - Rhaphidostegium sphaerotheca. }\end{array}\right.$ littorale Hpe. - Rhaphidostegium.

littoreum de Not, - Rhynchostegium curvisetum.

livens Schwaegr. - Pilotrichella.

Llanosii Duby in Mém... Genève, 1876, p. 10, t. III, f. 1 et in Fl. 1877, n. 5.

Cortic, - As. : Ins. Philippin.

lonchopelma C. M. - Isopterygium.

lonchophyllum Mont. - Pterogoniella.

lonchopyois C. M. - Thuidium.

longicaule Bryol. jav. - Sematophyllum.

longicollum W. et M. - Webera.

longiscupidatum Mitt. - Brachythecium.

longicuspis (Arn.). Par

Amblystegium longicuspe Am. M. As. bor. 1890, II, p. 123.

H. aduncum $\delta$ molle binerve San. in Bihang...p. 38 et in Hedwig. 1887.

2? Paludic. - As. : Jenissei infer.

longiflorum P. B. - H. longisetum.

longifolium (Mitl.) Jaeg. Ad. II, p. 568.

Amblystegium longifolium Mitt. M. austr, am. p. 571.

Ster.

- Am. merid. : Ins. Maclov.

longifolium $\left\{\begin{array}{l}\text { C. M. - Anomodon. } \\ \text { Mitt. - Eurhynchium. } \\ \text { Schultz. - Amblystegi }\end{array}\right.$

var, petrophitum Brid. Amblystegium riparium var. longifolium.

longifrons C. M. - Pterobryella. - Amblystegium riparium var, 'petrophilum.

longinerve $\{$ Duby. - Sematophyllum.

longipes Besch. in Ann. sc. nat, 1893, p. 388.

H. longisetum W. P. Sch. in Savat. M. Jap. n. 724.

2.

- As, : Japon.

longipes Lindb. - Eurhynchium elinocarpum.

longirostralum C. M. - Rhaphidostegium.

longirostrum Ehrh. - Enrhynchium striatum.

longisen $\{$ Schleich. - H. aduncum.

longissimum Raddi. Sch. - H. longipes (1).

Lorentzianum Meteorium.

p. 767.

1. Ad terr. argill, cale, in decliv, silvat. - Eur. : Yavar. super.

Exs.: Rab. Bryoth. eur. n. 488.

(1) longisetwem Brid, Bryol. univ. II, p. 542 ; C. M. Syn. II, p. 508.

H. longiflorum P. B. Prodr. p. 65.

" Forsan Amblystegii serpentis var. ». Brid. 1. e. - Delendum. 
loreum $\left\{\begin{array}{l}\text { L. - Hylocomium. } \\ \text { montanum, capsulis subrotundis Dill. - Hylocomium Inreum. }\end{array}\right.$

var. heterophyllum Brid. - Hylocomium loreum.

loricalycinum C. M. - Thuidium.

loriforme Hpe. - Mierothamnium.

loxense Hook, - Rhaphidostegium.

$\gamma$ rivulare C. M. - Rhaphidostegium loxense var. lithophilum.

loxocarpum Angstr. - Ectropothecium inflectens,

lucens L. - Pterygophyllum.

lucidulum H. f, et W. - Plagiothecium.

lucidum eor. - Plagiothecium.

Ludwoigianum Spreng. - Rhynchostegium confertum.

Ludroigii Brid. - Enrhynchium Stockesii.

luridum $\left\{\begin{array}{l}\mathrm{Hedw} .-\mathrm{H} \text {. palustre. } \\ \mathrm{Sw} . \text { - Amblystegium fluviatile. }\end{array}\right.$

lusitanicum W. P. Sch. op. cit, p. 781.

Ster. In rivul. - Eur. : Lusitan.

luteolum $\{$ C. M. - Brachythecium laetum.

Mitt. - Homalothecium.

Tuteo-nitens $\{$ Ren, et Card. - Plagiothecium.

W. et Dy. - Rhynchostegium.

lutescens $\left\{\begin{array}{l}\text { Drumm. - Brachythecium glareosum. } \\ \text { Huds. - Camptothecium. } \\ \text { crispum, Lycopodii facie Dill, - H. rugosum. }\end{array}\right.$

luxurians $\{$ Dz. et Mk. - Sematophyllum.

Duby. - Sematophyllum pycnophyllum.

Luzoniae C. M. - Ectropothecium.

lychnites (Mitt.) Jaeg. Ad. 1I, p. 562.

Stereodon lychnites Mitt. M. Ind. or. p. 114.

2.

- As. : Khasia, M. Neilgherr., Ceylan.

lycopodioides Schroaegr. Suppl. I, II, p. 300; C. M. Syn. II, p.423; Bryol. eur. VI (mon. p. 45), l. 613-614; W.P. Sch. op. cit. p. 732.

Amblystegium lycopodioides de Not. Briol. ital. p. 138.

H. aduncum var. rugosum $H$. et $T$. Muscol. brit. $p$, 111 .

H. diastrophyllum Lam, et DC. Fl. fr, I, p. 528.

H. rugosum $W$. et $M$. Bot. Tasehb. p. 362 .

H. scorpioides Schultz Fl. Starg. n. 923.

H. Stereodon lycopodioides Brid. Bryol. univ. II, p, 632 (excl. syn. Dill.).

2. In pratis spongios. - Eur.: Reg. campestr. zon. intermed. et sept., montan. et subalp. zon. merid. As. : Jenissei sup, et med. (1). Am. sept. : Groenland.

Exs.: Rab. Bryoth, eur, n. 752, 914, 1200.

var. americanum Ren, $-\mathrm{H}$. hamifolium.

var. brevifolium Berggr. - H. brevifolium.

var. hamatum Ren. - H. hamifolium.

var. miquelonense R. et C. - H. scorpioides var. miquelonense.

subsp. Wilsoni Ren, - H, Sendtneri var. Wilsoni.

lycopodioides $\times$ fluitans San. Beschr. $p .50$.

Amblystegium lycopodioides $\times$ fluitans L. et A. M. As, bor. 1890, $I I$, p. 122.

2.

- Eur. : Lappon. As. : Jenissei med.

(1) Formae : genuinum, lapponicum, lapponicum-Sahlbergii, majus, majusHolleri. (Sanio in L. et Arn. I. c.). 
Mac-Leanum Rehm. M. Afr, austr. n. 677.

Ster.

- Afr.: Transvaal.

Macounii Kindb, in Bull. Torr, bot. Club, p. 279 et in Mac. Cat, p. 224.

H. Halleri Drumm. M. bor, am. I ed., p. 191.

1. Terr. - Am. sept.: M. Rupestr.

macroblepharum W. P. Sch. - Microthamnium.

macrobolax C. M. - Ectropothecium.

macrocarpon Hsch. - Hylocomium.

macrocomum C. M. - Brachythecium.

var. robustius C. M. - Brachythecium macrocomum var, robustius. macroclontium Hsch. - Microthamnium.

macrogynum Besch. in Ann. sc. nat. 1892, I, p. 91.

2. Ad rup. madid, in silv. - As. : Yunnan.

macrorliynchum Hsch. - Rhaphidostegium.

macrostegium $\mathrm{S}$, et L. - Eurhynehium ?

macrotheca C. M. - Porotrichum macrocarpum.

madagassum C. M. - Trichosteleum.

maderense Mitt. - Amblystegium.

? magellanicum P. B. Prodr. p. 66 ; Brid. Bryol. univ. II, p. 541 ; C. M. Syn. 11, p. $27(1)$. - Am. merid. : Fret. Magellan.

mahahaicum C. M. - Porotrichum.

Muilusiae C. M. - Rhaphidostegium.

malacoblastum C. M. - Ectropothecitim.

mulacobolum C. M. - Microthamnium.

malacodes (Mitt.) Jaeg. Ad. II, p. 594.

Ctenidium malacodes Mitt. M. austr, am. p. 509.

Cortic. - Ais. merill. : And. Nov. Granat, et Quitens.

mammillatum Funk. - H. fastigiatum.

mammosum C. M. - Trichosteleurn,

Mandoni W. P. Sch, in Mandon Pl. Boliv. n. 171l.

- Am. merid. : And. Boliv.

marginatum $\left\{\begin{array}{l}\text { H. f. et W. - Hypnodendron. } \\ \text { W. et M. - Mnium serratum. }\end{array}\right.$

maritimum C. M. - Rhaphidostegium.

Martianum $\{$ Ltz. - Trichosteleum.

marylandi Sendin. - Thuidium minutulum.

maslandicum C. M. - Rhaphidostegium demissum var. marylandicum.

mascarenicum C. M. - Thuidium.

mauritianum Bel, Voy. Ind. or. Bot. II, Crypt. p. 93, t. 10, f. 3; C. M. Syn. II, p. 407 .

Ad arbor. - Afr.: Ins. Franciae.

Maximovickzii Borsz. - Myuroclada concinna.

M'Bangae C. M. - Isopterygium.

mediterraneum Sendtn, - Eurhynchium circinatum,

medium Dicks, - Leskea polycarpa.

megapelma C. M. -- Rhynchostegium.

(1) a Verosimiliter Mniadelphus n, C, M, 1, c. 
megaptilon Sull. - Camptothecium.

megasporium Duby. - Rhaphidostegium.

melanocarpum C. M. - Brachythecium oxyrhynchum.

menadense Bryol, jav. - Rhynchostegium.

Mensiezii Hook. - Hypnodendron.

meridense C. M. - Brachythecium.

meridionale W. P. Sch. - Eurhynchium striatum var. meridionale.

Mertensii Weimm. - Hylocomium.

mexicanum Mitt, in sched. ; Jaeg. Ad. II, p. 562.

$$
\text { - Am. sept. : Mexic. }
$$

Meyenianum Hpe. $\left\{\begin{array}{l}\text { - Ectropothecium. } \\ \text { - Thuidium. }\end{array}\right.$

micans Wils, in Hook. Fl. brit. V, II, p. 86; C. M. Syn. II, p. 290; W. P. Sch. Syn. II ed. p. 784.

Chrysobryum micans Lindb, in Sull. Ic. M. Suppl. p. 91, t. 67.

H. Novae Cesareae Aust. in Lesq. et Jam. Man. p. 356 et M. Appal. n. 440.

Rhaphidostegium Novae Cesareae Ren. et Card. in Rev. bryol. 1893, p. 21.

Rhynchostegium Novae Cesareae A ust. in Coult. Bot. Gaz. I, p. 30.

Stereodon micans Mitt. M. Ind. or. p. 114.

2. ot et fr. ign. Ad rup. et sax. irror., praecip. ad catar. - Eur.: Britann. As. : Sikkim. Am, sept.: New Jersey, Pensilv.

Exs. : Rab. Bryoth. eur. n. 545.

micans $\{$ H. f. et W. - Camptochaete gracilis.

Sw. - Plagiothecium.

micranthum Wils. - H. callichroum.

microcarpoides C. M. - Rhaphidostegium.

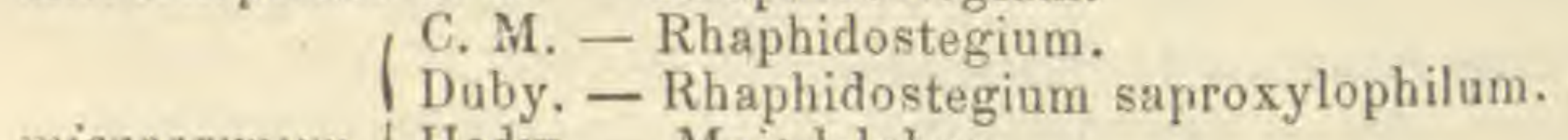

microcarpum / Hedw. - Mniadelphus.

Hook. - Trichosteleum brachypelma.

Hsch. - Trichosteleum ambiguum.

var. Sull, - Rhaphidostegium microcarpum var, anisocarpon.

microcladum $\left\{\begin{array}{l}\text { C. M. - Thuidium. } \\ \text { Dz. et Mk. - Trichosteleum. } \\ \text { Hpe. (fid. C. M.). Trichosteleum Kurzii. } \\ \text { Tayl. - Rhaphidostegium. }\end{array}\right.$

microcranthum P. B. - Mniadelphus microcarpus.

microdendron C. M. - Homalia.

microphyllum $\left\{\begin{array}{l}\text { Hsch. - Pseudo-Leskea muricola. } \\ \text { Muihlenb. - Thuidium gracile. } \\ \text { Sw. - Pseudo-Leskea. }\end{array}\right.$

micropodon Brid. - Leptodon trichomitrium.

micropyxis C. M. - Rhaphidostegium.

microthamnioides C. M. in Ule Bryoth, brasil, n, 189.

In silv, paludos, $-A m$, merid. : Brasil, austr. or.

microthamnioides C. M. (Abh. Brem.) - Trichosteleum.

microtheca C. M. - Pterogoniella.

microvagum C. M. - Lembophyllum.

Mildeanum W. P. Sch. $\left\{\begin{array}{l}\text { Brachythecium acutum. } \\ \text { Brachythecium salebrosum var. palustre. }\end{array}\right.$ 
$\operatorname{minimum}\left\{\begin{array}{r}\mathrm{P}, \mathrm{B} .- \text { Rhaphidostegium microcarpum. } \\ \text { foliis ovato-lanceolatis, capitulis erectis, operculis conicis } \\ \text { Hall. - Amblystegium subtile. }\end{array}\right.$ minusculum Wils. - Thuidium.

minutirameum C. M. - Isopterygium.

minutissimum S, et L. - Amblystegium.

minululum $\left\{\begin{array}{l}\text { Hedw. - Thuidium. } \\ \text { Hsch. - Thuidium Schiedeanum. } \\ \text { Hsch. - Thuidium versicolor. }\end{array}\right.$

minutum Mitt. - Rhegmatodon.

Miquelii Bryol. jav. - Isopterygium.

miradoricum C. M. - Isopterygium.

Mittenii Spr. - Helicodontium.

mixlum C. M. -- Porotrichum.

mnioides $\left\{\begin{array}{l}\text { Hook. - Rhizogonium. } \\ \text { Schwaegr. - Rhizogonium sublasilare. }\end{array}\right.$

Moènkemeyeri C. M. - Thamnium.

Mohrianum C. M. in Linn. 1874, p. 656.

H. affine Besch. Prodr. bryol. mexic. p. 108.

1. Lignic, - Am. sept. : Mexic.

Molendoanum W. P. Sch, op. cit, p, 739.

2. Ad rup. schist. calc. - Eur. : Salisburg. infer.

Molkenboërianum C. M. - Rhaphidostegium.

molle Dicks. Fasc. II Pl. crypt. p. 11, t. 5, f. 8; W. P. Sch. op. cut. p. 775 (1).

Amblystegium molle Lindb. M. Scand. $p .33$

H. Closteri Aust. M. Appal, n, 429 .

1. Ad sax. rivul. alp. - Eur.: Spitzberg, Alp. Scot., Sabaud. (M. Blanc.). Am. sept, : Groënland, Carol. sup., Virgin. occ., Oregon.

Exs. : Sull. et Lesq. M, bor. am. II ed. n. 451.

"var, Schimperianum (Ltz.) W. P. Sch. l.c.

Amblystegium Schimperianum var. Schimperianum Lindb. 1.e.

H, Schimperianum Ltz. Moosst. p. 123, $t .5$.

Limnobium Schimperianum de Not. Epil. p. 160.

In font. frigid. - Eur. : Lappon., Tirol., Alp. Sabaud. (M. Blanc.).

molle $\left\{\begin{array}{l}\text { C. M. p.p. }\left\{\begin{array}{l}-\mathrm{H} . \text { alpestre. } \\ \text { Wils. }- \text { Hilatatum. }\end{array}\right. \\ \text { Wilatatum. }\end{array}\right.$

Molleri S. M. - Thamnium,

molliculum $\left\{\begin{array}{l}\text { Lindb. - Brachythecium. } \\ \text { Sull. - Isopterygium. }\end{array}\right.$

molluscoides Sull. - Fetropothecium sodale.

molluscum Hédw. M. frond. IV, p. 56, t. 22; Brid. Bryol, univ. II, p. 519 ; C. M. Syn. II, p. 297; Bryol, eur. VI (mon. p. 29), t. 598;

W. P. Sch. op. cil. p. 769.

Ctenidium molluscum Lindb. M. Seand. p. 38.

H. compressum Roth Fl. Germ. III, p. 286.

H. Crista castrensis ej. op, oit. p. 282.

(1) "Descriptio $H$. mollis in C. M. Svn. II, p. 431, part, ab $H$. dilatato, part. ab $H$. alpestivi desumpta videtur, , W. P. Sch. I. c. 
H. filicinum cristum castrensem repraesentans Dill. Hist. M. p. 254 p.p., t. $36, f .20 \mathrm{~A}-\mathrm{B}$

H. Halleri Timm. Prodr. fl. Megap. n. 829.

H. Timmii Brid. M. Rec. II, $I I, p .123$.

H. Stereodon subrectifolius ej. Bryol. univ, II, p. 619.

2. Ad arb. rad, rup. et sax. praepr. calc. - Eur. : E reg. campestr. usq. in subalp. As. : Kamschatka, Caucas. A fr. : Alger. Am, sept.: Terr. nov., Nov. Scot., New Brunswick, Gaspes., Ottawa, reg. sept. et or.

Exs, : Mac. Canad. M. n. 344.

Rab. Bryoth, eur, n. 1244.

Sull. et Lesq. M. bor. am. II, p. 471.

« var. condensatum W.P. Sch. op. et $l$. cc.

Ad terr. silvat. - Eur. : Ut typ. Am. sept. : Reg. sept. et or.

Exs, : Drumm. M. bor, am. II ed, n. 149 ?

Rab. Bryoth. eur, n. 492.

\& var. erectuna W. P. Sch. op. et $l$. cc.

Ad terr. arenos. vel humos. humidiuse. - Eur. : Gall, merid. (Massilia), etc. Am. sept. : Ut praeced.

« var. gracile Boul. M. Fr. ; Husn. Muscol. gall. p. 409.

Ut et ubi typ.

"var. squarrosulum Boul, et Husn. ll. cc.

H. delitescens Boul. prius.

Ut et ubi typ.

Monbutloviae C. M. - Plagiothecium.

moniliforme Wahlenb. -- Myurella julacea.

var. apiculatum Sormm. - Myurella apiculata.

monoicum Bryol, jav. - Sematophyllum.

Montagnei $\left\{\begin{array}{l}\text { C. M. - Ectropothecium. } \\ \text { Sull. - Eetropothecium crassicaule. }\end{array}\right.$

montanum Wils. mss.; Sull. M. of U. Sl. p. 72 et Ic. M. p. 181, t. 113;

James in Proced. of the Acad. sc. Philad. 1855; W. P. Sch. op. cit. p. 780 .

Amblystegium montanum Lindb. M. Scand. p. 33.

H. rivulorum S. et L. in Sull. M. of U. St. l. c.

1. Ad rup. madid. - Eur. : Norveg. merid. Am. sept. : Terr. nov,, M. Alb., Oniario.

Exs. : Sull. et Lesq. M. bor. am. I ed, n. 306 et II ed. n. 453.

montanum Lam, -- Antitrichia curtipendula.

monumentorum Duby. - Ectropothecium.

Moorei Broth. - Rhynchostegium.

Moorii Rehm. M. Afr. austr. n. 396. - Afr. : Austral.

morense Schleich. - Lencodon sciuroides var. morensis.

Morettii Garov. - Ptychodium plicatum.

Moritzi $\left\{\begin{array}{l}\text { C. M. - Ectropothecium. } \\ \text { Duby. - Rhacopilum spectabile. }\end{array}\right.$

Moseri Kindb. in Ott. Natur. IV, p. 65 et in Mac. Cat.p. 229.

1. Ad Populos, - Am. sept, : Terr, nov., New Brunswick.

mosquitense Brid. - Isothecium myurum.

Mossmannianum C. M. in Bot. Zeit. I851, p. 565.

H. cupressiforme var. minus H. f. et W. Fl. of the N. Zeal. II, p. 111 et Fl. Tasm, II, p. 212. 
Stereodon cupressiformis var. Mossmannianus Mitt, in Journ. of the Linn. Soe, 1859, p. 83.

1. Cortic. et lignic, - Pac.: Austral, or., Nov, Zeland., Tasman.

? Mougeotianum A. Rich, in Fl. Nov. Zeel. p. 57; C. M. Syn. II, p. 13 (1).

Rhacopilum Mougeotianum Jaeg. Ad. II, p. 6().

$$
\text { - Pac. : Nov. Zeland. }
$$

mucidum C. M. - Mierothamnium.

mucronatum $\left\{\begin{array}{l}\text { C. M. - Acrocladium. } \\ \text { P. B. - Rhacopilum tomentosum. }\end{array}\right.$

Mühlenbeckii Hartm, - Plagiothecium.

Mühlenbergense P. B. - H. stellatum.

Mühlenbergii P. B. - Cylindrothecium compressum.

Mülleri $\left\{\begin{array}{l}\text { C. M. - Rhynchostegium. } \\ \text { Hpe. - Amblystegium. }\end{array}\right.$

? multiflorum Schoaegr. Suppl. I, II, p. $202 ;$ C. M. Syn. I1, p. 320.

Leskea multiflora Brid. Bryol. univ. $I I, p, 291$.

Ster. Terr. - Afr.: Ins. Borbon.

multiflorum $\left\{\begin{array}{l}\text { P. B. - Leskea polycarpa. } \\ \text { Tayl. }\{\text { (fia. C. M.). - Pylaisia heteromalla. }\end{array}\right.$ mundemonense $\mathrm{Hpe}$ - Rhaphidostegium.

mundulum Hook. f. et Wils. Fl. of the N. Zeal. II, p. 112, t. 91 f. I et Handb. p. 476.

1.

- Pac. : Nov. Zeland.

mundulum Sull. - Ectropothecium gracilisetum.

mundum C. M. - Ectropothecium?

murale Hedw. - Rhynchostegium.

muricatulum $\left\{\begin{array}{l}\text { C. M. - Thuidium Pamperum. } \\ \text { Hpe. - Thuidium. }\end{array}\right.$

muricolum C. M. - Thuidium.

muriculatum H. f. et W. - Eurhynchium.

mutabile Brid, - Lescuraea striata.

muticum Sw. - H. Schreberi.

mycostelium Hpe. - Ectropothecium.

Hedw. - Isothecium myurum.

Lag. -. Camptothecium lutescens.

L. - Eurhynchium.

brevius et crassius, capsulis cernuis Dill. - Rhynchostegium murale.

myosuroides crassius, capsulis erectis Dill. - Isothecium myurum.

sericeum, tenuius, capsulis erectis Dill. - H. cupressiforme var. tectorum.

setis brevissimis Dill. - Forstroemia trichonitrion.

tenuius, capsulis nutantibus Dill. - Eurhynchium myosuroides.

var. fliforme Web. - Pylaisia polyantha.

var, praelongum Web. - Camptothecium lutescens.

var, stoloniferum C. M. - Eurhynchium.

-var. Huds. - Rhynchostegium murale.

myosurum $\left\{\begin{array}{l}\text { Gmel. - Isothecium myurum. } \\ \text { Schrad. - Eurhynchium myosuroides. }\end{array}\right.$

(I) An Hypopterygium ?, C. M. 1. c. 
myurum Poll. - Isothecium.

nabambissense C. M. - Thuidium.

nano-Crista-castrense C. M. - Ectropothecium.

nano-globeum C. M. - Isopterygium.

nano-operculatum C. M. - Microthamnium.

nano-pennatum Broth. - Rhynchostegium.

nano-polymorphum C. M. in Linn. 1878-79, p. 498.

1.

- Am. merid. : Venezuela.

nanopyxis C. M. - Rhaphidostegium.

nanothecium C. M. - Rhaphidostegium.

nanum C. M. - Rhaphidostegium (1).

napaeum Limpr. - H. irrigatum.

napoanum de Not, in Mem. Acad... Torino, II ser., XVIII, p. 438 c. ic. - Am. merid. : Columb.

natalense $P a r$.

H. brevifolium Rehm. M. Afr a a astr. n. $675 b$.

Ster.

- Afr. : Natal.

Naumanni C. M. \{ $\begin{aligned} & \text { Hypnodendron. } \\ & \text { Thuidium. }\end{aligned}$

naviculare Brid. - Phyllogonium viscosum.

Neckera $\left\{\begin{array}{l}\text { Schwaegr. - Thamnium neckeroides. } \\ \text { W. P. Sch. - Porotrichum Valdiviae. }\end{array}\right.$

neckeraceum C. M. - Rhaphidostegium.

neckeraeforme Hpe. - Porotrichum.

neckeroides $\left\{\begin{array}{l}\text { Hook. (fid. C. M.). - Thamnium. } \\ \text { H. f. et W. - Thamnium alleghaniense. } \\ \text { Mac. - Thamnium alopecurum. }\end{array}\right.$

neckeroideum Mont. - Porotrichum insularum.

neelgheriense $\left\{\begin{array}{l}\text { C. M. - Orthothecium. } \\ \text { Bryol, jav. - Orthothecium Celebesiae. }\end{array}\right.$

var. ceylanicum C. M. - Orthothecium celebesiae var. ceylanicum. neglectum C. M. - H. palustre var. julaceum.

Nelsoni (Broth.) Par.

Stereodon Nelsoni Broth. in EEfv. of Finska Vet. - Soc. Foerh. 1895, p. 70.

2. $\delta^{7}$ ign. Lignic. - Pac. : Tasman.

nematocaulon C. M. - Rhaphidostegium.

nematogonium C. M. - Brachythecium.

nemorosum Koch in Brid. Bryol. univ. II, p. 422; C. M. Syn. II, p. 255;

Bryol. eur. VI (mon. p. 24), t. $593 ;$ W. P. Sch. Syn. II ed. p. 766.

H. subrectifolium Sull. M. Allegh. n. 15.

Stereodon nemorosus Lindb.

2. Lignic. - Eur. : Palatin., Bavar. As. : Caucas. occ. Am. sept. : New Brunswick, Carol, sept., Mexic.

Exs. : Rab. Bryoth. eur. n. 483.

nepalense $\left\{\begin{array}{l}\text { Br. p.p. - Trichosteleum turgidellum. } \\ \text { Schwaegr. - Trichosteleum. }\end{array}\right.$

nervatulum C. M. - Isopterygium.

(1) nanum Vill. Pl. Dauph. III, p. 915; Brid. Bryol. univ. II, p. 549; C. If. Syn. II, p. 509. - Quid? Delendum. 
nervosum $\left\{\begin{array}{l}\text { C. M. - Leskea. } \\ \text { Hook, }\end{array}\right.$

nevadense Lesq. - Campto-Leskea prionophylla.

Niam-Niamiae C. M. - Trichosteleum?

nictans Wils. in sched.

Stereodon nictans Mitt. M. Ind. or. p. 98 .

1.

- As. : Sikkim.

Nielnerianum C. M. - Sematophyllum. nlgrescens Sw. - Papillaria.

nigricans $\left\{\begin{array}{l}\text { Hpe. - Pilotrichella flexilis. } \\ \text { Hook. - Pilotrichella, } \\ \text { Vill. - Cinclidotus aquaticus }\end{array}\right.$

nigricaule Brid. - Rhaphidostegium?

nigro-viride $\left\{\begin{array}{l}\text { C. M. - Brachythecium. } \\ \text { Turn. }\end{array}\right.$

nitens $\left\{\begin{array}{l}\text { Schreb. - Camptothecium. } \\ \text { Timm. - H. cupressiforme. }\end{array}\right.$

nitidulum Wahlenb. - Plagiothecium.

nitidum (Hook. f. et Wils.) C. M. Syn. II, p. 382.

Leskea nitida $H$. $f$. et W. in Lond. Journ. of bot. 1844, p. 551 et $\mathrm{Fl}$. Antaret. $11, p .416, t$ 154, f. 6 .

Stereodon nitidus Mitt. M. austr. am. p. 535.

2 ?

- Am. merid. : Fuegia, ins. Eremit, et Stat.

nitidum Whalenb. - Plagiothecium nitidulum.

nitrophilum Spr. Cat. p. 20 et exs. n. 1428.

- Am. merid. : And. Quitens.

nivale Llz. Moosst. 1864, p. 122, t. 5, f. B.; W. P. Sch. op. cit. p. 794.

2. Inter lapid. aq. nival irror. - Eur.: Alp. Carinth.

nodiflorum Wils. - H. polygamum.

norfolkianum C. M. - lsopterygium.

norvegieum W. P. Sch, Syn. I ed, p. 637 et 11 ed. p. 778.

Amblystegium viridulum Lindb. $M$. Scand. $p .33$.

H. viridulum Hartm. Skand. Fl. V ed. p. 324; C. M. Syn. II, p. 417 .

Limnobium norvegicum Bryol. eur. VI (mon. p. 6), $t .576$.

1. In rivul. - Eur. : Lappon., Norveg. As. : Jenissei inf. Am. sept. : Groenland.

Notarisii | Boul. - Thuidium decipiens.

nolerophilum $\mathrm{Sb}-\mathrm{H}$. ambiguum.

Nove Ang. et L. - Amblystegium irriguum var. spiniforme.

Novae Angliae $\left\{\begin{array}{l}\text { Mac. - H. chloropterum, } \\ \text { S. et L. - Brachythecium. }\end{array}\right.$ Novae Cesarece Aust. - H. micans

Novo Cesarece Aust. - H. micans.

novo-caledenicht. - Ectropothecium ?

novo-caledonicum C. M. - Eurhynchium.

novo-granatense Hpe. - Plagiothecium.

nubigena (Mitt.) Jaeg. Ad, II, p.603.

Stereodon nubigena Mitt. M. Ind. or. p. 109.

Ster. - As.: Sikkim.

nudicaule Schwaegr. - Leucodon domingensis, 
? nuka-hivense W. P. Sch. in Jardin Enum. p. 20 (nom .).

Microthamnium macroblepharum? (fid. Besch.).

- Pac. : Nouka-Hiva.

mutans $\left\{\begin{array}{l}\text { Nees, - Ectropothecium. } \\ \text { W. et M. - Webera. }\end{array}\right.$

Nuttalii Wils. - Camptothecium.

Oakesii Sull. - Hylocomium.

obliquerostratum Mitt, - Helicodontium.

obliquifolium C. M. - Rhaphidostegium galipense.

oblongifolium Hpe. in Linn. 1859 , p. 641.

Amblystegium oblongifolium Mitt, in Tians. and Proced, of the roy.

Soc, of Victoria, 1893, p. 87.

Ster. Aquat. - Pac. : Austral. or., Tasman.

oblongifolium $\mathrm{S}$. et $\mathrm{L}$. - H. chinense.

obscurum $\left\{\begin{array}{l}\text { Brid. - Rhynchostegium curvisetum var. longinerve? } \\ \text { C. M. - Leskea obscura. }\end{array}\right.$

obtusatum Wahlenb. - Plagiothecium denticulatum var. obtusifolium.

obtusifolium Hpè. et C. M. in Bot. Zeit. 1856, p. 457.

1. Ad arbor. - Am. merid. : Brasil. austr. or.

obtusifolium $\left\{\begin{array}{l}\text { Brid. - Plagiothecium denticulatum var. obtusifolium. } \\ \text { Dicks. - Rhynchostegiom rusciforme var. inundatum. } \\ \text { Hook. - Rhynchostegium. }\end{array}\right.$

obtusum Vill. - H. stramineum. .

obtusulum Mitt. - Amblystegium.

occidentale Sull. et Lesq. in Sull. Ic. M. Suppl. p. 105, ı. 81 (1).

Ad arbor. - Am. sept. : Oregon.

occidentale Hpe. - Brachythecium.

ochraceum Turn, hb. et in Wils. Bryol. brit. p. 400; W. P. Sch. Syn. 1 ed. p. 639 et 11 ed. p. 782.

Amblystegium ochraceum Lindb. M. Soand. p. 33.

Limnobium ochraceum Bryol. eur. VI (mon. Suppl. p. 2), t. 580.

Stereodon ochraceus Mitt. in Jowrn. of the Linn. Soe. VIII, p. 42.

2. Ad sax. et rup. irror. riv. frigid. - Eur.: Spitzberg, ins. Ursor. ;

e reg. mont. usq. in subalp. per tot. zon. interm. et sept., rariss.

fructif. As. : Jenissei, Caucas. occ. Am. sept. : Groenland, fret.

Davis, sin. Hudson, Labrador, Terr. nov., Nov. Scot., New Brunswick, lac. Super., Saskatchewan, M. Alb., Allegh., Catskill et Selkirk, Columb. Brit., Alaska, Sitka, Washington, Oregon, Wyoming, reg. sept. et or.

Exs.: Mac. Canad, M. n. 360.

Rab. Bryoth. eur, n, 693, b et c, 844.

Sull. et Lesq. M. bor. am. 11 ed, n. 452.

Un. itin. 1867, n. 9.

« var. flaccidum Milde.

Montana.

- Eur.: Siles? Am. sept.: Washington, Oregon,

ochron Schwaegr. - Ectropothecium dealbatum.

octodiceroides C. M. - Taxithelium.

odontocalyx C. M. - Stereophyllum. 
oedipodium Mitt. - Brachythecium.

oedistegum C. M. - Brachythecium.

ceneum Mitt. - Camptothecium.

Oldhami (Mitt.) Jaeg. Ad. II, p. 595.

Stereodon Oldhami Mitt. in Journ. of the Linn. Soo. 1864, p. 154.

2. Rupic. - As. : Japon.

Olfersii Hsch. - Rhaphidostegium.

omalosekos W. et Dy. - Stereophyllum.

opacodon Sull. in Proced. of the Am. Acad... 1854 et in U. St. Expl.

Exped. Wilkes, p. 14, t. 11 .

- Pac. : Ins. Hawaï.

orbiculare Hpe. - Amblystegium.

arbiculatum Mitt. - Psendo-Leskea.

oreganum Sull. - Eurhynchium.

Ornellanum Mdo. Moosst. p. 109 (fid. Jaeg. Ad. II, p. 605) et Bayern's

Laubm, p. 267.

Scleropodium Ornellanum Mdo. in Lts, Bryol. Notizb. p. 69.

- Eur. ; Alp. Algov., Tirol. merid.

omithopodioides $\left\{\begin{array}{l}\text { Fl. Dan. - Isothecium myurum } \\ \text { Huds. - Pterogonium gracile. } \\ \text { L. - Rhacopilum tomentosum. } \\ \text { Scop. - Neckera complanata. }\end{array}\right.$

? Orsinianum (de Not.) Jaeg. Ad. II, p. 566.

Amblystegium Orsinianum de Not. Epil. p. 141.

- Eur.: Apennin.

orthocarpon $\left\{\begin{array}{l}\text { Angstr. - Plagiothecium piliferum. } \\ \text { Hsch. - Plagiothecium orthocarpum. } \\ \text { la Pyl. - Cylindrothecium eoncinnum. } \\ \text { Nees. - Hypnodendron Reinwardti. }\end{array}\right.$

orthocladon P. B. - Amblystegium.

orthorhynchum Brid. - Eurhynchium Stokesii.

orthothecioides Kindb, - H. uncinatum var, orthothecioides.

orthothecium $\left\{\begin{array}{l}\text { C. M. - Trichosteleum. } \\ \text { Schwaegr. -- Pylaia }\end{array}\right.$

oxycladon Brid - Brachythecilaisia secunda.

oxyodon W. et Dy. - Ectropothecium.

oxcy-ha Schwaegr. - Microthamnium,

pachynchum $\mathrm{Dz}$, et Mk. - Brachythecium.

pachypuron Tayl. - Eurhynchium Teesdalii.

pach poma Schwaegr. - Amblystegium radicale

pacifhecium Hpe. - Microthamnium,

pacificum C. M. - Ectropothecium.

Paivanum W. P. Sch, in Mandon Pl. Madeir, n. 45.

palanense C. M. - Trichosteleum.

palalinum Neck. - Pterogonium gracile.

paleatum Hpe, in Nuov. Giorn. bot. ital. 1872, p. 286.

- As. : Borneo.

pallens W. P. Sch, in Lechl. Pl. Magell. ; C. M. in Fl. 1885, p, 429.

Lignic. - Am, merid. : Patagon. austr. ?, Fuegia,

pallens W. et M. - Bryum. 
pallescens (Hedw.) P. B. Prodr. p. 67.

H. cupressiforme var. foliis angustioribus Drumm. M. bor. am. I ed. n. 206 et 207.

H. pelitnochroon Lobarz. in Haiding. Nature. Abh. 1847, I, p. 51.

H. recurvans Brid. Bryol. univ. II, p, 614.

H. reptile Rich, in Mich. Fl. Am. bor. II, p. 315; Brid. op. cit. p. 525; C. M. Syn. II, p. 290; Bryol. eur. VI (mon. p. 18), t. 587; W. P. Sch. Syn. II ed. p. 748.

Leskea hispidula Brid. Sp. M. p. 79.

L, pallescens Hedw. Sp. M. p. 219, t. 55, /. 1-6; Brid. op. cit. p. 319.

Stereodon pallescens Lindb. in Act. Soc. sc. Fenn. 18j3, p. 254.

St. reptilis Mitt. in Trans. of the Linn. Soc. 1891, p. 180.

1 (false 2 in C. M.). Cortic., lignic. et rupic. - Eur. : Scandin., Fenn., Dania, Boruss. oce., Francon., Thuring., Hercyn., Alp, Helvet., Tirol., Sąlisburg., Ross, or. ; deest in Britann. As.: Japon., Jenissei super., Persia. Am. sept. : Vulg. : ins. Miquel., Nov. Sc tt., New Brunswick, Gaspes., Ottawa, Ontar, lae. Super., Manitobra, Athabasca, Assiniboine, Columb. brit., reg. sept. et or.

Exs. : Mac. Canad. M. n. 345.

Sull, et Lesq. M. bor. am. Il ed. n. 477.

Un. itin. 1864, p. 94.

«var. protuberans (Brid.) Par.

H. pallescens Bryol. eur. VI (mon. p. 17), t. 586; W. P. Sch. op, cit. p. 747.

H. reptile var. protuberans Lesq. et Jam. Man. p. 390.

H. Stereodon pallescens Brid. Bryol. univ. II, p. 612.

Stereodon pallescens var. protuberans Lindb. $l$. $c$.

1. Ad arb., praesert. Acer., lignic., rarius saxic. - Eur.: Silva nigr., Thuring., Hercyn., Sudet. As.: Saghalien, Jenissei sup., Caucas. occ. Am. sept. : New Brunswick, Gaspes.

Eas, : Rab. Bryoth, eur. n, 1196.

* var. subjulaceum (W.P. Sch.) Par.

H. perichaetiale Bryol, eur. VI (mon. p. 18), t. 588.

H. reptile var, subjulaceum W. P. Sch. Syn. I ed. $p, 619$ et II ed. l.c.

Stereodon pallescens var. perichœetialis Lindb. $l . c$.

Rupic. - Eur.: Scandin.

pallescens (1) $\left\{\begin{array}{l}\text { W. Arn. - Mierothamnium. } \\ \text { Bryol. eur. - H. pallescens var. protuberans. }\end{array}\right.$

pallidifolium Mitt. - Rhynchostegium.

pallidirostrum $\mathrm{A} . \mathrm{Br}$. - Eurhynchium pumilum.

pallidius $\mathrm{H}$ pe. - Rhynchostegium.

pallidum $\left\{\begin{array}{l}\text { Brid, - Hookeria albicans. } \\ \text { Hook. - Microthamnium reptans. }\end{array}\right.$

palmatum Sw. - Fissidens.

Paludella W. et M. - Paludella squarrosa.

paludosum $\left\{\begin{array}{l}\text { W. Arn. - Leskea polycarpa var. paludosa. } \\ \text { Sull. - Thuidium. }\end{array}\right.$

palustre L. Sp.pl. p. 1593 ; C. M. Syn. I1, p. 424; W. P. Sch. Syn. I ed.

p. 634 et II ell.p. 772.

Amblystegium palustre Lindb. M. Scand. p. 33.

H. adnatum Turn. Muscol. Hibern. p. 165.

H. aquatile Mart, Fl. Erlang. crypt.p. 19, t. I, f. 4.

(1) pallescens Vill. Pl. Dauph. III, p. 909 ; Brid. Bryol, univ. II, p. 546 ; C. M. Syn. II, p. 509.

"An Hylocomium brevirostre? ». Brid, 1. c. - Delendum. 
H. fluviatile Turn. op. eit.

H. heterophyllum Neck. Meth. M. p. 168.

H. heterophyllum aquaticum polycephalum repens Dill. Hist. M. p. 932, t. $37, f .27 \mathrm{~A}$.

H. luridum Hedw. M. frond. IV, p. 99, t. 38.

H. palustre $\gamma$ aquatile $C . M . l$. $c$.

H. Stereodon palustris Brid. Bryol. univ. $I I$, p. 639.

H. Stereodon palustris $\beta$ aquatilis $e j . l$. $c$.

H. Stereodon palustris $\gamma$ ferrugineus $e j . l$. $c$.

Limnobium palustre Bryol. eur. VI (mon. p. 2), t. 574.

Neckera palustris Willd. Prodr. fl. Berol. $n$. 913.

Stereodon palustris Mitt. M. Ind. or. p. 98.

1. Ad lign, et sax. secus rivul. mont. - Eur. : Tota. As. : Jenissei, Tibet. occ., Cauc. occ. et centr. Am. sept.: Anticosti, New Brunswick, Gaspes., Ontar., lac. Super., Assiniboine, M. Rupestr. et Selkirk, Columb. brit., Idaho, New Jersey, Vermont, New York.

Exs. : Drumm, M. bor, am. I ed. n. 195.

Mac. Canad. M, n, 356.

var. fluviatile $\mathrm{Sw}$. - Amblystegium.

"var. hamulosum W. P. Sch. op. el l. cc.

Limnobium palustre var. hamulosum Bryol, eur. $l$. c. $t .575$.

Ad lign. irror. - Eur. : In alpin. Am. sept.: M. Alb. et Rupestr., Utah.

* vor. julaceum (Brid.) W. P. Sch. op. et l. cc.

H. intertextum Brid. Mant. M. p. 167.

H. intextum Voit. M. Herbip. p. 106.

H. neglectum C. M. Syn. II, p. 347.

H. ruderale var. intricatum Brid. Sp. M. II (in add.).

H. Stereodon intextus ej. Bryol. univ. II, p. 584.

H. St. neglectus ej. op. cit. p. 564 ?

Leskea palustris ej. Sp. M. II, p. 68 et Bryol. univ. II, p. 304.

Limnobium palustre $z$ julaceum Bryol. eur. $l$. $c$.

An rup, et sax. silic. saep, inund, - Eur. : Reg. montan. et subalp.

Exs.: Rab. Bryoth, eur. n. 393.

"var. laxum W. P. Sch. op. et l. cc.

Limnobium palustre var, laxum Bryol. eur. l. e.

Ut et ubi praeced.

var. polare Husn. - H. polare.

" var. subsphaericarpon (Schleich.) W. P. Sch. op. et l. cc.

Amblystegium palustre var. subsphaericarpon Lindb. $l$. c.

H. sphaerocarpon Spreng. Syst, veg. IV, p. 201.

H. Subsphaericarpon Schleich. Cent. II P $l$. Helv, n. 46 ,

Limnobium sulusphaericarpon Brid. Bryol. univ. II, p. 641.

Ad rup. irror. occ, et centr.

Exs.: Rab, Bryoth, eur. n. 550.

$$
\text { Un, itin. 1863, n. } 40 .
$$

var. tenellum W. P. Sch. Syn. II ed. p. 773.

H. Roësei ej. Coroll. p. 131.

Ad rup. granitic. - Eur. : Thuring. 
W. et M. - Aulacomnium.

higtescens, etc. $\{$ Vill. - Amblystegium riparium?

erectum, coma lutea, basi nigricante Dill. - Brentelia arcuata.

palustre

erectum, summitatibus aduncis Dill. (fid. C. M.).-H. aduncum.

erectum, summitatibus aduncis Dill. (fid. C. M. et W. P. Sch.). - H. cuspidatum.

erectum trichodes, ramulis crebris, luteo et rufo-virentibus glabris Dill. - Camptotbecium nitens.

extremitatibus cuspidatis et pungentibus Dill. - H. cuspidatum.

Pampae C. M. - Rhynchostegium.

panduraefolium C. M. - Porotrichum.

papillatum $\left\{\begin{array}{l}\text { Harv. - Trichosteleum. } \\ \text { Sull. - Trichosteleum stigmosum. }\end{array}\right.$

papillosissimum $\mathrm{Hpe}$ - Rhaphidostegium.

papillosum Hsch. - Trichosteleum.

paradoxum $\left\{\begin{array}{l}\text { H. f. et W. - Brachy thecium. } \\ \text { Mont. - Cylindrothecium concinnum. }\end{array}\right.$

paraphysale $\left\{\begin{array}{l}\text { C. M. - Hylocomium macrocarpum. } \\ \text { Hpe. - Microthamnium. }\end{array}\right.$

paramattense Hpe. et C. M. -- Rhynchostegium.

parietinum $\left\{\begin{array}{l}\text { L. - Hylocomium splendens. } \\ \text { L. - H. Schreberi. } \\ \text { Murr. - Thuidium tamariscinum. }\end{array}\right.$

var. elongatum Lindb. - H. Schreberi var. elongatum.

var. Laevigatum Lindb. - H. Schreberi var. laevigatum.

parvifolium C. M. - Thuidium involvens.

parvulum C. M. - Clasmatodon.

passaicense L. et J. - Plagiothecium.

patale H. f, et W. - H. chrysogaster.

patens Hook. - Meteorium.

Patientia Lindb. - H. arcuatum.

Patrisiae Brid. - Crossomitrium.

patulum $\left\{\begin{array}{l}\text { C. M. - Meteorium tovariense. } \\ \text { Hpe. - Rhynchostegium. } \\ \text { Sw, - Meteorium. }\end{array}\right.$

paulense Geh. et Hpe. - Ectropothecium.

pauperum C. M. - Thuidium.

Pechueli C. M. - Rhaphidostegium?

Peckii Aust. - H. aduncum var. plumulosum.

pectinalum Mitt. - Rhynchostegium.

pedunculatum (Mitt.) Par.

Acanthocladium pedunculatum Mitt. in Proc. of the Linn. Soc. of N. S.

Wales, 1882, p. 102.

- Pac. : Nov. Hebrid. (Aneitum).

pelitnochroon Lob. - H. pallescens.

pellucidum $\left\{\begin{array}{l}\text { Dz. et Mk. - Rhynchostegium javanicum. } \\ \text { Wils. - H. vernicosum. }\end{array}\right.$

pendulinum Besch. - Microthamnium.

pendulum Rehm. M. Afr. austr. n. 404.

$$
\text { - Afr. : C. B. Sp. }
$$

pendulum $\left\{\begin{array}{l}\text { C. M. - Eurhynchium. } \\ \text { P. }\end{array}\right.$

P. B. - Pilotrichella mollis. 
pennaeforme Thbg. - Hypopterygium.

Dicks. - Neckera pumila.

Hall. - Neckera.

aqualıcum lucens, longis latisque foliis Dill. - Pterygophyllum lucens.

compressum et splendens, capsulis ovatis Dill. - Neckera complanata.

pennatum

ornithopodioides, pinnulis pellucidis Dill. - Rhacopilum tomentosum.

trichomanoides, splendens, ramosum Dill. - Homalia trichomanoides.

undulatum crispum, setis et capsulis brevibus Dill. Neckera crispa.

undulatum crispum, setis et capsulis brevibus var. minor N. pumila.

undulatum, Lycopodii instar sparsum Dill. - Plagiothecium undulatum.

pensilvanieum Poir. - Cylindrothecium compressum.

pentastichum W. Arn. - Pilotrichella imbricata.

perangustum C. M. - Ectropothecium.

percircinale C. M. - Rhaphidostegium.

perichaetiale Bryol. eur. - H. pallescens var. subjulaceum.

perintricatum C. M. in Dusen M. Camer. n. 293.

- Afr. : M. Cameroon.

perplanicaule C. M. l. c. n. 704 .

- Afr.: M. Cameroon.

perscissum C. M. - Thuidium.

persistens C. M. - Thuidium.

perspicuum (Mitt.) Jaeg. Ad. II, p. 582.

Stereodon perspicuus Mitt. M. Ind. or. p. 96.

1.

- As. : Sikkim.

perspicuum Hpe. - Microthamnium thelistegum.

var. molle Hpe, - Microthamnium thelistegum var. molle.

var. teres Hpe. - Microthamnium thelistegum var. teres.

peruvianum Mont. - Stereophyllum.

Pervilleanum W. P. Sch. - Rhaphidostegium.

pervirens C. M. - Helicodontium.

peroiride angstr. - Ectropothecium.

petraeum C. M. in Dusen M. Camer, n. 668.

- Afr. : M. Cameroon.

petraeum Boul. - H. procerrimum.

petrophilum Weinm. - Brachythecium populeum var, rufescens.

Philippianum C. M. - Homalothecium.

philippinense Duby. - Rhynchostegium.

phleoiles Desv. - Pilotrichella.

phoeniceum C. M. - Rhaphidostegium.

phryscophyllum W. Arn, - Hookeria aurea.

Phyllogonium C, M. - Acrocladium politum.

phyllorhizans P. B. - H. cordifolium.

physaophyllos W. et Dy. - Isothecium.

Pickeringii Sull, - Sematophyllum.

piliferum Schreb. - Eurhynchium.

pilosul. alpina Brid. - Brachythecium cirrosum.

pilosulum Mitt. - Leptohymenium. 
pinelorum Jaeg. - Rozea pterogonioides.

piniforme C. M. - Porotrichum.

pinnatifidum $\left\{\begin{array}{l}\text { Mac. - Camptothecium Nuttallii. } \\ \text { Sull. - Camptothecium. }\end{array}\right.$

pinnatulum $\mathrm{Hpe}$. - Thuidium.

pinnatum Lam. - Hylocomium splendens.

pinnicaule C. M. - Rhynchostegium.

piriforme W. et M. - Leptobryum.

planifolium Brid. $\left\{\begin{array}{l}\text { (fid. C. M.) - Plagiothecium silesiacum. } \\ \text { (fid. Lindb.) - Plagiothecium elegans. }\end{array}\right.$

planiusculum Mitt. - Rhynchostegium.

planum Brid. - Taxithelium.

var. acuminulatum C. M. - Taxithelium planum var. acuminulatum.

var. flavescens Brid. - Taxithelium planum var. flavescens.

var. instralum Schwaegr. - Trichosteleum.

platyacron C. M. - Sematophyllum.

plicatile (Milt.) Lesq. et Jam. Man. p. 394 (1).

H. Bourgaeanum Sb, in Jaeg. $1 d$. II, p. 525 .

Stereodon plicatilis Mitt. in Journ, of the Linn. Soc. VIII, p. 40.

2. Rupic. - Am. sepl. : Fret. Davis, Alberta, Saskatchewan. M. Rupestr., Columb. brit., Montana, Calif.

Exs. : Mac. Canad. M. n. 342.

plicatulum (Lindb.) Jaeg. Ad. II, p. 580.

Stereodon plicatulus Lindb, in Act. Soc. sc. Fenn. 1872, p. 254.

2. Lignic. - As. : Amour, Saghalien, Jenissei med, et inf.

plicatum Schleich. - Ptychodium.

plintophilum C. M. - Microthamnium.

plumaeforme Wils. in Lond. Journ, of. bot. 1848, p. 277, t. 10 ; C. M.

Syn. II, p. 297.

H. Rodgersianum Sull, et Lesq. in Proced. of the Am. Acad... 1859, p. 280 fid. Mitt.).

Stereodon plumaeformis Mitt. in Journ. of the Linn. Soc. 1864, p. 154.

2. Ad. rup. et terr. - As. : Japon., ins. Loo-Choo, Chin. or.

plumosiforme W. P. Sch. Brachythecium.

plumosum $\left\{\begin{array}{l}\text { Brid., C. M. - Brachythecium salebrosum. } \\ \text { Hedw. p.p. }\left\{\begin{array}{l}\text { Brachythecium glareosum. } \\ \text { Mitt. p.p. - Brachythecium salebrosum. }\end{array}\right. \\ \text { Schwaegr. - Brachythecium. } \\ \text { Sull. - Brachythecium tarapense. } \\ \text { Sw. - H. incurvatum. }\end{array}\right.$

* var. salebrosum $\{$ C. M. - Brachythecium.

C. M. - Brachythecium œdistegum (fid. Mitt.).

" var. turgidum Lindb. - Brachythecium salebrosum $v$ ar. turgidum.

Plumularia C. M. - Trichosteleum.

plumulosum $\left\{\begin{array}{l}\text { Dz, et Mk. - Thuidium. } \\ \text { C. M. p.p. - Thuidium Meyenianum. } \\ \text { C. M.? - Thuidium trachypodium. }\end{array}\right.$

pohliaecarpum S. et $\mathrm{l}$. - - Isopterygium.

polare Lindb. in Oefo... XIII, p. 350; W. P. Sch. Syn. 11 ed. p. 780.

Amblystegium polare Lindb. M. Scand. p. 33. 
H. palustre var. polare Husn. Musc. gall. p. 411, t. 119, f. 13.

Ster.

Finmarck., Alp. gall., Pyren. Am. sept.: Groenland.

politum H. f. et W. - Acrocladium.

polyandrum Angstr. - Ectropothecium.

polyanthos (1) Engl. Bot. - H. cupressiforme var. resupinatum.

polyanthum Schreb. - Pylaisia polyantha.

var. pallidifolium C. M. - Pylaisia heteromalla.

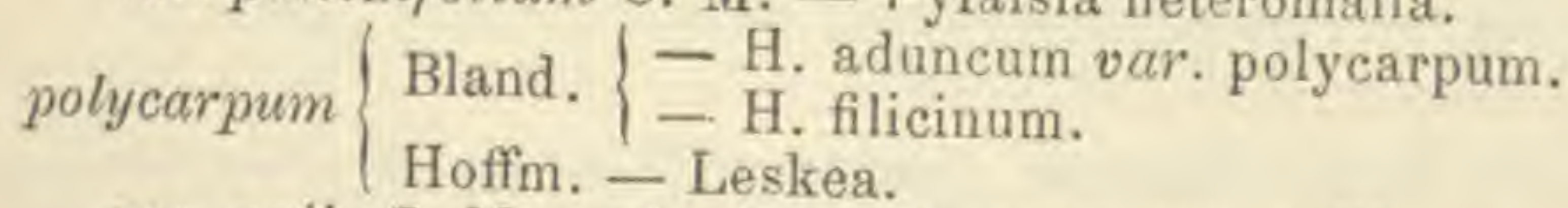

var. exile C. M. - Leskea polycarpa var, exilis.

polycephalum Neck. - Cryphaea heteromalla.

polychaeton Bryol. jav. II, p. 154, t. 253.

2.

- As. : M. Java.

polygamum W. P. Sch. Coroll. p. 131 et op. cit.p. 726.

Amblystegium polygamum Bryol. eur. VI (mon. p. ), t. 572 ,

$\mathrm{H}$, nodiflorum Wils, mss.

H. stagnatum ej. mss.

H. stellatum Drumm. M. bor. am. I ed. n. 184 p.p.

Syn. In prat. uligin. inq. aren. aquos. - Eur. : Spitzberg, ins. Ursor., reg. sept. et intermed. As.: Japon., Jenissei inf, et med. Am. sept. : Groenland, Labrador. Terr. nov., ins. Miquel., Massachuss., New Jersey, Ontar., Wísconssin, Washington, Columb. brit. Pac. : Nov. Zeland.

Exs. : Rab. Bryoth. eur. n. 755, 1000.

Savatier. Pl, Jap. n. 715 p.p.

Un, itin. 1867, n. 15.

" var, brevicuspis (Lindb.) Par.

Amblystegium polygamum var, brevicuspis Lindb. in Broth. Enum. M.
Cauc, p. 104.

- As. : Caucas.

"var. fallaciosum (Jur.) Ren. et Card. in Rev. bryol. 1893, p. 25.

Amblystegium fallaciosum Lindb.. . e.

H, fallaciosum Jur, in Rab. Bryoth, exer, $n .647$,

- Eur. : Ubi typ. Am. sept.: Wyoming.

"var. longinerve Ren. et Card. in Bot. Centralbl. 1840, n. 51,

- Am. sept. : Vancouver.

"var. minus W. P. Sch. Syn. I ed. p. 404 et II ed. $l$. c.

Amblystegium polygamum var, minus Bryol. eur, l. c.

Ut et ubi typ, in Eur.

polymorphum $\left\{\begin{array}{l}\text { H. et T. }- \text { H. chrysophyllum } \\ \text { Turn. }- \text { H. Elodes. } \\ \text { Wils. }- \text { H. Sommerf.ldti. }\end{array}\right.$

var. chrysophyllum Rryol. eur. - H. chrysophyllum var. tenellum.

var, minus Sull, - H. chrysophyllum var. tenellum?

polypodioides $\mathrm{Sw}$, - Fissidens,

polyrhizon R rid. - Brachythecium plumosum.

polysetum Bland. - Brachythecium populeum.

(1) polyanthos Brid. Bryol. univ. II, p. 541 ; C. M. Syn. II, p. 508.

H. Confertum P. B. Prodr: p. 62 .

Quid? Delendum. 
polystictum $\{$ H. f. et W. - Taxithelium.

polystictum Mitt. - Eurhynchium.

polytrichoides Hedw. - Lepidopilum.

Poeppigianum Hpe. - Ectropothecium vesiculare.

populeum $\{$ Drumm. - Brachythecium reflexum.

var, erythropodum Brid. - Brachythecium populeum.

var, nutans Brid, - Brachythecium populeum.

Porotrichum C. M. - Porotrichum longirostre.

porphyrhizon Lindb. - Amblystegium.

porrectirameum C. M. in Dusen M. Camer, $n .3$.

- Afr. : M. Cameroon.

porrigens Wils, - Thuidium scitum.

porto-ricense Balb. - Helicodontium capillare.

Povellianum C. M. - Trichosteleum samoanum. praecox $\mathrm{Sw}$. - Eurhynchium strigosum var. imbricatum.

praegracile (Mitt.) Jaeg. Ad. II, p. 595.

Ctenidium praegracile Mitt, M. austr, am. p, 510.

- Am. merid. : And. Quitens.

praelongum $\left\{\begin{array}{l}\text { C. M. p.p. - Eurhynchium hians. } \\ \text { L. - Eurhynchium. } \\ \text { Turn. - Eurhynchium Stokesii. }\end{array}\right.$

var. abbreviatum Brid. - Eurhynchium.

var, atro-virens Brid. - Eurhy nchium praelongum var. atro-virens.

var. Clarionis Brid. - Eurhynchium praelongum.

var. filescens Brid. - Eurhynchium striatulum.

var. orthorhynchum Brid, - Eurhynchium Stokesii.

var. pallidirostrum Brid. - Eurhynchium pumilum.

var. scariosum C. M. p.p. $\{$ - Eurhynchium praelongum var, atrovi- Eurhynchium speciosum.

var. speciosum Brid. - Eurhynchium speciosum.

var. Stokesii Brid. - Eurhynchium.

var. Sull, - Eurhynchium Sullivantii.

prisophyllum Hpe. - Brachythecium.

pratense Koch in Brid. Bryol. univ. 11, p. 769; Bryol. eur. VI (mon. p. 43), t. 6l1; W, P. Sch. Syn. II ed. p, 759.

H, amonum Hook. in Drumm. M. bor, am. I ed. n. 196 p.p.

H. cupressiforme var. complanatum Hpe. Veg. cell. Hercyn. exs, n. 96.

H. curvifolium C. M. II, p. 293 p.p.

Isopterygium pratense Lindb. M. Scand. p. 39.

2. vel ps. 1. In pratis uligin, - Eur.: Spitzberg, Lappon., Scandin., German. fere tota, Siles., vall. Rhen,; 9 deest in Brit. As. : Japon. Am. sept. : Groenland, Terr. nov., Nov. Angl., New Jersey, Pensilv., New Brunswick, Minnesota, Columb. brit, Vancouver, Indiana, Illinois, Wisconssin, Florid.

Exs. : Faurie Pl. Jap. n. 178 p.p., 214.

Mac. Canad, M. n. 354.

Rab. Bryoth. eur. n. 394, 761, 1049.

Sull. et Lesq. M. bor. am. II ed. n. 484.

var. hamatum W. P. Sch, - H. arcuatum.

Preverianum Saut. in sched.; Jaeg. Ad. II, p. 560.

H. chrysophyllum var, subnivale Mdo. Moosst. $p, 99$.

- Eur. : Alp. Algov., Carinth., Salisburg. 
Preussii Broth. - Brachythecium.

prionophyllum C. M. - Pseudo-Leskea.

prislocalyx C. M. - Thuidium.

procerrimum Mdo, in Fl. 1866 (nom.); W. P. Sch, op. cit. p. 764.

Ctenidium procerrimum Lindb.

H. petraeum Boul.

2. Ad sax. praecip. calcar. - Eur.: Norveg. (Dovre), Alp. Helv., Tirol., Rhaet., Stir. As. : Caucas. centr.

Ex. : Rab. Bryoth. eur, n. 807.

procerum C. M. - Sematophyllum.

procumbens Mitt. - Brachythecium.

proliferum $\left\{\begin{array}{l}\text { Drumm. - Thuidium delicatulum. } \\ \text { L. - Thuidium tamariscinum. }\end{array}\right.$

L. - Hylocomium splendens.

« var, compactum \{ Drumm, (fid. Kindb) - Thuidium recognitum.

var. umbratum Drumm. (fid. Mitt.). - Thuidium quadrifarium.

prolixum $\left\{\begin{array}{l}\text { Dicks. }- \text { Rhynchostegium rusciforme var. prolixum. } \\ \text { Vill. }- \text { H. filicinum. }\end{array}\right.$

propinquum Harv, - Rhaphidostegium.

proreptile C. $M$. in Dusen $M$. Camer. $n .217$.

- Afr.: M. Cameroon.

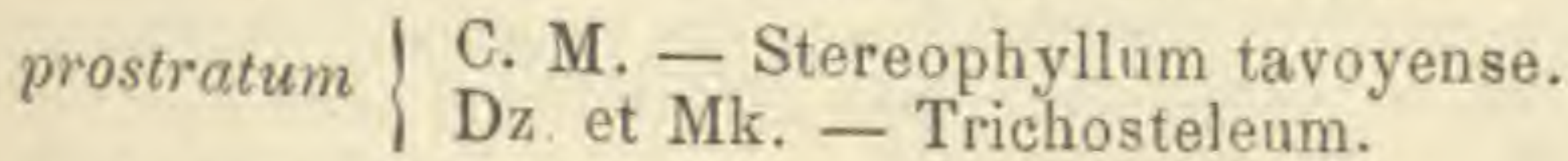

protensum (W. P. Sch.) Par.

Limnobium protensum W. P. Seh. in Mandon Pl. Boliv. n. 1710.

- Am. merid. : And. Boliv.

protensum $\left\{\begin{array}{l}\text { Rrid. - H. stellatum var. protensum. } \\ \text { Rich. - Thuidium delicatulum. }\end{array}\right.$

protractulum C. M. - Microthamnium.

pseudo-amonum Bel. - Trichosteleum.

pseudo-arcticum Kindb, in Bull. Torr. bot. Club. XVII, p, 280 et in Mac.

Cat, p. 242 .

1. Ad lapid. in rivul. - Am. sept. : Columb. brit.

pseudo-altenuatum C. M. - Anomodon.

pseudo-brachythecium (C, $\left.M_{s}\right) \mathrm{Par}$.

Heterophsllum pseudo-brachythecium C. M, in Dusen M. Camer, n. A 8. - Afr. : M. Cameroon.

pseudo-callidum C. M. - Rhaphidostegium xylophilum.

pseudo-commulatum la Pyl. - Hyocomium flagellare.

pserdo-confertum C. M. - Rhynchostegium.

pseudo-cupressiforme C. M. in Bot. Zeit. 1862, p. 13.

2. Lignic. - Afr. : Madeir, Teneriff.

pseudo-delicatulum $\{$ C. M. - Thuidium.

Raddi. - Eurhynchium Stokesii.

pseudo-Drepanium C.M. et Kindb. in Bidr. p. 454 (nom.) et in Mac. Cat.

p. 240 .

2. Ster. Lignic. - Am. sept. : Ontario.

pseudo-fastigiatum C. M. et Kindb. in op. cc. pp. 424 et 235.

2. Ad rad, arb. - Am, sept.: Ontario, Columb. brit. 
pseudo-homomallum C. M. - Pylaisia? pseudo-involvens C. M. - Thuidium. pseudo-laetum C. M. - Brachythecium. pseudo-lutescens Hpe. - Camptothecium. pseudo-montanum Kindb. in Mac. Cat. p. 243.

1. Rupic. - Am. sept.: Ontario.

Exs.: Mac. Canad. M. n. 539.

pseudo-murale Hpe. - Rhynchostegium. pseudo-piliferum Hpe. - Eurhynchium. pseudo-planum $\mathrm{Hpe}$. - Trichosteleum. pseudo-plumosum $\left\{\begin{array}{l}\text { Brid. - Brachythecium plumosum. } \\ \text { C. M. p.p.-Thelia asprella. } \\ \text { Mont. - Brachythecium cedistegum ? }\end{array}\right.$
var. asperulum Brid. - Brachythecium plumosum.
var. polyrhizon Brid. - Brachythecium plumosum.
pseudo-populeum W. P. Sch. - Brachythecium. pseudo-pratense Kindb. in Mac. Cat. p. 239.

2. Lignic. - Am. sept: Ontario. pseudo-protensum C. M. - Thuidium pseudo-recognitum $\mathrm{Hpe}$ - Thuidium acuminatum. peudo-reptans C. M. - Microthamnium. pseudo-rufescens Hpe. - Sematophyllum. pseudo-rutabulum Hpe. - Brachythecium. pseudo-salebrosum Hpe. - Homalothecium Bonplandii. pseudo-sericeum $\left\{\begin{array}{l}\text { C. M. - Homalothecium, } \\ \text { Mac. - Camptothecium nevadense. }\end{array}\right.$ pseudo-silesiacum L. et J. - Plagiothecium. pseudo-stramineum C. M. miss.; W. P. Sch. Syn. II ed. p. 736.

Amblystegium pseudo-stramineum Lindb. M. Scand. $p .33$.

H. aduncum var. pseudo-stramineum Rent. et Card. in Rev. bryol, 1893. p. 25.

H. fluitans var. pseuro-stramineum Milde Bryol. Siles,

H. sudeticum W, P. Sch. mss.

1. In palud. silvat. - Eur.: Scandin., Sudet., Saxon., Gall. centr. (Arvern.). Am. sept. : Wyoming.

Exs. : Rab. Bryoth. eur, n. 848. pseudo-stramineum Hpe. - H. stramineoides. pseudo-striatum C. M. - Eurynchium. pseudo-tanytrichum Bryol. jav. II, p. 150, t. 248.

H. Hornschuchii $D z$. et Mk, in Ann. so. nat. 1844, p. 307.

2. In silv. - As, : M. Java. pserdo-Teesdalii Hpe. - Rhynchostegium. pseudo-triste C. M. - Leskea. pseudo-uncinatum Hpe. in Linn. 1859, p. 639.

H. uncinatum (fid. Mit.).

$$
\text { - Pac. : Alp. Austral. fel. }
$$

pseudo-velutinum $\mathrm{Hpe}$. - Brachythecium. psilocaulon Card. - H. aduncum. pterogonioides C. M. - Rozea. ptychocarpon Schwaegr. - Ptychomium. pubescens Hook. f. et Wils. Fl. of the N. Zeal. II, p. $113, t .91, f .3$ et
Handb. p. 475. 
Puiggarii Geh, et Hpe. - Mierothamnium.

pulchellum $\left\{\begin{array}{l}\text { Brid. - Plagiothecium nitidulum. } \\ \text { Br. et Sch. - Plagiothecium Miihlenbeckii. } \\ \text { Dicks. - Plagiothecium. } \\ \text { Hedw. - Eurhynchium strigosum. } \\ \text { Mac. p.p. - Plagiothecium piliferum. }\end{array}\right.$

var. nilidulum L. et J. - Plagiothecium nitidulum.

pulchrum $\left\{\begin{array}{l}\text { Drumm. p.p. - Brachythecium acuminatum. } \\ \text { Hook. - Hypnum Haldanianum. }\end{array}\right.$

pulvinale Hpe. - Rhaphidostegium.

pulvinatum H. f, et W. - Camptochaete.

pumilum $\left\{\begin{array}{l}\text { Gmel. - Neckera. } \\ \text { Wils. - Eurhynchium. }\end{array}\right.$

punctatulum C. M. - Rhaphidostegium.

punclatum Schrank. - Mnium.

punctulatum $\left\{\begin{array}{l}\text { Bals. et de Not. - Thuidium. } \\ \text { Harv. - Trichosteleum. }\end{array}\right.$

pungens Hedw. - Sematophyllum.

pungifolium $\mathrm{Hpe}$. - Sematophyllum.

purpureum Geh. et Hpe. - Thuidium.

purum L. Sp.pl.p. 1594; Brid. Bryol. univ. 1I, p. 425 ; C. M. Syn. II,

p. 379; Bryol. eur. VI (mon. p. 52), t. 379; W. P. Sch. op. cit. p. 791 .

H. cupressiforme, vulgare, foliis obtusis Dill. Hist. M. p. 309, t. 40, f. 45.

H. elegans Ehrh. Crypt. exs. n. 242.

H. illecebrum L. Fl. Suec. n. 1052 .

H, purum $\beta$ illecebrum Brid. M. Rec. II, II, p. 91 et Bryol. unix. II, p. $427 ; C . M . l . c$.

Pleurozium purum Kindb. Check-List of Eur, a. N. Amer. M. p. 19.

2. Terr. in umbros., ad marg. silv. - Eur.: Reg. campestr, tota. As.: Japon., Caucas. centr. et or. Afr. : Alger.. ins. S. Helen. (indig. ?), ins. Azores, - Am. sept. : Ins. Miquelon.

Exs. : Rab. Bryoth. eur. n. 494.

purum Ehrh. - H. Schreberi.

var. illecebrum Brid. - H. purum.

var. $\beta$ Huds. - H. Schreberi.

pusillum Hsch. - Trichosteleum.

pycnodontium C. M. - Ectropothecium.

pycnophyllum C. M. - Sematophyllum.

pycnopteron C. M. - Plagiothecium.

pycnothecium C. M. in sched. ; Jaeg. Ad. II, p. 585.

$$
\text { - As. : Sikkim. }
$$

pyrenaicum. - Thuidium.

pyrenaicum Spr. - Hylocomium Oakesii.

pyrrhophyllum C. M. - Rhaphidostegium fulvum.

quadrangulare Schwaegr. - Pilotrichella longipes.

quitense Mitt. - Pilotrichella.

Rabenhorsti Mdo. in sched. 1864 (2).

- Eur.: Tirol. merid.

- Eur.: T

(1) pygmaeum Vill. Pl. Dauph. III, P. 909; Brid. Bryol, univ. II, P. 546; C. M.
Syn. II, p. 509.

2) Leskea nervosa? „ Brid. 1. c. - Delendum.

(2) An $H$. revolventis var. ? Jaeg. 1. c. 
? radiatum Schwaegr. Suppl. I, II, p. 204; C. M. Syn, II, p. 250.

Isothecium radiatum Brid. Bryol. univ. $I I, p .358$.

- Afr. : Ins. Borbon.

radicale $\left\{\begin{array}{l}\text { Drumm. - Amblystegium porphyrizon. } \\ \text { Hsch. - Rhynchostegium tenuifolium. } \\ \text { P. B. - Amblystegium radicale. }\end{array}\right.$

radicans Brid. - Isopterygium.

radicosum Mitt. - Pseudo-Leskea congesta.

radiculosulum C. M. - Stereophyllum.

radiculosum C. M. - Stereophyllum.

ramicolo Hpe. - Sematophyllum.

ramulosum C. H. - Thuidium.

Ravaudi Boulay Fl.crypt. de l'Esl... 1872,p. ～;W. P. Sch.op. cit.p.763.

H, fastigiatum var. Ravaudi Husn. Muscol. gall. p. 400, t. 115, $f f .1-8$.

2. Rupic. - Eur. : Alp. Delphinat.

recognitum $\left\{\begin{array}{l}\text { Hpe. - Thuidium hastatum. } \\ \text { Hedw. - Thuidium. } \\ \text { Wils. p.p. - Thuidium quadrifarium. }\end{array}\right.$

recurvans $\left\{\begin{array}{l}\text { Brid. }- \text { H. pallescens. } \\ \text { Schwaegr. }- \text { Rhaphidostegium. }\end{array}\right.$

var. Sull. - Rhaphidostegium.

recurvatum (Lindb. et Arn.) Par.

Stereodon recurvatus L, et A. M. As, bor. 1890, II, p. 149.

1.

- As. : Jenissei.

recurvulum (Hpe.) Par.

Orontobryum recurvulum Hpe. in sched. - As.: Bhotan.

reduncum W. P. Sch, in Lechler Pl. Peruv, n. 3103 et 3108.

Ctenidium reduncum Mitt. M. austr. p. 509.

Ster.

- Am. merid. : And. Peruv.

reflexum $\left\{\begin{array}{l}\text { C. M. p.p. - Pseudo-Leskea congesta. } \\ \text { W. et M. - Brachythecium. }\end{array}\right.$

Regnellii Hpe. - Eurhynchium clinocarpum.

regulare C. M. - Ectropothecium.

Reichenbachianum Ltz. Moosst. p. 167.

1.

- Am. sept.: Mexic.

Reichenbachianum Hüb, - Eurhynchium velutinoides.

Reichhardti Rehm. M. Afr. austr. n, 402.

$$
\text { - Afr. : Austr. }
$$

Reinwoardti $\left\{\begin{array}{l}\text { C. M. - Hypnodendron. } \\ \text { Sull. - Hypnodendron subspininervium. }\end{array}\right.$

relaxum Hook. f. et Wils. Fl. of the N. Zeal. II, p. 110, t. 90, f. 1 et Handb, $p, 479$.

2.

- Pac. : Nov. Zeland. sept. et med.

remotifolium $\left\{\begin{array}{l}\text { H. f. et W. (fid. Jaeg.). - Eurhynchium asperifolium. } \\ \text { Grev, - Thuidium. } \\ \text { Mitt. - Eurhynchium clinocarpum. }\end{array}\right.$

Renauldi Kindb. in Bidr. p. 452 (nom.) et in Mac. Cat.p. 238.

2. Rupic. et terr. - Am. sept.: Terr. nov., New Brunswick, Gsspes., Ontar, Columb. brit. 
renitens Wils, in sched.

Stereodon renitens Mitt. M. Ind. or. p. 94 .

1. Cortic. - As. : Sikkim.

Hook. et Grev. - Hookeria guadalupensis.

Poll. \{ (fid. Bryol. eur.). - Plagiothecium silesiacum.

( fid. C. M.). - Amblystegium serpens.

(fid. Lindb.). gen. monotyp. - Dolichotheca.

crispum, cupressiforme, minus et foliolis magis confertis Dill. -H. cupressiforme.

crispum, cupressiforme, minus et foliolis minus confertis Dill. H. cupressiforme var. filiforme.

repens filicinum crispum Dill. - H. commutatum.

filicinum plumosum Dill. - Brachythecium salebrosum.

filicinum trichodes palustre Dill. - H. filicinum var. trichodes.

triangularibus parvis foliis, praetongum Dill. - Eurhynchium Stokesii.

triangularibus foliis reflexis, majus Dill. - Hylocomium squarrosum.

trichodes, arboreum majus, cauliculis ramosis Dill. - Anomodon attenuatus.

replicatum Hpe. in Nuov. Giorn. bot. ital. 1872, p. 279.

1.

$$
\text { - As. : Ceylan. }
$$

Sw. - Microthamnium.

reptile $\mathrm{Rich}$. - $\mathrm{H}$, pallescens.

var. protuberans L. et J. - H. pallescens var, protuberans.

var. subjulaceum W. P. Sch. - H. pallescens var. subjulaceum.

reptiliforme de Not. Epil, p. 162.

- Eur. : Alp. centr. (M. S. Bernard. min.).

restitutum $\mathrm{Hpe}$ - Rhaphidostegium.

resupinatum Tayl. - Pylaisia heteiomalla.

Wils. - H. cupressiforme var. resupinatum.

reticulatum $\left\{\begin{array}{l}\text { Dz. et Mk. - Ectropothecium. } \\ \text { Duby. - Ectropothecium Dubyanum. }\end{array}\right.$

H. f. et W. - Rhizogonium.

retroflexum Hook. - H. glaucocarpum.

revolutum (Mitt.) Jaeg. Ad. I1, p. 585.

H. Heufleri Jur, in Abh. K.K. zool. bot, Ges, in Wien, 1861 ; W. P. Sch. Syn. II ed. p. 760; Rab. Bryoth. eur, n. 694, 909, 1199; Un. it n. 1863 , n. $47,49$.

H. Watsoni (fid. Austin).

Stereodon revolutus Mitt. M. Ind. or. p. 97.

Ster. Lignic. et rupic., in silv. abiegn. et betul. - Eur. : Spitzberg,

Scandin., Alp. Transilv., Carintb., Tirol. merid., Rhaet., Vall. Tellin., Alp. Delphinat., Pyren. As.: Alatau, Caucas., Tibet. occ. Am. sept. : Groenland, M. Rupestr., Wyoming, Montana.

* var. Villardi Ren, et Card. in Bot. Centralbl. 1890, n. 51.

Ad rup. humid. - Am. sept. : Montana.

revolvens Swo. M. Suec. p. 38, t. 7, f. 14; C. M. Syn. II, p. 323 (excl. syn. Hartm.); Bryol. eur. VI (mon. p. 32), t. 601; W. P. Sch. op. cit. p. 736.

Amblystegium revolvens de Not. Briol. ital. p. 140. 
A. intermedium $\beta$ revolvens Sanio in Lindb. et Arn. M. As. bor. 1890, $I I, p, 118(1)$.

H. ambiguum Schrad. (fid. C. M.; of. Brid. op. cit. pp. 603 et 624).

H. Stereodon aduncus \& revolvens Brid. Bryol. univ. II, p. 625.

1. In paludib. profund. - Eur. : Spitzberg, ins. Ursor., zon. septentr. tota ; reg. montan., subalp. et alp. zon. intermed.; in Alp. merid. sterile. As. : Penins. Samojed. et Tschntschica, Ienissei, verosim. artica tota. Ant. sept. : Groenland, Labrador, Anticosti, Gaspes., lac. Super., M. Rupestr., Alaska, Ohio sept. Am. merid. : Antaret. (fid. C. M.).

Exs.: Mac. Canad. M. n. 387.

Rab. Bryoth. eur. n. 996.

Sull. et Lesq. M. bor. am. II ed. n. 464 (H. intermedium Lindb. fid. Ren.).

Un. itin. 1864, n. 61 ; 1867, n. 30 .

var. intermedium L. et J. $-\mathrm{H}$. Cossoni. rhaphidorhynchum C. M. - Rhynchostegium.

rhaphidostegum C. M. - Thuidium.

rhinophyllum C. M. - Trichosteleum.

Rlizophoreti C. M. - Trichosteleum.

Richardi Schwaegr. - Rhaphidostegium subsimplex.

Richardsoni (Milt.) Lesq. et Jam. Man. p. 404.

Amblystegium Richardsoni Lindb. M. Scand. p. 34.

H. Breidleri Jur. in Hedwig. 1875, p. 182; W. P. Sch, op, cit. p. 786.

H. trifarium Drumm. M. bor. am. I ed. p. 211 .

Stereodon Richardsoni Mitt. in Journ, of the Linn. Soc. VIII, p. 42.

1. Paludic. - Eur.: Norveg. sept., Alp. Stir. As. : Jenissei, Am. sept.: Groenland, New Brunswick, Ontario, Saskatchewan.

« var. robustum (Lindb. et Arn.) Par.

Amblystegium Richardsoni var. robustum L. et A. M. As. bor. 1890, II, p. 125.

- As. : Jenissei infer.

rigidissimum C. M. - Eurhynchium.

rigidiusculum Bland. - Eurhynchium Stokesii.

rigidulum $\mathrm{Br}$. - Rhynchostegium curvisetum.

rigiulum $\left\{\begin{array}{l}\text { Hsch, et Reinw, - Sematophyllum. } \\ \text { Schwaegr. - Hookeria. }\end{array}\right.$

var. Braunianum Bryol, jav. - Sematophyllum rigidum var. Braunianum,

var. convolutum Bryol jav. - Sematophyllum rigidum var. convolutum. riparioiles Hedw. - Rhynchostegium rusciforme.

var. speciosum Schwaegr. - Eurhynchium. riparium L. - Amblystegium.

var. homomallum

var. oligophyllum

var. pallidum

var. trichopodium Brid. - Anblystegium riparium var, trichopodium.

var. Schwaegr. - Rhynchostegium rusciforme var. longinerve?

ripicolum C. M. in sched.; Jaeg. Ad. II, p. 753.

- As. : Sikkim.

rivale $\mathrm{Hpe}$. - Rhynchostegium.

rivicola Mitt. - Amblystegium. 
rivulare $\left\{\begin{array}{l}\text { Brid. - Rrachythecium albicans. } \\ \text { Br. - Brachythecium. } \\ \text { Ehrh. - Rhynchostegium rusciforme. }\end{array}\right.$

var. Novae Brunsviciae Kindb. - Brachythecium rivulare var. obtusulum.

rividarioides C. M. - Brachythecium.

rivulorum S. et L. - HI. montanum.

Robillardi Duby. - Leucomium.

robusle-pinmatum Hpe. - Ectropothecium.

robustum Hook, - Hylocomium.

Rodgersianum S. et L. - H. plumaeforme?

Roëseanum Hpe. - Plagiothecium.

Roësii W. P. Sch. - H. palustre var. tenellum.

roseum $\mathrm{W}$. et $\mathrm{M}$. - Rhodobryum.

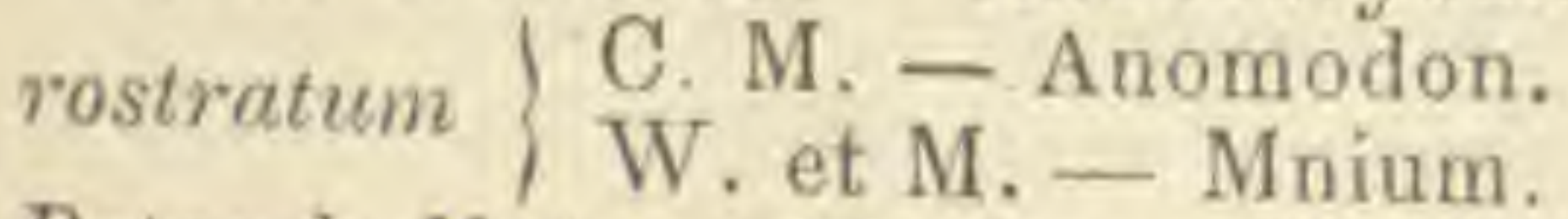

Rotae de Not. - H. exannulatum var. Rotae.

rotulalum P. B. - Hypopterygium.

rotundatum Hpe. - Homalia.

rotundifolium $\left\{\begin{array}{l}\text { Dicks. - Rhynchostegium confertum. } \\ \text { Scop. - - Rhynchostegium. }\end{array}\right.$

rotundifrondeum C. M. - Porotrichum.

Royae Aust. - Rhynchosteginm (1).

rubrum Vill. - H. filicinum var. trichodes.

ruderale C. M. - Stereophyllum.

var. intricatum Brid. - H. palustre var. julaceum.

rufescens $\left\{\begin{array}{l}\text { Dicks. - Orthothecium. } \\ \text { H. f. et W. - Orthothecium chryseum. }\end{array}\right.$

rufo-chryseum W. P. Sch. in Savat, M. Jap. n. 724; Besch. in Ann. sc. nat. $1893, p .387$.

2.

- As.: Japon.

Riugelii C. M. - Anomodon apiculatus.

rugiselum $\{\mathrm{Hpe}$-- Eurhynchium clinocarpum?

Hpe. (mss., fid. C. M.) - Trichosteleum.

rugosum Ehrh. Dec. n. 291 (an L. ?); C. M. Syn. II, p. 423; Bryol.

eur. VI (mon. p. 41), t. 610 ; W. P. Sch. op. cit. p. 745.

Hylocomium rugosum de Not. Epil.

H. Iutescens crispum, Lycopodii facie Dill. Hist. M. p. 289, t. 37, f. 24 A.B.D.

H, rugulosum W. et M. Bot. Taschb. p. $363 ;$ Drumm. M. bor, am. I ed. n. 198.

H. Stereodon rugosus Brid. Bryol, univ, II, p. 633.

Rhytidium rugosum Kindb. Laubm, Stho, und Norweg.

2. In apric. praecip. argill, et turfos, montan, exsicc., ad tecta stram. Eur. : Fere tota, rariss. fructif. As.: Yunnan, Amour, Ochotsk, Taimyr, Jenissei, Caucas. Am sept.: Groenland, Jabrador, sin. Hudson, Ontar., lac. Super., M. Rupestr., reg, sept.

Exs. : Sull, et Lesq. M. bor. am. II ed. n. 485.

Un, itin. 1867, n. 3 .

rugosum W. et M. - H. lycopodioides.

rugulosum eor. - H. rugosum.

repestre Schleich. - H, alpestre.

rupincolum P. B. - Brachythecium acuminatum var. rupincolum.

rurale Weiss. - Barbula,

(1) rubricaule Brid. Bryol, univ. II, p. 542 ; (:. M. Syn. II, p. 503.

Ex ins, Melville, - Quid? Delendum? 
ruscifolium Neck. ruscifolium Neck.
var. rotundifolium $\mathrm{Sm}$.
rusciforme Weiss.

var, alopecuroides Brid.

var. atlanticum Brid. - Rhynchostegium rusciforme var. lutescens.

$\left.\begin{array}{l}\text { var. flaccidum } \\ \text { var. fontanum }\end{array}\right\}$ Brid. - Rhynchostegium rusciforme.

var. inundatum Brid. - Rhynchostegium rusciforme var. inundatum.

var. longisetum Brid. - Rhynchostegium rusciforme.

var. prolixum Brid. - Rhynchostegium rusciforme var. prolixum.

var. rotundifolium Brid. - Rhynchostegium rusciforme.

rutabuloides Brid. - Rhynchostegium curvisetum.

rutabulum $\left\{\begin{array}{l}\text { Urumm. - Brachythecium rivulare. } \\ \text { L. - Brachythecium. } \\ \text { Mac. - Brachythecium platycladum. }\end{array}\right.$

var, aureo-nitens Brid. - Brachythecium rutabulum.

var. brevirostre Brid. - Hylocomium.

var. campestre (:. M. - Brachythecium.

var. chrysostomum Brid, - Brachythecium plumosum.

var. crenulaium Brid, - Brachythecium rutabulum.

var. cuspidatum Web. - Eurhynchium striatum.

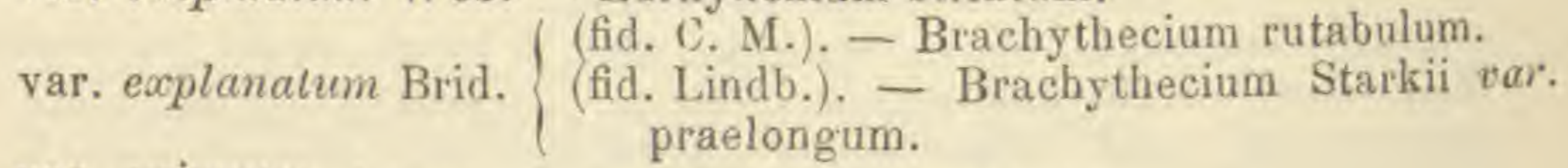

$\left.\begin{array}{l}\text { var. exiguum } \\ \text { var. flaccidum }\end{array}\right\}$ Brid. - Brachythecium rutabulum.

var. flavescens Brid?, Hpe.
var. laxifolium Brid.

var. Longisetum Brid. - Brachythecium rivulare var. longisetum.

var, piliferum Leyss. - Eurhynchium.

var, ruscifolium Web. I

var. rusciforme Ligtht. - Rhynchostegium rusciforme.

var. tenerrimum Brid. - Rhynchostegium curvisetum.

var. virens Turn.

var. $\delta$ Huds. $\}$ - Rhynchostegium rusciforme.

var. 5 H. f. et W. - Brachythecium subpilosum.

var. Sm. - Hylocomium brevirostrum.

Rutenbergii C. M. - Hylocomium?

ruthenicum Weinm. - Climacium.

rutilans \& C. M. - Ectropothecium.

Wils. - Plagiothecium pulchellum.

sabinaefolium Brid. - Anomodon rostratus.

sagittaefolium Voit. - Hylocomium triquetrum.

Saladinianum Neck. - Forstroemia trichomitria.

salaense Hpe. - Rhaphidostegium.

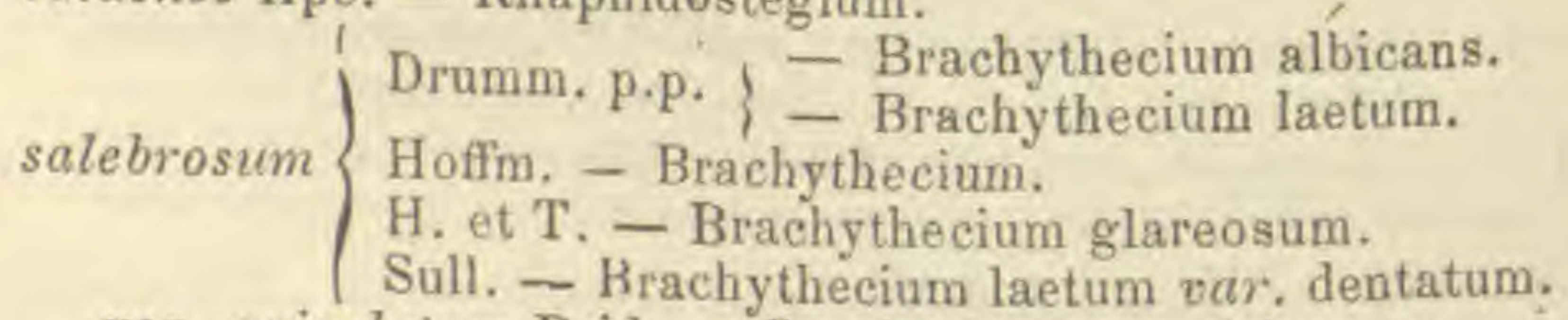

var. apiculatum Brid, - Brachytheeium salebrosum.

var. capillaceum W. et M. - Brachythecium salebrosum var. cylindricum.

var. paraphysigerum Brid. - Brachythecium salebrosum.

var. texanum L. et J. - Brachythecium salebrosum var. texanum.

var. Torreyanum Brid. - Brachythecium salebrosum. 
salicinum Spr. - Eriodon salicicola.

Salleanum Besch. - Microthamnium.

samoanum $\left\{\begin{array}{l}\text { C. M. - Thuidium. } \\ \text { Mitt. - Trichostelenm. }\end{array}\right.$

sandwichense H. et W. Arn. - Ectropothecium.

saprobolax C. M. in Ule Bryoth, brasil. $n, 186$.

lignic, - Am, merid. : Brasil, austr. or.

saproxylophilum C. M. - Rhaphidostegium.

sarmentosum Wallenb. Fl. Lapp. p. 380 ; Bryol. VI (mon. p. 48), l. 619 ;

W. P. Sch. op. cit. p. 788.

Amblystegium sarmentosum de Not. Briol. ital. p. 135.

H. stramineum var. Sull. et $L$. M. bor. am. I ed, $n .311$ b.

H. trifarium B sarmentosum Rab. Deutsch. Krypt. Fl. II, p. 290.

H. Stereodon stellatus \& Terrae Novae Brid. Bryol, univ, II, p. 603.

2, In uligin. - Eur. : Alp. et subalp. reg. interm. et sept. : Spitzberg,

Septem Irisul,, ins. Ursor., Scot., Cambrovall, Hibern., Sudet.,

Alp. omn. As. : Penins. Samojed. et Tschutschica, Jenissei inf.

Am. sepl.: Groenland, Labrador, Anticosti, Terra nov., New Brunswick, Nov. Angl.

Exs.: Mac. Canad. M. n. 363 p.p.

Rab. Bryoth. eur. n. 760.

Sull, et Lesq. M. bor. am. II ed., n. 461.

Sauteri W. P. Sch. mss.; C. M. Syn. II, p. 685; Bryol, eur. VI (mon. p. 21), t. 685; W. P. Sch. op. cit.p. 750.

Stereodon fastigiatus $\beta$ Sauteri Lindb. M. Scand. p. 38.

1. Ad rup. calc. v. dolomit. madid, - Eur.: Norveg., Austr, inf.,

Salisburg., Francon., Tirol., Rhaet.

Exs, : Rab. Bryoth. eur. n. 500.

Un itin. 1863, n. 87.

savaicum C. M. - Ectropothecium.

Savesianum C. M. - Sematophyllum.

sascatile $\left\{\begin{array}{l}\text { Brid, - Brachythecium plumosum. } \\ \text { H. f. et W. - Stereophyllum leucostegum. }\end{array}\right.$

erectum ramulis teretibus, foliis subrotundis saturate viridibus

Dill. - Encalypta streptocarpa.

saxetorum Mitt. M. Ind. or. p. 84.

- As: : ?

sasicola Voit. - Brachythecium populeum.

scaberulum Mont. - Trichosteleum hamatum.

scabrellum Bryol. jav. - Sematophyllum.

scabrifolium H. f. et W. - Philonotis appressa,

scabrisetum Schwaegr. - Eurhynchium.

scabrum \} Koch. - Eurhynchium praelongum var. atro-virens.

Mitt. - Brachythecium.

sculare $\{\mathrm{A} . \mathrm{Br}$ - - Sematophyllum.

Zenk et Dietr. - H. Crista castrensis.

scariosifolium C. M. in Act. Hort. Petrop. X, 1867, f. 1.

Stereodon scariosifolius Broth. Enum. M. Caro. p. 126.

1. Ad arbor. - Eur.: Batoum.

scariosum Tayl. - Rhynchostegium.

scaturiginum Brid. - Ectropothecium.

Schiedeanum C. M. - Thuidium. 
Schimperi Br. - Rhynchostegium demissum.

Schimperianum $\mathrm{Br},-\mathrm{H}$. imponens.

Schimperianum L.tz. - H. molle var. Schimperianum.

schistocalyx $\left\{\begin{array}{l}\text { C. M. - Thuidium. } \\ \text { Sull. - Thuidium subinvolvens. }\end{array}\right.$

sciureum Mitt. - Homalothecium.

Schlagintweitii Sendtn. - Orthothecium?

Schleicheri $\left\{\begin{array}{l}\text { de Not. - Rhynchostegium curvisetum. } \\ \text { Hedw. f. - Eurhynchium abbreviatum. }\end{array}\right.$

var. curvisetum Schwaegr. - Rhynchostegium.

var. obscurum firid. - Rhyachostegium curvisetum var. longinerve?

Schlimii C. M. - Rhaphidostegium.

Schlosseri Sendtn. - Rigodium.

Schmidii C. M. - Thamnium.

Schraderi C. M. - Plagiothecium.

Schreberi Willd Prodr. Al. Berol. n. 955; Bricl. Bryol. univ. II, p. 420; C. M. Syn. 11, p. 384; Bryol. eur. VI (mon. p. 52), t. 620; W. P. Sch. op. cit. p. 790.

Hylocomium parietinum Lindb. M. Scand. p. 37.

H. Schreberi de Not. Briol. Ital. p. 92.

Hypnum compressum Schreb. Spic. fl. Lips. p, 96.

H. cupressiforme tenuius et compressum Dill. Hist. M. p. 312, t. 40, f. 47.

H. curlandicum Brid. Mant. M. p. 160.

H. cuspidatum $\beta$ inerme Weiss Crypt. Goett. p. 253.

H. inerme Schrank Prim. Fl. Salisb. n. 845.

H. muticum Sw. M. Suec. p. 60.

H. parietinum L. Fl. Suec. n. 1020.

H. purum Eltrh. Crypt. exs, n. 311.

H. purum 3 Huds, Fl. Angl, p, 504.

H. Schreberi $\beta$ curlandicum Brid. Bryol. univ. $I 1, p .421$.

Pleurozium Schreberi Mitt. M. austr. am. p. 537.

Stereodon Schreberi ej. M. Ind. ox. p. 110.

2. In ericet, turfos, silvat., etc. - Eur. : Vulgatiss.; Spitzberg. As, : Japon., Yunnan, Sikkim (ster.), Caucas. Ant. sept.: Groenland, Labrador, Terr. nov, ins. Miquel., Nov. Scot., New Brunswick, Gaspes., Ontar, Manitoba, Saskatchewan; Columb. brit., Alaska, Sitka; sept. et temper, tot., merid. except. Am. merid. : And, Nov. Granat, et Quitens.

Exs.: Drumm. M. bor. am. I ed. n. 208.

Faurie Pl. Japon. n, 565, 835.

Mac. Janad. M. n. 364.

Sull. et Lesq. M. bor. am. II ed. n. 455, 456 .

var. curlandicum Brid. - H. Schreberi.

* var, elongatum (Lindb.) Par. Hylocomium parietinum var. elongatum Lindb. in Act. Soc. sc. Fenn. 1872,
pp. 251-252.

- As. : Amour, Saghalien.

"f. longiramea Besch. Fl. bryol. Japon. p. 390.

Ster.

Exs. : Faurie, n. 835.

"var. laevigatum (Lindb.) Par.

Hylocomium parietinum var, laevigatum Lindb. in op. et $l$. cc. - As. : Amour, Saghalien.

var. orthocarpum Brid. - Cylindrothecium eoncinnum. Schullsii Bland. - Amblystegium riparium var, trichopodium. 
Schwaneckeanum C. M. - Rhaphidostegium.

Schoeinfurthii C. M. - Taxithelium.

scilubum Aust. - Plagiothecium latebricola?

scitum P. B. - Thuidium.

var. astivale Aust. - Thuidium scitum var, cestivale.

sciuroides L. - Leucodon.

scoparium W. et M. - Dicranum.

var, $\beta$ eor. - Dicranum Schraderi.

Sclerodontium C. M. - Dimerodontium pellucidum.

scorpioides L. Sp.pl.p. 1592; C. M. Syn. II, p. 418; Bryól. eur. VI (mon. p. 44), t.612; W. P. Sch. op. cit. p. 796.

Amblystegium scorpioides Lindb. M. Scand. p. 33.

H. crassum Sahum. Pl. Sael. II, p. 84 .

H. fuscum Schleich. Cent. IV Pl. Helv. n. 24.

H. scorpioides, palustre, magnum, Lycopodii instar sparsum Dill. Hist. M. p. 290, t. 37, f. 25.

H. squarrosum Timm. Prodr. Al. Megap. p. 827.

H. Stereodon scorpioides Brid, Bryol. univ. II, p. 637.

2. In turfos. uligin. - Eur. : E planit. usq. in reg. mont. zon. interm, et sept. : Spitzberg. As. : Penins. Tschutschica. Am. sept. : Groenland., Island., Labrador, Anticosti, Terr. nov., ins. Miquel., Ontario, M. Rupestr., Ohio.

Exs. : Drumm. M. bor. am. I ed, n. 200.

Mac. Canad. M, n. 366 .

Rab. Bryoth. eur. n. 10 c, 771.

Sull, et Lesq. M. bor. am. II ed. n. 459.

Un, itin. 1864, n. 79,80 .

" var. julaceum Sanio in Bot. Centralbl. 1880.

Absque loco spec.

"var. miquelonense Ren. et Card. in Husn. Muscol.gall. p. 394, t. 113, f.2.

H. lycopodioides var. miquelonense ear. Fl. Miquelon, p. 53.

- Am. sept. : Ins. Miquelon. scorpioides $\left\{\begin{array}{l}\text { Schultz. - H. lycopodioides. } \\ \text { Timm, - Hylocomium squarrosum. }\end{array}\right.$ Scorpiurus Mont. - Rhaphidostegium.

palustre, magnum. Lycopodii instar sparsum Dill. - H. scol-

sculellatum Tayl. - Hypopterygium Tamarisei.

secundifolium C. M. - Rhaphidostegium.

secundum Mont. (fid Mitt). - Brachytheeium plumosum.

selenthecium C. M. - Trichosteleum.

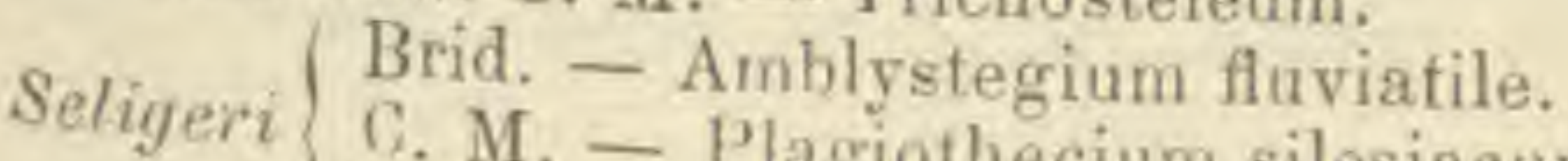

C. M. - Plagiothecium silesiacum.

Sw. p.p. - Plagiothecium Mühlenbeckii.

Sellowii $\{$ C. M. - Rhynchostegium campylocarpum.

semense C. Msch. - Rhynchostegium.

semi-manimill - Pseudo-Leskea.

semi-nerme C.sum C. M. - Trichosteleum.

emi-nerve C. M. - Helicodontium.

semi-revolutum C. $M$. in Bot. Zeit. 1855, p. 784.

H. drepanophyllum ej. Syn. II, p. 319?

2?

- Afr.: C. B. Sp.
f. austr.,n. 412 .

semi-lortulum C. M. $\{$ - Rhynchostegium. 
semi-tortum $\left\{\begin{array}{l}\text { Mitt. (M. a.). - Rhynchostegium. } \\ \text { Mitt. (M. I.or). - Rhynchostegium Hookeri. }\end{array}\right.$

Sendtneri W. P. Sch. Bryol. eur. Suppl. III-IV (Hypnum) t. II et op. cit. . 730 .

Amblystegium aduncum $\beta$ legitimum Sanio in L. et A. M. As. bor. 1890, II.

A. Sendtneri de Not. Epil.

2. In turfac. et prat. uligin. - Eur. : E reg. campestr. usq. in subalp., ab Ital. super. usq. ni L.appon. As, : Jer issei med. et inf. Am. sept.: Terr. nov,, New Brunswick, Ottawa, Ontario, Manitoba, M. Rupestr., Columb, brit., Wisconssin.

Exs, : Mac. Canad. M. n. 384 p.p.

Rab. Bryoth. eur. n. $646,757,850$.

Un. itin. 1864, n. 81, 97.

* var. gracilescens Sanio in Bot. Centralbl. 1880.

"var. Flageyi (Ren.) Par.

- Eur. : German. or.

Hypnum Wilsoni var. Flageyi Ren, in Husn. Muscol. gall. p. 395, t. 113.

In turfos. editior. - Eur. : Jurass.

« var. jenisseiense (San.) Par.

Amblystegium latifolium var. jenisseiense Lindb. et Arn. op. cit. p. 120.

H. aduncum $\delta$ molle $\dagger+$ jenisseiense San. Bryol. Fragm. in Hedwig. 1887.

- As. : Jenissei inf.

* var. occidentale (R. et C.) Par.

H. Wilsoni var, occidentale Ren. et Card. in Husn. Muscol. gall, p. 394, t. 111, f. $9,10,11$.

- Am. sept. : Idaho, Montana.

* var. robustum (Lindb.) Par.

Amblystegium Sendtneri var. robustum Lindb. M. Scand. p. 33.

- Eur. : Suecia.

* var. triviale Sunio in Bot. Centralbl. $1880, p .18$.

- Eur. : Angl., Gall. or., German. sept.

a var. vulgare ej. in op. cit. $p$. 15.

In paludos. - Eur. : Gall. or.

\& var. Wilsoni W. P. Sch, op. el ll. cc. $t .3$.

Amblystegium latifolium L. et A. op. et l. ce.; Ren. in op. oit. p. 395, $t$. $113, f .5$.

A. Wilsoni Lindb. M. Seand. p. 33.

H. aduncum $\delta$ molle Sanio Beschr... p. 36 et Bryol. Fragm. II, in Hedvig. 1887.

H. Wilsoni Ren. et Card. in Rev, bryol. 1893, p. 25.

H. lycopodioides subsp. Wilsoni Ren. in Husn. Muscol. gall. p. 375.

In uligin. saep, inund. - Eur. : Angl, Boruss, etc. As. : Jenissei inf. Am. sept.: Now Jersey.

Exs. : Rab. Bryoth, eur. n. 915.

Sendtneri Mac. - H, conflatum.

Sendtnerianum C. M. - Plagiothecium pulchellum.

senodictyon C. M. - Rhynchostegium.

sentosum Sull. - Trichosteleum (1).

(1) sepultum Vill. PI. Dauph..., p. 912 ; Brid. Bryol, univ. II p. 547 ; C. If. Syn. II, p. 509.

"An $H$, stramineum? Brid. 1. c. - Delendum, 
Sequoieti C. M. in Fl. 1875, p. 91 ; Lesq. et Jam. Man. p. 392 (1).

H. circinale $S$. et L. M. bor. am, II ed. n. 474; Mac. Canad. $M$. n. 347 p.p.

Cortic, - Am. sept. : Terr. nov. (? Card.) ; Columb. brit., Alaska, Sitka, Vancouver, Calif.

sericeum $\left\{\begin{array}{l}\text { Funk. - Brachythecium velutinum var. sericeum. } \\ \text { L. - Homalothecium. } \\ \text { gracile, albicans, capsulis subrotundis Dill. - Brachythe cium } \\ \text { albicans. } \\ \text { ramosius et tenuius, capsulis acuminatis Dill. - Pylaisia } \\ \text { polyantha. } \\ \text { surculis longioribus et teretioribus, capsulis incurris Dill. - } \\ \text { Camptothecium lutescens }\end{array}\right.$

var. praelongum Weiss. -- Campthothecium lutescens.

seriolum Hpe. - Ischyrodon.

serpens L. - Amblystegium (2).

var. compactum H. f. et W. - Amblysteginm.

var. varium C. M. pp. - Amblystegium $\left\{\begin{array}{l}\text { orthocladon. } \\ \text { radicale. }\end{array}\right.$

serratum $\left\{\begin{array}{l}\text { P. B. }- \text { Mierothamnium. } \\ \text { W. et M. - Mnium. }\end{array}\right.$

serrulatum $\left\{\begin{array}{l}\text { Hedw. - Rhynchostegium. } \\ \text { Hsch. }\left\{\begin{array}{l}\text { - Rhynchostegium huitomalcum. } \\ \text { Sull. - Rurhynchium strigosum. } \\ \text { Turn. - Rhynchostegium frondicola. }\end{array}\right.\end{array}\right.$

setaceum Weiss, - Barbula convoluta.

setigerum P. B. - Hypopterygium commitatum.

setosum P. B. - Brachythecium acuminatum var. setosum.

sibiricum C. M. - Myucella Careyana.

Sieberi C. M. - Mniodendron.

Sigmatella C. M. - Thuidium.

sigmatodontium C. M. - Sematophyllum.

var. elongatum Biyol. jav. - Sematophyllum sigmatodontium var. elongatum.

silesiacum

W. et M. - Plagiothecium.

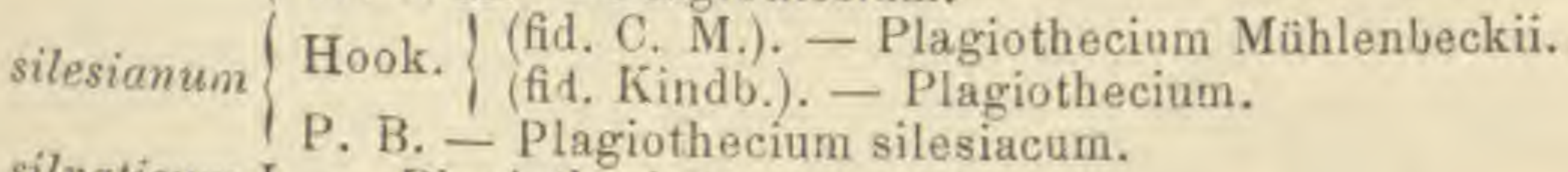

silvaticum L. - Plagiothecium.

similans Bryol. jav. II, p. 147, t. 244.

2. Ad arbor. - As.: M. Java.

simodense Sull, et Lesq. in Proced. of the Am. Acad... I85i, p. 280 (3).

2.

- As. : Japon.

Sipho P. B. - Amblystegium riparium.

siphotheca C. M. - Thuidium.

Stateri Hpe. - Ectropothecium.

Smallii S. et L. - Isopterygium.

Smithii | Dicks. - I.eptodon.

Lindb. - H. arcticum.

(1) Cf. Cardot in Rev. 1rryol. 1890, p. 18.

(3) De varietatibus Bridelit cf. W. P. Sch. Syn. II ed., p. 710,

(3) "An Miorothamnium? " Jaeg. Ad. II, p. 610. 
sodale Sull. - Ectropothecium.

solitarium Brid. - Jaegerina.

solutum Tayl, - Rigodium.

Sommerfeldti Myr. in Vet. Ak. Arsb. Stockh. 1831, p. 328 et in Hartm.

Handb, iskand. Fl. Ved.p. 331 ; Bryol. eur. VI (mon. p. 12), t. 582 ;

W. P. Sch. op. cit. p. 722.

Campylium hispidulum iar. Sommerfeldti Lindb. in Act. Soc. sc. Fenn. 1872.

H. afline Sommerf. Fl. Lapp. Suppl.

H. subalpinum $S p r$ : in sched.

H. polymorphum (Hedw.) (1) Wils. Bryol. brit.

H. stellatum $\beta$ polymorphum Myr. Coroll. p. 32; Drumm. M. bor. am. $I$ ed. $n .186$.

H. stellatum $\beta$ tenellum C. M. Syn. $I I, p .435$.

H. Stereodon stellatus $\beta$ polymorphus Brid. Rryol. univ. II, p. 602.

1. Ad arb. rad, ad sax. viar. cavar., arces vetust. et ped. mur. antiquor. - Eur. : Tota, in reg. campestr. et montos. As. : Amour, Jenissei, Obi, Caucas. Am. sept: Sin. Hudson, New Rrunswick, Ottawa, Ontar., Columb. brit., Mexic.

Exs. : Mac. Canad. M, n. 328.

Rab. Bryoth. eur. n. 396.

Un. itin. 1867, n, 29.

* var. stellulatum W. P. Sch. op. cit. p. 723.

Ut typ. - Eur. : Suecia.

Sommerfeldti Mac. - H. decursivulum.

sordidum C. $M$. in Bot. Zeit. 1856, p. 457.

Amblystegium sordidum Mitt. M. austr. am. p. 571.

Ster.

- Am. sept. : Mexic.

Soyausi C. M. - Eetropothecium.

sparsifolium Rehm. M. Afr. austr. n. 398.

- Afr.: Orange.

sparsifolium Hpe, - Porotrichum sparsiflorum.

sparsile Mitt. - Amblystegium.

sparsipilum Bryol. jav. - Eetropothecium.

sparsiraneum Geh. et $\mathrm{Hpe}$. - Rhynchostegium.

sparsum H. f. et W. - Thuidium.

spathulaefolium C. M. - Homalia.

speciosisstnum Sull. - Pterobryella.

speciosum $\left\{\begin{array}{l}\text { Brid. - Eurhynchium. } \\ \text { C. M. - Hypopterygium Thouini. }\end{array}\right.$

spectabile H. f. et W. - Climacium ruthenicum.

Spegazainii C. M. - Brachythecium.

sphacelatum Duby. - Trichosteleum.

sphaerocarpum $\left\{\begin{array}{l}\text { C. M. - Ectropothecium. } \\ \text { Spreng. - H palustre var. subsphaericarpon. }\end{array}\right.$

sphaerotheca C. M. - Rhaphidostegium.

spiculiferum $\left\{\begin{array}{l}\text { Mac. p.p. - Eurhynchium stoloniferum. } \\ \text { Mitt. - Iso: hecium. }\end{array}\right.$

spiculosum $\left\{\begin{array}{l}\text { Hpe. - Sematophyllum. } \\ \text { Mitt. - Eurhynchium. }\end{array}\right.$

spiniforme $\left\{\begin{array}{l}\text { H. f. et W. - Rhizogonium Hookeri. } \\ \text { L. - Rhizogonium. }\end{array}\right.$

(1) Cf. W. P. Sch. Syn. I ed. p. 602 et II ed. p. 725. 
spininerve Sull. - Hypnodendron Vescoanum.

spininervium Hook. - Hypnodendron.

spinosum Sibth. - Jsothecium myurum?

spinulosum Sull. et Lesq. in Proced. of the Am. Acad... 1859, p. 280.

1.

- As. : Japon.

spinulosum Hedw. - Amblystegium serpens.

spirale C. M. - Trichosteleum papillosum.

spiripes C. M. in Bot. Zeit. 1857, p. 582.

Stereodon spiripes Mitt. M. aristr. am. p. 534.

1.

- Am. merid. : Nov. Granat.

? splanchnifolium Brid. Sp. M. I1, p. 161 (1).

- Afr.: Ins. Borbon.

splendens Hedw, - Hylocomium.

splendidulum Hsch. - Ectropothecium.

sprengetii C. M. - Eurhynchium.

Sprucei $\left\{\begin{array}{l}\text { Br. - Amblystegium. } \\ \text { Mitt. - Eriodon radicalis. }\end{array}\right.$

squalidissimum C. M. - Brachythecium.

squamosum Neck, - Fontinalis.

squamulosum C. M. - Microthamnium.

squarrosulum $\left\{\begin{array}{l}\text { Brid. - H. chrysophyllum. } \\ \text { Voit. - Heterocladium dimorphum. }\end{array}\right.$

squarrosum $\left\{\begin{array}{l}\text { L. - Hylocomium. } \\ \text { Timm, - H. scorpioides. }\end{array}\right.$

var. Loreum Web. - Hylocomium.

stagnatum Wils. - H. polygamum.

Starki Brid. - Brachythecium.

stellare W. et M. - Mnium.

stellatifolium Hpe. - Thuidium.

stellatum Schreb. Spic. Fl. Lips. p. 92; C. M. Syn. II, p. 435 ; Bryol. eur. VI (mon. p. 1 i), t. 584; W. P. Sch. op. cit.p. 725.

Amblystegium stellatum Lindb. M. Scand. p. 32.

H. coma lutoscente, extremitatibus stellatis Dill. Hist. M. p. 302, t. 39, f. 35 .

H. comosum Vill. Pl. Dauph. III, p. 904.

H. Mühlenbergense P. B. Prodi. p. 66.

H. Stereodon stellatus Brid. Bryol. univ. $I I, p .600$.

2. In prat. uligin. et terr. spong. - Eur. : Spitzberg, ins. Ursor. ; reg. campestr. et mont, rar. alp. As. : Penins. Samojed, Taimyr, Jenissei, Caucas. occ. et centr. Am. sept. : Groenland, Labrador, fret. Hudson, Anticosti, Tert. nov., ins. Miquel., Gaspes., Ontar., lac. Super, Manitoba, Assiniboine, Athabascą, M. Rupestr., Columb. brit., reg. sept., centr. et or.

Exs.: Mac. Canad, M. n. 33 !'.

Rab. Bryoth. eur. n. 759.

Sull. et Lesq. M. Lor. am. II, p. 515.

var, chrysophyllum Drumm.
var, minus W, et M.

\& var. protensum Roehl. Deutsch. Fl. III, p. 103; Bryol. eur. et W. P. Sch. $l l . c c$.

Amblystegium protensum Lindb.. . c.

(1) Nec in Bryol, univ. nec in C. M. Syn. nec in Besch. Fl. bryol. Rèunion, etc. memoratur. 
H. protensum Brid. M. Rec. II, II, p. 85, t. 2, f. 3.

H. Stereodon stellatus $\beta$ protensus $e j$. Bryol. univ. $I I, p .602$.

Ad sax. madid. praecip. calc. - Eur. : Reg. montan. As.: Jenissei, Caucas. centr. Am. sept. : Ontario, M. Rupestr., Columb. brit., New York.

Exs, : Mac. Canad. M. n. 331.

Rab. Bryoth, eur. n. 497.

var. polymorphum Myr. - H. Sommerfeldti.

« var. subdecursivulum Kindb. in Mac. Cat. p. 225.

Ster. Paludic. - Am. sept. : Ontario.

var. tenellum C. M. - H. Sommerfeldti.

"var. virens de Not. Epil. p. 171.

Ut et ubi typ.

stellulatum (Mitt.) Par.

Ctenidium stellulatum Mitt. Fl. Vit. p. 399.

- Pac. : Ins. Societat.

stenocarpum C. M. - Sematophyllum.

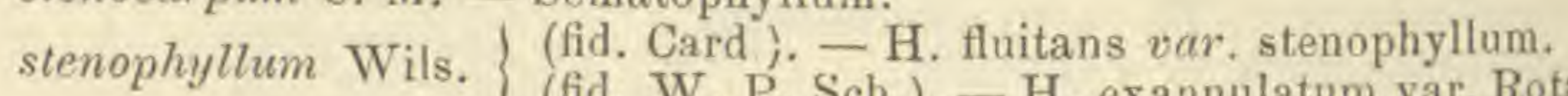
stenop. W. P. Sch.). - H. exannulatum var. Rotae. stenopyxidium C. M. - Rhaphidostegium.

stenosekos W. et Dy. - Isopterygium.

stephomichos eor. - Leucomium.

stereopoma Spr. - Brachythecium.

sticticolum C. M. - Rhaphidostegium. "

stigmatophyllum Hpe. - Microthamnium.

stigmosum C. M. - Trichosteleum.

stissophyllum Hpe. - Trichosteleum.

Slokesii Turn. - Eurhynchium.

stoloniferum $\left\{\begin{array}{l}\text { Hook. - Eurhynchium. } \\ \text { P. B. - Anomodon obtusifolius. }\end{array}\right.$

stranineolum C. M. - Ectropothecium.

stramineoides Sb. in Jaeg. Ad. II, p. 754.

H. pseudo-stramineum Hpe. in Linn. 1871-73, p. 518.

Rhynchostegium pseudo-stramineum Mitt. in Trans, and Proced. of the roy. Soc. of Victoria, 1883, p. 88.

Ster.

- Pac. : Austral. or. (Nor. Vales.).

stramineum Dicks. Fasc. II, Pl. crypt. p. 6, t. I, f. 9; C. M. Syn. Il,

p. 378; Bryol. eur. V1 (mon. p. 49), t. 617; W. P. Sch. op. cil. p. 792.

Amblystegium stramineum de Not. Briol. ital. p. 137.

H. obtusum Vill. Pl. Dauph. III, n. 912.

H. Stereodon stramineus Brid. Bryol. univ. II, p. 568.

2. In prat. uligin. et turfac. aquos. - Eur.: Spitzberg, ins. Uraor.; a Iappon. usq. ad Ital. super. As. : Jenissei. Am. sept. : Groenland, Labrador, fret. Hudson, Anticosti, Terr. nov., ins. Miquel., New Brunswick, M. Alb., Pensilv., Ottawa, M. Selkirk, Columb. brit.

Exs.: Drumm. M. bor. am. I ed. p. 210.

Mac. Canad. M. p. 473.

Rab. Bryoth. eur. n. 645 et b, 847 .

Sull. et Lesq. M. bor. am. II, n. 460 .

Un. itin. 1863, n. $96 ; 1864$, n. 36.

" var. acutifolium (Arn+) Par.

Amblystegium stramineum vas, acutifolium Arn. M. As. bor, 1890, II, p. 129. 
- var. apiculatum (Arn.) Par.

Amblystegium stramineum var. apiculatum Arn. op. et $l$. $c c$.

- As. : Jenissei inf.

\& var. compactum Milde. Bryol. Sil. p. 370 .

- Eur. : German., Gall. Am. sept. : Groenland.

* var. exiguum Ren. Fl. Miquel, p. 57.

- Eur. : Gall. Am. sept. : Ins. Miquel.

a var, laxifolium C. M. in Deulsch. Nord-Pol. Exped.

- Eur. : ? Am, sept.: Groenland.

"var. patens (Lindb.) Par.

Amblystegium stramineum var. patens Lindb. M. Scand. p. 34 et Adn. n. 62 .

In fossis turfac. - Eur.: Fennia.

" var. procerum Aman in Rev. bryol. 1889, p. 91.

Ad rup. gneiss. humid. - Eur. : Alp. Rhset.

var. $\beta$ Schwaegr. $-\mathrm{H}$. trifarium.

var. Sull. - H. lycopodioides.

Strangei Mitt. et F. v. Müller in Proced. of the Linn. Soc. 1879 (extr. vol.), $p$.

Acanthocladium Strangei eor. in Proced. of the Linn. Soc. of N. S. Wales, p. 102.

- Pac.: Nov. Caledon. (ins, Pinorum).

strangulatum Hpe. - Rhaphidostegium.

var. prostruta Hpe. - Rhaphidostegium strangulatum var. prostrata. stratum C. M. in Dusen M. Camer. n. 837.

- Afr.: M. Cameroon.

strepsiphyllum Mont. - Sematophyllum.

var. densum Bryol. jav. - Sematophyllum strepsiphyllum var. densum. striatellum C. M. - Plagiothecinm Mühlenbeckii.

striatulum Spr. - Eurhynchium.

striatum Schreb, - Eurhynchinm.

var. Durieui Mont. - Eurhynchium striatum var. meridionale.

strigosum $\{$ Hoffm. - Eurhynchium.

Neck. - Pylaisia polyantha.

var. circinatum Brid. - Eurhynchium.

var. diversifolium Lindb. - Eurhynchium.

var. ramosum Neck. - Camptothecium lutescens.

strumiferum $\mathrm{Hpd}$. - Rhynchostegium.

strumosum $\{$ C. M. - Leucomium.

Struthiopter Gmel. - Cynodontium polycarpum var. strumiferum.

Stuartii C.

subarti C. M. - Thuidium.

subacutifolium C. M. - Rhynchostegium.

subaequans $\mathrm{H}$ pe. - Plagiothecium.

subalbidum S. et L. - Isopterygium.

subalpinum Spr. - H. Sommerfeldti.

subbasilare $\left\{\begin{array}{l}\text { Hook. - Rhizogonium. } \\ \text { Schwaegr. - Rhizogoni }\end{array}\right.$

subbrachycar Schwaegr. - Rhizogonium mnioides.

subbreviseturpum Hpe. - Rhaphidostegium.

subcampanifum Hpe. - Ectropothecium.

subcapillatorme (3eb, et Hpe. - Microthamnium.

subcapillatum C. M. - Homalothecium. 
subcapillisetum C. M. in Dusen M. Camer. $n, a 17$.

- Afr. : M. Cameroon.

subchrysophyllum Ansi Enum. M. Longob. sup., mem. in Rev, bryol. $1876, p .63$.

Ster.

- Eur, : Etrur. (M. Pisan).

subcircinale Ltz. - Rhaphidostegium.

subclavatum Hpe. - Rhynchostegium tenuifolium.

subcompressiforme C. M. mss.; Jaeg. Adl. II, p. 593.

- Afr.: Teneriffa.

subcompressulum Par.

H. compressulum Besch. Not. M. des 1. S. Paul et Amsterd. 1875, p. 5.

Ster. - Afr. : Ins. Amsterdam.

subcompressum (Br. et Sch.) C. M. Syn. 1I, p. 253.

Leskea subcompressa $B r$. et Sch. in W. Sch. M. Abyss. Coll. II, n. $581 b$. 2. - Afr. : Abyss.

subconfertum C. M. - Rhynchostegium. subcupressiforme W. P. Sch. - H. canariense. subciovicollum C. M. - Isopterygium. subdelicatulum Hpe. - Thuidium. subdenticulatum C. M. - Ectropothecium.

subdiminutivum Geh. et Hpe. - Microthamnium.

subenerve W. P. Sch. Syn, I ed. p. 634 et II ed. p. 772.

Amblystegium subenerve Bryol. eur. VI (man. p. 8), t. 563 .

1. Ad sax. humidiuse. - Eur.: M. Pinifer., Tirol., Gastunia. subenerve Hpe. et C. M. - Rhynchostegium. suberectum $\left\{\begin{array}{l}\text { Hpe. - Thuidium. } \\ \text { Mitt. - Eurhynchium. }\end{array}\right.$ subfalcatum L. et J. - Plagiothecium.

subflaccum C. M. et Kindb. in Bidr. p. 454 (nom.) et in Mac. Cat. p. 249. Cylindrothecium Drummondii Mac. Canad. M. n. 436 p.p.

2. Ster. Terr. - Am, sept. : Ontario.

subflavum H. f, et W, - Stereophyllum leucostegum. subgranulatum Geh. et Hpe. - Thuidium.

subhirsutum, viticulis gracilibus erectis, capsulis teretibus Dill. - Anomodon viticulosus.

subhomomallum C. M. - Pylaisia.

subhumile C. M. - Rhaphidostegium.

subimponens Lesq. in Trans. of the Am. Phil. Soc. XIII, p. 14; Sull. Ic. M. Suppl. p. 103, t. 79; Lesq. et Jam. Man. p. 393.'

Stereodon plumifer Mitt. in Proced. of the Linn. Soc. 1864, p. 4I, t. 7.

2. Rupic. - Am. sept.: Terr. nov,, New Brunswick (? Card.): Columb. brit., Vancouver, Washington, Idaho sept., Oregon, Calif. Exs. : Mac. Canad. M. n. 349.

Sull. et Lesq. M, bor. am. Il ed, n. 476 .

a var, cristula Kindb. in Bull. Torr. bot, Club, p. 280 et in Mac. Cat. p. 237.

H. cristula ej. Enum. Bryin, exot. 1888.

Rupic. in Quercel. - Am. sept. : Vancouver.

subimponens Hpe, - Ectropothecium amabile. 
subincurvans $W . P$. Sch. in Breutel M. Capens.

$$
\text { - Afr.: C. B. Sp. }
$$

sublimatum Ltz. - Ectropothecium.

submacrocarpum $\mathrm{Hpe}$ - Hylocomium.

submacrodontium Geh. et Hpe. - Mierothamnium.

submammillosulum C. M. - Isopterygium.

submicrotheca C. M. - Pterogoniella.

submolluseum Besch. in Ann. sc. nat. $1892, I$, p. 93.

1. Silvic. - As, : Yunnan.

subnemorosum C. $M$. in sched.; Jaeg. Ad. $1 I$, p. 592.

- Am. merid. : And. Nov. Granat.

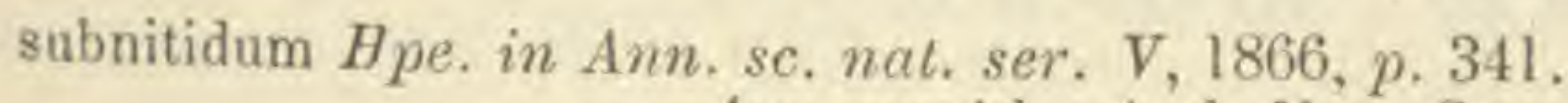

-Am. merid. : And. Nov. Granat.

subnudum C. M. - Thuidium.

var. C. M. - Thuidium subnudum var.

subobscurum Hpe. - Microthamnium.

suboligophyllum Hpe. - Amblystegium.

subperspicuum C. M. - Microthamnium.

subpilosum H. f, et W. - Brachythecium.

subpinnatum $\{$ Hpe. - Thuidium.

subplicatum Lindb. - Hylocomium squarrosum var. subpinnatum.

- Brachythecium subpilosum.

subplumaeforme C. M. in sched.; Jaeg. Ad. $1 I$, p. 595.

- As.: Japon.

subpungens C. M. - Sematophyllum.

subpycnophyllun C. M. - Sematophyllum.

subrectifolium Sull. - H. nemorosum,

subrhinophyllum C. M. - Trichosteleum.

subrolundum Hpe. - Rhynchostegium.

subrusciforme C. M. - Rhynchostegium.

subrutabulum C. M. - Brachythecium.

subscabriselutum C. M. - Trichosteleum.

subscabrum C. M. - Rhaphidostegium.

subsecundum W. Arn. - Rhaphidostegium caespitosum.

subserratum C. M. - Thamnium subseriatum.

subserrulatum C. M. - Rhynchostegium.

subsimplex $\left\{\begin{array}{l}\text { Hedw. - Rhaphidostegium. } \\ \text { Sull. }\end{array}\right.$

subsphaericarpon. - Plagiothecium micans.

subspininerviupon Schleich. - H. palustre var. subsphaericarpon.

subsquarrosulum. H. M. - Hypnodendeon.

substigmosum C. Mpe. - Eurhynchium.

substrigosum C. M. - Trichosteleum.

(1) Mosum Mac. p.p. - Eurhynchium strigosum.

substrumulosun, $\{$ Hpe, - Rhaphidostegium Welwitschii.

subsulcatum W. P. W. P. Sch. - Rhynchostegium surrectum.

subtamariscinu. P. Sch. - H. sulcatum var. subsulcatum.

subtenue Jam $\mathrm{H}$ e. - Thuidium.

subtile Hoffm, - Brachythecium reflexum.

subtricostalum. - A mblystegium.

subulatulum C. M. - Sciaromium.

subulatum C. M. - Trichosteleum.

suburceolupe. - Sematophyllum.

subver rulum Hpe, et Ltz. - Ectropothecium.

subvolvatum Geh. - Isopterygium. 
succedaneum H. f. et W. - Rhaphidostegium.

sudeticum W. P. Sch. - H. pseudo-stramineım. suecicum Hartm. - Thedenia.

suleatum W. P. Sch. Syn. I ed. p. 699 et II ed. p. 744.

Amblystegium glaucum var, sulcatum Lindb. M. Scand. $p$. 32."

2. Ad sax. et terr. umbr. vel humidiusc. - Eur. : E reg. subalp. usq. in alp. super.

Exs. : Un, itin. 1863, n. 84.

« var. subsuleatum W. P. Sch. Syn. II ed, l, c.

H. subsulcatum ej. Syn. I ed. l. c.; Rab. Bryoth. eur. n. 910, 997: Un. itin. $1863, n .85$.

Ut et ubi typ.

sulfureum Geh. et Hpe. - Brachythecium.

Sullivantiae $\left\{\begin{array}{l}\text { Lindb., Spr. - Plagiothecium Roëseanum? } \\ \text { Sult. }\end{array}\right.$

Sullivantii Spr. - Eurhynchium. graminiwior

sumatranum Bryol. jav. II, p. 149, t. 247.

1 vel syn. - As, : Sumatra.

superbum C. M. - Porotrichum.

surculare (Mitt.) Jaeg. Ad. II, p. 608.

Stereodon surcularis Mitt. M. Ind. or. p. 112.

2 ?

- As, : Khasia.

surinamense Dz. et Mk. - Ectropothecium.

surreclum Mitt. - Rhynchostegium.

Swartzii $\{$ Brid. - H. incurvatum.

Turn. - Eurhynchium praelongum var. atro-virens.

var. minus Turn. - Eurhynchium pumilum.

symmetricum R. et C. $-\mathrm{H}$. uncinatum subsp. symmetricum.

tabescens C. M. - Trichosteleum.

tahitense Angstr. - Ectropothecium.

tamariscellum C. M. - Thuidium.

Tamarisci Sw. p.p. $\left\{\begin{array}{l}\text { - Hypoterygium. } \\ \text { - Hypopterygium commutatum. }\end{array}\right.$

tamariscifolium Neck. - Thuidium tamariscinum.

var. $\beta$ Neck. - Thuidium recognitum.

tamariscinum $\left\{\begin{array}{l}\text { Brid. p.p. - Thuidium mascarenicum. } \\ \text { C. M. - Thuidium recognitum. } \\ \text { Hedw. - Thuidium. } \\ \text { Hsch. - Thuidium aequinoctiale. } \\ \text { Sull. - Thuidium delicatulum. }\end{array}\right.$

var. delicatulum $\left\{\begin{array}{l}\text { Brid. }\{\text { - Thuidium delicatulum? } \\ \text { Mont. - Thuidium Antillarum? }\end{array}\right.$

var. prolensum Brid. - Thuidium delicatulum.

var. recognitum Brid. - Thuidium.

var. tenerrimum Brid. - Thuidium Antillarum?

tanytrichum Mont. in Ann. sc. nat. 1845, IV, p. 88 et Syll.p. 9; C. M.

Syn. II, p. 391 ; Bryol. jav. II, p. 151, t. 249.

Stereodon tanytrichus Mitt. M. Ind. or. p. 112.

2.

- As, : Sikkim, Java.

tanytrichum Duby. - Ectropothecium procerum.

tavoyense Hook. - Stereophyllum. 
taxifolium $\left\{\begin{array}{l}\text { L. }- \text { Fissidens. } \\ \text { minus, basi }\end{array}\right.$ minus, basi capsulifera Dill. - Fissidens.

taxiforme $\left\{\begin{array}{l}\text { Brid. - Isopterygium. } \\ \text { exiguum, versus extremitatem capsuligerum Dill. - Fissi- } \\ \text { dens bryoides. } \\ \text { palustre, majus et erectum capsuligerum Dill. - Fissi- } \\ \text { dens adiantoides. }\end{array}\right.$

Taylori Mitt. - Brachythecium cónosiomum.

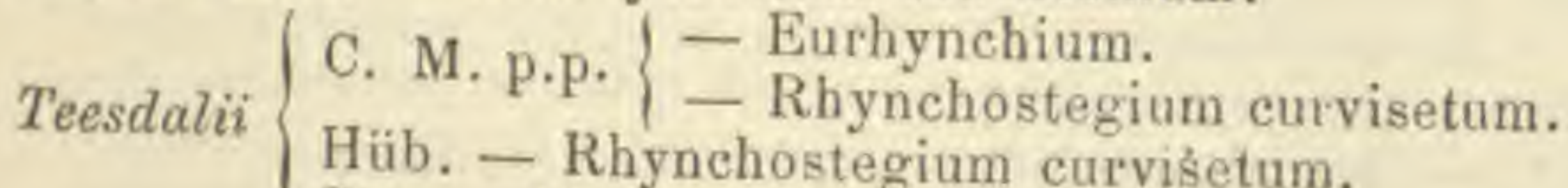

Sm. - Eurhynchium.

var. Wils, - Rhynchostegium curvisetum.

tenaci-insertum C. M. - Ectropothecium.

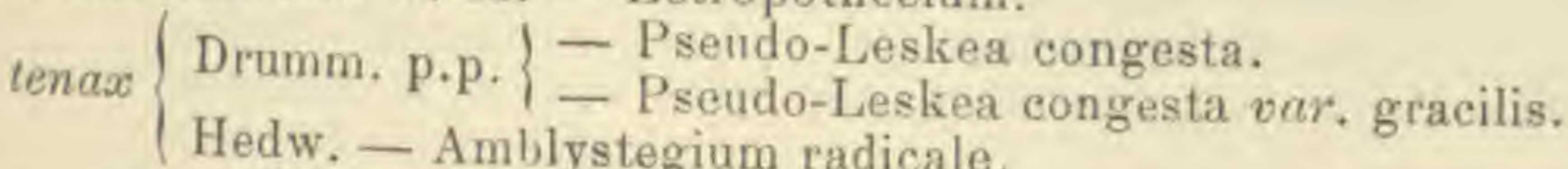

tenellum \{ Dicks. - Rhynchostegium.

Schwaegr. - Rhynchostegium cur isetnm.

Teneriffae $\left\{\begin{array}{l}\text { Bourg. exs - Rhynchosteyium Bourgceanum. } \\ \text { Mont. - Rhynchostegium }\end{array}\right.$

tenerrimum C. M. - Rhynchostegium curvisetum.

lenerum $\left\{\begin{array}{l}\text { H. f. et W. - Plagiothecium micans. } \\ \text { Sw. - 1 sopterygium }\end{array}\right.$

tenuatipes C. M. - Ectropothecium.

tenue $\{$ C. M. - Leptohymenium.

tenuicaule rad. - Amblystegium serpens var. tenue.

enuicaule Spr. - Eurhynchium Vaucheri var, fagineum.

tenuifolium $\left\{\begin{array}{l}\text { Hedw. - Rhynchostegium. } \\ \text { Schleich. }\end{array}\right.$

tenuinerve Mitt.

tenui-pine Mitt. - Austinia,

tenui-pinnatum C. M. - Brachythecium.

tenuirostre $\left\{\begin{array}{l}\text { C. M. - Helicodontium. } \\ \text { Hook. - Rhaphidostegium. }\end{array}\right.$

var. C. M. - Helicodontium tenuirostre var.

tenuisetum (Lindb, ) Par.

Amblystegium tenuisetum Lindb. M. Scand. p 32,

- Eur. : Suecia (Stockholm).

tenuisetum Sull, - Taxithelium.

tenuius Vill. - Eurhyncyium myosuroides (1).

lequedamense Hpe. - Rhaphidostegium.

Ternstroemice Brid. - Pilotrichella.

Terrae novae var. australe H. f, et W. - Ectropothecium australe,

terrestre $\left\{\begin{array}{l}\text { Aubl. - Pilotrichella quinquefaria? } \\ \text { C. M }\end{array}\right.$

tetragonim $\mathrm{Sw}$ - Ectropothecium.

Teysmanni Bryol. - Pilotrichella.

Thedenii Haryol, jav. - Isopterygium.

thelidiclyon Sartm. - Brachythecium.

thelipodian S, et L. - Rhaphidostegium.

theliporitin C. M. - Sematophyllum pungens.

iporum C. M. - Sematopyllum. (1) tenuissimum Vill. Pl. Dauph. p. 905 ; Brid. Bryol. univ. II, p. 546 ; C. M.
yn. II, p. 509 .

c. - Delendum. 
thelistegum C. M. - Microthamnium.

Thieleanum C. M. - Porotrichum.

Thomasii Brid. - Brachythecium salebrosum var. Thomasii.

Thouini Schwaegr. - Hypopterygium.

Thunbergii Brid. - Pilotrichella.

thuringicum $\left\{\begin{array}{l}\text { Brid, - Eurhynchium strigosum. } \\ \text { W. et M. - Rhynchostegiun confertum. }\end{array}\right.$

tibetanum Mitt. - Amblystegium.

Timmii Brid. - H. molluscum.

Tocaremae Hpe. - Rhynchostegium.

tokiadense Mitt. - Homalothecium.

tomentosum Hedw. - Rhacopilum.

Tommasinii Sendtn. - Eurhynchium Vaucheri.

var. fagineum $\mathrm{H}$. Miull, - Eurhynchium Vaucheri var. faginenm. tongense C. M. - Trichosteleum.

torquatum Hedw. - Schlotheimia.

torrentis C. M. et Kindb. in Mac. Cat. p 243.

H. Goulardi Mac. Canad. M. n. 503.

Ster. ? Ad rup. arenac. - Am. sept. : M. Rupestr.

torluosum Web. - Barbula.

Tourettii Brid. - Scleropodium illecebrum.

tovariense C. M. - Rhaphiảostegium galipense.

toxarion $\left\{\begin{array}{l}\text { Mitt. p.p. - Rigodium } \begin{array}{l}\text { 年achypodiun. } \\ \text { implexum. } \\ \text { Lechleri. } \\ \text { solutum. }\end{array} \\ \begin{array}{l}\text { Schwaegr. - Rigodium. } \\ \text { Wils. - Rigodium solutum. }\end{array}\end{array}\right.$

trachaelocarpa Ângstr. - Rhaphidostegium.

trachelocurpum C. M. - Rhaphidostegium calabarense.

trachyamphorum C. M. - Trichosteleum.

trachychaeton F. Müll. Anal. draw. of Austr. M., I, ı. 15.

- Pac.: Austral, fel.

trachynoton C. M. - Rhynchostegium.

trachypelma C. M. - Rhynchostegium.

trachypodium C. M. - Brachythecium.

trachypyxis C. M. - Rhaphidostegium.

trichocladum (Tayl.) Jaeg. A $l . I I, p, 594$.

Ctenidium trichocladum Mitt. M. austr. am. p. 510.

Neckera trichoclada C. M. Syn. II, p. 89.
Pterogonium trichocladum Tayl. in Lond. Journ. of bot. 1847, p. 336.

1. Cortic. - Am. merid.: And. Quitens.

trichocladon Bryol. jav, - Eurhynchium.

Trichocolea C. M. -- Sernatophyllum.

trichocoleoides C. M. - Sematophyllum.

trichodes $\left\{\begin{array}{l}\text { Brid. - H. flicinum var. trichodes. } \\ \text { Poll. - Camptothecium nitens. } \\ \text { Web. - Meesea uliginosa. } \\ \text { capsulis oblongis, setis brevioribus Dill. - Leskea poly- } \\ \text { carpa. } \\ \text { serpens, setis et capsulis longis erectis Dill. - Amblystegium } \\ \text { serpens. }\end{array}\right.$

trichophyllum Sw. - Lepyrodon.

trichophorum Spr. - Plagiothecium piliferum.

trichopodium Schultz. - Amblystegium riparium var. trichopodium. 
var. Kochii Lindb. - Amblystegium.

trichomanoides | Drumm. -. Homalia Macounii.

Schreb. - Homalia.

trichostegum 6. M. - Rhaphidostegium.

tricoslatum Sull. - Hypnodendron.

trifarium Web. et Mohr. Schoo. Reis.p. 177, t. 2, f. 2 a-d; C. M. Syn. II, p. 381 ; Bryol. eur. VI (mon. p. 50), t. 618; W. P. Sch. op. cit. p. 793.

Amblystegium trifarium de Not. Briol ital. p. 137.

H. illecebrum Schultz Fl. Starg. p. 318 (excl. syn. Brid. H. uliginosum).

H. stramineum $\beta$ foliis latioribus Schwaegr. Suppl. $I, I I, p .212, t .89$.

H. uliginosum Schleich. Cent. III Pl. Helv, n. 54 ?

H. Stereodon trifarius Brid. Bryol. univ. II, p. 567.

2. In turfac. profund. - Eur. : Reg. montan. et subalp. zon. interm., planit. German. septentr, reg. campestr. Scandin. As.: Ochotsk, Jenissei. Am, sept. : Groenland, Ontario, lac. Huron, M. Rupestr., Columb. brit., Ohio.

Exs. : Mac. Canad. M. n. 365.

Rab. Bryoth, eur, a. 751.

Sull. et l.esq. M, bor. am. II, p. 462 .

trifarium Drumm. - H. Richardsoni.

var. sarmentosum Rab. - H. trifarium.

lrinitense C. M. - Ectropothecium.

triquetrum L - Hylocomium.

var, brevirostre Poll. - Hylocomium.

var. minus W. et M. - Hylocomium brevirostre.

trismegistum Mont. - Mniodendron Khortalsii.

trisle C. M. - Leskea.

triviale C. M. - Ectropothecium.

trochelophyllum Hpe. - Trichosteleum.

trunialulum C. M. - Trichosteleum.

tuloferum Hpe. - Rhaphidostegium.

tumidiusculum Lam. $\left\{\begin{array}{l}\text { - Eurhynchium Boscii. } \\ \text { - Isothecium myurum. }\end{array}\right.$

Tundrae (Arn.) Par.

Amblystegium Tundrac Arn.'M. As. bor. 1890, II, p 128.

2. Paludic, - As. : Jenissei infer.

tunguraguanum (Mitt.) Jaeg. Ad. II, p. 584.

Stereodon tunguraguanus Mitt. M. austr. am. p. 534. 2.

- Am. merid. : And. Quitens.

turbinatum W. et M. - Bryum.

turfaceum Lindb. - Plagiothecium.

turgescens W. P. Sch. Syn. I ed. p, 647 et II ed. p. 794.

Amblystegium turgescens L. et A. M. As. bor, 1890, 11, $p 122$.

त et fr. ign. In paludos. et ad rip. lacuum. - Eur. : Spitzberg. ins.

Ursor., Seandin., Salisburg., Stir., Helvet., Alp. Bavar., Tirol.

As.: Jenissei inf. Am. sept. Groenland, fret. Davis, M. Rupestr. et

Selkirk. Am. merid. : And. Boliv.

Exs.: Mac. Canad. M. n. 483.

Mandon Pl. Boliv. n. 1709.

Rab. Bryoth. eur. n. 490.

c var. tenue Berggr. M. Spetsb. n. 151 b et in K. Sv. Vet. Ah. Handl. n. 7, p. 91 . 
turgidellum C. M. - Trichosteleum.

turgidicaule C. M. - Stereophyllum guarapense.

turgidum $\left\{\begin{array}{l}\text { Dz. et Mk. - Sematophyllum. } \\ \text { Hartm. - Brachythecium cirrosum. } \\ \text { Wahlenb. - Aulacomnium. }\end{array}\right.$

tutuilum Sull. - Ectropothecium.

ulicon Tayl, - Rhynchostegium.

uliginosum Schleich. - H. trifarium?

umbilicatulum C. M. in Rev. bryol. 1876, p. 4 (nom.).

Isopterggium umbilicatulum Mitt. in Trans. and Proced. of the roy. Soc. of Victoria 1883, p. 86 .

- Pac.: Austral. or. (Nov. Vales.).

umbilicatum C. M. in Linn. 1867-69, p. 623.

1.

- Pac. : Austral. or.

\& var. protractum C. M. l, c.

- Pac. : Austral. or.

umbratum Ehrh. - Hylocomium.

umbrosum Hook, f. - Sciaromium.

uncinatum Hedw. M. frond. IV, p. 65, t. 25; C. M. Syn. II, p. 322;

Bryol. eur. VI (mon. p. 31), t. 600 ; W. P. Sch. op. cil. p. 738.

Amblystegium aduncum Lindb. M. Scand. p. 33.

A. uncinatum de Not. Epil.

A. uncinatum $\alpha$ suetum San, in L. et A. M. As. bor. 1890, II, p. 118 (1).

H. contiguum Nees in Hüb. Muscol. germ. p, 676.

H. Stereodon uncinatus Brid. Bryol. univ. II, p. 629 .

H. Stereodon uncinatus $\beta$ bicolor ej. op. et $l$. co.

Leskea Deinbollii Sw, (fid. Hartm. Skand. Fl. V ed. p. 332).

1. Lignic., v. in udis petros, et sec. rivul. lapidos. - Eur. : Spitzberg, Septem Ins, ins. Ursor, ; e reg. montan, infer. usq. in alp. vulgatiss. As. : Japon., Kamschatka, Amour, Saghalien, Ochotsk, penins. Samojed., Jenissei, Obi, Altaï sinens., Sikkim, Caucas, Afr.: Ins. Kerguelen. Am. sept. ; Groenland, 1-abrador, fret. Hudson ; ab Anticosti, Terr. nov. et ins. Miquel. ad mar. Behring et fret. Kotzebuë; tota, merid. except. Am. merid. : And. Quitens.. reg. antaret. Pac. : Nov, Zeland, fret, reg. Georges, Austral. (Victoria).

Exs.: Drumm. M. bor, am. I ed, n, 202.

Faurie Pl. Jap. n. 1055.

Mac. Canad. M. n 335.

Rab. Bryoth. eur. n. 792, 1195, 1242.

Sull. et Lesq. M. bor, am. II ed, n, 463.

Un. itin. 1864, n. 12 .

" var. abbreviatum Bryol, eur. el W. P. Sch. ll, cc.

In udis alp. - Eur. et Am. sept. : Ubi typ.

" $f$. alpina Ren. in Husn. Muscol. gall. p. 379.

Terr. - Eur. : Alp., Pyren.

"var. drepanoides (San.) Par.

Amblystegium uncinatum var, drepanoides San, in op. et 7. oc.

- As. : Jenissei sup. (1) Formae : medium, medium-fuscellum, plumosun (an var, plumosum W.
P. Sch.?). 
" var. fragile Lesq. et Jam. Man, p. 383.

H. Jamesii Aust, in Coult. Bot. Gas. I1, p. 142.

Ut et ubi typ. in $A m$. sept.

* var. gracilescens Bryol. eur, el W. P.Sch. ll. cc.

Ad terr. in uligin. - Eur. et Am. sept. : Reg. alp. ; ins. Miquelon, Labrador.

"var, gracillimum Berggr. M. Spetsb, n. 134 c et in K. So. Vet, Ak. Handl. XIII, $n .7, p .86$.

Rupic, - Eur, : Spitzberg, ins. Ursor.

"var, micropterum Kind, in Mac. Cat. p. 229.

- Am. sept.: Labrador.

* var, orthothecioides Lindb. in Oefv..., p. 540.

Amblystegium orthothecioides ej. M. Scand. $p, 33$.

Rupic. - Eur. : Spitzberg, Septem Ins,, ins. Ursor, Lappon. kolaëns.,

Scandin, sept., Fennia. As.: Siber. Am. sept.: liroenland, Labrador, ins. Miquel.

"var. plumosum W, P. Sch. Syn. 1 ed. p. 612 et II ed. l. c.

Ad lign. madid. et sax. - Eur. et $A m$, sept. : Ubi typ.

Exs, : Mac. Canad M. n. 374.

Rab. Bryoth, eur. n. 548.

var. plumosum Mac. - Amblystegium riparium.

« var. plumulosum Bryol. eur. et W. P. Sch. ll. cc.

Amblystegium uncinatum var, plumulosum San. in op. et $l$. cc. (1).

H. Peckii Aust. in Rep. Reg. Univ. of St. of New-York, XXV, p. 71.

Ad arb. trunc. et ramul. - Eur. et Am. sept. : Ubi typ.

Bxs. : Un. itin. 1864, n. 56.

" var. subestriatum Kindb. in op. et l. cc.

Terr. - Am. sept. : New Brunswick, Columb. brit.

Eass. : Mac. Canad. M. n. 376.

" var, subjulaceum Bryol, eur, et W. P. Sch.ll. cc.

Secus rivul. - Eur. et Am, sept. : In alpin. frigidior.

- var, subsulcatum Warnst, in Hedwig. 1887, Heft I1. - Am. sept. : Groenland.

3. subsp. symmetricum Ren. ct Card. in Bot. Gaz. XIV, p. 99.

Terr. - Am. sept.: ldaho, Montana, Oregon, Washington, ins. Vancouver.

uncinulatum Jur. - H. canarieńse.

undatum $\left\{\begin{array}{l}\text { P. B. - Hookeria. } \\ \text { Schrank. - Plagiothecium undulatum. }\end{array}\right.$

undulatum $\left\{\begin{array}{l}\text { L. - Plagiothecium. } \\ \text { Schrank. }\end{array}\right.$

unguiculatum $\left\{\begin{array}{l}\text { H. f. et W. - Thuidium furfurosum. } \\ \text { La Tour. - Eurhynehium striatum. }\end{array}\right.$ Unicostatum C. M. et Kindb. in Bidr. p. 454 (nom) et in Mac. Cat. p. 224.
2. - Am. sept. : New Brunswick, Ottawa, Ontario.

upoloviense C. M. - Sematophyllum macrorhynchum.

urceolatem Hisch. - Ectropothecium. 
utahense L. et J. - Brachythecium. vaciillans eor. - Amblystegium.

vagans $\left\{\begin{array}{l}\text { Drumm. - Brachytheciun rivulare. } \\ \text { Harv. - Rhynchostegium. }\end{array}\right.$

vagum Hsch. - Lembophyllum.

Vaillantii Thuill. - Scleropodium illecebrum.

Valdiviae C. M. - Porotrichum.

var. pallidurn Ltz. - Porotrichum Valdiviae var. pallidum.

Vallis-clausae Brid. - Amblystegium fluviatile.

varieflexum Hpe. - Microthamnium.

variegatum W. et Dy. - Taxithelium.

varium $\left\{\begin{array}{l}\text { H. f. et W. - Thuidium gracile. } \\ \text { P. B., Drumm. - Amblystegium radicale. }\end{array}\right.$

Vaucheri Lesq. Cat. M. suiss., p. 48; W. P. Sch. Syn. I ed, p.697 et II ed. p. 765.

Stereodon cupressiformis var. Vaucheri L. et A. M. As, bor. 1890, $I I, p .148$.

St. Vaucheri Lindb, M. Scand. p. 38.

Ster.

- Eur.: Ins. Ursor. ; Alp. calc. : M. Chassàron Jurass., M. Righi Helvet., etc. As.: Jeniss. sup. et inf., Obi, Alatau, Caucas. Am. sept. : Montana.

« var. coelophyllum Mdo. Moosst. aus d. Allg. Alp. p. 107.

H. cœlophyllum ej. in Ltz. Moosst. p. 146.

- Eur.: Alp. Algov., Tirol.

« var. davoense Aman in Rev. bryol. I889, $p, 91$.

Ad rup. dolomit. - Eur, : Alp. Rhaet.

« var. julaceum Husn, Muscol. gall. p. 406.

Hypnum cupressiforme var. julaceum Zett.

Stereodon cupressiformis var, julaceus Brid. Bryol. univ. II, p. 608?

$$
\text { -- Eur.: Scandin.; Alp. ? Pyren. ? }
$$

Vaucheri W. P. Sch. - Eurhynchium.

vellereum Mitt. - Brachythecium.

velutinoides $\left\{\begin{array}{l}\mathrm{Br} . \text { - Eurhynchium. } \\ \text { Voit. - Eurhynchium strigosum. }\end{array}\right.$

velutinum $\left\{\begin{array}{l}\text { Duby. - Brachythecium oxyrhynchum. } \\ \text { L. - Brachythecium. } \\ \text { capsulis ovatis cernuis Dill. - Brachythecium. }\end{array}\right.$

var. intricatum Brid. - Brachythecium velutinum var, intricatum.

var. microcarpon (.. M. - Brachythecium Fendleri.

var. murale Neck, - Rhynchostegium.

var. sericeum Brid. - Brachythecium velutinum var. sericeum.

var. Poll. - Pylaisia polyantha.

ventrifolium C. M. - Trichosteleum.

venustum $\left\{\begin{array}{l}\text { de Not. - Brachythecium olympicum. } \\ \text { Duby. - Ectropothecium Moritzii. } \\ \text { Hsch. et Reinw. - H. glaucocarpum. }\end{array}\right.$

vernicosum Lindb, in Hartm. Skand. Fl. VIII ed., 1861; W. P. Soh.

Bryol. eur. Suppl. III-IV, t. (Нурпии) 4 еt Syn. II ed. p. 729.

Amblystegium lycopodioides $\beta$ rernicosum L. et A. M. As. bor. II, p. 121.

A. vernicosum Lindb. M. Scand. p. 33 .

H. Cossoni (fd. L. et $J$.).

H. aduncum Drumm, M. bor, am, ed. I, n. 201.

H. intermedium Lindb. in Hartm. op, oit. X ed. ?

H, pellucidum Wils, mss, 1860 . 
2. In prat. et turfos. - Eur.: Spitzberg, ins. Ursor.; ab Ital. super. usq. in zon. arct., et reg. campestr. usq. in subalp., in illa frequentius. As. : Jenissei inf. Am. sept.: Groenland, Anticosti, New Brunswick, New-York, Pensilv., lac. Super, Saskatchewan, Columb. brit., Vancouver.

Exs. : Mac. Canad. M. n. 384.

Rab. Bryoth, eur, n. 547, 1197 b.

Un. itin. 1864, n. 84, 102.

« var. gigas (Lindb.) Par.

Amblystegium vernicosum var. gigas Lindb. $l, c$.

- Eur. : Suecia, Fennia.

* var. lapponicum (Norr.) Par.

Amblystegium vernicosum var. Iapponicum Nos r.; Lindb. l. c.

- Eur. : Lappon., Fennia.

"var. majus (Lindb.) Par.; Ren. in Husn. Musc. gall. p. 391, .. 112, f. 3 .

Amblystegium vernicosum var, majus Lindb, $l$. $c$.

- Eur.: Rar. : Suecia. As.: Siberia.

Vernieri Duby. - Trichosteleum.

verrucosum $\left\{\begin{array}{l}\text { Dz. et Mk. - Ectropothecium Dozyanum. } \\ \text { Hpe. - Ectropothecium. }\end{array}\right.$

verruculosum C, M. - Isopteryyium.

versicolor C. M. - Thuidium.

resiculare Sehwaegr. - Ectropothecium.

vesiculosum Brid. - Hookeria.

virens $\mathrm{Sw}$. - Rhynchostegium rusciforme.

virescens Boul. - H. falcatum var, vireseens.

viride $\left\{\begin{array}{l}\text { Lam. - Brachythecium populeum. } \\ \text { Lam. et DC. - Amblystegium serpens. }\end{array}\right.$

viride-factum $C, M$. in Dusen $M$. Camer, $n, 365$.

- Afr. : M. Cameroon.

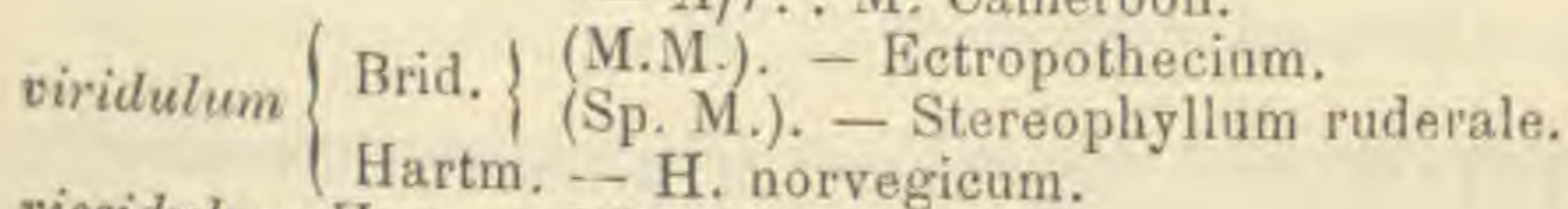

viscidulum $\mathrm{H}_{\text {pe. }}-$ Microthamnium.

vitellinum Brid. - H. commutatum.

viticulosum L. - Anomodon.

var, brachycarpon C. M. - Anomodon obtusifolius.

viviparum Neck. - Isothecium myurum.

volvatum Hpe. - Microthamnium.

Vriesei Dz. et Mk. - Rhynchostegium.

vulgare $\left\{\begin{array}{c}\text { dentalum, operculis cuspidatis Dill. - Eurhynchium stria- } \\ \text { tum. } \\ \text { sericeum recurvum, capsulis erectis cuspidatis Dill. - Homalo- } \\ \text { theciun }\end{array}\right.$ thecium sericeum.

triangulum, masimum el pallidum Dill. - Hylocomium triquetrum.

Waghornei Kindb. in Mac. Cat, p. 234.

Wahlenbergii W. et M. - Webera albicans.

Wallichii Brid. - Aerobryum.

Wallisi Hook. - Pseudo-Leskea. 
Walterianum (Hpe.) Jaeg. Ad. II, p. 584.

Drepano-Hypnum Walterianum Hpe. in Linn. 1876, p. 322.

Isoptervgium Walterianum Mitl, in Trans, and. Proced. of the roy. Soc. of Victoria, 1883, p. 86.

Stereodon Walterianus ej. in op. cit. p. 87.

- Pac. : Austral. or. (Vietoria).

Watsoni Lesg. el Jam. in Proced. of the Am. Acad. p. 138 et Man. p. 386.

H. Heufleri fid. Aust. in Bull. Torr. bot. Club, VII, p. 6).

H. imponens Jam. in Bot. King Exped. p. 410.

H. plicatile (fid. Aust. in op. et $l$ oc.).

2. Rupic. - Am. sept.: Utah.

Webbianum C. M. - Homalia.

Weinmanni Nees. - Brachythecium?

Whippleanum Sull. - Thuidium.

Whightii Mitt. - Stereophyllum.

Wilkesianum Sull. - Cylindrothecinm.

Wilsoni Ren, et Card. - H. Sendtneri var. Wilsoni.

var. Flageyi Ren. - H. Sendtneri var. Flageyi.

var. occilentale R, et $\mathrm{C}$ - - H. Sendtneri var. occidentale.

Wissgrillii Garov. Bryol. Austr. p. 79; C. M. Syn. II, p. 408.

Ad sax. irror. - Eur. : Austria infer.

Wolkensii Broth. - Rhynchostegium.

Wrightii Sull. - Homalia (1).

Zeyheri Spreng. - Rhynchostegium,

Zemliae Jens, in Kindb. Enum. Bryin.

land.

- Eur. : Spitzberg, Nov. Zemlia. Am. sept. : Groen-

Zierii W. et M. - Plagiobryum julaceum.

Zippelii Dz. et Mk. - Pseudo-Leskea.

Zollingeri C. M. - Eetropotheeium.

Zuratskae Mac. (errat!). - Amblystegium Juratzkanum.

n. 8048 Drege. - Rhaphidostegium Dregei. (2).

HYPNUM STEREODON Brid. Bryol. univ. $I I, p .550$ (vid. STEREODON).

HYPOPTERYGIUM Brid. Bryol. univ. II, p. 709 ( 78 spec.).

apiculatum Thro, et Mitt, in Journ. of the Linn. Soc. 1872, p. 309.

2.

- As. : Ceylan.

Arbuscula Brid. - H. Thouini.

arcuatum C. M. - Rhacopilam.

argentinicum Lts. in Linn. 1878-79, p. 404.

1. Ad arbor. et tetr. - Am. merid.s Argentin. subtropic., Paraguay. (1) xerampelinum Vill. Pl. Dauph. III, p. 902 ; Brid. Bryol. univ. II, p. 544;
C. M. Syn. II, p. 508 .

"An $H$. aduneum? " Brid, 1. c. - Delendurn.

(2) In Enum. Kindb. nom. nud, :

H. Filicinella $G$. $M$.

Humpei Kindb.

Helmsi $C . M$.

Kiaerí $C, M$.

nigritellum.
H. nivescens $C, M$. polymorphoides $C$. $M$. plumulatum $C_{2}, M$. reflectifolium $C$. $M$. submolliculum (an Isopterygium? B.M.) 
aristatum Bryol. jav. $11, p .12, t .141$.

I. fr. ign.

- As. : Java.

Balantii C. M. in Fl. Marchica, 1891-93.

Filicic. - Pac. : Nov. Zeland? (in horto ad Balantium quoddam lectum).

brasiliense Sull. - H. Tamarisci.

brevifolium Broth. in Bol. d. Soc. Brot. VIII, 1890.

2 .

- Afr.: Ins. S. Thom.

Cameruniae C. M. in Dusen M. Camer, n. 38.

- Afr. : Cameroon.

Campenoni Ren. et Card. in Bull. Soc. roy, bot. Belg. 1894, II, p. 136.

Ster. - Afr. : Madagascar.

capense W. P. Sch. in Breutel M. Capens.

- Afr.: C. B. Sp.

ceylanicum Mitt. - H. tenellum.

Chamaedrys Bryol, jav. II, p. 10, t. 139.

2. fr. ign. Ad arbor. - As. : M. Java.

ciliatum (Hedio.) Brid. Bryol. univ. $[1$, p. $710 ;$ C. M. Syn. II, p. 6.

Catharomnium ciliatum H. f. et Wils. Fl. of the N. Zeal. II, p. 119.

Pterigynandrum ciliatum Hedw. Sp. M. p. 84, t. 17.

Pterogonium ciliatum Schwaegr. Suppl. I, II, p. 108. 2.

- Pac. : Nov. Zeland. sept. et med, Tasman.

Colensoi Par.

H. flaccidum Colenso in Trans. of the N. Zeal. Inst, 1888, p. 44.

- Fac. : Nov. Zeland.

commutatum C.M. Syn. 1I, pp. 6 et 659 .

Hypnum setigerum P. B. Prods, p, 70.

H. Tamarisci Sw. Fl. Ind. oce. III, p. I825 (quoad pl. Pacif.).

H. setosum Wils. in sched.

H. tamariscinum Brid. op. cit. p. 715 p.p.; Hook. Handb. of the N. Zeal. Fl. p. 488 .

Leskea tamariscina Hedw. Sp. M. p. 212, t. 51 (exol, spec. Jamaicae). 2.

- Pac. : Nov. Zeland, ins. Auckland.

Concinnum (Hook.) Brid. op. cil. p. 7[4; C. M. Syn. II, p. 6.

Leskea concinna Hook. M. ex. t. 34 .

2. Rupic. - Am merid. : Chile. Pac. : Austral, or., Nov. Zeland, sept. et med., ins. Auckland.

convolutaceum C. M. - Rhacopilum.

debile Reichdl. in Novara Exped. Bot. I, p. 194, t. 35.

Rupic. in silv. - Pac.: Taiti.

didictyon C.M.Syn. II, p. 9 .

Hypoum laricinum $H$. $f$, et Wils. in sched. antarct.

2. Ad arbor, - Am. merid. : Chile, Fuegia, ins. Eremitae.

dircolor Mitt. in Hook. Handb. of the N. Zeal. Fl. p. 488.
2.

land).

falcatum C. $M$. in Fl. 1886, p. 514 .

- Pac.: Nov. Zeland, sept., Austral, or (Queens-

4. Tertin Mitt. in Joun n. of the Linn. Soc. 1863, $p 164$.

Terr, - Afr. : Ins. Fernando-Po, S. Thom. 
Fauriei Besch. in Ann. sc. nat. 1893, p. 391. 1. - As. : Japon.

filiculaefurme (Hedwo.) Brid. op. cit. p. 712; C. M. Syn. II, pp. 5 et 659. Hookeria filiculaeformis Sm. in Trans. of the Linn. Soc. IX, p. 278.

Hypnum filiculaefor:me P. B. Prodr. p. 64.

Leskea filiculaeformis Hedro. Sp. M. p. 212, t. 50.

Pterygophyllum filiculaeforme Brid. Mant. M. p. 151.

2. Ad arbor. - Pac. : Nov. Zeland. sept. et med.

flaccidum Mitt. $F l$. Vit, p. 390.

Ster.

- Pac. : (sine loc. spec.).

faccidum Col, - H. Colensoi.

flavescens Hpe. in Linn. 1847, p. 95 ; C. M. Syn. II, p. 659.

H. nivale C.M. l. c. p. 9 ; Mitt. M. austr. am. p. 331.

H. serrulatum Lindb. mss.; Angstr, in Oefv,.. 1876, n. 4, p. 21 .

H. silvaticum Mitt. M, austr, am. p. 329.

H. tamariscinum C. M. in Linn. 1847, p. 213.

] (Mitt.); 2? (C. M.). Ad arbo". et rup. - Am. merid. : And. Venezuel. et Peruv. ; Brasil.

flavo-limbatum C. M. Syn. II, p. 10; Mitt. M. Ind. or. p. 148.

2.

- As. : Nepal., Khasia.

flexisetum $H$ pe, in Krause $M$. Valdiv.

Ad arbor. - Am. merid. : Valdivia.

glaucum Sull, - H. Smithianum.

grandi-stipulaceum Ren, et Card. in Bull. Soc. roy. bot. Belg. 1893, II, p. 99.

Ster. Lignic. - Afr. : Madagascar.

hemiloma C. M. in Linn. 1876, p. 256.

Ster, Ad arbor. - Afr. : Ins. Anjouan.

Hildebrandti C. M. in Hildebr. M. Madag. n. 2094.

- Afr. : Madagascar merid.

humile Mutt. in Bryol. jav. II, p. 15, ı. 143.

1. - As.: M. Java.

incrassato-limbatum C. M. Syn. II, p. 8: Mitt. M. austr. am.p. 33I.

2. Ad arbor. et saxa humid. - Am. sept.: Mexic. Am. merid. : Brasil. or.

japonicum Milt. in Journ. of the Linn. Soc. 1864, p. 155.

Syn.

- As.: Japon.

javanicum (Hpe.) Jaeg. Ad. II, p, 66.

H. Struthiopteris Bryol. jav. II, p. 8, t. 137.

Lopidium javanicum Hpe, in Linn. 187.1, p. 672.

2.

- As. : Sumatra, Java.

laricinum (Hook.) Brid.op. cit. p. 714 p.p. ; C. M. Syn. II, p. 7 p.p.

Hypnum laricinum Hook. M. ex. t. 35 (excl. spec. Andin.). 2. reg. lacustr., C. B. Sp.

Exs. : Rehm. M. Afr. austr, n. 298.

laricinum $\left\{\begin{array}{l}\text { Ängstr. } \\ \text { Brid. p.p. } \\ \text { Mitt. - H. falcatum. }\end{array}\right.$ 
Lehmannii Besch, in Journ, de bot. 1894, $p$.

I. Lignic, - Am. merid.: And. Quitens.

limbatulum C. M. in Linn. 1869-70, p. 27.

H. Struthiopteris Miti. M, Ind. or. p. 149?

Ster.

- As. : Ceylan.

longirostrum W. P. Sch. in Pervillé M. Mad, n. 805.

- Afr. . Madagascar.

lutescens Hsch. in Linn. 1841, p. 144; C. M. Syn. 1I, p. 11.

- Afr.: C. B. Sp.

macrorhynchum Angstr. in Oefv... 1876, p. 21.

1.

- Am. merid. : Brasil, austr. or.

marginatum Colenso in Trans. of the N. Zeal. Inst., 1888, p. 44.

- Pac. : Nov. Zeland.

mauritianum Hpe. in Besch. Fl. bryol. Réunion, etc. p. 186.

H. laricinum Brid. op. cit. p. 714 p.p. ; C. M. Syn. II, p. 7 p.p. ; Angstr. 2 . in Oefv... 1872, n. 5, p. 143.

*var, nanum Besch. op, et l. cc.

- Afr. : Ins. Franciae.

- Afr. : Ins. Franciae.

monoicum Hpe. Symb. 1874, p. 527.

1.

- Am. merid. : Brasil. austr. or.

Mülleri Hpe. in Linn. 1856, p. 215.

Pterobrynm Mülleri Mitt. in Trans. and Proced. of the roy. Soc. of Vic2. toria, $1883, p . \times 1$.

Nadeaudianum Besch. Fl. bryol. Taiti, etc., p. 58.

- Pac. : Austral, fel., ins, Lord Howe.

1. In argill. vulcan. - Pac. : Taiti.

nanum C. M. in Rev. bryol. 1878, p. 59 (nom.).

nematosum C. M. M. Polyn. p. 80.
$\quad 2$. - Afr.. Ins. Franciae.

- Pac.: Austral. or. (Nov. Valesia).

nivale C. M. $-\mathrm{H}$. flavescens.

neo-caledonicum Besch. Fl. bryol. Nov. Caled. p. 222.

1. Ad rup. humid. - Pac. : Nov, Caled.

norfolkianum C. M. mss.; Jaeg. Ad. II, p. 64 (nom.). - Pac.: Ins. Norfolk.

nossi-beanum C. M. in Rev. bryol. 1877, p. 15 (nom.). - Afr, : lns. Comores.

Novae Seelardiae C. M. in Bot. Zeit. 1851, p. 562.

H. Sinithianum H. f. et W. Fl, of the N. Zeal. II, p. 118 (fid. Mitt.).

2. Ad arbor. - Pac. : Austral. fel, Nov. Zeland., Tasman.

\& var. chilensis Ltz. in Bot. Zeit. 1866, p. 187.

- Am. merid. : Valdivia.

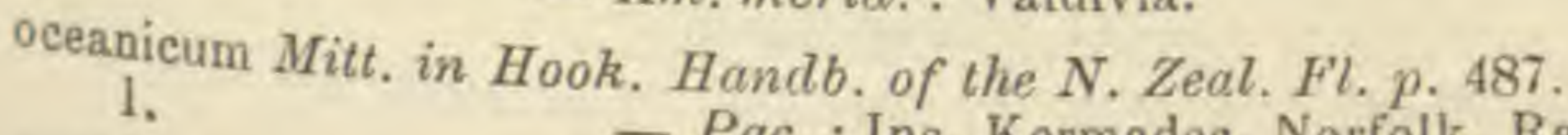

pallens Mitt. - H. Struthiopteris. 
pennaeforme Hsch. in Linn. 1841, p. 143; Brid. op, cit. p. 717? C. M. Syn. II, p. 10.

Hypnum pennaeforme Thbg. Prodr. Fl. Capens. II, p. 175.

1. Rupic. - Afr. : C. B. Sp.

Exs.: Rehm. M. Afr, austr. n. 30l.

pinnatum (Hpe.) Jaeg. Ad. $I I$, p. 66.

Lopidium pinnatum Hpe. in Linn. 1874, p. 672.

2.

- Pac. : Austral. or.

Pirottue Brisai in Ann. d. real. Istit. bot. d. Roma, 1893, fasc. II.

2. Ad terr, humid, - Afr. : Litt. occ, mar. Erythraei.

planatum C. M. in F. v. Müller's Fragm. phyt. Austr. XI, p. 115.

- Pac. : Austral, or. (Queensland).

plumarium Mitt. M. austr. am. p. 329.

Lopidium plumarium Hpe. Enum. M. Brasil. p. 90.

1. Ad arbor. et rup, humid, - Am. merid. : Brasil., ins, Chiloë. Pac.: Ins. Auckland.

pseudo-Tamarisei C. M. in Linn. 1876, p. 645.

H. Tamarisci Besch. Prodr. bryol. mexio. p. 111.

1. Lignic,, ad arbor. et sax. in silv. humid, - Am. sept. : Mexic.

rigidulum Mill. M. austr, am, p. 329.

1. Ad arbor. - Am, sept : And. Costa Rie. Am, merid. : And. Nov. Granat.

rotulatum (Hedw.) Brid. op. cil. p. 7I3; C. M. Syn. II, p. 9.

Hookeria rotulata Sm. in Trans, of the Linn. Soc. IX, p. 279.

Hypnum rotulatum P. B. Prodr. p. 69.

Leskea rotulata Hedw. Sp. M. p. 213, t. 5.

Pterygophyllum rotulatum Brid. Mant. M. p. 151.

1 (Handb.) ; 2 (Brid.). - Pac. : Nov. Zeland. sept. rotulatum $\left\{\begin{array}{l}\text { H. f. et W. }- \text { H. viridulum. } \\ \text { Mont. - H. tenellım. }\end{array}\right.$

Schmidii C. M. - Rhacopilum.

Scottiae C. M. in Linn. 1867-68, p. 619.

H. discolor (fid. Mitt.).

2. - Pac. : Austral, or. subtropic.

seutellatum C. M. Syn. II, p. 7 . Hypnum laricinum Hook. M. ex, t. 35 (spec. Capens, in tab. 34 delin. exel.).
2 ? $\quad$ - Am, meril. : Nov. Granat. et And. Quitens. - Am, merill. : Nov. Granat. et And. Quitens.

semi-globosum C. M. in Ule Bryoth. brasil. n. 153.

Ad saxa irror. - Am. merid. : Brasil, austr. or.

semi-marginatulum C. M. M. Polyn, p. 80.

2 ?

- Pac. : Ins. Fidji, Samoa.

serrulatum lindb. - H, flavescens.

setosum Wils, - H. commutatum.

silvaticum Mitt. - H. Havescens.

sinicum Mitt. in Trans, of the Linn. Soc. 1891, p. 169.

2?

- As, : Hong-Kong.

Smithianum Hook. f. el Wils. Fl. Tasman. II, p. 217.

H. glaucum Sull. in U. St. Expl. Exped. p. 26.

H. Smithianum var. $\beta$ H. f. et $W, F l$. of the N. Zeal. II, p: 118 , 
2. Ad arbor. secus rivul. - Pac.: Nov. Zeland,, Austral. (Victoria), Tasman.

var. $\beta$ H. f, et W. - H. Smithianum.

spectabile C. M. - Rhacopilum.

sphaerocarpum F. Ren. in Rev. bryal. 1889, p. 88.

1. - Afr. : Ins. Franciae.

strumiferum C. M. -- Rhacopilum.

Struthiopteris Brid. op. cil. p. 7l6; C. M. Syn.II, p. 4.

Hypnum Struthiopteris Schwaegr. Suppl. I, II, p. 182.

Hypopterygium pallens Mitt. in Trans. and Proced. of the roy. Soc. of Victoria, 1883, p 76.

Lopidium pallens H. f, et W. Fl. of the N. Zeal. II, p. 119.

1. Ad arbor, et filic. - As. : M. Neilgherr. ; Ceylan? Afr. : Ins, Borbon. Pac.: Ins. Fidji (fid. Mitt.), Austral. or., Nov, Zeland, sept. et med., Tasman.

Struthiopteris Bryol. jav. - H. javanicum.

Mitt. - H. limbatulum?

subhumile Ren. et Carl. in Bult. Soc. roy. bot. Belg. 1893, 11, p. 27.

- Afr. : Madagascar (Diego Suarez).

subtrichocladon Broth. in Bol. d. Soc. Brot. VIII, 1890.

Ster. Ad arbor. - Afr.: Ins. S. Thom., Usambara.

tahitense Angstr. in Oefv... 1873, n. 5, p. 121.

Ster.

- Pac. : Taïti.

Tamarisci (Swo.) Brid. op. cit.p. 715 p.p. ; C. M. Syn. II, p. 8; Mitt. M. uustr. am, p. 330.

Hookeria tamariscina Sm, in Trans. of the Linn. Soc. IX, p. 279 p.p.

Hypnum scutellatum Tayl. (fid. Mitt. l. o.).

H. Tamarisci Sw. Fl. Ind. oec. III, p. 1825 (exel. spec. ins. Franciae et Mar, Pacif.).

H. brasiliense Sull. in U. St. Exppl. Exped, p. 26, t. 26.

Leskea tamariscina Hedro. M. firond. p 21z, t. 51.

Pterygophyllum jungermannioides Brid. Mant. M. p. 154.

Pt. tamariscinum ej. $l$. o. p.p.

1. Rupic. - Am. sept. : Cnba, Jamaic. Am.'merid. : And. Nov. Granat. et Quitens.

Tamarisci Besch. - H. pseudo-Tamarisci.

tamariscinum $\left\{\begin{array}{l}\text { Brid. p.p. }\left\{\begin{array}{l}- \text { H. eommutatum. } \\ \text { C. M. }- \text { H. flavescens. }\end{array}\right.\end{array}\right.$

tenellum C. M. in Bot. Zeit. 1854, p. 557; Bryol. jav. 11, p. 13, t. 142.

H. ceylanicum Mitt. M. Ind. or: $p, 148$.

H. rotulatum Mont. M. Neilgherr. n. 3 .

1 (Bryol jav.); 2 (C. M.). Ad arbor. - As. : M. Neilgherr., Ceylan.

Thouini (Schoaegr.) Mont. in Ann. so. nat. 1845, III, p. 86; in Hist. d.

Chil. Bot. crypt. t, 2, f. 4 el Syll. p. 1; C. M. Syn. II, p. 4.

Hypnum Arbuseula P. B. Prods. p. 61 ?

H. Thouini Sehwaegr. Suppl, III, II, II, t. 289.

H. Arbuscula Brid. op, eit. p. 717 ,

H. speciosum C. M. in Linn. 1844, p. 683.

2. terr. Magellan.

- Am. merid. : Ins. Chiloë, Chile, Patagon, austr.,

tibetanum Mitt. M. Ind. ar. p. 148.

1.

- As.: Tibet oce. 
tomentosum C. M. - Rhacopilum.

torulosum W. P. Sch, in Besch. Fl. bryol. Réunion, etc. p. 185.

H. tamariscinum Brid. op. cit. p. 715 p.p.

1. Ad arbor, et rup. - Afr. : Ins. Borbon., Franciae, Madagasc. sept. «var. Kameruniae Broth. in Engler's Bot. Jahrb. 1894, p. 217. - Afr. : M. Cameroon.

«var. nossi-beanum Besch. op. et l. cc. - Afr. : Ins. Nossi-Be,

trichocladon Bryol. jav. $I I$, p. $9, t .138$.

2. Ad arbor. - As.: Ins. Halmaheira Molucc., Java.

uliginosum C. M. in Linn. 1880-83, p. 470.

Ster. Paludie. - Am. merid. : Argentin. Buenos-Ayr.

viridissimum C. $M$. in Linn. 1876, p. 255.

Ad arbor. - Afr.: Usambara, ins. Enjouan.

viridulum Mitt. in Hook. f. Handb. of the N. Zeal. Fl. p. 487.

$\mathrm{H}$ rotulatum H.f. et W. Fl. of the N. Zeal. Fl. II, p. 118.

I. - Pac.: Nov. Zeland. sept. et med, Austral. or. (Queensland), Victoria.

Vriesei Bryol.jav. II, p. 11, t. 140.

2. fr. ign: $\quad-A s$.: Ins. Ceram.

vulcanicum Colenso in Trans. of the N. Zeal. Inst. 1888, p, 43.

- Pac. : Nov. Zeland.

ILLECEBRARIA Hpe, in Ann. sc. nat. 1865, V ser., IIÍ. julacea Hpe. - Angstroemia.

Illecebrina C. M. mss. (sect, HrPNi).

ISCHYRODON C. M. in Linn. 1875, p. 443 (3 spec.).

leptocladus Rehm. M. Afr. austr, n. 633.

$$
\text { - Afr.: C. B. Sp. }
$$

Rehmanni C. M. in Rehm. l. c. n. 91 .

$$
\text { - Afr. : C. B. Sp. }
$$

seriolus (Hpe.) C. M. in Linn. . c.

Fabronia seriola ej. in Bot. Zeit. 1864, p, 367.

Hypnum seriolum Hpe, in M. Ecklon.

1. Saxic. $-A f r$. : C. B. Sp.

Exs, : Rehm. M. Afr. austr. n. 351 et b.

\& var, albicans C. M. in Rehm. l. c. n. 352.

- Afr. : C. B. Sp.

Isocarpus Mitt. M. austr. am. p. 63 (sect. DiCRANt).

ISOCLADUS Lindb. in Oefo... 1862, p. I34.

macrophyllus Lindb. - Sphagnum.

Isolrepanium Mitt. M, austr. am, p. 363 (sect. LEPIDOPLI). 
ISOPTERYGIUM ej. op. cit. p. 497 (93 spec.).

acuminatum Bosu, in Journ. of bot. 1892, p. 99.

- Pac. : Tasman.

affusum Mitt. M. autr. am. p. 499 .

Ster. $\quad-$ Am. merid. : Amazon., Brasil.

albescens (Mitt.) Jaeg. Adl. II, p. 499.

Hypnum albescens Sehwaegr. Suppl. III, I, I, II, t. 226; C. M. Syn. II, p. 279 .

Stereodon albescens Mitt. M. Ind, or. p. 104.

1 .

neo, Celebes.

- As. : Nepal., Khasia, M. Neilgherr., Java, Bor-

albulum Jaeg. - Plagiothecium micans.

Anderssonii (Angstr.) Par.

Plagiothecium Anderssonii Angstr. in Oefv... 1872, n. 4, p. 15.

1.

- Pac. : Ins. Sandwic. (Honolulu).

anomalum Broth, in Mitth. aus d, deutsch. Schutzgeb. 1893, 111 (nom). - Afr.: Togo.

argentatum Broth. in op. et $l$. cc. (nom.).

- Afr. : Togo.

argyroleucon C. M. in Besch. Fl, bryol. Réunion, etc. p. 178 ; Ren. in

Rev. bryol. 1889, p. 84 descript. fruct.).

l. $-A f r$.: Ins. Franciae. argyroleucon Ren. et Card. (M. Masc. Mad.). - Taxithelium argyrophyl-
lum.

arquifolium (Bryol. jav.) Par.

Hypnum arquifolium Bryol. jav. II, $p .186, t .284$.

2. $f$ et $\mathrm{fr}$. ign.

- As, : Amboine, Java.

assamicum (Mitt.) Jaeg. Ad. II, p. 498.

Stereodon assamicus Mitt. M. Ind. or. p. 104.

1.

atrotheca Jaeg. - Brachythecium.

- As. : Assam.

austro-pusillum (C. MC.) Jaeg. Ad. II, p. 501.

Hypnum austro-pusillam C. M. in Linn. 1871-73, p. 159.

1.

- Pac. : Austral. or. (Queensland).

? bancanum (Bryol. jav.) Jaeg. Ad. II, p. 508.

Hypnum bancanum Bryol. jav. II, p. 188, t. 286.

I. In silv, - $A s$, : Ins. Banca.

Boivini Besch. Fl. bryol. Réunion, etc. p. 175.

Microthamnium Boivini W. P. Sch, in Jaeg. Ad. ?

1.

Borreri Lindb. - Plagiothecium elegans.

- Afr.: S. Maria de Madagascar.

brachyneuron (C.M.) Mitl. M. austr. am. p. 498.

Aypnum brachyneuron C. M. in Bot. Zeit. 1845, p. 109 et Syn. 1I, p. 278.

1. Cortic. - Am. merid. : Brasil, austr. or.

byssicaule (C. M.) Jaeg. Ad. II, p. 502.

Hypnum byssicaule $C . M$. M. Polyn. p. 86.

1. Ad littus. - Pac. : Ins. Samoa. 
byssicladus (C.M.) Pur.

Taxicaulis byssicladus $C . M$, in Dusen $M$, Camer. $n .128$. -Afr.: M. Cameroon.

Cacti (C.M.) Par.

Hypnum Cacti $C$, $M$. in Linn. 1878-79, p. 437 .

1.

- An. mierid. : Argentin, Urug.

Cameruniae C. M. in Dusen M. Camer. n. 684. - Afr.: M. Cameroon.

candidulnm (C. M.) Jaeg. Ad. $I I, p .501$.

Hypnum candidulum C. $M$. in Linn. 1875, p. 460.

Ster. Rupic. - Afr. : Niam-Niam.

candidum (C. M.) Jaeg, Ad. I1, p. 503.

Hypnum candidum $C, M$. in Linn, 1867-68, $p, 624$.

1.

- Pac. : Austral. or.

? capillipes (Bryol. jav.) Jaeg. Ad.,p. 508.

Hypt.um capillipes Bryol. jav. 1I, pp. 188 et 228, t. 287.

1.

- As. : Java, Sumatra.

chlorosum (Hpe.) Par.

Hypnum chlorosum Hpe, in Fl. p. 1881.

1.

- Am. merid, : Brasil. austr, or.

Chrismari (C.M.) Mitt. M. austr. ant.p. 500.

Hypnum Chrismari C. M. Syn. II, p. 682.

Plagiothecium Chrismari Besch. Prodr. bryol. mexic. p. 107.

1.

- Am. sept. : Mexic.

chryseolum Besch. Fl. bryol. Réunion, elc. p. 173.

1.

- Afr.: Ins. Borbon.

clerophilum Besch. in Journ, de bot. I890, p.

1. Arenic. - As. : Tonkin.

Combue Besch. Fl. bryol. Réunion, etc. p. 173.

1. $\quad-A f r$.: Ins. Nossi-Comba.

compressicaule (C. M.) Par.

Taxicaulis compressicaulis C. M. in Dusen M. Camer. n. 758.

conangium (C. M.) Par. - Afr. : M. Cameroon.

Taxicaulis conangius $C, M$. in Dusen M. Camer. n. 872. - Afr. : M. Cameroon

cordovense (C. M.) Jaeg. Ad. II, p. 502

Hypnum cordovense C. M. in Linn. 1874, p. 651.

1. Lignic. in silv. - Am. sept. : Mexic. curvicollum (C. M.) Mitt. M. autr, am. p. 498.

Hypnum curvicollum C. M. Syn. II, p. 684.

1. Cortic. - Am. merid. : Brasil, austr. or.

delicatulum Jaeg. -- Rhaphidostegium. densifolium Lindb. - Rhynchostegium.

var. concavum Broth. - Rhynchostegium densifolium var. coneavum. deplanatum Mitt. - Rhynchostegium. depiessum Mitt. - Rhynchostegium. 
distichaceum (Mitl.) Jaeg. Ad. II, p. 505.

Stereodon distichaceus Mitt. M. Ind. or. p. 105.

1 .

- As.: Nepal, Himalaya oce.

Draytoni (Sull.) Jaeg. Ad. 1I, p. 508.

Hypnum Draytoni Sull. in Proced. of the Am. Acad... 1854.

- Pac. : Ins. Sandwic.

elegans Lindb. - Plagiothecium.

erythrangium (C. M.) Par.

Taxitaulis erythrangius C.M. in Dusen M. Camer, n. 763 .

- Afr. : M. Cameroon.

Eudorae (Sull.) Jaeg. l. c.

Hypnum Eudorae Sull. in op. et $l$. cc.

- Pac. : Ins. Sandwic.

? eutrypherum (C. M.) Par.

Hypnum eutrypherum $C . M$. in Linn. 1878-79, $p, 497$.

1.

- Am. merid. : Venezuela.

flaccidum (Sull. et Lesq.) Mitt. in Trans. of the Linn, Soc. 1891, p. 176.

Hypnum flaccidum $S$, et $L$.

1. Terr. - As. : Japon.

fuegianum Besch. - Plagiothecium magellanicum.

gemmigerum (C. M.) Par.

Taxicaulis gemmigerus C. M. in Dusen M. Camer, n. 43 , - Afr.: M, Cameroon.

geophilum Jaeg. - Rhynchostegium. grbbosulum Jaeg. - Rhaphidostegium. gracilisetum Jaeg. - Ectropothecium.

gurapense Besch, in Rev. bryol. 1885, p. 19 (nom.) et in Journ. de bot. $1891, p$.

1. Cortic. - Am. merid. : Paraguay.

Exs. : Bal. Pl. Parag. n. 3619.

Herminieri W. P. Sch, in Besch. Fl. bryol. Antill. fr. p. 82.

I. In rivul, - Am. sept. : Guadalup. hospitans (Hpe.) Jaeg. Ad. II, p. 560.

Hypnum hospitans Hpe. in Ann. se. nat. V ser., V, 1866, p. 313. 1 .

- Am. merid. : And. Nov. Granat.

intortum (P. B.) Besch. Fl. bryol. Réunion, elc. p. 175.

Hypnum aoratum Duby in Mém... Genève? (fid. Besoh. l. c.) (1).

H. intortum P. B. Prodr. p. 65; C. M. Syn. II. p, 398.

Isotheciam intortum Brid, Bryol. univ. II, $p, 383$.

2. ? Ad arbor. et terr. - Afr.: Ins. Franciae.

" var. Chenagoni Ren. et Card. in Bull. Soc. roy. bot. Belg. 1893, I, p. 126.

Ivoreanum $-A f r$, : Madagascar.

(Mitt.) Jaeg. Ad, II, p, 5115.

Stereodon Ivoreanus Mitt. M. Ind. or. p. 105.

Ster.

- As. : Nepal, M. Neilgherr.

(1) Cf. Trichosteleum aoratum. 
Jamesii Jaeg. - Rhaphidostegium.

leiotheca Ren. et Card. in Bull. Soc. roy. bot. Belg. 1894, II, p. 134. 1. - Afr.: Ins. Borbon.

leptoblastum Besch. Fl. bryol. Réunion, etc. p. 174.

Hypnum leptoblastum C. M. 'n Linn. 1876, p. 280.

1. $-A f r$.: Ins. Anjouan.

leptomiton (C. M.) Jaeg. Ad. II, p. 502.

Hypnum leptomiton C. M. in Linn. 1874, p. 652.

1.

- Am. sept.: Guatemala.

lepturum (C. M.) Par.

Taxicaulis lepturus C. M. in Dusen M. Camer, n. 248.

- Afr.: M. Cameroon

leuco-glaueum (C. M.) Par.

Taxicaulis leuco-glaucus C. M. l, c. n. 848 .

- Afr. : M. Cameroon.

leucophanes (Hpe.) Jaeg. Ad. II, p. 505.

Hypnum leucophanes Hpe, in Bot. Zeit. 1858, p. 169.

1.

- Afr. : C. B. Sp.

leucophyllum (Hpe.) Mitt. M. austr. am. p. 499.

Hypnum leucophyllum Hpe. in C. M. Syn. II, p. 280.

1. Cortic. - Am. merid. : Chile.

lignicola (Mitt.) Jaeg. Ad. II, p. 498.

Hypnum lignicola Mitt. in Hook. Joum of bot. 1856, p. 355.

Stereodon lignicola Mitt. M. Ind. or. p. 104.

I. Lignic. - As, : Pegu.

lonchopelma (C. M.) Jaeg. l. c.

Hypnum lonchopelma C. M. M. Polyn, p. 87.

1 .

- Pac.: Ins. Samoa.

longitheca (Mitt,) Jaeg. l. c.

Stereodon longitheca Mitt. op, et l. cc.

2. Lignic. - As.: Sikkim.

ma-coense Besch. in Bull. Soc. bot. Fr. 1887, p. 99.

1. Lignic. - As. : Tonkin.

M'Bangae (C. M.) Jaeg. Ad. II, p. 501.

Hypnum M'Bangae C. M. in Linn. 1875, p. 460.

1. Cortic. - Afr.: Niam-Niam.

microplumula (C. M.) Par.

Taxicaulis microplumula $C, M$. in Dusen $M$. Camer, n. 922. - Afr.: M. Cameroon.

minutirameum (C. M.) Jaeg. Ad. II, p. 500.

Hypnum minutirameum C. M. Syn. II, p. 689; Bryol. jav. II, p. 191,
t. 290 .

1. Rupic. - As. : Java, ins. Banea, Borneo.

\& var, tonkinense Besch, in Bull. Soc. bot. Fr. 1894, p. 85.

Ad rad, arb. - As, : Tonkin. 
Miquelii (Bryol. jav.) Jaeg. Ad. II, p. 509.

Hypnum Miquelii Bryol. jav. II, p. 187, t. 285.

Syn. In silvis. - As. : Sumatra, M. Java, ins. Banca, Borneo.

miradoricum (C. M.) Jaeg. Ad. $I I, p .502$.

Hypnum mi adoricum C. M. in Linn. 1876, p. 650.

1. Ad arbor. in silv. - Am. sept. : Mexic.

molliculum (Sull.) Mitt. Fl. Vit. p. 399.

IIypnum molliculum Sull. in U. St. Expl. Exped. Wilkes, p. 14, t. II et in Proced. of the Am. Acad..., 1854.

1. Lignic. - Pac.: Ins. Sandwic., Fidji, Kermadec, Raoul, lord Howe.

Müllerianum Jaeg, - Plagiothecium.

nanoglobum (C. M.) Par.

Hypnum nanoglobum C. M. in Fl. 1886, p. 284.

1. Ad arbor. - Afr.: Ins. S. Thom.

nematocaulon Jaeg. - Rhaphidostegium.

nervatulum (C. M.) Par.

Hypnum nervatulum $C . M . M$. Polyn. p. 87. 1.

- Pac. : Ins. Samoa.

nitidum Lindb. -- Plagiothecium.

var. pulchellum Jindb. - Plagiothecium pulchellum.

nivescens (C. M.) Par.

Hypnum nivescens C. M. in Dusen M. Camer. n. A 10.

- Afr. : M. Cameroon.

norfolkianum (C. M.) Jaeg. Ad. I1, p. 501.

I. molliculum ( $f$ d. Mitt.).

Hypnum nitidulum Hpe. in Linn. Neve Folge, p. 254.

H. norfolkianum C. M. in Linn. 1871-73, p. 160 .

1.

- Pac. : Ins. Norfolk.

ochrangium (C.M.) Par.

Taxicaulis ochrangius C. M. in Dusen M. Camer. n. 355.

pallido-imbricatum (C.M.) Par.

- Afr. : M. Cameroon.

Taxicaulis pallido-imbricatus $C, M . l$. e. n. 876.

- Afr. : M. Cameroon.

pallidulum (Mitt.) Jaeg. Ad. II, p. 49 8.

Stereodon pallidulus Milt. M. Ind. or. p. 105.

1. Terr. - As. : Himalaya occ.

planissimum Mitt, M. austr. am, p 498.

Ster. tens.

- Am. sept. : Jamaïc. Am. merid. : And. Qui-

plano-squarrosum (C. M.) Par.

Taxicaulis plano-squarrosus C. M. in Dusen M. Camer, n. 696.

plumirameum (C. M.) Piv.

- Af $r$, : M. Cameroon.

Taxicaulis plumiramens $C, M . l, c, n, 683$.

- Afr, : M. Cameroon. 
pohliaecarpum (Sull, et Lesq.) Mill. in Trans. of the Linn. Soc. 1891,p.176.

Hypnum pohliaecarpum $S$. et $L$.

2. Terr, - As, : Japon.

prasiellum Besch, in Journ, de bot. 1\$94, p. 60.

1.

- Afr. : Congo gall. (Brazzaville).

pratense Lindb. - Hypnum.

pulchellum Jaeg. - Plagiothecium.

radicans (Brid.) Besch. Fl, bryol. Réunion, elc. p. 175.

Hypnum radicans Brid. Mant. M. p. 184; C. M. Syn. II, p. 281.

Leskea serrulata Brid. Bryol. univ. II, p. 763.

- Afr. : Ins. Borbon. ?

ramivagum C. M. in Dusen M. Camer. n. 797.

- Afr. : M. Cameroon.

repens Lindb. - Plagiothecium silesiacum.

robustum Broth. in Bot. Centralbl. 1888, n. 87.

2.

- Pac. : Austral. or. (Queensland).

saporense Besch. in Ann. sc. nat. VII ser., II, p. 96.

Ad arbor. - Afr. : lns. Mayotte.

Smallii (Sull. et Lesq.) Mitt. in Trans, of the Linn. Soc. 1891, p. 176.

Hypnum Smallii S. et L. in Proced. of the Am. Acad.... 1859, p. 281.

2. Lignic. - As. : Japon., ins, Bonin.

stenosekos (Welw. et Duby) Jaeg. Ad. II, p. 503.

Hypnum stenosekos W. et D. in Mém... Genève, 1871, p. 14, t. I, f. 2 .

1. Ad arbor. - Afr, : Angola.

? streptopodium Besch. Fl. bryol. Antill. fr. p. 83.

1.

- Am. sept. : Guadalup.

subalbidum (Sull. et Lesq.) Mitt. in op. et l. cc.

Hypnum subalbidum $S$. et $L$. in op, et $l$, ee .

1. Lignic. - As, : Japon, ins. Bonin.

subdepressum Jaeg. - Rhaphidostegium.

subfalcatum Jaeg. - Plagiothecium.

subeurvicollum (C. M.) Par.

Hypnum subeurvicollum C. M. in Ule Bryoth. bras. $n .87$.

- Am. merid. : Brasil. austr. or.

subleptoblastum C. M. in Besch. Fl. bryol. Réunion, elc. p. 174.

1. Lignic. - Afr. : Ins. Mayotte, Nossi-Comba.

submammillosulum (C. M.) Par. Hypnum submammillosulum C. M. in Geh. Neue Beitr. zur Moosf. d.
Neu Guin. p. 8, t. 7.

1. Ad arbor. - Pac. : Nov. Guin, merid.

submicrothecium Mitt. - Pterogoniella submicretheca.

subtenerum Besch. in Rev. bryol. 1885, p. 19 et in Journ. de bot. 1891.
1. - Am. merid: Paraguay.

- Am. merid: Paraguay.

Exs. : Bal. Pl. Parag. n. 3686.

subverrucosum (Geh.) $\mathrm{Par}$.

Hypnum subverrucosum Geh, Neve Beitr. sur Moosfl. v. New Guinea, p. 9.

1. Ad arbor. - Pac. : Nov, Guin, merid. 
taxiforme (Brid.) Jaeg. Ad. 1I, p. 502.

Hypnum taxiforme Brid. Bryol. univ. II, p. 392; C. M. Syn. II, p. 281.

2. Terr. - Afr. : Sierra Leone.

taxirameum (Mitt.) Jaeg. Ad. II, p. 505.

Stereodon taxirameus Mitt. M. Ind, or. p. 105.

2 ?

- As. : Himalaya, Khasia, Assam, Ceylan.

tenerifolium Mitt. M. austr, am. p. 499.

).

- Am. merid. : Amazon.

tenerum (Sio.) Mitt. op. et $l$. cc.

Hypnum fygmaeum $C . M . S y n . I I, p .288$.

H. tenerum Sic. $\mathrm{Fl}$. Ind. occ. III, p. 1817 ; C. M. l. c. p. 397.

Isothecium tenerum Brid. Bryol. univ. II, p. 385.

Leskea pygmaea Tayl. in Lond. Journ. of bot. 1848, p. 197.

1. Ad arbor. - Am. sept.: Ludovic., ins. Bermud., Antill. omn. Am. merid.: Nov. Granat., Amazon., And. Quitens. et Peruv.

Textori (Sande-Lac.) Mitt. in Trans. of the Linn. Soc. 1891, p. 176.

Rhynchostegium Textori S, Lac. in Miq. Ann. Mus, bot. Lugd. Bat. I1, p. 299.

$$
\text { - As. : Japon. }
$$

Teysmanni (Bryol.jav.) Jaeg. Ad. II, p. 499.

Hypnum Teysmanni Bryol, jav. II, p. 192, t. 290.

2.

- As. : Sumatra.

trichocaule $(C, M$.) Par.

Taxicaulis trichocaulis C. M, in Nuov. Giorn. bot. ital. 1891, p. 601 (nom).

Ster. - As. : Birman, super.

turfacerm Lindb. - Plagiothecium.

umbilicatulum Mitt. - Hypnum.

verruculosum (C. M.) Besch. Fl. bryol, Reiunion, etc. p. 174.

Hypnum verruculosum C. M, in Linn. 1876, p. 278.

Coric. - Afr. : Ins. Anjouan.

virenti-rameum (C. M.) Par.

Taxicaulis virenti-rameus C. M. in Disen M. Camer, $n$ 71 .

$$
\text { - Afr. : M. Cameroon. }
$$

Yokoskae Besch, in Ann. sc, nat. 1893, X $\vee I I I$, p. 386.

1.

Fixs. : Savatier n. $6 \overline{83}$ p.p.

Wallerianum Mitt. - Hypnum (1).

ISOTHEGIUM Brid, Bryol, univ. II, p. 355 (I3 spec.).

acuticuspis (Mitt.) Kindb. in Mac. Cat. p. 204.

Eurhynchium acuticuspis Jaeg. Ad. II, p. 413.

Hypnum acuticuspis Mitt, in Journ. of the Linn. Soc. VIII, p. 31; Lesq. et Jam. Man. p. 349.

(1) In Enum, Kindberg. nom, nud. :

I. Baileyi C. $M$ concavum Lindb.

I. fissidentifolium C.M. nervatocaulon $C . M$. 
1. myosuroides subsp, brevinerve Kindb.

2. $\quad-A m$. sept. : Columb. brit., Terr. nov.

aggregatum (Mitt.) Kindb. in op. ec l. cc.

Eurhynchium aggregatum Jaeg. Ad. II, p. 360.

Hypnum aggregatum Mitt. in op. cit. p. 35, t. 6; Lesq. et Jam. Man.p. 350. 2 . - Am. sept. : Columb. brit., ins. Vancouver.

alopecurum Brid. - Thamnium.

amonum Brid. - Rhaphidostegium.

Andrieuxii Mont, - Rosea.

anguslatum Mitt. - Camptochaete.

apiculatum Hüb. - Myurella.

apocladum (Mitt.) Kindb. in op. et l. cc.

Eurhynchium apocladum Jaeg. Ad. II, p. 376.

Hypnum apocladum Mitt. in op. el l. ce. ; Lesq. et Jam. l. c. 2. - Am. sept. : Litt. sept. occid.

Arbuscula Brid. - Camptochaete.

var. deflexa H. f. - Camptochaete deflexa.

Archeri H. f. et W. - Hypnodendron.

aureum Spr. - Camptothecium.

Beyrichii Mont. - Cylind tothreium plicatum.

bifarium Brid. - Rhizogonium.

brachycladon Kindb, in Rev, bryol. I895, p. 82 .

Ster. Ad rupes humidas. - Am. sept. : Ins. Vancouver.

Brewerianum (Lesq.) Kindb, in op. et $l$. cc.

Eurhynchium Brewerianum Jaeg. Ad. II, p. 413.

Hypnum Brewerianum Lesq. in Trans. of the Am. Phil. Soc. XIII, p. 12; Lesq. et Jam. Man. p. 319.

2. Rupic. - Am. sept, : Columb. brit., ins. Vancouver, Washington, Oregon, Nevada, Calif.

Exs. : Mac. Canad. M. n. 294 p.p. (Hypnum).

Sull, et Lesq. M. bor. am. II ed. n. 426 (Hypnum).

" var. lutescens (Sull.) Ren, et Cas.d. in Rev. bryol. 1893, p. 20.

Hypnum Brewerianum var. lutescens Lesq. et Jam. l. c.

H. Brewerianum var. Sull. M. bor, am. p. 71 .

Ut et cum typ.

Exs. : Sull. et Lesq. M. bor. am. II ed, n. 427 (Hyрnum).

bryiforme Brid. - Brachythecium acuminatum.

Buchanani Brid, - Papillaria.

Cardoti Kindb, in Bull. Torr. bot. Club. XVII, p. 278 (nom.).

2. Cortic. - Am. sept. : Columb. brit., ins. Vancouver.

catenulalum Hüb. - Pseudo-Leskea catenulata.

chryseum Spr, - Orthothecium.

circinans Saut. - I. myurum var. circinans.

Colensoi H. f. et W. - Mniodendron comatum.

comatum eor. - Mniodendron.

comosum Brid. - Mniodendron.

compressum Hpe. - Cylindrothecium.

crassiusculum $\left\{\begin{array}{l}\text { Bourg. - Rhaphidostegium auricomum. } \\ \text { Brid. p.p. - Rhaphidostegium. }\end{array}\right.$

crispifolium Brid. - Thuidium.

cymbifolium Lindb. - Porotrichum. 
diversiforme (Mitt.) Besch. in Ann. sc. nat. 1893, XVIII, p. 371.

Hypnum diversiforme Mitt, in Trans. of the Linn. Soc. 1891, p. 185.

2.

Exs. : Faurie n. 217.

elegans Brid. - Plagiothecium.

flexile Brid. p. p. $\left\{\begin{array}{l}\text { (fid. Besch.). - Pilotrichella Mascarenae. } \\ \text { (fid. C. M.). - Pilotrichella flexilis. } \\ \text { (fid. C. M.). - Lembophyllum cochlearifolium. } \\ \text { (fid. Hpe.). - Pilotrichella Billardieri. }\end{array}\right.$

gracile $\mathrm{H}$. f. et W. - Camptochaete.

hakkodense Besch. in Ann. sc. nat. 1893, XV1II, p. 371.

1. Ad arbor. - As. : Japon.

Exs, : Faurie n, 826.

hessastichum Brid. - Pilotrichella.

Holtii Kindb. - Eurhynchium myosuroides var, rivulare.

homomullum $\mathrm{Spr}$. - Orthothecium intricatum.

Howei Kindb. in Rev, hryol. 1895, p. 82.

Lignic. - Am, sept. : Calif.

imbricalum Brid. - Pilotrichella versicolor.

insidiosum Mont. - Cylindrothecium concinnum.

intermedium Thiele. - Porotrichum Thieleanum.

inturtum Brid. - Isopterygium.

intricatum Boul. - Orthothecium.

julaceum Brid. - Myurella.

var. atratum Brid. - Myurella julacea.

Kerrii Hook. - Hypnodendron.

laxifolium Rrid. - Thuidium.

lentum (Mitt.) Kindb, in Mac. Cat. p. 203.

Earhynchium lentum Jaeg. Ad. II, p. 376.

Hypnum lentum Mitt. in Journ, of the Linn. Soc. VIII, p, 36.

H. stoloniferum Mac. Canad. M. n. 292 p.p.

2. Ad arbor. - Am. sept. : Litt. sept. occ. ; ins. Vancouver.

leptochaelon Brid. - Rhaphidostegium.

livens Brid, - Pilotrichella.

longiselum W. P. Seh. - Erythrodontium.

lutescens Spr. - Camptothecium.

marginatum H. f, et W. - Hynodendron.

Mensiezii Brid. - Hypnodendron.

minus Sull. - Anomodon obtusifolius,

molle Mitt. - Pilotrichella.

moniliforme Hüb. - Myurella julacea.

mulabile Spr. - Lescuraea striata.

myosmoides $\left\{\begin{array}{l}\text { Brid. - Eurhynchium. } \\ \text { subsp. brevinerve Kindb. - 1. acuticuspis. } \\ \text { subsp, hylocomioides Kindb. - Eurhynchium myosuroides } \\ \text { var, hylocomioides. }\end{array}\right.$

myi:rellum Kindb. in Bull. Torr, bot. Club, XVII, p. 269 et in Mac. Cat. p. 204.

2. Lignic. - Am. sepl. : Columb. brit,, ins. Vancouver.

myuram (Poll.) Brid. Bryol. univ. I1, p. 367 ; Bryol. eur. V (mon. p. ),

t. 533 ; W. P. Sch. Syn. II ed p. 629.

Hypnum alopecuroides Lam. Enoyel, meth, bot.

H. curvatum Sw Fl, Suec. $1798, p .64$.

H, mosquitense Brid. Sp. M. II, p. 147. 
H. myosuroides Hedw. M. frond. IV, p. 20, t. 8.

H. myosuroides var. $\beta$ L. Sp. pl. p. 1130.

H. myosuroides, crassius, capsulis erectis Dill. Hist. $M . p, 316$, t. 41, f. 50.

H. myosuron Gmel. Syst. nat. II, p. 1346.

H. myurum Poll. Pal. III (1777), n. 1054; Brid. Mant. M. p. 164; C. M. Syn. 1I, p. 498.

H. ornithopodioides $F l$. Din.

H. spinosum Sibth. ?

H. vagum Neck. in Act. Acad. Theod.-palat. IJ, p. 453.

H. viviparum Neck. Fl. Gall. Belg. II, p. 475.

I. myurum $\beta$ mosquitense Brid. Bryol, univ, II, p. 369 (patria suspect. !)

I. viviparum Lindb. M. Scand. p. 36.

Leskea curvata Voit $M$. Herbip. p. 72.

L. incurvata Wahlenb. Fl. Lapp. p. 368.

L. myosuroides Hedw. Fund. M. II, p. 93.

L. myura Boul. M. Est Fr. p. 326.

L. prolifera Lumnitz Fl. Posen, n. 1069.

L. vivipara Timm. Prodr. Fl. Megap, n. 808.

2. Ad rad. arbor., saxa rupesq. granit. et arenac. - Eur. : Reg. campestr. As. : Caucas. A fr. : Alger.

Exs. : Rab. Bryoth. eur. n. 190, 485.

" var. circinans (Saut.) Bryol. eur. et W. P. Sch. ll. cc.

Hypnum circinans W. P. Sch. mss.; C. M. Syn. II, p. 500.

I. circinans Saut. in Regensb. Diar. bot. 1850, p. 444 .

Ut typ. - Eur. : Salisburg.

« var. elongatum Bryol. eur. et W. P. Sch. ll. cc.

Hand raro ad terr, in silv, et ericet, - Eur.: Ubi typ.

var. filescens Ren. - Eurhynchium myosuroides var. cavernarum.

« var. gracilius Besch. Cat. M. Alger, p. 34.

Rupic. - Afr. : Alger.

f. humilis Gravet. - Eurhynchium myosuroides var. cavernarum var. mosquilense Brid, - I. myurum.

var. rivulare Holt. - Eurhynchiurn myosuroides var. rivulare.

" var, robustum Bryol, eur, et W, P. Sch, ll. cc.

Ut typ. - Eur. : Reg. mont. et subalp.

«var. scabridum Limpr. Laubm. Deutschl. III, p. 42. .

Ad rupes gneiss. - Eur. : Stiria .

«var. tumidiusculum (Lam.) Hüb. Muscol. germ. p. 603.

H. myosuroides var. crassun Web. Spic. $f$. Goett p. 94.

H. tumidiusculum Lam. Syn. fl. Gall. p, 109.

Ad rup. argill. et calcar. - Eur. : Stiria.

* var. vermiculare Mdo. Moosst. Alg. Alp. p. 88.

Ad rup. humid. - Eur. : Alp. Algov.

neckeroides Brid. - Thamnium.

neilgheriense Mont. - Orthothecium.

nigricans Brid. - Pilotrichella.

obtusatulum Kindb. - Eurhynchium.

ornithopoclioides Boul. - Pterogonium gracile.

orthocarpum Brid. - Plagiothecium.

pallidum Brid. - Microthamnium reptans.

pandum $\mathrm{H}$. f. et W. - Thamnium.

patens Brid. - Meteorium.

pendulum Bria. - Eurhynchium.

pentastichum $\left\{\begin{array}{l}\text { Brid. - Pilotrichella imbricata. } \\ \text { C. M. - Pilotrichella quinquefaria. }\end{array}\right.$ 
Philippianum Spr. - Homalothecium.

physaopbyllos (Welw. el Duby) Jaeg. Ad. Il, p. 366.

Hypnum physaophyllos $W$. et $D$. in Mém... Genève, 1871, $p, 10, t .4, f .2$.

2. Ad arbor. et terr. - Afi. : Angola.

polyanthum Spr. - Pylaisaea.

pulvinatum H. f. et W. - Camptochaete.

pumilum H. f. et W. - Thamnium.

radialum Brid, - Hypnum.

radicans Brid. - Papillaria nigrescens.

ramulosum Mitt. - Camptochaete.

repens Spr. - Platygyrium.

Richardi Brid. - Rhaphidostegium subsimplex.

rufescens Hüb. - Orthothecium.

var. chryseon Hiib. - Orthothecium chryseum.

Schleicheri Spr. - Cylindrothecium cladorhizans.

sericeum Spr. - Homalothecium.

$\beta$ fallax Boul. - Homolothecium fallax.

Sieberi H. f. et W. -. Mniodendron.

spiculiferum Mitt. - Eurhynchium.

spininerviem $\mathrm{H}$. f. et W. - Hypnodendron.

stenocarpum W. P. Sch. -- Cylindrothecium.

stoloniferum Brid. - Eurhynchium.

striatum Spr. - Lescuraea.

$\beta$ saxicola Boul. - Lescuraea striata var. saxicola.

strictum Boul. - Orthothecium.

subserialum Lindb, - Thamnium Sandei.

subsinuplex Brid. p.p. - Rhaphidostegium.

sulcrum H. f. et W. - Climacium.

tenerum Brid, - Isopterygium.

tenuifolium Brid, - Rhynchostegium.

tetragonem Brid. - Pilotrichella.

var. piligerum Mont. - Meteorium longissimum.

tetrastichem Brid. - Pilotrichella longipes?

Thunbergii Brid. - Pilotrichella.

trachypodium Brid, - Brachythecium.

trichophorem Mont. - Pilotrichella.

viviparum Lindb. - I. myurum.

JAEGERIN A C. M. in Linn. 1876, p. 274 (5 spec.).

flagellifera C. M. in Rev, bryol. 1877, p. 1.

- Afr.: Ins. Comores.

formosa Besch. Fl. bryol. Réunion, etc., p. 122.

Ster. Ad rad, arb. - Afr, : Ins. Borbon.

Robillardi C. M. in Besch. op. et l. cc.

Ster.

solitaria (Brid.) Besch. op, cit. p. 120.

- Afr.: Ins. Franciae.

Hypnum solitarium Brid. Mant. M. p. 184 et Bryol. univ. II, p. 510.

Pilotrichum solitarium C. M. Syn. 11, $p, 163$.

2. Ad rad et trunc. arb. - Afr.: Ins. Borbon, Francise.

" var. nossi-beana Besch. op. cit. p. 121.

v. var, ramosa ej. $l$. $c$.

- Afr.: Ins. Nossi-Be, Madagascar sept.

- Ins, Borbon. 
stolonifera $C, M$, in Linn. 1876, $p 274$.

Pilotrichum stoloniferum ej. in Bot. Zeit. 1862.

2. Ad arbor. - Afr. : Ins. Anjouan, Mayotte.

"var. clavata $C, M$, in op, el $l$. cc.

Ut typ. - Afr. : Ins. Anjouan.

JUNGERMANNIA Dill. ; L. Sp. 1662.

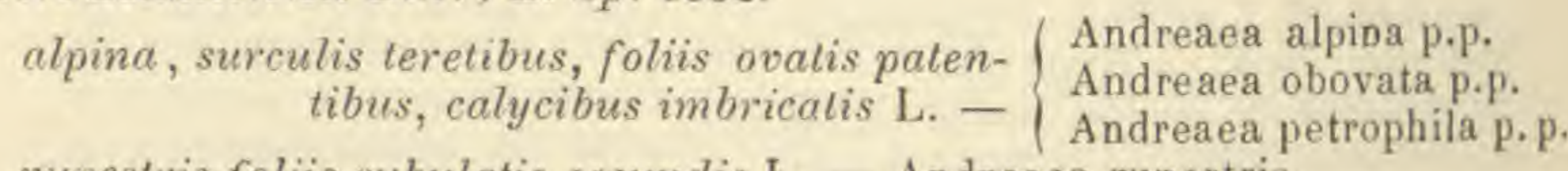
rupestris foliis subulatis secundis L. - Andreaea rupestris.

JURATZKAA Ltz. in Bot. Zeit. 1866, p. 188.

semi-nervis Lt\%. - Helicodontium.

KLEIOWEISIA Bayerh. in Jahresb. d. Ver. für Naturk. in Herzogth.

Nassai, 1849, V, p. 3.

rostellata Bayerh. - Hymenostomum.

KOELREUTERA Hedlo. Fund. M. I.

hygrometrica Hedw. - Funaria.

KRAUSEELLA C. M. in Bot. Centralbl. 1883, n. 2-4 (1) (l spec.). tschutschica $C, M . l . c$.

Tetraplodon Múlleri Lindb, et Am. M. As, bor. 1890, II, p. 61.

T. tschutschicus Lindb. in Rev, bryol. 1884, p. 19.

1.

- As. : Penins. Tschutsch.

LAMPROPHYLLUM W. P. Sch. Coroll. p. 101 (Cyatophorum splendidissimum); Lindb. in Oefv..., 1867.

Spec, omn. (Lindbergianae) Weberae sunt ejusd. nom.

LASIA Brid. Mant, M. p. 133.

Spec omn. non indicatae sunt FORSTROEMLE ejusd. nom. acicularis Spreng. - Macromitrium filiforme.

marginata Brid. - Anomodon rostratus.

ohioensis Jaeg. - Leptodon.

orthotrichoides Raddi. - Macromitrium filiforme.

Smithii Brid. - I eptocion.

subcapillata Brid. - Homalothecium.

trichomilrium Brid. - Leptodon.

L.EERSIA Hedw. Fund. M. II, p. 88.

affinis L. - Encalypta apophysata.

alpina Lindb. - Encalypta commutata.

brevicollis Lindb. - Encalypta.

ciliala Hedw. - Encalyptu.

cirrata Willd. - Dicranoweisia.

contorta L. - Encalypta streptocarpa. cuspidata Schrank. - Pottia lanceolata. extinctoria Leyss. - Encalypta vulgaris.

var. pilifer a Lindb. - Encalypta vulgaris var. pilifera.

var. $\beta$ Leyss. - Encalypta ciliata.

(1) Cf. Lindb, in Rev. bryol. 1884, p. 19. 
fimbriata Brid. - Encalypta ciliati.

laciniata Hedw. - Encalypta ciliata.

lanceolata Hedw. - Pottia.

marginala Hedw. - Encalypta vulgaris.

procera L. - Encalypta.

pulvinata Hedw. - Grimmia.

rhabdocarpa Lindb. - Encalypta.

var. gymnostoma L. et A. - Encalypta rhabdocarpa var, gymnostoma.

Selwoyini Dna E, G. Britton. - Encalypta.

sibirica L. et A. - Encalypta ciliata var. sibirica.

spathulata Lindb. - Encalypta.

vulgaris Hedw, - Encalypta.

$\beta$ alpina Hedw. - Encalypta rhabdocarpa.

Leiocystis Lindb. M. Scand. p. 27 (sect. Crnodontir).

Leiodon Lindb. M. Scand. $p .12$ (sect. Polytrichi= Pogonatum).

Leiogonium C. M. M. Polyn. p. 69 (sect. PhyLLogonit).

Leiolecythis C. $M$. in Linn. 1874, p. 620 (nom., sect. FunariaE).

Leiomela Mitt. M. austr, am. p. 268 (subsect. Bartramiaz).

LEIOMITRIUM Mitt. in Phil. Trans. of the roy. Soc. 1879 (extr. vol.), p. 390. plicatum Mitt. - Orthotrichum.

Leiodicranum Limpr. Laubm. Deutschl. I, p. 366 (sect. Dicrani).

Leionotus C. M. M. Polyn. p. 57 (sect. Leucophanis).

Leiophyllum C.M. Syn. $I I, p .41$ (sect. NeCKerar).

Leiopodium Kindb. Check-List, of Eur, and N. Am M. p. 22 (sect. EURHYNchul sensu Kindb.).

Leiostoma Mitt, in Proced, of the roy. Soc. 1879 (extr. vol. p. 99), antea M. austr. am.p. 201, sect. MAcroMITRII).

Spec. Omn. MACROMITRIA ejusd. nom.

LEIOTHECA Brid. Bryol. univ. I, p. 304.

Spec. omn, non indicatae sunt Macromitria ejusd. nom.

clavellata Brid. - Drummondia.

LEMBOPHYLLUM Lindb, in Act. Soc, sc. Fenn, 1872 , p. 277 (10 spec.). auriculatum (Mont.) Par.

Acrocladium auriculatum Mitt, M. austr. am. p. 532 p.p.

Coelidium (1) auriculatum Jaeg. Ad. II, p. 318.

Hypnum auriculatum Mont. Voy. au Póle Sud, Crypt. p. 331, t. 20, f. 3 et Syll.p. 8; C. M. Syn. II, p. 273.

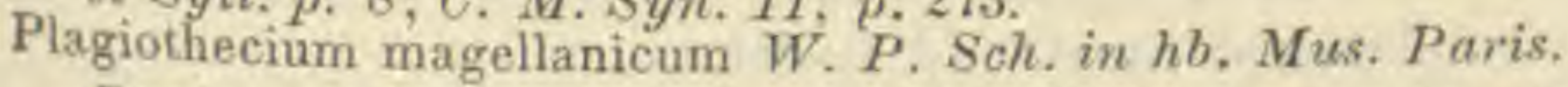

Rupic, et terr. - Am. merid. : Patagon. austr,, terr. Magell., Fuegia. Pac. : Nov. Zeland.

chlamydophyllum (Hook, f. et Wils.) Par.

Acrocladium auriculatum Mitt. op. et $l$. $c c, p . p$.

Colidium chlamydophyllum Jaeg. op, cit. p. 384 .

Hypnum chlamydophyllum $H$. $f$. et $W$. in Lond. Journ. of bot. 1844, p. 552 et Fl. Antaret. I, p. 139, t. 61: C. M. Syn. II, p. 374.

Stereodon auriculatus Mitt. in Journ. of the Linn. Soo. 1859, p. 88.

(1) Nomen jam abusum. Caelidium Vogel in Linn. 1839, p. 472 (Legrominosae); Hook, f. et Wils. FI. of the N. Zeal, II, p. $110(1855)$; Reichdt. in Reise d. Freg. Novara $(1870)$. In Indice, p. 272, ut syn. modo servandum. 
1. In silv. humid. - Am. merid.: Fuegia? (fid. Handb. of $N$. Zeal. Fl.) Pac. : Nov. Zeland. sept. et med, Austral. (Victoria), Tasman., ins. Campbell.

chlorocladon (C. M.) Par.

Camptochaete ramulosa (fid. Mitt.).

Hypnum chlorocladum C. M. in Linn. 1867-68, p. 622.

2 ?

- Pac. : Austral. (Victoria).

clandestinum (Hook. f. et Wils.) Lindb. Contrib, ad Fl. brynl. As. bor. or. 1872, p. 277 (in adn.).

Coelidium clandestinum Jaeg. $l$. $c$.

Hypnum clandestinum $H$. f. et W. Fl. Tasm. II, p. 201; Fl. of the N. Zeal. III, t, 90, f. 3 et Handb. p. 480.

Porotrichum clandestinum Mitt. in Trans. and Proced. of the roy. Soc. of Victoria, $1883, p .84$.

1. In silv, humid. - Pac. : Nov. Zeland, med., Austral. (Victoria), Tasman.

cochlearifolium (Schwaegr.) Lindb. l. c.

Colidium cochlearifolium Jaeg. op. cit. p. 383.

Hypnum cochlearifolium Schwaegr. Suppl. I, II, p. 22I, t. 88; C. M. Syn. II, p. 373; H. f. et W. Fl. Tasm. II, p. 211, Fl. of the N. Zeal. II, p. 111 et Handb. p. 480.

H. flexile Hook. M. ex, $t, 110$.

Isothecium cochlearifolium Mitt. in Hook. Journ. of bot. 1856, p. 264.

I. flexile Brid. Bryol. univ. II, p. 361 p.p.

Porotrichum cochlearifolium Mitt. in Trans. and Proced. of the roy. Soc. of Victoria, p. 84 .

Stereodon cochlearifolius Mitt. in Journ. of the Linn. Soc. 1859, p. 88.

2. Rupic. - Am, merid : Ins. Chiloë. Pac. : Nov. Zeland, sept. et med., Austral. (Victoria), Tasman, ins. Auckland, Campbell.

- var. minus (Hpe.) Par.

Hypnum cochlearifolium var, minus Hpe in Linn. 1872, p. 75 (nom.).

Ut typ. ? - Pac. : Tasman.

divulsum (Hosk. f. et Wils.) Lindb. in op. et $l$. cc.

Hypnum divulsum $H$. $t$. et $W$. in Lond. Journ. of bot. 1844, p, 556 ; Fl. of the N. Zeal. II, p. III, $t .90, f .4$ et Handb. p. $481 ; C . M$. Syn. II, p. 466.

Porotrichum divulsum Mitt. in Trans, and Proced. of the roy. Soc, of Victoria, 1883, p. 84.

Thamniella divulsa Besch. Fl. bryol. Nov. Caled. p. 240,

2. Ad terr. humid. - Pac. : Nov. Zeland. sept. et med., Austral. (Victoria), Tasman.

inflatum (Hook. f. et Wils.) Par.

Colidium inflatum Jaeg. Ad. II, $p .384$.

Hypnum inflatum $H$. $f$. et $W$. Fl. of the N. Zeal. II, p. 111, t. 90, f. 5 et Handb. p. 481.

\section{Ster.
icro-vagum (C.M.) Par.}

Hypnum micro-vagum C. M. in Trans. of the N. Zeal. Inst. 1893, p. 275. - Pac. : Nov. Zeland. sept, et med.

Rupic. - Pac. : Nov. Zeland.

porotrichoides (Besch.) Par.

Thamniella porotrichoides Besch. op, et $l$. oc.

2. Ad rup. humid. - Pac. : Nov. Caledon.

vagum (Hsch.) Lindb. in op. et $l$. cc.

Hypnum vagum Hsch. in Sieber M. Nov. Holl. n. 23; C. M. Syn. II, p. 466. 
Porotrichum vagum Mitt. in op. et $l$. oc.

Rigodium vagum Reichdt, in Reise d. Freg. Novara, Rot., I, p. 188.

Thamniella vaga Besch, op, et $l$. ce.

2.

- Pac. : Nov. Zeland. sept. ?, Austral. or., Tasman.

LEPIDOPILUM Brid. Bryol, univ. 11, p. 267. (129 spec.).

acutum Mitt. M. austr. am. p. 379.

2? - An. merid.: And. Quitens.

affine C. M. in Linn. 1848, p. 192.

Hookeria affinis ej. Syn. II, p. 199.

- Am. merid. : Guian. batav.

albescens Hpe. - Eriopus.

amplirete (Sull.) Mitt. op. cil. p. 382.

Cylindrothecium amplirete Sull. in Proced. of the Am Acad... 1861, p. 284 et in Wiright M. Cubens, n. 72.

Ster. - Am. sept. : Cuba.

anceps Mitt. op. cit. p. 378.

Ad arbor. - Am. merid. : And. Quitens.

angolense (Welw. et Duby) Jaeg.

Hookeria angolensis $W$. et $D$. in Mém... Genève, $1871, p .18, t .5, f .5$.

Lepidopilum versicolor Mitt. ? (1)

2. Ad terr. humos, - Afr. : Angola.

angustifrons Hpe. in Linn. 1863, p. 153; Mitt. op. cit. p. 384.

l. $\quad-A m$. merid. : And. Nov. Granat.

Antillarum Mitt, op, cit. p. 377.

Syn. $\quad-A m$, sept. : Martinic., ins, S. Vincent, Barbades.

apophysatum Hpe. in Besch. Prodr. bryol. mexic. p. 85.

1. Ad arbor. - Am. sept. : Mexic,

arcuatum Mitt, op. cil. p. 374.

1. - Am. merid. : And. Quitens.

armatum Mitt op, cit. p. 380 .

- Am. merid. : And. Quitens.

aureo-fulvum $C . M$. in Linn. 1878-79, p. 495.

1. $\quad-A m$ merid. : Venezuela.

aureo-purpureum C. M. in Ule Bryoth. brasil. $n .94$.

- Am. merid. : Brasil. subtropic: or.

aurescens ej. in op. cit. p. 435.

Ster.

- Am. merid. : Argentin. subtropic.

aurifolium Mitt. op. cit. p. 371 .

2. Ad arbor. - Am. merid. : And. Quitens.

australe Broth. in Oefv.... 1890, p.

2. Ad arbor. - Pac. : Austral. or. (Queensland).

binerve Brid. - Hookeria scabriseta.

(1) Cf. Mitt, in Journ, of the Linn, Soc, 1886, p. 309. 
brachychaete C. $M$, in Dusen $M$. Camer. n. $45 i$.

- Afr. : M. Cameroon.

brevifolium Mitt. op. cit. p. 385.

Ad arbor. - Am. merid. : And. Quitens.

brevipes Mitt. op. cit. p. 376.

- Am. merid. : And. Peruv.

brunneolum C. M. in Linn. 1876, p. 139.

Ster. $\quad-A f r$.: Ins. Anjouan.

caespitosum Besch. Fl. bryol. Réunion, etc, p. 138.

2 ? In silvis, - Afr. : Ins. Borbon.

callochroum C. M. in Dusen M. Camer. n. 258 a.

- Afr.: M. Cameroon.

calvum Mitt. op, cit. p. 377.

- Am. merid. : And. Peruv.

caudatum C. $M$. in Fl. $1875, n, 34-35$.

2.

- Am. merid. : And. Nov. Granat.

caviusculum Mitt. op. cit. p. 383.

- Am. merid. : And. Quitens.

chloroneuron (Tayl.) Milt. op. cit. p. 385.

Hookeria chloroneura Tayl. in Lond. Journ. of bot. 1846, p. 61; C. M. Syn. II, p. 197.

- Am. meridl. : M. Chimborazo et Pichincha.

chloroneuron Hpe, et Ltz, - L. Krauseanum.

cladorhizans Besch. in Marie M. Gundalup. n. 43 et in Journ. de bot. $1894, p .63$.

1. Cortic. - Am. sept. : Guadalup.

contignum Ren. et Card, in Bull. Soc. roy, bot. Belg. 1894, I, p. 193.

2 ? Ster. In silv. - Am. sept. : Costa Rica.

convallium (Brid.) Mitt. op. cit. p. 377.

Hookeria convallium C. M. Syn. II, p. 200.

Ptersgophyllum convallium Brid. Bryol. univ, $I I, p .354$.

- Am. merid. : "In convallibus Andium."

cubense Sull. in Proced. of the Am. Acad... 1861 ; Milt. op. cit. p. 384.

2 ? $\quad-A m$. sept. : Cuba.

curvifolium Mitt. op. cit. p. 374.

- Am. merid. : And. Quitens.

cuspidans Mitt. op. cit. p. 378.

2? $\quad$ - Am. merid. : And, Quitens.

daltoniaceum Hpe. in Linn. 1863, p. 152 ; Mitt. op. cit. p. $37 \mathrm{l}$.

Daltonia binervis Hpe, in Ann. sc, nat. V ser., IV, p. 364.

Ad arbor. - Am. merid. : And. Nov. Granat.

daltonioides W. P. Sch, in Besch. Fl, bryol. Antill. fi. p. 56.

1. Ad ramul. fructic. - Am. sept. : Guadalup.

Darntyi ej. in Besch. Fl. biryol. Réunion, etc. p. 140.

1. Ad arbor, annosior. - Afr. : Ins. Franciae.

Decaisnei Besch. Prodr. bryol, mexic. p. 84.

1.

- Am. sept. : Mexic. 
Deppeanum (C. M.) Besch, op. et l, cc.

Hookeria Deppeana C. M. Syn. II, p. 196.

Lepidopilum subenerve Hsch. in Deppe M. Mexic,

1.

- Am. sept. : Mexic.

devexum Mitl, in Journ, of the Linn. Soc, 1863, p. 159.

1. - Afr. : M. Cameroon.

diaphanum (Sw.) Mitt. M. aust, . am. p. 382.

Hookeria diaphana $W$. Arn. Dispos. M. p. 56 ; C. M. Syn. II, p. 199.

Hypnum diaphanum Suc. Prodr. Fl. Ind. occ. p. 140.

Pterygophyllum diaphanum Brid. Bryol. univ. II, p. 345.

- Am. sept. : Jamaic.

divaricatum (Dz. et Mk.) Milt. op. cit. p. 379.

Hookeria divaricata D. el M. Prodr. fl. bryol. Surin. p. 49, t. 13.

- Am. sept. : Venezuela.

diversifolium Ren. el Card. in Bull. Soc, roy. bot. Belg. 1394, II, p. 127. Ster.

Duseni C. M. in Dusen $M$. Camer. n. 40; Broth. in Engler's Bot. Jahrb. $1894, p .201$ (descriptio).

1. - Afr.: M. Sameroon.

epiphyllum Mitt. - Crossomitrium.

erectiusculum (Tayl.) Milt. op. cit.p. 371.

Hookeria erectiuscula Tayl. in Lond. Jowin. of bot. 1846, p. 60.

- Am. merid. : And. Quitens, et Chilens.

erubescens $C . M$. in $\mathrm{Fl}$. $1875, n, 34.35$.

2 ?

- Am. merid. : And. Nov. Granat.

excelsum C. $M$. in op. et $l$. cc.

2 .

falcatulum C. $M$, in Linn. 1976, p. 648.

- Am. merid. : And. Nov. Granat

Ster. Ad arbor. in silv. - Am. sept. : Mexic.

flaccidissimum Besch. in Marie M. Guadalup.

flavescens Geh. et Hpe. Enum. M. Brasil. p. 52.

Puiggaria splendens Duby Choix de M. ex. 1880, p. 8, t. II, f. 4 (fid. Hpe. in $\mathrm{Fl}, 1880, n .21)$.

$$
\text { - Am. merid. : Brasil. }
$$

flexicaule $\mathrm{Hpe}$ - Eriopus.

flexifolium (C. M.) Mitt. M. austr. am. p. 375 p.p.

Hookeria flexifolia C. M. Syn. II, p. 206.

Neckera biductulosa Schwaegr. Suppl. I, I1, p. 155.

Pilotrichum biductulosum P. B. Prodr.p. 82; Brid. Bryol. univ, 11, p.266.

2? Ad arbor. - Am. merid.: Ins. Trinitat., Guian., Amazon., And. Quitens. et Peruv.

flexifolium Mitt. p.p - I. subflexifolium.

flexuosum Besch, Fl, bryol. Réunion, etc. p. 139.

1.

floresiantin $-A f r$ : Ins. Borbon.

I. In silven. et Card, in Bull. Soc. roy. bot. Belg. 1894, I, p 194.

1. In silv, - Am, sept. : Costa-Rica. 
fontanum Mitt. - Crossomitrium.

frondosum Mitt. op, cit. p. 381 .

- Am. merid. : Nov. Granat.

fruticolum C. M. in Ule Bryoth. brasil. n. 74.

- Am. merid. : Brasil. austr. or.

furcatum Thw, el Mitt. in Journ. of the Linn. Soc. 1872, p. 310. - As.: Ceylan.

fuscidulum Mitt. M. austr. am. p. 372.

2.

- Am. merid. : And, Quitens.

? genuflexum C. M. in Linn. 1876, p. 648.

Ster.

- Am. sept. : Mexic.

Glaziovii Hpe. Enum. M. Brasil.p. 50.

1.

- Am. merid. : Brasil. austr. or.

goniothecium C. M. in Linn. 1878-79, p. 49.

- Am. merid, : Venezuela.

gracile Mitt. op. cit.p. 377.

2 ?

- Am. merid. : And. Quitens.

Grevilleanum (Tayl.) Mitt. op. cit. p. 381 p.p.

Hookeria Grevilleana Tayl. in Lond. Journ. of bot 1846, p. 60; C. M. Syn. II, p. 196.

Ad arbor. et saxa. - Am. merid. : Ins. Trinitat., Guian., And. Quitens, et Peruv.

Grevilleanum Mitt. p.p: $\left\{\begin{array}{l}\text { - L. Mittenii. } \\ - \text { L. obtusulum. }\end{array}\right.$

Hanningtoni Mitt. in Journ. of the Linn. Soc. 1886, p. 309.

1. - Afr. : M. Usagara.

Herminieri W. P. Sch. - 'rossomitrium.

Humbloti Ren, et Card. in Bull. Soc. roy. bot. Belg. 1894, II, p. 128.

Ster. - Afr. : Magn. Comor.

imbricatifolium Mitt. M. austr, am. p. 372.

Ster. Saxic. - Am. merill, : And. Quitens. et Peruv. inflexum Mitt. op. cit. p. 375.

2 ?

- Am. merid.: And. Quitens.

integerrimum Mitt. op. cit. p. 382 .

- Am. merid. : And. Quitens.

intermedium (C. M.) Mitt. op. cit. p. 377.

Hoỏkeria intermedia C. M. Syn. II, p. 195.

1.

- Am. merid, : Ins. Trinitat.

Isleanum Besch. Fl. bryol. Reunion, etc. p. 138.

1. Ad gramina? - Afr. : Ins. Borbon.

Krauseanum C. M. in Linn. 1874, p. 608.

Hookeria erectifolia ej. Syn. II, p. 197.

L. chloroneuron Hpe, et Ltz. in Bot. Zeit 1868, p. 816.

2. Ad arbor. - Am. merid. : Aquator.

laete-nitens Ren. et Card. in Bull. Soc. roy. bot. Belg. 1894, I, p. 194. 2 ? - Am. sept. : Costa Rica.

laevisetum Bpe, Enum, M. Brasil. p. 51.

1.

- Am. merid. : Brasil. austr, or. 
Laskii Mitt, in Journ. of the Linn. Soc. 1886, p. 309.

1. Ad arbor. - Afr. : M. Usagara.

latifolium (C. M.) Mitt. M. austr. am.p. 180.

Hookeria latifolia C. M. Syn. II, p. 199.

Ster.

- Am. merid. : Ins. Trinitat.

leiomitrium C. M. in Linn. 1878-79, p. 495.

1.

- Am. merid. : Venezuela.

leiopus C. M. in Dusen M. Camer. n. 358.

- Afr. : M. Cameroon.

livens Besch, in Bull. hb. Boissier, 1894, p. 396.

2? I ignic. - Am. sept. : And, Costa Ric.

longicuspes C. M. in Ule Bryoth Brasil. n. 172.

Ad arbor. - Am. merid. : Brasil. austr. or.

longifolium Hpe. in Ann. sc. nat. V ser., IV, p. 365 ; Mitt. op, cit. p. 384, - Am. merid. : And. Nov. Granat.

lorifolium Hpe. Symb. 1874 , p. 504.

L. loriforme ej. Enum. M. Brasil, p. 51.

- Am. merid. : Brasil. austr. or.

loriforme Hpe. - L. lorifolium.

macropus Bryol. jav. II, p. 41, t. 164.

1. Aquat. - As. : M. Java.

maculatum C. $M$. in Fl. 1875 , n. 34-35.

Ster.

- Am. merid : And. Nov. Granat.

membranaceum (C. M.) Mitl. op. cit.p. 369.

Hookeria membranacea C. M. Syn. II, p, 200.

2? Ster.

Trinitat, Yenezuela, And. Quitept.: Barbades, Am. merıd.: Ins,

Mittenii C. M. in Linn. 1874 , p. 607.

L. Grevilleanum Mitt. op. cit. p. 381 p.p.

2.

- Am. merid. : Amazon.

mniaceum C. $M$. in Fl. 1875, n. 34-35.

2.

- Am. merid. : And. Nov. Granat.

Mohrianum C. M. in Linn. 1876, p. 649.

L. Sartorii ej. in sched.

L. subenerve Besch. Prodr. bryol. mexic. p. 84?

Ad arbor. in silv. - Am. sept. : Mexic.

monilidontium Hpe. Symb. 1874, p. 504.

1. Ad arbor. - Am. merid.: Brasil. austr, or.

Moseni Broth, in Bihang till K. Sv, vet. Akad. Handl, n, 1895, n. 3.

2. Ad saxa humida. - Am. merid. : Brasil. or.

Miilleri Hpe. in Linn. 1847, p.84.

Hookeria Mülleri C. M. Syn. II, p. 195 .

L. subenerve ej. in Linn. 1847, p. 2.4.

1. Ad arbor. et fol. emort. - Am, merid.: Venezuela, And. Nov. Granat. et Quitens.

muricatulum C. M. in Dusen M. Camer. n. 678 .

- Afr. : M. Cameroon. 
nitidum Besch. Prodr. bryol. Mexic. p. 85.

- Am. sept. : Mexic.

niveum (C. M.) Par.

Hookeria nivea C. M. in Fl. 1886, p. 281.

Ster. Ad arbor. - Afr.: Ins. S. Thom.

nndum Mitt. op. cit. p. 376.

- Am. merid. : M. Chimborazo.

nutans $\mathrm{H}$ pe. - Eriopus.

oblongifolium Mitt. op. cit. p. 383.

2. Ad arbor. - Am. merid. : Brasil. or.

obtusulum C. M. in Linn. 1874, p. 606.

L. Grevilleanum Mitt. op. cit. p. 381 p.p.

2. Ad arbor. et sax. - Am. merid. : Brasil, aequinoct.

ovalifolium (Duby) Par.

Puiggaria ovalifolia Duby Choix de M. ex. $1880, p .8, t .3, f .4$.

Ad arbor. - Brasil austr. or.

Patrisiae Mitt. p.p. - Crossomitrium Spruceanum.

pectinatum Mitt. op. cit. p. 381 .

2 ?

- Am. merid. : And. Quitens.

pergracile C. M. in Fl. $1875, n$. 34-35.

1. Filicic. - Am. merid. : And. Nov. Granat.

phyalothecium (C. M.) Par.

Hookeria phyalothecia C. M. in Journ. of Bot. 1877, p. 229 (nom.).

Cortic. - Am. sept. : Costa Rica.

phyllorhizum Mitt. op. cit. p. 385.

- Am. sept. : Cuba.

piliferum Besch. Frodr. bryol. mexic. p. 85 .

2. Cortic. - Am. sept. : Mexic.

platyphyllum Ren. et Cardd. in Bull. Soc. roy. bot. Belg. 1894, 1, p. 192.

1. In silv. - Am. sept. : Costa Rica.

Polakowskyi (C. M.) Par.

Hookeria Polakowskyii C. M. in Journ. of Bot. 1877, p. 229 (nom.).

Cortic. - Am. sept. : Costa Rica.

polytrichoides (Hedw.) Brid. Bryol. univ. II, p. 269 ; Mitt. op. cit. p. 373.

Chaetophora Perrini Brid. op. cit. p. 336 ?

Daltonia polytrichoides $W$. Ain. Disp. M. p. 55.

Hookeria Perrini Spreng. in Neu. Entdeck. III, p. 4.

H. polytrichoides ej. Syst. veg. IV, p. 197; C. M. Syn. II, p. 205.

H. rigida $W$. Arn.? fid. Mitt.).

Hypnum polytrichoides Hedue. Sp. M. p. 244, t. 61.

Neckera polytrichoides Schwaegr. Suppl. III, I, II, t. 231.

Orthotrichum polytrichoides Brid. M. Rec. p. 244, $t .61$.

Pilotrichum polytrichoides ej. Mant. M. $p, 140$.

Polla binervis ej. Bryol. univ. I, p. 856 .

Syn. Ad arbor. - Am. sept. : Mexic., Costa Rica, Jamaic., Hispaniola, Porto Rico, Antill. gall. Am. merid.: Venezuela, Amazon., And.

Nov. Granat,, Quitens., Peruv. et Chilens. " var. costa-ricense Ren. et Card. in Bull. Soc. roy. bot. Belg. I894,
p. 192 . 
In silv. - Am. sept. : Costa Rica.

"var. pellucens Besch. Fl. bryol. Antill. fr.p. 57.

$$
\text { - Am. sept. : Guadalup. }
$$

pumilum Mill. op. cit. p. 381 .

- Am. merid. : And. Quitens. et Peruv.

purpurascens W. P. Sch, in Besch. op. vit. p. 55.

2.

- Am. sept. : Guadalup.

purpuratum Mitt. $M$. Ind. or. p. 116. 1.

- As. : Sikkim, Ceylan.

radicale Mitt. M. austr, am. p. 378

2. Filieic. - Am. sept. : Guadalup., Martinic. Am. merid. : And. Nov. Granat. et Quitens.

robustum Mitt. op. cit. p. 386 .

- Am. merid. : And. Nov. Granat. et Quitens.

Sartorii C. M, - L. Mohrianum.

secundum (Griff.) Mitt. M. Ind. or. p. 116.

Hookeria secunda Griff. Not. p. 477 et Ic. Pl. Asiat. I1, t. 99, f. 2. 1. - As. : Khasia, Ceylan.

semi-laeve Mill. M. austr. am, p. 385.
2.

And, Quitens.

- Am. sept.: Costa Rica, Am. merid: Panama,

spinosum (C. M.). Jaeg. Ad. II, p. 232.

Hookeria spinosa C. M. Syn. II, p. 677.

- As. : Java.

splendidissimum Mitt. - Cyatophorum.

Splitgerberi Mitt. - Crossomitrium.

Sprucei Mitt. - Actinodontium.

stillicidiorum Mitt. op. cit. p. 373.

2? Ster. Ad saxa irror. - Am. merid. : And. Quitens.

streptogoneum $C$. M. in Dusen M. Camer. n. 107.

subaurifolium Geh. et Hpe. in Fl. 1881 .

- Afr.: M. Cameroon.

Cortic. - Am. merid. : Brasil. austr, or.

subdivaricatum Ren. et Card. in Bull. Soc. roy. Belg. 1894, I, p. 195.

2? $\quad$ Am. sept. : Costa Rica.

subenerve Brid, Bryol. univ. II, p. 268 ; Mitt. op. cit.p. 383.

Daltonia scabriseta W. Arn. Disp. M. p. 54.

Neckeria subenervis Hpe. in Linn. 1348, p. 84; C. M. Syn. II, p. 196.

Pilotrichum seabriseta Schwaegr. Suppl, I. II, p. 153, t. 82.

1. Ad arbor scabrisetum Birid. Mant. M. p. 141.

mexid. - Am. sepl.: Mexic.? Porto-Rico, Antill. gall. Am. merid. : Venezuela, Columb., Guian. gall., And. Quitens.

subenerve $\left\{\begin{array}{l}\text { Besch. - L. Mohrianum? } \\ \text { C. M - L. Mülleri. } \\ \text { Hsch. - L. Deppeanum. }\end{array}\right.$

subepiphyllam Besch. - Crossomitrium. 
subflexifolium C. M. in Linn. 3874, p. 605.

L. flesifolium Mitt. op. cit. $p, 3: 5 p \cdot p$.

2.

- Am. merid. : Amazon.

subfuscum Mitt. op. cit, p. 376 .

Ad arbor. - Am. merid. : Amazon,, Brasil.

subpolytrichoides C. $M$. in Linn. 1878-79, p. 495.

1. - Am. merid. : Venezuela.

subsubulatum Geh. et Hpe. Enum. M. Brasil. p.,51.

Puiggaria elegans Duby Choix de $M$. ex. 1880, p. 7, t. 3, f. I. - Am. merid. : Brasil.

subulatum Mitt. op. cil. p. 380.

- Am. meriel. : Brasil. or.

sumatranum Bryol. jav. II, p. 42, t. 165.

Hookeria incurva Dz. et Mk, M. frond. ined. Archip, ind. p. 109.

1. Ad arbor. - As, : M. Sumatra.

surinamense C. M. in Linn. 1848, p. 193.

Hookeria surinamensis ej. Syn, $I I$, p. 207.

Syn.? Ad arbor. - Am. merid. : Guian. batav,

tenuifolium Milt, op. cit. p. 382.

Ster.

- Am. merid. : M. Chimborgzo.

Thwaitesianum Mitl. M. Ind. or. p. 116.

1.

- As. : Ceylan.

tortifolium Mitt. M. austr, am. p. 374.

2. Ad saxa irror. - Am. merid. : And. Nov. Granat. et Quitens.

undulatum Hpe. et Ltz. in Bot. Zeit. 1869.

1. Ad arbor - Am. merid. : Aquator.

utacamundianum (Mont.) Mitt. M. Ind. or. p. 116.

Hookeria Lindenbergii Hpe. in Linn. 1847, p. 85.
H. utacamundiana Mont. in Ann. sc. nat. 1842, p. 247 et Syll. p. 13; C. M. Syn. II, p. 197.

2. In silvis. - As, : M. Neilgherr.

v enustum Tayl. mss. ; Milt. M. austr. am. p. 371.

2. Ad arbor. -- Am. merid : And. Quitens.

versicolor Mitt. in Journ. of the Linn. Soc. 1863, p. 159.

Hookeria versicolor ej. in op. cit. 1886, p. 309.

L, angolense $W$. et $D$. (fid. Mist. . c.). 1.

- Afr. : Ins. Fernando-Po, Kilima N'Djaro.

Wallisii C. M. in Fl. 1875, n. 34-35.

2. $\quad$ - Am. merid. : And. Nov. Granat. (1).

LEPTANGIUM Mont, mss.; Mitt. M. austr. am. p. 239.

Spec. omn. non indicatae sunt GIGASPERMA ejusd. nom.

Perrotletii Mont. - Erpodium.

(1) In Enumer. Kindberg. nom. nud. :

L. Swartzii W.P. Sch. 
LEPTOBARBULA W. P. Sch. Syn. II ed. p. 181 (3 spec.).

berica W. P. Sch. l. c. (1).

Didymodon tenuis de Not. Syll. n. 268.

Leptotrichum berisum de Not. Cron. briol. ital. I, p. 14.

L. tenue $W, P$, Sch. Syn. I ed. (quoad pl. ital.), C, M. Syn, I, p. 447 (p.p. et excl, syn. Hedw, et Brid.) et II, p.611; Mac. Canad. M. n. 486.

Trichostomum berieum de Not. Epil. p. 509.

Tr, tenue Bryol, eur. II (mon. p. 13), t. 171.

2. Saxic. - Eur. : Normannia, Ital. super. et merid., ins. Minore. Am. sepl. : Columb. brit.

meridionalis W. P. Sch. op. cit. $p, 182$.

Trichostomum bericum Husn. Muscol, gall. p. 91 p.p.

2. Ad sax. calear. - Eur.: Gallopruv.

Winteri W. P. Sch. op. cit. p. 183.

Trichostomum bericum Husn, op. et $l$. ec. p.p.

2. Ad rup. calcar. - Eur. : Vall. fl. Sarre (Mondorf).

Leptobryella C. M. in Bull. Soc. bot. Fr. 1878, p. 66 (sect. PteroBRYELLAE).

LEPTOBRYUM W. P. Sch. Coroll. p. 54 (2 spec.).

minus Philib. - L. piriforme var. minus.

piriforme (Hedvo.) W. P. Sch. Coroll. p. 64 et Syn, II ed. p. 390.

Bryum aureum Schreb. Spic. Fl. Lips, p. 81.

Br. mnioides Gmel. Syst. nat. II, p. 1330.

Br. pendulum Ehrh. Crypt. exs. n. 163.

Br. piriforme Hedw. Hist. M. I, t. 3, f. 12; Bryol, eur. IV (mon. p. 45), t. 335 ; C. M. Syn. I, p. 330 ; Drumm. M. bor. am. I ed. n. 271.

Br. rupeum Neck. Meth. M. p. 220.

Br. trichodes aureum capitulis piriformibus nutantibus Dill. Hist. M.p. 391 , t. $50, f .60$.

Br. Webera piriformis Brid. Bryol. univ. I, p. 631 .

Hypnum piriforme $\boldsymbol{W}$. et $M$. Bol. Taschb. p. 274.

Mnium piriforme L. Sp. pl. p. 1576.

Webera piriformis Hedic. M. frond. $I, p .5, t .3$.

Syn. Ad mur., rup., terr. arenac, et turfos, in umbros. - Eur.: A reg. campestr. usq. in alp. : Spitzberg. As. . Japon, penins. Samojed. et Tschutschica, Obi, Jenissei, Ochotsk, Tibet occ., Caucas. Am. sept. : Groenland, Labrador, Anticosti; ab Atlantic. ad Pacif. ; Vancouver. Am. merid.: And. Quitens., Brasil. subtropic. or. Pac.: Nov. Zeland. Tasman.

Exs. : Mac. Cansd. M. n. 159.

Rab. Rryoth. eur. 93 et b, 1282.

Sull. et Lesq. M. bor. am. II, p. 276.

* var. antarcticum C. $M$. in Fl. 1885, p. 403.

- Am. merid. : Fuegia.

"var. fuegianum ej. in Forchungsreise... Bot. p. 37.

- Am. merid. : Fuegia.

"var. Hubnerianum Rab. Kryplfl. v. Sachs. I, p. 483, Limpr. Deutschl. Laubm. 11, p. 217 .

Ad stagn, - Eust: Saxon.

(1) $L$. berica $=$ L. meridionalis (fid. Philib, in Rev, bryol. 1882, p. 17) $=$ L. Winleri, fid. Limpricht Laubm. Deatschl, I, p+p. 596-599). 
* var. minus Husn. Muscol. gall, p. 221.

L. minus Philib. M. Gall. n. 768.

- Eur. : Valesia

sericeum (Hpe. et C. M.) Par.

Bryum sericeum Hpe, et C. M. in Linn. 1853, p. 494.

- Pac. : Tasman.

Leptocalpe Mitt. M. auslr, am. p. 403 (sect. Erpodi).

LEPTOCHL $\mathbb{E N A}$ Mont. in Ann. sc. nat. 1845, 1V, p. 105 (4 spec.).

chilensis Mont. I. c. p. 106 et in Gay Hist. Chil. Bot. crypt. l. 4, f. I; Syll.p. 35 ; C. M. Syn. I, p. 237.

Mielichhoferia chilensis Mitt. M. austr. am. $p, 324$.

1. Ad arbor. - Am. merid. : Chile.

graciliseta Hpe, in Linn. 1863, p. 130.

Mielichhoferia graciliseta Mitt. op. et $l$. ec.

Syn.

- Am. merid. : And. Nov. Granat.

microdonta Mitt, in F. v, Müller's Fragm. Phyt. austr. X1, Suppl. 1881, p. 114.

Mielichhoferia microdonta Mitt. in Trans. and Proced. of the roy. Soc. of Victoria, $1883, p$. 73 (nom.).

- Pac. : Alp. Austral. or., Victoria, Tasman.

Re hmanni C. M. in Reltm. M. Afr. austr. n. 216, 543 et b. - Afr.: Transvaal, C. B. Sp.

Leptodictyon W. P. Sch. Syn. I ed. p. 595 (subgen. Amblystegi).

LEPTODON Mohr. Obs. p. 27 (13 spec.).

Reccarii C. M. in Nuov. Giorn. bot, ital. 1872, p. 19.

2.

$$
\text { - Afr.: Abyssin. }
$$

Boryanus W. P. Sch. Syn. I ed. p. 464 et II ed. p. 562 (nom.) et in Besch. Fl. bryol. Réunion, etc. p. 118.

Ster. Cortic. - Afr. : Ins. Borbon.

circinatus Sull. - Alsia abietina.

coronatus C. M. - Lasia.

flexuosus (Harv.) Jaeg. Ad. $1 I, p .106$.

Neckera camptoclada Ren. et Card. in Bull. Soc, roy. bot. Belg. 1895, 11 ,

N. flexuosa Harv, in Lond. Journ. of bot. 1840, p. 14 et in Hook. Ic. pl. rar. t. 21, f. 3; C. M. Syn. II, p. 119.

2.

- As. : Nepal., Himalaya, Calcutta, Bhotan.

floridanus Lindb. Krit. Grausk. Moss. Dill. p. 53.

1 .

- Am. sept. : Florida.

immersus Sult. $\rightarrow$ L. trichomitrium var. immersus.

japonicus Besch. mss.

Exs. : Faurie n. 51, As. : Japon, $240,770,2731$. 
longisetus Mont. Hist, des 1. Canar. p. 20 et Syll. p. 25.

Neckera longipedunculata C.M. Syn. II, p. 119.

2 . - Afr. : Teneriff.

Exs. : Bourg. PI. Canar. n. 620.

"var, flagellifera $e j, l, c$.

$$
\text { - Afr. : Ins. Canar. }
$$

mollis Rehm. M. A fr. austr. n. 602 b.

- Afr. : Transvaal.

nitidus (Lindb.) Sull. Ic. M. Suppl. p. 80, l. 60; Lesq. et Jam. Man. p. 279 .

Forstroemia nitida Lindb. in Oefv... 1869, p. 73.

Lasia nitida Jaeg. Ad. II, p. 107.

Neckera Macounii Sull. Canad. Nat. II ser., II, pp, 79 et 397.

1. Cortic. - Am. sepi.: Ontario.

ohioensis Sull. M. Allegh. n. 89 et Ic. M. p. II', t. 72; Lesq. et Jam. Man. p. 278 .

Forstroemia ohioensis Lindb. in op. cit. p. 75.

Lasia ohioensis Jaeg. Ad. II, p. 108.

Neckera ohioensis C. M. Syn. II, p. 93.

1. Cortic. - Am. sept. : Ohio.

Exs : Sull. et Lesq. M. bor, am. II ed, n. 354 .

Pluvini (Brid.) Jaeg. Ad. II, p. 106.

Neckera Pluvini Brid. in Steud. Nomenol. crypt.p. 295.

Pilotrichum Pluvini ej. Bryol. univ. II, p. 260.

procumbens (C. M.) Jaeg. Ad. II, p. 107.

Neckera procumbens C. M. Syn. II, p. 80.

Trachypus procumbens Mitt. M. Ind, or. p. 127.

2.

$$
\text { - As. : Bombay, Malabar. }
$$

rigidulus (Wils.) Jaeg. $l$. $c$.

Neckera rigidula Wils, in sehed. ; Mitt, op. cit. p. 120.

2.

- As. : Kashmir.

Smithii Mohr. Observ, p. 27; Brid. Bryol, univ. II, p. 197 ; Bryol. eur. V, t. 439 ; W. P. Sch. Syn. II ed.p. 562.

Hookeria convoluta Spreng. Syst. veg. IV, II, p. 324.

Hypnum circinatum Santi Viagg. p. 209, t. 6.

H. Smitbii Dicks. Fasc. II Pl. crypt p. 10, t. 5, f. 4.

Lasia Smithii Brid. Mant. M. p. 1 ?3.

Neckera bipinnata Schleich. Crypt. Helvet. Cent. IV, n. 22 ,

N. Smithii C. M. Syn. II, pp. 118 et 669.

Orthotrichum Smithii Brid. M. Rec. II, II, p. 33.

Pilotrichum Smithii P. B. Prodr. p. 83.

Polylrichum Smithii Hull. 249.

Pterigynandrum Smithii Brid. Sp. M. p. 140.

Pterogonium Smithii Sw, in Schrad. Journ. II, p. 173.

2. Ad sax., mur. et praepr. arb. annosior. - Eur.: Reg. occ. et merid. As, : Caucas, occ. Afr.: Sept. et austr, ins. Canar., Kilima N'Djaro. Am, merill.: Chile, ins. Juan Fernandez. Pac. : Nov. Zeland.

Exs. : Rab. Bryoth. eur. n. 240, 528, 688, 992, 1240 et b, 1423. Rehm. M. Afr. austr. n. 316 et b.

(1) In knumer, Kindberg, nom, nud,

L. filiformis $W$. P. Sch. 
trichomitrium Mohr. - Forstroemia.

var. immersus Sull, - Forstroemia trichomitrium var. immersa. var. irriguus Ren, - Fortroemia trichomitrium var. irrigua.

LEPTODONTIUM Hpe, in Linn, 1847 , p. 70 (35 spec.).

acutifolium Mitt, M. ausli, am. p. 51 .

Didymodon acutifolius Jaeg. Ad. I, p, 209.

Rupic. - Am. sept. : Guatemala. Am. merid. : Ind. Quitens.

aggregatum C. M. in Bot. Zeil. 1847, p. 829.

Didymodon aggregatus Jaeg. Ad. I, p. 210.

Trichostomum aggregatum $C$. $M$. Syn. $I, p, 580 ;$ Bryol. jav. $I, p .98, t .80$.

2. - As, : Java.

arachnoideum C. M. in Linn. 1878-79, p. 324.

Ster. $\quad-A m$. merid. : Argentin. subtropic.

armatum Rehm. M. Afr. austr. n. 466. - Afr. : Transvaal.

\& var. brevifolium ej. l.c. n. 467.

- Afr. : Transvaal.

brasiliense Mitl. M. austr. am. p. 52 .

Didymodon brasiliensis Jaeg. Ad. I, p. 207.

Ster. Cortic, et rupic. - Am. merid. : Brasil, austr, or.

braunioides $C . M$. in Linn. 1878-79, p. 325 .

Ster. $\quad-$ Am. merid. : Argentin, subtropic.

brevirostrum Mitt. - Holomitrium serratum.

brevisetum Mitt. op. cit. p. 59.

Didymodon brevisetus Jaeg. Ad. I, p. 208.

- Am. sept. : Mexic.

canadense Kindb. in Mac. Cat. p. 45.

2. Ad lapid. in rival. - Am. sept. : Ontario.

capituligerum C. M. in op. cit. p. 323.

Ster. Lignic,, ad rup., terr. et tecta, - Am. merid. : Argentin. Cordob. et subtropic.

cirrifolium Mitt. op. cit. p. 52.

Didymodon cirrifolius Jaeg. Ad, $I$, p. 208.

Ster. $\quad-A m$. merid. : And. Quitens.

citrinum Hpe. Enum. M. Brasil. p. 10.

Didymodon citrinum Jaeg. Ad. $I, p, 209$.

Trichostomum citrinum Hpe. Symb. 1872, p. 37.

densifolium Mitt. op, et l. cc. Didymodon densifolius ej. an Lond. Journ. of bot. 1851, p. 53; C. M.
Syn. Il, p. 627.

- Am. merid. : And. Quitens.

dentatum (Wils.) Par.

Didymodon dentatus Mitt. M. Ind. or. p. 23.

Trichostomum dentatum Wils, in Keve bot. Journ, IX, p. 299 p.p.

Ster. Ad arbor. - As, : Sikkim. 
epunctatum (C. M.) Par.

Didymodon epunctatus Jaeg. Ad, I, p. 210.

Encalypta squarrosa Brid. Sp. M. I, p. 93.

Neckera viticulosoides P. B. Prodr. p. 78.

Trichostomum epunctatum C. M. Syn. 1, p. 579.

Tr, squarrosum Brid. Bryol. univ. I, p. 498 (excl, syn. Hook.).

2. Terr. - Afr : Usambara, ins. Borbon., Madagascar sept.

"var. paludosum Ren. et Card. in Butl. Soc. roy. bot. Belg. 1893, 1, p. 115.

In sphagnet. - Afr. : Madagascar.

filescens (Hpe.) Mitt, M. austr. am. p. 50.

Didymodon filescens Jaeg. $l$. $c$.

Trichostomum filescens Hpe. in Linn. 1863, p. 28.

2. Ad tecta stramin. - Am. merid. : And. Nov. Granat.

flexifolium Hpe. - Didymodon.

gemmascens Mitt. - Didymodon flexifolius $\beta$ gemmiferus.

Johannis Meyeri C. M. in Fl. 1888, p. 412 .

Ster. $\quad-A f_{r}$ : : Kilima N'Djaro.

longicaule Mitt. M. austr, am. p. 52.

Didymodon longicaulis Jaeg. Ad. I, p. 209.

Ster.

- Am. merid.: M. Pichincha.

Inteolum (Besch.) Par.

Didymodon luteolus Jaeg. Ad. $I, p .210$.

Trichostomum luteolum Besch. Prodr. bryol, mexic. p. 34.

Ster. - Am. sepl. : Mexic.

luteum (Tayl.) Mitt. op. cit. p. 50.

Didymoiton luteus Tayl. in Lond. Journ. of. bot. 1846, p, 48.

Trichostomum luteum Hpe. in Ann. se. nat. V ser., V, p. 294.

Tr. ulocalys? C. M. Syn. I, p. 578 .

Boliv

- Am. merid. : And. Nov. liranat., Quitens, et

Exs. : Mandon Pl. Boliv. n. 1616.

matucamense Besch, in Bull. Soc. bot. Fr. 1885, p. LVIII.

Ster. - $\quad-A m$. merid. : Peruv.

papillosum $H_{p e}$. in Fl. 1865, n. 37.

Didymodon papillosus Jaeg. Ad. I, p. 208.

Ad rivul. - Am, merid. : Peruv, or.

papillatum H. et W. - Zygodon Preissianus.

pseudo-sulfureum $(C, M$. $)$ Par.

Trichostomum psendo-sulfureum C. M. in Journ. of Bot. 1877, p. 228 (nom.).

Cortic. - Am, sept. : Costa Rica.

Quennoae C. M. in Linn. 1878-79, p. 322.

2. Ad arbor. - Am, merid. Argentin. subtropic.

radicosnm Mitt. in Journ. of the Linn. Soc. 1886, p. 301.

Didymodon radicosus ej. in op. cit. 1863, p. 149.

Exs, ; Dusen M. Cafr. : M. Cameroon, Usagara, Kilima N'Djaro, 
recurvifolium Lindb. - Didymodon.

rhacomitrioides Ltz. et C. M, in Linn. 1878-79, p. 321.

1 et 2. Rupic, et terr. - Am. merid. : Argentin. subtropic.

squarrosum (Hook.) Par.

Didymodon squarrosus Hook. M. ex. t. 150.

Trichostomum squarrosum Sehwaegr. Suppl. II, I, p. 78, t. 113 ; Brid. Bryol. univ. I, p. 498 p.p. ; C. M. Syn. I, p. 578.

2. - As. : Nepal., Sikkim, Khasia. Afr. : Abyss.

Exs. : W. Schimp. Pl. Abyss, n, 818.

stellatum (Brid.) Par.

Dicranum stellatum Brid. Bryol. univ. I. p. 413.

Didymodon stellatus Jaeg. Ad. I, p. 210.

Trichostomum stellatum C. M. Syn. I, p. 579.

2. Ad terr. humid. - Afr. : Ins. Borbon. Am. sept. : Mexic.

stiriacum Limpr, - Didymodon.

subalpinum $\left\{\begin{array}{l}\text { de Not., Lindb. - Trichostomum. } \\ \text { 1.tz. - Dichodontium pellucidum var. serratum (fid. Limpr.). }\end{array}\right.$ subcirrifolium (C. M.) Par.

Didymodon subcirrifolius Jaeg. Ad. I, p. 208.

Trichostomum subcirrifolium C. M. in Linn. 1874, p. 601.

Ster. - Am. merid. : And. Nov. Granat.

subdenticulatum (C. M.) Par.

Didymodon subdenticulatus Jaeg. Ad. I, p, 207.

Trichostomum subdenticulatum C. M. Syn. II, p. 626; Biyol. jav. I, p. $97, t .79$.

2 .

- As. : Java.

subgracile Ren. et Card. in Bull. Soc. roy. bot. Belg. 1892, I, p. 153.

Ster.

- Am. sept. : Costa Rica.

sulfuremu (C. M.) Mitt, M. austr, am. p. 51 .

Didymodon sulfureus Jaeg. Ad. I, p. 208.

Trichostomum sulfureum C.M. Syn. II, p. 626.

2.

- Am. sept. : Nicaragua.

\& var, panamense Ltz, Moosst. p. 161.

Didymodon sulfureus var. panamensis Jaeg. l. e. - Am. sept. : Panama.

transvaaliense Par.

Trichostomum sulfureum Rehm. M. Afi. austr. n. 471.

$$
\text { - Afr. : Transvaal. }
$$

tenuifolium (C. M.) Par.

Didymodon tenuifolius Jaeg. Ad. I, p. 209.

Trichostomum tenuifolium C. M. in Bot. Zeit. 1859, p. 229.

Ster.

- As. : Java.

ulocalyx (C. M.) Mitt. op. et l. cc.

Didymodon ulocalyx Jaeg. Ad. I, p. 208 ,

Trichostomum squarrosum Hsch. in Deppe et Schiede M. Mexic.

Tr. ulocalys C. M. Syn. I, p. 578.

2 .

tens.

- Am. sept. : Mexic. Am. merid. : And, Qui- 
zygodontoides C. M. in Linn. 1878-79, p. 326.

Ster. Ad arbor. ? - Am. merid. : Argentin, subtropic. (1).

LEPTOHYMENIUM Schwaegr. Suppl. III, I, 1I, t. 246 (23 spec.).

affine W. P. Sclt, in Besch. Prodr. bryol. mexic. p. 102.

1. - Am. sept. : Mexic. (Orizaba).

Ahnfeldti Ângstr. - Heterocladium heteropterum.

Barteri (Mitl.) Par.

Stereodon Barteri Mitt, in M. hb. Hook. 1860, p. 51, t. 5, f. 2.

1. Cortic. - Afr. : Niger inf.

bicolor (Lindb.) Jaeg. Ad. II, p. 346.

Pterigynandrum bicolor Lindb. mss.

Pt. squarrosum Hpe. Symb. 1870, p. 281 et Enum. M. Brasil. p. 57. - Am. merid. : Brasil. austr. or.

Bonplandi Besch. op. et l. cc. (nom.).

- Am. sept. : Mexic.

brachycladon (Brid,) Jaeg. Ad. II, p. 347.

Neckera brachyclada $C, M$. Syn. II, p, 88.

Pterigynandrum brachycladon Brid. Bryol. univ. II, p. 185 (excl. syn. Pterog. decumbente Schwaegr.). Plerogonium ascendens Schwaegr. Suppl. III, I, II, t. 243 (cum perist.
simpl. false observato fid, C. M. l. c.).

1. Lignic. - Am, sept. : Massachnssets, Pensilv.

? brachystegium Besch, in Ann. sc. nat. 1892, I, p. 85.

1. Silvic. - As. : Yunnan.

brasiliense Jaeg. - Erythrodontium.

Breutelii W. P. Sch. mss.

Neckera Breutelii C. M. in Bot. Zeit. 1858, p. 165.

- Afr.: C. B. Sp.

consanguineum Hpe. - Erythrodontium.

cristalum $\mathrm{H}$ pe. - Pterigynandrum filiforme var. cristatum.

cylindricaule Besch. - Erythrodontium.

var. rupestris $\mathrm{H}$ pe. - Erythrodontium cylindrocaule var. rúpestris.

dentatum Schuaegr. Suppl. IV, p. 332.

Neckera dentata $C, M . S y n . I I, p .88$. 1.

Pleuropus dentatus Griff. in Schwaegr, l. c. - Afr $\mathrm{A}: \mathrm{C}$. B. Sp.
elajochlo-serratum $\mathrm{Hpe}$ - Pterogonium gracile var. duplicato-serratum

elajochloron Lobarz. - Pterigynandrum filiforme var. duplicato-serratum fabronioides C.M. in Besch. Fl. bryol. Réunion, etc. p. 151.

Pterigynandrum fabronioides ej. in Rev. bryol. 1876, p. 59.

Ster, Rupic. - Afr. : Usambara, ins. Franciae, Nossi-Comba.

(1) In Enumer. Kindberg. nom. nud.

L. chiloënse $C . M$.

laxifolium Hook.

lutescens Tayl. (an Didymodon luteus ?).

procumbens $C$. $M$.

L. pumilum $C, M$. pungens Milt. repens $C . M$. syntrichioides $C . M_{\text {. }}(c f$. Didymodon). Wallisii $C . M$. (of. Didymodon). 
Ferrieri Marie in Ann. sc. nat. VII ser., II, p. 95.

$\delta$ et fr. ign. Ad arbor. - Afr. : Ins. Mayotte.

fliforme Hüb. - Pterigynandrum.

var. alpestre Rab. - Pterigynandrum filiforme var. heteropterum. gracile Rab. - Pterogonium.

heteropterum Rab. $\left\{\begin{array}{l}\text { (fid. C M.). - Heterocladium. } \\ \text { (fid. Lindb.). - Pterigynandrum filiforme var. hete- } \\ \text { ropterum. }\end{array}\right.$ hirtellum Schwaegr, - Thelia.

hokinense Besch, in Ann, sc. nat. 1892, I, p. 82.

2. Ad arbor, et saxa. - As. : Yunnan.

julaceum $\left\{\begin{array}{l}\text { Besch, - Erythrodontium teres. } \\ \text { Br. et Sch, - Cylindrothecium Schimperi. } \\ \text { Hpe. - Erythrodontium squarrosum. }\end{array}\right.$

latifolium Jaeg. - Erythrodontium.

longisetaceum (C. M.) Jaeg. A l. II, p. 345.

Neekera longisetacea C. M. Syn. II, p. 86 .

1.

- As. : Bombay.

longisetum Hpe. - Erythrodontium cylindricaule.

loriferum (Lindb.) Jaeg. Ad. II, p. 346.

Pterigynandrum loriferum Lindb. mss. ; Angstr. in Oefr.... 1876, p. 45.

- Am. merid. : Brasil, austr. or.

microphyllum Schwaegr. - Thuidium Haplohymenium.

myuroides W. P. Sch. in Besch. Prodr. bryol. mexic. p. 101.

Neckera teres C. M. Syn. II, p. 98 p.p.

1 ?

- Am. sept. : Mexic.

nattougense (Hpe.) Jaeg. Ad. II, p. 345.

Leskea nattougensis Hpe. in sched.

- As. : Birman.

oblongifolium Ren, el Card. in Bull. Soc. roy. bot. Belg. 1895, 1, p. 74.

Ster. - $\quad-A s$. : Sikkim.

? patulum W. P. Sch, in op, cit. p. 10\%.

1.

- Am. sept. : Mexic.

pilosulum (Mitt.) Jaeg, Ad. II, p. 345.

Hypnum pilosulum Jaeg. op. cit. p. 608.

Stereoson pilosulus Mitt. M. Ind. or, p. 113.

2.

- As. : Khasia, Assam super.

procumbens $C$. $M$. in Linn. 1878-79, p. 482.

Ster. $\quad-$ Am. merid. : Venezuela.

psilurun (Mitt.) Jaeg. l. c.

Stereodon psilurus Mitt. M. Ind, or, p. 112

Ster.

- As. : Nepal. or.

repens $\mathrm{Hpe}$ - - Platygyrium.

Schweinfurthii Sb. - Erythrodontium.

squarrosum Jaeg. - Erythrodontium.

stramineum (C. M.) Jaeg. l. c.

Neckera straminea C. M. Syn. II, p. 99

Platygyrium stramiaeum Sb. in Jaeg. Ad. II, p. 743.

2.

- As. : Nepal. Afr. : Abyssin. 
striatum A. Br. - Lescuraea.

tenue (Hook.) Schroaegr. Suppl. III, I, II, t. $246 \mathrm{c}$.

Hypnum tenue C. M. Syn. II, p. 452.

Neckera tenuis Hook. in Trans. of the Linn. Soc. IX, p. 315, t. 27, f. 3 .

Pterigynandrum tenue Brid. Bryol. univ. II, p. 187.

Pterogonium tenue Schwaegr. Suppl. II, I, p. 30, t. 108.

Stereodon tenuis Mitt. M. Ind. or. p. 114. 2.

- As. : Nepal., Sikkim, Khasia, Bhotan.

teres Jaeg. - Erythrodontium.

Warmingii Sb. - Erythrodontium.

Leptoneura Limpr. Deutschl. Laubm. I, p. 166 (sect. EPHEMERI).

Leptopogon Milt. $M$. austr. am. p. $15 \overline{7}$ (sect. Barbul.E).

LEPTORHYNCHO-HYPNUM Hpe. in Linn. 1876.

glauco-viride ej. - Rhaphidostegium

Leptophascum C. M. in Fl. 1888, n. 1 (sect. PHAsCI).

Leptostomopsis ej. in op. cit. 1890, p. 475 (sect. BRY1). LEPTOSTOMUM R. Br. in Trans. of the Linn. Soc. X, p. 130, t. 2 ,
f. $2 .(8$ spec.).

densum Thw, et Mitl. in Journ. of the Linn. Soc. 1872, p. 305. - As. : Ceylan.

erectum R. Br. in op. cit. p. 323 ; Brid. Bryol. univ. I, p. 125 ; C. M.

Syn. 1, p. 187.

Gymnostomum Leptostomum Hook. M. ex. II, p. 2, t. 169.

1. Kupic. - Pac. : Austral, or. extratopic.

flexipile C. M. in Bot. Zeit. 1851, p. 547.

Gymnostomum gracile Mossm. M. exs, n, 725.

L. inclinans $R$. Br. (fid. Mitt.).

2, Rupic. - Pac. : Austral, fel., Nov. Zeland., Tasman.

gracile R. Br. in op. cit. p. 32l ; Brid. op. cit. p. 127; C. M. Syn. II,

p. 187; Handb. of N. Zeal. Fl. p. 435.

Gymnostomum gracile Hook. M. ex. II, p.2, t. 22.

2.

- Pac. : Nov. Zeland., ins. Campbell.

inclinans $R$, Br. in op. cit. p. 302; Brid. op. cit. p. 126 ; C. M. Syn. I, p. 185.

Gymnostomum inclinans Hook. M. ex. II, p, 2, t. 168 .

L. flexipile C. M. (fid. Mitt.).

2. Rupic. in silv. paludos, - Pac. : Nov. Zeland., Alp. Austral, et Tasman, occid.

car. longiseta Hpe. in Linn. 1856, p. 207 (nom.).

Ut typ. - Pac. : Austral, fel.

macrocarpum (Hedvo.) R. Br. in op. cit. p. 322; Brid. op, cit, p. 125 ;

C. M. Syn. $I 1, p .186$.

Bryum macrocarpum Hedvo. M. fiond. III, p. 28, t. 10.

Orihopyxis macrocarpa P. B. Prodr. p, 79.

2. Ad arbor. et rup. - Pac.: Taiti, Austral., ins. Norfolk, Nov. Zeland., Tasman. 
Menziezii (Hook.) Rob. Br. in op. cit. p. 321; Brid. op. cit. p. 128; C. M. Syn. I, p. 186.

Gymnostomum Menziezii Hook. M. ex. II, p. 2, t. 5.

2. Ad arbor. - Am. merid. : Cap Horn, Fuegia, ins. Eremit., Staaten. pusillum H. f, et W. - Mielichhoferia.

splachnoides Hook. et Arn. in Capt. Beechey's Voy. p. 53; C. M. Syn. I, p. 185.

L. sulcinerve Kze in Poepp. Pl. Chil. III, n. 52 (269).

2. Ad arbor. et rup. - Am. merid. : Chile, Valdiv., ins. Chiloë.

squarrosum Tayl. - Zygodon.

sulcinerve Kze. - L. splachnoides.

LEPTOTHECA Schwaegr. Suppl. II, II, p. 135, t. 137 (4 spec.).

Gaudichaudii Schwaegr. op. et l. cc. ; Brid. Bryol. univ. I, p. 838; C. M. Syn. I, p. 183.

Aulacomnium Gaudichaudii Mitt. in Jowrn. of the Linn. Soc. 1859, p. 94. Brachymenium? ovatum $H$. f. et W. in Lond. Journ. of bot. 1844, p. 545 et Fl. Antarct. II, p. 412, t. 153, f. 4; C. M. Syn. I, p. 180.

Bryum Gaudichaudii Spreng. Syst. veg. IV, p. 212.

Hymenodon ovatus $C . M$. Syn. $I I, p .557$.

2 vel syn. Terr. - Am. merid. : Ins. Maclov. Pac. : Austral, or. (Nov. Valesia, Victoria), Nov. Zeland., Tasman.

speciosa Hook. f. et Wils. in Hook. Ic. pl. rar. t. 748; C. M. Syn. I, p. 184 et 11, p. 557.

Brachymenium Jamesoni Tayl. (fid. Mitt. M. austr. am. p. 283).

Bryum speciosum Mitt. in Lond, Journ. of bot. 1851, p. 56?

2.

- Am. sept. : Jamaic.

Spegazzinii C. M. in Fl. J385, p. 398.

Ster. $\quad-A m$. nerid. : Fuegia.

Wrightii Sull. in Proced. Am. Acad.... V, p. 281.

Pteromninm Wrightii Jaeg. Ad. $I, p .585$.

Ps. 1. Lignic. - Am. sept. : Florida, Cuba, ins. S. Vincent.

LEPTOTRICHUM Hpe. in Linn. $1847, p .74$.

Spec. omn. non indicatae sunt Ditricha ejusd. nom.

amplexans Mitt. - Dicranella.

australe Mitt. - Lophiodon strictus.

avimontanum W. P. Sch. - Ditrichum vaginans.

bericum de Not. - Leptobarbula.

canadense Jaeg. - Dichodontium.

capillaceum Mitt, - Distichium.

cylindricum Husn. - Trichodon.

dicranellotdes C. M. - Trichostomum.

divaricatum Mitt. - Dicranella.

elongatum Jaeg. -- Trichostomum.

ferrugineum Mitt. - Ditrichum brachycarpum.

flaccidulum Mitt. - Microdus.

flexifolium Hpe. - Trichostomum laxifolium.

glaciale Jur. - Ditrichum vaginans var, nivale.

Griffilhii Mitt. - Dicranella.

himalayanum Mitt. - Dichodontium Hookeri. 
Hornschuchii C. M. - Ditrichum proscriptum.

inclinatum Mitt. - Distichium.

Khasianum Mitt. - Campylopodium.

Kunzeanum C. M. - Microdus tenuis.

longirostre C. M. - Microdus.

Molendianum Ltz. - Ditı ichum homomallum var. zonatum.

molliculum Mitt. - Dicranella.

Monlagnei C. M. - Ditrichum conicum.

Mülleri Hpe. - Lophiodon.

neurophyllum Spr. - Ditrichum gracile.

nitidulum Mitt. - Mierodus.

nivale (., M. - Ditrichum vaginans var. nivale.

patulum Mitt. - Dicranella.

pomiforme Mitt. - Microdus.

pusillum Hpe. - Ditrichum tortile.

Reinwardti Mitt. - Dichodontium.

séliferum Mitt. - Dicranella.

spirate Mitt. - Dicranella.

tenue $\left\{\begin{array}{l}\text { Bryol. eur. - Leptobarbula berica. } \\ \text { C. M. p.p. - Trichostomum. }\end{array}\right.$

var. glaciale W. P. Sch. - Ditrichum vaginans var. nivale tortuosum Wils. - Dicranoweisia indica.

trichophyllum Mitt. - Dicranella.

vaginans Un. crypt, itin. - Ditrichum areticum.

Vallis Gratiae Hipe. - Ceratodon condensatus.

virens Mitt. - Cynodontium.

Wahlenbergii Mitt. - Cynodontium virens var. Wahlenbergii.

sonatum I.tz. - Ditrichum homomallım var. zonatum,

LEPYRODON Hpe, in Ann. sc. nat. 1865 (12 spec.).

australis Hpe. in sched.

Leucodon austrulis Jaeg. Ad. 11, p. 124.

- Pac. : Nov. Zeland.

capensis Rehm, M. Afr, austr.

glaueus $\left(C, M\right.$.) $P_{a r}$.

$$
\text { - Afr.: C. B. Sp. }
$$

Leucodon glaucus Jaeg. $l$. c.

Neckera glauca C. M. in Bot. Zeit. 1859, p. 230.

2. Ad arbor. - Am. merid. : Chile.

implexus (Kze.) Par.

Leucodon hexastichus Mont. in Ann. sc. nat. 1845, p. 101 et Syll. p. 24.

L. implexus Kre. in Poëpp. Coll. pl. Chill. III, n. 274 .

L. Kunzeanus C. M, in Linn. 1844, p. 697.

Neckera implexa C. M. Syn. II, p. 93. 2 ,

- Am. merid. : Chile, Pac, : Nov. Zeland.

Lagurus (Hook.) Mitt. M. austr, am. p. 421.

Leucodon Lagurus Hook. M. ex. t. 126; Brid. Bryol, univ. II, p. 211.

Neckera Lagura C. M. Syn. II, p. 96.

Stereodon Lagurus Mitt. in Journ. of the Linn. Soc. 1859, p. 88.

2. Ad arbor. - Am. merud. : And. Chilens., fret. Magellan., Fuegia, ins. Eremitae. Pac. : Alp. Austral, or., Tasman., ins. Campbell.

mauritianus Besch. Fl. bryol. Réunion, etc., p. 120.

2.

- Afr. : Ins, Franciae. 
parvulus Mitt. M. austr. am. p. 422.

Leucodon parvulus Jaeg. Ad. II, p, 122.

Terr. - Am. merid. : Chile, ins. Juan Fernandez, Mas a Fuero.

? perplexus Ren. el Card. in Bull. Soc. roy. bot. Belg. 1895, 1, p. 66.

2? - As. : Sikkim.

rigidus Bryol. jav. $I I, p .104, t .215$.

Ad arbor. - As. : Sumatra.

suborthostichus (C. M.) Ltz. in Bot. Zeit. 1866, p. 187.

- Leucodon tomentosus C. M. in Linn. 1847, p. 210.

Neckera suborthosticha ej. Syn. II, p. 112.

Leucodon suborthostichus Jaeg. Ad. II, p. 123.

2. Ad arbor. - Am. merid. : Venezuela, And. Quitens., Valdiv.

tomentosus (Hook.) Mitt. op. et l. ce.

Leucodon tomentosus Hook. M. ex. t. 37; Brid. Bryol. univ. II, p. 212.

Neckera tomentosa C. M. Syn. II, p. 111.

2? Ad arbor. - Am. mericl. : And. Nov. Granat, Quitens. et Peruv.; Chile, Brasil. austr. or.

trichophyllus (Sw.) Mitt. op. et $l$. cc.

Hypnum trichophyllum Su. Prodr. Fl. Ind. occ. p. 141.

Leucodon trichophyllus Jaeg. op. cit. p. 122.

Muscus terrestris, repens, major, ramulis circa extremitatem conglomeratis, foliolis multis et minimis caulem ambientibus Sloane Cat. Jam, p. 12.

Neckera trichophylla Brid. Bryol. univ. II, p. 227; C. M. Syn. II, p. 111.

2. -Am. sept. : Jamaic., Guadalup. Am. merid. : Ins. Trinitat., Venezuela.

"f. robustior Besch. Fl. bryol. Antill. fr, p. 50.

Meteorium sericeum W. P. Sch, in Husn. M. Antill. n. 183.

Lignic. - Am. sept. : Guadalup.

LESGURAA Bryol, eur. V (4 spec.).

filamentosa Lindb. - Pseudo-Leskea atro-virens var. filamentosa.

var. subcatenulata Sael. - Pseudo-Loskea atro-virens var. subcatenulata

var. subnitidula Lindb. - Pseudo-Leskea atro-virens var. subnitidula. imperfecta C. M. et Kindb. in Bidr. 454 (nom.) et in Mac. Cat. p. 170.

2. Ad ter'r. et rad. arb, - Am. sept. : Columb. brit.

Exs. : Mac. Canad. M. n. 89.

insignis de Not. - L. striata var, saxicola?

mutabilis Lindb. - L. striata.

patens Lindb. - Psendo-Leskea patens.

plicata I.indb. - Ptychodium.

rigidula Kindb. - Leskea nervosa.

robusta Lindb, in Act. Soc. sc. Fenn. 1872, p. 245.

2.

- As. : Saghalien.

saxicola Milde. - L. striata var. saxicola.

striata (Schucuegr.) Bryol. eur. V, ८. 459; W. P. Sch. Syn. II ed, p, 620.

Anomodon mutabilis Mont. Hist. d. I. Canar. p. 17.

A. striatus Hüb, Muscol. germ. p. 559 .

Grimmia mutabilis Opitz.

Gr. plicata Opitz.

Hypnum mutabile Brid. Sp. M. II, p. 156. 
Isothecium mutabile Spr. M. Pyr. n. 93.

I. striatum ej. l. c. et in Ann, and Mag. of nat. hist. 1849.

Leptohymenium striatum A. Braun in sched.

L. mutabilis Lindb. in Act. Soc. se. Fenn. 1872, p. 247.

Leskea bulbifera Froëhl. in Brid. op. et l. cc, (fld. C. M.).

L. mutabilis Boul. M, E. Fr. p. 325.

Maschalocarpus striatus Spreng. Syst. veg. IV, I, p. 158.

Neckera striata C. M. Syn. II. p. 81.

Pterigynandrum mutabile Brid. Bryol, univ. II, p. 190.

Pt. striatum Duby Bot. gall. p. 563.

Pterogonium striatum Schwaegr. Suppl. I, I, p. 103, t. 27.

2. Ad arbor, humilior, praecip. Fagorum frutices. - Eur.: In mont. editior. et subalp. zon, interm. atque merid, rar. sept. As. : Caucas. occ. Afr. : Alger, ins. Canar. Am, sept. : (Fid. Jaëg. Ad. IJ, p. 340 , sin. loc.).

Eœs.: Un, itin. 1867, n. 135.

« var. saxicola Bryol, eur. et W. P Sch, ll. cc.; Ltz. et Mdo. Moosst. pp. 144, 347-149.

Anomodon striatus var. saxicola Hartm. Skand. Fl. VIII ed. p. 351 (non $1 I$ ed., p. 26).

Isothecium striatum $\beta$ saxicola Boul. M. Fr. p. 143.

L. insignis de Not. Epil. p. 216? (in adnot.),

L. saxicola Milde Bryol. Siles, p. 288.

Leskea atro-virens? Lindb. in Th. Fries Bot. Not. 1865, p. 74 in adn.

Saxic. - Eur. : Reg. subalp. et alp. zon. sept. As. : Jenissei med., Caucas, occ. et centr.

Exs. : Un. itin. 1863, p. 63, 64.

xanthophylla (Hpe, et Ltz.) Jaeg. Ad. II, p. 360.

Anomodon xanthophyllus Hpe. et Ltz. in Krause M. Ecuador.

Sciuro-Leskea xanthophylla eor. in Bot. Zeit. 1869

1. Ad arbor. - Am. mexid. : Equator.

LESKEA Hedw. Fund. M. II, p. 93, t. X, fig. $62-65$ (32 spec.).

abbreviata W. P. Sch. - Haplophymeninm.

aciculata Tayl. - Lindigia.

acidodon Mont. - Rhegmatodon.

acuminata Hedw. - Brachythecium.

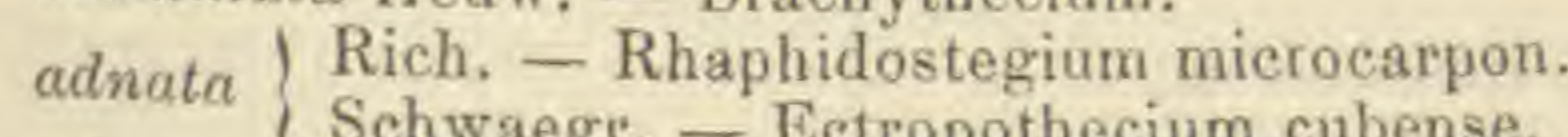

affinis Hsch. - Rhaphidostegium.

albicans Hedw. - Hookeria.

? algarvica W. P. Sch. Syn. II ed. p. 597.

Ster. Ad terr. arid. in castanet. - Eur. : Lusitan. (Algarb.).

ambigua Schwaegr. - Trichosteleum.

amblyocarpa Hpe. - ? Platygyrium.

andicola Brid, - Mierothamnium.

angustata Tayl. - Anomodon.

? angustifolia Tryl, in Lond. Journ. of bot. 1847, p. 379; C. M. Syn: II, p. 680 .

Ster. Ad arbor. - Am. sept. : Jamaic.

apophysata Hsch. - Rhynchostegium.

arcuala Brid. - Rhaphidostegium recurvans.

asprella Bryol. eur. - Thelia.

assimilis Mitt. - Thuidium.

atro-virens Hartm. - Pseudo-Leskea. 
? atro-virens Lindb. - Lescuraea striata var, saxicola. attenuata Hedw. - Anomodon.

aurea Harv. - Cylindrothecium.

Austini Sull. Ic. M. Suppl. p. 81, t. 61 ; Lesq. el Jam. Man. p. 303.

1. Ad arbor. et rup. - Am. sept.: New Jersey, Illinois, Minnesota, Kansas.

badensis $\mathrm{A} . \mathrm{Br},-$ Hypnum Haldanianum.

Beyrichii Hpe. - Brachythecium acuminatum.

binervula Mdo. - Orthothecium.

blepharophylla Mitt. - Thuidium.

Bonplandii Hook. - Homalothecium.

borbonica Belang. - Trichosteleum.

brachyclados Schwaegr. - Pseudo-Leskea atro-virens var. brachyulados.

Breutelii W. P. Sch, in Breulel M. Capens.

$$
\text { - Afr. : C. B. Sp. }
$$

Exs, : Rehm. M. Afr. austr. n. 357.

bulbifera Froëhl. $\left\{\begin{array}{l}\text { - Lescuraea striata (fid. C. M.). } \\ \text { - L. nervosa (fid. Limpr.). }\end{array}\right.$

caespilosa $\left\{\begin{array}{l}\text { Brid. - Rhaphidostegium Kegelianum var. tenue. } \\ \text { Hedw. - Rhaphidostegium. }\end{array}\right.$

var, adunca Hpe. - Rhaphidostegium microcarpum.

var. subsquarrosa Brid - Rhaphidostegium Kegelianum var. tenue. californica Hpe. - Camptothecium Nuttallii.

campylocarpa Hpe. - Camptothecium Nuttallii.

capillaris Hedw. - Helicodontium.

capillata Mitt. - Pseudo-Leskea.

Cardoti Kindb. -.- L. obscura.

carnifolia C. M. in Rehm. M. Afr. austr. n. 358

$$
\text { - Afr. : C. B. Sp. }
$$

cacenulata Lindb. - Pseudo-Leskea.

var. rupestris Bryhn, - L. rupestris.

cavifolia Wils. - Rhaphidostegium.

chlorina W. P. Sch, in Breutel M. Capens.

- Afr.: C. B. Sp.

chrysea Hartm. - Orthothecium.

circinalis $\mathrm{Hpe}$. - Rhaphidostegium.

cirrifolia Schwaegr. - Rhaphidostegium.

complanata Hedw. - Neckera.

compressa $\left\{\begin{array}{l}\text { Hedw. - Cylindrothecium. } \\ \text { Sull. - Cylindrothecium Sullivantii. }\end{array}\right.$

concinna Hook. - Hypopterygium.

confervoides Spr. - Amblystegium.

congesta Brid. p.p. $\left\{\begin{array}{l}\text { - Hookeria aurea. } \\ \text { - Homalothecium. }\end{array}\right.$

consanguinea Mont. - Anomodon.

constricta Brid. - Rhaphidostegium.

conlarlula Mitt. - Thuidium.

crispa Schrank. $\left\{\begin{array}{l}\text { - Neckera. } \\ - \text { Plagiothecium undulatum. }\end{array}\right.$

cristata Hedw. - Eriopus.

curvala Voit. - Isothecium myurum.

curvirostris Harv. - Rhaphidostegium.

cylindrica $\{$ Brid. - Pterigynandrum filiforme.

Hsch. - Ectropothecium. 
cymbifolia Mitt. - Thuidium.

cyrtophylla Kindb. in Mac. Cat. p. 169.

2. Rupic. - Am. sept. : Manitoba.

decurvata Milt, in Jown of the Linn. Soc. 1864, p. 154.

2. Rupic. - As. : Japon.

Deinbollii Sw. - Hypnum uncinatum.

dendroides Hedw. - Climacium.

densa Hook. - Erythrodontium.

denticulata Sull. M. Allegh. n. 62, M. of U. St.p. 59 et Ic. M. p. 125

ı. 78 ; Lesq. et Jam. Man. p. 302.

Hypnum fabronicefolium C. M. Syn. 11, p. 271 .

2. Ad rad, arb. - Am. sept. : New Brunswick, reg. centr. et merid.

Exs. : Sull. et Lesq. M. bor. am. I ed. n. 245.

denticulata $\left\{\begin{array}{l}\text { Sull, p.p. - Pylaesia subdenticulata. } \\ \text { Timm. - Plagiothecium. }\end{array}\right.$

depressa Hedw, - Hookeria.

distans $\left\{\begin{array}{l}\text { Jaeg. } \rightarrow \text { Eurhynchium circinnatum. } \\ \text { Mont. - Cladomnion gracile. }\end{array}\right.$

Duisabonae Mont, - Rhaphidostegium.

elongata W, et M. - Webera.

ericoides $\{\mathrm{Dz}$, et $\mathrm{Mk}$, - Sauloma hamata.

exilis Schwaegr. - L. polycarpa var. exilis,

extensa Spreng. - L. nervosa.

Fabronia Hook. - Microthamnium.

falcata $\mathrm{Dz}$, et Mk. - Rhaphidostegium Molkenboëri.

fallax Rehm. M. Afr. austr, n. 635 .

- Afr. : Transvaal.

" var, robusta ej. $l, c, n, 636$.

\section{- Afr. : Transvaal.}

fasciculosa Hedw. (fid. C. M.). - Eurhynchium strigosum.

Fendleri Sull. - Brachythecium.

flamentora Kindb. -- Pseudo-Leskea atro-virens var. filamentosa.

fliculaeformis Hedw. - Hypopterygium.

fliformis Sibth. - Pylaesia polyantha.

fimbriata Dz. et Mk. - Chaetomitrium.

flaccidu Brid. - Plagiothecium denticulatum.

flagellaris Schrank, - Hypnum Halleri.

flexilis $\left\{\begin{array}{l}\text { Hedw. - Pilotrichella. } \\ \text { Hook, - Papillaria Buchanani. } \\ \text { Hsch. - Papillaria illecebra. }\end{array}\right.$

var. pentasticha Brid. - Pilotrichella imbricata.

foribunda $\mathrm{Dz}$. et $\mathrm{Mk}$. - Papillaria.

fragilis H. f. et W. - Leskea tristis.

Froëlichii Brid. - Pseudo-Leskea catenulata.

fuegiana Besch, in Miss, sc. Cap Horn, V, Bot. p. 298.

Ster. - Am. merid. : Fuegia.

fulva $\left\{\begin{array}{l}\text { Harv. - Stereophyllum. } \\ \text { Hsch. - Rhaphidostegium. }\end{array}\right.$

fulvastra Mitt, - Thuidium.

? Gayana Mont. - Ptychomnion ptychocarpum. 
glabella Hedw. - Homalia.

glaucina Mitt. - Thuidium.

gracilescens Hedw. Sp. M. p. 222, t. 56 .

Hynnum gracilescens $P$. B. Pr. p. 64 .

Leskea obscura Lesq. et Jam. Man. p. 301 p.p.

1. Ad rad, arbor, inund, - Am. sept. : Pensilv., reg. merid gracilis Mitt. - Thuidium.

gracillima Mitt. - Schwetschkea.

grandiretis Lindb. in Broth. Enum. M. Caucas, p. 97

1. Fr. ign. Cortic. - As, : Caucas. centr.

gymnopoda Tayl. - Porotrichum.

hamosa Ångstr. - - Plagiothecium denticulatum.

Haplohymenium Mitt. - Thuidium.

hastata Mitt. - Thuidium.

Hedwigii Wils. - Rhaphidostegium.

helvola Mont. - Brachythecium.

heteroclados W. P. Sch, - Meteorium diclados.

kelerophylla Hsch. - Papiliaria illecebra.

hispeda Mitt. - Sciaromium.

hispidula Brid. - Hypnum pallescens.

homomalla Hpe. - Rhaphidostegium.

Hookeri Mitt. - Thuidium.

imbricata Hook. f. et Wils. Fl. Tasman. 1I, p. 202, t. 175, f. 3 .

Cryphaea imbricata Mitt, in Trans, and Proced. of the roy. Soc. of Victoria, 1883, p. 80.

1. Rupic. - Pac. : Tasman.

imbricatula Hedw. $\left\{\begin{array}{l}\text { (fid. C. M.). - Anomodon rostratus. } \\ \text { (fid. Card.). - Brachythecium acuminatum. }\end{array}\right.$

imponderosa Tayl, - Lindigia.

inclinata W. et M. - Bryum.

incompleta Giriff. - Homalothecium?

incrassata Lindb. in Broth. Enum. M. Cauc. p. 96.

2. Cortic. - As.: Caucas. occ. et centr.

incurvata $\left\{\begin{array}{l}\text { Hedw. - Pseudo-Leskea atro-virens. } \\ \text { Myr. - Anomodon longifolius. } \\ \text { Wahlenb, - Isothecium myurum. }\end{array}\right.$

var. brachyclados Brid. - Pseudo-Leskea atro-virens var, brachyclados.

var. simplex

var. subserrulata Brid. - Pseudo-Leskea atro-virens.

var. Thomasii |

intricata $\left\{\begin{array}{l}\text { Hartm. - Orthothecium. } \\ \text { Mitt. - Thuidiun. }\end{array}\right.$

var. suberecla C. Hartm. - Orthothecium striatum.

investis Mitt. - Thuidium.

involvens Hedw, - Thuidium.

irrorala Sendtn. - Orthothecium intricatum.

julacea $\{$ Brid. - Hypnum palustre var. julacea.

Kegeliana C. M. - Rhaphidostegium.

var. tenuis Hpe. - Rhaphidostegium Kegelianum var. tenue.

lata Bryol. eur. Wils. - Plagiotheeium.

laevifolia Mitt. - Pseudo-Leskea.

lueviuscula Mitt. - Thuidium.

lanceolata Hpe. et C. M. - Helicodontium. 
lata lapponica Lindb. - Orthothecium chryseum $f$. lapponica.

latebricola Wils. - Plagiothecium. $(52 e-6.742)$

latifolia Lindb. in Broth. Enum. M. Cauc. p. 97.

1. Ster. Ad rup. calcar. - As. : Caucas. occ.

laxifolia Hook. - Thuidium.

leucostega Brid. - Stereophyllum.

longifolia $\left\{\begin{array}{l}\text { Ehrb. - Camptothecium lutescens. } \\ \text {.pr. - Anomodon. }\end{array}\right.$

longirostris Brid. - Rhaphidostegium longirostratum.

lucens Lam. et DC. - Pterygophyllum.

Ludwigiana Brid. - Rhynchostegium confertum,

marchica Willd. - Philonotis.

maritima Hook. - Rhaphidostegium.

mauritiaua Besch. Fl. bryol. Réunion, etc.p. 146.

1.

mexicana Besch. Prodr. bryol. mexic. p. 89 ,

$$
\text { - Afr: : Ins. Franciae. }
$$

Anomodon mexicanus Jaeg. Ad. II, p. 300 .

Cortic. - Am. sept. : Mexic.

microcarpa $\left\{\begin{array}{l}\text { Brid, - Rhaphidostegium. } \\ \text { W. P. Sch. - L. obscura. }\end{array}\right.$

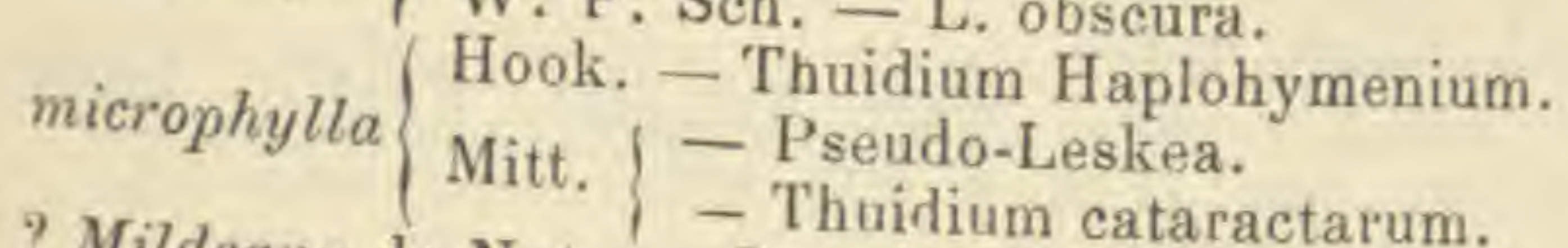

? Mildeanu de Not. - Pseudo-Leskea tectorum.

minuscula Mitt. - Thuidium.

minutula Brid. - Helicodontium capillare.

milrala $\mathrm{Dz}$. et $\mathrm{Mk}$. - Rhegmatodon rufus,

mollis Hedw. - Pilotrichella.

moniliformis Wils. - Myurella julacea.

Moseri Kindb. mss.

б' ign.

multiflora Brid. - Hypnum.
mutabitis Boul. - Lescuraea striata.

- Am, sept. : New Brunswick.

myosuroides $\left\{\begin{array}{l}\text { Hartm. - Isothecium } \\ \text { Hedw. - Isothecium myurum. } \\ \text { Roth. - Eurhynchium. }\end{array}\right.$

myura Boul. - Isothecium.

nattongensis $\mathrm{H}_{\mathrm{pe}}$ - Leptohymenium.

nervosa (Schwoaegr.) Myr. Coroll. p. 52; Bryol. eur. V (mon p. 4),

t. $472 ;$ W. P. Sch. Syn. II ed. p. 595.

Anomodon nervosus Hüb. Muscol. germ. p. 561.

A, rigidulus Kindb. Laubm. Schwed. $u$. Norro, p. II.

Hypnum nervosuma $W$, et $M$. Bot. Taschb. p. 157.

Lescuraearvosum C. M. Syn. II, pp. 470 el 690.

Leskea bulbifera ${ }^{2}$ Kindb. Enum. Bryin. p. 23.

L. extensa Spreng. Froêt. in Brid. Sp. M. II, p. ól (fid. Limpr.).

L. norvega Spreng. Nov. pl. Cent. n. 86 .

Maschalocarpu Sommerf. Suppl. ad Fl. Lapp.

Pterigynandrur nervosus Spreng. Syst, veg. IV, I, p. 158.

Pterogonium nervosum Brid. Bryol. univ, II, p. 189.

2. Cortic.

Caucas - Eur. : Ex Alp. reg. infer, usq. ad arbor. limit. As.: pes., Ottawa. sept.: Labrador, Terr. Nov,, New Brunswick, GasColumb.tawa, Ontar., Manitoba, reg. sept. occ., M. Rupestr., 
Exs. : Drumm. M. bor. am. Il ed. n. 89.

Mac. Canad. M. n, 252 p.p.

Rab. Bryoth. eur. n. 445 et b, 1187.

var. flagellifera Kindb. - Anomodon heteroideus.

var. rupestris Hartm. - L. rupestris.

« var. sibirica Arn. M. As. bor. 1890, II, p. 109.

- As. : Jenissei med.

nervosa Sull. - L. obscura.

nigeriana Mitt. - Thuidium.

nigrescens Kindb. - Anomodon heteroideus.

nitens Brid. - Acrocladium Auberti.

nitida $\mathrm{H}$. f. et W. - Hypnum.

nitidula Wahlenb. - Plagiothecium.

norvegica Sommerf. - L, nervosa.

Novae-Hollandiae Schwaegr. - Rhizogonium.

obscura Hedro. Sp. M. p. 223, t. 37 (el p.p. in hb.) ; Brid. Bryol. unio. II. p. 300 ; Sull. Ic. M. p. 123, t. 77 ; Lesq. et Tam. Man. p. 301.

Anomodon obscurus Jaeg. Ad. II, p. 300.

Hypnum obscurum P. B. Prodr. p. $67 ; C$. M. Syn $I I, p .470$.

L. Cardoti Kindb. in Rev. bryol. 1895, p. 83.

L. microcarpa W. P. Sch. in Sull. M. of U. St. p. E.9.

L. nervosa Sull, M. Allegh. n. 69.

1. Ad radices arb. inund, - As. : Japon. Am. sept. : Pensilv., Ludovic.

Exs. : Drumm. M. bor. am. II ed. n. 105, 106.

Faurie PI. Japon. n. 183.

Sull. et Lesq. M. bor. am. II ed. n. 365 p.p.

olsura Hedw. p.p. (hb.). - L. gracilescens.

obscuriuscula Mitt. - Pseudo-Leskea.

ornithopodioides Brid. - Rhacopilum tomentosum.

paleacea Wils. - Plagiothecium

pallescens Hedw. - Hypnum.

pallida Sehwaegr. - Microthamnium.

paludosa, Hedw. - L. polycarpa var. paludosa.

var, polycarpa Hartm. - L. polycarpa.

palustris Brid. - L. polycarpa var. paludosa. palustris Brid. - L. polycarpa var. paludosa.
papillosa (Pseudo-Leskea ?) Lindb. in Bot. Not. 1872 ; W.P. Sch. Syn. II
ed. p. 597 .

Heterocladium papillosum Lindb. M. Scand, p. 37.

Ster.

- Eur. : Lapp. Tornens. As. : Jenissei sup.

parvula Hpe. - Clasmatodon.

patens $\left\{\begin{array}{l}\text { Hsch. - Sematophyllum pungens. } \\ \text { Lindb. }\end{array}\right.$

pellucida Hook. - Dimerodontium.

pellucinervis Mitt. - Anomodon.

pennata Labill, - Cyatophorum bulbosum.

? pentasticlia Hsch. - Pilotrichella quinquefaria.

Philippeana Boul, - Homalothecium.

pilifera $\mathrm{Sw}$.... Plagiothecium.

plumaria Mitt. M. austr. am, p. 568.

1. Cortic. - Am. merid. : And. Quitens.

plumosa Sw. $\left\{\begin{array}{l}\text { Brachythecium. } \\ \text { Hypnum incurvatum. }\end{array}\right.$ Polenbnrgii Lobarz. in Haiding. Naturvo. Abh. 1847, p. 55; C. M.
Syn. II, p. 481 .

Ster. Lignic, - Eur. : M. Beskides. 
polyanthos $\left\{\begin{array}{l}\text { Harv. - Hypnum celatum. } \\ \text { Hedw. - Pylaisaea. }\end{array}\right.$

var. paludosa Rryhn. - Thedenia suecica.

var. sericeola Brid. - Orthothecium intricatum.

var. Sull. - Rhynchostegium cylindricarpum.

polycarpa Ehrh. Crypt. exs. n. 96 ; Brid. Bryol. univ. II, p. 314 ; Bryol. eur. $V$ (mon. p. 2), t. $470 ;$ W. P. Sch. Syn. II ed.p. 594.

Hypnum medium Dicks. Fase. II Pl. crypt. p. 12 ; Dremm. M. bor. am. I ed. n. 213.

H.-multiflorum P. B. Prodr. $p$. 66.

H. polycarpum Hoffm. Deutsch. Fl. II, p. 6T: C. M. Syn. II, pp. 469 et 690 .

H. trichodes, capsulis oblongis setis brevioribus Dill. Hist. M. p. 331, $t, 42$, f. 65 .

L. paludosa var. polycarpa Hartm. Skand, Fl. V ed. p. 337.

1. Lignic. - Eur.: Vulgatiss. As. Amour, Jenissei, Obi, Caucas. Am. sept. : New Brunswick, Ottawa, Ontar, lac. Super,, Columb. brit., temperata tota.

Exs. : Mac, Canad, M. n. 251.

Rab. Bryoth. eur. n. 782 et b.

Sull, et Lesq. M. bor. am. II ed, n. 364 .

Un itin. 1867, n. 7.

" var, exilis (Schwaegr.) Milde Bryol. Siles. p. 260.

Hypnum polycarpum var. exilis C. M. l. c.

L. exilis Schwaegr. Suppl. I, II, p. 174, t. $85(1)$; Stark. in Brid. Mant. M. p. 145 et Bryol. univ. II, p. 306.

L. polycarpa var, tenella Bryol, eur. l. c, fig. $\beta$

Ut typ. - Eur. : Locis siccior.

var, gigantea Ltz, - L. polycarpa var. paludosa?

"var. paludosa Bryol, eur. et W. P. Sch. ll. cc.

Hypnum heterophyllum, aquaticum, polycephalum Dill. Hist. M. p. 293, t. 37, f. $27 \mathrm{~B}$ ?

$\mathrm{H}$, inundatum Dicks. Fase. IV Pl. crypt. $p$ 17.

H. paludosum W. Arn. Disp, p. 66.

H. palustre Hffm. Deutsch. Fl. II, p. 64 .

L. paludosa Hedw. M. Frond. IV, p. 2, t. I; Brid. Bryol, univ. II, p. 315.

L. palustris Brid. M. Rec. II, II, p. 38

L. polycarpa var. gigantea Ltz. Moost. p. 103 ?

Ad rad. arb. sæepius inund. - Eur.: Passim. As. : Amour. Am. sept. : Washington, Oregon, Idaho.

Exs. : Rab. Bryoth, eur, n. 381, 783.

var. tenella Bryol. eur. - L. polycarpa var, exilis.

polyclada Tayl. - Thuidium.

prionophylla Bryol, jav. - Pseudo-Leskea.

pristocalyx Mitt. -- Thuidium.

prolifera Lumnitz. - Isothecium myurum.

prolixa Mitt. - Sciaromium?

prostrata Tayl. - Plagiothecium elegans.

pseudo-tristis (C. M.) Jaeg. Ad. II. p. 298.

Hypnum pseudo-triste C. M. in Bot. Zeit. 1855, p. 786.

Ster, - Afr, : C, B. Sp.

pterogonioides Harv. - Rozea,

(1) Cf. W. P. Sch, Syn, I ed. p. 488 et II ed. p. 596. 
pulckella $\left\{\begin{array}{l}\text { Hedw. - Plagiothecium. } \\ \text { Kaulf. - Hypnum pallescens. }\end{array}\right.$

pulvinata Wahlenb. - Myrinia.

pungens Sw. - Sematophyllum.

pusilla Mitt. in Trans. of the Linn. Soc. 1891, p. 188.

2. Cortic. - As, : Japon.

pygmaea $\left\{\begin{array}{l}\text { Dz. et Mk. - Schwetschkea. } \\ \text { Tayl. - Isopterygium tenerum. }\end{array}\right.$

radicans Schrank. - Anomodon, attenuatus. "

ramentosa Mitt. - Thuidium.

ramuligera Mitt. - Pseudo-Leskea.

ramusculosa Mitt. - Thuidium.

recurvans Mich, - Rhaphidostegium.

remotifolia $\left\{\begin{array}{l}\text { C. M. - Pilotrichella. } \\ \text { Hook. - Eurhynchium scabrisetum. } \\ \text { Lindb. - Pseudo-Leskea. }\end{array}\right.$

repens Hartm. - Platygyrium.

rostrata Hedw. - Anomodon.

rolulata Hedw. - Hypopterygium.

rubricaulis Tayl, - Zygodon Preissianus.

? rufa Reinw. et Hsch. - Rheymatodon.

rufescens Schwaegr. - Orthothecium.

var. chrysea Brid. - Orthothecium chryseum.

rupestris Berggr. in Bidr. till Skand. bryol. p. 9.

L. catenulata var. rupestris Bryhn in Norsk. Mag. naturw. 1891.

L. nervosa (fid. Limpr.).

L. nervosa $\beta$ rupestris Hartm. Skand. Fl. II ed. 10, p. 38.

Pseudo-Leskea rupestris Kindb. Laubm. Schwed. u. Norve, p. 6.

Rupic. - Eur. : Alp. Norveg. (Dovre).

rupincola Hedw, - Brachythecium acuminatum var, rupincola.

( (fid. C. M.). - Pseudo-Leskea atro-virens var. Saviana. Saviana de Not. $\left\{\begin{array}{c}\text { fid. Limpr.). - Pseudo-Leskea atro-virens var, brachy- } \\ \text { clados. }\end{array}\right.$

sciuroides $\left\{\begin{array}{l}\text { Dz. - et Mk. - Cladomnion octangulum. } \\ \text { Hook. - Cladomnion. } \\ \text { Hornsch. - Cylindrothecium neglectum. }\end{array}\right.$

scopula Mitt. - Pseudo-Leskea.

secunda Hook. -- Pylaisaea.

Seligeri Brid. - Plagiothecium silesiacum.

seminervis Kze. - Helicodontium.

sericea Hedw. - Homalothecium.

serrulata Brid. - Isopterygium radicans.

seligera Mitt. - Sciaromium.

setosa Hedw, - Brachythecium acuminatum var. setosa.

Smithii $\mathrm{Sw}$ - Hypnum areticum.

sparsifolia Mitt. - Thuidium.

spinosa Mitt. - Sciaromium.

splendens Web. - Pylaisaea polyantha.

Sprucei Br. - Amblystegium.

squarrosa Mich. - Rhaphidostegium recurvans.

straminea Hsch. et Reinw. p. p. $\{$ - Sematophyllum hermaphroditum.

stratosa Mitt. - Pseudo-Leskea.

striata Schwaegr. - Hookeria aurea.

striatella Brid. - Plagiothecium Mühlenbeckii.

stricla Ltz. - Orthothecium. 
subcompressa Br. et Sch. - Hypnum.

subenervis Schwaegr. - Myrinia pulvinata.

subfalcata Mitt. - Thuidium.

subobtusifolia C. M. et Kind. in Bidr. p. 454 (nom.) et in Mac. Cut. p. 169.

1. Ad arbor. subinund. - Am. sept. : Columb. brit.

Exs, : Mac. Canad. M. n. 533.

subpinnata Brid. $\left\{\begin{array}{l}\text { - Rhaphidostegium Kegelianum var. tenue. } \\ \text { - Taxithelium planum. }\end{array}\right.$

subrufa Wils, - Orthothecium intricatum.

subtilis Hedw. - Amblystegium.

subulacea Mitt. - Psendo-Leskea.

sulcala Hook. - Climacium.

superba Tayl. - Porotrichum.

tamariscells Mitt. - Thuidium.

tamariscina $\left\{\begin{array}{l}\text { Hedw. p.p. }\left\{\begin{array}{l}\text { Hypopterygium commutatum. } \\ \text { - Hypopterygium Tamarisci. }\end{array} \text { W. P. Sch. - Thuidium orthocarpum. }\right.\end{array}\right.$

teclorum Lindb. - Pseudo-Leskea.

tenuirostris $\left\{\begin{array}{l}\text { Br. et Sch, - Rhynchostegium cylindricarpum. } \\ \text { Hook. - Helicodontium. }\end{array}\right.$

teretiuscula Mill. M. auslr, am. p. 567.

1.

- Am. merid. : And. Quitens.

trichomanoides Hedw. - Homalia.

tristis Cesati in de Not. Syll.p. 67; W. P. Sch. Syn. II ed. p. 596.

Anomodon fragilis Wils. in Lond. Journ. of bot. 1818, p. 275, t. 10.

A. ? tristis Sull. M, and Hepat. of U. St. 1856.

Haplohymenium Sieboldi Dz. et Mk. in Ann. sc. nat. 1844, p. 310 et M. frond ined. Archip. Ind p, $12 t$ t. 40.

Hypnum emarginatum Schleioh in sched.

H. fragile C. M. Syn. II, p. 471 .

H. triste ej" op, cit. p. 478.

L. fragilis H.f. et W. in Drumm. M. bor. am. II ed. n. 101.

Neckera Sieboldi C. M. op. cit. p. 81 .

2. Cortic. - Eur. : Rhaet., Tirol. merid., Ital. super. As. : Japon., China or., Himalaya et Tibet oce., Nepal. Am. sept. : A Montreal usq. ad Ludovic.

Exs.: Rab. Bryoth. eur, n. 922.

Sull. et Lesq. M. bor. am. II ed, n. 363.

umbrosa Mitt. - Sciaromium.

undata Hedw. - Hookeria.

varia Hedw. - Amblystegium radicale.

velutina Schrank. - Brachythecium.

viticulosa Spr. - Anomodon.

vivipara | Timm. - Isothecium myurım.

Wallichii Willd. - Anomodon viticulosus.

Watlichii Mitt. - Pseudo-Leskea.

Wollei Aust. in Bull. Torr. bot. Club V, p. 22 ; Lesq. et Jam. Man. p. 304. Amblystegium Wollei Card. in Rev, bryol. 1893, p. 24.

Ster.

- Am. sept. : Niagara, lac. Super.

LBSKEELLLA Limpr. Laubm. Deutschl. II, pp. 747 et 756 (subgen. L.RSKE.E).

LESKIA Hedro, Fund. M. II, p. 98, t. 10, f. 62-63= LESKE.A. 
LESKIA HEMIRAGIS Brid. Bryol, univ. $I I$, pp. 334 et 764. striata Brid. - Hookeria aurea.

LESKIA OMALIA Brid. Bryol. univ. II, pp. 325 et 764 .

complanata Brid. - Neckera.

cymbifolia Brid. - Taxithelium planum.

decomposita Brid. - Porotrichum.

flabellata Brid. - Homalia.

inflectens Brid. - Ectropothecium.

involvens Brid. - Thuidium.

leucostega Brid. - Stereophyllum.

ornithopodioides Brid, - Rhacopilum tomentosum.

rutilans Brid, - Ectropothecium.

var. porto-ricensis Brid. - Ectropothecium conostegum.

trichomanoides Brid. - Homalia.

I.ESQUEREUXIA Lindb. Contr. ad $f$. crypt. As, bor. or. 1872, pp. 245-247 $=$ LESCURAA.

Leucoblastia C. $M$. in Linn. $1878-79$, p. 438 (subsect. HyPNi).

Leucobryella C. M. in Linn. 1874, p. 556 (sect. Syrrhopodontis).

LEUCOBRYUM Hpe. in Linn. 1839, p. 42 (74 spec.).

aduncum Bryol. jav. I, p. 13 et II, p. 221, $\iota, 11$; Mitt. M. Ind. or. p. 26.

L, brachyphyllum Wils, in Kew Journ. bot. IX, p. 293.

2. - As. : Nepal, , Sumatra, Jaya, ins. Banca, Penang,

Malacca, Rorneo.

afro-glaucum C. M. in Dusen M. Camer. n. 259.

- Afr. : M. Cameroon.

albidum (Brid.) Lindb, mss.

Bryum albidum et glaucum, fragile, minus, foliis erectis, setis oblongis Dill. Hist. M. p. 546, t. 83, f. 8 .

Dieranum albidum Brid. Mant. $M, p .67$.

D. glaucum $\beta$ albidum W. et $M$. in Brid. Bryol. univ. I. p. 409.

L. minus Sull. M. of U. St. p. 24; Lesq. et Jam. Man. p. 91 (1).

2. Lignic. et terr. in palud. - Am. sept. : New Jersey, Ohio. angustifolium Wils. in Kew Journ. bot. IX, p. 293.

L. Bowringii Mitt. M. Ind. or. p. 26.

- As. : Hong-Kong, Khasia, Ceylan, Sumatra.

angustum Hpe. Symb. 1870, p. 270.

Ster. $\quad-A m$. merid. : Brasil, austr. or.

Antillarum W. P. Sch. in Besch. Fl. bryol. Antill. fr. p. 16.

Ster.? $\quad-A m$. sept.: Guadalup.

" $f$. crispula Besch. l. c.

$$
\text { - Am. sept. : Martinic. }
$$

argentinicum C. M. in Linn. 1878-79, p. 249.

Ster. $\quad-A m$. merid. : Argentin. subtropic.

auriculatum C. M. in Geh, Neue Beitr. zur Moosfl, v. Neu Guin. p. 2.

Ster. - Pac. : Nov. Guin. merid.

(1) Cf, Dna E. G. Britton in Bull, Torr. bot. Slub, 1892, p. 91. 
Boivinianum Besch. Fl. bryol. Réunion, etc. p. 48.

Ster. Ad rup. umbros. - Afr. : S. Maria de Madagasc.

boninense Sull. et Lesq. in Proced. of the Am. Acad... 1859.

2.

- As. : Ins. Bonin.

Boryanum Besch. op. cit. p. 47.

DIcranum megalophyllum Brid. Mant. M. p. 67 p.p.

Sphagnum iridans Brid. Sp. M.I, p. 20 p.p.

Sph. javanense P. B. Prodr. p. 88 pp.

? Sph. javense Brid. Bryol. univ. I, p. 19 p.p.

Ster.

- Afr.: Ins. Borbon.

Bowringii Mitt, - L. angustifolium.

brachyphyllum $\left\{\begin{array}{l}\text { Hpe. - L. candidum. } \\ \text { Wils. - L. aduncum. }\end{array}\right.$

Cameruniae C. M. in Dusen M. Camer. n. 67. - Afr. : M. Cameroon.

candidum (Brid.) Jaeg. Ad. I, p. 158.

Bryum candidum fragile foliis recurvis Dill. Hist. M. p. 364, t. 46, f. 22 .

Dicranum brachyphyllum Hsch, in Sieb. M. Nov. Holland.

D. candidum Brid. Bryol. univ. 1, p. 409.

L. brachyphyllum Hpe, in Linn. 1839, p. 42; C. M. Syn. I, p. 76 (1).

2. - Pac. : Austral. or, Nov.-Zeland., Tasman.

"var. major Jaeg. Ad. I, p. 159.

- Pac. : Austral, felix.

chlorophyllosum C. M. Syn. II, p. 535 ; Bryol. jav. I, p. 12, . 10.

Syrrhopodon rigidus Duby in Zolling. Pf. n. 3370 .

1.

- As, : Celebes, Sumbawa.

Cladopanthus C. M. - L. piliferum.

clavatum Hpe. Symb. 1877, p. 716.

Dicranum juniperoideum Hsch. Fl. Brasil. I, p. 10.

Ster.

- Am. merid. : Brasil. austr. or.

comorense C. M. in Linn. 1876, p. 235.

Ster. Ad arbor. - Afr.: Ins, Anjouan, S. Maria de Madagasc.

conocladulum C. M. mss.

- Pac.: Austral, or. (Queensland).

conocladum Besch. Fl. Nov. Caled, p. 202.

"var, repens ej. $l . c$.

- Pac.: Nov, Caledon.

- Pac. : Nov. Caledon.

erispum C. M. Syn. I, p. 78.

L. Martianum Hpe. in Linn. 187, p. 67.

L. tenuifolium Sull. in Proced. of the Am. Acad... 1861, p. 279.

ter. $\quad-A m$. sept.: Guadalup., Cuba, Jamaic. Am. merid. : Ins. Trinitat., Venezuela, Novi Granat., Brasil., Pecuv.

cucullatum Broth. in Engler's Bot. Jahrb. 1894, p. 180.

Ster. Lignic. - Afr. : Usambara.

falcalum C. M. - L. javense.

var, hawä̈ense Reichdt, - L. javense var, hawaïense.

(1) \& Var. $\beta$ Schwaegr. Suppl, II, II, p. 119, t, 187 B forsan spec. propr , C. M. l.o. 
Havo-mucronatum $C$. $M$. in Linn. 1878-79, p. 464.

2.

- Am. merid. : Venezuela.

giganteum C. M. Syn. I, p. 79 et II, p. 536.

Dicranum megalophyllum Raddi Critt. Brasil. p. 3 (fid. Hpe. et Mitt.).

L. longifolium Hpe. in Linn. 1847, p. 68.

L. robustum Sull. in Proced. of the Am. Acad... 1861, p. 279.

Ster. Lignic. et terr. - Am. merid. : Venezuela, And. Columb., Brasil. austr. or.

" var. tenuifolium C. M. in Linn. 1878-79, p. 464.

Ut typ. - Am. merid. : Venezuela.

glaucum (Linn.) W. P. Sch. Coroll. p. 19 el Syn. II ed. p. 109.

Bryum albidum et glaucum, fragile majus, foliis erectis, setis brevioribus Dill. Hist. M. p. 362, t. 46, f. 20.

Br. glaucum L. Sp. pl. p. 1582 .

Dicranum glaucum Hedw. Sp. M. p. 135 ; Brid. Bryol. univ. I, p.p. 407 et 811 .

Fuscina glauca Sckrank Baïers Fl. II, p. 457.

Glaucodipsis frigida K. Sch. Mooslob. p. 16.

Hypnum glaucum Weiss Crypt. Goett. p. 208.

L. vulgare Hpe, in Linn. 1839, p. $42 ;$ C. M. Syn. I, p. 74.

Mnium glaucum Gmel. Syst, nat.

Oncophorus glancus Bryol. eur. t. 97-98.

2. In silvat, et ericet. subhumid. - Eur.: Tota, merid. calidior, et arct. glacial, except. As. : Cancas, Afr. : Canar., Madeir, Am. sept, : Terr. nov., ins. Miquelon, Nov. Scot., New Brunswick, Ottawa, Ontar., Guspes., fret. Behring, reg. centr. et or.; Jamaic.? Am. merid. : And. Nov. Granat.? Venezuela? Brasil. ? Pac. : Ins. Hawai (fid. Mitt.).

Exs. : Drumm, M, bor, am. I ed. n. 45, 46.

- Mac. Canad. M. n. 55.

Rab. Bryoth. eur. n. 32 .

Sull. et Lesq. M. bor. am. II ed. n. 97

goyazense Broth. in Hedioig. 1895, p. 118.

2. Ster. Rupic. - Am. merid. : Brasil, or. (Goyaz).

guadalupense Lindb. in Oefv... 1864, p. 608.

Ster.

- Am. sept. : Guadalup.

Gueinzii C. M. in Rehm. M. A fr. austr, $n, 74$ et 454.

Ster.

- Afr. : Transvaal, C. B. Sp.

heterodictyon Besch. in Journ. de bot. 1891 .

2.

- Afr. : Madagascar. Hollianum Dz. et Mk. in Pl. Jungh. p. $319 ;$ Bryol. jav. I, p. 17 et II,
p. 222, t. 13.

Ster.

- As. : Sumatra, Java, Borneo, Tonkin.

homalophyllum Broth. in Bol. d. Soc. Brot. VIII, 1890.

Ster.

- Afr.: Ins. S. Thom.

lsleanum Besch. Fl. bryol. Réunion, etc. p. 48.

L. juniperoideum? (ex ips I).

Ster.

- Afr.: Ins. Rorbon.

javense (Brid.) Mitt. M. Ind. or. p. 25.

L. falcatum C. M. Syn. I, p. 79:Bryol.jav. I, p. 15, t. 14,

Sphagnum javanense P. B. Prodr. p. 88 p.p.
Sph. javense Brid. Bryol. univ. I, p. 19 ; Schwaegr. Suppl. II, I, p. 4, t. 102. 
Ster. Lignic. - As. : Nepal., Khasia, Ceylan, Sumatra, Java, ins. Banca, penins. Malay., Borneo, Hong-Kong, Tonkin, Japon. Pac. : Ins. Sandwic.

- var, hawaïense (Reichdt). Par.

L. falcatum var, javense Reichdt, Beitr. p.567.

Lignic, in silv. - Pac. : Ins. Hawaï.

juniperoideum (Brid.) C. M. in Linn. 1844, p. 689 et Syn, 1, p. 78.

Dicranum juniperoideum Brid. Bryol. univ. I, p. 409.

Ster.

(fid. Brid.).

- Afr. : Ins. Canar., Azor., Madeir, ; Borbon.

laeve Mitt. wss. ; C. H. Wright M. Mad. p. 4 (nom).

- Afr. : Madagascar.

laminatum Mitt. in Bonplandia, 1861, p. 366.

Ster.

- Pac. : Ins, Fidji.

leucophanoides C. M. in Fl. 1886, p. 279.

Ster. Ad. arbor. - Afr. : Ins. S. Thom.

longifolium Hpe. in Linn. 1839, p. 42 ; C. M. Syn. 1, p. 77.

Dicranum albicans Schwaegr. Suppl. II, II, p. 122, t. 186.

D. megalophyllum Raddi Critt. Brasil. p. 3 (fid. C. M.).

Sphagnum iridans Brid. Sp. M.I, p. 20.

? Sph. macrophyllum ej. Bryol, univ, p. 753.

2. Ad arbor. rup. et terr. - Am. sept. : And. Costa. Ricens., Jamaic.,

Guadalup. - Am. merid. : Equat., Brasil. austr. or., And. Peruv.

longifolium Hpe. (Linn. 1847). - L. giganteum.

Mac-Leanum Rehm, M, Afr, austr. n. 455.

Ster.

- Afr. : Transvaal.

madagassum Besch. Fl. bryol. Réunion, etc. p. 49.

Ster.

madagassum C. M. - L. Rutenbergianum.

- Afr. : Madagasc

Martianum (Hsch.) Hpe. in Linn. 1839, p. 42 ; C. M. Syn. I, p. 76.

Dicranum Martianum Hsch. Fl. Brasil. p. 11 .

2. Terr, et lignic., rar. rupic. - Am. sept. : Guadalup., Porto Rico. Am. merid.: And. Nov. Granat., Venezuela, Guian., Amazon., Brasil. or. Pac. : Nov. Caledon.

Martianum Hpe. - L. crispum.

mauritianum C. M. in Rev, bryol. 1878, p. 59 (nom.). - Afr.: Ins. Francise.

microcarpum $C, M$. in Linn. 1878-79, p. 464.

2.

microcarpum C. M. - L. papuense.

- Am. merid. : Venezuela.

minus Hpe. in Linn. 1844, p. 42.

L. vulgare $\beta$ minus C. M. Syn. I, p. 75 .

L. sediforme Lesq. et Jam. Man. p. 91 (1).

2. In paludosis. - Am. sept. : Florid., Ludovic.

var. sediforme Ren. et Card - L. minus

(1) Cf, Dna E, G, Britton in Bull. Torr. bot. Club, 1892, pp. 189-191. 
molle C. M. mss,

$$
\text { - Afr. : Midagascar. }
$$

molliculum Broth, in Engler's Bot. Jahrb. 1894, p. 180.

Ster.

-- Afr. : Usambara.

mueronifolium A. Br. in C. M. Syn. II, p. 536; Bryol. jav. I, p. 18.

Ster. $\quad-A s$. : Java.

Naumanni C. M. in Engler's Bot, Jahr.b. 1883, p. 85 et in Forchungsreise.... Bot. p. 51 .

Ster. Ad arbor. - Pac. : Nov. Guinea.

neilgherrense C. $M$. in Bot. Zeit. 1854, p. 556

Disranum megalophyllum Mont. in Perrottet $M$. Neilgh.

2.

- As. : M. Neilgherr.

neilghiriense Mitt. - L. triviale.

neo-caledonicum Duby in Besch. Fl. bryol. Nov, Caled. p. 203.

- Pac.: Nor. Caledon.

obtusifolium C. M. - Schistomitrium.

papuense $\operatorname{Par}$.

L. microcarpum C. M. in Engler's Bot. Jahrb. 1883, p. 85 et in For shungsreise... Bot. $p .50$.

2. Ad arbor. - Pac. : Nov. Guinea.

pentastichum Bryol. jav. I, p. 16, t. 15.

2.

- As. : Java.

Perrotti Ren, et Card, in Bull. Soc, roy. bot. Belg. 1894, II, p. 112 et M. Masc. Mad. n. 11.

Ster. In silv. - Afr, : Ins. Franciae, Madagasc.

phyllanthum Lindb. - Leucophaanes Gardnerianum.

piliferum (Dz. et Mk.) Jaeg. Ad. I, p. 163 (1).

Cladopanthus piliferus Dz. et Mk. M frond. ined. Archip. ined. p. 80, t. 28 ; Rryol. jav. I, p. 18, t. 13.

L. Cladopanthus C. M. Syn. I. p. 78.

2. Ad arbor. - As. : Java.

pungens C. M. M. Polyn. p. 56.

Ster.

- Pac. : Ins. Fidji, Samoa.

Rehmanni C. M. in Rehm. M. Afr. austr. n. 75.

Ster. $\quad-$ Afr.: C. B. Sp.

robustum Sull, - L. giganteum.

retractum Besch, in Ann. sc. nat. 1893, XVIII, p. 334.

L. sanctum W. P. Seh, in Savatier M. Jap. n. 109.

$$
\text { - As. : Japon. }
$$

rugosum Mitl. Sam. M. p. 192.

Ster. Ad arbor. - Pac. : Ins. Samoa.

Rutenbergianum Besch. in litl.

L. madagassum C. M. in Abhandl. Brem. VII, p. 204.

- Afr. : Madagascar.

(1) "An Schistomitrium? aut gen, propr, "Cladopanthus " restituendum? Jaeg. Ad. II, p. 654 , 
sanctum (Brid.) Hpe, in Linn. 1839, p. 42; C. M. Syn. 1, p. 77; Bryol. jav. $I, p .14, t .12$.

Dicranum glaucum $\gamma$ sanctum Brid. Bryol, univ, $1, p .811$.

D. sanctum Nees in Schwaegr. Suppl. II, II, p, 1श1, t. 186.

Octoblepharum sanctum Mist. in Proced, of the roy. Soc. 1879 (extr. vol,) p. 99 .

2. Ad mur. sepulcror. - As. : Nepal., Sumatra, Java, Singapore, ins. Banca, Borneo, Celebes, Japon. Pac.: Ins. Fidji, Samoa, Nov. Hebrid.

sanctum W. P. Sch. - L. retractum.

scabrum Sande Lav, in Mig. Ann. mus. bot. Lugdun. Batav. II, p. 292. - As. : Japon., Hong-Kong.

sediforme C. M. Syn, $I_{,}$p. 75.

Dicranum glaucum $\beta$ albidum Brid. in hb, reg. Berol.

L. minus var, sediforme Ren. et Card. in Rev. bryol. 1892, p. 79.

2.

- Am. sept. : Florid., Ludovic.

sediforme Lesq. et J. - I. minus.

Seemanni Mitt. Fl, vit. p. 387.

Ster.

- Pac. : Ins, Sandwic. (Oahu).

selaginoides C. M. mss, ; Jaeg. Ad. II, p. 762; Broth. in Engler's Bot.

Jahrb. I\&94, p. 179 (descriptio).

Ster. Paludic. - Afr. : Reg. lacustr., Madagascar.

sericeum Broth. in sched.

- As. : Archip. Ind. or.

sordidum Angstr. in Oefv.... 1876, n. 4, p. 7.

Ster. $\quad-A m$. merid. : Brasil, austr. or.

speirostichum C. M. in Rev. bryol, 1876, p. 3 (nom.).

L. Teysmannianum forma (fid. Hpe.).

- Pac. : Austral. or. (Nov. Valesia).

squarrosulum Broth, in Bihang till K. Sv. Vet.-Ak. 1895, $n .3$.

Ster, Lignic, et terr, - Am. merid. : Brasil, or.

stenophyllum Besch. Fl. bryol. Nov. Caled.p. 204.

- Pac. : Nov. Caledon.

subchlorophyllosum Hpe, in Linn. 1876, p. 304.

- Pac. : Austral. or.

subulatum Hpe. in Linn. 1852, p. 359.

Terr. - Am. sept. : Cuba, Porto Rico.

tahitense Angstr. in Oefv.... 1873, n. 5, p. 118.

Ster. Lignic, et terr, - Pac, : Ins, Taiti.

tenuifolium Sull. - L, crispum.

Teysmannianum Bryol. jav. I, p. 16, t. 15 .

Ster, $\quad-$ As. : Java. Pac. Austral, or. (Nov. Vales.)?

triviale C. M. in Linn. 1869-70, p. 30,

L. neilgherriense Mits. M. Ind. or. p. 26 (fid. C. M.).

L. vulgare Wils, in Kew Journ. bot. IX, p. 293.

Ster.

- As. : Khasia ?, Sikkim, Calcutta. 
vulgare $\left\{\begin{array}{l}\text { Hpe. }- \text { L. glaucum. } \\ \text { Wils. }- \text { L. triviale. }\end{array}\right.$

$\beta$ minus $\mathrm{C} . \mathrm{M} .-\mathrm{L}$. minus.

Widgrenianurn Ångstr. in Oefv..... 1876, n. 4, p. 6.

- Am. merid. : Brasil. austr. or.

Wightii Mitt. M. Ind. or. p. 25.

- As.: Madras (1).

LEUGODON Schwaegr. Suppl. I, II, p. I et II, I, p. 82, t. 125 (32 spec.) Alopecurus Brid. - Braunia sciuroides.

Arbuscula Welw. et Duby in Mém... Genève, 1871, p. 4, t. I.

Ster, Cortic, -- Afr. : Angola.

assimilis (C. M.) Jaeg. Ad. II, p. 121.

Neckera assimilis C. M. Syn. II, p. 92.

2. Cortic, $-A f r$. : C. B. Sp.

Exs. : Rehm. M. Afr. austr, n, 319 b et 605 b.

* var. gracilis C. M. in Rehm. l. c. n. 320 .

- Afr. : C. B. Sp.

australis Jaeg. - Lepyrodon.

bartramioides Hook. - Cryptopodium Hookeri.

Beccarii C. M. - L. Dracaenae.

brachypus Brid. Bryol. univ. II, p. 211; Sull. 1c. M.p. 111, t.70;

Lesq. et Jam. Man. p. 288.

Neckera brachypus C. M. Syn. II, p. 108.

2. Ad arbor. et rup. $-A m$. sept. : Nov. Scot., Gaspes,, Ontar., reg. or.

Exs. : Sull. et Lesq. M. bor. am. II ed. n. 351.

calycinus Hook. - Dicnemon.

eanariensis Schwaegr. Suppl. 1, II, p. 3. Astrodontium canariense ej. Suppl. II, I, p. 128, t. 134; Brid. Bryol.
univ. II, p. 229.

Hedwigia Schmidtii Hook. M. ex. t. 170.

Hypnum canariense Brid. M. Rec. II, II, p. 145.

H. flagellis instar caudae vulpinae Dill. Hist. M. p. 306, t. 39, f. 41.

Neckera canariensis Brid. Sp. M. II, p. 109.

Plaubelia canariensis Brid. mss.

2. Cortic. - Afr. : Ins, Canar., Madeir., ins. Azor.

Ecs. : Bourg. Pl. Can. n, 1587.

Husnot M. Can. n. 121.

Mandon PI. Madeir. n. 32 .

capensis W. P. Sch. in Breutel M. Capens.

L. assimilis $C . M$. (fid. Hpe.).

$$
\text { - Afr.: C. B. Sp. }
$$

coronatus Mitt. - Lasia.

(1) In Enum, Kindberg. nom. nud, :

L. Baileyi C. $M$.

Eggersii C.M.

interruptum $C, M$.

L. laticaule $C, M$. spinidorsum $C, M$. subcandidum $C . M$. 
corsicus W. P. Sch. in Ltz. Bryol, Not, p. 59.

Astrodontium corsicum Jaeg. Ad, II, p. 117.

- Eur.: Corsica.

cryptotheca Hpe. Ic. M. t. 17.

Astrodontium clyptotheca Besch. Prodr. bryol. mexic. p. 73,

Neckera cryptotheca C.M. Syn. II, p. 109 . - Am. sept. : Mexic.

curvirostris Hpe. Ic. M. t. 16.

Astrodontium curvirostre Besch, op, cit. p. 74.

Neckera curvirostris $C, M$, Syn, $11, p$. 108 .

2.

- Am. sept. : Mexic.

domingensis (Spreng.) Mitt. M. austr. am. p. 409.

Hypnum nudicaule Schwaegr. Suppl. I, II, p. 223, ex Hispaniola?

Neckera domingensis Spreng. in Brid. Bryol. univ. II, p, 259;C. M. Syn. II, p. 95 .

Pilotrichum flagelliferum Brid. op. et l. cc.

Pterigynandrum nudicaule $e j$. op, cit. $p .182$,

2.

- Am. sept. : Dosta Rica, Cuba, S. Doming.,

Barbades. Am. merid.: Ins. Trinitat., Venezuela, And. Peruv., Brasil.

Dracaenae Vent, in Nuov. Giorn. bot. ilal. 1872, 1, p. 20.

L. Beccarii $C$. M. in Linn. 1875, p. 450.

2. Cortic. - Afr.: Abyssin.

flagellaris (Lindl.) Broth. Enum. M. Cauc, p. 138.

Fissidens flagellaris Lindb. $l, c$.

2. Ster. Cortic. - As. : Caucas, occ.

geniculatus Mitt. - Lasia.

glaucus Jaeg. - Lepyrodon.

gracilis $\mathrm{H}$ pe. - cladomnium.

hexastichus Mont. - Lepyrodon implexus.

immersus Lindb. in Oefv..., 1869, p. 72.

Fissidens immersus $e j$, in Broth. Enum. M. Cauc.

L. caucasicus Jur. et Milde Beitr... p. 599 .

L. Stevenii C. M. in Act. Hort. Petrop. F. I.

2. Ad arbor, et rup. - As. : Caucas,, Talysch, M. Ararat.

implexus Kze.- Lepyrodon.

involutaceus Jaeg. - Edicladium.

julaceus (L.) Sull. Ic. M. p. 110, t. 69 et M. Allegh. n. 87; Lesq. et Jam.

Man. p. 288.

Hypnum julaceum L. Sp. pl. p. 1596. H. julaceum perichaetio setas paene aequante Dill. Hist. M. p. 321, t. 41,

Neckera pseudalopecura C. M. Syn. II, p. 92.

Pterigynandrum julaceum Hedw. M. frond. IV, p. 51, t. $20 ;$ Brid. Bryol. univ, $I I, p .181$.

Pterogonium julaceum Schwaegr. Suppl. I, $I$, t. 100.

2. Cortic. - Am. sept. : Reg. or., centr. et merid.

Exs : Drumm. M. bor. am. II ed. n. 91. Sull, et Lesq. M, bor. am. II ed, n, 350 .

Kunzeanus C. M. - Lepyrodon implexus. 
laevifolius Broth. mss.

Ster. Cortic. - As. : Japon.

Lagurus Hook, - Lepyrodon.

var. borealis $\left\{\begin{array}{l}\text { Lindb. - Orthothecium chryseum } f \text {. lapponica. } \\ \text { Wils, - Myurium Hebridarum. }\end{array}\right.$

madagascariensis Brid. - Pilotrichella.

morensis Schwaegr. - Leucodon sciuroides var, morensis.

nitidus Hook. f. et Wils. Fl. of the N. Zeal. II, p. 99, t. 87, f. 4 et Handb. p. 457.

Stereodon Lyallii Mitt. in Journ. of the Linn. Soc. IV, II, p. 89.

Ad arbor. - Pac. : Nov. Zeland. sept. et med.

orientalis (C. M.) Jaeg. Ad. II, p. 121.

Neckera orientalis C. M. in Bot. Zeit. 1856, p. 437.

Ster.

- As. : India (sine loco spec.).

pacificus W. P. Sch. in Jardin Enum. p. 20 (nom.); Besch. Fl, bryol.

Taïti, etc., p. 33 (descript.).

Cortic. - Pac. : Nouka-Hiva.

pallidus Hook. - Leucoloma Sieberianum.

parvulus Jaeg. - Lepyrodon.

pendulus Lindb. in Act. Soc. sc. Fenn. 1872, p. 273.

Fissidens pendulus Lindb. et Arn. M. As. bor. 1890, II, p. 162.

2 .

- As. : Amour.

piriformis C. M. in sched.

- As. : Japon, centr.

Pohlii Schwaegr. Suppl. III, I, I, t. 232.

Neckera Pohlii C. M. Syn. II, p. 114.

Pterobryum Pohlii Mitt. M. aust, am. p. 426.

2.

- Am. merid. : Brasil.

rigidus Bryol. jav. II, p. 104, t. 215.

1. Cortic. - As. : Sumatra.

rufescens Hsch, et Reinw, - Edicladium.

rugosus Hook. - Dienemon.

Rutenbergii C. M. in Abhandl. Brem. VII, p. 210.

- Afr. : Madagasc.

sapporensis Besch. in Ann. sc. nat. 1893, XVIII, p. 360.

2. -As. : Japon.

Exs. : Faurie n. 114, 239, 1428 (f. gracilis), 3531.

seabrisselus Tayl, - Eurhynchium suberectum.

Schweinfurthii C. M. in Linn. 1875, p. 447.

2. Cortic. - Afr. : M. occ. mar. Erythraei.

sciuroides (L.) Schroaegr. Suppl. I, II, p. 1 et II, I, p. 82, t. 125; Brid. Bryol. univ. II, p. 208 ; Bryol. eur. V, t. $468 ;$ W. P. Sch. Syn. II
ed.p. 574 .

Cecalyphum sciuroides P. B. Prodr. p. 51.

Dicranum sciuroides $S w$. M. Suec. p. 32.

Fissidens sciuroides Hediv. Sp. M. p. 161.

Fuscina sciuroides Schrank Baïers Fl. II, p. 452.

Hypnum arboreum, sciuroides Dill. Hist. M. p. 309, t. 41, f. 54.

H. sciuroides $L, S p, p l, p, 1596$. 
Neckera sciuroides C. M. Syn. II, pp. 107 et 668.

Pterigynandrum sciuroides Brid. Sp. M. I, p. 134,

Pterogonium sciuroides Turn. Muscol. Hib. p. 32.

Trichostomun sciuroides W. et M. Bot. Taschb. p. 132.

2. Ad arbor., praecip. Querc. - Eur.: Tota, frigid. except. As. : Jenissei sup., Cancas, occ. et centr., Kurdistan; Kashmir (ster.). Afr. : Alger, Am. sept. : New Brunswick, Gaspes., Ottawa, Ontar., New-York.

Exs. : Mac. Canad. M, n. 237.

Rab. Bryoth, eur. n. 137, 1191.

* var. morensis (Schwaegr.) Bryol, eur, el W. P. Sch, ll. co.

Hypnum morense Schleich. in sched.

L, morensis Schuaegr. l. c.; Brid. Bryol, univ. II, p, 210.

Neckera sciuroides $\beta$ cylindrocarpa C. M. Syn. II, p. 108.

Ut typ. - Eur. : Scotia, Anglia, Helvet., reg. merid. tota. Afr. : Alger., ins. Canar., Madeir.

Exs. : Bourg, Pl. Canar. n. 1588.

secundus (Harv.) Milt. M. Ind. or. p. 124.

Astrodontium secundum Besch. in Ann. sc. nat. 1892, I, p. 73.

Neckera Harveyana C. M. Syn. $11, p .11 \mathrm{C}$.

N. stricta ej. $l, c, p, 112$.

Sclerodontium secundum Harv. in Lond. Journ. of bot. 1840, p. 11 et in Hook. Ic. pl, rar. t. 21, f. I.

Scl. strictum ej. $l l . c c, f, 2$.

2" Cortic. - As. : Nepal., Himalaya et Tibet occ., Alp. Yunnan., Japon.

sekistos Welw. et Duby in Mèm..... Genève, 1871, p. 3.

2. Cortic. - Afr. : Angola.

sericeus Hsch. in Mundt el Maire M. Capens.

Astrodontium sericeum Jaeg. Ad. II, p. 117.

Neckera sericea C. M. Syn. II, p. 113.

2. Cortic. - Afr.: Transvaal, C. B. Sp.

Exs. : Rehm. M. Afr, austr. n. 32l, 604.

Stevenii C. M. - L. immersus.

submersus Hpe. mss.; Jaeg. I. c.

Astrodontium submersum Besch. Prodr. bryol. mexic, p. 74.

2 ?

- Am. sept. : Mexic.

suborthostichus Jaeg. - Lepyrodon.

subsericeus C. M. in Rev. bryol. 187\%, n. I (nom.).

tenuis W. P. Sch. hb. - Afr. : Ins. Comores.

Astrodontium tenue Besch. l. o.

Ster. - Am. sept. : Mexic.

comentosus $\{$ C. M. - Lepyrodon suborthostichus. Hook. - Lepyrodon.

Thomsoni Mitt. M. Ind, or. p. 124.

1.

- As.: Himalaya oce.

trichophyllus Jaeg. - Lepyrodon (1).

1; In Enum. Kindberg, nom. nudum :

L. spurio-secundus $C, M$. 
LEUGODONIOPSIS Ren. et Card. in Bull, Soc. roy. bot. Belg. 1894, I, p. 177 (2 spec.).

Horeana eor, in op. cil. 1895, p. 66.

Ster. - Am. merid. : Brasil, or.

plicata eor. in op. cit. 1894, 1, p. 177.

Ster. Cortic. - Am. sept. : Costa Rica.

LEUCOLEPIS Lindb. de Mn. europ. p. 80 . acanthoneura Lindb. - Rhizogonium Menziezii.

LEU GOLOMA Brid. Bryol, univ. II, p. 218 ( 35 spec.).

acutum Mitt. mss. ; C. H. Wright M. Madag. p. 3 (nom.). - Afr. : Madagascar.

aduncum (Hpe.) Par.

Dicranum aduncum Hpe. Enum. M. Brasil. p. 16.

Ster.

- Am. merid.: Brasil, austr. or.

albo-cinctum Ren. et Card. in Bull. Soc, roy. bot. Belg. 1892,II, p. $100 \mathrm{el}$ M. Masc. Mad. n. 158.

Ster.

$$
\text { - Afr. : Madagascar. }
$$

albulum (Sall.) Besch. Fl. bryol. Antill. fr. p. 12.

Dicranum albulum Sull. M. Cubens. p. 278.

Poëcilophyllum albulum Mitt. M. austr, am. p. 93. Arbor. et lignic. - Am. sept. : Cuba, Jamaic., Guadalup., ins. S. Vincent.

amblyacron C. M. in Besch. Fl. bryol. Réunion, elc. p. 25.

Ster.

$$
\text { - Afr. . Ins. Franciae. }
$$

ambreanum Ren, et Card. in op. cit. 1891, II, p. 181 et M. Masc. Mad. n. 4.

Ster. Lignic. - Afr. : Madagascar.

amœne-virens Mitt. M. Ind. or. p. 13.

Rupic. - As. : Khasia, Madras, Ceylan.

angustifolium Brid. - L. bifidum?

Arbuscula C. M. in Jaeg. Ad. II, p. 760 (nom.).

asperrimum (C. M.) Par.

$$
\text { - Afr. : Madagascar. }
$$

Dicranum asperrimum C. M. in Linn. 1878-79, p. 472.

$$
\text { - Am. merid.: Venezuela. }
$$

austro-scoparium C. M. in sched.; Broth. in Defv. of Finska Vet.-Soc, Foerh. 1895, p. 48.

2.

- Pac. : Austral. or. (Queensland).

bifidum Brid. Bryol, univ. 1I, p. 218.

Dieranum brevisetum ej, l. c. p. 467.

D. Commersonianum C. M. Syn. I, p. 353.

Hypnum bifidum Brid. M. Reo. II, II, p. 51, $t . I, f .4$.

L. bifidum ej. Bryol. univ. II, p. 752 ?

Trichostomum bifidum ej. Mant. M.p. 54.

Tr. Leucoloma Schwaegr. Suppl.II, I, p. 76, t. 122.

2? Ad arbor. - Afr. : Ins. Rorbon., Franciae, Madagasear. 
* var. orthothecioides Besch. Fl. bryöl. Réunion, elc. p. 22.

L. Crepini Ren. et Card. in op. cit. 1892, II, p. 102.

Ster. Terr. - Afr. : Ins. Franciae.

biplicatum (Hpe.) Par.

Dicranum-biplicatum Hpe. Symb. 1877, p. 717.

Ster.

- Am. merid. : Brasil. austr. or.

birmense C. M. in Nuov. Giorn. bot. ilal. 1891, p. 601 (nom.). - As. : Birman. super.

Boivinianum Besch, op. cit. p. 28.

2.

- Afr. : Ins. Anjouan.

caespitulans (C. M.) Besch. op. cil. p. 24.

Dicranum caespitulans C. $M$. in Linn. 1876, p. 240.

Ster.

- Afr. : Ins. Anjouan, Mayotte.

caldense C. M. mss. ; Angstr. in Oefo.... 1876, n. 4, p. 6.

Ster. Cortic. - Am. merid. : Brasil, austr. or.

candidulum C. M. in Besch. op. cit. p. 26.

Ster. $\quad-A f r$. : Ins. Franciae.

Catharinae C. M. in Ule Bryoth. brasil. n. 115.

Cortic. et rupic. - Am. merid. : Brasil. subtropic, or.

chryso-basilare (C. M.) Besch, op. et l. cc.

Dicranum chryso-basilare C. M. in Linn. 1876, p. 238.

Ster. Ad arbor. - Afr. : Ins. Anjouan.

"var. gracilicaulon Besch.l. c.

Dicranum chryso-basilare var, gracilicaulon C. M. $l$. c. - Afr.: Ins. Anjouan.

cinclidiontoides Beseh. op. cit p. 22.

Ster.

- Afr.: Ins. Borbon.

clavinerve C. M. in Oefv.... 1893.

2. Rupic. - Pac. : Austral. or. (Queensland).

Crepini Ren. et Card, - L. bifidum var. orthothecioides.

Crügerianum (C. M.) Par.

Dicranum Crügerianum C. M. Syn. II, p. 188.

Poëcilophyllum (rígerianum Mitt, M. austr. am. p. 92.

2. - Am. merid. : Ins. Trinitat.

cryptocarpum (C. M.) Par:

Dicranum cryptocarpum C. M. in Linn. 1874, p. 626.

cuneifolium (Hpe,) Par.

- Am, sept. : Mexic.

Dicranum cun ifolium Hpe. in Abhandl. Brem. VII, p. 206. - Afr. : Madagascar.

decolor Wright in Lond. Journ. of bot. 1892, p. 263.

- Afr. : Zanzibar.

dichelymoides (C. M.) Besch. Fl. bryol. Réunion, etc. p. 22.

Dicranum dichelymoides C. M. in Linn, 1876, p. 240.

Ster.

- Afr. : Ins, Anjouan, Madagascar. 
drepanocladium (C. M.) Par.

Dicranum drepanocladium C. M. in Fl. 1890, p. 473.

Ster. In gramin, edit. - Afi. : Kilima NDjaro.

Dubyanum Besch. op. cit. p. 28.

Ster.

- Afr. : Ins. Franciae.

ecaudatum (C.M.) Par.

Dicranum ecaudatum C. M. in Linn. 1878-79, p. 473.

- Am. merid. : Venezuela.

Eckloni (Ltz.) Jaeg. Ad.

Dicranum Eckloni Ltz. Moosst. p, 158.

Ster. - Afr.: C. B. Sp.

Fraseri (Mitt.) Par.

Dicnemonella Fraseri Mitt. in F. v. Müller's Fragm. Phyt. austral. XI, p. 114.

Sclerodontium Fraseri Mitt. in Trans, and Proced. of the roy. Soc. of Viotoria, 1883, p. 54.

- Pac. : Austral, or. (Nov. Vales.).

fuscifolium Besch, op. cit, p. 27.

Ster. $\quad-A f r$ : Ins. Borbon.

gracilescens Broth, in Bol. da Soc. Brot. 1890.

Ster. Ad arbor. - Afr. : Ins. S. Thom.

Grandidieri Ren. et Card, in op. cit. 1892, II, p. 101 et M. Masc.

Mad. n. 167.

Ster.

- Afr. : Madagascar.

Hildebrandti $C . M$. in Hildebr. M. M $\alpha d, n$. 2122 .

- Afr.: Madagascar.

holomitrioides C. M. in Jaeg. Ad. 1I, p. 760 (nom.).

- Afr. : Madagascar.

Holstii Broth. in Engler's Bot. Jahrb. 1894, p. 178.

2. Ster. Cortic. - Afr. : Usambara.

incanum (Hook. f.) Milt. mss.

Dicranum incanum H. f. Handb. of N. Zeal. Fl. p. 410.

- Pac. : Nov. Zeland.

insigne (C. M.) Par.

Dicranum insigne C. M. in Linn. 1869-70, p. 33.

Ster.

-As. : Ceylan.

Isleanum Besch, in litt.

L. secundifolium ej. op. cit. p. 25 .

Ster.

- Afr. : Ins. Seychelles.

Leichardti (Hpe.) Par.

Dicranum Leichardti Hpe, in Linn. 1869-70, p. 514.

Poecilophyllum Leichardti Mitt. in Trans, and Proced. of the roy. Soc. of 2 Victoria, 1883, p. 54 .

- Pac. : Austral. or.

Lepervanchei Besch. op. cit. p. 23.

Ster.

- Afr. : Ins. Borbon.

lucinerve Mitt. mss.

Lignic, - As, : Tonkin 
macrodon (Hook.) Par.

Dicranum macrodon Hook. Ic. pl, rar. t. 349; C. M. Syn. I, p. 377.

Poëcilophyllum macrodon Mitt. M. austr, am. p. 93. - Am. merid. : And, Quitens.

Mariei Besch. in Journ. de bot. 1891, p.

2.

molle (C. M.) Mitt. M. Ind, or. p. 13.

J)icrauum molle C. M. Syn. I, p. 354 ; Bryol. jav. I, p. 65, t. 53, f. 1-6. Syrrhopodon prolifer Duby in Moritzi Verz. p. 137 (fid, Bryol, jav.) (1).

2. Ad arbor. - As.: Hong-Kong, ins. Ceram, Sumbawa, M. Java, Sumatra.

mollissimum Mitt. M. austr, am. p. 91 .

Lignic. - Am. merid. : Venezuela, And, Quitens.

Moseni Broth. in Bihang till Sv. Vet.-Akad. Handl, 1895, n. 3.

Ster, Rupic. - Am. merid. : Brasil. or.

nitens (Tho, et Milt.) Par.

Poêcilophyllum nitens Thw. et Mitt. in Journ. of the Linn. Soc. 1872, p. 297.

Ster. Ad arbor. - As. : Ceylan.

pallescens Jaeg. - L. Zeyheri.

persecundum C. M. in Besch. op. cit. p. 26.

Ster.

- Afr.: Ins. Franciae.

Prionodon Besch. op. cil. p. 29.

Ster. Ad arbor, - Afr.: Ins. Borbon., Franciae.

procumbens (Mitt.) Par.

Poëcilophyllum procumbens Mitt. M. austr, am. p. 94.

Lignic. - Am. merid. : Venezuela, And. Nov. Granat, et Peruv. pumilum (C. M.) Par.

Dicranum pumilum C. M. in Abhandl. Brem. VII, p. 206.

- Afr. : Madagasear.

rectum Lac. mss. ; C. H. Wright M. Mad, p. 4 .

- Afr. : Madagascar.

Rehmanni C. M. in Rehm. M. Afr, auslr, n, 29, 29 b, 443.

Riedlei Besch. in Journ. de bot. 1891.

$$
\text { - Afr.: Transvaal, C. B. Sp. }
$$

2.

- Am. sept. : Ins. S. Thomas.

rugescens C. M. in Rev, bryol. 1878, p. 69 (nom.).

Rutenbergii (C. M,) Pur.

- Afr. : Austral.

Dicranum Rutenbergii C. M. in Abhandl. Brem. V1I, p. 205.

Sanctae Mariae Besch. op, cil. p. 23.

$$
\text { - Afr. : Madagascar. }
$$

Ad arbor. in silv. primaev. - Afr. : Madagascar, ins, S. Maria,

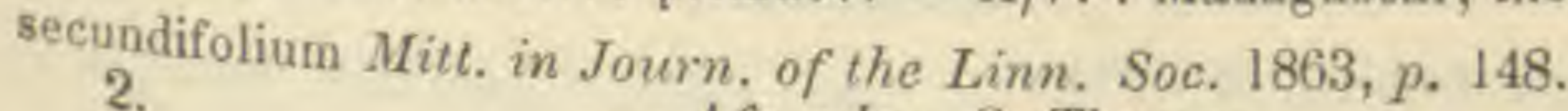

- Afr.: Ins. S. Thomas.

(1) Cf, Duby in Mém,.. Genève, 1869, p. 6 . 
secundifolium Besch. - L. Isleanum.

serratum Broth, in Bail. Syn, of the Queensl. Fl. IV Suppl. p. 95 (nom.) et in Oefv... 1890.

2. (Cortic. - Pac. : Austral, or. (Queensland).

serrulatum Brid. Bryol. univ. 1, p. 752.

Dicranum Bridelianum C. M. Syn. I, p. 354.

Poécilophỵllum serrulatum Mitt. M. austr. am. p. 93.

2.

- Am. sept. : Antill. gall., Hispaniola, Porto-Rico.

seychellense Besch, op. cit, p. 22.

Ster. Ad arbor. - Afr. : Irs. Seychelles.

Sieberianum (Hsch.) Par.

Dicnemonella Sieberiana Hpe. in sched.

Dicranum Sieberianum Hsch. in Sieb. M. Nov. Holl. n. 16 ; C. M. Syn. I, p. 352 et $I I, p .588$.

Leucodon pallidus Hook. M. ex. II, p. 12, t. 172.

Neckera pallida C. M. Syn. II, p. 113.

Sclerodontium pallidum Schwaegr. Suppl. II, I, p. 124, ı. 134

Lignic. - Pac. : Austral. or., Nov. Zeland., Tasman.

"var. $\beta$ Hook. f. Handb. of N. Zeal. Fl. p. 410.

Ad rup. madid. - Pac. : Nov. Zeland.

sinuosulum C. M. in Besch. l. c.

Ster.

- Afr. : Ins. Franciae.

sinuosum (Brid.) Besch. l. c. p. 27. Dicranum sinuosum Brid. Bryol. univ. I, p. 427 p.p.; C. M. Syn. I,
p. 354 .

Trichostomum ferrugineum Brid. Mant. M. p. 83.

Tr. longifolium ej. Bryol. univ, I, p. 496 (incl. var. $\beta$ humile).

- Afr. : Ins. Borbon., Franciae.

« var, setifolium Besch, l. c.

- Afr. : Ins. Borbon.

Sprengelianum (C. M.) Par.

Dicranum fasciatum Spreng. Syst. veg. IV, II, p. 322.

D. Sprengelianum C. M. Syn. I, p. 353.

Exs. : Rehm. M. Afr. austr. n. 30 .

squarrosulum (C. M.) Par.

Dicranum squarrosulum C. M. in Abhandl. Brem. VII, p. 206.

Ster,

- Afr. : Madagascar. subbiplicatum Ren. el Card, in Bull. Soc. roy. bot. Belg. II, 1894, p. 109.
2 ?
$-A f r$.: Ins. Borbon., Diego Suarez. - Afr. : Ins. Borbon., Diego Suarez.

subcaespitulans Besch. op, cit. p. 25.

Ster.

- Afr. : Ins. Borbon.

subchrysobasilare C. M. in Jaeg. Ad. $I I, p .760$ (nom.).

- Afr. : Madagascar.

subimmarginatum (C.M.) Par.

Dicranum subimmarginatum C. M Syn. II, p. 589.

Poëcilophyllum subimmarginatum Mitt. M. austr. am. p. 94.

2?

- Am. sept. : Costa-Rica. 
subintegrum Broth. in Bail. Syn. of Queensl. Fl. IV Suppl. p. 96 (nom.) et in Oefv.... 1890.

2. $\sigma^{\top}$ et fr. ign. Ad arbor. - Pac. : Austral. or. (Queensl.)

subsecundifolium Broth. in Engler's Bot. Jahrb. 1894, p. 177.

2. Ster. $\quad-A f r$.: Usambara.

Talazaccii Ren, et Card, in Bull. Soc. roy. bot. Belg. 1895, I, p. 58. - Afr. : Madagascar.

Taylori Mitt. - Syrrhopodon.

tenerum Mitt. $M$. Ind. or. p. 13.

- As. : Ceylan, penins. Malay.

tenuifolium Mitl. Sam. M.p. 192.

Dicranum oceanicum C. M. M. Polyn. p. 62.

Ster.

- Pac. : Ins. Fidji, Samoa, Nov. Caledon.

terricolum Broth. in op. cit. p. 178.

2. Ster. Terr, - Afr. : Usambara.

Therioti Ren. et Carl. in op. et l. cc.

Ster.

- Am. merid. : Brasil. or.

thraustum (Hpe.) Besch. op. cit. p. 39.

Dicranum thraustum $H_{p e}$, in Linn. 1874, p. 209.

Ster.

- Afr. : Madagascar.

Thuretii Besch. op. cit. p. 24.

tortellum (Mitt.) Par.

- Afr. : Madagascar.

Poécilophyllum tortellum Mitt. M. austr. am. p. 94.

triforme (Mitt.) Par.

- Am. merid. : Ins. Trinitat., Orénoc., Amazon.

Poëcilophyllum triforme Mitt. op. cit. p, 94 .

Ster. Ad arbor. - Am, merid. : Brasil. austr. or.

vincentinum (Mitt.) Par.

Poëcilophyllum vincentinum Mitt. op, cit. p. 93.

Ster.

Ins. Trinitat.

- Am. sept. : Ins. S. Vincent. Am. merid. :

Woodii Rehm, et Mac-Lea in Rehm. M. Afr. austr, n. 444.

Ster.

zanzibarense Besch, in Journ. de bot. 1891.

Ster.

Zeyheri (C. M.) Par.

Dicranum pallescens Wils, in Breutel M. Capens.

D. Zeyheri C. M. Syn. I, p. 353 .

Leucoloma pallescens Jaeg. Ad. Weisia nov. sp. Zeyher Pl. Capens. n. 496.
2 ?

- Afr.: C. B. Sp. (1).

(1) In Enum. Kindberg. nomina nuda :

L. Eggersii C. $M$.

Fraseri $C . M$. (an potius: Mitt.?)

onchophorellum $C$. $M$.

L. saudwicense Ángstr. selaginoides $0 . M$, 
LEUCOMIUM Mitt, in Journ. of the Linn. Soc. X, p. 181 (2.3 spec.). acrophyllum (Hpe.) Mitt. M. austr. am. p. 501.

Hypnum acrophyllum Hpe. in Ann. sc. nat. V ser., IV, p. 325.

Lignic. - Am. merid. : And, Nov. Granat.

aneurodictyon (C. M.) Jaeg. Ad. II, p. 539.

Hypnum aneurodictyon C. M. Syn. II, p. 681 ; Bryol. jav. II, p. 184. t, 282 (excl, f. 21).

2. - As. : Borneo, Java, Sumatra.

attenuatum Mitt. op. cit. p. 503.

$$
\text { - Am. sept. : Ins. S. Vincent. }
$$

commixtum (C. M.) Par.

Hypnum commixtum C. M. in Engler's Bot. Jahrb. 1883, p. 88 et in Forchungsreise... p. 64.

2. Ad arbor. - Afr. : Monrovia.

compressum Mitt. op. cit. p. 502.

Lignic. - Am. merid. : Ins. Trinitat, Amazon,, And. Peruv.

contractile Mitt. op. cit. p. 502.

2 ? Lignic. - Am. merid. : Brasil. austr. or.

crinitifolium (C. M.) Mitt. op. cit. p. 501.

Hypnum crinitifolium C. M. Syn. II, p. 237.

2

- Am. merid. : And. Chilens.

cuspidatifolium (C. M.) Mill. op. et l. cc.

Acosta cuspidata C. M. in Linn. 1848, p. 192.

Hypnum cuspidatifolium ej. Syn. II, p. 237.

L. cuspidatum Jaeg. Ad. II, p. 539 .

2. Lignic. - Am. mericl. : Guian. batav.

cuspidatim Jaeg. - L. cuspidatifolium.

debile (Sull.) Mitt. Sam. M. p. 181.

Mookeria debilis Sull. in Proced. Am. Acad... Jamuar, 1854 et in Exped. Wilkes, M. p. 23, t. 21 .

Hypnum debile C. M. M. Polyn. p. 81 .

Pterygophyllum debile Jaeg. Ad. II. p. 248.

1 et syn. Lignic. - Pac.: Ins. Fidji, Samoa, Nuka-Hiva, Nov. Caled. flexuosurn (Sull.) Mitt. M. austr. am. p. 501.

Hypnum flexuosum Sull. in Proced. Am. Acad... 1861.

2. - Am. sept. : Cuba.

Hillianum (Hpe.) Jaeg. Ad. II, p. 539.

Ectropothecium Hillianum Mitt. in Trans. and Proced. of the roy. Soc. of Viotoria, $1883, p .87$.

Hypnum Hillianum Hpe. in Linn. 1876, p. 322.

Ster.

- Pac. : Austral.

lignicola Spr. in Mitt, op. cit. p, 503. la Spr. in Mitt. op. cit. p. 503.
Cortic. et lignic. - Am. merid. : Amazon., And. Peruv., Brasil.
austr. or.

limpidum Tho, et Mitt, in Journ of the Linn. Soc. 1872, p. 320.

Syn.

- As. : Ceylan.

mahorense Besch. in Ann. sc. nat. VII ser., II, p. 97.

I. Terr. - Afr. : Ins. Mayotte. 
Mariei Besch, in Journ. de bot, 1894, p.

2 ? Cortic. - Am. sept. : Guadalup.

Moseni Broth, in Bihang till Sv. Vet. Akad. Handl. 1895, n. 3.

1. Ad rup. et terr. secus rivul. - Am. merirl. : Brasil. or.

perglaucum C. M. in Dusen M. Camer. n. 93.

- Afr. : M. Cameroon.

perpellucidum C.M. l. c. n. 457 .

- Afr.: M. Cameroon.

Robillardi (Duby) Jaeg. Ad. II, p. 540.

Hypnum Robillardi Duby in Mém... Genève, 1876, p. 9, t. $11 \mathrm{f} .6 \mathrm{et}$ in Fl. 1877, n. 5 .

1. Ad arbor. - Afr. : Ins. Franciae.

scabrum Besch. in Marie M. Guadalup. n. 540 bis et 662 .

2? Ad arbor. - Am. sept. : Guadalup.

serratum Besch, in Journ. de bot. $1894 p$.

Syn. Lignic. - Am. sept. : Guadalup.

strephomischos (Welvo, et Duby) Jaeg. l. c.

Hypnum strephomischos W. et D. in Mém... Genève, 1871, p. 10, t. I, f. 6. Lignic. - Afr. : Angola.

strumosum (Hsch.) Mitt. op. cit. p. 502.

Hookeria strumosa Hsch. Fl. Brasil. I, p. 69.

Hypnum strumosum C. M. Syn. II, p. 238.

Syn. Cortic, lignic, et saxic. - Am, merid. : Amazon., Brasil. austr. or.

LEU COPHANES Brid. Bryol, univ. I, p. 763 (36 spec.).

albescens C. M. in Bot. Zeit. 1864, p, 347.

Ster.

Nov, Guin.

albo-nitens C, M. M. Polyn. p. 58.

Ster. $\quad-$ Pac. : Ins. Samoa.

angustifolium Ren. el Card. in Bull. Soc. roy. bol. Belg. 1894, II, p. 113.

Ster. Lignic. - Afr. : Ins. Borbonise.

asperum (Mitt.) C. M. M. Polyn. p. 57.

Arthrocormus asper Jaeg. $4 d, I I, p .168$.

Octoblepharum asperum Mitt. Sam. M. p. 178.

Ster. - Ad arbor. - Pac. : Ins. Samoa.

australe Broth. in Bail. Syn, of the Queensl. Fl. IV Suppl. p. 96 (nom.)

et in Oefv... 1890, p.

2. ot et fr. ign. Ad arbor. - Pac. : Austral. or. (Queensland).

blepharioides W. P. Sch, in Jardin Enum. p. 20 (nom.).

- Pac. : Nouka-Hiva.

Blumii C. M. Syn. II, p. 537; Bryol. jav. I, p. 24, t. 16.

2.

- As.: Java.

calymperaceum C.M. in Dusen M. Camer, n. 57.

Cameruniae C. M. L. c. n. 117.

- Afr. : M. Cameroon.

- Afr. : M. Cameroon. 
candidum (Hsch.) Lindb. in Oefv... 1864, p. 602; Bryol. jav. I, p. 24, t. 16.

L. Reinwardtianum $C, M$. Syn. $I, p, 82$.

Syrrhopodon candidus Hsch. in Nov. Act, Acad. Léop. XIV, II, Suppl. p. $701, t .39, f . b$.

2.

- As.: Ins. Philipp., Celebes, Amboine, Borneo, ins. Saparoea, Banca, Singapore, Java, Sumatra, Ceylan. Pac.: Nov. Guin.

compactum Broth. in sched.

- As. : Archip. Ind, or.

cuspidatum C. M. - L. glaucum.

densifolium Mitt. in Bonpl. 1861, p. 366.

Octoblepharum densifolium ej. Fl. Vit. p. 387.

- Pac. : Ins, Fidji, Admiral.

fragile Brid. Bryol. univ. I, p. 765; C. M. Syn. I, p. 83.

- Pac. : Ins, Ualan (Sandwic. ?).

Gardnerianum C. M. - Ochrobryum.

glaueum (Schwaegr.) Mitt. M. Ind. or. p. 25.

Arthracormus Hookeri Hpe. in Bot. Zeit. 1847, p. 922.

Didymodon sphagnifolius? W. Arrn.

L. cuspidatum C. M. Syn. I, p. $83 ;$ Bryol. jav. I, p. 25.

Syrrhopodon glaucus Schwaegr, Suppl. II, II, p. 103, t. 181.

2 .

Ins. Marians.

- As. : Nepal.? ins. Rauwack Molucc. Pac.:

guadalupense Lindb. in Oefv... 1864, p. 608.

2.

- Am. sept. : Guadalup.

Hildebrandti C. M. in Linn. 1876, p. 234.

Ad arb., popr. filic. - Afr. : Ins. Borbon., Franciae, Anjouan, S. Maria.

hispidulum (Mitl.) C. M. M. Polyn. p. 57.

Octoblepharum hispidulum Mitt. Sam. M.p. 178.

Ster.

- As.: M. Java.

Korthalsii Dz. et Mk. - L. octoblepharioides.

? Leanum Sull. - Brothera.

minutum C. M. in Geh. Neue Beitr. z. Moosfl. $x$. Neu Guin. p. 2.

Ster.

- Pac. : Nov. Guin. marit.

Molleri C. $M$. in $\mathrm{Fl}, 1886$, p. 285.

Ster.

$$
\text { - Afr. : lns. S. Thom. }
$$

nukahivense Besch. Fl. bryol. Taili, etc. p. 20.

Syrrhopodon speciosus W. P. Sch. in Jard. Enum. p. 19.

Rupic, - Pac. : Nuka-Hiva.

obtusatulum C, M. in Dusen $M$. Camer, n. 706 .

- Afr. : M. Cameroon.

octoblepharioides Brid. Bryol. univ. I, p. 763 ; C. M. Syn..I, p. 82;

Bryol. jav. I, p. 25.

L. Korthalsii $D z$. et $M k+M$. frond. ined. Arehip. ind. p. 65, t. 23.

Voy. H. M. S. Challenger,

Bot. III, p. 25.9 .
Syrrhopodon octoblepharis Nees in Schwaegr. Suppl. IV, t. 311 a.

2. Cortic. - As, : Nepal., Amboine, Borneo, ins. Banca, M. Java, Sarawak, Sumatra. Pac. : Nov. Guin., Nuka-Hiva, ins. Admiral. 
papillosum (Mitt.) C. M. M. Polyn. p. 57.

Octoblepharum papillosum Mitt. Sam. M. p. 179.

Ster.

- As. : M. Java.

pucciniferum C. M. in Engler's Bot. Jahrb. 1883, p. 85 et in Forchungsreise... Bot. p. 49.

Ster. Ad Pandan. et Cycad. - Pac. : Ins. Anachoret.

Radula Jaeg. - Octoblepharum.

recurvum (Milt.) C. M. M. Polyn. p. 57.

Octoblepharum recurvam Mitt. Sam. M. p. 179.

2. Ad arbor. - Pac. : Ins. Samoa.

Reinwardtianum C. M. - L. candidum.

Rodriguezii C. M. in Bull. Soc, roy. bot. Belg. 1894, II, p. 113, et in Ren. et Card. M. Masc. Mad, exs. n. 110.

Ster.

- Afr, : Ins, Borbon.

scabrum (Mitt.) C. M. M. Polyn. p. 57.

Octoblepharum scabrum Mitt. Sam. M. p. 178.

Ster.

- Pac. : Ins, Samoa.

Seychellarum Besch. Fl. bryol. Réunion, etc, p. 49.

2.

Afr: : Ins. Seychelles.

smaragdinum (Mitt.) Par.

Octoblepharum smaragdinum Mitt. in Bonpl. 1861, p. 366 .

Ster.

- Pac. : Ins. Fidji, Admiral.

sordidum C. M. in Engler's bot. Jahrb. 1883, p. 85 et in Forchungsreise... Bot. p. 50.

Ster. Ad arbor. - Pac. : Nov, Guin.

speciosum C. M. - Schistomitrium.

? sphagnoides Welro. et Duby in Mém.... Genève, 1871, p. 19.

Ster. In spongios. inter, rup. - Afr. : Angola.

squarrosum Brid. - Arthrocormus Schimperi.

subglaucescens $C$. $M$. in sched.

- As. : Timorlaut.

Tetensi C. M. M. Polyn. p. 57.

Ster.

- Pac. : 1ns. Pelew.

unguiculatum Mitt. in Jo:rn. of the Linn. Soc. 1863, p. 150.

Ster, $\quad-A f r$ : : Ins. Principis.

vitianum C. M. M. Polyn. p. 58 .

Ster.

- Prtc. : Ins, Fidji.

\section{LICHENASTRUM Dill.}

alpinum $\left\{\begin{array}{l}\text { atro-rubens Dill. - Andraza alpina. } \\ \text { nigricans Dill. - Andraza rupestris. }\end{array}\right.$

Ligularia C. M. Syn. M. I, p 754 (sect. Scht.otherMiak)

Ligulina $C, M$. in Dusen M. Camer. (sect. HyPNi).

LIMBELLA C. $M$. in Fl. 1885, p. 429? (sect. Hypsi), postea gen. propr. =

SCIAROMIEM.

Spec, omn. Sciaromis ejusd, nom. 
Limnobiella C. $M$. in Linn. 1875, p. 465 (sect. HypNi).

Limnobiopsis ej. in Linn. 1878-79, p. 443 (sect. HYPNI).

LIMNOBIUM Bryol. eur. V, gen. propr.; W. P. Sch. Syn. I ed. p. 633. (sect. Hypni.) (1)

Spec. omnes non indicatae sunt HypNA ejusd, nom.

ambiguum de Not. - Hypnum alpestre.

palustre de Not. - Hypnum ambiguum.

Schimperianum de Not. - Hypnum molle var. Schimperianum.

LIMNOBRYUM Rab. Krypt. Fl. Sachs. I, p. 502.

palustre Rab. - Aulacomnium.

var. polycephalum Rab. - Aulacomnium palustre var. polycephalum.

LINDIGIA Hpe, in Linn, $186^{\circ} \mathrm{l}-62$, p. 527 (13 spec.).

aciculata (Tayl.) Jaeg. Ad, II, p, 378.

Hyrnum aciculatum C. M. Syn. II, p. 224.

Leskea aciculata Tayl, in Lond. Journ. of bot. 1847, p. 339.

Lindigia bypnoides Hpe, in Ann. sc. nat. V ser., IV, p. 377 (ex ips!).

Meteorium aciculatum Mitt. M. austr. am. p. 448.

1. Ad arbor. - Am. merid. : And. Quitens. et Peruv.

Cameruniae C. M. in Dusen M. Camer. n. 32.

- Afr.: M. Cameroon.

capillacea (Hsch) Hpe. Enum. M. Brasil. p. 58.

Meteorium capillaceum Jaeg. Ad. II, p. 155.

Pilotrichum capillaceum Hsch. Fl. Brasil. I, p. 58; C. M. Syn. II, p. 157.

Ad rad, arbor. - Am, merid. : Brasil, austr, or.

curtipes Hpe. in Linn. 1861-62, p. 528.

L. pilotrichelloides Jaeg, $l$. c.

1. Ad arbor. - Am. merid. : And, Nov, Granat.

curtipes Jaeg. - L, imponderosa.

debilis (Wils.) Jaeg. l. c. p. 379.

Meteorium debile Wils. mss.; Mitt. in Kew Journ. bot... p. 352 et M, austr. am. p. 448.

1. Ad arbor. - Am. merid.: And. Quitens.

densiretis Hpe, et Ltz, in Bot. Zeit. 1866, p.

1. Ad arbor. - Am. merid. : And. Equator.

Hildebrandti $C$. $M$. in Hildebr. M. Mad. n. 2112 .

- Afr. : Madagascar.

hypnoides Hpe, - L. aciculata.

imponderosa (Tayl.) Jaeg. l. c. p. 378.

Cryphaea helictophylla Wils, in Lond. Journ of. bot. 1846, p. 463.

Leskea imponderosa Tayl, ibid. p. 62.

L. curtipes Jaeg. $l$, c.

L. pilotrichelloides Hpe, in Ann, sc. nat. V ser, $p .376$ (ex ips !)

Meteorium imponderosum Mitt, op. cit. p. 442.

Pslotrichum imponderosum C. M. Syn. II, p. 174.

Ster. Venezuela, And. Quitens. 
Lorentzi C. M. in Linn. 1878-79, p. 399.

1.

- Am, merid. : Argentin. subtropic.

macrotheca Jaeg. - Porotrichum macrocarpum.

paupera C. M. in Ule Bryoth, brasil n. 70.

- Am. merid. : Brasil subtropic or.

pilotrichelloides $\left\{\begin{array}{l}\text { Jaeg. }- \text { L. curtipes. } \\ \text { Hpe. - L. imponderosa. }\end{array}\right.$

subvaginata C. M. in Dusen M. Camer, n. 774.

- Afr. : M. Cameroon.

tenella Hpe, in Besch. Prodr, bryol, mexic. p. 104.

$1 \quad-$ Am. sept. : Mexic. (M. Orizaba).

trichomitria C. M. in Linn, 1878-79. p. 491.

- Am. merid. : Venezuela (1).

LOPHIODON Hook. f. et Wils. in Lond. Journ. of bot. 1844, p. 543 (2 spec.).

Mülleri (Hpe,) Jaeg. Ad. 1, p. 175.

Ditrichum Miilleri Mitt. in Trans. and Proced. of the roy. Soc. of Victoria, $1883, p .50$.

Leptotrichum Mülleri Hpe. in Linn. 1856, p. 206. 1.

- Pac. : M. Austral. fel.

strictus Hook. f. et Wils. l. c. et Fl. Antarct. I, p. 130, t. 59, f. 2; C. M. Syn. I, p. 457 et $I I, p .613$.

Cynontodium australe Mitt. M. austr. am. p. 12.

Didymodon longifolius $H$. f. et W. Fl, of the N. Zeal. II, p. 72.

Didymodon longifolius var. penicillatus eor. Fl. Antarct. Crypt. p. 102.

Distichium capillaceum eor. $F$ \% of the N. Zeal.

Ditrichum australe Mitt. in Trans. and Proced. of the roy. Soc. of Victoria, $1882 . p .51$.

D. strictum Hpe. in Fl. 1867, p. 181-182.

Leptotrichum australe Mitt. in Journ. of the Linn. Soc. 1859, p. 66.

Trichostomum australe H.f. et W. Fl. Tasm. II, p. 177 . 1.

- Afr, : Ins. Kerguelen, Marion. Am, merid, : Chimborazo, Fuegia, ins. Maclov. Pac. : Nov. Zeland., Tasman, ins. Auckland, Campbell.

LOPIDIUM H. f. et W. Fl. of the N. Zeal. II, p. 119.

Spec. omn. non indicatae sunt BYPOPTERYGIA ejusd. nom. pallens $\mathrm{H}$. f. et W. - Hypopterygium Struthiopteris.

LORENTZIA Hpe, in Nuov. Giorn. bot. ital. 1872, p. 288.

longirostris Hpe. - Thuidium velatum.

LORENTZIELLA C. M. in Jinn. 1878-79, p. 229 (5 spec.).

Giberti $C$. $M$, in $F l$. $1888, n$. I.

Syn. Terr. - Am. merid. : Monte Video.

glauca $C . M$. in Linn..,$c$.

Syn, vel androg. Terr. - Am, merid, : Argentin. Urug.

(1) In Enumer. Kindb. nomen nudum:

L. papillipes $C . M$. 
globiceps C. M. in op. cit. p. 231.

2 ? Terr. - Am. merid. : Argentin. Cordob.

paraguensis Besch. Not. M. Parag. p. 259

In herbos. - Am. merid. : Paraguay.

Exs. : Bal. Pl. Parag. n. 1258.

uruguensis C. M. mem. a Besch. $l, c$.

- Am. merid. : Uruguay.

LYELLIA R. Br. in Trans. of the Linn. Soc. XII, II, p. 561 (2 spec.).

? bifurcata Bel. Voy. Ind. or. Bot, II, Crypt. p. 99 ; C. M. Syn. I, p. 228;

Milt. M. Ind. or. p. 155 (1).

Ster.

- As. : Sikkim, M. Ghates.

erispa R. Br. l. c. p. 562 ; Bricl. Bryol. univ. I, p. 227 ; Mitt. l. o.

i.

- As. : Nepal., Sikkim, Bhotan, Alp. Yunnan.

MACOUNIA Kindb, Enum. Bryin. ex. 1888.

sciuroides K. - Pseudo-Leskea.

Macrobryum C. $M$, in Linn. $1880-83$, p. 353 (sect. Acaulon. = SpHCranGIUM ?)

MACROCOMA Hsch. in hb. Kunzeano, gen. propr.; C. M. Syn. I, p. 720 (sect. MAcromitrit).

elegans Hsch. - Macromitrium lycopodioides.

MACROHYMENIUM C. $M$. in Bot. Zeit. 1847, p. 825.

Spec. omn. non indicatae sunt RHEgmatodontes ejusd. nom. cuspidatum Mitt. - Rhegmatodon?

rufum C. M. p. p. $-\left\{\begin{array}{l}\text { Rhegmatodon acidodon. } \\ \text { Rhegmatodon. }\end{array}\right.$

Macromidium C. M. in Linn. 1878-79, p. 380 (sect. BraUniaE).

MAGROMITRIUM Brid. Mant. M. p. 132 et Bryol. univ. I, p. 306. (311 spec.).

abyssinicum $C . M$. Syn. I, p. 722 .

M. Iycopodioides Br. et Sah, in W. Sch. M. Abyss. n. 431.

2?

- Afr. : Abyssin. aciculare Brid. Mant. M. p. 132 et Bryol. univ. I, p. 307 ; C. M. Syn. I,
p. 744.

Lasia acicularis Spreng. in Steud. Nom. Crypt.

Leiotheca acicularis Brid. Bryol. univ. 1, p. 730.

Orthotrichum aciculare Hook, et Grev, in Brevoster Edinb. Journ. I, p. 114.

0 . breve $P . B$. Prodr. p. 80.

o. pallidum ej. l. c. p. 81 .

Schlotheimia acicularis Brid. Sp. M. $I I, p, 21$.

Trichostomum arbustorum ej. op. eit. 1, p. 241. 2. - Afr. : Ins. Borbon., Franciae, Rodriguez.

aciculare C. M. (M. Brasil). - M. filicaule.

acuminatum C. M. - Schlotheimia.

(1) "Forsan sp. Pogonati quaedam. " (Mitt. 1. c.). 
acutifolium Brid. - M. longirostre.

acutirameum Mitt, in Journ, of the Linn. Soc. 1877, p. 62 .

Ster.

- Afr. : Ins. Tristan d'Acunha.

adstrictum Ângstr. - M. owahiense.

amœenum Hsch. in Sieb. M. Nov. Holl.; C. M. Syn. I, p. 740.

2.

- Pac. : Austral.

anacamptophyllum C. M. in Linn. 1878-79, p. 371.

1. Terr. et ad arb. ? - Am. merid. : Argentin, subtropic.

angulatum Mitl. Sam. M. p. 167.

2? Ad arbor. - Pac. : Ins. Samoa.

angulosum Thw. et Mitt. in Journ. of the Linn. Soc. 1872, p. 300.

- As, : Ceylan.

angustifolium Dz. et Mk. M. frond. ined. Archip. ind. p. 16 et Ann. sc. nat. 1844,11, p. 311 ; C. M. Syn. I, p. 743; Bryol. jav. 1, p. 119,

ı. 97 ; Mitt. M. Ind. or. p. 53 .

2 .

- As. : Amboine, Borneo, Java, Sumatra.

apiculatum (Hook.) Brid. Bryol. univ. I, p. 311; C. M. Syn. 1, p. 727 ;

Mitt, $M$. austr, am, p. 203 .

Leiotheca apiculata Brid. op. oit, pp. 734 et 796.

M. longirostre Hsch, in Deppe et Schiede M. Mexic.

M. macrostomum Sohwaegr. Suppl. II, II, II, t. 190.

Orthotrichum apiculatum Hook. M. ex. p. 13, $t .45$.

2. Ad arbor. - Am. sept. : Mexic., Guatemala, Costa Rica. Am. merid. : And. Nov. Granat., Brasil. austr. or.

apiculatum C. M. - M. brevipes.

appendiculatum (R. et C.) Par.

Colaochaetium appendiculatum Ren. et Card. in Bull. Soc. roy. bot. Ster. Belg. 1894, II, p. 120 et M. Masc. Mad. n. 218.

- Afr. : Madagasc. (Diego Suarez).

appressifolium Mitt. in Journ. of the Linn. Soc. 1872, p. 302.

M. orthostichum Bryol, jav, (fid. Mitt.).

- As. : Java.

Archeri Mitt. in Journ. of the Linn. Soc. 1859, p. 78 et in Fl. Tasman. II,

p. $183, t .173, f .6$.

M. linearifolium (fid. Mitt.).

2. Cortic, - Pac, : Austral, or, Tasman.

argutum Hpe, in Linn. 1849, p. 581 ; C. M. Syn. II, p. 647.

- Am. merid. : Brasil. austr. or.

aristatum Milt. in Handb. of N. Zeal. Fl, p. 432.

Ster.

- Pac. : Nov. Zeland. sept.

asperulum Mitt. in Fl. Tasman. II, p. 376; Handb. of N. Zeal. Fl.p. 429.

M. fimbriatum H. f. et W. Fl. of the N. Zeal. II, p. 77.

M. microphyllam eor. op. cit. p.p. 79-80 p.p.

Ad arbor, - Pac. : Nov. Zeland., Tasman,

assamicum (Griff.) Mitl. M. Ind. or. p. 50.

Orthotrichum assamicum Griff. Not. p. 402 et Ie. Pl. asiat. II, t. 77, f. 11.

Cortic. - As. : Assam super.

astroideum Mitt, in Trans, of the roy. Soc, (extr, vol.) p. 389

- Afr. : Ins, Rodrignez. 
atrum C. M. in Dusen M. Camer, n. 306.

- Afr. : M. Cameroon.

attenuatum Hpe, in Ann. sc. nat. V ser. IV, p. 329.

2. Ad arbor, - Am. merid.: And. Nov. Granat.

aurescens Hpe, in Linn. 1859-60, p. 633.

- Pac : Austral, or.

anreum C. M. in Bot. Zeit. p. 580.

$2 . \quad-$ Am. merid. : And. Nov. Granat.

Baileyi Mitt in Trans. and Proced. of the roy. Soc. of Victoria, 1883, p. 63.

- Pac. : Austral, or. (Queensland).

barbense Ren. et Card, in Bull. Soc, roy. bot. Belg. 1892, I, p. 157.

1.

- Am. sept. : Costa-Rica.

Beecheyanum Mitt. Sam. M. p. 167.

Lignic. - Pac. : Ins. Samoa.

Belangeri C. M. in Bot. Zeit. 1862, p. 374.

- Afr. : Ins. Borbon.

Blumei Nees in Schwaegr. Suppl. IV, t. 316; C. M. Syn. I, p. 735 ; Bryol. jav. I, p. II2, t. 89.

Leiotheca Blumei Duby in Moritzi Verz. p. 155.

Schlobheimia teres Dz. et Mk. in Ann. sc. nat. 1844, II, p. 314.

2. Ad arbor, - As. : Borneo, M. Java, Sumatra.

Boivini C. M. - M. rufescens.

brachiatum H. f. et W. - Cryptocarpus apiculatus.

brachyearpum Mitt. M. austr. am. p. 204.

- Am. merid. : And. Peruv.

brachypodium C. M. in Bot. Zeit. 1857, p. 778.

Leiostoma brachypoda Mitt, in Proced. of the Linn. Soc. 1879 (extra-vol.), p. 99.

- Pac. : Ins. Pinorum.

brachyrhynchum (Schwaegr.) W. P. Sch. in C. M. Syn. I, p. 745.

M. punctatum $H$. et Gr. (fid. Mitt. M. austr. am. p. 212).

M. viticulosum Brid. Bryol. univ, I, p. 738. M. viticulosum Brid. Bryol. univ, I, p. 738.
Schlotheimia brachyrhyncha Schivaegr. Suppl. II, II, I, p. 53, t. 168;
Brid. l. c. p. 800 .

Schl. viticulosa Raddi Critt. Brasil. p. 4.

2. Saxic. - Am. mend. : Brasil. austr. or.

brasiliense Mitt. M. austr. am. p. 197.

1. Cortic. - Am, merid, : Brasil.

Braunii C. M, Syn. II, p. 643 ; Bryol. jav. I, p. 117, t. 94.

2.

- As. : Java.

brevipes C. M. Syn. I, p. 728 ; Mitt. op. cit. p. 202.

M. apiculaium ej. in Bot. Zeit. 1845, p. 525.

Orthotrichum elegans Hsch. in M. Sieber n. 21. 2. merid. : Ins. Trinitat.

-Am. sept. : Antill. gall., Porto-Rico. $-A m$.

brevisetaceum Hpe. in Linn. 1874, p. 663.

Ad arbor. - Pac.: Ins. Lord Howe.

brevisetum Mitt. Fl. Vit. p. 379.

- Pac.: Ins. Oahu. 
Brownei C. M. - Schlotheimia.

caducipilum Lindb. in Oefv... 1864, p. 605.

2.

- Pac.: Nov. Zeland.

cospilans C. M. - M. confusum.

caldense Ångstr. in Oefv... 1876, n. 4, p. 12.

1. $\quad-A m$, merid. : Brasil, austr, or.

calocalyx C. M. in Abhandl. Brem. VII, p. 208.

2 ?

- Afr. : Madagascar.

calvescens Bryol. jav. 1, p. 125, t. 103.

2. $\quad$ - As. : Java.

calycinum Mill. M. Ind. or. p. 49.

Aulacomitrium calycinum ej, in Trans. of the Linn. Soc. 1891, p. 161.

II, parvulum Wils. in Kew Journ. bot. IX, p. 327.

1. - As. : Japon., Ceylan.

calymperoideum Mitl, in Hook. Journ. of bot. 1856, p, 354 et M. Ind. or. p. 50.

2? Ad arbor. -- As, : Penins. Malay.

capillicaule C. M. in Ule Bryolh. Brasil. n. 135.

Cortic. - Am. merid. : Brasil, austr. or.

carinatum Mitt. in Trans. and Proced. of the roy. Soc. of Victoria, 1883, p. 64.

catharinense Par.

- Pac. : Absque loco (Austral. vel Tasman.).

M. prolongatum C. M, in Ule B,yoth. brasil. $n$. 134.

Cortic. - Am. merid. : Brasil, austr, or.

celebense Par.

M, reflexifolium Lac. Sp. nov. M. Arehip, ind. p. 8, $t, 5-6$.

2.

- As, : Celebes.

ceylanicum Mitt. op. cit. p. 52.

M. tersum Wils, in op. cit. p. 328.

2 ?

Chamissonis C. M. - Schlotheimia.

chimborazense Spr. - Micromitrium.

cirrosum (Hedro.) Brill. Bryol, univ. I, pp. 316, 738 et 798; C. M. Syn. I, p. 732 ; Mitt. M. austr. am. p. 205 .

Anoectangium cirrosum Hedw. Sp. M. p. 42, ¿. 5.

Hypnum eirratum Brid. M. Reo. II, II. p. 185.

H. cirrosum Sic. Prodr. p. 142.

Neckera cirrosa ej. Fl. Ind. oec. III, $p, 1802$.

Orthotrichum cirrosum Hook, et Giev, in Brewster Edinb. Journ. I, p. 130.

Schlotheimia cirrosa Sehwaegr. Suppl. III, I, I, t. 201.

2. Ad arbor. et rup. - Am. sept.: Panama, Cuba, Jamaic., PortoRico, Antill, gall. Am. merid. : Columb., Brasil. occ. et austr. or. cirrosum Duby. - M. elongatum.

clavatum W. P. Sch, in Jaeg. Ad. I, p. 417 (nom.).

- Am. sept. : Guadalup.

clavellatum $\left\{\begin{array}{l}\text { Kze. - Drummondia obtusifolia. } \\ \text { Schwaegr. }\end{array}\right.$ 
comatum Mitt. in Trans. of the Linn. Soc, 1891, p. 163.

- As, : Japon.

concinnum Mitt. in Bryol. jav. I, p. 132, t. 110.

2.

- A. : Java.

confusum Mitt. in Journ. of the Linn. Soc. 1886, p. 305.

M. caespitans C. M. in Rehm. M. Afr. austr. n. 159.

M. lycopodioides ej. l. o. n. 16 b. et 166.

M. tenue var. brachypus ej. l. c. n. 162.

2.

- Afr. : Natal, C. B. Sp.

Eas. : Rehm. M. Afr. austr. n. 159.

constrictum Hpe. ct Ltz. in Bot. Zeit. 1869, p.

Ad arbor. - Am. merid. : And. Aquator.

contextum Hpe, in Ann, sc. nat. V ser., IV, p. 331 ; Mitt. M. austr. am. p. 207.

Ad arbor. - Am. merid. : Nov. Granat.

contortum Thro, et Mitt. in Journ. of the Linn. Soc. 1872, p. 301.

- As. : Ceylan.

corrugatum Wils, - M. sulcatum.

crassiusculum Ltz, in Bot. Zeit. 1866, p. 187.

2? Ad rup. marit. - Am. merid. : Valdivia.

crenulatum Hpe. in Linn. 1863, p. 145 ; Mitl. op. cit. p. 213.

2. Ad arbor. - Am. sept.: And. Costa Ric. Am. merid. : And. Nov. Granat.

crispatulum Mitt. op. cit. p. 210.

- Am. merid. : And. Quitens.

cuspidatum Hpe. Ic. M. t. 20 ; C. M Syn. I, p. 731 ; Bryol. jav. I, p. 115, t. 92.

M. elongatum Dz. et Mk. in Ann, sc. nat. $1844, I I, p, 311$.

2.

- As. : Borneo, Java, Sumatra.

cylindricum Mitt. op. cit. p. 210.

- Am. merid. : M. Chimborazo.

Damellii C. $M$. in Rev. bryol. 1877, p. 43 (nom.).

- Pac. : Austral. or. (Queensland).

dawsoniaemitrium $C, M$. in Rehm. M. Afr. austr. n. 160.

- Afr. : C. B. Sp.

densum Mitt, M. Ind. or. p. 51 .

2? $\quad-A s$. : Nepal.

denudatum Jaeg. Ad. $1, p .424$.

M. Mülleri W. P. Sch, in Besch. Prodr. bryol. Mexic. p. 45.

1.

- Am. sept. : Mexic. (Orizaba).

diaphanum C. M. in Linn. 1871-73, p. 151.

1. $\quad-P a c$. : Austral. or. (Queensland.). - Pac. : Austral. or. (Queensland.)
Didymodon Schwaegr. Suppl. II, II, II, p. 138, t. 190; C. M. Syn. I,
p. 741; Mitt. M. austr, am. p. 20I.

1. Cortic. - Am. merid.: And. Nov, Granat. et Quitens., Brasil. austr. or.

divaricatum Milt. op. cit. p. 217.

- Am. merid. : And, Quitens. 
diversifolium Brouh. in Heduig. 1895, p. 126.

2. Cortic. - Am. merid. : Brasil, or. (Goyaz).

domingense Jaeg. Ad. I, p. 427.

M. insularum Mitt. op. cit. p. 200.

- Am. sept. : Guadalup., S. Doming.

Doeringianum Hpe. Enum, M. Brasil, p, 24.

- Am. merid. : Brasil. austr. or.

Dregei Hsch, in Linn. 1841, p. 131; C. M. Syn. I, p. 721.

1. $\quad-A f r$. : Kilima N'Djaro, Transvaal, C. B. Sp.

Exs. : Rehm. M. Afr, austr. n. 158, 509.

Dregei Sull. - M. Sullivantii.

Drummondii Hpe. - Ulota.

dubium W. P. Sch, in C. M. Syn. 1, p. 723; Mitt. op. cit. p. 207.

- Am. sept, : Antill., S. Christoph.

Durandi Ren. et Card. in Bull. Soc. roy. bot. Belg. 1892, I, p. 159.

2 ? 3 ign. $\quad-$ Am. sept. : Costa-Rica.

Duseni C. M. in Dusen. M. Camer. n. 73.

- Afr. : M. Cameroon.

elegans Duby Choix de Crypt. ex. 1867.p. 6, c. ic.

- Afr. : r. B. Sp.

ellipticum Hpe. in Nuov. Giorn. bot. ital. [872, p. 274.

2.

- As. : Ceylan.

elongatum Dz. et Mk. in Zolling. Syst. Verz. p. 25 ; Bryol. jav. 1, p. 116, t. 93.

M. cirrosum Duby in Moritzi Cat. p. 135.

2.

- As. : M. Java.

elongatum Dz, et Mk. (Ann. sc. nat.). - M. cuspidatum.

erosulum Mitt. in Journ. of the Linn. Soc. 1859, p. 78; Handb. of $N$.

Zeal. Fl. p. 431.

M. microstomum H. f. et W. Fl. of the N. Zeal. II, p. 79 p.p.

2 ?

- Pac. : Nov, Zeland.

exsertum Broth. in Oefo.., 1893.

2. $\quad$ - Pac. : Austral. austr. or.

Eucalyptorum C. M. et Hpe. in Linn. 1853, p. 500 et 1856, p. 10.

M. microphyllum (fid. Mitt.).

1. Lignic. - Pac. : Austral, or. (Victoria), Tasman.

falcatulum C. M. in Linn. 1874, p. 558 .

2.

- As. : Ins. Philippin.

fasciculare Milt. M. Ind, or. p. 51 ,

M. Reinwardti Wils, in Keev Journ. bot. p. 327. 1.

- As. : Ceylan. Pendleri C. M. in Linn. I878-79, p. 486.

ferrugineum C. M. - Schlotheimia.

- Am. merid. : Venezuela.

filicaule C. M. Syn. I, p. 745 ; Mitt. M. austr. an. p. 199.

M. aciculare ej. in Gardn. M. Brasil. n. 53 b.

2.

- Am, merid. : Brasil. austr. or., Chile. 
filiforme (Hook. et Grev.) Schwaegr. Suppl. II, II, I, p. 61, 1. 171; C. M. Syn. I, p. 720 ; Mitt. op. cil. p. 197.

Chaetophora orthotrichoides Brid. Bryol. univ, II, p. 339?

Lasia orthotrichoides Raddi in sched.

Leiotheca filiformis Brid. op. cit. I, pp. 727 et 795 .

Orthotr.chum filiforme $H$, et Grev, in Brewster Edinb. Journ. I, p. 116, t. 4.

1. Cortic. in silv. - Am. merid. : Brasil. austr., Chile.

fimbriatum (P. B.) Schoaegr. Suppl. II, I, p. 37, t. 1I1; C. M. Syn. I, p. 739 .

M. uncinatum Brid. Bryol, univ. I, pp. 308, 735 et 797.

Orthotrichum fimbriatum $P . B$. Prodi $, p, 80$.

Weisia uncinata Brid. Mant. M. p. 42.

Ad arbor. - Afr.: Ins. Tristan d'Acunha? Borbon., Francie; Madagascar sept. Am. sept. : Porto-Rico (fid. Duby).

a var. chloromitrium Besch. Fl. bryol. Réunion, etc. p. 71.

Ut typ. - Afr. : Ins. Francis.

fimbriatum H. f. et W. - M. asperulum.

Fitz-Geraldi Lesq. el Jam. Man. p. 178.

1. Cortic. - Am. sept. : Florida.

flexuosum Mitt. op. cit. p. 208.

- Am. merid, : And. Quitens.

flexuosum. W. P. Sch. - M. Schimperi.

fragile Mitt. - Micromitrium.

fragilifolium Lindb. in A ngstr. Prim. lin. p, 11 (nom.).

- Am. merid. : Brasil, austr. or.

frigidum C. M. in Bot. Zeit. 1857, p 579.

1. - Am. merid. : And. Nov. Granat.

frondosum Mitl. op. cit. p. 217.

- Am. merid. : And. Quitens.

fulvum Mitt. M. Ind. or. p. 52.

2.

- As. : Ceylan.

funicaule W. P. Sch. in Besch. op. cit. p. 71.

1. Ad arbor, - Afr. : Ins. Franciae.

fuscescens Schroaegr. Suppl. II, II, II, p. 129, t. 191; C. M. Syn. l, p. 748 .

- Pac. : Ins. Mariann.

galipense C. M. Syn. I1, p. 643 ; Mitt. M. uustr. am. p. 213.

2. Cortic. - Am, merid. : And. Venezuel.

Geheebii C. M. in Linn. 1876, p. 308.

- Pac. : Austral. or. (Nov. Valesia).

Giesbreghtii Besch, Prodr. bryol, mexic. p. 44.

1. $\quad-A m$. sept. : Mexic.

"var. brevifolium Besch. . c.

- Am. sept. : Mexic. (Orizaba).

glaucum Mitt. Sam. M, p. 167.

2? Cortic. - Pac. : Ins. Samoa.

Glaziovii Hpe. Symb. 1874, p. 493. 
globirameum C. M. in Bot. Zeit. 1857, p. 779.

Ster.

- Pac: Nov. Hibernia.

goniopodium Mitt. M. austr, am. p. 198.

Cortic. - Am. merid. : Brasil. tropic,

goniorhynchum Mitt. - Micromitrium.

var. glaucescens C. M. - Micromitrium goniorhynchum var. glaucescens.

gracile (Hook.) Schucaegr. Suppl. II, II, p. 39, t. 112 ; Brid. Bryol. univ. I, p. 315 ; C. M. Syn. I, p. 733 ; Fl. of the N.Zeal. II, p. 78 et Handb. p. 429.

Leiotheca gracilis Brid. op. cit. p. 730.

M. Mossmannianum C. M. (fid. Mitt.),

Orthotrichum gracile Hook. M. ex. p. 13, t. 27.

2 ? Cortic. - Pac. : Nov. Zeland.

gracile C. M. - Schlotheimia.

guatemalense C. M. Syn. II, p. 644; Mitt. M. austr. am. p. 214.

2 . - Am. sept. : Guatemala.

gymnostomum Sull, et Lesq. in Proced. Am. Acad... 1859, p. 278. (I)

Dasymitrium gymnostomum Lindb. Contrib. ad fl. crypt. As, bor, or. p. 229.

2. Cortic. et rupic. - As. : Japon,, China.

Exs, : Faurie Pl. Japon. n. 4483.

Harioti Besch, in Bull. Soc, bot. Fr. 1885, p. LXI et in Miss. sc. Cap Horn, V, Bot. p. 278, t. 3, f. 12 .

Ster. $\quad-$ Am. merid, : Fuegia.

Hectori Mitt. in Handb. N. Zeal. Fl. p. 430.

- Pac. : Nov. Zeland.

hemitrichodes Scliwaegr. Suppl. II, II, II, p. 136, t. 193; C. M. Syn. 1,

p. $736 ; \mathrm{Fl}$. of the N. Zeal. II, p. 79 et Handb. p. 431.

M. Sieberi Schieaegr. in litt. ad Hook. et in sched.

2.

Hildebrandtii C. M. in Linn. 1876, p. 76.

- Pac. : Austral., Nov. Zeland.

Lignic. - Afr. : Ins. Anjouan.

Ad Thw. et Mitt, in Jounn. of the Linn. Soc. 1872, p. 302.

Hornschuchii Hpe. Symb. 1870, p. 274.

M. microstomum Hsch. Fl. Brasil. I, p. 21.

1 .

- Am. merid. : Brasil, austr. or.

hamile Bryol. jav. I, p. 128, t. 106.

humillimum (Mill.) Par.

- As. : M. Java.

Aulacomitrium humillimum Mitt, in Trans, of the Linn. Soo. 1891, p. 161.

- As. : Japon.

Husnoti W. P. Seh, in Besch. Fl. bryol. Antill. fr. p. 26.

Ad arbor. - Am. sept. : Martinic.

hyalinum Broth. in Engler's Bol. Jahrb. 1894, n. 185.

- Afr. : Usambara.

(1) "An proprium genus sensa Hampei? \$. Jaeg. Ad. II, p. 697. 
hymènostomum Mont, in Ann. sc. nat. 1845, IV, p. 120 el Syll, p. 31; C. M. Syn, I, p. 723; Mitt. M. austr. am. p. 204.

2.

- Am. merid.: Chile austr., Fuegia, Cap Horn.

immersum C. M - Schlotheimia tecta.

incurvifolium (Hook. et Grev.) Schwoaegr. Suppl. II, II, II, p. $144 ;$ C. M.

Syn. I, p. 750 ; Bryol. jav. I, p. 174; Fl. of the N. Zeal. II, p. 779 et Handb. p. 431.

Ad arbor. - As. : Ins. Ternate. Pac. : Tahiti, ins. Pitcairn, etc.. fret. reg. Georges; Nov. Zeland.?

incurvifolium Mont. $\left\{\begin{array}{l}- \text { M. subtile. } \\ - \text { M. uncinatum? }\end{array}\right.$

incurvum (Lindb.) Par.

Dasymitrium incurvum Lindb, in Seem. Journ. of bot. 1864, p. 385.

M. japonicum C. M. Syn. I, p. 740.

- As. : Japon., Tonkin, China.

insularum Sull, et Lesq. in Proced. Am. Acad... 1859, p. 278.

2. Ad arbor. - As. : Japon.

insularum Mitt. - M. domingense.

intermedium Mitt. in Trans. and Proced, of the roy. Soc. of Victorta 1883, p. 63.

- Pac. : Austral. or. (Queensland).

intortifolium Hpe. mss. ; C. M. in Bot. Zeit. 1862, p. 362.

- Am. merid. : Brasil. austr. or.

involutifolium (Hook. et Grev.) Schwaegr. Suppl. II, II, II, p. 144;

C. M. Syn. I. p. 749 .

Leiotheea involutifolia Brid. Bryol, univ. I, p. 733.

Orthotrichum involutifolium $H$. et Gr, in Brevster Edinb. journ. I, p. 117 , t. 5 .

- Pac. : Fret. reg. Georges, Nov. Zeland.

involutifolium Mont. - M. Schmidii.

involutum Mitt, mss.; C. H. Wright M. Mad. p. 6.

- Afr. : Madagascar.

jamaicense Mitt, M. austr. am. p. 209.

- Am. sept. : Jamaic.

Jamesoni C. M. - Schlotheimia.

japonicum $D z$, et $M k$, in $A n n$. sc. nat. 1844, II, p. 311.

M. spathulare Mitt. M. Ind, or, p. 50.

2 ?

- As. : Madras, Deylan.

japonicum C. M. - M. incurvum.

javanicum Bryol, jav, I, p. 123, t. 101.

2.

- As. : Java.

julaceum C. M. -- Schlotheimia.

Kegelianum C. M. - Schlotheimia.

Krausei Lta. in Bot Zeil. 1866, p. 187.

1. Ad arbor. - Am. meriel.: Valdivia.

laevifolium Mitt. M, austr. am. p. 203.

- Am. merid. : Venezuela, Guian. 
laevisetum Mill. op. cit. p. 214.

- Am. merid. : And. Quitens., Brasil.

lamprocarpum C. M. in M. Polakouskyani et in Bull. Soc, roy. bot. Belg. 1892. I, p. 158.

2? ơ ign.

- Am. sept. : Costa-Rica.

laxo-torquatum C. M. in Besch. Fl. bryol. Réunion, etc. p. 74.

Ster. - Afr. : Ins. Franciae.

laxum C. M. - Schlotheimia.

Leiboldtii Hpe. in Bot. Zeit. 1870, p. 50.

1.

- Am. sept. : Mexic.

Leprieurii Mont. in Ann. sc. nat. I ser., XIV,p. 347, t. 20 et Syll.p. 32 ;

C. M. Syn. I, p. 724; Mitl. op. cit. p. 200.

Ad arbor. - Am, merid. : Guian. gall.

leptophyllum Besch. Prodr. bryol. mexic. p. 46.

1.

- Am. sept. : Mexic.

levatum Mitt, in Journ, of the Linn. Soe. p. 152.

2. Curtic. et rupic. - Afr. : M. Cameroon.

liberum Mitt. M. austr. am. p. 214.

- Am. merid. : And. Quitens.

ligulare Mitt. in Journ. of the Linn. Soc. 1859, p. 78 et Handb. of $N$. Zeal. Fl. p, 430.

M. नreissioides (fid. Mitt.).

2?

- Pac.: Nov. Zeland., Austral. or. (Queensland).

liliputanum C. $M$. in $F l .1890, p .483$.

Ster. $\quad-A f r$ : M. Aberdare.

linearifolium C. $M$. in Linn. 1871-73, p. 154 .

2?

- Pac. : Austral. or.

linearifolium C. M. - Schlotheimia longifolia.

longicaule C. M. Syn. 1, p. 742; Bryol. jav. 1, p. 119, t. 96.

2.

- As. : Java.

longifolium (Hook.) Brid. Bryol. univ. I, pp. 309 et 738 ; C. M. Syn. I, p. 737; Mitt. M. austr. am. p. 210.

M. oblongum Mitt. op. cit. p. 211,

M. scabrisetum Wils. in Trans, of the Linn. Soc. X.X, p. 163; C. M. Syn. II, p. 647 (fid. Mitt.).

Orthotrichum longifolium Hook, M. ex, p. 13, t. 44.

Schlotheimia longifolia Sohwoegr, Suppl. III, I, I, t. 201.

Schl. oblonga Tayl. in Lond. Journ. of bot. 1846, $p .46$.

2. Ad arbor. - Am. sept. : Costa Rica. Am. merid. : Columb., And.

Nov. Granat., Quitens. et Boliv. ; ins. Gallapagos? Brasil. auste. or.

Exs. : Mandon Pl. Boliv. n. 1655.

- var: brevifolium C.M., . $c$.

Ut typ. - Am. merid. : Columb. "var, viridissimum Ren. et Card. in Bull. Soc. roy bot. Belg. 1892, 1,
p. 156 .

Ut typ. - Am. sept. : Costa-Rica.

longifolum Wils. - M, sulcatium, 
longipes (Hook.) Schwaegr. Suppl. II, II, p. 147, t. 139; Brid. Bryol. univ. I, pp. 317 et 737 ; C. M. Syn. I, p. 729.

Orthotrichum longipes Hook. M, ex. p. 13, t, 24.

2 ? Ad arbor. ? - Pac, : Nov. Zeland., ins. Norfolk, Tasman.

longipilum A. Br. in C. M. Syn. II, p. 642; Bryol.jax. I, p. 114, t. 91 ,

2 .

- As. : Java.

longirostre (Hook.) Schwaegr. Suppl. II, I, p. 38, t. 112 ; Brid. Bryol. univ. I, p. 310 ; C. M. Syn. I, p. 729 ; Mitt. op. cit. p. 212; Fl. of the N. Zeal. II, p. 78 et Handb. p. 429.

M. acutifolium Brid. op. cit. p. 735.

M. Paccivanum de Not. (fid. Handb. $l$. c.).

Orthotichum acutifolium Hook. et Grev: in Brewster Edinb. Journ. I, p. $118, t .5$.

0. longirostre Hook. M. ex. p. 13, t. 25.

2? - Am. merid. : Chile, ins, Chiloë. Pac.: Nov. Zeland, Tasman., ins. Auckland, Campbell, Chatam.

longirostre Hsch. - M. apiculatum.

lycopodioides (Burch.) Schwaegr. Suppl. II, II, II, p. 141, t. 193; C. M. Syn, 1, p. 721 .

Macrocoma elegans Hsch. in sched.

Maschalocarpus Ecklonii Spreng. Syst, veg. IV, II, p. 321.

Orthotrichum lycopodioides Burch. Cat, geogr. pl. Afr. austi. extratr. n. 5141-47.

2.

Exs. : Rehm. M. Afr. austr, n. 165 pp., 513 b.

lycopodioides ! C. M. p.p. - M. confusum.

I Br. et Sch. - M. abyssinicum.

macrocarpum C. M. in Journ. of Bot. 1877, p. 229 (nom.).

Cortic. - Am. sept. : Costa-Rica.

macropelma C. M. in Bot. Zeit. 1856, p. 420.

2? $\quad-A f r .:$ C. B. Sp.

Exs. : Rehm. M. Afr. austr. n. 167.

Mac Leai (Rehm.) Par.

Dasymitrium Mac Leai Rehm. M. Afr. austr, n. 508.

- Afr. : Transvaal.

macrorhynchum Milt. in Bryol. jav. I, p. 133, $t .111$.

2. Filicic. - As. : Java.

macrostomum Schwaegr. - M. apiculatum.

macrothele C. M. in Bot. Zeit. 1848, p. 766 et Syn. 1, p. 742 ; Milt. op. cil. p. 212.

2.

- Am. merid. : Columb, And. Peruv.

Mannii Jaeg. Ad. I, p. 425.

M. Menziezii Mitt. in Journ. of the Linn. Soc: 1863, p. 152.

2 .

cipis.

- Afr. : Sierra Leone, ins. Fernando-Po, Prin-

Martianum C. M. - Schlotheimia.

mauritianum Schwaegr. Suppl. II, II, II, p. 127 ; C. M. Syn. I, p. 726;

Fl. of the N. Zeal. II, p. 79 et Handb. p. 430 .

Nov. Zeland, sept.

- Afr. : Usambara, ins, Franciae, Madagascar. Pac. : 
megapterum C. M. in Dusen M. Camer. $n .508$.

- Afr.: M. Cameroon.

Menziezii C. M. in Bot, Zeit. 1862, p. 361.

- Pac. : Taiti.

Menziezii Mitt. - M. Mannii.

mexicanum Mitt. op. cit. p. 198.

1.

- Am. sept. : Mexic.

microcarpon C. M. Syn. 1, p. 727; Mitt, M. austr. am. p. 202.

2. - Am. merid. : Chile.

microphyllum (Hook. et Grev.) Brid. Bryol. univ. I, p. 737 ; C. M. Syn. I, p. 721 .

Orthotrichum microphyllum $H$. et Gr. in Brewster Edinb. Journ. $I$, p. $121, t .6$.

1. Cortic, - Afr. : Ins. S. Helena, Transvaal,, C. B. Sp. Am. merid. : Austr. (fid. Fl, Tasman, p. 184). Pac.: N, Zeland. merid., Tasman., Austral. (Victoria).

Exs. : Rehm. M. Afr. austr. n. 510.

microphyllum $\{$ H. f. et W. p.p. - M. asperulum.

Mont. - M. squarrosulum?

microstomum (Hook. el Grev.) Schwaegr. Suppl. II, II, II, p. 130;

C. M. Syn. I, p. 727; Handb. of N. Zeal. Fl. p. 431.

Leiotheca microstoma Brid. Bryol. univ. I, p. 729.

Orthotrichum microstomum $H$. et Gr. in Brewster Edinb. Journ. I, p. $114, t .4$.

Nov. Zeland. ?

- Pac. : Ins. Sandwic., Austral. fel., Tasman.;

microstomum $\left\{\begin{array}{l}\text { H. ., et W. P.p. - M. erosulum. } \\ \text { Hsch. - M. Hornschuchii. }\end{array}\right.$

microtheca Mill, M. austr. am. p. 208.

- Am. merid. : And. Quitens.

minutum Mitt. in Journ. of the Linn. Soc. 1872, p. 303.

Miquelii Mitt. in Bryol. jav. I, p. 130, t. 108.

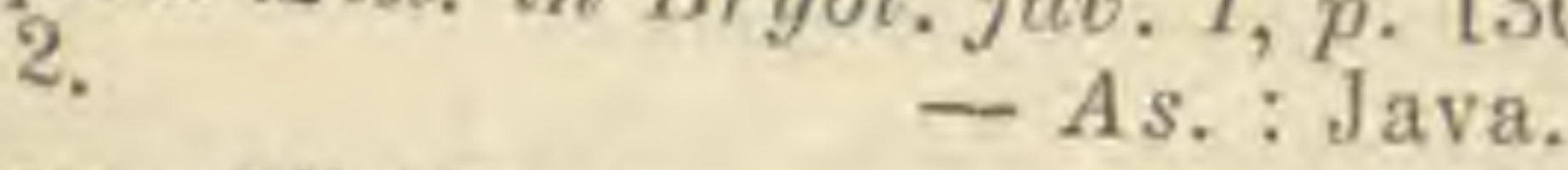

Moorcroftii (Hook, el Grev.) Schooegr. Suppl. II, 11, I, p. 167, Ł. 172; C. M. Syn. I, p. 736; Mitt. M. Ind, or, p. 50.

Leiotheca Moorcroftii Brid. Bryol, univ. I, pp. 727 et 795,

M. pileatum Wils, in Kew Journ. bot. IX, p.327.

M. tortuosum $e j, l, c$.

Orthotrichum Moorcroftii H, et Gr, in op. cit. p. 116, t. 4.

2. Ad arbor. - As. : Nepal., Sikkim, Khasia, Birman, super.

Moseni Broth. in Bilang till K. Sv. Vet, Akad. 1895, n. 3.

2. Cortic. - Am. merid. : Brasil, or.

Mossmannianum C. M. in Bot. Zeit. 1851, p. 561.

M. gracile Hook. (fid. Mitt.).

- Pac. : Nov. Zeland.

mucronatulum C. M. in Rev. bryol. 1887, p. 57 (nom.).

- Pac. : Nov, laled.

mueronifolium (Hook, et Grev.) Schwaegr. Suppl. II, II, I, p. 61, t. 170 ;

C. M. Syn. 1, p. 746 ; Mitt. M. austr. am, p. 202.

Leiotheca mucronifolia Brid. Bryol. univ. I, pp. 729 et 795 , 
Orthotrichum mucronifolium $H$. et Gr. in op. oit. $I, p .116, t, 4$.

1. Rupic. - Am. sept. : Florida, Cuba, Antill. gall., Jamaiç., ins, S. Vincent., Barbades. Am. merid.: Ins. Trinitat., Guian., Amazon., Brasil. or.

Mülleri Hpe. in Linn. 1859-60, p. 634.

M. pusillum Mitt. ?

- Pac, : Austral, or.

Mïlleri W. P. Sch. - M. denudatum.

Müllerianum Mitt. - M. uncinatum.

neelgheriense C. M. - M. sulcatum.

negrense Mitt. op. cit. p. 208.

Ad arbor. - Am. merid. : Amazon.

neo-caledonicum Besch. Fl, bryol. Nov. Caled. p. 211.

-- Pac. : Nov. Saledon.

nepalense (Hook. et Grev.) Schoaegr. Suppl. II, II, II, p. 134, t. 192;

C. M. Syn. 1, p. 725 ; Mitt. M. Ind. or. p. 50.

Leiotheca nepalensis Brid. Bryol. univ. I, p. 732.

Orthotrichum nepalense $H$. et $G r$. in op, eit. p. 117, t. 4 .

2. Cortic. - As. : Nepal., Sikkim, penins, Malay., ins. Philipp., Hong-Kong, Alp. Yunnan.

Nietneri C. M. in Linn. 1869-70, p. 39.

Ster.

- As. : Ceylan.

nigrescens Kze. - Ptychomitrium nigricans.

nigricans Mitt. M. Ind. or. p. 53.

2 ? Ad arbor, - As. : Coorg, Ceylan.

nitidum Hook. f. et Wils. in Lond. Journ. of bot. 1844, fasc. Mart. ;

C. M. Syn. I, p. 735 ; Milt. M. austr. am. p. 199.

1 (Mitt.) \& (C. M.). Cortic. - Am. merid. : Brasil. austr. or.

noumeanum Besch. Fl. bryol. Nov. Caled, p. 208.

Ad arbor. - Pac. : Nov. Caledon.

Novae Valesiae C. M. in Rev. bryol. 1876, p. 3 (nom.).

- Pac. : Austral, or. (Nov. Vales.).

oblongum Mitt. -. M. longifolium.

obtusum Mitt. op. cit. p. 201.

- Am. merid. : Guian., Amazon.

ochraceum (Dz. et Mk.) C. M. in Bot. Zeit. 1845, p. 544 et Syn. I, p. 732;

Bryol. jav. 1, p. 118 et, $t .95$.

Schlotheimia ochracea $D z$. et Mk. in Ann. sc, nat. 1844, II, p. 314.

2.

- As. : M. Java, Sumatra. orthophyllum Mitt. in Journ. of the Linn. Soc. 1859, p. 79 et Handb. of
N. Zeal. Fl. p. 430 .

2.

- Pac. : Nov. Zeland.

orthostichum Nees in Sclwoaegr. Suppl. IV, $t .316 ; C$. M. Syn. I, p. 745; Bryol. jav. 1, p. 129 et II, p. 226, t. 107.

2.

- As. : Celebes, ins. Bali, M. Java.

Osculatianum de Not, in Mill. M. austr. am. p. 216.

- Am. merid. : Guian., And. Quitens.

Ottonis C. M. - Schlotheimia. 
ovale Mitt. op. cit. p. 209.

- Am. merid. : And. Quitens.

owaihense C. M. in Bol. Zeil. 1864, p. 359.

M. adstrictum Angst, in Oefv ... 1872, n. 4, p, 19.

M. Reinwardti Sull. in Wilkes Exped. Bot. M. p. 7? 1.

- Pac. : Ins. Oahu (Sandwic.), Societat., Taïti.

pacificum Besch. Fl. bryol. Nov. Caled. p. 209.

1. Cortic. - Pac. : Nov. Caledon.

Paccivanum de Not. - M. longirostre.

paraphysatum Mitt, op. cil. p. 198.

1. $\quad-$ Am. merid. : And. Quitens., ins. Chiloë.

parvulum Wils: - M. calycinum.

paucidens C. M. in Linn. 1878-79, p. 487.

2.

- Am. merid. : Venezuela.

pellucidum Mitt. op. cit. p. 203.

Ster. Ad arbor. - Am. merid. : Amazon.

penicillatum Mitt. op. cit. p. 217.

- Am. merid. : And. Quitens.

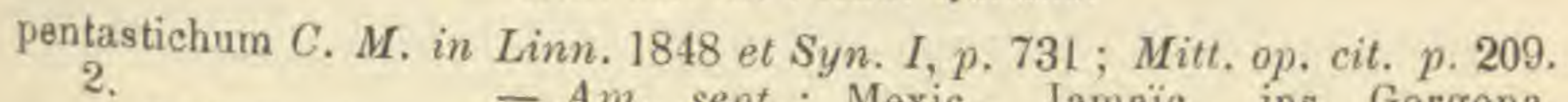

- Am. sept.: Mexic., Jamaic., ins. Gorgona,

Tabago, Am. merid. : Guian. batav., M. Chimborazo.

peraristatum Broth. in EEfv.... 1893.

2. Ad ramul. arb. - Fac.: Ins. Lord Howe.

perichaetiale (Hook. et Grev.) C. M. in Bot. Zeit. 1845, p. 544 et Syn. I,

p. 733 ; Mitt. op. cit. p. 216.

Leiotheca perichaetialis Brid. Bryol. univ. I, p. 731.

M. truncatum C. M. ( fid. Mitl.

Orthotrichum perichaetiale H. et Grev. in op. cit. p. 127, t. 6. 2? $\quad$ Schlotheimia perichaetralis Schwaegr. Suppl. II, II, I, p. $56, t, 169$.

S. Vincent Am. Am. sept. : Antill. gall., Porto-Rico, ins, perpusillum C. M. in Linn. 1876, p. 640.

Perrottetii C. M. Syn. I, p. 721 ; Mitt. M. Ind. or. p. 49.

M. tenue Mont. M. Neelgher.

1.

- As. : Sikkim, M. Neelgher., Ceylan.

phyllorhizans C. M. in Besch. Not. M. Parag. p. 262.

Ad arbor. - Am. merid. : Paraguay.
Exs. : Bal. P1. Parag. n. 59, 1237, 1240.

pileatun Wils, - M. Moorcroftii.

piliferum Sclwoaegr. Suppl. II, II, I, p. 66, t. 172; Brid. Bryol. univ. I,

p. $597 ;$ C. M. Syn. I, p. 730

Orthotrichum piliferum W. Arn. Disp. M. p. 16.

p. 477.

2. Ad arbor. - Pac. : Ins. Sandwic. ; Nov. Zeland. ?

piriforme C. M. Syn. II, p. 645 ; Mutl. M. austr. am. p. 206.

2. Ad arbor. - Am. merid. : And. Venezuela. 
plano-caespitosum C. M. in Linn. 1874, p. 560.

2.

- As. : Ins. Philippin.

Poeppigii Duby Choix de crypt. ex. 1867, p. 5, c. ic.

2. - Am. merid. : And. Chilens.

Powe!lii Mitl. Sam. M. p. 168.

Ad arbor. - Pac. : Ins. Samoa.

praelongum Mitt, M. austr. am. p. 207.

S. Christoph.

- Am. sept. : Jamaic., Dominic., ins. S. Vincent,

productinerve C. M. in Dusen M. Camer. n. 662.

- Afr. : M. Cameroon.

progressum Hpe. \$ymb. 1877, p. 723.

- Am. merid. : Brasil. austr. or.

proliferum Mitt. op. cit. p. 217.

- Am. merid. : And. Nov. Granat., Brasil. tropic.

prolongatum Mitt. in Trans. of the Linn. Soc. !891, p. 162.

- As. : Japon.

prolongatum C. M. - M. catharinense.

prorepens (Hook.) Schwasgr. Suppl. II, II, I, p. 62, t. I71 ; C. M. Syn. I,

p. 725 ; Fl. of the N. Zeal. II, p. 79 et Handb. p. 431.

Leiotheca prorepens Brid. Bryol. univ. I, pp. 305, 727, 795.

Orthotrichum prorepens Hook. M. ex. p. 12, t. 120.

2 ?

- Pac. : Austral., ins. Norfolk, Nov. Zeland.

pseudo-fimbriatum. Hpe. Symb. 1874, p. 494.

- Am. merid. : Brasil. austr. or.

ptychomitrioides Besch. Fl. bryol. Nov. Caled. p. 208 (1).

2

- Pac.: Nov. Caledon.

Puceinianum de Not. in Jaeg. Ad., I, p. 426 (nom.).

- Am. merid. : Columb. pulchellum (Hsch.) Brid. Bryol. univ. I, pp. 313 et 737; C. M. Syn. I,
p. 722.

Orthotrichum Hornschuchii $H$. et Grev, in op. cit. p. 129, t. 6.

Schlotheimia pulchella Hsch, in Hor, phys. Berol. p. 61, t. 12.

2? Cortic. - A fr.: C. B. Sp.

Exs. : Rehm. M. Afr. austr. n. 164.

pulchrum Besch. op. cit. p, 210.

2? - Pac.: Nov. Caledon. ? punetatum (Hook et Grev.) Brid. Bryol. univ. I, p. $739 ;$ C. M. Syn. I,
p. 748 ; Mitt. M. austr. am. p. 211 .

Orthotrichum punctatum $H$. et $G r$. in op, cit. p. 119, $t .5$.

tens. et Peruv., Brasil.

Am. merid. : Columb., Nov. Granat., And. Qui-

pungens Mitt. in Bryol. jav. I, p. 122, t. 99 .

2.

- As. : Java.

(1) a An proprium genus Ptyehomitriella Balansae n? (Jaeg. Ad. I1, p. 630). 
pusillum Mitt. in Journ. of the Linn. Soc. 1859, p. 78; Fl Tasm. II, p. $183, t .173$, f. 5 .

M. Mülleri Hpe. ?

2? Rupic. - Pac. : Tasman.

quinquefarium Hsch. Fl. Brasil. I, p. 26; C. M. Syn. I, p. 748; Mitt. M. austr. am. p. 218.

- Am. merid. : Brasil.

ramentosum Thwo el Mill. in Journ. of the Linn. Soc. 1872, p. 301.

- As. : Ceylan.

ramosissimum Milt. op, cit. p. 205.

M. undulatum Hpe. in Ann. sc. nat. V ser, IV, p. 332.

Ster.

- Am. merid, : And. Nov. Granat.

recurvifolium (Hook, et Grev.) Brid. Bryol. univ. I, p. 740; C. M. Syn. I, p. 750; Bryol. jav. I, p. 135; Fl. of the N. Zeal. II, p. 78. - As. : Java. Pac. : Nov. Zeland.

reflexifolium Mitt. op, cit. p. 211.

- Am. sept. : Guatemala.

reflexifolium Lac. - M. celebense.

Regnellii Hpe. in C. M. Syn. I, p. 738; Mitt.op. cit. p. 210.

2. Cortic. et rupic. - Am. merid. : Brasil. or.

Rehmanni (C. M.) Par.

Dasymitrium Rehmanni C. M. in Rehm, M. Afr. austr. n. 157. $-A f r$. : C. B. Sp.

Reinwardti Schwaegr. Suppl. II, II, I, p. 69, t. 173; C. M. Syn. I, p. 735 ; Bryol. jav. I, p. 126, t. 104.

Leiotheca Reinwardti Brid. Bryol. univ. I, p. 796.

I. Ad arbor. - As. : Borneo, Java. Pac. : Ins. Societ, Taïti, Tasman.

Reinwardti $\left\{\begin{array}{l}\text { Sull. - M. owaïhense? } \\ \text { Wils. - M. fasciculare. } \\ \text { Zoll. p.p. - M. salakanum. }\end{array}\right.$

repandum C. M. in Engler's. Bot. Jahrb. 1883, p. 87 et in Forchungsreise... Bot. p. 60.

2. Ad arbor. - Pac. : Austral. (Queensland).

retusulum C. M. in Linn. 1878-79, p. 486.

2.

- Am. merid. : Venezuela.

retusum Hook. f. et Wils. Fl. of the N. Zeal. II, p. 79, t. 85, f. 86 et Handb. p. 432,

-Pac. : Nov, Zeland. sept.

rhabdocarpum Mitt. M. austr. am. p. 199 ; Lesq. et Jam. Man, p. 179.

1. - Am, sept. : Florid. Am, merid. : And. Quitens.

rhaphidophyllum C. M. in Linn. 1878-79, p. 487.
$\quad 2$.

rhizoinatosum C. M. in Besch. Fl. bryol. Réunion, elc. p. 72.

Secus rivul. - Afr. : Nossi-Be.

Richardi Schwaegr. Suppl. II, II, I, p. 70, t. 173; Brid. Bryol. univ. I, p. $798 ;$ C. M. Syn. I, p. 740; Mitt. op. eit. p. 200.

2. Ad arbor. - Am. merid, : Guian., Brasil. anstr. or. 
rufescens Besch. op. cit. p. 74.

M. Boivini C. M. in Rev, bryol.

2. Cortic. - Afr. : Ins. Borbon., Comor. magna, Madagascar sept. rugifolium C. M. in Dusen M. Camer, n. 263. - Afr. : M. Cameroon.

rugifolium C. M. - Schlotheimia. rugulosum Angstr. in Oefv... 1876, n. 4, p. 12. - Am. merid. : Brasil. austr. or.

Runcinatella C. M. in Linn. 1878-79, p. 488.

1.

- Am. merid. : Venezuela.

rupestre Mitt. in Journ, of the Linn. Soc. 1864, p. 150.

Dasymitrium rupestre Lindb. Contrib, ad fl. orypt. As. bor. p. 229.

2. Rupic. - As, : Japon.

Saddleanum Besch. in Bull. Soc. bot. Fr. 1885, p. LXI et in Miss, sc. Cap Horn, V, Bot., p. 279, t. 3, f. 13.

Ster. $\quad-$ Am, merid. : Fuegia.

salakanum C. M. Syn. I1, p. 646 ; Bryol. jav. I, p. 121, t. 98.

M. Reinwardti Zoll. Coll n. 1742 b. p.p.

1. Ad arbor. - As, : M. Java.

" var, majus Besch. Fl. bryol. Nov. Caled.p. 210.

Ut typ. - Pac. : Nov. Caledon.

Sanctae Mariae Ren. et Card. in Bull. Soc. roy. bol. Bely. 1894, 11, p. 120 et M. Masc. Mad. n. 217.

- Afr. : Ins. S. Maria Madag.

sarcotrichum C. M. in Dusen M. Camer. n. 233.

Sartorii C. M. in Linn. 1876, p. 641 .

Ad arbor. - Am. sept. : Mexic.

"var. gracilescens $C . M, l . c$.

Ut et ubi typ.

" var, robustius $C, M . l$. c.

Ibid.

Savatieri Besch. Fl. bryol. Taiti, etc., p. 25.

2. Cortic. - Pac. : Taiti.

saxatile Mitt, M. austr. am. p. 200.

Saxic. - Am, merid. : Ins. Juan Fernandez. scabrisetum Wils. in Trans. of the Linn. Soc. XX, p. 163; C.M. Syn. II,
p. 647 .

M. longifolium Hook, (fid. Mitt.).

- Am. merid. : Ins. Gallapagos.

Schaalianum C. M. in Jaeg. Ad. II, p. 689 (nom.).

- As. : Japon.

Schimperi Jaeg. Ad. I, p. 407.

M. flexuosum W. P. Seh, in Besch. Prodr. bryol, mexic. p. 45.

- Am. sept. : Mexic. (Orizaba).

Schmidii C. M. in Bot. Zeit. 1853, p. 61 ; Mitt. M. Ind. or. p. 51.

M. involutifolium Mont. M. Neelghers.

2.

- As. M. Neelgherr., Ceylan. 
Schwaneckeanum Hpe. in Lin». 185̄2, p. 360.

Ad arbor. - Am. sept. : Ins. Porto Rico.

scleropelma Ren. et Card. in Bull. Soc. roy. bot. Belg. 1892, I, p. 157.

2. Cortic. - Am. sept, : And. Costa Ricens.

scleropodium Besch. Fl. bryol. Réunion, elc, p. 69.

1? $\quad-A f r_{\text {. }}$ : Ins. Borbon.

scoparium Mitt. M. auslr. am. p. 206.

Trinitat.

- Am. sept. : Jamaic., Martinic. Am, merid.: Ins.

Scottiae C. M. in Linn. 1867-68, p. 618.

1.

- Pac. : Austral, or., Tasman.

secundum C. M. in Bot. Zeit. 1856, p. 420.

Ster.

Exs, : Rehm. M. Afr, austr. n. 168 .

Seemanni Mitt. M. Ind. or. p. 51 .

2. - As. : Ind. or., Ceylan. Afr. : Ins. S. Helena.

semi-diaphanum Ren. et Card. in Bull. Soc. roy. bot. Belg. 1893, II, Ster. p. 19 et M. Masc. Mad.n. 172.

- Afr. : Madagascar.

semi-hispidum C. M. in Dusen. M. Camer. n. 855.

- Afr. : M. Cameroon.

semi-nudum Thw, et Mitt. in Journ. of the Linn. Soc. 1872, p. 303.

- As. : Ceylan.

semi-pellucidum Dz. el Mk. in Ann. sc. nat. 1844, I1, p. 311 ; C. M.

Syn. I, p. 743; Bryol. jav. I, p. 127, t. 105.

2. Ad arbor. - As. : Borneo. Pac. : Nov. Guinea, ins. Anachoret.

Semperi C. M. in Linn. 1874, p. 559.

2.

- As. : Ins. Philippin.

serpens (Hook. et Grev.) Brid. Bryol. uuiv. I, p. 736; C. M. Syn. I, p. 739.

Orthotrichum serpens $H$. et Grev, in Brewster Edinb. Jowrn. $I, p, 119, t .5$,

2. Ad arbor. - Afr. : C. B. Sp.

serpens Mont. - M. sulcatum.

serricolum C. $M$. in Ule Bryoth. brasil. n. 21 .

- Am. merid. : Brasil. austr. or.

serrulatum Mitt,M austr. am. p. 215.

- Am. merid. : And. Quitens.

serrulatum C. M. - M. venezuelense.

Sieberi Schwaegr. - M. hemitrichoides.

sinuatum C. M, - Schlotheimia.

sordide-virens C. M. in Linn. 1871-73, p. 153.

2 .

Pac. : Austral. or. (Queensland).

Masen, et Card, in Bull. Soc. roy, bot. Belg. 1891, II, p 186 et M. 2 ?

spalhulare Mitt. -- M. japonicum.

- Afr $r$ : Madagascar.

speirostichum C.M. M. Polyn. p. 68.

2.

- Pac. : Ins. Samoa. 
spirale Hpe. mss. ; Mitt. in Trans. and Proced. of the roy. Soc. of Victoria, 1883, p. 63.

- Pac. : Absque loco (Austral, vel Tasman.).

Sprengelii C. M. - Schlotheimia.

squarrosum C.M. M. Polyn. p. 68.

- Am. merid. : Quito.

squarrosulum C. M. in Bot. Zeit. 1853, p. 61 ; Mitt. M. Ind. or. p. 49.

M. microphyllum Mont, in Perrot. M. Neelgherr. n. 58?

1.

- As. : M. Neelgherr.

stellulatum (Hook. et Gr.) Brid. Bryol. univ. pp. 314 el 741; C. M. Syn. I, p. 747; Milt, M. austr. am. p. 204.

M. Swainsoni H. $f$. et W. in Gardn. M. Brasil. n. 60.

M. xanthocarpum Hsch. $\mathrm{Fl}$. Brasil. I, p. 26.

Orthotrichum stellulatum $H$. et Grev, in op. cit, p. 119.

Schlotheimia stellulata Hseh. in Hor. phys. Berol. p. 61, t. 12.

2.

- Am. merid. : Orinoc., Brasil.

stenophyllum Mitt. op. cit.p. 215.

- Am. sept. : Jamaic.

stolonigerum C. M. in Linn. 1878-79. p. 489.

1.

- Am. merid. : Venezuela.

stratosum Mitt. op. cit. p. 199.

1.

- Am. sept. : Jamaic.

striatum Mitl. in Bryol. jav. 1, p. 134.

2.

- As. : M. Borneo.

subcirrosum C. M. in Bol. Zeit. 1862, p. 373.

2. Ad rup. trachyt. - Am. sept, : Costa Rica.

sublaeve Mitt. M. austr. am. p. 208.

- Am. merid. : And, Quitens.

submucronifolium Hpe. et C. M. in Linn. 1853, p. 499.

- Pac. : Nov. Zeland.

subnitidum C. M. in Linn. 1878-79, p. 488.

1.

- Am. merid. : Venezuela.

subpungens Hpe. in Linn, 1876, p. 249.

Lignic. - Afr. : Ins. Anjouan.

subscabrum Mitt. op. cit. p. 215.

- Am. merid. : And, Quitens.

subtile Schuaegr. Suppl. II, II, II, p. 140, t. 192 ; C. M. Syn. I, p. 744.

M, incurvifolium Mont. in Voy, au Pôle Sud.

2.

- Pac. : Taïti, ins. Eimeo.

subtortum (Hook, et Grev.) Sclwoaegr. op. cit. p. $145 ;$ C. M. Syn. I, p. 750 .

Leiotheca subtorta Brid. Bryol. univ. I, p. 'I34.

Orthotrichum subtortum $H$. et Grev. in op. cit. p. 117, t. 5.

- As. : Ind. or. Afr.: Madagasear. - As. : Ind. or. Afr. : Madagascar.
subulatum Mitt. in Trans, and Proced. of the roy. Soc. of Victoria, 1883,
p. 64 .

- Pac. : Austral. or. (Victoria).

subuligerum Bryol. jav. I, p. 124, t. 102.

2.

- As. : Celebes, M. Java. 
sulcatum (Hook. et Grev.) Brid. Bryol. univ. I, pp. 319 et 738 ; C. M.

Syn. I, p 738; Fl. of the N. Zeal. 11, p. 77 et Handb, p. 428.

M. corrugatum Wils. in Kew Journ. bot. IX, p. 328 .

M. longifolium ej, $l$, $e$.

M. neelgheriense C.M. Syn. I. p. 737.

M serpens Mont. M. Neelgher.

Orthotrichnm sulcatum $H$. et Gr. op. cit. p. 129.

Schlotheimia sulcata Hook. M. ex. p. 14, t. 156.

2. Ad arbor. - As. : Nepal., Khasia, M. Neilgherr., Rombay, Madras, Ceylan, penins. Malay., Borneo. Pac. : Nov. Zeland.

"var. Iutescens C. M. in Jaeg. Ad. I, p. 425.

Ubi?

Sullivantii C. M. in Bot. Zeit. 1862, p. 361; Lesq. et Jam. Man. p. 178, t. 2.

M. Dregei Sull. M. of U. St. p. 35 et Ic. M. p. 59, t. 37.

1. Ad arbor. - Am. sept. : Georgia.

Exs. : Sull. et Lesq. M. bor. am. I ed. n. 128, et II ed. n. 193.

Sumichrasti Duby Choix de Crypt. I867, p. 7, t. 3, f. I ; Mitt. M. austr. am. p. 203.

2. Cortic. - Am. sept. : Mexic.

Swainsoni (Hook.) Brid. Bryol. univ. I, p. 318; C. M. Syn. I, p. 747; Mitt. op. cit. p. 205.

Leiotheca Swainsoni Brid. op, cit. p. 730.

Orthotrichum Swainsoni Hook. M. ex. p. 13, t. 127.

2. Ad arbor. - Am. sept.: Cuba. Am. merid.: Nov. Granat., Brasil.

Swainsoni H. f. et W. - M. stellulatum.

tasmanicum Broth. in Oefo. of Finska Vet. Soc. Foerth. 1895, p. 60.

1. Lignic. - Pac, : Tasman.

tenax C. M, in Engler's Bot. Jahrb. 1883, p. 83 et in Forchungsreise... p. 38.

2. Ad frutic. Ericae. - Am. merid. : Fret. Magell.

lenerum Kze. - Ptychomitrium nigricans.

tenue (Hook, el Grev.) Brid. Bryol, univ. I, p. 740 ; C. M. Syn. I, p. 720.

Maschalocarpus declinatus Spreng. Syst. veg. IV, I, p. 158.

Orthotrichum tenue $H$, et Giev. in op. cit. p. 120, t. 5 .

- Afr.: Transvaal, Natal, ins. Borbon.

Exs. : Rehm. M. Afr, austr. n. 161 et 511.

var. bracheypus C. M. - M. confusum.

"var: brevirameum Rehm, M. Afr. austr. n. 512.

- Atr. : Transvaal.

" var. leptocladum C. M. in Rehm. l. c, n. 163.

- Afr. : C. B. Sp.

tenue Mont. - M. Perrottetii.

tersum Wils. - M, ceylanicum.

thraustophyllum C. M. in Dusen M. Camer. n. 15?.

- Afr. : M. Cameroon.

Tocaremae Hpe. in Linn. 1861-62, p. 524; Mitt. op. cit. p. 206.

2. Ad arbor. - Am, merid. : And. Nov, liranat, 
tomentosum Hsch. Fl. Brasil. I, p. 21; C. M. Syn. I, p. 734; Mitt. op. cit. p. 204 (1).

2 . - Am. sept. : Mexic. Am. merid: Monte Vìdeo.

Tonduzii Ren. et Card. in Bull. Soc. roy. bot. Belg. 1892, I, p. 151. 1. - Am. sept. : Costa Rica.

tongense Sull. in Am. Expl. Exped. p. 7, t. 5.

Leiostoma tongense Mitt. in Proced. of the Linn. Soc. 1879 (extra vol.), p. 99.

(ins. Pinorum). - Pac. : Ins. Tonga, Lord Howe, Nov. Caledon.

tortuosum W. P. Sch. in Besch. Prodr. bryol. Mexic. p. 45. - Am. sept. : Mexic.

tortuosum Wils. - M. Moorcroftii.

torulosum Mitt. M. Ind. or. p. 53.

2?

- As. : Ceylan.

trachypodium Mitt. M, austr. am. p. 213.

- Am. merid. : And. Quitens.

Trianae C. M, in Bot. Zeit. 1857, p. 580.

2.

- Am. merid. : And. Nov. Granat.

trichomilrium C. M. - Schlotheimia.

trichophyllum Mitt. op. cit. p. 207.

- Am. merid. : And. Quitens.

truncatum C. M. - M. perichaetiale.

tumidulum Mitt, op, cit. p. 201.

Cortic., rar. saxic. $-A m$, merid. : And. Peruv.

turgidum C. M. in Dusen M. Camer. n. 274.

- Afr. : M. Cameroon.

tylostomum Mitt. - Micromitrium.

ulophyllum Mitt. op. cit. p. 206.

- Am. merid. : And, Quitens.

Ulota W. P. Sch, in Breutel M. Capens.

- Afr. : C. B. Sp.

uncinatum C. M. in Bot. Zeit. 1853, p. 62.

M. incurvifolium Mont. in Perrot. M. Neelgher, n. 61 ?

M. Müllerianum Mitt. M. Ind. or. $p_{+} 51$.

2.

- As, : M. Neilgherr. Afr. : C. B. Sp.

uncinatum Brid. - M. fimbriatum.

undatifolium $C . M$. in Fl. 1886, p. 278.

2. Ad arb. - $A f r$. : Ins. S. Thom.

undulatum (Hook. et Grev.) Schwaegr. Suppl. II, II, II, p. 137; O.M. Syn. 1, p. 749; Bryol. jav. I, p. 134.

Leiotheca undulata Brid. Bryol. univ. I, p. 733.

Orthotrichum undulatum $H$, et Grev. in op. eit. p. $117, t .4$.

- As. : Ins. Ternate. (1) a An propr. gen, : Brachymitrium tomentosum? " (Hpe., das Moosbild,
p. 8). 
undulatum Hpe. - M. ramosissimum.

urceolatulum C. M. in Abhandl. Brem. VII, p. 208.

2.

- Afr. : Madagascar.

urceolatum (Hook.) Schrodegr. Suppl. II, II, II, p. i28, I. 189; BridBryol. univ. I, p. 312 ; C.M. Syn. I, p. 726.

Leiotheca urceolata Brid. op. cit. p. 730.

Orthotrichum urceolatum Hook. M. ex. II, p. 13, t. 124.

2 .

- Afr. : Ins. S. Helena, Madagascar.

venezuelense $\boldsymbol{P a r}$.

M. serrulatum C. M. in Linn. 1878-79, p. 490.

2.

- Am. merid. : Venezuela.

vernicosum W. P. Sch, in Besch. Fl, bryol. Antill. fr. p. 28.

- Am. sept. : Guadalup.

virescens $C, M$. in Nuov. Giorn, bol. ital. 1872, p. 15.

2 ?

- Afr. : Abyssin.

viridissimum Mitt, in Trans, and Proced. of the roy. Soc. of Victoria. 1883, p. 64.

- Pac. : Austral. or. (Queensland).

viticulosum Brid. - M. brachyrhynchum.

Wagnerianum C. M. Syn. II, p. 642; Mitt. op. cit, p. 202.

2. Ad arbor. - Am. sept.: Jamaic. Am. merid.: And. Venezuel, Guian.

Weymouthii Broth. in Oefv. of Finska Vet.-Soc. Foerh. 1895, p. 50 . Ad ligna et ramul. Myrtac. - Pac. : Nov. Zeland., Tasman.

weisioides C. M. in Linn. 1871-73, p. 153.

1.

- Pac. : Austral. or.

Whiteleggei Broth. et Geh in op. et l. cc.

- Pac. : Austral. or. (Queensland, Nov. Vales.).

santhocarpum Hsch. - M. stellulatum.

Yaleanum Broth. et Geh. in op. cit. p. 58.

2. Ad ramul, arbor. - Pac. : Nov. Guinea.

Zippelii Bryol. jav. 1, p. 123, t. 100.

2. $-A s$. : Amboine.

Zollingeri Mitt, in Bryol. jav, I, p. 113, t. 90.

2.

- As. : Java (1).

Malacosphagnum C. M. in Fl. 1887, p. 404 (Sph. rigida).

Mallacodium C. M. Syn. II, p. 320 (sect. Hypnt).

MaSCHALANTHUS Sch. Fl. Starg. p, 356.

filiformis Sch. - Pterigynandrum.

(1) In Enum. Kindb. nomina nuda:

I. bifasciculatum C. M.

caloblastum C. M.

caloblastoides C. $M$.

cylindromitrium $C . M$.

dimorphum G.M.

Hahmi $C . M$.

Hartmanni $C, M$.

M. lonchomitrium C. M.

macrominides $C, M$.

Savesü C.M.

subserrulatum (C, M.) (an M, ve nezuelense?).

vittatum $C$. $M$. 
MASCHALOCARPUS Spreng. Einleit. p. 279.

argentatus Hpe, - Struckia argyreola.

declinatus Spreng. - Macromitrium tenue.

Eckloni Spreng. - Macromitrium lycopodioides.

filiformis Spruce. - Pterigynandrum.

gracilis Spreng. - Pterogonium.

intricalus Spreng. - Pylaisia.

nervosus Spreng. - Leskea.

repens Spreng. - Platygyrium.

striatus Spreng, - Lescuraea.

Weinmannianus Spreng. - Brachythecium albicans.

MEESEA Hedw. Fund. M. II, t. 9, f. $56-57$ (sub Meesia). (10 spec.).

Albertini Bryol. eur. IV (mon, p. 7), ı. 310; W. P.Sch. Syn.II ed.p. 500.

Bryum triquetrum Drumm. M. bor. am. I ed. n. 244.

Diplocomium hexastichum Funk Moostaschb, p. 43, t. 27 et in Brid. Bryol, univ. II, p. 68.

Meesea hexagoma Albert. mss, in Brid. Bryol. univ. II, p. 68; C. M. Syn. $I, p .466$.

1. In turfos. - Eur. : Neomark, Siles,, magn. Ducat. Badens., Bavar. Am. sept. : Fret. Smith., Saskatchewan.

Exs. : Un itin. 1864, n, 54.

alpina Funk, - M. uliginosa var, alpina.

angustifolia Brid. - M, uliginosa.

austro-georgica C. M. Bryol. austr. Georg. p. 31.

Ster. Aquat. - Am. mernd. : Austr. Georgia.

Bolleana C. M. in Bot. Zeit. 1862, p. 338.

Hydrogonium Bolleanum Jaeg. Ad. II, p. 669.

Ster. Ad rup. (humid, ?) - Afr. : Ins. Cap. Viridis S. Nicolas.

Un itin. 1864, n. 73

var. angustifolia Rab. - M. uliginosa var. alpina.

\section{Imaent after}

a var, minor Schwaegr. Suppl. I, I, p. 82; Bryol, eur., C. M. et W. P. Sch. ll. cc.

Amblyodon minor P. B, Prodr, $p, 41$.

Bryum trichodes vas. minor Drumm. M. box. am. I ed., n. 246.

M. minor Brid, op. eit, p. 62.

Ut typ. - Eur. : In alp. et supraalp. : Spitzberg., ins. Parry, ete. Am. sept. : Groenland, Ontario, M. Rupestr., M. Alb.

curviseta Schwaegr. - Webera polymorpha var. brachycarpa.

dealbata Hedw. - Amblyodon.

demissa H. et H. - Plagiobryum.

hexagona Alb. - M. Albertini.

longiseta Hedw. M. frond. 1, p. 36, ut. 21 et 22 ; Bryol. eur. IV

(mon. p. 6), t. 309 ; C. M. Syn. I, p. 465; W. P. Sch. op. cit. p. 500.

Amblyodon longisetus $P, B, P r o d r, p, 41$.

Diplocomium longisetum Brid. op. cit. p. 66 p.p. (1). Diplocomium longisetum Brid. op. cit. p. 66 p.p. (1).
Syn. In turfos, profund, - Eur. : Reg. campestr. et montan., rar. alp.
per zon. intermed. et septentr. As. : Jenissei. Am. sept. I Ins. Sabine, New Brunswick, Ontario, Manitoba, Ohio, Nov. Anglis.

1) « Synonyma coetera incerta, quum planta cum $M$. tristicha simili persacpe commutara sit. $₫$ C. M. L. c. 
Exs. : Rab. Bryoth, eur. n. 362, 1336.

Sull, et Lesq. M. bor. am. II ed. n. 244, 245.

Un. itin. 1867, n. 49.

longiseto triquelra Lindb. et Arn. - M. longiseto $x$ tristicha.

longiseto $\times$ tristicha (Lindb. el Arn.) Par.

M. Iongiseto $\times$ triquetra Lindb. et Ain. M. As. bon. 1890, II, p. 30.

Syn, vel dicl.

- As. : Jenissei inf.

Macounii Aust. - Amblyodon dealbatus.

macrantha Mitt. - M. Mülleri.

minor Brid. - M. uliginosa var. minor.

Millenii C. M. - Entosthodon.

Mülleri C. M. et Hpe. in Linn. 1856,p. 208.

M. macrantha Mitt. in Kew Journ. bot. VIII, p. 260; Handb. of N. Zeal. Fl. p. 444.

2. In sphagnet. - Pac. : Alp. Austral, merid. or., Nov. Zeland. merid.

nutans Willd. - Bryum longisetum.

stricta Brid, - M. uliginosa var. alpina.

slygia Brid. - Cinclidium.

trichodes Spruce - M. uliginosa.

tristicha $($ Funk) Bryal. eur. IV (mon. p. 8), t. 311 ; C. M. Syn. 1, p.664;

W. P. Sch. op, cit. p. 501 .

Bryum triquetrum Hook. et Tayl. Muscol. brit., I ed, $t, 28$.

Diplocomium longisetum Rrid. op, cit. $p, 66$ p.p.

D. tristicha Funk Moostaschb. p. 43, t. 27.

M. triquetra Angstr, in Nov. Act. Soc. Upsal. 1844, p. 357.

Mnium triquetrum L. Sp. p. 1578.

2. In turfos, profund. - Eur.: Reg. campestr. et mont. super. zon. interm, et septentr. : Spitzberg, ins. Ursorum; deest in Britann. As. : Jenissei. Am. sept.: Groenland, Anticosti, Ontario, M. Rupestr., Culumb. brit., Washington, Idaho, New Jersey.

Exs, : Mac. Canar. M. n. 157.

Rab. Bryoth. eur, n. 736 et $c$.

Sull. et Lesq. M. bor. am. Il ed. n, 246.

Un. itin. 1867, n. 40, 41, 42 ,

"var. gigantea Sanio in Hedwig. n. 3 .

Submersa. - Eur. : Boruss. or.

"var. timmioides Sanio in op. et. $l$. cc.

Ad rip. lac. - Eur.: Borussia.

triguetra Angstr. - M, tristicha.

tschutsehica C. M, in Bot. Centralbl. 1889, n. 2-4.

Ster. In palud. - As. : Penins. Tschutschica.

uliginosa Hedw, M. frond. I, p. I, ul. 1 et 2 ; Brid. Biyol, univ. II, p, 60 ;

Bryol. eur. IV (mon. p. 5), t. 308; C. M. Syn. I, p. 465; W. P. Sch.
op. cil. p. 499 .

Amblyodon uliginosus P. B. Prods, p. 41 .

Bryum trichodes $L$. Sp. M. p. 1385.

B. trichodes var. Iongiseta Dirmm. M. bor. am. I ed, n. 247.

p. $389, t$, 4ureum, eapsulis incurvis obtusis in setis longis Dill. Hist, M.

IIynum trich, $f .58$.

H. trichodes Spi. in Ann. and Mag. of nat. hist. II, 111 ser., p. 369.
. 
Mnium uliginosum Gmel. Syst. nat. p. 1329.

Mn. trichodes L. jun. Meth. M. p. 367.

Webera trichodes Hedw. Fund. M. II, p. 95.

Polyg. Ad terr. uligin, et rup. irrig. - Eur.: Reg. campestr. As.: Kamschatka, penins. Tschutschica, Jenissei inf., Sikkim, Caucas. occ. et centr. Am. sepl. : Groenland, Labrador, Anticosti, Gaspes., Nov. Scot., Ontario, Athabasca, M. Rupestr., Columb. brit, Minnesota, etc : reg. or. et centr.

Exs. : Mac. Canad. M. n. 156.

Rab. Bryoth, eur. n. 100, 439, 737.

Sull. et Lesq. M. bor, am. 11 ed. n. 247.

Un. itin. 1864, n. $76 ; 1867$, n. 35.

* var, alpina Bryol. eur., C. M. et W. P. Sch. ll. cc.

Bryum trichodes Drumm. M. bor. am. I ed. n. 245.

M. uliginosa Funk in Bot. Zeit. 1825, p. 274.

M. angustifolia Brid. op. cit. p. 62 .

M. stricta ej. op. cit. p. 61 .

M. uliginosa var. angustifolia Rab. Deutsch. Krypt. II, III, p. 195.

Ut typ. - Eur . : In subalp. et alp.

Exs. : Rab. Bryoth: eur. n. 440.

Sull, et Lesq. M. bor. am. II ed. n. 248.

vagans C. M. - Philonotis.

MEGalostyliUm $D z$, et $M k$. $M$. frond, ined. Archip, ind.

brevisetum eor. - Dicranum.

MEIOTHECIUM Mitt. in Journ. of the Linn. Soc. 1868.

Spec. omn, non indicatae sunt PTERoGONIRLLA ejusd, nom.

Fabronia Besch. - Pterogoniopsis.

MERCEYA W. P. Sch. Syn. II ed. p. 852.

latifolia Kindb. - Scopelophila.

ligulata Spr. (1) - Scopelophila.

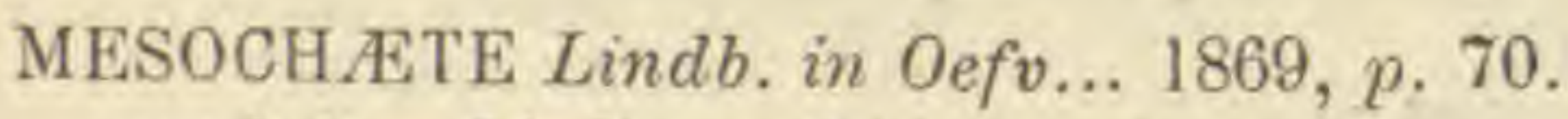

undulata Lindb. - Rhizogonium.

MESODON Hpe, in Ann. sc. nat. V ser., 1V, p. 366.

onustus Hpe. - Entodon.

? MESOTUS Mitt. in Handb. of N. Zeal. Fl. p. 462 (2 spec.).

acutus Mitt. in Trans, and Proced of the roy. Soc. of Victoria, 1883, p. 52.

Inter Sphuerophora. - Pac. : Austral., Tasman.

celatus Mill. in Handb. of N. Zeal. Fl. l. c.

Stiticola. - Pac. : Nov. Zeland, med.

METEORIUM Brid. Bryol, univ. Il, p. 264 (80 spec.).

aciculatum Mitt. - Lindigia.

acuminatum Mitt. - Garovaglia.

(I) In Enum. Kindb, nom, nudum :

M. acutiuscula Lindb. 
aeruginosum Mitt. - Papillaria.

? ambiguum (Hsch.) Mitt. M. austr. ain. p. 446.

Pilotrichum ambiguum Hsch. Fl. Brasil. I, p. 59; C. M. Syn. II, p. 157.

Ster.

- Am. merid. : Brasil. austr. or.

amblyacis Mitt. - Papillaria.

ancistrodes (Mont.) Par.

Hookeria ancistrodes Mont. in Ann. sc. nat. 1845, p. 676, in 7 ist. Chil. Bot. crypt. t. 4, f. 4 et Syll. p. 14.

Meteorium genuflexum Mitt. op. eit. p. 436.

Pilotrichum genuflexum C. M. Syn. II, p. 152.

2. Ad arbor. - Am. merid. : Chile.

ancistrodes Ren. et Card. - M. himalayense.

appressum Mitt. - Papillaria.

atro-luteum Jaeg. - Papillaria.

attenuatum Thw. et Mitt, in Journ. of the, Linn. Soc. 1872, p. 316.

Ster. - As. : Ceylan.

aureo-nitens (Hook.) Par.

Brachythecium aureo-nitens ,Jaeg. Ad. II, p. 407.

Hypnum aureo-nitens Hook. in Schwaegr. Suppl. III, 1, I, t. 221: C. M. Syn. II, p. 377 .

M. auro-nitens Mitt. M. Imd. or. p. 91.

- As. : Nepal., Sikkim, Khasia, M. Neilgherr.

aureum (Griff.) Mitt. M. Ind. or. p. 89; Bryol. jav. I, p. 91, t. 206.

Neckera aurea Griff. Not. p. 459 et Ic. pl. asiat. II, t. 87, f. 11.

Trachypodium filamentosum W.P.Sch. in Savat, M. Japon. n. 627 (f crma).

2. - As.: Himalaya, Khasia, M. Java, Japon.

auro-niten's $\{$ Mitt. (M. I. or.). - M. aureo-nitens.

Mitt. (M. a. am.). - M. Hornschuchii.

? Balansaeanum Besch, in Journ. de bot. 1890, p.

Ster.

- As. : Tonkin.

barbipendulum C. M. in Ule Bryoth, brasil. n. 65.

- Am. merd. : Brasil. austr. or.

biforme C. M. - Pilotrichella.

Billardieri Mitt. - Pilotrichella.

biplicatum Mitt. - Pterobryum.

brasiliense Sull. - M. longissimum.

brevisetum Milt. M. austr. am. p. 447.

- Am. merid. : And. Quitens.

copense Angstr. - Aërobryum pseudo-capense.

camilacer W. P. Seh. Aërobryum.

capillare Mitt. - Papillaria.

cerinum H. f. et W. - Papillaria.

commutatum Mitt. M. Ind. or. p. 89.

- As. : Sikkim. Compressum Mitt, in Trans. and Proced. of the roy. Soc. of Vicloria, 1883,
p. 83.

Ster.

- Pac. : Austral, or. (Queensland).

consanguineum Hpe. - Papillaria. 
consimile Mitt. - Pilotrichella.

convolvens Mitt. op. cit. p. 90.

- As, : Malabar, Ceylan.

cordatum (Harv.) Mitt. op. cit. p. 88.

Hypnum cordatum Harv, in Lond. Journ. of bot. 1840, p. 20 et in Hook. Ic. pl. rar. t. 24, f. 9; C. M. Syn. II, p. 451.

- As, : Nepal., Kbasia.

crassicaule $\left\{\begin{array}{l}\text { Rryol. jav. - Pterobryum. } \\ \text { Mitt. - Pterobryum ceylanicum. }\end{array}\right.$

crinitum Mitt. - Pilotrichella.

cubense Mitt. - Pilotrichella.

cuspidiferum Tayl. - Papillaria kermadecensis.

debile Wils. - Lindigia.

denticulatum Mitt. - Papillaria.

Deppii Mitt. - Papillaria.

dicladioides C. M. in Rev. bryol. 1876, p.4 (nom.).

- Pac. : Austral, or. (Nov, Vales.).

diclados W. P. Sch. in Besch. Prodr. bryol. mexic. p. 83.

Leskea heteroclados ej. in Hb. Museum Paris.

Ster,

- Am. sept. : Mexic.

dimorphum Mitt. ... Pilotrichella.

divergens Mitt. M. Ind. or. p. 87.

Ster.

- As. : Himalaya subtropic.

diversifolium Besch, op. cit, p. 82 .

2. Cortic. - Am. sept, : Mexic. (Cordoba).

Eavesianum Mitt. - Papillaria.

elongalum Mitt. - Pilotrichella.

enerve Thw. et Mitt. in op. cit. p. 317 .

Ster.

- As. : Ceylan.

erinaceum Spr. - Pilotrichella crinita.

Eurhynchium C. M. in Ule Bryoth. brasil. n. 165.

- Am. merid. : Brasil. austr. or.

excavatum Mitt. - Pilotrichella.

filamentosum (Hook.) Mitt. M. Ind. or, p. 9l.

Daltonia filamentosa W. Arn. Disp. M. p. 55.

Neckera filamentosa Hook. M. ex, $t, 158$.

Pilotrichum filamentosum Brid. Bryol. univ. II, p. 264 ; C. M. Syn. II. p. 153.

Ad arbor, - As, : Nepal., Sikkim, M. Neilgherr., Java.

filescens (Schwaegr.) Jaeg. Ad. II, p. 153.

Neckera filescens Schwaegr. in sched.

Pilotrichum filescens Duby Choix de crypt, ex. 1869, p. 13, t. 3, f. 3.

Ster. Ad arbor. - Am. sept. : Mexic.

Filicis C. M. in Ule Bryoth, brasil. n. 164.

Ad arbor. - Am. merid. : Brasil. austr. or.

filiferum Mitt. - Pilotrichella.

Filipendula H. f. et W. - Papillaria.

flaccillum Mitt. - Papillaria. 
flammeum Mitt. op, cit. p. 88. 2? - As, : Sikkim.

flexicaule H. f, et W. - Papillaria.

flexile Mitt. - Pilotrichella.

flexipes Mitt. - Garovaglia.

flexipilum Lindb. mss. ; Angstr. in Oefo... 1876, n. 4, p. 39. -- Am. merid. : Brasil. austr, or.

floribundum $\left\{\begin{array}{l}\text { Dz. et Mk. - Papillaria. } \\ \text { Sull. - Papillaria aeruginosa? }\end{array}\right.$

Foulkesianum Mitt. - Garovaglia.

frondosum Mitt. - Garovaglia.

fulvum Mitt. - Papillaria.

funale Mitt. - Pilotrichella.

fuscescens Bryol. jav. - Papillaria.

fusco-viride Mitt. - Papillaria.

genuflexum Mitt. - M, ancistrodes.

guadalupense W. P. Sch. in Besch. Fl. bryol. Antill. fr. p. 44.

2. Ster. - Anı. sept. : Guadalup.

guianense Mont. Syll, p. 24; Mitl. M. austr, am. p. 430.

- Am. merid. : Guian.

Harveyi Bryol. jav. - Papillaria semi-torta.

helictophyllum (Mont.) Mitt. Fl. Vit. p. 395.

Cryphaea helictophylla Mont. in Voy. au póle Sud, Crypt. p. 322 et Syll. p. 25.

Dendropogon helictophyllus Jaeg. Ad. II, p. 102.

Pilotrichum helictophyllum C. M. Syn. II, p. 17 .

2. Ad arbor. - Pac. : Taiti, Nuka-Hiva.

\section{helictophyllum Sull - M. intricatum?}

Henscheni C. M. mss.; Ángstr. in Oefv... 1876, n. 4, p. 38.

Ster. In aren. humid. $-A m$. merid. : Brasil, austr. or.

hexastichum Mitt. - Pilotrichella.

himalayense $P$ ar.

M. ancistrodes Ren. et Card. in Bull. Soc. roy. bot. Belg. 1895, I, p. 72.

Ster.

hispidum Mitt. - Trachypus.

- As, : Sikkim, Bhotan.

Hornschuchii Par.

M. auro-nitens Mitt. M. austr. am. p. 446 (descript fruot. in Angstr.

Pr. lin. p. 37).

Plotrichum aureo-nitens Hsch. Fl. Brasil. I, p. 59; C. M. Syn. II, p. 156.

Hookeri Mill. $M$. Ind. or, p. 86.

- As. : Sikkim, Khasia, Alp. Yunnan.

Hookeri Mitt. (1. c. p. 89). - Papillaria sparsa.

Husnoli W. P. Sch. - Porotrichum insularum.

illecebrum Mitt. - Papillaria.

imbricatum Mitt. - Pilotrichella.

implanatum Mitt. $M$. austr. am, p. 445.

2? Arbor, et rupic. - Am. merid. : Brasil. anstr. or.

imponderosum Mitt. - Lindigia. 
infuscatum Milt, M. Ind, or, p. 91 .

- As. : Sikkim.

inordinatum Mitt. - Pilotrichella.

intricatum Mitt. Sam. M. p. 171, t. 5 A.

M. helictophyllum Sull, in Wilkes Exped. p. 22?

Trachypus helictophyllus Mitt. in Bonpl. 1861, p. 366,

2. Ad arbor. - Pac. : Ins, Fidji, Samoa.

involutifolium Mitt. - Pilotrichella.

javanicum Lac. - Aërobryum.

kermadecense Mitt. - Papillaria.

Kurzii Bryol. jav. 11, p. 89, t. 204.

2. - As. : M. Java.

laevifolium Mitt. - Pilotrichella.

lanosum Mitt. - Aërobryum.

leuconeuron Dz. et Mk. - Papillaria.

leucotrichum Mitt. -- Pilotrichella.

limbatum Mitt. - Papillaria flavo-limbata.

livens Mitt. Pilotrichella.

longebarbatum Mitt. - Pilotrichella.

longissimum (Raddi) Mitt. M. austr. am. p, 436.

Hypnum longissimum Raddi Critt. Brasil. 9 ; Brid. Bryol. unir. 1I, p. 510.

Isothocium tetragonum var. piligerum Mont. in Ann. se. nat. 1839, p. 54 ?

M. brasiliense Sinll. in Am. Expl. Exped. p, 21, t. 19.

Neckera longis ina C. M. Syn. II, p. 130.

Pilotrichum citrifolium Hsch. Fl. Brasil. I, p, 60.

P. longissimum Hpe, Enum. M. Brasil. p. 4,

Ad arbor. - Am. merid. : Brasil. or.

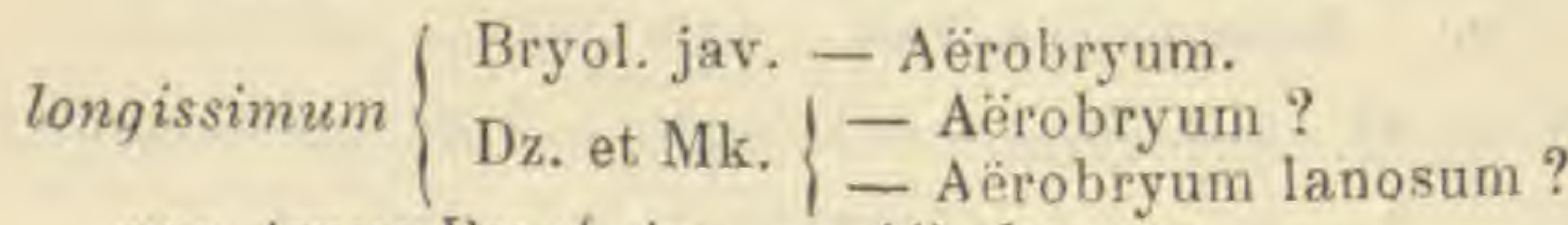

var. tenue Bryol. jav. - Aërobryım.

Lorentzi C. M. in Linn. 1874-79, p. 420.

2.

- Am. merid. : Argentin, subtropic.

luteo-nigrum C. M. in Ule Bryoth. brasil. n. 171.

- Am. merid. : Brasil, austr. or.

macranthum $\mathrm{Dz}$. et $\mathrm{Mk}$. - Pilotrichella nigricans.

macrocarpum Mitt, op. cit. p. 437.

Ad arbor. - Am. merid. : And Peruv.

maxiense Sull. - Pilotrichella

membranaceum Mitt. - Pilotrichella.

mexicanum Mitt, - Pterobryum cochlearifolium.

molle Mitt. - Pilotrichella Cumingii.

nematosum C. M. - Garovaglia.

nigrescens $\left\{\begin{array}{l}\mathrm{Dz} \text {. et Mk. - Papillaria leuconeura. } \\ \text { Mitt. - Papillaria. }\end{array}\right.$

nigricans Mitt. - Pilotrichella.

nitens $\mathrm{H}$. f. et W. - Pilotrichella.

nitidum (Wils.) Mitt. M. Ind. or. p. 87.

Pilotrichum nitidum Wils. in sched.

- As. : Sikkim, Khasia.

nitidum Sull. - Pilotrichella inordinata.

Erstedtianum Mitt. - Papillaria. 
onustum $S p r$. in Mitt. $M$, austr. am. p. 445.

2? Rupic. - Am. merid. : And. Peruv.

orbifolium Mitt. - Pilotrichella cochlearifolia. pachygaster Mitt. - Pilotrichella.

patens (Hook.) Mitt. op. et $l$. cc.

Hypnum patens Hook. M. ex, $t, 56$.

Isothecium patens Brid. Bryol, univ. II, p. 364.

Ster.

- Am. merid. : And. Nov, Granat.

patulum (Swo.) W. P. Sch. in M. Lherminier.

Hypnum cirriferum Spreng. in Brid. op. eit. p. 410.

H. patulum Sw. Prodr. p. 140 ; Brid. op. cit. p. 514.

Pilotrichum patulum Brid. op, cit. pp. 544 et 771 : C. M. Syn. II, p. 155.

2. Ad arbor. - Am. sept. : Mexic., And. Costa Ric, Cuba, Jamaic., Hispaniola, Antill. gall. Am. merid. : Guian., Amazon., And. Quitens, et Peruv.

pendulum Sull. M. of U. St. p. 81 et Ic. M. p. 117, t. 73; Lesq. et Jam. Man. p. $286^{\circ}$.

2? ot ign. Ad arbor. - Am. sept. : Ludovic, occid.

penicillatum Dz, et Mk. Prodr. fl. bryol. Surin. p. 45, $t$. II.

2. Ad arbor. - Am. merid. : Venezuela.

pensile Mitt. in Trans. of the Linn. Soc. 1891, p. 172.

Ster,

peruvianum Mitt. - Pilotrichella.

phaeum Mitt. - M. reclinatum.

phymatodes Besch. in Journ. de bot. 1890, p.

2. Ad fol, emortua. - As, : Tonkin.

piligerum C. M. in Ule Bryoth, hrasil. n. 170 .

- Ad arbor. - Am. merid, : Brasil. austr. or.

polytrichum Dz. et Mk. - Papillaria.

prolixum Bosw. in Lond. Journ. of bot. 1892, p. 97.

1? - Pac. : Austral. (Nov. Vales.),

psetido-patulum C. M. miss, ; Angstr, in Oefv... 1879, n. 4, pp. 39-40.

2?

Paiggarii (Geh, et Hpe.) Par.

- Am. merid. : Brasil. austr. or.

Pilotrichum Puiggarii $G$, et Hpe. in $\mathrm{Fl} .1881$,

- Am. merid. : Brasil. austr. or.

punctulatum (C.M.) Mitl, M. Ind. or. p. 91.

Pilotrichum punctulatum C.M. in Bot. Zeit. 1854, p. 571.

2. Ster,

- As. : M. Neilgherr., Ceylan. pusillum Hook, f. et Wils. Fl. of the N. Zeal.p. 101, t. 88, $f$ I et Handb.
p. 460 .

- Pac. : Nov. Zeland. sept.

quinquefarium Mitt. - Pilotrichella.

quitense Mitt. - Pilotrichella.

reclinatum (C.M.) Mitt. op. cit. p. 87.

M. phaeum Mitt. op. et l, cc, ; Bryol. jav. II, p. 86, t. 201.

Pilotrichum phaeum Wils. in sched.

P. reclinatum C. M. in Bot. Zeit. 1854, p. 572.

Celebes. - As.: Sikkim, M. Neilgherr., Ceylan, Java, 
recurvifolium (Hsch.) Mitt. M. austr. am. p. 444.

Neckera patula Schwaegr. Suppl. II, II, I, p. 45, t, 165 (excl. syn. Hedw. et $S w .$.

Pilotrichum patulum Brid. Bryol. univ. II, p. 759 (excl. syn. Hedw.).

P. recurvifolium Hsch. Fl. Brasil. I, p. 58; C. M. Syn. II, p. 155.

2? Ad arbor. - Am. merid. : Brasil.

Reginae Mitt, - Papillaria.

remolifolium Mitt. - Pilotrichella.

retrorsum Mitt. - Papillaria.

rigens Ren. et Card, in Bull. Soc. roy. bot. Belg. 1895, I, p. 71.

Ster. - As. : Sikkim.

rigidum Mitt. - Pilotrichella.

rotundifolium Mitt. op. cit. p. 437.

Ad arbor. - Am. merid. : Brasil.

rufifolium Thw. et Mitt. in Journ. of the Linn. Soc. 1872, p. 316.

1. - As.: Ceylan.

rugulosum Ångtr. in Oefv... 1876 n. 4, p. 38.

Ster.

- Am. merid. : Brasil. austr. or.

rutilans Bryol. jav. II, p. 90, l. 205.

2. Ad arbor. - As, : Java, Sumatra.

sarmentosum Mitt. - Papillaria.

scabriusculum Mitt, -.- Garovaglia.

scariosum Ltz. Moosst. p. 165.

Ster.

- Am. sept. : Panama.

Schmidii Mitt. - Garovaglia.

semi-tortum Bryol. jav. - Papillaria.

sericeum W. P. Seh. - Lepyrodon trichophyllus var. robustior.

serrulatum Mitt. - Trachypus?

seligerum Mitt. - Garovaglia.

sinuatum Mitt. - Pilotrichella.

solutum Milt. M. Ind. or. p. 88.

Ster.

- As. : Sikkim.

sparsum Mitt. - Papillaria.

speciosum Mitt. -- Aërobryum.

spiculatum Mitt. - Pilotrichella.

squarrosum (Hook.) Milt. op. cil.p. 87 ; Bryol. jav. II, p. 85, t. 200.

Neckera squarrosa Hook. in Wall. Cat. n. 7619; Harv. in Lond. Joxlrs. of bot. 1810, p, 14 et in Hook. Ie. pl. var. $t .22, f .3$.

Pilotrichum squarrosum C. M. Syn. II, p. 154.

2. Ad ramul. arb. - As. : Nepal., Himalaya, Khasia, Pegu, M.

Neilgherr., Madras, Ceylun, Sumatra, Java, penins. Malay.

"var. brevifolium C. M. in Nuov. Giorn. bot. ital. 1891, p. 601 (nom.).

Ster.

- As. : Birman, super.

stellatum Ltz. Moosst. p. 165 .

Ster.

Batav.

- Am. sept. : Jamaic. Am. merid. : Grian.

Stevensii Ren. et Card. in Bull. Soc. roy. bot. Belg. $1895,1, p .72$.
Ster.

- As, : Sikkim. 
sticticolum (C.M.) Jaeg. Ad. II, p. 147.

Pilotrichum sticticolum C. M. in Linn. 1874, p. 614.

Ster. Lichenicol. - Am. merid, : Nov, Granat.

stramineum (C. M.) Mitl. M. auslr. am. p. 446.

Pilotrichum stramineum C. M. Syn. II, p. 157.

Ster. Ad arbor. - Am. merid. : Chile.

striatulum Mitt. - Aërobryum.

striatum Lindb, in Oefv.... 1864, p. 603.

2. $\quad-A m$. merid. : Valdivia.

subambiguun (Hpe.) Par.

Pilotrichum subambiguum Hpe. Enum. M. Brasil. p. 46.

2. Ster. Cortic, lignic. et terr. - Am. mernd. : Brasil. austr. or.

sublivens Besch. - Pilotrichella.

subulifolium W. P. Sch. - Papillaria.

tenue W. P. Sch. in Besch. Prodr. bryol. mexic. p. 82.

Ster. --Am. sept. : Mexic. (Orizaba, Cordoba).

tenuissimum (Hook. f. et Wils.) Mitt. op, cit. p. 447. Cryphaea tenuissima $H$. f. et W. in Lond. Journ. of bot. 1846, p. 453,
$t$. $15 \mathrm{E}$.

Pilotrichum tenuissimum C.M. Syn. II, p. 174.

2. Ad arbor. - Am. merid. : And. Nov. Granat. et Quitens,

teres Mitt. - Papillaria.

Ternstroemiae Mitt. - Pilotrichella.

tetragonum Mitt, - Pilotrichella.

Thunbergii Mitt. - Pilotrichella.

tortipile Mitt. - Pilotrichella.

tovariense (C. $M$ ) Milt. op. cit. p. 444.

Hypnum patulum C. M. in Linn. 1847, p. 92.

Pilotrichum recurvifolium Hpe. op, et l. oc.

P. tovariense C. M. Syn. II, p. 156.

2.

- Am. merid. : Venezuela, And. Quitens.

trichophoroides Mitt. - Pilotrichella.

trichophorum Sull. - Pilotrichella cubensis.

tumido-aureum C. M. in Jaeg. Ad. II, p. 148 (nom.).

- As. : Sikkim.

tumidum (Dicks.) Mitt. M. Ind. or. p. 86; Bryol. jav. II, p. 85, t. 199.

Neckera tumida Dicks. miss. in Hook. M. ex. adnot. t. 158.

Pilotrichum tumidum Brid. Bryol. univ. II, p. $265 ;$; . M. Syn. II, p. 153 ,

2. Filicic. - As. : Nepal. (fid. C. M.), Madras, Ceylan, Sumatra, M. Java, ins. Ceram, Sarapsea, Celebes.

turgescens Mitt. - Pilotrichella.

ustulatum Bosw. in Lond. Journ. of bot. 1892, p. 98.

Ster. $\quad-A s$. : Ceylan.

vaginans (Welvo, et Duby) Jaeg. Ad. II, p. 150.

Neckera vaginans $W$. et $D$. in Mém... Genéve, 1871, p. 4, t. 3, f. I.

Ster. Ad ramul. Coffeae arab. - Afr. : Angola.

versicolor Mitt. - Pilotrichella.

viride Mitt. - Pilotrichella. 
viridulum Mitt, - Papillaria.

vitianum Sull. - Aërobryum.

vulcanicum Milt. Fl. Vit. p. 395.

Ster.

- Pac. : Ins. Hawaï.

Wagneri Ltz. Moosst. p. 165.

2.

- Am. sept. : Panama.

Wallichii Mitt. - Aërobryum.

Welwitschii (Duby) Jaeg. Ad. II, p. 147.

Neckera Welwitschii Duby in Mém.... Genève, 1871, t. 3, f. 2.

Ster. Ad arbor. - Afr. : Angola.

Widgrenianum (Ångstr.) Milt. M. austr. am. p, 446.

Neckera cordata Hsch, in Sellow M. Brasil.

Pilotrichum Widgrenianum Angstr. mss, et Prim. lin. p, 38 (deseript. locuplet.) ; C. M. in Bol. Zeit. 1856, p. 438.

Ster. Cortic, et lignic. - Am, merid, : Brasil, or.

Wightii Mitt. - Garovaglia (1).

METEORIDIUM $C . M$, Syn. $I I, p, 672$ (primum subsect, Neckerae, pośtea gen. propr.).

remotifolium C. M. - Pilotrichella.

METZLERIA W. P. Sch. Syn. II ed. p. 100 (I spec.).

alpina $e j . l . c$.

Atractylocarpus alpinus Lindb in Utk. till etc.

Metzleriella alpina Limpr. Laubm. Deutschl.

1. In terr. humos. turf, - Eur. : Norveg. occ., Alp. Helvet. (Faulhorn, Sustenpass), Stir., Tirol.

Exs. : Rab. Rryoth, eur. n. 1315.

MetZleriella Limpr. Lai $b m$. Deutschl. (= Metzleria).

MIGROBRYUM W. P. Sch. Syn. I ed, p. 10 (2 spec.).

Floërkeanum (Web, et Mohr ) W. P. Sch, l.c.

Acaulon Floërkeanum C. M. in Bot. Zeit. 1847, p. 99 et Syn. I, p. 21, 1I, p. $519 ;$ W. P. Sch. Coroll. p. 4.

Phascum Floërkeanum W. et M. Bot. Taschb. pp. 70 et 451 ; Brid. Bryol. univ. $I$, p. 26 ; Bryol. eur. I (mon. p. 8), t. 2.

$\mathrm{Ph}$, minutum Roehl, in Ann. d. Wett. Ges. I, p. 185.

1. In argill, denndat. humid, - Eur. : Prcecip. media. Afr.: Alger. Am. sept. : Perrar. : Illinois (semel lect.), Kansas.

Exs. : Rab. Bryoth, eur. n. 1102.

« var, badium W. P. Sch, l. c.

Acaulon Floërkeanum $\beta$ badium C. M. l. c.

Phascum badium Voit M. Herbisp. p. 7 ; Brid. op. oit. p. 27.

$\mathrm{Ph}$. Floërkeanum Voit in Sturm Fl. Crypt. II, p. 14.

Ph. Floërkeanum var, badium Brid. Mant. M. p. 5 .

Ut et abi typ. in Eur.

(1) In Enumer. Kindb. nomina nuda :

M. disciflorum Geh. et Hpe. horridum Mitt.

patentissimum $C . M$. 
a var. Henrici Ren. et Card. in Bot. Gaz. 1889, p. 91.

In arenos. - Am. sept. : Kansas.

Uleanum (C. M.) Par.

Acaulon Uleanum C. M. in Ule Bryoth, brasil, n. 2.

1. Terr. - Am. merid. : Brasil, subtropic. or.

Microcalpe Spr. Cat. ; Mitt. M. austr, am. p. 494 (sect. Semathophylli = Rhaphidostegium).

Microcarpidium C. M. in Linn. $1876, p .282$ (subsect. Hypnt=RHAPHJDosTEGIUM p. max. p.).

MICRODUS W. P. Sch. in hb. Mus. Paris (35 spec.).

afro-exiguus (C. M.) Par.

Dicranella afro-exigua C. M. in Dusen M. Camer, $n$. b. - Afr. : M. Cameroon.

apiculatus (Dz. et $M k$.) Par. Seligeria apiculata Dz. et Mk. in Zoll. Syst. Verz. I, p. 24; Bryol. jav. I,
p. 91, t. 75. 2.

austro-exiguus (C.M.) Par.

$$
\text { - As, : Java. }
$$

Angstroemia austro-exigua C. M. in Rev, bryol. 1887, p. 57.

- Pac. : Nov. Caledon.

crispulus Besch. Fl. bryol. Antill. fr. $p, 5$.

- Am. sept. : Guadalup. vel Martinic.

debilis (Hook. f. el Wils.) Besch. in hb. Mus. Paris.

Dicranella debilis Lesq. et Jam. Man, p. 66; Mitt. M. austr. am. p. 30 p.p.

Dicranum debile H. f. et $W$, in Drumm. M. bor, am. I ed. n. 5l, II ed. $n .51$ et $52 ;$ Sull. M. of U. St. p. 21 et Ic. M. p. 33, t. 20.

2. Terr. - Am. sept. : de Carol. merid. ad Florid.; Cuba.

Exs. : Sull. et Lesq. M. bor. am. If ed. n. 62.

densus (Hook.) Besch. in hb. Mus. Paris,

Dicranella densa Mitt, op. cit. p. 36.

Dieranum densum Hook. M. exot. $t .140$; Brid. Bryol. univ. $1, p .464$;

2. Rupic. - Am. merid. : And. Nov. Granat., Quitens. et Peruv euchlorus (Mont.) Besch, l. c.

Angstroëmia euchlora $C . M$. Syn. I, p. 442.

Jicranella euchlora Ltz. in Bot. Zeit, 1866, p. 186; Mitt. op. eit. p. 35.

Dicranum euchlorum Mont. in Amn. sc. nat. $1845, I \mathrm{~V}, \mathrm{p} .112 \mathrm{et}$. Syll.
p. 45 .

1. Rupic. et lignic. - Am. merid. : Chile.

exiguus (Schwoagr.) Besch, l. c.

Angstroëmia exigua $C . M$. Syn. I, p. 444.

Coscinodon longirostris Hsch. Fl. Brasil. I, p. 9.

Dicranell aum debile Jaeg. Ad. p.p. (excl. syn. Hsch.).

Weisin exigugua Mitt. M. axstr, am. p. 30.

2. Ad exigua Schwaegr. Suppl. II, II, II, t. 179. Ins, Trinitat. - Am. sept. : Cuba, ins. S. Vincent. Am. merid. : 
flaccidulus (Mitl.) Besch. l. c.

Dicranella flaccidula Mitt. Sam. M, p. 177.

Leptotrichum flaccidulum ej. in Bonpl. 1861, p. 365 .

Seligeria flaccidula C. M, in Jaeg Ad. II, p. 659 .

- Pac. : Ins. Samoa, Viti.

globicarpus (C. M.) Par.

Seligeria globicarpa C. M. in Linn. $1878-79, p$. 659.

2.

- Am. merid. : Venezuela.

Hilarianus (Mont.) Besch.l. c.

Angstroemia Hilariana C. M. Syn. I, p. 442.

Dicranella Hilariana Mitt. op. eit. p. 31.

Dicranum Hilarianum Mont. in Ann. sc. nat. 1839, p. 52, t. I, f. 2 et Syll. p. 44.

D, innovans C, M. in Bot. Zeit. 1844, p. 709.

D. parvulum var. H. f. et W. in Lond. Joum. of bot. 1844, p. 151.

D. Sellowii Hsoh. Fl. Brasil. I, p. 14.

2. Terr. - Am. merid. : Brasil. austr. or., Monte Video.

infuscatus (Thw. el Mitt.) Par.

Dicranella infuscata $T$, et M. in Journ. of the Linn. Soc. 1872, p. 295. 1 . - As. : Ceylan.

integer (C.M.) Par.

Angstroemia integra $C . M$. in Bot. Keit. 1857, p. 777.

2.

- Pac. : Ins. Fidji.

Liebmanni W. P. Sch, in Besch. Prodr. bryol. mexic. p. 18.

Angstroemia microdonta $C . M$. Syn. II, p. 606.

Dicranoweisia microdonta W. P. Sch. in sched. olim.

Dicranum microdus Kze. in hb. Mus. Paris.

2. Ad terr. argill. - Am. sept. : Mexic.

limosus Besch. Fl. bryol. Réunion, etc. p. 16.

1. Ad terr. et in sabulos. - Afr. : Ins. Mayotte, Nossi Be, Madagascar.

Lindigianus (Hpe.) Besch. in hb. Mus. Paris.

Dicranella Lindigiana Mitt. M. austr. am. $p_{.} 30$.

Seligeria Lindigiana Hpe. in Ann. sc. nat. N. ser. III, p. 353.

- Am. merid. : And. Nov, Granat.

linearifolius (Hsch.) Par.

Seligeria linearifolia C. M. Syn. II, p. 604; Bryol. jav. I, p. 92.

Weisia linearifolia $H$ sch, in Schwaegr. Suppl. II, II, II, p. 92, t. 179.

2.

- As. : Java.

longirostris (Schwaegr.) W. P. Sch. in Besch. Prodr. bryol. mexic. p. 13.

Coscinodon longirostris Brid. Bryol. univ. I, p. 376.

Dicranella Duchassaingii W. P. Seh. in Husn. M. Antill, n. 124,

D. longirostris Mitt, op. cit. p. 30.

Leptotrichum longirostre C. M. in Bot. Zeit. 1847, p. 806.

Seligeria longirostris ej. Syn. I, p. 421.

Trematodon Iongirostris Schwaegr. Suppl. I, p. 343.

Weisia Belangeriana Mont. hb. (Mus. Paris).

W. longirostris Schwaegr. Suppl. II, I, p. 54, t. 117. 2. Rupic. - Am. sept.: Mexic. (Orizaba), Guadalup. Am. merid.
Brasil.

lutarius Besch. Fl. bryol, Réunion, etc. p. 16. 
Martianus (Hpe.) Besch. l. C.

Angstroemia Martiana Hpe.Symb. 1872, p. $4 \mathrm{l}$.

Cynodontium debile Jaeg. Ad. p.p. (excl. syn. Sohrcaegs., C. M, et Mitt. loc. insul., ic, et exs.).

Dicranella Martiana Hpe. Enum. M. Brasil. p. 14.

Dicranum parvulum Hsch. Fl. Brasil. I, p. 14 p.p.

2. Ad terr, argill. - Am. merid. : Brasil, austr. or.

minutus (Hpe.) Besch, op, cit. p. 17 .

Ångstroemia minuta Hpe. in Linn. 1874, p. 209.

- Afr. : Madagascar.

Miquelianus (Mont.) Besch. in hb. Mus. Paris.

Seligeria Miqueliana C. M. Syn. I, p. 423 ; Bryol. jav. I, p. $90, t .74$.

Weisia macrorhyncha Mont. in Ann. so. nat. 1845, IV, p. 117 et Syll. p. 48 .

W. Miqueliana ej. $l l . e c, p p, 118$ et 48.

2. In terr. argillos. - As. : Borneo, Java, ins. Banca.

nitidulus (Mitt.) Par.

Leptotrichum nitidulum Mitt. in M. herb. Hook. et in Trans, of the Linn. Soe. $X X I I I(1860), p .5 \mathrm{~L}, t .5, f .1$.

2. Terr. - Afr. : Niger.

ovatus Besch, Prodr. bryol, mexic. p. 18.

2.

$$
\text { - Am. sept. : Mexic. }
$$

pallens (Hook. f. et Wils.) Par.

Seligeria pallens $C . M$. Syn, I, p. 423.

Weisia pallens $H$. f. et W. in Hook. Io, pl. rar, t. 739 A.

2 ?

- Pac. : Austral, or.

pallidisetus (Schwaegr.) Besch, Fl. bryol. Réunion, elc. p. 17.

Coscinodon pallidisetus Brid. Bryol. univ. $1, p .377$.

Seligeria pallidiseta $C, M$. Syn. I, p, 422.

Weisia pallidiseta Schooagr. Suppl. II, p. 54, t. 117.

2.

- Afr. : Madagascar.

paraguensis Besch. in Journ. de bot. 1890, p.

$2 . \quad-A m$, merid. : Paraguay.

Exs. : Bal, PI. Parag. n, 366l.

pomiformis (Griff.) Besch, in hb. Mus. Paris.

Angstroemia exigua Wils, in Kew Journ. bot. IX, p. 296.

Dicranella pomiformis Jaeg. Ad. I, p. 76.

Didymodon pomiformis Griff. Not, p. 431 et Ic. pl. asiat. II, t. 80, t. 3.

Leptotrichum pomiforme Mitt. M. Ind. or. $p, 8$.

2. Rupic, et ad terr. argill. - As. : Himalaya or, Khasia, Ceylan.

pseudo-debilis (C.M.) Par.

Angstroemia pseudo-debilis C. M. in Journ, of bot. 1877, $p$. (nom.'.

pusillus (Hpe.) Besch. . l. c, - Am. sept. : Costa-Rica.

Angstroemia pusilla Hpe. in Ann, se, nat, V ser., III, p. 358.

Dicranella pusilla Mitt. M. austr, am, p. 31. - Am. merid. : And. Nov. Granat.

Postratus (C. M.) Beseh. l. c.,

Seligeria rostrata C. M. in Linn. 1878-79, p. 469. 2.

- Am. merid. : Venezuela. 
Sartorii W, P. Sch, in Besch. Prodr. bryol, mexic. p. 18.

2.

- Am. sept. : Mexic.

subangulatus (Mitt.) Besch, in hb. Mus. Paris.

Dicranella subangulata Thw. et Mitt. in Journ. of the Linn. Soo. 1872, p. 296.

2.

- As. : Ceylan.

tenuirostris (Kze.) Besch. l. c.

Angstroemia tenuirostris C. M. Syn. I. p. 441.

Dicranella tenuirostris Mitt. M. austr. am. p. 30.

Dicranum tenuirostre Kze, in Poepp. Pl. Chil. III, n. 232 et in Schovaegr. Suppl, IV,p. 3C8.

2.

- Am. merid. : Guian.

tenuis (Kze.) Par.

Dicranella Kunzeana Mitt. op. oit. p. 34.

Leptotrichum Kunzeanum C. M. in Bot. Zeit. 1847, p. 806.

Seligeria Kunzeana C. M. Syn. I, p. 421 et II, p. 604.

Weisia tenuis Kze, in Poepp. Pl. Chil. IV,n. 230.

2.

Chile.

- Am. sept.: Costa-Rica. Am. merill. : Peruv.,

MICROMITRIUM W. P.Sch, herb, (6 spec.).

brevicaule Besch. Fl. bryol. Nov. Caled. p. 211.

1. Cortic. - Pac. : Nov. Caled.

chimborazense (Spr.) Jaeg. Ad. 1, p. 435.

Macromitrium chimborazense Spr, in Mitt. M. austr. am. p. 218.

- Am. merid. : M. Chimborazo.

fragile (Mitt.) Jaeg. l. c.

Macromitrium fragile Mitt. op, et l. oc.

ते et fr. ign.

- Am. sept. : Guadalup. Am. merid.:

Amazon.

goniorhynchum (Dz. et Mk.) Jaeg. I. c. Macromitrium goniorhynchum Mitt. M. Ind. or. p. $53 ;$ Bryol. jav, I.
p. 111, t.88.

Schlotheimia goniorhyncha $D_{\text {z, et }} \mathrm{Mk}$. in $\mathrm{Pl}$, Jungh, $I, p .358$.

2. Cortic, - As, : Khasia, Sumatra, Java, Celebes.

* var, glaucescens (C.M.) Par. Macromitrium goniorhynchum var. glaucescens C. M. in Linn. I869-70,
p. 39 .

- As. : Ceylan.

Schlumbergeri W. P.Sch. in Besch. Prodr. bryol. mexic. p. 47. - Am. sept. : Mexic. (Orizaba).

tylostomum (Mitt.) Jaeg. l. c.

Macromitrium tylostomum Mitt. in Bryol. jav. I, p. 131, t. 109.

2.

- As. : Java.

MICROMITRIUM Aust. M. Appal.

Austini Aust. - Ephemerum.

megalosporum Aust. - Ephemerum tenerum.

synoicum Aust. - Ephemerum. 
MICROPOMA Lindb, in Notiz.

niloticum lindb. - Physcomitrium.

MICROSTEGIUM Lindb. in Oefv.... 1864, p. 593.

niloticum Lindb. - Physcomitrium.

MICROTHAMNIUM Mitt. M. austr. am. p. 503 ( 88 spec.).

acrorhizon (Hsch.) Jaeg. Ad. II, p. 494.

Hypnum acrorhizon Hsch. Fl. Brasil. I, p. 75; O. M. Syn. II, p. 274.

1. Ad arbor. et saxa. - Am. merid. : Brasil. or.

afro-elegantulum C. M. in Dusen M. Camer. n. 283.

- Afr.: M. Cameroon.

andicola (Hook.) Mitt. op. cit. p. 506 p.p.

Hypnum andicola Hook. M. ex. t. 83 p.p.

H. reptans C. M. Syn. II, p. 268 p.p.

Leskea andicola Brid. Bryol. univ. II, p. 297.

1 ?

- Am. merid. : And. Nov. Granat, et Quitens.

andicola Mitt. p.p. - M. volvatum.

ankeriense Kiaër in Borgen M. Mad, n. 62.

- Afr, : Madagascar.

Aptychella Broth. in Bihang till Sv. Vet.-Akad. Handl. 1895, n. 3.

1. Cortic. - Am. merid. : Brasil. or.

? argillicola Ren. et Card. in Bull. Soc. roy. bot. Belg. 1894, 11, p. 133 et M. Masc. Mad. n, 241.

Ster. In terra argill. - Afr. : Madagasc. centr.

atro-viride Besch, in Journ. le bot. 1894, p.

1. Cortic. - Am. sept. : And. Costa Ric.

aureum Besch. Fl. bryol. Réunion, etc. p. 171.

1. Cortic. - Afr. : Ins. Borbon.

Bescherellei Ren, et Card. in Bull. Soc. roy, bot. Belg. 1894, II, p. 132 et M. Masc. Mad. n. 239.

Ster. Terr. secus rivul. - Afr. : Ins, Borbon.

Ressoni Ren, el Card. in op. cit. 1893, I, p. 12:3 et M. Masc. Mad. n. 235. Ster. $\quad-A f r$ : Madagascar.

brachycarpum Ren. et Card. in op. cit. 1894, II, p. 132 el M. Masc. Mad. n. 240 .

- Afr. : Madagascar (Betzile).

brachysteliophilum C. M. in Ule Bryoth. brasil. n. 68.

- Am. merid. : Brasil. austr. or.

brachythecioides Ren. et Card. in Bull. Soc. roy. bot. Belg. 1895, I, p. 77. Ster.

- As. : Sikkim.

breviusculum Mitt. op. cit. p. 506.

1? - Am. merid. : And. Quitens.

byssicomum C. M. in Dusen M. Camer. n. 214.

- Afr. : M. Cameroon.

eampaniforme (Hpe.) Jaeg. Ad. I1, p. 493.

Chryso-Hypnum campaniforme Hpe. Symb. 1870, p. 281.

1. Cortic, - Am. merid, : Brasil, austr. or. 
camptorhynchum Jaeg. - M. Widgrenii.

caudiforme (C. M.) Par.

Hypnum caudiforme $C . M$. in Fl. $1886, p .524$.

Ster. - Afr.: Mossamedes.

chlorizans (Welw. et Duby) Jaeg. Ad. II, p. 491.

Hypnum chlorizans W. et D. in Mém.... Genève, 1871, p. 13, t. 4, f. 6.

2. Ad rivul, in silv. - Afr.: Angola.

clarescens (Wils.) Jaeg. Ad. $I 1$, p. 496.

Hypnum clarescens Wils. in sched.

Stereodon clarescens Mitt. M. Ind, or, p. 100.

2.

- As. : Himalaya occ.

decurvans Lindb. - M. substriatum.

diminutivum (Hpe.) Jaeg. Ad. II, p. 492.

Hypnum diminutivum Hpe. in Linn. 1847, p. 86; C. M. Syn. 11, p. 270.

1. Lignic. - $\Lambda$ m. merid. : Venezuela.

discriminolum Jaeg. - Hylocomium macrocarpum.

disparifolium Jaeg. - M. substriatum?

elegantulum (Hook.) Mitt. M. austr. am. p. 504.

Hypnum elegantulum Hook. M. ex. t. 84 ; Brid. Bryol. univ. II, p. 41I; C. M. Syn. II, p. 267.

H. erythropodium C. M. in Bot. Zeit. 1844, p. 742.

H. filidens ej. $l, c,\left(\mathbf{1}_{i}\right.$,

2. Cortic., liguic, et saxic. - Am. sept. : Mexic., Guadalup. Am. merid. : Venezuela, Amazon., Brasil. austr. or.

epruinosum C. M. in Ule Bryoth. brasil. n. 69.

- Am, merid. : Brasil. austr. or.

eurystomum Besch. Not. M. Parag. p. 269.

1. $\quad-$ Am. merid.: Paraguay.

Exs. : Bal. Pl. Parag. n. 1199, 1209, 1278.

expallescens (Hpe.) Jaeg. Ad. 1I, p. 491.

Chryso-Hypnum expallescens Hpe. Symb. 1870, p. 278.

2. Cortic. - Am. merid, : Brasil, austr. or.

Fabronia (Hook.) Jaeg. Ad. II, p. 492

Helicodontium Fabronia Schwaegr. Suppl. III, II, II, t. 294. Helicodontium Fabronia Schwaegr. Suppl. III, II, II, t. 294. 17 ; o. M.
Hypnum Fabronia Hook. in Lond. Jowrn. of bot. 1840, II, p.
Syn. II, p. 270 .

Leskea Fabronia Hook. l. c

Stereodon Fabronia Mitt. M. Ind. or. p. 99.

2.

- As, : Nepal., Sumatra.

flavidum Ängstr. - M. simorhynchum.

flexile Ren. et Card. in Bull. Soc. roy. bot. Belg. 1890, I, p. 185.

Ster. - Afr. : Madagascar.

frondosum (Mitt.) Jaeg. Ad. $I$, p. 495.

Stereodon frondosus Mitt. in Journ. of the Linn. Soc. 1863, p. 158.

1.

- Afr. : Ins. Fernando-Po.

(1) Cf. Mitt. op. cit. p. 505 . 
fruticellum (Mitt.) Jaeg. $l$. c.

Stereodon fruticellus Mitt. in op. et $l$. cc.

1 ,

- Ins. Fernando-Po.

glabrifolium (C, M.) Par.

Hypnum glabrifolium C. M. in Fl. 1890, p. 496.

Ster.

- Afr. : Kilima N'Djaro, Usambara.

gracile Jaeg. - Camptochaete.

heterostachys (Hpe.) Jaeg. Ad. II, p. 496.

Hypnum heterostachys Hpe. Symb. 1872, p. 519.

1. Cortic., lignic. et terr. - Am. merid. : Rrasil. austr. or.

humile Besch. Not. M. Parag. p. 269.

I?

Exs. Bal Pl -Am. merid. : Paraguay.

incompletum (Spr.) Jaeg. Ad. II, p. 493.

Hyocomium incompletum Spr. Cat. p. 17.

- Am. merid. : And. Quitens. et Peruv.

Jamesoni (Tayl.) Mitt. M. austr. am. p. 508. Hypnum Jamesoni Tayl. in Lond. Journ. of bot. 1846, p. 63; C. M.
Syn. II, p. 454.

Cortic. - Am. merid. : And. Quitens.

Langsdorffii (Hook.) Mitt. op. cit. p. 507.

Hypnum Langsdorffii Hook. in Kth. Syn. pl. Equat. I, p. 62; Brid. Bryol, univ. II, p. 391;C, M. Syn. II, p. 259.

Cortic. et lignic. - Am. merid. : Orinoc., Nov. Granat,, And. Quitens., Brasil.

Lehmannii Besch, in Journ. de bot. 1894, p.

1. Cortic. - Am. sept. : And. Costa Ric.

leptoreptans Broth, in Boll. d. Soc. Brot. VIII, 1890.

1. Ad arbor. - Af $r$ : Ins. S. Thom.

lepto-squarrosum C. $M$. in Dusen $M$. Camer. n. 840.

- Afr..: M. Cameroon.

limosum Besch. Fl. bryol. Réunion, etc, p. 172.

I. Ad terr. arenos, humid. - Afr. : Ins. Borbon.

loriforme (Hpe.) Mill. op. cit. p. 508.

Hypnum loriforme Hpe. in Linn. 1863, p. 160.

Cortic, - $A m$, merid. : And. Nov. Granat.

macroblepharum (W. P. Sch.) Besch. Fl. bryol. Taïti, etc., p. 51.

Hypnum macroblepharum W. P. Sch, in Jardin Enum. p. 20 (nom.).

1. Cortic, et rupic, in humid. - Pac. : Nuka-Hiva.

macrocarpum Jaeg. - Hylocomium.

macrodontium (Hsch.) Mitt. M. austr. am. p. 507.

Hypnum macrodontium Hsch. Fl. Brasil. I, p, 82; C. M. Syn. II, p. 276. 1.

thadagassum Besch. op. cit. p. 171.

- Am. merid. : Brasil, or.

- Afr. : Madagascar sept. occ. 
malacobolum (C. M.) Jaeg. Ad. II, p. 497.

Hypnum malacobolum C. M. Syn. II, p. 689; Bryol. jav. II, p. 154, t. 252.

2.

Java, Sumatra.

- As. : Borneo, ins. Ceram, Ternate, Celebes,

mexicanum (Besch.) Jaëg. Ad, II, p. 592.

Eurhynchium mexicanum Besch, Prodr. bryol. mexic. p. 104.

1. - Am. sept. : Mexic. (Orizaba).

mollissimum C. M. in Hildebr. M. Mad. n. 2081.

- Afr. : Madagascar.

mucidum (C.M.) Par.

Hypnum mucidum C. M. in Rev, bryol. 1887, $p 57$ (nom.).

- Fac. : Nov. Caledon.

nano-operculatum (C.M.) Par.

Hypnum nano-operculatum C. M. in op. et $l$. $c o$. (nom.).

- Pac. : Nov. Caled.

nervosum Kiaër in Borgen M. Mad. n. 61.

- Afr. : Madagascar centr.

oxypoma (Schwoaegr.) Mitt. M. austr. am. p. 505 (I).

Hypnum oxypoma Schwaegr. Suppl. III, II, I, t. 259; C. M. Syn.II, p. 453 ,

- Am. merid. : And. Peruv.

oxystegum Spr, in Mitt. op, et l. cc.

- Am. merid. : And. Peruv.

pachythecium (Hpe.) Par.

Hypnum pachythecium Hpe. Enum. M. Brasil, p. 72. - Am. merid. : Brasil. austr. or.

Palmarum C. M. in Dusen M. Camer, n. 470.

- Afr. : M. Cameroon.

paraphysale (Hpe.) Par.

Hypnum paraphysale Hpe. l. c. p. 75.

- Am. merid. : Brasil. austr. or.

patens (Hpe.) Jaeg. Ad, II, p. 472.

Chryso-Hypnum patens Hpe, in Bot. Zeit. 1870, p. 35.

1.

- Afr. : Natal.

pendulinum (Hpe.) Jaeg. Ad. 1I, p. 490.

Chryso-Hypnum pendulinum Hpe. in op. cit. p. 52.

Hypnum pendulinum Besch. Prodr. bryol. mexic. p. 109.

1.

- Am. sept. : Mẹxic. (Vera-Cruz).

perspicuum Jaeg, - M. thelistegum.

plinthophilun (C. M.) Par.

Hypnum plinthophilum C. M. in Linn, 1878-79, p. 438.

1. $\quad-A m$. merid.: Uruguay.

(1) " An ab M. elegantulo diversum ? n. Mitt. 1. c. 
prionacis C. M. in Dusen M. Camer, n. 224.

$$
\text { - Afr.: M. Cameroon. }
$$

protractulum (C. M.) Besch. Fl. bryol. Réunion, elc. p. 172.

Hypnum protractulum C. M. in Linn. 1876, p. 277.

Ster. Ad arbor. - Afr. : Ins. Anjouan.

pruinosum Ångstr. mss.; C. M. in Ule Bryoth, brasil. n. 181.

Co tic.- Am. merid. : Brasil. austr. or.

pseudo-reptans (C. M.) Jaeg. Ad. II, p. 494.

Hypnum pseudo-reptans C. M. in Bot. Zeit. 1856, p. 439.

1.

Exs. : Rehm, M. Afr. austr. n. 418.

- Afr. : C. B. Sp.

Pniggarii (Geh. el Hpe.) Par.

Hypnump Puiggarii G. el H. Enum. M. Brasil. p. 74.

1. Lignic. - Am. merid. : Brasil. austr. or.

pumilum Jaeg. - Thamnium.

reptans (Swo.) Mitl. M. austr. am. p. 506.

Hypnum pallescens W. Arn. in Brid. Bryol. univ. II, p. 386.

H. pallidum Hook, in Kunth Syn. pl. Equat. $I, p$. 63 .

H. reptans Sw. Fi. Ind. ooc. II, p. 1819; Brid. op. cit. p. H8; C. M. Syn. II, p. 268.

Isothecium pallidum Brid. op. cit. p. 386.

Leskea pallida Schwaegr. Suppl. III, II, II, t. 291.

1. Lignic. et terr. - Am. sept. : Cuba, Jamaic., Guadalup., Martinic. Am. merid. : Ins. Trinitat, Venezuela, And Quitens.; Peruv.,
Brasil.

* var. syuarrosulum Besch. Fl. bryol. Antill. fr. p. 88.

- Am: sept. : Guadalup.

rhaphidostegioides Broth. in Engler's Bot. Jahrb. 1894, p. 205.

1. - Afr.: Usambara.

" var. pallidum Broth. in op. et $l$. cc.

Cum typo.

"var, viride Broth, in op. et $l$. cc.

Cum typo.

Salleanum Besch, in litt,

Hypnum Salleanum ej. Prodr. bryol, mexic. p. 109.

2. - Am. sept. : Mexic, (Cordoba).

saproadelphus C. $M$. in Dusen $M$. Camer. n. 499.

Sellowii (Hsch.) Mitt. op. cit. p. 507 .
Hookeria Sellowi

Hypnum argute Hsch. Fl. Brasil. I, p. 66. 1.

- Am. merid. : Brasil.

serratum (P. B.) Besch. Fl. bryol. Réunion, etc. p. 170.

Hypnum serratum P. B. Prodr. p. 70; Brid. Bryol. unio. II, p. 501;

C. M. Syn. II, p. 453 .

1. Saxic, - Afr. : Ins. Borbon.

serrula (Mitl.) Jaeg. Ad. I1, p. 497.

Stereodon serrula Mitt. M. Ind. or, p. 114.

Ster, Ad filices, - As. : Himalaya. 
simorhynchum (Hpe.) Jaeg. Ad. II, p. 494.

Chryso-Hypnum simorhynchum Hpe. Symb. 1870, p. 279 et Enum. M. Brasil. p. 72.

M. flavidum Angstr. Prim. lin. p. 43.

1. Lignic. et rupic. - Am. merid. : Brasil. or.

squamulosum (C. M.) Jaeg. Ad. II, p. 490.

Hypnum squamulosum C. M. in Bot. Zeit. 1856, p. 440.

1. $\quad-$ Afr.: C. B. Sp.

stigmatophyllum (Hpe.) Jaeg. Ad. II, p. 493.

Hypnum stigmatophyllum $H$ pe. in sched.

- As. : Sikkirn.

Stuhlmanni Broth, in Engler's Bot. Jahrb. 1894, p. 205.

1. Fr. ign.

- Afr. : Regio lacustr.

subcampaniforme (Geh. et Hpe.) Par.

Hypnum subcampaniforme Geh. et Hpe. Enum. M. Brasil. p. 73.

1. - Am. merid. : Brasil.

subdiminutivum (Gelt, et Hpe). Par.

Hypnum subdiminutivam $G$, et H. 1, c. p. 75.

1. Cortic. - Am. merid. : Brasil. austr. or.

subelegantulum Broth. in Boll. d. Soc. Brot. VIII, 1890.

1. Lignic. - Afr. : Ins. S. Thom.

submicrocarpum Jaeg. - Hylocomium.

submacrodontium (Geh. el Hpe.) Jaeg. Ad, II, p. 775.

Hypnum submacrodontium G. et H. l. c. p. 72.

1.

- Am. merid. : Brasil. or.

subobscurum (Hpe.) Jaeg. Ad. II, p. 490.

Hypnum subobscurum $H_{p e}$, in Ann. sc. nat. V ser, $I I I, p .318$.

- Am. merid. : And. Nor. Granal.

subperspicuum (C.M.) Par.

Hypnum subperspicuum C. M. in Linn. 1878-79, p. 497.

1.

- Am. merid. : Venezuela.

snbstriatum Mitt. $M$. austr, am $p .504$.

Hypnum disparifolium Tayl. in Lond. Journ. of bot. 1848, p. 195 तt C. M. Syn. II, p. 439 ?

M. decurvans Lindb. (fid. Angstr. Prim. lin. p. 43).

M. disparifolium Jaeg. Ad. II, p. 496?

2? Cortic. - Am. merid. : And. Nov. Granat. et Quitens.; Brasil. or. subvolvatum (C. M.) Jaeg. All. II, p. 493.

Hypnum subvolvatum C. M. in sched.

- Am. merid. : And. Nov. Granat.

tamarisciforme (Hpe.) Jaeg. Ad. $11, p .775$.

Rhizo-Hypnum tamarisciforme Hpe. Symb. 1877, p. 734.

1.

- Am. merid. : Brasil, austr. or.

thelistegum (C. M.) Mitt. op. cit. p. 504.

Hypnum perspicunm Hpe, in Linn. 1861-62, p. 529 (fid. Mitt. 1. c.)

H. reptans Hsch. in Deppe et Schiede M. Mexic. n. 1094.

H. thelistegum C. M. Syn. II, p. 269. 
I. perspicuum Jaeg. Ad. II, p. 490.

1. Cortic. - Am. sept. : Mexic,, Cuba, Jamaic. Am. merid, : Venezuela, Amazon., Nov. Granat., And. Quitens, et Peruv., Brasil.

«var. molle (Hpe.) Par.

H. perspicuum var, molle Hpe. in Ann. sc. nat. V ser, $I I I, p .317$.

Ut typ. - Am. merid. : And. Nov. Granat.

\& var. teres (Hpe.) Par.

$\mathrm{H}$, perspicuum var. teres Hpe. $l$. c.

Ut et ubi praeced.

trichostegium C. M. in Dusen M. Camer. n. 694. - Afr.: M. Cameroon.

varieflexum (Hpe.) Jaeg. Ad. II, p. 496.

Hypnum varieflexum Hpe. in sched. - As. : Pegu.

versipoma (Hpe.) Jaeg. Ad. II, p. 775.

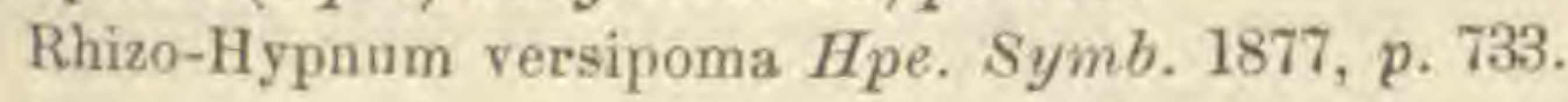

1. - Am. merid. : Brasil, austr. or.

viscidulum (Hpe.) Mitt. op. cit. p. 507.

Hypnum viscidulum $H_{p}$ e. in Ann. sc. nat. V ser., III, p. 319.

Cortic. - Am. sept. : Guatemala. Am. merid. : And. Nov. Granat. volvatum (Hpe.) Jaeg. Ad. II, p. 493.

Hypnum volvatum $H$ pe, in op. et $l$. cc.

M. andicola Mitt. p.p. (fid. Hpe.). - Am. merid. : And. Nov. Granat.

Widgrenii Angstr. Prim. lin. p. 43.

Chryso-Hypnum camptorhynchum Hpe. Symb. 1870, p. 280 et Enum. M. Brasil. p. 72 .

M. camptorhynchum Jaeg. Ad. II, p. 494.

1. Cortic. et lignic. - Am. merid. : Brasil. austr, or (1).

MICROTHECIUM W. P. Sch, in Jaeg. Ad.

Boivini ej. - Isopterygium.

Micro-Thuidium Kindb. Check-list of Eur. and N. Amer, M.p. 20.

Microweisia W. P. Sch. Syn, I ed. p. 49 (subgen. Wrisiae).

MIELICHHOFERIA Riyol. germ. 11, p. 179 (59 spec.).

acuminata C. M. in Linn. 1878-79, p. 278.

Syn.?

- Am. merid. : M. Argentin. Tucum.

andina Sull. in U. St. Expl. Exp. 1859, p. II, t. \&.

Syn.? $\quad$ - Am. merid. : And. Boliv. et Peruv.

Exs. : Mandon, Pl. Bol. n. 1651 bis.

argentifolia Mitt. M. austr. am, p. 325.

Haplodontium argentifolium Jaeg. Ad. I, p. 568 .

2.

- Am. merid. : And. Quitens.

1) In Enum. Kindb. nomina nuda:

M. longo-reptans C. M.

M. pseudo-elegans $C . M$. 
auriseta C. M. in Linn. 1878-79, p. 270.

Syn.

- Am. merid. : M. Argentin. Tucum.

"var, alpina C. M. l. c. p. 271.

Ut et ubi typ.

australis Hpe. in Linn. 1859-60, p. 626.

2. - Pac. : Alp. Austral, or.

austro-Georgica C. M. Bryol, austr. Georg. p. 17.

Ster.

- Am, merid. : Austr.-Georg.

basilaris Br. et Sch. in W. Sch. M. Abyss, n. 440; C. M. Syn. I, p. 230.

Syn.

- Afr. : Alp. Abyss., M. Cameroon.

bogotensis Hpe. in Ann. sc. nat. V ser., IV, p. 335.'

Syn. $\quad-A m$, merid. : And. Nov, Granat.

boliviana W. P. Sch, in Mandon Pl, Boliv, $n, 1649$.

- Am. merid. : And. Boliv.

Breutelii W. P. Sch, in Breutel M. Capens.

$$
\text { - Afr. : C. B. Sp. }
$$

brevicaulis Hsch. Fl. Brasil. I, p. 8, t. I, f. 2; C. M. Syn. I, p. 234.

Syn.

- Am. merid.: And. Nov. Granat., Brasil.

austr. or., Chile, Monte-Video.

campylocarpa (Hook. et Arn.) Mitt. op. cit, p. 322.

M. campylotheca C.M. Syn. I, p. 231.

Pohlia minor Hsch. in Deppe et Schiede M. Mex. n. 1078 p.p.

Weisia campylocarpa Hook. et Arn. Ic. pl. rar. t. 186.

Syn.

And. Peruv.

- Am. sept. : Mexic.(M. Orizaba). Am. merid. :

campylocarpa (Mitt. (1876). - M. kerguelensis.

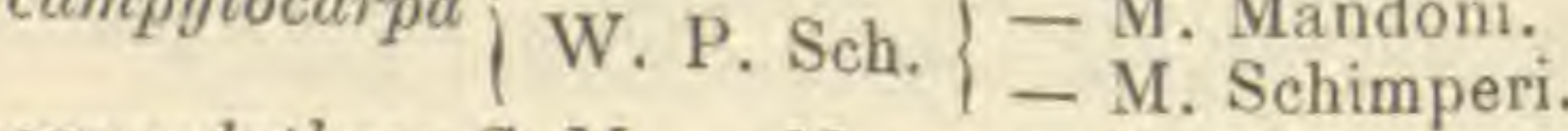

campylotheca C. M. - M. campylocarpa.

caucasica W. P. Sch. in Broth. Enum. M. Cauc. p. 31.

Syn. Spelunic. - As. : Daghestan.

chilensis $\left\{\begin{array}{l}\text { Hpe. - Brachymenium Meyenianum. } \\ \text { Mitt. - Leptochlaena. }\end{array}\right.$

clavata Br. et Sch in W. Sch. M. Abyss. n. $474 ;$ C. M. Syn. I, p. 232.

M. pallucida Hpe. Ic. M. Dec. III, t. 27.

Weisia reticulata Hook. Bot. Misc. I, 1830, p. 121, t. 29.

2.

Exs. : Rehm. M. Afr. austr, n. 208.

- Afr. : Abyss, C. B. Sp.

clavellata Mitt. op. cit. p. 321.

Syn.?

- Am. merid. : And. Nov. Granat.

coarctata C, M. in Linn. 1878-79, p, 276.

Syn.

-- Am. merid. : Argentin.

crassinervia Jur. - Bryum gemmiparum.

cuspidifera Kindb. in Mac. Cat. p. 110.

2. Ad rup. humid. - Am. sept. : M. Rupestr.

eygnicolla W. P. Sch. in Mandon Pl. Boliv. n. 165!

- Am. merid. : And. Boliv. 
defecta Sanio. - Webera erecta.

demissa C. M. in Bot. Zeit. 1858, p. 155.

2.

- Am. merid. : Chile.

densifolia Angsir. in Oef $x \ldots 1873, n .5, p .139$.

$2 . \quad-A f r$. : Ins. Franciae.

diplodonta Mitt. op. cit. p. 325.

Haplodontium diplodontum Jaeg. Ad. I, p. 568.

2.

- Am. merid. : And. Quitens.

Eckloni Hsch. in Linn. 1841, p. 118 ; C. M. Syn. I, p. 230.

Oreas capensis Br. in Coll. Zeyher.

Schizhymenium bryoides Harv, in Hook. Ic. pl. rar, III, t. 202.

Syn, Terr. - Afr. : C. B. Sp. Pac. : Austral. or. (Victoria), Tasman.

elongata Bryol. germ. - M. nitida var. elongata.

erecta Kindb. - Webera.

graciliseta Mitt. - Ieptochlaena.

himalayana Mitt. M. Ind. or. p, 65.

2.

- As. : Himalaya occ.

humipetens (C. M.) Par.

Haplodontium humipetens C. M. in Linn. 1878-79, p. 284.

Ster.

- Am. merid. : Argentin. Salt.

hymenostoma Br. et Sch. in W. Sch. M. Abyss. n. 469; C. M. Syn. 1, p. 229.

Syn.

immersidens C. $M$, in Linn. p. 270 .

- Afr : Alp. Abyss.

- Am. merid. : M, Argentin.

Jamesoni Tayl. in Lond. Journ. of bot. 1847, IV, p. 331 ; C. M. Syn. I, p. $233 ;$ Mitt. M. austr, am. p. 324 .

Bryum annotinum Brid. Bryol. univ, $I$, p. 848.

Br. turbinatum $\beta$ minus $K t h$. Syn. pl. Equin. $I, p .57$.

Didymodon megalocarpus W. Arn. Disp. M. p. 36 .

Haplodontium Jamesoni Hpe, in Ann, sc. nat. V ser., IV, p. 336.

H. megalocarpum Jaeg. Ad $1, p, 568$.

M. megalocarpa Mitt. op. cit. p. 325.

Splachnum turbinatum Brid. Bryol, univ, 1, p. 780.

Syn.

- Am. merid. : And. Nov. Granat., M. Pichinchá.

kerguelensis C. M. in Engler's Bot. Jahrb. 1883, p. 77 et in Forchungsreise.... Bot. p. 12.

M. campylocarpa Mitt. in Journ. of the Linn. Soc. 1876.

1 et syn. Rupic. - Afr. : Ins. Kerguelen.

leptoclada C, M. in Linn. 1878-79, p. 274.

Syn.

- Am. merid. : Argentin. Salt.

Lindigii Hpe. in Linn. 1861-62, p. 520 ; Mitt. M. austr, am. p. 323.

Syn. Terr. - Am. merid. : And. Nov, Granat.

longiseta C. M. Syn. 1, p. 236; Milt. op. cit. p. 321.

Bryum nutans $\beta$ minus Kth. Syn. pl, Equin. $I, p .58$. Syn.

nandez.

- Am. merid. : And. Quitens., ins. Juan Fer-

longiseta. Mitt. (Handb. p. 437). - M. tenuiseta. 
Lorentziana C. M. in Linn. 1878-79, p, 273.

Syn. - Am. merid. : Argentin. sept.

macrocarpa (Hook.) Br. et Sch. in Lond. Journ. of bot. 1843, II, p. 665.

M. nitida var. macrocarpa C. M. Syn. I, p. 235.

Weisia macrocarpa Hook, in Drumm. M. bor. am. n. 74.

2. Rupic. - Am. sept, : M. Rupestr., Mexic.

Mandoni Par.

M. campylocarpa W. P. Sch, in Mandon Pl. Boliv, n. 1654. - Am. merid. : And. Boliv.

megalocarpa Mitt. - M. Jamesoni.

microdonta Mitt. - Leptochlaena.

micropoma C. M. in Linn. 1878-79, p. 267.

Syn. - Am. merid. : Argentin. Tucum.

\& var. brunnescens C. M. op, cit. p. 268.

Ut et ubi typ.

microstoma Hpe. - M. pusilla.

nana (Tayl.) C. M. Syn. II, p. 565 ; Mitt. op. cit.p. 321.

Schishymenium nanum Tayl. in Lond. Journ. of bot. 1848, p. 191.

2 ?

- Am. merid. : And. Quitens.

nitida Bryol. germ. II, p. 183, t. 41; Bryol. eur. IV, t. 328; C.M. Syn. I, p. 234; W. P. Sch. Syn. II ed. p. 386.

Apiocarpia Mielichhoferi Hüb. Muscol. germ. p. 154.

Oreas Mielichhoferi Brid. Bryol. univ. I, p. 381.

Weisia Mielichhoferiana Funk in $H$. et $H$. Crypt. Cent. I, dec. IV to in Bot. Zeit. 1819, p. 86 .

2. Ad rup, micac., talcos,, etc. - Eur. : Alp. Salisb., Tirol., Helvet, rar. Scandin, ; Pyren. As. : Caucas. occ. et centr.

Exs. : Rab. Bryoth, eur. n. 1331.

" var. asperula Breidl. Laubm. Steierm. p. 18.

Ut typ. - Eur. : Stir., Carinth., Tirol.

"var. elongata Bryol. eur. t. $329 ;$ C. M. l. c. p. $235 ;$ W. P. Sch. op. cit. p. 387 .

Apiocarpia elongata Hüb. l. r. p. 155.

M. elongata Bryol. germ. l. c. p. $186, t .41, f .2$

Oreas elongata Brid. op. cit. $I I, p .382$.

Weisia elongata Hook. $M$. ex. II, $t .102$.

W. Mielichhoferiana $\beta$ elongata Sehwaegr. Suppl. $1 I, I, p .47$, Ł. 114.

Ut typ. - Eur. : Alp. Salisb., Gall. centr. (Arvern.), Pyren.

Exs. : Rab. Bryoth, eur. n. 675.

" var. gracilis Bryol. eur., C. M. et W. P. Sch. $l l, c c$.

Ut typ. - Eur. : Scotia (semel lect. et ster.), Alp. Salisb. ; Etrur. (?).

« var, intermedia Bryol. eur., C. M. et W. P. Sch. ll. cc.

Ut typ. - Eur. : Norveg., Alp. Salisb., Vall. Tell., Arvern., Pyren.

var. macrocarpa C. M. - M. macrocarpa.

ochracea C. M. in Linn. 1878-79, p. 275.

Syn. Terr. - Am. merid. : M. Argentin. Tucum.

ovalis Mitt. in Journ. of the Linn. Soc. 1863, p. 154.

2. - Afr. : M. Cameroon.

Pampae C. $M$ in Linn. $1880-83$, p. $36 \mathrm{~L}$.

- Am. merid. : Argentin. Buenos Ayr. 
pectinata $C . M$. in $\mathrm{Fl}$. 1875, n. 34-35.

- Am, merid. : And. Nov. Granat.

pernana (C.M.) Par.

Haplodontium pernanum C. M. in Linn. 1878-79, p. 282. 2.

-- Am. merid. : M. Argentin. Tucuman.

"var. robustior (C. M.) Par.

Haplodontium pernanum var. robustior C. M. in op. cit. p. 283.

Ut et ubi typ.

pellucida Hpe. - M, clavata.

plenrogyna Mont. in Ann. sc. nat. 1845, IV, p. 117 et Syll. p. 35 ; C, M. Syn. I, p. 233; Mitl. M. austr. am. p. 323.

plumosa C. M. in Bot. Zeit. 1862, p. 328.

Ster,

- Am. merid. : And. Peruv.

pohlioidea C. M. in Linn. 1878-79, p. 271.

Syn, $\quad-A m$. merid. : Argentin. sept.

punctulata Mitt. op. cit. p. 322.

Syn. ?

- Am. merid. : And. Quitens.

pusilla (Hook, f. et Wils.) Mitl. op, eit. p. 321.

Leptostomum pusillum H. f. et W. in Lond. Journ. of bot. 1844, III, $p, 154 ; C . M$. Syn. $I, p .188$,

M. microstoma Hpe, in Ann. sc. nat. V ser., IV, p. 325.

Syn. ?

austr. or.

- Am. merid. : And. Nov. Granat., Brasil.

rigidula W. P. Sch, in Mandon Pl. Boliv. n. 1652.

- Am. merid. : And. Boliv.

sanguinolenta (C. M.) Par.

Haplodontium sanguinolentum C. $M$. in Linn. 1878-79, p. 281. 2.

- Am. merid. sept. : Argentin. sept.

Schiedeana C. M. Syn. I, p. 230 ; Mitl. op. cit. p. 320.

Pohlia minor Hseh, in Deppe et Schiede M. Mexic, n. 1078 p.p.

Syn.

Schimperi Besch, in litt.

- Am. sept. : Mexic.

M. campylocarpa W. P. Sch, in W. Sch. M. Abyss, n. 1027.

Schimperi Dz. et Mk. - Arthrocormus.

-Afr. : Abyssin.
- Arthrocormus.
Zeit. 1853, p. 20.

- As. : M. Neilgherr.

sericea W. P. Sch. in Mandon Pl. Boliv. n. 1653.

- Am. merid. : And. Boliv.

sericea Dz. et Mk. - Hymenodon.

seriola (C. M.) Par.

Haplodontium seriolum C. M. in Linn. 1878-79, p. 284.

Ster.

serridens C. M. in Linn. 1878-79, p. 268.

Syn. $\quad-A m$. merid.: M. Argentin. Salt. et Tucum. 
Spegazzinii C. $M$. in Fl. 1885 , p. 399.

Syn. Rupic. - Am. merid. : Fuegia.

subobliqua Hpe. in Bot. Zeit. 1869.

- Am. merid. : And, Nov. Granat.

tenuiseta Mitt. in Handb. of N. Zeal. Fl. p. 750.

M. longiseta ej, in op. cit. p. 437.

1. - Afr.: 1ns, Marion. Pac.: Alp. Nov. Zeland. med.

trifaria Dz. et Mk. - Arthrocormus Schimperi.

Vallis Gratiae Hpe, mss.

- Afr, : C. B. Sp.

Exs. : Rehm. M. Afr. austr. n. 542 (1).

MILDEELLA Limpr. Deutschl, Laubm. I, p. 191. bryoides Limpr. - Phascum.

MITRAPOMA Duby Choix de Crypt. ex. 1880, p. 4. cilialum Duby. - Eriopus setigerus.

MITTENIA Lindb. in Oefv. Vet. Ak. Foerh. 1862, p. 606 (1 spec.).

Plumula (Mitt.) Lindb, in op. et $l$. cc.

Mniopsis (2) Plumula Mitt. in Journ. of the Linn. Soc. 1856, p. 94; H. f. et W. Fl. Tasman. $I I, p .187, t .173, f .7$.

2. Lignic. - Pac. : Tasman.

MNIADELPHUS C. M. in Bot. Zeit. 1847 et in Linn. 1848, p. 196 (30 spec,).

acuminatus Jaeg. - Distichophyllum.

adnatus (Hook. f. et Wils.) Jaeg. Ad. II, p. 225.

Hookeria adnata H. 1. et W. Fl. of the N. Zeal. p. 123, i. 93, f. 4 et Handb. p. 494.

1. Ad fol. emort. et Trichoman. - Pac. : Nov. Zeland, sept.

amblyophyllus (Hook. f. et Wils.) Jaeg. l. c. p, 224.

Distichophyllum amblyophyllum Mitt. in Trans, and Proced. of the roy. Soc. of Victoria, 1883, $p .7 \%$.

Hookeria amblyophylla $H$. f. et $W$. op. cit. p. 3 .

2. - Pac. : Nov. Zeland, sept. et med., Tasman.

andicola (Spr.) Jaeg. l. c. p. 222.

Distichophyllum andicola $S p r$. in Mitt. M. austr, am,p. 395 .

1. Ad arbor. - Am. sepl. : Cuba. Am. merid. : And. Quit. et Peruv. apiculatum Mitt. -- Eriopus.

(1) In Enumer, Kindb. nomen nudum:

M. Tofiana $C . M$.

(2) Nom. jam abusum: Mniopsis (gen. Hepaticarum) Dumort. Comm. bot. (2) Nom. Jam abusum: Mniopsis (gen. Hepaticarum) Dumort. Coc. Brasil.
p. 114 (1882); (gen, Podostemmearum) Mart. et Zucc. Nov. gen. et spec.
1, p. 3 (1824). 
auratus C. M. Syn: $I I, p .26$.

Distichophyllum auratum Mitt. op, cit. p. 396.

2.

- Am. merid. : Ins. Trinitat.

Beccarii C. M. - Distichophyllum.

ceylanicus Mitt, - Distichophyllum.

contortifolius (Mont.) C. M. Syn. II, p. 23.

Hookeria contortifolia Mont. in Ann. so. nat. 1843, p. 240 et Syll, p. 15.

Ster.

- Pac. : Ins. : Sandwic.

crispulus (Hook. f. et Wils.) C. M. Syn. II, p. 25.

Distichophyllum crispulum Mitt. in Trans, and Proced. of the roy. Soc. of Victoria 1883, p. 77

Hookeria crispula $H$. f. et $W$. in Lond. Journ. of bot. 1844, p. $550 ; \mathrm{Fl}$. of the N. Zeal. II, p. 122, t. 93, f. 2 et Handb. p. 493.

- Pac. : Nov. Zeland., Tasman., ins. Auckland.

cubensis (Mitt.) C. M. in Jaeg. Ad. II, p. 222.

Distichophylium cubense Mitt. op. eit. p. 395.

Hookeria adnata var. Sull. in Proced. Am. Acad.... 1861, p. 285.

1. Ad arbor. - Am. sept. : Duba.

cuspidatus C. M. - Distichophyllum.

Dicksoni C. M. - Distichophyllum.

Duseni C. $M$. in Dusen M. Camer. n. 70.

- Afr. : M. Cameroon.

elongatus (Mitt.) Jaeg. l. c.

Distichophyllum elongatum Mitt. op. cit. p. 395.

1. Ster. $\Lambda d$ rup. irror. - Am. merid. : And. Nov. Granat.

flaccidus (Hook. f. el Wils.) Hpe. in C. M. Syn. 1I, pp. 22 et 661.

Distichophyllum flaccidum Mitt. op. et $\mathrm{l}$. ce.

Hookeria flaccida $H$. f. et $W$, in Lond. Jowrn. of bot. 1844, p. 549 et Fl. 2. Antaict. II, p. 422, t. I55, $f$. 5 .

- Am. merid. : Fuegia, ins. Eremitae.

flavescens C. M. - Distichophyllum.

flexuosus (Mitt.) Jaeg. Ad. 11, p. 225.

Hookeria flexuosa Mitt. in Handb. of N. Zeal. Fl. p. 494.

- Pac. : Nov. Zeland. med.

Freycineti C. M. - Distichophyllum.

Geheebii Hpe. mss.; Jaeg. Ad. II, p. 773.

- Am. merid. : Brasil, austr. or.

gracilis Jaeg. - Distichophyllum.

Graeffeamus C. M. M. Polyn. p. 79. 1.

Griffthii Mitt. - Distichophyllum.

- Pac, : lns. Fidji.

heterophyllus Wils, - Distichophyllum.

Hornschuchii C. M. Syn. II, p. 22.

Hookeria mniifolia Hseh. in Linn. 1841, p. 141.

2? Lignic. - Afr. : C. B. Sp.

humifusus Wils, - Distichophyllum?

jungermannioides C. M. - Distichophyllum ? 
Krausei Ltz. Moosst. p. 163.

2 ? Ad rup. irror, - im. merid. : Valdivia.

limbatulus C. M. - Distichophyllum.

limpidus (Tho. et Mitt.) Par.

Distichophyllum limpidum Thu, et Mitt. in Journ. of the Linn. Soc. 1872, p. 311 .

Ster.

- As. : Ceylan.

microcarpus (Hedno.) C. M. Syn. 1I, p. 20.

Distichophyllum microcarpum Mitt. in Trans. and Proced, of the roy. Soc. of Victoria, 1883, p. 77.

Hypnum microcarpum Hedw. Sp. M. p. 214, t. 59.

H, microcranthum P. B. Prods. p. 66.

Pterygophyllum microcarpum Brid. Bryol. univ. II, p. 242.

2. Ad rup. humid, - Pac. : Nov. Zeland., Tasman.

Montagneanus C. M. - Distichophyllum.

mucronatus Jaeg. - Distichophyllum.

nanus Dz. et Mk. - Distichophyllum

obovatus Mitt. - Distichophyllum.

Palmarum (Mitt.) Jaeg. Ad. II, p. 222.

Distichophyllum Palmarum Mitt. op. cit. p. 394.

Ad arbor. - Am. merid. : And. Nov. Granat.

paradoxus C. M. - Distichophyllum.

parvulus W. P. Sch, in Besch, Fl. bryol. Antill. fr. p. 53.

1 .

- Am. sept. : Guadalup.

procumbens C. M. - Distichophyllum Eremitae.

pulchellus (Hook, f. et Wils.) Hpe. in C. M. Syn. II, p. 23.

Distichophyllum pulchellum Mitt. in Trans, and Proced of the roy. Soc. of Victoria, 1883, p. 77.

Hookeria pulchella $H$. $f$. et W. in Lond. Journ. of bot. 1844, p. 548 : $F l$. Antarct. I, p. 142, t. $62 ; \mathrm{Fl}$. of the N. Zeal. II, p. 122, t. 92, f. 8 et Handb. p. 494.

Mniodictyon pulchellum W.P. Seh herb.

2. Ad rup. aquatic. $-P a c$. : Nov. Zeland., Tasman., ins. Auckland, penins, Banks.

pungens (Milt.) Jaeg. Ad. II, p. 222.

Distichophyllum pungens Mitt. M. austr, am. p. 394.

1. Rupic. - Am. merid. And. Peruv.

pusillus (Mitl.) Jaeg. l. c.

Distichophyllum pusillum Mitt. op. et $l$. oc.

1. Ad filic. - Am. merid. : Nov. Granat.

quadrifarius (Hook.) C. M. Syn. II, p. 21. Hookeria quadrifaria Hook. M. ex. t. 119 ; Sehwaegr. Suppl. II, II, I,
p. 32, t. 162 .

Pterygophyllum quadrifarium Brid. Bryol. univ. II, p. 347.

2. Rupic, et terr, in silv, - Pac, : Nov. Zeland.

rotundifolius (Hook. f. el Wils.) C, M. Syn. II, p. 21. undifolius (Hook. f. el Wils.) G. M. Syn. II, p. 21 .
Hookeria rotundifolia H. f. et W. Fl. of the N. Zeal. II, p. 122, t, 93, f.I
et Handb. p. 493.

2. Lignic, - Pac. : Nov, Zeland, sept, et med. 
semiserrulatus (Col.) Par,

Hookeria semiserrulata Colenso in Trans, of the N. Zeal. Inst. 1888, p. 45 - Pac. : Nov. Zeland.

sinuosus (Hook. f. el Wils.) Jaeg. Ad. II, p. 224.

Distichophyllum sinuosum Mill. in Trans, and Prooed. of the roy. Soo. of Victoria, $1883, p .77$.

Hookeria sinuosa H. f. et W. Fl. Tasman, II, p. 219, t. 177, f. 3 et Handb p, 494.

2 . - Pac. : Nov. Zeland., Tasman.

spathulatus $\left\{\begin{array}{l}\text { C. M - Distichophyllum. } \\ \text { Mitt - Distichophyllum. }\end{array}\right.$

succulentus Mitt, M. Ind. or. p. 145.

2 ? Ster.

- As, : M. Neilgherr.

tortilis Jaeg. - Distichophyllum.

undulalus Jaeg. - Distichophyllum.

vitianus C. M. - Distichophyllum.

Wallisii C. M. in Fl. 1875, n. 34-35.

Ster. Filicic. - Am. merid. : And. Nov. Granat.

wawreanus Reichdt. Beitr. p. 575.

2. Ad arbor. - Pac. : Ins. Sandwic.

Zürnii C. M. et Schlieph. mss.

- Pac. : Ins. Auckland. (1).

MNIOBRYUM W. P. Sch. in Bryol. eur. conspect. subgen. Bryi; Limpr. Laubm. Deutschl. II, p. 272, gen. propr.

Spec, omnэs sunt WEBERaE ejusd. nom.

MNIODENDRON Lindb. in Oefv.... I861, p. 375 (17 spec.).

aristinerve Mill, in Journ. of the Linn. Soc. 1872, p. 322.

- As. : Borneo.

brevifolium Reichdt, in Novara Exped. Bot. p. 189, l. 34.

- Pac. : Ins. Soulou, Nov, Zeland.

camptotheca Duby in Besch. Fl. bryol. Nov. Caled. p. 2 亿3.

2. Terr. in silv. - Pac. : Nov. Caled, merid.

Colensoi Besch. .- Mn. comatum.

comatum (C. M.) Jaeg. Ad. II. p. 620.

Hyprodendron Colensoi Mitt. in Trans. and Proced. of the roy. Soc. of Victoria, 1883, p. 90 .

Hypnum comatum C. M. Syn. II, p. 692.

H. comosum Mossm. M. Nov. Zeland. n. 720.

Isothecium Colensoi $H$. $f$. et $W$. Fl. Tasm. II, p. 207, t. 176, $f, I$.

1. comatum Hook. f. Handb. of N. Zeal. Fl. p. 467.

In. Colensoi Besch. Fl. bryol. N. Caled. p. 244.

2. Ad arbor. et rup. - Pac. : Nov. Zeland., Tasman.

(1) In Enum. Kindb. nomina nuda :

$\mathrm{M}_{\mathrm{n}}$, aristatus $C . M$.

Baileyi C. M.

bogotensis Hpe.

Mn. Hahnii $C . M$. monofarius Geh. et Hpe. nigricaulis Mitt. 
comosum (la Bill.) Jaeg. Ad. II, p. 619.

Bryum dendroides Sw. Meth. M. p. 34, t. I, f. 2.

Hypnodendron comosum Mitt. in Trans, and Proced of the roy. Soc. of Victoria, $1883, p .20$.

Hypnum comosum la Bill. Pl. Nov, Holl. I1, p. 107, t. 253, f. 2; C. M. Syn. II, p. 503.

Isothecium comosum Brid. Bryol, univ. II, p. 374.

Mnium dendroides $P, B$. Prodr. p. 74 .

2. Ad rup. aquat. - Pac. : Austral. or., Tasman,, ins, Campbell.

deltoideum Thw. et Milt, in Journ. of the Linn. Soc. 1872, p. 321.

Ster. - As. : Ceylan.

divaricatım (Hsch. et Reinw.) Lindb. in Oefo.... 1861, p. 375; Bryol. jav. 1I, p. 136, t. 234 p.p.

Bryum ferrugineum Jungh, in Tidjschr, voor nat. Gesch. en Pliys. 1840, p. 293.

Hypnum divaricatum Hsch, et Reinw, in Nov. Act. Acad. Cas, Leop. XIV. $I I$, Suppl. p. 723, t. 40;C. M. Syn. II, p. 505.

2. - As. : Celebes, Borneo, Java, Sumatra, Pac.: Nov. Caled.?

Hellwigii Broth. in Engler's Bot. Jahrb. XVI, p. 29.

2. - Pac. : Nov. Guinea.

humile Lindb. in Bryol. jav. I1, p. 138, t. 235.

2. $q$ et fr. ign. - As. : Celebes.

Korthalsii (Dz. et Mk.) Bryol. jav. II, p. 139, t. 236.

Hypnum Korthalsii Dz, et Mk. in Ann. sc. nat. 1844, II, p, 307; C. M. Syn. II, p. 497.

H. trismegistum Mont. in Lond, Journ. of bot. 1844, p. 633 et in $4 n$ n. sc. nat. $1845, I V, p .87$.

2 .

Sumatra.

- As.: Japon., ins. Ceram, Batjan, M. Java,

kroneanum (C. M.) Jaeg. Ad. $I I, p, 620$.

Hypnum comosum C. M. Syn. II, p. 51$) 3$ (quoad loc, ins. Arekland).

H. kroneamum ej, in Rev. Bryol. 1877, p. 53.

2 ? Ster.

- Pac. : Ins. Auckland.

microloma Mitt. mss.; Geh. in Fl. 1886, n. 22.

- Pac. : Ins. Soulou.

Milnei Mill, in Proced. of the Linn. Soc. of N. S. Wales, 1882, p. 103.

Hypnodendron Milnei Mitt. Fl. Vit, p. 401.

Ster.

- Pac. : Ins. Nov. Hebrid. (Aneitum.).

Sieberi (C. M.) Jaeg. Ad. II, p. 619. Hypnodendron Sieberi Mitt. in Trans and Proced. of the roy. Soc. of
Victoria, 1883, p. 90.

Hypnum comosum Hsch, in Sieber M. Nov, Holl. n. 4.

H. Sieberi C. M. Syn. II, p. 504.

lsothecium Sieberi H. f. et W. Fl. Tasm. II, p. 296.

2.

ins, Auckland.

- Pac. : Austral. or. (Nov. Vales.), Nov. Zeland.,

tahiticum Besch. Fl. bryol. Tuiti, etc., p. 55.

2. Terr, - Fac, : Taïti. 
Wallisii (C. M.) Jaeg. Ad. 11, p. 62I.

Hypnum Wallisii $C . M$. in Linn. 1874, p. 571.

2.

- As.: M. ins. Philippin. (1).

MNIODICTYON W. P. Sch. herb.

pulchellum W. - Mniadelphus.

Mniolepidopilum C. M. in Fl. 1875, n. 34-35 (sect. LepidopiLi).

MNIOMALIA C. M. M. Polyn, p. 60 (4 spec.).

Bernouillii C. M. in Forchungsreise... Bot. p. 44 (nom.).

Ster.

-A A sepl. : Guatemala.

Naumanni C. M. in Engler's Bot. Jahrb. 1883, p. 84 et in Forchungsreise... Bot. p. 43.

Ster.

- Pac. : Nov. Hannov.

semi-limbata (Mitt.) C. M. M. Polyn, p. 60.

Drepanophyllum semi-limbatum Mitt. Sam. M. p. 194, t. VI E.

Ster.

- Pac.: Ins. Samoa.

viridis (Mitt.) C. M. op. cit, p. 61.

Drepanophyllum ramulinum Spr. M. And, et Amaz, n. 555.

Dr. viride Mitt. M. austr. am, p. 318.

Ster.

- Am. merid.: And. Quitens., Brasil. aequin.

MNIOPSIS Mitt, in Journ. of the Linn. Soc. 1859, p. 94.

Plumula Mitt. -- Mittenia.

MNIUM Dill., L. emend. (67 spec.).

aciculare Gmel. - Rhacomitrium.

acutum Lindb. - Mn. Trichomanes.

aculeatum Mitt. in Trans. of the Linn. Soc. 1891, p. 167.

Mn. japonicum Lindb, (fid. Beseht).

2.

- As. : Japon.

affine Bland. M. exs. fasc, III, n. 153; Bryol. eur. IV (mon. p. 30), t. 397 ; C. M. Syn. I, p. 159; W. P. Sch. Syn. II ed. p. 476.

Astrophyllum cuspidatum Lindb. M. Scand. p. 14.

Bryum aciphyllum Voit in Sturm Deutsch. Fl. II, p. 12 (excl. var.).

Beyum affine Brid. Mant. M. p. 119; Drumm. M. bor, am. I ed. n. 256.

Br. cuspidatum Schreb. Spic. Fl. Lips, p. 84.

Br. pendulum, foliis variis pellucidis, capsulis ovatis Dill. Hist. M. p. 413, t. $03, f .79$ K. L. M.

Br. polymorphum Neck. Meth. M.p. 218.

Br. Polla aftinis Brid. Bryol, univ, $I, p, 704$.

Br. Polla spinosa ej. op, eit. p. 701 p.p.

Hypnum aciphyllum $W$. et $M$. Bot. Tasohb. p. 295 p.p.

H. cuspidatum Sehrank Baïers Fl. II, p. 471 .

Mn, cuspidatum Neck. in Act. Ac. Th. Palat. II, p. 444.

Mn. cuspidatum $\beta$ affine Roehl. Deutsch. Fl. III, p. 97.

Mu, cuspidatum $\beta$ Hedw. Sp. M. p. 193, t. 45, f. 7.

Mn, serpyllifolium $\beta$ cuspidatum L. Sp. Pl. p. 1577.

(1) In Enum. Kindb, nomen nudum:

Mn, brevifolium Mitt. (nom. mutandum; $c f, n, 2$ ). 
Mn. serpyllifolium var. 2 Scop. Fl. Cain. II ed., II,p. 314 p.p.

Mn. serpyllifolium $\beta$ rotundifolium Lam. Fl. fr. I ed. I, p. 48.

Muscus squamosus foliis latis subrotundis Tournef.

Polla affinis Brid. op, cit. p. 817.

P. spinosa ej. op. et l. cc. p.p.

2. In silvat. et dumet, ad terr, humidiusc - Eur. : Reg. camp. et montana. As. : Japon.. penins. Samojed., Jenissei, Obi, Ochotsk. Caucas. occ. et or. Afr. : Alger., Madeir., Teneriff. Am. sept. : Groenland, fret. Smith, Terr. nov., ins. Miquelon, New Brunswick, Nov. Scot., Gaspes., Ontario, Manitoba, Columb. brit., Sitka, Washington, temperata tota.

Exs, : Faurie Pl. Japon. n. 16อ̄.

Mac, Canad. M, n, 193.

Rab. Bryoth, eur, n, 328.

Sull. et Lesq. M. bor, am. II ed n. 301.

Un. itin. 1867, n. 45.

var. ciliare C: M. - Mnium ciliare.

\& var. elatum Bryol. eur., C. M. et W. P. Sch, ll, cc.

Astrophyllum Seligeri Lindb. M. Scand p. 14.

Mn. insigne Mitt, in Hook, Jown, of bot. i856, p. 230; Sull. Ic. M. Suppl. p. 53, t. 37.

Mn. Seligeri Jur. mss.

In uligin. - Eur. : Pussim; Scandin. As. : Japon., Caucas. occ., Syria. Am, sept. : Ins. Miquelon, Ontario, Columb. brit., ins. Vancouver, Washington, Minnesota, Kansas, reg occ.

Ex. : Drumm. M. bor, am. II ed. p, 79.

Faurie PI. Japon. n 175.

Mac. Canad. M. n, 194.

Rab. Bryoth. eur. n. 1120 a et b, 1283 .

Sull, et Lesq. M. bor. am. II ed. n. 302.

Un, itin. 1869, n, 44.

"var. humile Milde Bryol. sil. p. 226.

In silv. Abiel. - Eur. : Baden.

* var. integrifolium Linab. in Oefv.... 1867, n. 6.

Mn. cuspidatum var, integrifolium ej. de Mn. Europ. p. 65.

$\operatorname{sia}\left(\sigma^{*}\right)$

- Eur. : Spitzberg, ins. Ursor., Alp. Scandin. ; Sile-

"var. jntermedium Kindb. in Mac. Cat. p. I39.

Mn. medium robustum ej. in Bull. Torr. Bot. Club, XVII, p. 27.

Ad terr, et rup, humid. - : New Brunswick, Columb. brit., ins.

Vancouver.

var. medium Husn, - Mnium medium.

" var, rugieum Bryol. eur., C. M. et W. P. Sch. Il. cc.

Astrophyllum rugicum Kindb. Arten Laubm. Schaced, und Nornceg. p. 61 .

Mn. insigne $\beta$ pumilum Lindb, de Mn. Europ, p, 66.

Mn. paludosum Warnst. Moosfl. Prox. Brandenb. p. 56.

Mn. rugicum Laur. in Bot. Zeit. 1827, I, p. 292. Mn. rugicum Laur. in Bot. Zeit. 1827, $I_{+}$p. 292.
Loc. siccior. frigidior. - Eur. : Passim. Am. sept. : Fret. Sraith,
Ontario, temperat.

Exs, : Drumm M. bor, am. II ed, n. 80.

Sull, et Lesq. M. bor. am. II ed. n. 303.

offine Sull. - Mn. Drummondii. 
albicans Wahlenb. -- Webera.

alpinum L. jun. - Bryum.

ambigurem H. Müll. - Mn, riparium.

annotınum L. - Webera.

androgynum L. - Aulacomnium.

angustifolium Neck. - Aulacomnium androgynum.

arcuatum Broth. Enuom, M. Caucas. p. 12. - As. : Japon.

arcuatum Dicks. - Breutelia. argenteum Hoflm. - Bryum.

Arrhenopterum Sm. p. p. - Aulacomnium heterostichum.

Auberti Schwaegr. - Bryum.

aureum P. B. - Hookeria.

$\beta$ majus Web. - Webera nutans.

australe Besch. - Mn. undulatum var. australe.

Beyrichianum Hseh. - Rhodobryum.

bicolor P. B. - Bryum atro-purpureum.

bifarium C. M. - Rhizogonium.

Blyttii Bryol, eur. - Mn. stellare.

caespiticium Brid. - Bryum.

capillaceum L. - Distichium.

capillare L. - Bryum.

carneum L. jun. - Webera.

chloroloma C. M. in Linn. p. 1880-83, p. 360.

- Am. merid.: Argentin. subtropic.

chrysocomum Hedw. - Breutelia arcuata.

ciliare W, P. Sch. op. cit. p. 477.

Astrophyllum ciliare Lindb. M. Scand. p. 14.

Bryum ciliare Grev, in Ann. of the Lye. Nov. Eborac, 1825, p. 275, $t, 23$.

Mrn. aftine var, ciliare C. M. Syn. 1, p. 159.

Mn. cuspidatum $\gamma$ ciliare Lindb. de Mn. Europ. $p, 65$.

2. Ad terr. arenos. humid. Eur. : Suecia, As. : Caucas. occ. et centr. Am. sept. : Montreal, Albany (fid. C.M.), Tennessee (fid. W. P. Sch.) (1).

cinclidioides Blytt in Hüb. Musc, germ. p. 416 ; Bryol, eur. IV (mon. p. 34), t. 402; W. P. Sch. op. cit. p. 488.

Astroribyllum cinclidioides Lindb. M. Seand. p. 13.

Bryum cinclidioides C. M. Syn. I, p. 250.

2. In prat. udis et in palud. profond. - Eur. : Scandin, Dania, Scot., Angl., Silva nigra, Boruss. oce.. Hassia, Saxon., Alp Stír., Salisb., Engad., M. Cenis, As. : Jenissei, Obi. Am. sept. : Groenland, New Brunswick, Nov, Angl., Ontario, ins. Vancouver.

Exs. : Rab. Bryoth. eur, n. 436 a etb, 1019.

Sull. et Lesq. M. bor. am. II ed. p. 295.

Un. itiu. 1867, n. 77.

cirratum L. - Dicranoweisia.

Commersonit Schwaegr. - Rhodolryum.

(1) Nec in Lesq. et Jam. Man., nec in Mac. Cat, indicatum. 
confertidens (Lindb, et Arn.) Par.

Astrophyllum confertidens L. et A. M. As. bor. 1890, II, p. 17 (1).

- As.: Jenissei.

conoideum Sm. - Zygodon.

coriaceum Griff. Not, p. 445 et 1c. pl. asiat. 11, t. 91, f. 3; Mitl. M.

Ind. or. p. 143.

Syn. Rupic. - As. : Khasia.

crispalum W. P. Sch. - Rhizogonium mierophyllum.

crispum Mitt. - Orthomnium.

crudum $\left\{\begin{array}{l}\text { Hedw. - Webera. } \\ \text { Lightf. - Mn. serratum. }\end{array}\right.$

curvatulum (Lindb.) Limpr. Laubm. Deutschl. II, p. 477.

Astrophyllum curvatulum Lindb. M. Scand. p. 14 et in Mitth. v. Soo. pro Faun, et Fl, Fenn. 1881, 2 a A pril (2).

A. medium subsp, curvatulum Kindb. Arten d, Laubm. Schwed. und Now, p. 60.

$$
\text { - Eur. : Lappon. Lul. As. : Jenissei inf. }
$$

cuspidatum Hedvo. Sp. M. p. 192, t. 45, ff. 5-7 (excl. v. $\beta$ ) ; Bryol. eur. IV (mon. p. 29), t. $396 ;$ C. M. Syn. I, p. $160 ;$ W. P. Sch. op. cit.p. 475.

Astrophyllum silvaticum Lindb. M. Scand. p. 14.

Bryum aciphyllum var. Voit in Sturm Deutsch. Fl. II, p. 12.

Br. cuspidatum Turn. M. Hibern. Spic, p, 131 .
Br. pendulum, foliis variis pellucidis, thecis ovatis Dill. Hist. M. p. 413, t. $53, f .79$ A. B. C.

Br, serpyllifolium var. $\gamma$ Huds, Fl. Angl. p. 492.

Br. Polla cuspidata Brid. Bryol. univ. I, p. 702.

Hypnum aciphyllum W. et $M$. Bòt. Taschb. p. 295 (excl. syn. Mn. affine Bland.).

Mn. serpyllifolium var. cuspidatum L. Sp. pl. I ed., II, p. 1113; Lam. Fl. fr. 1 ed., $I, p .40$.

Mn. silvaticum Lindb. de Mn. Europ. p. 59.

Polla cuspidata Brid. op. cit. p. 817.

Syn. Lignic., rupic. et terr. in silvat. - Per tot. orb. terr. (C. M.), Eur.: Vulgatiss. As.: Japon., Amour, Jenissei, Obi, Talysch. Himalaya occ., Caucas. oce. et centr. Am. sept : Terr. nov., ins. Miquelon, de New Brunswick ad Columb. brit., temperat. tota.

Exs. : Faurie Pl. Japon, n. 833, 3513.

Mac. Canad. M. n. 189.

Rab. Bryoth. eur, n. 102, 435 et b.

Sull. et Lesq. M. bor. am. Il ed. n. 300.

var. $\beta$ Hedw, $-\mathrm{Mn}$. affine.

var. affine Roëhl. - Mn. affine.

var. ciliare Lindb. - Mn. ciliare.

var. integrifolium Lindb. - Mn. affine var, integrifolium.

* var. tenellum Kindb. in Mac. Cat. p. 136.

Terr. - Am. sept. : New Brunswick.

cuspidatum $\left\{\begin{array}{l}\text { Neck. - Mn. affine. } \\ \text { Wils. - Mn. Trichomanes. }\end{array}\right.$

cyclophyllum Schwaegr. - Bryum.

cylindricum $\left\{\begin{array}{l}\text { Hoffm. - Mnium rostratum. } \\ \text { Hsch. - Mninm? (Cf. Brid. Bryol. univ. 1, p. 172). }\end{array}\right.$

(1) Ut videtur subsp. Mn, undulati.

(2) * Forsan $M$, medio nimis aff, "Lindb. 
decrescens W. P. Sch, in Savatier M. Japon. n. 476 a ; Besch, in Ann. sc. nat. 1893, p. 344.

Ster.

- As. : Japon.

decurrens C. M. et Kindb, in Bidr, p. 455 (nom.) et in Mac. Cat. p. 140. 2. Rupic. - Am. sept. : Columb. brit.

Exs. : Mac. Canad. M. n. 517.

dendroides P. B. - Mniodendron comosum.

dichotomum P. B. - Bryum.

dilatatum Wils. in Kew Journ. bot. IX, p. 368 ; Mitt. M. Ind. or. p. 143. - As. : Khasia.

dimorphum C. M. in Linn. 1878-79, p. 467.

2.

- Am. merid. : Venezuela.

distichum C, M. - Rhizogonium.

domingense Brid, - Rhodobryum Antillarum.

Drummondii Br. et Sch, in Lond. Journ. of bot. $1843,11, p .440 ; C . M$, Syn. I, p. $157 ;$ W. P. Sch. op. cit. p. 478; Suli, M. of U. St. p. 47 et lc. M. p. 83, t. 51 .

Astrophyllum Drummondii Lindb. M. Scand. p. 14.

Bryum affine Wils, in Hook. Journ. bot. 1841, p. 440.

Br. spinosum Drumm. M. bor am. I ed. n. 257 (cum Mn. spinuloso).

Mn. affine Sull. M. Allegh. p. 26, n. 92 p.p.

Syn., rar. I. Terr. in silv. humid, - Eur. : Karelia rossica, Livon., Siles. super. As. : Jenissei. Am. sept. : New Brunswick, Nov.

Scot., Gaspes., Ontario, Manitoba, M. Rupestr., Columb: brit., Oregon, M. Alb., New Hampshire, reg. sept. et or.

Exs. : Mac. Canad. M, n. I91.

Sull. et Lesq. M. bor. am. I ed. n. 199 et II ed. n. 299.

Duvalii Schwaegr. - Bryum.

Eckloni C. M. in Bot. Zeit. 1855, p. 749.

Syn.

Exs. : Rehm. M. Afr. austr. n. 261.

ellipticum $\left\{\begin{array}{l}\text { Brid. - Mn. punctatum. } \\ \text { Hoffm - Mn }\end{array}\right.$

erythrocaulon Schwaegr. - Rhodobryum.

extinctorium L. f. - Encalypta vulgaris.

fosciculare Funk, - Aulacomnium palustre var. fasciculare.

Fillionii Saut, - Mn. serratum var. Fillionii.

flagellare Lindb. - Rhizogonium.

fontanum L. - Philonotis.

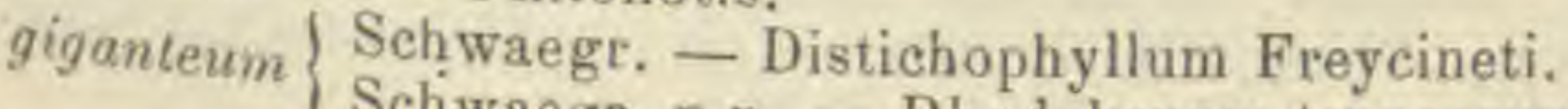

glabrescens Kindb. ined.

- Am. sept. : Columb. brit., Alaska, Sitka, Vancouver.

glaciale Schleich. - Webera albicans var. glacialis.

glaucum Gmel. - Leucobryum.

gracile $\left\{\begin{array}{l}\text { Funk, - Bartramia CEderi. } \\ \text { Schleich }\end{array}\right.$

Greffeanum C. M. - Bryum pallens.

grandifolium Tayl. p.p. $\left\{\begin{array}{l}\text { - Rhodobryum Antillarum. } \\ \text { heteromallum Ghodobryum. }\end{array}\right.$ 
heterophyllum (Hook) Schoaegr. Suppl. II, II, p. 22, l. 159; C.M. Syn. J, p. 164 ; Mitt. op. cit. p. 143.

Astrophyllum heterophyllum Lindb. in Notiz...IX, p. 52.

Bryum heterophyllum Hook, in Trans. of the Linn. Soc. IX, p. 318, $t, 27$, $f$. 4 et 1o.pl. $r a v . t, 20, f .2$.

Br. Polla hetmrophylla Brid Bryol, univ, $I, p p .690$ et 853 .

2. - As. : Caucas. occ. et centr., Nepal,, Himalaya. A m. sept. : (Fid. Bryol. Eur. IV, mon. p. 24 sin. loc.).

helerostichum Brid. - Aulacomnium.

var. humilis C. M. - Aulacomnium heterostichum var, humilis.

Hildebrandtii C. M. in Hildebr. M. Mad. n. 2109.

- Afr. : Madagascar centr.

Hookeri C. M. - Rhizogonium.

hornum L.Sp. pl. ed. II, p. 112 ; Hedw. Sp. M. p. 188; Bryol. eur. IV (mon. p. 22), t. 390 ; C. M. Syn. I, p. $165 ;$ W. P. Sch. op. cit. p. 491. Astrophyllum hornum Lindb. M. Scand. $p .14$.

Bryum hornum Huds. Fl. Angl. I ed., p. 415.

$\mathrm{Br}$. stellare hornum silvarum, capsulis magnis nutantibus Dill. Hist. M. p. $402, t .51, f .71$.

Br. stellatum Lam. et DC. Fl. fr. III ed., II, p. 507.

Br. Polla horna Brid. Bryol. univ. I, p. 695.

Hypnum hornum $W$. et $M$. Bot. Tasch b. 293.

Mn. homum var. sublaeve Milde in Flora, $18 ; 0$ ( $\delta$ Mn. horni).

Mn. hornum $\alpha$ serratifolium Weiss Pl. crypt. fl. Goett. p. 149.

Mn stellatum Lam. Fl. fr. I ed., p. 39.

Polla horna Brid. op. eit. p. 817.

2. Ad rup. ct terr, humid, in silv. - Eur. : Reg. campestr., priecip. arenac, et granitic. Afr.: Alger. Am. sepl.: Terr. nov., ins. Miquelon, Anticosti, Nov. Scotia, New Brunswick, Ontario, M. Nov. Angliae. Pensilv., Carol. sept.

Exs. : Mac. Canad. M. n. 195.

Rab. Bryoth. eur. n. 38 et b.

Sull. et Lesq. M. bor. am. II ed, n. 296.

Un. itin. 1867, n. 43.

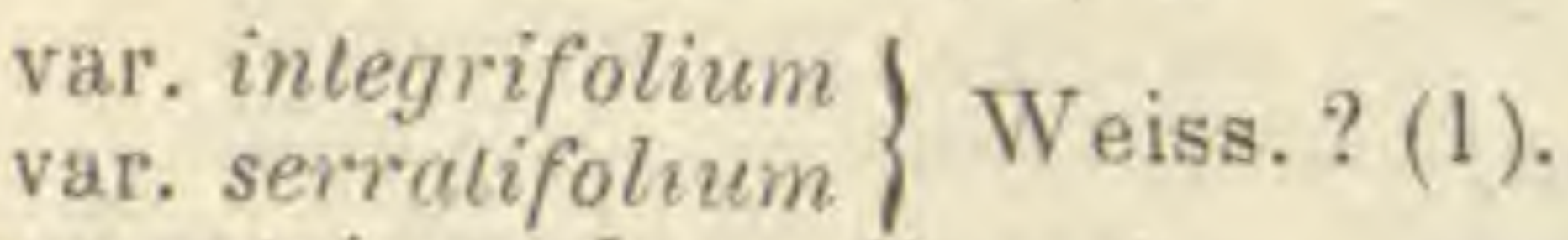

hygrometricum L. - Funaria.

hymenophylloides Hüb. Muscol. germ, p. 416; Bryol. eur. IV (mon. p. 37), t. 399 ; C. M. Syn. I. p. 156 ; W. P. Sch. op. cit. p. 490.

Astrophyllum hymenophylloides Lindb. M. Scand. $p .14$.

Bryum hymenophylloides Haitm. Shand. Fl. III ed., p, 292.

2. $\delta$ et fr. ign. Ad terr. et ad rup humid. - Eur. : Norveg., Alp. Carinth., Stir., Tirol., Rhoet., Helvet. As.: Jenissei. Am. sept. Groesland, Labrador, New York, M.Rupestr.

Exs. : Rab. Bryoth. eur. n. 978.

Un. itin. 1863, n. 26.

hymenophyilum Bryol, eur. IV (mon. p. 5), t. 399; C. M. Syn. 1, p. 157.

Cinclidium? hymenophyllum Lindb. de Mn. Eur. p. 75.

2. 9 et fr. ign. Ad ter. et in rup. fissur. - Eur. : Spitzberg, Norveg.,

Lappun. As. : Jenissei inf. Am. sept. : Groenland, Labrador, Nor.

Scot., M. Rupestr.

Exs, : Un. itin. 1867 , n. $41,42$.

(1) Cf. Brid. Sp. M. III, p. 48 in obs. 
inmarginatum (Lindb.) Broth. Enum. M. Caucas. p. 12.

Astrophyllum immarginatum Lindb. in sched.

2. Fr. ign. - As, : Caucas,

inclinatum Lindb, de Mn. Europ. p. 4 × (1).

Astrophyllum inclinatum Lindb. M. Scand. p. 14.

A. orthorhynchum var. inclinatum Kindb. Art. d. Laubm. Sehwed. und Norw., p. 62.

Bryum marginatum var, Drumm, M. bor. am. I ed. n. 259.

Mn. orthorhynchum var, tenellum W. P. Sch. op. et $l, c c$.

2. Ad arb. et rup. - Eur. : Lappon. Pitens., Norveg. Am. sept. : Ontario, M. Ripestr., Columb. brit.

Exs. : Mac. Canad, M. n. 551.

inordinatum Brid. - Aulacomnium palustre.

insigne Mitt $-\mathrm{Mn}$. affine var, elatum.

var, pumilum Lindh, - Mn. affine var, rugicum.

integrifolium Brid. - ? (2).

integrnm Bryol. jav. I, p. 153, t. 122.

2. Arbor. et aquat. - As.: Japon., Sumatra.

intermedium Ludw. - Bryum intermedium.

var. Roehl. - Br, inclinatum.

japonicum Lindb. in Act. Soc. sc. Fenn. 1872, p. 226.

Mn. aculeatum Mitt. (fid. Besch.).

2 .

Exs: : Faurie n. 405, 408. - As. : Japon. (ins. Nippon).

japonicum W. P. Sch. - Mn. trichomanes.

kilima n'djaricum C. $M$. in Fl. $1888, p .407$.

Mn, rostratum Mitt, in Jowrn. of the Linn. Soo. 1886, p. 307.

Ster. In gramin. - Afr. : Kilima N'Djaro.

lacustre Hland, - Bryum.

lanatum P. B. - Bryum argenteum var. lanatum.

laterale Hoffin. - Bartramia Halleriana.

latifolium \{ Gmel, - Desmatodon.

ligulatum Schwaegr. - Bryum Sehleicheri var. Jatifolium.

Ligulatum Brid. - Mn. undulatum.

Lindigii Hpe. - Rhizogonium.

longirostrum Brid. - Mn. rostratum.

lucidum Dna E. G. Britt. in Bull. of Torr. bot. Club, 1890, p. 2.

Br. simplex Kindb

Mn. Roellii Broth. in Bot. Centralbl. 1890, n. 52.

Mn. simplex Kindb, in Rev. bryol. 1895, p. 22.

2. Ad rivul, glacial. - Am. sept. : Washington, Oregon.

lycopodioides (Hook.) Schwaegr. Suppl. 11, I1, p. 24, L. 160; Bryol. eur. IV (mon. p. ), t. 392; C. M. Syn. I, p. 164 et II, p. 55t; W. P. Seh. op. cit. p. 481 .

Astrophyllum lycopodioides Lindb. M. Scand. p. 14.

Bryum lycopodioides Hook, in Lond. Joum. of bot. 1810, II, p. 11.

$\mathrm{Br}$. Polla lycopodioides Brid. Bryol. univ. I, p. 853 .

Min, arthorhynchum var. Iycopodioides Husn. Muscol. gall.p. 255.

(1) Cf, Philibert in Rev, bryol. 1895, p. 76.

(2) Cf. Brid. Sp. M. III, p. 48 in obs, 
Polla lycopodioides Brid. op. cit. II, p. 817.

2. In silv. acer. - Eur. : Fennia, Alp. Salisburg., Julian., Helvet. ; Pyr. As. : Nepal.

Exs. : Rab. Bryoth. eur. n. 248.

lycopodioides $\left\{\begin{array}{l}\text { Lesq, et Jam, - Mn. pseudo-lycopodioides. } \\ \text { Mitt. p.p. - Mn. Thomsoni. }\end{array}\right.$

macro-ciliare C. $M$. et Kindb. in Bidr. p. 455 (nom:).

Syn. Rupic. et ad terr. humid. - Am. sept. : Ontario, Columb, brit. madagascariense Kiaër in Borgen M. Mad. n. 16.

- Afr. : Madagascar centr.

magnirete (Lindb. et Arn.) Par.

Astrophyllum magnirete L. et A. M. As. bor. II, p. 21 ,

2. - As. : Ienissei infer.

majus $\left\{\begin{array}{c}\text { ranis longioribus bifurcatis Dill. - Aulacomnium palustre. } \\ \text { minus ramosum, capitulis pulverulentis crebrioribus Dill. - } \\ \text { Aulacomnium palustre var. polycephalum. }\end{array}\right.$ marchicum Hedw. - Philonotis.

marginatum $\mathrm{P}, \mathrm{B},-\mathrm{Mn}$. serratum.

var. apiculatum Lindb. - Mn. serratum var. apiculatum.

var, integrifolium Lesq. - Mn. serratum var. integrifolium.

var. riparium Husn. - Mn. riparium.

Maximoviczii Linclb, in Act. Soc. sc. Fenn. 1872, p. 224.

2.

$$
\text { - As. : Japon. (ins. Nippon). }
$$

medium Bryol. eur. IV (mon. p. 32), t. 398 ; C. M. Syn. I, p. 160 el II, p. 554 ; W. P. Sch. op. cit. p. 477.

Astrophyllum medium Lindb. M. Scand. p. 14.

Mn affine var. medium Husn. Muscol. gall. p. 254.

Syn, In uligin. et ad scaturig. silv. - Eur. : Spitzberg, Suecia, M. Pinifer, Bohem., Morav., Hercyn., Stir., Salisb., Tirol., Voges., Helvet., Alp. Jurass., Pyr.. etc. As. : Jenissei, Sikkim, Cancas. occ. et or. Am. sept. : New Brunswick, Massachussets, New York, New Jersey, M. Wasatch, Idaho, Oregon, Washington, ins. Vancouver, Columb. brit.

Exs. : Rab. Bryoth. eur. n. 1166.

medium * robustum Kindb, - Mn. insigne var. intermedium.

megapolitanum $\left\{\begin{array}{l}\text { Gmel. - Timmia. } \\ \text { P. B. - Timmia austriaca. }\end{array}\right.$

membranaceum Brid. - Aulacomnium heterostichum var. humile.

Menziezii (). M. - Rhizogonium. microphyllum $\mathrm{Dz}$, et $\mathrm{Mk}$. - Rhizogonium.

minutulum Besch. in A un. sc, nat. 1893, p. 346.

2?

Exs. : Faurie n. 3515 p.p.

- As. : Japon.

murale L. jun. - Barbula.

Neevii C. M. - Mn. venustum.

Niagarae Kindb. in Mac. Cat. p. 141.

Syn. Terr. - Am. sept. : Niagara.

Exs. : Mac. Canad. M. n. 581 .

Nietneri C. M. in Linn. 1869-70, p. 32.

Mn. rhynchophorum Mitt. M. Ind. or. quoad pl. Ceylan.? (fid. C. M. l. .).).

Syn.

- As. : Ceylan. 
nigricans Brid. - Bryum turbinatum.

Novae Hollandiae C. M. - Rhizogonium.

Novae Vallesiae C. M. in Rev. bryol. 1876, p. 4 (nom.).

Mn. rostratum (fid. Mitt.).

- Pac. : Austral, or. (Nov. Valles.).

nutans P. B. - Webera.

orthorhynchum Bryol. eur. IV (mon p. 25), t. 391 ; C. M. Syn. I, p. 163.

Astrophyllum orthorynchum Lindb. M. Scand. p, 14 ,

Bryum marginatum $\beta$ orthorhynchum Hartm. Skand. Fl. IV ed., p. 405.

Br. serratum Schrad. Spic. fl. germ. $I, p .71$ ?

Br. Polla orthorhyncha Brid. Bryol. univ. I, p. 691 (fid. Limpr.).

Mn. serratum Schrad. in Gmel. Syst. nat. XIII ed., II, II, p. 1330 ?

Mn. serratum * orthorhynchum Hartm. Skand. Fl. V ed., p. 345.

Mn. serratum penninum de Not. Syll. n. 175.

Mn. serratum $\beta$ tenerius Schwaegr. Suppl. I, II, p. 129, t. 78.

2. Ad terr. silvat, et in fissur. rup. - Eur. : E reg. subalp. inf usq. in reg. alp. sup.; Spitzberg; Britann. (ster.). As. : Japon., Jenissei med., Saghalien, Tibet occ., Caucas. occ. et centr. Am, sept. : Groenland, Labrador, Pensilv., M. Rupestr., Columb. brit., Colorado.

Ess. : Faurie Pl. Japon. n. 219.

Mac. Canad. M. n. 479 p.p.

Rab. Bryoth. eur. n. 39.

Un. itin. 1867 , n. 46.

" var, nivale Pfeff. Bryol. Stud. p. 61.

In fiss. rup. schist. - Eur. : Helvet.

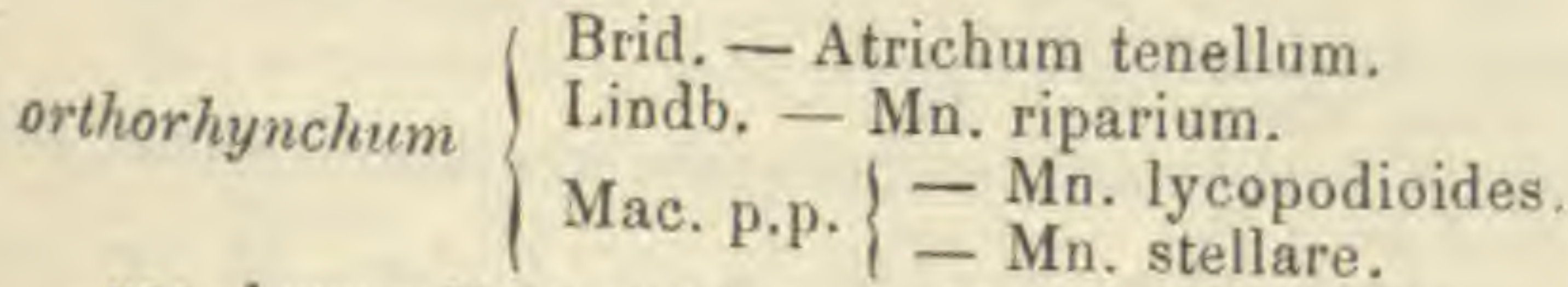

var. lycopodioides Husn. - Mn. lycopodioides.

var, tenellum W. P. Sch. - Mn, inclinatum,

osmundaceum Dicks. - Schistostega.

pallens P. B. - Bryum.

palmifolium P. B. - Conomitrium.

paludosum Warnst. in Abhandl. d. bot. Ver, d. Prov. Brandenb. 1885.

- Eur. : Borussia (Brandenb.).

paludosum $\{$ L. jun. - Seligeria pusilla .

palustre $\mathrm{W}$ arnst. - Mn. affine var, rugicum.

- Aulacomnium.

ar. fasciculare C. M - Aulacomnium palustre var. fasciculare.

var. Aagelliferum Mart. - Aulacomnium palustre var. polycephalum.

var. imbricatum C. M. - Aulacomnium palustre var. imbricatum.

var. majus Schwaegr. - Aulacomnium palustre var. polycephalum.

var. polycephalum C. M. - Aulacomnium palustre var, polycephalum. papillosum C. M. - Aulacomnium.

paramattense C. M. - Rhizogonium.

farvulum Mitt. in Trans, of the Linn. Soc. 1891, p. 168.

1. Lignic. - As, : Simla.

pellucens Gmel. - Dichodontium pellucidum.

pellucidum L. - Tetraphis.

pendulum Sm. - Breutelia.

pensilvanicum Brid, - Mn. serratum var, apiculatum? 
perangustis et brevibus foliis Dill, - Aulacomnium andinumbgy, piriforme I., - Leptobryum.

Pohlia Hffm. - Webera elongata. polycephalum Brid. - Aulacomnium palustre var. polycephalum. polycarpum C. M. -- Rhizogonium mnioides. polytrichoides L.

var, $\alpha$ L. - Pogonatum nanum.

var. $\beta$ L. - Pogonatum aloides.

var. $\gamma$ L. - Pogonatum pensilvanicum.

var. longifructu Ehrh. - Pogonatum aloides.

var. rotundifructu Ebr. - Pogonatum nanum. poiniforme L. jun. - Bartramia. piliferum Gmel. - Rhodobryum roseum. proliaum Neck. - Aulacomnium palustre var, polycephalum. pseudo-Iycopodioides C. M. et Kindb. in Bidr. 455 (nom.) et in Mac. Cal. p. 140.

Mn. Iycopodioides Lesq. et Jam. Man. p, 246; Sull, et Lesq. M. bor. am. II ed. n. 298.

Mn, orthorhynchum Mac. Canad. M, n, 471.

2. Ad terr, et rad, arbor, - Am. sept. : Terr. nov., Nov. Scot., New Brunswick, Gaspes., Ontar., M. Rupestr., Columb. brit., Nov. Angl., reg. or.

pseudo-punctatum $\mathrm{Br}$. et Sch. - Mn. subglobosum. pseudo-triquetrm Hedw. - Bryum.

pulchellum P. B. - Webera.

punctatum Hedio. Sp. M. p. 193: Bryol. eur. IV (mon. p. 19), เ. 387;

C. M. Syn. 1, p. 155 ; W. P. Sch l. c. p. 489.

Astrophyllum punctatum Lindb. M. Scand. p. 14.

Bryum ellipticum Brid. Mant. M. p. 119.

$\mathrm{Br}$. pendulum serpylli folio rotundiore pellucido, thecis ovatis Dill. Hist. $M, p, 410^{\circ}, t .53, f .81 \mathrm{~A}-\mathrm{D}$.

Bryum punctatum Schreb. Spio. Fl. Lips. p. 85; Drumm. M. bor, an. $I$ ed. $n .253,254$ et 272 p.p.

Br. serpyllifolium Neck. Meth. M. p. 216.

$\mathrm{Br}$. serpyllifolium $\alpha$ punctatum $\mathrm{Huds}$. Fl, angl. I ed. p. 4i7.

Br. Polla elliptica Brid. Bryol. univ, l, p. 765.

Br. Polla punctata ej. op. eit. p. 706.

Hypnum punctatum Schrank Prim. Fl. Salisb, n. 847.

Mn. ellipticum Brid. Sp. M. III, p. 53.

Mn. reticulatum Mitt. (pid. Besch).

M. serpyllifolium Neck, in Act. Acad. Theod. Palat. II, p. 444.

M. serpylhfolium $\alpha$ punctatum $L$. Sp. pl. I ed. p. 1113.

Polla punctata Brid. Bryol. univ. II, p. 817.

2. Ad rup. humid. et secus riv. : calcar. fugit, - Eur. : Reg. campestr. montos., rar, alp. As. : Japon., Saghalien, Amour, Jenissei, Obi, Sikkim, Caucas. Afr. : Temperat. (?); liti. occ. mar. Errthr. Am. sept. : Groenland, Labrador, Anticosti, Terr. nov., ins. Miquelon, Nov. Scot., New Brur.swick, Gaspes., Ontario, M. Rupestr., Columb, brit., Alasks, Unalaska, Sitka, ins. Vancouver, ins, reg. Charlotte, Washington, reg. sept. et or.

Exs. : Faurie P1. Japon. n. 106, 830.

Mac. Canad. M. n. 200.

Rab. Bryoth eur. n. 327 a et b.

Savatier PI. Japon. n. 489, 518.

Sull, et Lesq. M. bor. am. II ed, n. 294.

Un. itin. 1864, n. 66.

var. 2 With. - Mn. rostratum. 
" var. elatum W. P. Sch. Syn. 1 ed. p. 398 et II ed, l. c.

In uligin. - Eur : Passim. Am. sept. : Ins. Miquelon, etc.

var. subglobosum Hpe. - Mn. subglobosum.

punctulatum Brid. - Barbula robusta.

purpureum L. - Ceratodon.

pusillum Gmel. - Dicranella cerviculata var. pusilla.

radiatum Wils, - Rhizogonium mserophyllum.

ramis brevibus inordinate progredientibus Dill. - Aulacomnium palus-

tre.

ramosum $\left\{\begin{array}{l}\text { Hook. - Mn. rostatum var, ramosum. } \\ \text { Huds. - Auiacomnium palustre var. polycephalum. }\end{array}\right.$

reclinatum Sm. - Aulacomninm palustre.

reticulatum Mitt. in Trans, of the Linn. Soc. 1891, p. 168.

Mn. punctatum Hedw, (fid, Besch).

2.

- As, : Japon.

rhynchophorum $\left\{\begin{array}{l}\text { Hook. - Mn. rostratum var, rhynchophorum. } \\ \text { Mitt. - Mn. Nietneri? } \\ \text { Wils. p.p. - Mn. succulentum. }\end{array}\right.$

rigidum Hsch. - Rhodobryum.

riparium Mitt. in Journ. of the Linn. Soc. 1864, p. 30 (in obs.); W. P.

Sch. op cit. p. 484.

Astrophyllum riparium Lindb. M. Seand. p. I4.

Mn. ambiguum H. Müll, in Verh. d. Naturalist. Ver. d. Rheinl, und Westfol.; Milde Bryol. sil. p. 229.

Mn. marginatum var, riparium Husn. Museol, gall, p. 256.

Mn. orthorhynchum Lindb. in Oefo... 1861, p. 276.

$\mathrm{Mn}$. serratum var. dioicum H. Mull. Westfal. Laubm. n. 323.

2. Ad rivul. - Eur. : Angl,, Belg., Westphal., Bhoengeb,, Neomarch., Morav., Saxon., Austria inf., Stir., Salisb., Hungar., Tirol., Helvet., etc. As, : Jenissei med,, Caucas. centr.

Thynchomitrium $\mathrm{C}, \mathrm{M}$. in Ule Bryolh. brasil. $n, 58$.

Terr. - Am, merid. : Brasil. austr. or.

Roelli Broth. - Mn. lucidum.

roseum Hedw. -- Rhodobryum.

vostratum (Schrad.) Schwaegr. Suppl. I, II, p. 136, t. 79; Bryol. eur. IV (mon. p. 27), t. 395; C. M. Syn. 1, p. 158 et II, p. 554.

Astrophyllum rostratum Lindb. M. Scand. $p, 13$.

Bryum longirostrum Brid. Mant. M. p. 119.

Br. pendulum serpylli folio longiore pellucido, thecis oblongis cuspidatis Dill. Hist. M. p. 415, t. 53, f. 80, A. B. C.

Br. punctatum var. 2 Hull Brit. Fl, II, p. 166.

Br. rostratum Schrad. Spic. fl. germ. p. 72.

B. serpyllifolium $\beta$ Huds, Fl. Angl. p. 492.

Br. Polla rostrata Brid. Bryol. univ. $I, p .700$.

Hypnum rostratum $W$. et $M$. Bot. Taschb, p. 296.

Mn. cylindricum Hoffm. Deutsch. Fl. p. 5\%.

Mn. ellipticum ej. $l$. $e$.

Mn. Iongirostrum Brid. Sp. M. III, p. 51 .

Mn. punctatum var, 2 With. Bot. arrang. brit. pl. IV ed., III, p. 806.

$\mathrm{Mn}$, serpyllifolium $\dot{\beta}$ rostratum Wahlenb. FI. Suee. I ed., p. 723.

Polla rostrata Brid. Bryol, univ, $I I, p$. 817.

Syu, In umbros. ad sax. humida et in mur. delaps, musc. per omn, terr. orb. tam frigidior. quam calidiss. 
Exs. : Mac. Canad. M. p. 192.

Mandon Pl. Boliv. n. 1668.

Rab. Bryoth. eur, n, 250.

Savatier Pl. Japon, n. 486.

" var. americanum Hpe. Symb. 1874, p. 500.

Mn. rostratum Mitt. M. austr. am, p, 319.

Terr. et lignic. - Am. sept. : Aquinort. Am. merid. : Venezuela, And. Nov. Granat. et Quitens., Brasil.

"var. ramosum $C, M . l . c$.

Br. ramosum Mitt. $M$. Ind. or. p. 75.

Br. neelgheriense Mont. (fid. Mitt. l. c.).

Br. truncorum Wils, in Kew Journ. bot. IX, p. 366 ,

Mn. ramosum Hook, in Lond. Journ. of bot. 1840, II, p. 11 et Ie, pl. rar. t. $20, f, 2$.

- As. : Nepal., M. Neilgherr. (?), Ceylan.

"var. rhynchophorum $C . M, l, c$.

Bryum longirostrum Griff. Not.p. 447 et Ic. pl. asiat. II, t. 91, f. 2.

Mn. rhynchophorum Hook. $l$. c. f. 3 .

Mn. rhynchophorum var. minutum Ren. et Card. in Bull. Soe. roy. bot, Belg. 1895, I, p. 63 (forma minor).

- As. : Nepal., Hinalaya, Khasia, M. Neilgherr.,

Ceylan, Penang, Yunnan. Pac. : Nov. Zeland.

var. spinosum Roehl. - Mn. spinosum.

rostratum $\left\{\begin{array}{l}\text { Mitt. }\{-\mathrm{Mn} \text {. rostratum var. americanum. } \\ \text { Wils. }-\mathrm{Mn} \text {. kilima n'djaricum? }\end{array}\right.$

rubellum $\mathrm{P}, \mathrm{B}$. - Webera carnea.

rugicum Laur. - Mn, affine var. rugicum.

rurale L. jun. - Barbula ruralis .

sapporense Besch. in Ann. sc. nat. 1393, p. 345.

$2 . \quad-A s$. : Japon.

Exs. : Faurie n. 172.

saxicolum C. M. in Dusen M. Camer, n. 42.

- Afr. : M. Cameroon.

schistoneuron Kze. - Rhodobryum gracilescens.

Schleicheri Brid. - Bryum.

scoparium Gmel. - Dicranum.

Seligeri Jur. -. Mn. affine var. elatum.

serpyllifolium Neck. - Mn. punctatum.

var. cuspidalum Lam. $\left\{\begin{array}{l}\text { - Mn. punctatum. } \\ - \text { Mn. affine. }\end{array}\right.$

var. punctatum L. - Mn. punctatum.

var. rostratum Wahlenb. - Mn. rostrutum.

var. rotundifolium Lam. - Mn. affine

var. undulatum Lam. - Mn. undulatum.

var. 2 Scop. - Mn, affine.

serpylli foliis lenuibus pellucidis Dill. $\left\{\begin{array}{l}\text { - Mn. stellare (fid. Limpr.). } \\ \text { - Tetraphis pellucida } \text {. }\end{array}\right.$

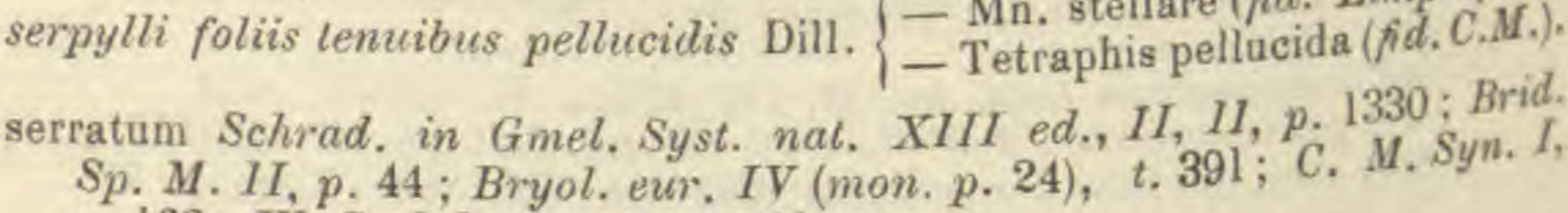

p. 153; W. P. Sch. op. cit. p. 481 .

Astrophyllum marginatum Lindb. M. Scand. p, 14.

Bryum marginatum Dicks. Fasc. II Pl. crypt. p. $9, t, 5, f . I$.

Br. serratum Schrad. Spic. Fl. germ, p. 71 ex p.? 
Br. Polla serrata Brid. Bryol. univ, I. p. 689.

Hypnum marginatum W. et M. Bot. Tasehb. p. 292.

H. serratum W. et M. Ind. Mus. pl. erypt. (1803).

Mn. crudum Lightf. Fl. Scot. II, p. 712.

Mn. marginatum P, B. Prodr. p. 75.

Syn. Ad terr. lapid. et in rup. fiss. in dumet. - Eur.: Passim ; Spitzberg. As. : Jenissei, Obi, Sikkim, Khasia, Caucas, Am. sept. : Anticosti, Gaspes., Ontario, M. Rupestr., Columb. brit., ins. Vancouver, Wyoming, reg. sept. et or.

Exs, : Mac, Canad. M. n. 196.

Rab. Bryoth. eur. n. 536, 1167.

Sull. et Lesq. M. bor. am. II ed. n. 297.

- var. apiculatum (Lindb.) Par.

Bryum pensilvanicum Brid. Mant. M. p. 119?

$\mathrm{Br}$. Polla serrata var pensilvanica ej. Bryol. univ. $I, p .690$ ?

Mn, marginatum var, apiculatum Lindb. de Mn. Europ. p. 47.

Mn. pensilvanicum Brid. Sp. M. III, p. 45?

- Eur. : Suecia. Am. sept. : Pensilv.?

var. dioïcum C. M. - Mn. riparium.

a var. Fillionii (Saut.) Pfeff. Bryol. Stud. p. 60.

Mn. Fillionii Sauter in Fl. 1867, p. 475.

Ut typ. - Eur. : Helvet., Rhaet.

- var. integrifolium (Lindb.) Par.

Mn. marginatum var, integrifolium Lindb, l. c.

- Eur. : Suecia.

"var. Macounii Kindb. in Mac. Cat. p. 139.

- Am. sept. : New Brunswick.

avar. orthorhynchum $\left\{\begin{array}{l}\text { Hartm. - Mn. orthorhynchum. } \\ \text { Hüb. - Atrichum tenellum. }\end{array}\right.$

var. penninum de Not. - Mn. orthorhynchum.

var. tenerius Schwaegr. - Mn. orthorhynchum.

setaceum $\left\{\begin{array}{l}\text { Ehrh. - Barbula convoluts. } \\ \text { L. - Trematodon ambiguus. }\end{array}\right.$

setosum C. M. - Rhizogonium.

silvaticum Lindb, - Mn. cuspidatım.

simplex Kindb. - Mn. lucidum.

spathulatum Mitl. in Trans. of the Linn. Soc. 1891, p. 166.

2.

- As. : Japon.

spathulatum Hsch. - Rhodobryum umbraculum.

speciosissimum W. P. Sch. - Mn. speciosum.

speciosum Mitt. in Trans, of the Linn. Soc. 1891, p. 166.

Mn. speciosissimum W. P. Sch. in Savatier M. Japon. n. 516, 948, 2430

$$
\text { - As. : Japon. }
$$

sphericarpum Hedw. - Philonotis.

sphcericum Sw. - Philonotis sphaericarpa.

spiniforme C. M. - Rhizogonium.

spinosum (Voil) Schroaegr. Suppl. I, 11, p. 130, t. 78; Bryol. eur. $1 \mathrm{~V}$ (mon. p. 26), t. 393; C. M. Syn. I, p. 162 et II, p. 554; W. P. Soh. op, cit. p. 483.

Astrophyllum spinosum Lindb. M. Scand.p. 14.

Bryum spinosum Voit in Sturm Fl. germ. erypt. XI, t. 16.

Br. Polla spinosa Brid. Bryol. univ. I, p. 701 p.p. 
Min. rostratum $\beta$ spinosum Roehl. Deutsch, Fl. III, p. 96.

Polla spinosa Brid, op. cit. $I I, p .817$.

2. In silv, acer, et pinet. - Eur. : E reg. montan. usq. in alp. As. : Caucas, occ. et centr. Am. sept. : M. Rupestr, centr.

Exs. : Rab. Bryoth, eur, n. 40 et b, 437, 473, 1168

«var. microcarpon (Lindb. et Arn.) Par.

Astrophyllum spinosum var. microcarpum Lindb. et Arn. M. As. bor. $1890, I I$, p. 23.

- As. : Jenissei sup.

spinulosum Bryol. eur. IV (mon. Supp. p. 4), t. 394; C. M. Syn. I, p. 162 et $I I, p .554 ;$ W. P. Sch. op. cit. p. 486.

Astrophyllum spinulosum Lindb.

Bryum spinosum Drumm. M. bor, am. I ed. n. 257 p.p.

Syn. Ad terr. silvat. - Eur.: Sudet., Morav., Francon., Thuring, Helvet, Tirol,, Alp., Pyren. As. : Caucas. occ. Am. sept. : New Brunswick, Nov, Scot., Gaspes., Ontario, Manitoba, Columb. brit., Washington, Idaho, Nova Angl., reg. or.

Exs. : Mac. Canad. M. n, 198.

Rab. Bryoth. eur. n. 249 et b.

Sull. et Lesq. M. bor. am. II ed, p. 304.

spurium Gmel. - Dicranum.

squarrosum L. f. - Paludella.

stellare Reich, Fl. Maino-Franc. II, p. 125 ; Hedro. Sp. M. p. 191, t.40, f. 1-4;Bryol. eur. IV (mon. p. 33), t. 399; C. M. Syn. I, p. 166: W. P. Sch. op. cit. p. 487.

Astrophyllum Blyttii Lindb. M. Scand. p. 14.

A. stellare ej. $l$. $c$.

Bryum stellare Roth. Fl, germ. III, p. 240.

Br. stellare roseum pendulum minus, capsulis et setis longioribus Dill. Hist. M. p. 413, t. 52, f. 78.

Br. stellatum Lam. et DC. Fl fr. I, p. 507 (fid. Brid.).

Br. Polla stellaris Brid. Bryol. univ. I, p. 691.

Hypnum stellare W. et M. Bot. Taschb. p. 294.
Mn. Blyttii Bryol. eur. IV (mon. Siepp. p. 6), t. 400; C. M. Syn. I, p. 15i: Rab. Bryoth. eur. n. 103.

Mn. orthorhynchum Mac. Canad. M. n. 471 p.p.

Mn. Serpylli foliis tenuibus pellucidis Dill. Hist. M. p. 232, t, 31, f. 2 A (fid. Limpr.).

2. In dumet, rarius in mont. quarz. quam in calcar. - Eur. : Spitzberg, Norveg., Scot, Angl,, Belg., Gall., Jurass., Alp., etc. As.: Japon., Amour, Jenissei, Caucas. oce. et centr. Am. sept.: New Brunswick, Gaspes., Ontario, M. Rupestr., reg. sept. et or.

Exs. : Faurie Pl. Japon. n. 77.

Mac. Canad. M. n. 199.

Rab. Bryoth, eur. n. 977.

Sull. et Lesq. M. bor. am. II ed, n. 305.

stellatum Lam. - Mn. hornum.

striatulum Mitl. in Trans. of the Linn. Soc. 1891, p. 167.

2. - As. : Japon.

subbasilare C. M. - Rhizogonium.

subenerve Schwaegr. - Eriopus remotifolius? subglobosum Bryol. eur. $1 \mathrm{~V}$ (mon. Supp. p. 3), t. $388 ;$ C. M. Syn. 1,
p. 56 ; W. P. Sch. op. cit. p. 490 .

Astrophyllum pseudo-punctatum Lindb, M. Scand, p. 13. 
Bryum mnioides Wils. in Lond. Journ. of bot. III, p. 42.

Cinclidium stygium Drumm. M. bos. am. I ed. n. 272 p.p.

Mn. punctatum ej, ibid. $n, 253$.

Mn. punctatum var. subglobosum Hpe, in litt.

Ma. pseudo-punctatum Br. et Sch, in Obs. orit, ad Drumm. et in Lond. Journ. of bot. II, p, 669.

Syn. In turfos. editior. - Eur. : Seandin., Angl, Hercyn., Neerland., Westphal., Helvet., Alp. Stir,, Tatra, Voges. As. : Jenissei. Am. sept.: Groenland, ins. Sabine, lac, Super. et Athabasca, M. Rupestr., Columb. brit.

Exs. : Mac. Canad. M. n. 201.

Rab. Bryoth, eur. n. 247, 730 .

Un, itin, $1864, n, 55$

subinclinatum Philib, in Rev. bryol. 1895, p. 40.

2. Ad terr. silic. secus rivul. - Eur. : Alp. Galloprovinciae

subulalum L. jun. - Barbula.

siscoulentum Mitt, M. Ind. or. p. 143.

Mn. rhynchophorum Wils. in Kew Jowin. bot. 1X, p. 367 p.p.

Syn. - As. : Nepal. or., Khasia, Assam ; Java?

tenerrimum C. iV. in Jaeg. Ad. I, p. 67 (nom.).

- As. : Sikkim.

Thomsoni W. P. Sch. Syn. II ed., p. 485.

Mn. lycopodioides Mitt. M. Ind. or, p. 142 ; Lindb. de Mn. curop, p, 52.

2 .

Exs. : Faurie Pl. Japon. n. 164, 1496.

Timmia Hoffin. - Timmia megapolitana.

tomentosum Sw. - Breutelia.

torlile $\left\{\begin{array}{l}\text { Brid. - Ptychomitrium polyphyllum. } \\ \text { Gmel. - Ditrichum. }\end{array}\right.$

tortuosum L. jun. - Barbula.

trichodes L. jun. - Meesea uliginosa.

Trichomanes Mill. in Hook. Journ. of bot. 1856, p. 231.

Mn, acutum Lindb. in Act. Soc, sc, Fenn. 1872, p. 227.

Mn, euspidatum Wils, in Kero Jowrn, bot. $1 X, p .367$.

Mn. japonicum W. P. Sch. in Savat. M. Japon.

In, rostratum Wils, in op. cit. p. 368.

2. Ad terr, humid, - As, : Himalaya oce., Japon,, China (ins. PihQuan).

Eas. : Faurie Pl. Japon. n. 7, 30, 97, 833, 3513.

trichamitrium Mitt. - Orthomnium.

triquetrum L. - Meesea tristicha.

truncorum Brid. - Rhodobryum.

turbinatum Hedw. - Bryum.

B Ludvoigüi Roehl. - Webera Ludwigii.

turgidum Wahlenb. - Aulacomnium.

uhiginosum Gmel, - Meesea.

umbraculum Schwaegr. - Rhodobryum.

umbratile Mitt. in Journ. of the Linn. Soc. VIII, p. 30; Sull. Ic. M.

Suppl.p. 51, t. 35 ; Lesq. el Jam. Man. p. 246.

2. Ad terr. et sax. - Am. sept. : M. Rupestr., Columb. brit.

Exs. : Mac. Canad. M. n. 520.

undulatum (L.) Hedw. Sp. M. p. 195 ; Bryol. eur. IV (mon. p. 20), l. 389 ;

C. M. Syn. 1, p. 161; W. P. Sch. op. cit. p. 479.

Astropayllum undulatum Lindh. M. Soand. 1. 13. 
Bryum dendroides Web. Spic. Fl. Goett. p. 117.

Bryum dendroides, polycephalum, phyllitidis folio undulato, pellucido, thecis ovatis pendulis Dill. Hist. $M . p .410, t .52, f .76 \mathrm{~A}-\mathrm{E}$.

Br. ligulatum Schreb. Spic. Fl. Lips. p, 84.

Br. serpyllifolium $\gamma$ undulatum Huds. Fl. Angl. p. 417.

Br. undulatum Roth Fl. Germ. III, I, p. 249.

Br. Polla ligulata Brid. Rryol. univ. I. p. 708.

Hypnum ligulatum $\boldsymbol{W}$. et $M$. Bot. Taschb. p. 298.

H. undulatum Schrank Baiers Fil. II, p. 474.

Mn. ligulatum Willd. Prodr. Fl. Berol, $p$. 331.

Mn. serpyllifolium $\delta$ undulatum $L, S p, P l$. II ed.

Polla ligulata Brid. op, cit. II, p. 817.

Polytrichum undatum Schrank Prim. fl. Salisb, n. 825.

2. In umbros. humid. - Eur. : Tota, arctic. except. As. : Ins. Nippon, Talysch, Sikkim., Caucas. oce. et centr., Syr. Afr.: Alger., Ténérif., Madeir., ins, Azor., C. B. Sp., ins. Borbon.

Exs. : Rab. Bryoth. eur. n. 41.

" var, australe (Besch.) Par.

Mn, australe Beseh. Fl, bryol. Réunion, etc. p. 100. - Afr.: Teneriff., ins. Borbon.

undulatum L. jun. - Atrichum.

Vallis-Gra'iae Hpe. - Rhizogonium.

venustum Mitt. in Kew Journ. bot. 1856, p. 231, t. 12 B; Sull. Ic. M. Suppl. p. 52, ı. 36; Lesq. et Jam. Man. p. 242.

Mn. Neevii C. M. in Fl. 1873, p. 480; Lesq et Jam. Man. l.c.

Syn. In rup. fiss. - Am. sept. : Columb. brit., ins, Vancouver, Washington, Oregon, Idaho, Montana.

Exs. : Mac. Canad. M. n. 190.

vesicatum Besch, in Ann. sc. nat. 1893, p. 345.

$2 . \quad-A s$. : Japon.

Exs. : Faurie n. 1339.

viridulum $\mathrm{Sw},-\mathrm{Weisia.}$

voxense Besch. in Bull. Soc. bot. Fr. 1894, p. 82.

Ster. Cortic. - As. : Tonkin.

Wrightii Sull. - Epipterygium.

Zierii P. B. - Plagiobryum julaceum (1).

MNIUM CINCLIDIUM Bryol. eur. IV.

arcticum Rryol, eur, - ('inclidium.

Stygium Bryol, eur. - Cinclidium.

MOENKEMEYERIA C. M. in Fl. 1886, p. 506 (2 spec.). mirabilis C.M. . c.

Syn. Terr. - Afr. : Old Calabar.

Wainionis C. M. in Act. Soc. sc. Fenn. 1891, n. 5.

Syn. Lignic. - Am. merid. : Minas Geraës.

(1) In Enum. Kindb, nom, nuda:

Mn. Novae Zelandiae C. M. । Mn. pellitum C, M. 
MOLENDOA Lindb, in Utkast till en nat. grupp. of Eur. bladm, p. 29. Spec, omn. non indicatae sunt ANGCTANGIA ejusd, nom.

lingucefolia Lindb. -- Anoectangium Schliephackeanum.

MOLLIA Schrank Fl. Salisb. p. 832.

aeruginosa Lindb. - Gymnostomum rupestre.

brachydontia Lindb. - Trichostomum mutabile.

Brolheri Lindb. - Barbula.

caespitosa Broth. - Barbula.

calcarea Lindb. - Gymnostomum.

var, gracillima Lindb, - Gymnostomum calcareum.

var. viridula Lindh, - Gymnostomum calcareum var. intermedium. condensa Lindb, - Hymenostomum tortile.

connivens Lindb. - Trichostonum.

corniculata L. et A. - Trichostomum.

crispa Lindb. - Systegium.

crispula Lindb. - Trichostomum.

var, viridula Lindb, - Trichostomum crispulum var, angustifolium. fallax Schrank. - Barbula.

flavo-virens Lindb. - Trichostomum.

fragilis Lindb. - Barbula Drummondii.

humilis Lindb. - Barbula caespitosa.

inclinata Lindb. - Barbula.

littoralis Braithw. - Trichostomum.

microstoma Braithw. - Hymenostomum.

var. obliqua Rraithw. - Hymenostomum microstomum var, obliquum.

muralis Schrank, - Barbula.

"uralis Schrank, - Barbula.

rutilans I.indb. - Weisia mucronata.

squarrosa Lindb. - Hymenostomum.

subulata Schrank. - Barbula.

tegularis Schrank. - Barbula muralis var, aestiva.

tenuirostris Lindb. - Didymodon cylindricus.

tenuis Lindb. - Gyroweisia.

tortilis Braithw. - Hymenostomum.

lortuos a Schrank. - Barbula.

var. inclinata Lindb. - Barbula inclinata.

unguiculata Schrank. - Barbula.

verticillata Lindb. - Eucladium.

viridula Lindb. - Weisia.

var, brevifolia Lindb. - Weisia viridula var. brevifolia.

var. gymnostoma Lindb. - Weisia viridula var. gymnostoma.

Wimmeriana Lindb, - Weisia.

var. subgymnostomoides Limpr. - Hymenostomum tortile.

MonoschISMA Duby Choix de Crypt. ex. 1867, p. 4.

viride Daby. - Papillaria Dubyana.

MONOGRANUM C. M. in Mac. Cat. p. 35 (nom.), (2 spec.).

dieranoides C. M. l. c. (nom.).

- Am. merid. : Valdivia.

stenodietyon Kindb. . . c.

Dieranum stenodictyon Kindb, in Bull. Torr. bot, Club, XVI, p. 9?.

Ster. Ad terr, silvat. - Am. sept. : Columb. brit. 
MORITZIA Hpe, in Linn. 1847, p. 82.

caripensis Hpe. - Acrocryphaea squarrosula.

MUSCUS Micheli Nov, gen. pl.

capillaceus aphyllus capitulo crasso bivavis Buxb., Dill, - Buxbaumia aphylla.

norvegicus umbraculo ruberrimo insignitus Dill. - Splachnum rubrum. pinnatus aquaticus ramosissimus, Linariae foliis Mich. - Conomitrium Julianum.

squamosus $\left\{\begin{array}{l}\text { aquaticus Mich. - Cinclidotus aquaticus. } \\ \text { foliis latis subroundis Tonrnef. - Mnium affine. }\end{array}\right.$

repens, major, ramulis circa extremitatem conglomeratis, folnolis multis et minimis capillaceis caulem ambientibus Sloane. - Lepyrodon trichophyllus.

terrestris $\left\{\begin{array}{r}\text { repens minor, cujus ramuli foliis multis et mimimis seria- } \\ \text { tim quadralo ordine dispositis cinguntur Dill. - Pilotri- }\end{array}\right.$ chella quinquefaria?

surculis Kali aut Illecebrae aemulis, foliis subrotundis squamatis incumbentibus Vaill. - Scleropodium illecebrum.

MYRINIA W. P. Sch. Syn. I ed., p. 482 (3 spec.).

brasiliensis (Hpe.) W. P. Sch, mss.

Anomodon brasiliensis Hpe. Symb. 1872, p. 56.

1. Saxic. et terr. - Am, merid. : Brasil. austr. or.

? Dieckei Ren. et Card. in Bot. Centralbl. 1890, n. 51.

2? Ad Popul. - Am. sept. : Oregon.

pulvinata (Wahlenb.) W. P. Sch. l. c. p. 483.

Helicodontium pulvinatum Lindb. M. Scand. $p, 37$.

Leskea pulvinata Wahlenb. Fl. Lapp. 1812, p.369; Brid. Bryol. univ. II, p. 316 ; Moc. Canad. M. p. 253.

L. subenervis Jehwaegr. Suppl. I, II, p. 176, t. 85; Brid. op. cit. p. 307.

Neckera pulvinata C. M. Syn. II, pp. 83 et 666 .

Syn. Ad trunc infim. et rad. proecip. Popul. - Eur. : Lappon., Seandin., Fennia, Britann., Burgund.; Tirol. ? As. : Jenissei. Am. sept.: Perrar. : Hudson Hope, Columb. brit.

tenuirostris Ltz. - Helicodontium.

MYURELLA Bryol, eur. V (4 spec.).

acuminata Lindb. et Arn. M. As. bor. 1890, II, p. 141.

2. In calcar. - As. : Jenissei med. apiculata (Hïb.) Bryol. eur. V (mon. p. 4-5), t. $560 ;$ W. P. Sch. Syn. II
ed.p. 589 .

Hypnum apiculatum Hartm. Skand. Fl, V ed., p. 326.

H. julaceum C. M. Syn. II, p. 465 p.p.

H. moniliforme var, apiculatum Somm. Suppl. Fl. Lapp.

Isothecium apiculatum Hub. Museol. ger'm. p. 598.

M. tenerrima Lindb. M. Seand. p. 37. M. tenerrima Lindb. M. Scand. p. 37.
? Pterigynandrum tenerrimum Brid. Mant. M. p. 130 et Bryol. unie. 11 ,
p. 196 .

2. Ad terr. petros, et in rup. fissur. humid. - Eur.: Spitzberg, Scandin., Tatra, Salisb., Stir,, Carinth., alp. Algov. et Bavar., Tirol., 
Helvet. As, : Jenissei med. et inf. Afr.: Alger. ?? Am. sept. : Groenland, Columb. brit, M. Uintah.

Exs. : Rab. Bryoth. eur. n. 1232.

Un itin. 1863, n. $58 ; 1867$, n. 5.

var. ciliata Chalub. - M. Careyana.

Careyana Sull. M. of U. St. pp. 61 et $81, t .5$ et Ic. M. p. 131, t. 88; Lesq. et Jam. Man. p. 300, t. 6.

Hypnum gracile Weinm. in Bull. Soc. imp. nat. Moscou, 1845, II, p. 492; C. M. Syn. II, p. 418.

H. sibiricum C. M. Syn. II, p. 418.

M. apiculata var. ciliata Chalub. Enum. M. frond. Tatr. p. 115.

M. gracilis Lindb, in Act. Soc. so, Fenn. 1872, p. 276 (in obs.).

M. julacea var, aspera Lindb. in Meddel. of Soc. Fauna et Fl. Fenn. 1876, Heft. I.

2. In fissur. rup. calcar. - Eur. : Rossia sept., Tatra, alp. Stir., Carniole. As, : Jenissei med. Am. sept. : Anticosti, Nov. Scot., New Brunswick, Ontario, lac. Super., Nov. Angl., New York, Pensilv., Minnesota, Carol. sept.

Exs. : Mac. Canad. M. n. 250.

Sull. et Lesq. M. bor. am. I ed. n. 250 et II ed, n. 373.

concinna Lindb. - Myuroclada.

julacea (Vill.) Bryol, eur. V (mon. p. 3), t. $560 ;$ W. P. Sch. op. et l. cc.

Hypnum julaceum Vill. Pl. Dauph. III, p. 909; C. M. Syn. II, p. 465 (excl, syn. Hartm, et Hub.) p.p.

H. monilitorme Wahlenb. Fl. Lapp. p. 376, t, 24; Drumm. M. bor. am. $I$ ed. $n .220$.

Isothecium julaceum Brid. Bryol, univ. II, p. 365 (incl. $\beta$ atratum).

I. moniliforme Hüb. Muscol. germ. p. 597 .

Leskea julacea Schworgr: in Schultes Reise auf d. Glockner, II, p. 363.

L. moniliformis Wils. Bryol, brit. p. 328, $t, 24$.

Pterigynandrum fragile Schleich. Cent. IV, $n .6$.

Pterogonium rotundifolium Engl, Bot, t. 2525.

2. Ad terr. petros et in fiss. rup. humid. - Eur.: Spitzberg, Seandin., Angl., Sudet., Tatra, Salisb., Stir., Carinth., Alp. Bavar. et Julian., Tirol, Helvet., vall. Rhen. med., Arvern., Delphinat. As. : Jenissei med. et infer. Am. sept. : Groenland, Labrador, Terr. nov., Anticosti, New Brunswick, Gaspes., Ontario, Manitoba, Athabasca, M. Rupestr., Oregon, Minnesota, Nov. Angl., New York.

Exs. : Mac. Canad. M, n. 249.

Rab. Bryoth. eur, n. 685.

Un, itin. 1867, n. 2.

var. aspern Lindb. - M. Careyana.

s var, gracilis Kindb. Laubm. Schwed. u. Norw. p. ४.

d et fr. ign. - Eur. : Norveg. (Dovre).

" var. scabrifolia Lindb. M. Scand. p. 37.

- Eur. : Fennia.

tenerrina Lindb, - M. apiculata.

MYURIUM W. P. Sch. Syn. I ed.p. 69 (2 spec.).

Hebridarum W. P. Sch. l. c. p. 696 et ed. II, p. 808.

Leucodon Lagurus var, borealis Wils. Bryol, brit. p. 31t, t. 6 .

2. Ad rup, irror. - Eur. : Ins. Hebrid. (ster.). Afr.: Ins. Canar.; Madeir. (c. fr. !). 
? herjedalicum W. P. Sch, $l l, c c$.

Eurhynchium cirrosum (fid. Husn).

Hypnum ? herjedalicum Hartm. Fl. Skand, IX ed, p. 9.

Ster.

- Eur. : Scandin. (1).

MYUROGLADA Besch, in Ann, sc. nat. 1893, p. 379 (1 spec.). concinna (Wils.) Besch. l. c.

Hypnum concinnum Wils, in Lond. Journ, of bot. 1848, p. 277, n. 42, t. 10 C; C. M. Syn. II, p. 374.

H. illecebrinum W. P. Sch, in Savaties M. Japon.

H. Maximowiczii Borozczou in Max. Prim. fl. Amur, p. 467.

Myurella concinna Lindb. in Act. Soc. sc. Fenn. 1872, p. 275.

2.

- As. : Japon., ins. Chiusan, Amour, Jenissei sup.

Exs. : Faurie, Pl. Jap. n. 5, 10, 43, 299 p.p., 740, 1497, 3508. Savatier n. 791.

Nanocarpidium C. M. in Geh. Neue Beilr. sur Moosfl. v. Neu Guin, p. 5 (sect. NECKERAE).

NANOMITRIUM Lindb. Man. M. II.

tenerum Lindb. - Ephemerum.

NEGKERA Hedw. Fund. M. II, p. 93 (158 spec.).

abietina Hook. - Alsia.

abyssinica Bryol. eur. V (mon. p. , nom.).

N. remota $\beta$ laxa Br. et Sch. in W. Sch, M. Abyss. n. 425.

- Afr.: Abyssin., litt. occ. mar. Erythr.

abyssinica U. M. - Cylindrothecium Schimperi.

acuminata Hook, - Garovaglia.

acutata Mitt. M. Ind. or. p. 121.

1.

- As. : Khasia.

acutifolia (Brid.) C. M. Syn. I1, p. 48.

N. Distichia acutifolia Brid. Bryol. univ. II, p. 757.

Ster. Ad sax. irror, - Afr. : Jns. Borbon.

"var. antitrichioides Besch. Fl. bryol. Réunion, elc.p. 133.

- Afr.: Ins, Borbon.

Adiantum Griff, - Cyatophorum?

adunca Willd. - Hypnum.

aequalifolia C. M. in Bot. Zeit. 1854, p. 569; Mitt. M. Ind. or. p. 120
$\begin{aligned} & \text { 1. } \\ & \text { - As. : M. Neilgherr. }\end{aligned}$

- As. : M. Neilgherr.

affinis Hook. - Pilotrichum.

africana Bryol. eur. $V$ (mon. p. nom.). - Afr. : C. B. Sp.?

africana C. M. - Papillaria.

albicans Willd. - Brachythecium.

alopecura C. M. - Braunia sciuroides

alopecuroides Mitt. - Thamnium.

(1) In Enum. Kindberg. nom, nud. :

M. Krausei $C$. $M$, 
amazonica Mitl. M. austr, am. p. 452.

Syn.

- Am. merid.: Amazon.

ambigua C. M. - Cleistostoma.

amblyacis C. M. - Papillaria.

amblyoglossa $C$. $M$, in Linn. 1878-79, p. 409.

1. $\quad-A m$. merid. : Argentin. subtropic.

ampullacea C. M. - Pilotrich olla.

anacamptolepis C. M. syn. $11, p .663$; Bryol. jav. II, p. 67, t. 186.

2. Ad arbor. - As.: Sumatra, Java.

andamana (C. M.) Par.

Distichia andamana $C$. $M$. in $F l .1878, n .6$.

2 .

- As, : Ins. Andaman.

Anderssonii C. M. - Pilotrichella.

andina Mitl. M. austr. am. p. 457.

- Am. merid. : And, Quitens.

angusta C. M. - Symphyodon. angustifolia C. $M$. in Bot. Zeit. 1847, p. 828 et Syn. II, p. 52; Mitt. op.
cit. p. 454.

1.

applanalula C. M. - Cylindrothecium.

- Am. sept. : Mexic.

appressa C. M. - Papillaria.

aptychodes Schlieph. - Pterogoniella.

Arbuscula Hpe. in Fl. 1878, n. 6.

Syn.

Arbusculum Lindb. - Porotrichum.

- As. : Penang.

arcuans Mitt. - Thamnium.

argentinica Ltz. in Linn. 1878-79, p. 411.

1. - Ain merid. : Argentin. subtropic.

Ascensionis Besch, in Journ. de bot. 1891, p.

Syn,

assimilis C. M. - Leucodon.

- Afr. : Ins. Ascension.

atro-lutea C. M. - Papillaria.

Auberti Brid, - Hookeria.

aurea $\left\{\begin{array}{l}\text { C. M. - Cylindrothecium. } \\ \text { Griff. - Meteorium }\end{array}\right.$

auregeens

aurescens Hpe. in Linn. i856, p. 212.
Ster.

- Pac. : Austral. or.

australasica C. M. - Porotrichum dendroides.

Avellanedae C. MI. - Pilotrichella.

Bauerlenii Geh. Neue Beitr. zur Moosfl, v. Neu Guin. p. 4, t. 2.

Syn. Ad arbor. - Pac. : Nov. Guinea merid.

Balfouriana C. M. - Spiridens.

Bundongiae C. M. - Cylindrothecium.

Reccariana Hpe, in Nuov. Giorn. bot. ital. 1872, p. 282.
Ster.

Berteroana W. P. Sch. mss. ; Mitt. M. austr, am. p. 454.

- Am. merid. : Chile. 
Besseri Jur. - Neckera Sendtneriana. var. costata R. Farneti. f. tenella Lindb. var. rotundifolia Husn - Neckera Sendtneriana var. rotundifolia. Beyrichii Schwaegr. - Cylindrothecium.

bicolorata C. M. in Engler's Bot. Jahrb. 1883, p. 85 et in Forchungsreise.., Bot, p. 47.

Ster. Ad arbor. - Pac. : Nov. Hannover.

biductulosa Schwaegr. - Lepidopilum flexifolium.

biformis Hpe. Enum. M, Brasil. p. 40.

Ster.

- Am. merid. : Brasil. austr. or.

Billardieri Hpe. - Pilotrichella.

bipinnata Schleich. - Leptodon Smithii.

birmensis $\mathrm{Hpe}$. in $\mathrm{Fl} .1878, n .6$.

2. Ster.

- As, : Birman.

blanda Harv. - Papillaria.

bogotensis Mitt. M. austr. ame. p. 454.

Ad arbor. - Am. merid. : And. Nov. Granat.

Roiviniana C. M. in Besch. Fl. bryol. Réunion, etc. p. 130.

Ster.

- Afr. : Ins. Nóssi-Be.

Bolleana C, M. in Bot. Zeit. 1859, p. 230 .

- Afr, : Ins, Cap Viridis.

Borgeniana Kiaër in Borgen M. Madag. n. 131, 144. - Afr. : Madagasc. centr. et or.

Boryana C. M. - Pterogoniella.

brachyclada Besch. in Ann. sc. nat. $1892, I, p .75$.

2. In silvis. - As. : Yunnan.

brachyclada C. M. - Leptohymenium.

brachypus C. M. - Leucodon.

brasiliensis Bryol, eur. V (mon. $p_{*} \quad$, nom.). - Am. merid. : Brasil.

brasiliensis C. M, - Pilotrichum.

Breutelii C. M. -- Leptohymenium.

brevinervis Broth, in Bihang till Sv. Vet. Akarl. Handl. 1895, n 3.

1. Ad arbor. - Am. merid. : Brasil. or.

breviramea C. M. - Pilotrichella.

brevirostris Griff. - ? Pylaisaea.

brevisela H. f. et W. - Cylindrothecium.

breviuscula C. M. in Dusen M. Camer, $n .242$.

- Afr. : M. Cameroon.

Buchanani C. M. - Papillaria.

caldensis Lindb. mss. ; Ångstr. in Oefv... 1876, n. 4, p. 40.

- Am. merid. : Brasil, austr. or.

" var, paulensis Geh, et Hpe, in Fl. 1881.

- Am. merid. : Brasil. austr. or.

californiea Hook, et Arn, - Alsia. 
camptoclada Ren. et Card. - Leptodon flexuosus.

canariensis Rrid. - Leucodon.

capensis Bryol. eur. V (mon. p.

- Afr.: C. R. Sp.

nom.).

Exs. : Rehm. M, Afr. austr. n. 327.

capensis C. M. - Aërobryum.

capillacea $\left\{\begin{array}{l}\text { C. M. - Dichelyma. } \\ \text { Griff. - ? Pylaisaea. }\end{array}\right.$

capillaris C. M. - Papillaria.

capilliramea C. M. - Papillaria.

celebesica C. M. in Geh. Neue Beitr. zur Moosfl. v, Neu Guin. p, 6.

- As, : Celebes.

cephalonica Jur. in Ung. et Ky. "die Insel Cypern. "

N. pennata var. cephalonica W. P. Sch. Syn. II ed. p. 565.

2 .

deir.

- Eur.: Ins. Cephalon. Afr.: Ins. Canar., Ma-

cernua C. M. - Cylindrothecium.

characea C. M. - Pilotrichella.

var. nigrescens C. M. - Pilotrichella characea var. nigrescens.

var, lenuis C. M. - Pilotrichella characea var, tenuis.

chilensis W. P. Sch in Ann. sc. nat. II ser., VI, p. 147, t. 9; C. M.

Syn. II, p. 56; Milt. M. auislr. am. p. 457.

1. Ad arbor. - Am. merid. : Chile.

chilensis Mitt, p.p. - N. Novae Granatae.

chlorocaulis C. M. Syn. II, p. 663 ; Mitt. op. cit. p. 454.

1.

chlorocaulis Sull. - N. oligocarpa.

- Am. sept. : Mexic.

chrysoclada C. M. - Papillaria.

chrysoneura Hpe. - Pilotrichella.

cirrifolia C. M. - Papillaria.

cirrosa Sw. - Macromitrium.

cladorhizans $\left\{\begin{array}{l}\text { C. M. - Cylindrothecium. } \\ \text { H. f. et W. - Cylindrotheci }\end{array}\right.$

Clastobryu $\mathrm{H}$. f. et W. - Cylindrothecium Drummondii.

clastobryum indicum.

coarctata C. M. p p. $\left\{\begin{array}{l}\text { Cylindrothecium flavescens. } \\ \text { Cylindrothecium rubicundum. }\end{array}\right.$

cochlearifolia C. M. - Pilotrichella.

columnaris Schwaegr. - Cylindrothecium.

comes Griff. - Cylindrothecium.

commulata C, M. - Pterogoniella.

Comorae C. M. in Linn. 1876, p. 268.

Ster. Ad arbor. - Afr.: Reg. lacustr., Usambara, ins. Anjonan, Mayotte, Madagasc., ins. Borbon., Franciae.

complanata (L.) Hïb. Muscol. germ. p. 576 ; Bryol. eur. V (mon. p. 9), t. 444 ; C. M. Syn. II, pp. 43 et 662 ; W. P. Sch. Syn. II ed.

Homalia complanata de Not. Epil. p. 199.

H. ornithomplanatum $L$. Sp. pl. p. 1588 .

H. pernatum

p. $268, t$, compressum et splendens, capsulis ovatis Dill. Hist. M. Leskea $268, t .34, f .7$.

L. Omalia colanata Hedve. Fund. M. II, p. 93, t. 10, f. 62-65.

. Onalia complanata Brid. Bryol. univ. $I I, p .327$. 
2. Ad arbor. silvat., rar. ad saxa. - Eur. : Tota. As. : Caucas., Persia. A fr. : Alger., ins. Canar. Am. sept. : Labrador, Terr, nov., Nov. Scot., New Brunswick., Nov. Angl., Pensilv., Tennessee.

Exs. : Rab. Bryoth, eur. n. 378, 379, 380, 609.

Sull, et Lesq. M. bor, am. II ed. n. 396.

var. falcata Warnst. - N. complanata var. secunda.

var. foliis obtusis Rab. - N Sendtneriana.

"var. longifolia W. P. Sch. Coroll. p. 100 et Syn. II ed. l.c.

Ster. In silv, umbros. - Eur. : Norveg. merid,, German.

var, obtusa Lindb. - N. Sendtneriana.

«var. secunda Gravet 1884.

N. complanata var. falcata Warnst, in Hedwig, 1885.

Ad rup. calc. soli exposit. - Eur. : Med. et or.

* var. tenella W. P. Sch. ll. cc.

N. tenella Kindb. Laubm. Schwed. und Norw, p. 5.

Ster. Ad rup. calc. umbros. et in spelunc. - Eur. : Suecia, German.

complicata C. M. - Cylindrothecium.

composita Hedw - Pilotrichum.

var. $\beta$ Schwaegr. - Pilotrichum affine.

compressa C. M. - Cylindrothecium.

consimilis Hpe. - T'ilotrichella.

convoluta Dz. et Mlis. - Pterobryum.

? cordata Hook. in Wall. Cat. n. 7623 et Ic. pl. rar. t. 22; descript, in

Lond. Journ. of bot. 1840 , p. 15 ; C. M. Syn. II, p. 158.

$$
\text { - As. : Nepal. }
$$

cordata Hsch. - Meteorium Widgrenianum.

coronata C. M. - Lasia.

crassa Hsch. - Prionodon densus.

crassicaulis C. M. - Pterobryum.

crenulata $\left\{\begin{array}{l}\text { C. M. - N. loriformis. } \\ \text { Harv. - ? Pterobryum crenulatum. }\end{array}\right.$

crinita Griff. Not. p. 464 et Ic, pl. asiat. II, t. 84, f. I; Mitt. M. Ind. or.

p. 120.

1. Rupic. - As. : Ceylan, Assam, Tonkin.

crinita Sull - Pilotrichella.

crispa (L.) Hedro. Fund. M. I1, p. 93, t. 14, f. 47-48; Bryol. ear. V pa (L.) Hedro. Fund. M. I1, p. 93, t. 14, f. 47-48; Bryoh. Syn. II
(mon. p.9), t. 4t3; C. M. Syn. II, pp. 54 el $664 ;$ W. P. Sch. 568.

Hypnum crispum $L . S p . p l . p .1589$.

H. pennatum undulatum crispum, setis et capsulis brevibus Dill. Hist. $\mathrm{M}$. p. $273, t .36 f .12 \mathrm{~A}$.

Leskea crispa Schrank Prim. Al. Salisb. p. 835.

N. Distichia crispa Brid. Bryol. univ. II, p. 246.

2. Ad arbor. silvat. et rup, umbr. praecip. calcar, - Eur. : Reg. montos. silvat. tota. As. : Caucas. occ. et centr. Afr. : Ins. Canar.. Madeir. Am. merid. : And. Quitens. ? (1).

Exs. : Rab. Bryoth. eur. n. 143 a et b.

a var. falcata Boulay M. Fr. II, p. 181.

Ad rup. sicc. - Eur. : Ubi typ.

(1) Cf, C. M, 1, c. 
« var, subplana Warnst. mss.

- Eur. : Belgium.

crispatula Hook. - Trachypus.

crispula Bryol. jav. $11, p .66, t .184$.

2. Ad arbor. - As. : Nepal., Sumatra, Java.

cryptotheca C. M. - Leucodon.

Cumingii C, M. - Pilotrichella.

cupressiformis Willd, - Hypnum.

curtipendula Hedw. - Antitrichia.

curvata Griff. - Cylindrothecium.

curvirostris $\left\{\begin{array}{l}\text { C. M. - Leucodon. } \\ \text { Schwaegr. - Rhaphidostegium neckeraceum. }\end{array}\right.$

cuspidifera Tayl. - Papillaria.

cyathipoma C, M. - Pilotrichella.

cyclophylla C. M. Syn. II, p. 664; Bryol. jav. II, p. 67, t. 185.

2 2? - As. : Java, Sumbawa.

? cylindracea Mont. - Pterobryum.

cylindricaulis C. M. - Erythrodontium.

cymbifolia C. M. - Pilotrichella.

decipiens W. et M. - Pterigynandrum filiforme var. heteropterum.

decolorans $\mathrm{Hpe}$ - Pilotrichella pseudo-imbricata.

decomposila C. M. - Porotrichum.

densa Wils. - Prionodon.

denticulata C. M. - Papillaria.

dendroides $\left\{\begin{array}{l}\text { Brid. - Climacium. } \\ \text { Hook. - Porotrichum. } \\ \text { Hseh. - Homalia javanica. } \\ \text { Mont. - Porotrichum leucocaulon? }\end{array}\right.$

$\beta$ americanum C. M. - Climacium americanum.

dentata $\left\{\begin{array}{l}\text { C. M. - Leptohymenium. } \\ \text { Griff. - Homalia. }\end{array}\right.$

Deppii Hsch. - Papillaria.

diaphana C. M. - Brannia.

diniorplia C. M. - Pilotrichella.

distans C. M. - Cylindrothecium.

disticha Hedro. M. frond. $I I I$, p. 58, t. $22 ;$ Mitt. M. austr. am. p. 451 .

Daltonia disticha W. Arn. Disp. p. 54.

Fontinalis disticha Sw. Pr. fl. Ind. oce. p. 138.

N. Distichia retusa Brid. Bryol. univ. II, p. 243.

Pilotrichum distichum $P$. B. Prodr, p. 83; C. M. Syn. II, p. 46.

P. truncatum $P . B . l$. c.

Syn. Ad arbor, et saxa. - Afr.: Ins. Fernando-Po, Benin, Togo. Am. sepl. : Florid., Mexic., Costa Rica, Antill. fere omn. Am. merid. : Amazon., Nov. Granat. Peruv,, Chile, Brasil. or.

diversicoma $\mathrm{Hpe}$ - Papillaria.

domingessis Spreng. - Leucodon.

Douglasii Hook. Bot. Misc. 1, p. 131, ı. 35; C. M. Syn. 11, p. 55; Lesq. et Jam. Man. p. 283.

2. Rupic. - Am. sept. : Columb, brit., Alaska, Vanconver, Washington, Oregon, Idaho, Calif.

Exs, : Mac. Canad. M. p. 241.

Sull. et Lesq. M. bor. am. p. 394. 
«var. Macounii Kindb. in Bull. Torr. bot. Club, XVII, p. 275 et in Mac. Cat. p. 163.

N. Douglasii ej. Enum. Bryin. exot.

Ad arbor. et sax. - Am. sept. : Columb. brit., ins. Vancouver.

Exs. : Mac. Canad. M. n. 389.

Dozyana ('., M. - Aërobryum longissimum.

Dregeana $\mathrm{Hsch}$. - Cylindrothecium.

Drummondii C. M. - Hedwigidium.

Dubyana Hpe. - Papillaria.

duplicata (Schoaegr.) Par.

Fissidens domincensis Brid. Bryol. univ. II, p. 707.

Hypnum duplicatum Sehwaegr. Suppl. I, II, p. 198 et $I I I, I I, I I$, เ. 279; C. M Syn. II, p. 585 (1).

Pterobryum duplicatum Mitt. M. austr. am. p. 427.

Ad arbor. - Am. sept. : S. Doming. Am. merid. : Nov. Granat., And. Quitens, et Peruv., Brasil. or.

Duseni C. M. in Dusen M. Camer. n. 105.

- Afr. : M. l'ameroon.

Eavesiana Hpe. - Papillaria.

efructifer $\alpha$ Griff. - Thamnium alopecuroides.

Ehrenbergii C. M. Syn. II, p. 51.

$$
\text { - Am. sept. : Mexic. }
$$

elegans Jur, in Bot. Zeit. 1866, p. 120.

N. intermedia (fid. Mitt. in Godman's Nat. hist. of the Azores, p. $305 ;$ sed dioica!).

2. Ad Laurum canariens. - Afr. : Madeir.

elegantula Griff, - N. exserta.

Eriodon C. M. - Eriodon conostomus.

eucarpa W. P. Sch. in Mandon Pl. Boliv. n. 1690.

- Am. merid. : And. Boliv.

Eugeniae Lindb. - N. taitensis.

exserta Hook, in Schwaegr. Suppl. III, I, II, t. 244; C. M. Syn. II,

p. 53 ; Mitt. M. Ind. or. p. 120.

N. elegantula Griff. Not. p. 464 et Ic. pl. asiat. II, t. 83, f. 5 ?

1. In fruticet. humid. - As. : Nepal., Sikkim, penins. Malay.

extans Besch, in Ann. sc. nat. VII ser. $I I$, p. 93.

1.

- Afr. : Ins. Mayotte.

falcala (:. M. - Dichelyma.

falcifolia Ren. et Card. in Bull. Soc. roy. bot. Belg. 1894, I, p. 184.

Ster. In silv. - Am. sept. : And, Costa-Ricens.

filamentosa Hook. - Meteorium.

filescens Schwaegr. - Meteorium.

filicina Hedw. - Pterobryum.

filifera C. M. - Pilotrichella.

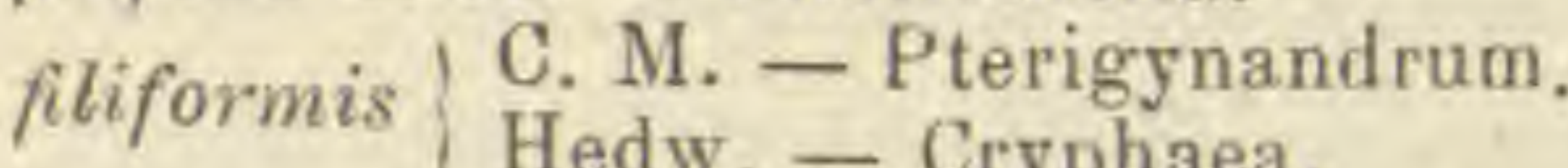

(1) Cf. C. M. 1, e. 
timbriata Harv, in Lond. Journ. of bol. 1840, p. 13 et in Hook. Ic. pl. rar. t. 21, f. 4; C. M. Syn. I1, p. 47; Mitt. op. cit. p. 122.

2.

- As, : Nepal, , Sikkim, Khasia.

flabellata $\left\{\begin{array}{l}\text { Hpe. - Porotrichum variabile. } \\ \text { Mitt. - Homalia. }\end{array}\right.$

flaccida C. M. Syn. II, p. $54 ;$ Bryol. jav. II, p. 63.

1.

-As. : Ceylan, Java.

faccida $\left\{\begin{array}{l}\text { Brid. - Anomodon obtusifolius? } \\ \text { Dz. et Mk. - N. loriformis. } \\ \text { Mitt. - N. Graeffeana?. }\end{array}\right.$

flagellacea Mitt. - Porotrichum.

flavescens $\left\{\begin{array}{l}\text { Hook. - Cylindrothecium rubicundum. } \\ \text { Schwaegr, - Cylindrothecium. }\end{array}\right.$

flevo-limbata C. M. et Hpe. - Pilotrichella.

flexilis C. M. - Pilotrichella.

flexuosa Harv. - Leptodon.

florihunda C. M. - Papillaria.

var. minor C. M. - Papillaria floribunda var. minor.

? floridana Aust. - Pilotrichella.

fontinaloides Lindb. - N. pumila.

$\beta$ Philippei Lindb. - N. pumila var. Philippeana.

foveolata Mitt. in Trans. of the Linn. Soc. XXIII, t. 5, f. 5 et M. austr. am, p. 453.

Pilotrichum toveolatum Hpe. Enum. M. Brasil. p. 44.

P. undulatum P. B. Prodr. p. 83 (fid. Mitt. l. c.).

merid. : Brasil, austr. or.

- Afr.: Occid. tropic. (sine loc. spec.). Am.

fruticosa Mitt. - Porotrichum.

funalis C. M. - Pilotrichella.

funitormis C. M. - Pilotrichella cuspidigera.

fuscescens $\{$ C. M. - Pterogoniella.

fusco-viridis C. M. - Papillaria.

Gennati Rola mss. in de Not. Epil. p. 775.

N. jurassica? (fid, Limpu. Laubm. Deutschl. II, p. 702).

Ster.

- Eur. : Ital. (Piazzatorre).

glabella Sw. - Homalia.

glauca C. M. - Lepyrodon.

glossophylla Mitt. - Homalia.

glyphotheca C. M. - Bladomnium sciuroides.

Goughiana Mitt, - Homalia.

gracilenta Bryol. jav. II, p. 62, t. 182.

2. Ad arbor. - As.: Sumatra, Java, Borneo, Ceram, Celebes. Pac.:

Ins. Samoa, Admiral.

gracilis C. M. - Pterogonium.

gracillima Tayl, - Schwetschkea.

Graeffeana C. M. M. Polyn. p. 72.

N. flaceida Mitt. in Bonpland 1861, p. 366 ?

Syn.

- Pac. : Ins. Fidji.

Grateloupii C. M. - Schwetschken.

guianensis Mont. - Pilotrichella. 
hamata C. M. - Sauloma.

Hampeana C. M. - Cylindrothecium.

hamulosa Vill. - Antitrichia curtipendula.

Harveyana C. M. - Leucodon secundus.

heteromalla Hedw. - Cryphaca.

heterophylla Brid. Sp. M. II, p. 32 ; C. M. Syn. II, p. 58.

Cryphaea heterophylla Brid. Bryol. univ. II, p. 352.

Daltonia heterophylla W. Arn, Disp. M. p. 54.

Fontinalis heterophylla Lour. Fl. Coohinch. II, p. 841 .

Hypnum heterophyllum Poir.

Pilotrichum heterophyllum $P$. B. Prodr. p. 83.

$$
\text { - As. : Cochinch. }
$$

hexasticha C. M. - Pilotrichella.

Hildebrandtii Reichdt. Beitr. p. 172.

Ster. Speluncic. - Pac. : Ins. Sandwic.

himalayana Mitt. M. Ind. or. p. 121.

Ster.

- As. : Sikkim.

hispida C. M. -- Pilotrichella.

Hoehnelii C. $M$. in Fl. 1890, p. 489.

Ster. - Afr. : M. Aberdare.

Hookeri Dz. et Mk. - N. plumula.

hookeriacea C. M. in Dusen M. Camer. n. r. - Afr. : M. Cameroon.

Hookeriana $\left\{\begin{array}{l}\text { Griff. - Cyatophorum. } \\ \text { Mitt. - Homalia. }\end{array}\right.$

Hornschuchiana C. M. Syn. II, p. 51 .

N. pennata Hsch. in Deppe et Schiede M. Mex. n. 1090.

1 .

- Am. sept. : Mexic.

Humboldti C. M. - Rhacocarpus.

humilis Mitt. in Trans, of the Linn. Soc. 1891, p. 174.

1. Ad arbor. - As. : Japon.

hygrometrica C. M. - Wardia.

hymenodontea C. M. in Bot. Zert. 1851, p. 564 .

N. pennata Wils, in Fl. Tasm. II, p, 204.

1. Ad arbor. - Pac. : Nov. Zeland,, Tasman.

hypnoides $\left\{\begin{array}{l}\text { Hedw. - Pilotrichum. } \\ \text { Hook. - Pilotrichum rugifolium. }\end{array}\right.$

illecebra C. M. - Pilotrichella.

illecebrina C. M. - Pilotrichella.

imberbis C. M. -- Hedwigidium.

imbricata $\left\{\begin{array}{l}\text { Hsch. - Pilotrichella rigida. } \\ \text { Schwaegr. }\left\{\begin{array}{l}\text { - Pilotrichella. } \\ \text { - Pilotrichella versicolor. }\end{array}\right.\end{array}\right.$

var. brachypoda Mont. - Pilotrichella guianensis.

imbricatula C. M. - Pilotrichella.

incurvata $\mathrm{Hsch}$. - Cylindrothecium.

implana Mitt. Sam. M. p. 169.

2, Ad arbor. - Pac. : Ins. Samoa.

implexa C. M. - I.epyrodon. 
indica C. M. - Lasia.

inermis C. M. - Rhacocarpus.

intermedia Brid. Mant. M.p. 137 ; C. M. Syn. II, p. 49.

Daltonia intermedia $W . A r n$. Disp. p. 54.

N. Distichia intermedia Brid. Bryol. univ. $I I$, p. 211.

1. Ad arbor. - Afr. : Ins. Canar., Madeir..

Exs, : Husnot M. Canar, n. 147.

Mandon Pl. Madeir. n. 30.

* var, lævigata W. P.Sch. in Mandon Pl. Madeir, n. 31 . - Afr. : Madeir.

Jagori C. M. - Sauloma.

Jamesoni Tayl. in Lond. Journ. of bot. 1846, p. 59; C. M. Syn. 11, p. 56 ; Mill. M. austr. am. p. 456.

javanica C. M. - Homalia.

- Am. merid. : Nov. Granat., And. Quitens., Chile.

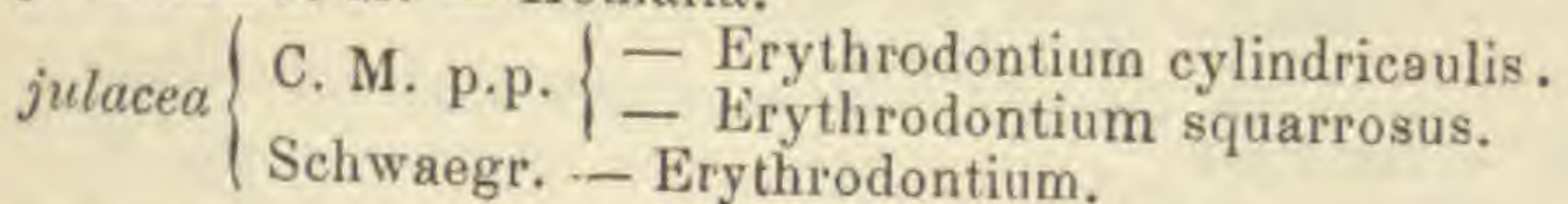

jurassica Aman in sched.; Limpr. Laubm. Deutschl. II, p. 701.

Ster. Ad rup. calcar. humid. - Eur. : Jurass. (M. Chasseron).

kealeensis Reichdt. Beitr. p. 571.

Ster. Rupic, in silv. - Pac. : Ins. Sandw ic.

Kegeliana C. M. - Pilotrichella.

kermadecensis C. M. - Papillaria.

Khorthalsiana $\mathrm{Dz}$. et $\mathrm{Mk}$. - Porotrichum.

Kurzii Hpe. mss. ; Jaeg. Ad. II, p. 183.

- As. : Birman. laevigata Hook. f. et Wils. Fl. of the N. Zeal. p. 103,t. 88, f. 3 et
Handb. p. 463. - Pac. : Nov. Zeland. med.

Lagura C. M. - Lepyrodon.

lancifolia Harv. - Sematophyllum.

latifolia Lindb. - Papillaria.

laxa C. M. - Schwetschkea?

Leichardti Hpe, in Linn. 1869.70, p. 520.

leiophylla C. M. - N. Sendtoeriana.

- Pac. : Austral. or. (Nov, Valesia).

Lepineana Mont. in Ann. sc. nat. 1848, p. 107 et Syll. p. 23; C, M.

Syn. II, p. 49; Bryol. jav. II, p. 61, t. 181.

N. undulata Mont. in Voy. au pôte S. Crypt. p. 218 p.p.

2. Ad arbor. et rupic. - As. : Celebes, Halmaheira, Ceram, M. Java,

Sumatra; Tonkin? Afr. : Ins. Franciae (ster. : var.?, vel sp. nov.?)

Rodriguez. Pac. : lns. Fidji, Samoa, Taïti, Arch. Gambier, Nov.

Guin. sept.

leptocarpa H. f. et W. - Cylindrothecium Jamesoni.

leptophylla W. P. Sch, in Besch. Prodr. bryol. mexic. $p 76$.

- Am. sept. : Mexic. (Orizaba).

1. Ad arbitt. in Hook. Journ. of bot. 1856, p. 263. 
leucocaulon C. M. - Porotrichum.

leucoclada C. M. - Dichelyma pallescens.

lencocolea Mitt. M. austr. am. p. 457.

- Am. merid. : Monte-Video.

leucocylus C. M. - Sauloma microcarpa.

leuconeura C. M. - Papillaria.

Liebmanni W. P. Sch, in Besch. Prodr. bryol. mexic, p. 76.

- Am. sept. : Mexic. (Orizaba).

Liebmanniana C. M. - Hedwigidium.

ligulaefolia Mitt. - Hoınalia.

Lindigii Hpe, in Linn. 1863 , p. 149 ; Milt. op. cit. p. 455.

1. Ad arbor. - Am. sept.: Guatemala? Am. merid. : And. Nov. Granat.

lingulata Mitt. in Trans. of the Linn. Soc. 1891, p. 173.

Ster.

- As. : Japon.

lineolata C. M. - Sauloma.

livens C. M. - Pilotrichella.

longe-barbata Hpe. - Pilotrichella.

longe-exserta Hpe, in Fl. 1878, n. 6. 1. - As. : Sikkim.

longifolia C. M. - Cylindrothecium.

longipedunculata C. M. - Leptodon longisetus.

longipes C. M. - Pilotrichella.

longirostris Hook. - Porotrichum.

longiseta $\{$ C. M. - Erythrodontium.

Hsch. - Erythrodontium cylindricaulis.

longiselacea C. M. - Leptohymenium.

longissima $\left\{\begin{array}{l}\text { C. M. - Meteorium. } \\ \text { Dz. et Mk. - Aërobryum. }\end{array}\right.$

longiuscula C. M. in Dusen M. Camer, n. 241.

- Afr: : M. Cameroon.

loriformis Bryol. jav. II, p. 63, t. 183.

N. crenulata C. M. in Bot. Zeit. 1849, p. 231.

N. flaccida $D_{z}$. et Mk, in Zolling. Verz. I, p. 26.

N. undulata Duby in Moritsi Cat.

2. Pac. : Ins. Fidji, Samoa.

-As.: Celebes, Ceram, ins. Banea, M. Java.

Ludoviciae C. M. - Pilotrichella.

lurida liriff. - Cylindrothecium.

luteo-virens Tayl. - Prionodon.

lutescens Willd. - Camptothecium.

Mac-Leana Rehm. M. Afr. austr. n. 616.

Ster.

- Afr. : Transvaal.

Macounii $\left\{\begin{array}{l}\text { Kindb. - N. Douglasii var. Macounii. } \\ \text { Sull. - Leptodon nitidus. }\end{array}\right.$

macrocarpa $\left\{\begin{array}{l}\text { Brid. - Porotrichum. } \\ \text { C. M. - Sauloma microcarpa. }\end{array}\right.$

macropelma C. M. - Braunia indica.

macropoda Hedw. - Cylindrothecium.

madagascariensis C. M. - Pterogoniella. 
madecassa Besch. Fl, bryol. Réunion, etc p. 130.

2 ?

- Afr. : Madagase., ins. Borbon.

Monkemeyeri C. M. - Pilotrichella.

Mariei Besch. in Ann. sc, nat. VII ser, , II, p. 93.

Ster. Ad arbor. - Afr.: Ins, Mayotte.

mascarena C. M. - Pilotrichella.

mechoacana C. M. - Cylindrothecium.

mediterranea Philib. - N. turgida?

Menziezii Hook, in Drumm. M. bor, am. I ed, n. $162 ;$ C. M. Syn. 11, pp. 48 et 663 ; Lesq. et Jam. Man. p. 282.

2. Ad arb. et rup. - Am. sept. : M. Rupestr. et Selkirk, Columb. brit., Alaska, ins. Vancouver, Washington, Oregun, Idaho, Montana, Calif.

Exs. : Mac, Canad. M. n. 238.

Sull. et Lesq. M. bor, am. II ed. n. 395.

- var. amblyclada Kindb. in Mac. Cal. p. 162.

N. oligocarpa Mac. Canad. M. n. 240 p.p.

Ster. Rupic. - Am. sept. : M. Rupestr.

"var. limnobioides Ren. et Card, in Bot. Centralbl. 1890, n. 51.

- Am. sept. : Oregon.

Mensiesii W. P. Sch. - N. turgida.

mexicana Bryol, eur. $V$ (mon. p. nom.). - Am. sept. : Mexic.

microcarpa W. P. Sch. in Besch. Prodr. bryol. mexic. p, 77.

1. - Am. sept. : Mexic.

minor Sull. - Anomodon obtusifolius.

Miqueliana C. M. - Papillaria polytricha.

Mohriana C. M. - Homalia.

moltis C. M. - Pilotrichella.

mollusca Mitt. M. austr, am. p. 455.

1. Rupic. - Am. mierid. : And. Nov. Granat.

Montagneana C. M: - Homalia.

Moritxii Hpe. in Linn. 1847, p. 91; C. M. Syn. $I I$, p. 48.

2. - Am. merid. : Venezuela.

mucronata Bryol. jav. II, p. 68, t. 187.

2.

bes. Pac, : Ins. Samoa, Nov. Truinea.

myura Schwaegr. - Cylindrothecium.

nano-disticha Geh. Neue Beitr. zur Moosfl. v. Neu Guin. p. 4, t. 3 B.

1. Ad arbor. - Pac. : Nov. Guinea merid.

natalensis Rehm. M. Afr. austr.

neglecta C. M. - Cylindrothecium.

Nietneri C. M. - Trachypus.

nigrescens Sehwaegr. - Papillaria.

var. brevifolia Hpe. -- Papillaria nigrescens var. brevifolia.

var. illecebra C. M. - Papillaria nigrescens var. illecebra.

nigricans Nees, - Pilotrichella. 
nitens W. P. Sch. in Besch. Prodr. bryol. mexic. p. 78.

2. Ster. - Am. sept. : Mexic.

nilens Mœnch. - Camptothecium. nodicautis C. M. - ? Trachypus.

Novae Granatae C. M. in Bot. Zeit. 1857, p. 581.

N. chilensis Mitt. M. austr. am. p. 457 p.p.

1 .

- Am. merid. : And. Nov. Granat.

obliquifolia Hsch. Fl. Brasil. I, p. 56; C. M. Syn. II, p. 57; Mitl. M. austr. am. p. 458.

Ster.

- Am. merid. : Brasil, austr. or.

obtusata Mont. in Ann. sc. nal. 1843, p. 240 et Syll. p. 23; C. M. Syn. 11, p. 58.

Ster. Ad arbor. - As. : Cochinch.

obtusata Mitt. - Homalia.

obtusifolia Tayl. in Lond. Journ. of bot. 1848, p. 193 ; C. M. Syn. II, p. 49 ; Mitt. op. cit. p. 456.

2.?

- Am. merid.: And. Nov. Granat. et Quitens,

octangula C. M. -- Cladomnium.

octodiceras C. M. - Papillaria.

Erstedtiana C. M. - Papillaria.

ohioensis C. M. - Leptodon.

oligocarpa Bryol. eur. V (mon. p. 7), t. $441 ;$ W. P. Sch. Syn, Il ed. p. 566.

N. chlorocaulis Sull. M. exs, I ed. n. 268.

N. pennata $\beta$ tenera $C$. M. Syn. II. pp. 50 et 663 .

N. pumila Wahlenb. Fl. Lapp. p, 367, n. 653.

1. In fissur. rup. vel later. occult. - Eur. : Scandin., Fennia, Tírol. As. : Jenissei sup. et med. $A m$, sept. : New Brunswick, Ontario, lac. Super., M. Rupestr., M. Alb., Nov. Mexic.

Exs, : Mac. Canad. M. n. 240 p.p.

Rab. Bryoth. eur. n. 1034.

Sull. et Lesq. M. bor, am. II ed. p. 393.

Un. itin. 1863, n. 54, 55.

oligocarpa Mac. p.p. - N. Menziezii var, amblyclada.

Orbignyana Ltz, Moosst. p. 164.

- Am, sept, : Mexic.

orientalis C. M. - Leucodon.

orthocarpa C. M. - Cylindrothecium concinnum.

orthorhyncha Besch. Prodr. bryol. mexic. p. 77.

1. In silvis. - Am, sept, : Mexic.

Osculatiana de Not. in Acad... di Torino, II ser., XVIII, p. $440 \mathrm{c}$, ic. - Am. merid. : Columb.

oxyphylla Mitt, in hb. Kew.

- As. : Bhotan.

Pabstiana C. M. - Homalia.

pachycarpa W. F. Sch. in Besch. Prodr. bryol. mexic. p. 76. - Am. sept. : Mexic.

pachygaster C. M. - Pilotrichella.

var. gracilis C. M. - Pilotrichella pachygaster var. gracilis. 
pallescens C. M. - Cylindrothecium.

pallida X. M. - Leucoloma Sieberianum.

palustris Willd. - Hypnum.

panduraefolia C. M. - Pilotrichella.

Parishiana Mitt. M. Ind. or. p. 121.

Syn. ?

- As. : Moulmein.

parrula Mitt. - Thamnium.

patagonica Brid. - Homalia glabella?

patula Schwaegr. p.p. - Pilotrichum recurvifolium.

Pechuelii C. M. - Porotrichum.

penduliramea C. M. - Homalia.

pennata (Hall.) Hedw. M. frond. III, p. 47, t, 19; Bryol. eur. V (mon.

p. 6), t. 440 ; C. M. Syn. 1I, pp. 50 et 673; W. P. Sch. Syn. II ed. p. 565 .

Cryptopodia pennata Roehl. Deutsch. Fl, IIT, p, 82.

Daltonia pennata $W$. Arr. Disp.p. 54 ,

Fontinalis pennata $L . S p . p l, p .1371 .15$

Hypnum pennatum Hall. Stirp. helvet. n. 1297, t. 45, f. 2.

N. Distichia pennata Brid. Bryol. univ. II, p. 238.

Pilotrichum pennatum $P, B$, Prodr. p. 83 .

Sphagnum pennatum, undulatum, vagina squamosa Dill. Hist, M. p. 250, t. $32, f .9$.

Weisia pennata Schrank Baiers Fl. II, p. 445.

1. Ad arbor. silvat. trunc. - Eur.: Reg. montosa infer. As.: Amour, Jenissei sup., Japon, Yunnan, Caucas, occ. Afr. : Ins, Canar., Fernando-Po, 1. B. Sp. $\sim A m$. sept. : Nov. Scot., New Brunswick, Gaspes., Ontar., Manitoba. Pac. : Nov. Zeland (1), Tasman.

Exs, : Drumm, M. bor. am. I ed. n. 161.

Mac. Canad. M. p. 239.

Rab. Reyoth, eur. n. 291 a et b, 1035 .

Sull, et Lesq. M. bor. am. II ed. n, 392.

var, cephalsnica W. P. Sch. - N. cephalonica.

s var. tasmanica Hpe. in Linn. 1852, p. 715.

N, hymenodonta (fid. Mitt.).

- Pac. : Tasman.

pennata Wils. - N. hymenodonta.

var. tenera C. M. - N. oligocarpa.

perichaetialis Hpe. - Papillaria.

perpusilla C. M. - Anisodon Bertrami.

Perrottetii C. M. - Symphyodon.

Pervilleana Besch. Fl. bryol. Réunion, elc. p. 131.

Ster. Secus rivul, - Afr. : lns. Nossi-Phale.

peterantha C. M. et Kindb, in Mac. Cat. p. 162 (subsp. N. oligocarpae),

I. Rupic, - Am. sept. : M. Rupestr.

Philippeana Bryol, eur. - N. pumila var. Philippeana,

phleoides C. M. - Pilotrichella.

phyllogonioides Sull. in Proced. of the Ant. Acad.... 1854 et in U. St.

Expl. Exped. Wilkes, p. 20, $t$. 17.

- As. : Ins. Philippin, (Luzon).

phyllogonioides C. M. - Pilotrichella.

(I) Fid. FI. Tasmanica ; in Handb. of N. Zeal, Fl. non indicata. 
planifolia $\left\{\begin{array}{l}\text { Hedw. - Trachyloma. } \\ \text { Hook. - Trachyloma Menziezii. } \\ \text { Reinw. et Hsch. - Trachyloma indicum. }\end{array}\right.$

platyantha (C.M.) Par.

Distichia platyantha C. M. in Fl. 1890, p. 1890, p. 489.

1. - Afr. : Kilima N'Djaro.

plicaefolia C. M. - Pilotrichella.

plumosa Reinw, et Hsch, in Nov. Act. Acad. Caes. Leop. Carol. XIV, II, p. 716 ; C. M. Syn. 11, p. 146 ; Bryol. jav. 11, p. 69.

Ster.

- As. : Java.

Plumula (Nees) C. M. Syn. II, p. 53.

N. Hookeri Dz. et Mk. in Ann. sc. nat. 1844, p. 313.

Pilotrichum Hookeri eor. M. frond, ined. Archip. ind. p. 135, t. 47.

P. Plumula Nees ab Es, in Brid. Bryol. univ. II, p. 759.

Syn. Ad arbor, et rup. - As. : Sumatra, Java, Borneo. Pac. : Noy. Caledon.

Pluvini Brid, - Ieptodon.

Pohlii C. M. - Leucodon.

Polakowskyi C. $M$, in Journ. of Bot, 1877, p. 229 (nom.).

Ad arbor, vetust. - Am. sept. : Costa Rica.

polyclada C. M. in Nuov. Giorn. bot, ital. 1896, p. 114. 2. - As. : China or. (prov. Schen-Si).

polytrichoides Schwaegr. - Lepidopilum.

Poeppigiana C. M. - Cladomnium gracile.

porodictyon Ren. el Card. in Bull. Soc. roy. bot. Belg. 1890, I, p. 180.

Ster. Ad arbor. - Am. sept. : Haîti.

? praelonga Ltz. in Bot. Zeit. 1866, p. 187.

Ster.

- Am. merid. : Valdiv.

praemollis C. M. - CEdicladium rufescens.

prionacis C. M. in Geh. Neue Beitr. zur Moosfl. v. N. Guin. p. 5, t.3A.

- Pac. : Nov. Guinea merid.

procumbens C. M. - Leptodon..

producta Hsch. - Lasia.

prostratula C. M. - Aërobryum.

pseudalopecura C. M. - Leucodon julaceus.

pseudo-crispa Rehm. M. Afr. austr, n. 328.

- Afr. : Natal.

pseudillecebra C. M. - Papillaria.

pseudo-imbricata C. M. - Pilotrichella.

pseudo-seductrix C. M. - Cylindrothecium.

pterops Rehm. - Porotrichum.

Puiggarii Geh. et Hpe. Enum. M. Brasil. p. 40.

1. $\quad-$ Am. merid. : Brasil.

pulchella $\left\{\begin{array}{l}\text { C. M. p.p. - Pterogoniella commutata. } \\ \text { Griff. }\end{array}\right.$

pulvinala C. M. - Myrimia.

pumila Hedw. $M$. frond. III, p. 49, t. 20 ; Bryol. eur. V (mon. p. 9),

t. 442 ; C. M. Syn. II, pp. 56 et $664 ;$ W. P. Sch. Syn. II ed. p. 567. 
Fontinalis pennata Huds. Fl. Angl. p. 468.

Hypnum Dicksoni Gmel. Syst. nat. p. 1342.

H. fontinaloides Lam. Encycl. meth. III, p. 164 (fid. Limpr.).

H. pennatum Dícks. Fasc. I Pl. crypt. p. 6.

H. pennatum undulatius crispum, setis ot capsulis brevibus var. minor Dill. Hist. M. p. 273, t. 36, f. $12 \mathrm{~B}$.

H. pumilum Gmel. l. c. p. 1341 .

N. fontinaloides Lindb. M. Scand. p. 40.

N. Distichia pumila Brid. Bryol. univ. II, p. 244.

Pilotrichum pumilum P. B. Prodr. p. 83.

2. dd arbor. prœcip. Conifer., tar. rup. - Eur. : Zon. intermed, rar. merid. : Norveg. occ. Afr.: Ins. Canar. $\Lambda \mathrm{m}$. sept, : ? (l)

Exs. : Rab. Bryoth. enr. n. 748 a et b, 1139 (forma), 1239.

a var, Philippeana Milde Bryol. siles. p. 282.

N. fontinaloides var. Philippei Lindb. M. Scand, p. 40.

N. Philippeana Bryol. eur. V (mon. p. 11), t. 445;C. M. Syn. II, p. 664.

N. pumila var, pilitera Jur. in Rab. Bryoth, eur. n. 749.

Ut typ. - Eur. : Rarior : Normann., Voges., Rhoengeb., Wuirtenb., Silva nigr., Westphal., Brandeb., Siles., Bavar., Pyren.

pumila $\left\{\begin{array}{l}\text { Hsch. }-\mathrm{N}, \text { urnigera. } \\ \text { Wahlenb. - N. oligocarpa. }\end{array}\right.$

pusilla Mitt. in Trans. of the Linn. Soc. 1891, p. 177.

Ad arbor. - As, : Japon.

pygmaea Ren. et Card. in Bull. Soc. roy. bot. Belg. 1893, II, p. 24 et M. Masc. Mad. n. 186.

Ster. - Afr. : Madagascar (Diego-Suarez).

pygmaea Dz, et Mk. - Schwetschkea.

quinquefaria C. M. - Pilotrichella.

ramulosa Mitt. - ? Climacium.

reclifolia Mitt, - Homalia.

recurvula (C.M.) Par.

Trachyloma recurvulum C. M. in Bail, Syn. of the Queensland Fl. IV 2 ?

Suppl. p. 98 (nom.), 6. 21, $f . I$; et in Oefo. 1893.

Reginae Hpe. - Papillaria. - Pac. : Austral. or. (Queensland).

Regnelliana C. M. - Entodon.

Reinoardti C. M. - Spiridens.

remota Br. et Sch, in W. Sch. M. Abyss. ; C. M. Syn, II, p. 51.

1. $\quad-A / r .:$ M. Cameroon, Abyss, litt. or. mar. Erythr.

var. laxa Br. et Sch. - N. abyssinica.

remotifolia Hsch, - Pilotrichella.

repens C. M. - Platygyrium.

retrorsa C. M. - Papillaria.

rigida C. M. - Pilotrichella.

rigidula Wils. - Leptodon.

rivalis Mitt. - Thamnium pumilum.

rostrata Griff, - Chionostomum.

rotundifolia Hartm. - N, Sendtneriana var, rotundifolia.

rufescens C. M. - Pilotrichella leucotricha.

rugulosa Mitt. M. Ind. or. p. 121.

Syn.?

- As. : Ceylan.

(1) Fid. Br. et Sch. a Drummond collecta; auctoribus americanis ignota. 
Sancte Catharinæ C. M. in Ule Bryolh. brasil. $n, 83$.

- Am. merid. : Brasil. austr. or.

scabridens C. M. in Bot. Zeit. 1847, p. 828 et Syn. II, p. 51.

1. Ad arbor. - Am. merid. : Chile austr., Valdiv.

scabriseta $\{$ C. M. - Eurhynchium suberectum.

Schwaegr, - Lepidopilum subenerve.

scalpellifolia Mitt. - Homalia.

Schlechtendalii Piep. - Anomodon viticulosus.

Schimperiana C. M. - Braunia.

Schmidii $\left\{\begin{array}{l}\text { C. M. - Pilotrichella. } \\ \text { Mitt. - Thamnium. }\end{array}\right.$

Schnyderi C. M. in Linn. 1880-83, p. 472.

- Am. merid. : Argentin. Buenos Ayr.

Scioana Briszi in Ann. del R. Islit. bot. di Roma, V, fasc. 2, 1893. - Afr. : Litt. occ. mar. Erythraei.

? sciuroides Hpe. Enum. Brasil. p. 43.

Ster.

- Am. merid. : Brasil. austr. or.

sciuroides C. M. - Leucodon.

$\beta$ cylindracea C. M. - Leucodon sciuroides vur, morensis.

Scottiae C. M. - Papillaria.

scrobiculata Nees ab Es. in Nov. Act. Acad. Caes, Leop. Carol. XVI,

Suppl. II, 1843, p. 478; C. M. Syn. II, p. 53.

1.

- As. : Manilla.

secunda C. M. - Braunia.

seduclrix Hedw. - Cylindrothecium.

semi-torta C. M. - Papillaria.

Semperiana Hpe. mss.; C. M. in Bot. Zeil. 1862, p. 381.

Ster.

- As. : Ins. Mindanao.

Sendtneriana Bryol. eur. V (mon, p. 10), t. 445 ; W. P. Sch. Syn. II ed. p. 569 .

Homalia Pourretiana Roumeg. in Bull. Soc. bot. Fr. 1870, p. 444.

N. Besseri Jur. Laubm. Osterr. Ung. p. 365.

N. complanata var. foliis obtusis Rab. Bryoth. eur. n. 379

N. complanata var, obtusa Lindlh. in Journ. of the Linn. Soo, 1870, p, 467.

N. leiophylla Gümbel in C. M. Syn. 11, pp. 44 et 662.

Omalia Besseri Lobarz, in Haiding. Naturw. Abhandl. I, p. 48? C. M. Syn. II, p. 45.

O. Sendineriana W. P. Seh. Coroll. p. 100.

2. Ad arbor. trunc et praepr, ad rup. calcar. - Eur. : Hungar. Bohem., Carinth., Austr. inf,, Salisb., Stir., Bavar., Tirol., Francon., Tergest. Etrur. As. : Persia, Caucas, occ. et centr.

Exs, : Rab. Bryoth. eur, n. 610 (var.).

" var. costata (R. Farneti) Par. Nar. costata (R. Farneti) Par.
Pavia, var. costata R. F. in Atti dell'Istit. bot. della $R$. unio. di

- Eur, : Ital. super.

«var. rotundifolia W. P. Sch, op. cit. p. 570.

N. Besserı var, rotundifolia Husn. Muscol. gall. $p$. 292.

N. Besseri forma tenella Lindb. Bidr. till Mooss. Syn. P. 22. p. 474.

N. Sendtneriana tenella Mdo, in Ltz. Moosst. p. 102.

Omalia rotundifolia W. P. Seh. Coroll. p. 101.

Ut typ. - Eur. : Suecia, Carinth., Tirol, merid. 
var, tenella Mdo, - N. Sendtneriana var, rotundifolia,

( C. M. - Leucodon.

Hedw. - Homalothecium,

serpens Willd. - Amblystegium.

serrulata Brid. - Trachypus.

setosa Hook. - Cyrtopus.

Sieboldi C. M. - Leskea tristis.

sinuata C. M. - Pilotrichella.

Smithii C. M. - Leptodon.

spathulaefolia Mitt. - Homalia.

spectubilis Griff, - Pterobryum crenulatum.

sphaerocarpa $\left\{\begin{array}{l}\text { C. M. - Hedwigidium squarrulosum. } \\ \text { Hook. - Cryphaea. }\end{array}\right.$

splachnoides Engl. Bot. - Daltonia.

splendens Hsch, et Reinw, - Pterobryum.

Spruceana Mitt. M. austr. am. p. 456.

- Am. merid, : And Quitens.

spurio-truncata C. M. in Dusen M. Camer, n. 706. - Afr.: M. Cameroon.

squarrosa $\left\{\begin{array}{l}\text { C. M. - Erythrodontium. } \\ \text { H }\end{array}\right.$

Hook. - Meteorium.

squarrulosa C. M. - Erythrodon tium.

Stracheyana Mitt. - Homalia.

straminea C. M. - Leptohymenium.

stimed - Rhaphidostegium circinale.

striata C. M. - Lescuraea.

stricta C. M. - Leucodon secundus.

subacutifolia Geh. et Hpe. in Fl. I881, p.

Ster.

- Am. merid. : Brasil. austr. or.

subdisticha Besch. in Ann. sc. nat. VII ser., II, p. 92.

subimbricata Hpe. - Pilotrichella.

- Afr. : Ins. Mayotte.

subintegra Lindb. - Hapillaria.

suborthosticha C. M. - Lepyrodon.

subpiligera Hpe. - Aërobryum.

subrecta Mitt. - Homalia.

subremota C. M. in Disen M. Camer. n. 281. - Afr. : M. Cameroon.

subrugulosa W. P. Sch. in Besch. Prodr, bryol. mexic. p. 77.

Ster. - Am. sept. : Mexic.

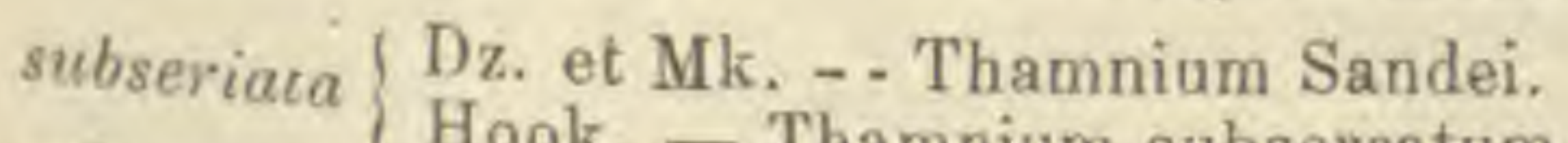

subserrata Hook., Mitt. - Thamnium subserratum.

subsphaericarpa W. P. Sch. in Mandon Pl. Boliv. n. 169I. - Am. merid. : And. Boliv.

substriala $\mathrm{Hpe}$. - Porotrichum.

subtilss Brid. - Amblystegium.

subtruncata Broth. in Mitth. aus d. deutsch. Schulageb. 1893, III. - Afr. : Togo.

subulata C. M. - Brachelyma. 
subuliformis Reinwo. et Hsch, in Nov. Act. Acad. Caes. Leop. Carol. XI7, p. 715 ; C. M. Syn. II, p. 146; Bryol. jav. II, p. 69.

Ster. - As. : Java.

sulcata C. M. - Climacium.

Sullivantri C. M. - Cylindrothecium.

sundaënsis C. M. in Bot. Zeit. 1856, p. 436.

1 .

- As. : Java.

taitensis W. P. Sch. in Hb. Mus. Paris (1850).

Calyptothecium praelongum Mitt. Sam. M. p. 190 (1868).

N. Eugeniae Lindb, in Reichdt. Voy. Novara, 1870 (nom.).

2. Ad arbor. - Pac.: Taiti, ins. Fidji, Samoa, Nov. Caledon.

Targioniana Mitt. - Homalia.

tasmanica Bryol. eur, V (mon. p. nom.).

- Pac. : Tasman.

lenax C. M. - Pilotrichella.

tenella $\left\{\begin{array}{l}\text { C. M. - Pilotrichella. } \\ \text { Kindb. - N. complanata var. tenella. } \\ \text { Schwaegr. - Cryphaea. }\end{array}\right.$

tenera Hsch. Fl. Brasil. I, p. 56; C. M. Syn. II, p. 58; Mill. M. auslr. am. p. 455.

Ster.

- Am. merid. : Brasil. austr.

tenuis $\left\{\begin{array}{l}\text { C. M. - Pilotrichella. } \\ \text { Hook. - Leptohymenium myuroides. }\end{array}\right.$

teretiuscula C. M. - Cylindrothecium.

Ternstroemicte C. M. - Pilotrichella.

tetragona C. M. - Pilotrichella.

tomentosa C. M. - Lepyrodon.

torta Sw. - Schlotheimia torquata.

tortipilis C. M. - Pilotrichella.

Trachyloma C. M. - Trachyloma Menziezii.

Trachypus C. M. - Trachypus bicolor.

trichoblepharis W. P. Sch. in Lechl. M. Chil. n. 818.

- Am. merid. : Chile.

trichoclada C. M. - Hypnum.

trichomanoides Hartm. - Homalia.

trichomitrium C. M. - Forstroemia.

trichophora W. P. Sch, in Krause M. Chil.

Ad arbor. - Am. merid. : Valdivia.

trichophora C. M. - Pilotrichella.

trichophoroides Hpe. - Pilotrichella.

trichophylla Brid. - Lepyrodon.

tricostata Sull. - Sciaromium.

truncala C. M. - Cylindrothecium.

umida Dicks. - Meteorium.

turgescens C. M. - Pilotrichella.

turgida Jur. in Verh. d. K. K. zool. bot. Ges. in Wien, 1861, 1. 414;

W. P. Sch. Syn. II ed, p. 570.

N. mediterranea Philib. in Rev. bryol. 1880, p. 81.

N. Menziezii W. P. Sch. Coroll. p. 100 et op. eit. p. 566 (fid. Husn.).

2. Ad arb. vetust. et pup. umbros. - Eur. Rhoengeb., Fichtelgeb.,

Thuring., Alp. Sabaud. (M. Blanc), Galloprov. (c. fr. .), Ital., ins.

Cephalon, et Leucate. A fr. : Alger. 
turgidula C. M. - Pilotrichella.

var. Iristis C. M. - Pilotrichella turgidula var, tristis.

ulophylla W. et M. - Ulota crispa.

undulata (P. B.) Hedio. M. frond. III, p.51, t.21; Mitt. M. austr. am.p. 452.

Daltonia undulata W. Arn. Disp. p. 54.

Fontinalis crispa Sw. Prodr. Fl. Ind. oce. p. 138.

Hypnum jamaicense Gmel. Syst. nat $I I, p .1341$.

N. Distichia undulata Brid. Bryol. univ. II, p. 241.

Neckeropis undulata Reichdt, in Voy. Novara, Bot. I, p, 181.

Pilotrichum undulatum P. B. Prodr. p. 83; C. M. Syn. II, p. 147. Sphagnum pennatum, undulatum vagina pilosa Dill. Hist. M. p. 294, .32 ,
f. 8 .

Syn. Ad arbor. - Am. sept. : Florida, Mexic., Antill, fere omn., intertropic. Am. merid. : Inter-tropic.; Paraguay; Patagon.? Pac. : Ins. Mariann. ?

undulata $\left\{\begin{array}{l}\text { Duby. - N. loriformis. } \\ \text { Mont. - M. Lepineana. }\end{array}\right.$

urceolata C. M. - Pterogoniella.

urnigera C. M. Syn. II, p. 57 ; Mitt. op. cit. p. 455.

N. pumila Hsch, in Deppe et Schiede M. Mexic. p. 1089.

1 .

- Am. sept. : Mexis.

uroclada Mitt. M. Ind. or. p. 122.

2.

- As. : Birmania.

uruguensis $C . M$. in Linn. $1888-79$, p. 412 .

Urvilleana C. M. Syn. II, p. 52 .

- Am. merid. : Uruguay.

N. Distichia pennata $\beta$ denticulata Brid. Bryol. univ. II, p. 240.

- Pac. : Taíti (??) ; ins. Carolin. (Oalau).

vaginans W. et Dy. - Meteorium.

Valentiniana Besch. Fl. bryol. Réunion, etc. p. 132.

- Afr. : Ins. Borbon.

versicolor C. M. - Pilotrichella.

Villae Ricae Besch. Not. M. Parag. p. 265.

Ad arbor. - Am. merid. : Paraguay.

Exs. : Balansa Pl. Parag. n. 1254.

virens $\mathrm{H}$. f. et W. -- Cylindrothecium.

voridis C. M. - Pilotrichella.

viridula Mitt. - Papillaria.

viticulae, formis Piep. - Anomodon viticulosus.

viticulosa $\mathrm{Hedw}$. - Anomodon viticulosis.
$\beta$ minor Hedw. - Anomodon obtusifolius.
viticulosoides

viticulosoides P. B. - Leptodontium epunctatum.

vulpina Mont. - Pterogoniella.

Wallichii DC. - Aërobryum.

Wehoitschii Dy. - Meteorium.

yesoana Besch. in Ann, sc. nal. 1893, p. 358.

Ess. : Faurie n. 47, 124, $823,35 \mathrm{I} 6$ (1).

(1; In Enum. Kindberg. nom, nuda :

N. Balansae C. M. (Neckeropsis).

Dillenii Lindb.

Fristedti $C, M$.

N. Hodgkinsoniae C. M.

laeviuscula Geh.

subsecunda Lindb. 
NECKERA DISTICHIA Brid. Bryol. univ, II, p. 238.

Spec. omn. non indicatae sunt NECKER ejusd. nom.

glabella Brid, - Homalia.

macropoda Brid. - Cylindrothecium.

pennata $\beta$ denticulata Brid. - Neckera Urvilleana.

retusa Brid. - Neckera disticha.

NECKEROPSIS Reichdt. in Novara Exp., Bot. I, p. 181.

undulata Reichdt. - Neckera.

NOTARISIA Hpe, in Linn. 1837, p. 379.

capensis Hpe. - Ptychomitrium crispatum.

ilalica $\mathrm{Hpe}$ - Ptychomatrium pusillum.

virginica Hpe. - Ptychomitrium incurvum.

OGHROBRYUM Mitt. Musc. austr, am. p. 107 (5 spec.).

Gardnerianum (C. M.) Mitl. op. cit. p. 108.

Leucophanes Gardnerianum C. M. Syn. I, p. 85.

L. phyllanthum Lindb. t. 12 et $M$. Ind. or. p. 26.

- As. : Nepal. ? Khasia, Madras, penins. Malay., Hong-Kong, Japon. Am. sept. : Mexic. ; Costa Rica? Am. merid. : Amazon., Brasil.

Kurzianum Hpe. in sched.

- As. : Pegu.

obtusifolium (C. M.) Milt, in op. et l. cc. (1).

Leucobryum obtusifolium C. M. in Bot. Zeit, 1857, p. 577.

Cortic. - Am. merid. : And. Nov. Granat.

? Rutenbergii C. M, in Abhandl. Brem. VII, p. 204.

- Afr. : Madagascar.

subulatum Hpe. mss. ; Jaeg. Ad. II, p. 655.

- As. : Birmania.

OCTOBLEPHARUM Hedw. M. frond. III, p. 15, t. 6 (18 spec.).

albidum Hedw. M. frond. 111, p. $15, t .6 ;$ C. M. Syn. I, p. 86; Bryol. jav. $1, p .27$.

Bryum albidum L. Sp. pl. p. 1583.

Br. nanum, lariginis folis albidis Dill. Hist. M. p. 364, t. 46, f. 21.

Br. octoblepharis Gmel. Syst. nat. II, p. 1331.

I. Cortic. et ad rup. umbros. -- As. : Japon., tropic. Afr.: Tropie.,

C. B. Sp, Am. sept. et merid. : Intertropic. Pac. : Ins. Sandwic.

Exs. : Dusen M. Camer. n. 116.

Rehm. M. Afr, austr. n. 453.

ampullaceum Mitt, M. austr, am. p. 109.

And. Peruv.

- Am. merid. : Ins. Trinitat., Guian., Amazob.,

angustifolium Mitt. op. cit. p. 110.

- Am. merid. : And. Quitens.

(1) * Sterile y (C. M.); " calyptra mitraeformis * (Mitt.). 
asperum Mitt. - Lencophanes.

cocuiense Mitt, op. cit. p. 109.

Ad Palm. - Am. merid. : Amazon.

curvirostre Dz. et Mk, in sched. ; Jaeg. Ad. 1, p. 170. - As. : Java?

cuspidatum C. M. in Forchungsreise... Bot. p, 57 (nom.).

- As.: Ins. Philippin.

cylindricum W. P. Sch. in hb. Hpe.; C. M. Syn. $1, p .87$.

1. $\quad-A m$. merid.: Columb., Guian., Amazon.

densifolium Mitt. - Leucophanes.

dentatum Mitt. - Arthrocormus.

fragillimum Ångstr. in Oefv.... 1876, n. 4, p. 6.

Ster. Terr. - Am. merid. : Brasil. austr. or.

hispidulum Mitt. - Leucophanes.

incrassalum Mitt. - Arthrocormus.

linearifolium C. M. in Engler's Bot. Jahrb. 1883, p. 84 et in Forchungsreise... Bot. 43.

Ster. Ad arbor. - Pac. : Nov. Hannov.

longifolium Lindb. in Oefv... 1864, p. 608.
1.

longifolium Mitt. - 0 . Mittenii.

microcarpon W. P. Sch. in sched.; Jaeg. Ad. I, p. 170.

l - Am. merid.: Surinam?

minus Hpe. Enum. M. Brasil. p. 11 .

- Am. merid. : Brasil. austr. or.

Mittenii Jacg. Ad. J, p. 169.

0. longifolium Mitt. op. eit. p. 110.

Ster. Ad rup. umbr. et terr. - Am. sept. : Guadalup. Am. merid. : Amazun,, Brasil. austr. or.

octoblepharioides Mitt. - Leucophanes.

popillosum Mitt. - Leucophanes.

perforatum $C: M$, in Hedwoig. I895, p. 119.

Ster.

- Am. meriel. : Brasil. or. (Goyaz).

pulvinatum Mitt. - Arthrocormus.

Radula Tho. et Mitt. in Journ. of the Linn. Soc. 1872, p. 298.

Leucophanes Radula Jaeg. Ad. II, p. 656.

Ster. - As, : Ceylan.

Rhaphidostegium C. M. in Hedwig. 1895. p. 119.

2 .

- Am. merid. : Brasil, or. (Goyaz).

recuroum Mitt. - Leucophanes.

sanctum Mitt, - Leucobryum.

scabrum Mitt - Leucophanes.

Schimperi Mitt. - Arthrocormus.

Scolopendrium Mitt. Fl. Vit. p. 387.

Syrrhopodon Scolopendrium Mitt. in Bonplandia, I861, p. 366.

Ster.

- Pac. : Ins. Fidji. 
serratum Hook. - Dissodon indicus. smaragdinum Mitt. - Leucophanes.

stramineum Mitt. M. austr. am. p. 110.

- A m. merid. : Amazon.

OCTODICERAS Brid. Bryol. univ. $1 I, 675$.

Species omn. Conomitria ejusd. nom.

CEDIGLADIUM Mitt.aSam. M. p. 195 (5 spec.).

involutaceum Mitt. 7 . c.

Leucodon involutaceus Jaeg. Ad. II, p. 121.

- Pac. : Ins, Samoa.

japonicum (Besch.) Par.

Endotrichum japonicum Besoh, in Ann. sc. nat. 1893, p. 361.

- As. : Japon.

purpuratum Mitt. Fl. Vit.p. 393.

Ster. $\quad$ - Pac. : Nov, Hebrid. (Aneitum).

rufescens (Hsch. et Reino,) Mitt. Sam. M. p. 195.

Leucodon rufescens $H$. et R. in Nov. Act. Acad. Cxs. Leop. XIV,II, Suppl.p. 712 ; C. M. Syn. II, p. $120 ;$ Bryol. jav. II, p. 103, t. 214.

Neckera praemolis $C . M$. l. c. p. $67 \mathrm{i}$.

Stereodon praemollis Mitt. M. Ind. or. p. 106.

2. - As.: Khasia, Ceylan, Sumatra, Java, Amboine. sinicum Mitt. in Trans. of the Linn. Soc. 1891, p. 171.

2 ?

- As. : Japon.

CEDIPODIU M Schwaegr. Suppl, II, I, p. 15, t. 105 (1 spec.).

Griffithianum (Dicks.) Schnaegr. l. c.; Brid. Bryol. univ. II, p. 83; Bryol. eur. III, t. $280 ;$ C. M. Syn. I, p. 128; W. P. Sch. Syn. II ell. p. 354 .

Bryum Griffithianum Dicks. Fase. IV Pl. orypt. p. 8, t. 10, f. 10.

Gymnostomum Griffithianum Sm. Fl. brit. III, p. 1162.

Physcomitrium Griftithii Angstr. Disp. M. Scand. p. 10.
Splachuum Froehlichianum With. Bot. arr, brit. pl. III ed., III, p. 794 (excl. syn.).

Spl. Griffithianum With. et Hull (ex Hook. et Tayl. Muscol, brit.p. 11, t. 7). Spl. ? succulentum Brid. M. Rec. II, III, p. 64 (in obs.).

Syn. Ad terr. humos, at in rup. fiss. - Eur. : Lappon., Alp. Scandip., M. Scot., Angl., Cambrovall. Am. sept. : Groenland.

Exs. : Rab. Bryoth, eur. n. 1159.

OLIGOTRIGHUM DC. Fl. fr. II, p. 492 (10 spec.).

aligerum Mitt, in Journ. of the Linn. Soc. VIII, p. 48, t. 8; Sull. Ic.

M. Suppl. p. 55, t. 3; Lesq. et Jam. Man. p. 258.

2. Ad terr. humid. - Am sept. : Columb. brit., M. Rupestr., Washington, Oregon.

Exs. : Mac. Canad, M. n. 218.

canaliculatum (Hook.) Mitt. M. austr, am. p. 606.

Catharinea canaliculata C. M. Syn. II, p. 199.
Polytrichum canaliculatum Hook. in Capt. Beechey's Voy. p. 54.

2.

- Am. merid. : (hile. 
« var, major Ltz. in Bot. Zeit. 1866, p. 186.

Ad arbor. - Am. merid. : Valdivia.

erosum (Hpe.). Lindb. in Notiz. 1867, p. 103; Mitt. M. austr. am. p. 646, n. 46.

Catharinea erosa Hpe, in Linn. 1863, p. 46.

2. - Am. merid. : And. Nov. Granat.

glabratum Lindb. - Psilopilum arcticum.

hercynicum DC. Fl. fr. II, p. 492 ; Bryol. eur. IV, t. 413; W. P. Sch. Syn. II ed.p. 531.

Atrichum hercynicum $P, B$, Prodr, $p, 42$.

Bryum incurvum Huds. Fl. Angl. II ed.

Catharinea hercynica Ehrh. Beitr. p. 190; Brid. Bryol, univ. 11, p.99; C. M. Syn. I, p. 196 et $I I, p .559$.

Catharinea hercynica var, sancta Brid. Br. univ. II, p. 101 ?

C. sancta ej. Mant. M. p. 203, n. 3 ?

C. sudetica Brid. Bryol. univ. II, p. 106 ?

0 . incurvum Lindb. in Hartm. Skand. Fl. IX ed., II, p. 4 (inter syn.).

Orthotrichum hercynicum Hoffm. Deutsch. Fl. II, p. 25.

Polytrichum hercynicum Hedw. M. frond. $I, p .48, \imath .15$.

2. Ad terr. denudat. granit., aren., rar. turf. - Eur. : Reg. montan. super. usq. in Alp, et Pyr. Am. sept. : Groenland, fret. Behring.

Exs. : Rab. Bryoth. eur, n. 114.

"var. latifolium C. M. et Kindb. in Mac. Cat. p. 149.

Ad mol. glacial. - Am. sept. : M. Selkirk.

incurvum Lindb. - O. hercynicum.

javanicum (Hpe.) Bryol. jav. I, p. 37, t. 28.

Catharinea javanica Hpe, Ic. M. t. 22; C. M. Syn. I, p. 196.

2.

- As. : Summ. M. Java.

javanicum $\mathrm{Dz}$, et Mk, - 0 , semi-lamellatum.

laevigatum Bryol. eur. - Psilopilum arcticum.

Molinae (Mont.) Llz. in Bol. Zeit. 1866, p. 186.

Catharinea Molinae C. M. Syn. I, p. 198.

Polytrichum Molinae Mont. in Arn. sc, nat. 1845, IV, p. 102 et in Hist. Chil. Bot. Crypt. t. 4, f. 3 .

2? Terr. - Am. merid. : Valdiv., Chil. austr.

? Nietneri (C. M.) Jaeg. Ad. I, p. 700.

Catharinea Nietneri C. M. in Linn. 1853, p. 36.

Ster.

- As. : Ceylan.

Riedelianum (Mont.) Milt. M. austr. am. p. 605.

Catharinea Riedleana Hpe. in Linn. 1847. p. 77; C. M. Syn. 1, p. 197.

Polytrichum nigricans $H$. $f$. et $W$. in Lond. Journ. of bot. 1844, p. 151.

P. Riedelianum Mont. in Ann. sc. nat. 1841, p. 269.

2.

- Am. merid. : Brasil. austr. or.

semi-lamellatum (Hook.) Mitt. M. Ind. or. p. 150.

Catlarinea semi-lamellata Hpe. in Linn. 1847, p. 79 ; C. M. Syn. I, p. 198.

P. javanicum Bryol.jav. (fid. Mitt. l. e.).

Polytrichum falcifolium Ginff. Not. p. 387 et Ic. Pl. asiat. II, t. 93, f. 1.

P. semi-lamellatum Hook. Io. pl. ras, $t, 194$ A. f. I.

2.

- As. : Himalaya or., Khasia.

*f. yunnanensis Besch. in Ann. sc. nat. 1892, I, p. 68.

Terr. - As. : Yunnan. 
tenuirostre (Hook.) Jaeg. Ad. I, p. 699.

Catharinea tenuirostris Brid. Bryol. univ. II, p. 101 ; C. M. Syn. I, p. 198.

Polytrichum tenuirostre Hook. M. ex. t. 75 ; Handb. of N. Zeal. Fl. p. 453.

2.

- Pac, : Nov, Zeland.

tschutschicum Lindb. et Arn. - Psilopilum.

undulatem Lam. et DC. - Atrichum undulatum.

$\beta$ minus eor. - Atrichum undulatum var, abbreviatum (1).

OMALIA vid. HOMALIA.

Omaliadelphus C. M. Syn. 11, p. 208 (subsect. HookeriaE).

ONCOPHORUS Brid. Bryol. univ, I, p. 389.

alpestris Lindb. - Cynodontium gracilescens var. alpestris.

Billardieri Brid. - Dicranum.

brevipes Rrid. - Cynodontium.

Bruntoni Lindb. - Dicranoweisia

cerviculatus Brid. - Dicranella.

var. uncinatus Brid. - Dicranella cerviculata var. pusilla. cirratus Lindb. - Cynodontium gracilescens var. inflexum. conglomeratus Brid. - Dicranum spurium.

crispatus Lindb. - Rhabdoweisia.

crispifolius Lindb. - Cynodontium.

cyathicarpus Mitt. - Amphoridium.

dichotomus Brid. - Dicranum.

falcatus Brid. -- Dicranum.

$\beta$ breviselus Brid. - Dicranum?

flavidus Brid. - Dicranella cerviculata.

fragilis Brid. - Dieranum spurium.

fugax Lindb. - Rhabdoweisia.

glaucescens Lindb, et Arn. - Cynodontium.

glaucus W. P. Sch. - Leucobryum.

gracilescens Lindb. - Cynodontium.

longirostris Brid. - Dicranum spurium.

Martianus Lindb. - Oreas.

obtusatus Lindb. - Cynodontium gracilescens var. alpestre.

polycarpos Brid. - Cynodontium.

$\beta$ atratus Brid. - Cynodontium polycarpum?

$\gamma$ laevigatus Brid. - Cynodontium polycarpum?

? pusillus Brid. - Dicranella cerviculata var. pusilla.

Schisti Lindb. - Cynodontium.

serrulatus Lindb. et Arn. - Oreoweisia.

sinensis C. M. - Cynodontium.

squarrosus Brid. - Dicranella.

3 abbreviatus Brid. - Dicranella squarrosa?

Starkii Brid. - Dicranum.

striatus Mitt. - Rhabdoweisia fugax.

? strigosus Brid. - ? Syrrhopodon.

(1) In Enum. Kindberg. nomina nuda (incl,, sub Oligotrioh., gen. Psilopilum et Polytrichadelphus).

O. argutum Mitt.

atrichopsis C. $M$.

glaucum Hpe.
O. Lescurii Sull. microdendrum $C, M$. nepalense Aingstr. 
strumifer Brid. - Cynodontium polycarpum var. strumifer.

var. fuscescens Weinm, - Cynodontium virens var. Wahlenbergii ?

var. substrumosus Brid. - Cynodontium polycarpum.

suecicus L. et J. - Cynodontium.

torquescens Lindb. et Arn. - Cynodontium.

virens Brid. - Cynodontium.

Wahlenbergii Brid. - Cynodontium virens var. Wahlenbergii.

Oreadella C. M. Syn. $I, p, 508$ (sect. Bartramiae).

OREAS Brid. Bryol. univ, I, p. 380 (1 spec.).

capensis $\mathrm{Br}$. - Mielichhoferia Eckloni.

elongata Brid. - Mielichhoferia nitida var. elongata.

Mielichlioferi Brid. - Mielichhoferia nitida.

Martiana Brid, op. cit. p. 383; Bryol. eur. IV, t. 314; C. M. Syn. 1, p. 509 ; W. P. Sch. Syn. 11 ed. p. 507.

Catoscopium Martianum Hüb. Muscol. germ. p. 153.

Grimmia Schubartiana Ltz. Moosst. p. I31, t. 5.

Onchophorus Martii Lindb. in Utk...p. 34 .

Weisia Martiana Hsch. in Bot. Zeit. 1859, II, p. 86.

I. Terr. et rupic. - Eur.: Summ. Alp. Carinth., Salisburg., Stir., Rhoet., Tirol., Helvet. As. : Sikkim.

Exs. : Rab. Bryoth. eur. n. 47, 1066.

OREOWEISIA W. P. Sch. Syn. 1 ed., p. 57 (subgen. Weisiae) et II ed.

p. 57 (gen. propr.) (12 spec.).

ampliata Mitt. M. austr. am. p. 53.

- Am. merid. : And. Quitens.

anomala Broth. in Ule Bryoth. brasil. n. 108.

Inter saxa. - Am. merid. : Brasil. austr. or.

auridens $(C, M$.) Par.

Weisia auridens C. M. in Linn. 1880-83, p. 436.

1.

- Am. merid. : M. Argent. Tucum.

- var, robusta (C. M.) Par.

Weisia auridens var, robusta $C, M$. op. oit. $p, 437$.

Ubi typ.

bogotensis (Hpe.) Mitt. l. c.

Weisia bogotensis Hpe. in Linn. 1869, p. 131.

Syn. Rupic. - Am. merid. : And. Nov. Granat. et Boliv.

Exs. : Mandon PI. Boliv. n. 1605.

brasiliensis Hpe. Symb. 1874, p. 485.

Weisia brasiliensis Hpe. Enum. M. Brasil.p. 14.

Syn.

Bruntoni Milde. - Dicranoweisia.

chilensis (Hpe.) Par.

Weisia chilensis Hpe, mss. ; C. M. in Bot. Zeit. 1862. p. 350.

$\mathrm{Syn}$,

erosa (Hpe.) Par.

- Ain. merid. And. Chilens.

Weisia erosa Hpe. mss. ; C. $M$. in op cit. 1858, p. 163.

1.

- Afr. : C. B. Sp. 
laxifolia (Hook.) Par.

Didymodon laxifolius Mitt. M. Ind. or. p. 23.

Grimmia flaccida Royle in sched.

Gr. laxifolia Hook. in Lond. Journ. of bot, 1840, p. 5 et Ic. pl. var. t. 194 B; C. M. Syn. I, p. 783.

Weisia laxifolia Hpe. in Jaeg. Ad. II, p. 634.

W. serrulata Wils. in Kew Journ. bot. IX, p. 291.

- As. : Himalaya, Yunnan.

Lechleri (C. M.) Par.

Weisia Lechleri C. M. in Bot. Zeit. 1862, p. 350 .

"var. minor (C.M.) Par.

Weisia Lechleri var, minor C. M. $l_{+} c_{+}$

- Am. merid. : Summ. Cordillier.

ligularis Mitt. M. austr. am. p. 53.

- Am. merid. : And. Nov. Granat. et Quitens.

obtusata Kindb. - 0. serrulata var. tenuior.

Schmidii (C. M.) Par.

Anoectangium Schmidii Mitt. M. Ind. or. p. 32 .

Zygodon Schmidii C. M. in Bot. Zeit. 1853, p. 60 .

2 .

- As. : M. Neilgherr.

serrulata (Funk) W. P. Sch. op. cil.p. 57.

Cynodontium serrulatum Jus. in Verh. d. zool. bot. Gesells, in Wien, 1871.

Onchophorus serrulatus Lindb. et Arn. M. As. bor. 1890, II, p. 93.

Trichostomum paradoxum Brid. Bryol. univ. I, p. 817 .

Weisia procera Laur. in Bryol. germ. II, II, p. 90, t. 33.

W. serrulata Funk in Brid. l.c. p. 804: C. M. Syn. I, p. 655.

W. torquescens Bryol. germ. l. c. p. $86, t .32$; Brid. l.c.p. 349.

1. In rup. fissur. humos. - Eur. : Spitzberg, Alp. Salisburg., Stir., Carinth., Helvet., Tirol., Bergam. As. : Amour. Am. sept. : Lac, Super., Alaska, New Jersey, Pensilv.

Exs, : Rab. Bryoth. eur. n. 1057.

"var. tenuior Kindb. in Mac. Cat. p. 15.

A. obtusata ej. in Rev, bryol. 1896, p. 18.

Ad rup. torrent. - Am. sept. : M. Rupestr. (1).

ORONTOBRYUM Hpe. in sehed.

recurvulum $\mathrm{Hpe}$. - Hypnum.

Orthocarpus C. M. Syn. I, p. 319 (sect. BRyI).

Orthodicranum ej. $l$. c. p. 37 ( (sect. Dicrani).

ORTHDDON (ser.16.870)

ORTHODONTIUM Schwaegr. Suppl. $I I, I I, I I, p .123$ (21 spec.)

aethiopicum C. M. in Bot. Zeit. 1855.

o. gracile ej. Syn. $I$, p. 238 p.p.

$$
\text { - Afr. : Abyss. }
$$

australe Hook. f. et Wils. in Lon . Journ. of bot. 1844, p. 545 ; Fl. An-

(1) In Enum. Kindb. nom. nudum:

0. laevifolia Lindb. 
tarct. 11, n. 412, t. 153, f. 5 et Fl. Tasm. 11, p. 188 ; C. M. Syn. 1, p. 239 et $I I, p .567$.

Apalodium australe Mitt. M. austr. am. p. 239.

1. Lignic. - Afr. : Ins. Marion. Am. merid. : Fuegia, ins. Eremit., Maclov. Pac. : Tasman.

confine Hpe. in Ann. sc. nat. 1865, V ser., IV, p. 338.

1. Filic. et lignic. - Am. merid. : And. Nov. Granut.

denticulatum Geh. et Hpe. in Fl. 1881, p.

1. - Am. merid, : Brasil. austr. or.

Emodi C. M. in Jaeg. Ad. I, p. 576 (nom.).

- As. : Sikkim.

Fendleri C. M. in Linn. 1878-79, p. 473.

1.

- Am. merid. : Venezuela.

gracile Schwogr. in litt. ad Wilson; Bryol. eur. IV, t. $330 ; C . M$.

Syn. I, p. 238 (excl. loc. Abyss.); W. P. Sch. Syn. II ed. p. 389.

Bryum (Pohlia) gracile Wils. in Gardn. M. brit. t. 31 App.

Stableria gracilis Lindb. in Utk. till en nat. grîpp. Eut. bladm. p. 29.

1 vel 2. Ad rup. arenar. vel terr. humos. - Eur. : Anglia, Gall, occ.

(Armoric.).

Exs. : Rab. Bryoth. eur, n, 677.

gracile C. M. p.p. - O. aethiopicum.

humile (Mont.) Mitt. M. austr. am. p. 275.

Bryum (Pohlia) humile Mont. in Ann. sc. nat. 1845, IV, p. 104.

0. tenue C. M. Syn. I, p. 240.

2.

- Am. merid. : Chil. austr.

inflatum (Mitt,) Par.

Apalodium inflatum Mitt. in Voy. of H. M. S. Challenger, Bot. IV, p. 198 (in adn.).

- Pac.: Austral. or. (Nov. Valesia).

infractum $D_{z}$. et $M k$. in Ann. sc. nat. 1844, p. 313 et $M$. frond. ined. Archip. Ind. p. $34, t .14 ;$ Bryol. jav. I, p. 135.

0. sulcatum C. M. Syn. I, p. 239.

1.

- As. : Ceylan, Java, Borneo.

julaceum Schwaegr. - Bryum Gilliesii.

lanceolatum Milt, in Kew journ. bot. 1856, p. 261.

Apalodium lanceolatum Mitt. in op, cit. p. 761 .

- Pac. : Austral. or., Tasman.

lineare Schroaegr. l. c. p. 124, t. 188; C. M. Syn. I, p. 238.

Apalodium lineare Mitt.

1.

- Afr. : C. B. Sp.

longisetum Hpe. in Linn. 1863, p. 129.

0 . pellucens ( $f i d$. Mitt) .

1. Terr, - Am. merid. : And. Nov. Granat.

loreifolium Besch. Fl. bryol. Réunion, elc. p. 89.

1. Cortic. - Afi: : Ins. Borbon.

Oorschoti Lac. - Splachnobryum.

Osculatianum de Not, in Acad.... Torin. II ser., XVIII, p. 443, t. 4.

- Am. merid. : Columb. 
ovale C. M. in Oefv, af Finska Vet. Soc. Foerh. 1893, p. 36.

1. Lignic. - Pac. : Austral. (Nov, Vales.).

pellucens (Hook.) Bryol. eur. IV (mon. p. 3) ; C. M. Syn. I, p. 240.

Apalodium pellucens Mitt. M. austr. am. p. 238.

Bryum (Pohlia) pellucens Hook. Ie. pl, rar, I, t. 34 .

1. - Am. merid. : And. Nov. Granat et Quitens.

pycnoblastum C. M. in Ule Bryoth. brasil. n. 132.

Filicic. - Am. merid. : Brasil. austr, or.

setaceum W. P. Sch, in Mandon Pl. Boliv, n. 1658.

- Am. merid. : And, Boliv.

sulcatum Hook. f. el Wils. in Hook. Ic. pl. rar. t. $739 \mathrm{~B} ; \mathrm{Fl}$. of the

N. Zeal. II, p. 81 et Handb. p. 436; C. M. Syn. II, p. 566.

1 vel syn. Lignic. et rupic. - Pac. : Austral. or., Nov. Zeland., Tasman.

sulcatum C. M. (Syn. I). - O. infractum.

tenellum Mitt. M. austr. am. p. 205.

Syn. $\quad-$ Am. merid. : And. Quitens., Brasil.

tenue C. M. -- 0, humile.

ORTHODON Bory Saint-Vincent in Schwaegr. Suppl. 11, p. 23, $t, 106$.

Spec. omn, non indicatae sunt DISSODoNTES ejusd. nom.

serratus Bory p.p. $\left\{\begin{array}{l}\text { Dissodon borbonicus. } \\ \text { Dissodon Isleanus. }\end{array}\right.$

ORTHOMNIUM Wils. in Kew Journ. IX, p. 368 (2 spec.).

crispum Wils.l.c.

Mnium crispum Mitt. M. Ind. or. p. 142.

2.

- As. : Sikkim.

trichomitrium Wils. $l$. c.

Mnium tricbomitrium Mitt. l. $c$.

Orthotrichum? bryoides Griff. Not. p. 404 et Ic. Pl, assiat. II, t. 77, f. 3.

2 .

- As. : Khasia.

Orthophyllaria C. M. Syn. I, p. 688 (sect. ОвтнотRichi).

Orthophyllina ej.l.c. p. 723 (sect. MACROMITRII).

Orthophyllum ej.l. c. p. 523 (sect. SyRRHOPODONTIS).

ORTHOPUS Lindb. M. Scand. p. 25 (nom., = Campylopus brevifolius),

ORTHOPYXIS P. B. Prodr. p. 78.

androgyna P, B. -- Aulacomnium.

aristata P. B. - Barbulata unguiculata.

heterosticha P. B. - Aulacomnium.

longicolla P. B. - Webera.

macrocarpa P. B. - Leptostomum.

megapolitana P. B. - Timmia.

palustris $\mathrm{P}$. B. - Aulacomnium.

ramosa P. B. - Aulacomnium palustre var. polycephalum.

squarrosa P. B. - Paludella. 
ORTHORHYNGHIUM Reichdt. in Verh. d. zool. bot. Ges. in Wien, 1868, p. 115 (4 spec.).

elegans (Hook. f. et Wils.) Reichdı. l. c.

Phyllogonium elegans H. f. et W. in Lond. Journ. of bot. 1844, p. 548 ; Fl. of the N. Zeal. $11, p .102, t .88, f .6$ et Handb. p. $462 ;$;. M. Syn $I 1, p, 21$.

Ad arbor. - Pac. : Austral felix, Nov. Zeland.

Hampeanum C. M. in Linn. 1869-70, p. 29.

Acrocladium politum (fid. Mitt.).

Phyllogonium elegans Hpe, in Müll. M. Austral. et in Linn, 1855-56, p. 212.

Ster.

- Pac. : Austral. felix.

Nietneri C. M. op. cil. p. 28.

Phyllogonium elegans Mitt. M. Ind. or. p. 115.

-. As, : Ceylan.

philippinense (Hpe.) C. M. op. cit. p. 80.

Phyllogonium philippinense Hpe. in sched.

Ster.

- As. : Ins. Basilan Philippin.

ORThostichella C. M. Syn. 11, p. 123 (primum subsect. Neckerae, postea gen. propr.).

Species omn. Pilotrichellae ejusd, nom.

0RTHOTHECA Brid. Bryol, univ. I, p. 778.

Species omn, non indicatae sunt SYRRHOPODonTes ejusd. nom.

Berteriana Brid, p p. $\left\{\begin{array}{l}\text { - Syrrhopodu. } \\ \text { - Syrrhopodon malouinensis. } \\ \text { - Syrrhopodon Urvilleanus. }\end{array}\right.$

Orthotheciella C. M. in Engler's Bot. Jarhb. 1883, p. 83 (sect. Hrpni sensu Müller.).

ORTHOTHECIUM Bryol. eur. V (10 spec.).

? binervulum Mdo, in lilt. 1861 ; Ltz. Moosst.p. 120; W. P. Sch. Syn. 11 ed., p. 805 .

Holmgrenia binervula Mdo, in Ltz. Moosst. p. 122.

Leskea binervula Mdo. Bayem Laubm. p. 218.

0. intricatum var, binervulum Husn. Muscol. gall. p. 317.

Fl, et $\mathrm{fr}$, ign. Ad niv. inter moles chaotic. calcar. - Eur. : Stiria, Alp. Bavar., Tirol. merid.

? Bollei Jaeg. - ? Pylaisia.

Celebesiae C. M. in Jaeg. Ad. II, p. 369.

Hypnum neelgheriense Bryol. jav. II, p. 228.

Oticodium Celebesiae C., M. in Kindb. Erum. Bryin. ex. 1888, p. 27. - As. : Celebes. chryseum (Schroaegr.) Bryol. eur. V (mon. p. 3), t. 465; W. P. Sch.
Syn. II etl.p. 631.

Holmgrenia chrysea Lindb. in Oefv, Vet.-Ak. Fberh. $1862, n .10$.

Hypum chryseum Sohwaegr: in Sohult. Reise auf d. Glockner, II,

H. P. $364: C . M . S_{y n}$. II, p. 385 .

B. rufescens $H$. $f$. et $W$. in Drumm. M. bor. am. I ed. $n, 221$.

Isothescens var, chryseum Rab. Deulsoh. Krypt. II, III, p. 298.

Isothecium chryseum Spr. in Ann. and Mag. of nat. hist. 1849. 
1. rufescens $\beta$ chryseum Hüb. Muscol. germ. p. 601.

Leskea chrysea Hartm. Skand. Fl. VI ed.

L. rufescens $\beta$ chryseum Brid. Bryol. univ. $I I, p .286$.

Pylaisia chrysea Vent. et Bott. Enum. p. 19.

Stereodon chryseus Mitt. M. Ind. or. p. 93.

2. Rupic. - Eur. : Spitzberg, ins. Ursorum, Alp. Lappon., Seandin,, Fenniae; Tatra, Salisb,, Stir., Austr. infer., Alp. Buvar. et Algov, Tirol., Helvet. As. : Tibet occ. Am. sept. : Groenland, M. Rupestr Exs. : Mac. Canad. M. n. 226.

Rab. Bryoth, eur. n. 994.

* var. cochlearifolia Lindb. Spitsb. Mossor. p. 543.

0. chryseum var. patula Kindb. Laubm. Schwed. u. Norw. p. 45? - Eur. : Spitzberg; Scandin.?

"f. lapponica (W. P. Sch.) Lindb. in Meddel. 1886, p. 254.

Brachythecium lapponicum W. P. Sch. Syn. I ed. p. 697.

Leskea lapponica Lindb. Spitsb. Mossor. p, 543.

Leucodon Lagurus var, borealis (Wils, ) Lindb. mss.

O. lapponicum Hartm. Skand. Fl. ed. X. II. p. 29.

Stereodon lapponicus Lindb. M. Scand. p. 38.

Ad niv. deliquesc. - Eur. : Lappon. Pitens.

var. patula Kindb. - 0. chryseum var, cochlearifolia?

chryseum Helb. Un. itin. - Camptothecium lutescens var. involuta. complanatum Kindb. - O. rufescens.

Durieui (Mont.) Besch. Cat. M. Alger. $\mu .34$.

Brachythecium Durieui de Not. Epil. p. 122.

Hypnum Durieui Mont. Syll. p. $9 ;$ C. M. Syn. II, p. 417 (1).

2. Fr, ign. Terr. - Eur.: Galloprov., Sardin., ins. Ponza. Afr. : Alger. (ins. Galita).

intricatum (Harlm.) Bryol. eur. V (mon. p. 4), t. 457; W. P. Sch. op. cit, p. 630 .

Holmgrenia intricata Lindb. in Oefv. Vet.-Ak. Foerh. 1862, n. 10.

Hypnum chrysophylloides C. M. Syn. II, p. 436 p.p.

H. irroratum C. M. Syn. II, p. 395 .

Isothecium homomallum $S p$. mss.

I. intricatum Boul. M. Fr. I, p. 148.

Leskea intricata Harlm. Skand. Fl. V ed. p. 336.

L. irrorata Sendtn. Beobacht, uber die Klimat. Verbreit. d. Laubm. p. 26.

L. polyantha $\beta$ sericeola Brid. Bryol. univ. $I I, p .313$.

L. subrufa Wils. Bryol. brit.

Pylaisia intricati Vent. et Bott. Enzm. p. 19.

P. sericea de Not. Epil. p. 207.

Stereodon subrufus Lindb. M. Scand. p. 38.

2. Rariss. fruct. Ad rup. calcar. humid. - Eur. : Scandin., Beskid., Sudet., Riesengeb., Boehmerwald, Tatra, Salisb., Carinth., Thuring., Westphal., Rhoengeb., Luxemb., Wurtemb., Francon., Alp. Bavar. et Algov., Tirol., Helvet. As. : Caucas. Am. sept. ; Groenland, M. Rupestr.

Eœs. : Rab. Bryoth, eur, n. 345 ,

Un. itin. 1867, n. 14.

var. binervulum Husn. - 0 . binervulum,

var. rubellum Husn. - 0 . strictum.

" var, sericeum Bryol. eur. l. c.

- Eur. : Norveg.

(1) Cf, Philibert in Rev. bryol, 1889, p. 51. 
lapponicum Hartm. - 0, chryseum $f$. lapponica.

neelgheriense (Mont.) Jaeg. Ad. Il, p. 369. Hypnum Bonplandi Mitt. M. Ind. or. p.p. (fid. C. M. in Linn. 1869-70,
p. 7 .

H. neelgheriense C. M. Syn. II, p. 462.

Isothecium neelgheriense Mont. in Ann. sc. nat. 1842, p. 246.

Pleuropus fenestratus Griff. Not. p. 468 et Ic. pl. asiat. II, t. 90, f. I 2 ? (p.p. ?).

* var. ceylanicum $(C, M$.) Jaeg. l. c.

Hypnum Bonplandi Mitt.l. c. p.p. (fid. C. M. l. e.).

$H$, neelgheriense var. ceylanicum C. M. in Linn. $l$. c.

- As. : Ceylan.

rubellum (Mitt.) Lesq. et Jam. Man. p. 315.

O. strictum Lts. (fid. Lindb. et Arn. M. As. bor, 1890, II, p. 154).

Stereodon rubellus Mitt, in Journ. of the Linn., Soc. VIII, p. 40.

2. Ster. ? supor. Am. sept.: Fret. Davis, M. Rupestr.

rubellum Kindb. - 0 . strictum.

rufescens (Dicks.) Bryol. eur. V (mön. p. 3), t. 460; W. P. Sch. op. cit. p. 631.

Holmgrenia rufescens Lindb. in Oefv. Vet.-Ak. Foerh. 1862, n. 10.

Hypnum caulibus vix ramosis, foliis subulatis aristatis, capsulis gracilibus Hall. Hist, stivp. Helvet. n. 1784. H. rufescens Dicks. Fase. III, Pl. crypt. p. 9, t. 8, f. I; C. M. Syn. II,
p. 384 . Isothecium chryseum Spr. M. Pyren. n. 90 et in Ann. and Mag. nat.
hist. 1849 .

1. rufescens Hüb. Museol. germ. p. 600 .

Leskea rufescens Schucaegr. Suppi. I, II, p. 284.

0. complanatum Kindb. Laubm. Sohwed. $x$. Norv. p. 45.

Pylaisia rufescens de Not. Epil. p. 206.

Stereodon rufescens Mitt. op, et $l$. $c c$.

2. In fissur. rup. irror. - Eur.: Alp. omn., praesert. calcar. As. : lenissei inter. Am. sept. : Fret. Davis.

Exs, : Rab, Bryoth. eur, n. 134, 290 a-c,

Un. itin. 1867, n. 13.

? Schlagintweitii (Sendtn.) Par.

Hypnum Schlagintweitii Sendtn. mss.; C. M. Syn. II, p. 395.

2.

- Eur. : Carinth.

strictum Ltz. Moosst. p. 122, t. 5; W. P. Sch. op. cit. p, 805.

Holmgrenia stricta $L t z, l . c$.

Toothecium strictum Bovi. M. Fr. I, p. 149.

Leskea intricata var, suberecta C. Hartm, Skand. Fl. Xed.p. 29.

0. intricatindb. Spitsb. Mossor. p. 543.

0. rubellum var, rubellum Husn. Muscol, gall, p. 317.

Stereodon Kinilb. Laubm. Schwed, u. Norw, p. 46.

Limpr.).

$\checkmark$ et fr. ign. In fissur, rup. - Eur. : Spitzberg, ins. Ursorum, Scandin., Fennia, Carinth., Helvet. Am. sept. : Groenland?

Orthothuidium W. P. Sch. in Besch. Prodr. bryol. mexic. p. 91 (subgen. Thuton). 
ORTHOTRICHUM Hedw. M, fiond, p. 96 (214 spec.).

abbrevialum Groenw. - 0. Sardagnae.

aciculare Hook. et Grev. - Macromitrium.

acuminatum Philib. in Rev. bryol. 1881 et in Husn, Muscol. gall. p, 167.

1. Cortic. - Eur. : Gall. centr., Galloprov,, Corsica, Etrur., Tirol.

acuminatum R. Br. - O. Brownii.

acutifolium $R$. Br. in Trans, of the $N$. Zeal. Inst. 1894, p. 436, t. XXIX, fig. 25.

1. Cortic. - Pac, : Nov. Zeland.

acutifolium Hook. et Grev. - Macromitrium longirostre..

sequatoreum Mill. M. austr. am. p. 184.

1. Cortic. - Am. merid. : And. Quitens.

aetnense de Not. - 0. rupestre var: aetnense.

affine Schrad. Spic. A. Germ. p. 67 ; Brid. Bryol. univ. 1, pp. 281 et 785 ;

Bryol. eur. III (mon. p. 7), t. 216; C. M. Syn. I, p. 705; W. P. Sch.

Syn. 11 ed.p. 321.

Bryum affine Gmel, Syst. nat. II, p. 1335 ?

Br. semi-vacuum Vill. Pl. Dauph. III, p. 868 ?

Dorcadium affine Lindb. M. Scand. p. 28.

O. octoblephare Brid. M. Rec. II, II, p. 24.

O. striatum Hedw. M. frond. II, p. 99, t. 36, f. 9 (fid. Limpr.).

o. umbonatum Brid. Bryol. univ. I, p. 787.

Polytrichum Bryi ruralis facie, capsulis sessilibus, majus Dill. Hist. M. p. $430, t .55, f .8$ (fid. Limpr.).

P. capsulis sessilibus, foliis brevibus rectis carinatis Dill. op. cit. p. 432, t. 55, f. 10 ? (fid. C. M.).

Sphagnum semi-vacuum P. R. Prodr. p. 89.

Weisia aftinis Roth. Fl. Germ. III, I, p. 217.

W. octoblepharis ej. op. oit. p. 218.

1. Cortic. -- Eur. : Vulgatiss. As, : Kamschatka, Caucas. Afr. : Septentr. Am. sept. : Fret. Smith, New Brunswick, Ontario, lac. Super., Idaho, Oregon, Washington, Vancouver.

Exs. : Rab. Bryoth. eur. n. 279 et b, 890 et b.

Sull, et Lesq. M. bor. am. II ed, n. 182.

var. fastigiatum Hüb. - - O fastigiatum.

var, neglectum Vent. - 0 . neglectum.

var. palens Groenw. - 0 . patens.

var. pulvinatum Vent. - 0 . appendiculatum.

var. pumilum $\left\{\begin{array}{l}\text { Hook. }-0 \text {. strangulatum. } \\ \text { H. et T. - O. fallax. }\end{array}\right.$

var. rupestre Brid. - 0 . rupestre.

var. Hook. - O. canadense.

affine Schwaegr. - 0 . fastigiatum.

alpestre Hsch, in sched. ; Bryol. eur. 111 (mon. Suppl. 1), t. 213 (1849);

C. M. Syn. I, p. $698 ;$ W. P. Sch. Syn. II ed. p. 325.

Dorcadium alpestre Lindb. l. $c$.

0. stramineum Bryol. eur. III (mon. p. 23) p.p. (1837).

0. stramineum var, alpestre Vent, in Vent. et Bott. Enum. p. 29.

1. Rupic., rar. cortic. - Eur. : Ins. Ursor., Alp. Norveg., Carinth., Salisb., Stir., Austr., Tatra, Rhoeet., Vall. Tell., Tirol.; Pyren. As. : Jenissei sup. Am sept, : Ontario, M. Rupestr., Idaho, Utah.

Exs. : Un, itin. 1863, n. 45. 
" var. majus Lesq. et Jam. Man. p. 169.

0. alpestre var. Sull. Ic. M. Suppl, p, 69, t. 51.

0. occidentale Jam, in Bot. King Exped. p. 402. - Am. sept. : Ubi typus.

var. Sull. - O. alpestre var. majus. alpestre Wils. - 0 . fastigiatum.

Amanni Culman in Rev, bryol. 1892, p. 57 (1).

1. Cortic. - Eur. : Gall. sept, or. (Compiègne).

americanum P. B. - Ulota Hutchinsiae (2).

Anderssonii C. M. - Ulota leiothecia.

angulosum P. B. - Schlotheimia quadrifida.

angustifolium Hook. f. et Wils. in Lond. Journ. of bot. 1844, p. 547; Fl. Antarct. I, p. 125, t. 57 et Handb. of N. Zeal. Fl. p. 433 ; C. M. Syn. I, p. 691 et 11, p. 638.

1. Rupic. - Afr. . Ins. Kerguelen. Pac. : Ins. Campbell.

anomalum Hedw. Sp. M. p, 162; Bryol. eur. III (mon, p. 10), t. 210; C. M. Syn. I, p. 694; W. P. Sch. op. cit. p. 308.

Brachytrichum anomalum Roehl. Ann. d. Wett. Ges. III, p. 194.

Doscadium anomalum Lindb. $l$. $c$.

Grimmia ovata Schrank Baiers Fl. II, p. 443.

0. aureum Mait. Fl. Erlang. orypt. p. 11, t. X1.

0 . humile Schleich. Cent. IV pl. Helv, n. 15.

0 . leptocarpum Wils, in Kew Journ, bot. IX, p. 326.

Weisia anomala Roth. Fl. Germ. III, I, p. 215.

W. ithyphylla $\beta$ minor Ehrh. Beitr. I, p. 191.

I. Ad mur., rup., tecta, rar. arbor. - Eur. : In reg. camp. vulg. As. : Jenissei sup., Kashmir, Himalaya et Tibet. occ., Pers., Caucas. Afr.: Alger. Am. sept.: Groenland, New Brunswick, Ontario, Saskatchewan, reg. sept. occ., M. Rupestr., Massachussets, New York.

Exs. : Mac. Canad M. n. 118 p.p.

Rab. Bryoth, eur, n. 381 .

Sull. et Lesq. M, bor. am. II ed. n. 177.

4 var. americanum Vent. in Mac. Cat. p. 86.

0, anomalum Drumm. M. bor. am. I ed.n. 148; Mac. Canad. M. n. 118 p p. Rupic. - Am, sept. : Alberta, Manitoba.

var, americanum Brid. - Ulota Hutchinsiae.

var. ciliatum Jur. - O. anomatum var. cylindricum.

* var. cylindricum W. P. Sch. Bryol. eur. Suppl. I-II (Orthotr.) t. 10 et op. cit. p. 303 (3).

0 . anomalum Wils. Bryol. brit. p. 177.

0. anomalum $\beta$ ciliatum Jur. Laubm. Oesterr. Ung. p. 213.

0. saxatile Wood. Not, and Obs, on the O. anomalum, in Physiol. 1860.

Ad sax. ealcar. - Eur. : Westphal., Bernina.

\& var. defluens Vent. in Husn. l. c.

0 . pellucidum Lindb. ?

- Eur. : Reg. montan. silic.

(1) An potius var. O. appendiculati? " (ej. I. c.).

3) Sec. Venturi in Rev. bryol. 1892, p. 4.

Sec. Venturi in Husnot Muscol. gall. p. 159, forma normalis. 
« var. saxatile Vent. $l$. c.

Dorcadium saxatile Lindb. $l$. $c$.

O. saxatile Brid. Bryol, univ. I, p. 275.

- Eur. : Anglia. As. : Caucas.

* var. Kindb. in Mac. Cat.p. 87.

o. Venturi Mac. Canad. M. n. 455.

Ad Thuy. occid. - Am. sept. : Ontario.

anomalum $\left\{\begin{array}{l}\text { Drumm. - O. anomalum var. americanum. } \\ \text { Engl. Bot. - o. cupulatum. } \\ \text { Rob. Br. O. Novae Zelandiae. } \\ \text { Wils. - o. cupulatum var. cylindricum. }\end{array}\right.$

anomalum $q \times$ stromineum $\delta$ Ruthe in Hedwig. 1873, n. 1

Ad Salic. - Eur. : Boruss. sept.

apiculatum Mitt. M. austr. am. p. 188.

2.

- Am. merid. : M. Pichincha.

apiculatum Hook. - Macromitrium.

appendiculatum W. P. Sch. ll. cc. t. 9 el p. 330.

O. affine $\beta$ pulvinatum Vent. in Jaeg. Ad. $I, p .458$.

0. fastigiatum $\beta$ appendiculatum Jur. Laubm. Oester\%. Ung. p. 203.

1. Ad arbor. ambulacr. - Eur. : Ins. Norderney, vall. Rhen., Siles., Austr. inf., Bavar., Ital. super.

Araucarieti C. $M$. in Ule Bryoth. brasil. n, 20.

- Am. merid. : Brasil. austr. or.

arcticum W.P. Sch. $l l . c c, t .5$ et p. 310 (1).

Dorcadium arcticum Lindb. M. Scand. p. 29.

1. Rupic. - Eur. : Spitzberg, Lappon. ross., Norveg. Am. sept. : Groenland.

arctum Rob.Br. in Trans. of the N. Zeal. Inst. 1894, p. 440,t. XLI, fig. 34.

1. Cortic. - Pac, : Nov. Zeland.

aristatum Hpe. in Linn. 1803, p. 145.

2. Cortic, - Am. merid. : And. Nov. Granat.

arislatum Turn. - 0 , diaphanum.

Arnellii Groenv. - 0. pallens.

assanicum Griff. - Macromitrium.

assimile C. M. Syn. I, p. 704 ; Mitt. M. austr. am. p. 185.

1. $\quad$ - Am. merid. : Chile.

atratum Mitt. in Journ, of the Linn. Soc. 1877, p. 66.

1. - Afr. : Ins. Kerguelen.

aurantincum Groënv. - 0. pallens var. parvum.

Aurantiorum C. $M$. in Linn. 1880-88, p. 443.

1. Ad Aurant. - Am. merid. : Argentin. Buenos Ayr.

aureum Mart. - 0 , anomalum.

auridens W. P. Sch, - O. Rogeri.

(1) "Species omnes sect. Orthotrichorum aretioorum in Husn, Mnscol. gall. p. 172, scilicet: 0. areticum, Barthii, Blyttii, Breutelii, brevinerve, mierable. phare, Sommerfeldti, formas unius speciei sistunt. \& (Vent. 1. c.). 
australe Jur, in Hedwig. $1867, n, 10$.

- Eur. : Hispan. (Arragonia).

avonense Rob. Br. in Trans, of the N. Zeal. Inst. 1894, p. 438, t. XL, fig, 29.

1. Cortic. - Pac. : Nov. Zeland.

Baldaccii Bott, et Vent, in Hedwig. 1892, p. 135; Vent. in Rev. bryol. $1893, n .97$.

1. Ad rup. calear. - Eur. : Montenegro ; Hispania (Cuença).

Barthii Sendtn. in Fl. 1849, p. 274 ; C. M. Syn. I, p. 693.

0 . Blyttii ? (fid, Vent, in Husn. l. c.).

1. Rupic. - Am. sept. : Groenland.

bellum C, M. in Linn. 1878-79, p. 360 .

1. Cortic. - Am. merid. : Argentin. subtropic.

benmorense Rob. Br. in Trans. of the N. Zeal. Inst. 1894, n. 430, t. XXXV11, fig. 12 .

1. Ad ramul, - Pac. : Nov. Zeland.

Blyttii W. P. Sch, ll.cc, I, 4 et $p, 311$.

0. Barthii ? oreutelii ? (fid. Vent. l. c.).

Dorcadium Blyttii Lindb. $l$. $c$.

1. Rupic. - Eur. : Lappon., Norveg. Am. sept. : Groenland.

Bolanderi Sull. Ic. M. Suppl. p. 64, t. 46 ; Lesq. el Jam. Mun. p. 167.

0. rupestre var, vulgare $f$, densior Veni.l. o. p. 156.

1. Rupic. - Am. sept. : Calif.

boreale Groenv. - 0 , pallens var, parvum?

brachytrichum W, P. Sch. mss.; Lesq. et Jam, in Proced. Am. Acad.

XIV, p. 140 et Man. p. 172.

0 . inflexum C. M. Syn. I, p. 690.

0. obtusifolium Dremm. M. bov. am. I ed. n. 157.

0. Rogeri Br, et Sch, Corr. M. Drumm. in Lond. Journ of bot, 1843, p. 667 .

2. Cortic. - Am. sept. : Ab Ontario ad M. Rupestr., Columb. brit.

Braunii Bryol. eur. III (mon. p. 16), t. 215 ; C. M. Syn. I, p. 702; W. P. Sch. Syn. II ed. p. 326.

0. strangulatum Aust. M. Appal. (fid. Vent.p. 182).

1. Ad arbor. praepr. junior. - Eur. : Vall. Rhen,, Palatin,, ins. Rügen, Salisb., Stir., Bavar., Tirol., Helvet. Am. sept. : New Brunswick.

Breutelit Hpe, - O. Pylaisœi.

var. ? Berggr. - O. pellucidem.

breve Rob. Br. in Trans, of the N. Zeal. Inst. 1894, p. 426, t. XXXV, fig. 3.

1. Cortic. - Pac. : Nov. Zeland.

breve P. B. - Macromitrium aciculare.

brevicolle Mitt. - Ulota.

brevirostrum Rob. Br, in Trans. of the $N$, Zeal. Inst. 1894, p. 436, $t$. XL, fig. 28.

I. Cortic. - Pac. : Nov. Zeland.

brevinerve Lindb. in Rev. bryol. 1887, p. 63.

Dorcadium brevinerve $e j, M$. Soand. $p, 28$.

1. Ad rup. madid, - Eur. : Lappon. Tornens. 
brevisetum Rob. Br. in Trans. of the N. Zeal. Inst. 1894.

1. Cortic et rupic. - Pac. : Nov. Zeland.

Brovnianum Sm. - Tetrodontium.

Brownii Par.

0. acuminatum Rob. Br. in Trans. of the N. Zeal. Inst. 1894, p. 434, t. $X X X I X$, fig. 21 .

1. Rupic. - Pac. : Nov. Zeland.

Bruchii $\left\{\begin{array}{l}\text { Hüb. - O. speciosum. } \\ \text { Wils, - Ulota. }\end{array}\right.$

? bryoides Griff. - - Orthomnium trichomitrium.

bullatum $C . M$. in $\mathrm{Fl} .1887, p .223$.

1.

- Am. sept. : Calif.

calcareum Rob. Br. in Trans. of the N. Zeal. Inst. 1834, p. 427, t. XXXVI, fig. 6.

1. Rupic. - Pac. : Nov, Zeland.

californicum Vent. in Hedwig. 1873, p. 5 (nom.).

- Am. sept. : Calif.

callistomum Fisch. Ost. in Bryol. eur. III (mon. p. ), t. 224; C. M.

Syn. II, p. 639; W. P. Sch. op. cit. p. 339.

1. Ad cort. Fagr. - Eur. : Helvet.

calvescens Carringt. - Ulota.

calvum Hook. f. et Wils. Fl. of the N. Zeal. p. 8, t. 85, f. 7 et Handb. p. 432 .

Cortic - Pac. : Nov. Zeland.

canadense Br. et Sch. in Lond. Journ. of bot. 1843, p. 667; C. M. Syn. I, p. 703.

O. affine var. Hook, in Drumm. M. bor. am. I ed. n. 149 et 151.

1.

Exs. : Sull, et Lesq. M. bor. am. II ed. n. 181.

canadense Sull, et Lesq. - O. ohioense.

canum Mitt. in Journ. of the Linn. Soc. VIII, p. 26.

- Airt. sept. : Columb. brit. ; Texas?

carinatum Mitt. - Ulota.

eaucasicum Vent. in Husn. Muscol. gall. p. 176.

1.

- As. : Caucas. centr.

chilense Mitt. - Ulota.

cirralum Bernh. - Ulota crispula.

cirrosum H. et Grev. -- Macromitrium.

citrinum Aust. - 0 , ohioense var. citrinum.

clausum Hsch. - Ulota Ludwigii.

clavellatum $\mathrm{H}$. et Grev. - Drummondia.

Clintonii Rob. Br. in Trans, of the N. Zeal. Inst. 1894,p. 429, t. XXXVI, fig. 10.

1. Cortie. - Pac. : Nov. Zeland.

coarctalum $\left\{\begin{array}{l}\text { Bryol. eur. - Ulota Bruchii. } \\ \text { H. et Grev, - Ulota fuegiana. } \\ \text { P. B. - Ulota Ludwigii. }\end{array}\right.$ 
columbicum Mitt. in Journ. of the Linn. Soc. VIII, p. 24 ; Lesq. et Jam. Man. p. 175.

0. pulchellum (fid. Sull, et Kindb.).

- Am. sept. : Ins. Vancouver.

commutatum $\mathrm{Br}$. - O. cupulatum var. Rudolphianum.

compositum Brid, - Pilotrichum.

concavifolium Griff. - Acrocryphaea.

confertum $\mathrm{Br},-0$. cupulatum.

conicorostrum Rob. Br. in Trans, of the N. Zeal. Inst. 1894, p. 425,

t. XXXV, fig. 1 .

1. Cortic. - Pac. : Nov. Zeland.

connectens Kindb. - Ulota crispa.

consimile Mitt, in op. et l. cc. ; Sull. Ic. M. Suppl.p. 59, t. 43; Lesq. et Jam. Man, p. 173.

- Am. sept. : Ins. Vancouver.

consimile Mac. - 0 . columbicum ? vel pulchellum ?

coralloides Duby in Mémoires.... Genève, I876, p. 4, t.11, f. 5 et in Fl. 1877, n. 6.

1. Yortic. - As. : Ins. Philippin.

Coulteri Mitt, in op, cit. p. 25 ; Lesq. et Jam. Man. p. 173.

1.

- Am. sept, : Calif.

crassifolium Hook. f. et Wils. in Lond. Journ. of bot. 1844, p. 546 ; C. M.

Syn. I, p. 691 et $I 1, p .638$.

Ulota crassifolia H.f. et W. Fl. Antarct. p. 125, t, 57, f. 8 et Handb. of 1 . N. Zeal. Fl., p. 438.

mit., Maclov, $-A f r$ : Ins, Kerguelen. Am, merid. : Ins, Ere"var. acutum $C . M . l . c$.

- Afr. : Ins, Kergnelen.

crenulatum Mitt. M. Ind. or. p. 48.

1.

- As. : Tibet occ.

cribrosum C. M. in Bot. Centralbl. 1883, n. 2-4.

Dorcadium cribrosum Lindb, et Arn. M. As, bor. 1890, II, p. 98. 1.

- As. : Penins. Tschutschica.

crispatum H. et Grev. - Ptychomitrium.

crispulum Bryol, eur. - Ulota.

crispum $\{$ Hedw. - Ulota.

H. et W. - Ulota phyllantha.

var. minus Schwaegr. - Ulota crispula.

var. $\beta$ Wahlenb. - Ulota Drummondii.

var. Brid. - Ulota fulva.

var. Hook, f. et W. - Ulota lutea.

croceum Hpe. - Ulota lutea.

cupulatum Hoffm. Deulsch. Fl. II, p, 26; Brid. Bryol. univ. I, p. 272;

Bryol. eur. III (mon. p. 8), t. 209 ; C. M. Syn. I, p. 700; W. P. Sch.

op. cit. p. 313.

Brachytrichum cupulatum Roehl. Ann. d. Wett, Ges. III, p. 195.

Dorcadium cupulatum Lindb, $I .0$.

0. anomalum Engl. Bot. $t .1423$.

, confertum Br, in Brid. l. e. p. 783 
O. urceolatum Sohleich. Cat. pl. Helv, p. 42.

Weisia cupulata Roth. Fl. Germ. III, I, p. 217.

1. Ad mur, et sax. praecip. calcar. - Eur. : Passim. As. : Kashmir, Himalaya occ., Mesopot., Ássyr., Pers., Kurdistan., Caucas., As. min. Afr. : Alger. Am. sept. : Sinus Baffin, Columb, brit., reg. or. et central., Calif.

Exs. : Mac. Canad. M. n. 583.

Rab. Bryoth. eur. n. 177, 891,

Sull. et Lesq. M. bor. am. II, n. 176.

var. calcareum Vent. - 0 . urnigerum var. calcareum.

var. Floerkei Bryol, eur. - v. cupulatum var. Rudolphianum.

«var. longifolium (Groenv.) Limpr. Laubm. Deutschl. II, p. 44.

0. longifolium Groenv. in Oefv... 1889, p. 175.

- Eur. : Helvet. occid.

«var. minus Sull. Ic. M. Suppl.p. 61, t. 44; Lesq. et Jam. Man, p. 165. O. Lescurii Aust. M. Appal. n. 163 et in Bull. Torr. bot. Club, VI, p.311. Cortic. - Am. sept. : Columb. brit., Ontario, Ohio.

" var. octo-striatum Limpr. $l . c$.

Ad rup. dolomit. - Eur. : Eifel, Stiria.

"var. parvulum Silll. l. c. ; Lesq. el Jam. Man. p. 166.

o. parvulum Milt. in Journ. of the Linn. Soc. VIII, p. 25.

O. Sturnici Sull, et Lesq. M. bor, am, I ed. n. 117 p.p.

- Am. sept. : Nov. Mexic.

var. Peckei Sull. - 0. cupulatum var. Porteri.

" var. Porteri Vent. in Husn. Muscol. gall. p. 160; Lesq. el Jam. Man.

p. 165 (emend.)

O. cupulatum (?) Drumm. M. bor. am. II ed. $n, 81$.

O. cupulatum var. Peckei Sull., Lesq. et Jam. ll. ce.

O. Peckei Aust. M. Appal. n. 162.

0. Porteri ej. ll. cc. n. 161 et VI, p. 341.

Rupic. - Am. sept. : New York, Pensilv.

" var. riparium Hüb. Muscol. germ. p. 381 ; Bryol, eur. et W. P. Sch. Ul. $c c$.

O. nudum $S m$. Fl. Brit. III, p. 1268.

Ad sax. arenac. ripar. - Eur. : Sept. et centr. Afr. : Alger. Am. sept. : Ottawa.

* var. Rudolphianum (Lehm.) W. P.Sch. Syn. I ed.p. 261 et II ed.l.c.

O. commutatum Br. in Brid. op. cit. p. 784.

O. cupulatum Drumm. M. bor. am. I ed. n. 152.

O. cupulatum var. Floerkei Bryol. eur, l. c.

o. Floẹrkei Hsch. in Brid. l. c. p. 783.

O. nudum Sm. p.p. (fid. Vent.).

O. nudum var. Rudolphiaunm Kindb. in Mac. Cat. $p ; 87$.

O. reflexum Hsch, mss.

O. Rudolphianum Lehm. in Fl. 1827, p. 656. Ubi praeced. - Eur. : Sept. et centr. Am. sept. : Niagara, Columb.
brit.

Exs. : Rab. Bryoth. eur. n. 1073.

capulatum (?) Drumm. $\left\{\begin{array}{l}-0 . \text { cupulatum var. Porteri. } \\ -0 \text {. cupulatum var. Rudolphianum. }\end{array}\right.$

var. sardagnanum Vent. - 0 . sardagnanum. 
curvatum Rob. Br. in Trans. of the N. Zeal. Inst. 1894, $\rho .442, t$. XLII, fig. 40.

1. Rupic. - Pac. : Nov. Zeland.

curvatum Brid. - Rhacomitrium patens.

curvifolium Wahlenb. - Ulota.

cyathiforme Rob. Br. in op. cit. p. 436, t. XXXIX, fig. 24.

1. Cortic. - Pac. : Nov. Zeland.

cylindricum Warnst. - 0 . speciosum.

cylindrocarpnm Lesq. in Trans. of the Am. Phil. Soc. XIII, p. 6; Lesq et Jam. Man. p. 173.

Cortic. et rupic. - Am. sept. : M. Rupestr., Calif.

Exs, : Sull. et Lesq. M. bor. am. II ed, n, 178.

cylindrothecium (male: cylindrothecum) Rob. Br. in op. cil. p. 432, t. XXXVIII, fig. 16.

1. Cortic. - Pac. : Nov. Zeland.

Darwini Mitt. - Ulota.

diaphanum Schrad. Spic. Fl. Germ. p. 69; Brid. Bryol. univ. I, p. 293 ;

Bryol. eur. III (mon. p. 26), t. 219: C. M. Syn. 1, p. 694; W. P.

Sch. op. cit. p. 333.

Bryum diaphanum Gmel, Syst. nat. II, p. 1335.

Dorcadium diaphanum Lindb, et Arr. M. As. bor. 1890, II, p. 1335.

0. aristatum Tu'n. Muscol. Hib , p. 100, t. 9, f. 2 .

0. heterophyllum P. B. Prodr. p. 80.

O. pilosum ej.l. c. p. 81 .

Weisia diaphana Roth Fl. germ. III, I, p. 223.

1. Arbor., rar. saxic. - Eur. : Reg. merid, et intermed., raro subsept. As. : Sibiria. Afr. : Alger., ins Canar. Am. sepl. : Texas.

Exs.: Rub. Bryoth. eur. n. 180, 1009, 1176.

"var. aquatica Davies mss.; Vent. in Hedroig. 1873, p. 39.

- Eur. : Anglia.

" var. ulmicola (Lag.) Hüb. l. c.

0. ulmicola Lag. in Ann, d, seienc, nat. n. 14, p. 186.

Ad Ulmos. - Eur. : Hambourg.

dilalatum Bryol, eur. - Uluta Bruchii.

Douglasii Duby Choix de crypt. ex. 1867, p. 3, c. ic. et in Mém... Genève, 1868, p. 293, t. I, f. 2 .

Drummondii Grev. - Ulota.

Duthiei Vent, in Rev. bryol. 1896, p. 27.

1. Rupic. - As. : Kashmir.

Eckloni Hsch. - Ulota.

elegans Schwoaegr. ap. Rich. in Franklin's App. p. 756.

Dorcadium elegans Lindb, et Arn. M. As. bor. 1890, II.

0. speciosum Lesq. et Jam. Man. p. 169 p.p.; Kindb. in Mac. Cat. p. 89 p.p.

I. Cortic. - As.: Jenissei, Obi. Am. sept. : M. Rupestr., Idaho. elegans $\mathrm{Hsch}$. - Macromitrium brevipes.

elegantulum W. P. Sch, in Lechl. Pl. Magell. n. 1290; Mitl. M. auslr.

am. p. 187.

Cortic. - Am, merid. : Patagon austr. 
elongatum Tayl. in Lond. Journ. of bot. 1846, p. $45 ;$ C. M. Syn. 1, p. 706 ; Mitt. op. el l. cc.

2. Cortic. - Am. merid. : And. Quitens.

epibryum de Not. M. Napoan. in Acad... d. Torino... II ser., XVIII, p. 448.

- Am. merid. : Columb.

erecium Rob. Br. in Trans, of the N. Zeal. Inst. 1894, p. 441, t. XLII, fig. 38 .

1. Cortic. - Pac. : Nov. Zeland.

eremitense Mitt. - Ulota Hermitei.

eroso-crenatum C. M. - Ulota.

erpodiaceum C. $M$. in Linn. 1878-79, p. 364.

2. Fr. ign. Cortic. - Am. merid. : Argentin, Cordob.

erythrostomum Groenv. in Nya Bidr. p. 12.

1. Rupic. - Eur. : Suecia.

euryphyllum Vent. in Bot. Centralbl. 1890, n. 51.

1. Ad saxa rivul. - Am. sept. : Washington.

exiguum Sull. M. of U. Sl. p. 33 et Ic. M. p. 55, t. 35.

2. Ad rad. arb. - Am. sept. : Carol. merid.

fallax W. P. Sch. Syn. I ed., p. 264 et II ed., p. 327.

Dorcadium Schimperi Lindb. M. Scand. p. 28.

0 , affine $\beta$ pumilum $H$. et T. Musc. Brit. p. 74 .

o. pumilum Bryol. eur. III (mon. p. 14), t. 211 ; Brid. Bryol. univ. I, p. 285 ?; C. M. Syn. I, p. 696; W. P. Seh. Syn. II ed., p. 327.

o. Schimperi Ol. Hammar Mon. Orthotr, et Ulot. 1852, p.9.

1. Ad arbor. campestr. - Eur.: Præpr. in reg. merid.; Britannia? As, : Caucas. occ. et centr. Afr.: Alger. Am. sept.: Ontario? Idaho.

Foss. : Drumm. M. bor. am. II ed. n. 82?

Rab. Bryoth. eur. n, 125 b, 372?

«var. truncatulum Aust. in Bull. Torr. bot. Club; V1, p. 344; Lesq. et Jam. Man. p. 171.

$$
\text { - Am. sept. : Rar. : Illinois. }
$$

fallax $\left\{\begin{array}{l}\text { Bryol. eur. - 0. pumilum. } \\ \text { Rab. - 0. patens. }\end{array}\right.$

fasciculare Brid. - Ulota phyllantha (1).

fastigiatum $\mathrm{Br}$, in Brid. Bryol. univ. I, p. 785; Bryol. eur. III (mon.

p. ) , t. 216 ; C. M. Syn. I, p. 698; W. P. Sch. op. cit.p. 322.

Dorcadium affine $\beta$ fastigiatum Lindb. $l$. $c$.

O. affine Schwaegr, Suppl. I, II, p. I9, t. 49.

0 . affine var. fastigiatum Hüb. Muscol. germ. p. 365.

0 . alpestre Wils. in Kew Journ. bot. IX, p. 326.

I. Ad arbor. campestr,, rar. ad saxa, - Eur. : Vulg.; desiderat. in Britann, As. : Kashmir, Himalaya occ. Afr. : Alger. Am. sepl, : Lac. super.

Exs. : Rab. Bryoth. eur. п. 434, 892.

var. appendiculatum Jur. - 0 . appendiculatum.

var. negleclum Limpr. - O. neglectum.

(1) fascroulatum Brid. Bryol, univ. 1, p, 297 ; C. M. Syn. 1, p. 718. delendam. Grimmia fasciculata Brid. Mant. M. p. 37. 
a var. robustum Limpr. Deutschl. Laubm. II, p. 83.

Ut typ. - Eur. : Neumark., Siles., Algov., Tirol.

ferrugineum $\mathrm{H}$. et $\mathrm{Gr}$. - Schlotheimia.

fliforme eor. - Macromitrium.

fimbriatum Rob. Br. in Trans. of the N. Zeal. Inst. 1894, p. 430, t. XXXVlI, fig. !3.

1. Rupic. - Pac.: Nov. Zeland.

firmum Vent, in Nuov. Giorn. bot. ital. 1872, p. 15. 1. - Afr. : Abyssin.

Raccum de Not. - 0 . rupestre.

flexifolium Rob. Br. in op. cit. p. 428, t. XXXVI, fig. 8.

1. Cortic. - Pac.: Nov. Zeland.

Floërkei Hsch. - O. cupulatum var. Rudolphianum.

Franzonianum de Not. - O. rupestre var. Franzonianum.

fuegianum Mitt. - Ulota.

fulvellum Mitt. - Ulota.

Germanum Mont. - Ulota.

gevaliense Groenv. - 0 . microcarpon.

glabellum Mitt. - Ulota.

glaucum Spreng. Syst. veg. IV, II, p. 323; C. M. Syn. I, p. 695.

1. Cortic. - Afr.: C. B. Sp.

gracile Hook, - Macromitrium.

gracillimum Rob. Br. in op. cit. p. 427, t. XXXV, fig. 5.

1. Rupic. - Pac. : Nov. Zeland.

graphiomitrium C. M. in Trans. of the N. Zeal. Inst. 1888, p. 291.

1. Arbor. - Pac. : Nov. Zeland.

groenlandicum Berggr. in Rev. bryol. 1877, p. 70 (nom.).

- Am. sept. : Groenland merid.

gymnostomum Br. in Brid. Bryol. univ. 1, p. 782 ; Bryol. eur. III (mon.

p. 8), t. 208; C. M. Syn. 1, p. 689 ; W. P. Sch. op. cit. p. 319.

Dorcadium gymnostomum Lindb. l. c. p. 29.

2. Ad Popul. tremul. - Eur. : Scandin. merid., Boruss. or., Siles., Rhoengeb., Salisb., vall. Rhen., Bavar., Helvet., Voges., Gall. med. occ. As.: Japon. Am. sept.: Terrra nova.

Exs: Rab. Bryoth. eur. n. 1074.

Hainesiae Aust. - o. speciosum var. Hainesiae.

Hallii Sull. et Lesq. in Lesq. el Jam. Man. p. I70; Sull. Ic. M. Suppl. p. $63, t .45$.

1. Rupic. ? et cortic. - Am. sept. : M. Rupestr., Montana.

Hendersoni Ren. et Card. in Bot. Gaz, 1890, p. 42, t. 7 A.

1. Cortic. - Am. sept. : Oregon.

hercynicum Hoffm. - Oligotrichum (1). *

heterophyllum P. B. - O. diaphanum.

Holmgreni Lindb.

0. Bolanderi (fid. Vent, in Husn. Muscol. gall, p. 126).

0 . rupestre var, vulgare $f$. densior Vent. in op. et l, ce. - Eur. : Scandin. ? Am. sept. : (Cf. O. Bolanderi).

1) heteromallum Schwaegr, in Brid. Bryol. univ, I, p. 297; C. M. Syn. 1,
p. 18 ? Delendum. 
Hookeri Mitt. M. Ind. or. p. 48.

1. Cortic. - As. : Nepal., Sikkim, Alp. Yunnan.

Hornschuchii $\mathrm{H}$, et Grev. - Macromitrium pulchellum.

hortense Bosw. in Lond. Journ. of bot. 1892, p. 97, t. 320. 1 ? - Pac. : Nov. Zeland.

humile Schleich. - O, anomalum.

Hurunui Rob. Br. in Trans, of the N. Zeal. Inst. 1894, p. 436, t. XL, fig. 26.

1. Ad rup. sicc. - Pac. : Nov. Zeland.

Hulchinsiae Sm. - Ulota.

imperfectum C. M. in Bot. Centralbl. 1883, n. 2-4.

Dorcadium imperfectum Lindb. et Arn. M. As. bor. 1890, II, p. 99.

1. Rupic. - As. : Penins. Tschutschica.

immersum Brid. - O, pallens.

inaequale Rob. Br. in op. cit. p. 429, t. XXXV1I, fig. $1 I$.

1. Cortic. - Pac. : Nov. Zeland.

incanum C. M. - Ulota.

inclinatum C. M. - Ulota.

incurvifolium $\mathrm{H}$. et $\mathrm{Gr}$. - Macromitrium.

inflexum C. M. - O. brachytrichum.

involutifolium $\mathrm{H}$. et $\mathrm{Gr}$. - Macromitrium.

Jamesianum Sull. Ic. M. Suppl. p. 71, t. 53; James in Bot. King Exped.

p. 401 ; Lesq. et Jam. Man. p. 177.
1. Ad rup. aren. - Am. sept. : M. Rupestr.? Columb. brit., Nevada. Jamesoni Arn. - Schlotheimia.

japonicum Sull. et Lesq. in Proced. of the Am, Acad... 1859, p. 277.

1. Cortic. - As. : Japon.

jutlandicum Brid. - Ulota phyllantha.

Killiasii C. M. in Bot. Zeil. 1859, p. $166 ;$ W. P. Sch. op. cit. p. 323.

Dorcadium Killiasii Lindb. M. Scand. p. 28.

0. speciosum var. Jur. Laubm. Oesterr. Ung. p. 202.

1. Ad rup. silic. - Eur. : Norveg. (Dovre), Alp. Helvet., Tírol., Carinth., Stir., Salisb. As. : Caucas, or. Am. sept. : Groenland.

Exs. : Rab. Bryoth. eur, n, 998. " var. macroblepharum W. P. Sch. op. et l. cc. et Bryol. eur. Suppl.
I-II, t. 7.

O. macroblepharum ej. Bryol. Suppl, I-II.

- Eur. : Spitzberg et ubi typ.

Kingianum Lesq. in Mem. Calif. Acad. I, p. 18; Sull. Ic. M. Suppl. p. 74, t. 55; Lesq. et Jam. Man. p. 170 (1).

Rupic. - Am. sept. : Calif.

laevigatum Zetterst, in Bull. Soc. Bot. Fr. 1862, p. 287 ; W. P. Seh. Bryol. eur. Suppl. I-II, (Orthotr. p. 2), t. 2 et Syn. II ed. p. 309.

Dorcadium laevigatum Lindb. M. Seand. p. 28.

1. Rupic. - Eur. : Norveg., Island. Am. sept. : M. Rupestr., Columb. brit,, Washington, 1daho, Oregon, Nevada occ.

Exs. : Mac. Canad. M. n. 454.

(1) Cf. Dna E. G. Britton in Bull. Torr. bot. Club, 1893, p. 401. 
lanceolatum Rob. Br. in Trans. of the N. Zeal. Inst. 1894, p. 429, t. XXXVI, fig. 9.

1. Cortic. - Pac. : Nov. Zeland.

laticiliatum Vent. in Broth. Some New Spec. of Austral. M. . II, p, 33.

1. Rupic. - Pac. : Tasman.

laterale Hpe. in Linn. 1876, p. 309.

? Ulota lateralis Jaeg. Ad. II, p. 691.

1. Cortic. - Pac. : Austral, or.

latifolium Rob. Br. in Trans, of the N. Zeal. Inst. 1894, p. 441, $t$. XLI, fig. 36 .

1. Cortic. et rupic. - Pac. : Nov. Zeland.

latorum $R$. Br. in op. cit. p. 431, t. XXXVII, fig. 15.

1. Rupic. - Pac. : Nov. Zeland.

latifolium Groenv, - 0. pallens var. parvum.

Laureri Hsch. - Ulota curvifolia.

Lawrencii Mitt. is Fl. Tusman. 11, p. 184, $t$. 172, f. 5.

- Pac. : Tasman.

laxifolium Wils. mss. ; Mitt. in Lond. Journ. of bot. 1851, p. 57 et M. austr. am.p. 184 ; C. M. Syn. II. p. 64 (1.

1. $\quad$ - Am. merid. : And. Quitens.

Lebruni Besch. in Bull. Soc. bot. Fr. 1885, p. LXII.

1.

- Am. merill. : Patagon. austr.

Leikipiae C. M. Fl. 1890, p. 483.

1 .

- Afr. : M. Aberdare.

leiocarpon Bryol. eur. III (mon. p. 28), t. 230; W. P. Sch.op. cit.p. 337.

Bryum striatum L. Sp.pl, p. 1579.

Dorcadium striatum Lindb. $l$. $c$.

Grimmia oblonga Schrank Baiers Fl. II, p. 443.

Gr. striata Hedw. Fund. M. II, p. 89.

0. striatum ej. M. frond. p. 90, t. 36 p.p. ; Brid. Bryol. univ. I, p. 290; C. M. Syn. I, p. 708 : Drumm. M. bor. am. 1 ed. n. 154.

0. Rogereri Sull. M. of U. St, p. 33.

Polytrichum, Bryi ruralis facie, capsulis sessilibus, majus Dill. Hist. M. p. $430, \imath .55, f .8$.

P. bryoides $\alpha$ striatum Weiss Crypt. Goett. p. 175 .

P. striatum Huds. Fl. Angl. p. 401.

Weisia ithyphylla var. major Ehrh. Beitr. I. p. 191.

W. polytrichoides Wigg. Prim. Fl. Hols. n. 821 .

W. striata Roth Fl. Germ. III, I, p. 120.

1. Cortic., lignic., rar. saxic. - Eur. : Vulg. As. : Caucas, Talysch. Afr,: Alger.; C. B. Sp. ? Am. sept.: Perrar.: lac. Super., Washington, Idaho. Am. merid. : And. Quitens.

Exs. : Rab. Bryoth, eur. n. 516, 888.

Sull. ot Lesq. M. bor. am. Il ed. n. 183.

" var. Rotae de Not. Erb. critt. ital. n. 1211.

Ad arb. campestr. et silv. - Eur, : Riesengeb., Ticin.

leiocarpum Mac. $\left\{\begin{array}{l}\text { - } 0 \text {. elegans. } \\ -0 . \text { speciosum? }\end{array}\right.$ leiolecythis C. M. in Nuov. Giorn. bot. ital. 1896, p. 107. - As. : China or. (prov. Schen-Si).

leiothecium C. M. - Ulota. 
leptocarpon Br. et Sch. in W. Sch. M. Abyss. n. 488; C. M. Syn. I, p. 706.

1. ? Ad Eric. acrophyam, - Afr. : M. Abyssin.

leptocarpon Wils. - 0 , anomalum.

Lescurii Aust. - O. cupulatum var. minus.

Letourueuxii Besch. Cat. M. Alger, p. 19.

- Afr. : Alger.

leucomitrium Br. in Brid. Bryol. univ. I, p. 789; Bryol, eur. III (mon. p. 26), t. 220 ; C. M. Syn. I, p. 695; W. P. Sch. op. cil. p. 333.

o. scanicum Groenv. Mon. p. 13.

1. Ad Acer., Popul. et Salic. ambul. - Eur. : Vall. Rhen., Bavar., Siles., Stir., Salisb., Tirol., Helvet. ; deest in Britann. et reg. sept.; rar. in mont. Gall., et in Apenn.

Exs. : Rab. Bryoth. eur. n. 434 p.p., 989.

Lobbianum Mitt. - Ulota.

lonchotheciuin C. M. et Kindb, - O. Roellii.

longifolium Hook. - Macromitrium.

longipes Hook. - Macromitrium.

longirostre Hook. - Macromitrium.

longithecium (male: longithecum) R. Br. in Trans, of the N. Zeal, Int. $1894, p .433, t$. XXXVIII, fig. 18.

1. Rupic. - Pac. : Nov. Zeland.

Lorentzi C. M. in Linn. 1878-79, p. 358.

1. Cortic. - Am. merid. : Argentin. subtropic.

Ludhoigii Schwaegr. - Ulota.

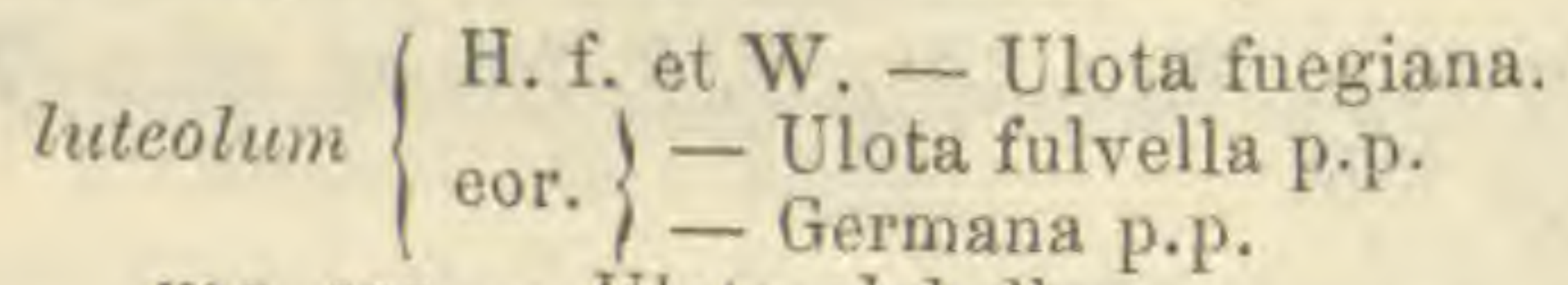

var, eor. - Ulota glabella.

luteum eor. - Ulota lutea.

lycopodioides Burch. - Macromitrium.

Lyellii Hook. et Tayl. Musc. Brit. p. 96, t. 22; Brid. Bryol. wniv. 1, p. 295, pp. 724 (incl. var. $\beta$ ) el 790 ; Bryol. eur. 111 (mon. p. ), t. 221 ; C. M. Syn. I, p. 709 ; W. P. Sch. op. cit. p. 336.

Dorcadium Lyellii Lindb. $l$. $c$.

2. Ad arbor. silv. - Eur. : Zon. intermed. et sept. As. : Caucas, occ. Afr. : Alger. Am. sept. : Columb. brit., ins, Vancouver, Washington, Oregon, Calif., reg. occ.

Exs. : Mac. Canad. M. n. 130.

Rab. Bryoth, eur. n. 518 et b, 1006.

Sull. et Lesq. M. bor. am. II ed. n. 184.

* var. papillosum (Hpe.) Sull. M. bor. am. II ed. p. 33; Lesq. el Jant. Man. p. 178.

O. pacificum Hpe, in hb. Mus. brit.

O. papillosum Hpe. in Linn. 1859, p. 458.

o. Sullivantii Aust. in Bull, Torr. bot. Club, 1879, p. 343 ?

S. Nevada Calif. - Am. sept. : Ins. Vancouver, Washington, Oregon,

Exs. : Sull. et Lesq. M. bor. am. II ed. n. 185.

« var. Pringlei C. M. in Mac. Cat. p. 92.

Rupic. - Am. sept. : Columb. brit. 
lyelloides Kindb. in Rev, bryol. 1896, p. 11 (1).

2. Cortic. et rupic. - Am. sept. : Ins. Vancouver.

Mac Leai Rehm. M. Afr. austr. n. 514. - Afr. : C. B. Sp. or.

macroblepharum W. P. Sch. - O. Killiasii var. macroblepharum. macrocalycinum Mitt. - Ulota. magellanicum Mont. -- Ulota.

magnothecium (male: magnothecum) $R$. Br. in Trans, of the N. Zeal. Inst. 1894, p. 435, ı. XXXIX, fig. 23.

1. Cortic. - Pac, : Nov. Zeland.

malseothecium C. M. in Linn. 1880-83, p. 444.

2? Cortic, - Am, merid, : M. Argentin. Tucuman. subtropic.

Mandoni W. P. Sch. mss.; Hpe, in Ann, sc, nat. V ser., IV, p. 332.

Ulota Mandoni Jaeg. Ad. I, p. 441.

2. Cortic, - Am. merid. : And, Nov. Granat. et Boliv.

marginatum C. M. - Ulota fuegiana.

Meyenianum Bpe. in C. M. Syn. II, p. 639.

1. -As.: Ins. Philippin. (Manilla).

microblepharis W. P Sch. Bryol. eur. Suppl, I-II Orlhot ich. p 2),

t. 2 et op. cut. p. 309.

Dorcadium microblephare Lindb. $l . c$.

1. Ad saxa calcar. - Eur. : Lappon, or., ins. Aland, Norvey. microcarpon de Not. Epil. p. 306; W. P. Sch. op, cit. p. 328.

a gevaliense Groenv, in Bot. Not. 1886, n. 1 (fid. Vent.).

0. pallens var. parvum Vent. in Hedwig. p.p. (fid. Limpr.).

0. pumilum forma Vent. l, c. p. 181.

1. Ad Morum alb. - Eur. : Rhoengeb., (2) lac. Major. As, : Caucas. occ.

microphyllum $\mathrm{H}$. et Gr. - Macromitrium.

microstomum eor. - Macromitrium.

minimifolium R. Br. in Trans. of the N. Zeal. Inst. 1894, p. 439, t. XL, fig. 31 .

1. Rupic. - Pac. : Nov. Zeland.

minutum ej. in op , cit. $p .437, t$. XL, $f .27$.

1. Cortic. - Pac. : Nov. Zeland.

mollissimum C. M. in Linn. 1875, p. 407.

Moorcroftii H, et Grev. - Macromitrium.

mucronifolium eor. - Macromitrium.

neglectum W. P. Sch. Syn. II ed., p. 330.

0. affine var. neglectum Vent. in Husn. Muscol, gall. p. 171.

0 . fastigiatum var, neglectum Limpr. Deutschl. Laubm. p. 83.

1. Ad frutic, - Eur. : Baden (W. P. Sch.) ; vulg. (Vent.).

nepalense H. et Gr. - Macromitrium.

(1) Sec. Dem E. G. Britton in Rev, bryol, 1896, p. 73, vix forma O. Lyellii.

(2) Species ad O. pallentem referenda (fid. Limpr. Laubm. Deutschl, II, p 66). 
nigritum Bryol. eur. - Ulota Hutchinsiae.

nivale Spr. in Lond. Journ. of bot. 1881.

- Am. merid. : And. Quitens.

nudum $R$. Br. in Trans. of the N. Zeal. Inst. 1894, p. 438, t. XL, fig. 30.

I. Ad ramul. - Pac. : Nov. Zeland.

nudum Sm. p.p. $\left\{\begin{array}{l}-0 \text {. cupulatum var. riparium. } \\ -0 \text {. cupulatum var. Rudolphianum. }\end{array}\right.$

nutans C. $M$. in Linn. 1878-79, p. 363.

1. Cortic. - Am. merid. : Argentin. Cordob.

obscurum Groenv. $\left\{\begin{array}{l}\text { - O. pallens (fid. Limpr.). } \\ - \text { O. pumilum var. obscurum (fid. Vent.). }\end{array}\right.$

obesum Rob. Br. in op. cit. p. 425, t. XXXIX, fig. 22.

1. Rupic. - Pac, : Nov. Zeland.

obliquum ej. in op. cit. p. 428, t. XXXVI, fig. 7.

1. Rupic. - Pac. : Nov. Zeland.

obtusatum ej. in op. cit. p. 439, t. XL, fig. 32.

1. Rupic. - Pac. : Nov. Zeland.

obtusifolium Schrad. Crypt. Gewo.p. 14; Brid. Bryol. univ. I, p. 287;

Bryol. eur. III (mon. p. 13), t. 208; C. M. Syn. I, p. 688; W. P.

Sch. op. cit. 388.

Dorcadium obtusifolium Lindb. $l$. c.

Weisia obtusifolia Roth Tent. fl. Germ. III, I, p. 218.

2. Ad arbor. praecip. campestr. - Eur.: Præcip. media : desider. in

Britann. As.: Jenissei, Himalaya occ., Caucas. occ. et centr.

Am. sept: Noy. Scotia, New Brunswick, Gaspes., Ontario, M.

Rupestr., Columb. brit., Washington, M. Adirondack, Pensilv.,

Idaho.

Exs.: Mac. Canad, M. n. 1є8.

Rab. Bryoth. eur, n. 517, 885, 1075.

Sull. et Lesq. M. bor. am. II ed. n. 173.

obtusifolium Drumm. - 0 . brachytrichum.

occidentale Jam. - 0 . alpestre var, majus.

octoblepharis Brid. - 0 . affine.

ohioense Sull. 1c. M. suppl. p. 66; Lesq. et Jam. Man. p. 170. 0. canadense Sull. M. of U. St. p. 34; Sull. et.Lesq. M. bon. am. I ed.
n. 121.

o. psilocarpon Mac. Canad. M. n. 123 p.p.

1. Cortic. - Am. sept. : New Brunswick, Ontario, New Jersey, Ohio, Montana, etc.

Exs. : Sulliv. et Lesq. M. bor. am. II ed. n. 181.

« var. citrinum Lesq. et Jam, l. c.

0. citrinum Aust. M. Appal. n. 170.

Ut et ubi typ. ornatum Rob. Br. in Trans. of the N. Zeal. Inst. 1894, p. 426, t. XXXV',
flg. 4 .

]. Ad rup. aren. - Pac. : Nov. Zeland.

orneum Wils. - 0. Shawii.

pacificum Hpe. - O. Lyellii var. papillosum.

Paivanum W. P. Sch. in Mandon Pl. Mad. n. 15.

O. tenellum (fid, Mitt. in Godman's Nat. hist. of Azores, p. 299).

- Afr. : Madeira. 
pallens Br. in Brid. Bryol. univ. I, p. 788; Bryol. eur. III (mon. p. 24), t. 218; C. M. Syn. I, p. 781 (incl. v. ß); W. P. Sch. op. cit. p. 331 . Dorcadium pallens Lindb. l. c.

Dorcadium pallens var. scopulorum ej. $l$. $c$.

0. Arnellii Groenv. Mon, p. 115 (fid. Vent, in op. cit. p. 189; spee. propr. sec. Limpr.).

0. immersum Brid. l. c. p. 786.

0. rufescens ej. Nya Bidr. p. 8.

0. scopulorum Lindb. in Notis... 1868, p. 257.

1. Ad arbor. junior, et frutic., rar. ad Popul., Salic., Abiet., rarius ad saxa. - Eur. : Reg. montana; Fennia, As,: Caucas. centr. et occ. Am. sept. : Columb. brit.

"var. crispula Vent. in Hedvig. 1873, p. 21.

Ad Abiel. - Eur. : Helvet., Tirol., Monte Baldo.

var. immersum C. M. - O. pallens.

« var. parvum Vent. l.c. (p.p. fid. Limpr.) et in Husn. Muscol. gall. p. 189.

Dorcadium pallidum Lindb. et Arn. M. As. bor. 1890, II, p. 95 .

0. aurantiacum Groenv. Monog. p. 16.

0 . boreale ej.l. c. p. 8 ?

0. latifolium ej. l. o. p. 15 emend.

0. pallidum ej.l. c. p. 15.

sei med, Am Eur.: Alp. edition, Norveg. septentr. As. : Jenissei med. Am, sept. : Wyoming.

pallens Brid. p.p. - 0 . Rogeri.

pallidum $\left\{\begin{array}{l}\text { Groenv. }-0 \text {. pallens var. parvum. } \\ (\alpha \text { et } \beta) \text { P. }\end{array}\right.$

papillosum Hpe.

paradoxum Groenv. in Oefo... 1889, p. 179.

1. Ad rup. gneiss. - Eur. : Helvet.

\& var. leucomitrioides Limpr. Deutschl. Laubm. II, p. 62.

Muric, - Eur. : Tirol.

paraguense Besch, in Journ. de bot. 1891.

1. - Am. merid. : Paraguay.

Eos. : Bal. Pl. Parag. n. 3628 p.p.

pariatum Mitt. M. austr, am. p. 186.

2.

- Am. merid. : Summ. And. Quitens.

parvithecium (male: parvithecum) Rob. Br. in Trans. of the N. Zeal.

Inst. $1894, p .440, t$. XLI, fig, 35 .

1. Cortic. - Pac. : Nov. Zeland.

parvulum ej. in op. cit. p. 439, t. XLI, fig. 33.

I. Cortic. - Pac. : Nov. Zeland.

parvulum Mitt. - 0. cupulatum var. parvulum.

patens Br, in Brid. Bryol, univ. I, p. 787 ; Bryol. eur. III (mon. p. 17).

ᄂ. 215; C. M. Syn, I, p. 703; W. P. Sch. op. cit. p. 321.

0. affine var. patens Garov. Enum. M. austr. p. 21 .

O. fallax Rab. Bryoth. eur. n. 125 ,

0. steamineum var, patens Vent. in Hedw. 1873, p. 20.

i. Ad arbor. et fructic. campestr. et silvat. - Eur. : Neerland, Belg., Gall. sept,, vall. Rhen., German,; Transilv., Stir., Bavar,, Helvet. palens Boul. - 0. stramineum (fid. Limpr.) 
patulum Mitt. op. cit. p. 184.

$$
\text { - Am. merid. : And. Quitens. }
$$

Peckii Aust. - 0. cupulatum var. Porteri.

pellucidum Lindb. in Oefo... XXIII, p. 550 .

0. anomalum var. defluens Vent. in Husn. Muscol. gall.p. 159?

0. Breutelii var.? Berggr? in K. Sv. Akad. Handl. XIII, n. 7, p. 53. - Eur. : Spitzberg.

penieillatum Mitt. op. cit. p. 185.

1. Cortic. - Am, merid. : And. Nov. Granat.

perforatum C. M. in Bot. Centralbl. 1883, n. 2-4.

Dorcadium perforatum Lindb. et Arn. M. As, bor. 1890, II, p. 98.

1. Ad ossa human., etc. - As. : Penins. Tschutschica.

perforatum Limpr. - 0 . urnigerum var, perforatum.

perichaetiale $\mathrm{H}$. et Gr. - Macromitrium.

Philiberti Vent. - 0, pumilum var. Philiberti.

phyllanthoides C. M. - Ulota.

phyllanthum Bryol. eur. - Ulota.

piliferum W. P. Sch, in Breutel M. Capens.

Exs. : Rehm. M. Afr. austr. . B. 516 .

piliferum Arn. - Macromitrium.

pilosum P. B. - O. diaphanum.

platyblepharis C. M. in Bot. Centralbl. 1883, n. 2-4.

Dorcadium platyblepharis Lindb. et Arn. M. As. bor. 1890, II, p, 98.

1. - As. : Penins. Tschutschica.

plicatım P. B. Prodr. 8L; C, M. Syn. I, p. 690.

Leiomitrium plicatum Mitt. in Philos. Trans. of the roy. Soc. 1879 (extra vol.), p. 390.

Ulota plicata Brid. Bryol. univ. $I, p .303$.

1. Cortic. - Afr. : Ins. Borbon., Franciae, Rodriguez.

plicatum Ludw, - Ulota Ludwigii.

Podocarpi C. M. in Linn. I878-79, p. 361.

1. Cortic. - Am. merid. : Argentin. subtropic,

polare Lindb. in Oefv,..p p. 537.

0. alpestre var. ? Berggr. in K. Sv. Akad. Handl. XIII, n. 7, p. 53. 1.

- Eur. : Spitzberg.

polytrichoides Brid. - Lepidopilum.

Porteri Aust. - O. cupulatum var. Porteri.

praemorsum Vent. in Bot. Centralbl. 1890, n. 51.

1. Rupic. - Am, sept. : Yellowstone Park.

Pringlei C. M. in Bull. Torr. bot. Club. 1885, p. 121 et in Fl. 1886,
p. 539 (1). p. 539 (1).
Cartic. - Am. sept. : Ins. Vancouver, Oregon, Idaho, Nevada,
Calif.

prorepens Hook, - Macromitrium.

(1) An O. Lyellii var. Pringlei ? Cf. Dna E, G. Britton in Bull. Torr, bot. Clab, $1893, \mathrm{p}, 399$. 
pseudo-tenellum Hpe. mss.; C. M. in Bot. Zeit. 1859, p. 230.

1 . - Afr. : C. B, Sp.

Exs. : Rehm. M. Afr. austr. n. 515 ?

psilocarpum James in Trans. of the Am. Phil. Soc. XIII, p. 110 ; Sull. Ic. M. Suppl.p. 68, t. 50 ; Lesq. et Jam. Man. p. 73.

0. pusillum Mitt. in Journ, of the Linn. Soc. VIII, p. 25.

1. Ad Popul. - Am. sept, : Lac. Erie, Massachussets, Pensilv., Missouri, Carol, merid., Florid.

Exs. : Sull. et Lesq. M. bor. am. II ed, n. 180.

psilocarpum Mac. p.p. - O. ohioense.

psilothecium C. M. et Kindb. in Mac. Cat. p. 91,

1. Lignic. - Am. sept. : Ottawa.

psychrophilum Mont. in d'Orbigny Voy. Am. merid. VII, Crypt. p. 89 ; C. M. Syn. I, p. 704 ; Mitt. M. austr. am. p. 186.

1 (C. M.); 2 (Mitl.). Rupic. - Am, merid. : And. Potos.

Puiggarii Duby (fid. H.pe. in Fl. 1889, n.21). - Schlotheimia appressifolia? -Schlotheimia Puiggarii?

pulchellum Engl. Bot.t. 1787; Brid. Bryol. univ. I, pp. 294 el 724; Bryol. eur. III (mon. p. 29), t, 223; C. M. Syn. 1, p. $711 ;$ W. P. Sch. op. cit. p. 334.

Dorcadium pulchellum Lindb.. . $c$.

0 . columbicum Mitt. (fdd. Kindb.).

0. consimile Mac. Canad. M. n. 125.

0. stenocarpum Brid. l. c. p. 271 .

1. Ad arbor, et frut. campestr., ram. Pom., Prun, - Eur.: Zon. septentr.; deest in Alp. et in Pyren. Am. sept.: Alaska, Columb. brit., ins. Vancouver, Oregon.

Exs. : Mac. Canad. M. n. 127.

Rab. Bryoth. eur. n. 887, 1079.

s var. leucodon Vent, in Bot. Centralbl. 1890, n. 51.

- Am. sept. : Washington, Vaucouver.

*var. longipes Sull. in Lesq. et Jam. Man. p. 175.

- Am. sept. : Oregon.

var. productipes Ren. et Card, in Bot. Gas. 1890, p. 43.

Cortic. -- Am. sept. : Oregon.

pulchellum Rab. - 0. Winteri.

var. Winteri Rraithw. - 0 . Winteri.

pulvinatum Rob. Br. in Trans. of the N. Zeal. Inst. 1894, p. 426,

t. XXXV, fig. 2,

1. Ad rup. aren. - Pac. : Nov, Zeland.

pumilum Sw. M. Suec. pp. 42 et 92, t. 4; W. P. Sch. Syn. I ed. p. 263 et II ed. p. 328.

Dorcadium pumilum Lindb. $l$. $o$.

0. fallax Br. in Brid. Bryol. univ. I, p. 787; Bryol. eur. III (mon.

0. p. $15, t, 211 ; C . M$. . Syn, I, p. 697.

1. Ad ar pumilum Boulay $M$. Fr. $I$, p. 335.

- Ad arbor. campestr. impr. Acer., Popul, Salic. -- Eur. : Fere tota. As. : Caucas, oce. Afr. : Ins, Canar. Pac. : Nov, Zeland. (?)

Eass. : Rab. Bryoth. eur. n. 224, 372.

a var. americanum Vent. in Husn, Muscol. gall. p. 180.

- Am. sept. : M. Appalach. 
" var. molle Vent. l, c.

O. Rogeri Boulay. M. Fr.; Husn. M. Gall. n. 264.

- Eur. : Normannia.

«var. obscurum (Groenv.) Vent. $I, c$.

0. obscurum Groenv. Bidr. p. 12 (fid. Vent. : non! fid. Limpr.).

- Eur. : Austria infer.

« var. Philiberti Vent. $l . c$.

o. Philiberti ej. in Rev. bryol. 1878.

- Eur. : Galloprov., Sardin.

pumilum Brid. - O, fallax.

punclalum H. et Grev. - Macromitrium.

pungens Mill. M. austr. am. p. 184.

1. Cortic. - Am. merid. : And. Quitens.

pusillum Mitt. - 0. psilocarpum?

pyenophyllum W. P. Sch. mss. ; C. M.Syn. I, p. 709; Mitt. op. cit. p. 188.

2. $\quad-$ Am. sept. : Mexic.

pygmaeothecium C. M. - Ulota.

Pylaisaei Brid. Bryol. univ. 1, pp. 722 et 790 ; C. M. Syn. I, p. 693.

o. Blyttii ? (quoad 0. Breutelii) Vent. in Husn. Muscol. gall. p. 175.

O. Breutelii Hpe. mss. ; Sendtn, in Fl. 1849, p. 273.

I. Rupic. - Eur. : Spitzberg, ins. Ursor. Am, sept. : Groenland.

quadrifidum $\mathrm{H}$, et $\mathrm{Gr}$. - Schlotheimia.

Quenoæ C. M. in Linn. 1880-83, p. 445.

1. Cortic. - Am. merid. : M. Argentin. subtropic. Tucuman. (1) Raui Aust. - 0. speciosum var. Raui.

recurvans W. P. Sch. mss, ; C. M. Syn. 1, p. 709.

1. $\quad-A m$ sept. : Mexic. (M. Orizaba).

recurvifolium (Hsch.) C. M. Syn. II, p. 640.

Syrrhopodon recurvifolius Hseh. in Linn. 184I, p. 118; C. M. Syn. I. p. 546 .

Ster. - Afr. : C. B. Sp.

recurvifolium $\mathrm{H}$, et Gr. - Macromitrium.

reflexum Rob. Br. in Trans. of the N. Zeal. Inst. 1894, p. 43l, t. XXXVII, fig. 14 .

1. Rupic. - Pac.: Nov. Zeland.

reflexum Hsch. - 0 . cupulatum var. Rudolphianum.

rhabdophorum Vent, in Bot. Centralbl. 1890, n. 51.

1.

- Am. sept. : Washington.

rivulare Turn. Musc. Hib. p. 96, t. 8; Brid. Bryol. univ. I, p. 292; Bryol. eu. III (mon. p. 25), t. $219 ; C$. M. Syn. 1, p. $699 ;$ W. P. Sch. op.
cit. p. 338 .

1. Ad saxa et rad. arbor. saep inund. - Eur. : Britann., Normann. Ad saxa et rad. arbor. saep inund. - Eur. : Britann., Nor, Oregon,
Belg., Voges, inf,, vall. Rhen. med., Harz. Am. sept. : Oregol.
Calif.

Exs. : Rab. Bryoth. eur. n. 883, 1077.

(1) radiculosum Brid, Bryol, univ. I, p. 791 ; C. M. Syn. I, p. 718. - Barhulo sect. Senophyllum ? Delend, 
robustum Rob. Br. in Trans, of the N. Zeal. Inst. 1894, p. 442, t. XLII, fig. 39 .

I. Rupic. - Pac. : Nov. Zeland.

robustum Wils. - Ulota.

Roellii Vent. in Bot. Centralbl. 1890, n. 51 (descript. mala) et in Rev. bryol. $1892, p .17$.

0. Ionchothecium C. M. et Kindb. in Mac. Cat, p. 90 ; Mac. Canad. M. n. 49 .

1. Rupic. - Am. sept. : Athabasca, Columb. brit., M. Rupestr., Washington, Oregon.

Rogeri Brid. Mant. M. p. 110 et Bryol, univ, I, p. 286 ; Bryol. eur. III (mon. p. 16), t. 212; C. M. Syn. I, p. 700; W. P. Sch. Bryol. eur. Suppl. I-II (Orthotrich., p. 8), t. 8 et Syn. II ed. p. 332 (1).

0. auridens W. P. Sch. Bryol. eur. Suppl. I-II, p. 9 (fid. Limpr.).

o. pallens $B r \cdot p \cdot p$.

0. subalpinum Limpr. in LX Jahresb. Schles. Gesells. p. 234.

0. ticinense de Not, Epil. p.310.

1. Ad Abiet, et Fag. - Eur. : Norveg., Siles., Bohem., Bavar, Tirol,, Helvet., Jurass, Voges., Gall, centr. (Cantal). Am. sept: Idaho.

Exs. : Rab. Bryoth, eur. n. 1259.

Sull, et Lesq. M bor. am. II ed. n. 174 ?

4 var. defluens Vent, in Husn. Muscol. gall. p. 187.

0 , stramineum var. defluens ej. in Hedwig. 1873, p. 19.

Caucas, occ.

- Ever. : Siles., Alp. Carinth., Pyren., Hispan. As. :

Rogeri $\left\{\begin{array}{l}\text { Br. et Sch. }-0 \text {. brachytrichum. } \\ \text { M. Gall, }- \text { o. pumilum var, molle. } \\ \text { Sull, - O. leiocarpon. }\end{array}\right.$

rabescens $M$ itt. M. austr, am. p. 188.

2.

- Am. merid. : And. Quitens.

Rudolphianum Lehm. - O. cripulatum var. Rudolphianum.

rufescens $\left\{\begin{array}{l}\text { Hpe. Ulota } \\ \text { Groenv. }-0 . \text { pallens. }\end{array}\right.$

rufulum Mitt. - Ulota.

rugifolium Hook. - Schlotheimia.

rupestre Schleich. Cent. III crypt. Helv, n, 24; Brid. Bryol. univ. I, pp. 279 et 784 ; Bryal. eur. III (mon. p. 19), t. 217; C. M. Syn. I, p. 707 ; W. P. Sch.op, cit. p. 316.

Dorcadium rupestre Lindb. $l$. $c$.

0. affine $\beta$ rupestre Brid. Sp. M. II, p. 7.

0. flaccum de Not. Epil, $p$ 301 et Erb. critt, ital. n. 818; W. P. Soh. op. cit. p. 315 p.p.

0 . rupestre $v a r$. flaccum Vent.

0. rupestre var. valgare ej, in Husn. Muscol. gall. p. 156.

0. rupincola Drumm. M. bor. am. I ed. n. 156.

0 . Sturnici de Not. Syll. p. 189 p.p.

. Watsoni Mac. Canad. M. n. I21.

1. Ad rup. et mol. arenac., basalt, granit. et mur. absque cemento calc, - Eur. : Reg. montana usq. in Alp. As. : Kasbmir, Himalaya occ., Caucas. Afr. : Alger, ins. Kergnelen. Am. sept. : M. Ru-

(1) Cf. Venturi in Rev. bryol. 1887, p. 58. 
pestr.; Columb, brit., Washington, Oregon, Idaho, Nevada, ('olorado, Calif.

Exs. : Un. itin. 1864, n. 15.

“ var. xtnense (de Not.) Vent. l. c. p. 157.

O. retnense de Not. Epil. p. 302 ; W. P. Sch. op. eit. p. 315.

O. Sturnici de Not. Syll. n. 189 p.p.

Ut typ. - Eur. : Stiria, Etna, Sierra de Guadarrama. As. : Caucas.

var. elongata Vent. - O. rupestre var. Sehlmeyeri.

var. flaccum Vent. - 0 , rupestre.

«var. Franzonianurn (de Not.) Vent. l. c. (1).

0 . Franzonianum de Not. mss.; Vent. in Rev. bryol. 1879, p. 55.

O. Shawii de Not. Epil. p. 303.

Cortic. - Eur. : Tirol., Longobard., Corsica.

* var. ovatum Vent. in Rev. bryol. $1880, p .68$ et in op. cit. p, 155.

- Eur. : Carinth. As. : Caucas. Afr: Abyss.

«?f. properistomata Vent. in Rev. bryol. 1896, p. 67.

Rupic. - Pac, : Tasman.

" ? $f$. rupestriformis Vent, in op. et $l$. cc.

Rupic. - Pac. : Tasman.

« var. rupincola (i'unk) Hüb. Muscol. germ. p. 369; W. P. Sch. Syn. II ed. p. 316.

0. rupincola Fosnk Moostaschb. p. 25, t. 23 ; Brid. op. cit. p. 284.

Ut et ubi typ. in Eur.

« var. Sehlmeyeri (Br.) Hüb. et W. P. Sch. ll. cc.

O. rupestre var, elongata Vent, in Hedwig. 1872.

O. rupestre vai. vulgare $f$. laxior ej. in Husn. Muscol. gall. p. 157.

O. Sehlmeyeri $\mathrm{Br}$, in Brid. op. cit. p, 784.

Ad basalt, et trachyt. - Eur. : Ubi typ. As. : Caucas.

var. Sturmii Jur. - 0. Sturmii.

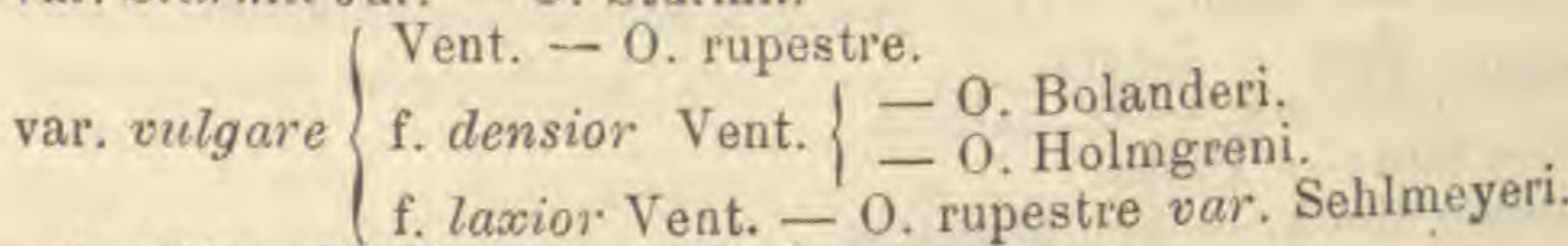

rupestre Mitt. (1876). - 0. rupicolum.

rupicolum C. M. in Engler's Bot. Jahrb. 1883, p. 80 et in Forchungsreise...p. "24.

0. rupestre Mitt. in Journ, of the Linn. Soc. 1876, n. 84.

1. Rupic. - Afr. : Ins, Kerguelen.

rupincola $\left\{\begin{array}{l}\text { Drumm. - O. rupestre: } \\ \text { Funk. - o. rupestre var, rupincola. }\end{array}\right.$

Sardagnae Vent. in op. cit. p. 161.

o. abbreviatum Groenv, Monog. (fid. Vent.).

O. cupulatum var, sardagnanum Vent. in Rev. bryol. 1882, p. 60.

O. sardagnanum Vent, in Rev. bryol. 1879.

1. Ad rup. calcar. - Eur. : German,, Tirol., Dalmat.

sardagnanum Vent. - O. Sardagnae.

(1) Cf. Philibert in Rev. bryol. 1882, p. 9. 
saxatile $\left\{\begin{array}{l}\text { Brid. }-0 \text {. anomalum var. saxatile. } \\ \text { Wood. }\end{array}\right.$

Schimperi 01. Hamm. - O. fallax.

scanicum Groenv. - 0 . leucomitrium.

Schlotthaveri Vent. in Bot. Centralbt. 1890, n. 51 (descript. mala) et in Rev. bryol. $1892, p .18$.

1. Cortic, et rupic. - Am. sept. : M. Rupestr. ; Idaho? Montana.

Schmidii C. M. - Ulota.

Schnyderi C. $M$. in Linn. 1880-83, p. 441.

2. Cortic. - Am. merid. : Argentin. Buenos-Ayr.

Sehlmeyeri Br. - 0. rupestre var. Sehlmeyeri.

Schubartianum Ltz, in Verhandl. d. Zool. bot. Ges, in Wien, 1867, p. 657, c. ic.; W. P. Sch. op. cit. p. 318.

0. Schubartzianum de Not. Epil. p. 303.

0, urnigerum Jur. Laubm. Estern. Ung: p. $210(p, p$.$) .$

0. urnigerum var. Schubartianum Vent. in Husn. Muscol, gall. p. 163.

1. Ad rup. micac. - Eur. : Norveg., Tirol., Helvet., Carinth., M. Bergam. As. : Caucas.

"var. laete-virens Limpr. Deutschl. Laubm. II, p. 49.
Rupic. - Eur. : Tirol.

Schubartzianum de Not. - o. Schubartianum.

scopulorum Lindb. - O. pallens.

serpens H. et Gr. - Macromitrium.

serrifolium C. $M$. in $F l$. 1890, p. 482.

Ster.

- Afr. : M. Kilima N'Djaro.

Shawii Wils. mss, ; W. P. Sch. Bryol, eur. Suppl. I-II (Orthotr., p. 1),

t. I et op. cit. p. 314 ,

0. orneum Wils, mss, ; Braithw. Brit. Mossfl. II, p. 70.

1. Cortic., praepr, ad Fraxin. et Caslan. - Eur. : Scot., Brandeb., Ticin., lac. Major., Corsica.

Shavoii de Not. - o. rupestre var. Franzonianum.

sibiricum Groenv. Monog.

Dorcadium sibiricum Lindb, et Arn. M. As. bor. 1890, II, p. 96.

1. Ad Aln, et Salic. - As, Jenissei inf. simenso W. P. Seh, in W. Sch. M. Abyss.

Smithii Brid. - Leptodon.

$$
\text { - Afr. : Abyssin. }
$$

Sommerfeldti W. P. Sch. Bryol. eur. Suppl. I-Il (Orthotr., p. ), t. 6 et op. cit. p. 312.

Dorcadium Sommerfeldti Lindb. M. Scand, p. 29.

0. anomalum var. $\beta$ Wahlenb.

1. Rupic. - Eur. : Norvegia,

sordidum Sull. Ic. M. Suppl. p. 67, t. 49; Lesq. et Jam. Man. p. 170.
1. Cortic. - Am. sept. : New Brunswick, Ontario, lac. Super., Massachussets, New York.

Exs. : Mac. Canad. M. n. 122 ?

speciosum Nees ab Es. in Sturm Deulsch. Fl. crypt. fasc. XVI; Brid. 
Bryol. univ. 1, p. 280; Bryol. eur. III (mon. p. 19), t. 217; C. M. Syn. I, p. 705; W. P. Sch. op. cit. p. 322.

Dorcadium speciosum Lindb. M. Scand. p. 28.

o. Bruchii Hüb.

o. cylindricum Warnst. in Hedw. 1885, n. 3 .

O. leiocarpum Mac. Canad. M. n. 126 p.p. ?

O. striatum Hedw. M. frond. II, t. 35, f. 1-3 (fid. Limpr.).

1. Cortic, - Eur. : Fere tota ; rar. in Britann. As.: Amour, Sikkim, Tibet occ., Caucas, Afr. : Alger. Am. sept.: Nov. Scot., New Brunswick, Gaspes,, Ontario, Manitoba, Saskatchewan, M. Rupestr., Columb. brit., ins. Vancouver, Washington, Montana, reg. occ. et or. (1).

Exs. : Drumm. M. bor. am. I ed. n. 155 et 158 (an 0 . elegans?).

Mas. Canad. M. n. 120 (id.).

Rab. Kryoth, eur. n. $433,889$.

Sull, et Lesq. M. bor. am. II ed, n. 185 (an O, elegans?).

Un itin. 1867, n. 87.

" var. fuscum Lindb. in Notis... 1873 el in Rev. bryol. 1887, p. 63.

Ad Betul. periodice inund. - Eur. : Scandin. ?

"var. Hainesiae Lesq. et Jam, Man. p. 169.

O. Hainensiae Aust, in Bull. Torr. bot. Club, VI, p. 342.

Rupic. - Am. sept. : Colorado.

« var. polycarpum Lesq. et Jam. l. c.

- Am. sept. : Colorado.

" var. Raui Lesq. et Jam. $l$, c.

0. Raui Aust. in op. cit. p. 343.

- Am. sept. : Colorado.

« var. Roellii Vent. in Bot. Centralbl. 1890, n. 51.

- Am. sept. : Washington, lllinois.

speciosum Lesq. et Jam. - 0. elegans (p.p. ?).

var, Jur. - O. Killiasii.

Sprucei Mont. in Lond. Journ. of bot. 1845, p. 186 ; Bryol. bur. IIl (mon. p. ), t. $214 ;$; C. M. Syn. I, p. 699 et II. p. $639 ;$ W. P. Seh.
op. cit. p. 338.

1. Ad arbor.. prœer. Salic. sœep. submers, - Eur. : Rar. : Britann., Belg., Gall.

Sprucei $\times$ diaphanum Philib. in Rev. bryol. $1883, p .8$.

Ad Salic, period. submersas. - Eur. : Gallia (Burgondia).

squarrosum $\left\{\begin{array}{l}\text { Griff. - Schlotheimia Grevilleana. } \\ \text { H. et (ir. - Schlotheimia. }\end{array}\right.$

stellatum Brid. Bryol, univ. 1, p. 274.

- Am. sept. : Massachussets. (2).

stellulalum H. et Gr. - Macromitrium.

stenocarpum Vent. in Bot. Centralbl. 1890, n. 51 (descript. mala) et in
Rev. bryol. p. 17.

1. Rupic. - Am. sept. : Oregon, Idaho, Washington.

(1) Localitates, preprimis Canadenses, dubiae, ob confusionem inter 0 . elegantem et O. speciosum.

(2) Cf. Venturi in Husn. Muscol. gall. pp. 171-172. 
stenocarpum Brid, - 0. pulchelluin.

Stevenii C. M. in Bot. Zeit. 1858, p. 164.

1.

- As. : Caucas. (Tiflis).

stramineum Hsch. in Brid. Bryol, uriv. I, p. 789; Bryol, eur. 111 (mon. p. 24), t. 218 p.p. ; C. M. Syn. I, p. 697; W. P. Sch. op. cit. p. 325. Dorcadium stramineum Lindb. M. Scand. p. 28.

0. patens Boulay M. Fr. I, p. 336 (fid. Limpr.).

0, umbonatum Brid. op. cit. p. 787 ?

Polytrichum Bryi ruralis facie, capsulis sessilibus, minus Dill. Hist. $M$. p. $431, t .55, f .9$.

1. Ad arbor., procip. Fag. et Acer., rar. Pin, et Popul. - Eur. : E reg. campestr, usq. in alp. As. : Caucas.

Exs. : Rab. Bryoth, eur. n. 373, 1076.

var. alpestre Vent. - 0 . alpestre.

var, defuens Vent. - O. Rogeri var. defluens.

" var, intermedium Vent, in Husn. Muscol. gall. p. 183.

- Eur. : Helvet. (Genève).

var, patens Vent. - O, patens.

"var. vexabile Limpr. Laubm. Deutschl. II, p. 68

0. stramineum de Not. Epil. p. 315.

Ad Sorbos. - Eur. : Isergeb., Riesengeb.

stramineum Bryol, eur. p.p. 1837, - 0. alpestre.

strangulatum P. B. Prodr. p. 81; Brid, Bryol, univ. I, p. 273; C. M. Syn. I, p. 702 ; Lesq. et Jam. Man. p. 172.

0. cupulatum (fid. Limpr, et Braithw.).

1. Cortic., interd. rupic. - Am. sept. : Nov. Scot., New Bruns wick, Ontario, reg. sept., centr. et or.

Esos. : Mac. Canad. M. n. 124.

Sull, et Lesq. M. bor, am. II ed. n. 179.

* var, mucronatum Vent, in Jaeg. Ad. I, p. 455.

Cortic. - Eur. : Ital. med.

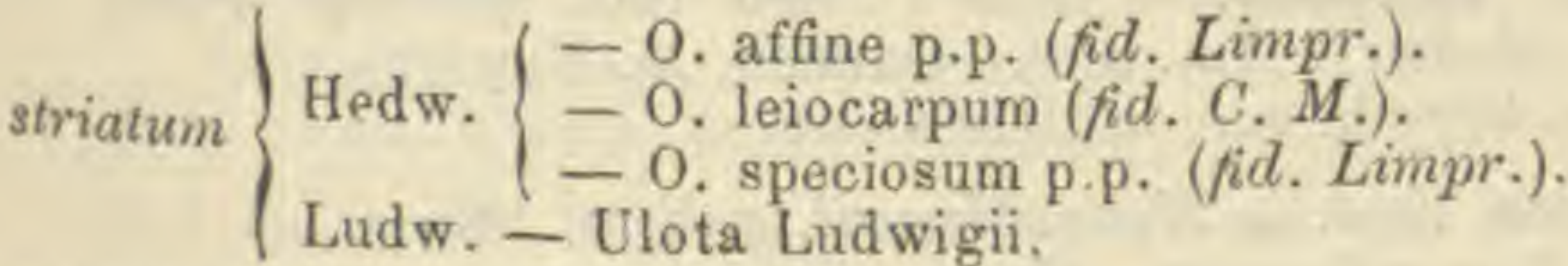

strictissimum Mdo, in Lts. Moosst. p. 169.

0. Sturmii (fid. Limpr.).

- Eur. : Alp. Austriae.

strictum Vent, in Centralbl. 1890, p. 419 (subsp. O. Lyellii).

2.

- Am. sept. : Washington.

strictum Brid. - Ulota Hutchinsiae.

Sturmil Hoppe et Hsch, in Bot. Zeit. 1819, p. 89; Brid. Bryol. univ, 1, p. 277 ; Bryol. eur. III (mon. p. 9), t. 209; C. M. Syn. I, p. 708;

W. P. Sch.op. cit. p. 314 .

Dorcadium rupestre var. Sturmii Lindb. M. Seand. p, 29 .

0. rupestre var. Sturmii Jur. Laubm. Oester. Ung, p. 201.

Polytrichum capsulis sessilibus, foliis brevibus rectis carinatis Dill. Hist. M. p. 432, t. 55, f. 10 (fid, Limpr.).

1. Kupic, - Eur, : E reg. campestr. usq. in alp.; io Scot. freq. ad 
arbor. As. : Caucas, Afr. : Alger, ins. Canar. Am. sept. : M. Rupestr., Columb brit., Oregon, Nevada, Colorado, Calif.

Exs. : Rab. Bryoth. eur, n, 884, 987, 1008.

Sull, et Lesq. M. bor. am. II ed. n. 175.

Sturmii $\left\{\begin{array}{l}\text { de Not. }-0 \text {. rupestre var, aetnense. } \\ \text { de Not. et plur. auct. }-0 \text {. rupestre. } \\ \text { Sull. et Lesq. p.p. - o. cupulatum var, parvulum. }\end{array}\right.$

subalpinum Limpr. - 0 . Rogeri.

subexsertum W. P. Sch, mss.; C. M. in Bot. Zeit. 1858, p. 154.

1? $\quad-A f r .:$ C. B. Sp.

Exs. : Rehm M. Afr. austr. n. 170.

? submarginatum Brid. Bryol. univ., 1, p. 792; C. M. Syn. I, p. 691.

Ster. - Am. sept. : Terr. nov.

subperforatum C. M. in Bot. Centralbl. 1883, n. 2-4.

Dorcadium subperforatum Lindb. et Arn. M. As. bor. 1890, II, p. 98.

1. - As.: Penins. Tschutschica.

subrepens Sommerf. - Ulota Drummondii.

subtortum H. et Gr. - Macromitrium.

subulatum Mitl, M. austr. am. p. 184.

Cortic. - Am, merid. : And. Quitens.

subulatum Rob. Br. - O, teremakauense.

sulcatum H. et Gr. - Macromitrium.

Sullivantii Aust. - 0. Lyellii var. papillosum.

Swoainsoni $\left\{\begin{array}{l}\text { Hook. - Macromitrium. } \\ \text { Steud. - Macromitrium stellulatum. }\end{array}\right.$

tasmanicum Hook. f. et Wils, in Lond. Journ. of bol. 1848, p. 27 el Fl.

Tasm. II, p. $184 ;$ C. M. Syn. I, p. 707.

1. Cortic. - Pac. : Austral, or., Tasman.

tenellum Br. in Brid. Bryol. univ. I, p. 786 ; Bryol. eur. III (mon. p. 15),

t. $212 ;$ C. M. Syn. I, p. 704; W. P. Sch. op. cit. p. 329.

Dorcadium tenellum Lindb. M, Scand. p. 28.

1. Ad arbor, campestr. - Eur: : Fere tota, praecip. merid. Afr. :

Alger.; Madeir.? Am. sept. : Ontario, M. Rupestr.

Exs. : Rab. Bryoth. eur. n. 1078 a et b.

* var. decipiens Vent. in Husn. Muscol. gall. n. 186.

Ut typ. - Eur. : German., Tirol.

var. pumilum Boul. - o, tenellum.

tenue H. et Grev. - Macromitrium.

teremakauense Par.

O. subulatum Rob. Br. in Trans, of the N. Zeal. Inst. 1894, p. 441. t. XLII, fig. 37.

1. Cortic. - Pac. : Nov, Zeland.

texanum Sull. Ic. M. p. 53, t. $34 ;$ Lesq. et Jam. Man. p. 166. Idaho, Colo-
1. Rupic. - Am. sept.: Columb. brit., ins. Vancouver, Ida, rado, Calif., Nov. Mexic.

Exs. : Mac. Canad. M. n. 119 p.p.

Sull. et Lesq. M. bor. am. II ed. n. 187.

Sull. et Lesq. M. bor. am. II ed. n. 187.
"var. globosum Lesq. in Mem. Calif. Acad. I, p. 17; Lesq. et Jam. $l$, c.
Ut et ubi typ.

Eics, : Mac. Canad. M. n. 119 p.p. 
ticinense de Not. -0 . Rogeri.

tortulosum Rob. Br. in Trans. of the N. Zeal. Inst. 1894, p. 432,

t. XXXVIII, fig. 17.

1. Ad ramul. - Pac. : Nov. Zeland.

tortum H. et Grev. - Schlotheimia torquata.

trachymitrium Mitt. op. cit. p. 1883.

Saxic. - Am. merid. : And, Quitens.

transvaaliense Rehm. M. Afr. austr. n. 517.

- Afr.: Transvaal.

truncato-dentatum C. M. in Linn. 1880-83, p. 442 ,

1. Cortic, $-A m$. merid. : And, Nov. Granat.

ulmicola Lag. - 0. diaphanum var. ulmicola.

ulotaefurme Ren. et Card. in Bot. Gasette 1890, p. 43, ८. 7 B.

1. Cortic. - Am, sept. : Oregon.

umbonatum Brid. (fid. C. M.). $\left\{\begin{array}{l}\text {-0. affine. } \\ -0 . \text { stramineum. }\end{array}\right.$

undulatum Mitt. op. el $l$. $c c$.

2.

- Am. merid. : Summ. And, Quitens.

undulatum $\mathrm{H}$, et Gr. p.p. $\left\{\begin{array}{l}\text { - Calymperes repens. } \\ \text { - Macromitrium. }\end{array}\right.$

undulatifolium C. $M$. in Fl. $1888, p .413$.

urceolatum $\left\{\begin{array}{l}\text { Hook. }- \text { Macromitrium. } \\ \text { Schleich. }-0 \text {. cupulatum. }\end{array}\right.$

urnaceum C. M. in Act. hort. Petrop. X, 1887, f. 1 .

1.

- As. : Caucas.

urnigerum Myr. in Coroll. fl. Ups. p. 71 ; Bryol. eur. III (mon. p. 29),

t. $222 ; C . M$. Syn. I, p. 710; W. P. Sch. op. cit. p. 318.

Dorcadium urnigerum Lindb. $l$. $c$.

1. Ad rup. humid. - Eur.: Voges, Rhoengeb., Harz, Tatra, Tirol,

Helvet. Am. sept. : Wyoming.

Exs. : Rab. Bryoth. eur. n. 886 p.p.

- var. calcareum Vent. in Husn. Muscol. gall. p. 164.

0. cupulatum var. calcareum ej. in Hedwig. 1872.

Ad rup. calcar. - Eur. : Helvet.

- var. confertum W. P. Sch. Syn. I ed. p. 277 et Il ed. p. 319.

Ut typ, - Eur. : Rhaet. (M. Albula).

Q var. perforatum (Limpr.) Vent, in op. cit. p. 163. 0. perforatum Limp\%. in Ann. Soc. so. Siles. 1884, p. 214 et Laubm.

Ad rup. calc. - Eur. : Alp. Tirol., Stir. As. : Caucas.

var. Schubartianum Vent. - O. Schubartianum.

var. Venturii Vent. et Bott. - O. Venturii.

urnigerum Jur. p.p. - O. Schubartianum.

Venturii de Not. Epil. p. 305; W. P. Sch. op. cit. p. 317.

0. urnigerum var, Venturii Vent. et Bott. Enum. p. 28.
1. Rupic. - Eur. : Sabaud., Ital, super., Tirol., Helvet. 
"var, fuscum Vent, in Rev. bryol. 1881, p. 47 et in op. cit. p. 164. - Eur. : Alp. Helvet. (Vales.).

" var. himalayanum Vent. in Rev. bryol. 1895, p. 52. Rupic. - As. : Himalaya.

Venturii Mac. - 0, anomalum var.

verrucost.m C. M. in Linn. 1878-79, p. 358.

1. Cortic. - Am. merid. : Argentin. subtropic.

vladikaukasum Vent. in op. cit. p. 167.

1. Cortic. - As. : Caucas. centr.

Wagneri Ltz. Moost, p. 162.

1. Rupic. - Am. merid. : M. Pichincha.

Wallisii C. M. in Linn. 1874, p. 604.

1.

- Am. merid. : And. Nov. Granat.

Watsoni Jam. in Bot. King Exped. p. 401 ; Sull. Ic. M. Suppl. p. 73,

t. 54 ; Lesq. et Jam. Man. p. 168.

1. Ad rup. humid, - Am. sept. : Nevada (M. Humboldt).

Watsoni Mac. - O. rupestre.

Winteri W. P. Sch. Bryol. eur. Suppl. I-II (Orthotr., p. ), t. 11 et op. cit. p. 335 .

O. pulchellum Rab, Bryoth, eur, n. 1079.

0. pulchellum var. Winteri Braithw. Brid. Moosft. II, p. 88.

1. Ad trunc. et ramul. Acer., Carpin., Coryl., Fraxin., Lonic. Eur. : Hibern., Voges, inf. (M. Schaumberg.) (1).

Osculatia de Not. in Acad. R. d. sc. di Torino... II ser., XVIII (1 spec.).

columbica de Not, in op, cit. p. 445.

- Am. merid. : Columb.

OSMUNDULA Rab. Crypt. Fl. Sachs. I, p. 609.

fissidentoides ej. - Fissidens osmundioides.

OTICODIUM C, M, in Linn. 1875, p. 469.

Celebesiae C. M. - Orthothecium.

Oxystegus Lindb. de Tortul. p. 213 (sect. Trichostomi).

Pachyfissidens $C . M$. Syn. $1, p .45$ (sect. Fissidentis).

Pachynoma Mitt. $M$. austr. am. p. 151 (sect. BARBULAR).

Palinocrapsis Lindb. M. Scand. p. 25 (sect. CAMPYLOPODIS).

PALUDELLA Ehrh. Phytophylae n, 96 (1 spec.).

squarrosa (L.) Brid. Mant. M. p. 115, t. 2,f. 3 et Bryol. univ. II, p. 1; Bryol. eur. IV, t. 312; C. M. Syn. I, p. 468; W. P. Sch. Syn. II ed. p. 502,

Bryum squarrosum L. Sp. pl. p. 1585; Drumm. M. bor. am. I ed. n. 248. Hypnum Paludella $W$. et M. Bot. Taschb. p. 274.

Nenium squarrosum L. f. Meth, M. p. 364 .

Orthopyxis squarrosa P. B. Prodr: p. 79.

(1; In Enumer. Kindb, nomen nudum:

o. ovatum Vent. 
2. In palud, spong. - Eur. : Spitzberg, ins. Ursor,, reg. subalp. et alp, zon, interm, et sept. As. : Penins. Tschutschica, Jenissei med. et inf., Ochotsk. Afr. : C. B. Sp. (fid. C. M.) Am. sept. : Groënland, Labrador, Anticosti, Gaspes., M. Rupestr., Columb. brit., New-York.

Eos. : Mac. Canad. M. n. 158.

Rab. Bryoth. eur. n. 42, 114, 1401.

Un. itin, 1867, n. 74 .

Panckowia Lindb. M. Scand. p. 34 (sect. Hypni=EurHynchIUM).

PAPILlaRiA C. M. Syn. II, p. 134 (primum subsect. Negkerae, postea gen. propr.) (104 spec.).

acinacifolia Besch, in litt.; Ren. in Rev. Bryol. 1888, p. 89.

2.

- Afr. : Ins. Franciae.

aeruginosa (Mitt.) Jaeg. Ad. II, p. 167.

Meteorium aeruginosum Mitt. Sam. M. p. 171, t. V B.

M. floribundum Sull. in Wilkes Exped. p. 22?

2. Ad arbor, - Pac. : Ins. Fidji, Samoa, Taïti.

africana (C.M.) Jaeg. Ad. $I I, p .176$.

Dendropogon capensis W. P. Sch. in Breutel M. Capens.

Neckera africana C. M. Syn. $11, p .137$.

2. - Afr.: M. Usagara, Kilima N'Djaro, G. B. Sp.

Exs, : Rehm. M. Afr. austr. n, 324.

"var, natalensis Rehm, l. c. n, 614.

- Afr. : Transvaal.

\& var, rupestris C. $M$. in Rehm. l, c. n. $324 b$,

- Afr. : C. B. Sp.

amblyacis (C. M.) Jaeg. Ad. II, p. 171.

Meteorium amblyacis Mitt. in Trans. and Proced. of the roy. Soc. of Viotoria, $1883, p .82$.

Neckera amblyacis $C$. M. in Linn. 1869-70, p. 521. 2.

- Pac. : Austral. or. (Nov, Vales.).

Angstroemiana C. M. in Angstr. Prim. lin. p. 53 ; Besch. Fl. bryol. Taili, etc., p. 36 (clescript. fruct.).

Cryphaea helictophylla Angstr. in Oef.... 1873, n. 5, p. 124.

Ad arbor. - Pac. : Taïti, Eimeo.

ankeriensis Kiaër in Borgen M. Madag.

- Afr. : Madagascar.

apophysata C. M. mss.; Jaeg. Ad. II, p. 678.

- As. : Sikkim.

appendiculata Ren, et Card, in Bull, Soc. roy. bot. Belg. 1893, I, p. 120.

Ster. Ad arbor. - Afr. : Madagascar.

appressa (Hsch.) Jaeg. I. c. p. 170.

Hypnum appressum Hsoh. Fl. Brasil. I, p. 90.

Meteorium appressum Mitt. M. austr. am. p. 443.

Neckera appressa C. M. Syn, II, pp, 136 et 670.

1. Terr. - Am. sepl. : Costa Rica. Am. merid. : And, Nov. Granat., Peruv, Brasil. austr. or.

auriculata Jaeg. - Trachypus. 
Baileyi Broth. in Bot. Centralbl. 1888, p. 86.

2. - Pac. : Austral. or. (Queensland).

bicolor Jaeg. - Trachypus.

blanda (Harv.) Jaeg. Ad. 1I, p. 175.

Neckera blanda Harv. in Lond. Journ, of bot. 1840, p. 14 et in Hook. Io. pl. $\operatorname{rar} . t .22 ; C . M$. Syn. II, p. 185.

Trachypus blandus Mitt. M. Ind. or. p. J27; Iryol, jav. II, p. 101.

2.

Ceylan, Java.

- As. : Nepal., Himalaya, Khasia, M. Neilgherr.,

"var, thuyodes Bryol. jav. l. c.

- As. : Java, Borneo, Ceram, Halmaheira.

Boiviniana Besch. Fl. bryol. Réunion, elc. p. 123; Ren. in Rev.

bryol. $1888, p .88$.

2. Ster. Ad arbor. - Afr. : Ins, Borbon., Franciae.

breviculifolia C. M. in Fl. 1890, p. 494.

Ster. $\quad-A f r$ : : Kilima N'Djaro.

Buchanani (Brid.) Besch. in Ann. sc. nat. 1892, I, p. 74.

Isothecium Buchanani Brid. Bryol, univ. II, p. 363.

Leskea Buchanani Hook. in Trans. of the Linn. Soc. $I X, p .320, t .28, f .3$.

Neckera Buchanani C. M. Syn. II, p. 670.

Trachypus Buchanani Mitt. M. Ind. or, p. 129.

Ad arbor. - As. : Nepal., Himalaya occ., Bhotan, M. Neilgberr., Ceylan, Alp. Yunnan.

caldensis Angstr. Prim. lin. p. 35.

Ster.

- Am. merid. : Brasil, austr. or.

callochlorosa C. M. in Act. Soc. sc. Fenn. 1891, n. 5.

2.

- Am. merid. : Minas Geraẹs.

Cameruniae (C. M.) Par.

Floribundaria Cameruniae C. M. in Dusen M. Camer, n. 81 .

- Afr. : M. Cameroon.

capillaris (C. M.) Jaeg. Ad. II, p. 168.

Meteorium capillare Milt. M. austr. am. p. 442.

Neckera capillaris C. M. Syn. II, p. 134 .

Pilotrichella capillaris Besch. Prodr, bryol, mexic. p. 80.

Pterogonii spec. Hsch. in Deppe et Sohiede M. Mexio, n. 1082.

2.

- Am. sept. : Mexic.

eapilliramea (C.M.) Jaeg. l. c.

Neckera capilliramea C. M. in Bot. Zeit. 1859, p. 237.

Ster.

- As. : Java.

Cardoti Broth. in Bihang till K. Sv. Vet. Akad. Handb. 1895, n. 3.

2. fr, ign.

- Am. merid. : Brasil.

catharinensis Par.

P. filipendula C. M. in Ule Bryoth. brasil. n. 166.

- Am. merid. : Brasil. austr. or.

cavifolia C. M. in Ule Bryoth. brasil. n, 173.

Rupic. - Am. merid. : Brasil. austr. or.

cerina (Mitt.) Par.

Trachypus cerinus Mitt. in Journ. of the Linn. Soc. 1859, p. 91.

Ad arbor. - Fac. : Austral., Nov. Zeland., Tasman. 
chloronema C. M. in Bull. Soc. roy. bot. Belg. 1895, I, p. 69.

Ster. - As. : Bhotan, Sikkim.

ehrysoclada (C. M.) Jaeg. op. cit. p. 174.

Neckera chrysoclada C. M. Syn. II, p. 139.

Trachypus atratus Mitt. ?

Ster. - As. : Weylan.

chrysonema C. M. in Bull. Soc. roy. bot. Belg. 1995, 1, p. 69.

Ster. - As. : Bhotan.

cirrifolia (Schoaegr.) Jaeg. op. cit. p. 176.

Hypnum cirrifolium Sehwaegr. Suppl. III, I, I, t. 218.

Neckera cirrifolia C, M. Syn. I1, p. 138.

Ster. - Afr. : Ins. Franciae.

consanguinea (Hpe.) Jaeg. op. cit. p. 169.

Meteorium consanguineum Hpe. herb.

Pilotrichella consanguinea Besch. Prodr, bryol. mexic. p. 80. - Am. sept. : Mexic.

crispatula Jaeg. - Trachypus.

crocea (Hpe.) Jaeg, op. cit. p. 171.

Pilotrichum croceum Hpe, in Linn. 1852, p. 715.

P. flexicaule Tayl.? - Pac. : Tasman.

cryphaeopsis C. $M$. in Ule Bryoth. brasil. n. 175.

Ad arbor. - Am. merid. : Brasil. austr. or.

cuspidifera (Tayl.) Jaeg. op. cit. p. 176,

Meteorium cuspidiferum Tayl. in H. f. et W. Fl. of the N. Zeal. II, p. 101.

Neckera cuspidifera $e j$, mss.

N. funiformis C. M. in Bot. Zeit. $1859, p .246$.

Trachyloma Taylorii Mitt. M. Ind. or, p. 92.

Trachypus cuspidiferus ej. op. cit. $p$. 128.

Ad arbor. - As.: M. Neilgherr, Ceylan. Pac.: Nov. Zeland. sept. et med., ins. Kermadec et Norfolk, Tasman.

declinata Jaeg. - Trachypus.

deltoidea (Besch.) Jaeg. op. cit. p. 172.

Pilotrichella deltoidea Besch. Fl. bryol. Nov, Caled. p. 227.

Ad frutic. - Pac. : Nov. Caledon.

denticulata (C. M.) Jaeg. op. cit. p. 170.

Meteorium denticulatum Mitt. M. austr. am. p. 443.

Neckera denticulata $C . M$. Syn. $I I, p .137$.

2.

- Am. merid. : Venezuela.

Deppei (Hsch.) Jaeg. op. cit. p. 168 ,

Meteorium Deppei Mitl. op. vit. p. 141.

Neckera Deppei Hsch. in Deppe et Schiede M. Mexie. ; C. M. Syn. II, p. 136.

Pilotrichella Deppei Besch. Prodr. bryol, mexio, p. 80.

Pilotrichum seriatum C. M. in Linn. 1847, p. 217.

Pterigynandrum seriatum Hsch. $l$. $c$.

1.

And. Nov. Granat.

diversicoma (Hpe,) Par.

- Am. sept. : Mexic. Am. merid.: Ins. Trinitat.,

Neckera diversicoma Hpe. Enum. M. Brasil. p. 42.

2.

- Am. merid. : Brasil, austr. or. 
Dubyana (Hpe.) Jaeg. l. c.

Monoschima viride Duby Choix de orypt. ex. 1867, p. 4.

Neckera Dubyana Hpe. Sp. nov. Mescic. in Verh. d. K. K, zool. bot. Ges. in Wien, 7 A pril. 1869.

Pilotrichella Dubyana Besch. Prodr. Bryol. mexic. p. 80.

Ad arbor. - Am, sept. : Mexic.

Eavesiana (Hpe.) Jueg. l. c.p. 170.

Meteorium Eavesianum Mitt. in Trans, and Proced. of the roy. Soc. of Vietoria, 1883, p. 82.

Neckera Eavesiana Hpe. in Linn. 1876, p. 319.

- Pac. : Austral. or. subtropic.

Feae C. M. in Nuov, Giorn. bot. ital. 1891, p. 601 (nom.).

Ster. - As. : Birman, super.

filifunalis $C . M$. in $F l .1890, p .493$.

Ster. $\quad-$ Afr. : M. Aberdare, Usambara.

Filipendula (Hook. f. et Wils.) Jaeg. l. c. p. 175.

Meteorium Filipendula $H$. f. et W. Fl. Tasm. II, p. 203, t. 175, f. 5 .

Ad arbor. - Pac. : Tasman.

Filipendula C. M. - P. catharinensis.

flaccida (Mitt.) Jaeg. l. c. p. 171.

Meteorium flaccidum Mitt. M. austr. am. p. 443.

Ster. - Am. merid. : And. Peruv.

flavo-limbata (C. M. et Hpe.) Par.

Meteorium limbatum (errat. !) Mitt. in Trans. and Proced, of the roy. Soc. of Victoria, 1883, p. 82.

Neckera flavo-limbata C. M. et Hpe. in Linn. 1853, p. 502.

Pilotrichella flavo-limbata Jaeg. Ad. II, p. 171.

Ster. - Pac. : Austral felix.

flexicaulis (Tayl.) Jaeg. l. c. p. 175.

Meteorium flexicaule H. f. et W. Fl. of the N. Zeal.p. 101 et Handb.p. 460.
P. crocea Hpe?

Pilotrichum flexicaule Tayl. mss.

Trachypus flexicaulis Mitt. in Journ. of the Linn. Soc. 1859, p. 91. - Am. merid. : Sine loc. spec. (1). Pac. : Nov. Zeland,, Austral. or., Tasman.

flexilis Jaeg. - P. illecebra.

floribunda $C, M$. in Linn. 1876, p. 267.

Hypnum floribundum C. M. Syn. II, p. 265.
Leskea floribunda Dz. et Mk. in Ann. sc. nat. 1844, II, p. 310 et M. frond.

Leskea floribunda Dz. et $M k$, in A
ined. Archip. ind. p. $162, t .53$.

Meteorium floribundum Bryol. jav. II, p. 91.

Neckera floribunda C. M. in Linn. 1868-69, p. 9. 2. heïra, Celebes, Tonkin, Japon. Pac.: Polynes. (absq. loc. spec.); Nov. Guin. sept. ?

" var. minor (C. M.) Par.

Neckera floribunda var, minor C. M. in op. et $l$. co.

- As. : Ceylan.

(1) Fid. Mitt. 1. c., qui non memorat eam in M. austr, am. 
floribundula (C. M.) Besch. Fl. bryol. Réunion, etc. p. 125.

Neckera floribundula C. M. in Linn. 1876, p. 266.

Ad arbor. - Afr. : Ins. Anjouan.

"var. Mac Leana Rehm. M. Afr. austr. n. 611.

- Afr. : Transvaal.

fulva (Mitt.) Jaeg. Ad. II, p. 171.

Yeteorium fulvum Mitt, in Journ. of the Linn. Soo. 1859, p. 85.

Ster.

- Pac. : Austral. (Victoria).

fulvastra Besch, op. cit. p. 124.

2. Ster.

fuscescens (Hook.) Jaeg. l. c. p. 174.

- Afr.: Usambara, ins. Borbon.

Daltonia fuscescens W. Am. Disp. p. 55.

Meteorium fuscescens Bryol. jav, If, p. 93, t. 207.

Neckera fuscescens Hook. M. ex. $t$. 157. Pilotrichum fuscescens Brid. Bryol. univ. II, p. 264; C. M. Syn. II,
p. 175 .

Trachypus fuscescens Mitt. M. Ind. or. p, 128.

2. Ad arbor. - As. : Nepal., Sikkim, Khasia, M. Neilgherr., Ceylan, Sumatra, Java, Ceram.

fusco-viridis (Hpe.) Jaeg. l. c. p. 173.

Meteorium fusco-viride Mitt. M. austr. am. p. 438.

Neckera fusco-viridis Hpe. in Linn. $1862, p .526$.

Ster. And. Nov. Granat.

- Am. sept. : Mexic. ; Guadalup. ? Am. merid. :

guarapiensis Besch. in Journ. de bot. 1891, p.

P. subnigrescens ej. in Rev, bryol. 1885 (nom.).

1. In silvis, - Am. merid. : Paraguay.

helminthbclada C. M. in Nuov. Giorn. bot. ital. 1896, p. 113.

Ster.

- As. : China or. (prov. Schen-Si).

* var. progrediens ej. in op. cit. p. 114.

Ster.

Henscheni C. M. mss. ; Angstr. in Oefv... 1876, n. 4, p. 35.

2 ? Ad arbor. - Am. merid. : Brasil. austr. or.

hispida Jaeg. - Trachypus.

Hookeri Jaeg. - P. sparsa.

illecebra (C. M.) Par.

Anomodon flexilis Hpe. in Linn. 1838, p. 356.

Antitrichia cuspidata Nees ab Es. in Linn. 1847, p. 681.

Leskea flexilis Hsoh. in Deppe et Sehiede M. Mexic. n. 1093.

L. heterophylla Hsch. ibid.

Meteorium illecebrum Mitt. M. austr. am. p. 437.

Papillaria flexilis $C . M$. Syn. II, $p .137$.

Pilotricia flexilis Jaeg. Ad. II, p. 172.

Pilotrichella illecebra Besch. Prodr. bryol. mexic, p. 81.

2. Ad arbor. - Am. sept. : Mexic., Guatemala, Jamaic, ins. Tabago.

Am, merid. : And. Nov. Granat., Quitens., Brasil.

* var. laevis Par.

P. illecebraria C. M. in Linn. 1874-79, p, 493.

- Am. merid. : Venezuela.

illecebraria C. M, - P. illecebra var. laevis, 
jumboana (C. M.) Par.

Floribundaria jumboana C. M. in Dusen M. Camer. n. 672. - Afr. : M. Cameroon.

kermadecensis (C. M.) Jaeg. Ad. $11, p, 169$.

Meteorium cuspidiferum Tayl. in Fl. of the N. Zeal.p. 101 p.p.

M, kermadecense Mitt, in Trans. and Proced. of the roy. Soc. of Victoria, 1883, p. 82 .

Neckera kermadecensis C. M. in Bot. Zeit. 1857, p. 779.

Pilotrichum nigrescens Hsch. in Sieb. M. Nov. Holl. n. i4; C. M. Syn.II, p. 135.

Trachypus Hornschuchii Mitt. in Journ. of the Linn. Soc. 1859, p. 90.

1. Ad arbor. - Pac. : Austral., Nov. Zeland., Tasman., ins. Kermadec, Raoul, Sunday, etc.

laeta Ren, et Card, in Bull. Soc, roy. bot. Belg. 1891, II, p. 192 el M. Masc. Mad. n. 38.

Ster. Ad arbor. - Afr. : Madagasc. sept.

laeviuscula Broth, in Ule Bryoth. brasil, n. 174.

Ad arbor. - Am. merid. : Brasil, austr. or.

latifolia (Lindb.) Jaeg. Ad. II, p. 166 (1).

Neckera latifolia Lindb, mss.; Hpe, Enum. M. Brasil. p. 42.

Ster.

- Am. merid. : Brasil. austr. or.

laxifolia C. M. in M. Dering; Angstr. in Oefv.... 1876, n. 4, p. 34.

Ad arbor. - Am. merid. : Brasil. austr. or.

leptonema C. M. in Bull. Soc. roy. bot. Belg. 1895, 1, p. 70.

Ster.

- As, : Bhotan.

leuconeura (C.M.) Jaeg. l.c.p. 171.

Meteorium leuconeurum Bryol. jav. II, p. 95, t. 209.

M. nigrescens Dz. et Mk. M. frond. ined. Archip. ind. p. 160.

Neckera leuconeura $C . M$. Syn. II, p. 171.

Pilotrichella leuconeura Besch. Fl, bryol. N. Saled. p. 227.

2. - As. : Sumatra, M. Java, Ceram, Halmaheira, Pac. : Nov. Caledon.?

lindigioides C. M. in Ule Bryoth, brasil. $n, 75$.

Ster.

- Am. merid. : Brasil. austr. or.

longifolia (W. P. Sch.) Jaeg. l, c. p, 169.

Pilotrichella longifolia W. P. Sch. in Besch. Prodr. bryol, mexic. p. 81.

Ster.

-Am. sept. : Mexic (Orizaba).

longipila (W. P. Sch.) Jaeg. l. c.

Pilotrichella longipila W. P. Sch, in Besch. Fl. bryol. Antill, fr. p. 40.

Pilotrichua longipilum $e j$, in $h b$, Mus. Paris.

P. piliferum $e j$. 7 . $c$.

Ster.

- Am. sept. : And. Costa Ric., Guadalup.

macrotis C. M. in Hildebr. M. Mad. n. 2103.

- Afr. : Madagascar.

media Angstr. in Oefv... 1876, n, 4, p. 36.

Ad arbor. - Am. merid. : Brasil, austr. or.

Mœnkemeyeri (C. M.) Par.

Neckera Monkemeyeri $C . M$. in Fl. 1886, $p .516$.

Ster.

- Afr. : Old Calabar.

(1) Jam ut Pilotrichella 1. c, citata. 
Molleri C. $M$. in Fl. 1886, p. 283.

Ster. ? Ad arbor. $-A f r$. : Ins. S. Thom.

Moseni Broth, in Bihang till K. Sv. Vet.-Akad. Handl. 1895, n. 3.

2. fr. ign. Ad arbor. - Am. merid. : Brasil. or.

Nietneri Jaeg. - Trachypus.

nigrescens (Sw.) Jaeg. Ad. II, p. 169.

Hypnum nigrescens Sw. Prodr. p. 141.

1sothecium radicans Brid. Bryol. univ. $I I, p$, 374,

Meteorium nigrescens Mitt. M. austr, am, p. 441; Lesq. et Jam. Man. p. 287.

Neckera nigrescens Schwaegr. Suppl. III, I, II, t. 244 (excl.syn.); C. M. Syn. II, pp, 134 et 670.

Pilotrichum paraphysale C. M. in Linn. 1847, p. 216.

Pterigynandrum nigrescens Sw. Fl. Ind. occ. III, p. 1778.

1. Ad arbor. - Am. sept. : Lac. Huron, Canad, or., Ludovic., Mexic.,

Costa Rica, Antill. fere omn. Am. merid.: Ins. Trinitat., Venezuela,

Nov. Granat., ins. Gallapag., Brasil. austr. or.

"var. brevifolia (Hpe) Par.

Neckera nigrescens var. brevifolia Hpe. Enum, M. Brasil, p. 43.

Ster.

- Am. merid.: Brasil, austr. or.

* var. illecebra (C, M.) Par.

Neckera nigrescens var. illecebra $C . M . l$. e.p. 135.

Pterigynandrum illecebrum Brid. Mant. M. p. 131.

- Am. sept. et merid. : Cum typ.

nitidula Rehm. M. Afr. austr. n. 612.

Ster.

- Afr. : Transvaal.

nodicaulis Jaeg. - Trachypus.

octodiceras (C. M.) Par.

Floribundaria octodiceras C. M. in Dusen M. Camer. p. 104.

Neckera octodiceras ej. in Fl. 1886, p. 516.

Ster.? Ad arbor. - Afr. : M. Cameroon.

Erstedtiana (C. M.) Jaeg. Ad. 11, p. 170.

Meteorium (Erstedtianum Mitt. M. austr. am, p. 441.

Neckera CErstedtiana C. M. Syn. $I I, p, 671$.

2 ?

- Am. sept. : Costa-Rica.

patentissima C. $M$. in Fl. 1886, p. 282 .

Ster.? Ad arbor. - A fr. : Usambara, ins. S. Thom.

paulensis Broth. in Bihang till $K$. Sv. Vet,-Akad. Handl. 1895, n. 3.

2. fr, ign.

- Am. merid. : Brasil. or.

perauriculata Broth, in op. el l. cc.

2, fr, ign,

- Am. merid. : Brasil. austr. or.

perichaetialis (Hpe.) Jaeg. l. c.

Neckera perichaetialis $H$ pe in Linn. 1874, p. 217.

Trachypus? perichaetialis Besch. Fl. bryol. Réunion. ete. p. 129.

- Afr. : Madagascar.
in Dusen M. Camer. n. 23.

- Afr. : M. Cameroon.

polytricha (Dz. el $M k$.) Jaeg. Ad. 1I, p. 173.

Meteorium polytrichum Dz. et Mk. M. frond, ined. Archip. ind, p. 131, t. 51-52; Bryol. jav. $I I$, p. 96. 
Neckera Miqueliana C. M. Syn. II, p. 138.

2. Celebes.

- As. : Sumatra, Java, Ternate, Halmaheira,

pseudo-fulvastra $C . M$. mss.

- Afr. : Madagascar.

pseudo-funalis $C . M$. in Linn. 1878-79, p. 493.

- Am. merid. : Venezuela.

pseudillecebra (C. M.) Par.

Neckera pseudillecebra C. M. in Journ. of Bot. 1877, p. 229 (nom.).

Ad arbor. - Am. sept. : Costa Rica.

pseudo-sinuata C. M. in Linn. 1878-79, p. 493.

- Am. merid. : Venezuela.

ptychophylla Angstr. in Oefv... 1876, n. 4, p. 35.

Ster.

- Am. merid. : Brasil, austr, or.

Reginae (Hpe.) Jaeg, l. c. p. 176.

Meteorium Reginae Mitt. in Trans, and Proced. of the roy. Soc. of Victoria, $1883, p .82$.

Neckera Reginae Hpe. in Linn. 1876, p. 319.

- Pac. : Austral, or. (Queensland).

Regnellii Broth, in Bihang till K. Sv. Vet.-Akad. Handl. 1895, n. 3.

2.

- Am. merid. : Brasil, or.

Renauldi Besch, in litt.; Ren. in Rev. bryol. 1888, p. 88.

2. Ster. $-A f r$.: Ins. Franciae.

retrorsa (Mitt.) Jaeg. Ad. II, p. 174.

Meteorium retrorsum Mitt. M. Ind. or. p. 90.

Neckera retrorsa C. M. in Linn. 1869-70, $p, 23$.

2 ?

- As. : Ceylan.

Robillardi C. M. in Besch. Fl. bryol. Réunion, etc. p. 125.

Ster.

- Afr. : Ins. Franciae.

Rutenbergii C. M, in Abhandl. Brem. VII, p. 209.

2 .

- Afr. : Madagascar.

sarmentosa (Mitt.) Besch. in hb. Mus. Paris.

Meteorium sarmentosum Mitt. in sched.

$$
\text { - As. : Bhotan. }
$$

Scottiae (C, M.) Par.

Neckera Scottiae C. M. in Linn. 1867-68, p 621.

Papillaria Filipendula (fid. Mitt.).

2 ?

- Pac. : Austral, or.

semi-torta (C. M.) Jaeg. l. c. p. 175.

Meteorium Harveyi Bryol. jav. II, p. II, p. 94, t. 208 (fid. C. M.).

M. semi-tortum ibid. p, 227 .

Neckera semi-torta C. M. Syn. II, p. 671 .

Trachypus Harveyi Mitt. M. Ind. or. p. 127.

1 (C. M.) 2 (Bryol. jav.).

Halmaheira, Celebes.

serpentina C. $M$. in Fl. 1890, p. 493.

Ster, In silvis. - Afr. : Kilima N'Djaro.

serrulata Jaeg. - Trachypus. 
sinuata (C. M.) Par.

Meteorium sinuatum Mitt. M. austr, am, p. 446.

Neckera sinuata C. M. Syn. II, p. 139.

Pilotrichella sinuata Besch. Prodr. bryol, mexic. p. 82.

Ster. - Am. sept. : Mexic.

socia Angstr, in Oefv.... 1876, n. 4, p. 35 .

Ster.

- Am. merid. : Brasil. austr. or.

sparsa (Mitt.) Par.

Meteorium sparsum Mitt. M. Ind. or. p. 89 (sub M. Hookeri; of. l. c. p. 158).

Papillaria Hookeri Jaeg. Ad. II, p. 174.

2.

- As. : Himalaya occ., Khasia.

squamata Angstr. in Oefv.... 1876, n. 4, p. 34 (nom.).

- Pac. : Austral.

squamatula C. M. mss.; Angstr. in op. cit. p. 35.

Ster. Ad arbor, - Am. merid. : Brasil. austr. or.

subbicolor Jaeg. - Trachypus.

subintegra (Lindb.) Jaeg. Ad. 11, p. 160.

Neckera subintegra Lindb, in Hpe. Enum. M. Brasil. p. 43.

Ster.

- Am. merid. : Brasil. austr. or.

subnigrescens Besch. - P. guarapiensis.

subpolytricha Besch, in Ann. sc. nat. 1892, I, p. 73.

Ster. In silvis. - As. : Y unnan.

subsquamatula C. M. in Linn. 1878-79, p. 493.

- Am. inerid. : Venezuela.

subulifolia (W. P. Sch.) Jaeg. l. c. p. 168.

Meteorium subulifolium W. P. Sch. Hb.

Pilotrichella subulifolia Besch. Prodr. bryol. mexic, p, 81. - Am. sept. : Mexic. (Orizaba).

tahitensis Ảngstr. - Meteorium helictophyllum.

teres (Mitt.) Jaeg. l. c. p. 173.

Meteorium teres Mitt. M. austr, am. p. 438.

Pilotrichella teres Besch. Prodr, bryol. mexio, p. 81.

2. In Quercetis. - Am. sepl.: Mexic. (Chiapas, Oajaca, Orizaba). Am. merid. : And. Quitens.

trachyblasta C. M. in Rev. bryol. 1892, p. 41 (nom.).

- As. : Ins. Nicobar?

usneoides Broth. in Act. Soc. sc. Fenn. 1891, n. 5 .

Ster.

- Am, merid. : Minas Geraẻs.

viridala (Milt.) Jaeg. l. c.p. 171.

Meteorium viridulum Mitt. op. cit. p. 444.

Neckera viriaula ej. in Kew, Journ. bot. III, p. 351 .

Ster. In silv. - Am. sept. : Costa-Rica. Am. merid. : And. Quitens.

Wagneri Ltz. Moosst. p. 165.

Ster.

- Am. merid. : Panama. 
Walkeri Ren. et Card. in Bull. Soc. roy. bot. Belg. 1895, I, p. 70. Ster. Ad arbor. - As. : Sikkim (1).

Papillidium C. M. in Linn. $1875, p .466$ (sect. HyPNI).

Paradricranum Limpr. Deutsch. Laubm. 1, p. 326 (sect. Dicranelda).

Paraleucobryum Lindb. M. Scand. p, 23 (sect. Dicrani).

Parapanckowia $e j . l . c .=$ Eurhynchium myosuroides.

Paraphysanthus Spruce Cat.; Mitt. M. austr. am. p. 451 (subsect, NrCKeraE).

Parasymhlepharis Lindb. M. Scand. p. 27 (sect. CynodontII).

Pegophyllum Mitt. M. austr. am. p. 11 ll (sect. Leveobrit).

PELEKIUM Mitt. Sam. M. p. 176.

Spec. omn. Thuida ejusd. nom.

Peromilla Spr. in Mitt. M. austr. am. p. 372 (sect. LePIDOPILI).

PEROMNIUM Schwaegr. Suppl. I, III, t. 250.

Spec. omn. non indicatae sunt Brachymenia ejusd. nom.

Wrighlii Jaeg. - I eptotheca.

PHAROMITRIU M W. P. Sch. Syn. I ed. p. 119 (1 spec.).

exiguum Aust. - 1 h. subsessile.

marginatum Jaeg. - Streptopogon.

subsessile (Brid.) W. P. Sch. op. cit. et $I I$ ed. p. 150.

Anoectangium acaule Roehl. Ann. Wett. Ges. II, p. 200.

A. subsessile Spreng. Syst. Veg. IV ed. I, p. 146.

Fiedleria subsessilis Rab. Deutsoh. Crypt, II, p. 98.

Gymnostomum acaule $W$. et $M$. Bot. Taschb. p. 79, $t .6 f .4-8$. Gymnostomum acaule W. et $M$. Bot. Taschb. p. $79, t .6$ f.
G. subsessile Schwaegr. Suppl. I, I, p. 27 ; Drumm. I ed.
n. 19.

Ph. exiguum Aust. in Bull. Torr. bot. Club, VI, p, 42.

Pottia acaulis Hpe. in Fl. 1837, I, p. 287.

P. subsessilis Bryol. eur. II (mon. p. 6), t. 117.

Pterigoneuron subsessile Jur. Laubm. Oesterr. Ung. p. 96.

Schistidium subsessile Brid Bryol. univ. I, p. 113 ; C. M. Syn. I, p. 566.

Tortula subsessilis Mitt. M. austr. am. p. 164.

1. In terr. argill, et ad mur. terra obtect. - Eur.: Palatin., German. tota, Helvet., Tirol, deest in Scandin., Britann., Gall. As.: Cancas. Am sept. : Saskatchewan, Columb. brit., reg. or. et centr. Am. merid. : And. Chilens.

Exs. : Rab. Bryoth eur. n. 156.

Sull. et Lesq. M. bor. am. n. 118.

PHASGONIA C. M. in Linn. 1880-83, p. 438 (2 spec.).

Balansae C. M. l. c. (nom.). - Pac : Nov. Caledon.

Lorentzi C. $M$. in op. cit. p. 439.

2.

- Am. merid. : Uruguay.

(1) In Enum, Kindberg. nom. nud. :

P. Filum $C . M$.

humilis Lindb.

Philippinarum C. M. 
PHASGUM Lin. Sp. pl. p.p. (25 spec.).

acaulon $\mathrm{L} .-\mathrm{Ph}$. cuspidatum.

var, majus Ehrh. - Ph, cuspidatum.

var, minus Ehrh. - Sphaerangium muticum.

var. $\beta$ L. - Sphaerangium muticum.

acuminatum Lindb. - Pleuridium subulatum.

affine Bryol. germ. - Ph, cuspidatum var. Schreberianum.

alternifolium $\left\{\begin{array}{l}\text { Dicks. - Archidium. } \\ \text { Kaulf. - Pleuridium. }\end{array}\right.$

apiculatum $\mathrm{H}$. f. et W. - Sphaerangium.

var, turgidum Mitt, - Sphaerangium apiculatum var, turgidum.

Arnoldii Rob. Br. - Pleuridium.

austro-crispum C. M. - Systegium.

axillare Dicks. - Pleuridium nitidum.

badium Bryol, germ. - Microbryum Floërkeanum var, badium.

Beyrichianum Schwaegr. - Sporledera.

brachypelma C. M. - Systegium.

brevipes Schwaegr. - Sporledera Hampeana.

Bruchu Spreng. - Archidium alternifolium.

bryoides Dicks. Fasc. IV Pl. crypt. 2, t. 10; Brid. Bryol. univ, 1, p. 754 ;

Bryol. eur. 1 (mon. p. 11), t. 6; C. M. Syn. I, p. 28 et II, p. 521;

W. P. Sch. Syn. II ed. p. 18.

Mildeella bryoides Limpr. Deutschl. Laubm. 1, p. 192.

Ph. elongatum Schultz Fl. Starg.p. 273.

$\mathrm{Ph}$. graniferum Wahlenb. in Oefv... 1806, p. 13, t. 4, f. 3.

Ph, gymnostomoides Brid. op cit. p. 48.

$\mathrm{Ph}$, pusillum Sehleich.

Pottia bryoides Lindb. in Oefv.... 1863, p. 410.

Tortula bryoides ej. M. Scond. p. 21.

1. In ruderat., eamp., ad agger. etc. - Eur. : A Suec. usq. in Ital. As. : Caucas. Am. sept. : Perrar, : Calif.

" var. atro-viride W. P. Sch. Syn. I ed, p. 19.

In umbros, humid, - Eur. : Úbi typ.

* var. brachycarpum ej. $l l . c c$.

Ut et ubi typ. in Eur.

" var. cernuum ej. $l l . c c$.

Ph. bryoides var. curvisetum Bryol, eur. l, $c$.

Ut et ubi typ. in Eur.

Eas. : Rab. Bryoth. eur. n. 303.

var. curvisetum Bryol. eur. - Ph. bryoides var. cernuum.

- var. piliferum Bryol. eur. et W. P. Sch. ll. cc.

Ad mur, et agg. sic, - Eur, : Ubi typ.

"var. Thornhillii Wils. Bryol. brit. p. ; W. P. Sch. Syn. II ed. l.c. Ut typ. - Eur. : Anglia.

bulbosum Voit. - Sphaerangium mutieum.

var. minimum de Not. - Sphaerangium triquetrum.

caldense Lindb. - Ephemerella.

calodictyum C. M. in Fl. $1888, n .1$.

- Am. merid. : Monte Video.

carinatum Hpe, Enum. M. Brasil. p. 4.

- Am. merid. : Brasil, anstr. or.

carniolicum Web. et Mohr Bot, Taschb. pp. 69 et 450; Brid. Bryol. 
univ. 1, p. 26; Bryol. eur. I (mon. p. 12), t.5; W. P. Sch. op. cit. p. 19.

Acaulon carniolicum C. M. Syn. I, p. 23 et II, p. 519.

Aschisma carniolicum Lindb. in Utk. till... p. 28.

Systegium carniolicum de Not. Epil. p. 741.

1 rariss. syn. Ad terr. limos. - Eur. : Gall. merid. (Monspel.), Carniol.; Neuwied? Helvet. ? Afr. : Tingit. Am. sept. : Texas occ.

" var. speciosum (Mor.) Par.

Aschisma carniolicum $\beta$ speciosum Limpr. Laubm. Deutsch. I, p. 196.

Phascum speciosum Moris in sched.

\section{- Eur. : Sardin.}

cernuum $\left\{\begin{array}{l}\text { Gmel, - Ph. curvicollum. } \\ \text { Lag. - Ph. cuspidatum var. curvisetum. }\end{array}\right.$

cohaerens Hedw. - Ephemerum.

confervoides Brid. - Ephemerum serratum.

crassinervium $\left\{\begin{array}{l}\text { Grev. - Ephemerella recurvifolia. } \\ \text { Schwaegr. - Ephemerum crassinervium. }\end{array}\right.$

var. Sull. - Ephemerum spinulosum.

crispum $\left\{\begin{array}{l}\text { C. M. p.p. - Systegium multicapsulare. } \\ \text { Hedw. - Systegium. } \\ \text { Sull. p.p. }\left\{\begin{array}{l}\text { Systegium nitidulum. } \\ \text { Systegium Sullivanti. }\end{array}\right.\end{array}\right.$

var. multicapsulare H. et T. - Systegium.

var. rostellatm $\mathrm{H}$. f. et W. - Systegium ludovicianum.

cristatum H. f. et W. - Ephemerum.

cryptocarpum C. M. in Ule Bryoth. brasil. n. 4.

Terr. - Am. merid. : Brasil. subtropic. or.

curvicollum Hedio. M. frond. 1, p. 32, t. II ; Brid. Bryal. univ. I, pp 24

et 754 ; Bryol. eur. I (mon. p. 11), t. 6; C. M. Syn. I, p. 27 et II,

p. 521 ; W. P. Sch. op. cit. p. 19.

Cycnea curvicolla Berk. Handb. brit. M. p. 301.

Ph. cernuum Gmel. Syst. nat. II, p. 1323.

Pottia curvicollis Mitt. in Ann. and Mag. of nat. hist. 1851, p. 311.

Pyxidium pendulum Ehrh. Beitr. IV, p. $44 ;$ Brid. Mant. M. p. 6 (fid.

C. M. ; non! fid. Lindb. Triohost, eur, p. 6).

I. In campestr. glareos, ad viar. marg., etc. - Eur.: Fere tota usq. ad Suec. merid. ; Graecia.

Exs. : Rab. Bryoth, eur. n. 154.

curvicallum $\mathrm{Sm}$. - $\mathrm{Ph}$. rectum.

curvisetum Dicks, - Ph. cuspidatum var, curvisetum.

curvulum Tayl. - Pleuridium nervosum.

cuspidatum Schreb. de Phasco, p. 8, t. I; Brid. Bryol. univ, I, p. 4l;

Bryol. eur. I (mon. p. 10), t.5; C. M. Syn. 1, p. 25 et I1, p. 521 ;

W. P. Sch. op. cit. p. 16.

Bryum bulbiferum Neck. Meth. M. p. 235.

$\mathrm{Ph}$, acaulon L. Sp. pl. p. 1570.

Ph. acaulon $\beta$ majus Ehrh. Hann. Mag. 1780, p. 235.

Pottia cuspidata Mitt. in Ann. and Mag. of nat. hist. 1851, p. 311.

Sphagnum acaulon bulbiforme majus Dill. Hist. M. p. 252, t. 32, f. I1.

Sph. acaulon bulbiforme minus ej. op. cit. f. 12 (fid. Lindb. Trichost. edr. p. 5 .

1. In camp. et agr. tam aren. quam argill. - Eur.: Tota, frigidiss. Am. merid. : And. Quitens.

Exs. : Rab. Bryoth. eur. n. 304, 852.

Sull, et Lesq. M. bor. am. II ed. a. 34 . 
\& var. curvisetum (Dicks.) Bryol, eur. (incl, v. elatum), C. M. (v. a et ら) et W. P. Sch. Il. cc.

Ph. cernuum Lag. in Ann. d. Cieno, nat. p. 14,

Ph. curvisetum Dicks. up. cil.p. 3, t. 4,f. 4; Brid. op, cit. p. 42.

Ph. elatum Brid. op. cit. p. 45 (incl. v. $\beta$ prolifera).

$\mathrm{Ph}$. grandiusculum ej. Sp. M. I, p. 9.

Ut et ubityp. in Eur.

var, elatum Bryol, eur. - Ph. cuspidatum var. curvisetum.

* var. macrophyllum (Wib.) Bryol, eur., C. M. ( $\beta$ p.p.) et W. P. Sch. ll. $c c$.

Ph. macrophyllum Wib. Fl. Werth. p. 282.

Ut et ubi typ. in Eur. et As.

var. maximum W. et M, - Ph. cuspidatum var. Schreberianum.

"var. piliferum (Schreb.) Hook. et Tayl. Muscol. brit. p. 8; Bryol. eur.,

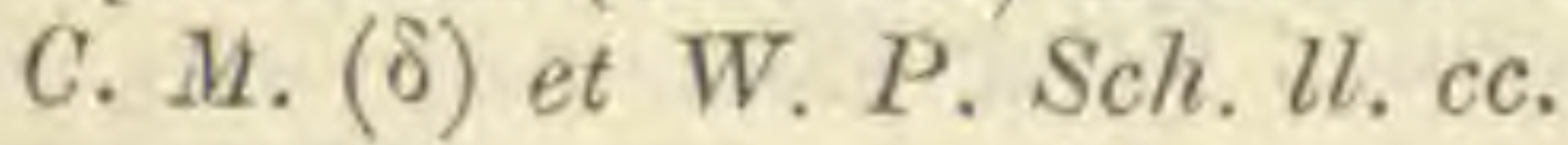

Ph. cuspidatum Drumm. M. bor. am. I ed. n. 5 et 7 .

Ph. piliferum Schreb. op. cit. p. 8, t. I, f. 7; Brid. op. cit. p. 38 ; Bryol. germ. p. 65, t 6, f. 17 (inel. var germmoforme, p. 68, t. 6, f. 17**, latifolium, $p .67, t .6, f .17^{* *}$, macrocarpon, $p .68, t .6, f .17^{* * *}$ et rufescens, $\left.p .67, t .6, f .17^{\star}\right)$.

Loc. steril. et praecip. in aren. marit. - Eur. : Ut typ. ; Rossia or. Afr. : Alger. Am, sept. : M. Rupestr., Saskatehewan, Idaho, reg. or. et centr.

Exs, : Rab. Bryoth, eur, n. 853.

"var, Schreberianum (Dicks.) Bryol. eur., C. M. $(\beta$ p.p. et $\gamma)$ et W. P. Sch. $l l . c c$.

Ph. affine Bryol. germ. I, p. 74, t. 7, f. 19 ; Brid. op. cit. p. 43.

$\mathrm{Ph}$, cuspidatum $\beta$ maximum $W$. et $M$. Bot. Tasehb, p. 63.

Ph. Schreberianum Dioks. Fasc. IV Pl. orypt. IV, t. 10; Brid. op. cit. p. 42.

Ut et ubi typ.

Exs. : Rab. Bryoth. eur. n. 853.

\&var. trichophyllum (Wallr.) C. M. l. c. (var. $\eta)$.

Ph, trichophyllum Wallr. in Linn. 1840, p. 679.

Ut et ubi typ.

cuspidatum Drumm. - Ph. cuspidatum var. piliferum.

cylindricum Tayl. - Tetrapterum capense var. cylindricum.

Dicksoni Brid. - Ephemerella recurvifolia.

disrumpens $C . M$, in $F l$. $1888, n .1$.

- Pac. : Austral.

Drummondit Wils, in Lond. Journ. of bot. 1848, p. 26, t. 1 A; C. M.

Syn. II, p.521. - Pac. : Austral. merid.

dubium la Pyl. in Desv. Journ. bot. 1813, p. 284, t. 19 ; Brid. Bryol. univ. 1, p. 43 ; C. M. Syn. 1, p. 30 . - Eur. : Gall. (Lutetia).

elatum Brid, - Ph. cuspidatum var. piliferum.

var, proliferum Brid. $-\mathrm{Ph}$. cuspidatum var. piliferum.

elegans $\mathrm{H}_{\text {sch. }}$ - Bruchia.

elongalum Schultz. - Ph. bryoides.

exigum $\mathrm{H}$. f. et W. - Pleuridium. 
flexuosum Schwaegr. - Bruchia.

Floërkeanum \{ Voit. - Microbryum Floërkeanum var, badium.

var. badium Brid. - Microbryurn Floërkeanum var, badium.

Flotownianum Funk. - Ephemerella.

Frucharti C. M. - Systegium.

globiferum $\mathrm{Br}$. - Archidium alternifolium.

globosum Schleich.- Sphaerangium muticum.

grandiusculum Brid. - Ph, cuspidatum var. curvisetum.

graniferum Wahlenb. - Ph. bryoides.

gymnostomoides Brid. - Ph. bryoides.

Halleri 0 . F. Müller, - Diphyscium foliosum.

Hallerianum Poll. - Diphyscium foliosum.

heterophyllum de Not. - Ephemerum cohaerens var. heterophyllum. Jamesoni Tayl. - Glyphocarpus humilis.

lamprocarpum C. $M$, in Fl. 1878-79, p. 232.

2.

- Am. merid. : Uruguay.

lamprothecium C. M. in op. cit. p. 233.

l. $\quad-$ Am. merid. : Uruguay.

lanceolatum Rob. Br. - Pleuridium.

leptophyllum $C . M$. in $F l$. 1888, n. 1.

$$
\text { - Afr, : C. B. Sp. }
$$

lilliputanum C. M. in Ule Bryoth. brasil. n, 133.

Terr. - Am. merid. : Brasil. subtropie or.

lonchophyllum C. M. in Ule Bryoth. brasit, n. 7

Terr. - Am. merid. : Brasil. subtropic. or.

longifolium Rob. Br. - Pleuridium.

Lucasianum Bryol, germ. - Physcomitrella patens var, $\beta$.

ludovicianum Sull. - Systegium.

macrophyllum Wib. - Ph. cuspidatum var. macrophyllum.

maximum Lightf. - Diphyscium foliosum.

megapolitanum Schultz. - Physcomitrella patens var. megapolitana.

minutum Roehl, - Microbryum Floërkeanum.

Mittenii C. M. - Systegium.

mnioides L. f. - Tetraplodon.

montanum Huds. - Diphyscium foliosum.

multicapsulare $\mathrm{Sm}$. - Systegium.

var. Mittenii Wils. - Systegium Mittenii.

muticum $\left\{\begin{array}{l}\text { Br., Drumm, - Sphaerangium triquetrum. } \\ \text { Schreb. - Sphaerangium muticum. }\end{array}\right.$

var, majus H. et T. - Sphaerangium.

var. minus eor. - Sphaerangium muticum var. minus.

var. piligerum de Not. - Sphaerangium mutieum var. cuspidatum.

var. rubrum Brid. - Sphaerangium.

nepalense Brid. Bryol. univ. 1, p. 755; C. M. Syn. I, p. 30.

$$
\text { - As. : Nepal. }
$$

nervosum $\left\{\begin{array}{l}\text { Drumm. - Pleuridium Sullivantii. } \\ \text { Hook. - Pleuridium. }\end{array}\right.$

nitidulum C. M. - Systegium.

nitidum Hedw. - Pleuridium.

occultum C. M. in Ule Bryoth, brasil. n. 5 .

Terr, - Am. merid. : Brasil, subtropic. or. 
papillosum Lindb. Trichost. eur. p. 5 et M. Scand. p. 21 (subsp. Ph. cuspidati?).

$$
\text { - Eur. : Suecia (Stockholm). }
$$

pachycarpum Schwaegr. - Ephemerella recurvifolia.

palustre Bryol. eur. - Sporledera.

palens Hedw. - Physcomitrella.

var. recurvifolium Sm. - Ephemerella vecurvifolia.

pedunculatum $\left\{\begin{array}{l}\text { Sm. - Splachnum sphaerieum. } \\ \text { L. - Tetraplodon mnioides. }\end{array}\right.$

peraristatum $C . M$. in Fl. $1888, n .1$.

$$
\text { - Afr.: C. B. Sp. }
$$

perpusillum C. M. - Hymenostomum?

piptocarpum DR. et Mont. Syll. p. 51.

$$
\text { - Afr. : Alger. (Blida). }
$$

piliferum Schreb. - Ph. cuspidatum var, piliferum.

var. gemmaeforme

var. latifolium

var. macrocarpon

var, rufescens

piriforme L. f. - Physcomitrium.

polycarpum Bryol. eur. - Systegium crispum.

pusillum Schleich. - Ph. bryoides.

rectum Sm. Fl. brit. III, p. 1153; Brid. Bryol. univ, 1, pp. 25 el 754;

Bryol. eur. I (mon. p. II), t. 6; C. M. Syn. I, p. 27 et II, p.521; W. P. Sch. op. cit. p. 20.

Bryella recta Berk. Handb, of Brit. M. 1863, p. 300.

Ph. curvicollum Engl. Bot. V, t. 330.

Pottia recta Mitt. in Ann, and Mag. of nat. hit. p. 311.

1. In terr. argill., in camp. praepr. marit. - Eur. : Angl.; Westphal. ? Gall, occid, et merid., Nassau, Ital., Sardin.; Graecia; semel in Alsat. Afr: : Alger.

recurvifolium Dicks. - Ephemerella.

recurvirostrum C. M. - Hymenostomum Halansaeanum.

repens With. - Cryphaea heteromalla.

Robinsoni Mont. - Pleuridium.

rostellatum Brid. - Hymenostomum.

Schimperianum Sull, - Sphaerangium.

serratum | Drumm. - Ephemerum serratum var, angustifolium.

Schreb. - Ephemerum.

var. angustifolium $\left\{\begin{array}{l}\text { H. f, et W. p.p. - Ephemerum hystrix. } \\ \text { eor. p.p. - Ephemerum spinulosum. }\end{array}\right.$

var. sloloniferum H. et T, - Ephemerum serratum.

Schreberianum Dicks. - Ph, cuspidatum var. Schreberianum.

sphaericarpon Abbot. - Systegium multicapsulare.

splachnoides Hsch. in Hor. phys. Berol. p. 57, t. 12; C. M. Syn. I,

p. 27 et $I I, p .521$.

Physedium splachnoides Brid. Bryol. univ. 1, p. 51.

2. - Afr. : C. B. Sp.

slogninum Wall. - Pleuridium nitidum.

stellatum Brid. Bryol. univ. I, p. 24 ; C. M. Syn. I, p. 29.

$$
\text { - Eur. : Anglia. }
$$

slenophyllum Voit $\left\{\begin{array}{l}\text { (fid. Lindb.). - Ephemerella recurvifolia. } \\ \text { (fid, W. P. Sch.). - Ephemerum. }\end{array}\right.$ 
stoloniferum Dicks, - Ephemerum serratum.

strictum Dicks. - Pleuridium nitidum.

subexsertum Hook. in Drumm. M. bor, am. I ed, n. 9 ; C. M. Syn, l, p. 26 et $I I, p .521$.

2 . - Am. sept. : Saskatchewan.

subulalum $\left\{\begin{array}{l}\text { Hedw. - Pleuridium alternifolium. } \\ \text { L. - Pleuridium. } \\ \text { EEd. - Diphyscium foliosum. }\end{array}\right.$

var. $\beta$ Huds. - Diphyscium foliosum.

Sullivani C. M. - Systegium.

Sullivantii C. M. - Systegium.

tenerum Br. - Ephemerum.

tenue Wils. - Pleuridium.

tetragonum Harv. - Tetrapterum capense.

var. cylindricum C. M. - Tetrapterum capense var. cylindricum. trichophyllum Wallr. - Ph. cuspidatum var, trichophyllum.

triquetrum R. Spr. - Sphaerangium.

truncatulum L, jun. - Pottia truncata.

uliginosum Gunth. - Sporledera palustris.

velutinum Hoffm. - Ephemerum serratum.

vernicosum C. M. mss.

- Am. merid. :

\& var. minus ej, in Ule Bryoth. brasil. n. 8.

Terr. - Am. merid. : Brasil, subtropic. or. (1).

Pheugodon Lindb. M. Scand. $p .27$ (sect. ONCHOPHORI=Dieranoweisia Bruntoni).

PHILONOTIS Brid. Bryol. univ. II, p. 5, t. 6 (167 spec.).

acicularis (C. M.) Par.

Bartramia acicularis C. M. Bryol, austr. Georg. p. 31 .

Ster. - Am. merid. : Austr. Georg.

acutissima (C. M.) Par.

Bartramia acutissima C. M, in Linn. 1880-83, p. 406.

2.

- Am. merid. : Argentin, subtropic.

adpressa Ferguss. $-\mathrm{Ph}$. fontana var. adpressa.

affinis (Hook.) Jaeg. Ad. II, p. 768.

Bartramia affinis Hook. M. ex. t. 176; C. M. Syn. I, p. 505; Fl. Tasm.II, p. 194.

B. Brownei Brid. Bryol. univ, II, p. 49.

Breutelia affinis Mitt. in Kew Journ. bot. 1856, p. 261.

Glyphocarpus affinis Jaeg. Ad. I, p. 525.

2.

- Pac. : Ausiral, or., Nov. Zeland., Tasman.

africana Rehm. M. Afr. austr, n. 193.

- Afr. : C. B. Sp., Natal.

afro-acuminata (C. M.) Par.

Bartramia afro-acuminata C. M. in Rehm. M. Afr. austr. n. 532.

- Afr. : C. B. Sp. or.

(1) In Enum. Kindb. nomina nuda :

$\mathrm{Ph}$. assimile $C . M$.

Ph. loreum $W$. 
alpicola Jur. - Ph. fontana var, alpicola.

alto-gracilis (C. M.) Par.

Bartramia alto-gracilis C. M. in Linn. $1878-79, p .464$.

$q$ et fr. ign. $\quad-$ Am. merid. : Venezuela.

amblyoblasta (C. M.) Jaeg. Ad. 1, p. 543.

Bartramia amblyoblasta C. M. in Linn. 1874, p. 631.

Ph. brachyclada var, inundata Besch. in Hahn-Winter M. Mexic.

Ster. Saxic, - Am. sept. : Mexic.

andina (Mitt.) Jaeg. Ad. I, p. 546.

Bartramia andina Mitt, M. austr, am. p. 261.

2. Ster. Ad rup. madid. $-A m$. sept. : M. Pichincha.

androgyna (Hpe.) Jaeg. Ad. 1, p. 551.

Bartramia androgyna Hpe. in Bot. Zeit. 1870, p. 34.

Syn.

- Afr. : Usambara, Natal.

angularis C. M. in Nuov. Giorn. bot. ital. 1896, p. 105.

2. Ster. $\quad-A s$. : Alp. Chin. or. (prov. Sechen-Si).

angusta Mitt. M. Ind. or. p. 61 .

Bartramia angustata Wils. in sched.

B. praetenuis ej. $l . c$.

2. - As. : Sikkim, Ceylan.

"var. tonkinensis Besch. in Bull. Soc. bot. Fr. 1887, p. 96.

Arenic. - As. : Tonkin.

angustissima (C. M.) Par.

Bartramia angustissima C. M. in Rev, bryol. 1887, p. 57 (nom.) - Pac. : Nov, Caled.

angustiuseula (C, M.) Par.

Philonotula angustiuscula C. M. in Dusen M. Camer. n. 86.

anisothecioides (C. M.) Par. - Afr. : M. Cameroon.

Bartramia anisothecioides C. M. in Engler's Bot. Jahrb. 1883, p. 79 et in Forehungsreise... Bot. p. 20.

B. australis Mitt. in Journ. of the Linn. Soo. 1876 ?

2. Stei. - Afr. : Ins. Kerguelen.

appressa (Hook. f. el Wils.) Mitt. in op. cit. 1859, p. 81.

Bartramia appressa $H . f$. et W. Fl. of the N. Zeal. II, p.89, $6.86, f .3$.

B. remotifolia eor. Fl. Tasm. II, p. 193, t. 174, t. 3 et Handb. of N. Zeal. Fl, p. 447.

Hypnum scabrifolium eor. in Lond. Journ. of bot. I844, p. 552 ; C. M. Syn. II, p. 487.

Ph, remotifolia Jaeg. Ad. I, p. 545.

2. Rupic. - Afr. : Ins, Marion, Kerguelen. Am. merid. : And. Quitens. Pac.: Nov. Zeland., Alp. Austral. or., Tasman., ins. Auckland.

appressa Mitt. (1876). - Bartramidula subexigua.

Arbuscula (C. M) Par.

Bartramia Arbuscula C. M. in Linn. 1875, p. 394.

2. Ster. Terr. - Afr. : Dar Fertit. 
Arnellii Husn. Muscol. gall. p. 268 ; Philib. in Rev. bryol. 1894, p. 1894, p. 14 (descriptio locupletior).

Ph. capillaris Milde Bryol. sil. p. 212.

$\mathrm{Ph}$. fontana var. capillaris Arn. in sched.

Ph. marchica var. capillaria Limpr. Krypt, von Schles. L, p. 117.

Ph. marchica var. tenuis Boulay M. Fr. I, p. 216.

2. In sabulos. - Eur. : Suecia, Brandebourg, Silesia, Boruss. oce., Westphal.

Arnoldi Mdo. - I'h. fontana var, alpicola.

asperifolia Mitt. M. Sam. p. 185.

Bartramia asperifolia ej, in Journ. of the Linn, Soc. X, p. 185.

2. Rupic. - Pac. : Ins. Fidji, Samoa.

atro-lutea C. M. in Rev. bryol. 1876, p. 4 (nom.).

australis (Mitt.) Par.

- Pac. : Austral. or. (Nov. Valesia).

Bartramia australis Mitt. in Handb. of N. Zeal. Fl.p. 448.

2.

- Pac. : Nov. Zeland, med.

australis Mitt. (1859). - Conostomum.

bagintensis (C. M.) Jaeg. Ad. II, p. 700 .

Bartramia bagintensis C. M. in Linn. 1875, p. 395.

Ster. Terr. - Afr. : Niam-Niam.

Balansaeana Besch. Not. M. Parag. p. 264.

1. Terr. - Am, merid. : Paraguay.

Exs. : Bal. Pl. Parag. n. 1195.

basaltica (C. M.) Par.

Philonotula basaltica C. M. in Dusen M. Camer, n. 436 . - Afr. : M. Cameroon.

Berteroana (C. M.) Besch. Fl. bryol. Antill. fr. p. 485.

Bartramia Berteroana C. M. in Linn. 1843, p. 590 et Syn. I, p. 485. 2.

- Am. merid. : Ins. Trinitat.

"var. flaccida (C, M.) Besch. l. c.

Bartramia Berteroana var, flaecida C. M. l. e.

Ph. fontana $\Theta$ lanata Brid. Bryol. univ, $I I$, p. 21.

$$
\text { - Am. sept. : Guadalup. }
$$

boliviana W. P. Sch. in Mandon Pl. Boliv. n. 1676.

- Am. merid. : Aud. Boliv.

borealis (Hag.) Limpr. Laubm. Deutschl. p. 565.

$\mathrm{Ph}$. fontana var. borealis Hagen in Norske Vid. Sels. 1888.

Ster. Ad rup. aqua nivali irror, - Eur. : Norvegia.

brachyclada Besch. Prodr, bryol. mexic. p. 59. 2. - Am. sept. : Mexic. (Orizaba).

var. inundata $\mathrm{Besch}$. $-\mathrm{Ph}$. amblyoblasta.

brevicuspis (C.M.) Par.

Philonotula brevicuspis C. M. in Dusen M. Camer, n. 492. - Afr. : M. Cameroon.

breviseta W. P. Sch, in Mandon Pl. Boliv. n. 1675 .

- Am. merid. : And, Boliv. 
byssiformis C. M. in Besch. Fl. bryol. Réunion, etc. p. 105.

Ster.

- Afr. : lns. Nossi Be.

caespitosa Wils. - Ph. fontana var. caespitosa.

var. syriaca $\mathrm{Ltz},-\mathrm{Ph}$. fontana var. syriaca.

caespitosula C. M. mss.; Angstr. in Defv.... 1876, n. 4, p. 16.

$\sigma^{\top}$ et fr. ign. Ad terr. humid, et saxa madida. - Am. merid. : Brasil, or.

calcarea W. P. Sch. Coroll. p. 86 et Syn. II ed. p. 520.

Bartramia calcarea Bryol. eur. IV (mon. p. 19), t 325; C. M. Syn. I, p. 475 .

B, crassinervis Wils, in Keu Journ. bot. IX, p. 370 p.p.

2. Ad scaturig. calcar. - Eur. : E reg. campestr. mont, usq. in alp. As. : Himalaya, Tibet. occ., Luristan, Caucas. occ. et centr.; Syr. Afr. : Alger. Am. sept. : Nevada, Utah, M. Alb., reg. or. (1).

Exs.: Rab. Bryoth. eur. n. 130, 176, 817, 965, 1117, 1407.

Sull, et Lesq. M. bor. am. II ed. n. 250?

var. mollis Limpr. - Ph. fontana var. caespitosa.

caldensis Angstr. in Oefv.... 1874, n. 4, p. 17.

2.

- Am. merid. : Brasil, austr. or.

calliantha W. P. Sch. in Mandon Pl. Boliv, n. 1678.

- Am. merid. : And. Boliv.

capillaris Lindb. in Hedo. 1867, p. 40 et in R. Hartm. Skand. Fl. X ed., p. 46.

$\mathrm{Ph}$, fontana var. capillaris Lindb, M. Scand. p. 15.

2. Ster. Loc. humid, et in fiss. rup. madid. - Eur.: Suecia, Dania ?

German.? Rhoengeb., Stiria, Belg., Gall, occid. et centr. (2).

capillaris Milde. - $\mathrm{Ph}$. Arnellii.

capillata Mitt. in Journ. of the Linn. Soc. 1877, p. 62.

2.

- Afr. : Ins. Tristan d'Acunha.

carinata Mitt. in Trans. of the Linn. Soc. 1891, p. 164; Besch, in Ann. sc. nat. 1893, XVIII, p. 350 (descript. locuplet.).

2. As. : Japon.

Exs. : Faurie n. 406, 440.

catenulata (Hpe.) Par.

Bartramia catenulata $\mathrm{H}_{p e}$, in Linn. 1859, p. 631. 2.

- Pac. : Alp. Austral, felicis.

comorensis (C. M.) Besch. in Fl. bryol. Réunion, etc. p, 104.

Bartramia comorensis C. M. in Linn. 1876, p. 245.

Terr. - Afr. : Ins. Borbon,, Anjouan, Nossi-Be, Mayotte, S. Maria, Madagasc.

costa-ricensis C. M. in London Journ. of bol. 1877, p. 228 (nom.).

Terr. - Am. sept. : Costa-Rica.

crenatula (C. M.) Par.

Bartramia crenatula C. M. in Linn. 1880-83, p. 420.

Ster.

- Am. merid. : Argentin. Cordob.

(1) Cf. Lesq. et Jam Man. p. 210.

12) Cr. Husn Rev, bryol 1890 , p. 42 ; Lindb. 1. c. n. 68 et W. P. Sch. op. cit.

p. 521 ; Limpr., Rab. Krypt. Fl, p. 562 ; Philib. in Rev. bryol, 1894, p. 2. 
curvata (Hpe.) Jaeg. Ad. I, p. 545.

Bartramia curvata Hpe. in Linn. 1861-62, p. 523.

1 (Mitt.) Syn. (Hpe.). Terr. - Am, merid. : And. Nov, Granat.

curvifolia Besch. op. cit. p. 104.

Ster. Ad sax, irror. - Afr. : Ins. Borbon.

curvula (C. M.) Par.

Bartramia curvula $C$. $M$. in $F l .1879, n$. 24.

Ster.

- Afr. : M. Kenia.

defecta (C. M.) Par.

Bartramia defecta C. M. in Linn. 1880-83, p. 419.

2.

- Am, merid. : Argentin, subtropic. Tucuman.

dimorpha W. P. Sch. - Ph. vagans.

Dregeana (C. M.) Jaeg. Ad. I, p. 551.

Bartramia Dregeana C. M. in Bot. Zeit. 1856, p. 419.

2.

$$
\text { - Afr. : C. B. Sp. }
$$

elegantula (Tayl.) Jaeg. Ad. I, p. 543.

Bartramia elegantula Tayl. in Lond. Journ. of bot. VI, p. 335 ; Mitt. M. austr. am, p. 259

- Am. merid. : And. Nov. Granat. et Quitens.

erythrocaulis (C. M.) Besch. Prodr. bryol. mexic. p. 60.

Bartramia affinis Hsch, in Deppe et Schiede M. Mexic.

B, erythrocaulis C.M. Syn. I, p. 473 .

2 .

- Am. sept. : Mexic.

falcata Mitt. - Ph. fontana var. falcata.

fertilis (Mitt.) Par.

Bartramia fertilis Mitt. in Kew Journ. bot. 1856, p. 260.

1.

- Pac. : Alp. Austral. or.

filamentosa (C, M.) Par.

Philonotula filamentosa C. M. in Dusen M. Camer. n. 511.

flaccidifolia (Mitt.) Par.

- Afr. : M, Cameroon.

Bartramia flaccidifolia Mitt. in Philos. Trans. of the roy. Soc. 1879 (extra vol.), p. 390.

Ster. Ad rup. madid. - Afr. : Ins. Rodriguez.

flavinervis (C. M.) Par.

Bartramia flavinervis C. M. in Fl. 1886, p. 511.

2. Ster.

Fxs. : Dusen M. Camer, n. 101.

floribundaria (C. M.) Par.

Philonotula floribundaria C. M. in Dusen M. Camer. n. 94. - Afr. : M. Cameroon. - Afr. : M. Cameroon.
fontana (L.) Brid. Bryol. univ. II, p. 18 ; W. P. Sch. Coroll. p. 86 el
Syn. II ed.p. 519 .

Bartrania crassinervis Wils. p.p. in sched.

B. fontana Schwaegr. Suppl. I, II, p. 61: Bryol. eur. IV (mon. p. 18), t. 324; C. M. Syn. I, p. 474; Drumm. M. bor. am. I ed, n. 241.

Bryum fontanum Sow. M. Sueo. p. 48. Bryum fontanum So, M. Sueo. p. 48 .
Br. interruptum Dicks. Fase. IV Pl. erypt. p. 13, t. 1I, f. 6 ? Brid. op.
cit. I, p. 685 . 
Br. palustre scopis teretibus stellatis, vertice multifidis Dill. Hist. $M$. $p .340, t .44, f .2$.

Didymodon denticulatus W. P. Sch, in Husn. M. Gall. n. 508.

Hypnum fontanum Schrank Baiers Fl. II, p. 472.

Mnium fontanum L. Sp. pl. p. 1574.

2. Ad font., rivul., etc. - Eur. : E reg. campestr, montosa usq. in alp.; Spitzberg, ins. Ursorum. As.: Penins. Tsehutschica, Obi, Jenissei inf., Japon., Alp. Yunnan., Tibet. oce., Sikkim, Pers. austr., Caucas. Af $r$.: Alger., Abyss., ins. Canar., Madeir. Am. sept.: Groenland, Labrador, Terr. nov., ins. Miquelon; a Nov. Scot. et New Brunswick usq. ad Columb. brit., fret. Behring et ins. Vancouver, a New York et Washington usq. ad Florid. et Calif.

Exs. : Kotschy Pl. Pers, austr, n. 634.

Mac. Canad. M. n. 153.

Sull. et Lesq. M. bor. am. 11 ed. n. 251 .

W. Schimper M. Abyss. n. 453.

Un. itin. 1864, n. 82-83.

"var. adpressa (Ferguss.) Limpr. Kryptfl. v. Schles. 1, p. 116.

Ph. adpressa Ferg. in sched.

Ster. In rivul. subalp. - Eur. : Anglia (Perthshire), Riesengeb., Tatra.

" var. alpicola (Jur.) Par.

Ph, alpicola Jur. in sched.; Ltz. Moost. p. 170.

Ph. Arnoldi Mdo, in sched.

$\mathrm{Ph}$. Kayseri $M$ do. in sched.

Ph. (? fontana var.) tomentella Mdo. in Ltz. l. c.

Alp. calcar. - Eur. : Tatra, Salisburg., Stiria, Alp. bavar., Tirol.

Exs. : Rab. Bryoth. eur. n. 1116.

"var. alpina Brid. op. cit. p. $20 ;$ W. P. Sch. op. el l. cc.

Bartramia fontana var. alpina Bryol. eur. et C. M. ll. eo.

Ut typ. - Eur. : Summ. Alp. As. : Nepal. Am. sept. : Labrador, reg. mont.

Exs. : Sull. et Lesq. M. bor. am. II ed. n. 252.

var. borealis Hagen. - $\mathrm{Ph}$, borealis.

* var. brachyphylla Kindb. in Mac. Cat.p. 107.

Paludic. - Am. sept. : New Brunswick.

" var. caespitosa (Wils.) W. P. Sch. Syn. 11. p. 520.

Ph. caespitosa Wils, M. brit. n. 287.

Ph. mollis Vent, in Rev, bryol. 1882, p. 42.

In uligin. vel turfac. - Eur. : Scandin , Angl., Belg., Boruss., Siles., Bad,, Würtemb., Helvet., Tirol., Carinth., Stir. Am. sept. : Groenland, Indiana, Illinois.

Eoss. : Kab. Bryoth, eur. n. 1210.

var. capillaris $\left\{\begin{array}{l}\text { Arn. }-\mathrm{Ph} \text {. Arnellii. } \\ \text { Lindb. }-\mathrm{Ph} \text {. capillaris. }\end{array}\right.$

- var. Columbiae Kindb. l. $c$.

Ad rup. humid. $-A m$. sept. : Columb, brit.

Q var. compacta W. P. Sch. l. c.

Ster.

var, dealbata Brid. - Ph. uncinata,

- var, falcata Brid. op. cit. p. 21 ; W. P. Sch. l. c.

Bartramia angustata Wils. in Kew Journ. bot. IX, p. 369.

B. falcata Hook. in Trans. of the Linn. Soo. IX, p. 317, t. 27, f. 4. 
B. fontana var. falcata Bryol. eur. et C, M. ll. co.

B. goniocladia Wils, in op. et $l$. $c c$.

Ph. falcata Mitt. M. Ind. or. p. 62.

Ut typ. -- Eur. : E reg. campestr. usq. in Alp. As. : Nepal., Sikkim, Tibet, occ., M. Neilgherr. Am. sept. : Groenland; ubi typ., sed rarior. Am. merid. : Fret. Magellan.

var. lanata Brid. - Ph. Berteroana var, flaccida.

- var. laxa Vent. in Rev. bryol. 1882, p. 45.

Ad rup. madid. - Eur. : Gall, centr. (Arvern.), Tirol.

4 var. microblasta Kindb. $l, c$.

Ad terr. humid. - Am. sept. : M. Selkirk.

« var, parvula Lindb. M. Scand. p. 15. - Eur. : Scandin., Fennia.

(" var. seriata (Mitt.) Breidl. Laubm. Steierm. p. 152.

Bryum lycopodiiforme Schleich. Cat. pl. Helv. II ed. p. $28 ;$ Lindb. $M$. Scand. p. 15, t. 69.

Ph. seriata Mitt. M. Ind. or. pp. 63 et 158 (1).

Ad rivul. in alp. - Eur. : Helvet., Engadin., Stiria, Gall. centr. (Arvern.).

* var. serrata Kind,b., , c.

Paludic. - Am. sept. : Columb. brit., fret. Behring.

« var. syriaca (Ltz.) Par.

Bartramia caespitosa var, syriaca Ltz. M. Ehrenb. p. 48, t. 15, t. 3-13. - As. : Syria.

fontanella (Hpe.) Jaeg. Ad. 1, p. 569.

Bartramia fontanella Hpe. in Linn. 1863, p. 140; Mitt. M. austr. am. $p, 261$.

2. Ad rivul. - Am. merid. : And. Nov. Granat.

fontanoides (Gill. et Grev.) Jaeg. Ad. I, p. 550.

Bartramia fontanoides $G$. et Gr, in Check's Journ. III, t. I; Mitt. op. cit. p. 256.

1.

- Am. merid. : And. Chilens.

garckioides C. M. in Lond. Journ. of. bot. 1877, p. 228 (nom.).

Terr. - Am. sept. : Costa-Rica.

Gardneri (C. M.) Jaeg. Ad. I, p. 553.

Bartramia Gardneri C. M. Syn. I, p. 477; Mitt. op cit. p. 261.

B. uncinata Hsch. Fl. Bras. I, p. 41; C. M. et Wils. in Fardner M. Brasil. $n .44$.

2. Ad rup, irror. - Am. merid. : Brasil. austr. or.

gemmascens (C. M.) Par.

Bartramia gemmascens C. M. in Fl. 1890, p. 479.

Ster. In graminos. - Afr. : Kilima N'Djaro.

Giraldii C. M. in Nuov. Giorn, bot. ital. 1896, p. 104.

2. Paludic. - As. : China or. (prov. Schen-Si).

glabriuscula Kindb, in Bidrag p. 453 (nom.) et in Mac. Cat. p. 107.

Webera fontana ej. in Ott. Nat. IV, p. 62.

(1) Cf. Cardot in Rev, bryol, 1886, p. 39. 
Ster. Ad cataract. - Am. sept. : New Brunswick.

Exs. : Mac. Canad. M. n. 578.

glaucescens (Hsch.) Par.

Bartramia glaucescens Hsch. Fl. Brasil. I, p. 40.

B. tenella $\gamma \operatorname{erecta} C . M$, Syn. I, p. 482 ?

2. Ad rup. et terr. humid, - Am. merid, : Brasil. austr. or. glomerata (Wils.) Mitt. M. Ind. or. p. 60.

Bartramia glomerata Wils, in sched.

2.

- As. : Sikkim.

gracilenta (Hpe.) Taeg. Ad. I, p. 552.

Bartramia gracilenta Hpe. in Ann. so. nat. V ser. $111, p .371$; Mitt. $M$. 2. austr. am, p. 260.

gracilescens W. P. Sch. mss.; Wright in Lond. Jown. of bot. 1892, p. 263 ,

- Afr. : Ins. Franciae.

gracillima Ångstr. Prim. lin. p. 17.

$q$ et fr. ign. Ad terr. humid, - Am, merid. : Brasil. austr, or.

graminicola (C. M.) Jaeg. Ad. I, p. 546.

Bartramia graminicola C. M. in Linn, 1874, p. 632.

- Am. sept. : Mexic.

Griffithiana (Wils.) Mitt. M. Ind. or: p. 59.

Bartramia Griffithiana Wils. in sched.

Weisia bartramioides Griff. Not, p. 407 et Ic. pl. Asiat. II, t. 78, f. 3. 2 ?

helenica (Besch.) Par. - As. : Himalaya sept. occ., Sikkim, Khasia.

Philonotula helenica Besch. in Journ. de bot. 1891, p.

1. Rupic. - Afr. : Ins. S. Helena.

heterophylla Mitt. $M$. Ind, an, p. 6l.

2.

humilis Brid. - Ph. tenella var: humilis.

hymenodon (C. M.) Jaeg. Ad.p. 540.

Bartramia hymenodon C. M. in Bot. Zeit. 1895, p. 220.

Ster.

imbricatula Mitt. op. et $l$. cc,

- Afr.: C. B, Sp.

Bartramia Griffithian Wils, in sehed. p.p.

B. tenella $e j . l$. $o$.

2.

incrassata (C. M.) Par,

- As. : Ceylan.

Bartramia incrassata C. M. in Fl. $1886, p .510$.

2. Ster.

japonica (W. P. Sch.) Par.

- Afr. : Angola.

Philonotula japonica W. P. Sch. in Savat. M. Jap. n. 509 p.p. ; Besch. 2 ?

in Ann, so. nat. 1893 , XVIII, p. 348 et in Farrie Pl. Jap. n. 51.

Jardini (Besch.) Par.

- As. : Japon.

Philonotula Jardini Besch. Fl. bryol. Taüti, ete., p. 29.

2. Fr. ign.

- Pac, : Taüti, Nuka-Hiva. 
Kayseri Mdo, - Ph. fontana var, alpicola.

kerguelensis Par.

Bartramia graminicola C. M. in Engler's Bot. Jahrb. 1883, p. 79 et in Forehungsreise... Bot, p. 20.

Ster. - Afr. : Ins. Kerguelen.

lancifolia Mitt. in Journ. of the Linn. Soc. 1864, p. 151.

2. Rupic. - As. : Japon.

latiuscula (C. M.) Par.

Philonotula latiuscula C.M. in Dusen M. Camer. n. 96 .

$$
\text { - Afr. : M. Cameroon. }
$$

laxa Limpr. Laubm. Deutschl. p. 563.

Ster. Ad mur, humid. et in foss, inund. - Eur. : Hannovr., Helvet. (Zurich) (1).

laxissima (C.M.) Bryol.jav. I, p. 154, t. 124.

Bartramia laxissima C. M. Syn. I, p. 480; Dz. et Mk. Pl. Jungh, I,

p. 333 .
Hypnum hastatum Duby in Moritzi Verz. d. Zoll. Pfl, v. Jav. p. 132, n. 1813.

2. Rupic. et terr. - As. : Assam, Java, ins. Banca.

leiophylla Kindb. - Anacolia Menziezii.

leptocarpa Mitt. op. cit, p. 60.

Bartramia mollis var. Wils, in sohed.

2.

- As. : Sikkim.

longicollis (Hpe.) Mitt. op. cit. p. 64; Bryol. jav. 1, p. 159, t. 129.

Bartramia dicranoides Wils. in Kew Journ. bot. IX, p. 369.

B. Hookeri ej. $l$. $c$.

B, longicollis Hpe. mss.; C. M. Syn. I, p. 478.

2 .

- As. : Sikkim, Java.

lutea Mitt. op. cit. p. 53.

Bartramia crassinervis Wils. in Kew Journ. bot. IX, p. 370 p.p.

B. uncinata ej. l.c.

2.

- As. : Sikkim.

luteo-viridis Besch. Fl. bryol. Réunion, etc. p. 104.

2. Ad. scaturig. - A fr. : Ins. Borbon., Franciae.

Macounii Lesq. et Jam. Man. p. 208.

Ph. marchica Brid. (fid. Kindb.).

2.

- Am. sept. : Ins, Vancouver, Washington.

"var. torquata Ren. et Geh. in Rev. bryol, 1896, p. 61.

- Am. sept. : Oregon.

macrocarpa (C.M.) Mitt. op. cit. p. 62.

Jartramia fontana $\beta$ falcata Mont. Crypt. Neilgh. n. 41 ?

B. macrocarpa C. M. in Bot. Zeit. 1853, p. 57.

2.

- As. : M. Neilgherr.

macrodictya (C.M.) Par.

Bartramia macrodictya C. M. in Linn, 1878-79, p. 463.

Ster.

- Am, merid. : Venezuela.

(1) "Probab. forma aquatica $P h$. marchicae " Limpr. I. c. 
marchica (Willd) Brid. Bryol, univ. 1I, p. 23 et 735; W. P. Sch. op. cit. pp. 86 et 518 .

Bartramia fontana $\beta$ marchica Hook, et Tayl. Muscol, brit. p. 87.

B. tontana $\beta$ pumila Turn. Musc. hib, p. 107, t. 19, f. I.

B. marchica Schwaegr. Suppl, I, II, p. 59; Bryol, ewr. IV (mon. p. 17), t. $323 ;$ C. M. Syn. I, p. 475.

Bryum marchicum Roth Fl. Germ. III, p. 236.

Leskea marchica Willd. Prodr. fl. Berol. n. 944, t. 6, f. 12.

Mnium marchicum Hed $x$. M. frond. II, p. 108, t. 39.

Ph. Macounii Lesq. et Jam. (fid. Kindb.).

2. In. prat. uligin. proecip. lutoso. aren. - Eur. : Reg. septentr, zonae interm.; desider. in Seandin. et Britann. As. : Japon., Caucas. oce. Afr, : Alger. Am, sept. Ontario, Columb. brit.; ins. Vancouver? Washington, Calif. ; Kansas?

Eøs. : Rab. Bryoth, eur. n, 574, 1017.

var. capillaris (Krypt. fl.). - Ph. Arnellii.

var. tenuis Boul. - Ph. Arnellii.

mauritiana Ångstr. in Oefv.... 1873, p. 140.

2. Saxic. - Afr. : Usambara, ins. Borbon., Franeiae.

" var. stricta Ren, et Card. in. Bull. Soc. roy. bot. Belg. 1894, II, p. 12.

Ster.

- Afi: : Madagascar.

microthamnia (C. M.) Par.

Philonotula microthamnia C. M. in Dusen M. Camer, $n, 109$. - Afr. : M. Cameroon.

minuta (Tayl.) Jaeg. Ad. 1, p. 543.

Bartramia miauta Tayl, in Lond. Journ. of bot. 1847, p. 335; C. M. Syn. I, p. 484 ; Mitt. M. austr. p. 259.

2.

- Am. merid. : And. Nov. Granat. et Quitens.

Mohriana (C. M.) Lesq. el Jam. Man. p. 219.

Bartramia Mohriana C. M. in Fl. 1873, p. 482.

2. Lignic, - Am. sept. : Ludovic.?, Florida.

mollis Dz, et Mk. in Ann. sc. nat. 1844, p. 300; Bryol. jav. 1, p. 155, t. 125 .

Bartramia mollis $C . M$. Syn. I, p. 484.

2.

- As. : Java, Sumatra.

mollis Vent. - Ph, fontana var. caespitosa.

molmonica Rehm. M. Afr. austr. n. 196.

Moritziana (Hpe.) Jaeg. Ad. I, p. 552.

$$
\text { - Afr. : Orange. }
$$

Bartramia Moritziana Hpe. mss. ; C. M. in Bot. Zeit. 1862, p. 338.

2.

- Am. merid. : Venezuela.

Mühlenbergii (Schroaegr.) Brid. Bryol. univ. II, p. 22 ; Lesq. et Jam. Man. p. 208.

Bartramia marchica Sull. M. of U. St. p. 49.

B. Mühlenbergii Schwaegr. Suppl. I, II, p. 58, t. 61 ; C. M. Syn. I, p. 472 .

2. Ad coll, arenos, et rup. humid, -- Am. sept. : Connecticut, Massachussets, Pensilv., Ohio, Wyoming, Montana, Washington, Kansas,

Exs. : Sull, et Lesq. M. bor. am. Il ed. n. 253.

var, tenella Brid. - Ph. tenella. 
nano-dendra C. M. in Bull. Soc. roy. bot. Belg. 1892, II, p. 1 ti0.

2. Ad terr. humid. - Am. sept. : Costa-Rica.

nanothecia (C. M.) Par.

Bartramia nanothecia C. M. in Fl. 1886, p, 277.

2, Terr. - Afr. : Ins. S. Thomas.

Niam-Niamiae (C. M.) Jaeg. Ad. II, p. 700.

Bartramia Niam-Niamiae $C, M$, in Linn. 1875, p. 394.

2. Fr. ign. Ad terr. gneiss. - Afr. : Niam-Niam.

nitida (Wils.) Mitt. M. Ind. or. p. 62.

Bartrumia nitida Wils. in Kew Journ. bot. IX, p. 370 ,

2.

- As. : Himalaya occ.

obtusata C. M. in Borgen M. Madag. n. 19 et in Bull. Soc. roy. bot. Belg. 1895, I, p. 61 .

- Afr. : Madagascar.

obtusifolia (Mitt.) Par.

Bartramia obtusifolia Mitt. Fl. Vit. p. 381.

Ster.

- Pac. : Ins. Ysabel.

Oraniae Rehm. M. Afr. austr. n. 192, 535 et 536.

Ster.

- Afr. : Transvaal, C. B. Sp.

orizabana W. P. Sch. in Besch. Prodr. bryol, mexic. p. 58.

1.

- Am. sept. : Mexic. (Orizaba).

Osculatiana (de Not.) Jaeg. Ad. I, p. 549.

Bartramia Osculatiana de Not. in Mitt. M. austr. amer, p. 259.

2.

- Am. merid, : And. Quitens.

Pabstiana (C. M.) Jaeg. Ad. I, p. 545.

Bartramia Pabstiana C. M. Syn. I, p. 486 ; Mitt. op. cit. p. 258.

2. Terr. - Am. merid, : Brasil. austr, or.

« var. plumosa $(C, M$.) Jaeg. l. c.

Bartramia Pabstiana var. plumosa C. M. $l$. $c$.

Ut et ubi typ.

pallida (Hpe.) Jaeg. Ad. II, p. 701.

Bartramia pallida Hpe. in Linn. 1876, p. 307.

B. radicalis var. $H$. $f$. et $W$. in Colenso $M . N$. Zel.

Ster.

- Pac. : Austral. subtrop. or., Nov. Zeland.

palustris Mitt. in Journ. of the Linn. Soo. 1864, p. 150.

- As. : Ghina or.

papillarioides (C. M.) Par. Bartramia papillarioides C. M, in Verhandl, d, bot. Ver. Prov. Brandent.
$\quad 1890$, p. 68.

- Afr. : Tropic. occid.

Pechueli (C. M.) Par.

Bartramia Pechueli C. M. in Fl. 1886, p. 510.

2. Ster.

- Afr. : Congo occid.

pendula Brid. - Breutelia.

penicillata Wright in Lond. Journ. of bot. 1892, p. 263.

Paludic. - Afr. : Ins. Ascension. 
perigonialis Besch, Fl. bryol. Réunion, etc. p. 105.

2. Loc, muscos, umbros, - $A$ fr. : Ins. Borbon.

pilicalyx C.M. mss.

- As. : Himalaya sept, occ,

polyclada C. M. in Ule Bryoth. brasil. n. 138.

Ad rup. aren. irror. - Am. merid. : Brasil, austr. or.

polymorpha (C.M.) Par.

Bartramia polymorpha C. M. in Engler's Bot. Jahrb. 1833, p. 79 et in Forschungsreise... Bot. p. 21.

$$
\text { - Afr. : Ins. Kerguelen. }
$$

pomangium (C.M.) Par.

Bartramia pomangium C. M. in Linn. 1880-83, p. 417.

2.

- Am. merid. : Argentin trop.

pseudo-fontana (C. M.) Jaeg. Ad. I, p. 548.

Bartramia pseudo-fontana C. M. in Bot. Zeit. 1856, p. 418; Mitt. M. Ind. or, $p, 62$.

2. Ster. $\quad-A s,:$ M. Neilgherr.

pseudo-mollis $(C, M$.$) Jaeg. Ad. I, p, 544$

Bartramia pseudo-mollis 6. M. in Linn. 1871-73, p. 150.

2.

- Pac. : Austral, or. (Nov. Vales.).

pulchella W. P. Sch. in Breutel M. Capens.

pungens (Mitt.) Par.

$$
\text { -.Afr. : C. B. Sp. }
$$

Bartramia pungens Mitt. in Philos. Trans. of the roy. Soc. 1879 (extr. vol.) $p, 390$.

2. Ad rup. madid, - Afr. : Ins. Rodriguez.

pusilla Mitt. - Conostomum.

pygmaeola (C. M.) Jaeg. Ad, 11, p. 701.

Bartramia pygmaeola C. M. in Linn. 1875, p. 396.

2. Fr. ign, - Afr. : Niam-Niam.

radicalis (P. B.) Brid. Bryol, univ, II, p. 16.

Bartramia longiseta Rich. in Mich. Fl. bor. Am. II, p. 301.

Bartramia radicalis P. B. Prodr. p. 44; C. M. Syn. 1, p. 485 ; Lesq. et Jam. Man. p. 206.

2. Ad terr. humid. et secus palud. - Am. sept.: Carolia., Virgin., Kansas.

Exs. : Sull, et Lesq. M. bor. am. II ed. n, 254.

"var. plumulosa (Ren. et Card.) Par.

Bartramia radicalis var. plumulosa Ren. et Card. in Bull, Soc, roy. bot. Belg. 1890, I, p. 177 .

$$
\text { - Am. sept. : Martinic. }
$$

remotifolia Jaeg. - $\mathrm{Ph}$. appressa.

Pevoluta Bryol. jav. 1, p. 158, t. 128.

2.

- As. : Java.

rigida Brid. Bryol. univ. 1I, p. 17; W. P. Sch. Coroll. p. 86 et Syn. II $e d, p, 517$.

Bartramia fontana Schwaegr. Sp. M. p. 92.

B. rigida Bals, et de Not, Pug. n. 1 ; Bryol, eur. IV (mon, p. 20), t. 326; C.M. Syn. I, p. 471 . 
1. In arenos, et ad rup. humid. - Eur. : Hibern., Cambrovall, Belg., Tirol. merid.. Ital. sup., Sicil., Algarv. As. : Caucas. occ. Afr.: Alger., ins. Azor., Canar., Madeir.

Exs. : Mandon Pl. Madeir. n. 25 b.

Rab. Bryoth, eur, n, 1018.

« var. gracilis W. P. Sch. Syn. $11 \mathrm{ed} . l . c$.

Bartramia calabrica Lindb. mss.

Ad scatur, in silv. - Eur.: Pisa, Calabr.

Roylei Mitt. - Bartramidula.

rufieuspis Besch, in Ann, sc. nat. 1892, I, p. 162.

2. Ad rivul. - As. : Yunnan.

rufiflora (Hsch.) Jaeg. Ad. 1, p. 543 ; Mitt. M. austr. am. p. 257.

Bartramia angulata Tayl. in Lond. Jowrn. of bot. 1846, p. 55 (fid. Wils. in C. M.); Mitt. l. c. p. 256.

B, rutiflora Hsch. Fl. Brasil. I, p. 40; C. M. Syn. I, p. 482.

2. Ad saxa irror. - Am, merid. : And. Quitens., Brasil. austr, or.

runcinata C. M. in Angstr. Prin. lin, p. 52.

$\mathrm{Ph}$. tahitensis Angstr. in Oefv.... 1872, n. 5, p. 120.

Philonotula runcinata Besoh. Fil. bryol. Taïti, eto. p. 28.

- Pac. : Taïti.

rupicola C. M. in Ule Bryoth. brasil. n. 35 .

- Am. merid. : Brasil. austr. or.

Ryani Philib. in Rev. bryol. 1894, p. 8.

2. Ad rup. humid. - Eur. : Norvegia.

scariosula (C, M.) Jaeg. Ad. I, p. 549 .

Bartramia scariosula C. M. in Linn. 1874, p. 595.

2.

- Am. merid. : Quito.

Schlumbergeri W. P. Sch, in Besch. Prodr. bryol. mexic. p. 59. - Am. sept. : Mexic. (Orizaba).

2. $\quad$ - As, : Java.

« var, perwaktiana Bryol. jav. l. c.

Bartramia prabaktiana Dz, et Mk. in Zoll. Syst. Vers. p. 31.

Rupic. - As. : Java.

seriala Mitt. - Ph. fontana var. seriata.

simplex (C. M.) Jaeg. Ad. II, p. 700.

Bartramia simplex C. M. in Linn. 1875, p. 393.

2. Ad terr. humid. - Afr. : N'Gama.

simplicissima (C. M.) Par.

Bartramia simplicissima C. M. in Linn. 1880-83, p. 414.

Fl, et fr. ign $\quad-A m$. merid. : Argentin. Buenos-Ayr.

Slateri (Hpe.) Jaeg. Ad. $I I, p .701$.

Bartramia Slateri Hpe, in Linn. p. 1876, p. 306.

- Pac. : Austral, or. (Nov. Vales.).

socia Mitt. in Journ. of the Linn. Soc. 1864, p. 151.

2. $\quad-A s$. : Japon. 
sparsifolia (Hpe.) Besch. Fl. bryol. Réunion, etc. p. 104.

Bartramia sparsifolia Hpe. in Linn. 1874, p. 211.

Ster.

- Afr. : Madagasc. or.

Exs, : Rab. Bryoth, eur. n, $128 ;.$

speciosa (Griff.) Mitt. M. Ind. or. p. 64.

Bartramia speciosa Griff. Not. p. 439 et Ie. pl. Asiat. II, t. 101, f. I.

2. - As. : Nepal, Khasia.

sphaericarpa (Sw.) Brid. Bryol. univ. 1I, p. 25 p.p.

Bartramia sphaericarpa Sohwaegr. Suppl. I, II, p. 59; C. M. Syn. I, p. 481 et II, p. 617; Mitt. M. austr. am. p. 261.

Bryum sphaericarpum Sw. Fl. Ind. oco. III, p. 1835.

Mnium sphaericarpum Hedw. M. frond. III, p. 93, $t .38 \mathrm{~A}$.

Mn. sphaericum Sw. Prodr p. 189.

2. Jamaic., ins. S. Vincent. Am. merid. : Venezuela. spiralis (Hpe.) Jaeg. Ad. I, p. 549.

Bartramia spiralis Hpe. Symb. 1872, p. 49.

$q$ et fr. ign. - Am. merid. : Brasil. austr. or.

striata (C. M.) Par.

Bartramia striata C. M. in Linn. 1880-83, p. 414.

Ster. - Am. merid. : Argentin. subtropic.

stenodictyon Ren. et Card. in Bull. Soc. roy. bot. Belg. 1893, 1, p. 118 et M. Masc. Mad, n. 177 . 2. - Afr. : Ins. Borbon.

" var, patentissima Ren, et Card. in op. cit. p. 119 et M. Masc. Mad. n. 221 .

- Afr. : Madagascar.

striatula (Mitt.) Jaeg. Ad. 1, p. 549.

Bartramia striatula Mitt. op. oit. p. 259.

2. Ad rup. humid. - Am. merid. : And. Nov. Granat.

stricta W. P. Sch. in Savat. M. Japon. n. 509 p.p.

Philonotula Savatieriana Besch. in Ann. sc, nat, 1893, XVIII, p. 349. 1.

subcapillaris Par.

- As. : Japon.

Philonotula capillaris C. M. in Dusen M. Camer, n. 402.

subcurvula $P$ ar.

Philonotula curvula C. M. l. c. n. 435 .

$$
\text { - Afr. : M. Cameroon. }
$$

subcordata Rehm. M. Afr. austr. n. 194.

subelegantula $P$ ur.

$$
\text { - Afr. : Natal. }
$$

Bartramia elegantula C. M. in Linn. 1880-83, p. 415.

2. Ad rup. humid, - Am, merid. : Alp. Argentin. subtropic.

subrnarchica Besch. Fl. bryol. Réunion, elc. p. 106.

Ster. Ad saxa rivul. - Afr. : Ins. Borbon,

- var. plumosa Ren, et Card. in Bull. Soc, roy. bot. Bely. 1893, I, p. 119. - Afr. : Ins, Borbon. 
subolescens (C.M.) Par.

Bartramia subolescens C. M. in Engler's Bot. Jahrb. 1883, p. 84 et in Forchungsreise... Bot. p. 41.

Ster,

- Afr. : Ins. Ascension.

subulosa (Griff.) Mitl. M. Ind. or. p. 61.

Bartramia subulosa Griff. Not. p. 438 et Ic. pl. Asiat. II, t. 101, f. 2.

2. Terr. - As. : Khasia.

tahitensis (C. M.) Jaeg. Ad. 1, p. 541 .

Bartramia tahitensis C. M. in Bot. Zeit. 1859, p. 220.

Philonotula tahitensis Besch. Fl. bryol. Taiti, etc, p, 28.

2.

- Pac. : Ins. Taïti.

tahilensis Ångstr. - Ph. runcinata.

tenella (C. M.) Besch. Fl. hryol. Antill. fr. p. 33.

Bartramia tenella C. M. Syn. I, p. 481; Mitt. M. austr. am. p. 259.

Ph. Mühlenbergii $\beta$ tenella Brid. Bryol. univ. II, p. 23.

2. Lignic. et terr. - Am, sept. : Florida, Costa Rica, Cuba, Jamaic., Haiti, S. Christoph., Porto-Rico, Martinic. Am. merid. : Ins. Trinit., Amazon., And. Nov. Granat. et Quitens.; Peruv., Brasil.

«var, coloradensis Ren. et Card. in Bot. Gaz. 1896, p. 51.

- Am. sept. : Colorado.

- var. gracillima (C. M.) Par.

Bartramia filiformis Hsch. Fl. Brasil. p. 40.

B. tenella var, gracillima C. M. $l, e$.

Terr. - Am. merid. : Brasil.

* var. humilis (Brid.) Par.

Anoectangium porto-ricense Spreng. in Brid. op. cit. p. 17.

Bartramia fontana Schwaegr. Sp. M. p. 92 .

B. tenella var. humilis C. M. $l . c$.

Ph. humilis Brid. op. et l. cc.

Ad saxa humid. - Am. sept. : Hispaniola, Porto-Rico.

tenuicula (Hpe.) Besch. Fl. bryol. Réunion, etc. p. 204.

Bartramia tenuicula Hpe. in Linn. 1874, $p, 210$.

$\mathrm{Ph}$, tenuicaulis Jaeg. Ad. I, p. $54 \mathrm{l}$.

tenuis (Tayl.) Jaeg. Ad. I, p. 553.

$$
\text { - Afr. : Madagascar. }
$$

Bartramia tenuis Tayl. in Phytol. 1844, p. 1095; C. M. Syn. I, p. 477;

2. H. f. et W. Fl. Tasman, II, p. 193, t. 174, f. 4 .

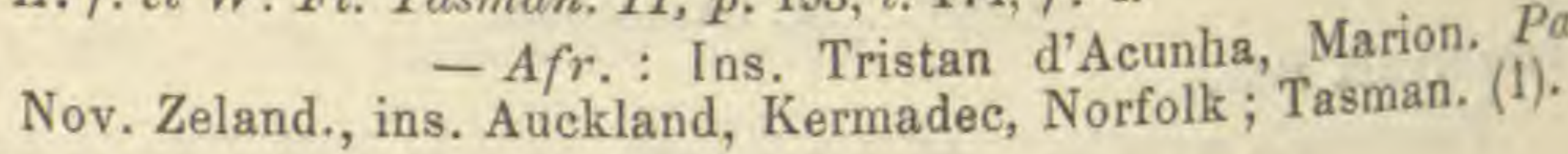

Thwaitesii Mitt. M. Ind, or. p. 60.

2.

- As. : Ceylan.

timmioides C. M. in Rev. bryol. $1876, p .4$ (nom.).

- Pac. : Austral. or. (Nov. Vales.).

tomentella Mdo. - Ph. fontana var, alpicola.

? tomentosa Brid. - Breutelia.

trichodonta (C, M.) Par.

Bartramia trichodonta C. $\mathrm{M}$. in Fl. 1886, p. 276.

2 Terr. - Afr. : Ins. S. Thomas.

(1) Cf Handb. of N. Zeal, Fl. p. 448. 
trichophylla Besch. Not. M. I. St-Paul et Amsterd. p. 5 .

Ster.

- Afr. : Ins. Amsterdam.

tricolor (C. M.) Par.

Bartramia 1ricolor C. M. in Fl. 1890, p. 478.

Ster. Paludic. - Afr. : Kilima N'Djaro.

Turneriana (Schwaegr.) Mitt. M. Ind. or. p. 62; Bryol. jav. I, p. 157,

t. 127.

Bartramia fontana $\beta$ marchica Griff. Not. p. 437.

B, nitida Wils, in sched. $n$. 561 .

B. Turneriana Schwaegr. Suppl. III, I, II, t. 238; C. M. Syn. I, p. 472.

2. Arenic., arbor. et ad rup. irror. - As. : Nepal., Sikkim, Khasia, Jəva. Pac. : Ins. Hawaï.

uncinata (Schwaegr.) Brid. Bryol. univ. I1, p. 221.

Bartramia scabrida Schwoaegr. Suppl. I, II, p. 57. B. uncinata ej. op. oit. p. 60;C. M. Syn. I, p. 476; Mitt. M. austr. am.
p. 261.

$\mathrm{Ph}$. fontana $\eta$ dealbata Brid. op, cit. p. 21.

2. Ad terr. humid. - Am. sept. : Costa-Rica, Guadalup, Martinic., ins. S. Vincent.

uncinatula C. M. in Rev. bryol. 1876, p. 4 (nom.).

- Pac. : Austral. or. (Nov. Vales.).

vagans (Hook. f. et Wils.) Mitt. in Journ. of the Linn. Soc. 1859, p. 80.

Bartramia vagans Mitt. M. austr, am. p. 262.

Bryum vagans $H$. f. et $W$. in Lond. Journ. of bot. 1844, p. 546 et $\mathrm{Fl}$. Antaret. II, p. 414, t. 154, f. I.

Meesea vagans C. M. Syn. I, p. 467 et II, p. 615.

Ph, dimorpha W. P. Sch, in Lechl. Pl, Chil. $n .3063$.

Ster.

versifolia (Hpe.) Jaeg. Ad. 1, p. 542 .

Bartramia versifolia Hpe. in Ann. sc. nat. ser. V, III, p. 371.

2.

Vescoana (Besch.) Par.

- Am. merid. : And. Nov, Granat.

Philonotula Vescoana Besch. Fl. bryol. Taüti, etc., p. 29.

2. $f$ et fr. ign.

Wallisii (C. M.) Jaeg. Ad. II, p. 701.

-Pac.: Taïti.

Bartramia Wallisii C. M. in Linn. 1874, p. 554.

Ster.

Zürniana C. M. et Schlieph. mss.

- As. : Ins. Philippin.

- Pac. : Ins, Auckland. (1).

Philonotula W. P. Sch. Syn. II ed. p. 424 (subgen. Philonotidis); Hpe. Symb. gen . propr.

Spec. omn, non indic. sunt PHLLONOTIDES ejusd. nom.

capillaris C. M. - Philonotis subcapillaris.

curvula C. M. - Philonotis subcurvula.

(1) In Enumer. Kindb, nomina nuda :

$\mathrm{Ph}$, afro-fontana Rehm.

boschbergiana $C$. $\dot{M}$

crystallina $C . M$.

fabroniacea $C . M$.

Oreades C. $M$.

Ph. stenodictyifolia C. M.

subluteola $C . M$.

Utriae C. $M$.

Woodii Relm. 
Philudora Mitt. $M$, austr, am, p, 416 (sect. CRYPHAEAE) postea gen. propr.

PHEENICORRYUM Lindb, in Oefv... 1861.

Reinwoardti Lindb. - Hypnodendron.

PHOTINOPHYLLUM Mitt. in Journ, of the Linn. Soc. 1868, p. 175. pellucidum Mitt. - Rhizogonium. subbasilare Mitt. - Rhizogonium.

PIYLLOGONIUM Brid. Bryol. univ. II, p. 671 (10 spec.).

angustifolium W. P. Sch, - Ph. cylindricum.

aurescens $C$, M. M. Polyn. p. 70.

$\mathrm{Ph}$. fulgens Hpe, et Ltz, in Krause M. Eouad.

Ph. viscosum Mitt. M. austr. am. p. 423?

Lignic. - Am. merid. : Equator.

aureum Mitt. op. cit. p. 424.

Ad arbor. - Am. sept. : Jamaic., ins. S. Christoph. Am. merid. :

And. Peruv.

caldense C. M. M. Polyn. p. 69.

- Am. merid. : Brasil. austr. or.

callichroum $\left\{\begin{array}{l}\text { Brid. - Ph. viscosum. } \\ \text { Mont. - Acrocladium politum: }\end{array}\right.$

cryptocarpon W. P. Sch. - Ph. cylindricum.

cylindricum Lindb. in Oefv.... 1864, p. 603.

Cryptogonium cylindricum $e j$. in op. cit. 1873.

Ph, angustifolium W. P. Sch. in Fl. Vit. p. 396 (fid. Mitt. Sam. p, 187.

Ph. cryptocarpon ej, in Jard. Enum. p. 19 (fid. C. M. M. Polyn. p. 69.)

2. Ad arbor. - Pac. : Taiti, ins. Fidji, Samoa, Marquis., Hawaï.

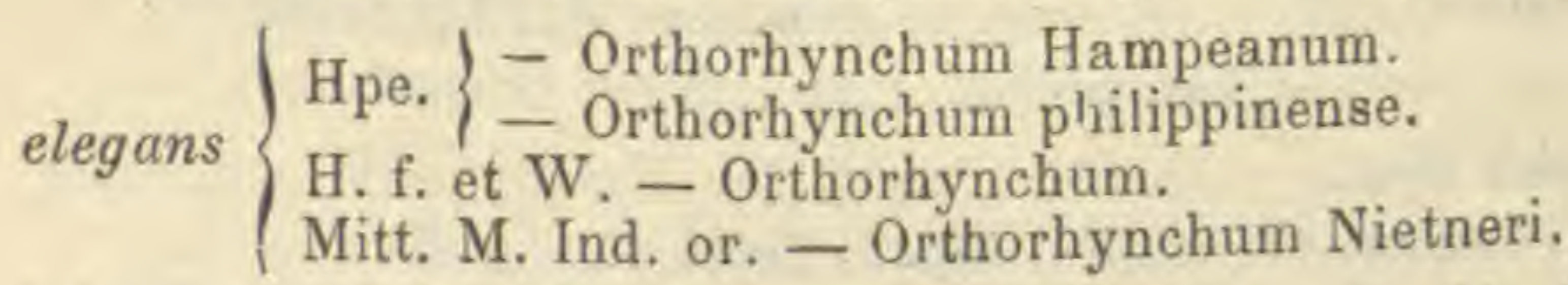

fulgens (Sw.) Brid. Bryol. univ. II, p.671; C. M. Syn. II, p. 2 p.p.;

Mitt. M. austr. am. p. 423.

Hypnum fulgens Sw. Prodr. Fl. Ind. ooc. p. 140.

Pterigynandrum fulgens Hedw. M. frond. IV, p. 10, t. 39 .

Plerogonium fulgens $S w$. Fl. Ind. occ. III, $p .1776$.

2. Ad arbor. - Am. sept. et merid. : Tropic.

fulgens $\left\{\begin{array}{l}\text { C. M. p.p. }\left\{\begin{array}{l}-\mathrm{Ph} \text {, viride. } \\ \text { Hpe. }-\mathrm{Ph} \text {. viscosum. }\end{array}\right. \\ \text { serra. }\end{array}\right.$

Hpe. et Itz. - Ph. aurescens.

var. viscosum Brid, - Ph, viscoum.

immersum Mitt, op. cit. p. 423.

Ad arbor, - Am. merid. : Brasil.

norvegicum Sull, - Bryoxiphium.

philippinense Hpe. - Orthorhynchum.

serra C. M. M. Polyn. p. 70.

Ph. fulgens Hpe. in Lindig M. Nov. Granat.

Ad arbor, - Am. merid. : And. Nov. Granat. 
speciosum C. M. M. Polyn. p. 70.

Nov. Granat., Equator.

-- Am. sept. : Costa Rjea. Am. merid.: Venezuela, viride Brid. Bryol. univ. 11, p. 673; Mitt. op. cit.p. 424.

$\mathrm{Ph}$, fulgens C. M. Syn. II, p. 2 p.p.

2. Ad arbor. - Am. sepl. : Mexic,, i,ns. S. Kitts. Am. merid. : Brasil. viscosum (P. B.) Mitt. op. cit. p, 424.

Hypnum naviculare Brid. Bryol, univ. $I I, p .540$.

Ph. aurescens C. M. M. Polyn, p. 30 ?

$\mathrm{Ph}$. callichroum Brid. $h b$.

Plt. fulgens C. M. Syn. II, p. 2 p.p.

$\mathrm{Ph}$, fulgens var: viscosum Rrid. op. cit. p, 673.

Pterigynandrum viscosum $P, B$, Prodr. $p, 87$.

2. - Afi: : Ins. Borbon., Tristan d'Acunha. Am. sept. : Costa Rica (1). Am. merid. : And. Quitens.

PHYLLOGONIUM EUSTICHIA Brid. Bryal, univ. II, p. 674.

longirostris Brid. - Eustichia.

norveyica Brid. - Bryoxiphium.

PHYSCOMITRELLA Bryol, eur. I (2 spec.).

Hampei Limpr. Laubm. Deutschl. I, p. 175.

Aphanorhegma patens var. anomalum Lindb, in Oefv... 1864, p. 580.

Ph. patens var. anomala Hpe. mss.; Milde Bryol. siles, p. 191.

Ph. patens var, pedicellata Bryol, eur. I, t. $3 \gamma$.

Physcomitrium sphaericum $\times$ Physcomitrella patens Limpr. l.e.

1. In stagnin. exsicc. - Eur. : Harz, Brandebourg, Siles.

patens (Hedw.) Bryol, eur. 1, t. 3 el VI, l. 637, f. 1-4; W. P. Sch. Coroll. p. 3 et Syn. 11 ed. p. 8; Jaeg. M. cleistoc. p. 44.

Aphanorhegma patens Lindb. in Oefv... 1861, p. 580.

Ephemerum patens Hpe. in Fl. 1837, p. 285; C. M. Syn. I, p. 33 et II, 1., 522 .

E. recurvifolium Hpe, in Veg. cell. German. sept. etc. n. 42.

Genthia patens Bayrhofer in Jahresber, d. Ver. f. Naturk, in Hersogt. Nassau, 1849, V Heft, p. 2.

Phascum patens Hedv. Stirp. 1, t. 10 ; Brid. Bryol. univ. I, p. 33.

l et syn. Ad terr, argill. humid - Eur. : Fere tota. As. : lenissei sup. Am. sept. : Ohio.

Exs. : Drumm. M. bor. am. Il ed, n. 5 (Phascum).

Rab. Bryoth, enr. n. 161, 1055 .

Sull, et Lesq. M. bor. am. JI ed. n. 30.

var, angustifolia de Not. - Ph. patens var. megapolitana.

* var, Lucasiana (Bryol. germ.) W.P.Sch. Syn. I ed.p. 9 et II ed. l. c.

Phascum Lucasianum Bryol. germ, $1, p, 44, t, 5$; Brid. op, cit. p. 32.

Ut et cum typ.

* var, megapolitana (Schultz) Bryol. eur. et W. P. Sch. ll. cc.

Phascum niegapolitanum Schults Suppl. Fl. Starg. p. 2, t. 1; Brid. op. cit. p. 44 .

Physcomitrella patens vait. angustifolia de Not, in Ev.b. critt. ital. Ser, II, n. 161.

Ut et cum typ.

var, pedicellata Bryol, eur. - Ph. Hampei.

(1) An Ph, speciosum? 
PHYSGOMITRIUM Brid. Bryol, univ. I, p. 97 c. tab, suppl, emerid. (66 spec.).

acuminatum (Schleich.) Bryol. eur. III (mon. p. II), t, 300; C. M. Syn. I, p. 114 et 11, p. 544 p.p.; W. P. Sch. Syn. II ed. p. 376.

Gymnostomum acuminatum Sehleich. Cat, pl. helv. IV ed., p. 40.

G. sphaericum var. Bryol. germ. I, p. 127 in not. 3 ?

1. In limos. - Eur.: Westphal., Helvet. (Vales. inf.), Salisb., Stir.. Tirol. (?), Ticin., Pyren, As. : Caucas. Afs. : Alger. (fid. Besch.). Am. sepl. : lllinois, Nebraska, Kansas, Texas.

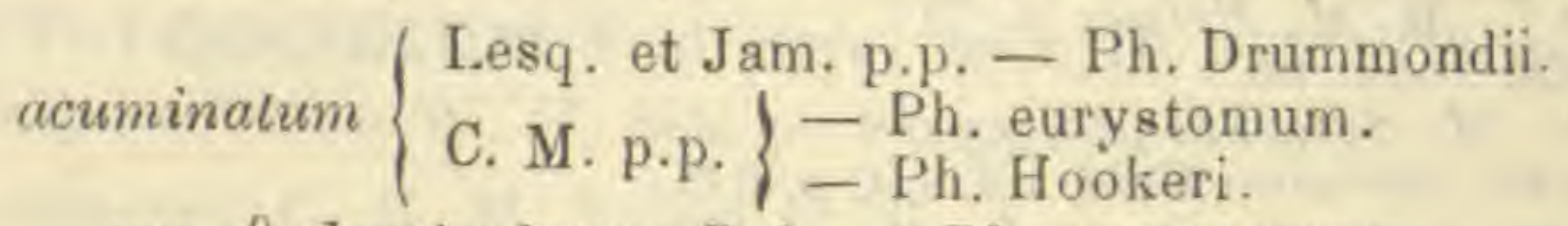

var. $\beta$ denticulatum $\mathrm{Rab},-\mathrm{Ph}$, eurystomum.

"var. patulum Lindb. in Broth. Enum. M. Caucas, p. 33 (nom.).

- As. : Caucas. occ.

A hnfeldti Hartm. - Entosthodon ericetorum var. Ahnfeldti. apophysatum Wils. - Entosthodon ericetorum.

argentinicum Par.

Ph. pusillum C. M. in Linn. $1880-83, p .359$.

- Am. merid.: Argentin. Buenos Ayr.

Auberti Besch Fl. bryol. Réunion, etc. p. 86.

- Afr. : Ins. Borbon. ? vel Tristan d'Acunha?

australe $D^{n n}$ E. G. Britton in Bull. Torr. bot. Club, 1894, p. 201, t. 199.

Gymnostomum tortipes Hook, in Drumm. M. bor, am. n. 25 .

1.

- Am. sept. : Florida.

Bonplandi $\left\{\begin{array}{l}\text { C. M. - Entosthodon. } \\ \text { de Not. - Entosthodon ericetorum. }\end{array}\right.$

brevisetum Mitt. in Journ, of the Linn, Soc. 1877, p. 65.

- Afr. : Ins. Inacessible.

brisbanicum C. M. in Linn. 1871-73, p. 146.

- Pac. : Austral, or. (Queensland).

Breutelii C. M. - Gigaspermum.

chlorodictyon C. M. in Linn. 1878-79, p. 258.

1 ?

- Am. merid. : Uruguay.

californicum $D^{\text {nat }}$ E. G. Britton in op. cil. p. 206, t. 203.

1. Terr. - Am. sept. : Calif.

capillipes C. M. in Hedioig. 1895, p. 127.

Ad terr. humid. - Am. merid. : Brasil. or. (Goyaz).

coloradense $D_{n A} E$. G. Britton in op. el l. cc. $t .202$.

1. In limos. - Am. sept. : Montana, Colorado. conicum Mitt. in Journ. of the Linn. Soc. 1859, p. Ty et in Fl. Tas-
man. II, p. 197 .

Ph. piriforme Handb. of N. Zeal. Fl. p. 451?

$\mathrm{Ph}$. subserratum Hpe. ?

- Pac. : Tasman.

cubense Mitt, M. austr, am. p. 240.

$\mathrm{Ph}$. immersum Sull, in Proced. of the Amer, Acad... 1861.

- Am. sept. : Cuba. 
cupulare $\dot{C}$. $M$. in Linn. 1878-79, p. 259.

1.

- Am. merid. : Uruguay.

cupuliferum Mitt. op. cit. p. 242.

Ph. spathulatum Sull, in op. et $l$. ce.

$$
\text { - Am. sept. : Cuba. }
$$

curvisetum Bryol, eur. - Funaria.

cyatbicarpum Mitt. M. Ind. or. p. 54.

$\mathrm{Ph}$. immersum Wils, in Kew Journ. bot. IX, p. 54.

- As. : Pendjab, Nepal.

dilatatum Ren. et Card. in Bull. Soc. roy. bot. Belg. 1890, I, p. 75.

Terr. - Afr. : Madagascar.

Drummondii Daa E. G. Britlon in op. cit. p. 205, t. 201.

Ph. acuminatum Lesq. et Jam. Man. p 198 p.p.?

Ph. Hookeri var. serratum R. et C. in Rev. bryol. 1892, p. 93 (fid. Dan $E$. G. Britt.).

$\mathrm{Ph}$, piriforme var, 3 Drumm. M. bor. am. I ed. n. 24.

Ph. turbinatum var. crassipes R. et C. in Bot. Gaz, 1894, p. 240.

1. Terr. - Am. sept. : Canada, Oregon, Missouri, Ludovic.

enerve (Hook. f. et Wils.) C. M. Syn. II, p. 545.

Goniomitrium enerve $H$. $f$. et W. in Lond. Journ. of bol. 1816, p. 142, t. $3 \mathrm{~A}$.

1. Terr. - Pac. : Austral. or.

ericetorum Bryol, eur. - Entosthodon.

eurystomum (Nees ab Es.) Sendln, in Denkschr. d. K. Bä̈er. bot. Gesells.

su Regensb. 1841, III, p. 142; W. P. Sch. Syn. II ed.p. 375.

Gymnostomum eurystomum Nees ab Es. mss.

G. sphaericum Bryol. germ. I, p. 127 in not. 3 ? Hüb. Moost. t. V, n. 5 b.

Ph, acuminatum C. M. p.p.

Ph. acuminatum $\beta$ denticulatum Rab. Deutsch. Kryptfl. II, III, p.87.

Ph. sphaericum Moug. et Nestl. Stirp. vog. rh. n. 708.

Ph. sphaericum var, cuspidatum Dz. et Mk. Prodr. fl. batav, $I I, I$, p. 70 c. ic.

Ph. sphaericum var. eurystomum Husn. Muscol. gall. p. 213.

Ph. sphaericum var. Huberiana Rab. Kryptfl. v. Sachsen, I, p. 368 et Bryoth. exr. n. 452.

Ph. sphaericum var. major Boulay M. Fr. p. 303.

1. In argill. humid. - Eur. : Neerland., vall. Rhen., Thuring., Boruss., Saxon., Siles,, Stir., Carinth., Austr, inf., Helvet.

Exs. : Rab. Bryoth. eur. n. 25 c, 54, 1221.

- var. subpatula (Lindb. et Arn.) Par.

Gymnostomum eurystomum var, subpatula L. et A. M. As. bor. 1890, II, p. 58.

$$
\text { - As. : Ienissei super. }
$$

fasciculare Hpe. - Funaria.

falcifolium C. M. in Hedroig. 1895, p. 127.

- Ain. merid. : Brasil. or. (Goyaz).

firmum Mitt, in Kevo Journ. bot. VIII, p. 259.

- Pac. : Austral. or.

flaccidum Mitt. in Trans. and Proced. of the roy. Soc. of Vicloria, 1883, p. 67.

- Pac. : Austral, or. (Nov. Vales,). 
flexifolium Mitt. in Melliss S. Helena, 1875, p. $36 \mathrm{I}$.

- Afr. : Ins. S. Helena.

Germanillae C. M. in Linn. 1878-79, p. 259.

1.

- Am. merid. : Argentin. Cordob.

Goniomitrium C. M. Syn. $11, p .545$ (1).

Goniomitrium acuminatum $H$. $f$. et $W$. in Lond. Joxrn, of bot, 1816, p. $143, t, 3$ B.

1. Terr, - Pac, : Austral. or.

Griffithii Angstr. - Edipodium.

hians Lindb. - Ph. Hookeri.

Hookeri Hpe. Ic. M. t. 30 (in abs. ad Ph. Thielei); Lesq. el Jam. Man.

p. $198 ; D^{\text {ia }}$ E. G. Brilton in op. cit, p. 201.

Gymnostomum latifolium Hook. in Drumm. M. bor. amer. I ed. n. 16: Scheaegr. Suppl. IV, ı. 304.

$\mathrm{Ph}$. acuminatum C. M. p.p.

Ph. hians Lindb. Manip. M. I, p. 51; Sull. Ic. M. Suppl. p. 26, t. 16.

$\mathrm{Ph}$. latifolium Lindb. in Oefv.... 1854, p. 595.

Ph. piriforme Sull. ot Lesq. M. bor, am. II ed, n, 234 p.p.

1. In terr, argill. - Am. sept.: Saskatchewan, Manitoba, Ontario, Montana, Dakota mer., Minnesota, Ohio, Kansas.

Exs. : Drumm. M. bor. am. II ed, n. 25.

var, serratum R. et C. - Ph. Drummondii.

immersum Sull. M. of U. St.p. 51, t. 4, Ic. M. p. 93, t. 56 et in Asa Gray

Man. bot. of U. St. I ed. p, 648; Lesq. et Jam. Man. l. c.; $I^{\text {na }}$ E. G.

Britton in op. cil. p. 190.

Gymnostomum immersum Sull in Proced. of Amer. Acad... 1861, p. 273.

Ph. sphaericum var. ? Sull. M. Allegh, n. 196.

1. Ad terr. alluv. - Am. sept. : Gaspes., New Jer'sey. New York, Pensilv. occ., Delaware, Carol. merid., Ohio, Missouri, Minnesota, Colorado.

Exs. : Sull, et Lesq. M. bor. am. II ed. n. 233.

inimersum $\left\{\begin{array}{l}\text { Sull. (Proced, . - Ph. cubense. } \\ \text { Wils. - Ph. cyathicarpum. }\end{array}\right.$

integrifolium Hpe. et C. M. in Linn. 1853, p. 490.

- Pac. : Austral. or.

? Jamesoni Tayl. in Lond. Journ. of bot. 1847, t. 239; C. M. Syn. I, p. 119.

Amphoritheca Jamesoni Hpe, in Ann. sc. nat. V ser., IIJ, p. 340.

Tortula limbata Mitt. M. austr, am. p. 168.

- Am. merid. : M. Pichincha.

japonicum (Hedro.) Mitt. in Trans, of the Linn. Soc. 1891, p. 164.

Entosthodon japonicus Lindb. in Oefv... 1864, p. 596 .
Gymnostomum japonicum Hedw. Sp. M. p. 34, t. I; Brid. Bryol waio. $I$, p. $67 ;$ C. M. Syn. I, p. 557.

Pottia japonica Jaeg. Ad, I, p. 199.

$$
\text { - As. : Japon. }
$$

Kellermanni $D^{n a}$ E. G. Britton in op, cil. p. 204, $t .200$.

1.

- Am. sept. : Nebraska, Kansas.

latifolium Lindb, - Ph. Hookeri.

(1) Cf. Geheeb in Rev. bryol. 1879, p. 15. 
laxum Hook. f. et Wils. Fl. Antarct. II, p. 399, t. 15l, f. 5 ; C. M. Syn. $I 1, p .546$.

Entosthodon laxus Mitt. in Journ, of the Linn. Soc. 1859, p, 80.

Ad rup. humid, - Afr, : Ins. Kerguelen, Marion. Am, merid.: Archip. antaret. Pac. : Alp. Austral, or., Tasman.

Lorentzi C. M. in Linn. 1878-79, p. 260.

1. - Am, merid. : Argentin, Gordob.

luteolum Besch. Note M. Parag. p. 263.

Terr. - Am. merid. : Paraguay.

Exs. : Bal. Pl. Parag. n. 1230.

Mac-Leai Rehm. M. Afr. austr. n. 519, 520.

$$
\text { - Afr. : C. B. Sp. }
$$

macrocyatheum C. $M$, in Journ. of bot. $1877, p .327$ (nom.).

In prat. udis. - Am. sept. : Costa Rica.

megalocarpum Kindb. in Bull. Torr. bol. Club, 1889, p. 94 el in Mac.

Cat. p. 102.

Ph. piriforme Drumm. M. bor: am. II ed. n. 22, 23, 24? (1).

1. Ad terr. humid. - Am, sept. : Ins. Vancouver, Washington, Oregon, Nevada, Calif.

Exs. : Mac. Canad. M. n. 147.

minutulum C. M. in Linn. 1871-73, p. 147.

1?

- Pac. : Austral, or.

niloticum (Del.) Lindb. mss. ; C. M. in Bol. Zeit. 1858, p. 154.

Gymnostomum niloticum Del. Fl. Eg. p. 43; Brid, Bryol. vniv. I, p. 756 ; C. M. Syn. I, p. 165.

Microporna nilotica Lindb. in Not... 1870, p. 56.

Microstegium niloticum ej. in Oefo.... 1864, p. 593.

Ph. Sesostris Ltz. (fid. Jaeg. Ad. I, p. 492).

1. Ad mur. et terr. - Afr. : Egypt. inf.

nodulifolium Mitt. in Trans, and Proced. of the roy. Soc. of Victoria, $1883, n .66$.

$$
\text { - Pac. : Austral. or. (Queensland). }
$$

nulans Wils. - Entosthodon.

obtuso-apiculatum C. M. in Ule Bryoth. brasil, $n, 24$.

- Am. merid. : Brasil. austr. or.

? Orbignyanum Mont, in Voy. Am. S. de d'Orbigny, VII, Ciyp', p. 87, t. $3, f .2$ et Syll, p. $30 ; C . M$. Syn. I, p. 117.

Gymnostomum Orbignyanum Mont. in Ann. sc. nat. 1837, p. 51.

Ad terr. arenos. - Am, merid. : Corrientes.

paraguense Besch. Note M. Parag. p. 262.

In limos, exsicc. et in graminos. - Am. merid. : Paraguay.

Exs. : Bal. Pl. Parag. n. 1229, 1231, 1232.

? Perroctetii Mont. - Entosthodon.

piriforme (L.) Brid. Bryol, univ, in ind.; Bryol. eur. 111 (mon. p. I1),

t. 299 ; C. M. Syn. 1, p. 116 ; W. P. Sch. op, cil. p. 376 (1).

Bryum piriforme L. Sp. pl. p. 1580.

Br. serpillifolium, pellucidum, capsulis piriformibus Dill. Hist. M. p. 345 , t. $44, f .61$.

1) Cf, Dai E. G. Brition in Bull. Torr. Bot, Club, 1894, pp. 189, 190 ot 192 . 
Gymnostomum longifolium Schleich. Cat. pl. Helv. IV ed., p. 40.

G. piriforme Hedw. Fund. M. II, p. 87.

G. Physcomitrium piriforme Brid. Bryol, univ. I, p. 98.

Phascum piriforme L. jun. Meth. M. p. 361 .

Pottia piriformis Ehrh. Beitr. I, p. 188.

1. In limos., agr. et camp. - Eur. : Tota, alpin. et frigidior. excl. As. : Caucas, Af $r$. : Alger., ins. Azor., Canar. Pac. : Austral. fel. (fid. Mitt.).

Exs. : Rab. Bryoth. eur. n. 55 b-d.

floridanum $\mathrm{R}$. et $\mathrm{C}$. - Ph. turbinatum.

piriforme $\left\{\begin{array}{l}\text { Auct. amer. - Ph. turbinatum. } \\ \text { Drumm. - Ph. megalocarpum? } \\ \text { var. } 3 \text { ej. - Ph. Drummondii. }\end{array}\right.$

var. Langloisii R. et C. - Ph. turbinatum var. Langloisii.

platyphyllum Kindb. in Mac. Cat.p. 269 (1),

1. Terr, - Am. sept. : Ottawa.

Puiggarii Geh. et Hpe. Enum. M. Brasil. p. 4.

- Am. merid. : Brasil.

pulchellum (Griff.) Mitt. M. Ind, or. p. 54.

Gymnostomum pulchellum Griff. Not. p. 394.

- As. : Assam super.

pusillum Hook, f. et Wils. Fl, of the N. Zeal. 11, p. 92, t.87, f. I et Handb. p. 451.

$$
\text { - Pac. : N. Zeland. sept. }
$$

pusillum C. M. - Ph. argentinicum.

pygmaeum Jam. in Bot. King Exped. p. 404; Lesq. et Jam. Man. p. 197. - Am. sept. : Utah (M. Wasatch).

repandum (Griff.) Mitt. op, et l. cc.

Gymnostomum repandum Griff. Not. p. 392.

$$
\text { - As. : Nepal., Assam. sup., Tonkin, Yunnan. }
$$

repens C. M. - Gigasperum.

Rottleri Hpe. - Entosthodon.

saharampurense $C$. $M$. mss.

Terr. - As. : Himalaya sept. occid.

Savatieri Besch. - Ph. subturbinatum.

serratum (Hook. f. el Wils.) C. M. Syn. I1, p. 545. Aphanorhegma serrata Sull. M. of. U. St.p. 52, t. 4 et 1t. M. p. 95, t. 57 .
Jaeg. M. cleist. p. 46.

Schistidium serratum Sull. M. Allegh. n. 198 et in Mem. of the Am. Acad.... 1846, p. 60, t. 2 o.

1. Terr. - Am. sept. : Oregon, reg. sept. et centr.

Exs. : Sull. et Lesq. M. bor. am. II ed. n. 231.

serratum $\alpha_{2} \times \mathrm{Ph}$. turbinatum $\sigma^{*}$ (?) $D^{\text {na }} D$. G. Britton in Bull. Torr bor. $C l u b, 1895$, p. $65, t .231$.

Schistidium serratum $H$. f. et W. in Dmemm. M. bor. am. II ed. n. 20.

- Am. sept. : Missouri (Saint-Louis).

(1) Specim. immatura, spec. dubia; cf. Dna E. G. Britton in op. cit. p. 199. 
serricolum C. M. in Ule Bryoth. brasil. n. 136.

Terr. - Am. merid. : Brasil, austr. or.

serrifolium C. M. in Linn. 1878-79, p. 257.

1.

- Am. merid. : Argent. Cordob.

serrulatum Mitt. M. austr. am. p. 241.

Terr. - Am. merid, : Brasil.

Sesostris Ltz. M. Ehrenb. p. 35, t. 7, f. 1-5 el t. 8, f. 6.22.

$\mathrm{Ph}$, niloticum Lindb, (fid. Jaeg. Ad. I, p. 492).

2.

- Afr. : Egypt. inf.

Soleirolii Mont. - Entosthodon Templetoni.

? spathulatum C. M. in Linn. 1844, p. 695 el Syn. 1, p. 118.

Terr. - Afr. : C. B. Sp.

* var. brevicollum C.M. $l l . c c$.

Gymnostomum spathulatum Hsch. in Linn. 1841, p. 115.

- Afr.: C. B. Sp.

spathulatum Sull. - Ph. cupuliferum.

sphaericum (Schwodegr.) Brid. Bryol. univ. in indice; Bryol. eur. III

(mon. p. ), t. 298; C. M. Syn. I, p. 115; W. P. Sch. op. cit. p. 375.

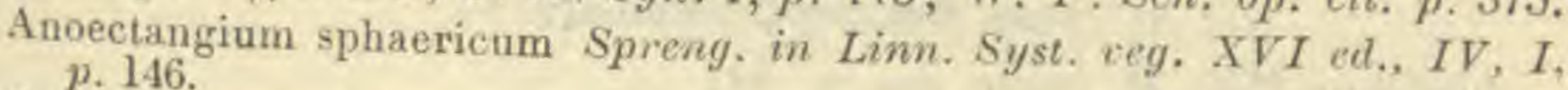

Gymnostomum sphaericum Schwaegr. in Schrad. Jown. IV, p. 15 c. ic et Suppl. I, I, p. 2J, t. 8.

G. Ph. sphaericum Brid. Bryol. univ, I, p. 97.

Ph. sphaericum $\beta$ caulescens C.M. I. c.

1. In terr, argill. - Eur, : Zon. intermed, ; rariss, in Britann, deest in Seandin. As. : Amour.

Exs. : Rab. Bryoth. eur. n. 25 a, 452. 855, 1389.

var. caulescens C. M. - Ph. sphaericum.

var. cuspidatum $\mathrm{Dz}$. et $\mathrm{Mk}$.

var. eurystoma Husn.

var. Hiuberiana Rab.

var. major Boul.

var. ? Sull. - Ph. immersum.

Ph, eurystomum.

strangulatum Kindb. - - Ph. turbinatum.

subrotundum W. P. Sch. - Ph. subsphaericum.

subserratum Hpe. in Linn. 1859-60, p. 623.

Ph. Conicum Mitl. in Fl. Tasman. p. 197? 1.

subsphaericum W. P. Sch. mss.; C. M. Syn. II, p. 544.

- Pac. : Austral. or.

Ph, subrotundum W. P. Seh. in hb. Mus. Paris.

- Am. sepl. : Mexic. (Orizaba).

subturbinatum W. P. Sch. in Savat. M. Japon. n. 825.

Ph. Savatieri Besch, in .Ann, sc, nat. $1893, p, 310$.

- As. : Japon.

- As. : Japon.

Thieleanm Bryol. eur. - Pyramidula.

Thieleanum Hpe. 1c. M. t. 30; C. M. Syn. I. p. 116 et I1, p. 544.

Terr. - Am. merid : Brasil. austr. or., Monte Video, 
turbinatum (Rich.) C. M. in Lesq. et Jam. Man. p. 198; Da E. G. Brilton in op. cil. pp. 192-199, ८. 198.

Gymnostomum dilatatum P. B. Piodiv. p. 59.

G. splachnoideum $e j . l$. $c$.

G. turbinatum Rich, in Mich, Fl, bor, am. II, p. 286.

G. Ph. splachnoides Brid. Bryol. univ. $I$, p. 99.

G. Ph. turbinatum ej. op. cit. p. 100.

Ph. Hookeri Mac. Canad. M. n. 146 p.p.

Ph. piriforme Aurt. amer. (fid. D ${ }^{\text {na }}$ E. G. Britton l. c.); Sull. et Lesq. M. bor. am. II ed, n, 234 p.p.

Ph. piriforme var. floridanum R. el C. in Rev. bryol. 1892, p. 93.

Ph. strangulatum Kindb. in Ott, Nat. IV, p. 60.

I. Terr. - Am. sept. : de Ontario ad Florid., Texas; Kansas? Calif.

var. crassipes $\mathrm{R}$, et $\mathrm{C}$. $-\mathrm{Ph}$. Drummondii.

a var. Langloisii (Ren. et Card.) D na E. G. Britton in op. cit. pp. 197 et $200, \iota .198$.

Ph. piriforme var. Langloisii R. et C. in Bot. Gas. 1889, p. 94 et M. Amer. sept. $n, 45$.

In paludos. - Am. sept. : Texas, Florid, Ludovic.

" var. tortipes (Brid.j Par.

G. Ph. tortipes Brid. Bryol. univ. I, p. 100.

- Am. sept. : Pensilv.?

turgidum Mitt. M. austr. am. p. 241.

- Am. merid. : M. Chimborazo.

umbonatum Mitt. op. et $l$. cc.

Terr. - Am. merid. : Brasil. or. (1).

PHYSCOMITRIUM ENTOSTHODON C. M. in Linn. 1844, p. 696.

\begin{tabular}{l|l} 
Bergianus & Curvipes
\end{tabular} C. M. - Eatosthodon.

Mathewsii $\left\{\begin{array}{l}\text { C. M. - Entosthodon. } \\ \text { C. M. - Entosthodon Mathewsii var. latifolium. }\end{array}\right.$

oblusifolius C. M. - Entosthodon.

PHYSEDIUM Brid. Bryol. univ. I, p. 51 .

pachycarpum C. M. - Ephemerella recurvifolia.

splachnoides $\mathrm{Br}$. - Phascum.

PILOPOGON Brid. Bryol. nniv. I, p. 519 (10 spec.).

calycinus W. P. Sch. mess,; C. M. Syn. II, p. 586; Mitt. M. austre am. p. 70 .

2.

- Am. sept. : Mexic. gracilis Brid. Bryol. univ. 1, p. 519 ; C. M. Syn. I, p. 348 ; Mill. op.
el l. ec. el $l$. ec.
Didymodon gracilis Hook, in Kunth Syn, pl. aequin. p. jl el M+exot, t. 5.
Thysanomitrium splendens $\mathrm{ej}$. in hb. Mont. (Mus. Paris).

(I) In Enum. Kindberg. nom. nuda :

Ph. brachypodium C. M, I Ph. subpusillum (C. M.) an Ph. argentinicum? 
2. Ad arbor. - Am. sept. : And. Costa Ricens., Jamaic., Guadalup. Am. merid. : And. Nov. Granat., Quitens. et Boliv.

* var. Pittieri Ren, et Card. in Bull. Soc. roy. Belg. 1892, II, p. 151.

Ad rup. madid. - Am. sept. : Summ. And, Costa Ricens.

liliputanus $C$. M. mss.

- Am. merid. : And. Boliv.

longe-fimbriatus W. P. Sch. in Mandon Pl. Boliv, n. 1713 bis.

- Am. merid. : And. Boliv.

longirostratus Mitt. op. et $l$. cc.

Am, merid. : And. Quitens.

microcarpus Geh. et Hpe, in Fl. 1881.

- Am. merid. : Brasil. austr. or.

Mohrii C. M. in Linn. 1874 , p. 626.

- Am sept. : Mexic.

nanus Hpe. in Linn. 1863, p. 137; Mitt. op. et l. ce.

2. Terr. $-A m$. merid. : And. Nov. Granat.

piliferus $\mathrm{H}$ pe. - Campylopus laevis.

subjulaceus Hpe. Symb. 1874 , p. 486.

2.

- Am. merid. : Brasil austr. or. (1).

Pilorhiza C. M. in Linn. !871-73, p. 158 (sect. Hook ERLaE).

PILOTRIChELLA C. M. Syn. 11, p. 129 (subsect. Neckerae, postea gen. gen. propr.) (129 spec.).

aeruginosa (C. M.) Par.

Orthostichella aeruginosa C. M. in Ule Bryoth, brasil. n. 195.

Ad arbor. - Am. merid. : Brasil. austr. or.

ampullacea (C. M.) Besch. Fl. bryol. Réunion, elc. p. 127.

Neckera ampullacea C. M. in Linn. 1876, p. 261.

Anderssonii (C. M.) Jaey. Ad. II, p. 166.

- Afr. : Usambara, ins. Anjouan.

Neckera Anderssonii C. M. in Bot, Zeit, 1855, p, 170.

Ster.

- Am. merid. : Ins. Gallapagos.

ankaratrensis Kinêr in Borgen M. Mad. n. 29.

- Afr. : Madagase, centr.

Araucarieti C. M. in Ule Bryoth. brasil. n. 169.

- Am. merid. : Brasil, austr. or.

araucariophila C. $M$. ibid. $n .168$.

Ad arbor. - Am. merid. : Brasil. austr. or.

atro-lutea (C. M.) Par.

Meteorium atro-luteum Jaeg. Ad. II, p. 152

Neckera atro-lutea C. M. in Linn. 1874, p. 614.

Ster.

- Am. merid. : And. Nov. Granat.

(I) In Eriumer, Kindberg, nom. nud, :

$\mathrm{P}$. grandis Ángstr. 
aureo-pallens (Geh. et Hpe,) Par.

Orthostichella aureo-pallens $\mathrm{G}$. et Hpe, in Fl. 1881.

- Am. merid. : Brasil. austr. or.

Avellanedae $(C, M$.) Par.

Neckera Avellanedae C. M. in Linn. 1878-79, p. 413.

2 .

- Am. merid. : Argentin, subtropic.

biformis (Hpe.) C. M. in Abhandl. Brem. VII, p. 209.

Meteorium biforme Besch. Fl. bryol. Réunion, etc., p. 128.

Pilotrichum biforme Hpe. in Linn. 1874, p. 218.

Ster. Arbor. - Afr. : Usambara, Madagascar.

Billardieri (Hpe.) Jaeg. Ad. II, p. 163.

Isothecium flexile Brid. Bryol. univ. II, p. 362 (fid. Hpe.).

Meteorium Billardieri Mitt. in Trans, and Proced. of the roy. Soc. of Victoria, 1833, p. 82 ,

Neckera Billardieri Hpe. in Linn. 1859-60, p. 637.

Ad arbor. - Pac. : Austral, or., Tasman.

bipinnata Husn. - Pilotrichum.

breviramea (C. M.) Jaeg. Ad. II, p. 173.

Neckera breviramea C. M. in Bot. Zeil. 1854, p. 570.

Trachypus bravirameus Mitt. M. Ind. or. p. 129.

2.

- As : M. Neilgherr.

caldensis Angstr. in Oefv.... 1876, n. 4, p. 34 .

Ster. $\quad-A m$. merid. : Brasil, austr. or.

calomicra Broth, in Bol. d. Soc. Brot. 1890.

Ster.

- Afr. : Ins. S. Thom.

capillaris Besch, - Papillaria.

capillicaulis (C.M.) Par.

Orthostichella capillicaulis $C . M$. in $F l .1890, p .491$.

Ster.

- Afr. : M. Aberdare.

Caroli C. M. in Angstr. Prim. lin, p. 52.

P. nigricans Angstr, in Oefv.... 1872, $n .5, p .118$.

- Am. merill. : Ins, Gallapagos.

characea (C. M.j Par.

Neckera characea $C, M$, in Linn. 1878-79. p, 418.

2.

- Am. merid. : Argentin. subtropic.

« var. nigrescens $(C, M$.) Par.

Neckera characea var, nigrescens $C, M$. in op. cil. p. 419.

2.

- Am. merid. : Argentin. subtropic.

- var. tenuis (C. M.) Par.

Neckera characea var, tenuis $C . M . l . c$. 2 .

- Air. merid. : Argentin, subtropic.

chlorotbrix C. $M$. in Fl. 189^), p. 490.

Ster. In silvis. - Afr. : Kilima N'Djaro.

chrysoneura (Hpe.) Besch. Fl. bryol. Réunion, elc. p. 126.

Neckera chrysoneura Hpe, in Linn. 1876, p. 263.

Filic. - Afr.: Ins. Anjouan, Transvaal.

Exs. : Rehm. M. Afr. austr. n. 609 b. 
cochlearifolia (C. M.) Besch. Prodr. bryol, mexic. p. 79.

Meteorium orbifolium Mitt. M. austr. am. p. 440.

Neckera cochlearifolia C. M. Syn. II, p. 130.

Pilotrichum cochlearifolium C. M. in Linn. 1843, p. 599.

2. - Am. sept. : Mexic., ins. Tabago.

"var, flagellifera Besch. l. c. - Am. sept. : Mexic.

communis (C. M.) Par.

Orthostichella communis C. M. in Dusen M. Camer, n. 651. - Afr. : M. Cameroon.

consanguinea Besch. - Papillaria.

consimilis (Hpe.) Jaeg. Ad. II, p. 167.

Meteorium consimile Mitt. M. austr. am. p. 447.

Neckera consimilis Hpe, in. Ann. sc. nat. $\dot{V}$ ser., IV, p. 360.

2. Ad arbor. - Am. merid. : And. Nov, Granat.

crinita (Sull.) C. M. in Ule Bryoth. brasil. n. 167.

Meteorium crinitum Mitt. M. austr. am. p. 431.

M. erinaceum Spr. Cat. n. 18.

Neckera crinita Sull. Expl. Exped. 1855, t. 10.

Ad arbor. - Am. sept. : Cuba. Am. merid. : Venezuela, Amazon, And. Quitens. et Peruv., Brasil, austr. or.

cubensis (Mitl.) Par.

Meteorium cubense Mitt. M. austr, am, p. 431.

M. trichophorum Sull.

Ster.

Cumingii (C. M.) Lta, in Krause $M$. Chile.

- Am. sept. : Cuba.

Meteorium molle Mitt. op. cit, p. 439.

Neckera Cumingii C. M. Syn. II, p. 132 et Bot. Zeit. 1855, p. 758.

2. - Am. merid. : Chile, Valdiv., ins. Chiloè, Juan Fernandez, Chonos, terr. Magellan.

curvifrons (C. M.) Par.

Orthostichella curvifrons C. M. in FI. 1890, p. 491.

Ster.

- Afr. : M. Aberdare.

cuspidans Ren. et Card. in Bull. Soc. roy. bot. Belg. 1890, I, p. 180.

Ster. Ad arbor. - Am, sept. : Haïti.

cyathipoma (C. M.) Par.

Neckera cyathipoma C. M. in Linn. 1878-79, p. 414.

2.

- Am. merid. : And. Boliv., Argentín. subtropic.

cymbifolia (Sull.) Jaeg. Ad. II, p. 158.

Neckera cymbifolia C. M. in Fl. 1875, p. 92; Lesq. et. Jam, Man. p. 284.

Pilotrichum cymbifolium Sull. M. of $i$. St. p. 81 el Ic. M. p. 122, $t, 76$ B.

2. $\sigma^{\hbar}$ et fr. ign. Ad arbor. $-A m$. sept. : Florida, Ludovic., Cuba.

debilinervis Ren. et Card. in Bull. Soc. roy. bot. Belg. 1895, I, p. 70.

Ster.

delicatula W.P. Sch. mss.

- Afr. : Ins. Borbon.

Callicosta delicatula Besch. Prodr, bryol. mexio. p. 83.

Pilotrichum delicatulum Jaeg. Ad. II, p. 140. Ster.

- Am. sept. : Mexic.

Deppei Besch. - Papillaria. 
densiramea. Broth. in Engler's Bol. Jahrb. 1894, p. 197.

Ster. Arbor. - Afr: : Usambara.

dimorpha (C. M.) Jaeg. Ad. 11, p. 772.

Meteorium dimorphum Mitt. in Trans. and Proced. of the roy. Soc, of Viotoria, 1883, p. 82.

Neckera dimorpha C. M. in Linn. 1871-73, p. 517.

Ster.

- Pac. : Austral. or.

dubia C. M. mss.

Ster.

- Pac. : Nov, Guinea. (M. Yule).

Dubyana Besch. - Papillaria.

Duseni (C. M.) Par.

Orthostichella Duseni C. M. in Dusen M. Camer. n. 262. - Afr.: M. Cameroon.

elongata (Mitt.) Jaeg. Ad. II, p. 158.

Meteorium elongatum Mitt. M. austr. am. p. 430.

Ster.

- Am. merid. : And. Peruv.

excavata (Mill.) Jaeg. l. c.

Meteorium excavatum Mitt. op. et $l$. $c c$.

Ster. austr. or.

- Am. merid. : And. Nov. Granat., Brasil.

filifera (C. M.) Jaeg. Ad. II, p. 165.

Meteorium filiferun Mitt. op. cit. p. 434 .

Neckera filifera C. M. Syn. II, p. 133.

Pilotrichum filiferum ej. in Bot. Zeit. 1848, p. 767.

Quitens.

-- Am. merid. : Venezuela, And. Nov. Granat. et

flavo-limbata Jaeg. - Papillaria.

flexilis (Svo.) Jaeg. Ad. 11, p. 162.

Hookeria flexilis Sm. in Trans, of the Linn. Soc. IX, p. 281.

Hypnum flexile Sw. Prodr. Fl. Ind. oco. p. 141.

H. nigricans Hpe. in Linn. 1817, p. 87.

Isothecium flexile Brid. Bryol. univ. II, p. 361.

Leskea flexilis Hedw. Sp. M. p. 234, t. 58.

Meteorium flexile Mith. op. eit. p. 438.

Neckera flexilis C. M. Syn. II, p. 129.

Pilotrichum turgidum ej. in Bot. Zeit. 1818, p. 767.

2. Ad arbor. - Am. sept. : And. Costa Ric., Jamaic. Am. merid. Venezuela, And. Nov. Granat., Brasil. austr. or.

floridana (Aust.) Ren, et Card. in Rev. bryol. 1893, p. 11.

? Neckera floridana Aust, in Coult. Bot. Gaz. IV, p. 152; Lesq. ct Jam. Man. p. 284.

Ster. Ad arbor. - Am. sept. : Florida.

funalis (Wils.) Jaeg. Ad. II, p. 170.

Meteorium funale Mitt. op. cit. p. 442.

Neckera funalis C. M. Syn. II, p. 136.

Pilotrichum funale Wils, in Ann, and Mag. of sat. Hist. 1847, p. 378.

Ster.

- Am, sept: Jamaic. Am, merid.: Guian. batav.

gracilicanlis (C, M.) Par.

Orthostichella gracilicaulis C. M. in Dusen M. Camer. n. I64.

- Afr. : M. Cameroon. 
ùrimaldii Ren, et Card. in Bull. Soc. roy. bot Belg. 1891, p. 192 et M. Masc, Mad, n. 39.

2. Arbor. - Afr. : Usambara, Madagascar or.

guianensis (Mont.) Par.

Neckera guianensis Mont. Syll. p. 24.

N. imbricata var, brachypoda ej. Cent. $I I, n .74$.

Ad ramul. in silv. - Am. merid. : Guian, gall.

Hampeana Kiaër in Borgen M. Mad. n. 30.

- Afr. : Madagascar centr.

hexasticha (Schwaëgr.) Jaeg. Ad. 11, p. 161.

Hypnum hexastichum Schwaegi: Suppl, I, II, p. 210.

Isothecium hexastichum Brid. Bryol. univ. II, p. 380.

Meteorium hexastichum Mitt. op. cit. p. 432.

Neckera hexasticha C. M. Syn. II, p. 126.

- Am. sept. : Costa Rica, Cuba, Hispaniola.

Holstii Broth. in Engler's Bot. Jahrb. 1894, p. 197.

Ster.

Husnoti Husn. - Pilotrichum.

- Afr. : Usambara.

illecebra Besch. - Papillaria.

illecebraria C. M. - Papillaria illecebra var. laevis.

illecebrina (C. M.) Par.

Neckera illecebrina C. M. in Linn. 1878-79, p. 416.

2. Ad arbor. - Am. merid. ; Argentin. subtrop.

imbricata (Schwaegr.) Besch. Prodr. bryol. mexic. p. 78 ,

Hypnum pentastichum W. Arn. Disp. p. 61 .

Isothecium pentastichum Brid. Bryol, univ. II, p. 378.

Leskea flexilis $\beta$ pentasticha ej. Sp. M. 11, p. 59 .

Meteorium imbricatum Mitt. in Journ. of the Linn. Soc. 1863, p. 156. Neckera imbricata Schwaegr. Suppl. II, II, I, p. 42 (excl. t. 165);C. M.
Syn. II, p. 128.

Pilotrichum imbricatum P. B. Prodi. p. 55, sub Hypno?

Ster.

Sierra Leone, Afr.: Ius. Fernando Po, M. Cameroon, Mexic.

imbricatula C. M. in Abhandl. Brem. VII, p. 209.

Neckera imbricatula ej, in Fl. 1888, p. 416 .

2. In silv. - Afi. : Kilima N'Djaro, Usambara, Madagascar (ster,!).

- var. nervosa Ren. et Card. in Bull. Soc. roy. bot. Belg. 1894, II, p. 126 et M. Masc. Mad. n. 228 .

impor Afr. : Madagascar.

imponderosa Besch. - Meteorium.

inflatifolia C. $M$, in Fl. 1886, p. 282.

2. Ster. Ad arbor. $-A f r$. : Ins. S. Thom.

inordinata (Mitt.) Broth. in Ule Bryoth. brasil. n. 179.

Meteorium inordinatum Mitt. M. austr. am. p. 435.

M. nitidum Sull. in Amer. Expl. Exped. 1855, $t, 20 \mathrm{~B}$.

involutifolia (Mitt.) Jaeg. Ad. 11, p. 159.

Meteorium involutifolium Mitt. in Jowin. of the Linn. Soc. 1863, p. 156.

Ster. $\quad-A f r$. : Sierra Leone, ins. Rodriguez. 
Isleana Besch. Fl. bryal. Réunion, elc. p. 126.

Ster. -. Afr.: Ins. Borbon.

"var. virescens Besch, l.c.

Ster,

- Afr. : Ins. Borbon.

isoclada Ren. et Card. in Bull. Soc. roy. bot. Belg. 1894, I, p. 180.

Ster. Ad ramul. - Am. sept. : Costa Rica.

Kegeliana (C. M.) Jaeg. Ad. II, p. 167.

Neckera Kegeliana C. M. in Bot. Zeit. 1858, p. 165.

Ster. - As. : Bombay.

Krausei Llz. Moosst. p. 164.

Ad arbor, - Am, merid.: Valdiv.

laevifolia (Mitt.) Jaeg. Ad. Jl, p. 164.

Meteorium laevifolium Mitt. op. cit. p. 441.

Quitens.

- Am. sept.: Jamaic. Am. merid. : Venezuela, And.

leptoclada $C$. M. in Fl. 1886, p. 282.

Ster. Ad arbor, - Afr. : Ins. S. Thom.

lepto-erioclada C. M. in Dusen M. Camer. n. 800.

- Afr. : M. Cameroon.

leuconeura Besch. - Papillaria.

leucotricha (Tayl.) Jaeg. Ad. II, p. 166.

Hypnum leucotrichum Tayl. in Lond. Journ. of bot. 1848, p. 196; C. M. Syn. II, p. 319.

Meteorium leucotrichum Mitt. cp. cit. p. 434.

Neckera rufescens C. M. Syn. II, p. 134.

Ad arbor. - Am. sept. : Jamaic. Am. merid. : Venezuela, And Nov. Granat., Quitens, et Peruv.

? livens (Schroaegr.) Jaeg. Ad. II, p. 161 (1).

Hypnum livens Schwaegr. Suppl. I, II, p. 211 et III, II, II, t. 284.

Isothecium livens Brid. Bryol. univ. II, p. 380.

Meteorium livens Mitt. op. cit. p. 433.

Neckera livens C. M. Syn. II, p. 128.

Ster.

- Am. merid. : Peruv.

longe-barbata (Hpe.) Jaeg. Ad. II, p. 166.

Meteorium longe-barbatum Mitt. op. cit. p. 436.

Neckera longe-barbata Hpe. in Linn. 1861-62, p. 525.

Ster. Ad arbor. - Am, merid. : And. Nov, Granat.

longifolia W. P. Sch. - Papillaria.

longinervis Ren. et Carl, in Bull. Soc. roy, bot. Belg. 1893, 11, p. 23 et M. Masc. Mad. n, 185.

2? Ster. Ad trunc. arb. - Afr. : Madagascar.

longipes (Mont.) Jaeg. Ad. 1I, p, 158.

Hypnum quadrangulare Schwaegr. Suppl. I, II, p. 212.

1sothechium tetrastichum Brid. Bryol. univ. II, p. 378 ?

Neckera longipes C. M. Syn. II, p. 123.

Pilotrichum longipes Mont. in litt.

Pterobryum Pohlii Mitt. op. cit.p. 438.

(1) a Forsan a $P$. nigricante non diversa \$. Mitt. l. c. 
2. Ad arbor. - Am. merid. : Guian. gall., Amazon., And. Peruv., Brasil. or.

longipila W. P. Sch. - Papillaria,

Ludoviciae (C. M.) Jaeg. Ad. 11, p. 158.

Neckera Ludoviciae C. $M$. in F7. $1875, p .92$.

Ster. Lignic. - Am. sept. : Ludovicia.

mascarenica (C. M.) Besch. Fl. bryol. Réunion, etc, p. 126.

Isothecium flexile Brid. Bryol, univ, II, p. 361 p.p.

Neckera mascarenica C. M. in Bot. Zeit. 1859, p. 237.

Ad ram. arbor. - Afr. : Ins. Borbon.

maniensis (Sull.) Jaeg. II, p. 159.

Meteorium mauiense Sull. in Am. Expl. Exped. p. 21, t. 19.

Rupic. - Pac. : Ins. Samoa, Sandwic.

mauritiana C. M. in Rev. bryol. 1878, p. 59 (nom.).

- Afr. : Ins. Franciae.

membranacea (Mitt.) Jaeg. Ad. II, p. 165.

Meteorium membranaceum Mitt. M. Ind. or. p. 88.

Ster.

- As. : Assam.

mexicana W. P. Sch, in Besch. Prodr. bryol, mexic. p. 79.

Ster.

- Am. sept. : Mexic.

mollis (Hedw.) Jaeg. Ad. 11, p. 164.

Hy pnum pendulum $P$. B. Prodr: $p .67$.

Leskea mollis Hedw. M. frond. IV, p. 40 ; Brid. Bryol. univ. $I I$, p. 292.

Stereodon mollis Mitt. in Journ. of the Linn. Soc. 1859, p. 88.

- Pac.: Austral. (Victoria), Nov. Hebrid, Nov.

. $\mathrm{Fl}$. Ttisman., II, p. 203.

- Pac. : Iiisd. loc.

nigricans (Hook.) Besch. Prodr. bryol. mexic. p. 79.

Hypnum nigricans Hook. in Kunth Syn. pl. Equin. 1, p. 64.

Isothecium nigricans Brid. Bryol. univ. $I I, p$. 363 .

M. nigricam macranthum Dz. et Mk. Prodr. fl. Surin. p. 47, t. 12.

Mit. nigricans Mitl. austr, am. p. 433.

Neckera nigricans Nees in Linn. 1846, p. 682; C. M. Syn. II, p. 132.

2. Ad arbor. - Am. sept. : Mexic., Cubs, Guadalup. Am. merid.:

Venezuela, And. Nov. Granat. et Quitens,

nigricans Ängstr. - P. Caroli.

nitens (Hook. f. et Wils.) Jaeg. Ad. II, p. 772.

Meteorium nitens H. f. et W. Fl. of the N. Zeal. II, p. 161, t. 87, f. 7 et Ster,

Handb. p. 460.

obovata Kiaër in Borgen M. Mad. n. 28.

- Pac. : Nov. Zeland. bor.

paichygaster (C. M.) Jaeg. Ad. II, p. 160.

- Afr. : Madagascar.

Meteorium pachygaster Mitt. M. austr. am. p. 432.

Neckera pachygaster $C . M$. Syn. II,, 126.

2?

- Am. merid. : And. Venezuel. 
* var. gracilis C. $M_{+}$in Bot. Zeit. 1857, p. 582.

- Am. merid. : And. Nov. Granat.

pachygastrella $C . M$. mss,; Angstr. in Oefv.... 1876, n. 4, p. 33 .

2? Ad arbor. - Am. merid. : Brasil, austr, or.

panduraefolia (C. M.) Jaeg. Ad. 1I, p. 159.

Neckera panduraefolia C. M. in Bot. Zeit. 1855, p. 767.

2 ?

- Afr. : C. B. Sp.

pentagona (Hpe. et Ltz.) Jaeg. Ad. II, p. $16 !$.

Pilotrichum pentagonum $H_{p e}$. et Ltz. in 13ot. Zeit. 1869, n. 28.

2. Ad arbor. - Am. merid, : Equator.

percapillaris C. M. in Dusen M. Camer. n. 654.

- Afr. : M. Cameroon.

peruviana (Milt.) Jaeg. Ad. II, p. 162.

Meteorium peruvianum Mitt. M. austr. am. p. 433.

- Am. merid. : Peruv.

phleoides (Desv.) Besch. Fl. bryol. Réunion, etc., p. 127.

Hypnum phleoides Desv, in Brid. Bryol. univ, II, p. 431.

Neckera phleoides C. M. Syn. II, p. 132.

Ster. Ad arbor. - Afr. : Ins. Borbon.

phyllogonioides (C. M.) Jaeg. Ad. II, p. I66.

Neckera phyllogonioides C. $M$, in Linn. 1869-70, p. 22.

Ster.

- Afr. : Ins. Ceylan.

Pinnatella Broth. in Engler's Bot. Jahrb, 1894, p. 198.

Ster. - Afr. : Usambara.

platyclada (C. M.) Par.

Orthostichella platyclada C. M. in Dusen M. Camer, n. 846.

- Afr. : M. Cameroon.

plicaefolia (C. M.). Jaeg. Ad. 11, p. 175.

Neckera plicaefolia C. M. in Bot. Zeit. 1854, p. 569.

Trachypus plicaefolius Mitt, $M$. Ind, or. p. 129.

Ster.

- As. : M. Neilgherr., Ceylan.

profnsicaulis (C.M.) Par.

Orthostichella profusicaulis $C . M$. in Fl. 1890, p. 492.

Ster.

- Afr. : Kilima N'Djaro.

pseudo-imbricata (C. M.) Besch. Fl. bryol. Réunion, etc. p. 126.

Neckera decolorans Hpe. in sehed.

N. pseudo-imbricata C. M. in Linn. 1876, p. 265.

2. Ad arbor - Afr.: Ins. Anjouan, Mayotte.

" var, pallescens (C. M.) Par.

Neckera pseudo-imbricata var. pallescens C. M. l. $c$.

Ut typ. - Afr. : Ins. Comores.

"var. rufescens (C. M.) Par.

Neckera pseudo-imbricata var. rufescens $C$. M. $l$. c.

Ut typ. - Afr. : Ins. Comor.

pseudo-rutilans C. M. mss.

Ster.

- As. : Sikkim. 
pulchella W. P. Sch, in Besch. Prodr. bryol. mexic. p. 78.

- Am. sept. : Mexic. (Orizaba), Costa Rica.

quinquefaria (C. M.) Jaeg. Ad. $I I$, p. $15 \%$.

Hypnum terrestre Aubl, Fl. Guian. IV, p. 962 ?

Isothecium pentastichum C. M. in Linn. 1848, p, 196.

Leskea? pentasticha Hseh. in M. Sieb. n. 29.

Meteorium quinquefarium Mitt. M. austr. am. p. 431.

Muscus terrestris, repens minor, cujus ramuli foliis multis et minimis seriatim quadrato ordine dispositis cinguntur Dill. Hist. M. p. 335, t, 43, f. 73 ?

Neckera quinquefaria $C . M$. Syn. II, .124.

Ster.

- Am. sept. : Guatemala, Costa Rica. Am. merid. : Ins. Trinitat., Guian. batav.

quitensis (Mitt.) Jaeg. Ad. 11, p. 161.

Hypnum quitense Mitt. in Spr. Cat. p. 15, n. 1012 ; Jaeg. l. c. p. 601.

Meteoriun quitense Mitt. M. austr. am. p. 439.

Ster.

- Am. merill. : And. Quitens.

Ragaziii Brizzi in Annuar. d. R. Institut. bot. di Roma, 1893, V, fasc. 2. 2? Ad arbor. - Afr.:

Rehmanni C. M. in Rehm. M. Afr. austr. n. 323.

- Afr. : Austral.

remotifolia (Hsch.) Besch. Proll. bryol. mexic. p. 82.

Leskea remotifolia $C, M$. in Linn. 1846, p. 216.

Meteoridium remotifolium $e j$, in $\operatorname{Linn}$. 1878-79, p. 492 .

Meteorium remotifolium Mitt. M. austr, am. p. 447.

Neckera remotifolia Hsch. in Deppe et Schiede M. Mexic. n. 1088 ; C. M. Syn. II, p, 672 .

2. Ad arb. et rupes, - Am. sepl. : Mexic., Costa Rica. Am. merid, : Venezuela, And. Quitens, Brasil. or.

rigida (C. M.) Besch. Prodr. bryol, mexic. p. 78.

Meteorium rigidum Mitt. op. cit, p. 439.

Neckera imbricata Hsch. in Deppe et Schiede M. Mexic.

N. rigida C. M. Syn. II, pp. 126 et 669.

2.

- Am. sept. : Mexic., Costa Rica.

rigidiuscula Husn, - Pilotrichum debile var: rigidiuscula. sericea (C.M.) Far.

Orthostichella sericea C. M. in Fl. 1890, p. 90.

Ster.

- Afr. : M. Aberdare.

Berricola C. M. in Ule Bryoth. brasil. n. 67.

- Am. merid. : Brasil anstr. or.

sinuata Besch. - Papillaria.

sordido-viridis C. M. in Dusen M. Camer. n. 369.

- Afr. : M. Cameroon.

spiculata (Mill.) Jaeg. Ad. II, p. 165.

Meteorium spiculatum Mitt. M. Ind. on p. 90.

Ster,

strictula (C, M.) Par.

- As. : Sikkim, Khasia, Ceylan.

Orthostichella strictula, G. M. in Rev, bryol. 1892, p. 41 (nom.).

- As. : Ins. Nicobar? Tanagra?

5ubheterocladia C. $M$. in Linn. $1873-79$, p. 493.

Ster.

- Am. merid. : Venezuela. 
subheterophylla (Geh, et Hpe.) Broth. in Ule Bryoth. brasil.n. 178. Pilotrichum subheterophyllum Geh. et Hpe. in Fl. 1881.

Ad arbor. - Am. merid. : Brasil, austr. or.

subimbricata (Hpe.) Besch. Fl. bryol. Réunion, elc. p. 126.

Neckera subi.nbricata Hpe. in Linn. 1874, p. 216.

Ster. In silvis, - Afr. : Madagasear.

subintegra Lindb. in Ångstr. Prim. lin. p. 34 (nom.).

- Am. merid. : Brasil. austr. or.

sublivens (Besch.) Par.

Meteorium sublivens Besch, op. cit.p. 127.

- Afr. : Ins. Borbon.

subpachygaster (C. M.) Par.

Orthostichella subpachygaster C. M. in Linn. 1878-79, p. 492.

- Am. merid. : Venezuela.

subpachygastrella Broth. in Bihang till K. Sv. Vet. Akad. Handl. 1895,

n. 3 .

2. fr. ign. Ad arbor. - Am. merid. : Brasil, or. (Minas Geraës).

subpendula (Geh, el Hpe.) Par.

Orthostichella subpendula G. et Hpe, in Fl. 1881 .

- Am. merid. : Brasil. austr. or.

subtenax C. M. in hb. Calcutta.

- As, : Sikkim.

tenax (C. M.) Jaeg. Ad. 11, p. 166.

Neckera tenax C. M. in Linn. 1869-70, p, 23.

Ster. $\quad-$ As. : Ceylan.

tenella (C. M.) Jaeg. Adl. I1, p. 165.

Neckera tenella C. M. in Bot. Zeit. 1859, p. 238.

Ster. - Am. sept. : Ins, S. Doming.

tenellula (C.M.) Par.

Orthostichella tenellula C. $M$. in Fl. 1890, p, 492.

Ster. In silvis. - Afr, : Kilima N'Djaro.

tenuinervis Ren. el Card. in Bull. Soc. roy. bot. Belg. 1894, 1, p. 181.

Ster. Ad arbor. - Am. sept. : Costa Rica.

tenuis (C. M.) Jaeg. Ad. II, p. 159.

Neckera tenuis C. M. Syn. II, p. 124.

2 ?

- Am. merid. : Brasil. austr. or.

teres Besch. - Papillaria.

Ternstroemiae (Brid.) Jaeg. Ad. 11. p. 165.

Hypnum Ternstroemiae Bvid. Bryol. wniv. 11, p. 431.

Meteorium Ternstroemiae Mitt. M, austr. am. p. 434.

Neckera Ternstroemiae C. M. Syn. II, p. 139.

Ster. Ad arbor. - Am. merid. : Nov. Granat.

tetragona (Sw.) Besch. Prodv, bryol, mexic. p. 78.

Hypnum tetragonum Sx. Prodi, Fl, Ind occ, p. 142.

1sothecium tetragonum Brid. Bryol, univ. $I I, p, 377$.

Meteorium tetragonum Mitt. op. oit. p. 431.

Neckera tetragona C. M. Syn. II, p. 125. 
Pterigynandrum aureum Brid. Mant. M. p. 101 ?

? Pt. quadrifarium ej. Bryol. univ. $I I, p$. 194?

Ad arbor. - Am. sept. : Mexic., Costa Rica, Jamaic. Am. nierid. :

Venezuela, And. Quitens., Peruv., Brasil. or. (Minas Geraës).

Thunbergii (Brid.) Jaeg. Ad. II, p. 162.

Hypnum Thunbergii Brid. Mant. M. p. 167.

Isothecium Thunbergii ej. Bryol. univ. II, p. $381 ;$;, M. Syn. II, p. 128.
Meteorium Thunbergii Mitt. op. cit. p. 432.

Ad arbor. ? - Am. sept. : Jamaic.

Tonduzii Ren. et Card. in Bull. Soc, roy. bot. Belg. 1894, I, p. 181.

Ster. - Am. sept. : Costa Rica.

tortipilis (C. M.) Jaeg. Ad. II, p. 166.

Meteorium tortipile Mitt. op. eit. p. 435.

Neckera tortipilis $C . M$. in Bot. Zeit, $p .76 \mathrm{~s}$.

Ster, Ad arbor. - Am. merid. : Brasil. austr. or.

trichophora (Mont.) Jaeg. Ad. 11, p. 163.

Isothecium trichophorum Mont. in Amn. sc, nat. 1843, p. 238 et Syll. p. 18.

Neckera trichophora C.M. Syn. II, p. 130.

Ster. Ad arbor. - Pac. : Ins. Sandwic.

trichophoroides (Hpe.) Jaeg. Adl. II, p. 163. Meteorium trichophoroides Mitt. in Trans. and Proced. of the roy. Soc. of
Victoria, 1883, p. 82 .

Neckera trichophoroides C. M. in Linn. 1874, p. 668.

Ster. - Pac. : Ins. Lord Howe.

turgescens (C. M.) Besch, Prodr, bryol. mexic. p. 79.

Meteorium turgescens Mitt, M. austr, am. p. 440.

Neckera turgescens $C . M$. Syn. II, pp, 131 et 670.

2. In silv. - Am. sept. : Mexio., Costa Rica, Jamaic., Guadalup. Arr, merid.: Nov. Granat., And. Quilens.

turgidellacea C. M. in Dusen M. Camer. n. 131.

turgidula (C. M.) Par.

Neckera turgidula C. M. in Linn. 1878-79, p. 417.

2 .

- var. tristis (C. M.) Par.

- Am. merid. : Argentin. subtropic.

Neckera turgidula var. thist

Ibid.

Uleana (C. M.) Par.

Orthostichella Uleana C. M, in Ule Bryoth. brasil. n. 76.

- Am. merid. : Brasil. sustr. or.

versicolor (C. M.) Jaeg. Ad. II, p. 162.

Dalionia imbricata Spreng. Syst, veg. IV, 1, p. 187.

Isothecium imbricatum Brid. Bryol. univ. II, p. 379.

Neceorium versicolor Mitt. op. cit. p. 432 .

Peckera imbricata Sohveagr. Suppt. II, 1T, I, p. 42, t. 165 texcl. syn.

N. versicalop , et Hedw.).

. Ad arbolor C. M. Syn. II, p. 127.

video.
- Am. merid. : And. Quitens., Brasil. austr. or., Monte-

viridis (C. M.) Jaeg. l. c.

Meteorium viride Mitt, op. cit, p. 433. 
Neckera viridis C. M. Syn. II, p. 125.

Orthostichella viridis ej. in Linn. 1878-79, p. 493.

2. - Am. merid.: Venezuela, And. Nov. Granat., Brasil, austr. or (1).

PILOTRIGHIDIU M Besch. Fl, bryol. Antill. fr. p. 69 (3 spec.).

Antillarum (Mitt.) Besch. $l$. c.

Hookeria Antillarum Mitt. M. austr am. p. 313.

H. varians var. Sull. in Proced. of the Amer. Acad., August. 1861.

2. Loc. humid. et ad arb. - Am. sept. : Cuba, Jamaic., Guadalup.

brunnescens (W. P. Sch.) Besch. op. cit. p. 70.

Hookeria brunnescens $\boldsymbol{W} . P$. Sch, $h b$.

2.

- Am. sept. : Guadalup.

eallicostatum (C. M.) Jaeg. Ad. II, p. 216.

Hookeria callicostata C. M. Syn. II, p. 216.

Ster. $\quad-A m$ merid. : Ins. Trinitat.

PILOTRICHUM P. B. Prodr. p. 37 (32 spec.).

abietinum Brid. - Alsia.

affine (Hook.) Bricl. Bryol. univ. 1I, p. 261; C. M. Syn. 11, p. 179;

Mitt. M. austr. am. p. 390.

Callicosta affinis C. M. in Linn. 1848, p. 188.

Daltonia affinis W. Arn. Disp. p. 54.

Neckera affinis Hook, M. ex. $t$. 122.

N. composita var. $\beta$ Schwaegr. Sp. M. I, II, p. 155. 2 . .. Am. sept. : Jamaic., ins. St-Vincent.

Amazonum Mitt. op. cit. p. 387.

Ster.

- Am. merid. : Amazon.

ambiguum Hsch. - Meteorium.

angustifolium C. M. - Pterobryum.

antipyrelicum C. M. - Fontinalis.

asperifolium Mitt. op. et $l, c c$.

2? Ad arbor. - Am, merid. : And. Nov. Granat.

Aurantium C. M. - Gatovaglia.

auro-nitens Hsch. - Meteorium Hornschuchii.

biduclulosum P. B. - Lepidopilum flexifolium.

biforme Hpe. - Pilotrichella.

biforme Hpe. - Pilotrichella.
bipinnatum (Schwaegr.) Brid. Bryol. univ. 11, p. 283 ; C. M. Syn. Il.
p. 178 ; Mitt. op. cit. p. 388.

Callicosta bipinnata C. M. in Limn. 1848, p. 189.

Daltonia bipinnata $W$. Arn. Disp. p. 55 .

Neckera bipinnata Sohweagr. Suppl. I, II, p. 156, t. 83.

2. Ad arbor. - Am. sept. : Jamaic., Guadalup. Am. merid. : Ins. Trinitat., Guian., Amazon., And. Quitens. et Peruv., Brasil.

(1) In Enumer, Kindberg, nom, nud. :

P. Ankasinae C. $M$.

P. decolorans C. $M$. 
"var. ovanescens C. M. Syn. IT, p. 179.

Callicosta evanescens ej. in Linn. l. c.

Ad arbor. - Am. nierid. : Ins. Trinitat., Guian. batav.

" var, filinerve $C, M, l, c$.

Ut et ubi praeced.

brasiliense (Hsch.) Hpe. Symb. 1874, p. 501.

Antitrichia brasiliensis Hsch, Fl. Brasil, I, p. 52.

Neckera brasiliensis C. M. Syn. II, p. 96.

Pterobryum brasiliense Mitt. op. cit.p. 427. 2. - Am. merid. : Amazon., 13rasil. atistr. or.

capillaceum Hsch. - Lindigia.

cilialum C. M. - Hedwigia.

var. secundum C. M. -- Hedwigia ciliata var. secunda.

var. slrialum C. M. - Hedwigia ciliata var. striata.

cirrifolium Hsch. - Meteorium longissimum.

cochlearifolium C. M. $\left\{\begin{array}{l}\text { - Pilotrichella. } \\ \text { - Pterobryum. }\end{array}\right.$

compositum (Svo.) P. B. Prodr. p. 82; Brid. Bryol. univ. II, p. 262; C. $M$. Syn. $I I, p .178$.

Callicosta composita C. M. in Linn. $1848, p ., 188$.

Daltonia composita $W . A r n$. Disp. p. 54 .

Hypnum compositum Sw. Prodr. fl. Ind. occ. p. 141.

Neckera composita Hedu. $S p$. M. p. 203, t. 46 .

Orthotrichum compositum Brid. M. Rec. II, II, p. 32, t. I, f. I.

2. In silv, - Am. sept. : Costa Rica, Jamaic. ; Guadalup. ? Am: merid. : Venezuela.

consimile C. M. - Cryphaea.

convolutum C. M. - Pterobryum.

coronatum C. M. - Erpodium.

cristatum Mitt. op. cil. p. 387.

2?

- Am, sept. : Jamaic.

croceum Hpe. - Papillaria.

cryphaeoides W. P. Sch. in Besch. Fl. bryol. Antill. fr. p. 45.

2. - Am. sept. : Guadalıp., Martinic.

cylindraceum C. M. - Pterobryum.

cymbifolium Sull. - Pilotrichella.

dalecarlicim C. M. - Fontinalis.

decurrens C. M. - Cryphaea attenuata?

debile Besch, op. cil. p. 48.

2.

- Am. sept. : Guadalup., Martinic.

* var. rigidiusculum W. P. Sch. in op, el $l$. ec.

Pilotrichella rigidiuscula Husn. M. Antill. n. 160.

delicatulum Jaeg. - Pilotrichella. - Am. sept. : Martinic.

densum (1) C. M. - Prionodon.

Deppei C. M. - Cryphaea patens.

(1) dentioulatum P. B. Prodr. p. 81 ; Brid. Bryol. univ. II, p. 266; C. M. Syn. II,
186 . - Afr. : Ins, Borbon. (An Mniadelphus? Deleatur). 
? disciflorum Geh, et Hpe. in Fl. 1881.

Ster.

- Am. sept. : Brasil austr. or.

distichum $\left\{\begin{array}{l}\text { (:. M. p.p. }\left\{\begin{array}{l}\text { Fontinalis. } \\ \text { P. B. - Nontinalis biformis. }\end{array}\right. \\ \text { Peekera. }\end{array}\right.$

divaricatum Mitt. M. austr. am p. 389 .

2 ? Ad arbor. - Am. sept. : Ins. S. Vincent.

diversifolium Ángstr. - Erpodium.

domingense C. M. - Erpodium.

dubium Mitl. op. cit. p. 390.

- Am. sept. : Guadalup.

elegans C. M. - Garovaglia.

elongatum C. M. - Prionodon.

exigum C. M. - Cryphaea.

fasciculatum $C . M$. mss.

- Am. sept. : Guatemala.

Fendleri C. M. in Linn. 1878-79, p. 492.

- Am. merid. : Venezuela.

filamentosum Brid. - Meteorium.

filescens Duby. - Meteorium.

filicinum P. P. - Pterobryum.

filiferum C. M. - Pilotrichella.

filiforme C. M. - Cryphaza.

var. squarrosulum C. M. - Acrocryphaea squarrosula.

filigranum C.M. mss.

- Am. sept. : Guatemala.

flagelliferum Brid. - Leucodon domingensis.

flexile Hpe. - Papillaria illecebra.

fontinaloides C. M. - Hydropogon.

foveolatum Hpe. - Neckera.

funale Wils. - Pilotrichella.

fuscescens C. M. - Papillaria.

genuflexum C. M. - Meteorium ancistrodes.

Gorveanum C. M. - Dendrocryphaea.

gymnostomum C. M. - Hydropogonella.

Hahneanum Besch. Fl. bryol. Antill. fr. p. 46.

2. Ad arbor. - Am. sept. : Guadalup., Martinic.

hamalum C. M. - Garovaglia.

helictophyllum C. M. - Meteorium.

Herminieri W. P. Sch, in Besch. op. cit. p. 47.

2. Ad arbor, - Am, sepl, : Guadalup.

heteromallum P. B. - Cryphaea.

var. aquatile C. M. - Cryphaea heterumalla var, aquatilis.

var. filıforme C. M. - Cryphaea glomerata.

heterophylla P. B. - Neckera.

Hookeri Dz. et Mk. - Neckera Plumula,

Hornschuchii C. M. - Pterobryum densum.

Husnoti W. P. Sch. in Besch, op, et l. cc.

Pilotrichella Husnoti Husn. M. Antili. fr, n. 159 a.

Ster. Ad arbor. - Am. sepl. : Guadalup. 
hypnoides (Hedw.) P. Beauv. Prodr. p. 83 ; Brid. Bryol. univ, 1I, p. 260 ; C. M. Syn. II, p. 179; Milt. op. cit. p. 390.

Callicosta hypnoides C. $M$. in Linn. 1848, p. 188.

Daltonia hypnoides $W$. Arn. Disp. p. 51 .

Fontinalis hypnoides Sw. Prodr. fl. Ind. oce. p. 138.

Neckera hypnoides Hedv, M. frond. III, p. 43, $t, 17$.

2.

- Am. sepl. : Jamaic.

imbricatum Brid. - Pilotrichella.

imponderosum C. M. - Lindigia.

inordinatum Hpe, - Pilotrichella.

intermedium Hpe. - Cryphaea.

Jamesoni Hpe. - Cryphaea.

julaceum $\left\{\begin{array}{l}\text { Hpe. - Acroeryphaea. } \\ \text { Hpe. }\end{array}\right.$

lumbatum Hpe. p.p. ?-Acrocryphaea mexicana.

Limbatum Hpe. - Rutenbergia.

Lindigii Hpe. - Porotrichum.

(Jongissimum $\mathrm{Hpe}$. - Meteorium.

longipes Mont. - Pilotrichella.

longipilum W. P. Sch, - Papillaria,

lophophyllum Sull. in Proced. of the Amer. Acad... 1861.

2? $\quad-$ Am. sept. : Cuba.

luteo-virens $\mathrm{C} . \mathrm{M}$. - Prionodon.

Lycopodium C. M. - Prionodon.

macranthoides Hpe. Enum. M. Brasil. p. 45.

Ster.

- Am. merid.: Brasil, austr, or.

microcyatheum C. M. - Hedwigia,

microthamnium $\mathrm{H}$ pe. - Porotrichum.

mucronatum Mitt. op. cit. p. 389.

Ster. In silv. $-A m$. sep $\iota$. : Costa Rica, Jamaic.

"var. elongatum" Ren. et Card. in Bull. Soc, roy. bot. Belg. 1894, I, p. 183.

Ut typ. - Am. sept. : Costa Rica.

nematosum (: M. - Climacium sulcatum.

nervosum C. M. - Cryphaea.

nigrescens Hsch. - Papillaria kermadecensis.

nitidum Hpe. - Porotrichum.

ils. - Meteorium.

nibale C. M. - Hedwigia.

oblusifolium Brid. - Hookeria microcarpa.

ovalifolium C. M. - Cryphaea.

paraphysale C. M. - Papillaria nigrescens.

palagonicum P. B. - Homalia glabella?

patens (:. M. - Cryphaea.

patulum $\{$ Brid. - Meteorium recurvifolium.

pennatum $\mathrm{C}$. M. - Meteorium.

pentagon P. R. - Neckera.

Pertagonum Hpe, et Ltz. - Pilotrichella.

phrottetii C. M. - Erpodium.

phliferm Wils. - Meteorium.

piliferum W. P. Sch. - Papillaria longipila,

piniforme Brid. - Porotrichum.

piritheca Ängstr. in Oefv... 1876, n. 4, p. 28. 
plicatum.C. M. - Garovaylia.

Plumula Nees ab Es. - Neckera.

Pluvini Brid. - Leptodon.

polylrichoides Brid, - Lepidopilum.

Powellii C. M. - Garovaglia.

procerum Milt. op. cil. p. 390.

2 ?

- Am. sept. : Ins. S. Vincent.

protensum C. M. - Cryphaea.

Puigyarii Geh, et Hpe. - Meteorium.

pumilum P. B. - Neckera.

punclulatum C. M. - Meteorium.

Ragazzii Brizzi in Annual: d. R. Istit. bot, di Roma, 1893, V, fasc. 2.

1. - Afr. : Choa.

ramosissimum Mitt. op. cit. $p .388$.

2? Ad arbor, - Am. merid. : And. Nov, Granat.

reclinalum $\mathrm{C}$. M. - Meteorium.

recurvifolium $\left\{\begin{array}{l}\text { Hpe, - Meteorium tovariense. } \\ \text { Hsch. - Meteorium. }\end{array}\right.$

rufescens C. M. - Dendropogon.

rugicaly:c C. M. - Pterobryum.

rugifolium C. M. Syn. II, p. 177.

Neekera hypnoides Hook. in sched.

2.

- Pac. : Ins. Hawaï.

scabriselum Brid. - Lepidopilum subenerve.

scariosum Ltz. - farovaglia.

Schiedeanum C. M. - Cryphaea.

seriatum C. M. - Papillaria Deppii.

serrulatum P. B. - Trachypus.

setigerum Sull. - Garovaglia.

setosum C. M. - Cyrtopus.

Smitliii P. B. - Leptodon.

solitarium C. M. - Jaegerina.

sphaerocarpum C. M. - Cryphaea.

spleagnifolium C. M. - Fontinalis biformis.

splendens C. M. - Pterobryum.

squamosum C. M. - Fontinalis.

squarrosum C. M. - Metcorium.

sticticolum C. M. - Meteorium.

stoloniferum C. M. - Jaegerina.

stramineum C. M. - Meteorium.

Stroembackii C. M. - Fontinalis hypnoides.

subambiguum Hpe. - Meteorium.

subrevalutam C. M. - Hedwigia.

sulfureum W. P. Sch. mss.; Jaeg, Ad. II, p. I42 (1).

- Pac. : Nov. Zeland.

subheterophyllum Geh. et Hpe. - Pilotrichella. Symphysodon C. M. - Pterohryom neckeroides. tamariscinum Hpe. - Porotrichuin.

tenellum C. M. - Cryphaea.

tenuicostatum Hpe. - Porotrichum.

(1) "An Meteorium? "Jaeg. 1. c. et p. 153. 
tenuissimum Hpe. - Meteorium.

Thieleanum Hpe. - Po rotrichum.

Tonduzii Ren. et Card. in Bull. Soc. roy. bot. Belg. 1894, I, p. 184.

Ster. In silv. - Am. sepl. : Costa Rica.

tovariense C. M. - Meteorium.

Trachypus C. M. - Trachypus bicolor.

trinitense Mitt. op. cit. p. 390 .

2 ?

- Am. merid. : Ins. Trinitat.

truncatum P. B. - Neckera disticha?

lumidum Brid. - Meteorium.

turgidum C. M. - Pilotrichella flexilis .

undulalum $\left\{\begin{array}{l}\text { P. B. - Neckera. } \\ \text { P. B. (fid. Mitt.). }\end{array}\right.$

vitianuin Sull. - Pterobryum.

Wallisii $C, M$. in Fl. 1875, n. 34-35.

- Am. merid. : And. Nov, Granat.

Widgrenianum Ângstr. - Meteorium (1).

Pinnatella C. M, in Linn, 1875, p. 456 (sect. HYPNI=POROTRICHUM).

PIREA Card. in Bull. Soc. roy. bot. Belg. 1894, I, p. 175 (1 spec.).

Mariae Card. in op. cit. p. 176.

2? Ad arbor. - Am. sept. : Costa Rica.

PLAGIOBRYUM Lindb. in Oefv. Vet. Akad. Foerh. 1862, n. 10 (7 spec.). demissum (H, et H.) Lindb. M. Scand. p. 17.

Bryum demissum Hook. M. ex. t.99; Bryol. eur. IV (mon. p. 31), t. 341 ;

C. M. Syn. I, p. 289; Drumm. M. bor. am. I ed. n. 250.
Meesea demissa H. et H. in Flora, 1819, p. 106; Brid. Bryol. univ. II, p. 64.

Pohlia demissa Hüb, Museol. germ, p. 466.

Zieria (2) demissa W. P. Sch. Coroll. p. 69 et Syn. II ed. p. 473 ; Rab. Bryoth. ewr. n. 1214.

2. Terr. - Eur. : In summ. Alp. cacum. Am. sept.: Perrar.: Colorado, summ. M. Rupestr., ins. Sabine.

Giraldii $(C, M$.). Par.

Bryum Giraldii C. M. in Nuov. Giorn. bot, ital. 1896, p. 94.

2. Terr. - As. : China or. (prov. Schen-Si.).

lamprocarpum (C. M.) Par.

Bryum lamprocarpum C. M. Bryol. Austr. Georg. p. 18.

Polyg.

leptocladon (Sull.) Par.

- Am. merid. : Austr. Georg.

Bryum Jeptocladon Sull. in Proced. An. Acad. 1861.

Zieria leptoclada Jaeg. Ad. $I, p, 605$.

2. Terr. - Am. sept. : Cuba.

(l) In Enum. Kindberg nom. nud. :

(2) Nom. microthamnium Hpe. I P. tenuicostatum Hpe.

(Rulaceae). 
macro-demissum (C. M.) Par.

Bryum macro-demissum C. M. mss.

- As. : Nepal. occid.

Wildii Broth, in Oefv. of Finska Vet. Soc. Foerh. 1890, p.

2.

- Pac. : Austral. or. (Queensland).

Zierii (Dicks.) Lindb, in op. et $l$. cc.

Bryum Zierii Deeks. Fase. I Pl. crypt. t.4, f. 10 ; Brid. Bryol, univ, I, p. 641 ; Bryol. eur. IV (mon. p. 29), t. 341 ; C. M. Syn. I, p. 288 et II, p. 572 ; Drumm. M. bor. am. I ed. n. 252.

Cladodium Zierii Hpe. Fl. Hercyn.

Hypnum Zierii $W$. et $M$. Bot. Taschb. p. 275 .

Mnium Zierii P. B. Prodr. p. 77.

Pohlia Zierii Schwaegr.Sp.M.p. 76.

Zieria julacea $W . P$. Sch, in op. et $l$. co.

2. In rup. fiss. madid. - Eur. : Reg. subalp. et alp. omn. Alp. et Apenn. ; Spitzberg, ins. Ursor., Britann., Pyren. As.: Caucas. centr. et or, Am, sept. : Groenland, M. Rupestr., Gaspesia.

Plagiocarpus Mitt. M. austr. am. p. 74 (sect. CAMPYLOPODIs).

Plagiodus ej. op. cit. p. 248 (sect. Funariae).

Plagiomela ej. op. cit. p. 270 (sect. Bartramiae).

PLAGIOPUS Brid. Bryol, univ. $1, p .596$.

EEderi Limpr. - Bartramia.

$\beta$ condensata Brid. - Bartramia CEderi var. condensata.

PLAGIOTHEGIUM Rryol, eur. V (77 spec.).

aciculari-pungens C. M. et Kindb. in Bidr, 454 (nom.) et in Mac. Cat. p. 216.

2. Ster. Terr. - Am. sept. : New Brunswick.

americanum Kindb. - Pl. bifariellnm.

andicola W. P. Sch, in Mandon Pl. Boliv. n. 1695.

H. andinum Hpe, in Ann. sc. nat 1865, V ser., V, p. 389.

- Am. merid. : And. Nov. Granat. et Boliv.

Anderssonii Ångstr. - Isopterygium.

antarcticum Mitt. in Journ. of the Linn. Soc. 1877, p. 71 (1) et in Philos.

Trans. of the roy. Soc. 1879 (extr. vol.), p. 36, $t$. III, $f .5$.

Hypnum antarcticum C. M. in Forehongsieise... Bot. p. 34.

$1-A f r$ : Ins, Kerguelen, Marion.

aomoriense Besch, mss.

$2 . \quad-A s$. : Japon.

Exs. : Faurie n. 40, 55, 220.

aptychopsis (C. M.) Por.

Hypnum aptychopsis C. M. in Fl. 1886, p. 517 .

1. Ad arbor. - Afr, : Old Calabar.

arboreum W. P. Sch. in Breutel M. Capens.

- Afr. : 0. B. Sp.

(1) " An Isopterygium? "Jaeg. Ad. II, p. 519. 
Arnoldi Milde in Hedwig. $1859, p, 50$.

1.

- Eur. : Francon, Siles.

attenuati-rameum Kindb. in Mac. Cal. p. 277.

Ster. Rupic. - Am. sept. : Quebec.

austro-pulchellum (C, M.) Par.

Hypnum austro-pulchellum $C, M$. in Englerrs Bot. Jahrb. 1883, p. 82 et in 1.

Forchungsreise... Bot. p. 35 .

- Afr. : Ins. Kerguelen. bifariellum Kindb. in Bull, Torr. bot. Club, XVIIX, p. 279 et in Mac.
Cat. p. 211.

Pl. americanum ej. Enum. Bryin. ex.

2. Ad terr. humid, in silv. - Am. sept. : Ins. Vancouver.

Borrerianum Spr. - Pl. elegans,

var. longinerve Spr. - Pl. elegans var. longinerve.

Bottinii (Breidl.) Vent, in Rev, bryol. 1882, p. 4.

Hypnum Bottinii Breidl, in Nuov. Giorn, bot. ital. XIII.

I. In paludos. - Eur : Etruria.

brasiliense Jaeg. - Pl. subaequans.

brevipungens Kindb. in Bidr. p. 453 (nom.) et in Mac. Cat. p. 215.

1. Rupic. - Am. sept, : Ontatio.

capense W. P. Sch. in Breutel M. Capens.

Chapmanni Duby in Mém... Genève, 1875, p. 8, t. 2, f. 2 .

- Afr. : C. B. Sp., litt. oce. mar. Erythr.

Chrismari Besch. - Isopterygium.

chrysobasis C. M. in Journ. of bot. 1877, p, 289 (nom.).

Lignie. - Am, sept. : Costa Rica.

corticolum Angstr. in Oef $v$... 1873, n. 5, p. 143 .

1.

decursivifolium Kindb. in Mac. Cat. p. 277.

Hypnum latehricola Mac. Canad. M. n. 304 p.p.

2. Ad conifer. semiputr. - Am. sept. : Ontario.

denticulatum (L.) Bryol, eur. (mon. p. 12), t. 50l ; W. P. Sch. Syn, II ed. p. 696 .

Fissidens denticulatus Willd. Prodr. fl. Berol. n. 922.

Hypnum denticulatum L. Sp, pl.p. 1588; C. M. Syn. II, p. 251 (una cum
H. silvatico).

H. denticulace

p. $266, t .34, f .5$.
.

Leskea deodon denticulatus Brid, Bryol, univ, $I I_{,} p, 551$.

L. flaceida Brid. Timm. Fl. Megap. n. 803 .

L. hamo Brid. op. cit. p. 308.

Pylaisasa angstr, in Th. Fries Bot. Not. 1866, p. 102.

1. Lignic radicans Dese, in Brid. op, cit, p, 282 .

berg, rarius rupic, v, terr. - Eur. : Zon, sept, et intermed. : Spitzberg, ins. Parry. As. : Japon., Amour, Saghalien, Jeniss, med. et sup, Obi, Sikkim, Talysch, Caucas, occ, et centr. Am. sept. : Groenland, Labrador, Anticosti, ins. Miquel., Nov. Scot., New Selkirk, Gaspes., Ottawa, Ontar., lac. Super., M. Rupestr. et Peruy, Alaska, Sitka, ins. Vancouver, reg. sept. et or. Am. merid. : Peruv. Pac, : Austral, or (var. ?), Tasman. 
Exs, : Drumm. M. bor. am. I ed, n. 164, 166 (Нурnит).

Mac. Canad. M. n. 310 (Hyрnum).

Rab. Bryoth. eur, n, 691.

Sull. et Lesq. M. bor. am. II ed. n. 531 (Hурпиm).

Un. itin. 1866, n. 57,$71 ; 1867, n .27$.

«subsp. aptychus Spr. in Lond. Journ. of bot. 1880, p. 35. Absque loco.

"var. crispatulum Linab. in Act. Soc. pr. Faun. et Fl. Fenn. 1872, p. 278.

Lignic. et ad terr. humid. - Eu* : Scandin., Fennia. As. : Amour.

a var. densum Bryol, eur. et W. P. Sch. ll. cc.

In fissur. rup. reg. subalp. et alp. in Eur, et Am. sept.

Exs. : Sull. et Lesq. M. bor. am. II ed. n. 532.

var. Donnii Lindb. - Pl. denticulatum var. obtusifolium.

«var. Graveti (Piré) Par.

Pl. Graveti Piré Nouv, rech, bryol... VII, p. 20.

Ad rup. madid. - Eur. : Belg., Silv. Nigra.

Exs. : Rab. Bryoth. eur. n. 1193.

var. laetum Aust. - Pl. passaicense.

a var. laxum Bryol. eur, et W. P. Sch. ll. cc.

Ad truncos deject, reg, subalp, in Eur. et Am, sept.

"var. microcarpum Ren. et Card. in Bot. Gaz. 1889, p. 98.

- Am. sept.: Washington, Idaho.

«var. myurum Bryol. eur, et W. P. Sch. Il. cc.

In fiss. rup. reg. subalp, et alp. in Eur.

« var. obtusifolium (Brid.) Par. Hypnum denticulatum var, obtusifolium Twrn. M. Hibern. p. 146, t, 14,
f. 2 .

H. Donianum Sm. Fl. brit. III, p. 1286 et Engl. Bot. t. 1446.

H. obtusatum Wahlenb. Fl. Lapp. p. 371 .

H. obtusifolium Brid. Mant. M.p. 153.

Pl. obtusifolium var. Donii Lindb. Animadv, p. 30.

Pl. Donianum Jaeg. Ad. II, p. 515.

Stereodon Donianus Mitt. M. Ind. or. p. 104.

Lignic. - As. : Sikkim. Am. sept. : Ubi typ. Am. merid. : Ins. Bremitae? Cap Horn? (fid. Handb. of N. Zeal. Fl.) Pac. : Nov. Zeland. med., Tasman.

" var. phyllorhizans Spr, in Lond. Journ. of bot. 1881.

$$
\text { - Eur. : Pyren. centr. }
$$

" var. secundum Lindb, in Acl. Soc. pr. Faun, et Fl. Fenn, l, c.

Lignic. - Eur. : Scandin., Fennia.

"var. squarrosum Kindb. in Bull. Torr. bot. Chub, XV1I, p. 179 et in Mac. Cal. p. 214.

Terr. - Am. sept. : Columb. brit., fret. Behring.

"var. sueculentum Wils. Bryol. brit. p. 407. var. sueculentum Wils. Bryol. brit. p. 407 .
Pl. succulentum Lindb. in Th. Fries Bot. Not. 1865, p. 143 et Animade.
$1867, p .29$.

$$
\text { - Eur. : Britann., Seandin. }
$$

" subsp. sulcatum Spr. in Lond. Journ. of bot. 1880, p. 355.

Absque loco. 
a var, tenellum Bryol. eur, et W. P. Sch. $7 l$. cc.

Ad truncos deject. reg. subalp. in Eur. et Am. sept.

Donianum Jaeg. - Pl. denticulatum var, obtusifolium.

elaiadelphus C. M. in Dusen M. Camer. n. 685.

- Afr.: M. Cameroon.

elegans (Hook.) W. P. Sch. Syn. II ed. p. 697.

Hypnum Borrerianum Spr. mss.; C. M. Syn. II, p. 279.

H. elegans Hook. M. ex. t. 9: Spr, in Ann, and Mag. of nat. Hist. 1849 et M. Pyr, n. 24; C. M. l. c, p, 260.

H. elegans $\beta$ collinum Wils. Bryol, brit. p. 408 ,

H. planifolium Brid. Bryol. univ. II, p. 411 (fid. Lindb.).

Isopterygium Borreri Lindb. in Act. Soc. pr. Faun. 3a X br 1881 (1).

1. elegans ej. Man. M. II, 1874, p. 416.

Isothecium elegans Brid. op. cil. p. 356.

Leskea prostrata Tayl. mss. (fid. Wils, l. c.).

P1. Borrerianum Spr. in Lond. Journ. of bot. 1880, p. 90.

PL. Schimperi Jur. et Milde in zool. bot. Verhandl. Wien, 1862, p. 968.

Rhynchostegium elegans Lindb. in Hedwig. 1863, p. 79.

2. Ad rup. et terr. - Eur. : Zon. intermed. et septentr.; in Britann. modo fructif. repert. $A s$. : Caucas, occ. $A m$. sept.: Labrador, Anticosti, Terr. Nov., ins. Miquel., Nov. Scot., M. Alb., New Jersey, Ontar., Columb. brit., ins, Vancouver, Washington, Oregon.

Exs. : Mac. Canad. M. n, 309 (Hypnum).

Rab. Bryoth. eur, n. 1093, $1189,1234$.

\& var, longinerve (Spr.) Par.

Pl, Borrerianum vas. longinerve $S_{\mu r}$..$c$.

In silv. arenos, - Eur. : Anglia (Yorkshire).

\&. var, nanum (Jur.) Par.

Pl. nanum Jur, mss, ; Milde in Bot. Zeit, 1864, Beil. 16.

-- Eur. : Westphal, Thuring., Siles.

a var, terrestre (Lindb.) Lesq. el Jam. Man. p. 366.

Rhynehostegium elegans var, terrestre Lindb, in Th. Fries Bot, Not. 1865, p. 139 et Arimadv. 1867, p. 38.

Terr. - Am. sept. : New Jersey (ster.).

Fitz-Geraldi Ren, et Cind, in Rev, bryol. 1893, p. 23.

Hypnum Fitz-Geraldi eor. in Lesq. et Jam. Man. p. 370.

Ster.

- Am. sept. : Florida.

fulvum Jaeg. - PI. micans var. fulvum.

Geninum (Mitt.) Jueg. Ad. $11, p .519$.

Hypnum geminum Lesq. et Jam. Man. p, 365.

Stereodon geminus Miti. in Journ. of the Linn. Soc. VIII, p. 39, t. 7. I.

- Am. sept.: M. Rupestr.

georgico-antarcticum (C. M.) Par:

Hypnum georgico-antarcticum C. M. Bryol, austs. Georg. p. 45.

Ster. Rupic. - Am. merid. : Austr. Georg.

Giraldii C. M. - Isopterygium

Graveti Piré. - Pl. denticulatum var. Graveti.

(I) Secundum Lindb. 1. c., spec. Anericana a sp. Europaea differt. - Cr. Spruce in Lond. Journ. of bot. 1880, p. 290 et in Rev, bryol. 1881, p. 52. 
homaliaceum Besch. in Ann. sc, not. 1893, XV111, p. 385.

1.

Exs. : Faurie n. 178.

homalophyllum (Mitt.) Jaeg. Ad. 11, p. 511.

Stereodon homalophyllus Mitt, in op. cit. 1863, p. 158.

1. Aquat. - Afr. : Niger.

Howeanum (C. M.) Jaeg. Ad. 11, p. 512.

Hypnum Howeanum $C . M$. in sehed.

- Pac. : Ins. Lord Howe.

incurvum de Not. - Hypnum incurvatum.

laetum Bryol. eur. V (mon. p. 7). t. 495; W. P. Sch. Syn. II ed.p. 691.

Hypnum denticulatum var. laetum Lindb. Animadv. p. 31 ; Mao. Canad. M. n. 311 .

Leskea laeta Wils. Bryol. brit, p. 408 in obs.

1. $\Lambda$ d stirp, putresc. et in rup. fissur. - Eur. : Suecia, Rhaet. As.: Jenissei med. et inf. Am. sept. : Groenland, Ontar., lac. Super., Columb, brit.

laevigatum W. P. Sch, in Savat. M. Japon. n. 691; Besch. in Ann, sc. nat. 1893, XVIII, p. 384.

2. $\sigma^{*}$ et fr. ign. $-A s$. : Japon.

lamprostachys (Hpe.) Jaeg. Ad. $11, p .515$.

Hypnum lamprostachys Hpe. in Linn. 1859-60, p. 639.

- Pac. : Austral. or.

lancifolium O. Debeaux in Act. Soc. Linn. Bordeaux, 1876, p. 173.

2 ? Ad rup. micaschist. littor. - As. : China or.

latebricola (Wils.) Bryol. eur. V (mon. p. 6), t. 494; W. P. Sch. op, cit. p. 690.

Hypnum latebricolum Lindb. mss. ; Lesq. et Jam. Man. p. 363.

H. scitulum Aust, in Bull. Torr, bot. Club, VI, p. 44 ?

Leskea latebricola Wils. Bryol. brit. p. 329.

2. Ad arb. trunc. viv. et deject. putresc. et ad stírp. Filic. - Eur.: Suec., Boruss. or., Westphal,, Thuring., vall, Rhen. inf., Angl. Am. sept. : Ontar., New York, New Jersey.

Exs. : Rab. Bryoth, eur, n. 543, 1233.

longisetulum $C$. $M$, mss.

- Am. sepl. : Guatemala.

longisetum Lindb. in Act. Soc. sc. Fenn. 1872, p. 232.

2 .

- As. : Japon., ins. Kiusiu.

lucidulum (Hook. f. el Wils.) Mitt. M. austr, am. p. 521. Hyprum Iucidulum H. f. et W. Fl. Antarct. II, p. 418, t. 155, f. I: C. M.
Syn. II, p. 349.

2 ? Rupic. - Am. merid.: And. Quitens,, Fuegia, ins. Eremitae, Maclor. lucidum (Hook. f. et Wils,) Par.

Amblystegium lucidum Jaeg. Ad, II, p. 547. Amblystegium lucidum Jaeg, Ad, II, p. 547 .
Hypnum lucidum $H$. f. el W. in Lond. Journ. of bot. 1844, p. 551; C.M.
Syn. II, p. 259.

$$
\text { - Am. merid. : Ins. Eremitae. }
$$

luteo-nitens (Ren. et Card.) Par. eo-nitens (Ren. et Card.) Par.
Hypnum luteo-nitens $R$ et C. in Bull. soc. roy. bot. Belg. XXX1, II, 1892,
p. 111 et M. Masc. Mad. r. 98 .

1. In graminos. - Afr. : Madagasc. 
magellanicum $C$. $M$. in Fl. 1885, $p, 425$.

Hypnum Donianum Mitt. $M$, aust, am. p. 520 iquoad loo. ins. Eremitae)?

lsopterygium fuegianum Besch, in Miss. se. Cap Horn, V, Bot. p. 301. - Am. merid. : Fuegia.

magellanicum W. P. Sch. - Jembophyllum auriculatum.

membranosulum C. M. in Rehm. M, Afr. auslr. n. 389.

- Afr. : C. B. Sp.

membranosum Kindh. in Bidr. 453 (nom.) el in Mac. Cal. p. 21.

Rhynchostegium? aneuron Kindb. in Ott. nat. IV, p. 65.

2 ? Lignic. - Am. sept. : Ontario.

micans (Swo.) Par.

Hypnum albulum C. M. Syn. II, p 280; Sull. M. of U. St p. 71 et Io. M. p. $179, t .112$; Sull. et Lesq. M. bor am. II ed. n. 418.

H. micans Sw. in Muhlenb. Cat, p. 104 et Adn. bot. p. 175; Lesq. et Jam. Man.p. 365.

H. subsimplex Sull. M. Allegh. n. 52 (fid, C. M.).

H. tenerum H. $f$. et W. in Drumm. M. bor, am. II ed. n. 108 el 109.

Isopterygium albulum Jaeg. Ad. $I I, p .502$.

Rhaphidostegium micans fien. et Card. in Rev. bryol. 1893, p. 21.

2. Lignic. et terr. - Am. sept. : Reg. merid.

e var, fulvum (Hook.) Par.

H. fulvum H. f. et W. l. e. n. 110 ; Sull. M. of U. St. p. 80 et Ic. M. p. $205, t .125$.

H. micans var. fulvum Lesq. et Jam, l. c.

Pl. fulvum Jaeg. Ad. $I I$, p. 516.

? Rhaphidotegium fulvum Ren, et Card. $1 . c$.

In paludos. - As. : Japon. Am. sept. : Ludovic.

Exs, : Faurie Pl. Japon. n. 18.

- var. submersum (Ren, et Card.) Par.

Rhaphidostegium micans var, submersum Ren, et Card. l.c.

- Am. sept. : Ludovicia.

"var. Ursorum (Sull.) Par.

H. albulum var. Ursorum Sull. M. bor. am. II ed. p. 75.

Terr. - Am, sepl. : Carol. super.

Monbuttoviae (C. M.) Jaeg. Ad. II, p. 514 .

Hypnum Monbuttoviae C. M. in Linn. 1875, p. 459.

1. Loc. humid. - Afr. : Monbonttou.

Morokae C. M. mss.

$$
\text { - Pac. : Nov. Guinea brit. }
$$

Müblenbeckii Bryol. eur. V (mon. p. 11), t. 499; W. P. Sch. op. cit. p. 702 .

Hypnum Mühlenbeckii Hartm. Skand. Fl. II ed., p.346.

B. pulchellum $B r$. et $S \mathrm{ch}$. in Drumm. M. bor. am. Lond. Joum, of bot. $1843, I I, p .668$.

H. Seligeri Swo, p.p.

H, silesianum Hook. in Dinemm, M. bor. I ed. n. I68 (fid. C. M.).

H. striatellum C.M. Syn. II, p. 282.

Leskea striatella Brid. Bryol. univ. IT, p. 762. PI, striatellum Lindb. in Th. Fries Bot. Not. $1865 ;$ p. 144 et Animadv.
p. 33 .

1. In rup. fissur. et ad abrupt. graminos. - Eur. : Reg. alp. et subalp., rar. mont. : Scandin,, Dania, Sudet, Alp. Salisb., Helvet., 
Pyren.; Scotia. Aml. sept. : Groenland, Labrador, Anticosti, Terr. Nov, ins. Miquel., Nov. Scot., New Brunswick, Ontar., reg. sept. et or.

Eoss. : Rab. Bryoth, eur, n. 901, 1092.

Sull, et Lesq. M. bor. am. II ed. n. 533 (Hypnum).

" var. chrysophylloides W. P. Sch. Syn. 1 ed.p. 581 et II ed.l.c.

Hypnum chrysophylloides $C$. M. Syn. II, p. 436 .

Ut typ. - Eur. : Nordland., Norveg. merid., Sudet.

Müllerianum W. P. Sch. Syn. I ed.p. 584 el 11 ed.p. 698; Sull. Ic. M. Suppl, p. 89, t. 66 (I).

Isopterygium Müllerianum Jaeg. Ad. II, p. 507.

2. In loc. excavat. soli imperv. - Eur. : Helvet., Tirol, merid, Alp. Bavar., Rhaet.; Pycen. As. : Caucas. occ. Am. sept.: M. Alb., New Jersey, Ohio. Pac. : Nov. Zeland.?

Exs, : Un. itin. 1863, n. 79.

nanum Jur, - Pl. elegans var. nanum.

neckeroideum Bryol. eur. V (mon. p. 16), t. 505; W. P. Sch. op, cit. p. 701.

PI, splendens W. P. Sch. in Savatier M. Japon, n. 700.

Stereodon neckeroideus Mitt. M. Ind. or. p. 103.

2. In praerupt. umbros. - Eur.: Rhaet., Salisburg. As. : Japon., Sikkim.

Exs. : Faurie Pl. Japon. n. 20.

Un. itin. 1863 , n. 82 .

" var. myurum Mdo. in Lts. Bryol. Notizb. 1865, p. 73.

PI, noricum $e j$. in sched.

Ut et ubi typus.

nemorale Jaeg. - Pl. silvaticum var, nemorale.

nitidifolium (Mitt.) Jaeg. Ad. II, p. 515.

Stereodon nitidifolius Mitt. in Journ, of the Linn. Soe. 1863, p. 158.

1. Cortic. - Afr. : Ins. Fernando-Po.

nitidulum (Wahlenb.) Bryol. eur. V (mon. p. 10), t. 498; W. P. Sch.op. cit. p. 694 .

Hypnum contextum Schleich. Crypt. helvet. Oent). III, $n .49$ (an Pl, pulchellum?

H, nitidulum Wahlenb. Fl. Lapp. $p, 370$.

H. nitidum W. et M. Bot. Taschb.
H. pulchellum Brid. Bryol. univ. II, p. 484 p.p.; C. M. Syn, II,
p. 277 p.p. H. 277 p.p.
M. n. $n$. 307 .

Isopterygium nitidum Lindb. Man. M. II, p. 416.

Leskea nitidula Wahlenb. in W. et M. op, cit p. 344 . Animadr.p. 31

Pl. nitidum Lindb. in Th. Fries Bot. Notiz. 1865, $p .145$ et Animadr obs.

Stereodon nitidulus Mitt, in Journ. of the Linn. Soc. 1861, p.

1. Lignic., ad fol. putresc. in loc. humid. - Eur. : Reg. montsma ef subalp.; Spitzberg, ins. Ursor. As. : Jenissei, Caucas. occ. et cenpes.,
Am. sept. : Groenland, fret. Davis, Anticosti, New York, Gases Ontar., lac. Super., Washington.

var. pulchellum Hartm. - Pl. pulchellum.

(1) An idem ac H, Mülleri H. f. et Wils. Fl, of the N. Zeal, If, p. 476 (nom. $)$ ? 
nilidum L.indb. - PI, nitidulum.

noricum Mdo. - Pl, neckeroideum var. myurum.

novo-granatense (Hpe.) Jaeg. Ad. II, p. 515.

Hypnum novo-granatense Hpe. in Linn. 1861-62, p. 531.

2. Lignic. et terr. - Am. merid. : And. Nov, Granat. et Quitens.

orthocarpum (Hsch.) Mitt. M. austr, am. p. 521.

Hypnum orthocarpum Hsch, in Fl. III, p. 520 (sinediagn.); C. M. Syn. $11, p .253$.

Isothecium orthocarpum Brid. Bryol. univ. II, p. 387 (nom. sol, memor.). 2.

\author{
- Am. merid. : Chile.
}

orthocladum Bryol, eut. - Pl, silvaticum var. orthocladum.

paleacum (Wils.) Jaeg. Ad. 1I, p. 518.

Leskea paleacea Wils. in sched.

Stereodon paleaceus Mitt. $M$. Ind. or. $p, 103$.

2.

- As. : Sikkim.

passaicense Aust, in Bull. Torr, bol: Club, V, p. 24 ,

Hypnum latebricola Mac. Canad. M. n. 304.

H. passaicense Lesq. et Jam. Man. p, 363.

Pl. denticulatum var. laetum Aust. M. Appal. n. 362.

2. Ad arbor. et rup. - Am. sept. : New Jersey, Ontar., Columb. brit. piliferum (Sw.) Bryol. eur. V (mon. p. 8), t. 496; W. P. Sch. op. cit. p. 692 .

Hypnum denticulatum var. Donianum Hook. in Drumm. M. bor, am. $I$ ed. $n .165$.

Hypnum denticulatum var. piliferum Wahlenb. Fl, Suec. I ed., I1, p. 710.

H. orthocarpon Angst. Disp. M. Soand. 1842, p. 2.

H. pulchellum Mae. Canad. M. n. 305 p.p.

H. trichophorum Spr. M. Pyr, n. 25 et in Ann. and Mag. of nat. list. 1849, II ser., III, p. 276; C. M. Syn. I1, p. 253; Mac. Canad. M. n. 305 .

Leskea pilifera Sw. Summ. veg. p. 41.

Neckera pilifera Spr. M. Pyr, n. 66.

Pl. trichophorum Kindb, in Mac. Cat. p. 212.

1. Ad rup. umbros, procip. vertic, vel excav, - Eur.: Scandin., Fennia, Pyren,, Corsica, Apenn. Emil. As, : Jenissei sup. Am. sept. : Tert, nov., New Brunswick, Gaspes., Ontar., Athabasca, M. Rupestr, et Selkiek, Columb. brit, fret. Behring, Washington, Oregon.

Exs. : Rab. Bryoth, enr. n. 632 ,

* var. brevipilum W. P. Sch. Syn. I ed. p. 578 et II ed. l. c.

Ut typ:-Eur. : Norveg.

plumigerum C. $M$, in Dusen $M$. Camer, $n$. 121.

- Afr. : M. Cameroon.

preudo-latebricola Kindb. in Mac, Cat, p, 211.

2. Lignic. - Am. sept. : Columb, brit.

preudo-silesiacum W. P. Sch. in Prnced. of the Am. Acad.... XIV, p. 140.

Hypnum pseudo-silesiacum Lesq, et Jam. Man. p. 370.

H. silesiacum H. f. et W. in Drumm. M. bor. am. II ed., n. 111 .

1.

- Am. sept. : Ohio, Montana.

Puiggarii Geh. el Hpe. mss, ; Jaeg. Ad. II, p. 776.

- Am. merid. : Brasil, austr. or. 
pulchellum (Dicks.) Bryol. eur. V (mon. p. 9), t. 497; W. P. Sch.op. cit. p. 693.

Hypnum pulchellum Dicks. Fasc. II Pl, crypt, t. 5, f. 6; Brid. Bryol. univ. II, p. 454 (una oum H, nitidulo); C. M. Syn. II, p.277 (ut Brid.)

H. rutilans Wils. Bryol. brit. p. 404 in obs.

H. Sendtneriamum C. M. op. cit. p. 394.

Isopterygium nitidum $\beta$ pulchellum Lindb. M. Scand. $p, 39$.

I. pulchellum Jaeg. Ad. II, p. 507.

Leskea pulchella Hedw. Sp. M. p. 220, $t, 55, f .7-12$.

Pl. nitidulum $\beta$ pulchellum Hartm. Skand. Fl. Xed.

Pl. nitidum var, suberectum Lindb, in Th. Fries Bot. Notiz. 1865, p. 145 et Animadv. p. 34 .

Stereodon pulchellus Mitt, in Journ. of the Linn. Soc, VIII, p. 39.

1. Ad terr. humos. et in rup. fissur. - Eur. : Reg. alp., rar, subalp. : Scandin., Sudet., Salisburg., Hercyn., Tirol., Helvet., Scot., Angl., Cambroval. As. : Jenissei. Am. sept. : Terr. nov, New Brunswick, Gaspes., Ontar.. Athabasca, M. Rupestr. et Selkirk, Colımb. brit., fret. Behring. Pac. : Nov. Zeland. med, ?

Exs. : Drumm. M. bor. am. II ed. n. 167 (Hypnum).

Mac. Canad. M. n. 306 p.p. (Hypnum).

Rab. Bryoth. eur. n. 1021.

Sull, et Lesq. M. bor, am. II ed. n. 530 (Hypnum).

Un. itin. 1863, n. 80.

pycnopteron (C. M.) Jaeg. Ad. II, p. 518.

Hypnum pycnopteron $C$. M. in sched.

- As. : Pegou.

radicisetum C. $M$, in Malpighia, 1896, p. 515.

l. $\quad-$ Am. merid. : Guian, brit.

Regnellii Ångstr. in Oefv.... 1876, p. 44 .

2? $\quad$ - Am. merid. : Brasil, austr. or.

repens Lindb. - Pl. silesiacum.

robustum Jaeg. - Hypnum.

Roëseanum (Hpe.) Bryol. eur. V (mon. p. 15), t.504; W. P. Sch. op. cit. p. 699.

Hypnum Roëseanum Hpe. in sched.

H. Stereodon cavifolius Brid. Bryol. univ, II, p. 510.

P1. silvaticum var, cavifolium Jur. in Rab. Bryoth, eur. n. 765.

Pl. silvaticum $\gamma$ Roesei Lindb. in Th. Fries Bot. Not. 1865, p. 143.

Pl. Sullivantiae Bryol. eur.? (fid. Lindb., Spr.).

2. Ad terr, arenos. et arenac.-argill. in silvat. - Eur.: Thuring. Baden, etc.

Exs. : Rab. Bryoth. eur. n. 564 b, 843 et b, 1298 et b.

sandwoicense Jaeg. - Eetropothecium.

Schimperi Jur, - Pl, elegans.

Schraderi (C. M.) Par.

Hypnum Schraderi C. M. in Linn. 1878-79, p. 496.

2.

- Am. merill. : Venezuela.

selaginelloides C. M. in Rehm. M. Afr. austr. n. 390 .

- Afr. : Austral.

Seligeri Lindb, - PI, silesiacum. silesiacum (Selig.) Bryol. eur. V (mon. p. 12), t. $500 ;$ W. P. Sch. op.
cit. p. 703 .

Hypnum planifolium Brid. Bryol, univ. II, p. 411 (fid. C. M.). 
H. repens Poll. Pal. $I I I, p .157$.

H. Seligeri C. M. Syn. II. p. 259.

H. silesiacum Selig. mss.; W. et M. Bot. Taschb, p. 343.

H. silesianum P. B. Prodr. p. 70.

H. Stereodon silesiacus Brid. op. cit. p. 554

Isopterygium repens Lindb. Man. M. II, p. 476.

Leskea Seligeri Brid. M. Rec. II, II, p. 47.

PI. repens Lindb. Animadv. p. 36.

Pl. Seligeri ej. in Th. Fries Bot. Not. 1865, p. 44.

1. Lignic, rar ad rup, arenae. - Eur.: Fere tota in silv, montos., proecip. aceros. As. : Japon., Caucas. occ, et centr. Am, sept. : Terr, nov., New Brunswick, Ohio, Washington.

Exs. : Rab. Bryoth, eur. n. 447, 690, 1297.

Un. itin. $1866, \mathrm{n}, 20$.

silvaticum (Huds.) Bryol, eur. V (mon. p. 14), t. 503; W. P. Sch. op. cit. p. 700 .

H. denticulatum $C . M$. Syn. $I I, p .251$ p.p.

H. denticulatum $\beta$ silvaticum Turn. Muscol. Hibern, spicil. p. 146.

$\mathrm{H}$. denticulatum pinnulatum, pinnulis rarioribus, simplicibus Dill. Hist. M. p. $267, t, 34, f, 6$.

H. silvaticum Huds. Fl. Angl. I ed. p, 4I9; L. Mant. pl. II, p, 310 .

H. Stereodon silvaticus Brid. Rryol. univ. II, p. 550.

2. Ad rup. humid, et terr, argill., rar, lignic. - Eur.: Passim. As.: Japon., Saghalien, Jenissei sup., Caucas. occ, et centr. Afr : Madeir. Am. sept.: New Brunswick, Gaspes., Ottawa, M, Selkirk, Columb. brit., reg, sept., or. et centr., Florida.

Exs. : Faurie Pl. Japon., n. 65.

Mac. Canad. M. n. 313 (Hypnum).

Rab. Bryoth, eur. n. 448, 1235.

Sull. et Lesq. M. bor. am. II ed. n. 534 (Hурпит).

Un. itin. 1866, n. 4.

var. cavifolium. Jur, -. Pl. Roëseanum.

var. nemorale (Mitt.) Par.

Pl. nemorale Jaeg. Ad. I1, p. 517.

Stereodon nemoralis Mitt. M. Ind. or. p. 104.

Filicic. - As. : Japon., Sikkim.

"var. orthocladum W. P. Sch. Caroll. p. 115 et op. eit.

Pl, orthocladum Bryol. eur, l. c. t. 504.

Terr. - Eur. : Ubi typ. As. : Japon., Caucas, occ. Am. sept. : Ubi typ. Exs. : Faurie Pl. Japon., n. 20.

var, Roesei Lindb, - Pl. Roeseanum.

( vor. squarrosum Kindb, in Bull. Torr, bot. Club, XYI1, p. 279 el in Mac, Cat. p. 214,

Terr. - Am. sept. : Columb. brit.

simostegium C. M, mss.

- As. : Himalaya sept. occ. (Dehra Doun).

sphagnadelphus C. M. in Rehm. M. Afr. austr. n. 389.

Ster. - Afr. : C. B. Sp.

splendens W. P. Sch. - Pl, neckeroideum.

striatellum Lindb. - Pl. Muhlenbeckii.

subaequans (Hpe.) Par.

Hypnum brasiliense Hpe Symb. 1877, p. 731. 
H. subaequans ej. Enum. M. Brasil. p. 71.

Pl. brasiliense Jaeg. Ad. II, p. 776.

1

- Am. merid. : Brasil, austr. or.

subfalcatum Aust, M. Appal, n. 366; Sull. Ic. M. Suppl.p. 90, t.67

Hypnum subfalcatum Lesq. et Jam. Man, p. 371.

Isopterygium subfalcatum Jaeg. Ad. II, p. 504.

Ster. In rup. fissur. - Am, sepl. : M. New Jersey et New York. subglaucum Thw. et Mitt. in Journ. of the Linn. Soc. 1872, p. 321

Ster. - As. : Ceylan.

subsimplex Besch. - Rhaphidostegium.

subsquarrosulum $C$. M. mss.

- As. : Himalaya sept. occ. (Dehra Doun).

succulentum Lindb. - Pl. denticulatam var, succulentum.

Sullivantiae Bryol. eur. V (mon, p. 16, nom.) (1).

Hypnum silesianum Drumm. M. bor. am. I ed. n. 168 (fid. Kindb.).

H. Sullivantiae Sull. M. of U. St. p. 80 et Io. M. p. 207, t. 126; Lesq. et Jam. Man. p. 368 .

2. Ad terr. et rup. arenac, humid. - Am, sept.: Terr, nov., ins. Miquelon, Nov. Scotia, New Brunswick, Nov. Anglia, Ontap., M. Selkirk, ins. Vancouver, Washington, Wyoming, Ohio.

Exs. : Mac. Canad. M. n. 312 (Hypnum).

Sull, et Lesq. M. bor, am. II ed. n. 535 (Hypnum.)

taxirameoides $C . M$. mss.

- As. : Himalaya sept. occ. (Dehra Doun).

tenerrimum Ảngstr. - Trichosteleum.

trichophorum Vent. et Bott. - Pl. piliferum.

trichopodium Kindb. - Pl. piliferum.

turfaceum (Lindb,) W. P. Sch. Syn. I ed. p. 692 et 11 ed. p. 695.

Hypnum turfaceum Lindb. in Oef. 1857, p. 121.

Isopterygium turfaceum ej. Man. M. II, 1874, $p .416$.

Stereodon turfaceus Mitt, in Journ. of the Linn. Soc. VIII, p. 39.

1. In terr. turfos. - Eur. : Scandin., Fennia. As. Amour, Saghalien, Jenissei sup. Am, sept. : Anticosti, ins. Miquel., Nov. Scot., New Rrunswick, M. Alb. et Allegh., New Jersey, Gaspes., Ottaws, Ontar., Manitoba, Athabasca, Columb. brit. Washington.

Exs. : Mae. Canad. M. n. 308 (Hypnum). undulatum (L.) Bryol. eur. V (man. p. 17), l. $506 ;$ W. P. Sch. op. cit.
p. 701 . p. 70L.
Hypnum pennatum, undulatum, Lycopodii instar sparsum Dill. Hist. $M$.
p. $271, t, 36, f .11$.

H. undatum Schrank Bä̈ers Fl. II, p. 480. H. undatum Schrank Bä̈ers Fl. II, p. 480 .
H, undulatum L. Sp. pl. II ed., p. 1589; Bryol. univ. II, p. 39i; O. M.
Syn. II, p. 257.

Lesken crispa Sehrank Prim. fl. Salisb. n. 835.

Stereodon undulatus Mitt, in , Journ. of the Linn. Soo. 1864, p. 39.

2. Ad terr. muscos. in ericet silvarum. - Eur. : E reg. montosa usq. Am. sept : Columb, brit., Alaska, Sitka, ins. Vancouver, Washington, Oregon, Calif.

(1) Forsan a Pl. Roëseano haud distincta spec. (Spr, in Lond. Journ. of bot. 1885 et in Rev, bryol. 1881, p. 53 ; Lindb. Animadv. p. 29). 
Exs. : Mac. Canad. M. n. 314 (Hypnum).

Rab. Bryoth. eur. n. 296.

Un, itin. 1866, n. 67.

unilaterale C. M. in Malpighia, 1896, p. 516.

Ster. - Am, merid. : Guian, brit.

Villae-Ricae Besch. Not. M. Parag. n. 271.

1. $\quad$ - Am merid.: Paraguay.

Exs. : Bal. PI. Parag. n, 1210 (1).

PLATYGYRIUM Bryol, eur. V ( 9 spec.).

amblyocarpum (Hpe.) Jaeg. Ad. II, p. 343.

Hypnum extenuatum? (fid. Mitt.).

Leskea amblyocarpa Hpe, in Linn. 1859-80, p. 638.

- Pac. : Austral. fel.

aureum Sb. - Cylindrothecium.

brevifolium (Wils.) W. P. Sch. mss.

Pylaisaea brevifolia Wils. in sehed.

P. decolor Jaey. Ad. II, p. 372 .

Stereodon brevitolius Mitt. M. Ind or. p. 92.

2? $\quad-$ As. : Sikkim.

? denticulifolinm C. M, in Nuov. Giorn, bot, ital. 1897, p.

Ster.

- As. : China or. (prov. Schen-Si).

ferricolum (C., И.) Jaeg. l. c. (false Pl. brevicollum).

Pterigynandrum ferricolum $C$. $M$. in Linn. $1875, p .454$.

2? Ster. Terr. - Afi. : Dar Fertit.

gautemaliense W. P. Sch. mss.; Jaeg. op. cit. p. 342.

- Am. sept. : Guatemala.

inflexum (Harv.) Jaeg. l. c.

Hypnum inflexum Harv, in Lond. Journ. of bot. 1840, II, p, 20 et in Hook. Ic. pl, rar, t. 24; C. M. Syn. II, p. 430.

Stereodon inflexus Mitt. M. Ind. or. p. 92.

2.

- As. : Nepal., Ava.

julaceum Bryol. jav. - Erythrodontium squarrulosum.

pertenue Sande Lac, Spec. nov. M. Archip. in.t. p. 12.

2. Ster. Ad arbor. - As.: Java.

repens (Brid.) Bryol. eur. V, t. 458; W. P. Sch. Syn. II ed. p. 622.

Anomodon repena ILúb, Muscol. germ. p. 558.

Anomodon repens $\beta$ majus de Not. Syll. $n .10$.

Bruchia repens Hsch. in Bot. Zeit. 1825, II. Beil. p. 10.

Cylindrothecium repens de Not. Eipil. p. 214.

Entodon palatinus Lindb. M. Scand. p. 39.

Hypnum palatinum Neck, in Act. Acad. Theod palat. II, p. 454 exel.syn.,

t. A, f. I (fid. Lindb.).
Isothecium repens Spr. in Ann. and Mag. of nat. hist, 1849, M. Pyr. n. 92 .

Leptohymenium repens $H_{p e}$, in Linn. 1835-36, p. 83.

Leskea repens Hartm. Skand. Fl. V ed., p. 340.

(i) In Enumer Kindberg. nom :

PI. belvolum $C . M$. 
Maschalocarpus repens Spreng. Syst, veg. IV, I, p. 159.

Neckera repens Schwaegr. Suppl. III, I, p, 2, t. 246; C. M. Syn. II pp. 87 et 666.

N. sericea Froehl. in Brid. Sp. M. II, p. 40; Drumm. M. bor, am. I ed n. 159.

Pl. repens var. orthocladon Mac, Canad. M. n. 259 p.p.

Pterigynandrum repens Brid. Bryol. univ. II, p. 183.

Pterogonium intricatum Drumm, M. bor. am. I ed, p. 75

Pt. repens Schwaegr. Suppl, I, I, p. 100, t. 27.

2. Ad arbor. silvat., praepr. Pin. et Betul., tecta stramin., rar, sax, Eur. : Planit, et reg. campestr. As. : Jenissei sup., Persia, Caucas. occ. et centr. Afr. : Alger. Am. sept.: New Brunswick, Gaspes., Ottawa, Ontar., M. Rupestr., reg. septr., occid,, or., centr. et merid.

Exs. : Drumm. M. bor, am. II ed. n. 98.

Rab. Bryoth. eur. n. 4 b et c, 990.

Sull. et Lesq. M. bor. am. II ed. n, 385 .

" var. gemmiclada Limpr. Laubm. Deutschl. III, p. 8.

Ut et ubi typ, in Eur.:

"var. orthoclados Kindb. in Mac. Cal. n. 172.

Lignic. - Am. sept. : Ottawa.

« var. rupestris Milde in sched.; Limpr. Kryptfl. Schles. I. p. 93.

Ad rup. arenac. et granit. - Eur. : Harz, Tirol.

"var. sciuroides (Saut.) Limpr. Laubm. Deutschl. 11I, p. 7.

Isothecium repens var. sciuroides Saut, in Brevtel M. frond. exs, n. 296.

Ad tecta straminea. - Eur. : Salisburg., etc.

rupestre Kindb. - Tripterocladium.

russulum (Mitt.) Jaeg. Ad. II, p. 342.

Stereodon russulus Mitt. $M$. Ind. or. $p .94$.

2 ?

- As. : Nepal. or., Sikkim.

squarrulosum Jaeg. - Erythrodontium.

stramineum $\mathrm{Sb}$. - Leptohymenium.

subjulaceum Jaeg. - Erythrodontium.

PLATY-HYPNUM Hpe. Moosbild. p. 18. nitidulum Hpe. - Isopterygium norfolkianum.

PLATYLOMA Kindb. Check-list of Eur. and N. Am. M. p. 22. Lescurii Kindb. - Amblystegium.

Platyphyllum C. M. Syn. 1, p. 247 (sect. BRYi).

Platysphagnum C. M. in Linn. 1874, p. 546 (nom.) et in Fl. 1887, p. 404 (SPHAgxa CXMBifolia).

Platystoma C. M. Syn. I, p. 776 (sect, Grimмiar).

Platystomium C. M. Syn. $I I$, p. 649 (sect. Gumbeliae).

PLAUBELIA Brid. Bryol, univ, 1, p. 522.

canariensis Brid, - Leucodon.

tortuosa $\left\{\begin{array}{l}\text { Brid. - Trichostomum Berteroanum. } \\ \text { Br. - Trichostomum mutabile. }\end{array}\right.$ 
PLEURIDIOPSIS Par. (2 spec.).

amblyocalyx (C.M.) Par.

Astomiopis amblyocalyx C. M. in Iinn, 1880-83, p. 391.

1 .

- Am. merid. : Alp. Argentin. subtropic.

subulata (C.M.) Par.

Astomiopsis subulata $C . M$. in op. et $l$.ee.

1 ?

- Am. merid, : Alp. Argentin, subtropic.

PLEURIDIU M Brid. Bryol. univ. II, p. 160 emend (23 spec.). acuminatum Lindb. - Pl. subulatum.

alternifolium Brid. Bryol. univ. II, pp. 161 et 769 ; Bryol. eur. V (mon. p. 15), t. 10 ; W. P. Sch. Syn. II ed.p. 26. Astomum alternifolium Hpe. in Linn. 1832, p. ; C. M. Syn. I, p. 14 et
II, $p .518$.

Phascum alternifolium Dicks. Fasc, I Pl. crypt.p. 2, t. I, f. 2 ,

Ph. subulatum Hedw. Stirp. t. 25.

Pl. Subulatum Lindb, in Oefv. Vet. Akad. Foerh. 1863, p. 408.

PI. Toepferi Ortel in Deutsch. bot. Monatsschr. 1884, p. 3.

1. In terr. argill. arenac. et argill. - Eur.: Zon, intermed. tota, in sept. passim. As. : Caucas. occ. Am. sept. : Reg. or. et centr.

Exs. : Rab. Bryoth, eur, n. 153.

Sull. et Lesq. M. bor. am. II ed. n. 36.

"var, Howei Ren. et Card. in. Rev. bryol. 1893, p. 30.

Terr. - Am. sept, : Calit.

"var. lancastriense Sull. M. bor, am. II ed. p. 9; Lesq. et Jam. Man. p. 44.

Ut typ. - Am. sept.: Ohio.

Eœs. : Sull, et Lesq. 1. c. n. 37.

"var, robustum Sull, Lesq. et Jam. $l l . c c$.

Archidiun Lescurii Aust, in Bull. Torr. bot, Dlub, VI, p. 144.

Ut typ. - Am. sept. : Alabama.

Exs. : Sull. et Lesq. I. c. n. 38.

Arnoldii (R. Br.) Par.

Phascum Arnoldit R. Br, in Trans. of the N. Zeal. Inst. 1893, p. 303.

Terr, - Pac. : Nov. Zeland.

axillare Lindb, - Pl, nitidum.

Bolanderi C. M. mss. ; Jaeg. M. cleist. p. 32; Lesq. et Jam. Man. l. c.

1. $\rightarrow$ Am. sept. : Calif.; Kansas?

brachycaulon (C. M.) Par.

Astomum brachycaulon C. M. in Fl. 1888, n. 1 .

1. Terr. - Pac. : Austral. or. (Nov. Vales.).

Breutelianum (Hpe.) Jaeg. M. cleist. l. c. et Ad. I, p. 222. Astomum Breutelianum Hpe. mss.; C. M. in Bot. Zeit. 1859, p. 97.

- Afr. : C. B. Sp.

caldense Lindb. mss. ; Ångstr. Prim. lin. p. 3 (nom.). - Am. merid.: Brasil, austr. or.

tstatum (C. M.) Mitt. M. Ind. or. p. 7 .

Astomum denticulatum C. M. in Bot. Zeit. 1853, p. 18.

- As. : M. Neilgherr. 
exiguum (Hook. f. et Wils.) Jaeg. M. cleist, p. 31 et Adl. I, p. 221.

Astomum Krauseanum Hpe. mss, ; C. M. Syn. I, p. 16.

Bruchia exigua C. M. in Bot. Zeit. 1847, p. 99.

Phascum exiguum $H$. f. et W. in Hook, Ic. pl, rar, $t .737 \mathrm{~B}$.

1.

- Fac, : Austral. or.

globiferum Brid. Bryol, univ. II, p. 162.

Astomum globiferum C. M. in Bot. Zeit. 1847, p. 98 et Syn, I, p. 16.

Terr. - Afr. : Ins. Franciae (fid. Brid.).

gracilentum Mitt, in Journ. of the Linn. Soc. 1859, p. 65 et in Fl. Tasin. II, p. 164, t. 171, f. 3.

1. $\quad$ - Pac.: Fret. reg. Georg., Austral., Tasman.

lanceolatum (R. Br.) Par.

Phascum lanceolatum R. Br. in Trans. of the N. Zeal. Inst. 1893, p. 302. Terr. - Pac. : Nov. Zeland.

longifolium (R. Br.) Par.

Phascum longifolium $R$. Br, in op, cit. p. 308.

Terr. - Pac. : Nov. Zeland.

nervosum (Hook.) Hook. f. et Wils. Fl. of the N. Zeal. 11, p. 58.

Astomum nervosum C. M. in Bot. Zeit. 1847, p. 98 et Syn. M. I, p. 15 p.p.

Phascum nervosum Hook. M. ex. t. 105.

Ph. curvulum Tayl, in M. Drummond (fid. Wils.),

1. Ad terr. argill. - Afr. : C. B. Sp. Pac. : Austral. or., Nov, Zeland.

Exs. : Rehm. M. Afr, austr. n. 462 et b.

nervosum Sull. - Pl. Sullivantii.

nitidum (Hedwo.) Brycl. eur. I (mon. p. 12), t. 9; W. P. Sch. op. cit. p. 24.

Astomum axillare Hpe. in Linn. 1838, p. 533.

A. nitidum Hpe. in Linn. 1832, p. ; C. M. Syn. I, p. 17 et II, p. 518.

Ephemerum nitidum Hpe. in Fl. 1837, p. 285.

Phascum axillare Dicks, Fasc. I Pl. crypt. p. 2, t. I; Brid. Bryol, univ. I, p. 35.

Ph. nitidum Hedw. Stirp. I, t. 34 et M. frond. I, p. 92, t. 34; Brid. op. cit. pp. 35 et 755 .

Ph. stagninum Wallr, in Linn. 1840, p. 680.

Ph. strictum Dicks. Fasc. IV Pl. crypt. $t$. 10, f. I; Brid. op. cit. p. 34.

Pl, axillare Lindb. M. Siand. p. 27.

Syn. In terr. argill, et stagn, exsicc. - Eur. : Fere tota. A fr. Alger.

Exs. : Rab. Bryoth. eur. n. 403.

"var, bulbilliferum Besch, in Husn, Muscol. gall. p. $t 6$.

Ut typ. - Eur. : Gall. centr. et occ.

Pappeanum (C. M.) Jaeg. M. Cleist. p. 31 et Ad. I, p. 221.

Astomum Pappeanum C. M. Syn. I, p. 15.

1. Terr. - Afr. : C. B. Sp.

Ravenelii Aust, in Bull. Torr, bot. Club, VI, p. 142 ; Lesq. et Jam. Man. p. 48 . Syn. Ad terr. arenos. - Am. sept, : Nov. Angl., New Jersey, Carol.
merid.

Robinsoni (Mont.) Mitt. M. austr. am. p, 26.

Astomum nervosum $C, M$. Syn. I, p. 15 p.p.

A. Robinsoni ej. in Bot. Zeit. 1856, p. 415 .

Phascum Robinsoni Mont, in Ann, se, nat. IV, II ser., p. 96.

1. Juan Fernandez. - Am. merid. : Brasil., Monte-Video, Chile, ins. 
stramineum Aust. -- PI. subulatum var. stramineum.

subnervosum (C. M.) Jaeg. Ad. $11, p .660$.

Astomum subnervosum C. M. in Linn, 1880-83, p. 35I.

2 .

- Am. merid. : Uruguay.

subulatum (L.) Bryol, eur, I (mon. p. 15), t.9; W. P. Sch. op. cit. p. 25.

Astomum subulatum Hpe. in Linn. 1832, p. ; C. M. Syn. I, p. 14 et $I I, p .5 \times 8$.

Bryum ericetorum Neck. Meth. M. p, 231.

Phascum acuminatum Lindb. in Hartm. Skand. Flor. IX ed. II, p. 78.

Phascum acuminatum L. Sp. pl. p. 1570; Brid. Bryol, univ. I, p. 37.

Pl. acuminatum Lindb, in Oefv. Vet. Akad. Foehr. 1863, p. 406.

Sphagnum acaulon trichodes Dill. Hist. M. p. 251, $t .32, f .10$.

Syn. In terr. argill, et ad silv. marg. - Eur. : Temperat, tota., rar, in sept. As. : China or. Afr.: Alger. Am. sept.: Rar.: Pensilv., Calif.

Exs. : Drumm. M, bor. am. II ed. n. 7 (Phascum).

Rab. Bryoth. eur. n. 152.

Sull. et Lesq. M. bor. am. II ed. n. 39.

a var. stramineum (Aus,) Lesq, in Lesq, et Jam. Man. p. 43.

Pl. stramineum Aust in Bull. Torr. bot. Club, VI, p. 142.

Pl. subulatum Lesq. in Trans, of the Am. Phil. Soc. XIII, p. 2.

Pl. subulatum var. Watson Bot. calif. $I I, p, 359$.

Ut et ubi typ. in Am, sept. :

subulatum $\left\{\begin{array}{l}\text { Lesq. - Pl, subulatum var. stramineum. } \\ \text { Lindb. - Pl. alternifolinm. }\end{array}\right.$

var. Wats. - Pl. subulatum var. stramineum.

Sullivantii Aust, in. op, et l, cc.

Ph, nervosum Drumm. M. bor. am. II ed. n. 6 ; Sull. M. of U. St. p. 16.

Pl. nervosum Sull. Ic. M. p. 19, t. 10, f. 1-17.

1. Ad terr, arenac. - Am. sept. : Pensilv., Carol, merid.

tenellum Mitt. in Journ. of the Linn. Soc. 1895, p. 65.

1.

$$
\text { Pac. : Tasman. }
$$

tenue (Wils.) Mitt, M. Ind. or. p. 7.

Phascum tenue Wils. in Kew Journ, bot. IX, p. 290.

$$
\text { - As. : Sikkim. }
$$

Toepferi Ortel. - Pl. alternifolium.

viride (C. M.) Par.

Astomum viride C. M. in Ft. $1888, n$. 1.

1. Terr, - Pac. : Austral, or. (Nov. Vales.).

PLEUROCH ATE Lindb, in Oefo... XXI.

Spec. omn. sunt Barbula ejusd. nom.

PLEUROPHAS CUM Lindb. in Lond. Journ. of bot. 1875 et in Rev. bryol. 1876, p. 29 (1 spec.)

grandiglobum Lindb. $l l$. cc.

$$
\text { - Pac. : Tasman. }
$$

PLeURopus Griff. No: ad pl. Asiat. II, p. 467 (1819).

densus Griff. - Cylindrothecium aureum.

dentatus Griff. - Leptohymenium. 
fenestratus Griff. - Orthothecium neilgherriense. pterogonioides Griff. - Rozea.

PLEUROWEISIA Limpr, in Jahresb. d. Schles. Gesells. 1884, p. 224. Schliephackei Limpr. - Anoectangium.

PLEUROZIOPSIS Kindb. Check-List of Eur. and N. Amer. M. p. 19. alaskana Kindb. - Hypnum.

prolifera Kindb. - Hylocomium splendens.

ruthenica Kindb. - Climacium.

triquelra Kindb. - Hylocomium.

PLEUROZIUM Sull. M. of U. St. p. 68; Kindb. op. et l. cc.

Spec. omn. non indicatae sunt Hylocomia ejusd, nom.

calvescens Kindb. - Hylocomium squarrosum var, subpinnatum.

flagellare Kindb. - Hyocomium.

megaptilon Kindb. - Camptothecium.

meridionale Kindb. - Eurhynchium striatum var. meridionale.

purum Kindb. - Hypnum.

pyrenaicum Kindb. - Hylocomium Oakesii.

Schreberi Sull. Hypnum.

striatum Kindb. - Eurhynchium.

PLEUROZYGODO :- Lindb. M. Scand. p. 29. aestivus Lindb. - Anoëctangium compactum.

Plicaria C. M. Syn. II, p. 454 (subsect. HyPNI).

Plicatella C. M. Syn. 1, p. 487 (sect. Bartramıæ).

Plumatella C. $M$, in Fl. 1896, p. 463 (sect. Papillaria).

Plumosaria Kindb. Check-List. of Eur. and N. Amer, M. p. 73 (sect. Brachyтнесі sensu Kindb.).

PQECILOPHYLLUM Mitt. $M$, austr. am. p. 92.

Spec. omn, sunt Leucolomata ejusd, nom.

POGONATUM P. Beauv. Prodr. p. 84 (156 spec.).

abbreviatum Mitt. M. austr. am. p. 615.

- Am, merid. : And. Nov. Granat.

afro-aloides (C. M.) Pur.

Polytrichum afro-aloides C, M. in Abhandl. Brem. VII, p. 204.

- Afr. : Madagascar.

akitense Besch. in Ann. sc. nat. 1893, p. 354 .

$2 . \quad-A s$. : Japon.

Exs. : Fanrie Pl. Japon. 1 et 1425.

albo-marginatum (C. M.) Jaeg. Ad. I, p. 728.

Polytrichum albo-marginatum C. M. in Linn. 1874, p. 172.

2.

- As. : M. ins, Philippin.

albo-vaginatum (Hpe.) Jaeg. Ad. I, p. 718.

Polytrichum albo-vaginatum Fpe. in Bot. Zeit. 1870, p. 51.

2.

- Am. sept. : Mexic.

aloides (Hedw.) P. B. Prodr. p. 84; Brid. Bryol. univ. II, p. 119; Bryol. eur. IV (mon. p. 6), t, 416; W. P. Sch. Syn. II ed.p. 535.

Catharinea alsides Roehl. Moosges, Deutsch. p. 192. 
Mnium polytrichoides $\beta$ L. Sp.pl. p. 1576.

Mnium polytrichoides var. longifruetu Ehrh, in Hann. Mag. 1780, p. 236.

P. aloides $\beta$ dicarpon Brid. op. cit. p. 121.

P. aloides $\delta$ rubellum $e j . l$. $c$.

Polytrichum aloëfolium var, 1 et 2 Scop. Fl. Carn. p. 134, n. 1.

P. aloides Hedw. M. frond. I, p. 37; C. M. Syn, I, p. 202.

P. mnioides Neck, Meth, M. p. 128,

P. nanum Weiss, Crypt. Goett. p. 173.

P. parvum Aloes folio serrato capsulis oblongis Dill. Hist. M, p. 429, t. 55, f. 7 .

P. rubellum Menz. in Trans. of the Linn. Soc, IV, p. 79, t. 7, f. 3; Brid. Mant. M. p, 201.

P. subrotundum $\beta$ Huds. Fl. Angl. p. 400.

2. In ericet. arid., ad vias silvat., etc. Eur. : Vulgatiss. As. : Japon., China, Kamschatka, Khasia, Tibet occ., Himalaya, Nepal., Bengal., M. Neilgherr., Ceylan, Caucas, Afr , Alger., Madeir., Canaries.

Exs. : Mandon P1. Madeir. n. 27.

Rab. Bryoth, eur. n. 116, 1136.

* var. defluens Brid. op. cit. 121 ; W. P. Sch. Syn. I ed.p. 439 et II ed.l.c.

P. aloides \& Dicksoni Brid, op, et $l$. cc.

P. aloides $\beta$ minus Wils. Bryol, brit, p. $207 ;$ Bryol. eur. l. c.

Polytrichum aloides $\beta$ defluens C. M. Syn. II, p. 203.

P. aloides $\beta$ Dicksoni Hook. et Tayl. Muscol. brit.

P. aloides $\beta$ et $\delta$ Mart. Fl. crypt. Erlang. p. 81 .

P. defluens Brid. Mant. M. p. 200.

P. Dicksoni Turn. Muscol. Hibern. p. 90, n. 13.

P. laterale Crome in Hoppe Taschb. III.

P. minimum ej, in op. cit, p. 108 et Landm. Samml. p. 48, n. 30.

P. nanum Hoffm. Deutsch. Fl. II, p. 24 (in obs.).

P. nanum var. Dicksoni Lindb. in Notiz. 1867, p. 140.

P. nanun var. minimum ej.. . $c$.

Ad foss. et viar. cav. latera. - Eur. : Ut typ.

Exs. : Rab. Bryoth, eur. n. 811.

var. dicarpon Brid. - P. aloides.

var. Dicksoni Brid. - P. aloides var. defluens.

* var. longicolla Mitt. in Trans. of the Linn, Soc. 1891, p. 192. - As. : Japon.

* var. magna (C. M.) Par.

Polytrichum aloides var. magna C. M. l. c.

In limos. silvestr. - Eur. : Enipont.

var. minus Rryol, eur. - P. aloides var, defluens.

var. rubellum Brid. - P. aloides.

var, Y Schwaegr. - P. oligodus.

aloides \{ Duby. - P. Subtortile.

Sande Lac. - P. inflexum.

alpinum (L.) Roehl. in Ann. Wett. Ges. III, p. 226 et Deutsch. Fl. III, p. 59 ; Brid. Bryol. univ. 1I, p. 129; Bryol. eur. IV (mon. p. 9),

t. 418 ; W. P. Sch. op. cit. p. 538.

Catharinea alpina Roehl. Moosg. Deutsch. p. 184.

P. ambiguum P. B. Prodr. p. 84 (fid. W. P. Sch.).

P. norvegicum ej. $l$, c. lexcl, syn. P. (Ederi Brid.).

Polytrichum alpinum $L$. Sp.pl.p. 1573; C. M. Syn. I, p. 210; Drumm.

M. bor. am. I ed, n. 282.

P. austro-alpinum F. v. Müller (fid. Mitt.).

P. alpinum $\alpha$ ciliatum Retz Fl. Scand. Piodr. II, p. 209, n. 1196. 
P. alpinum ramosum, capsulis summitate ellipticis Dill. Hist. M. p. 427, t. $55, f .4$.

P. ferrugineum Brid. Sp. M. I, p. 61.

P. norvegicum Hedw. Sp. M. 99, t. 22, f. 1-5.

P. urnigerum $\beta$ Huds. Fl. Angl, p. 400.

2. In petros. abrupt. gramin. - Eur. : Reg. subalp. et alp. As. : Septentr. tota, Caucas. Afr. : Ins. Kerguelen. Am. sept. : Groënland, Labrador, sin. Baffin, Terr, nov., New Brunswick, Gaspes, Ontar,, lac. Super., M. Rupestr. et Selkirk, Columb. brit., mar. Behring, fret. Kotzebuè, Sitka, Vancouver. Idaho, reg. septr., occ., or. et centr. Pac. : Austral. felix, Nov. Zeland, Tasman.

Exz. : Mac. Canad. M. n. 220.

Rab. Bryoth. eur. n. 284.

Sull, et Les 1. M. bor. am. II ed. n. 320.

Un. itin. 1867, n. 79.

"var. arcticum (Sw.) Brid. Bryol. univ. II, p. 131 ; Bryol. eur. el W. P. Sch. ll. cc.

P. ambiguum P. B. Prodr. p. 84 (fid. Lindb.).

P. arcticum Roehl. in Ann. Wett. Ges. 1II, p. 226.

P. Pylaisaei Brid. op. cit. p. 744.

Polytrichum alpinum $\beta$ angustifolium Lindb. in Not. 1867, p. 130.

Polytrichum alpinum $\beta$ arcticum Wahlenb. Fl. Suec, I ed., II, p. 738.

Polytrichum alpinum $\gamma$ cylindricum Lindb. $l$. $c$.

Polytrichum a! ${ }_{2}$ num $\beta$ silvaticum ej. M. Scand. $p .12$.

P. ambiguum Mich. Fl. Am. bor. II, p. $29 ;$ Brid. Sp. M. I, p. 62.

P. arcticum Sw. M. Suec. p. 76 et 109, t. 8, f. 17.

P. silvaticum Menz, in Trans. of the Linn. Soe. IV, p. 83, t. 7,f. 6.

Ut typ. - Eur. : Alp. editiss. et zon. arctic. : Spitzberg, ins. Parry, Ursorum. Am. sepl. : Groenland, Terr, nov., Unalaska.

« var. brevifolium (R. Br.) Brid. op. et l. cc.; W. P. Sch. Syn. I ed. p. 441 et $I 1$ ed. $l$, c.

P. alpinum o campanulatum Bryol. eur. l. $c$.

P. campanulatum Brid. op. cit. p. 133.

Polytrichum alpinum $\beta$ brevifolium $C . M$. $l$. c.

P. alpinum $\delta$ campanulatum $e j, l . c$.

P. brevifolium R. Br. Suppl. App, ad it. Parray. p. 494.

P. campanulatum Hsch. Hor. phys. Berol., p, 67, t. 13 (?)

Ut et ubi praeced. in Eur. et Am. sept.

var. campanulalum Bryol, eur. .- P. alpinum var. brevifolium.

(s var. furcatum (Brid.) Par.

P. furcatum Brid. Bryol. univ. II, p. 133.

Polytrichum alpinum var. furcatum C.M. $l$. c.

P. furcatum Hsch. in op. et l. ec.

Ut praeced. - Am, sept. : Arctic, occ.

"var, mierodontium Kindb. in Ott. Nat. V et in Mac Cat. p. 152. - Am. sept. : Mar. Behring.

"var. septentrionale (Su.) Brid. Bryol, eur. et W. P. Sch. ll. cc.
P. septentrionale Roehl. in Ann. Wett. Ges. III, p. 226 et Fl. Deutseh. III, p. 58 .

P. norvegicum P. B. Prodr. p. 84 (fid. Lindb.).

Polytrichum alpinum $\beta$ laeve Retz Fl. Scand. Prodr. II, p. 299.

P. hyperboreum Wahlenb. Fl. Lapp. p. 347 (fd. Lindb.).

P. (Ederi Brid. M. Rec. II 1, p. 99, n. 76 (fid. Lindb.).

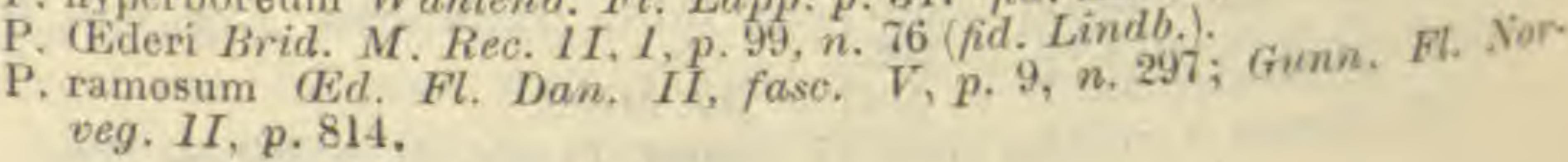


P. septentrionale Sw. M. Suec.pp. 77 et 107, t. 9, f. 18 p.p.; C. M. Syn. I, p. 223; Drumm. M. bor. am. I ed. n. 283.

P. sexangulare angstr, in Fr. Summ. veg. Scand, $I, p .90, n .7(p, p . ?)$.

Ubi praeced. - Eur.: Alp, editiss. et reg. arctic. As, : Caucas. Am. sept. : Groenland, M. Rupestr., mar. Behring.

" var, simplex W. P. Sch. Coroll, p. 91 et Syn. II ed. p. 539.

Ut praecedent. - Eur. : Alp. Norveg. (Dovre), Island. Am. sept. : Groenland.

ambiguum P. B. $\left\{\begin{array}{l}\text { (fid. Lindb.). - P. alpinum var. areticum. } \\ \text { (fid. W. P. Sch.). - P. alpinum. }\end{array}\right.$

andinum (Hpe.) Mitt. M. austr, am. p. 615.

Polytrichum andinum Hpe. in Linn, 1863, p. 147.

- Am. merid. : And, Nov. Granat.

angolense (Welw, et Duby) Par.

Polytrichum angolense $W$, et $D$. in Mém... Genève, 1870, p. 3, t. I, f. 2 .

In pascuis humid. - Afr.; Angola.

arcticum Roehl. - P. alpinum var. arcticum.

arcuatum Mitt. op. cit. $p .617$.

- Am. merid. : And. Nov. Granat.

aspervimum Besch. in Ann. sc. nat. 1893, p. 355.

2.

Exs. : Faurie Pl. Japon. n. 1884 p.p.

atro-virens Mitt. in Journ. of the Linn. Soc. VIII, p. 49.

- Am. sept. : Columb. brit., Sitka.

australasicum (Hpe. et C. M.) Jaeg. Ad. 1, p. 718 ,

Polytrichum australasicum Hpe. et C. M. in Linn. 1853, p. 500. 2. Ad terr. umbros. - Pac. : Austral. or. subtropic., Nov. Zeland,
Tasman.

austro-alpinum (C.M.) Par.

Polytrichum austro-alpinum C. M. in Engler's Bot. Jahs-b. 1883,p. 77 et in Forchungsreise... Bot. $p .12$.

Ster.

austro-georgicum $(C, M$. $)$ Par.

-Afr.: Ins, Kerguelen.

Polytrichum austro-georgicum C. M. Bryol. austr. Georg. p. 13.

Baldwini (C. M.) Par. - Am, merid. : Austr. Georgia.

Polytrichum Baldwini ¿. $M$. in $F l .1896, p .439$.

P. Junghunii Sull, in Exped. Wilkes, p. 92 (fid. C. M.).

2.

- Pac. : Ins. Sandwic.

barbanum Ren. et Card. in Bull. Soc. roy. bot. Belg. 1892, 11, p. 170.

2 .

Belangeri (C.M.) Besch. Fl. bryol. Réunion, etc. p. 109. Catharinea intermedia Belanger Voy. Ind. or. Bot. II, Crypt.p. 101, $t .11$,
f. 3 .

Polytrichum Belangeri C. M. Syn. I, p. 222 et II, p. 564.

2. Ad terr. lapidos. - Afr. : Ins. Francise.

Bernoullii (C. M.) Par.

Polytrichum Bernoullii $C . M$. in Bull. hb. Boissier, p. 178.

- Am. sept. : Guatemala. 
Bescherellei Hpe, in Besch. Prodr, bryol. mexic. p. 63.

In silvis. -- Am. sept. : Mexic.

Bisseti (C. M.) Par.

Polytrichum Bisseti $C$. M. mss.

- As. : Japon.

Borgeni (Hpe.) Jaeg. Ad. I, p. 717.

Polytrichum Borgeni Hpe, in Bot, Zeit. 1870, p. 35 .

2.

- Afr. : Natal.

brachyphyllum P. B. Prodr. p. 84; Brid. Bryol. univ. II, p. 113; Lesq. et Jam. Man. p. 261.

P. vaginans Brid. Sp. M. I, p. 68 .

Polytrichum brachyphyllum Rich. in Mich. Fl. Am. bor. II, p. 295; C. M. Syn. I, p. 201; Sull. Io. M. p. 77, t. 48.

2. Terr. - Am. sept. : New Jersey, Pensilv., Carol., Georg., Alabama, Ludovic.

Exs. : Drumm. M. bor. am. II ed. n. 69.

Sull. et Lesq. M. bor. am. J ed. n. 211 et II ed. n. 317.

brachythecium Besch. Fl. bryol. Réunion, etc. p. 109.

- Afr.: Ins. Borbon.

brasiliense Jaeg. - Polytrichum.

brevicaule P. B. - P. pensilvanicum.

breviurnaceum C. M. in Dusen M. Camer. n. 129.

- Afr. : M. Cameroon.

Briosianum R. Farnelti $M$. d. prov. Pavia, III cent., p. 27, t. 26, f. 2-13.

2. In calcar. irror. - Eur.: Ital. super. (Pavia).

Camerae (C. M.) Par.

Polytrichum Camerae C. M. mss.

- Pac. : Austral, or. (Queensland, Nov, Vales.).

campanulatum Brid. - P. alpinum var. brevifolium.

camptocaulon (C. M.) Par.

Polytrichum camptocaulon C. M. in Aet. Soc. sc. Fenn. 1891, n. 5.

2. Ad terr. arenac. - Am. merid. : Brasil. or. (Minas Geraës).

campylocarpum (C. M.) Mitt. M. uustr, am. p. 618.

Polytrichum campylocarpum C. M. Syn. I, p. 209 et II, p. 503.

2.

- Am. sept. : Mexic. Am. merid. : Columb.

catharinelloides (C. M.) Par.

Polytrichum catharinelloides $C$. M. mss.

- As, : Barman. (Tenasserim).

capense (Hpe.) Jaeg. Ad. I, p. 711.

Polytrichum capense Hpe. Io. M. t. 21; C. M. Syn. I, p. 203.

- Afr.: Transvaal, C. B. Sp.

Exs, : Rehm. M. Afr. austr. n. 573.

capillare (Rich.) Brid. Bryol, univ. II, p. 127; Sull. M. Allegh, n. 115

et Ic. M. p. 79, t. $49 ;$ W. P. Sch. op. cil. p. 536.

P. intertextum la Pyl. in Brid. op. oit. p. 742. P. intertextum la Pyl. in Brid. op. oit. p. 742.
P. longidens Angstr. in Theden. Nya. bot. Not. $1852 ;$ W. P. Seh. Syn. 1
ed., p. 441 .

P. yuccaefolium $P . B$. Prodr. p. 85 . 
Polytrichum capillare Rich. in Mich. Fl. bor. am. II, p. 294; Wahlenb, Fl. Lapp. p. 347 ; C. M. Syn. II, p. 127.

P. urnigerum C. M. op. cit. p.p. ; Drumm, M. bor, am. I ed. n. 284 p.p.

P. urnigerum $\beta$ capillare Wahlenb. Fl. Suec. I ed., II, p. 739.

2. Ad tert, denudat, sec fluvios in silvat. - Eur. : Lappon. tota, Suecia, Fennia. As. : Jenissei inf., Amour. Am. sept. : Groenland, Terr. nov., ins. Miquel., M. Alb., Adirondack et Rupestr.

Exs. : Sull. et Lesq. M. bor. am. II ed. n. 318.

"var. minus (Wahlenb.) Par.

P. longidens Angstr. in op. et $l$. co. (fid, Lindb.).

Polytrichum capillare $\beta$ minus Wahlenb. Fl. Lapp. p. 348.

P. urnigerum $\beta$ capillare Hartm. Skand. Fl. III ed., p, 286.

Ut typ. - Eur. : Lappon., Suecia.

Carionis (C. M.) Par.

Poly trichum Carionis C. M. in Bull. hb. Boissier, 1897, p. 177. - Am. sept. : Guatemala.

circinatum Besch. Fl. bryol. Nov, Caled. p. 220.

Ad, terr. argill. - Pac. : Nov. Caledon.

cirratum Brid. - P. convolutum var. cirratum.

elavatum (Dz, et Mk.) Bryol. jav. I, p. 40, t. 30.

Polytrichum clavatum Dz. et $M k$, in Pl. Jungh. p. 326.

2.

$$
\text { - As. : M. Java. }
$$

comosum W. P. Sch, hb.

Polytrichum comosum C. M. Syn. II, p. 561 .

- Am. sept. : Mexic. (M. Orizaba).

consobrinum Ren. et Card. in Bull. Soc. roy. bot. Belg. 1892, 11, p. 171.

2. - Am. sept. : Costa Rica.

contortum (Menz.) Lesq. in Mem. Calif. Acad. 1, p. 27; Sull. 1c. M.

Suppl. p. 58, t. 42, Lesq. et Jam. Man. p. 262.

P. dentatum Lesq. in Mem. l. c p.p.

P. laterale Brid. Bryol. univ. II, p. 112.

Polytrichum contortum Menz. in Trans. of the Linn. Soc. IV, p. 78, t. 7, f. 2 ; C. M. Syn. I, p. 215 et I1, p. 563.

2. Ad terr. argill. in silvat. - As : Saghalien. Am. sept. : M. Rupestr., Columb. brit., Alaska, Calif.

- var, pallidum (Lindb.) Par. Polytrichum contortum var. pallidum Lindb. in Aot. Soc. se. Fenn. 1872,
p. 239.

$$
\text { - As. : Saghalien. }
$$

contorfum Mae. - P. erythrodontium.

convolutum (L.) Brid. Bryol, univ. II, p. 110.

Polytrichum convolutum L. f. Mant. M. p. 374, t. 4, f. 2; C. M. Syn. I,

P. pachynet $I I, p .563$.

2.

pachyneuron Hpe. in Cinn. 1847, p. 80.

"var. cirratum (Sw.) Par.

- As.: Java. Afr.: Ins. Borbon.

P. cirratum Brid. op. et l. ce. ; Bryol, jav. I, p. 44, t. 34.

Polytrichum cirratum Sw. in Schrad. Bot. Journ. IV, p. 176, t. 4? lof. C. M. l. c.).

P. convolutum $\beta$ cirratum C. M. l. c. 
P. leucomitrium Hsch, in Nov. Act. Caes, Leop. XIV Acad., II, Suppl. p. 732 .

Sandwic. - As. : Java, Borneo. Afr.: C. B. Sp. ? Pac.: Ins.

convolutum P. B. p.p - P. tortile.

crispulum Besch. Fl, bryol. Antill, fr. p. 37.

Terr. - Am. sept. : Guadalup.

cubense Sull. - P. tortile.

cucullatum (Hpe.) Mitt, M. austr. am. p. 613.

Polytrichu.s cucullatum Hpe. in Ann. sc. nat. V ser., IV, p. 348 . - Am. merid. : And. Nov. Granat.

cuspidatum Besch. Prodr. bryol. mexic. p. 62.

2. In silvis. - Am. sept. : Mexic.

cylindricum W. P. Sch. in Besch. op. cit. p. 67.

2. $\quad$ - Am. sept. : Mexic. (Orizaba).

dendroides Brid. - Polytrichadelphus.

dentatum (Menz.) Brid. Bryol. univ. 11, pp. 122 et 744 ; Sull. Ic. M.

Suppl. p. 57, t. 41 ; Lesq. et Jam. Man. p. 261.

P. urnigerum Mac. Canad. M. n. 219 p.p.

Polytrichum capillare var. dentatum Lindb. in Act. Soo, se. Fenn. 1872, p. 266.

P. capillare var. oxycalyx ej. in Bot. Not. 1867, $p, 137$.

P. dentatum Menz. in Trans. of the Linn. Soc. IV, p. 80, t. 7, f. 4; C. M. Syn. I, p. 208.

P. urnigerum W. Arn. Disp. p. 71 ; Drumm. M. bor. am. I ed, n. 284.

2. Terr. - As, : Saghalien, Amour. Am. sept. : M. Rupestr. et Selkirk. Alaska, litt. mar. Behring.

Exs. : Mac. Canad. M. n. 544.

ericifolium Besch. Prodr. bryol. mexic. p. 66.

2.

- Am. sept. : Mexic. (Orizaba).

erythrodontium Kindb. in Mac. Cat. p. 150.

P. contortum Mac. Canad. M. n. 430.

Polytrichum erythrodontium Kindb. in Bidrag, p. 453 (nom.).

2. In silv, humid, - Am. sept. : Alaska, Vaneouver.

fasciculatum P. B. - P. urnigerum.

fastigiatum Mitt. M. Ind. or. p. 154.

- As. : Himalaya.

Feae C. M, in Nuov. Giorn. bot. ital. 1891, p. 601 (nom.).

- As. : Barman, super.

flexicaule Mitt. M. Ind. or, p. 152.

Ster.

- As. : Assam, Alp. Yunnan.

flexibilifolium C. M. in Dusen M. Camer. n. 18.

- Afr. : M. Cameroon.

furcatum Brid. - P, alpinum var, furcatum.

fuscatum Mitt. op. cit. p. 154.

Gardneri (C. M.) Jaeg. Ad. I, p. 714.

Polytrichum brevicaule $\mathrm{Hsch}$. Fl. Brasil. I, p. 47. 
P. Gardneri C. M. Syn. II, p. 560.

P. pensilvanicum H. $f$. el W. in Gardn. M. Brasil. n. 15 ; C. M. Syn. I, p. 205 p.p.

2. Terr. - Am. merid. : Parana, Brasil. or.

Germaini (C. M.) Par.

Polytrichom Germaini C. M. in Nuov. Giorn. bot. ital. 1897, p. 14.

- Am. merid. : And. Boliv.

giganten Brid, - Polytrichadelphus.

glaciale Mill, $M$. austr. am. p. 614.

- Am. sept. : Mexic. (summ. m. San Felipe).

Glaziovii (Hpe.) Jaeg. Ad. 1, p. 716.

Pólytrichum Glaziovii Hpe. Symb, 1874, p. 54.

2 ?

- Am. merid. : Rrasil. austr. or.

gracilifolium Besch. Fl. bryol. Réunion, etc. p. 108.

2. $\quad-A f r$ : Ins. Borbon.

Gेraeffeanum (C.M.) Jaeg. $l, c$.

Polytrichum Graeffeanum C. M. M. Polyn. p. 61 .

2. Terr. - Pac. : Ins. Fidji, Samoa.

grandifolium (Lindb.) Jaeg. Ad. I, p. 715.

Polytrichum grandifolium Lindb, in Aot. Soc. so. Fenn. 1872, p. 264.

2.

Exs. : Faurie Pl. Japon. n. 550.

- As. : Amour, Japon.

Savat. PI. Japon. n. 536.

Gullweri (Hpe.) Jaeg. Ad. 11, p. 717.

Polytrichum Gullweri Hpe. in Linn. 1876, p. 315.

Ster.

- Pac. : Tasman.

gymnophyllum (Wits.) Mitt. M. Ind. or. p. 152.

Polytrichum gymnophyllum Wils. in sehed. p.p.

- As. : Sikkim, Khasia.

hamatifolium Ren. et Card, in Bull. Soc. roy. bot. Belg. 1892, I1, p. 172.

2. In paludos. - Am. sept.: Costa Rica.

hexagonum Milt. op, cit. p. 151.

- As. : Nepal., Khasia, M. Neilgherr., Ceylan.

Hildebrandti C. M, in Hildebr. M. Mad. n. 2133.

- Afr. : Madagascar.

himalayanum Mitt. op. cit. p. 151. nan? Japon.

- As. : Himalaya sept. occid. (Dehra Doun); Yun-

Holstii (Broth.) Par.

Polytrichum Holstii Broth, in Engler's Bot. Jahrb. 1894, p. 191.

$2 \delta^{x}$ ign.

Humboldtianum (Hpe.) Jaeg. Ad. II, p. 718.

Polytrichum Humboldtianum Hpe. Moosb. p. 10 (nom.).

- Am. mericl. : ?

inflexum Lindb. in Not. Saellsk... 1867, p. 100.

P. slotdes Sande Lac, in Miq. Ann. mus, bot. Lugd, Bot. II, p. 292(fid. Mitt.)

2 .

- As. : Japon. 
integerrinum Hpe. hb. (nunc in hb. British Museum).

- As. : Himalaya sept. occ.

internedium Roehl. - P. nanum.

interxtum Brid. - P. capillare.

japonicum Sull. et Lesq. in Proced. of the Am. Acad... 1868, p. 278. - As. : Japon.

Junghunianum (Dz. et Mk.) Bryol.jav. I, p. 41, t. 36 .

Polytrichum Junghunianum Dz. et Mk. in Pl. Jungh. p. 323.

2. Ad mur, et terr. limos. - As. : Java, Sumatra.

«var. incurvum (Dz. et Mk.) Bryol, jav. l. c.

Polytrichum Junghunianum var. incurvum $D z$, et $M k$. in op. et l.ec.

$$
\text { -- As. : M. Java. }
$$

«var. sikkimense Ren. el Carl. in Bull. Soc. roy. bot. Belg. 1895, I, p. 65 .

- As.: Sikkim.

laterale $\left\{\begin{array}{l}\text { Brid. }- \text { P. contortum. } \\ \text { W. P. Sch, }- \text { P. nuka-hivense. }\end{array}\right.$

laxifolium Besch. Fl. bryol. Antill. fr. p. 37.

Ster. Terr. - Am. sept. : Guadalup.

leptocarpum Besch, Prodr. bryol. mexic, p. 65.

- Am. sept.: Mexic. (M. Orizaba).

leucopogon Ren. et Card. in op. cit. p. 64.

2.

- As. : Sikkim.

leptopelma (C.M.) Par.

Polytrichum leptopelma C. M, in Bull. hb. Boissier, 1897, p. 178. - Am. sept. : Guatemala.

Liebmannianum W. P. Sch. mss.

Polytrichum Liebmannianum C. M. Syn. II, p. 563. - Am. sept. : Mesic. (M. Orizaba).

longidens Ångstr. $\left\{\begin{array}{l}\text { (fid, Lindb.) } \\ \text { (fid. W. P. Sch.). P. - capillare var. minus. }\end{array}\right.$ longisetum Brid. - Polytrichadelphus.

loricalyx (C. M. Par.).

Polytrichum loricalyx C. M. in Bot. Centralbl. 1883, n. 2-4. 2. - As. : Penins. Tschutsehica.

\& var. brachypodon (C.M.) Par.

Polytrichum loricalyx var. brachypodon C. M. l. c.

- As. : Ibidem. Macounii Kindb. in Bull. Torr. bot. Club, XVI, p. 96 et in Mac.
Cat.p. 152 .

Polytrichum Macounii ej. in Bidrag.p. 453 (nom.).

2. Rupic. et terr. - Am. sept, : Columb, brit., Alaska, Vaneouver. Eos. : Mac. Canad. M. n. 546.

macrophyllum Bryol. jav. I, p. 45, $t, 35$.

Polytrichum convolutum Dz. et $\mathrm{Mk}$. Pl. Jungh. p. 323 .

2. Ad terr, arenac, - As. : Sumatra, Java, ins. Batjam. 
macropogon W. P. Sch, in Besch, Prodr. bryol. mexic. p. 67.

- Am. sept. : Mexic. (Vera-Cruz).

? madagassum (Hpe.) Besch. Fl. bryol. Réunion, elo. p. 104.

Ster,

- Afr. : Madagascar.

magellanicum P. B. - Polytrichadelphus.

marginatum Mitt. M. Ind. or. p. 153.

- As. : Ceylan.

micro-capillare (C, M.) Par.

Polytrichum micro-capillare C. M. in Bot. Centralbl. 1883, n. 2-4.

2.

- As. : Penins. Tschutchica.

microdendron (C. M.) Par.

Polytrichum microdendron C. M. in Nuov. giorn. bot. ital. 1896, p. 93. - As, : China or. (prov. Schen-Si).

microphyllum (Dz. et Mk.) Bryol, jav. I, p. 39, t. 29.

Polytrichum microphyllum $\mathrm{Dz}$. et $\mathrm{Mk}$. in Pl. Jungh. p. 326.

2. Rupic. - As. : Borneo, Java.

microstomum (R. Br.) Brid. Bryol. univ. 11, p. $745 ;$ Mill. M. Ind. or.
p. 15l.

P. minutum Brid. op. cit. p. 127 ?

Polytrichum microstomum $R$. Br. in Trans. of the Linn. Soo. XII, p. 569; C. M. Syn. I, p. 210.

P. urnigerum? Griff. Not. p. 389.

2.

Nepal., Khasia, M. As. : Himalaya, sept. occid. (Dehra-Doun), minutum Brid. - P. microstomum?

Molleri (C. M.) Par.

Polytrichum Molleri C. M. in Fl. 1886, p. 277,

2. Terr. - Afr.: Ins. S. Thomas.

nanum (Neck.) P. B. Prodr. p. 84 ; Brid. Bryol. univ. 1I, p. 117 ; Bryol.

eur. IV (mon. p. 5), t. $415 ;$ W. P. Sch. Syn. 11 ed. p. 534.

Catharinea nana Roehl. Moossg. Deutsch, p. 188.

Mnium polytrichoides $\alpha$ L. Sp. pl, p. 1576 .

Mnium polytrichoides var, rotundifructu Ehr.h, in Hann, Mag. 1780, p, 236.

P. intermedium Roehl. Deutschl. Fl. II ed. III, p. 60; Brid. op. cit.
p. 117 .

P. nanum var. semi-diaphanum Brid. op. et $l$. ce.

P. pumilum P. B. Prodr. p. 84 ; Brid. op cit. $p$. 116 ?

P. pusillum P. B. l. o.; Brid. op. cit. p. I19?

Pyn.).
subrotundum Lindb. in Hartm. Skand. Fl. IX ed., p. 44, n. 11 (inter Polytrichum aloëfolium $\beta$ foliis integerrimis Scop. Fl. Carn. II ed, II,
p. 3ro, n. 1290.

P. ericoides Hoffm. Deutsch. Fl. II, p. 24, n. 7 .

P. nanum dium Brid. Mant. M. p. 117.

P. nanum, Neck. Meth. M. p. 119 (177I); C. M. Syn. I, p. 204. p. 428, $t$. 55 , 6 .

P. nanum $t .55, f .6$.

P. polytrich var. $\beta$ Weiss Fl. Goett. p. 175.

P. polytrichoides Broekm. Laubm. Mechl, p. 111.

P. semi-dum Sw. M. Suec. p. 77, t. 9, f. 19.

P. subrotunhanum Brid. Mant. M. p. 200. subrotundum Huds. Fl, Angl I ed, n. 400. 
2. In ericet., pinet., ad silvar. marg., etc. - Eur. : Tota. As, : Septentr. Afr.: Alger., Madeir., Canaries.

Exs. : Rab. Blyoth. eur. n. 288.

\& var. longisetum (Hpe) Bryol. eur. l. c. t. 7 \& ; W. P. Schl. l. c.

Polytrichum nanum var, longisetum Hpe, in C.M. l. c.

P. subrotundum var. longisetum Lindb, in Not. 1867, p. 143.

Ut typ. - Eur. : Saxon., Alp. Delphinat.

var. semi-diaphanum Brid. - P. nanum.

nanum $\times$ aloides J. Brunnthaler in Oesterr. bot. Zeitsch. 1897, n. 2.

In scbistos. - Eur. : Austr. sept. or. (Gansbach.).

Neesii (C. M.) Mitt. M. Ind. or p. 151.

Polytrichum aloides Reinw, et Hsch. in Nov. Act. Acad. Car. XIV, IJ,

P. Neesii C. M. Syn. II, p. 151.

2. $\quad-A s$. : M. Neilgherr., Java.

neglectum (Hpe.) Jaeg. Ad. I, p. 727.

Polytrichum neglectum Hpe. in Bot. Zeit. 1869, n. 52.

\section{- Am. merid. : And. Nov. Granat.}

neo-caledonicum Besch. Fl. bryol. Nov. Caled. p. 219.

Ad terr. argill. - Pac. : Nov. Caledon.

norvegicum $\mathrm{P} . \mathrm{B} .\left\{\begin{array}{l}\text { (fid. C. M.). }-\mathrm{P} \text {. alpinum. } \\ \text { (fid. Lindb.). }-\mathrm{P} \text {. alpinum var. septentrionale. }\end{array}\right.$

nudicaule (Wright) Par.

Polytrichum nudicaule Wright in Lond. Journ. of bot. 1891, p. 106.

2. - As. : China centr.

nudiusculum Mitt. M. Ind. or. p. 153 (1).

Ceylan.

- As. : Himalaya sept. occid. (Dehra-Doun), Khasia,

nuka hivense (C. M.) Besch. Fl. bryol. Taïti, etc. p. 32.

P. laterale W. P. Sch. in Jasdin Enum. p. 21.

Polytrichum nuka-hivense C. M. in Bot. Zeit. 1859, p. 205.

2. In fissur. rup. - Pac.: Nuka-Hiva.

obscuratum Mitt. M. austr, am. p. 618 .

- Am. merid. : M. Pichincha.

obtusatulum (C. M.) Par.

Poly trichum obtusatulum C. M. in Abhandl. Brem. VIII, p. 204. - Afr. : Madagascar.

obtusum (C. M.) Jaeg. Ad. 1, p. 727.

Polytrichum obtusum C. M. in Linn. 1871-73, p. 171.

Ster.

- As. : Ins. Philippin.

ochromitrium (C. M.) Par.

Polytrichum ochromitrium C.M. mss.

- As. : Himalaya, septr. oceid. (Dehra-Doun).

octangulare (C. M.) Milt. op. cit. p. 617.

Polytrichum octangulare $C . M$. Syn. II, p. 564.

2.

- Am. sept. : Costa Rica.

(1) False a P. mediusculum Mitt. 1. c. p. 155 ” in Jaeg. Ad. 1, p. 711. 
oligodus (Kze.) Milt. op, cit. p. 613.

Cephalotrichum oligodus Bryol, eur. IV (mon. Pogonati).

Polytrichum aloides var. $\gamma$ Schwaegr. Sp. M. I, p. 13.

P. Jamesoni Tayl. in Lond. Journ. of bot. 1848, p. 188; C. M. Syn. II,
p. 561 .

P. oiigodus Kze, in Poepp. Pl. Chil. Coll. I, n. 271; C. M. Syn. I, p. 206.

P. polysetum H, et Arn. (fid. Mitt. in Lond. Jowrn. of bot. 1851, p. 50).

2. In humid. secus rivul, $-A m$. merid. : And. Nov. Granat., Quitens, et Boliv., Chile.

otaruense Besch. in Ann. sc. nat. 1893, p. 352.

2.

Eas. : Faurie Pl. Japon n. 79.

patulum (Harv.) Mitl. M. Ind, or p. 152.

Polytrichum patulum Harv. in Hook. Ic. pl. rar, t. 18, f. I; C. M. Syn. I,
p. 210. - As. : Nepal.

paucidens Besch, in Ann. sc. nat. 1892, I, p. 70.

2 In silvis. - As.: Yunnan.

pellucens Besch, in Ann. sc. nat. 1893, p. 351.

2. - As.: Japon.

Exs. : Savat. Pl. Japon, n. 538.

pensilvanicum (Hedw.) Par.

Mnium polytrichoides $\gamma L . S p . p l, p .1576$.

P. brevicaule P. B. Prodr. p. $84(1805)$; Brid. Bryol. univ. II, pp. 114 et $743 ;$ Sull. M. of U. St. p. 41 et Ic. M. p. 75, t. 47; Lesq.et Jam. Man. p. 260 .

P. capillare Mac, Canad. M. n. 377.

Polytrichum acaulon capillaceum, capsulis cylindricis Dill. Hist. M. p. 434, t. $55, f .12$.

P. brevicaule Brid. M. Rec. $I I, I, p .87, n, 66$.

P. pensilvanicum Hedvo. Sp. M. p.96, t. 21, /. 1-6 (1801-4; C. M. Syn. I, p. 205.

P. tenue Menz. in Trans, of the Linn. Soc. IV, p. 68.

2. Ad terr. argill. humid. - Am. sept. : Nov. Scot., New Brunswick, Ontar., reg. or. et merid.

Exs. : Drumm. M. bor. am. Il ed. n. 70.

Sull, et Lesq. M. bor. am. Il ed. n. 316.

" var. Torreyanum (Brid.) Par.

P. Torreyanum Brid. Bryol. univ. II, p. 115.

Polytrichum pensilvanicum var. Torreyanum $C . M . l, c$.

Ut et ubi typ.

perichaetiale (Mont.) Jaeg. Ad. I, p. 719 .

Polytrichum perichaetiale Mont. in Ann, sc, nat. 1841, p. 2E2et Syll. p. 28;

C. M. Syn. I, p 207; Mitt. M. Ind. or, p. 155 ,

2. Terr. et rupic. - As. : Nepal., Himalaya, sept. occid. (Dehra-Doun), M. Neilgherr.

Petersianum (C. M.) Jaeg. Ad. I, p. 722.

Polytrichum Petersianum C. M. in Linn. 1874, p. 575.

2. Terr, - Am . merid. : Brasil.

perpusillum (C.M.) Par.

Polytrichum perpusillum C. M. in Hedwig, 1897, p. 90.

2. Ad rip, rivul. - Am. merid. : Paraguay.

Exs. : Balansa PI. Parag. n 3618 . 
Pittieri Ren, et Card. in Bull. Soc, roy, bot. Belg. 1891, I, p. 169. 2. $\sigma^{*}$ ign. In silv, humid, - Am. sept. : And. Costa Ricens.

- Plaeanum Besch. Fl. bryol. Antill. fr. p. 38.

2. - Am. sept. : Martinic.

polare (C. M.) Jaeg. Ad. 1, p. 724.

Polytrichum polare C. M. in Bot. Zeit. 1859, p. 205.

2 .

- Am. sept. : Groenland.

polycarpum (W. P. Sch.) Par.

Polytrichum plurisetum C. M. in Linn. 1878-79, p. 265.

P. polycarpum C. M. in Nuov. Giorn, bot. ital. 1897, p. 14.

Trichopilum polycarpum $W$. P. Seh, in Mandon Pl. Boliv, n. 1684.

2. - Am. merid. : And. Boliv., Alp. Argentin Tucuman.

«var. angustatum W. P. Sch. l. c. n. 1685. - Am. merid. : And Bolio.

« var. brevipes (C. M.) Par.

P. plurisetum var, brevipes C. M. in Linn. l. $c$.

- Am. merid. : Alp. Argentin subtropic.

polysetulum (C. M.) Par.

Polytrichum polysetulum $C . M$. mss.

- As. : Himalaya sept. occid. (Dehra-Doun).

polythamnium (C.M.) Par.

Polytrichum polythamnium C. M. in Nuov. Giorn. bot. ital. 1896, p. 93. 2. - As. : China or. (prov. Schen-Si).

procerum W. P. Sch. mss.; Jaeg. Ad. 1, p. 727.

Polytrichum procerum Lindb, in Notis... 1867, p. 98. - Am. sept. : Mexic.

proliferum (Griff.) Mitt. Ind. or. p. 152.

Polytrichum proliferum Griff. Not.p. 488 et Io. pl. Asiat. II, t. 93, f. 2. - As. : Khasia.

pseudo-alpinum (C. M.) Jaeg. Ad. I, p. 724.

P. alpinum (rid. Mitt.).

Polytrichum pseudo-alpinum C. M. in Bot. Zeit. 1855, p. 750.

2. - Pac. : Austral. fel. subalp.

psilopoloides (C. M.) Jaeg. Ad. I, p. 721 .

Polytrichum psilopoloides $C$. M. in Linn. 1874, p. 576.

2. - Am. merid. : And. Nov. Granat.

pulverulentum P. B. - P. urnigerum.

punilum Brid. - P. nanum.

purpurascens (Hpe.) Mitt. M. austr. am. p. 616.

Polytrichum purpurascens Hpe. in Linn. 1863, p. 148. - Am. merid. : And. Nov, Granat.

pusillum P. B. - P. nanum.

Pylaisaei Brid. - P. alpinum var. arcticum.

rhopalophorum Besch, in Ann. sc. nat. 1893, p. 354.

2.

Exs. : Savatier Pl. Japon. n. 534. 
robustiusculum Jaeg. Ad. 1, p. 726.

P. robustum W. P. Sch, in Beseh. Prodr. Bryol, mex, p. 66. - Am. sept. : Mexic.

robustum Mitt. M. austr. p. $6 \mathrm{I} 6$.

P. Wilsoni Jaeg. Ad, I, p. 725.

- Am. sept. : Jamaic.

robustum $\left\{\begin{array}{l}\text { Jaeg. - - Polytrichadelyhus magellanicus. } \\ \text { W. P. Sch. - P. robustiusculum. }\end{array}\right.$

rubenti-viride (C.M.) Par.

Polytrichum rubenti-viride $C$. $M$. in $F l, 1886, p .277$.

2. Terr. $-A f r$. : Ins, S. Thomas.

rubiginosum $(C, M$.) Par.

Polytrichum rubiginosum $C . M . h b$.

- Pac. : Nov. Zeland.

rufisetum (Wils.) Mitl. M. Ind. or. p. 153.

Polytrichum rufisetum Wils, in sched.

- As, : Sikkim.

Rutenbergii (C.M.) Par.

Polytrichum Rutenbergii C. M. in Abhandl. Brem. VII, p. 205.

2.

- Afr.: Madagascar.

Sartorii (C. M.) Jaeg. Ad. I, p. 720.

Polytrichum Sartorii C. M. in Linn. 1874, p. 621.

- Am. sept, : Mexic.

Schlumbergeri W. P. Sch, in Besch. Prodr. bryol. mexic. p. 66.

Schmitzii (Ltz.) Besch. op. cit. p. 63 .

Polytrichum Schmitzii Ltz. Moosst. p. 156.

- Am. sept.: Mexic.

semi-angulatum Brid. - Polytrichadelphus.

semi-nudum (Wils.) Mitt. M. Ind. or: p. 152.

Polytrichum se mi-nudum Wils. in sched. p.p.

- As. : Sikkim, Ceylan.
semi-pellucidum (Hpe.) Mitt. M. austr, am. p. 617.

Polytrichum convolutum Hook, in Kunth. Syn. Fl. Equin. I, p. 48.

P. semi-pellucidum Hpe. in Linn, 1847, p. 80; C. M. Syn. I, p. 214 et II, p. 563 .

P. tortile C. M. in Linn. 1847, p. 208.

2. Ad terr. humid. - Am, merid. : And. Venezuel,, Nov, Granat. et Quitens.

septentrionale Roehl. - P. alpestre var. septentrionale.

serpentinum (C.M.) Par.

Polytrichum serpentinum $C, M$. mss.

- Pac.: Nov. Guin, brit.

simense (Br. et Sch.) Jaeg. Ad, I, p. 719.

Cephalotrichưn simense Br, et Sch. in W. Sch. M. Abyss, n. 427 et Bryol. eur. IV (mon. Pogonati).

Polytrichum simense C. M. Syn. I, p. 206.

Syn.

-Afr. : Alp. Abyssin., M. Cameroon. 
sphaerothecium Besch, in Ann. sc. nat. 1893, XV1II, p. 353.

- As. : Japon.

spinulosum Mitt. in Journ. of the Linn. Soc. 1864, p. 156.

- As.: Japon.

Stevensii Ren. et Card, in Bull. Soc. roy. bot. belg. 1895, 1, p. 65.

2.

- As.: Sikkini.

subaloides (C. M.) Jaeg. Ad. I, p. 711 .

Polytrichum subaloides C. M. in Bot. Zeit. 1862, p. 12.

2.

- Afr. : Pico d. Teneriff.

«var. minor (C. M.) Par.

Polytrichum subaloides var. minor C. M. l. c.

Ut et ubi typ.

subbifarium Mitt. M. austr. am. p. 618.

- Am. merid.: Venezuela, Nov. Granat.

subcontortum (Hpe.) Mitt. op. cit. p. 616.

Polytrichum subcontortum Hpe, in Ann. sc, nat. V ser., IV, p. 349.

- Am. merid.: And. Nov. Granat.

subgracile (Hpe.) Par.

Polytrichum subgracile Hpe. in Bot. Zeit. 1870, p. 51.

2.

- Am. sept. : Mexic.

subrotundum Lindb. - P. nanum.

subtortile (C. M.) Jaeg. Ad. I, p. 718.

P. aloides Duby in Pl. Zolling, $n .853$.

P. Teysmannianum $\beta$ tortile Bryol. jav, I, p. 44.

Polytrichum aloides Hsch.et Reinw, in Nov. Act. Acad. Caes. Leop. XIV, II, Suppl.p. 732 ?

P. subtortile C.M. Syn. I, p. 216 et II, p. 563.

2. - As.: Java.

subulatum (Menz.) Brid. Bryol. unvv, 11, p. 122.

Polytrichum subulatum Menz. in Trans. of the Linn. Soc. IV, p. 303; C. M. Syn. I, p. 207.

2.

$$
\text { - Pac. : Nov. Zeland. }
$$

taïtense W. P. Sch. in Vesco Pl. Ocean.; Besch. Fl. bryol. Taïti, etc., p. 3I.

tenellum (C. M.) Par.

$$
\text { - Pac, : Taïti. }
$$

Polytrichum tenellum C. M, in Nuov. Giorn. bot. ital. 1897, p, 18. - Am. merid. : And. Boliv.

Teysmannianum (Dz. et Mk.) Bryol. jav. I, p. 43, t. 32.

Polytrichum Teysmannianum Dz. et Mk. in Pl. Jungh. p. 323.

2. Ad terr. argill, - As, : Java.

var, tortile Bryol. jav. - P. subtortile.

thelicarpum (C. M.) Par.

Polytrichum thelicarpum C. M. in Nuov. Giorn. bot. ital. 1896, p. 94. 2. - As. : China or. (prov. Schen-Si).

Thomsoni (Mitt.) Jaeg. Ad. I, p. 719.

Polytrichum pungens Wils. in sched. p.p. 
P. Thomsoni Mitt. M. Ind. or. p. 155.

2.

- As. : Himalaya occ.

tolucense (Hpe.) Besch. Prodr. bryol. mexic. p. 63.

Polytrichum tolucense Hpe. Sp, M. nov, Mexio, in Verh. d. K. K. zool. bot, Ges, in Wien, Ta April. 1869.

2.

- Am. sept. : Mexic.

Torreyanum Brid. - P. pensilvanicum var. Torreyanum.

tortile (Sw.) P. B. Prodr. p. 85; Brid. Bryol, univ, II, p. 108; Mitt. M. austr. am. p. 618 (1).

P. convolutum P. B. l. c, p. 84 p.p.

P. tortile var. domingense Brid. op. et $l$ oc.

Polytrichum convolutum Hedw. Sp. M. p. 94, t. 10, f. 35.

P. cubense Sull, in Proced. Am. Acad... 1861.

P. domingense Brid. Mant, M. p. 201.

P. tortile Swo. Fl. Ind, occ. III, p. 1839 ; C. M. Syn. I, p. 215 et II, p. 563 .

2. Ad terr. argillos. - Afr. : Ins. Fianciae. Am. sept.: M. Jamaic, Cuba, Gurdalup., Martinic. Am. merid. : Peruv, Boliv. Pac.: Nov. Zeland.

var. domingense Brid. - P. tortile.

tortipes (Wils.) Jaeg. l. c.

Polytrichum tortipes Wils in sched.; Mitt. M. Ind. or. p. 155.

2 .

- As. : Sikkim.

urnigerum (L.) P. B. Prodr. p. 84 ; Brid. Bryol, univ, I1, p. 124 ; Bryol. eur. IV (mon. p. 8), t. 417; W. P. Sch. Syn. 11 ed., p. 536.

Bryum urnigerum Neck. Del. gall. belg. II, p. 462, n. 20.

Catharinea pulverulenta Roehl. Deutsch. Moosg. p. 216,n. 55 b.

C. urnigera ej. l. c. n. 55 .

P. fasciculatum $P, B . l, c$.

P. pulverulentum $e j, l, c$.

P. urnigerum var. tasciculatum Brid. l. c.

P. urnigerum var. pulverulentum ej. $l$. $c$.

Polytrichum alpinum var. $\beta$ Huds. Fl. Angl. I ed., p. 100.

P, asillare Lam, Fl. fr. I, p. 43.

P. dubium Scop, Fl. Carn.p. 136 et II ed. n. 1291.

P. fasciculatum Mich. Fl. Am, bor. II, p. 294.

P. pulverulentum Reyn. in Act. Lansanne, II, p. 11, t. 2.

P. ramosum setis ex alis urnigeris Dill. Hist. M. p. 427, t. $55, f .5$.

P. urnigerum L. Sp. pl. p. 1573; C. M. Syn. I, p. 208.

2. In silv. loc. accliv. petros, ad viar, agger. graminos, etc. - Eur.: E reg. campestr. usq, in alp. As, : Japon., Kamschatka, Jenissei, Obi, Persia, Cancas. A f $r$. : Ins. Canar. Am, sept. : Terr. nov., Nov. Scot., New Brunswick, Gaspes., Ontar., M. Selkirk, Alaska, Unalaschka, reg. septr., or, et centr., M. Jamaic.

Exs. : Mac. Canad. M. n. 219 p.p.

Rab. Bryoth. eur. n. 115.

Sull. et Lesq. M. bor. am. II ed. n. 319.

"var. crassum Bryol. eur. et W. P. Sch. Ul. cc.

Ut typ. - Eur, : In subalp. humid.

var. fasciculatum Brid. - P. urnigerum.

(1) Cf. Besch. F1, bryol, Antill, fr. p. 35. 
« var, humile Brid, op. el l, cc, : W. P. Sch. Syn. I ed. p. 440 el II ed. l. c.

Polytrichum urnigerum var, humile Wahlenb. Fl. Lapp. p. 347.

In siccior. - Eur. : Reg, alp.

var. nigrescens Brid. - Polytrichum gracile.

var. pulverulentum Brid. - P. urnigerum.

* var. tetragonum (Lindb.) Par.

Polytrichum urnigerum var, tetragonum Lindb. in Notis... 1867, p. 136.

Ut typ. - Eur. : Fennia.

« var. tsangense Besch. in Ann. sc. nat. 1892, I, p. 70.

- As. : Yunnan.

var. C. M. - P. capillare.

urnigerum $\left\{\begin{array}{l}\text { Drumm. p p. - P. capillare. } \\ \text { Griff. - P. microstomum? }\end{array}\right.$

usambaricum (Broth.) Par.

Polytrichum usambaricum Broth. in Engler's Bot. Jahrb. 1894, p. 194.

2. ot ign. Terr. - Afr. : Usambara.

vaginans Brid. - P. brachyphyllum.

varians (Hpe.) Mitt. M. austr. am. p. 619.

Polytrichum varians Hpe, in Ann. sc, nat. V ser. IV, p. 350.

viride Mitt. $l$. $c$. - Am. merid. : And. Nov. Granat.

- Am. merid, : And. Nov. Granat.

vitiense Mitt. Fl. Vit. p. 403.

- Pac. : Ins. Fidji.

volvatum (C. M.) Par.

Polytrichum volvatum C. M. in Bull. hb. Boissier, 1897, p. 177.

- Am. sept.: Guatemala.

Wallisii (C. M.) Jaeg. Ad, I, p. 722.

Polytrichum Wallisii C. M. in Linn. 1871-73, p. 171.

2.

- As. : M. ins. Philippin.

Wilsoni Jaeg. - P. robustum.

yunnanense Besch. in Ann. sc. nat. 1892, I, p. 69.

2. In silvis, - As. : Yunnaa (1).

POHLIA Brid. Mant. M. p. 115 et Bryol. univ. I, p. 607.

Spec. omn. non indicatae sunt WEBER $\approx$ ejusd. nom.

affinis $\mathrm{H}$. et H. - Webera polymorpha var. affinis.

arclica $\mathrm{R}$. Br. - Bryum.

var. purpurascens Schwaegr. - Bryum purpurascens.

arcuata $\mathrm{H}$, et $\mathrm{H}$. - Webera acuminata var. arcuata.

brachycarpa eor. - Webera polymorpha var. brachycarpa.

var. polyseta Schwaegr. - Webera acuminata var. polyseta. (1) In Enum. Kindberg. nom. nud. (Pogonatum, Polytrichadelphus et Polytri-
chum):

P. breviceps Mitt.

occanianum $C . M$.

B. pallens Besoh. (delend., Besch. in litt. 1) 
bryoides R. Br. - Bryum Rrownii.

calophylla Schwaegr. - Bryum.

cirrifera de Not. - Bryum Warneum.

clavata W. P. Sch. - Bryum.

curviseta $\mathrm{H}$. et W. - Webera polymorpha var. brachycarpa.

cylindrica eor. - Webera elongata.

demissa Hüb. - Plagiobryum.

dimorpha de Not. - Webera polymorpha.

elongala Hedw. - Webera.

var. acuminata Hüb. - Webera acuminata.

var. cylindrica Brid. - Webera elongata.

flexuosa Hook. - Bryum.

Gilliesii Mont. - Bryum.

gracilis $(\mathrm{H}$. et $\mathrm{H}$. - Webera polymorpha var. gracilis.

gracitis $\left\{\begin{array}{l}\text { Lindb. - Webera commutata var. gracilis. } \\ \text { Wils. - Orthodontium. }\end{array}\right.$

$\left.\begin{array}{l}\text { val. pulchella Hüb. } \\ \text { var. xanthocarpa Hüb. }\end{array}\right\}$ - Webera acuminata var, polyseta.

Greenii Brid. - Webera polymorpha var. affinis?

humilis Mont. - Orthodontium.

imbricata Schwaegr. - Bryum.

inclinata Hüb., Sw. - Bryum.

intermedia Brid. - Bryum.

lacustris Hüb. - Bryum.

laete-virens de Not. - Webera cucullata.

latifolia Br. - Bryum calophyllum.

longisela Hüb. - Bryum.

microcarpa Hsch. - Bryum.

minor $\left(\begin{array}{l}\text { Brid. p.p. ? - Webera polymorpha var. affinis. } \\ \text { Hsch. }\end{array}\right.$

Hsch. - Mielichhoferia Schiedeana.

Schleich. - Webera acuminata var. minor.

var. affinis Brid. p.p.? - Webera polymorpha var. affinis.

var. Greenii Brid. - Webera polymorpha var. affinis?

nutans Lindb. - Webera.

pallens $\mathrm{Br}$. - Bryum.

paradoxa Hüb. - Bryum cuspidatum.

patens $\mathrm{H}$, et H. - Webera acuminata var. arcuata,

pallescens Hook. - Orthodontium.

platyphylla Schwaegr. - Bryum.

polymorpha H. et H. - Webera.

var. brachycarpa Hüb. - Webera polymorpha var. brachycarpa.

var, polyseta Hüb. - Webera acuminata var. polyseta.

var, tenella Hüb, - Webera acuminata var, tenella.

polyseta H. et H. - Webera acuminata var. polyseta.

proligera Lindb. - Webera,

pulchella $\mathrm{H}$. et $\mathrm{H}$. - Webera acuminata var. pulchella.

purpurascens $\mathrm{R}$. Br. - Bryum.

rutilans Lindb. - Webera Schimperi.

tenella H. et H. - Webera acuminata var. tenella.

turbinata Schwaegr. - Bryum compressidens.

uliginosa $\mathrm{H}_{\mathrm{r}}$ - - Bryum.

Varenensis de Not. - Bryum Warneum.

vegeta $\mathrm{H}$. et H. - Webera acuminata var. arcuata.

zanthocarpa H. et H. - Webera acuminata var. polyseta.

Zierii Schwaegr. - Plagiobryum.

Weigelii Lindb. - Webera ludwigii. 
Polyodon W. P. Sch. Syn. I ed. p. 454 (subgen. Buxвaumiar).

POLYPODIOPSIS C. M. in Linn. 1875, p, 358 (sect. Fissidentis); Jaeg. Ad. $I I, p .48$ (gen. propr.).

Metzgeria Jaeg. - Fissidens.

Polyptychium C. M. in Linn. 1874; p. 600 (sect. Bartramiae).

POLYTRIChADELPhUS C. M. Syn. 1, p. 201 (sect. Catharinaz) ; Mitt. M. austr. am. p. 607 (gen. propr.) (25 spec.).

Abriaquiae (C. M.) Jaeg. Ad. II, p. 717.

Catharinea Abriaquiae $C . M$. in $F l .1875, n$. 34-35. 2 .

- Am. merid. : And. Nov. Granat.

aristatus (Hpe.) Mitt. M. austr. am. p. 609.

Catharinea aristata Hpe. in Linn. 1863, p. 147.

2.

- Am. merid. : And. Nov. Granat.

Arnoldi (Hpe.) Jaeg. Ad. I, p. 708.

Catharinea Arnoldi Hpe, in Linn. 1874, p. 664.

- Pac. : Alp. Austr. or.

australasicus (Hpe.) Jaeg. Ad. II, p. 717.

Catharinea austrulasica Hpe. in Linn. 1876, p. 315.

Ster.

- Pac. : Austral. or, subtropic.

ciliatus (Hook. f. et Wils.) Mitt. op. cit. p. 608.

Catharinea ciliata C. M. Syn. I, p. 201 et II, p. 560.

Polytrichum ciliatum $H$. f. et W. in Lond. Journ. of bot. 1847, p. 290, t.10.

2. Ad terr, turfos. - Am. merid. : And. Nov. Granat.

croceus Mitt. - P. semi-angulatus.

dendroides (Hedio.) Mitt. op. cit. p. 611. Catharinea dendroides Hpe. in Linn. 1847, p. 78; C. M. Syn. I, p. 199 et
II, p. 559.

Gymnopilum dendroides W. P. Sch. herb.

Pogonatum dendroides Brid. Bryol. univ. II, p. 112.

Polytrichum dendroides Hedw. Sp. M. p. 102; Mont in Cl. Gay Fl.

2. Chil. VII, p. 70, t. I. gon. occ., terr. Magellan., Fuegia, ins. Eremitae. Pac.: Nor,
Zeland.

ericoides (Hpe.) Mitt. op, et $l$. cc.

Polytrichum ericoides Hpe. in Ann. sc. nat. $V$ ser, $I V, p .350$.

Ster.

- Am. merid. : Nov. Granat.

flexuosus (C. M.) Mitt. op. cit. p. 609.

Polytrichum flexuosum C. M. Syn. I, p. 2I2.

2. Rupic. - Am. merid. : Venezuela.

giganteus (Hook.) Mitt. op. et l. cc.

Pogonatum giganteum Brid. Bryol. univ. II, p. 123.

Polytrichum giganteum Hook. M. ex. t. 65; C. M. Syn. I, p. 212

2. Ad arbor. - Am. merid. : And. Nov. Granat. 
grossidens (C.M.) Par.

Catharinea grossidens C. M. in Nuov. Giorn. bot. ital. 1897, p. 713.

- Am. merid.: And. Boliv.

horridus Mitt. in Journ. of the Linn. Soc. 1859, p. 98.

2 ?

P. magellanicum Hedw, Sp. M. t. 20, f. 3.

mitae, Maclov., Cáp, Horn,

innovans (C. M.) Jaeg. Ad. I, p. 707.

Catharinea innovans C. M. in Bot. Zeit. 1851, p. 548.

P. magellanicum (fid. Mitt.)

2. Terr. - Pac.: Tasman.

integrifolius (C. M.) Par.

Catharinea integrifolia C. M. in Nuov. Giorn. bot. ital. 1897, p. 84.

Ster.

- Am. merid. : And, Boliv.

longisetus (Hook.) Mitl. op. cit. p. 611.

Pogonatum longisetum Brid. Bryol. univ, II, p. 128.

Polytrichum longisetum Hook. M. ex, t. 66;C. M. Syn. I, p. 217 et II, 2. - Am. merid. : And. Nov. Granat.

Lyallii Mitt. in Journ. of the Linn. Soc. 1864, p. 49, t. 8; Lesq. et Jam. Man. p. 259.

Oligotrichum Lyallii Lindb. Obs, de Polytr, in Aot. Soc, $p r$. Faun et Fl. Fenn. IX, $p .102$.

2. In silv, conifer, - Am. sept. : M. Rupestr., Columb. brit,, Oregon, Colorado, Idaho, M. Calif.

magellanicus (L.) Mitt. in Journ. of the Linn. Soc. 1859, p. 97.

Catharinea innovans C. M. (fid. Mitt.).

C, magellanica Brid. Bryol, univ. II, p. 106 ; I. M. Syn. I, p. 201.

C. pseudo-Pol, trichum Raddi in Mem. math, edi fis. d. Soc. ital. Moden. $X V I 1 I, p .443, t, 18, f .1$.

Gymnopilum magellanicum W. P. Sch. herb.

Pogonatum magellanicum $P . B$. Prodr. $p .84$.

P. robustum Jaeg, Ad. I, p. 717 .

Polytrichum magellanicum L. Suppl. p. 449

P. robustum Lindb. in Notis... 1867, p. 99 (fid. Beseh.).

2.

Am. merid.: Terr. Magellan., Fuegia, ins. polycarpus (Col.) Brolh, in lilt.

Polytrichum polycarpum Col. in Trans. and Prooed. of the N. Zeal. Inst. 1887, p. 276.

$$
\text { - Pac. : Nov, Zeland. }
$$

purpurens Mitt. $M$. austr: am, p. 610.
2.

- Am. merid. : And. Quitens.

rubiginosus Mitt, op. et $l$. cc.

Saxic. - Am. merid.: And. Nov. Granat, et Quitens.

semi-angulatus (Brid.) Mill, op. cit. p. 609.

Catharinea magellanica Hsch. Fl. Bras. I, p. $47 ;$ C. M. Syn. II, p. 560.

C. semi-angulara Hpe. Enum. M. Brasil. p. 36.

Pogonatum semi angulatum Brid. Bryol. univ. $11, p .744$,

Polytrichadelphus croceus Mitt, in Journ. of the Linn. Soc, 1859, p. 98.

Polytrichum semi-angulatum Sill. in U. St. Expl. Exped. t. 6.

2. Terr, et saxic, $-A m$. merid. : Brasil, austr, or. 
squamosus (Hook. f. et Wils.) Mitl. op. cit. p. 612.

Catharinea squamosa C. M. Syn. I, p. 200 et II, p. 560.

Polytrichum squamosum $H$. $f$. et $W$. in Lond. Journ. of bot. 1844, i p. 539 et Fl. Antarct. II, p. 411, t. 153, f. 8 .

2. $\quad-A m$. merid.: Fret. et terr. Magellan,, ins. Eremitae, Maclov. Pac. : Nov. Zeland. sept,?

subflexuosus (Ltz.) Jaeg. Ad. I, p. 709.

Polytrichum subflexuosum Ltz. Moosst. p. 157.

2.

- Am. sept. : Mexic.

Trianae (C. M.) Mitt. op. cit. p. 611.

Catharinea Trianae Hpe, in Ann, sc. nat. $V$ ser., $I V, p, 346$.

Polytrichum Trianae C. M. in Bot. Zeit. 1857, p. 577.

2.

- Am, merid. : Nov. Granat.

umbrosus Mitt. M. auslr. am. p. 610.

Terr. - Am. merid. : And. Boliv., Chile.

Valenciae (C. M.) Par.

Catharinea Valenciae C. M. in Linn. 1878-79, p. 468.

2. $\quad$ - Am. nierid. : Venezuela (1).

P OLYTRICHUM Dill. emend. Hist. M. p. 4395 (99 spec.).

acaulon, capillaceum, capsutis cylindricis Dill. - Pogonatum pensilvanicum.

afro-aloides C. M. - Pogonatum.

albo-marginatum C. M. - Pogonatum.

albo-vaginatum $\mathrm{Hpe}$ - - Pogonatum.

aloëfolium Scop. (1 et 2). - Pogonatum aloides.

$\beta$ foliis integris Scop (3), - Pognnatum nanum.

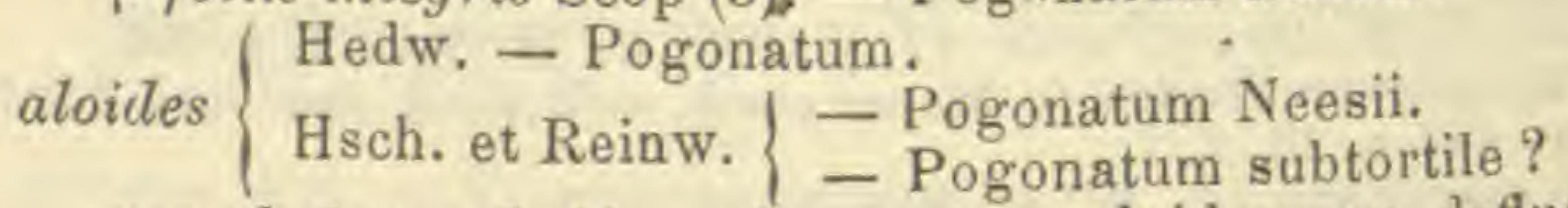

var. defluens C, M. - Pogonatum aloides var. defluens.

var. Dicksoni H. et T. - Pogonatum aloides var. defluens.

var, $\alpha$ et $\beta$ Mart. - Pogonatum aloides var. defluens.

alpestre $\left\{\begin{array}{l}\text { Hoppe. - Polytrichum strictum. } \\ \text { Sw., Hartm. - Polytrichum Swartzii. }\end{array}\right.$

var. affine Brid, - Polytrichum juniperinum var. affine. alpinum L. - Pogonatum.

var, angustifolium Lindb. - Pogonatum alpinum var. arcticum.

var. arcticum Wahlenb. - Pogonatum alpinum var, arcticum.

var. brevifolium C. M. - Pogonatum alpinum var. brevifolium.

var. campanulatum C. M. - Pogonatum alpinum var. brevifolium.

var. ciliatum Retz. - Pogonatum alpinum.

var. cylindricum Lindb. - Pogonatum alpinum var. arcticum.

var. furcatum C. M. - Pogonatum alpinum var, furcatum.

var. laeve Retz. - Pogonatum alpinum var. septentrionale.

var. silvaticum Lindb. - Pogonatum alpinum var. arcticum.

var. $\beta\{$ Huds. - Pogonatlim urnigerum.

alpinum ramosum, capsulis e summitace ellipticis Dill, - Pogonatuoi alpinum.

(1) De nom, nud, in Enum. Kindberg. cf. Pogonatum. 
altisetum C. $M$, in $\mathrm{Fl} .1897, p .328$.

- Am. merid. : And. Venezuel.

" var. humilisetum C. M. in op. cit. p. 329.

- Am. merid. : And. Venezuel, M. Pichincha.

ambiguum Mich. - Pogonatum alpinum vav. arcticum.

andinum Hpe. - Pogonatum.

angolense W. et Dy. - Pogonatum.

angustalum $\left\{\begin{array}{l}\text { Brid, - Atrichum. } \\ \text { Griff. p.p. ? - Atrichum undulatum var. subserratum. }\end{array}\right.$

angustifolium Mitt. M. auslr, am. p. 622 .

- Am. merid. : Brasil. tropic.

angustifolium W. P. Sch. - P. verrucosum.

Antillarum Rich. in Brid. Bryol. univ. II, pp. 138 et 747 ; C. M. Syn. I,

p. 219 ; Milt. M. austr, am. p. 620.

P. appressum Schwaegr. Suppl. I, II, p. 311 et II, II, p. 5, t. 152.

P. scabriusculum Brid. Mant. M. p. 195.

P. setifolium Sw. Adnot, bot. p. 146, n. 9.

2. Ad rup. madid, et terr. in silv. - Am. sept. : And. Costa Ricens., S. Doming. Am. merid.: Venezuela, And. Quitens., Brasil. austr. or.

appressum Brid. Bryol. univ. II, p. 141 et 747 ; C. M. Syn. 1, p. 219.

- Afr.: Ins. Borbon.

appressum Schwaegr. - P. Antillarum.

Apulejae Commers, - P. remotifolium.

( - Ulota Bruchii?

arboreum Ed. F1. dan. t. $648 .\left\{\begin{array}{l}\text { - Ulota crispa? } \\ \text { - Ulota crispula? }\end{array}\right.$

arcticum Sw. - Pogonatum alpinum var. arcticum.

aristatum W. P. Sch. mss. (fid. Hpe.) ; Lindb. in Nolis... 1867, p. 99, n. 12.

- Am. merid. : And. Nov. Granat.

aristalum Hpe. - Polytrichadelphus.

aristiflorum Milt. M. austr. am. p. $\$ 20$.

P. Sprucei Lindb, in Notis.... 1867, p. 99.

Rupic. et terr. - Am. sept. : Jamaic. Am. merid. : Venezuela, Nov.

Granat., And. Quitens. et Boliv, Brasil.

assimile $\mathrm{Hpe}$, in $\mathrm{Fl} .1881$.

- Am. nerid. : Brasil. austr. or.

atrichoides C. M. in Rehm. M. Afr. austr, n, 273.

Ster.

- Afr. : C. B. Sp.

allenuatum Menz. - P. formosum.

var. aurantiacum Turn. - P. gracile,

aurantiacum Hoppe. - P. gracile.

var, $\beta$ Wahlenb. - P. formosum.

australasicum Hue, et C. M. - Pogonatum.

australe H. f. et W. - Psilopilum.

austro-alpinum $\left\{\begin{array}{l}\text { C. M. - Pogonatum. } \\ \text { F. y. Müller. - Pogonatum alpinum. }\end{array}\right.$

austro-Georgicum C. M. - Pogonatum.

Autrani Ren, et Card, in Bull. T6. Boissier, 1894, p. 33.

2. Ad rivul, - As, ; M. Liban. 
axillare Lam. - Pogonatum urnigerum.

Balduini C. M. - Pogonatum.

Bernoullii C. M. - Pogonatum.

Bisseti C. M. - Pogonatum.

boreale Kindb. Laubm. Schwed. $u$. Norveg., et in Mac. Cat. p. 155. - Am. sept. : Unalaschka.

Borgenii Hpe. - Pogonatum.

brachymitrium C. M. in Linn. 1878-79, p. 468.

2.

- Am. merid. : Venezuela.

brachyphyllum Rich. - Pogonatum.

brachypyxis C. M. in Ule Bryoth. brasil. n, 40.

Terr. - Am. merid. : Brasil, austr. or.

brasiliense Hpe. Symb. 1872, p. 53.

Pogonatum brasiliense Jaeg. Ad. I, p. 728.

- Am. merid. : Brasil. austr. or.

breve C. M. in Hedwig. 1897, p. 90.

- Am. merid. : Alp. Argentin. subtropic. Tucuman.

brevicaule $\left\{\begin{array}{l}\text { Brid. - Pogonatum pensilvanicum. } \\ \text { Hsch. - Pogonatum Gardneri. }\end{array}\right.$

brevifolium R. Br. - Pogonatum alpinum var. brevifolium.

Bryi ruralis facie, capsula ses- $[$ - Orthotrichum affitie (fid. Limpr.). sili majus Dill.

Bryi ruralis facie, capsula sessili minus Dill. - 0. stramineum.

bryoides var. capillaceum Weiss. $\left\{\begin{array}{l}\text { - Ulota Bruchii ? } \\ \text { - Ulota crispa? } \\ \text { - Ulota crispula? }\end{array}\right.$

var, strialum Weiss. - Orthothrichum leiocarpum.

Buchanani Relem. M. Afr. austr. n. 580.

Ster.

- Afr. : Natal.

calopogon Besch. Fl. bryol. Réunion, etc. p. 115.

- Afr.: Ins. Borbon., Franciae.

" $f$. majus Besch. l. c.

- Air.: Ins. Borbon.

Camerae C. M. - Pogonatum.

campanulalum Hsch, - Pogonatum alpinum var. brevifolium.

campophilum C. M. in Ule Bryoth. brasil. n, 147

- Am. merid. : Brasil. austr. or.

camptocaulon C. M. - Pogonatum.

campylocarpum C. M. - Pogonatum.

canaliculatum Hook. - Oligotrichum.

capense Hpe. - Pogonatum.

capillare $\left\{\begin{array}{l}\text { Mac, - Pogonatum pensilvanicum. } \\ \text { Rich }\end{array}\right.$

var, dentatum Lindb. - Pogonatum dentatum.

var. minus Wahlenb. - Pogonatum capillare var. minus.

var. oxycaly $x$ Lindb. - Pogonatum dentatum.

capillaceum, crispum, calyptris acutiz pilosissimis Dill. (-Ulota Bruchii. capillaceum, crispum, calyptris acutiz pilosissimis Dill. $\left\{\begin{array}{l}\text {-Ulota crispula. } \\ \text { - Ulotacrispula }\end{array}\right.$
$\begin{gathered}\text { capsulis sessilibus foliis brevibus } \\ \text { rectis carinatis Dill. }\end{gathered}$

- O. Sturmii (fid. Limpr.). 
capsulis subrotundis Huds. - Pogonatum nanum.

Carionis C. M. - Pogonatum.

Chimborassi Llz. Moosst. p. 156.

2. Rupic. - Am. merid. : M. Chimborazo.

cilialum H. f. et W. - Polytrichadelphus.

cirratum Sw. - Pogonatum.

clavatum Dz. et Mk, - Pogonatum.

Commersonianum Brid. - P. subpilosum.

commune L. Sp. pl. 1573 p.p. ; Brid. Bryol. univ. 11, p. 148; Bryol. eur. IV (mon. p. 13), t. 425; C. M. Syn. I, p. 220; W. P. Sch. Syn. II ed. p. 545.

P, conmune $\alpha$ majus Weiss Pl. crypt. Fl. Goett. p. 168.

P. commune $\alpha$ serrulatum Retz Fl. Scand. Piodr. II, p. 209, n. 1194.

P. commune $\alpha$ yuccacfolium Ehrh, in Hann. Mag. 1780, p, 235.

P. pallidisetum Drumm. M. bor. am. I ed. n. 279.

P. propinquum R. Br. Suppl ad it. Parray. p. 194; Brid. op. cit p. 150.

P. quadrangulare Gilib. in Steud. Nom. crypt. p. 353.

P. quadrangulare vulgare, Yuccae foliis serratis Dill. Hist. M. p. 420, t. 54, f. 1 .

P. serratum Schrunk Baiers F'. II, p. 446.

P. yuccaefolium Ehrh. Pl. crypt. exs. n. 214 .

2. In turf. uligin. et palud, silvat. - Eur. : Tota ; Spitzberg. As. : Japon., Kamschatka, Amour, Saghalien, Obi, Jenissei, Ochotsk, Caucas. Afr. : Ins. Azores, Canar, Madeir.; ins. Borbon.? Madagascar? M. Cameroon. Am. sept. : Groenland merid., Terr. nov., ins, Miqnel, Nov. Scot., New Brunswick, Ontario, Sitka, Washington, Oregon, Idaho, reg. sept., or. et centr. Am. merid. : And. Peruv., Brasil. Pac.' Austral. merid., Nov. Zeland., Tasman., ins. Chatham.

Eas. : Drumm, M. bor. am. II ed, n, 72.

Rab. Bryoth. eur. n. 119.

Sull et Lesq. M. bor, am. II ed. n. 329.

- var. africanum C. M. in Rehm. M. Afr. austr. n. 276.

- Afr. : C. B. Sp.

var. allenuatum $\mathrm{H}$. et T. (1), - P. formosum p.p.

var. auruntiacum Wahlb. - P. gracile p.p.

* var, brevifolium Geh, in Lindb. et Arn. M. As. bor. 1890, I.

- As. : Alatan.

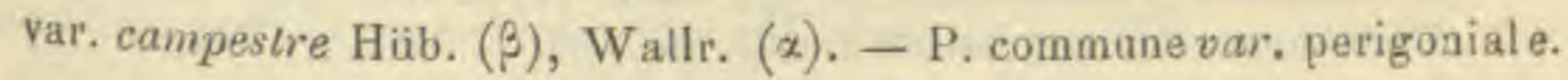

" var. canadense Kindb, in Mac. Cat. p. 156.

P. commune Mac. Canad. M. n. 225.

Ad terr, humid. in silv. - Am. sept. : New Brunswick, Gaspes., Ontar.,

M. Selkirk.

Exs. : Mac. Canad. M. n. 563.

var, ciliatum Retz. - P. juniperinum.

* var. Ehrenbergii Ltz. M. Ehrenb. p. 49, t. 14, f. 11-16 et t. 15, f. 1-2. - As. : Syria.

(1) $P$. formosum a $P$. gracili non distinguunt et utrumque ad $P$. commune revocant, s Brid. Bryol, univ. II, p. 154. 
" var, fastigiatum Wils, Bryol. brit. p. 212.

P. cubicum var. fastigiatum Lindb. in Notis... 1867, p. 119.

-- Eur. : Suecia, Scot.

var. formosum Drumm, - P. juniperinum.

var. humile Sw, W. P. Sch, - P. commune var. minus.

\&var. Mac-Leanum Rehm. M. Afr. austr, n. 577.

$$
\text { - Afr. : Transvaal. }
$$

var. majus Weiss. - P, commune.

"var. Maximowiczii Lindb. in Act. Soc. sc. Fenn. 1872, p. 224.

- As. : Japon. (ins. Nippon).

var. medium Weigg. - P. juniperinum.

« var. minus Weiss Pl. crypt. Al. Goett. p. 171 p.p.; Bryol, eur. et C. M. $l l . c c$.

P. commune var. humile Sro, Adn. bot. p. 14l; W. P. Sch. Syn. Ied. p. 449 et II ed, p. 546.

P. commune $\beta$ L. Sp. pl. I ed., II, p. 1009 p.p.

P. cubicum Lindb. in Notis.... 1867, p. Li7.

P. quadrangulare Juniperi foliis brevioribus et rigidioribus Dill. Hist. M. p. 424, n. 2 excl. syn. (fid. Lindb.).

P. yuccaefolium Hoppe in Stur $m$ Deutseh. Fl. II, p. 4 p.p.

In loc, siccior. - Eur. : Hic illic. Afr.: C. B. Sp. Am. sept.: New Jersey, Unalaschka.

var. minus $\left\{\begin{array}{l}\text { Brid. - P. commune var. pygmaeum. } \\ \text { Weigg. - P. piliferum. }\end{array}\right.$

« var. perigoniale (Rich.) Bryol. eur, C. M. et W. P. Sch, ll. cc.

P. commune var. campestre Wallr. Fl. crypt. germ. I, p. 201; Hũb. Muscol, germ, p. 525.

P. perigoniale Rich, in Mich. Fl. bos, am. II, p. 295 ; Brid. op. eit. p, 150.

P. yuccaefolium $\beta$ perigoniale Mart, Fl. crypt. Erlang. p. 83.

Ut praeced. - Eur. : Hic illic, Am. sept. : Ontario, Columb, brit., reg. sept., or., centr. et merid. Fac. : Austral, felix.

Eoss, : Drumm. M. bor. am. II ed. n. 73?

Sull. et Lesq. M, bor. am. II ed. n. 330.

var. piliferum Weiss. - P. piliferum.

var, pilosum Ehrh. - P. piliferum.

a var. pygmaeum (Lindb.) Par.

P. commune $\beta$ minus Brid. Bryol. univ. II, p. 150? (fid. Lindb.).

P. cubicum var. pygmaeum Lindb. in Notis.... 1867, p. 118.

In spongiosis. - Eur. : Fennia.

var. serrulalum Ret\%. -- P. commune.

- var. uliginosum Hüb. Múscol. germ. p. 535.

P. commune $\gamma$ yuccaefolium de Not. Epil. p. 330.

In turfos, silvat. - Eur. : Central.

Exs. : Rab. Bryoth. eur, n, 120.

var, yuccaefolium $\left\{\begin{array}{l}\text { Ehrh. }- \text { P. commune. } \\ \text { de Not. - P. commune var, uliginosum. }\end{array}\right.$

var. $\beta$ L. - P. commune var. minus.

var, $\gamma$ L. $-\mathrm{P}$. piliferum.

commune $\left\{\begin{array}{l}\text { C. M. p.p. - P. subpilosum. } \\ \text { Mac. - P. commune var, canadense. } \\ \text { Schrank, - P. juniperinum. }\end{array}\right.$ 
comorense C.M. in Besch. Fl. bryal. Réunion, elc. p. 115.

2.

$$
\text { - Afr.: Comor. magna. }
$$

compressum H. f. et W. - Psilopilum.

conforme Mitl. M. austr. am. p. 621 .

- Am. meril. : And. Quitens.

conorhynchum Kindb. in Mac. Cal. p. 154.

2. In paludos. - Am. sept.: M. Selkirk.

contorlum Menz. - Pogonatum.

var. pallidum Lindb. - Pogonatum contortum var. pallidum.

controversum $\left\{\begin{array}{l}\text { Brid. - Atrichum undulatum var. abbreviatum. } \\ \text { Hedw. - Atrichum angustatum. }\end{array}\right.$

$\left\{\begin{array}{l}\text { Dz. et Mk. - Pogonatum macrophyllum. } \\ \text { Hedw. - Pogonatum tortile. }\end{array}\right.$

convolutum $\left\{\begin{array}{l}\text { Hook. - Pogonatum tortile. } \\ \text { Hoon }\end{array}\right.$

L. - Pogonatum.

var. cirratum C. M. - Pogonatum convolutum var, cirratum. coronatum Brid. - P. formosum.

crassiselum Lam, et DC. - P, sexangulare.

croceum Hpe. in Linn. 1852, p. 715.

- Pac. : Tasman.

cubicim Lindb. - P. commune var. minus.

var. fastigialum Lindb. - P. commune vur. fastigiatum.

var. pygmaeum Lindb. - P. commune var. pygmaeum.

cucullalum $\mathrm{H}_{\mathrm{pe}}$. - Pogonatum.

cuspidigerum C. M. in Nuov. Giorn, bot. ital. 1897, p. 16.

- Am. merid. : And. Boliv.

cuspidirostrum W. P. Sch. in Mand. Pl. Boliv. n. 1687; C. M. in Nuov.

Giorn. bot. ital. $1897, p .16$.

- Am, merid, : And. Boliv.

cylindricum Sw. - Atrichum angustatum.

decipiens Limpr. in LXVIII Jahresb. d. Schles. Ges. f. Vaterl. Cullur.

1890,11, p. 93 et Laubm. Deutsehl. $I I$, p. 618.

P. ohioense (fid. Kindb.).

2. In petros. - Eur. : Thuring., Riesengeb.

defuens Brid. - Pogonatum aloides var. defluens.

dendroides Hedw. - Polytrichadelphus.

densifolium Wils, in sched.; Mitt, M. Ind. or. p. 155.

2.

- As. : Sikkim.

densifolium Hpe. - P. Novae Hollandiae.

denlalum $\left\{\begin{array}{l}\text { Lesq. p.p. - Pogonatum contortum. } \\ \text { Menz. - Pogonatum. }\end{array}\right.$

Dicksoni Turn. - Pogonatum aloides var, defluens.

domingense Brid, - Pogonatum tortile.

dubium Scop. - Pogonatum urnigerum.

Duseni C. M. in Dusen M. Camer. n. 346.

- Afr. : M. Cameroon.

elatum P. B. Prodr. p. 85; Brid Bryol, univ. II, p. 152 ; C. M. Syn. 1, p. 22I.

P, purpurascens Brid. Mant. M, p. 197.

2. In sphagnet, - Afr. : Ins. Borbon., Franciae. 
elegans Welvo. et Duthy in Mém... Genève, 1870, p. 8, t. 11, $f .1$.

2. In dumet. rupestr. humidiusc. - Af $r$ : : Angola.

elongatum P. B. Prodr. p. 85 ; Brid. Bryol. univ. II, p. 156; C. M. Syn. I, p. 222 ; Milt. M. austr. am. p. 622 . - Am, merid. : Fret. Magell.

equisetiforme C. M. in Linn. 1874, p. 579.

Ster. $\delta^{x}$ et fr. ign. In paludos. - Am. sept, : Costa Rica. Am. merid. : And. Nov, Granat.

ericoides $\left\{\begin{array}{l}\text { Hpe. - Polytrichadelphus. } \\ \text { Hoffm. - Pogonatum nanum. }\end{array}\right.$

erytlerodontium Kindb. - Pogonatum.

falcifolium Griff. - Oligotrichum semi-lamellatum.

fasciculatum Mich, - Pogonatum urnigerum.

ferruyineum Brid. - Pogonatum alpiuum.

flaccido-gracile C. M. in Relm. M. A fr. austr, n. 274.

- Afr. : Austral.

flexicaule C. M. l. c. n. 275 et b.

- Afr.: Austral.

flexuosum C. M. - Polytrichadelphus.

formosum Hedvo, Sp. M. p. 92, t. 19; Brid. Bryol. univ. 1I, p. 151; Bryol. eur. IV (mon. p. 9), t. 420 ; C. M. Syn. 1, p. 224; W. P. Sch. Syn. II ed. p. 541 ; Lesq. et Jam. Man. p. 264 p p.

Atrichum anomalum Milde (fid. Limpr, Laubm. Deutschl. I1, p. 619.

P. attenuatum Menz, in Trans, of the Linn. Soc. $1 \mathrm{~V}, p .72, t, 6, f, 2$.

P. aurantiacum $\beta$ Wahlenb. Fl. Upsal. p. 387.

P. commune $\beta$ attenuatum H. et T. Muscol. brit. p. 26 p.p.

P. commune $\beta$ aurantiacum Wahlenb. Fl. Suec. I ed., II, p. 737 p.p.

P. coronatum Brid. op. cit. p. 748?

P. formosum var, a quadrangulare Hartm. Skand. Fl. I ed., p. 404.

P. formosum $\beta$ superbum Fiedl. Syn. Laubm. Mecklenb. p. 97.

P. marginatuin Hedvo. Sp, MI. p. 8 excl. syn. 'fid. Sehwaegr.)

P. stans Thuill, herb.

P. superbum Schultz Syll, in Ephem. bot. Ratisb. p. 152.

2. In silvat. - Eur. : Reg. montos, usq. in subalp., rar, in planit. As. : Japon., Caucas., Syria. Afr. : Alger., Madeir.; ins. Amsterdam? Am. sept. : Groenland, Terr. nov., Miquel., New York, lac. Erie, Columb, brit., Alaska, Sitka, Washington.

Exs. : Mac. Canad. M. n. 429.

Rab. Bryoth, eur, n. 118.

Sull, et Lesq. M. bor. am. II ed. n. 323 .

var. aurantiacum Hartm, - P. gracile.

var. gracile Vent, et Bott. - P. gracile.

" var. pallidisetum (Funk) Brid, Bryol, eur, et W. P. Sch.ll. cc.

P. pallidisetum Funk Moostsehb. p. 69, t. 55.

Ut typ. - Eur. et Am. sept. : In subalp. As. : Japon.

var, superbum Fiedl, - P. formosum.

formosum Lesq. et Jam. p.p. - P. ohioense.

furcatum Hsch, - Pogonatum alpinum var. furcatum.

Gardneri C. M. - Pogonatum.

Germaini C. M. - Pogonatum.

Giesbreghtii Besch, Prodr. bryol. mexic. p. 67.

2.

- Am. sept. : Mexic. 
giganteum Hook. - Polytrichadelphus.

glabratum Wahlenb. - Psilopilum arcticum.

glabrum Brid. - P. remotifolium.

Glasiovii Hpe. - Pogonatum.

gracile (Dicks.) Menz. in Trans. of the Linn. Soc. IV, p. 73, t. 6, f. 3; Brid. Bryol. univ. II, p. 154 ; Bryol. eur. $1 \mathrm{~V}$ (mon, p. 10), t. 421; C. M. Syn. I, p. 225 ; W. P. Sch. op. cit. p. 540.

Catharinea Dixoni Braithw, in Journ, of the bot. brit. eto. XXIII, Aug. 1885.

Pogonatum urnigerum \& nigrescens Brid. op. cit. p. 124.

P. atteruatum $\beta$ aurantiacum Turn. Muscol. Hibern. p. 83.

P. anrantiacum Hoppe Bot. Taschb. 1800, p. 131.

P. commune $\beta$ attenuatum H. et T. Muscol. brit. p. 26 p.p.

P. commune $\beta$ aurantiacum Wahlenb. Fl. Suec. I ed.. II, p, 737 p.p.

P. formosum $\beta$ aurantiacum Hartm. Skand. Fl. I ed. p. 404 et II ed, p. 324.

P. formosum var, gracile Vent. et Bott. Enum. crit. p. 30.

P. formosum $\beta$ rupestre Brid. l. $c$.

P. longisetum $S w ., M$. Suec. p. 76, $t, 8, f .16$.

P. Iongisetum $\beta$ aurantiacum Brid. Sp. M. I, p. 60.

P. marginatum $W$. et $M$. Ind, mus. pl. crypt. (1803).

P. nigrescens $D C$. Fl. fr. $I I, p .490$.

2. In turfos., rar. in rup. fiss. - Eur. : E reg. campestr. usq. in subalp. per zon, intermed, et septentr. As. : Japon., Jenissei, Obi, Talysch, Caucas. Am. sept.: Terr. nov., ins. Miquel., New Brunswick, Ontal., lac. Super., M. Rupestr. et Selkirk, Columb. brit., litt. mar. Behring, fret. Kotzebué, Mimesota, Ohio. Pac. : Nov. Zeland,

Exs. : Mac. ('anad. M. n. 478.

Rab. Bryoth. enr. n. 122, 286.

Sull. et Lesq. M. bor, am. II ed, n. 324.

var, rupestre Brid. - P. gracile.

Graeffeanum C. M. - Pogonatum.

grandifoluum Lindb. -. Pogonatum.

Gulliveri Hpe. - Pogonatum.

gymnophyllum Wils. - Pogonatum.

helveticum Schleich. - P. s'xangulare.

hercynicum Hedw. - Oligotrichım.

Hoehneli C. M. in Fl. 1890. p. 471 .

2. In herbos. - Afr. : Kilima N'Djaro, reg. lacustr.

Holstii Broth. - Pogonatum.

Hoppii Hsch. - P. piliferum var. Hoppii.

Humbolltianum Hpe. - Pogonatum.

kyperborewan I R. Br: - P. piliferum var. hyperboreum.

Wahlenb. (fid. Lindb.). - $\mathrm{P}$. alpinum var, septentrionale.

ineplicalem Voit. - P. juniperinum.

innovans C. M. - Polytrichadelphus.

intermedium Brid. - Pogonatum nanım.

involutum Hpe. symb. 1877, p. 727 .

Ster.

- Am. merid.: Brasil. alstr. or.

Janesoni Tayl, - Pogonatum oligodus,

Junghunianum Dz. et Mk. - Pogonatum.

var, incurvum eor. - Pogonatum Junghunianum var. incurvum.

juniperellum C. M. in A bleandl. Brem. VII, p. 205.

2.

- Afr. : Madagascar. 
juniperifolium Hoffm, - P. juniperinum.

juniperiforme W. P. Sch, in Lechler Pl. Peruv. n, 2281 ; Mitt. M. austr. am. p. 621 .

Rupic. - Am. merid. : Chile.

juniperinum Hedlo. Sp. M. p. 89, t, 18, f. 6-10; Brid. Bryol. univ. II, pp. 136 el 746; Bryol. eur. IV (mon. p. 12), t. 423; C. MI. Syn. I, p. 218 ; W. P. Sch. Syn, II ed.p. 543.

P. commune Schrank Baiers Fl. II, p. 446.

P. commune $\beta$ ciliatum Retz. Fl. Scand. Prods, n. 1194.

P. commune var. formosum Drumm. M. bor, am. 1 ed. n. 276.

P. commune $\beta$ medium Weigg. Fl. Pom. Rug. p. 679.

P. implicatum Voit M. Herbip. p. 59.

P. juniperifolium Hoffm. Dextsch. Fl. II, p. 24, n. 2.

P. pallidisetum var. Drumm. l. c. n. 280.

P. quadrangulare Juniperi foliis brevioribus et rigidioribus Dill. Hist. M. p. $424, t .54, f .2$ (fid. C. M.).

2. In ericet. humid., pasc. silvat., etc. - Eur. : Tota. As. : Japon., Kamschatka, penins, Samojed, Jenissei, Obi, Taimyr, Ochotsk, Irkoutsk, Kashmir, Caucas., As. min. Afi: : Alger, Madeir., ins, Canar., S. Helena, Tristan d'Acunlia, M. Cameroon, C. B. Sp. Am. sept. : Groenland, Labrador, fret. Smith., sin. Baffin et Hudson; de Terr. nov. ad ins. Vancouver et fret. Kotzebuë: tota temper., Costa Rica. Am. merid.: Venezuela, And. Quitens., et Boliv., Valdiv, fret. Magellan. Pac. : Alp. Austral. merid. or., Nov. Zeland., Tasman., ins. Auckland.

Exs. : Drumm. M. bor. am. I ed. n. 277 et II ed. n. 71.

Mac. Canad. M. n, 223.

Miandon Pl. Madeir. n. 29.

Rab. Bryoth, eur. n. 810, b c.

Sull. et Lesq. M, bor. am. II ed. n. 327.

"var. affine Roehl. Deutsch. Fl. III, p. 58; Lindb, in Notis... 1867, p. 123.

P. alpestre $\beta$ affine Funk in Moostschb. p. 88, t. 84; Brid. Bryol. univ. $I I, p .140$.

Ut typ. - Eur. : German.

var. alpestre Bryol, eur, - P. strictum.

" var. alpinum W, P. Sch. Syn. I ed. p. 447 et 11 ed. p. 544.

Ut typ. - Eur. : In subalp. usq. ad niv. aetern. As. : Kashmir. Ant. sept. : Wisconssin.

var. gracile Wablenb. - P. strictum.

* var. integrum C.M. l. c.

- Am. mevid. : Chile.

var. strichm Liljebl., Bryol, eur. - P. strictnm.

" var. Waghornei Kindb. in Mac. Cat. p. 155.

- Am. sepl. : Labrador.

var. W, et M. - P. strictum.

laevigalum Wahlenb. - Psilopilum arcticum.

laevipilum Hpe. - P. piliferum var, laevipilum.

laterale Crome. - Pogonatum aloides var. defluens.

latidens C. M. in Dusen M. Camer. n. 512 . - Afr. : M. Cameroon, 
leioneuron Besch. in Ann. sc. nat. VII ser., II, p. 91 et in Marie M. Mad. n. 9.

$$
\text { - Afr: : Ins. Mayotte. }
$$

leplopelma C. M. - Pogonatum.

leucomitrium Hsch. - Pogonatum convolutum var, cirratum.

Libani Ren. et Card. mss.

2.

$$
\text { - As. : M. Liban. }
$$

Liebmannianum C. M. - Pogonatum.

ligulalum Mitt. - Atrichum Mïlleri.

longifolium Bryol, eur. - Dawsonia superba?

longiselum $\left\{\begin{array}{l}\text { Hook. } \\ \text { Sw. - Polytrichadelphus. }\end{array}\right.$

var. aurantiacum Brid. - P. gracile.

longissimum $C, M$, in Hildebr. M. Mad, n. 2125.

- Afr.: Madagascar.

loricaly $x$ C. M. - Pogonatum.

var. brachypodon i. M. - Pogonatum loricalyx var, brachypodon.

Macounii Kindb, - Pogonatum.

macrorhaphis C. M. Bryol, austr, Geoig. p. 14.

Ster. In lapidos. - Am, merid. : Austr. Georg.

madagassum Hpe. - Pogonatum?

magellanicus $\left\{\begin{array}{l}\text { Hedw. p.p. - Polytrichadelphus horridus. } \\ \text { L. - Polytrichadelphus. }\end{array}\right.$

mahense Besch. Fl. bryol, Réunion, etc. p. 116.

2.

- Afr. : M. ins. Seychelles.

mammillatum Lindb. M. Scand. p. 12 (subsp. P. juniperini).

2.

- Eur. : Fennia, As. : Caucas. centr.

marginatum $\left\{\begin{array}{l}\text { Hedw. - P. formosum. } \\ \text { Schwaegr. - Psilopilum arcticum. } \\ \text { W. et M. - - P. gracile. }\end{array}\right.$

mauritianum C. M. in Besch. op. cit.p. 117.

Ster. $\quad-A f r$ : Ins. Franciae.

micro-capillare C. M. - Pogonatum.

microcephalum C. M. in Engler's Bol. Jahrb. 1883, p. 77 et in Forschungsreise... Bot. p. $1 \mathrm{i}$.

Ster. - Afr. : Ins. Kerguelen.

microdendron C. M. - Pogonatum.

microplyyllum Dz. et Mk. - Pogonatum.

microstomem $\mathrm{R}$. Br. - Pogonatum.

minimum Crome. - Pogonatum aloides var. defluens.

minioides Neck, - Pogonatum aloides.

Molinae Mont. - Oligotrichum.

Molleri C. M. - Pogonatum.

nanocephalum C. M. Bryol. auslr. Georg. p. 16.

Ster. Rupic, - Am, merid. : Austr. Georg.

nano-globulus $C . M$. in $\mathrm{Fl}$. 1888, p. 408 .

Rupic. in herbos, - Afr.: Kilima N'Djaro, reg. lacustr.

narum $\left\{\begin{array}{l}\text { Hedw. - Pogonatum nanum. } \\ \text { Hoffn. - Pogonatum aloides var. defluens, } \\ \text { Weiss, - Pogonatum aloides. }\end{array}\right.$ 
var. $\beta$ Weiss. - Pogonatum nanum.

var. Dicksoni Lindb. - Pogonatum nanum var. defluens.

nanum capsulis rotundatis galeritis, Aloës folio non serrato Dill. Pogonatum nanum.

Neesii C. M. - Pogonatum.

neglectum Hpe - Pogonatum.

nigrescens DC. - P. gracile?

nigricans $\mathrm{H}$. f. et W. - Oligotrichum Riedelianum.

norvegicum $\left\{\begin{array}{l}\text { Hedw. (fid. Brid.). - P. sexangulare. } \\ \text { Hedw. (fid. Lindb.). - Pogonatum alpinum var. septentrio- } \\ \text { nale, } \\ \text { Hedw. (fid. W. P. Sch.). - Pogonatum alpinum. }\end{array}\right.$

Novae Hollandiae Jaeg. Ad. I, p. 732.

P. densifolium Hpe. in Linn. 1859-60, p. 635.

$$
\text { - Pac. : Alp. Austral. or. }
$$

nudicaule Wright. - Pogonatum.

nuka-tivense C. M. - Pogonatum.

obtusatulum C. M. - Pogonatum.

obtusum C. M. - Pogonatum.

octangulare C. M. - Pogonatum.

Ederi Brid. $\left\{\begin{array}{l}\text { (fid. C. M.). - P. sexangulare. } \\ \text { (fid. Lindb.). - Pogonatum alpinum var. septentrionale. }\end{array}\right.$

ohioense Ren. et Card. in Rev. bryol. 1885, p. 11, in Bot. Gaz. 1888,

p. 199, t. 17 et M. Amer. sept n. 70 et b.

P. formosum Lesq. et Jam. Man. p. 264 p.p.

2. Ad terr. in silv. - Am. sept. : Anticosti, New Brunswick, Gaspes., Ontar., lac. Erie et Super., Columb. brit., reg. sept., or. et centr.

Exs. : Mac. Canad. M. n. 22l.

oligodus Kze. - Pogonatum.

pachyneuron Hpe. - Pogonaturn convolutum.

pallidicaule C. M. in Ule Bryoth. brasil. n. 41.

Terr. - Am. merid. : Brasil. austr. or.

pallidiselum $\left\{\begin{array}{l}\text { Drumm. }-\mathrm{P}, \text { commune. } \\ \text { Funk, }-\mathrm{P}, \text { formosum var. pallidisetum. }\end{array}\right.$

var. Drumm. - P. juniperinum. parvum Aloës folio serrato, capsulis oblongis Dill. - Pogonatum aloides. patagonicum C. M. in Hedwig. 1897, p. 90.

- Am. merid. : Argentin. Patagon.

patens C. M. in Nuov, Giorn. bol. ital. 1897, p. 17. - Am. merid. : And. Boliv.

putulum Harv. - Pogonatum.

paulense Geh. et Hpe. in Fl. 1881.

- Am. merid. : Brasil, austr. or.

pensilvanicum $\left\{\begin{array}{l}\text { Hedw, - Pogonatum. } \\ \mathrm{H}, \mathrm{f} \text { et W. - Pogonatum Gardneri. }\end{array}\right.$

var. Torreyanum C. M. - Pogonatum pensilvanicum var. Torreyanum. Ferichaetiale Mont. - Pogonatum.

perigoniale Rich. - P. commune var perigoniale.

perpusillum C. M. - Pogonatum.

Pervillei Besch. Fl. bryol, Réunion, etc. $p 114$.

Z,

-Afr. : Madagasc. sept. 
"var. leptocaule Besch. l. c. -. Afr. : Ins, Borbon.

\section{Petersianum C. M. - Pogonatım.}

piliferum Schreb. Spic. A. Lips. p 74; Brid. Bryol. univ. 11, pp. 142 et 747 ; Bryol, eur. IV (mon p. II), t. 422 ; C. M. Syn. I, p. 217 ; W. P. Sch. Syn. II ed. p. 542.

P. commune var. $\gamma$ L. Sp. pl p. 1573.

P. commune var. $\beta$ minus Weig. Fl. Pomer. Rug. n. 679.

P. commune vas. $\beta$ piliferum Weiss Crypt. Goett. p. 172.

P. commune var. $\beta$ pilosum Ehrh. in Hann. Mag. 1780, p. 235.

P. pilifolium Gray Nat. arr. brit. pl. I, p. 720 .

P. pilosum Neck. Meth, M. p. 128.

P. quadrangulare minus, Juniperi foliis pilosis Dill. Hist. M. p. 426, t. 54, f. 3 .

2. In ericet. sicc. et arenos. steriliss. - Eur. : Tota ; Spitzberg., ins. Parry. As.: Japon., Saghalien, Amour, Taimyr, Jenissei, Obi, Ochotsk, Caucas. Afr. : Madeir., ins. Canar. Am. sepl.: Groenland, Labirador, de ins. Miquel, ad Alaska et ins. Vancouver; tota temper. Am. merid. : Ins. Juan Fernandez, fret. Magellan., Cap. Horn. ; ins. Maclov. ? (1) Pac: Austral.

Exs. : Drumm. M. bor. am. I ed. n. 278.

Mac. Canad. M. n. 222.

Mandon Pl. Madeir. n. ¿88.

Rab. Bryoth. eur. n. 121.

Sull. et L.esq. M. bor. am. JI ed, n. 325.

" var, aequinoctiale Llz. Moosst. p. 157.

- Am. merid. : M. Pichincha.

- var. alpestre Wulfsb. in Christiania.... Forhandl. 1875 et in Rev. bryol. 1887, p. 45.

- Eur. : Norvegia.

"var. australe Ren. et Card. in Bull. Soc. roy, bol. Belg. 1894, II, p. 125.

- Afr, : Ins, Comor. magn.

"var. fastigiatum (Lindb.) Far.

P. pilosum var. fastigiatum Lindb. M. Seand p. 12.

- Eur. : Fennia.

"var. gracile Lindb, in Oefv.... 1866, p. 548, n. $76 \beta$.

Ster. - Eur. : Spitzberg.

\& var. Hoppei (Hsch.) Bryol. eur. el W. P. Sch.ll.co.

P. Hoppei Hsch. in Fl. II, p. 106 et V1, p. 16; Brid. Bryol. univ. II, pp. 143 et 747.

In siccior. - Eur, : Summ, Alp. As. : Cancas, or. Am. sept. : M. Rupestr., Idaho.

\& var, hyperboreum (R. Br.) C. M. l. c. p. 218; W. P. Sch. Syn. II ed. p. 543 (in $a d n$.).

P. hyperboreum R. Br. in Neve bot. Zeit. VII, Beil, p. 114 et in App. ad iter Parray. p. 194; Sehwaegr. Suppl. II, p.8, t. 153 ; Brid. Bryol. univ. II, pp. 144 et 747.

chica, Jenissei. Am. sept. : Groenland, ins. Melville. 
" var, laevipilum (Hpe.) Sull. M. bor, am. II ed. p. 55.

P. laevipilum Hpe. in Linn. 1859, p. 459.

-- Am. sept. : Sierra Nevada Calif., M. Rupestr.

piliferum Mitt. - P. trachynoton ?

pilifolium C. M. in Hedwig 1897, p. 92.

$\sigma^{7}$ et fr. ign.

- Am. merid. : La Plata.

pilifolium Gray. - P. piliferum.

pilosum Neck. - P. piliferum.

var, fastigiatum Lindb, - P. piliferum var, fastigiatum.

plurirameum C. M. Bryol. austr, Georg. p. 15.

Ster.

- Am. merid. : Austr. Georg.

plurisetum C. M. - Pogonatum polycarpum.

var. brevipes C. M. - Pogonatum polycarpum var. brevipes.

Polakowskyi C. M. in Journ, of bot. 1877, p. 227 (nom.).

Terr. - Am. sept. : Costa Rica.

polycarpum $\{$ C. M. - Pogonatum.

Col. - Polytrichadelphus.

polysetum H. et Arn. - Pogonatum oligodus.

polythamnium C. M. - Pogonatum.

polytrichoides Brockm. - Pogonatum nanum.

Preussii Broth, in Engler's Bol. Jarb. 1894, p. 193.

2.

- Afr. : M. Cameroon.

prionotrichum C. M. in Hedv. 1897, p. 92 .

- Am. merd. : Argentin. subtropic.

prionctum C. M. in Hedwig. 1897, p. 91.

- Am. merid.: And. Argentin. subtropic. Tucuman.

procerum Lindb, - Pogonatum.

proliferum Griff. - Pogonatum.

propinquum $\mathrm{R}$. Br. - $\mathrm{P}$, commune.

pseudo-alpinum C. M. - Pogonatum.

psilopiloides C. M. - Pogonatum.

pulverulentum Reyn. - Pogonatum urnigerum.

pumilum Sw. - Pogonatum nanum.

pungens $C$. $M$. in $\mathrm{Fl}$. 1888, p. 408.

Ster.

- Afr. : Kilima N'Djaro.

pungens Wils, - Pogonatum Thomsoni.

purpurans Besch. Fl. bryol. Réunion, etc, p. 114.

Ad terr. humid, - Afr. : Ins. Borbon.

purpurascens $\left\{\begin{array}{l}\text { Brid. - P. elatum. } \\ \text { Hpe. - Pogonatum. }\end{array}\right.$

Gilib. - P. commune.

Juniperi foliis brevioribus et rigidioribus Dill, (fid.

quadrangulare $\left\{\begin{array}{l}\text { Auct. omn.). - P. juniperinum. } \\ \text { Juniperi foliis brevioribus et rigidioribus Dill. (fid. }\end{array}\right.$ Lindb.) - P. commune var, minus. minus, Juniperi foliis pilosis Dill. - P. piliferum. vulgare, Yuccae foliis serralis Dill. - P. commue.

. in Mand. Pl. Boliv, n. 1686.

- Am. merid. : And. Boliy. 
ramosum / Gunn., WEd. - Pogonatum alpinum var, septentrionale. j setis ex alis setigeris Dill. - Pogonatum urnigerum.

Rehmanni C. M. in Rehm. M. Afr. austr. n. 270.

$-A f r$. : C. B. Sp.

* var. julaceum Rehm. l. c. n. 576 et b.

- Afr. : Transvaal.

remotifolium P. B. Prodr. p. 86 ; Brid. Bryol, univ. 11, p. 147 ; C.M.

Syn. I, p. 222.

P. Apulejae Commers, in hb. Mus, Paris (1).

P. glabrum Brid. op. cit. p. $141 ;$ C. M. l. c. p. 220.

In lacun. exsicc. - Afr. : Ins. Borbon., Franciae.

remotifolium Brid. p.p. - P. Swartzii ?

Rhacomitrium C. M. in Journ. of bot. 1877, p. 227 (nom.).

Terr. - Am. sept. : Costa Rica.

rhynchomitrium $C$. M. in Linn. 1874, p. 577.

2.

- Am. merid.: And. Nov. Granat.

Riedelianum Mont. - Oligotrichum.

robustum C. M. in Hildebr. M. Mad. n, 2126.

- Afr. : Madagascar.

robustum Lindb. - Polytrichadelphus magellanicus.

rubellum Menz. - Pogonatum aloides.

rubenti-viride C. M. - Pogonatum.

rubescens Mill. M. austr. am. p. 622.

- Am. merid. : And. Quitens.

rubiginosum C. M. - Pogonatum.

rufiselum Wils. - Pogonatum.

Rutenbergii C. M. - Pogonatum.

Sartorii C. M. - Pogonatum.

scebriusculum Brid. - P. Antillarum.

Schmilaii Ltz, - Pogonatum.

secundulum C. M. in Nuov. Giorn, bol. ital. 1897, p. 15.

- Am. merid.: And. Boliv.

- var. angusticaule ej. $l$. c.

Ut typ.

semi-angulatum Sull. - Polytrichadelphus.

semi-diaphanum Brid. - Pogonatum nanum.

semi-lamellatum Hook. - Oligotrichum.

semi-nudum Wils. - Pogonatum.

semi-pellucidum $\mathrm{H}_{\text {pe. }}$ - Pogonatum.

septentrionale Sw. p.p. $\{$ - Pogonatum alpinum var. septentrionale. serratum Schrank, - P. commune.

serrulatum Hpe. $h b$.

- Pac. : Nov. Zeland.

setifolium Sw. - P. Antillarum.

(1) Cf, Bescherelle FI. bryol. Rèunion, etc. p. 111. 
sexangulare Floerke in Hoppe Bot. Taschb. 1800, p. 150: Brid. Bryol. univ. 1I, p. 145 ; Bryol. eur. IV (mon. p. 7), t. 419; W. P. Sch. op. cit. p. 540.

P. crassisetum Lam, et DC. Fl. fr. II, p. 436.

P. helveticum Schleich. Crypt. helv. Cent. III, n. 16.

P. hyperboreum Wahlenb. Fl. Lapy. p. 347 (fid. C. M.).

P. norvegicum Hedw. Sp. M. p. 99, t. 22, t. 1-5.

P. Ederi Brid. M. Rec. IJ, I, p. 99.

P. septentrionale Sw. M. Suec. p. 77, t. 9, f. 18 p.p. (1); C. M. Syn. I, p. 223.

2. In depressis nivos, - Euv. : Summ. Alp. ; Spitzberg?, ins. Ursor, Lappon., Norveg. As. : Kamschatka. Am. sept.: Groenland, ins. Melville, M. Rupestr. et Selkirk, Columb. brit., Alaska, Oregon.

Exs. : Mac. Canad. M. n. 428.

Rab. Bryoth, eur, n, 285, 732, 1327.

Un. itin. 1867, n. 80.

a var. nivale Kindb. in Hedro. 1896, p. 67. - Am. sept. : Oregon.

sexangulare Angstr. p.p. - Pogonatum alpinum var. septentrionale. silvaticum Menz. - Pogonatum alpinum vas, arcticum.

sinense C. M. - Pogonatum.

Smithii Hall. - Leptodon.

Spegazzinii C. M. in Fl. 1885, p. 399.

Ster. ? Terr. - Am. merid.: Fuegia austral.

Sprucei Lindb. - P. aristiflorum.

squamosum H. f. et W. - Polytrichadelphus.

slans Thuill, - P. formosum.

striatum Huds - Orthotrichum leiocarpum.

var. Y Neck. $\left\{\begin{array}{l}\text { - Ulota Bruchii ? } \\ \text { - Ulota crispa? } \\ \text { - Ulota erispula? }\end{array}\right.$

strictum Banks mss.; Menz, in Trans, of the Linn. Soc. IV, p. 77, t. 7, f. I; Brid. Bryol. univ. II, p. $139 ;$ W. P. Sch. Coroll. p. 92 et Sym. II ed. $p, 544$.

P. alpestre Hoppe Bot. Tasehb. 1801, p. 198, n. 2; Brid. op. cit. p. 140; Drumm. M. bor, am, I ed. n. 28I.

P juniperinum var. W. et M. Bot. Taschb. p. 220 ; Engl. Bot. XXXIV, c. 2435.

P. juniperinum var. alpastre Bryol. eur. IV (mon.p. 12 ot 13), t. 424; C. M. Syn. I, p. 218.

P. juniperinum var. gracile Wahlenb. Fl. Lapp. p. 34.

P. janiperinum var strictum Wallm. in Liljebl. Sv. Fl. III ed., p. 527; Bryol, eur, et C. M. Il.cc.

2. In turfos. et uligin. - Eur. : E reg. campestr. usq. in alp.; Spitzherg. As. : Saghalien, Amour, Penins. Tschutschiea, Obi, Jenissei, Alatan. Am. sept. : Groenland, Labrador, Anticosti, Terr. nov., ins. Miquel.. Nov. Scot., New Brunswiek, Gaspes., M. Rupestr. et Selkirk, Columb. brit., Sitka, fret. Kotzebuë, Wyoming, reg, sept. et or. Am. merid. : Patagon, austr, Fuegia.

Exs. : Mac. Canad. M. n. 224.

Rab. Bryoth. eur. n, 117, 1010

Sull. et Lesq. M. bor. am, 11 ed, n, 328.

(1) Cf. C. M. 1. c., Lindb. in Notis... 1867, p. 128 et W. P. Soh. I. C. 
subaloides C. M. - Pogonatum.

var. minor C. M. - Pogonatum subaloides var. minor.

subappressum Besch. Fl. bryol. Réunion, elc. p. 111.

- Afr. : Ins. Borbon.

subcarinatum Hpe. Symb. 1874, p. 500.

- Am. merid. : Brasil. austr, or.

subcontortum Hpe. - Pogonatum.

subflexuosum Lt\%. - Polytriehadelphis.

subformosum Besch. op. cit. p. 117.

- Afr.: Ins. Borbon.

subgracile Hpe. $\left\{\begin{array}{l}\text { - Pogonatum. } \\ \text { - P. subearinatum. }\end{array}\right.$

subpilosum P. B. Prodr. p. 86.

P. Commersonianum Brid, Bryol, univ. II, p. 153.

P. commune C. M. Syn. I, p. 220 p.p.

- Afr. : Usambara, ins. Borbon.

subremotifolium Geh, et Hpe. in Fl. 1881.

In rupestr. - Am, merid. : Brasil, austr. or.

subrotundum Huds. - Pogonatum nanum.

var. longisetum Lindb. - Pegonatum nanum vai: longisetum.

var. $\beta$ Huds. - Pogonatum aloides.

substrictum Hpe. in Krause M. Ecuador.

- Am. merid.: And. Equator, Chile austr.

sublortile C. M. - Pogonatum.

subulatum Menz. - Pogonatum.

Sullivani Hpe. in Linn. 1876, p. 316.

2.

- Pac. : Austral, or.

superbum Schultz. - P. formosum.

Swartzii Hartm. Skand. Fl. V ed. p. 361 ; C. M. Syn. II, p. 565 .

P. alpestre $S w$ Summ. veg. Scand p. 40; Hartm. Skand. Fl. IV ed,p. 2,

P. commune" Swartzii C. Hartm. Skand. Fl. IX ed. II, p. 43.

P, remotifolium Brid. Bryol. univ. II, p. 147 (quoad spec. a Kamschatka)?

2. Paludic. - Eur. : Penins. Scandin., Fennia. As. : Kamschatka?

tenellum C. M. - Pogonatum.

tenue Menz, - Pogonatum pensilvanicum.

tenuirostre Hook, - Oligotrichum.

Teysmannianum $\mathrm{Dz}$, et $\mathrm{N} \mathrm{k}$, - Pogonatum.

thelicarpum C. M - Pogonatum.

Thomsoni Mitt. - Pogonatum.

Thysanomitrium C. M. in Linn. $1874, p .578$.

2.

- Am. merid. : And. Nov. Granat.

timmioides C. M. Bryol. austr. Georg. p. 15.

Ster. In lapidos, - Am. merid. : Austr. Georg.

tolucense Hpe. - Pogonatum.

tortile $\{$ C. M. p.p. - Pogonatum semi-pellucidum.

Sw. - Pogonatum.

tortipes Wils. - Pogonatum.

trachynotum C. $M$. in Fl. 1885, p. 399.

P. piliferum Mitt. M. austr. am. p. 620 ?

Ster. Terr. - Am, merid, : Fuegia. 
Trianae C. M. - Polytrichadelphus.

trichodes C. M. in Rehin. M. Afr. austr. n. 277 el 578. - Afr.: Transvaal, C. B. Sp.

trichodon $\mathrm{H}$. f, et W. - Psilopilum.

Tristani Duby in Mém.... Genève, 1875, p. 6, t. 1, f. 2.

2. $\quad-A f r$.: I. Tristan d'Acunha.

tuberculosum C. M. in Engler's Bot. Jahrb. 1883, p. 77 et in Forschungsreise... Bot. p. 11 .

Ster. $\quad-A f r .:$ Ins. Kerguelen.

tumescens C. M. in Hedwig. 1897, p. 91 .

- Am. merid. : And. Argentin.

* var. pygmaeocaulon C. M. in op, et $l$. cc.

Ubi typ.

undulalum $\left\{\begin{array}{l}\text { Hedw. - Atrichum. } \\ \text { Schrank - Mnium. }\end{array}\right.$

var. minus $\left\{\begin{array}{l}\text { Funk; W. et M. - Atrichum tenellum. } \\ \text { Hedw. - Atrichum undulatum var. abbreviatum. } \\ \text { Mieh. A }\end{array}\right.$

var. subserratum H. f. et W. - Atrichum undulatum var. subserratum.

var. tenellum Wahlenb. - Atrichum tenellum.

var. I H. f. et W. - Atrichum undulatum var. attenuatum.

var. Sw. - Atrichum tenellum.

urnigerum $\{$ L. - Pogonatum.

W. Arn. - Pogonatum dentatum.

var. capillare Hartm. - Pogonatum.

var. humile Wahlenb. - Pogonatum urnigerum var. humile.

var. tetragonum Lindb. - Pogonatum urnigerum var. tetragonum.

var. C. M. - Pogonatum capillare.

var. $\beta$ Huds. - Pogonatum alpinum.

usambaricum Broth. - Pogonatum.

varians $\mathrm{Hpe},-$ Pogonatum.

verrucosum $P$ ar.

P. angustifolium W. P. Sch. mss,; C. M. in Bull. hb. Boissier, 1897, p. 178 .

- Am. sept.: Guatemala.

volvatum C. M. - Pogonatum.

Wallisii C. M. - Pogonatum.

xanthophilum Wils, in sched. ; Mitt. M. Ind. or. p. 156.

2.

- As. : Sikkim.

yuccaefolium $\left\{\begin{array}{l}\text { Ehrh. - P. commune. } \\ \text { Hoppe - P. commune var. minus. } \\ \text { P. B. - Pogonatum capillaie. }\end{array}\right.$

var. perigoniale Mart. $-\mathrm{P}$, commune var, perigoniale.

yuccoides Rehm, M. Afr. austr. n. 575 .

Ster. $\quad-A f r .:$ Transvaal (1).

POROPHYLLUM W. P. Sch, herb.

Spec. omne Porotricha ejusd. nom.

(1) De nom. nud, in Enum. Kindberg. ef. Pogonatum. 
Porotheca Limpr. Laubm. Deutsch. 11, p. 632 (sect. PoLyTrichi).

POROTRIGHUM Brid. Bryol. univ. II, p. 275 (sect. Curmachi); Bryol. jav. II, gen. propr. (13i spec.).

alopecuroides (Hook.) Bryol. jav. t, 193.

Hypnum alopecuroides Hook. in Lond. Journ. of bot. 1840, p. 20 et Ic. pl. rar.t. 24, f. $5 ;$ C. M. Syn. Il, pp. 501 et 692.

Neckera alopecuroides Mitt. M. Ind. or. p. 123.

N. efruetifera Griff. Ic. pl. asiat. II, $t .87, f .3$ ?

Thamnium alopecuroides Bryol. jav. II, p. 73.

Ster. - As. : Nepal,, ins. Sumbawa.

* var. donghamense (Besch.) Par.

Thamnium alopecuroides var. donghamense Besch, in Bull. Soc. bot. Fr. $1897, p .97$.

Ad rup. madid. - As. : Tonkin.

alopecurum Lindb. - Thamnium.

ambiguum Bryol. jav. t. 192.

Thamnium ambiguum ibid. $I I, p .172$.

2. Ad arbor. - As. : Sumatra.

\& var, javanicum (Bryol. jav.) Jaeg. Ad. II, p. 215.

Thamnium ambiguum var, javanicum Bryol. jav, l.c.

- As. : Java.

aneitense Mitt. Fl. Vit. p. 397.

Thamnium aneitense ej. in Proced. of the Lirn. Soc. 1879 (extra-vol.), 2. p. 101.

$$
\text { - Pac.: Nov. Hebrid. (Aneitum). }
$$

angustulum C. M. mss. ; Jaeg. Ad. II, p. 206.

- Am. merid.: Nov. Granat.

anisopleuron Kiä, in Borgen M. Mad. $n .42$.

- Afr. : Madagasc. centr.

arbusculum (Lindb.) Ångstr. Prim. lin. p. 41.

Neekera arbuscula Lindb. mss.

- Am. merid. : Brasil.

arbusculum Mitt. - Comptochaete.

Bertrandi Ren. el Card. in Bull. Soc. roy, bot. belg. 1890, 1. p. 181.

Ad arbor. - Am. sept. : Haïti.

biforme C.M. mss.

Ster.

- As.: Sumatra sept. occ.

bolivianum C. M. in Nuov. Giorn. bot. ital. 1897, p. 149.

Ster.

- Am. merid. : And. Boliv.

Bonianum Besch, in Bull. Soc. bot. Fr. 1887, p. 97.

Ster, Rupic. - As. : Tonkin.

Rraunii Broth. in Engler's Bol. Jahrb. 1894. p. 200.

2. Ster. $\Lambda$ d arbor. - Afr. : M. Cameroon.

brunneolum C. $M$. $h b$.

- As. : Java, Birman.

caesium Mitt, M. austr, am, p. 467.

Ster.

- Am. nerid.: And. Quitens. 
callochroum C. M. in Dusen M. Camer. n. 321 .

- Afr. : M. Cameroon.

campylochaete C.M. mss.

Ad arbor. - Pac. : Nov. Zeland.

Carantae C. M. mss. ; Jaeg. Ad. II, p. 206.

- Am. merid. : Nov, Granat.

caudatum Broth, in Bol. cl. Soc. Brot. 1890.

2. Ster.

- Afr. : Ins. S. Thomas, Togo, Usambara.

Chenagoni $C, M$, mss.

- Afr. : Madagascar.

clandestinum Mitt. - Lembophyllum.

cobanense C. M. in Bull. hb. Boissier, p. 202.

Ster. Ad arbor. in silv. primaev. - Am. sept. : Guatemala,

cochlearifolium Mitt. - Lembophyllum.

comorense Hpe. in Linn. 1876, p. 270.

Ad arbor. - A/r. : Usambara, ins. Anjouan, Mayotte.

confertum Mitt. - Thamnium.

crassipes Ren. et Card in Bull. Soc. roy. bot. Belg. 1894, I, p. 185.

1.? Ad arbor, - An. sept. : Costa Rica.

crenulatum C. M. $h b$.

- Am. sept.: Haiti.

cymbifolium (Lindb.) Mitt. in Trans. of the Linn. Soc. 1891, p. 175.

Isothecium cymbifolium Lindb, in Act. Soc, sc, Fenn, 1872, p. 231.

2. $\quad-A s$. : I. Kiusiu Japon.

decompositum (Brid.) Mitt. M. austr, am, p. 463.

Leskea Omalia decomposita Brid. herb.

Neckera decompositi C. M. Syn, 1I, p. 42.

Pterygophyllum decompositum Brid. Bryol. univ. II, p. 764.

Ster. In silv, - Am. sept. : Costa Rica, Hispaniola.

deflexum Mitt. - Camptochaete.

decurvatum Hpe. in Trans, and Proced of the roy. Soc. of Victoria, 1883,

p. 84 (nom.).

- Pac. : Absque loco.

dendroides (Hook.) Mitt. Fl. Vit. p. 397.

Climacium neckeroides Brid. Bryol. univ. II, p. 276.

Neckera australasica C. M. Syn. II, p. 42.

N. dendroides Hook. M. ex, t. 69. N. dendroides Hook. M. ex, t. 69.
2. Ad arbor. - Pac. : Ins. Fidji, Owyhee, Nov. Caledon. (ins. Pino-
rum).

denticulatum Mitt. M. austr, am. p. 462.

Ad arbor. - Am. merid. : Brasil.

divulsum Mitt. - Lembophyllum.

Duseni C. M. in Dusen M. Camer. n. 243.

- Afr. : M. Cameroon.

elatulum (C. M.) Jaeg. Ad. II, p. 21)6.

Hypnum elatulum C. M. in Linn. 1874, $p, 617$.

2.

- Am. merid. : And. Nov. Granat. 
elegantissimum Mitt. Sam. M. p. 187.

Hypnum elegantissimum C. M. M. Polyn. p. 90.

2. Ad arbor. - Pac. : Ins. Samoa.

ellipticum Bryol. jav. 11, p 70, t. 190.

2. - As, : Sumatra, M. Java.

Engleri Broth. in Engler's Bot. Jahrb. 1894, p. 200.

2. Ster. $\quad-A f r$ : Reg. lacustr.

expansum (Tayl.). Mitt. M. austr, am, p. 467.

Hypnum expansum Tayl, in Lond. Journ. of bot. 1846, p. 64 (fid. Mitt.). 2 ? -- Am. merid.: And, Quitens.

explanatum Mitt. op. cit. $p 468$.

2. - Am. merid.: And. Quitens, et Peruv.

fasciculatum (Sw.) Mitt. op. el l. cc.

Hypnus: fasciculatum Sw. Prodr. Fl. Ind. oce. p, 140; Brid. Bryol. univ. $I I, p .396 ; C$. M. Syn. II, p. 226.

2. Ad arbor, et rup. humid. - Am. sept.: M. Jamaic. An. merid.: Venezuela, And. Quitens, et Peruv. Brasil. austr, or.

filiferum Mitt. op. et $l$. $c c$.

Ster. Peruv.

- Am. merid.: Venezuela, And. Quitens, et filiferum Hpe. - P. Glaziovii.

flabellatum Mitt. - Homalia.

flagellare (C. M.) Jaeg. Ad. II, p. 210.

Hypnum flagellare C. M. in Bot. Zeit. 1854 (fid. Jaeg.).

Ad terr. in silv. - Am, merid. : Venezuela.

flagellaceum (Mitt) Par.

Neckera flagellacea Mitt. in Trans. of the Linn. Soe. XXIII, p. 52, t. $5, f .6$.

Ster.

- Afr.: Niger.

flagelliferum (Hpe.) Mitt. M. austr. am, p. 469.

Hypnum flagelliferum Hpe, in Ann. sc, nat. V ser., IV, p. 309.

flaviusculum (C. M.) Par.

- Am. merid. : And. Nov. Granat.

Pinnatella flaviuşcula $C . M$. mss.

Ster.

- Pac. : Nov. Guin, brit.

fruticosum (Mitt.) Jaeg. Ad. 1I, p. 210.

Neckera fruticosa Mitt. M. Ind. or. p. 122.

2.

- As, : Sikkim.

fruticosum Mitt. - Camptochaete.

Geheebii C. M, in Linn. 1876, p. 272.

Ster.

Glaziovii Par.

- Afr.: Ins. Anjouan, Mayotte.

Hypnum filiferum Hpe. Symb. 1874, p. 506.

2 ? Ster. - Am. merid. : Brasil. austr. or.

gracile Mitt. - Camptochaete.

grandidens $C, M, h b$. 
gymnopodum (Tayl.) Milt. M. austr. am. p. 465.

Hypnum gymnopodum C. M. Syn. II, p. 226.

Leskea gymnopoda Tayl. in Lond. Journ. of bot. 1846, p. 62.

Ster, - Am. merill.: And. Quitens.

humile Milt. op. cil. p. 466.

Ster.

- Am. merid.: And. Quitens.

imbricatum Milt. in Spr. Cat. M. Amaz. et And. n. 1348.

- Am. merid. : And, Nov. Granat. et Quitens.

insularum Mitt. M. austr. am. p. 464.

Hypnum neckeroideum Mont. in hb. Mus. Paris.

Leskea angustata Tayl. '? fid. Mitt.).

Meteorium Husnoti W. P. Sch, in Husnot M. Antill. n. 163.

2? Ad arbor. - Am. sept. : Guadalup., Martinic., ins. Dominic.

Khorthalsianum (Dz. et Mk.) Milt. op. cit. p. 463.

Neckera Khorthalsiana Dz. et Mk. Prodr. bryol. Surin. p. 42, t. 9. - Am. merid. : Venezuela, Guian. batav.

Krauseanum Hpe, et Ltz. in Bot. Zeit. 1869.

Dendro-Leskea Krauseana Hpe. in op. cit. n. 28.

P. longirostre $\beta$ minus ear. in Krause $M$. Ecuador.

1. In silvis. - Am. merid. : Equator.

Kühlianum Bryol. jav. t. 189.

Thamnium Kiuhlianum ibid. II, $p, 71$.

2. - As. : Java.

Kurzianum Hpe. mss, ; Jaeg. Ad. I1, p. 212. - As. : Sikkim.

lancifrons (Hpe.) Mitt. op. cit. p. 462.

Hypnum lancifrons Hpe, in Linn. 1863, p. 158.

2. - Am. merid. : And. Nov. Granat.

latifolium Bryol. jav. II, p. 69, t. 188.

2. $\sigma^{t}$ et fr. ign. - As. : Sumatra.

latinerve Mitt. in Voy. H. M. S. Challenger, $I 11$, p. 81.

Ster, Rupic. - Am. merid.: Ins. Juan Fernandez.

laxum Bryol. jav. t. 191.

Thamnium laxum ibid. II, p. 72.

2. In silvis. - As. : Sumatra, ins. Ceram.

Lehmannii Besch, in Bull. hb. Boissier, 1894, p. 395.

2. Ad arbor. - Am. merid. : And. Quitens.

lepto-Meteorium C. M. in Dusen M. Camer, n. 127.

$$
\text { - Afr.: M. Cameroon. }
$$

leptodendron C. M. l. c. n. 2 .

$$
\text { - Afr.: M, Cameroon. }
$$

leucocaulon (C. M.) Mitt. op. cit. p. 463.

Neckera dendroides Mont. in Voy. de d'Orbigny, VII, II, p. 110 ?

N. leucocaulon C. M. Syn. II, p. 42 .

2. Ad arbor. - Am. merid. : Chile.

liguliferum Bryol. jav. $t$.

Thamnium liguliferum ibid. $11, p .72$.

2. Ad arbor. - As. : Sumatra. 
Lindigii (Hpe.) Mitt. op. cit. p. 461.

Pilotrichum Lindigii Hpe, in Ann, se. nat. V ser., $1 \mathrm{~V}, p .341$.

Ster.

- Am. merid. : And. Nov. Granat.

linearifolium Geh. et Hpe. in Fl. 1881.

- Am. merid. : Brasil, austr. or.

longirostrum (Hook.) Mitt, op. et l, cc. p.p. (fid. Ren. e! Card.).

Climacium Porotrirhum longirostrum Brid. Bryol. univ. II, p. 275.

Hypnum expansum Tayl, in Lond. Journ. of bot. 1846, p.61 (fid. Wils.).

H. floridum ej. in op, cit. 1847, p. 339 (fid. Mitt.); C. M. Syn. II, p. 226.

H. Porotrichum C. M. op. cit. p. 223.

Neckera longirostris Hook. M. ex. t. I.

Poropbyllum longirostrum W. P, Sch. hb.

2. Ad arbor., lignic, et terr. - Afr. : M. Cameroon, Am. merid. : And.

Nov. Granat, Quitens, et Boliv., Brasil. austr. or.

var. minus Hpe. et Ltz. - P. Krauseanum.

longirostrum Mitt p.p. - P. plagiorhynchum.

lopidioides C. M. in Dusen M. Camer, n. 4 C9.

- Afr. : M. Cameroon.

Lorentzi C. M. in Linn. 1878-79, p. 40 :

1. Saxic. - Am. merid. : Argentin. subtropic.

Loriae C. M. mss.

Ster.

- Pac. : Nov. Guin. brit.

macrocarpum (Brid.) Par.

Hypnum macrocarpum C. M. Syn. II, p. 224.

Lindigia macrocarpa Jaeg. Ad. II, p. 379.

Neckera macrocarpa Brid. Bryol. univ. 1I, p. 233 ; Mitt. M. Ind. or. p. 122.

- As. : Nepal.

madagassum Kiaër in Besch. Fl, bryol. Réunion, elc, p. 191.

Ster.

- Afr.: Madagascar.

mahahaicum (C. M.) Jaeg. Ad., II, p. 207.

Hypnum mahahaicum C. M. in Linn. 1874, p. 569.

2.

- As. : M. ins. Philippin.

mayumbense Besch, in Journ. de bot. 1894, p. 44.

2. $\quad-A f r$. : Congo gall. (Brazzaville).

mexicanum W. P. Sch, in Besch. Prodr. bryol. mexic. p. 102.

2.

- Am. sept. : Mexic. (Orizaba).

microthamniella $C$. M. mss.

- Pac. : Nov. Guin, brit.

microthamnium (Hpe.) Par.

Pilotrichum microthamnium Hpe. Enum. M. Brasil. p. 47.

Ster. - Am. merid. : Brasil. austr, or.

microthecium C. M. in Nuov. Giorn. bot. ital. 1897, p. 55. - Am. merid. : And. Boliv.

minus Hpe, in Ann. sc. nat. V ser., IV, p. 376; Mitt. M, austr. am p. 467.

- Am. merid. : And. Nov. Granat.

minutum Mitt. op. cit, p. 465.

Ster.

- Am. sept. : Cubs. 
mixtum (C. M.) Jaeg. Ad. II, p. 205.

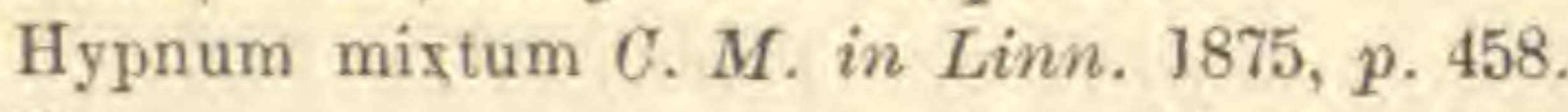

Ster.

- Afr. : Monbouttou.

Morokae C. M. mss.

Ster.

- Pac. : Nov, Guin. brit.

neckeraeforme (Hpe.) Mitt. M. austr. am. p. 464.

Hypnum neckeraeforme Hpe. in Ann. sc. nat, V ser, IV, p. 309.

1. In silv, ad arbor. - Am. sept, : And, Costa Ric. Am. merid. : And. Nov. Granat.

nitidum (Hpe.) Mitt. op. cit. p. 460.

Pilotrichum nitidum Hpe. in op. cit. p. 304.

Ster. - Am. merid. : And. Nov. Granat.

Novae Cambriae Hpe. in Trans. and Proced. of the roy. Soc. of Vicloria, 1883, p. 84 (nom.).

$$
\text { - Pac. : Absque loco. }
$$

oblongi-frondeum Broth. in Engler's Bot. Jahrb. 1894, p. 200.

2. Ster. Cortic. - Afr. : Usambara.

obtusatum Lindb. et Arn. - Thamnium.

orbiculare Hpe, in Trans, and Proced. of the roy. Soc. of Victoria, 1883, p. 84 (nom.).

- Pac.: Absque loco.

panduraefolium (C.M.) Mitt. op. cit. p. 468.

Hypnum panduraefolium C. M. in Bot. Zeit. 1855, p. 788.

$$
\text { - Am. merid. : Chile. }
$$

patulum Geh, et Hpe. in Fl. 1881.

Pechuelii (C. M.) Par.

Neckera Pechuelii C.M. in Fl. 1886, p. 515.

Ster.

- Afr. : Congo infer.

pennaeforme C. M. in Rehm. M. Afr. austr. n, 333.

P. madagassum Kiaër? (fid. Mitt. in Journ. of the Linn. Soc. 1886,p. 311).

Thamnium complanatum W. P. Sch. ? (fid. Mitt. l. c.).

$$
\text { - Afr. : Kilima N'Djaro, C. B. Sp. }
$$

" var. Chauveti Ren, et Card. in Bull. Soc. roy. bot. Belg. 1894, 11, Ster. p. 126 et M. Mcsc. Mad, n. 229.

* var, trachyphyllum $C, M, l, c, n, 334$.

$$
\text { - Afr, : Natal. }
$$

pennaefrondeum C. M. in Linn. 1876, p. 271.

Ster. - Afr. : Ins, Anjouan.

pergracila C. M. in Dusen M. Camer. n. 405.

$$
\text { - Afr. : M. Cameroon. }
$$

perrotundatum $C, M . l, c . n, 681$.

$$
\text { - Afr.: M. Cameroon. }
$$

piliferum Mitt. - Thamnium.

pinnatelloides C. M. in Linn. 1878-79, p. 409.

Ster. 
piniforme (Brid.) M. M. austr. am. p. 465.

Homalia pendulina W. P. Sch. in hb. Mus, Paris.

Hypnum piniforme $C . M . S y n . I 1, p .228$.

Pilotrichum piniforme Brid. Bryol. univ. II, p. 260.

2 ?

- Am. sept. : Guadalup.

Pittieri Ren. et Card, in Bull. Soc. roy. bot. Belg. I, p. 188.

2. $\sigma^{*}$ ign. In silv. - Am. sepl, : Costa Rica.

plagiorhynchum Ren, et Card. in op, cit. p. 186.

P. longirostrum Mitt. op. cit. p. 461 p.p.

2. $\delta$ ign.

- Am. sept.: Costa Ríca. Am. merid.:

And. Quitens.

plicatulum Milt. op. cit. p. 461 .

Ster.

- Am. merid. : Ins. Trinitat.

plicatulum Mitt. (1891). - Thamnium.

plumosum Ren. et Card. in op. cit. p. 191.

2. In silv, ad arbor. - Am. sept : Costa Rica.

porrectulum $C$. M. in Linn, 1878-79, p. 408.

Ster.

- Am. merid, : Argentin. subtropic.

psendo-pilaceum Hpe. in Trans. and Proced. of the roy. Soc. of Victoria, $1883, p .84$ (nom.).

- Pac. : Absque loco.

pterops Rehm. M. Afr, austr. n. 621.

Neckera pterops ej. l. c. n. 329.

- Afr. : Kilima-N'Djaro, Natal.

punctulatum C. M. in Dusen M. Camer. n. 78.

$-\Lambda$ r. : M. Cameroon.

Quintasii Broth. in Bol. d. Soc. Brot, 1890.

2. Ster.

- Afr.: Ins. S. Thomas.

ramosissinum Hpe Symb. 1874, p. 505.

2. $\sigma^{t}$ et fr. ign. $\quad-$ Am. merid. : Brasil. austr, or.

ramulosum C. M. in Dusen M. Camer. n. 282. $-A f i$. M. Cameroon.

ramulosum Mitt. - Camptochaete.

rigidum Mitt. - Thamnium.

riograndense $C . M$. mss.

Ster.

- Am. merid. : Brasil. (Rio grande do Sul).

Robillardi C. M. in Besch. Fl. bryol. Réunion, etc., p. 133.

2.

$-A / r$, : Ins. Borbon., Franciae.

rostrifolium (C. M.) Par.

Thamniopsis rostrifolia C. M. in Rev, bryol. 1878, p. 72 (nom.).

- Afr. : Austral.

rotundi-frondeum (C. M.) Jaeg. Ad. II, p. 205.

Hypnum rotundi-frondeum $C . M$, in Linn. $1875, p, 456$.

Ster.

- Afr.: Monbouttou.

ruficaule C.M. in Fl. 1890, p. 488.

Ster.

- Afr : Kilima N'Djaro. 
scaberulum Ren, et Card. in Bull. Soc roy. bot. Belg. 1893, II, p. 25 et M. Masc, Mad. n. 230.

2. Ad ramul. - Afr. : Madagascar.

scalpellifolium Mitt. - Homalia.

scoposum Hpe. in Ann. sc. nat. V ser., IV, p. 374; Mitt. op. cit. p. 460. - Am. merid. : And. Nov. Granat.

setoso-flagellosum C. M. mss.; Jaeg. Ad. II, p. 206.

- Am. merid. : Nov. Granat.

sparsiflorum (Hpe.) Milt. op. cit. p. 465.

Hypnum sparsiflorum Hpe. in Linn. 1863, p. 157.

Ad arbor. - Am, merid. : And. Nov. Granat.

stolon aceum Hpe, in Linn. p. 154 ; Mitt. op. cit. p. 466.

P. superbum Tayl. (fid. Mitt.).

Porophyllum stolonaceum $W . P$. Sch, $h b$.

Ad arbor. - Am, sept.: Costa Rica? Am. merid.: And. Nov. Granat. stoloni-rameum C. M. in Dusen M. Camer. n. 920 .

$$
\text { - Afr.: M. Cameroon. }
$$

striatum Mitt. op, cit. p. 462.

Ster. Rupic. - Am, merid. : Brasil.

Stuhlmanni Broth. in Engler's Bat. Jahrb. 1894, p. 199.

2. Ster. - Afr. : Reg. lacustr.

subambiguum (C. M.) Par.

- Pinnatella subambiguua $C$. $M$. mss.

Ster.

- As. : Sunuatra (ins. Engano).

subcucullatum Hpe. Enum. M. Brasil, p. 56.

Ster.

- Am. merid. : Brasil. austr. or.

subpennaeforme C. $M$. in Fl. 1890, p. 488.

Ster. In silv. - Afr. : Kilinı N'Djaro.

subpunctula tum C. $M$, in Dusen M. Camer. n. 218.

- Afr.: M. Cameroon.

subsecundum Kiaër in Borgen. M. Mad. n. 41.

- Afr. : Madagase. centr.

subseriatum Mitt. - Thamnium Sandei.

substolonaceum Besch. in Bull. Soc, roy. bot. Belg. 1894, 1, p. 189.

2. In silv. - Am. sept. : And. Costa Ric.

substriatum (Hpe.) Mitt. M. austr. am. p. 463.

Neckera substriata Hpe. in Ann. se. nat. V ser, $I V, p .340$.

Ster. $\quad-$ Am. merid. : And. Nov. Granat.

superbum (Tayl.) Mutt, op, cit. p. 459.

Hypnum superbum C. M. Syn. II, p. 225.

Leskea superba Tayl. in Jowrn. of bot. 1846, pp. 61 et $452, t .16$.

P. stolonaceum Hpe, (fid. Mitt.).

Porophyllum superbum $W . P . S c h . h b$.

tens.

- Am. merid.: Columb., And. Nov. Granat. et Qui-

tamariscinum (Hpe.) C. M. in Linn. 1876, p. 272.

Pilotrichum tamariscinum Hpe. in op. cit. 1874, p. 219.

Ster.

- Afr. : Madagasc., ins. Anjouan. 
tenuicostatum (Hpe,) Par.

Pilotrichum tenuicostatum Hpe. Enum. M. Brasil.p. 47.

Ster. $\quad-A m$. merid.: Brasil. austr. or.

Thieleanum (C. M.) Mitt. op. cit. p. 465.

Hypnum Thieleanum $C . M$. Syn. $I I, p .227$.

Isothecium intermedium Thiele in hb. reg. Berol.

Pilotrichum piniforme $\mathrm{Hsch}$. Fl. Brasil. I, p. 58.

Ster. - Am. merid. : Brasil.

undulatum C. M. in Bull. hb. Boissier, 1897, p. 203.

- Am. sept. : Guatemala.

usagarum Mitt, in Journ. of the Linn. Soc. 1886, p. 315.

Ster. - Afr. : M. Usagara.

vagum Mitt. - Lembophyllum.

Valdiviae (C. M.) Mitt. M. auslr, am, p. 467.

Hypnum Neckera W. P. Sch. in Lechler pl. Chil, n, 631 .

H. Valdiviae C. M. in Bot. Zeit. 1855, p. 783.

- Am. merid. : Chile.

- var. pallidum (Ltz.) Jaeg. Ad. I1, p. 209.

Hypnum Valdiviae var, pallidum Ltz. in Bot. Zeit. 1866, p. 188 ,

variabile Hpe. in Ann. sc. nat. V ser, IV, p. 375; Mitt. op. cit. p. 464.

Neckera flabellata Hpe. in Linn. 1861-62, $p .525$.

Ad arbor, - Am. merid. : And. Nov. Granat.

POTAMIUM Mitt. M. austr, am. p. 472.

Species omn. Pterogoniellae ejusd. nom.

POTTIA Ehrh. Beitr. 1I, p. 175 (83 spec.).

acaulis $R$. Br. in Trans. of the N. Zeal. Inst. 1893, p. 290.

Rupic. - Pac. : Nov. Zeland.

acaulis Hpe. - Pharomitricm subsessile.

affinis Fürnr. - P. Heimii,

Alfredii $R$. Br. in Trans, of the N. Zeal. Inst. 1893, p. 290.

Terr. - Pac., Nov. Zeland.

amblyophylla (Hook.) C. M. Syn. 1, p. 557 .

Barbula amblyophylla Jaeg. Ad, I, p. 273.

Gymnostomum aniblyophyllum Hook. Bot. Mise. I, 1830, p. 352, t. 75.

Tortula amblyophylla Mitt. M. austr. am. p. 155.

2.

And. Chilens.

- Am, merid. : Brasil. ausir. or., Monte-Video,

Anderssonii Sb. - P. magellanica.

angustifolia (Lindb.) Par.

Tortula angustifolia Lindb. in Broth. Enum. M. Caucas. p, 44.

1. Ad aren, argill, humid. - As. : Caucas. occ.

antarctica W. P. Sch. - P. magellanica.

asperula Mitt. in Seeman Journ. of bot. Januar. 1871.

P. Mittenit var. asperula Corbiere M. de la Manche, p. 236; Husnot Musc. gall. p. $77, t, 21$.

P. truncata Wils. M. Brit. n. 90 p.p.

- Eur. : Hibern, et Angl, merid, ins. Jersey. 
asperula C. M. - P. Uleana.

assimilis $R . B r$. in op. cit. p. 294.

Terr. - Pac. : Nov, Zeland.

bahiensis C. M. - Hyophila.

Barbula C. M. - Hyophila.

Bickertonii $R$. Br, in op. cit. p. 292.

Terr. - Pac. : Nov. Zeland.

bicolor C. M. - Barbula.

blanda C. M. - Hyophila.

brachyodus (Hpe.) Jaeg. Ad. I, p. 192.

Anacalypta brachyodus Hpe. in Linn. 1859-60, p. 624.

Tortula adusta Mitt. in Trans and Proeed. of the roy. Soc. of Victoria, 1883.

- Pac.: Austral. or.

brachyphylla Hpe. in hb. Melbourne.

- Pac. : Austral. (Victoria).

brevicaulis (Tayl.) C. M. Syn. 1, p. 556 .

Gymnostomum brevicaule Tayl. in Lond. Journ. of bot. 1846, p. 42. 1 ? - Pac. : Austral. or. (Victoria).

brevicaulis de Not. - P. lanceolata var, angustata.

Brownii Par.

P. macrocarpa $R . B r$, in op. et $l$. oc.

Terr. - Pac, : Nov. Zeland.

brunnea (C. M.) Par.

Trichostomum brunneum C. M. in Linn. 1878-79, p. 315. 2. - Am. merid. : Alp. Argentin, subtropic.

bryoides Lindb. - Phascum.

caespitosa (Br.) C. M. Syn. I, p. 517 et II, p. 621; W. P. Sch. Syn. II ed. p. 157.

Anacalypta caespitosa Furnr, in $\mathrm{Fl}$. 1829, II, Erganz. p. 25; $\mathrm{Br}$. in Bryol. germ. II, II, p. 146, t. 37; Bryol. eur. 11 (mon, p. 3), t. 26.

Dermatodon caespitosus Hüb. Muscol. germ. p. 111.

Desmatodon caespitosus de Not. Syll. p. 203.

Gymnostomum carbunculoides de Not. in sched.

Trichostomum caespitosum Jur. Laubm, Oesterr. Ong. p. 106.

Weisia caespitosa Br. in Brid. Bryol. univ. I, p. 808.

W. tenella Brid. op. cit. p. 809 ?

I. Ad terr. argill, - Eur. : Angl,, Normann., Alsat., Palatin., Westphal., Sardin.

caespitulosa (Hpe. et C. M.) Par.

Anacalypta caespitulosa Hpe. et C. M. in Linn. 1853, p. 491. - Pac. : Austral.

caucasica (Lindb.) Par.

Tortula caucasica Lindb. in Broth. Enum. M. Caneas. p. 43.

1. Ad rupes schistos. - As, : Caucas, centr.

cavifolia Ehrh. Beitr. II, p. 187 ; Bryol. eur. II (mon. p. 7), t. 118;

C. M. Syn. I, p. 550; W. P. Sch. op. et l. cc.

Aloina pusilla Kindb, Laubm. Schwed. $u$. Norveg. p. 137.

Bryum ovatum Dicks. Fasc. II Pl, orypl. p. 4. 
$\mathrm{Br}$, pusillum Hedw. Fund $M$. II, p. 32.

Gymnostomum ovatum Hedw. M. frond. $I$, p. $16, t .6 ;$ Brid. Bryol. univ. I, p. 59; Drumm. M. bor. am. I ed. n. 17 et 18.

G. ovatum $\beta$ gracile $H$. et T. Muscol. brit. p. 12.

G. ovatum $\beta$ oblongum Brid, op. et $l$, cec.

G. pulvinatum Lag, in Ann. cienc. nat. n. 14, p. 71 .

G. pusillum Hedw. Fund. M. II, pp. 32 et 87 .

Pottia ovata Furnr. in op. oit. p. 10.

P. pusilla Lindb. in Oefv. Vet Akad. Foerh. 1863, p. 410.

Ptorigoneuron cavifolium Jur. Laubm. Oesterr. Ung. p. 96.

Tortula pusilla Mitt. M. austr. am. p. If5.

1. In camp. incult., gramin., etc. - Eur: : Vulgatiss. As.: Persia, Mesopot., Caucas. Afr. : Alger. Am. sept. : Saskatchewan, M. Rupestr., Columb. brit., Washington, Nevara, Idaho. Am. merid.: And. Quitens.

Exs. : Rab. Bryoth. eur. n, 2 ;.

var. barbuloides DR. - Barbula cavifolia.

"var. epilosa W. P. Sch. Syn. 1 ed. p, 122 et II ed. l. c.

Gymnostomum ovatum $\delta$ epilosum Brid. op. cit. p. 61 .

P. cavifolia $\beta$ imbricata Bryol. our. l. o.

In glareos, calcar. - Eur. : Hic illic.

var, gracilis Wils, - Barbula cavifolia.

var. imbricata 13ryol. eur. - P. cavifolia var. epilosa.

«var. incana Bryol. eur. $l$. $c$.

Gymnostomum ovatum $\gamma$ incanum Bryol. germ. p. 130, t. 9, f. 5 b; Brid. op. et $l$. $c c$.

Ut typ. - Eur. : In reg, mont. et subalp. ut in zon. frigidior.

* var. Perraldieri Besch. Cat. M. Alg. p. 9.

$$
\text { - Afr. : Alger. }
$$

ceratodontea C. M. - Gymnostomum.

chottica Trabut Atl. Al. Alg. l. VII et in Rev. bryol. 1887, p. 13.

Paludic. - Afr. : Alger, austr. occ. (el Kh'eider).

circinata C. M. - Hyophila.

commutata Limpr. Deucschl. Laubm. I, p. 537.

P. minutula
P. Starkeana Jur. in op. et $l$. ce.p.p.

1. Ad terr. argill, calc. - Eur. : Istria.

compacta W. et I)y. - Hyophila.

conica Fürnr. - P. Starkeana var brachyodus.

contermina C. M. - Hyrphila.

crinita Wils. in Bryol, eur. II (mon. Suppl.), t. 123; C. M. Syn. II, p. $622 ; W$. P. Sch. op. cit. p. 153.

Gymnostomum Wilsoni Hook. Bot. Misc, p p.

P. Mittenii var, crinita Corbiere Museinees de la Manche, p. 236; Husn. Muscol. gall. p. 77, t. 22.

1. Ad litt. marit. - Eur. : Britann., Armoric., Normana, ; Rhoengeb.? (ster.).

Exs. : Rab. Riyotb. eur. n. 805.

crinila de Not. - P. Notarisii.

cincullata (Hpe.) Jaeg. Ad. I, p. 193.

Anacalypta cucullata Hpe. in Ann. se. nat. V ser., III, p. 335. 
Weisia cucullata Mitt. $M$, austr, am. p, 140 ,

- Am. merid. : And. Nov. Granat.

cuneifolia Solms-Laub. M. Algarv.; W. P. Sch. op. cit. p. 154.

1? Ad terr. argill. arenac. - Eur. : Algarv.

curvicollis Mitt. - Phascum.

curvirostra Ehrh. - Gymnostomum.

cuspidata Mitt. - Phascum.

cylindrica C. M. - Hyophila,

denticulata C. M. - Hyophila.

Douglasii $R$. Br. in Trans. of the N. Zeal. Inst. 1893, p. 293.

Terr. - Pac. : Nov. Zeland.

eustoma $\left\{\begin{array}{l}\text { C. M. - P. truncata. } \\ \text { Hpe. - P. lanceolata var. gymnostoma. }\end{array}\right.$

var. auripes J. Lange. - P. pallida.

var. major Ehrh. - P. lanceolata var. gymnostoma.

var. minor Ehrh. - P. truncata.

var. truncata Hpe. - P. truncata.

flaccida C. M. - Splachnobryum.

flavipes Mont. in Ann. sc. nat. 1845, 1V, p. $122 \mathrm{et}$ in Cl. Gay. Hist. Chil. Bot. crypt. t. 3, f. 2; Syll. p. 51; C. M. Syn. I, p. 552.

Tortula flaccidiseta Mitt. M. austr. am. p. 165.

1. Terr. - Am. merid. : Chile.

fusco-mucronats C. M. in Engler's Bot. Jahrb. 1883, p. 79 et in Forschungsreise... Bot. p. 22. 2 ?

$$
\text { - Afr. : Ins. Kerguelen. }
$$

Gardneriana C. M. - Hyophila.

gedeana Sande Lac. Spec. nov. M. Archip. ind. p. 4, t. 2 B. 1.

$$
\text { - As. : Java. }
$$

glauco-viridis (C. M,) Par.

Trichostomum glauco-viride C. M. in Linn, 1880-82, p. 471.

Ster.

$$
\text { - Am. merid. : Uruguay. }
$$

grata $R, B r$. in op. et $l$. cc.

Terr. - Pac. : Nov. Zeland.

Güssfeldti Schlieph. in Bericht der deutsch. Bot. Gesells. 1884, p. 461. 1 ?

- Am. merid. : And. Argentin.

gymna (C. M.) Par.

Trichostomum gymnum C. M. in Linn. 1878-79, p. 312.

2.

- Am. merid. : Argentin. subtropic.

gymnostomoides W. et Dy. - Hyophila.

Heimii (Hedw.) Bryol. eur. II (mon. p. 12), t. 124; C. M. Syn. 1, p. 551

(excl. loc. antarct.); W. P. Sch, op. cit. p. 155. (excl. loc. antarct.); W. P. Sch, op. cit. p. 155 .
Bryum Heimii Dicks. Fase. II Pl. orypt. p. 4 ; Gmel. Syst. nat. II,
p. 1333 .

Br. truncatum $\beta$ L. Fl. Suec. n. 1001? Br. truncatum $\beta$ L. Fl. Suec. n. 1001 ?
Gymnostomum affine Bryol. germ $I$, pp. 138 et $140 ;$ Brid. Bryol univ. I.
p. 72 . p. 72 .
G. Heimii Hedv. M. frond. $1, p .80, t .30 ;$ Bryol. germ. l. c. t. $8 ;$ Brid.
Bror. 1 . 14 (var. 2) et 15 (var. 3 ).

G. obtusum Tunn. Musool. Hibern. p. 9, t. 1. 
G. systylium Funk in sohed.

P. affinis Fürnr, in op, cit, p. 10.

P. Heimii var, affinis Lindb. Trichost. Eur. p. 10.

$\left.\begin{array}{l}\text { P. Heimii var. chlorophyllosa } \\ \text { P. Heimii var. intermedia }\end{array}\right\}$ C. M. op. cit. p. 552.

P. Krausei Warnst. in Hedvig. 1885, n. 3.

Tortula Heimii Mitt. M, austr, am. p. 165 p.p.

I. rar. syn. In terr. humid, praecip. salsos, - Eur. : Zon. merid. usq. in sept.; Britann., Neerland., Hungar,, German. tota, Alp. Carinth.; Tirol. merid,, Helvet. Am. sept. : Groenland, Labrador, sin. Hudson, M. Rupestr., litt. m. Behring. Colorado, Utah, Nevada, Montana, Idaho. Am, merid. : And. Chilens.

Exs. : Rab. Rryoth. eur. n. 58, 401, 807, 1303.

Sull. et Lesq. M. bor. am. II ed. n. 115 .

var. affinis Lindb, - P. Heimii.

" var. aretica Lindb. in Oefv... XXIII, p. 551.

Gymnostomum obtusifolium R. Br. Suppl. App. ad iter Parray. p. 299.

P. obtusifolia C. M. Syn. I, p. 556 .

- Eur.: Spitzberg, ins. Ursor. As.: Penins.

Tschutschica. Am. sept. : Ins. Melville.

var. chlorophyllosa C. M. - P. Heimii.

" var. cylindrica Bryol. eur. et W. P. Sch.ll. cc.

Ut et ubi typ.

var. intermedia C. M. - P. Heimii.

* var. longiseta (Lindb. et Arn.) Par.

Tortula Heimeii var. longiseta L. et A. M. As. bor. 1890, p. 68

- As. : Jenissei inf.

heimioides Kindb. in Mac. Cat. p. 43.

I?

- Am. sept. : M. Rupestr.

Hollii C. M. - Hyophila contorta.

humillima (Angstr.) Par.

Anacalypta humillima Angstr. in Oefv... 1876, n. 4, p. 10.

- Am. merid. : Brasil. austr. or.

imperfecta (C. M.) Par.

Trichostomum imperfectum C. M. in Linn. 1878-79, p. 314.

2.

- Am. merid. : Argentin. subtropic.

inflexa (Tayl.) C. M. in Linn. 1853, p. 491 (nom.).

Gymnostomum inflexum Tayl. in Lond. Journ. of bot. 1846.

Weisia inflexa Mitt. in Trans. and Proced. of the roy. Soc. of Victoria, 1883, p. 58.

- Pac. : Austral. or.

intermedia Fürnr. - P. lanceolata var. gymnostoma.

involuta C. M. - Hyophila.

involutifolia C. M. - Hyophila.

japonica Jaeg. - Fintosthodon.

javanica C. M. - Hyophila.

julacea Dz, el Mk. in Pl. Jungh. p. 335 ; Bryol. jav. I, p. 62, l. 50.

1. Terr. - As. : Java.

Krausei Warnst. - P. Heimii.

Kunzeana C. M. - Gymnostomum. 
lanceolata (Dicks.) C. M. Syn, 1, p. 548; W. P. Sch. op, cit. p. 157.

Afzelia lanceolata Ehrh. Beitr. VII, p. 4.

Anacalypta lanceolata Roeht. Moosg. Deutsch. I, p. 108; Bryol. eur. II (mon. p. 4), t. 127.

Bryum cuspidatum Gmel. Syst. nat. II, p. 1332.

Br, lanceolatum Dicks. Fasc. III Pl. crypt. p. 4.

Br. pulvinatum $\beta$ Poll. Pl. Palat. n. 1016.

Coscinodon connatus Brid. Bryol. univ. I, p. 374.

C. lanceolatus ej. op. cit. p. 372.

Dermatodon lanceolatus Hüb. Muscol. germ. p. 112.

Desmatodon lanceolatus de Not, Syll. p. 115.

Dicranum latifolium Turn. Museol. Hibern. Spic. p. 79 (exel. syn.).

Encalypta lanceolata Hedw. Sp. M. p. 63.

Grimmia connata Kaulf.

Gr. lanceolata $W$. et $M$. Bot. Taschb. p. 137.

Leersia cuspidata Schrank Baiers Fl. I1, p. 442.

L. lanceolata Hedw. M. frond. $I I I, p .66, t .23$.

Tortula lanceolata Lindb. M. Scand. p. 21.

Weisia connata Wallr. in Comp. III, p. 142.

Weisia lanceolata Roehl. Deutsch. Fl. II ed. p. III, p. 51.

1. In arv., camp., ad agger., etc. - Eur. : Vulgatiss,, frigidiss. except. As.: Japon., Caucas., As. min. Afr. : Alger.

Exs. : Rab. bryoth. eur. n. 252.

« var. aciphylla (Web. et Mohr.) Par.

Coscinodon aciphyllus Brid. Bryol. univ. I, p. 373.

Grimmia aciphylla $W$. et $M$. Bot. Taschb. I, pp. 137 et 457.

Tortula lanceolata var. aciphylla Lindb.

Weisia aciphylla Wahlenb. in Nov. Act. Holm. 1806, p. 133, t. 4, f. 1.

Ut typ. - Eur. : Septentr. As. : Caucas.

" var. angustata C. M. Syn. I, p. $549 ;$ W. P. Sch. op. cit. p. 158.

Anacalypta lanceolata var. angustata Bryol. eur. l. c, t. 125.

Entosthymenium mucronifolium $B r$. in Fr. Mëller M. Scand. et in Fl. 1829, p. 387.

P. brevicaulis de Not.

P. lanceolata var. brachyodus Lindb. de Trichost. Eur. p. 11

Ut typ, - Eur. : Merid. As. : Smyrn. Afr. : Alger.

var. brachyodus Lindb. - P lanceolata var. angustata.

- var. gymnostoma W. P. Sch. Syn. II ed. p. 158 (1).

Bryum truncatulum Ehrh. Crypt. n. 14.

Gymnostomum Heimii Timm. Fl. Megap. n. 725.
G. intermedium Turn. Muscol. Hibern, p. 7, t. I, f, a-i; Brid. Bryol. univ. $I$, p. 69. univ. I, p. 69 .
G. truncatulum $\beta$ Hoffm. Fl. germ. II, p. $27 ;$ H. et T. Muscol. brit. II ed.,
p. 22 .

G. truncatum Roehl. Fl. Deutsch. III, p. 38 et Ann. Welt. Ges. p. 122.

G. truncatum var. majus $(\alpha)$ W. et M. Bot. Taschb. p. 81; (3) Wahlenb. Fl Carpat. p. 333

P. eustoma Hpe, in Fl. 1829, II. Ergans. p. 10.

P. eustoma $\alpha$ major Ehrh. Beitr. II, p. 187; C. M. Syn. I, p, 553.

P. intermedia Fürn. in $F$. 1829, II, Erganz. Bl. p. 10.

P. lanceeolata vai. subgymnostoma Lindb. de Trichost. Eur. p. 11.

P. major $\gamma$ suhcylindrica Bryol. eur. $l$. $c$.

P. truncata Mac. Canad. M. n. $62 p p$.

P. truncata $\beta$ major Bryol. eur. $l$. $c, p$. 9.

P. truncata $\gamma$ subcylindrica Bryol. eur. l. $\theta$.

(I) Spec. propria, fid. Lindb. Man. M. I, p. 67. 
Tortula intermedia Lindb. M. Scand. p. 21.

Ut typ. - Eur. - Cum typ. Afr. : Alger. Am. sept.: Saskatchewan.

a var. leucodonta W. P. Sch. l c.

P. leucodonta Jaeg. Ad. I, p. 193.

Ut typ. - Eur. : Merid.

latifolia (Sclewaegr.) C. M. Syn. I, p. 549; W. P. Sch. op. et l. cc.

Anacalypta lanceolata $\beta$ sibirica $E$. G. et G. G. Borsezczowe? (fid. Lindb. et Arn.).

A. latifolia Bryol. germ. II, p. 135, t. 36; Bryol. eur. 11 (mon. p. 5), t. 128.

Dermatodon latifolius Hüb. Muscol. germ. p. 115.

Desmatodon bulbosus de Not. Syll. p. 103.

Didymodon bulbosus Hartm. Skand. Fl. IV ed. p. 382.

Grimmia latifolia $W$. et M. Bot. Taschb. p. 147.

P. pilifera var. mutica Lindb. de Trichost, Eur, p. 223.

Stegonia latifolia Vent. in Rev. bryol. 1883, p. 96.

Tortula bullata var, mutica Lindb. M. Scand. p. 21.

Weisia latifolia Schwaegr. Suppl. I, I, p. 61, t. j8; Brid. Bryol. univ. I, $p, 356$.

1. Ad terr. humos, denudat. - Eur.: Spitzberg, summ. Alp. Norveg., Scot. centr. ; Salisb., Stir., Tirol.; Jurass. As. : Jenissei inf. Am. sept. : Groenland, M. Rupestr., Columb. brit., Colorado.

Exs. : Rab. Bryoth. eur. 11. 56, 611 .

\& var. pilifera (Dicks.) C. M. et W. P. Sch. ul. cc.

Anacalypta latifolia $\beta$ pilifera Bryol. germ. l. c. p. 237; Bryol. eur. l. c.

Bryum piliferum Dicks. Fasc. IV Pl, orypt.

Coscinodon pilifer Brid. Bryol. univ. 1, p. 818.

Dermatodon Funkii Hüb. Muscol. germ. p. 115.

Dicranum bullatum Sommerf. Suppl. Fl. Lapp.p. 55 (excl.syn.).

Didymodon bullatus Hartm. Skand. Fl. III ed., II, p. 277 et IV ed. p. 382.

P. Iatifolia Lindb. de Trichost. Eur, p. 223.

Tortula bullata Lindb. M. Scand. $p, 21$.

Trichostomum piliferum $S_{m}$. Fl. brit. III, p. 1245.

Weisia latifolia Drumm. $M$, bor, am. I ed. n. 70.

W. pilifera Funk in sched, et in Walls. Comp. III, p. 149.

Loc. siccior. - Eur. : Ubi typ. As.: Caucas. Am. sepl. : M. Rupestr., Columb. brit.

Leonardi R. Br, in Trans. of the N. Zeal. Inst. 1893, p. 293.

Terr. - Pac.: Nov. Zeland.

Leprieurii Mont. - Hyophila,

leucodonta Jaeg. - P. lanceolata var, leucodonta.

ligularifolia C. M. in Hedwig. 1895, p. 123.

1? Terr. - Am. merid. . Brasil. or. (Minas Geraës).

Lindbergii (Kindb.) Par.

Tortula Lindbergii Kindb. Enum. Bryin, exot, p. 44.

T. pungers Lindb.

1. Ad rup, calcar. - As. : Caucas, centr.

littoralis Mitt. in Seeman Journ. of bot. Januar. 1871; Braithw. Brit. Moos. Fl. p. 198.

1. In calcar, - Eur. : Anglia, Ducat. Badens. Am. sept. : Columb. brit.

longifolia R. Br. in op. cit. p. 292.

Ters, - Pac. : Nov. Zeland. 
longirostris C. M. $\{$ (Syn. p. 552), - Gymnostomum. (Syn. p. 562). - Gymnostomum Kunzeanum.

Lorentzi $C . M$. in Linn. 1878-79, p. 309.

2. $\quad-$ Am. merid.: Alp. Argentin. Tucuman.

Lorentziana C. M. in op. cit. p. 310.

2.

- Am. merid. : Argentin. Cordob.

Mac-Leana Rehm. M. Afr. austr. n. 460.

- Afr.: C. B. Sp.

macrocarpa W. P. Sch. in Ann. sc. nat. II ser. VI, p. 145, t. 8; C. M. Syn. $1, p .556$.

Tortula macrocarpa Mitt, M, austr. am. p. 166.

1. Terr. - Am. merid. : Chile.

macrocarpa $\mathrm{R}$. Br. - P. Brownii.

magellanica W. P. Sch. in Lechler M. Antarct. n. 1091 el 1213.

Gymnostomum magellanicum Angstr. in Oefv... 1872, n. 4, p. 3 .

P. Anderssonii Sb. in Jaeg. Ad. II, p. 666 .

P. antarctica W. P. Sch. l. c. n. 1199 .

P. Heimii H. f. et Wils, in C. M. Syn. I, p. 552 (quoad loe, ins. Eremitae).

Tortula Heimii Mitt. M. austr. am. p. 165 p.p.

1 .

- Am. merid. : Fret. Magellan., ins. Eremitae.

marginata C. M. in Trans. of the N. Zeal. Inst. 1892, p. 290.

Syn. Terr. - Pac. : Nov. Zeland.

megapoda C. M. in Hedwig. 1897, p. 101.

1 ? $\quad$ - Am. merid.: Patagon.

mexicana Hpe. mss.; C. M. Syn. I, p. 544.

Tortula mexicana Mitt. op. cit. p, 166.

1.

- Am. sept. : Mexic.

microthecia (C. M.) Par.

Trichostomum microthecium C. M. in Linn. 1880-82, p. 420.

2.

- Am. merid. : Uruguay.

minutula (Schwaegr.) Fïrnr, in Fl. 1829, II, Erganz. p. 25; Bryol. eur. II (mon. p. 8), t. 119 ; C. M. Syn. I, p. 555 ; W. P. Sch. Syn. II ed. p. 151.

Gymnostomum Davallianum Sm. in Kon. Sims. Ann. bot. I, p. 577 (fid. Lindb.).

G. minutulum Schwaegr. Suppl. I, I, p. 25, t. 9; Sehleich. Cat. pl. Helv. n. 29 ; Brid. Bryol. univ. 1, p. 61 .

G. truncatum var, minimum Voit. M. Herbip. p. 16 (excl. syn. Ehrh.).

P. Starkei var. gymnostoma Lindb. de Trichost. Eur, p. 229.

Tortula Davallii Lindb, in Meddel. 1886, p. 252 p.p.

Tortula Starkeana var. Davallii ej. M. Scand. p. 21 .

1. In terr. nud. praepr. argill. camp., etc. - Eur. : Tota, arctic. except. Af $r$. : Alger. Am. sept. : Perrar. ; Calif.

Exs. : Rab. Bryoth, eur. n. 27, 63, 854, 954.

Sull, et Lesq. M. bor, am. II ed. n, 117.

var. conica Bryol, eur. - P. Starkeana var, brachyodus.

" var, rufescens (Schultz) Bryol. eur., C. M. et W. P. Sch. ll. cc.

Gymnostomum rufescens Sohultz Fl. Starg. p. 278 et in Bryol. germ. I,

p. 121, t. 9 ; Brid. op. cit. p. 62.

G. truncatum W. et M. Bot. Taschb. p, 80. 
P. rufescens Fürnr, in op, et $l$. ce.

Ut et ubi typ. in Eur.

var. cylindrica H. Müll, - P. Starkeana var, brachyodus.

Miltenii Corbière $\left\{\begin{array}{l}\text { var. asperula. - P. asperula. } \\ \text { var. crinita. - P. crinita. } \\ \text { var, viridifolia. - P. viridula. } \\ \text { var. Wilsoni. - P. Wilsoni. }\end{array}\right.$

Mülleri Duby - Hyophila.

mulica Vent. - P. Starkeana var. brachyodus.

Naumanni C. M. in Engler's Bot. Jahrb.1883, p. 79 et in Forschungsreise... Bot. p. 22.

Syn,

- Afr. : Ins, Kerguelen.

Notarisii W. P. Sch. op. cil. p. 8 šl.

P. crinita de Not. Epil. p. 586.

1. In pascuis. - Eur. : Sardin.

nuda $(C . M$.) Par.

Trichostomum nudum C. M. in Linn. 1880-82, p. 422.

2.

- Am. merid. : Argentin. Cordob.

obliqua $R$. Br. in Trans. of the N. Zeal. Inst. 1893, p. 294.

Terr, - Pac, : Nov, Zeland.

oblusifolia C. M. - P. Heimii var, arctica.

Octoblepharum Spr. mss.

Spadophyllum octoblepharum Hpe. mss.; Jaeg. Ad.II, p. 666.

Weisia Octoblepharum Mitt. M. austr. am. p. 140.

- Am. merid. : Amazon.

redipodioides C. M. in Engler's Bot. Jahrb. 1883, p. 79 et in Forschungsreise... Bot.p. 22 ,

2.

- Afr. : Ins. Kerguelen.

Erstedtiana C. M. - Hyophila.

Orbigayana C. M. in Linn. 1878, p. 311.

2 .

- Am. merid. : Chile.

ovalifolia Hpe. - Hyophila.

ovala Fürnr. - P. cavifolia.

pallida Lindb. de Torlul. et Trichost. Europ. 1863; p. ; W. P. Sch. op. cit. p. 154.

P. eustoma var. auripes C. M. mss.; J. Lange in Naturh. For. Vid. Meddel. $1860, p, 15$.

In arenos. marit. - Eur. : Isthm. Gaditan.

pallida Braithw, - P. viridula.

papillinervis Ltz. - Hyophila.

paraguensis (Besch.) Par.

Anacalypta paraguensis Besch. Not. M. Parag. p. 261.

Ad arbor. - Am. merid.: Paraguay.

Exs.: Balansa n, 1220.

Patouillardi Besch, in Journ. de Bot. 1894, p. 43, t. I, fig. 1-4.

1. In arena. $-A f r$. : Gabes.

perpusillla (C.M.) Par.

Trichostomum perpusillum C. M. in Journ. of Bot. 1877, p. 227 (nom.).

Terr. - Am. sept, : Costa Rica. 
physcomitrioides C. M. in Hedwig. 1897, p. 101.

- Am. merid. : La Plata.

pilifera lindb. - P. latifolia var pilifera.

var. mutica Lindb. -- P. latifolia.

piriformis Ehrh, - Physcomitrium.

Poeppigiana C. M. - Hyophila.

pusilla Lindb. - P. cavifolia.

recta Lindb. - Phascum.

reflexifolia C. M. - Hyophila.

riparia Aust. M. Appal. n. 112; Sull. Ic. M. Suppl.p. 34, t. 21; Lesq. et Jam. Man. p. 102.

$\sigma$ ign. Ad rup. madid. - Am. sept. : New Jersey et New York merid.

Roscheri Ltz. - Hyophila.

rubiginosa Wats. - Barbula.

rufescens $\left\{\begin{array}{l}\text { C. M. - Hyophila. } \\ \text { Fürnr. - P. minntula var, rufescens. }\end{array}\right.$

Ryani Philib. in Rev, bryol. 1896, p. 28.

1

- Eur. : Norveg. sept.

samoana C. M. - Hyophila.

serrata R. Br. in Trans. of the N. Zeal. Inst. 1893, p. 291.

Terr. - Pac. : Nov. Zeland.

spathulata C. M. - Hyophila.

spathulato-linearis (C. M.) Par.

Trichostomum spathulato-lineare C. M. in Linn. 1878-79, p. 316.

Ster. - Am. merid. : Argentin. subtropic.

Spegazzinii C. $M$. in $F l .1885, p .414$.

In palud montos, - Am. merid. : Fuegia.

Starkeana (Hedio.) C. M. Syn I, p. 547; W. P. Sch. op. cit. p. 156.

Anacalypta Starkeana Bryol. germ. II, p. 138, t. 36, f. 2; Bryol. eur. II (mon. p. 2), t. 125.

Bryum minutum Dicks. Fase. IV Pl. crypt. p. 7, t. 10, f. 17.

Br. Starkeanum Hoffm. Deutsch. Fl. $11, p .32$.

Dermatodon Starkii Hüb. Muscol. germ. p. 109.

Desmatodon Starkii de Not. Syll. p. 205.

Grimmia Starkeana W. et M. Bot. Taschb. p. 137.

Tortula Starkeana Lindb. M. Scand. p. 21.

Weisia Starkeana Hedu. M. frond. III, p. 83, t. 34; Brid. Bryol. univ. I. p. 353.

1. In terr. calc argill, agr. et camp. steril. - Eur. : Zon. intermed. et merid. As. : Syria, A fr. Alger, ins, Canar. Am, sept. : Utah, Calif.

Exs. : Rab. Bryoth. eur. n, 251, 831.

Sull, et Lesq. M, bor. am. II ed. n. 119.

var. affinis Braithw, - P. Starkeana var. brachyodus.

* var. bracbyodus C. M. el W.P.Sch, ll, cc.

Anacalypta affinis Fürnr. in Fl. 1829, II, Erganz. p. 10.

A. Starkeana var, brachyodus Bryol. eur. l. c.

? Dermatodon affinis Hüb. Muscol germ. p. 110. ? Dermatodon affinis Hub. Muscol germ. p. 110.
Gymnostomum conicum Schwaegr. Suppl. I, I, p. 26, t. 9; Brid. op, oit.
p. 63 .

G. reflexum Brid. $l$. $c$,

P. conica Fürnr. l. e.

P. minutula $\gamma$ conica Bryol. eur. II (mon. p. 8), t. 119; C. M. Syn. I, p. 555 (incl. $\gamma \gamma$ oblonga). 
P. minutula var, cylindrica H. Müll. Westfal. Laubm.n. 434.

P. mutica Vent. Erb. critt. ital. II ser., n. 160; de Not. Epil, p. 592.

P. Starkii var. aftinis Braitho. Brit. Moos. Fl.

Weisia affinis $H$, et T. Muscol, brit. p. 44, t. 14 ; Brid. op. cit. p. 354.

Ad mur. et rup. - Eur.: Occid.; Britann. marit., Westphal., Gall. mer, Sardin., Istria, Tirol.

Exs. : Rab. Bryoth. eur. n. 1052.

var, gymnostoma Lindb, - P. minutula.

stellatifolia (Hpe.) Jaeg. Ad. I, p. 193.

Anacalypta stellatifolia Hpe. Symb. 1872, p. 37.

- Am. merid. : Brasil, austr. or.

Stevenii R. Br. in Trans. of the N. Zeal. Inst. 1893, p. 291.

Tert. - Pac. : Nov. Zeland.

subcaespitosa (Hpe.) Par.

Anacalypta subcaespitosa Hpe. in Linn. 1863, p. 127.

Weisia subcaespitosa Mitt. M. austr. am. p. 140.

1. Terr, - Am. merid. : And. Nov. Granat.

subcrenulata C. M. - Hyophila.

subsessilis Bryol. eur. - Pharomitrium.

systyliopsis C. M. in Hedroig. 1897, p. 101.

1? - Am. merid. : La Plata.

tasmanica Broth. in Oefv. af Finska Vet. Soc, Foerh. 1895, p. 57.

1. Terr. - Pac. : Tasman.

thraustophylla (̊̊ngstr.) Par.

Anacalypta thraustophylla Angstr. in Oefo... 1876, n. 4, p. 10.

- Am. merid. : Beasil. austr. or.

Tortula | C. M. -- Hyophila.

Sull. - Hyophila Wrightii.

truncata (Hedio.) Fürnr. l. c. p. 10 ; Bryol. eur. II (mon. p. 9), t. 120.

Bryum exiguum, creberrimis capsulis rufis Dill. Hist. M. p. 31, t. 45, f. 7 F-K.

Br. truncatulum L. Sp, pl,p, 1584.

Br. truncatum Grmel. Syst. nat. 1 , p. 1334.

Gymnostomum circumscissum Roehl. in Ann. Wett. Ges. 1I, 1, p. 122.

G. cuspidalum ej. in op. cit. p. 130.

G. truncatulum Hedw. Furd. M. II, p. 87; Brid. Bryol. univ, I, p. 67.

G. truncatum Hedw. M. frond. I, p. 13, t.5; Bryol. germ. p. 132, t. 9, f. 6 p.p.

Phascum truncatulum L. jun. Meth. M. p. 361.

P. eustoma C. M. Syn. I, p. 553.

P. eustoma $\beta$ minor Ehrh. Beitr. II, p. 188.

P. eustoma $\beta$ truncata Hpe. in $\mathrm{Fl}$. 1837, I, p. 287.

P. truncatula Lindb. de Trichost. Europ. p. 8.

Tortula truncatula Lindb. M. Scand. $p .2$.

1. In arv., ad agger, ete. - Eur.; Vulgatiss. in reg. med. As. : Japon,, Obi, Cochinch., As. min. Afr.: Septentr., ins. Canar. Am. sept. : Ontario; de Nov. Angl. ad Pensilv.

Exs.: Faurie P1. Jap. n. 5.

Mac. Canad. M. n. 62 p.p.

Rab. Bryoth. eur, n. 797.

Sull. et Lesq. M. bor, am. II ed. n. 116.

"var, archidioides Besch. Cal. M, Alger. p. 4.

- Afi.: Alger. 
var. major Bryol, eur. - - P. lanceolata var. gymnostoma. var. subcylindrica $\left\{\begin{array}{l}\text { Bryol. eur. - P. lanceolata var. gymnostoma. } \\ \text { James. - P. Wilsoni. }\end{array}\right.$

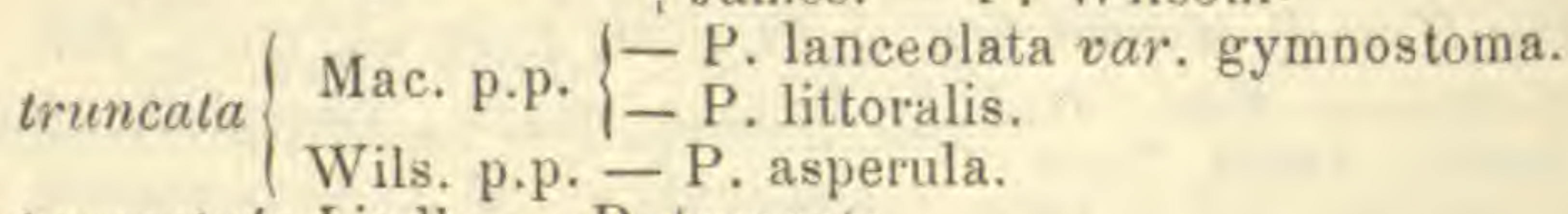

truncatula Lindb. - P. truncata.

Uleana Par.

P. asperula C. M. in Hedwig. 1895 p. 123.

Rupic. - A $w_{t}$, merid. : Brasil. or. (Gryaz).

venusta Jur. in Ung. el Ky. "die Ins. Cypern " p. 167; W. P. Sch. op. cit. $p .154$.

1 ? Ad terr. nud. - As. : Ins. Cypr. Afr.: Egypt. infer.

vernicosa (Hook,) Hpe. in C. M. Syn. I, p. 557; Bryol. jav. I, p. 63, t. 51 .

Gymnostonum vernicosum Hook, in Wall. Cat. n. 7549, Ic. pl. rar. t. 17, f. 4 et in Lond. Journ. of bot. 1840, II, p. 2.

Hymenostylium vernicosum Mitt. M. Ind. or. p. 33.

2. Ad mur. - As. : Nepal, Java

viridula Mitt. in Seeman Journ. of bot. Januar. 1871.

P. Mittenii var. viridifulia Corbière M. de la Manche p. 235.

P. pallida Braithw, in Lond. Journ. of bot. VIII, p. 255.

1. Ad mur. - Eur. : Hibern. et Angl, merid, Normann. marit.

vitiana C. M. - Hyophila.

Wagneri C. M. - Hyophila.

Wilsoni (Hook.) Bryol, eur. II (mon. p. 14), t. 122 ; C. M. Syn. I, p. 554 et $11, p .622 ; W$. P. Sch. op. cit.p. 152.

Bryum exiguum, creberrimis capsulis rufis Dill. Hist. M. p. 347, ᄂ.45, f. $7 \mathrm{~A}-\mathrm{E}$.

Gymnostomum Combae de Not. Syll. et Epil.?

G. solivagum Green in Brid. Bryol. univ. I, p. 69?

G. Wilsoni Hook. Bot. Misc. I, p. 143, t. 41 p.p.; Wils. Suppl. Engl. Bot. t. 2710.

P. Mittenii var. Wilsoni Corbièse in op. et 7 . cc.

P. truncata var. subcylindrica James in Bot, King. Exped, p. 399.

I. In terr. arenos. lapid. - Eur. : Britann., Gall. merid. occ.; Sardin.? Etrur, Am, sept. : Nevada.

Exs. : Rab. Bryoth. eur. n. 955.

Wrightii R. Br. in Trans. of the N. Zeal. Inst. 1893, p. 291.

Terr, - Pac.: Nov. Zeland.

Wrightii C. M. - Hyophila.

xanthocarpa C. M. - Gymnostomum.

Zeyheri Hpe. - Hyophila.

Zollingeri C. M. - Isarbula spathulata.

Pottiella Limpr. Laubm. Deutschl. 1, p, 188 (sect. PHascı).

POWELLIA Mitt, in I.ond. Journ, of bot. 1867, p. 187 (1 spec.). involutifolia Mitt. in op. et l. cc., $\iota .6 \mathrm{D}$.

Cortic. - Pac. : Ins. Samoa, N. Caledon. austral.

Prælongularia C.M. in Nuov. Giorn. bot. ital. 1896, p. 124 (nom., sect. HYPNI $=$ EURHYNCHIUM $p p$.). 
PRIONODON C. M. in Bot. Zeit. 1844, p. 129 (28 spec.).

africanus Rehm. M. Afr, austr. n. $606 \mathrm{~b}$.

Ster.

- Afr. : Transvaal.

auriculatus Angstr, in Oefv... 1876, n. 4, pp. 31-32.

Ster. Ad arbor. - Am. merill. : Brasil. austr. or.

bolivianus C. M. in Nuov. Giorn. bot, ital. 1897, p. 146.

- Am. merid. : And. Boliv.

caldensis Broth, in Bihang till Sv. Vet.-Akad. Handl, 1895, n. 3.

2. fr. ign. Ad arbor, - Ant. merid. : Brasil. or.

ciliatus Besch. Fl. bryol. Réunion, etc. p. 120.

Ster.

- Afr.: lns, Borbon.

densus (Sw.) C. $M$, in Bot. Zeit. 1844, p. 129, t. I (sub nom. false inscriplo $\mathrm{Pr}$. Ehrenbergii); Mitl, M. austr, am. p. 418.

Hypnum densum Sw. Prodr. Fl. Ind. occ. p. 141 et in Hedw. Sp. M. p. $282, t, 74$.

Neckera crassa Hsch. Fl. Brasil. I, p.,56 et in Deppe et Schiede M. Mexic.

N, densa Wils, in Lond, Journ. of bot. 1847, p. 292, t. II.

Pilotrichum densum C. M. Syn. II, p. 160.

2. Ad arbor. - Am. sept.: Mexic., Costa Rica, Jamaic. Am. merid. : Venezuela, And. Quitens, ? Brasil. or.

dichotomus Hpe. in Linn. 1863, p. 150 ; Mitt. op. cit. p. 420.

2. Ad arbor. - Am. sept. : Costa Rica. Am, merid.: And. Nov. Granat.

divaricatus Milt. op. et l. $c c$.

- Am merid. : And. Nov. Granat et Quitens.

elongatus (Hook. f. et Wils.) Jreg. Ad. II, p. 127.

? Bartramia elongata Mitt. in Handb. of N. Zeal. Fl, p. 449.

Breutelia elongata ej. in F, v. Mülles's Fragm. Pltyt. austral. XI, p. 114.

Hgpnum elongatum $H$. f. et W. in Lond. Journ, of bot. 1844, p. 551 et $F l$. Antarct. I, p. 137, t. 60, f. 3.

Pilotrichum elongatum C. M. Syn. II, pp, 161 et 674 .

Ster.

- Pac : Ins. Auckland, Campbell, Tasman.

flagellaris Hpe. in Ann, sc, nat. $V$ ser., $I V, p .356$; Mitt. M, austr. an. p. 419 .

- Am. merid. : And. Nov. Granat.

fnsco-lutescens Hpe. in op, cit. p. 357; Mitt. op. et $l$. cc. - Am. merid. : And. Nov. Granat.

haïtensis Ren, et Card. in Bull. Soc, roy. bot. Belg. 1894, 11, p. 125.
2.

- Am, sept. : Haiti.

Jamesoni C. M. in Nuov. Giorn. bot. ital. 1897, p. 146 (nom.).

- Am. merid. : And. Quitens.

Kunerti $C . M$. mss.

Ster.

- Am. merid. ; Brasil. (Rio grande do Sul).

geniculatus $C . M$, in Fl. $1897, p .338$.

Ster. - Am, merid. : Nov, Granata.

laeviusculus Milt. op. et $l$, ccc.

- Am. merid. : And. Nov. Granat.

longissimus Ren. et Card. in Bull. Soc. roy. bot. Belg. 1894, I, p. 178.

2. Ad arbor. - Am. sept. : And. Costa Rica. 
luteo-virens (Tayl.) Milt. op. cit. p. 417.

Neckera luteo-virens Tayl. in Lond. Journ. of bot. 1846, p. 59 c. ic. et p. $452, t .16 \mathrm{~N}$.

Pilotrichum luteo-virens C. M. Syn. II, p. 161.

- Am. merid. : And, Quitens, et Boliv.

lycopodioides Hpe. in Linn. 1863, p. 150; Milt. op. cit.p. 418.

Hylomnium frondiforme $S p r$, Cat.

2. Ad arbor. - Am. merid. : And. Nov. Granat, et Quitens.

Lycopodium (C. M.) Jaeg. Ad. II, p. 127.

Pilotrichum Lycopodium C. M. in Bot. Zeit. 1857, p. 581 .

P. Mülleci Hpe. in Ann. so. nat. V ser., IV, p. 356; Mitt. op. cit. p, 121.

Ster. Saxic. - Am. merid. : And. Noy, Granat.

Mülleri Hpe. - Pr. Lycopodium.

pinnatus Hpe, in op. cit. p. 355 ; Mitt. op. cit. p. 417 .

- Am. merid. : And. Nov. Granat.

patentissimus Besch, in Bull. hb. Boissier 1894, p. 394.

2? Ad arbor. - Am. merid. : And. Quitens.

ramosus Hpe. mss. ; Jaeg. Ad. II, p. 128.

- Am. sept. : Mexic.?

Rehmanni Mitt, in Journ. of the Linn. Soc. 1886, p. 311.

Ster. ciae?

- Afr. : Kilima N'Djaro, Transvaal ; ins. Fran-

robuslus Hpe. - Breutelia grandis.

rubiginosus Hpe. Symb. 1870, p. 278.

Ster. $\quad-A m$, merid.: Brasil. austr. or.

simplex C. M. in Fl. 1897, p. 339 .

Ster. $\quad-A m$. merid. : Venezuela.

subgeniculatus C. M. in op. cit. p. 338 .

Ster. $\quad-A m$, merid.: Venezuela.

undulatus Mitt. op. cit. p. 420.

- Am. merid. : And. Nov. Granat et Quitens.

Prionothrix C. M. in Fl, 1888, p. 417 (subsect. HyPN).

Protobium C. M. in Linn. 1880-83, p. 344 (sect. ARCHIDI).

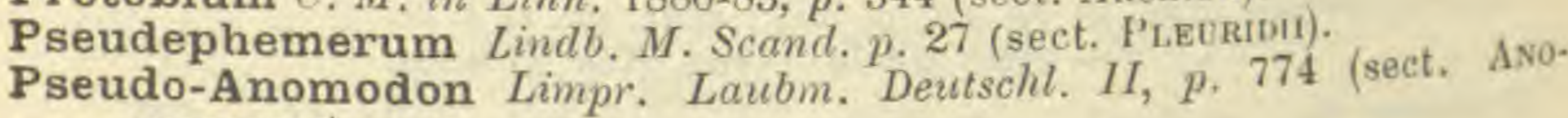
MODONTIS).

Pseudo-Braunia Lesq. el Jam. Man. p. 153 (subgen. Brauniak). Pseudo-Braunia Lesq. el Jam. Man. p. 153 (subgen. Brausiak).
Pseudo-Gampylopus Limpr. Deutsehl. Laubm. 1, p. 381 (sect. CaMPY-
Lopodis).

Pseucuo-Ghotomitrium Hpe. is Nuov. Giorn, bot. ital. 1872, p. 287 (sect, HYPNI).

PSEUDO-LESKEA Bryol, eur. V (61 spec.). amblystegiella C. M. in Nuov. Giorn. bot. ital. 1897, p. 160.

- Am. merid. : And. Boliv.

andina W. P. Sch, in Mandon Pl. Boliv, n. 1694.

- Am. merid. : And. Boliv. 
angustifolia (Hpe, et C.M.) Par.

Hypnum angustifolium Hpe. et C. M. in Bot. Zeit. 1855, p. 788.

Thuidium angustifolium Jaeg. Ad. II, p. 318.

$$
\text { - Afr. : C. B. Sp. }
$$

atro-virens (Dicks.) Bryol. eur. V (mon, p. 2), t. 477 ; W. P. Sch. Syn. II ed. p. 603.

Hypnum atro-virens Dicks. mss. ; Sm. Engl. Bot. n. 2422 et Fl. brit. III,
p. 1307 .

H. filamentosum Bert. Amoen. p. 438; C. M. Syn. II, p. 478.

H. filamentosum $\beta$ tenue $C . M$. .. c. p. 479.

H. filiforme Vill. Pl. Dauph. III, p. 906.

H. implexum Brid. M. Rec. II, II, p. 150, t. 4, f. 3 .

H. incurvatum $P$. B. Prodr. p. 65 .

Leskea atro-virens Hartm. Skand. Fl. V ed. p. 337.

Leskea incurvata Hedu. Sp. M. p. 216, t. 53 ; Brid. Bryol, univ. II, p. 320.

Leskea incurvata var. simplex

$\left.\begin{array}{l}\text { Leskea incurvata var. Subserrulata } \\ \text { Leskea incurvata var. Thomasii }\end{array}\right\}$ Brid. l. c.?

2. Ad sax. in loc. decliv. vel excav. humid, - Eur. : Reg. subalp. et alp., rar. montana; ins. Ursor. As.: Caucas. Am. sept. : Groenland, fret. Hudson, Terr. nov., Niagara, lac. Huron et Super., M. Rupestr. et Selkirk, Columb. brit., Vancouver, Washington, Oregon, Montana, Idaho, Wyoming.

Exs. : Mac. Canad. M. n. 437.

Rab. Bryoth. eur. n. 781, 991, 1184.

Un, itin. 1867, n. 7, 32 .

"var. atricha Kindb. in Mac. Cal. p. 180 (propria spec. serius).

Rupic. - Am. sept. : Columb. brit.

"var. brachyclados (Schwaegr.) Bryol. eur. et W. P. Sch. ll. cc. (1).

H. filamentosum var. brachyclados C.M. l. $c$,

Leskea brachyclada Schwaegi. Suppl. I, II, p. 173 ; Brid, op. cit. p. 322.

L. incurvata var: brachyclada Brid. Sp. M. II, p. 81 .

L. Saviana de Not. Syll. n. 87 (fid. Limpr.).

Ad saxa unbrosa et arb. rad, in silvat. - Eur.: Reg. subalp. As.: Caucas. Am. sept. : Wyoming.

"var. flamentosa Boulay M. de la Fr. p. 162.

Lescuraea filamentosa Lindb. M. Scand. p. 36.

Leskea filamentosa Kindb. Laubm. Schwed. u. Norveg. p. 12.

- Am. sept.: Washington, Oregon, Montans.

" var. papillosa (C. M.) Par.

Hypnum filamentosum ô papillosum C.M...$c$.

Leskea Saviana de Not. Syll.p. 63 (fid. C. M.).

- Eur. : Apenn. Etrur. et Picen.

* var. subcatenulata (Scel.) Par.

- Eur. : Karelia.

"var. subnitidula (Lindb.) Par.

Lesquereuxia filamentosa var, subnitidula Lindb. in Act. Soc. Fenn. VI, n. 4 (nom.).

- Eur. : Lappon. Kolaëns.

"var, tenella Limpr. Laubm. Deutschl. II, p. 812.

(1) Cf. Hagen in Rev.'bryol. 1891, p. 7 et Boulay M. de la Fr. p. 162. 
Ad rup. calcar, - Eur. : Riesengeb., Salisburg., Alp. Bavar.

Exs, : Rab. Bryoth, eur. n. 6.

austro-catenulata (C.M.) Par.

Hypnum austro-catenulatum C. M. in Engler's Bot. Jahrb. 1883, p. 83 et in Forschungsieise,.. Bot, p. 36.

Ster.

- Afr.: Ins. Kerguelen.

capensis W. P. Sch, in Breutel M. Capens.

$$
\text { - Afr.: C. B. Sp. }
$$

capillata (Mitt.) Besch. in Ann. sc. nat. 1892, I, p. 77.

Leskea capillata Mitt. M. Ind. or. p. 130.

Ps, L. ? intermedia Sande-Lac. in Miq. Ann. Mus, bot, Lugd. Batav. II, p. 297 .

Thuidium capillatum Jaeg. Ad. $I I, p, 318$.

Th. nipponense W.P. Sch. in Savatier M. Jap. n. 616.

Th. papillatum (erratim !) Jaeg. l. c. p. 320.

1.

- As. : Sikkim, Yunnan, Japon.

catenularia C. M. in Nuov. Giorn, bot. ital. 1897, p. 97.

- Am. merid.: And. Boliv.

catenulata (Bred.) Bryol. eur. V (mon. p. 3), Ł. 478; W. P. Sch. op, cil. p. 604 .

Grimmia catenulata W. et M. Bot. Taschb. p. 151.

Hypnum catenatum Vill. $\mathrm{Pl}$. Dauph. III, p. 909?

H. catenulatum Brid. Sp. M. II, p. 154 et Bryol. univ. $I I$, p. $450 ;$ C. M. Syn. II, p. 477 .

Isothecium catenulatum Hüb. Muscol. germ. p. 599.

Leskea catenulata Lindb. M. Scand, p. 31.

L. Froehlichii Brid. Sp. M. II, p. 70 et Bryol. univ. II, p. 305.

Pterigynandrum catenulatum ej. M. Rec. II, I. p. 64, t. 5, f. 4 .

Pterogonium catenulatum Schleich. Crypt. helvet. exs. et Cat. pl. Hele. p. 30.

Pt. filiforme Engl. Bot.? (Brid. ex Hook.).

Thu dium catenulatum de Not. Epil. p. 235.

2. Ad sax. umbros. præcip. calcar., rar. ad arb. rad. - Eur. : Reg. mont. et subalp. Britann., Seandin., Siles., Westphal, Relg., Wurtemb., Jurass., Helvet., Astur., etc. As. : Jenissei sup., Caucas. occ. et centr. Am. sept, : New York (fid. W. P. Sch.).

Exs. : Rab. Bryoth. eur. n. 642 et b, 780 et b, 1183.

Un, itin. 1867, n. 4 .

calenulata Mac. - Ps, L. malacoclada.

catenulatula C. M. in Hedwig. 1897, p. 139.

chalaroclada (C. M.) Par.

- Am. merid. : Argentin. subtropic.

Hypnum chalarocladum C. M. in Engler's Bot. Jahrb. 1883, p. 82 ot in Ster.

Forsehungsreise... Bot. p. 36.

claviramea C. M. in Rehm. M. Afr. austr. n. 355.

$$
\text { - Afr. : Ins. Kerguelen. }
$$

Anomodon clavirameus Jaeg. Ad. II, p. 305.

Hypuum clavirameum C. M. Bot. Zeit. 1855, p. 787.

$$
\text { -Afr. : C. B. Sp. }
$$

"var. acuminata $C, M, l, c, n, 356$.

\& var. aquatica Rehm. l. c. n. 642.

$$
\text { - Afr.: C. B. Sp. }
$$

- Afr. : Transvaal. 
" var. denudata (C. M.) Par.

Hypnum clavirameum var. denudata C. M. in Abhandl. Brem. VII, p. 213.

- Afr. : Madagascar.

compressa (Mitt.) Par.

Amblystegium compressum Mitt, in Trans, of the Linn. Soc. 1891, p. 186.

1. - As. : China.

congesta (Wils.) Bryol. eur. V (mon. p. 2).

Hypnum congestum Wils. mss.

H. radicosum Mitt, in Journ. of the Linn. Soc. VIII, p. 31 ; Lesq. et Jam. Man. p. 320.

H. reflexum C. M. Syn. II, p. 448 (quoad pl. Drumm.).

H. tenax Drumm, M. bor. am. I ed. n. 225 p.p.

Ps. L. radicosa Kindb, in Mac, Cat. p. 181.

2. Ad terr. et rad. arb. - Am. sept.: M. Rupestr.

"var. gracilis Lesq. el Jam. l. c.

Hypnum tenax Drumm. l. c.p.p.

Ps. L. rigescens Lindb. in Act. Soc. Fenn. X, p. 247.

Ps. L, sciuroides Kindb. (fid. Card.).

Ut typ. - Am. sept. : Washington, Oregon, Wyoming.

crispula Bryol. jav. II, p. 125, t. 228.

2. $\quad$ - As. : Java.

cryptocolea Besch, in Bull. Soc. bot. Fr. 1887, p. 97.

1. Rupic. - As. : Tonkin.

"var. thelidia Besch. l. c.

Muric. - Ubi typ.

decipiens Kindb. - Ptyehodium.

desmioclada (C. M.) Par.

Hypnum desmiocladum C. M. in Engler's Bot. Jahrb, 1883, p. 83 et in Ster.

- Afr. : Ins, Kerguelen.

falcicuspis C. M. et Kindb, in Bidrag, p. 454 (nom.) et in Mac. Cat.p. 182.

2. Rupic. - Am. sept. : Columb. brit,; Yellowstone Park.

Exs. : Mac. Canad. M. n. 510.

? filım (C. M.) Par.

Hypnum filum C. M. in Engler's Bot. Jahrb. 1883, p. 83 et in Forschungsreise... Bot. p. 36 .

Ster. - Afr. : Ins. Kerguelen.

fuscifolia $C, M$. mss.

- As. : Himalaya sept, occid. (Dehra-Doun).

gracilis (Jur.) W. P. Sch. Syn. II ed., p. 853.

Amblystegium gracile Jur. in Verh. d. zool. bot. Ges. in Wien, 1864.

Thaidium pulchellum (fid. Limpr.).

1. Saxic. - Fiur. : Tirol. merid., Istria.

helerocladioides Kindb. - Ps. Leskea patens.

intermedia Lac. - Ps. L. capillata.

laevifolia (Mitt.) Jaeg. Ad. II, p. 309.

Leskea laevifolia Mitt. M. Ind. or. p. 130.

Ster. ? 
Laplatae C. M. in Hedivig. 1897, p. 138.

- Am. merid. : La Plata.

latifulia Sande-Lac. in Miq. Ann, mus. bot. Lugdun. Batav., pp. 185 et $297, t .2$.

Amblystegium latifolium Mitt, in Trans, of the Linn. Soo. 1891, p. 186. - As. : Japon.

laxifolia Rehm. M. Afr, austr. n. 640.

Ster.

- Afr.: Transvaal.

Leikipiae (C. M.) Par.

Anomodon Leikipiae C. M, in Fl. 1890, p. 495.

Ster. - Afr. : M. Aberdare.

Liebmanni Bryol, eur. $V$ (mon. p. 2, nom.).

Ps. L. subcatenulata W. P. Sch, in Besch. Prodr, bryol. mexic, p. 90. 1. - Am. sept. : Mexic.

Mac-Owaniana Relim. M. Afr. austr. n. 6.43. - Afr. : C. B, Sp. or.

malacoclada C. M. et Kindb, in Bidrag, p. 454 (nom.) el in Mac. Cal. p. 182 .

Ps. I. catenulata Mac. Canad. M. n. 460 .

2. Ad rup. siccior. - Am, sept. : Columb. brit

microphylla (Suc.) Sb. in Jaeg. Ad. II, p. 739.

Hypnum microphyllum Sw. Prodr. Fl. Ind. occ. $p .142 ;$ C. M. Syn. II, p. 491 .

H. Stereodon microphyllus Brid. Bryol. univ, II, p. 649 (exel. sp. Pensilvan.).

Leskea microphylla Mitt. M. austr. am. p. 568 p.p.

Thuidium microphyllum Jaeg. Ad. II, p. 317.

1. Ad terr, et rad, arb. - Am. sept. : Caba, Jamaic.

minuta $C . M$. in Nuov. Giorn. bot. ital. 1897, p. 96.

- Am. merid. : And. Boliv.

muricola $(C, M$.) $S b$. in op. et $l$. cc.

Hypnum microphyllum Hsch. Fl. Brasil.

H. muricolum $C . M . S y n . I I, p, 492$.

Thuidium muricolum Jaeg. Ad. II, $p, 31$.

1. Ad mur, - Am. merid. : Brasil. austr. or., Paraguay.

obscuriuscula (Mitt.) Sb. in op. el $l$. cc.

Leskea obscuriuscula Mitt. M. Ind. or. p. 130.

Thuidium obscuriusculum Jaeg. op, cit. p. 319.

1.

- As. : Assam super.

oligoclada Kindb. in Bull. Torr, bot. Club, XVII, p 277 et in Mac. Cal. p. 180.

Ps. L. atro-virens Br.eur. (fid. Card.).

2. Ad rup. madid. - Am. sept : Ins. Vancouver.

orbiculata (Mitt.) Jneg. Ad. II, p. 309.

Hypnum orbiculatum Mitt. M. Ind. or. p. 84.

1.

- As. : Khasia.

papillarioides C. M. in Nuov. Giorn. bot. ital. 1896. p. 118

Ster.

- As. : China or. (prov. Schen-Si). 
patens (Lindb.) Limpr. Laubm. Deutschl. II, p. 806.

? Leskea patens Lindb. in Soc. pr. Faun. et Fl. Fenn. 9a Octobr. 1880.

Lesquereuxia patens ej. in Meddel. of Soc. pr. Faun. et Fl. fenn. 1887, Heft $\mathrm{XIV}, \mathrm{pp} .75-77$.

Ps. Leskea heterocladioides Kindb. in Rev. bryol. 1895, p. 83.

Ps. Leskea ticinencis Bott, in Proc. verb. Soc. Tose. so, nat. 18 Gennaio 1891.

2. Rupic. - Eur. : Scandin., Alp. Scot., Stiriæ, Carinth., Helvet., Galliæ, Ticin.

paraguensis Besch. Not. M. Parag, p. 267.

1. $\quad-A m$. merid. : Paraguay.

Exs. : Balansa Pl. Parag. n. 1200, 1201, 1203, 1204, 1205, 1206, 1211. paraguensis Besch. (1885). - Thuidium subnudum var. paraguensis.

Perraldieri Besch. Cat. M. Alger, p. 33.

- Afr.: Alger. (Kabyl. or.).

plagiostoma C. M. in Nuov. Giorn. bot. ital. 1872, p. 20.

1. $\quad$ - Afr.: Abyssin.

u var, attenuata $C, M . l, c$.

Ut et ubi typ.

praelonga W. P. Sch, in Besch. Prodr. bryol, mexic. p. 89.

Heterocladium mexicanum ej. in sched.

1 .

- Am. sept. : Mexic.

prionophylla (C. M.) Bryol. jav. II, p. 124, t. 227.

Hypnum nervosum Hook. Ic. pl. rar. t. 24, f. 3 ; Harv, in Lond. Journ. of bot. $1840, p .21$.

H. prionophyllum C. M. Syn. $I I, p .481$.

Leskea prionophylla Mitt. M. Ind. or. p. 132.

2. - As, : Nepal., Sikkim, Khasia, M. Neilgherr., Ceylan, Java, Celebes.

pseudo-gracilis (C.M.). Par.

Haplocladium pseudo-gracile C. M. in Hedwig. 1897, p. 139.

1.

pseudo-vagans $C . M$. mss.

- Am. merid: Argentin. subtropic. (Chaco).

Ster.

- As. : Himalaya sept. occid. (Dehra-Doun).

rudicosa Kindb. - Ps. L. congesta.

ramuligera (Mitt.) Sb. in Jaeg. Ad. II, p. 739.

Leskea ramuligera Mitt. op. et $l$. cc.

Thuidium ramuligevum Jaeg. Ad. II, p. 319.

1.

- As. : Nepal., Himalaya occ.

remotifolia (Lindb.) Par, (subsp. Ps. L. catenulalae?)

Leskea remotifolia Lindb, in Broth. Enum. M. Caucas. p. 96.

- As. : Caucas, occ.

igescens Lindb. - Ps. L. congesta var. gracilis.

rupestris Kindb. - Leskea.

Rusbyana C. M. in Nuov. Giorn. bot. ital. 1897, p. 95.

1. - Am. merid. And. Boliv.

sciuroides Kindb. in Bull. Torr. bot. Club, p. 296 et in Mac. Cat. p. 180.

Macounia sciuroides Kindb. Enum. Bryin. exot.

Ps. L. congesta var. gracilis L. et $J$. (fid. Card.),

2. Rupic. - Am. sept. : M. Rupestr, Columb, brit. 
« var. denudata Kindb. in Mac. Cat. p. 181.

2. Rupic. - Am. sept. : M. Selkirk.

Exs. : Mac. Canad. M. n. 564.

scopula (Mitl.) Sb, in op, cit. p. 740.

Leskea scopula Mitt. M. Ind. or. p. 131.

Thuidium scopulum Jaeg. Ad. II, p. 323.

1. - As. : Himalaya occ.

semensis C. M. in Nuov. Giorn. bot. ital. 1872, p. 21.

Hypnum semense Vent. $l$. $c$.

- Apr.: Abyssin.

siamboniea C. M. in Hedwig. 1897, p. 138.

- Am. merid. : And. Argentin. subtropic. Tucuman.

stellatifolia Sb. - Thuidium.

stenophylla Ren. el Carl, in Bot. Centralbl. 1890, n. 51.

1? 2? Ad Alnos et sax. in decliv. humid. - Am. sept. : M. Selkirk, Washington.

Exs. : Mac. Canad. M. n. 580 .

stratosa (Mitt.) Sb. in Jaeg. Ad. 11, p. 739.

Anomodon stratosus Jaeg. op. cit. p. 305.

Leskea stratosa Mitt. M. Ind. or. p. 131.

I.

- As. : Assam super.

subatrovirens $\mathrm{Sb} .-\mathrm{Ps}$. L. subfilamentosa.

subcatenulata W. P. Sch. - Ps. L. Liebmanni,

subfilamentosa Kiceër in Besch. Fl. bryol. Réunion, etc. p. 147.

Ps. L. subatro-virens $S b$. in op. et $l$. $c c$.

- Afr. : Usambara, Madagascar.

subulacea (Mitt.) Sb. in op. cit. p. 140.

Leskea subulacea Mitt. op. et $l$. cc.

Thuidium subulaceum Jaeg. Ad. II, p. 323.

1.

- As. : Khasia.

tectorum (A. Br.) W. P. Sch. Syn. II ed. p. 605.

Hypnum dimorphum C.M. Syn. II, p. 490.

Hypnum dimorpham $\beta$ tectorum Rab. Krytpfl. II, 3, p. 263.

H. Stereodon tectorum Brid. Bryol. univ. II, p. 582.

Leskea ? Mildeana de Not. Epil. p. 247.

Leskea tectorum Lindb. Adn. bot. in Bot. Notis. 1864.

Pterogonium tectorum A. Br. in Brid. $l$. $c$.

2. In tigill. et lign. tectorum, ral. ad arb. trunc. - Eur. : Reg. med., rar. sept. et merid., fere semper ster. ; Spitzberg., ins. Ursor.; vitgratiss, in valle Rhen. ; Arvern,, Jurass. : Norvegia merid. (fruct !) : desider, in Britann. As. : Sibir. occid. Am. sept. : Groenland.

Exs. : Rab. Bryoth. eur. n. 600.

tenuissima Besch. Fl. bryol. Réunion, etc. p. 147.

2 ?

- Afr. : Ins. Franciae.

ticinensis Bott. - Ps. Leskea patens.

tonkinensis Besch. in Bull. Soc, bol. Fr. 1887, p. 98.

Rupic. - As. : Tonkin.

trichodes Besch, in Bull. Soc. Bot. Fr. 1887, p. 98.

1. Rupic. - As.: Tonkin. 
uruguensis C. M. in Hedwig. 1897.

- Am. merid. : Argentin. Urug.

Wallichii (Hook.) Sb. in op. cit. p. 739.

Hypnum Wallichii Hook. in Schwaegr, Suppl. III, I, I, t. 219; C. M. Syn. $I I, p .464$.

Leskea Wallichii Mitt. M. Ind, ov, p. 132.

2 .

- As. : Nepal., Himalaya.

Zippelii (Dz. et Mk.) Bryol. jav. II, p. 126, t. 229.

Hypnum Zippelii Dz. et Mk. in Ann. sc. nat. 1844, p. 310; C. M. Syn. II,

2. p. 480.

- As. : Amboine, Java.

Pseudo-polytrichum C. M. Syn. I, p. 123 (sect. Polyrricai).

Pseudo-rhynchostegium Lindb. Animadv, p. 27.

PSILOPILUM Brid, Bryol. univ, II, p. 95 (13 spec.).

aequinoctiale W. P. Sch. in Mandon Pl. Boliv. n. 1683.

Catharinea aequinoctialis C. M. in Nuov, Giom. bot. ital. 1897, p. 10.

- Am. merid. : And. Boliv.

antarcticum (C.M.) Par.

Catharinea antarctica C. M. in Engler's Bot. Jahrb. 1888, p. 77, in Forschungsreise... Bot. p. 10 et Bryol, austr. Georg. p. 13.

Ps. trichodon antarcticum Mitt. in Journ, of the Linn. Soc, 18\%6.

2. - $A f r$, : Ins. Kerguelen. Am. merid.: Austr. Georg.

arcticum Brid. Bryol. univ. II, p. 96; W. P. Sch. Coroll. p. 89 et Syn. II ed. p. 533 .

Catharinea glabrata Hook. Tour in Iceland, I, p. 195.

C. laevigata Brid., Mant. M. p. 102.

Oligotrichum giabratum Lindb. in Notis.... 1867, p. 143.

0 . laevigatum Bryol. eur. IV (mon. $p$, $5, t, 4.414$.

Polytrichum glabratum Wahlenb. in W. et M. Ind. M. Mackensies Ioel. P. 434.

P. laevigatum ej. $F l$. Lapp. p. $349, t, 22$.

P. laevigatum Lindb. in Defv... XVIII, $p .190, n, 40$.

P. marginatum Schwaegr. Suppl. I, II, p. 329.

2. In arenos, ripar. et terr. turfac. - Eur.: Zon, arctic. : Spitzberg, Septem. Ins., etc. As. : Penins. Samojed, Taimyr, Jenissei. Am. sept. : Groenland, Labrador, litt. mar. Behring.

atistrale (Hook. f. et Wils.) Jaeg. Ad. 1, p. 697.

Polytrichum australe $H$. f. et W. FI. of the $N$. Zeal. $I I, p .95, t .87, f .3$ et Handb, p. 454.

2? Ad rup. et terr, - Afi: : Ins. Marion. Pac. : Nov. Zeland, Tasman. compressum (Hook. f. et Wils.) Mill. M. austr. am. p. 607.

Catharinea compressa C. M. Syn. I, p. 195 et II, p. 559 .
Polytrichum compressum H. f. et Wils. in Lond. Jorrn. of bot. 1844, 2. p. 539 et Fl. antarct. II, p. 410, t. 153, f. 7.

ins, Eremit.

- Afr.: Ins. Karguelen. Am. merid.: Fuegia,

crispulum Hook. f. et Wils. Fl. of the N. Zeal. II, p. 85, t. 87, f. 3 et

Handb. $p, 453$.
2 ,

- Pac. : Nov. Zeland., Tasman. 
gymnostomulum (C. M.) Par.

Catharinea gymnostomula C. M. in Linn. 1878-79, p. 264. 2. - Am. merid. : Alp. Argentin. subtropic.

laevigatum Lindb. -- Ps, arcticum.

piriforme (Hpe.) Jaeg. Ad. II, p. 716.

Atrichum piriforme ej. Ad. I, p. 706.

Catharinea piriformis Hpe, in Linn. 1871-73, p. 517.

2.

- Pac. : Austral. or.

pygmaeum (C. M.) Par.

Catharinea pygmaea C. M. in Nuov, Giorn. bot. ital. 1897, p. 11. - Am. merid. : And. Boliv.

tapes (C. M.) Par.

Catharinea tapes C. M. Bryol, austr. Georg. p. 12.

Ster. - Am. merid. : Austr. Georg.

trichodon (Hook. f. et Wils, ) Mitt. op. et ll. cc.

Catharinea trichodon C.M. Syn. I, p. 195.

Polytrichum trichodon $H$. $f$. et W. in Lond. Journ. of bot. 1847, p. 289, t. 10.

2. Terr. - Afr. : Ins. Kerguelen. Am. merid. : Summ. And. Nov. ùranat., M. Pichincha.

trichodon Mitt. (1876). - Ps. antarcticum.

tschutschicum (C. M.) Pas:

Catharinea tschutschica C. M. in Bot. Centralbl. 1883, n. 24.

Oligotrichum tschutschicum Lindb. et Arn. M. As. bor. 1890, 11, p. 10. 2. - As. : Penins. Tschutschica.

Ulei Broth, in Ule Bryo!h. Brasil. n. 151.

- Am. merid. : Brasil. austr. or.

Psilotheca C. M. Syn. 1, p. 513 (sect. Encalyptae).

PTERIGONEURUM Jur. Laubm. Oesterr. Ung. p. 95. cavifolium Jur. - Pottia. lamellatum Jur. - Barbula cavifolia. subsessile Jur. - Pharomitrium.

PTERIGYNANDRUM Hedw. Sp. M. p. 80 (emend.) (2 spec.). algerianum P. B. - Rhynchostegium tenellum. apiculatum Brid. - Eurhynchium hians. appressum Rrid. - Pylaisia intricata. aureum Brid. $\left\{\begin{array}{l}\text { (Mant. M.) - Pilotrichella tetragona. } \\ \text { (Bryol. univ.) -- Cylindrothecium. }\end{array}\right.$ bicolor (1) Lindb. - Leptohymenium. brachycladon Brid. - Leptohymenium. brasiliense Hpe. - Erythrodontium. carolinianum Brid. - Cylindrothecium seductrix. catenulatum Brid. - Ps. Leskea.

(1) Boscit Brid, Bryol, univ. 1I, p. 750; C. M. Syn. 11, p. 75. - Quid? Delendum. 
ciliatum Hedw. - Hypopterygium.

cirrosum Brid. - Brachythecium albicans.

crinitum Brid. - Anomodon rostratus.

decipiens Lindb. - Pt. filiforme var. heteropterum.

fabronioides C. M. - Leptohymenium.

ferricolum C. M. - Platygyrium.

filiforme (Timm.) Hedw, M. frond. IV, p. 18, t. 7; Brid. Bryol. univ. II, pp. 77 el 750 ; Bryol. eur. V, Ł. 460; W. P. Sch. Syn. II ed.p. 618.

Encalypta filiformis Roth Fl. germ. 1II, p. 155

Grimmia filiformis $W$. et $M$. Bot. Tasehb. $p$. 150.

Hypnum cylindricum Dicks. Crypt. Fasc. II, p. 12.

H. filiforme Timm. Prodr. fl. Megap, n, 817 .

Leptohymenium filiforme Hüb. Muscol. germ. p. 552.

Leskea cylindrica Brid. Sp. M. p. 60.

Maschalanthus filiformis Sohultz Fl. Starg. p. 356.

Maschalocar pus filiformis Spreng. Einleit. p. 297.

Neckera filiformis C.M. Syn. II, p. 89.

Pterogonium caespitosum Engl. Bot. t, 2526.

Pt. filiforme Schwaegr. Suppl. I, I, p, 100; Drumm. M. bor. am. I ed. n. 77 .

2. Ad trunc. imos arbor. silvat. et sax. umbros. - Eur. : E reg. campestr. usq. in subalp.; Spitzberg, Lappon. As.: Cancas. occ. et centr. Afr. : $\Lambda$ lger., ins, Canar. Am, sept, : Groenland, Terr. nov., New Brunswick, Gaspes., Ontar., M. Rupestr. et Selkirk, Columb. brit., Montana, Wyoming, Idaho.

Ess, : Mac. Canad. M. n. 244

Rab. Bryoth, eur. n. 637.

Sull. et Lesq. M. bor, am. II ed, n, 348.

var. crassius Hartm. - Pt, filiforme var. heteropterum.

(c) vâr. cristatum (Hpe,) Lesq. et Jam. Man. p. 289.

Leptohymenium cristatum Hpe. in Linn. 1859, p. 459.

Ut typ. - Am. sept. : Calif.

"var, heteroptrum (Brid.) Bryol, eut, et W. P. Sch. ll. cc.

Leptohymenium elajochloron Lobarz. in Haiding. Naturw. Abh, I, p. 61 .

L. filiforme $\beta$ alpestre Rab. Deutsch. Kryptft, 1I, III, p. 250.

L. heteropterum Hüb. Muscol, germ. p. 553 .

Neckera decipiens W. et M. Bot. Taschb. I, pp. 241 et 473.

Pterigynandrum decipiens Lindb. M. Scand. p. 36 .

Pt. filiforme $\beta$ crassius Hartm. Skand. Fl. ed. IX.

Pt. heteropterum Brid. Bryol. univ. 11, p. 176.

Pterogonium decipiens Kindb. Laubm. Schwed. u. Norv. p. 13.

Pt. heteropterum Br. in Schwaegr. Suppl. III, I, t. 210 b.

Ad saxa. - Eur.: In subalp. Afr.: Alger. Am. sept.: Washington.

"var, minus Lesq. et Jam. l. c.

Ut praeced, - Am. sept. : M. Adirondack.

- var. Saelanii (Lindb.) Par.

Pt. Saelanii Lindb, M. Scand. p, 37 (subsp, Pt. filiformis).

- Eur. : Lappon, or.

flavescens Brid, - Fabronia.

fragile Schleich. - Myurella julacea.

fulgens Hedw. - Phyllogonium.

gracile Hedw, - Pterogonium.

heleropterum Brid. - Pt. filiforme var. heteropterum.

hirtellum Hedw. - Thelia.

illecebrum Brid, - Papillaria nigrescens var. illecebra. 
julaceum Hedw. - Leucodon.

latifolium Ảngstr. - Erythrodontium.

lineolatum Duby. - Sauloma.

longifolium Schleich. - Anomodon.

longirostre Brid. - Eustichia.

loriferum Lindb. - Leptohymenium.

madagassum C. M. - P'terogonium.

marginatum Rich. - Anomodon rostratus.

mutabile Brid. - Lescuraea striata.

myurum Brid. - Cylindrothecium.

nervosum Brid. - Leskea.

$\beta$ cylindraceum Roebl. - Anomodon longifolius.

var. longifolium Brid. - Anomodon longifolius.

nigrescens $\mathrm{Sw} .-$ Papillaria.

nudicaule Brid. - Leucodon domingensis.

obtusifolium Brid. - Cylindrothecium seductrix.

papillosulum C, M. el Kindb. in Bidrag, p. 454 (nom.) et in Mac. Cat.

p. 165.

2. Rupic. - Am. sept. : Columb. brit.

Exs, : Mac. Canar. M. n. 553.

plumulosum Brid. - Anomodon longifolins.

pulchellum Brid. - Pterogoniella.

quadrifarium Brid, - Pilotrichella tetragona?

repens Brid. - Platygyrium.

Saelanii Lindb. - Pt. filiforme var. Saelanii.

Schoeinfurthii C. M. - Erythrodontium.

sciuroides Brid. - Leucodon.

serialum Hsch. - Papillaria Deppii.

Smithii Brid. - Leptodon.

squarrosum $\mathrm{Hpe}$ - Leptohymenium bicolor.

strialum Duby. - Lescuraea.

subcapillatum Hedw. - Homalothecium.

subjulaceum C. M. - Erythrodontium.

tenerrimum Brid. - Myurella julacea.

tenue Brid, - Leptohymenium.

trichomitrion Hedw, - Forstroemia.

urceolalum Brid. -- Pterogoniella.

viscosum P. B. - Phyllogonium.

PTEROBRYELla C. M. in Linn. 1872, p. 182 (subgen. HyPNi) et Bull.

Soc. bot. Fr. 1878, p. 66 (gen. propr.) (6 spec.).

brevi-acuminata Besch, in Bull. soc. bot. Fr. 1878, p. 67.

2. Ster. $\quad-$ Pac.: Nov. Caledon.

longifrons $C . M$. in op. cut. p. 65 .

Hypnodendron speciosissimum Milt. Fl. Vit.p. 401 p.p.

Hypnum longifrons C. M. in Linn. 1871-73, p. 180 .

Plerobryum elatum Lindb, in Defv.... 1861, p. 601 et in Cuming M. Philipp. n. 2198.

Pt. longifrons C. M. in Bot. Zeit. 1859, p. 24i.

2.

- As. : M. ins. Philippin.

praenitens (Hpe.) C. M, in op, et $l$. cc.

Dendro-Hypnum praenitens Hpe. in Linn. 1874, p. 671. Dendro-Hypnum praenitens Hpe. in Linn. $1874, p .671$.
Hypnodendron praenitens Mitt. in Trans. and Proced. of the roc. So.
of Victoria, $1883, p .90$.

2.

- Pac. : Ins, lord Howe. 
speciosissima (Sull.) C. M. in op. el l, cc.

Hypnodendron speciosissimum Mitt. Fl. Vit.p. 401 p.p.

Hypnum speciosissimum Sull, in Proced. of the Am. Acad... III, p. 75. 2. - Pac. : Ins. Fidji.

Vieillardi $C . M$, in op. cit. p. 67.

2. Ster. - Pac. : Nov. Caledon.

wagapensis $C, M$, in op. cit. $p .66$.

2 . Ster.

- Pac. : Nov. Caledon.

PTEROBRYUM Hsch. Fl. Brasil. I, p. 50 (39 spec.).

acutum Mitt. in Trans. and Proced, of the roy. Soc. of Victoria, -1883, p. 81 .

Ster.

- Pac. : Austral, or. (Queensland).

angustifolium (C. M.) Mitt. M. austr. am. p. 426; Besch. Fl. bryol. Antill. fr. p. 49.

Pilotrichum angustifolium C. M. Syn. II, p. 181.

2. tat.

- Am. sept. : Antill. gall. Am. merid. : Ins. Trini-

f. flagellifera Besch. 1. c. - Pt. integrifolium.

arbuscula Milt. in Trans. of the Linn. Soc. 1891, p. 171. - As. : Japon.

Eoss.: Faurie Pl. Japon, n, 3537.

australinum Mitt. in Trans. and Proced. of the roy. Soc. of Victoria 1883, p. $8 \mathrm{I}$.

Ster. land).

- Pac.: Austral. (ins, sin. Moreton, Queens-

biplicatum (C. M.) Jaeg. Ad. 11, p. 728.

Meteorium biplicatum C. M. in Fl. 1878, n. 6 .

Ster. - As. : Sikkim.

brasiliense Mitt. - Pilotrichum.

ceylanicum Thuo, et Mitt. in Journ. of the Linn. Soc. 1872, p. 315.

Endotrichum ceylanicum Jaeg. Ad. $I 1, p .138$.

Meteorium crassicaule Mitt. M. Ind. or. p. 84.

$$
\text { - As. : Ceylan. }
$$

clandestinum Mitt. - Lembophyllum.

cochlearifolium (Hsch.) Jaeg. Ad. II, p. 142.

Cryptotheca cochlearifolia Hsch. in Deppe et Schiede M. Mexic.

Meteorium mexicanum Mitt. M. austr. am. p. 433.

Pilotrichum cochlearifolium C. M. Syn. II, p. 182.

1. - Am. sept. : Mexic.

cochlearifolium Mitt. - Lembophyllum.

convolutam (Dz, et Mk.) Bryol. jav. II, p. 77.

Neckera convoluta Dz. et Mk. in Ann. so. nat. 1844, p. 312.

Pilotrichum convolutum C. M. Syn. II, $p .182$. Symphyodon convolutus Dz. et Mk. M. frond. ined. Archip. ind. p. 88 ,
t. 50 . 2.

- As. : M. Java. 
crassicaule (C.M.) Par.

Endotrichum crassicaule Jaeg. Ad. 1I, p. 138 (excl. syn. Mitten.).

Meteorium crassicaule Bryol. jav 1I, p. 97, t. 210.

Neckera crassicaulis C. M. Syn. II, p. 132.

2 .

- As.: Sumatra, Java.

crassiusculum (C, M.) Par.

Symphysodon crassiusculus $C . M . h b$.

- Pac. : Nov. Guin. brit.

crenulatum (Harv.) Jaeg. Ad. I1, p: 145.

Neckera crenulata Harv. in Lond. Joum. of bot. 1840, p. 13 et in Hook. Ic. pl. rar, t. 21, f. 6; C. M. Syn. II, p. 183 ; Mitt, M. Ind. or. p. 123.

N. spectabilis Griff. Not. p. 463 et Io. pl. asiat. II, t. 88, f. 3 . 1 ? - As. : Nepal., Himalaya, Khasia.

cylindraceum (Mont.) Bryol. jav. 11, p. 78.

? Neckera cylindracea Mont. in Ann. sc. nat, 1848, p. 109 et Syll. p. 23.

Pilotrichum cylindraceum C. M. Syn. II, p. 182.

Pt. dextrum W. P. Sch. in Jardin Enum. p. 19 (nom.).

2.

- As. : Sumatra, Java. Pac. : Taïti; ins. Samoa?

cylindraceum Mitt. - Pt. rugicalyx.

cymbifolium Sull. Ic. M. t, 76; Mitt. M. austr, am. p. 426.

Ster, Lignic. - Am. sepl. : Cuba.

densum (Schwaegr.) Hsch. Fl. Brasil. 1, p. 50; Milt. M. austr. am. p. 425.

Cryptotheca densa Hsch. in Deppe et Schiede M. Mexic.

Pilotrichum Hornschuchii C. M. Syn. II, p. 179.

Pterogonium densum Schwaegr. Suppl. III, I, II, t. 243 (excl.syn. Sw.) quoad pl. Brasil.

2. Ad arbor. - Am. sept. : Mexic., Guatemala. Am. merid.: Venezuela, And. Quitens., Brasil.

dextrum W. P. Sch. - Pt. cylindraceum.

diversinerve Mitt. - Trachyloma.

dumosum Besch. Fl. bryol. Nov. Caled. p. ¿25.

1 ? Ad arbor. - Pac. : Nov. Caledon.

duplicatum Mitt. - Neckera.

elalum Lindb. - Pterobryella longifrons.

excelsum C. M. mss.; Jaeg. Ad. $11, p, 145$.

- Am. merid.: Nov. Granat.

fasciculatum Mill. in Trans. of the Linn. Soc. 1891, p. 172.

Ster.

- As. : Japon.

Fendleri C. M. in Linn. 1878-79, p. 491.

2.

- Am. merid.: Venezuela.

filicinum (Sw.) Mitl. M. austr. am. p. 425.

Fontinalis filicina Sw. Prodr. fl. Ind. oce. p. 138.

Neckera filicina Hedw. M. frond. III, $t$. 18, $f, 45$.

Pilotrichum filicinum P. B. Prodr. p. 83; Brid. Bryol, univ, II, p. 257; 2. C. M. Syn. II, p. 180.

flagelliferum Mitt. in Journ, of the Linn. Soc. 1886, p. 352.

$$
\text { - Afr. : M. Usagara. }
$$

gracile Mitt. - Camptochaete. 
Hanningtoni Mitt. in op. et $l$. cc.

- Afr. : M. Usagara, Usambara.

humile Mitt, in Trans. and Proced. of the roy. Soc. of Victoria, 1883, p.81.

Ster. - Pac. : Austral. or. (Queensland).

Husnotianum Besch, Fl, bryol. Antill. fr. n. 49.

Ster.

- Am. sept. : Guadalup., Martinic.

imbricalum Dnby. - Climacium japonicum.

integrifolium Hpe. mss, ; Besch, in Journ. de bot, 1894, p. 62.

Pt. angustifolium $f$. flagellifera Besch. Fl. bryol. Antill. fr.p. 49.

2. Ad rad. arb. - Am. sept. : Guadalup.

involutum Thw. et Mitt. in Journ. of the Linn. Soc. 1872, p. 315.

- As.: M. Ceylan.

julaceum Broth. in Engler's Bot. Jahrb. 1894, p. 116.

Ster. - Afr. : Usambara.

Lindbergii C. M. in Ule Bryoth. brasil, n. 77 .

- Am. merid. : Brasil, austr. or.

longifrons C. M. - Pterobryella.

Lorentzi C. $M$. in Linn. $1878-79, p .422$.

$2 . \quad-$ Am merid. : Argentin, subtropic.

Micholitzii Broth. in Oefv, af Finska Vet. Soc. Foehr. 1895, p. 64.

2. Ster,

- Pac. : Nov. Hibern.

Mülleri Mitt. - Hypopterygium.

nanum (C. M.) Par.

Symphysodon nanus $C, M . h b$.

Ster, - Pac. : Nov, Guin, brit.

neckeroides (Dz. et Mk.) Bryol. jav. 1I, p. 76.

Pilotrichum Symphysodon C. M. Syn. JI, p. 181.

Symphysodon neckeroides Dz. el Mk. in Ann. sc, nat, 1S44, p. 314.

2. Ad arbor. - As. : Sumatra, M. Java, Borzeo.

obliquifolium Hsch. Fl. Brasil. I, p. 51 ; C. M. Syn. II, p. 183.

Ster, Ad arbor. - Am. merid. : Brasil. austral.

planifolium Mitt. - Trachyloma.

Pohlii Mitt. - Pilotrichella longipes.

pusillum Ångstr. in Oefo.... 1876, $n, 4, p .32$.

Ster.

- Am. merid : Brasil. austr. or.

Pugicalyx (C. M.) Jaeg. Ad, 11, p. 142.

Pilotrichum rugicalyx C. M. M. Polyn. $p .75$.

Pt, cylindraceun Mitt. Sam. M. p. 191?

2.

- Pac.: Ins. Fidji, Samoa.

splendens (Hsch. et Reinw.) Bryol. jav. II, p. 78.

Neckera splendens $H$. et $R$. in Nov. Act. Caes, Leop. Garol. XIV, 1829, $11, p .714$.

Pilotrichum splendens C. M.Syn. II, p. 675 .

2. Ster. - As.: Java.

stolonaceum C. M. in Linn. 1878-79, p. 423.

Ster. - Am. merid, : Argentin, subtropic. 
sulcatum Mitt. - Climacium.

trichomanoides Spr. in Mitt. M. austr, am. p. 425.

Ad arbor. - Am. merid. : And. Quitens. et Perav.

vitianum (Sull.) Mill. Fl. Vit. p. 394.

Cryptotheca vitiana Mit. Sam. M. p. 172.

Pilotrichum vitianum Sull. in Proced. of the Am. Acad.... 1855 et in Wilkes Exped. 1859, p. 20, t. 18.

2. Ad arbor. - Pac. : Ins. Fidji, Samoa.

Whiteleggei Broth. in Oefv, af Finska Vet.-Soc. Foehr. 1895, p. 63.

2. Ster. Vales,).

- Pac. : Austral. or. (Queensland, Nova

PTEROGONIDIUM C. $M$. mss.

Spec. omn. Pterogoniellie ejusd. nom.

PTEROGONIELla W. P. Sch. in herb. Mus. Paris (40 spec.). andina (Mitt.) Jaeg. Ad. 1I, p. 111.

Meiothecium andinum Mitt. M. autr. am.p. 470.

- Am. merid.: Anid. Quitens.

aptychodes (Schlieph.) Jaeg. Ad. II, p. 113.

Meiothecium aptychodes Mitt. op. cit. p. 471 .

Neckera aptychodes Schlieph. in Bot. Zeit. 1857, p. 382.

1. Cortic. - Am. merid. : Brasil. austr. or.

argentata Jaeg. - Strückia argyreola.

Boryana (Mont.) Jaeg. Ad. II, p. 111.

Meiothecium Boryanum Mitt, op. cit. p. 469.

Neckera Boryana C.M. Syn. II, p. 75 .

Pterogonium Boryanum Mont. mss.

Pt. urceolatum Schwaegr. in Weigelt M. Surinam.

1. Ad arbor. - Am. sept. : Haïti, ins. S, Vincent. Am. merid. : Ins. Trinitat., Guian., Amazon.

capillaris (C. M.) Par.

Sauloma, capillaris C. M. in Engler's Bot. Jahrb. 1896, p. 326.

Ster. - Pac. : Ins. Samoa.

cassiquiariensis (Spr.) Jaeg. Ad. 1I, p. 115.

Potamium cassiquiariense $S p r$, in Mitt. op. cit. p. 472.

1. Ad arbor. inundat. - Am, merill. : Amazon.

commutata (C. M.) Jaeg. . . c.

Neckera commutata C. M. in Bot. Zeit. 1857, p. 385.

N. pulchella $C . M$. Syn, II, p. 78 p.p.

Potamium commutatum Mitt. op. et l. ce.

1. Lignic. - Am. merid. : Brasil. austr. or.

deceptiva (Mitt.) Jaeg. $l$. c.

Potamium deceptivum Mitt, op. cit, p. 475.

1. Ad arbor. et rup. inundat. - Am. merid. : Amazon.

diversifolia Ren. et Card. in Bull. Soc. roy. bot. Belg. 1890, I, p. 179 ot
M. Masc. Mad. n. 33.

1. Ad arbor, - Afr.: Madagascar. 
Fabronia (Besch.) Par.

Meiothecium Fabronia Beseh. in Journ, de Bot. 1891.

Pterogoniopsis Fabronia ej. in Rev. bryol. 1885, p, 18 et in Bal. Pl. Parag. n. 3693 p.p.

1.

- Am. merid. : Paraguay.

fuscescens (Hsch.) Jaeg. Ad. II, p. 114.

Neckera fuscescens $C . M . S y n . I I, p .77$.

Pterogonium fuscescens $H$ sch. in sched.

I. - Afr.: C. B. Sp.

hamata Jaeg. - Sauloma.

homalophylla (Besch.) Jaeg. Ad. 1I, p. 116.

Potamium homalophyllum Besch. $\mathrm{Fl}$, bryol. Antill. fr. p. 52.

1. $\quad$ - Am. sept. : Guadalup.

intexta (Mitt.) Jaeg. Ad. 11, p. 112.

Meiothecium intextum Mitt. Sam. M. p. 185.

2.

- Pace : Ins. Samoa.

Jagori Jaeg. - Sauloma.

lagenifera (Mitt.) Jaeg. Ad. 11, p. 111.

Meiothecium lageniferum Mitt. $M$. austr, am. p. 470.

leucodontacea (C. M.) Par.

- Am. merid. : Brasil. tropic.

Aptychus leucodontaceus C. M. in Malpighia, 189b, p. 517 .

- Am. merid. : Guian. brit.

lineolata Jaeg. - Sauloma.

lonchophylla (Mont.) Jaeg. Ad. II, p. 115.

Hypnum lonchophyllum Mont. Syll. p. 10.

Potamium lonchophyllum Mitt, op, cit, p. 473.

Aquat. - Am. merid. : Guian. gall.

longidens (C. M.) Jaeg: l. c.

Potamium longidens Aingstr. Prim. lin. p. 41.

Pterogonium longidens $C$. M. mss.

1.

- Am. merid. : Brasil. austr, or.

madagascariensis (Brid.) Besch. Fl. bryol. Réunion, elc. p. 119.

Leucodon madagascariensis Brid. Bryol. univ. II, p, 213.

Neckera madagascariensis $C . M$. Syn. $I, p, 75$.

1.

- Afr.: Madagascar.

microcarpa Jaeg. - Sauloma.

tnicrotheca $(C, M$.) Jaeg. Ad. II, p. 113.

Hypnum microtheca C. M. in Linn. p. 1848, p. 199 et Syn. II, p. 393

1. Ad arbor. - Am. merid. : Ins. Trinitat, Surinam.

nana (Besch.) Jaeg. Ad. 1I, p. 114.

Meiothecium nanum Besch, Fl. bryol. Antill, fr. p. 51.

1. Inter musc. al. - Am, sept, : Guadalup.

negrensis (Spr.) Jaeg. Ad. II, p. 113.

Meiothecium negrense $S p$, in Mitt. $\boldsymbol{M}$, austr. am, p, 471.

- Am. merid. : Amazon.. And. Quitens, et Peruy. 
pacimoniensis (Spr.) Jaeg. Ad. I1, p. 115.

Potamium pacimoniense Spr. in Mitt. op. oit. p. 474.

1. Ad arbor. demersos in fluv. - Am. merid.: Amazon., Brasil, or. patens W. P. Sch, herb.

Meiothecium scabriusculum var, patens Besch, Fl, bryol, Antill. fr. p, 52.

1. Ad arbor. - Am. sept. : Martinic.

pulchella (Hook.) W. P. Sch. herb.

Neckera pulchella $C$. M. Syn. II, p. 78 p.p.

Potamium pulchellum Mitt. op, cit. $p$. 472.

Pterigynandrum pulchellum Brid. Bryol. univ, II, p. 179 p.p.

Pterogonidium pulchellum C. M. mss.

Pterogonium pulchellum Hook. M. ex. t. 4.

1. $\quad-$ Am. merid. : Ins. Trinitat., And. Nov. Granat., Amazon.

revolubilis (Mitt.) Jaeg. Ad. II, p. 112.

Meiothecium revolubile Mitt. op. cit. p. 471. - Am: merid. : Orinoc.

samoana (C. M.) Par.

Sauloma samoana C. M. in Engler's Bot. Jahrb. 1896, p. 326 (nom.).

- Pac.: Ins. Samoa.

Sanctae Mariae Besch. Fl. bryol. Réunion, etc. p. 119.

Ad radic. Rhizophor, - Afr.: S. Maria d. Madagasc.

sarcophylla (C. M.) Par.

Aptychus sarcophyllus C. M. in Dusen M. Camer. n. d p.p.

Potamium sarcophyllum ej. in Malpighia, 1896, p. 517.

- Afr. : M. Cameroon.

scabriuscula (Besch.) Jaeg. Ad. 11, p. 114.

Meiothecium scabriusculum Besch. Fl. bryol. Antill. fr. p. 51.

1. - Am. sept.: Guadalup.

Schimperi Besch. Fl. bryol. Réunion, etc. p. 118. 1. - Afr.: Ins. Franciae.

stratosa (Mitt.) Jaeg. Ad. 1I, p. 112.

Meiothecium stratosum Mitt. Sam. M. p. 185.

2.

- Pac. : Ins. Samoa.

Stuhlmanni Broth, in Engler's Bot. Jahrb. 1894, p. 208. 1. - Afr. : Usambara.

submicrotheca (C.M.) Jaeg. l. c.

Hypnum submicrotheca C. M. in Bot. Zeit. 1857, p. 781. Hinn. Soc. 1879 Isopterygium submicrotheca Mitt. in Proced. of the (extra vol.), p. 102.

1. Ad arbor, - Pac. : Nov. Caledon. (ins. Pinorum). subtilissima (C, M.) Par.

Pterogonidium subtilissimum C. M. in Bull. hb. Boissier, 1897, p. 209. - Am. sept.: Guatemala.

sulcata (Mitt.) Jaeg. Ad. I1, p. 111.

Meiothecium sulcatuin Mitt. M. austi, am. p. 470. - Am. merid, : Brasil, tropic. 
tenera (Mitt.) Jaeg. Ad. II, p. 112.

Meiothecium tenerum Mitt, op, et $l$. cc.

- Am. merid. : Brasil. or.

tenuis (C.M.) Par.

Sauloma tenuis C. M. in Engler's Bot. Jahrb. 1896, p. 326 (nom.).

- Pac. : Nov. Guinea.

urceolata (Brid). Jaeg. Ad. II, p. 115.

Meiothecium urceolatum Mitt. in Melliss's S. Helena, p. 363.

Neckera urceolata C. M. Syn. II, p. 77.

Pterigynandrum urceolatum Brid. Bryol. univ. II, p. 187.

Pterogonium urceolatum Schwaegr. Suppl. II, I, p. 33, t. 110.

1 ?

- Afr. : Ins. Tristan d'Acunha.

usambarica Broth. in Engler's Bot. Jahrb. 1894, p. 208.

1 .

- Afr. : Reg. lacustr.

vulpina (Mont.) Jaeg. l. c.

Neckera vulpina Mont, in Ann, sc. nat. II ser., II, p. 204, t. 4 et Syll. p. $23 ;$ C. M. Syn. II, p. 79.

Potamium vulpinum Mitt. op. eit. p. 473.

1. Rupic. - Am. merid. : Orinoc.

Warmingii Jaeg. - Erythrodontium.

Weigeltiana (Hpe.) Jaeg. Ad. 11, p. 114.

Pterogonium Weigeltianum Hpe, in sched.

- Am. merid. : Surinam.

PTEROGONIOPSIS C. M. in Linn. 1878-79, p. 436 (1 spec.).

cylindrica $e j . l . c$.

1. $\quad-A m$, merid, : Argentin, Urug.

Fabronia Besch. - Pterogoniella.

PTEROGONIUM Sw. M. Suec. p. 26 (10 spec.).

abruptum Wright in Lond. Journ. of bot. 1892, p. 264.

- Afr.: Zambes. or.

ambiguum Hook. - Cleistostoma.

ascendens Schwaegr. - Leptohymenium brachycladon.

aureum Hook. - Cylindrothecium.

Beyrichianum Hpe. Enum. M. Brasil. n. 55. 1.

- Am. merid. : Brasil. austr.

Boryanum Mont. - Pterogoniella.

brachypterum Mitt. in Journ. of the Linn. Soc. VIII, p. 37; Lesg, et Jam. Mun. p. 290.

1. Lignic. - Am. sept. : Ontario, Columb, brit.

caespitosum Engl. Bot. - Pterigynandrum filiforme.

carolinianum Schwaegr. - Cylindrothecium seductrix.

catenulatum Schleich. - Psendo-Leskea.

ciliatum Schwaegr. - Hypopterygium.

commutatum C. M. - Pterogoniella.

consanguineum Mont. - Anomodon. 
curvifolium Mitt, in Phrl. Trans, of the Roy. Soc. 1879 (extravol.) p. 392, t. 37 :

J. Cortic. - Afr. : Ins, Rodriguez.

decipiens Wright in Lond. Journ. of bot. 1892, p. 264. - Afr.: Zambes. or.

decipiens Kindb. - Pterigynandrum filiforme var. heteropterum.

declinatum Hook. - Rhegmatodon.

decumbens Schwaegr. - Pterobryum.

densum Schwaegr. - Pterobryum.

filiforme $\left\{\begin{array}{l}\text { Engl. Bot. - Pseudo-Leskea eatennlata? } \\ \text { Schwaegr, - Pterigynandrum. }\end{array}\right.$

favescens Hook. - Fabronia.

fulgens Sw. - Phyllogonium.

fuscescens Hsch. - Pterogoniella.

gracile (Dill.) Sw. M. Suec. p. 26; Bryol. eur. V, t. 461; W. P. Sch. Syn. 11, p. 575.

Encalypta gracilis Roth Fl. Germ. 1II, p. 154.

Grimmia ornithopodioides W. et M. Rot. Taschb, p. 148.

Hypnum circinatum Brot.

H. gracile L. Syst. veg. p. 952.

H. gracile ornithopodioides Dill. Hist, M. p. 322, t. 41, f. 55 .

H. ornithopodioides Huds. Fl. Angl. p. 430.

H. palatinum Neck. Enum. pl. Palat. p. 454, t. I, f. I.

1sothecium ornithopodioides Boul. M. Fr, I, p, 145.

Leptohymenium gracile $H \ddot{u} b$, Muscol. germ, p. 554.

Maschalanthus gracilis Spreng. in Schrad. Journ, bot. II, p. 467.

Neckera gracilis C. M: Syn $I I, p, 97$.

Pterigynandrum gracile Hedw. M. frond. IV, p. 10, t.6; Brid. Bryol. univ. $11, p .174$.

Pterogonium ornithopodioides Lindb. in Oef $v . ., 1863, p .411, n .53$.

2. Ad arb. annosior. rad., ad rup. et in lapidos. - Eur.. Praecip. zon. merid.; Norveg. occ. Afr. sepl. : Madeir., ins. Canar., Usambara, C. B. Sp. Am, sept. : Calif. Am. merid.: Patagon.?

Exs. : Rab. Bryoth. eur. n. 475, 686.

Sull, et Lesq. M. bor, am. II ed, n, 349.

Un. itin. 1863 , n. 62.

* var. capense C. M. in Rehm. M. Afr, austr, n. 318 .

$$
\text { - Afr.: : . B. Sp. }
$$

" var, cavernarum Pfeiff. Bryogr. Stud. p. 73.

Ad. pariet, spelunc. granit, - Eur. : Tirol.

" var. duplicato-serratum Lesq. el Jan. Man. p. 290.

Leptohymenium duplicato-serratum Hpe, in Linn, 1859, p. 460.

Rupic. - Am, sept, : Calif.

gracile Mitt, - Erythrodontium rotundifolium?

hamatum Hpe. - Sauloma.

heteropterum $\mathrm{Br}$ ( (fid. C. M.). - Heterocladium.

heteropterum Br. $\left\{\begin{array}{l}\text { (fid, Lindb., W. P. Sch.). - Pterigynandrum fliforme } \\ \text { var heteropterum. }\end{array}\right.$

hirtellum Schwaegr. - Thelia.

indicum Mont. - Forstroemia.

intricatum $\left\{\begin{array}{l}\text { Drumm. - Platygyrium repens. } \\ \text { Schwaegr. - Pylaisia. }\end{array}\right.$

Jagori Jaeg. - Sauloma.

Jamesoni Tayl. - Cylindrothecius. 


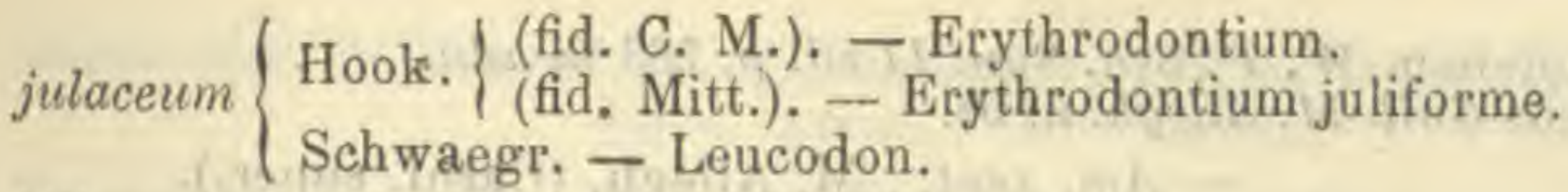

kilimandscharicum C. $M$. in Fl. 1890, p. 494.

Ster.

laxum Wils. - Schwetschkea.

lineolatum C. M. - Sauloma.

longidens C. M. - Pterogoniella.

madagassum (C, M.) Par.

Pterigynanàrum madagassum C. M. in Abhandl. Brem, VII, p. 211.

2.

$$
\text { - Afr. : Madagascar. }
$$

marginatum $\left\{\begin{array}{l}\text { Schwaegr. - Anomodon rostratus. } \\ \text { Schwein.? Bryol. eur. - Clasmatodon parvulus. }\end{array}\right.$

microcarpon Harv. - Sauloma.

myurum Hook. - Cylindrothecium.

neckeroides Griff. —? Homalothecium.

nervosum Schwaegr. - Leskea.

octoblepharis Schleich. - Fabronia.

ornithopodioides Lindb. - Pt. gracile.

peregrinum W. P. Sch, in Jardin Enum. p, 20 (nom.).

- Am. sept. : Calif. (S. Francisco).

perpusillum de Not. - Habrodon Notarisii.

procurrens Mitt, - Heterocladium.

productum Hsch. - Leptodon.

pulchellum Hook, - Pterogoniella.

repens Schwaegr. - Platygyrium.

rotundifolium Engl. Bot. - Myurella julacea.

sciuroides Turn, - Leacodon.

Smithii Sw, - Leptodon.

spec. ? Hsch, - Papillaria capillaris.

squarrosum Griff. - Erythrodontium juliforme.

squarrulosum Mont. - Erythrodontium.

striatum Schwaegr. - Lescuraea.

subcapillatum Schwaege, - Homalothecium.

? subenerve Spr. - Habrodon Notarisii.

tectorum A. Br. - Pseudo-Leskea.

tenue Schwaegr. - Leptohymenium.

trichocladon Tayl. - Hypnum.

trichomitrion Schwaegr. - Forstroemia.

w.ceolatum Schwaegr. $\left\{\begin{array}{l}(\text { M. Weig.). - Pterogoniella Boryana. } \\ (\text { Suppl.). - Pterogoniella. }\end{array}\right.$

viridissimum $C . M . m s s$.

Ster,

Weigeltianum (Hpe). - Pterogoniella (1).

Pterygodon Lindb. M. Scand. p. 12 (sect. Polytrichi),

PTERYGOPHYLLUM Brid. Mant. M. p. 149 et Bryol, univ. II, p. 341

(27 spec.).

acuminatum (C.M.) Par.

Hookeria lucens $\beta$ acuminata C. M. Syn. II, p. 202.

(1) In Enum, Kindb. nom. nudum:

Pt. cylindricum $C . M$. 
Pt. acutifolium W. P. Sch. Syn. II ed. p. 583 in adn.

Pt. lucens Sull. M. Allegh.n. 58.

2 .

- Am. sept. : M. Allegh. (Carol. super.).

acutifolium (Hook.) Besch. Fl. bryol. Antill. fr. p. 53.

Hookeria acutifolia Hook, in Schwaegr. Suppl. II, II, I, p. 36, ı. 163; C. M. Syn. II, p. 202; Bryol. jav. II, p. 33, t. 157; Mitt. M. Ind or. p. 116 et M. austi: am. p. 338.

H. Grevilleana Griff. Notul, p. 473 et Io. pl, asiat. $t .2, f .4$.

1. Ad terr. et rup, madid, - As. : Nepal., Java. Am. sept. : Guadalup. Am. merd. : And. Quitens.

acutifolium W. P. Sch. $-\mathrm{Pt}$. acuminatum.

albicans Rrid. p.p. $\left\{\begin{array}{l}\text { - Hookeria. } \\ \text { - Hookeria Auberti. } \\ \text { - Hookeria vesiculosa. }\end{array}\right.$

anomalum (Schwaegr.) Mitt. M. austr. am. p. 397.

Hookeria anomala C. M. Syn. II, p. 204; Lesq. el Jam. Man. p. 293.

Rhacopilum anomalum Schwaegr. Suppl. III, II, II, p. 278.

Ster. ? - Am. sepl. : Bor. occid. ?? Am. merid.:

Fuegia? ins. Eremitae.

apiculubum Jaeg. - Eriopus.

arcuatum Brid. - Rhacopilum.

asplenioides Brid. - Eriopus.

atro-virens (Col.) Par.

Hookeria atro-rirens Colenso in Trans, of the N. Zeal. Inst. 1888, p. 46. - Pac, : Nov. Zeland.

Blumeanum Bryol. jav. - Hookeria.

chonoticum Mitt. in Voy. H. M. S. Challenger, III, p. 81 (in adn.).

Ster.

- Am, merid. : Archip. Chonos.

complanatum (Hpe.) Jaeg. Ad. 11, p. 246.

Distichophyllum complanatum Mitt. in Trans. and Proed. of the roy. Soc. of Victoria, 1883, p. 77.

Hookeria complanata Hpe. in Linn. 1876, p. 320.

2?

- Pac. : Austral.

convallium Brid, - Lepidopilum.

debile Jaeg. - Leucomium.

decompositum Brid. - Porotrichum.

denticulatum (Hook. f. et Wils.) Mitl. op. et l. cc.

Hookeria denticulata $H$. $f$. et $W$. in Lond. Journ. of bot. $1844, p .550 \mathrm{et}$ in Fl. Antarct. I, p. 45, t. $62 ;$ C. M. Syn. II, p. 203.

2. Ad terr. humid. - Am. merid.: Ins. Juan Fernandez, Eremit., Maclov. Pac. : Tasman., ins. Auckland, Campbell.

\& var. latitolia C. M. $l, c$.

Ut typ. - Pac. : Ins. Auckland.

depressum Brid. - Hookeria.

diaphanum Brid. - Lepidopilum.

falcatum Brid. - Hookeria.

filiculaeforme Brid. - Hypopterygium.

flavum (Col.) Par. Hookeria flava Colenso in Trans, and Proced. of the N. Zeal. Inst. 1888,
p. 46. 
fragile Mitt. in Voy. H. M. S. Challenger, 111, p. 81 (in adn.).

- Am, merid. : Chile merid.

hepaticaefolium (Hpe, et C. M.) Jaeg. Ad. II, p. 247.

Hookeria hepaticaefolia Hpe. et C. M. in Linn. 1853, p. 503.

Pt. nigellum ( $f i d$. Mitt.). 2.

--Pac. : Austral. or. (Victoria).

Hookeri Jaeg. l. c.

Hookeria robusta $H$. f. et W. Fl. Tasm. 1I, p. 220, t. 177, f. 4 .

Pt. obscurum (fid. Mitt.).

- Pac. : Tasman.

indicum Bel. - Stereophyllum.

jungermannioides Brid. - Hypopterygium Tamarisci.

laete-virens Brid. - Hookeria.

Levieri Geh. in Rev. bryol. 1881, p. 27.

2. Ad rup. madid. - Pac. : Tasman.

lucens (L.) Brid. Bryol. univ. II, p 343; Bryol. eur. V, t. 448; W. P. Sch. op. cit. p. 582.

Hookeria lucens Sm. in Act. Linn. Soc. IX, p. 275; C. M. Syn. II, p. 201.

Hypnum lucens L.Sp.pl.p. 1589 ,

$\mathrm{H}$. pennatum, aquaticum, lucens, longis latisque foliis Dill. Hist. M. p. $270, t .34, f .10$.

Leskea lucens Lam. et DC. Fl. fr. 1I, p. 513.

₹. Ad rivul. et scaturig., ad font. frigid, in crypt. - Eur.: Tota in silvat. montos. Afr. : Ins. Madeir. Am. sept.: Columb. brit, Vancouver, Oregon, Idaho, Tennessee, Calif.

Exs, : Mand. Pl. Madeir. n. 35.

Rab. Bryoth. eur. n. 2, 587, 1289.

var. acuminatum W. P. Sch. - Pt. nipponense.

lucens Sull. - Pt. acuminatum.

Inacroneuron (Col.) Par.

Hookeria macroneura Colenso in Trans, and Proced. of the N. Zeal. Inst. $1885, p .283$.

maculatum (Col.) Par.

- Pac. : Nov, Zeland.

Hookeria maculata Colenso in op. cit. p. 284.

- Pac. : Nov. Zeland.

magellanicum Besch, in Miss. sc. Cap Horn, V, Bot. p. 297.

Ster, Ad terr, humid, - Am. merid. : Terr, Magellan. megablastum (C.M.) Par.

Hookeria megablasta C. $M$. in $\mathrm{Fl}$. $1896, p .460$.

Ster,

microcarpum Brid. - Mniadelphus.

- Pac. : Ins. Sandwic,

mniaceum (C. M.) Jaeg. Ad. 11, p. 246.

Hookeria mniacea C. M. in Bot. Zeit. 1859, p. 247.

Ster.

Montagnei Bel. - Ectropothecium.

- Afr. : C. B. Sp.

natalense Rehm, - Hookeria.

nigellum (Hook. f. et Wils.) Jaeg. Ad. 1I, p, 247.

Hookeria nigella $H$. f. et W. Fl. of the N. Zeal. II, p. 124, t. 93, f. 6 et Handb. p. 496. 
2. Ad rup. aquatic. - Prc. : Austral, or, Nov. Zeland., Tasman, ins. Auckland, Kermadec.

nipponense Besch, in Ann. sc. nat. 1893, p. 362.

Pt. lucens var, acuminatum W. P. Sch. in Savat. M. Jap. n. 562.

2. - As. : Japon.

obscurum (Mont.) Mitt. in Journ. of the Linn. Soc. 1859, p. 96 et op. cit. p. 398.

Hookeria obscura Mont. in Ann. sc. nat. 1844, IV, p. 93; C. M. Syn. II, p. 204.

1? (C. M.) 2? (Fl. Tasm.). Ad rup. humid. - Am. merid. : Chile austr., Valdiv. Pac. : Tasman.

pallescens Brid. - Hookeria.

pennatum Brid. - Cyatophorum bulbosum.

quadrifarium Brid, - Mniadelphus.

radiculosum Brid. - Stereophyllum.

Rehmanni C. $M$. in Rev. bryol. 1878, p. 72 (nom.).

- Afr.: Austr.

rigidum Brid, - Hookeria.

robustum (Hook. f. et Wils.) Jaeg. Ad. II, p. 247.

Hookeria robusta $H$. f. et W. Fl. of the N. Zeal. II, p. 124, t. 93, f. 5 et Handb. p, 495.

2. In silv, humid. - Pac. : Nov. Zeland sept.

rotulatum Brid. - Hypopterygium.

sexfarium (Col.) Par.

Hookeria sexiaria Colenso in Trans, and Proded. of the N. Zeal. Inst. 1888, p. 45 .

- Pac. : Nov. Zeland.

Struthiopteris Brid. - Hypopterygium.

sublimbatum Mitt. in Voy. H. M. S. Challenger, III, p. 81 (in adn.).
Ster.
$-A m$. merid. : Chile merid. (vulc. Osorno)

sublucens $C . M$. in op. et $l$. $c c$.

- Afr. : Austral.

subrotundum (Hpe.) Jaeg. Ad. II, p. 246.

Distichophyllum subrotundum Mitt. in Trans. and Proced, of the roy. Soc. of Victoria, 1883, $p .77$.

Hookeria subrotunda Hpe. in Linn. 1876, p. 321.

Ster.

- Pac. : Austral. or.

tamariscinum Brid, - Hypopterygium Tamarisci.

undatum Brid. - Hookeria (1).

PTILIUM de Not. Bryol. ital.

Crista-castrensis de Not. - Hypnum.

PTILOCladUS Lindb, in Act. Soc. sc. Fenn. 1872, p. 278.

Spec, omn. Camptochaetr ejusd, nom. (1) * Pterygophylla nervosa forsan genus proprium " Chylophyllwm * consti-
tuenda , Jaeg. Ad. II, p. 38 .

$P t$. enervia : acutifolium, acuminatum, lucens ot forsan sublweens. 
Ptychobryum C. M. in Fl. $1878, n .6$ (sect. Pterobryı).

PTYGHODIUM W. P. Sch. Syn. İ ed. p. 527 (8 spec.).

affine Limpr. Laubm. Deutschl. I1, p. 802.

2. Ad rup. gneiss. - Eur. : Stiria.

decipiens Limpr. op. cit. II, p. 749.

Pseudo-Leskea deoipiens Kindb. in Nuov Giom. bot. ital. 1896, p. 17.

2. $\Lambda$ d rup. aren. decomp. - Eur.: Tatra, Stiria, Carinth, Tirol, Ticin.

erectum Culm. $-\mathrm{Pt}$. plicatum var, erectum.

hakoniense (Mitt.) Par.

Hypnum hakoniense Mitt. in Journ. of the Linn. Soc. 1891, p. 185. 2. - As, : Japon.

leucodonticaule C. M. in Nuov. Giorn, bot. ital. 1897.

Ster.

oligocladon Limpr, op. cit. p. 801 .

- As. : China or. (prov. Schen-Si).

2. Rupic. - Eur.: Stiria? Salisb., Pinzgov.

Pfundtneri Limpr. op. cil. p. 793.

2. Ad rup. arenac. decompos, - Eur.: Stiria, Salisburg., Carinth., Tirol,, Vorarlberg, Helvet.

plicatum (Schleich.) W. P. Sch. Syn. I ed.p. 527 et II ed. p. 638.

Brachythecium plicatum Bryol. eur. VI (mon. p. 21), t. 550 .

Hypnum Morettii Garovagl.

H. plicatum Schleich, cent. IV Pl. helv. n. 27; C. M. Syn. II, p. 363.

H. Stereodon plicatus Brid. Bryol. univ. II, p. 636 .

Lescuraea plicata Lindb. M. Scand. $p .35$.

2. Ad sax. calcar., rar. granit., umbros. - Eur. : Reg. mont. sup. et subalp.; ins. Ursor. As. : Caucas. centr.

Exs, : Un, itin. 1863, n. 32.

" var, erectum (Culm.) Par.

Pt. plicatum var, erectum Culm. in Rev. b̈ryol. 1884, p. 89.

Ster. - Eur, : Alp. Helvet.

tanguticum Broth. in litt. ad C. M.

- - As. : China occ. (proy. Tangut).

\section{PTYCHOMITRIUM Bryol. eur. III (54 spec.).}

acutifolium Hook. f. et Wils. Fl. Tasm. II, p. 180, t. 173, f. 2.

Glyphomitriu.n acutifolium Mitt, in Journ. of the Linn. Soc. 1859, p. 73.

1. Rupic. - Pac. : Austral, merid., Tasman.

Adamsoni (Mitt.) Jaeg. Ad. I, p.381.

Glyphomitrium Adamsoni Mitt, in op. et l. oc.

Rupic. - Pac. : Austral. merid, (Melbourne).

afúre Hpe. mss. ; Jaeg. Ad. I, p. 384.

- Am. merid. : Brasil.

angnstifolium W. P. Sch. in Mandon Pl Boliv. n. 1630 bis.

- Am. merid. : And. Boliv.

australe (Hpe.) Jaeg, Ad. I, p. 383.

Brachysteleum australe Hpe. in Linn, 1856, p. 209. 
Glyphomitrium australe Mitt, in Trans, and Proced. of the roy. Soc. of Victoria, $1883, p .57$.

$$
\text { - Pac. : Alp. Austral. fel. }
$$

Balansae Besch. N. M. Parag. p. 261 el in Bal. Pl. Parag. n. 1235.

Ad tecta. - Am. merid. : Paraguay.

brevifolium (C. M.) Par.

Brachysteleum brevifolium G. M. in Linn. 1878-79, p. 357.

Syn. Rupic. - Am. merid. : Argentin. Cordob.

chimborazense (Spr.) Jaeg. Ad. I, p. 381.

Glyphomitrium chimborazense Spr. in Mitt, M. austr. am. p. 107.

Saxic. - Am. sept.: Ins. S. Vincent. Am. merid.: And. Quitens, crassinervium W. P. Sch. mss.; Jaeg. Ad. I, p. 384.

$$
\text { - Afr.: C. B. Sp. }
$$

crispatum (Hook, et Grev.) W. P. Sch. Syn. 11 ed, p. 291 (nom.).

Brachypodiun crispatum Brid. Bryol. univ. I, pp. 147 et 717.

Brachysteleum crispatum Hsch. in Linn. 1841, p. 126; C. M. Syn. I, p. 768 p.p.

Encalypta crispata Schwaegr. Suppl. $I, I, p .60, t .17$.

Glyphomitrium crispatum Brid. Mant. M. p. 30.

Grimmia crispata Hook. Bot. Misc. 1830, p. 133, t. 36.

Notarisia capensis Hpe. in Linn. 1837 , p. 379.
Orthotrichum crispatum H. et Grev. in Brewster Edinb. Journ. I, 1824, p. 115.

1. Ad arbor, et saxa. - Afr. : C. B. Sp.

Exs. : Rehm. M. Afr, austr, n, 141 et 495.

cucullatifolium (C. M.) Jaeg. Ad. I, p. 382.

Brachysteleum crispatum $\beta$ brachycarpum Hsch. in op. et $l$. co.

Br. cucullatifolium C. M. Syn. I, p. 769.

1. Rupic. - Afr. : Orange, C. B. Sp.

Exs. : Rehm. 1. c. n. 142 et 496.

Cumingii Duby Choix de M. ex... 1880, I, t. I, f. 2.

Pt. Fernandezianum? (fid. Hpe. in Fl. 1880, $n$. 21). - Am. merid. : Valdivia.

cylindraceum (C.M.) Par.

Brachysteleum cylindraceum C. M. in Rev. bryol. 1887, p. 57.

Pt. Mandoni Besch. ibid. 1885, p. 18.

Exs. : Balansa M. Parag. merid. 3686.

Cylindrothecium (C. M.) Par.

Brachysteleum Cylindrothecium C. M. in Bull, hb. Boissier, 1897, p. 199. - Am. sept. : Guatemala.

dentatum (Mitt.) Jaeg. Ad. I, p. 380.

Glyphomitrium dentatum Mitt. in Journ. of the Linn. Soc. 1872, p. 149. Rupic. - As. : China, Japon.

Drummondii Sull. - Glyphomitrium. emersum (C. M.) Par.

Brachysteleum emersum C. M. in Linn. 1880-82, p. 448. 1. - Am. merid. : Argentin, subtropic. 
Fernandezianum (Mitt.) Jaeg. Ad. I, p. 382.

Glyphomitrium Fernandezianum Mitt. in Journ. of the Linn, Soc. 1859, p. 74 et M. austr. am. p. 107.

- Am. merid. : Ins, Juan Fernandez.

fluviatile (C. M.) Par.

Brachysteleum fluviatile $C . M$. in Ule Bryoth, brasil, n. 13.

- Am. merid, : Brasil. austr. or.

Gardneri Lesq. in Mem. Acad. Calif. I, p. 16: Lesq. et Jam. Man. p. 156.

1. Rupic, - Am. sept. : Columb. brit,, Washington, Oregon, Idaho, Calif.

geniculatum Hpe. - Campylosteleum saxicola.

helenicum (Mitt.) Par.

Glyphomitrium helenicum Mitt, in Melliss's Helena, 1875, p. 389. - Afr. : Ins. S.Helena.

Hieronymi Besch, in Journ. de bot. 1891. 1.

- Am. merid. : Argentin.

Howeanum (Hpe.) Jaeg. Ad. II, p. 683.

Brachysteleum Howeanum Hpe. in Linn. 1874, p. 662.

Glyphomitrium Mülleri (fid. Mitt.).

1. Rupic. - Pac. : Ins. L.ord Howe.

ineurvum (Schwaegr.) Sull. Ic. M. p. 63, t. 39 et M. of U. St. p. 35 ; Lesq. el Jam. Man. p. 157, t. 476.

Brachysteleum Hampeanum C. M. in Linn. 1843, p. 597.

Br. incurvum $6 j$. Syn. $I, p .770$.

Grimmia Hookeri Drumm. M. bor, am. I ed, n. 61.

Gr. incurva Mühlenb. Cat. pl. Am. sept. p. 78.

Gr. Mühlenbergii Brid. Bryol. univ. 1, p. 181.

Notarisia virginica Hpe. in Cinn. 1837, p. 379.

Pt. pusillum Sull. M. Allegh. n. 135; Br. et Sch. in Lond. Journ. of bot. 1843$, p. $665 ; 1)$.

Weisia incurva Schwaegr. Suppl, II, I, p. 51, t. 116.

1. Ad rup. arenac. - Am. sept. : Niagara, New-York occ., Ohio et Georg. merid.

Exs.: Drumm. M. bor. am. II ed, n 28, 29.

Sull. et Lesq. M. bor. am. II ed. n. 195.

indicum (Willd.) Jaeg. Ad. I. p. 382.

Brachysteleum indicum C.M. Syn. I, p. 768.

Glyphomitrium indicum Mitt. M. Ind. or. p. 46.

Trichostomum indicum Willd. in Roemer und Usteri Mag, fôr die 1. Bot. $1787, I V, p .7, t .1$.

isoskelos (Duby) Par.

$$
\text { - As, : Ind. or. }
$$

Brachysteleum isoskelos Duby Choix de $M$. ex. 1880, p. 3, t. 2, f. 3 .

Terr. - Am. merid. : Brasil, austr. or.

lepidomitrium W. P. Sch. hb, et in Besch. Prodr. bryol, mexic. p. 4I.

Brachysteleum lepidomitrium C. M. Syn. I, p. 767 .

Glyphomitrium lepidomitrium Mitt. M. austr, am. p. 106. 1.

- Am. sept. : Mexic.

(l) Cf. Renauld in Rev, bryol. 1885, p. 32. 
ligulatum (Mitt.) Jaeg. Ad. 1, p. 382.

Brachysteleum ligulatum $C . M$. in $\mathrm{Fl}$. 1885, p. 423.

Glyphomitrium ligulatum Mitt. op. oit. $p, 107$.

L Am. merid.: Fuegia, ins. Eremitae.

Lindigii (Hpe.) Jaeg. Ad. 1, p. 380.

Brachysteleum Lindigii Hpe. in Linn. 1863, p. 144.

Glyphomitrium Lindigii Mitt. op. cit. p. 105,

1. Rupic. - Am. merid.: And. Nov. Granat.

lineare (C. M.) Jaeg. Ad. II, p. 684.

Brachysteleum lineare C. M. in sched.

$$
\text { - As. : Japon. }
$$

lobuliferum (Mitt.) Jaeg. Ad. I, p. 380.

Glyphomitrium lobuliferum Mitt. op, cit. p. 106.

Rupic. - Am. merid. : And. Nov. Granat.

Mandoni W. P. Sch. in Mandon Pl, Boliv. n. I630.

$$
\text { - Am. merid. : And. Boliv. }
$$

Mandoni Besch. - Pt. cylindraceum.

microcarpum (C. M.) Par.

Brachysteleum microcarpum C. M. in Nuov. Giorn. bot. ital. 1896, p. 107. Rupic. - As. : China or, (prov. Schen-Si).

Mittenii Jaeg. Ad. I, p. 380.

Glyphomitrium serratum Mitt, in Journ, of the Linn. Soc. 1859, p. 73 et in Fl. Tasm. II, p. 181, t. 173, f. 3.

I. Rupic. - Pac.: Tasman.

Mülleri (Mitt.) Jaeg. Ad. I, p, 382.

Glyphomitrium Mülleri Mitt. in Journ. of the Linn. Soc. l. c,

- Pac. : Victoria, ins. Lord Howe.

nigricans (Kze.) W. P. Sch. Syn. II ed. p. 290.

Brachysteleum crispatum C. M. Syn. I, p. 768 p.p.

Br. polyphyllum ej, l, c. p. 767 p.p. (quoad pl. Madeir.).

Glyphomitrium pulvinare Mitt, Contrib. to the orypt. fl. of Atlant. Isl. p. 2.

Macromitrium nigrescens $\mathrm{Kze}$, in $\mathrm{Fl}$. 1830, p. 373 .

M. tenerum ej. $l$. $c$.

Pt. pulvinare Jaeg. Ad. I, p. 381.

1. Ad saxa granit. humid. - Eur. : Algarb. Afr.: Madeir., Tenerifta, in s. Azor.

Exs. : Bourgeau Pl. Canar. n. 1141.

Husnot PI. Canar. n. 132.

Mandon Pl. Madeir. n, 10.

pachyphyllum (C. M.) Par.

Brachysteleum pachyphyllum C. M. in Ule Bryoth, brasil, $n .12$. - Am. merid. : Brasil, austr. or.

polyphylloides (C.M.) Par. yphylloides (C. M.) Par.
Brachysteleum polyphylloides C. M. in Nuov. Giorn, bot, ital. 1896, p. 107.
1. $\quad$-As. . China or. (prov. Schen-Si).

polyphyllum (Dicks.) Bryol. eur. III (mon. p. 4), t. 229; W. P. Sch.op. cit. $p, 289$. cit. $p, 289$.
13ryum cirratum, setis et capsulis hrevioribus et pluribus Dill. Hist. M.
p. $378, t .48, f .41$. 
Br. polypyllum Dioks. Fasc. III Pl. orypt. p. 7.

Brachysteleum polyphyllum . C. M. Syn. I, p. 767 (excl. loc, Madeir.).

Cecalyphum tortile $P$. B. Prodr. $p .52$.

Dicranum aggregatum Brid. Sp. M. I, p. 203.

D. polyphyllum Sm. Fl Brit. III, p. 1225 .

Glyphomitrium polyphyllum Mitt.; Lindb. M. Scand. p. 29.

Mnium tortile Brid. op. cit. $I I I$, p. 64.

Rhacomitrium falcifolium Brid. Mant M. p. 82.

Rh. lingulatum ej. Bryol. univ. $I, p, 777$.

Rh. polyphyllum

Rh. polyphyllum var. cirratum

Rh. polyphyllum var, falcifolium

Rh. polyphyllum var. tortile Brid. op. cit.p. 225

Trichostomum cirratum $\mathrm{Sm} . \mathrm{Fl}$. Brit. III, p. 1239.

Tr. polyphyllum Schwaegr. Suppl. $I, I, p .153, t .39$.

Tr. serratum Sohleich. Cent. II Pl, helvet. n. 19.

1. Ad mur, et saxa silic. sicc. - Eur.: Reg. mont., praecip. occid.; Suec., Norveg., Fichtelgeb., Thuring., Hanovr., vall. Rhen., Britann., Hispan. sept., Gall. occ., Tirol., Helvet. Afr. : Madeir., ins. Canar., Azor.

Exs. : Mandon P1. Madeir. n. 12.

Rab. Bryoth, eur. n. 515, 571 et b.

procerum W. P. Sch, in Mandon Pl. Madeir. n. 11 ,

- Afr. : Madeir.

pulvinare Jaeg. - Pt. nigricans.

pusillum (Bals. et de Not.) Bryol. eur. 111 (man. p. 5), $t$ 229; W. P.

Sch, Syn, 11 ed. p. 291.

Brachysteleum glyphomitrioides C. M. Syn. I, p. 769.

Grimmia glyphomitrioides B. et de Not. Prodr. bryol. Mediol. p. 153.

Notarisia italica Hpe, in Linn. 1837, p. 379.

Ptychomitrium glyphomitrioides Vent. et Bott. Enum. crit. p. 68.

1. Rupic. - Eur. : Longobard, Pyren. centr. As, : Caucas. occ.

Exs. : Rab. Bryoth eur, n. 305.

pusillum Sull. - Pt. incurvum.

pygmaeum Lesq. et Jam, in Proced. of the Am. Acad... XIV, p. $136 \mathrm{el}$ Man. p. 157 .

1. Rupic. ? - Am. merid. : Missouri, Kansas.

Reichenbachianum (Ltz.) Besch. Pradr. bryol. mexic. p. 42.

Brachysteleum Reichenbachianum Ltz. Moost, p. 162.

1.

$$
\text { - Am. sept. : Mexic. }
$$

rugosum (Mitt.) Jaeg. Ad. I, p. 380.

Glyphomitrium rugosum Mitt. $M$. austr, am, $p, 105$.

- Am. sept. : Mexic.

Sellowianum (C. M.) Jaeg. Ad. 1, p. 382.

Brachysteleum crispatum Hsch. Fl. Brasil. I, $p, 20$.

Br. Sellowianum C. M. Syn. I, p. 769 et II, p. 619.

Glyphomitrium Sellowianum Mitt. op. cit. p. 106.

Cortic, et rupic. - Am. merid. : Brasil. austs. or., Monte-Video.

serratum Bryol. eur. III (mon. p. 4).

Brachysteleum serratum C. M. Syn. I, p. 768.

Glyphomitrium serratum Mitt. M. austr, am. p. 106. 
sinense (Mill.) Jaeg. l, c.

Glyphomitrium sinense Mitt. in Journ. of the Linn. Soc 1872, p. 149. - As. : China or., Japon.

Soulae C. M. in Bull. Soc, roy, bot. Belg. 1894, 1I, p. 118 et in Ren. et Card. M. Masc. Mad. n. 169.

1. - Afr. : Madagascar.

speciosum Wils. - Pt. Tortula.

subbaffine (C.M.) Par.

Brachysteleum subbafine C. M. in Ule Bryoth, brasil. n. 11 . - Am. merid. : Brasil, austr. or.

subdentatum Besch. Not. M. Paraguay, p. 262 et in Bal. Pl. Parag. n. 1238.

I. In silv. - Am. merid.: Paraguay.

Tortula (Harv.) Jaeg. Ad. I, p. 383.

Didymodon Tortula Harv. in Lond. Journ. of bot. 1840, 11, p, 4 et in Hook. Io. pl. rar. t. 18 ; C. M. Syn. I, p. 161.

Glyphomitrium Tortula Mitt. M. Ind. or. p. 46.

Pt. speciosum Wils, in Kew Journ. bot. IX, p. 325. Rupic. - As.: Nepal., Sikkim, Himalaya sept. occid. (DehraDoun), M. Neilgherr., Alp. Yunnan.

uruguense (C. M.) Par.

Brachysteleum uruguense C. M. in Linn. 1880-82, p. 446.

1. $\quad-$ Am merid.: Uruguay.

vaginatum Besch. Not. M. Parag. p. 262 et in Bal. Pl. Parag. n. 1234.
1. Rupic. in silv. - Am. merid.; Paraguay.

vernicosum (C.M.) Par.

Brachysteleum vernicosum C. M. in Linn. 1880-82, p. 450.

1 . - Am. merid. : Argentin. Tucuman.

Wilsoni Sull. et Lesq. in Proced. of the Am. Acad... 1859, p. 277.

Glyphomitrium Wilsoni Mitt. in Trans. of the Linn. Soc. 1891, p. 159.

1. Ad rup. et terr, - As. : Japon (1).

PTYGHOMNION Mitt. M. austr. am. p. 536 (Achyrophyllum, sect, STEREODONTIS ej. in Journ. of the Linn. Soc. 1859, p. 88) (9 spec.) aciculare (Brid.) Mitt. l. c.

Hypnum aciculare Brid. M. Rec. II, 1I, p. 158, t. 5, f. 2 et Bryol. unit. $I I, p .505 ;$ C. M.Syn. II, p. 441.

H. cucullifolium P. B. Prodr. p. 62.

Stereodon Ptychomnion Mitt, in Journ. of the Linn. Soc. 1859, p. 89.

2. Ad arbor, et terr. - Am. merid.: Chile, Valdiv., ins. Chiloë et Juan Fernandez, terr. Magellan. Pac. : Ins. Sandwic., Taiti, AusTeland sept. et med., Nov. Caledon., Tasman., ins. Auckland et Campbell.

cygnisetum (C.M.) Par.

Ectropothecium cygnisetum Mitt. in Trans. and Proced. of the roy. Soc. of Victoria, 1883, p 87.

(1) In Enum. Kindberg. nom, nud.:

Pt. Spegazziri $O, M$. 
Eurhynchium eygnisetum Jaeg. Ad. II, p. 428.

Hypnum aciculare $H$. et $W$. Fl, antarct. p.p.

H. cygnisetum C. M. in Fl. $1885, p .425$.

2. austr, or. Pac. : Ins, Auckland.

densifolium (Brid.) Jaeg. Ad. 11, p. 617.

Hypnum densifolium Brid. Sp. M. p. 204 et Bryol, univ. II, p, 514 ;C. M. Syn. II, p. 442.

t.

land, sept.

- Afr. : Ins. Tristan d'Acunha. Pac.: Nov. Ze-

fruticetorum C. M. in Ule Bryoth. brasil, n. 86 .

- Am. merid. : Brasil, austr. or.

itatiaiense Broth, in Ule Bryoth. brasil. n. 190.

In frutic. - Am, merid. : Brasil, austr. or.

latifolium Ångstr. Prim. lin. p. 46.

Ster.

- Am. merid. : Brasil, austr, or.

Leichardti (Hpe.) Jaeg. Ad, II, p. 618.

Dendro-Hypnum Leichardti Hpe, in Linn. 1869-70, p. 523.

2.

- Pac, : Austral, or. (Nov. Vales.).

ptychocarpon (Schwaegr.) Mitt. op. cit. p. 536.

Hypnum ptychocarpon Schwaegr. in Linn. 1844, p. 561, t. 10; C. M. Syn. II, $p, 459$.

Leskea? Gayana Mont. in Ann. so. nat. 1845, IV, p. 95 et in (ll. fay Hist. Chil. Bot, crypt. t. $3, f .4 ;$ Syll. p. 20.

2. Cortic. - Am. merid. : Chile austr,, Valdiv., Patagon. austr.

subaciculare Besch, in Bull. Soc. bot. Fr. 1885, p. LXVIl el in Miss. sc.

Cap Horn, V, Bot. p. 305, t. 5, f. 20.

2. $\quad$ - Am. merid. : Ins, Juan Fernandez, Chile, Patag. austr.

PTYCHOSTOMUM Hsch, in Neue Bot. Zeit. V. Sylloge, p. 62.

caespiticium Brid. - Bryum pendulum var. compactum.

cernuum $\left\{\begin{array}{l}\text { Hsch. }- \text { Bryum. } \\ \text { Sw }\end{array}\right.$

compactum Sw. - Bryum pallens var, arcuatum.

compactum Hsch. - Bryum pendulum var. compactum.

$\beta$ spadiceum Hsch. - Bryum pendulum var. spadicenm.

pendulum Hach. - Bryum.

pulchellum R. Br. - Bryum melvilleanum.

radiculosum Hedw. - Bryum pendulum.

\section{Ptychothecium Milt. M, austr, am. p. 68 (sect, Dicrani).}

PUIGgarla Duby Choix de M. ex. 1880, $p, 7$.

elegans Duby - Lepidopilum subsuleatum.

ovalifolia Duby. - Lepidopilum.

splendens Duby. - Lepidopilum flavescens.

PUNGENTELLA $C, M$.

Spec, omn, non indicatue sunt sematophylda ejusd. nom.

gracilicaulis C. M. - S. bolivianum.

lamprophylla C. M. - Rhaphidostegium.

upoloviensis C. M. - Sematophyllum macrorhynchum 
PYCNAPOPHYSCIUM Rchb. Ic. erypt. angustatum Rehb. - Tetraplodon.

Pycneura C. M. in Fl, 1888, n. 1 (sect. Bruchiat).

Pycnocaulon C. M. in Linn. 1871-74, p. 144 (sect. Acaulon = SphaeranGIUM).

Pycnophyllum C. M. Syn. I, p. 567 (sect. Triсновтомi).

Pycnosphagnum C. M. in Linn. 1874, p. 545 (nom.) et in $\mathrm{Fl} .1887$, p. 404 (Sphagna acutifolia).

PYCNOTHECIUM W. P. Sch, in Mandon Pl. Madeir.

Mandoni W. P. Sch. - Sciaromium prolixum.

Pyloecium C. M. in Forschungsreise... Bot. p. 56 (sect. HyPN $1=$ SematoPHYLLUM).

PILAIEA Lindb. Man. M. $1, p .70$.

PILAISAEA Desv. Journ, bot. V, p, 24.

PILAISEA $e j$. in Lem. Dict. XLIV, $p .128$.

PYLAISAA Brid. Bryol, univ. $I I, p .281 ; B r$. et Sch. in Hook. Lond. Journ, of bat. 1848, II, p. 669 et Bryol. eur V.

PYLAISEA Fïrnr. in Fl. II, Erg. Bl. p. 60.

PYLAISIA W. P. Seh. Syn. II ed. p. 023 (39 spec.).

africana C. M. in Rehm, M. Afr, austr, n. 345 .

- Afr. : Austr.

? alpicola (Lindb.) Par.

Stereodon alpicola Lindb. in Mitt. Scc.pv. Faun, et Fl. Fenn. 4 a $9 \mathrm{br} .1882$ (nom.); Arn. M. As. bor. $1890,11, p .153$ (descript.).

Ster. In fiss, rup. - Eur. : Fennia. As, : Jenissei sup. aomoriensis Besch, mss, et in Faurie Pl. Jap. n. 180 bis el 553.

1. Ad arbor. - As.: Japon.

boliviana W. P. Sch, in Mandon Pl. Boliv. n. 1692.

- Am. merid. : And. Boliv.

? Bollei de Not. Epil.p. 207.

? Orthothecium Bollei Jaeg. Ad. II, p. 368.

Ster. In silv, - Eur.: Ins, Ischia.

brachythecioides $C$. M. mss.

Cortic. - As. : Himalaya sept. occid. (Dehra-Doun).

brevifolia Wils. - Platygyrium.

? brevirostris (Griff.) Jaeg. Ad. II, p. 745.

Neckera brevirostris Griff. Not. p. 456 et Ic. Pl. asiat. II, t. $85, f, 1, I_{1}, I^{u,}$
Stereodon brevirostris Mitt. M. Ind. or. p. 94.

Cortic. - As. : Himalaya sept, occid. ? Khasia.

Brotheri Besch. in Ann. sc. nat. 1893, p. 369.

1. - As.: Japon.

? camurifolia (Mitt.) Jaeg. Ad. II, p. 379.

Stereodon camurifolius hitt, op. cit. p, 96.

1.

- As. : Nepal. 
? capillacea (Griff.) Jaeg. A d. II, p, 745.

Neckera capillacea Griff. Not.p. 457 et Ie. Pl. asiat. II, t. 89, f. 3.

Stereodon capillaceus Mitt. op. cit. p. 94.

$$
\text { - As. : Khasia. }
$$

chrysea Vent. et Bott. - Orthothecium.

complanatula C. M. in Nuov. Giorn. bol, ilal, 1897.

1.

- As. : China or. (prov, Schen-Si).

condensata (Mitt.) Jaeg. Ad. II, p. 272.

Stereodon condensatus Mitt. op. eit. p, 93 ,

1.

- As. : Himalaya oce.

denticulate Jaeg. - P. subdenticulata.

dicranelloides C. M. hb.

Ad ramul, - As, : Sikkim.

Duseni C. $M$. in Dusen $M$. Camer. n. 810 .

- Afr. : M. Cameroon.

entodontea C, M. in Nuov. Giorn. bot. ital. 1896, p. 111.

1.

- As. : China or. (prov. Schen-Si).

erectiuscula (Sull. et Lesq.) Mitt. in Trans, of the Linn. Soc. 1891, p. 180.

Hypnum erectiusculum S. et $L$. in Proced of the Am. Acad... IV, p. 281.

2.

- As. : Japon.

extenta (Mitt.) Jaeg. Ad. II, p. 372.

P. speciosa Wils, in sched, p.p.

Stereodon extentus Mitt. M. Ind, or. p. 95.

1.

- As. : Nepal., Sikkim.

faleata Bryol, eur. V (mon. p. 3, nom.); W. P. Sch. in Besch. Prodr. bryol. mexic. p. I03.

1. - Am. sepl, : Mexic. (M. Orizaba).

filari-acuminata C. M. et Kindb. in Bidr, p. 454 (nom.) et in Mac. Cal. p. 174.

1. In terr. subinund. - Am. sept. : Columb. brit.

heteromalla Br, et Sch, in Lond. Journ. of bot. 1843, II, p. 669 in correct. ad Drumm, M. bor, am. n. 222 ; Lesq. et Jam. Man. p. 308.

Hypnum multiflorum Tayl. in Fl. Hibern. Mackay, II, p. 46 (fid. C. M.).

H. polyanthum Drumm. M. bor, am. I ed. n. 222 p.p.

H. polyanthum var. pallidifolium C. M. Syn. II, p. 337 .

H. resupinatum Tayl. in Spr. M. Pyr, Ann, and. Mag. of nat, hist. 1849, n. 46 .

P. polyantha var. heteromalla Limpr, Laubm. Deutschl. III, p. 12.

Stereodon polyanthos var. heteiomalla Lindb. et Arn. M. As. ber. 1893, I1, $p, 153$.

I. Cortic, et rupic. - $A s$, : Jenissei sup, $A m$. sept. : Niagara, Saskatchewan, M. Rupestr., Columb, brit., Minnesota.

homomalla Jaeg. - Rhaphidostegiurn.

intricata (Hedw.) Bryol, eur. V (mon. p. 3, nom.); Sull. M, of U. St. p. 62 te Ic. M. p. 139, t. 88; Lesq. et Jam. Man. p. 309.

Anomodon intricatus Hpe. in Linn. 1839, p. 46.

Hypnum appressum Brid. Sp. M. II, p. 161 .

H. intricatum C. M. Syn. II, p. 338 .

Maschalocarpus intricatus Spreng. Syst, veg. IV, $I, p .159$.

Pterigynandrum appressum Brid. Bryol. univ. Il, p. 186.

Pt. intricatum Hedvo, Sp. M. p. 85, t, 18; Brid. op. cit. p. 179. 
Pterogonium intricatum Schwaegr. Suppl. $I, I, p .100$.

Stereodon intricatus Lindb. et Arn. op, cit. p. 151.

1. Cortic. et lígnic. in silv. - Eur.: Rossia occid. (fid. Lindb.). As. : Jenissei sup., Obi. Am. sept. : Nov. Scot., New Brunswick, Gaspes, Ottawa, Ontar., lac. Erie, Assiniboine, reg. sept., or., centr. et merid.

Exs. : Drumm. M. bor. am. II ed. n. 87.

Mac. Canad. M. n. 262 p.p.

Sull. et Lesq. M. bor. am. II ed. n. 380.

"var. crassipes Lindb. in Act. Soc. sc. Fenn. 1872, p. 258.

Stereodon intricatus var, crassipes Lindb. et Arn. $l$. c.

- As. : Saghalien.

intricata $\left\{\begin{array}{l}\text { Mac. p.p. - P. ontariensis. } \\ \text { Vent. et Bott. - Orthothecium. }\end{array}\right.$

Jamesii S, et L. - P. subdenticulata var, obscura.

nana Mitt, in Trans, of the Linn. Soc. 189I, p. 180.

1. Cortic. - As. : Japon.

obtusa Lindb. in op. cit. p. 257.

Stereodon obtusus Lindb, et Amn. op, cit. p. 153.

1.

- As, : Saghalien.

ontariensis C. M. et Kindb. in Bidrag p. 454 (nom.) et in Mac. Cat.

p. 174 .

P. intricata Mac. Canad. M.n. 262 p.p.

1. Ad terr. et arb. rad. - $A$ m. sept. : Gaspes., Ontario.

plagiangia C. M. in Nuov. Giorn. bot. ital. 1897, p.

- As. : China or. (prov. Schen-Si).

polyantha (Sclireb.) Bryol. eur. V, t. 455; W. P. Sch. Syn. Il ed. n. 624.

Hypnum filiciforme Huds. Fl. Angl. I ed., p. 497.

H. filifolium L. Mant, $p l$. II, p. 310.

H. filiforme Huds. op, cit. p. 421

H. myosuroides var filiforme Web. Spic. fl. Goett. p. 93.

H. polyanthum Schreb. Spic. fl. Lips. p. $97 ;$ C. M. Syn. II, p. 337: Drumm, M. bor, am. I ed. n. 222 (fid. Kindb.).

H. sericeurn ramosius et tenuius, capsulis acuminatis Dill. Hist. M.p. 327. t. $42, f .62$.

H. strigosum Neek. Meth. M. p. 179.

H. velutinum var. Poll. Pl. Palat.

Isothecium polyanthum Spr. in Ann. and Mag. of nat. hist. 1849.

Leskea filiformis Sibth. Fl. Osson. p. 303 ?
L. polyantha Hedv. M. frond. IV, p. 4, t. 2 ; Brid. Bryol. univ, II, p. 31 .

L. splendens Wib. Fl. Werth. p. 340?

Stereodon polyanthus Mitt, in Journ, of the Linn. Soc. VIII, p. 40.

1. Ad arb. camp., lign. fabref., rar. ad mur. et sax. - Etcr.: Vulgatiss, in reg. camp. As. : Japon., Ochotsk, Obi, Jenissei, Cancas. Afr. : Alger. Am. sept, : Infrequens; Terr. nov., New Brunswick, Gaspes., Ontar., Saskatchewan, M. Alb. et Rupestr., Nov. Mexic.

Exs. : Mac. Canad. M. n. 260.

Rab. Bryoth. eur. n. 382.

" var, alpicola Kindb. Laubm. Schwed. und Norro. p. 38.

Ut typ. - Eur. : Scandin.

" var. brevifolia (Lindb. et Arn.) Par.

Stereodon brevifolius $L$. et A. op. cit. p. 152.

- As. : Sibir. occ, Jenissei sup. 
a var, coloradensis Ren. et Card. in Bot. Gaz. 1894, p. 238.

- Am. sept. : Colorado.

- var. homomalla Lindb. in Acl. Soc. sc. Fenn. 1872, p. 279.

Stereodon polyanthus var. homomalla $L$. et $A$. op. et $l$. cc.

- As. : Jenissei sup., Obi.

" var, longicuspis (Lindb. et Arn.) Par.

Stereodon polyanthus var. longicuspis $L$. et $A$. op. et $l$, oc.

- As. ; Jenissei sup., Obi.

var. paludosa Bryhn. - Thedenia suecica.

\& var, subjulacea (Lindb. et Arn.) Par.

Stereodon polyanthus var. subjulacea $L$, et $A$. op. et $l$. $c$.

- As. : Jenissei sup., Obi.

? pseudo-homomalla (C. M.) Jaeg. Ad. II, p. 745.

Hypnum pseudo-howomallum C. M. in Rev. bryol. 1876, p. 4. - Pac. : Austral. or. (Nov. Vales.).

pseudo-Platygyrium Kindb. in Mac. Cat. p. 173.

I. Lignic. - Ain. sept. : Ontario, Wisconssiu.

radicans Brid. - Plagiothecium denticulatum.

revolutifolia Kindb. mss.

$$
\text { - Am. sept. : Canada. }
$$

rufescens de Not. - Orthothecium.

secunda (Hook.) Jaeg. Ad. II, p. 372.

Hypnum orthothecium Schwaegr. Suppl. III, I, I, t. 220; T. M. Syn. II p. 338 .

Leskea secunda Hook. Ie. pl. rar, t. 23, f. $I$ et in Lond. Journ, of bot. $1840, p .16$.

Stereodon orthothecius Mitt. M. Ind. or. p. 101.

1 (C. M.) 2 (Mitt.). Samoa.

Selwyni Kindb. in Ott. Nat. II, p. 156, in Mac. Cat.p. 174 el Canad. M. n. 434 .

P. intricatae forma (fid. Card.).

1. Lignic. - Am, sept. : Ontario.

sericea de Not. - Orthothecium intricatum.

? simlaënsis (Mill.) Jaeg. Ad. II, p. 373.

Stereodon simlaënsis Mitt. op. cit. p. 95 .

1.

speciosa Wils, in sched. p.p.

- As. : Himalaya occ.

Stereodon speciosus Mitt, op. cit. p. 95 .

1.

$$
\text { - As. : Sikkim. }
$$

speciosa Wils. p.p. - P. extenta.

subdenticulata Bryol. eur. V(mon. p. 2, nom.) ; Sull. Ic. M. p.I37, t. 87 ;

Lesq. et Jam. Man. p. 308.

Hypnum fabroniaefolium C. M. Syn. II, p. 271.

Leskea denticulata Sull. M. of U. St. p. 62 et Ic. M. p. $125, t .78$.

P. denticulata Jaeg. ad. $1 I, p .371$.

Pylaisiella subdenticulata Kindb. Check-list of Eur, and N. Am. M. p. 21. 
1. Cortic. - Am. sept. : New Jersey, Ohio, Indiana.

Exs. : Sull. et Lesq. M. bor. am, Il ed. n. 367, 382.

« var. obscura Lesq. et Jam. Man. p. 310.

P. Jamesii Sull. et Lesq. M. bor. am. II ed. n. 383.

Ad terr, et rad. arb. $-A m$. sept. : Massachussets.

subfalcata Bryol. eur. V (mon. p. 3, nom.); W. P. Sch. in Besch. Prodr. 1. bryol, mexic. p. 103 .

$$
\text { - Am. sept. : Mexic. }
$$

subhomomalla (C. M.) Jaeg. Ad. II, p. 373.

Hypnum subhomomallum $C . M$. in bot. Zeit. 1857, p. 781 .

Rhaphidostegium crassiusculum (fid, Mitt. in Proced. of the roy. Soc. 1879 (extr. vol.), p, 101 . 1. - Pac.: Ins. Pihor., Nov. Zelandia.

suecica Lindb. - Thedenia.

var. compacta Lindb. - Thedenia suecica var, compacta.

tenella Wils, in sched.

Stereodon tenuirameus Mitt. M. Ind. or, p, 94,

2 ? Cortic. - As, : Sikkim, Java.

tenera $C$. M. mss.

Ster.

- As. : Himalaya sept. occid. (Dehra-Doun).

tenuirostris Jaeg. - Rhaphidostegium cylindricarpum.

velutina Bryol. eur. V (mon. p. 3, nom.); sull. M. of U. St. p. $63 \mathrm{el}$ Ic.

M. p. 140, t. 89; Lesq. et Jam. Man. p. 310.

Pylaisiella velutina Kindb, Check-List. of Eur, a. N. AmBr, M. p. 21.

1. Cortic. - Am. sept.: Terr. nov., New Brunswick, Gaspes., Ottawa, Ontar, lac. Erie et Super., reg. sept., or, et merid.

Exs. : Mac. Canad. M. n. 470 .

Sull. et Lesq. M. bor. am. II ed. n. 381 .

PYLAISIELLA Kindb. Check-list of Eur. and N. Amer. M. p. 21. subdenticulata Kindb. - Pylaisia.

velutina Kindb. - Pylaisia.

PYLAISIOPSIS W. P. Sch. herb. subcapillata W. P. Sch. - Homalothecium.

PYRAMIDIUM Brid. Bryol. univ. $1, p .107$. tetragonum Brid. - Pyramidula.

PYRAMIDULA Brid. Mant. M. p. 20 (1 spec.).

tetragona Brid. l.c.; W. P. Sch. Coroll. p. 60 et Syn. II ed. p. 374.

Gymnostomum piriforme juvenile Voit. M. Herbip. p. 17.

G. tetragonum Schwaegr. Suppl $I, I, p, 22, t .8$.

Physcomitrium tetragonum Bryol. eur. III, t. 298. Physcomitrium tetragonum Bryol. eur. III, t. 298. 108 ; C. M. Syn. I,
Pyramidium tetragonum Bril. Bryol. kniv. I, p.
p. 113

1. In agr. subhumid, - Eur.: Suecia, ins. Aland, German., Tirol. merid,, Helvet., Pedemont., Gall. centr. (Arvern.); desid. in Britanu, Am, sept. : Colorado, Indiana, Kansas, Texas.

Exs.: Rab. Bryoth. eur. n. 155, 352 et b, $1162,1352$.

Sull, et Lesq. M. bor. am. II ed. n, 232. 
PYRAMITRIUM Wallr. fid. Hpe. in Linn. 1872, p. 513 (sect. ENCALYPTA A). Mitt. in Trans, and Proced. of the roy. Soc. of Viotoria, 1883, p. 61 (gen. propr.).

Spec, omn. Encalyptae ejusd. nom.

Pyridium C. M. in Linn. 1874, p. 597 (sect. Bartramiz).

PYRRHORRYUM Mitl. in Journ. of the Linn. Soc. 1868, p. 174.

Spec. omn. Rhizogonta ejusd. nom.

PYXIDIUM Ehrh. Beitr. IV, p. 44. pendulum Ehrh. - Phascum curvicollum.

RAINERIA de Not. Syll, M, p. 275. splachnoides de Not. - Tayloria splachnoides var. obtusa.

RAUIA Aust. in Bull. Torr. bot, Club, V, p. 23. scita Aust. - Thuidium.

REHMANIELLA C. M. in Bot, Centralbl. 1881, n. 37 (1 spec.). africana $C . M . l, c$.

Sphærangium africanum Rehm. M. Afr, austr, n. 171 et 518. 1. - Afr. : Orange.

RENAULDIA C. M. in Ball. Soc. roy. bot. Belg. 1891, II, p. 190 (2 spec.). dichotoma C.M.. . $c$. - Afr. : Madagascar.

hildebrandtielloides C. M. l. c. ; Ren, et Card. M. Masc. Mad. n. 226.

2. REMYELLLA (see $p \cdot 1108)$

Reticularia C. M. Syn, II, p. 535 (sect. CoNomirru, sensu Muller.).

Rhabdogrimmia Limpr. Laubm. Deutsch. I, p. 759 (sect. Grimmiae).

Rhabdotheca C. M. Syn, I, p. 519 (sect. EncaLyptaE).

RHABDOWEISIA Bryol, eur. I (8 spec.).

crenulata (Mitt.) Par.

Didymodon crenulatus Mitt. M. Ind. or. p. 23.

Rh. denticulata Wils. in Kew Journ. bot. IX, $p .293$.

1.

- As. : Sikkim.

eyathiearpa (Mont. ?) Mitt. M. austr, am. p. 54 (1).

1. Rupic. - Am. merid.: And. Nov. Granat, et Quitens.

denticulata (Brid.) Bryol. eur. I (mon. p. 5), t. 42; W. P. Sch. Syn. II ed. $p .59$.

Bryum crispatum Dicks. Fasc. III Pl. crypt.p. 3, t. 7, f. 4.

Uncophorus crispatus Lindb. M. Seand. p. 27.

Weisia crispata Brid. M. Rec. II, I, p. 73.

W, denticulata Brid. Mant. M. p. 40 et Bryol. univ. I, p. $342 ;$ C. M. Syn. $I, p, 650$.

W. fugax $\beta$ Roehl. Deutsch, Fl. III, p. 49.

(1) Cf. Mitt, 1, c, 
W. striata Drumm. M. bor. am. I ed, n. 68.

W. striata $\beta$ major $H$. et T. Muscol. brit. 11 ed., p. 81, t. 15.

1. In rup. fissur. et pariet, excav., etc. - Eur. : Reg. mont. et subalp. Am. sept. : Terr. nov., lac. Super., Pensilv., M. Alb. et Rupestr.

Exs. : Sull, et Lesq. M, bor. am. II, n, 56.

denticulata $\left\{\begin{array}{l}\text { Mitt. - Rh. sikkimensis. } \\ \text { Wils. - Rh. crenulata. }\end{array}\right.$

fugax (Hedw.) Bryol. eur. I, (mon. p. 4), t. 41; W. P. Sch. op. cit. p. 58.

Grimmia crispata Roth Fl. Germ. III, I, p. 145.

Gr. striata W. et M. Bot. Taschb. p. 325.

Oncophorus striatus Lindb. M. Seand. p. 27.

Weisia fugax Hedw. Sp. M. p. 64, t. 13, f. 5-10; Brid. Bryol. univ. I, p. $340 ;$ C. M. Syn. I, p. 649 .

W. leptodon Plaub. in Brid. op. cit. p. 34 I.

W. pumila Brid. op. cit. p. 338.

W. striata Kaulf. in Sturm Fl. Germ. II, fasc. XVI, t. 24.

W. striata $\alpha$ minor $H$. et $T$. op. et $l$. cc.

1. In fiss. rup. praepr. aren., granit. et micac. schist. - Eu .: Med. et sept. in reg. montan, et sibalp. As. : Japon. Am. sept. : M. Alb., Ontar., lac Super. Am. merid.: Ins. Juan Fernandez (fid. Mitt.).

Exs. : Drumm. M. bor. am. II ed, n, 34.

Rab. Bryoth. eur. n. 33 a et b, 1225.

Sull, et Lesq. M. bor. am. 11 ed. n. 56.

Lindigiana (Hpe.) Mitt. M. austr. am. p. 54.

Weisia Lindigiana Hpe, in Ann. sc. nat. V ser., p. 352. 1. - Am. merid. : And. Nov, Granat.

Schisti Rryol, eur. - Cynodontium.

sikkimensis C. M. in Linn. 1880-82, p. 435.

Rh. denticulata Mitt. (fid. C. M.; ubi? an ead, ac Rh. crenulata?). - As. : Sikkim.

sphaerothecia (C. M.) Par.

Weisia sphaerothecia C. M. in Linn. 1880-82, p. 434.

1.

- Am. merid. : Alp. Argentin. Tucuman.

vulcanica (C. M.) Mitt. op. cil. p. 55.

Weisia vulcanica C. M. Syn. I, p. 649.

1. In speluncis. - Am. sept. : Mexic.

RHAGELOPUS Bryal.jav. $1, p .37$ ( 1 spec.). inermis Mitt. - Rh. pilifer.

pilifer Bryol.jav. l. c, t. 27.

Rh. inermis Mitt. mss. (fid. (.. M.).

2. Lignic, et rupic. - As. : Tonkin, Borneo, Java. Pac. : Nov. Gainea.

RHAGO CARPUS Lindb, in Oefv.... 1862 (12 spec.).

apiculatus (Ren. et Card.) Par.

Harrisonia apiculata $R$. et C. in Bull. Soc, roy. bot. Belg. 1894, I, p. 174.

Ster. In silv. - Am. sept, : Costa Rica.

australis (Hpe.) Par.

Harrisonia australis Hpe, in Linn. 1859-60, p. 636. 
H. Humboldti (fid. Mitt.).

Hedwigia Humboldti $\beta$ australis $H . f$, et W. Fl. Tasm, p. 179.

- Pac. : Austral, or., Tasman., Nov. Zeland. sept. cucullatus (Rehm.) Par.

Harrisonia cucullata Rehm. M. Afr. arstr. n. 313.

Ster. - Afr. : C. B. Sp.

cuspidatus (Rehm.) Par.

Harrisonia cuspidata Rehm. l. c. n. 312.

Ster. - Afr. : C. B. Sp.

excisus (C. M.) Par.

Harrisonia excisa C. M. in Bot. Zeit. 1868, p. 48. Rupic. - Am. merid. : Summ. Cordill.

Humboldti (Spreng.) Lindb. in op. et l. cc.

Anoectangium Humboldti Brid. Bryol, univ. II, p. 165.

Braunia Humboldti $H . f$. Handb. of N. Zeal. Fl. p. 423.

Harrisonia Humboldti Spreng. Syst. veg. IV, I, p. 145.

Hedwigia Humboldti Hook. M. ex. t. 137.

Neckera Humboldti C. M. Syn. 1I, p. 102.

1. Rupic. - Afr. : Ins. Borbon.? Am. sept. : Mexic., Guadalup., ins. S. Christof. Am, merid, : And. Nov. Granat., Boliv, et Chilens.; Brasil. austr. or., Peruv., archip. Magell., ins. Eremitae, Maclov., Fuegia. Pac.: Austral, or., Nov. Zeland., Tasman,, ins. Auckland.

Exs. : Lechler P1. Peruv, n. 2252.

Mandon Pl. Boliv. n. 1639.

"var. argentinicus (C. M.) Par.

Harrisonia Humboldti var. argentinica C. M. in Linn. 1878-79, p. 375.

Ster. Rupic. - Am. merid. : Argentin. subtropic.

" var. rufipilus (Ren. et Card.) Par.

Harrisonia Humboldti var. rufipila $R$ et C. in Bull. Soo. roy. bot. Belg. 1893, II, p. 21.

In sphagnet. - Afr. : Madagascar.

inermis (C. M.) Lindb, in op. et $l, c c$.

Harrisonia inermis Ängstr. Prim. lin. p. 29.

Hedwigia decalvata Mitt. M. austr. am. p. 408.

Neckera inermis C, M. in Bot. Zeit. 1862, p. 382.

Rupic. - Am. merid. : Brasil, austr. or.

obliquo-inermis (C. M.) Par.

Harrisonia obliquo-inermis C. M. in Lle Bryoth. brasil. n. 163.

Ad rup. humid. - Am. merid. : Brasil, austr. or.

orbiculatus (Milt.) Par.

Harrisonia orbiculata Jaeg. Ad. II, p. 85.

Hedwigia orbiculata Mitt. M. austr. am. $p .407$.

2.

- Am merid. : And. Chilens.

piliferus (Rehm.) Par.

Harrisonia pilifera Rehm. M. Afr. austr. n. 314 .

$-A f r,:$ C. B. Sp.

piliformis Broth, in Act. Soc. sc. Fenn. 1891, n. 5 .

2.

- Am. nuerid. : Brasil. or. (Minas Geraës). 
Rehmanni (C. M.) Par.

Harrisonia Rehmanni C. M. in Rehm. M. Afr. austr. n. 270.

Ster.

- Afr. : C. B. Sp.

RHACOMITRIUM Brid. Bryol. univ. I, p. 207 (81 spec.).

aciculare (L.) Brid. Bryol. univ. I, p.219; Bryol. eur. $1 I I$ (mon.p 6), t. 262 ; W. P. Sch. Syn. 11 ed. p. 274.

Bryum aciculare L. Sp. pl. p. 1583.

Br. montanum, hemiheterophyllum, operculis acutis Dill. Hist. $M$. p. $366, t .46, f .25$.

Br. nigrescens Vill. Pl. Dauph. III, II, p. 881, t. 54 (fid. Limpr.).

Campylopus acicularis Wahlen 3 . Fl. Suec. $I I$, p. 749.

Dicranum aciculare Hedw. M. frond. III, p. 79, t. 33.

Grimmia acicularis C. M. Syn. I, p. 801.

Hypnum aciculare Scop. Fl. Carn. II ed. p. 1225.

Mnium aciculare Gmel. Syst. nat. I1, p. 1328.

Rh. obtusifolium Brid. Mant. M. p. 80.

Trichostomum aciculare P. B. Prodr. p. $90 ;$ Drumm. M. bor, an. I ed. n. 133.

Tr, aciculare $\alpha$ obtusifolium W. Arn. in Mém. Soc. hist. nat. Paris, 1I, p. 271.

Tr. obtusifolium P. B. Prodr. p. 91.

2. Ad sax. (calc. except.) sœp. irror. rivul. - Eur. : Fere tota, in reg. carnpestr. montos. et montan. Afr.: Madeir. Air. sept.: Labrador, Terr. nov., Nov. Scot., Iac. Super., M. Rupestr., Columb. brit., Alaska, Sitka, reg. occ., sept., or. et centr.

Exs. : Mac. Canad. M. n. 97.

Rab. Bryoth. eur. n, 220, 1178.

Sull. et Lesq. M. bor. am. II ed, n. 217.

* var. brachypodium Besch. in Ann. sc. nat. 1893, p. 338.

Ad lapid. in rivul. - As. : Japon.

Exs. : Faurie n. 202 .

affine Lindb. - Rh. heterostichum var. alopecurum.

alopecurum Brid. - Rh. heterostichum var, alopecurum.

attenuatum C. M. et Kindb, in Bidr. 455 (nom.) et in Mac. Cat. p. 73.

ot ign. Saxic. - Am, sept. : M. Selkirk.

aquaticum Brid. - Rh. protensum.

aterrimum (C. M.) Par.

Grimmia aterrima U. M. in Engler's Bot. Jahrb. 1883, p. 81 et in Forschungsveise... Bot. p. 28.

Ster. Rupic. - Afr. : Ins. Kerguelen.

austro-Georgicum $P$ ar.

Grimmia austro-patens C. M. Bryol. austr. Georg. p. 40 (1889).

Ster. Aquat.? - Am, merid. : Austr. Georg.

austro-patens C. M. in Rehm. M. Afr. austr. n. 139 (1878).

- Afr. : C. B. Sp.

borbonicum Brid. - Rh. lanuginosum.

brachypus (C. M.) Par.

Grimmia brachypus C. M, in Nuov. Giom, bot. ital. 1897, p. 65.

- Am. merid. : And. Boliv.

brevipes C. M. mss. ; Jaeg. Ad. $1 I$, p. 683.

- As. : Japon. 
brevipes Kindb. - Rh, micropus.

brevisetum Lindb. Contrib. ad Fl. As. bor. 1872, p. 244.

Grimmia breviseta Lindb. et Am. M. As. bor. 1890, II, p. 102.

2.

- As, : Saghalien.

canadense Brid. $-\left\{\begin{array}{l}\text { Rh. canescens ? } \\ \text { Rh. lanuginosum? }\end{array}\right.$

canescens (Hedw.) Brid. Bryol. univ. 1, p. 208; Bryol. eur. $1 I I$ (mon. p. 12), t. 270 ; W. P. Sch. op. cit. p. 280.

Bryum canescens Hoffm. Deutsch, Fl, II, p. 41.

Br. hypnoides Schreb. Spic, Fl, Lips. p. 77.

Br, hypnoides a Neck. Meth. M, p, 227.

Br. hypnoides $\beta$ L. Sp, pl, p. 1585.

Br. hypnoides $\beta$ pilosum Retz. Prodr. Fl. Scand. n. 1234.

Br. hyphoides hirsutie canescens, vulgare Dill. Hist. M. p. 368, t. 47, f. 27.

Grimmia canescens C. M. Syn. I, p.807.

Gr. ericoides var. canescens Lindb. M. Scand. p. 29.

Gymnostomum canescens Schrank Baiers. Fl. II, p. 436.

Hypnum canescens pilosum Weiss Krypt. Goett. p. 213.

Rh. canadense Brid. op. oit, p. 217?

Rh. canescens $\beta$ brevisetum ej. op. cit. p. 310.

Rh. ericoides var, canescens Lindb. in Oefv. Vet. Akad. Foerh. 1866, p. 553.

Trichostomum canadense Rich. in Mich. Fl. Am. bor. II, p. 296 (1).

Tr. canescens Timm, Fl. Megap. Prodi.p. 215.

Tr. hypnoides Hedw. Fund. M. II, p. 91, $t .8, f .43-44$

2. Ad terr. arenac. sice. - Eur.: Tota in reg. montos.; Spitzberg, ins. Parry, Ursor. As : Japon., penins. Tschutschica, Jenissei, Sikkim, Ceylan. Afr.: Septentr., Madeir. Am. sept.: Groenland, Labrador, fret. Hudson, Terr. nov., Miquel,, Gaspes., lac. Super., M.Rupestr. et Selkirk, Columb, brit, litt. mar. Behring, Vancouver, Idaho, reg. sept., occ. or. et centr.

Exs. : Faurie Pl. Japon, n. 201, 1386, 3542.

Mac. Canad. M. n. 103.

Rab. Bryoth, eur. n. 219 a-d, 1013.

Sull. et Lesq, M. bor. am. n. 221 .

" var. Delamarei Ren. et Card. Fl. ins. Miquel.p. 46 (subspec.).

Ster, In turfos. - Am. sept.: Ins. Miquel.

"var. epilosum H. Müll. Westf. Laubm, n. 333; Milde Bryol. sil. p. 160.

Ut typ. - Eur. : Westphal., Boruss., Tatra, Stiria, Rhoëngeb. As. : Japon.

Ecs.: Faurie Pl. Japon. n. 52, 163, 179, 200, 3543,

- var, ericoides (Dicks.) Bryol, eur. l. c. t, 271; W, P. Sch, op. el l, cc.

Bryum elongatum Hoffm. Deutsch, Fl. II, p. 41 .

$\mathrm{Br}$, ericoides Dicks. Fasc. IV Pl. orypt. p. 14.

Br. hypnoides var, barbatum Retz. l. $c$.

Br. hypnoides $\gamma$ L. $l$. c.

Br. hypnoides Ericae facie, capsulis barbatis, alpinum Dill. Hist. M. p. 371, $t, 47, f .31$.

Grimmia canescens $\beta$ ericoides $C . M . l . c$.

Gr. ericoides Lindb. . c.

Hypnum canescens Wib. Spic. Fl. Goett. $p 82$.

Rh, canescens var. intermedium Vent. et Bott. Enum. p. 62.

Rh. ericoides Brid. Bryol. univ. I, p. 210.

(1) Cf. C. M. I, p. 806 in syn. ad Grimmiam lanuginosam. 
Trichostomum elongatum Ehrh. Crypt. n. 233.

Tr. ericoides Schrad. Spic. Fl. germ. p. 62.

In ericet. et rupestr. aren. - Eur. : E reg. montan. sup. usq. in Alp. As. : Caucas. Am. sept. : M. Selkirk, Columb. brit., Sitka, Vancouver.

Exs, : Mac. Canad. M. n, 417.

var. intermedium Vent. et Bott. - Rh. canescens var. ericoides.

"var. lutescens Lesq, et Jam. Man. p. 151.

Ad rup. uinbr. - Am . sept.: (Columb. brit., Calif.

Exs. : Sull, et Lesq. M. bor. am. I1, p. 222.

"var. muticum Kindb, in Bull. Torr. bot. Club, p. 272 et in Mac. Cat. p. 77.

Rupic. - Am. sept, : Alp. Columb. brit.

« var. prolixum Bryol. eur. l. c. t. 271; W. P. Sch. op. et l.cc.

In ericet. umbros. - Eur. : Passim.

"var, robustum (Lindb, et Arn.) Par.

Grimmia ericoides var. robusta L. et A. M. As. bor. $1890, I I, p .101$. - As, : Jenissei inf.

var. strictum Schlieph. - R, mollissimum.

capense Ltz. Moosst. p. 163.

2. Ad arbor. - Afr. : C. B. Sp.

cataractarum A. Br. - Rh. protensum.

var. 3 H. f. et W. - Rh. lamprocarpum.

Cheesemani C. M. hb. - Pac. : Nov. Zeland. sept.

chlorocarpum (Mitt.) Par.

Dryptodon chlorocarpus Mitt. in F. v. Müller's Fragn. Phyt. austal. XI. p. 114.

Grimmia chlorocarpa Mitt. in Trans. and Proced. of the roy. Soc. of Victoria, 1883, p. 56.

Rh. crispulum var. $\beta$ H. f. Handb. of N. Zeal. Fl. p. 426.

2 ? Rupic. - Afr. : Ins. Kerguelen. Pac. : Nov. Zeland., Tasman.

chrysoblastum (C. M.) Par. Grimmia chrysoblasta C. M. in Engler's Bot. Jahrb. 1883, p. 81 et in
Forsehungsreise... Bot. p. 31 .

Gr. lanuginosa Mitt. in Journ. of the Linn. Soc. 1876, p. 84.

Ster. Rupic. - Afr.: Ins. Kerguelen.

conterminum (C. M.) Jaeg. Ad. I, n. 376.

Grimmia contermina C. M. Syn. $I I, p .655 ;$ Mitl. M. austr. am. p. 103. 2.

- Am. sept. : And. Costa-Ricens.

convolutum Mont. in Ann. sc. nat. 1845, IV, p. 122 et Syll. p. 37.

Grimmia convoluta C. M. Syn. I, p. $802 ;$ Mitt. op. et $l$. ce.

2? Ad arbor. - Am. merid. : Chile.

erispipilum (Tayl.) Jaeg. Ad. I, p. 374.

Grimmia crispipila C. M. Syn. I, p. 806; Mitt. op. cit. p. 104.

Trichostomum crispipilum Tayl. in Lond. Journ. of bot. 1846, p. 47. 2?

Peruv, et Boliv. - Am. merid.: And. Nov. Granat., Quitens., Exs. : Mandon Pl. Boliv. n. 1636. 
crispulum Hook. f. et Wils. Fl. Tasm. p. 181, t. 173, f. 4.

Dryptodon crispulus eor. in Lond. Journ. of bot. 1844, p. $544 \mathrm{et} \mathrm{Fl.} \mathrm{An-}$ taret. $I, p .57$.

Grimmia crispula $C . M$. Syn. I, p. 804.

2? Rupic. in rivul. - Afr.: Ins. Kerguelen. Pac.: Tasman., ins. Campbell.

var. $\beta$ H. f. et W. - Rh, chlorocarpum.

cucullatifolium Hpe, in Linn. 1863, p. 143.

Grimmia cucullatifolia Mitt. op. cit. p. 102.

2. Ad arbor, et sax. irror. - Am. meril, : And, Nov. Granat.

cylindricum W. P. Sch, hb. et in Besch. Prodr. bryol. mexic. p. 40.

Grimmia cylindrica C. M. Syn. I, p. 805; Mitt. op. cit. p. 103.

2.

- Am. sept. : Mexic. (M. Orizaba, etc.).

depressum Lesq. in Mem. Calif. Acal. I, p. 14; Lesq. et Jam. Man. p. 148.

2. Ad rup. madid. - Am. sept. : Calif.

didymum (Mont.) Jaeg. Ad. I, p. 368.

Grimmia didyma Mont. in Ann. sc. nat. 1845, IV, p. 122 et Syll. p. 37; 2 ?

C. M. Syn. I, p. 802; Mitt. op. cit. p. 102

dimorphum (C. M.) Par.

- Am. merid. : Chile austr.

Grimmia dimorpha C. M. in Nuov. Giom. bot. ital, 1897, p. 65.

- Am. merid.: And. Boliv.

durum (C, M.) Par.

Grimmia dura C. M. in Dusen M. Camer. n. 296.

- Afr. : M. Cameroon.

ellipticum (Turn.) Bryol, eur. III (mon. p. 5), t, 261; W. P. Sch.

Syn. 11 ed, $p, 273$.

Campylopus ellipticus Brid. Mant. M. p. 76. (1919)

Dicranum ellipticum Turn. Muscol. Hibern. p. 76, t. 6, f. 2, (1804)

Dryptodon ellipticus Brid. Bryol. univ. I, p. 204. (18,

Grimmia elliptica C. M. Syn. I, p. 799. (1249)

T'richostomum ellipticum H. et T. Muscol. brit. p. 62, t. 19. (15/8)

2. Ad rup. granit., schist, et micac. irror. - Eur. : E reg. montan. usq. in Alp. zon. septentr. : Scandin., Scot., Hibern., Cambrovall.

Ess. : Rab. Biyoth, eur, n. 1005, 1117.

emersum (C. M.) Jueg. Ad. I, p. 375.

Grimmia emersa C. M. in Bot. Zeit. 1851, p. 562.

Rh. symphyodontum $\dot{H}$. $f$. et $W$, ?

2. Ad arbor. - Pac. : Tasman.

ericoides Brid. - Rh. canescens var. ericoides.

var. canescens Lindb. - Rh. canescens.

falcifolium Brid. - Ptychomitrium polyphyllum.

fasciculare (Schrad.) Brid. Bryol. univ. I, p. 218; Bryol, eur. III (mon. p. 8), t. 267; W. P. Sch. op. cit. p. 278.

Bryum fasciculare Hoffm. Deutskh. Fl. II, p. 41.

Br. hypnoides var. virescens Retz. Prodr. Fl. Scand. n. 1234.

$\mathrm{Br}_{\mathrm{r}}$. hypnoides et hirsutie virescens Dill. Hist. M. p. 370, t. 47, f. 28.

Br. lutescens Dicks. Fasc. IV Pl. crypt.p. 14.

Grimmia fascicularis C.M. Syn. $I, p .809$. 
Rh. virescens Lindb, in Act. Soe. sc. Fenn. 1871, p. 68 ,

Trichostomum fasciculare Schrad, Spic. fl. Germ. p, 61; Drumm. M. bor. am. I ed. n. 132.

Tr. maritimum Blytt mss.; Hartm. Skand. Fl. III ed. p. 283.

Tr. saxatile Tayl. in Trans, of the Edinb. bot. Soc. II, I, 1845, p. 1 ,

2. Ad rup. madid, - Eur.: E reg. montan. usq. in alp.; Spitzberg, ins. Parry, Ursor. As.: Japon. Am. sept.: Groenland, l.abrador, Terr. nov., ins. Miquel, New Brunswick, Nov. Scot., New York, M. Alb., Allegh., Rupestr. et Selkirk, lac. Super., Columb. brit., Alaska, Unalaska, ins. reg. Charlotte.

Exs. : Mac. Canad. M. n. 416.

Rab. Bryoth. eur. n. 314.

* var, nigricans Warnst. ined.

- Am. sept. : Groenland.

var. 2 et $3 \mathrm{H}, \mathrm{f}$, et W. - Rh. symphyodontum.

fastigiatum Wallr. - Rh. heterostichum var. alopecurum.

flavipes Brid. - Barbula Brebissoni.

fontinaloides Brid. - Cinclidotus.

funale Hüb. - Grimmia.

fuscescens Wils. in Kew Journ. bot. IX, p. 324.

Grimmia fuscescens Mitt. M. Ind. or, p. 44.

2.

- As. : Sikkim.

geronticum C. M. in Verh. d. K. K. zool. bot. Ges. in Wien, 1869, p. 224.

Rh. Ianuginosum Ltz, in Bot. Zeit. 1866, p. 187.

2. Arenic. - Am. merid. : Chile.

glaciale (C. M.) Par.

Grimmia glacialis C. M. Bryol. austr. Georg. p. 41.

Ster. Rupic. - Am. merid. : Austr. Georg.

heterostichum (Hedw.) Brid. Bryol, univ. 1, p. 214; Bryol. eur. III

(mon. p. 9), t. 265; W. P. Sch. op. cit. p. 277.

Bryum heterostichum Hoffm. Deutsch. Fl. II, p. 40.

Br. hypnoides, hirsutie canescens vulgare Dill. Hist. M. p. 368, t, 47, f. 27 A. F, G.

Br. secundum Gmel. Syst. nat. II, p. 1333.

Dryptodon carnosus Brid, op. vit. p. 206.

Grimmia heterosticha $C . M$. Syn. I, p. 807.

Trichostomum carnosum Dicks, mss.; Brid. Bryol, univ. I, p. 206.

Tr. heterostichum Hedw. M. frond. II, p. 70, t. 25.

Tr. stenocarpum Hpe. mss.; Hüb. Muscol. germ. p. 208.

2. Ad rup, et sax. quarzos. - Eur. : Tota, in reg. campestr. et mont. As.: Japon. Am, sept. : Groenland, Labrador, M. Salkirk, Alaska, Vancouver, Washington, Oregon, Idaho. Am. merid. : Ins. Maclov.

Pac. : Nov. Zeland., Tasman.

Exs. : Mac. Canad. M. n. 99.

Rab. Bryoth. eur, n, 218.

Sull, et Lesq. M. bor, am. II ed. n. 220.

Un. itin. 1863 , n. 13 ; n. 1867 , p. 99.

« var. alopecurum Hüb. Museol. germ. p. 208; Bryol. eur. l. c. t. 266;
W. P. Sch. op. et l. ec.

Grimmia affinis Lindb. M. Scand. p. 29.

Gr. heterosticha var. alopecura C. M. l. c,

Gr. sublurida Stirton in Soott, nat. 1887, p, 36. Gr. sublurida Stirton in Soott, nat. $1887, p, 36$.
Rh. affine Lindb. in Aet. Soo, se. Fenn. 1875, p. $552 ;$ Mac. Canad. M.
n. 499 .

Rh. alopecurum Brid, op, cit, p. 215. 
Rh. fastigiatum Wallr. Fl. Krypt. I, p. 175.

Trichostomum affine Schleich. Cat, pl. helv, 1807, p. 31 et Cent, IV, n. 18.

Tr. alopecurum Schk. Deutsch, M. p. 77, t. 35.

Tr. fasciculare var. Tayl. in Mac Kay Fl. Hib. II, p. 20 in obs.

Tr. saxatile Tayl, in Trans. of the bot. Soc. of Edinb. II, I, p. I.

Loc. humid, - Eur. : Reg, montan. usq. in subalp., praecip. zon. sept. Am. sept. : Terr, nov., Nov, Scot,, M. Selkirk, Columb, brit.

Exs. : Un. itin. 1864, n. 27.

\& var. gracilescens Bryol. eur. et W. P. Sch. ll. cc.

Grimmia heterosticha $v a r$. gracilescens $C, M . l, c$.

Ut et ubi praeced. in Eur, Pac. : Tasman.

var. microcarpum Husn. - Rh. microcarpum.

var. obtusum Kindb. - Rh. varium.

"var. micropoides Kindb. in Hedwo, 1896, p. 65.

- Am. sept. : Washington.

* var. occidentale Ren. el Card. in Bot. Gaz. 1890, p. 41.

Rupic, - Am. sept. : Washington, Oregon.

8 var, tasmanicum Hpe. in Linn. 1852, p. 714.

- Pac. : Tasman.

himalayanum (Mitt.) Jaeg. Ad. I, p. 375.

Grimmia himalayana Mitt. M. Ind. or. p. 45.

Rh. pusillum Wils, in Kew Journ. bot. IX, p. 324 p.p.

Rh. subsecundum Wils, in op. oit. p. 325 p.p.

2.

- As. : Nepal., Sikkim.

hyalino-cuspidatum (C. M.) Par.

Grimmia hyalino-cuspidata C. M. Bryol. austr. Georg.p. 39.

1. Rupic. - Am, merid. : Austr. Georg.

hypnoides Lindb. - Rh. lanuginosum.

incanum C. M. in Verh. d. K. K. sool. bot. Ges, in Wien, 1869, p. 224.

2.

- Afr.: C. B. Sp.

Exs. : Rehm. M. Afr. austr, n. 140.

incurvum Hüb. - Grimmia elatior.

japonicum (Dz. et $M k$.) $\mathrm{Par}$.

Grimmia japonica Dz, et Mk. M. frond, ined. Arehip, ind. p. 130, t, 41,

$$
\text { - As, : Japon. }
$$

javanicum Bryol. jav, 1, p. 105, t. 84.

2.

- As. : Java.

Jenseni Kindb. in Rev. bryol. 1896, p. 20.

Rh, sudeticum var, papillosum Jensen; Lge. Fl. Groenl.

Ster.

- Am. sept. : Groenland.

laevigatum (Mitt.) Jaeg. Ad. I, p. 373.

Grimmia laevigata Mitt. M. austr. am. p. 104.

Ster.

- Am. merid. : Fret. Magellan., ins. Eremitae.

lamprocarpum (C. M.) Jaeg. Ad. I, p. 368.

Grimmia lamprocarpa C. M. Syn. I, p. 802.

Rh. cataractarum var. 2 et $3 H$. $f$. et $W$, in sched.

2 .

- Ami, merid. : Ins, Maclov. 
lanuginosum (Hedwo.) Brid. Bryol. univ. 1, p. 215; Bryol. eur. III (mon. p. 11), t.269; W. P. Sch. op. cit. p. 279.

Bryum hypnoides L. Sp. pl.p. 1584 (exol. varr.).

Bryum hypnoides, poiycephalum, lanuginosum, montanum Dill. Hist. M. p. $372, t .47, f .32$.

Br. lanuginosum Hoffm. Deutsch. Fl. II, p. 42.

Hypnum canescens Web. Spic. fl. Goett. p. 211,

H. canescens $\beta$ hirsutum Weiss Crypt. Goett. $p$. 211 .

Grimmia hypnoides Lindb. M. Scand. p. 29.

Gr. lanuginosa C. M. Syñ. I, p. 806.

Rh. borbonicum Brid. op. cit. $p 218$.

Rh. canadense ej. op. cit. $p .217$ ?

Rh. hypnoides Lindb. in Oef. Vet. Akad. Foerh. 1866, p. 552.

Trichostomum canadense Rich. in Mich. Fl. Am. bor, II, p. 296?

Tr. hypnoides Willd. Prodr. fl. Berol. n. 916.

Tr. lanuginosum Hedu. M. frond. III, p. 3, t. 2; Drumm. M. bor. am. I ed. n. 134.

Tr. ramigerum Timm. Prodr. fl. Megap. n. 774.

Tr. serratum Ehrh. Crypt. exs. n.94.

2. In lapidos, arenac, v. granit. - Eur, : Vulgatiss, usq, in zon, arctic. As. : Japon., Kamschatka, Taimyr, penins. Samojed, et Tschutschica, Jenissei inf., Sikkim. Afr.: Madeir, ins. S. Helena, Kerguelen. Am. sept. : Fret. Smith et Huds., Groenland, sin. Baffin, Labrsdor, ins. Miquel., Nov. Scot., Gaspes., M. Rupestr., Columb. bril., litt. mar. Behring, Vancouver, fret. Korzebuë, Idaho, reg, sept, et or. Am. merid.: And. Nov. Granat, et Quitens,, Chile, ins. Chiloë, archip. Chonot., fret. Magellan., Fuegia, ins. Eremitae, Maclov. (1) Pac. : Austral. fel., ins. Campbell.

Exs. : Faurie Pl. Japon. n. ‘5, 817.

Mac. Canad. M. n. 102.

Rab. Bryoth, eur. n. 374.

Savatier M. Japon. n. 279.

Sull, et Lesq. M. bor. am. II ed. n. 223.

var. pruinosum H. f, et W. - Rh. pruinosum.

" var. robustum Lindb. Hepat, in Hibern. lect. p. 549.

Ad rup. sicc, et ventos. - Eur. : Passim.

" var. sardwicense Reichdt. Beitr. p. 568.

Ad terr. vulean, - Pac. : Ins. Sandwic.

«var. squalidum Brid. Bryol. univ. I, p, 216.

Campylopus squalidus ej. Mant. M. p. 77.

$$
\text { - Afr. : Ins Borbon. }
$$

"var, subimberbe Hartm. Shand. Fl. III ed. p. 283.

In umbros. - Eur. : Scandin. Am. sept.: Ins, Miquelon.

lanuginosum $\left\{\begin{array}{l}\text { Bryol. jav. - Rh. sundaicum. } \\ \text { Ltz. - Rh. geronticum. } \\ \text { Mitt. (1876). - Rh. chrysoblastum. } \\ \text { Sull. - Rh. rigidissimum. }\end{array}\right.$

Lepervanchei Besch. Fl. bryol. Réunion, etc. p. 63.

2. Lignic, - Afr. : Ins. Borbon.

lingulatum Brid. - Ptychomitrium polyphyllum.

lorifolium Hpe. mss. ; Jaeg. Ad. 1, p. 376.

- As. : Sikkim.

(1) Localit. Amer. australioris forsan ad $R h$. geronticum pertinent. 
Macounii Kindb, in Bull. Torr. bot. Club, p. 93, in Mac. Cat. p. 73 et Canad. $M, n, 418$.

2? Ad rup. et sax. - Am. sept.: M. Rupestr. et Selkirk, Columb. brit.

membranaceum (Mitl.) Par.

Grimmia membranacea Mitt. in Journ. of the Linn. Soc. 1877, p. 61.

Rupic. - Am, sept, : Ins. Bermud.

microcarpon Brid. - Rh. sudeticum.

microcarpum (Hedw. p. p.) Brid. Bryol. univ. 1, p. 211 p. p. ; Bryol. eur.

III (mon. p. 10), l.268; W. P. Sch. op. cil. p. 279.

Bryum hypnoides vai, microcarpum Retz. Prodi, fl, Scand. n. 1234.

Bryum hypnoides var: $\gamma$ Huds. Fl. Angl. p. 410.

Bryum hypnoides alpinum setis et capsulis exiguis Dill. Hist. M. p, 370, t. $47, f .29$ A. B. C.

Br, microcarpum Gmel. Syst, nat. p. 1332.

Dicranum aciculare $\gamma$ Turn. Muscol, Hibern. p. 67.

D. microcarpum Schrad. Samml. I, n. 44 .

Grimmia ericoides Brid. op. cit. p. 768.

Gr. microcarpa C. M. Syn. I, p. 804.

Gr. ramulosa Lindb. M. Scand. $\mu .29$.

Rh. heterostichum var. microcarpum Boulay M, Fr, I. p. 360 p.p.

Rh. ramulosum Lindb, in Act. Soe, se. Fenn. 1875, p. 550.

Trichostomum microcarpum Hedw. Sp. M. p. 112, t. 23 p p.; Funk in Bot.

Tasehb. n. 26 ; Drumm. M. bor. am. I ed.n. 128.

2. Ad rup. et sax. sicc. - Eur. : Reg. subalp. silvat. zon. intermed., campestr. zon sept.; rar. in Alp. merid. Am. sept.: Groenland, Labrador, Terr. nov., Nov. Scot., Gaspes., M. Alb., Allegh. et Selkirk, lac. Super,, Columb, brit., Oregon, Idaho.

Exs. : Mac. Canad. M. n. 101.

Rab. Bryoth. eur. n. 217, 1014.

Sull. et Lesq, M, bor. am. Il ed. n. 219.

Un, itin. 1867, n. 102.

" var. grimmiaceum de Not. Epil. p. 675.

- Eur. : Helvet.

- var, Palmeri Kindb. in Mac. Cal. p. 267.

Rh. Palmeri ej. in Rev, bryol. 1896, p. 10.

- Am. sept. : Ins, mar. Behring.

microcarpum Mont. - Rh. symphyodontum?

var, sudeticum Hüb. - Rh. sideticum.

micropus Kindb. in Mac. Cat. p. 77.

Rb. brevipes ej. in Bull. Torr. bot. Club, XVII, $p, 2$; 2 .

2? Rupic. - Aim. sept, : M. Rupestr., Columb. brit.

mollissimum Philib, in Rev. bryol. 1885, p. 22.

Rh. canescens var. strictum Sohlieph, in Linepr. Laubm. Deutselt, I, p. 811 .

2. In aren. glacial, - Eut. : Alp. Valesiae, Rhaet.

Nevit (C. M.) Wats. Bot. Calif. II, p. 381; Lesq. el Jam. Man. p. 148.

Grimmia Nevii C. M. in Fl. $1873, p .483 \mathrm{el}$ in Butl. Torr. bot. Club, V, $p, 6$.

2. Rupic. - Am. sept. : Nov. Seol., Columb, brit., ins, mar. Behring, Oregon, Idaho.

Exs. : Mac. Canad. M, n. 485. 
nigritum (C. M.) Jaeg. Ad. I, p. 368.

Grimmia nigrita $C . M$. Syn, $, p, 801$.

Gr. symphyodonta ej, l. c. p. 809 (fid. Mitt. M. austr. am. p. 103).

Rh. protensum var. H. f. et W. in sched.

2.

- Am. merid. : lns. Eremitae.

nigro-viride C. M. in Rehm. M. Afr. austr, n. 139.

- Afr. : Austral.

obscurum Kindb. - Rh. robustifolium.

oblusifolium Brid. - Rh. aciculare.

obtusum Brid. - Rh. sudeticum.

oreganum Ren, et Card. - Rh. varium.

orthotrichaceum (C. M.) Par.

Grimmia orthotrichacea C. M. in Engler's Bot. Jahrb. 1883, p. 81 et in Forschungsreise... Bot. p. 29.

Ster. Rupic. - Afr, : Ins. Kerguelen.

Palmeri Kindb. - Rh. micrncarpum var. Palmeri.

papeetense Besch. Fl. bryol. Taz̈ti, etc. p. 25.

2.

- Pac. : Taïti.

patens (Dicks.) 그b. Muscol. germ. p. 198; W. P. Sch. Syn. II ed. p. 272 .

Bryum patens Dicks. Fiasc. II Pl. crypt. p. 6, t. 4, f. 8.

Campylopus patens Brid. Mant, M. p. 73.

Dicranum arcuatum Schleich.

D. patens Sm, Fl. Brit. III, p. 1213.

Dryptodon patens Brid. Bryol. univ. I, p. 192.

Fissidens patens Wahlenb. Fl. Lapp, p. 334.

Grimmia arcuata de Not. Mant. M. n. 77 et Syll. p. 252.

Gr. patens Bryol. eur. III (mon. p. 18), t. 246; C. M. Syn. I, p. 797.

Orthotrichum curvatum Brid. op, cit. p. 791.

Trichostomum patens Schwaegr. Suppl, I, I, p. 1515, t. 37 ; Drumm. M. bor. am. I ed.p. 131.

2. Ad rup. quarzos, madid. - Eur.: Reg. subalp. et alp., montan. in zon. sept. Am. sept.: Groenland, M. Alb. et Rupestr., Columb. brit., fret. Behring, Vancouver, Washington, Oregon, Idaho, reg. or.

Exs. : Mac. Canad. M. n. 96.

Rab. Bryoth. eur. n. 315.

polyphyllum Brid.

$\left.\begin{array}{l}\text { var. cirratum Brid. } \\ \text { var. falcifolium Brid. } \\ \text { var. lortile Brid. }\end{array}\right\}-$ Ptychomitrium polyphyllum.

protensum Al. Br. in Hüb. Muscol. germ. p. 2ll; Bryol. eur. III (mon. p. 6), t. 263; W. P. Sch. op. cit. p. 274. (mon. $p .6), t .263 ;$ W. P. Sch. op. cit. p. 274.
Bryum hypnoides aquaticum, calyptris nigris acutis Dill. Hist. M. p. 367,
$t .46, f .26$ (1).

Bryum hypnoides var, $\eta$ Huds. Fl. Angl. p. 411.

Br. nigrescens Vill. Pl. Dareph. III, p. 889 (fid. C. M.).

Br, rivulare Hoffm. Deutsch. Fl. II, p. 37.

Dicranum aciculare $\beta$ fluitans Turn. Muscol. Hibern. p. 67.

D. aquaticum Brid. Sp. M. I, p. 190.

D, subulatum Roëhl. Moosg. Deutsch, p. 347.

Grimmia aquatica $C . M$. Syn. $I, p .800$.

Hypnum aciculare $\beta$ aquaticum Web. Spic. fl. Goett. p. 84.

(1) Cf. W. P. Sch. Syn. I ed. p. 230 et 11 ed. p. 375. 
Rh. aquaticum Brid. Bryol. univ. I, p. 222 ? Lindb, in Act. Soc. sc. Fenn. 1875, p. 554 .

Rh. cataractarum Al. Br. in Brid. op. cit. p. 776.

Trichostomum aciculare $\beta$ acutifolium $W$. Arn. in Mém. Soc. hist. nat. Paris, II, p. 271.

Trichostomum aciculare $\beta$ aquaticum W. et M. Bot. Taschb. p. 192.

Tr. aquaticum Brid, M. Ree. II, I, p. 102.

Tr. cataractarum Hartm. Skand. Fl. III ed, p. 283.

Tr, fasciculare $\beta$ protensum Hartm. in op. et $l$, cc.

2. In rup. later, scepe rorat., nunquam submers. - Eur. : Temperata tota, e reg. campestr. usq. in subalp. As. : Caucas. occ. A fr. : Ins. Kerguelen. Am. sept. : Groenland, Vancouver, Am. nerid.: Fuegia (teste Handb. of N. Zeal. Fl.). Pac. : Nov. Zeland.

Exs, : Rab. Bryoth. eur. n. 221.

Un. itin. 1863 , n. 40 ; 1867 , n. 98.

var, nigritum H. f. et W. - Rh. nigritum.

pruinosum C. M. in Verh. d. K. K. sool. bot. Ges, in Wien, 1869, p. 224.

Rh. lanuginosum var. pruinosum $H$. $f$. et W. Fl. of the $N$. Zeal. et Handb. p. 427.

2. Rupic. - Afr. : Ins. Amsterdam. Pac. : Nov. Zeland., Tasman., ins. Campbell.

pseudo-patens C. M. in Rev. bryol. $1878, p .3$.

- Pac. : Austral, or. (Nov. Vales.).

ptychophyllum Mitt. in Hook. Handb. of N. Zeal. Fl. p. 426.

- Pac. : Nov. Zeland. merid.

Puecinianum de Not. in Acad. r. di sc. Torino... III ser., XVIII, p. 452.

- Am. merid. : Chile austr.

pusillum Wils, p.p. - Rh. himalayanum.

ramulosum Lindb. - Rh. microcarpum.

rigidissimum (C.M.) Par.

Grimnia rigidissima C. $M$. in Fl. $1896, p .455$.

Rh. lanuginosum Sull. in Exped. Wilkes, p. 8.

Ster.

- Fac : Ins. Sandwic.

riparium Brid, - Cinclidotus.

robustifolium Kindb. in Bull. Torr. bot. Club, XVII, p. 272 et in Mac.

Cat. p. 73 .

Rh. obscurum ej. in Mac, Canad. M. n. 419.

2. Rupic. - Am. sept. : Alp. Columb. brit. et ins. Vancouver.

rupestre Hook. f. el Wils. Fl. of the N. Zeal. 1I, p. 65; Mitt. M. auslr. am. p. 102.

Dryptodon rupestris eor. in Lond, Journ. of bot. 1844, p. 544 et Fl. Antartet. $I I$, p. $402, t .152, f .$, .

Grimmia rupestris C. M. Syn. I, p. 803 et $I I, p .655$.

2.

- Afr.: Ins. Kerguelen. Am. merid.: Fret. Magellan., Fuegia, ins. Eremitae. Pac.: Nov-Zeland., Tasman.

sessile W. P. Sch. in Lechler Pl. Magell, exs.

- Am. merid. : Fret. Magellan.

Seychellarum Besch. Fl bryol. Réunion, elc. p. 64.

speciosum (C. M.) Par.

- Afr. : Ins. Seychelles.

Grimmia speciosa C. M. in Bot. Centralbl. 1890, n. 5.

2. Rupic. in Quercet. - Am. sept. : Ins. Vancouver. 
strictifolium (Mitt.) Jaeg. Ad. 1, p. 367.

Grimmia strictifolia Mitt. M. Ind. or. p. 44.

2 ?

- As.: Sikkim.

subcanescens C. M. mss. ; Jaeg. Ad. II, p. 683 .

Terr. - As, : Japon.

subcrispipilum (C. M.) Jaeg. Ad. I, p. 374.

Grimmia subcrispipila C, M. in Bot. Zeit. 1862, p. 374.

2.

- Am. merid. : And. Chilens.

subheterostichum C. M. mess. ; Jaeg. Ad. 1, p. 373.

- As. : Sikkim, vall. super. fl. Gange.

sublamprocarpum (C. M.) Par.

Grimmia sublamprocarpa C. M. in Fl. 1885, p. 422.

Ad sax. marit. - Am. merid. : Fuegia austr.

sublanuginosum W. P. Sch. in Mandon Pl. Boliv. n. 1637.

- Am. merid. : And. Boliv.

subnigritum (C. M.) Par.

Grimmia subnigrita $C$. M. in Fl. 1885, p. 421.

Rupic. - Am. sept. : Fuegia.

suborthotrichaceum (C. M.) Par.

Grimmia suborthotrichacea C. M. in Es gler's Bot. Jahrb. 1883, p. 81 d in Forschungsreise.., Bot. p. 30.

2. Rupic. - Afr. : Ins. Kerguelen.

subsecundum (Hook, et Grev.) Jaeg. Ad. 1, p. 370.

Grimmia subsecunda Mitt. M. Ind, or. p. 45.

Trichostomum subsecundum H. et Grev. mss.

Yunnan.

- As. : Nepal, Sikkim, Himalaya sept. occid, alp.

subsecundum Wils. p.p. - Rh. himalayanum,'

sudeticum (Funk) Bryol, eur. III (mon. p. 7), t, 264; W. P. Sch. Syn. II ed. p. 276.

Bryum aciculariforme $H o f f m$. Fl. Germ. II in Add.?

Br. hpynoides $\delta$ Huds. Fl. Angl. p. 480.

Br. hypnoides var. obtusum Retz. Prodr. Fl. Scand: $n .1231$.

Br. hypnoides alpinum operculis obtusis Dill. Hist. M. p. 371, L. 47, f. 30 (fid. Lindb.).

Dryptodon sudeticus Brid. Bryol. univ. $I, p .195$.

Grimmia microcarpa C. M. Syn. I, p. 804 p.p.

Gr. oblusa Lindb. M. Scand, p. 29.

Gr. procera Bals. et de Not. Pug. M. n. 17.

Rh. microcarpum Bid. op. cit. p. 211 p.p.

Rh. microcarpum $\beta$ sudeticum Hiib. Muscol. germ. p. 202.

Rh, obtusum Brid. Mant. M. p. 79 et Bryol. univ, I, p. 213.

Trichostomum gracile Hsch, mss,; Hüb. l. c.

Tr. microcarpum Hedw. Sp. M. p. 112, t. 23 p.p.

Tr. obtusum Sm. Fl. Brit. III, p. 1244.

Tr. nudum Sehleieh. Cent III Crypt. Helv, n. 19?

Tr. patens $\beta$ Sehwaegr. Suppl. $I, I, p, 152, t .37$ ? Tr. patens $\beta$ Sehwaegr. Suppl. I, I, p. 152, t. 37 ?
Tr. sudeticum Funk Stimp. erypt. Fase. $27, n .670 ;$ Drumm. M. bor. ant-
I ed. $n .129$. I ed. n. 129.
2. Ad rup, madid., praepr. granit, vel gneiss. - Eur. : Reg. subalp. et
alp.; i.rs. Ursor. As, : Caucas. oce. Am. sepl. : Groenland, Labrador, M. Alb., Allegh,, Catskill, Selkirk et Rupestr., Terr, nov., Nov. Scot., Pensilv., lac. Super., Columb, brit., Uregon, Idaho. 
Exs. : Mac. Canad. M. n. 98.

Rab. Bryoth, eur. n. 313.

Sull, et Lesq. M. bor. am. II ed. n. 218.

Un. itin. 1867, n. 96 et 101 .

var, papillosum Jensen. - Rh. Jenseni.

" var, validior Jur. Laubm. Oester. Ung. p. 179.

Ut typ. - Eur. : Alp. Stir., Carinth., Tirol. Helvet.

sulcipilum (C. M.) Par.

Grimmia sulcipila C. M. Syn. I, p. 805.

2.

- As. : Coromandel.

sundaicum C. M. in Verk. d. K. K. zool. bol. Ges. in Wien, 1869, p. 224.

Grimmia sundaica Mitt. in Trans. and Proced. of the roy. Soc. of VicLoria, $1883, p .56$.

Rh. lanuginosum Bryol.jav. I, p. 104; Zoll. hb. n. 448 et Coll. n. 430.

2. Ad lapid. et ter $\%$ - As. : Java.

symphyodontum (C.M.) Par.

Grimmia nigrita C. M. (fid. Mitt. M. austr, am., . 103).

Gr. symphyodonta Syn. I, p. 809.

Rh. emersium $(C, M$.$) ?$

Rh. microcarpum Mont. in Voy, au pöle S., Bot. orypl.p. 2S1?

Rh. symphyodon Jaeg. Ad. I, p.375; Mitl, in Fl. Tasm. II, p. 181, t. 173, f. 4.

2. Rupic. - Am. merid.: Fuegia, ins. Eremit., Maclov. Pac.: Nov. Zeland, Tasman.

symphyodon Jaeg., Mitt. - Rh. symphyodontum.

tenuinerve Kindb, in Rev, bryol. 1896, p. 19.

- Am. sept. : Alaska, Columb. brit.

varium (.Mitt.) Lesq. el Jam. Man. p. 150.

Grimmia varia Mitt. in Journ. of the Linn. Soc. VIII, p. 21.

Rh. heterostrichum var. obtusum Kindb. in Mac. Canad. M. n. 100.

Rh. oreganum Ren. et Card. in Bot. Gaz. 1888, p. 198, t. 15.

1. (Mitt.) 2 (Lesq. et Jam.). Rupic. - Am. sepl. : Columb. brit., Vancouver, Washington, Oregon.

Exs, : Mac. Canad. M. n. 104.

virescens Lindb. - Rh, fasciculare.

valcanicum Ltz, Moosst. p. 163.

2. Rupic. - Am. merid. : M. Hinitza.

Willii (C. M.) Par.

Grimmia Willii C. M. Bryol. austr. georg. p. 40.

Ster. Rupic, - Am. merid.: Austro-Georg.

aygodonticaule (C. M.) Par.

Grimmia zygodonticaulis C. M. in Engler's Bot. Jahrb. 1883,p. 81 et in Forschungsreise... Bot. p. 28.

2. Rupic. - Afr. : Ins. Kerguelen (1).

RHACOPILUM P. B. Prodi. p. 36 (42 spec.).

aeruginosum C. $M$. in Rev, bryol. $1877, p .43$ (nom.).

- Pac. : Anstral. or. (Queensland).

(1) In Enum. Kindberg. nom, nud. :

Rh. canaliculatum Mitt. 
africanum Mitt, in Journ. of the Linn. Soc. 1863, p. 162.

2. Ad rup. madid. - Afr.: M. Cameroon, Togo, Kilima N'Djaro? Madagascar, ins. Franciae, Rodriguez.

Exs. : Dusen M. Camer. n. 24.

angustatum W. P. Sch, in Besch. Prodr. bryol. mexic. p. 112.

1. $\quad-A m$. sept.: Mexic. (Orizaba).

angusti-stipulaceum C. M. in Linn. 1876, p. 255.

Ster. - Afr.: Ins. Anjouan.

anomalum Schwaegr. - Pterygophyllum.

a reuatum (Hedw.) Jaeg. II, p. 58.

Hypnum arcuatum Hedw. Sp. M. p. 245, t. 62.

Hypopterygium arcuatum $C . M$. Syn. II, p. 13.

Pterygophyllum arcuatum Brid. Bryol. wiviv. $I I$, p. 348.

Rupic. et terr. - Pac. : Austral. or. (Victoria), Tasman.

aristatum Mill. in Journ. of the Linn. Soc. 1864, p. 155.

Ster.

- As.: Japon.

Auberli P. B. - Hookeria.

australe $\mathrm{H}$. f, et W. - Rh. strumiferum.

Ayresii Mitt. in Journ. of the Linn. Soc. 1886, p. 308.

- Afr. : Ins. Franciae.

brevipes C. M. in Dusen M. Camer. n. 5I ; Broth. in Engler's Bot. Jahrb.

$1894, p .217$ (descript.).

2. Cortic. - Afr. : M. Cameroon.

Büttneri Broth, in op. cit. p. 215.

2.

- Afr. : Togo.

capense C. M. in Rehm, M. Afr. austr. n, 297.

Lignic, et saxic. - Afr. : Reg. lacustr., Usambara, Kilima N'Djaro, Natal.

caudatum $C . M$, in $F l .1896, p .455$.

- Pac. : Nov. Guinea (M. Arfak, Port Moresby, etc.).

convolutaceum Hpe. in Lehm. Pl. Preiss. 11, p. 19.

Hypopterygium convolutaceum C. M. Syn. II, p. 13.

Rh. cristatum (fid, Mitt.).

2.

- Pac.: Taïti, Austral. or. (Queensland), ins. King,

Norfolk, Nov. Caledon., Tasman.

crinitum Hpe, in Linn. 1869-70, p. 525.

2?

- Pac. : Austral. or.

cristatum Hook. f. et Wils. Fl. of the N. Zeal. II, p. 121, t. 92, f. 7 et

Handb. p. 491 .

Rh. tomentosum C. M. in Bot. Zeit. 1851, p. 563 ? (fid. Mitt. in Handb. l. c.).

Ad terr. humid. in silv. - Pac. : Austral. or. (Victoria), Nov. Zeland., Tasman,, ins, Kermadec, Norfolk.

cuspidigerum (Schucaegr.) Mitt. Fl. Vit. p. 391.

Hookeria tomentosa var. subintegrifolia W. Arn. Disp. p. 58 . Bot. p. 227;

Hypnum cuspidigerum Schwaegr. in Freyoinet Voy. 1826, Bot. p. 227

C. M. Syn. II, p. 14.

Rh. tomentosum Sull, in Exped. Wilkes, p. 27.

2? In silvis, - Pac. : Ins, Sandwic., Samoa, Norfolk, Nov. Caledon. 
demissum Bryol.jav. 11, p. 18, t. 146.

Rh. tomentosum Dz, et Mk. in Zolling Verz, p. 25.

2. Ad rad, arb. - As. : Celebes, M. Java. Pac. : Taïti.

gracile Mitt. in Voy. of H. M. S. Challenger, Bot. III, p. 43.

Ster.

- Afr.: Ins. Ascensionis.

gracillimnm C. M. in Fl. 1896, p. 455.

Ster.

- Pac : Ins. Nov, Hebrid.

indicum Mitt. M. Ind. or. p. 136.

Rh. Schmidii $C, M$. ? (ex ips.).

2 ?

-As. : Celebes, ins. Ceram, Java, Ceylan.

insigne Hsch. - Rh. tomentosum.

intermedium Hpe. in Linn. 1861, p. 164 ; Mitt. M. austr. am. p. 333.

2. Ad arbor. - Am. merid. : Nov. Granat.

laetum Mitt, in Journ. of the Linn. Soc. 1859, p. 93 et in Handb. of N. Zeal. Fl.p. 491 .

2 ?

- Pac. : Nov. Zeland., ins, Kermadec.

leptotapes C. M. in Dusen M. Camer. n. 16.

- Afr.: M. Cameroon.

longe-aristatum C. M. in Nuov. Giorn. bot. ital. 1872, p. 19.

Rh. africanum Mitt.?(fid. Mist.).

$\sigma$ et fr. ign.

- Afr. : Abyssin.

Lotiae C. M. in Fl. 1896, p. 456 .

- Pac.: Nov, Guin. brit.

- var, brevicaudata C. M. in op. et $l$. cc.

Ubi typ.

"var, paraphysalis $C . M$. in op. et $l$. oc.

Ut typ.

mauritianum C. M. in Besch. Fl. bryol. Réunion, etc. p. 184.

Lignic. - Afr. : Choa, ins. Franciae.

microdictyon Besch in Ann. sc. nat. VII ser, , II, p. 98.

Ster,

- Afr. : Ins. Mayotte.

microphyllum Besch, Fl. bryol. Taïti, etc, p. 57.

2. Ster.

- Pac.: Nuka-Hiva.

mioides P. B. - Rh, tomentosum.

Mougeolianum Jaeg. - Hypnum?

mucronatum Mitt. - Rh. tomentosum.

Naumanni C. M. in Engler's Bot. Jahrb. 1883, p. 84 el in Forschungsreise... Bot. p. 42.

- Afr : Ins, Ascension.

orthocarpioides Broth. in Bol. d. Soc. Brot. VIII, 1890.

2 .

- Afr.: Ins. S. Thomas.

orthocarpon Wils, in sched. ; Mitt. M. Ind. or. p. 136.

2? - As. : Nepal, Sikkim, Khasia.

pectinatum C. M. in Linn. 1875, p. 424.

Ster. Terr. - Afr.: Dar Fertit.

plicatum Ren. et Card. in Bull. Soc, roy. bot. Belg. 1893, 1, p. 128.

Ster. 
polythrincium Spr. in Mitt. M. austr. am. p. 332.

2.

- Am. merid. : And. Quitens.; Peruv.

praelongum W. P. Sch, in Besch. Fl. bryol. Réunion, etc. p. 183.

- Afr. : Madagascar, ins. Borbon.

« var. nossi-beanum Besch. l. c.

- Afr.: Ins. Mayotte, Nossi-Be.

" var. subintegrum Besch. $l$. c.

- Afr.: Ins. Franciae.

purpurascens C. M. in Linn. 1876, p. 326.

Ster.

- Pac.: Austral. merid. (Victoria).

robustum Hook. f. et Wils. Fl. of the N. Zeal. II, p. 21, t.92,f.5 et Handb. p. 491.

1? In silvis. - Pac. : Nov. Zeland. sept., ins. Chatham.

Schmidii (C.M.) Jaeg. Ad. II, p. 56.

Hypopterygium Schmidii C. M. in Bot. Zeit. 1854, p. 558.

Rh. tomentosum var. africanum Mont. in Perrottet M. Neilgh.

Rh. indicum Mitt. (fid. C. M.).

Celebes?

- As. : M. Neilgherr. ; Ceylan? Java? ins. Ceran?

* var. tonkinense Besch. in Bull. Soc. bol. Fr. 1887, p. 96.

Rupic. - As. : Tonkin.

spectabile Rernin, et Hsch, in Nov. Act. Acad. Caes. Leop. XIV, p. 72I,

t. 40); Bryol. jav. 11, p. 16, tt. 144 et 145.

Hypnum Moritzi Duby in Mor. Pl. Zolling. p. 131 ,

Hypopterygium spectabile $C . M$. Syn. $I I, p .12$.

2. Ad arb. et terr. - As. : M. Java, Sumatra. Pac.: Ins. Fidji, Samoa, Nov. Guinea, Nov. Caled.

speluncae C. M. in Linn. 1875, p. 425.

Ster. Rupic, et arbor, - Afr. : Bongo, Usambara, Kilima N'Djaro.

strumiferum (C. M.). Jaeg. Ad. $I I, p .58$.

Hypopterygium strumiferum C. M. in Bot. Zeit. 1851, p. 563.

Rh, australe $H$. $f$. et $W$. Fl. of the N. Zeul. p. 121, $t .92, f .7$,

2. Rupic, et lignic. - Pac.: Nov. Zeland., Tasman.

thomeanum Brolh. in Bol. d. Soc. Brol. VIII, 1890.

2. Ad arbor. - Afr. : Ins. Thome.

tomentosum (Hedw.) Brid. Bryol. univ. 11, p. 719.

Hookeria tomentosa Grev.

Hypnum mucronatum $P . B$. Prodi, p. 66.

H. ornithopodioides $L . S p, p l, p, 1589$. H. ornithopodioides $L . S p_{+} p l . p$. 1589 .
H. pennatum ornithopodioides, pinnulis pellucidis Dill. Hist. M. $p .{ }^{2} 0$,
t. $34, f .9 \mathrm{~A}, \mathrm{~B}$.

H. tomentosum Hedw. M. frond. IV, p. 48, t. 19.

Hypopterygium tomentosum C. M. Syn. $11, p .12$.

Leskea ornithopodioides Brid. Mant. M, p. 143.

L. Omalia ornithopodioides Brid. Bryol. univ. II, p. 330.

Rh. insigne Hsch, in Sieber Pl. ins. Trinitat, n. 19.

Rh. mnioides P. B. Prodr. p. 87.

Rh. mucronatum Mitt. in , Jown. of the Linn. Soc. 1863, p. 162.

Rh. tomentosum $\beta$ africanum Brid. Bryol. univ. II, p. 719.

1. Ad arbor., rup. et terr. - As.: Java. Afr. : Inter-tropic. : C. B. Sp. Am. sept. : Inter-tropic. ; ins. Bermud. Am. merid.: Inter-tropic.; Paraguay, Chile, ins. Juan. Fernandez.

Exs.: Bal. Pl. Parag. n. 3677. 
var. africanum $\left\{\begin{array}{l}\text { Brid. }- \text { Rh. tomentosun. } \\ \text { Mont. }\end{array}\right.$

var. Angstr. - Rh. mauritianum.

"var. gracile Besch. Prodr. bryol. mexic. p. 112.

- Am. sept. : Mexic.

"var. longe-aristatum C. M. mss.

- Am. sept. : Guatemala.

tomenlosum $\left\{\begin{array}{l}\text { Dz. et Mk. }- \text { Rh. demissum. } \\ \text { Sulliv, }- \text { Rh. cuspidigerum. }\end{array}\right.$

RHAMPHIDIUM Mitt. $M$, austr, am, $p, 45$.

macrostegium Mitt. - Trichostomum dicranelloides.

RHAPHIDORHYNCHUM W. P. Sch. Syn.ed. I, p. 564 (sect. КнynchostkGII) : Besch., Mitt. gen. propr.

Spec. omn. non indicatae sunt RHAPHIDOSTEgIA ejusd. nom. borbonicum Mitt. - Trichostomum subrhinophyllum. confertulum Besch. - Trichosteleum.

RHAPHIDOSTEgIUM Bryol, eur. V (subgen. Rhynchostegi); W. P. Sch. gen. propr. (2l:4 spec.).

acistrostegium (Sull.) Jaeg. Ad. II, p. 468.

Hypnum acistrostegium Sull. in Proced. of the Am. Acad... 1861, p. 278.

Sernatophyllum acistrostegium Mitt. M. austr: am. p. 488.

- Am. sept. : Cuba.

adhaerens Besch. Fl. bryol. Réunion, etc. p. 164.

1. Cortic. - Afr.: Ins, Borbon.

affine (Hsch.) Jaeg. Ad. II, p. 461 .

Hypnum conterminum C. M. Syn. II, p. 341 .

Leckea affinis Hsch. Fl. Brasil. I, p. 71 .

Senatophyllum affine Mitt. op. oit. p. 483.

Syn. Cortic. in silv. - Am. merid. : Brasil. austr. or. afro-demissum (C. M.) Par.

Hypnum afro-demissum C. M. in Abhandl. Brem. VII, p. 212. I.

- Afr. : Madagascar.

agnatum (Hpe) Jaeg. Ad. $I I, p, 458$.

Hypnum agnatum Hpe. mss.

Sematophyllurn agnatum Mitt, op, cit, p. 481.

- Am. merid. : And. Bogotens.

albi-alare $(C, M$.) Par.

Heterophyllum albi-alare C. M. in Dusen M. Camer. $n, 691$.

- Afr. : M. Cameroon.

ambiguum (Harv.) Jaeg. Ad. 11, p. 471.

Hgpnum ambiguum Harv, in Hook. Io, pl. rar. t. 24, f. A et in Lond, 1. Journ. of bot. 1840, II, p. 20; C. M. Syn. II, p. 340 .

amblystegiocarpum (C, M.) Par.

$-A s$. : Nepal.

Hypnum amblystegiocarpum C. M. in Fl. 1886, p. 285.

1. Ad arbor. $-A f r$, : Ins, S. Thoma, 
amaenum (Hedw.) Par.

Hypnum amaenum Hedw. Sp. M. p. 292, t. 77; C. M. Syn. II, p. 316.

Isothecium amaenum Brid. Bryol. univ. II, p. 382 p.p.

Sematophyllum amaenum Mitt. op, cit. p. 487.

1. - Am. merid : And. (fid. Handb.), Fuegia, ins. Eremitae. Pac. : Austral, or., Nov. Zeland.

amnigenum Broth. in Bihang till K. Sv. Vet.-Akad. Handl. 1895, n. 3.

1. Ad ligna demersa in fluv. - Am. merid.: Brasil. or. ampullatum (C. M.) Par.

Aptychus ampullatus C. M. in Hedw. 1897, p. 124. 1.

- Am. merid. : La Plata.

andinum (Mitt.) Jaeg. 11, p. 460.

Sematophyllum andinum Mitt. op, cit. p. 483.

Lignic. - Am. merid. : And. Quitens.

andungense (Welwo, et Duby) Jaeg. Ad. II, p. 456.

Hypnum andungense W. et Dy. in Mém.... Genève, 1871, p. 14, t. I. f. I.

Ad arbor. et terr. humid. - Afr. : Angola.

"var. major (Welvo, et Duby) Par.

Hypnum andungense var, major W. et Dy. l.c.

Rupic. - Afr. : Ubi typ.

angusticymbeum (C. M.) Besch. Fl. bryol. Réunion, etc. p. 162.

Hypnum angusticymbeum C. M. in Linn. 1876, p. 283.

apaloblastum (C. M.) Broth. mss.

$$
\text { - Afr. : Ins. Anjouan. }
$$

Aptychus apaloblastus C. M. in Bull. hb. Boissier. 1897, p. 213. - Am. sept. : Guatemala.

argyrophyllum Besch, in Journ. de bot. 1884, p. 59.

2 ? Ster.

- Afr.: Congo gall.

argyro-viride (Hpe.) Jaeg. Ad. $1 I, p .476$.

Rhyncho-Hypnum argyro-viride Hpe. Symb. 1870, p. 292.

1. Ad arbor. - Am. merid. : Brasil. austr. or.

asperifolium (Thw, et Milt.) Jaeg. Ad. II, p. 474. Sematophyllum asperifolium T. et M. in Jowrn. of the Linn. Sno. 1872,
p. 319.

2.

asperulifolium $(C, M$.) Par.

$$
\text { - As, : Ceylan. }
$$

Aptychus asperulifolius C. M. in Dusen M. Camer. n. 14 . - Afr. : M. Cameroon.

aureolum (Hpe). Jaeg. Ad. II, p. 775.

Hypnum aureolum Hpe Symb. 1877, p. 736.

1. Ad rup. humid, et terr. - Am. merid. : Brasil. austr. or.

" var. minus (Hpe.) Par.

Hypnum aureolum var. minus Hpe. l.e.

Cortic. - Am. merid. : Ubi typ.

? aureolum Besch. - Rh. nanum. aureo-sulfureum (C. M.) Jaeg. Ad. II. p. 456.

Hypnum aureo-sulfureum C. M. in Linn. 1874, p. 615.

1. Ad arbor, - Am. merid.: And, Nov, Granat. 
aureo-viride (C. M.) Par.

Aptychus aureo-viridis C. M. in Hedwig. 1897, $p, 122$

1. Cortic. - Am. merid. : Argentin. subtropic. Tucuman.

aurescens (Besch.) Jaeg. Ad. II, p. 750.

Rhaphidorhynchum aurescens Besch. Not. M. I. S. Paul, et Amsterdam, p. 5 .

1. Ster. - Afr.: Ins. Amsterdam.

auricomum Jaeg. - Rh. Welwitschii.

Ayresii W. P. Sch. hb.; Jaeg. Ad. II.

- Afr.: Ins. Franciae.

Barnesi Ren. et Carl. in Bull. Soc. roy. bot. Belg. 1890, I, p. 182.

1. - Am. sept.: Mexic.

Bernoullianum (C. M.) Par.

Stigmatella Bernoulliana C. M. in Bull. $h b$. Boissier, 1897, p. - Am. sept. : Guatemala.

Beyrichii (Hsch.) Jceg. Ad. II, p. 460.

Hypnum Beyrichii Hsch. Fl. Brasil. I,p. 81, t. 4, f. I; C. M. Syn. II, p. 403.

1. Lignic. - Am. merid. : Brasil. austr. or.

Boivini W. P. Sch. hb. ; Jaeg. Ad. 11 .

borbonicum Besch. - Trichostelenm,

Boswellii (Geheeb) Par.

Hypnum Boswellii Geh. in Abhandl. Brem. VII, p. 212 (nom.).

brachyacrus (C. M.) Par.

- Afr. : Madagascar.

Aptychus brachyacrus C. M. in Nuov. Giorn. bot. ital. 1897, p. 59. 1 .

- Am. merid. : And. Boliv.

brachycarpum (Hpe.) Jaeg. Ad. II, p. 462.

Hypnum brachycarpum Hpe. Ic. M. t. $11 ;$ C. M. Syn. II, p. 328.

1, In silv. - Afr. : C. B. Sp.

Exs. : Rehm. M. Afr, austr. n, 420.

brachycormum (C. M.) Par.

Heterophyllum brachycormum C. M. in Dusen M. Camer. n. 260.

brachydictyon Jaeg. - Trichosteleum.

brachyoxum (C.M.) Par.

Heterophyllum brachyoxum C.M. in Dusen M. Camer. n. 341 .

brachypelma (C. M.) Jaeg. Ad. II, p. 463 .

- Afr. : M. Cameroon.

Hypnum brachypelma C. M. Syn. II, p. 404.

H. microcarpum Hook. in Wall. Cat. n. 7657, in Lond Journ. of bot. 1840, p. 18 et Ic. pl. rar. t. 23, f. 4.

Stereodon brachypelma Mitt. $M$. Ind. or, $p .102$.

1 .

brachypus (Hpe.) Par.

$$
\text { - As. : Nepal. }
$$

Hypnum brachypus Hpe. Enum. M. Brasil. p. 78. 1 .

- Am. merid. : Brasil austr. or. 
brachytheciiforme (C.M.) Par.

Aptychus brachytheciiformis C. M. in Dusen M. Camer, n. 708. - Afr. : M. Cameroon.

brevi-horridum (C. M.) Par.

Heterophyllum brevi-horridum C. M. in Dusen M. Camer. n. 462. - Afr. : M. Cameroon.

brevi-mucronatum (C, M.) Par.

Hypnum brevi-mucronatum C. M. in Ule Bryol, brasil. $n$. 88 .

- Am. merid. : Brasil. subtropic. or.

caespitosum (Svo.) Jaeg. Ad, II, p. 454.

Hypnum caespitosum Siv. Fl. Ind, oce. III, p. I807; C. M. Syn. II, p. 330 p.p.

H. densifolium Spreng. in Brid. Bryol. univ. II, p. 591.

H. leptochaeton? Wils, in Lond. Journ. of bot. 1844.

H. subsecundum W. Arn. Disp. p, 62.

H. Stereodon pallidisetus Brid. op. et $l$. co.

Leskea caespitosa Hedw. Sp. M. p. 233, t. $49 ;$ Brid. op. cit. p. 228 p.p.

L. caespitosa $\beta$ subsquarrosa Brid. op. cit. p. 289 (vera spec., fid. C. M.).

Sematophyllum caespitosum Mitt. M. austr. am. p. 479.

1. Ad arbor. -- Am. sept.: Mexic.? Cuba, Hispaniola, Porto-Rico, Guadalup., Martinic. Am. merid. : Ins. T'rinitat., Columb., Venezuela, Brasil.

" subsp. abbreviatum Besch. Fl. bryol. Antill. fr. p. 75.

Ad terr. et lapid. - Am. sept. : Martinic.

"subsp. coelophyllum Besch. op. cit. p. 73.

- Am sept. : Guadalup.

subsp. galipense Besch. - Rh. galipense.

* subsp. Husnoti Besch. op, cit. p. 74.

- Am. sept. : Guadalup.

« subsp. megalodictyon Besch. op. cit. p. 73.

- Am. sept. : Guadilap.

«subsp. stramineum Besch. op. cil. p. 74.

Cortic. - Am. sept. : Guadalup.

calabarense Par.

Hypnum trachaelocarpum $C . M$. in $F l, 1886, p, 524$.

1. Cortic. - Afr. : Nov. Calabar.

callidioides (C. M.) Jaeg. Ad. II, p. 470.

Hypnum callidioides C. M. in Linn. 1856, p. 213.

Rhaphidorhynchum callidioides Mitt. in Trans. and Prooed. of the roy. Soc. of Victoria, 1883, p. 85; F. v. Müller Austral. M. $t_{+} \mathrm{XIV}$. 1. - Pac. : Austral. fel., Tasman.

callidum (Morot.) Jaeg. $l$, c. Hyprum callidum Mont. in Ann. se. nat. 1845, IV, p. 90 et Syll. p. 7 :
B. M. Syn. II, p. 313 .

Sematophyllum callidum Mitt. op. eit. p. 489.

1. Cortic - Am. merid. : Chile, Valdiv.

calliferum Geh, et Hpe. in Rev. bryol. 1881, p. 27.

1. $\quad$ - Pac.: Austral. or. (Victoria), Tasman.

Cambouei Ren, et Card, in Bull. Soc. roy, bot. Belg. 1890, I, p. 183.

1. Cortic. - Afr.: Madagascar. 
campicolutn Broth, in Bihang till K. Sv. Vet.-Akad. Handl. 1895, n. 3.

1. Lignic. secus rivul, - Am. merid. : Brasil. or.

capilliferum (Thw, et Mitt.) Jaeg. Ad. 11, p. 474.

Sematophyllum capilliferum T. et M. in Journ. of the Linn. Soe. 1872,

2 ?

$$
\text { - As.: Ceylan. }
$$

carolinianum Jaeg. - Rh. demissum var. carolinianum.

cataractitis (C.M.) Par.

Hypnum cataractitis C. M. in Ule Bryoth. brasil, n.92.

- Am. merid.: Brasil, subtropic. or.

catilliforme (C.M.) Par.

Aptychus catilliformis C. M. in Heduig. 1897, p. 124.

I. Cortic. - An. merid.: Monte-Video.

Catillum (C. M.) Jaeg. Ad, II, p. 459.

Hypnum Catillum $C . M$. in Linn. 1875, $p .467$.

Ster. Ad arbor. - Afr. : Niam-Niam.

cavifolium (Wils.) Jaeg. Ad. II, p. 458.

Hypnum cavifolium C. M. Syn. II, p. 342 ,

Leskea cavifolia Wils. in Lond. Journ of bot. 1844, III, p. 161. Rupic. - Am. merid.: Brasil, austr. or.

cerviculatum (Hook. f. et Wils.) Jaeg. Ad. 11, p. 469.

Hypnum cerviculatum $H$. f. et W. Fl. of the N. Zeal. 1I, $p .113$, t.95, f. 2 et Handb. p. 473.

H. leptorhynchum $v a r ., \beta \mathrm{Fl}$. Antaret. $I, p .141$.

Rhaphidorhynchum, cerviculatum Mitt. in Trans, and Proced. of the roy. Soc. of Victoria, $1883, p .85$.

Stereodon cerviculatus Mitt. in Journ. of the Linn. Soc. IV, p. 87 .

2. Cortic. - Pac.: Nov. Zeland. sept,, ins. Auckland, Austral, or. (Victoria). Tasman.

ceylonense (Hpe.) Jaeg. Ad. II, p. 464.

Hypnum ceylonense Hpe. in Nuov. Giorn. bot. ital. 1872, p. 276.

1. - As. : Ceylan.

chlorocormum (C.M.) Par.

Aptychus chlorocormus C. M. in Nuov. Giorn, bot, ital, 1897, p. 58 . - Am. merid. : And, Boliv.

chlorothecium Besch. Not. M. Paraguay, p. 270.

Cortic. - Am. merid. : Paraguay.

Eoss.: Bal, Pl. Parag. n. 1272.

chrysostegum (C.,M.) Jaeg. l. c.

Hypnum chrysostegum C. M. Syn. II, p, 686 .

Sematophyllum chrysostegum Mitt. M. austr. am. p. 485.

1. Lignic. - Am, merid. : Venezuela. chrysotis (C.M.) Par.

Aptychus chrysotis C. M. in Dusen M. Camer: n. 19.

circinale (Hpe.) Besch. op. et l. cc.

$$
\text { - Afi : M. Cameroon. }
$$

H. concavifolium $H$. f.e $\mathrm{W} W$.

H. Hampeanum $C$, M. Syn. II, $p, 326$.

Leskea circinalis $H p e, I o, M, \imath, 5$, 
Neckera straminea Hsch. Fl. Brasil. I, p. 54 (fid, C. M.).

Sematophyllum cireinale Mitt. op, cit. $p, 486$.

1. Cortic. et ad rad. arb. - Am. sept.: Mexic. Am. merid, : Brasil. austr. or., Paraguay.

Exs. : Bal. P1. Parag. n. 1218, 3691.

circinale Besch. (1885), - Rh. circinicaule.

circinicaule (C.M.) Par.

Aptychus circinicaulis C. M. in Hedwig. 1897, p. 125.

Hypnum circinicaule C. M. in Rev. bryol. 1887, p. 57 (nom.).

Rh. circinale Besch, in Rev, bryol. 1885, p. 19 et in Bä. Pl. Parag. n. 3692 .

- Am. merid. : Paraguay.

cirrifolium (Schwaegr.) Jaeg. Ad. II, p. 474.

Hookeria cirrifolia W. Arn. Dispos.

Hypnum cirrifolium Schwaegr. in Freycinet Voy... Bot. I, p. 12; C. M. Syn. II, p. 281; Bryol. jav. II, p. 144.

Leskea cirrifolia Schwaegr. Suppl. III, II, II, t. 290.

Sematophyllum cirrifolium Mitt. in Voy. H. M. C. Challenger, Bot. III, p. 261.

1. Lignic. - As.: Ins. Rauwack Molucc. Pac. : Ins. Admiral. cochleatulum (C. M.) Par.

Aptychus cochleatulus C. M. in Hedwig. 1897, p. 124.

Ster. Cortic. - Am. merid. : Argentin. subtropic. Tucuman.

cochleatum Broth, in Bihang till K. Sv, Vel.-Akad. Handl. 1895, n. 3.

1. Ad arbor. in fluv. - Am. merid.: Brasil, or.

concinnum (C. M.) Par.

Aptychus concinnus C. M. in Malpighia, 1896, p. 516.

1. $\quad-A m$. merid. : Guian. brit.

condensatulum (C. M.) Par.

Aptychus condensatulus C. M. in Hedwig. 1897, p. 122.

1.

- Am. merid. : Argentin. subtropic. Tucuman

confertissimum (Mitt.) Jaeg. Ad. II, p. 458.

Stereodon confertissiuus Mitt. M. Ind. or. p. 102.

1.

- As. : Assam super.

congruens (Hpe.) Jaeg. Ad. II, p. $46 \mathrm{I}$. Hypnum congruens Hpe. in Linn. 1859, p. 643; F. v. Müller Austral.
M. $t$, XIII.

Rhynchostegium congruens Mitt. in Trans, and Proced. of the roy. Soc. 1 . of Vistoria, 1883, p. 89.

- Pac. : Austral, or.

constrictum (Brid.) Besch. Fl. bryol. Réunion, etc., p. 166.

Hypnum constrictum C. M. Syn. II, p. 316.

Leskea constricta Brid. Sp. M. II, p. 79 et Bryol. univ. II, p. 290. 1 ? - Afr.: Ins. Borbon.

contiguum (Hook. f. et Wils.) Par.

Hypnum contiguum $H$. f.et W. Fl. Tasman. II, p. 213, t. 177, f. 2

Rhaphídorhynchum contiguum Besch. Note M. I. St-Paul et Amstevd. p. 3 . Rhyncho-Hypnum subpungens Hpe. et C. M. in Trans. and Proced. of the roy. Soc. of Victoria, 1883, $p .89$.

Sematophyllum contiguum Mitt. Fl. Vit. $p .398$.

Stereodon contiguns ej. in Journ, of the Linn. Soc, 1859, p. 87. 
1. Lignic. - Afr.: Ins. Saint-Paul, Am. sept. : Sine loco (fid. Hanlb.). Pac.: Ins. Fidji, lord Howe, Austral. or. (Queensland, Nov. Valesia), Nov. Zelaiıd. sept. et med., Nov. Caledon., Tasman.

crassiusculum (Brid.) Besch. Fl. bryol. Réunion, etc. p. 156.

Hypnum crassiusculum Brid. Sp. M, II, p, 242; C. M. Syn. II, p. 405.

Isothecium crassiusculum Brid. Bryol, univ, II, $p .384$ p.p.

1. Lignic. et terr. - Afr. : Ins. Canar., Tristan d'Acunha, Borbon., Franciae. Am. merid. : Nov, Granat, ? (fid. Brid.).

crinitifolium Jaeg. - Rh. tequedamense.

crispans Besch. Fl. bryol. Réunion, elc. p. 158.

- Afr. : Ins. Borbon.

crispulifolium (C. M.) Par.

Hypnum crispulifolium C. M. in Journ. of Bot. 1877 p. 229 (nom.).

Lignic. - Am. sept. : Costa Rica.

cucullatifolium (Hpe.) Jaeg. Ad. II, p. 459.

Hypnum cucullatifolium Hpe. in Ann. se. nat. V ser., p. 328.

Sematophyllum cucullatifolium Mitt. M. austr. am. p. 482.

In udis. - Am, merid.: And. Bogotens.

curvirostre (Harv.) Jaeg. Ad. II, p. 460.

Hypnum curvirostre C. M. Syn. 1I, p. 408.

Leskea curvirostris Harv. in Lond. Journ. of bot. 1840, p. 16 et in Hook. Ic. pl. $\operatorname{rar} . t .28, f .1$.

Stereodon Harveyanus Mitt. M. Ind. or. p. 102.

$$
\text { - As. : Nepal. }
$$

curoulum Jaeg. - Rh. propinquum.

cuspidatulum (C.M.) Par.

Hypnum cuspidatulum C. M. in Rev. bryol. 1887, p. 57 (nom.).

- Pac. : Nov. Caledon.

cuspidatum W. P. Sch. hb.; Jaeg. Ad. II. p. 457.

1.

- Afr. : Madagascar.

cuspidiferum (Milt.) Jaeg. Ad. II, p. 457.

Sematophyllum cuspidiferum Mitt. M. austr, am. $p .480$.

1.

- Am. merid. : And. Quitens.

cylindricarpum (C. M.) Kindb, in Mac, Cat, p. 208.

Hypnum cylindricarpum C. M. Syn. II, p. 308; Sull. Ic. M. p. 173, t. 109, Lesq. et Jam. Man. p. 356.

Leskea polyantha var. Sull. M. Allegh. $n, 60$.

L. tenuirostris Br, et Soh, in litt. ad Sull.

Pylaisia tenuirostris Jaeg. Ad. II, p. 370 .

2. Lignic. $-A m$. sept, : Labrador, Terr, nov., New Brunswick; a

New Jersey ad Ohionem et reg, merid. et or.

Exs. : Sull. et Lesq. M. bor, am. i. 445.

cylindricum Jaeg. - Rh. leptocarpon.

cyparioides (Brid.) Jaeg. Ad. 1I, p. 470.

Hypnum cyparioides Brid. M. Reo. II, II, p. 138, t. 3, f. 4 ; C. M. Syn, II, $p, 312$.

H. leptorhynchum Brid. Mant. M. p. 179 p.p.

H. Stereodon leptorhynchus ej. Bryol, univ. II, p. 621 p.p. 
cyparissoides Broth. - Eetropothecium.

Danckelmanni (C.M.) Par.

Hypnum Danckelmanni $C$. M. in Fl. 1886, p. 524.

$$
\text { - Afr. : M. Cameroon. }
$$

Debeltei Besch. Fl. bryol. Réunion, elc. p. 162.

Cortic. - Afr.: Ins. Borbon.

decolor Besch, op. cil. p. 165.

2 ? Cortic. - Afr.: Ins. Seychell.

decumbens (Wils.) Jaeg. Ad. II, p. 468.

Hypnum decumbens Wils. mss.

Sematophyllum decumbens Mitt. M. austr. am. p. 488.

Lignic. - Am. merid.: And. Bogot. et Quitens, Brasil. austr. or.

decurvifolium (Mitt.) Jaeg. Ad. II, p. 475.

Sematophyllum decurvifolium Mitt. op. cit. p. 495.

1. Cortic. - Am. merid. : Amazon.

delicatulum (Jam.) Par.

Hypnum laxepatulum Lesq. et Jam. Man. p. 358.

Isopterygium delicatulum Jaeg. Ad. $I I, p .504$.

Rhynchostegium delicatulum Jam. in Sull. Ic. M. Suppl. p. 93, t. 69.

2? đ ign. - Am. sept. : New Hampshire.

demissum (

Eurhynchium demissum Milde Bryol. Biles. p. 308.

Hypnum demissum Wils. Engl. Bot. Suppl. t. 2740; C. M. Syn. II. $p, 327$.

H. flavescens Wils. mss.

H. Schimperi Br. mss, : Rab. Deutseh. Kryptfl. II, III, p. 286.

Rhaphidorhynchum demissum Mitt. in Trans. of the Linn. Soc. 1891, p. 175 Rhynchostegium demissum Bryol. eur. V (mon. p. 4), t. 507; W. P. Sch. Syn. II ed. p. 678.

1. Ad sax. quarz, adrep. in silv. montos, - Eur. : Scot, Hibern., Cambrovall., Voges., Alsat,, Helvet, Ital. super. As. : Japon. Am. sept, : Terr. nov., New krunswick, Virgin, occ.

Exs. : Rab. Bryoth, eur. n. 34l, 541.

Sull. et Lesq. M. bor. am. II, p. 440 (Hypnum).

" var. carolinianum (C, M.) Par.

Hypnum carolinianum $C, M . l, c$.

H. demissum Sull. M. Allegh. $n, 48$.

H. demissum var. carolinianum $L$, et $J$. Man. p. 355.

H. demissum var, Sull. et Lesq. M. bor, am. I ed. $n .298$ b.

Rh. carolinianum Jaeg. Ad. II, p. 454.

Ad sax. irror. - Am. sept. : Carol. super.

Exs. : Sull. et Lesq. M. bor. am. Il ed. n. 441. (Hypnum).

\& var. marylandicum (C. M.) Par.

Hypnum marylandicum $C . M$. op. cit. p. 328.

H. demissum var, marylandicum L. et. J. Man. p. 356.

H. demissum var, marylandium Sull. M. Allegh. n. 49; B. et L. M. bor. am. 1 ed, n. $298 \mathrm{c}$.

Rh. marylandicum Jaeg. l. c.

Rupic. - Am. sept. : Maryland.

Exs. : Sull, et Lesq. M. bor. am. Il ed. n. 462. (Нурпин).

demissum Lange. - Rh. Welwitschii. 
diaphanodictyon (C.M.) Par.

Aptychus diaphanodictyus C. M. in Hedwig. 1897, p. 120.

1.

- Am. merid. : Argentin, subtropic. Tucuman.

Dicnemonella (C. M.) Par.

Aptychus Dicnemonella C. M. in Dusen M. Camer, n. 112.

- Afr.: M. Cameroon.

divaricatulum (C.M.) Jaeg. Ad. II, p. 475.

Hypnum divaricatulun C. M. in sched.; Hpe. Symb. 1884, p. 517 (errat.

H. divaricatum in Enum, p, 70.

- Am. merid. : Brasil. austr. or.

Dregei (C. M.) Jaeg. Ad. II, p. 473.

Hypnum Dregei C. M. Syn. II, p. 311 .

H. n. 8048 Diege e.xs.

Rhynchostegium Breutelianum W. P. Seh, in Lreut. M. Capens.

1.

Exs. : Rehm. M. Afr, austr. n. 411.

Duisaboanum (Mont.) Besch. Fl. bryol. Réunion, elc. p. 159.

Hypnum Duisabonae C. M. Syn. II, p. 305.

Leskea Duisabonae Mont. in Ann. sc. nat. III ser., 1845, p. 97 et Syll. p. 19.

Rh. Duisabonae Jaeg. Ad. II, p. 457.

Rupic. - Afr.: Madagascar, ins. Franciae.

* var. granulosum Besch. op. cit. p. 160.

Cortic, in silv. - Afr.: Ins, Borbon.

- var. Le Duceanum (Mont.) Besch, op. et l. cc.

Hoskeria Le Duceana Mont. Syll. p. 13.

- Afr.: Ins. Galega.

" var. lutescens Besch, op, et l. cc.

- $A f r$.: Ins. Franciae.

"var. nossianum Besch, op. et l. cc.

- Afr. : Ins. Nossi-Comba.

"var. rigidiusculum Besch, op, et $l$. cc.

Hypnum Lecoultriae Duby Choix de M. ex. 1876, p. 8, t. I, †. 3

Sematophyllum Lecoultriae Jaeg. Ad. II, p. 453 .

- Afr.: Ins. Franciae.

" var, rufulum Besch. op. cit.p. 161.

- Afr.: lns. Franciae.

Duisabonæ Jaeg. - Rh. Duisaboanum.

enerve Besch. in litt.

Stereophyllum enerve ej. in Rev, bryol. 1885, p. 19 et in Bal. Pl. Parag. exs, n. 3634.

- Am. merid. : Paraguay.

erythropodium (Mitt.) Jaeg. Ad. 11, p. 469.

Sematophyllum erythropodium Mitt. M. austr, am. p. 489.

Lignic. - Am. merid, : Venezuela, And. Bogotens.

falcatulum Besch. Fl. bryol. Antill. fr, p. 76 ,

- Am. sept: Guadalup. 
fallax Besch. Not. M. Parag. n. 270.

1. Cortic. - Am. merid. : Paraguay.

Exs. : Bal. Pl. Parag. n. 1213, 1219.

flaccidifolium (C. M.) Jaeg. Ad, $I I, p .458$.

Hypnum flaccidifolium C. M. Syn. II, p. 333.

Sematophyllum flaccidifolium Mitt. op. cit. p. 481.

- Am. merid. : Ins. Trinit.

flagellicaule (C.M.) Par.

Heterophyllum flagellicaule C. M. in Dusen M. Camer. n. 667. -. Afr. : M. Cameroon.

flavidum (Mitt.) Jaeg. Ad. II, p. 458.

Sematophyllum flavidum Mitt, op. cit, p. 482.

Lignic. - Am. merid, : And. Bogotens.

fluminale $(C, M$.) Par.

Aptychus fluminalis $C, M$. in Dusen $M$. Camer, $n .665$. - Afr.: M. Cameroon.

fragilirostrum (Hpe.) Jaeg. Ad. II, p. 464.

Hypnum fragilirostrum Hpe. in Linn. 1863, p. 163.

Sematophyllum fragilirostrum Mitt. op, cit. p. 485.

Rupic. - Am. merid. : And. Bogotens.

frullaniadelphus (C. M.) Jaeg. Ad. II, p. 463 .

Hypnum frullaniadelphus $C . M$. in Linn. 1869-70, p. 16.

1.

- As. : Ceylan.

fulvifolium (Mitt.) Par.

Sematophylium fulvifolium Mitt. in Philos. Trans. of the roy. Soc. 1879 (extr. vol.), p. 393, t. 37 D.

1.

- Afr. : Ins. Rodriguez.

fulvum (Hsch.) Jaeg. Ad. II, p. 460.

Hypnum pyrrophyllum $C$. M. Syn. II, p. 344 .

Leskea fulva Hsoh. Fl. Brasil. I, p. 73.

Sematophyllum fulvum Mitt. op. cit. p. 482.

1.

- Am. merid. : Brasil.

fulvum Ren, et Card. - Plagiothecium micans var. fulvum.

fusco-viride Besch, in Rev. bryol. 1885, p. 19 et in Journ. de bol. 1891, p.

Eœs. : Bal. PI. Parag. n. 3682.

- Am. merul.: Paraguay.

galipense (C. M.) Par.

Hypnum caespitosum $C . M$. Syn. II, p. 331 p.p

H. dissolutum Sull. in Proced. of the A m. Acad.... 1861.

H. galipense C. M. in Bot. Zeit. 1848, p. 780.

H. obliquifolium ej. in op. cit. 1845, p. 110.

H. tovariense ej. in op. cit. $1848, p .780$.

Rh. caespitosum subsp, galipense Besch. Fl. bryol. Antill. fr. p, 74.

Sematophyllum galipense Mitt. op. cit. p. 480.

1. Ad arb., rup. et terr. - Am. sept.: Cuba, Jamaic., Guadalup., Tabago. Am. merid. : Venezuela, And. Quitens, et Peruv., Brasil. aequinoct. et austr. or.

gibbosulum (C. M.) Besch. Fl. bryol. Réunion, etc. p. 162.

Hypnum gibbosulum C. M. in Linn. 1876, p. 282.

Isopterygium gibbosulum Jaeg. Ad. II, p. 501. 
glaucinum Besch, - Trichosteleum.

glauco-viride (Hpe.) Jaeg. Ad. II, p. 470.

Leptorhyncho-Hypnum glaueo-viride Hpe. in Linn. 1876, p, 325

Rhynchostegium glauco-viride Mitt. in Trans, and Proced. of the roy, Soc. of Victoria, 1883, p. 89.

1. Cortic. - Pac. : Austral, or.

Glaziovii (Hpe.) Jaeg. Ad. 1I, p. 472.

Hypnuru Glaziovii Hpe. Symb. 1876, p. 524.

1. Cortic. - Am. merid. : Brasil, anstr, or.

globosum Besch, in Rev. bryol. 1885, p. 19 et in Journ. de bot 1891, p.

1. Ad rup. itror. - Am, merid. : L'araguay.

Exs. : Bal. Pl. Parag. n. 3633.

glutinosum (C. M.) Par.

Aptychus glutinosus C, M. in Dusen M. Camer, n. 407.

- Afi. : M. Cameroon.

grammicarpum (C.M.) Par.

Aptychus grammicarpus C. M. in Malpighia, 1896, p. 517.

1.

- Am. merid.: Guian. brit.

grandicellulosum (C, M.) Par.

Aptychus grandicellulosus C. M. in Heduig. 1897, p. 120.

1. $\quad-$ Am merid. : Argentin. subtropic. Tucuman.

Gueinzii (Hpe.) Jaeg. Ad. II, p. 473.

Hypnum cupressiforme var. Hsch, in Drege M. Capens,

H. Gueinzii Hpe. Ic. M. t. 12 ; C. M. Syn. II, p. 311.

1. $-A f r$.: C. B. Sp.

Exs. : Rehm. M. Afr. austr. n. 409 et b, 659.

"var. prostrata (C, M.) Jaeg. l. c.

Hypnum Gueinzii var. prostrata C.M. $l$. $c$.

Cortic. $-A f r$. : C. B. Sp.

Hampei (Besch.) Jaeg. Ad. II, p. 457.

Rhynchostegium Hampei Besch. Prodr. bryol. mexic. p. 105

- Am. sept. : Mexic.

hamulosum W. P. Sch. hb. ; Jaeg. Ad. II.

- Afr. : Ius, Borbon.

Hedwigii (Wils.) Jaeg. Ad. II, p. 461.

Leskea Hedwigii Wils, in Kew Journ. bot. 1II, p. 353.

Sematophyllum Hedwigii Mitt. M. austr. am. p. 484.

helenicum (Mitt.) Par.

- Am. merid. : And. Quitens.

Sematophyllum helenicum Mitt. in Melliss's S. Helena, 1875, p. 363.

1. Cortic. - Afr. : Ins. S. Helena.

? Henoni Jaeg. - Hypnum.

homomallum (Hpe.) Jaeg. Ad, 11, p. 749.

H. Drammondii Tayl. in Lond. Journ. of bot. 1846, p. 63 .

H. homomallum C. M. Syn. II, p. 336; H. f. Han $7 b$, of N. Zeal. Fl. p. 474 .

Leskea homomalla Hpe, Io, M. t. 6 et in Pl. Preiss. n. 2465.

Pylaisia homomalla Jaeg. Ad. II, p. 373 . 
Rhaphidorhynchum homomallum Mitt. in Trans. and Proced. of the roy. Soc. of Victoria, $1883, p, 84$.

Rhynchostegium homomallum Besch.

2. Cortic. (ad Banksiam Menziezii). - Pac. : Austral, occ. et or., fret. King's Georges, Nov. Zeland. sept, Nov. Caledon., Tasman.

humile (Harv.) Jaeg. Ad. II, p. 463.

Hypnum humile Harv, in Lond. Journ. of bot. 1840, II, p. 19 et in Hook. Ic. pl. rar. t. 23, f. $9:$ C. M. Syn. II, p. 329.

Stereodon humilis Mitt. M. Ind. ois. p. 102.

1 .

- As. : Nepal, Ceylan.

inconspicuum (Hsch.) Jaeg. Ad. II, p. 459.

Hypnum inconspicuum Hsch. Fl, Brasil. I, p. 86; C. M. Syn. II, p. 332.

Sematophyllum inconspicuum Milt. M. austr. am. p. 481.

1.

- Am. merid. : Brasil.

incurvum (Hpe.) Jaeg. Ad. II, p. 476.

Hypnum incurvum Hpe. Symb. 1876, p. 522 .

1. Cortic. - Am. merid. : Brasil, austr. or.

insulosum (Sull.) Jaeg. Ad. II, p. 471.

Hypnum insulosum Sull.

Sematophyllum insulosum Mitt. op, cit. p, 489.

Lignic. - Am. sept. : Cuba. Guadalup.

irrepens (Duby) Jaeg. Ad. II, p. 457.

Hypnum irrepens Dy. in Mém... Genève, 1876, p. 13, t. 11, f. 4 et in Fl. $1877, n .5-6$.

1.

- Afr.: Ins. Franciae.

Jamesii (Sull.) Kindb. in Mac. Cat. pp. 209 et 276.

Hypnum Jamesii $L$. et J. Man. p. 358.

Isopterygium Jamesii Jaeg. Ad. II, p. 504.

Isothecium? Dawsoni Kindb, in Ott. Natur. IV, p. 65.

Rhynchostegium Jamesii Sull. 1c. M. Suppl. p. 92, t. 68.

1 .

- Am. sept. : Anticosti, Terr. nov., New Bruns. wick, New Hampshire, Gaspes., Columb. brit.

Jolliffii (Mitt.) Jaeg. Ad. II, p. 457.

Hypnum Jolliffii $H$. f. Handb. of N. Zeal. Fl. p. 474.

Rhaphidorhynchum Jolliffii Mitt. in Trans, and Proced, of the roy. Soc. of Victoria, 1883, p. 84 .

Stereodon Jolliffi Mitt. in Fl. Tasman. II, p. 213.

1. Ad rup. et terr. - Pac. : Nov, Zeland, sept. et med., Tasman.

Kegelianum (C. M.) Ren. et Card. in Bot. Gaz. 1890, p. 61.

Hypnum Kegelianum C, M. Syn. II, p. 325.

Leskea Kegeliana ej. in Linn, 1848, p. 198.

Sematophyllum Kegelianum Mitt. op. cit. p. 486.

1. Cortic. et lignic. - Am, sept.: Mississipi, Jamaic., Hispaniola. Ain, merid.: Irs. Trinit., Guian. batav., And. Quitens. et Peruv., Brasil. aequinoct., Paraguay.

" var. floridanum Ren, el Card, in op. et l. cc.

Ut typ. ? - Am. sept. : Florida.

“ var, tenue (Hpe.) Par.

Hypnum Kegelianum var. tenue C.M. l. c.

Leskea caespitosa Brid. Bryol. univ. II, p. 289 p.p.

L. Kegeliana var, tenuis Hpe. Enum. M. Brasil. p. 58. 
L. subpinnata Brid. op. cit. p. 287.

Saxic, - Am. sept. : Hispaniola, Porto-Rico. Am. merid.: Brasil. austr. or.

Krakakammae (C. M.) Jaeg. Ad. $1 I, p, 476$.

Hypnum Krakakammae C. M. Syn. II, p. 285.

1. In silv. - Afr.: C. B. Sp.

lamellosum W. P. Sch, in Mandon Pl. Boliv. n. 1657.

- Am. merid. : And. Boliv.

lamprocladum (C.M.) Par.

Aptychus lamprocladus C. M. in Dusen M. Camer. n. 21. - Afr. : M. Cameroon.

lamprophyllum (Milt.) Jaeg. Ad. II, p. 477.

Hypnum caespitosum Sull. in Proced. of the Am. Acad... 1861, p. 289 et in Wright M. Cubens, n. 127.

Pungentella lamprophylla C. M. in Engler's Bot. Jahrb. 1896, p. 330.

Sematophyllum lamprophyllum Mitt. op, vit. p. 496.

- Am. sept. : Cuba.

latitextum Ren. et Card. in Bull. Soc. roy. bot. Belg. 1895, I, p. 76.

I?

- As. : Sikkim.

laxe-patulum (Lesq. et Jam.) Par.

Hypnum laxe-patulum L. et J. Man. p. 358.

Rhynchostegium delicatulum Jam. mss.; Sull. Ic. M. Suppl, p, 93, Ł. 69.

$\sigma$ ign. - Am. sept. : New Hampshire.

laxo-alare $(C . M$.) Par.

Aptychus laxo-alaris C. M. in Hedwig. 1897, p. 123.

Ster. - Am. merid. : Argentin. subtropic. Tucuman.

lasum W. P. Sch. hb. ; Jaeg. Ad. II. - Afr.: Ins. Franciae.

leptobolax (C. M.) Par.

Aptychus Ieptobolax C. M. in Dusen M. Camer, $n .700$.

- Afr. : M. Cameroon.

leptocarpon (Schroaegr.) Jaeg. Ad. II, p. 467.

Hypnum cylindricum Hseh. et Reinw, in Nov. Act. Acad. Crs. Leop. XIV, I1, Suppl p. 728 (fid. C. M.): Bryol. jav. II. p. 178, t. 277.

H. leptocarpon Schwaegr. Suppl. II, II, II, p. 17I, t. 200; C. M. Syn. II, p. 316; Bryol. jav. II, p. 177, t. 276.

$\mathrm{Rh}$. cylindricum Jaeg. $l$. $e$.

Semainphyllum leptocarpon Mitt. in Journ, of the Linn. Soc, 1864, p. 5.

Stereodon leptocarpus ej. M. Ind. or. p. 102. 1. - As. : Ceylan, Sumatra, M. Java, Borneo.

leptochaeton (Schwaegr.) Besch. Fl. bryol. Antill. fr. p. 81.

Hypnum leptochaeton Schwaegr. Suppl. I, II, p. 296 ; C. M. Syn. II, p. $28 \mathrm{~b}$.

Isothecium leptochaeton Brid. Bryol, univ. II, p. $3 \dot{81 .}$

Sematophyllum leptochaeton Mitt. M. austr. am. p. 496.

1. Cortic. - Am. sept. : Martinic. Am. merid. : Guian., Brasil, austr. or. leptophyllum (Mitt.) Jaeg. Ad. II, p. 468.

Sematophyllum leptophyllum Mitt, M. austr, am, p. 488. 2 ?

- Am. merid. : Chile, 
leptorhynchoides (Mont.) Jaeg: Ad. II, p. 470,

Hypnum leptorhynchoides Mont. in litt. (deest in Syll.).

Stereoton leptorhynchoides Mitt. M. Ind. or. p. 103.

1.

- As. : M. Neilgherr.

leptorhynchum (Brid.) Besch. Fl. bryol. Réunion, etc. p. 164.

Hypnum leptorhynchum Brid. Mant. M. p. 179 p.p. ; C. M. Syn. 11, p. 313,

H. Stereodon leptorhynchus Brid. Bryol, univ, II, p, 621 p.p.

1. Cortic, in silv. - Afr. : Madagascar sept., ins. Borbon., Franciae. Pac. : Austral. or. (Victoria).

leptothecium (Mill.) Jaeg. Ad. II, p. 459.

Sematophyllum leptothecium Mitt. M. austr. am. p. 482.

- Am. merid. : And. Bogotens,

leucocytus (C, M, Jaeg. Ad. $I I, p .469$.

Hypnum leptorhynchum $H$. f. et W. Fl. Antarct. I, p. 141 (exol. v. $\beta$ ).

H. leucocytus C. M. Syn. II, p. 314.

Stereodon cyparioides Mitt. in Journ, of the Linn. Soc. 1859, p. 87.

1. Auckland, Tasman.

- Pac. : Austral., Nov. Zeland. sept. et med., ins.

leucostomum (Hpe.) Par.

Hypnum leucostomum Hpe. Enum. M. Brasil. p. 81. 1.

- Am. merid. : Brasil austr. or.

lignieolum (Ångstr.) Jaeg. Ad. 11, p. 466.

Sematophyllum lignicolum Angstr. in Oef.... 1876, $p, 42$.

- Am. merid. : Brasil, austr. or.

lilliputianum (Mont.) Jaeg. Ad. 11, p. 468.

Hypnum liliputianum Mont. in Cl. Gay Hist. Chil. Crypt. t. 20, f. 3.

Sematophyllum lilliputianum Mitt. op. cit. p. 488.

- Am. merid. : Chile.

Lindigii (Hpe.) Jaeg. Ad. 11, p. 465.

Hypnum Lindigii Hpe. in Linn. 1862, p. 530.

Sematophyllum Lindigii Mitt. op. cit. p. 487.

1. Cortic. - Am. merid.: And. Nov. Granat.

littorale (Hpe.) Jaeg. Ad. II. p. 459.

Hypnum littorale Hpe, in Nuov. Giorn. bot. ital. 1872, p. 287.

1. Cortic. - As. : Borneo.

longicollum (Hpe.) Par. Aptychus longicollis Hpe. in sched.; C. M. in Bull. hb. Boissier, 1897,
p. 213. 1.

longirostratum (Brid.) Jaeg. All. 11, p. 472.

Hypnum longirostratum C. M. Syn. II, p. 393.

Leskea longirostris Brid. Bryol. univ. II, p. 311.

Sematophyllum longirostratum Mitt. op. cit. p. 190.

1. Cortic. - Am. sept. : Ins. Porto-Rico.

loucoubense Besch. Fl. bryol. Réunion, etc. p. 165.

In silv. - Afr.: Ins. Nossi Be, S. Maria de Madagasc.

loxense (Hook.) Jaeg. Ad. II, p. 456. Hypnum loxense Hook. in Kunth Syn. pl. aequinoct. I, p. 62; C. M.
Syn. II, p. 331 . 
H. Stereodon loxensis Brid. Bryol. univ, II, p. 590 .

Sematophyllum loxense Mitt. op. cit. p. 479.

1. Ad arbor. et rup. irror. - Am. merid. : And. Nov. Granat, Quitens. et Peruv. ; Brasil. austr, or.

" var, lithophilum (Hsch.) Par.

H. lithophilium Hsch. Fl. Bras. I, p. 84.

H. loxense $\beta$ rivulare $C . M$. op. cit. $p .332$.

Rh. loxense $\beta$ rivulare Jaeg. Ad. II, $p, 456$.

Secus rivul. - Am. merid. : Brasil. austr. or.

var, rivulare Jaeg. - Rh. loxense var. lithophilum.

lucidum W. P. Sch. hb.; Jaeg. Ad, II.

- Afr.: Ins. Franciae.

? ludovicianum Ren. et Card. ined.

- Am. sept. : Ludovicia.

macrocytus (C. M.) Par.

Aptychus macrocytus C. M. in Hedwig. 1897, p. 120.

1 .

- Am. merid. : Argentin. subtropic.

macrorhynchum (Hsch.) Jaeg. Ad. II, p, 466.

Hypnum macrorhynchum Hsch. op. oit. p. 81 ; C. M. Syn. II, p. 329.

Sematophyllum macrorhynchum Mitt. op. cit, p. 487.

1? Cortic. - Am. merid. : Brasil. atstr. or.

mahense Besch. Fl. bryol. Réunion, etc. p. 167.

Mailusiae (C. M.) Par.

- Afr. : Ins. Seychelles.

Hypnum Mailusiae C. M. in Ule Bryoth. brasil. n. 181.

- Am. merid. : Brasil. subtropic. or.

maritimum (Hook.) Jaeg. Ad. II, p. 454.

Hypnum maritimum $C . M$. Syn. II, p. 328.

Leskea maritima Hook. M. ex, $t$. 166; Brid. Bryol. univ. 1I, p. 294.e

1. Terr.? - Afr. : C. B. Sp.

marylandicum Jaeg. - Rh. demissum var. marylandicum.

megasporum (Duby) Besch. Fl. bryol, Réunion, etc. p. 166.

Hypnum megasporum Dy. in Mém.... Genéve, 1876, p. 12, t. 1, f. I.

2 (Duby), syn. (Besch.). Lignic. - Afr. : Madagascar sept., ins, Bowbon., Franciae.

meiotocladium Besch. Fl. bryol. Antill. fr. p. 80.

- Am. sept. : Guadalup.

micans W. P. Sch. in Besch. op, cit. p. 75.

Ster. - Am. sept. : Guadalup.

micans Ren. et Card, - Plagiothecium.

var. submersum eor, - Plagiothecium micans var, submersum. micrangium (C. M.) Par.

Aptychus micrangius C. M. in Hedwig. 1897, p. 122.

1.

- Am. merid. : And. Argentin, subtropic.

microcarpoides (C. M.) Par.

Hypnum microcarpoides C. M. in Linn. 1878-79, p. 441.

1. In silv. - Am. merid, : Uruguay. 
microcarpum (Brid.) Jaeg. Ad. II, p. 462.

H. crassiusculum H. f. et W. in Drumm. M. bor, am. II ed, n. 107.

H. microcarpum C. M. Syn. II, p. 326; Sull. M. of U. St. p 71 et Io. M. p. 175, t. $110 ;$ L. et J. Man. p. 357.

H. minimnm P. B. Prodr. p. 66.

Leskea adnata Rich. in Mich. Fl. Am. bor. II, p. 314 .

L. caespitosa var. adunca Hpe, in Linn, 1839, p. 47.

L. microcarpa Brid. Bryol, univ. $I I$, p. 289.

1. Cortic. - Am. sept.: Terr. nov, et Columb. brit. (? Cardot) ; ab Ohione usq. ad Floridam; Virgin. occ.

Exs. : Sull. et Lesq. M. bor. am. II ed. n. 443 (Hypnum).

" var. anisocarpum Sull.; Jaeg. op. et l. cc.

H. admistum Sull. M. Cub. Wright in Proced of the Am. Acad... 1861, p. 289 .

H. microcarpon var. ej. M. bor. am. II ed., p. 74.

Sematophyllum admistum Mitt. M. austr. am. p. 485.

Rupic. - Am. sept. : New Jersey, Cuba.

Exs. : Sull, et Lesq. M. bor. am. II ed, n. 444 (Нypnum).

microcladum (Tayl.) Jaeg. Ad. $1 I$, p. 476.

II. esmeraldicum C. M. Syn. II, p. 392.

H. microcladum Tayl. in Lond. Journ. of. bot, 1846, p. 64.

Sematophyllum microcladum Mitt. op. eit. p. 495.

Trichosteleum microcladum Jaeg. Ad. II, p. 487.

1.

- Am. merid. : And, Quitens.

microdontum Besch. Fl. bryol. Réunion, etc. p. 163.

Cortic. - Afr. : Ins. Nossi-Be.

micropyxidium (C.M.) Par.

Aptychus micropyxidius C. M. in Malpighia, 1896, p. 518 .

- Am. merid.: Guian, brit.

micropy xis (C.M.) Par.

Hypnum micropyxis C. M. in Linn. 1880-83, p. 440.

1.

- Am. merid. : Argentin. Cordob.

microstegium W. P. Sch. - Trichosteleum.

Molkenboerianum (C. M.) Jaeg. Ad. II, p. 467. Hypnum Molkenboerianum C. M. Syn. II, pp. 317 et $685:$ Bryol. jav. II,
p. 179 .

Leskea falcata $D z$. et $M k$. in Ann. sc. nat. 1844, IV, p. 310.

1 (C. M.) 2 (Bryol. jav.). In silv. - As. : Java, Borneo, ins, Ceram. molle $W . P . S c h, h b$.

- Am. sept. : Guadalup.

monostictum (Thw. et Mitt.) Jaeg. Ad. II, p. 474. Sematophyllum monostictum T. et M. in Journ. of the Lirn. Soc. 1872 ,
p.318. l.

mundemonense (Hpe.) Pur.

- As. : Ceylan.

Hypnum mundemonense Hpe. Enum. M. Brasil. p. 83 . I.

- Am. merid. : Brasil. austr. or.

nanocephalum (C.M.) Par.

Aptychus nanocephalus C. M. in Hedwig. 1897, p. 121.

1. Saxic. et terr. $-A m$. merid. ; Argentin. subtropic. 
"var. subglauculum (C.M.) Par.

Aptychus nanocephalus var. subglauculus C. M. l. c.

Ubi typ.

nanopyxis $(C, M)$ Par.

Hypnum nanopyxis C. M. in Abhandl. Brem. VII, p. 212.

1.

- Afr. : Madagascar.

? nanothecium (C. M.) Jaeg. Ad. II, p. 750.

Hypnnm nanothecium C. M. in Rev. Bryol. 1878, p. 59 (nom.).

- Afr. : Ins. Franciae.

nanum (C. M.) Par.

Hypnum nanum C. M. in Rev. bryol. 1887, p. 57.

Rh, aureolum? Besch, in op, cit. $1885, p .19$ et in Bal, Pl. Parag, n. 3695 A. - Am. merid. : Paraguay.

neckeraceum (C. M.) Jaeg. Ad. $1 I, p .468$.

Hypnum neckeraceum C. M. Syn. II, p. 318.

Neckera curvirostris Schwaegr. Suppl. $1 I I, I, I I, t, 230$.

Stereodon curvirostris Mitt. $M$. Ind. or. p. 97 .

2.

- As. : Nepal., Khasia.

nematocaulon (C. M.) Besch. Fl. bryol. Réunion, elc. p. 162.

Hypnum nematocaulon C. M. in Linn. 1876, p. 281.

lsopterygium nematocaulon Jaeg. Ad. II, p. 501. - Afr. : lns. Anjouan.

nigricaule (Brid.) Jaeg. Ad. II, p. 476.

Hypnum nigricaule Brid. Sp. M. p. 95 et Bryol. univ. II, p. $393 ;$ C. M. Syn. 11, p. 286.

Ster.

- Afr. : Sierra Leone.

noduliferum (Mitt.) Jaeg. Ad. I1, p. 472.

Sematophyllum noduliferum Mitt. M. austr. am. p. 491.

- Am. merid. : Fuegia, ins. Eremitae.

Novae Cesareae Ren, et Card. - Hypnum micans.

oblique-rostratum (Mitt.) Jaeg. Ad. I1, p. 472.

Sematophyllum oblique-rostratum Mitt. op. cit, p. 490.

- Am. merid. : And. Quitens.

Olfersii (Hsch.) Jaeg. Ad. II, p. 469.

Hypnum Olfersii Hsch. Fl. Brasil. I, p. 83; C. M. Syn. II, p. 287.

Sematophyllum Olfersii Mitt. op. cit. p. 489.

1.

- Am. merid, : Brasil.

orbatum Besch, mss.

Ad saxa rivul. - Am. merid, : Brasil. or.

ovale Broth, in Bail. Syn. of the Queensl. Fl. IV Suppl. p. 99 (nom.) el in Oefv.... 1890, p.

1.

- Pac.: Austral, or. (Queensland).

ovalifolium Besch. Fl. bryol. Réunion, etc. p. 159.

In silv, $-A f r$. : Ins. Nossi Be.

pallens W. P. Sch. hb.; Jaeg. Ad. II.

papillosissimum ( $H_{p e .)}$ Par,

- Afr.: Ins. Franciae.

Hypnum papillosissimum Hpe. Enum. M. Brasil. p. 79.

- Am. merid. : Brasil. austr. or. 
? Pechuelii (C.M.) Par.

Hypnum Pechuelii $C . M$. in Fl. 1886, p. 523.

Ster. Ad arbor, - Afr. : Tropic. occid.

peralare Broth. in Engler's Bot. Jahrb. 1894, p. 206.

1. $\quad-A f r$. : Usambara.

percircinale (C. M.) Par.

Hypnum percircinale C. M. in Rev. bryol. 1887, p. 57 (nom.) et in Bal. Pl. Parag. n. 3693 p.p.

$$
\text { -- Am. merid. : Paraguay. }
$$

perlaxum (C. M.) Par.

Aptychus perlaxus C. $\dot{M}$, in Dusen $M$, Camer, n. d p.p.

- Afr. : $M$. Cameroon.

perrevolutum Broth. in Engler's Bot. Jahrb. 1894, p. 206.

1. Cortic. - Afr. : Reg. lacustr.

Pervilleanum (W. P. Sch.) Beseh. mss.

Hypnum Pervilleanum W. P. Seh, in hb. Mus. Paris; C. M. in Abhandl. Brem. VII, p. 212.

Rhynchostegium Pervilleanum Jaeg. Ad. II, p. 442.

1.

- Afr. : Madagascar.

phaeniceum (C. M.) Jaeg. Ad. II, p. 749.

Hypnum phaeniceum $C$. M. in Fl. 1878, n. 6 .

Syn.

- As. : Ins. Andaman.

piliferum W. P. Sch. hb.; Jaeg. Ad. 11 .

- Afr. : lns. Borbon.

plectophyllum Besch. Fl. bryol. Antill. fr. p. 75.

plumularium (Mitt.) Par.

$$
\text { - Am. sept.: Guadalup, }
$$

Sematophyllum plumularium Mitt. in Melliss's S. Helena, 1875, p. 364.

1. Cortic. - Afr.: Ins, S, Helena.

polyearpum W. P. Sch, hb, ; Jaeg. Ad. II.

- Afr.: Ins. Franciae.

prominulum (Mitt.) Jaeg. Ad. II, p. 472.

Sematophyllum prominulum Mitt, $M$. austr, am. p. 491.

- Am. merid. : And. Peruv.

propinquum (Harv.) Jaeg. Ad, I1, 473.

Hypnum curvulum Harv. in Lond. Journ. of bot. 1840, p. 18 et in Hook. Ic. pl, rar, t. 23, f. 7 ; C. M. Syn. II, p. 310 (fid. Mitt. l. c.).

H. propinquum Harv. $l i$. ec. p. 19 et t. $24 ; C . M . l$. e. p. 309 .

Rh. curvulum Jaeg. i. o.

Stereodon propinquus Mitt. M. Ind. or. p. 96.

$$
\text { - As. : Nepal, Assam super. }
$$

protensum Ren. et Card. in Bull. Soc. roy. bot. Belg. 1899, I, p. 183 et
M. Masc. Mad. n. 92 .

2. Ster.

- Afr, : Ins. Borbon,

pseudo amoenum Besch. - Trichosteleum.

preudo-brachythecium (C. M.) Par.

Heterophyllum pseudo-brachythecium C. M. in Dusen M. Camer. n. as.

$$
\text { - Afn. : M. Cameroon, }
$$


pseudo-callidioides Broth. in Act. Soc. se. Fenn. 1891, n, 5 .

1. Lignic. - Am. merid, : Minas ưeraès.

pseudo-callidum Jaeg. - Rh. xylophilum.

pseudo-cyparissoides Broth. mss.

- Am. sept. : Guatemala.

pterocladium Besch, - Trichosteleum.

pulvinale (Hpe.) Jaeg. Ad. $11, p .775$.

Hypnum pulvinale Hpe. Symb. 1877, p. 735 (in Enum. p. 82 : H. pulvinatum).

1. Terr, - Am, merid, : Brasil. austr, or.

punctulatum (C. M.) Par.

Hypnum punctulatum C. M. in Abhandl. Brem. VII, p. 213.

$$
\text { - Afr. : Madagascar. }
$$

pylaisiadelphum Besch. in Ann. sc. nat. 1892, I, p. 90.

1. Cortic. - As. : Yunnan. ramulinum (Thw. et Mitt.) Jaeg. Ad. II, p. 473.

Sematophyllum ramulinum $T$. et $M$. in Journ. of the Linn. Soo. 1872, p. 319.

2.

$$
\text { - As.: Ceylan. }
$$

recurvans (Schwaegr.) Jaeg. Ad. II, p. 466.

Hypnum amœnum Hook. in Drumm. M. bor, am. I ed. n. 196.

H. cupressetorum Brid. Bryol, univ, II, p, 409 .

H. demissum Mac. Canad. M. n. 443.

H. recurvans Schwaegr. Suppl. II, II, p. 289, t. 146; C. M. Syn. II, p. 307 ,

H. recurvans var, Sull, M. Allegh, n. 18 .

H. Stereodon recurvans Brid. Bryol. univ. II, p. 614,

Leskea arcuata ej. Sp. M. II, p. 54 .

L. recurvans Mich, Fl. Am. bor. II, p. $3 \mathrm{ll}$.

L. squarrosa ej. op. cit. p. 312 .

Khynchostegium recurvans Besch. Prodr. bryol. mexic. p. 107.

2. Cortic. et lignic. - Am. sept.: Terr. nov., Miquel,, New Brunswick, Gaspes., Ottawa, Ontario, reg. sept,, austr. et or,

Exs.: Mac. Canad. M. n. 299 (Hypnum).

replicatum Besch. Fl. bryol. Réunion, etc. p. 158.

- Afr. : Ins. Borbon.

resupinatum W. P. Sch. hb.; Jaeg. Ad. Il.

- Afr.: Ins. Francise.

thaphidorhynchum C. M. in Rehm. M. Afr. austr, n. 370 .

Richardi Jaeg. - Rh. subsimplex.

$$
\text { - Afr.: C. B. Sp. }
$$

rigidicaule (C.M.) $\mathrm{Par}$.

Heterophyllum rigidicaule C. M. in Dusen M. Camer, n. 794.

$$
\text { - Afr. : M. Cameroon. }
$$

rivuletorum (C, M.) Par.

Aptychus rivuletorum C. M. in Dusen M. Camer, n. 210.

Rodriguezi Par.

- Afr.: M. Cameroon.

Sematophyllum incurvum Milt. in Philos. Trans. of the roy. Soc. 1879 1.

(extr. vol.), p. 393, t. 38 A.

$$
\text { - Afr, : Ins, Rodriguez. }
$$


Roëllii Ren, et Card, in Bot. Centralbl, 1890, n. 51 .

1. Lignic. in silv. - Am. sept. : Columb. brit., Washington.

Exs. : Mac. Canad. M. n. 444.

roridum (Mitt.) Jaeg. Ad. II, p. $466^{\circ}$.

Sematophyllum roridum Mitt. M. austr. am. p. 487.

Cortic. -- Am. merid. : And. Nov. Granat.

rubricaule Besch. Fl. bryol. Réunion, etc. p. 161.

Cortic. - Afr. : Ins. Nossi Be.

ruficaule (Thw. et Mitt.) Jaeg. Ad. $` I I, p .474$.

Sematophyllum ruficaule $T$. et M. in Journ. of the Linn. Soc. 1872, p. 319.

2 . - As. : Ceylan.

rufo-viride Besch. Fl, bryol. Réunion, elc. p. 157.

- Afr. : Ins. Seychell., Nossi Comba.

rufulum Besch. Fl. bryol. Antill. fr. p. 80.

- Am. sept. : Guadalup.

salaense (Hpe.) Jaeg. Ad. I1, p. 473.

Hypnum salaense Hpe. in Nuov. Giom. bot. ital. 1872, p. 287.

2.

- As. : Borneo.

sanguisetum (C. M.) Par.

Cupressina sanguiseta C. $M$. in $F l .1897, p .340$.

- Am. merid. : Venezuela.

saproxylophilum (C. M.) Jaeg. Ad. II, p. 463.

Hypnum microcarpum? Duby in Moritzi Syst. Verz, d. Zoll. Pf. p. 131.

H. saproxylophilum C. M. Syn. II, p. 334; Bryol. jav. II, p. 216, t. 317.

1 (Bryol. jav.) 2 (C. M.).

- As, : Java.

Sauloma (C. M.) Par.

Aptychus Sauloma C. M. in Dusen M. Camer. n. 27.

- Afr. : M. Cameroon.

Schlimii (C. M.) Jaeg. Ad, II, p. 472.

Hypnum Schlimii C. M. in Bot. Zeit. 1818, p. 781 et Syn. II, p. 310.

Sematophyllum Schlimii Mitt. M. austr, am. p. 491.

Lignic. - Am. merid. : Venezuela.

Schwaneckeanum (C. M.) Jaeg. Ad. II, p. 471.

Hypnum Schwaneckeanum C. M. in Bot. Zeit. 1858, p 172.

Sematophyllum Schwaneckeanum Mitt. op. cit. p. 490.

- Am. sept. : Cuba.

Scorpiurus (Mont.) Jaeg. Ad. II, p. 468.

Hypnum Scorpiurus Mont. in Ann. sc, nat. 1845, IV, p. 90 et Syll. p. 8: C. M. Syn. 1I, p. 314.

Sematophyllum Scorpiurus Mitt. M. austr. am. p. 488.

Lignic. - Am, merid. : Chile, Valdiv.

secundifolium (C. M.) Jaeg. Ad. II, p. 458.

Hspnum lithophilum $H$. f. et W. Fl. Antaret. $I I, p .420, t .155, f .4$.

H. secundifolium C. M. Syn. II, p. 343.

Sematophyllum secunditoliam Mitt. op. cit, p. 481.

Ster. $\quad-$ Am. merid. : Fuegia, ins. Eremit.

semi-tortulum (C. M.) Par.

Aptychus semi-tortulus C. M. in Bull. hb. Boissier, 1897, p. 213.

1. $\quad-$ Am. sept. : Guatemala. 
sentosum Besch. - Trichosteleum.

sericifolium (Mitl.) Jaeg. Ad. 1I, p. 460.

Hypnum Beyrichii Wright M. Cubens. n. 111.

Sematophyllum sericifolium Mitt. op. eit. p. 483.

Lignic. - Am. sept. : Cuba.

serifolium (C.M.) Par.

Aptychus serifolius C. M. in Hedwig. 1897, p. 123.

1, Cortic. - Am. merid. : Argentin. Urug.

sinuosulum Besch Fl, bryol. Réunion, elc. p. 1fil.

Saxic. - Afr. : Ins. Borbon.

sphaerotheca (C. M.) Jaeg. Ad. II, p. 458.

Acirhynchum cupressinum Hpe, in sohed.

Hypnum lithophilum Hsch, in Mundt et Maire M. Capens.

H. sphaerotheca C.M. Syn. II, p. 333 .

Rhynchostegium inclinatum $W$. P. Sch. in Breutel M. Capens.

1 . - Afr. : C. B. Sp.

Exs. : Rehm. M. Afr. austr, n. 421.

"var. procerum C, M. in Rehm, l, c. n. 422.

- Afr. : Natal.

splendidulum (Hpe.) Par.

Leskea splendidula Hpe. in Trans, and Proced. of the roy. Soc. of Victoria, 1883, p. 85 (nom.).

- Pac. : Absque loco.

stenopyxidium (C. M.) Par.

Hypnum stenopyxidium C. M. in Linn. 1878-79, p. 439.

1. In silv. - Am. merid. : Uruguay.

sticticolum (C. M.) Jaeg. Ad. II, p. 465.

Hypnum sticticolum C. M. in Linn. 1874, p. 616.

1. Ad Lichenes. - Am. merid.: And. Nov. Granat.

strangulatum (Hpe.) Jaeg. Ad. II, p. 474.

Hypnum strangulatum Hpe, in Bot. Zeit. 1858, p. 169.

1 .

- Afr. : C. B. Sp.

" var, prostrata (Hpe.) Jaeg. l. c.

Hypnum strangulatum var. prostratum Hpe. l.c.

Ut et ubi typ.

strictum Besch. Fl. bryol. Réunion, etc. p. 163.

- Afr.: Ins. Seychell.

subadnatum C. M. et Kindb. in Bidrag p. 454 (nom.) et in Mac. Cat.

p. 209 ,

1 ? Cortic. - Am. sepl. : Gaspes., Ontar.

subbrachycarpum (Hpe.) Jaeg. Ad. 11, p. 462.

Hypnum subbrachycarpum Hpe. in Ann. sc. nat. V ser., p. 327.

Sematophyllum subbrachycarpum Mitt. op. eit. p. 484.

1. Cortic, - Am. merid. : And, Nov, Granat.

subcircinale (Ltz.) Jaeg. Ad. 1I, p. 465.

Hypnum subcircinale Ltz. Moosst. p. 167.

I.

- Am. sept. : Jamaic. 
subeurvulum (C. M.) Par.

Aptychus subeurvulus C. $M$. in Dusen M. Camer, n. 762. - Afr. : M. Cameroon.

subdemissum Kindb. in Mac. Cat. p. 208.

1. Rupic. - Am. sept.: Alaska.

subdemissum W. P. Sch. - Trichosteleum.

subdepressum (Hpe.) Par.

1sopterygium subdepressum Jaeg. Ad. II, p. 776.

Rhyncho-Hy pnum subdepressum Hpe. Symb. 1877, p. 734.

1.

- Am. merid. : Brasil, austr, or.

subfulvum Broth, in Bihang till K. Sv. Vet.-Akad. Handl. 1895, n. 3.

1. Terr. secus fluv. - Am. merid. : Brasil. or.

subhumile (C.M.) Jaeg. Ad. $I 1, p .4$ i.

Hypnum subhumile C. M. Syn. II, p. 330.

Stereodon subhumilis Mitt. M. Ind. or: p. 102.

1.

- As. : M. Neilgherr.

subnervatum (Mitt.) Jaeg. Ad. II, p. 461.

Sematophyllum subnervatum Mitt, $M$. austr, am. p. 483.

- Am. merid. : And. Quitens.

subscabrisetulum Besch. - Trichosteleum.

subscabrum (C. M.) Jaeg. Ad. II, p. 465.

Cupressima subscabra C. M. in Fl. 1897, p. 341.

Hypnum subscabrum C. M. Syn. 1I, p. 314.

Sematophyllum subscabrum Mitt. op. cit. p. 486.

1. Arbor. - Am. merid. : Venezuela, And, Nov. Granat.

subsecundum (Hpe.) Jaeg. Ad. I1, p. 463.

Rhyncho-Hypnum subsecundum Hpe. Symb. 1870, p. 285.

1. Lignic. - Am. merid. : And. Nov. Granat.

subsimplex (Hedro.) Besch. Fl. bryol. Antill. fr. p. 30.

Hypnum brachypoma Schwaegr. in Weig. M. Surinam.

H. Richardi ej. Suppl. I, II, p. 205, t. 93 (forma minor sec. Mitt.); C. M. Syn. II, p. 285.

H. subsimplex Hedw. Sp. M. p. 270, t. 69 ; C. M. Syn. II, p. 283.

Isothecium Richardi Brid. Bryol. univ. II, p. 358.

I. subsimplex ej. l. c. p. 357.

Plagiothecium subsimplex Besch. Prodr. bryol. mexic. p. 107.

Rh. Richardi Jaeg. Ad. II, p. 475.

Sematophyllum subsimplex Mitt. op. cit. p. 494.

1. Lignic. - Am. sept. : Mexic., Guadalup., Martinic., Barbad., ete. Am. merid. : Ins, Trinitat., Nov. Granat., Guian., Amazon., And. Quitens, et Peruv., Brasil. austr. or. ; tert. Magellan?.

subsphaerocarpum (Hpe.) Jaeg. Ad. II, p. 460.

Hypnum subsphaerocarpum Hpe. Symb. 1876, p. 523.

1.

- Am. merid. : Brasil. a:1str. or.

substrumiferum (Hpe.) Jaeg. Ad. $I I$, p. 457.

Rhyncho-Hypnum substrumiferum Hpe. Symb. 1870, p. 286.

1. Cortic. - Am. merid. : Brasil, austr. or. 
subulatulum Besch, in Marie M. Mayotte n. 157.

- Afr. : Ins. Mayotte.

suocedaneum (Hook. f. et Wils.) Jaeg. Ad. 11, p. 461.

Hypnum succedaneum H. f. et W. Fl. Antarct. II, p. 420; C. M. Syn. II, p. 341.

Sematophyllum succedaneum Mitt. op. cit. p. 484.

Ster. - Am. merid. : Brasil.

tegeticula Bosw. in Journ. of bot. 1892, p. 98.

1.

- Pac. : Nov. Caledon.

temperatum (C. M.) Par.

Aptychus temperatus C. M. in Hedwig. 1897, p. 123.

1 .

- Am. merid. : La Plata.

tenerifolium (C.M.) Par.

Aptychus tenerifolius C. M. in Hedwig. 1897, p. 121.

1 .

- Am. merid. : Argentin subtropic. Tucuman.

tenuirostre (Hook.) Jaeg. Arl. II, p. 469.

Hypnum tenuirostre Hook. M. ex. t.111 ; Brid. Bryol, univ. II, p. 616; C. M. Syn. II, p. 343 ; H. f. et W. Fl. of the N. Zeal. II, p. $113 \mathrm{et} \mathrm{Fl}$. Tasm. II, p. 213.

Rhaphidorhynchum tenuirostre Mitt. in Trans. and Proced. of the roy. Soc. of Victoria, $1883, p .85$.

- Pac. : Nov. Zeland. med., Tasman.

tequendamense (Hpe.) Jaeg. A l. II, p. 472.

Hypnum erithmifolium Hpe. in Ann. se. nat. V ser, p. 326.

H. tequendamense ej. in Linn. 1861-62, $p .529$.

Rh. crinitifolium Jaey. Ad. II, p. 461.

Sematophyllum crinitifolium Mitt. op. cit. p. 484.

S. tequendamense eJ. op. cit. p. 491 .

1. Cortic. - Am. merid. : And. Nov. Granat.

thelidictyon (Sull. el Lesq.) Par.

Hypnum thelidictyon S. et L. in Proced. of the Am. Acad... 1859, p. 280.

Rhaphidorhynchum thelidictyon Mitt. in Trans. of the Linn. Soc. 1891, $p, 175$.

Trichosteleum thelidictyon Jaeg, Ad. II, p. 483.

1. Rupic. - As. : Japon., Hong-Kong.

trachœlocarpa (Ångstr.) Besch. Fl. bryol. Taz̃ti, etc. p. 50.

Hypnum tracholocarpa Angstr. in Oefv... 1873, n. 5.

Trichosteleum tracholocarpa Jaeg. Ad. II, p. 479.

1.

$$
\text { - Pac. : Taïti. }
$$

trachypyxis (C.M.) Par.

Hypnum trachypyxis $C$. M. in Abhandl. Brem. VII, p. 213. 1.

- Afr. : Madagascar.

trichostegum (C. M.) Par.

Hypnum trichustegum C. M. in Linn. 1878-79, p, 499. I.

- Am. merid. : Venezuela.

tristiculum (Mitt.) Jaeg. 1I, p. 458.

Stereodon tristiculus Mitt. M. Ind. or. p. 102.

1.

- As. : Khasia, Assam super., Ceylan.

tuliferum Jaeg. - Rhynchostegium. 
Warmingii (Hpe.) Jaeg. Ad, 11, p. 466.

Rhyncho-Hypnum Warmingii Hpe. Symb. 1870, p. 292.

1.

- Am. merid. : Brasil. austr. or.

Welwitschii W. P. Sch, herb.

Isothecium crassiusculum Mont, in Bourg. Pl. Canar, n. 617.

Hypnum arrectum Mitt. in Journ, of the Linn. Soc. IX?

H. subtrumulosum Hpe. mss.: C. M. in Bot. Zeit, 1862, p. 12.

Rh. auricomum Jaeg. $A d . I I, p, 467$.

Rh. demissum Lange in Bot. Tidskrift, 1868, p. 251.

Rhynchostegium Welwitscbii W. P. Sch, in litt. 1846 et Syn. II ed. p, 679 ,

Sematophyllum auricomum Mitt. in Joum. of the Linn. Soc. 1863, p. 5 c. ic. in $t . I I$.

1. Cortic. - Eur. : Ins. Elba, Lusitan. merid. Afr,: Alger. (Kabyl. min.), Madeir., Teneriff.

xylophilum (Milt.). Jaeg. Ad. II, p. 470.

Hypnum callidum Sull. in Proced. of the Am. Acad.... 1861, p. $288 \mathrm{et}$ in Wright $M$. Cubens, $n$. 115.

$H$. pseudo-callidum $C, M$. in sched.

Rh. pseudo-callidum Jaeg. $l$. $o$.

Sematophyllum xylophyllum Mitt. M. austr. am. p. 499.

- Am. sept. : Cuba (1).

Theest $m$ p.1067 (REMYELLA C. M. in Fl. 1896, p. 477 (1 spec.).

hawaica C. M. in op. et l. c.c.

Ad ramul. - Pac.: Ins. Sandwic.

RHEGMATODON Brid. Bryol. univ. II, p. 204 (21 spec.).

acidodon (Mont.) Par.

Leskea acidodon Mont, in Ann. so, nat. 1845, p. 96, t. 5, f. 4 et Syll. p. 19.

Macrohymenium acidodon Besch. Fl. bryol. Réunion, etc., p. 150.

M. rufum C. M, in Bot. Zeit. 1847, p. 825, p. p.

Rh, rufus ej. Syn. II, p. 30, p.p.

- Afr.: Madagasc., ins. Seychell., Borbon.

" var. acutissima (Besch.) Par.

Macrohymenium acidodon var, acutissima Besch, op. cit. p. 151.
Rh. madagassus Geh. Reliq. Ruterb. in Abhandl. v. Naturio. Ver, su Brem. 1882, p. 211.

- Afr: Madagascar, ins. Seychell.

brasiliensis Lindb. mss. ; C. M. in Bot. Zeit. 1862, p. 374.

1. Lignic. - Am. merid. : Brasil. austr. or.

cuspidatus (Mitt.) Par.

Macrohymenium cuspidatum Mitt. in litt. ad Kiaër in Christ. Vid, Forh. $1882, p, 45$.

$$
\text { - As. : Khasia. }
$$

declinatus (Hook.) Brid. Bryol. univ. II, p. 204; C. M. Syn. II, p. 30; Mitt. M. Ind. or. p. 127.

Pterogonium declinatum Hook, in Trans, of the Linn. Soc. 1X, t. 26, f. 3.

1. Ad arbor. - As. : Nepal., Khasia.

(1) In Enum. Kindb. nom, nud, :

Rh. Acicula $C, M$.

angustum $O . M$. Rh. gastrophyllun $C . M$.
virescentifolium $C . M$. 
densus W. P. Sch. hb.; Kiaër in op. cit. p. 37.

Rh, orizabanus Jaeg. Ad. II, p. 741.

Ad arbor. - Am. sept. : Mexic.

Feanus C. M. in Nuov. Giorn. bot. ilal. 1891, p. 601 (nom.).

- As,: Birman, super.

filiformis W. P. Sch. in Besch, Prodr. bryol. mexic. p. 87.

1. $\quad-A m$. sept. : Mexic.

? fusco-luteus W. P. Sch. in op. cit. p. 88.

gracillimus (C. M.) Par.

- Am. sept. : Mexic.

Nacrohymenium gracillimum C. M. in litt. ad Kiaër, in op. cit. p. 19.

- Pac. : Taïti.

hypnoides W. P. Sch. in op. cit. p. 88 .

Ster. $\quad-A m$. sept. : Mexic.

laevis (Thoo. el Mitl.) Par.

Macrohymenium laeve T. et $M$. in Journ. of the Linn. Soc. 1872, p. 317.

1.

- As. : Ceylan.

madagassus Geh. - Rh. acidodon var, acutissima.

minutus (Mitt.). Par.

Hypnum minutum Mitt. $M$ austr. am.p. 549.

1 ?

- Am. merid. : And. occid.

Mülleri (Dz. et Mk.) C. M. in Linn. 1869-70, p. 21.

Macrohymenium Mülleri $D z$, et $M k$. $M$. frond. ined. Archip. ind. 1. p. 168-169 et Bryol. jav. II, p. 114.

Nietneri C. M. in Linn. 1869-70, p. 20.

- As. : Sumatra, Java, Borneo.

Macrohymenium Nietneri Mitt, in Journ. of the Linn. Soc. 1873, p. 318. 1.

orizıbanus Jaeg. - Rh. densus. - As. : Ceylan.

orthostegius Mont. in Ann. sc. nat. 1842, p. 248 ; et Syll. p. 13; C. M.

Syn. II, p. $29 ;$ Mitl. M. Ind. or. p. 127.

? Anhymenium polysetum Griff. Not. p. 472 et Ic. pl. asia:. II, t. 97, f. 2.

1. Cortic. - As. : Assam, M. Neilgherr., Ceylan.

palustris Broth. - Rh. schlotheimioides.

polycarpus (Griff.) Mitl. M. Ind. or. p. 127.

Anhymenium polycarpum Griff. Not. p. 471 et Ic. pl. asiat. II, t. 97, f. 1. - As, : Sikkim, Khasia, Assam.

rufus (Reino. et Hsch.) C. M. Syn. II, p. 30 p.p.

Leskea mitrata Dz. et Mk. in Ann. so, nat. III ser., II, 1844, p. 311.

? L. rufa $R$. el $H$. in Nov. Act. Acad. Caes. Leop. XIV, p. 2, Suppl. 1826, pp. 716-717.

Macrohymenium rufus C. M. in Bot. Zeit. 1817, p. 825 p.p. ; Bryol.jav. II, 1. p. 112 .

rufus C. M. p.p. - Rh. acidodon.

schlotheimioides Spr. in Milt. M. austr. am. p. 560.

Rh. palustris Broth. in sohed.

1. Cortic. et ad rad. arb. - Am, nerid. : And. Quitens., Brasil. or. 
« var. minor Broth. in Bihang till K. Sv. Vet.-Akad. Handl. 1895, n. 3. - Am. merid. : Brasil.

secundus Kiaër in Christ. Vid. Forh. 1882, n. 24, p. 28, t. 11, f. 5, 7 et $t$. III, f. 1-5.

1. - Afr.: Madagascar.

serrulatus (Dz. et Mk.) Bryol. jav. II, pp. 1I1-112.

Macrohymenium serrulatum Dz. et Mk. M. frond. ined. Archip. ind. 1. pp. 170-171, $t .56$.

strictus C. M. in Linn. 1869-70, p. 21 .

Macrohymenium strictum Bryol. jav. II, p. 114.

1.

- As.: Borneo.

RHIZOGONIUM Brid. Bryol, univ. 1I, p. 664 (4l spec.).

ucanthoneuron C. M. - Rh. Menziezii.

aeruginosum $\mathrm{H}$. f. et W. - Hymenodon.

aristatum Hpe. in Linn. 1876, p. 314.

- Pac. . Tasman.

bifarium (Hook.) W. P. Sch. in Bot. Zeit. 1844, p. 125; Handb. of N. Zeal. Fl. p. 485.

Hypnum bifarium Hook. M. ex. t. 57.

Isothecium bifarium Brid. Bryol, univ. II, p. 356.

Mnium bifarium C. M. Syn. 1, p. 172 et II, p. 554.

2. Ad rup. et terr. - Pac. : Austral, Nov. Zeland. sept. et med., ins. Auckland et Chatham, Tasman.

brevifolium Broth. in Bail. Syn. of the Queensl. Fl. IV Suppl. p. 97 (nom.) et in Defv... 1890.

2. Lignic. - Pac. : Austral, or, (Queensland).

distichum (Swo.) Brid. Bryol. univ. 11, p. 665. Hypnum distichum Sw. in Sohrad. Jouin. IV, p. 179, t. $3, f+$ A (exol.
syn. Brid.).

Mnium distichum C. M. Syn. I, p. 173.

2. Ad rup. aquat. - Pac : Austral. or., Nov. Zeland, sept. et med, Tasman.

distichum C. M. - Rh. Mûlleri.

Dozyanum Sande Lac. in Miq. Ann. Mus. bot. Lugd. Batav. II, p, 295.

2.

Eas. : Savatier PI. Japon, n. 479.

flagellare (Sull. et Lesq.) Par.

Mnium flagellare $S$. et $L$. in Proced. of the Am. Acad... 1859, p, 277.

Trachycistis flagellaris Lindb, in Aot. Soc. Fenn. 1872, p. 241.

2. Rupic. - As. : Amour, Saghalien, Japon.

Exs. : Faurie PI. Japon. n. 829.

Geheebi $C . M$, in Rev, bryol. $1876, p .3$ (nom.). - Pac. : Austral, or. (Nov, Vales.).

gracillimum Hpe. in Linn. 1876, p. 314.

Ster. - Pac. : Austral. or.

Graeffeanum (C. M.) Jaeg. Ad. I, p. 682.

Mnium Graeffeanum C. M. M. Polyn. p. 61.

Ster.

- Pac. : Ins. Samoa. 
Helmsii (C. M.) Par.

Mnium Helmsii $C$. M. mss.

- Pac. : Nov. Zeland.

Hookeri (C. M.) Jaeg. Ad. I, p. 685.

Hypnum spiniforme $H$. f. et $W$. in sched. antarct.

Mnium Hookeri $C . M$. Syn. II, p. 555.

Rh. spiniforme $\beta$ H.f. et W. Fl. antaret. I, p. 137.

Rıpic. - Pac. : Nov. Zeland. med., ins. Auckland, Campbell, Austral. or. (Victoria), Tasman.

latifolium Bryol, jav. II, p. 2, t. 133.

2. Ad arbor. et terr. - As, : Ins, lianca, Borneo.

latifolium Ảngstr. - Rh. spiniforme (fid. C. M.).

Lindigii (Hpe.) Mitt. M. austr. am. p. 328.

Mnium Lindigii Hpe. in Ann. sc. nat. V ser., IV, p. 345.

Lignic. - Am. sept.: And. Costa Ric. Am. merid.: And. Nov. Granat.

longicollum $(C . M$.) $P a r$.

Mnium longicollum C.M. mss.

- Am. merid.: Valdivia.

lingiflorum (Mitt.) Jaeg. Ad. 1, p. 6×5.

Pyrrhobryum Iongiflorum Mitt. Sam. M. p. 174.

2 ? Lignic. - As. : Ins. Labuan.

mauritianum Hpe. in Besch. Fl. bryol. Réunion, etc. p. 101.

- Afr.: Ins. Borbon., Franciae.

medium Besch. Fl, bryol. Nov. Caled. p. 217.

- Pac. : Nov. Caledon.

Menziezii (Hook.) Jaeg. Ad. I, p. 686.

Bryum Menziezii Hook. Bot. Mise. I, 1880, p. 36, t. 19.

Hypnum acanthoneuron Sohwaegr. Suppl. III, II, I, 4 258 b.

Leucolepis acanthoneura Lindb.

Mnium Menziezii C. M. Syn. I, p. 177; Lesq. et Jam. Man. p. 249.

Rh. acanthoneuron C. M. in Bot. Zeit. 1817, p. 803 .

2. couver, Idaho.

- Am. sept. : Alaska, Columb, brit, Sitka, Van-

Exs. : Mac. Canad. M. n. 202 (Mnium).

Sull. et Lesq. M. bor. am. II ed, n. 306 (Mnium).

microphyllum (Dz. et Mk.) Jaeg. Ad. I, p. 686.

Mnium crispatum W. P. Soh. in Savatier M. Jap. n. 476.

Inium microphyllum $D$. et $M k$. $M$. frond. ined. Arch. ind, p. 26, t 12 ; C. M. Syn. I, p. 176,

Mn. radiatum Wils, in Lond. Journ of bot. VII, p. 274, t. $10 \mathrm{~A} ;$ C. $\boldsymbol{M}$. l. c. $I I, p .556$.

Rh. radiatum Jaeg. $l, o$.

Trachycystis microphylla Lindb. Obs, de Mn. europ. p. 80 ,

2. Rupic. - As. : China, Japon.

Exs.: Faurie Pl. Japon. n. 1827.

maioides (Hook.) W. P. Sch, in Bot. Zeit. 1344, p. 125.

Aulacomnium chilense $C$. $M$. in Bot. Zeit. 1813, p. 61!, t. 3.

Hypnum mnioides Hook. M. ex. t. 77 .

H. subbasilave Schwaegr. Suppl, $t, 256$.

H. Stereodon mnioides Brid. Bryol iviv, II, p 559. 
Mnium polycarpum C. M. Syn. I, p. 176.

Rh. polycarpum ej. in Forschungsreise... Bot. p. 37.

2. Lignic. et rupic. - Am. merid.: And. Nov. Granat. et Chilens., Patagon. austr., terr. Magellan., Fuegia, ins. Eremitue. - Pac. : Austral.? Nov. Zeland, sept, et med., Tasman.

\& var. contortum Hook. f. et Wils. Fl. Tasm. p. 215.

Rh. Hookeri
Rh. Mossmannianum G. M. (fid. Mitt. itidem.

Ut et ubi typ. in Pac.

" var. lutescens $H$. f. et W. op. et $l$. cc.

Ut et ubi typ. in Pac.

Mossmannianum C. M. in Bot. Zeit. 1851, p. 547.

Rh. Hookeri C. M. (fid. Mitt.).

Rh. mnioides var. contortum (fid. Hook. f. Handb. p. 485).

2. Lignic. - Pac. : Austral, Tasman.

Mülleri Hpe. in Linn. 1846, p. 211.

Rh. distichum C. M. (fid. Handb. p. 484).

- Pac. : Austral. fel.

nanum C. $M$, in Fl. 1896, p. 438.

Ster.

- Am. merid. : Guian. brit.

Novae Caledoniae Besch. Fl. bryol. Nov. Caled. p. 217.

Terr. - Pac. : Nov. Guin. merid. (var.), Nov. Caledon.

\& var. minus Besch. $l$. c.

Lignic. - Pac. : Nov. Caledon.

Novae Hollandiae Brid. Bryol. univ. II, p. 664, t. suppl. Il, f. 1, 2 et 3 ad sinistr.

Fissidens Novae Hollandiae ej. $M$. Rec. II, I, p. 143, $t .6, f .11$.

Hypnum fissidentoides ej. Sp. M. II, p. 89.

Leskea Novae Hollandiae Schwaegr. Suppl, I, 1I, $t .83$.

Mnium Novae Hollandiae C. M. Syn. I, p. 173 et II, p. 554.

Rhizopelma Novae Hollandiae ej. in Bot. Zeit. 1847, p. 803.
Skitophyllum Novae Hollandiae la. Pyl. in Desv. Journ. bot. 1813, V. p. 59, t. $36, f .17$.

2. Lignic. - Pac. : Austral. or., Nov. Zeland. sept. et med., ins. Auckland, Tasman.

paramattense (C.M.) Jaeg. Ad. $1, p, 684$.

Mnium paramattense C. M. Syn. II, p. 555.

2. Ster.

- Pac. : Austral. or.

pellucidum (Mitt.) Jaeg. Ad. I, p. 683.

Photinophyllum pellucidum Mitt. Sam. M. p. 175.

Rh. reticulatum Hpe, in Linn. 1859-60, p. 636.

1 .

- Pac. : Austral., Nov. Zeland., Tasman.

pennatum Hook. f. et Wils. Fl. of the N. Zeal. II, p. 116, t. 92,f. 2 et

Handb. p. 484.

2. Ad arbor, - Pac. : Nov. Zeland. med.

Pervilleanum Besch. Fl. bryol. Réunion, etc. p. 101.

- Afr.: Madagasc. sept.

piliferum H. f. et W. - Hymenodon.

polycarpum C. M. - Rh. mnioides. 
pungens Sull. in Proced. of the Am. Acad... III, p. 28, Ł. 26.

2 . - Pac: Ins. Sandwic.

pusillum $C . M$. mss.

- Pac.: Nov. Guin. brit. (M. Yule).

radiatum Jaeg. - $\mathrm{Rh}$. microphyllum.

remotifolium $C . M$. nss.

Ster.

- Pac.: Nov. Guin, brit. (M. Yule).

reticulatum (Hook. f. et Wils.) Mitt. M. austr. am. p. 327.

Goniobryum reticulatum Lindb. Obs. de Mn. europ. p. 83.

Hypnum reticulatum $H$. $f$. et $W$. in Lond. Jourre of bot. 1844, p. 553; H. et T. Fl. Antaret. II, t. 154, f. 5 ; C. M. Syn. I, p. 174 et II, p. 554. - Am. merid.: Patagon. austr., ter. Magellan., Fuegia, ins. Eremitae.

reticulatum Hpe. - Rh. pellucidum.

setosum Mitt. Fl. Vit. p. 384.

Mnium setosum C. M. M. Polyn. p. 61.

Pyrrhobryum setosum Mitt. Sam. M. p. 174.

2. Ad arbor, - Pac.: Ins. Samoa, Taïti, Nov. Hebrid. (Aneitum).

spiniforme (L.) Br. in Fl. 1846, p. 134.

Hypnum erectum, non ramosum, spinarum halecum aemulnm Dill. Hist. M. p. 332, t. $43, f .8 .68$

H. spiniforme L. Sp. pl. p 1587.

H. Stereodon spiniformis Brid. Bryol. univ. II, p. 557.

Mnium spiniforme C.M. Syn. I, p. 175.

Pyrrhobryuin spiniforme Mitt. Sain. M. p. 174.

Rh. latifolium Angstr, in Vet. Akad. Förrh. 1872, n. 4, p. 18.

Syn. Cortic., lignic. et saxic. -- As. : Nepal., Sikkim, Assam, penins. Malay., Japon., ins. Philippin., Celebes, Borneo, Java, Sumatra, Ceylan. Afr.: M. Cameroon, Kilima NDjaro, Usambara, ins. Fernando Po, C. B. Sp., Madagasc., ins. Franciae. Am. sept.: Ludovic., Alabama, Florid, Mexic., Antill, Am. merid. : Tropic. et subtropic. Pac.: Ins. Sandwic., Taïti, Nov. Guinea, Nov. Caled., Nov. Zeland sept., Austral. fel,, ins. Kermadec, Tasman.

Exs. : Dusen M. Camer. n. 483.

Rehm. M. Afr, austr, n. 262.

" var. acunhense Besch. Fl. bryol. Réunion, etc. p. 100. - Afr. : Ins. Tristan d'Acunha? vel Franciae?

"var, brevifolium Besch. op. el l. cc. - Afr.: Ins. Borbon.

" var. comorense C. M. in Linn. :876, p. 215.

Cortic. - Afr. : Ins. Anjouan.

" var. elatum Bryol. jav.

- As. : Java, Sumbawa.

* var. pumilum C. M. in Fl. 1896, p. 438.

- Pac. : Ins. Sandwic.

$\operatorname{var}, \beta$ H. f. et W. - Rh. Hookeri.

strictım C. M. in Angstr. Prim. lin. p. 51.

Cryptopodium bartramioides Angst $r$. in Oef $v \ldots . .1372, n+4, p .51$.

$\sigma^{t}$ et fr. ign.

- Pac. : Ins, Sandwic. 
subbasilare (Hook.) W. P. Sch. in Bot. Zeit. 1844, p. 125.

Goniobryum subbasilare Lindb, in Oefv... 1864, p. 607.

Hypnum mnioides Schwaegr. Suppl. III, II, I, n. 257 a.

H. subbasilare Hook. M. ex. t. 10.

H. Stereodon subbasilaris Brid. Bryol. univ. II, p. 559.

Mnium subbasilare C. M. Syn. I, p. 174 et $I I, p .555$.

Trachyloma subbasilare Mitt. in Journ. of the Linn. Soc. 1859, p. 86.

1. Lignic. et terr. - Am. merid: Archip. Magellan., Fuegia, ins, Eremitae. Pac. : Ins. Samoa (1), Noy. Zeland, med, Tasman.

taxiforme Hpe. in Linn. 1876, p. 312.

Ster.

- Pac. : Austral. or.

undulatum (Lindb.) Par.

Mesochaete undulata Lindb. in Oefv..., 1869, p. 70.

2 .

- Pac. : Austral. or.

venustum Mitt, in Lond. Journ. of bot, VIII, p. 23I, t. 12, f. B. ?

Vallis-Gratiae (Hpe.) Par.

Mnium Vallis-Gratiae Hpe, in Bot. Zeit. 1859, p. 205.

2.

Exs. : Rehm. M. Afr. austr. n. 263 b.

RHIZO-HYPNUM Hpe. Symb. p. 733 el Enum. M. Brasil, p. 71.

tamarisciforme Hpe. - Microthamnium.

versipoma Hpe. - Microthamnium.

RHIZOPELMA C. M. in Bot. Zeit. 1847, p. 803.

Novae Hollandiae C. M. - Rhizogonium.

RHODOBRYUM W. P. Sch. Syn. I ed. p. 381 (subgen. BRYI, gen. propr. in herb.) (95 spec.).

alto-limbatum Hpe. in Linn. 1869-70, p. 517.

Bryum alto-limbatum Mitt. in Trans. and Proced. of the roy. Soc, of Victoria, 1883, p. 73.

- Pac. : Austral, occid.

alto-pedunculatum (C, M.) Por.

Bryum alto-pedunculatum $C$. M. in Ule Bryoth. brasil. n. 26.

- Am, merid. : Brasil, austr. or.

alto-roseum (C. M.) Par.

Bryum alto-roseum C. M. in Dusen M. Camer, $n .784$. - Afr.: M. Cameroon.

andicola (Kunth.) Par.

Bryum andicola Kth. Syn. pl. Equinoct. I, p. 58 ; Brid. Bryol. univ. I, p. 667 ; C. M. Syn. 1, p. 256.

Br. Lechleri C. M. (fid. Mitt.).

2.

et Chilens. 
andino-roseum (C. M.) Par.

Bryum andino-roseum C. M. in Fl. 1897, p. 330.

2.

- Am. meridt. : And. Venezuel.

Antillarum W. P. Sch. $h b$.

Bryum Antillarum W. P. Sch. in Besch. Fl. bryol. Antill. fr. p. 32.

Br. Polla rosea var, domingensis Brid. Bryol. univ. $I, p$. 698.

Br. domingense Steud. Nom. crypt. p. 87.

Mnium domingense Brid. Mant. M.p. 119.

Mn. grandifolium Tayl, in Lond. Journ. of bot. 1847, p. 336 p.p.

2.

- Am. sept. : Guadalup,

argutidens (Rehm.) Par.

Bryum argutidens Rehm. M. Afr. austr, n. 556 et $b$.

Ster. $\quad-A f r$. : Transvaal.

Beyrichianum (Hsch.) W. P. Sch. Syn. II ed.p. 464 (nom.).

Bryum Beyrichianum C. M. Syn. I, p. 249 p.p.

Br. roseum W. Arn. in Act. Soc. Wern. V, p. 201.

Mnium Beyrichianum Hsch. Fl. Brasil. I, p. 45.

2. Ad rup. umbros. - Am. merid.: Columb., And. Nov. Granat,, Quitens, et Paruv, ; Chile, Brasil. or.

breviramulosum Hpe. in Linn. 1876, p. 311.

Bryum breviramulosum Mitt, in Trans, and Proced. of the roy. Soc. of Vietoria, $1883, p .73$.

- Pac. : Austral, or. (Victoria), Tasman.

campylothecium (Tayl.) Par.

Bryum campylothecium Tayl. in Lond. Journ. of bot. 1846, p. $52 ;$ C. M. Syn. I, p. 254.

Ad arbor. et rup. - Pac. : Austral, or., Nov.Zeland., ins. Campbell, Tasman.

caulifolium (C. M.) Par.

Bryum caulifolium C. M. in Nuov, Giorn. bot. ital. 1897, p. 20.

- Am. merid. : And. Boliv.

chalarorhodon (C.M.) Par.

Bryum chalarorhodon C. M. in Dusen M. Camer, n. 207.

$$
\text { - Afr. : M. Cameroon. }
$$

coloratum (C. M.) Par.

Beyum coloratum. M. in Linn. 1878-79, p. 296.

- Am. merid.: And Boliv.

Commersoni (Schwaegr.) Par.

Bryum Commersoni Brid. Mant. M. p. 119; C. M. Syn. I, p. 249.

Br. Polla Commersoni Brid. Bryol, univ. I, p. 710.

Mnium Commersoni Schwaegr. Swppl. I, II, p. 131, t. 80.

2.

Pac. : Austral. or., ins. Lord Howe.

- Afr.: Kilima N'Djaro, ins. Borbon., Franciae.

comatum (Besch.) Par.

Bryum comatum Besch. Prodt: bryol. mexic. p. 55.

- Am. sept. : Mexic.

confluens (C. M.) Par.

Bryum confluens C. M. in Bull. hb. Boissier, 1897, p. 179.

Ster.

- Am. sept. : Guatemala. 
crispatum Hpe, in Linn. 1876, p. 310.

Bryum crispatum Mitt, in Trans, and Proced. of the roy. Soc. of Victoria, $1883, p .73$.

Syn. - Pac. : Austral or.

cygnopelma C. M. in Bull. hb. Boissier, 1897, p. 550.

2.

- Am. sept. : M. Jamaic.

Decaisnei (Dz. et Mk.) Par.

Br. conicum Dz. et Mk. in Ann. so. nat. 1844, p. 300.

Br. Decaisnei eor. M. frond. ined. Arch. ind. p. 19, t. 9; C. M. Syn. I, p. 251 ; Bryol. jav. I, p. 149.

2. Lignic. - As. : M. Java.

Ehrenbergianum (C.M.) Par.

Bryum Ehrenbergianum C. M. Syn. I, p. 255.

2. -Am. sept. : Mexic.

ellipticifolium Brizsi in Ann. d. R. Istit. bot. di Roma, 1893, V, fasc. 2. In silv. - Afr. : Choa.

erythrocaulon (Schucaegr.) Par.

Bryum erythrocaulon Brid. Mant. M. p. 119; C. M. Syn. I, p. 262.

Br. Polla erythrocaulis Brid. Bryol, univ. I, p. 711.

Mnium erythrocaulon Schwaegr. Suppl. I, II, p. 127, t. 80.

Ster. - Afr. : Ins. Franciae, Rodriguez; Usambara.

fluminale $(C, M$.) Par.

Bryum fluminale C. $M$. in Dusen $M$. Camer, $n .666$.

- Afr. : M. Cameroon.

gigaxteum (Hook.) W. P. Sch. Syn. II ed., p. 464 (nom.).

Bryum giganteum Hook, in Schwaegr. Suppl. II, II, I, p. 20, t. 158; C. M. Syn. I, p. 248.

Br. Polla rosea $\gamma$ gigantea Brid. Bryol, univ. I, p. 854.

Br. Sollyanum Griff. Not. p. 446 et Io. pl. Asiat. t. 91, f. I.

2. Ad terr, humid, - As. : Nepal., Sikkim, Khasia, Ceylan, Java, Borneo. Afr. : Ins. Borbon. Pac. : Ins, Hawai.

Glaziovianum Hpe. Symb. 1874, p. 496.

2. Ad terr. umbros. - Am. merid. : Brasil, austr. or. globicoma (C. M.) Par.

Bryum globicoma C. M. in Nuov. Giorn, bot.ital. 1897, p.

Ster.

$$
\text { - As. : China or. (prov. Schen-Si). }
$$

globirhodon (C. M.) Par.

Bryum globirhodon C. M. in Dusen M. Camer. n. 235.

Goudotii (Hpe.) Par.

$$
\text { - Afr.: M. Cameroon. }
$$

Bryum Goudotii Hpe, in Ann. se, nat. V ser, IV, p. 340. 2.

- Am. merid. : Summ. And. Nov, Granat.

Graeffeanum (C.M.) Par.

Bryum Graeffeanum C. M. M. Polyn.p. 63.

2. Ad arbor. - Pac. : Ins. Fidji.

grandifolium (Tayl.) W. P. Sch, Syn, II. p. 464 (nom.).

Bryum grandifolium c. M. Syn. I, p. 250.

Mnium grandifolium Tayl. in Lond. Journ. of bot. 1847, p. 336. 
2.

Quitens, et Boliv.

- Am. merid. : Venezuela, And. Nov. Granat., Exs. : Mandon Pl. Boliv, n 1666 bis.

Hieronymi (C.M.) Par.

Bryum Hieronymi C. M. in Linn. 1878-79, p. 285.

2.

- Am. merid. : Argentin. subtropic.

horizontale Hpe. Symb. 1874 , p. 498.

2. Terr. - Am. merid. : Brasil. austr. or.

lato-cuspidatum (C, M.) Par,

Bryum Iato-cuspidatum C. M. in Bull. hb. Boissier, 1897, p. 180.

Ster. In silv, primaev. - Am. sept.: Guatemala.

* var diaphanulum (C.M.) Par.

Bryum lato-cuspidatum var, diaphanulum C. M. in op. et $l$. ce. - Am. sept. : Guatemala.

laxiroseum (C. M.) Par.

Bryum Iaxiroseum C. M. in Linn. 1876, p. 243.

Ster. Terr. in silv. - Af, : Ins. Anjouan.

Lechleri (C. M.) Par.

Bryum Lechleri C. M. in Bot. Zeit. 1856, p. 416.

Br, truncorum W. P. Sch. in Lechler Pl. Chil. n. 626 b.

2. Ad arbor. - Am. merid. : Valdiv.

leptorhodon (C.M.) Far.

Bryum leptorhodon C. M. in Nuov, Giorn. bot. ital. p. 1896, p. 95.

Ster.

- As. : China or. (prov. Schen-Si).

lepto-roseum (C, M.) Par.

Bryum lepto-roseum C, M. in Dusen M. Camer. n. 660.

- Afr. : M. Cameroon.

leptothecium (Tayl.) Par.

Bryum leptothecium Taul. in Phytol. 1844, n. 41, p. I094; C. M. Syn. I, p. 254.

Br. truncorum H. f. et W. Fl. Tasman. II, p. 192; Fl. of the N. Zeal. II, p. 87 et Handb. p. 439.

- Pac.: Ins. Societat., Austral. fel., Nov. Zeland, ins, Campbell et Norfolk, Tasman.

leptothrix (C. M.) Par (1).

Bryum integrifolium Rehm. M. Afr. austr. n. 226.

Br. leptothrix C, M. l, c. n. 554 et in M. Mac-Orcanianis n. 20.

- Afr. : Sierra Leone, Natal, Madagascar.

leucocanthum Hpe. in Linn. 1874, p. 663.

Bryum leucocanthum Mitt, in Trans. and Proced. of the roy. Soc. of Victoria, $1883, p .73$. 2.

- Pac. : Ins. Lord Howe.

Liebmanni $W, P . S c h . h b$.

Bryum Liebmanni ej, in Besch. Prodr. bryol. mexic. p. 56.

2?

- Am. sept. : Mexic.

(1) Cl. Mitten in Journ. of the Linn. Soc. 1886, p. 307 conjungit. Rh. Zeptothrix, giganteum et grandifolium at var, Rh. rosei. 
limbato-marginatum (C.M.) Par.

Bryum limbato-marginatum C. $M$, in Fl. 1896, p. 440.

Ster. - Pac. : Ins. Sandwic.

Lindigianum (Hpe.) Par.

Bryum Lindigianum Hpe. in Ann. sc. nat. V ser, IV, p. 340. 2. - Am. merid. : And. Nov. Granat.

Lorentzianum (C. M.) Par.

Brsum Lorentzianum C. M. in Linn. 1878-79, p. 286.

2.

- Am. merid. : Argentin. subtropic.

macrorhodon (C. M.) Par.

Bryum macrorhodon C. M. in op. cit. p. 288 (nom.).

- As. : Japon.

medianum (Mitt.) Par.

Bryum medianum Mitt. M. Ind, or, p. 74.

2.

- As. : Khasia, M. Neilgherr.

megalostegium (Sull.) Par.

Bryum megalostegium Sull. in Am. Expl. Exped. 1859, p. 9, t. 7.

2. - Pac. : Ins. Samoa, Sandwic., Kermadec, Raoul. micro-comosum (C.M.) Par.

Bryum micro-comosum C. M. in Nuov, Giorn. bot, ital. 1897, p. 19. - Am. merid. : And. Boliv.

microrhodon (C.M.) Par.

Bryum microrhodon C. M. in Linn. 1878-79, p, 288 (nom.). - As. : Japon.

micro-roseum (C. M.) Par.

Bryum micro-roseum $C$. $M$. in hb. Saharampur. - As. : Simla.

minuti-rosatum (C.M.) Par.

Bryum minuti-rosatum C. $M$. in Fl. 1888, p. 408.

Br. roseum Mitt. in Journ. of the Linn. Soc. 1886, p. 307 ?

Ster, In graminos. - Afr. : Kilima N'Djaro. mniopsis (C. M.) Par,

Bryum mniopsis C. $\boldsymbol{M}$. in Cinn. 1874, p. 580 .

Ster. - Am. merid.: And. Nov. Granat.

nanorhodon (C. M.) Par.

Bryum nanorhodon C. M. in Besch, Fl, bryol. Réunion, eto, p. 96.

Ster. - Afr.: Ins. Franciae.

'nano-rosula (C.M.) Par.

Bryum nano-rosula C. M. in Nuov. Giorn, bot, ital. 1897, p.

Ster. - As. : China or. (prov, Schen-Si).

neilgheriense (Mont.) Par.

Bryum neilgheriense Mont. in C. M. Syn. I, p. 255 et Syll.p. 32. 2. - As.: M. Neilgherr.

olivaceum Hpe, in Linn. 1876, p. 311. Bryum olivaceum Mitt. in Trans. and Proced. of the roy. Soe of Vio-
toria, 1883, p. 73 .

Ster.

- Pac.: Austral, or. subtropic. 
ontariense (Kindl.) Par.

Bryum ontariense Kindb. in Bull. Torr. bot. Club, 1889, p. 96 et in Mac. Cat. p. 135.

Br. roseum Lesq. et Jam. p.p.

2. Lignic, et rupic, in silv. - Am. sepl.: New Brunswick, Ontario, Ohio, Kansas.

Exs. : Mac. Canad. M. n. 184 (Bryum.).

platense (C.M.) Par.

Bryum platense C. M. in Hedwig. 1897, p. 95.

Ster. - Am. merid.: La Plata.

Preussii (Broth.) Par.

Bryum Preussii Broth. in Engler's Bot. Jahrb. 1894, p. 187.

2.

- Afr.: M. Cameroon.

procerum W. P. Sch. $h b$.

Bryum procerum ej, in Besch. Prodr. bryol, mexic, p. 55.

$$
\text { - Am. sept. : Mexic. }
$$

pseudo-giganteum (C.M.) Par.

Bryum giganteum Sull, in Exped. Wilkes. p. 9.

$\mathrm{Br}$. pseudo-giganteum C. M. in Linn. 1878-1879, p. 288 (nom.) et in $\mathrm{Fl}$. $1896, p .439$.

Ster.

- Pac. : Ins. Sandwic.

pseudo-marginatum (Geh, el Hpe.) Par.

Bryum pseudo-marginatum $\mathrm{G}$, et $\mathrm{H}$, in $\mathrm{Fl}$. 1881 .

2.

- Am. merid. : Brasil. austr, or.

ptychothecium (Besch.) Par.

Bryum ptychothecium Besch. in Ann. so. nat. 1892, I, p. 66.

2.

- As. : Yunnan.

pusillum (Broth.) Par.

Bryum pusillum Broth, in Oefv... 1890.

2. Ad arbor. - Pac. : Austral. or. (Queensland).

pycnopyxis (C. M.) Par.

Bryum pyenopyxis C. M. in Linn. 1878-79, p. 474.

2.

- Am. merid.: Venezuela.

pycnothecioides (C.M.) Par.

Bryum pycnothecioides C. M. in Nuov, Giorn, bot, ital. 1897, p.

Ster.

- As. : China or. (prov, Schen-Si).

pyrothecium (Hpe. et C. M.) Par.

Bryum pyrothecium Hpe. et C. M. in Linn. 1853, p. 495.

Syn.

- Pac. : Austral, or., Tasman.

Quintasii (Broth.) Par.

Bryum Quintasii Broth, in Bol. da Soc. Brot. VIII, 1890.

2. Ster. Ad arbor. - Afr. : Ins. S. Thomas.

rhodocephalum C. M. in Bot. Zeit. 1838, n. 47.

- Am. merid.: Equator. ?

rigidum (Hsch.) Par.

Bryum rigidum C. M. Syn. I, p. 263. 
Bryum patens Wils. in Lond. Journ. of bot. 1844, p. 155; C. M. l. c. p. 250 (fid. Mitt.).

Mnium rigidum $\mathrm{Hsch}$. Fl. Brasil. I, p. 46.

2. Rupic. - Am. merid. : Brasil., Monte Video.

robustulum (C. M.) Par.

Bryum robustulum C. M. in Engler's Bot. Jahrb, 1883, p. 77 et in Forschungsreise... Bot, p. 14.

Syn.

- Afr. : Ins. Kerguelen.

robustum (Hpe.) Par.

Bryum robustum Hpe, in Linn. 1856, p. 205.

- Pac. : Austral. fel.

roseodens (C.M.) Par.

Bryum roseodens C. M. in Rev. bryol. 18;6, p. 3 (nom.).

(Nov, Valesia).

- Am. merid.: Nov. Granat. Pac.: Austral. or.

roseolum (C. M.) Par.

Bryum roseolum C. M. in Linn. 1878-79, p. 287.

Fl. et $\mathrm{fr}$, ign. $\quad-$ Am, merid. : Argentin. subtropic.

roseum (Sclveb.) W. P. Sch. hb.

Bryum Commersoni Wils. in Kew Journ. bot. IX, p. 367.

Br. Bryo Commersoni affine ej. op. cit.

Br. Bryo neilgherriensi affine ej. op. cit.

Br. roseum Schreb. Spic. Fl. Lips, p. 84; Bryol. eur. IV (mon. p. 56), t. $365 ;$ C. M. Syn. I, p. 247; W. P. Sch. Syn. II ed. p. 463.

Br. stellare roseum majus, capsulis ovatis pendulis Dill. Hist, M. p. 411, t. $52, f .77$.

Br. Zollingeri Wils. op. oit.

Br. Polla rosea Brid. Bryol, univ. I, p. 696.

Hypnum roseum W. et M. Bot. Taschb. p. 207.

Mnium pr aliferum Gmel. Syst. Nat. I1, p. 1330.

2. Ad terr. et rad, arb. in silvat. - Eur. : Reg. campestr. et mont. As. : Japon., Jenissei med., Nepal., Himalaya, Tibet. oce., Caucas. Afr.: Kilima N'Djaro (?), Madagascar (Baron, n. 5053). Am. sepl.: Calif.?

Exs. : Rab. Bryoth. eur. n. 1194, 1119.

« var. brachycarpum (Wright) Par. Bryum roseum var. brachycarpum Wright in Lond. Journ. of bot. 1892,
p. 263.

- As. : Himalaya.

rosulatulum (C, M.) Par.

Bryum rosulatulum C. $M$. in Fl. $1890, p .474$.

Sterr. In graminos. - Afr. : Kilima N'Djaro.

rosulatum (C. M.) Par.

Brachymenium rosulatum Beseh. Prodr. bryol. mexic. p. 51.

Bryum rosulatum C. M. in Bot. Zeit. 1856, p. 416.

2.

- Am. sept. : Mexic.

rosulicoma (Ren. el Card.) Par.

Bryum rosulicoma $R$, et C. in Bull. Soc. roy. bót. Belg. 1892, I, p. 166.

2. Ster. Lignic. - Am. sept.: Costa Rica.

saprophilum (C.M.) Par.

Bryum saprophilum C. M. in Dusen M. Camer. n. 752. 
Sartorii W. P. Sch, hl.

Bryum Sartorii ej. in Besch. op. cit. p. 56.

2.

- Am sept.: Mexic.

simplex (Kindb.) Par.

Bryum simplex Kindb. in Bitrag p. 453 et Mac. Cat. p. 135.

Ster. Rupic. - Am. sept. : Columb. brit.

spathulosifolium (C.M.) Par.

Bryum spathulosifolium C. M. in Fl. 1890, p. 474.

Ster. In graminos. - Afr. : Kilima N'Djaro, Usambara.

stenothecium Hpe. Symb. 1874, p. 497.

Terr. in silv. - Am. merid, : Brasil. austr. or.

streptorhodon (C. M.) Par.

Bryum streptorhodon C. M. in Bull. hb. Boissier, 1897, p. 179

- Am. sept.: Guatemala.

suberythrocaulon $\mathrm{Par}$.

Bryum erythrocaulon C. M. in Krause M. Ecuador.

- Am. merid. : And. Equator.

subfasciculatum Hpe, in Linn. 1876, p. 312.

Bryum subfasciculatum Mitt. in Trans. and Proced. of the roy. Soc. of Viotoria, 1883, p. 73 .

Ster.

- Pac. : Austral, or. subtropic.

subleptothecium (C. M.) Par.

Bryum subleptothecium C. M. in Rev, bryol. 1876, p. 3 (nov.).

- Pac. : Austral. or. (Nov. Valesia).

subroseum (Besch.) Par.

Bryum subroseum Besch. op. cit. p. 56.

2.

- Am. sept. : Mexic.

subtomentosum Hpe. in Linn. 1869-70, p. 516.

Bryum subtomentosum Mitt. in Trans, and Proced. of the roy. Soc. of Victoria, $1883, p .73$.

Br. truncorum H.f. et W. Fl. of the N. Zeal.

2. toria).

- Pac. : Austral. or. et merid, (Nov. Vales, Vic-

Swarzianum $(C, M$.) Par.

Bryum Beyrichianum C. M. Syn. I, p. 249 p.p.

Br. Swarzianum ej. M. Polyn. p. 63 . 2.

- Am. sept. : Jamaic. Am. merid.: Venezuela.

syntrichioides (C. M.) Par.

Bryum syntrichioides C. M. in Rehm. M. Afr. austr. n. 228 et 557 . - Afr. : Orange, Transvaal, Natal.

truncorum (Brid.) W. P. Sch. hb.

Bryum truncorum Brid. Mant. M. p. 119; C. M. Syn. I, p. 254.

Br. Polla truncorum Brid. Bryol. univ. I, p. 699.

Mnizm giganteum Schwaegr. Sp. M. p. 28 p.p.

Mn, truncorum Brid. Sp. M. III, p. 50.

2. Ad terr, humid, - Afr. : Ins. Borbon., Franciae, Tristan d'Acunha, Inaccessible, Am, sept.: Mexic (?) 
umbraculum (Burch.). W. P. Sch. Syn. 11 ed.p. 464.

Bryum umbraculum Burch. in Hook. M. ex, t. 133 ; C. M. Syn. I, p. 248.

Br, Polla umbraculum Brid. Bryol. univ. 1, p. 698.

Mnium spathulatum Hsch, in Linn. 1841, p. 135.

Mn. umbraculum Schwaegr. Suppl. II, II, I, p. 22, t. 157.

2. Terr. in silv. - Afr.: Kilima N'Djaro, Usambara, reg. lacustr., C. B. Sp., Natal.

utriculosum (C.M.) Par.

Bryum utriculosum C. M. in Bull. hb. Boissier, 1897, p. 180.

Ster.

- Am. sept, : Guatemala.

verticillatum Hpe. Symb. 1874, p. 496.

Bryum verticillatum ej.l. c. 1872, p. 51.

Terr. in silv, - Am. merid. : Brasil, austr, or.

Zollingeri (Duby) Par.

Bryum Zollingeri Dy. in Moritzi Syst. Verz. p. 133; C. M. Syn. I, p. 340 et II, p. 569; Bryol. jav. I, p. 150 .

2. Ad terr. humid. - As. : Nepal., M. Neilgherr., Ceylan, Java.

Rhodoweisia C. M. in Linn. 1876, p. 298 (Weisia tophicola ej.).

RHYNCHO-HYPNUM Hpe. Fl. Hercynica, 1873 et Moosb. p. 20.

Spec. omn. non indicatae sunt RHAPHIDOSTEGIA ejusd. nom. Aintipodum Hpe. - Rhynchostegium. apophysalum Hpe. - Rhynchostegium. subpungens Hpe. et C. M. - Rhynchostegium.

RHYNCHOSTEGIELLA Bryol. eur. $V$ (sect. RHYNCHOSTEgn); Limpr.

Laubm. Deutschl. IV, p, 207 (gen. propr.).

Spec, omn, non indicatae sunt RHYNCHOSTEGIA ejud. nom.

Teesdalii Limpr. - Eurhynchium.

RHYNCHOSTEgIOPSIS C. M. in Nuov. Giorn. bot. ilal. 1897, p. 163. Spec. omn. non indicatae sunt ECTROPOTHECla ejusd. nom.

flexuosa. C. M. - Leucomium.

RHYNGHOSTEGIUM Bryol, eur. V (187 spec.).

acanthophyllum (Mont.) Jaeg. Ad. II, p. 430.

Hypnum acanthophyllum Mont, in Ann. sc, nat, 1845, IV, p. 90 et Syll. p. 9 ; C. M. Syn. II, p. 398.

1. Cortic. - Am. merid. : Chile.

acutifolium (Hook. f. et Wils.) Jaeg. Ad, I1, p. 442.

Hypnum acutifolium $H$. $f$. et $W$. in Lond. Journ. of bot. 1844, p. 553 et Fl. Antaret. p. 138, t. 60, f. 5 .

Ster.

- Pac. : Ins. Campbell.

afro-rusciforme C. M. in Dusen M. Camer. n. 664 .

- Afr.: M. Cameroon.

altisetum C. M. in Hedwig. 1897, p. 132. 2?
man. $\quad-A m$, merid.: And. Argentin. subtropic. Tucu- 
ambiguum W. P. Sh. in Mandon Pl. Boliv. $n .1698$.

- Am. merid. : And. Boliv.

amblyacron (C. M.) Jaeg. Ad. II, p. 443.

Hypnum amblyacron $C . M$. in sched.

- As. : Sikkim.

anceps (Bryol.jav.) Jaeg. Ad. II, p. 438.

Hypnum anceps Bryol. jav. II, p. 161, t. 260.

1. - As. : Java.

androgynum Bryol, eur, - Eurhynehium speciosum.

? aneuron Kindb. - Plagiothecium membranaceum.

Antipodum (Hpe.) Par.

Rhyncho-Hypnum Antipodum Hpe. in Trans. and Proced. of the roy. Soc. of Victoria, 1883, p. 88.

1. Paludic. - Pac. : Austral. or.

apophysatum (Hsch.) Jaeg. Ad. II, p. 439.

Leskea apophysata Hsch. Fl. Brasil. I, p. $74 ;$ C. M. Syn. II, p. 27.

Rhyncho-Hypnum apophysatum Hpe. Symb. 1870, p. 283.

1. Cortic. - Am. merid. : Brasil, austr. or.

aquaticum (Hpe.) Jaeg. Ad. II, p. 444.

Hypnum aquaticum Hpe, in Linn, 1863, p. 161.

In rivul, ad saxa, - Am, merid. : Aquat., Brasil. austr. or.

aristatum (Hook. f. et Wils.) Jaeg. Ad. 11, p. 436.

Brachythecium aristatum Mitt. in Trans, and Proced. of the roy. Soc. of Victoria, $1883, p .89$.

Hypnum aristatum H. f. et W. Fl. Tasman. II, p. 210, t. 176, f. 6 et Handb. of N. Zeal. Fl. p. 478.

1. Lignic, et ad terr. humid. - Pac. : Austral. or., Nov. Zeland, sept. et med., Tasman.

asperisetum (C. M.) Jaeg. Ad. II, p. 438.

Hypnum asperisetum C. M. in Bot. Zeit. 1858, p. 171.

Syn.

- As, : Java.

Assumptionis Besch, Not. M. Paraguay. p. 271.

Eos. : Balansa PI. Parag. nerid. 1273.

atlanticum Bryol, eur. - Rh rusciforme var. atlanticum.

austro-montanum (Hpe.) Par.

Hypnum austro-montanum Hpe, in F. v. Müller's Fragm. XI, Suppl. p. 51.

- Pac. : Austral. or.

Berteroanum (Mont.) Jaeg. Ad. II, p. 432.

Hypnum Berteroanum Mont. in Ann. sc. nat. 1845, IV, p. 83 et Syll. p. $6 ;$ C. M. Syn. II, p. 243 .

2. Terr. - Am. merid. : Chile, ins, Juan Fernandez.

Beskeanum (C. M.) Jaeg. Ad. $I$, p. 441.

Hypnum Beskeanum C. M. in Bot. Zeit. 1857, p. 384.

H. megapolitanum Hsoh. Fl. Brasil.?

1. Lignic. - Am, merid. : Brasil. or.

blandum Hpe. in Besch. Prodr. bryol. mexic. p. 107.

- Am. sept. : Mexic. 
bolivianum W. P. Sch, in Mandon Pl. Boliv. n. 1696.

- Am. merid. : And. Boliv.

Bourgœanum (Mitt.) Par.

Hypnum Bourgœanum Mitt. in Godman's Nat. hist. of the ins. Azor. 1870, p. 309 .

H. Teneriffae Bourg. Pl. Canas. exs n. 1235.

1.

- Afr.: Teneriffa.

brachypterum (Hsch.) Jaeg. Ad. II, p. 438.

Hypnum brachypterum Hsch. in Linn. 1841, p. 142 ; C. M. Syn. II, p. 248.

1 ? - Afr. : C. B. Sp.

Brandegei (Aust.) Par.

Hypnum Brandegei Aust. in Coult. Bot. Gaz. III, p. 31.

Ster.

- Am. sept. : Colorado.

Breutelianum W. P. Sch. - Rhaphidostegium Dregei.

brevicuspis C. $M$. in Hedwig. 1897, p. 134.

Terr. - Am. merid.: Argentin. subtropic.

Brotheri Par.

Hypnum julaceum Broth. in Bihang till K. Svet.-Akad. 1895, n. 3.

Ster. - Am. merid. : Brasil. austr. or.

bulnense Broth. in Engler's Bot. Jalırb. 1894, p. 213.

1.

- Afr. : Usambara.

cacticolum (C. M.) Par.

Hypnum cacticolum $C$. M. in Linn. 1880-83, p. 479.

Syn.

- Am. merid. : Argentin. Buenos-Ayr.

callistomum Besch. Prodr, bryol. mexic. p. 106.

Cortic. - Am. sept. : Mexic. (Orizaba).

? calocsience (Aust.) Par.

Hypnum calocsiense Aust. in Coult. Bot. Gaz. IV, p. 161.

1.

- Am. sept. : Florida.

campylocarpum (C. M.) Jaeg. Ad. II, p. 440.

Hypnum campylocarpum C. M. Syn. II, p. 249.

H. Sellowii ej. in Linn. 1847, p. 219; Hpe, in op. cit. p. 85.

1 .

- Am. merid. : Venezuela.

campylocladulum C. M. in Hedwig. 1897, p. 134.

1. Ad marg, rivul. - Am. merid. : Argentin. subtropic, Tucuman. cataractile (C. M.) Par.

Hypnum cataractile C. M. mss.

- As. : Himalaya sept. occid.

celebicum (Bryol, jav.) Jaeg, l. c.

Hypaum celebicam Bryal. jav. II, p. 159, t. 258.

1.

- As, : Tonkin, Celebes.

chrysophylloides (Hpe.) Jaeg. Ad. II, p. 434.

Hypnum chrysophylloides Hpe. in Bot. Zeit. $186^{\circ}$, p. 52.

-- Am. merid. : And. Nov. Granat.

circinatum de Not. - Eurhynchium.

cirrosum de Not. - Eurhynchium. 
Comorae (C. M.) Besch. Fl. bryol. Réunion, etc. p. 157 et in Ann. sc. nal. VII, p. 96 (descript, amplior).

Hypnum Comorae C. M. in Linn. 1876, p. 281.

Cortic. in silv. - Afr. : Usambara, ins, Anjouan, Mayotte.

complanum (Mitt.) Jaeg. Ad. II, p. 440.

Hypnum complanum Mitt. M. austr. am. p. 553.

- Am. merid. : Chile.

compressifolium (Mitt.) Par.

Hypnum compressifolium Mitt. Fl. Vit. p. 400.

Syn. $\quad-$ Pac.: Ins. Kermadec, Raoul, Sunday.

compridense (C. M.) Par.

Hypnum compridense C. M. in sched.; Broth. in Bihang till. Sv. Vet.Akad. 1895, n. 3 (descript.).

1. Terr. - $A m$. merid. : Brasil. austr. or.

conchophyllum (Tayl.) Jaeg. Ad. II, p. 433.

Hypnum conchophyllum Tayl. in Lond. Journ. of bot. 1848, p. 195; C. M. Syn. II, p. 250. 1.

- Am. merid. : M. Pichincha.

confertum (Dicks.) Bryal. eur. V (mon. p. i), t. 510 ; W. P. Sch. Syn. 11, ed. p. 683.

Eurhynchium confertum Milde Bryol. siles. p. 309.

Hypnum clavellatum Hedw. $M$. frond. $I V, p .80$.

H. confertum Dicks. Fasc. IV Pl. crypt. p. 17, t. 11, f. 14; Brid. Bryol. univ. II, p. 405; C. M. Syn. II, p. 345.

H. laete-virens Sm. Fl. brit. III, p. 1290 ; Brid. Bryol. univ. II, p, 408.

H. Ludwigianum Spreng. Anleit, zu Kenntn. d. Gew. III, p. 297, t. 7, f. 16.

H. rotundifolium Dicks. Fasc. II Pl. crypt. (excl. syn. Scop. et With.).

H. serrulatum Turn. M. Hibern. p. 148 et Sm. l. c. (excl. syn. Hedw ).

H. thuringicum W. et M. Bot. Taschb. p. 322 (excl. syn. Brid, et Hedw.).

Leskea Ludwigiana Brid. Sp. M. II, p. 161.

2. Ad saxa, lapid. in dumet., mur. umbr., etc. - Eur. : Zona intermed., rar. merid., rar. supra reg. campestr. ascend. As.: Caucas. occid. Afr. : Alger., ins. Azor, Canar,, Madeira.

Exs. : Mandon P1. Madeir. n. 42.

Rab. Bryoth, eur. n. 842, 906.

* var. brevifolium (Milde) Limpr. Laubm. Deutschl, IV, p. 225.

Eurhynchium confertum var. brevifelium Milde, op. et $l$, co.

Ad rup. arenac. - Eur. : Lotharingia.

* var. Daldinianum de Not. Epil. p. 73.

- Eur. : Ital. super. (Locarno).

* var. Delognei (Piré) Boulay M. France, 1, p. 97.

Rh. Delognei Piré in Bull. Soc. roy. bot. Belg. 1871, p. 100.

Ad mur. fontium. - Eur. : Belgia.

var. elatior Mdo. - Rh. murale.

${ }_{3}$ var. hercynicum (Hpe.) Jaeg. Ad. II, p. 305.

Eurhynchium hercynícum Milde Bryol. siles. p. 309.

Hypnum hercynicum Hpe. in sched. et $\mathrm{Fl}$. hercynica.

Rh. hercynicum Limpi: Laubm. Deutschl. IV, p, 227.

Ad rupes arenac. - Eur, : Harz.

a f. minutula W. P. Sch. Syn. I ed.p. 569; Mdo. Bayer. Laubm. p. 228. - Eur.: Francon., Bavar. 
congruens Mitt. - Rhaphidostegium.

convolutifolium (Hpe.) Broth. in Oefv, af Finska Vet.-Soc. Akad. 1895, p.67.

Amblystegium convolutifolium .Jaeg. Ad. II, $p, 549$.

Hypnum convolatifolium Hpe. in Linn. 1869-70, p. 611 .

Rh. strictiusculum Broth. in Bailey Contr: to the Queensl. Fl. IV, p. 21 (nom.).

1. Cortic, et lignic. - Pac. : Austral. or. (Queensland), Tasman. cormophilum C. M. in Dusen M. Camer. n. 257. - Afr. : M. Cameroon.

crassinervium de Not. - Eurhynchium.

crossomitrioides C. M. mss.

- Am. merid. : Paraguay.

cueullatum (Mitt.) Par.

Hypnum cucullatum Mitt. in Kew Journ. bot. VIII, p. 265.

- Pac. : Austral. or.

cupressinum Besch. Prodr. bryol. mexic. p. 106.

Ster. - Am. sept. : Mexic.

curvisetum (Brid.) W. P. Sch. op. cit.

Eurhynchium Teesdalii Milde Bryol. siles. p. 313 p.p.

Hypnum curvisetu,n Brid. Sp. M. I, p. 111.

H. laxo-pinnatum Brid. Bryol. univ. II, p. 405.

H. rigidulum $B r$, mss. ; Rab. Deutsch. Kryptfl. II, III, p. 286.

H. rutabuloides Brid. Bryol, univ. II, p. 488 (ut syn.).

H. rutabulum $\gamma$ tenerrimum $e j$. op. et $l$. $c c$.

H. Sehleicheri Spreng. Syst. veg. XVI, IV ed. 1, p. 208 p.p.; de Not. Syll. $n, 44$.

H. Schleicheri $\beta$ curvisetum Schwaegr. Suppl. I, II, pp. 239 et 241 ; Brid. Bryol. univ. II, p. 404.

H. Teesdalii Hüb, Muscol. germ. p. 618 p.p.; C. M. Syn. II, p. 400 p.p.

H. Teesdalii var. Wils. Bryol. brit. p. 351 (in obs.).

H. tenellum Schwaegr. Suppl. II, I, II, p. 161, t. 144 (excl. syn.).

H. Teneriffae Mont. Hist. nat. Ins. Canar., Crypt. p. $3, t$. III, f. Iet Syll.p. 9 .

Rhynchostegiella curviseta Limpr. Laubm. Deutschl. IV, p. 211.

1. Ad saxa humid, praecip. secus rivul, et eatar. - Eur. : Reg. campestr. zonae intermed. et merid.; vall. Rhen., Helvet. occid,, Westphal., Austr. infer., Siles., Bavar., reg. mediterr. tota, Afr.: Alger., ins. Canar., Madeir. Am. sept. : Philadelphia.

- var. Jacquini (Garov.) Par.

Hypnum curvisetum var. longinerve Lindb. in Sourn. of the Linn. Soc, 1868, p. $69 ;$ Rab. Bryoth. eur, n. 1299.

Soc. $1868, p .69 ;$ Rab. Bryoth. eur, n. 1299 .
H. Jacquini Garov. Bryol. austr. pp. 82 et 87 ; C. M. II, p. 481.
H. obscurum Brid. Sp. M. II, p. II5?

H. riparium var. Schwaegr. Suppl. I, II, p. 195?

H. Schleicheri var, obscurum Brid. Bryol. univ. II, $p, 405$ ?

Rhynchostegiella Jacquini Limpr. Laubm. Deutschl. IV, p. 215. Rhynchostegiella Jacquini Limpr. Laubm. Deutscht. Austr. infer., Stir.,
Ad rup. irror. - Eur.: Palat., Helvet., Bavar., Aus.
Siles.

delicatulum Jam. - Rhaphidostegium.

Delognei Piré. - Rh. confertum var. Delognei.

demissum Bryol. eur. - Rhaphidostegium.

densifolium (Lindb.) Par.

Isopterygium densifolium Lindb. in Broth. Enum. M. Oane. p. 130.

2. Ad rup. calcar, - As, : Caucas, occid. 
" var, concavum (Broth.) Par.

Isopterygium densifolium var. concavum Broth. op. cit. p. 531.

- As. : Cum typ.

dentiferum (Hpe.) Jaeg. Ad. II, p. 437.

Hypnum dentiferum Hpe. in Linn. 1859, p. 642.

1 .

- Pac. : Austral, felix.

deplanatum W.P. Sch. mss.

Hypnum deplanatum Sull. M. of U. St. p. 70, Ic. M. p. 171, t. 108 et M. Allegh. n, 50; C. M. Syn. II, p. 260 ; Lesq. et Jam, Man. p. 359.

Isopterygium deplanatum Mitt. M. austr. am. p. 498 (in obs, ad I. planissimum).

2. ơ ign. Ad terr, et sax. in silv. - Am. sepl. : Ottawa, Ontar., Manitoba, reg. or. et centr.

Exs, : Mac. Canad. M. n. 300 (Hypnum).

Sull, et Lesq. M. bor. am. Il ed. n. 438 (Hypnum).

depressum (Br.) Bryol. eur. V (mon. p. 8), t.512; W. P. Sch. op. cit. $p .682$.

Hypnum confertum $\zeta$ depressum Brid. Bryol. univ, $I I, p .767$.

H. depressum Br. in Bot. Zeit. 1824, p. 763; C. M. Syn. 1I, p. 258.

Eurhynchium depressum Milde Bryol. siles, p. 299.

Isopterygium depressum Mitt. M. autr. am. p. 498 (in obs. ad I. planissimum).

Plagiothecium depressum Limpr. Laubm. Deutschl. IV, p.

2. Ad rup. et sax, quarz., rar, calear. - Eur.: Zon. intermed.: Cambrovall., Normann., Suec., Westphal., Francon., vall. Rhen. med. et inf., Austr. super. As.: Cuncas. Am. sepl. : Pensilv.

Exs. : Rab. Bryoth. eur. n. 796, 1090, 1236.

distans Besch. Fl. bryol. Réunion. etc. p. 156.

- Afr.: Usambara, reg. lacustr., ins. Borbon.

" var. breve Kiaër in Borgen M. Mad. (absque no ).

- Afr. : Madagascar.

\& var, cordifolium Kiaër l. c. n. 49.

- Afr. : Madagascar centr.

distratum (Hpe.) Jaeg. Ad. II, p. 435.

Hypnum distratum Hpe. in Linn. 1859, p. 642.

1. Cortic. vel lignic. - Pac. : Austral, felix.

divergentifolium Broth, mss.

Rh. plagiothecioides ej, prius.

Ster.

drepanocladioides (C.M.) Par.

- As. : Japon.

Hypnum drepanocladioides C. M. in Linn. 1880-83, p. 478.

Fl, et fr. ign.

- Am, merid. : Argentin Buen. Ayr.

Duthiei $C$. M. mss.

Dulhiei Broth. - Rh. kashmirense.

- As. : Himalaya sept, occid.

elachistos (Duby) Besch. Fl. bryol. Nouv. Caled. p. 242.

Hypnum elachistos Duby mss.

Cortic.

- Pac. : Nov, Caledon

elegans Lindb. - Plagiothecium.

var. terrestre lindb. - Plagiothecium elegans var. terrestre. 
elusum (Mitt.) Jaeg. Ad. II, p. 436.

Hypnum elusum Mitt, in Hook. Handb. of the N. Zeal. Fl. p. 478. 1. - Pac. : Nov. Zeland, med.

Eriocladella C. M. in Dusen M. Camer, $n, 205$.

- Afr. : M. Cameroon.

erythropodium Mitt. - Sematophyllum.

exilissimum Jaeg. - Helicodontium.

expallescens (C.M.) Jaeg. Ad. II, p. 439.

Hypnum expallescens C. M. in Linn. 1876, p. 659 .

Terr. in silv. - Am. sept. : Mexic.

Fabroniadelphus (C. M.) Jaeg. Ad. $11, p .430$.

Hypnum Fabroniadelphus C. M. in Linn. 1869-70, p. 15.

- As. : Ceylan.

ferriviae C. M. in Ule Bryoth. brasil. $n .63$.

- Am. merid. : Brasil. austr. or.

finitimum (Hpe.) Jaeg. Ad. II, p. 439.

Hypnum finitimum Hpe. Symb. 1876, p. 520. 1.

- Am. merid. : Brasil, austr. or.

Fissidens (C. M.) Par.

Hypnum Fissidens C. M. in Linn. 1880-83, p. 479.

1. In uligin. - Am. merid. : Argentin. Buenos Ayr.

fissidentellum Besch. Not. M. Parag. p. 270.

Ad terr. ferrug. - Am. merid. : Paraguay.

Exs. : Balansa Pl. Parag, n. 1217.

fissidentoides (Broth.) Par.

Hypnum fissidentoides Broth, in Engler's Bot. Jahrb. 1893, p. 479.

2? Cottic. - Pac.: Nov. Guinea.

frondicola (C. M.) Jaeg. Ad. 11, p. 437.

Hypnum frondicola $C . M$. in sched.

H. serrulatum Sull. in Proced. of the Am. Acad... 1861, p. 287 et in Wright M. Cub. n. 103.

- Am. sept. : Cuba.

Funckii de Not. - Eurhynchium cirrosum var. Funcki.

Gaudichaudii (Mont.) Jaeg. Ad. II, p. 440.

Hypnum Gaudichaudii Mont. in Ann. so. nat. 1843, p. 238, io. in Voy. Bonite, Crypt. t. 150, f. I et Syll. p. 7; C. M. Syn. II, p. 249.

H. praelongum Sull. in Exped. Wilkes, p. 16?

1. Cortic, - Pac. : Ins. Hawaï.

geophilum Aust. M. Appal. n. 345; Sull. Ic. M. Suppl. p. 94, t. 70.

Hypnum depressum Sull. et Lesq. M. bor. am. II ed. n. 437.

H. geophilum Lesq. et Jam. Man. p. 358.

Isopterygium geophilum Jaeg. Ad. II, p. 503 .

1. Ad terr. argillos. - Am. sept.: New Jersey, New York, Pensilv, Maryland, Wisconsin.

glaucescens Mitt. - Hypnum extenuatum.

glauco-virescens (C.M.) Par.

Hypnum glauco-virescens C. M. in Linn, 1878-79, p. 445. 
glauco-viride Mitt. - Rhaphidostegium.

globipyxis $(C . M$.) Par.

Hypnum globipyxis C. M. in op, cit. p. 449.

I.

- Am. merid. : Argentin. Jujuiens.

Hahnianum Sb. in Jaeg. Ad. I1. p. 443.

Rh. obtusifolium Besch, in sehed.

Ad lapid, in rivul. - Am. sept. : Mexic.

Hampei Besch. - Rhaphidostegium.

Haussknechtii Jur. Beitr. p. 601.

Ster.

- As.: Kurdistan.

herbaceum (Mitt.) Jaeg. Ad, 1I, p. 434.

Hypnum herbaceum Mitt. M. Ind. or. p. 81 . 1.

-As. : Sikkim, Khasia.

hercynicum Limpr. - Rh. confertum var. hercynicum.

homalioeaulon (C.M.) Par.

Hypnum homaliocaulon C. M, in Linn. 1878-79, p, 446.

1.

- Am. merid. : Argentin Cordob.

homalobolax C. M. in Besch. Fl. bryol. Réunion, etc. p. 156.

- Afr. : Ins. Franciae.

homomallum Besch. - Rhaphidostegium.

Holstii Broth, in Engler's Bot. Jalırb. 1894, p. 213.

1. Cortic. - Afr.: Usambara.

Hookeri Sb. in Jaeg. Ad. II. p. 435.

H. semi-tortum Mitt. M. Ind. or, p. 81 .

- As. : Sikkim.

huitomalconum (C. M.) Besch. Prodr. bryol, mexic, p. 107.

H. huitomalconum C. M. Syn. II, p. 248.

H. serrulatum Hsch, in Deppe et Soh. M. Mexic. n. 1095.

- Am. sept. : Mexic.

humillimum (Mitt.) Jaeg. Ad. II, p. 429.

Hypnum humillimum Mitt. op. cit. p. 80 .

1. Cortic. - As, : M. Neilgherr.

inclinatum (Mitt.) Jaeg. Ad. II, p. 432.

Hypnum inclinatum Mitc. in Jous . of the Linn. Soc. 1864, p. 152.

1.

- As. : Japon.

inclinatum W. P. Sch. - Rhaphidostegium sphaerotheca.

ineurvum (Hpe.) Par.

Hypnum incurvum Hpe, in F, v. Müller's Fragm. XI, Suppl. 51.

- Pac. : Austral. or.?

icerme (Mitt.) Jaeg. Ad. 11, p. 441.

Hypnum inerme Mitt. M. austr, am. p. 554 .

Ad ramul, arbor. - Am. merid.: And. Quitens.

Jamesii Sull. - Rhaphidostegium.

javanicum (Bel.) Besch. Fl. bryol. Nouv. Caledon, p. 243.

Hypnum javanicum Belanger Voy. Ind. or. Bot. IT, Crypt. p. 8, t. X, f. I;

C. M. Syn. II, p. 247; Bryol. jav. II, p. 158, t. 257. 
H. pellucidum Dz. et $M k$. in Ann. se, nat. 1844, p. 308.

1. - As, : Java, Sumatra.

"var. majus Besch, op. et l. cc.

- Pac.: Nov. Caledon.

julaceum Rehm. M. Afr. austr. n, 375 .

- Afr. : Orange.

kashmirense Par.

Rh. Duthiei Broth. mss.

- As. : Kashmir.

laevisetum Geh. in Rev. bryol. 1876, p. 4 (nam.).

- Pac. : Austral. or. (Nov. Valesia).

lamasicum (Spr.) Jaeg. Ad. II, p. 441.

Hypnum lamasicum Spr, in Mitt, op, et $l$. co.

Saxic. et terr. - Am, merid. : And. Quitens, et Peruv., Brasil.

latifolium Geh, in Rev. bryol. 1896, p. 4 (nom.).

- Pac. : Austral. or. (Nova Valesia).

lepidopilum C.M. mss.; Jaeg. Ad. $I I$, p. 442.

- As. : Japon.

leptomerocarpon (C. M.) Besch. Prodr. bryal. mexic. p. 107.

Hypnum Jeptomerocarpon C. M. Syn. II, p. 354.

H. megapolitanum Hsch, in Deppe et Schiede M. Mexic, n, 1096.

- Am. sept. : Mexic.

leptomitophyllum C. M. in Nuov. Giorn. bot. ital. 1897, p.

Ster.

- As. : China or. (prov. Schen-Si).

leptopteridium C. M. in Hedwig. 1897, p. I33.

1.

- Am. merid. : Argentin. subtropic. Tueuman.

Letourneuxii Besch. Cat. M. Alger p. 38.

- Afr.: Alger.

leucodictyon C. M. in Hedwig. 1897, p. 133.

1.

- Am. merid. : Argentin. subtropic. Tucuman.

limbelloides C. M. in Fl. 1896, p. 475 .

Ster.

- Pac. : Ins. Sandwic.

Limnobiella C. $M$. in Fl. 1897, p. 340.

Ster. Aquat. - Am. merid. : And. Venezuel.

linosum W. P. Sch. in Mandon Pl. Boliv, n, 1699.

- Am. merid. : And. Boliv.

littoreum (de Not.) Bott. in Nuov. Giorn. bot. ital. 1890, p. 260.

Hypnum littoreum de Not. Syll. n. $43 ;$ C. M. Syn. II, p. 399.

Rhynchostegellia littorea Limpr. Laubm. Deutschl. IV, p. 214.

Rhynchostegium curvisetum ear. littoreum Vent. et Bott. Enum, crit. p. 7.

Rh. mediterraneum Jur. in Verh. d. zool. bot. Ges. in Wien, 1874, p. 378.

1. Terr. - Eur.: Galloprov., Ligur., ins. Elba, Corsica, Sardinia, Sicilia, Hispan. merid.

locarmense de Not. - Eurhynchium velutinoides.

Iuteo-nitens (Welen, et Duby) Jaeg. Ad. II, p. 436.

Hypnum luteo-nitens $W$. et Dy. in Mém... Genève, 1871, p. 11, t. 4, f. I.

Rupic. - Afr. ; Angola. 
luxatum (Mitt.) Par.

Hypnum luxatum Mitt. in Kew Journ. bot. 1856, p. 64.

- Pac. : Austral. or. (Victoria).

Mandoni W. P. Sch, in Mandon Pl. Boliv. n. 1710.

- Am. merid. : And. Boliv.

mediterraneum Jur. - Rh. littoreum.

megapelma C. M. in Dusen M, Camer, n. 231 ; Broth. in Engler's Bot. Jahrb. 1894, , p. 212 (descript.).

1. Lignic. - Afr. : M. Cameroon.

megapolitanum (Bland.) Bryol. eur, V (mon, p. 8), t. 511; W. P. Sch. op. cit. $p .684$.

Eurhynchium megapolitanum Milde Bryol. siles. p. 311.

Hypnum confertum var. megapolitanum $\mathrm{Br}$, in sched.

H. megapolitanum Bland. M. exs, $n .147$ et in Sturm Deutsoh. Fl. II, fasc. 9 ; Brid. Bryol. univ. II, p. 491 ; C. M. Syn. II, p. 353.

2. Ad terr, arenos, vel denud. - Eur. : Reg. campestr. zon. intermed. sept. : German. fere tota, Palat., Hercyn., Austr. infer., Stir., Gall. merid. As. : Persia, Caucas, or., Syria. Afr.: Alger., ins. Canar.

Exs, : Rab. Bryoth. eur. n. 340, 486, $1140,1342$.

"var. meridionale W.P. Sch. Syn. I ed.p. 569 et $l$. c.

In pinet, aren. marit. - Eur. : Gall. merid,, Sardin. Afr. : Alger.

menadense (Bryol.jav.) Jaeg. Ad. II, p. 437.

Hypnum menadınse Bryol. jav. II, p. 156, t. 255.

1.

- As. : Tonkin, Celebes.

meridionale de Not. - Eurhynchium striatum var. meridionale.

micro-asperum C. M. mss.

- As. : Himalaya sept. occid.

micro-pinna C.M. mss.

- As. : Himalaya sept, occid.

microtheca Ren. et Card. in Bull, Soc, roy. bot. Belg. 1894, II, p. 130.

1. Cortic. - Afr. : Madagascar (Diego-Suarez).

minutum C. M. in Nuov. Giorn. bot. ital. 1897, p. 61 .

Moorei (Broth. et Geh.) Par,

- Am. merid. : And. Boliv.

Hypnum Moorei Broth. et Geh. in Oefe. af Finska. Vet.-Soc. Foerh. 1895, p. 66.

2. Ad rup. irror, - Pac. : Tasman,

Mülleri (Bryol.jav.) Jaeg. Ad. II, p. 444.

Hypnum Mülleri Bryol. jav. II, p. 162, $t, 261$.

1.

-As. : Sumatra, M. Java,

murale (Hedw.) Bryol. eur. V (mon. p. 10), t. 514; W. P. Sch. op. cil. p. 685 .

Eurhynchium murale Milde Bryol, siles. p. 228.

Hypnum abbreviatum Hedw. Sp. M. p. 249, t. 65, f. 1-4.

H. clavellatum L. Sp. pl. p. 1596.

H. confertum Hedw, M. frond. IV, p. 79, t. 30; C. M. Syn. II, p. 346.

$\mathrm{H}$. myosuroides brevius et crassius, capsulis cernuis Dill, Hist. M. p. 318, t. $41, r .52$.

H. myosuroides $\gamma$ Huds. Fl. Angl.p. 430.

H. velutinum $\beta$ murale Neck. Meth. p. 172. 
H. Stereodon muralis Brid. Bryol. univ. II, p. 586 (incl. vars, abbreviatus, elongatus, hispanicus, spadiceus, subcirrosus).

1. Ad sax. et rup. umbr., ad mur. basin humid. - Eur. : Fere tota in reg. campestr. As. : Caucas., Syria. Afr. : Alger.

Exs. : Rab. Bryoth. eur. n. 293, 384, 1428.

"var. complanatum Bryol, eur, et W. P. Sch. ll. cc.

Ad rup. madid., praecip. calcar. - Eur. : Cum typo.

"var. julaceum Bryol, eur. et W. P. Sch. ll. cc.

In siccior. apric. et in subalp. - Eur. : Cum typo.

"var. subalpinum Ren. in Rev. bryol. 1885, p. 57.

- Eur.: Pyren.

muriculatum Mitt. - Eurhynchium.

myosuroides de Not. - Eurhynchium.

nano-pennatum (Broth.) Par.

Hypnum nano-pennatum Broth, in Bail. Syn. of the Queensl. Fl. IV, Suppl. p. 99 (nom.) et in Defv,... 1890.

1. Cortic. - Pac.: Austral. or. (Queensland).

nanothecium C. M. mss.

$$
\text { - As. : Himalaya sept. occid. }
$$

Novae Cesareae Aust. - Hypnum micans.

obscurum Besch. Fl. bryol. Taüti, etc., p. 48.

Ster. Secus torrent. - Pac. : Taïti.

obtusifolium (Hook.) Jaeg. Ad. 11, p. 443.

Hypnum arcticum forma C. M. Syn. II, p. 432.

H. obtusifolium Hook, in Drumm. M. bor. am. I ed. n. 193; Lesq. et Jam. Man. p. 400.

Scleropodium obtusifolium Kindb. in Mac. Cat. p. 202.

Stereodon obtusifolius Mitt. in Journ. of the Linn. Soc. VIII, p. 42.

1. Aquat. - Am. sept.: M. Rupestr., Columb. brit., Washington, Oregon, Montana, Idaho, Calif.

obtusifolium Besch. - Rh. Hahnianum.

obtusissimum Geh. in Rev. bryol. 1876, p. 4 (nom.).

- Pac. : Austral. or. (Nova Vales.).

obtusum Geh. in Rev, bryol. 1876, p. 4 (nom.).

- Pac. : Austral. or. (Nova Vales.).

œdipyxis $C . M$. mss.

- As. : Himalaya sept. occid.

pallenticaule C. M. in Nuov, Giorn, bot. ilal. 1897, p.

- As, : China or. (prov. Schen-Si).

pallidifolium (Mitt.) Jaeg. Ad. II, p. 435.

Hypnum pallidifolium Mitt, in Journ, of the Linn. Soc. 1864, p. 153.

1.

- As. : Japon.

Exs. : Faurie Pl. Jap. n. 54.

pallidius (Hpe.) Jaeg. Ad. I1, p. 441.

Hypnum pallidius Hpe.Symb. 1874, p. 521.

1. $\quad-A m$. merid. : Brasil, austr. or.

Pampae (C. M.) Par.

Hypnum Pampae C. M. in Linn. 1878-79, p. 448.

1. Lignic, et rupic. - Am. merid. : Argentin. Cordob. 
paramattense (Hpe. et C. M.) Mitt. in Trans, and Proced, of the roy. Soc. of Victoria, 1883, p. 88 (nom.).

- Pac. : Austral. or. (Nova Vales.).

patentifolium C. M. in Nuov. Giorn. bot. ital. 1897, p.

- As. : China or. (prov. Schen-Si).

patulum (Hpe.) Jueg. Ad. II, p. 436.

Hypnum patulum Hpe. in Linn. 1871-73, p. 162.

- Pac. : Austral, or.

pectinatum (Mitt.) Par.

Hypnum pectinatum Mitt. in Phil. Trans. of the roy. Soc. 1879 (extra vol.), p. 395.

In humid. - Afr. : Ins. Rodriguez.

pennireptile C. M. in Dusen M. Camer, n. 270.

- Afr.: M. Cameroon.

percomplanatum $C$. M. mss.

- As. : Himalaya sept, occid.

perfilare $C . M$. mss.

- Afr.: Choa (Ankober).

perintricatum C. M. in Dusen M. Camer, n. 677 .

- Afr.: M. Cameroon.

Pervilleanum Jaeg. - Rhaphidostegium.

philippinense (Duby) Jaeg. Ad. II, p. 438.

Hypnum philippinense Duby in Mém... Genève, 1876, p. 11, t. II, f. 3 et in Fl. 1877, n. 5-6.

2. Cortic. (ad Arecam Cathecu). - As. : Ins. Philipp.

piliferum de Not. - Eurhynchium.

pinnicaule (C.M.) Par.

Hypnum pinnicaule C. M. in Linn. 1878-79, p. 447.

1. fr. ign. Rupic. - Am. merid.: Argentin. Cordob.

Pirottae Brizi. - Eurhynchium.

Plagiotheciella C. M. in Hedwig. 1897, p. 132.

$1 . \quad-A m$. merid.: And. Argentin. subtropic. Tucuman,

plagiothecioides Broth. - Rh. divergentifolium.

planifolium C. M. in Nuov. Giorn. bot. ital. 1897, p. 156.

- Am, merid. : And. Boliv.

* var, tenue ej, in op. et l. cc.

Ubi typ.

planiusculum (Mitt.) Jaeg. Ad. II, p. 430.

Hypnum planiusculum Mitt. M. Ind. or. $p, 81$.

1. Ad rup. humid. - As. : Himalaya sept. occ., Sikkim.

praecox de Not. - Eurhynchium strigosum var. praecox.

preelongum de Not. - Eurhynchium.

var, Swarzii Vent, et Bott. -- Eurhynchium praelongum var, atrovirens.

Progelii Saut. - Eurhynchium strigosum. 
pseudo-confertum (C. M.) Jaeg. Al. II, p. 431.

Hypnum pseudo-confertum C. M. in Bot. Zeit. 1858, p. 170.

1.

$$
\text { - Afr. : C. B. Sp. }
$$

pseudo murale (Hpe.) Jaeg. Ad. 11, p. 442.

Hypnum pseudo-murale Hpe. in Linn. 1859-60, p. 643.

- Pac. : Austral. or.

pseudo-serrulatum (Kindb.) Mac. Canad. M. n. 456.

Eurhynchium pseudo-serrulatum Kindb. mss.

1. Terr, in silv. - Am. sept. : Terra nov., New-Brunswick, Ottawa. pseudo-stramineum Mitt. - Hypnum stramineoides. pumilum de Not. - Eurhynchium. recurvans Besch, - Rhaphidostegium.

recurvirameum $C . M$. in $F l .1896, p .475$.

Ster.

- Pac. : Ins. Sandwic.

revelstokense (Kindb,) Par.

Eurhynchium revelstokense Kindb, mss.

$$
\delta \text { ign. } \quad-A m \text {. sept. : Columb. brit. }
$$

Rhaphidorhynchum (C. M.) Par.

Hypnum Rhaphidorhynchum C. M. Syn. II, p. 354,

1. Lignic. - Afr. : Ins. Tristan d'Acunha, Cap. B. Sp. Pac. : Austral. or. (Victoria).

rigescens C. M. in Bull. $h b$. Boissier, 1897, p. 566.

Syn, Lignic. - Am. sept. : M. Jamaic.

rivale (Hpe.) Jaeg. Ad. II, p. 433.

Hypnum rivale Hpe. Symb. 1874, p. 522,

1.

- Am. merid. : Brasil. austr. or.

romanum Brizi. - Eurhynchium.

rotundifolium (Scop.) Bryol, eur. V (mon. p. 9), t. 513; W. P. Sch. op. cit. p. 685 .

Eurhynchium rotundifolium Milde Bryol, siles, p. 310.

Hypnum confertum $\beta$ rotundifolium Brid. Bryol. univ. II, p. 407.

H. intertextum Voit.

H. rotundifolium Scop. Fl. Carn. II ed., n. 1333 ; Brid. op. cit. p. 768 ; C. M. Syn. 1I, p. 245 .

2. Ad lapid. et rad. arbor. in dumet. - Eur.: Zon, intermed. et merid. : Hungar., Austr. infer., Stir., Carinth., Carniol., Tirol., Helvet, vall, Rhen. med., Gall. centr. (Lutetia), Roma, etc. As. : Japon., Caucas, occid.

Exs. : Faurie Pl, Japon. n. 100.

Rab. Bryoth, eur. n. 634, 1430.

? Royze (Aust.) Par.

Hypnum Royae Aust. in Coult. Bot. Gaz. III, p. 3I.

2.

- Am, sept. : Calif.

rusciforme (Weiss) Bryol, eur. V (mon. p. 11), t. 515; W. P. Sch. op. cit. p. 686 .

Eurhynchium rusciforme Milde Bryol. siles, p. 312.

Hypnum alopecuroides var, hibernicum Hook. in $h b, D C$, Hypnum alopecuroides var, hibernicum Hook. in hb. DC.
H. rusciforme foliis rusciformibus, capsulis subrotundis Dill. Hist. M.
p. $298, t .38, f .31$. 
H. hydropteryx K. Seh. mss.; Geh, in Bot. Zeit. 1871, p. 40.

H. riparioides Hedw. M. frond. $I V, p .10, t .4$.

H, rivulare Ehrh. Crypt. exs, n. 252.

H. ruscifolium Neck. Meth. M. p. 181.

$\mathrm{H}$, ruscifolium $\gamma$ rotundifolium Sm. Fl. brit. III, p. 1293.

H. rusciforme Weiss Crypt. Goett. p. 225; Brid. Bryol, univ. II, p, 497 (incl. var. alopecuroides, flaccidum, fontanum, longisetum, rotundifolium); C. M. Syn. II, p. 425.

H. rutabulum var. ruscifolium Web. Spic. Fl. Goett. p, 91 ,

H. rutabulum var, rusciforme Lightf. Fl. Scot. $I I, p$. 748.

H. rutabulum var. virens Turn. Muscol. Hibern. p. 179.

H. rutabulum var. $\delta$ Huds. Fl. Angl. p. 497.

H. virens $S w$.

2. Ad saxa immersa, lignaq. irror, mur. molendin., rup. madid, etc. - Eur. : Tota campestr. et montana, As. : Japon., Yunnan., Tibet. occ., Himalaya, Nepal,, Luristan, Caucas. occ. et centr. Afr.: M. Sinaï, Alger., ins. Canar. Am, sept,: Terr. nov., New Brunswick, Nov, Scot., Gaspes., Ontar., Columb. brit., Vancouver, Oregon, reg. sept., or, et centr.

Exs. : Faurie Pl, Jap. n. 56 b.

Mac. Canad. M. n. 301 (Hypnum).

Rab. Bryoth. eur. n, 385.

Sull. et Lesq. M. bor, am. 11 ed, n. 439 (Hyрnum).

var. atlanticum Bryol. eur...- Rh. rusciforme var. lutescens,

" var. complanatum H. Schulze in Kryptfl. v. Schles. I, p. 86.

In aq. stagn. vel lentè fluent. - Eur.: Ubi typ.

" var. inundatum (Brid.) Bryol. eur. et W. P. Sch. ll, cc.

Hypnum aquaticum Poll. Pal. III, p. 1020.

Hypnum inundatum Brid. M. Rec. II, II, t. 5 , f. 3.

H. obtusifolium Dicks. mss.

H. rusciforme var. inundatum Brid. Bryol. univ. II, p. 500.

In inund. vel irror. praecip. calcar. - Eur.: Ubi typ. As. : Syria. Am. sept. : Ubi typ.

Exs. : Rab. Bryoth. eur. n. 596.

\& var. lutescens W. P. Sch. $l l, c c$.

H. atlanticum Desf. in Brid. M. Rec. II, I1, p. 121, t. 4?

H. flagellare, saxatile, capsulis gracilibus Dill. Hist. M. p. 306, t. 39, f. 42.

H. rusciforme ô atlanticum Brid. Bryol. univ. II, p. 499? Lesq. et Jam. Man. p. 360.

Rh. rusciforme $\beta$ atlanticum Bryol. eur. l. c. t. 516, fig. $\beta$ 1-2, 4-8.

Ut et ubi praeced. in Eur, et Am. sept.

Exs. : Rab. Bryoth. eur. n. 1091.

" var. prolixum (Dicks.) Bryol. eur. et W. P. Sch. ll. ce.

Hypnum aquaticum, prolixum, foliis ovatis Dill. Hist. M. p. 298, t. 37, f. 32 ect. $85, f .2$ a.

H. prolixum Dicks. Fasc. II Pl. orypt. p. 13.

H. rusciforme $\beta$ prolixum Turn. Muscol. Hibern. p. 153; Brid. Bryol. univ. $I I, p, 499$.

Ut et ubi praeced. in Eur. - As. : Japon.

Exs. : Rab. Bryoth, eur, n. 386.

Savat. P1. Jap, n. 186.

"var. rigens de Not. hb.; Brisi in Annuar R. 1stit. bot. di Roma, 189.2, p. 7 .

Ad rup. irror. - Eur. : Sardinia. 
ruscoides $P$ ar.

H. subrusciforme C. $M$ in Linn. 1874, p. 658.

Rh. subrusciforme Jaeg. Ad. II, p. 443.

- Am. sept. : Mexic.

ruvenzorense (Broth.) Par.

Hypnum ruvenzorense Broth. in Engler's Bot. Jahrb. 1897, p. 279.

Ster. In silv. humid. - Afr. : Regio lacustr.

Savatieri Par.

Rhynchostogium subconfertum W. P. Sch. in Savatier M. Japon. n. 683; Besch, in Ann. sc. nat. 1893, p. 380.

- As. : Japon.

saxitapes C. M. in Dusen M. Camer. n. 302.

- Afr. : M. Cameroon.

scariosum (Tayl.) Jaeg. Ad. II, p. 440.

Hypnum scariosum Tayl. in Lond. Journ. of bot. 1846, p. 65; C. M. Syn. II, p. 467; Mitt. M. austr. am. p. 553.

Lignic. - Am. merid. : And. Nov. Granat. et Quitens.

schoanum C. M. mss.

- Afr.: Choa (Ankober.).

seláginellifolium $C . M$. in $F l .1896, p .475$.

Ster.

- Pac.: Ins. Sandwic.

Sellowii (Hsch.) Jaeg. Ad. II, p. 439.

Hypnum Sellowii Hsch. Fl. Brasil. I, p. 79; C. M. Syn. II, p. 248; Mitt. op, cit. p. 552.

- Am. merid. : Brasil. austr. or., Uruguay.

semi-tortulum (C. M.) Par.

Hypnum semi-tortulum C. M. in Linn. 1880-83, p. 477.

1.

- Am. merid. : Argentin. Buen. Ayr.

semi-tortum (Mitt.) Jaeg. Adl. II, p. 740.

Hypnum semi-tortum Mitt. M. austr, am. p. 556.

2 ?

- Am. merid. : And. Nov. Granat.

senodictyon (C. M.) Jaeg. Ad, $1 I, p .438$.

Hypnum senodictyon C. M. Syn. II, p. 247.

1. $-A f r$ : C. B. Sp.

serrulatum (Hedvo.) Jaeg. Ad. II, p. 436.

Hypnum serrulatum Hedw. Sp. M. p. 238, t. 60; Brid. Bryol, univ. II, p. $390 ;$ C. M. Syn. II, p. 246; Sull. M. of U. St. p. $70 \mathrm{el} \mathrm{Ic.} \mathrm{M.p.} \mathrm{167,}$ t. 106 ; Lesq. et Jum. Man. p. 359.

I. Terr. in silv. - Am. sept. : Ontar., Columb. brit., Oregon, reg. sept., centr. or. et merid.

Exs.: Drumm. M. bor. am. II ed. n. 118 (Hypnum).

Sull. et Lesq. M. bor. am. II ed. n. 436 (Нурпит).

* subsp, eriense (Kindb.) Par.

Eurhynchium serrulatum subsp. eriense Kindb. mss.

Terr. in silv. - Am. sept. : Ontario.

* subsp. hispidulum (Kindb.) Par.

Eurhynchium serrulatum subsp. hispidulum Kindb. mss.

Fl, et fr. ign. - Am. sept. : Columb. brit. 
sparsirameum (Geh. et Bpe.) Par.

Hypnum sparsirameum Geh. et $\mathrm{Hpe}$. in $\mathrm{Fl} .1881$.

1.

- Am. merid. : Brasil, austr. or.

speciosum Vent. et Bott. - Eurhynchium.

sphaeropyxis Rehm. M. Afr. austr, n. 372.

- Afr.: Orange.

Stokesii de Not. - Furhynchium.

striatellum W. P. Sch. - Rigodium Lechleri.

striatulum Wils. - Eurhynchium.

striatum de Not, - Eurhynchium.

strictifolium Broth. - Rh. convolutifolium.

strigosum de Not. - Eurhynchium.

var. diversifolium de Not. - Eurhynchium strigosum var. diversifolium.

strumiferum (Hpe.) Par.

Hypnum strumiferum Hpe. in F. v. Müller's Fragm. XI, Suppl. p. 51.

- Pac. : Austral, or.?

subacutifolium (C. M.) Jaeg. Ad. II. p. 443.

Hypnum subacutifolium C. M. in Rev. bryol. 1877, p. 53 (nom.).

- Pac. : Ins. Auckland.

subclavalum Jaeg. - Rh. tenuifolium.

subconfertum (C. M.) Jaeg. Ad. II, p. 431.

Hypnum subconfertum C. M. in Bot. Zeit. 1856, p. 438.

1.

- Afr. : C. B. Sp.

subconferlum W. P. Sch. - Rh. Savatieri.

subenerve (Hpe.et C. M.) Jaeg. Ad. II, p. 430.

Hypnum subenerve Hpe. et C. M. in Bot, Zeit. 1855, p. 785.

- Afr. : C. B. Sp.

subinclinatum (W. P. Sch.) Kindb. - Rhaphidostegium sphaerotheca?

subintegrifolium (Kindb.) Par.

Eurhynchium subintegrifolium Kindb. mss.

2? Lignic. - Am , sept. : Columb, brit.

subpungens (Hpe, et C. M.) Par.

Rhycho-Hypnum subpungens Hpe. et C. M. in Trans. and Proced. of the roy. Soc. of Victoria, 1883, p. 89.

- Pac. : Austral. or.

st:brotundum (Hpe.) Jaeg. Arl. II, p. 433.

Hypnum subrotundum Hpe. in Ann. sc. nat. V ser., p. 322.

Lignic. - Am. merid. : And. Nov. Granat:

subrusciforme W. P. Sch. in Mandon Pl. Boliv. n. 1697 (1862).

- Am. merid. : And. Boliv.

subrusciforme C. M. - Rh, ruscoides.

subserrulatum (C. M.) Jaeg. Ad. II, p. 437.

Hypnum subserrulatum C. M. in Bot. Zeit. 1856, p. 439.

1? $-A f r$. : C. B. Sp.

subspeciosum C. M. in Nuov. Giorn. bot. ilal. 1897, p.

Eurhynchium subspeciosum ej. in op. oit. 1896, p. 124.

- As. : Chins or, (prov. Sehen-Si). 
subvagans Hpe. mss. : Jaeg. Ad. II, p. 435.

- As.: Ind. or. (Yomah).

surrectum (Mitt.) Jaeg. Adl. II, p. 430.

Hypnum surrectum Mitt. in Journ. of the Linn. Soc. 1863, p. 6, t. 11.

H. substrumulosum W. P. Seh. in Mandon M. Madeir, n. 44.

1. Saxic. - Afr. : Madeira.

taphrophilum C. M. in Hedwig. 1897, p. 13 5̌.

- Am. merid. : Argentin temperat.

Teesdalii Bryol, eur. - Rh. curvisetum.

teesdalioides W. P. Sch. in Breutel M. Capens.

Eurhynchium teesdalioides Jaeg. Ad. II, p. 425.

Rh. pseudo-confertum (fid. Hpe.).

$$
-A f r \text {. : C. B. Sp. }
$$

tenelliforme Ren. et Card. in Bull. Soc, roy. bot. Belg. 1894, Il, p. 130.

1. Lignic. - Afr. : Ins. Borbon.

tenellum (Dicks.) Bryol. eur, $V$ (mon. p. 5), t. 508; W. P. Sch. op. ctt. p. $₫ 80$,

Hypnum exiguum Bland. Fasc. II Crypt. exs. n. 98.

H, tenellum Dicks. Fasc. $1 \mathrm{~V} \mathrm{Pl}$. crypt. t. 11, t. 12 ; C. M. Syn. II, p.396.

H. Stereodon algirianus Desf. in Brid. Bryol. univ. II, p. 592.

Pterigynandrum algirianum $P$. B. Prodr. $p, 86$.

1. Ad saxa et mur. antiq. - Eur. : Rariss. in Suec., rar. in zon. intermed.: Voges., Silv. nigr., Francon., Jurass., etc.; vulg. in zon. merid. As.: Caucas, occ. et centr. Afr.: Septentr, tota, Madeir., M. Sinaï.

Eøs. : Rab. Bryoth. eur. n. 383, 542 et b, 904.

var. brevifolium Lindb. - Amblystegium densum.

" var. meridionale Boulay.

Ut typ. - Fur. : Gall, merid. Afr.: Alger.

tenerrimum Jaeg. - Homalothecium.

tenuifolium (Hedro.) Jaeg. Ad. II, p. 435.

Hypnum collatum H. f. et W. Fl. Tasman. II, p. 209, t. 176, f. 5 (incl. var. $\beta$ laxifolium, $\gamma$ minus et $\delta$ ).

H. confertum ear. Fl. of the N. Zeal. II, p. 108 (incl. vas' majus).

H. megapolitanum eor. Fl. Antarct. : Hpe. in Linn, 1855, p. 213.

$\mathrm{H}$ radicale Hsch, in Sieber M. Nov. Holl. n. 2 .

H. subclavatum Hpe, in C. M. Syn. II, p. 247.

H. tenuifolium Hedw. Sp. M. p. 283, t. 75; C. M. Syn. II, p. 348.

Isothecium tenuifolium Brid. Bryol, univ. II, p. 283.

Rh. subclavatum Jaeg. l. c. p. 436.

1. Lignic., ad arb., terr. et sax. - Am. merid. : And. Chilens., Brasil. austr., ins, Juan Fernandez. Pac.: Austral, or., Nov, Zeland. sept. et med.. Tasman.

tenuivagum C.M. in Dusen M. Camer. n. 49; Broth. in Engler's Bot. Jahrb. 1897, p. 279 (descript.).

Ster. Rupic, - Afr. : M. Cameroon.

Textori Sande Lac. - Isopterygium.

thamnicaulon C. M. mss.

- As. : Himalaya sept. occid.

thamnophilum C. M. in Ule Bryoth. brasil. n. 90.

Lignic, - Am. merid. : Brasil, austr. or. 
Tocaremae (Hpe.) Jaeg. Ad. II, p. 441.

Hypnum Tocaremse Hpe, in Ann. sc, nat. $V$ ser., p. 322.

Cortic. - Am . merid. : And, Nov. Granat.

trachychaeton $F$. v. Müller Austral. M. $t . X V$.

- Pac.: Austral. or, merid. (Victoria).

trachynoton (C. M.) Par.

Hypuum trachynoton C. $M$. in Linn. 18\%8-79, p. 499.

Fl. et fr. ign.

- Am. merid.: Venezuela.

trachypelma (C. M.) Jaeg. Ad. 11, p. 438.

Hypnum trachypelma C. M. in Bot. Zeit. 1857, p. 780.

Syn. $\quad-$ Fac.: Ins. Kermadec.

Trieblingii C. M. in Hedwig. 1897, p. 135.

- Am. merid. : La Plata.

tuloferum (Hpe.) Par.

Hypnum tuloferum Hpe. in Linn. $1859, p .644$.

Rhaphidostegium tuloferum Jaeg. Ad. II, p. 469.

- Pac. : Austral. or.

ulicon (Tayl.) Jaeg. Ad. II, p. 436.

Hypnum ulicon Tayl. in Lond. Journ. of bot. 1847, p. 337; C. M. Syn. II, p. 444 ; Mitt. M. austr. am. p. 555.

Rupic? - Am. merid. : And. Nov. Granat, Quitens, et Peruv.

vagans (Harv.) Jaeg. Ad. II, p. 435.

Hypnum vagans Harv, in Hook. Io. pl. rar. t. 24, f. 2; C. M. Syn. II, 2 . p. 249 ; Bryol. jav. II, p. 160 ; Mitt. M. Ind. or, p. 81 .

nate.

- As. : Nepal., Sikkim, Java, ins. Ceram, Ter-

Vaucheri Vent. et Bott. - Eurhynchium.

Volkensii (Broth.) Par.

Hypnum Volkensii Broth. in Engler's Bot. Jahrb. 1894, p. 211.

1. Cortic, in silv. humid. - Afr. : Kilima N'Djaro.

Vriesei (Dz. et Mk.) Jaeg. Ad. II, p. 437.

Hypnum Vriesei Dz. et Mk. in Ann. sc. nat. 1844, p. 310; Bryol. jav. II, 1 . p. $157, t .256$.

Welwoitschii W. P. Sch. - Rhaphidostegium.

$$
\text { - As. : Borneo; Tonkin? }
$$

Zeyheri (Spreng.) Jaeg. Ad. 11, p. 430.

Hypnum Zeyheri Spreng. mss.; C. M. in Bot. Zeit. 1855, p. 785.

1. Cortic. - Afr. : C. B. Sp. (1).

Rhystogonium C. M. M. Polyn. p. 69 (sect. Phyllogonil).

Rhystophyllina C. M. in Nuov. Giorn. bot. ital. 1897, p. 42 (nom., sect. HOOKeriz).

Rhystophyllum Ehrh. Crypt, exs. n. 97; C. M. Syn. II, p. 46 (subsect. RBCKERAE).

Rhystotis C. $M$. in Fl. $1896, p .463$ (sect. Meteorir).

(1) In Enum. Kindberg. nom. nuda :

Rh. perexiguum $C$. $M$.

I Rh. pseudo-melanangium $C, M$. 
Rhytiadelphus Lindb. M. Scand. p. 37 (sect. HyLocomn).

Rhytidium Sull. mss.; W. P. Sch. Syn. I ed. p, 615 (subgen. HYPNı).

RIGODIUM Kze herb. ; C. M. Syn. II, p. 418 (15 spec.).

Alaguelae (C. M.) Par.

Hypnum Alaguelae C. M. in Journ, of Bot. 1877, p. 230 (nom.).

Lignic. - Am. sept. : Costa Rica.

argentinicum (C. M.) Par.

Hypnum argentinicum C. M. in Linn. 1880-83, p. 480.

Fl, et fr. ign. tropic.

- Am. merid. : Argentin. Tucum, sub-

brachypodium (C.M.) Par.

Hypnum brachypodium C. M. Syn. II, p. 445.

H. toxarion Mitt. p.p.

2.

- Am, merid. : Chile.

breviramulosum Broth. mss.

- Am. merid. : Brasil.

gracile Ren, et Card. in Bull. Soc. roy. bot. Belg. 1894, 1, p. 197.

2.

- Am. sept. : And. Costa Ricens.

implexum Kae. mss. ; Schu, in Linn. 1844, p. 559, t. 9.

Heterocladium implexum Ltz. in Bot. Zeit. 1866, p. 189.

Hypnum implexum C. M. Syn. II, p. 445.

2. Terr. - Am. merid. : Chile, Valdivia.

kilimandscharieum (Broth.) Par.

Hypnum kilimandscharicum Broth. Jahrb. 1897, p. 280.

2. Ad arbor. - Afr. : Kilima N'Djaro.

Kunerti $C, M$. mss.

Ster.

- Am. merid. : Brasil. (Rio-Grande do Sul.).

Lechleri W. P. Sch. in Lechler Pl. Chil. n. 620 a.

Eurhynchium striatellum ej. $l$. c. (fid. Mitt. M. austr. am. p. 557).

Heterocladium Lechleri
Heterocladium prolixum ej. l. o. (fir. Hpe. et Ltz. in Bot. Zeit. l. c.).

Hypnum arborescens $C . M$. in Bot. Zeit. 1858, p. 172.

H, toxarion Mitt. l.e. p.p.

2. Cortic. - Am. merid. : Chile.

leptodendron C. M. in Nuov. Giorn. bot, ital. 1897, p. 62.

2.

- Am. merid. : And. Boliv.

nano-fasciculare C.M. $h b$.

- Am, merid.: Valdivia.

Schlosseri (C. M.) Par.

Brachythecium Schlosseri Jaeg. Ad. II. p. 403.

Hypnum Schlosseri Sendtn. mss.; C. M. Syn. II, $p_{\sim}{ }^{451}$.

Thamniella Schlosseri Geh. in Rev. bryol. 1897, p. 79.

2.

- Pac. : Austral, or. (Nov. Vales.).

solutum (Tayl.) Par. Syn. II, p. 446.

H. toxarion Wils, in Lond. Journ. of bot. 1846, p. 453.

- Am. merid. : And. Quitens. 
Tamarix C. M, in Hedwig. 1897, p. 139.

Ster. $\quad-A m$ merid. : Fuegia.

toxarion (Schwaegr.) W. P. Sch, herb. (1).

Hypnum toxarion Sehwaegr. Suppl. I, II, p. 283; Brid. Bryol. univ, II, p. $443 ;$ C. M. Syn. II, p. $446 ;$ Mitt. l. c.

- Am. merid. : Tota occid, et anstral.

vagum Reichdt. - Lembophyllum (2).

ROTTLERIA Brid. Bryol. univ. 1, p. 105.

gymnostomoides Brid. - Entosthodon Rottleri. javanica Brid, - Hyophila.

ROZEA Besch Prodr. bryol. mexic. p. 97 (8 spec.).

Andrieuxii (Mort.) Besch. op. cit. p. 101.

Hypnum Andrieuxii C. M. Syn. II, p. 348.

Isothecium Andrieuxii Mont. Syll. p. 18. - Am. sept. : Mexic.

Bourgeaeana Besch. op. cit. p. 98.

$$
\text { - Am. sept. : Mexic. }
$$

chrysea Besch. op. et $l$. cc.

- Am. sept.: Mexic.

pterogonioides (Harv.) Besch. in Ann. sc. nat. 1892, I, p. 84.

Hypnum pinetorum Jaeg. Ad. II. p. 610.

H. pterogonioides C. M. Syn. II,, 349 .

Leskea pterogonioides Harv. in Lond. Journ. of bot. 1840, p. 17 et in Hook. Ic. pl. rar, t. 24, f. 8.

Pleuropus pterogonioides Griff. Not, p. 470.

Stereodon pinetorum Mitt. M. Ind. or. p. 93.

2.

- As.: Nepal., Himalaya, Yunnan.

Schimperi Besch. Prodr. bryol. mexic. p. 100.

- Am. sept. : Mexic.

stricta Besch. op. et $l$. $c c$.

$$
\text { -Am. sept. : Mexic. }
$$

subjalacea Besch. op. cit. p. 99.

$$
\text { - Am. sept. : Mexic. }
$$

viridis Besch. op. et $l$, cc.

$$
\text { - Am. sept. : Mexic. }
$$

RUDIA W. P. Sch. mss. (1 spec.).

? Clarazii Jaeg, - Helicodontium.

fluminensis (Hpe.) W. P. Sch. mss, ; Jaey. Ad. II.

Hypnum fluminense Hpe. mss.

- Am. merid.: Brasil. austr or.

1) R. brachypodium, implexum, Lechleri, solutum et toxarion unam et eamdem spec. sistunt, sec. Mitt. M. austr. am. p. 557.

(2) In Enumer. Kindberg. nom. nudum: $R$. concatenatum Lindb. 
Rutabularia Kindb. Check-list of Eur, and N. Amer, M. p. 73 (sect. BRACHYTHECI sensu Kindb.).

RUTENBERGIA Geh. et Hpe, in Abhandl. Brem. VII, p. 110 (4 spec.). borbonica Besch. Fl. bryol. Réunion, etc. p. 190.

Ster. - Afr. : Ins. Borbon.

cirrata Ren. et Card. in Bull. Soc. roy. bot. Belg. 1894, 11, p. 125.

Ster. - Afr. : Madagascar.

limbata (Hpe). Besch. op. et l. cc.

? Pilotrichum limbatum Hpe. in Linn. 1874, p. 220.

- Afr.: Madagascar.

madagassa Geh, et Hpe. op. et l. cc.

2.

- Afr. : Madagascar.

SACCOPHORUM $P, B$. Prodr. $p .30$.

aphyllus P. B. - Buxbaumia.

Salebrosaria Kindb. Check-list of Eur. and N. Amer. M. p. 33 (sect. BRACHYTHECIl sensu Kindb.).

SAPROMA Brid. Bryol, univ, 1, p. 52. cyrtophyllum Brid. - Bruchia vogesiaca? vogesiacum Brid. - Bruchia vogesiaca.

SAULOMA Hook, f, et Wils, Fl, of the N. Zeal. II, p. 122 (9 spec.). baliensis Bryol. jav. - Ectropothecium.

capillaris C. M. - Pterogoniella.

chloroclada C. M. - Pterogoniella.

hamata (Hpe.) Bryol. jav. II, p. 110. t. 219.

Leskea ericoides Dz, et Mk. M. frond. ined. Archip, ind.p. 178.

Neckera hamata C. M. Syn. II, pp. 78 et 666.

Pterogoniella hamata Jaeg. Ad. II, p. 113.

Pterogonium Hpe. mss.

Syn. - As.: Sumatra, Java.

intexta C. M. - Pterogoniella.

Jagori Bryol, jav. $1 I$, p.' 109.

Neckera Jagori C. M. in Bot. Zeit. 1864, p. 373.

Plerogoniella Jagori Jaeg. Ad. II, p. Ill.

Pterogonium Jagori C. M. in Forschungsreise... Bot. p. 58.

1. Cortic. - As. : Ceylan, Java, Malaeca, Amboine, Celebes. julacea C. $M$. in Dusen M. Camer, n. M. lineolata (Duby) Par. - Afr. : M. Cameroon.

Neckera lineolata C. M. Syn. II, $p .176$.

tzi Verz. d. Zoll. Pf. p. 130 .

Pterogoniella lineolata $J a e g$. Ad. $I I, p .113$.

Pterogonium lineolatum C. M. in Linn. 1869-70, p. 22.

S. microcarpa var. lineolata Bryol. jav. II, p. 168.

1. Saxic. - As, : Ceylan, Java. 
lonchocarpa $C . M$. mss.

- As. : Ins. Andaman.

microcarpa (Harv.) Bryol. jav. II, p. 108, t. 218.

Neckera leucocytus C. M. Syn. $I I, p .76$.

Neckera macrocarpa (err. typogr., ej. l. c. p. 78.

Pterogoniella microcarpa Jaeg. Ad. II, p. 112.

Pterngonium microcarpum Harv, in Lond. Journ. of bot. 1840, p. 12 et in Hook. Ic. pl. rar, t. 24, f. 12 ,

1. Cortic. - As. : Nepal., Ceylan, Sumatra, Java, Borneo, Banca, Amboine. Pac. : Nov, Guin.

var. lineolata Bryol. jav. - S. lineolata.

" var. minor Ren. et Card. in Rev. bryol. 1896, p, 101.

Cortic. - As. : Java, Amboine.

plagiothecioides C. M. mss.

Ster. - As.: Ins. Andaman.

samoana C. M. - Pterogoniella.

stratosa C. M. - Pterogoniella.

tenella (Hook. f. et Wils.) Mitt. in Journ, of the Linn. Soc. 1859, p. 89 et in Handb. of N. Zeal. Fl. p. 493.

Hookeria tenella $H$. $f$. et $W$. Fl. of the N. Zeal. II, p. 122, t. 92, f. 8.

2. Lignic. et rupic. - Pac. : Austral. or., Nov. Zeland., Tasman.

tenuis C. M. - Pterogoniella.

Zetterstedti (C. M.) Jaeg. Ad. II, p. 732.

Distichophyllum Zetterstedti Mitt. in Trans. and Proced. of the roy. Soc. of Victoria, 1883, p. 77.

Homalia Zetterstedti Jaeg. op. eit. p, 199.

Hookeria Zetterstedti C. M. in Linn. 1871-73, p. 158.

2.

- Pac. : Austral.

Scabridaria Kindb. Check.list of Eur. and N. Amer. M. p. 22 (sect. EURHYnCHII sensu Kindb.).

SCHISTIDIUM Brid. Mant. M. p. 20 a Bryol univ. $I, p .113$.

Spec, omn. non indicatae sunt GrimMie ejusd, nom.

alpicola Limpr. - Grimmia apocarpa var. alpícola.

apocarpum Wils. - Gieheebia cataractarum.

$\operatorname{arcuatum} \mathrm{H}$. f, et W. - Eccremidium.

australe Wils. - Hedwigidiom Drummondii ?

caespiticium Brid. - Stylostegium.

cilialum | Brid. - Hed wigia.

dominghense. - Hedwigia nivalis.

dominghense Spreng. - Erpodium.

Drummondii Tayl. - Hedwigidium.

gracile Limpr. - Grimmia apocarpa var. gracilis.

imberbe

$\begin{aligned} & \text { var. atro.virens } \\ & \text { var. grncile }\end{aligned}$
Bryol, germ. - Hedwigidium imberbe.

marginatum H. f. et W. - Streptopogon.

nervosum P. B. - ?

nudum Schleich. - Braunia sciuroides.

Perrolletii Mont. - Erpodium.

pulchellum H. f. et W. - Eccremidium. 


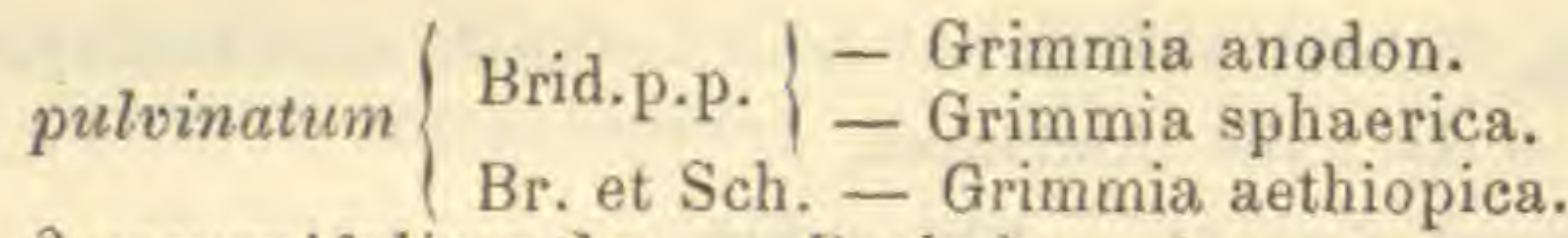

? recurvifolium Spr. - Barbula.

repens Brid, - Gigaspermum.

serratum H. f. et W. - Physcomitrium.

striatum Brid. - Amphoridium lapponieum.

subsessile Brid. - Pharomitrium.

torquatum Brid, - Helicophyllum.

SGHISTOMITRIUM Dz, et Mk. M. frond, ined. Archip. ind. p. 67 (6 spec.).

acutifolium Mitt, in Journ. of the Linn. Soc. 1886, p. 302.

Ster.

- Afr. : M. Usagara, Natal, Madagascar.

africanum Rehm. M. Afr. austr. n. 456.

Ster.

- Afr. : Transvaal.

apieulatum Dz. et Mk. op. cit. p. 68, t. 24 et 25 ; C. M. Syn. I, p. 81;

Bryol. jov. I, p. 19, Ł. 13.

Syrrhopodon apiculatus Dz. et Mk. in Ann. sc. nat. 1844, II, p. 315.

2. Cortic. - As. : Sumatra, Java, Borneo.

Gardnerianum Mitt. - Ochrobryum.

Lowii Mitt. in op. el $l$. cc.

$$
\text { - Afr. : Kina-Bahu. }
$$

robustum Bryol. jav. I, p. 21, t. 18.

2.

- As. : Java.

speciosum (Dz. et Mk.) Hpe. in Bot. Zeit. 1847, p. 922 ; C. M. Syn. II, p. 536.

Leucophanes speciosum C. M. Syn. I, p. 81 .

Spirula speciosa Dz. et Mk. M. frond. ined. Archip, ind. p. 72, t. 26 ; Bryol.jav. I, p. 22, $t$. 13 D.

Syrrhopodon speciosus eor, in Ann. so. nat. 1844, II, p. 315.

2. Cortic. - As, : Java.

\section{SCHISTOPHYLLLM (vid. SKITOPHYLLUM).}

SCHISTOSTEGA Web, et Mohr Bot. Taschb. p. 92 ( 1 spec.).

osmundacea (Dicks.) Web. et Moltr. l. c., t. 6; Brid. Bryol. univ. l, p. 109; Bryol. eur. I11, t. $279 ;$ C. M. Syn. I, p. $38 ;$ W. P. Sch. Syn. 11 ed. p. 352 .

Bryum pennatum With. 821.

Dicksonia pusilla Ehrh. Crypt. Dec, n. 65.

Gymnostomum osmundaceum Hoffm. Deutsch. Fl. II, p. 28.

G. pennatum Hedw. M. frond. 1, p. 77, t. 29.

Mnium osmundaceum Dicks. Fasc. I Pl. crypt. p. $3, t . I$.

Sch. pennata H. et $T$. Muscol, brit. p. 14, t. 8 .

2. In crypt. et cavit. declivit. ; calcar. fugit. - Eur. : Sept. et med. Scandin., Karelia, Britann.; German., Salisb., Ardenn., Palatin., Normann., Armoric. Aryern., Pren. Am. sept. : Ontar., M. Rupestr. et Selkirk, Columb. brit., New York, M. Alb.

Exs. : Mac. Can. M. n. 137.

Rab. Bryoth, eur. n. 503.

pennata $\mathrm{H}$. et T. - Sch. osmundacea. 
Schistostegiopsis C. M. in Linn. 1876, p. 362 (sect. Fissidentis).

SGHIZOMITRIUM Bryol, eur. V (mon. Hookeria) pro mem. (4 spec.). daltonioides W. P. Sch. herb.

Callicostella daltonioides Jaeg. Ad, 1I, p. 261. - Am. merid. : Guian. gall.

Leprieurii W. P. Sch. herb.

Callicostella Leprieurii Jaeg. Ad. II, p. 261 (1). - Am. merid. : Guian, gall.

obliquum (Hpe.) W. P. Sch. herb.

Callicostella obliqua Jaeg. l. c. (2).

Hookeria obliqua Hpe, in sched.

- Am. merid. : Brasil. austr. or.

obscurum W. P. Sch. herb.

Callicostella obscura Jaeg. $l$. $e$. - Am. sept. : Ins. S. Cristoph.

papillatum Sull. - Hookeria oblongifolia (3).

SCHIZHYMENIUM Harv, in Hook. Ic. pl. rar. III. bryoides Harv. - Mielichhoferia Eckloni. nanum Tayl. - Mielichhoferia.

Schizophascum C. $M$. in Fl. 1888, n. 1 (sect, PHascI).

SGHLIEPHAGKEA C. M. in FI. 1875, n, 34-35 ( $\mathrm{l}$ spec.). prostrata $C . M$. in op. et $l$. cc.

1. $\quad-A m$. merid.: And. Nov. Granat.

SGHLOTHEIMIA Brid. Mant. M. p. 114, t. II, f. 10 (115 spec.). acicularis Brid, - Macromitrium.

acuminata Reinwo. et Hsch. in Nov. Act. Leop. XIV, II, Suppl. 1829, p. 711 ; C. M. Syn, 1, p. 764; Bryol. jav. I, p. 135.

Macromitrium acuminatum $C$. M. in Bot. Zeit. 1845, p. 544.

Fl. et fr. ign. - As. : Java.

affinis C. M. Syn. I, p. 761 .

Schl. squarrosa H. f. et W, in Gardn. M. Brasil. n. 66 ?

Sebl, torquata C. M. ibid,

2.

- Am. merid. : Brasil.

1) " Forsan var. H. scabrisetae. Jaeg. 1. c.

(2) " Forsan var. H. microcarpae. "Jaeg. 1, c.

(3) Sec, Jaeg. Ad. II, p. 734, huic gen. pertinent :

H. Martiana.

Merkelii.

Olfersiana.

Forsan quoque :

H. longipedunculata.

H. microcarpa.

pallida.

papillata.

scabriseta,

etc. 
angustata Mitt. M, austr. am. p, 223.

Cortic. - Am. merid. : And. Quitens, et Peruv.

apiculata Lindb. in Ångstr. Prim. lin. p. 13 (nom.).

- Am. merid. : Brasil. austr. or.

appressifolia Mitt. op. cit. p. 22!.

- Am. merid. : Brasil.

Appunii C. $M$. in Fl. 1897, p. 333 (nom.).

- Am. merid. : Guian. brit.

Araucarieti C. M. in Ule Bryoth, brasil. austr. or.

- Am. merid. : Brasil. austr. or.

argantinica $L t z$. et $C . M$. in Linn. 1878-79, p. 373 .

2.

- Am. merid, : Argentin, subtropic.

argentinica Besch. - Schl. paraguensis.

badiella Besch. Fl. bryol. Réunion, etc. p. 81).

2. Cortic. - Afr. : Madagascar, ins. Borbon.

« var, brevifolia Ren. in Rev. bryol. 1889, p. 82.

- Afr.: Ins. Franciae.

" var. helicophylla Besch, op. et l. cc.

- Afr. : Madag. sept., ins. Borbon.

"var. longicaulis Besch. op. et l, cc.

Cortic. - Afr. : Ins. Borbon.

Baileyi Broth. in Bail. Syn. of the Queensl. Fl. IV Suppl. (nom.) et in Oefv.... 1890.

2. Lignic. - Pac. : Austral. or. (Queensland, Nov. Vales.).

Balfourei Mitt. in Trans. of the roy. Soc. of Edinb. 1887, p. 333.

Boiviniana Besch, op. cit. p. 78.

$$
\text { - Afr. : Ins. Socotora. }
$$

\section{- Afr. : Ins, Comor. magn.}

brachyphylla Ren. et Card. in Bull. Soc. roy. bot. Belg. 1894, 1I, p. 118 et M. Masc. Mad. n. 214.

1 ?

$$
\text { - Afr. : Ins. Borbon. }
$$

brachyrhyncha Schwaegr. - Macromitrium.

breviseta Angstr. Prim, lin. p. 14.

2. Cortic. - Am, merid. : Brasil. austr. or.

Brownei Brid. Bryol. univ. 1, p. 799; Schwaegr. Suppl. II, II, I, p. 52 ,

t. 167 ; C. M. Syn. 1, p. 755; Hook. f. et Wils. Fl. of the N. Zeal. II,

p. 77 et Handb. p. 427 .

2. Cortic. ? - Pac, : Austral, Nov. Zeland, sept.

bursata Ren. et C'ard. mss.

$$
\text { - Afr.: Ins. Franciae. }
$$

Campbelliana C. M. Syn. $I, p .753$ et $I I, p, 647$.

Schl, quadrifida $H$. f. et W. Fl. Antarct. $I, p .126, t .58, f . I$.

Ad arbor. et rup. - Pac. : Ins. Campbell.

Campylopus C. M. in Act, Soc, sc. Fenn. 1891, n. 5.

2. Cortic. - Am. merid. : Minas Geraës.

capillaris Hpe. Symb. 1874, p. 495. 
Chamissonis Hsch. Fl. Brasil, I, p. 31; C. M. Syn. 1, p. 757; Mitt. M. austr. am. p. 2:27.

Macromitrium Chamissonis C. M, in Bot. Zeit. 1845, p. 543. - Am. merid. : Brasil.

chlorophyllosa C, M. - Schl, Mülleri.

ciliolata C. M. in Bull. $h b$. Boissier, 1897, p. 560 .

Cortic. - Am. sept. : Jamaic.

cirrosa Schwaegr. - Macromitrium.

clavata Geh. et Hpe. Enum. M. Brasil, p. 27.

- Am. merid. : Brasil. austr. or.

Commersoniana Besch, Fl. bryol. Réunion, etc. p. 78.

2. Ster. $\quad-A f r$ : Ins. Franciae.

compacta C. M. Syn. 1, p. 763.

Schl. squarrosa? H. f. et W. in Lond, Journ, of bot. 1844, fasc. Mart.

Schl. trichomitria C. M. in Bot. Zeit. 1845, p. 107 (jure, fid. Mitt. op. 2. cit. p. 228).

conica Ren. et Card. in Bull. Soc. roy. bot. Belg. 1893, I, p. 115 et M. Masc. Mad. n. 67.

Ad saxa granit. - Afr. : Madagascar.

cispidata C. M. in Rehm. M. Afr. austr. n. 155 et 504.

- Afr. : C. B. Sp.

" var. brevipedunculata Rehm. l. c. n. 156. - Afr. : C. B. Sp.

cuspidifera Mitt. M, austr. am. p. 222.

Ster. - Am. merid. : Brasil.

elata Mitt. op. cit. p. 225.

Rupic. - Am. merid. : Brasil. austr. or.

emergens Mitt. op. cit. p. 222.

- Am. merid. : Brasil.

excorrugata C. M. in Hildebr. M. Mad. n. 2094.

fasciculata Mitt. op. cit. p. 221.

- Afr.: Madugascar.

- Am. merid. : Brasil.

ferruginea (Hook. el Grev.) Brid. Bryol. univ. I, p. 743; C. M. Syn. I, p. 555 .

Macromitrium ferrugineum C. M. in Bot. Zeit. 1845, p. 544 .

Orthotrichum ferrugineum $H$. et Gr, in Brewster Edinb. Journ. I, p. 118, t. 5 .

2. Cortic. - Afr. : C. B. Sp.

fornicata Duby in Mém.... Genève, 1876, p. 5, t. 3, f. 3; Besch. op. cil. p. 79.

2. Cortic, in sily. - Afr, : Ins Borbon., Franciae.

foveolata Ren. et Card. in Bull. Soc. roy. bot. Belg. 1894, 11, p. 119 et M, Masc. Mad. n. 170 . Ster. - Afr. : Ins. Saneta Maria Madagase.

fulva Ángstr. - Ulota.

furcata Mitt, in op, cit. $p, 222$.

Ster. Am, merid. : Brasil, ? 
fusco-viridis Hsch. Fl. Brasil. I, p. 32; C. M. Syn. I. p. 754; Mill. op. cit. p. 226 .

2. Cortic. - Am. merid. : Brasil.

glauca C. M. Syn. II, p. 648.

Schl. trichomitria Schwaegr. (fid. Mitt. op. oit. p. 228).

2.

- Am. merid. : Venezuela.

Glaziovii Hpe. Enum. M. Brasil. p. 26.

Cortic. - Am. merid. : Brasil. austr. or.

goniorhyncha Dz, et Mk. -- Macromitrium.

gracilis Hsch. op. cit. p. 35; C. M. Syn. I, p. 764; Mitl. op. cit. p. 228.

Macromitrium gracile C. M. in Bot. Zeit. 1845, p. 544 .

Fl, et fr. ign.

- Am. merid. : Brasil.

gracillima Besch. in Bull. Soc. bot. Fr. 1885, p. LXI et in Miss. sc.

Cap Horn, V, Bot. p. 280, t. 3, f. 11.

Ster. $\quad-A m$. merid.: Patag. austr.

grandiareolata C. M. in Linn. 1878-79, p. 485.

- Am. merid. : Venezuela.

Grevilleana Mitt. M. Ind. or. p. 52.

Orthotrichum squarrosum Griff. Not. p. 403.

2? Terr. - As. : Khasia, M. Neilgherr., Ceylan. Afr. : Transvaal,

Exs. : Rehm. M. Afr, austr. n. 502.

Henscheriana C. M. in Linn. 1874, p. 644.

$2 . \quad-A m$. merid. : Brasil.

illecebra W. P. Sch. in Besch. op. et l. cc.

- Afr. : Ins. Burbon.

immersa Mitt, M. austr. am. p. 221.

- Am, merid, : Brasil.

immersa C. M. - Schl, tecta.

Jamesoni (W, Arn.) Brid. Bryol, univ. I, p. 742; C. M. Syn. 1, p. 757; Mitt. op. cit. p. 224.

Macromitrium Jamesoni C. M. in Bot. Zeit. 1845, p. 543.

Orthotrichum Jamesoni W. Arn. in Trans. of Wern. Soc. V, p. 201.

2. Cortic. et rupic. - Am. merid.: Brasil, austr. or.

" var, elata Hpe. Enum. M. Brasil. p. 28.

- Am. merid. : Brasil. austr. or.

julacea Hsch. op. cit. p. 30 ; C. M. Syn. I, p. 761 ; Mitt. op, citl. p. 224.

Macromitrium julaceum C. M. in Bot. Zeit. 1845, p. 543.

2.

- Am. merid. : Brasil. austr. or.

juliformis Geh. et Hpe. in Fl. 1881.

- Am. merid. : Brasil, austr. or.

Kegeliana C. M. Syn. I, p. 754 ; Mitt. op. cit. p. 227.

Macromitrium Kegelianum ej. in Linn. 1848, p. 187.

2. Cortic. - Am. merid. : Guian. batav.

Krauseana Hpe. et Ltz. in Bot. Zeit. 1869.

Cortic. - Am. merid. : Equator.

laete-virens Broth. in Engler's Bot. Jahrb. 1894, p. 185.

2. Cortic. - Afr, : Usambara. 
lasiomitria $C . M$. in Fl. $1897, p .333$.

- Am. merid. : And. Venezuel.

laxa Hsch. op. cit. p. 33; C. M. Syn. I, p. 762; Mitt. op. cit. p. 227.

Macromitrium laxum C. M. in Bot. Zeit. 1845, p. 543.

2.

- Am. merid. : Brasil.

linealis C. M. in Abhandl. Brem. VII, p. 208. -- Afr. : Madagascar.

longifolia Hsch. op. cit. p. 34; C. M. Syn. 1, p. 759; Mitt. op. cit. p. 226. Macromitrium linearifolium C. M. in Bot. Zeit. 1845, p. 543.

2.

- Am. merid. : Monte-Video.

longifolia Schwaegr. - Macromitrium.

Mac Leai Rehm, M. Afr. austr, n. 503.

- Afr.: Transvaal.

macromitrioides C. M. in Malpighia, 1896, p. 514 .

Ster.

- Am. merid. : Guian. brit.

malacophylla Besch. Fl. bryol. Réunion, etc. p. 80 .

- Afr. : Ins. Borbon.

Martiana Hsch. op. cit. p. 32 ; C. M. Syn. I. p. 760; Mitt. op. cit. p. 224.

Macromitrium Martianum C. M. in Bot. Zeit. 1845, p. 543.

Cortic. - Am. merid. : Brasil. austr. or.

Merkelii Hsch. - Schl, rugifolia.

microcarpa W. P. Sch. in M. Perville hb. Mus. Paris.

- Afr. : Madagascar.

microphylla Besch, op. cit. p. 76.

2. $\quad$ - Afr.: M. Madagasear.

Mohriana C. M. in Linn. 1876, p. 642.

1. $\quad-A m$. sept. : Mexic.

mollis Rehm. M. Afr, austr. n. 506 et 507.

- Afr. : Transvaal.

Mülleri Hpe. Enum. M. Brasil. p. 28.

Schl. chlorophyllosa $C . M$. in sched.

- Am. merid. : Brasil. austr. or.

nitida Schwaegr. Suppl. 11, 11, I, p. 51, t. 167 ; Brid. Bryol. univ. 1, p, 798; C. M. Syn. I, p. 754 ; Mitt. op. cit. p. 223.

2. Cortic. Am. merid, : Brasil. austr. or.

* var. fuscata Hpe. Enum. M. Brasil. p. 26.

- Am. merid. : Brasil. austr. or.

nitida Wils, et C. M. - Schl. Sprengelii.

nossi-beana C. M. in Besch. Fl. bryol. Réunion, etc. $p 83$. - Afr.: Ins, Nossi-Be.

oblonga Tayl. - Macromitrium longifolium.

ochracea Dz, et Mk. - Macromitrium.

Crrstedtiana C. M. Syn. 11, p. 648; Mitt op. cit. p. 224.

2.

- Am. sept. : And. Costa Ricens. 
Ottonis Schwaegr. Suppl. II, II, I, p. 54, t. 168; Brid. Bryol. univ. I. p. 801 ; C. M. Syn. I, p. 754 ; Mitt, op. cit. p. 223.

Macromitrium Ottonis C. M. in Bot. Zeit. 1845, p. 544.

2.

- Am. merid.: Monte Video.

Pabstiana C. M. in Bot. Zeit. 1855, p. 762.

Schl. nitida Schwaegr. (fid. Mitt, op. cit, p. 224).

2. Cortic. - Am. merid. : Brasil, austr. or.

paraguensis Besch. Not. M. Parag. p. 262.

Schl. argentinica ej. in Rev. bryol. 1885, p. 18 et in Bal. M. Parag. n. 3675 .

Cortic. - Am. merid. : Paraguay.

Exs. : Bal. Pl. Parag. n. 1236, 1239.

patula Mitt. M. austr. am. p. 225.

- Am. merid. : Brasil.

pellucida C. M. in Bull. hb, Boissier, 1897, p. 561.

2. Cortic. - Am. sept. : M. Jamaic.

percorrugata $C, M$. in Sikora Pl. Mad. n, 14338.

- Afr, : Madagascar.

perichaetialis Schwaegr. - Macromitrium.

Perroti Ren. et Card. in Bull. Soc. roy. bot. Belg. 1896, 1, p. 312.

Cortic. - Afr. : Madagascar.

phaeochlora Besch. Fl. bryol. Réunion, ele. p. 82.

Cortic. - Afr. : Ins, Borbon., Franciae.

pilicalyx Broth. et Geh. in Defv. of Finska Vet-Soc. Foerh. 1895, p. 61 .

2.

- Pac. : M. Nov. Guineae.

pilomitria C. M. in Nuov. Giorn. bot. ital. 1897, p. 39.

- Am. merid. : And. Boliv.

Puiggarii Geh, et Hpe. in Fl. 1881.

Orthotrichum Puiggarii Duby.

- Am. merid. : Brasil. austr. or.

pulchella Hsch, - Macromitrium.

pungentissima $C . M$, in Linn, 1878-79, $p .485$.

- Am. merid. : Venezuela.

quadrifida Brid. Manl. M. p. 114 ; C. M. Syn. 1, p. 753.

Orthotrichum angulosum $P, B$. Prods. $p .90$.

O. quadrifida $H$. et Grev. in Brewst. Edinb. Journ. I, p. 128.

d'Acunha?

- Afr.: Ins. Borbon.; ins. Franciae? Tristan

quadrifida H, f, et W. - Schl, Campbelliana.

recurvifolia Hsch. op, cit. p. $35 ;$ C, M. Syn. I, p. 762 ; Mitt. op . cit. p. 225.

2. Rupic. - Am. merid. : Brasil.

Regneli Aingstr. in Oefv.... I876, n. 4, p. 13.

2. Cortic. - Am. merid. : Brasil, auste. or,

rhystophylla C. M. in Rev. bryol. 1887, p. 57.

- Pac. : Nov. Caledon. 
Richardi Besch. Fl, bryol. Réunion, elc. p. 81 (1).

2 ? $-A f r$.: Ins. Borbon.

rigescens Broth. in Engler's Bot. Jahrb, 1894, p. 186.

2.

- Afr. : Usambara.

Robillardi Duby in Mém.... Genève, 1876, p. 6, Ł. 2, f. 6 .

2 ?

- Afr, ; Ins. Franciae.

rufo-aeruginosa C. M. in Linn. 1875, p. 410.

2. Filicic. - Afr. : Natal.

rufo-pallens C. M. in Rehm. M. Afr. austr. n. 154.

- Afr.: C. B. Sp.

rugifolia (Hook.) Brid. Bryol. univ. 1, p. 322 (excl. syn. Schroaegr.)

et 741 ; C. M. Syn. I, p. 760; Mitt. op. cit. p. 226.

Macromitrium ragifolium $C$, M. in Bot. Zeit. 1845, p. 543.

Orthotrichum rugifolium Hook. M. ex, t. 128.

Schl. Merkelii Hsch. Fl. Brasil. I, p. 29, t. I.

2. Cortic. - Am. merid. : Brasil, austr. or.

rugifolia $\left\{\begin{array}{l}\text { Sch waegr. - Schl, sinuata. } \\ \text { Sull, - Schl. Sullivantii. }\end{array}\right.$

sarcotricha C. M. in Bull. hb. Boissier, 1897, p. 196.

Cortic. - Am. sept. : Guatemala.

Sartorii W. P. Sch, in Besch. Prodr, bryol. mexic. p. 47.

- Am. sept. : Mexic.

Schweinfurthii C. M. in Linn, 1875, p. 408.

2. Cortic. - Afr. : Monbouttou.

serricalyx C. M. in Ule Bryoth, brasil. n. 19.

- Am. merid. : Brasil. austr. or.

sinuata Hsch. op. cit. p. 31 ; C. M. Syn. I, p. 761 ; Mitt. op. cit. p. 225.

Macromitrium sinuatum C. M. in Bot. Zeit. 1845, p. 543.

Schl. rugifolia Sehwaegr, Suppl. II, II, t. 139; Wils, et C. M, in Gardn. M. Brasil. n. 68 .

2. Cortic. - Am. merid. : Brasil, austr. or.

sphaeropoma Duby Choix de Crypt.., 1867, p. 9.

2. Cortic. - Am. sept. : Mexic.

Sprengelii Hsch. op. cit. p. $34 ;$ C. M. Syn. 1, p. 758 ; Mitt. op. cit. p. 222.

Macromitrium Sprengelii C. M. in Bot. Zeit. 1845, p. 543.

Schl, nitida Wils, et $C_{i}, M$. in Gardner M. Brasil. n. 65.

2 .

- Am. merid. : Brasil, austr, or.

squarrosa (Hook. el Grev.) Brid. Bryol, univ. I, p. 324; Schwaegr. Suppl. I, 11, p. 39, t. 562; C. M. Syn. 1, p. 751 .

Orthotrichum squarrosum $H$. et $\mathrm{Gr}$, in Brewster. Edinl, Journ, I, p. 128.

Cortic. - Afr. : Madagasc, sept., ins. Borbon.

squarrosa $\left\{\begin{array}{l}\text { H. f. et W. - Schl. compacta? } \\ \text { eor. - Schl. affinis? }\end{array}\right.$

sublaevifolia C. M. in Nuov. Giorn. bot. ital. 1897, p. 39.

- Am. merid. : And. Boliv.

(1) Quid: Schl. Richardi W, P. Soh, (C. M, in Reliq. Rutenberg. p. 208)? 
sublaxa Hpe, Symb. 1874, p. 495.

2. -Am. merid. : Brasil, austr. or.

subleiophylla C. M. in Ule Bryoth, brasil. $n .57$.

- Am. merid. : Brasil, austr. or.

subrecurvifolia C. M. mss.

- Am. merid. : Brasil. (Rio Grande do Sul).

subsinuata Geh, et Hpe. in Fl. 1881,

- Am. merid. : Brasil. austr. or.

sulcuta Hook. - Macromitrium.

Sullivantii C. M. Syn. I, p. 756 ; Lesq. el Jam. Man. p. 180.

Schl, rugifolia Sull. M. Allegh. II, n. 146.

2. Cortic. - Am. sept. : Reg. merid.

Exs. : Drumm. M. bor. am. II ed. n. 85.

Sull, et Lesq. bor, am. II ed. n. 192.

surinamensis $D z$. et Mk. Prodr. Al. Surin. p. 12, t. 6 .

2. Cortic. - Am. merid. : Guian. batav.

tecta Hook. f. et Wils. in Lond. Journ. of bot. 1844, p. I57; C. M.

Syn. I, p. 752 ; Mitt. op. cit. p. 220.

Macromitrium immersum C. M. in Bot. Zeit. 1845, p. 542.

Schlotheimia immersa ej. in op. cit. 1844, $p .740$.

2. Cortic. - Am. merid. : Brasil. austr. or.

tenuiseta C. M. in Abhandl. Brem. VII, p. 208.

- Afr. : Madagascar.

teres Dz, et Mk. - Macromitrium Blumei.

torquata (Hedro.) Brid. Bryol. univ. I, p. 353 (excl. syn. P. B.); C. M.

Syn. 1, p. 758 ; Mitt. op. cit. p. 223.

Hypnum torquatum Hedw. Sp. M. p. 246, $t .63$.

Neckera torta Sw. Fl. Ind. occ. III, p. 1800.

Orthotrichum tortum $H$. et Gr. in Brewst. Edinb. Journ. I, p. 127.

Schl. torta Schwaegr. Suppl. I, II, p. 243.

Cortic. - Am. sept. : Cuba, Jamaic.

torquata C. M. - Schl. affinis.

torta Schwaegr. - Schl. torquata.

tortilis Hpe. Symb. 1872, p. 38 .

$$
\text { - Am. merid. : Brasil. austr. or. }
$$

trichomitria Schvaegr. Suppl. II, II, I, p. 55 ; Brid. Bryol. univ. I, p. 801 ; C. M. Syn. I, p. 763; Mitt. op. cit. p. 228.

Macromitrium trichomitrium C. M. in Bot. Zeit. 1845, p. 543.

2. Cortic. - Am. merid. : Brasil, or,, Monte-Video.

trichomitria C. M. (Bot. Zeit.).\{ - Schl, compacta?

trichophora Ren. el Card. in Bull. Soc. roy bot. Belg. 1893, I1, p. 21.

Ster. Cortic. - Afr. : Madagascar.

trypanoclada W. P. Sch. in M. Pervillè Mus. Paris.

- Afr. : Madagascar.

uncialis Geh, et $\mathrm{Hpe}$, in $\mathrm{Fl} .1881$.

- Am. merid. : Brasil, austr. or.

unguiculata Mitt. op. cil. p. 226.

- Am. merid. : And. Peruv. 
ventrosa $C . M$. Syn. $I, p .756$.

2 .

- Afr. : C. B. Sp.

viticulosa Raddi. - Macromitrium brachyrhynchum.

Wainioi Broth. in Act. Soc. sc. Fenn. 1891, n. 5.

2. Cortic. - Am. merid. : Minas Geraës.

Wallisii C. M. in Linn. 1871-73, p. 173.

- As. : M. ins. Philippin. (1).

SCHAENOBRYUM $D z$, et $M k$. $M$. Archip, ind. $t, 60$.

julaceum eor. - Acrocryphaea concavifolia.

SCHLUMBERGERIA W. P. Sch, mss.

vulcanica ej - Ângstroemia brevipes.

SGHRADERELLA C. M. in Linn. 1878-89, p. 501 (1 spec.).

pungens $C . M . l, c$.

- Am. merid.: Venezuela.

SCHWETSGHKEA C. M. in Linn. 1875, p. 429 (14 spec.).

boliviana C. M. in Nuov. Giorn. bot, ital. 1897, p. 53 .

- Am. merid. : And. Boliv.

Duseni C. M. in Dusen M. Camer. n. 491.

- Afr. : M. Cameroon.

gracillima (Tayl.) Jaeg. Ad. II, p. 288.

Anomodon gracillimus Jaeg. op. cit. p. 301.

Hypnum columbicum C. M. in Bot. Zeit. 1856, p. 459.

Leskea gracillima Mitt. M. austr. am. p. 567.

Neckera gracillima Tayl. in Hook. Lond. Journ. VII, p, 192; C. M. Syn. II, p. 567.

1. Cortic. et saxic. - Am. merid. : And. Nov. Granat. et Quitens.

Grateloupii (Mont) C. M. in Linn, 1875, p. 433.

Anomodon Grateloupii Mont. in Ann. sc. nat. 1845, p. 100, t. 5, f. 3.

Neckera Grateloupii C. M. Syn. II, p. 82.

1. Cortic. - Afr. : Ins. Borbon.

guatemaliensis (Hpe.) C. M. in Linn. 1875, p. 434 et in Bull. hb. Boissier, 1897, p. 202.

Clasmatodon guatemaliensis Hpe, in sched.

1 ,

- Am. sept : Guatemala.

japonica Besch. in Ann. sc. nat. 1893, VII ser., XVIII, p. 362.

1. Cortic. - As.: Japon.

laxa (Wils.) Jaeg. op. el l $l$. cc.

Neckera laxa C. M. Syn. II, p. 83.

Pterogonium laxum Wils, in Cond. Journ. of bot. 1843, p. 276, t. $10 \mathrm{E}$.

1. Cortic. - As, : China orient.

minuta C. M. in Nuov, Giorn. bot. ital. 1897, p. 53.

- Am. merid. : And. Boliv.

Monbuttoviae C. M. in Linn. 1875, p. 433.

1. fr. ign.

- Afr. : Monbouttou.

(1) In Enum, Kindberg, nom. nudum :

Schl. Balfourii Mitt. 
pygmaea (Dz, et Mk.) C. M. in op. cit, p. 434.

Anacamptodon pygmaeus Bryol. jav. II, $p .180 . \quad$ (1554-1871)

Leskea pygmaea $D z$. et $M /$. $M$. frond. ined. Archip. ind. p. 47, t. 49. (1949-48)

Neckera pygmaea eor. in Ann. sc. nat. $1844, p .313 ; C$. M. Syn. II. $p, 82$.

- As. : Borneo.

Rehmanni C. M. in Rehme. M. Afr. austr. n. 346 .

$$
\text { - Afr.: C. B. Sp. }
$$

Schweinfurthii C. M. in Linn. 1875, p. 432.

1. Terr. - Afr.: Niam-Niam.

sinensis C. M. in Nuov. Giorn. bot. Ital. 1896, n. 111.

1.

- As. : China or. (prov. Sehen-Si).

usambarica Broth. in Engler's Bot. Jahrb. 1894, p. IC9.

1. Cortic. - ifr. : Usambara (1).

SCIADOCLADUS Lindb, in Oefv... 1861.

Spec. omn, sunt HYPNODENDRA ejusd nom.

Sciarodium C. M. Syn. II, p. 526 (sect. Cokomıtril sensu Müller.).

SCIAROMIUM Mitt. M. austr. am. p. 571 (26 spec.).

arboreum (Broth.) Par.

Echinodium arboreum Broth, in Oefv... 1893, $p$.

2. Cortic. - Pac,: Austral, or. (Nov. Vales.).

Cheesemani $C . M$. mss.

- Pac. : Nov. Zeland. sept.

confluens (C. M.) Par.

Hypnum confluens C. M. in Fl. 1885, p. 429 ,

H. conspissatum Sull. in Wilkes, Expl. Exped. p. 12?

Limbella confluens C. M. in Erforsehungsieise... Bot $p .37$.

Ster. Aquat. - Am. merid. : Fuegia.

conspissatitum (C.M.) Par.

Limbella conspissatula C. M. in Hedwig. 1897, p.

Ster. Ad rip. rivul. - Am. merid. : Argentin. Patagon.

conspissatum (Hook. f. el Wils.) Mitt. op. cit. p. 572.

Hypnum conspissatum $H$. f. et W. in Lond. Journ. of bot. 1844, p. 553 et Fl. Antarct. II, p. 419, t. 155: C. M. Syn. II, p. 422 (2).

Limbella conspissata $C$. M. in Erforschungs eise.... Bot.p. 37.

Ster. Aquat. - Afr. : Ins. Kerguelen. Am. merid. : Ins. Maclov. erassinervatum Mitl. op. el $l$. cc.

Ster. Ad saxa irror. - Am, merid. : And, Nov, Granat. drepanophyllopsis (C. M.) Par.

Limbella drepanophyllopsis C. M. in Heduig. 1897, p. 118.

Ster. - Am. merid. : And. Argentin. subtropic.

(1) In Enum. Kindb. nom, nudum:

Schw. aristaria Rehm.

(2) Cf. Ltz, in Bot. Zeit. I866, p. 188. 
glauco-viride $\mathrm{Mitt}, \mathrm{Fl}$. Vit. $p .400$.

Echinodium glauco-viride Jaeg. Ad. II, p. 380.

Hypnum glauco-viride Mitt. in Handb. of the N. Zeal. Fl.p. 473. - Pac. : Ins. Kermadec, Norfolk.

hispidum (Hook. f. et Wils.) Par.

Echinodium hispidum Jaeg. op. et $l$. oc.

Hypnum aristatum Sull. in Proced. of the Amer. Acad.... 1854.

H. hispidum H. f. et W. in Lond. Journ. of bot. 1884, p. 552 et $\mathrm{Fl}$. Antaret. I, p. 140, t. 61; C. M. Syn. II, p. 421.

Leskea hispida Mitt. in Journ. of the Linn. Soc. 1859, p. 91.

2. Ad rup. inund, - Pac. : Austral. or., Nov. Zeland,, Tasman., ins. Norfolk, Auckland.

? aequirameum (C.M.) Par.

Echinodium aequirameum Jaeg. op. et $l$. ce.

Hypnum requirameum $G, M$. in sohed. (1).

- As.: Birman.

Krauseanum (C.M.) Par.

Limbella Krauseana C. M. in Erforschungsieise.... Bot. p. 37 et in Hedwig. 1897, p. 118.

Ster. Ad ramul, secùs rivul, - Am. merid. : Chile austr.

leptolomaceum (C. M.) Par.

Limbella leptolomacea C. M. in Fl. 1896, p. 467.

Ster.

- Pac. : Ins. Hawaï.

limbatulum $(C, M$.$) Par.$

Hypnum limbatulum C. M. in Erforschungsreise... Bot. p. 37 (nom.).

Limbella limbatula ej. in $\mathrm{Fl}$. 1896, p. 466.

Ster.

- Pac. : Ins. Hawaï.

limbatum (Sull.) Jaeg. Ad. 1I, p. 556.

Hypnum limbatum Sull. in Proced. of the Amer. Acad.... 1854 et in Wilkes Expl. Exped. p. 18, $t .16$; Hook. f. Handb. of the N. Zeal. Fl. p. 473 (2).

Limbella limbata C. M. in Fl. 1896, p. 466.

Ster. Rupic. - Pac. : Nov. Zeland, ins. Hawaï.

lonchocormum (C. M.) Par.

Limbella lonchocorma C. M. in Hedwig. 1897, p. 118.

Ster. Ad rivul. - Am. merid. : Brasil. austr. or.

marginatum (Hpe.) Par.

Limbella marginata C. M. in Hedwig. 1897, p. 119.

Urocladium marginatum $H p e . h b$. - As.: Birman. (Moulmein).

obscurifolium Mitt. M. austr, am, p. 571 .

Ster. - Am. merid. : And. Chilens.

pachyloma (Mont.) Par.

Grimmia pachyloma Mitt. op. cit.p. 97.

Gymnostomum pachyloma Mont. in Ann. sc. nat. 1838, IX, p. 51 et Syll. p. 50; C. M. Syn. II, p. 653.

Limbella pachyloma C. M, in Hedvig. 1897, p. 119.

Ster. Ad scaturig. thermal. - Am. merid. : Chile.

(1) An idem ac Sc. marginatum ? Cf, C. M, in Hedwig. 1897, p. 119.

(2) * An Isothecii marginati forma? " Mitt. in Handb. I. c. 
pachylomatum (C, M.) Par.

Limbella pachylomata C. M. in op. cit. p. 118.

Ster. Aquat. in torrent. - Am. merid. : Argentin. Patagon. platylomatum (C. M.) Par.

Limbella platylomata C. M. in op, cit.p. 117.

Ster.

- Am. merid. : Argentin. Patagon.

prolixum (Mitt.) Par.

Echinodium prolixum Jaeg. Ad. II, p. 381.

Leskea prolixa Mitt. in Journ. of the Linn. Soe. 1863, p. 7, .1 .1$.

Pycnothecium Mandoni W. P. Sch. in Mandon M. Madeir, $n 33$.

Scleromnium Knyi Jur. in Bot. Zeit. 1866, pp. 21 et 178.

2. - Afr. : Ins. Azor., Madeir.

setigerum (Mitt.) Par.

Echinodium setigerum Jaeg. Ad. I1, p. 379.

Leskea setigera Mitt, in Journ. of the Linn. Soc. 1863, p. 8, t. I.

Ster.

- Afr.: Madeir.

spinosum (Mitt.) Par.

Echinodium madeirense Jur, in op. et $l$. cc.

E. spinosum Jaeg. op. et $l$. ec.

Leskea spinosa Mitt. in op. et l. co.

2. $\quad-A f r$.: Ins. Azor., Madeir.

subtricostatum (C. M.) Par.

Hypnum subtricostatum C. M. in Erforschungsreise... Bot. p. 37 (nom.). - Pac. : Ins. Hawaï,

tricostatum (Sull.) Milt. Fl. Vit. p. 400.

Neckera tricostata Sull. in op. et l. cc. c. ic. In silv. - Pac. : Ins. Hawaï.

umbrosum (Mitt.) Par.

Echinodium umbrosum Jaeg. op. cit.p. 380.

Hypnum umbrosum H.f. Handb. of the N. Zeal. Fl. p. 473.

Leskea umbrosa Mitt, in Journ. of the Linn. Soc. 1859, p. 92.

2.

- Pac.: Nov. Zeland.

SCIURO-HYPNUM Hpe, Moosb. p. 19. Borgeni Hpe. - ? Brachythecium.

SCIURO-LESKEA $H_{p e .}$ xantophylla Hpe, et Ltz. - Lescuraea.

Sclerarchidium C. M. in Fl. 1888, n. 1 (sect. АвCнIDII).

SCLEROBRYUM C. M. in sched. Banguetiae C. M. - Bryum.

Sclerodictyon C. M. Syn. 1, p. 315 (sect. BRYi).

SCLERODONTIUM Schroagr. Suppl. $11,1, p .124, t .144$.

Fraseri Mitt. - Lencoloma. pallidum Schwaegr, - Leucoloma Sieberianum. pellucidum Schwaegr. - Dimerodontium. 
secundum Harv, - Leucodon.

striclum Harv. - Leucodon.

SCLEROMNIUM Jur. in Bot. Zeit. 1866, p. 21 .

Knyi Jur. - Sciaromium prolixum.

tenax C. M. - Leucodon Cameruniae.

SGLEROPODIUM Bryol, eur. VI (6 spec.).

? ambiguzım Jaeg. - Scleropodium illecebrum var. piliferum,

caespitusum (Wils.) Bryol. eur. VI (mon. p. 2), t. 556.

Eurhynchium caespitosum Milde Bryol. siles, p. 305.

Hypnum caespitans C. M. Syn. II, p. 354.

H. caespitosum Wils, in Suppl. Engl, Bot. t. 2878 et Bryol. brit, p. 344.

2. Ad mur. arenac., terr, ad rad. arbor. loc. saepius inundat. - Eur. : Anglia, Neerland,, Belgia, Gall. occid. merid., Pyren. Am. sept. : Alaska, Vancouver, Washington, Oregon, Idaho, Calif.

Exs. : Mac. Canad. M. n, 200 p.p.

Sulliv. et Lesq. M. bor. am. Il ed, n. 510. (Hypnum.)

" var, laeve Ren. et Card. in Bot. Gaz. 1890, p. 61.

- Am. sept. : Oregon.

californicum (Lesq.) Ren. et Card, in Rev. bryol. 1893, p. 20.

Brachythecium californicum Jaeg. Ad. II, p, 392.

Hypnum californicum Lesq. in Trans. of the Amer. Phil. Soc. XIII, p. 13 ; Lesq. et Jam. Man. p. 346.

2. Arenic. et rupic. $-A m$. sept. : Calif.

illecebrum (Vaill., Schwaegr.) Bryol. eur. VI (mon. p. 3), t. 557.

Brachythecium illecebrum de Not. Epil. p. 112.

Eurhynchium illecebrum Milde Bryol. siles, , p. 305.

Hypnum blandum Lyell in $H$. et T. Muscol. brit. II ed., p. 176, t. 5 .

H. crassum la Tourretle in Brid. Bryol, univ, II, p. 429.

H. cupressiforme, rotundius, vel Iliecebrae aemulum Dill, Hist. M. p. 3Il, t. $40, f .46$ A. B.

H. illecebrum Schwaegr. Suppl. I, II, p. 225 (1).

H. illecebrum $\beta$ Tourretti Brid. l. o.

H. Tourrettii Brid. Mant. M, p. 173 .

H. Vaillantii Thuill.

Muscus terrestris, surculis Kali ant Illecebrae aemulis, foliis subrotundis squamatius incumbentibus Vaill. Bot. Par. p. 137, t. XXV, fig. 7,

2. Loc. gramin, ad viar. latera, mur. et rup. terra obtect. - Eur.: Britann., Dania, Gallia centr. (Lutetia), vall. Rhen. med., Austr. infer., Bavar.; copiose in zona merid. Afr.: Alger, ins. Azor., Canar., Madeir. Am. sept, : Alaska, Washington, Calif.

Exs : Bourgeau Pl. Canar. n. 615 (Hурпит).

Rab. Bryoth, eur. n. 1099.

Sull, et Lesq. M. bor. am. Il ed, n. 508, 509 (Нурпиm).

" var. piliferum (de Not.) Par.

Brachythecium ambiguum de Not. Epil. p, 112.

Hypnum illecebrum piliferum ej. Syll, $n+29$.

Scl, ambiguum Jaeg. Ad. II, p. 410 .

Ut typ. - Eur. : Sardin.

(1) " $H$. illecebrum herbarii Linnoeani ad Aulacomnium turgidum pertinet." W. P. Sch. Syn. II ed. p. 660 . 
Krausei Ren. et Card, - Brachythecium,

Macounii (Kindb.) Par.

Eurhynchium Macounit Kindb. in Rev. bryol. 1895, p. 85 .

Hypnum caespitosum Mac. Canad. M. n. $290 \mathrm{pp}$. 1.

- Am. sept. : Ins. Vancouver.

Novae Angliae Besch. - Brachythecium.

ornellanum Mdo. in Ltz. Bryol. Notizb. p. 69.

Brachythecium ornellanum Vent. et Bott. Enum. crit. p. 9.

Hypnum cyclophyllum Mdo, in Un. itin. 1863, n. 95.

H. ornellanum Mdo. Moosst. Alg. Alp. p. $109 ;$ Par. Index, p. 663.

2 (semel fructif. lect. !). Ad rup. schistos. - Eur. : Summ. Alp. Algov. et Longobard.

purum Limpr. - Hypnum.

subcaespitosum (Kindb.) Par.

Eurhynchium subcaespitosum Kindb. in Rev, bryol. 1895, p. 84.

Ster. Ad rup, madid, - Am. sept. : Ins, Vancouver.

Sclerostomum Hook. f. et Wils. Handb. of the N. Zeal. Fl. p. (sect. Hedwigiz sensu H. f. et W., Hedwigidium Bryol. eur.).

SCOLODIUM C.M. (?) in sched.

filamentosum C. M. - Meteorium.

Scopella C. M. in Fl. 1890, p. 474 (nom., sect. Dicrani).

SGOPELOPHILA Mitt. in Journ. of the Linn, Soc. 1869 , p. 135, n. 14 in obs. (sect. WrisiaE) ; Lindb. Contrib. ad fl. crypt. As. bor. or. p. 269 (gen, propr.) (5 spec.).

acutiuscula Lindb. in Broth. Enum. M. Caucas. p. 37.

2. Ad rup, schistos. - As, : Cancas. (Imeretia).

agoyanensis (Mitt.) Spr. in Journ. of bot. 1881, p. 12 .

Hyophila agoyanensis Jaeg. Ad. I, p. 206.

Weisia agoyanensis Mitt. M, austr. am. p. 135.

Rupic. - Am. merid. : And. Quitens.

Duthiei $C . M$. mss.

- As. : Himalaya sept. occid.

latifolia (Kindb.) Ren. et Card, in Rev. bryol. 1892, p. 92.

Merceya latifolia Kindb. in Bull. Tory. bot. Club, 1889, n. 4 et in Mac. Cat. p. 97 .

Ster. Terr. in reg. mont. - Am. sept. : Ins, Vancouver, Calif.

Exs. : Mac. Canad, M. n. 459.

ligulata $S p r$, in op. et $l$. cc.

? Encalypta ligulata ej. M. Pyren. n. 331 et in Ann. and Mag. of nat. Hist. 1849, M. Pyr, n. 337 .

Merceya ligulata W. P. Sch. Syn. II ed, p. 852.

Weisia ligulata Mitt, in Journ. of the Linn. Soc. ll. oc.

Zygodon linulatus C. M. Syn. II, p. 635.

2. $q_{x}$ et fr. ign. Ad rup. humid, - Eur. : Alp. Salisb., Pyren. 
Scorpidium W. P. Sch. Syn. I ed.p. 650 (subgen. HyPsi).

ScORPIURIUM W. P. Sch. Syn. I ed. p. 650. rivale ej. - Eurhynchium circinatum var, deflexifolium.

SGOULERIA Hook. in Drumm. M. bor. am. n. 63 et Miscell, bot. 1, p. 33. t. 18 (4 spee.). aquatica Hook. $l l . c c$.

Grimmia Scouleri C. M. Syn. II, p. 654; Lesq. et Jam. Man. p. 137.

Sc. aquatica var. catilliformis C. M. in Bot. Centralbl. 1890, n. 51 .

Sc. aquatica vart virescens Kindb. in Bull. Torr. bot. Club, 1889, p. 93 .

Sc. Jülleri Kindb. in Mac. Cat, p. 62.

2. Ad rup, irror. - Am. sept.: Ins. Observatory, Vancouver, Columb. brit., Washington, Idaho, Oregon, Calif.

Exs.: Drumm. M. bor. am. I ed. n. 63.

var, catilliformis C. M. - Sc. aquatica.

" var. nigrescens Kindb. in Bull. Torr. bot. Club. 1889, p. 94.

Sc. Neevii C. M, in eod. op. 1890, p. 273.

Ut typ. - Am. sept. : M. Selkirk, Columb. brit,, ins. Vancouver.

Exs. : Mac. Canad. M. n. 388.

var. virescens Kindb. op. cit., 1889, p. 93 (1), - Sc. aquatica.

marginata $D^{n a}$ E. G. Britton in Bull. Torr. bot. Club, 1895, p. 42, t. 227.

Ad rup. irror. - Am. sept. : Washington, Calif.

Mülleri Kindb. - Sc. aquatica.

Neevii C. M. - Se. aquatica var. nigrescens.

patagonica (Mitt.) Jaeg. Ad. 11, p. 74.

Grimmia patagonica Mitt. M. austr, am. p. 96.

Ad rup. irror. - Am. merid.: Patagon.

Rschewini Lindb. et Arn. M. As. bor. 1890, II, p. 100.

2. Ad rup. in rivul. - As. : Jenissei infer.

SBKRA Adans. $11, p .14$.

minor Lindb. - Cinclidotus fontinaloides.

SELIGERIA Bryol. eur. II (14 spec.).

acuta de Not. - Blindia.

acutifolia Lindb. $-\mathrm{S}$. pusilla var, acutifolia.

var. longiseta Lindb. - S. pusilla var. longiseta.

apiculata Dz. et Mk. - Microdus.

brevifolia Lindb, - S. pusilla.

calcarea (Dicks.) Bryol. eur. II (mon. p. 4), t. 110; C. M. Syn. 1, p. 419.

Bryom calcareum Dicks. Fasc. Pl. crypt. II, p. 3, t. 4 .

Grimmia calcarea $S m$. Fl. brit. $1 I I$, p. 1187

Weisia calcarea Hedw. Sp. M. p. 66, t. II; Irid. Bryol. univ. 1, p. 351;

Diumm. M. bov am. I ed, $n$. 5 ,

1. Ad rup. cretac, - Eur. : Britann., Gall., Daria, i,s. Rügeo, West-

(1) Ce, Dan E. G. Britton in Bull. Torr. bot. Club, 1895, pp. 36-43. 
phal., Rhoengeb., Thuring. Am, sept.: Vermont, Ontario, lac. Winnipeg.

Exs.: Rab. Bryoth., eur. n, 228.

calcicola Mitt. - S. subcernua.

calycina Mitt. - S. subcernua.

campylopoda Kindb. in Mac. Cat, p. 41.

S. recurvata Mac. Canad. M. n. 60 p.p.

1. Ad rup. madid. - Am. sept. : Ontario. compacta Philib, in liev. bryol. 1897, p. 49.

I. - Eur.: Galloprov.

erassinervis Lindb. Not. ur Saellsk, pro Faun. et Fl. fenn, 1868, p. 259;

W. P. Sch. Syn. II ed. p. 129.

1. Ad rup. calcar, - Eur. : Suecia.

diversifolia Lindb. in Oefv.... 18b4; W. P. Sch. op. cit. p. 128.

1 ?

- Eur. : Suecia, Fennia.

Doniana C. M. - Anodus.

erecta Philib. - S. recurvata var, pumila.

flavidula C. M. - Microdus.

globicarpa C. M. - Microdus.

globifera Hpe. - Globulina.

Kunzeana C. M. - Microdus.

Lindigiana Hpe. - Microdus.

Innearifolia C. M. - Microdus.

longifolia Lindb. in Broth, Enum. M. Caucas. p. 65 (1.). - As.: Caucas.

longirostris C. M. - Microdus.

Miqueliana C. M. - Microdus.

Mœenkemeyeri C. $M$. in Fl. 1886, p. 508.

2. Terr. - Afr.: Old Calabar.

pallens C. M. - Microdus.

pallidiseta C. M. - Microdus.

paucifolia Carruth. - S. subcernua.

polaris Berggr. M. Spetsb. n. 24 et in K. Sv. Vet. Ak. Handl. XIII, n. 7, p. 41.

1. Rupic. - Eur, : Spitzberg.

pusilla (Hedwo.) Bryol. eur. II (mon. p. 4), t. 110 ; C. M. Syn. I, p. 418.

Afzelia pusilla Ehrh. Pl. crypt. exs. n. 183 et Beitr. VII, p. 100.

Bryum minutum Gmel. Sysi. Nat. II, p. 1335.

Br. paludosum L. Sp. Pl. p. 1584.

Br. pusillum Hoffm. Deutsch. $F l . I I, p, 33$.

Br. trichodes acaulon palustre minimum, setis et capsulis brevissimis Dill. Hist. M. p. 387, t. 49, f. 53.

Grimmia pusilla Selvad. Samml. I, p. 10, n. 39.

Gr. Seligeri W. et M. Bot. Taschb. pp. 140 et 459.

Mfnium paludosum L. jun. Meth. M. p. 365.

S. brevifolia Lindb.

S. pusilla var. brevifolia Lindh, in K. Sv. Vet. Ak. Foerh. 1864, p. 187.

Swartzia pusilla Ehrh. Hann. Magaz. 1780-82.

Weisia calcarea Sull. M. Allegh, n. 142.

Weisia calcarea $\beta$ Schwaegr, Suppl. I, 1, p. 68.

(1) Ut videtur subsp. S. tristichx. 
W. paludosa Brid. Musc. Rec. II, I, p. 74.

W. pusilla Hedio. M. frond. II, p. 68, t. 29; Brid. Bryol. univ. I, p. 319; Drumm. M. bor. am. I ed. n. 35 ,

W. Seligeri Bryol. germ. II, p. 105, t. 34, f. 26 ; Brid. op cit. p. 350.

1. Loc umbros. ad sax. et rup. calear., schist. et quarz. - Eur.: Sporadice per tot. reg. campestr. As, : Jenissei super., Caucas. Am, sept.: Gaspes., lac. Erie, New York, New Jersey, Missouri.

Exs. : Mac, Canad. M. n. 59.

Rab. Bryoth. eur. n. 572, 608.

"var. acutifolia W. P. Sch. Syn. II ed.p. 125.

S, acuifolia Lindb. in Hartm. Skand. Fl. IX ed., II, p. 75.

S. acutifolia var. longiseta ej. in Not. ur. Saellsk, pro Faun. et Fl fenn. $1868, I X, p, 261$.

S. pusilla $\beta$ Lacroixiana de Not. Epil. p. 656.

Ut et ubi typ. in Eur.

var. brevifolia Lindb. - s. pusilla.

var. Lacroixiana de Not. - S. pusilla var, acutifolia.

recurvata (Hedwo.) Bryol. eur. II (mon. p. 6), t. 112; C. M. Syn. 1, p. 419:

Bryum recurvatum Hoffm. Deutsehl. Fl. II, p. 31 .

Br. setaceum Jaeg. Mise. II, t. 5.

Grimmia parasitica Voit in Sturm Deutschl. Fl, orypt, fasc, 11 .

Gr. recurvata Hedw. M. fiond. I, p. 102, t. 38 .

Weisia parasitica Roeht. Deutseh. Fl, III, p.51.

W. recurvata Brid. Bryol. univ. I, p. 352.

S. setacea Lindb. in Oefv.... Vet. Akad. Foerh. 1863, p. 413 ,

1. Ad mur. rup. et sax. quarz., rar. calcar. umbros. - Eur.: F reg. campestr. usq. in subalp. per zon. med, et sept. As. : Caucas. An. sept.: Pensilv., Ontario, M. Rupestr.

Ess. : Mac. Canad. M. n. 60 p.p

Rab. Bryoth, eur, n. 59, 171, 1158.

* var. arcuata Lesq. et Jam. Man. p. 97.

Weisía Seligeri H. f. et W. in Drumm. M. bor. am. n. 66 .

Ad rup, molass, - Am. sept, : Lac. Winnipeg, M. Rupestr.

" var. brevifolia Zett. in Vid. Selsk. Foerh, 1871 (nom.); Lindb. el Arn. M. As, bor. 1890, II, p. 83 (descript.). - As. : Jenissei inter.

* var. pumila W. P. Sch. Syn. II ed.p. 127.

S. erecta Philib, in Rev, bryol. 1879, p. b7 (fid. Lindb. ot Arn. op. cil. p. 841).

S. setacea var. pumila Lindb. Selig. Soandin.

$$
\text { - Eur. : Cum typ. As. : Rossia orient. }
$$

recurvata Mac. p.p. - S. campylopoda.

rostrata C. M. - Microdus.

setacea Lindb. $-\mathrm{S}$. recurvata.

var, brevifolia Zett. - S. recurvata var. brevifolia.

var, pumila Lindb. - S. recurvata var. pumila.

subcernca W. P. Sch. Supp'. Bryol. eur. fasc. I-II (Srbigera) t. 1 et Syn, II ed.p. 128.

Pryum paueifolium Dicks. Fasc. Pl crypt. IV (fid Lindb., t. II, f. 3.

Gymnostomum paucifolium Engl. Bot. n. 2506 (fid. Lindb.).

S. calcicola Mitt, in Seem. Journ. bot. 1864, Il p. 191, t. 19, f. 1-6.

S. calycina ej. mss.; Lindb. in Oefo.... 186i, XXI, p. 188.

S. paucifolia Carruth. (fid. Braithw, 1. 17); Linds, in Not. we. Saellsk...1868. Calcic. - Eur. : Anglia (Yorkshire). 
subimmersa Lindb. M. Scand, p. 25.

1. Rupic. - Eur. : Fennia.

trifaria Lindi. - S. tristicha.

var, patula Lindb. - S. tristicha var, patula.

tristicha Bryol. eur. 11 (mon. p. 5), t. 111 ; C. M. Syn. I, p. 420.

Grimmia trifaria W. et $M$. Rot. Taschb. pp. 141 et 160.

Gr. Tristicha Schwaegr. Suppl. I, I, p. 84, t. 26.

S. trifaria Lindb. M. Scand. p. 26.

Weisia tristicha Brid. Bryol, univ, I, p. 355.

1. Ad rup. irror. - Eur.: Fere tota. As.: Jenissei med., Caucas. Am. sept. : Perrar. : Ohio.

Exs. : Rab. Bryoth, eur. n. 726 a et b.

« var. patula (Lindb.) Par.

S. trifaria $\$$ patula Lindb. op. et $l$, cc.

- Eur. : Suecia.

tristichoides Kindb. in Rev. bryol. 1896, p. 20.

- Eur. : Norvegia.

SEMATOPHYLLUM Mitt. in Journ. of the Linn. Soc. 1868 (92 spec.).

acislrostegium Mitt. - Rhaphidostegium.

acutirameum (Mitt.) Jaeg. Ad. 11, p. 449.

Stereodon acutirameus Mitt. M. Ind. or. p. 106.

I.

- As. : Khasia, Ceylan.

admistum Mitt. - Rhaphidostegium microcarpon var. anisocarpon.

adspersum (Hpe.) Jaeg, op. cit. p. 451.

Hypnum adspersum Hpe, in Nuov. Giom, bot. ital. 1872, p. 284.

2 ?

- As. : Borneo.

affine Mitt. - Rhaphidostegium.

afro-nemorosum (C. M.) Par.

Trismegistia afro-nemorosa C. M. in Dusen M. Camer, n. 686 .

- Afr.: M. Cameroon.

agnalum Mitt. - Rhaphidostegium.

alto-pungens (C.M.) Jaeg. op. cit. p. 450.

Hypnum alto-pungens $C$. M. in Linn. 1871-73, p. 179.

- As. : M. ins. Philippin.

ambiguum Mitt. - Trichosteleum.

amoenum Mitt. - Rhaphidostegium.

andinum Mitt. - Rhaphidostegium.

aneuron (Duby) Jaeg. op. cil. p. 453.

Hypnum aneuron Dy, in Mém... Genève, 1876, p. 12, t. 3, f.5 et in $\mathrm{Fl}$.

- Afr.: Ins. Franciae.

angulibasis (C. M.) Par.

Pungentell $x$ angulibasis $C . M$. mss. - As. : Amboine.

apiocarpum Mitt, - Trichosteleum. 
aquicolum (C.M.) Far.

Hypnum aquicolum $C . M$. in Linn. 1878-79, p. 455.

F1. et fr. ign. - Am. merid. : Argentin. Cordob.

arrectum Mitt. - Trichosteleum.

arthrocormoides (C. M.) Par.

Pungentella arthrocormoides C. M, in sched.

Ster. - Pac. : Nov. Guin. brit.

asperifolium Thw. et Mitt. - Rhaphidostegium.

auricomem Mitt. - Rhaphidostegium Welwitschii.

Balansæanum Besch. $\mathrm{Fl}$ bryol. Nov. Caled. p. 237, - Pac.: Nov. Caledon.

Baldwini (C. M.) Par.

Hypnum sigmatodontium Angstr, in Vet. Akad. Foerh. 1872, n. 4, p. 15? (C. M.).

Pungentella Baldwini C. M. in Fl. 1896, p. 471.

I.

- Pac. : Ins. Sandwic.

baviense Besch, in Journ. de bot. 1890, p.

I. Saxic. - As. : Tonkin.

bogosicum (Bryol.jav.) Jaeg. op. cet. p. 451.

Hypnum bogosicum Bryol. jav, II, p. 217, $t .318$.

2. Ad arbor. - As. : Borneo, M. Java.

bolivianum Par.

Pungentella gracilicaulis C. M. in Nuov. Giorn. bot. ital. 1897, p. 58. -- Am. merid. : And, Boliv.

borbonicum: $\left\{\begin{array}{l}\text { Besch. (FI. N. Cal.). - Trichostelenm subrhinophyllum. } \\ \text { Mitt. (FI. Vit.). - Sematophyllum Pickeringii. }\end{array}\right.$

Braunii (C. M.) Jaeg. op. cit, p. 448.

Hypnum Braunii C. M. Syn. II, p. 687; Bryol. jav. II, p. 212, $t .312$.

Sterendon Brauni Mitt. M. Ind, or. p, 106.

2.

- As. : Sumatra, Java, Borneo, Celebes.

" var. oxyporon (Bryol. jav.) Jaeg. l. c.

Hypnum Braunii var, oxyporon Bryol, jav. t.c. 1.

- As. : Ceylan, M. Java, Borneo.

brevi.cuspidatum (Mitt.) Jaeg. op. cit. p. 447.

Acroporium brevicuspidaturu Mitt. Sam. M. p. 183.

Hy pnum brevicuspidatam C.M. M. Polyn. p. 87 .

Pungentella brevicuspidata C. M, in Engler's Bot. Jahrb. 1896, p. 330.

1. Cortic. - Pac. : Ins. Hawai, Samoa, etc.

brevisetulum (C, M.) Jaeg. op, cit, p. 449.

Hypnum brevisetulum C. M. M. Polyn. p. 87.

Pungentella brevisetula C. M. in Engler's Bot. Julerb. 1896, p. 330. - Pac. : [ns. Samoa.

Bruchii (Dz, et Mk.) Jaeg. op. cit. p. 446.

Hypnum Bruchii Ds. et Mk, in Anr. sc, nat. 1814, II, p. 306 ; Bryol, 2. jav. $I I, p .142$, t. 240 ; U. M. Syn. II, p. 388. 
calderense (Sull.) Jaeg. op. cit. p. 445.

Hypnum calderense Sull. in Procert. of the Am. Acad.... 1854 et in U. St. Expl. Exped. Wilkes, $p$. 17, $t .15$. - As. : Ins. Philippin.

callidum Mitt. - Rhaphidostegium. capillarisetum (C, M.) Par,

Pungentella capillariseta $C$. M. in $F l, 1896, p .470$. - Pac. : Ins. Sandwic.

capilliferum Thw, et Mitt. - Rhaphidostegium.

caudatun (Bryol. jav.) Jaeg. op. cit. p. 451.

Hypnum caudatum Bryol. jax. II, p. 219, t. $320 a . b$.

Ster. - As. : M. Java.

chrysostegum Mitt. - Rhaphidostegium. circinale Mitt. - Rhaphidostegium. cirrifolium Mitt. - Rhaphidostegium.

? citrinum (Hpe.) Par.

Hypnum citrinum Hpe, Enum. M. Brasil. p. 70. 1 . - Am. merid. : Brasil. austr. or. complanatulum (C. M.) Jaeg. op. cit.p. 445.

Acanthodium rigidum Mitt. Sam. M. p. 182 ? (fid. C. M.).

Hypnum complanatulum $C, M . M$. Polyn, p. 89.

Ster. Cortic, et rupic. - Pac.: Ins. Fidji, Samoa, Nov. Guinea. condensatum (C.M.) Par.

Pungentella condensata C. M. in Micholitz M. Philipp. n. 180 . - As. : Ins. Philippin.

consanguineum (Hpe.) Jaeg. op, cit, p. 449.

Hypnum consanguineum Hpe. in Nuov. Giorn. bot. ital. 1872, p. 277. 1.

consanguineum Mitt. - Trichosteleum. contiguum Mitt, - Rhaphidostegium.

convolutum (Bryol. jav.) Jaeg. op. cit. p. 452.

Hypnum convolutum Bryol. jav, II, p. 215, $t .315$.

$$
\text { - As. : Java, Borneo. }
$$

crinitifolium Mitt. - Rhaphidostegium tequedamense. cucullatifolium Mitt, - Rhaphidostegium. cuculligerum (Lac.) Jaeg, op. cit. p. 451.

Hypnum cuculligerum Bryol. jav. II, p. 218, t. 319. 2. - As. : Java.

cuspidiferum Mitt. - Rhaphidostegium. decumbens Mitt. - Rhaphidostegium. decurvifoluum Mitt. - Rhaphidostegium.

deflexifolium (Mitl.) Par.

Acanthodium deflexifolium Mitt. in hb. Griff.

dicranifolinm (C. M.) Par.

Pungentella dicranifolia C. M. in sched.

Ster, - As.: Sumatra (ins, Engano). 
erythrocanlon (Angslr.) Jaeg. op. cil. p. 450.

Hypnum erythrocaulon Angstr. in Oefv.... 1873, n. 5, p. 149.

1 . -Afr.: Ins. S. Helena.

erythropodium (Hpe.) Jaeg. op. et l, ce.

Hypnum erythropodium Hpe, in Linn. 1871-73, p. 161 .

Rhynchostegium erythropodium Mitt. in Trans, and Proced. of the roy. Soc. of Viotoria, 1883, p. 89.

1. Ad rup. madid. - Pac. : Austral. or. erythropodium Mitt. - Rhaphidostegium. flaccidifolium Mitt. - Rhaphidostegium. flavidum Mitt. - Rhaphidostegium. fluviale Mitt. - Trichosteleum. fragilirostrum Mitt. - Rhaphidostegium. fulvifolium C. M. - Rhaphidostegium. fulvum Mitt. - Rhaphidostegium.

fuseo-flavum $(C, M$. $) \mathrm{Par}$.

Pungentella fusco-flava $C$. M. in Fl. 1896, p. 470.

1? - Pac.: Ins. Sandwic.

"var. cuspidatissima (C.M.) Par.

Pungentella fusco-flava var. cuspidatissima C. M, in op, et $l$. ec.

Ubi typ.

"var. robusta (C.M.) Par.

Pungentella fusco-flava var. robusta C. M. in op. et $l$. ce.

Ubi typ.

galipense Mitt. - Rhaphidostegium.

gedeanum (C. M.) Jaeg. op. cil. p. 448.

Hypnum gedeanum C. M. Syn. II, p. 390; Bryol.jav. II, p. 208, t. 307.

Leskea straminea Hsch. et Reinw, in Nov. Act. Acad. Coesar. Leop. XIV, II, Suppl.p. 717, t. 40, p.p.

Stereodon gedeanus Mitt. M. Ind. or. p. 106.

2. - As. : Ceylan, Java.

glaucirameum (C.M.) Par.

Pungentella glauciramea $C . M$. in sched. - As. : Ins. Celebes.

gracilicaule (Bryol, jav.) Jaeg. op. cit, p. 452.

Hypnum gracilicaule Bryol.jav. $I I, p .211, t, 314$.

1.

- As. : M. Java.

gtianense Mitt. M, austr. am. p. 478.

1 vel syn.

- Am. merid. : Guian., Amazon.

Hedvoigii Mitt. - Rhaphidostegium.

helenicum Mitt. - Rhaphidostegium.

hermaphroditum (C. M.) Besch. Fl. bryol. Nov. Caledon, p. 237.

Hypnum hermaphroditum C. M. Syr. II, pp. 384 et 689; Biyol. jav. II, p. $206, t .305$.

Leskea straminea Hsch. et Reinu, in op et l. oc. p.p.

Syn. Cortic. - As, : Sumatra, Java, Celebes. Pac.: Nov. Caledon. hyalinum (Reinv.) Jaeg. op. cit, p. 449.

Hypnum hralinum Reino, in Schroaegr. Suppl. 1II, I, II, p. 227; C. M. 2 . Syn. Iİ. p, $390 ;$;ryol.jav. II, p. 205, t. 304.

- As. : Sumatra, Java, ins. Banca, Borneo, Celebes. 
implanum Mitt. M. austr. am. p. 478.

1 vel syn. Cortic. - Am. merid. : Brasil, austr, or.

inconspicuum Mitt. - Rhaphidostegium.

incurvum Mitt. - Rhaphidostegium Rodriguezi.

insulosum Mitt. - Rhaphidostegium.

inundatum Mitt, - Trichosteleum.

Jungneri (Broth.) Par.

Acanthocladium Jungneri Broth. in Engler's Bot. Jahrb. 1897, p, 278.

1. Cortic. - Afr. : M. Cameroon.

Kegelianum Mitt. - Rhaphidostegium,

lamprophyllum Mitt. - Rhaphidostegium.

lancifolium (Harv.) Jaeg. Ad. II, p. 445 (excl. syn. H. korthalsii et trismegistum (1).

Hypnum lancifolium C. M. Syn. II. p. 497; Biyol. jav. II, p. 141, t. 239. Neckera lancifolia Harv. in Hook. Ic. pl. rar, t. 21, f. 5 et in Lond. Journ. of bot. $1840, p .14$.

Stereodon lancifolius Mitt. M. Ind. or. p. 110.

2.

- As.: Nepal.

Lecoultriae Jaeg. - Rbaphidostegium Duisabonae var, rigidiusculum.

Lepinei Besch. Fl. bryol. Taiti, elc. p. 48.

Syn.

- Pac.: Taïti.

leptocarpon Mitt. - Rhaphidostegium.

lepto-cylindricum (C. M.) Par.

Pungentella lepto-cylindrica $C . M$. in $F l .1896, p .470$.

I. -Pac.: Ins. Sandwic.

leplophyllum Mitt. - Rhaphidostegium.

leptothecium Mitt. - Rhaphidostegium.

? leucolomoides (C. M.) Par.

Horridium leucolomoides C. M. in sched. - As. : Ins. Andaman.

Levieri (C. M). Par.

Pungentella Levieri C. M. in Nwov. Giorn, bot. ital. 1897, p. 152. 1.

- Am. merid. : And. Boliv.

lignicolum Ângstr. - Rhaphidostegium.

lilliputianum Mitt, - Rhaphidostegium.

Lindigii Mitt. - Rhaphidostegium.

longicaule (Bryol, jav.) Jaeg. op. cit. p. 447.

Hypnum longicaule Bryol, jav. II, p. 209, $t, 309$.

2.

-. As. : M. Java

longinerve (Duby) Jaeg. op. cit. p. 453. ginerve (Duby) Jaeg. op. cit. p. 453 .
Hypnum longinerve Dy. in Mém... Genève, 1876, p. 9, t. I, f. 2 et in Fl.
$1877, n .5$. 1.

- Afr.: Ins. Franciae.

longirostratum Mitt. - Rhaphidostegium.

loxense Mitt, - Rhaphidostegium.

(1) An potiús Symphyodon ? Cf. Mitt. 1. c. 
luridissimum (C.M.) Broth. in litt.

Cupressina luridissima $C . M$. in Fl. 1896, p. 473 .

- Pac.: Ins. Sandwic.

luxurians (Dz. et Mk.) Jaeg. op. cil. p. 446.

Hypnum luxurians Dz. et Mk. in Ann. sc. nat. 1844, II, p. 307; Bryol. jav. II, p. 143, t. 24l ; C. M. Syn. II, p. 388.

1 et syn. (Bryol. jav.) ; 2 (C. M.). - As. : Sumatra Java.

Mac-Gregorii Broth. et Geh, in Oefv. of Finska Vet.-Soc. Foerh. 1895, p. 68 .

Ster.

- Pac. : Nov Guinea.

macrorhynchum (Mitt.) Jaeg. op. cit. p. 447.

Acroporium macrorhynchum Mitt. Sam. M. p. 183.

Hypnum upoloviense C. M. M. Polyn. p. 87.

Pungentella upoloviensis C. M. in Engler's Bot. Jahrb, 1896, p. 329.

2. Cortic. - Pac. : Ins. Samoa.

macrorhynchum Mitt. (M. austr. am.). - Rhaphidostegium.

macrotis (C.M.) Par.

Pungentella macrotis C. M. in Micholitz M. Philipp. n. 162.

- As. : Ins. Philippin.

megasporum Ren, et Card. - Rhaphidostegium.

var. densum eor. - Rh. megasporum var. densum.

microcarpum (Mitt.) - ? ( $)$.

microcladum (C.M.) Par.

Pungentella microclada C. $M$, in sched.

Ster.

- Pac. : Nov. Guin, rrit.

microcladum Mitt. - Rhaphidostegium.

micro-cormum (C.M.) Par.

Pungentella micro-corma C. M. in Dusen M. Camer, n. 669 . - Afr.: M. Cameroon.

microthelium (C. M.) Par.

Pungentella microthelia $C . M$. in sched.

Ster.

- Pac. : Nov, Guin, brit.

Mitteni: Par.

Acroporium lamprophyllum Mitt. Sam. M. p. 183.

Hypnum lamprophyllum C. M. M. Polyn. p. 88.

2? Cortic. - Pac. : las. Samoa.

monoicum (Bryol, jav.) Jaeg. op. et l, cc.

Hypnum monoicum Bryol. jav. II, p. 207, t. 306.

1. In silvis. - As. : Sumatra, M. Java, Borneo.

monosticlum Thw. et Mitt. - Rhaphidostegium.

(1) " S. microcarpum (Sw. Fl. Ind, occ., sub Leskea). Hab.; Ins. Ind, occident. Nectz), Fl. Negro, San Gabriel (Spruce.) ". (Mitt. M. austr. am. p. 493). Quid? Nec in Brid. Bryol, univ., nec in C. M. Syn. Leskea mierocarpa Swarziana repedior! L. microcurpa Brid. = Rhaphidostegium microcarpon, in America meridionali nondum, ni fallor, indicatum. 
Nietnerianım (C. M.) Jaeg. op. cit. p. 449.

Hypnum Nietnerianum C. M. in Linn. 1869-70, p. 14.

2.

- As. : Ceylan.

noduliferum Mitt. - Rhaphidostegium.

oblique-rostratum Mitt. - Rhaphidostegium.

ochreifolium (C. M.) Par.

Pungentella ochreifolia C. M. in Dusen M. Camer. n. 27.

- Afr.: M. Cameroon.

Olfersii Mitt. - Rhaphidostegium.

papillosum Mitt. - Trichostelenm.

Pickeringii (Sull.) Besch. Fl. bryol. Taüli, etc., p. 49.

H. borbonicum Mitt. Sam. M. p. 184.

Hypnum daltonioides W. P. Sch. in Jardin Enum. p. 20.

H. Pickeringii Sull, in Exped. Wilkes M. p. 18, t. 15.

Sematophyllum borbonicum Mitt. Fl. Vit, p. 398.

Sigmatella Pickeringii $C . M$. in Fl. 1896, p. 469.

Trichosteleum Pickeringii Jaeg. Ad. I1, p. 486.

1. Terr. et cortic. - Pac. : Ins. Fidji, Samoa, Hawai, Taiti, Salomon, Nov. Caled.

platyacron (C. M.) Jaeg. op. cit. p. 446.

Hypnum platyacron C. M. M. Polyn. p. 89 (nom.).

?

plumularium Mitt. - Rhaphidostegium.

procernm (C. M.) Jaeg. op. cit. p. 446.

Hypnum procerum C. M. Syn. II, p. 389 ; Bryol. jav. II, p. 209, t. 308.

H. tanytrichum Duby in Moritzi Syst. Verz, d. Zoll. Pflanz. p. 130 (1).

2.

- As, : M. Java.

prominulum Mitt. - Rhaphidostegium.

pseudo-rufescens (Hpe.) Jaeg. op. el l. cc.

Hypnum pseudo-rufescens Hpe, in Nwov, Giorn. bot. ital. 1872, p. 285.

1. Ad arbor. - As. : Singapore, Borneo. Pac. : Nov. Guinea.

punctuliferum Thwo et Mitt. in Journ. of the Linn. Soc. 1872, p. 318.

2.

- As, : Ceylan.

pungens (Sio.) Mitl. M. austr. am. p. 477.

Hypnum pungens Hedw. Sp. M. p. 237, t.60; C. M. Syn. II, p. 387.

H. thelipodium C. M. op. cit. p. z75.

Leskea patens $\mathrm{Hsch}$. Fl. Brasil. I, p. 72.

L. pungens Sw. Fl. Ind, occ. III, p. 1806; Brid. Rryol. univ. 1I, p. 291.

Cortic. - Am. sept. et merid. : Intertropic.

a vai. robustum Besch. Fl. bryol. Anlill. fr. p. 71.

- Am. sept. : Guadalup.

pungifolium (Hpe.) Par.

Hypnum pungifolium Hpe. Enum, M. Brasil. p. 80.

1.

- Am. merid. : Brasil. austr.

pusillum Mitt. - Trichosteleum.

(1) Omnibus specim. collect. H. tanytrichum verum admistum est. 
pyenophyllum (C. M.) Jaeg. op. cit. p. 452.

Hypnum luxurians Duby in Moritzi Syst. Verz. Zoll. Pfl. p. 131.

H. pycnophyllum C. M. Syn. 1I, p. 406; Bryol. jav. II, p. 816, t. 316.

2. Ad arbor. - As.: Java.

ramicola (Hpe.) Jaeg, op. cit. p. 448.

Hypnum ramicola Hpe. in Nuov. Giorn. bot. ital. 1872, p. 285.

2 ? - As.: Borneo.

ramulinum Thw. et Mitt. - Rhaphidostegium. restitutum (Hpe.) Par.

Hypnum restitutum Hpe. Enum. M. Brasil. p. 69.

1. - Am. merid.: Brasil austr. or.

rhynchophyllum (C.M.) Par.

Pungentella rhynchophylla $C$. M. in Dusen M. Camer, n. a 5 .

- Afr. : M. Cameroon.

rigidum (Hsch, et Reinw,) Mitt. Fl. Vit. p. 398.

Hypnum rigidum $H$. et $R$. in Nov. Act. Acad. Coes. Leop. XIV, II, Suppl.p. 331 ; Bryol. jav. II, p. 140, t. 237 et 238 ; C. M. Syn. II, p. 498 ,

2. Ad arbor. - As. : Sumatra, M. Java, Borneo. Pac.: Nov. Caledon.

"var. Braunianum (Bryol. jav.) Jaeg. Ad. II, p.

Hypnum rigidum var. Braunianum Bryol. jav, l. c.

- As. : Java.

* var, convolutum (Bryol, jav.) Jaeg. Ad. II, p.

Hypnum rigidum var. convolutum Bryol. jav. l. c.

- As. : Java.

roridum Mitt. - Rhaphidostegium.

rubrisetum Mitt. - Trichosteleum.

ruficaule Thw, et Mitt. - Rhaphidostegium.

Savesianum (C.M.) Par.

Hypnum Savesianum C. M. in Rev. bryol. 1887, p. 57 (nom.). - Pac. : Nov. Caledon.

scabrellum (Bryol, jav.) Par.

Hypnum scabrellum Bryol. jav. II, p. 214, $t .315$ s.

Ster. - As.: Sumatra, Celebes.

scalare (A. Br.) Jaeg. op. cit. p. 451.

Hypnum scalare A. Br, in C. M. Syn. II, p. 688 ; Bryol, jav. 11.p. 219, t. 320 .

Ster. - As. : Java.

Schlimii Mitt. - Rhaphidostegium.

Schwaneckeanum Mitt. - Rhaphidostegium.

scorpiurus Mitt. - Rhaphidostegium.

secundifolium Mitt. - Rhaphidostegium.

senlosum Mitt. - Trichosteleum.

sericifolium Mitt. - Rhaphidostegium.

sigmatodontium (C. M.) Jaeg. op. cil. p. 448.

Hypnum sigmatodontium C. M. Syn. II, p. 687; Bryol. jav. II, p. 211, t. 311.

Syn.

- As. : Sumatra, Java. Pac. : Ins. Hawaï, Nov.

Guinea. 
« var. elongatum (Bryol, jav.) Jaeg. l. c.

Hypnum sigmatodontium var. elongatum Bryol. jav. $l$. $c$.

- As. : Borneo, Celebes.

sigmocarpum (C. M.) Par.

Pungentella sigmocarpa $C . M$. in sched.

- As. : Amboine.

spiculosum (Hpe.) Jaeg. op. cit. p. 449.

Hypnum spiculosum Hpe. in sched.

- As.: Sikkim.

stellatum Ren. et Card, in Bull. Soc. roy. bot. Belg. 1896, I, p. 320.

Ster.

- Afr. : Madagascar.

stenocarpum (Hpe. el C. M.) Mitt. M. austr. am. p. 478.

Hypnum stenocarpum $H$, et C. $M$, in Bot. Zeit. 1857, p. 384 .

1. Ad arbor. - Am. merid. : Brasil. austr. or.

strepsiphyllum (Mont.) Jaeg. l. c.

Hypnum strepsiphyllum Mont. in Lond. Journ. of bot. 1844, III, p. 632 in Ann. sc. nat. 1845, IV. p. 91, et Syll. p. 8; C. M. Syn. II, p. 389; Bryol. jav. II, p. 210, t. 310.

2. Cortic. - As. : Sumatra, Java, Borneo, ins. Ceram et Halmaheira.

- var. densum (Bryol. jav.) Jaeg. l.c.

Hypnum strepsiphyllum var. densum Bryol. jav. l. $c$.

- As. : Sumatra, Java.

* var. minus Ren, et Card. in Rev. bryol. 1896, p. 105.

- As, : Java.

subauriculatum (Hpe.) Par.

Hypnum subauriculatum Hpe. $h b$.

Trismegistia subauriculata C. M. in Fl. 1896, p. 474.

Ster.

- Pac.: Ins. Sandwic.

subbrachycarpum Mitt. -- Rhaphidostegium.

submitratum Jaeg. - Trichosteleum.

subnervatum Mitt. - Rhaphidostegium.

subpilotrichella (C.M.) Par.

Trismegistria subpilotrichella C. M. in Dusen M. Camer. n. 812 .

- Afr. : M. Cameroon.

subpungens (C.M.) Jaeg. op. cit. p. 453.

Hypnum subpungens $C . M$. in Linn. 1874, $p .655$.

Cortic. in silv, - Am. sept. : Mexic.

subpungifolium Broth. in Act. Soc. sc. Fenn. XIX, 189I, n. 5.

1. -Am. mericl.: Minas Geraës.

subpyenophyllum (C. M.) Jaeg. op. cit. p. 452.

Hypnum subpyenophyllum C. M. in Linn. 1874, p. 565.

1. fr. ign, $-A s$. : M. ins. Philippin.

subscabrellum Ren. et Card. in Bull. Soc. roy. bot. Belg. 1896, 1, p. 321.
Ster. $\quad$ - Afr. : Madagascar.

subscabrum Mitt. - Rhaphidostegium.

subsimplex Mitt. - Rhaphidostegium. 
subtrichocolea (C. M.) Par.

Trismegistia subtrichocolea C. M. in Dusen M. Camer, n. 30 . - Afr. : M. Cameroon.

subulatum (Hpe.) Jaeg. op. et l. cc.

Dicranum diminutivum Brid. Bryol. univ. I, p. 814 ?

Hypnum subulatum Hpe. Ic. M. t. 9; C. M. Syn. II, p. 402; Bryol. jav. $11, p, 213, t .313$.

2.

- As. : Sumatra, Java, Manilla.

succedaneum Mitt. - Rhaphidostegium.

tequedamense Mitt. - Rhaphidostegium.

theliporum (C. M.) Jaeg. op. cit. p. 450.

Hypnum theliporum C. M. M. Polyn. p. 88.

Pungentella thelipora C. M. in Engler's Bot. Jahrb. 1896, p. 330.

- Pac. : Ins. Fidji, Samoa.

Trichocolea $(C . M$.) Par.

Hypnum Trichocolea C. M. in Fl. 1888, p. 417.

Lignic. - Afr, : Kilima N'Djaro, Usambara.

trichocoleoides (C. M.) Par.

Hypnum trichocoleoides $C . M$. in $F l .1886, p .283$.

Ster.

- Afr.: Ins. S. Thoma, M. Cameroon.

turgidum (Dz. et Mk.) Jaeg. op. cil. p. 447.

Hypnum turgidum Dz. et Mk. in Ann. se. nat. 1844, II, p. 309; Bryol. jav. II, p. 204, t. 303; C. M. Syn. II, p. 390.

Pungentella turgida C. M. in Engler's Bor. Jahrb. 1896, p. 330 .

Stereodon turgidus Mitt. M. Ind. or. p. 106.

2.

Pac. : Ins. Samoa.

- As. : Ceylan, Sumatra, Java, Borneo, Celebes.

ulicinum Mitl. M. austr. am. p. 478.

1 vel. syn. Ad arbor. - Am. merid. : And. Quitens., Brasil.

vincentinum Mitt. - Trichosteleum.

xylophilum Mitt. - Rhaphidostegium (1).

Senodictyon C. M. Syn. I, p. 325 (sect. BRyI).

Senophyllaria $C$. M. in Linn. 1878-79, p. 311 (sect. Pottrae).

Senophyllum $C$. M. Syn. $I, p .606$ (sect. BaRbulaE).

SERPO-HYPNUM Hpe. Moosb, p, 19 (nom.).

Serridium C. $M$. in Fl. 1896, p. 435 (sect. Fissidentis).

SIGMATELla C. M. Syn. 11, p. 292 (subsect. Hypar, postea gen. propr.).

Spec. omn, non indicatae sunt TaxitheLIA ejusd. nom.

Bernoulliana C. M. - Rhaphidostegium.

glabriseta C. M. - Trichosteleum.

Guianae C. M. - Trichosteleum.

impellucida C. M. - Trichosteleum.

1) In Enum, Kindb, nom, nuda :

S. leucobolax C.M. micro-lecythis C. $M$.

S. pseudo-subulatum $C$. $M$. 
perhamosa C. M. - Trichosteleum.

Pickernngii C. M. - Sematophyllum.

tenerrima C. M. - Trichosteleum.

Zürniana C. M. et Schlieph. - Trichosteleum.

SIMOPHYLLUM Lindb, Rev. crit. Ic, l. dan. p. 74.

microstomum Lindb. - Hymenostomum.

viridulum Lindb. - Weisia.

SKITOPHYLLUM La Pyl. in Journ. bot. Desvaux, 1813, n. V, p. 31 .

Spec. omn. non indicatae sunt Fissidentes ejusd. nom.

adiantoides $\beta$ marginatum La Pyl. - Fissidens decipiens .

congestum La Pyl. - Fissidens grandifrons.

Dillenii La Pyl, - Conomitrum.

fontanum La Pyl. - Conomitrium Julianum.

gracile La Pyl. - Fissidens incurvus.

Julianum Lindb. - Conomitrium.

Novae Hollandiue La Pyl. - Rhizogonium.

semi-completum La Pyl. - Conomitrium Hedwigii.

tamarindrfolium La Pyl. - Fissidens incurvus var. tamarindifolius.

viridulum Lindb. - Fissidens bryoides.

Weberi La Pyl. - Amblystegium riparium

SGLLANIA Lindb.

cosia Lindb. - Leptotrichum glaucescens.

SOLMSIA Hpe. in Nuov. Giorn. bot. ital. 1872, p. 273.

Spec. omn. Braunfrlsiae ejusd, nom.

SOLMSIELLA C. M. in Bot. Centralbl. 1884, n. 31 (2 spec.).

eeylonica (Thto. et Mitt.) C.M. l. c.

Erpodium ceylanicum Thw. et M. in Journ. of the Linn. Soc. 1872, p. 306, t. 5 A,

i. Cortic. -- As. : Ceylan.

javanica $C, M . l . c$,

1. Cortic. - As, : Java.

SORAPILLA Mitt. M. austr. am. p. 603 (L spec.).

Sprucei Milt. l, c.

- Am. merid. : And. Quitens.

SPADOPHYLLUM Hpe, in Jaeg. Ad. 11. p. 666.

Octoblepharum Hpe. - Pottia.

Spathularia C. M. Syn. II, p. 229 (subgen. HyPNı sens. Muller.).

Spathulidium C. M. in Linn. 1876, p. 298 (sect. WEISLAE = GYROWEISIA).

SPHAERANGIUM W. P. Seh. Syn. I ed, p. 12 (14 spec.).

africanum Rehm. - Rehmanniella.

apiculatum (Hook, f. et Wils.) W. P. Sch. Syn. I ed.p. 12.

Acaulon apiculatum Jaeg. M. Cleist. p. 20. 
Phascum apiculatum $H . f$. et W. Fl. N. Zeal. p. 59, t. 83, f. 1 (1).

1. Terr. - Pac. : Nov. Zeland, Tasman.

" var. turgidum (Mitt.) Par.

Acaulon turgidum Mitt. in Trans. and Proced. of the roy. Soc. of Victoria, $1883, p .58$.

Phascum apiculatum var. turgidum Mitt. in H. f. et W. . c.

Ut typ. - Pac.: Tasman.

brisbanicum (C. M.) Jaeg. Ad. 1, p. 184 .

Acaulon brisbanicum C. M. in Linn. 1871-73, p. 144.

1 vel 2.

- Pac. : Austral. or.

capense (C. M.) Jaeg. $l, c$.

Acaulon capense C. M. in Bot. Zeit. $1856, p .415$.

A. muticum C. M. Syn. I, p. 22 p.p.

2.

- Afr.: C. B. Sp.

integrifolium (C. M.) Jaeg. l. c.

Acaulon integrifolium C. M. in Bot. Zeit. 1855, p. 745.

2. Terr. - Pac. : Austral. or.

Lorentzi (C.M.) Par.

Acaulon Lorentzi C. M. in Linn. 1880-82, p. 353.

2.

- Am. merid. : Argentin. Urug.

Lorentzi Beşch. - Sph. nanum.

mediterraneum (Limpr.) Par.

Acaulon mediterraneum Limpr. Laubm. Deutschl. I, p. 180.

A. pellucidum Fleisch. et Warnst. Bryoth. eur. merid. n. 2?

2 .

- Eur. : Sardinia.

muticum (Schreb.) W. P. Sch. l. c.

Acaulon muticum C. M. in Bot. Zeit. 1847, p. 99 et Syn. I, p. 22 et II, p. 519 ; Bryol. eur. I (mon. p. 8), t. 4 .

Phascum acaulon $\beta$ L. Sp. Pl. p. 1570.

Phascum acaulon $\beta$ minus Ehrh. Hannov, Magaz. 1780, p. 235.

Ph. bulbosum Voit $M$. Herbip. p. 8.

Ph. globosum Schleich.

Ph. muticum Schreb. de Phasco, p. 8, t. I; Brid. Bryol. univ. I, p. 22 (inel, var, rubrum).

Ph. muticum $\alpha$ majus $H$. et T. Muse. brit. p. $7, t .5$.

Sphagnum acaule bulbiforme minus Dill. Hist. M. p. 252, t. 32, f. 12 A. B.C.

Ps. 2. In campestr, aren., argill., in ericet. humos., etc. - Eur.: Fere tota, hand copiose. Afr. : Alger.; C. B. Sp. "? Am. sept. : Calif.

Exs. : Rab. Bryoth. eur. n. 151 arc.

Sull. et Lesq. M. bor. am. Il ed. n. 32.

* var. cuspidatum W. P. Sch. l. c.

Acaulon piligerum Limpr, $l$. $c$.

Phascum muticum var. piligerum de Not. Syll. p. 306.

Ut typ. - Eur. : Sardin., Graecia.

- var, minus (H. et T.) W. P. Sch. l. c.

Acaulon minus Jaeg. M. Cleist. p. 19.

(1) " Ubi calyptra sub f. 5 delineata delenda est et capsulae apiculus in fig. 3 et 4 calyptram veram repraesentat y. Mitt, in Journ. of the Linn. Soc. 1859, p. 71. 
Phascum muticum $\beta$ minus H. et T. l. o.; Brid. l. o. p. 23.

In maritim. - Eur. : Anglia, Gall. Afr. : Alger.

nanum (C.M.) Par.

Acaulon nanum C. M. in Fl. $1888, n .1$.

Sph. Lorentzi Besch. in Rev, bryol. 1885, p. 17 et in Bal. Pl. Parag. n. 3624.

1 ? Terr. - Am. merid. : Paraguay.

pellucidum Fl, et Warnst. - A. mediterraneum?

rufescens (Jaeg.) Lesq. et Jam. Man. p. 40.

Acaulon rufescens Jaeg. op. et $l$. oce.

A. triquetrum var. Sull. et Lesq. M. bor, am. II ed. n. 31.

I.

- Am. sept. : Reg. orient. et centr.

Schimperianum (Sulliv.) W. P. Sch. l. c. ; Lesq. et Jam. Man. p. 41.

Acaulon Schimperianum Sull. Ic. M. p. 18, t. 9.

Phascum Schimperianum ej. M. of U. St. p. 15.

- Am. sept. : Illinois, Texas.

Exs. : Sull, et Lesq. M. bor. am. II ed. n. 33 .

Sullivani $(C, M$.) Par.

Acaulon Sullivani $C . M$. in $F l .1888, n$. I.

2.

- Pac. : Austral. or.

triquetrum (Spr.) W. P. Sch. l.c.

Acaulon triquetrum C. M. Syn. I, p. 22 et II, p. 519 ; Bryol. eur. I (mon. p. 3), t. l.

Phascum bulbosum var. minimum de Not. Syll. p. 306.

$\mathrm{Ph}$, muticum Br. in M. Sardin. Müller. itin.; Drumm. M. bor. am. n. 8; Moug. et Nestl. Stirp. Voges, rhen. n. 802.

Ph. triquetrum Spr. in Lond. Journ, of bot. IV, 1815, p. 189 et in Engl. Bot. Suppl, $t, 2901$.

Ps, 2. In agger, et campestr. argill. arenac. - Eur.: Anglia, vall. Rhen. med., Saxon., Galloprov., Sardin. Afr.: Alger. Am, sept.: Nov. Angl., New Jersey, Carol. merid., Saskatchewan.

Exs. : Rab. Bryoth, eur. n. 164, 1054, 1156.

Sull, at Lesq. M. bor. am. II ed., n. 31.

" var. desertorum Besch, in Journ. de bol. 1894, p. 43. In arenac. - Af $r$ : : Gabes.

Uleanum (C. M.) Par.

Acaulon Uleanum C. M. in $\mathrm{Fl}$. 1888. $n .1$.

- Am. merid. : Brasil, austr, or.

vesiculosum (C. M.) Par.

Acaulon vesiculosum C. M. in op, et $l$. co.

- Am. merid. : Plata.

SPHÆROCEPHALUS Neck., Lindb.

Spec. omn. Aulacomnia ejusd. nom.

Sphærostegium C. M. in Fl. 1885, p. 426 (subgen. HyPN sensu Muller.).

SPHAROTHECIUM Hpe. in Ann, sc. nat. V ser., III, p. 361.

Spec. omn. CaMpylopodes ejusd. nom. 
SPHAGNU M Dill, Hist. M. p. 240 emend. (230 spec.).

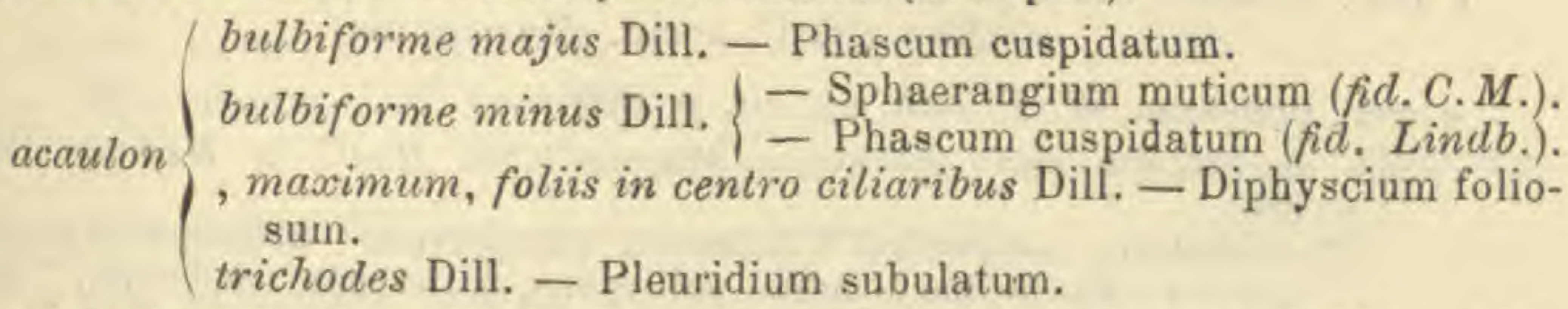
aciphyllum C. M. in Fl. 1887, p. 419; Warnst. in Hedwig. 1890, p. 202, $t$. IV, fig. $10^{\mathrm{B}}, 10^{\mathrm{b}}$ et $t$. VII, f. 11 .

Ster. - Am. merid. : Brasil. austr. or.

aconiense de Not. - Sph. squarrosum. aculeatum Warnst. - Sph. tumidulum.

acutifolioides Warnst. in Hedwig. 1890, p. 192, t. IV, fig. $4^{\text {a }} 4^{\text {b }}$ et $t$. VII, fig. 16.

Ster. ? - As.; Assam.

acutifolium Ehrh. Crypt. exs. n. 72 p.p.; C. M. Syn. 1, p. 96 p.p.; W. P. Sch. Mém. Sph. p. 61, tt. XIII et XIV et Syn. II ed., p. 825; Ritss. et Warnst. in Verh. d. bot. Ver. für Brandenburg, 188x, p. 112; Lindb. Torfm. p. 138 ; Rüss. Beitr. p. 37.

Hypnum cubile $\beta$ Neck. Meth. M. p. 189.

Sph. Ascherbachianum Breut, in Bot. Zeit, 1824, p. 459.

Sph. alpinum Ruehl.

Sph. capillaceum Wahlenb. Fl. Lapp.

Sph. capillifolioides Breut. in op. cit. p. 438; Brid. Bryol. univ. I, p. 751.

Sph. capillifolium Ehrh. Hann. Mag. 1780, p. 35; Brid. op. cit. p. 11.

Sph. gracile Rich. in Mich..Fl. bor. am. II, p. 285.

Sph. intermedium Hoffm. Deutseh. Fl. II, p. 22 (fid. C. M.).

Sph. nemoreum Scop. Fl. Carn. p. 161.

Sph. palustre L. Sp. pl, p. 1569 p.p. (fid. W. P. Sch.).

Sph. palustre $\beta$ capillaceum Weiss Orypt, Goett. p. 265.

Sph. palustre, molle, deflexum, squamis capillaceis Dill. Hist. M. p. 243,

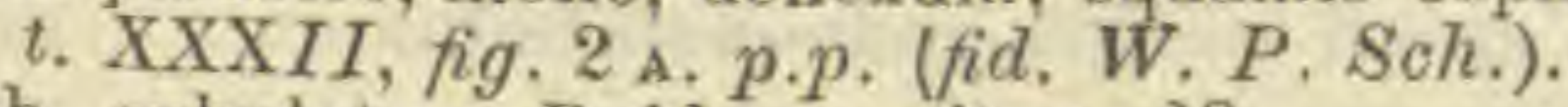

Sph. subulatum Brid. op. cit. p. 18.

1. In silvis et ericet. humid., ad scaturig. - Eur. : Tota: Spitzberg. As.: Septentr., Nepal., Syria.Afr.: Septentr., ins. Azor. Am. sept. : Vulg.; Groenland. Am. merid.: And. Nov. Granat, et Boliv., Valdiv. Pac.: Nov. Zeland.

Exs. : Rab. Bryoth. eur, n. 202, 203, 204.

Sull, et Lesq. M. bor, am. II ed. n.

"var. alpinum Milde Bryol. siles. p. 382.

Ut typ. - Eur.: Reg. subalp. et alp.

var. aquaticum Schlieph. - Sph. subnitens.

var. borbonicum Ren. et Card. - Sph, obtusiusculem var. purpurascens $f$. dasybrachyclada.

" $f$. campicolum (C. M.) Warnst. in Hedwig. 1890, p. 208.

Sph. campicolum C. $M$. in sched.

- Am.merid. : Brasil, austr. or. (ins. S. Catharina).

var, $\beta$ capillifolium Ehrh., Bryol. germ. - Sph. recurvum.

"var. coloratum Roell (1) in Hedurig. 1893, p. 296.

f. molle ej. in op. cit. p. 297.

Ut typ. - Am. sept. : Washington.

(1) Cl, Roell et Warnstorf easdem subformas vel formas, imo forsan varietates diverso nomine nimis probabiliter salutaverunt. 
"var. Corbieri Card. in Corb. Musc. de la Manche, pp. 208 et 364. - Eur.: Gall. occid. (Normannia).

«var. deflexum W. P. Sch. op. cit. p. 826.

Sph. acutifolium var. speciosum Warnst. (fid. Roell in Hedwig. 1893, p. 303).

ff. capitatum, compactum * deflexum, compactum * Schimperi, gracile, gracile * Schliephackeanum, pallescens, pallescens * deflexum, * flaccidum et * versicolor Roell in op. et $l$. co.

Ut typ. - Eur.: In alp. et zon. frigidiore usq. in arctica. Am. sept. : New Jersey, lndiana, Washington.

a var. densum Warnst. in Hedwig. 1884, p. 117.

Ut typ. - Eur.: Stiria septentr.

" $f$. diblastum (C. M.) Warnst. in Heduig. 1890, p. 208.

Sph. diblastum C. $M$. in Fl. 1897, p. 416 . - Am. merid.: Argentin.

* var. elegans Braithw.

f. dimorphum Roell in Hedwig. 1893, p. 297.

- Am. sept.?: Wisconssin.

var, elegans f. plumosa Roell. - Sph. tenellum.

var. fallax Warnst. $\left\{\begin{array}{l}- \text { Sph. Girgensohnii. } \\ - \text { Sph. Rüssowii. }\end{array}\right.$

var. flavicaule Warnst. - Sph. quinquefarium.

var. Aavicomans Card. - Sph, subnitens var. flavicomans.

«var. flavo-rubellum Warnst. in Bot. Gaz. 1890, p. 193.

- Am. sept. : New Hampshire.

"var. fuscum Roell in Bol. Centralbl. 1891, pp. 2l-22.

- Am. sepl. : Wisconssin.

var. Gerstenbergeri Warnst. - Sph, quinquefarium.

"var. gracile Roell System. (1) pp. 16-17.

f. flagelliforme ej. in Hedwig. 1893, p. 304.

- Am. sept.: Washington.

var. gracile Rüss. - Sph. Warnstorffii.

" var. immersum Schlieph. mss.; Warnst. Sph. eur. n. 104 et in Hedwig. 1884, p. 117.

Aquat. - Eur.: Westphal.

var. laete-virens Braithw. - Sph. subnitens.

var. laxum Warnst. - Sph. subnitens.

var. luridum Hüb., ff. deflexa, elongata, )

laete-virens, limosa, plumosa, sguar-
rosula, stricta et violacea.

var. meridense Hpe. - Sph. meridense.

(1) a Spezielle Systematik der Torfmoose. Versuch einer Gruppirung der (NordAmerikanichen) Torfmoose nach natürlichen Formenreihen,

\section{Formenreihen, \\ 373 Varietaeten, \\ 325 Formen}

and zarlrkichen unter und nebenformen enthaltend. Sit brevius dictum : "Tot specimina, quot nomina. 0 Lindbergii Sehimperique manes ! 
\& var. nanum (C. M.) Warnst. in Hedwig. 1890, p. 2 (18.

Sph. nanum C. M. in sched.

- Am. merid. : Brasil, austr, or. (ins, S. Catharina).

var. pallens Warnst. - Sph. quinquefarium.

" var. pallescens Warnst, in Bot, Gaz. 1890, p. 193.

- Am. sept. : Massachussets, New Hampshire.

"f. dasy-drepanoclada Warnst. in op. cit. p. 194.

- Am. sept. : New Hampshire.

\& var. patulum W. P. Sch. in op. et l. cc.

In pratis uligin, - Vulg. in Eur., As, et Afr. septentr.

var. plumosum Milde. - Sph. subnitens.

var. polyphyllum Warnst. - Sph. Rüssowii.

"var, pulchellum Warnst, in Hedwig. 1884, p. 116.

-- Eur. : Lappon.

"var. purpurascens Warnst. in Bot. Gas. 1890, p. 193.

Sph, acutifolium var, purpureum H. Müll. M. Westphal, n, 236.

New Hampshire.

- Eur. : German. occid. Am. sept.: Massachussets,

"var. purpureum W. P. Sch, in op, et l. cc.

In turfos, profund. mont, editior. - Eur. : Vulg. Am, sept. : Tota ;

ins. Miquelon.

Exs. : Rab. Bryoth, eur. n. 205.

var. purpureum H. Müll. $-\mathrm{Sph}$, acutifolium var. purpurascens.

var. quinquefarium Braithw. - Sph. quinquefarium.

var. robustum C. M. ?, Rüss. - Sph. Rüssowii.

var. roseum Limpr. - Sph. Rüssowii.

var, rubellum Rïss. - Sph. tenellum var rubellum.

var. Schillerianum Warnst. - Sph, subnitens.

a var. Schlotthaueri Roell in Hedroig. 1893, p. 296.

- Am. sept. : Indiana.

var, silesiacum Warnst. $-\mathrm{Sph}$, quinquefarium.

var. speciosum Warnst. (fid, Roell). - Sph. acntifolium var, deflexum.

var. squarrosulum Warnst. - Sph. subnitens.

var, sirictiforme Warnst. - Sph. Rïssowii.

var. tenellum W. P. Sch. - Sph, tenellum.

var, tenerum Aust. - Sph. tenerum.

var, tenue $\{$ Braithw. - Sph. tenellum.

var. tenue Bryol. germ. - Sph. Girgensohni.

a var. versicolor Warnst. in Bot. Gaz. 1890, p. 193.

- Am. sept.: Massachussets. New Hampshire.

\& $f$. robusta et subf. catoclada Warnsl. in op. et $l$. cc.

- Am. sept. : Vermont.

" var. Villardi Roell in Hedwig. 1893, p. 297.

- Am. sept. : Washington.

"var. viride Warnst. in op, et $l$. cc.

- Am. sept. : Massachussets.

acutifolium $\left\{\begin{array}{l}\text { Funk, n. 8. - Sph. quinquefarium. } \\ \text { H. f. et W, - Sph. fimbriatum. } \\ \text { Mitt. - Sph. Reichardti. } \\ \text { Rab, n, 204. - Sph, quinquefarium. }\end{array}\right.$ 
var. auriculatum Warnst. - Sph. Rüssowii.

acutiforme Schlieph.
et Warnst. $\left\{\begin{array}{c}\text { var. pseudlo-Schimperi Warnst. }- \text { Sph. tenellum. } \\ \text { văr. rubellum Schlieph. et Warnst. }- \text { Sph, tenel- } \\ \text { lum var, rubellum. } \\ \text { var. lenellum Schlieph. } \\ \text { et Warnst. } \\ \text { f. flavum Jens. - Sph. tenellum. }\end{array}\right.$ acutum Warnst. in Allgem. Bot. Zeitschr... in Karlsruhe, 1895, n. 7-8.

\section{- As.: Borneo.}

rquifolium Warnst. in Hedwig. 1891, p. 23, t. 1, fig. $9^{\mathrm{a}}, 9^{\mathrm{b}}$ et $t$. IV, fig. i.

- Afr.: Madagasear.

affine Ren. et Card, in Rev. bryol. 1885, p. 44; Card. Sph. d'Europe, pp. 35-36, t. Il, fig. 9 et 10 et $t$. III, fig. 5 .

Sph. imbricatum var. affine Warnst. in Bot. Gaz. 1890, p. 250 et in Hedwig. 1891, pp. 140, t. XIV, fig. 4 a, 4 b et $t . X X$, fig. I.

New-York, Florida.

- Am. sept. : Canada, New Jersey, Massachussets, africanum Welwo, et Duby in Mém... Genève, 1871), p. 2, t. I, fig. 1. - Afr. : Angola.

albicans Warnst. in Hedwig. 1893, p. 1, t. I, fig. 2 a-2 f.

Ster. - Afr.: Regio lacustr.

alpinum $\left\{\begin{array}{l}\text { L. - Dicranum elongatum var. orthocarpum. } \\ \text { Ruehl. - Sph. acutifolium. } \\ \text { Schrank. - Sph. cuspidatum. }\end{array}\right.$ ambiguum Hüb. - Sph. rigidum var. compactum. andinum Hpe. - Sph. medium.

Àngstroemi Hartm. Skand. Fl. VII-X ed.; W. P. Sch. Syn. II ed. p. 842; Lindb. Torfm. p. 140 ; Riiss. Beitr. p. 79.

Sph. insulosum Angstr. mss.; W. P. Sch. Syn. I ed., p. 683; Rab. Bryoth. eur. n. 703.

Sph, molluscum $W . P . S c h$. Vers... p. 72 (quoad pl, lapponicam.).

- Eur. : Lappon., Spitzberg.

(f) dasy-anoclada Rüss. (fid. Warnst. in Hedro, 1893, p. I). - As. : Sibiria (Kolyma).

angustifolium Jens. - Sph. recurvum var, parvifolium.

angusti-limbatum Warnst. in Allgem. Bot. Zeitschr... in Karlsruhe 1895 , n. $7-8$. - Afr. : Anstral.

antarcticum Mitt, in Journ. of the Linn. Soc. 1859, p. 100; Warnst. in Hedroig. 1890, p. 252, t. XIII, fig. 23-27 et $t$. XIV, fig. c, d.

Sph. compactum var. Hook. f, et Wils. Crypt. antarct. p. 122.

Sph. cristatum Hpe. (fid. Warnst, l, c.).

Sph. procerum W. P. Sch. hb. (nunc in hb. Kew.).

Ad terr. humid. - Pac. : Ins. Campbell, Tasman.

"var. fluctuans Warnst, in op. et $l$. cc.

Ubi typus. 
Antillarum W. P. Sch. in hb. Kewo.; Warnst. in Herlwig. 1891, p. 147, t. XV, fig. 11 a, 11 b el $t$. XXI, fig. 0 .

- Am. merid. : Ins. Trinitat.

Antillarum Besch. - Sph. Lesueurii.

Arbogasti Ren. et Card. in Bull. Soc, roy. bot. Belg. 1893, II, p. 8;

Warnst. in Hedwig. 1896, 1, t. III, fig. 7 a-7 e.

- Afr. : Madagascar, ins. S. Maria.

arboreum W. P. Sch. in Lechler Pl. Peruv. n. 2529 p.p.; Warnst. in

Hedwig. 1891, p. 32, t. II, fig. 23 a, 23 b, el t. V, fig. r.

Sph. medium (fid. Warnst, in Bot. Gaz. 1890, p. 252).

Cortic, - Am. merid. : And. Peruv.

arboreum L. - Cryphaea heteromalla.

Ascherbachianum Breut. - Sph, acutifolium.

assamicum C. $M$. in $\mathrm{Fl}$. 1887, p. 411 .

Ster.

- As, : Assam.

auriculatım W. P. Sch. Mém. Sph. p. 79, t. 24 et Syn. II ed. p. 844.

Sph. subsecundum var. auriculatum Lindb. Torfm. p. 28.

Sph, subsecundum var, isophyllum Rüss. Beitr. p. 73 (fid. Jaeg.).

- Eur. : Anglia. Am. sept.: Septentr, et centr.

auriculatum $\left\{\begin{array}{l}\text { Lesq. (ex ipso !) }- \text { Sph. mendocinum. } \\ \text { Rab. n. } 713 \text { et } 714,- \text { Sph. neglectum. }\end{array}\right.$

Austini Sull, in Aust. M. Appal. I, n, 2 et lc. M. Suppl. p. 9, t. 1; W. P. Sch. op. cit. p. 849; Lindb. Man. M. II, p. 391, t. 1, fig. 10 (1).

1 (Warnst.) ; 2 (Lindb.). -Eur.: Anglia, Suec.,

Brandeb., Westphal., Siles, Am. sept. : Canada, Terr, nova, ins.

Miquelon, Massachussets, New Jersey, Ludovic. or., Mississipi. Exs. : Braithw. Sph. brit, n, 1 et 2.

Warnst. Sphagnoth. eur, n. 29, 30, 77; Eur. Torfm, ser. I, n. 13 et 14 ; ser, II, n. 101 et 102.

* var. congestum (Warnst.) Card. in Rev. bryol. 1883, p. 76.

- Eur. : Gall. sept. or. (Ardenn.).

" var. cristatum (Warnst.) Par.

Sph. imbricatum var. cristatum Warnst, in Hedw, 1891, b. XIV, fig. 5 a,

5 b et $t$. XX, fig. $\mathrm{f}$,

Ubi typ.

var. glaucum $\left\{\begin{array}{l}\text { f. imbricatum } \\ \text { f. squarrosulum } \\ \text { f. subsquarrosum }\end{array}\right\}$ Roell. $\left\{\begin{array}{l}- \text { Sph. Austini var, imbri- } \\ \text { eatum. } \\ - \text { Sph. Austini var. sub- } \\ \text { laeve. } \\ - \text { Sph. Austini var. imbri- } \\ \text { eatum. }\end{array}\right.$

" var. imbricatum (Hsch.) Lindb. Contr. ad f. crypt. As, bor, or. p. 280 et in Bot. Not. 1873, p. 45.

Sph. Austini var. glaucum Roell $f$. imbricatum et subsquarrosum ej. in Hedwig. 1897, p. 54.

Sph. eymbifolium var, condensatum C. M. Syn, I, p. 92 p.p. (fid. Lindb.).

Sph. imbricatum Hsch, in hb, reg. Berol. (fid. Txuss. Beits. 1865, p. 21);

Warnst, in Bot, Gaz. 1890, p. 249 et in Hedwig. 1891, p, 139. 
- Eur.: Ins. Hebrid, As,: Kamschatka. Am. sept.: Labrador, Canada, Terr. nova, sept. et occid, Arkansas, Florid., Ludovic., Alabama, Mississipi.

\& var. laxum Roell System, p. 107 et f. fusco-flavescens ej. in Hedroig. 1897, p. 54 .

- Am. sept. : Arkansas.

"var. sublaeve (Warnst.) Par.

Sph. Austini var. glaucum Roell f. squarrosulum ej. in Hedvig. 1897, p. 54-55.

Sph. imbricatum var. sublaeve Warnst. in op. et $l$. oc.

Ubi typ.

australe Mitt. in Journ. of the Linn. Soc. 1859, p. 100; Fl. Tasman. II, p. 162; Warnst, in Hedwig. 1890, p. 259, t. XXII, fig. 18, 19 et t. XIV, fig. e.

Sph. compactum var. ovatum $H . f$. et W. Fl. Antarct. p. 122.

Sph. confertum Avch, et Mitt. in op, et $l$. cc.

- Pac. : Nov. Zeland, Tasman, ins, Campbell.

australe W. P. Sch. $\{$ (fid. Warnst. 1890). - Sph. cymbifolium. austro-molle C. M. - Sph. capense.

Balfourianum Warnst. in Hedwoig. 1891, t. XVII, fig. 21 a, 21 b et t. $X X I I, f i g .2$.

- Afr. : Ins. Franciae.

balticum Jens. - Sph. recurvum var, molle.

batumense Warnst. in Schrift. d. Naturforsch. Gesells, in Dansig, N. F., IX, Heft. II, 1896. - As. : Caucas. (Batoum).

Beccarii Hpe. in Nuov. Giorn. bot. ilal. 1872, p. 278; Warnst. in Heducig. 1891, p. 148, t. XV, fig. 12 a, 12 b et t. XXI, fig. p. - As. : Borneo.

Bernieri Besch. - Sph. cuspidatum.

Bescherellei Warnst. in Hedw, 1890, p. 240, t. XI, fig. 1-2 et t. XIV, fig. g.

Sph. patens Besch. Fl. bryol. Reunion, ete. p. 329.

Ster.? - Afr.: Ins. Borbon.

Bessoni Warnst. in Bull. Soc. roy. bot. Belg. 1893, $11, n .8$ et in Hedroig. $1893, p . \mathrm{I}, t$. I, fig. 3 a-3 f.

- Afr. : Madagascar.

Beyrichianum Warnst. in Hedvoig. 1897, p. 157.

- Afr. : Pondo-Land.

bicolor Besch. - Sph. medium.

Bolanderi Warnst, in Hedroig. 1891, p. 173, t. XIX, fig. 34 a et 34 b.

- Am. sept. : California.

Bordasii Besch. Fl. bryol. Réunion, etc. p. 189; Warnst. in Hedroig. 1891, p. 25, $t$. II, $f$. 17 a, 17 b et $t$. IV, fig. 9 .

Sph. coronatum Rehm. M. Afr. austr, n. 432 p.p.

- Afr.: Austral. ; ins. Franciae.

borneoense Warnst. in Allgem. Bot. Zeitschr... in Karlsruhe, 1895. 
brachybolax C. M. in Ule Bryoth. brasil. n, 78 .

- Am. merid : Brasil. austr. or. (ins. S. Catharina). brachycladum C. M. in Wainio M. brasil. n. 8; Warnst. in Hedwig. 1891, p. 43, t. 1II, fig $35 \mathrm{a}, 35$ b et $t$. V, fig. ec.

rina, Serra do Mar).

brasiliense Warnst. in Act. Soc. sc. Fenn. 1891, n. 5 et in Hedwoig. 1891, p. 150, t. XV, fig. 14 a, 14 c et $\iota$. XXII, fig. s $\alpha, s \beta, \mathrm{s} \gamma$.

Sph. brevirameum Hpe. forma? Warnst. l. $c$.

Sph. papillosum var. plumosum Rüss. mss.

- Am. merid. : Brasil. or. (Minas Geraës).

"var. carneum Warnst, in op. et $l, c c$., $f$. dasy-brachyclada Warnst. in op. et l. ec. et in Hedoo. 1891, p. 15l. sub nom. f. brachy-dasyclada.

Ster. - Am. merid. : Ubi typ.

var. chlorinum Warnst. - Sph. brasiliense var. glaucescens.

"var. glaucescens W arnst, in op. el l. cc.

Sph. brasiliense var. chlorinum ej. in Heduig. 1891, p, 151.

Sph, squarrosulum Warnst. in op. et $l$, oc.

$$
\text { - Am. merid. : Ubi typ. }
$$

brevifolium Roell p.p. - Sph. recurvum var. parvifolium.

brevirameum Hpe. - Sph. erythrocalyx var. papillosum $f$. brevirameum. caldense C. M. in Bot. Zeit 1862, p. 327; Warnst. in Hedroig. 1891, p. 24, t. II, fig. 18 a, 18 b.

- Am. merid. : Brasil, or.

var. scorpioides Hpe, - Sph. ryclophyllum. campicolum C. M. - Sph. acutifolium $f$. campicolum.

capense Hsch. in Linn. 1841, p. 113; C. M. Syn. I, p. 103; Warnst. in

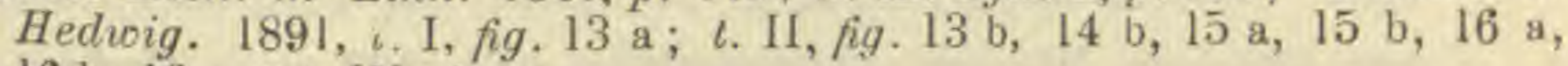
$16 \mathrm{~b}, 16 \mathrm{c}$ et $t . \mathrm{IV}$, fig. $\mathrm{n}$.

Sph. austro-molle C. M. in Rehm. M. Afr. austr. n. $16 \mathrm{~b}, 433 \mathrm{~b}, \mathrm{c}$, et in Fl. $1887, p, 419$.

Sph, mollissimum ej. in $l l$. cc. n. 17 et 434 b et $p, 418$.

capillaceum Wahlenb. - Sph. acutifolium.

$$
\text { - Afr. : Cap. B. Sp. }
$$

capillifolioides Breut. - Sph, acutifolium.

capillifolium $\{$ Ehrh. - Sph. acutifolium.

I Moug. et Nestl, n. 1. - Sph. quinquefarium.

Cardoti Wurnst. in Bull. Soc, roy. bot. Belg. 1893, II, p. 8 et in Hedwoig.

$1893, p .1, t$. I, fig. $4 \mathrm{a}, 4$ b et t. Il, fig. $4 \mathrm{c}, 4 \mathrm{~g}$.

- Afr. : Madagascar.

carneum C. M. in Ule Bryoth. brasil. n. 1289 et 1290; Warnst. in Hedroig. $1897, p .145$.

$$
\text { - Am. merid. : Brasil. or. (Ouro Preto). }
$$

cavifolium $\left\{\begin{array}{l}\text { var. lapponicum Warnst. }- \text { Sph. Duseni. } \\ \text { var, laricinum Warnst. }- \text { Sph. laricinum. } \\ \text { var. subsecundum Warnst. }- \text { Sph. subsecundum. }\end{array}\right.$

centrale C. Jensen in Sv. Vel. Akad, Handl. XXI, III, n. 10, p. 34 .

Sph. intermedium Rüss. 1894 (inol, varr. glaucescens, fusco-flavescens, flavo-fuscescens, fuscescens, Rüss, et pallescens (Warnst).

$$
\text { - Eur.: Septent". }
$$


ceylonicum Mitt. mss.; Warnst. in Hedwig. 1890, p. 195, t. IV, fig. 7 a, $7 \mathrm{~b}$ et $t$. VII, fig. 14 .

Ster. ? - As. : Ceylan.

chilense Ltz, in Bot. Zeit. 1866, p. 185.

I.

- Am. merid. : Valdivia.

chinense Brid. Bryol, univ. I, p. 750; C. M. Syn. I, p. 104. - As. : China.

comosum C. M. in Fl. 1887, p. 413; Warnst. in Hedwig. 1891, p. 35, t. II, fig. 26 a, 26 b, t. III, fig. 26 c et $t$. V, fig. u. - Pac, : Austral, or. (Nova Vales.).

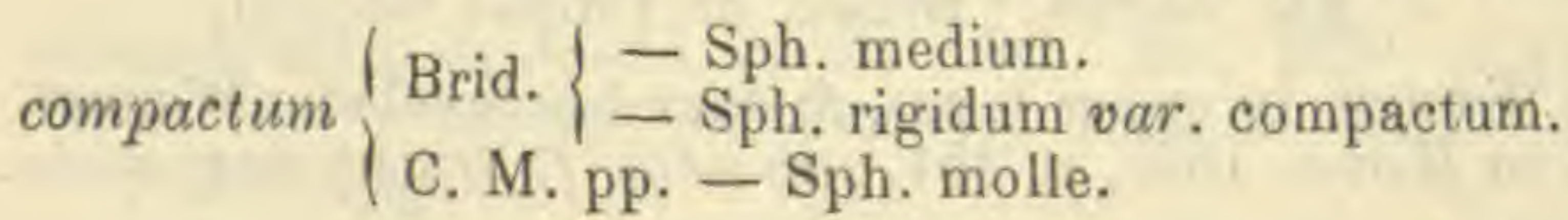

var. ambiguum H. f, et W. - Sph. subsecundum.

var. ovatum H. f. et W. - Sph. australe.

var. ramulosum C, M. - Sph. molle.

var. rigidum Bryol. germ. - Sph. rigidum.

var. turgidum Roell. - Sph. rigidum var. compactum?

var. H. f. et W, - Sph. antarcticum.

condensalum Brid. - Sph. ericetorum?

confertum Arch. et Mitt. - Sph, australe.

contortum Schultz Fl. Slarg. p. 64! (fd. Limpr. in litt. 18 a A pil 1888 ad Warnst. in Hedvo. 1888, pp. 266-267; Warnst. l. c. e spec. origin.) ; Brid. op. cit. 1, p. 7.

Sph. laricinum Spr. (fid. Warnst. l. c. et in Bot. Gaz. 1890, p. 24).

sachussets.

- Eur.: Mecklembourg. Am. sept.: Canada, Mas-

Exs. : Funk, Deutschl. M. n. 6.

"var. albescens Warnst. Sphagnoth. eur. n. 123 et in Hedwig. 1884, n. 7-8.

- Eur.: Hannovria.

" var. Beckmanni Warnst. Sphagnoth. eur, n. 126 et in Hedwig. l. c.

- Eur. : Hannovria.

" var. brachycladum Warnst. Sphagnoth. eur. n. 128 et 129 et in Hed. wig. l. $c$.

- Eur.: Brandebourg, Hannovria.

* var. compactum Warnst. (ubi?), ff. heterophyllum Roell Syst. p. 81 et

Schimperi ej. in Hedwig. 193, p. 313.

- Am. sept.: Washington.

\& var, corniculatum Reell System, p. 86.

- Am. sept. : Indiana, Arkansas.

- var, deflexum Gravel mss.; Warnst. in Hedwig. l, c.

- Fur. : Belgia.

var. laricinum Wils. - Sph. laricinum.

* var. Lindbergii Roell in Bot. Centrabbl. 1×91, pp. 21-22.

- Am. sept. : Indiana.

a var. squarrosulum Gravet mss.; Warnst. Sphngnoth eur. n. 125 et in Hedroig. l. c. 
" $f$. robustum Roell System. p. 83.

- Am. sept.: Washington.

var. subsecundum Wils. - Sph. subsecundum.

var. Wils. - Sph. khasianum.

convolutum Warnst. in Hedwig. 1890, p. 220, ı. VIII, fig. 10-12 et ८. X, fig. 6 .

? Sph. hypnoides W. P. Sch. in hb. Kew.

Ster. ?

$$
\text { - Afr.: C. B. Sp. }
$$

Cordemoyi Warnst, in Hedwig. 1897, p. 150.

- Afr. : Ins. Borbon.

coronatum C. M. in Fl. 1887, n. 12; Warnst. in Hedwig. 1891, p. 27,

t. II, fig. 19 a, 19 b et $t$. IV, fig. h.

Ster,

Exs. : Rehm. M. Afr, austr. n. 9 p.p.

coronatum Rehm. p.p. - Sph. Bordasii.

var. cuspidatum Rehm. n, 10. - Sph. oxycladum.

coryphaeum Warnst. in Hedwig. 1890, p. 189, t. IV, fig. 2 a, 2 b, 2 c. et

t. fig. 18.

- Am. merid. : And. Nov. Granat.

costa-ricense Warnst, in Bull. hb. Boissier, 1894, p. 401.

- Am. sept. : Costa-Rica.

crassicladum Warnst. in Bot. Centralbl. 1889, n. 45 c.ic.

- Eur.: Anglia (Cheshire).

crassisetum Brid. - Sph. cymbifolium.

crassum C. M. - Sph, medium.

cribrosum Lindb. - Sph. macrophyllum var, floridanum.

cristatum Hpe. in Linn. 1874, p. 661.

Sph. antarcticum (fid. Warnst. in Hedwig. 1890, p. 252).

- Pac. : Alp. Austral. or.

curvifolium Wils. $\left\{\begin{array}{l}\text { fid. Warnst.), - Sph. recurvum. } \\ \text { (fid. W. P, Sch, - Sph. laricinum. }\end{array}\right.$

cuspidatiforme Breut. - Sph. cuspidatum.

cuspidatulum C. M. in Linn. 1874, p. 549; Warnsl. in Hedwig. 1890, p. 225, $t$. VIII, fig. 20-23.

Sph. Fer G. M. in Nuov, Giom. bot, ital. 1891, p. 601, nom. (fid. Warnst.).

Ster.

- As. : Khasia, Birman. super.

cuspidatum Ehrh. Dec. crypt. n. 25] ; Brid. Brysl. univ. I, p. 14; C. M.

Syn. I, p. 96; W. P. Sch. Syn. II ed. p. 831 ; Lindb. Torfm. p. 135;

Rïss. Beitr. p. 55; Warnst. "die Cuspidat... Gr. p. 205, t. 1, fig. 13-14.

Sph. alpinum Schrank Baiers Fl. II p. 435.

Sph. Bernieri Besch, in hb. Mus. Paris, 1879, (fid. Warnst. in Hedwig. 1890 , p. 236, t. IX, fig. $30-38$.

Sph. capillifolium $\beta$ cuspidatum Wahlenb. Fl. Lapp. p. 301.

Sph. cuspidatiforme Breut. in Fl. 1824, $p .407$.

Sph. cuspilatum $\beta$ immersum W. P. Sch. Mém. Sph.t. XVI, fig. $\beta$ let $\beta 2$.

Sph, gabonense Besch. in hb. Mus. Paris, 1883 (fid. Warnst, in Hedwig. 1890, p. 236, t. 1X, Ag. 26-29).

Sph. laricinum Aust. M. Appal. n. 31 ; C, M. Syn. I, p. 97; Angstr. in Rab. Bryoth, eur, n. 712 .

Sph. Naumanni G. M. in Engler's Bot. Jahrb. 1883, p. 87 et in Fors- 
chungsreise...p. 59 (fid. Warnst. in Hedwig. 1890, p. 236, t. I, fig. 28, 29 a, 29 b et 31 .

Sph. palustre, molle, deflexum, squamis capillaceis Dill. H. M. p. 243, t. XXXII, fig. 2 A. (fid. C. M.).

Sph. variabilevar. 2 p.p. Warnst. Eur. Torfm, p. 69.

1 (W. P. Sch. Mém.) 2 (ej. Syn.). In turf. aquos. e reg. campestr. nsq. in subalp. - Eur.: Fere tota. As.: Septentr. Afr.: Gabon, Madagascar. Am. sept. : Canada, Terr. nova; reg. or. et merid., de Labrador ad Florid. et Ludovic. Am. merid.: Ins. Trinitat.; Brasil. ? Pac.: Nov. Zeland., Austral. or. (Queensland).

Exs, : Braithw. Sph. brit. n. 50-52.

Ehrh. Fl. crypt. n. 251.

Erb. crit. ital, n. 1214 (fid. Limpr.).

Gravet, Sph. Belg, n. 37, 38, 40-46,

Jack, Lind, et St. Krypt. bad. n. 222-224, 571.

Limpr. Bryoth. siles, n. 197 a et b.

Moug. et Nestl. Stirp. vog, rhen. n. 40 (cum Sph. recurvo mixt.). H. Müller, Westfal. Laubm, n. 232.

Rab. Bryoth, eur. n. 210, 211 (excl, 211 c.), 609, 716 b (excl. 716).

Warnst. Sphagnoth. eur. n. 49,50, 96-99, 116-119, 182-183, 196.

Warnst. Samml. eur. Torfm. ser. 1, n. 96; ser. I1, n. 196.

var. biforme (Braithw.) Mac. - Sph. Duseni.

var. crispulum Warnst. - Sph. Duseni.

var. deflexum Warnst. - Sph. Duseni.

" var. falcatulum (Besch.) Par.

Sph. cuspidatum Sull. in Wilkes Expl. Exped. p. I (fid. Besch.).

Sph, cuspidatum var. falcatum Warnst, in Hedwig. 1890, p. 236, t. IX, fig. $14-17$ et $t$. X, fig. 20.

Sph. falcatulum Besch. in Bull. Soc. bot. Fr. 1885, p. Lxvir et in Mss. so. Cap Horn, V, Bot., p. 306, t. 6, fig. 21.

- Am. merid.: Patag,, ins, Stat., cap. Horn.

«var. falcatum Rüss. Beitr. sur Kentn. d. Torfm. p. 59; W. P. Sch. Syn. 11 ed. p. 832.

f. pumila Gravet; Warnst. in Hedwig. 1884, p. 125,

f. rigida Warnst. in Abh... l. o.p. 207.

Ut typ. - Eur. : Ubi typ. Am. sept. : Ubi typ.; ins. Miquelon.

var. falcatum Warnst. - Sph. cuspidatum var. falcatılum.

"var. hypnoides (A. Br.) W. P. Sch. Syn. II ed. p. 832 et Mém. Sph.

t. XVI, fig. $\varepsilon$.

Sph. hypnoides A, Br. in Fl. 1825, p. 62 et in Brid. Bryol. univ. I, p. 752. Sph. laxifolium var. hypnoides C. M. Syn. I, p. 98.

Ut et ubi typ. in Eur, et Am. sept.

var. immersum W. P. Sch. - Sph. cuspidatum.

var. Zaxifolium Rab. (n. 716), - Sph. Duseni.

"var. majus Rüss. Beitr.... p. 58 p.p.

Sph. riparium Angstr. in Rab. Bryoth. eur. n. 707 (fid. Jaeg.).

Ut et ubi typ. in Eur. et in Am. sept.

var. majus Jens. - Sph. Duseni.

var. mendocinum Card. - Sph. mendocinum.

var. microporum (Warnst.) Par. Sph. falcatulum var. microporum Warnst. in Allgem. Bot. Zeitsohr.. in
Karlsmuhe, 1895 . 
«var. miquelonense Ren. et Card. in Bull. soc. roy. bot. Belg. XXVI, I p.p. ; Warnst. o die Cuspidat... Gr. p. 209, t.I, fig. $24 \mathrm{a}, 24$ b et t. II, fig. $\mathrm{h} \alpha$ et $\mathrm{h} \beta$.

Sph, cuspidatum var. Torreyanum Ren. et Card.p.p. (fid. Warnst. l. c.). chussets, ins. Miquelon.

-- Eur.: Anglia (Lancashire). Am. sept. : Massa-

miquelonense R. et C. p.p. - Sph. clispidatum var. Torreyanum (fid.

Warnst.).

f. mollis Warnst. - Sph. cuspidatum var. plumulosum.

«var. monocladum v. Klinggraef in Hedworg. 1882, p. 2; Warnst. " die Cuspidat... Gr. "p. 208, $\iota$. I, fig. 27 a, 27 b, 28, 3I et t. II, fig. $\mathrm{c} \alpha, \mathrm{c} \beta, \mathrm{c} \gamma$.

$$
\text { - Eur.: Boruss. occid. }
$$

var. patens Ângstr, - Sph. Wulfianum.

" var. plumosum Bryol. germ. 1, p. 24, t. IV, fig. 9*; W. P. Sch. in op. et l. cc., fig. 5 ; Ruiss. Beitr... p. 60 ; Warnst. \& die Cuspidat... Gr. » p. 207, t. I, fig. 22 a, 22 b, 23 et t. II, fig. g.

Sph. cuspidatum Crome Samml. deutsch. Laubm. n. 5; Funk, Crypt. Gew. Fichtelgeb. n. 347 .

Sph. laxifolium C. M. Syn, I, p. 97.

f. serrata Schlieph. Beitr... 1865; Warnst. in op. cit. p. 208, t. I, fig. $15-16$.

f. truncata Schlieph, l. c.; Warnst. l. e. fig. 17.

Mississipi.

- Eur.: Ubi typ. As.: Java? Am. sept. : Reg. alp.,

Exs. : Rab. Bryoth. eur. n 210 b, 211 b, 716 a et b.

var, plumosum Rab. (211 c, 717, 952). - Sph. Duseni.

\& var. plumulosum W. P. Sch. in op. et l. cc. fig. $\gamma \mathrm{l}$ et $\gamma 2$.

Sph. cuspidatum $f$. mollis Warnst. Samml. eur. Torfm. $n$. 95-96 et "die Cuspidat... Gr. n, p. 207.

Sph. cuspid atum var. polyphyllum Schlieph. in Warnst. " die Cuspidat. . Gr. " l. c., . II, fig. $\mathrm{k}$.

Sph. hypnoides Al. Braun (fid. Warnst. l. c.). subf. crispula Warnst. $l$. $c$.

- Eur. : Ut et ubi typ. Am. sept.: Reg. alp.

var. plumulosum Rab. (n. 210 a, 2:1). -- Sph. cuspidatum var. submersum.

var. polyphyllum Schlieph. - Sph. cuspidatum var. plumulosum.

var. Rauei Aust. - Sph. recurvum.

subsp. riparium Lindb. - Sph. spectabile.

var. serratum (Aust.) $\left\{\begin{array}{l}\text { Lesq. et Jam. }- \text { Sph. trinitense. } \\ \text { Warnst. }-\mathrm{Sph} \text {. cuspidatum var. submersum } \\ f \text {. serrulata. }\end{array}\right.$

var. speciosum Rüss. - Sph. spectabile.

" var. submersum W. P. Sch. Mém. Sph. p. 67, t. XVI, fg. 1 $\beta, 2 \beta$ et Syn. II ed. l. c.; Warnst. « die Cuspidat...Gr. " p. 2in, t. I, fig. $182 \mathrm{l} \mathrm{a}$, b et $t$. II, fig. f.

Sph. cuspidatum var. plumulosum Kab. Bryoth. eur. n. 210 a, 211.

f. serrulata Warnst. in Hedwig. 1890, p. 235.

Sph. serratum Aust. in Bull. Torr, bot. Club, 1877, p. 145 (fid. Warnst. l. c.).

In turfos, - Eur. : Brandebourg, etc. Am. sept. : Sept. et orient. ; Ludovie. ( $f$. serrulata).

"var. tenellum Warnst. in Hedwoig. 1884, p. 125.

- Eur. : Brandebourg. 
\& var. Torreyanum Sull. M. bor. am. II ed., p. 4; Warnst. "die Cuspidat... Gr. » p. 209, t. I. fig. 26 et 30 .

Sph. cuspidatu.n var, miquelonense Ren, et Card. p.p. (fid. Warnst, l. o.). Sph. cuspidatum var. Torreyi Braithw. Sph. brit. p. 82 p.p. (fid. Warnst. l. o.).

Sph. Torreyanum Sull. in Mem. Acad... IV, p. $175 ;$ C. M. Syn. II, p. 539.

- Eur.: Anglia (Shropshire, fid. Boswell.). Am.

sept. : Ins. Miquelon, New Jersey, Massachussets; reg. merid.

var. Torreyi Braithw. - Sph. cuspidatum var. Torreyanum.

" var, uplandense Angstr. in Rab. Bryoth, eur. n. 715.

- Eur. : Lappon. (Uplandia).

var. $\alpha$ Rüss. f. $\left\{\begin{array}{l}\text { mollissima Rüss. } \\ \text { recurvum Rüss. } \\ \text { typicum Rüss. }\end{array}\right\}$ Sph. recurvum.

cuspidatum $\left\{\begin{array}{l}\text { Crome, Funk, - Sph. cuspidatum var. plum } \\ \text { Lindb. - Sph. Lindbergii. } \\ \text { Mitt. }\left\{\begin{array}{l}\text { - Sph, cuspidatulum. } \\ \text { - Sph. rufulum. }\end{array} \text { - Sph. Seemanni. }\right. \\ \text { Sulliv. - Sph, cuspidatum var. falcatulum. } \\ \text { W. P. Sch. Syn, I ed, - Sph. recurvum. }\end{array}\right.$

cyclophyllum Sull. et Lesq. M. bor. am. I ed. n. 5 et 11 ed. $n .8$; Sull. M. of U. St. p. 11 et Ic. M. p. 13, t. VI, et Suppl. p. 16, t, VII.

Hemitheca cyclophylla Lindb. Hvitmossor. 1882.

Sph. caldense $\beta$ scorpioides Hpe. Symb. 1874, p. 480 et in Glaziou M. Brasil. n. 7042.

Sph. Drummondii Wils, mss, ; Braithw. Sph. Eur. et N. Amer.

Sph. laricinum var. cyclophyllum Lindb. in Aot. Soc. so. Femn. 1872, p. 280 et Man. M. II, p. 403.

Sph, obtusifolium var, turgidum $H$. f. et $W^{*}$. in Drumm, M. bor. am. II 2. ed., n. 17.

Carol., Ludovic.

- Eur. : Fennia, Am, sept. : New Jersey merid.,

Exs. : Aust. M. Appal. I ed., n. 25.

"var. macrophyllum Warnst. in Act. Soc, sc. Fenn. 1891, n. 5, f. Ster. dasy-anocladum Warnst. $l . c$.

cymbifolioides $\left\{\begin{array}{l}\text { Breut. - Sph. cymbifolium, } \\ \text { C. M. - Sph. cymbophyllum. }\end{array}\right.$

cymbifolium Ehr. Hann. Mag. 1780, p. 235 ; Brid. Bryol. univ. 1, p. 2; C. M. Syn. 1, p. 92; W. P. Sch. Mém. Sph. p. 69, t. XX et Syn. II ed. p. 847 ; Lindb. Torfm. p. 143 ; Rüss. Beitr.... p. 77.

Sph, australe W. P. Sch. in hb. Besch. (fid. Warnst, in Bot. Gas. 1890, p. 250).

Sph. crassisetum Brid. Sp. M. I, p. 15.

Sph, cymbifolioides Breut, in Fl. p. 435.

Sph. cymbifolium var, magellanicum Brid. Bryol. univ. I, p. 4.

Sph. latifolium Hedw. Sp. M. p, 27; Moug. et Nestl. Stirp. vog, rhen. n. $113 ;$ A. de Breb. M. Norm. n. 99.

Sph. magellanicum Brid. M. Rec. II, I, p. 14, t. II, fig. 1.
Sph. molle, deflexum, squamis cymbiformibus Dill. Hist. M. p. 240, t. XXX, fig. 1 .

Sph. oblongum P. B. Piodr, p. 6 ; Brid. Bryol. univ, I, p. 6.

Sph, obtusifolium (Ehrh.) Hook, et Tayl. Musc. brit, p. 3, t, IV; Funk, Crypt. Gevo, Fichtelgeb, n. 230. 
Sph. palustre L. (fid. Lindb.).

Sph. subbicolor Hpe. in Fl. 1880, p. 440 (fid. Warnst. in Bot. Gaz. 1890, p. 250 .

Sph. vulgare Rich, in Mich. Fl. bor. am. II, p. 285.

2. Secus rivul. mont. praepr. arenac. et granit., in ericet. humid., etc, - Eur. Tota. As.: Japon., Saghalien, Caucas. occid, Java, ins. Banca. Afr. : Teneriffa, ins. Azor. Am. sept. : De Labrador et Columb, brit. usq. ad Florid. : Jamaic., Guadalup., Cuba. Am. merid. : And. Nov. Granat. et Quitens., Brasil,, Chile. Pac.: Austrul. or., Tasman.

Exs. : H. Müll. M. Westfal. n. 223.

Rab. Bryoth. eur. n, 207, 803.

" var, atro-viride Schlieph. mss. ; Warnst, in Hedwig. 1884, n. 7-8.

- Eur. : Thuring. Am. sept. : Ubi typ.

var. borbonense P. B. - Sph. cymbifolium var. patens.

* var. brachycladum Roell in Hedwig. 1893, p. 316, f. bicolor ej. $l$. c. - Am. sept.: Washington.

- var. compactum Schlieph. et Warnst. in op. et l. cc.

- Am. sept. : Wisconssin, Washington.

ff. brachycladon et strictum Roell in Hedwig. 1893, p. 317.

- Am. sept. : Washington.

var. compactum Rïss. - Sph. medium.

" var. condensatum Hook. Fl. antarct. $I 1$, p. 398.

- Am. merid. : Fret. Magellan.

var. condensatum C. M. (fid. Lindb.). - Sph. Austini var. imbricatum.

* var. congestum Roell in Hedwig. 1893, p. 315.

- Am. sepl. : New Jersey.

$f$. bicolor et * strictum ej. in op. et $l$. cc.

- Am. sept.: Washington.

var. congestum $\left\{\begin{array}{l}\text { Rab. (n. 722), - Sph, medium var. laeve } f \text {. purpu- } \\ \text { rascens. } \\ \text { W. P. Sch. - Sph. medium. }\end{array}\right.$

"var. contortum Roell in op. cit. p. 316.

- Am. sept. : Wisconssin.

- var, deflexum Schlieph. mss, ; Warnst. Sphagnoth. eur. n. 195 el in Hedwoig. 1884, n. 7-8.

- Eur. : Belgia, Hannov., Thuring.

"var. fuscum Warnst. in Hedworg. l. c.

- Am. sept. : Indiana.

* var. globiceps Schlieph. mss, f. fuscescens Roell in op. el l. cc.

- Am. sept. : Indiana.

var. Hampeanum f. gracilis Warnst. - Sph. guadalupense.

" var. imbricatum Roell Syst. p. 96, f. bicolor ej. in Hedwig. 1893, p. 316.

- Am. sept. : Wisconssin.

subsp. intermedium Rüss. - Sph, papillosum var. intermedium.

"var. laeve Warnst. in Bot. Gaz. 1890, p. 251, f. glaucescens, subf. squarrosula.

Sph. glaueum v. Klingg. 1872.

- Am. sept. : Massachussets. 
"var. laxum Roell System. p. 97.

- Am. sept. : Indiana.

f. bicolor Roell in Hedwig. 1893, p. 316.

- Am. srpt. : Washington.

$f$. fuscescens Roell in op. et l. cc.

- Am. sept.: Wisconssin.

var. longifolium Hsch. - Sph. erythrocalyx var, laeve.

« var. ludovicianum Ren. et Card. in Bull. Soc, roy. bat. Belg. 1894, I, p. 4 .

Sph. Iudovicianum Warnst. in Hedwiy. 1891, p. 161, t. XVIII, fig. 26 a, 26 b et $t$. XXIII, fig. gg.

sissipi.

- Am. sept.: New Jersey, Florid., Ludovic,, Mis-

var. magellanicum Brid. - Sph. cymbifolium.

var. papillosum W. P. Sch. - Sph. papillosum.

var. Paradisii Besch. - Sph. medium.

" var. patens Brid. Bryol. univ. I, p. 4 p.p.

Sph. cymbifolium C.M. Syn. I, p. 91 p.p.

Sph. cymbifolium var, borbonense P.B. Prodr. p. 88?

Sph. patens Brid. Sp. M. I, pp. 13-14 p.p.

- Afr. : Ins. Borbon.

var, patens Brid. (quoad pl. Hispaniolae). - Sph, meridense.

a var. plathyphyllum Roell in Hedwig. 1893, p. 316.

- Am. sept.: Wisconssin.

$f$. complanata Roell in op. et $l$. cc.

- Am. sept.: New Jersey.

" var. purpurascens Schlieph. mss.; Warnst. Sphagnoth. eur. n. 150 et in Hedroig. 1884, n, 7-8.

- Eur.: Belgia.

"var. rigidum Roell in op. et $l$. cc.

- Am. sept. : Indiana.

« var, Roellii Schlieph. mss.

- Am. sepl.: Wisconssin.

a var. Schliephackeanum Roell in op. et $l$. cc. et f. squarrosula ej.l.c. - Am. sept.: New Jersey.

var. squarrosum Breut. - Sph. squarrosum.

"var. squarrosulum Bryol. germ. I, $p 8$.

If. deflexum, globiceps, immersum et pyenocladum Gravet mss.; Warnst. in Hedwig. 1884, n. 7-8.

- Eur. : Hassia ( $f$. globiceps), Belgia.

Exs, : Rab. Bryoth, eur. n. 721.

" var. sublaeve Limpr, mss.; Warnst, in op. et l. cc.

- Eur. : Germania.

" var. tenue Roell in Bot. Centralbl. 1891, pp. 21-22.

- Am. sept. : New Jersey.

C. M. pp. $\left\{\begin{array}{l}\text { Sph. cymbifolium var, patens. } \\ \text { Sph. Pylaisei }\end{array}\right.$ 
cymbophyllum F. v. Müller in Mossmann's Laubm. Samml, n. 767 (1854). Sph. cymbifolioides C, M, in Bot. Zeit. 1862, p. 546; Warnst, in Hedvig. $1891, p .36, t . I I I, f i g .27$ a. 27 b et $t$. V, fig. v.

Sph. contortum Wils.? (fid. Mitt.).

2.

- Pac. : Austral, or., Tasman.

dasyphyllum Warnst. in Hedioig. 1892, p. 196, t. XVI, fig. 7-9.

Ster.?

-. Am. sept. : Connecticut.

decipiens Sull, et Lesq. - Sph. subsecundum var. obesum.

degenerans Warnst. in Bot. Centralbl. 1889, n. 17 et in Hedwig. p. 42, t. XIV, fig. 7 a, 7 b et $t$. XX1, fig. i, $\mathrm{k} \alpha, \mathrm{k} \beta$.

Ster. -Eur: Anglia (Cheshire).

"var. immersum Warnst. in Bol. Centralbl. 1889, n. 17, c. ic.

Ubi typ.

densum C. M. et Warnst. in Hedwig. 1897, p. 147 et in Ule Biyoth. brasil. $n .1743$.

- Am, merid. : Brasil. or. (Serra do Itatiaia).

diblastum C. M. - Sph. acutifolium $f$. diblastum.

domingense C. M. - Sph. mexicanum.

Drummondii Wils. - Sph. cyclophyllum.

dubiosum Warnst. in Hedwoig. 1891, p. 20, t. I, fig. 7 a, 7 b et $t . V$, fig. dd.

- Am. sept. : Terra nov. Pac. : Austral, merid.

Duseni C. Jens. in litt. ; Riiss. et Warnst. in Silzungsber. d. Dorpater Naturforsch. Gesells, 1889, p. 99.

Sph. cavifolium $\delta$ lapponicum Warnst. Eur. Toifm.n. 90.

Sph. cuspidatum var. biforme (Braithw.) Mae. Canad. M. n. 8.

Sph. cuspidatum var. crispulum Warnst. in Hedwig. 1884, p. 121.

Sph, cuspidatum var. d+flexum ej, in op. et l, cc.

Sph. cuspidatum var. Iaxifolium Rab. Biryoth."eur. n. 716.

Sph. cuspidatum var. majus Rüss, Beitr... p. 58 p.p.

Sph. cuspidatum var. plumosum Rab. Bryoth. eror. n. 211 (Sph. recurvo immixt.), 717 et 952.

Sph laricinum Angstr, in Oefv. Vet. Akad. Foerh. 1864, p. 197; Rab. Bryoth. eur. n.712.

Sph, majns (Rû̀ss.) C. Jens, in De danske Sph. Arten, p. 106.

Sph. mendocinum Warnst. in Hedwig. 1888, p. 275 et in " die Cuspidat.. Gr. " $1889, p .210, t$ I. f. 34 et t. II, fig. $\mathrm{L} \alpha, 1 \beta$ et $\mathrm{m}$.

Sph. obtusum var. Duseni Warmst. Samml. eur. Torfm. ser. $I$, n. 97.

Sph. porosum Sehlieph. mss, ; Warnst. Rüchbliek in Fl. 1884.

- Eur, ; Lappon., Fennia, Rossia, Dania, German., Belg., Salisb., Stir. As. : Siber. occid. Am. sept. : Anticosti, Maine, New Hampshire, New York, Wisconssin.

e var. parvifolium, $f$. tenuis, subf. subfalcata Warnst. Eur. Torfm. ser. $111, n .281$ et in Hedroig. 1893, I.

- Am. sept. : New Hampshire.

elegans C. M. in Fl. 1887, p. 413; Warnst. in Hedroig. 1890, p. 224, t. VIIl, fig. 17-19 et $t . \mathrm{X}$, fig. 9 .

Ster. $\quad-$ Pac.: Nov. Zeland. austr.

Exs. : Helms, N Seeland. M. n. 45.

ellipticum C. M. et Warnst. in Hedroig. 1897, p. 165 et in Ule Bryoth. brasil. n. 1752 . - Am. merid. : Brasil. or. (Serra do Itatiaia). 
ericetorum Brid. Bryol. univ. I, p. 17; C. M. Syn. 1, p. 103; Warnst, in Bot. Centralbl. 1882, n. 3 el in Hedwig. 1890, p. 227, $t$, VIII, fg. 28-29 et $t$. X, fig. 1-12 (non Besch., fill. Warnst. in op. cit. 228). Sph. condensatum Brid. Bryol, univ. p. 16 ?

- Afr. : lns, Borbon.

erosum Warnst, in Hedwig. I890, f. 242, t. XI, fig. 5-6 et t. XIV, fig. i. Ster. ? - Pac.: Nov. Zeland.

erythrocalyx Hpe. in C. M. Syn. 1, p. 92; Warnst. in Hedwig. 1891, p. 156, t. XV1, fig. 17 a, 17 b.

Sph. medium Limpr: (fid. Warnst, in Bot. Gaz. 1890, p. 252).

- Am. merid. : Boliv., Peruv., Brasil. austr. or.

" var, laeve Warnst, in Heduig. l, c. p. 157.

Sph. cymbifolium $\beta$ longifolium Hsch. Fl. Brasil. I, p, 3 (fid. Hpe. ad Sph. perich.).

Sph. perichaetiale Hpe. in C. M.l. c. (fid. Warnst. l. c. t. XV, fig. 15 a, 15 b et $t$. XX, fig. t).

Sph. peruvianum Mitt. M. austr, am, p. 62 (fid. Warnst. l. e. fig. 16 a, $16 \mathrm{~b}$ et $t . X X I 1$, fig. $\mathrm{u} \alpha$ et $\mathrm{u} \beta$.)

Sph. suberythrocalyx C. M. in sched. (fid. Warnst. l. c. t. XVI, fig. 18 a, 18 b et XXII, fig, w).

et Boliv., Brasil. austr. or.

- Am. sepl. : Guadalup. Am. merid. : And. Peruv., "var, papillosum $f$. brevirameum Warnst. in Heduig. 1891, p. 156.

Sph. brevirameum Hpe. Symb. 1874, p. 479.

- An. merid. : Brasil, austr, or.

falcalulum Besch, - Sph. euspidatum var. falcatulum. fallax v. Klingg. - Sph, recurvum var, mucronatum.

Feae C. M. - Sph. cuspidatulum.

fimbriatum Hook, f. et Wils. M. antarct. p. 92, Fl. Antarct. p. 398 et Bryol. brit. p. 21 ; W. P. Sch. Mém. Sph. p. 64, t. XV et Syn. II ed. p. 829 ; Lindb. Torfmoss. p. 137; Rüss. Beitr... p. 51.

Sph, acutifolium $H$. f. et W. in Drumm. M. bor. am. I ed., n. 4; C. M. Syn, II, p. 538 .

Sph, subulatum $B r$. in $h b$. Kew. Sph, subulatum Br: in hb. Kew.
p. 40 .

I. In prat. torfac. - Eur. : Spitzberg, Dovre; fere tota. As.: Japon. Am. sept.: Groenland, Canada, Terra nova, ins. Miquelon, Maine, ming, Alaska, Sierra Nevada Calif, A m. merid. : Fret. Magell., ins. Eremit., Maclov.

- var. arcticum C. Jens. mss.; Warnst. in Bot. Gaz. 1890, p. 128. - Am. sept. : Groenland.

« var, densum Roell in Bot. Centralbl. 1891, n. 21-22.

- Am. sept.: Wyoming.

"var. flagelliforme Warnst. $f$. viridis Roell in Hedroig. 1893, p. 307. - Am. sept. : Wymming.

" var. gracilescens Roell in op. cit.p. $306, f$. viridis ej. l. c. - Am. sept. : W yoming.

"var, robustum Braitho, Sph, brit. n. 44. -- Eur. : Brandebourg. Am. sept. : Ubi typ. 
var. strictum Lindb. - Sph. Girgensohni.

"var. submersum Roell System. p. 38, "Schliephackeanum ej. in Hedroig. p. 306 et $f$. tenellum ej. $l$. c .

- Am. sept. : New Jersey.

" var. tenue Gravet mss. ; Warnst. in Hedioig. 1890, p. 128.

- Am sept.: Ins. Miquelon, Massachussets, New Hampshire, New Jersey, M. Alb., Wyoming, Sierra Nevada Calif.

fimbriatum $\left\{\begin{array}{l}\text { Mitt. }- \text { Sph. Girgensohni. } \\ \text { Rab. (n. 20 b et 718). - Sph. Girgensohni. } \\ \text { Wils. }\end{array}\right.$

I Wils. - Sph. Thomsoni.

var. strictum Lindb. - Sph. Girgensohni.

Fitz-Geraldi Ren. in Lesq. el Jam. Man. p. 23 el in Rev. bryol. 1885 , p. 46; Warnst. in Hedwig. 1890, p. 232, t. IX, fig. 7-13, t. X, fig. 18

et a die Cuspidat... Gr. »t. I, fig. 54, 55 a et b, 56 a, b, c, 57 a, b et t. II, fig. w.

2. Lignic. - Am. sept: Florida.

flaccidum Besch. Note M. Parag. p. 272; Warnst. in Hedvoig. 1891, p. 42, t. 3 , fig. 34 a, 34 b et t. V, fig. hb. - Am. merid. : Paraguay.

flavicans Warnst. in Allgem. bot. Zeitst $/$.... in Karlsruhe, 1895, n. 11. - Am. sept. : Mexic. (Oajaca).

flavicaule Warnst. in Hedwig. 1890, p. 190, fig. 3 a, 3 b, et t. VII, fig. 17 (erratim sub $\mathrm{Sph}$. flavo).

Ster. ? - Am. merid.: Venezuela, Peruv.

flexuosum Dz. et Mk. - Sph, recurvum. floridanum Aust. - Sph, macrophyllum var, floridanum.

fluctuans C. M. in Fl. 1887, p. 414 .

Ster.

- Afr. : C. B. Sp.

fontanum C. M. in Ule Bryolh. brasil. n. 174; Warnst. in Helloig. 1891, p. 38, t. III, fig. $30 \mathrm{a}, 30 \mathrm{~b}$ el t. V, fig. x.

Sph. late-truncatum Warnst, in sched.

- An. merid. : Brasil. austr. or.

fuscum (W. P. Sch.) v. Klinggr. in Schrift. d. Phys.-oecon. Gesells. in Koenigsberg, XIII, I, p. 4, n. 4 .

Sph, acutifolium var: fuscum W. P. Sch. Mem. Sph. p. 63, t. XIII, fig. \& et Syn. II ed. p. 826.

1. In turf. profund. mont. editior. - Eur. : Lappon,, Voges., Alp., ete. Am. sept. : Labrador, Canada, Alaska, Terra nov., ins. Miquelon, sept. occid., Indiana, Minnesota, M. Rupestr., Washington, Vancouver.

Exs. : Rab. Bryoth. eur. n. 710.

- var. compactum Roell in Fl. 1886, p. 25, f. strictum ej. in Hedroig. 1893, p. 294.

- Am. sepl.: Washington.

" var. densum ej. in Bot. Centralbl. 1891, pp. 2l-22.

- Am. sept. : Washington.

If. deflexum, strictum et virescens ej, in op. et $l . c c$.

$-A m$. sept. : Washington.

- var, filiforme Roell in Hedwig. 1893, p. 295.

- Am. sept. : Indiana. 
"var. flaccidum Roell in op. et $l$. cc. - Am. sept.: Washington.

"var. fuscescens Warnst. in Bot. Gaz. 1890, p. 135.

- Am. sepl. : New Hampshire.

$f$. dasy-anoclada ej. in op. et $l$. c.

- Am. sept. : New Hampshire.

$f$. robusta $e j$. in op. el $l$. $c c$.

- Am. sept. : Vermont.

* var. fusco-viride Rüss, mss.; Warnst, in op. et l. cc.

- Am. sept.: New Hampishire, Massachussets.

$f$. robusta Warnst. in op. el $l$. cc.

- Am. sept. : Massachussets.

subf. drepanoclada Warnst. in op. el l. cc.

- Am. sept, : New Hampshire, Massachussets

* var. gracile Roell in Hedwig. 1893, p. 294.

- Am. sept.: Washington, Michigan.

ff. strictum el virescens $e j$. in op et $l$. cc.

- Am. sept. : W ashington.

" var. robustum Roell in Cenlralbl. 1891, n. 21-22.

- Am. sept. : Washington.

$f$. virescens ej. in Hedroig. 1893, p. 294.

- Am. sept.: Washington.

* var. stellaris Roell in op. et $l$. cc.

- Am. sept. : Washington.

ff. deflexum, strictum et vit escens ej. in op. et l. cc.

- Am, sept. : Washington.

gabonense Besch. - Sph. cuspidatum.

Garberi Lesq. el Jam, in Proced. Am. Acadl. XIV, p. 133, et Man. p. 18;

Warnst. in Hedroig. $1890, p .245, t . \mathrm{XI}$, fig. 7-9 et $t$. XIV, fig. $\mathrm{n}$.

Sph, humile Aust. in Bull. Torr. bot. Club, VII, p. 2.

2. - Am. sept. : Labrador, Terra nov., Maine, New Jersey, Florida.

- var. sphaerocephalum Warnst, in Hedwoig. 1893, n. 1.

- Am. sept. : Maine.

a var. squarrosulum Warnst. in op. et $l$. cc.

- Am. sept. : New Jersey, Florida.

"var. subsquarrosum ej, in op. et l. cc.

- Am. sept. : Labrador, Maine, Terra nova.

gedeanum Ds. et Mk. in Verh. d. k. Acad, v. Wet. Amsterdami, 1854 el Bryol. jav. p. 28, t. 19; Warnst. in Hedrig. 1890, p. 99, t. v, $12 \mathrm{a}, 12$ b et t. VII, fig. 9 .

$$
\text { - As. : Khasia, Java. }
$$

georgianum Schwein. - Sph. macrophyllum.

Girgensohni Rüss. Beitr.... p. 46 ; Sull. 1c. M. Suppl. p. 14, ı. 17; W. P. Sch. Syn. II ed. p. 827.

Sph. acutifolium var. fallax p.p Warast, Eur. Torfm. p. 42.

Spl. acutifnlium \& lenue Bryol. germ, I, p. 22. 
Sph. fimbriatum Mitt, M. Ind, or, p. 156 (n. 1285); Wils, in hb. Ind. or. n. 1288 ; Rab. Bryoth. eur. n. 201 b et 718.

Sph. fimbriatum var. strictum Lindb. in Oefv.... 1862 et Torfm. bygg. p. 138.

Sph. Hookeri C. M. in Linn. 1874, p. 547.

Sph. leptocladum Besch. in hb. Mus. Paris.

Sph. strictum Lindb. Torfm. p. 138 (in obs. et syn.) in Aot. Soe. so. Fenn. 1872, p. 263 et Hvitm. p. 51.

Sph. Warnstorffi Roell in Fl. 1886, p.p.

2. In scaturig. silvat. - Eur.: Tota usque in arctica. As.: Amour, Saghalien, Japon., Yunnan, Sikkim. Am. sept. : Groenland, Canada, Alaska, Terra nov., ins. Miquelon, New Hampshice, Washington.

Exs. : Austin, M. Appal, n. 20.

Braithw. Sph. brit. n. 42 a.

Broth. M. Fenn. n. 99.

Fell. M. Suec. n. 184.

Rab. Bryoth, eur. n. 801 .

"var. albescens Roell System. p. 34 ; f. irregularis ej. in Hedroig. 1893, p. 306 .

- Am. sept. : Washington.

" var. coryphaeum Rïss. in Warnst. Samml. eur. Torfm. ser. I, n. 26 ; Warnst. in Bol. Gaz. 1ศ90, p. 29.

Alb.

- Am. sept, : Massachussets, New Hampshire, M.

- var. deflexum Schlieph. mss.; $f$. densum Roell in op. el l. cc.

- Am. sept.: Washington.

" var. densum Gravet (incl. var. pulchrum et molle ejusd.) mss.;

Warnst. in Hedioig. 1884, p. 119.

- Eur.: Belgia.

"var. flagellare Schlieph. (fid. Roell in Hedwig. 1897, p. 51).

$f$. ochraceum Roell in op. et $l$. ce.

- Am. sept.: Wisconssin.

"var. gracilescens Gravet mss.; Warnst. in op. et $l$. cc.

- Eur. : Belgia. Am. sept.: Ubi typ.

$f$. ochraceum Roell in op, et $l$. cc.

- Am. sept. : Wisconssin.

"var. molle Rüss. in Warnst. Samml. eur. Torfm. ser. I1, n. 115; Warnst. in Bot. Gaz. 1890, p. 130.

- Am. sept.: Labrador, Canada, Terra nov., ins.

Miquelon, sept. occid., Washington.

t. flagellare Roell in Hedwig. 1893, p. 306.

- Am. sept. : Washington.

val, molle Gravet.

var, pulchrum Giravet.

var, roseum Limpr. - Sph. Rüssowii.

"var. sphaerocephalum Warnst. in Hedwig. 1893, n. 1. - Am. sept. : Maine.

* var. squarrosulum Rïss, et W, P. Sch. in op, et l. cc.

In graminos, humid. - Eur.: Ubi typ., rarius. Am. sept. : New Jersey.

* var. stachyodes Rüss. in Warnst. Samml. eur. Torfns, ser. I, n. 50;

Warnst. in Bot. Gaz. 1890, p. 129.

- Am. sepl.: New Hampshire. 
" var, strictum Rüss, el W. P. Sch, in op. el $l$. cc.

In turfos. parum bumid. - Eur. : Ubi typ. Am, sept. : Labrador, New Jersey.

glaucum v. Klinggr, - Sph. cymbifolium var. laeve $f$. glancescens subf. squarrosula.

Godmanni Warnst, in Hedwig. 1890, p, 189, t. IV, fig. 1 a, 1 b et $t$. VII, fig. 19.

Ster. - Afr, : Ins. Azor.

gracile Rich. - Sph, acutifolium var, gracile.

gracilescens Hpe, in Bot. Zeit. 1862, p. 327; Warnst. in Heducig. 1891, p. 37, t. III, fig. 28 a, 29 et t. V, fig. w el in Ule Bryoth. brasil. n. 1077, 1108, 1305-6, 1753.

Sph. submolluscum Hpe. Symb. 1877, p. 715.

2.

or,

- Am. merid. : Brasil. or. (Minas Geraës) et austr.

"var. minutulum $f$. brachy-dasyclada C. M. et Warnst. in Hedroig. 1897 et in Ule Bryoth. brasil. $n .1751$.

- Am. merid. : Brasil. or.

gracilum C.M. in Nuov. Giorn. bot. ital. 1897, p. 7

- Am. merid. : And. Boliv.

Griffithianum Warnst, in Hedroig. 1891, p. 151, t. XV1, fig. 19 a, 19 b et ı. XXII, fig. X. - As.: Ind. or. (sine loco spec.).

guadalupense W. P. Sch, in hb. Mus. Paris et in Besch. Fl. hryol. Antill. fr. p. 90 ; Warnst. in Heduig. 1891, p. 148, t XV, fig. I3 a, 13 b et t. XXI, fig. $\mathrm{g} \alpha, \mathrm{g} \beta, 2 \alpha, 2 \beta$.

Sph. cymbifolium var. Hampeanum $f$. gracilis Warnst, in Bot, Centralbl. $1882, p, 133$.

Sph. Guyoni Warnst. in Deutsch. bot. Monatschr. 1884, n. 2.

Sph. Husnoti W. P. Seh. (fid. Warnst, in Hedwig. 1891, p. 148).

-Am. sept, : Guadalup, Martinic. Am. merid. : Brasil, or, (Minas Geraës).

guatemalense Warnst. in Hedwig. 1890, p, 243, t. XII, fig. 20 et $t$. XIV, fig. 1 .

Ster,

- Am. sept. : Guatemala.

Guyoni Warnst. - Sph. guadalupense.

Hahnianum (: M, - Sph, medium.

helenicum Warnst. in Hedroig. 1891, p. 19, t. I, fig. 5 a, 5 b et t. IV, fig. e.

- Afr. : Ins, S. Helena.

Helmsii Warnst, in Hedwig. 1890, p. 224, t. XIIL, fig. f.

Sph. novo-zelandicum O. M. in Helms N. Seeland, M. $n, 43$.

Ster.

- Pac, : Nov, Zeland.

Herminieri W. P. Sch, in Besoh. Fl, bryol, Antill, fr. p. 91.

Sph. porto-ricense var, Card. in Bull. Soc. ray. bot, Belg. 1894 (1).

- Am, sept, : Guadalup.

heteromallum polyeephalum Dill, - Cryphaea heteromalla.

(1) Cf. Warnst. in Hedwig. 1889, p. 304, t. IX, fig. 12 et 1890, n. 11-12. 
Hildebrandti C. M. - Sphagnum tumidulan var. microphyllum $f$. euryclada.

Holleanum Dz. et Mk, in Verh. d. k. Akad. l. Wissensch. et Bryol, jav. I, p. $29, t .20$.

Sph. sericeum
Sph. seriolum C. M. (fid. Warnst, in Bot. Ga.s. 1890, p. 197).

Ad arbor, - As. : Java.

Exs. : Zolling. n. 2217.

Hookeri C. M. - Sph. Girgensohni.

humile $\left\{\begin{array}{l}\text { Aust. }- \text { Sph. Garberi. } \\ \text { W. P. Sch. }\left\{\begin{array}{l}\text { (fid. Card., Lindb.). }- \text { Sph. rigidum. } \\ \text { (fd. Warnst.). }- \text { Sph. molle forma. }\end{array}\right.\end{array}\right.$

Husnoti W. P. Sch, in Besch. Fl. bryol. Antill. fr. p. 90.

Sph. guadalupense (fid. Warnst, in Hedwig. 1891, p. 148).

Exs.: Husnot, M. Ant. fr. n. 189.

hymenophyllophilum $C . M$, in Ole Bryoth, brasil, n. 97.

- Am. merid. : Brasil, austr, or. (ins. S. Catharina).

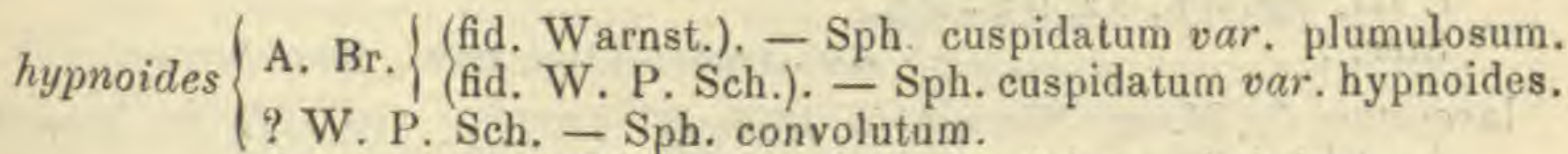

imbricatum $\left\{\mathrm{H}\right.$ sch. $\left\{\begin{array}{l}\text { (fid. Lindb.). }- \text { Sph. Austini var. imbricatum. } \\ \text { (fid. Rüss. et Warnst.). - Sph. Austini. }\end{array}\right.$ imbricatum $\begin{aligned} & \text { W. P. Sch. }- \text { Sph. tumidulum var, microphyllum } f \text {. dasy- } \\ & \text { clada. }\end{aligned}$

var. affine Warnst. - Sph. affine.

var. cristatum Warnst. - Sph. Austini var. cristatum.

var. sublaeve Warnst. - Sph. Austini var. sublaeve.

immersun: $\left\{\begin{array}{l}\text { Bryol germ. }- \text { Sph. rigidum var. compactum. } \\ \text { Casseb. }- \text { Sph. papillosum. }\end{array}\right.$

insulosum Ângstr., Rab. n. 703. - Sph. Ängstroemi.

intermedium $\left\{\begin{array}{l}\text { Funk, n.10. }- \text { Sph. quinquefarium. } \\ \text { Hoffm. } \begin{array}{l}\text { (fid. C. M.). Sph. acutifolium. } \\ \text { (fid. Lesq. et Jam.) - Sph. recurvum. } \\ \text { (fid. Mac.). Sph. mendocinum. }\end{array} \\ \text { (fid. Rüss.). - Sph. centrale. }\end{array}\right.$

var. pseudo-Lindbergii C. Jens. - Sph. obtusum var, pseudo-Lindbergii.

iridans Brid. - Leucobryum longifolium.

irritans Warnst. in Allyem. Bot. Zeitschr.... in Karlsruhe, 1895, n. 7-x. - Pac. : Ins. Chatham.

Islei Warnst. in hb. Mus. Paris (G. de l'Tsle, n. 42) et in Hedwoig. 1891, p. $19, t . \mathrm{l}, \mathrm{fig} .6 \mathrm{a}, 6$ b et $t . \mathrm{IV}, \mathrm{fig} . \mathrm{f}$.

\section{- Afr. : Ins. Amsterdam.}

Itaoolumitis C. M, et Warnst. in Hedroig. 1897, p. 172 el in Ule Bryoth. brasil. $n, 1302$.

- Am. merid.: Brasil. or.

Itatiaiae C. M. et Warnst. in op. el l. eit, p. 145 el n. 1741-2.

- Am. merid. : Brasil. or.

japonicum Warnst, in Allgen. Bot. Zeitschr.... in Karlsruhe, n. 12.

- As, : Japon. 
javanense P. B. - Leucobryum Boryanum?

? javense Schwaegr. $\left\{\begin{array}{l}\text { (fid. Besch.). - Leucobryum Boryanum. } \\ \text { (fid. C, M.). - Leucobryum falcatum. }\end{array}\right.$

Junghunianum Bryol. jav. I, p. 27, t. 18; Warnst. in Hedvig. 189?, p. 198, $t$. V, fig. 11 a, 11 b et $t$. VII, fig. 10.

Sph. Thomsoni C.M. (fid. Warnst. l. c.).

(quoad Sph. Thomsoni).

Khasianum Mitt. M. Ind. or. p. 156; Warnst. in Hedroig. 1891, p. 40, t. III, fig. $32 \mathrm{a}, 32$ b et $t$. V, fig. z.

Sph. contortum var. Wils, in Kew Journ. bot. IX, p. 290.

Sph. obtusifolium Griff. Not. p. 386 ?

Klinggraëffii Roell.

$$
\text { - As. : Khasia. }
$$

- Am. sept. : Washington.

* var. laxum Roell System. p. 98.

- Am. sepl. : Washington.

labradorense Warnst. in Hedwig. 1892, p. 174, t. XVI, fig. 1-3, et 1893, t. III, fig. $3 \mathrm{a}, 8 \mathrm{z}, 9 \mathrm{a}-9 \mathrm{~h}$.

Ster,? $\quad-A m$. sept.: Terra nov., New Jersey.

laceratum C. M. et Warnst, in Hedwig. 1897, p. 149 et in Ule Bryoth. brasil.n. 1294.

- Am, merid. : Brasil. or. (Minas Geraës).

lacteolum Besch. Note M. ins. S. Paul et Amsterdam, p. 5; Warnst. in Hedwig. 1890, p. 254, t. XIII, fig. 31-32 et $t$. XIV, fig. fa.

- Afr. : Ins. Amsterdam.

lanceolatum Warnst. in Hedwig. 1890, p. 219, t. VIII, fig. 7-9 et t. X, fig. 4-5.

Ster. ?

Exs.: Colenso n. 41 a,

- Pac. : Nov. Zeland.

lancifolium C. M, et Warnst. in Hedwig. 1897, p. 154.

- Pac. : Austral, or. (Nov. Vales.).

Langloisii Warnst, in Hedwig. 1897, p. 166.

- Am. sept. : Ludovicia.

laricinum Spr. mss. 1847; W. P. Sch. Syn. 11 ed. p. 845; Lindb Man. M. II, p. 401 el Hvitm. p. 25.

Sph, cavifolium var, laricinum Warnst. Eur. Torfm. n. 86.

Sph. contortum Schultz (fid. Warnst. in Hedivig. 1888, p. 207 et in Bot. Gaz. 1890, p. 245).

Sph. contortum var, laricinum Wils, Bryol, bril. p. 23.

Sph. curvitolium ej, mss, ; Hunt in Mem. lit. phil. Soc. of Manchester, 111 sér. III, p. 233.

Sph. neglectum Angstr. (fid. Lindb. l. c.).

Sph. subsecundum C. M. (quoad pl. americanam, fid. Lindb. l. e.).

2. In paludos. - Eur. : Scandin., Fennia, Iivon., Bornss., Rhaet., In paludos. - Eur.: Scandin., Fennia, Livon., New York, Ohio,
Anglia. Am. sept. : Massachussets, New Jersey, New Indiana.

Exs. : Austin M. Appal. 1 ser., n. 26.

" var. congestum C. Jens, mss. ; Warnst. in Hedvoig. 1884, n. 7-8. - Eur. : Dania.

" var, crispulum Schlieph. mss.; Warnsl, in op. et l. cc. - Eur. : Hassia, 
var. cyclopliyllum Lindb. - Sph. cyclophyllum.

* var. falcatum Schlieph. mss.; Wurnst. in op. el l. cc., et Sphagnoth. eur. $n .185$.

- Eur.: Dania, Hassia.

$f$. viride Roell in Hedwig. 1893, p, 310 .

- Am. sept.: Indiana.

" var. floridanum Ren. el Card. in Rev. bryol. 1885, p. 46.

Sph. plicatum Warnst. in Hedwig. 1891, p. 169, t. XIX, fig. 32 a, 32 b et t. $X X I V$, fig. pp.

- Am. sept. : Massachussets, Florida, L.udovic.

var. platyphyllum Lindb. - Sph. neglectnm.

var. teretiusculum Lindb. - Sph. neglectum.

laricinum $\left\{\begin{array}{l}\text { Angstr. - Sph. Duseni. } \\ \text { Aust. }- \text { Sph. cospidatum. } \\ \text { Rab. n. 712. - Sph. mendocinum. } \\ \text { W. P. Seh. (fid. Warnst.). - Sph. recurvem var. pulchrum. }\end{array}\right.$ late-truncalum Warnst. - Sph. fontanum.

latifolium Hedw. - Sph. cymbitolium.

var, squarrosum Wahlenb. - Sph. squarrosum.

laxifolium C. M. - Sph. cuspidatum var. plumosum.

var, hypnoides C. M. - Sph. cuspidatum var. hypnoides.

var. laxum Lesq. ef Jam. - Sph. subsecundum var. Lescurii.

leionolum C. M. - Sph. Whiteleggei.

leplocladum Besch. - Sph. Girgensohni.

Lescurii Sull. - Sph. subsecundum var. Lescurii.

Lesueurii Warnst. in Hedwig. 1890, p. 204, t. V, fig. 16 a, 16 b et t. VI, fig. 5 .

Sph. Antillarum Besch. Fl. bryol. Antill. fr. p. 89 ; Husnot, M. Ant. fr. n. 191 .

- Am. sept. : Guadalup.

limbatum Mitt. M. austr. am. p. 625; Warnst. in Hedroig. 1890, p 201, t. V, fig. $14 \mathrm{a}, 14$ b et $t$. Vl, fig. 7 .

Ster.? - Am. merid. : Venezuela.

Limprichtii Roell p.p - Sph. obtusum.

var. parvifolium (Sendtn.) Roell. - Sph. recurvum.

Lindbergii W. P. Sch. Versuch, ein Entwoick, d. Torfm. p. 67, tt. XXV et

XXVIl et Syn. II ed. p. 832; Warnst. \& die Cuspidat... Gr. op. 201, Ł. I, fig. 1-6 et $\iota$. II, fig. a; Linilb. Torfm. p. 136.

Sph. cuspidatum Lindb. in Bot. Notiz. p. 122.

1. In paludos, et ad rip. lac. - Eur. : Ins. Ursorum, Lappon., Sudet., Alp. Stir. Am sept.: Groënland, Labrador, Canada, Alaska, Terra nov., ins. Miquelon, New Hampshire, New York, M. Alb.

Exs. : Berggr. M. Spitzb, n. 163.

Braithw. Sph. brit. n, 45.

Brentel M. frond. n, 24.

Kerner F. exs. Austr. Hung, n. 330.

Limpr. Bryoth. siles, n. 100.

Rab. Bryoth. eur. n. 301, 701.

Warnst. Sphagnoth. eur, n. 136, 176.

* var, brachycladum Roell $f$. fiscum ej. in Hedwig. 1897, p. 65.

- Am. sept. : Labrador, Groenland.

var. compactum Limpr. - Sph. Lindbergii var. congestum. 
« var. congestum Gravet mss.; Warnst. in Hedwig. 1884, p. 120. Sph, Lindbergii var. compactum Limpr. Syst. d. Torfm. 1881, p. 319. - Eur. : Lappon., ad mare articum; Riesengeb.

\& var. mierophyllum $f$. brachy-dasyclada Warnst. in Hedwig. 1893, I, t. III, fig. 10 a, 10 b et $t$. IV, fig. $10 \mathrm{c}-10 \mathrm{f}$. - Am. sept, : Ins. S. Georges.

Ionchocladum $C . M$. in Fl. 1896, p. 436.

Ster.

- Pac.: Ins, Sandwic.

lonchophyllum C. M. in Ule Bryoth. brasil. n. 1105 et in Hedwig. 1897, p. 152.

In turfos. - Am, merid, : Brasil. or, (ins, S. Catharina).

longifolium W. P. Sch. in Mandon Pl. Boliv. $n$. 1602; Warnst, in Hedvoig. 1890, p. 234.

Ster. ?

- Am, merid. : And. Boliv.

longistolo C. M. in Ule Bryoth. brasil. n. 1227 et in Bedwig. 1897, p. 169 ,

In turfos. - Am. merid. : Brasil. austr. or. (Rio de Janeiro).

loricalum C. M. - Sph. medium.

Iudovicianum Warnst. - Sph, cymbifolium var. ludovicianum.

luridum Hüb, $-\mathrm{S}_{\mathrm{p}} \mathrm{h}$. subnitens.

macrocephalum Warnst. in Hedwig. 1893, 1, t. XI, fig. $6 \mathrm{a}-6 \mathrm{~g}$.

Ster. ? Ad terr. humid. - Pac.: Tasman.

macrophyllum Bernh. in Brid. Bryol. univ. I, p. 10 (haud p. 753, quod est Lencobryum longifolium); C. M. Syn. I, p. 91 et 11, p. 538; Null. 1c. $M . p .1, t .1$ et $M$. of U. St. p. 12 ; Warnst in Hedwig, 1890, p. 229, t. IX, fig. 1-6 et t. IX, fig. 13-15.

Isocladus macrophyllus Lindb. Torfm. p. 134.

Sph. georgianum Schvein. (fid. Sull.). 2 . vic., Alabama, Mississipi.

Exs. : Aust. M. Appal. ser. I, n. 41.

Drumm. M. am, bor. II ed. n. 18.

Sull, M. Allegh. II, n, 207.

Sull. et Lesq. M. bor. am. I ed, n, I et II ed. n. 1 .

Rab. Bryoth. eur. n. 1447.

* var. floridanum Card. in Bull. Soc. roy. bol. Belg. 26, I, p. IF', Warnst. in Hedwig. 1890, p. 231, $t$. X, fiq. 16-19 et 1893, $1, t$. IV, fig. 12 b et $12 \mathrm{c}$.

Sph. cribrosum Lindb. Hvitm. 1882, p. 74.

Sp. floridanum Aust, in Bull. Torr, bot. Club, VII, p. 15.

Ster.

- Am, merid. : Florid, Ludovic. or.

macrophyllum Brid. (p. 753). - Leucobryum longifolium.

macro rigidum C. M. in Fl. 1887, p. 417; Warnst. in Hedro. 1890, p. 251 ,

t. XIII, fig. 29-30 et $t$. XIV, fig. b.

Ster.

- Pac. : Nov. Zeland. austr.

madegassum C. M. - Sph. tumidulum var. mierophyllum $f$. euryclada. magellanicum Brid. - Sph. cymbifolium.

majus (Rüss.) C. Jens. - Sph. Dusenii.

malaccense Warnst. in Hedroig. 1892, p. 175, $t$. XVI, fig. 4-6.

Ster. ?

- As.: Penins. Malace. 
SPH

1199

marginatum W. P. Sch, in Breulel M. Capens.; Warnst. in Hedwig. 1891, p. 28, t. Il, fig. 20 a, 20 b et $t$. IV, fig. 0 . - Afr. : C. B. Sp.

mauritianum Warnst, in Hedwig. 1891, p. 17, t. I, fig. $3 \mathrm{a}, 3 \mathrm{~b}$ et $t$. IV, fig. c.

- Afr.: Ins. Franciae.

maximum Warnst. in op. cit. p. 160, $t$, XVIII, fig. $25 \mathrm{a}, 25 \mathrm{~b}$ et $t$. XXIII, $f g . \mathrm{ff}$.

Sph, australe $W, P$, Seh. in hb. Besch.

- Pac, : Nov. Zeland, Tasman.

medium Limpr. in Bot. Centralbl. 1881, p. 113.

Sph. andinum Hpe. in Ann. sc. nat. ser. V, p. 334.

Sph, arboreum W. P. Sch. p.p. (fid Warnst.).

Sph. bicolor Besch. in Bull. Soo. bot. Fr. 1885, p. txvm.

Sph. compactum Brid. Bryol. univ, 1, p. 16 p.p.

Sph. crassum C. M, in $h b$. Rom,

Sph. cymbifolium var. compactum Rüss, Beitr..., p, 80.

Sph, cymbifolium var, congestum $W, P$, Sch. Mém. Sph. 74, t. XII, fig. 3 et Syn. II ed. p. 848.

Sph. cymbifolium var. Paradisii Besch, $h b$.

Sph. cymbifolium var, purpurascens Rüss, in op. et $l$, cc.

Sph. Hahnianum C. M. mss. 1880 .

Sph. loricatum C. M. in Fl. 1887, p. 409.

Sph, tursum ej, in op. cit. p, 410 .

2. - Eur.: Fere tota. Am. sept.: Labrador, Terr. nova, ins. Miquelon; reg. or., de Canada ad Florid. Am. merid.: De Brasil,, Peruv. et Chile ad Patagon.

"var. brachycladum $f$. bicolor Roell in Hedroig. 1993, p. 315 .

- Am. sept, : Indiana.

$f$. fuscescens $e j$, in op. et $l$. $c e$.

- Am. sept.: Wisconssin.

"var. congestum Schlieph, et Warnst, (ubi?),

- Am. sept.: Wisconssin.

f. purpureum Roell in Hedwig. $[897, p, 51$.

-- Am. sept. : Michigan.

"var. glauco-fuscescens Warnst. in Ule Bryoth. brasil. n. 198.

- Am. merid. : Brasil. austr. or.

" var. gracile Roell in Bot. Centralbl. 1891, pp. 2I-22.

- Am. sept.: Wisconssin.

f. fuscum ej. in Helloig. 1891, p. 315 .

- Am. sept, : Wisconssin.

* var, imbricatum Raell in op. el $l$. cc.

- Am. sept. : Washington, Michigan.

* var, immersum Warnst. in Hedwig. 1884, n. 7-8.

- Eur. : Thuring. Am. sept. : New Jersey.

f. viride Roell in Hedroig. 1897, p. 52.

- Am. sept. : Indiana.

"var. laeve (Rüss.) Warnst. in Bot, Gas, 1890, p. 253, f. albescens ej. in op. cit. p. 254 .

- Am. merid : Chile. 
f. fuscescens Warnst, in op. cit.p. 253.

- Am. sept. : Massachussets.

f. purpurascens (Rüss.) Warnst. in op. el l.cc.

Sph. cymbifolium var, congestum Rab. Bryoth. eur, n. 722 .

New Hampshire.

$$
\text { - Eur. : }
$$

Am. sept. : Massachussets,

ff. virescens et versicolor Warnst. in op. et $l$. cc.

\section{Vermont.}

- Am. sept. : Massachussets, New Hampshire,

«var, laxum Roell System, p. 95, ff. bicolor, fuscescens et viride ej. in Hedwig. 1893, p. 315 .

$$
\text { - Am. sept.: Wisconssin. }
$$

mendocinum Sull. et Lesq. M. bor. am, II ed. n. 23; Sull. Ic. M. Suppl. p. 12, t. III; Warnst. "die Cuspidat... Gr.» p. 210, t. I, fg. 34 et t. Il, fig. I $\alpha, 1 \beta, \mathrm{m}$ et in Hedroig. 1893, I, t. IV, fig. $11 \mathrm{a}-1 \mathrm{l} \mathrm{g}$.

Sph, auriculatum Lesq, in Mem. Calif. Acad. 1, p. 4 (ex ips. !).

Sph. cuspidatum var. laxifolium Rab. Bryoth. eur. n. 716.

Sph. cuspidatum var, mendocinum Card. in Bull. Soo, roy. bot. Belg. XXVI, I.

Sph. cuspidatum var, plumosum Rab, l. c.n.211 $c$. (Sph, recuryo mixt.), 717,952 .

Sph. intermedium Mac. Canad. M. n. 9.

Sph. laricinum Rab. Bryoth. eur. n. 712

Sph, subsecundum var. oblongifolium Lesq. in op, et $l$. oc.

- Eur.: Lappon., Fennia, Rossia, Dania, Salisb., Stir., Belg. Am. scpt. : Ontario, Massachussets, New Hampshire, ins. Vancouver, Sierra Nevada Calif.

Exs. : Warnst. Eur. Torfm, ser. I, n. 97 ; ser. II, n. 192.

* var, gracilescens Warnst, in Hedoig. 1893,1. - Am. sept. : Canada, Calif.

" var. recurvum Roell in Hedwig. 1897, p. $\mathrm{C2}$.

$$
\text { - Am. sept.: Washington. }
$$

" var, robustum ej. in op. et $l$. co.

$$
\text { - Am. sept. : Calif. }
$$

mendocinum Warnst. - Sph. Dusenii.

meridense C. M. Syn. I, p. 95 et II, p. 538; Warnst. in Hedwig. 1890, p 200, t. V, fig. 13 a, 13 b et $\iota$. VII, fig. 8.

Sph. acutifolium var. meridense Hpe. in Linn. 1817, p. 66.

Spl. cymbifolium var. patens Brid. Bryol, univ. I, p. 4 (excl, syn. Sph. cymbifolio borbonense $P . R$.).

Sph. subsecundum C. M. in Linn. 1817, p. 209.

- Am, sept. : Hispaniola. Am. merid.: Ins. Trini-

tat., Venezuela, Columb., And. Nov. Granat., Boliv.

mexicanum Mitt. M austr. am. p. 624 ; Warnst. in Hedwig. 1890, p. 247,

t. XII, fig. 11-13 et t. XIV, fig. m.

Sph. domingense C. M. in Coll. Eggers. 1887.

$$
\text { - Am. sept. : Mexic., Haïti. }
$$
microcarpum Warnst. in Hedwig. 1891, p. 170, t. XIX, fig. 3I a, 31 b et
t. XXIV, fig. 00 . 
microphyllum Warnst. in Hedwig. 1891, p. 172, t. XIX, fig. 33 a, 33 b. - Am. sepl. : Calif.

minutulum C. M. et Warnst. in Hedroig. 1897, p. 166 et in Ule Bryolh. brasil. n. 1749.

- Am. merid.: Brasil. or. (Serra do Itatiaia.).

mirabile C. M. et Warnst. in op. el l. cit. p, 161 et $n, 1287$.

- Am. merid.: Brasil. or. (Minas Geraës).

mobilense Warnst. in Hedwig. 1892, t. XVII, fig. 16-19.

- Am. sept. : Alabama.

Mohrianum Warnst. in Hedroig. 1892, p. 179, t. XVI, fig. 13-15.

- Am. sept. : Alabama.

molle Sull. M. Allegh, n. 205, M. of U. St. p. 13 et Ic. M. p. 7, t. IV; C. M. Syn. I, p. 104; Lindb. Hioilm. p. 33.

Sph. compactum C. M. Syn. I, p. 98 et $1 I, p .539$ (excl. syn. Sph. strictum).

Sph. compactum $\delta$ ramulosum C. M. in op. cit. pp. 99 et 539 .

Sph. humile W. P. Sch. (ubi? fid. Warnst. in Bot. Gaz. 1890, p. 226 et in Hedwig. 1890, p. 209).

Sph. molluscoides Rab. B̈ryoth. eur. n. 1149.

Sph. tabulare Sull, M. Allegh. n. 204 et M. of U. St.p. 12. 2 .

- Eus.: Suec. Am. sept.: New Jersey, Carol. merid., Georg, Florid., Lidovic., Alabama; Kansas?

Exs. : Braithw. Sph. brit. n. 21 (excl, specim, infer. ad sinistr.) et 21 "c. Broth. M. Fenniae, 1, n. 44

H. Müll. M. Westfal, n. 222.

Rab.Bryoth, eur, n. 556, 1248.

" var, compactum Gravet miss.; Warnst, in Hedroig. 1885, p. 115 (1). - Eur.: Belgia.

var. fluitans W. P. Sch, - Sph. molluscum var. immersum.

var, Mülleri Braithw. - Sph. Mülleri.

«var. squarrosılum Gravet mss.; Warnsl. in op. cit. p. II4.

- Eur. : Belgia.

*var. tenerum (Sull.) Braitho. Sph. brit.p. 55.

Sph, tenerum Sull. $M$. of U. St. p. II.

Ems. Sull -Am. sept.: New Jersey.

Eos, : Sull, et Lesq. M, bor, am. I ed. n. II.

molle (Sull.) Lindb., Rab. n. 550. - Sph. Mülleri.

molliculum Mitt. in Journ, of the Linn. Soc. 1859, p. 99; Warnst, in Hedwig. 1891, p. 34, t. II. fig. 25 a, 25 b el $\iota$. V, fig. t.

Sph, Mossmantianum C. M. in hb. Kew.

- Pac. : Tasmann.

mollissimum C. M. 1 - Sph. capense.

mollutscoides C. M. - Sph. Mülleri.

Rab. n. 1149, - Sph. molle,

molluscum Br, in Fl. 1825, p. 633; Brid. Bryol. univ. I, p. 753; C. M. Syn. I, p. 93; W. P. Sch. Mém. Sph. p. 76, t. XXI et Syn. II ed. p. 846; Warnst. "die Cuspidal.... Gr. " p. 225, t. I, fig. 51 a, b, c, $52 \mathrm{a}, \mathrm{b}, \mathrm{c}, 53 \mathrm{a}, \mathrm{b}, \mathrm{c}$, d et $t$. II, fig. $\mathrm{v} \alpha, \beta$ et $\gamma$.

(1) An potius hnic varietati syn. C. Mulleri typo ducta, referenda? 
Sph. tenellum Bryol. germ. I, p. 8, t. I. fig. 2; Lindb. in Bot. Notiz. p. 142 ; Rüss. Beitr... p. 75 ; H. Müll. M. Westfal. n. 226.

2. In locis spongios, et ad mont. latera, rar. in turfac, - Eur, : Zon. intermed. et septentr. As.. : Japon. Am. sept. : Labrador. Terra nov., ins. Miquelon, Anticosti, Maine, New Jersey, Oregon, Van. couver.

Exs. : Blandow, M. frond. n. 205.

Braithw. Sph. brit. n. 11, 12.

Breutel, M. frond, n. 25.

Broth. M. Fenn. n. 100.

Faurie Pl. Japon. n. 14191, 14192.

Gravet, Sph. Belg. n. 69, 70.

Limpricht Bryoth. siles. n. 150.

Moug. et Nestl. Stirp. vog. rhen. n, 808.

Rab. Bryoth. eur, n, 213, 720 (p.p. Sph. subsecundo intermixl), $1150, \mathrm{~b}, \mathrm{c}, \mathrm{d}$.

Warnst. Sphagnoth. eur. n. 35, 84, 132, 133, 191-194.

Warnst. Samml, eur. Torfm. sez. II, n. 108.

" var. compactum (Warnst.) Par.

Sph, tenellum var. compactum Warnst. in Hedwig. 1884, p. 114 et Sphagnoth. eur. n. 193.

- Eur.: Hassia.

- var. immersum W. P. Sch. Syn. II ed.p. 846.

Sph, molle $\beta$ fluitans ej. Vers.... t. XII, fig. 6 et Syn. I ed. p. 682.

In turfos. - Eur.: Jurass, helvet.

" var. suberectum (Grav.) Par.

Sph. tenellum var. suberectum Gravet mss. ; Warnst. in Hedwig. 1884, p. 114.

- Eur, : Gall. sept. or. (Ardenn.).

molluscum W. P. Sch. p.p. - Sph. Ångstroemi.

Moorei Warnst. in Pap. and Proced. of the roy. Soc. of Tasman. 1894-

1895, p. 16 (nom.) et in Allgem. bot. Zeilschr... in Karlsrue, 1895.

Ad terc humid. - Pac.: Nov. Zeland.

Mossmannianum C. M. - Sph. molliculum.

Mougeoti W. P. Sch. - Sph. recurvum.

mueronatum C. M. in Fl. 18,7, p. 421 .

Sph. tumidulum Besch.? (fid. Warnst. in Hedwig. 1891, p. 130).

Ster. - Afr. : Madagascar.

Mülleri W. P. Sch. Vers... p. 73, t. 26, Syn.II ed. p. 686 el II ed.p. 841 .

Sph. molle Lindb. in Rab. Bryoth. eur. n. 556, Torfm.... p. 140 et Bids. till Moss... p. 414; Rüss. Beitr... p. 78; Sull. Io. M. p. 9, t. V.

Sph. mollo var. Mülleri Braithw. Sphag. p. 54, t. XII.

Sph. molluscoides C. M. Syn. I, p. 99.

2. In palud, et turf. - Eur.: Suec., German. sept., Ardenn., Neerland., Westphal., ete. Am. sept. : New Jersey, Tennessee, Georg., Florid., Alabama, Ludovie.

nanum C. M. $\{$ - Sph. acutifolium $f$. nanum (fid. Warnst. 1890). - Sph. oxyphyllum var, nanum (fid. Warnst, 1897). Naumann C. M. - Sph. cuspidatum. neglectum Angstr. in Oefv. Vet. Akad. Foerh. 1864, p. 201.

Sph. auriculatum Rab. Bryoth, ewr, n. 713, 714. 
Sph. laricinum var. platyphyllum (Sull.) \} Lindb. Man. M. II, pp. 402-403.
Sph. laricinum var. teretiusculum

Sph. neglectum var. Aust. M. Appal. p. 7, n. 27.

Sph. neglectum var. ?

Sph. platyphyllum speo. nov.? Sull. mss. 1868.

Sph. platyphyllum Wainst. in Fl. 1884.

Sph. subsecundum var. isophyllum Rüss. Beiti.... p. 73 (fid. Warnst.).

2. $\quad$ - Eur.: Scandin., Fennia, Livon,, Esthon. Am. sept. : Massachussets, New Jersey, Virgin.

" var, turgescens (Warnst,) Par.

Sph. platyphyllum var. turgescens Warnst. in Hedwig. 1884, n. 7-8.

- Eur. : Westphal.

neglectum Ångstr. - Sph. laricinum.

var. Aust. - Sph. neglectum.

var. ? Sull. - Sph, neglectum.

negrense Mitt. M. austr. am. p. 624; Warnst. in Hedioig. 1891, p. 146,

t. XV, fig. 10 a, 10 b et $t$. XXI, fig. $\mathrm{n}$.

Ad rup. irror. - Am. merid. : Anazon.

nemoreum Scop. - Sph. acutifolium.

nitidum Warnst. in Allgem. bot. Zeitschr.... in Karlsruhe, 1895.

- Am. sept. : Terra nova.

nodosum hirsutie incanum Dill. - Hedwigia ciliata.

novo-zelandicum Mitt. in Journ. of the Linn, Soc. 1859, p. 99; Warnst. in Hedwoig. 1891, p. 33, t. 1I, fig. 24 a, 24 b, el t. V, fig. s.

- Pac. : Nov. Zeland., Austral. or., Tasman.

novo-zelandicum C. M. - Sph. Helmsii.

obesum Wils. - Sph. subsecundum var, obesum.

oblongum P. B. - Sph. cymbifolium.

obovatum Warnst. in Hedioig. 1891, p. 18, t. I, fig. 4 a, 4 b et $1 \mathrm{~V}$, fig. d. - Afr. : Madagascar.

obtusifolium $\left\{\begin{array}{l}\text { Ehrh. - Sph cymbifolium. } \\ \text { Griff. - Sph. khasianum? }\end{array}\right.$

var, turgidum H. f. et W. - Sph. cyelophyllum.

obtusiusculum Lindb. in hb. Kero.; Warnst. in Hedroig. 1890, p. 196, t. IV, fig. 8 a, 8 b et $t$. VII, fig. 13.

Ster.? - Afr. : Ins. Borbon., Franciae, Madagascar.

" var. purpurascens $f$. dasy-brachyclada Warnst, in op. eit. p. 157.

Sph. acutifolium var, borbonicum Ren. et Card. mss.

- Afr. : Ins. Borbon.

obtusum Warnst. « die Cuspidat.... Gr. " $t$. I, fig. 47 a, b, c, d, et $\iota$. II, fig. t et u; Rüss. in Silsungsber. d. Natur. Gesells. in Dorpal, 1889. Sph. cuspidatum var. majus Rüss, Beitr...p. p. 58 p.p.

Sph. Limprichtii Roell in Fl. 1886 p.p. (1).

(1) a In System. d. Torfm, in Fl. 1886, conjungit Roell Sph. Limpriohtii suo formas sequentes: ambiguum Sehlieph., gracile Roell, laricinum Roell, molle Roell, obtusum Warnst., parvifolium (Sendtn.) Warnst, porosum Sehtieph. et Warnst, pseudo-Lindbergii $C$. Jens., robustum Limpr., squarrosulum Roell, tenellum Warnst., teres Roell. "

Warnst. " die Cuspidat.... Gr. ", p. 225. 
Sph. recurvum var. Limprichtii Schlieph. mss.; Warnst. in Hedwig. 1884, p. 121.

Sph. recurvum var. obtusum Warnst. p.p. ; Limpr. Kryptog. Fl. Deutschl. p. 132.

2. -- Eur.: Rossia occid, Fennia, ins. Aland, Dania, Germania or , Bohem., Stir., Austria infer., Bavar., Belg. (1).

Exs. : Warnst. Sphagnoth. eur. n. 45.

Warnst. Samml. eur. Torfm. ser. II, n. 193.

" var. aquaticum Warnst. in op. et l. cc.

- Eur. : Brandeburg.

var. Dusenii Warnst. - Sph. Dusenii.

e var. pseudo-Lindbergii (C. Jens) Warnst. in op. el l. cc. t. I, fig. 49 a, b, c, 50 a et b.

Sph. intermedium var. pseudo-Lindbergii $C$. Jens. in Cat... Soc. Copenhague.... 1883, p. 23 .

$$
\text { -- Eur. : Dania, Livon., Esthon. }
$$

« var. tenellum Warnst. in Hedwig. 1884, p. 121.

- Eur. : Brandebourg.

f. sphaerocephala Warnst. « die Cuspidat... Gr.."p. 224.

- Eur. : Brandebourg.

$f$. teres Warnst. in op. el $l$, cc.

- Eur.: Brandebourg.

oligodon Rehm. M. Afr. austr. n. 14; C. M. in Fl. 1887, p. 412; Warnst.

in Hedwig. 1891, p. 39, เ. III, fig. 31 a, 31 b et t. V, fig. y.

Ster.

- Afr. : Natal.

oligodon Rehm. n. 14l. - Sph Rehmanni.

orlandense Warnst, in Hedwig. 1892, p. 177, t. XVI, fig. 10-12.

Ster. ?

- Am. sept. : New Jersey, Florid.

ouro-pratense C. M. et Warnst. in Ule Bryoth. brasil. n. 1283 et in

Hedvoig. 1897, p. 172.

In turfosis. - Am. merid : Brasil: or. (Serra de Ouro-F'reto).

ovalifolium Warnst. in Act. Soc. sc. Fenn. 1891, p. 23, ı. I, fig. 11 a,

11 b et $\iota$. IV, fig. 1.

Ster.

- Am. merid. : Brasil. or. (Minas Geraës).

« var. angustatum Warnst. in Hedroig. 1895, p. 130.

- Am. merid. : Brasil. or. (Goyaz).

"var. robustius C. M. et Warnst. in Ule Bryoth. brasil. n. 1295 et in Hedwoig. 1897.

- Am. merid. : Brasil. or. (Minas Geraës).

"var. tenuissimum C. M. et Warnst. ll. cc. n. $13 \cap 3$.

Ubi praeced.

ovatum Hpe, in Linn. 1874, p. 546 et in Kurz M. Himal. n. 546.

- As. : Sikkim.

ovatum W. P. Sch. - Sph. medium. oxycladum Warnst. in Hedioig. $1891, p .15, t .1$, fig. 1 a, 1 b et t. IV,
fig. a.

Sph. coronatum var. cuspiatum Rehm. M. Afr. austr. n. 10.

$$
\text { - Afr. : Austral. }
$$

(1) a In America boreali false indicatum a Warnst. in Hedwig. 1894, p. 337. 
oxyphyllum Warnst. in Hedwig. 1890, p. 192, t. IV, fig. 5 a, 5 b $\epsilon t$. VII, fig. 15.

- Am. merid. : Brasil, austr. or.

" var. nanum (C. M.) Warnst. in Hedwig. 1897, p. 150.

Sph. nanum C. M. in Ule Bryoth. brasil. n. 416.

- Am. merid. : Brasil. or. (ins. S. Catharina).

pallidum Warnst. in Hedwig. 1891, p. 171, t. XIX, fig, $30 \mathrm{a}, 30 \mathrm{~b}$ et t. XXIV, fig. nn. - Afr.: Ins. Borbon.

palustre $\left\{\begin{array}{l}\text { Broth. n. 43. - Sph. papillosum. } \\ \text { L. }\left\{\begin{array}{l}\text { (fid. Lindb.). - Sph. cymbifolium. } \\ \text { (fid. W. P. Sch.). - Sph. acutifolium. }\end{array}\right.\end{array}\right.$

$\beta$ capillaceum Weiss. - Sph. acutifolium.

palustre, molle, deflexum, (fid. C. M.). - Sph. cuspidatum. squamis capillaceis Dill. (fid. W. P. Sch.). - Sph. acutifolium p.p. palustre, molle, deflexum, squamis cymbiformibus 1)ill. - Sph. cymbifolium.

panduraefolium C. M. in Fl. 1887, p. 418; Warnst. in Hedw. 1891, p. 26, t. 1, fig. $12 \mathrm{a}, 12$ b el $t$. IV, fig. m.

Ster.

$$
\text { - Afr.: C. B. Sp. }
$$

Exs. : Rehm. M. Afr, austr. n. 15.

papillosum Lindh. in Act. Soc. sc. Fenn. 1872, p. 280 (in add.), Hvat. Moss. p. 14 et Man. M. II, p. 392, t. I, fig. II; Braitho. in Monthl. Micr. Journ. 1873, p. 214, n. 6 et Sph. pp. 29 et 35, n. 3, t. IV; Warnst. in Hedurig. 1891, p. 158 el Eur. Torfm. p. 137.

Sph. cymbifolium var. papillosum W. P. Sch. Syn. II ed. p. 848.

Sph. immersum Casseb. in Wett.Laubm. Sphagnum, 1832, n.8 (fid.Lindb.). Sph. palustre Broth. M. Fenn, n. 43.

2. In loc. humid. mont. - Eur.: Scandin., Dania, Fennia, Hercyn., Westphal., Britann., Gallia. As. : Caucas. oec. Am. sept.: Labrador, Canada, Alaska, Terr. nov., reg. or. et merid., Indiana, Wisconssin, Washington.

Exs. : Braithw. Sph. brit, n. 3-6, 8 a.

"var. abbreviatum Gravet mss.; Warnst. in Hedwig. 1884, n. 7-8 et Sphagnoth, eur. n. 200.

$$
\text { - Eur. : Belgia. }
$$

"var. bracbycladum Schlieph. mss.

$$
\text { - Am. sept. : Indiana. }
$$

" var. confertum Lindb, in op. et l. cc.; Braitho, in Monthl. Micr. Journ. 1873, p. 215.

Java. Am. sept. : Ubi typ.

" var. intermedium (Rüss.) Warnst. in Hedwoig. 1891, t. VL, fig. 23 a, 23 b et $t$. XXIII, fig. dd.

Sph. cymbifolium subsp. intermediam Rüss. in "Zur Anat. d. Torfm. ", Dorpat, 1887; Limpr. in Bot. Centralbl. 1881, p. 313.

Ubi typ. in Eur. et Am. sept.

"var. normale Warnst. in Hedwig. 191, p. 160, t. XVII, fig. 24 a, t. XVII, fig. 24 b et $t$. XXIII, fig. ee et ee?

Ubi typ. 
a var. patens $f$. nigrescens Schlieph. mss. - Am. sept.: Wisconssin.

var, plumosum Rüss, - Sph. brasiliense.

* var. stenophyllum Lindb. in op. et l. cc.

...Eur. : Fennia, Anglia.

c var. sublaeve Warnst. in Hellwig. ll. cc.

Ut typ. in Eur. et Am. sept.

Pappeanum C. M. Syn. I, p. 101; Warnst. in Hedwig. 1890, p. 248, t. XII, fig. 14-17 et t. XIV, fig. $\mathrm{k}$.

- Afr.: C. B. Sp, reg. lacustr.

Exs. : Rehm. M. Afr. austr. n. ${ }_{2} 2$.

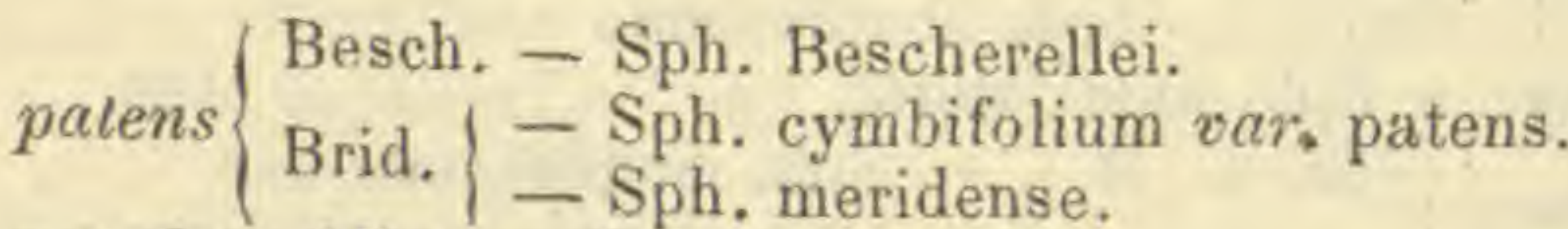

patulum Mitt. - Sph. squarrosum.

paucifibrosum Warnst, in Hedwig. 1891, p. 152, t. XII, fig. 20 a, $20 \mathrm{~b}$ et $t$. XXII, fig. $\mathrm{y}$.

$$
\text { - Am. merid. : Brasil. }
$$

pennatum $\left\{\begin{array}{l}\text { planum Dill. - Homalia glabella? } \\ \text { undulatum, vagina pilosa Dill. - Neckera undulata. } \\ \text { undulatum, vagina squamosa Dill. - Neckera pennatr. }\end{array}\right.$ pentastichum Brid. - Sph. recurvum.

perforatum Wurnst, in Ule Bryoth. brasil. n, 1757, 1892 et in Heduig.

1891, p. 23, ı. I, fig. 10 a, 10 b et $\iota$. IV, fig. k.

- Am. merid. : Brasil. or. (Minas Geraës).

"var. rotundifolium ej. in op, cit. 1895, p. 130.

- Am. merid. : Brasil. or. (Goyaz).

perichaetiale Hpe. - Sph. erythrocalyx var. laeve.

peruvianum Mitt. - Sph. erythrocalyx var. Iaeve.

planifolium C. M. in Fl. 1887, p. 415; Warnst. in Hedwig. 1890, p. 226,

$t$. VIII, fig. 24-27 et $t$. X, fig. 10-11.

Ster.

- Afr.: Gabon.

platycladum C. M. in Fl. 1887, p. 417 .

Ster.

- Am. sept. : Mexic.

platyphylloideum Warnst. in Act. Soc. sc. Fenn. 1891, n. 5, in Ule Bryoth. brasil. n. 1755 et in Hedwig. 1891, p. 21, $\iota . \mathrm{I}, \mathrm{fig} .8 \mathrm{~s}, 8 \mathrm{~b}$ et t. V, fig. ee.

Ster.

- Am. merid. : Brasil. or. (Minas Geraës).

platyphyllum Sull., Wurnst. - Sph. neglectum.

var. turgescens Warnst. - Sph, neglectum var. turgescens.

plicalum Warnst. - Sph. laricinum var. floridanum.

varr, elongata. laele virens, limo-

plumosum $\left\{\begin{array}{l}\text { sum,luridum, plumosum, Schil- } \\ \text { lerianum, squarrosulum, sub- } \\ \text { mersum?, violaceum, }\end{array}\right.$ Roell. - Sph. subnitens. varr. Gerstenbergeri, quinquefarium et silesiacum (Warnst.)

Roell. - Sph. quinquefarium.

plumulosum var. luridum (Hüb.) f. dimorphum Roell. - Sph. subnitens.

porosum $\{$ Lindb. - Sph. squarrosum.

Schlieph. et Warnst. - Sph. Dusenii. 
porto-ricense Hpe. in Linn. 1852, p. 369; Sull, Ic. M. pp. 3 et 14, t.2 ; Lindb. Hvitm. p. 9; Braitho. in Monthl. Micr. Journ. 1875, p. 47, n. 21 et Sph. pp. 29 et 32, n. 1; Warnst, in Hedwig. 1891, p. 138, t. XIV, fig. 3 a, 3 b et $t$. XX, fig. d.

Sph. Herminieri W. P. Sch. (fid. Wasnst. in Bot. Gaz. 1890, p. $249(1)$; Card. in Bull. Soc. roy. Belg. .

Sph. Sullivantianum Aust. in Am. Joum. sc. 1863, p. 252.

2? - Am. sept.: New Jersey, reg. merid., M. PortoRic. ; Guadalup. (Sph. Herminieri).

Exs. : Aust. M. Appal. ser. I, n. 1.

Sull, et Lesq. M. bor, am. II ed., n. 2 .

praemorsum Z. D. - Sph. rigidum var. compactum.

procerum W. P. Seh. - Sph. antarcticum.

pseudo-acutifolium C.M. et Warnst. in Heduig. 1897, p. 118 et in Vle

Bryoth, brasil, n. 1745.

- Am. merid. : Brasil. or. (Serra do Itatiaia).

pseudo-cuspidatum Warnst. in Hedioig. 1890, p. 218, t. VIII, fig. 4-6 et t. X, fig. 3.

Ster. ? - Afr. : Madagascar.

pseudo-cymbifolium C. M. in Linn. 1874, p. 547; Warnst. in Hedwig. $1891, p .141, t$. XIV, fig. 6 a, 6 b et $\iota$. XX, fig. $g, \mathrm{~h} \alpha, \mathrm{h} \beta$.

Sph, cymbifolium Mitt. M. Ind. or. p. 156; Wils. in hb. Ind. or, n. 1289 ; Warnst. in Bot, Gaz. 1890, p. 250.

Ster.

- As. : Sikkin.

pseudo-medium Warnst. in Hedwig. 1891, t. XVIII, fig. 27 a, $27 \mathrm{~b}$ et t. XXIV, fig. hb.

- Am. sept. : Guatemala?

pseudo-recurvum Roell p.p. - Sph, recurvum.

pseudo-rigidum Besch. - Sph. Weddelianum.

pseudu-rufescens Warnst, in Hedwig. 1893, I, t. II, fig. 5 a, 5 l.

Ster. ? In palud. - Pac. : Tasman.

pugionalum C. M. - Sph. tumidnlum.

Puiggarii C. $M$. in Fl. 1887 , p. 409.

Sph. submolluscum Hpe. Enum. p. 2; Warnst. in Hedwig. 1891, p. 145, t. $X I V$. fig. 9 a, 9 b et $t . X X I$, fig. $\mathrm{m}$.

Ster

Exs.: Ule Bryoth. brasil. n. 411, $413,414$.

pulch-icoma C. M. - Sph, recurvum.

pumilum C. M. et Warnst. in Hedvoig. 1897, p. 163 el in Ule Bryoth. brasil. n. 1750.

- Am. merid. : Brasil. or. (Serra do Itatiaia).

purpuratum C. M. hb. ; Warnst. in Hedioig. 1890, p. 267, l. V, fg. 18 a, b, c, et t. VI, fig. 4 .

Ster.? rina, S. Jose, S. Pablo).

purpureun W. P. Sch. hb. (nune in hb. Kew) ; Warnst. in Hedvig. 1890 , p. 197 , Ł. IV, fig. 9 a, 9 b et $\iota$. VII, fig. 12.

Ster? - Afr. : Ins. Franciae.

(1) Cf. Warnst. in Hedwig. 1889, p. 304, t. VI11, fig. 7 et t. IX, fig. 8-11; 1890, n. $11-12$. 
pyenocladulum C. M. in Fl. 1887, p. 420; Warnst, in Hedwig. 1891, p. 130.t. XIV, fig. $2 \mathrm{a}, 2 \mathrm{~b}, 2$ c et $t$. XX, fig. c.

Sph. mollissimum C. M. in Rehm. M. Afr. austr. n. 17.

Ster.

Exs. : Rehm. M. Afr. austr. n. 13.

pycnocladulum Ren. - Sph. tumidulum.

pycnocladum ...ngstr. - Sph. Wulfianum.

Pylaesii Brid. Bryol. univ. 1, p. 749 ; Sull. Ic. M. p. 12, t. V1.

Hemitheca Pylaesii Lindb. Hvitm. p. 76.

Sph. cymbifolium C. M. Syn. I, p. 91 p.p.

Sph. sedoides var. Sull. M. Allegh. n. 208 (fid. Warnst. in Bot. Gaz. 1890, pp. 242, 243); Sull. et Lesq. M. bor. am. I ed. n. 3, 4 et II ed. n. 57.

2.

reg. or. usq. ad Floridam.

- Am. sept. : Labrador, Terr. nov., ins. Miquelon,

Exs. : Aust. M. Appal. n. 23-24.

«var. ranosum Warnst. Samml. eur. Torfm. ser. I, n. 98 el in Bot. Gaz. $1890, p .233 ; f$. ferruginea ej. $l . c$.

- Am. sept. : New Hampshire.

$f$. nigricans $e j . l$. $c$.

- Am. sept. : New Hampshire, ins. Miquelon.

f. versicolor ej. . c.

- Am. sept. : New Hampshire.

quinquefarium (Braitho.) Warnst. in Hedwig. I885, pp. 222-224 et 1886, n. 6 .

Sph. acutifolium Funk Deutsch, Laubm. n. 8; Rab. Bryoth. eur. n. 204.

Sph. acutifoliuru var. flavicaule Warnst. Eur. Torfm. n. 50.

Sph. acutifolium var. Gerstenbergeri ej. in Fl. 1882, p. 206.

Sph. acutifolium var. pallens ej. in Hedvig. 1881, p. 116.

Sph. acatifolium var. quinquefarium Braitho. Sph. Eur, and N. Amer.

Sph. acutifolium var. silesiacum Warnst, in op. oit. p. 18.

Sph, intermedium Funk Kryptog. Gew. n. 16.

Sph. plumosum var. Gerstenber yeri (Warnst.)

Sph. plumosum var. quinquefarium (Braithw).

Sph. plumosum var, silesiacum (Warnst.).

Roell in Fl. 1886 .

Sph. Warnstorffii var, pallens (Warnst.).

Sph. Warnstorffii var, pseudo-patulum

1. rar. 2 .

Terra nov., reg. or.

Exs, : Warnst. Sphagnoth. eur. n. 52, 56.

- var. roseum Jur. mss. ; Warnst. in Bot. Gaz. 189C, p. I9L.

- Eur. : Austria.

$f$. dasy-homalo-anoclada et $f$. dasy-homalo-drepanoclada Warnst. in op. el $l, c c$.

- Am, sept. : New Hampshire.

* var. viride f. homaloclada Warnst. in op. et l. c.c.

- Am. sept, : Vermont. recurviforme Warnst. in Allgem. Bot. Zeitschr... in Karlsruhe, 1895,
n. 5 .

- Pac. : Ins. Fidji.

recurvum P. B. Prodr. p. 88 ; Brid. Bryol, univ. 1, p. 13; W. P. Sch. Syn. II ed. p. 830 et Mém. Sph. t. XVI, fig. 1-10; Warnst. a die Cuspidat. .. Gr.»p. 213, t. 2, fig. p. 
Sph. acutifolium $\beta$ capillifolium Bryol. germ. I, p. 20, t. III, fig. 8.

Sph. cuspidatum W. P.Sch. Syn. I ed. p. 675.

Sph. cuspidatum $\alpha f$. typica, $\beta$ recurvum et $\gamma$ mollissimum Rüss. Beits.

Sph. cuspidatum Ehrh. p.p. ; W. P. Sch. Syn. ed. I, p. 675 (excl. varr.); C. M. Syn. 1, p. 96 p.p. ; Lindb. Torfm. p. 136; Rüss. et Warnst. in Sitzungsber. d. Dorpater Naturf. Gesells. 1889, p. 69 ; Rab. Bryoth. ewr. n. 202, 708.

Sph. cuspidatum var. plumosum Rab. Bryoth, eur, n. 209.

Sph. cuspidatum var. Rauei Aust. in Rau et Harv. Cat. p. 49.

Sph. cuspidatum var, Rab. Bryoth. eur. n. 715.

Sph. flexuosum Dz. et Mk. Prodr. fl. Batav. II, I, p. 76.

Sph. intermedium Hoffm. Deutsch. Fl. II, p. 22 (fid. Braithw., Lesq. et Jam., Lindb.).

Sph. Limprichtiiv, parvifolium (Sendtn.) Roell Syst. d. Torfm. in Fl. 1886.

Sph. Mougeoti W. P. Sch. in Moug. et Nestl. Stirp. vog. rhen. n. 1306.

Sph. palustre, molle, deflexum, squamis capillaceis Dill. Hist. M. p. 243, t. XXXII, fig. 2 a p.p. (fid. W. P. Sch.).

Sph. pentastichum Brid. Sp. M. I, p. 16.

Sph. pseudo-recurvum Roell in Bot. Centralbl. 1889, n. B8 p.p.

Sph. recurvifolium Wils. mss. ; Hunt in Mem. litt. phil. Soc. of Manchester, $p, 233$.

Sph. riparium Angstr. in Oefv. Vet. Akad. Foerh. 1864, p. 21.

Sph. variabile var. intermedium Warnst. Eur. Torfm. p. 60.

2. In scatur., secus rivul. et in turfos. - Eur. : E reg. campestr. montos. usque in montana super.; Spitzberg. Am. sept. : Groenland, fret. Kotzebuë, Canada, ins. S. Georges, reg. or., ins. Miquelon. Am. merid. : A Brasil. usque ad And. Columb. per Boliviam.

Exs. : Braithw. Sph, brit. n. 47.

Crome Samml. deutsch. Laubm. n. 4 p.p.

Funk, Deutsch. Laubm. n. 9.

Gravet, Sphagnoth. belg. n. 15-35; 36 p.p.

Jack, Lind. et St. Krypt. badens. n. 221.

limpr. Bryoth. siles, n. 196.

H. Miiller, Westfal. Lanbm. n. 231.

Rab. Bryoth. eur. n. 211 (Sph. mendoeino intermixt.), II48a et b.

Warnst. Sphagnoth. eur. n. 46, 48, 87-95, 109-114, 177-179, I81.

Warnst. Samml. eur. Torfm. ser. I, n. 89-94; ser. II, n. 194, 195.

"var. amblyophyllum Riiss. (ut subsp.) ; Warnst. in Bol. Gaz. 1890, p. 219 et " die Cuspidal... Gr. », p. 216, ८. 1, fig. 7 b.

Sph. caldensi-recurvum $C$. $M$. in sched.

Sph. pulchricoma $C$. M. (fid: Warnst. in op, cit., $t$. XXXIX, fig. a el b, et t. XLI, fig. a et b) in Ule Bryoth. brasil. n. 1736, 1737 et 1740 (I).

Sph. recurvum var. squarrosulum Roell System. p. 46.

$f$. viride ej. in Hedwig. $1893, p .307$.

Sph. recurvum forma Card. in Bull. Soc. roy. bot. Belg. XXVI, I; Warnst. in Hedwig. 1890, p. 235.

Sph. rufulum C. M. (fid, Warnst. in op. cit. p. 217).

Sph. Serrae C. M. (fid. Warnst. in Heduig. 1890, p. 235).

f. immersa Schlieph. et Warnst. " die Cuspidat... Gr. "p. 217.

Sph. squarrosum Brid. hb.; Hsch. Fl. Brasil. I, p. 4.

- Eur.: Ubi typ. Am. sept.: Washington, Michigan, Ludovic. Am. merid. : Brasil,, fiet. Magellan,, ins. Eremitae. Pac. : Nov. Zeland.

Exs. : Gravet, Sphagnoth. belg. n. 19-21, 31, 32, 34, 35.

Ule, Bryoth. brasil. n. $1109,1292,1293,1738,1739$.

Warnst. Sphagnoth. eur. п. 87, 91, 92, 94, 95, 109, 110, 112, $113,178,181$. 
subsp. angustifolium (C. Jens.) Rüss. - Sph. recurvum var, parvifolium.

var. balticum Rüss, - Sph. recurvum var. mollissimum.

var. brevifolium Lindb. - Sph., recurvum var. mollissimum.

f. Broëckii Card. - Sph. recurvum var. parvifolium $f$. tenuis.

"var. deflexum Gravet mss.; Warnst. in Hedwig. 1884, p. 121.

- Eur. : Belgia.

"var. fallax Warnst. in Heduig. $1884, p .122$ (1).

- Eur.: Brandebourg.

"var. fibrosum Schlieph. mss.; Warnst. in op. cit. p. 123.

- Eur.: Tirol.

var. gracile Gravet. - Sph. recurvum var. parvifolium $f$. tenuis.

var. humile Schlieph. et Roell. - Sph, recurvum var. parvifolium $t$. tenuis.

\& var, immersum Schlieph. et Warnst, in op. cit. p. J22, f. tenellum eor. l. c.

- Eur.: Thuring.

" var. indianensis Roell in Bot. Centralbl. 1891, pp. 21-22.

- Am. sept. : Indiana.

f. crispum ej. in Hedsoig. 1893, p. 107.

- Am. sept. : Indiana.

var, Limprichtii Schlieph., Warnst, - Sph. obtusum.

* var. majus Ångstr. mss.

- Am. sep'. : Washington.

* capitatum Roell in Hedroig. 1893, p. 308.

- Am. sept. : Indiana.

*var. mollissimum Rüss, Beitr.... 1865, p. 61; Warnst. " die Cuspidat... Gr. "p. 22l, t. I, fig. 38 a, b, c, 44 a, b, c, 45 a, b et t. Il, fig. s.

Sph. balticum Rüss. mss.; C. Jens. in De danske Sph. Art. 1890, p. 100.

Sph. recurvum var. balticum Riss. in Sitzungsber. d. Natur\%. Gesells, in Dorpat, 1889.

Sph. recurvum var. brevifolium Lindb. in Braithw. the $\$ p h, \ldots, 1880$. $f$. dasyclada subf. anoclada Warnst. in op. cit. p. 222.

Sph. recurvum var. strictum ej. in $\mathrm{Fl}$. 1882, subff. delicatula et homoloclada

$f$. euryclada

Warnst. "die Cuspidat... Gr. * p. 222.

- Eur.: Lappon., Norveg., Fennia, ins. Aland, Livon., Esthon., Anglia, Scotia. Am. sept. : Groenland.

"var. mueronatum Ruiss. (ut subsp.) in op. et l. cc.; Warnst. in Bol. Gaz. 1890 , p. 218 et « die Cuspidat... Gr. o p. 217, t. I, fig. 35, 36 a et b, 37 c, 42 a et b, et t. II, fig. 9.

Sph. fallax var. Klinggr, Topoy. Fl. West. Preuss, p. 128.

$f$. fluitans subf. strictifolia Warnst. in op. et $l$. ec.

- Eur.: Anglia. As, : Japon.

Exs. : Faurie, Pl. Japon, n. 12800, 14494.

Warnst. Sphagnoth. eur. n. 114. 
f. riparioides Warnst. in op. cit. $p, 218$.

- Eur. : Anglia (Cheshire). As, : Caucas. occ. Am. sept. ; Ubi typ. Am. merid. : Boliv.

Exs. : Gravet, Sphagnoth. belg. 0. 16, 18, 22, 28, 33 (omn. ad f. riparioidem pertin.).

Warnst. Sphagnoth. eur. n. 45, 49, 91), 91, 93, 109, 110,111 (114 ad $f$. fluitantem subf. strictifoliam), 177, 178.

Warnst. Samml. eur. Torfm. n, 89-91.

var. obtusum Warnst. - Sph. obtusum.

" var. parvifolium (Sendtn.) Warnst. in Fl. 1883, p. 374 et \& die Cuspidat... Gr. " p. 219, t. I, fig. $37 \mathrm{~d}, \mathrm{e}, \mathrm{f}, 43 \mathrm{a}, \mathrm{b}$ et $\iota$. II, fig. r.

Sph. angustifolium (subsp.) C. Jens, in op. cit. p. 104.

Sph. brevifolium Roell p.p. in Bot. Centralbl. 1889, n. 38.

Sph. recurvum subsp. angustifolium (C. Jens.) Rüss. in op. et $l$. cc.

$f$. tenuis $v$. Klinggr.; Warnst, in op. et $l$. co.

Sph, recurvum var. Broeckii Card. in Rev, bryol. 1884.

Sph. recurvum var. gracile Grav, Sphagnoth. belg. n. 29.

Sph. recurvum var, humile Schlieph. et Roell mss.

Sph. recurvum var. squamosum Angstr. in Grav. Sph. belg. n. 30 .

subf. brachyclada (Rüss.) Warnst. in op. et $l$. oc.

subf. capitata Gravet mss, ; Warnst. in op, et l. oc.

subf. crispula (Rüss.) Warnst. in op. et $l$. co.

$f$. filiforme subff. Inbricaule et viride Roell in Hedwig. 1893, p. 308 ,

$f$. Warnstorffii $C$. Jens, mss. ; Warnst, in op. et $l$. cc.

- Eur.: Belgia, Thuring. Am. sept. : Ubi typ.

(f: filiforme Wisconssin; subf. rubricaule Washington ; subf. viride New Jersey).

Exs. : Gravet, Sphagnoth. belg. n. 15, 17.

Jack, Lind. et St. Krypt. badens, n. 22I.

Warnst. Sphagnoth. eur. n. 48, 179.

Warnst. Samml. eur. Torfm. ser. I, n. 92-94.

a var. pulchrum Linclb. in Braitho. Sph. of Fur. and N. Amer.;

Warnst. in Bot. Gaz. 1890, p. 218 et \& lie Cuspidat... Gr. " p. 215,

t. I, fig. $37 \mathrm{a}, 40 \mathrm{a}, \mathrm{b}, \mathrm{c}$, d et t. II, fig. o.

Sph. laricinum (Spr.) W. P. Sch. in Un, itin. 1865 (fid. Warnst.).

* dimorphum Roëll in Hedwig. 1893, p. 308.

Washington Eur.: Anglia (Cheshire). Am. sept. : Passim, Exs. Braithw Sph brit. 48 .

"var. rigidulum $f$, ochraceum Roell in op. et $l$. cc.

- Am. sept. : Wisconssin.

var. squamosum Ângstr. - Sph. recurvum var. parvifolium $f$. tenuis. var, squarrosulum Roell. - Sph. recurvum var. amblyophyllun.

var. strictum Warnst. - Sph. recurvum var. mollis $f$. dacyclada subf. anoclada.

"var. Warnstorffii $C$. Jens. mss. ; Warnst. in Hedvoig. 1884, p. 122 (I).

-- Eur. : Dania, Livon., Thuring.

* var. Winteri Warnst. in Heduig. 1884, p. 123 el \& die Cuspidat... Gr. t. I, fig. 46 a, b. c, d, e.

- Eur.: Brandebourg. 
Rehmanni Warnst, in Hedwig. 1891, p. 16, t. I, fig. $2 \mathrm{a}, 2$ b et t.1V, fig. b. Sph, oligodon Rehm. M. Afr. austi, n, 431.

\section{- Afr.: Transvaal.}

Reichhardti Hpe. in Expl. Novara, p. 175: Warnst. in Hedroig. 1890, p. 206, t. V, fig. 17 a, 17 b et $t$. VI, fig. 1, 2 et 3 .

Sph. acutifolium Mitt. Fl. Vit. p. 404.

$$
\text { - Afr. : lns. S. Paul. }
$$

rigidulum Warnst. in Hedwig. 1890, p. 241, $t$. XI, fig. 3-4 et $t$ XIV,

fig.h.

Ster.?

- Pac. : Ins, Hawaï.

rigidum (Bryol. germ.) W. F. Sch. Mém. Sph.p. 71, t. XIX, Syn. ell. I, p. 678 et ed. $\Pi$, p. 839 .

Sph. compactum $\beta$ rigidum Bryol. germ. $I, p .14, t .1 I$, fig. 5 ; C. M. Syn.I, p. $99 ;$ Lindb. Torfm. p. 139.

Sph. humile W. P. Sch, in Sull. Ic. M. p. 5, t. 3 et Mém. Amer. Acad.. N. S. p. 175 (fid. Card., Lindb.).

Sph. strictum Sulliv, M. Allegh. p. 49 et n. 201.

1. In ericet. humid. et ad rup. rorid. - Eur. : Zon. intermed. et sept. Afr. : Ins. Azor. Am. sept. : Arctic., Canada, Terr, nova, ins. Miquelon: de New Jersey ad Florid, et Alabama, Calif.

Exs. : Rab, Bryoth. eur. n, 601.

"var. compactum (Brid.) W. P. Sch. in op. et l. cc.

Sph. ambiguum Hüb. Musc. germ. p. 25.

Sph. compactum Brid. Bryol. univ. I, p. 16 et p. 752 p.p.; C. M. Syn. I, p. $98 ;$ Lindb. Hvitm. p. 37.

Sph. immersum Bryol. germ. I, p. 11, t, 2, fig. 4.

Sph. praemorsum Z. D.M. Thuring. n. 18.

In turfos, siccior. vel mont. altior. - Eur.: Ut typ. Am. sept.: Labrador, Canads, ins. Vancouver et Miquelon; de Maine ad Florid. et Alabama; Calif. Pac, : Tasman.

Exs. : Funk, Samml. Krypt. Gew. n. 548.

De Brebisson, M. Norman. n. 100.

H. Müller, Westfal. Laubm. n. 228.

Rab. Bryoth. eur. n, 602.

f. purpurascens Warnsl. in Hedwig. 1884, p. 114. - Eur. : Norveg.

\& var. squarrosum Rüss. Beitr...p. 77.

-Am. sept. : Ins. Miquelon, New Jersey, Massachussets, Pensilv., Florid., Alabama.

riparium Àngstr. $\left\{\begin{array}{l}- \text { Sph. recurvum (fid. W. P. Sch.). } \\ - \text { Sph. cuspidatum } \beta \text { majus (fid. Jaeg.). } \\ - \text { Sph. spectabile (fid. Warnst.). }\end{array}\right.$

rivulare Warnst. in Hedroig. 1897, p. 160.

- Am. merid. : Brasil, or. (Minas Geraës).

robustum (Rüss.) Roell. - Sph. Rüssowii.

rotundatum C. M. et Warnst. in Hedroig. 1897, p. 152 el in Ule Bryoth. brasil. n. 1760 .

- Am. merid. : Brasil. or. (Serra do Itatiaia.).

rotundifolium C. M. et Warnst. in op. et l. ce. p. 159 et n. 1756. - Am. merid. : Brasil. or. (Serra do Itatiaia). - 
rubellum ( H. Müll, n, 227. - Sph. Rüssowii.

Rab. n. 951 et 1249 . - Sph. tenellum.

Wils. - Sph, tenellum var. versicolor.

rufescens Bryol. germ. - Sph. subsecundum var. rufescens.

rufulum C. M. in Linn. 1874, p. 548; Wainst. in Hedwig. 1890, p. 234.

Sph. cuspidatum Mitt. M. Ind. or. p. 156, n. 1290, 1291; Wils. in hb. Ind. or, iisd. num. (fid. C. M.).

Sph. recurvum var. amblyophyllum (fid. Warnst, in Heduig. 1890, p. 226 et \& die Cuspidat... Gr. o pp. 213 et 217.

Ster. - As. : Sikkim.

Ruissowii Warnst. in Hedwoig. 1886, p. 225.

Sph. acutifolium var. fallax p.p. Warnst. Eur. Torfm. p. 42.

Sph. acutifolium var. polyphyllum ej. in Fl. 1882, p. 206.

Sph. acutifolium var, robustum Rüss. Beitr... p. 39,

Sph. acutifolium var, roseum Limpr, mss.; Milde Bryol. siles. p. 382.

Sph, acutifolium var. strictiforme Warnst. in Fl. 1883, p. 373.

Sph. acutiforme var, auriculatum ej. in Hedwig. 1884, p. 117 et Sphagnoth, eur. n. 152.

Sph. Girgensohini \& roseum Limpr. Kryptog. Fil. Deutschl. IV, p. 109.

Sph. robustum (Riiss.) Roell in Fl. 1886 (p.p. ?).

Sph. rubellum H. M. Westfal. Laubm. n. 227.

Sph. Warnstorffii var, auriculatum (Warnst.) $f$. defleza, var. fallax (Warnst. p.p.), fimbriatum ( Warnst.p.p.). polyphyllum (Warnst.), strictiforme (Warnst.). strictum $f$. deflexa, squarrosa et teres Roell in Fl. 1886.

Sph. Wilsoni var. roseum (Limpr.) Roell in op. et l. co.

2. rar. 1. - - Eur.: German. As. : Siber. occid. Am. sept. : Labrador, Terra nov., ins. Miquelon, New Brunswick, Maine, New Hampshire, M. Rupestr., Washington.

Exs. : Rraithw. Sphagnoth. brit. n. 42 b ot.

Warnst. Sphagnoth. eur. n. 57, 151, 152, 155.

( var. fallax Roell in Bot. Centralbl. 1891, pn. 2I-22, $f$. pallens ej. in Hedwig. 1893, p. 305 (1).

$$
\text { - Am. sept. : Washington. }
$$

« var. girgensohnioides Rüss. mss.; Warnst. in Bot. Gaz. 1890, p. 132 .

- Am. sept.: Vermont, New Hampshire.

"var. laxum $f$. pallens et purpurascens Roell Syst, p. 30 et in Hedwig. l. c.

- Am. sept.: Washington.

* var. obscurum Rüss, mss.; Warnst. in op. cit. p. 133.

- Am. sept. : New Hampshire.

« var. poëcilum Rüss. mss. ; Warnst, in op. cit. p. 132.

- Am. sept. : Vermont, New Hampshire.

“ vas, rhodochroum Rüss. mss.; Warnst. in op. et l. co. ; $f$. dasy-anoclada Warnst. l. c.

- Am. sept. : New Hampshire.

Rutenbergii C. M. in Abhandl. Brem VII, p. 203.

Ster. - Afr. : Madagascar.

(1) " Hicrher rechne ich auch die ron mir in Systematik S, 27 unter Sph. Warnstorffii miki, var. fallar Warnst., $f$. squarrosula mihi und $f$. teres mihi angeftihrten Formen *. Roell I. c. 
Schimperi $\left\{\begin{array}{l}\text { var. gracile } \\ \text { var. tenellum }\end{array}\right\}$ Roell. -- Sph, tenellum.

Scortecchini C. $M$, in Hedwig. 1897, p. 153.

- Pac. : Austral. or. (Queensland).

sedoides Brid. Bryol. univ. 1, p. 750 : Sull. Ic. M. p. 11, t. VI.

Sph. cymbifolium C. M. Syn. I, p. 91 p.p.

Sph. Pylaisaei var. (fid. Warnst. in Bot. Gaz. 1890, p. 242).

- Am. sept. : New York, Carol. infer.

var. Sull. et Lesq. - Sph. Pylaisaei.

Seemanni C. M. M. Polyn. p. 56.

Sph. cuspidatum Mitt. in Bonplandia, 1861, p. 366.

Ster. - Pac. : Ins. Fidji.

semi-vacuum P. B. - Orthotrichum affine.

sericeum C. M. in Bot. Zeit. 1847, p. 481 el Syn. I, p. 90 ; Bryal. jav. 1, p. 30, t. 21; Warnst. in Hedvig. I890, p. 222, t. VIII, fig. 13-16 et t. X, fig. 7-8.

Ster.? - As, : Sumatra sept., Java.

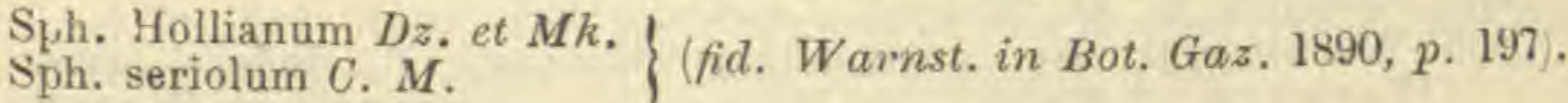

seriolum C. M. in Fl. 1887, p. 421 (de syn. of. Sph. sericeum).

Ster. - As. : Sumatra.

Serrae C. M. - Sph, recurvum var. amblyophyllum.

serratum Aust. $\left\{\begin{array}{c}(\text { fid. C. M.). - Sph. trinitense. } \\ \text { (fid. Warnst.). }- \text { Sph. cuspidatum var, snbmersum } \\ f \text {. serrulata. }\end{array}\right.$ serrulatum Warnst. in Hedvig. 1893, 1, t. I, flg. $1 \mathrm{a}-1 \mathrm{~g}$.

Ster.? Submers. - Pac. : Tasman.

simile Warnst. in Hedwoig. 1894, pp. 326 et 335.

- Am. sept.: Wisconssin.

simplicissimum Lour. - Gymnostomum.

sparsifolium V arnst. in Heducig. 1894, pp. 320 et 324.

- Am. sept. : Guadalup.

sparsum Hpe. Symb. 1870, p. 267; Warnst. in Heduig. 1890, p. 203,

t. IV, fig. 15 a, 15 b et VI, fig. 6.

- Am. merid. : Nov. Granat., Brasil. austr. or.

speciosum v. Klinggr. - Sph. spectabile.

spectabile W. P. Sch. Syn. 11 ed. p. 834.

Sph. cuspidatum subsp. riparium Lindb, Hvitm. p. 69.

Sph. cuspidatum var. speciosum Rüss. Beitr. p. 57, fig. 3, 49, 64 (fid. Warnst. in Bot. Gaz. 1890, p. 217); Rab. Bryoth. eur. n. 1350.

Sph. riparium Angstr. in Oefv. Vet. Akad. Foerh 1864, p. 198 ; Warnst. "die Cuspidat... Gr, " p. 203, t. I, fig. 7-12et t. II, fig. b $\alpha, b$, c, d, e ; Rab. Bryoth. ewr. n. 707. Rab. Bryoth. eur. n. 707 .
Sph. speciosum v. Klinggr. in Sehrift. d. Phys. oecon. Gesells. in Koe-
nigsb. 1872 .

Sph. variabile $\alpha$ speciosum Warnst. Eur. Torfm. p. 62 .

- Eur. : Lappon., Scandin., Fennia, Livon, Esthon.,
German. sept. et med., Bohem., Salisb., Stir., etc.; Anglia. Am. sept. :

Groënland, fret. Kotzebuë, Columb, brit.; septentr. tota. 
squarrosulum Lesq. - Sph. squarrosum vur. sq uarrosulım.

var, laxum Schlieph., Roell. - Sph. teres var. laxum.

squarrosum Pers. Prodr. p. 88; Brid. Bryol. univ. 1, p. 5 ; C. M. Syn. I, p. 94; W. P. Sch. Mém. Sph. p. 69, t. 17 et Syn. Il ed. p. 835; Lindb. Bidrag .... p. 414, Hvitm. p. 42 et Torfm. p. 139; Rüss. Beitr. p. 62.

Sph. aconiense de Not. mss.; Lindb. Torfm, p. 138 (ut syn.).

Sph. cymbifolium var, squarrosum $B r$. in Bryol. germ. I, p. 11 in obs.

Sph. latifolium $\beta$ squarrosum Wahlenb. Fl. Upsal. p. 391.

Sph. patulum Mitt. mss.; Braithw, in Monthl. Mior. Journ. 1874, II (ut. syn.).

Sph. porosum Lindb. in op. et $l$. ec.

Sph. teres var. squarrosum Warnst. Eur. Torfm.p. 121.

1. In montos. silvat. scaturigin., rar. in turfac. - Eur.: Zon. intermed., rar. sept. ; Spitzberg, ins. Ursorum. As. : Amour, Japon. Afr.: Ins. Azor, Am, sept.: Labrador, fret. Davis, Alaska, mar. Behring, ins. S. Paul, S. Georges, Pribyloff, Terr. nov., ins Miquelon, sept., centr.. et or.

Exs.: Faurie, PI. Japon, n, 14494.

Funk, Samml. Krypt. Gew. n. 207.

H. Müll. Westfal, Laubm, n. 230 .

Moug. et Nestl. Stirp. vog. rhen, n. 209.

Rab. Bryoth, eur. n. 1250 b.

"var. compactum Warnst. in Hedwig. 1884, p. 120.

- Am. sept. : Groenland.

- var. cuspidatum Warnst. in op. et $l$. cc.

- Eur. : Bohemia.

"var. densum Roell System. p. 64, $f$. deflexum * versicolor ej. in Hedwig. 1893, p. 310.

- Am. sept. : Washington.

"var, elegans Roell in Hedroig. l. c.

- Am. sept. : Washington.

«var. humile Schlieph. (ubi ?).

- Am. sept. : Miehigan.

" var. imbricatum W. P. Sch, Syn. 11 ed.p. 836.

Groenland, Washington.

- Eur. : Suecia, Rhoengeb., Thuring. Am. sepl. :

"var. immersum Beckmann mss, ; $f$. robustum Roell in op. et $l$. cc.

- Am. sept.: Washington, Michigan.

* var. molle Roell in op. et $l . c c$.

- Am. sept, : Washington.

* var. patulum Roell in Hedroig. 1897, p. 49 (nom.).

- Am. sept. : Michigan.

* var. robustum Roell in op. et $l$. cc.

- Am. sept.: Washington.

‘ var. semi-squarrosum Rüss. mss.; Warnst. in Bot. Gaz. 1890, p. 224.

Sph, squarrosum Rab. Bryoth, eur, $n .1250$.

New Hampshire.

- Eur.: Westphal., Alp. Helvet. Am. sept. : Canada,

"var. spectabile (Rüss.) ; Warnst, in op. el l. cc.

hire.

- Am. sept. : Vermont, Massachussets, New Hamps- 
* var. squarrosulım (Lesq.) W. P. Sch. Syn. l ed. p. 677 et II ed. l. c. Sph. squarrosulum Lesq. in Mem. Acad. Calif. I, p. 3

Sph. teres var. squarrosulum Warnst. in op. cit. p. 225.

In turfac. - Eur. : Suec., Westphal., Jurass. helv.; Spitzberg ? Am. sept. : Arctic., Canada, Terr. nova, ins. Miquelon, Columb. brit., Washington, Minnesota, Calif. Am. merid. : Fret. Magellan?

Exs. : Moug. et Nestl. Stirp. vog. rhen. n. 1305.

Rab. Bryoth. eur. n, 212.

squarrosum $\left\{\begin{array}{l}\text { Hsch, -- Sph. recurvum var. amblyophyllum. } \\ \text { Rab. n. I250. - Sph. squarrosum var. semi-squarrosum. }\end{array}\right.$

var. teres W. P. Sch. - Sph. teres.

strictum $\left\{\begin{array}{l}\text { Lindb. - Sph. Girgensohnii. } \\ \text { Sull. - Sph. rigidum. }\end{array}\right.$

Stuhlmanni Warnst, in Allgem, bot. Zeitschr... in Karlsruhe, 1895, n. 7.8. - Afr.: Reg. lacustr.

subacutifolium Warnst. in op. cil. n. 5.

- As. : Japon.

Exs. : Savatier., Pl. Japon. n. 534.

subrquifolium Hpe. Enum. M. Brasil. p. 3.

- Am. merid. : Brasil austr. or.

subbicolor Hpe. - Sph. cymbifolium

subcontortum Hpe. in Linn. 1876, p. 301.

Sph. subsecundum var. subcontortum Jaeg. Ad. II, p. 626.

Ster.

- Pac. : Austral. or.

subcuspidatum C. M. et Warnst. in Hedwig. 1897, p. 151.

In turfos. - Pac.: Nov. Zeland. (Otago).

subcuspidatum W. P. Sch. $\left\{\begin{array}{c}- \text { Sph. molle } \\ - \text { Sph. recurvum var. } \\ \text { mollissimum }\end{array}\left\{\begin{array}{c}\text { p.p. (fid. Warnst. } \\ \text { in Hedwig. } 1890, \\ \text { p. 234. }\end{array}\right.\right.$ suberythrocaly $x$ C. M. - Sph. erythrocalyx var. Iaeve.

sicbhirsutum obscure virens, capsulis rubellis Dill. - Grimmia apocarpa. submolliculum Warnst. in Hedwig. 1897, p. 164.

- Pac. : Tasman.

submollissinum Hpe. - Sph. Puiggarii.

submolluscum Hpe. $\left\{\begin{array}{l}\text { - Sph. gracilescens. } \\ \text { - Sph. Puiggarii. }\end{array}\right.$

submucronalum C. M. - Sph. tumidulum.

subnitens Rüss. el Warnst, in Verh. d. bot. Ver. für Brandenburg, 1888 , p. 1.5

Sph. acutifolium de Bréb, M. Normann, n. 125.

Sph. acutifolium var: aquaticum Schlieph. in Hedvig. 1884.

Sph. acutifolium nar, laete-virens Braithw. Sph. Eur. and N. Amer. 1880.

Sph. acutifolium var. laxum Warnst. Eur. Torfm. pp. 48-50.

Sph. acutifolium var luridum $H u ̈ b$.) Warnst, in op. et $l$. oc., If. deflesa, elongata, laete-virens, limosa, plumosa, squarrosula, stricta et violacea ej. Sphagn. Rückblick in Fl. 1881.

Sph. acutifolium var. plumosum Milde Bryol. siles. p. 382.

Sph, acutifolium var. Schillerianum Warnst. in Fl. 1882.

Sph. acutifolium var. squarrosulum ej. Eur. Torfm. $l$. $c_{\text {. }}$

$\mathrm{Sph}$. capillifolium (eum $\mathrm{Sph}$, quinquefario immixt.) Moug. et Nestl. Stirp. vog. rhen. n. 1 .

Sph. luridum (Hüb.) Warnst. in Hedurig. 1886, p. 230.

$\mathrm{sph}$ plumosum varr. elongatam, laete-virens, limosum, luridum, plamo- 
sum, Schillerianum, squarrosulum, submersum et violaceum Roell Syst. d. Torfm. in Fl. 1886.

Sph. plamulosum Roell Syst. p. 19, var. luridom (Hub.)f. dimorphum ej. in Hedwig. 1893, p. 295.

1 et 2 .

- Eur.: Sept. et med. As. : Yunnan. Afr. : Ins. Azor. Am. sept.: Labrador, Alaska, Terr, nov., ins. Miquelon, sept. et sept. or., Indiana, Calif.

Exs. : Delavay, Pl. Yunnan. n. 2049, 4737.

« var. flavicomans (Ren. el Card.) Warnst. in Bot. Gaz. 1890, pp. 194-196.

Sph. acutifolium var. flavicomans $R$. et C. in Rev, bryol, 1885, p. 55 et Sph. d'Eur. p. 68, not.

Exs. : Warnst. Eur. Torfm. ser. I, n. 77.

"var, griseum Warnst. in Schrift. d. Naturf. Gesells. in Danzig., N.F. IX, Hefl 2, 1896.

- Eur. : Westphal.

\& var. obscurum Warnst. in Bot. Gaz. 1850,p. 196.

- Am. sept. : Massachussets.

" var. pallescens Warnst. in Ann. sc. nat. 1892, 1, p.

- As. : Yunnan.

"var. viride Warnst. in Bot. Gaz. 1890, p. 196.

- Am. sept. : Massachussets.

subovalifolium C. M. et Warnst, in Hedwig. 1897, p. 162 et in Ule

Bryoth. brasil. $n .1754$

- Am. merid. : Brasil. or. (Serra do Itatiaia).

subpulchricoma C. $M$. in Fl. 1887, p. 115.

Ster. $\quad$ - Am, merid. : Brasil. subtropic.

subrecurvum Warnst. in Allgem, bot. Zeitschr... in Karlsruhe, 1895,

n. $\tau=8$.

$$
\text { - As, : Java. }
$$

subrigidum Hpe. et Ltz. in Bot. Zeit. 1868, n. 47.

$$
\text { - Am. merid. : Summ. Cordill. Equat. }
$$

subsecundum Bryol. germ. 1, p. 17, t. III; Brid. Bryol, univ. I, p. 8;

C. M. Syn. I, p. 100 (excl. varr.); W. P. Sch. Mém. Sph. p. 78,

t. XXII-XXIII et Syn. II ed. p. 843; Lindb. Torfm. p. 141 et Hvitm. p. 28.

Sph. cavifolium var. subsecundum Warnst. Eur. Torfm. p. 81.

Sph. compactum $\beta$ ambiguum $H$. f. et $W$. Fl. $N$. Zealand, $I I$, p. 57.

Sph. contortum Rab. Bryoth. eur. n. 302, 551, 552, 706, 807.

$\mathrm{S}$ ph. contortum (Schultz.) var. subsecundum Wils. Bryol, brit. p. 22, t. LX.

Sph. subsecundum var. heterophyllum Rüss, Beitr...p. $72 ;$ Lindb. Torfm. p. 141.

2. In turfac, et foss, prat. uligin, - Eur.: Fere tota, As, : Caucas. occ. et centr. Afr.: Alger. Am. sept.: Terr. nov., ins. Miquelon, reg. sept. et or. usq. ad Floridam. Am. merid, : Brasil. Pac. : Nov. Zeland., Tasman.

Exs. : Funk, Samml. Krypt. Gew. n. 626.

H. Müll. Westfal. Laubm. n. 224. 
Moug. et Nestl. Stirp. vog, rhen. n. 806 .

Rab. Bryoth. eur. n. 208, 704, 705, 719.

var, auriculatum Lindb. - Sph, auriculatum.

var. contortum W. P. Sch, - Sph. subsecundum var. rufescens.

"var. Dieckei ff. aureum, laxum, versicolor et viride Roell in Hedwig. 1893, pp. 312-313.

- Ani. sept.: Wisconssin.

var. gracile C. M. - Sph, tenellum Pers. (fid. C. M.).

var. heterophyllum Rüss. - Sph. subsecundum.

"var. indianensis Roell in Bot. Centralbl. 1891, pp. 21-22.

- Am. sept. : Indiana.

«var. intermedium Warnst. (ubi?) f. viride Roell in Hedwig. 1893, p. 311 .

- Am. sept. : Washington.

var. isophyllum Rüss. $\left\{\begin{array}{l}-\mathrm{Sph} \text {. auriculatum (fid. Jaeg ). } \\ -\mathrm{Sph} \text {. neglectum (fid. Warnst). }\end{array}\right.$

" var. Jensenii Warnst. in Hedwig. 1884, n. 7.8.

- Eur. : Ins. Bornholm.

"var. latifolium Roell in Hedwig. 1893, p. 312.

- Am, sept. : New Jersey.

var. lasum Lesq, et Jam. - Sph. subsecundum var. Lescurii.

"var. Lescurii Sull. M. bor. am. II ed.p. 16.

Sph. Lescurii ef. M. bor. am. I ed. n. 6.

Sph. subsecundum var. laxum Lesq. et Jam. Man. p. 19.

- Am. sept.: Passim cum typo.

" var. majus Roell System. p. 77, $f$. albescens, * capitatum, * deflexum, * dimorphum et ${ }^{*}$ patulum ; $f$. Schimperi et $f$. virescens," capitatum et "patulum ej. in Hedroig. 1893, p. 311 .

f. Schimperi); Washington.

- Am. sept. : Indiana ( $f$. albescens," dimorphum et

" var. molle Warnst. (ubi ")

- Am. sept.: Wisconssin.

"var, natans Schlieph. (ubi?)

- Am. sept. : Wisconssin.

"var, obesum (Wils.) W. P. Sch. Syn. II ed.p. 844.

Sph. decipiens Sull. et Lesq. in hb. Kew.
Sph. obesum Wils. Bryol. brit. p. 22: Warnst. in Bot. Gas. 1870, p. 247.

Sph. subsecundum var. turgidum C. M. Syn. I, p. 101 ?

Sph. turgidum (C. M. Roell in $\mathrm{Fl} .1886$.

In aq. stagn. mont. editior. et in silvat. turfac. - Eur. : Sept. et med. Am, sept. : Sept. occid.

Exs. : H. Müll. Westfal, Laubm. n. 235 b.

var. oblongifolium Lesq. - Sph. mendocinum,

« var.psend o-molle Ren. et Card. in Rev. bryol. 1885, p. 45.

- Am. sept. : Florid.

« var. robustum el $f$. compactum Roell in Hedvig. 1893, pp. 311-312. 
" var. Roederi Roell System. $p .77$ f. dimorphum ej. in Hedwig. l. c.

- Am. sept. : New Jersey.

" var, rufescens (Bryol. germ.) Warnsl. in Hedroig. 1888, p. 267.

Sph. rufescens Bryol. germ. p. 15, t. II, fig. 6*.

Sph. subsecundum var. contortum C. M. et W. P. Sch, ll. cc.

-- Eur. : Lappon., Baden. Am. sept.: A. Labrador, Canada et Terr, nov, usq. in Connecticut; Washington, Calif.

Exs. : H. Müll. Westfal. Laubm. n. 225.

" var. simplicissimum Milde Bryol. siles, p. 393.

- Eur. : Silesia.

\& var. strictum Roell System. p. 77 f. Schimperi ej. in Hedwig. 1893, p. 310 .

- Am. sept. : Indiana.

var. subcontortum Jaeg. - Sph. subcontortum.

« var. tenellum Warnst. in Hedwig. 1884, n. 7-8.

- Eur, : Brandeburg., Thuring.

" var, teres et ff. myurum, versicolor et viride Roell in Hedvig. l. c. - Am. sept. : Washington.

var, turgidum C. M. - Sph, subsecundum var, obesum?

"var. virescens Angstr. mss.; Warnst. in Hedwig. l. c. - Eur. : Thuring.

subsecundum C. M. p.p, - Sph. Iaricinum.

subtursum C. M. in Hedwig. 1897, p. 171 et in Ule Bryoth. brasil. n. 414.

In turfos. - Am. merid. : Brasil or. (ins. Catharina).

a var. squarrosulum Warnst, in op. et $l$. cc. n. 413.

Ut et ubi typus.

subulatum $\left\{\begin{array}{l}\text { Brid. - Sph, acutifolium. } \\ \text { Br. - Sph. fimbriatum. }\end{array}\right.$

subundulatum C. M. et Warnst. in op. et $l$. cc. p. 152 et n. 1298.

Ouro preto).

- Am. merid. : Brasil. or. (Minas Geraes, Serra do

Sullivantianum Aust. - Sph. porto-ricense.

tabulare Sull. - Sph. molle.

tenellum (W, P. Sch.) v. Klinggr. in Schrift. d. Phys.-oecon. Gesells, in Koenigsberg, 1872, I, p. 4, n. 5; Warnst. in Bot. Gas. 1890, p. 135 ; Lindb. Torfm. p. 142.

Sph, acutifolium var, elegans $f$. plumosa Roell in Fl. 1886.

Sph. acutifolium var, tenellum W. P. Sch. Mon. Sph. t. XIII. fig. $\gamma$ et Syn. II ed. p. 826.

Sph. acutifolium var, tenue Braithw. $S p h$, brit.

Sph. acutiforme var. pseudo-Schimperi Warnst. in Hedvoig. J884, p. 118?

Sph. acutiforme var, tenellum Sohlieph. et Warnst, in Fl. 1884, p.p.

Sph, Schimperi $\left\{\begin{array}{l}\text { var, gracile } \\ \text { var. tenellum }\end{array}\right\}$ Roell in $\mathrm{Fl}, 1886$.

Sph. subsecundum var. gracile C. M. Syn. I, p. 101 ?

Sph. Wilsoni Roell in op. et l. cc. p.p.

2. In turf. profund. mont. editior, - Eur. : Lappon., Helvet, Jurass.,

Pyren. Am. sept.: Labrador, Canada, Ter1. nov., ins. Miquelon, sept. or.

Exs. : Rab. Bryoth. eur. n. 711. 
var. compactum Warnst. - Sph. molluseum var. compactum.

f. flavum (C. Jens.) Par.

Sph. acutiforme var. tenellum $f$. flavum C. Jens. mss.; Warnst. in Hedwig. 1884, p. 118.

- Eur.: Ubi typ.

" var. pallescens Warnst. in Bot. Gaz. 1890, p. 137.

- Am. sept. : Massachussets, New Hampshire.

- var. pallido-glaucescens Warnst, in Schrift. d. Naturf. Gesells in Dansig, N. F., Heft 2, 1896.

- Eur. : Westphal.

« var. rubellum (Wils.) Warnst. in op. et $l$. cc.

Sph. acutifolium var. rubellum Rüss. Beitr. p. 41.

Sph. acuttforme var. rubellum Schlieph. et Warnst, in Fl. 1884.

Sph. rubellum Wils. Bryol. brit. p. 19, t. LX; W. P. Sch. Mém. Sph. p. 75, t. XX et Syn. II ed. p. 826; Lindb. Torfm. p. 142.

In palud. montos. - Eur. : Zona intermed. Am. sept. : Canada, New Brunswick, Massachussets, ins. Miquelon.

Exs. : Rab. Bryoth. eur. n. 555.

var. suberectum Gravet. - Sph. molluscum var. suberectum.

« var. versicolor Warnst. in op. et l. cc.

Sph. rubellum Rab. Bryoth. eur, n. 951 et 1249.

sachussets.

- Eur. : Suecia, Wetsphal., Anglia. Am. sept. : Mas-

"var. viride Warnst. in op. et $l$. cc.

- Am. sept. : Massachussets.

tenellum Bryol. germ. - Sph. molluscum.

tenerum (Aust.) Warnst, in Hedwig. 1890, p. 194, t. IV, fig. 6 a, 6 b.

Sph. acutifolium var, tenerum Aust. mss.

Ster.?

- Am. sept.: New Jersey, Connecticut.

tenerum Sull, et Lesq. - Sph. molle var. tenerum.

tenuifolium Warnst. in Allgem. bot. Zeitschr... in Karlsruhe, 1895, n. 6. - Am. sept. : Labrador.

teres Ångstr. in Hartm. Skand. Fl. VIII ed., p. 417; W. P. Sch. Syn. II ed. p. 836 ; Lindb. Torfm. p. 138.

Sph. squarrosum var, teres W.P. Sch. Syn. I ed. p. 677; Rüss. Beitr... p. 64.

Sph. teres var. gracile Warnst. Eur. Torfm. p. 125.

2. In paludosis. - Eur. : Spitzberg. Lappon., Scandin., Fennia, Sudet., Thuring, Siles., Neerland., Taunus, Anglia. As.: Caucas. occ. Am. sept. : Labrador, Canada, Columb. brit., Washington, ins. Miquelon, sept. or.

Exs. : H. Müll. Westfal,-Laubm:n. 229.

Rab. Bryoth. eur. n. 554. "var. compactum Warnst. If. bicolor et fuscum Roell. in Hedroig. 1893,
p. 308 .

- Am. sept.: Washington.

var. concinnum Berggr. - Sph. fimbriatum.

* var. densum ff. bicolor, fuscum et viride Roell in op. cit. p. 309.

-Am. sept. : Washington. 
var. gracile Warnst. - Sph. teres.

"var. imbricatum Warnst, in Bot. Gaz. 1890, p. 224.

New Hampshire.

- Eur.: Westphal. Am. sept.: Massachussets,

«var. laxum Warnst. in Hedwig. 1884, p. 120.

Sph. squarrosulum var. laxum Schlieph. mss.; Roell Torfm. d. Threr. Fl... IV Heft, p. 10.

- Eur. : Thuring.

var. squarrosum Warnst. - Sph. squarrosum.

var. squarrosulum Warnst. - Sph. squarrosum var, squarrosulum.

"var. submersum Warnst. in Hedwig. 1884, p. 120.

- Eur. : Dania. Am. sepl. : Passim ut typ.

ff. complanatum, squarrosulum et strictum Roell in Hedwig. 1893, p. 309.

- Am. sepl. : New Jersey.

"var. subsquarrosum Warnst. in op. et $l$. $c c$.

sets.

- Eur. : Lappon. Westphal. Am. sept. : Massachus-

Exs. : Rab. Bryoth. eur, n. 702, 1153.

\& var. subteres Braitho. (ubi?) $f$. virescens Roell in op. el l. $c c$.

- Am. sept.: Washington.

f. fibrorum * virescens Roell in Hedwig. 1897, p. 52 (nom.).

- Am. sept. : Indiana.

"var, tenellum Roell in Bot. Centralbl. 1891, pp. 21-22, ff. complanatum, fusco-virescens el versicolor ej. in Hedwig. $l$. $c$.

- Am. sept. : Washington.

Thomsoni C. M. in Linn. 1874, p. 545 .

Sph. fimbriatum Wils. in hb. Ind. or, n. 1293.

Sph, Junghunianum Mitt. M. Ind. or. p. 156.

Ster.

- As. : Ins. Philippin., Khasia, Sikkim.

Torreyanum Sull. - Sph. cuspidatum var: Torreyanum.

trachynotum S. M. - Sph. Whiteleggei.

transvauliense C. M. mss.; Warnst. in Hedwoig. 1891, l. II, fig. 2 a, 2 b et $t$. V, fig. 9 . - Afr. : Transvaal.

trigonum C. M. et Warnst, in Hedrorg. 1897, p. 158 et in Ule Bryoth. brasil. $n$. 1634-1635.

- Am. merid. : Brasil, or.

f. brachy-dasyclada Warnst. in op. et l. cc. n. 1636 .

Ut et ubi typ.

trinitense C. M. Syn. I, p. 102 et in Fl. I887, p. 406; Warnst. in Hedioig. $1890, p .235, t .1 \mathrm{X}$, fig. $18-25$ et $t$. X, fig. 21.

Sph, cuspidatum vas. serratum (Aust.) Lesq. et Jam. Man. p. 15.

Sph, serratum Aust. in Bull. Torr, bot. Club, 1877, p. 145 (fid. C. M.). - Am. sept. : Florida. Am. merid. : Ins, Trinitat.

truncatum Hsch. in Linn. 1841, p. 114; C. M. Syn. I, p. 103; Warnst. in Hedioig. 1891, p. 28, t. II, fig. 21 a, 21 b et L. IV, fig. p. - Af $r:$ C. B. Sp. 
tumidulum Besch. Fl. bryol. Réunion, elc., p. 188 ; Warnst. in Hedwig. 1891, p. 128, t. XIV, fig. 1 a, 1 b et t. X, fig. a, b a, b. $\beta$.

Sph. aculeatum Warnst. in Bot. Centralbl. 1882.

Sph. pugionatum C. M. in sched.

Sph. pycnocladulum Ren. in sehed.

Sph. submucronatum C. M. in Sikora M. Mad.n. 14341. J Hedwig. 1897. - Afr.: lns. Borbon., Rodriguez, Madagasear.

* var. microphyllum $f$. dasyclada Warnst. in Hedwig. 1891, p. 129.

Sph. imbricatum W. P. Sch, in hb. Kew.

$$
\text { - Afr.: Ins. Borbon. }
$$

$f$. euryclada Warnst. in op. et $l$. $c c$.

Sph. Hildebrandti C. M. in Fl. 1887, p. 415.

Sph. madegassum ej. in op, cit. p. 420 .

Exs. : Hildebr. n. 2106 .

turfaceum Warnst. in Schrift. d. Naturf. Gesells, in Dansig, N. F 1X, Heft. 1I, 1896.

In turfos, - Eur. : Westphal.

turgescens Warnst. in Ule Bryoth. brasil. n. 1530 el in Hedwig. 1895, p. 131.

- Am. merid. : Brasil. or. (Goyaz.).

turgidum (C. M.) Roell. - Sph. subsecundum var, obesum?

tursum C. M. -. Sph. medium.

Uleanum C. M. in Fl. 1888, p. 416; Warnst. in Hedwig. 1891, p. 41, ı. III, fig. 33 a, 33 b et $t$. V, fig. aa.

Ster. - Am. merid. : Brasil. subtropic. or.

undulatum Warnst. in Hedroig. 1894, pp. 317 et 334.

$$
\text { - Pac. : Patagon. }
$$

vancouveriense Warnst, in op. cit. pp. 309 et 332.

- Am. sept. : Columb. brit.

variabile Warnst. $\left\{\begin{array}{l}\text { var. } \alpha \text { speciosum ej, }-\mathrm{Sph} \text {. recurvum. } \\ \text { var. 1. intermedium ej. }-\mathrm{Sph} \text {. recurvum. } \\ \text { var. } 2 \text { ej. - } \mathrm{Sph} \text {. cuspidatum. }\end{array}\right.$

vesiculare C. M. et Warnst. in Ule Bryoth. brasil. $n .1301$ et in Hedwig. 1897, n. 1301.

$$
\text { - Am. merid. : Brasil. or. (Itacolumi). }
$$

violascens C. $M$. in $F l .1887$, p. 422.

Ster. - Afr. : Mozambic.

vitianum W. P. Sch, in hb. Kew.; Warnst. in Hednig. 1891, p. 144, t. XIV, fig. 8 a, 8 b et $t$. XXl, fig. I. - Pac.: Ins. Fidji.

vulgare Mich. - Sph. cymbifolium.

Waghornei Warnst. in Hedvig. 1894, pp. 329 et 336.

$$
\text { - Am. sept. : Terra nov. }
$$

Wallisii C. M. in Linn. 1874, p. 573

Ster.

- Am. merid. : And. Nov. Granat.

Warnstorffii Rüss, in Sitzungsber. d. Dorpater Nalurf. Gesells, 1887, p. 315.

Sph. acutifolium var. gracile Rüss, Beitn...p p, 44 . 
Sph. acutiforme var. tenellum Sehlieph. et Warnst. p.p. in Ft. 1884 p.

Sph. Wilsoni var. tenellum $f$. purpurea Roell in Fl. 1886.

2.

- Eur. : Septentr. et med. Am. sept. : Labrador, Canada, Alaska, Terr. nov., ins. Miquelon, Minnesota, Montana, M. Rupestr., sept. occ.

varr. auriculalum (Warnst.), fallax (Warnst. p.p.) fimbriatum (Warnst.), polyphyllum (Warnst.) et $f$. deflexa Roell. - Sph. Rüssowii.

varr. pallens (Warnst.) et pseudo-palulum Roell. - Sph. quinquefarium.

"var, purpurascens Rüss. mss.; Warnst. in Bol. Gaz. 1890, p 140. shire.

- Am. sept.: Vermont, Massachussets, New Hamp-

ff. squarrosa et teres Raell. - Sph. Rüssowii.

" var, versicolor Rüiss, mss.; Warnst. in op. et $l$. cc. - Am. sept. : Ubi praeced.

« var. viride Rüss, mss.; Warnst. in op. et l. cc.

- Am. sept. : Massachussets, Vermont.

Warnstorffii Roell p.p. - Sph. Girgensohnii.

Weberi Warnst. in Hedwig. 1890, p. 217, t. VIII, fig. 1, 2 et $t$. X, fig. I. Ster. - Pac. : M. ins. Samoa.

Weddelianum Besch. in hb. Mus. Paris; Warnst. in Hedroig. 1891, p. $163, t$. XVIII, fig. 28 a, 28 r, t. XIX, fig. 28 a et $t$. XXIV, fig. ii, kk.

Sph. pseudo-rigidum Besch. l. e.

- Am. merid. : Brasil. or. (Minas Geraës), Peruv.

" var. fuscescens $f$. dasyclada Warnst. in op. cit. p. 164.

\section{- Am. merid. : Ut typ.}

* var. pallescens $f$. dasyclada subf. orthoclada Warnst. in op. et $l$. cc. - Am, merid. : Ubi typ.

Wheeleri C. $M$. in Fl. 1887, p. 416.

$\rightarrow$ Ster. $\quad$ - Pac. : Ins. Hawaï.

Wilcoxii $C, M$. in op. cit. p. 407.

Ster.

- Pac. : Austral, or. (Nova Vales.).

Wilsoni Roell p.p. - Sph. tenellum.

var. roseum Limpr. - Sph. Rüssowii.

var. tenellum f, purpurea Roell. - Sph. Warnstorffii.

Whiteleggei C. M. in op. cil. p. 408; Warnst. in Hedwig. 1891, p. 154, t. XVil, fig. 22 a, 22 b, 22 e el t. XXIV, fig. aa, bb, cc.

Sph. cymbifolium (fid. Warnst. in Bot. Gaz. 1890, p. 250).

Sph. Ieionotum C. M. in Fl. l. $c$.

Sph. trachynotum ej. in Helms M. Nov. Zeland. n. 44.

Ster.

- Pac.: Austral, or. (Nova Vales.).

Wrightii $C, M$. in op. cit. p. 411 .

Sph. cymbifolium Sull. in Wright M. Cubens. n. 1.

- Am. sept. : Cuba, Guadalup.

Wulfianum Girgens, in Arch. Nat. Livon.-Esthon, und Kurland, 2e sers. II, 1860, p. 178; W. P. Sch. Syn. II ell, p. 838; Rüss. Beitr... p. $66 ;$ Lindb. Hvitm. p. 57. 
Sph. cuspidatum var, patens Angstr. mss.; Lindb. in Opfv. Vet,... 1862, p. 137.

Sph. pyenocladum Angstr. in Oefv, Vet. 1862, p. $202 ;$ Rab. Bryoth, eur. n. 709.

1. In silvat. et pinetis humid, - Eur. : Lappon., Fennia, Livon., Esthon. Am. sept.: Canada, Maine, New Hampshire, New York, Wisconssin, Minnesota, Vancouver.

" var. squarrosulum Rüss. Beitr...p. $66 ;$ W. P. Sch. in op. et l. cc.

Ut typ. - Eur. : Scandin. merid. Am. sept. : Cauada, New York.

* var. versicolor Warnst. in Bot. Gaz. 1890, p. 225.

- Am. sept. : Vermont, New Hampshire.

« var. viride Warnst. in op. et $l$. cc.

- Am. sept. : Massachussets, New Hampshire.

xerophilum Warnst. in Hedwig. 1897, p. 167.

In arena humid. - Am. sept. : Alabama.

SPIRIDENS Nees ab Esenb, in Nov. Act. XI, I, p. 143, t. 17.

aristifolius Mitt. Sam. M. p. 193.

S. Reinwardti Sull. in U. St. Expl. Exped. Wilkes, M. p. 25 (pro planta Samoana).

- Pac. : Ins. Fidji, Samoa.

Balfourianus Grev. in Ann. and Magaz, of nat. Hist. 1848, p. 326,

t. 18; W. P. Sch. in Mem. Akad. Dresde, 1865, ı. III, fig. b.

Neckera Balfouriana C. M. Syn. 1I, p. 121.

2. Ad Filic. arbor. - Pac. : Ins. Fidji, Societat, Morea, Taït, Nov. Caledon.

capilliferus Mitt. op. cit. p. 194.

Ster. Ad arbor. - Pac. : Ins. Samoa.

flagellosus W. P. Sch, in op, cit. $t$. IV.

Sph. Reinwardti Sull. in op, cit. p. 26 p.p.

Ad arbor. - Pac. : Ins. Fidji, Samoa, Nov. Hebrid., Nov. Caledon.

longifolius Lindb. in Cumming Pl. Philipp. n. 2210 el in O.fo... 1864,

p. 600 ; W. P. Sch. in op. cil., l. IIl, fig. 1 .

Sph. Reinwardti Mont. in Hook. Lond. Journ. of bot. IV, p. 10.

Fl. et fr. ign.

- As. : Ins. Philippin.

Mülleri Hpe. in Linn. 1874, p. 665.

- Pac. : Ins. Lord Howe.

Reinwardti Nees in op. et l, cc.; Brid. Bryol. univ. 11, p. $280 ;$ Bryol. jav. II, p. 174, t. I94; W. P. Sch. in op. et l. cc., t. Ill, fig. I.

Neckera Reinwardti $C . M$. Syn. II, p. 120.

2. Lignic. - As. : Ins. Tidor, Java. Pac. : Nov. Guinea.

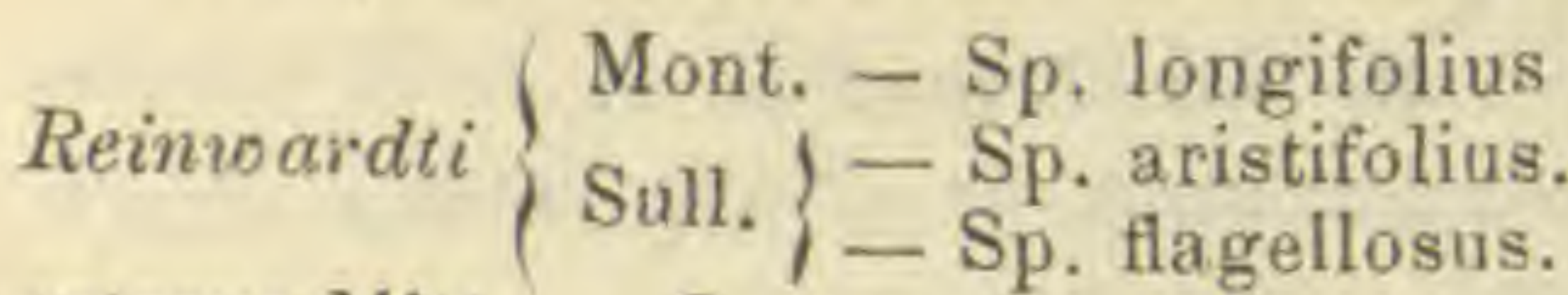

setosus Mitt. - Cyrtopus.

Vieillardi W. P. Sch. in op. el $l$. cc., t. II.

2.

- Pac. : Nov. Caledon.

Spiridentella C. M. in Hedroig. $1897, p .133$ (sect. RHIzogosil $=$ Rh.
Helmsii). 
SPIRLLA Dz. et Mk. M. frond. ined. Archip. ind. p. 62, t. 26. speciosa eor. - Schizomitrium.

SPLA GHNOBRYUM C. M. in Verhandl, d. K.K. zool. bot. Gesellsch. in Wien, 1869, p. $50 \mathrm{l}$ (22 spec.).

aquaticum C. M. in Linn. 1876, p. 241.

Ster. Aquat. - Afr. : Somali.

atro-virens Besch. in Rev. bryol. 1891, p. 76.

Ster.

- Am. sept. : Guadalup.

Baileyi Broth. in Bot. Centralbl. 1888, p. 85. 2 .

- Pac. : Austral. or. (Queensland).

Bernouillii C. M. in Verhandl... p. 505.

2.

- Am. sept. : Guatemala.

Boivini C. M. in Besch. Fl. bryol. de la Réunion, elc. p. 15.

Aquat. - Afr.: Ins, Nossi Be.

byssoides C. M. in Nuov. Giorn, bot. ital. 1891, p. 601 (nom.).

- As. : Birman. super.

erosulum C. M. in Dusen M. Camer. $n .437$.

- Afr. : M. Cameroon.

flaccidum (Havv) C. M. in Linn. 1871-73, p. 175.

Didymodon flaccidus Mitt. in Hook. Journ. of bot. 1856, p. 353.

Potila flaccida C. M. Syn. I, p. 548.

Weisia flaccida Harv. in Hook. Io, pl. rar. t. 18, f. 3 et in Lond. Journ. of bot. 1840, II, p. 6 .

Ad terr. humid. - As. : Nepal., penins. Malay.

gracile Besch. in Ann. sc. nat. VII ser., II, p. 89.

2. Terr. - Afr.: Ins. Mayotte.

indicum Ape. et C. M. in Linn. 1871-73, p. 174.

- As. : Calcutta.

inundatum C. M. in Besch. op. et $l$. cc.

Fr. ign. Aquat. - Afr.: Ins. Nossi Be.

julaceum Besch, in Rev. bryol. l. c.

2. Terr. - Am. sept, : Guadalup.

laevidorsum Besch. in op. et l. cc.

Ster. Ad arbor. - Am. sept.: Fuadalup.

Lorentzi C. M. in Linn. 1880-82, p. 355.

Mariei Besch, in Rev. bryol. I. c. - Am. merid. : Argentin. temper.

2. Terr. - Am. sept. : Guadalup. obtus:m (Hook.) C. M. in Verhandl... p. 504.

Didymodon splachnifolius Hook. M. ex. p. 10, t. 126.

Dissodon rotundifolius C.M. Syn. I, p. 140.

Syrrhoporton obtusus Schwaegr. Suppl. II, I1, t. 182.

Weisia obtusa Brid. Bryol. univ. I, p. 358.

W. obtusifolia Rich, in Schwaegr. l. c. p. 106.

W. splachnifolia Mitt. M. austr. am. p. 111 (excl. planta Peruviana).

2. Terr. - Am. sept. : Dominic., Jatnaic.

Oorschoti (Lac.) C. M. in Linn. 1876, p. 293.

Orthodontium Oorsehoti Lae. Sp. nov. Arehip. ind. $p+11$.

2. Muric. - As, : Java. 
Spruceanum C. M. in Linn. 1871-73, p. 175.

Weisia splachnifolia Mitt. M. austr. am. p. 141 (quoad pl. Peruvianam). Ad saxa irror. - Am, merid, : And. Peruv,

tenerum C. M. in Dusen M. Camer. n. 88. - Afr. : M. Cameroon.

Valdiviae C. M. in Bull. hb. Boissier, 1897, p. 175.

Ster. - Am. merid.: Valdivia.

Wrightii C. M. in Vorhandl.... p. 505.

Entosthodon minimus Hunt in Proced. litt. and phil. Soc. of Manchester, $\mathrm{XI}, p .9$.

? Dissodon rotundifolius Sull. in Wright, M. Cub.n. 54 .

2. Muric. et rupic. - Eur. : Hibernia. Am. sept. : Cuba.

Wulfschlaegelii C. M. in op. cit. p. 504.

2. Terr. - Am. merid.: Surinam.

SPLAGHNUM Linn. Fl. Suec. (8 spec.).

Adansianum Hsch. - Tetraplodon mnioides var. Adansianum.

ampullaceum L. Sp. Pl. p. 1592; Brid. Bryol. univ. 1, p. 259 (incl, v. $\beta$ Turnerianum); Bryol. eur. III (mon. p. 10), t. 294; C. M. Syn. I, p. I46; W. P. Sch. Syn. II ed. p. 369.

Bryum ampullaceum, foliis thymi pellucidis, collo strictiore Dill. Hist. $M$. p. $342, t .44, f .3$.

Spl. sagittaefolium With. Bot. arrang. p. 791, $t .18, f, 2$.

Spl. Turnerianum Dicks. Fasc. Pl. crypt. II, p. 3, t. 10, f. II.

l et 2. In turfac, exerement. animal. herbiv, insidens, - Eur. : Tota zon. intermed. et septentr., e reg. campestr. usq. in montana super. As.: Septentr., Caucas. Am. sept.: Ins. Miquel, Terr nov., New Brunswick, Nov. Scotia, Anticosti, reg, septr. occ., Nov. Anglia, New Jersey, Pensilv., Ohio, etc.

Ex. : Mac. Canad, M. n. 145.

Rab. Bryoth. eur. n. $43,573$.

Sull. et Lesq. M. bor. am. II ed. n. 230.

Un, itin. crypt, 1864, n. 75, 76.

var. Turnerianum Brid. - Spl. ampullaceum. angustatum L. f. - Tetraplodon. arcticum $\mathrm{R}$. Br. - Tetraplodon mnioides. attenuatum Brid. - Tayloria tenuis.

bavaricum Schrank. - Spl. sphaericum.

Brewerianum Hedw. - Tetraplodon mnioides var. Brewerianum.

bryoides Zoeg. - Tetraplodon mnioides.

canescens P. B. - Tetraplodon mnioides var, canescens.

exserlum R. Br. - Tetraplodon mnioides.

fastigiatum Dicks. - Tetraplodon mnioides var, fastigiatum.

flagellare Brid. - Tayloria serrata var, flagellaris.

Froehlichianum $\left\{\begin{array}{l}\text { Brid. - Edipodium Griffithianum. } \\ \text { Hedw. - Dissodon. }\end{array}\right.$

gracile Schwaëgr. - Spl. sphaericum.

Griffithianum With, et Hull. - Edipodium. Gunnii Wils, in Lond. Journ. of bot. $1848, p .26, t$. I b ; C. M. Syn. II,
p. 552 .

2? Ad Filices emort. - Pac. : Tasman, 
helveticum Schleich. - Tayloria serrata var. flagellaris.

heterophyllum Drumm. - Spl. vasculosum.

intermedium Drumm. - Spl. sphæricum.

Juressi Schwaegr. - Entosthodon Templetoni.

ligulatum $\left\{\begin{array}{l}\text { Dicks. - Dissodon splachnoides. } \\ \text { Hoffm. - Tayloria tenuis. }\end{array}\right.$

longicollum Schroaegr. Suppl. II, II, p. 87, t. 178 (excl. syn. Dicks.); C. M. Syn. I, p. 148 (1). - Afr. : C. B. Sp.

longicollum Dicks. - Tayloria tenuis.

longisetum Schrank. - Spl. sphaericum.

luteum L. Fl. Suec, p. 954 ; Brid. Bryol. univ. I, p. 260 ; Bryol. eur. III

(mon. p. 12), t. 296; C. M. Syn. I. p. 147; W. P. Sch. Syn. 11 ed. p. 371 .

Spl. luteum var. melanocaulon Wahlenb. in Magaz. Ges. Naturf. Berlin, 1811, p. 294, n. $1 ;$ C. M. . . c.

Spl. luteum var. pygmaeum Norr. in Notiss... 1873, p. 300.

Spl. melanocaulon Schwaegr. Suppl. II, p. 28, t. 109; Brid. op. cit. p. 261.

2. In uligin. silvat, zon. sept. - Eur. : Scandin., Fennia, Rossia sept. As.: Kamschatka, Obi, Jenissei med. Am. sept.: Reg. sept. occ., M. Rupestr., Columb. brit.

Exs. : Drumm. M. bor. am. I ed, n. 33.

Rab. Bryoth. eur. n. 728.

var. melanocaulon $\left\{\begin{array}{l}\text { Brid. (M. M.). - Spl. luteum. } \\ \text { C. M. - Spl. Iuteum. }\end{array}\right.$

magellanicum Schwaegr. - Dissodon.

melanocaulon Sehwaegr. - Spl. Iuteum.

mnioides Hedw. - Tetraplodon mnioides.

var. majus H. et T. - Tetraplodon mnioides var. Brewerianus. octoblepharum H. f. et W - Dissodon.

var. $\beta$ eor. - Dissodon plagiopus.

ovatum $\left\{\begin{array}{l}\text { Hedw. - Spl. sphæricum. } \\ \text { Schleich. - Tayloria tenuis }\end{array}\right.$

paradoxum R. Br. - Tetraplodon mnioides var. Adansonianus.

pedunculatum Lindb. - Spl. sphaericum.

plagiopus Mont. - Dissodon.

propinquum $\mathrm{R}$. Br. - Tetraplodon mnioides.

punctalum Brid. - Dissodon Froehlichianus.

purpurascens $\mathrm{H}$. f. et W. - Dissodon.

purpureum With. - Tayloria tenuis.

pusillum P. B. - Spl, sphaericum.

refractum Brid. - Spl. sphaericum.

reticulalum Sw. - Dissodon Froehlichianus.

rubrum L. Fl. Suec. p. 963 ; Brid. Bryol. univ. I, p. 262; Bryol. eur. 111 (mon.p. I1), t. 295 ; C. M. Syn. I, p. 146; W. P. Sch. Syn. II ed. p. 370 .

Muscus norvegicus umbraculo ruberrimo insignitus Dill. Hist. M. p. 547, t. $83, t .9$.

2. In uligin. silvat. zon. Sept. - Eur, : Seandin., Fennia, Rossia sept. As. : "In omn. Sibiria vulg. s (fid. Weimmann): Ochotsk, Jenissei med. Am. sept. : Maine, New Brunswick, M. Rupestr., reg. sept, oceid.

(1) “ Forsan Entosthodon „ C. M. 1. c. 
Eas. : Drumm. M, bor. am. 1 ed, n, 32.

Rab. Bryoth. eur. n. 924.

ruyosum Sm. - Spl. vasculosum.

saggitnefolium With. - Spl. ampullaceum.

scabrisetum Hook, - Dissodon.

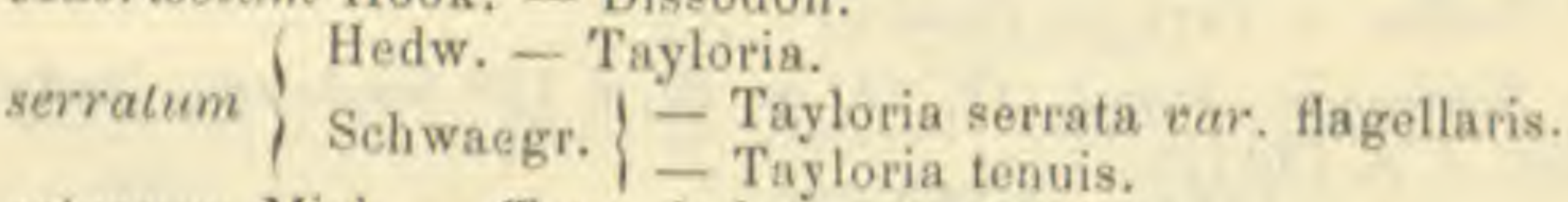

setaceum Mich. - Tetraplodon angustatus.

sphericum L. f. Meth. M.p. 33, 1, I, f. 1; Brid. Bryol. univ. I. p. 256 ;

Bryol. eur. III (mon. p. 8), t. $292 ;$ C. M. Syn. I, p. 144; W. P. Sch.

Syn. II eil. p. 368.

Bryum ampullaceum foliis serpylli pellucidis, collo erassiore Dill. Hish, $M$. $p .314, t .44, f .4$.

Phascum pedunculatum Huds. Fl. Angl. II ed, p. 397 ,

Spl, bavaricum Sehrank.

Spl. gracile Schwaegr. Suppl. I, I, p. 52, t. 15; Brid. op. cit.p. 251.

Spl, intermedium Drumm. M. bor, am. 1 ed., n. 39.

Spl. longisetum Schrank Baiers. Fl. 11, p. 441.

Spl, ovatum Hedw. Sp. M. p, 43, t. 8; Bvid. op. cit. p. 253.

Spl. pedunculatum Lindb. M. scand, p. 19.

Spl. pusillum P. B. Prodr. p. 89; Brid. op. cit. p. 257 ?

Spl. relractum Brid. Sp. M. I, p. 145.

Spl, viride Vill. Pl. Dauph. p. 861, t. 44.

2. In umbros. humid, stercore bov, hospes, - Eur. : Reg. subalp. zon. intermed., montana zon. sept. As. : Jenissei. Am. sept. : Labrador, Manitoba, M. Rupestr, Colnmb, brit., Alaska.

Exs, : Drumm. M. bor. am. 1 ed. n. $35,36$.

Mac. Canad. M. n. [44.

Rab. Bryoth. env, n, 124, 256, 814, 1387.

Un. itin. crypt. 1867, n. 78.

squarrosum Hook. - Dissodon Isleanus.

? succulentum Brid, - Ėdipodium Griffithianum.

tenue Dieks. - Tayloria.

var, flagellare Roehl. - Tayloria serrata var, flagellaris.

turbinatum Brid, - Mielichhoferia Jamesoni.

Turnerianum Dicks. - Spl. ampullaceum.

urceolatun Hedw, - Tetraplodon urceolatum var, eavifolius.

var, minus Wahlenb, - Tetraplodon mnioides,

vasculosum L. Sp. Pl. 11 ed, p. 1572; Brid, Bryol, unie, I, p. 257; Bryol. ekr, III (mon. p. II), t. 294 ; C. M. Syn. 1, p. 145; W. P. Sch. Syn. II ed. p. 368.

Spl. heterophyllum Drumm. M. bor, am. I ed. n. 37.

Spl. visculosum var, acutifolium Grev. Scott. erypt. A. t. 311.

Spl. rugosum Sm. $\mathrm{Fl}$, brit. III, p. 1173 .

2. In uligin, et depress, zon. sept, usq. in Alp. - Eur. : Spitaberg. ins. Ursorum, Scandin., Scotis. As.: Jenissei inf. Am. sept. : Groen-

land, Labrador, fret. Smith, Sitka; probab. aretic. tota.

Exs. : Dramm, M. bor. an. I ed, u. 34.

Rab, Bryoth. eur. u. $729,1388$.

Un. itin, erypt. 1867 , n. 72.

var, acutifolium Grev, - Spl, vasenlosum.

viride Vill. - Spl. sphoericum.

Wormskioldii Hornem, Fl. Dan. t, 1659; Bryol. eur, III (anan. p, 7).

t. 291 ; C. M. Syn, I, p. 143; W. P. Sch. Syn. II ed. p. 360. 
Aplodon Wormskioldii $R$. Br. Vermisch. Schrift. I, p, 442.

Eremodon Wormskioldii Brid. Bryol. univ. I, p. 237.

Tetraplodon Wormskioldii Lindb. M. Scand. p. 19.

1. In turfos, zon, sept, aret. et subarct. - Eur.: Spitzberg, ins. Uirsor. Lappon., Norveg. (Dovre). As. : Jenissei infer. Am. sept. : Arctica, tota.

SPORLEDERA Hpe, in Linn. 1837, p. 279 (9 spec.).

Beyrichiana Hpe. in op. el l. cc.

Bruchia Beyrichiana C. M. Syn. I, p. 18; Lesq. et Jam, Man. p. 47.

Phascum Beyrichianum Schwaegr. Suppl. IV, p. 301.

1 .

- Am. sepl. : New Jersey, Maryland, Illinois.

Drummondii Hpe. - Bruchia flexuosa.

Eckloniana Hpe mss.

Bruchia Eckleniana J. M. Syn. I, $p, 19$.

2. - Afr.: C. H. Sp.

flexuosa Hpe. - Bruchia.

Hampeana (C. M.) Milt. M. austr. am. p. 25 (1).

Bruchia Hampeana C. M. Syn. I. p. 18.

Br. Schwaegrichenii Jaeg. M. Cleistoc. p. 36.

Phascum brevipes Schwaegr. Suppl. IV, p. $303 \mathrm{~b}$. 1.

- Am. sept. : Ludovic. Am. mexid. : Chile.

Lindigiana Hpe. in Ann. sc. nal. V ser. 1II, p. 338.

1.

- Am. merid. : Nov. Granat.

minuta Mitl. in Handb. of the N. Zeal. Fl. p. 223.

Bruchia minuta ej. in Journ. of the Linn. Soc. 1859, p. 65 et in $\mathrm{Fl}$. Tasm. II, p. 165, t. 17I, f. 4 .

1. Terr. - Pac. : Nov. Zeland., Tasman.

palustris Hpe. in op. l. cc.; W. P. Sch. Coroll. p. 6 et Syn. II ed, p. 27.

Astomum Hpe. in $\mathrm{Fl} .1837, \mathrm{p} .285$.

Bruchia palustris C. M. Syn. I, p. 19.

Phascum palustre Br. et Sch. in Mem. Soc. Mus. Strasb. II, p. 2, t. A (1835) et Bryol. eur. I (mon. p. 11), t. 7 (1837).

$\mathrm{Ph}$, uliginosum Hüb, mss, in Genth. Fl. Nassau, p. 146.

Pleuridium alternifolium $\beta$ germanicum Brid. Bryol. univ. II, p. 162.

Pl. palustre Bryol, eur. I (mon. p. 15), t. 10 (1850).

I. In prat. uligin., turfos. zon interm. et septr. -- Eur. : Vall. Rhen. med., Suec. Inerid., etc. Am. sept. : Rar. : New Jersey, Ludovicia.

Exs: Drumm. M. Lor. am. II ed. n. 8 (Pleuridium).

Rab. Bryoth. eur. n. 502, 596.

Sull. et Lesq. M. bor. am. II ed. n, 40 (Pleuridium).

Ravenelii Jaeg. - Bruchia.

Rehmanni (C. M.) Par.

Bruchia Rehmanni C. M. in Fl. 1888, n. 1 .

- Afr. : C. B. Sp.

setifolia Jaeg. - Rruchia flexuosa var. microcarpa.

subenervis Hpe. in Ann. sc. nat. V ser., III, p. 337.

1.

- Am. sept. : Nov. Granat.

(1) Cr. Dna E, G. Britton in Bull. Torr. bot. Club, 1894, p. 370. 
Whiteleggei (C. M.) Par.

Bruchia Whiteleggei $C$. $M$. in op. et $l$. cc.

1.

- Pac. : Austral. or.

SPRUCEA Hook. f. et Wils. in sched. M. Antarct.

perichatialis eor. - Holomitrium.

Squarridium C. M. in Linn. 1878-79, p. 422 (sect. METEoRu).

STABLERIA Lindb, in Utk, till. en nat.... p. 20. gracilis Lindb. - Orthodontium.

Starkeella Kindb. Check-list. of Eur. and N. Amer. M. p. 23 (sect. Eurhynchu sensu Kindb. = Brachythecium).

STEGONIA Vent. in Rev. bryol. 1883, p. 96.

latifolia ej. - Pottia.

Stegotheca Mitt. M. austr. am, p. 220 (sect. SchlothelMiAe).

STENODESMUS Mitt. M. autr. am. p. 347 (sect. Hookeriae); Jaeg. Ad II, p. 262 (gen. propr.).

tenuicuspis Jaeg. - Hookeria.

STENOCARPIDIUM C. M. in Hedwig. 1897, p. 144 (1 spec.).

Leucodon $C . M$. in op. et $l$. $c c$.

1. $\quad-A m$. merid. : Argentin. subtropic. (Chaco).

STENODICTYON Mitt. op. cit.p. 348 (id.); Jaeg. l.c. (id.).

nitidum Jaeg. - Hookeria.

STENOTHECIUM C. M. in Nuov. Giorn. bot. ilal. 1891, p. 601 (nom.).

Spłc. omn. Le:PToHYMENia ejusd. nom.

Stephanostoma Mitt. in Journ. of the Linn. Soc. 1872, p. 307 (sect. ERPODII).

STEREODON (HYPNUM Brid. Bryol. univ. II, pp. 550 et 770) Mitt. M. Ind. or. p. 92.

Spec. omn. non indicatae sunt HYPNA ejusd. nom.

abielinus Brid. - Thuidium.

abyssinicus Mitt. - Cylindrothecium.

acicularis Mitt. - Ptychomnium.

acutirameus Mitt. - Sematophyllum.

adnatus Brid. - Amblystegium.

$\beta$ loevigatus Mitt. - Amblystegium ?

aduncus var. longipes Brid. - $\mathrm{H}$. aduncum.

var. revolvens Brid. - Hypnum revolvens.

var, sterilis Brid.

var. tenuis Brid.

algirianus Brid, - Rhynchostegium tenellum.

alpicola Lindb. - Pylaisia.

angustatus Mitt. - Camptochaete.

angustifolius Mitt. - Cylindrothecium.

angustus Mitt. - Symphyodon.

asper Mitt. - Symphyodon.

assamicus Mitt. - Isopterygium.

Auberti Brid. - Acrocladium.

aureus Mitt. - Cylindrothecium.

auriculatus Mitt. - Lembophyllum chlamydophyllum. 
Barteri Mitt. - Leptohymenium.

Blandovoii Brid. - Thuidium.

borbanicus Mitt. - Trichosteleum.

Braunii Mitt. - Sematophyllum.

brevirostris Mitt. - ? Pylaisia.

Buitenzorgii Mitt. - Ectropothecium.

caliginosus Mitt. - Cylindrothecium.

camurifolius Mitt. - Pylaisia.

canariensis Mitt. - Pylaisia.

caperatus Mitt. - Pylaisia.

capillaceus Mitt. - Pylaisia?

cavifolius Brid. - Plagiothecium Roëseanum.

cerviculatus Mitt. - Rhaphidostegium.

Chamissonis Brid. - Ectropothecium.

chryseus Mitt. - Orthothecium.

chrysophyllus var. squarrosulus Brid. - Hypnum callichroum.

circularis Mitt. - Hypnum Bambergeri.

clarescens Mitt. - Microthamnium.

cochlearifolius Mitt. - Lembophyllum.

comes Mitt. - Cylindrothecium.

compactus Mitt. - Amblystegium.

compressifolius Mitt. - Ectropothecium.

condensatus Mitt. - Pylaisia.

confertissimus Mitt. - Rhaphidostegium.

confervoides Brid. - Amblystegium.

contiguum Mitt. - Rhaphidostegium.

var. aduncoides Brid. - Hypnum aduncoides.

var. chrysocomus Brid. - Hypnum cupressiforme.

var. complanatus Brid. - Hypnum cupressiforme.

var. compressus Brid. - Hypnum eupressiforme var.

compressum.

var. conicus Brid. - Hypnum cupressiforme.

var. corruscans Brid. - Hypnum cupressiforme.

var. crispatissimus Brid. $\{$ - Hypnum fastigiatum.

- Hypnum hamulosum (fis. Br.).

var. decipiens Brid. - Hypnum cupressiforme.

var, fragilis Rrid. - Hypnum cupressiforme.

var. hamulosus Brid. - Hypnum fastigiatum.

var. julaceus Brid. - Hypnum Vancheri var. julaceum?

var. lacunosus Brid. - Hypnum cupressiforme var.

lacunosum.

var. Lauri Brid. - Hypnum cupressiforme var. Lauri.

cupressiformis

var. Leucanthemum Brid. - Hypnum?

var. longisetus Brid. - Hypnum cupressiforme var. longisetum.

var. mammillatus Brid. - Hypnum cupressiforme var. mammillatum.

var. Mossmannianum Mitt. - Hypnum Mossmannianum.

var. nigro-viridis Brid. - Hypnum cupressiforme var. tectorum.

var. plumosus Brid. - Hypnum cupressiforme.

var. regularis Brid. - Ectropothecium.

var. striatus Brid. - Hypnum eupressiforme.

var subjulaceus Mitt. - Hypnum cupressiforme var. subjulaceum.

var. lectorum Brid, - Hypnum cupressiforme var. tectorum.

var. tenuifolius Brid, - Hypnum cupressiforme.

var. Vaucheri Mitt. - Hypnum Vaucheri. 
curvatus Mitt. - Cylindrothecium. curviculatus Mitt. - Rhaphidosteginm.

curviroslris Mitt. - Rhaphidostegium neckeraceum.

cygnicollis Mitt. - Ectropothecium.

cyparoides Mitt. - Rhaphidostegium leucocytus.

cyperoides Mitt. - Eetropothecium.

decolor Mitt. - Platygyrium brevifolium.

defleaus Mitt. - Camptochaete.

denticulatus Brid. - Plagiothecium.

var, brunneus Brid. - Plagiothecium?

var. abtusifolius Brid. - Plagiothecium denticulatum var, obtusifolium.

var. silvaticus Rrid. - Plagiothecium?

diffusus Mitt. - Ectropothecium.

dimorphus Brid. - Heterocladium.

distichaceus Mitt. - Isopterygium.

Donianus Mitt. - Plagiothecium denticulatum var, obtısifolium.

echinutus Mitt. - Symphyodon.

enervis Lindb. - Amblystegium.

erinaceus Mitt. - Symphyodon.

erraticus Mitt, - Symphyodon.

extenuus Mitt. - Pylaisia.

Fabronia Miti. - Microthamnium.

fastigiulus var. Sauteri Lindb. - Hypnum Sauteri.

filiformis Lindb. - Hypnum cupressiforme var. filiforme.

flavescens Mitt. - Fabronia.

fluitans $\left\{\begin{array}{l}\text { var. aduncoides Brid. - Hypnum fluitans var. falcatum ? } \\ \text { var. minor Brid, - Hypnum fluitans var. submersum? } \\ \text { var. nigricans } \text { Brid, - Hypnum fluitans? } \\ \text { var. scoparzus Brid. - Hypnum fluitans? } \\ \text { var. Weiss. - ? }\end{array}\right.$

fragilis Brid. - Hypnum chrysophyllum.

frondosus Mitt. - Microthamnium.

fruticellus Mitt. - Microthamnium.

fulvo-nitens Mitt. - Cylindrothecium.

Gardneri Mitt. - Cylindrothecium myurum.

gedeanus Mitt. - Sematophyllum.

geminus Mitt. - Plagiothecium.

glaucocarpus Mitt. - Plagiothecium.

glauco-virens Mitt. - Chionostomum.

gracilas Mitt. - Camptochaete.

gralus Brid. - Thuidium.

Griffithii Mitt. - Cylindrothecium.

Haldanei Lindb. - Hypnum Haldanianum.

Harveyanus Mitt. - Rhaphidostegium curvirostre.

himulayanus Mitt. - Hylocomium.

homalophyllus Mitt. - Plagiothecium.

humilis Mitt. - Rhaphidostegium.

iclinotocladus Mitt. - Ectropothecium.

incurvatus var. Blyttii Lindb. - Hypnum Blyttii.

inflexus Mitt. - Platygyrium.

intextus Brid - Hypnum palustre var. julaceun.

intricatus Lindb, et Arn. - Pylaisia

var. craszipes eor. - Pylaisia intricata var. crassipes.

Ivoreanus Mitt. - Isopterygium.

Jolliffi Mitt. - Rhaphidostegium.

juliformis Mitt. - Erythrodontium.

Kneiffii Mitt. - Hypnum aduncum var, Kneiffii.

Lagurus Mitt. - Lepyrodon. 
lancifolius Mitt. - Sematophyllnm.

lapponicus Lindb. - Orthothecium chryseum $f$. lapponica.

latus Mitt. - Cylindrothecium.

Laureri Brid. - Rhynchostegium?

laxus Rrid. - ?

leiophyllus Mitt. - Ectropothecium.

leptocarpus Mitt. - Rhaphidostegium.

leptorhynchoides Mitt. - Rhaphidostegiam.

leptorynchus $\left\{\begin{array}{l}\text { Brid. - Rhaphidostegium. } \\ \text { Mitt. }\end{array}\right.$

var. viridulus Mitt. Rhaphidostegium cyparioides.

lignicola Mitt. - Isopterygium.

longitheca Mitt. - Isopterygium.

loxensis Brid. - Rhaphidosteginm.

luridus Mitt. - Cylindrothecium.

Lyallii Mitt. - Leucodon nitidus.

macrocarpus Mitt. - Hylocomium.

mammillatus Lindb. - Hypnum cupressiforme var. mammillatum.

microphyllus Brid. $\left\{\begin{array}{l}\text { - Pseudo-Leskea. } \\ \text { - Thuidium varium }\end{array}\right.$

minutulus Brid. $\left\{\begin{array}{l}\text { - Thuidium. } \\ \text { - Thuidium }\end{array}\right.$

var. acuminatus Brid, - Thuidium.?

var. submuticus Brid. - Thuidium. ?

mnioides Brid. - Rhizogonium.

mollicellus Mitt. -. Eetropothecium.

mollis Brid. - Hypnum alpestre.

var. heleromallus Brid. - Hypnum alpestre.

miratis Brid, - Rhynchostegium.

var, abbreviatus

var. elongatus

var. hispanicus

var. spadiceus

var. subcirrhosus

neckeroideus Mitt. - Plagiothecinm.

neglectus Brid. - Hypnum palustre var. julaceum.

nemoralis Mitt. - Plagiothecium silvaticum var. nemorale.

nepalensis Mitt. - Trichosteleum.

nitens Brid. - Camptothecium.

nitidifolius Mitt. - Plagiothecium.

nitidulus Mitt. - Plagiothecium.

Novae Zelandiae Brid. - Rhaphidostegium tenuirostre.

obtusifolius Mitt. - Rhynchostegium.

obtusus Lindb. et Arn. - Pylaisia.

orientalis Mitt. - Eurhynchium.

ortholhecius Mitt. - Pylaisia secunda.

paleaceus Mitt. - Plagiothecium.

pallescens $\left\{\begin{array}{c}\text { var. perichatiale Mitt. - Hypnnm pallescens var. subjula- } \\ \text { ceum. } \\ \text { var. protuberans Mitt. - Hypnum pallescens var. protuberans. }\end{array}\right.$

pallidisetus Brid. - Rhaphidostegım caespitosum.

pallidulus Mitt. - Isopterygium.

palustris $\left\{\begin{array}{l}\text { var. aquatilis Brid. - Hypnum palustre. } \\ \text { var. ferrugineus Brid. - Hypnum. }\end{array}\right.$

papillatus Mitt. - Trichosteleum.

papillosus Mitt. - Trichosteleum.

penicillatus Mitt. - Eurhynchium.

Perrottetii Mitt. - Symphyodon. 
pilosulus Mitt. - Leptohymenium.

pinetorum Mitt. - Rozea pterogonoides.

planus Mitt. - Taxithelium.

planulus Mitt. - Symphyodon.

plicatus \& Brid. - Ptychodium.

plicart. - Cylindrothecium.

plumifer Mitt. - Hypnum subimponens. polyanthos Mitt. - Pylaisia.

var. brevifolius Mitt. et A. - Pylaisia polyantha var. brevifolia.

var. heteromallus eor. - Pylaisia polyantha var. heteromalla,

var. homomallus eor. - Pylaisia polyantha var. homomalla.

var. longicuspis eor. - Pylaisia polyantha var. longicuspis.

var, subjulaceus eor. - Pylaisia polyantha var. subjulacea. polymorphus Mitt. - Hypnum Elodes. praecox Brid. - Eurynchium strigosum var, praecox. praemollis Mitt. - Edicladium rufescens. propinquus Mitt. - Rhaphidostegium. prorepens Mitt. - Cylindrothecium. protuberans Brid. - Hypnum pallescens var. protuberans. pseudo-striatus Mitt. - Eurhynchium. Psilurus Mitt. - Leptohymenium. pulchellus Mitt. - Cylindrothecium. punctulatus Mitt. - Trichosteleum. radicalis Brid, - Amblystegium. recurvans Brid. - Hypnum pallescens.

var. squarrosus Brid, - Hypnum? reptile Mitt. - Hypnum pallescens. reticulatus Mitt. - Ectropothecium. revolutus Mitt, - Hypnum Heufleri. riparius Mitt. - Amblystegium.

rostellatus Mitt. - Ectropothecium. rostratus Mitt. - Chionostomum.

rubellus Mitt. - Orthothecium strictum. rubicundus Mitt. - Cylindrothecium. ruderalis Brid. - Stereophyllum.

var, tenellus Brid. - Stereophyllum?

rufescens Mitt. - Orthothecium.

russulus Mitt. - Platygyrium.

scaturigineus Mitt. - Ectropothecium.

Schwaegrichenii Mitt, - Cylindrothecium flavescens. scilus Brid. - Thuidium.

sciuroides Mitt. - Cladomnium.

serpens Brid. - Amblystegium.

var, aurantiacus Brid. - Amblystegium serpens.

var. brachyclados

var, byssoides

var, clavatus

Brid. - Amblystogium?

var. contextus Brid. - Amblystegium serpens.

var. crassinervius Brid. - Amblystegium?

var. crispabilis

var. cylindrious
var. excentricus Brid. - Amblystegium serpens.

var. falciformis Brid. - Amblystegium?

var. macrocarpus Brid, - Amblystegium serpens.

$\left.\begin{array}{l}\text { var. patentissimus } \\ \text { var. pensilvanicus }\end{array}\right\}$ Brid. - Amblystegium?

\begin{tabular}{l|l} 
var. repens & Brid. - Amblystegium serpens. \\
var. spinulosus & Brid.
\end{tabular} 
var. subtilis Brid. - Amblystegium

var. tenuis Brid. - Amblystegium serpens var, tenuis.

var. viridis Brid. - Amblystegium serpens.

serrula Mit1. - Microthamnium?

silesiacus Brid. - Plagiothecium.

silvaticus Brid. - Plagiotbecium.

simlaënsis Mitt. - Pylaisia.

speciosus Mitt. - Pylaisia.

spiniformis Brid. - Rhizogonium.

Starkii Brid. - Brachythecium.

var. tenellus Brid. - Brachythecium velutinum.

stissophyllus Mitt. - Trichosteleum.

stellatus $\left\{\begin{array}{l}\text { var. hispidulus Brid. - Hypnum hispidulum. } \\ \text { var. polymorphus Brid. - Hypnum Sommerfeldti. } \\ \text { var. protensus Brid.- Hypnum stellatum var. protensum. } \\ \text { var. Terrae Novae Brid, - Hypum sarmentosum. }\end{array}\right.$

subbasilaris Brid. - Rhizogonium.

subhumilis Mitt. - Rhaphidostegium.

subrectifolius Brid. - Hypnum molluscum.

subrufulus Lindb. - Orthothecium intricatum.

subsphaericarpos Brid. - Hypnum palustre var. subsphaericarpos.

succosus Mitt. - Ectropothecium.

suecicus Lindb. - Thedenia.

taxirameus Mitt. - Isopterygium.

tectorum Brid. -- Pseudo-Leskea.

tenuirameus Mitt. - Pylaisia tenella.

tenuirostris Brid. - Rhaphidostegium.

tenuis Mitt. - Leptohymenium.

Terrae novae Brid. - Hypnum imponens.

Thomsoni Mitt. - Cylindrothecium.

tristichus Mitt. - Rhaphidostegium.

tuberculatus Mitt. - Ectropothecium.

turfaceus Mitt. - Plagiothecium.

turgidus Mitt. - Sematophyllum.

uncinatus var. bicolor Brid. - Hypnum uncinatum.

undulatus Mitt. - Plagiothecium.

varius Brid. - Amblystegium radicale.

venustus Mitt. - Chaetomitrium leptopoma.

virginianus Brid. - Thuidium gracile var. lancastriense.

STEREOPHYLLUM Mitt, in Journ, of the Linn. Soc. 1859 (48 spec.).

aftixum C. M. in Bull. hb. Boissier, p. 217.

1.

- Am. sept. : Guatemala.

aptychopsis C. M. in Hedvig. 1897, p. 130.

1.

- Am. merid.: Argentin, subtropic. (Chaco).

Bassaeanum C. M. in Dusen M. Camer. n. 7 .

- Afr. : M. Cameroon.

brevipes (C. M.) Mitt. M. austr, am. p. 542 .

Euglossophyllum brevipes Hpe. Symb. 1870, p. 277.

Glossophyllum brevipes ej. Enum. M. Rrasil. p. 60.

Hypnum brevipes C. M. Syn. II, p. 232.

1.

- Am. merid. : Brasil. austr. or.

Büttneri Broth. - St. rivulare. 
chlorophyllum (Hsch.) Mitt. op, cit. p. 544 p.p.

Hypnum chlorophyllum Hseh. Fl. Brasil. I, p. 89; C. M. Syn, II, p. 261; p.p. (quoad pl. Brasil.).

Pilosium chlorophyllum C. M. in Fl. 1897, p. 340. 2.

- Am. merid.: Brasil. or.

chlorophyllum Mitt. $\left\{\begin{array}{l}\text { (quoad pl. Crüger.). }- \text { St. Crügerianum. } \\ \text { (quoad pl. Sprucean). }\left\{\begin{array}{l}\text { St. psendo-radiculosum. } \\ \text { - St. subchlorophyllum. }\end{array}\right.\end{array}\right.$

combaniense Besch. in Ann. sc. nat. VII ser., II, p. 97.

1.

- Afr. : Ins. Mayotte.

contorte-operculatum (C. M.) Mitt. op. cit. p. 543.

Hypnum contorte-operculatum, C. M. Syn. II, p. 682.

1.

- Am. sept. : Costa Rica.

Crügerianum (C. M.) Par.

Hypnum chlorophyllum C. M. Syn. I1, p. 261 p.p.

Pilosium Crügerianum C. $M$. in $\mathrm{Fl}$. 1897, p. 340.

St. chlorophyllum Mitt. op, et $l$. ce.

- Am. merid. : Ins. Trinitat.

cubense Mitl, op, cit. p. 544 .

1. Cortic. - Am. sept. : Cuba.

cultelliforme (Sull.) Mitl. op, et l, cc.

Hypnum cultelliforme Sull. in Proced. of the Am. Aead.... 1861, p, 289.

1. Ad rup. umbr. - Am. sept. : Cuba. Am, merid. : And. Peruv. emodicolum (C. M.) Par.

Euglosophyllum emodicolum C. M. in sched.

- As. : Himalaya sept. occ.

enerve Besch. - Rhaphidostegium.

flaccisetum (C. M.) Par.

Pilosium flaccisetum C. M. in $\mathrm{Fl}$. 1897, p. 339.

- Am. merid. : Guian.

flavo-brunneum C.M. in Dusen M. Camer, n. 50.

- Afr.: M. Cameroon.

fuegianum Besch, in Bull. Soc. bot. Fr. 1885, p. 67 (syn. excl.) et in Miss. sc. Cap Horn, V, Bot. p. 302, $t .5, f .19$.

Ster.

- Am. merid. : Fuegia.

fulvum (Harv.) Par.

Hypnum fulvum $C, M$. Syn. II, p. 353.

Leskea fulva Harv, in Lond. Journ. of bot. 1840, p. 16 et in Hook. Io. pl. $\operatorname{rar}, t, 23, f .2$.

Ster. ?

-As. : Nepal,, Himalaya.

gracile (Hpe.) Par.

Glossophyilum gracile Hpe. Enum. M, Brasil p. 60.

I.

- Am. merid, : Brasil. or.

guarapense Berch. Not. M. Paraguay, p. 269.

Hypnum turgidicaule C. M. in Rev. bryol, 1887, p. 57 et in Bal. M. 1.

- Am. merid. : P'araguay. 
homalioides Besch. in Jou'n. de bol. 1891, p. 348.

Homalia paraguensis ej. in Rev. bryol. 1885, p. 18 et in Bal. M. Parag. n. 3680 a.

1. Cortic. - Am. merid.: Paraguay.

indicum (Bel.) Mitt, M. Ind. or. p. 117.

Hookeria obtusifolia Harv, in Lond. Journ. of bot. 1840, p, 15 et in Hook. Ic. $p l, \mathrm{rar}^{2}, t, 24, f .11$.

Hypnum indicum C. M. Syn. II, p. 232.

Pterygophyllum indicum Belang. Voy. Ind. or., Crypt. p. 87, t. 9, f. 2.

2. Terr. ? et cortic. - As. : Nepal, Carnate.

jamaïcense C. M. in Bull. hb. Boissier, 1897, p. 565.

1. $\quad-$ Am. sept. : Jamaic.

laetc-virens Broth, in Engler's Bot. Jahrb. 1894, p. 110.

l. - Afr.: Usambara.

leptopes C. $M$. in Dusen M. Camer, n. 67 .

- Afr.: M. Cameroon.

leptostegium (Hpe.) Jaeg. Ad. II, p. 776.

Complanato-Hypnum leptostegium Hpe. Symb. p. 732.

Glossophyllum leptostegium ej, in Enum. M. Brasil p. 61 .

1.

- Am. merid. : Brasil. austr. or.

lepturum Mitt. - Brachythecium.

leucostegum (Brid.) Mitt. M, qustr. am. p. 543.

Hypnum flavo-nitens C. M. in Bot. Zeit. 1844, p. 742.

H. Gardnerianum ej, in op. et $l$. $c c$.

H. leucostegum ej. Syn. II, p. 344.

H. saxatile $H$. f. et W. in Lond. Journ. of bot. 1844, p. 164; C. M. op. et l. cc. fid. Mitt.).

H. subflavum eor, in Lond. Journ. of bot. et in Gardner M. Brasil. n. 121.

Leskea leucostega Brid. Bryol. univ. II, p. 333.

St. saxatile Jaeg. Ad. II, p. 543.

1. Cortic., lignic. et rupic. - Am. sept.: Cuba, ins. Porto-Rico. Am, merid. : Amazon., Brasil. or.

ligulatnm (C. M.) Jaeg. Ad. 11, p. 541 .

Hypnum ligulatum C. M. in Bot. Zeit. 1856, p. 438.

l. $\quad$ - As.: Bombay.

limnobioides Ren. in Rev. fr, de bot. $1891, p$., , in Bull. Soc. roy. bot.

Belg. 1893, I, p. 126 et M. Masc. Mad. n. 93.

I.

- Afr.: Ins, Borbon, Franciae..

longisetulum (C. M.) Par.

Pilosium longisetulum C. M. in Fl. 1897, p. 340 (nom.).

- Am. sept. : Guatemala.

medium Besch, in Rev. bryol. 1878, p. 58 (nom.).

- Am. meridl. : Paraguay.

microslegum Jaeg. - St. tavoyense.

Mohandiae (C. M.) Par.

Englossophyllum Mohandiae C. M. mss.

- As. : Himalaya sept. occid.

nitens Mitt. in M. herb. Hook., 18150, p. 5l, t. 5, f. 3.

1. Lignic. - Afr. : Ins. Fernando-Po. 
obtusum Mitt. M. austr, am. p. 542 .

1. - Am. merid. : And. Peruv., Brasil. tropic.

odontocalyx (C. M.) Jaeg. op. et l.cc.

Hookeria radiculosa Hsch. in Drege M. Capens.

Hypnum odontocalyx C. M. Syn. 1I, p. 232.

1.

- Afr. : C. B. Sp.

omalosekos (Welwo, et Duby) Jaeg. op. el l.cc.

Hypnum omalosekos W. et Dy. in Mém. Soc... Genève, 1871, p. 9, t. 4, f. 3 .

1. Cortic. - Afr. : Angola.

papilliferum Mitt. op. cit. p. 544.

1. - Am. merid. : Guayaquil.

paraguense Besch. Not. M. Parag. p. 268.

1. Cortic. - Am. merid. : Paraguay.

parvifolium Jaeg. - Thuidium involvens

peruvianum (Mont.) Mitt. op. cit. p. 542.

Hypnum peruvianum Mont. in Voy. Bonite, Crypt., t. 150, f. 2 et Syll. p. $6 ;$ C. M. Syn. II, p. 244.

1. Lignic. - Am. merid.: Guayaquil.

pseudo-radiculosum (C. M.) Par.

Pilosium pseudo-radiculosum C. M. in Fl. 1897, p. 310 (nom.).

St. chlorophyllum Mitt, op. et l. cc. p.p. et in Spruoe M. Amaz. n. 1321. - Am. merid. : Amazon.

pycnoblastum C. M. in Bull. hb. Boissier, 1897, p. 217.

- Am. sept. : Guatemala.

radiculosulum (C. M.) Jaeg. Adl. II, p. 541 .

Hypnum radiculosulum $C, M$, in Linn. 1876, p. 650.

- Am, sept. : Mexic.

radiculosum (Hook.) Mitt. M. austr. am. p. 542 .

Hookeria radiculosa Hook. M. ex. t. 51.

Hypnum radiculosum C.M. Syn. II,, 231.

Pierygophyllum radiculosum Brid. Bryol. univ. II, p. 346.

1. Cortic. et saxic. - Am. sept.: Jamaic. Am. merid.: Venezuela, And. Peruv., Brasil. trop.

rhamphostegium (Hpe.) Par.

Euglossophyllum radiculosum Hpe. Symb. p. 277.

Glossophyllum rhamphostegium ej. Enum, M. Biasil. p. 59.

Cortic. - Am. merid. : Brasil. or.

rigescens Broth. in Engler's Bot. Jahrb. 1894, p. 211.

1. Cortic. - Afr.: Usambara.

rigulare Mitt. in M. herb. Hook., 1860, p. 52, t. 5, f. 4.

St. Bütneri Broth. in Mittheil. aus den deutsch. Schutzgeb. VI, III, p, 5.

Ster. Ad rup. et terr. - Afr. : Niger, T'ogo.

ruderale (Brid.) Mitt. M. austr. am. p. 543.

Hypnum ruderale C. M. Syn. II, p. 352.

H. Stereodon ruderalis Brid. Bryol, univ. II, p. 585 .

H. viridulum ej. Sp. M. p. 181.

1. - Am. sept.: Hispaniola.

rufescens Broth. in op. cit. p. 210.

1.

- Afr.: Reg. lacustr. 
subchlorophyllum (C. M.) Par.

Pilosium subchlorophyllum C. M. in Fl. 1887, p. 340 (nom.).

St. chlorophyllum Mitt. op. et l. ec. p.p et in Spruce M. And. n. 1318. - Am. merid. : And. Peruv.

saxatile Jaeg. - St. lencostegum.

seminerve Mitt. - Helicodontium.

tavoyense (Hook+) Jaeg. Ad. II, p. 543 .

Hookeria prostrata Harv, in Lond. Journ. of bot. 1840, p. 15 et in Hook, Ic. pl. rar.t. $20, f .5$.

Hypnum tavoyense Hook, in Wall. Cat. n. 7655; Harv. in op, cc. p. 19 et $t .24, f . I ; C . M$. Syn. II, p. 245.

H. prostratum C. M. Syn. II, p. 345 .

St. microstegum Jaeg, op, et $l$. ce.

1 ? Cortic. - As. : Penins. Malay.

Wrightii (Mitt.) Jaeg. op. et l. cc.

Hypnum Wrightii Mitt. M. Ind, or, p. 82. 1.

- As. : Khasia, Himalaya, Madras (1).

Stokesiella Kindb. Check-lisb. of Eur. and N. Amer, M. p. 22 (sect. EURHYNCHI1).

STREBLOPII.UM Ångstr. in Oefv... 1876, n. 4, p. 18.

Regnellii ej. - Brachymenium.

StReblothichum $P$. B. Prodr, $p, 89$.

Spec. omn. Barbulae ejusd. nom.

STREPHEDIUM P. B. Prodr. p. 89.

Spec. omn. Funariae ejusd, nom.

STREPTOGALYPTA C. M, in Linn. $1878-79$, p. 354 (I spec.).

Lorentzi C. M. in op, et $l$, cc.

Syn.

- Am. merid. : Uruguay.

STREPTOPOGON Wils. mss.; Mitt. in Lond. Journ. of bot. 1851. p. 51 (22 spec.).

australis Mitt, in Journ. of the Linn. Soc. 1877, p. 66.

Williae spec. ? C. M. in Forschur gsreise... Bot. p. 45.

Ster,

- Afr. : Ins. Kerguelen, Marion.

bolivianus C. M. in Nuov. Giorn. bot. ital. $1897, p, 49$.

- Am. merid. : And. Boliv.

calymperifolius C. M. in Abhandl. Brem, VII, p. 207.

Ster.

- Afr. : Madagascar.

cavifolius Mitt. M. austr. am. p. 180.

Ster. Cortic. - Am. merid. : And. Quitens.

clavipes Spr, in Milt. op. cil. p. 179 1.

- Am. merid. : And. Nov. Granat.

(1) In Enum. Kindb. nom. nuda : St. lato-acutum C. $M$.

St. peracutum C. $M$. 
crispatulus (C, M.) Par.

Barbula crispatula C. M. in Hedwig. 1897, p. 104.

Ster.

- Am. merid. : Patagonia.

crispatus (Hpe.) Jaeg. Ad. II, p. 670.

Barbula crispata Hpe, in Linn. 1876, p. 304.

Cortic. - Pac. : Austral. or., Tasman.

erythrodontus (Tayl.) Mitt. op. el $l$. cc.

Barbula erythrodonta Tayl. in Lond. Journ. of bot. 1846, p. 50, t. XV F ; C. M. Syn. I, p. 606 et II, p. 630.

1. Cortic. - Am. merid. : And. Nov. Granat. et Quitens. Pac. : Ins. Sandwic. (fid. Sull.).

gemmascens Mitt. - Didymodon flexifolius $\beta$ gemmigerus.

Hampeanus Besch. in litl.

Calymperes Lindigii Hpe. in Ann. so. nat. V, ser. III, p. 342 ; Mitt. M. austr. am. p. 127.

Ad arbor. - Am. merid.: Nov. Granata.

Hildebrandti C. M. in Hildebr. M. Mad. n. 2095.

- Afr. : Madagascar.

latifolius Mitl. op. cit. p. 179.

2. Cortic. - Am. merid.: And. Nov. Granat.

marginatus (Hook. f. et Wils.) Mitt, in Journ. of the Linn. Soc. 1859, p. 72 .

Pharomitrium marginatum Jaeg. Ad. I, p. 189.

Schistidium marginatum Hook. et Wils. in Lond. Journ. of bot 1844, p. 539 et Fl. antarct. II, p. 399, t. 151, f. 6; C. M. Syn. I, p. 566 et $I I, p .624$.

1 ?

- Afr. : Ins, Kerguelen.

maveganensis Besch, in Marie M. Mad. n. 269.

- Afr. : Ins. Mayotte.

? mayottensis Besch, in Ann, sc. nat. 1885,11, p. 88 .

$\uparrow$ et fr. ign. $\quad-A f r$. : Ins. Mayotte.

mnioides (Schroaegr.) Mitt. in Journ. of the Linn. Soc. 1859, p. 78.

Barbula mnioides Schwaegr. Suppl. IV,p. 310; C. M. Syn. I, p. 632.

Tortula mnioides Hook. f. Handb. of the N. Zeal. Fl. p. 420.

2. Cortic. - Am, merid. : And. Quitens., Chile, Valdiv, Pac.: Nov. Zeland. sept., Tasman.

" var. prostrata (Mont.) Par.

Barbula prostrata Mont. in Ann. sc. nat. 1845, p. 157; Fl. Chil. VII, p. 148 et Syll. p. 40.

Tortula prostrata Mitt. M. austr. am. p. 172.

Ut et cum typ.

Parkeri Mitt, mss. ; C. H. Wright M. Mad. p. 4 (nom.).

- Afr. : Madagasc. centr.

Rutenbergii C. M. in Abhandl. Brem. V1I, p. 207. 1.

- Afr. : Madagascar.

Schenckii Broth. in Hedroig. 1894, p. I28.

Ster. $\quad-A m$. merid. : Brasil. austr. or.

setiferus Mitt. M. austr. am. p. 180.

1. Filicic. - Am. merid, : And, Nov. Granat. 
Wilhelmii (C. M.) Par.

Barbula Wilhelmii C. M. in Hedwig. 1897, p. 104 (nom).

Cortic. - Pac. : Austral, or. (Victoria), Tasman.

Strigodium C. M. Syn, II, p. 434 (subsect. HYPNi sens, Müller.).

STRUGKIA C. M. in Rev. bryol 1893, p. 94 et in Archiv. var. fr. Naturges. Mecklenbourg, 1893 (4 spec.).

argentata (Milt.) C. M. ll. cc.

Hypoum argentatum Mitt. M. Ind. or. p. 77 p.p.

- As.: Himalaya sept. occid.

argyreola $C . M . l l, c c$.

Maschalocarpus argentatus Hpe, in sched.

- As. : Sikkim.

Griffithii $C, M, l l . c c$.

$$
\text { - As. : Assam. }
$$

pallescens $C . M . M l . c c$.

Hypnum argentatum Mitt. M. Ind. or. p.p.

- As. : Himalaya bor. occid.

STYLOSTEGIUM Bryol, eur. II (I spec).

caespiticium (Schwaegr.) Bryol, eur. 1I, t. 113; W. P. Sch. Syn. II ed. p. 130.

Anoectangium caespiticium Schwaegr. in Schrad. Neu Journ. bot. IV, p. $13, t .2 \mathrm{~A}$.

Blindia caespiticia Lindb. M. Scand. p. 25.

Bl. Stylostegium C. M. Syn. I, p. 345 et $I I, p .584$.

Gymnostomum caespiticium W. et M. Bot. Taschb. pp. 77 et 452 .

G. subulatum Bryol. germ. I, p. 147, t. 10? Brid. Bryol. univ. I, p. 104.

Schistidium caespiticium Brid. Bryol. univ. I, p. 119.

1 et '2. Ad rupes humid. - Eur. : Summ. Alp. Scot., Scandin., Helvet., Rhaet, Salisburg.

Exs. : Rab. Bryoth, eur, n. 426.

SWARTZIA Hedio. M. frond. $I 1, p .72, t .27, f .7$.

capillacea Hedw. - Distichium.

cernua Poir. - Bryum pendulum.

inclinala Hedw. - Distichium.

pilifera Brid. - Desmatodon latifolius.

pusilla Ehrh. - Seligeria.

radiculosa Hedw, f. - Bryum pendulum.

trifaria Hedw. - Didymodon luridus.

SYMBLEPHARIS Mont. in Ann, sc. nat. 1837, p. 252 (16 spec.).

asiatica Besch. in Ann. sc. nat. I, p. 50.

1. In silv. - As. : Alp. Yunnan.

boliviana C. M. in Nuov. Giorn. bot. ital. 1897, p. 39.

S. Lindigii W. P. Sch, in Mandon Pl. Boliv, n. 1656. - Am. merid. : And. Boliv.

brevisela Wils. - Dichodontium Reinwardti. 
Chrismari C. M. Syn. I1, p. 614.

1. Lignic. - Am. sept. : Mexic.

? circinnata Besch. Fl. bryol. Réunion, elc, p. 20.

Fr. ign.

- Afr.: Comor. magna, ins. Borbon.

cirrifolia Lindb. in Angstr. Prim. lin. p. 5 (nom.).

- Am. mevid. : Brasil. austr. or.

densifolia Wils. - Holomitrium Griffithianum.

dilatata Wils. p.p. $\left\{\begin{array}{l}\text { - Dichodontium Hookeri. } \\ \text { - Dichodontium Reinwardti. }\end{array}\right.$

fragilis Mitt. M. austr. am. p. 49.

1.

- Am, merid. : And. Quitens.

helicophylla Mont, in Ann. sc. nat. 1837, XVIII, p. 252 et Syll, p. 46;

C. M. Syn. I, p. 461 .

1. - Am. sept, : Mexic.

himalayana Mitt. mss.

- As. : Himalaya.

Hookeri Wils, - Dichodontium.

jamaicensis C. M. in Bull. hb. Boissier, 1897, p. 555.

2. $\quad-$ Am. sept. : Jamaic.

Lindigii Hpe. in Linn. 1863, p. 136.

1. Cortic. - Am. merid. : And. Nov. Granat.

Lindigii W. P. Sch. - S. boliviana.

microtheca C. M. in hb. Saharampur, n. 5203.

- As. : Himalaya sept. occid.

CErstedtiana C. M. Syn. II, p. $6 \mathrm{I} 3$.

S. holicophylla (fid. Mitt. M. austr, am. p. 48).

2. $\quad-$ Am. sept. : And. Costa-Ric. Am. merid.: And.

Quitens.

perichxtialis Wils. - Holomitrium.

pumila Hook. - Holomitrium.

pusilla Hpe. mss.; Jaeg. Ad. II, p. 636.

Reinwardti Bryol, jav. - Dichodontium.

- As. : Ind. or. (sine loc. spec.).

socotrana Mitt, in Trans. of the roy. Soc. of Edinb. 1887, p. 331.

2.

tenuis W. P. Sch. mss.

$$
\text { - As. : Simla. }
$$

usambarica Broth, in Engler's Bot. Jahrb. 1894, p. 179.

- Afr. : Usambara.

SYMPHYODON Mont. in Ann. sc. nat. 1841 , p. 279, c. ic. (8 spec.). angustus (C.M.) Jaeg. Ad. I, p. 362,

Neckera angusta C. M. Syn. II, p. 67.

Stereodon angustus Mitt. M. Ind. or. $p .110$.

2.

- As.: Bombay.

asper (Mitt.) Jaeg. op, et $\mathrm{l}$. ec.

Stereodon asper Mitt. op. et l. ce.

2 ?

- As. : Khasia. 
echinatus (Mitt.) Jaeg. op. et 6 . cc.

Stereodon echinatus Mitt. op, et l. cc.

2.

- As. : Sikkim.

erinaceus (Mitt.) Jaeg. op. et l. cc.

Stereodon erinaceus Mitt. op, et l. $l c c$.

2.

- As, : Khasia.

erraticus (Mitt.) Jaeg, op. et l, cc.

Stereodon erraticus Mitt. op. cit. p. 111.

Ster.

- As. : Nepal., Sikkim, Ceylan.

Perrottetii Mont. in Ann. sc. nat. 1841, p. 279, t. 17 (quoad perist. erron.) et Syll. p. 21.

Neckera Perrottetii C. M. Syn. II, pp. 72 et 665 .

Stereodon Perrottetii Mitt. M. Ind. or, p. 110.

2. Cortic. - As. : M. Neilgherr., Ceylan, Java, ins. Ceram, Halmaheira.

planulus (Mitt.) Jaeg. Ad. II, p. 362.

Stereodon planulus Mitt. M. Ind. or. p. 111.

- As. : Himalaya or., Khasia.

scabrisetus Hpe. in sched.; Jaeg. op. el l. cc.

- As, : Sikkim.

SYMPHYSODON $D z$. et $M k$. $M$. frond. Archip. ind. $p .88$,

Spec. omn. Pterobrya ejusd. nom.

SYNTRICHIA Web. et Mohr Bot. Taschb. p. 2l4, t. 8, t. 4-5.

Spec. omn. non indicatae sunt Barbulae ejusd. nom.

alpina Brid. - Barbula subulata.

ericetorum Brid. - Barbula unguiculata var. patsgonica.

hyperborea Brid. - Barbula mucrosifolia var. arctica.

laevipila $\left\{\begin{array}{l}\text { var, mulica Schultz. - B. Iatifolia. } \\ \text { var. Ahnf, - B. papillosa. }\end{array}\right.$

montana Nees (fid. C. M.) - B. laevipila.

I (fid. Lindb.). - B. intermedia.

mucronifolia $\mathrm{R}$. Br. - B. mucronifolia var, arctica.

norvegica W. et M. - B. aciphylla.

var. alpina Wahlenb, - B. acipbylla.

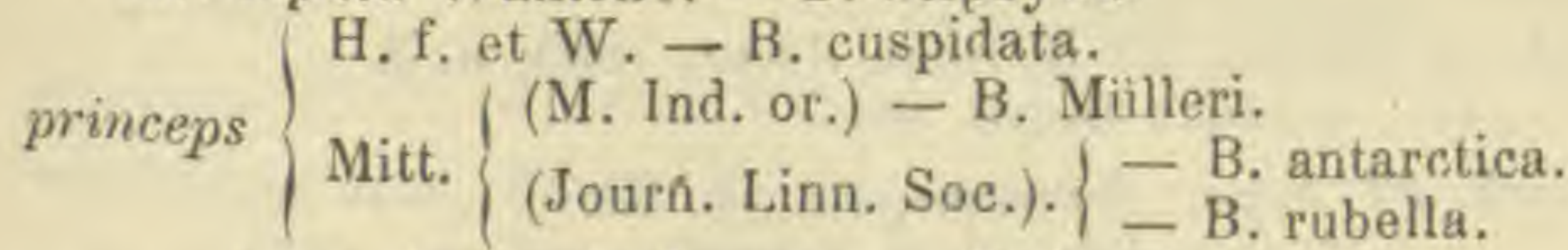

ruralis $\left\{\begin{array}{l}\text { var. laevipila Spreng. - B. laevipila. } \\ \text { var. latifolia } \mathrm{Br},-\mathrm{B} \text {. latifolia. }\end{array}\right.$

subulala , var, inermis Brid. - B. inermis.

var. macrocarpa Brid. - B, subulata?

lenera P. B. - ? Deleatur.

SYRIGOTHECIUM Mitt. M. austr. am. p. 497 (I spec.).

Sprucei Mitt, op. et $l$. cc.

- Am. merid. : And. Quitens.

Syrrhodictyon C, M. in Linn. 1830-83, p. 397 (sect. Dicrani, nom.). 
SYRRHOPODON Schwaegr. Suppl. II, II, p. 110 (215 spec.).

acanthoneuros C. M. - S. prolifer var. acanthoneuros.

aculeo-serratus Besch. Fl. bryol. Réunion, etc., p. 61.

Ster.

- Afr. : Ins. Borbon.

adpressus Brolh. in Micholits M. Nov. Guin n. 135.

- Pac.: Nov, Guinea.

africanus (Mitt) Besch. Ann. sc. nat. 1895-96, I, p.

Calymperes africanum $\mathrm{Par}$ : Index, $p .227$.

Thyridium africanum Mitt. in Journ. of the Linn. Soc. 1886, p. 303.

Ster. - Afr. : M. Usagara.

afro-ciliatus C. M. in Dusen M. Camer. n. 66 .

- Afr.: M. Cameroon.

afro-tristichus C. M. l. c. n. I55.

- Afr.: M. Jameroon.

alabamensis Lesq. et W. P. Sch. in Jaeg, Ad. II, p. 677.

S. texanus Sull, p.p.

- Am. sept. : Alabama.

albidus Thw. et Mitt. in Journ. of the Linn. Soc. 1878, p. 298.

Ster.

- As. : Ceylan.

albo-vaginatus Schwaegr. Suppl. I1, I1, p. 112, t. 131; C. M. Syn. I,

p. 541 ; Bryol.jav. I, p. 60.

Calymperes albo-vaginatum W. Arn. Disp. M. p. 14.

Cleistostoma albo-vaginatum Brid. Bryol. univ. I, p. 156.

2. - As. : Ins. Rauwack Molıce. Pac. : Ins. Fidji, Samoa, Admiral., Nov. Caled. (ins, Pinorum).

albo-vaginatus $\left\{\begin{array}{l}\text { Besch. }-\mathrm{S} \text {. Sartorii. } \\ \text { H. f. et W. }-\mathrm{S} \text {. floridanus. }\end{array}\right.$

Andamaniae C. M. mss.

- As.: Ins. Andaman.

andamensis (C. M.) Par.

(alymperes andamense $C . M$. in hb. Hpe, n. 2545.

Thyridium andamense Besch. in Ann. so, nat. 1895-1896, p. 277. - As. : Ins. Andaman.

andamensis Hpe. - Calymperes.

androgynus Besch. - S. rigidus. anomalus Broth. in Bihang till K. Svet, Akad. 1895, n. 3.

2. Cortic. - Am. merid. : Brasil. or. apertifolius Besch. Fl. bryol. Réunion, etc., p. 62.

Ster. - Afr. : Ins. Franciae.

apiculatus $\mathrm{Dz}$. et Mk. - Schizomitrium.

argenteus Broth. in Act. Soc. sc. Fenn. XIX, I891, n. 5.

$2 . \quad-$ Am. merid.: Brasil. or. (Minas Geraës). argentinicus Ltz. in Linn. 1878-79, p. 356.

Fl. et fr. ign. - Am. merid. : Argentin. subtropic.

argentinicus Besch. - S. paraguensis.

? aristifolius Mitt. Sam. M. p. 176.

Ster, Cortic, - Pac, : Ins, Samoa.

armatus Mitt. in Journ, of the Linn. Soc, 1863, p. 15I.

2. $\quad-A f r$. : Littor. tropic. (sine loc. spec). 
asper Mitt. in op. cit. 186r, p. 303.

Ster. $\quad-A f r$ : M. Usagara, Kilima N'Djaro.

asperrimus Broth. in Oefv. af Finska Vet.-Soc Foerh. 1895, p. 55.

2. - Pac. : Ins. Ducis York (Mioko).

atro-virens Broth. in Oefo... 1893.

2. Cortic. - Pac, Nov, Guinea.

badius W. P. Sch. in Besch. Fl. bryol. Antill. fr. p. 23.

$\mathrm{Fr}$. ign.

- Am. sept. : Guadalup.

Banksii C. M. in Bot. Zeit. 1858, p. 162.

1. - Pac.: Taït, ins. Vanikoro, Tuokuro.

Bernoullii C. M. in Bull, hb. Boissier. 1897, p. 189.

- Am. sept. : Guatemala.

Berteroamus (Brid.) C. M. Syn. I, p. 539.

Dicranum Berteroanum Brid. Bryol, univ, I, p. 445.

Orthotheca Berteroana ej. op. cit. p. 778 p.p.

2. Cortic. - Ain. sept.: Porto-Rico, Jamaic., ins. S. Vincent. Am. merid.: Ins. Trinitat., And. Peruv., Brasil, tropic.

bornensis (Hpe.) Jaeg. Ad. 1, p. 316.

Trachymitrium bornense Hpe, in Nuov. Giom. bot, ital. 1872, p. 280.

2.

- As. : Borneo.

"var. javanicus Ren. et Card. in Rev. bryol. 1896, p. 100 et in Ann.

du jard. bol. de Buitenzorg, 1897, ler Suppl. p. 5, l. II, A.

- As. : Java.

brachystelioides C. M. in Nuov. Giorn. bot. ital. 1877, p. 48.

-. Am. merid. : And. Boliv.

brevis C. M. in sched.

- Pac. : Nov. Guin. brit.

caespitosus Thw, et Mitt, in Journ. of the Linn. Soc. 1872, p. 298.

Stor. - As.: Ceylan.

calymperidianus Besch. Fl. bryol. Antill. fr.p. 21.

Fr. ign. $\quad-A m$. sept.: Guadalup.

Campylopus C. M. in Engler's Bot. Jahrb. 1883, p. 86 et in Forschungsreise..., Bot. p. 53.

2. Ster.

- Pac. : Nov. Guinea.

candidus Hsch. - Leucophanes.

capillaceus Hpe. Enum. M. Brasil. p. 9.

Lignic. - Am. merid. : Brasil. austr. or.

carassensis Broth, in Acl. Soc, sc. Fenn. XIX, 1891, n. 5.

2. Terr. - Am, merid. : Brasil. or. (Minas Geraës).

cavifolius Lac. Sp. nov. M. Archipel. ind. p. $5 . t$. 3 c.

2. fr. ign. Ligaic, - As. : Ins. Banca, Borneo.

ceylonensis $\mathrm{Par}$.

S. parvulus Thw. et Mitt. in op. cit. p. 229.

Thyridium parvulum Sb, in Jaeg. Ad. II, p. 679.

- As. : Ceylan.

Chenagoni Ren. et Card. in Bull. Soc. roy. bot. Belg. 1890,1, p. 175.

Ster.

- Afr. : Madagascar. 
ciliatus (Hook.) Schwaegr. Suppl. I1, II, p. 114, t. 130; C. M. Syn. 1, p. 144 ; Bryol. jav. I, p. $60, t .48$.

Trachymitrium ciliatum Brid. Bryol, univ, I, p. 159.

Weisia ciliata Hook, M. ex, t. 171 .

2. Cortic., lignic. et terr. - As. : Sumatra, ins. Banca, Borneo, Celebes, Amboine. Ternate. Puc. : Ins. Admiral., Nov. Guinea. ciliolatus Geh, et Hpe. in $\mathrm{Fl} .1881$.

Ster. - Am. merid. : Brasil. austr. or. cincinatus Hpe. Symb. 1874, p. 481 . - Am. merid. : Brasil. austr. or. circinatus (Britl.) Besch, Fl. bryol. Antill, fr. p, 22.

? Dicranum circinatum Brid. Bryol. univ. I, p. 446.

Orthotheca circinata ej. op. cit. p. 779 .

S. sordidus C. M. in Bot. Zeit. 1848, p. 766 et Syn. I, p. 537.

- Am. sept. : Guadalup. Am. merid.: Venezuela,

Nov, Granat.

circinatus $\mathrm{W}$. P, Sch: $-\mathrm{S}$. Schimperianus.

cirrifolius W. P. Sch, in Breutel M. Capens.

$$
\text { - Afr. : C. B. Sp. }
$$

clavatus Schwaegr. Suppl. III, II, II, t. 299; C. M. Syn. I, p. 532.

Sc. fasciculatus (fid. Mitt.).

Ster. - Pac. : Austral. or. (Nov. Valesia).

Codonoblepharum C. M. Syn. I, p. 529.

Codonoblepharum undulatum Dz. et Mk. M. frond. ined. Archip, ind. p. $96, t .32 ;$ Bryol. jav. I, p. 52 .

S. undulatus Lindb. in Oefv... 1864, $p, 605$.

Thyridium Codonoblepharum Ren. et Card. in Rev, bryol. 1896, p. 100.

2. Ad arbor. - As. : Sumatra, Java, ins. Banca, Borneo, Celebes. compactulus $C . M$. in Fl. 1897, p. 332.

S. prolifer C. M. Syn. I, p. 542 (quoad pl. Moritz.).

Ster. - Am. merid. : Venezuela.

confertus Lac. Sp. nov. M. Archip. ind. p. 4, t. 2 c.

2. Ad arbor. - As. : Sumatra, ins. Banca. congolensis Besch. in Journ. de bot. 1894, p. 43. 2 ?

$$
\text { - Afr.: Congo gall. (Brazzaville). }
$$

constrictus Sull, in U. St. Fxpl. Exped. Wilkes, 1859, p. 6.

Thyridium constrictum Mitt. Sam. M.p. 188. - Pac. : Ins. Hawaï, Samoa, etc.

crassinervis (Milt.) Par.

Calymperes crassinerve Jaeg. Ad. I, p. 329

Codonoblepharum crassinerve C. M. M. Polyn, p. 67.

Thyridium crassinerve Mitt. in Proced. of the Linn. Soc. 1868, p. 189. - Pac. : Ins, Samoa.

crassus Broth. in Micholitz M. Nov. Guin. n. 133.

Ster.? -Pac.: Nov. Guinea.

crispatus Hpe. in Ann, sc, nat. V ser., V, p. 335.

Ster. - Am. merid.: And. Nov. Granat.

crispus Aust. in Bot. Gas, II, p. 109.

? Calymperes crispum ej. in op. cit. IV, p. 151.

Ster. - Am, sept. : Florida. 
croceus Mitt, M. Ind, or. p. 41.

Calymperes aurantium Hpe. mss, in Bryol, jav. Suppl. p. 223 (fid, Lacoste.

C. heterophyllum A. Br. mss. in Bryol.jav. p. 223 (fid. Lacoste). Arbor. - As.: Ceylan (fid. Besch.), Sumatra, Java, Singapore, ins. Banca, Labuan.

croceus Mitt. (Sam. M.). - Syrrhopodon subcroceus.

cryptocarpus Dz. et $M k$. Prodr. Al. bryol. Surinam, p. 14, t. 7.

2. Cortic. - Am, merid. : Guian batav.

cryptodus Mitt. M. austr, am. p. 119.

- Am. merid. : And. Peruv.

cylindrothecius C. M. in Linn. 1878-79, p. 484.

- Am. merid. : Venezuela.

cyrtophyllus Besch. Fl. bryol. Reiunion, etc. p. 59.

Lignic. - Afr. : Ins, Borbon.

decolorans C. M. in Bull. hb. Boissier, 1897, p. 188.

In silv, primaev, - Am. sept. : Guatemala.

Dregei Hsch. in Linn. 1841, p. 116 ; C. M. Syn. I, p. 530.

S. perichaetialis Br, in Reg. Bot. Zeit. 1846, p. 132.

2. Cortic. et rupic. - Afr. : C. B. Sp., Pondoland.

dubius Schwaegr. - Zygodon Schwaegrichenii.

Duseni C. M. in Dusen M. Camer, n. 513.

- Afr.: M. Cameroon.

elatior Hpe. Symb. 1874, p. 482.

Terr. -- Am. merid. : Brasil, austr. or.

elatus Mont. in Ann. sc. nat. III, p. 198 et Syll. p. 46; C. M.

Syn. 1, p. 545.

Ster. Cortic. - Am. merid. : Guian. gall.

elongatus Sull, in Proced. of the Am. Acad... 1861, p. 280.

- Am. sept. : Cuba.

epapillosus C. M. in Linn. 1878-79, p. 483.

- Am. merid. : Venezuela.

erectifolius C. M. in Rehm. M. Afr, austr, $n .128$.

- Afr. : C. B. Sp.

? excelsus Sull. - Amphoridium Sullivantii.

fallax Lac. Sp. nov. M. Archipel. ind. p. 5, t. 3 B.

2. Cortic. - As. : Ins. Banca, Borneo.

fasciculatus Hook. et Grev, in Brewosler Edinb. Journ. of sc. 111, p. 225 (1); Schwoegr. Suppl, IV, t. 299; C. M. Syn. I, p 529.

Calymperes fasciculatum Mitt. $M$. Ind. or, $p .41$.

Codonoblepharum fasciculatum Bryol, jav. I, p.53.

S. undulatus A. Br. in Bot. Zeit. 1817 , p. 938 (fid. Hpe.).

Thyridium fascienlatum Mitt. Sam. M. p. 189.

2. Lignic. - As.: Nepal., Java, Singapore, penins. Malay., Borneo, ins. Ternate et Arrow Molucc. Afr,: Ins. Franciae, Am, merid.: Chile. Pac. : Austral,, ins. Piteairn, Samoa.

(1) a Curn ic. ubi calyptra ad naturam delineata est, non obstante observatione cl. Múlleri I. c. n Mitt. M. Ind, or. p. 41. 
fastigiatus Dz. et Mk. - S. Gardneri var. fastigiatus.

fimbriatulus Sb. in Jieg. Ad. II, p. 677.

S. fimbriatus C. M. in Linn. 1871-73, p. 151.

Ster.

- Pac. : Austral. or.

fimbriatus Mitt. M. austr, am. p. 122.

Cortic. - Am. merid. : Amazon.

fimbriatus $\mathrm{C}$. M. $-\mathrm{S}$. fimbriatulus.

flabelliformis $C . M$. in sched.

- As. : A mboine.

flammeonervis C. M. in Linn. I874, p. 557 .

Ster.

- As.: Ins, Philippin.

flavescens C. M. Syn. I, p. 541.

$2 . \quad-$ Am. sept.: Guadalup,, ins. S. Vincent. Am. meria. : Ins. Trinitat.

flavescens Hpe. $-\mathrm{S}$. Schwaneckeanus.

flavifolius C. M. M. Polyn. p. 66 .

Ster.

- Pac. : Ins, Samoa.

Hlavus C. M. in Bot. Zeit. 1855, p. 763; Bryol. jav. I, p. 61, ı. 49.

2.

- As. : Java.

flexiareolatus C. M. in Linn. 1878-79, p. 484.

- Am. merid. : Venezuela.

flexifolius Mitt. M. austr. am. p. 118.

- Am. merid. : And. Peruv.

floridanus Sull. M. of U. St. p. 31 et Ic. M. p. 49, t. 31 ; Lesq. et Jam. Man. p. 185.

S. albo-vaginatus H.f. et W. in Drumm. M. bor. am. II ed., n. 37; Sull. M. Allegh, n. 171.

2. Lignic. - Am, sept. : Floric., Ludovic.

fragilis Hpe. in Ann. sc. nat. Vser., III, p. 342.

- Am. merid.: And. Nov. Granat.

Gardneri (Hook.) Schwaegr. Suppl. II, I1, p. 110, t. 131; C. M. Syn. I, p. 538 ; Bryol. jav. I, p. $54, \iota .43$.

Calymperes Gardneri Hook. M. ex. t. 146.

Cleistostoma Gardneri Brid. Bryol. univ. I, p. 155.

Weisia Mac-Clellanai Griff. Not, p. 408.

2.

- As. : Nepal., Khasia, Ceylan, Java.

" var. fastigiatus Bryol. jav. l.c. p. 55.

S. fastigiatus Dz. et Mk, in Pl. Jungh. I, p. 334 .

- As.: Khasia, Ceylan, Java.

Gaudichandi Mont. in Ann. sc. nat. II ser., II, p. 376, t. 16 et Syll. p. 46 ; C. M. Syn. I, p. 542.

S. undulatus C. M. in Bot. Zeit. 1844, p. 727.

2. Cortic. et liguic. - Am. sept.: Caba, Guadalup. Am. merid. : Amazon., Brasil. austr. or.

Geheebii $P$ ar.

S. gracilis Geh. Neue Beitr, zur Moosfl. v. Neu Guin., p. 2, t. I.

2.

- Pac. : Nov. Guin. merid. 
glauco-virens Mill. Sam, M. p, 176.

Ster. Arbor, - Pac, : Ins. Samoa.

glaucophyllus Ren. et Card. in Bull. Soc, roy. bot. Belg. 1890, 1, p. 174.

Fr. ign. Lignic. et terr. - Afr.: Ins. Borbon., Franciae.

"var. rufus eor. in op. cit. $1894,11, p .116$.

S, rufus ear. M. Maso. Mad. n. 114 .

\section{- Afr. : Madagascar.}

glaucus Schwaegr, - Leucophanes.

Glaziovii Hpe. Symb. 18i4, p. 483; Broth, in Bihang till K. Sv. Vet.

Akad. 1895, n. 3 (descript. fruct.).

Cortic. et terr. - Am. merid. : Brasil, austr. or.

goyaziensis Broth. in Hedwig. 1895, p. 122.

2. Cortic, - Am, merid, : Brasil. or.

gracilescens Broth. in Act. Soc. sc. Fenn. XIX, 1891, n. 5.

Ster. $\quad$ - Am. merid. : Minas Geraës.

gracilis Mitt. Fl. Vit. p. 388.

- Pac. : Sine loc. spec.

gracilis Geh. - S. Geheebii.

Graeffeanus $C . M . M$. Polyn. $p .66$.

2.

- Pac.: Ins. Fidji, Samoa.

graminifolius Ren. el Card. in Bull. Soc. roy. bot. Belg. XXXI, 1892, 11, p. 104.

Ster. Lignic. - Afr. : Madagascar.

Griffithii Mitt. M. Ind. or. p. 40

2.

- As. : Singapore. Pac. : Nov, Guin.

havaïcus C. $M$. in Fl. $1896, p_{.} 437$.

Ster. $\quad$ - Pac. : Ins, Sandwic.

helicophyllus Mill. M. austr. am. p. 119.

- Am. merid. : And. Peruv.

lieterophyllus $\left\{\begin{array}{l}\text { Lac. - Calymperes retusum. } \\ \text { Mitt. - Calymperes. }\end{array}\right.$

hispido-costatus Ren. el Card. in op. cit. p. 103.

Ster. Lignic. - Afr, : Madagascar.

Hobsoni Hook. et Grev. in Breunsler Edinb. Journ. of sc., III, p, 224; C. M. Syn. I, p. 535 .

Calymperes Hobsoni Grev. in Ann. of the Lyc. of nat. Hist. of Nero York, V, 1824, p. 271, c. ic.

? Cleistostoma incompletum Brid. Bryol. univ. I, p. 158.

S. incompletus Schwaegr. Suppl. II, II, p. 119.

S. semi-completus ej. l. c. II, II, II, p.97.

2. -Am. sept. : Cuba. Am. merid.: Ins. Trinitat, Guian., Brasil. or.

Hobsoni Busch. - S. Mohri.

Hornschuchii Mart. Fl. Brasil. p. 6; C. M. Syn. I, p. 528.

- Am. merid. : Amazon., Brasil, austr. or.

Husnoti Besch. Fl. bryol. Antill. fr., p. 21.

Fr. ign. - Am. sept. : Guadalup., Martinic.

incomplelus Schwaegr. - S. Hobsoni. 
inflexıs Mitt, M. austr. am. p. 117.

- Am. merid. : And. Nov. Granat.

involutus Schooegr. Sunpl. II, II, o. 117, t. 132; C. M. Syn. 1, p. 538; Bryol. jav: l, p. 59.

Cleistostoma involutum Brid. Bryol. univ. I, p. 157.

S. Jardini W. P. Sch. in Jardin Enum. p. 20.

2 . Samoa, Taïti.

- As. : Ins. Banca, Rauwack Molucc. Pac.: Ins.

iridans Mitt. op. et l. cc.

$$
\text { - Am. merid. : Equator. }
$$

Isleanus Besch. Not. M. I. S. Paul el Amst., p. 3.

Fr. ign.

- Afr. : Ins. S. Paul.

Jamesoni Tayl. in Lond. Journ. of bot. 1847, p. 331 ; C. M. Syn. I, p. 545.

Tortula armata Mitt. op, cit, p. 163.

- Am. merid.: And, Quitens.

Jardini W. P. Sch. - S. involutus.

Junquillian Mitt. in Bryol. jav. L, p. 57, t. 46.

Thyridium Junquillian $S b$. in Jaeg. Ad. II, p. 679.

2.

- As.: Borneo.

Kurzii Hpe. - Calymperes prionotum.

labeanus Bryol. jav. 1, p. 56, เ. 45.

2. - As.: Borneo, ins. Labuan, Celebes.

laevigatus Mitt. Fl. Vit.p. 389.

- Pac.: Ins. Hawaï, Samoa.

laeviusculus Broth. in Hedwoig. 1895. p. 122.

2. Cortic. - Am, merid.: Brasil. or (Goyaz).

lamprocarpus Mitl. in Journ, of the Linn. Soc. 1863, p. 151.

2 ?

- Afr. : Ins. Fernando-Po.

Lepervanchei Besch. Fl. bryol. Réunion, etc. p. 62.
Fr. ign.
- Afr. : Usambara, ins. Borbon.

Leprieurii Mont. in Ann. se. nat. 111, p. 197 et Syll. p. 46; C. M. Syn. I, p. 541.

2. Cortic. - Am. merid, : Guian, gall., Amazon.

leptrdontioides Besch. Fl. bryol. Réunion, etc., p. 59.

Fr. ign. - Afr. : Madagascar sept.

Leucoloma C. M. in Engler's Bot. Jahrb. 1883, p. 86 el in Forschungs reise... Bot. p. 52.

Ster. Ad arbor. - Pac. : Nov. Guinea.

ligulatus Mont. Syll. p. 49.

Cortic. - Am. sept. : Guadalup. Am. merid. : Guian.

littoralis C, M. in Hildebr. M. Mad, n. 2057.

- Afr.: Ins. Nossi-Be.

longifolius Lindb. mss. ; Angstr, in Defv.... 1876, n. 4, p. 7.

- Am. merid, : Brasil. austr. or.

longiselaceus $\mathrm{C} . \mathrm{M} .-\mathrm{S}$, rigidus.

lox:orhynchus Ângstr. - Hyophila. 
luteus (Mitt.) Jaeg. Ad. I, p. 315.

Codonoblepharum Iuteum C. M. M. Polyn. p. 67.

Thyridium luteum Mitt, in Proced of the Linn. Soo, 1868, p. 188, Cortic. et rupic, - Pac. : Ins. Fidji, Samoa.

lycopodioides (Sw.) C. M. Syn. I, p, 538.

Bryum lycopodioides Sw. Prodr. Fl. Ind oco. p. 139.

? Dicranum lycopodioides ej. Fl. Ind. ooc. III, p. 1066; Brid. Bryol. univ. $I, p .444$.

Orthotheca lycopodioides Brid. op, cit. I, p. 778.

2. Cortic. - Am. sept. : Hispaniola, Jamaic,, S. Doming., Porto-Rico, Antill, gall. Am. merid, : Ins. Trinitat,, Venezuela, And, Nov. Granat. et Quitens., Brasil.

macro-prolifer C. $M$. in Fl. 1897, p. 332.

Ster. $\quad-A$ m. merid.: Venezuela.

mahensis Besch. Fl. bryol. Réunion, elc., p. 61.

- Afr. : Ins. Seychelles.

malouinensis C. M. Syn. I, p. 53 .

Orthotheca Berteriana Brid. Bryol. univ, 1, p. 778 p.p.

2 ?

- Am. merid. : Ins. Maclov.

malouinensis Ảngstr, - S. mauritianus.

mammillatus C. M. M. Polyn. p. 66 .

Ster.

- Pac. : Ins. Samoa.

mammillosus C. M. M. Polyn. p. 66.

Ster. $\quad$ - Pac.: Nov. Caledon.

Manii C. M. in sched.

- As. : Ins. Andaman.

mauritianus C. $M$. in Ångstr. Prim. lin. p. 54.

S. malouinensis Angstr. in Oefv.... 1873, p. 141.

Fr. ign.

- Afr. : Ins. Franciae.

maveganensis Besch, in Ann. sc. nat. VII ser. $11, p .88$.

Ster.

- Afr.: Ins. Mayotte.

Micholtzii C.M. mss.

- As. : Ins. Philippin. (Mindanao).

microbolacus C. M. in Besch. Fl. bryol. Réunion, etc., p. 60.

S. microbolax Sb, in Jaeg. Ad. $I I$, p. 678.

$$
\text { - Afr.: Ins. Nossi Be. }
$$

mitrobolax $\mathrm{Sb},-\mathrm{S}$, microbolacus.

Miquelianus C. M. Syn. 1, p. 535.

S. surinamensis Dz. et Mk. Prodr. fl. bryol. Surinam. p. 12, t. 6.

2 .

- Am. merid. : Surinam, Amazon.

Mobri C. M. in Linñ. 1874, p. 633.

S, Hobsoni Besch. Prodr. bryol. mexio. p. 29.

Cortic. - Am. sept. : Mexic.

Mülleri (Dz. et Mk.) Bryol, jav. II, p. 224.

Calymperes Mülleri Mitt. M. Ind. or. p. 42.

Calymperidium Mülleri Bryol. jav. I, p. 51, t. 42 (excl. fig. 17, 20 et 21).

2. Cortic. - As.: Ceylan, Sumatra, Java, ins. Banca, Borneo, Celebes,

Pac.: Ins. Samos, Nov. Guinea. 
nossi-beanus Besch. Fl. bryol. Réunion, etc., p. 59.

Fr. ign.

- Ins. Mayotte, Nossi Be.

"var. borbonicus Ren. el Card. in Bull. Soc. roy. bot. Belg. 1894, II, p. 117.

Secus rivul. - Afr. : Ins. Borbon.

Novae-Valesiae C. M. in Rev. bryol. 1876, p. 3 (nom.) (1).

- Pac. : Austral. (Nov. Vales.).

novo-guineensis $\mathrm{Par}$.

S. strictifolius Geh. Neue Beitr. zur Moosfl. v. Neu Guin. p. 8.

Ster.

- Pac. : Nov. Guin. merid.

obliquirostris C. M. Syn. 1, p. 543 .

2. $\quad-A f r .:$ C. B. Sp.

obscurus Rehm. M. Afr. austr. n. 126.

- Afr.: Orange.

obtusifolius Lindb, in Oefv... 1864, p. 605.

2 ? $\quad$ - Pac.: Taiti.

obiusus Schwaegr. - Splachnobryum.

octoblepharis Nees. - Leucophanes octoblepharoides.

pachyneurus $C . M$. in sched.

- As.: Ternate.

pallidus Mitl. $M$. austr. am. p. 121.

- Am. merid. : And. Quitens.

papillosus C. M. in Bot. Zeit. $184 \times$, p. 766 et Syn. I, p. 543.

2. Cortic. Ain. merid, : And, Columb.

papuanus Broth. in Oefv... of Finska Vet.-Soc. Foerh. 1895, p. 54.

2. - Pac : Nov. Hibern.

paraguensis Besch, in Journ, de bot. 1891, p. 349.

S. argentinicus ej. in Rev, bryol, 1885, p. 17.

2. Cortic. - Am. merid. : Paraguay.

parasiticus (Sw.) Besch. in Ann, sc. nat. 1895-96, I, p. 298.

Anictangium parasiticum Brid. Sp. M. I, p. 270

Brachypodium? parasiticum Brid. Bryol. univ. I, p. 149; C. M. Syn. I, p. 750.

Bryum parasiticum Sw. Prodr. Al. Ind. occ. p. 139.

Calymperes parasiticum Hook. et Grev. in Breuster Edinb. Jown. I; p. 131 ; Mitt. M. austr. am. p. 127,

Encalypta parasitica Sw, Fl. Ind. oce. III, p. 1739.

Glyphomitrium parasiticum Brid. Mant. M. p. 21.

Weisia parasitica Mohr in Koen. and Simps. Ann. bot. II. p. 415.

Arbor. -- Am. sept. : Haïti, Am. merid. : And. Quitens.

parvicaulis C. $M$. in sched.

Ster.

- Pac. : Nov. Guinea brit.

parvulus W. P. Sch, in C. M. Syn. 1,p. 544.

2 ,

- Am. sept. : Mexic.

parvulus Thw, et Mitt. - S. ceylonensis.

paucifimbriatus C. M. in Dusen M. Camer. n. 828. - Afr.: M. Cameroon.

(1) a An S. Gaudichaudi forma? "Sb. in Jaeg, Ad. II, p. 677. 
perasper C. M. in sched,

Ster.

- Pac. : Nov. Guin. brit.

perichrtialis $\mathrm{Br}$. - $\mathrm{S}$. Dregei.

perundulatus Broth, in Micholitz M. N. Guin, n. 134 .

- Pac. : Nov. Guinea.

phragmidiaceus $C . M$. in Fl. 1886, p. 511.

Ster.

- Afi: : Gabon.

piriformis C. M. in Rehm. M. Afr. austr, n. 488.

- Afr.: Transvaal.

Platycerii Mitt. Fl. Vit, p. 388.

- Afi. : Ins, S. Paul. Pac.: Ins, Lord Howe.

polytrichoides Besch. Fl. bryol. Nov. Caled. p. 206.

- Pac, : Nov. Caledon.

pomiformis (Hook.) Hpe. in C. M. Syn. 1, p. 531.

? Grimmia pomiformis Brid. Bryol, univ, I, p. 187.

Weisia pomiformis Hook. M. ex, t. 131.

2. Rupic. - Afr, : C. B. Sp.

* var, truncicola Rehm. M. Afr, autstr. n. 124.

Cortic. - Afr. : C. B. Sp.

prolifer Schwaegr. Suppl. II, II, II, p. 99, t. I80; C. M. Syn. I, p. 542 p.p.

2. Lignic. et rupic. - Am. merid. : And. Nov. Granat. et Peruv.? Brasil. austr. or.

* var. acanthoneuros $C, M, l, c$.

S. acanthoneuros ej. in Bot. Zeit. 1845, p. 106.

- Am. merid.: Brasil, or.

prolifer $\{$ C. M. (quoad pl. Venezuel.). - S. compactulus.

pusillus Mitt. M. austr. am. p. 120.

Duby. - Leucoloma molle.

Cortic. - Am. merid. : And. Nov. Granat.

Quintasi Broth. in Bol. da Soc. Brot. VIII, 1890.

2. Fr. ign. Cortic. - Afr.: Ins. S. Thoma.

? Rauei Aust. - Dicranum fulvum.

recurvifolium $\left\{\begin{array}{l}\text { Hsch. - Orthotrichum, } \\ \text { Wils. - Calymperes. }\end{array}\right.$

recurvulus Mitt. M. auslr. am. p. 120.

Reinwardti Hsch, - Zygodon.

- Am. sept.: Cuba.

repens Harv. in Lond. Journ. of bot. 1840, II, p. 7 et in Hook. Ic. pl.

rar, $t, 22, f .4$.

Calymperes repens C. M. Syn. I, p. 526 .

Orthotrichum undulatum Hook, et Grev, in Brewster Edinb. Journ. of sc. p. 17, t. 4 p.p.

Thyridium repens Sb. in Jaeg. Ad. II, p. 679.

Ster. Cortic. - As. : Ceylan, Penang, ins. Banca, Ternate.

repens Bryol. jav. - S, subrepens.

revolutus Dz. et $\mathrm{Mk},-\mathrm{S}$, rufescens.

rigescens Schwaegr, Suppl. 1I, II, II, p. 102, l. 181; C. M. Syn. 1, p. 533. 
rigidus Hook. et Grev. in Brewster Edinb. Journ, of sc. III, p. 226; C. M. Syn. I, p. 536 .

Calymperes androgynum Mont, in Ann, sc. nat. III, p. 195.

S. androgynus Besch. Fl. bryol. Antill. fr. p. 23.

S. longisetaceus $C . M$. Syn. I, p. 535 .

2. Cortic. - Am sept.: Antill. gall., Porto Rico, ins. S. Vincent. Am. merid.: Ins. Trinitat, Guian., Nov. Granat.

rigidus Duby, - I.eucobryum chlorophyllosum.

Rodriguezii Ren. el Card. in Bull. Soc, roy. bot. Belg. 1894, II, p. 115 et M. Masc. Mad, n. 19.

Ster, - Afr.: Ins. Borbon.

"var. sublaevis eor. in op, cit. p. 116.

Cum typ.

rotundatus Broth. in Oefv.... 1893.

Ster. ? - Pac. : Nov. Guin.

rubiginosus Mitt. M. austr. am. p. 125.

Thyridium rubiginosum $S b$, in Jaeg. Ad. II, p. 679.

Cortic. - Am. merid. : Orinoc.

rufescens Hook, et Grev, in op. cit. p. 227 ; C. M. Syn. 1, p, 534.

S. revolutus Dz. et Mk. M. frond. ined. Archip. ind. p. 59, t. 22; Bryol. jav. I, p. 58 .

Trachymitrius revolutum Hpe, in Nuov. Giorn. bot. ilal. 1872, p. 280.

1. Cortic. - As.: Sumatra, Java, Penang, Singapore, ins, Banca et Labuan, Borneo, ins. Philippin. Pac. : Ins. Mariann.

rufus Ren, et Card, - S. glaucophyllus var, rufus.

rupestris Milt. M. auslv, am, p. 124.

Ster. Rupic. - Am. merid. : Amazon.

Sanctae Catharinae C. M. mss.

- Am, merid. : Brasil. austr, or.

Sartorii C. M, in Linn. 187 , p. 633.

S. albo-vaginatus Besch. Prodr. bryol, mexic, p. 29.

- Am. sept, : Mexic.

scaber Mitt. M. austr. am. p. 119.

Lignic. - Am. sept, : Cuba.

scaberrimus $C, M$. in Malpighia, 1896, p. 513.

Ster. $\quad-A m$. merid. : Guian, brit.

Schimperianus Par.

S. circinatus W. P. Soh. in Besch. Prodr. bryol. mex. p. 28.

- Am. sept. : Mexic.

Schwaneckeanus C. M. in Bot. Zeit. 1855, p. 763.

S. flavescens Hpe. in Linn. 1852, p. 360.

2.

- Am. sept. : Porto-Rico, Antill. gall.

Scolopendrium Mitt. - Octoblepharum.

Seignaei Besch. Fl. bryol. Réunion, etc., p. 63.

Fr, ign. Fr. ign.
semi-circularis C. M. in Verhandl. l. bot. Ver. Prov. Brandenb. 1890,
p. 67 . 
semi-completus Schwaegr. - S. Hobsoni.

semi-liberus (Mitt.) Besch. in litt.

Calymperes semi-liberus Mitt. M. Ind. or. p. 41.

2. Arbor, - As, : Penins. Malay.

Semperi C. M. in Linn. $1874, p .557$.

Ster.

- As. : 1ns. Philippin.

serpentinus C. M, in Nuov. Giorn. bol. ilal. 1897, p. 48.

- Am. merid. : And, Boliv.

Serra C. M. in Engler's Bot. Jahrb. 1883, p. 8t et in Forschungsreise....

Bot., p. 53.

Ster, Cortic. - Pac. : Nov. Guin.

serrulatus Wils. - Calymperes heterophyllum.

silvaticus Mitt. M. austr. am. p. 121.

Cortic. - Am. merid, : And. Quitens.

Smithii Besch, in litt.

Calymperes disciforme Lesq. et Jam. Man. p. 184.

Arbor. - Am. sept.: Florida.

sordidus ' $)$. M. - S. circinatus

sparsus Ren. et Card. in Bull. Soc. roy. hot. Belg. 1891, 11, p. 186.

Ster. Lignic. - Afr. : Madagascar centr.

speciosus W. P. Sch, in Jardin Enum ...p. 19 (nom.).

- Pac. : Nouka Hiva.

speciosus Dz. et Mk. - Schizomitrium.

spiculosus Hook. et Grev. in Brewster Edinb. Journ. of sc. III, p. 226;

C. M. Syn. 1, p. 534 .

2. Rupic. - As.: Surnatra, Singapore, ins. Banca et Labuan, Borneo.

spininervis Lindb. mss, ; Angstr, in Oefv.... 1876, n. 4, p. 7.

- Ani. merid. : Brasil. austr. or.

spiralis Ren. et Card. in op. cit. p. 185 et M. Masc. Mad. n. 113.

Ster. Terr, aren. - Af $r$ : Madagascar.

Spruceanus Mill. op, cit. p. 114.

2.

- Am. merid. : Amazon.

strictifolius Mitt. Fl. Vil. p. 388.

Ster.

- Pac. : Ins. Samoa.

strictifolius Geh. - S. novo-guineensis.

strietus Tho, et Mitt. in Journ. of the Linn. Soc. 1872, p. 299. - As.: Ceylan.

strigosus (Brid.) Mitt. M. austr. am. p. 125.

Oncophorus strigosus Brid. Bryol. univ. I, p. 405; C. M. Syn. I, p. 367.

Ster.

- Am. sept. : Hispaniola.

Stuhlmanni Broth. in Engler's Bot. Jahrb. 1897, p. 240.

2.

subciliatus C. M. in sched.

- Pac.: Nov, Guin. brit. (M. Yule).

subcrocens Besch, in litt.

Calymperes croceus C. M. M. Polyn. p. 63 .

S. croceus Mitt. Sam, M. p. 175.

Arbor, - Pac, : Ins, Fidji, Samoa. 
subdisciformis (C. M.) Besch, in Ann. sc. nat. 1895-96, p. 305,

Calymperes subdisciforme $C . M$, in Dusen M. Camer, n. 500 . - Afr. : M. Cameroon.

subfasciculatus (Hpe.) Par.

Codonoblepharum subfasciculatum Hpe. in Linn. 1876, p, 603.

1 hyridium subfasciculatum $S b$, in Jaeg. Ad. II, p. 679.

- Pac.: Ins. Tuo-Kuro.

subflavus Ren, et Card. in Bull. Soc, roy. bot. Belg. 1896, 1, p. 310.

Ster. Cortic. - A fi. : Madagascar (Úliego-Suarez). subinteger Lindb. inss.; Angstr. in Oefv.... 1876, n. 4, p. 7.

- Am. merid, : Bracil, austr. or.

subluteus $(C, M$.) Par.

Codonoblepharum subluteum C.M. M. Polyn. p. 67.

Thyridium subluteum $S b$, in op, et $l$. ce.

Ster.

- Pac. : Ins. Samoa.

subpolytrichoides C. M. in Engler's Bot. Jahrb. 1883, p. 86 et in Fors. chungsreise... Bot., p. 53 .

Ster. Cortic. - Pac. : Nov. Guin.

subrepens C. M. in Linn. 1874, p. 556 (nom.).

S. repens Bryol. jav. II, p. 224.

Thyridium subrepens $S b$, in op. et $l$. $c c$.

-. As. : Archip. ind. (sin loc. spec.).

subspiculosus C. M. M. Polyn. p. 67

Ster. $\quad-P a c .:$ Ins. Samoa.

subulatus Luc. Sp. nov. M. Archip. ind. p. $5, t .3 \mathrm{~A}$.

2. Cortic. - As.: Sumatra, Celebes. Pac, : Nov. Guin, merid. subviridis Besch. Fl. bryol. Antzll. fr. p. 22.

Fr. ign.

- Am. sept. : Guadalup.

Sullivantii Bryol. jav. I, p. 58, t. 47.

2 .

-As, : Java.

surinamensis $\mathrm{Dz}$. et $\mathrm{Mk}$. - S. Miquelianus.

taïtensis Sull. in U. St. Expl. Exped. Wilkes, 1859, M. p. 6, t. 4.

Calymperes Daemelii Hpe. mss.

C. taitense Mitt. Sam. M. p. 172.

Ster. Rupic, et terr. - Pac.: Ins. Fidji, Samoa, Taüt, Nouka Hiva, Arch. Gambier, Nov. Hebrid.

Taylori Schwaegr. Suppl. II, II, p. 115, t. 132 ; C. M. Syn. I, p. 545.

Blindia Taylori Hpe. mss. (fid. Besch, in litt.).

Cloistostoma Taylori Brid. Bryol. univ, I, p. 156.

Leucoloma Taylori Mitt. M. Ind. or. p, 13.

1, Lignic. - As, : Nepal., penins. Malay.

tenellifolius (C. M.) Besch. in Ann. sc. nal. 1895-96, p. 305.

Calymperes tenellifolium C. M. in Dusen M. Camer, n. 432.

- Afr. : M. Cameroon.

tenellus Mitt. in Proc. of the Linn. Soc. 1879 (extra-vol.) p. 99.

- Pac. : Nov. Caledon. (ins. Pinorum).

tenuifolius (Sull.) Mitt, M. austr. am. p. 117.

Calymperes tenuifolium Sull, in Proced, of the Am. Acad.... 186?.

Lignic, - Am, sept. : Cuba. 
terebellum C. M. in Bol. Zeit. 185i, p. 777.

2.

- Pac. : Nov, Caledon. (ins. Pinorum).

texanus Sull. M. of U. St. p. 103 et Ic. M. Suppl. p. 32, t. 20, p.p.; Lesq. et Jam. Man. p. 185.

2. o ign. - Am. sept. : A Carol. sept. usq. ad Florid.

lexanus Sull, p.p. - S. alabamensis.

tortilis Hpe. Symb. 1872, p. 38.

2.

- Am. merid. : Brasil. austr.

torluosus Hsch. - Amphoridinm eyathicarpum.

trachyphyllus Mont. Syll. p. 47.

2 ? - As, : Singapore, ins, Labuan, Borneo.

tristichus Nees in Schwaegr. Suppl. IV, t. 3LI; C. M. Syn. I, p. 540;

Bryol. jav. I, p. 55, t. 44 .

2. Cortic. - As. : Ceylan, Sumatra, Java, Amboine.

tristichus Mitt. - S. laevigatıs.

tubulosus Lac. Sp. nov. M. Archip. ind. p. 7, t. 4 в.

2. Ster.

- As.: Sumatra, Borueo.

uncinifolius C. M. in Reltm. M. Afr. austr. n. 129 et 486 .

- Afr. : C. B. Sp., Transvaal.

A. Br. - S. fasciculatus.

undululus C. M. - S. Gaudichandi.

Lindb. - S. Codonoblepharum.

Urvilleanus C.M. Syn. $1, p .540$.

Orthotheca Berteriana Brid, Bryol, univ. I. p. 778 p.p.

2 .

- Am. merid. : Brasil. austr. or.

vaginans Broth, in Bihang till K. Sv. Vet.-Akad. 1895, n. 3.

2. Cortic. et lignic. - Am. merid. : Brasil, or.

venezuelanus Milt. M. austr, am, p. 125.

- Am, merid. : Venezuela.

vittatus Wils. - Calymperes heterophyllum.

Vriesei Lac. Sp. nov. M. Archip. ind. p. 6, t. 4 A.

2. Cortic. - As.: Java.

Wainioi Broth. in Act. Soc. so. Fenn. XIX, 1895, n. 5.

Ster. Cortic, - Am. merid. : Minas Geraës.

Wallisii C. M. in Linn. 1874, p. 555

Thyridium Wallisii $S b$, in .Jaeg. Ad. II, p. 679.

Sters.

- As. : Ins. Philippin.

W Jlwitschii (Duby) Besch. in Ann. sc. nat. 1895-96, I, p. 307.

Calymperes Welwitschii Duby in Mém.... Genève, 1871, p. 20. t.8.

Ster. Ad rad. arb. secus rivul. - Afr. : Angola.

xanthophyllus Milt. M. austr, am. p, 115.

Terr. - Am. merid.: Amazon (1).

(1) In Enum. Kindb, nomen nud, :

$\mathrm{S}$, braunioides $C, M$. 
SYSTEGIU M W. P. Sch. Syn. I ed., p. 30 (17 spec.).

abbreviatum Thw. et Mitt. in Journ. of the Linn. Soc. 1872, p. 299.

Terr. - As. : Ceylan.

austro-crispum (C. M.) Par.

Phascum austro-crispum C. M. in Trans. of the N. Zeal. Inst. 1893, p. 274 .

1. Terr. - Pac. : Nov. Zeland.

brachypelma (C. M.) Par.

Phascum brachypelma $C . M$. in $F l .1888, n .1$.

- Pac. : Australia.

carniolicum de Not. - Phascum.

crispum (Hedro.) W. P. Sch. l, c. et Syn. 11 ed. p. 31.

Astomum crispum Hpe, in Linn. 1837, p. 385 ; Bryol. eur. 1 (mon. p. 13), t. 10.

A. polycarpum Hpe. mss.; C. M. in Bot. Zeit. 1847, p. 98.

Mollia crispa Lindb. M. Scand, p. 22.

Phascum crispum Hedw. Fund. M. II, p. 85 et M. frond. I, p. 25, t. 9 ; Brid. Bryol. univ. I, p. 46; C. M. Syn. I, p. 24.

Simophyllum erispum Lindb. Rev. crit. ic. ft. dan. p. 38.

Weisia crispa Mitt. in Ann. and Magaz. of nat. Hist. II ser, VIII, $1851, p .316$.

W. Iongifolia Mitt. l.e. p. 317 .

1. In campestr. argill.-aren, et praecip. calc. - Eur.: Tota, arctic. except. As.: Japon. Afr.: Alger., Egypt. Am, sept. : Saskatchewan, Missouri, Indiana, Pensilv, Kansas, Texas, Ludovic.

Exs. : Drumm. M. bor. am, II ed. n, 9 (Phascum).

Rab. Bryoth. eur, n. 30, 653.

"var. Philiberti Husn. Muscol. gall. p. 427.

- Eur. : Galloprov.

crispum Lac. - S. japonicum.

Drummondii Kindb. in Mac. Cat. p. 12.

Gymnostomum phascoides Hook. in Drumm. M. bor, am.n. 12 (fid. Kindb.).

Ad terr. humid, - Am. sept. : Saskatchewan.

erythrostegium W. P. Sch. - S. ludovicianum.

Forsythii Geh. - S. Levieri.

Frucharti (C. M.) Par.

Phascum Frucharti C. M. in Fl. 1888, n. I.

- Am. merid. : Monte-Video.

japonicum Besch. mss.

S. crispum Lac. Prol. fl. Japon. in Ann. Mus, bot. Lugd. Batav. I, 1865-68.

$$
\text { - As, : Japon. }
$$

Levieri (Limpr.) Par.

Astomum Levieri Limpr, in LXXIII Jahresber. d. Schles. Gesells, firr vaterl, Cultur, 1896, p. , et in Fl. et Warnst. Bryoth. eur. merid. n. 4 .

S. crispum var. Philiberti Husn.?

S. Forsythii
S. multicapsulare $\{$ Geh. ad inter. in Fl. 1886, n. 22.

1. Térr. - Eur. : Hassia, Toscan., Istria 
Lindigii Hpe, in Ann. sc, nat. V ser., 111, p. 337.

Weisia Hampei Mitt. M. austr, am. p. 131.

1 .

- Am. merid. : And. Nov. Granat.

ludovicianum (Sull.) Jaeg. Ad. I, p. 35.

Astomum Iudoviciazum Sull. Ic. M. p. 2l, t. 12; Lesq. et Jam. Man. p. 52.

Phascum crispum var. rostellatum H. f. et W. in Drumm. M. bor. am. II ed., n. 10.

Ph. ludovicianum Sull. M. of U. St. p. 16.

S, erythrostegium W.P. Sch. in Proced. of the Am. Acad. XIV, p, 140.

I. Terr. - Am. sept. : Florid., Ludovic.

Mittenii (Bryol. eur.) W. P. Sch. l. c.

Astornum Mittenii Bryol, eur. I (mon. p. 3), $t, 13$.

Phascum multicapsulare $\beta$ Mittenii Wils. Bryol. brit.

Ph. Mittenii C. M. Syn. II, p. 520.

1 et polyg. In arv, et ad viar. marg. - Eur. : Anglia merid.

mollifolium C. $M$. in Hedwig. 1895, p. 117.

Terr. - Am. merid. : Brasil. or. (Goyaz.).

multicapsulare $(S m$.$) W. P. Sch.$. . c.

Astomum multicapsulare Bryol, eur. (mon. p, 3), t. 14.

Phaseum crispum C. M. Syn. I, p. 24 p.p.

Phascum crispum $\beta$ multicapsulare $H$. et T. Muscol. brit. p. 6.

Ph. muiticapsulare Sm. Fl. Brit. I11, p. 1152; Brid. Bryol. univ. I, p. 48.

Ph. sphaericarpon Abbot $\mathrm{Fl}$. Bedf. p. 230.

I et polyg. In terr. argill. campor. et tumul. denud. - Eur.: Anglia.

multicapsulare Geh. - S. Levieri.

nitidulum (Bryol. eur.) Jaeg. Ad. 1, p. 35.

Astomum nitidulum Bryol. exr. I mon. $p, 3)$; Lesq. et Jam. Man. p. 52.

Phascum crispum Sull. M. Allegh, n. 211 p.p.

Ph. nitidulum C. M. Syn. II, p. 519.

1. Terr. - Am. sept.: Ohio.

Exs. : Sull, et Lesq. M. bor. am. II ed. n. 47 (Astomum).

«var. pygmaeum (Lesq. et Jam.) Pai.

Astomum nitidulum var, pygmaeum Lesq. in L. et .J. $l$. c.

Ut et typ.

rostellalum Boulay. - Hymenostomum.

squarrosum Boulay. - Hymenostomam.

subacaule Mitt. - Hymenostomum.

Sullivani (C. M.) Par.

Phascum Sullivani $C . M$. in Fl. $1888, n .1$.

1 .

- Pac. : Austral. or.

Sullivantii (Bryol. eur.) Jaeg. Ad. 1, p. 35.

Astomum Sullivantii Bryol. eur. I (mon. p. 2) ; Sull. Io. M. p. 20, t. II; Lesq. et Jam. l. c.

Phascum erispum Sull. M. Allegh. n. 211 p.p.

Ph. Sullivantii C. M. Syn. II, p. 519.

1. Terr. - Am. sept.: Reg. or., Kansas, Ludovic.

Exs, : Sull, et Lesq. M. bor. am. II ed, n. 46 (Astomum). 
unguiculatum Mitt. in Journ. of the Linn. Soc, 1886, p. 304.

- Afr.: Gua Chiropa (Quid ?) (1).

SYSTYLIUM Hsch. Comment. de Voitia et Systylio, p. 19, t. 2. splachnoides Hsch. - Dissodon.

Taeniocladium Mitt. Sam, M, p. 18 (sect. NeCKrese).

TAMARISCELLA $C, M$, Syn. II, p. 482 (subsect. HypNi), postea gen. propr. Spec. omn. non indicatae sunt Thuidia ejusd, nom. nuda C. M. - Amblystegium Haplocladium.

Tanytrix C. M. in A bhandl. Brem. VII, p. 213 (subgen. Hypni).

Tapeinodon Mitt, (fid. Lindb. Man. M. I, p. 47 in obs.) = SplachnoBRYUM.

TAXICAULIS C. M. Syn. $I I, p .277$ (subsect. HyPNi), postea gen. propr.

Spec. omn, non indicatae sunt IsOpterygia ejusd. nom. compressicaulis C. M. - Taxithelium.

nivescens C. M. p.p. - Rhaphidustegium.

TAXITHELIUM Spr. Catal. ; Mitt. M. austr, am. p. 496 (40 spec.). acuminulatum Jaeg. - T. planum var. acuminulatum.

afro-acuminulatum (C.M.) Par.

Hypnum afro-acuminulatum C. M. in Engler's Bot. Jahrb. 1883, p. 88 et in Forschungsreise... Bot. p. 64 .

1. Cortic. - Afr.: Tropic. occid. argyrophyllum Ren, et Card. in Bull. Soc, roy. bot. Belg. 1894, II, p. 131 et M. Masc. Mad. n. 140.

1. Lignic. - Afr.: Madagascar (Diego-Suarez). callicostelloides (C, M.) Par.

Sigmatella calticostelloides $C . M$. in Dusen $M$. Camer. $n$. a 18 . - Afr.: M. Cameroon.

capillipale (C.M.) Par.

Sigmatella capillipalis $C . M$. mss. - Pac. : Nov, Guinea (Onin).

compactulum (C. M.) Par.

Sigmatella compactula C. M. mss. - As.: Borneo.

compressicaule (C. M.) Broth. in Engler's Bot. Jahrb. 1897, p. 265.

Isopterygium compressicaulum Par. Index, p. 706.

Tasicaulis compressicaulis C. M. in Dusen M. Camer, n. 758.

1. Fr. ignot. Cortic. - Afr.: M. Cameroon. fraternum (Hpe.) Par.

Hypnum fraternum $H_{p e}, h b$. (nunc in hb. British Museum). - As, : Ins. Andaman.

(1) In Enum. Kindb. nom. nudum :

$\mathrm{S}$, recurvifolium $C$. $M$. 
glabratum Broth. et Geh, in Bull. hb. Boissier, 1896, p. 401. - Afr. : Congo.

glabrisetum (C. M.) Par.

Sigmatella glabriseta C. M. in Engler's Bot. Jahrb. 1896, p. 329. - Pac.: Ins. Samoa.

glabriusculum (C. M.) Broth. in Engler's Bot. Jahrb. 1897, p. 266.

Isopterygium anomalum ej. in Mitth, aus d. deutsch. Schutsgeb. 1893, 111 (nom.),

Sigmatella glabriuscula $C, M$. in sehed.

1. Fr. ign, Rupic. - Afr. : Liberia (Monrovia), Togo.

glaucophyllum Besch. Fl. bryol. Réunion, elc., p. 169.

1.

- Afr. : Madagascar, ins. Nossi Ke.

Guianae (C.M.) Par.

Sigmatclla Guianae C. M. in Malpighia 1896, p. 518.

- Am. merid. : Guian. britann.

hemicuspis (C. M.) Par.

Sigmatella hemicuspis C. M. in Dusen M. Camer: $n .800$. - Afr. : M. Cameroon.

impellucidum (C. M.) Par.

Sigmatella impellucida C. M. in Malpighia, 1896, p. 518.

- Am. merid. : Guian, britann.

leptopunetatum (C. M.) Broth. in Engler's Bot. Jahrb. 1897, $\rho .266$.

Sigmatella leptopunctata C. M. in sched.

1. Fr. ign. Rupic. - Afr. : Liberia (Monrovia).

leptosquarrosum (C. M.) Par.

Sigmatella leptosquarrosa C. M. in Hedwig. 1895, p. 129.

- Am. merid, : Reasil. or. (Goyaz).

leptustigmatum (C. M.) Par.

Sigmatella leptostigmata $C, M$. mss.

- Pac. : Nov. Guinea (Sorou).

micrangium (C. M.) Par.

Sigmatella micrangiı C. M. in Dusen M. Camer. $n$. i. - Afr.: M. Cameroon.

microthamnioides (C. M.) Par.

Sigmatella microthamnioides C. M. in Hedwig. 1897, p. 11 . - Am. merid. : Argentín. subtropic. (Shaco), nanangium (C. M.) Par.

Sigmatella nanangia $C . M$. mss. - Pac. : Nov. Guirea britann.

nossianum Besch. Fl. bryol Réunion, etc., p. 169.

I. - Afr.: Ins. Nossi Be.

Octodiceras (C. M.) Jaeg. All. 11, p. 489.

Hypnum Octodiceras C. M. in Linn. $1875, p .463$.

I. Cortic. - Afr. : Niam-Niam.

opacifolium (C. M.) Par.

Sigmatella opacifolia $C$. M. mss. - Pac.: Nov, Guinea (dndai). 
perminutulum (C. M.) Par.

Sigmatella perminutula $C$. M. in Dusen M. Camer. n. 475 , - Afr.: M. Cameroon.

perminutum (C. M.) Broth, in Engler's Bot, Jahrb. 1897, p. 267.

Sigmatella perminuta C. M. in Dusen M. Camer. n. 1030,

I. Rupic. - Afr.: M. Cameroon.

perplanicaule (C.M.) Broth. in op. cit. p. 26 .

Hypnum perplanicaule $C$. M. in Dusen M. Camer. $n$. 704; Par. Index, p. 667 .

Ster. Ad rup, in rivul, - Afr.: M. Cameroon.

planulum Besch. op. cil. p. 168.

1. Cortic. - Afr.: Ins. Mayotte, Nossi Be.

planum (Brid.) Milt. M. austr. am, p. 496.

Hjpnum concavum Hook. in Kth. Syn. pl. Equin. p. 63; Brid. Bryol. univ. $I I, p .501: C . M$. Syn. II, p. 261.

H. crassicollum Tayl. in Lond. Journ. of bot. 1847, p. 337; C. M. op. cit. p. 313 .

H. planum Brid. Sp. M. 11, p. 97 et Bryol. univ. II, p. 394; C. M. op. eit. p. 264 .

Leskea Omalia cy...bifolia Brid. Bryol. univ. II, p, 333.

L. subpinnata ej. op. cit. p. 287 p.p.

Stereodon planus Mitt, in Journ. of the Linn. Soc. 1863, p. 157.

1. Lignic, et rupic. - Afr.: Niger (fid. Mitt.). Am. sept.: Florid, Panama, Antill. omn. Am. merid. : Orinoc., Guian., Amazon., And. Quitens, et Peruv., Brasil.

- var. acuminulatum (Hsch.) Par.

Hypnum planum Hsch. Fl. Brasil. 1, p. 76.

H. planum $\beta$ acuminulatum C. M. Syn. II, p. 265.

Taxithelium acuminulatum Jaeg. Ad, II, p. 489.

- Am. merid. : Amazon.

"var. distichum Besch, Fl. bryol, Antill. fr. p. 81.

- Am. sept. : Guadalup., Martinic.

"var. flavescens $(C, M$, $)$ Par.

Hypnum planum var. flavescens $C$. M. op. et $l$. ec.

- Am. merid. : Ins. Trinitat.

polystictum (Hook.) Jaeg. Ad. 1I, p. 489.

Hypaum polystictum Hook. f. Handb, of the N. Zeal. Fl. p. 482.

Ster. Ad Lichenes (Stictas). - Pac. : Nov. Zeland. sept.

pseudo-acuminulatum (C.M.) Par.

Sigmatella pseudo-acuminulata C. M. in Bull. hb. Boissier, 1897, p. 214.

Aquat. ? In silv. primaev. - Am. sept. : Guatemala.

Quelchii (C.M.) Par,

Sigmatella Quelchii C. M. in Malpighia, 1896, p. 519.

- Am. merid.: Guian, britann.

ramivagnm (C. M.) Broth in Engler's Bot. Jahrb. 1897, p. 266.

Isopterygium ramivagum C. $M$, in Dusen $M$. Camer. n. 797 ; Par. Index, p. 740 .

Ad ramul, - Afr, : M. Cameroon. 
rotundatulum (C. M.) Broth, in op. cit.p. 265.

Sigmatella rotundatula C. M. in Dusen M. Camer. n. 703.

1. Ad rad. arbor. - Afr. : M. Cameroon.

Schweinfurthii (C. M.) Jaeg. Ad. II, p. 489.

Hypnum Schweinfurthii C. M. in Linn. 1875, p. 462.

1. Terr, - Afr. : Niam-Niam.

scutellifolium Besch. Fl. bryol. Réunion, etc., p. 170.

1. Terr. - Afr, : Madagascar, ins. Nossi Comba.

stigmopyxis (C. M.) Par.

Stigmatella stigmopyxis C. M. in Nuov. Giorn. bot. ital. 1897, p, 15.

1. - Am. merid. : And. Boliv.

subjulaceum Besch, in sched.

- Am. sept. : Guadalup.

subscabrellum (C. M.) Par.

Stigmatella subscabrella $C$. M. in sched.

Ster. $\quad-A s$. : Sumatra sept. occ.

tenuisetum (Sull.) Mitl. Fl. Vit. p. 397.

Hypnum tenuisetum Sull. in Proced. Am, Acad... III.

Trichosteleum tenuisetum Jaeg. ad. II, p. 480.

- Pac. : Ins Samoa.

trichochrete (C. M.) Par.

Stigmatella trichochaete C.M. in sched.

- As. : Ins. Andaman.

? variegatum (Welwo ét Duby) Jaeg. op. cit. p. 489.

Hypnum ? variegatum $W$, et $D$. in Mem..., Genève, 1871, $p .12, t .4, f .4$.

2. Palud. - Afr, : Angola.

Zürnianum (C. M. et Schlieph.) Par.

Hypnum Zürnianum C. M. et Schlieph, in sched.

- Pac. : Ins. Auckland.

TAYLORIA Hook, in Journ. of Sc. and Arts, III, p. 144 (emend) (18 spec.).

Spec, omn, non indicatae sunt Dissodontes ejusd. nom.

acuminata Hsch. -- T. splachnoides.

Boryana Mitt. - Dissodon borbonicus.

Cochambae C. M. in Nuov. Giomo. bot. ital. 1897, p. 11.

- Am. merid. : And, Boliv.

cuspidata Hartm. - T, splachnoides var. angustifolia.

Delavayi Besch, in Ann. Sc. nat. 1892, I, p. 59.

I. In silvis. - As. : Yunnan.

Jamesoni (Tayl.) C. M. Syn. I, p. 135 ; Mitt. M. austr. am. p. 249.

Brachymitrium Jamesoni Tayl. in Lond. Journ. of bot. 1846, p. 44; Wils. in eod, op, p. 448, $\iota$. XV A.

T. limbata Spr, in Journ. of the Linn. Soc. V, p. 47.

- Am. merid. : And. Quitens.

Kilimandscharica Broth. in Engler's Bot, Jahrb, 1897, p. 242.

2. Ad Senecion. Johnstoni, - Afr. : Kilima N'Djaro. 
laciniata Spr, in Journ. of the Linn. Soc. V, p. 48; Mitt. op. et l. cc. Cortic, $-A m$. merid, : And, Quitens.

limbata Spr. - T. Jamesoni.

lingulata Lindb. - Dissodon splachnoides.

Mandoni C. M. in Nuov. Giorn. bot. ital. 1897, p. 11.

Brachymitrium Jamesoni W. P. Sch. in Mandon Pl, Boliv, n. 1644.

Ad arbor. - Am, merid. : And. Boliv.

Moritziana C. M. Syn. I, p. 134; Mitt. op. cit. p. 250.

Lignic. - Am. sept. : Costa Rica. Am. merid.: And. nov. Granat., Quitens, et Boliv.

« var. carbonaria C. M. in Linn. 1878-79, p. 463.

- Am. merid. : Venezuela.

obliqua Sendtn. - T. splachnoides.

obtusissima Broth. in Engler's Bol. Jahrb. 1895, p. 62.

2. Ster. $\quad$ - Pac. : Tasman.

orbispathulata C. M. in Dusen M. Camer. n. 230.

- Afr. : M. Cameroon.

papulata C. M. in Bot. Zeit. 1868, n. 47, p. 48.

Lignic. - Am. merid. : Chile.

parvula Phil. et Amann, in Rev. bryol. 1889, p. 56.

2. Humic. in silv. - Eur. : Alp. Rhaet.

pichinchensis C. M. Syn. I1, p. 549.

Weisia Jamesoni Tayl. in Lond. Journ. of Bat. 1847, p. 330.

- Am. merid. : M. Pichincha.

Raineriana de Not. - T. splachnoides var, obtusa.

Rudolphiana (Bryol. germ.) Bryol. eur. 111 (mon. p. 10), t. 287: C.M.

Syn. I, p. 136 el II, p. 550; W. P. Sch. Syn. II ed. p. 362.

Eremodon Rudolphianus Bryol. germ. I1, p. 176, t. 40.

Syn. et polyg. Ad Acer. et Fagos muscos. - Eur.: Alp. Salisb., Austr. super., Bavar., Carinth., Helvet.

serrata (Hedio.) Bryol. eur. III (mon. p. 6), t. 284; C. M. Syn. I, p. 133;

W. P. Sch. op. cil. p. 359. Splachnum serratum Hedw. Sp. M. p. 53. t. 8; Brid. Bryol. univ. I,
p.245.

Syn, et polyg. Ad terr. stercore vaccino conspurcatam. - Eur. : In silv. Aces: reg. subalp. per tot. Alp. zon. intermed; deest in Britann. et in Scandil. Am. sept. : Terr. nov., Oregon, Columb. brit., Washíugton, Vaucouver, Alaska, M, Calif.

E.xs.: Mac. Canad. M. n. 140.

Rab. Bryoth, eur. n. 612.

"var. flagellaris (Brid,) Bryol. eur. l. c. t. 285 ; C. M. op. et l. ce.

Splachnum flagellare Brid. op. eit. p. 247.

Spl. helveticum Schleich. Centr. II, n. 9.

Spl. serratum Sehwaegr. Suppl. I, I, p. 49 p.p.

Spl, tenue var. flagellare Roehl. Deutseh. Fl. III, p. 43.

In humid. valde umbrosis. - Eur.: Cum typ. Am. sept. : Cum typ.; Groenland.

var, tenuis Bryol. eur. - T. tenuis. 
spathulata (Hook. f. et Wils.) C. M. Syn. I, p. 134.

Eremodon spathulatus $H$. f. et W. in Lond. Journ. of bot. 1846, p. 448, t. XV B.

- Am. merid. : Absque loco.

splachnoides (Schleich.) Hook. in Journ. of Sc. and Arls, I11, p. $144 \mathrm{el}$ M. ex. t. 173 ; Brid. Bryol. univ. 1, p. 266 ; Bryol. eur. III (mon. p. 8), t. 286; C. M. Syn. I, p. 136; W. P. Sch. Syn. II ed. p. 361.

Hookeria splachnoides Schleich, in Brid l,c, et Sohvoaegr. Suppl. I, II, p. $340, t, 100$.

T. acuminata Hsch, in Fl., 1826, $I, p .78$ (1).

T. obliqua Sendtn. in sched.

Syn, et polyg. Lignic, et ad terr. humidiusc. substant. animal. imbibit. - Eur.: Reg. subalp. zon. intermed. et sept.: deest in Britann. Am sept. : Gaspesia, Nevada, Columb. brit., M. Rupestr., M. Humboldt.

Exs.: Drumm. M. bor. am. I ed. n. 47.

" var. angustifolia Bryol. eur. l.c.

T. cuspidata Hartm. Fl. Skand.

1. splachnoides var. apiculata ej. postea.

T. splachnoides var. cuspidata C.M.l.c.

- Eur. : Alp. Norveg.

var. apiculata Hartm.
var. cuspidala C. M.

\& var, obtusa Bryol, eur, et C.M. $l l . c c$.

Raineria splachnoides de Not. Syll. M. p. 275.

T. Raineriana ej. Epil. p. 472.

- Eur. : Ad limit. super. silvar.

tenuis (Dicks.) W. P. Sch. Syn. II ed.p. 360.

Grimmia splachnoides $S m$. Fl. brit. III, p. 1197.

Splachnum attenuatum Brid. Bryol. univ. I, p. 248.

Spl, lingulatum Hoffm. Fl. Germ. p. 23, n, 4 .

Spl. longicollum Dicks. Fasc. Pl. crypt. IV, t. 10, f. 9.

Spl. ovatum Schleich, in sched.

Spl. parpureum With. Arrung. p. 794, t. 18, f. 9.

Spl. serratun Schwaegr, Suppl. I, I, p. 49 p.p.

Spl. tenue Dicks. op. cit. 11, p. 2.

T. serrata 8 tenuis Bryol, eur. l. c.; C. M. op. cit. p. 133.

Syn. et polyg. Ad terr. humid. praepr. turfos. - Eur. : Scot., Scandin., et per tot. Alp. jugum. Am. sept. : Groenland, Nov. Scotia, New Brunswick, Gaspesia, Montana, Vermont.

Exs. : Mac. Canad. M, n. 141.

Uleana C. $M$. in Hedwig. $1895, p .126$.

2. Cortic. - Am. merid. : Brasil, or. (Goyaz.).

TEICHODONTIU M C. M. in Nuov. Giorn, bot. ital. 1897 , p. 119 (I spec.). Rusbyanum C. $M$. in op. et $l$. cc.

Macromitriuin Rusbyanum Dna E. G. Britt. in Bull. Tor\%. bot. Club, Decembr. 1896.

- Am. merid. : And. Boliv.

TETRACMIS Brid. Bryol, univ. 1, p. 129 int. syn. (= TETraphis).

(1) Cf. Lindb. in Rev, bryol, 1884, pp. 17-18 et Aman op, cit. 1889, p. 56. 
TETRAGOGINODON (I) Rob. Br, in Trans, of the N. Zeal. Inst. 1896, pp, $551-553$ (l spec.).

Hectori ej. in op. et $l$. cc.

Ad rup. calcar. - Pac. : Nov. Zeland.

TETRAPHIS Hedw. Fund. M. II, p. 87, t, 7, f. 32 (2 spec ).

Brovniana Brid, - Tetrodontium.

cylindrica Voit. - T, pellucida.

geniculata Girgens. mss. ; Milde in Bot. Zeit. 1865, p. 155; W. P. Sch. Bryol. eur. Suppl. Tetraphis, p. I, t. I.

Georgia geniculata Lindb. Contrib. ad fl. crypt. As. bor. or. 1872, p. 239.

Lignic. - As. : Japon,, Saghalien, Amour. Am. sept.: Terr. nov.? Idaho, Oregon, Columb. brit., Washington, Vancouver, Sitka.

Exs. : Mac. Canad, M, n. 442.

oblonga Turn. - T. pellucida.

ovala Funk. - Tetrodontium Brownianum.

pellucida (L.) Hedro. Sp. M. p. 43, t. 7, f. I a-f; Brid. Bryol. univ. I, p. $134 ;$ Bryol. eur. II, t. 196.

Bryum diaphanum Web, Spic. Fl. Goett. p. 190.

Br. pellncidum Abbot Fl. Pedf. p. 237.

Georgia Mnemosyna Ehrh, Hann. Mag. 1780, p. 931; C. M. Syn. I, p. 182.

G. pellucida Rab. Deutsch. Kryptfl. II, III, p. 231, n. 6470.

Mnium pellucidum $L . S p, p l . p .1574$.

Mn. Serpylli foliis tenuibus pellucidis Dill. Hist. M. p. 232, t. 31, f. 2 (fid. C. M.).

T. cylindrica Voit. M. Herbip. p. 17, n. 1.

'T. oblonga Turn. Musc, hibern. p. 12.

1. Lignic., rupic. et ad terr. turfos. in silv, - Eur. : E reg. campestr. usq. in alp. As. : lenissei, Obi, Caucas. occ. et centr. Am. sept. Labrador, Athabasca, Saskatchewan, Vancouver, Canad. tot., Terr. nov., ins. Miquel., reg. bor.. or., centr. et occ.

Exs. : Drumm. M. bor, am. I ed. n. 31 et II ed. n. 26.

Mac. Canad. M, n. 136.

Rab. Bryoth, eur. n. 457.

Sull. et Lesq. M, bor. am. II ed, n. I61.

* var. obtusifolia Kindb. in Hedwo. 1896, p. 66 (nom.).

- Am. sept. : Washington.

repanda Funk. - Tetrodontium.

rigida Hedw. f. - Tetrodontium Brownianum.

TETRAPLODON Bryol, eur. I1I (8 spec.). angustatus (L.f.) Bryol. eur. III (mon. p. 4), t. 228; C. M. Syn. I,
p. 130 .

Pycnapophyscium angustatum Rehb. Ic. orypt. Pycnapophyscium angustatum Rehb. Ic. orypt.
Splachnum angustatum L. f. Desc, meth. M. p. 33; Brid. Bryol, univ. I,
p. 248.

Spl. setaceum Mich. Fl. Am. bor. II, p. 788; Brid. op. cit. p. 250. 
1. In animal. carnivor, excrement. et murium cadav. - Eur, : Rar. in reg. subalp. tract. Alp., copiose in reg. silvat. et turf. Lappon., Scandin., Scotiae, Sudet. Am sept : Vulgatiss, in reg. arctic. et sept. ; Terr. nov., M. Alb. et Adirondack, lac. Super.

Exs, : Drumm. M, bor. am. I ed, n, 42 (Splachnum).

Mac. Canad. M. n. 142.

Rab. Bryoth. eur, n. 1267.

Sull. et Lesq. M. bor. am. II ed, n. 228.

«var. Anzei de Not. Epil.

Ad Larices. - Eur. : Ital. super.

"var. latifolius Lindb. et Arn. M. As. bor. 1890, II, p. 61. - As. : Ienissei infer.

australis Sull. el Lesq. M. bor. am. I ed. n. 151 ; Sull. M. of U. St. p. 53, Ł. 4 et Ic. M. p. 97, t. 58; Lesq. et Jam. Man. p. 192.

Spl. setaceum H. f. et W. in Drumm. M. bor. am. 11 ed. n. 27.

1. In palud. et ad sterc. mulorum. - Am. sept. : Nov. Scotia; a New Jersey ad Florid.

Exs. : Sull. et Lesq. M. bor. am. II ed, n. 227.

Brenoerianus de Not. - T. mnioides var, Brewerianus,

bryoides Lindb. - T. mnioides.

fuegianus Besch. in Bull. Soc, bot. Fr. 1895, p. 64 et in Miss. sc. Cap Horn, $\boldsymbol{V}$, Bot. p. 281, t. 4, f. 14.

1. $\quad-$ Am. merid. : Patagon. austr., terr. Magell.

mnioides (L. f.) Bryol. eur. III (mon p. 5), t. 289 ; C. M. Syn. I, p. 130.

Phascum mnioides L. f. Melh. M. p. 6.

Ph. pedunculatum L. Syst. veg. p 944.

Splachnum arcticum $R$. B̈r. Fil. ins. Melville, p. 301.

Spl. bryoides Zoega Fl. Island p. 239?

Spl. exsertum $R$. Br. l. c.

Spl. mnioides Hedw. M. frond. II, p. $35, t . I I$; Brid. Bryol. univ, I, p. 240.

Spl. propinque a R. Br. l.c.

T. bryoides Lindb. M. Scand. p. I9.

1. In Alp. reg. silvat. et turfosis, nec non in sterc. animal. - Eur.: Spitzberg, ins. Ursor., Scand., Scot., Angl., Hibern., Alp. Salisb., Helvet.; Sudet., Belg. As.: Kamschatka, penins. Tchutschica, Ienissei inf., Japon., Alp. Yunnan, Sikkim. Am. sept. : Groenland, fret. Smith, Labrador, Terr. nov., ins, Miquelon; a New Bruns wick usq. ad m. Behring; Columb. brit., M. Rupestr., Washington, Vancouver, Sitka, M. Adiroudack, Alb. et Catskill.

Exs.: Drumm. M. bor. am. I ed. n. 40 et 41 (Splachnum).

Mac. Canad, M. n. 143.

Sull. et Lesq. M. bor. am, 11 ed, n. 229 ,

* var. Adamsianus (Hsch.) Bryol. eur. el C. M. Il. cc.

Splachnum Adamsianum Hsch. in Hor. phys. Berol. p. 58, t. 12; Brid. Bryol. univ. I, p. 250.

Spl. paradoxum Adamsianum R. Br. l. c.

Ut typ. - As. : Aretic. Am. sept. : Arctic.

« var. Brewerianus (Hedvo.) Bryol. eur. el C. M. Ul. co.

Bryum ampullaceum, foliis et ampullis angustioribus Dill Hist. M. p. 345, t. $44,1.5$.

Br. canescens Vill. Pl. Dauph. III, p. 883?

Splachnum Brewerianum Hedw, M. frond. p. 105, t. 38 ; Brid. Bryol. univ, I, $p .251$. 
Spl. canescens P. B. Prodr. p. 88 ?

Spl. fastigiatum Dicks. Fasc. Pl. crypt. III, p. 2.

Spl. mnioides $\beta$ majus $H$. et $T$. Muscol. brit. p. 20.

T. Brewerianus de Not. Epil.p. 466.

Locis humidior. - Eur. : Ubi typ. Am. sept. : Copiose in arctic.

«var. cavifolius W. P. Sch. Syn. 1 ed. p. 304 et 11 ed. p. 365.

Splachnum urceolatum Hedw. M. frond. II, p. 39, t. 13; Brid. Bryol. univ. $I, p .242$ p.p.

Ut typ. - Eur. : Scandin. As.: Aretic, Am. sepl. : Aretic.

Mülleri Arn. et Lindb. - Krauseella tchutschica.

pallidus Hagen in Det Kong. Norske Vid. Selsk. Skrift. 1893, p. 75.

- Eur. : Scandia.

tasmanicus Hpe. in Linn. 1876, p. 302; Weymouth in Pap. and Proced. of the roy. Soc. of Tasman. 1894-95, p. 206-207 (descript. locupletior).

Splachnum Gunnii (fid. Mitt.) (1).

$$
\text { - Pac. : Tasman. }
$$

tchutschicus C. M. in Bot. Centralbl. I883, n. 2-4.

1.

- As. : Penins. Tchuschica, perrar.

tchutschicus Lindb. - Krauseella.

urceolatus Bryol. eur. III (mon. p. 7), ı. 290; C. M. Syn. I, p. 13I.

1. Locis gramin. apric. ventis verberat. - Eur. : Summ. Alp. Helvet.,

Bavar., Carinth., Stir., Salisburg. ; deest in Scandin. et in Britann. As. : Sikkim, Caucas. Am. sept Labrador, summ. M. Rupestr., fret, Kotzebuë, mar. Behring, Colorado.

Exs, : Drumm. M. bor. am. I ed. n. 38 (Splachnum).

Rab. Bryoth. eur. n. 65 b.

Wormskioldii Lindb. - Splachnum.

TETRAPTERUM Hpe. in litt. ad C. M. Syn. I, p. 29 (I spec.).

australe $\mathrm{H}$ pe. - T. capense var. cylindricum.

capense Hpe. mss. ; Jaeg. M. Cleist. p. 26.

Phascum tetragonum Harv, in Hook, bot. Mise I, p. 124, t. 31 ; C. M. I. c. et $I I, p .521$.

2.

Exs. : Rehm. M. Afr. austr. n. 76.

* var. cylindricum (Tayl.) Par.

Astomum cylindricum Mitt. in Journ, of the Linn. Soc. 1859 , p. 70.

Phascum cylindricum Tayl. in Lond. Journ, of bot. 1846, p. 42.

$\mathrm{Ph}$. tetragonum var. cylindricum $C, M . l$. $c$.

T. australe Hpe, in Linn. 1853, p. 489.

T. cylindricum Joeg. M. Cleist. p. 27.

- Pac. : Austral. or., Tasman.

cylindricum Jaeg. - T. capense var. cylindricum.

Tetrastichium Mitt. M, austr. am. p. 359 (sect. LePIDOPILI).

(1) " Tetraplodon tasmanious a Splachno Gunnii foliis integerrimis jam recedit! " Geh. in Rer, bryol. 1897, p. 70. 
TETRODONTIUM Schwaegr. Suppl, II, p. 102 (2 spec.).

Brownianum (Dicks.) Schwaegr. Suppl. I1, p. 102, t. 128 ; Bryol. eur. 11 (mon. p. 4), t, 197.

Bryum Brownianum Dicks. Fase. Pl. erypt. IV, p. 7, t. 10, f.' 16.

Georgia tetrodontia C. M. Syn. I, p. 181 .

Grimmia Browniana Engl, Bot. t. 1422.

Ortholrichum Brownianum Sm. Fl. brit. III, p. 1269.

Tetraphis Browniana Brid. Rryol. univ. I, p. 133.

T. ovata Funk in Hoppe Deutsch. Tasehb. 1802, p. 41; Brid. op, oit. pp. 131 et 762.

T. rigida Hedwo, f. Obs. bot. Fasc. I, p. 7, t. 2.

Tetrodontium ovatum Schwaegr. op. cit. p. 101 .

T. Brownianum $\beta$ rigidum Jur. Laubm. Oester, Ung. p. 222.

T. varium $\left\{\begin{array}{l}\alpha \text { foliatum } \\ \beta \text { frondiferum }\end{array}\right\} \begin{gathered}\text { Lindb. in Defv. Vet. Ak. Foerh. 1863, p. 414, } \\ n, 60 \text { et } p, 415 .\end{gathered}$

1. Ad rup. quarz. madid, praepr. ad pariet. vertical. vel terram spectant. - Eur. : Britann, Scandin., Sudet,, Bohem., Harz, Thuring., Voges., Pyren.

Exs.: Rab. Bryoth, eur, n. 657.

var. repandum $\mathrm{H}$ pe. $-\mathrm{T}$. repandum.

var. rigidum Jur. - T. Brownianum.

ovalum Schw. - T. Brownianum.

repandum (Funk). Schwaegr, et Bryol, eur. ll, cc.

Georgia Browniana $\beta$ repanda Lindb. in Notiz... 1867, p. 153.

G. repanda C. M. Syn. I, p. 181.

Tetraphis repanda Funk in Sturm Fl. germ. crypt. II, fasc. 17; Brid. Bryol. univ. I, p. 132.

Tetrodontium Brownianum var. repandum Hpe. in Flora 1837, $I$, p. 280.

T. varium $\gamma$ flagelliferum Lindb. in Oefv. Vet. Ak. Foerh. 1863, p. 415.

1. Ad saxa aren. vel granit. humida. - Eur.: Siles., Sudet, Beskides, Tatra, Salisb., Stir., Helvet., Hercyn., Arvern., Pyren. As. : Caucas. centr. Ain. sept. : Perrar. : M. Alb.

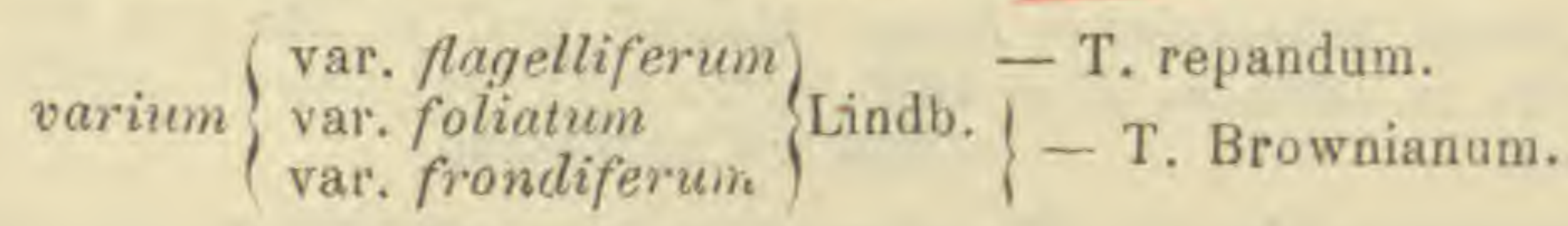

THAMniEli,A Besch. Fl. bryol. Nov. Caled. p. 239

? Arbuscula Besch, - Camptochaete.

divulsa

porotrichoides Besch. - Lembophyllum.

? pulvinata Besch. - Camptochaete.

vaga Besch. - Lembophyllum (1).

THAMNIOPSIS Mitt. M. austr, am. p. 365 (subsect. HoOKERI E) ; C. M. in Linn. 1878-79, p. 408 (sect. Porotitcti), in Rehm, M. Afr. austr. gen. proprium .

(1) In Enum. Kindb. nom, nuda :

Th. brisbanica C. $M$.

Leichhardti Hpe. et C. M. (an Ptychomnion Leichhardti ?).

Schlosseri C. M. (an Rigodium Schlosseri ?). 
THAMNIUM Bryol, eur, V (39 spec.).

Spec. omn. non indicatae sunt Porotricha ejusd. nom. africanum (Welvo, et Duby) Jaeg. Ad. 11, p. 216.

Hyprum africanum $W$. et $D$. in Mém... Genève, 1871, $p, 12, t .3, f .4$.

Ster. Ad arbor, - Afr.: Ins. S. Thom., Angola.

alleghaniense (C. M.) Bryol. eur. V (mon. p. 4); Lesq. et Jam. Man. p. 362 .

Hypnum alleghaniense C. M. Syn. 1I, p. 502 ; Sull. Ic. M. p. 161, t. 103.

H. neckeroides H. $f$. et W. in Drumm. M. bor. am. II ed. n. J19.

1. et syn. Ad saxa ir ror. - Am. sept.: Nov, Scot., Ottawa, Ontario, Pensilv., Ohio, Missouri, Arkansas.

Exs.: Mac. Canad. M. n. 302.

Sull. et Lesq. M. bor. am. II ed. n. 422 .

alopecurum (L.) Bryol. eur. l. c. t. 518; W. P. Sch. Syn, II ed. $p, 688$.

Hyprium alopecurum L.Sp. pl. p. 1594; Brid. Bryol. univ. 1I, p.444; C. M. Syn. II, p. 501 .

H. Arbuscula Brid. M. Rec. II, II, p. 96.

$\mathrm{H}$. dendroides, obscurius, setis et capsulis brevioribus subnutantibus Dill. H. M. p. 315, t. $41, f .49$.

H. neckeroides Mac. Canad. M. n. 445.

Isothecium alopecurum Spr. M. Pyren, n. 82 et in Ann, and Mag. nat. hist. 1849.

Porqtrichum alopecurum Mitt. M. austr, am. p. 467.

2. Ad spelunc. pariet. humid., terr. et rup. unbros. tam quarz. quam ealcar. - Eur, : Reg. campestr, et mont. totius, aretic, except. As.: Japon., Himalaya sept. occid,, Pers., Caucas. Afr.: Septentr., ins. Azor., Canar, Madeir. Ans, sept. : Columb. brit.

Exs. : Faurie, Pl. Jap. n. 304, 504.

Mandon, Pl. Madeir. n. 42 bis.

Rab. Bryoth, eur. n. 292, 902 a, b.

var. elongatum Husn, - Th. alopecurum var. protensum.

"var. Lemani Schnetaler in Husn. Muscol. gall. p. 348 et in Bot. Centralbl. $n .1885, n .37$ et $1886, n .7$.

Submers. - Eur. : Lac. Leman.

var. pendulum Mdo. - Th. alopecurum var. protensum.

" var. protensum Turn, Muscol. Hibern. p. 163.

Th. alopecurum rar, elongatum Husn. Muscol, gall. p. 348.

Th. alopecurum $\beta$ pendulum Mrlo. Bayer. Laubm. p. 221.

Ad cataractas. - Eur. : Passim.

andinum W. P. Sch. in Mandon Pl. Boliv. n. 1712.

- Am. merid. : And. Boliv.

angustifolium Holt in Journ. of bot. 1886, p. 65.

Ster. In calcar. - Eur. : Anglia (Derbyshire).

arbusculans (C. M.) Jaeg. Ad. II, p. 216.

Hypnum arbusculans $C$. M. in Linn., 1874, p. 618 .

2.

- Am. sept. : Chile.

arcuans (Mitt.) Jaeg. Ad, II, p. 215.

Neckera arcuans Mitt. M. Ind. or. p. 123.

1.

- As. : Sikkim, M. Neilgherr. 
Bigelowii (Jaeg.) Ad. 11, p. 731; Lesq. el Jam. Man. p. 362.

Eurhynchium Bigelowi Jaeg. op. cit. p. 418.

Hypnum Bigelowii Sull. in Pacif. R. B. IV, p. 189, t. 9 .

2.

M. Calif.

- Am. sept. : Vancouver, Columb. brit., Oregon,

Exs. : Mac. Canad. M. n. 303 (Hypnum).

complanatum W. P. Sch. in Breulel M. Capens.

- Afr.: C. B. Sp.

confertum (Mitt.) Par.

Porotrichum confertum Mitt. in Voy. H. M. S. Challenger, 11I, p. 81.

Ster. Ad arbor. - Am. merid. : Ins. Juan Fernandez.

decolorans (Welw. el Duby.) Jaeg. Ad. 11, p. 216.

Hypnum decolorans W. et D. in Mém.... Genève, 1871, t. 3.

Speluncic. - Afr.: Angula.

decumbens Besch, in Bull. Soc. bot. Fr. 1885, p. 67 et in Miss, sc. Cap Horn, V, Bol. p. 294, t. 5, f. 18.

Ster. - Am. merid.: Terr. Magellan.

Duthiei C. M. in sched.

Ster.

- As. : Himalaya sept. occid.

eflagellare Angstr. in Oefv. . 1872, n. 4, p. I3 (sub. Th. flagellare: $c$. err. in op. cil. 1873, n. 5, p. 15l).

2. Lignic. - Pac. : Austral. or. (Nov. Vales.).

fluviaticum C. M. in Dusen M. Caner, n. 787 .

- Afr.: M. Cameroon.

Hildebrandti (C. M.) Besch. Fl. bryol. Réunion, etc., p. 135.

Hypnum Hildebrandti $C$. M. in Linn. 1876, p. 287.

Ad saxa irror. - Afr. : Kilima N'Djaro, Usambara, ins, Anjonan, Mayotte, Mascaren.

latifolium Bryol. jav. II, p. 69, t. 188.

- As. : Sumatra.

Leibergii (Dna E. G. Britton) Ren. et Carl. M. Am, sept. p. 55.

Hypnum Leibergii Dna E. G. Br. in Bull. Torr, bot. Club, 1889, p. 111.

2. Ad Quarzit. - Am, sepl. : Idaho, Washington.

Ieptopteris C. M. in Dusen $M$. Camer, n. 239.

- Afr. : M. Cameroon.

lombrophyllaceum C. M. in Nuov. Giorn. bol, ilal, 1897, p. 150.

- Am. merid. : And. Boliv.

miero alopecurum Kindb. in Rev. bryol. 1895, p. 81.

Ster.

- Am. sept. : Oregon.

Mcenkemeyeri (C. M.) Par.

Hypnum Monkemeyri C. M. in Flora, 1886, p. 517.

Ster.

- Afr.: Ins. Fernando Po.

Molleri (C. M.) Par.

Hypnum Molleri C. M. in Fl. 1886, p. 284.

Ster. Terr. - Afr, : M. Cameroon, ins. S. Th $\cdot \mathrm{m}$. 
neckeroides (Hook.) Bryol. eur. V (mon. p. 4).

Hypnum Neckera Schwaegr. Suppl. III, 1I, II, t. 288.

H. neckeroides Hook. M. ex. t. 58; C. M. Syn. II, p. 502.

Isothecium neckeroides Brid. Bryol. univ. II, p. 373.

2. - Am. sept.: Columb. brit., Washington (1). Am. merid. : Chile. Pac. : Nov. Zeland.

Eas. : Lechler, Pl. Chil. n. 631.

obtusatum (Lindb. et Arn.) Par.

Porotrichum obtusatum L. et A. M. As. bor. 1890, II, p. 158.

Ster. Ad arbor. - As. : lenissei med.

pandum (Hook. f. et Wils.) Jaeg. Ad. 11, p. 216.

Isothecium pandum $H$. $f$. et $W$. Fl. of the N. Zeal., t. 89, f. I.

Arbor. et rupic. - Pac. : Nov. Zeland. bor. et med, Austral. or. (Queensland, Nov. Vales.).

parvulum (Mitt.) Jaeg. op. cit. II, p. 215.

Neckera parvula Mitt. M. Ind. or. p. 123.

Ster.

- As. : M. Neilgherr.

perpusillum C. M. in Rev, bryol. 1877, p. 43 (nom.).

- Pac. : Austral. or. (Nov. Vales.).

planissimum C. $M$. in Dusen $M$. Camer, n. 20 .

- Afr. : M. Cameroon.

plicatulum Sande Lac, in Miq. Aus, bot. Lugdun. Balav. II, p. 299.

Porotrichum plicatulum Mitt. in Trans. of the Linn. Soc. 1891, p. 175. - As. : Japon.

profusum C. M, in Dusen M. Camer. n. 224 a.

pumilum (Hook. f. et Wils.) Par. - Afr. : M. Cameroon.

Isothecium pumilum H. f. et W. Fl. Tasman. II, p. 206, t. 175, f. 7.

Microthamnium pumilum Jaeg. Ad. II. p. 492.

Neckera rivalis Mitt. in Journ. of the Linn. Soc. 1859, p. 89.

2. Rupic. - Pac. : Austral. or. (Nov. Vales.), Tasman.

Sandei Besch. Fl. bryol. Japnn, p. $38 \mathrm{I}$.

Isothecium subseriatum Lindb. in Act. Soc. sc. Fenn. 1872, p. 231.

Neckera subseriata Dz. et Mk. in Herb. Mus. Lugd. Batav.

Porotrichum subseriatum Mitt. in Trans. of the Linn. Soc. 1891, p. 175.

Thamnium Yokohamae? C. M. in $h b$. Sb.

Th. subseriatum ej, in Journ. of the Limn. Soc. 1865, p. 155; Sande Lac. in Prolusio Fl. Jap.

I.
Exs. : Faurie Pl. Japon. n. $45,68,82,215$.

Savatier PI. Japon. n. 689.

scariosum Broth. in Engler's Bot. Jahrib. 1897, p. 256.

2. $\quad$ Afr.: Orient. german.

Schmidii (C. M.) Jaeg. Ad. $I I, p .215$.

Hypnum alopecurum Mont, in Perrottet M. Neilgh.

H. Schmidii C. M. in Bot. Zeit. 1854, p. 574.

Neckera Schmidii Mitt. M. Ind. or. p. 123.

2.

- As. : M. Neilgherr.

(1) Sec. Ren. et Card, in Obs. 1894, Th. Leibergii. 
serpenticaule $C . M$. in Dusen $M$. Camer, $n, 102$.

- Afr. : M. Cameroon.

subfasciculatum C. M. in Ule Bryoth. brasil. $n$. I82.

Ster.

- Am. merid. : Brasil, austr. or.

subseriatum Mitt. - Th. Sandei.

subserratum (Hook.) Besch. Fl. bryol. Japon, p. 382.

Hypnum subserratum C. M. Syn. 1I, p. 228.

Neckera subseriata Hook. Io, pl, rar. $t, I, f .7$.

N. subserrata ej. in Lond. Journ. of Bot, 1810, II, p. 13: Mitt. M. Ind. or. p. 122.

Rupic. - As. : Nepal,, Simla, Sikkim, Himalaya sept. oecid.

tenerascens Burch. in Pap. and Proced. of the roy. Soc. of Tasman.

$1893, p .204$ (nom.). - Pac. : Tasman.

thyrsodes C. M. in Nuov. giorn, bot. ital. 1897, p. 149.

Th. andinum $W . P . S c h . ?$

2 ?

- Am. merid. : And. Boliv.

Yokohamae C. M. - Th. Sandaei?

THEDENIA Bryol, eur. I ( 1 spec.).

suecica Bryol. eur. l. c. t. 454 ; W. P. Sch. Syn. II ed. p. 591 (1).

Hypnum suecicum Hartm. Skand. Fl. VI ed. p. 358.

Pylaisia suecica Lindb. Man. M. 1, p. 70.

Stereodon suecicus ej. M. Scand. p. 38.

1 .

- Eur.: Suec, Norveg.

«var. compacta (Lindb.) Jaeg. Ad. I1, p. 737.

Pylaisia suecica var. compacta Lindb. op. et 7 . oo.

Rupic. - Eur. : Lappon.

THELIA Sull. Ic. M. et M. of U. St. (5 spec.).

asprella (Schwaegr.) Sull. 1c. M. p. 129, t. 81 et M. of U. St. p. 60 ; Lesq. et Jam. Man. p. 299.

Brachythecium asprellum Jaeg. Ad. II, p. 398.

Hypnum asprellum Schwaegr. Suppl. I, II, p.246; Brid. Bryol. univ. II, p. 480 .

H. hirtellum $\beta$ furcatum C. M. Syn. II, p. 469 .

H. pseudo-plumosum ej. op. cit. p. 352 p.p.

Leskea asprella Bryol. our. V (mon. p. 2).

2. Ad rad. arbor. - Am. sept. : Lac. Erie, reg, sept., centr. et occ.; Kansas.

Exs, : Drumm. M. bor. am. II ed. n. 129.

Sull, et Lesq. M. bor. am. II ed, n. 37I.

compacta Kindb, in Oltawa Nat. IV, p. 62 et in Mac. Cat. p. 166.

Th, hirtellum Mar. Canad M. n. 248.

2. Ad Acer. - Am, sept. : New Brunswick, Ontario.

(1) Cr. Philib. in Rev. bryol. 1889 , p. 60. 
hirtella (Hedlo.) Sull. Ic. M. p 128, t. 80 et M. of U. St. p. 60 ; Lesq. et Jam. Man. p. 299.

Hypnum hirtellum C. M. Syn. II, p. 468.

Leptohymenium hirtellum Sohwaegr. Suppl. IV in exo, ad $t .32$ ?.

Pterigynandrum hirtellum Hedw. Sp. M. p. 89, t. 18, f. 2-6; Brid. Bryol. univ. $I I, p .188$.

Pterogonium hirtellum Schwaegr. Suppl. I, I, p. 108.

2. Cortic. - Am. sept. : Ontario, reg. sept., centr., or, et merid.

Exs. : Drumm. M. bor, am. I ed. n. 79 et Il ed, p. 90 (Pterogonium). Sull. et I.esq. M. bor. am. I ed. n. 247 et II ed. n. 370.

hirlella Mac. - Th. compacta.

Lescurii Sull. Ic. M.p. 130, t. 82 et M. of U. St.p. 60 ; Lesq. et Jam. op. et $l$. $c c$.

Arenic., rar. ad arbor. - Am. sept. : Reg. centr., or. et merid.

Exs. : Sull. et Lesq. M. bor. am. I ed, n. 249 et II ed. $n .372$.

robusta Duby in Flora, 1875 et Chaix de $M$. ex. 1875, p, 10, t. I, f. I;

Lesq. et Jam. op. et $l$. cc.

- Am. sept. : Florida.

Thelidium C. M. in Linn. 1875, p. 466 (sect. HхPNı sensu Müller. = Trichostrleum, posteà gen. propr.).

Theliphyllum C. M. Syn. $11, p .408$ (sect. HyPNi sensu Müller.).

THIEMEA C. M. in Bot. Centralbl, 1881, n. 37 (1 spec.).

Hampeana $C$. $M$. in op, et $l$. cc.

Funaria saxicola Hpe, in Jaeg. Ad. II, p. 697.

1 ?

- As. : Birman., Pegu.

Thuidiella W. P. Sch. in Besch. Prodr. bryol. mexic. p. 91 (subgen. Tнuidi).

THUIDIUM Bryol, eur. V (244 spec.).

abietinum (L.) Bryol, eur. V (mon. p.9), t. 485; W. F. Sch. Syn. II, p. 615 .

Hypnum abietinum L. Sp. pl. 1591 ; C. M. Syn. $1 I, p .482$.

$\mathrm{H}$. lutescens, alis subulatis tenacibus Dill. Hist. $M, p, 280, t, 35, f, 17$.

H. Stereodon abietinus Brid. Bryol. univ, $I I$, p. 573.

2. In ericet. sicc, et abiegn. arenos, - Eur.: Vulgatiss., rar. fructif.; Spitzberg. As. : Amour, penins. Tchutschica, Ienissei, Obi, Taimyr, Cauoas., Kashmir. Am. sept. : Groenland, Terr, nov., New Brunswick, Nova Scot., Ottawa, Ontario, M. Rupestr., Columb. brit., Athabasca, reg. sept.

Eiss. : Drumm. M. bor. am, ed. n. 216 (Hypnum).

Mac. Canad, M. n. 273.

Rab. Bryoth, eur, n. 770 et b.

Sull. et Lesq. M, bor, am. II ed, n. 413 (Hypnum).

aculeo-serratum Ren. et Card. in Bull. Soc. roy. bot. Belg. 1893, I, p. 121 et M. Masc. Mad. n. 231.

2. Ster.

- Afr. : Madagasear. 
acuminatum Milt. M. austr. am. p. 579.

Hypnum pseudn-recognitum Hpe, in Enum. M. Brasil. p. 85 et in Fl. 1881.

Thuidium pseudo-recognitum Broth. in Bihang till K. Sv. Vet. Akad. Handl. $1895, n .3$.

Ad rup. humid. et rad. arb. - Am. sept. : Jamaic. Am. merid. : Brasil, austr. or.

aequatoriale Mitt. in Spr. M. Amaz. et And. n. 1471.

Hypnum delicatulum Hsch. $\mathrm{Fl}$. Brasil.

- Am. merid. : Brasil. austr. or.

aequinoctiale Mitt, in sched.

Hypnum tamariscinum Hsch, Fl, Brasil.

- Am. merid. : Brasil. austr. or.

aestivum Aust. - Th. scitum var, aestivale.

afro-capillatum Broth, in Engler's Bot. Jaherb. 1897, p. 284.

1.

- Afr. : Regio lacustr.

Alleni Aust. in Bull. Torr. bot. Club, VII, p. 16.

Hypnum Aileni Lesq. et Jam. Man. p. 327.

Ster. Paludic, - Am. sept. : Connecticut.

amblyostomum (C. M.) Par.

Hypnum amblyostomum C. M. in Linn. 1880-83, p. 483.

1. Cortic. - Am. merid. : Argentin. Buenos-Ayr.

* var, attenuatifolium (C.M.) Par.

Hypnum amblyostomum var, attenuatifolium C.M. in op. eit. $p, 485$.

Ut et ubi typ.

a var. paludicolum (C.M.) Par.

Hypnum amblyostomum var. paludicolum C. M. in op. cit, p. 484.

Lignic. in paludos. - Am. merid. : Ubi typ.

amblystegioides C. M. in Rev. bryol. 1876, p. 4 (nom.).

Th. furfurosum (fid. Mitt.).

$$
\text { - Pac. : Austral. or. (Nov. Vales.). }
$$

angolense Welw. et Duby in Mémoires... Genève, 1871, p. 17, t. 5, f. 4 .

1. Cortic, in silv. $-\Delta f r$ : Angola.

angustifolium Jaeg. - Pseudo-Leskea.

angustifrons (C.M.) Par.

Tamariscella angustifrons $C, M$. in sched.

Ster.

- As, : Himalaya sept, occid.

Antillarum Besch. Fl. bryol. Antill. fr, p. 70.

H. tamariscinum $\delta$ delicatulum Brid, Bryol. univ, $I I, p .441$ ?

H. tamariscinum $\zeta$ tenerrimum ej. op. oit. p. 443 ?

2. - Am. sept. : Costa Rica, Antill. gall.

Araucariae C. M. in Ule Bryoth. brasil. n. I91.

Terr. - Am. merid. : Brasil. anstr. or.

Arzobispae (C. M.) Jaey. Ad. 1I, p. 319.

Hypnum Arzobispae C. M. in Fl. 1875, n. 34-35.

H, intermedium Hpe, Prodr. Fl. Nov. Granat. p. 103.

I. Rupic. - Am. merid. : And. Nov. Granat. 
assimile (Mitt.) Jaeg. Ad, 1I, p. 326.

Leskea assimilis Mitt. M. Ind. or. p. 133.

2.

- As. : Yunnan, Himalaya occ., Sikkim.

? assurgeus (Sull. et Lesq.) Mitt. in Trans. of the Linn. Soc. 1891, p. 190.

Hypnum assurgeus Sull. et Lesq. in Proced. of the Am. Acad. 1860, p. 279.

2. Lignic. $-A s$. : Japon., ins, Loo Choo.

? austro-serpens (C. M.) Par.

Hypnum austro-serpens $C . M$. in Linn. 1878-79, p. 459.

1. - Am, merid.: Uruguay.

bello-confertum $C$. $M$. in sched.

Ster.

- Pac. : Nov, Guin. oceid. (ins. Aron).

bifarium Bryol. jav. II, p. 123, t. 226.

2 ?

- As. : Java, Sumatra.

\& var. pertenue Bryol. jav. l.c.

- As.: Celebes.

bipinnatulum Mitt. in Trans. of the Linn. Soc. 1891, p. 190.

I.

As.: Japon.

Blandowii (Web. et Mohr) Bryol, eur. V (mon. p. 10), t. 486; W. P. Sch.

Syn. Il ed.p. 616.

Hypnum abietinum var, paludosum Wahlenb. Fl. Suec, II, p. 698 .

H. affine Crome Naohl. II, n. 20.

H. Blandowii W. et M. Bot. Taschb. I, p. 332 ; C. M. Syn. II, p. 454,

H. laricinum Wils, in Hook. Brit. f.. II ed., I, p. 87 et in Engl. Bot. Suppl.t. 2760.

H. Stereodon Blandowii Brid. Bryol, univ. II, p. 577.

1. In turfos, uligin. - Eur. : Seandin., German. sept., Dan., Neerland, Britann. As.: Kamschatka, Saghalien, Ienissei. Ami. sept. : Groenland, ins. Miquelon, Anticosti, Nov. Scotia, New Brunswick, Ottawa, Ontario, M. Rupestr., Columb. brit., Vermont, New York, Ohio, Wisconssin, Washington, Colorado.

Exs.: Drumm. M. bor. am. I ed. n. 215 (Hypnum).

Mac. Cansd. M. n. 274.

Rab. Bryoth, eur. n. 141 b.

Sull, et Lesq. M. bor. am. II ed. n. 414 (Hypnum).

Un. itin. 1865 , n, 95, 96 .

blepharophyllam (C.M.) Jaeg. Ad. II, p. 329.

Hypnum blepharophyllum C. M. in Bot. Zeit. 1854, p 573.

H tamariscinum var, delicatulum Mont. in Perrot. M. Neilghorr.?

Leskea amblyophylla Mitt. M. Ind. or. p. 133.

2.

- As. : M. Neilgherr.

Bolanderi $(G, N$. Best) Par, Claopodium Bolanderi G. N. Best in Bull. of the Torr. bot. Club, 1897,
p. 431.

2. Rupic. - Am. sept, : Calif.

Bonianum Besch. in Bull. Soc. bot. Fr. 1887, p. 98. 1 .

- As. : Tonkin.

borbonicum Besch, Fl. bryol. Réunion, etc, p. 148.

1 .

- Afr, : Ins. Borbon. 
brachypyxis (C.M.) Par.

Hypnum brachypyxis C. M. in Journ. of Bot. 1877, p. 229 (nom.).

Lignic. - Am. sept. : Costa Rica.

brachypyxis C. M. - Th. Lorentzi.

Brachythecium (Hpe. et Ltz.) Jaeg. Ad. II, p. 320.

Cyrto-Hypnum Brachythecium Hpe, et Ltz. in Bot, Zeit. 1869, p.

1. In silv. mont. - Am. merid. : Equator

Brandisi (C, M.) Jaeg. op. cit. p. 328.

Hypnum Brandisi C. M. in Fl. $1878, n$. 6.

2. - As, : Himalaya bor. oec.

brasiliense Mitt. $M$. austr. am. p. 579.

Ster. $\quad-A m$. merid. : Brasil, aequinoct.

byssoideum Besch. in Ann. sc. nut. VII ser., II, p. 95.

1. Terr. - Afr. : Ins. Mayotte.

byssoideum C. M. - Th. guatemalense.

byssophorum C. $M$. in sched.

Ster. $\quad-P a c$, : Nov, Guin. brit.

caldense Broth, in Bihang till K. Sv. Vel.-Akad. Handl. 1895, n. 3.

1. Lignic. - Am. merid. : Brasil. or.

calopteris C. M. in sched.

- As. : Himalaya sept. occid.

calyptratum (Sull.) Par.

Hypnum calyptratum Sull. in Pac. R. R. IV, p. 190, t. 10 ; Lesq. et Jam. Man. p. 324.

1. Terr. - Am. sept. : Calif.

campanulatum Mitt. op. cit. p. 574.

Lignic. - Am. merid. : And. Quitens.

Campbellianum (Hpe.) Jaeg, op. cit. p. 326.

Cyrto-Hypnum Camplilianum Hpe. in Linn. 1874, p. 670.

2. - Pac. : Ins. Nov. Hebrid.

capillatum Jaeg. - Pseudo-Leskea.

Carantae (C. M.) Jaeg. op. cit. p. 330.

Hypnum Carantae C. M. in Fl. 1875, n. 34-35.

2. Fr. ign. Rupic, - Am. merid. : And. Nov. Granat.

casuarinum (C. M.) Jaeg, op. cit, p. 331 .

Hypnum casuarinum C. M. in Linn. 1874, p. 569.

$\delta$ et fr. ign. $\quad-A s,:$ M. ins, Philippin.

? cataractarum (C. M.) Par.

Hypnum cataractarum C. M. in Linn. 1878-79, p. 458.

Leskea microphylla Mitt. M. austr. am. p. 568.

1. Ad rup. irror. - Am. merid. : And. Peruv., Brasil, austr. or. catenulatum de Not. - Pseudo-Leskea.

eandatulum $C$. $M$, in sched.

Ster.

- Pac.: Nov. Guin. brit.

ehacoanum C. M, in Hedwig. 1897, p. 143.

I.

- Am. merid. : Argentin, subtropic. (Chaco). 
Chenagoni C. $M$ in Bull. Soc. roy, bot. Belg. 1894, II, p. 129.

Th. integricalyx ej. in Ren. M. Mase-Mad, n. 134.

1. - Afr.: Madagascar (Diego Suarez).

chilense Mitt. op, cit. p. 579.

Ster.

- Am. merid. : Chile.

chloropsis (C.M.) Par.

Hypnum chloropsis $C . M$. in $\mathrm{Fl} .1886, p .525$.

Ster. Rupic. - Afr. : Gabon.

chrysopteris (C.M.) Par.

Tamariscella chrysopteris $C . M$. in sched.

Ster. - As. : Himalaya sept. occid.

ciliatum Mitt. op. cit. p. 576.

- Am. merid. : And. Peruv.

complanum Mitt, op, cit. p. 575.

l. $\quad-A m$. merid.: Ins. Trinitat.

concinnum C. M. in sched.

- As.: Himalaya sept. occid.

contortulum (Wils.) Jaeg. op. cit.p. 322.

Hypnum contortulum Wils. in sched.

Leskea contortula Mitt. M. Ind. or. p. 134.

- As. : Sikkim.

crenulatum Mitt. Fl. Vit. p. 402

1.

- Pac. : Ins. Sandwic.

crispifolium (Hook.) Lindb. in Act. Soc. sc. Fenn. 1872, p. 272.

Claopodium crispifolium Card. M. Am. bor. p. 50.

Hypnum crispifolium Hook. M. ex. t. $31 ;$ C. M. Syn. II, p. 450; Lesq. et Jam. Man. $p .329$.

Isothecium crispifolium Brid. Bryol. univ. 1I, p. 360 .

2. Ad terr. et rup. humid. - As. : $\Lambda$ mour. Am. sept. : Alaska, Vancouver, Columb. brit., Washington, Oregon, Idaho, Calif.

Exs. : Mac. Canad. M. n. 275, 276,

Sull. et Lesq. M, bor, am, II ed. p. 405.

curvatum Mitt. in Melliss's S. Helena, 1875, p. 365.

Ster.

- Afr. : Ins. Tristan d'Aetnha.

cygnisetum (Hpe.) Jaeg. Ad. II, p. 318.

Cyrto-Hypnum cygnisetum Hpe, in sched.
Tamariscella oygniseta C. M. in Nwov, Giorn. bot, ital. 1891, p. 601. - As. : Birman.

cylindraceum Mitt. M. austr, am. p. 574.

- Am. merid. : And. Quitens.

cylindraceum Mitt. - Th. fugisanum.

cylindrangium $C . M$. in sched.

- As, : Himalaya sept. occid.

eylindrella C. M. in Hedwig. 1897, p. 142.

1. $-A m$. merid.: And. Argentia. subtropic.

cymbifoliolum (C. M.) Par.

Hypnum cymbifolium Sull, in Exped. Wilkes, p. 17? (C.M).

Tamariscella cymbifoliola $C$. M. in Fl. 1896, $p$ 476.

- Pac. : Ins. Sandwic. 
cymbifolium (Dz. el Mk.) Bryol. jav. $11, p .165, t .221$.

Hypnum cymbifolium Dz. et $M k$. in Ann. se. nat. 1844, p. 306; C. $M$. Syn. Iİ, p. 485.

Leskea cymbifolia Mitt. $M$. Ind, or. p, 183.

2. Rupic. - As.: Japon., Alp. Yunnan, Kashmir, Himalaya, Sikkim, Nepal., Khasia, M. Neilgherr., ins. Nicobar, Sumatra, Java, penins. Malay., ins. Ceram, Halmaheira, Saparaea, Amboine, Celebes.

decipiens de Not. Epil. p. 233; W. P. Sch. Syn. II ed., p. 612 (1).

Amblystegium glaucum var. decipiens Lindb.

Hypnum Notarisii Boulay M. Fr. p. 597.

1. In uligin. et ad rivul. - Eur.: Britann. ? Finmarck.? Alp. Helvet., Arvernia, Pyren,, Ital. super, As. : Caucas.

Exs.: Rab. Bryoth, eur, n, I182.

delicatulum (Hedio.) Mitt. in Journ. of the Linn. Soc. XII, p. 578; W. P. Sch. Syn. II ed., p. 615.

Hypnum delicatulum L. Sp. $p l$. I ed., II, p. 1125, n. 16 (quoad sol. pl. Americ.); Hedw. M. frond. IV, p. 87, t. 33.

H. filicinum, Tamarisci foliis minimis non splendentibus, setis, capsulis et alis brevioribus Dill. Hist. M. p. $546, t .83, f .6$.

H. proliferum Drumm. M. bor. am. J ed. n. 136.

H. protensum Rich, in Mich. Fl. Am. bor: I1, p. 317.

H. tamariscinum Sull. M. Allegh, n. 3; Sull. et Lesq. M. bor. am. I ed, n. 272 .

H. tamariscinum $\gamma$ protensum Brid. Sp. M. II, p. 139 et Bryol. univ. II, p. 441.

H. tamariscinum $\delta$ delicatulum ej. $l l . c c$.

Th. protensum Jaeg. Ad. $I I, p, 330$.

Th. recognitum var, delicatulum Warnst, in Bot. Centralbl. 1881, n. 6.

Thuyidium delicatulum Lindb. Man. M, II, 1874, $t$ I, f. 8.

2. In silvatic. paludos. - Eur. : Fennia (ins. Hogland, ster.), German. fere tota (fid. Limpr.), Gall. austr. (Ardèche), Alp. Rhaet., Astur, As. : Japon., Ienissei med. et super, Caucas. occ. Am. sept. : Labrador, ins. Miquelon, Terr. nov., Nova Scot., New Brunswick, Ottawa, Ontario, Saskatchewan, copiose in reg. sept., centr., or. et merid., ins. Jamaic., Haïti, S. Vincent. Am. merid.: Venezuela, And. Nov. Granat, Amazon., And. Quitens et Peruv., Brasil. austr. or.

Exs.: Drumm. M. bor. am. I ed. n. 213 et II ed. n. 136 (Hypnum).

Faurie, PI. Japon, n. 57.

Mac. Canad. M. n. 272.

Rab. Bryoth, eur. n. 7.

Sull. et Lesq. M. bor, ain. I ed, n.272 et II ed, n. 404 (Hypnum).

delicatulum Bryol. eur. - Th. recognitum.

denticulnsum (Mitt.) Jaeg. Ad. 11, p. 324.

Hypnum denticulosum Mitt. in Hook. Handb, of the N. Zeal. Fl, p. 472.

Ster.

- Pac.: Nov. Zeland, sept.

diaphanulum C. M. in. sched.

Ster.

- Pac. : Nov. Guin. brit.

djuriense (C. M.) Jaeg. Ad. II, p. 313 .

Hypnum djuriense C. $M$. in Linn. $1875^{\circ}, p .472$

1. Fr. ign. Ster. - Afr. : Djour.

(1) Cf Philib. in Rev. bryol. 1884, p. 3. 
dubiosum Warnst. in Schrift. d. Naturf. Gesells, in Danzig, 1896, p. 65. - Eur. : Westphal.

eccremocarpum (C. M.) Mitt. M. austr. am. p, 577.

Hypnum eccremocarpum C. M. Syn. II, p. 195.

H. Stereodon minutulus Brid. Bryol. univ, II, p. 578. .

1.

- Am. sept. : Haïti.

elodioides Ren, et Card. in Hedwig. 1893, p. 251.

Th. paludosum elodioides G. N. Best in Bull. of the Torr. bot. Club, 1896, p. 90.

1. - Am. sept. : New York, Indiana.

erectum Duby in Fl. 1875, p. 284 et Choix de Cr. ex... 1875, p. 10, t. Il, f. 3 .

Hypnum erectum Lesq. et Jam. Man. p. 323.

1.

- Am. sept. : Florida.

erosulum Mitt. - Th. faulense.

exasperatum Mitt. M. austr. am. p. 576.

1. Cortic, - Am. merid. : Brasil.

fallax Kindb. - Amblystegium.

faulense (Reichdt.) Jaeg. Ad. 11, p. 321.

Hypnum faulense Reichdt. in Verh. d. K. K. zool, et bot. Gesells, in Wien, 1868, p. 196.

Th. erosulum Mitt. Sam. M. p. 186.

1. Cortic. et rupic. - Pac. : Ins. Fidji, Samoa, Stewart.

Fauriei Par.

Th, micropteris Besch, in Ann. sc. nat. 1893. p. 367 et in Faurie, Pl. 1. Japon. n. 50, 177, 199, 205, 1499.

ferricolum (C. M.) Jaeg. Ad. II, p. 222.

Hypnum ferricolum C. M. in Linn. 1875, p. 471.

1. Fr. ign. Terr. - Afr, : Dar Fertît.

filarium Mill. $M$. austr. am. p. 579.

2. Ster. Ad rad, arb. - Am. merid. : Brasil. or.

filicinum Kindb. - Hypnum.

filiforme Welw. el Duby in Mèm.... Genève, 1871, p. 16, t. 4, f. 7.

Ster. Cortic, et rupic. - Afr. : Angola.

firmulım C. M. in Hedwig. 1887, p. 143.

Ster. $\quad-A m$, merid. : Argentin. subtropic. Tucuman.

fissicalyx (C. M.) Par.

Pelekium fissicalyx C. M. in Engler's Bot. Jahrb. 1883, p. 87 et in Forschungsveise.... p. 59.

1. Terr. - As, : Amboine.

Frontinoae (C. M.) Jaeg. Ad. 11, p. 319.

Hypnum Frontinoae C. M. in Fl. 1875, n. 34-35.

1.

- Am. merid. : Venezuela, Nov. Granat.

fueiforme (Brid.) Besch. Fl. bryol. Réunion, etc., p. 150.

Hypnum fuciforme Brid. Sp. M. II, p. 135 et Bryol. univ. II, p. 432 ; C. M. Syn. II, p. 487 .

Ster. Terr, in silv. - Afr. : Ins. Borbon., Franciae. 
fujisanum Par.

Th. cylindraceum Mitt. in T) ans. of the Linn. Soc. 1891, p. 190.

I.

- As. : Japion.

fulvastrum (Mitt.) Jaeg. Ad. II, p. 322.

Hypnum fulvastrum Hook. Handb. of the N. Zeal. Fl. p. 471.

H. furfurosum $H$. f. et $W$. $F l$, of the $N$. Zeal. II, p. 107, $t, 88, f .7$ (p.p.).

Leskea fulvastra Mitt, in Journ. of the Linn. Soc. 1859, p. 92.

2. Zeland. sept. et med.

- Afr.: lns. Tristan d'Acunha. Pac, : Nov.

furfurosum (Hook. f. el Wils.) Jaey. Ad. II, p. 322 .

Hypnum furfurosum $H$. f. et W. Fl. of the $N$. Zeal, 11, p. 107, t. 88, f. 7 (p.p.) et Handb. p. 475; F'l. Tasm. II, p. 208, t. 176, f, 2.

H. unguiculatum eor. Fl. Tasm. $l l, c e, f$. S.

Th. hristatum (fid. Mitt.).

2. Ad rup. humid. - Pac. : Nov. Zeland., Austral. or., Tasman.

fuscatum Besch. in Ann. sc. nat. 1892, 1, p. 78.

1. In silvis. - As. : Yunnan.

fuscissimum (C.M.) Par.

Haplocladium fuscissimum C. M. in Nrov. Giorn, bot. ital. 1897, p.

- As. : China or. (prov. Schen-Si).

GiraIdii (C.M.) Par.

Abietinella Giraldii C. M. in Nuov. Giorn, bot, ital. 1896, p. 115.

Ster. $\quad-A s$. : China or. (prov. Schen-Si).

glaucescens W. P. Sch. in Besch. Prodr. fl. mexic, p. 90.

1. $\quad-$ Am. sept. : Mexic.

glaucinum (Mitt.) Bryol. jav. 1I, p. 117, t. 222.

Leskea glaucinea Mitt. M. Ind.or. p. 133.

2. Cortic, et mic. - As. : Japon,, Sikkim, Khasia, Ceylan, Sumatra, Java, Celeb s. Amboine, ins. Halmaheira, Saparæa.

gracile (Br. et Sch.) Bryol. eur. V (mon. p. 5).

Hypnum abietinum $\beta$ minor Hook, in Drumm, M. bor, am, 1 ed, n. 217.

H. gracile B1, et Sch. in Lond. Journ. of bot. 1843, p. 668 p.p.: C. M. Syn. II, p. 488 ; Sull. M. Allegh. n. 5 et Ic. M. p. 156, t. 100; Lesq. et Jam. Man. p. 324.

H. Grayanum Sull. in sched. 1850.

H. microphyllum Mühlenby. Cat. p, 99 (fid. Sull.).

H. Stereodon microphyllus Brid. Bryol. univ. II, p. 649 (quoad pl. Pensilv.).

H. varium H.f. et W. in Drumm. M. bor. am. I ed. n.110 et 141 (fid. Sull.).

Leskea gracilis Mitt. in Proced. of the Linn. Soo. 1864, p. 44.

Th, microphyllum G. N. Best in Bull. of the Torr. bot. Club, 1896, p. 87.

1. Lignic., rupic. et terr. - Eur.: Suecia. As. : Ienissei super., Obi. Am. sept.: New Brunswick, Ottawa, Ontario, Saskatchewan, Terr, nov., reg. sept., orient, et merid.

Exs. : Mac. Canad. M. n. 270.

Sull. et L.esq. M. bor. am. I ed, n, 277 et II ed, n. 410 (Вурпиin).

* var. lancastriense (Sull. et Lesq.) Card. M. Am. sept, p. 49.

Hypnum caespitosum filamentosum minimura subflexum Dill. Hist. $M$. p. $282, t .36, f .18$ ?

H. virginianum Brid. Bryol. univ. II, p. 576 ; Drumm. M. bor, am. I ed. n. 144 .

Th. virginianum Lindb. M. Scand. p. 36; G N. Best in Tom, bot. Club. 1896, p. 86, fig. 261. 
Ut et ubi typ. in Am. sept.; Mexic.

Exs. : Sull, et Lesq. M. bor, am. I ed. n. 278 et 11 ed. n. 411 (Hypnum).

* var. Ravenelii (Sull. et Lesq.) Card. op. et l. cc.

Hypnum gracile var. Ravenelii Sull. et Lesq. M bor, am, I ed. n. 279.

Muric. et saxic. - Am. sept. : Carol. infer., Florida.

Exs. : Sull. et Lesq. M. bor. am. II ed, n. 412 (Hypnum.)

gracile Lindb. - Th, pallens.

granulatum (Hpe.) Par.

Hypnum granulatum Hpe. Symb. 1877, p. 737.

- Am. merid. : Hrasil. austr. or.

gratum (P. B.) Jaeg. Ad. II, p. 322.

Hypnum gratum P. B. Prodr. p. $64 ;$ Brid. Bryol. univ. II, p. 579; U. M. Syn. I1.p. 496.

1 ? Rupic., ad rad. et trunc. arbor. - Afr.: Benin, Cameroon, Niger. guatemalense Par.

Th. byssoideum C. M. in Bull, hb. Boissier, 1897, p. 219.

- Am. sept. : Guatemala.

haplohymenioides $C . M$. in sched.

- As. : Himalaya sept. occid.

Haplohymenium (Harv.) Jaeg. Ad. II, p. 317.

Hypnum Haplohymenium Harv. in Lond. Journ. of bot. 1840, II, p. 21; C. M. Syn, II, p. 489 .

Leptohymenium microphyllum Schwaegr. Suppl. III, II, I, t. 271.

Leskea Haplohymenium Mitt. M. Ind. or. p. 135.

L. microphylla Hook. in Wallich Cat. n. 7638.

1. hastatum (C. M.) Jaeg. Ad. I1. p. 331 .

- As.: Himalaya, Nepal.

Hypnum hastatum C. M. Syn. II, p. 485.

H. recognitum Hpe, in Preiss Pl. Nov. Holl. II, p. 119.

Leskea microphylla Mitt. in Journ. of the Linn. Soc. 1859, p. 93.

2. Ad rup. madid. - Pac. : Austral. or., Tasman.

hatschullianum Hpe. hb. (nunc in hb. British Museum). - As.: Ins. Andaman.

hawaïense Reichdl. Beitr. p. 579.

Hypnum cymbifolium Sull, in U. St, Expl. Exped. II, p. 17.

2. Ad rup, madid. umbros. - Pac, : Ins. Sandwic.

hispidipes $C . M$, in sched.

- Pac.: Nov. Guin. (Onin).

histricosum Mitt. in Seeman's Journ. of bot. 1863, I, p. 356. 2. - Eur. : Anglia (Sussex).

Holzingeri Ren. et Card. in Bot. Gaz. 1894, p. 240, t. 22, f. A. 2 .

- Am. sept.: Oregon.

Hookeri (Milt.) Besch. in Ann. sc. nat. 1892, I, p. 83.

Leskea Hookeri Mitt. M. Ind. or, p. 132.

Ster.

- As. : Alp. Yunnan, Sikkim, Nepal.

incompleto-pinnatum C. M. in Pap. and Proced. of the roy. Soc. of Tasman. 1894-1895, p. 209 (nom.). 
integricalyx C. M. - Th. Chenagoni.

integripilum $C . M$, in sched.

- Pac. : Nov, Guin. brit.

intermedium Mitt. in Kevo Journ. of bot. III, p. 353 et M. auslr. am. p. 573.

1. Rupic. - Am. merid.: And. Nov. Granat. et Quiters.

intermedium Philib. - Th. Philiberti.

intricatum (Mitt.) Jaeg. Ad. 1I, p. 317.

Leskea intricata Mitt. in Journ. of the Linn. Soc, 1863, p. 161.

1.

- Afr.: M. Cameroon.

investe (Mitt.) Jaeg. op. cit. p. 316.

Hypnum investe Mitt. in Hook. Tourn. bot. 1856, p. 355.

Leskea investis ej. M. Ind. or. p. 135 .

1. Rupic. $-A s$.: Penins, Malay. (Moulmein).

involvens (Hedw.) Mitt, M. austr, am. p. 575.

Hookeria parvifolia Tayl. in Lond. Journ. of bot. 1843, p. 193 (fid. Mitt.).

Hypnum gratum Brid. Bryol. univ. II. p. 579 p.p.

H. involvens $P . B$. Prodr. $p, 65 ; C . M$. Syn. II, p. 496.

H. parvifolium C. M. Syn. II, p. B33.

Leskea involvens Hedw. M. frond, IV, p. 27, t. 11.

L. Omalia involvens Brid. Bryol. univ. 11, p. 326 ,

Stereophyllum parvifolium Jaeg. Ad. II, p. 512.

Th. petradelphus C. M. in Mitth, aus d. deutsch. Schutzgeb. 1893, 1II, p. 5 .

1. Cortic. et lignic. - Am. sept.: Cuba, Jamaïc, Mrtinic. Am. merid. : Venezuela, Guiana, And. Quitens. et Peruv.

" var. thomeanum Broth, in Bol. da Soc. Brot. 1890, p.

Rupic. et ad rad. arbor. - Afr. : Ins. S. Thomas, Cameroon, Togo. iodopteris (C.M.) Par.

Tamariscella i, lopteris C. M. in sched.

Ster. - As. : Himalaya sept. occid.

Jacquemonti (Br. et Sch.) Par.

Hypnum Jacquemonti Br. et Sch, in W. Sch, M. Abyss. n. 481; C. M. Syn. II, p. 489.

1. Cortic. - Afr.: Abyss.

japonicum Dz. et Mk. (fid. Sande Lac. in Miquel Ann. Mus. bot. Lugdun.

Batav. II, p. 247.)

Th. tamarisciforme W. P. Sch. in Savatier M. Jap, n. 613 a.

2.

Exs. : Faurie, Pl, Japon, n. 31, 409.

Kiaeri C. M. in Borgen M. Mad. n. 126 ; Jaeg. Ad. II, p. 740.

$$
\text { - Afr. : Madagascar. }
$$

laevipes Mitt. in Journ. of the Linn. Soc, 1886, p. 318.

I. Cortic. - Afr, : Kilima N'Djaro, Usambara.

laeviusculum (Mitl.) Jaeg. Ad. II, p. 324.

Hypnum laeviusculum Mitt, in Hook. f. Handb. of the N. Zeal. Fl. p. 471 .

Leskea laeviuscula ej. in Journ. of the Linn. Soc. 1859, p. 92.

2.

-Pac. : Nóv. Zeland. sept, et med., Austral. or.,

Tasman. 
lasiomitrium Jaeg. - Th. plumulosum.

? laterala (C. M.) Par.

Hypnum laterale C. M. in Linn. 1878-79, p. 457.

1.

- Am. merid. : Uruguay.

laxifolium (Hook.) Mac. Cat. p. 187.

Claopodium laxifolium Card. M. Am. sept. p. 150.

Eurhynchium laxifolium Jaeg. Ad. II, p. 426.

Hypnum laxifolium Schwaegr. Suppl. II, II, p. 159, t. 143; C. M. Syn. II, p. 449 ; Lesq. et Jam. Man. p. 329.

1sothecium laxifolium Brid. Bryol. univ. II, p. 359.

Leskea laxifolia Hook, M. ex. t. 30 .

2.

- Am. sept. : Litt. Alaska et Columb. brit.

leptocladum (Tayl.) Mill. M. austr, am. p. 573.

Hypnum leptocladum C. M. Syn. II, p. 495.

Leskea leptoclada Tayl. in Lond. Journ. of bot. 1847, p. 339.

1.

- Am. merid. : And. Quitens. et Boliv.

? leptopteris (C.M.) Par.

Haplocladium leptopteris C. M. in Nuov. Giorn. bot. ilal. 1896, p. 116.

Ster. - As. : China or. (prov. Schen-Si).

leskeaefolium Ren, el Card. in Bull. Soc. Roy, bot. Belg. 1894, I, p. 199.

1. $\quad-$ Am. sept. : Costa Rica.

leskeoides Kindb. - Th. Whippleanum.

leuconeuron (Sull.) Lesq. in Mem. Calif. Acad. 1, p. 31.

Claopodium leuconeuron Card. M. Am, sept, p. 59.

Hypnum leuconeurum Sull. ic. M. p. 102, t. 80; Lesq. et Jam. Man. p. 328.

Ad Querc. agrifol. - Am, sept.: Montana, Calif.

Exs. : Sull, et Lesq. M. bor. am. Il ed. n. 407 b.

lignicola Kindb. in Bidrag p. 453 (nom.) el in Mac. Cat. p. 185.

Th. gracile var. (vix !) G. N. Best in Sull. of the Torr. bot. Club, 1896, p. 88 .

1. Lignic. - Am. sept. : Ontario, Manitoba, Columb. brit.

* var. Roellii Ren. el Card. in Hedroig. 1897, p. 50.

- Am. sept. : Ohio.

lonchopodum (C.M.) Par.

Pelekium lonchopodum C. M. in Geh. Neue Beitr. zur Moosfl, v. Nev Guin.,p. 7.

Th. trachypodon (fid. Geh. l. c.).

Cortic. - Pac. : Nov. Guin. merid.

lonchopyx is $(C . M)$ Par.

Hypnum lonchopyxis C. M. in Journ. of bot. 1877, p. 229 (nom.).

Lignic. - Am. sept. : Costa Rica.

longicuspes Broth. in Bihang till K. Sw. Vet.-Akad. 1895, n. 3.

1. Lignic. - Am, merid.: Brasil. or.

longinerve Lindb. in Ann. Soc. sc. Fenn. 1872, p. 272 ,

Syn. lignic. - As. : Amour.

Lorentzi Par.

Th. brachypyxis C. $M$. in Hedreig. 1897, p. 142.

l.

- Am. merill. : And. Argentin. 
loricalycinum (C. M.) Par.

Hypnum loricalycinum C. M. in Fl. 1890, p. 498.

Ster. In silv. - Afr. : Kilima N'Djaro.

? macropilum (C.M.) Par.

Haplocladium macropilum C. M. in Nuov. Giorn. bot. ital. 1896, p. 116.

1.

- As. : China (prov, Schen-Si).

Manianum C. M. in sched.

Ster.

- As.: Ins. Andaman.

mascarenicum (C, M.) Besch. Fl. bryol. Réunion, etc., p. 150.

Hypnum mascarenicum $C . M . S y n . I I, p .485$.

H. tamariscinum Brid. herb.

2.

- Afr. : Ins. Borbon.

matarumense Besch, op. cit. p. 149.

Ster.

- Afr.: Ins, Borbon.

mexicanum Milt. $M$. austr. am. p. 577.

1.

- Am. sep... Mexic.

Meyenianum (Hpe.) Bryol. jav. II, p. 121, t. 224.

Hypnum cymbifolium Duby in Moritzi Syst. Verz. p. 131.

H. kuripanum $D z$. et $M k$, in Zolling. Verz, 1854, pp. 27 et 32.

H. Meyenianum Hpe. $1 c$. M. 1844, $t .8$.

H. plumulosum C. M. Syn. $I I, p .486$.

1. Ad rup. calcar. - As. : Java, ins. Banca, Banda, Saparcea, Philippin.

? microcalycinum (C. M.) Par.

Haplocladium microcalycinum C. M. in sched.

- As. : Himalaya sept. occid. (Dehra-Doun).

microcladum (C. M.) Jaeg. Ad. 11, p. 323.

Hypnum microcladum $C . M$. in sched.

$$
\text { - As.: Pegu. }
$$

microphyllum $\left\{\begin{array}{l}\text { Best. - Th. gracile. } \\ \text { Jaeg. - Pseudo-Leskea. }\end{array}\right.$

microphyllum lignicolum G. N. Best. - Th. lignicola.

micropteris C. M. in Dusen M. Camer, n. 65.

Th. gratum (fid. Broth.).

$$
\text { - Afr.: M. Cameroon. }
$$

micropteris Besch. - Th. Fauriei.

minuseulum (Wils.) Jaeg. Ad. $I I$, p. 322.

Hypnum minusculum Wils, in sched.

Leskea minuscula Mitt. M. Ind. or. p. 134.

1. Lignic. - As, : Khasia.

minutulum (Hedwo.) Bryol. eur. V(mon. p. 5), t. 481; W. P. Sch. Syn. 11 ed. p. 609.

Hypnum bavaricum Voit in Sturm Fl. Germ. II, fasc. 14.

H. Martianum Sendtn. in Regensb. Denkschr, III, 1841, p. 150.

H. minutulum Hedu: M. frond. IV.p. 90, t. 34; C. M. Syn. II, p. 492.

H. Stereodon minutulus Brid. Bryol. unix, II, p. 578.

1. Lignic, -- Eur, : Vall, Rhen, med., Bavar,, Salisb. ; Stir.? Afr.: Ins. Azor. Am. sepl.: New Brunswick, Ottawa, Ontario, tota temper. copiose. 
Exs. : Drumm. M. bor, am, Il ed, n. 137 (Hypnum). Mac. Canad. M. n. 268 p.p.

Rab. Bryoth, eur, n. 540.

Sull. et Lesq. M. bor. am. II ed. n. 406 (Hypnum).

minutulum. Mitt. - Th. Wrightii.

miradaricum Jaeg. - Th. tamariscinum var. mexicanum.

Molkenboeri Sande Lac. in Miquel Ann. Mus, bot. Lugdun. Balav. II, p. $298, t .2$.

-As.: Japon.

Exs. : Faurie Pl. Jap. n. 35̃22.

muricatulum (Hpe.) Jaeg. Ad. II, p. 319.

Hypnum muricatulum Hpe. in Linn. 1847, p. 88 (false H. muriculosum in Amn. sc. nat.) ; C. M. Syn. II, p. 493.

I.

- Am. merid. : Venezuela.

muricolum Jaeg. - Pseudo-Leskea.

nabambissense (C. M.) Jaeg. Ad. II, p. 322.

Hypnum nabambissense C. M. in Linn. 1875, p. 470.

I.

- Afr. : Niam-Niam.

nano-delicatulım (Hpe.) Jaeg. Ad. II, p. 325.

Hypnum nano-delicatulum Hpe, in Linn. 1876, p. 323.

Th. Pennula C. M. in Bail. Syn. of the Queensland Fl. IV, Suppl. p. 99.

Fr. ign.

- Pac. : Austral. or. (Queensland).

nanophyllum $C . M$, in $F l$. 1896, $p, 476$.

- Pac.: Ins. Sandwic.

Naumanni (C. M.) Far.

Hypnum Naumanni C. M. in Engler's Bot. Jahrb. 1883, p. 87 et in Forschungsveise... p. 56 .

2. Ad arbor. - Pac. : Nov. Hannov., Nov. Mecklenb., Nov. Guinea. nigerianum (Mitt.) Par.

Leskea nigeriana Mitt. in M. hb. Hook. 1860, p. 52, t. 5, f. 8 .

I vel syn. - Afr.: Niger.

nipponense W. P. Sch. - Pseudo-Leskea capillata.

niveo-calycinum $C, M$. in Hellwig... 1897, p. 140.

1.

- Am. merid. : Argentin. subtrop. (Chaco).

nutans Besch. Fl. bryol. Nov. Caledon. p. 238.

2. Rupic. - Pac. : Nov. Caledon.

obscuriusculum Jaeg. - Psendo-Leskea.

occultirete C. M. in Hedwig. 1887, p. 142.

1.

- Am. merid. : Argent. subtropic. Saltens.

orthangium (C. M.) Par.

Tamariscella orthangia C. M. in sched.

- As. : Himalaya sept. oceid.

orthocarpum Besch. Prodr, bryol. mexic. p. 90.

Leskea tamariscina W. P. Sch. in hb. Mus. Paris.

2.

- Am. sept : Mexic. 
paltens Lindb, mss, 1865; W. P. Sch, Syn. Il ed.p. 611.

Hypnum pallens Lindb, mss, in M. nov. Scand. 1868.

Th. gracile Lindb. in Not. w. Saellsk. pro Faun. et Fl. fenn. Voerh, $1868, I X, p, 268$.

1.

- Eur. : Suec, merid.

paludosum (Sulliv.) Rau et Herv. Cat. p, 38.

Elodium paludosum Aust. M. Appal, n, 306.

Hylocomium paludosum Jaeg. Ad. $11, p .611$.

Hypnum paludosum Sull. M. Allegh, n. 7, M. of D. St.p, 68 et Ie. M. p. $157, t .101$.

1. Paludic. - As.: Japon. Am. sept.: Rhode-Island, Massachuss., Vermont, Ohio sept, ete.

Exs. : Sull. et Lesq. M. bor. am. II ed. n, 281 et II ed. n. 415. papillariaceum (C.M.) Par.

Haplocladium papillariaceum C, M. in Nuov, Giorn. bot. ital. 1897, p. - As. : China or. (prov. Schen-Si).

paraguense Besch, in Rev, bryol. 18×5, p. 18 et in Journ. de bot. 1891, p. 346 .

1. Lignic. - Am. merid.: Paraguay.

Exs. : Bal. Pl. Parag, h. 3688.

pauperum (C. M.) Mill. M. austr. am. p. 576.

Hypnum muricatulum C. M. in Bot. Zeit. 1848, p. 779.

H. pauperum ej. Syn, II, p. 493.

1. Lignic. - Am, merid.: Venezuela.

pelekioides Broth. in Engler's Bot. Jahrb. 1893, p. 479.

1. - Pac.: Nov. Guinea.

pellucens Ren, et Card. in Bull. Soc. roy. bot. Belg. 1894, I, p. 198

I. In silvat. - Am. sept. : Costa Rica.

pennula C. M. - Th, nano-delicatulum.

perbyssaceum C. M. in Dusen $M$. Camer. $u, 267$.

Rupic. - Afr : : M. Cameroon.

perintricatum (C. M.) Par.

Hypnum perintricatum C. M. in Dusen M. Camer, n. 293; Par. Index, p. 667 .

- Afr.: M. Cameroon.

perrigidum C, M. in Bull, hb. Boissier, $1897, p, 567$.

- Am. sept. : Jamaic.

perscissum (C. M.) Besch. Fl. bryol. Réunion, etc., p. 148.

Hy pnum perscissum $C$. $M$. in Linn. 1876, p. 286

1. Cortic. - Afr.: Ins. Anjouan, Mayotte.

persistens (C. M.) Par.

Hypnum persistens $C$. M. in Linn. 1880-83, p. 485 ,

Ster. $\quad-$ Am, merid.: M. Argentin. Buenos Ayr.

peruvianum Mitt, M. austr. am. p. 578.

Boliv.; Peruv.

- Am. merid.: And. Nov. Granat. Quitens, et

petradelplus C. M. - Th. involvens var, thomeanum. 
Philiberti Limpr. Laubm. Deutschl. II, p. 835.

Th. intermedium Philib. in Rev. bryol. 1893, p. 33(1); G. N. Best in Torr. bot. Club, 1896, p. 84, fig. 260.

Th. recognitum var. radicans Kindb. in Kev, bryol. 189?, p. 103.

2. In calcar. humid. - Eur.: Voges., Jurass., Sabaud., Helvet., Bavar., Anglia, Stir. Am. sept. : New Jersey, Pensilv.

pinnatulum Lindb. in sched. ; $\AA$ ingstr. in Oefv.... 1876, p. 46.

Hypnum pinnatulum Hpe. Enum. M. Brasil.p. 87.

1. Lignic. - Am. merid. : Brasil. or.

pinnatulum Rehm. - Th. Rehmanni.

plicatum Mitt. Fl. Vit. p. 402.

- Pac. : Ins. Sandwic.

plumulosiforme (Hpe.) Jaeg. Ad. Il, p. 333.

Hypnum plumulosiforme Hpe. in Linn. 1876, p. 324.

2.

- Pac. : Austral. or. (Nov. Vales.).

plumulosum (Dz. et Mk.) Bryol.jav. 11, p. II8, t. 223.

Hypnum lasiomitrium C. M. in Bot. Zeit. 1862, p. 393.

H. plumulosum Dz. et Mk. in Ann. se. nat, 1844, p. 308 et M. Archip. ind. p. 13.

Th. lasiomitrium Jaeg. Ad. II, p. 333.

$2 . \quad-$ As. : Ceylan, Sumatra, Java, Borneo, Ceram, Amboine, Molucc. Pac. : Ins. Admiral., Fidji, Nov. Uiuinea. pristocalyx (C. M.) Jaeg. Ad. 11, p. 323.

Hypnum pristocalyx C, M. in Bot. Zeit. 1854, p. 573.

Leskea pristocalyx Mitt. M. Ind. or. p. 133.

2.

- As. : M. Neilgherr.

protensum Jaeg. - Th. delicatulum.

pseudo-zquatoriale (C.M.) Par.

Tamariscella pseudo-æquatorialis C. M. in Hedwig. 1897, p. 140.

Ster.

- Am. merid. : And. Argentin. subtropic.

« var. casuarina (C. M.) Par.

Tamariscella pseudo-requatorialis var, casuarina C.M. l.c.

Tucuman.

- Am. merid.: And. Boliv., Argentin, subtropic.

pseudo-delicatulum (C. M.) Jaeg. Ad. II, p. 326 .

Hypnum pseudo-delicatulum $C$. M. in Fl. 1875, n. 34-35.

2. Ster. Filicic. - Am. merid. : Nov. Granat.

pseudo-involvens (C. M.) Besch. Fl. bryol. Réunion, etc., $p .148$.

Hypnum pseudo-involvens $C$. M. in Linn. 1876, p. 285.

1. Cortic. - Afr. : Tropic. orient., ins. Anjouan, Mayotte.

psendo-protensum (C. M.) Mitt. M. austr. am. p. 578.

Hypnum pseudo-protensum C. M. in Bot. Zeit. 1848, p. 779 et Syn. II, p.484.

2. Ster. Cortic. - Am, merid.: Venezuela.

pseudo-recognitum Broth. - Thuidium acuminatum.

pseudo-Tamarisci Limpr. Laubm. Deulschl. II, p. 831 (1).

2. Muric. ct terr. in umbros. - Eucr. : Tirol., Carinth., Carniol.

(1) Cr. Limpr. op, cit, p. 832. 
pulchellum de Not. Epil. p. 235; W. P. Sch. Syn, 11, p. 611.

Pseudo-Leskea gracilis (fid. Limpr.).

1. - Eur.: Ticin. (Locarno).

pulchellum A. Kerner. - Th. punctulatum.

pulvinatulum C. M. in Hedioig. 1897, p. 141.

Ster.

- Am. merid.: Uruguay.

punctulatum de Not. Evb, critt. ilal. n 909 el Epil. p. 234; W. P. Sch. op. cit. p. 610.

Hypnum punctulatum Bals. et de Not. Prodr. bryol. Mediol. p. 78 et Syll. M. p. 12; C. M. Syn II, p 488.

Th. gracile var. lancastriense (fid. Limpr.).

Th, pulchellum A. Kerner Fl. exs. austr. hung. n. 1930.

1. Terr. - Eur. : Rhaet., Ticin., Lombard., Pedem.; Transilv., Stir. As. : Caucas. occ. (1).

Exs.: Rab. Bryoth. eur. n. 769.

purpureum (Geh. et Hpe.) Par.

Hypnum purpureum $\mathrm{G}$. et $\mathrm{Hpe}$ in $\mathrm{Fl} .1881$.

2. - Am. merid. : Brasil. austr.

pusillum Mitt. M. austr, am. p. 577.

1 .

- Am. merid. : Venezuela.

pycnangiellum C. M. in Dusen M. Camer, $n$. 225; Broth. in Engler's Bot.

Jahrb. 1897, p. 283.

2. Lignic, rupic. et ad rad, arbor. - Afr. : M. Cameroon.

pycnothallum (C. M.) Par.

Tamariscella pycnothalla C. M. in Nuov. Giorn. bot. ital. 1896, p. 116.

2.

- As. : Uhina or. (prov.-Schen $\mathrm{Si}$ ).

pygmaeum (Sull.) Bryol. eur. V (mon, p, 6).

1. Rupic. - Am. sept.: Rar, : Canada, New Jersey, Pensilv, Ohio.

Exs. : Sull. et Lesq. M. bor. am. I ed, 11. 277 et II ed. n. 408.

quadrifarium Mitl, in Trans. of the Linn. Soc. 1891, p. 189.

Hypnum pygmaeum Sull. M. of U. St. p. 67 et Ic. M. p. 153, t. 98; Lesq. et Jam. Man. p. 322 .

Hypnum proliferum var. compactum Drumm, M. bor, am, I ed, n. 214.

H. recognitum Funk e.xs. n. 436 p.p.

Th. recrgnitum Wils. M. Amer, exs. p.p.

2. sept. : Canada.

- Eur. : Voges, Alp. centr. (St Gothard). Am

ramentosum Mitt. Sam. M. p. 186.

Leskea ramentosa ej. in Bonpl. 1861.

- Pac. : Ins. Fidji, Samoa, Norfolk, Austral, or.

ramuligerum Jseg. - Psendo-Leskea.

ramulosum (Hpe.) Jaeg. Ad. II, p. 323.

Hypnum ramulosum Hpe. in C. M. Syn. II. p. 486.

Th. crispifolium (fid. Barnes in Bot. Gaz. 1891, p. 206).

2.

- Am. sept. : Washington.

(1) Cf. Venturi in Rev. bryol. 1880, p. 102. 
ramusculosum (Mitt.) Jaeg. Ad. II, p. 317.

Leskea ramusculosa Mitt, in Journ, of the Linn. Soc. 1863, p. 161.

1. - Afr. : Ins. Fernando Po.

recognitum (Hedro.) Lindb. Man. M. II, p. 416, t. 1, f. 9; W. P. Sch. op. cit. p. $6 \mathrm{I} 4$.

Hypnum delicatulum L. Sp.pl. II ed. p. 1590 (quoad sol. pl. europ.).

H. recognitum Hedw. M. frond. IV, p. 92, t. 35.

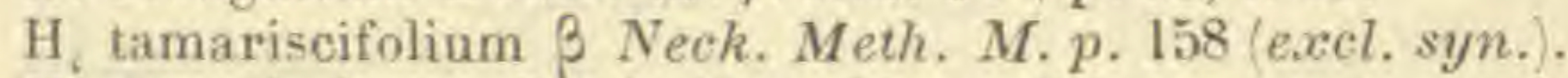

H. tamariscinum C. M. Syn. Il, p. 483.

H. tamariscinum $\beta$ recognitum Brid, Bryol. univ, $I I, 440$.

Th. delicatulum Bryol, evr. V (mon. p. 8), t. 484; Warnst, Maerk. Laubm. n. 163.

z. Lignic,, rupic. et terr. - Eur, : Media tota. As. : Japon., Obi, lenissei, Ross. or., Caucas., Persia. A fr. Alger. Am. sept. : Groenland, Labrador, New Brunswick, Nov. Scot., Ottawa, Ontario, Columb. brit., M. Kupestr., reg. sept. , centr., or. et merid. (1).

Exs. : Drumm. M. bor. am. I ed. n. 214 (fid. Best 1. c.).

Faurie Pl. Japon. n. i04, 174, 1426.

Mac. Canad. M. n. 271.

Rab. Bryoth. eur, n. 768.

Sull, et Lesq. M. bor. am. II ed, n. 404 (fid. Best 1. c.).

var. radicans Kindb. - Th. Philiberti.

recognilum Wils. p.p. - Th. quadrifarium.

Rehmanni $S b$, in Jaeg. Ad, II, p. 741.

Th. pinnatulum Rehm. M. A fr, austr. n. 360 .

$$
\text { - Afr. : Natal. }
$$

remotifolium (Grev.) Par.

Eurhynchium remotifolium Jaeg. Ad. II, p. 422 p.p.

Hypnum remotifolium Grev, in Trans. of Werner. Soc. Edinb. V, p. 483; 1.

C. M. Syn. II, p. 490; Lesq. et Jam. Man. p. 327.

remotifolium Jaeg p.p. - Eurhynchium scabrisetum.

rhaphidostegum (C. M.) Mitl. M. austr. ani. p. 577.

Hypnum rhaphidostegum C. M. Syn. II, p. 494.

1.

- Am. merid. : Chile.

rostratum W. P. Sch. in sched.; Jaey, Ad. II, p. 246.

- Am. sept. : Guatemala.

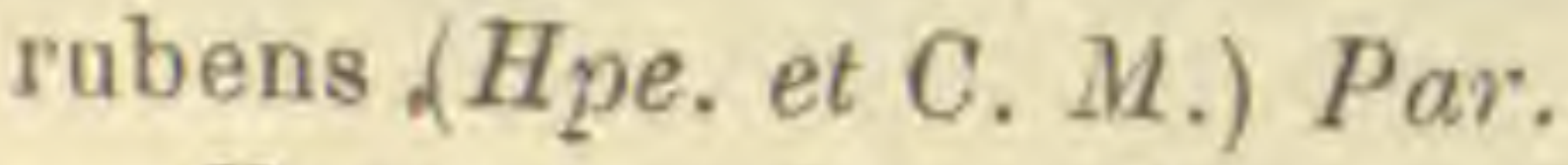

Hypnum rubens Hpe. et C. M. in Trans. and Proced of the roy. Soc. of Victoria, 1883, p. 91.

- Pac. : Austrai. or.

rubiginosum Besch, in Ann. sc. nat. 1892, I, p. 80.

1. In silvis. - As. : Yunnan.

sachalinense Lindb. in Act. Soc. sc. Fenn. 1872, p. 244.

2 .

- As, : Saghalien.

1) "Vulgatiss, D. Lesq. et Jam. Man. p. 325. "Nondum in America septentrionali observatum n. W. P. Sch. 1. c. - Spectant ne potius localitates omn. Americ, ad Th. quadrifanum? Ct. G. N. Best in Torr, bot, Club 1896, pp. 83-84. 
? sambokiphila (C. M.) Par.

Haplocladium sambokiphilum C. M. in Ule Bryoth. brasil. n. 96.

- Am. merid. : Brasil. austr, or.

samoanum Mill. Sam. M. p. 186.

Hyprium samoanum C. M. M. Polyn, p. 88.

Cortic. et rupic. - Pac.: Ins, Fidji, Samoa, Salomon.

scabrosulum Mitt. M. austr. am. p. 574.

1. Cortic., lignic, et terr, - Am, merid. : Amazon., Brasil. trop.

Schiedeanum (C. M.) Mitt. M. austr. am. p. 576.

Hypnum minutulum Hsch, in Deppe et Schiede M. Mexic.

H. Schiedeanum C. M. Syn. II, p. 494.

1.

- Am. sept. : Mexic.

schistocalyx (C, M.) Mitt. op. cit. p. 575.

Hypaum schistocalyx C. M. Syn. II, p. 691 .

1 ? Cortic. - Am. sept. : Costa Rica, Nicaragua, Cuba. Am. merid.: Amazon.

Schlumbergeri W. P. Sch, in Besch. Prodr. bryol, mexic. p. 92,

2.

- Am. sept. : Mexic.

scitum (P. B.) Aust. M. Appal. n. 300.

Hypnum abietinum var. minor Drumm. M, bor. am. I ed. n. 217.

H. intertextum wühlemb, in Sull, M. Allegh, n, 6 .

H. porrigens Wils, ibid.

H. scitum P. B. Prodr. p. 69 ; Sull. Io. M. p. 155 , t. 99 ; I. M. Syn. II, p. $488 ;$ Lesq. et Jam. Man. p. 323

H. Stereodon scitus Brid. Bryol. univ. 1I, p. 575.

Rauia scita A ust, in Bull. Tor, bot. Club, VII. p. 16.

1. Cortic. et saxic. - Am. sept.: New Brunswick, Ottawa, Ontario, reg. sept.

Exs. : Mac. Canad. M. n. 268 p.p., 269.

Sull, et Lesq. M. bor. am. II ed. n. 409.

" var. aestivale Aust. M. Appal. n, 301.

Hypnum scitum var. aestivale Lesq. et Jam. $l$. o.

Th. aestivum A ust. in Bull. Torr. bot. Club, V, p. 23.

Ut typ. - Am. sept.: Canada, New Jersey, Vermont, New York, Pensilv., Wisconssin, Carol. sept.

"var. lonchoneuron Kindb. in Mac. Cat. p. 184.

Lignic. - Am, sept. : Ontario.

scoparium Wils, in sched. ; Jaeg. Ad, 11, p. 333.

- As, : Himalays.

scopulum Jaeg. - Pseudo-Leskea.

semi-lunare C. M. in Hedwig. 1897, p. 141.

- Am. merid. : Argentin. subtropic, Tucuman.

semi-tortulum (C. M.) Jaeg. Ad. II, p. 318.

Hypnum semi-tortulum C. M. in Linn. 1869-70, p. 17.

Ster.

- As, : Ceylan.

Sigmatella (C. M.) Jaeg. Ad. II, p. 321.

Hypnum Sigmatella C. M, in Linn, 1875, p. 473,

I. Terr. - Afr.: Djour. 
siphotheca (C.M.) Jaeg. l. c

Hypnum siphotheca $C . M$. in Bot. Zeit., 1858, p. 171.

1. $\quad-$ Am. sept. : Guatemala. Am. merid. : Venezuela, sparsifolium (Mitt.) Jaeg. Ad. II. p. 3l4.

Leskea sparsifolia Mitt. M. Ind. or. p. 135.

1.

- As. : Nepal., Himalaya sept. occid.

" var, altisetum C. M. in sched.

- As.: Himalaya sept. occid.

sparsum (Hook. f. et Wils.) Jaeg. Ad. II, p. 332.

Hypnum sparsum H. f. et W. Fl. of the N. Zeal. II, p. 109, t. 89, f. 5 et Handb. $p, 471$.

Th. furfurosum var, ? (fid. Mitt.).

2. $\quad-$ Pac. : Nov, Zeland. sept. et med,, Alp. Austral. or. (Queensland), Tasman.

stellatifolium (Hpe.) Jaeg. op. cit. p. 317.

Hypnum stellatifolium Hpe. Symb. 1874, p. 525.

Pseudo-Leskea stellatifolia Sb. in Jaeg, op. cit, p, 739.

1.

- Am. sept. : Brasil. austr. or.

striinerve (C.M.) Par.

Tamariscella striinervis C. M. in Nuov. Giorn. bot. ital. 1891, p. 601 (nom.).

Ster.

- As. : Birman. super.

Struthiopteris C. M. in Hildebrandt M. Mad. n. 2075.

- Afr. : Madagascar merid.

Stuartii (C. M.) Jaeg, op. cit. p. 332.

Hypnum hastatum Hpe. in Linn. 1852, p. 715 .

H. Stuartii C. M. in Bot. Zeit. 1856, p. 459.

Th. furfurosum (fid. Mitt.).

2.

- Pac. : Tasman.

subbifarium Broth. in Engler's Bot. Jahrb. I893, p. 478.

2. Fr. ign. $\quad$ - Pac.: Nov, Guinea.

subdelicatulum (Bpe.) Par.

Hypnum subdelicatulum Hpe. Enum. M. Brasil. p. 84

2. Ad rup. umbrat. - Am. merid.: Brasil. austr. or.

suberectum (Hpe.) Jaeg. Ad. I1, p. 312 .

Hypnum suberectum Hpe. in Linn. 1859-60, p. 638; F. v. Müller, M. A ustr, t. XXII.

- Pac. : Austral. or.

subfalcatum (Mitt.) Par.

Leskea subfalcata Mitt. in M. hb. Hook. 1860, p. 53, t. 5, f. 7.

1. Ad rup. madid. - Afr: : Niger.

subgracile (Hpe.) Jaeg. op. cit. p. 314 .

Cyrto-Hypnum subgracile Hpe. Symb. 1870, p. 284.

1 .

- Am. merid. : Brasil. austr, or.

subgranulatum (Geh, et Hpe.) Par.

Hypnum subgranulatum Geh. et Hpe. Enum. M. Brasil. n. 87.

- Am. merid.: Brasil. 
subinvolvens $C . M$. in sched.

Hypnum schistocalyx Sull. in Wright M. Cub, n. 96 et in Proced. Am. Acad.... 1861, p. 286.

- Am. sept. : Cuba.

? sublaevifolium (C. M.) Par.

Haplocladium sublaevifolium $C$. M. mss.

- As. : Himalaya sept, occ.

subnudum (C. M.) Par.

Hypnum subnudum C. M. in Rev, bryol. 1887, p. 57 (nom.).

- Am. merid. : Paraguay.

Exs, : Balansa Pl. Parag. n. 3673.

\& var. Bescherellei Par.

Hypnum subnudum var, C. M. l. c. (nom.).

Pseudo Leskea paraguensis Besch. in Bal. Pl. Parag. n. 3679 A et in Rev. bryol. $1885, p .18$.

- Am. merid. : Paraguay.

subperseissum C. M. in Rev, bryol. 1878, p. 59 (nom.).

- Afr. : Ins. Franciae.

subpinnatum (Hpe.) Par.

Hypnum subpinnatum Hpe, in Fl. 1881.

Lignic. - Am. merid. : Brasil. or.

subscissum C. M. in Besch. Fl. bryol. Réunion, elc., p. 149.

1. Secus rivul. - Afr. : Tropic. or., ins. Mayotte, Nossi Be.

subserratum Ren. et Card. in Bull. Soc. roy. bot. Belg. 1893, I, p. 122 et M. Masc. Mad. n. 190.

2 . 우 et fr. ign.

- Afr.: Comor. magna.

subtamariscinum (Hpe.) Par.

Hypnum subtamariscinum Hpe, Enum. M. Brasil, p, 85.

Th. brasiliense Mitt.?

2. Terr. in silv. - Am. merid. : Rrasil. or.

subulaceum Jaeg. - Pseudo-Leskea.

talongense Besch, in Ann. sc. nat. 1892, I, p. 81.

1. In silv. -- As. : Yunnan.

tamariscellum (C, M.) Bryol. jav. II, p. 120.

Hypnum tamariscellum C. M. in Bot. Zeit. 1851, p. 573.

Leskea tamariscella Mitt. M. Ind. or. p. 134. 1. - As. : Tonkin, M. Neilgherr., Sumatra.

tamariscifolium Lindb. - Th. tamariscinum.

tamarisciforme W. P. Sch. - Th. japonicum.

tamariscinum (Hedio.) Bryol, eur, V (mon. p. 7), t. 483; W. P. Sch. Syn. II ed.p. 613.

Hypnum delicatulum C. M. Syn. $I I, p .484$.

H. delicatum Ehrh. Dec. n. 30 .

H. flicinum Tamarisci folis minoribus non splendentibus Dill. Hist. M. p. $276, t .35, f .14$.

H. parietinum Murr, in L. Syst. veg. p. 590.

H. proliferum $L . S p$. $p l$. 1590 .

H, tamariscifolium Neck. Meth. M. p. 158 (excl. syn.).

H. tamariscinum Hedu. Sp. M. p. 262, t,67: Brid. Bryol. univ, I1, p. 438.

Th. tamariscifolium Lindb. Man. M. $11, p, 415, t .1, f .7$. 
2. Rupic. et terr. in silvat. - Eur.: Fere tota. Afr.: Ins. Azor., Madeir., Transvaal. Am. sept.: Temperata tota.

Exs. : Rab. Bryoth. eur. n. 20.

Rehm. M. Afr, austr. n. 646.

Sull, et Lesq. M. bor. am. II ed. n. 403.

"var. mexicanum W. P. Sch. in Besch. Prodr. bryol. mexic. p. 92.

Th. miradorium Jaeg. Ad. II, p. 329.

Card.).

- Am. sept. : Mexic., Costa Rica; Haïti (fid. Ren. et

tenellum W. P. Sch. in sched.; Jaeg. Ad. 11, p. 319.

- Afr. : Ins. Borbon.

tenuissimum Welwo. et Duby in Mém... Genève, 1871, p. 18, t. 5, f. 2.

1. Ad rivul. - Afr. : Angola.

thamnicladum (C. M.) Par.

Tamariscella thamniclada $C . M$. in sched.

- As. : Himalaya sept. occid.

tomentosum W. P. Sch. in Besch. op. cit. p. 93.

Ster.

- Am. sept. : Mexic.

torrentium C. M. in Rehm. M. Afr, austr, n. 644.

- Afr. : Transvaal.

Torskii Kiaer in sched. ; C. M. in Hedwig. 1897, p. 144.

Ster.

- Am. merid. : Argentin temper.

trachyacron (C. M.) Par.

Tamariscella trachyacra $C . M$. in sched.

- As. : Birman. sup.

trachypodum (Mitt.) Bryol. jav. 11, p. 122, t. 225.

Hypnum plumulosum f. M. Syn. II, p. 486 p. p. ?

Leskea trachypoda Mitt. M. Ind. or. p. 133.

Pelekium trachypodum Jaeg. Ad. II, p. 324.

1.

-- As, : Nepal., Sumatra, Javu.

tripinnatum (C. M.) Par.

Tamariscella tripinnata C. M. in Nuov. Giorn, bot. ital. 1897, p. 161. - Am. meril. : And. Boliv.

Türckheimii C. M. in Bull. hb. Boissier, 1897, p. 219.

- Am. sept. : Guatemala.

urceolatum Ltz. Moosst. p. 167.

2

- Am sept. : Jamaic., Guadalup.

vancouveriense Kindb. - Heterocladium.

varians Welwo. et Duby in Mém... Genève, $1871, p .16, t .5, f .3$.

1. Ad arbor, rad. - Afr.: Angola.

velatum (Mitt.) Par.

Lorentzia longirostris (fid. Mitt.).

Pelekium velatum Mitt. Sam. M. p. 176, t. VI, C.

1. Saxic. - As. : Borneo, Java. Pac.: Ins. Admiral, Samoa. ventrifolium (C. M.) Pur.

Tamariscella ventrifolia C. M. in B̈ull. hb. Boissier, 1897, p. 220.

Ster. Cortic. et terr. - Am. sept. : Guatemala. 
venustulum Besch. in Ann. sc. nat. 1892, I, p. 78.

1. Ad rivul. - As. : Yunnan. Afr.: Usambara.

verrucipes C. $M$. in Malpighia, 1896, p. 159.

- Am. merid. : Guian. brit.

versicolor (C. M.) W. P. Sch, in Breut. M. Capens.

Hypnum minutulum $\mathrm{Hsch}$. in Drege M. Capens.

H. versicolor C. M. Syn. $I I, p .494$.

1. Cortic. - Afr. : C. B. Sp.

vestitissimum Besch. in Ann. sc. nat. 1892, I, p. 79.

2.

- As, : Yunnan.

virginianum Lindb. - Th. gracile var. lancastriense.

viride Mitt. in Trans. of the Linn. Soc. 1891, p. 188.

Ster.

- As. : Japon.

Whippleanum (Sull.) Jaeg. Ad. II, p. 323.

Claopodium Whippleanum Card. M. Am. sept. p. 50.

Hypnum Whippleanum Sull, in Bot. Pac. R. R. Surv. (Whipple), p. 190, t. 9 ; Lesq. et Jam. Man. p. 328.

Th. leskeoides Kindb. in Bull. Torr, bot. Club, 1890, p. 277.

2. Rupic. - Am. sept. : Vancouver, Calif. infer.

Wrightii Jaeg. Ad. II, p. 315.

Th. minutulum Mitt. $M$. austr. am, $p .577$.

1.

- Am. sept. : Cuba, Jamaic. (1).

THUYIDIUM Lindb. M. Scand. (= Thüidium).

THYRIDIUM Mitt. M. austr. am. p. 114.

Spec. omn. non indicatae sunt syrropontes ejud. nom.

crassinerve Mitt. - Calymperes.

parvulum $\mathrm{Sb}$. - Syrrhopodon ceylonensis.

THYSANOMITRIUM Schwoegr. Suppl. $I I, t$. 118.

Spec. omn. non indicatae sunt CAMPyLOPODEs ejus.l. nom.

arotocarpum $\beta$ Moritzi Hpe. - Campylopus porphyreodictyon.

ciliatum Brid. - Syrrhopodon.

havaicum C. M. -- Campylopus sandwicensis.

introflexum Hpe. - Campylopus erectus.

jamaicense C. M. - Campylopus Cinchonae.

Mülleri Hpe. - Campylopus Richardi.

phascoideum Hpe. - Campylopus comosus.

piriforme Rab. - Campylopus turfaceus.

scabrisetum Hpe. - Campylopus Sellowianns.

splendens Hook, - Pilopogon gracilis.

uncinatum Harv, - Dicranodontium.

(1) In Enum. Kindberg. nom. nuda:

denniceps C. $M$.

micro-tamariscinum C. $M$. 
TIMMIA Hedw. M. frond. I, p. 83 (6 spec.).

austriaca Hedhn. Sp. M. p. :76, t. 42, f. 1-7; Brid. Bryol, univ. 11, p. 71; Bryol. eur. IV (mon. p. 7), t. 408; C. M. Syn. 1, p. 189; W. P.Sch. Syn. II ed., p. 525.

Mnium megapolitanum P. B. Prodr. p. 74.

T. polytrichoides $\beta$ lutescens Brid. Sp. M. III, p. 99.

2. In silvat. umbr. et ad rivul. - Eur.: Spitzberg. ins. Ursor., tot, jugum alp. As. : Alp. Yunnan., Jenissei med. et infer., Himalaya, Tibet occ.? Am. sept.: Groenland, M. Rupestr., Columb. brit., Vancouver, Washington, Idaho, Montana, Colorado.

Exs. : Mac. Canad. M. n. 213.

Sull. et Lesq. M. bor. am. II ed. n. 312 .

var. alpina Hartm. - T. megapolitana.

var. bavarica Hüb. - T. megapolitana.

" var. brevifolia Ren. et Card. in Bot. Gaz, 1894, p. 238.

- Am. sept. : Colorado.

var. umbilicata Hartm. - T. megapolitana.

bavarica Heul. - T. megapolitana.

comata Arn. et Lindb. M. As. bor. 1890, II, p. 24.

Ster.

- As. : Jenissei med. et infer.

cucullata Rich. - T. megapolitana.

Hookeri W. P. Sch. Syn. 11 ed. p. 525 (nom.).

- As. : Tibet.

megapolitana Hedro. M. fr. I, p. 83, t. 3I ; Brid. Bryol. univ. II, p. 69;

Bryol. eur. IV (mon. p. 6), t. 407; C. M. Syn. I, p. 189; W. P. Sch. Syn. Il ed., p. 523.

Bryum foliis lanceolatis falcatis, setis alaribus, capsula ovata inclinata Hall. Hist. St. Helv, n. 1779.

Mnium megapolitanum Gmel. Syst. nat. II, p. 1327.

Mn. Timmia Hoffm. Deutsch. Fl. II, p. 58 .

Orthopy sis megapolitana $P, B$. Prodr. $p .79$.

T. alpina Laurer in $\mathrm{Fl} .1827, p .292$.

T. austriaca $\left\{\begin{array}{l}\beta \text { alpina Hartm. Skand. Fl. III ed., II, p. } 292 . \\ \gamma \text { bavarica Hüb. Muscol. germ. p. } 514 . \\ \beta \text { umbilicata Hartm. Skand. Fl. II ed. }\end{array}\right.$

T. bavarica Heuler Comm. de Timmia, p. 19, f. 3 .

T. cucullata Rich, in Mich. Fl. Am. bor. II, p. 304 .

T. megapolitana $\beta$ bavarica Brid. op. cit. p. 271.

T. polytrichoides Brid. Mant. M. p. 122.

T. polytrichoides $\alpha$ viridis Brid. $s p . M . I I I, p .99$.

T. salisburgensis Hoppe mss. ; Laurer in Fl. 1827, p. 295.

T. viridis Brid. Bryol. univ. II, p. 70.

1. In turfos. et cryptis vel sub iup. - Eur.: Per tot. Alp. tract zon. intermed. et septentr. : desideratur in Britann. (W: P. Sch.); Scotia (C. M.), Pyren. As. : Jenissei, Caucas, occ. et centr., Himalaya sept. occid., Kashmir. Afr.: Alger. Am. sept. : Groenland, ins. Melville, Gaspes.. Ottawa, Ontario, Athabasca, Saskatchewan, M. Rupestr., Vancouver, W
Exs.: Mac. Canad. M. n. 213.

Rab. Bryoth. eur, n. 66, 67, 525, 625.

Un. itin. 1863 , p. $52 ; 1867$, n. 49.

var, bavarica Brid. - T. megapolitana. 
"var, brevifolia E. G. et G. G. Borsczczov in Arn. et Lindb. M. As. bor. $1890,11, p .25$.

Ster. - As, : Taimyr.

var. norvegica Lindb. - T. norvegica.

norvegica Zett. in Oefv. Vet Akad. Foerh. 1862, p. 364; W. P. Sch. Syn. 11 ed. p. 526.

T. megapolitana $\beta$ norvegica Lindb. in Oefv. Vet. Akad. Foerh. 1864, n. 6 , p. 337.

2. Rupic. - Eur.: Spitzberg, ins. Ursor., Norveg., Scot.; Stiria (fertil., fid. Juratzka). As.: Jenissei infer., Caucas, centr. Am. sept. : Groenland, M. Rupestr., Athabasca.

Exs. : Mac. Canad. M. n. 586.

Rab. Bryoth, eur. Ii. 1023.

polytrichoides Brid. - T. megapolitana.

$\beta$ lutescens Brid. - T. austriaca.

$\alpha$ viridis Brid, - T. megapolitana.

salisburgensis Hoppe. - T. megapolitana.

sibirica Arn. et Lindb. M. As. bor. 1890, 1I, p. 24.

Ster.

- As. : Jenissei med. et infer.

viridis - Brid. - T. megapolitana.

TIMmiel.LA de Not. Cron. briol. ital. I, p. 14 (sect. Trichostomi); Limpr.

Laubm. Deutschl. I, p. 590 (gen. propr.).

anomala I.impr. - Trichostomum.

Barbula Limpr. - Trichostomum.

flexiseta Limpr. - Trichostomum flexipes.

TORTElla C. M. Syn. I, p. 599 (sect. Barbulae); Limpr. op. cit. p. 599 (gen. propr.).

Spec. omn. sunt BARBULA ejusd. nom.

TORTULA Hedw. Sp. M. p. 122.

Spec. omn. non indicatae sunt Barbulae ejusd. nom.

acuminata $\left\{\begin{array}{l}\text { Brid. (M. Rec.). - B. cuneifolia. } \\ \text { Brid. (Spec. M.). - B. unguiculata var. brachypus. } \\ \text { Sw. ? Mitt. - B. marginata. }\end{array}\right.$

acutu Brid. - B. gracilis.

adusta Mitt. - Pottia brachypus.

aestiva P. B. - B, muralis var. aestiva.

aloides de Not. p.p $\left\{\begin{array}{l}\text { - B, aloides. } \\ - \text { B. ambigua. }\end{array}\right.$

ambigua Roehl. - B. muralis.

amblyophylla Mitt. - Pottia.

amcena Brid. - B. unguiculata.

Anderssonii sngstr. - B. australis.

andina Mitt. - Trichostomum.

angustifolia Lind'. - Pottia.

anomala Mitt. - Trichostomum.

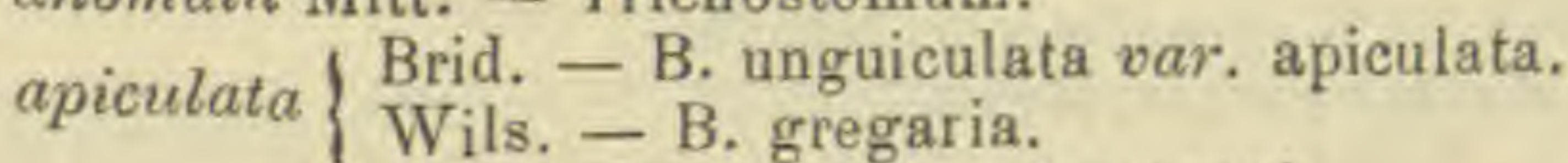

arcuata Mitt. $\left\{\begin{array}{l}\text { - Syrrhopodon Jamesoni. } \\ - \text { Trichostomum campylocarpum. }\end{array}\right.$

aristata $\mathrm{Sm} .-\mathrm{B}$. unguiculata.

atlantica Brid. - Eucladium verticillatum. 
barbata $\mathrm{Sm}$. - B. unguiculata.

bermudana Mitt. - Trichostomum.

Berteroana Mitt. - Trichostomum.

bifrons de Not. - B. rigida var. pilifera.

bombayensis Mitt. - Didymodon.

brachydontia Mitt, - Trichostomum mutabile.

brachyphylla Mitt. - B. Hampeana.

brevicaulis Hook, et Grev. - B. fallax var, brevicaulis.

brevifolia $\mathrm{Sm}$. - B. fallax var. brevifolia.

brevirostris Grev. - B. rigida.

bryoides $\left\{\begin{array}{l}\text { Hook. - Desmatodon Laureri. } \\ \text { Lindb. - Phascum. }\end{array}\right.$

bullata Lindb. - Pottia latifolia var. pilifera.

var. mutica Lindb. - Pottia latifolia.

cacuminata Wils, - Gymnostomum recurvum.

caespitosa Hook. et Grev. - B. marginata.

var. eor. - B. Knightii.

calcicola Mitt. - Trichostomum.

campylocarpa Mitt. (quoad pl. Guatemal.). - Barbula Godmaniana.

canaliculata Mitt. - Trichostomum.

caucasica Lindb. - Pottia.

cernua Lindb. - Desmatodon.

chilensis Mitt. - Trichostomum.

chloronotos Brid. - B. membranifolia.

cirrala $\left\{\begin{array}{l}\text { Lag. }- \text { B. caespitosa. } \\ \text { W. Arn. - Trichostomum Barbula (fid. Limpr.). }\end{array}\right.$

cirrifolia Mitt. - Trichostomum.

comosa? Wils, - B. hastata.

conlortifolia Mitt. - Trichostomum.

crassinervia de Not. - B. chloronotos.

crispula Mitt. - Trichostomum.

crocea Brid. - B. paludosa.

var. humilis Lindb. - B. paludosa var. Funkiana.

curta Sw. - Ditrichum tortile var. pusillum.

curvata Schlecht. - B. inclinata.

cylindrica Mitt. $\left\{\begin{array}{l}\text { - Didymodon. } \\ \text { - Hyophila circinata. }\end{array}\right.$

danica Lge, - B. pulvinata.

Davallii Lindb. - Pottia minutula.

decipiens $\left\{\begin{array}{l}\text { Brid. }- \text { B. agraria, } \\ \text { Sibth. }- \text { B. unguiculata. }\end{array}\right.$

dubia P. B. - B. unguiculata.

enervis Hook. et Grev. - B. rigida.

ericaefolia Lindb. - B. ambigua.

ericetorum $\mathrm{Sm}$. - B. unguiculata var, patagonica.

erubescens Mitt. - Didymodon.

eucalyptrata Lindb. - Desmatodon latifolius var, glacialis.

exlenuata de Not. - B. Vahliana.

fallax $\left\{\begin{array}{l}\text { Hook, et Grev. - B. unguiculata. } \\ \text { Wils. - B. nigrescens. }\end{array}\right.$

var. $\gamma$ H. et Gr. - B. fallax var. brevicaulis.

var. stricta de Not. - B. gracilis var. viridis.

var. Wils. - Geheebia cataractarum.

flavescens Brid. - B. fallax.

var. Wils. - B, gracilenta.

flaviseta Mitt. - Pottia flavipes.

var. minor Lindb. - Trichostomum flavo-virens var, viridi-flavum. flexuosa Brid. - ? Deleatur. 
var. Hook. - B, calycina?

fragilis Wils. - B. Drummondii.

fuegiana Mitt. (1876). - B. semi-rubra.

Funkiana Hook, et Grev. - B. paludosa var. Funkiana.

fuscescens Hook. e: Grev. - B. Australasiae.

gigantea Lindb. - Geheebia cataractarum.

goettingensis Brid. - R. muralis.

Heimii Mitt. - Pottia.

var. arctica Lindb. - Pottia Heimii var. aretica.

var, longiseta Lindb. - Pottia Heimii var. longiseta.

hercynica Schrad. - B. subulata.

humilis $\left\{\begin{array}{l}\text { Brid. - B. caespitosa. } \\ \text { Drumm. - B. amplexa. } \\ \text { Hook. - B. obtusifolia. } \\ \text { Turn. - B. unguiculata. }\end{array}\right.$

imberbis Sm. - B. fallax.

inclinata var. $\beta$ Hook. et Grev. - B. inclinata var. leptotheca.

indica Hook. - Trichostomum orientale.

inflexa Lindb. - Trichostomum orientale var. inflexum.

insulana de Not. - B. cylindrica.

intermedia $\left\{\begin{array}{l}\text { Lindb. - Kottia lanceolata var. gymnostoma. } \\ \text { Mitt. - B. caespitosa. }\end{array}\right.$

jamaïcensis Mitt. - Trichostomum.

lacustris P. B. - Didymodon rubellus.

laevipila $\left\{\begin{array}{l}\text { var. marginata Lindb.- B. laevipila var. meridionalis } \\ \text { var. propagulifera Lindb. - B. pagorum. } \\ \text { var. Wils. - B. Mülleri. }\end{array}\right.$

laevipilaeformis de Not. - B. laevipila var. meridionalis.

lamellata Lindb. - B. cavifolia.

lanceolata $\left\{\begin{array}{l}\text { P. B. - B, unguiculata var. obtusifolia. } \\ \text { Lindb. - Pottia. }\end{array}\right.$

var. aciphylla I.indb, - Pottia lanceolata var. aciphylla.

latifolia Lindb. - Desmatodon.

var. mutica I.indb. - Desmatodon Iatifolius var. glacialis.

Laureri lindb. - Desmatodon.

limbata Lindb. - B. sublimbata.

Lindbergii Kindb. - Pottia.

linoides Brid. - B. unguiculata.

longifolia Mitt. - Didymodon.

lusitanica Brid. - Trichostomum Barbula.

macrocarpa Mitt. - Pottia.

marginata Kze. - B. Kunzeana.

melanocarpa Mitt. - Hyophila Barbula.

mexicana Mitt. - Pottia.

mnioides Hook. - Streptopogon.

montana Lindb. - B. intermedia.

mucronata Lindb. - B. Brebissonii.

mucronifolia $\left\{\begin{array}{l}\text { de Not. - B. alpina. } \\ \text { Hook. - B. mucronifolia var. arctica. }\end{array}\right.$

var. arctica Hook. et Grev. - B. mucronifolia var, arctica.

mucronulata $\left\{\begin{array}{l}\text { Sm. - B. unguiculata. } \\ \text { Sw. - B. unguiculata var, cuspidata. }\end{array}\right.$

var. $\beta$ Turn. - B. unguiculata var. cuspidata.

Mïlleri H. f. et W. - B. antarctica.

muralis var. goettingensis Brid. - B. muralis.

mutica $\left\{\begin{array}{l}\text { Brid. - B. euneifolia. } \\ \text { Lindb. - B. latifolia. } \\ \text { Mitt. - Trichostomum. }\end{array}\right.$ 
nervosa $\left\{\begin{array}{l}\text { Rrid. - B. inclinata. } \\ \text { Engl. Bot. - B. revoluta. }\end{array}\right.$

Northiana Grev. - B. caespitosa.

norvegica Wahlenb. - B. aciphylla.

oblongifolia Wils. - R. Vahliana.

obscura Mitt. - B. Wrightii.

occidentalis Mitt. - Trichostomum.

cenea Mitt. - Didymodon.

pallnes Brid. - $B$, agraria,

parvula Hook, et Grev. - B. atro-virens.

pellucida $\left\{\begin{array}{l}\text { de Not. - B. sublimbata. } \\ \text { Hook. et Grev. - B. agraria. }\end{array}\right.$

pilosa Schrad. - B. muralis.

platyphylla Mitt. - Desmatodon amblyophyllus.

princeps de Not. - B. Mülleri.

prostrata Mitt. - Streptopogon mnioides var. prostrata.

punctulala Mitt. - B, robusta.

pungens Lindb. - Pottia Kindbergii.

pusilla Mitt. - Pottia cavifolia.

rectifolia Mitt. - B. gracilis.

reflexa Brid. - $\mathrm{B}$. fallax.

revoluta H. et T. - B. Hornschuchiana.

rigida $\left\{\begin{array}{l}\text { Brid. - B. ambigua } . \\ \mathrm{Sm} .-\mathrm{B} \text {. aloides. }\end{array}\right.$

rivalis Mitt. - Trichostomum.

robusta var. $\beta$ H. f. et W. - B. rubra.

rosulata Wils. - B. mucronifolia.

rotundifolia Hartm. - B. papillosa.

( var. alpina de Not. - B. aciphylla.

var. crinita de Not. - B. intermedia.

var. laevipila Hook, et Grev. - B. laevipila.

ruralis $\left\{\begin{array}{l}\text { var. latifolia W. Arn. - B. latifolia. } \\ \text { var, minor Wils. - B. intermedia. }\end{array}\right.$

var. rupestris Wils. - B. intermedia.

var. I. Spr. - B. intermedia.

var. H. et T. - B. papillosa.

var. Wils. - B. caninervis.

Saussuriana P. B. - Ceratodon purpureus.

Schlimii Mitt. - Trichostomum.

semi-vaginata D na E. G. Britt. - Trichostomum.

serrulata Mitt. - B. rubra.

setosa P. B. - B. convoluta.

sinuosa Rab. - Didymodon.

spathulaefolia de Not. - B. cuneifolia.

Sprengelii Hook, et Grev. - Trichostomum Berteroanum?

squamigera de Not. - B. membranifolia.

var. pollioidea de Not. - B. grisea.

Starkeana Lindb. - Pottia.

var, Davallii Lindb. - Pottia minutula.

stellata $\left\{\begin{array}{l}\text { Hook. et Grev, - B, agraria. } \\ \text { Lindb. - B, rigida. }\end{array}\right.$

stricta Brid. - B. unguiculata.

suberecta Hook. - Desmatodon obliquus.

subsessilis Mitt. - Pharomitrium.

subulata Drumm.

$\left.\begin{array}{l}\text { var. laevifolia Lindb. } \\ \text { var, mucronifolia Roehl. }\end{array}\right\}-$ B, mucronifolia.

systylia Lindb, - Desmatodon. 
tenuirostris Mitt. - Didymodon eylindricus.

torluosa var. inclinata Drnmm. - B. Drummondii.

truncatula Lindh. - Pottia truncata.

Turneri Brid. - Didymodon rubellus.

unguiculata Turn. - Didymodon rubellus.

Valulii 3 subflaccida Lindb. - B. Vahliana.

verlicillata Mitt. - Eucladium.

vinealis $\left\{\begin{array}{l}\text { de Not. p.p. - B. cylindrica. } \\ \text { var. glacialis } \mathrm{Spr} \text { - Geheebia cataractarum. } \\ \text { var. Wils, - B. constricta. }\end{array}\right.$

virescens de Not. $\left\{\begin{array}{l}\text { (Epil.). L. B. pulvinata? } \\ \text { (M. ital.). - B. ruralis var, virescens. }\end{array}\right.$

TRACHYCYSTIS Lindb. Mniac. eur. p. 80.

Spec. omn. RHizogonia ejusd. nom.

TRACHYLOMA Brid. Bryol, univ. II, p. 277 (10 spec.).

africanum Rehm. M. Afr. austr. n. 332; Broth. in Engler's Bot. Jahrb. 1894, p. 198 (descriptio).

Calyptothecium africanum Mitt. in Journ. of the Linn. Soc. 1886, p. 312.

2. Cortic. - Afr. : M. Usagara, Kilima N'Djaro, Usambara ; austral.

Antipodum C. M. et Schlieph, in sched.

- Pac. : Ins, Auckland.

arborescens Mitt. $\left\{\begin{array}{l}\text { (Sam. M.). - Hypnodendron subspininervium. } \\ \text { (M. Ind. or.). - Hypnodendron. }\end{array}\right.$

Archeri Mitt. - Hypnodendron.

arcuatum Mitt. - Hypnodendron spininervium var, arcuatum.

Buftoni (Broth.) Par.

Calyptothecium Buftoni Broth, in op, cit. 1895, p. 65.

2.

- Pac. : Tasman.

comosum Mitt. - Mniodendron.

cylindricum Lindb. ? Jaeg. - Tr. planifolium.

diversinerve Hpe. in F. v. Müller's Fragm. Phyt. Austr. X1, Suppl. III, p. 50.

Pterobryum diversinerve Mitt. in Trans. and Proced. of the roy. Soc. of Victoria, 1883, $\mu, 81$.

Ster?

- Pac. : Austral. (Victoria).

Helmii $C . M$. in sched.

Ad arbor. - Pac. : Nov. Zeland. sept.

indicum Mill. M. Ind. or. p. 91 ; Bryol. jav. II, p. 82, t. 197.

Neckera planifolia Reinw. et Hseh. in Nov. Act. Acad. Caes, Leop. Carol. XIV, $p, 714$.

Ster.

- As. : Ceylan, Java, Pac. : Nov. Guinea,

Junghunii Mitt. - Hypopterygium vitiense.

Menziezii Par.

Neckera planifolia Hook. M. ex. t. 23; H. f. et W. Fl. of the N. Zeal. II,

p. 103 et Fl. Tasm. II, p. 205.

N. Trachyloma C. M. Syn. II, p. 44.

Tr. planifolium Jaeg. Ad. II, p. 201; Brid. Bryol. univ. II, p. 278 p.p.: Handb. of the N. Zeal, Fl. p. 463.

2? Lignic. - Pac. : Nov. Zeland., Tasman. 
Mülleri Hpe. in F. v. Müller's Fragm. Phyt. Austral. XI, Suppl. 1II, p. 50 .

Ster. - Pac. : Austral. (Victoria).

Novae Guineae C. M, in sched.

Ster.

- Pac. : Nov. Guin, brit.

planifolium (Hedw.) Brid. op. et l. cc.p.p.

Neckera planifolia Hedw. Sp. M. p. 206, t. 48; C. M. Syn. II, p. 45.

Pterobryum planifolium Mitt. in Trans. and Proced. of the roy. Soc. of Victoria, 1883, p. 81.

Tr, cylindricum Lindb. (?) Jaeg. Ad. II, p. 204.

¿. Lignic. - Pac. : Nov. Zeland. sept. et med.

planifolium Jaeg. - Tr. Menziezii.

slipitatum Mitt. - Hypnodendron.

subbasilave Mitt. - Rhizogonium.

Taylori Mitt. - Papillaria cuspidigera.

TRACHYMITRIUM Brid. Bryol, univ. 11, p. 159.

Spec. omn. sunt syrropodontes ejusd. nom.

Trachynotus C. M. M. Polyn. p. 57 (sect. Leucophanis).

TRACHYPODIUM W. P. Sch, in Savatier M. Japon.

filamentosum W. P. Sch. - Meteorium aureum forma.

TRA ChYPUS Reinw, et Hsch. in Nov. Act. Acad. Caes. Leop. Carol. XIV, II, Suppl. p. 708, t. 39 (20 spec.).

atratus Milt. M. Ind. or. p. 129.

Pilotrichella chrysoclada $C . M$. ?

2.

- As, : M. Neilgherr., Ceylan.

auriculatus Mill. op. et $l$. $c c$.

Papillaria auriculata Jaeg. Ad. II, p. 178.

2.

- As. : Sikkim.

baviensis Besch, in Journ. de bot. 1890, p. 203.

Ster. Saxic. - As. : Tonkin.

bicolor Reinu. et Hsch, in op, et l. cc.

Neckera Trachypus C. M. Syn. 11, p.672.

Papillaria bicolor Jaeg. Ad. II, p. 177.

Pilotrichum Trachypus $C$. M. op. eit. $p$. 162.

2 .

Nietneri? fid. C. M.), Sumatra, Java, ins, Ceram.

bicolor Mitt. p.p. - Tr. Nietneri?

blandus Mitt. - Papillaria.

brevirameus Mitt. - Pilotrichella.

Buchanani Mitt. - Papillaria.

cerinus Mitt. - Papillaria.

crispatulus (Hook.) Milt. M. Ind. or. p. 129.

Hypnum crispatulum Hook, in Trans. of the Linn. Soc. IX, p. 321.

Neckera crispatula ej. M. ex. t. 152; Brid. Bryol. univ. II, p. 237; C. M. Syn. 1I, p. 140.

Papillaria crispatula Jaeg. Ad. II, p. 178.

2. - As.: Yunnan, Himalaya sept. occ., Nepal., Sikkim, Khasia, Ceylan, ins. Andaman, Java, ins. Halmaheira. 
cuspidiferus Mitt. - Papillaria.

declinatus Milt. op. et $l$. co.

Papillaria declinata Jaeg. op. oit, p. 177.

2?

- As. : Nepal., Himalaya occ., Java.

Feae C. M. in Nuov. Giorn. bot, ital. 1891, p. 601 (nom.).

Ster.

- As. : Birman. super. (Tenasserim).

pexicaulis Mitt. - Papillaria.

fuscescens Mitt. - Papillaria.

grossiserratus $C$. $M$. in op, et $l$. cc.

Ster.

- As. : Birman, super. (Tenasserim).

Harveyi Mitt. - Papillaria semi-torta.

helictophyllus Mitt. - Meteorium intricatum?

? himantophyllus $C$. $M$. in sched.

- As.: Sikkim.

hispidus (C.M.) Par.

Meteorium hispidum Mitt. $M$. Ind. on . p. 89.

Neckera hispida C. M. in Bot. Zeit. 1854, p. 579.

Papillaria hispida Jaeg. op. et $l$. oo.

2?

- As.: M. Neilgherr., Ceylan.

Hornschuchii Mitt. - Papillaria kermadecensis.

humilis Lindb. in Act. Soc. sc. Fenn. 1872, p. 230.

2. Rupic. - As, : Japon. (ins. Kiu-Siu).

Massarti Ren. et Card. in Rev. bryol. 1896, p. 103.

Ster.

- As. : Java.

Nietneri (C. M.) Par.

Neckera Nietneri C. M. in Linn, 1869-70, p, 25.

Papillaria Nietneri Jaeg. Ad. II, p. 177.

2.

- As. : Ceylan.

nodicaulis (C. M.) Besch. Fl. bryol. Réunion, etc., p. 129.

Neckera nodicaulis C. M. in Linn. 1876, p. 269.

Papillaria nodicaulis Jaeg. Ad. II, p. 179.

Ster. Ad arbor. - $A f r$.: Ins. Anjouan.

ornans (Reichdt.) C. M. in Fl. 1896, p. 465.

Hemiragis ornans Reichdt. Beitr. p. 577.

Hookeria ornans Par. Index, p. 581.

Ster. Filicic. - Pac. : Ins. Sandwic.

? perichaelialis Besch. - Papillaria.

plicaefolius Mitt. - Pilotrichella.

procumbens Mitt. - Leptodon.

rugosus (Mont.) Lindb. in Oefv.... 1864, p. 602 et in Cumming Pl.

Philipp. n. 2197.

Dicnemon rugosus? Mont. in Hook. Journ. bot. 1845, p. 10.

2.

- As. : Ins. Philippin., Celebes.

Rutenbergii C. M. in Abhandl. Brem. $\nabla 1 I$, p. 209.

Ster.

- Afr. : Madagascar.

serrulatus (P. B.) Besch. Fl. bryol, Réunion, ele., p. 128.

Hypnum ericetorum Brid. Sp. M. II, p. 97. 
Meteorium serrulatum Mitt, in Journ. of the Linn. Soc. 1863, p. 156.

Neckera serrulata Brid. Bryol, univ. II, p, $238 ;$ C. M. Syn. II, p, 140.

Papillaria serrulata Jaeg. Ad. I1, p. 178.

Pilotrichum serrulatum P. B. Prodr, $p .83$.

Ster.

Madagascar, ins. Borbon.

- Afr.: Ins. Fernando Po, Kilima N'Djaro,

subbicolor C. M. in sched. ; Jaeg. Ad. 11, p. 177.

- As. : Sikkim.

subcrispatulus $C . M$. in sched.

- As. : Himalaya sept. occid.

TREMATODON Rich. in Mich. FI. Am. bor. II, p. 289 (65 spec.).

acicularis Kindb. in Rev. bryol. 1896, p. 18.

Paludic. - Am. sept. : Columb. brit.

acutus C. M. Syn. I, p. 458; Bryol. jav. I, p. 88, t. 72, fig. [-25.

Tr. longicollis $\beta$ crispatissimus Hsch. in Nov. Act. Acad. Caes, Leop. Carol. XIV, II, Suppl.p. 102 ?

1.

- As, : Java.

affinis Bryol. eur. $-\mathrm{Tr}$, reflexus.

ambiguus (Hedw.) Hsch. in Fl. 1819, p. 88; Bryol. eur. I (mon. p. 5),

t. 96 ; C. M. Syn. I, p. 457; W. P. Sch. Syn. II ed. p. 68.

Dicranum ambiguum Hedw, M. frond. III, p. 87, t. 36 .

Mnium setaceum L.Sp.pl.p. 1576 ?

Tr. vulgaris Brid. Bryol, univ. I, p. 386.

1. In turfos. et uligin, - Eur.: E reg. montos, usq. in alp. Am. sept. :

Terr. nov.. ins. Miquel., Nov. Scot, New Brunswick, Ontario,

Columb. brit., reg. or.

Exs. : Mac. Canad. M. n. 24.

Rab. Bryoth. our. n. 410, $122 \pi$.

Sull, et Lesq. M. bor, am. II ed. n. 96.

ambiguus Hsch. (FI. Bras.). - $\mathrm{Tr}$. vaginatus.

$\beta$ brevicollis Schwaegr, - Tr. brevicollis.

angolensis Welw. el Duby in Mém... Genève, 1870, p. 13, t. 1V, f. 5 .

2. In pase. herbos. - Afr. : Angola.

anomalus $\mathrm{H}$ pe. - $\mathrm{Tr}$. gymuostomus.

arcuatus Mitt, in Hook. Handb. of the N. Zeal. Fl. p. 415.

2.

-Pac. : Nov. Zeland. bor.

aureus C. M. in Ule Bryoth, brasil. n. 15.

- Am, merid. ; Brasil, austr. or.

Baileyi Broth. in Bail. Syn. of the Queensland Fl. IV Suppl. p. 95

(nom.) el in Oefv. of Finska Vet.-Soc. Foerh. 1890, p.

Terr. - Pac. : Austral. or. (Queensland).

bolivianus C. M. in Nuov. Giorn. bot. ital. 1897, p. 38 .

- Am. merid.: And. Boliv.

borbonicus Besch. Fl. bryol. Réunion, elc., p. 19.

1 .

- Afr.: lns. Borbon.

brachypus Mont. hb.; Mitt M. austr. am. p. 46.

Tr. gymnostomum Lindb.?

1 .

- An. merid. : Brasil. 
brevicollis Hsch. in Fl. 1819, p. 88 ; Brid. Bryol univ. 1, p. 385 ; Bryol. eur. I (mon. p. 5), t. 95 ; C. M. Syn. I, p. 457; W. P. Sch. Syn. II ed. p. 67.

Tr. ambiguus $\beta$ brevicollis Schwaegr. Suppl. II, p. 69.

1. Terr. - Eur.: Rariss. in reg. supraalp. zon. interm. et sept. : Norveg., Tirol., Alp. Helvet., Valesia. Am. sepl. : Groenland.

brevifolius Broth, in Ule Bryoth. brasil. n. 106.

Rupic. - Am. merid. : Brasil. austr. or.

brevirostris Hpe. in Ann. sc. nat. ser. V, V, p. 336.

1 ?

- Am. merid. : And. Nov. Giranat.

capillifolius $C$. M. in sched.

-. As. : Himalaja sept. occid.

capillipes $C . M$. in sched.

- As. : Ins. Philippin. (Luzon).

ceylonensis C. M. in Bot. Zeit. 1864, p. 350 .

Tr, longicollis Wils, et Mitt, in hb. Ind, or, n. 45 ,

1.

- As. : Ceylan.

Cheesemani C. M. in sched.

- Pac.: Ins. Kermadec.

conformis Mitt. M. Ind. or. p. 12.

I. $\quad-A$ s.: Nepal, Sikkim.

crispatissimus Hsch. Fl. Bras. I, p. 10; Hpe. Enum. M. Bras. p. 13.

Arenic. - Am. merid. : Brasil, austr, or., Monte Video.

decipiens Mitt. - Wilsoniella pellucida.

divaricatus Bryol. eur. I (mon. p. 4, nom.); C. M. Syn. I, p. 460.

$$
\text { - Afr.: C. B. Sp. }
$$

Fendleri C. M. in Linn. 1878-79, p. 470.

I. $\quad-$ Am. merid.: Venezuela

flexifolius C. $M$. in $\mathrm{Fl} .1886$, p. 278.

2. Terr. - Afr.: Ins. S. Thomas.

flexipes Mitt, in Fl. Tasman. II, p. 173, t. 172, f.6; Handb. of the $N$. Zeal. Fl.p. 415.

2? Terr. - Pac. : Nov. Zeland., Tasman.

fontinatoides Roehl. - Cinclidotus.

gymnostomus Lindb. in sched, ; C. M. in Bot. Zeit. 1859.

Tr. anomalus Hpe. Symb. 1870, p. 271.

Tr. brachyus (neo: brevipas, ut ait Angsts. Prim, lin. p. 5) Mont. in Mitt. M. austr. am. p. 46 ?

2. Terr. - Am, merid. : Brasil. austr. or .

heterophyllus Broth. in Hedwig. 1895, p. 118.

- Am. mevidl. : Brasil. or. (Goyaz).

Hildebrandti C. $M$. in Linn. 1876, p. 241.

I. Humic. - Afr.: Ins. Anjouan.

Hookeri C. M. in Bot. Zeil 1864, p. 350.

Tr. Iongicollis Wils, et Mitt. in hb. Ind. or. n. 48 .

1.

- As. : Sikkim. 
humilis Mitt, M. austr, am. p. 47.

$2 ?$

- Am. sept. : Cuba. Am. merid. : And. Quitens.

intermedius Welı. et Duby in Mém... Genève, 1870, p. 12, t. III, f. 6.

2. In limos, - Afr. : Angola.

\& var. nanus Welwo et Duby in op. el l. cc.

Ad terr, madid. in rupestr. - Afr. : Ibid.

Jardini W. P. Sch. - Wilsoniella.

lacunosus Ren. et Card. in Bull. Soc. roy. bot. Belg. 1893, II, p. 9 et

M. Masc, Mad. n, 152.

2. Ad terr. argill, humid, - Afr. : Madagascar.

lacustris C. M. in Hedwig. 1895, p. 118.

- Am. merid. : Brasil. or. (Goyaz).

latinervis C. $M$. in Fl. 1896, p. 445.

- Pac. : Ins. Sandwic.

ligulatus Rehm. M. Afr. austr. n. 22 .

- Afr. : Natal.

linguaeformis Besch, in Marie M. Mayotte, n. 221 p. p.

- Afr. : Ins. Mayotte.

longescens C. M. in Rev. bryol. 1876, p. 3 (nom.).

- Pac. : Austral. or. (Nov. Valesia).

longicollis Rich. in Mich. Fl. Am. bor. II, p. 289; Brid. Bryol. univ.

I, p. 388; Bryol. eur. Suppl. fasc. III-1V; C. M. Syn. I, p. 458;

Sull. Ic. M. p. 31, t. 19; W. P. Sch. Syn. I1 ed. p. 68.

Cynontodium Trematodon P. B. Prodr. p. 52.

Dicranum longicollum Brid. Sp. M. I, p. 203.

Tr. Solmsii Boll in Verh. d. Sot. Ver. d. Prov. Brandenb. 1865.

1. -Eur.: Pouzolles, ins. Ischia. As.: Japon.,

Assam; Sikkim ? Am. sept.: New Jersey, Pensilv., reg. merid.

Exs. : Drumm. M. bor. am. Il ed. n. 55 .

Rab. Bryoth, eur. n, 1065, 1269.

Sull. et Lesq. M. bor. am. II ed, n. 95.

Besch. - Tr. uncinatus.

Duby. - Tr. paucifolius.

H. f. et W. - Tr. suberectus.

longicollis

Hsch. - Tr. reflexus.

Mont. - Tr. Schmidii.

Wils. - Tr. megapophysatus.

Wils. et Mitt. $\left\{\begin{array}{l}\text { - Tr. ceylonensis. } \\ \text { - Tr. Hookeri. }\end{array}\right.$

$\beta$ crispatissimus Hsch. $-\mathrm{Tr}$. acutus.

longiroslris Sehwaegr. - Microdus.

Mac-Leai Rehm. M. Afr. austr. n, 439.

\section{- Afr. : Transval.}

mayottensis Besch, in Ann. sc. nat. VII ser., II, p. 84.

- Afr.: Ins. Mayotte.

megapophysatus C. M. in Bot. Zeit. 1864, p. 350 .

Tr. longicollis Wils, in $h b$. Ind. or, $n .46$.

I.

Exs.: Faurie Pl. Japon. n. 618, 763. 
microthecius Besch. in Bull. Soc. bot. Fr. 1894, p. 78.

1. Ad terr. limos, - As. : Tonkin.

minutulus $C . M$. in Dusen $M$. Camer. n. a.

- Afr.: M. Cameroon.

nitidulus W. P. Sch. in Besch. Prodr. bryol. mexic. p. 17.

1 .

- Am. sept. : Mexic. (Orizaba).

Novae Caledoniae C. M. in Th. Savin M. N. Caled, n. 17.

- Pac. : Nov, Caledon.

Novae Hannoverae C. M. in Engler's Bot. Jahrb. 1883, p. 83 et in Forschungsreise .. p. 46.

1. Terr. - Pac. : Nov. Hannov.

nudus C. M. in Dusen M. Camer. $n .370$.

- Afr.: M. Cameroon.

palettifolius C. M. in Besch. Note M. Paraguay, p. 260.

Terr. - Am. merid. : Paraguay.

Exs. : Balansa Pl. Parag. n. 1257.

pallidens C. M. in Linn. 1876, p 242 .

2. Terr. - Afr.: Ins. Anjouan, Nossi-Be.

paradoxns Hsch, in Linn. 184I, p. 122; C. M. Syn. I, p. 456.

1.

- Afr, : C. B. Sp., ins. Borbun.

paucifolius C. M. Syn. I, p. 459; Bryol, jav, 1, p. 89, t. 73, f. 1-3อ̆

Tr. longicollis Duby in Zollinger Coll. $n 1943$.

1 (C. M.) ; 2 (Bryol. jav.) -As.: M. Neilgherr.,

Pechueli C. $M$. in Fl. 1886, p. 508.

1. - Afr.: Stanley Pool.

reflexus C. M. Syn. I, p. 459.

Tr. aftinis Bryol. eur. (mon. p. 4, nom.)?

Tr. longicollis Hsch. Fl. Brasil. I, p. 9.

1. Rupic. et ad terr, argill. - Am. merid. : Brasil, austr. or.

Reineckii C. M. in Engler's Bot. Jahrb. 1896, p. 320.

Ad terr. tophac. apric. - Pac. : Ins. Samoa.

reticulatus C. M. in Abhandl. Brem. VII, p. 205.

- Afr. : Madagascar.

sabulosus Griff. Not. p. 4I3 et Ic. pl, asiat. pl. LXXXII, f. I; Mitt. M.

Ind. or. p. 13.

$$
\text { - As.: Assam, Bhotan. }
$$

Schmidii C. M. in Bot. Zeit. 1853, p. 40.

Tr. longicollis Mont. in Perrottet M. Neilgh. n. 54 .

1. Terr, - As. : M. Neilgherr.

Serrae C. M. in Ule Bryoth. brasil. n. 105.

Terr, $-A m$. merid. : Brasil, austr. or.

setaceus Hpe. in Besch. Note M. I. S. Paul et Amsterdan, p. 2.

1.

- Afr. : Ins. S. Paul.

Solmsii Boll, - Tr. longicollis.

squarrosulus $C$. $M$. in $\mathrm{Fl}$. 1896, p. 478 .

- Pac.: Ins, Sandwic. 
squarrosis C. M. in Bot. Zeit. 1857, p. 381.

1. Terr, - Am, merid, : Brasil, austr. or.

subambiguus Besch. Fl, bryol, Réunion, etc., p. 20.

1.

- Afr. : Ins. Rorbon.

suberectus Mitt. in Hook. Handb. of the N. Zeal. Fl. p. 415.

Tr. longicollis $H$. f. et W. Fl, of the N. Zeal. II, p. 69 .

2.

- Pac, : Nov. Zeland.

tenellus W. P. Sch. in Besch. Fl. bryol. Antill. fr. p. 4.

1. Rupic. Am, sept. : Guadalup.

tonkinensis Besch. in Journ. de bot. 1890, p. 201.

Terr. - As : Tonkin.

uncinatus C. M. in Linn. 1874, p. 628.

Tr, longicollis Besch. in Prodr, bryol. mexic, p. 17.

1. - Am. sept. : Mexic.

vaginatus C. M. in Bot. Zeit. 1857, p. 380.

Gymnostomum Barbula Gardn. M. Brasil. n. 4.

Tr. ambiguus Hsch. Fl. Brasil. I, p. 10.

1. Rupic, et terr. - Am. merid. : Brasil, austr. or.

Victoriae C. M. in Dusen M. Camer. n. 309.

- Afr. : M. Cameroon.

vulgaris Brid, $-\mathrm{Tr}$, ambiguus.

TRENTEPOHLIA Roth. in Usteri Ann. bot. X, p. 52. erecta Roth. - Webera annotina.

Tricherpodium C. M. in Linn. 1875, p. 419 (sect. ERPodI).

TRIGHODON W. P. Sch, Coroll. p. 36 et Syn. II ed, p. 138 (2 spec.). cylindricus (Hedro.) W. P. Sch. op. et $l$. cc.

Ångstroemia cylindrica C. M. Syn. $T, p .441$ et $I I, p .610$.

Ceratodon cylindricus Bryol. eur. II (mon. p. 6), $t .192$, $^{\circ}$

Dicranum cylindricum W. et M. Bot, Taschb, p. 202.

Didymodon cylindricus Wahlenb. $\mathrm{Fl}$, Suec, p. 754 ,

Ditrichum cylindricum Lindb. M. Scand. p. 27.

D. tenuifolium Kindh, Eur and N. Am. Jiryin, p. 178.

Leptotrichum cylindricum Husn. Musc, gall, p. 61 .

Trichostomum cylindricum Hedw. Sp, M. p. 107, t.24; Brid. Bryol. univ.1, p. 491.

Tr. tenuifolium Schrad.:Bot. Journ. II, p. 58.

Tr. tenue Schrad. (fid. W. P. Sch.).

2. In terr. arenos. humid. - Eur. : E planit, ubi rar., usq. in reg, alp. As. : Ieniss, med, et sup., Obi. Am. sept. : Columb. brit., Ontario, Nevada, Pensilv. M. Alb. et Allegh.

Exs. : Mac. Canad. M. n. 4 II.

Rab. Bryoth, enr. n. 856, 948, 962.

? flexifolius Ren, et Card. in Bot. Gaz. 1889, p. 94, t. XIII, f. A el M. Amer. sept. n. 20.

1. Arenic. - Am. sept. : Florida.

oblongus Lindb. - Ceratodon.

Trichomitrium C. M. in Nuov. Giorn, bot. ital. 1897, p. 127 (nom., sect, Schlotheimiae). 
TRICHOPIIUM W. P. Sch. in Mandon Pl. Boliv. polycarpum W. P. Sch, - Pogonatum.

TRIGhOSTELEUM Mitt. M. austr. am. p. 492 (sect. Sematophyl.t) at Sam. M. p. 181 (gen. propr.) (103 spec.).

altisetulum $C . M$. in sched. - Pac. : Nov. Guin. brit.

ambiguum (Schroaegr.) Par.

Hypnum Hornschucbii Hpe. (in contextu H, subulati) Ic. M. t. 9; C. M. Syn. II, p. 406.

H. microcarpum Hsch. Fl. Brasil. 1, p. 81, t. 4.

Leskea ambigua Schwaegr. Suppl. II, II, II, t. 198.

Sematophyllum ambiguum Mitt. M. austr. am. p, 492.

Tr. Hornschuchìi Jaeg. Ad. 1I, p, 484.

1. Lignic. - Am. merid. : Amazon., And. Peruv.

aoratum (Duby) Jaeg. Ad. 11, p. 482.

Hypnum aoratum Duby in Mém... Genève, 1876, p. 13, t. I, f. 6.

Isopterygium intortum? (fid, Besch.).

1. Cortic. - Afr. : Ins. Franciae. apiocarpum (Mitt.) Jaeg. Ad. II, p. 481.

Sematophyllum apiocarpum Mitl. op. cit.p. 493. 1 . - Am. merill. : Ins. Trinitat.

arrectum (Mitt.) Jaeg. op. cit. p. 484.

Sematophyllum arrectum Mitt. op. cit. p. 494.

1. Lignic. - Am. merid. : Amazon.

bartramiocarpum (C. M.) Jaeg. op. cit. p. 478.

Hypnum bartramiocarpum C. M. Syn. II, p. 633.

2 ? - As.: Java.

Basilaniae (C. M.) Jaeg. op. cit.p. $4 \times 7$.

Hypnum Basilaniae C. M. in Linn. 1875, p. 466 (nom.).

- As. : Archip. ind.

bistrumosum (C. M.) Jaeg. op, el l. cc.

Hypnum bistrumosum C. M. in Linn. 3874, p. 566.

I. - As.: M. ins. Philippin.

borbonicum (Bel.) Jueg. op. cit. p, 486 .

Hypnum borbonicum C. M. Syn. II, p. 315 .

Leskea borbonica Belang. Voy. Ind. or. Bot. II, Crypt.p. 97, t. II, f. 2.

Rhaphidostegium borbonicurn Besch. Fl. bryol. Réunion, ete., p. 166.

Stereodon borbonicus Mitt. in Journ. of the Linn. Soe. 1863, p. 157.

1. Cortic. et lignic. - Af $r$ : Tropic. occ. litt., Usambara, ins, Seychelles, Mayotte, Mascaren.

Boschii (Dz. et Mk.) Jaeg. op. cil. p. 487.

Hypnum Boschii Dz. et Mk. in Ann. sc. nat. $1844, I V, p .306 ;$ C. $M$. Syn. II, p. 404; Bryol, jav. II, p. 175, t. 274.

1. Cortic, As.: Sumatra, Java, Banca, Ho rneo.

brachydictyon (Besch.) Jaeg. Ad. II, p. 482.

Rhaphidostegium brachydietyon Besch. Fl. bryol. Antill. fr. p. 78.

1. Cortic. - Am, sept. : Guadalup. 
bunodicarpum (C. M.) Par.

Hypnum bunodicarpum C. M. in Engler's Bot. Jahrb. 1883, p. 85 et in Forschungsreise... p. 48.

1. Cortic. - Pac. : Nov. Hannov.

chloropterum (C. M.) Kindb. Enum.

Hypnum chloropterum $C . M$. in $F l .1886, p .522$.

1. Cortic. - Afr. : Ins, Fernando Po.

confertulum (Besch.) Jaeg. Ad. II, p. 750.

Rhaphidorhynchum confertulum Besch. Note M. I. S. Paul et Amsterd. p. 3 .

- Afr. : Ins. S. Paul.

consanguineum (Mitt.) Jaeg, op. cit. p. 485.

Sematophyllum consanguineum Mitt. M. austr, am, p. 493.

- Am. merid. Brasil, austr. or.

cyathothecium (C. M.) Jaeg. op. cit. p. 480.

Hypnum eyathothecium $C . M$. M. Polyn, $p, 82$.

1 et 2.

- Pac. : Ins, Fidji, Samoa.

diaphanum Brolh. in Hedwig. 1895, p. 69.

1. Ad ramul, arb. - Pac, : Nov. Hibern.

dicranelloides Broth, in Bol. da Soc. Brot. VIII, 1890.

1. Rupic. - Afr, : Ins, S. Thomas.

dicranoides Broth. in Billang till K. Sv. Vet.-Akad. Handl. 1895, n. 3.

1. Cortic, - Am. merid.: Brasil.

distichophyllum (Hpe.) Jaeg. Ad II, p. 482.

Hypnum distichophyllum Hpe. in Bryol. jav. II, p. 167, t. 266.

2? - As.: Ins. Luzon., Celebes, Java.

epiphyllum Ren. et Card. in Rev. bryol. 1896, p. 106.

Ster. Ad fol. Querc. - As. : Java.

fissum Mill. Sam. M. p. I82.

2. Cortic. - Pac. : Ins. Samoa.

flagelliferum Broth. in Bihang till K. Sv.-Akad. Handl. $1895, n .3$.

Ster. Cortic. - Am. merid. : Brasil. or.

fluviale (Mitt.) Jaeg. Ad. II, p. 485.

Sematophyllum fluviale Mitt. M. austr, am. p. 493.

1.

- Am. merid. : Novo Granat.

fuscocaule (C. M.) Par.

Hypnum fuscocaule C. M. M. Polyn. p. 85.

Ster.

- Pac. : Ins. Samo2.

glaucinum (Besch.) Jaeg. Ad. 11, p. 482.

Rhaphidostegium glaucinum Besch, Fl. bryol. Antill. fr. p. 79. 1.

- Am. sept. : Guadalup.

Gottscheanum (Hpe.) Jaeg. op. cil. p. 478.

Hypnum Gottscheanum Hpe. in Linn. 1874, p. 568.

2.

$$
\text { - As. : Ins. Philippin. }
$$

graminicolor Jaeg. - Eurhynchium Sullivantii. 
grosso-mammillosum (C. M.) Par.

Hypnum grosso-mammillosum $C . M$. in sched.

Ster.

- Pac. : Nov, Guin. brit.

guineense (Ångstr.) Jaeg. op. cil. p. 479.

Cylindrothecium guineense Aingstr, mss.

Hypnum guineense $C . M$, in Linn. 1875, p. 465 (nom.).

- Pac. : Nov, Guinea.

hamatum (Dz. et Mk.) Jaeg. op. cit. p. 486.

Hypnum hamatum Ds. et Mk. in Ann. se. nat. 1844, p. 307 et M. frond. Archip, ind. p. 11 ; Bryol, jav. II, p. 176, t. 275.

H. scaberulum Mont. in Lond. journ. of bot. 1844, p. 632 et in Ann. se. nat. $1845, I V, p .92, t . V, f .2 ; C . M$. Syn. II, p. 272.

Tr. scaberulum Besch. Fl. bryol. Taïti, eto., p. 51 .

1. Lignic. - As.: Sumatra, Java, Banca, Borneo, Celebes. Pac, : Taïti (var.? fid. Besch.), ins. Sandwic.

" var. semi-mammillosum (C. M.) Par.

Hypnum hamatum var, semi-mammillosum C. M. in Geh. Neue Beitr. sur Moosfl, v. Neu Guin., p. 11 .

- Pac. : Nov. Guin. sept.

herpeticum (C. M.) Jaeg. op. cit. p. 480.

Hypnum herpeticum C. M. M. Polyn, p, 84 .

1. - Pac.: Ins, Samoa.

Hornschuchii Jaeg. - Tr. ambiguum.

inclinatum Kiaër in Borgen M. Madec.

- Afr.: Madagascar.

instratum (Brid.) Jaeg. op. cit. p. 478.

Hypnum instratum Brid. Bryol. univ, II, p. 394; C. M. Syn. II, p. 265; Bryol.jav. II, p, 169, t. 268 p.p.

$\mathrm{H}$. planum var. instratum Sohwaegr. Suppl. $111, I I, I I, t, 280$.

1. Cortic. et rupic. - As.: Java, Banca, Celebes, ins. Rauwack Molucc.

inundatum (Milt.) Jaeg. op. cit, p, 484.

Sematophyllum inundatum Mitt. M. austr, am. p. 494.

1. Lignic, rupic. et terr. $-A m$. merid. : Amazon.

isocladum (Bryol. jav.) Jaeg. op. cit. p. 478.

Hypnum isoeladum Bryol. jav. II, p. 173, t. 272.

1. In silv. - As. : Ins. Banca.

Kaërnbaehii Broth, in Engler's Bot. Jahrb. 1893, p. 480.

1.

Pac. : Nova Guin.

Kerianum Broth. in Bailey Syn. of the Queensland Fl. IV Suppl. p. 99 (nom.) et in Oefv. af Finska Vet.-Soc. Foehr. 1890.

1. Cortic. - Pac. : Austral. or. (Queensland).

Kuilui (C. M.) Kindb, Enum.

Hypnum Kuilui C. M. in Fl. 1886, p. 523.

Ster. Cortic. - Afr. : Tropic, occid.

Kurzii $S b$. in Jaeg. Ad. 11, p. 480.

H. microcladon Hpe. (fid. C. M. in sehed.).

Afr.: Pegu. 
laetum Ren. et Card. in Bull. Soc, roy, bot. Belg. 1892, I1, p. 110.

Lignic. - Afi: : Madagascar.

Lindbergii (Bryol. jav.) Jaeg. Ad. II, p. 478.

Hypnum Lindbergii Bryol. jav. II, p. 172, t. 271.

1 .

- As. : Java, Borneo, ins. Ceram, Saparcea.

madagassum (C.M.) Jaeg. op. cit. p. 481 .

Hypnum madagassum C. M. in Linn. 1875, p. 465 (nom).

- Afr. : Madagascar.

mammillipes Broth. in Engler's Bot. Jahrb. 1894, p. 207.

1. Cortic. - Afr. : Usambara.

mammosum (C. M.) Jaeg. op. cit. p. 487.

Hspnum mammosum C. M. Syn. II, p. 684; Bryol. jav. II, p. 174, t. 273.

- As. : Java, Sumatra.

Martiantm (Ltz.) Jueg. op. cit. p. 485.

Hypnum Martiannm Ltz. Moosst.p. 166.

2.

- Am. merad.: Guian. batav.

microcalyx Ren. et Card. in Bull. Soc. roy. bot. Belg. 1896, 1, p. 319.

1. Lignic. - Afr. : Congo.

microcladum (Dz. et Mk.) Jaeg. op. cit. p. 487.

Hynum microcladum $D z$. et $M k$, in Ann. sc. nat. $1844, I I, p .308$; C. $M$. Syn. II, p. 274 ; Bryol.jav. II, p. 145, t. 242.

1. - As.: Borneo, Celebes. Pac.: Nov, Guinea.

microstegium (W. P. Sch.) Jaeg. op. cit. p. 482.

Rhaphidostegium microstegium W. P. Sch, in Besch. Fl. bryol. Antill. fr l.

- Am. sept. : Guadalup.

microthamnioides (C. M.) Par.

Hypnum microthamnioides C. M. in Abhandl. Brem. VII, p. 212.

Ster.

nepalense (Schwaegr.) Jaeg. op. cit. p. 478.

Hypnum nepalense Schwaegr. Suppl. III, I, II, t. 226; U. M. Syn. II, p. 226 ; Bryol. jav. II, p. 168, t. 267.

H. punctulatum Harv. (fid, C. M.).

Stereodon nepalensis Mitt. M. Ind. or. p. 100.

1. Lignic. - As. : Nepal., Bengal., Java, Borneo, Amboine.

Niam-Niamiaa (C. M.) Jaeg. A ll. II, p. 488

Hypnum Niam-Niamiae C. M. in Linn. 1875, p. 468.

Ster. Terr. - Afr. : Niam-Niam.

novo-guineense (Geh.) Par.

Hypnum novo-guineense Geh. Neve Beitr. zur Moosfl, v, Neu-Guinea, p. $8, t .6$.

2.

- Pac. : Nov, Guinea merid.

Orthothecium (C. M.) Jaeg. Ad. $11, p, 480$.

Hypnum Orthothecium C.M. M. Polyn. p.

2.

- Pac. : Ins. Samoa.

palanense (Hpe.) Jaeg. op, cit. p. 486.

Hypnum palanense Hpe. in Linn. 1874, p. 567.

2.

- As.: M. ins. Philippin. 
pallido-scabrum C. M. in sched.

-- Pac. : Nov. Guin brit.

papillatum (Harv.) Par.

Acanthodium papillatum Mitt. Sam. M. p. 182.

Hypnum papillatum Harv, in Lond. Journ. of bot. $1840, I I, p .18$ et in Hook. Ic. pl. rar. I, t. 23; C. M. Syn. II, p. 273 (1); Bryol. jav. II, p. $171, t, 270$.

Sematophyllum papillatum Mitt. Fl. Vit. p. 398.

Stereodon papillatus Mitt, M. Ind, or. p. 113 (1).

1 ? (C. M.). Polyg. (Bryol. jav.).

- As.: Nepal., Sumatra, Java, ins. Banca, penins, Malay., Borneo, Celebes. Pac, : Ins. Ovalau, Samoa, Nov. Guinea.

papillosum (Hsch.) Par.

Hypnum papillosum Hsch. Fl. Brasil. I, p. 82, t. 4; C. M. Syn. II, p. 272,

H. spirale C. M. in Linn. 1848, p. 200.

Sematophyllum papillosum Mitt. M. austr. am. p. 492.

Stereodon papillosus ej, in Journ. of the Linn. Soc, 1863, p. 517.

Tr. spirale Jaeg. Ad, II, p. 485.

1. Lignic. - Afr. : Tropic, occid, litt, Am. merid.: Guian., Amazon., Brasil.

perhamosum (C. M.) Broth. in Engler's Bol. Jahrb. 1897, p. 277.

Sigmatella perhamosa $C . M$. in Dusen $M$. Camer. $n .924$.

1. Lignic. - Afr. : Cameroon.

perpygmaeum (C, M.) Par.

Hypnum perpygmaeum $C$. M. in sched. - As. : Sumatra (ins, Engano).

Perrotti Ren, et Card. in Bull. Soc. roy. bol. Belg. 1892, II, p. 109.

1. In silv. - Afr. : Madagascar.

Pickeringii Jaeg. - Sematophyllum.

Plumularia (C. M.) Jaeg. Ad. II, p. 482.

Hypnum Plumularia C. M. Syn. II, p. 681; Bryol. jav. II, p. 166, t. 265 ,

Syn. - As. : Java.

pluripunctatum Ren. et Card. in op. cit. 1, p. 184.

Ster. - Am. sepl. : Martinic.

prostratum (Dz. et Mk.) Jaeg. Ad. II, p. 483.

Hypnum prostratum Dz. et $M k$, in Ann. so, nat. 1844, II, p. 309 et M. frond. Arohip. ind. p. 13; C. M. Syn. II, p. 271; Bryol. jav. II, p. $170, t .269$.

- As.: Java.

pseudo-amoenum (Belang.) Jaeg. op. cil, p. 479.

Hypnum peudo-amonum Bel. Voy. Ind. or. Bot. II. Crypt.p. 87; C. M. Syn. II, p. 266.

Rhaphidostegium pseudo-amonum Besch. Fl. bryol, Réunion, etc., p. 166. 1. - Afr.: Ins. Borbon.

pseudo-planum (Hpe.) Jaeg. op. el l. cc.

Hypnum pseudo-planum Hpe. mss. ; C. M. in Linn. 1875, p. 465 (nom.). - As. : Ind. or.

(1) "Pedunculus breviusculus „ C. M. I. c. " Pedicellus longissimus " Mitt. l.c. 
pterocladium (Besch.) Jaeg. Ad. II, p. 482.

Rhaphidostegium pterocladium Besch. Fl. bryol, Antill. fr, p. 78.

1. Cortic. - Am. sept. : Martinic.

punctipapillosum (C. M.) Par.

Hypnum punctipapillosum $C . M$. in sched.

Ster.

- As.: Ins. Andaman.

punctulatum (Harv.) Jaeg. op. eit. p. 477.

Hypnum punctulatum Harv, in Lond. Journ. of bot. 1840, p. 18 et in Hook. Io. pl. rar. I, t. 23, f. 10.

Stereodon punctulatus Mitt. M. Ind. or. p. 101.

1 ,

- As. : Madras.

pusillum (Hsch.) Jaeg, op. cit. p, 484.

Hypnum pusillum Hsch. Fl. Brasil. I, p. 85; C. M. Syn. II, p. 405.

Sematophyllum pusillum Mitt. M. austr. am. p. 494.

1. In turfos, - Am. merid. : Brasil.

rhinophyllum (C.M.) Par.

Hypnum rhinophyllum C.M. M. Polyn. p. 85.

1. - Pac.: Ins. Fidji.

Rhizophoreti (C. M.) Jaeg. Ad. II, p. 480.

Hypnum Rhizophoreti C. M. M. Polyn. p. 83.

1.

- Pac.: Ins. Samoa.

rubrisetum (Mitt.) Jaeg. op. cit. p. 481.

Sematophyllum rubrisetum Mitt. M. austr. am. p. 492.

1. - Am. merid. . Amazon., And. Quitens.

rugisetum (Hpe.) Jaeg. op, cit. p. 486.

Hypnum rugisetum Hpe. mss.; C. M. in Linn. 1875, p. 466 (nom.).

Absque loco.

samoanum (Mitt.) Jaeg. op, cit. p. 479.

Hypnum Powellianum C. M. M. Polyn. p. 84.

H. samoanum Mitt. Sam. M. p. 184.

1 .

- Pac. : Ins. Fidji, Samoa.

scaberulum Besch. - Tr. hastatum.

scabrellum (Bryol. jav.) Jaeg. op. cit, p. 484.

Hypnum scabrellum Bryol. jav. II, p. 214, t. 315; Hpe. in Nuov. Giorn. bot. ital. 1872, p. 284 (desoript. locupletior).

- As. : Sumatra, Borneo, Celebes.

selenithecium (C. M.) Par.

Hypnum selenithecium C. M. in Engler's Bot. Jahrb. 1883, p. 86 et in Forschungsreise... Bot. p. 55.

1. Ad arbor. - Pac.: Nov. Guinea, Nov. Hannov., Archip. Duc d'York.

semi-mammillosum (C. M.) Broth. in sched. (1).

Hypnum semi-mammillosum $C$. M. mss.

Cortic. - Pac.: Archip. d'Entrecasteaux (ins. Ferguson), Nov. Guin. brit. 
sentosum (Sull.) Jaeg. op. cit. p. 481.

Hypnum sentosum Sull. in Proced of the Amer. Acad.... 1861, p. 288.

Rhaphidostegium sentosum Besch, Fl, bryol. Antill. fr. p. 77.

Sematophyllum sentosum Mitt. M. austr. am. p, 493.

1. Cortic. - Am. sept. : Cuba, Guadalup.

"var. majus (Besch.) Par.

Rhaphidostegium sentosum var, majus Beseh. op. et l. co. - Am. sept. : Guadalup.

sphacelatum (Duby) Jaeg. Ad. 1I, p. 480.

Hynum sphacelatum Duby mss. ; C. M. in Linn. 1875, p. 465 (nom.). - Pac. : Nov. Caledon.

spirale Jaeg. - Tr. papillosum.

Staudtii Broth, in Engler's Bot. Jahrb. 1897, p. 277.

1. Lignic. - Afr. : Cameroon.

-stigmosum Mitt. Sam. M. p. 181.

Hypnum papillatum Sull. in Wilkes Exped. M. n. 17 .

H. stigmosum C.M.M. Polyn. p. 84. 1 . - Pac.: Ins. Fidji, Samoa.

stissophyllum (Hpe.) Jaeg. Ad. II, p. 483.

Hypnum stistophyllum Hpe. in C. M. Syn. II, p. 273; Bryol. jav. II, p. 176.

Stereodon stissophyllus Mitt. M. Ind, or. p. 101. 1 . - As. : Khasia, Ceylan, Java.

subdemíssum (W. P. Sch.) Jaeg. op. cit, p. 484.

Rhaphidostegium subdemissum W. P. Sch. in Besch. Fl, bryol, Antill. fr. $p .76$.

$$
\text { - Am. sept.: Guadalup. }
$$

subinstratum (Besch.) Jaeg. op. cit. p. 486.

Sematophyllum subinstratum Besch. Fl. bryol. Nov. Caled, p. 238.

1. - Pac. : Nov. Caledon.

subplanum Besch. mss, ; Jaeg. op. cit.p. 480. - Pac. : Nov. Caledon.

subpyenocylindricum Broth. in Boll. da Soc. Brot. V11I, 1890.

1. Cortic. - Afr. : Ins. S. Thomas.

subrhinophyllum (C. M.) Jaeg. op. cit. p. 485.

Hypnum subrhinophyllum F. M. in Linn. 1875, p. 466.

Rhaphidorhynchum borbonicum Mitt. in Proced. of the roy. Soc. 1879 (extr. vol.), p. 101.

Sematophylum subrhinophyllum Besch. Fl. bryol. Nov, Caled, p. 238.

1 . - Pac. : Nov. Caledon.

subscabrizetulum (C. M.) Jaeg. op. cil. p. 486.

Hypnum subscabrisetulum C. M. in Linn. 1876, p. 284.

Rhaphidostegium subscabrisetulum Besch. Fl. bryol. Réunion, etc, p. 166.

1. Cortic. - Afr.: Ins. Anjouan.

substigmosum (C.M.) Par.

Hypoum substigmosum C. M. in Engler's Bot. Jahrb, 1883, p. 86 et in Forschungsreise.... p. 55.

Ster. Cortic. - Puc. : Nov, Guinea. 
subulatulum (C. M.) Jaeg. op cil. p. 484.

Hypnum subulatuluin C. M. in Linn. 1876, $p .284$.

Rhaphidostegium subulatulum Besch. Fl, bryol. Réunion, ete., p. 166.

1. Cortic. - Afr. : Ins. Anjouan.

tabescens (C. M.) Kinc'b. Enum.

Hypnum tabescens C. M. in Geh. Neue Beitr. zur Moosfl, v. Neu Guinea, p. 7.

1 .

- Pac. : Nov. Guinea merid

tenero-papillosum (C. M.) Par.

Thelidium tenero-papillosum C.M. mss.

- As. : Ins. Philippin. (Mindanao).

tenerrimum (Ångstr.) Jaeg. op. cit. p. 479.

Plagiothecium tenerrimum Angstr. in Oefv... 1872, n. 4, p. 16.

Sigmatella tenerrima $C . M$. in Fl. $1896, p .469$.

Syn.

- Pac. : Ins. Sandwic.

tenuisetum Jaeg. - Taxithelium.

thelidictyon Jaeg. - Rhaphidostegium.

tongense (C, M.) Jaeg. op. et $l . c c$.

Hypnum tongense C. M. M. Polyn. p. 83.

1.

- Pac. : Ins. Tonga.

trachaelocarpum Jaeg. - Rhaphidostegium.

trachyamphorum (C. M.) Par.

Hypnum trachyamphorum C. M. in Engler's Bot. Jahrb. 1883, p. 85 et in Forschungsreise... p. 49.

1. Cortic. - Pac.: Ins. Fidji, Samoa, Nov. Hannov.

trochalophyllum (Hpe.) Jaeg. op. cit.p. 480.

Hypnum trochalophyllum (Hpe. fid. C. M. in sched.).

- As. : Birman.

truncatulum Jaeg. - Ectropothecium.

turgidellum (C.M.) Par.

Hypnum nepalense Bryol.jav. p.p.

H. turgidellum C. M. in Engler's Bot. Jahrb. 1883, p. 87 et in Forschungsreise... p. 58.

1. Cortic. - As, : Amboine, Timorlaut.

unipapillosum (C. M.) Par.

Hy pnum unipapillosum C. M. in sched.

Ster.

- Pac. : Nov. Guin. brit.

ventrifolium (C. M.) Jaeg. op. cit.p. 479.

Hypnum ventrifolium C. M. M. Polyn.p. 84.

1. fr. ign. - Pac. : Ins. Fidji.

Vernieri (Duby) Jaeg. op. cit, p. 480.

Hypnum Lepineanum W. P. Sch. in Jardin Enum... p. 20 (nom.).

H. Vernieri Duby in Mém.... Genève, 1875, p.9, t.2, f. 6 .

1 (Besch.); 2 (Duby). Lignic. et terr, - Pac. : Taiti, Nuka-Hiva. 
vincentinum (Mitt.) Jaeg. op. cit. p. 482.

Sematophyllum vincentinum Mitt. M. austr. am. p. 493. 1.

- Ain. sept. : Guadalup., ins. S. Vineent (1).

TRICHOSTOMUM Hedw. M. frond, t. 27 (151 spec.).

acaulon C. M. in Linn. 1878-79, p. 320.

2.

- Am. merid. : Argentin. Cordob.

aciculare P. B. - Rhacomitrium.

var. acutifolium W. Arn. - Rhacomitrium protensum.

var. aquaticum W. et M. - Rhacomitrium protensum.

var. obtusifolium W. Arn. - Rhacomitrium aciculare.

affine Schleich. - Rhacomitrium heterostichum var. alopecurum.

afro-phaeum Rehm. M. Afr. austr. n. 120 el 473.

- Afr. : Orange, Transvaal.

aggregatum C. M. - Leptodontium.

aloides Koch. - Barbula.

alopecurum Schrank. -- Rhacomitrium heterostichum var, alopecurum.

alpigenum Vent. - Didymodon rubellus var. dentatus.

amblyophyllum C. M. - Desmatodon.

amblystegium C. M. in Nuov. Giorn. bot. ital. 1897, p. 118 (nom.).

$\mathrm{Tr}$, inclinatum Hpe. (ubi ? fid. C. M.).

- Am. merid. : And. Nov. Granat.

andinum Sull. U. St. Expl. Exped. 1859, p. 5 c. ic.

Tortula andina Mitt. M. austr. am. p, 147.

2.

- Am. merid. : And, Peruv.

ancectangioides C. M. in Nuov. Giorn. bot, ital. 1897, $p$.

Ster.

- As.: China or. (prov. Schen-Si).

anomalum W. P. Sch. Coroll. p. 28 et Syn. II ed. p. 178.

Barbula anomala Bryol. eur. II (mon. p. 45), t. $169 ;$ C. M. Syn. I, p. 603.

Timmiella anomala Limpr. Laubm. Deutschl. I, p. 592.

Tortula anomala Mitc. M. Ind. or. p. 28.

1. Muric. et terr. - Eur. : Tirol. merid., Ital. super., Gall. merid. (Monspel.). As. : Himalaya. Am. sept. : Calif., Florida.

Exs. : Rab. Bryoth, eur. n. 461.

Anomodon Bals, et de Not. - Didymodon.

apiculatum Rob. Br. in Trans, of the N. Zeal. Inst. 1896, p. 484, t. XLI, fig. 3 .

1. Ad terr. humid. - Pac. : Nov. Zeland.

aquaticum $\left\{\begin{array}{l}\text { Brid. - Rhacomitrium protensum. } \\ \text { Schleich, - Cinclidotus riparius. }\end{array}\right.$

arbustorum Brid, - Macromitrium aciculare.

arcuatum (Mitt.) C. M. in Nuov. Giorn. bot. ilal. 1897, p. 119 (nom.).

Tortula arcuata Mitt. M. austr. am. p. 165 p.p.

- Am. merid. : And. Quitens.

Aronis Ltz. - Gyroweisia.

(1) In Enum. Kindb. nom. nuda :

Tr. pallidifrons $C$. $M$. 
a tro-rubens Besch, in Ann. sc. nat. 1892, 1, p. 55.

2. Terr. in silv. - As.: Alp. Yunnan.

«var. circinans Besch. l. c.

$$
\text { - As.: Ibid. }
$$

atro-virens Rehm. M. Afr. austr, n, 119 et 495 .

- Afr. : Transvaal, Natal.

A ustralasiae Jaeg. - Barbula.

australe $\mathrm{H}$. f. et W, - Lophiodon strictus.

austro-alpigenum C. M. in Engler's Bot. Jahrb. 1883, p. 80 el in Erforschungsreise... p. 24.

Ster. - Afr. : Ins. Kerguelen.

avonense Rob. Br. in Trans. of the N.Zeal. Inst. 1896, p. 481, t. XXXIX, fig. 5 .

1. Ad terr. humid. - Pac. : Nov, Zeland.

Ayresianum W. P. Sch. in Besch. Fl. bryol. Réunion, etc., p. 54.

Ster. - Afr. : Ins. Borbon.

azoricum Card, in Ann. Rep. of the Missouri Bot. Gard. p. 58.

1 vel subsyn. - Afr. : Ins. Azor.

Bainsii Rehm. M. Afr. austr. n. 469.

$$
\text { - Afr.: Transvaal. }
$$

Bambergeri W. P. Sch. Syn. 11 ed. p. 173.

2. Muric. - Eur. : Tirol, merid. ; Stiria (ster.).

Barbula Schwaegr. Suppl. I, I, p. 144, t. 36; Bryol, eur. 11 (mon. p. 5),

ı. 170 ; C. M. Syn. I, p. 583 ; W. P. Sch. Syn. I1 ed. p. 127.

Barbula lusitanica Kindb. Eur. and N. Am. Bryin, p. 252.

Timmiella Barbula Limpr. Laubm. Deutschl. I. p. 594.

Tortula cirrata W. Arn. in Mém. Soc. hist. nat. Paris, II, p. 287.

T. Iusitanica Brid. Sp. M. I, p. 249.

Tr. barbuloides Brid. Bryol, univ, I, p. 493.

I. Ad mur., rup. et terr. calear. - Eur, : Reg. mediterr. tota. As. : Minor, Pers, austr. A fr. : Septentr., Abyss., ins. Canar., Madeir.

Exs. : Mandon Pl. Madeir, n. 8.

barbuloides Brid. - Tr. Barbula.

basiflorum Schrank. - Ceratodon purpureus.

bericun $\{$ de Not. - Leptobarbula.

bericum $\{$ Husn. p. p. - Leptobarbula meridionalis.

bermudanum (Mitt.) Par.

Tortula bermudana Mitt. in Journ. of the Linn. Soc. 1877, p. 60.

2. In aren, calcar. - Am, sept. : Ins. Bermud.

Berteroanum (Spreng.) C. M. Syn. 1, p. 568.

Barbula Sprengelii Schwaegr. Suppl.II, p. 64, t. 119 ; Brid. Bryol. univ. I, p. 532.

Plaubelia tortuosa Brid. op. cit. I, p. 522.

Tortula Berteroana Mitt. M. austr. am. p. 154.

Weisia Berteroana Spreng. Syst. veg. IV, p. 156.

2.

- Am. sept.: Haïti.

Bescherellei W, P. Sch, in Besch. Prodr. bryol, mexic. p. 33.

Didymodon macromitrium W. P. Sch. in sched.

Hyophila Bescherellei $C$. M. in Fl. 1875, n. 34-35

2. Ad mur., rup. et terr, $-A m$. sept : Mexic.

bifidum Brid. - Leucoloma. 
Bimsii Rob. Br. in Trans. of the N. Zeal. Inst. 1896, p. 486, t. XLIII, fig. 10.

1. Ad rup. humid. - Pac. : Nov, Zeland.

Blumii Dz. et Mk. - Campylopus Dozyanus.

bombayense $\{$ C. M. - Didymodon.

brachydon

brachydontium $\mathrm{Br}$. - Tr. mutabile.

brachyphyllum Wils, - Barbula gregaria.

brasiliense (Broth.) Par.

Atractylocarpus brasiliensis Broth. in Ule Bryoth. brasil. n. 109.

Paludic. - Am, merid.: Brasil, austr. or.

brevicaule Hpe. in C. M. Syn. 1, p. 567; Bryol. jav. I, p. 95, t. 77.

2. Ad terr. calc. et vulcan, - As, : Java, Pac. : Nov. Caledon.

brevifolium Sendtn. in C. M. Syn. I, p. 572.

Didymodon brevifolius Kindb. Eur. and N. Am. Bryin. p. 275.

- Eur.: Bosnia.

brevifolium Hpe. ot Ltz. - Tr. Krauseanım.

blevirostrum Rob. Br. in op. cit, p. 481, t. XXXIX, fig. 4 .

Ad terr, humid. - Pac, : Nov. Zeland,

brunneum C. M. - Pottia.

Buchanani Rob. Br. in op. cit. p. 482, t. XXXIX, fig. 6 .

Ad terr, humid. - Pac, : Nov. Zeland.

caespitosum W. P. Sch. in sched.; Jaeg. Ad. 1, p. 240.

- Eur. : Hibern.

caespitosum Jur, - Pottia.

calcareum Rob. Br. in op. cit. p. 480, $\iota$. XXXIX, fig. 2.

1. Ad rup. humid, - Pac. : Nov, Zeland.

calcareum Lindb. - Gymnostomum.

calcicola Hpe. Ic. M. t. 29 ; C. M. Syn. I, p. 587.

Tortula calcicola Mitt. in Trans. and Proced. of the roy. Soc. of Victoria, $1883, p .60$.

2. Rupic. - Pac. : Austral. or. (Victoria).

Cameruniae (Broth.) Par.

Timmiella Cameruniae Broth. in Engler's Bot. Jahrb. 1897, p. 238.

2. Terr. - Afr. : Cameroon.

campylocarpum C. M. Syn. II, p. 628.

Tortula arcuata Mitt. M. austr, am. p. 163 p.p.

2. -Am. sept. : Mexic., Costa Rica. Am. merid.: Nov, Granat. ? And, Boliv, ?

Exs. : Mandon Pl. Boliv, n. 1617.

campylopyxis C. M. in Nuov, Giorn, bot. ital. 1897, p. 118.

- Am. merid. : And. Boliv.

canadense Rich. $\left\{\begin{array}{l}\text { - Rhacomitrium eanescens? } \\ \text { - Rhacomitrium lanuginosum? }\end{array}\right.$

canaliculatum (Mitl.) Par.

Tortula canaliculata Mitt. M. austr. am. p, 147 .

- Am. sept. : Cuba. 
canaliculatum Sull. - Tr. nivale.

canescens Timm. - Rhacomitrium.

capillaceum Sm. - Distichium.

carassense Broth. in Ule Bryolh. brosil. n. 128.

Terr. - An. merid, : Brasil, austr. or.

carnosum Brid. - Rhacomitrium heterostichum.

cataractarum Hartm. - Rhacomitrium protensum.

cernuum Lindb. - Desmatodon.

chilense Mont, in Ann. sc. nat. 1V, p. 109 et Syll.p. 38; C. M. Syn. I, p. 576 .

Tortula chilensis Mitt. M. austr, am. p. 146.

2. Ad terr. arenac. - Am. merid. : And. Quitens., Chile anstr.

chlorophyllum C. M. in Linn. 1874, p. 635.

2. Ad terr. in silv. - Am. sept. : Mexic.

chrysopus C. M, in Sikora Pl. Mad. n. 14346.

- Afr. : Madagascar.

circinans W. P. Sch. - Barbula nitida (fid. Limpr.).

cirratum Hpe. Ic. M. t. 24; C. M. Syn. I, p. 584.

2. - Pac. : Austral, or., ins. Lord Howe.

cirratum Sm. - Ptychomitrium polyphyllum.

cirrifolium (Mitt.) Par.

Tortula cirrifolia Mitt. in Godman's Nat. hist. of the I. Azor., 1870, p. 276.

2. Terr. - Afr. : Madeir.

cilrinum Hpe, - Leptodontium.

Clintoni C. M. in Linn. 1874, p. 636.

Tr. crispulum Besch. Prodr. bryol. mexic. p. 33.

2. Ad arbor. et terr. - Am. sept. : Mexic.

Cockayini Rob. Br. in Trans. of the N. Zeal. Inst. 1896, p. 486, t. XLII, fig. 8 ,

In fissur, rup. - Pac. : Nov. Zeland.

? coloradense Aust, in Coult. Bot. Gaz. II, p. 90; Lesq. et Jam. Man. p. $4 \mathrm{I} 3$.

Ster.

- Am. sept. : Colorado; Calif.?

compactulum C. M. in Linn. 1878-79.

Ster. Rupic. - Am. merid. : Argentin. Cordob.

compactum Wils, in hb. W. P. Sch.; Jaeg. Ad. I, p. 240.

- Eur. : Hibern.

conicum Hpe, in C. M. Syn. I, p. 575.

Ceratodon conicus Lindb. M. Scand. p. 27.

2. Muric. - Eur.: Suec., Fenn., Ferman. sept. As. : Caucas. Am. sept. : Columb. brit.

connivens (Lindb.) Par.

Mollia connivens Lindb. in Broth. Enum. M. Caucas, p. 48.

2. Fr. ign, Ad rup. granit, et schist. - As. : Caucas. occ. et centr. contortifolium (Mitt.) Jaeg. Ad. I, p. 246.

Tortula contortifolia Mitt. M. austr. am. p. 147. 
conlortifolium Rob. $\mathrm{Rr}$. - Tr. maoricum.

convolutum Brid. - Barbula atro-virens.

cordalum Milde. - Didymodon.

corniculatum (Wahlenb.) Schwaegr. Suppl. 11, p. 75, t. 118; Brid. Bryol. univ. I, p. 494 ; C. M. Syn. I. p. 584,

Encalypta corniculata Wahlenb. in Berl. Mag. V, p. 295, t. 7, f. 2.

Mollia corniculata Arn. et Lindb. M. As. bor. 1890, II, p. 70.

2. Terr, - As, : Kamschatka.

crassinerve Hpe. in Linn. 1859-60, p. 456.

Tr. flavo-virens var. crassinerve Lesq. et Jam. Man, p. 108.

2. Terr. - Am. sept. : M. Calif.

crispipilum Tayl. - Rhacomitrium.

crispulum Br. in Fr. Müll. M. Sard. et in Fl. 1829, p. 295, t. 4; Bryol. eur. 11 (mon. p. 7), t. 173; C. M. Syn. 1, p. 571; W. P. Sch. Syn. II ed. $p .171$.

Didymodon crispulus Wils. in Engl. Bot., II Suppl.t. 2734 (fid. Lindb.). Mollia crispula Lindb. M. Scand. p. 21 .

Tortula crispula Mitt. in Melliss's S. Helena, p. 360.

2. Ad mur., terr. et rup. - Eur. : Zon. merid., praecip. mediterr. As. : Ienissei infer. (?); Caucas. A fr.: Alger ; S. Helen. (indig. ?). Am. sept. : Rar. : Kansas, Calif, merid.

Exs, : Rab. Bryoth. eur, n. 532.

\& var. algarvicum W. P. Sch. op. cit. p 172.

- Eur. : Algarb.

- var. angustifolium Bryol. eur., C. M. et W. P. Sch. ll. cc.

Didymodon rigidulus $\beta$ trifarius Hartm. Skand. Fl. III ed., II, p. 176.

Mollia crispula $\beta$ viridula Lindb. M. Scand. p. 21.

Tr, crispulum var, viridulum Braithw, Brit. Moosfl. p. 243.

Tr. planum Lindb, in Oefv. Vet. Akad. Foerh. 1859, p. 210, n. 84.

Tr. trifarium C. Hartm. Skand. Fl. VII ed., p. 381.

Tr. viridulum $\mathrm{Br}$, in $\mathrm{Fl}$. 1829, $p$, $201, t .5$.

Ad terr. aren. argill. humid. - Eur. : Alsat., Helvet, Rhaet., Tirol, Bavar., Stir., Salisb.

Exs. : Rab. Bryoth. eur. n. 533 et b.

«var. brevifolium Bryol. eur., C. M. et W. P. Sch. ll. cc.

Ut typ. - Eur.: Cum typ. Afr. : Alger.

- var. elatum W. P. Sch. op. et l. cc.

Ad rup. humid, interdum irror. - Eur.: Hibern., Angl, Pyren,

Astur, Afr. : Alger.

« var. longifolium W. P. Sch. op, et l. cc.

Ut typ. - Eur.: Galloprov.

« var. psendo-Weisia W. P. Sch. op. et $l$. cc.

- Eur. : Algarb. Afr. Alger.

crispulum Besch. - Tr. Clintoní ?

var. robustum W. P. Sch. - Barbula cirrifulia

var, viridulum Braithw. - Tr. crispulum var, angustifolium. curvifolium $\mathrm{Br}$. - Tr. inflexum.

curvithecium Rob. Br. in Trans. of the N. Zeal. Inst, 1896, p. 487,

t. XLIII, fig. 13.

Ad rup. humid, - Pac. ; Nov, Zeland, 
cuspidatum W. P. Sch. op. cit.p. 181.

Tr. mutabile forma (fid. Geh. in Fl. 1886, n. 22 et Limpr. Laubm. Deutschl. I, p. 579).

Ster. Ad rup. calcar. - Eur, : Westphal.

cuspidatum Bryol. jav. - Didymodon.

cylindricum $\left\{\begin{array}{l}\text { C. M. - Didymodon. } \\ \text { Hedw. - Trichodon. } \\ \text { Lindb. - Ceratodon oblongus. }\end{array}\right.$

decipiens Schultz. - Grimmia Schultzii.

delicatulum Wils. $\left\{\begin{array}{l}\text { - Ditrichum laxissimum. } \\ \text { - Ditrichum tortipes. }\end{array}\right.$

densifolium C. M. - Leptodontium.

dentatum Rehm. M. Afr. austr. n. $46 \dot{8}$.

$$
\text { - Afr. : Transvaal. }
$$

dentatum Wils. $\left\{\begin{array}{l}\text { - Barbula Wallichii. } \\ \text { - Leptodontium. }\end{array}\right.$

dicranoides (false. : dicranelloides) W. P. Sch. in litt. ad C.M. et in Besch. Prodr, bryol, mexic. p. 31.

Barbula macrostegia Kindb. Eur. and N. Am. Bryin. p. 262.

Leptotrichum dicranoides $C . M$. Syn. II, p. 612 .

Ramphidiurn macrostegium Mitt. M. austr. am. p. 45.

Tr. lepterhynchum W. P. Sch. in hb. Mus, Paris.

T'r. macrostegium Sull, in Wright M. Cubens n. 24.

2. Ad terr. aruill. - Am. sept.: Ludovic., Mexic., Cuba, Jamaic., Guadalup. Am. merid. : And, Quitens., Brasil, tropic.

difficile Duby. - Ditrichum Boryanum.

diffractum Mitt. - Barbula nitida.

distans Hpe, - Didymodon leptocarpus.

Ehrenbergii Ltz. M. Ehrenb. p. 25, t. 4, f. 1-6 et t. 5, f. 7-19.

Didymodon Ehrenbergii Kindb. Eur, and N. Am. Bryin. p. 281.

Hydrogonium Ehrenbergii Jaeg. Ad. II, p. 669.

H. moditerraneum Fitz-Ger. et Bott, in Nuov. giorn. bot. ital. April. 1881.

Tr. mediterraneum C. M. in Rev, bryol. 1879, p, 33; Husn. Muscol. gall. p. 85 .

$\delta$ et fr. ign. Ad mur. et lapid. calcar. sœpius submers. - Eur. : Galloprov., Emilia. As. : M. Sinaï.

* var. Algeriae (Besch.) Par.

Tr. mediterraneum var, Algeriae Besch. Bat. M. Alg. p. 11.

Ad cataract, - Af $r$. : Alger.

ellipticum H. et T. - Rhacomitrium.

elongatum Hook. f. et Wils. Fl. Tasman, II, p. 176, t. 173, f. I; Rob. Br. in Trans. of the N. Zeal. Inst. 1896, t. XL, fig. 10.

Cynontodium elongatum Mitt. M. austr. am. p. 43 .

Ditrichum elongatum Mitt. in Trans. and Proced. of the roy. Soc. of Victoria, $1883, p .51$.

Leptotrichum elongatum Jaeg. Ad. I, p. 230.

1. Ad terr, humid. - Am. merid.: Chile? Pac.: Nov. Zeland, Austral, or., Tasman.

elongatum Ehrh. ericoides Schrad. - Rhacomitrium eanescens var. ericoides.

erosum Rehm. M. Afr. austr. n. 472. 
exasperalum Schwaegr. - Campylopus.

falcatum Rob. Br. in Trans. of the N. Zeal. Inst. 1896, p. 480, t. XXXIX, fig. 1.

2. Ad terr. humid. - Pac. : Nov. Zeland.

"var. $\beta$ ej. op. et $l$. cc., fig. I A.

Ut et ubi typ.

fasciculare Schrad. - Rhacomitrium.

$\beta$ protensum Hartm. - Khacomitrium protensum.

Fendleri C. M. in Linn. 1878-79, p. 481.

2.

- Am. merid. : Venezuela.

ferrugineum Brid. - Leucoloma sinuosum.

filescens Hpe. - Leptodontium.

filiformifolium Rob. Br, in op. cit. p. 482, t. XXXIX, fig. 7 .

2. Ad terr. humid, - Pac. : Nov. Zeland.

«var. $\beta$ ej. op. et $l$. cc., $t$. XL, fig. 7 a.

Ut et ubi typ.

Aavicans C. M. - Barbula obtusifolia.

flavipes Steud. - Barbula Brebissonii.

flavo-virens $\mathrm{Br}$. in Fr. Müller M. Sardin. in Fl. 1829, p. 304, t. 7; Bryol. eur. 11 (mon. p. 6), t. 172 ; C. M. Syn. 1, p. 585 ; W. P. Sch. Syn. II ed., p. 174.

Barbula flavo-virens Kindb. Eur, and N. Am. Bryin, p, 254.

Didymodon tricolor Bals, et de Not. in Mém. Acad. Torin. 1838, p. 333.

Mo.lia flavo-virens Lindb. M. Scand. p. 21.

Tortula flavo-virens ej. de Tortul. p. 252.

2. In terr. aren. silvat. maritim. - Eur. : Anglia et Neerlandia (ster.); Galloprov., Sardin., Hispan. Afr.: Alger., ins. Azor. Am, sept.: Florida.

Exs. : Rab. Bryoth. eur. n. 1370.

var. crassinerve Lesq, et Jam. - Tr. crassinerve.

var, minor Lindb, - Tr. flavo-virens var, viridi-flavum.

* var. viridi-flavum (de Not.) Jaeg. Ad. I, p. 248.

Barbula viridi-flava Kindb. Eur, and N. Am. Bryin. p. 254.

Tr. flavo-virens var. minor Lindb. Trichost. $p, 15$.

Tr. viridi-flavum de Not. Epil. p. 503.

Ad rup. aren. et calcar. - Eur. : Istria.

flexicaule Bryol, eur. - Ditrichum.

flexifolium Brid. - Didymodon.

flexipes Bryol. eur. II (mon. p. 6), t. $17 \mathrm{I} ;$; C. M. Syn. I, p. 584; W. P.

Sch. op. cit, p. 179.

Barbula flexiseta Kindb, op. cit. p. 252.

Timmiella flexipes Limpr. Laubm. Deutschl. I, p. 595.

Tr. flexisetum Br. in Fr: Müller M. Sardin.; de Not. Syll. et Epil.

2. Ad terr. siccam et in dumetis, - Eur. : Sardin., Algarb. Am. sept. : Calif.

Eacs.: Rab. Bryoth, eur. n. 148.

flexisetum C. M. in Nuov. Giorn. bol. ital. 1897, p. - As.: China or. (prov. Schen-Si).

flexisetum $\mathrm{Br},-\mathrm{Tr}$, flexipes. 
fontanum C. M. in Linn. 1878-79, p. 295.

Hydrogonium fontanum Jaeg. Ad. II, p. 669.

Ster. Subaquat, - Afr. : Somali.

fontinaloides Hedw. - Cinclidotus.

fragile C. M. - Barbula Drummondii.

funale $\left\{\begin{array}{l}\text { Hsch. - Grimmia elatior. } \\ \text { Schwaegr. - Grimmia. }\end{array}\right.$

fusco-mucronalum C. M. - Desmatodon.

glaucescens $\left\{\begin{array}{l}\text { Sull. - Ditrichum subglaucescens. } \\ \text { Sw. - Ditrichum. }\end{array}\right.$

glauco-viride Ren. et Card. in Bull. Soc. roy. bot. Belg. 1894, 11, p. 113 et M. Masc. Mad. n. 166.

Ster. - Afr. : Ins. Borbon.

glauco-viride C. M. - Pottia.

gracile Rob. Br. in Trans. of the N. Zeal Inst. 1896, p. 486, $t$. XLIII, fig. 9.

2. Ad rup. humid. - Pac. : Nov. Zeland.

gracile $\left\{\begin{array}{l}\text { Hsch. - Rhacomitrium sudeticum. } \\ \text { Mdo. - Zygodon. }\end{array}\right.$

gracilescens C. M. - Leptodontium.

gracillimum C. M. in Linn. I878-79, p. 313.

2. Rupic. - Am. merid. : Argentin. Cordob.

grimmioides C. M. - Leptodontium.

Guepini C. M. - Barbula.

gymnum C. M. - Pottia.

Hallii (Tortula?) Rob. Br. in op. cit. p. 482, t. XL, fig. 8.

1. Lignic. - Pac. : Nov. Zeland.

heterostichum Hedw. - Rhacomitrium.

homomallum Bryol, eur. - Ditrictum.

var. densum W. P. Sch. - Ditrichum vaginans.

Hoppeanum Schultz. - Desmatorlon latifolius var. glacialis.

hyophilaceum C. M. in Bull. hb. Boissier, 1897, n. 191.

2.

- Am. sept. : Guatemala.

hypnoides $\{$ Hedw. - Rhacomitrium canescens.

imper Willd. - Rhacomitrium lanuginosum.

imperfectum C. M. - Pottia.

inclinans W. P. Sch, in Besch. Prodr. bryol. mexic. p. 32.

2.

- Am. sept. : Mexic.

inclinatum $\left\{\begin{array}{l}\text { C. M. - Desmatodon cernuus. } \\ \text { Hpe. - Tr. amblystegium. }\end{array}\right.$

incurvum Hsch. - Urimmia elatior.

indicum $\left\{\begin{array}{l}\text { Schwaegr. }-\mathrm{T}_{i} \text {, orientale. } \\ \text { Willd. - Ptychomitrium. }\end{array}\right.$

indigens Ren, et Card. in Bst. Gaz. 1896, p. 50, t. IV, f. A.

2 ? of ign.

inflexum Br. in Fr. Müller M. Sardin. in Fl. 1829, p. 402, t. 6; C. M.

Syn. 1, p. 587; W. P. Sch. op. cit. p. 173. Mr. \&. t 178

Barbula inflexa Kindb. Eur, and N. Am. Bryin. p. 254.

Tortula inflexa Lindb. Trichost. eur, p. 44

Tr. curvifolium Br. mss,; de Nol, Syll, et Epil. 
2. Ad rup. calcar. - Eur. : Galloprov., Sardin., Istria, ins. Melit., Minorc., Algarb. As. : Japon. Afr. : Alger.

interruptum (Mitt.) Besch. Note M. I. S. Paul et Amsterd., p. 4.

Didymodon interruptus Mitt, in Hook. Handb, of the N. Zeal. Fl, p. 425.

Ad Lycopod, - Afr. : Ins. Amsterdam. Pac. : Nov. Zeland.

involutum Sull. in Proced. of the Amer. Acad... 1861, p. 277 et in

Wright M. Cub. n. 25.

$$
\text { - Am. sept. : Cuba. }
$$

« var. minor Sull, in op. et l. cc.

- Am. sept. : Ibid.

jamaicense (Mitt.) Par.

Tortula jamaicensis Mitt, M. austr, am. p. 517.

2? - Am. sept. : Jamaio.

juniperinum C. M. in Bot. Zeit. 1862, p. 349 .

2 ? Ster. Muric. - Am. merid. : Peruv.

Krauseanum Par.

Angstroemia brevifolia Hpe. et Ltz. in sched.

Tr. brevifolium eor. in Bot. Zeit. $1869, p$.

2. Terr. - Am. merid. : Equator.

Krintjingianum $\mathrm{Dz}$, et Mk. - Ceratodon purpureus.

laetum Kze. in Poepp. Pl. Chil. ; C. M. Syn. I, p. 574.

Tortula laeta Mitt. $M$. austr. am. p. 159.

2. Terr. - Am. merid: Paraguay, Chile austr.

lamprothecium C. M. in Linn. 1874, p. 637.

2. Terr. - Am. sept. : Mexic.

lamprothecium C. M. (1897). - Tr. sublamprothecium.

Lamyanum W. P. Scb. - Didymodon Lamyi.

lanuginosum Hedw. - Rhacomitrium.

latifolium Schwaegr. - Desmatodon.

$\beta$ Laureri Hüb. - Desmatodon Laureri.

$\beta$ muticum C. M. - Desmatodon latifolius var. glacialis.

Laureri Schultz. - Desmatodon.

laxifolium Hook. f. et Wils. Fl. of the N. Zeal. II, p. 72; Rob. Br. in Trans. of the N. Zeal. Inst. 1896, t. XLIII, fig. 12.

Dicranum flexifolium Hook. M. exot. . 144.

Ditrichum flexifolium Hpe, in Linn. 1867, pp. 181-182.

D. Jaxifolium Mitt. in Trans. and Proced. of the roy. Soc. of Victoria, $1883, p .51$.

Leptotrichum flexifolium Hpe, in Jaeg. Ad, I, p. 240 et II, p. 763.

Ad terr. humid. - Afr.: Austr. Am. merid. : Anstr. (fid. Jaeg.)

Pac. : Nov. Zeland., Austral, or. (Victoria), Tasman.

Leikipiae C. M. in Fl. 1890, p. 481.

Ster. $\quad-$ Afr.: M. Kenia.

leiodontium $C . M, h b$.

$$
\text { - Af }: \text { : C. B. Sp. }
$$

Leptodon Mitt. - Campylopus.

leptorhynchum W. P. Sch. - Tr. dicranoides.

leptotheca C. M. in Linn. 1867-68, p. 625.

2 .

- Pac. : Austral. or. 
Leucodon C. M. in Bull. hb. Boissier, 1897, p. 192.

- Am. sept. : And. vulcan. Guatemal.

Leucoloma Schwaegr. - Leucoloma bifidum.

ligulatum (Tortnla?) Rob. Br. in op, cit. p. 485, $t$. XLII, fig. 5.

1. Ad rup. humid. - Pac. : Nov. Zeland.

linealifolium C. M. in Linn. 1878-79, p. 481.

2.

- Am. merid. : Venezuela.

lineare $\mathrm{Sm} .\left\{\begin{array}{l}\text { - Dichodontium pellucidum. } \\ \text { - Tr. tophaceum. }\end{array}\right.$

linearifolium Rob. Br, in op. cit. p. 485, t. XLII, fig. 7 .

1. Ad rup. humid. - Pac. : Nov. Zeland.

lingulatum Hook. f. et Wils. Fl. of the N. Zeal. II, p. 71, t.84, f. 4 et

Handb, p. 416 ; Rob. Br, in Trans; of the N. Zeal. Inst, 1896.

- Pac. : Nov. Zeland.

«var. $\beta$ eor. op, et ll.cc.

- Pac. : Ibid.

linoides $\left\{\begin{array}{l}\text { Brid. }- \text { Barbula unguiculata. } \\ \text { Engl. Bot. }\left\{\begin{array}{l}\text { - Didymodon luridus. } \\ \text { - Tr. tophaceum. }\end{array}\right.\end{array}\right.$

littorale Mitt. in Seem. Journ. of bot. 1868, p. 99, t. 77, f. 7-9; W. P.

Sch. Syn. II ed.p. 180.

Didymodon littoralis Kindb. Eur. and N. Am. Bryin. p. 275.

Mollia littoralis Braithw. Brit. Mossf. p. 224.

Fr. ign. Ad rup. marit. - Eur.: Anglia merid,, Normann. marit.; Bade? (fid. Limpr.) ; Norveg., Tirol. (fid. Hagen).

lonchobasis C. M. in Nuov. Giorn. bot. ilal. 1896, p. 102.

Ster.

- As. : China or. (prov. Schen-Si).

longifolium \{ Brid. - Leucoloma sinuosum.

Dz. et Mk. - Ditrichum Boryanum.

$\beta$ humile Brid. - Leucoloma sinuosum.

longirostre Hartm. - Dicranodontium.

luridum Spr. - Didymodon.

luteolum Besch. - Leptodontium.

luteum Hpe. - Leptodontium.

macrostegium Sull. - Tr. dicranoides.

mahaliesmontanum Rehm. M. Afr. austr. n. 470.

$$
\text { - Afr. : Transvaal. }
$$

Mandoni C. M. - Leptodontium.

mediterraneum C. M. - Tr. Ehrenbergii.

var. Algeriae Besch, - Tr. Ehrenbergii var. Algeriae.

melanocarpum Mitt. - Hyophila Barbula.

micrangium C. M. - Desmatodon.

microcarpum W. P. Sch. in Besch. Fl. biyol. Antill. fr. p. 24.

Calymperes involutum ej. in $h b$. Boissier.

-Am. sept.: Guadalup., Martinic.

microcarpum Hedw. $\left\{\begin{array}{l}\text { - Rhacomitrium. } \\ \text { - Rhacomitrium sudeticum. }\end{array}\right.$

microthecium C. M. - Pottia.

Mildeanum Jur. Beitr... p. 592.

2. Muric. - As. : Persia. 
minutifolium Rob. Br. in Trans. of the N. Zeal. Inst. 1896, p. 484, t. XLI, fig. 2 .

Ad rup. humid. - Pac. : Nov. Zeland.

monspeliense W. P. Sch. Syn. 11 ed. p. 175.

Didymodon monspeliensis Kindb. Eur. and N. Am. Bryin, p. 273.

Tr. triumphans var. monspeliense Husn. Musc. gall. p. 89.

1. Ad terr. aren, calcar. - Eur. : Gall. merid. (Monspel.).

Moretoni (Tortula)? Rob. Br. in op. cil. p. 483, t. XL, fig. 9.

1. Lignic, - Pac. : Nov. Zeland.

Mosis Ltz. - Gyroweisia.

mucronatulum Card. in Ann. Rep. of the Missouri Bot. Gard. 1897, p. 57.

Ster. - Afr. : Ins. Azor.

mucronaturn Besch. Fl. bryol. Nov. Caled. p. 205.

Ster.

- Pac.: Nov. Caledon.

mutabile Bryol. eur. 11 (mon. p. 8), t. 174; C. M. Syn. l, p. 571; W. P. Sch. Syn. II ed. p. 170.

Didymodon Benthami W. Arn. (fid. C. M.).

D. brachydontius Wils. in Engl. $\mathrm{Fl} . \mathrm{V}, \mathrm{p}, 30$.

D. crispulus $e j$. (fid. C. M.).

Hymenostylium Mülleri $\mathrm{Br}$, in $\mathrm{Fl}$. 1829, p. 386, f, 1-13.

Mollia brachydontix Lindb. M. Scand. p. 21.

Plaubelia tortuosa $\mathrm{Br}$. in $\mathrm{Fr}$. Müll. M. Sardin.

Tortula brachydontia Mitt. M. austr. am p. 148.

Tr. brachydontium $\mathrm{Br}$. in $\mathrm{Fl}$. 1829, p. 393, $t, 3$.

2. Ad rup. humid. fissur. et terr. petros. humid. - Eur. : Ins. Brit., reg. merid.; rar. et ster. in reg. sept. As.: Caucas. Afr. : Alger., Maroc, Madeir., ins. Canar. Am. merid. : And. Quitens. Pac. : Nov. Zeland. sept.

Exs. : Mandon PI. Madeir. n. 7.

Rab. Bryoth. eur. n. 870, 960.

" var. cylindricum W. P. Sch. op. cit. p. 171.

- Eur.: Algarb.

"var. densum Bryol. eur. l. $c$.

Ut et ubi typ. in Eur.

« var. eophocarpum W. P. Sch. op. et l. cc. - Eur.: Algarb.

var. robustius Jur. - Tr. nitidum.

var, unguiculatum Husn. -- Hymenostomum.

muticum (Mitt.) Par.

Tortula mutica Mitt. in Phil. Trans. of the roy. Soo. 1879 (extr. vol.) p. 389 .

Ster. - Afr. : Ins. Rodriguez.

Neesi Bryol. jav. - Didymedon.

nervosum $\mathrm{Br}$. - Barbula atro-virens.

nigricans Brid. - Cinclidotus riparius.

nitidum W. P. Sch, - Barbula.

nodulosum Aust. in Bull. Torr. bot. Club, VI, p. 74.

Ditrichum vaginans var. Lesq. et Jam. Man. p. 106.

$$
-A m, \text { sept }: \text { ? }
$$

nudum \{ C. M. - Pottia.

$$
\text { Schleich. - Rhacomitrium sudeticum. }
$$


obliquum C. M. - Desmatodon.

obscurum de Not. - Dicranoweisia Bruntoni.

obtusifolium Hpe. in Bot. Zeit. 1870, p. 49.

2. Ad rup. calcar. - Anı. sept. : Mexic.

obtusifolium $\left\{\begin{array}{l}\text { P. B. - Rhacomitrium. } \\ \text { W. P. Sch. - Desmatodon Schimperi. }\end{array}\right.$

obtusum Sm. - Rhacomitrium sudeticum.

occidentale (Mitt.) Jaeg. Ad. 1, p. 245.

Tortula occidentalis Mitt. M. austr. am. p. 155.

2. Terr. - Am. merid. : And. Peruv.

ceneum C. M. - Didymodon.

ceruginosum Lindb. - Gymnostomum rupestre.

oocarpum Rehm. M. Afr. austr, n. 117 et 474.

- Afr. : Orange, Transvaal.

"var. lanceolatum ej.l.c. n. 474 b.

- Afr.: Transvaal.

orientale Willd. herb. ; C. M. Syn. I, p. 568.

Barbula indica Brid. Bryol. univ. I, pp. 544 et 828 ((excl. syn. Willd.); Bryol. jav. I, p. 99, t. 81.

Tortula indica Hook. M. ex. II, p. 7, t. 135 (excl. syn. Willd.); Mitt. M. Ind. or. p. 30.

Tr. orientale Schroaegr. Suppl. I, I, p. 142, t. 36.

2. Muric. - As. : Nepal., Bengal., Ceylan, Java, ins. Ceram, Banca, Borneo. Pac : Nov. Guin. oceid, (ins, Kei).

orthotrichoides C. $M$. in Linn. 1874, p. 601 .

Ster.

- Am. merid. : Nov. Granat.

ovatum W. et M. - Grimmia commutata.

pallidisetum H. Müll. Zeitschır, d. Rhein. Nalurf. Ges. 1864, p.

W. P. Sch. Suppl. Bryol. eur. III-IV, t. 2 et Syn. II ed. p.

Didymodon pallidisetus Kindb. Eur. and M. Am. Bryin. p. 274.

Tr. triumphans var. pallidisetum Husn. Muscol. gall. p. 89.

1. In fissur. rup. calcar. - Eur.: Westphal., Thuring., Rhoengeb., Helvet.

pallidum $\left\{\begin{array}{l}\text { Brid. - Ditrichum Boryanum. } \\ \text { Hedw. - Ditrichum. }\end{array}\right.$

$\beta$ strictum Schwaegr. - Ditricham pallidum.

papillosum Sm. - Ceratodon purpurens.

paradoxum Brid. - Oreoweisia serrulata.

patens Schwaegr. - Rhacomitrium.

var. $\beta$ Schwaegr. - Rhacomitrium sudeticum.

$\beta$ funale $H$. et T. - Grimmia funalis.

pellucidum Wils. - Wilsoniella.

pensilvanicum Spreng. - Barbula unguiculata.

? perangustum Besch. Note M. I. S. Paul et Amsterd. p. 4.

Ster. $\quad-A f r$ : Ins. Amsterd.

perichaetiale Hook, - Holomitrium.

perpusillum C. M. - Pottia.

persicum Jur. et Milde Beitr... p. 592.

Ster.

- As, : Pers. austr. 
phaeum Hook. f. et Wils. Fl. of the N. Zeal. II, p. 72, t. 84, f. 5 et Handb. p. 416.

- Pac.: Nov. Zeland, bor.

Philiberti W. P. Sch. Syn. II. ed.p. 175.

Didymodon Philiberti Kindb. Eur, and N. Am. Bryin. p. 273.

Tr. triumphans var. Philiberti Husn, Muscol. gall. p. 89.

1. Ad mur. argill, aren. - Eur. : Gall. merid, (Monspel.). piliferum Sm. $\left\{\begin{array}{l}\text { (fid. C. M.) - Desmatodon latifolius var. brevicaulis. } \\ \text { (fid. lindb.) - Pottia latifolia var, pilifera. }\end{array}\right.$ piriforme Lesq. et Jam. Man. p. 109.

2.

- Am. sept. : Florida.

planum Lindb. - Tr. crispulum var. angustifolium.

plicatulum C. M. in Linn. 1878-79, p. 423.

1.

- Am. merid. : Uruguay.

pseudo-sulfureum C. M. - Leptodontium.

pulvinatum W. et M. - Grimmia.

$\beta$ alpestre eor. - Grimmia alpestris.

pumilum C. $M$. in $F l .1890$, p. 480.

Ster.

- Afr. : Kilima N'Djaro.

pungens (Mitt,) Par.

Didymodon pungens Mitt. in Journ. of the Linn. Soc. 1863, p. 150.

Afr. : M. Cameroon.

purpuratum (Mitt.) Par.

Rhamphidium purpuratum Mitt. in Godman's Nat. hist. of Ins, Azor., p. 290.

- Afr. : Madeir,, ins. Azor.

pusillum Hedw. - Ditrichum tortile var, pusillum.

var. 2 et 3 Hedw. - Ditrichum vaginans.

radiculosum Rob. Br. in Trans, and Proced. of the N. Zeal. Inst. 1896, p. 489, t. XXXIX, fig. 3 .

Ad terr. humid. - Pac. : Nov. Zeland.

ramigerum Timm. - Rhacomitrium lanuginosum.

ramulosum W. P. Sch, in Besch. Prodr. bryol, mexic, p. 33.

2.

- Am. sept. : Mexic.

recurvirostre Lindb. - Didymodon rubellus.

reflexidens $\mathrm{Hpe}$. - Desmatodon.

reflexum Lindb. - Gyroweisia.

$\beta$ gymnostomum Lindb. - Gyroweisia tenuis.

repandifolium Rob. Br. in op. cil. p. 487, $t$. XLIII, fig. 11 .

I. Ad rup. humid. - Pac. : Nov. Zeland.

repens C. $M$. in $F l .1890$, p. 481 .

Ster.

- Atr. : Kilima N'Djaro.

repens Schwaegr. - Amblystegium serpens.

rigidiusculum W. P. Sch, in Mandon Pl. Boliv. n. 1617 bis.

- Am. merid. : And. Boliv.

rigidulum Sm., Bryol. eur. - Barbula.

rigidulum $\times$ nitidum Boul. - Barbula spadicea. 
riparium Rehm. M. Afr, austr, n. 121. - Afr. : Natal.

riparium W. et M. - Cinclidotus. rivale (Mitt.) Par.

Tortula rivalis Mitt. $M$. aust, am. $p .147$.

Tr. canaliculatum Sull. in Proced. of the Amer. Acad. 1861. Ad rivul. - Am. sept. : Cuba. rostratum Rob. Br. in op. cit. p. 485, t. XLII, fig. 6. In fissur, rup. - Pac. : Nov. Zeland.

rosulatum C. M. in Nuov. Giorn. bot. ital. 1897, p.

Ster. - As. : China or. (prov. Schen-Si).

rubellum Rab. - Didymodon.

$\beta$ spectabile Rab. - Geheebia cataractarum.

rubiginosum C. M. in Linn. 1867-68, p. 625.

Tortula rubiginosa Mitt. in Trans. and Proced. of the roy. Soc. of Victoria, $p .1883, p .60$. - Pac. : Austral. or. (Victoria).

rubripes Mitt. in Hook. f. Handb. of the N. Zeal. Fl. p. 417.

2. $\quad$ - Pac. : Nov. Zeland.

rufisetum C. M. in Rehm. M. Afr, austr. n. 115. - Afr. : C. B. Sp.

Sartorii C. M. - Desmatodon.

saxatile Tayl. - Rhacomitrium fasciculare.

saxicola Hsch. - Campylosteleum.

Schimperi Mont. - Desmatodon.

Seblimii C. M. in Bot. Zeit. 1857, p. 579.

Tortula Schlimii Mitt. M. austr, am. p. 148.

2 .

- Am. merid. : And. Nov. Granat.

? scitulum Aust, - Distichium inclinatum.

sciuroides W. et M. - Leucodon.

Searellii Rob. Br. in op. ctt. p. 484, $t$. XLII, fig. 4.

1. Ad terr. humld, - Pac, : Nov. Zeland.

semi-vaginatum W. P. Sch. in Mandon Pl. Boliv. n. 1658.

Tortula semi-vaginata $D^{\text {na }}$ E. G. Britton in Bull. Torr. bot. Club, Decembr. 1896.

- Am. merid. : And. Boliv.

serratum Ehrh. - Rhacomitrium lanuginosum.

setosum H. f. et W. - Ditrichum affine.

sinense C. M. - Leptodontium.

sinuosum Mitt. - Didymodon.

spathulato-lineare C. M. - Pottia.

squarrosum Brid. - Leptodontium expunctatum.

stellatum C. M. - Leptodontium.

stenocarpum Hpe. - Rhacomitrium heterostichum.

strictum \{ Bryol. eur. - Ceratodon chloropus. 
subalpinum de Not. Syll. M.p. 184 ; C. M. Syn. I1, p. 525.

? Didymodon subalpinus Jaeg. Ad. I, p. 211 (1).

Leptodontium subalpinum Lindb. de Tortul. p. 227 (in obs.); de Not. Epil. p. 49.

$$
\text { Ad rivul. - Eur. : Pedemont. }
$$

subanomalum Besch. Prodr. bryol. mexic, p. 33.

1. - Am. sept. : Mexic.

subcirratum Hpe. Symb. 1874, p. 483.

2. $\quad-A m$. merid. : Brasil. austr. or.

subcirrifolium C. M. - Leptodontium.

subdenticulatum C. M. - Leptodontium.

sublamprothecium Par.

Tr. lamprothecium C. M. in Bull, hb. Boissier, 1897, p. 556.

$$
\text { - Am. sept. : Jamaic. }
$$

subsecundum $\mathrm{H}$. et Grev, - Rhacomitrium.

subulatum Bryol. eur. - Ditrichum.

sudeticum Funk. - Rhacomitrium.

sulphureum \& C. M. - Leptodontium.

Rehm. - Leptodontium transvaaliense.

sulphuripes C. M. in Nuov, Giorn. bot. ital. 1896, p. 103.

- As. : China or. (prov. Sehen Si).

syntrichioides C. M. - Didymodon?

systylium C. M. - Desmatodon.

? tenue Hedro. Sp. M. p. 107, t. 24; Brid. Bryol. univ. 1, p. 491 (2).

Coscinodon pullulans Brid. op. cit. p. 371.

Ditrichum tenue Hpe, in Fl. 1867, pp. 181-182.

Grimmia pullulans Spreng. Pl. min. cogn. Pug. III, p. 94.

Leptotrichum tenue C. M. Syn. I, p. 447 (excl. syn. Bryol. eur.) et II, p. 611 .

Weisia capilacen Brid. op. cit. p 359.

- Am. sept. : Pensilv.

Exs. : Drumm. M. bor. Am. Il ed. n. 58 ?

tenue, Schrad. - Trichodon cylindrieus.

tenue, W. P. Sch. Coroll. - Leptobarbula berica.

var. glaciale W. P. Sch. - Ditrichum vaginans var. glaciale.

Lenuifolium $\left\{\begin{array}{l}\text { C. M. - Leptodontium. } \\ \text { Schrad. - Trichodon cylindricus. }\end{array}\right.$

tenuirostre Lindb. - Didymodon cylindricus.

Thomsoni C. M. - Desmatodon.

tonkinense Besch. in Bull. Soc. bot. Fr. 1887, p. 96.

2.

- As. : Tonkin.

tophaceum Brid. Mant. M. p. 84 el Bryol, univ. I, p, 495 (incl. $\beta$ leuco(richum); Bryol. eur. 11 (mon. p. 9), t. $175 ;$ C. M. Syn, I, p. 573 et $I I, p .624 ;$ W. P. Sch. Syn. II ed. p. 169.

Anacalypta tophacea Fürni. (fid. Lindb.) ; Br. in Bryol. germ. II, p. 148, t. 37 .

Barbula brevifolia Lindb.

B. tophacea Mitt. M. Ind. or, p. 35

(1) "Suspectissima species! " Jaeg. l. c. In W. P. Sch. Syn, deest.

(2) Secund. Lesq. et Jam. Man. p. 106, incerta spec., ab Hedwigio a nemine visa. 
Ceratodon purpureus
C. stenocarpus Wils. in Kew Journ. bot. IX, p. 299?

Dicranum pellucidum var. Su. in Schrad. Bot. Journ. II. p. 177.

Didymodon tophaceus Jur. Laubm. Oester. Ung. p. 100.

D. trifarius $H$. et T. Musc. brit.

Tr. lineare Sm. Fl. brit. III, p. 1247?

Tr. linoides (Dicks. sub Bryo, sed false fid, Wils,) Engl. Bot.t. 2295.

2. Ad rup, et mur. calcar. perpet. aq. calcar. irror. - Eur. : Media tota, Gall. sept., Italia, Sardin. Astur., etc. As. : Tibet., Caucas., Minor. Afr.: M. Sinai, Alger., C. B. Sp. Am. sept.: Ontario, Niagara, New York, Texas, Calif. Am. merid. : And. Boliv.

Exs. : Mandon Pl. Boliv. n. 1619.

Sull. et Lesq. M. bor. am. Il ed. n. 151.

"var. acutifolium W. P. Sch. Syn. 11 ed. p. 70.

Tr. tophaceum var. brevicaule ej. Syn. I ed. p. 150.

Tr, tophaceum var: humile Bryol, eur. $l$. c.

Ad rup. et terr. aren, calcar, - Eur.: Suecia, Dania, German, sept., Anglia. Afr. : Alger.

var. brevicaule W. P. Sch. - Tr. tophaceum var. acutifolium.

* var. brevifolium (Dicks.) Bryol, eur. l. c.

Bryum brevifolium Dicks. Fasc. pl. crypt. 1I, p. 4 (fid. Wils.).

Locis minus aquos. - Eur. : Ubi typ.

var. humile Bryol, eur. - Tr. tophaceum var, acutifolium.

"var. laxum Kindb. in Nuov. Giorn. bot. ital. 1896, p. 15.

- Eur. : Ital. (Ticin.).

torquescens W. P. Sch. mss. C. M. in Bot. Zeit. 1859, p. 229.

1. $\quad-$ Afr.: Abyss., C. B. Sp.

Tortella C. $M$. in Linn. 1878-79, p. 319.

Ster.

- Am. merid. : Argentin. subtropic.

tortile $\left\{\begin{array}{l}\text { Schrad. - Ditrichum tortile. } \\ \text { Wils, - Barbuls comosa }\end{array}\right.$

$\beta$ pusillum Bryol. eur. - Ditrichum tortile var. pusillum.

tortuloides Sull. et Lesq. in Proced. of the Amer. Acad. 1859, p. 277.

1. Rupic. - Afr. : C. B. Sp.

tortum Schrank. - Ceratodon purpureus.

tovarense C. M. in Fl. 1897, p. 331,

- Am. merid. : And. Venezuel.

trachyneuron (Kindb.) Par.

Didymodon trachyneuron Kindb. Eur, and N. Am. Bryin. p. 275.

Ster. - Am. sept. : Canada (Quebec).

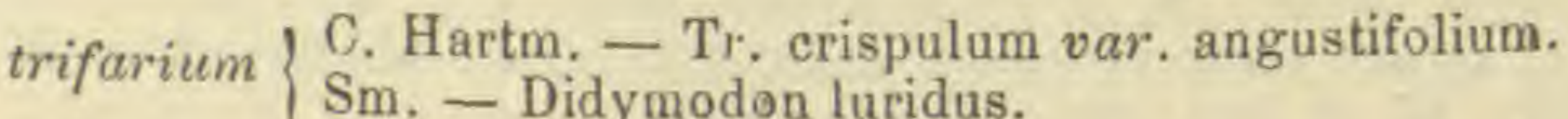

triumphans de Not. M. ital. mss. ; W. P. Sch. Syn. I ed. p. 690; Suppl.

Bryol. eur. fasc, 11I-1V et Syn. II ed. p. 176.

Didymodon triumphans Kindb. in op. cit. $p .273$.

1. In pasc. aren. ster. - Eur. : Liguria. Afr. : Alger.

var. monspeliense Husn. - Tr. monspeliense.

var. pallidisetum Husn. - Tr. pallidisetum.

var. Philiberti Husn. - Tr. Philiberti. 
ulocalyx C. M. - Leptodontium.

umbellatum Schwaegr. - Campylopus.

umbrosum C. M. in Linn. 1878-79, p. 318.

Syn. Muric, rupic. et terr. - Am. merid. : Argentin, Cordob.

undatum W. P. Sch. - Barbula commutata.

vaginans Sull. - Ditrichum.

vaginatum Dz. et Mk. M. fiond. ined. Archip, ind. p. 134, l. 42; Bryol. jav. $I, p .98$.

2. Terr. - As.: Sumatra.

vaginalum Hook. - Holomitrium.

vancouveriense Broth. $\mathrm{l} b$.

Didymodon vancouveriensis Kindb. in op. eit.p. 252.

- Am. sept. : Ins. Vancouver.

vernieosum Ren. el Card, in Bull. Soc. roy. bot. Belg. 1896, I, p. 308.

2 :

- Afr. : Ins. Borbon.

viridiflavum de Not. - Tr. flavo-virens var. viridiflavum.

viridulum $\mathrm{Br} .-\mathrm{Tr}$. crispuIum var, angustifolium.

Wallisi C. M. in Linn. 1874, p. 603.

2. Paludic. - Am. merid. : And. Nov. Granat.

Warnstorfii Limpr, Laubm. Deutsclil. I, p. 587 (1).

Barbula lingulata Warnst. in Hedwig. 1885, n. 3 .

2. Fr. ign. Ad lapid. calc. et aren. rip. flum. et lacuum. - Eur.: Helvet.

Winteri Husn. - Leptobarbuls.

Woodii Husn. - Barbula.

xanthocarpum W. P. Sch. mss, ; C. M. in Bot. Zeit. $1859, p, 229$.

Ceratodon xanthocarpus Hseh. (fd. Jaeg. Ad. I, p. 310 .

1 ?

- Afr.: C. B. Sp.

TRIDONTIUM Hook, f. Ic. pl, rar, II, t, 148.

Spec. omn, Dichodonti ejusd, nom.

TRIMATIUM Froehl. in hb. Bridel.

tophaceum Froehl. - Eucladium verticillatum.

TRIPLOCOMA La Pyl. in Journ. bot. Desvaux, n. 5 .

polytrichoides La Pyl. - Dawsonia.

TRIPTEROGLADIUM C. M. in Fl. 1875, p. 79 et in Rev, bryol. 1875, p. 46 ( 2 spec.). compressulum (C. M.) Jaeg. Ad. 11, p. 748.

Eurhynchium compressulum Jaeg. op. oit. p. 428.

Hyprium compressulum C.M. in op. et ll. co, ; Lesq. et Jam. Man. p. 331. 1.

- Am. sept.: Oregon.

(I) "An Tr. Wainstorfii ot et Tr, Ehrenbergii $q$ unicse et ejusd. spec. ? ". Limpr. 1. c. 
leucocladulum (C.M.) Jaey, op. cit, p. 748.

Eurhynchium leucocladulum Jaeg. op. cit. p. 428.

Hypnum leucocladulum C. M. in op. et l. co.; Lesq. et Jam. Man. p. 330.

Platygyrium rupestre Kindb. in Bull. of Torr. bot. Club, 1890, p. 276; Mac. Canad. M.n. 469.

Tr. rupestre Card. M. Am. sept. p. 50, n. 1068.

1. Rupic. - Am. sept. : Columb. brit., Oregon, Idaho.

TRIQUETRELLA C. M. mss. (2 spec.).

filiformis C.M. mss.

- Pac. : Austral, merid. (Adelaïde).

triquetra C. M. mss.

- Pac.: Austral.

Trismegistia C. M. M. Polyn. p. 89 (sect. Hypsi=Sematophyllum).

TRISTIGHIOPSIS C. M. in Linn. $1880-82, p .394$ ( 1 spec.).

mirabilis $C . M$. in op. et $l$. ce.

1. $\quad-$ Am, mevid. : Alp, Argentin. subtropic.

TRISTIGHIUM C. M. in Linn. 1878-1879, p. 235 (1 spec.).

Lorentzi C. M, in op. et l. cc.

1. - - Ain. merid.: Alp. Argentin.

TROGHOBRYUM Breidl, et G, Beck in Verh, d. K.K. zool.-bot. Ges, in Wien, 6 Febr. 1884 , c. ic. (1 spec.).

carniolicum Breidl. et G. Beck in op. et l. ec.

Ad saxa calcar, madida. - Eur. : Carniol.

Tropinotus C.M. M. Polyn.p. 58 (sect. Jeucophanis).

Turgidella C. $\mathrm{M}$. in Fl. 1896, p. 484 (sect. Pilotrichellae).

ULEA C. M. in H dwig. 1897, p. 102 (2 spec.).

palmicola C. M. in op. et l. $c c$.

i. Ad Cocoüm eriospatham. - Am. merid. : Brasil. austr. or.

yesensis Besch, in litt.

1. - As. : Japon.

Exs. : Faurie n. 11 b et 554.

Ulobryum C'. M. in Fl. 1896, p. 435 (sect. LeucobryI).

ULOTA Brid. Bryol, univ. I, p. 298 (57 spec.).

americana Mitl. in Journ. of the Linn. Soc. VIII, p. 26; Lesq. et Jam Man. p. 162 (1).

Orthotrichum crispum Dremm. M. bor, am. I ed. n. 153 (fid. D Da E. G. Bitton in Bull. Torn. bot. Club, 1894, p. 65).

Ulota curvifolia (id.).

U. intermedia (fid. Ren. et Car.d.'

1. Cortic, et rupic, - As. : Japon. Am, sept.: Nov. Seot., New Brunswick, Gaspes., lac. Huron et Super., Columb. brit.

(1) Cf. Venturi in Rev. bryol. 1892, p. 2. 
americana $\{$ Limpr. - U. Hutchinsiae.

$\beta$ nigrita Limpr. - U. Hutchinsiae.

anceps Vent. in Oefv... 1893, p. et in Pap. ant Proced. of the roy. Soc. of Tasman. 1893, p. 201.

1. Cortic. - Pac. : Tasman.

Anderssonii Jaeg. - U, leiothecia

angustissima $C . M$. in Hedwig. 1897, p. 104.

Ster.

- Am. merid. : Valdivia,

Barclayi Mitt. in Journ. of the Linn. Soc. VIII, p. 26 ; Sull. Ic. M. Suppl.p. 75, t. 56; Lesq. et Jam. Man. p. 164.

Orthotrichum Barclayi Kindb. Eur. and N. Am. Bryin.p. 305.

1.

- Am. sept. : Sitka.

bellissima Besch. in Ann, sc. nat. 1892, I, p. 57 .

1. Cortic, - As.: Yunnan.

bicolor Brid. - U. Drummondii.

brevicollis (Mitt.) Jaeg. Ad. I, p. 442.

Orthotrichum brevicolle Mitt. M. austr. am. p. 192.

- Am. merid. : Valdivia.

Bruchii Hsch. in Brid. Bryol. univ. I, p. 894; W. P. Sch. Syn. I ed. p. 256 et II ed. p. 303.

Orthotrichum Bruchii Wils, Bryol. brit. p. 188, $t .45$.

0. coarctatum Bryol. eur. III (mon, p. 21), t. 227; C. M. Syn. I, p. 713.

O. dilatatum Bryol. eur. l. c. (mon. p. 22).

U. coarctata W, P. Sch. Coroll. p. 4l.

U. dilatata ej. $l$. $c$.

Ulotrichum coarctatum ej. Compend. Bryol, eur.

Weissia Bruchii Lindb. M. Scand. p. 28 (1).

1. Ad arb. silvat. praepr. Fagos junior, et Abieles. - Eur. : Reg. montana. Am. sept. : Terr. nov., lac. Erie, Ontario, Columb. brit., reg. or.

Exs. : Mac. Canad. M. n. 453 p.p.

Rab. Bryoth. eur. n. 569, 880.

Un. itin. 1867, n. 17.

Bruchii Mac. p.p. - U, obtusiuscula.

calvescens Wils, in W. P. Sch. Syn. II ed. p. 303 el Suppl. Bryol. eur. fase. $I I I-I V$.

Orthotrichum calvescens Carrington in Trans. of the bot. Soo. of Edinb. $V I I, p .386$.

U. vittata Mitt. in Journ. of the Linn. Soe. 1864, p. 3.

1. Ad ramul. fructic., rar. ad truncos arb. junior. - Eur. : Anglia, Hibernia. Afr. : Madeir.

Eøs, : Mandon PI. Madeir. n. 17.

Rab. Bryoth. eur. n. 520.

camptopoda Kindb. - U. crispa.

earinata Milt, in Journ, of the Linn. Soc. 1859, p. 75.

Orthotrichum carinatum ej. $M$. austr. am. p. 190.

I. $\quad-A m$. merid.: Ins. Chiloë.

(1) De syn, antiquior. cf. C. M. Syn. 1, p. 713 ad 0, crispum. 
chilensis (Mitt.) Jaeg. Ad. 1, p. 442.

Orthotrichum chilense Mitt. op. cit. p. 193.

- Am. merid. : Valdiv.

coarclata W. P. Sch. - U. Bruchii.

cochleata Vent, in Defv.... 1893, p.

et in Pap. and Proced. of the roy.

Soc. of Tasman. 1893, p. 201.

1. Cortic. - Pac. : Tasman.

connectens Kindb. - U. crispa.

crassifolia $\mathrm{H}$. et T. - Orthotrichum.

crenato-erosa (C. M.) Par.

Orthotrichum crenato-erosum C. M. in Fl. 1885, p. 420.

2. Lignic. - Am. merid, : Fuegia occid.

crispa (Hedw.) Brid. Bryol. univ. 1, p. 299; W. P. Sch. Syn.Il ed.p. 304.

Bryum crispum Hoffm. Deutseh. Fl. II, p. 25.

Grimmia cipillata Maench. Fl. Marp. p. 731.

Gr. silvatica Willd. Prodr. Fl. Berol. n. 906.

Orthotrichum connectens Kindb, in Ottawa Nat. IV, p. 64.

o. crispum Hedw. Sp. M. p. 162; Bryol, eur. $11 I$ (mon.p. 23), t. 228 ; C. M. Syn. I, p. $712(1)$.

0. ulophyllum Kindb. Eur. and N. Am. Bryin. p. 307.

Neckera ulophylla W. et M. Bot. Taschb, p. 236.

Ulota camptopoda Kindb. in Mac. Cat. p. 85; Mac. Can. M. n. 582.

U. connectens ej. in op. et l, cc.; Mac. Canad. M. n. 557 .

Ulotrichum crispum Compend. Bryol. eur.

Weissia crispa Roth. Fl. Germ. III, I, p. 222.

W. ulophylla Ehrh. Beitr. I, p. 191.

1. Ad trunc. et ramul. arb. silvat. praepr. Fugorum, Abietum et Betul. - Eur.: Fere tota, As, : Saghalien, Amour, Cancas. oce. Afr.: Ins. Canar. Am. sept.: Terr. nov., New Brunswick, Nov. Scotia, Gaspesia, reg. sept. et or. Pac. : Tasman.

Exs, : Mac. Canad. M, n. 113 p.p.

Rab. Bryoth, eur. n. 178, 521.

Sull. et Lesq. M. bor. am. II ed, n. 90 ,

var. crispula Hamm. - U. crispula.

« var, minor Lesq. et Jam. Man. p. 162.

U. intermedia W.P. Sch. ?

Cortic. - Am. sept.: Ins. Miquelon, Terr. nov., Ontario, lac. Huron, Columb. brit.

crispula Br. in Brid. Bryol. univ. I, p. 793; W. P. Sch. Syn. II ed. p. 305 .

Orthotrichum cirratum Bermh. in Brid. op. cit. p, 301 (sub 0, crispo).

0. crispulum Bryol. eur. III (mon.p. 23), $t .228 ;$;. M. Syn. I, p. $713(1)$.

O. crispum $\beta$ minus Sohwaegr. Suppl. I, II, p. 25.

U. crispa var. crispula Hammar Mon. Orthotr. Sueciae, p. 24.

Ulotrichum crispulum Compend. Bryol. eur.

Weissia crispula Lindb. M. Scand. p. 28.

1. Ad arbor. junior. - Eur. : Fere tota. As. : Caucas, centr. et occ. Am. sept.: Terr, nov., Anticosti, New Brunswick, Nov. Scotia, Gaspesia, Ontario, reg. sept. et or. 
Exs. : Mac. Canad, M, n. 114.

Rab. Bryoth. eur, n. 179.

Sull. et Lesq. M. bor. am. Il ed. n. 179.

$\beta$ ambigua W. P. Sch. - U. intermedia.

" var. dolosa Ren. et Card. in Bot. Gaz. 1896, p. 51.

- Am. sept. : District of Columbia.

curvifolia (Wahlenb.) Brid. Bryol. univ. I, p. 302; W. P. Sch. Syn. II ed. p. 302 .

Orthotrichum curvifolium Wahlenb. Fl. Lapp, p, 365; Bryol. eur. III (mon. p. 21), t. 226; C. M. Syn. I, p. 715.

O. Laureri $\mathrm{Hsch}$. in $\mathrm{Fl}$. 1827, p. 656 .

Ulotrichum curvifolium Consp. Bryol. ewr.

Weissia curvifolia Lindb. M. Scand. p. 28.

2. Ad sax. granit. latera. - Eur. : Rariss, in reg. alp. zon. interm., frequent. in reg. montan, et subalp. zonae sept. : Scandin., Fenn., Alp. Cariuth., Salisb,; deest in Britann. Am. sept.: Groenland, Ontario.

Exs. : Rab. Bryoth. eur. n. 182, 222.

Un, itin. 1867, n. 88.89.

Darwinii Mitt, in Journ, of the Linn. Soc. 1859, p. 77.

Orthotrichum Darwinii ej. M. austr. am. p. 192.

1 ? - Am. merirl. : Fuegia.

dilatata W. P. Sch. - U. Bruchii.

Drummondii (Grev.) Brid. Bryol. univ. I, p. 299; W. P. Sch. Syn. Il ed. p. 300 .

Macromitrium Drummondii Hpe, in Bot. Zeit. 1837, p. 280.

Orthotrichum crispum $\beta$ Wahlenb. $\mathrm{Fl}$. Lapp.

0. Drummondii Grev. Seot. Crypt. Fl. II, t. 115; Bryol. ewr. III (mon p. 12), t. 210; C. M. Syn. I, p. 712.

O. subrepens Sommerf. Suppl. Fl. Lapp. p. 191, t. 1, f. 2.

Ulotrichum bicolor Brid. op. cit. p. 792 .

U. Drummondii Conspect. Bryol eur.

Weissia Drammondii Lindb. M. Scand. p. 28

1. Ad trunc. Alnorum, Betul. et Sorb. aucupar. - Eur.: Zon. sept., rar. intermed.; Scandin., Scot,, Hibern., Westphal., Voges., Hercyn., Sudet., Riesengeb., Tatra; Transilv. ? Am. s"-pt. : Canada, Terr, nov., ins. Miquelon.

Exs.: Rab. Bryoth. eur, n. 881 .

dura C. M. in Dusen M. Camer, n. 351.

- Afr. : M. Cameroon.

Eckloni (Hsch.) Par.

Orthotrichum Eekloni Hsch, in Linn. 1841, p. 129; C. M. Syn, I, p. 715.

1 ? Rupic. - Afr. : C. B. Sp.

eremitensis (false Hermitei) Mitt, in Journ, of the Linn. Soc. 1859, p. 75.

Orthotrichum eremitensis ej. . austr. am. p. 189.

O. Iuteolum $H$. f. et $W$. Crypt. antaret. p.p.

1. - Am. merid. : Fuegia, ins. Eremitae, cap. Horn.

fuegiana Mitt. in Journ of the Linn. Soc. 1859, p. 76.

Orthotrichum coarctatum $H$. et Grev.?

O. fuegianum Mitt. M. austr. am. p. 192.

o. luteolum H. f. et W. Crypt. antarcl. (quoad ic, calyptrae).

O. marginatum Ángstr. in Oefo.... 1872,n. 4, p. 4.

U. marginata Jaeg. Ad. $1 I, p .691$. 
fulva Brid. Bryol. univ. 1, p. 3ul; C. M. Syn. I, p. 718.

Orthotrichum crispum var. Brid. Sp. M. II, p. 5.

Schlotheimia fulva Angstr. in Oefv... 1873, n. 5, p. 141.

1. Cortic. - Afr. : Madagase. sept., ins. Borbon., Franciae.

fulvella Mitt. in Journ. of the Linn. Soc. 1859, p. 75.

Orthotrichum fulvellum ej. M. austr. am. p. 191.

o. luteolum $H$. f. et W. Ciypt. antaret. p.p.

1 .

- Am. merid. : Fuegia, ins. Eremitae.

Germanae (Mont.) Jaeg. Ad. 1, p. 441.

Orthotrichum Germanae Mont. in Ann. sc. nat. 1845, p. $121 ;$ C. M. Syn. I, p. 715 et $I I, p, 641$.

0. luteolum $H$. f. et W. Fl. Antarct. II, p. 403, t. 152, f. 2 (p.p.).

1. Cortic. $-A m$. merid. : Chile, ins. Eremit.

Exs. : Lechler. Pl. Chil, n. 527.

glabella Mitt. in Journ. of the Linn. Soc. 1859, p. 75.

Orthotrichum glabellum ej. M. austr. am. p. 189.

O. Iuteolum var. $H$. $f$. et $W$. Crypt. antarct.

1.

- Am. merid. : Fuegia, ins. Eremit., cap. Horn.

gymnomitria C. M. in Hedwig. 1897, p. 104.

1. $\quad-$ Am. merid.: Patagonia.

Hermilei Mitt. - U. eremitensis.

Hutchinsiae (Sm.) W. P. Sch. Coroll. p. 41 et Syn. II ed. p. 306.

Orthotrichum americanum P. B. Prodr. p. 80; Brid. Bryol. univ. I, pp. 278 et 720.

O. anomalum $\beta$ americanum Brid. Sp. M. II, p. 10.

O. Hutchinsiae Sm. Engl. Bot. t. 2532; Frid. op. cit. pp. 277 et 720 ; Bryol. eut. III (mon. p. 20), t. 226; C. M. Syn. I, p. 692.

O. nigritum Bryol. eur. III (mon. p. II), t. 225 ; C. M. Syn. I, p. 692.

0. strictum Brid. Bryol. univ. p. 289.

U. americana Limpr, Laubm. Deutschl. II, p. 21.

U. americana $\beta$ nigrita ej. op, et $l$. ce.

U. nigricans ej. op. cit. $p .792$.

U. nigrita $W, P$. Sch. Coroll, p. 41.

Ulotrichum Hutchinsiae Comp. Bryol. eur.

Weissia americana Lindb. M. Scand. p. 28.

1. Ad rup. et sax, silic. praepr. granit. - Eur.: Reg. montan, zon. interm. et sept. Am. sept. : Canada, Idaho, reg. sept, et or.

Exs. : Drumm. M. bor. am. I ed. n. 117 et II ed. n. 83 (Orthotrichum).

Mac. Canad. M. n. 117.

Rab. Brynth. eur. n, 278, 879, 1007.

Sull. et Lesq. M. bor, am. II ed, n. 188.

"var. rufescens ( $D^{\text {nin }}$ E. G. Britton) Par.

Weissia americana var, rufescens Dna E. G. Br, in Bull. Torr. bot. Club, 1894, p. 69.

Ad Piceas marianam et rubram. - Am. sept. : M. Adirondack, lac. Super.

incana (C. M.) Par.

Orthotrichum incanum C. $M$. in Fl. 1885, p. 419.

1. Cortic. et lignic. - Am, merid. : Fret. Magellan., Fuegia. inclinata (C. M.) Par.

Orthotrichum inclinatum C. M. in op, et $l$. cc.

Lignic, - Am. merid. : Fuegia occ, 
intermedia W. P. Sch, Syn, 11 ed. p. 305.

Orthotrichum crispum Drumm. M. bor. am, n. 153 p.p.

O. intermedium Kindb. Eur. and N. Am. Bryin. p. 307.

U. americana Mitt.? (fid. Ren. et Card.).

U. crispa Mac. Canad, M.n. 113 p.p.

U. crispula $\beta$ ambigua $W . P . S c h$. Syn. I ed. p. 258.

Weissia nlophylla $\beta$ intermedia Braithe. Brit. Mossf. II, p. 93.

1. Ad Acer., Fagos, Fraxin. - Eur, : Scot., Hass, super., Oldenbourg, Rhoengeb., Tatra, Siles., Austr. inf., Salisb., Carinth., Tirol. Am. sept. : Terr, nov., ins. Miquelon, Ontario.

japonica (Sull. et Lesq.) Mill. in Trans. of the Limn, Soc. 1891, p. 162.

Orthotrichum japonicum Sulliv. et Lesq. in Roger's N. Pac. Expl. Exped. - As. : Japon.

? lateralis Jaeg. - Orthotrichum.

leiothecia (C. M.) Jaeg. Ad. I, p. 439.

Orthotrichum Andersonii Angstr. in Oef... 1872, n. 4, p. 5.

O. leiothecium C. M. in Bot. Zeit. 1862, p. 350.

U. Anderssonii Jaeg. Ad. II, p. 691.

1. Cortic. - Am. merid. : Fret. Magell.

Lobbiana Mitt. in Journ. of the Linn. Soc. 1859, p. 75.

Orthotrichum Lobbianum ej. M. austr. am. p. 192.

1 ?

- Am. merid. : Ins. Chiloë, Patag.

Ludwigii (Schwaegr.) Brid. Bryol. univ. 1, pp. 302 et 794; W. P. Sch. Coroll. p. 41 et Syn. II ed. p. 30I.

Orthotrichum clausum Hsch, in sched.; C. M. Syn. I, p. 714.

0. coaretatum P. B. Prods. p. 80; Brid. Brynl. univ. I. p. 713 (1.

0. Ludwigii Sehwaegr. Sreppl. I, II, p. 24, t. 51; Bryol. eur. III (mon. p. 12), t. 225 ; C. M. Syn. I, p. 714.

0. plicatum Ludus. in sched.

O. striatum ej. in Krypt. Geveaechs. n. 120.

Ulotrichum Ludwigii Bryol. ene. Consp. III.

Weissia coarctatia Lindb. M. Scand. p. 28.

1. Ad arb, silvat. praepr. junior. - Eur. : Fere tota ; rariss. in Britann. Am. sept.: Terr. Nov, Anticosti, Nov. Scot., New Brunswick, Gaspes., Ontario, reg. sept. or.

Exs. : Drumm. M. bor. am. I ed. n. 146 (Orthotrichum).

Mac. Canad. M. n. 112.

Rab. Bryoth. eur. n. 519.

Sull, et Lesq. M. bor. am. 11 ed. n, 189.

lutea Mitt. in Journ. of the Linn. Soc. 1859, p. 77.

Orthotrichum erispum var. H. f. et W. Fl. Tasm, I, p. 184 (fid, Mitt).

0. croceum Hpe, in F, v. Müller's Fragm. Pliyt, Austral. XI, Suppl. p. 48 .

O. luteum H. f. et W. op. et l. cc. et Handb. of the N. Zial. Fl. p. 433.

1 . -Pac. : Nov. Zeland., Tasman.

macrocalycioa Mitt. in op. cit. p. 75.

Orthotrichum macrocalycinum ej. M. arestr. am. p. 190.

1. Cortic. - Am. merid, ; Fret. Magellan, Fuegia, Port Famine.

Mundoni Jaeg. - Orthotrichum. 
magellanica (Mont.) Jaeg. Ad. I, p. 442.

Orthotrichuin magellanicum Mont, in Voy, au Póle S., Crypt.t. 20, f. 2; C. M. Syn. I, p. 716 .

Cortic. - Am. merid. : Fret. Magellan.

marchica Warnst. - U. Bruchii var. marchica.

marginata Jaeg. - U. fuegiana.

maritima C. M. et Kindb. Bidr. p. 455 (nom.) et in Mac. Catol. p. 84.

Orthotrichum maritimum eor, in Kindb. Eur, and N. Am. Bryin. p. 308.

U. phyllantha Mitt. in Journ. of the Linn. Soc. VIII, p. 26; Mac. Canad. M. n. 116 p.p.

Ster. Rupic. - Am. sept.: Ins. Miquelon, Columb. brit., Vancouver, Alaska, M. Behring.

megalospora Vent, in Bot. Centralbl. 1890, n. 5 ,

Orthotrichum megalosporum C. M. et Kindb. in op. cit. p. 305.

Ulota subulifolia eor. in Mac. Cat.

Syn.

- Am. sept. : Washington.

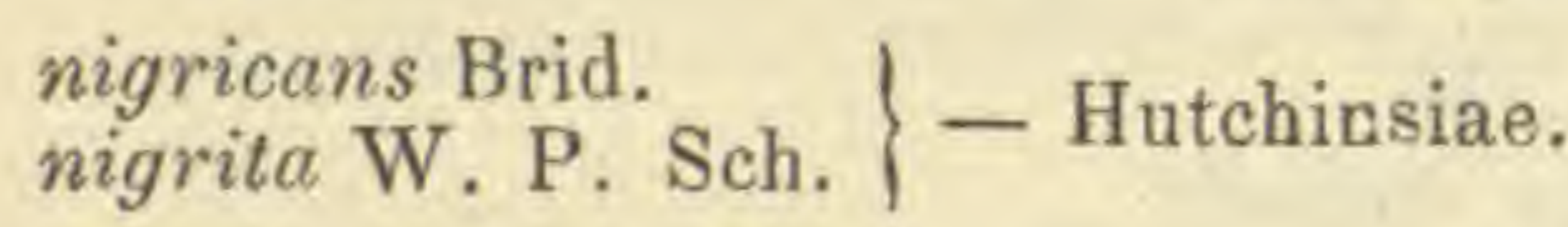

nipponensis Besch. in Ann. sc. nat. 1893, p. 339.

1. - As: Japon.

Exs. : Faurie Pl. Jap. n. 11 b, 554.

obtusiuscula C. M. et Kindb. Bidr. p. 455 (nom.) et in Mac. Cat. p. 82.

Orthotrichum obtusiusculum eor. in op. cit. p, 307.

U. Bruchii Mac. Canad. M. n. 453 p.p.

1. Cortic. - Am, sept. : Columb, brit., Vancouver.

Exs, : Mac. Canad, M. n. 523.

palmicola C. M. mss.

- Am. merid. : Brasil. austr. or. (ins. S. Catarina).

phyllantha Brid. Mant. M. p. 113; W. P. Sch. Coroll. p. 41 et Syn. 11 ed. $p .306$.

Orthotrichum crispum $H$. f. et $W$. in sched. $M$. antarct.

O. fasciculare La Pyl. in Brid. Bryol, univ. I, p. 790.

0. jutlandicum Brid. op. cit. p. $296 ;$ C. M. Syn. I, p. 717.

o. phyllanthum Steud. Nom. crypt. p. $304 ;$ Bryol. eur. III (mon. p. 30), t. 223.

Ulotrichum phyllanthum Bryol. eur. Consp.

Weissia phyllantha Lindb. M. Scand. p. 28.

2. Rariss. fructif. Ad arb., praepr. Quercuum et Salic., rar, rupic. Eur. : Littus mar. German,, Anglia, Hibern. (c. fr. l), Gall. sept. Am. sept. : Ins. Miquelon, Nov. Scot., Terr. nov., Vancouver, Oregon (c. fr.!). Am. merid.: Fret. Magellan., ins. Eremitae, etc.

Exs. : Mae. Canad. M. n. 116 p.p.

Rab. Bryoth, eur. n. 570 et b, 949.

pleyllantha Mac. p.p. - U. maritima.

phyllanthoides (C. M.) Par.

Orthotrichum phyllantoides C. M. in Engler's Bot. Jahrb. 1883, p. 80 et in Forschungsreise.... p. 25.

Ster. Rupic. ? - Afr. : Ins. Kerguelen.

pilifera Nees. - Macromitrium. 
plicata Brid. Bryol. univ, I, p. 726 (excl. syn. Hook; C. M. Syn. I, p. 764) (1).

Ster. - Am. sept. : Terr. nov.

plicata Brid. I, p. 303. - Orthotrichum.

pygmaeothecia (C.M.) Par.

Orthotrichum pygmaeothecium C. M. in Fl. 1885, p. 418.

1. Cortic. - Am. merid. : Fuegia.

Rehmanni Jur, in Verh. d. zool.-bot. Ges. in Wien, 1864, p. 191.

Orthotrichum Rehmanni Kindb. Eur. and N. Am. Bryin. p. 307.

1. Cortic. in subalp. - Eur. : Tatra, Salisb., Stir. As.: Caucas, occ. reptans Mitt. in Trans. of the Linn. Soc. 1891, p, 161.

1. Cortic. - As.: Japon.

robusta Mitt. M. Ind. or. p. 49.

Orthotrichum robustum Wils, in Kew Journ. bot, IX. p. 327. 1. - As. : Sikkim.

rufescens (Hpe.) Jaeg. Ad. I, p. 441.

Orthotrichum rufescens Hpe. in Ann. sc, nat, V ser, IV, p. 334.

Ster. Cortic. - Am. merid, : And. Nov. Granat.

rufula (Mitt.) Jaeg. op. cit. p. 442.

Orthotrichum rufulum Mitt. M. austr, am. p. 191.

- Am. merid.: Valdivia.

Savatieri Besch. in Bull. Soc, bot. Fr. 1885, p. LXII et in Miss. sc. Cap

Horn, V, Bot. p. 275, t. 3, f. 10.

1. - Am. merid. : Patagon. austr.

scabrida Kindb. in Bidr, p. 453 (nom.) et in Mac. Cat. p. 83.

Orthotrichum scabridum ej. Eur. and N, A m. Bryin. p. 306.

U. americana Mac. Canad. M. n. 115.

$$
\text { - Am. sept. : M. Rupestr. }
$$

Schmidii (C. M.) Jaeg. Ad. $1, p .437$.

Orthotrichum Schmidii C. M. in Bot. Zeit. 1853, p. 60.

1. - As. : M. Neilgherr.

subulata Kindb. in Bidr. p. 455 (nom.) et in Mac. Cat. p. 82.

Orthotrichum subulatum C. M. et Kindb. in op, et $l$. oc,

Cortic. - Ain. sept. : Columb. brit.

subulifolia C. M. et Kindb. - U. megalospora.

viridis Vent. in Oefv.... 1893, $p$.

Soc. of Tasman. $1893, p .202$,

et in Pap. and Proced, of the roy.

1. Cortic. - Pac. : Tasman.

vittala Mitt. - U. calvescens.

Weymouthi Burch. in Pap. and. Proced. of the roy. Soc. of Tasman. 1893, p. 200 (nom.).

Cortic. - Pac. : Nov, Zeland.

ULOTRICHUM W. P. Sch. Conspect. Bryol. eur.

Spec. omn. sunt Ulotas ejusd. nom. 
Ulozygodon C. $M$. op. cit. p. 680 (sect. ZYGodontis).

Umbracularia C. M. Syn. 1, p. 146 (sect. Splichni).

UROCLADION Hpe. mss.; Jaeg. Ad. II, p. 729. marginalum Hpe. - Sciaromium.

Urolepidopilum C. $M$. in $F l .1875, n . .34-35$ (sect. LePIDOPILI).

Vaginella C. $M$. Syn. I, p. 492 (sect. Bartramiat).

Vallidens C. $M$. in Linn. $1880-83, p .432$ (sect. Barbulae.).

Velutinaria Kindb. Check-List. p. 73 (nom., sect. Brachythegir sensu Kindb.).

VENTURIELLA C. M. in Linn, 1875, p. 421 (1 spec.).

sinensis (Vent.) C. M. in op. et l. cc.

Erpodium sinense Vent. in Rab. Bryoth. eur, n, 1211.

I ? Ad Popul. - As. : Shang Haï.

Vesicularia C. M. Syn. $I I, p .233$ (subsect. HvpNi = Eстropotнксüм).

sandroichensis C. M. - Eetropothecium Didrichseni.

VOITIA Hsch. Comment de Voitia et Systylio, p 5, t. 1 (I spec.).

Hookeri Mitt. - V. nivalis var. stenocarpa.

hyperborea Grev, et Arn. - V. nivalis var. hyperborea.

nivalis Hsch. l. c. ; Brid. Bryol. univ. I, p. 54 ; Bryol. eur. I, t. 7 ; C. M.

Syn. I, p. 35 et II, p. 522; W. P. Sch. Syn. II ed.p. 21.

1. In stercore vaccino et ad aren. micac. ab aq. nival. irror. - Eur.: Alp. Carinth., Tirol.

Exs. : Rab. Bryoth, eur. n. $36 \pi$.

" var. hyperborea (Grev. et Arn.) W. P. Sch. op. cil.p. 22.

V. hyperborea Grev, et Arn. in Act. Soc. Wern. IV,p. 109,t. 7; Brid. op. cit. $p .55 ; C . M$. op. et $l$. ec.

Groenland, ins. Melville.

- Eur. : Spitzberg. As. : Fret. Sinjawin. Am. sept. :

"var. stenocarpa (Wils.) Par.

V. Hookeri Mitt. M. Ind. or. p. 56.

V. stenocarpa Wils. in Kew Journ. bot. IX. p. 329.

\section{- As. : Sikkim.}

slenocarpa Wils. - V. nivalis var. stenocarpa.

vogesiaca Hsch. - Bruchia.

WARDIA Harr. in Hook. Consp. of the bot. mag. II, p. I83, t. 15 (1 spec.). hygrometrica Harv. in op. et l. cc. ; Card. Mon. p. 129.

Neckera hygrometrica C. M. Syn. II, p. 667.

2. Ad rup. irror. - Afr. : C. B. Sp.

Exs. : Rehm. M. Af. austr. p. 302.

WEBERA Hedw. Hist. M. p. 95 (139 spec.).

acuminata (H. et H.) W. P. Scll. Coroll. p. 64 el Syn. II ed. p. 391.

Bryum acuminatum Bryol. eur. IV (mon. p. 21), t. 343; C. M. Syn. I, p. 326.

Pohlia acuminata H. et H. in Fl. 1819,II, p.94 et in Brid. Bryol. unio. I, p. 610 .

P. elongata $\gamma$ acuminata Hüb. Muscol. gem. p. 473.

W. elongata $\beta$ acuminata Sehwaegr. Sp. M. p. 49. 
1. In decliv, et fiss. rup. - Eur.: Reg. subalp. : deest in Rritann. et Scandin. As. : Caucas, centr. Am. sept.: New Brunswick, M. Adirondack et Rupestr., Wisconssin, Colorado, reg. sept. et or.

Exs. : Mac. Canad. M. n. 521.

Sull, et Lesq. M. bor. am. n. 264.

« var. $\operatorname{arcuata}(H$. et H.) W. P. Sch. op. et l. cc.

Bryum acuminatum var. arcuatum Bryol. eur. l. c., t. 344.

Pohlia arcuata $H$, et $H$. in op. eit. p. 98 ; Brid. op. cit. p. 614.

P. patens H. et H. et Brid. op. cit. pp. 101 et 620 p.p.

P. vegeta eor. op. et ll. cc. p.p.

Ut typ. - Eur. : In pascuis alp. usq. in reg. supraalp.

var. minor (Schleich.) W. P. Sch. op. et l. cc.

Bryum acuminatum $\beta$ minus Bryol. eur. l. c. $t .343$.

Br. polymorphum C. M. Syn. I, p. 329 p.p.

Pohlia minor Schleich. Cent. pl. helv. $I V, n .19 ;{ }^{\top} H$, et $H$. op. et l. cc. ; Brid. op. cit. p. 611 p.p.

W. elongata $\beta$ minor Schwaegr. Sp. M p. 49.

Ut et ubi praeced.

* var. polyseta (H. et H.) W. P. Sch. op. et l. cc.

Bryum acuminatum $\gamma$ polysetum Bryol. eur. l. c. t. 314.

Br. polymorphum C. $M$. op. et l. cc. p.p.

Pohlia brachycarpa var. polyseta Schwaegr. Sp. M. p. 72.

$\left.\begin{array}{l}\text { P. gracilis } \gamma \text { pulchella } \\ \text { P. gracilis } \beta \text { xanthocarpa }\end{array}\right\}$ Hüb. Muscol. germ. p. 472.

P. polymorpha $\gamma$ polyseta ej. op. cit. $p .470$.

P. polyseta

$\left.\begin{array}{l}\text { P. pulchella } \\ \text { P. xanthocarpa }\end{array}\right\}$ H. et H. op. cit.pp. 97 et $99 ;$ Brid. op. cit.pp. 613 et 617.

Ut et ubi praeced.

« var. tenella (H. et H.) W. P. Sch. op. et l. cc.

Bryum acuminatum $\delta$ tenellum Bryol. eur. $l l$. cc.

Pohlia polymorpha $\delta$ tenella Hüb. op. cit. p. 470.

P. tenella $H$. et $H$. op. cit. p. $95 ;$ Brid. op. eit. p. 614.

Ut et ubi praeced.

acuminatula (C. M.) Par.

Bryum acuminatulum $C$. $M$. in sched.

- As. : Himalaya sept. occid.

affinis Br. - Bryum cuspidatum.

afıo-cruda (C.M.) Par.

Ster.

- Afr. : Kilima N'Djaro.

aggregata (C.M.) Par.

Bryum aggregatum C. M. in Bull, hb. Roissier, 1897, p. 181.

- Am. sept. : Guatemala.

alba (Lindb. et Arn.) Par.

Pohlia alba $L$. et A. M. As. bor, 1890, II, p. 53.

2. Terr. - As. : Jenissei med.

Alberti Corbiére in Rev. bryol. 1889, p. 33.

2. Muric. - Eur. : Galloprovine. 
albicans (Wahlenb.) W. P. Sch. Coroll. p. 64 et Syn. II ed. p. 407.

Bryum albicans Brid. Bryol. univ. I. p. 656 ; C. M. Syn, I, p. 295.

Bryum carneum Drumm. M. bor. am. I ed. n. 260.

Br. Wahlenbergii Schwaegr. Suppl. I, II, p. 92, t. 70; Bryol. eur. IV (mon. p. 44), t. 354 .

Hypnum Wahlenbergii $W$. at M. Bot. Taschb. p. 280.

Lamprophyllum albicans Lindb, in Oefv... 1867, p. 75 .

Mniobryum albicans Limpr. Laubm. Deutschl. II, p, 277.

Mnium albicans Wahlenb. Fl. Lapp. p. 353.

Pohlia albicans Lindb. M. Scand. p. 17.

2. Ad terr. glareos. ster. aqua imbib, et rup. madid, - Eur. : E reg. campestr, usq. in subalp. As. : Penins. Samojed., Jenissei, Caucas. occ. et centr. Afr. : Alger., ins. Kerguelen. Am. sept. : Groenland, Labrador, Terr, nov., Nov. Scot., New Brunswick, Gaspes., Ontario, M. Rupestr. et Selkirk, Columb. brit,, reg. sept., centr., or. et merid. Am. merid. : And. Nov. Granat. et Boliv., M. Pichincha, Chile, ins. Falkland. Pac. : Nov. Zeland, Austral, or., ins. Falkland. Stewart,

Exs. : Mac. Canad. M. n. 165.

Rab. Bryoth. eur. n. 361, 1002.

Sull, et Lesq. M. bor. am. II ed, n. 274.

"var. glacialis (Schleich.) W. P. Sch, op, et l. oc.

Bryum albicans $\beta$ glaciale $C$. $M$. op. et $l$. oo.

Br. glaciale Schleich. in Brid. op. cit. p. 852.

Br. Schleicheri Schwaegr. Sp. M. p. 55.

Br. Wahlenbergii $\beta$ glaciale Hüb. Muscol. germ. p. 456 ; Bryol. pur. l. c. p. 45 .

Mnium glaciale Schleich. Cent. pl. helv. III, n. 51.

Pohlia albicans var. glacialis Lindb. M. Scand. p. 17.

Ad font. et in uligin, frigid. - Eur. : Reg. alp. ; ins. Ursorum. As. :

Himalaya, Tibet. occ., Cancas, centr. Am. sept : Groenland.

Eas. : Un. itin. 1863, n, 48.

"var. nigricans Lesq. et Jam. Man. p. 223.

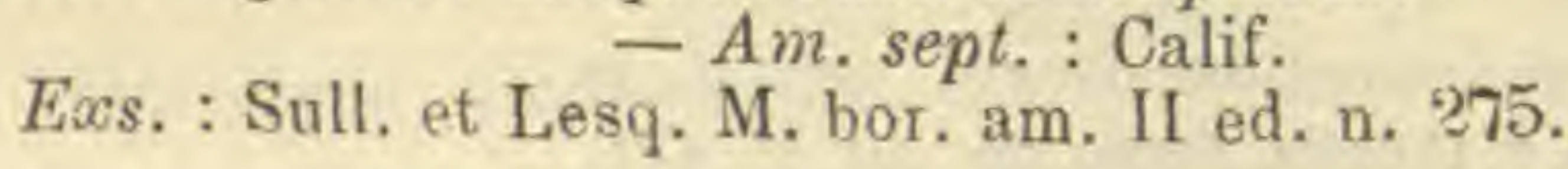

"var. speciosa Mitt. M. Ind. or, p. 66. - As. : Tibet. occ.

"var. urceolata Ren. et Card. M. Am. sept.p. 35.

$$
\text { - Am. sept. : Oregon. }
$$

alpina Hsch., Moug. et Nestl. - W, longicolla.

alticaulis (C.M.) Par.

Bryum alticaule C. M. in Engler's Bot. Jahrb. 1883, p. 83 et in For'schungsreise.... p. 37.

Ster. In turfac. - Am, merid. : Fuegia.

* var. robestior (C. M.) Par.

Bryum alticaulis var, robustior C. M. in op, et l. $e c$.

Ut et ubi typ.

ambigua Limpr, Laubm. Deutschl. II, p. 237.

1. - Eur.: Alp. Salis5, (Lungau).

ampliretis (C. M.) Par.

Bryum amplirete C. M. Bi.yol, austr. Georg.p.

Ster.

- Am, merid.: Austr. Georgia. 
annotina (Hedw.) Schwaegr. Sp. M. p.52; W. P. Sch. Syn. II ed.p. 400. Bryum annotinum Huds, Fl. Angl. I ed. p. 414? Hedw. Sp. M. p. 184, t. 43 ; Brid. Bryol. univ. I, p. 662; Bryol. eun. IV (mon. p. 40), t. $352 ;$ C. M. Syn. 1, p. 331.

Br. annotinum lanceolatum pellucidum capsulis oblongis pendulis Dill. Hist. M. p. 339, t. $50, f .68$.

Br, decipiens Lam. et DC. Syn. Fl. gall. n, 1301 ; Brid. op. cit. p. 687? Hypnum annotinum $\boldsymbol{W}$. et $\boldsymbol{M}$. Bot. Tasehb.p. 280.

Lamprophyllum annotinum Lindb. in Oefv .... 1867, p. 75.

Mnium annotinum L. Sp. pl. p. 1576 (vix ! fid. W. P. Sch.).

Pohlia annotina Lindb, M. Scand, $p, 17$.

Trentepohlia erecta Roth, in Uster. Ann, bot. X, p. 52.

2. In arvis arenos. humid. - Eur. : Reg. campestr. ab Ital. usq. in Lappon.; Spitzberg, ins. Parry. As.: Penins. Samojed., Obi, Jenissei. Afr.: Alger. Am. sept.: Groenland, ins. Sabine, Nov. Scotia, Gaspes., Ontario, Manitoba, Athabasca, Assiniboine, M. Selkirk, ins. Vancouver, Washington, Nov. Angl., Kansas.

Exs. : Mac. Canad. M. n. 162.

Rab. Bryoth, eur. n. 86, 968.

Sull, et Lesq. M. bor. am. II ed, n. 271.

"var, angustifolia W. P. Sch. op. cit. p. 401.

In paludosis. - Eur. : Anglia.

" var. decurrens Ren. et Card. in Bull. Soc. roy. bot. Belg. 1893, 1, p. 116 et M. Masc. Mad. n. 30.

Ad terr. silic.-argill. humid, - Afr. : Madagascar.

\&var, filiformis W. P. Sch. op. et $l$. cc.

$$
\text { - Eur. : Lappon. }
$$

« var. lapponica W. P. Sch, op. el $l, c c$.

- Eur. : Lappon.

"var. tentifolia W. P. Sch. op, et \%. cc.

Hic, illic cum typ. in Eur.

antaretica (Hook. f. et Wils.) Jaeg. Ad. I, p. 599.

Bryum antarcticum H. f. W. Fl. antarot. $I I, p .414, t .153, f .6 ; C . M$. Syn. $I I, p .572$.

$$
\text { - Am. merid.; Ins. Cockburn. }
$$

aptychoides (C.M.) Par.

Bryum aptychoides C. M. in Engler's Bot. Jahrb. 1883, p. 78 et in Forschungsreise.... p. 17.

Ster.

$$
-A \text { fr. : Ins. Kerguelen. }
$$

austro-albicans (C. M.) Par.

Bryum albicans Mitt. in Journ. of the Linn. Soc, 1876 (fid. C. M.).

Br. austro-albicans C. M. in Engler's Bot. Jahrb. 1883, p. 78 et in Forschungsreise.... p. 15.

Ster.

$$
\text { - Afr. : Ins. Kerguelen. }
$$

austro-cruda (C. M.) Par.

Bryum austro-crudum C. M. in op. ce, pp. 78 et 16.

Br, erudum Mitt, in op. et l. c. (fid. C. M.).

2. Fr. ign. - Afr. : Ins. Kerguelen.

austro-elongata (C.M.) Par.

Bryum austro-elongatum $C . M$. in op, et $l l$. ce.

Br. elongatum Mitl. in op. et l. ce, (fid. C. M.).

Syn. Rupic. - Afr. : Ins. Kerguelen. 
austro-nutans C. $M$, in Rehm. M. Afr. austr. n. 221 et 551.

- Afr. : Transvaal, C. B. Sp.

austro-polymorpha C. M. in Engler's Bot. Jalurb. L883, p. 78 et in Forschungsreise... p. 16.

Syn.

- Afr. : Ins. Kerguelen.

bicolor $\mathrm{H}$, et $\mathrm{H}$. - W. nutans var, bicolor.

Bigelowi (Sull.) Lesq. et Jam. Man. p. 223.

Bryum Bigelowii Sull, in Pac, R. Rep. IV, p. 187, t. 5.

W. Ludwigii var, microphylla Kindb. in Mac. Cat. p. 117.

2. Rupic.? - Am. sept. : Sonora.

Bolanderi (Lesq.) Lesq. el Jam. Man. p. 220.

Bryum Bolanderi Lesq. in Mem. Calif. Acad. I, p. 22.

2.

- Am. sept. : Calif.

brachydontia (Hpe.) Jaeg. Ad. I, p. 592.

Bryum brachydontium Hpe. in C. M. Syn. I, p. 327.

W. Hampeana Bryol. jav. I, p. 137, t. 175.

1 (Bryol. jav.); 2 (C. M.) Saxic. - As. : Java.

brachymeniacea $C$. M. in Rehm. M. Afr. austr. n. 224 et 553.

- Afr. : C. B. Sp.

Breidleri Jur. - W. Ludwigii.

brevicollu Sande Lac. - W. scabridens.

brevinervis (Arn, et Lindb.) Par.

Pohlia brevinervis A. et L. M. As, bor. 1890, II, p. 51.

2. Terr. - As. : Jenissei med.

Brideliana (C. M.) Jaeg. Ad. I, p. 600.

Bryum Bridelianum C. M. Syn. I, p. 341.

Br. W. flexuosa Brid. Bryol. univ. $I$, p. 813 .

Paludic. - Am. sept. : Terr, nov. (1).

caespitosa $\mathrm{H}$. et $\mathrm{H}$. - W. nutans var. caespitosa.

? calopyxis (C. M.) Par.

Bryum calopyxis C. M. in Linn. $1880-83$, p. 377 .

Syn. - Am. merid. : Argentin, subtropic.

camptotrachela Ren. et Card. in Bot. Gaz. 1888, p. 199, t. I6.

Bryum camptotrachelum Kindb. Eur. and N. Am. Bryin., p. 385 (ut subsp. W. nutantis).

2.

- Am. sept. : Calif.

canaliculata C. M. et Kindb. in Mac. Cat. p. 113.

Bryum canaliculatum Kindb. op. et $l$. cc. (ut. subsp. W. nutantis).

W. albicans var. deffexa Kindb. in Bull. Torr. bot. Club, XVII.

W. nutans var. deflexa Kindb. in sched.

1 ? Rupic. - Am. sept. : Columb, brit., Vancouver.

Cardoti Ren. in Bol. Gaz. 1889, p. 95, t. XIII, B.

Bryum Cardoti Kind. op. cit. p. 388 (ut subsp. W. commutatre). 2.

- Am. sept. : Oregon.

carinata Limpr. - W. cucullata var. carinata. 
carnea W. P. Sch. Coroll. p. 67 et Syn. II ed. p. 405.

Bryum carneum L. Sp. pl. 1587; Brid. Bryol. univ. I, p. 652 ; Bryol, eur. IV (mon. p. 43), t. 253; C. M. Syn. I, p. 294.

Br. coarctatum Schultz Ephem. bot. Reg. Syll. pl. II, p. 91.

Br. compactum Dicks. Fase. IV pl. crypt. IV, p. 15, t. II, f. 11 ; Brid. op. cit. p. 686.

Br. delicatulum Hedw. M. frond. 1, p. 52, t. 20.

$\mathrm{Br}$. lanceolatum pellucidum. capsulis subrotundis, pedunculis carneis Dill. Hist. $M, p .400, t .50, f .69,-A-F$ et var, foliis, surculis et setis longioribus op. cit. p. 401.

Br. melanodon Brid. op. cit. p. 845

Br. pallidisetum ej. Mant. M. p. 117.

Br. rubellum ej. Bryol, univ. I, p. 650.

Hypnum carneum W. et M. Bot. Taschb. p. 278.

Lamprophyllum carneum Lindb. in Oefv.... 1867.

Mniobryum carneum Limpr. Laubm. Deutschl. II, p. 275.

Mnium carneum L. jun. Meth. M. ap. Ludw. p. 366.

Mn. rubellum $P$. B. Prodr. p. 76.

Pohlia carnea Lindb. M. Scand. p. I7.

2. In agr. argill. et pasc. humid. - Eur. : Fere tota, supra reg. campestr. non ascend. As. : Caucas, occ, et or. A fr. : Alger., Egypt. infer. $A m$. sept. : Nov. Scot., Columb, brit., Illinois.

Exs. : Mac. Canad. M. n. 163 p.p.

Rab. Bryoth. eur. n. 236, 441.

Sull. et Lesq. M. bor. am. II ed. n. 441.

carnea Rab. n. 1021. - W. pulchella.

clandestina Hedw. - Bartramia Halleriana.

clayaeformis (Hpe.) Jaeg. Ad. I, p. 591.

Bryum clavaeforme Hpe. in Linn. 1869-70, p. 519.

Br. nutans $H$. f. et W. Fl. of. the N. Zeal.?

Syn.

- Pac: Austral. fel.

columbica Kindb. Bidr. p. 453 (nom.) et in Mac. Cat. p. 115.

Bryum columhicum Kindb. Eur. and N. Am. Bryin. p. 386.

Bryum carneun var. pulchellum Drumm. M. bor. am. I ed. n. 261 p.p.

W. pulchella Mac. Canad. M.n. 164.

2. Ad terr. humid. -- Am. sept. : Athabasca, M. Selkirk, Columb. brit. commutata W. P. Sch. Syn. 11 ed. p. 403.

Bryum commutatum Wats. Bot. Calif. II, p. 391 ; Boulay M. Fr. 1 , p. 278 (excl. var. $\beta$ ).

Br. Ludwigii Brid. Bryol. univ. I, p. 647? Bryol. ext. IV (mon. p. 38), t. 354:C. M. Syn. I, p. 332.

Pohlia commutata Lindb. M. Scand, p. 17.

W. Ludwigii W. P. Soh. Coroll. p. 67; Rab. Bryoth, eur, n. 1215; Sull. et Lesq. M. bor. am. II ed, $n, 270$.

2. Ad terr, humid, et in nligin. - Eur.: Reg. subalp. et alp. As.: Caucas. Am. sept.: Gaspes, M. Selkirk, Wașhington, Oregon, Calif.

Exs, : Mac. Canad, M. n. 423.

var, elongata Payot.

var. $\beta$ filum IIusn.

"var. gracilis (Schleich.) W. P. Sch. op. cit.p. 404.

Bryum commutatum var. gracile Boulay M. Fr. I, p. 279.

Br. gracile Sohleich, in Neu bot. Zeit. VI, p. 57 ; Brid. op. cit. p. 688.

Br. Ludwigii $\beta$ gracile Bryol eur. l. c. p. 39 ; C. M. Syn. I, p. 333 et II, p. 583

Pohlia gracilis Lindb, M. Scand, p. 17. 
W. gracilis de Not. Epil. p. 418.

W. Ludwigii $\beta$ gracilis W. P. Sch. Coroll. et $l$. $o$.

In terr, aren. et turfos. humid. - Eur. : Summ. Alp., e reg. interm. moy. in septentr.; Pyren. As. : Jenissei infer.,Caucas. Am. sepl. : Oregon.

Exs. : Rab. Bryoth. eur. n. 237, 1286.

Un. itin. 1864, n. $56,66$.

compactilis (C.M.) Par.

Bryum compactile C. M. in hb. Scharampur, n. 6334.

- As, : Himalaya sept. occid.

contracta (C. M.) Par.

Bryum contractum $C$. $M$. $m s s$.

- As. : Himalaya sept. occid.

crassidens (Lindb.) Kindb. Enum. Bryin. p. 22.

Bryum crassidens Kindb. Eur. el N. Am. Bryin. p. 384.

Pohlia crassidens Lindb. in Rev. bryol. 1883, p. 5 .

W. trachydontea Sanio in Bot. Centralbl. 1883, n. 7.

2. Terr. et rupic. - Eur. : Lappon. torn., Norveg. (Dovre). crassinervis (Lindb.) Par.

Pohlia crassinervis Lindb. in Act. Soc, pro Faun. et Fl. Fenn. 2 a April 1881.

$\sigma$ et fr. ign.

- Eur.: Lappon, suec.

cruda (L.) Schwaegr. Sp. M. p. 50; W. P. Sch. Syn. II ed. p. 398.

Bryum crudum Schreb. Spic. Fl. Lips, p. 83; Bryol. "eur. IV (mon.p. 37), t. 348; C. M. Syn. I, p. 333.

Br. elongatum Drumm. M. bor. am. I ed, $n, 270$.

$\mathrm{Br}$. lucidum James $\mathrm{Pl}$. Kaneanae.

Br. pendulum hornum molle foliis et lanceolatis et gramineis Dill. Hist. $M$. p. 401, t. 51, f. 70 (fid. C. M.).

Br. stellare hornum, silvarum, capsulis magnis nutantibus Dill. op. cit. p. 402, t. 51,f. 71 (fid. Limpr.).

Br. Polla cruda Brid. Bryol. univ. I, p. 693.

Hypnum crudum $W$. el M. Bot. Taschb. p. 290.

Lamprophyllum crudum Lindb. Revis, critic. ic. p. 87.

Mnium crudum L. Sp. pl. p. 1576 ; Hedvo, M. frond. I, p. 99, t. 88,

Pohlia cruda Lindb. M. Scand. p. 57.

W. intermedia Schleich. Cent. pl. helv. IV, n. 18.

2. et syn., rar. 1. In fissur. rup. - Eur. : E reg. campestr. mont. usq. in supraalp.; Ross, or., Spitzberg, ins. Ursorum. As.: Japon., Amour., Talysch, Obi, Jenissei, Sikkim, Khasia, Kashmir, Caucas. Afr. : Alger., ins. Kerguelen. Am. sept.: Groenland, Labrador, fret. Sinith., Terr. nov., Nov. Scotia, New Brunswick, Gaspes., Ontar., lac. Super., Athabasca, Alaska, mar. Rehring, Columb. brit., Vancouver, M. Rupestr, et Selkirk, Washington, Oregon, Idaho, reg. sept. et or., Mexic., Guatemala. Am. merid.: Fret. Magell. Pac. : Nov. Zeland.

Exs. : Faurie Pl. Japon., n. 3533 p.p

Mac. Canad. M. n. 161 .

Rab. Bryoth. eur. n. 1024.

Sull. et Lesq. M. bor. am. II ed. n. 269.

Un. itin. 1864, n. $50,53,58,72 ; 1867$, n. 104.

* var. densa Thériot in Rev. bryol. 1898, p. 23.

- Eur. : Alp. Delphinat.

"var. minor W. P. Sch. Coroll. p, 65 el Syn. $I 1$ ed. p. 398.

Bryum crudum var. minus Bryol. eur. l. c.

Br. longicollum « dioícum "Sw. M. Suec, p. 49, t. $6, f, 13$ ? 
Bryum nitescens Kindb. in Bot. Notiz. 1896.

Br. W. nitens Kindb. in Bot. Not. 1882, p. 146.

Ut typ. - Eur. : Summ. Alp Am, sepı. : Groenland, Labrador.

var. minor Ren, et Card. - W. cruda var. oregonensis.

"var, oregonensis $P a$.

W. cruda var, minor Rén. et Card. in Bot. Gaz. 1890, p, 43.

- Am. sept. : Oregon.

" var. subglobosa W. P. Sch. op. el $l$. cc.

Terr. - Eur. : Norveg.

crudoides (Sull. et Lesq.) Par.

Bryum crudoides Sull. et Lesq. in Proced. of the Amer. Acad..., 1859, p. 278.

2.

- Am. sept, : Fret. Behring.

cueullata (Schroaegr.) W. P. Sch. Coroll, p. 86 el Syn. II ed. p. 397.

Bryum cucullatum Schwaegr. Suppl. I, II, p. 94, $t .68 ;$ Brid. Bryol. univ. I, p. 649; Siryol. eni: IV (mon. p. 27), t. 313; C. M. Syn 1, p. 328.

Br. obtusifolium Vill. Pl. Dauph. III, p. 882.

Lamprophyllum cucullatum Lindb. Revis. crit. ic. p. 87.

Pohlia cucullata Schwaegr. Sp. M. p. 73 : Brid. op. cit. p. 840.

P. laete-virens de Not. Mant. p. 7 et Syll. p. 111.

1. Ad terr. humid., praecip, in depress. nivos. - Eur.: Reg. subalp. et alp.: Spitzberg, ins. Ursorum; deest in Britann. As. : Penins. Tschutschica. Am. sept. : Groenland, Labrador. Columb. brit., Oregon, Calif., reg. or.

Excs. : Mac. Canad. M. n. 468 p.p.

Rab. Bryoth. eur. n. 442, 1216.

Sull. et Lesq. M. bor. am. II ed. n. 265.

* var. carinata (Brid.) Boulay in Rev. bryol, 1888, p. 44 et in Husn. Musc. gall. p. 229.

Bryum carinatum Brid. Bryol. univ. I, p. 649 (ut syn.); Boulay M. Fr. p. 280 et in Husn. M. Gall. n. 772.

Br. cymbuliforme Cardot in Rev. bryol. 1887, p. 22.

Br. naviculare ej. in op. cit. 1886, p. 27.

W. carinata Limpr. Lavbm. Deutschl. II, p. 261.

2. Ad terr. humid. sabulos. - Eur. : Alp. Sabaud. (M. Blanc), Pyren.

« var. Haussmanni de Not. Epil. p. 430.

- Eur. : Tirol. (Botzen).

cucullata Mac. exs. p.p. - W. polymorpha.

cucullatiformis (Kindb.) Par.

Bryum cucullatiforme Kindb. Eur, and N. Am. Bryin. p. 287.

1.

- Am $m_{+}$sept. : Alaska.

cylindrica (Mont.) W. P. Sch, in Besch. Prodr. bryol. mexic. p, 52.

Bryum cylindricum Mont. herb. (mus. Paris).

I. $\quad-A m$. sept. : Mexic.

delicatula (Wils.) Mitt. M. Ind. or. p. 66.

Bryum delicatulum Wils. in Kexo Journ. bot. IX, p. 332.

2? - As. : Sikkim, Khasia.

Demawendi (C, M). Par.

Bryum Demawendi $C . M$. in sohed.

- As, : Persia (M. Demawand). 
Diphyscium Ehrh. - Diphyscium foliosum.

Drummondii (C. M.) Lesq. et Jam. Man. p. 219.

Bryum carneum var. pulchellum Drumm. M. bor. am. I ed. n. 261 p.p.

Br. Drummondii C. M. in Bot. Zeit. XX, p. 328.

Br. nutans var. minor Drumm. l. c. n. 263.

Mniobryum vexans (fid, Kindb.).

2. Ad terr. humid. - Am. sept. : M. Rupestr., Sitka.

Eckloniana (C. M.) Jaeg. Ad. 1, p. 600.

Bryum Ecklonianum C. $M$, in Bot. Zeit. 1855, p. 752.

Syn. Rupic. - Afr. : C., B. Sp.

elongata (Dicks.) Schwaegr. Sp. M. p. 48; W. P. Sch. Syn. II ed.p.394,

Bryum cylindricum Dicks. Fase. IV Pl. crypt.p. 12, t. 11, f. 4 (fid. C. M).

Br. elongatum ej. op. cit. p. 8; Bryol. eur. IV (mon. p. 32), t. 345 (excl. var. $\beta): C$. M. Syn. I, p. 336.

Br. foliis gramineis pellucidis, cauliculo rubente Dill. Hist. M. p. 359, t. $46, f .17$.

La:mprophyllum elongatum Lindb. Revis, crit. ic... p. 27.

Leskea elongata $W$. et $M$, Bot. Taschb.p. 243.

Mnium Pohlia Hoffm. Deutsch. Fl. II, p. 48.

Pohlia cylindrica $H$. et $H$, in $F l$. 1819, I, p. 93.

P. elongata Hedw. M. frond. I, p. 96, t. 36 (1); Brid. Bryol. univ. I, p. 608 .

P. elongata $\beta$ cylindrica Brid. op, cit. $p .610$.

Syn. vel 1. Ad marg. viar. cav. et parietes inque fiss. rup. quarz. Eur.: E. reg. camp. mont. usq. in Alp. per zon. interm. et sept. As, : Japon., Alp. Yunnan., Amour, Himalaya, Kashmir, Nepal., Caucas. occ. et centr. Af $r$. : Alger., Kilima N'Djaro, ins. Kerguelen. Am. sepl.: Groenland, New Brunswick, reg. sept, et or.

Exs. : Rab. Bryoth. eur, n. 273, 360.

Sull. et Lesq. M. bor. am. II ed. n. 266.

var. acuminata Schwaegr. - W. acuminata.

" var, humilis W. P. Sch. Coroll. p. 65 et Syn. II ed. l.c.

Ut typ. - Eur. : Salisburg. Carinth., Stiria. Am. sept, : Colorado.

\& var. macrocarpa (Hsch.) W. P. Sch. op. et l. cc.

Bryum elongatum $\gamma$ macrocarpum Bryol, eur. et C. M. op, et l. cc.

Br. W. macrocarpa Brid. op, cit. p. 628.

W. macrocarpa Hsch, in Bot. Zeit. 1819, I, p. 104.

Ut typ. - Eur. : In subalpin.

var. minor Sch waegr. - W, acuminata var. minor.

? emergens (C.M.) Par.

Bryum emergens $C$. M. in Linn. 1878-79, p. 306.

Syn. Terr. - Am. merid. : M. Argentin. Tucuman.

Emodi-acuminata (C. M.) Par.

Bryum Emodi-acuminatum C. M. in sched.

- As. : Himalaya sept, occid.

Emodi-carnea (C. M.) Par.

Bryum Emodi-carneum C. M. in sched.

- As. : Himalaya sept. occid.

(1) Cf. Limpr. Laubm. Deutschl. II, p. 241 in adn. 
Emodi-cruda (C. M. Par.).

Bryum Emodi-crudum C. $M$, in sched.

- As. : Himalaya sept. occid.

erecta (Lindb.) Limpr, Laubm. Deutschl, II, p. 239.

Mielichhoferia defecta Sanio in Bot. Centralbl. 1883, p. 7.

M. erecta Kindb. Enum. Bryin. p. 22.

Pohlia erecta Lindb. in Rev. bryol. 1883, p. 7.

2. Ad terr. arenac. - Eur. : Norveg. (Dovre).

erythrocanlis (Hpe.) Jaeg. Ad. 1I, p. 704.

Bryum erythrocaule $H$ pe. in Linn. 1871-73, p. 516.

Syn,

- Pac. : Austral. or.

faleata Besch. Prodr. bryol, mexic. p. 53.

1.

- Am. sept. : Mexic. (Orizaba).

fasciculata Hsch. $\left\{\begin{array}{l}-\mathrm{W} \text {. longicolla var. (fid. Limpr.). } \\ -\mathrm{W} \text {. nutans (fid. C. M.). }\end{array}\right.$

filum (W. P. Sch.) Par.

Bryum commutatum var. elongata Boul. M. Fr. I; p. 279.

Br. filum W. P. Sch. Syn. II ed. p. 470; Par. Index, p. 182.

W. commutata var. elongata Payot, Fl. M. Blanc, II, p. 36.

W. commutata var. filum Husn. Muscol. gall. p. 230.

Ster. Ad rivul. - Eur. : Norveg., Alp. Sabaud. (M. Blanc).

flexuosa (Hook.) Mill. M. Ind. or. p. 66.

Bryum flexuosum C. M. Syn. I, p. 327.

Pohlia flexuosa Hook. in Wall. Catal. n. 7591; Harv, in Lond. Journ. of Bot. 1840, p. 9 et in Hook. Ic. pl. $\operatorname{rar}, t, 19, f .5$.

Syn.? - As. : Himalaya, Nepal.

gracilicarpa Hpe. Symb. 1874, p. 499.

Syn. $\quad-A m$, merid. : Brasil, austr, or

gracilis $\left\{\begin{array}{l}\text { de Not. }- \text { W. commutata var. gracilis. } \\ \text { Mac. - W. subculiata. }\end{array}\right.$

grande Kindb. - W. Ludwigii var. latifolia.

gregaria Rehm. M. Afr. austr. n. 549.

- Afr. : Transvaal.

gymnophylla C. M. in Besch. Fl. bryol. Réunion, etc., p. 92.

Bryum gymnophyllum ej, in Rev, bryol. 1877, p. 15.

1. $-A f r$ : Comor. magn.

Halleriana Hedw. - Bartramia.

Hampeana Bryol, jav. - W. brachydontia.

himalayana Mitl. M. Ind. or. p. 66.

Bryum acuminatum Wils, in Kew Joum. bot. 1X, p. 332.

1. $\quad-A s$ : Sikkim.

inflexa (C. M.) Par.

Bryum inflexum C. M. Bryol. austr. Georg. p. 200.

Ster. $\quad-$ Am. merid. : Austro-Georg.

integridens (C. M.) W. P. Sch, in Besch. Prodr. bryol, mexic. p. 52.

Bryum integridens C. M. Syn, I, p. 338. 
integriuscula (C.M.) Par.

Bryum integriusculum C.M. in sched.

- As. : Himalaya sept. occid.

intermedia $\left\{\begin{array}{l}\text { Schleich. - W. cruda. } \\ \text { Schwaegr, - Bryum. }\end{array}\right.$

iwozanica Besch. in Ann. sc. nat. I893, p. 342.

2 ? - As, : Japon.

Exs. : Faurie Pl, Japon. n, 8539.

julacea de Not. - Bryum filiforme.

juniperina (C.M.) Par.

Bryum juniperinum $C, M$. in sched.

- As. : Himalaya sept. occid.

Korbiana (C. M.) Jaeg. Ad. 1, p. 591.

Bryum Korbianum C. M. in $F l .1874, n .31$.

2. In fossis aquat. - Afr. : Oasis Dachel.

leptoblepharon (C., M.) Jaeg. op. cit. p. 600.

Bryum leptoblepharon C. M. Syn. I, p. 337; Rehm. M. Afr. austr. n. 550?

1. . - Afr.: Transvảal ? C. B. Sp.

leptocarpa Bryol. jav. 1, p. 136, t. 112.

Bryum elongatum Dz. et Mk. M. frond. ined. Archip. ind. p. 25.

2. - As. : Borneo.

leptodontia (Mitt.) Jaeg. op. cit. p. 592.

Bryum leptodontium Mitt. M. austr. am. p. 293.

- Am. merid. : And. Nov. Granat.

leptopoda Hpe. Symb. 1874, p. 499.

Syn. $\quad-A m$, merid. : Brasil, austr. or.

Lescuriana (Sull.) Lesq. et Jam. Man. p. 221.

Bryum Lescurianum Sull, in Mem. of the Amer. Acad... IV, p. 171, Ic. M. p. 81, t. 50 et M. of U. St. p. 44; C. M. Syn. II, p. 582 .

Br. pulchellum Sull. M. Allegh. n. 101.

2. $\Lambda \mathrm{d}$ terr, humid. - Am. sept. : Nov. Scot., New Brunswick, reg. ur., Arkansas.

Eœs.: Mac. Cánad, M. n. 163 p.p.

Sull, et Lesq. M. bor. am. Il ed, n. 273.

limbata (C. M.) Jaeg. Ad. I, p. 598.

Bryum limbatum C. M. Syn. II, p. 573.

2.

- Am. sept. : Costa Rica.

longibracteata (Broth.) Par.

Bryum longibracteatum Kindb. Eur. and N. Am. Bryin. p. 384.

Pohlia longibracteata Broth. in Bot. Centralbl. 1890, n.51 et in Roell M. Am. sept, n. 276.

2. In terr, argill. - Am. sept. : Washington.

longicolla (Sw.) Hedw. Sp. M. p. 169, t. 41, f. 1-5; W. Sch. Syn. II, p. 395.

Bryum Boissieri de Not. Syll. p. 134.

Br, cylindricum Dicks. Fasc. IV Pl. crypt. p, 12, t. II, f. 4 (fid. Limpr.).

Br, elongatum var, alpinum Bryol, eur. IV (mon. p. 32), t. 346.

Br. elongatum var. longicollum $H$. et T. Muscol. brit. p. 123. 
Br. Hornschuchii Spreng. Syst. veg. IV ed. p. 212.

Br. longicollum Sw. M. Sueo. pp. 49 et $99, t .6 ;$; . M. Syn. I, p. 836.

Br. W. alpina B̈rid. Bryol. univ. I, p. 626.

Br. W, grimsulana ej. op. cit, p. 628.

Br. W. longicolla ej. op. cit. p. 625.

Hypnum longicollum $W$. et M. Bot. Taschb. p. 291.

Lamprophyllum longicollum Lindb. Revis, orit. ic... p. 26.

Orthopyxis longicolla $P . B$. Prodr. $p .79$.

Pohlia longicolla Lindb. M. Scand. p. 18.

W. alpina Hsch. in Fl. 1819, I, p. 104.

W. alpina var. brachycarpa ej. in op. et $l$. co.

W. fasciculata ej. in op. et $l$. co. (fid. Limpr.).

W. longicolla var. Boissieri de Not. Epil. p. 425.

W. pennina de Not. in sched.

1. In fissur. rup. humid. - Eur.: Reg, subalp., rarius alp. As. : Japon., Kashmir, Caucas. occ. et centr. Am. sept. : Groenland, Wyoming, Oregon, Washington, M. Cascades.

Exs. : Rab. Bryoth. eur. n. 359, 873.

Un. itin. 1865, n. 52.

longifolia (C. M. et Hpe.) Jaeg. Ad. I, p. 599.

Bryum longifolium C. M. et Hpe. in Linn. 1856, p. 205.

W. nutans (fid. Mitt.).

Syn. In sphagnet. - Pac. : Austral. felix.

Ludwigii (Spreng.) W. P. Sch. Syn. II ed. p. 402.

Bryum Breidleri Mac. Canad. M, n. 425.

Br. cyclophyllum var, laxitolium
Br. cyclophyllum var. lyccense

Br, laxifolium Warnst. in Hedwig. 1887, p. 53.

Br. Ludwigii Spreng. in Schwaegr. Suppl. I, II, p. 95, t. 68; Brid. Bryol. univ. I. p. 647 p.p.?

Br. sudeticum Ludw. Krypt. Gew. Riesengeb. Cent. $I$, n. 3 .

Br. Weigelii Brid. op. et l. cc. (1).

Mnium turbinatum $\beta$ Ludwigii Roehl. Deutsch. Fl. III, I, p. 95.

Pohlia Ludwigii Broth. Enum. M. Caucas. p. 27.

P. Weigelii Lindb. in Meddel... p. 1886, p. 252.

W. Breidleri Jur, in Verh. d. K.K. zool. bot. Ges. in Wien, 1870, p. 168, c. $i c$.

2. Ad. terr. humid, vel uligin. - Eur. : Reg. subalp.; Spitzberg, ins. Parry, Ursorum. As. : Cancas. occ. Am. sept. : Groenland, Columb. brit., Oregon.

"var. elata W. P. Sch, op. et l. cc.

Ster, In paludos, - Eur. : Scotia.

var. gracilis W. P. Sch. - W, commutata var. gracilis.

* var. latifolia W. P. Sch. op. et l. cc.

Bryum grande Kindb. Eur, and N. Am. Bryin. p. 387 (ut subsp. .

Ster. - Eur.: Alp. Sabaud. (M. Blanc), Pyren. centr.

" var. lutescens Limpr. Laubm. Deutschl. II, p. 270.

Bryum lut scens Kindb. in op. cil. p. 386.

W. pulchella Jur. Laubm. CEsterr. Ung. p. 257 p.p.

Ad terr. argill. humid, - Eur. : Siles, ? Stiria, Helvet.

var. microphylla Kindb. - W. Bigelowii. 
" var. subcarnosa Berggr. M. Spetsb, n. 65 el in K. Sv. Vet, Akad. Handl. XIII, n. 7, ,. 59.

- Eur. : Spitzberg, ins. Ursor. Am. sept. : Groenland.

Ludwigii W. P. Sch. (Coroll.). - W. commutata.

Mac-Leai Rehm. M. Afr. austr. n. 548.

- Afr. : C. B. Sp.

macrocarpa Hsch. - W. elongata var, macrocarpa.

manca (C. M.) Par.

Bryum mancum C. M. in Linn. 1878-79, p. 304.

Syn.

- Am. merid. : M. Argentin. Tucum.

Mandoni W. P. Sch. in Mundon Pl. Boliv, n. 1660.

- Am. merid. : And, Boliv.

Mangiferae (C. M.) Par.

Bryum Mangiferae C. M. in sched.

Cortic. - As. : Himalaya sept. occid.

mexicana Besch. in Bull. Soc. bot. Fr, 1873, p. LXIII.

2. - Am. sept. : Mexic.

Meyeniana Hpe. - Brachymenium.

micro-apiculata C. M. et Kindb. Bidr. p. 455 (nom.) et in Mac. Cat. p. 45.

Bryum canadense Kindb. Eur. and N. Am. Bryin. p. 389.

Ster. Ad rup. humid. - Am. sept. : M. Rupestr., Columb. brit. microcaulon C. M. et Kindb. Bidr. l. c. (nom.) et in Mac. Cal. p. 114. - Am. sept.: Fret. Hudson (ins. Digge).

micro-commutata (Kindb.) Par.

Bryum micro-commutatum Kindb. in Bot. Notis. 1896.

Br. norvegicum ej. Eur, and $N$. Am. Bryin. p. 389.

- Eur. : Alp. Norveg.

micro-denticulatum C. M. et Kindb. in op. et $l$. $c c$.

Br. microdontium Kindb. op. cit. p. 388 (ut subsp. W. commutatae).

2. Juxta niv. aetern. - Am. sept. : M. Columb, brit.

mnioides W. P. Sch. in Besch. Fl. bryol. Antill. fr. p. 30.

- Am. sept. : Guadalup.

Montis Cavi Rehm. M. Afr. austr. n. 552.

1. - Am. sept.: C. B. Sp. or.

Mülleriana W. P. Sch, in Besch. Prodr. bryol. mexic. p. 52. 1. - Am. sept. : Mexico.

multiflora (C. M.) Hpe. Enum. M. Brosil. p. 35.

Bryum multiflorum C.M. Syn. $I, p .339$.

W, pulchella Hsch. Fl. Brasil. I, p. 43.

1. Muric. - Am, merid. : Brasil. austr, or.

mutabilus Hedw. - W. nutans.

neapolitana de Not. - Bryum juliforme.

nemicaulon (C. M.) Par.

Bryum nemicaulon C. M. in Nuov. Giorn. bot. ital. 1896, p. 96.

1.

- As. : China or. (prov, Schen-Si). 
nevadensis (C. M.) Par.

Bryum nevadense C. M. in Linn. 1878-79, p. 304.

Terr. - Am. merid. : Argentin. Salt.

nitens Kindb. - W. couda var. minor.

nudicaulis (Lesq.) Lesq. et Jam. Man. p. 220.

Bryum nudicaule Lesq. in Mem. Calif. Acad. I, p. 21; Sull. 1o. M. Suppl. p. 49, t. 34.

W. microcaulon C. M. et Kindb. Bidrag. (nom,) et in Mac, Cat, p, 115. 2 .

- Am. sept. : Calif.

nutans (Schreb.) Hedw. M. frond. I, p. 10, t. 4; W. P. Sch. Syn. II ed. p. 396.

Bryum laxum Reichdt. Exp. Novara, p. J76, t. 3I.

Bryum nutans Schreb. Spic. Fl. Lips, p. 81; Bryol. eur. IV (mon. p. 34), t. $343 ;$; . M. Syn. I, p. 335.

Br. piriforme $\beta$ Weiss Crypt. Goett. p. 153.

Br. trichodes Hedw. Fund. M. I, t. 4, f. 16-20.

Br. trichodes laete-virens capitulis cernuis oblongis Dill. Hist. M.p. 391, t. $50, f .61$.

Br. umbonatum Wallr. Fl. crypt. germ. I, III, p. 272?

Br. W. fasciculata Bred. Bryol. univ. I, p, 627.

Br. W. nutans ej. op. cit, p. 634 .

Hypnum nutans $W$. et $M$. Bot. Tasohb, p. 289.

Lamprophyllum nutans Lindb. Revis, crit. ic. p, 25.

Mnium aureum $\beta$ majus Web. Spic. Fl. Goett. n. $182 \beta$.

Mn. nutans P. B. Prodr. p. 75.

Pohlia nutans Lindb. M. Scand, $p .18$.

W. fasciculata Hsch. in Fl. 1819, II, p, 103 (fid. C. M.).

W. mutabilis Hedu: Frend. M. II, p. 104, t. 6, f. 28.

W. trichodes ej. op. cit. p. 95.

1. Ad rup. arenac., terr. umbr. et in ericet.; calcar. tugit. - Eur. :

Fere tota; Spitzberg, ins. Parry. As. : Japon., Kamschatka, Saghalien, Amour, Talysch, Taimyr, Obi, Jenissei, Alatau, Ochotsk, Caucas. Afr.: C. B. Sp., ins. Kerguelen; de Atlantic. ad mar. Behring, temperata tota. Am. merid. : Ins. Chiloè, Eremit., Fuegia. Pac. : Nov. Zeland., Austral, or., Nov, Caledon., Tasman,, ins. Auckland.

Exs. : Drumm. M. bor. am. I ed. n. 262 (Bryum).

Faurie Pl. Japon. n. 3533 p.p.

Mac. Canad. M. n. 160.

Rab, Bryoth. eur, n. 272, 584 .

Sull, et Lesq. M. bor. am. II ed, n. 267.

Un, itin. 1865, n. 54, 61, 65, 68 .

" var. bicolor (H. el H.) Hüb. Musc. germ. p. 429; W. P. Sch. op. et l. $c c$.

Bryum nutans $\gamma$ bicolor Bryol. eur. l. c.

Br. W. bicolor Brid. op. cit. p. 630.

W. bicolur $H$. el $H$. in op. eit. p. 102.

In depress. humid, - Eur. : Reg. subalp.; Spitzberg, ins. Parry. As.: Kasbmir. Ain. sept. : Labrador, Alaska, ins. Miquelon, M. Alb., etc,

* var. caespitosa $(H$. et H.) Hüb. et W. P. Sch. op. et ll. cc.

Bryum nutans var. caespitosum Bryol. eur. $l$. $e$.

Br. W. caespitosa Brid. op. cit. p. 629.

W. caespitosa $H$. et $H$. in op. et $l$. co.

In montosis umbr. - Eur, : Reg. subalp. et alp. Am. sept. : Colorado. 
"var, hokinensis Besch. in Ann. sc. nal. 1892, I, p. 65.

In silv. - As. : Yunwan.

* var. longiseta (Thomas) Hüb. et W. P. Sch. op. el l. cc.

Bryum nutans \& longisetum Bryol, eur. l.c.

Br. W. longiseta Thomas in Brid, op. cit. p. 636.

In turfosis. - Eur. : Hic. illic. Am. sept, : Colorado.

Exs.: Rab. Bryoth. eur, n. 585.

\& subsp. Macounii (Kindb.) Par.

Bryum Macounii Kindb. Eur. and N. Am. Bryin. p. 385.

Rupic. - Am. sept. : Ins. Vancouver.

(" var. macrospora Kindb, in Bull. Torr, bot. Club, XVII, p, 273.

-Am. sept. : Summ. M. Columb. brit.

a var. minor (Brid.) Par.

Br. nutans, minus Kth. Syn. Pl. Equinoct. I, p. 58.

Br. W. nutans $\beta$ minor Brid. op. cit. $p$. 842.

- Eur. : Corsica. Am. merid, : Andes (1).

*var. pseudo-cucullata Limpr. Laubm. Deutschl. II, p. 250.

- Eur. : Summ. Riesengeb (2).

" var. rufescens Lindb, in Berggr. M. Spetsb. n. 60 c.

- Eur.: Spitzberg, ins. Parry. Am. sept. : Groenland.

« var. sphagnetorum W. P. Sch. Coroll. p. 66 et Syn. II ed. p. 397.

In sphagn. soc. Aulacomnio palustri. - Eur.: Reg. subalp, et alp. Am. sept. : Groenland.

« var. strangulata (Nees) W. P. Sch. op. el ll. cc.

Bryum nutans var. pinetorum H. Müll. Westfal. Laubm. n. 272.

W. strangulata Nees in Hub. Muscol. germ. p. 428.

In ericetis humid. et pinetis. - Eur. : Reg. subalp. Am. sept. : Labrador.

Exs. : Rab. Bryoth, eur. n. 838.

"var. subdenticulata (Brid.) Hüb. el W. P. Sch. op. et l. cc.

Bryum nutans $\delta$ subdenticulatum Bryol.'eur. l. c.

Br. W. pendula Brid. op. cit. p. 636 .

Br. W. subdenticulata ej, op. cit. p. 634 .

Rupic. Et terr. - Eur.: Reg. subalp. et alp. Am. sept. : Froenland;

ins. Miquelon.

" var. uliginosa W. P. Sch. op. et ll, cc.

In uligin. - Eur. : Reg. alp. Am, sept.; Groenland.

œedoneura (C.M.) Par.

Bry um cedoneurum C. M. in Nuov. Giorn. bot. ital. 1896, p. $9 i$. 2.

- As. : China or. (prov. Schen Si).

Erstedtiana (C. M.) Jaeg. Ad. I, p. $\$ 590$.

Bryum (Erstedtianum C, M. Syn. II, p. 583.

1.

- Am. sept. : And. Costa-Ricens.

(2) "An spec. propria? " Limpr. 1. c. 
paucifolia Hpe. in Ann. sc. nat. V ser., IV, p. 344.

Bryum paucifolium Mitt. M. austr. am. p. 292.

- Am. merid. : Nov. Granat.

pauperum (C. M.) Par.

Bryum pauperum C. M. in hb. Soharampur, n. 6360.

Ad mal, glacial. - As. : Himalaya sept. occid.

Payoti Limpr. - Bryum.

pennina de Not. - W. longicolla.

perdecurrens (C.M.) Par.

Bryum perdecurrens $C . M$, in sched.

- As. : Himalaya sept. occid.

philonotidea (C. M.) Por.

Bryum philonotideum C. M. in Fl. 1885, p. 403.

Ster. In palud, montos, - Am. merid. : Fuegia.

picta (Mitt.) Jaeg. Ad. I, p. 599.

Anisostichium pictum Mitt. in Journ. of the Linn. Soc. VII, Bot. p. 119.

(Veraguas).

- Am. sept.: Jamaic. Am. merid: Columb. occid.

piriformis Hedw. - Leptobryum.

plumaefolia (C. M.) Par.

Bryum plumaefolium $C . M$. in $\mathrm{Fl}$. 1896, p. 450.

- Pac. : Ins. Sandwic.

polycarpa (Mitt.) Jaeg. Ad. I, p. 596.

Bryum polycarpum Mitt. M. austr. am. p. 293.

- Am. sept.: Guatemala.

polymorpha (H. et H.) W. P. Sch. Coroll, p. 65 et Syn. II ed. p. 392.

Bryum polymorphum Bryol. eur. IV (mon. p. 25), t. 344; C, M. Syn. I, p. 229 p.p. (1).

Pohlia dimorpha de Not, Spic, n, 4 et Syll.p. 142 (an potizs ad W. acuminat. referenda?

P. polymorpha H. et H. in Fl. 1819, p. 95; Bria. Bryol. univ. I, p. 619.

W. cucullata Mao. Canad. M. n. 468 p.p.

1. Ad terr. et in fissur. rup. - Eur.: Reg. subalp, et alp.; Spitzberg. As.: Penins. Tschutschica, Kamschatka. Alp. Yunnau., Himalaya, Kashmir, Caucas. occ. Am. sept. : Groenland, Labrador, Columb. brit., Sitka, Oregon, Calif.

Exs. : Rab. Bryoth, sur, n, 1285.

- v var, affinis (H. et H.) Ḧ̈b. op. cil. p. 416; W. P. Sch, op. et l. cc.

Bryum polymorphum $\rho$ afline Bryol. eur. $l, c$.

Pohlia affinis $H$. et $H$. in op. cit., .97.

P. Greenii Brid. Mant. M. p. 115 ?

P. minor Brid, Mant. M. p. 115 et Fryol. univ. I, p. 611 p.p.?

P. minor var. affinis ej. Bryol. venit. i. c. p. 612 p.p.

P. minor var. Greenii ej. Mant. M. et Bryol, univ, ll. ce. ?

P. minor var. polyphylla ej. Bryol, ur.iv. l. c.

Loe. siccior. vel frigidior. - Eur. : Reg. alp. et supraalp. 
" var. brachycarpa (H. et H.) Hïb. et W. P. sch, op. et ll. cc.

Bryum polymorphum $\varepsilon$ brachycarpum

Br. polymorphum $\varepsilon \beta$ curvisetum

Bryol. eur. l.c.

Meesia curviseta Schwaegr. Suppl. III, I, p. 234.

Pohlia brachycarpa $H$. et $H$. in op. cit. p. 96 ; Brid. Bryol. univ. I, p. 616.

P. curviseta H. et H. in op. cit. p. 98 ; Brid. op. cit, p. 618.

« var. Camonia (Rota) de Not. Epil. p. 429.

Bryum Camonium Rota Cat. M. Bergom, mss.

- Eur. : Ital. super.

* var. gracilis (H. el H.) W. P. Sch. op. el $l l$. cc.

Bryum polymorphum $\delta$ gracile Bryol. eur. l. c.

Pohlia gracilis $H$. et $H$. in op. cit. p. $160 ; B$ rid. op. et $l$. ec.

Ut et ubi praeced.

" subsp. pseudo-acuminata (Kindb.) Par.

Bryum pseudo-aruminatum Kindb. Eur. and N. Am. Bryin. p. 390.

Rupic. - Eur. : Norveg.

* var. stricta (Bryol, eur.) W. P. Sch. op. et ll. cc.

Bryum polymorphum $\gamma$ strictum Bryol. eur. $l$. c.

Utt et ubi praeced.

polymorphoides Kindb. in Mac. Cat. p. III.

Bryum polymorphoides ej. Eur, and N. Am. Bryin. p, 387.

Ad nives aetern. - Am. sept. : M. Selkirk.

polysetula (C.M.) Par.

Bryum polysetulum C. M. in sched. - As. : Himalaya sept. occid.

pomiformis Hedw. - Bartramia.

proligera (Lindb.) Kindb. Enum. Bryin. dovr. App. n. 309 (1).

Bryum proligerum Kindb. Eur, and N. Am. Bryin. p. 384.

Pohlia proligera Lindb. mss.

2. Ad terr. argill.-arenos. - Eur.: Norveg.? Stir., Carinth., Tirol.; Alp. Bavar.? Helvet.?

pseudo-nutans Par.

Bryum austro-nutans C. M. in Engler's Bot. Jahrb. 1883, p. 78 et in Forsehungsreise... p. 16.

Br, nutans Mitt. in Journ. of the Linn. Soo. 1876 (fid. C. M.).

Syn. Rupic. - Afr. : Ins. Kerguelen.

Puiggarii Geh, et Hpe, in Fl. 1881.

2. $\quad$ - Am. merid. : Brasil. austr. or.

pulchella (Hedio.) W. P. Sch. Coroll. p. 67 et Syn. 11 ed. p. 404 p.p.

Bryum carneum $\beta$ pulchellum $H$. et T. Muscol, brit. p. 119; Boulay $M$. Fr. $I, p, 282$.

Br, pulchellum Hedu. M. frond. III, p. 95, t. 38; Brid, Bryol. univ. I, p. 651 p.p. ; Bryol. eur. IV (mon. p. 42), t. 352 p.p.; C. M. Syn. I, p. 332 p.p.

Mnium pulchellum P. B. Prodr. p. 76 .

Pohlia pulchella Lindb. M. Scand. p. 17.

W. carnea Rab. Bryoth. eur. n. 1021.

(1) " An W. annotina var, tenuifolia?". (Limpr. Laubm. Deutschl. 11. p. 268), 
WEB

1359

2. Ad rip. fluvior. - Eur.: Scandin. sept. et med, Fennia ; Salisb, ? Ardenn., Sabaud. As. : Jenissei. Am. sept. : Columb. brit., Idaho. pulchella $\left\{\begin{array}{l}\text { Hsch. }- \text { W. multiflora. } \\ \text { Jur. p.p. W. W. Jutescens. } \\ \text { Mac. - W. columbica. } \\ \text { W. P. Sch. p.p. - W. vexans. }\end{array}\right.$ pulvinata (C. M.) Par.

Bryum pulvinatum C. M. Bryol, austr, Gearg. p. 21.

Syn. Rupic. - Am. merid. : Austr. Georgia.

pycno-decurrens C. M, et Kindb. Bidr. p. 455 (nom.) et in Mac, Cat. p. 114.

Bryum nicrosporum Kindb. Eur. and N. Am. Bryin. p. 388.

2. Terr, et rupic. ad niv, aetern, - Am. sept, : Columb, brit. rigescens (Wils.) Mitl. M. Ind. or. p. 65.

Bryum rigescens Wils, in Kew Journ. bot. $1 X, p .366$.

2 ?

- As. : Himalaya.

rigida (Lindb.) Par.

Epipterygium rigidum Lindb, in Broth. Enum. M. Caucas, p. 30.

2. Ad terr, argill.-arenac. humid. - As: Imeretia. rubella Philib, in Rev, bryol. 1896, p. 85 .

2. In graminos, -- Eur. : Helvet. (M. S. Bernard. maj.). Rusbyana (C. M.) Par.

Bryum Rusbyanum C. M. in Nuov. Giom. bot, ital. 1897, p. 21.

- Am. merid. : And. Boliv.

rutilans (Brid.) W. P. Sch. Syn. II ed.p. 400.

Bryum rutilans Brid. Bryol. unix, I, p. 684; C. M. Syn. I, p. 274 (excl. syn.).

Ster. - Am. sept. : Ins. Melville.

rutilans W. P. Sch. (Coroll.). - W. Schimperi.

sacra Ltz. M. Ehrenb. p. 40, l. 9.

Bryum syriacum Jur, et Milde?

2.

- As. : M. Sinaï.

saprophila Broth, in latt. ad C. M.

Bryum saprophilum C. M. in Nuov. Giorn. bot. ital. 1896, p. 97.

2 ?

- As. : China or. (prov. Kansu).

scabridens (Mitt.) Jaeg. Ad. I, p. 592.

Bryum scabridens Mitt, in Journ. of the Linn. Soc. 1864, p. 151.

W. brevicolla Sande Lac. in Miq. Ann. mus. bot. Lugd. Batav. II, p. 294.

2. - As. : Japon.

Schimperi (C, M.). W. P. Sch. Syn. I ed. p. 338 et II ed. p. 400.

Bryum gelidum Hagen in $K$. Nosske Vid.-Selsk. Skrift. 1888-90, p. 11 (ex ipso l)

$\mathrm{Br}+$ rutilans Bryol, ewr. IV (mon. Suppl. p. 5), t. 350.

$\mathrm{Br}$. Schimperi $C, M$. Syn. $I, p, 334$.

Pohlia rutilans Lind b. M. Scand. p. 18.

W. rutilans W.P. Seh. Coroll. p. 66.

1 et syn. Rupic, et terr, in paludos. - Eur.: Spitzberg, ins. Parry, Ursorum, Alp. Norveg. Am, sept. : Ins. Sabine, fret. Smith. 
schisticola (C. M.) Par.

Bryum schisticolum C. M. in Nuov, Giorn. bot. ital. 1897, p. 21.

Webera spectabilis W. P. Sch. in Mandon Pl. Boliv, n. 1659.

2. In schistos. - Am. merid. : And. Boliv.

Seleri (C.M.) Par.

Bryum Seleri C. M. in Bull. hb. Boissier, 1897, p. 181.

2.

- Am. sept. : Guatemala.

sessilis Lindb. - Diphyscium.

sinaïtica Ltz, M. Ehrenb. p. 42, $\iota .10$.

Bryum syriacum ơ (fid. Jur. et Milde).

+ et fr. ign. - Afr. : M. Sinaï.

spectabilis (C. M.) Jaeg. Ad. I, p. 589.

Bryum spectabile C. M. Syn. II, p. 583.

1. Ad rup. humid. - Am. sept.: Mexic., Costa Rica, Guatemala. Am. merid.: And. Noy, Granat.

spectabilis W. P. Sch. - W. schisticola.

sphagnadelphus (C. M.) Besch. in Miss. sc. Cap Horn, p. 285.

Bryum nutans Mitt. M. austr. am. p. 292?

Br. sphagnadelphus C. $M$. in Fl. 1885, p. 402.

Syn. Paludic. - Am. merid, : Patagon. austr., Fuegia.

sphagnicola (Bryol. eur.) W. P. Sch. Coroll. p. 66 et Syn. II ed. p. 399.

Bryum Sphagni C. M. Syn. I, p. 330 p.p.

Br. sphagnicola Bryol. eur. IV (mon. Suppl, p. 6), t. 349.

Pohlia sphagnicola Lindb. et Arn. M. As. bor. 1890, II, p. 53.

2. In sphagnet. profund. - Eur.: Spitzberg, Norveg., Carinth., Rhöngeb., Brandeb.; Pomeran.? As. : lenissei. inf. Am. sept.: Groenland, Nov. Scotia, M. Adirondack.

strangulata Nees, - W. nutans var. strangulata.

strictipes (C. M.) Par.

Bryum strictipes C. M. in hb. Scharampur, n. 8042.

- As. : Himalaya sept. occid.

subcarnea W. P. Sch, in Saval. M. Japon. n. 405 ; Besch. in Ann. sc. nat. 1893, p. 342.

2 .

- As. : Japon.

subcucullata C. M. el Kindb. Bidr. p. 455 (nom.) el in Mac. Cal. p. 113.

Bryum subcucullatu $\mathrm{n}$ Kindb. Eur. and N. Am. Bryin. p. 388.

W. gracilis Mac. Canad. M. n, 424.

2 In fissur. rup. - Am. sept. : Summ. M. Columb. brit.

subcurvata (Mitt.) Jaeg. Ad. 1, p. 589.

Bryum subcurvatum Mitt. M. austr. am. p. 291.

- Am. merid. : And. Nov. Granat.

subpolymorpha (Kindb.) Par.

Bryum subpolymorphum Kindb. Eur. and N. Am. Bryin. p. 390.

2.

- Am. sept. : M. Columb. britann.

synoico-cruda (C. M. Par.).

Bryum synoico-crudum C. M. in Engler's Bot. Jahrb. p. 83 et in Forschungsreise.... p. 37.

Br. crudum Mitt. M, austr. am. p. 293 ?

Syn. In gramin. - Am. merid. : Fret. Magell. 


\section{WEB}

tapintzensis Besch, in Ann. sc. nal. 1892, 1, p. 65.

Syn. Ad rivul. - As.: Yunnall.

tasmanica (Broth.) Par.

Mniobryum tasmanicum Broth in Oefv, af Finska. Vet.-Soc, Foerh. 18!3, p. 37 et in Pap. and Proced. of the roy. Soc. of Tasman. 1895, p. 203.

2. Ster. Ad terr. humid. - Pac. : Tasman.

tenuifolia (Hook. f. el Wils.) Japg. op. et l. cc.

Bryum tenuifolium $H$. f. et W. in Lond. Journ. of bot. 1844, p. 546; C. M. Syn. I, p. 335 .

2 .

- Pac. : Nov. Zeland.

Tozeri (Grev.) W. P. Sch. Coroll. p. 67 et Syn. II ed.p. 406.

Anisostichium Tozeri Mitt. in Journ. of the Linn. Soc. 1863, p. 119.

Bryum marginatum Br. in Fr. Müller M. Sardin. 1827.

Br. Tozeri Grev. Scot. crypt. Fl. V, t. 285 ; Bryol, eur. IV (mon. p. 41), t. 353 ; C. M. Syn. I, p. 298 ef $I I, p .574$.

Epipterygium Tozeri Lindb.

2. In terr. argill. et aren.-argill, humid. - Eur.: Britann., Normann., reg. merid. As. : Java. Afr.: Alger., ins. Azor., Canar., Madeir. Am. sept.: Vancouver, Oregon. Calif, merid.

Exs.: Rab. Bryoth. eur. n. 581 .

Sull. et Lesq. M. bor. am. Il ed. n. 272.

trachydontea Sanio. - W. crassidens.

trematodontea (C. M.) Par.

Bryum trematodonteum C. M. in Bot. Zeil. 1853, p. 33.

1. $\quad-A s,:$ M. Neilgherr.

trichodes Hedw. $\left\{\begin{array}{l}- \text { Meesea uliginosa. } \\ -\mathrm{W} \text {. nutans. }\end{array}\right.$

vexans (Limpr.) I'ar.

Bryum pulchellum Bryol. eur. (mon. p. 42), t. 352 p.p.

Mniobryum vexans Limpr. Laubm. Deutsohl. II, p. 273.

W. pulchella $W . P . S c h+p \cdot p$.

2. Terr. in subalp. - Eur, : Stir., Pinzgov., Engadin.

viridata (C. M.) Par.

Bryum viridatum C. M. Bryol. austr. Georg. p. 21.

Ster. Rupic. - Am. merid. : Austr. Georgia.

viridis (Arn. et Lindb.) Par.

Pohlia viridis A. et L. M. As. bor. 1890, II, p. 55.

2. Terr. - As. : Jenissei super.

Wilsoni Jaeg. - Brachymenium.

Woodii Rehm. M. Afr, austr, n. 547 et b.

- Afr. : Natal, Transvaal.

yunnanensis Besch, in Ann. sc. nut. 1892, 1, p. 64.

Syn. In silv. - As. : Yunnan.

Weberiopsis C. M. in Fl. 1897, p. 328 (nam., secl. Conomitri (sensu Muller). 
WEISIA Hedw. Fund. M. II, p. 90 (24 spec.).

aciphylla Wahlenb. - Pottia lanceolata var. aciphylla.

acuta $\left\{\begin{array}{l}\text { Hedw. - Blindia. } \\ \text { Hook. et Tayl. - Dicranum fulvellum. }\end{array}\right.$

$\begin{aligned} & \beta \text { rupestris } \\ & \gamma \text { rupincola }\end{aligned} \mid$ Brid. - Blindia acuta.

affinis $\left\{\begin{array}{l}\text { Hook. et Tayl. - Pottia Starkeana var. brachyodus. } \\ \text { Roth. - Orthotrichum }\end{array}\right.$

agoyanensis Mitt. - Scopelophila.

amblyodon Brid. - W. viridula var. amblyodon.

anomala Roth. - Orthotrichum.

apiculata Kiaër in Borgen M. Madag. n. II,

- Afr. : Madagasc. centr.

apiculata $\mathrm{Br}$.

var, gymnostomoides Rab.
var, subglobosa Rab.

arborea Mitt. - Hyophila.

argentinica C. M. - Hymenostomum.

atro-virens Bryol, germ. - Dicranoweisia compacta.

auridens C. M. - Oreoweisia.

var. robusta C. M. - Oreoweisia auridens var. robusta.

? Ayresii W. P. Sch, in Besch. Fl. bryol. Réunion, elc., p. 14.

$1 . \quad-A f r$. : Ins. Franciae.

Barbula Mitt. - Hyophila.

barbulacea C. M. in Linn. 1874, p. 634.

2.

- Am. sept.: Mexic.

bartramioides Griff. - Philonotis Griffithiana.

Belangeriana Mont. - Microdus longirostris.

Bergiana Hsch, - Entosthodon.

Berteroana Spreng. - Trichostomum.

bicolor H. f. --Gymnostomum.

blanda Mitt. - Hyophila.

bogolensis Hpe. - Oreoweisia.

brachycarpa Jur. - Hymenostomum microstomum var. brachycarpa.

brachypelma C. M. - Hymenostomum.

Brandegei Aust. - W. viridula var. amblyodon.

brasiliensis Hpe. - Oreoweisia.

Breutelii C. M. - Gymnostomum.

Bruchiana Bryol. germ. - W. viridula.

Bruntoni de Not. - Dicranoweisia.

caespitos $\alpha$ Br. - Pottia.

calcarea $\left\{\begin{array}{l}\text { C. M. - Gymnostomum. } \\ \text { Drumm. - Seligeria. } \\ \text { Sull. - Seligeria pusilla. }\end{array}\right.$

var. gracillinia 5 . M. - Gymnostomum calcareum.

var. tenella C. M. - Gymnostomum caleareum var. tenella.

var. viridula C. M. - Gymnostomum calcareum var. intermedium

var. $\beta$ Schwaegr. - Seligeria pusilla.

californica $\mathrm{Hpe}$ - - W. viridula.

calycina Hedw. -- Holomitrium.

campylocarpa Hook. - Mielichhoferia campylotheca.

capillacea Brid. - Trichostomum tenue.

capilliseta C. M. in Ule Bryoth. brasil. n. 31 et 32.

- Am. merid. : Brasil, austr. or. 
cataractarum Mitt. - Hyophila.

chilensis Hpe. - Oreoweisia.

ciliata Hook. - Syrrhopodon.

cirrata Hedw. - Dicranoweisia.

var. crispula Wahlenb. - Dicranoweisia.

var. cylindrica Wahlenb. - Didymodon.

commutata Braithw. - Gymnostomum curvirostre.

comosa Hpe - Garckea phascoides.

compacta Brid. - Dicranoweisia.

condensata Brid. - Dicranoweisia compacta.

connata Wallr. - Pottia lanceolata.

contecta H. f. et W. - Dicranoweisia.

contermina Mitt. - Hyophila.

controversa $\mathrm{H} \in \mathrm{dw}$. - W. viridula.

var. densifolia Wils. - W. viridula var. densifolia.

var. stenocarpa Wils. - W. viridula var. stenocarpa.

convoluta C. M. et Kindb. Bidr, p. 453 (nom.) et in Mac. Cat. p. 14.

1. In fissur, rup. - Am. sept. : M. Rupestr.

crispa $\left\{\begin{array}{l}\text { Roth. - Ulota. } \\ \text { Timm. - W. viridula. }\end{array}\right.$

crispata $\left\{\begin{array}{l}\text { Brid. - Rhabdoweisia denticulata. } \\ \text { C. M. - Hymenostomum. } \\ \text {.lur. - W. viridula var. gymnostomoides. }\end{array}\right.$

cripula $\left\{\begin{array}{l}\text { Hedw. - Dicranoweisia. } \\ \text { Wils. - Dicranoweisia antarctica. }\end{array}\right.$

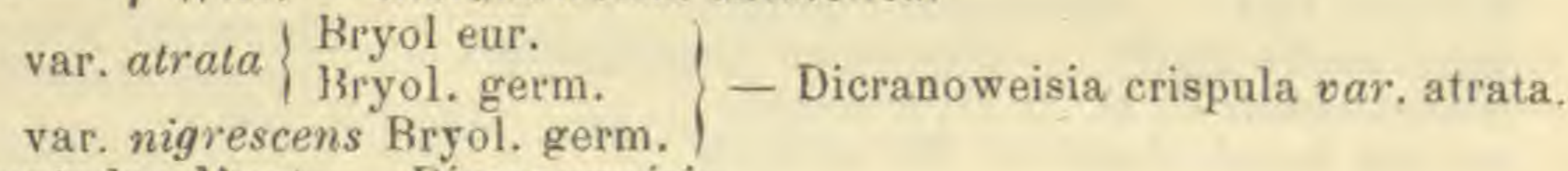

var. nigrescens Bryol. germ. !
ptodon Mont. - Dicranoweisia.

cucullata $\left\{\begin{array}{l}\text { C. M. - Hymenostomum. } \\ \text { Mitt. - Pottia. }\end{array}\right.$

cupulala Roth. - Orthotrichum.

curvicaulis Brid. - W. viridula.

curvirostris C. Ml. - Gymnostomum.

var. lacustris Brid. - Didymodon rubellus.

var. microcarpa C. M. - Gymnostomum eurvirostre var. microcarpa.

var. pallidiseta C. M. - Gymnostomum curvirostre var. cataractarum.

var. revoluta Brid. - Didymodon rubellus.

cylindrica $\mathrm{Br}$. - Didymodon.

cyrnaea Brid. - W. viridula.

densifolia Wils. - W, viridula var. densifolia.

denticulata Brid. - Rhabdoweisia.

diaphana Roth. - Orthotrichum.

Dicksoni $\left\{\begin{array}{l}\text { Brid. - Dicranoweisia cirrata. } \\ \text { Gmel. - W. viridula. }\end{array}\right.$

dubia Roehl. - W. viridula.

edentula \{ Mitt. - Hymenostomum.

elongata Hook. - Mielichhoferia nitida var. elongata.

erosa $\mathrm{Hpe}$. - Oreoweisia.

erythrogona Brid. Bryol. univ. I, p. 337 ; C. M. Syn. I, p. 664 (1).

2. Ster. - Am. sept. : ?

exigua Sebwaegr. - Microdus.

(1) Spec. dubia, ab anctor, recentior, non memorata. 
falcata $\left\{\begin{array}{l}\text { Bryol. germ. - Dicranoweisia crispula. } \\ \text { Kindb. - Gymnostomum. }\end{array}\right.$

fallax Kindb. - W. viridula.

fastigiala Kindb. - Blindia acuta.

flaccida Harv. - Splachnobryum.

flavipes Hook. f. et Wils. Fl. of the N. Zeal. I, p. 59, t. 83, f. 2 et Handb. p. 404.

1. Terr. - Pac. : Nov. Zeland,, Austral, or., Tasman.

flexuosa Bryol. germ. - Dicranum fulvellum.

fornicata Brid. - Bryum calophyllum.

Forsteri Brid. - Zygodon.

fugax Hedw. - Rhabdoweisia.

var. $\beta$ Roebl. - Rhabdoweisia denticulata.

Ganderi Jur. in Verh. d. K. K. zool. bot. Ges. in Wien, 1875, p. 780 et

Laubm. Oesterr: Ung. p. 13.

W. mucronata $\beta$ Ganderi Boulay M. Fr. I, p. 550 .

1. In pascuis. - Eur. : Pusterthal, Tirol, Gall. or. (Ardèche).

geniculata Brid. - Campylosteleum saxicola.

groënlandica Kindb. - Pottia.

gymnostomoides $\left\{\begin{array}{l}\text { Brid. - W. viridula var, gymnostomoides. } \\ \text { Bryol. germ. -- W. viridula var. amblyodon. }\end{array}\right.$

gypsacea Schl ich. - Eucladium verticillatum.

Hampei Mitt. - Systegium Lindigii.

heleromalla Hedw. - Ditrichum homomallum.

Hildebrandit C. M. - Gyroweisia.

humilis Bryol. germ. - W. viridula.

immersa Brid. - Campylopus flexnosus.

incarnata Schwaegr. - Discelium nudum.

incerta Mitt. - Barbula.

incurva Mitt. - Hyophila.

indica Wils. $\left\{\begin{array}{l}\text { - Dicranoweisia. } \\ \text { - Dicranoweisia alpina. }\end{array}\right.$

inflexa Mitt. - Pottia.

involutifolia Mitt. - Hyophila.

irrorata Mitt. - Eucladium.

ithyphylla $\left\{\begin{array}{l}\alpha \text { major Ehrh. - Orthotrichum leiocarpum. } \\ \beta \text { minor Ehrh. - Orthotrichum anomalum. }\end{array}\right.$

Jamesoni $\left\{\begin{array}{l}\text { Mitt. - Gymnostomum. } \\ \text { Tayl. - Tayloria pichinchensis. }\end{array}\right.$

Kunzeana C. M. - Gymnostomum marginatum.

lanceolata Roehl. - Fottia.

latifolia i Schwaegr. - Pottia.

laxifolia $\mathrm{Hpe.} \mathrm{-} \mathrm{Oreoweisia.}$

Lechleri C. M. - Oreoweisia.

$\beta$ minor C. M. - Oreoweisia Lechleri var, minor.

Leprieurii Mitt. - Hyophila.

leptocarpa W, P. Sch. mss. ; Besch. in « Deux Excurs. bot.... par L. Leresche et $E$. Levier \$. p. 171.

- Eur, : Lusit. (Cintra). Afr. : Alger.?

leptodon Plaub. - Rhabdoweisia fugax.

leptotrichacea C. M. in Nuov. Giorn. bot. ilal. 1897, p.

$$
\text { - As. :China or. (prov. Schen-Si). }
$$


ligulata Mitt. - Scopelophila.

Lindigiana Hpe. - Rhabdoweisia.

Lindigii Mitt. - Hyophila.

lineaefolia C. M. - Hymenostomum?

linearifolia Hsch: - Microdus.

longicollis Link. - Entosthodon Templetoni.

longipes Sommerf. - ngstroemia.

longirostris $\left\{\begin{array}{l}\text { Mitt. - Gymnostomum Kunzeanum. } \\ \text { Schwaegr. - Microdus. }\end{array}\right.$

longiseta Lesq. el Jam. Man. p. 5 t.

W, viridula var. australis Aust. M. Appal. Suppl. n. 466 et in Bull. Torr. bot. Club, VII, p. 4.

2. Terr. - Am, sept. : Carol. merid., Florid., Ludovic., Mississipi.

lurida Mitt. - Barbula.

Mac-Clellandi Griff. - Syrrhopodon Gardneri.

macrocarpa Hook. - Mielichhoferia.

macrorhyncha Mont. - Microdus Miquelianus.

Martiana Hsch. - Oreas.

mauritiana W. P. Sch. in Besch. Fl. bryol. Réunion, etc., p. 14. - Afr.: Ins. Franciae.

melanostoma Mitt. - Hyophila.

micacea C. M. - Hymenostomum.

microcarpa H. f. et W. - Dieranoweisia.

microdes Schwaegr.
microdonta Hedw.

microstoma Bryol. germ. - W. viridula var. amblyodon.

microstoma C. M. - Hymenostomum.

var. brachycarpa C. M. - Hymenostomum microstomum var. brachycarpa.

var. brevirostris C. M. - Hymenostomum microstomum var. brevirostris.

var. elala C. M. - Hymenostomum microstomum var. elata.

var. obliqua C. M. - Hymenostomum microstomum var, obliqua. Mielichhoferiana Funk. - Mielichhoferia nitida.

$\beta$ elongata Schwaegr. - Mielichhoferia nitida var. elongata. minutissima Mitt - Hyophila.

Miqueliana Mont. - Microdus.

monoclados Brid. - Barbula vinealis.

mucronata Bryol. eur. I (mon. p. 7), t. 23; W. P. Sch. Syn. II ed.p. 53.

Gymnostomum micrestonum var. Schultz Fl. Starg. p. 279.

G. rutilans Hedw. Sp. M. p. 37, t. 3, f. 8-11.

Hymenostomum rutilass Bryol. germ. I, p. 201, t. 12; Brid. Bryol. univ. $I I, p .78$.

Mollia rutilans Lindb. in Braithu. Brit. Mossfl. I, p. 238.

W. apiculata $B r$. in Bryol. germ. II, II, p. 40, t. 26.
$\beta$ gymnostoma
$\gamma$ subglobosa
Rab. Deutseh. Kryptfl. II, p. 126.

W. mueron Br. in Spreng. L. Syst, veg. IV V. p. 158.

W. viridula var, stenocarpa Rab. Bryoth, exr. $n$. 355 .

1. Ad terr. argill. inter dumeta. - Eur. : Rar.; reg. med. Afr. : Alger.

Exs. : Rab. Bryoth. enr, n. 607.

var, Ganderi Boul. - W. Ganderi.

mutabilis Hedw. - W. viridula.

navicularis Mitt. - Barbula. 
nervosa Hook. - Barbula atro-virens. nigrita Hedw. - Catoscopium.

nivalis Brid. - Campylopus.

nova spec. n, 496 Zeyh. - Leucoloma Zeyheri.

nuda Mitt. in Trans. and Proced. of the roy. Soc. of Victoria, 1883, p. 59. - Pac. : Austral. or.

nuda H. et T. - Discelium.

nudiflora C. M, et Hpe. in Linn. 1853, p. 456.

Syn.

- Pac. : Austral. felix.

4 var. major Hpe. in Linn. 1856, p. 205 (nom.).

Ubi typ.

obscura Roehl. - W. viridula.

obtusa Brid. - Splachnobryum.

obtusifolia $\left\{\begin{array}{l}\text { C. M. - Hyophila. } \\ \text { Rich. - Splachnobryum. } \\ \text { Roth. - Orthotrichum. }\end{array}\right.$

occulta Wallrr. in Linn. 1840, p. 682; C. M. Syn. I, p. 664 (1).

- Eur.: Hercynia merid.

octoblepharis $\left\{\begin{array}{l}\text { Mitt. - Pottia. } \\ \text { Roth. - Orthotrichum affine. }\end{array}\right.$

Erstedtiana Mitt. - Hyophila.

Pabstiana C. M. - Gymnostomum.

pallens $\mathrm{H}$. f, et W. - Microdus.

pallescens W. P. Sch, in hb. DR. ; Besch. Cat. M. Alger, p. 5.

1.

- Afr. : Alger.

pallidiseta Schwaegr. - Microdus.

paludosa Brid. - Seligeria pusilla.

parasitica $\left\{\begin{array}{l}\text { Mohr. - Calymperes. } \\ \text { Roehl. - Seligeria recurvata. }\end{array}\right.$

pennata Schrank. - Neckera.

pentasticha Hedw, - Conostomum australe.

phascoides C. M. - Hymenostomum rostellatum.

pilifera $\left\{\begin{array}{l}\text { Funk. - Pottia latifolia var. pilifera. } \\ \text { Roehl. - Grimmia. }\end{array}\right.$

Poeppigiana Mitt. - Hyophila.

polytrichoides Wigg. - Orthotrichum leiocarpum.

pomiformis Hook. - Syrrhopodon.

procera Laur, - Oreoweisia serrulata.

pulicaris Besch. - Hymenostoraum.

pumila Brid. - Rhabdoweisia fugax.

punctulata Mitt. - Hyophila.

pusilla Kindb. in Rev. bryol. 1896, p. 20.

Gymnostomum tenue ej. in Mac. Cat. p. 14 p.p.

2. Ad rup. calcar. - Am. sept. ; Ontario (Owen Sound).

pusilla Sw. - Seligeria diversifolia.

radians Hedw. (fid. C. M.). - Entosthodon.

recurvata Brid, - Seligeria.

recurvirostra Hedw.

recurvirostris Schwaegr. $\{$ - Didymodon rubellus. 


\section{WEIBIA}

reflexa Brid. - Gyroweisia.

reticulata Hook. - Mielichhoferia clavata.

revoluta Schleich. - Didymodon rubellus.

rigescens $\mathrm{C}$. M. - Gymnostomum.

riparia Hpe. - Dicranoweisia.

Rohlfsiana C. M. - Gyroweisia.

Roscheri Mitt. - Hyophila.

rosea Wahlehb, - Discelium nudum.

rostellata Lindb. - Hymenostomum.

rubella Roehl. - Didymodon.

Rudolphiana Bryol, germ. - W. viridula var. gymnostomoides.

Rugeliana. W. P. Sch. - W. viridula var. Rugeliana.

rupestris $\left\{\begin{array}{l}\text { C. M. - Gymnostomum rupestre. } \\ \text { Hedw. - Blindia acuta. }\end{array}\right.$

var. compacta C. M. - Gymnostomum rupestre var. compacta.

var. ramosissima C. M. - Gymnostomum rupestre var. ramosissima.

var. stelligera C. M. -. Gymnostomum rupestre var. stelligera. samoana Mitt. - Hyophila.

Schisti Brid. - Cynodontium.

? sclerodonta Hpe. in sched.

$$
\text { - Afr. : C. B. Sp. }
$$

Seligeri $\left\{\begin{array}{l}\text { Bryol. germ. - Seligeria pusilla. } \\ \text { H. f. et W. - Seligeria recurvata var. arcuata. }\end{array}\right.$

Sellowii Schwaegr. - Holomitrium crispulum var. gracile.

semi-involuta C. M. - Hymenostomum.

senocarpa C. M. - Hymenostomum.

serrulata $\left\{\begin{array}{l}\text { Funk. - Oreoweisia. } \\ \text { Wils. - Oreoweisia laxitolia. }\end{array}\right.$

simplex Brid. Bryol. univ. 1, p. 803; C. M. Syn. I, p. 664 (1)

Patria ign. (hb. DC.).

socotrana Mitt. - Gymnostomum.

sphaerothecia C. M. - Rhabdoweisia.

splachnifolia Mitt. $\{$ - Splachnobryum obtusum.

splachnoides Thunb. - Dissodon.

squarrosa C. M. - Hymenostomum.

Starkeana Hedw. - Pottia.

stillicidiorum Mitt. - Gymnostomurn.

striata Kaulf: - Rhäbdoweisia fugax.

stiata Roth. - Orthotrichum leiocarpum.

var. major H. et T. - Rbabdoweisia denticulata.

var. minor eor. - Rhabdoweisia fugax.

stricta $\mathrm{H}$. f. et W, - Blindia.

subacaulis Mitt. - Hymenostomum.

subcaespitosa Mitt. - Hyophila.

submicacea C. M. - Hymenostomum.

? tenella W. P. Sch, hb.

$$
-A f r: \text { C. B. Sp. }
$$

tenella Brid. - Pottia caespitosa.

tenuirostris H. et T. - Didymodon cylindricus.

tenuis $\left\{\begin{array}{l}\text { C. M. - Gyroweisia. } \\ \text { Kze. - Microdus. }\end{array}\right.$

tenuiseta W. P. Sch. - W. viridula var, tenuiseta. 
Termiditarum C. M. - Hymenostomum. tophicola C. M. - Gyrow eisia.

toquescens Bryol. germ. - Oreoweisia serrulata,

tortifolia H. f. et W. - Dicranoweisia.

tortilis $\left\{\begin{array}{l}\text { C. M. - Hymenostomum. } \\ \text { Spreng. - W. viridula. }\end{array}\right.$

Tortula Mitt. $\left\{\begin{array}{l}\text { - Hyophila. } \\ \text { (quoad pl. Cubens.). - Hyophila Wrightii. }\end{array}\right.$

trichodes $\mathrm{H}$. et T. - Brachyodus.

tristicha Brid. - Seligeria.

truncicola de Not. - Dicranum montanum.

turbinata Drumm. - Dissodon splachnoides.

umbrosa Mitt. - Gymnostomum.

uncinala Brid. - Macromitrium fimbriatum.

vaginans Brid. - Holomitrium.

venezuelensis C. M. - Gymnostomum.

verticillata Brid. - Eucladium.

virens $\mathrm{Brid}$. - $\mathrm{W}$. viridula.

viridissima Brid. - Bartramia subulata?

viridula (L.) Bricl. Bryol. univ. 1, p. 334 ; Bryol. eur. I (mon. p. 5), t.21; C. M. Syn. I, p. 651 ; W. P. Sch. Syn. 11 ed., p. 51.

Afzelia crispa Ehr.h. Crypt. exs, n. 222.

Bryum capillaceum breve pallide et laete virens, capsulis ovatis Dill. Hist. M. p. 380, t. $48, f .43$.

$\mathrm{Br}$. controversum Hoffm. Deutsch. Fl. II, p. 34 .

$\mathrm{Br}$, Iuteolum ej. op. et $l$. co.

Br. paludosum $\beta$ viridulum Web. Spic. Fl. Goett. p. 11.

$\mathrm{Br}$, virens Dicks. Fasc. II Pl, crypt. p. 4 .

Br. viridulum $L . S p, p l, p, 1584$.

Dicranum xanthodon Hedw. Sp. M. p. 145, t. 30.

Grimmia controversa W. et M. Bot. Taschb. p. 133.

Gr. crispa Roth. Tent. III.

Gr. viridula ej. op, et $l$. $c c$.

Hymensstomum subglobosum Bryol. germ. I, p. $n^{103 ;}$ Brid. Bryol.
univ. II,. . 79.

H. tortile Rab. Bryoth. eur, n. 408.

Mnium viridulum Sio. Meth. M. p. 365 .

Mollia viridula Lindb. M. Scand. p. 21 .

Simophyllum viridulum Lindb. Revis, crit, ic. At, dan. p. 5I.

W. Bruchiana Bryol. germ. II, II, pp. 36 et 38, tt. 26 et 28.

W. californicat Hpe, in sched.

W. controversa Hedw. M. frond. III, p. 12, t. 5; Drumm. M. bor. am. $I$ ed. $n .67$ et II ed. n. 32,33 .

W. crispa Timm. Prodr. A. Megap. p. 736.

W. curvicaulis Brid. Bryol, univ. I, p. 336.

W. cyrnaea ej. op. cit, $p, 803$.

W. Dicksoni Gmel. Syst. nat. II, p. 1334

W. dubia Roehl. Moosges, p. 149.

W. edentula Sull. in Proced. of the Amer, Aead... 1861 (fid. Mitt.).
W. fallax

W. humilis. Wryol, germ. l. e.

W. microdes Schwaegr. Suppl. I, I, p. 77.

W. microdonta Hedw. Sp. M. p. 67, $t .11, f .7-12$.

W. mutabilis Brid. Sp. M. I, p. 103 . W. obscura Roehl. in Ann. Wett. Ges. III, p. 99 ; Brid. Bryol. univ. I,
p. 337 ?

W. tortilis Spreng. Syst. veg. IV, II, p. 381.

W. virens Brid. M. Rec. II, I, p. 69.

1. In pascuis, agris, ad mur. terr. obtect., etc., rar. ad saxa. - Reg. temperat. in Eur., As., Afr., Am, sepl. et merid. Pac. : Taïti? Nov. Zeland., Tasman. 


\section{WEI AYA}

Exs.: Faurie Pl, Japon. n. 4. 209, 212.

Mac. Canad. M. n. 515.

Rab. Bryoth. eur. n. 169, 354 .

Rehm. M. Afr. austr. n. 438.

Sull, et Lesq. M. bor. am. 11 ed, n. 49.

" var. amblyodon (Brid.) Bryol. eur. l. c. t. 22 ; C. M. op. cit. p. 652 ;

W. P. Sch. op. cit. p. 52.

W. amblyodon Brid. Bryol. univ. I, p. 805 .

W. Brandegei Aust. in Bull. Torr. bot. Club, VI, p. 46.

W. gymnostomoides Bryol. germ. 11, 11, p. 34, t. 25 .

W. microstoma ibid. p. 52, t. 37.

Ut typ. - Eur.: Cum typ. Am. sept. : Colorado.

* var, arenicola Limpr. Laubm. Deutschl. 1, p. 257.

Ad rup. aren, desaggreg. - Eur.: Silesia.

var. australis Aust. - W. longiseta.

"var, brevifolia (Lindb.) Par.

Mollia viridula var, brevifolia Lindb, in Broth. Enum. M. Caucas, p. 51. Ad rup. calcar. - As. : Imeretia.

"var. canaliculata Hpe. Prodr. Fl. Nov. Granat., p. 15. - Am. merid. : Nov. Grànat. Brasil. austr. or.

«var. cylindrica W. P. Sch, in Mandon M. Madeir, n. I.

- Afr.: Madeir.

"var, densifolia (Wils.) Bryol. eur, C. M. et W. P. Sch, op. et ll. cc.

W. controversa var. densifolia Wils, Ëryol. brit.

W. densifolia Wils. mss.

Ut et cum typ. in Eur. et Am, sept.

Exs. : Rab. Bryoth. eur. n. 794, 795.

« var. gymnostomoides (Brid.) Bryol. eur, l. c. t. 22; C. M. et W. P. Sch. op. et ll. cc.

Gymnostomum Rauanum Aust. in Bull. Torr bot. Cluh, V, p. 21.

Hymenostomum microstomum ej. M. Appal. $n, 63$.

W. crispata Jur. Laubm. Oesterr. Ung. p. 11 (fid. C. M.).

W. gymnostomoides Brid. op. eit. p. 342 .

W. Rudolphiana Bryol.germ. II, II, p. 33, t. 25.

Ut typ. - Eur.: Cum typ. As.: Minor, Caucas. Am. sept.: Nov. Angl., New Jersey, Pensilv.

"s subsp. longirostris Kindb. in Hedwo. 1896, p. 59.

- Am. sept. : Illinois.

var. mucronata C. M. - W. mucronata.

* var. nitida Ren, et Card. in Bot. Gaz. 1889, p.91 et M.Amer, sept.n. 3. Arenic. - Am. sept. : Florid., Ludovic.

\& var. Rugeliana (W. P. Sch.) Ren, et Card. in Rev. bryol. 1892, p. 73.

W. Rugeliana W.P. Soh. mss.

- Am. merid. : Georgia.

“ var. stenocarpa (Bryol. germ.) Bryol. eur., C. M. et W. P. Sch. op. et $l l . c c$.

W. controversa var. stenocarpa Bryol. germ. $I, p .45, t .17$.

Ut typ. - Eur.: Cum typ. Am, sept.: Arkansas, Kansas.

\& var. stereodon C. M. in Rehm, M. A fr. austr, n. 20.

- Afr.: C. B. Sp. 
( var. subglobosa W. P. Sch. mss. ; Limpr. Laubm. Deutschl. 1, p. 256. Hymenostomum subglobosum Bryol. germ.?

In silvat. - Eur. : Bade.

“ var. tenuiseta (W, P. Sch.) Besch. in Ann. sc, nat. 1893, p. 330.

W. tenuiseta W.P. Seh. in Savat. M. Japon. n, 53.

$$
\text { - As. : Japon. }
$$

viridula Roth. - Fissidens exilis?

vulcanica $\left\{\begin{array}{l}\text { Brid. - Angstroemia. } \\ \text { C. M. - Rhabdoweisia. } \\ \text { Hook. - Angstroemia brevipes. }\end{array}\right.$

Wagneri Mitt. - Hyophila.

Welwitschii W. P. Sch, - Campylosteleum strictum.

Wimmeriana (Sendtn.) Bryol. eur. I (mon. p. 4), t. 20; C. M. Syn. I, p. 653 p.p. ; W. P. Sch. op. cit. p. 50.

Gymnostomum Wimmerianum Sendtn, in $F l .1840, I, p, 50$ et in $R$. Denkschr. 1841, p. 142.

G. trafoiense $W, P$, Sch, in sched.

Mollia Wimmeriana Lindb, M. Scand, p. 21.

1. In fiss. rup. humo repletis, - Eur. : Alp. Norveg., Sudet, Salisb., Tirol., Rhaet,., Helvet., M. Baldo, Gall, centr. (Arvernia), Lusitan. Exs. : Rab. Bryoth. eur. n. 453.

Wimmieriana C. M. p. p. - Hymenostomum murale.

Wolffi Lesq. et Jam. Man. p. 57.

2. Terr. - Am. sept, : Illinois.

zonata Brid. Bryol. univ. I, p. 364 ; C. M. Syn. I, p. 665.

Conostomum variegatum Brid, op. et l. ece.

Ster.

-Eux.: German., Pyren. or.

Weisiella $C . M$. in Fl. 1896, p. 446 (sect. Dicranellak).

WEISIODON W. P. Sch. Coroll. p. 9. reflexus W. P. Sch. - Gyroweisia.

WEISIOPSIS Bryol. eur. I (subgen. W EISIAE, = Gyroweisia reflexa).

WEISSIA Ehrh. Beitr. 1 .

Spec. omn, non indicatae sunt vLota ejusd, nom.

coarctata Lindb. - U. Ludwigii.

incurva Schwaegr. - Ptychomitrium.

Templetoni $\left\{\begin{array}{l}\text { Griff. - Entosthodon Wallichii. } \\ \text { Hook. - Entosthodon. }\end{array}\right.$

ulophylla Ehrh. - U, crispa.

$\beta$ inlermedia Braithw. - U. intermedia.

WILdIA C. M. et Broth, in Oefv, af Finska Vet,-Soc. Foerh, 1890 (1 spec.). solmsiellacea C.M. et Broth. in op. et l. cc.

Aulacopilum Wildii Broth, mss.

Syn. Cortic. - Pac. : Austral, or. (Queensland).

WILLIA C. M. Bryol, austr. Georg. p. 35 (1 spec.)

grimmioides $C, M$, op et $l$. $c c$.

2. Rupic. - Am, merid, : Austr, Georgia. 
WILSONIELLA C. M. in Bot. Centralbl. 1881, n. 37 (5 spec.).

crispidens C. M. in Dusen M. Camer, n. 308; Broth. in Engler's Bol. Jarhb. 1897, p. 244 (descript.).

i. Terr. ad vias, - Afr, : M. Cameroon.

Jardini (W. P. Sch.) Besch. Fl. bryol. Taït, etc., p. 54.

Trematodon Jardini W. P. Sch. in Jardin Enum. p. 20.

1. Terr. - Pac. : Taïti.

Karsteniana $C . M$. in op. et $l$. cc.

1 .

- Pac.: Austral. or.

pellucida $C . M$, in op. et $l, c c$.

Trichostomum decipiens Mitt. M. Ind, or. p. 13.

? Tr. pellucidum Wils, in Kew Journ. bot. IX, p. 321 .

1 .

- As. : Ceylan, Javá.

tonkinensis Besch, in Journ. de bot. 1890, p. 201.

Terr. - As. : Tonkin.

ZIERIA W. P. Sch. Coroll. $p .68$.

Spec. omn. Plagtobrya ejusd. nom.

ZYGODON Hook. et Tayl, Muscol, brit. p. 70 (107 spec.).

acutifolius C. M. in Bot. Zeit. 1853, p. 58.

Codonoblepharum acutifolium Jaeg. Ad. I, p. 397.

2. - As. : M. Neilgherries.

affinis Bryol. jav. 1, p. 107, t. 85 .

2. - As.: Java.

affinis W. P. Sch. $-Z$. mexicanus.

andinus Mitt. M. austr. am. p. 236.

- Am. merid. : M. Pichincha.

angustatus $W . P$. Sch, in C. M. Syn. I, p. 676.

Syn. $\quad-A m$. sept.: M. Orizaba.

anœetangioides C. $M$. in Fl. 1896, p. 449.

- Pac. : Ins. Sandwic.

anomalus Dz. et Mk. in Ann. sc. nat. 1884, p. 316 el M. Archip. ind. IV,

p. 92, t. 31; Bryol. juv. 1, p. 106; C. M. Syn. I, p. 672; Hook. f. et

Wils, Fl. Tasman. $11, p .185$.

Z. Reinwardti Mitt, in Joum. of the Linn. Soc. $1859, p .74 ;$ H. f. et W. Fl, of the N. Zeal. II, p. 81 et Handb. p. 434.

Syn.

- As.: Java. Pac.: Tásman.

Araucariae C. M. in Ule Bryoth. brasil, n, 22.

- Am. merid. : Brasil. sustr, or.

aristalus Lindb. - Z. Stirtoni.

asper C. M. in sched.

- As. : Himalaya sept. occid.

aureus C. M. in Fl. $1875, n .34$ et 35 .

2.

- Am. merid. : And. Nov, Granat.

Bolleanus C. M, in Bot. Zeit. 1859, p. 230.

2.

- Afr.: Ins. Capit, viridis (S. Nicolas). 
borbonicus Besch. Fl. bryol. Réunion, etc., p. 65.

Syn. - Afr. : Ins. Borbon.

brachyodus C. M. et Hpe. in Linn. 1856, p. 210.

2.

- Pac. : Austral, felix.

Brebissoni Bryol, eur. - $\mathrm{Z}$. conoideus.

breviciliatus Thwo, et Mitt. in Journ. of the Linn. Soc. 1872, p. 304.

Syn. - As. : Ceylan.

brevicollis Mitt. M. austr. am. p. 234.

Codonoblepharum brevicolle Jaeg. Ad. I, p. 396.

- Am. merid. : And. Quitens.

brevipes C. M. in Nuov. Giorn, bot, ital. 1897, p. 121.

- Am. merid. : And. Boliv.

«var. longius pedicellatus $e j$.

Ut typ.

brevisetus Wils, in Kew Journ. bot. IX, p. 325; Mitt. M. Ind. or. p. 47. 2. Dortic. - As. : Sikkim.

Brownii Schwaegr. Suppl. IV, p. 317; C. M. Syn. I, p. 674; Hook. f. et Wils. Fl. of the N. Zeal. II, p. 481 et Handb. p. 434.

1 (C. M.) ; 2 (Handb.). Lignic. et rupic. - Afr.: Ins. Kerguelen. Pac. : Nov. Zeland., Austral. or., Tasman.

caldensis Angstr. in Oefv... 1876, n. 4, p. 15.

1. Lignic. - Am. merid. : Brasil, austr, or.

californicus Hpe. - Amphoridium.

campylophyllus C. M. Syn. I, p. 680.

2. - Am. sept. : Mexic.

ceratodontoides $C . M$. in $\mathrm{Fl}$. $1875, n .34-35$.

1. $\quad-$ Am. merid.: And. Nov, Granat.

cernuus $C . M$. in sched.

$$
\text { - Afr.: C. B. Sp. }
$$

Cesatii de Not. - Z. Forsteri.

circinatus W. P. Sch, in Besch. Prodr. bryol, mexic. p, 43.

2.

- Am. sept.: Mexic. (Cordoba).

coarctatus W. P. Sch, in Lechler Pl: Chil. n. 2697. - Am. merid. : Peruv., Chile.

compactus C. M. - Anoëctangium.

conoidens (Dicks.) Hook. et Tayl. Muscol. brit. p. 71, t. 21 (var. a);

W. P. Sch. Syn. I ed. p. 250 el 11 ed. p. 296.

Bryum conoideum Dicks. Fasc. IV Pl. crypt. p. 9, t. 11.

Mnium conoideum Sm. Fl. brit. III, $p .1345$.

Z. Brebissoni Bryol. eur. III (mon. p. 8), t. 206.

$Z$. conoideus $\alpha$ minus Hook, et Grev. in Brewster Edinb. Journ.... 1824 , p. 132.

2. Cortic. - Eur. : Rariss. ; Norveg. occid., Britann., Normann.

conoideus $\left\{\begin{array}{l}\text { Auct. amer. }-Z \text {. rufo-tomentosus. } \\ \text { Brid., C. M. }- \text { Z. Forsteri. }\end{array}\right.$

$\alpha$ minus $H$. et $\mathrm{Gr} .-\mathrm{Z}$. conoideus.

$\beta$ succulentus eor. $-\mathrm{Z}$. Forsteri. 
corralensis Ltz. in Bot. Zeit. 1866, p. 187.

Ceratodon corralense Jaeg. Ad. I, p. 309.

Muric. - Am. merid. : Valdivia.

crenulatus Mitt, M. austr. am, p. 238.

Ster. - Am. merid. : And. Quitens.

crispatus Kindb, - Amphoridium.

cyaihicarpus Mont. - Amphoridium.

cylindricarpus C. M. in Bot. Zeit. 1853, p. 59 .

1.

- As. : M. Neilgherr.

cylindricus W. P. Sch, in C.M. Syn. 1, p. 672.

2.

- Am. sept, : Mexic. (M. Orizaba).

dentatus Breidl. - Z $\mathrm{Z}$. viridissimus var. dentatus.

denticulatus Tayl. in Lond. Journ. of bol. 1847, p. 329; C. M. Syn. I, p. 679 ; Mitt. M. austr. am. p. 232.

2.

- Am. merid. : And. Quitens, et Chilens.

Drummondii Tayl. in op, cit. 1846, p. 46; C. M. Syn. I, p. 668.

Z. Menziezii (fid. Mitt.).

2. Cortic. - Pac. : Austral, or.

Duseni C. M. in Dusen M. Camer, n. 277.

- Afr. : M. Cameroon.

Ehrenbergii C. M. in Linn. 1844, p. 672 et Syn. I, p. 676.

2.

- Am. sept. : Mexic.

erosus Mitt. in Journ. of the Linn. Soc. 1886, p. 305.

Cortic. - Afr. : Kilima N'Djaro.

erythrocarpus C. M. in Linn. 1878-1879, p. 365 .

2. Cortic. - Am. merid. : Argentin. subtropic.

excelsus C. M. - Anoëctangium.

fasciculatus Mitt. M. austr. am. p. 231.

2. Cortic. - Am. merid. : And. Quitens.

Fendleri C. M. in Linn, 1878-79, p. 484.

1.

- Am. merid.: And. Venezuelens.

ferrugineus W. P. Sch. in Mandon Pl. Boliv, n. 1627; C. M. in Nuov.

Giorn. bot, ital. 1897, p. 120. - Am. merid.: And. Boliv.

\& var. viridis C. M. in op. et $l$. $c c$.

Ubi typ.

filiformis Ltz. Moost. p. 162.

Ster. Rupic. - Am. merid.: And. Quitens.

firmus C. $M$, in Fl. 1896, p. 450 .

Ster, ? Terr. ? - Pac. : Ins. Sandwic.

Forsteri (Dicks.) Wils. Bryol. brit.p. 194, t, 46; W. P. Sch. Syn, 1 ed. p. 250 et II ed. p. 298.

Amphidium pulvinatum Nees in Sturm Deutschl. Fl. erypl. II, fasc. 17.

Bryum Forsteri Dicks, Fase. III Pl. crypt. p. 4, t. 7, f. 8.

Euzygodon Forsteri Jur. Laubm. Oesterr. Ung. p. 192.

Gagea compacta Raddi Nuov, Race, Dec. II.

Grimmia Forsteri Sm. Fl. brit. III, p. 1196.

Gymnocephalus conoideus Schwaegr. Suppl. I, II, p. 87. 
Weisia Forsteri Brid. Bryol. univ, I, p. 357.

Z. Cesatii de Not. Cron. d. briol. ital, in comm. II, p. 204.

Z. conoideus Brid. op. cit. p. 590; Bryol. eur. III (mon. p. 8), t. 207 C. M. Syn. I, p. 667 .

Z. conoideus $\beta$ succulentus $H$. et Grev. in Bievoster Edinb.journ.... 1824.

1. Ad arbor. annosior: - Eur.: Angl. merid., Gall. occid. et'merid., vall. Rhen, med., Sardin., Ital.

Exs. : Rab. Bryoth. eur. n. 882, 1325.

Glaziovii Hpe. Symb. 1874 , p. 492.

Syn.

- Am. merid. : Brasil. austr. or.

Goudotii Hpe. in Ann. sc. nat. V ser, $I V, p .325$.

2.

- Am. merid.: And. Nov. Granat.

gracilis Wils. M. brit. $n, 200$.

Amphoridium gracile de Not. Epil. p. 278.

Didymodon gracilis W. P. Sch. in Un. crypt. itin. $1863, n .16$ el 17.

D. subalpinus Card. in Rev. bryol. 1887, p. 21 (fid. Limpr.).

Leptodontium graeile de Not.

Trichostomum gracile Mdo, Bayern's Laubm. p. 79.

Z. Nowellii W. P. Sch. Syn. II ed. p. 297 ; Rab. Bryoth. eur. n. 1080, 1254 .

Z. viridissimus var. saxicola Mdo, Bav, Schliersee, p. 96.

2. Ad mur, et rup. calcar. - Eur. : Angl. merid., Helvet., Tirol., Alp. Algov, et Bavar.

" var. alpina (W. P. Sch.) Par.

Z. Nowellii var. alpina W. P. Sch. op. et $l$. cc.

- Eur. : Tirol. merid.

gracilis Jur. p. p. - Z, viridissimus var. dentatus.

gymnus C. $M$. in Linn. 1878-79, p. 485.

Syn.

- Am. merid.: Venezuela.

Haleakalae C. M. - Anoectangium.

hamatus Milt. M. austr. am. p. 233.

Ster.

- Am, merid. : And. Quitens.

Hookeri Hpe, in Linn. 1859, p. 632.

2. Cortic. - Pac. : M. Austral, fel.

Hornschuchianus C. M. - Anoectangium.

humilis Thro, et Mitt, in Journ. of the Linn. Soc. 1872, p. 304.

2. Cortic. - As. : Ceylan.

Hyadesi Besch. in Bull. Soc. bot. Fr. 1885, p. LX et in Miss. sc. cap Horn, V, Bot. p. 273, t. 3, f. 9 .

I. $\quad-$ Am. merid. : Patag. austr., Fuegia.

hymenodontoides C. M. - Anoectangium.

integrifolius C. M. - Amphoridium.

intermedius Bryol. eur. III (mon. p. 9) ; C. M. Syn. I, p. 67I ; Hook. $f$. et Wils. Fi. of the N. Zeal. 1I, p. 80 et Handb. p. 434 (1).

2. - Afr.: Abyss. Am. merid.: Chile (fid. Handb.). Pac. : N. Zeland., Austral. felix, Tasman.

Eiss. : W. Sch. Pl. Abyss, n. 457.

jamaïcense C. M. - Anoectangium.

(I) De patria cf. C. M. 1, e. 
Kilimandscharious C. M. - Amphoridium.

Krausei Ltz. Moosst. p. 163.

2. Cortic. - Am. merid. : Valdivia.

lapponicus Bryol, eur. - Amphoridium.

leptobolax C. M. in Rehm. M. Afr. austr. n. 499.

- Afr. : C. B. Sp.

Liebmanni W. P. Sch. in C. M. Syn. 1, p. 673 ,

2. Cortic. - Am, sepl. : Mexic. (M: Orizaba).

ligulatus C. M. - Scopelophila.

liliputanus C. M. in Nuov, Giorn. bot. ital. 1897, p. 122.

- Am. merid. : And, Boliv.

linearifolius Mitt. M. austr. am. p. 236.

Z. papillatus ej. in Kew Journ, bot, III, p. 356.

- Am. merid. : And. Quitens.

linearis C. M. - Anoectangium Mandoni.

linguiformis C. M. in Bot. Zeit. 1858, p. 163.

Codonoblepharum linguiforme Jaeg. Ad. I, p. 397.

2. Cortic. - Am, merid : Columb., And. Nov. Granat., Brasil. austr. or.

Mac-Leanus Rehm. M. Afr. austr. n. 501.

- Afr.: Transvaal.

Menziezii (Schioaegr.) W. Arn. Dispos. p. 15; C. M. Syn. I, p. 668.

(Oodonoblepharum Menziezii Schwaegr. Suppl. II, p. 142, t. 137; Brid. Bryol. univ. I, p. $594 ;$ H. f. et W. Fl. Tasm. II, p. 186 et Handb. of N. Zeal. $\mathrm{Fl} . \mathrm{p} .435$.

2. Lignic. et terr. - Am. merid. : Chile, ins, Chiloë, Päe: Nov. Zeland,, Austral. fel., Tasman.

mexicanus Jaeg. All. $1, p, 390$.

Z. affinis W. P. Schuin Besch. Prodr. bryol. mexio. p. 42.

2. $\quad-$ Am. sept.: Mexic. (M. Orizaba).

minutus C. $M$. et Hpe, in Linn. $1856, p .211$.

2.

- Pac. : Austral. felix, Tasman.

Moritzianus C. M. in Linn. 1847, p. 199 ; Syn. I, p. 678 et II, p. 637.

2. Cortic. - Am. merid. : And. Venezuelens.

Mougeotii W. P. Sch. - Amphoridium.

mucronatus Broth. in.Trans. of the N. Zeal.1Inst. 1896, p. 441, t. XXIX, fig. 26.

Syn. Cortic. - Pac. : Nov. Zeland.

neglectus C. $M$. in sched.

Codonoblepharum neglectum Jaeg. Ad. I, p. 396.

$Z$. obtusifolius $H$. $f$. et $W$. Fl. of the $N$. Zeal. II, p. 80 et Handb. p. 434. 1 .

- Pac. : Nov. Zeland.

nivalis $H_{p e}$, in Ann, sc. nat. V ser., III, p. 326.

Ster.

- Am. merid. : Summ. And. Nov. Granat.

Nowellii W. P. Sch. - Z. gracilis.

var, alpina W. P. Seh. - Z, gracilis var. alpina. 
obtusifolius Hook. M. ex. t. 159; Brid. Bryol. univ. I, p. 594 ; C. M. Syn. 1, p. 670 ; Mitt. M. Ind. or. p. 47.

Codonoblepharum obtusifolium Jaeg. Ad. I, p, 397. 1. - As. : Nepal., Sikkim.

obtusifolius $\mathrm{H}$. f. et W. - Z, neglectus. ochraceus C. M, in Linn. 1878-79, p. 36 ;.

2. - Am. merid. : Argentin. subtropic.

ovalis Mitt. M. austr. am. p. 235.

- Am. merid. : M. Chimborazo.

palmarum C. M. in Linn. 1880-83, p. 440.

Ster. Cortic. - Am. merid. : Uruguay subtropic.

papillatus Mont. in Ann, sc. nat. 1845, p. 106 et Syll.p. 37; C. M. Syn. 1, p. 669 .

Codonoblepharum papillatum Jaeg. Ad. I, p. 396.

2. Cortic. - Am. merid, : Chile austr.

papillatus Mitt. - Z Z linearifolius.

parvulus Geh. et Hpe. Enum. M. Brasil. p. 23.

- Am. merid. : Brasil.

paucidens C. M. in Nuov. Giorn. bot. ital. 1897, p. 220.

- Am. merid. : And. Roliv.

pentastichts (Mont.) C. M. Syn. I, p. 675.

Aulacomnium pentastichum Mont. in Ann. so. nat. 1845, p. 103 in Gay Hist. Chil. Bot. Crypt. t. 5, f. I et Syll. p. 31.

2.

Exs. : Lechler M. Chil. n, 528.

perpusillus Thw. et Mitt. - Hypnodon.

peruvianus Sull. in U. St. Expl. Exp. 1859, p. 6, t.4; Mitt. M, austr. um. p. 233.

Codonoblepharum peruvianum Jaeg. Ad. $I, p, 396$.

- Am. merid, : And. Peruv.

pichinchensis (Tayl.) Mitt. in Kevo Journ, bot. III, p. 356 et M. austr. am. p. 237.

? Didymodon pichinchensis Tayl. in Lond. Journ. of bot. 1848, p. 280; C. M. Syn. I, p. 581 .

- Am. merid. : M. Chimborazo et Pichincha.

pilosulus $C . M$. in Linn. 1878-79, p. 484 .

2. $\quad-A m$. merid.: Venezuela.

piriformis W. P. Sch, in Mandon Pl. Boliv, n. 1628.

- Am. merid. : And. Boliv.

Preissianus Hpe. in Linn 1859-60, p. 633.

Didymodon papillatus? Preiss M. Nov. Holl. n. 2449.

Leptodontium papillatum H. $t$. et W. Fl. of the N. Zeal. t. 85.

Leskea rubricaulis Tayl, mss. (fid. Mitt.).

2.

- Pac. : Australia.

pungens C. M. in Bot. Zeit. 1862, p. 361 .

Codonoblepharum pungens Jaeg. Ad. I, p. 397.

1. Cortic. - Am. merid, : Venezuela. 
pusillus C. M. - Anoectangium euchloron.

pygmaeus $C$. $M$, in Linn. 1878-79, p. 368.

2. $\quad-A m$. merid. : Argentin. subtropic.

quitensis Mitt. M. austr. am. p. 238.

Ster. $\quad-$ Am. merid.: And. Quitens,

recurvifolius W. P. Sch. in Mandon Pl. Boliv, n. $1629 ;$ C. M. in Nuov.

Giorn. bot. ital. 1897, p. 120.

- Am. merid. : And. Boliv.

Rehmanni C. M. in Rehm. M. Afr. austr. n. 149 el 498.

- Afr. : C. B. Sp.

Reinwardti (Hsch.) A. Br. in Bryol. eur. IV (mon, p. 9); C. M. Syn. I,

p. 678; Dz. et Mk. M. frond. ined. Archip. ind. p. $94 ;$ Bryol. jav. I, p. $109, t .87$.

Syrrhopodon Reinwardti Hsch. in Nov, Act. Phys. Medik. Akad. Leop. XIV,$I I$, p. 700, t. 39; Schvaegr. Suppl. IV, t. 312.

Syn. vel polyg. Cortic. - As. : Ceylan, Java. Pac. : Nov. Zeland.

Reinoardti H. f. et W., Mitt. - Z. anomalus.

rufo-tomentosus $D^{n a} E, G$, Britton ined.

Z. conoideus Auot, arieric.

2.

Am. sept, : Virgin., reg. or.

rugifolius C. M. in Rehm. M. Afr. austr. n. 151.

$$
\text { - Afr. : C. B. Sp. }
$$

runcinatus C. $M$, ibid. $n .150$.

- Afr.: C. B.Sp.

rupestris Lindb. - Z viridissimus var rupestris.

Schenkei Broth. in Hedwig. 1894, p. 129.

2? Cortic. - Am. merid. : Brasil, austr. or.

Schimperi Hpe. mis, ; C. M. in Linn. 1844, p. 671 el Syn. 1, p. 677. 2. - Afr.: Abyss.

Schmidii C. M. - Qreoweisia.

Schwaegrichenii $C . M$. in Linn. 1844, p. 669 et Syn. I, p. 669.

Syrrhopodon dubius Schwaegr. Suppl. IV, p. 312.

2.

- Pac. : Austral.

semi-tortus Mitt. in Journ. of the Linn. Soc. 1863, p. 152. - Afr. : M. Cameroon.

Sendtneri (Jur.) Vent. et Bott. Enum. crit. p. 26.

Euzygodon Sendtneri Jur. Laubm. Desterr. Ung. p. 191.

1. Cortic. - Eur. : Istria.

Sendinerianus C. M. - Anoectangium.

setulosus Mitt. M. austr. am. p. 237.

- Am. merid. : And. Nov. Granat.

sordidus C. M. in Bot. Zeit. 1857, p. 579 ; Mitt. M. austr. am, p. 230.

2. Cortic. - Am. merid. : And. Nov. Granat.

spathulaefolius Besch, Prodr, bryol. mexic. p. 43.

2.

- Am, sept. : Mexic. 
squarrosus (Tayl.) C. M. Syn. 1, p. 675; Mitt. M. austr. am. p. 237.

Aulacomnium flexifolium $H$. $f$. et $W$. in Lond. Journ of bot. 1846, p. 448, t. 15.

Leptostomum squarrosum Tayl. in eod. op. p. 43.

- Am. merid. : Summ. M. Pichincha.

stenocarpus Tayl. in Lond. Journ. of bot. 1847, p. 300; C. M. Syn. I, p. 673 ; Mitt. op. cit. p. 234.

2. $\quad-A m$. merid. : And. Quitens.

Stirtoni W. P. Sch. in Trans. of the bot. Soc. of Edinb., IX.

Z. aristatus Lindb. in Aot. Soc, sc. Fenn. 1875, p. 542.

2. Ad rup, marit. - Eur. : Scot., Hibern., Angl., Armoric., Norman. strictissimus C. M. in Rehm. M. Afr. austr. n. 144.

- Afr. : C. B. Sp.

strictus Mitt. - Drummendia.

subcyathicarpus C. M. in Rehm. M. Afr. austr. n. 146.

- Afr. : C. B. Sp.

subdenticulatus Hpe. in Ann. sc. nat. V ser., IV, p. 326; Mitt. M. austr. . am. p. 232.

Sullivantii C. M. - Amphoridium.

tenellus Mitt. - Anoectangium euchloron.

tenerrimus Kze. - Anoectangium laxifolium.

tetrugonostomus A. Br. in Bryol. eur. IV (mon. p. 9); C. M. Syn. 1, p. 677 et 11, p. 637 ; Bryol. jav. I, p. 108, t. 86.

1 et syn. $\quad-A s$, M. Neilgherr., Ceylan, Java.

torquatus $\left\{\begin{array}{l}\text { Broth. - Anoectangium. } \\ \text { Liebm. - Grimmia. }\end{array}\right.$

transvaaliensis Rehm. M. Afr. austr. n. 500.

- Afr.: Transyaal.

trichomitrius Hook. $f$. el Wils. in Lond. journ. of bot. 1846, p. 143,

t. 4 B ; C. M. Syn. 1, p. 677 et 11, p. 637.

2? Cortic. - Afr. : C. B. Sp.

tristichus C. M. in Bot. Zeit. 1855, p. 764.

2. Terr. - Afr. : C. B. Sp.

Eas, : Rehm. M. Afr. austr. n. 145.

uncinatus Matt. M. austr. am. p. 234.

Codonoblepharum uncinatum Jaeg. Ad. I, p. 396.

- Am. merid. : Ins. Chiloë.

ventricosus C. M. in Linn. 1844, p. 668 et Syn. 1, p. 674.

Cortic. - Am. merid. : And. Chilens.

viridatus C. M. - Anoectangium.

viridissimus (Dicks.) Brid. Bryol. univ. I, p. 592 (excl. syn. Grimmia

Forsteri) ; Bryol. eur. 111 (mon. p. 7), t. 206 (excl. syn. Weisia Forsteri) ; C. M. Syn. 1, p. 671.

Amphoridium viridissimum de Not. Epil. p. 274.

Bryum viridissimum Dicks. Fasc. IV Pl. crypt. p. 9, t. 10, f. 8.

Dicranum viridissimum $S m$. Musc. brit. III, p. 1224.

Gymnostomum viridissimum $H$. et T. Musc. brit. p. 10, t. 6 (excl. syn. Grimmia Forsteri); Dromm. M. bor. dm. I ed. n. 27. 
2. Cortic., rar. ad rup. calcar, - Eur. : Norveg, occid, ; zon. occid. et merid. As. : Caucas. Afr. : Alger. Am. sepl.: Sinus Hudson.

E.cs. : Rab. Bryoth, eur, n. 524.

« var. dentatus (Breidl.) Limpr. Laubm. Deutschl. II, p. 12.

Z. dentatus Breidl. mss,

Z, gracilis Jur. Laubm. Oesteri. Ung. p. 190 p.p.

Cortic. - Eur. : Alp. Salisb., Stir., Algov, et Bavar., Vorarlberg.

"var. rupestris (Lindb.) Hartm. Skand. Fl. IX ed. p. 52.

Amphoridium rupestre de Not. Epil. p. 274.

Z. rupestris Lindb. M. Scand. p. 29.

Z. viridissimus var, sasicola Mdo, in Rab. Bryoth. eur. n. 626 .

Ad rup. basalt. et trachyt. - Eur.: Suecia, Fennia, Hassia super., Thuring., Rhoengeb., Francon., Tirol., Bavar., Stiria.,

var. saxicola Mdo $\left\{\begin{array}{l}\text { (Bav. Schl,). }- \text { Z. gracilis. } \\ \text { (Rab. exs.). - Z. viridissimus var. rupestris. }\end{array}\right.$

? viridissimo affinis Wils. - Drummondia stricta.

Volkensi Broth. in Engler's Bot. Jahrb. 1897, p. 241.

Syn. $\quad-A f r:$ : Kilima N'Djaro.

Welwitschii Duby in Mém... Genève, 1871, p. 20, t. I, f. 7 (1).

1. $-A f r$ : Angola.

ZYGOTRICHIA Brid. Bryol. univ. I, p. 520.

cylindrica Tayl. $\left\{\begin{array}{l}\text { - Barbula cylindrica (fid. W, P. Sch.). } \\ \text { - Didymodon flexifolius (fid, C. M.). }\end{array}\right.$

leucostoma Brid. - Barbula.

Zygotrichodon W. P. Sch. Syn. II ed., p. 169 (subgen. Ттісновтомі).

(1) In Enum.Kindb. nom. nud. :

Z. tenerrimus C. M. (an Anoectangium laxifolium ?). 


\section{ERRATA}

pp. 743 : lata inter: lapponica et latebricola, p. 744.

745 : loco : nervosa Hedw. p.p..., lege : obscura.

V 792 : de : Un. itin. 1864, n. 73 ad: eurviseta Schwaegr. ad M. uliginosam pertinet; post: Sull. et Lesq. M. bor. am. II ed. n. 248 , p. 794 collocandum.

- 833 : rhynchomitrium ante rhynchophorum.

$\checkmark 870$ : ORTHODON inter Orthodicranum et ORTHODONTIUM, p 868.

929 : stenodictyon ante : striata.

929 : subcordata ante : subourvula.

955 : longissimum post : longipilum.

V 978 : eatharinelloides post : Carionii, p. 979.

$\checkmark 1108$ : genus REMYELLA ante genus : RENAUIDIA p. 1067.

1223 : Whiteleggei inter : Wheeleri et Wilooxii.

1343 : post : afro-cruda (C. M) Par., lege :

Bryum afro-crudum C. M, in Fl. 1890, p. 478. 